\title{
Remedial Action Plan and Site DESIGN FOR STABILIZATION OF THE INACTIVE URANIUM MILL TAILINGS Sites at Slick Rock, Colorado
}

\section{Appendix A to Attachment 3, TABles}

Final

September 1995

\author{
Appendix B of the \\ Cooperative Agreement \\ No. DE-FC04-81AL16257
}

\section{DISCLAIMER}

This report was prepared as an account of work sponsored by an agency of the United States Government. Neither the United States Government nor any agency thereof, nor any of their employees, makes any warranty, express or implied, or assumes any legal liability or responsibility for the accuracy, completeness, or usefulness of any information, apparatus, product, or process disclosed, or represents that its use would not infringe privately owned rights. Reference herein to any specific commercial product, process, or service by trade name, trademark, manufacturer, or otherwise does not necessarily constitute or imply its endorsement, recommendation, or favoring by the United States Government or any agency thereof. The views and opinions of authors expressed herein do not necessarily state or reflect those of the United States Government or any agency thereof. 


\section{INTENDED FOR PUBLIC RE:LASE}

This report has been reproduced from the best available copy. Available in paper copy and microfiche.

Number of pages in this report: 613

DOE and DOE contractors can obtain copies of this report from:

Office of Scientific and Technical Information

P.O. Box 62

Oak Ridge, TN 37831

(615) 576-8401

This report is publicly available from:

National Technical Information Service

Department of Commerce

5285 Port Royal Road

Springfield, VA 22161

(703) $487-4650$ 


\section{DISCLAIMER}

Portions of this document may be illegible in electronic image products. Images are produced from the best available original document. 
APPENDIX A TO ATTACHMENT 3

TABLES 


\section{LIST OF TABLES}

Table

Page

1.1 Maximum concentration of constituents for ground water protection . . . . . . 1

3.1 Monitoring well information for the NC processing site, Slick Rock, Colorado ... 3

3.2 Monitoring well information for the UC processing site, Slick Rock, Colorado . . 4

3.3 Static ground water levels for the NC and UC processing sites, Slick Rock, Colorado ................................. 5

3.4 Hydraulic parameters for the NC and UC processing sites, Slick Rock,

Colorado . . . . . . . . . . . . . . . . . . . . . . . . . . . . 14

3.5 Background ground water quality data by parameter for the alluvium, NC and UC processing sites, Slick Rock, Colorado . . . . . . . . . . . . . 15

3.6 Background ground water quality statistics by parameter for the alluvium, NC processing site, Slick Rock, Colorado . . . . . . . . . . . . . . 45

3.7 Summary of regulated constituents in alluvial background ground water, NC processing site, Slick Rock, Colorado . . . . . . . . . . . . . . . 55

3.8 Ground water quality measurements exceeding MCLs in alluvial background ground water, NC and UC processing sites, Slick Rock, Colorado . . 57

3.9 Background ground water quality statistics by parameter for the alluvium, UC processing site, Slick Rock, Colorado . . . . . . . . . . . . . . . . 59

3.10 Summary of regulated constituents in alluvial background ground water, UC processing site, Slick Rock, Colorado . . . . . . . . . . . . . . . 69

3.11 Background ground water quality data by parameter for the Entrada Formation, UC processing site, Slick Rock, Colorado . . . . . . . . . . . . 71

3.12 Background ground water quality statistics by parameter for the Entrada Formation, UC processing site, Slick Rock, Colorado . . . . . . . . . . . . . . 92

3.13 Summary of regulated constituents in the Entrada Formation background ground water, UC processing site, Slick Rock, Colorado . . . . . . . . . . . . 102

3.14 Ground water quality measurements exceeding MCLs in Entrada Formation background ground water, UC site, Slick Rock, Colorado . . . . . . . 104

3.15 Background ground water quality data by parameter for the Navajo Sandstone, NC and UC processing sites, Slick Rock, Colorado . . . . . . . . . . 106

3.16 Background ground water quality statistics by parameter for the Navajo Sandstone, NC processing site, Slick Rock, Colorado 


\section{LIST OF TABLES (Continued)}

Table

Page

3.17 Summary of regulated constituents in the Navajo Sandstone background ground water, NC processing site, Slick Rock, Colorado . . . . . . . . . . 147

3.18 Ground water quality measurements exceeding MCLs in Navajo Sandstone background ground water, NC and UC processing sites, Slick Rock, Colorado .................................. 149

3.19 Background ground water quality statistics by parameter for the Navajo Sandstone, UC processing site, Slick Rock, Colorado . . . . . . . . . . . 151

3.20 Summary of regulated constituents in the Navajo Sandstone background ground water, UC processing site, Slick Rock, Colorado . . . . . . . . . . . 161

3.21 Tailings pore fluid water quality data by parameter, NC and UC processing sites, Slick Rock, Colorado . . . . . . . . . . . . . . . . . . . . 163

3.22 Tailings pore fluid water quality statistics by parameter, NC processing site, Slick Rock, Colorado . . . . . . . . . . . . . . . . . . . . . . . . 191

3.23 Summary of regulated constituents in tailings pore fluid samples, NC processing site, Slick Rock, Colorado . . . . . . . . . . . . . . . . . . . 200

3.24 Tailings pore fluid measurements exceeding maximum concentration limits, NC and UC processing sites, Slick Rock, Colorado . . . . . . . . . . . . . . 202

3.25 Tailings pore fluid water quality statistics by parameter, UC processing site, Slick Rock, Colorado . . . . . . . . . . . . . . . . . . . . 207

3.26 Summary of regulated constituents in tailings pore fluid samples, UC processing site, Slick Rock, Colorado

3.27 Baseline ground water quality data by parameter for the alluvium, NC and UC processing sites, Slick Rock, Colorado . . . . . . . . . . . . . 219

3.28 Baseline ground water quality statistics by parameter for the alluvium, NC processing site, Slick Rock, Colorado . . . . . . . . . . . . . . . . 312

3.29 Summary of regulated constituents in alluvial baseline ground water, NC processing site, Slick Rock, Colorado . . . . . . . . . . . . . . 322

3.30 Ground water quality measurements exceeding MCLs in alluvial baseline ground water, UC and NC processing sites, Slick Rock, Colorado . . . . . . . . . 324

3.31 Baseline ground water quality statistics by parameter for the alluvium, UC processing site, Slick Rock, Colorado 


\section{LIST OF TABLES (Continued)}

Table

Page

3.32 Summary of regulated constituents in alluvial baseline ground water,

UC processing site, Slick Rock, Colorado .

3.33 Baseline ground water quality data by parameter for the Entrada

Formation, UC processing site, Slick Rock, Colorado . . . . . . . . . . . . . . 344

3.34 Baseline ground water quality statistics by parameter for the Entrada

Formation, UC processing site, Slick Rock, Colorado . . . . . . . . . . . . . 375

3.35 Summary of regulated constituents in the Entrada Formation baseline ground water, UC processing site, Slick Rock, Colorado . . . . . . . . . . . . 385

3.36 Ground water quality measurements exceeding MCLs in Entrada Formation baseline ground water, UC processing site, Slick Rock, Colorado . . . . . . . . 387

3.37 Baseline ground water quality data by parameter for the Navajo Sandstone, UC processing site, Slick Rock, Colorado . . . . . . . . . . . . . . . . . 390

3.38 Baseline ground water quality statistics by parameter for the Navajo Sandstone, UC processing site, Slick Rock, Colorado

3.39 Summary of regulated constituents in the Navajo Sandstone baseline ground water, UC processing site, Slick Rock, Colorado . . . . . . . . . . . . 430

3.40 Ground water quality measurements exceeding MCLs in Navajo Sandstone baseline ground water, UC processing site, Slick Rock, Colorado

3.41 Information for private wells located in the vicinity of the Slick Rock processing sites .......................... 434

3.42 Monitoring well information for the Burro Canyon disposal site, Slick Rock, Colorado . . . . . . . . . . . . . . . . . . . . . . . . 435

3.43 Static ground water levels for the Burro Canyon disposal site, Slick Rock, Colorado . . . . . . . . . . . . . . . . . . . . . . 436

3.44 Hydraulic parameters for the Burro Canyon disposal site, Slick Rock, Colorado

3.45 Background ground water quality data by parameter for the upper sandstone unit, Burro Canyon disposal site, Slick Rock, Colorado

3.46 Background ground water quality statistics by parameter for the upper sandstone unit, Burro Canyon disposal site, Slick Rock, Colorado

3.47 Summary of regulated constituents in the upper sandstone unit, Burro Canyon disposal site, Slick Rock, Colorado 


\section{LIST OF TABLES (Continued)}

Table

3.48 Ground water quality measurements exceeding MCLs in the upper sandstone unit, Burro Canyon disposal site, Slick Rock, Colorado . . . . . . . . . 486

3.49 Background ground water quality data by parameter for the middle sandstone unit, Burro Canyon disposal site, Slick Rock, Colorado . . . . . . . . . 488

3.50 Background ground water quality statistics by parameter for the middle sandstone unit, Burro Canyon disposal site, Slick Rock, Colorado . . . . . . . . 535

3.51 Ground water quality measurements exceeding MCLs in the middle sandstone unit, Burro Canyon disposal site, Slick Rock, Colorado . . . . . . . . . 542

3.52 Background ground water quality data by parameter for the lower sandstone unit, Burro Canyon disposal site, Slick Rock, Colorado . . . . . . . . . 544

3.53 Background ground water quality statistics by parameter for the lower sandstone unit, Burro Canyon disposal site, Slick Rock, Colorado . . . . . . . . 576

3.54 Ground water quality data by parameter for monitor wells 684 and 685 , NC and UC processing sites, Slick Rock, Colorado . . . . . . . . . . . . . . 583 
Table 1.1 Maximum concentration of constituents for ground water protection

\begin{tabular}{|c|c|c|c|}
\hline Constituents with MCLs ${ }^{\mathrm{b}}$ & $\mathrm{mg} / \mathrm{L}$ & Constituents with MCLs ${ }^{b}$ & $\mathrm{mg} / \mathrm{L}$ \\
\hline Arsenic (As) & 0.05 & Carbon tetrachloride & 0.005 \\
\hline Barium (Ba) & 1.0 & p-Dichlorobenzene (benzene, $1,4 \mathrm{di}-$ ) & 0.075 \\
\hline Cadmium (Cd) & 0.01 & 1,1-Dichloroethylene (ethene,1,1 di-) & 0.007 \\
\hline Chromium (Cr) & 0.05 & Endrin & 0.0002 \\
\hline Lead (Pb) & 0.05 & Ethylene dichloride & 0.005 \\
\hline Mercury (Hg) & 0.002 & Lindane & 0.004 \\
\hline Molybdenum (Mo) & 0.1 & Methoxychlor & 0.1 \\
\hline Nitrate $\left(\mathrm{NO}_{3}\right)$ & 44.0 & Methylchloroform & 0.2 \\
\hline Selenium (Se) & 0.01 & Toxaphene & 0.005 \\
\hline Silver $(A g)$ & 0.05 & 2,4-D & 0.1 \\
\hline $\begin{array}{l}\text { Combined radium } \\
\text { (Ra-226 and }-228 \text { ) }\end{array}$ & $5.0^{c}$ & $2,4,5-\mathrm{TP}$ & 0.01 \\
\hline $\begin{array}{l}\text { Combined uranium } \\
(U-234 \text { and }-238)\end{array}$ & $30.0^{C}$ & Trichlorethylene & 0.005 \\
\hline $\begin{array}{l}\text { Net gross alpha } \\
\text { (excluding radon and uranium) }\end{array}$ & $15.0^{\mathrm{c}}$ & Vinyl chloride & 0.002 \\
\hline
\end{tabular}


Table 1.1 Maximum concentration of constituents for ground water protection ${ }^{a}$ (Concluded)

\begin{tabular}{|c|c|}
\hline Constituents without MCLs & Constituents without MCLs \\
\hline Antimony (Sb) and compounds, NOS $^{d}$ & Nickel (Ni) and compounds, NOS ${ }^{d}$ \\
\hline Aluminum phosphide ${ }^{e}$ & Strontium sulfide ${ }^{e}$ \\
\hline Beryllium $(\mathrm{Be})$ and compounds, NOS ${ }^{d}$ & Sulfide (S) \\
\hline Calcium chromate $^{\mathrm{e}}$ & Thallium (Th) and compounds, NOS ${ }^{d}$ \\
\hline Carbon disulfide ${ }^{e}$ & $\operatorname{Tin}(\mathrm{Sn})$ \\
\hline Carbon oxyfluoride ${ }^{e}$ & Vanadium (V) \\
\hline Copper (Cu) & Vanadic acid, ammonium salt ${ }^{e}$ \\
\hline Cobalt (Co) & Vanadium pentoxide ${ }^{e}$ \\
\hline \multirow[t]{2}{*}{ Cyanides (CN), NOS ${ }^{d, e, f}$} & inc $(Z n)$ \\
\hline & Zinc phosphide $^{e}$ \\
\hline
\end{tabular}

asummarized from EPA Proposed groundwater standards, April 1989, 40 CFR 192.02.

b Maximum concentration limits. Concentrations of these constituents shall not exceed background or the MCL limits, whichever is higher.

Units are $\mathrm{pCi} / \mathrm{L}$.

Not otherwise specified. Members of compounds not specified in Appendix 1.

Added when Appendix I replaced Appendix IX of 40 CFR 264.

foluble salts and complexes. 
TABLE 3.1 MONITORING WELL INFORMATION FOR THE NC PROCESSING SITE, SLICK ROCK, COLORADO

SITE: SRKOI SLICK ROCK (BOTH SITES)

REPORT DATE: 06/17/93

\begin{tabular}{|c|c|c|c|c|c|c|c|c|c|c|c|c|}
\hline $\begin{array}{c}\text { LOCATION } \\
10\end{array}$ & $\begin{array}{c}\text { NORTH } \\
\text { COORDINATE } \\
\text { (FT) }\end{array}$ & $\begin{array}{c}\text { EAST } \\
\text { COORDIHATE } \\
\text { (FT) }\end{array}$ & $\begin{array}{c}\text { GROUND } \\
\text { ELEVATION } \\
\text { (FT MSL) }\end{array}$ & $\begin{array}{l}\text { BOREHOLE } \\
\text { DEPTH } \\
\text { (FT) }\end{array}$ & $\begin{array}{l}\text { BOREHOLE } \\
\text { DIAMETER } \\
\text { (INCHES) }\end{array}$ & $\begin{array}{l}\text { CASING } \\
\text { ELEVATION } \\
\text { (FT MSL) }\end{array}$ & $\begin{array}{l}\text { CASING } \\
\text { DEPTH } \\
\text { (FT) }\end{array}$ & $\begin{array}{l}\text { CASING } \\
\text { DIAMETER } \\
\text { (INCHES) }\end{array}$ & $\begin{array}{c}\text { SCREEN } \\
\text { BEGINHING } \\
\text { DEPTH (FT) }\end{array}$ & $\begin{array}{c}\text { SCREEN } \\
\text { LENGTH } \\
\text { (FT) }\end{array}$ & $\begin{array}{l}\text { FLOW } \\
\text { CODE }\end{array}$ & $\begin{array}{l}\text { FORMATION } \\
\text { OF } \\
\text { CONPLETION }\end{array}$ \\
\hline $\begin{array}{l}0501 \\
0503 \\
0504 \\
0512 \\
0686 \\
0687 \\
0690\end{array}$ & $\begin{array}{l}58537.7 \\
58246.7 \\
58094.9 \\
58394.2 \\
58619.9 \\
57223.2 \\
57927.8\end{array}$ & $\begin{array}{l}63677.8 \\
63269.3 \\
63088.4 \\
63267.2 \\
63769.6 \\
62932.9 \\
61902.3\end{array}$ & $\begin{array}{l}5454.80 \\
5457.90 \\
5448.50 \\
5450.40 \\
5455.10 \\
5492.80 \\
5506.90\end{array}$ & $\begin{array}{r}22.00 \\
27.00 \\
19.00 \\
20.00 \\
22.00 \\
195.00 \\
182.00\end{array}$ & $\begin{array}{l}8.000 \\
8.000 \\
8.000 \\
8.000 \\
6.000 \\
6.000 \\
6.000\end{array}$ & $\begin{array}{l}5456.48 \\
5459.39 \\
5450.81 \\
5452.67 \\
5457.29 \\
5494.14 \\
5509.41\end{array}$ & $\begin{array}{r}22.00 \\
27.00 \\
19.00 \\
20.00 \\
22.00 \\
195 . \\
182.00\end{array}$ & $\begin{array}{l}4.000 \\
4.000 \\
4.000 \\
4.000 \\
2.000 \\
2.000 \\
2.000\end{array}$ & $\begin{array}{l}12.00 \\
20.00 \\
14.00 \\
12.00 \\
15 . \\
173 . \\
160 .\end{array}$ & $\begin{array}{r}9.0 \\
6.0 \\
4.0 \\
8.0 \\
5.0 \\
20.0 \\
20.0\end{array}$ & $\begin{array}{l}\mathbf{0} \\
\mathbf{0} \\
\mathbf{D} \\
\mathbf{0} \\
\mathbf{0} \\
\mathbf{U} \\
\mathbf{U}\end{array}$ & $\begin{array}{l}A L \\
A L \\
A L \\
A L \\
A L \\
\text { NA } \\
\text { NA }\end{array}$ \\
\hline
\end{tabular}

FORMATION OF COMPLETION CODE:

AL - ALLUVIUM

NA - NAVAJO SANDSTONE

FLOW RELATIONSHIP CODE:

O- ON-SITE

D - DOWN GRADIENT

U - UPGRADIENT

DATA FILE: M: IDARTISRKOI YMHI 10001.DAT 
TABLE 3.2 MOHITORING WELL IHFORMATIOH FOR THE UC PROCESSING SITE,

SLICK ROCK, COLORADO

SITE: SRKO1 SLICK ROCK (BOTH SITES)

REPORT DATE: 06/29/95

\begin{tabular}{|c|c|c|c|c|c|c|c|c|c|c|c|c|}
\hline$\underset{\text { ID }}{\text { LOCATION }}$ & $\begin{array}{c}\text { NORTH } \\
\text { COORDINATE } \\
\text { (FT) }\end{array}$ & $\begin{array}{c}\text { EAST } \\
\text { COORDINATE } \\
\text { (FT) }\end{array}$ & $\begin{array}{c}\text { GROUND } \\
\text { ELEVATION } \\
\text { (FT MSL) }\end{array}$ & $\begin{array}{l}\text { BOREHOLE } \\
\text { DEPTH } \\
\text { (FT) }\end{array}$ & $\begin{array}{l}\text { BOREHOLE } \\
\text { DIAMETER } \\
\text { (INCHES) }\end{array}$ & $\begin{array}{l}\text { CASING } \\
\text { ELEVATION } \\
\text { (FT MSL) }\end{array}$ & $\begin{array}{l}\text { CASING } \\
\text { LENGTH } \\
\text { (FT) }\end{array}$ & $\begin{array}{l}\text { CASING } \\
\text { DIAMETER } \\
\text { (INCHES) }\end{array}$ & $\begin{array}{c}\text { SCREEN } \\
\text { BEGINNING } \\
\text { DEPTH (FT) }\end{array}$ & $\begin{array}{c}\text { SCREEN } \\
\text { LENGTH } \\
\text { (FT) }\end{array}$ & $\begin{array}{l}\text { FLON } \\
\text { CODE }\end{array}$ & $\begin{array}{l}\text { FORMATION } \\
\text { OF } \\
\text { COMPLETION }\end{array}$ \\
\hline $\begin{array}{l}0505 \\
0506 \\
0507 \\
0508 \\
0509 \\
0510 \\
0551 \\
0552 \\
0553 \\
0554 \\
0555 \\
0556 \\
0557 \\
0558 \\
0559 \\
0560 \\
0668 \\
0669 \\
0670 \\
0684 \\
0685 \\
0688 \\
0702 \\
0703 \\
0704\end{array}$ & $\begin{array}{l}58621.3 \\
59877.7 \\
60019.9 \\
59547.6 \\
59201.7 \\
59726.1 \\
58464.81 \\
58480.06 \\
58498.13 \\
59171.94 \\
59128.84 \\
58533.37 \\
58559.45 \\
58131.86 \\
58410.30 \\
59348.92 \\
58670.83 \\
59555.2 \\
59797.4 \\
60988.0 \\
62187.5 \\
60020.8 \\
58881.87 \\
58719.29 \\
59173.01\end{array}$ & $\begin{array}{l}60065.9 \\
58895.7 \\
58704.2 \\
59575.2 \\
60131.0 \\
59228.0 \\
58510.72 \\
58476.35 \\
58539.82 \\
58549.51 \\
58569.09 \\
58255.91 \\
58270.92 \\
58863.79 \\
59120.23 \\
58463.56 \\
58711.47 \\
59550.5 \\
59171.8 \\
58964.8 \\
58927.9 \\
57956.9 \\
59277.12 \\
58732.28 \\
58879.14\end{array}$ & $\begin{array}{l}5436.40 \\
5431.10 \\
5431.50 \\
5437.30 \\
5434.80 \\
5436.40 \\
5524.49 \\
5524.82 \\
5524.47 \\
5500.87 \\
5502.45 \\
5528.27 \\
5527.06 \\
5524.79 \\
5515.27 \\
5492.83 \\
5522.93 \\
5438.80 \\
5435.89 \\
5430.20 \\
5426.30 \\
5453.60 \\
5489.55 \\
5522.34 \\
5489.25\end{array}$ & $\begin{array}{r}19.00 \\
21.00 \\
20.00 \\
20.00 \\
22.00 \\
26.00 \\
80.00 \\
80.00 \\
25.00 \\
50.00 \\
35.00 \\
95.00 \\
45.00 \\
82.00 \\
52.00 \\
25.00 \\
249.00 \\
107.00 \\
96.00 \\
23.00 \\
27.00 \\
70.00 \\
70.00 \\
55.00 \\
61.50\end{array}$ & $\begin{array}{l}8.000 \\
8.000 \\
8.000 \\
8.000 \\
8.000 \\
8.000 \\
8.000 \\
8.000 \\
8.000 \\
8.000 \\
8.000 \\
8.000 \\
8.000 \\
8.000 \\
8.000 \\
8.000 \\
6.000 \\
6.000 \\
6.000 \\
6.000 \\
6.000 \\
6.000 \\
8.000 \\
8.000 \\
8.000\end{array}$ & $\begin{array}{l}\mathbf{5 4 4 1 . 0 5} \\
\mathbf{5 4 3 1 . 3 7} \\
\mathbf{5 4 3 3 . 0 6} \\
\mathbf{5 4 3 9 . 7 7} \\
5436.80 \\
\mathbf{5 4 3 8 . 5 9} \\
\mathbf{5 5 2 4 . 0 0} \\
\mathbf{5 5 2 5 . 0 0} \\
\mathbf{5 5 2 5 . 0 0} \\
\mathbf{5 5 0 0 . 5 0} \\
\mathbf{5 5 0 2 . 0 0} \\
\mathbf{5 5 2 9 . 0 0} \\
\mathbf{5 5 2 7 . 0 0} \\
\mathbf{5 5 2 6 . 0 0} \\
\mathbf{5 5 1 5 . 0 0} \\
\mathbf{5 4 9 2 . 0 0} \\
\mathbf{5 5 2 4 . 9 1} \\
\mathbf{5 4 4 0 . 5 0} \\
\mathbf{5 4 3 7 . 7 6} \\
\mathbf{5 4 3 2 . 5 1} \\
\mathbf{5 4 2 8 . 3 4} \\
\mathbf{5 4 5 5 . 4 6} \\
\mathbf{5 4 8 6 . 5 0} \\
\mathbf{5 5 2 6 . 5 0} \\
\mathbf{5 4 9 1 . 6 6}\end{array}$ & $\begin{array}{l}19.00 \\
19 . \\
20.00 \\
19 . \\
22.00 \\
24 . \\
58 . \\
80 . \\
24 . \\
49.5 \\
33.00 \\
90 . \\
42 . \\
80 . \\
52 . \\
24.00 \\
153.0 \\
107.00 \\
96.00 \\
23.00 \\
27.00 \\
70.00 \\
68 . \\
55 . \\
60 .\end{array}$ & $\begin{array}{l}4.000 \\
4.000 \\
4.000 \\
4.000 \\
4.000 \\
4.000 \\
4.000 \\
4.000 \\
4.000 \\
4.000 \\
4.000 \\
4.000 \\
4.000 \\
4.000 \\
4.000 \\
4.000 \\
2.000 \\
2.000 \\
2.000 \\
2.000 \\
2.000 \\
2.000 \\
4.000 \\
4.000 \\
4.000\end{array}$ & $\begin{array}{l}11.00 \\
12.00 \\
10.00 \\
12.00 \\
12.00 \\
15.00 \\
46 . \\
68 . \\
12 . \\
37.5 \\
21.00 \\
78.0 \\
30.0 \\
68.0 \\
38.0 \\
12.00 \\
111 . \\
100 . \\
84 . \\
11.0 \\
15 . \\
53 . \\
55 . \\
41.8 \\
46.00\end{array}$ & $\begin{array}{r}8.0 \\
7.0 \\
10.0 \\
7.0 \\
10.0 \\
9.0 \\
10.0 \\
10.0 \\
10.0 \\
10.0 \\
10.0 \\
10.0 \\
10.0 \\
10.0 \\
10.0 \\
10.0 \\
40.0 \\
5.0 \\
10.0 \\
10.0 \\
10.0 \\
15.0 \\
10.0 \\
10.0 \\
10.0\end{array}$ & $\begin{array}{l}0 \\
D \\
D \\
0 \\
0 \\
0 \\
U \\
U \\
0 \\
U \\
0 \\
U \\
0 \\
U \\
U \\
0 \\
U \\
0 \\
0 \\
D \\
D \\
U \\
0 \\
U \\
0\end{array}$ & $\begin{array}{l}A L \\
A L \\
A L \\
A L \\
A L \\
A L \\
J E \\
H A \\
A L \\
J E \\
A L \\
N A \\
A L \\
H A \\
J E \\
A L \\
N A \\
H A \\
N A \\
A L \\
A L \\
\text { NA } \\
\text { JE } \\
\text { JE } \\
\text { JE }\end{array}$ \\
\hline
\end{tabular}

FORMATION OF COMPLETION COOE:

AL - ALLUVIUM

JE - JURASSIC ENTRADA SANDSTONE FORMATION

FLOW RELATIONSHIP CODE:

MA - NAVAJO SANDSTONE

$U$ - UPGRADIENT

DATA FILE: IDARTISRK01YMHI 10000.DAT 
TABLE 3.3 STATIC GROUHD HATER LEVELS FOR THE HC AND UC PROCESSING SITES,

SLICK ROCK, COLORADO

SITE: SRKO1 SLICK ROCK (BOTH SITES)

REPORT DATE: 09/28/94

\begin{tabular}{|c|c|c|c|c|c|c|c|c|c|c|c|}
\hline$\underset{10}{\text { LOCATION }}$ & $\begin{array}{l}\text { NORTH } \\
\text { COORDINATE } \\
\text { (FT) }\end{array}$ & $\begin{array}{c}\text { EAST } \\
\text { COORDINATE } \\
\text { (FT) }\end{array}$ & $\begin{array}{l}\text { FORMATION } \\
\text { OF } \\
\text { COMPLETION }\end{array}$ & $\begin{array}{l}\text { FLOW } \\
\text { CODE }\end{array}$ & $\begin{array}{l}\text { CASING } \\
\text { ELEVATION } \\
\text { (FT MSL) }\end{array}$ & $\begin{array}{l}\text { GROUND } \\
\text { ELEVATION } \\
\text { (FT MSL) }\end{array}$ & LOG DATE & $\begin{array}{l}\text { LOG } \\
\text { TIME }\end{array}$ & $\begin{array}{l}\text { DEPTH FROH } \\
\text { TOP OF } \\
\text { CASING (FT) }\end{array}$ & $\begin{array}{c}\text { DEPTH FROM } \\
\text { GROUND } \\
\text { (FT) }\end{array}$ & $\begin{array}{l}\text { GROUNDWATER } \\
\text { ELEVATION } \\
\text { (FT MSL) }\end{array}$ \\
\hline 0501 & 58537.7 & 63677.8 & AL & o & 5456.48 & 5454.80 & $\begin{array}{l}02 / 04 / 86 \\
03 / 31 / 86 \\
06 / 27 / 86 \\
06 / 30 / 86 \\
10 / 11 / 87 \\
02 / 20 / 88 \\
05 / 15 / 90 \\
12 / 02 / 90 \\
03 / 29 / 91 \\
08 / 27 / 91 \\
12 / 09 / 91 \\
10 / 09 / 92 \\
02 / 16 / 94\end{array}$ & $\begin{array}{l}13: 45 \\
11: 00 \\
15: 40 \\
10: 30 \\
15: 05 \\
13: 10 \\
13: 15 \\
13: 10 \\
11: 24 \\
14: 15 \\
10: 55 \\
15: 32 \\
10: 40\end{array}$ & $\begin{array}{l}17.03 \\
15.48 \\
15.55 \\
15.91 \\
17.00 \\
16.72 \\
17.53 \\
17.47 \\
17.25 \\
17.55 \\
17.37 \\
17.08 \\
17.40\end{array}$ & $\begin{array}{l}15.35 \\
13.80 \\
13.87 \\
14.23 \\
15.32 \\
15.04 \\
15.85 \\
15.79 \\
15.57 \\
15.87 \\
15.69 \\
15.40 \\
15.72\end{array}$ & $\begin{array}{l}5439.45 \\
5441.00 \\
5440.93 \\
5440.57 \\
5439.48 \\
5439.76 \\
5438.95 \\
5439.01 \\
5439.23 \\
5438.93 \\
5439.11 \\
5439.40 \\
5439.08\end{array}$ \\
\hline 0503 & 58246.7 & 63269.3 & AL & 0 & 5459.39 & 5457.90 & $\begin{array}{l}02 / 04 / 86 \\
03 / 31 / 86 \\
06 / 27 / 86 \\
06 / 28 / 86 \\
10 / 11 / 87 \\
02 / 20 / 88 \\
05 / 15 / 90 \\
12 / 02 / 90 \\
03 / 29 / 91 \\
08 / 08 / 91 \\
12 / 09 / 91 \\
10 / 09 / 92 \\
02 / 16 / 94\end{array}$ & $\begin{array}{l}15: 45 \\
11: 15 \\
16: 16 \\
10: 00 \\
11: 30 \\
15: 00 \\
10: 20 \\
13: 16 \\
15: 25 \\
16: 15 \\
12: 07 \\
11: 43 \\
10: 25\end{array}$ & $\begin{array}{l}20.55 \\
19.82 \\
18.88 \\
18.91 \\
20.33 \\
20.85 \\
21.11 \\
21.13 \\
21.85 \\
21.00 \\
21.12 \\
20.74 \\
20.84\end{array}$ & $\begin{array}{l}19.06 \\
18.33 \\
17.39 \\
17.42 \\
18.84 \\
19.36 \\
19.62 \\
19.64 \\
20.36 \\
19.51 \\
19.63 \\
19.25 \\
19.35\end{array}$ & $\begin{array}{l}5438.84 \\
5439.57 \\
5440.51 \\
5440.48 \\
5439.06 \\
5438.54 \\
5438.28 \\
5438.26 \\
5437.54 \\
5438.39 \\
5438.27 \\
5438.65 \\
5438.55\end{array}$ \\
\hline 0504 & 58094.9 & 63088.4 & $A L$ & D & 5450.81 & 5448.50 & $\begin{array}{l}02 / 04 / 86 \\
03 / 31 / 86 \\
06 / 30 / 86 \\
10 / 11 / 87 \\
02 / 21 / 88 \\
05 / 15 / 90 \\
12 / 02 / 90 \\
04 / 03 / 91 \\
08 / 27 / 91 \\
12 / 09 / 91 \\
10 / 09 / 92 \\
02 / 16 / 94\end{array}$ & $\begin{array}{l}17: 35 \\
11: 45 \\
13: 45 \\
09: 41 \\
08: 45 \\
15: 00 \\
13: 19 \\
11: 50 \\
13: 00 \\
13: 38 \\
12: 00 \\
10: 28\end{array}$ & $\begin{array}{l}11.28 \\
10.90 \\
10.00 \\
10.20 \\
11.04 \\
11.95 \\
12.30 \\
11.68 \\
12.94 \\
13.75 \\
13.45 \\
13.01\end{array}$ & $\begin{array}{r}8.97 \\
8.59 \\
7.69 \\
7.89 \\
8.73 \\
9.64 \\
9.99 \\
9.37 \\
10.63 \\
11.44 \\
11.14 \\
10.70\end{array}$ & $\begin{array}{l}5439.53 \\
5439.91 \\
5440.81 \\
5440.61 \\
5439.77 \\
5438.86 \\
5438.51 \\
5439.13 \\
5437.87 \\
5437.06 \\
5437.36 \\
5437.80\end{array}$ \\
\hline 0505 & 58621.3 & 60065.9 & AL & 0 & 5441.05 & 5436.40 & $02 / 18 / 86$ & $16: 45$ & 10.41 & 5.76 & 5430.64 \\
\hline
\end{tabular}

FORMATION OF COMPLETION CODE:

FLOW RELATIONSHIP COOE:

AL - ALLUVIUM

O - ON-SITE

D - DOWN GRADIENT 
TABLE 3.3 STATIC GROUND HATER LEVELS FOR THE NC AND UC PROCESSING SITES,

SLICK ROCK, COLORADO

SITE: SRKO1 SLICK ROCK (BOTH SITES)

REPORT DATE: $09 / 28 / 94$

\begin{tabular}{|c|c|c|c|c|c|c|c|c|c|c|c|}
\hline$\underset{\text { ID }}{\text { LOCATION }}$ & $\begin{array}{c}\text { NORTH } \\
\text { COORDINATE } \\
\text { (FT) }\end{array}$ & $\begin{array}{c}\text { EAST } \\
\text { COORDINATE } \\
\text { (FI) }\end{array}$ & $\begin{array}{l}\text { FORMATION } \\
\text { OF } \\
\text { COMPLETION }\end{array}$ & $\begin{array}{l}\text { FLOW } \\
\text { CODE }\end{array}$ & $\begin{array}{l}\text { CASING } \\
\text { ELEVATION } \\
\text { (FT MSL) }\end{array}$ & $\begin{array}{l}\text { GROUND } \\
\text { ELEVATION } \\
\text { (FT MSL) }\end{array}$ & LOG DATE & $\begin{array}{l}\text { LOG } \\
\text { TIME }\end{array}$ & $\begin{array}{l}\text { DEPTH FROM } \\
\text { TOP OF } \\
\text { CASING (FT) }\end{array}$ & $\begin{array}{l}\text { DEPTH FROM } \\
\text { GROUND } \\
\text { (FT) }\end{array}$ & $\begin{array}{l}\text { GROUNDHATER } \\
\text { ELEVATION } \\
\text { (FT MSL) }\end{array}$ \\
\hline 0505 & 58621.3 & 60065.9 & $A L$ & 0 & 5441.05 & 5436.40 & $\begin{array}{l}03 / 31 / 86 \\
06 / 28 / 86 \\
07 / 16 / 86 \\
10 / 13 / 87 \\
02 / 20 / 88 \\
05 / 14 / 90 \\
12 / 02 / 90 \\
03 / 27 / 91 \\
11 / 21 / 91 \\
10 / 13 / 92 \\
02 / 16 / 94\end{array}$ & $\begin{array}{l}12: 30 \\
10: 20 \\
10: 15 \\
13: 59 \\
11: 45 \\
10: 00 \\
13: 47 \\
11: 20 \\
11: 30 \\
08: 30 \\
16: 16\end{array}$ & $\begin{array}{r}9.91 \\
9.09 \\
9.50 \\
10.15 \\
10.00 \\
10.23 \\
11.23 \\
10.75 \\
13.16 \\
12.60 \\
12.45\end{array}$ & $\begin{array}{l}5.26 \\
4.44 \\
4.85 \\
5.50 \\
5.35 \\
5.58 \\
6.58 \\
6.10 \\
8.51 \\
7.95 \\
7.80\end{array}$ & $\begin{array}{l}5431.14 \\
5431.96 \\
5431.55 \\
5430.90 \\
5431.05 \\
5430.82 \\
5429.82 \\
5430.30 \\
5427.89 \\
5428.45 \\
5428.60\end{array}$ \\
\hline 0506 & 59877.7 & 58895.7 & AL & D & 5431.37 & 5431.10 & $\begin{array}{l}02 / 05 / 86 \\
03 / 31 / 86 \\
06 / 30 / 86 \\
10 / 10 / 87 \\
02 / 19 / 88 \\
12 / 02 / 90 \\
03 / 28 / 91 \\
08 / 08 / 91 \\
11 / 20 / 91 \\
10 / 08 / 92 \\
02 / 16 / 94\end{array}$ & $\begin{array}{l}13: 56 \\
13: 20 \\
15: 20 \\
15: 25 \\
13: 30 \\
15: 29 \\
12: 15 \\
12: 00 \\
14: 35 \\
14: 20 \\
13: 56\end{array}$ & $\begin{array}{r}9.85 \\
9.34 \\
9.11 \\
10.20 \\
9.64 \\
10.70 \\
10.15 \\
11.19 \\
10.74 \\
10.63 \\
10.29\end{array}$ & $\begin{array}{r}9.58 \\
9.07 \\
8.84 \\
9.93 \\
9.37 \\
10.43 \\
9.88 \\
10.92 \\
10.47 \\
10.36 \\
10.02\end{array}$ & $\begin{array}{l}5421.52 \\
5422.03 \\
5422.26 \\
5421.17 \\
5421.73 \\
5420.67 \\
5421.22 \\
5420.18 \\
5420.63 \\
5420.74 \\
5421.08\end{array}$ \\
\hline 0507 & 60019.9 & 58704.2 & AL & D & 5433.06 & 5431.50 & $\begin{array}{l}02 / 05 / 86 \\
03 / 31 / 86 \\
06 / 28 / 86 \\
06 / 29 / 86 \\
10 / 10 / 87 \\
02 / 19 / 88 \\
05 / 13 / 90 \\
12 / 02 / 90 \\
03 / 28 / 91 \\
08 / 08 / 91 \\
12 / 05 / 91 \\
10 / 08 / 92 \\
02 / 16 / 94\end{array}$ & $\begin{array}{l}11: 30 \\
13: 25 \\
15: 00 \\
15: 20 \\
13: 30 \\
10: 30 \\
15: 48 \\
15: 32 \\
11: 15 \\
14: 00 \\
10: 30 \\
11: 54 \\
13: 40\end{array}$ & $\begin{array}{r}9.90 \\
9.38 \\
9.65 \\
9.65 \\
10.49 \\
9.59 \\
10.70 \\
10.90 \\
10.30 \\
11.70 \\
10.66 \\
11.28 \\
10.38\end{array}$ & $\begin{array}{r}8.34 \\
7.82 \\
8.09 \\
8.09 \\
8.93 \\
8.03 \\
9.14 \\
9.34 \\
8.74 \\
10.14 \\
9.10 \\
9.72 \\
8.82\end{array}$ & $\begin{array}{l}5423.16 \\
5423.68 \\
5423.41 \\
5423.41 \\
5422.57 \\
5423.47 \\
5422.36 \\
5422.16 \\
5422.76 \\
5421.36 \\
5422.40 \\
5421.78 \\
5422.68\end{array}$ \\
\hline 0508 & 59547.6 & 59575.2 & AL & 0 & 5439.77 & 5437.30 & $\begin{array}{l}02 / 18 / 86 \\
03 / 31 / 86 \\
06 / 29 / 86\end{array}$ & $\begin{array}{l}14: 22 \\
12: 55 \\
13: 50\end{array}$ & $\begin{array}{l}14.32 \\
13.24 \\
13.65\end{array}$ & $\begin{array}{l}11.85 \\
10.77 \\
11.18\end{array}$ & $\begin{array}{l}5425.45 \\
5426.53 \\
5426.12\end{array}$ \\
\hline
\end{tabular}

FORMATION OF COMPLETION CODE:

AL - ALLUVIUM
FLOW RELATIOHSHIP CODE:

O - ON-SITE

- DOWN GRADIENT 
TABLE 3.3 STATIC GROUND HATER LEVELS FOR THE NC AND UC PROCESSING SITES,

SLICK ROCK, COLORADO

SITE: SRKO1 SLICK ROCK (BOTH SITES)

REPORT DATE: 09/28/94

\begin{tabular}{|c|c|c|c|c|c|c|c|c|c|c|c|}
\hline$\underset{\text { ID }}{\text { LOCATION }}$ & $\begin{array}{c}\text { NORTH } \\
\text { COORDINATE } \\
\text { (FT) }\end{array}$ & $\begin{array}{l}\text { EAST } \\
\text { COORDINATE } \\
\text { (FT) }\end{array}$ & $\begin{array}{c}\text { FORHATION } \\
\text { OF } \\
\text { COMPLETION }\end{array}$ & $\begin{array}{l}\text { FLOW } \\
\text { CODE }\end{array}$ & $\begin{array}{l}\text { CASIHG } \\
\text { ELEVATION } \\
\text { (FT MSL) }\end{array}$ & $\begin{array}{l}\text { GROUND } \\
\text { ELEVATION } \\
\text { (FT MSL) }\end{array}$ & LOG DATE & $\begin{array}{l}\text { LOG } \\
\text { TIME }\end{array}$ & $\begin{array}{l}\text { DEPTH FROM } \\
\text { TOP OF } \\
\text { CASING (FT) }\end{array}$ & $\begin{array}{c}\text { DEPTH FRON } \\
\text { GROUND } \\
\text { (FT) }\end{array}$ & $\begin{array}{l}\text { GROUNDWATER } \\
\text { ELEVATION } \\
\text { (FT MSL) }\end{array}$ \\
\hline 0508 & 59547.6 & 59575.2 & AL & 0 & 5439.77 & 5437.30 & $\begin{array}{l}10 / 09 / 87 \\
02 / 18 / 88 \\
12 / 02 / 90 \\
03 / 27 / 91 \\
08 / 28 / 91 \\
12 / 05 / 91 \\
10 / 10 / 92 \\
02 / 16 / 94\end{array}$ & $\begin{array}{l}10: 00 \\
14: 00 \\
15: 18 \\
16: 00 \\
11: 00 \\
13: 52 \\
15: 55 \\
14: 18\end{array}$ & $\begin{array}{l}14.25 \\
14.12 \\
14.64 \\
14.50 \\
14.64 \\
16.00 \\
15.87 \\
16.21\end{array}$ & $\begin{array}{l}11.78 \\
11.65 \\
12.17 \\
12.03 \\
12.17 \\
13.53 \\
13.40 \\
13.74\end{array}$ & $\begin{array}{l}5425.52 \\
5425.65 \\
5425.13 \\
5425.27 \\
5425.13 \\
5423.77 \\
5423.90 \\
5423.56\end{array}$ \\
\hline 0509 & 59201.7 & 60131.0 & $A L$ & 0 & 5436.80 & 5434.80 & $\begin{array}{l}02 / 18 / 86 \\
03 / 31 / 86 \\
06 / 28 / 86 \\
07 / 15 / 86 \\
10 / 10 / 87 \\
02 / 20 / 88 \\
12 / 02 / 90 \\
03 / 27 / 91 \\
08 / 28 / 91 \\
11 / 21 / 91 \\
10 / 13 / 92 \\
02 / 16 / 94\end{array}$ & $\begin{array}{l}15: 20 \\
12: 35 \\
15: 15 \\
10: 00 \\
10: 15 \\
10: 30 \\
15: 09 \\
14: 09 \\
13: 40 \\
09: 25 \\
09: 50 \\
14: 06\end{array}$ & $\begin{array}{r}11.14 \\
10.51 \\
9.42 \\
9.20 \\
10.98 \\
10.71 \\
11.93 \\
11.45 \\
12.20 \\
11.96 \\
11.60 \\
11.33\end{array}$ & $\begin{array}{r}9.14 \\
8.51 \\
7.42 \\
7.20 \\
8.98 \\
8.71 \\
9.93 \\
9.45 \\
10.20 \\
9.96 \\
9.60 \\
9.33\end{array}$ & $\begin{array}{l}5425.66 \\
5426.29 \\
5427.38 \\
5427.60 \\
5425.82 \\
5426.09 \\
5424.87 \\
5425.35 \\
5424.60 \\
5424.84 \\
5425.20 \\
5425.47\end{array}$ \\
\hline 0510 & 59726.1 & 59228.0 & $A L$ & 0 & 5438.59 & 5436.40 & $\begin{array}{l}02 / 18 / 86 \\
03 / 31 / 86 \\
06 / 28 / 86 \\
10 / 09 / 87 \\
02 / 20 / 88 \\
05 / 14 / 90 \\
12 / 02 / 90 \\
03 / 28 / 91 \\
08 / 28 / 91 \\
12 / 05 / 91 \\
10 / 08 / 92 \\
02 / 16 / 94\end{array}$ & $\begin{array}{l}13: 00 \\
13: 05 \\
13: 50 \\
13: 30 \\
09: 10 \\
13: 49 \\
15: 22 \\
09: 45 \\
12: 15 \\
15: 12 \\
16: 47 \\
14: 21\end{array}$ & $\begin{array}{l}15.93 \\
15.09 \\
14.84 \\
15.87 \\
15.82 \\
16.21 \\
16.21 \\
16.10 \\
16.22 \\
16.13 \\
15.90 \\
16.25\end{array}$ & $\begin{array}{l}13.74 \\
12.90 \\
12.65 \\
13.68 \\
13.63 \\
14.02 \\
14.02 \\
13.91 \\
14.03 \\
13.94 \\
13.71 \\
14.06\end{array}$ & $\begin{array}{l}5422.66 \\
5423.50 \\
5423.75 \\
5422.72 \\
5422.77 \\
5422.38 \\
5422.38 \\
5422.49 \\
5422.37 \\
5422.46 \\
5422.69 \\
5422.34\end{array}$ \\
\hline 0512 & 58394.2 & 63267.2 & $A L$ & 0 & 5452.67 & 5450.40 & $\begin{array}{l}02 / 04 / 86 \\
03 / 31 / 86 \\
06 / 30 / 86 \\
10 / 11 / 87 \\
02 / 20 / 88 \\
12 / 02 / 90 \\
04 / 05 / 91\end{array}$ & $\begin{array}{l}16: 10 \\
11: 10 \\
11: 50 \\
13: 33 \\
13: 00 \\
13: 14 \\
08: 30\end{array}$ & $\begin{array}{l}12.48 \\
11.05 \\
11.74 \\
12.42 \\
12.19 \\
12.95 \\
12.70\end{array}$ & $\begin{array}{r}10.21 \\
8.78 \\
9.47 \\
10.15 \\
9.92 \\
10.68 \\
10.43\end{array}$ & $\begin{array}{l}5440.19 \\
5441.62 \\
5440.93 \\
5440.25 \\
5440.48 \\
5439.72 \\
5439.97\end{array}$ \\
\hline
\end{tabular}

FORMATION OF COMPLETION CODE:

FLOW RELATIONSHIP COOE:

AL - ALLUVIUM

O- ON-SITE 
TABLE 3.3 STATIC GROUND HATER LEVELS FOR THE NC AND UC PROCESSING SITES,

SLICK ROCK, COLORADO

SITE: SRK01 SLICK ROCK (BOTH SITES)

REPORT DATE: 09/28/94

\begin{tabular}{|c|c|c|c|c|c|c|c|c|c|c|c|}
\hline$\underset{\text { ID }}{\text { LOCATION }}$ & $\begin{array}{l}\text { NORTH } \\
\text { COORDINATE } \\
\text { (FT) }\end{array}$ & $\begin{array}{l}\text { EAST } \\
\text { COORDINATE } \\
\text { (FT) }\end{array}$ & $\begin{array}{c}\text { FORMATION } \\
\text { OF } \\
\text { COMPLETION }\end{array}$ & $\begin{array}{l}\text { FLON } \\
\text { CODE }\end{array}$ & $\begin{array}{l}\text { CASING } \\
\text { ELEVATION } \\
\text { (FT MSL) }\end{array}$ & $\begin{array}{l}\text { GROUND } \\
\text { ELEVATION } \\
\text { (FT MSL) }\end{array}$ & LOG DATE & $\begin{array}{l}\text { LOG } \\
\text { TIME }\end{array}$ & $\begin{array}{l}\text { DEPTH FROM } \\
\text { TOP OF } \\
\text { CASING (FT) }\end{array}$ & $\begin{array}{l}\text { DEPTH FROM } \\
\text { GROUND } \\
\text { (FT) }\end{array}$ & $\begin{array}{c}\text { GROUNDWATER } \\
\text { ELEVATION } \\
\text { (FT MSL) }\end{array}$ \\
\hline 0512 & 58394.2 & 63267.2 & AL & 0 & 5452.67 & 5450.40 & $\begin{array}{l}08 / 08 / 91 \\
12 / 10 / 91 \\
10 / 09 / 92 \\
02 / 16 / 94\end{array}$ & $\begin{array}{l}16: 05 \\
14: 32 \\
14: 22 \\
10: 34\end{array}$ & $\begin{array}{l}12.71 \\
14.16 \\
14.10 \\
14.00\end{array}$ & $\begin{array}{l}10.44 \\
11.89 \\
11.83 \\
11.73\end{array}$ & $\begin{array}{l}5439.96 \\
5438.51 \\
5438.57 \\
5438.67\end{array}$ \\
\hline 0551 & 58464.81 & 58510.72 & JE & $\mathbf{U}$ & 5524.00 & 5524.49 & $\begin{array}{l}12 / 02 / 90 \\
12 / 09 / 90 \\
03 / 28 / 91 \\
08 / 05 / 91 \\
12 / 11 / 91 \\
10 / 10 / 92 \\
02 / 16 / 94\end{array}$ & $\begin{array}{l}14: 24 \\
09: 25 \\
15: 47 \\
12: 48 \\
15: 21 \\
13: 52 \\
10: 24\end{array}$ & $\begin{array}{l}46.75 \\
46.93 \\
46.21 \\
45.90 \\
46.02 \\
45.40 \\
47.74\end{array}$ & $\begin{array}{l}47.24 \\
47.42 \\
46.70 \\
46.39 \\
46.51 \\
45.89 \\
48.23\end{array}$ & $\begin{array}{l}5477.25 \\
5477.07 \\
5477.79 \\
5478.10 \\
5477.98 \\
5478.60 \\
5476.26\end{array}$ \\
\hline 0552 & 58480.06 & 58476.35 & NA & $U$ & 5525.00 & 5524.82 & $\begin{array}{l}12 / 02 / 90 \\
12 / 11 / 90 \\
03 / 27 / 91 \\
08 / 24 / 91 \\
12 / 12 / 91 \\
10 / 10 / 92 \\
02 / 16 / 94\end{array}$ & $\begin{array}{l}14: 21 \\
12: 20 \\
10: 25 \\
09: 50 \\
10: 10 \\
15: 15 \\
10: 22\end{array}$ & $\begin{array}{l}49.95 \\
67.86 \\
49.20 \\
49.17 \\
49.05 \\
48.57 \\
52.19\end{array}$ & $\begin{array}{l}49.77 \\
67.68 \\
49.02 \\
48.99 \\
48.87 \\
48.39 \\
52.01\end{array}$ & $\begin{array}{l}5475.05 \\
5457.14 \\
5475.80 \\
5475.83 \\
5475.95 \\
5476.43 \\
5472.81\end{array}$ \\
\hline 0553 & 58498.13 & 58539.82 & $A L$ & 0 & 5525.00 & 5524.47 & $\begin{array}{l}12 / 02 / 90 \\
03 / 29 / 91 \\
02 / 16 / 94\end{array}$ & $\begin{array}{l}14: 28 \\
10: 15 \\
10: 22\end{array}$ & $\begin{array}{l}\text { DRY } \\
\text { DRY } \\
\text { DRY }\end{array}$ & $\begin{array}{l}\text { DRY } \\
\text { DRY } \\
\text { DRY }\end{array}$ & 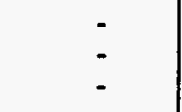 \\
\hline 0554 & 59171.94 & 58549.51 & JE & $U$ & 5500.50 & 5500.87 & $\begin{array}{l}12 / 02 / 90 \\
12 / 11 / 90 \\
03 / 28 / 91 \\
08 / 05 / 91 \\
12 / 06 / 91 \\
10 / 15 / 92 \\
02 / 16 / 94 \\
02 / 17 / 94\end{array}$ & $\begin{array}{l}14: 52 \\
08: 45 \\
09: 50 \\
15: 58 \\
14: 20 \\
08: 35 \\
13: 10 \\
13: 33\end{array}$ & $\begin{array}{l}34.97 \\
34.58 \\
34.90 \\
34.71 \\
34.71 \\
34.28 \\
\text { DRY } \\
35.09\end{array}$ & $\begin{array}{r}35.34 \\
34.95 \\
35.27 \\
35.08 \\
35.08 \\
34.65 \\
\text { DRY } \\
35.46\end{array}$ & $\begin{array}{c}5465.53 \\
5465.92 \\
5465.60 \\
5465.79 \\
5465.79 \\
5466.22 \\
- \\
5465.41\end{array}$ \\
\hline 0555 & 59128.84 & 58569.09 & AL & 0 & 5502.00 & 5502.45 & $\begin{array}{l}12 / 02 / 90 \\
03 / 29 / 91 \\
02 / 16 / 94\end{array}$ & $\begin{array}{l}14: 48 \\
10: 40 \\
13: 22\end{array}$ & $\begin{array}{l}\text { DRY } \\
\text { DRY } \\
\text { DRY }\end{array}$ & $\begin{array}{l}\text { DRY } \\
\text { DRY } \\
\text { DRY }\end{array}$ & $\dot{-}$ \\
\hline 0556 & 58533.37 & 58255.91 & NA & U & 5529.00 & 5528.27 & $\begin{array}{l}12 / 02 / 90 \\
12 / 13 / 90\end{array}$ & $\begin{array}{l}14: 16 \\
13: 33\end{array}$ & $\begin{array}{l}54.15 \\
54.0\end{array}$ & $\begin{array}{l}53.42 \\
53.27\end{array}$ & $\begin{array}{l}5474.85 \\
5475.00\end{array}$ \\
\hline
\end{tabular}

FORMATION OF COMPLETION CODE:

AL - ALLUVIUM

JE - JURASSIC ENTRADA SANDSTONE FORMATION

FLON RELATIONSHIP CODE:

NA - NAVAJO SANDSTONE

O- ON-SITE

U - UPGRADIEN 
TABLE 3.3 STATIC GROUND WATER LEVELS FOR THE NC AND UC PROCESSING SITES,

SLICK ROCK, COLORADO

SITE: SRKO1 SLICK ROCK (BOTH SITES)

REPORT DATE: 09/28/94

\begin{tabular}{|c|c|c|c|c|c|c|c|c|c|c|c|}
\hline$\underset{\text { ID }}{\text { LOCATION }}$ & $\begin{array}{l}\text { HORTH } \\
\text { COORDINATE } \\
\text { (FT) }\end{array}$ & $\begin{array}{c}\text { EAST } \\
\text { COORDINATE } \\
\text { (FT) }\end{array}$ & $\begin{array}{l}\text { FORMATION } \\
\text { OF } \\
\text { COMPLETION }\end{array}$ & $\begin{array}{l}\text { FLON } \\
\text { CODE }\end{array}$ & $\begin{array}{l}\text { CASIHG } \\
\text { ELEVATION } \\
\text { (FT MSL) }\end{array}$ & $\begin{array}{l}\text { GROUND } \\
\text { ELEVATIOH } \\
\text { (FT MSL) }\end{array}$ & LOG DATE & $\begin{array}{l}\text { LOG } \\
\text { TIME }\end{array}$ & $\begin{array}{c}\text { DEPTH FRON } \\
\text { TOP OF } \\
\text { CASING (FT) }\end{array}$ & \begin{tabular}{|} 
DEPTH FRON \\
GROUND \\
(FT)
\end{tabular} & $\begin{array}{l}\text { GROUNDWATER } \\
\text { ELEVATION } \\
\text { (FT MSL) }\end{array}$ \\
\hline 0556 & 58533.37 & 58255.91 & NA & u & 5529.00 & 5528.27 & $\begin{array}{l}03 / 29 / 91 \\
08 / 05 / 91 \\
12 / 12 / 91 \\
10 / 15 / 92 \\
02 / 16 / 94\end{array}$ & $\begin{array}{l}13: 24 \\
14: 20 \\
11: 39 \\
10: 41 \\
10: 11\end{array}$ & $\begin{array}{l}52.95 \\
52.61 \\
53.29 \\
53.70 \\
56.50\end{array}$ & $\begin{array}{l}52.22 \\
51.88 \\
52.56 \\
52.97 \\
55.77\end{array}$ & $\begin{array}{l}5476.05 \\
5476.39 \\
5475.71 \\
5475.30 \\
5472.50\end{array}$ \\
\hline 0557 & 58559.45 & 58270.92 & AL & 0 & 5527.00 & 5527.06 & $\begin{array}{l}12 / 02 / 90 \\
03 / 29 / 91 \\
02 / 16 / 94\end{array}$ & $\begin{array}{l}14: 14 \\
10: 30 \\
10: 14\end{array}$ & $\begin{array}{l}\text { DRY } \\
\text { DRY } \\
\text { ORY }\end{array}$ & $\begin{array}{l}\text { DRY } \\
\text { DRY } \\
\text { DRY }\end{array}$ & : \\
\hline 0558 & 58131.86 & 58863.79 & NA & U & 5526.00 & 5524.79 & $\begin{array}{l}12 / 02 / 90 \\
12 / 14 / 90 \\
03 / 29 / 91 \\
08 / 07 / 91 \\
12 / 11 / 91 \\
10 / 12 / 92 \\
02 / 16 / 94\end{array}$ & $\begin{array}{l}14: 01 \\
09: 08 \\
10: 56 \\
10: 18 \\
13: 15 \\
15: 10 \\
10: 43\end{array}$ & $\begin{array}{l}53.16 \\
53.5 \\
52.61 \\
52.55 \\
52.16 \\
52.30 \\
55.34\end{array}$ & $\begin{array}{l}51.95 \\
52.29 \\
51.40 \\
51.34 \\
50.95 \\
51.09 \\
54.13\end{array}$ & $\begin{array}{l}5472.84 \\
5472.50 \\
5473.39 \\
5473.45 \\
5473.84 \\
5473.70 \\
5470.66\end{array}$ \\
\hline 0559 & 58410.30 & 59120.23 & JE & 0 & 5515.00 & 5515.27 & $\begin{array}{l}12 / 02 / 90 \\
12 / 11 / 90 \\
02 / 16 / 94\end{array}$ & $\begin{array}{l}14: 08 \\
08: 30 \\
12: 57\end{array}$ & $\begin{array}{l}\text { DRY } \\
\text { DRY } \\
\text { DRY }\end{array}$ & $\begin{array}{l}\text { DRY } \\
\text { DRY } \\
\text { DRY }\end{array}$ & $\because$ \\
\hline 0560 & 59348.92 & 58463.56 & AL & 0 & 5492.00 & 5492.83 & $\begin{array}{l}12 / 02 / 90 \\
03 / 29 / 91 \\
02 / 16 / 94\end{array}$ & $\begin{array}{l}14: 56 \\
10: 42 \\
13: 24\end{array}$ & $\begin{array}{l}\text { DRY } \\
\text { ORY } \\
\text { DRY }\end{array}$ & $\begin{array}{l}\text { DRY } \\
\text { DRY } \\
\text { DRY }\end{array}$ & $:$ \\
\hline 0634 & - & - & NA & $U$ & - & 5433.40 & $\begin{array}{l}02 / 01 / 86 \\
06 / 27 / 86\end{array}$ & $\begin{array}{l}12: 30 \\
15: 00\end{array}$ & $\begin{array}{c}16.00 \\
-\end{array}$ & - & - \\
\hline 0635 & - & - & ss & N & - & 5450.00 & $\begin{array}{l}02 / 01 / 86 \\
06 / 28 / 86\end{array}$ & $\begin{array}{l}10: 15 \\
10: 45\end{array}$ & $\begin{array}{l}12.90 \\
12.27\end{array}$ & - & - \\
\hline 0668 & 58670.83 & 58711.47 & NA & $\mathbf{U}$ & 5524.91 & 5522.93 & $\begin{array}{l}02 / 02 / 86 \\
03 / 31 / 86 \\
06 / 29 / 86 \\
10 / 11 / 87 \\
02 / 17 / 88 \\
12 / 02 / 90 \\
12 / 13 / 90\end{array}$ & $\begin{array}{l}15: 40 \\
14: 10 \\
14: 00 \\
13: 35 \\
09: 00 \\
14: 39 \\
11: 10\end{array}$ & $\begin{array}{l}59.20 \\
59.27 \\
59.08 \\
58.82 \\
88.51 \\
58.91 \\
58.8\end{array}$ & $\begin{array}{l}57.22 \\
57.29 \\
57.10 \\
56.84 \\
86.53 \\
56.93 \\
56.82\end{array}$ & $\begin{array}{l}5465.71 \\
5465.64 \\
5465.83 \\
5466.09 \\
5436.40 \\
5466.00 \\
5466.11\end{array}$ \\
\hline
\end{tabular}

FOPMATION OF COMPLETION CODE:

HA - NAVAJO SANDSTONE

AL - ALLUVIUM

JE - JURASSIC ENTRADA SANDSTONE FORMATION

SS - SANDSTONE
FLOH RELATIOHSHIP CODE:

$U$ - UPGRADIENT

O - ON-SITE

N - UNKNOWN 
TABLE 3.3 STATIC GROUND HATER LEVELS FOR THE NC AND UC PROCESSING SITES, SLICK ROCK, COLORADO

SITE: SRKO1 SLICK ROCK (BOTH SITES)

REPORT DATE: $09 / 28 / 94$

\begin{tabular}{|c|c|c|c|c|c|c|c|c|c|c|c|}
\hline$\underset{\text { ID }}{\text { LOCATION }}$ & $\begin{array}{l}\text { MORTH } \\
\text { COORD INATE } \\
\text { (FT) }\end{array}$ & $\begin{array}{c}\text { EAST } \\
\text { COORDINATE } \\
\text { (FT) }\end{array}$ & \begin{tabular}{|} 
FORMATION \\
OF \\
COMPLETION
\end{tabular} & $\begin{array}{l}\text { FLOW } \\
\text { CODE }\end{array}$ & $\begin{array}{l}\text { CASING } \\
\text { ELEVATION } \\
\text { (FT MSL) }\end{array}$ & $\begin{array}{l}\text { GROUND } \\
\text { ELEVATION } \\
\text { (FT MSL) }\end{array}$ & LOG DATE & $\begin{array}{l}\text { LOG } \\
\text { TIME }\end{array}$ & $\begin{array}{l}\text { DEPTH FROM } \\
\text { TOP OF } \\
\text { CASIHG (FT) }\end{array}$ & $\begin{array}{l}\text { DEPTH FROM } \\
\text { GROUND } \\
\text { (FT) }\end{array}$ & $\begin{array}{l}\text { GROUNDWATER } \\
\text { ELEVATION } \\
\text { (FT MSL) }\end{array}$ \\
\hline 0668 & 58670.83 & 58711.47 & NA & $U$ & 5524.91 & 5522.93 & $\begin{array}{l}03 / 27 / 91 \\
11 / 18 / 91 \\
10 / 11 / 92 \\
02 / 16 / 94\end{array}$ & $\begin{array}{l}15: 15 \\
08: 40 \\
13: 40 \\
10: 33\end{array}$ & $\begin{array}{l}58.05 \\
57.99 \\
57.67 \\
60.25\end{array}$ & $\begin{array}{l}56.07 \\
56.01 \\
55.69 \\
58.27\end{array}$ & $\begin{array}{l}5466.86 \\
5466.92 \\
5467.24 \\
5464.66\end{array}$ \\
\hline 0669 & 59555.2 & 59550.5 & NA & $u$ & 5440.50 & 5438.80 & $\begin{array}{l}02 / 04 / 86 \\
03 / 31 / 86 \\
06 / 29 / 86 \\
10 / 09 / 87 \\
02 / 18 / 88 \\
12 / 02 / 90 \\
12 / 13 / 90 \\
04 / 01 / 91 \\
08 / 24 / 91 \\
11 / 19 / 91 \\
10 / 12 / 92 \\
02 / 16 / 94\end{array}$ & $\begin{array}{l}11: 45 \\
12: 50 \\
10: 04 \\
15: 00 \\
12: 05 \\
15: 16 \\
07: 15 \\
10: 45 \\
13: 45 \\
09: 30 \\
11: 03 \\
14: 16\end{array}$ & $\begin{array}{r}0.75 \\
0.33 \\
0.09 \\
0.78 \\
\text { FLOWING } \\
1.07 \\
0.75 \\
0.95 \\
.95 \\
0.65 \\
1.0 \\
0.78\end{array}$ & $\begin{array}{r}-0.95 \\
-1.37 \\
-1.61 \\
-0.92 \\
\text { FLOWING } \\
-0.63 \\
-0.95 \\
-0.75 \\
-0.75 \\
-1.05 \\
-0.70 \\
-0.92\end{array}$ & $\begin{array}{r}5439.75 \\
5440.17 \\
5440.41 \\
5439.72 \\
- \\
5439.43 \\
5439.75 \\
5439.55 \\
5439.55 \\
5439.85 \\
5439.50 \\
5439.72\end{array}$ \\
\hline 0670 & 59797.4 & 59171.8 & NA & $u$ & 5437.76 & 5435.89 & $\begin{array}{l}02 / 03 / 86 \\
03 / 31 / 86 \\
06 / 18 / 86 \\
10 / 11 / 87 \\
02 / 18 / 88 \\
12 / 02 / 90 \\
12 / 12 / 90 \\
03 / 31 / 91 \\
08 / 24 / 91 \\
11 / 20 / 91 \\
10 / 13 / 92 \\
02 / 16 / 94\end{array}$ & $\begin{array}{l}14: 55 \\
13: 00 \\
09: 55 \\
10: 00 \\
09: 00 \\
15: 25 \\
11: 30 \\
13: 05 \\
15: 00 \\
08: 20 \\
13: 50 \\
14: 23\end{array}$ & $\begin{array}{l}2.85 \\
2.34 \\
2.72 \\
3.68 \\
1.78 \\
3.25 \\
3.20 \\
2.88 \\
3.50 \\
3.13 \\
2.89 \\
2.67\end{array}$ & $\begin{array}{r}0.98 \\
0.47 \\
0.85 \\
1.81 \\
-0.09 \\
1.38 \\
1.33 \\
1.01 \\
1.63 \\
1.26 \\
1.02 \\
0.80\end{array}$ & $\begin{array}{l}5434.91 \\
5435.42 \\
5435.04 \\
5434.08 \\
5435.98 \\
5434.51 \\
5434.56 \\
5434.88 \\
5434.26 \\
5434.63 \\
5434.87 \\
5435.09\end{array}$ \\
\hline 0675 & 57457.6 & 60088.4 & $A L$ & $\mathbf{N}$ & 5443.17 & 5443.20 & $\begin{array}{l}03 / 31 / 86 \\
06 / 28 / 86\end{array}$ & $\begin{array}{l}14: 50 \\
13: 00\end{array}$ & $\begin{array}{l}12.40 \\
11.45\end{array}$ & $\begin{array}{l}12.43 \\
11.48\end{array}$ & $\begin{array}{l}5430.77 \\
5431.72\end{array}$ \\
\hline 0684 & 60988.0 & 58964.8 & AL & 0 & 5432.51 & 5430.20 & $\begin{array}{l}06 / 20 / 86 \\
06 / 29 / 86 \\
04 / 06 / 87 \\
10 / 13 / 87 \\
02 / 19 / 88 \\
12 / 02 / 90\end{array}$ & $\begin{array}{l}15: 20 \\
12: 25 \\
15: 30 \\
08: 50 \\
14: 50 \\
15: 51\end{array}$ & $\begin{array}{l}12.94 \\
13.73 \\
13.83 \\
15.21 \\
15.08 \\
16.11\end{array}$ & $\begin{array}{l}10.63 \\
11.42 \\
11.52 \\
12.90 \\
12.77 \\
13.80\end{array}$ & $\begin{array}{l}5419.57 \\
5418.78 \\
5418.68 \\
5417.30 \\
5417.43 \\
5416.40\end{array}$ \\
\hline
\end{tabular}

FORMATION OF COMPLETION CODE:

NA - NAVAJO SANDSTONE

AL - ALLUVIUM
FLOW RELATIONSHIP CODE:

$U$ - UPGRADIENT

N - UNKNOWN
O - ON-SITE 
TABLE 3.3 STATIC GROUND HATER LEVELS FOR THE NC AND UC PROCESSING SITES,

SLICK ROCK, COLORADO

SITE: SRKO1 SLICK ROCK (BOTH SITES)

REPORT DATE: $09 / 28 / 94$

\begin{tabular}{|c|c|c|c|c|c|c|c|c|c|c|c|}
\hline$\underset{\text { ID }}{\text { LOCATION }}$ & $\begin{array}{l}\text { NORTH } \\
\text { COORDINATE } \\
\text { (FT) }\end{array}$ & $\begin{array}{l}\text { EAST } \\
\text { COORDINATE } \\
\text { (FT) }\end{array}$ & $\begin{array}{c}\text { FORMATION } \\
\text { OF } \\
\text { COMPLETION }\end{array}$ & $\begin{array}{l}\text { FLOH } \\
\text { CODE }\end{array}$ & $\begin{array}{l}\text { CASIMG } \\
\text { ELEVATION } \\
\text { (FT MSL) }\end{array}$ & $\begin{array}{l}\text { GROUND } \\
\text { ELEVATION } \\
\text { (FT MSL) }\end{array}$ & LOG DATE & $\begin{array}{l}\text { LOG } \\
\text { TIME }\end{array}$ & $\begin{array}{l}\text { DEPTH FROM } \\
\text { TOP OF } \\
\text { CASING (FT) }\end{array}$ & $\begin{array}{c}\text { DEPTH FRON } \\
\text { GROUND } \\
\text { (FT) }\end{array}$ & $\begin{array}{l}\text { GROUNDUATER } \\
\text { ELEVATIOH } \\
\text { (FT MSL) }\end{array}$ \\
\hline 0684 & 60988.0 & 58964.8 & AL & 0 & 5432.51 & 5430.20 & $\begin{array}{l}03 / 28 / 91 \\
08 / 06 / 91 \\
11 / 19 / 91 \\
10 / 15 / 92 \\
02 / 16 / 94\end{array}$ & $\begin{array}{l}15: 30 \\
14: 05 \\
14: 12 \\
10: 50 \\
11: 36\end{array}$ & $\begin{array}{r}5.90 \\
16.30 \\
16.28 \\
16.20 \\
15.93\end{array}$ & $\begin{array}{r}3.59 \\
13.99 \\
13.97 \\
13.89 \\
13.62\end{array}$ & $\begin{array}{l}5426.61 \\
5416.21 \\
5416.23 \\
5416.31 \\
5416.58\end{array}$ \\
\hline 0685 & 62187.5 & 58927.9 & AL & 0 & 5428.34 & 5426.30 & $\begin{array}{l}06 / 20 / 86 \\
07 / 15 / 86 \\
04 / 07 / 87 \\
10 / 13 / 87 \\
02 / 19 / 88 \\
12 / 02 / 90 \\
03 / 28 / 91 \\
08 / 06 / 91 \\
11 / 20 / 91 \\
10 / 08 / 92 \\
02 / 16 / 94\end{array}$ & $\begin{array}{l}14: 00 \\
13: 00 \\
15: 00 \\
09: 10 \\
15: 50 \\
16: 02 \\
16: 25 \\
15: 38 \\
13: 15 \\
09: 50 \\
11: 42\end{array}$ & $\begin{array}{l}11.26 \\
11.53 \\
11.55 \\
12.95 \\
12.72 \\
13.45 \\
13.20 \\
14.10 \\
13.71 \\
13.43 \\
13.33\end{array}$ & $\begin{array}{r}9.22 \\
9.49 \\
9.51 \\
10.91 \\
10.68 \\
11.41 \\
11.16 \\
12.06 \\
11.67 \\
11.39 \\
11.29\end{array}$ & $\begin{array}{l}5417.08 \\
5416.81 \\
5416.79 \\
5415.39 \\
5415.62 \\
5414.89 \\
5415.14 \\
5414.24 \\
5414.63 \\
5414.91 \\
5415.01\end{array}$ \\
\hline 0686 & 58619.9 & 63769.6 & $A L$ & 0 & 5457.29 & 5455.10 & $\begin{array}{l}06 / 26 / 86 \\
07 / 15 / 86 \\
04 / 07 / 87 \\
10 / 13 / 87 \\
02 / 21 / 88 \\
12 / 02 / 90 \\
03 / 29 / 91 \\
08 / 26 / 91 \\
12 / 10 / 91 \\
10 / 09 / 92 \\
02 / 16 / 94\end{array}$ & $\begin{array}{l}09: 00 \\
14: 50 \\
09: 35 \\
12: 15 \\
11: 10 \\
13: 06 \\
14: 30 \\
15: 57 \\
09: 56 \\
16: 41 \\
10: 52\end{array}$ & $\begin{array}{l}13.78 \\
16.55 \\
15.00 \\
17.54 \\
17.18 \\
18.90 \\
17.75 \\
17.95 \\
17.83 \\
17.40 \\
17.86\end{array}$ & $\begin{array}{l}11.59 \\
14.36 \\
12.81 \\
15.35 \\
14.99 \\
16.71 \\
15.56 \\
15.76 \\
15.64 \\
15.21 \\
15.67\end{array}$ & $\begin{array}{l}5443.51 \\
5440.74 \\
5442.29 \\
5439.75 \\
5440.11 \\
5438.39 \\
5439.54 \\
5439.34 \\
5439.46 \\
5439.89 \\
5439.43\end{array}$ \\
\hline 0687 & 57223.2 & 62932.9 & NA & U & 5494.14 & 5492.80 & $\begin{array}{l}06 / 26 / 86 \\
07 / 17 / 86 \\
04 / 05 / 87 \\
10 / 12 / 87 \\
02 / 17 / 88 \\
12 / 02 / 90 \\
12 / 14 / 90 \\
04 / 03 / 91 \\
08 / 27 / 91 \\
12 / 10 / 91 \\
10 / 07 / 92\end{array}$ & $\begin{array}{l}07: 00 \\
10: 15 \\
14: 40 \\
13: 30 \\
13: 30 \\
13: 31 \\
14: 35 \\
09: 50 \\
10: 00 \\
11: 13 \\
15: 44\end{array}$ & $\begin{array}{l}46.98 \\
55.90 \\
34.52 \\
40.49 \\
40.53 \\
41.09 \\
41.03 \\
41.78 \\
41.96 \\
41.71 \\
40.70\end{array}$ & $\begin{array}{l}45.64 \\
54.56 \\
33.18 \\
39.15 \\
39.19 \\
39.75 \\
39.69 \\
40.44 \\
40.62 \\
40.37 \\
39.36\end{array}$ & $\begin{array}{l}5447.16 \\
5438.24 \\
5459.62 \\
5453.65 \\
5453.61 \\
5453.05 \\
5453.11 \\
5452.36 \\
5452.18 \\
5452.43 \\
5453.44\end{array}$ \\
\hline
\end{tabular}

FORMATION OF COMPLETION CODE:

AL - ALLUVIUM

MA - NAVAJO SANDSTONE
FLOW RELATIONSHIP CODE:

O - ON-SITE

- UPGRADIENT 
TABLE 3.3 STATIC GROUND HATER LEVELS FOR THE NC AND UC PROCESSING SITES,

SLICK ROCK, COLORADO

SITE: SRKOI SLICK ROCK (BOTH SITES)

REPORT DATE: 09/28/94

\begin{tabular}{|c|c|c|c|c|c|c|c|c|c|c|c|}
\hline$\underset{\text { ID }}{\text { LOCATION }}$ & $\begin{array}{l}\text { MORTH } \\
\text { COORDINATE } \\
\text { (FT) }\end{array}$ & $\begin{array}{l}\text { EAST } \\
\text { COORDINATE } \\
\text { (FI) }\end{array}$ & $\begin{array}{c}\text { FORMATION } \\
\text { OF } \\
\text { COMPLETION }\end{array}$ & $\begin{array}{l}\text { FLOW } \\
\text { CODE }\end{array}$ & $\begin{array}{l}\text { CASING } \\
\text { ELEVATION } \\
\text { (FT MSL) }\end{array}$ & $\begin{array}{l}\text { GROUND } \\
\text { ELEVATION } \\
\text { (FT MSL) }\end{array}$ & LOG DATE & $\begin{array}{l}\text { LOG } \\
\text { TIME }\end{array}$ & $\begin{array}{l}\text { DEPTH FROM } \\
\text { TOP OF } \\
\text { CASING (FT) }\end{array}$ & \begin{tabular}{|} 
DEPTH FROM \\
GROUND \\
(FT)
\end{tabular} & $\begin{array}{l}\text { GROUNDWATER } \\
\text { ELEVATION } \\
\text { (FT MSL) }\end{array}$ \\
\hline 0687 & 57223.2 & 62932.9 & NA & U & 5494.14 & 5492.80 & $02 / 16 / 94$ & $10: 11$ & 40.71 & 39.37 & 5453.43 \\
\hline 0688 & 60020.8 & 57956.9 & NA & U & 5455.46 & 5453.60 & $\begin{array}{l}06 / 24 / 86 \\
07 / 16 / 86 \\
04 / 06 / 87 \\
10 / 09 / 87 \\
02 / 17 / 88 \\
12 / 02 / 90 \\
12 / 13 / 90 \\
03 / 28 / 91 \\
08 / 08 / 91 \\
12 / 06 / 91 \\
10 / 07 / 92 \\
02 / 16 / 94\end{array}$ & $\begin{array}{l}08: 30 \\
13: 05 \\
09: 00 \\
10: 20 \\
10: 25 \\
15: 54 \\
09: 40 \\
12: 44 \\
10: 25 \\
11: 12 \\
14: 00 \\
11: 10\end{array}$ & $\begin{array}{l}30.52 \\
31.56 \\
26.28 \\
31.42 \\
29.47 \\
31.52 \\
31.65 \\
31.18 \\
32.40 \\
30.58 \\
34.43 \\
30.29\end{array}$ & $\begin{array}{l}28.66 \\
29.70 \\
24.42 \\
29.56 \\
27.61 \\
29.66 \\
29.79 \\
29.32 \\
30.54 \\
28.72 \\
32.57 \\
28.43\end{array}$ & $\begin{array}{l}5424.94 \\
5423.90 \\
5429.18 \\
5424.04 \\
5425.99 \\
5423.94 \\
5423.81 \\
5424.28 \\
5423.06 \\
5424.88 \\
5421.03 \\
5425.17\end{array}$ \\
\hline 0690 & 57927.8 & 61902.3 & $N A$ & U & 5509.41 & 5506.90 & $\begin{array}{l}06 / 24 / 86 \\
07 / 18 / 86 \\
04 / 05 / 87 \\
10 / 12 / 87 \\
02 / 16 / 88 \\
12 / 02 / 90 \\
12 / 14 / 90 \\
04 / 03 / 91 \\
08 / 07 / 91 \\
11 / 18 / 91 \\
10 / 07 / 92 \\
02 / 16 / 94\end{array}$ & $\begin{array}{l}09: 20 \\
09: 42 \\
11: 00 \\
10: 40 \\
12: 30 \\
13: 40 \\
11: 10 \\
14: 00 \\
15: 45 \\
12: 50 \\
10: 20 \\
11: 24\end{array}$ & $\begin{array}{l}72.55 \\
72.63 \\
71.61 \\
72.92 \\
71.64 \\
74.10 \\
73.80 \\
73.42 \\
73.88 \\
73.68 \\
72.80 \\
72.66\end{array}$ & $\begin{array}{l}70.04 \\
70.12 \\
69.10 \\
70.41 \\
69.13 \\
71.59 \\
71.29 \\
70.91 \\
71.37 \\
71.17 \\
70.29 \\
70.15\end{array}$ & $\begin{array}{l}5436.86 \\
5436.78 \\
5437.80 \\
5436.49 \\
5437.77 \\
5435.31 \\
5435.61 \\
5435.99 \\
5435.53 \\
5435.73 \\
5436.61 \\
5436.75\end{array}$ \\
\hline 0702 & 58881.87 & 59277.12 & JE & 0 & 5486.50 & 5489.55 & $\begin{array}{l}12 / 02 / 90 \\
12 / 10 / 90 \\
03 / 31 / 91 \\
08 / 07 / 91 \\
12 / 07 / 91 \\
10 / 11 / 92 \\
02 / 16 / 94\end{array}$ & $\begin{array}{l}13: 55 \\
13: 40 \\
16: 05 \\
13: 44 \\
10: 35 \\
11: 50 \\
12: 52\end{array}$ & $\begin{array}{l}42.51 \\
42.95 \\
43.30 \\
43.70 \\
43.38 \\
43.50 \\
44.10\end{array}$ & $\begin{array}{l}45.56 \\
46.00 \\
46.35 \\
46.75 \\
46.43 \\
46.55 \\
47.15\end{array}$ & $\begin{array}{l}5443.99 \\
5443.55 \\
5443.20 \\
5442.80 \\
5443.12 \\
5443.00 \\
5442.40\end{array}$ \\
\hline 0703 & 58719.29 & 58732.28 & JE & 0 & 5526.50 & 5522.34 & $\begin{array}{l}12 / 02 / 90 \\
12 / 10 / 90 \\
03 / 30 / 91 \\
08 / 07 / 91 \\
12 / 07 / 91\end{array}$ & $\begin{array}{l}14: 42 \\
09: 48 \\
16: 12 \\
11: 40 \\
13: 12\end{array}$ & $\begin{array}{l}37.30 \\
37.35 \\
37.86 \\
37.94 \\
37.75\end{array}$ & $\begin{array}{l}33.14 \\
33.19 \\
33.70 \\
33.78 \\
33.59\end{array}$ & $\begin{array}{l}5489.20 \\
5489.15 \\
5488.64 \\
5488.56 \\
5488.75\end{array}$ \\
\hline
\end{tabular}

FORMATION OF COMPLETION CODE:

NA - MAVAJO SANDSTONE

JE - JURASSIC ENTRADA SANDSTONE FORMATION
FLOW RELATIONSHIP CODE:

U - UPGRADIENT

O - ON-SITE 
TABLE 3.3 STATIC GROUHD WATER LEVELS FOR THE NC AND UC PROCESSING SITES,

SLICK ROCK, COLORADO

SITE: SRKOI SLICK ROCK (BOTH SITES)

REPORT DATE: $09 / 28 / 94$

\begin{tabular}{|c|c|c|c|c|c|c|c|c|c|c|c|}
\hline $\begin{array}{c}\text { LOCATION } \\
\text { ID }\end{array}$ & $\begin{array}{c}\text { MORTH } \\
\text { COORDIHATE } \\
\text { (FT) }\end{array}$ & $\begin{array}{l}\text { EAST } \\
\text { COORDINATE } \\
\text { (FT) }\end{array}$ & $\begin{array}{l}\text { FORMATION } \\
\text { OF } \\
\text { COMPLETION }\end{array}$ & $\begin{array}{l}\text { FLOW } \\
\text { CODE }\end{array}$ & $\begin{array}{l}\text { CASING } \\
\text { ELEVATION } \\
\text { (FT MSL) }\end{array}$ & $\begin{array}{l}\text { GROUND } \\
\text { ELEVATION } \\
\text { (FT MSL) }\end{array}$ & LOG DATE & $\begin{array}{l}\text { LOG } \\
\text { TIME }\end{array}$ & $\begin{array}{l}\text { DEPTH FROH } \\
\text { TOP OF } \\
\text { CASING (FT) }\end{array}$ & $\begin{array}{l}\text { DEPTH FROM } \\
\text { GROUND } \\
\text { (FT) }\end{array}$ & $\begin{array}{c}\text { GROUNDWATER } \\
\text { ELEVATIOH } \\
\text { (FT MSL) }\end{array}$ \\
\hline 0703 & 58719.29 & 58732.28 & JE & 0 & 5526.50 & 5522.34 & $\begin{array}{l}10 / 11 / 92 \\
02 / 16 / 94\end{array}$ & $\begin{array}{l}09: 55 \\
10: 36\end{array}$ & $\begin{array}{l}37.72 \\
37.82\end{array}$ & $\begin{array}{l}33.56 \\
33.66\end{array}$ & $\begin{array}{l}5488.78 \\
5488.68\end{array}$ \\
\hline 0704 & 59173.01 & 58879.14 & JE & 0 & 5491.67 & 5489.25 & $\begin{array}{l}12 / 02 / 90 \\
12 / 08 / 90 \\
04 / 01 / 91 \\
08 / 24 / 91 \\
12 / 12 / 91 \\
10 / 12 / 92 \\
02 / 17 / 94\end{array}$ & $\begin{array}{l}15: 03 \\
10: 45 \\
14: 48 \\
11: 40 \\
14: 03 \\
13: 45 \\
10: 02\end{array}$ & $\begin{array}{l}28.97 \\
29.17 \\
29.81 \\
29.62 \\
29.61 \\
29.70 \\
30.46\end{array}$ & $\begin{array}{l}26.55 \\
26.75 \\
27.39 \\
27.20 \\
27.19 \\
27.28 \\
28.04\end{array}$ & $\begin{array}{l}5462.70 \\
5462.50 \\
5461.86 \\
5462.05 \\
5462.06 \\
5461.97 \\
5461.21\end{array}$ \\
\hline 0806 & - & - & NR & $\mathbf{N}$ & - & - & $02 / 02 / 86$ & $12: 35$ & 1.20 & - & - \\
\hline
\end{tabular}

FORMATION OF COMPLETION CODE:

JE - JURASSIC ENTRADA SANDSTONE FORMATION

NR - NO RECOVERY OF DATA FOR CLASSIFYING

FLOW RELATIONSHIP CODE:

DATA FILE: M: IDARTISRK01 \GWL10000.DAT

- UNKNOWN

FIELDS DISPLAYED HITH A DASH INDICATE THE DATA IS UNAVAILABLE 
Table 3.4 Hydraulic parameters for the NC and UC processing sites, Slick Rock, Colorado

\begin{tabular}{lccc}
\hline \multicolumn{1}{c}{ Hydraulic property } & $\begin{array}{c}\text { Dolores River } \\
\text { alluvium }\end{array}$ & $\begin{array}{c}\text { Entrada } \\
\text { Formation }\end{array}$ & $\begin{array}{c}\text { Navajo } \\
\text { Sandstone }\end{array}$ \\
\hline $\begin{array}{l}\text { Average hydraulic conductivity } \\
\text { (NC site) }\end{array}$ & $\begin{array}{c}23 \mathrm{ft} / \mathrm{day} \\
8.1 \times 10^{-3} \mathrm{~cm} / \mathrm{s}\end{array}$ & Not determined & Not determined \\
$\begin{array}{l}\text { Average hydraulic conductivity } \\
\text { (UC site) }\end{array}$ & $\begin{array}{c}14 \mathrm{ft} / \mathrm{day} \\
4.9 \times 10^{-3} \mathrm{~cm} / \mathrm{s}\end{array}$ & Not determined & $2.4 \times 10^{-2} \mathrm{ft} / \mathrm{day}$ \\
$8.5 \times 10^{-6} \mathrm{~cm} / \mathrm{s}$
\end{tabular}


TABLE 3.5 BACKGROUND GROUND HATER QUALITY DATA BY PARAMETER FOR THE

ALLUVIUM, NC AND UC PROCESSING SITES, SLICK ROCK, COLORADO

SITE: SRKO1 SLICK ROCK (BOTH SITES)

09/09/82 TO 02/22/94

REPORT DATE: 09/28/94

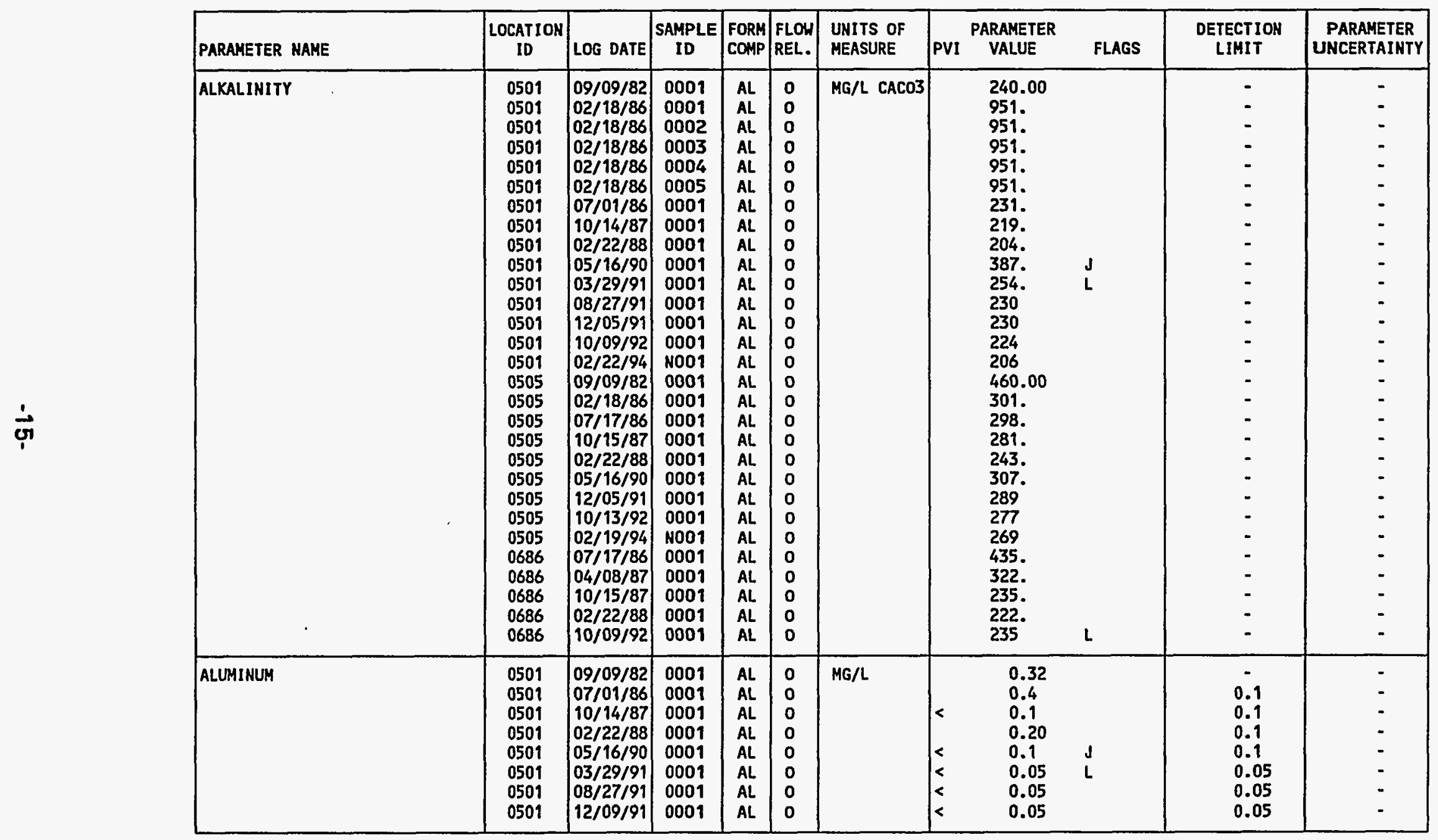

FORHATION OF COMPLETION CODE:

AL - ALLUVIUM

PARAMETER VALUE IHDICATOR (PVI): < - LESS THAN DETECTION LIMIT OTHER PARAMETER VALUE FLAGS:

$J$ - ESTIMATED VALUE

L - LESS THAN THREE BORE VOLUMES REMOVEd BEFORE SAMPLING
FLOW RELATIONSHIP CODE:

O- ON-SITE

SAMPLE ID CODES:

0001 - FILTERED SAMPLE (.45 MICRONS)

0002 - FILTERED REPLICATE SAMPLE (.45 MICRONS)

0003 - FILTERED REPLICATE SAMPLE (.45 MICRONS)

0004 - FILTERED REPLICATE SAMPLE (.45 MICRONS)

NOOI - UNFILTERED SAMPLE 
TABLE 3.5 BACKGROUND GROUND WATER QUALITY DATA BY PARAMETER FOR THE ALLUVIUM, NC AND UC PROCESSING SITES, SLICK ROCK, COLORADO

SITE: SRK01 SLICK ROCK (BOTH SITES)

02/22/94

REPORT DATE: $09 / 28 / 94$

\begin{tabular}{|c|c|c|c|c|c|c|c|c|c|c|c|}
\hline PARAMETER NAME & $\underset{\text { ID }}{\text { LOCATION }}$ & LOG DATE & $\begin{array}{c}\text { SAMPLE } \\
\text { ID }\end{array}$ & $\begin{array}{l}\text { FORM } \\
\text { COMP }\end{array}$ & $\begin{array}{l}\text { FLOW } \\
\text { REL. }\end{array}$ & $\begin{array}{l}\text { UNITS OF } \\
\text { MEASURE }\end{array}$ & PVI & $\begin{array}{l}\text { PARAMETER } \\
\text { VALUE }\end{array}$ & FLAGS & $\begin{array}{l}\text { DETECTION } \\
\text { LIMIT }\end{array}$ & $\begin{array}{l}\text { PARAMETER } \\
\text { UNCERTAINTY }\end{array}$ \\
\hline ALUMINUM & $\begin{array}{l}0501 \\
0505 \\
0505 \\
0505 \\
0505 \\
0505 \\
0505 \\
0505 \\
0686 \\
0686 \\
0686 \\
0686\end{array}$ & $\begin{array}{l}10 / 09 / 92 \\
09 / 09 / 82 \\
07 / 17 / 86 \\
10 / 15 / 87 \\
02 / 22 / 88 \\
05 / 16 / 90 \\
11 / 21 / 91 \\
10 / 13 / 92 \\
07 / 17 / 86 \\
04 / 08 / 87 \\
10 / 15 / 87 \\
02 / 22 / 88\end{array}$ & $\begin{array}{l}0001 \\
0001 \\
0001 \\
0001 \\
0001 \\
0001 \\
0001 \\
0001 \\
0001 \\
0001 \\
0001 \\
0001\end{array}$ & $\begin{array}{l}A L \\
A L \\
A L \\
A L \\
A L \\
A L \\
A L \\
A L \\
A L \\
A L \\
A L \\
A L\end{array}$ & $\begin{array}{l}\mathbf{0} \\
0 \\
0 \\
0 \\
0 \\
0 \\
0 \\
0 \\
0 \\
0 \\
0 \\
0\end{array}$ & $M G / L$ & $\begin{array}{l}< \\
< \\
< \\
< \\
< \\
< \\
< \\
<\end{array}$ & $\begin{array}{l}0.05 \\
1.44 \\
0.2 \\
0.1 \\
0.16 \\
0.1 \\
0.05 \\
0.05 \\
0.3 \\
0.1 \\
0.1 \\
0.17\end{array}$ & & $\begin{array}{l}0.05 \\
0.1 \\
0.1 \\
0.1 \\
0.1 \\
0.1 \\
0.05 \\
0.05 \\
0.1 \\
0.1 \\
0.1 \\
0.1\end{array}$ & $\begin{array}{l}- \\
- \\
- \\
- \\
- \\
- \\
- \\
-\end{array}$ \\
\hline AMMONIUM & $\begin{array}{l}0501 \\
0501 \\
0501 \\
0501 \\
0501 \\
0501 \\
0501 \\
0501 \\
0501 \\
0501 \\
0501 \\
0501 \\
0505 \\
0505 \\
0505 \\
0505 \\
0505 \\
0505 \\
0505 \\
0686 \\
0686 \\
0686 \\
0686\end{array}$ & $\begin{array}{l}02 / 18 / 86 \\
02 / 18 / 86 \\
02 / 18 / 86 \\
02 / 18 / 86 \\
02 / 18 / 86 \\
10 / 14 / 87 \\
02 / 22 / 88 \\
05 / 16 / 90 \\
03 / 29 / 91 \\
08 / 27 / 91 \\
12 / 09 / 91 \\
10 / 09 / 92 \\
02 / 18 / 86 \\
07 / 17 / 86 \\
10 / 15 / 87 \\
02 / 22 / 88 \\
05 / 16 / 90 \\
11 / 21 / 91 \\
10 / 13 / 92 \\
07 / 17 / 86 \\
04 / 08 / 87 \\
10 / 15 / 87 \\
02 / 22 / 88\end{array}$ & $\begin{array}{l}0001 \\
0002 \\
0003 \\
0004 \\
0005 \\
0001 \\
0001 \\
0001 \\
0001 \\
0001 \\
0001 \\
0001 \\
0001 \\
0001 \\
0001 \\
0001 \\
0001 \\
0001 \\
0001 \\
0001 \\
0001 \\
0001 \\
0001\end{array}$ & $\begin{array}{l}A L \\
A L \\
A L \\
A L \\
A L \\
A L \\
A L \\
A L \\
A L \\
A L \\
A L \\
A L \\
A L \\
A L \\
A L \\
A L \\
A L \\
A L \\
A L \\
A L \\
A L \\
A L \\
A L\end{array}$ & $\begin{array}{l}0 \\
0 \\
0 \\
0 \\
0 \\
0 \\
0 \\
0 \\
0 \\
0 \\
0 \\
0 \\
0 \\
0 \\
0 \\
0 \\
0 \\
0 \\
0 \\
0 \\
0 \\
0 \\
0\end{array}$ & $M G / L$ & $\begin{array}{l}< \\
< \\
< \\
< \\
< \\
< \\
< \\
< \\
< \\
< \\
<\end{array}$ & $\begin{array}{l}0.6 \\
0.6 \\
0.6 \\
0.5 \\
0.5 \\
0.1 \\
0.1 \\
0.1 \\
0.1 \\
0.1 \\
0.1 \\
0.1 \\
4.6 \\
5.2 \\
4.0 \\
4.0 \\
4.3 \\
4.6 \\
1.3 \\
0.1 \\
0.6 \\
0.1 \\
0.1\end{array}$ & $\begin{array}{l}\text { J } \\
\text { L } \\
\text { J }\end{array}$ & $\begin{array}{l}0.1 \\
0.1 \\
0.1 \\
0.1 \\
0.1 \\
0.1 \\
0.1 \\
0.1 \\
0.1 \\
0.1 \\
0.1 \\
0.1 \\
0.1 \\
0.1 \\
0.1 \\
0.1 \\
0.1 \\
0.1 \\
0.1 \\
0.1 \\
0.1 \\
0.1 \\
0.1\end{array}$ & $\begin{array}{l}- \\
- \\
- \\
- \\
- \\
- \\
- \\
- \\
- \\
- \\
- \\
- \\
- \\
- \\
- \\
- \\
- \\
- \\
-\end{array}$ \\
\hline AMMONIUM (TOTAL) & 0501 & $02 / 22 / 94 \mid$ & N001 & AL & o & $M G / L$ & $<$ & 0.1 & & 0.1 & - \\
\hline
\end{tabular}

FORMATION OF COMPLETION CODE:

AL - ALluviUm

PARAMETER VALUE INDICATOR (PVI): < - LESS THAN DETECTION LIMIT

OTHER PARAMETER VALUE FLAGS:

$J$ - ESTIMATED VALUE

l. - LESS THAN THREE bORE VOLUMES REMOVED BEFORE SAMPLING
FLOW RELATIONSHIP CODE:

O- ON-SITE

SAMPLE ID COOES:

0001 - FILTERED SAMPLE ( 45 MICRONS)

0002 - FILTERED REPLICATE SAMPLE (.45 MICRONS)

0003 - FILTERED REPLICATE SAMPLE (.45 MICRONS)

0004 - FILTERED REPLICATE SAMPLE (.45 MICRONS)

NOO1 - UNFILTERED SAMPLE 
TABLE 3.5 BACKGROUND GROUND WATER QUALITY DATA BY PARAMETER FOR THE

ALLUVIUH, MC AND UC PROCESSING SITES, SLICK ROCK, COLORADO

SITE: SRKO1 SLICK ROCK (BOTH SITES)

09/09/82 TO 02/22/94

REPORT DATE: $09 / 28 / 94$

\begin{tabular}{|c|c|c|c|c|c|c|c|c|c|c|c|}
\hline PARAMETER MAME & $\underset{\text { ID }}{\text { LOCATIOH }}$ & LOG DATE & $\underset{\text { ID }}{\text { SAMPLE }}$ & $\begin{array}{l}\text { FORM } \\
\text { COMP }\end{array}$ & $\begin{array}{l}\text { FLOW } \\
\text { REL. }\end{array}$ & $\begin{array}{l}\text { UNITS OF } \\
\text { MEASURE }\end{array}$ & PVI & $\begin{array}{l}\text { ARAMETER } \\
\text { VALUE }\end{array}$ & FLAGS & $\begin{array}{l}\text { DETECTION } \\
\text { LIMIT }\end{array}$ & $\begin{array}{l}\text { PARAMETER } \\
\text { UNCERTAINTY }\end{array}$ \\
\hline AMMONIUM (TOTAL) & 0505 & |02/19/94 & NOO1 & $A L$ & 0 & MG/L & \multicolumn{3}{|c|}{3.1} & 0.1 & - \\
\hline ANTIMONY & $\begin{array}{l}0501 \\
0501 \\
0501 \\
0501 \\
0501 \\
0505 \\
0505 \\
0505 \\
0505 \\
0686 \\
0686\end{array}$ & $\begin{array}{l}05 / 16 / 90 \\
03 / 29 / 91 \\
08 / 27 / 91 \\
12 / 09 / 91 \\
10 / 09 / 92 \\
07 / 17 / 86 \\
05 / 16 / 90 \\
11 / 21 / 91 \\
10 / 13 / 92 \\
07 / 17 / 86 \\
04 / 08 / 87\end{array}$ & $\begin{array}{l}0001 \\
0001 \\
0001 \\
0001 \\
0001 \\
0001 \\
0001 \\
0001 \\
0001 \\
0001 \\
0001\end{array}$ & $\begin{array}{l}A L \\
A L \\
A L \\
A L \\
A L \\
A L \\
A L \\
A L \\
A L \\
A L \\
A L\end{array}$ & $\begin{array}{l}0 \\
0 \\
0 \\
0 \\
0 \\
0 \\
0 \\
0 \\
0 \\
0 \\
0\end{array}$ & $M G / L$ & $\begin{array}{l}< \\
< \\
< \\
< \\
< \\
< \\
< \\
< \\
< \\
< \\
<\end{array}$ & $\begin{array}{l}0.003 \\
0.003 \\
0.003 \\
0.003 \\
0.003 \\
0.003 \\
0.003 \\
0.003 \\
0.003 \\
0.003 \\
0.003\end{array}$ & $\begin{array}{l}\mathrm{J} \\
\mathrm{L}\end{array}$ & $\begin{array}{l}0.003 \\
0.003 \\
0.003 \\
0.003 \\
0.003 \\
0.003 \\
0.003 \\
0.003 \\
0.003 \\
0.003 \\
0.003\end{array}$ & $\begin{array}{l}- \\
- \\
- \\
- \\
- \\
- \\
- \\
-\end{array}$ \\
\hline ARSENIC & $\begin{array}{l}0501 \\
0501 \\
0501 \\
0501 \\
0501 \\
0501 \\
0501 \\
0501 \\
0501 \\
0501 \\
0501 \\
0501 \\
0501 \\
0505 \\
0505 \\
0505 \\
0505 \\
0505 \\
0505 \\
0505 \\
0686 \\
0686 \\
0686\end{array}$ & $\begin{array}{l}09 / 09 / 82 \\
02 / 18 / 86 \\
02 / 18 / 86 \\
02 / 18 / 86 \\
02 / 18 / 86 \\
02 / 18 / 86 \\
07 / 01 / 86 \\
10 / 14 / 87 \\
05 / 16 / 90 \\
03 / 29 / 91 \\
08 / 27 / 91 \\
12 / 09 / 91 \\
10 / 09 / 92 \\
09 / 09 / 82 \\
02 / 18 / 86 \\
07 / 17 / 86 \\
10 / 15 / 87 \\
05 / 16 / 90 \\
11 / 21 / 91 \\
10 / 13 / 92 \\
07 / 17 / 86 \\
04 / 08 / 87 \\
10 / 15 / 87\end{array}$ & $\begin{array}{l}0001 \\
0001 \\
0002 \\
0003 \\
0004 \\
0005 \\
0001 \\
0001 \\
0001 \\
0001 \\
0001 \\
0001 \\
0001 \\
0001 \\
0001 \\
0001 \\
0001 \\
0001 \\
0001 \\
0001 \\
0001 \\
0001 \\
0001\end{array}$ & $\begin{array}{l}A L \\
A L \\
A L \\
A L \\
A L \\
A L \\
A L \\
A L \\
A L \\
A L \\
A L \\
A L \\
A L \\
A L \\
A L \\
A L \\
A L \\
A L \\
A L \\
A L \\
A L \\
A L \\
A L\end{array}$ & $\begin{array}{l}0 \\
0 \\
0 \\
0 \\
0 \\
0 \\
0 \\
0 \\
0 \\
0 \\
0 \\
0 \\
0 \\
0 \\
0 \\
0 \\
0 \\
0 \\
0 \\
0 \\
0 \\
0 \\
0\end{array}$ & $M G / L$ & $\begin{array}{l}< \\
< \\
< \\
< \\
< \\
< \\
< \\
< \\
< \\
< \\
< \\
< \\
< \\
< \\
< \\
< \\
< \\
< \\
< \\
< \\
< \\
< \\
< \\
<\end{array}$ & $\begin{array}{l}0.01 \\
0.01 \\
0.01 \\
0.01 \\
0.01 \\
0.01 \\
0.01 \\
0.01 \\
0.01 \\
0.01 \\
0.01 \\
0.01 \\
0.005 \\
0.01 \\
0.01 \\
0.01 \\
0.01 \\
0.01 \\
0.01 \\
0.005 \\
0.01 \\
0.001 \\
0.01\end{array}$ & $\begin{array}{l}\mathrm{J} \\
\mathbf{L}\end{array}$ & $\begin{array}{l}0.01 \\
0.01 \\
0.01 \\
0.01 \\
0.01 \\
0.01 \\
0.01 \\
0.01 \\
0.01 \\
0.01 \\
0.01 \\
0.01 \\
0.005 \\
0.01 \\
0.01 \\
0.01 \\
0.01 \\
0.01 \\
0.01 \\
0.005 \\
0.01 \\
0.01 \\
0.01\end{array}$ & $\begin{array}{l}- \\
- \\
- \\
- \\
- \\
- \\
- \\
- \\
- \\
- \\
- \\
- \\
- \\
- \\
- \\
-\end{array}$ \\
\hline BARIUM & 0501 & $09 / 09 / 82$ & 0001 & AL & 0 & $\mathrm{MG} / \mathrm{L}$ & & 0.091 & & - & - \\
\hline
\end{tabular}

FORMATION OF COMPLETION COOE:

AL. - ALLUVIUH

PARAMETER VALUE INDICATOR (PVI): < - LESS THAN DETECTION LIMIT

OTHER PARAMETER VALUE FLAGS:

$J$ - ESTIMATED VALUE

L - LESS tHAN THREE BORE VOLUMES REMOVED BEFORE SAMPLING
FLOH RELATIONSHIP CODE:

O - ON-SITE

SAMPLE ID CODES:

0001 - FILTERED SAMPLE (. 45 MICRONS)

0002 - FILTERED REPLICATE SAMPLE (.45 MICRONS)

0003 - FILTERED REPLICATE SAMPLE (.45 MICRONS)

0004 - FILTERED REPLICATE SAMPLE (.45 MICRONS)

NOO1 - UNFILTERED SAMPLE 


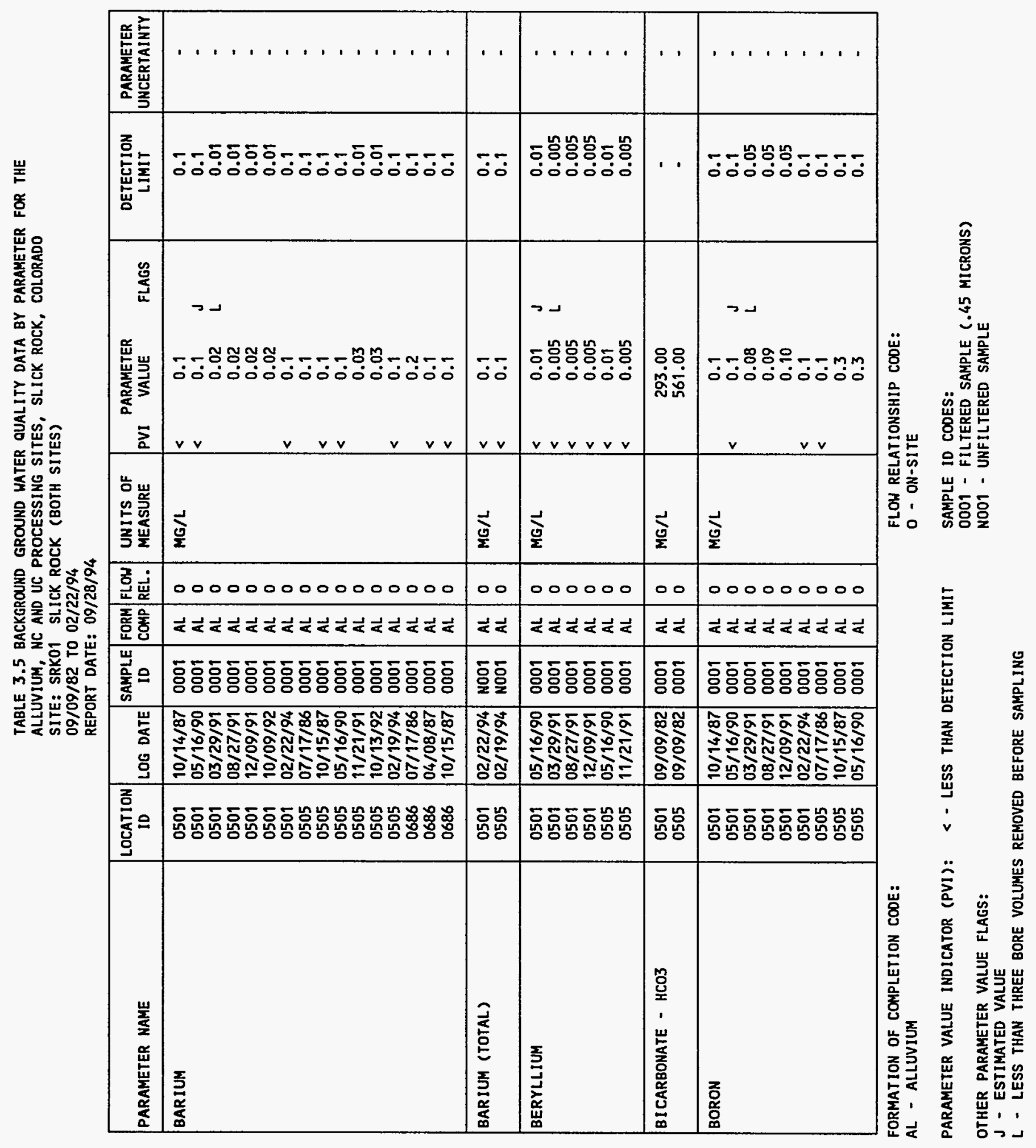


TABLE 3.5 BACKGROUND GROUND MATER QUALITY DATA BY PARAMETER FOR THE ALLUVIUM, NC AND UC PROCESSING SITES, SLICK ROCK, COLORADO

SITE: SRKO1 SLICK ROCK (BOTH SITES)

09/09/82 TO 02/22/94

REPORT DATE: 09/28/94

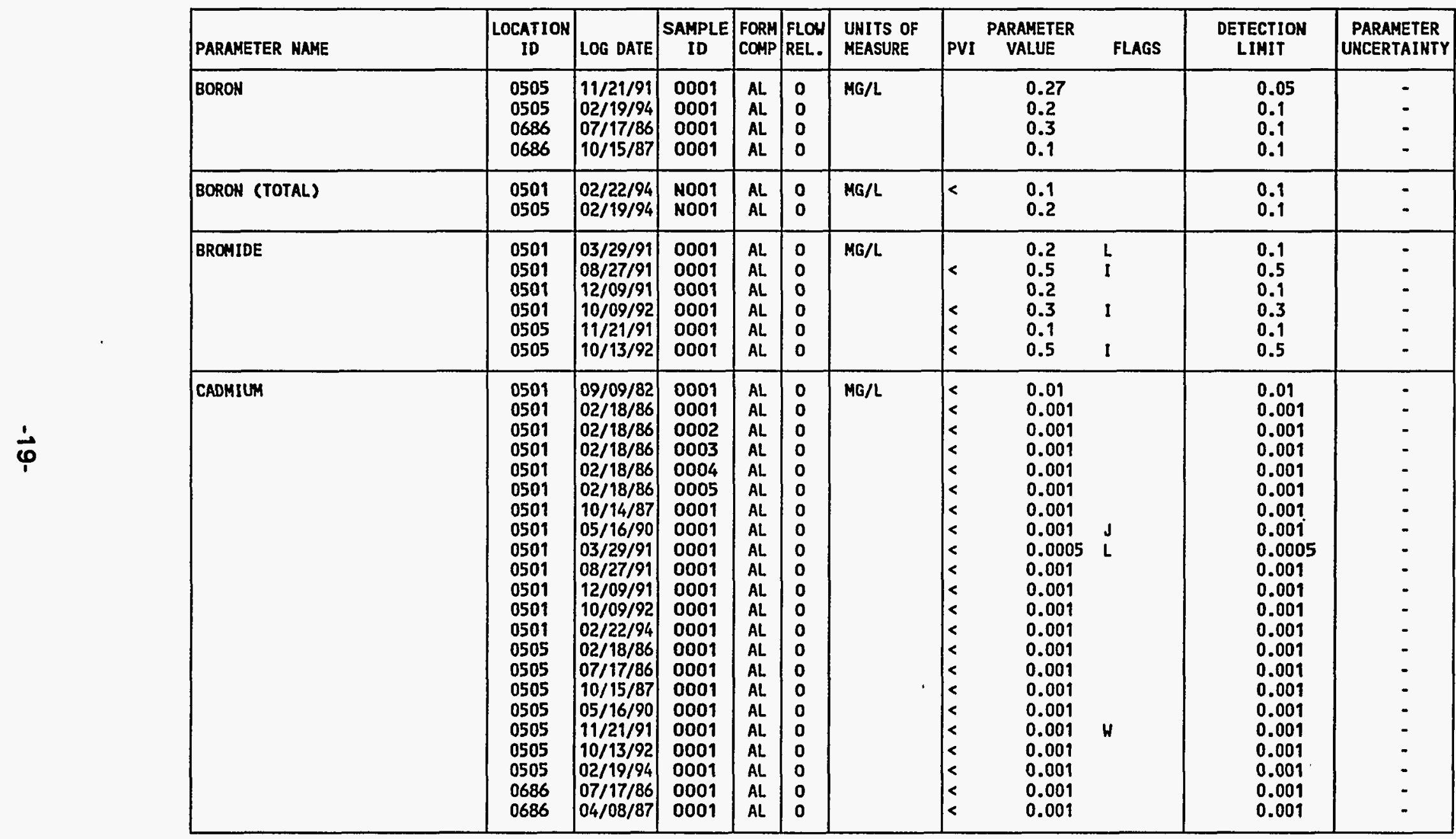

FORMATION OF COMPLETION CODE:

AL - ALLUVIUM

PARAMETER VALUE INDICATOR (PVI): < - LESS THAN DETECTION LIMIT

OTHER PARAMETER VALUE FLAGS:

1 - INCREASED DETECTION LIMIT DUE TO REQUIRED DILUTION

J - ESTIMATED VALUE

L - LESS THAN THREE BORE VOLUMES REMOVED BEFORE SAMPLING

$H$ - POST-DIGEST SPIKE OUT OF CNTR LIM WHILE SAMP ABS $<50 \%$ SPIKE
FLOH RELATIONSHIP CODE:

O- ON-SITE

SAMPLE ID CODES:

0001 - FILTERED SAMPLE (.45 MICRONS)

0002 - FILTERED REPLICATE SAMPLE (.45 MICRONS)

0003 - FILTERED REPLICATE SAMPLE (.45 MICRONS)

0004 - FILTERED REPLICATE SAMPLE (.45 MICRONS)

NOO1 - UNFILTERED SAMPLE 
TABLE 3.5 BACKGROUND GROUND HATER QUALITY DATA BY PARAMETER FOR THE

ALLUVIUM, NC AND UC PROCESSING SITES, SLICK ROCK, COLORADO

SITE: SRKO1 SLICK ROCK (BOTH SITES)

09/09/82 TO 02/22/94

REPORT DATE : $09 / 28 / 94$

\begin{tabular}{|c|c|c|c|c|c|c|c|c|c|c|c|}
\hline PARAMETER NAME & $\underset{\text { ID }}{\text { LOCATION }}$ & LOG DATE & $\begin{array}{c}\text { SAMPLE } \\
\text { ID }\end{array}$ & $\begin{array}{l}\text { FORM } \\
\text { COMP }\end{array}$ & $\begin{array}{l}\text { FLOW } \\
\text { REL. }\end{array}$ & $\begin{array}{l}\text { UNITS OF } \\
\text { MEASURE }\end{array}$ & PVI & $\begin{array}{l}\text { ARAMETER } \\
\text { VALUE }\end{array}$ & FLAGS & $\begin{array}{l}\text { DETECTION } \\
\text { LIMIT }\end{array}$ & $\begin{array}{l}\text { PARAMETER } \\
\text { UNCERTAINTY }\end{array}$ \\
\hline CAOMIUM & 0686 & $10 / 15 / 87$ & 0001 & AL & $\mathbf{0}$ & $M G / L$ & $<$ & \multicolumn{2}{|l|}{0.001} & 0.001 & - \\
\hline CADMIUM (TOTAL) & $\begin{array}{l}0501 \\
0505\end{array}$ & $\begin{array}{l}02 / 22 / 94 \\
02 / 19 / 94\end{array}$ & $\begin{array}{l}\text { N001 } \\
\text { N001 }\end{array}$ & $\begin{array}{l}\text { AL } \\
\text { AL }\end{array}$ & $\begin{array}{l}\mathbf{0} \\
\mathbf{0}\end{array}$ & MG/L & $<$ & \multicolumn{2}{|l|}{$\begin{array}{l}0.001 \\
0.001\end{array}$} & $\begin{array}{l}0.001 \\
0.001\end{array}$ & $\because$ \\
\hline CALCIUM & $\begin{array}{l}0501 \\
0501 \\
0501 \\
0501 \\
0501 \\
0501 \\
0501 \\
0501 \\
0501 \\
0501 \\
0501 \\
0501 \\
0501 \\
0501 \\
0501 \\
0505 \\
0505 \\
0505 \\
0505 \\
0505 \\
0505 \\
0505 \\
0505 \\
0505 \\
0686 \\
0686 \\
0686 \\
0686\end{array}$ & $\begin{array}{l}09 / 09 / 82 \\
02 / 18 / 86 \\
02 / 18 / 86 \\
02 / 18 / 86 \\
02 / 18 / 86 \\
02 / 18 / 86 \\
07 / 01 / 86 \\
10 / 14 / 87 \\
02 / 22 / 88 \\
05 / 16 / 90 \\
03 / 29 / 91 \\
08 / 27 / 91 \\
12 / 09 / 91 \\
10 / 09 / 92 \\
02 / 22 / 94 \\
09 / 09 / 82 \\
02 / 18 / 86 \\
07 / 17 / 86 \\
10 / 15 / 87 \\
02 / 22 / 88 \\
05 / 16 / 90 \\
11 / 21 / 91 \\
10 / 13 / 92 \\
02 / 19 / 94 \\
07 / 17 / 86 \\
04 / 08 / 87 \\
10 / 15 / 87 \\
02 / 22 / 88\end{array}$ & $\begin{array}{l}0001 \\
0001 \\
0002 \\
0003 \\
0004 \\
0005 \\
0001 \\
0001 \\
0001 \\
0001 \\
0001 \\
0001 \\
0001 \\
0001 \\
0001 \\
0001 \\
0001 \\
0001 \\
0001 \\
0001 \\
0001 \\
0001 \\
0001 \\
0001 \\
0001 \\
0001 \\
0001 \\
0001\end{array}$ & $\begin{array}{l}A L \\
A L \\
A L \\
A L \\
A L \\
A L \\
A L \\
A L \\
A L \\
A L \\
A L \\
A L \\
A L \\
A L \\
A L \\
A L \\
A L \\
A L \\
A L \\
A L \\
A L \\
A L \\
A L \\
A L \\
A L \\
A L \\
A L \\
A L\end{array}$ & $\begin{array}{l}0 \\
0 \\
0 \\
0 \\
0 \\
0 \\
0 \\
0 \\
0 \\
0 \\
0 \\
0 \\
0 \\
0 \\
0 \\
0 \\
0 \\
0 \\
0 \\
0 \\
0 \\
0 \\
0 \\
0 \\
0 \\
0 \\
0 \\
0\end{array}$ & MG/L & & \multicolumn{2}{|c|}{$\begin{array}{l}107.00 \\
163 . \\
163 . \\
163 . \\
163 . \\
163 . \\
99.6 \\
134 . \\
150 . \\
108 . \\
108 . \\
114 . \\
104 . \\
106 . \\
135 \\
179.00 \\
137 . \\
113 . \\
93 . \\
102 . \\
116 . \\
110 . \\
115 . \\
94.2 \\
73.8 \\
112 . \\
111 . \\
127 .\end{array}$} & $\begin{array}{l}0.01 \\
0.01 \\
0.01 \\
0.01 \\
0.01 \\
0.01 \\
0.01 \\
0.01 \\
0.01 \\
0.5 \\
0.5 \\
0.5 \\
0.5 \\
0.5 \\
-. \\
0.01 \\
0.01 \\
0.01 \\
0.01 \\
0.01 \\
0.5 \\
0.5 \\
0.5 \\
0.01 \\
0.01 \\
0.01 \\
0.01\end{array}$ & $\begin{array}{l}- \\
- \\
- \\
- \\
- \\
- \\
- \\
- \\
- \\
- \\
- \\
- \\
- \\
- \\
- \\
- \\
- \\
- \\
- \\
- \\
- \\
- \\
- \\
- \\
- \\
- \\
-\end{array}$ \\
\hline CALCIUM (TOTAL) & $\begin{array}{l}0501 \\
0505\end{array}$ & $\begin{array}{l}02 / 22 / 94 \\
02 / 19 / 94\end{array}$ & $\begin{array}{l}\text { N001 } \\
\text { N001 }\end{array}$ & $\begin{array}{l}\text { AL } \\
\text { AL }\end{array}$ & $\begin{array}{l}\mathbf{0} \\
\mathbf{0}\end{array}$ & MG/L & \multicolumn{3}{|c|}{$\begin{array}{l}131 \\
90.6\end{array}$} & $\begin{array}{l}0.5 \\
0.5\end{array}$ & - \\
\hline CHLORIDE & 0501 & $09 / 09 / 82$ & 0001 & AL & $\mathbf{0}$ & MG/L & \multicolumn{3}{|c|}{58.00} & - & - \\
\hline
\end{tabular}

FORMATION OF COMPLETION COOE:

AL - ALLUVIUM

FLOH RELATIONSHIP CODE:

PARAMETER VALUE INDICATOR (PVI): < - LESS THAN DETECTION LIMIT

OTHER PARAMETER VALUE FLAGS:

$J$ - ESTIMATED VALUE

L - LESS THAN THREE BORE VOLUMES REMOVED BEFORE SAMPLING

SAMPLE ID CODES:

0001 - FILTERED SAMPLE (.45 MICRONS)

0002 - FILTERED REPLICATE SAMPLE (.45 MICRONS)

0003 - FILTERED REPLICATE SAMPLE (.45 MICRONS)

0004 - FILTERED REPLICATE SAMPLE (.45 MICRONS)

NOO1 - UNFILTERED SAMPLE 
TABLE 3.5 BACKGROUND GROUND WATER QUALITY DATA BY PARAMETER FOR THE

ALLIUVIUM, NC AND UC PROCESSIHG SITES, SLICK ROCK, COLORADO

SITE: SRK01 SLICK ROCK (BOTH SITES)

$09 / 09 / 82$ TO 02/22/94

REPORT DATE: $09 / 28 / 94$

\begin{tabular}{|c|c|c|c|c|c|c|c|c|c|c|c|}
\hline PARAMETER MAME & $\underset{\text { ID }}{\text { LOCATION }}$ & LOG DATE & $\underset{\text { SAMPLE }}{\text { ID }}$ & $\left|\begin{array}{l}\text { FORM } \\
\text { COMP }\end{array}\right|$ & $\begin{array}{l}\text { FLON } \\
\text { REL. }\end{array}$ & $\begin{array}{l}\text { UNITS OF } \\
\text { MEASURE }\end{array}$ & PVI & $\begin{array}{l}\text { PARAMETER } \\
\text { VALUE }\end{array}$ & FLAGS & $\begin{array}{l}\text { DETECTION } \\
\text { LINIT }\end{array}$ & $\begin{array}{l}\text { PARAMETER } \\
\text { UNCERTAINTY }\end{array}$ \\
\hline CHLORIDE & $\begin{array}{l}0501 \\
0501 \\
0501 \\
0501 \\
0501 \\
0501 \\
0501 \\
0501 \\
0501 \\
0501 \\
0501 \\
0501 \\
0501 \\
0501 \\
0505 \\
0505 \\
0505 \\
0505 \\
0505 \\
0505 \\
0505 \\
0505 \\
0505 \\
0686 \\
0686 \\
0686 \\
0686\end{array}$ & $\begin{array}{l}02 / 18 / 86 \\
02 / 18 / 86 \\
02 / 18 / 86 \\
02 / 18 / 86 \\
02 / 18 / 86 \\
07 / 01 / 86 \\
10 / 14 / 87 \\
02 / 22 / 88 \\
05 / 16 / 90 \\
03 / 29 / 91 \\
08 / 27 / 91 \\
12 / 09 / 91 \\
10 / 09 / 92 \\
02 / 22 / 94 \\
09 / 09 / 82 \\
02 / 18 / 86 \\
07 / 17 / 86 \\
10 / 15 / 87 \\
02 / 22 / 88 \\
05 / 16 / 90 \\
11 / 21 / 91 \\
10 / 13 / 92 \\
02 / 19 / 94 \\
07 / 17 / 86 \\
04 / 08 / 87 \\
10 / 15 / 87 \\
02 / 22 / 88\end{array}$ & $\begin{array}{l}0001 \\
0002 \\
0003 \\
0004 \\
0005 \\
0001 \\
0001 \\
0001 \\
0001 \\
0001 \\
0001 \\
0001 \\
0001 \\
0001 \\
0001 \\
0001 \\
0001 \\
0001 \\
0001 \\
0001 \\
0001 \\
0001 \\
0001 \\
0001 \\
0001 \\
0001 \\
0001\end{array}$ & $\begin{array}{l}A L \\
A L \\
A L \\
A L \\
A L \\
A L \\
A L \\
A L \\
A L \\
A L \\
A L \\
A L \\
A L \\
A L \\
A L \\
A L \\
A L \\
A L \\
A L \\
A L \\
A L \\
A L \\
A L \\
A L \\
A L \\
A L \\
A L\end{array}$ & $\begin{array}{l}0 \\
0 \\
0 \\
0 \\
0 \\
0 \\
0 \\
0 \\
0 \\
0 \\
0 \\
0 \\
0 \\
0 \\
0 \\
0 \\
0 \\
0 \\
0 \\
0 \\
0 \\
0 \\
0 \\
0 \\
0 \\
0 \\
0\end{array}$ & $M G / L$ & & $\begin{array}{l}81 . \\
81 . \\
82 . \\
82 . \\
82 . \\
64 . \\
69 . \\
89 . \\
66 . \\
75 . \\
62 . \\
59 . \\
49 . \\
75.9 \\
133.00 \\
74 . \\
77 . \\
40 . \\
49 . \\
49 . \\
62 . \\
49 . \\
41.5 \\
40 . \\
39.3 \\
38 . \\
55 .\end{array}$ & $\begin{array}{l}J \\
\text { L }\end{array}$ & $\begin{array}{l}1 . \\
1 . \\
1 . \\
1 . \\
1 . \\
1 . \\
1 . \\
1.0 \\
0.5 \\
1 . \\
1 . \\
1 . \\
0.5 \\
1 . \\
1 . \\
1 . \\
1 . \\
1 . \\
1 . \\
1 . \\
0.5 \\
1 . \\
1 . \\
1 . \\
1 .\end{array}$ & $\begin{array}{l}- \\
- \\
- \\
- \\
- \\
- \\
- \\
- \\
- \\
- \\
- \\
- \\
- \\
- \\
- \\
- \\
- \\
- \\
- \\
-\end{array}$ \\
\hline CHROMIUM & $\begin{array}{l}0501 \\
0501 \\
0501 \\
0501 \\
0501 \\
0501 \\
0501 \\
0501 \\
0505 \\
0505 \\
0505\end{array}$ & $\begin{array}{l}09 / 09 / 82 \\
10 / 14 / 87 \\
05 / 16 / 90 \\
03 / 29 / 91 \\
08 / 27 / 91 \\
12 / 09 / 91 \\
10 / 09 / 92 \\
02 / 22 / 94 \\
07 / 17 / 86 \\
10 / 15 / 87 \\
05 / 16 / 90\end{array}$ & $\begin{array}{l}0001 \\
0001 \\
0001 \\
0001 \\
0001 \\
0001 \\
0001 \\
0001 \\
0001 \\
0001 \\
0001\end{array}$ & $\begin{array}{l}A L \\
A L \\
A L \\
A L \\
A L \\
A L \\
A L \\
A L \\
A L \\
A L \\
A L\end{array}$ & $\begin{array}{l}0 \\
0 \\
0 \\
0 \\
0 \\
0 \\
0 \\
0 \\
0 \\
0 \\
0\end{array}$ & $M G / L$ & $\begin{array}{l}< \\
< \\
< \\
< \\
< \\
< \\
< \\
< \\
< \\
< \\
<\end{array}$ & $\begin{array}{l}0.01 \\
0.01 \\
0.01 \\
0.01 \\
0.01 \\
0.01 \\
0.01 \\
0.01 \\
0.07 \\
0.01 \\
0.01\end{array}$ & $\begin{array}{l}J \\
\mathbf{L}\end{array}$ & $\begin{array}{l}0.01 \\
0.01 \\
0.01 \\
0.01 \\
0.01 \\
0.01 \\
0.01 \\
0.01 \\
0.01 \\
0.01 \\
0.01\end{array}$ & $\begin{array}{l}- \\
- \\
- \\
- \\
- \\
- \\
- \\
-\end{array}$ \\
\hline
\end{tabular}

FORMATION OF COMPLETION COOE:

AL - ALLUVIUM

PARAMETER VALUE INDICATOR (PVI): < - LESS THAN DETECTION LIMIT

OTHER PARAMETER VALUE FLAGS:

$J$ - ESTIMATED VALUE

L - LESS THAN THREE BORE VOLUMES REMOVED BEFORE SAMPLING
FLOW RELATIONSHIP CODE:

O - ON-SITE

\section{SAMPLE ID CODES:}

0001 - FILTERED SAMPLE (.45 MICRONS)

0002 - FILTERED REPLICATE SAMPLE (.45 MICRONS)

0003 - FILTERED REPLICATE SAMPLE (.45 MICRONS)

0004 - FILTERED REPLICATE SAMPLE (.45 MICRONS) 
TABLE 3.5 BACKGROUND GROUND WATER QUALITY DATA BY PARAMETER FOR THE ALLUVIUM, NC AND UC PROCESSING SITES, SLICK ROCK, COLORADO

SITE: SRKO1 SLICK ROCK (BOTH SITES)

09/09/82 TO $02 / 22 / 94$

REPORT DATE : $09 / 28 / 94$

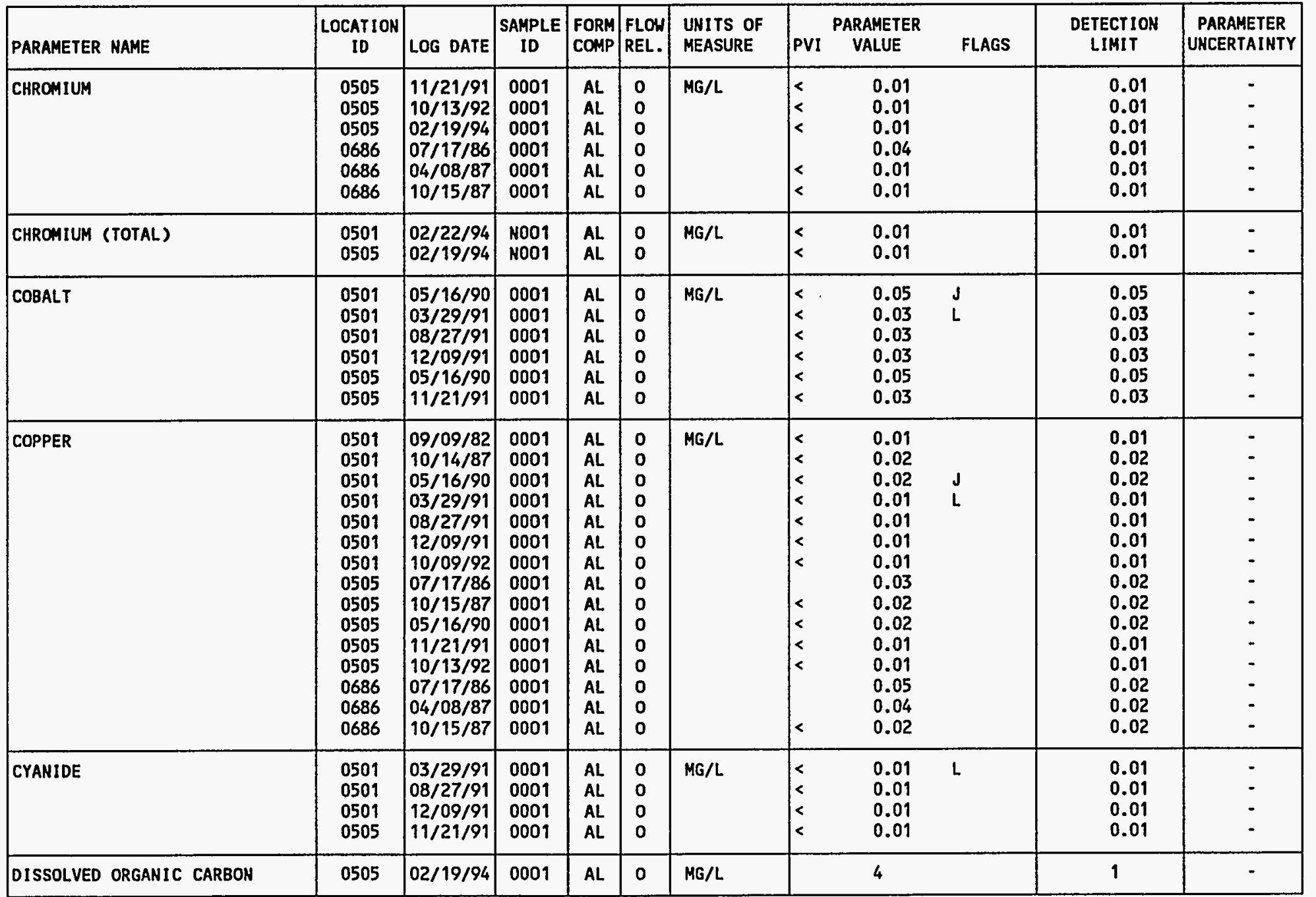

FORMATION OF COMPLETION CODE:

AL - ALLUVIUM

FLOW RELATIONSHIP CODE:

PARAMETER VALUE INDICATOR (PVI): < - LESS THAN DETECTION LIMIT

SAMPLE ID CODES:

ODO1 - FILTERED SAMPLE (.45 MICRONS)

OTHER PARAMETER VALUE FLAGS:

NOO1 - UNFILTERED SAMPLE

J - ESTIMATED VALUE

$L$ - LESS THAN THREE BORE VOLUMES REMOVED BEFORE SAMPLING 
TABLE 3.5 BACKGROUND GROUND WATER QUALITY DATA BY PARAMETER FOR THE ALLUVIUA, NC AND UC PROCESSING SITES, SLICK ROCK, COLORADO

SITE: SRKO1 SLICK ROCK (BOTH SITES)

O9/09/82 TO 02/22/94

REPORT DATE: $09 / 28 / 94$

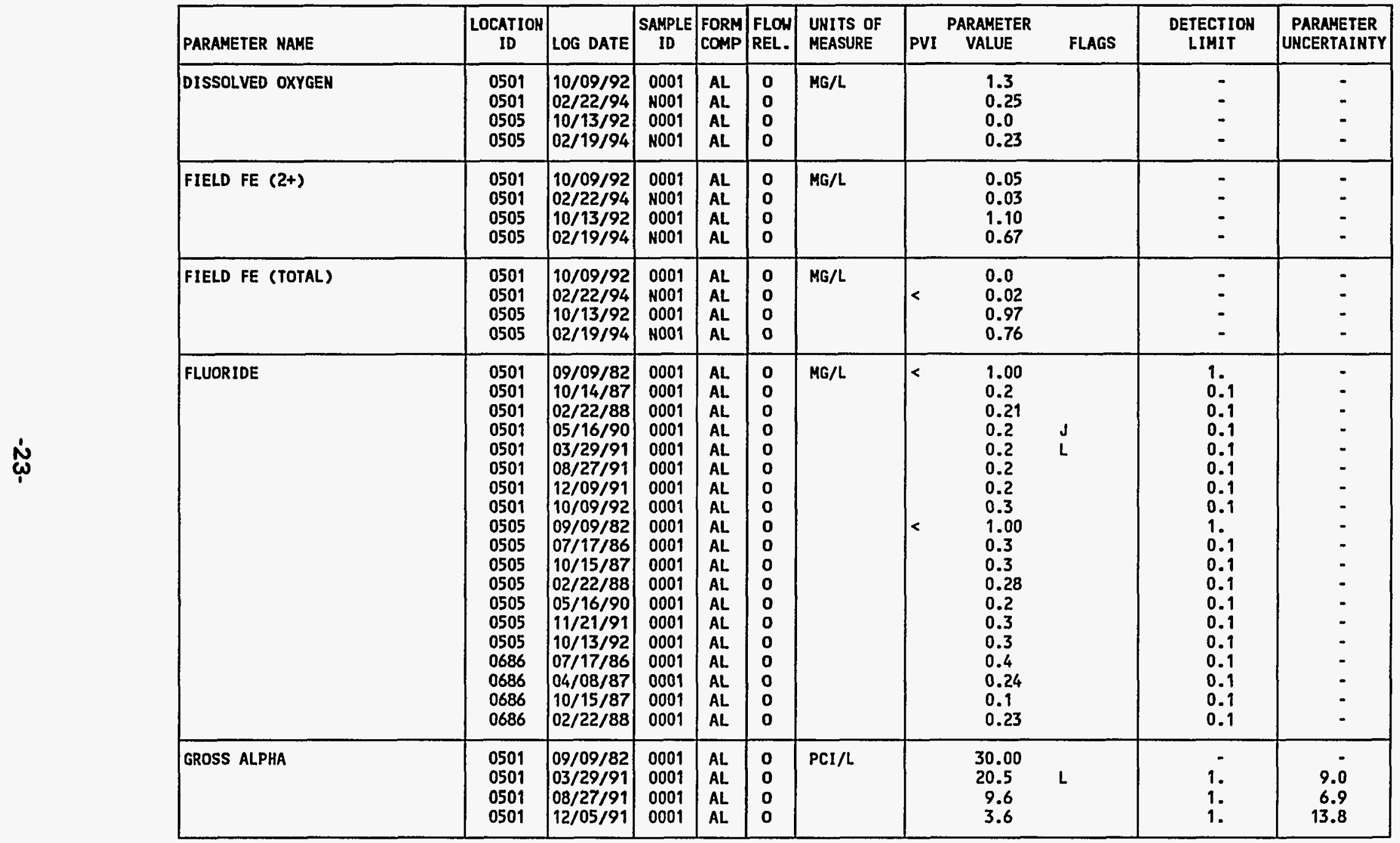

FORMATION OF COMPLETION COOE:

aL - alluViUi

PARAMETER VALUE INDICATOR (PVI): < - LESS THAN DETECTION LIMIT

OTHER PARAMETER VALUE FLAGS:

$J$ - ESTIMATED VALUE
L - LESS THAN THREE BORE VOLUMES REMOVED BEFORE SAMPLIHG
FLOW RELATIOHSHIP CODE:

O- ON-SITE

\section{SAMPLE IO COOES:}

0001 - FILTERED SAMPLE (.45 MICRONS)

NO01 - UNFILTERED SAMPLE 
TABLE 3.5 BACKGROUND GROUND HATER QUALITY DATA BY PARAMETER FOR THE ALLUVIUM, HC AND UC PROCESSING SITES, SLICK ROCK, COLORADO

SITE: SRK01 SLICK ROCK (BOTH SITES)

09/09/82 TO 02/22/94

\begin{tabular}{|c|c|c|c|c|c|c|c|c|c|c|c|}
\hline PARAMETER NAME & $\underset{\text { ID }}{\text { LOCATION }}$ & LOG DATE & $\begin{array}{c}\text { SAMPLE } \\
\text { ID }\end{array}$ & $\begin{array}{l}\text { FORM } \\
\text { COMP }\end{array}$ & $\begin{array}{l}\text { FLOW } \\
\text { REL. }\end{array}$ & $\begin{array}{l}\text { UNITS OF } \\
\text { MEASURE }\end{array}$ & PVI & $\begin{array}{l}\text { PARAMETER } \\
\text { VALUE }\end{array}$ & FLAGS & $\begin{array}{l}\text { DETECTION } \\
\text { LIMIT }\end{array}$ & $\begin{array}{l}\text { PARAMETER } \\
\text { UNCERTAINTY }\end{array}$ \\
\hline GROSS ALPHA & $\begin{array}{l}0501 \\
0501 \\
0505 \\
0505 \\
0505\end{array}$ & $\begin{array}{l}10 / 09 / 92 \\
02 / 22 / 94 \\
12 / 05 / 91 \\
10 / 13 / 92 \\
02 / 19 / 94\end{array}$ & $\begin{array}{l}0001 \\
0001 \\
0001 \\
0001 \\
0001\end{array}$ & $\begin{array}{l}A L \\
A L \\
A L \\
A L \\
A L\end{array}$ & $\begin{array}{l}0 \\
0 \\
0 \\
0 \\
0\end{array}$ & $\mathrm{PCI} / \mathrm{L}$ & & $\begin{array}{r}17.0 \\
20.2 \\
0.0 \\
7.7 \\
13.7\end{array}$ & $\begin{array}{l}n \\
n \\
*\end{array}$ & $\begin{array}{c}12.2 \\
4.2 \\
1 . \\
16.1 \\
3.9\end{array}$ & $\begin{array}{r}9.2 \\
4.5 \\
17.6 \\
10.5 \\
2.8\end{array}$ \\
\hline GROSS ALPHA (TOTAL) & $\begin{array}{l}0501 \\
0505\end{array}$ & $\begin{array}{l}02 / 22 / 94 \\
02 / 19 / 94\end{array}$ & $\begin{array}{l}\text { N001 } \\
\text { N001 }\end{array}$ & $\begin{array}{l}A L \\
A L\end{array}$ & $\begin{array}{l}0 \\
0\end{array}$ & $\mathrm{PCI} / \mathrm{L}$ & & $\begin{array}{l}19.9 \\
10.9\end{array}$ & $\star$ & $\begin{array}{l}3.7 \\
4.2\end{array}$ & $\begin{array}{l}3.4 \\
3.6\end{array}$ \\
\hline GROSS BETA & $\begin{array}{l}0501 \\
0501 \\
0501 \\
0501 \\
0505 \\
0505\end{array}$ & $\begin{array}{l}03 / 29 / 91 \\
08 / 27 / 91 \\
12 / 05 / 91 \\
10 / 09 / 92 \\
12 / 05 / 91 \\
10 / 13 / 92\end{array}$ & $\begin{array}{l}0001 \\
0001 \\
0001 \\
0001 \\
0001 \\
0001\end{array}$ & $\begin{array}{l}A L \\
A L \\
A L \\
A L \\
A L \\
A L\end{array}$ & $\begin{array}{l}0 \\
0 \\
0 \\
0 \\
0 \\
0\end{array}$ & $\mathrm{PCI} / \mathrm{L}$ & & $\begin{array}{r}9.9 \\
11.5 \\
0.6 \\
12.6 \\
0.0 \\
8.5\end{array}$ & $\begin{array}{l}\mathrm{L} \\
* \mathrm{~N} \\
{ }^{*} N\end{array}$ & $\begin{array}{r}0.5 \\
0.5 \\
0.5 \\
10.6 \\
0.5 \\
14.5\end{array}$ & $\begin{array}{l}4.6 \\
4.3 \\
7.8 \\
6.9 \\
9.9 \\
9.0\end{array}$ \\
\hline IRON & $\begin{array}{l}0501 \\
0501 \\
0501 \\
0501 \\
0501 \\
0501 \\
0501 \\
0501 \\
0501 \\
0501 \\
0501 \\
0501 \\
0501 \\
0501 \\
0501 \\
0505 \\
0505 \\
0505 \\
0505 \\
0505 \\
0505\end{array}$ & $\begin{array}{l}09 / 09 / 82 \\
02 / 18 / 86 \\
02 / 18 / 86 \\
02 / 18 / 86 \\
02 / 18 / 86 \\
02 / 18 / 86 \\
07 / 01 / 86 \\
10 / 14 / 87 \\
02 / 22 / 88 \\
05 / 16 / 90 \\
03 / 29 / 91 \\
08 / 27 / 91 \\
12 / 09 / 91 \\
10 / 09 / 92 \\
02 / 22 / 94 \\
09 / 09 / 82 \\
02 / 18 / 86 \\
07 / 17 / 86 \\
10 / 15 / 87 \\
02 / 22 / 88 \\
05 / 16 / 90\end{array}$ & $\begin{array}{l}0001 \\
0001 \\
0002 \\
0003 \\
0004 \\
0005 \\
0001 \\
0001 \\
0001 \\
0001 \\
0001 \\
0001 \\
0001 \\
0001 \\
0001 \\
0001 \\
0001 \\
0001 \\
0001 \\
0001 \\
0001\end{array}$ & $\begin{array}{l}A L \\
A L \\
A L \\
A L \\
A L \\
A L \\
A L \\
A L \\
A L \\
A L \\
A L \\
A L \\
A L \\
A L \\
A L \\
A L \\
A L \\
A L \\
A L \\
A L \\
A L\end{array}$ & $\begin{array}{l}0 \\
0 \\
0 \\
0 \\
0 \\
0 \\
0 \\
0 \\
0 \\
0 \\
0 \\
0 \\
0 \\
0 \\
0 \\
0 \\
0 \\
0 \\
0 \\
0 \\
0\end{array}$ & $M G / L$ & $\begin{array}{l}< \\
< \\
< \\
<\end{array}$ & $\begin{array}{l}0.71 \\
0.25 \\
0.25 \\
0.25 \\
0.25 \\
0.25 \\
0.05 \\
0.03 \\
0.05 \\
0.05 \\
0.03 \\
0.03 \\
0.03 \\
0.03 \\
0.03 \\
5.20 \\
0.16 \\
0.31 \\
0.24 \\
0.12 \\
0.67\end{array}$ & $\begin{array}{l}J \\
\text { L }\end{array}$ & $\begin{array}{l}- \\
0.03 \\
0.03 \\
0.03 \\
0.03 \\
0.03 \\
0.03 \\
0.03 \\
0.03 \\
0.03 \\
0.03 \\
0.03 \\
0.03 \\
0.03 \\
0.03 \\
- \\
0.03 \\
0.03 \\
0.03 \\
0.03 \\
0.03\end{array}$ & $\begin{array}{l}- \\
- \\
- \\
- \\
- \\
- \\
- \\
- \\
- \\
- \\
- \\
- \\
- \\
- \\
- \\
-\end{array}$ \\
\hline
\end{tabular}

FORMATION OF COMPLETION CODE: AL - ALLUVIUM

PARAMETER VALUE INDICATOR (PVI): < - LESS THAN DETECTION LIMIT OTHER PARAMETER VALUE FLAGS:

* - DUPLICATE AKALYSIS NOT HITHIN CONTROL LIMITS

J - ESTIMATED VALUE

L - LESS THAN THREE BORE VOLUMES REMOVED BEFORE SAMPLING

N - SPIKE SAMPLE RECOVERY NOT WITHIN CONTROL LIMITS
FLOH RELATIONSHIP CODE:

O - ON-SITE

SAMPLE ID CODES:

0001 - FILTERED SAMPLE (.45 MICRONS)

0002 - FILTERED REPLICATE SAMPLE (.45 MICRONS)

0003 - FILTERED REPLICATE SAMPLE (.45 MICRONS)

0004 - FILTERED REPLICATE SAMPLE (.45 MICRONS)

NOO1 - UNFILTERED SAMPLE 
TABLE 3.5 BACKGROUND GROUND WATER QUALITY DATA BY PARAMETER FOR THE

ALLUVIUH, HC AND UC PROCESSING SITES, SLICK ROCK, COLORADO

SITE: SRKO1 SLICK ROCK (BOTH SITES)

09/09/82 TO 02/22/94

REPORT DATE: 09/28/94

\begin{tabular}{|c|c|c|c|c|c|c|c|c|c|c|c|}
\hline PARAMETER HAME & $\underset{\text { ID }}{\text { LOCATION }}$ & LOG DATE & $\underset{\text { ID }}{\text { SAMPLE }}$ & $\begin{array}{l}\text { FORM } \\
\text { CONP }\end{array}$ & $\begin{array}{l}\text { FLOW } \\
\text { REL. }\end{array}$ & $\begin{array}{l}\text { UNITS OF } \\
\text { MEASURE }\end{array}$ & PVI & $\begin{array}{l}\text { ARAMETER } \\
\text { VALUE }\end{array}$ & FLAGS & $\begin{array}{l}\text { DETECTIOK } \\
\text { LIMIT }\end{array}$ & $\begin{array}{l}\text { PARAMETER } \\
\text { UNCERTAINTY }\end{array}$ \\
\hline IRON & $\begin{array}{l}0505 \\
0505 \\
0505 \\
0686 \\
0686 \\
0686 \\
0686\end{array}$ & $\begin{array}{l}11 / 21 / 91 \\
10 / 13 / 92 \\
02 / 19 / 94 \\
07 / 17 / 86 \\
04 / 08 / 87 \\
10 / 15 / 87 \\
02 / 22 / 88\end{array}$ & $\begin{array}{l}0001 \\
0001 \\
0001 \\
0001 \\
0001 \\
0001 \\
0001\end{array}$ & $\begin{array}{l}A L \\
A L \\
A L \\
A L \\
A L \\
A L \\
A L\end{array}$ & $\begin{array}{l}0 \\
0 \\
0 \\
0 \\
0 \\
0 \\
0\end{array}$ & MG/L & & $\begin{array}{l}0.58 \\
0.92 \\
0.59 \\
0.07 \\
0.06 \\
0.58 \\
0.65\end{array}$ & & $\begin{array}{l}0.03 \\
0.03 \\
0.03 \\
0.03 \\
0.03 \\
0.03 \\
0.03\end{array}$ & $\begin{array}{l}- \\
- \\
- \\
- \\
-\end{array}$ \\
\hline IRON (TOTAL) & $\begin{array}{l}0501 \\
0505\end{array}$ & $\mid \begin{array}{l}02 / 22 / 94 \\
02 / 19 / 94\end{array}$ & $\begin{array}{l}\text { H001 } \\
\text { H001 }\end{array}$ & $\begin{array}{l}A L \\
A L\end{array}$ & $\begin{array}{l}0 \\
0\end{array}$ & MG/L & $<$ & $\begin{array}{l}0.03 \\
0.58\end{array}$ & & $\begin{array}{l}0.03 \\
0.03\end{array}$ & - \\
\hline LEAD & $\begin{array}{l}0501 \\
0501 \\
0501 \\
0501 \\
0501 \\
0501 \\
0501 \\
0505 \\
0505 \\
0505 \\
0505 \\
0505 \\
0686 \\
0686 \\
0686\end{array}$ & \begin{tabular}{|l|}
$09 / 09 / 82$ \\
$10 / 14 / 87$ \\
$05 / 16 / 90$ \\
$03 / 29 / 91$ \\
$08 / 27 / 91$ \\
$12 / 09 / 91$ \\
$10 / 09 / 92$ \\
$07 / 17 / 86$ \\
$10 / 15 / 87$ \\
$05 / 16 / 90$ \\
$11 / 21 / 91$ \\
$10 / 13 / 92$ \\
$07 / 17 / 86$ \\
$04 / 08 / 87$ \\
$10 / 15 / 87$
\end{tabular} & $\begin{array}{l}0001 \\
0001 \\
0001 \\
0001 \\
0001 \\
0001 \\
0001 \\
0001 \\
0001 \\
0001 \\
0001 \\
0001 \\
0001 \\
0001 \\
0001\end{array}$ & $\begin{array}{l}A L \\
A L \\
A L \\
A L . \\
A L \\
A L \\
A L \\
A L \\
A L \\
A L \\
A L \\
A L \\
A L \\
A L \\
A L\end{array}$ & $\begin{array}{l}0 \\
0 \\
0 \\
0 \\
0 \\
0 \\
0 \\
0 \\
0 \\
0 \\
0 \\
0 \\
0 \\
0 \\
0\end{array}$ & $M G / L$ & $\begin{array}{l}< \\
< \\
< \\
< \\
< \\
< \\
< \\
< \\
< \\
< \\
< \\
< \\
< \\
< \\
<\end{array}$ & $\begin{array}{l}0.01 \\
0.01 \\
0.01 \\
0.005 \\
0.005 \\
0.005 \\
0.02 \\
0.01 \\
0.01 \\
0.01 \\
0.005 \\
0.02 \\
0.01 \\
0.001 \\
0.01\end{array}$ & $\begin{array}{l}\mathrm{J} \\
\mathrm{L} \\
1\end{array}$ & $\begin{array}{l}0.01 \\
0.01 \\
0.01 \\
0.005 \\
0.005 \\
0.005 \\
0.02 \\
0.01 \\
0.01 \\
0.01 \\
0.005 \\
0.02 \\
0.01 \\
0.01 \\
0.01\end{array}$ & $\begin{array}{l}- \\
- \\
- \\
- \\
- \\
- \\
- \\
- \\
- \\
- \\
-\end{array}$ \\
\hline LEAD-210 & $\begin{array}{l}0501 \\
0501 \\
0501 \\
0505 \\
0505 \\
0505\end{array}$ & $\begin{array}{l}08 / 27 / 91 \\
12 / 05 / 91 \\
02 / 22 / 94 \\
07 / 17 / 86 \\
12 / 05 / 91 \\
02 / 19 / 94\end{array}$ & $\begin{array}{l}0001 \\
0001 \\
0001 \\
0001 \\
0001 \\
0001\end{array}$ & $\begin{array}{l}A L \\
A L \\
A L \\
A L \\
A L \\
A L\end{array}$ & $\begin{array}{l}0 \\
0 \\
0 \\
0 \\
0 \\
0\end{array}$ & $\mathrm{PCI} / \mathrm{L}$ & & $\begin{array}{l}1.1 \\
1.5 \\
0.0 \\
0.7 \\
2.9 \\
0.0\end{array}$ & J & $\begin{array}{l}1.5 \\
1.5 \\
0.0 \\
1.5 \\
1.5 \\
1.8\end{array}$ & $\begin{array}{l}1.0 \\
1.4 \\
0.0 \\
1.3 \\
1.0 \\
1.1\end{array}$ \\
\hline LEAD-210 (TOTAL) & $\begin{array}{l}0501 \\
0505\end{array}$ & $\begin{array}{l}02 / 22 / 94 \\
02 / 19 / 94\end{array}$ & $\begin{array}{l}\text { N001 } \\
\text { N001 }\end{array}$ & $\begin{array}{l}\text { AL } \\
\text { AL. }\end{array}$ & $\begin{array}{l}0 \\
0\end{array}$ & $\mathrm{PCI} / \mathrm{L}$ & & $\begin{array}{l}0.0 \\
0.6\end{array}$ & & $\begin{array}{l}0.0 \\
1.7\end{array}$ & $\begin{array}{l}0.0 \\
0.9\end{array}$ \\
\hline MAGNESIUM & 0501 & $|09 / 09 / 82|$ & 0001 & AL & 0 & MG/L & & 32.00 & & - & - \\
\hline
\end{tabular}

FORHATIOH OF COMPLETION CODE:

AL - ALLUVIUM

PARAMETER VALUE INDICATOR (PVI): < - LESS THAN DETECTION LIMIT

OTHER PARAMETER VALUE FLAGS:

1 - INCREASED DETECTION LIMIT DUE TO REQUIRED DILUTION

$J$ - ESTIMATED VALUE

L - LESS THAN THREE BORE VOLUMES REMOVED BEFORE SAMPLING
FLOW RELATIONSHIP CODE:

O - ON-SITE

\section{SAMPLE ID CODES:}

0001 - FILTERED SAMPLE (.45 MICRONS)

NOO1 - UNFILTERED SAMPLE 
TABLE 3.5 BACKGROUND GROUND WATER QUALITY DATA BY PARAMETER FOR THE ALLUVIUM, NC AND UC PROCESSING SITES, SLICK ROCK, COLORADO

SITE: SRK01 SLICK ROCK (BOTH SITES)

$09 / 09 / 82$ TO $02 / 22194$

REPORT DATE : $09 / 28 / 94$

\begin{tabular}{|c|c|c|c|c|c|c|c|c|c|c|c|}
\hline PARAMETER NAME & $\underset{\text { ID }}{\text { LOCATION }}$ & LOG DATE & $\begin{array}{c}\text { SAMPLEE } \\
\text { ID }\end{array}$ & $\begin{array}{l}\text { FORM } \\
\text { COMP }\end{array}$ & $\begin{array}{l}\text { FLOW } \\
\text { REL. }\end{array}$ & $\begin{array}{l}\text { UNITS OF } \\
\text { MEASURE }\end{array}$ & PVI & $\begin{array}{c}\text { PARAMETER } \\
\text { VALUE }\end{array}$ & FLAGS & $\begin{array}{l}\text { DETECTION } \\
\text { LIMIT }\end{array}$ & $\begin{array}{l}\text { PARAMETER } \\
\text { UNCERTAINTY }\end{array}$ \\
\hline MAGNESIUM & $\begin{array}{l}0501 \\
0501 \\
0501 \\
0501 \\
0501 \\
0501 \\
0501 \\
0501 \\
0501 \\
0501 \\
0501 \\
0501 \\
0501 \\
0501 \\
0505 \\
0505 \\
0505 \\
0505 \\
0505 \\
0505 \\
0505 \\
0505 \\
0505 \\
0686 \\
0686 \\
0686 \\
0686\end{array}$ & $\begin{array}{l}02 / 18 / 86 \\
02 / 18 / 86 \\
02 / 18 / 86 \\
02 / 18 / 86 \\
02 / 18 / 86 \\
07 / 01 / 86 \\
10 / 14 / 87 \\
02 / 22 / 88 \\
05 / 16 / 90 \\
03 / 29 / 91 \\
08 / 27 / 91 \\
12 / 09 / 91 \\
10 / 09 / 92 \\
02 / 22 / 94 \\
09 / 09 / 82 \\
02 / 18 / 86 \\
07 / 17 / 86 \\
10 / 15 / 87 \\
02 / 22 / 88 \\
05 / 16 / 90 \\
11 / 21 / 91 \\
10 / 13 / 92 \\
02 / 19 / 94 \\
07 / 17 / 86 \\
04 / 08 / 87 \\
10 / 15 / 87 \\
02 / 22 / 88\end{array}$ & $\begin{array}{l}0001 \\
0002 \\
0003 \\
0004 \\
0005 \\
0001 \\
0001 \\
0001 \\
0001 \\
0001 \\
0001 \\
0001 \\
0001 \\
0001 \\
0001 \\
0001 \\
0001 \\
0001 \\
0001 \\
0001 \\
0001 \\
0001 \\
0001 \\
0001 \\
0001 \\
0001 \\
0001\end{array}$ & $\begin{array}{l}A L \\
A L \\
A L \\
A L \\
A L \\
A L \\
A L \\
A L \\
A L \\
A L \\
A L \\
A L \\
A L \\
A L \\
A L \\
A L \\
A L \\
A L \\
A L \\
A L \\
A L \\
A L \\
A L \\
A L \\
A L \\
A L \\
A L\end{array}$ & $\begin{array}{l}0 \\
0 \\
0 \\
0 \\
0 \\
0 \\
0 \\
0 \\
0 \\
0 \\
0 \\
0 \\
0 \\
0 \\
0 \\
0 \\
0 \\
0 \\
0 \\
0 \\
0 \\
0 \\
0 \\
0 \\
0 \\
0 \\
0\end{array}$ & $M G / L$ & & $\begin{array}{l}46.7 \\
46.7 \\
46.7 \\
46.7 \\
46.7 \\
29 . \\
36 . \\
41.9 \\
29.6 \\
28.7 \\
30.3 \\
28.3 \\
27.5 \\
35.6 \\
75.00 \\
65.7 \\
52.2 \\
41.9 \\
45.5 \\
50.4 \\
48.7 \\
55.0 \\
42.1 \\
20.9 \\
30.3 \\
26 . \\
30.9\end{array}$ & $\begin{array}{l}\mathrm{J} \\
\mathrm{L}\end{array}$ & $\begin{array}{l}0.001 \\
0.001 \\
0.001 \\
0.001 \\
0.001 \\
0.001 \\
0.001 \\
0.001 \\
0.001 \\
0.1 \\
0.1 \\
0.1 \\
0.1 \\
0.1 \\
- \\
0.001 \\
0.001 \\
0.001 \\
0.001 \\
0.001 \\
0.1 \\
0.5 \\
0.1 \\
0.001 \\
0.001 \\
0.001 \\
0.001\end{array}$ & $\begin{array}{l}- \\
- \\
: \\
- \\
- \\
- \\
- \\
- \\
- \\
- \\
- \\
- \\
- \\
- \\
- \\
- \\
- \\
- \\
- \\
-\end{array}$ \\
\hline MAGNESIUM (TOTAL) & $\begin{array}{l}0501 \\
0505\end{array}$ & $\begin{array}{l}02 / 22 / 94 \\
02 / 19 / 94\end{array}$ & $\begin{array}{l}\text { N001 } \\
\text { N001 }\end{array}$ & $\begin{array}{l}\text { AL } \\
\text { AL }\end{array}$ & $\begin{array}{l}0 \\
0\end{array}$ & $M G / L$ & & $\begin{array}{l}33.9 \\
41.2\end{array}$ & & $\begin{array}{l}0.1 \\
0.1\end{array}$ & - \\
\hline MANGANESE & $\begin{array}{l}0501 \\
0501 \\
0501 \\
0501 \\
0501 \\
0501 \\
0501\end{array}$ & $\begin{array}{l}02 / 18 / 86 \\
02 / 18 / 86 \\
02 / 18 / 86 \\
02 / 18 / 86 \\
02 / 18 / 86 \\
07 / 01 / 86 \\
10 / 14 / 87\end{array}$ & $\begin{array}{l}0001 \\
0002 \\
0003 \\
0004 \\
0005 \\
0001 \\
0001\end{array}$ & $\begin{array}{l}A L \\
A L \\
A L \\
A L \\
A L \\
A L \\
A L\end{array}$ & $\begin{array}{l}0 \\
0 \\
0 \\
0 \\
0 \\
0 \\
0\end{array}$ & $M G / L$ & $<$ & $\begin{array}{l}0.26 \\
0.26 \\
0.26 \\
0.26 \\
0.26 \\
0.04 \\
0.01\end{array}$ & & $\begin{array}{l}0.01 \\
0.01 \\
0.01 \\
0.01 \\
0.01 \\
0.01 \\
0.01\end{array}$ & $\begin{array}{l}- \\
- \\
- \\
-\end{array}$ \\
\hline
\end{tabular}

FORMATION OF COMPLETION CODE:

$A L$ - ALLUUVIUM

PARAMETER VALUE INDICATOR (PVI): < - LESS THAN DETECTION LIMIT

OTHER PARAMETER VALUE FLAGS:

$J$ - ESTIMATED VALUE

$L$ - LESS tHAN THREE BORE VOLUMES REMOVED BEFORE SAMPLING
FLOW RELATIONSHIP CODE:

0001 - FILTERED SAMPLE (. 45 MICRONS)

0002 - FILTERED REPLICATE SAMPLE (.45 MICRONS)

0002 - FILTERED REPLICATE SAMPLE (.45 MICRONS)

0004 - FILTERED REPLICATE SAMPLE (.45 MICRONS)

NOO1 - UNFILTERED SAMPLE 
TABLE 3.5 BACKGROUND GROUND MATER QUALITY DATA BY PARAMETER FOR THE ALLUVIUN, NC AND UC PROCESSING SITES, SLICK ROCK, COLORADO

SITE: SRKOI SLICK ROCK (BOTH SITES)

09/09/82 TO 02/22/94

REPORT DATE: $09 / 28 / 94$

\begin{tabular}{|c|c|c|c|c|c|c|c|c|c|c|c|}
\hline PARAMETER NAME & $\int_{10}^{\text {LOCATION }}$ & LOS DATE & $\begin{array}{c}\text { SAMPLE } \\
\text { ID }\end{array}$ & $\begin{array}{l}\text { FORM } \\
\text { COMP }\end{array}$ & $\begin{array}{l}\text { FLOW } \\
\text { REL. }\end{array}$ & $\begin{array}{l}\text { UNITS OF } \\
\text { MEASURE }\end{array}$ & PVI & $\begin{array}{l}\text { PARAMETER } \\
\text { VALUE }\end{array}$ & FLAGS & $\begin{array}{l}\text { DETECTION } \\
\text { LIMIT }\end{array}$ & $\begin{array}{l}\text { PARAMETER } \\
\text { UNCERTAINTY }\end{array}$ \\
\hline MANGANESE & $\begin{array}{l}0501 \\
0501 \\
0501 \\
0501 \\
0501 \\
0501 \\
0501 \\
0505 \\
0505 \\
0505 \\
0505 \\
0505 \\
0505 \\
0505 \\
0505 \\
0686 \\
0686 \\
0686 \\
0686\end{array}$ & $\begin{array}{l}02 / 22 / 88 \\
05 / 16 / 90 \\
03 / 29 / 91 \\
08 / 27 / 91 \\
12 / 09 / 91 \\
10 / 09 / 92 \\
02 / 22 / 94 \\
02 / 18 / 86 \\
07 / 17 / 86 \\
10 / 15 / 87 \\
02 / 22 / 88 \\
05 / 16 / 90 \\
11 / 21 / 91 \\
10 / 13 / 92 \\
02 / 19 / 94 \\
07 / 17 / 86 \\
04 / 08 / 87 \\
10 / 15 / 87 \\
02 / 22 / 88\end{array}$ & $\begin{array}{l}0001 \\
0001 \\
0001 \\
0001 \\
0001 \\
0001 \\
0001 \\
0001 \\
0001 \\
0001 \\
0001 \\
0001 \\
0001 \\
0001 \\
0001 \\
0001 \\
0001 \\
0001 \\
0001\end{array}$ & $\begin{array}{l}A L \\
A L \\
A L \\
A L \\
A L \\
A L \\
A L \\
A L \\
A L \\
A L \\
A L \\
A L \\
A L \\
A L \\
A L \\
A L \\
A L \\
A L \\
A L\end{array}$ & $\begin{array}{l}0 \\
0 \\
0 \\
0 \\
0 \\
0 \\
0 \\
0 \\
0 \\
0 \\
0 \\
0 \\
0 \\
0 \\
0 \\
0 \\
0 \\
0 \\
0\end{array}$ & $M G / L$ & $<$ & $\begin{array}{l}0.01 \\
0.02 \\
0.01 \\
0.02 \\
0.02 \\
0.02 \\
0.02 \\
0.32 \\
0.38 \\
0.22 \\
0.24 \\
0.39 \\
0.37 \\
0.39 \\
0.33 \\
1.27 \\
0.30 \\
0.20 \\
0.18\end{array}$ & $\begin{array}{l}J \\
L\end{array}$ & $\begin{array}{l}0.01 \\
0.01 \\
0.01 \\
0.01 \\
0.01 \\
0.01 \\
0.01 \\
0.01 \\
0.01 \\
0.01 \\
0.01 \\
0.01 \\
0.01 \\
0.01 \\
0.01 \\
0.01 \\
0.01 \\
0.01 \\
0.01\end{array}$ & $\begin{array}{l}- \\
- \\
- \\
- \\
- \\
- \\
- \\
- \\
- \\
- \\
- \\
- \\
-\end{array}$ \\
\hline MANGANESE (TOTAL) & $\begin{array}{l}0501 \\
0505\end{array}$ & $\begin{array}{l}02 / 22 / 94 \\
02 / 19 / 94\end{array}$ & $\begin{array}{l}\text { N001 } \\
\text { N001 }\end{array}$ & $\begin{array}{l}\text { AL } \\
\text { AL }\end{array}$ & $\begin{array}{l}\mathbf{0} \\
\mathbf{0}\end{array}$ & $M G / L$ & & $\begin{array}{l}0.02 \\
0.32\end{array}$ & & $\begin{array}{l}0.01 \\
0.01\end{array}$ & $\begin{array}{l}- \\
-\end{array}$ \\
\hline MERCURY & $\begin{array}{l}0501 \\
0501 \\
0501 \\
0501 \\
0501 \\
0501 \\
0505 \\
0505 \\
0505 \\
0505 \\
0686 \\
0686 \\
0686\end{array}$ & $\begin{array}{l}09 / 09 / 82 \\
10 / 14 / 87 \\
05 / 16 / 90 \\
03 / 29 / 91 \\
08 / 27 / 91 \\
12 / 09 / 91 \\
07 / 17 / 86 \\
10 / 15 / 87 \\
05 / 16 / 90 \\
11 / 21 / 91 \\
07 / 17 / 86 \\
04 / 08 / 87 \\
10 / 15 / 87\end{array}$ & $\begin{array}{l}0001 \\
0001 \\
0001 \\
0001 \\
0001 \\
0001 \\
0001 \\
0001 \\
0001 \\
0001 \\
0001 \\
0001 \\
0001\end{array}$ & $\begin{array}{l}A L \\
A L \\
A L \\
A L \\
A L \\
A L \\
A L \\
A L \\
A L \\
A L \\
A L \\
A L \\
A L\end{array}$ & $\begin{array}{l}\mathbf{0} \\
\mathbf{0} \\
\mathbf{0} \\
\mathbf{0} \\
\mathbf{0} \\
\mathbf{0} \\
\mathbf{0} \\
\mathbf{0} \\
\mathbf{0} \\
\mathbf{0} \\
\mathbf{0} \\
\mathbf{0} \\
\mathbf{0}\end{array}$ & MG/L & $\begin{array}{l}< \\
< \\
< \\
< \\
< \\
< \\
< \\
< \\
< \\
< \\
< \\
< \\
< \\
<\end{array}$ & $\begin{array}{l}0.002 \\
0.0002 \\
0.0002 \\
0.0002 \\
0.0002 \\
0.0002 \\
0.0002 \\
0.0002 \\
0.0002 \\
0.0002 \\
0.0002 \\
0.0002 \\
0.0002\end{array}$ & $\begin{array}{l}J \\
L\end{array}$ & $\begin{array}{l}0.002 \\
0.0002 \\
0.0002 \\
0.0002 \\
0.0002 \\
0.0002 \\
0.0002 \\
0.0002 \\
0.0002 \\
0.0002 \\
0.0002 \\
0.0002 \\
0.0002\end{array}$ & $\begin{array}{l}- \\
- \\
- \\
- \\
- \\
- \\
- \\
- \\
-\end{array}$ \\
\hline MOLYYBDENUM & $\begin{array}{l}0501 \\
0501\end{array}$ & $\begin{array}{l}09 / 09 / 82 \\
02 / 18 / 86\end{array}$ & $\begin{array}{l}0001 \\
0001\end{array}$ & $\begin{array}{l}A L \\
A L\end{array}$ & $\begin{array}{l}0 \\
0\end{array}$ & MG/L & & $\begin{array}{l}0.06 \\
0.13\end{array}$ & & 0.01 & - \\
\hline
\end{tabular}

FORMATION OF COMPLETION CODE:

AL - ALLUVIUM

PARAMETER VALUE INDICATOR (PVI): < - LESS THAN DETECTION LIMIT

OTHER PARAMETER VALUE FLAGS:

$J$ - ESTIMATED VALUE

$L$ - LESS THAN THREE BORE VOLUMES REMOVED BEFORE SAMPLING
FLOH RELATIONSHIP CODE:

O - ON-SITE

SAMPLE ID CODES:

0001 - FILTERED SAMPLE (.45 MICRONS)

NO01 - UNFILTERED SAMPLE 
TABLE 3.5 BACKGROUND GROUND MATER QUALITY DATA BY PARAMETER FOR THE ALLUVIUM, NC AND UC PROCESSING SITES, SLICK ROCK, COLORADO

SITE: SRK01 SLICK ROCK (BOTH SITES)

DITE: $02 / 22 / 94$

REPORT DATE: $09 / 28 / 94$

\begin{tabular}{|c|c|c|c|c|c|c|c|c|c|c|c|}
\hline PARAMETER NAME & $\underset{\text { ID }}{\text { LOCATION }}$ & LOG DATE & $\underset{\text { ID }}{\text { SAMPLE }}$ & $\begin{array}{l}\text { FORM } \\
\text { COMP }\end{array}$ & $\begin{array}{l}\text { FLOW } \\
\text { REL. }\end{array}$ & $\begin{array}{l}\text { UNITS OF } \\
\text { MEASURE }\end{array}$ & PVI & $\begin{array}{l}\text { PARAMETER } \\
\text { VALUE }\end{array}$ & FLAGS & $\begin{array}{l}\text { DETECTION } \\
\text { LIMIT }\end{array}$ & $\begin{array}{l}\text { PARAMETER } \\
\text { UNCERTAINTY }\end{array}$ \\
\hline MOLYYBDENUM & $\begin{array}{l}0501 \\
0501 \\
0501 \\
0501 \\
0501 \\
0501 \\
0501 \\
0501 \\
0501 \\
0501 \\
0501 \\
0501 \\
0501 \\
0505 \\
0505 \\
0505 \\
0505 \\
0505 \\
0505 \\
0505 \\
0505 \\
0505 \\
0686 \\
0686 \\
0686 \\
0686\end{array}$ & $\begin{array}{l}02 / 18 / 86 \\
02 / 18 / 86 \\
02 / 18 / 86 \\
02 / 18 / 86 \\
07 / 01 / 86 \\
10 / 14 / 87 \\
02 / 22 / 88 \\
05 / 16 / 90 \\
03 / 29 / 91 \\
08 / 27 / 91 \\
12 / 09 / 91 \\
10 / 09 / 92 \\
02 / 22 / 94 \\
09 / 09 / 82 \\
02 / 18 / 86 \\
07 / 17 / 86 \\
10 / 15 / 87 \\
02 / 22 / 88 \\
05 / 16 / 90 \\
11 / 21 / 91 \\
10 / 13 / 92 \\
02 / 19 / 94 \\
07 / 17 / 86 \\
04 / 08 / 87 \\
10 / 15 / 87 \\
02 / 22 / 88\end{array}$ & $\begin{array}{l}0002 \\
0003 \\
0004 \\
0005 \\
0001 \\
0001 \\
0001 \\
0001 \\
0001 \\
0001 \\
0001 \\
0001 \\
0001 \\
0001 \\
0001 \\
0001 \\
0001 \\
0001 \\
0001 \\
0001 \\
0001 \\
0001 \\
0001 \\
0001 \\
0001 \\
0001\end{array}$ & $\begin{array}{l}A L \\
A L \\
A L \\
A L \\
A L \\
A L \\
A L \\
A L \\
A L \\
A L \\
A L \\
A L \\
A L \\
A L \\
A L \\
A L \\
A L \\
A L \\
A L \\
A L \\
A L \\
A L \\
A L \\
A L \\
A L \\
A L\end{array}$ & $\begin{array}{l}0 \\
0 \\
0 \\
0 \\
0 \\
0 \\
0 \\
0 \\
0 \\
0 \\
0 \\
0 \\
0 \\
0 \\
0 \\
0 \\
0 \\
0 \\
0 \\
0 \\
0 \\
0 \\
0 \\
0 \\
0 \\
0\end{array}$ & $M G / L$ & $<$ & $\begin{array}{l}0.12 \\
0.13 \\
0.13 \\
0.13 \\
0.11 \\
0.03 \\
0.08 \\
0.06 \\
0.05 \\
0.06 \\
0.06 \\
0.07 \\
0.05 \\
0.05 \\
0.14 \\
0.14 \\
0.06 \\
0.1 \\
0.05 \\
0.05 \\
0.06 \\
0.05 \\
0.24 \\
0.1 \\
0.08 \\
0.11\end{array}$ & $\begin{array}{l}\mathrm{J} \\
\mathrm{L}\end{array}$ & $\begin{array}{l}0.01 \\
0.01 \\
0.01 \\
0.01 \\
0.01 \\
0.01 \\
0.01 \\
0.01 \\
0.01 \\
0.01 \\
0.01 \\
0.01 \\
0.01 \\
0.05 \\
0.01 \\
0.01 \\
0.01 \\
0.01 \\
0.01 \\
0.01 \\
0.01 \\
0.01 \\
0.01 \\
0.1 \\
0.01 \\
0.01\end{array}$ & $\begin{array}{l}- \\
- \\
- \\
- \\
- \\
- \\
- \\
- \\
- \\
- \\
- \\
- \\
- \\
- \\
- \\
- \\
- \\
- \\
- \\
-\end{array}$ \\
\hline MOLYBDENUM (TOTAL) & $\begin{array}{l}0501 \\
0505\end{array}$ & $\left|\begin{array}{l}02 / 22 / 94 \\
02 / 19 / 94\end{array}\right|$ & $\begin{array}{l}\text { N001 } \\
\text { N001 }\end{array}$ & $\begin{array}{l}A L \\
A L\end{array}$ & $\begin{array}{l}0 \\
0\end{array}$ & MG/L & & $\begin{array}{l}0.04 \\
0.05\end{array}$ & & $\begin{array}{l}0.01 \\
0.01\end{array}$ & - \\
\hline NET GROSS ALPHA * & $\begin{array}{l}0501 \\
0501 \\
0501 \\
0501 \\
0501 \\
0501\end{array}$ & $\begin{array}{l}09 / 09 / 82 \\
03 / 29 / 91 \\
08 / 27 / 91 \\
12 / 05 / 91 \\
10 / 09 / 92 \\
02 / 22 / 94\end{array}$ & $\begin{array}{l}0001 \\
0001 \\
0001 \\
0001 \\
0001 \\
0001\end{array}$ & $\begin{array}{l}A L \\
A L \\
A L \\
A L \\
A L \\
A L\end{array}$ & $\begin{array}{l}0 \\
0 \\
0 \\
0 \\
0 \\
0\end{array}$ & $\mathrm{PCI} / \mathrm{L}$ & & $\begin{array}{r}-61.92 \\
4.72 \\
-2.75 \\
-9.43 \\
1.91 \\
-2.44\end{array}$ & & $\begin{array}{l}- \\
- \\
- \\
- \\
-\end{array}$ & $\begin{array}{l}- \\
- \\
- \\
-\end{array}$ \\
\hline
\end{tabular}

* Net GROSS ALPHA (GROSS ALPHA - URANIUM) WITH 1 MG URANIUM 0686 PCI

FORMATION OF COMPLETION CODE:

$$
\text { AL - ALLUVIUM }
$$

PARAMETER VALUE INDICATOR (PVI): < - LESS THAN DETECTION LIMIT OTHER PARAMETER VALUE FLAGS:

I - INCREASED DETECTION LIMIT DUE TO REQUIRED DILUTION J - ESTIMATED VALUE

L - LESS THAN THREE BORE VOLUMES REMOVED BEFORE SAMPLING
FLOW RELATIONSHIP CODE:

$$
\text { D - ON-SITE }
$$

SAMPLE ID CODES:

0001 - FILTERED SAMPLE (.45 MICRONS)

0002 - FILTERED REPLICATE SAMPLE (.45 MICRONS)

0003 - FILTERED REPLICATE SAMPLE (.45 MICRONS)

0004 - FILTERED REPLICATE SAMPLE (.45 MICRONS)

NO01 - UNFILTERED SAMPLE 
TABLE 3.5 BACKGROUHD GROUND MATER QUALITY DATA BY PARAMETER FOR THE ALLUVIUN, NC AND UC PROCESSIHG SITES, SLICK ROCK, COLORADO

SITE: SRKO1 SLICK ROCK (BOTH SITES)

$09 / 09 / 82$ TO $02 / 22 / 94$

REPORT DATE: $09 / 28 / 94$

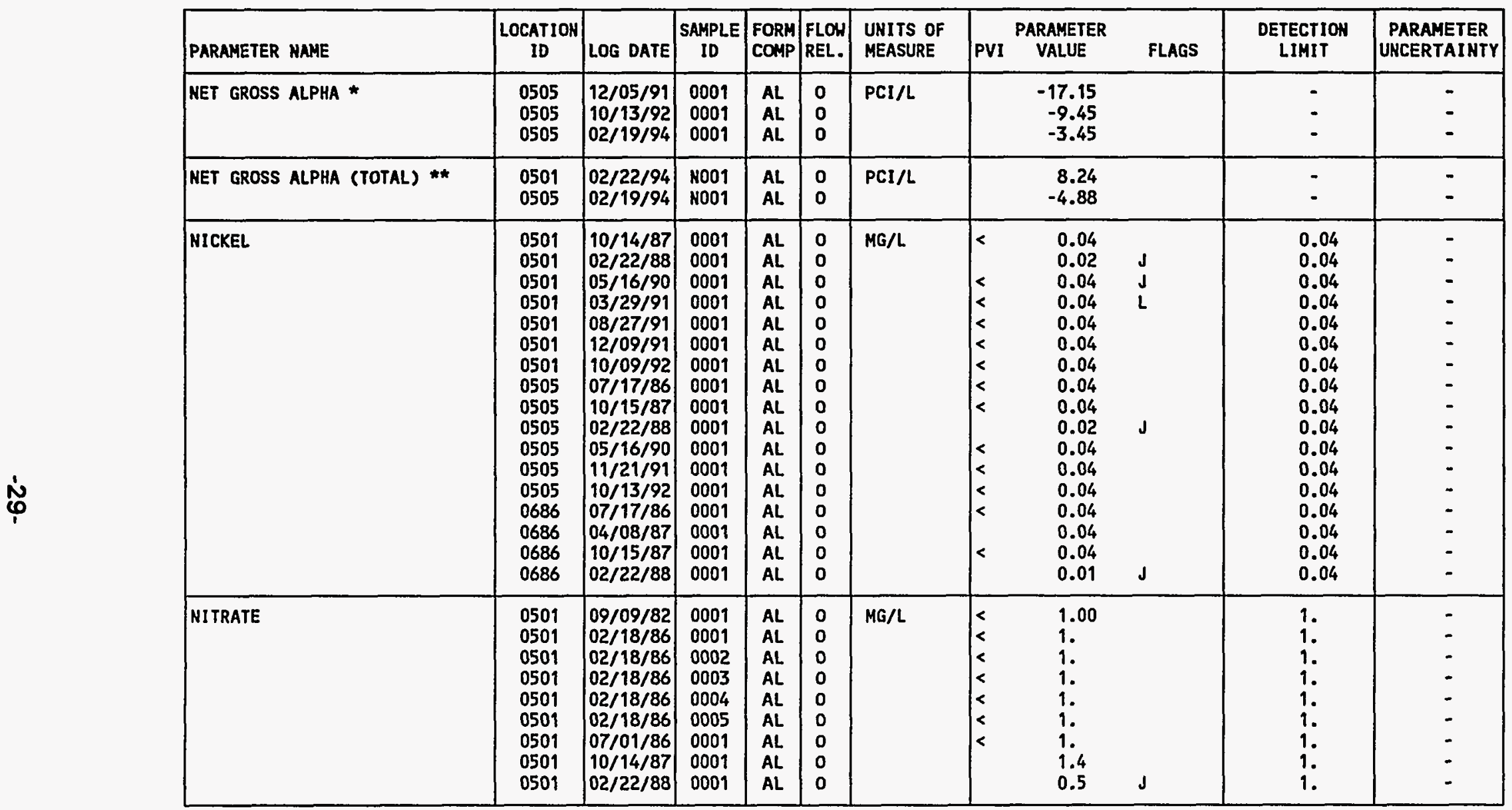

* NET GROSS ALPHA (GROSS ALPHA - URANIUM) WITH 1 MG URANIUM = 686 PCI

** NET GROSS ALPHA (TOTAL) (TOTAL GROSS ALPHA - TOTAL URANIUM)

FORMATION OF COMPLETION CODE:

AL - ALLUVIUM

FLOW RELATIONSHIP CODE:

O- ON-SITE

PARAMETER VALUE INDICATOR (PVI): < - LESS THAN DETECTION LIMIT

SAMPLE ID CODES:

0001 - FILTERED SAMPLE (.45 MICRONS)

0002 - FILTERED REPLICATE SAMPLE (.45 MICRONS)

0003 - FILTERED REPLICATE SAMPLE (.45 MICRONS)

0004 - FILTERED REPLICATE SAMPLE (.45 MICRONS)

$J$ - ESTIMATED VALUE

L - LESS THAH THREE BORE VOLUMES REMOVED BEFORE SAMPLING

NOO1 - UHFILTERED SAMPLE 
TABLE 3.5 BACKGROUND GROUND WATER QUALITY DATA BY PARAMETER FOR THE ALLUVIUM, NC AND UC PROCESSING SITES, SLICK ROCK, COLORADO

SITE: SRKO1 SLICK ROCK (BOTH SITES)

09/09/82 TO $02 / 22 / 94$

REPORT DATE : $09 / 28 / 94$

\begin{tabular}{|c|c|c|c|c|c|c|c|c|c|c|c|}
\hline PARAMETER NAME & $\begin{array}{c}\text { LOCATION } \\
\text { ID }\end{array}$ & LOG DATE & $\begin{array}{c}\text { SAMPLE } \\
\text { ID }\end{array}$ & $\begin{array}{l}\text { FORM } \\
\text { COMP }\end{array}$ & $\begin{array}{l}\text { FLOH } \\
\text { REL. }\end{array}$ & $\begin{array}{l}\text { UNITS OF } \\
\text { MEASURE }\end{array}$ & PVI & $\begin{array}{l}\text { PARAMETER } \\
\text { VALUE }\end{array}$ & FLAGS & $\begin{array}{l}\text { DETECTION } \\
\text { LIMIT }\end{array}$ & $\begin{array}{l}\text { PARAMETER } \\
\text { UNCERTAINTY }\end{array}$ \\
\hline NITRATE & $\begin{array}{l}0501 \\
0501 \\
0501 \\
0501 \\
0501 \\
0505 \\
0505 \\
0505 \\
0505 \\
0505 \\
0505 \\
0505 \\
0505 \\
0686 \\
0686 \\
0686 \\
0686\end{array}$ & $\begin{array}{l}05 / 16 / 90 \\
03 / 29 / 91 \\
08 / 27 / 91 \\
12 / 09 / 91 \\
10 / 09 / 92 \\
09 / 09 / 82 \\
02 / 18 / 86 \\
07 / 17 / 86 \\
10 / 15 / 87 \\
02 / 22 / 88 \\
05 / 16 / 90 \\
11 / 21 / 91 \\
10 / 13 / 92 \\
07 / 17 / 86 \\
04 / 08 / 87 \\
10 / 15 / 87 \\
02 / 22 / 88\end{array}$ & $\begin{array}{l}0001 \\
0001 \\
0001 \\
0001 \\
0001 \\
0001 \\
0001 \\
0001 \\
0001 \\
0001 \\
0001 \\
0001 \\
0001 \\
0001 \\
0001 \\
0001 \\
0001\end{array}$ & $\begin{array}{l}A L \\
A L \\
A L \\
A L \\
A L \\
A L \\
A L \\
A L \\
A L \\
A L \\
A L \\
A L \\
A L \\
A L \\
A L \\
A L \\
A L\end{array}$ & $\begin{array}{l}0 \\
0 \\
0 \\
0 \\
0 \\
0 \\
0 \\
0 \\
0 \\
0 \\
0 \\
0 \\
0 \\
0 \\
0 \\
0 \\
0\end{array}$ & MG/L & $\begin{array}{l}< \\
< \\
< \\
< \\
< \\
< \\
< \\
< \\
< \\
< \\
< \\
<\end{array}$ & $\begin{array}{l}1.0 \\
1.0 \\
7.3 \\
1.0 \\
1.4 \\
1.00 \\
1.0 \\
1.0 \\
1.0 \\
0.4 \\
1.0 \\
1.3 \\
2.0 \\
1.0 \\
1.6 \\
1.0 \\
0.1\end{array}$ & $\begin{array}{l}J \\
L \\
J \\
J \\
J\end{array}$ & $\begin{array}{l}1 . \\
1 . \\
1 . \\
1.0 \\
1.0 \\
1 . \\
1 . \\
1 . \\
1 . \\
1 . \\
1 . \\
1 . \\
1.0 \\
1 . \\
1 . \\
1 . \\
1 .\end{array}$ & $\begin{array}{l}- \\
- \\
- \\
- \\
- \\
- \\
- \\
- \\
- \\
- \\
- \\
-\end{array}$ \\
\hline NITRATE (TOTAL) & $\begin{array}{l}0501 \\
0505\end{array}$ & $\begin{array}{l}02 / 22 / 94 \\
02 / 19 / 94\end{array}$ & $\begin{array}{l}\text { N001 } \\
\text { N001 }\end{array}$ & $\begin{array}{l}\mathrm{AL} \\
\mathrm{AL}\end{array}$ & $\begin{array}{l}0 \\
0\end{array}$ & $M G / L$ & $<$ & $\begin{array}{l}1 \\
1\end{array}$ & & $\begin{array}{l}1 \\
1\end{array}$ & $\dot{-}$ \\
\hline NITRITE AND NITRATE & $\begin{array}{l}0501 \\
0501 \\
0501 \\
0501 \\
0505 \\
0505 \\
0686\end{array}$ & $\begin{array}{l}02 / 22 / 88 \\
05 / 16 / 90 \\
03 / 29 / 91 \\
08 / 27 / 91 \\
02 / 22 / 88 \\
05 / 16 / 90 \\
02 / 22 / 88\end{array}$ & $\begin{array}{l}0001 \\
0001 \\
0001 \\
0001 \\
0001 \\
0001 \\
0001\end{array}$ & $\begin{array}{l}A L \\
A L \\
A L \\
A L \\
A L \\
A L \\
A L\end{array}$ & $\begin{array}{l}0 \\
0 \\
0 \\
0 \\
0 \\
0 \\
0\end{array}$ & $M G / L$ & $\begin{array}{l}< \\
< \\
<\end{array}$ & $\begin{array}{l}0.5 \\
1 . \\
0.20 \\
1.64 \\
0.4 \\
1.0 \\
0.1\end{array}$ & $\begin{array}{l}J \\
J \\
L \\
J \\
J\end{array}$ & $\begin{array}{l}1 . \\
1.05 \\
0.05 \\
0.05 \\
1 . \\
1 . \\
1 .\end{array}$ & $:$ \\
\hline PH & $\begin{array}{l}0501 \\
0501 \\
0501 \\
0501 \\
0501 \\
0501 \\
0501 \\
0501 \\
0501\end{array}$ & $\begin{array}{l}09 / 09 / 82 \\
02 / 18 / 86 \\
02 / 18 / 86 \\
02 / 18 / 86 \\
02 / 18 / 86 \\
02 / 18 / 86 \\
07 / 01 / 86 \\
10 / 14 / 87 \\
02 / 22 / 88\end{array}$ & $\begin{array}{l}0001 \\
0001 \\
0002 \\
0003 \\
0004 \\
0005 \\
0001 \\
0001 \\
0001\end{array}$ & $\begin{array}{l}A L \\
A L \\
A L \\
A L \\
A L \\
A L \\
A L \\
A L \\
A L\end{array}$ & $\begin{array}{l}0 \\
0 \\
0 \\
0 \\
0 \\
0 \\
0 \\
0 \\
0\end{array}$ & su & & $\begin{array}{l}6.70 \\
7.2 \\
7.2 \\
7.2 \\
7.2 \\
7.2 \\
7.16 \\
7.17 \\
7.66\end{array}$ & & $\begin{array}{l}- \\
: \\
: \\
- \\
- \\
-\end{array}$ & $\begin{array}{l}- \\
: \\
: \\
- \\
- \\
-\end{array}$ \\
\hline
\end{tabular}

FOPHATION OF COMPLETION CODE: AL - ALLUVIUM

PARAMETER VALUE IMDICATOR (PVI): < - LESS THAN DETECTION LIMIT OTHER PARAMETER VALUE FLAGS:

$J$ - ESTIMATED VALUE

L - LESS THAN THREE BORE VOLUMES REMOVED BEFORE SAMPLING
FLOW RELATIONSHIP CODE:

$$
\text { O- ON-SITE }
$$

SAMPLE ID CODES:

0001 - FILTERED SAMPLE (.45 MICRONS)

0002 - FILTERED REPLICATE SAMPLE (.45 MICRONS)

0003 - FILTERED REPLICATE SAMPLE (.45 MICRONS)

0004 - FILTERED REPLICATE SAMPLE (.45 MICRONS)

NO01 - UNFILTERED SAMPLE 
TABLE 3.5 BACKGROUND GROUND HATER QUALITY DATA BY PARAMETER FOR THE

ALLUVIUH, HC AND UC PROCESSIHG SITES, SLICK ROCK, COLORADO

SITE: SRKO1 SLICK ROCK (BOTH SITES)

09/09/82 TO 02/22/94

REPORT DATE: 09/28/94

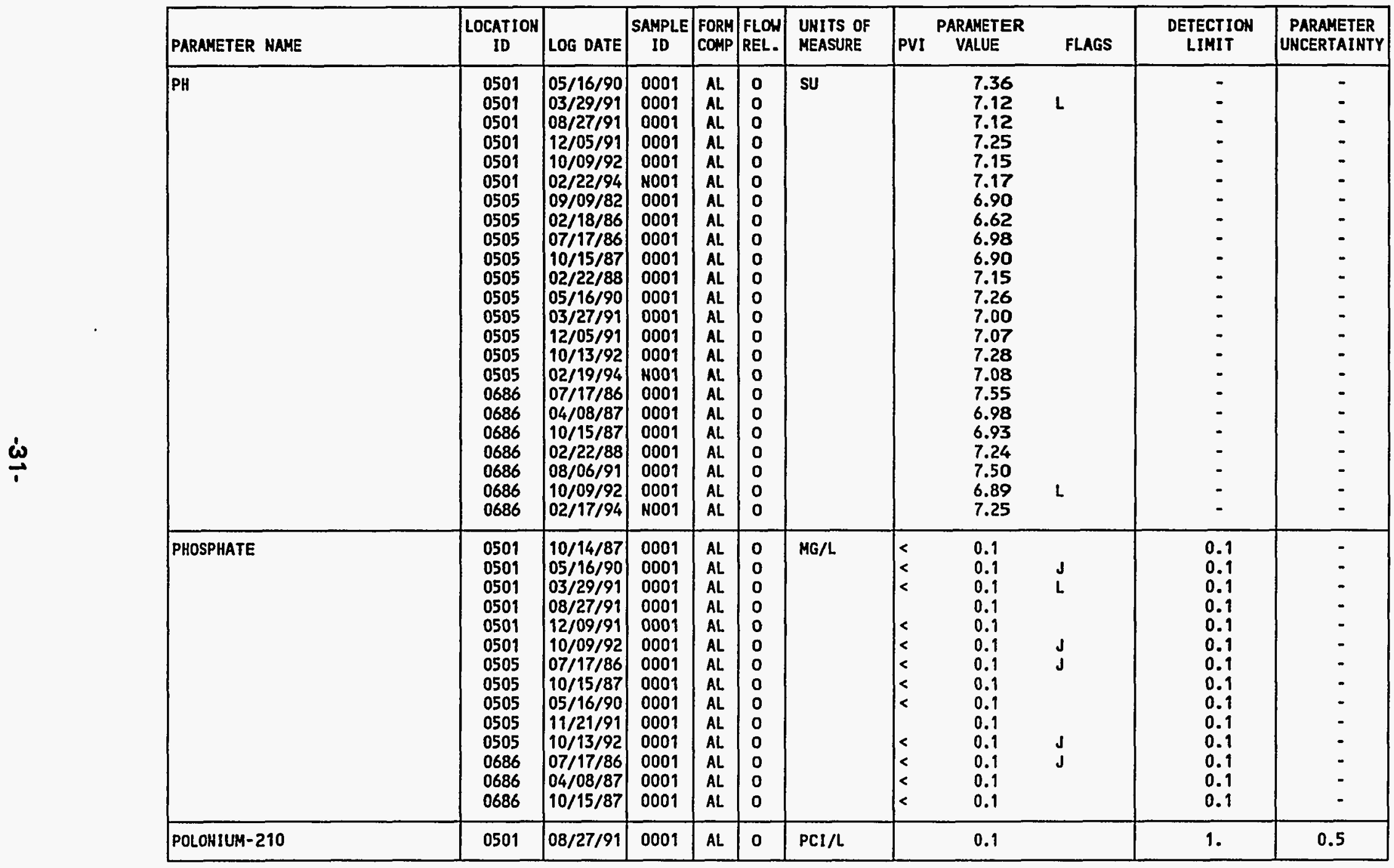

FORMATION OF CONPLETION CODE:

FLOH RELATIONSHIP CODE :

AL - ALLUVIUM

O- ON-SITE

PARAMETER VALUE INDICATOR (PVI): < - LESS THAN DETECTION LIMIT

OTHER PARAMETER VALUE FLAGS:

SAMPLE ID CODES:

0001 - FILTERED SAMPLE (.45 MICRONS)

$J$ - ESTIMATED VALUE

NO01 - UNFILTERED SAMPLE

L - LESS THAN THREE BB̈RE VOLUMES REMOVED BEFORE SAMPLING 
TABLE 3.5 BACKGROUND GROUND HATER QUALITY DATA BY PARAMETER FOR THE

ALLUVIUM, NC AND UC PROCESSING SITES, SLICK ROCK, COLORADO

SI TE: SRKO1 SLICK ROCK (BOTH SITES)

$09 / 09 / 82$ TO $02 / 22 / 94$

REPORT DATE: $09 / 28 / 94$

\begin{tabular}{|c|c|c|c|c|c|c|c|c|c|c|c|}
\hline PARAMETER HAME & $\underset{\text { LOCATION }}{\text { ID }}$ & LOG DATE & $\begin{array}{c}\text { SAMPLE } \\
\text { ID }\end{array}$ & $\begin{array}{l}\text { FORM } \\
\text { COMP }\end{array}$ & $\begin{array}{l}\text { FLOW } \\
\text { REL. }\end{array}$ & $\begin{array}{l}\text { UNITS OF } \\
\text { MEASURE }\end{array}$ & PVI & $\begin{array}{l}\text { ARAMETE } \\
\text { VALUE }\end{array}$ & FLAGS & $\begin{array}{l}\text { DETECTION } \\
\text { LIMIT }\end{array}$ & $\begin{array}{l}\text { PARAMETER } \\
\text { UNCERTAINTY }\end{array}$ \\
\hline POLONIUM-210 & $\begin{array}{l}0501 \\
0501 \\
0505 \\
0505 \\
0505\end{array}$ & $\begin{array}{l}12 / 05 / 91 \\
02 / 22 / 94 \\
07 / 17 / 86 \\
12 / 05 / 91 \\
02 / 19 / 94\end{array}$ & $\begin{array}{l}0001 \\
0001 \\
0001 \\
0001 \\
0001\end{array}$ & $\begin{array}{l}A L \\
A L \\
A L \\
A L \\
A L\end{array}$ & $\begin{array}{l}0 \\
0 \\
0 \\
0 \\
0\end{array}$ & $\mathrm{PCI} / \mathrm{L}$ & & $\begin{array}{l}0.0 \\
0.0 \\
0 . \\
0.2 \\
1.6\end{array}$ & * & $\begin{array}{l}1.0 \\
0.1 \\
1.0 \\
0.1\end{array}$ & $\begin{array}{l}0.3 \\
0.1 \\
0.5 \\
1.0 \\
0.3\end{array}$ \\
\hline POLONIUM-210 (TOTAL) & $\begin{array}{l}0501 \\
0505\end{array}$ & $\begin{array}{l}02 / 22 / 94 \\
02 / 19 / 94\end{array}$ & $\begin{array}{l}\text { N001 } \\
\text { N001 }\end{array}$ & $\begin{array}{l}A L \\
A L\end{array}$ & $\begin{array}{l}0 \\
0\end{array}$ & PCI/L & & $\begin{array}{l}0.1 \\
0.2\end{array}$ & * & $\begin{array}{l}0.1 \\
0.1\end{array}$ & $\begin{array}{l}0.1 \\
0.1\end{array}$ \\
\hline POTASSIUM & $\begin{array}{l}0501 \\
0501 \\
0501 \\
0501 \\
0501 \\
0501 \\
0501 \\
0501 \\
0501 \\
0501 \\
0501 \\
0501 \\
0501 \\
0501 \\
0501 \\
0505 \\
0505 \\
0505 \\
0505 \\
0505 \\
0505 \\
0505 \\
0505 \\
0505 \\
0686 \\
0686 \\
0686 \\
0686\end{array}$ & $\begin{array}{l}09 / 09 / 82 \\
02 / 18 / 86 \\
02 / 18 / 86 \\
02 / 18 / 86 \\
02 / 18 / 86 \\
02 / 18 / 86 \\
07 / 01 / 86 \\
10 / 14 / 87 \\
02 / 22 / 88 \\
05 / 16 / 90 \\
03 / 29 / 91 \\
08 / 27 / 91 \\
12 / 09 / 91 \\
10 / 09 / 92 \\
02 / 22 / 94 \\
09 / 09 / 82 \\
02 / 18 / 86 \\
07 / 17 / 86 \\
10 / 15 / 87 \\
02 / 22 / 88 \\
05 / 16 / 90 \\
11 / 21 / 91 \\
10 / 13 / 92 \\
02 / 19 / 94 \\
07 / 17 / 86 \\
04 / 08 / 87 \\
10 / 15 / 87 \\
02 / 22 / 88\end{array}$ & $\begin{array}{l}0001 \\
0001 \\
0002 \\
0003 \\
0004 \\
0005 \\
0001 \\
0001 \\
0001 \\
0001 \\
0001 \\
0001 \\
0001 \\
0001 \\
0001 \\
0001 \\
0001 \\
0001 \\
0001 \\
0001 \\
0001 \\
0001 \\
0001 \\
0001 \\
0001 \\
0001 \\
0001 \\
0001\end{array}$ & $\begin{array}{l}A L \\
A L \\
A L \\
A L \\
A L \\
A L \\
A L \\
A L \\
A L \\
A L \\
A L \\
A L \\
A L \\
A L \\
A L \\
A L \\
A L \\
A L \\
A L \\
A L \\
A L \\
A L \\
A L \\
A L \\
A L \\
A L \\
A L \\
A L\end{array}$ & $\begin{array}{l}0 \\
0 \\
0 \\
0 \\
0 \\
0 \\
0 \\
0 \\
0 \\
0 \\
0 \\
0 \\
0 \\
0 \\
0 \\
0 \\
0 \\
0 \\
0 \\
0 \\
0 \\
0 \\
0 \\
0 \\
0 \\
0 \\
0 \\
0\end{array}$ & $M G / L$ & & $\begin{array}{l}6.00 \\
5.72 \\
5.73 \\
5.71 \\
5.72 \\
5.72 \\
4.75 \\
3.8 \\
4.42 \\
4.1 \\
3.9 \\
4.1 \\
3.82 \\
3.96 \\
3.8 \\
10.00 \\
10.2 \\
6.64 \\
5.1 \\
5.19 \\
5.7 \\
5.63 \\
5.94 \\
4.7 \\
6.08 \\
4.35 \\
3.3 \\
3.42\end{array}$ & $\begin{array}{l}J \\
\mathbf{L}\end{array}$ & $\begin{array}{l}- \\
0.01 \\
0.01 \\
0.01 \\
0.01 \\
0.01 \\
0.01 \\
0.01 \\
0.01 \\
0.01 \\
0.01 \\
0.01 \\
0.01 \\
0.01 \\
0.1 \\
- \\
0.01 \\
0.01 \\
0.01 \\
0.01 \\
0.01 \\
0.01 \\
0.01 \\
0.1 \\
0.01 \\
0.01 \\
0.01 \\
0.01\end{array}$ & $\begin{array}{l}- \\
- \\
: \\
- \\
- \\
- \\
- \\
- \\
- \\
- \\
- \\
- \\
- \\
- \\
- \\
- \\
- \\
- \\
- \\
-\end{array}$ \\
\hline POTASSIUM (TOTAL) & 0501 & $02 / 22 / 94$ & N001 & AL & 0 & $M G / L$ & & 3.6 & & 0.1 & - \\
\hline
\end{tabular}

FORMATION OF COMPLETION CODE:

AL - ALLUVIUM

PARAMETER VALUE IndICATOR (PVI): < - LESS THAN DETECTION LIMIT

OTHER PARAMETER VALUE FLAGS:

* - DUPLICATE ANALYSIS NOT WITHIN CONTROL LIMITS

$J$ - ESTIMATED VALUE

l - LESS THAN THREE BORE VOLUMES REMOVED BEFORE SAMPLING
FLOW RELATIONSHIP CODE:

O- ON-SITE

SAMPLE ID CODES:

0001 - FILTERED SAMPLE (.45 MICRONS)

0002 - FILTERED REPLICATE SAMPLE (.45 MICRONS)

0003 - FILTERED REPLICATE SAMPLE (.45 MICRONS)

0004 - FILTERED REPLICATE SAMPLE (.45 MICRONS)

NOO1 - UNFILTERED SAMPLE 
TABLE 3.5 BACKGROUND GROUND MATER QUALITY DATA BY PARAMETER FOR THE

ALLUVIUH, NC AND UC PROCESSING SITES, SLICK ROCK, COLORADO

SITE: SRKOI SLICK ROCK (BOTH SITES)

09/09/82 TO 02/22/94

REPORT DATE: $09 / 28 / 94$

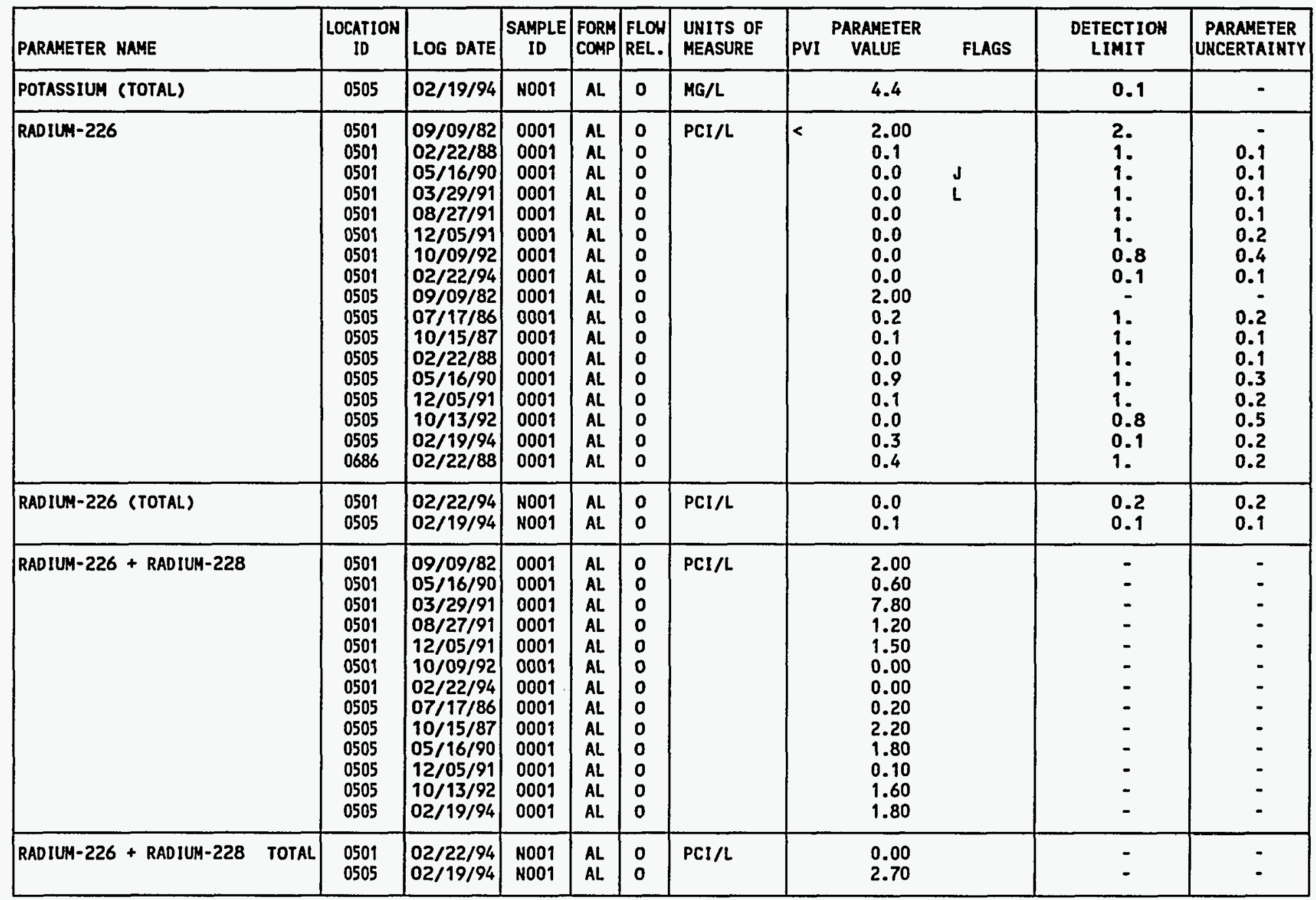

FOPHATION OF COMPLETION CODE:

$A L$ - ALLUVIUM

PARAMETER VALUE INDICATOR (PVI): < - LESS THAN DETECTION LIMIT

OTHER PARAMETER VALUE FLAGS:

$J$ - ESTIMATED VALUE

$\ell$ - LESS THAN THREE BORE VOLUMES REMOVED BEFORE SAMPLING
FLOH RELATIONSHIP CODE:

O - ON-SITE

SAMPLE ID CODES:

0001 - FILTERED SAMPLE (.45 MICRONS)

NO01 - UHFILTERED SAMPLE 


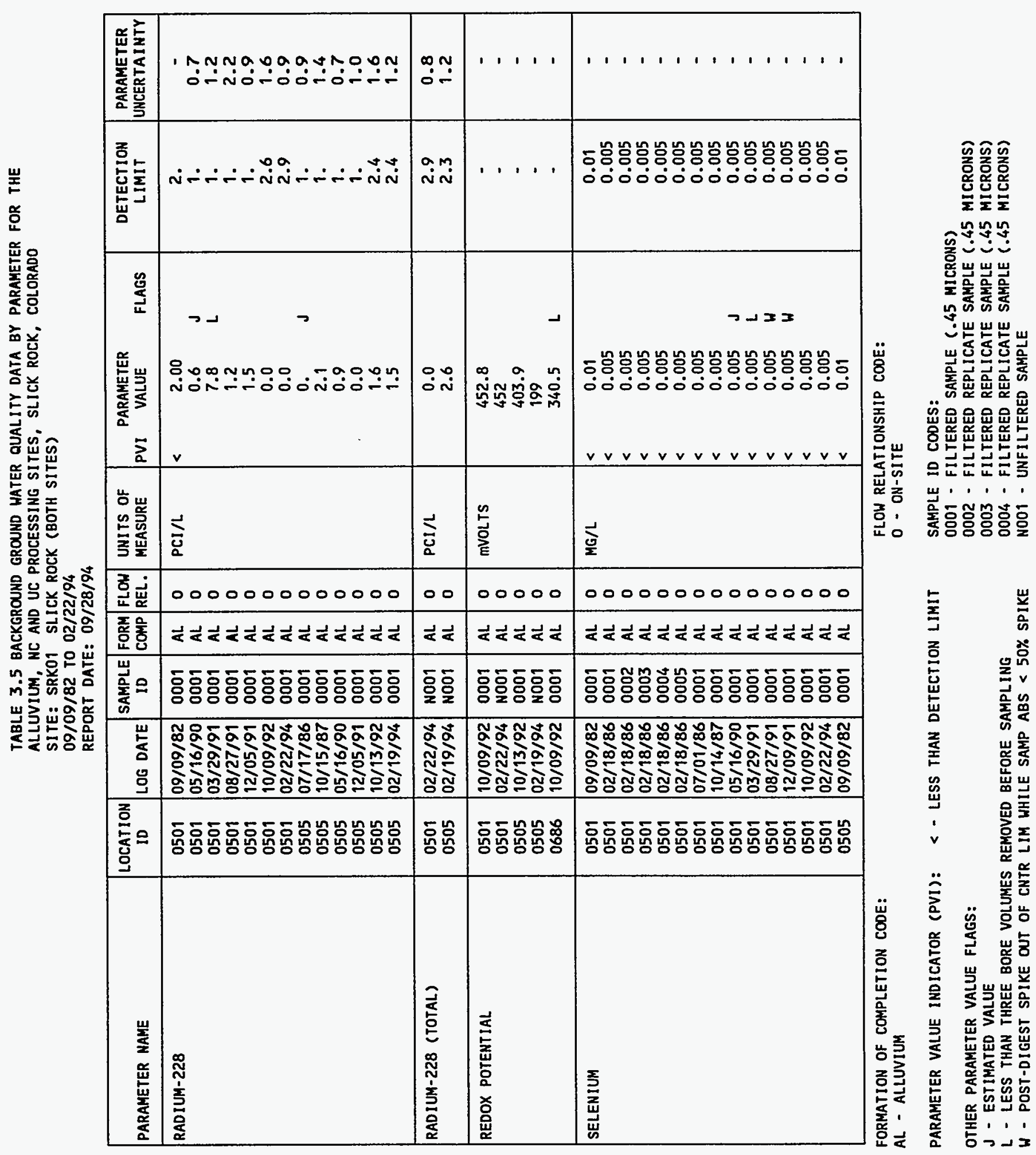


TABLE 3.5 BACKGROUND GROUND HATER QUALITY DATA BY PARAMETER FOR THE ALLUVIUH, NC AND UC PROCESSIMG SITES, SLICK ROCK, COLORADO SITE: SRKO1 SLICK ROCK (BOTH SITES)

O9/09/82 TO $02 / 22 / 94$

REPORT DATE: $09 / 28 / 9$

\begin{tabular}{|c|c|c|c|c|c|c|c|c|c|c|c|}
\hline PARAMETER NAME & $\underset{\text { ID }}{\text { LOCATION }}$ & LOG DATE & $\begin{array}{c}\text { SAMPLE } \\
\text { ID }\end{array}$ & $\begin{array}{l}\text { FORM } \\
\text { COMP }\end{array}$ & $\begin{array}{l}\text { FLOW } \\
\text { REL. }\end{array}$ & $\begin{array}{l}\text { UNITS OF } \\
\text { MEASURE }\end{array}$ & PVI & $\begin{array}{l}\text { PARAMETER } \\
\text { VALUE }\end{array}$ & FLAGS & $\begin{array}{l}\text { DETECTION } \\
\text { LIMIT }\end{array}$ & $\begin{array}{l}\text { PARAMETER } \\
\text { UNCERTAINTY }\end{array}$ \\
\hline SELENIUH & $\begin{array}{l}0505 \\
0505 \\
0505 \\
0505 \\
0505 \\
0505 \\
0505 \\
0686 \\
0686 \\
0686\end{array}$ & $\begin{array}{l}02 / 18 / 86 \\
07 / 17 / 86 \\
10 / 15 / 87 \\
05 / 16 / 90 \\
11 / 21 / 91 \\
10 / 13 / 92 \\
02 / 19 / 94 \\
07 / 17 / 86 \\
04 / 08 / 87 \\
10 / 15 / 87\end{array}$ & $\begin{array}{l}0001 \\
0001 \\
0001 \\
0001 \\
0001 \\
0001 \\
0001 \\
0001 \\
0001 \\
0001\end{array}$ & $\begin{array}{l}A L \\
A L \\
A L \\
A L \\
A L \\
A L \\
A L \\
A L \\
A L \\
A L\end{array}$ & $\begin{array}{l}0 \\
0 \\
0 \\
0 \\
0 \\
0 \\
0 \\
0 \\
0 \\
0\end{array}$ & MG/L & $\begin{array}{l}< \\
< \\
< \\
< \\
< \\
< \\
< \\
< \\
< \\
< \\
<\end{array}$ & $\begin{array}{l}0.005 \\
0.005 \\
0.005 \\
0.005 \\
0.007 \\
0.005 \\
0.005 \\
0.005 \\
0.002 \\
0.005\end{array}$ & 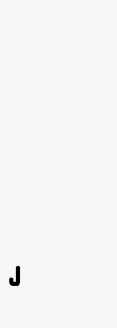 & $\begin{array}{l}0.005 \\
0.005 \\
0.005 \\
0.005 \\
0.005 \\
0.005 \\
0.005 \\
0.005 \\
0.005 \\
0.005\end{array}$ & $\begin{array}{l}- \\
- \\
- \\
- \\
- \\
- \\
-\end{array}$ \\
\hline SELENIUM (TOTAL) & $\begin{array}{l}0501 \\
0505\end{array}$ & $\begin{array}{l}02 / 22 / 94 \\
02 / 19 / 94\end{array}$ & $\begin{array}{l}\text { N001 } \\
\text { N001 }\end{array}$ & $\begin{array}{l}A L \\
A L\end{array}$ & $\begin{array}{l}0 \\
0\end{array}$ & MG/L & $<<$ & $\begin{array}{l}0.005 \\
0.005\end{array}$ & & $\begin{array}{l}0.005 \\
0.005\end{array}$ & - \\
\hline SILICA - SIO2 & $\begin{array}{l}0501 \\
0501 \\
0501 \\
0501 \\
0501 \\
0501 \\
0501 \\
0501 \\
0501 \\
0505 \\
0505 \\
0505 \\
0505 \\
0505 \\
0505 \\
0505 \\
0505 \\
0686 \\
0686 \\
0686 \\
0686\end{array}$ & $\begin{array}{l}09 / 09 / 82 \\
10 / 14 / 87 \\
02 / 22 / 88 \\
05 / 16 / 90 \\
03 / 29 / 91 \\
08 / 27 / 91 \\
12 / 09 / 91 \\
10 / 09 / 92 \\
02 / 22 / 94 \\
09 / 09 / 82 \\
07 / 17 / 86 \\
10 / 15 / 87 \\
02 / 22 / 88 \\
05 / 16 / 90 \\
11 / 21 / 91 \\
10 / 13 / 92 \\
02 / 19 / 94 \\
07 / 17 / 86 \\
04 / 08 / 87 \\
10 / 15 / 87 \\
02 / 22 / 88\end{array}$ & $\begin{array}{l}0001 \\
0001 \\
0001 \\
0001 \\
0001 \\
0001 \\
0001 \\
0001 \\
0001 \\
0001 \\
0001 \\
0001 \\
0001 \\
0001 \\
0001 \\
0001 \\
0001 \\
0001 \\
0001 \\
0001 \\
0001\end{array}$ & $\begin{array}{l}A L \\
A L \\
A L \\
A L \\
A L \\
A L \\
A L \\
A L \\
A L \\
A L \\
A L \\
A L \\
A L \\
A L \\
A L \\
A L \\
A L \\
A L \\
A L \\
A L \\
A L\end{array}$ & $\begin{array}{l}0 \\
0 \\
0 \\
0 \\
0 \\
0 \\
0 \\
0 \\
0 \\
0 \\
0 \\
0 \\
0 \\
0 \\
0 \\
0 \\
0 \\
0 \\
0 \\
0 \\
0\end{array}$ & $M G / L$ & & $\begin{array}{l}5.17 \\
8.3 \\
9.5 \\
9 . \\
7.4 \\
8.6 \\
8.8 \\
9.1 \\
8.8 \\
7.57 \\
4 . \\
9.8 \\
8.2 \\
10 . \\
10.7 \\
11.3 \\
10.3 \\
4 . \\
11.9 \\
9.6 \\
8.4\end{array}$ & $\begin{array}{l}J \\
L\end{array}$ & $\begin{array}{l}- \\
2 . \\
2 . \\
2 . \\
0.1 \\
0.1 \\
0.1 \\
0.1 \\
0.1 \\
-. \\
2 . \\
2 . \\
2 . \\
2 . \\
0.1 \\
0.1 \\
0.1 \\
2 . \\
2 . \\
2 . \\
2 .\end{array}$ & $\begin{array}{l}- \\
- \\
- \\
- \\
- \\
- \\
- \\
- \\
- \\
- \\
- \\
- \\
- \\
- \\
- \\
-\end{array}$ \\
\hline SILICA - SIO2 (TOTAL) & $\begin{array}{l}0501 \\
0505\end{array}$ & $\begin{array}{l}02 / 22 / 94 \\
02 / 19 / 94\end{array}$ & $\begin{array}{l}\text { N001 } \\
\text { N001 }\end{array}$ & $\begin{array}{l}A L \\
A L\end{array}$ & $\begin{array}{l}0 \\
0\end{array}$ & $M G / L$ & & $\begin{array}{r}8.5 \\
10.1\end{array}$ & & $\begin{array}{l}0.1 \\
0.1\end{array}$ & $\dot{-}$ \\
\hline SILVER & 0501 & $09 / 09 / 82$ & 0001 & AL & 0 & HG/L & $<$ & 0.01 & & 0.01 & - \\
\hline
\end{tabular}

FORMATIOH OF COMPLETION CODE:

AL - ALLUVIUM

FLOW RELATIONSHIP CODE:

PARAMETER VALUE INDICATOR (PVI): < - LESS THAN DETECTION LIMIT

SAMPLE IO COOES:

DOO1 - FILTERED SAMPLE (.45 MICRONS)

OTHER PARAMETER VALUE FLAGS:

NOO1 - UNFILTERED SAMPLE

$J$ - ESTIMATED VALUE

L - LESS THAN THREE BORE VOLUMES REMOVED BEFORE SAMPLING 


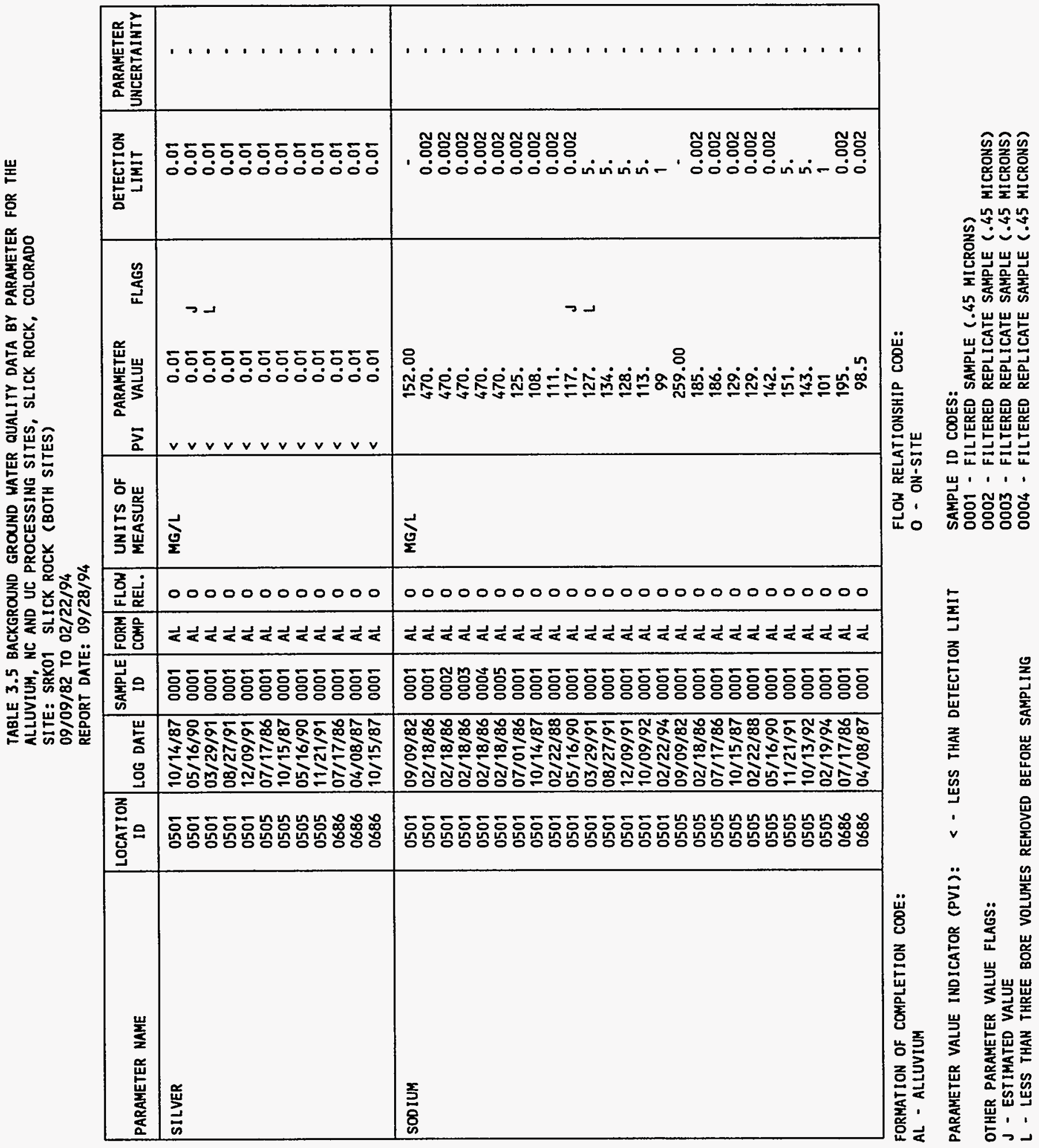


TABLE 3.5 BACKGROUND GROUND WATER QUALITY DATA BY PARAMETER FOR THE

ALLUVIUM, NC AND UC PROCESSING SITES, SLICK ROCK, COLORADO

SITE: SRKO1 SLICK ROCK (BOTH SITES)

09/09/82 TO 02/22/94

REPORT DATE: $09 / 28 / 94$

\begin{tabular}{|c|c|c|c|c|c|c|c|c|c|c|}
\hline PARAMETER MAME & $\underset{\text { LOCATIOH }}{\text { LO }}$ & LOG DATE & $\begin{array}{c}\text { SAMPLE } \\
\text { ID }\end{array}$ & $\begin{array}{l}\text { FORM } \\
\text { COMP }\end{array}$ & $\begin{array}{l}\text { FLON } \\
\text { REL. }\end{array}$ & $\begin{array}{l}\text { UNITS OF } \\
\text { MEASURE }\end{array}$ & $\begin{array}{l}\text { PARAKETER } \\
\text { PVI VALUE }\end{array}$ & FLAGS & $\begin{array}{l}\text { DETECTION } \\
\text { LIMIT }\end{array}$ & $\begin{array}{l}\text { PARAMETER } \\
\text { UNCERTAINTY }\end{array}$ \\
\hline SOOIUH & $\begin{array}{l}0686 \\
0686\end{array}$ & $\mid \begin{array}{l}10 / 15 / 87 \\
02 / 22 / 88\end{array}$ & $\begin{array}{l}0001 \\
0001\end{array}$ & $\begin{array}{l}\text { AL } \\
\mathbf{A L}\end{array}$ & $\begin{array}{l}0 \\
0\end{array}$ & MG/L & $\begin{array}{l}92 . \\
90.2\end{array}$ & & $\begin{array}{l}0.002 \\
0.002\end{array}$ & - \\
\hline SOOIUN (TOTAL) & $\begin{array}{l}0501 \\
0505\end{array}$ & $\begin{array}{l}02 / 22 / 94 \\
02 / 19 / 94\end{array}$ & $\begin{array}{l}\text { N001 } \\
\text { H001 }\end{array}$ & $\begin{array}{l}A L \\
A L\end{array}$ & $\begin{array}{l}0 \\
0\end{array}$ & MG/L & $\begin{array}{l}95 \\
99\end{array}$ & & $\begin{array}{l}1 \\
1\end{array}$ & - \\
\hline SPECIFIC CONDUCTANCE & $\begin{array}{l}0501 \\
0501 \\
0501 \\
0501 \\
0501 \\
0501 \\
0501 \\
0501 \\
0501 \\
0501 \\
0501 \\
0501 \\
0501 \\
0501 \\
0501 \\
0505 \\
0505 \\
0505 \\
0505 \\
0505 \\
0505 \\
0505 \\
0505 \\
0505 \\
0505 \\
0686 \\
0686 \\
0686 \\
0686 \\
0686 \\
0686 \\
0686\end{array}$ & $\begin{array}{l}09 / 09 / 82 \\
02 / 18 / 86 \\
02 / 18 / 86 \\
02 / 18 / 86 \\
02 / 18 / 86 \\
02 / 18 / 86 \\
07 / 01 / 86 \\
10 / 14 / 87 \\
02 / 22 / 88 \\
05 / 16 / 90 \\
03 / 29 / 91 \\
08 / 27 / 91 \\
12 / 05 / 91 \\
10 / 09 / 92 \\
02 / 22 / 94 \\
09 / 09 / 82 \\
02 / 18 / 86 \\
07 / 17 / 86 \\
10 / 15 / 87 \\
02 / 22 / 88 \\
05 / 16 / 90 \\
03 / 27 / 91 \\
12 / 05 / 91 \\
10 / 13 / 92 \\
02 / 19 / 94 \\
07 / 17 / 86 \\
04 / 08 / 87 \\
10 / 15 / 87 \\
02 / 22 / 88 \\
08 / 06 / 91 \\
10 / 09 / 92 \\
02 / 17 / 94\end{array}$ & $\begin{array}{l}0001 \\
0001 \\
0002 \\
0003 \\
0004 \\
0005 \\
0001 \\
0001 \\
0001 \\
0001 \\
0001 \\
0001 \\
0001 \\
0001 \\
N 001 \\
0001 \\
0001 \\
0001 \\
0001 \\
0001 \\
0001 \\
0001 \\
0001 \\
0001 \\
\text { N001 } \\
0001 \\
0001 \\
0001 \\
0001 \\
0001 \\
0001 \\
\text { N001 }\end{array}$ & $\begin{array}{l}A L \\
A L \\
A L \\
A L \\
A L \\
A L \\
A L \\
A L \\
A L \\
A L \\
A L \\
A L \\
A L \\
A L \\
A L \\
A L \\
A L \\
A L \\
A L \\
A L \\
A L \\
A L \\
A L \\
A L \\
A L \\
A L \\
A L \\
A L \\
A L \\
A L \\
A L \\
A L\end{array}$ & $\begin{array}{l}0 \\
0 \\
0 \\
0 \\
0 \\
0 \\
0 \\
0 \\
0 \\
0 \\
0 \\
0 \\
0 \\
0 \\
0 \\
0 \\
0 \\
0 \\
0 \\
0 \\
0 \\
0 \\
0 \\
0 \\
0 \\
0 \\
0 \\
0 \\
0 \\
0 \\
0 \\
0\end{array}$ & UNHO/CN & $\begin{array}{c}1110.00 \\
1000 . \\
1000 . \\
1000 . \\
1000 . \\
1000 . \\
790 . \\
950 . \\
1050 . \\
820 . \\
1268 . \\
1240 \\
1229 \\
709 \\
955 \\
2100.00 \\
1150 . \\
1000 . \\
900 . \\
850 . \\
990 . \\
1126 . \\
1180 \\
1144 \\
834 \\
600 . \\
490 . \\
750 . \\
800 . \\
1357 \\
447 \\
769\end{array}$ & 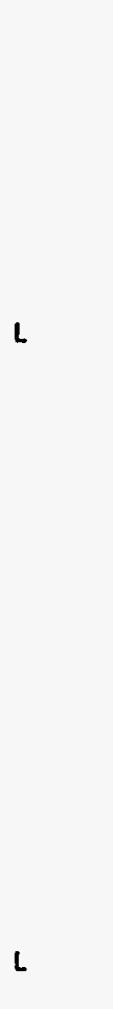 & 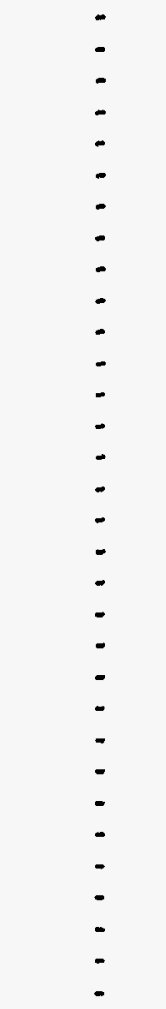 & 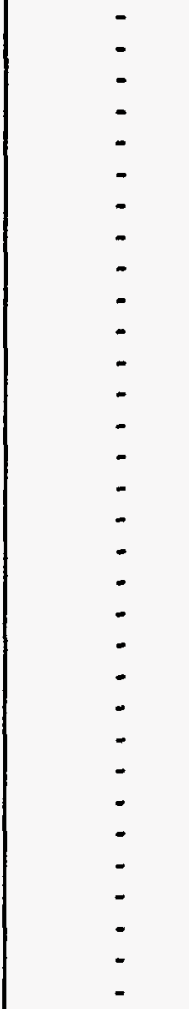 \\
\hline
\end{tabular}

FORMATION OF COMPLETION CODE:

AL - ALLUVIUM

PARAMETER VALUE INDICATOR (PVI): < - LESS THAN DETECTION LIMIT

OTHER PARAMETER VALUE FLAGS:

$L$ - LESS THAN THREE BORE VOLUMES REMOVED BEFORE SAMPLING
FLOH RELATIONSHIP CODE:

O - ON-SITE

SAMPLE ID CODES:

0001 - FILTERED SAMPLE (.45 MICRONS)

0002 - FILTERED REPLICATE SAMPLE (.45 MICRONS)

0003 - FILTERED REPLICATE SAMPLE (.45 MICRONS)

0003 - FILTERED REPLICATE SAMPLE (.45 MICRONS)
0004 - FILTERED REPLICATE SAMPLE (.45 MICRONS)

N001 - UMFILTERED SAMPLE 


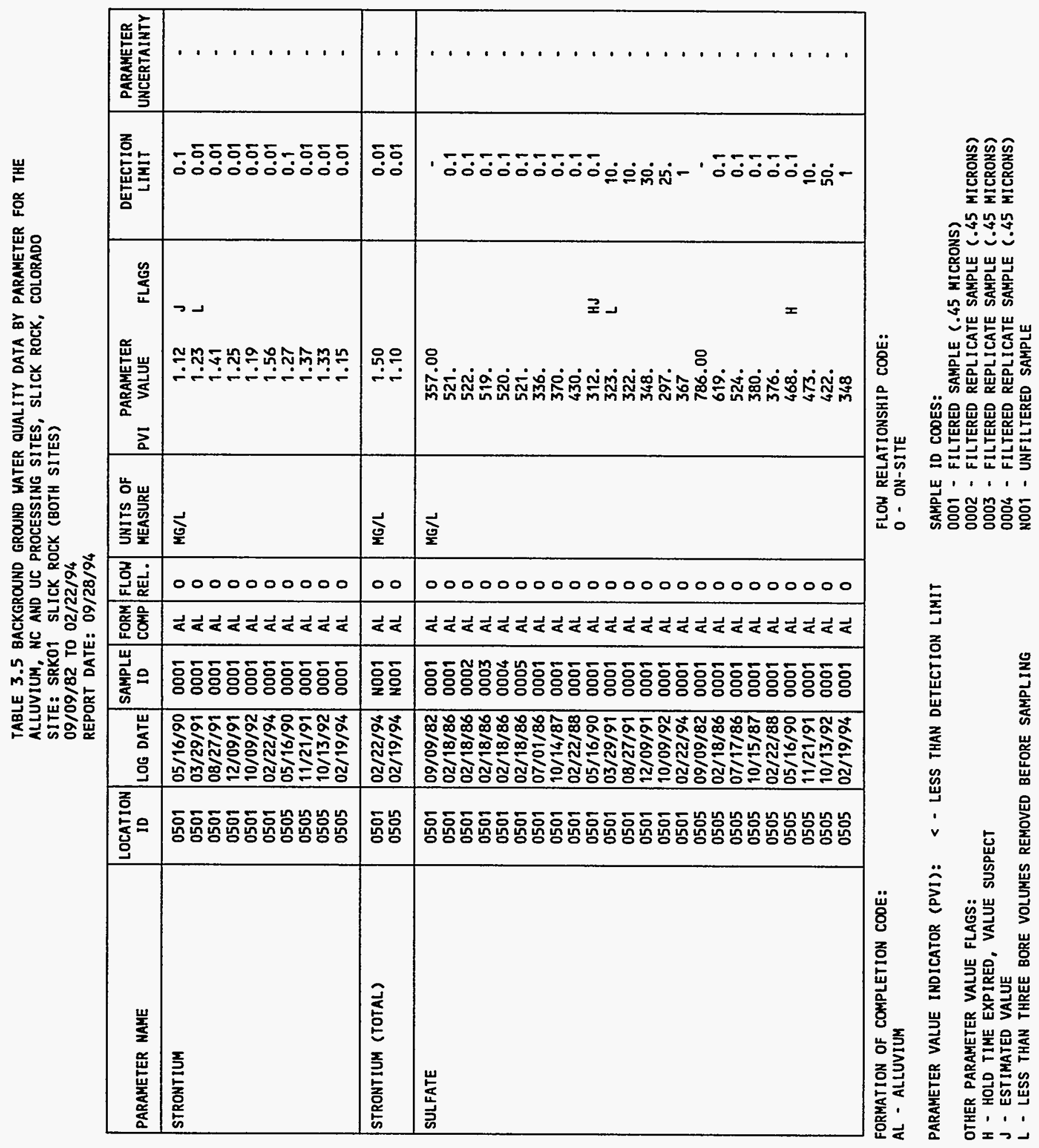


TABLE 3.5 BACKGROUND GROUND MATER QUALITY DATA BY PARAMETER FOR THE ALLUVIUH, HC AND UC PROCESSIHG SITES, SLICK ROCK, COLORADO

SITE: SRKOI SLICK ROCK (BOTH SITES)

09/09/82 TO 02/22/94

REPORT DATE : $09 / 28 / 94$

\begin{tabular}{|c|c|c|c|c|c|c|c|c|c|c|c|}
\hline PARAMETER MAME & $\begin{array}{c}\text { LOCATION } \\
\text { ID }\end{array}$ & LOG DATE & $\begin{array}{l}\text { SAMPLE } \\
\text { ID }\end{array}$ & $\begin{array}{l}\text { FORM } \\
\text { COMP }\end{array}$ & $\begin{array}{l}\text { FLOW } \\
\text { REL. }\end{array}$ & $\begin{array}{l}\text { UNITS OF } \\
\text { MEASURE }\end{array}$ & PVI & $\begin{array}{l}\text { PARAMETER } \\
\text { VALUE }\end{array}$ & FLAGS & $\begin{array}{l}\text { DETECTION } \\
\text { LIMIT }\end{array}$ & $\begin{array}{l}\text { PARAMETER } \\
\text { UNCERTAINTY }\end{array}$ \\
\hline SULFATE & $\begin{array}{l}0686 \\
0686 \\
0686 \\
0686\end{array}$ & $\begin{array}{l}07 / 17 / 86 \\
04 / 08 / 87 \\
10 / 15 / 87 \\
02 / 22 / 88\end{array}$ & $\begin{array}{l}0001 \\
0001 \\
0001 \\
0001\end{array}$ & $\begin{array}{l}A L \\
A L \\
A L \\
A L\end{array}$ & $\begin{array}{l}0 \\
0 \\
0 \\
0\end{array}$ & MG/L. & & $\begin{array}{l}223 . \\
286 \\
269 \\
316\end{array}$ & & $\begin{array}{l}0.1 \\
0.1 \\
0.1 \\
0.1\end{array}$ & $\begin{array}{l}- \\
- \\
-\end{array}$ \\
\hline SULFIDE & $\begin{array}{l}0501 \\
0501 \\
0501 \\
0501 \\
0501 \\
0505 \\
0505 \\
0505 \\
0686\end{array}$ & $\begin{array}{l}07 / 01 / 86 \\
03 / 29 / 91 \\
08 / 27 / 91 \\
12 / 09 / 91 \\
10 / 09 / 92 \\
07 / 17 / 86 \\
11 / 21 / 91 \\
10 / 13 / 92 \\
07 / 17 / 86\end{array}$ & $\begin{array}{l}0001 \\
0001 \\
0001 \\
0001 \\
0001 \\
0001 \\
0001 \\
0001 \\
0001\end{array}$ & $\begin{array}{l}A L \\
A L \\
A L \\
A L \\
A L \\
A L \\
A L \\
A L \\
A L\end{array}$ & $\begin{array}{l}0 \\
0 \\
0 \\
0 \\
0 \\
0 \\
0 \\
0 \\
0\end{array}$ & MG/L & < & $\begin{array}{l}0.1 \\
0.3 \\
0.1 \\
1.0 \\
0.8 \\
0.1 \\
0.3 \\
0.1 \\
0.1\end{array}$ & $L$ & $\begin{array}{l}0.1 \\
0.1 \\
0.1 \\
0.1 \\
0.1 \\
0.1 \\
0.1 \\
0.1 \\
0.1\end{array}$ & $\begin{array}{l}- \\
- \\
- \\
= \\
= \\
-\end{array}$ \\
\hline TEMPERATURE & $\begin{array}{l}0501 \\
0501 \\
0501 \\
0501 \\
0501 \\
0501 \\
0501 \\
0501 \\
0501 \\
0501 \\
0501 \\
0501 \\
0501 \\
0501 \\
0501 \\
0505 \\
0505 \\
0505 \\
0505 \\
0505 \\
0505 \\
0505 \\
0505\end{array}$ & $\begin{array}{l}09 / 09 / 82 \\
02 / 18 / 86 \\
02 / 18 / 86 \\
02 / 18 / 86 \\
02 / 18 / 86 \\
02 / 18 / 86 \\
07 / 01 / 86 \\
10 / 14 / 87 \\
02 / 22 / 88 \\
05 / 16 / 90 \\
03 / 29 / 91 \\
08 / 27 / 91 \\
12 / 05 / 91 \\
10 / 09 / 92 \\
02 / 22 / 94 \\
09 / 09 / 82 \\
02 / 18 / 86 \\
07 / 17 / 86 \\
10 / 15 / 87 \\
02 / 22 / 88 \\
05 / 16 / 90 \\
03 / 27 / 91 \\
12 / 05 / 91\end{array}$ & $\begin{array}{l}0001 \\
0001 \\
0002 \\
0003 \\
0004 \\
0005 \\
0001 \\
0001 \\
0001 \\
0001 \\
0001 \\
0001 \\
0001 \\
0001 \\
N 001 \\
0001 \\
0001 \\
0001 \\
0001 \\
0001 \\
0001 \\
0001 \\
0001\end{array}$ & $\begin{array}{l}A L \\
A L \\
A L \\
A L \\
A L \\
A L \\
A L \\
A L \\
A L \\
A L \\
A L \\
A L \\
A L \\
A L \\
A L \\
A L \\
A L \\
A L \\
A L \\
A L \\
A L \\
A L \\
A L\end{array}$ & $\begin{array}{l}0 \\
0 \\
0 \\
0 \\
0 \\
0 \\
0 \\
0 \\
0 \\
0 \\
0 \\
0 \\
0 \\
0 \\
0 \\
0 \\
0 \\
0 \\
0 \\
0 \\
0 \\
0 \\
0\end{array}$ & C - DEGREE & & $\begin{array}{l}18.00 \\
12 . \\
12 . \\
12 . \\
12 . \\
12 . \\
12.5 \\
15.0 \\
12.5 \\
12.0 \\
11.1 \\
14.4 \\
13.4 \\
14.6 \\
11.8 \\
15.00 \\
10 . \\
11.5 \\
13.0 \\
9.5 \\
10.5 \\
9.0 \\
12.7\end{array}$ & $\mathbf{L}$ & $\begin{array}{l}- \\
- \\
- \\
- \\
- \\
- \\
- \\
- \\
- \\
- \\
- \\
- \\
- \\
- \\
- \\
- \\
- \\
-\end{array}$ & $\begin{array}{l}- \\
- \\
- \\
- \\
- \\
- \\
- \\
- \\
- \\
- \\
- \\
- \\
- \\
- \\
- \\
- \\
- \\
-\end{array}$ \\
\hline
\end{tabular}

FORMATION OF COMPLETION CODE:

AL - ALLUVIUM

PARAMETER VALUE INDICATOR (PVI): < - LESS THAN DETECTION LIMIT

OTHER PARAMETER VALUE FLAGS:

$L$ - LESS THAN THREE BORE VOLUMES REMOVED BEFORE SAMPLING
FLOW RELATIONSHIP CODE:

O - ON-SITE

SAMPLE ID CODES

0001 - FILTERED SAMPLE (.45 MICRONS)

0002 - FILTERED REPLICATE SAMPLE (.45 MICRONS)

0003 - FILTERED REPLICATE SAMPLE (.45 MICRONS)

0004 - FILTERED REPLICATE SAMPLE (.45 MICRONS)

NO01 - UNFILTERED SAMPLE 
TABLE 3.5 BACKGROUND GROUND WATER QUALITY DATA BY PARAMETER FOR THE ALLUVIUM, NC AND UC PROCESSING SITES, SLICK ROCK, COLORADO

SITE: SRKO1 SLICK ROCK (BOTH SITES)

$09 / 09 / 82$ TO $02 / 22 / 94$

REPORT DATE : 09/28/94

\begin{tabular}{|c|c|c|c|c|c|c|c|c|c|c|c|}
\hline PARAMETER NAME & $\underset{\text { ID }}{\text { LOCATION }}$ & LOG DATE & $\underset{\text { ID }}{\text { SAMPLE }}$ & $\begin{array}{l}\text { FORM } \\
\text { COMP }\end{array}$ & $\begin{array}{l}\text { FLOW } \\
\text { REL. }\end{array}$ & $\begin{array}{l}\text { UNITS OF } \\
\text { MEASURE }\end{array}$ & PVI & $\begin{array}{l}\text { PARAMETER } \\
\text { VALUE }\end{array}$ & FLAGS & $\begin{array}{l}\text { DETECTION } \\
\text { LIMIT }\end{array}$ & $\begin{array}{l}\text { PARAMETER } \\
\text { UNCERTAINTY }\end{array}$ \\
\hline TEMPERATURE & $\begin{array}{l}0505 \\
0505 \\
0686 \\
0686 \\
0686 \\
0686 \\
0686 \\
0686 \\
0686\end{array}$ & $\begin{array}{l}10 / 13 / 92 \\
02 / 19 / 94 \\
07 / 17 / 86 \\
04 / 08 / 87 \\
10 / 15 / 87 \\
02 / 22 / 88 \\
08 / 06 / 91 \\
10 / 09 / 92 \\
02 / 17 / 94\end{array}$ & $\begin{array}{l}0001 \\
N 001 \\
0001 \\
0001 \\
0001 \\
0001 \\
0001 \\
0001 \\
\text { N001 }\end{array}$ & $\begin{array}{l}A L \\
A L \\
A L \\
A L \\
A L \\
A L \\
A L \\
A L \\
A L\end{array}$ & $\begin{array}{l}0 \\
0 \\
0 \\
0 \\
0 \\
0 \\
0 \\
0 \\
0\end{array}$ & C - DEGREE & & $\begin{array}{r}12.7 \\
8.7 \\
13.5 \\
9.0 \\
14.5 \\
11.0 \\
18.2 \\
17.2 \\
8.8\end{array}$ & $\mathbf{L}$ & $\begin{array}{l}- \\
- \\
- \\
- \\
- \\
- \\
-\end{array}$ & $\begin{array}{l}- \\
- \\
- \\
- \\
- \\
- \\
- \\
-\end{array}$ \\
\hline THALLIUM & $\begin{array}{l}0501 \\
0501 \\
0501 \\
0501 \\
0501 \\
0505 \\
0505 \\
0505\end{array}$ & $\begin{array}{l}05 / 16 / 90 \\
03 / 29 / 91 \\
08 / 27 / 91 \\
12 / 09 / 91 \\
10 / 09 / 92 \\
05 / 16 / 90 \\
11 / 21 / 91 \\
10 / 13 / 92\end{array}$ & $\begin{array}{l}0001 \\
0001 \\
0001 \\
0001 \\
0001 \\
0001 \\
0001 \\
0001\end{array}$ & $\begin{array}{l}A L \\
A L \\
A L \\
A L \\
A L \\
A L \\
A L \\
A L\end{array}$ & $\begin{array}{l}0 \\
0 \\
0 \\
0 \\
0 \\
0 \\
0 \\
0\end{array}$ & $M G / L$ & $\begin{array}{l}< \\
< \\
< \\
< \\
< \\
<\end{array}$ & $\begin{array}{l}0.01 \\
0.01 \\
0.01 \\
0.01 \\
0.005 \\
0.01 \\
0.01 \\
0.005\end{array}$ & $\begin{array}{l}J \\
L\end{array}$ & $\begin{array}{l}0.01 \\
0.01 \\
0.01 \\
0.01 \\
0.005 \\
0.01 \\
0.01 \\
0.005\end{array}$ & $\begin{array}{l}- \\
- \\
- \\
- \\
- \\
-\end{array}$ \\
\hline THORIUM-230 & $\begin{array}{l}0501 \\
0501 \\
0501 \\
0505 \\
0505 \\
0505\end{array}$ & $\begin{array}{l}08 / 27 / 91 \\
12 / 05 / 91 \\
02 / 22 / 94 \\
07 / 17 / 86 \\
12 / 05 / 91 \\
02 / 19 / 94\end{array}$ & $\begin{array}{l}0001 \\
0001 \\
0001 \\
0001 \\
0001 \\
0001\end{array}$ & $\begin{array}{l}A L \\
A L \\
A L \\
A L \\
A L \\
A L\end{array}$ & $\begin{array}{l}0 \\
0 \\
0 \\
0 \\
0 \\
0\end{array}$ & $\mathrm{PCI} / \mathrm{L}$ & & $\begin{array}{l}0.5 \\
0.5 \\
0.3 \\
0.5 \\
1.5 \\
0.1\end{array}$ & & $\begin{array}{l}1 . \\
1 . \\
0.2 \\
1 . \\
1 . \\
0.1\end{array}$ & $\begin{array}{l}0.6 \\
0.7 \\
0.1 \\
0.4 \\
0.7 \\
0.1\end{array}$ \\
\hline THORIUM-230 (TOTAL) & $\begin{array}{l}0501 \\
0505\end{array}$ & $\begin{array}{l}02 / 22 / 94 \\
02 / 19 / 94\end{array}$ & $\begin{array}{l}\text { N001 } \\
\text { N001 }\end{array}$ & $\begin{array}{l}\text { AL } \\
\text { AL }\end{array}$ & $\begin{array}{l}0 \\
0\end{array}$ & $\mathrm{PCl} / \mathrm{L}$ & & $\begin{array}{l}0.3 \\
0.4\end{array}$ & & $\begin{array}{l}0.2 \\
0.1\end{array}$ & $\begin{array}{l}0.1 \\
0.1\end{array}$ \\
\hline THORIUM-232 & 0501 & $09 / 09 / 82$ & 0001 & AL & 0 & $\mathrm{PCI} / \mathrm{L}$ & $<$ & 0.10 & & 0.1 & - \\
\hline TIN & $\begin{array}{l}0501 \\
0501 \\
0501 \\
0501 \\
0501 \\
0505 \\
0505\end{array}$ & $\begin{array}{l}05 / 16 / 90 \\
03 / 29 / 91 \\
08 / 27 / 91 \\
12 / 09 / 91 \\
10 / 09 / 92 \\
07 / 17 / 86 \\
05 / 16 / 90\end{array}$ & $\begin{array}{l}0001 \\
0001 \\
0001 \\
0001 \\
0001 \\
0001 \\
0001\end{array}$ & $\begin{array}{l}A L \\
A L \\
A L \\
A L \\
A L \\
A L \\
A L\end{array}$ & $\begin{array}{l}0 \\
0 \\
0 \\
0 \\
0 \\
0 \\
0\end{array}$ & MG/L & $\begin{array}{l}< \\
< \\
< \\
< \\
< \\
< \\
<\end{array}$ & $\begin{array}{l}0.005 \\
0.005 \\
0.005 \\
0.005 \\
0.005 \\
0.005 \\
0.005\end{array}$ & $\begin{array}{l}J \\
\mathbf{L} \\
W\end{array}$ & $\begin{array}{l}0.005 \\
0.005 \\
0.005 \\
0.005 \\
0.005 \\
0.005 \\
0.005\end{array}$ & $\begin{array}{l}- \\
: \\
- \\
- \\
-\end{array}$ \\
\hline
\end{tabular}

FORMATION OF COMPLETION CODE:

AL - ALLUVIUH

PARAMETER VALUE INDICATOR (PVI): < - LESS THAN DETECTION LIMIT

OTHER PARAMETER VALUE FLAGS:

$J$ - ESTIMATED VALUE

L - LESS THAN THREE BORE VOLUMES REMOVED BEFORE SAMPLING

$W$ - POST-DIGEST SPIKE OUT OF CNTR LIM HHILE SAMP ABS < 50\% SPIKE
FLOW RELATIONSHIP CODE:

O - ON-SITE

SAMPLE ID CODES:

0001 - FILTERED SAMPLE (.45 MICRONS)

NO01 - UNFILTERED SAMPLE 
TABLE 3.5 BACKGROUND GROUND WATER QUALITY DATA BY PARAMETER FOR THE ALLUVIUN, NC AND UC PROCESSIHG SITES, SLICK ROCK, COLORADO

SITE: SRKO1 SLICK ROCK (BOTH SITES)

09/09/82 TO 02/22/94

REPORT DATE: 09/28/94

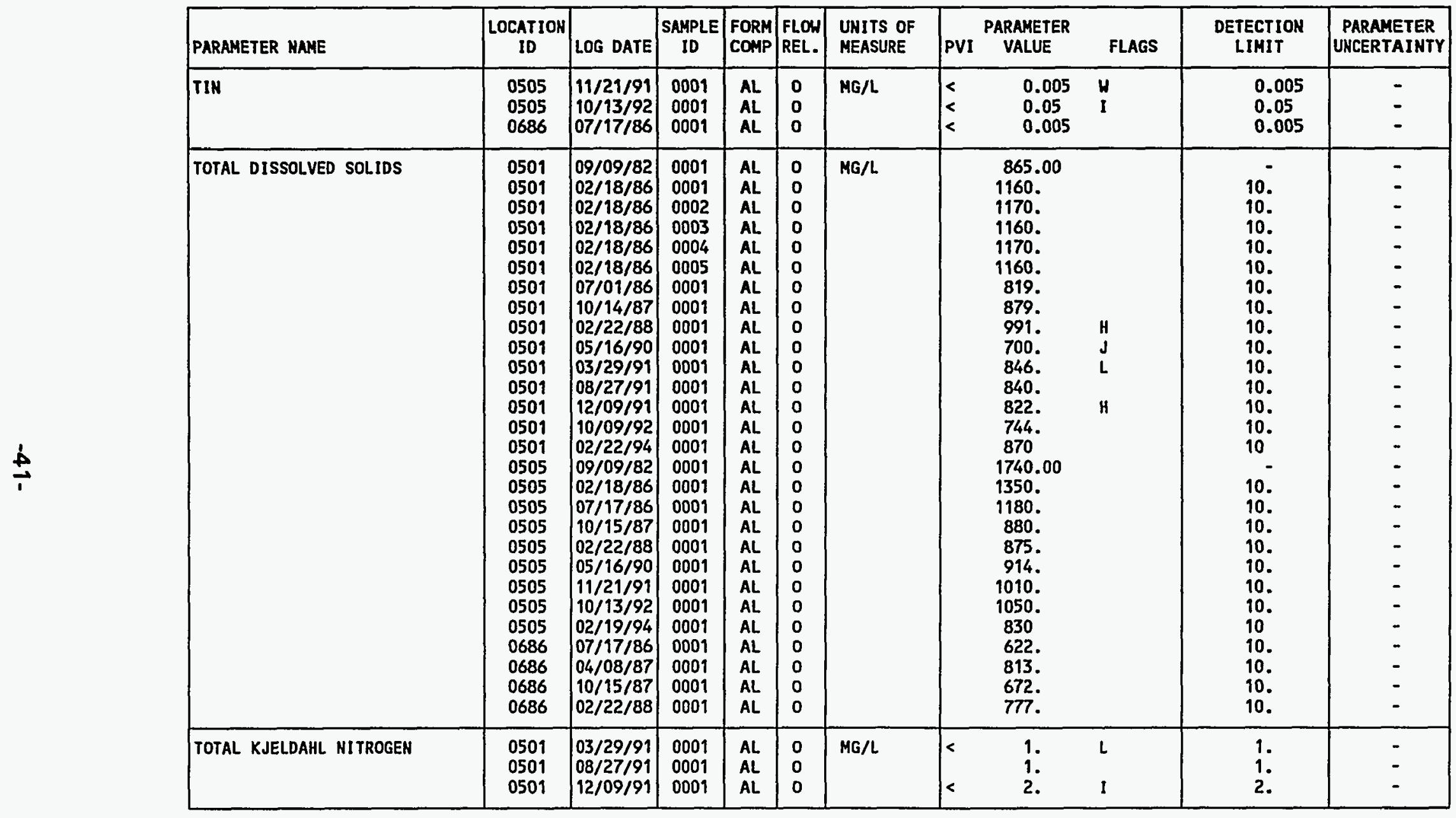

FORMATION OF COMPLETION CODE:

AL - ALLUVIUM

PARAMETER VALUE INDICATOR (PVI): < - LESS THAN DETECTION LIMIT

OTHER PARAMETER VALUE FLAGS:

H - HOLD TIME EXPIRED, VALUE SUSPECT

I - INCREASED DETECTION LIMIT DUE TO REQUIRED DILUTION

$J$ - ESTIMATED VALUE

L - LESS THAN THREE BORE VOLUMES REMOVED BEFORE SAMPLING

$H$ - POST-DIGEST SPIKE OUT OF CNTR LIM HHILE SAMP ABS < $50 \%$ SPIKE
FLOW RELATIONSHIP CODE:

$$
\text { O - ON-SITE }
$$

\section{SAMPLE ID CODES:}

0001 - FILTERED SAMPLE (.45 MICRONS)

0002 - FILTERED REPLICATE SAMPLE (.45 MICRONS)

0003 - FILTERED REPLICATE SAMPLE (.45 MICRONS)

0004 - FILTERED REPLICATE SAMPLE (.45 MICRONS) 
TABLE 3.5 BACKGROUND GROUND WATER QUALITY DATA BY PARAMETER FOR THE ALLUVIUM, NC AND UC PROCESSING SITES, SLICK ROCK, COLORADO

SITE: SRKO? SLICK ROCK (BOTH SITES)

09/09/82 TO 02/22/94

PEPORT DATE: $09 / 28 / 94$

\begin{tabular}{|c|c|c|c|c|c|c|c|c|c|c|c|}
\hline PARAMETER MAME & $\begin{array}{c}\text { LOCATION } \\
\text { ID }\end{array}$ & LOG DATE & $\begin{array}{c}\text { SAMPLE } \\
\text { ID }\end{array}$ & $\begin{array}{l}\text { FORM } \\
\text { COMP }\end{array}$ & $\begin{array}{l}\text { FLOW } \\
\text { REL. }\end{array}$ & $\begin{array}{l}\text { UNITS OF } \\
\text { MEASURE }\end{array}$ & PVI & $\begin{array}{l}\text { PARAMETER } \\
\text { VALUE }\end{array}$ & FLAGS & $\begin{array}{l}\text { DETECTION } \\
\text { LIMIT }\end{array}$ & $\begin{array}{l}\text { PARAMETER } \\
\text { UNCERTAINTY }\end{array}$ \\
\hline TOTAL KJELDAHL NITROGEN & 0505 & $11 / 21 / 91$ & 0001 & AL & 0 & MG/L & & 3. & & 2. & - \\
\hline TOTAL ORGAHIC CARBON & $\begin{array}{l}0501 \\
0501 \\
0501 \\
0501 \\
0501 \\
0501 \\
0505 \\
0505 \\
0505\end{array}$ & $\begin{array}{l}03 / 29 / 91 \\
08 / 27 / 91 \\
12 / 09 / 91 \\
10 / 09 / 92 \\
02 / 22 / 94 \\
02 / 22 / 94 \\
11 / 21 / 91 \\
10 / 13 / 92 \\
02 / 19 / 94\end{array}$ & $\begin{array}{l}0001 \\
0001 \\
0001 \\
0001 \\
0001 \\
N 001 \\
0001 \\
0001 \\
N 001\end{array}$ & $\begin{array}{l}A L \\
A L \\
A L \\
A L \\
A L \\
A L \\
A L \\
A L \\
A L\end{array}$ & $\begin{array}{l}0 \\
0 \\
0 \\
0 \\
0 \\
0 \\
0 \\
0 \\
0\end{array}$ & $M G / L$ & & $\begin{array}{l}2 . \\
2 . \\
2 . \\
2 . \\
9 \\
9 \\
3 . \\
4 . \\
3\end{array}$ & $\mathrm{~L}$ & $\begin{array}{l}1 . \\
1 . \\
1 . \\
1 . \\
1 \\
1 \\
1 . \\
1 .\end{array}$ & $\begin{array}{l}- \\
\dot{-} \\
- \\
- \\
- \\
-\end{array}$ \\
\hline TURBIDITY & $\begin{array}{l}0501 \\
0505\end{array}$ & $\begin{array}{l}02 / 22 / 94 \\
02 / 19 / 94\end{array}$ & $\begin{array}{l}\text { N001 } \\
\text { N001 }\end{array}$ & $\begin{array}{l}A L \\
A L\end{array}$ & $\begin{array}{l}0 \\
0\end{array}$ & NTU & & $\begin{array}{l}0 \\
1\end{array}$ & & : & - \\
\hline URANIUM & $\begin{array}{l}0501 \\
0501 \\
0501 \\
0501 \\
0501 \\
0501 \\
0501 \\
0501 \\
0501 \\
0501 \\
0501 \\
0501 \\
0501 \\
0501 \\
0501 \\
0505 \\
0505 \\
0505 \\
0505 \\
0505 \\
0505 \\
0505 \\
0505\end{array}$ & $\begin{array}{l}09 / 09 / 82 \\
02 / 18 / 86 \\
02 / 18 / 86 \\
02 / 18 / 86 \\
02 / 18 / 86 \\
02 / 18 / 86 \\
07 / 01 / 86 \\
10 / 14 / 87 \\
02 / 22 / 88 \\
05 / 16 / 90 \\
03 / 29 / 91 \\
08 / 27 / 91 \\
12 / 05 / 91 \\
10 / 09 / 92 \\
02 / 22 / 94 \\
09 / 09 / 82 \\
02 / 18 / 86 \\
07 / 17 / 86 \\
10 / 15 / 87 \\
02 / 22 / 88 \\
05 / 16 / 90 \\
12 / 05 / 91 \\
10 / 13 / 92\end{array}$ & $\begin{array}{l}0001 \\
0001 \\
0002 \\
0003 \\
0004 \\
0005 \\
0001 \\
0001 \\
0001 \\
0001 \\
0001 \\
0001 \\
0001 \\
0001 \\
0001 \\
0001 \\
0001 \\
0001 \\
0001 \\
0001 \\
0001 \\
0001 \\
0001\end{array}$ & $\begin{array}{l}A L \\
A L \\
A L \\
A L \\
A L \\
A L \\
A L \\
A L \\
A L \\
A L \\
A L \\
A L \\
A L \\
A L \\
A L \\
A L \\
A L \\
A L \\
A L \\
A L \\
A L \\
A L \\
A L\end{array}$ & $\begin{array}{l}0 \\
0 \\
0 \\
0 \\
0 \\
0 \\
0 \\
0 \\
0 \\
0 \\
0 \\
0 \\
0 \\
0 \\
0 \\
0 \\
0 \\
0 \\
0 \\
0 \\
0 \\
0 \\
0\end{array}$ & MG/L & & $\begin{array}{l}0.134 \\
0.0498 \\
0.0668 \\
0.591 \\
0.0534 \\
0.0565 \\
0.0334 \\
0.034 \\
0.0416 \\
0.026 \\
0.023 \\
0.018 \\
0.019 \\
0.022 \\
0.033 \\
0.071 \\
0.0398 \\
0.0304 \\
0.035 \\
0.0323 \\
0.026 \\
0.025 \\
0.025\end{array}$ & $\begin{array}{l}J \\
L\end{array}$ & $\begin{array}{l}. \\
0.003 \\
0.003 \\
0.003 \\
0.003 \\
0.003 \\
0.003 \\
0.003 \\
0.003 \\
0.003 \\
0.001 \\
0.001 \\
0.001 \\
0.001 \\
0.001 \\
- \\
0.003 \\
0.003 \\
0.003 \\
0.003 \\
0.003 \\
0.001 \\
0.001\end{array}$ & $\begin{array}{l}- \\
- \\
- \\
i \\
- \\
- \\
i \\
- \\
- \\
- \\
- \\
- \\
- \\
- \\
- \\
- \\
- \\
-\end{array}$ \\
\hline
\end{tabular}

FORMATION OF COMPLETION COOE:

AL - ALLUVIUM

PARAMETER VALUE INDICATOR (PVI): < - LESS THAN DETECTION LIMIT

OTHER PARAMETER VALUE FLAGS

$J$ - ESTIMATED VALUE

L - LESS THAN THREE BORE VOLUMES REMOVED BEFORE SAMPLING
FLOH RELATIONSHIP CODE:

O - ON-SITE

0001 - FILTERED SAMPLE (.45 MICRONS)

0002 - FILTERED REPLICATE SAMPLE (.45 MICRONS)

0003 - FILTERED REPLICATE SAMPLE (.45 MICRONS)

0004 - FILTERED REPLICATE SAMPLE (.45 MICRONS)

N001 - UNFILTERED SAMPLE 
TABLE 3.5 BACKGROUHD GROUND WATER QUALITY DATA BY PARAMETER FOR THE ALLUVIUM, NC AND UC PROCESSING SITES, SLICK ROCK, COLORADO

SITE: SRKO1 SLICK ROCK (BOTH SITES)

$09 / 09 / 82$ TO $02 / 22 / 94$

\begin{tabular}{|c|c|c|c|c|c|c|c|c|c|c|c|}
\hline PARAMETER NAME & $\underset{\text { ID }}{\text { LOCATION }}$ & LOG DATE & $\begin{array}{c}\text { SAMPLE } \\
\text { ID }\end{array}$ & $\begin{array}{l}\text { FORM } \\
\text { COMP }\end{array}$ & $\begin{array}{l}\text { FLOW } \\
\text { REL. }\end{array}$ & $\begin{array}{l}\text { UNITS OF } \\
\text { MEASURE }\end{array}$ & PVI & $\begin{array}{l}\text { PARAMETER } \\
\text { VALUE }\end{array}$ & FLAGS & $\begin{array}{l}\text { DETECTION } \\
\text { LIMIT }\end{array}$ & $\begin{array}{l}\text { PARAMETER } \\
\text { UNCERTAINTY }\end{array}$ \\
\hline URAKIU:H & $\begin{array}{l}0505 \\
0686 \\
0686 \\
0686 \\
0686\end{array}$ & $\begin{array}{l}02 / 19 / 94 \\
07 / 17 / 86 \\
04 / 08 / 87 \\
10 / 15 / 87 \\
02 / 22 / 88\end{array}$ & $\begin{array}{l}0001 \\
0001 \\
0001 \\
0001 \\
0001\end{array}$ & $\begin{array}{l}A L \\
A L \\
A L \\
A L \\
A L\end{array}$ & $\begin{array}{l}0 \\
0 \\
0 \\
0 \\
0\end{array}$ & MG/L & & $\begin{array}{l}0.025 \\
0.0404 \\
0.0636 \\
0.051 \\
0.0475\end{array}$ & & $\begin{array}{l}0.001 \\
0.003 \\
0.003 \\
0.003 \\
0.003\end{array}$ & $\begin{array}{l}- \\
- \\
-\end{array}$ \\
\hline URANIUM (TOTAL) & $\begin{array}{l}0501 \\
0505\end{array}$ & $\begin{array}{l}02 / 22 / 94 \\
02 / 19 / 94\end{array}$ & $\begin{array}{l}\text { NOOI } \\
\text { N0O1 }\end{array}$ & $\begin{array}{l}A L \\
A L\end{array}$ & $\begin{array}{l}0 \\
0\end{array}$ & MG/L & & $\begin{array}{l}0.017 \\
0.023\end{array}$ & JN & $\begin{array}{l}0.001 \\
0.001\end{array}$ & - \\
\hline VANADIUH & $\begin{array}{l}0501 \\
0501 \\
0501 \\
0501 \\
0501 \\
0501 \\
0501 \\
0501 \\
0501 \\
0505 \\
0505 \\
0505 \\
0505 \\
0505 \\
0505 \\
0505 \\
0686 \\
0686 \\
0686\end{array}$ & $\begin{array}{l}09 / 09 / 82 \\
07 / 01 / 86 \\
10 / 14 / 87 \\
05 / 16 / 90 \\
03 / 29 / 91 \\
08 / 27 / 91 \\
12 / 09 / 91 \\
10 / 09 / 92 \\
02 / 22 / 94 \\
09 / 09 / 82 \\
07 / 17 / 86 \\
10 / 15 / 87 \\
05 / 16 / 90 \\
11 / 21 / 91 \\
10 / 13 / 92 \\
02 / 19 / 94 \\
07 / 17 / 86 \\
04 / 08 / 87 \\
10 / 15 / 87\end{array}$ & $\begin{array}{l}0001 \\
0001 \\
0001 \\
0001 \\
0001 \\
0001 \\
0001 \\
0001 \\
0001 \\
0001 \\
0001 \\
0001 \\
0001 \\
0001 \\
0001 \\
0001 \\
0001 \\
0001 \\
0001\end{array}$ & $\begin{array}{l}A L \\
A L \\
A L \\
A L \\
A L \\
A L \\
A L \\
A L \\
A L \\
A L \\
A L \\
A L \\
A L \\
A L \\
A L \\
A L \\
A L \\
A L \\
A L\end{array}$ & $\begin{array}{l}0 \\
0 \\
0 \\
0 \\
0 \\
0 \\
0 \\
0 \\
0 \\
0 \\
0 \\
0 \\
0 \\
0 \\
0 \\
0 \\
0 \\
0 \\
0\end{array}$ & $M G / L$ & $\begin{array}{l}< \\
< \\
< \\
< \\
< \\
< \\
< \\
< \\
< \\
< \\
< \\
< \\
< \\
< \\
<\end{array}$ & $\begin{array}{l}0.05 \\
0.23 \\
0.01 \\
0.02 \\
0.01 \\
0.01 \\
0.01 \\
0.01 \\
0.01 \\
0.05 \\
0.24 \\
0.01 \\
0.02 \\
0.01 \\
0.01 \\
0.01 \\
0.39 \\
0.2 \\
0.01\end{array}$ & $\begin{array}{l}\mathbf{J} \\
\mathbf{L}\end{array}$ & $\begin{array}{l}0.05 \\
0.01 \\
0.01 \\
0.01 \\
0.01 \\
0.01 \\
0.01 \\
0.01 \\
0.01 \\
0.05 \\
0.01 \\
0.01 \\
0.01 \\
0.01 \\
0.01 \\
0.09 \\
0.01 \\
0.2 \\
0.01\end{array}$ & $\begin{array}{l}- \\
- \\
- \\
- \\
- \\
- \\
- \\
- \\
- \\
- \\
- \\
- \\
- \\
- \\
-\end{array}$ \\
\hline VANADIUM (TOTAL) & $\begin{array}{l}0501 \\
0505\end{array}$ & $\begin{array}{l}02 / 22 / 94 \\
02 / 19 / 94\end{array}$ & $\begin{array}{l}\text { N001 } \\
\text { N001 }\end{array}$ & $\begin{array}{l}\text { AL } \\
\text { AL }\end{array}$ & $\begin{array}{l}0 \\
0\end{array}$ & $M G / L$ & $<$ & $\begin{array}{l}0.01 \\
0.01\end{array}$ & & $\begin{array}{l}0.01 \\
0.01\end{array}$ & - \\
\hline ZINC & $\begin{array}{l}0501 \\
0501 \\
0501 \\
0501 \\
0501 \\
0501 \\
0501\end{array}$ & $\begin{array}{l}10 / 14 / 87 \\
05 / 16 / 90 \\
03 / 29 / 91 \\
08 / 27 / 91 \\
12 / 09 / 91 \\
10 / 09 / 92 \\
02 / 22 / 94\end{array}$ & $\begin{array}{l}0001 \\
0001 \\
0001 \\
0001 \\
0001 \\
0001 \\
0001\end{array}$ & $\begin{array}{l}A L \\
A L \\
A L \\
A L \\
A L \\
A L \\
A L\end{array}$ & $\begin{array}{l}0 \\
0 \\
0 \\
0 \\
0 \\
0 \\
0\end{array}$ & MG/L & $\begin{array}{l}< \\
< \\
< \\
< \\
<\end{array}$ & $\begin{array}{l}0.005 \\
0.015 \\
0.005 \\
0.005 \\
0.005 \\
0.005 \\
0.05\end{array}$ & $\begin{array}{l}\mathbf{L} \\
\mathbf{L}\end{array}$ & $\begin{array}{l}0.005 \\
0.005 \\
0.005 \\
0.005 \\
0.005 \\
0.005 \\
0.05\end{array}$ & $\begin{array}{l}- \\
- \\
- \\
- \\
-\end{array}$ \\
\hline
\end{tabular}

FORMATION OF COMPLETION CODE:

AL. - ALLUVIUM

PARAMETER VALUE INDICATOR (PVI): < - LESS THAN DETECTION LIMIT

OTHER PARAMETER VALUE FLAGS:

$\mathrm{J}$ - ESTIMATED VALUE

L. - LESS THAH THREE BORE VOLUMES REMOVED BEFORE SAMPLING

N - SPIKE SAMPLE RECOVERY NOT WITHIN CONTROL LIMITS
FLOH RELATIONSHIP CODE:

O- ON-SITE

SAMPLE ID COOES

0001 - FILTERED SAMPLE (.45 MICRONS)

N001 - UNFILTERED SAMPLE 
TABLE 3.5 BACKGROUND GROUND HATER QUALITY DATA BY PARAMETER FOR THE ALLUVIUM, NC AND UC PROCESSING SITES, SLICK ROCK, COLORADO

SITE: SRKO1 SLICK ROCK (BOTH SITES)

$09 / 09 / 82$ TO $02 / 22 / 94$

REPORT DATE : $09 / 28 / 94$

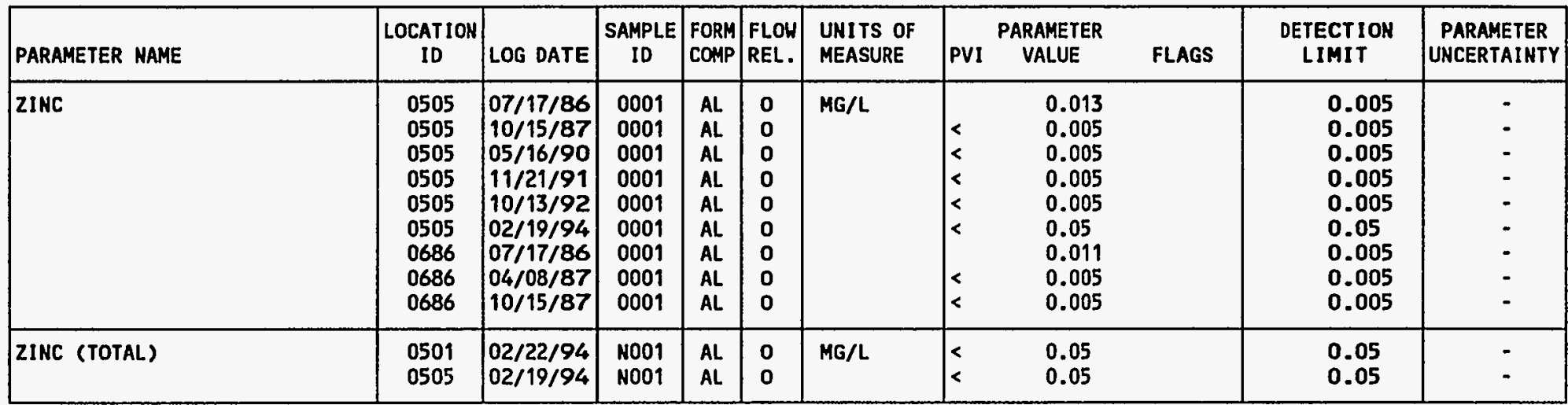

FORMATION OF COMPLETION COOE:

AL - ALLUVIUM

FLOW RELATIONSHIP CODE:

O - ON-SITE

PARAMETER VALUE INDICATOR (PVI): < - LESS THAN DETECTION LIMIT

SAMPLE ID CODES:

0001 - FILTERED SAMPLE (.45 MICRONS)

N001 - UNFILTERED SAMPLE

DATA FILE NAME: IDARTISRKO1IGWQ10023.DAT 
TABLE 3.6 BACKGROUND GROUHD WATER QUALITY STATISTICS BY PARAMETER

FOR THE ALLUVIUM, NC PROCESSING SITE, SLICK ROCK, COLORADO

SITE: SRKOI SLICK ROCK (BOTH SITES)

09/09/82 TO 02/22/94

REPORT DATE: 09/28/94

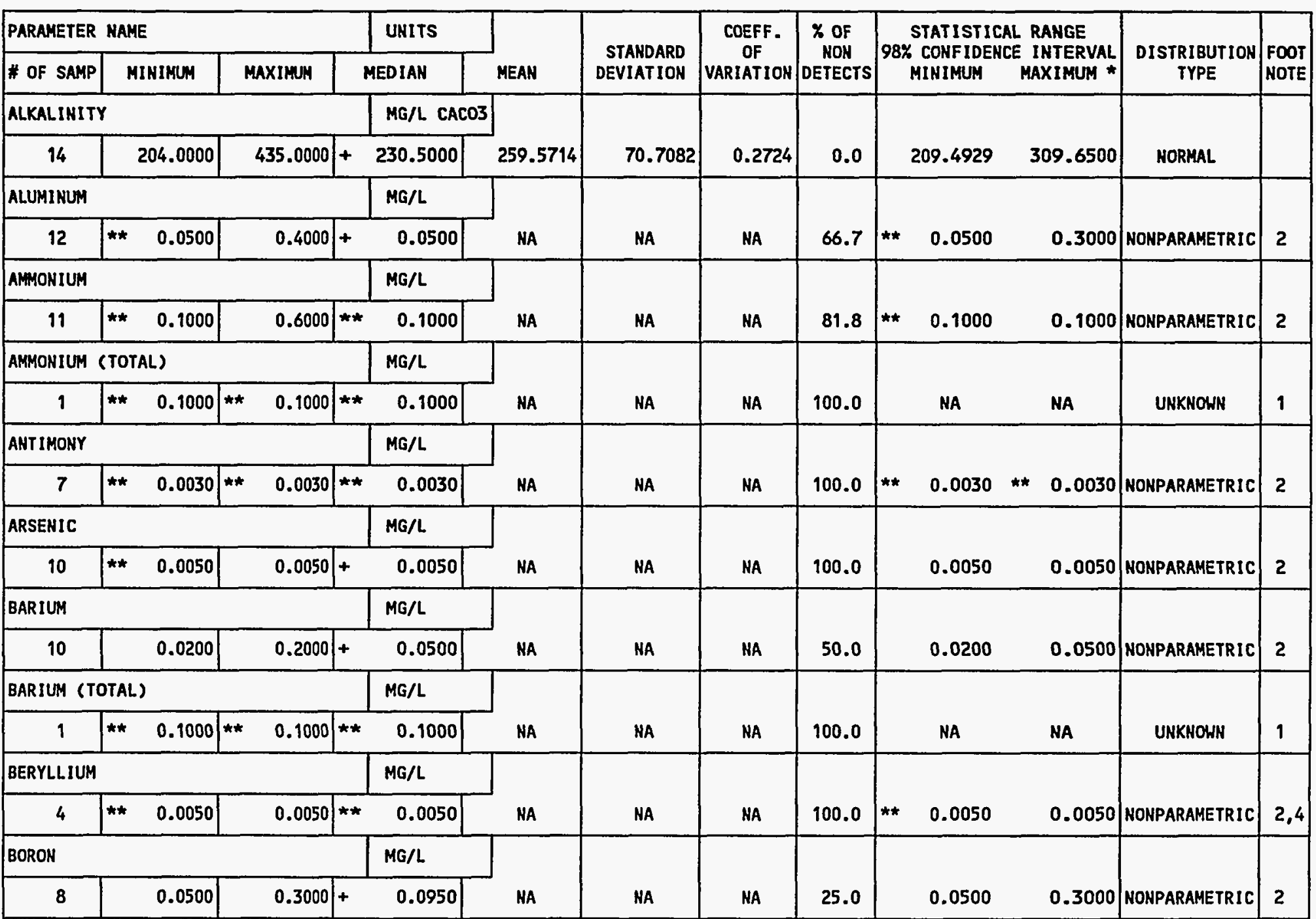

** The reported value is the minimum detection limit of the data set

+ The sample size is even, so the median value is the arithmetic average of the two middle values

* The statistical maximum is the 99 percent one sided confidence interval, $\alpha=0.01$

1) A minimum of 4 samples must be available for the statistical analysis.

2) The nonparametric distribution was used because the nondetected values comprise more than $15 \%$ of the samples.

4) The stat. range is the $87.5 \%$ confidence interval due to a sample size of 4 . The maximum is the $93.8 \%$ one sided confidence int. 
TABLE 3.6 BACKGROUND GROUHD HATER QUALITY STATISTICS BY PARAMETER

FOR THE ALLUVIUM, NC PROCESSING SITE, SLICK ROCK, COLORADO

SITE: SRKO1 SLICK ROCK (BOTH SITES)

$09 / 09 / 82$ TO $02 / 22 / 94$

REPORT DATE: $09 / 28 / 94$

\begin{tabular}{|c|c|c|c|c|c|c|c|c|c|c|c|c|c|}
\hline PARAMETER & NAME & & & & UNITS & & & & & STATISTIC & AL. RANGE & & \\
\hline \# OF SAMP & MINIMUM & & AXIMUM & & MED IAN & MEAN & DEVIATIOH & VARIATION & DETECTS & $\begin{array}{l}98 \% \text { CONFIDEN } \\
\text { MINIMUM }\end{array}$ & MAXIMUM * & $\begin{array}{l}\text { DISTRIBUT ION } \\
\text { TYPE }\end{array}$ & $\begin{array}{l}\text { FOOT } \\
\text { NOTE }\end{array}$ \\
\hline BORON (TO & TAL) & & & & MG/L & & & & & & & & \\
\hline 1 & ** $\quad 0.1000$ & ** & 0.1000 & ** & 0.1000 & NA & NA & NA & 100.0 & NA & HA & UHKHOWN & 1 \\
\hline BROMIDE & & & & & $M G / L$ & & & & & & & & \\
\hline 4 & 0.1500 & & 0.2500 & + & 0.2000 & NA & NA & NA & 50.0 & 0.1500 & 0.2500 & MONPARAMETRIC & 2,4 \\
\hline CADMIUM & & & & & MG/L & & & & & & & & \\
\hline 10 & $* * \quad 0.0005$ & & 0.0005 & + & 0.0005 & NA & NA & NA & 100.0 & 0.0005 & 0.0005 & NONPARAMETRIC & 2 \\
\hline CADHIUH (1 & IOTAL) & & & & $M G / L$ & & & & & & & & \\
\hline 1 & ** $\quad 0.0010$ & $\star \star$ & 0.0010 & $\star \star \star$ & 0.0010 & NA & NA & NA & 100.0 & NA & NA & UNKNOWN & 1 \\
\hline CALCIUM & & & & & MG/L & & & & & & & & \\
\hline 13 & 73.8000 & & 150.0000 & & 111.0000 & 114.0308 & 19.1015 & 0.1675 & 0.0 & 99.8274 & 128.2341 & NORMAL & \\
\hline CALCIUM (1 & TOTAL) & & & & MG/L & & & & & & & & \\
\hline 1 & 131.0000 & & 131.0000 & & 131.0000 & NA & NA & NA & 0.0 & NA & NA & UHKNOWN & 1 \\
\hline CHLORIDE & & & & & MG/L & & & & & & & & \\
\hline 13 & 38.0000 & & 89.0000 & & 62.0000 & 60.0923 & 15.5863 & 0.2594 & 0.0 & 48.5027 & 71.6819 & HORMAL & \\
\hline CHROMIUM & & & & & $M G / L$ & & & & & & & & \\
\hline 10 & $* * \quad 0.0100$ & & 0.0400 & & 0.0100 & NA & NA & NA & 90.0 & 0.0100 & 0.0100 & NONPARAMETRIC & 2 \\
\hline CHROMIUM & TOTAL) & & & & $M G / L$ & & & & & & & & \\
\hline 1 & $\star * \quad 0.0100$ & $\star \star$ & 0.0100 & $\star \star$ & 0.0100 & NA & NA & NA & 100.0 & NA & NA & UNKHOWN & 1 \\
\hline COBALT & & & & & $M G / L$ & & & & & & & & \\
\hline 4 & ** $\quad 0.0300$ & ** & 0.0300 & ** & 0.0300 & NA & NA & HA & 100.0 & 0.0300 & ** 0.0300 & NONPARAMETR IC & 2,4 \\
\hline
\end{tabular}

** The reported value is the minimum detection limit of the data set

+ The sample size is even, so the median value is the arithmetic average of the two middle values

- The statistical maximum is the 99 percent one sided confidence interval, $\alpha=0.01$

1) A minimum of 4 samples must be available for the statistical analysis.

2) The nonparametric distribution was used because the nondetected values comprise more than $15 \%$ of the samples.

4) The stat. range is the $87.5 \%$ confidence interval due to a sample size of 4 . The maximu is the $93.8 \%$ one sided confidence int. 
TABLE 3.6 BACKGROUND GROUND HATER QUALITY STATISTICS BY PARAMETER

FOR THE ALLUVIUM, NC PROCESSING SITE, SLICK ROCK, COLORADO

SITE: SRKO1 SLICK ROCK (BOTH SITES)

$09 / 09 / 82$ TO 02/22/94

REPORT DATE: 09/28/94

\begin{tabular}{|c|c|c|c|c|c|c|c|c|c|c|c|c|}
\hline \multicolumn{3}{|c|}{ PARAMETER NAME } & \multirow[b]{2}{*}{ MEDIAN } & \multirow[b]{2}{*}{ MEAN } & \multirow{2}{*}{$\begin{array}{c}\text { STANDARD } \\
\text { DEVIATION }\end{array}$} & \multirow{2}{*}{$\begin{array}{c}\text { COEFF. } \\
\text { OF } \\
\text { VARIATION }\end{array}$} & \multirow{2}{*}{$\mid \begin{array}{c}x \text { OF } \\
\text { NOH } \\
\text { DETECTS }\end{array}$} & \multirow{2}{*}{\multicolumn{3}{|c|}{$\begin{array}{c}\text { STATISTICAL RANGE } \\
\text { 98\% CONFIDENCE INTERVAL } \\
\text { MINIMUM MAXIMUM * }\end{array}$}} & \multirow[b]{2}{*}{$\begin{array}{c}\text { DISTRIBUTION } \\
\text { TYPE }\end{array}$} & \multirow{2}{*}{$\begin{array}{l}\text { FOOT } \\
\text { NOTE }\end{array}$} \\
\hline \# OF SAMP & MIHIMUM & MAXIMUM & & & & & & & & & & \\
\hline COPPER & & & $M G / L$ & \multirow[b]{2}{*}{ NA } & \multirow[b]{2}{*}{ NA } & \multirow[b]{2}{*}{ MA } & \multirow[b]{2}{*}{77.8} & \multirow[b]{2}{*}{ ** } & \multirow[b]{2}{*}{0.0100} & \multirow[b]{2}{*}{0.0500} & \multirow[b]{2}{*}{ NONPARAMETRIC } & \multirow[b]{2}{*}{2} \\
\hline 9 & ** 0.0100 & 0.0500 & 0.0100 & & & & & & & & & \\
\hline \multicolumn{3}{|l|}{ CYANIDE } & $\mathrm{MG} / \mathrm{L}$ & \multirow[b]{2}{*}{ NA } & \multirow[b]{2}{*}{ NA } & \multirow[b]{2}{*}{$\mathrm{HA}$} & \multirow[b]{2}{*}{100.0} & \multirow{2}{*}{\multicolumn{2}{|c|}{ NA }} & \multirow[b]{2}{*}{ HA } & \multirow[b]{2}{*}{ UNKNOWN } & \multirow[b]{2}{*}{1} \\
\hline 3 & ** $\quad 0.0100$ & 0.0100 & 0.0100 & & & & & & & & & \\
\hline \multicolumn{3}{|c|}{ DISSOLVED OXYGEN } & $M G / L$ & \multirow[b]{2}{*}{ NA } & \multirow[b]{2}{*}{ NA } & \multirow[b]{2}{*}{ KA } & \multirow[b]{2}{*}{0.0} & & & & & \\
\hline 2 & 0.2500 & 1.3000 & 0.7750 & & & & & & MA & NA & UNKNOWN & 1 \\
\hline FIELD FE \& & $(2+)$ & & MG/L & & & & & & & & & \\
\hline 2 & 0.0300 & 0.0500 & 0.0400 & NA & NA & HA & 0.0 & & NA & NA & UNKNOWN & 1 \\
\hline FIELD FE ( & (TOTAL) & & $M G / L$ & & & & & & & & & \\
\hline 2 & 0.0000 & 0.0100 & 0.0050 & NA & NA & NA & 50.0 & & HA & NA & UNKNOWN & 1 \\
\hline FLUORIDE & & & $M G / L$ & & & & & & & & & \\
\hline 11 & 0.1000 & 0.4000 & 0.2000 & 0.2255 & 0.0745 & 0.3304 & 0.0 & & 0.1634 & 0.2875 & NORMAL & \\
\hline GROSS ALPH & & & $\mathrm{PCI} / \mathrm{L}$ & & & & & & & & & \\
\hline 5 & 3.6000 & 20.5000 & 17.0000 & 14.1800 & 7.3663 & 0.5195 & 0.0 & & 1.8363 & 26.5237 & NORMAL & \\
\hline GROSS ALPH & HA (TOTAL) & & $\mathrm{PCI} / \mathrm{L}$ & & & & & & & & & \\
\hline 1 & 19.9000 & 19.9000 & 19.9000 & NA & NA & HA & 0.0 & & NA & MA & UNKNOWN & 1 \\
\hline GROSS BETA & & & PCI/L & & & & & & & & & \\
\hline 4 & 0.6000 & 12.6000 & 10.7000 & 8.6500 & 5.4800 & 0.6335 & 0.0 & $\star \star *$ & 0.5000 & 21.0923 & NORMAL & \\
\hline IRON & & & MG/L & & & & & & & & & \\
\hline 13 & 0.0300 & 0.6500 & 0.0500 & NA & NA & NA & 46.2 & ** & 0.0300 & 0.5800 & HONPARAMETRIC & 2 \\
\hline
\end{tabular}

** The reported value is the minimum detection limit of the data set

+ The sample size is even, so the median value is the arithmetic average of the two middle values

* The statistical maximum is the 99 percent one sided confidence interval, $\alpha=0.01$

1) A minimum of 4 samples must be available for the statistical analysis.

2) The nonparametric distribution was used because the nondetected values comprise more than $15 \%$ of the samples. 
TABLE 3.6 BACKGROUND GROUND WATER QUALITY STATISTICS BY PARAMETER

FOR THE ALLUVIUM, NC PROCESSING SITE, SLICK ROCK, COLORADO

SITE: SRK01 SLICK ROCK (BOTH SITES)

09/09/82 TO 02/22/94

REPORT DATE: $09 / 28 / 94$

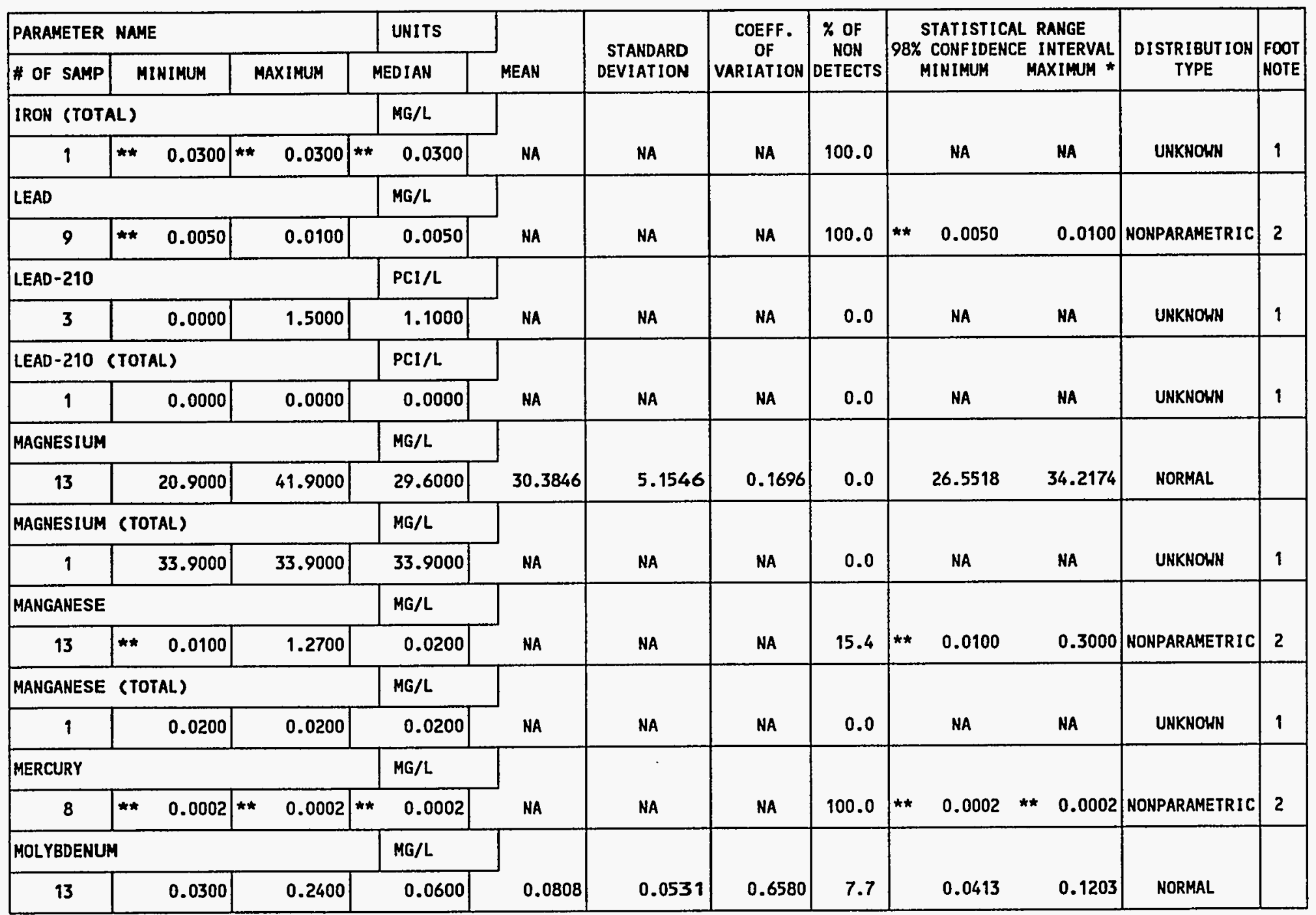

** The reported value is the minimum detection limit of the data set

* The statistical maximum is the 99 percent one sided confidence interval, $\alpha$ a 0.01

1) A minimum of 4 samples must be available for the statistical analysis.

2) The nonparametric distribution was used because the nondetected values comprise more than $15 \%$ of the samples. 
TABLE 3.6 BACKGROUND GROUND YATER QUALITY STATISTICS BY PARAMETER FOR THE ALLUVIUH, NC PROCESSING SITE, SLICK ROCK, COLORADO

SITE: SRKOI SLICK ROCK (BOTH SITES)

09/09/82 TO 02/22/94

REPORT DATE: $09 / 28 / 94$

\begin{tabular}{|c|c|c|c|c|c|c|c|c|c|c|c|}
\hline \multicolumn{3}{|c|}{ PARAMETER MAME } & UNITS & \multirow[b]{2}{*}{ MEAN } & \multirow{2}{*}{$\begin{array}{l}\text { STANDARD } \\
\text { DEVIATION }\end{array}$} & \multirow{2}{*}{$\begin{array}{c}\text { COEFF. } \\
\text { OF } \\
\text { VARIATION }\end{array}$} & \multirow{2}{*}{$\begin{array}{c}* \text { OF } \\
\text { MON } \\
\text { DETECTS }\end{array}$} & \multirow{2}{*}{\multicolumn{2}{|c|}{$\begin{array}{c}\text { STATISTICAL RANGE } \\
\text { 98\% CONFIDENCE INTERVAL } \\
\text { MINIMUH }\end{array}$}} & \multirow{2}{*}{$\begin{array}{l}\text { DISTRIBUTION } \\
\text { TYPE }\end{array}$} & \multirow{2}{*}{$\begin{array}{l}\text { FOOT } \\
\text { NOTE }\end{array}$} \\
\hline \# OF SAMP & MINIMUN & MAXIMUM & MEDIAN & & & & & & & & \\
\hline \multicolumn{3}{|c|}{ MOLYBDENUM (TOTAL) } & $M G / L$ & \multirow[b]{2}{*}{ MA } & \multirow[b]{2}{*}{ NA } & \multirow[b]{2}{*}{ HA } & \multirow[b]{2}{*}{0.0} & \multirow[b]{2}{*}{ MA } & \multirow[b]{2}{*}{ HA } & \multirow[b]{2}{*}{ UNKNOWH } & \multirow[b]{2}{*}{1} \\
\hline 1 & 0.0400 & 0.0400 & 0.0400 & & & & & & & & \\
\hline \multicolumn{3}{|c|}{ NET GROSS ALPHA $\star * *$} & $\mathrm{PCI} / \mathrm{L}$ & \multirow[b]{2}{*}{ MA } & \multirow[b]{2}{*}{ NA } & \multirow[b]{2}{*}{ NA } & \multirow[b]{2}{*}{0.0} & \multirow[b]{2}{*}{-9.4300} & \multirow[b]{2}{*}{4.7200} & \multirow[b]{2}{*}{ NONPARAMETRIC } & \multirow[b]{2}{*}{9,5} \\
\hline 5 & -9.4300 & 4.7200 & -2.4400 & & & & & & & & \\
\hline \multicolumn{3}{|c|}{ 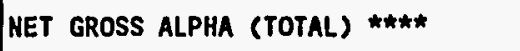 } & PCI/L & \multirow[b]{2}{*}{ NA } & \multirow[b]{2}{*}{ NA } & \multirow[b]{2}{*}{ NA } & \multirow[b]{2}{*}{0.0} & \multirow[b]{2}{*}{ NA } & \multirow[b]{2}{*}{ NA } & \multirow[b]{2}{*}{ UNKHOWN } & \\
\hline 1 & 8.2400 & 8.2400 & 8.2400 & & & & & & & & 1 \\
\hline HICKEL & & & $M G / L$ & & & & & & & & \\
\hline 11 & $* * \quad 0.0400$ & 0.0400 & 0.0400 & NA & NA & NA & 72.7 & 0.0400 & $* * \quad 0.0400$ & NONPARAMETRIC & 2 \\
\hline NITRATE & & & MG/L & & & & & & & & \\
\hline 12 & $\star \quad 1.0000$ & 7.3000 & 1.0000 & NA & NA & NA & 58.3 & 1.0000 & 1.6000 & NONPARAMETRIC & 2 \\
\hline NITRATE (T & (OTAL) & & $M G / L$ & & & & & & & & \\
\hline 1 & $* \quad 1.0000$ & 1.0000 & 1.0000 & NA & NA & NA & 100.0 & NA & NA & UNKNOWN & 1 \\
\hline NITRITE AN & ID HITRATE & & $M G / L$ & & & & & & & & \\
\hline 5 & 0.2000 & 1.6400 & 0.5000 & NA & NA & NA & 40.0 & 0.2000 & 1.6400 & NONPARAMETRIC & 2,5 \\
\hline PH & & & SU & & & & & & & & \\
\hline 16 & 6.8900 & 7.6600 & 7.1700 & NA & NA & NA & 0.0 & NA & NA & UNKNOWH & \\
\hline
\end{tabular}

*** NET GROSS ALPHA (GROSS ALPHA - URANIUM) WITH 1 MG URANIUH $=686 \mathrm{PCI}$

**** NET GROSS ALPHA (TOTAL) (TOTAL GROSS ALPHA - TOTAL URANIUM)

** The reported value is the minimum detection limit of the data set

- The sample size is even, so the median value is the arithmetic average of the two middle values

* The statistical maximum is the 99 percent one sided confidence interval, $a=0.01$

1) A minimum of 4 samples must be available for the statistical analysis.

2) The nonparametric distribution was used because the nondetected values comprise more than $15 \%$ of the samples.

5) The stat. range is the $93.8 \%$ confidence interyal due to a sample size of 5 . The maximm is the $96.9 \%$ one sided confidence int.

9) The nonparametic distribution was used because the data failed the normal distribution test and includes values $\leq 0$. 
TABLE 3.6 BACKGROUND GROUND WATER QUALITY STATISTICS BY PARAMETER FOR THE ALLUVIUM, HC PROCESSING SITE, SLICK ROCK, COLORADO

SITE: SRKO1 SLICK ROCK (BOTH SITES)

09/09/82 TO 02/22/94

REPORT DATE: $09 / 28 / 94$

\begin{tabular}{|c|c|c|c|c|c|c|c|c|c|c|c|}
\hline \multicolumn{3}{|c|}{ PARAMETER NAME } & UNITS & \multirow[b]{2}{*}{ MEAN } & \multirow{2}{*}{$\begin{array}{l}\text { STANDARD } \\
\text { DEVIATION }\end{array}$} & \multirow{2}{*}{\begin{tabular}{|} 
COEFF. \\
OF \\
VARIATION
\end{tabular}} & \multirow{2}{*}{$\mid \begin{array}{c}\text { X OF } \\
\text { NON } \\
\text { DETECTS }\end{array}$} & \multirow{2}{*}{\multicolumn{2}{|c|}{$\begin{array}{c}\text { STATISTICAL RANGE } \\
\text { 98\% CONFIDENCE INTERVAL } \\
\text { MINIMUM } \\
\text { MAXIMUM * }\end{array}$}} & \multirow{2}{*}{$\begin{array}{l}\text { DISTRIBUTION } \\
\text { TYPE }\end{array}$} & \multirow{2}{*}{$\begin{array}{l}\text { FOOT } \\
\text { NOTE }\end{array}$} \\
\hline \# OF SAMP & MINIMUM & MAXIMUM & MEDIAN & & & & & & & & \\
\hline \multicolumn{3}{|l|}{ PHOSPHATE } & MG/L & \multirow[b]{2}{*}{ NA } & \multirow[b]{2}{*}{ NA } & \multirow[b]{2}{*}{ NA } & \multirow[b]{2}{*}{88.9} & \multirow[b]{2}{*}{0.1000} & \multirow[b]{2}{*}{0.1000} & \multirow[b]{2}{*}{ NONPARAMETRIC } & \multirow[b]{2}{*}{2} \\
\hline 9 & $* \quad 0.1000$ & 0.1000 & 0.1000 & & & & & & & & \\
\hline \multicolumn{3}{|c|}{ POLONIUH-210 } & PCI/L & \multirow[b]{2}{*}{ NA } & \multirow[b]{2}{*}{ MA } & \multirow[b]{2}{*}{ NA } & \multirow[b]{2}{*}{0.0} & \multirow[b]{2}{*}{ NA } & \multirow[b]{2}{*}{ NA } & \multirow[b]{2}{*}{ UNKHOWN } & \multirow[b]{2}{*}{1} \\
\hline 3 & $\star * \quad 0.1000$ & 0.1000 & 0.1000 & & & & & & & & \\
\hline \multicolumn{3}{|c|}{ POLONIUM-210 (TOTAL) } & $\mathrm{PCI} / \mathrm{L}$ & \multirow[b]{2}{*}{ NA } & \multirow[b]{2}{*}{ NA } & \multirow[b]{2}{*}{ NA } & \multirow[b]{2}{*}{0.0} & \multirow[b]{2}{*}{ NA } & & & \\
\hline 1 & 0.1000 & 0.1000 & 0.1000 & & & & & & NA & UNKNOWN & 1 \\
\hline POTASSIUM & & & $M G / L$ & & & & & & & & \\
\hline 13 & 3.3000 & 6.0800 & 3.9600 & 4.1385 & 0.7017 & 0.1696 & 0.0 & 3.6167 & 4.6602 & NORMAL & \\
\hline POTASSIUM & (TOTAL) & & $M G / L$ & & & & & & & & \\
\hline 1 & 3.6000 & 3.6000 & 3.6000 & NA & NA & NA & 0.0 & NA & NA & UNKNOWN & 1 \\
\hline RADIUM-226 & & & $\mathrm{PCl} / \mathrm{L}$ & & & & & & & & \\
\hline 8 & 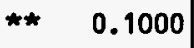 & 0.4000 & 0.1000 & NA & NA & NA & 0.0 & 0.1000 & 0.4000 & NONPARAMETRIC & 9 \\
\hline RADIUA-226 & (TOTAL) & & $\mathrm{PCI} / \mathrm{L}$ & & & & & & & & \\
\hline 1 & $\star * \quad 0.2000$ & 0.2000 & 0.2000 & NA & NA & NA & 0.0 & NA & NA & UNKNOWN & 1 \\
\hline RADIUM-226 & + RADIUH-22 & & $\mathrm{PCI} / \mathrm{L}$ & & & & & & & & \\
\hline 6 & 0.0000 & 7.8000 & 0.9000 & NA & NA & NA & 0.0 & 0.0000 & 7.8000 & NONPARAMETRIC & 9,6 \\
\hline RADIUM-226 & + RADIUM -22 & (TOTAL) & PCI/L & & & & & & & & \\
\hline 1 & 0.0000 & 0.0000 & 0.0000 & NA & NA & NA & 0.0 & NA & NA & UNKNOWN & 1 \\
\hline
\end{tabular}

** The reported value is the minimum detection limit of the data set

+ The sample size is even, so the median value is the arithmetic average of the two middle values

* The statistical maximum is the 99 percent one sided confidence interval, $\alpha=0.01$

1) A minimu of 4 samples must be available for the statistical analysis.

2) The nonparametric distribution was used because the nondetected values comprise more than $15 \%$ of the samples.

6) The stat. range is the $96.9 \%$ confidence interval due to a sample size of 6 . The maximum is the $98.5 \%$ one sided confidence int.

9) The nonparametic distribution was used because the data failed the normal distribution test and includes values $\leq 0$. 
TABLE 3.6 BACKGROUND GROUND HATER QUALITY STATISTICS BY PARAMETER

FOR THE ALLUVIUM, HC PROCESSING SITE, SLICK ROCK, COLORADO

SITE: SRKO1 SLICK ROCK (BOTH SITES)

09/09/82 TO 02/22/94

REPORT DATE: 09/28/94

\begin{tabular}{|c|c|c|c|c|c|c|c|c|c|c|c|c|}
\hline \multicolumn{3}{|c|}{ PARAMETER MAME } & UNITS & \multirow[b]{2}{*}{ MEAN } & \multirow{2}{*}{$\begin{array}{r}\text { STAKDARD } \\
\text { DEVIATION }\end{array}$} & \multirow{2}{*}{$\begin{array}{c}\text { COEFF. } \\
\text { OF } \\
\text { VARIATION }\end{array}$} & \multirow{2}{*}{$\begin{array}{c}\% \text { OF } \\
\text { NON } \\
\text { DETECTS }\end{array}$} & \multirow{2}{*}{\multicolumn{3}{|c|}{$\begin{array}{c}\text { STATISTICAL RANGE } \\
\text { 98\% CONFIDENCE INTERVAL } \\
\text { MINIMUM MAXIMUM * }\end{array}$}} & \multirow{2}{*}{$\begin{array}{c}\text { DISTRIBUTION } \\
\text { TYPE }\end{array}$} & \multirow{2}{*}{$\begin{array}{l}\text { FOOT } \\
\text { HOTE }\end{array}$} \\
\hline \# OF SAMP & MINIMUM & MAXIMUN & MEDIAN & & & & & & & & & \\
\hline \multicolumn{3}{|l|}{ RADIUAM-228 } & PCI/L & \multirow[b]{2}{*}{ MA } & \multirow[b]{2}{*}{ NA } & \multirow[b]{2}{*}{ NA } & \multirow[b]{2}{*}{0.0} & \multirow[b]{2}{*}{$\star \star$} & \multirow[b]{2}{*}{1.0000} & \multirow[b]{2}{*}{7.8000} & \multirow[b]{2}{*}{ NONPARAMETRIC } & \multirow[b]{2}{*}{9,6} \\
\hline 6 & $* \quad 1.0000$ & 7.8000 & 1.0000 & & & & & & & & & \\
\hline \multicolumn{3}{|c|}{ RADIUM-228 (TOTAL) } & $\mathrm{PCI} / \mathrm{L}$ & \multirow[b]{2}{*}{ NA } & \multirow[b]{2}{*}{ NA } & \multirow[b]{2}{*}{ NA } & \multirow[b]{2}{*}{0.0} & \multirow{2}{*}{\multicolumn{2}{|c|}{ NA }} & \multirow[b]{2}{*}{ NA } & \multirow[b]{2}{*}{ UNKHONN } & \multirow[b]{2}{*}{1} \\
\hline 1 & ** 2.9000 & 2.9000 & 2.9000 & & & & & & & & & \\
\hline \multicolumn{3}{|c|}{ REDOX POTENTIAL } & mVOLTS & \multirow[b]{2}{*}{ NA } & \multirow[b]{2}{*}{ HA } & \multirow[b]{2}{*}{ NA } & \multirow[b]{2}{*}{0.0} & \multirow{2}{*}{\multicolumn{2}{|c|}{ HA }} & & & \\
\hline 3 & 340.5000 & 452.8000 & 452.0000 & & & & & & & NA & UNKNOWN & 1 \\
\hline SELENIUM & & & MG/L & & & & & & & & & \\
\hline 11 & ** $\quad 0.0050$ & 0.0050 & 0.0050 & NA & NA & MA & 100.0 & ** & 0.0050 & 0.0050 & NONPARAMETRIC & 2 \\
\hline SELENIUM & (TOTAL) & & $M G / L$ & & & & & & & & & \\
\hline 1 & ** $\quad 0.0050$ & 0.0050 & 0.0050 & NA & NA & NA & 100.0 & & HA & NA & UNKNOWN & 1 \\
\hline SILICA - S & 8102 & & $M G / L$ & & & & & & & & & \\
\hline 12 & 4.0000 & 11.9000 & 8.8000 & 8.6167 & 1.8070 & 0.2097 & 0.0 & & 7.1989 & 10.0345 & NORMAL. & \\
\hline SILICA - S & SIO2 (TOTAL) & & MG/L & & & & & & & & & \\
\hline 1 & 8.5000 & 8.5000 & 8.5000 & HA & NA & NA & 0.0 & & NA & NA & UNKHOWN & 1 \\
\hline SILVER & & & $M G / L$ & & & & & & & & & \\
\hline 8 & 0.0100 & 0.0100 & 0.0100 & $H A$ & NA & NA & 100.0 & $\star \star$ & 0.0100 & 0.0100 & NONPARAMETRIC & 2 \\
\hline SODIUM & & & MG/L & & & & & & & & & \\
\hline 13 & 90.2000 & 195.0000 & 113.0000 & 118.2846 & 27.0479 & 0.2287 & 0.0 & & 98.1725 & 138.3967 & NORMAL & \\
\hline
\end{tabular}

* The reported value is the minimum detection limit of the data set

+ The sample size is even, so the median value is the arithmetic average of the two middle values

* The statistical maximum is the 99 percent one sided confidence interval, $\alpha=0.01$

1) A minimum of 4 samples must be available for the statistical analysis.

2) The nonparametric distribution was used because the nondetected values comprise more than $15 \%$ of the samples.

6) The stat. range is the $96.9 \%$ confidence interval due to a sample size of 6 . The maximum is the $98.5 \%$ one sided confidence int.

9) The nonparametic distribution was used because the data failed the normal distribution test and includes values $\leq 0$. 
TABLE 3.6 BACKGROUND GROUND HATER QUALITY STATISTICS BY PARAMETER

FOR THE ALLUVIUM, NC PROCESSING SITE, SLICK ROCK, COLORADO

SITE: SRK01 SLICK ROCK (BOTH SITES)

09/09/82 TO 02/22/94

REPORT DATE: $09 / 28 / 94$

\begin{tabular}{|c|c|c|c|c|c|c|c|c|c|c|c|}
\hline \multicolumn{3}{|c|}{ PARAMETER NAME } & UNITS & \multirow[b]{2}{*}{ MEAN } & \multirow{2}{*}{$\begin{array}{l}\text { STANDARD } \\
\text { DEVIATI ION }\end{array}$} & \multirow{2}{*}{$\begin{array}{c}\text { COEFF. } \\
\text { OF } \\
\text { VARIATION }\end{array}$} & \multirow{2}{*}{$\begin{array}{c}\% \text { OF } \\
\text { NON } \\
\text { DETECTS }\end{array}$} & \multirow{2}{*}{\multicolumn{2}{|c|}{$\begin{array}{c}\text { STATISTICAL RANGE } \\
\text { 98\% CONFIDENCE INTERVAL } \\
\text { MINIMUM MAXIMUM * }\end{array}$}} & \multirow{2}{*}{$\underset{\substack{\text { DISTRIBUT ION } \\
\text { TYPE }}}{\text { DIO }}$} & \multirow{2}{*}{$\begin{array}{l}\text { FOOT } \\
\text { HOTE }\end{array}$} \\
\hline \# OF SAMP & MINIATM & MAXIMUH & MEDIAN & & & & & & & & \\
\hline \multicolumn{3}{|c|}{ SODIUM (TOTAL) } & MG/L & \multirow[b]{2}{*}{ HA } & \multirow[b]{2}{*}{ MA } & \multirow[b]{2}{*}{ NA } & \multirow[b]{2}{*}{0.0} & \multirow[b]{2}{*}{ NA } & \multirow[b]{2}{*}{ NA } & \multirow[b]{2}{*}{ UNKNOWN } & \multirow[b]{2}{*}{1} \\
\hline 1 & 95.0000 & 95.0000 & 95.0000 & & & & & & & & \\
\hline \multicolumn{3}{|c|}{ SPECIFIC CONDUCTANCE } & UMHO/CM & \multirow[b]{2}{*}{889.0000} & \multirow[b]{2}{*}{278.3468} & \multirow[b]{2}{*}{0.3131} & \multirow[b]{2}{*}{0.0} & \multirow[b]{2}{*}{707.9354} & \multirow[b]{2}{*}{1070.0646} & \multirow[b]{2}{*}{ NORMAL } & \\
\hline 16 & 447.0000 & 1357.0000 & +810.0000 & & & & & & & & \\
\hline \multicolumn{3}{|l|}{ STRONTIUM } & $M G / L$ & \multirow[b]{2}{*}{1.2933} & \multirow[b]{2}{*}{0.1621} & \multirow[b]{2}{*}{0.1253} & \multirow[b]{2}{*}{0.0} & \multirow[b]{2}{*}{1.0707} & \multirow[b]{2}{*}{1.5160} & & \\
\hline 6 & 1.1200 & 1.5600 & 1.2400 & & & & & & & NORMAL & \\
\hline STRONTIUM & (TOTAL) & & MG/L & & & & & & & & \\
\hline 1 & 1.5000 & 1.5000 & 1.5000 & HA & NA & NA & 0.0 & HA & NA & UNKNOWN & 1 \\
\hline SULFATE & & & $M G / L$ & & & & & & & & \\
\hline 13 & 223.0000 & 430.0000 & 322.0000 & 323.0000 & 51.2510 & 0.1587 & 0.0 & 284.8910 & 361.1090 & NORMAL & \\
\hline SULFIDE & & & $M G / L$ & & & & & & & & \\
\hline 6 & ** 0.1000 & 1.0000 & 0.2000 & NA & NA & NA & 33.3 & 0.1000 & 1.0000 & NONPARAMETRIC & 2,6 \\
\hline TEMPERATU & & & C - DEGR & & & & & & & & \\
\hline 16 & 8.8000 & 18.2000 & 12.9500 & 13.0938 & 2.5808 & 0.1971 & 0.0 & 11.4149 & 14.7726 & NORMAL & \\
\hline THALL IUM & & & $M G / L$ & & & & & & & & \\
\hline 5 & 0.0050 & 0.0050 & 0.0050 & NA & NA & NA & 100.0 & 0.0050 & 0.0050 & NONPARAMETRIC & 2,5 \\
\hline THOR IUM-2 & & & $\mathrm{PCI} / \mathrm{L}$ & & & & & & & & \\
\hline 3 & 0.3000 & 0.5000 & 0.5000 & NA & NA & NA & 0.0 & NA & NA & UNKNOWN & 1 \\
\hline
\end{tabular}

** The reported value is the minimum detection limit of the data set

+ The sample size is even, so the median value is the arithmetic average of the two middle values

* The statistical maximum is the 99 percent one sided confidence interval, $\alpha=0.01$

1) A minimum of 4 samples must be available for the statistical analysis.

2) The nonparametric distribution was used because the nondetected values comprise more than 15\% of the samples.

5) The stat. range is the $93.8 \%$ confidence interval due to a sample size of 5 . The maximum is the $96.9 \%$ one sided confidence int.

6) The stat. range is the $96.9 \%$ confidence interval due to a sample size of 6 . The maximum is the $98.5 \%$ one sided confidence int. 
TABLE 3.6 BACKGROUND GROUHD HATER QUALITY STATISTICS BY PARAMETER

FOR THE ALLUVIUA, NC PROCESSING SITE, SLICK ROCK, COLORADO

SITE: SRKO1 SLICK ROCK (BOTH SITES)

$09 / 09 / 82$ TO 02/22/94

REPORT DATE: 09/28/94

\begin{tabular}{|c|c|c|c|c|c|c|c|c|c|c|c|c|}
\hline \multicolumn{3}{|c|}{ PARAMETER NAME } & UNITS & \multirow[b]{2}{*}{ MEAN } & \multirow{2}{*}{$\begin{array}{r}\text { STANDARD } \\
\text { DEVIATION }\end{array}$} & \multirow{2}{*}{$\begin{array}{l}\text { COEFF. } \\
\text { OF } \\
\text { VARIATION }\end{array}$} & \multirow{2}{*}{$\mid \begin{array}{c}x \text { OF } \\
\text { NON } \\
\text { DETECTS }\end{array}$} & \multirow{2}{*}{\multicolumn{3}{|c|}{$\begin{array}{c}\text { STATISTICAL RANGE } \\
\text { 98\% CONFIDENCE INTERVAL } \\
\text { MINIMUM MAXIMUM * }\end{array}$}} & \multirow{2}{*}{$\begin{array}{c}\text { OISTRIBUTION } \\
\text { TYPE }\end{array}$} & \multirow{2}{*}{$\begin{array}{l}\text { FOOT } \\
\text { NOTE }\end{array}$} \\
\hline \# OF SAMP & MINIMUM & MAXIMUM & MEDIAN & & & & & & & & & \\
\hline \multicolumn{3}{|c|}{ THORIUH-230 (TOTAL) } & PCI/L & \multirow[b]{2}{*}{ NA } & \multirow[b]{2}{*}{ NA } & \multirow[b]{2}{*}{ HA } & \multirow[b]{2}{*}{0.0} & \multirow{2}{*}{\multicolumn{2}{|c|}{ NA }} & \multirow[b]{2}{*}{ NA } & \multirow[b]{2}{*}{ UNKHOWN } & \multirow[b]{2}{*}{1} \\
\hline 1 & 0.3000 & 0.3000 & 0.3000 & & & & & & & & & \\
\hline \multicolumn{3}{|l|}{ TIN } & MG/L. & \multirow[b]{2}{*}{ NA } & \multirow[b]{2}{*}{ NA } & \multirow[b]{2}{*}{ NA } & \multirow[b]{2}{*}{100.0} & \multirow[b]{2}{*}{ ** } & \multirow[b]{2}{*}{0.0050} & \multirow[b]{2}{*}{$\star \quad 0.0050$} & \multirow[b]{2}{*}{ NONPARAMETRIC } & \multirow[b]{2}{*}{2,6} \\
\hline 6 & $* * \quad 0.0050$ & 0.0050 & 0.0050 & & & & & & & & & \\
\hline \multicolumn{3}{|c|}{ TOTAL DISSOLVED SOLIDS } & NG/L. & \multirow[b]{2}{*}{799.6154} & \multirow[b]{2}{*}{97.5035} & \multirow[b]{2}{*}{0.1219} & \multirow[b]{2}{*}{0.0} & & & & & \\
\hline 13 & 622.0000 & 991.0000 & 819.0000 & & & & & & 727.1142 & 872.1166 & NORMAL & \\
\hline TOTAL KJE & LDAHL NITROGE & & $M G / L$ & & & & & & & & & \\
\hline 3 & ** 1.0000 & 1.0000 & 1.0000 & NA & NA & NA & 66.7 & & NA & NA & UNKNOWN & 1 \\
\hline TOTAL ORG & ANIC CARBON & & HG/L & & & & & & & & & \\
\hline 5 & 2.0000 & 9.0000 & 2.0000 & 3.4000 & 3.1305 & 0.9207 & 0.0 & ** & 1.0000 & 8.6458 & NORMAL & \\
\hline TURBIDITY & & & NTU & & & & & & & & & \\
\hline 1 & 0.0000 & 0.0000 & 0.0000 & NA & NA & NA & 0.0 & & NA & NA & UNKNOWN & 1 \\
\hline URANIUM & & & $M G / L$ & & & & & & & & & \\
\hline 13 & 0.0180 & 0.0636 & 0.0334 & 0.0348 & 0.0137 & 0.3933 & 0.0 & & 0.0246 & 0.0450 & NORMAL & \\
\hline URANIUM C & TOTAL) & & MG/L & & & & & & & & & \\
\hline 1 & 0.0170 & 0.0170 & 0.0170 & NA & NA & NA & 0.0 & & NA & MA & UNKNOWN & 1 \\
\hline VANADIUM & & & $M G / L$ & & & & & & & & & \\
\hline 11 & ** $\quad 0.0100$ & 0.3900 & 0.0100 & NA & NA & NA & 72.7 & ** & 0.0100 & 0.2300 & NONPARAMETRIC & 2 \\
\hline VANADIUM & (TOTAL) & & $M G / L$ & & & & & & & & & \\
\hline 1 & ** $\quad 0.0100$ & 0.0100 & 0.0100 & NA & NA & HA & 100.0 & & NA & NA & UHKNOWN & 1 \\
\hline
\end{tabular}

** The reported value is the minimum detection limit of the data set

* The statistical maximum is the 99 percent one sided confidence interval, $\alpha=0.01$

1) A minimum of 4 samples must be available for the statistical analysis.

2) The nonparametric distribution was used because the nondetected values comprise more than $15 \%$ of the samples.

6) The stat. range is the $96.9 \%$ confidence interval due to a sample size of 6 . The maximum is the $98.5 \%$ one sided confidence int. 
TABLE 3.6 BACKGROUND GROUND HATER QUALITY STATISTICS BY PARAMETER

FOR THE ALLUVIUN, NC PROCESSING SITE, SLICK ROCK, COLORADO

SITE: SRKO1 SLICK ROCK (BOTH SITES)

$09 / 09 / 82$ TO $02 / 22 / 94$

REPORT DATE: $09 / 28 / 94$

\begin{tabular}{|c|c|c|c|c|c|c|c|c|c|c|c|c|}
\hline \multicolumn{4}{|c|}{ PARAMETER NAME } & UNITS & \multirow[b]{2}{*}{ MEAN } & \multirow{2}{*}{$\begin{array}{r}\text { STANDARD } \\
\text { DEVIATION }\end{array}$} & \multirow{2}{*}{$\begin{array}{c}\text { COEFF. } \\
\text { OF } \\
\text { VARIATION }\end{array}$} & \multirow{2}{*}{ 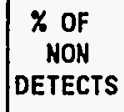 } & \multirow{2}{*}{\multicolumn{2}{|c|}{$\begin{array}{l}\text { STATISTICAL RANGE } \\
\text { 98\% CONFIDENCE INTERVAL } \\
\text { MINIMUM }\end{array}$}} & \multirow{2}{*}{$\begin{array}{c}\text { DISTRIBUTION } \\
\text { TYPE }\end{array}$} & \multirow{2}{*}{$\begin{array}{l}\text { FOOT } \\
\text { NOTE }\end{array}$} \\
\hline \# OF SAMP & & INIMUA & MAXIMUM & MEDIAN & & & & & & & & \\
\hline \multicolumn{4}{|l|}{ ZINC } & $M G / L$ & \multirow[b]{2}{*}{ NA } & \multirow[b]{2}{*}{ NA } & \multirow[b]{2}{*}{ NA } & \multirow[b]{2}{*}{70.0} & \multirow[b]{2}{*}{0.0050} & \multirow[b]{2}{*}{0.0150} & \multirow[b]{2}{*}{ NONPARAMETRIC } & \multirow[b]{2}{*}{2} \\
\hline 10 & $\star \star$ & 0.0050 & 0.0250 & 0.0050 & & & & & & & & \\
\hline \multicolumn{4}{|c|}{ ZINC (TOTAL) } & $M G / L$ & & & & & & & & \\
\hline 1 & ** & 0.0500 & 0.0500 & 0.0500 & HA & NA & NA & 100.0 & NA & NA & UNKNOWN & 1 \\
\hline
\end{tabular}

** The reported value is the minimum detection limit of the data set

* The statistical maximum is the 99 percent one sided confidence interval, $a=0.01$

1) A minimum of 4 samples must be available for the statistical analysis.

2) The nonparametric distribution was used because the nondetected values comprise more than $15 \%$ of the samples.

INPUT DATA FILENAME: M: IDARTISRK01\GHQ10025.DAT 
Table 3.7 Summary of regulated constituents in alluvial background ground water, NC processing site, Slick Rock, Colorado

\begin{tabular}{lccc}
\hline \multicolumn{4}{c}{ Constituents with MCLs } \\
\hline Parameter & MCLs & Mean or median & Statistical maximum \\
\hline Arsenic & 0.05 & $0.01^{\mathrm{e}}$ & $0.01^{\mathrm{e}}$ \\
Barium & 1.00 & $0.1^{\mathrm{e}}$ & $0.1^{\mathrm{e}}$ \\
Cadmium & 0.01 & $0.001^{\mathrm{e}}$ & $0.001^{\mathrm{e}}$ \\
Chromium & 0.05 & $0.01^{\mathrm{e}}$ & $0.01^{\mathrm{e}}$ \\
Net gross alpha & 15.0 & -2.44 & 4.72 \\
Lead & 0.05 & $0.01^{\mathrm{e}}$ & $0.01^{\mathrm{e}}$ \\
Mercury & 0.002 & $0.0002^{\mathrm{e}}$ & $0.0002^{\mathrm{e}}$ \\
Molybdenum & 0.10 & $0.0808^{\mathrm{d}}$ & $0.1203^{\mathrm{d}}$ \\
Nitrate & 44.0 & $1.0^{\mathrm{e}}$ & 1.6 \\
Radium-226 and $-228^{\mathrm{b}}$ & 5.00 & 0.90 & 7.80 \\
Selenium & 0.01 & $0.005^{\mathrm{e}}$ & $0.005^{\mathrm{e}}$ \\
Silver & 0.05 & $0.01^{\mathrm{e}}$ & $0.01^{\mathrm{e}}$ \\
Uranium & 0.044 & $0.035^{\mathrm{d}}$ & $0.045^{\mathrm{d}}$ \\
\hline
\end{tabular}


Table 3.7 Summary of regulated constituents in alluvial background ground water, NC processing site, Slick Rock, Colorado (Concluded)

\begin{tabular}{lcc}
\hline \multicolumn{3}{c}{ Constituents without MCLs } \\
\hline Parameter & Mean or median & Statistical maximum \\
\hline Antimony & $0.003^{\mathrm{e}}$ & $0.003^{\mathrm{e}}$ \\
Beryllium & $0.01^{\mathrm{e}}$ & $0.01^{\mathrm{e}}$ \\
Cobalt & $0.05^{\mathrm{e}}$ & $0.05^{\mathrm{e}}$ \\
Copper & $0.02^{\mathrm{e}}$ & 0.05 \\
Cyanide & $0.01^{\mathrm{e}}$ & $0.01^{\mathrm{e}}$ \\
Nickel & $0.04^{\mathrm{e}}$ & $0.04^{\mathrm{e}}$ \\
Sulfide & 0.20 & 1.00 \\
Thallium & $0.01^{\mathrm{e}}$ & $0.01^{\mathrm{e}}$ \\
Tin & $0.005^{\mathrm{e}}$ & $0.005^{\mathrm{e}}$ \\
Vanadium & $0.01^{\mathrm{e}}$ & 0.23 \\
Zinc & $0.005^{\mathrm{e}}$ & 0.015 \\
\hline
\end{tabular}

${ }_{\text {All }}$ units are $\mathrm{mg} / \mathrm{L}$ unless otherwise noted.

bunits are $\mathrm{pCi} / \mathrm{L}$.

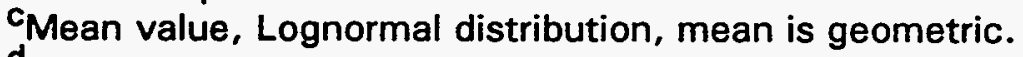

Mean value, Normal distribution, mean is arithmetic.

'Statistical values are below laboratory detection limits in Table 8.1 of the Technical Approach Document (DOE, 1989).

fValue is an observed maximum, rather than a statistical maximum, because less than four samples were available for statistical analysis. 
TABLE 3.8 GROUND WATER QUALITY MEASUREMENTS EXCEEDING MCLS IN ALLUVIAL

BACKGROUND GROUND HATER, NC AND UC SITES, SLICK ROCK, COLORADO

SITE: SRKO1 SLICK ROCK (BOTH SITES)

$09 / 09 / 82$ TO $02 / 22 / 94$

REPORT DATE: $10 / 03 / 94$

\begin{tabular}{|c|c|c|c|c|c|c|c|c|c|c|c|}
\hline PARAMETER NAME & $\begin{array}{l}\text { TOTAL } \\
\text { \# OF } \\
\text { SAMP. }\end{array}$ & $\begin{array}{l}\text { UNITS } \\
\text { OF } \\
\text { MEASURE }\end{array}$ & $\begin{array}{l}\text { MAXIMUM } \\
\text { CONC. } \\
\text { LIMIT }\end{array}$ & LOC. & LOG DATE & SAMP & $\mid \begin{array}{c}\text { FORM } \\
\text { OF } \\
\text { COMP }\end{array}$ & $\begin{array}{l}\text { HYDR } \\
\text { FLOW } \\
\text { REL. }\end{array}$ & $\begin{array}{l}\text { RESULT EXCEEDING MAX. } \\
\text { CONCENTRATION LIMIT } \\
\text { VALUE FLAGS }\end{array}$ & $\begin{array}{l}\text { DETECTION } \\
\text { LIMIT }\end{array}$ & $\begin{array}{l}\text { PARAMETER } \\
\text { UNCERT. }\end{array}$ \\
\hline ARSENIC & 15 & MG/L & 0.0500 & - & - & - & - & - & - & - & - \\
\hline ARSENIC (TOTAL) & 0 & MG/L & 0.0500 & - & - & - & - & - & - & - & - \\
\hline BARIUM & 16 & $M G / L$ & 1.0000 & - & - & - & - & - & - & - & - \\
\hline BARIUM (TOTAL) & 2 & MG/L & 1.0000 & - & - & - & - & - & - & - & - \\
\hline CADMIUM & 16 & MG/L & 0.0100 & - & - & - & - & - & - & - & - \\
\hline CADMIUM (TOTAL) & 2 & MG/L & 0.0100 & - & - & - & - & - & - & - & - \\
\hline CHROMIUM & 16 & $M G / L$ & 0.0500 & $0505 \mid$ & |07/17/86 & 0001 & AL & 0 & 0.07 & 0.01 & - \\
\hline CHROMIUM (TOTAL) & 2 & MG/L & 0.0500 & - & - & - & - & - & - & - & - \\
\hline GROSS ALPHA & 8 & PCI/L & 15.0000 & $\begin{array}{l}0501 \\
0501 \\
0501\end{array} \mid$ & $\begin{array}{l}03 / 29 / 91 \\
10 / 09 / 92 \\
02 / 22 / 94\end{array} \mid$ & $\left|\begin{array}{l}0001 \\
0001 \\
0001\end{array}\right|$ & $\begin{array}{l}A L \\
A L \\
A L\end{array}$ & $\begin{array}{l}0 \\
0 \\
0\end{array}$ & $\begin{array}{ll}20.5 & L \\
17.0 & \text { N } \\
20.2 & \end{array}$ & $\begin{array}{r}1 . .2 \\
12.2 \\
4.2\end{array}$ & $\begin{array}{l}9.0 \\
9.2 \\
4.5\end{array}$ \\
\hline GROSS ALPHA (TOTAL) & 2 & PCI/L & 15.0000 & 0501 & 02/22/94 & N001 & AL & 0 & 19.9 & 3.7 & 3.4 \\
\hline LEAD & 14 & MG/L & 0.0500 & - & - & - & - & - & - & - & - \\
\hline LEAD (TOTAL) & 0 & MG/L & 0.0500 & - & - & - & - & - & - & - & - \\
\hline MERCURY & 12 & $M G / L$ & 0.0020 & - & - & - & - & - & - & - & - \\
\hline MERCURY (TOTAL) & 0 & MG/L & 0.0020 & - & - & - & - & - & - & - & - \\
\hline MOLYYBDENUM & 20 & MG $/ \mathrm{L}$ & 0.1000 & $\mid \begin{array}{l}0501 \\
0505 \\
0505 \\
0686 \\
0686\end{array}$ & $\begin{array}{l}07 / 01 / 86 \\
07 / 17 / 86 \\
02 / 22 / 88 \\
07 / 17 / 86 \\
04 / 08 / 87\end{array}$ & $\left|\begin{array}{l}0001 \\
0001 \\
0001 \\
0001 \\
0001\end{array}\right|$ & $\begin{array}{l}A L \\
A L \\
A L \\
A L \\
A L\end{array}$ & $\begin{array}{l}0 \\
0 \\
0 \\
0 \\
0\end{array}$ & $\begin{array}{l}0.11 \\
0.14 \\
0.1 \\
0.24 \\
0.1\end{array}$ & $\begin{array}{r}0.01 \\
0.01 \\
0.01 \\
0.01 \\
0.0 .1\end{array}$ & $\begin{array}{l}- \\
- \\
-\end{array}$ \\
\hline
\end{tabular}

< - THE DATA IS fLAGged AS A NON-DETECT, SO tHE RESULT IS AN ESTIMATED VALUE OR THE DETECTION LIMIT

\section{FORHATION OF COMPLETION CODE:}

AL - ALLUVIUM

OTHER PARAMETER VALUE FLAGS:

I - INCREASED DETECTION LIMIT DUE TO REQUIRED DILUTION

L - LESS THAN THREE BORE VOLUMES REMOVED BEFORE SAMPLING

N - SPIKE SAMPLE RECOVERY NOT WITHIN CONTROL LIMITS
FLOW RELATIONSHIP CODE:

$O$ - ON-SITE

SAMPLE ID CODES:

0001 - FILTERED SAMPLE (.45 MICRONS)

NOO1 - UNFILTERED SAMPLE 
TABLE 3.8 GROUND HATER QUALITY MEASUREMENTS EXCEEDING MCLS IN ALLUVIAL

BACKGROUND GROUND WATER, NC AND UC SITES, SLICK ROCK, COLORADO

SITE: SRKO1 SLICK ROCK (BOTH SITES)

09/09/82 TO $02 / 22 / 94$

REPORT DATE: $10 / 03 / 94$

\begin{tabular}{|c|c|c|c|c|c|c|c|c|c|c|c|}
\hline PARAMETER NAME & $\begin{array}{l}\text { TOTAL } \\
\text { \# OF } \\
\text { SAMP. }\end{array}$ & $\begin{array}{c}\text { UNITS } \\
\text { OF } \\
\text { MEASURE }\end{array}$ & $\begin{array}{c}\text { MAXIMUM } \\
\text { CONC. } \\
\text { LIMIT }\end{array}$ & LOC. & LOG DATE & SAMP & $\begin{array}{l}\text { FORM } \\
\text { OF } \\
\text { COMP }\end{array}$ & $\begin{array}{l}\text { HYDR } \\
\text { FLOW } \\
\text { REL. }\end{array}$ & $\begin{array}{c}\text { RESULT EXCEEDING MAX. } \\
\text { CONCENTRATION LIMIT } \\
\text { VALUE FLAGS }\end{array}$ & $\begin{array}{l}\text { DETECTION } \\
\text { LIMIT }\end{array}$ & $\begin{array}{l}\text { PARAMETER } \\
\text { UNCERT. }\end{array}$ \\
\hline MOLYBDENUM & 20 & $M G / L$ & 0.1000 & 0686 & $\mid 02 / 22 / 88$ & 0001 & AL & 0 & 0.11 & 0.01 & - \\
\hline MOLYBDENUM (TOTAL) & 2 & MG/L & 0.1000 & - & - & - & - & - & - & - & - \\
\hline NET GROSS ALPHA * & 8 & PCI/L & $15.0000 \mid$ & - & - & - & - & - & - & - & - \\
\hline NET GROSS ALPHA (TOTAL) ** & 2 & PCI/L & 15.0000 & - & - & - & - & - & - & - & - \\
\hline NITRATE & 18 & MG/L & 44.0000 & - & - & - & - & - & - & - & - \\
\hline NITRATE (TOTAL) & 2 & $M G / L$ & $44.0000 \mid$ & - & - & - & - & - & - & - & - \\
\hline$R A-226 \& R A-228$ & 12 & PCI/L & 5.0000 & 0501 & $03 / 29 / 91$ & 0001 & AL & 0 & 7.8 & - & - \\
\hline RA-226 \& RA-228 (TOTAL) & 2 & PCI/L & 5.0000 & - & - & - & - & - & - & - & - \\
\hline SELENIUM & 17 & MG/L & 0.0100 & - & - & - & - & - & - & - & - \\
\hline SELENIUM (TOTAL) & 2 & $M G / L$ & 0.0100 & - & - & - & - & - & - & - & - \\
\hline SILVER & 12 & $M G / L$ & 0.0500 & - & - & - & - & - & - & - & - \\
\hline SILVER (TOTAL) & 0 & $M G / L$ & 0.0500 & - & - & - & - & - & - & - & - \\
\hline URANIUM & 20 & $M G / L$ & 0.0440 & $\begin{array}{l}0686 \\
0686 \\
0686\end{array}$ & $\begin{array}{l}04 / 08 / 87 \\
10 / 15 / 87 \\
02 / 22 / 88\end{array}$ & $\left|\begin{array}{l}0001 \\
0001 \\
0001\end{array}\right|$ & $\begin{array}{l}A L \\
A L \\
A L\end{array}$ & $\begin{array}{l}0 \\
0 \\
0\end{array}$ & $\begin{array}{l}0.0636 \\
0.051 \\
0.0475\end{array}$ & $\begin{array}{l}0.003 \\
0.003 \\
0.003\end{array}$ & $\overline{-}$ \\
\hline URANIUM (TOTAL) & 2 & MG/L & 0.0440 & - & - & - & - & - & - & - & - \\
\hline
\end{tabular}

* NET GROSS ALPHA (GROSS ALPHA - URANIUM) WITH 1 MG URANIUM = 686 PCI

** TOTAL NET GROSS ALPHA (TOTAL GROSS ALPHA - TOTAL URANIUM)

FORMATION OF COMPLETION CODE:

AL - ALLUVIUM

DATA FILE NAME: IDARTISRK01\GWQ10023.DAT
FLOW RELATIONSHIP CODE:

O - ON-SITE

SAMPLE ID CODES:

0001 - FILTERED SAMPLE (.45 MICRONS) 
TABLE 3.9 BACKGROUND GROUND UATER QUALITY STATISTICS BY PARAMETER

FOR THE ALLUVIUM, UC PROCESSING SITE, SLICK ROCK, COLORADO

SITE: SRKO1 SLICK ROCK (BOTH SITES)

$09 / 09 / 82$ TO $02 / 19 / 94$

REPORT DATE: 09/30/94

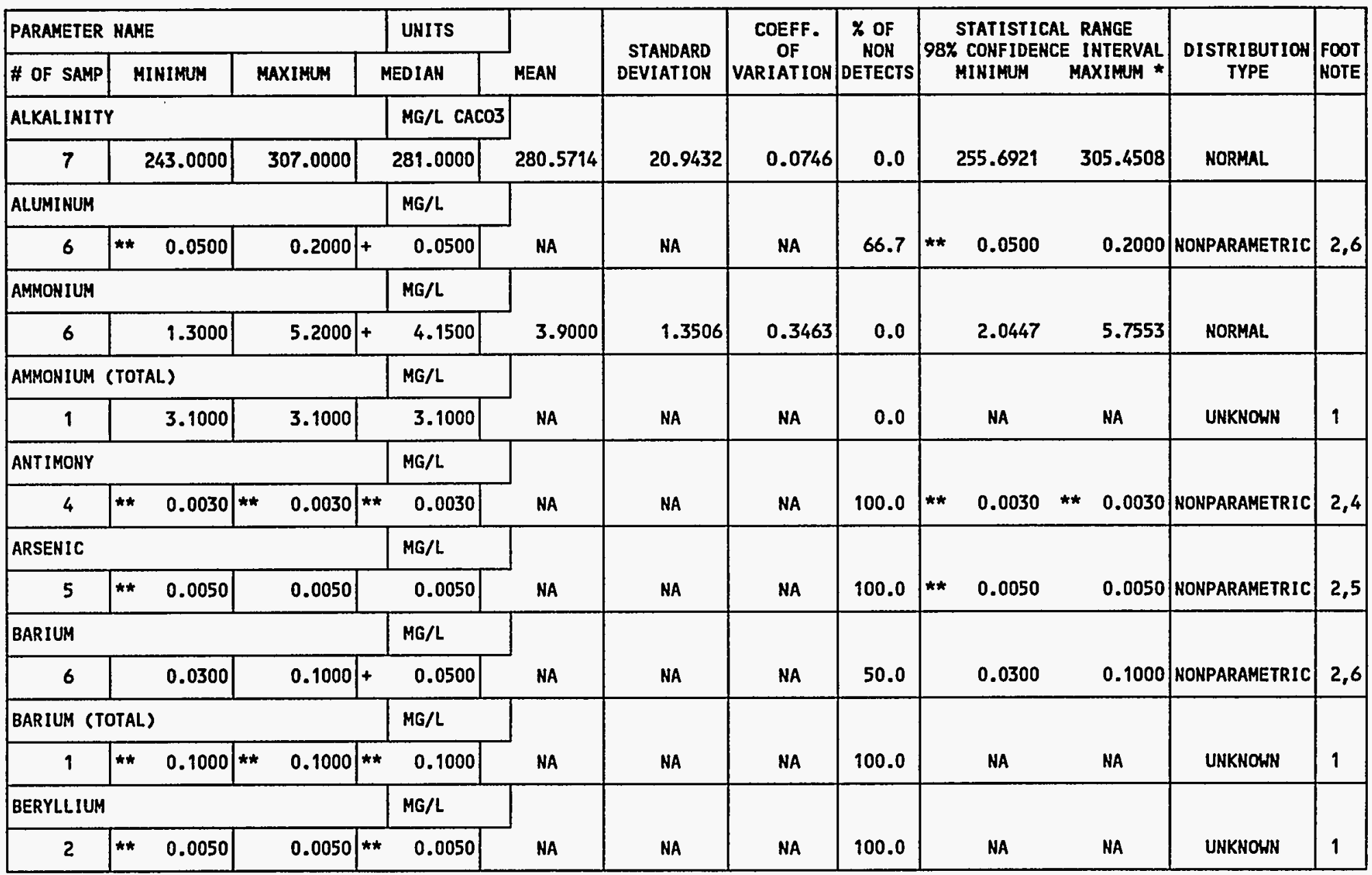

** The reported value is the minimum detection limit of the data set

+ The sample size is even, so the median value is the arithmetic average of the two middle values

* The statistical maximum is the 99 percent one sided confidence interval, $\alpha=0.01$

1) A minimum of 4 samples must be available for the statistical analysis.

2) The nonparametric distribution was used because the nondetected values comprise more than $15 \%$ of the samples.

4) The stat. range is the $87.5 \%$ confidence interval due to a sample size of 4 . The maximum is the $93.8 \%$ one sided confidence int.

5) The stat. range is the $93.8 \%$ confidence interval due to a sample size of 5 . The maximum is the $96.9 \%$ one sided confidence int.

6) The stat. range is the $96.9 \%$ confidence interval due to a sample size of 6 . The maximum is the $98.5 \%$ one sided confidence int. 
TABLE 3.9 BACKGROUND GROUND WATER QUALITY STATISTICS BY PARAMETER

FOR THE ALLUVIUM, UC PROCESSIMG SITE, SLICK ROCK, CO

SITE: SRKO1 SLICK ROCK (BOTH SITES)

$09 / 09 / 82$ TO 02/19/94

REPORT DATE: $09 / 30 / 94$

\begin{tabular}{|c|c|c|c|c|c|c|c|c|c|c|c|}
\hline \multicolumn{3}{|c|}{ PARAMETER NAME } & UNITS & \multirow[b]{2}{*}{ MEAN } & \multirow{2}{*}{$\begin{array}{r}\text { STANDARD } \\
\text { DEVIATION }\end{array}$} & \multirow{2}{*}{$\begin{array}{c}\text { COEFF. } \\
\text { OF } \\
\text { VARIATION }\end{array}$} & \multirow{2}{*}{$\begin{array}{c}\% \text { OF } \\
\text { NON } \\
\text { DETECTS }\end{array}$} & \multirow{2}{*}{\multicolumn{2}{|c|}{$\begin{array}{l}\text { STATISTICAL RANGE } \\
\text { 98\% CONF IDENCE INTERVAL } \\
\text { MINIMUM } \\
\text { MAXIMUM * }\end{array}$}} & \multirow{2}{*}{$\begin{array}{c}\text { DISTRIBUTION } \\
\text { TYPE }\end{array}$} & \multirow{2}{*}{$\begin{array}{l}\text { FOOT } \\
\text { NOTE }\end{array}$} \\
\hline * OF SAMP & MINIMUN & MAXIMUM & MEDIAN & & & & & & & & \\
\hline \multicolumn{3}{|l|}{ BORON } & $M G / L$ & \multirow[b]{2}{*}{ NA } & \multirow[b]{2}{*}{ MA } & \multirow[b]{2}{*}{ HA } & \multirow[b]{2}{*}{20.0} & \multirow[b]{2}{*}{0.0500} & \multirow[b]{2}{*}{0.3000} & \multirow[b]{2}{*}{ NONPARAMETRIC } & \multirow[b]{2}{*}{2,5} \\
\hline 5 & 0.0500 & 0.3000 & 0.2700 & & & & & & & & \\
\hline \multicolumn{3}{|c|}{ BORON (TOTAL) } & $M G / L$ & \multirow[b]{2}{*}{ NA } & \multirow[b]{2}{*}{ NA } & \multirow[b]{2}{*}{ NA } & \multirow[b]{2}{*}{0.0} & \multirow[b]{2}{*}{ HA } & \multirow[b]{2}{*}{ NA } & \multirow[b]{2}{*}{ UNKNOAN } & \multirow[b]{2}{*}{1} \\
\hline 1 & 0.2000 & 0.2000 & 0.2000 & & & & & & & & \\
\hline \multicolumn{3}{|l|}{ BROMIDE } & $M G / L$ & \multirow[b]{2}{*}{ NA } & \multirow[b]{2}{*}{ NA } & \multirow[b]{2}{*}{ NA } & \multirow[b]{2}{*}{100.0} & \multirow[b]{2}{*}{ HA } & \multirow[b]{2}{*}{ NA } & & \\
\hline 2 & 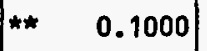 & 0.2500 & 0.1500 & & & & & & & UNKHOWN & 1 \\
\hline CADMIUM & & & MG/L & & & & & & & & \\
\hline 6 & 0.0010 & 0.0010 & 0.0010 & NA & NA & HA & 100.0 & 0.0010 & 0.0010 & NONPARAMETRIC & 2,6 \\
\hline CADMIUM (T & TOTAL) & & $M G / L$ & & & & & & & & \\
\hline 1 & 0.0010 & 0.0010 & 0.0010 & NA & NA & NA & 100.0 & NA & NA & UNKNOWN & 1 \\
\hline CALCIUM & & & $M G / L$ & & & & & & & & \\
\hline 7 & 93.0000 & 116.0000 & 110.0000 & 106.1714 & 9.7471 & 0.0918 & 0.0 & 94.5925 & 117.7504 & NORMAL & \\
\hline CALCIUM $(T$ & TOTAL) & & $M G / L$ & & & & & & & & \\
\hline 1 & 90.6000 & 90.6000 & 90.6000 & NA & NA & NA & 0.0 & NA & NA & UNKNOWN & 1 \\
\hline CHLORIDE & & & MG/L & & & & & & & & \\
\hline 7 & 40.0000 & 77.0000 & 49.0000 & 52.5000 & 12.9390 & 0.2465 & 0.0 & 37.1293 & 67.8707 & NORMAL & \\
\hline CHROMIUM & & & $M G / L$ & & & & & & & & \\
\hline 6 & 0.0100 & 0.0700 & 0.0100 & NA & NA & NA & 83.3 & 0.0100 & 0.0700 & NONPARAMETRIC & 2,6 \\
\hline
\end{tabular}

** The reported value is the minimum detection limit of the data set

+ The sample size is even, so the median value is the arithmetic average of the two middle values

* The statist ical maximum is the 99 percent one sided confidence interval, $\alpha=0.01$

1) A minimum of 4 samples must be available for the statistical analysis.

2) The nonparametric distribution was used because the nondetected values comprise more than $15 \%$ of the samples.

5) The stat. range is the $93.8 \%$ confidence interval due to a sample size of 5 . The maximum is the $96.9 \%$ one sided confidence int.

6) The stat. range is the $96.9 \%$ confidence interval due to a sample size of 6 . The maximum is the $98.5 \%$ one sided confidence int. 
TABLE 3.9 BACKGROUND GROUND WATER QUALITY STATISTICS BY PARAMETER

FOR THE ALLUVIUM, UC PROCESSING SITE, SLICK ROCK, COLORADO

SITE: SRKO1 SLICK ROCK (BOTH SITES)

$09 / 09 / 82$ TO $02 / 19 / 94$

REPORT DATE: $09 / 30 / 94$

\begin{tabular}{|c|c|c|c|c|c|c|c|c|c|c|c|c|c|}
\hline \multicolumn{5}{|c|}{ PARAMETER NAME } & UHITS & \multirow[b]{2}{*}{ MEAN } & \multirow{2}{*}{$\begin{array}{r}\text { STANDARD } \\
\text { DEVIATION }\end{array}$} & \multirow{2}{*}{$\begin{array}{c}\text { COEFF. } \\
\text { OF } \\
\text { VARIATION }\end{array}$} & \multirow{2}{*}{$\mid \begin{array}{c}\text { \% OF } \\
\text { NON } \\
\text { DETECTS }\end{array}$} & \multirow{2}{*}{\multicolumn{2}{|c|}{$\begin{array}{c}\text { STATISTICAL RANGE } \\
\text { 98\% CONFIDENCE INTERVAL } \\
\text { MINIMUM MAXIMUM * }\end{array}$}} & \multirow{2}{*}{$\begin{array}{c}\text { DISTRIBUTION } \\
\text { TYPE }\end{array}$} & \multirow{2}{*}{$\begin{array}{l}\text { FOOT } \\
\text { NOTE }\end{array}$} \\
\hline \# OF SAMP & & HIMUH & & IXIMUM & MEDIAN & & & & & & & & \\
\hline \multicolumn{5}{|c|}{ CHROMIUN (TOTAL) } & MG/L & \multirow[b]{2}{*}{ MA } & \multirow[b]{2}{*}{ NA } & \multirow[b]{2}{*}{ NA } & \multirow[b]{2}{*}{100.0} & \multirow[b]{2}{*}{ NA } & \multirow[b]{2}{*}{ MA } & \multirow[b]{2}{*}{ UNKNOWN } & \multirow[b]{2}{*}{1} \\
\hline 1 & ** & 0.0100 & ** & 0.0100 & 0.0100 & & & & & & & & \\
\hline \multicolumn{5}{|l|}{ COBALT } & $M G / L$ & \multirow[b]{2}{*}{ NA } & \multirow[b]{2}{*}{ NA } & \multirow[b]{2}{*}{ NA } & \multirow[b]{2}{*}{100.0} & \multirow[b]{2}{*}{ NA } & \multirow[b]{2}{*}{ MA } & \multirow[b]{2}{*}{ UNKNOWN } & \multirow[b]{2}{*}{1} \\
\hline 2 & ** & 0.0300 & $\star \star$ & 0.0300 & 0.0300 & & & & & & & & \\
\hline \multicolumn{5}{|l|}{ COPPER } & $M G / L$ & \multirow[b]{2}{*}{ NA } & \multirow[b]{2}{*}{ NA } & \multirow[b]{2}{*}{ NA } & \multirow[b]{2}{*}{80.0} & & & & \\
\hline 5 & \#* & 0.0100 & & 0.0300 & 0.0100 & & & & & $* * \quad 0.0100$ & 0.0300 & MONPARAMETRIC & 2,5 \\
\hline CYANIDE & & & & & $M G / L$ & & & & & & & & \\
\hline 1 & $* \star$ & 0.0100 & $\star \star *$ & 0.0100 & 0.0100 & NA & NA & NA & 100.0 & NA & NA & UNKNOWN & 1 \\
\hline DISSOLVED & ORG & INIC CARE & & & $M G / L$ & & & & & & & & \\
\hline 1 & & 4.0000 & & 4.0000 & 4.0000 & NA & NA & NA & 0.0 & NA & NA & UNKNOWN & 1 \\
\hline DISSOLVED & OXY & & & & MG/L & & & & & & & & \\
\hline 2 & & 0.0000 & & 0.2300 & 0.1150 & NA & NA & NA & 0.0 & NA & NA & UNKNOWN & 1 \\
\hline FIELD FE & $(2+)$ & & & & $M G / L$ & & & & & & & & \\
\hline 2 & & 0.6700 & & 1.1000 & 0.8850 & NA & NA & NA & 0.0 & NA & NA & UNKNOWN & 1 \\
\hline FIELD FE ( & (TOT) & & & & $M G / L$ & & & & & & & & \\
\hline 2 & & 0.7600 & & 0.9700 & 0.8650 & NA & NA & NA & 0.0 & NA & NA & UNKNOWN & 1 \\
\hline FLUORIDE & & & & & $M G / L$ & & & & & & & & \\
\hline 6 & & 0.2000 & & 0.3000 & 0.3000 & 0.2800 & 0.0400 & 0.1429 & 0.0 & 0.2250 & 0.3350 & NORMAL & \\
\hline GROSS ALPH & & & & & $\mathrm{PCl} / \mathrm{L}$ & & & & & & & & \\
\hline 3 & ** & 1.0000 & & 13.7000 & 7.7000 & NA & NA & NA & 0.0 & NA & NA & UNKNOWN & 1 \\
\hline
\end{tabular}

** The reported value is the minimum detection limit of the data set

+ The sample size is even, so the median value is the arithmetic average of the two middle values

* The statistical maximum is the 99 percent one sided confidence interval, $\alpha=0.01$

1) A minimum of 4 samples must be available for the statistical analysis.

2) The nonparametric distribution was used because the nondetected values comprise more than $15 \%$ of the samples.

5) The stat. range is the $93.8 \%$ confidence interval due to a sample size of 5 . The maximum is the $96.9 \%$ one sided confidence int. 
TABLE 3.9 BACKGROUND GROUND HATER QUALITY STATISTICS BY PARAMETER

FOR THE ALLUVIUM, UC PROCESSING SITE, SLICK ROCK, COLORADO

SITE: SRKO1 SLICK ROCK (BOTH SITES)

$09 / 09 / 82$ TO $02 / 19 / 94$

REPORT DATE: $09 / 30 / 94$

\begin{tabular}{|c|c|c|c|c|c|c|c|c|c|c|c|}
\hline \multicolumn{3}{|c|}{ PARAMETER NAME } & UNITS & \multirow[b]{2}{*}{ MEAN } & \multirow{2}{*}{$\begin{array}{r}\text { STANDARD } \\
\text { DEVIATION }\end{array}$} & \multirow{2}{*}{$\begin{array}{c}\text { COEFF. } \\
\text { OF } \\
\text { VARIATION }\end{array}$} & \multirow{2}{*}{$\begin{array}{c}x \text { OF } \\
\text { NON } \\
\text { DETECTS }\end{array}$} & \multirow{2}{*}{\multicolumn{2}{|c|}{$\begin{array}{c}\text { STATISTICAL RANGE } \\
\text { 98\% CONFIDENCE INTERVAL } \\
\text { MINIMUM }\end{array}$}} & \multirow{2}{*}{$\begin{array}{l}\text { DISTRIBUTION } \\
\text { TYPE }\end{array}$} & \multirow{2}{*}{$\begin{array}{l}\text { FOOT } \\
\text { NOTE }\end{array}$} \\
\hline \# OF SAMP & MINIMUM & MAXIMUM & MEDIAN & & & & & & & & \\
\hline \multicolumn{3}{|c|}{ GROSS ALPHA (TOTAL) } & $\mathrm{PCI} / \mathrm{L}$ & \multirow[b]{2}{*}{ NA } & \multirow[b]{2}{*}{ NA } & \multirow[b]{2}{*}{ NA } & \multirow[b]{2}{*}{0.0} & \multirow[b]{2}{*}{ NA } & \multirow[b]{2}{*}{ NA } & \multirow[b]{2}{*}{ UNKNOWN } & \multirow[b]{2}{*}{1} \\
\hline 1 & 10.9000 & 10.9000 & 10.9000 & & & & & & & & \\
\hline \multicolumn{3}{|l|}{ GROSS BETA } & $\mathrm{PCI} / \mathrm{L}$ & \multirow[b]{2}{*}{ NA } & \multirow[b]{2}{*}{ MA } & \multirow[b]{2}{*}{ NA } & \multirow[b]{2}{*}{0.0} & \multirow[b]{2}{*}{ NA } & \multirow[b]{2}{*}{ NA } & \multirow[b]{2}{*}{ UNKNOWN } & \multirow[b]{2}{*}{1} \\
\hline 2 & $\star * \quad 0.5000$ & 8.5000 & 4.2500 & & & & & & & & \\
\hline \multicolumn{3}{|l|}{ IRON } & MG/L & \multirow[b]{2}{*}{0.4900} & \multirow[b]{2}{*}{0.2790} & \multirow[b]{2}{*}{0.5695} & \multirow[b]{2}{*}{0.0} & & & & \\
\hline 7 & 0.1200 & 0.9200 & 0.5800 & & & & & 0.1585 & 0.8215 & NORMAL & \\
\hline IRON (TOTA & AL) & & MG/L & & & & & & & & \\
\hline 1 & 0.5800 & 0.5800 & 0.5800 & NA & NA & NA & 0.0 & NA & NA & UNKNOWN & 1 \\
\hline LEAD & & & $M G / L$ & & & & & & & & \\
\hline 5 & ** $\quad 0.0050$ & 0.0100 & 0.0050 & NA & NA & NA & 100.0 & 0.0050 & 0.0100 & NONPARAMETRIC & 2,5 \\
\hline LEAD -210 & & & $\mathrm{PCI} / \mathrm{L}$ & & & & & & & & \\
\hline 3 & $* * \quad 1.5000$ & 2.9000 & 1.5000 & NA & NA & NA & 0.0 & NA & NA & UNKNOWN & 1 \\
\hline LEAD-210 & (TOTAL) & & $\mathrm{PCI} / \mathrm{L}$ & & & & & & & & \\
\hline 9 & ** $\quad 1.7000$ & 1.7000 & 1.7000 & HA & NA & NA & 0.0 & NA & NA & UNKNOWN & 1 \\
\hline MAGNESIUH & & & $M G / L$ & & & & & & & & \\
\hline 7 & 41.0000 & 55.0000 & 48.7000 & 47.8429 & 5.2086 & 0.1089 & 0.0 & 41.6553 & 54.0304 & NORMAL & \\
\hline MAGNESIUM & (TOTAL) & & $M G / L$ & & & & & & & & \\
\hline 1 & 41.2000 & 41.2000 & 41.2000 & NA & NA & NA & 0.0 & NA & NA & UNKNOWN & 1 \\
\hline MANGANESE & & & MG/L & & & & & & & & \\
\hline 7 & 0.2200 & 0.3900 & 0.3700 & 0.3314 & 0.0724 & 0.2186 & 0.0 & 0.2454 & 0.4175 & NORMAL & \\
\hline
\end{tabular}

** The reported value is the minimum detection limit of the data set

+ The sample size is even, so the median value is the arithmetic average of the two middle values

* The statistical maximum is the 99 percent one sided confidence interval, $\alpha=0.01$

1) A minimum of 4 samples must be available for the statistical analysis.

2) The nonparametric distribution was used because the nondetected values comprise more than $15 \%$ of the samples.

5) The stat. range is the $93.8 \%$ confidence interval due to a sample size of 5 . The maximum is the $96.9 \%$ one sided confidence int. 
TABLE 3.9 BACKGROUND GROUND MATER QUALITY STATISTICS BY PARAMETER

FOR THE ALLUVIUM, UC PROCESSING SITE, SLICK ROCK, COLORADO

SITE: SRKO1 SLICK ROCK (BOTH SITES)

09/09/82 TO 02/19/94

REPORT DATE: $09 / 30 / 94$

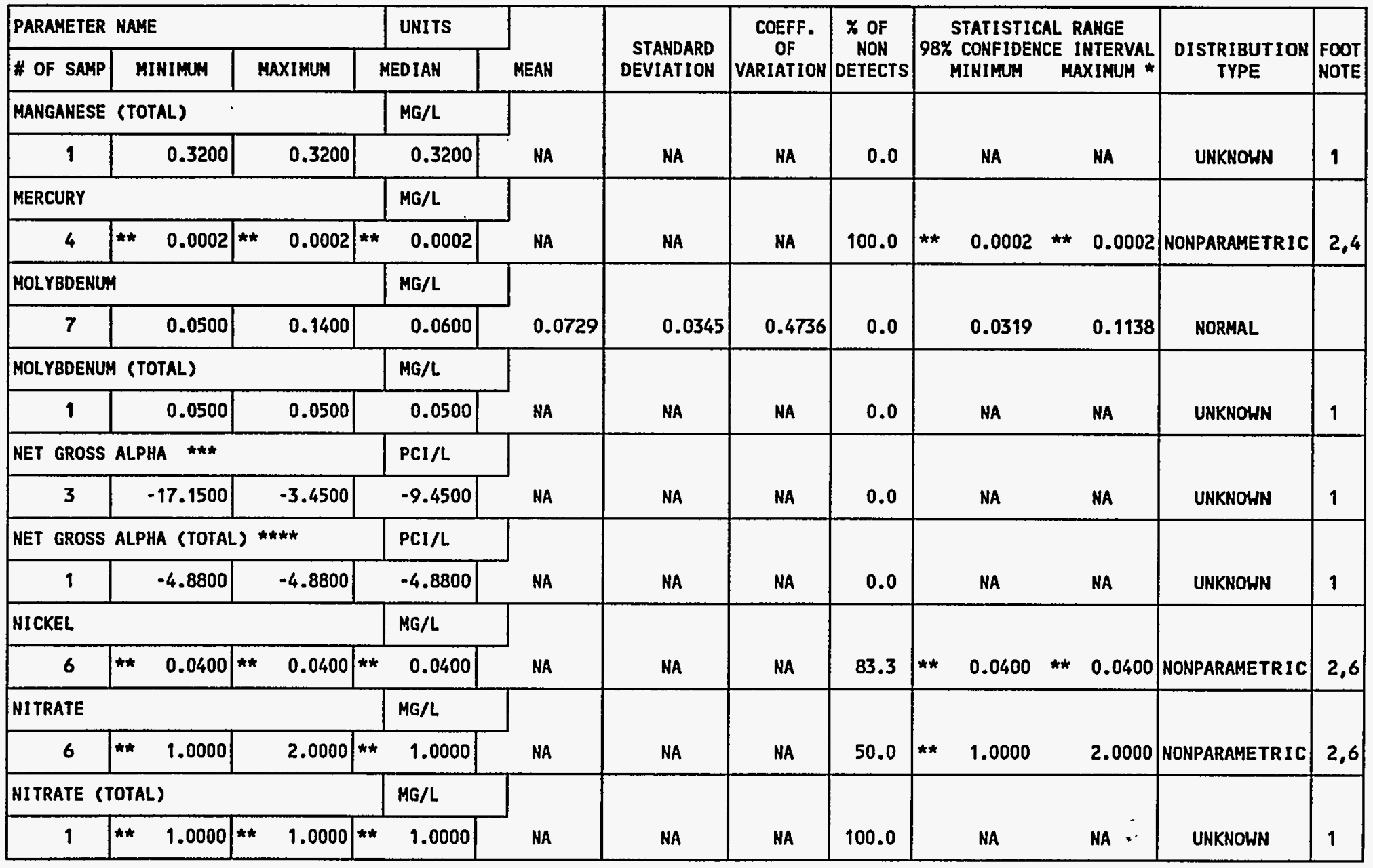

*** NET GROSS ALPHA (GROSS ALPHA - URANIUM) HITH 1 MG URANIUM $=686$ PCI

**** NET GROSS ALPHA (TOTAL) (TOTAL GROSS ALPHA - TOTAL URANIUM)

** The reported value is the minimum detection limit of the data set

* The statistical maximum is the 99 percent one sided confidence interval, $\alpha=0.01$

1) A minimum of 4 samples must be available for the statistical analysis.

2) The nonparametric distribution was used because the nondetected values comprise more than $15 \%$ of the samples.

4) The stat. range is the $87.5 \%$ confidence interval due to a sample size of 4 . The maximum is the $93.8 \%$ one sided confidence int.

6) The stat. range is the $96.9 \%$ confidence interval due to a sample size of 6 . The maximum is the $98.5 \%$ one sided confidence int. 
TABLE 3.9 BACKGROUND GROUND WATER QUALITY STATISTICS BY PARAMETER FOR THE ALLUVIUM, UC PROCESSING SITE, SLICK ROCK, COLORADO

SITE: SRKO1 SLICK ROCK (BOTH SITES?

09/09/82 TO 02/19/94

REPORT DATE: $09 / 30 / 94$

\begin{tabular}{|c|c|c|c|c|c|c|c|c|c|c|c|}
\hline \multicolumn{3}{|c|}{ PARAMETER NAME } & UNITS & \multirow[b]{2}{*}{ MEAN } & \multirow{2}{*}{$\begin{array}{r}\text { STANDARD } \\
\text { DEVIATION }\end{array}$} & \multirow{2}{*}{$\begin{array}{c}\text { COEFF. } \\
\text { OF } \\
\text { VARIATION }\end{array}$} & \multirow{2}{*}{$\begin{array}{c}\% \text { OF } \\
\text { NON } \\
\text { DETECTS }\end{array}$} & \multirow{2}{*}{\multicolumn{2}{|c|}{$\begin{array}{l}\text { STATISTICAL RANGE } \\
\text { 98\% CONFIDENCE INTERVAL } \\
\text { MINIMUM MAXIMUM * }\end{array}$}} & \multirow{2}{*}{$\begin{array}{c}\text { DISTR IBUTION } \\
\text { TYPE }\end{array}$} & \multirow{2}{*}{$\begin{array}{l}\text { FOOT } \\
\text { NOTE }\end{array}$} \\
\hline \# OF SAMP & MINIMUM & MAXIMUM & MEDIAN & & & & & & & & \\
\hline \multicolumn{3}{|c|}{ NITRITE AND NITRATE } & $M G / L$ & \multirow[b]{2}{*}{ NA } & \multirow[b]{2}{*}{ NA } & \multirow[b]{2}{*}{ NA } & \multirow[b]{2}{*}{50.0} & \multirow[b]{2}{*}{ NA } & \multirow[b]{2}{*}{ NA } & \multirow[b]{2}{*}{ UNKNOWN } & \multirow[b]{2}{*}{1} \\
\hline 2 & ** $\quad 1.0000$ & $\star \star \quad 1.0000$ & $\star \star \quad 1.0000$ & & & & & & & & \\
\hline \multicolumn{3}{|l|}{$\mathrm{PH}$} & su & \multirow[b]{2}{*}{ NA } & \multirow[b]{2}{*}{ HA } & \multirow[b]{2}{*}{ NA } & \multirow[b]{2}{*}{0.0} & \multirow[b]{2}{*}{ NA } & \multirow[b]{2}{*}{ NA } & \multirow[b]{2}{*}{ UNKNOWN } & \\
\hline 8 & 6.9000 & 7.2800 & 7.0750 & & & & & & & & \\
\hline \multicolumn{3}{|l|}{ PHOSPHATE } & $M G / L$ & \multirow[b]{2}{*}{ HA } & \multirow[b]{2}{*}{ NA } & \multirow[b]{2}{*}{ NA } & \multirow[b]{2}{*}{80.0} & & \multirow[b]{2}{*}{0.1000} & \multirow[b]{2}{*}{ NONPARAMETRIC } & \\
\hline 5 & ** $\quad 0.1000$ & 0.1000 & 0.1000 & & & & & 0.1000 & & & 2,5 \\
\hline POLONIUM-2 & & & $\mathrm{PCI} / \mathrm{L}$ & & & & & & & & \\
\hline 3 & ** 0.1000 & 1.6000 & 0.2000 & NA & NA & NA & 0.0 & NA & NA & UNKNOWN & 1 \\
\hline POLONIUM-Z & 210 (TOTAL) & & $\mathrm{PCI} / \mathrm{L}$ & & & & & & & & \\
\hline 1 & 0.2000 & 0.2000 & 0.2000 & NA & NA & NA & 0.0 & NA & NA & UHKNOWN & 1 \\
\hline POTASSIUM & & & $M G / L$ & & & & & & & & \\
\hline 7 & 4.7000 & 6.6400 & 5.6300 & 5.5571 & 0.6355 & 0.1144 & 0.0 & 4.8022 & 6.3121 & NORMAL & \\
\hline POTASSIUM & (TOTAL) & & $M G / L$ & & & & & & & & \\
\hline 1 & 4.4000 & 4.4000 & 4.4000 & NA & NA & NA & 0.0 & NA & NA & UNKNOWN & 1 \\
\hline RADIUM-226 & & & $\mathrm{PCl} / \mathrm{L}$ & & & & & & & & \\
\hline 7 & $* * \quad 0.1000$ & 0.9000 & 0.1000 & NA & NA & NA & 0.0 & 0.1000 & 0.9000 & NONPARAMETRIC & 9 \\
\hline RADIUM-226 & S (TOTAL) & & $\mathrm{PCI} / \mathrm{L}$ & & & & & & & & \\
\hline 1 & 0.1000 & 0.1000 & 0.1000 & NA & NA & NA & 0.0 & NA & NA & UNKNOWN & 1 \\
\hline
\end{tabular}

** The reported value is the minimum detection limit of the data set

+ The sample size is even, so the median value is the arithmetic average of the two middle values

* The statistical maximum is the 99 percent one sided confidence interval, $\alpha=0.01$

1) A minimum of 4 samples must be available for the statistical analysis.

2) The nonparametric distribution was used because the nondetected values comprise more than $15 \%$ of the samples.

5) The stat. range is the $93.8 \%$ confidence interval due to a sample size of 5 . The maximum is the $96.9 \%$ one sided confidence int.

9) The nonparametic distribution was used because the data failed the normal distribution test and includes values $\leq 0$. 
TABLE 3.9 BACKGROUHD GROUHD MATER QUALITY STATISTICS BY PARAMETER

FOR THE ALLUVIUM, UC PROCESSING SITE, SLICK ROCK, COLORADO

SITE: SRKOI SLICK ROCK (BOTH SITES)

09/09/82 TO 02/19/94

REPORT DATE: 09/30/9

\begin{tabular}{|c|c|c|c|c|c|c|c|c|c|c|c|}
\hline \multicolumn{3}{|c|}{ PARAMETER NAME } & UNITS & \multirow[b]{2}{*}{ MEAN } & \multirow{2}{*}{$\begin{array}{r}\text { STAKDARD } \\
\text { DEVIATION }\end{array}$} & \multirow{2}{*}{$\begin{array}{c}\text { COEFF. } \\
\text { OF } \\
\text { VARIATION }\end{array}$} & \multirow{2}{*}{$\begin{array}{c}x \text { OF } \\
\text { NON } \\
\text { DETECTS }\end{array}$} & \multirow{2}{*}{\multicolumn{2}{|c|}{$\begin{array}{c}\text { STATISTICAL RANGE } \\
\text { 98\% CONFIDENCE INTERVAL } \\
\text { MINIMUM }\end{array}$}} & \multirow{2}{*}{$\begin{array}{c}\text { DISTRIBUTION } \\
\text { TYPE }\end{array}$} & \multirow{2}{*}{$\begin{array}{l}\text { FOOT } \\
\text { NOTE }\end{array}$} \\
\hline * OF SAMP & MINIMUN & MAXIMUM & MEDIAN & & & & & & & & \\
\hline RADIUM-226 & $5+$ RADIUH-22 & & $\mathrm{PCI} / \mathrm{L}$ & \multirow[b]{2}{*}{1.2833} & \multirow[b]{2}{*}{0.8998} & \multirow[b]{2}{*}{0.7012} & \multirow[b]{2}{*}{0.0} & \multirow[b]{2}{*}{0.0472} & \multirow[b]{2}{*}{2.5195} & \multirow[b]{2}{*}{ NORMAL } & \\
\hline 6 & 0.1000 & 2.2000 & 1.7000 & & & & & & & & \\
\hline RADIUM-226 & 6 + RADIUN-22 & (TOTAL) & $\mathrm{PCl} / \mathrm{L}$ & \multirow[b]{2}{*}{ NA } & \multirow[b]{2}{*}{ NA } & \multirow[b]{2}{*}{ NA } & \multirow[b]{2}{*}{0.0} & \multirow[b]{2}{*}{ NA } & \multirow[b]{2}{*}{ HA } & \multirow[b]{2}{*}{ UNKNOWH } & \multirow[b]{2}{*}{1} \\
\hline 1 & 2.7000 & 2.7000 & 2.7000 & & & & & & & & \\
\hline \multicolumn{3}{|l|}{ RADIUM-228 } & $\mathrm{PCI} / \mathrm{L}$ & \multirow[b]{2}{*}{ NA } & \multirow[b]{2}{*}{ NA } & \multirow[b]{2}{*}{ NA } & \multirow[b]{2}{*}{0.0} & \multirow[b]{2}{*}{1.0000} & \multirow[b]{2}{*}{2.1000} & \multirow[b]{2}{*}{ NONPARAMETRIC } & \\
\hline 6 & ** $\quad 1.0000$ & 2.1000 & 1.2000 & & & & & & & & 9,6 \\
\hline RADIUA-228 & B (TOTAL) & & $\mathrm{PCI} / \mathrm{L}$ & & & & & & & & \\
\hline 1 & 2.6000 & 2.6000 & 2.6000 & NA & NA & NA & 0.0 & NA & NA & UNKNOWN & 1 \\
\hline REDOX POTE & ENTIAL & & mVOLTS & & & & & & & & \\
\hline 2 & 199.0000 & 403.9000 & 301.4500 & NA & NA & NA & 0.0 & NA & NA & UNKNOWN & 1 \\
\hline SELENIUM & & & MG/L & & & & & & & & \\
\hline 6 & ** $\quad 0.0050$ & 0.0070 & 0.0050 & NA & NA & NA & 83.3 & 0.0050 & 0.0070 & MONPARAMETRIC & 2,6 \\
\hline SELENIUM ( & (TOTAL) & & MG/L & & & & & & & & \\
\hline 1 & ** $\quad 0.0050$ & $\begin{array}{ll}* & 0.0050\end{array}$ & 0.0050 & NA & NA & NA & 100.0 & NA & NA & UNKNOWN & 1 \\
\hline SILICA - S & $s 102$ & & $M G / L$ & & & & & & & & \\
\hline 7 & 4.0000 & 11.3000 & 10.0000 & 9.1857 & 2.4802 & 0.2700 & 0.0 & 6.2394 & 12.1321 & NORMAL & \\
\hline SILICA - S & 5102 (TOTAL) & & $M G / L$ & & & & & & & & \\
\hline 1 & 10.1000 & 10.1000 & 10.1000 & NA & NA & NA & 0.0 & NA & NA & UNKNOWN & 1 \\
\hline
\end{tabular}

** The reported value is the minimum detection limit of the data set

+ The sample size is even, so the median value is the arithmetic average of the two middle values

* The statistical maximum is the 99 percent one sided confidence interval, $\alpha=0.01$

1) A minimum of 4 samples must be available for the statistical analysis.

2) The nonparametric distribution was used because the nondetected values comprise more than $15 \%$ of the samples.

6) The stat. range is the $96.9 \%$ confidence interval due to a sample size of 6 . The maximu is the $98.5 \%$ one sided confidence int..

9) The nonparametic distribution was used because the data failed the normal distribution test and includes values $\leq 0$. 
TABLE 3.9 BACKGROUND GROUND HATER QUALITY STATISTICS BY PARAMETER

FOR THE ALLUVIUM, UC PROCESSING SITE, SLICK ROCK, COLORADO

SITE: SRKO1 SLICK ROCK (BOTH S

$09 / 09 / 82$ TO $02 / 19 / 94$

REPORT DATE : $09 / 30 / 94$

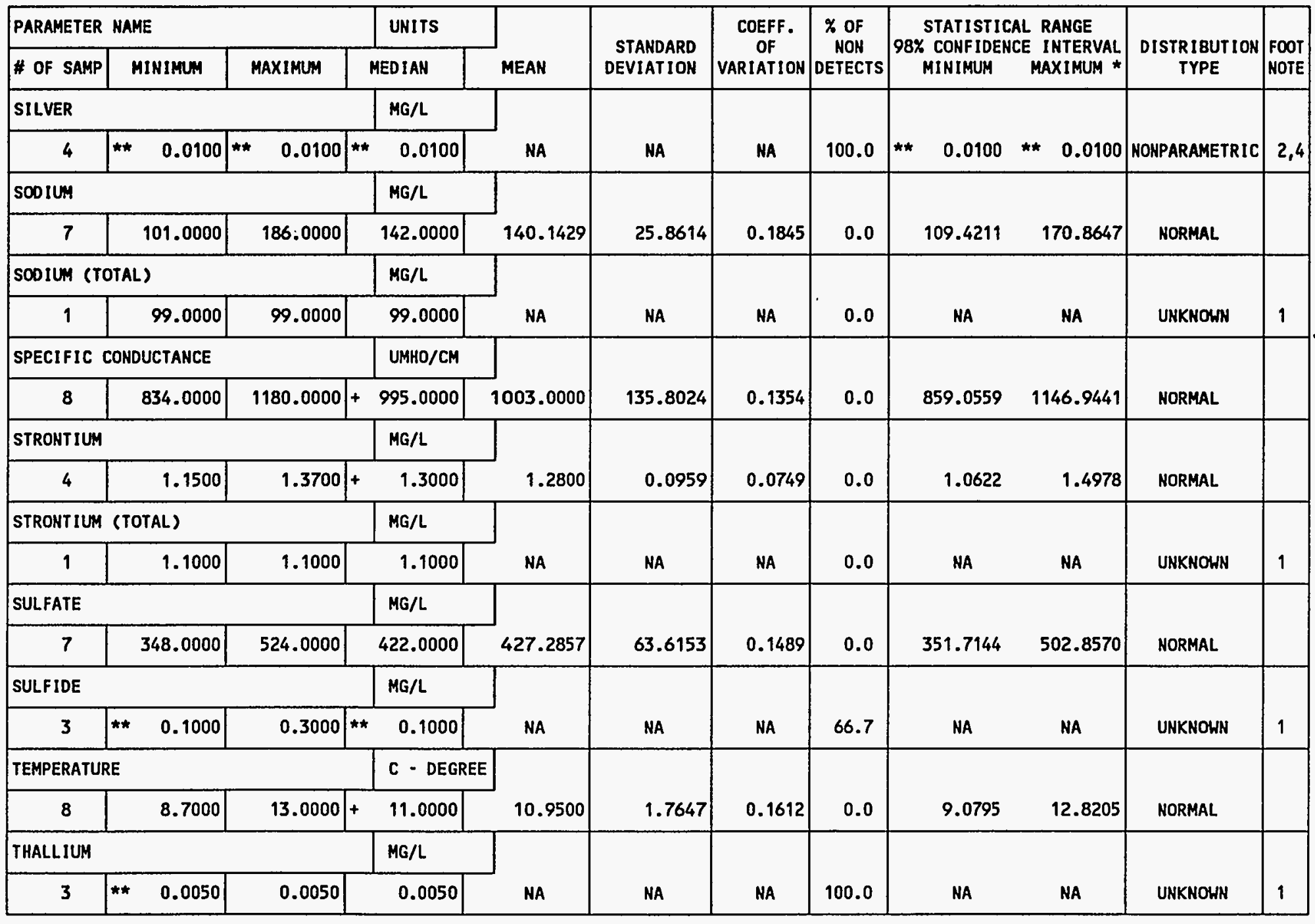

** The reported value is the minimum detection limit of the data set

+ The sample size is even, so the median value is the arithmetic average of the two middle values

* The statistical maximum is the 99 percent one sided confidence interval, $\alpha=0.01$

1) A minimum of 4 samples must be available for the statistical analysis.

2) The nonparametric distribution was used because the nondetected values comprise more than $15 \%$ of the samples.

4) The stat. range is the $\mathbf{8 7 . 5 \%}$ confidence interval due to a sample size of 4 . The maximum is the $93.8 \%$ one sided confidence int. 
TABLE 3.9 BACKGROUND GROUND WATER QUALITY STATISTICS BY PARAMETER

FOR THE ALLUVIUH, UC PROCESSING SITE, SLICK ROCK, COLORADO

SITE: SRKOI SLICK ROCK (BOTH SITES)

$09 / 09 / 82$ TO 02/19/94

REPORT DATE: $09 / 30 / 9$

\begin{tabular}{|c|c|c|c|c|c|c|c|c|c|c|c|}
\hline \multicolumn{3}{|c|}{ PARAMETER NAME } & UNITS & \multirow[b]{2}{*}{ MEAN } & \multirow{2}{*}{$\begin{array}{r}\text { STANDARD } \\
\text { DEVIATION }\end{array}$} & \multirow{2}{*}{$\begin{array}{c}\text { COEFF. } \\
\text { OF } \\
\text { VARIATION }\end{array}$} & \multirow{2}{*}{ 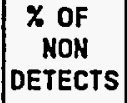 } & \multirow{2}{*}{\multicolumn{2}{|c|}{$\begin{array}{c}\text { STATISTICAL RANGE } \\
\text { 98\% CONFIDENCE INTERVAL } \\
\text { MINIMUM } \\
\text { MAXIMUM * }\end{array}$}} & \multirow{2}{*}{$\begin{array}{c}\text { DISTRIBUTION } \\
\text { TYPE }\end{array}$} & \multirow{2}{*}{$\begin{array}{l}\text { FOOT } \\
\text { NOTE }\end{array}$} \\
\hline \# OF SAMP & MINIMUN & MAXIMUN & MEDIAK & & & & & & & & \\
\hline \multicolumn{3}{|c|}{ THORIUM-230 } & PCI/L & \multirow[b]{2}{*}{ NA } & \multirow[b]{2}{*}{ NA } & \multirow[b]{2}{*}{ NA } & \multirow[b]{2}{*}{0.0} & \multirow[b]{2}{*}{ MA } & \multirow[b]{2}{*}{ HA } & \multirow[b]{2}{*}{ UNKNOWN } & \multirow[b]{2}{*}{1} \\
\hline 3 & 0.1000 & 1.5000 & 0.5000 & & & & & & & & \\
\hline \multicolumn{3}{|c|}{ THORIUH-230 (TOTAL) } & $\mathrm{PCI/L}$ & \multirow[b]{2}{*}{ NA } & \multirow[b]{2}{*}{ NA } & \multirow[b]{2}{*}{ NA } & \multirow[b]{2}{*}{0.0} & \multirow[b]{2}{*}{ NA } & \multirow[b]{2}{*}{ NA } & \multirow[b]{2}{*}{ UNKNOWN } & \multirow[b]{2}{*}{1} \\
\hline 1 & 0.4000 & 0.4000 & 0.4000 & & & & & & & & \\
\hline \multicolumn{3}{|l|}{ TIN } & $M G / L$ & \multirow[b]{2}{*}{ NA } & \multirow[b]{2}{*}{ NA } & \multirow[b]{2}{*}{ NA } & \multirow[b]{2}{*}{100.0} & & & & \\
\hline 4 & $\begin{array}{ll}* & 0.0050\end{array}$ & 0.0250 & 0.0050 & & & & & 0.0050 & 0.0250 & NONPARAMETRIC & 2,4 \\
\hline TOTAL DISS & SOLVED SOLIDS & & MG/L & & & & & & & & \\
\hline 7 & 830.0000 & 1180.0000 & 914.0000 & 962.7143 & 123.5512 & 0.1283 & 0.0 & 815.9426 & 1109.4860 & NORMAL & \\
\hline TOTAL KJEL & DAHL NITROGE & & MG/L & & & & & & & & \\
\hline 1 & 3.0000 & 3.0000 & 3.0000 & NA & NA & NA & 0.0 & NA & NA & UNKNOWN & 1 \\
\hline TOTAL ORGA & INIC CARBON & & $M G / L$ & & & & & & & & \\
\hline 3 & 3.0000 & 4.0000 & 3.0000 & NA & NA & NA & 0.0 & NA & NA & UNKNOWN & 1 \\
\hline TURBIDITY & & & NTU & & & & & & & & \\
\hline 1 & 1.0000 & 1.0000 & 1.0000 & NA & NA & NA & 0.0 & NA & NA & UNKNOWN & 1 \\
\hline URANIUM & & & MG/L & & & & & & & & \\
\hline 7 & 0.0250 & 0.0350 & 0.0260 & 0.0284 & 0.0041 & 0.1461 & 0.0 & 0.0235 & 0.0333 & NORMAL & \\
\hline URANIUM (TC & OTAL) & & $M G / L$ & & & & & & & & \\
\hline 1 & 0.0230 & 0.0230 & 0.0230 & NA & NA & NA & 0.0 & NA & NA & UNKNOWN & 1 \\
\hline VANADIUM & & & $M G / L$ & & & & & & & & \\
\hline 6 & $\star * \quad 0.0100$ & 0.2400 & 0.0100 & NA & MA & NA & 66.7 & 0.0100 & 0.2400 & NONPARAMETRIC & 2,6 \\
\hline
\end{tabular}

* The reported value is the minimum detection limit of the data set

* The statistical maximum is the 99 percent one sided confidence interval, $\alpha=0.01$

1) A minimum of 4 samples must be available for the statistical analysis.

2) The nonparametric distribution was used because the nondetected values comprise more than $15 \%$ of the samples.

4) The stat. range is the $87.5 \%$ confidence interval due to a sample size of 4 . The maximm is the $93.8 \%$ one sided confidence int.

6) The stat. range is the $96.9 \%$ confidence interval due to a sample size of 6 . The maximum is the $98.5 \%$ one sided conf idence int. 
TABLE 3.9 BACKGROUND GROUND WATER QUALITY STATISTICS BY PARAMETER

FOR THE ALLUVIUH, UC PROCESSIHG SITE, SLICK ROCK, COLORADO

SITE: SRKO1 SLICK ROCK (BOTH SITES)

09/09/82 TO 02/19/94

REPORT DATE: $09 / 30 / 94$

\begin{tabular}{|c|c|c|c|c|c|c|c|c|c|c|c|c|c|c|}
\hline \multicolumn{6}{|c|}{ PARAMETER MAME } & UHITS & \multirow[b]{2}{*}{ MEAN } & \multirow{2}{*}{$\begin{array}{r}\text { STANDARD } \\
\text { DEVIATION }\end{array}$} & \multirow{2}{*}{$\begin{array}{l}\text { COEFF. } \\
\text { OF } \\
\text { VARIATION }\end{array}$} & \multirow{2}{*}{$\underset{\text { NON }}{\times \text { OF }}$} & \multirow{2}{*}{\multicolumn{2}{|c|}{$\begin{array}{l}\text { STATISTICAL RANGE } \\
\text { 98\% CONFIDENCE INTERVAL } \\
\text { MINIMUM MAXIMUM * }\end{array}$}} & \multirow{2}{*}{$\begin{array}{c}\text { DISTRIBUTION } \\
\text { TYPE }\end{array}$} & \multirow{2}{*}{$\begin{array}{l}\text { FOOT } \\
\text { HOTE }\end{array}$} \\
\hline \# OF SAMP & & INIMUM & & XXIMUIH & & MEDIAN & & & & & & & & \\
\hline \multicolumn{5}{|c|}{ VANADIUM (TOTAL) } & & MG/L & \multirow[b]{2}{*}{ NA } & \multirow[b]{2}{*}{ NA } & \multirow[b]{2}{*}{ NA } & \multirow[b]{2}{*}{100.0} & \multirow[b]{2}{*}{ NA } & \multirow[b]{2}{*}{ NA } & \multirow[b]{2}{*}{ UNKNOWN } & \multirow[b]{2}{*}{1} \\
\hline 1 & $* *$ & 0.0100 & ** & 0.0100 & \# & 0.0100 & & & & & & & & \\
\hline \multicolumn{6}{|l|}{ ZINC } & $M G / L$ & \multirow[b]{2}{*}{ NA } & \multirow[b]{2}{*}{ NA } & \multirow[b]{2}{*}{ NA } & \multirow[b]{2}{*}{83.3} & \multirow[b]{2}{*}{ ** $\quad 0.0050$} & \multirow[b]{2}{*}{0.0250} & \multirow[b]{2}{*}{ NONPARAMETRIC } & \multirow[b]{2}{*}{2,6} \\
\hline 6 & $\star \star$ & 0.0050 & & 0.0250 & ** & 0.0050 & & & & & & & & \\
\hline \multicolumn{5}{|c|}{ ZINC (TOTAL) } & & $M G / L$ & \multirow[b]{2}{*}{ NA } & \multirow[b]{2}{*}{ NA } & \multirow[b]{2}{*}{ NA } & \multirow[b]{2}{*}{100.0} & \multirow[b]{2}{*}{ NA } & \multirow[b]{2}{*}{ NA } & \multirow[b]{2}{*}{ UNKNOWN } & \multirow[b]{2}{*}{1} \\
\hline 1 & ** & 0.0500 & ** & 0.0500 & $\star \star$ & 0.0500 & & & & & & & & \\
\hline
\end{tabular}

** The reported value is the minimum detection limit of the data set

* The statistical maximum is the 99 percent one sided confidence interval, $\alpha=0.01$

1) A minimum of 4 samples must be available for the statistical analys is.

2) Ahe nomperatric

ndetected values comprise more than $15 \%$ of the samples.

6) The stat. range is the $96.9 \%$ confidence interval due to a sample size of 6 . The maximum is the $98.5 \%$ one sided confidence int.

INPUT DATA FILENAME: IDARTISRKO1\GWQ10072.DAT 
Table 3.10 Summary of regulated constituents in alluvial background ground water, UC processing site, Slick Rock, Colorado

\begin{tabular}{|c|c|c|c|}
\hline \multicolumn{4}{|c|}{ Constituents with MCLs ${ }^{\mathrm{a}}$} \\
\hline Parameter & MCLs & Mean or median & Statistical maximum \\
\hline Arsenic & 0.05 & $0.01^{e}$ & $0.01^{e}$ \\
\hline Barium & 1.00 & $0.1^{e}$ & $0.1^{e}$ \\
\hline Cadmium & 0.01 & $0.001^{e}$ & $0.001^{e}$ \\
\hline Chromium & 0.05 & $0.01^{e}$ & 0.07 \\
\hline Net gross alphab & 15.0 & -9.45 & $-3.45^{f}$ \\
\hline Lead & 0.05 & $0.01^{e}$ & $0.01^{\circ}$ \\
\hline Mercury & 0.002 & $0.0002^{e}$ & $0.0002^{e}$ \\
\hline Molybdenum & 0.10 & $0.07^{d}$ & $0.11^{d}$ \\
\hline Nitrate & 44.0 & 1.00 & 2.00 \\
\hline Radium-226 and $-228^{b}$ & 5.00 & $1.28^{d}$ & $2.52^{d}$ \\
\hline Selenium & 0.01 & $0.005^{e}$ & 0.007 \\
\hline Silver & 0.05 & $0.01^{e}$ & $0.01^{e}$ \\
\hline Uranium & 0.044 & $0.028^{d}$ & $0.033^{d}$ \\
\hline
\end{tabular}


Table 3.10 Summary of regulated constituents in alluvial background ground water, UC processing site, Slick Rock, Colorado (Concluded)

\begin{tabular}{lcc}
\hline \multicolumn{3}{c}{ Constituents without MCLs } \\
\hline Parameter & Mean or median & Statistical maximum \\
\hline Antimony & $0.003^{\mathrm{e}}$ & $0.003^{\mathrm{e}}$ \\
Beryllium & $0.01^{\mathrm{e}}$ & $0.01^{\mathrm{e}, \mathrm{f}}$ \\
Cobalt & $0.05^{\mathrm{e}}$ & $0.05^{\mathrm{e}, \mathrm{f}}$ \\
Copper & $0.02^{\mathrm{e}}$ & 0.03 \\
Cyanide & $0.01^{\mathrm{e}}$ & $0.01^{\mathrm{e}, \mathrm{f}}$ \\
Nickel & $0.04^{\mathrm{e}}$ & $0.04^{\mathrm{e}}$ \\
Sulfide & $0.10^{\mathrm{N}}$ & $0.30^{f}$ \\
Thallium & $0.01^{\mathrm{e}}$ & $0.01^{\mathrm{e}, \mathrm{f}}$ \\
Tin & $0.005^{\mathrm{e}}$ & 0.025 \\
Vanadium & $0.01^{\mathrm{e}}$ & 0.24 \\
Zinc & $0.005^{\mathrm{e}}$ & 0.025 \\
\hline
\end{tabular}

${ }^{\text {aAll }}$ units are $\mathrm{mg} / \mathrm{L}$ unless otherwise noted.

bunits are $\mathrm{pCi} / \mathrm{L}$.

cMean value, Lognormal distribution, mean is geometric.

Mean value, Normal distribution, mean is arithmetic.

eStatistical values are below laboratory detection limits in Table 8.1 of the Technical Approach Document (DOE, 1989).

f $V$ alue is an observed maximum, rather than a statistical maximum, because less than four samples were avaiable for statistical analysis. 
TABLE 3.11 BACKGROUND GROUND YATER QUALITY DATA BY PARAMETER FOR THE ENTRADA FORMATION, UC PROCESSING SITE, SLICK ROCK, COLORADO

SITE: SRKO1 SLICK ROCK (BOTH SITES)

03/29/89 TO 02/17/94

REPORT DATE: 09/28/94

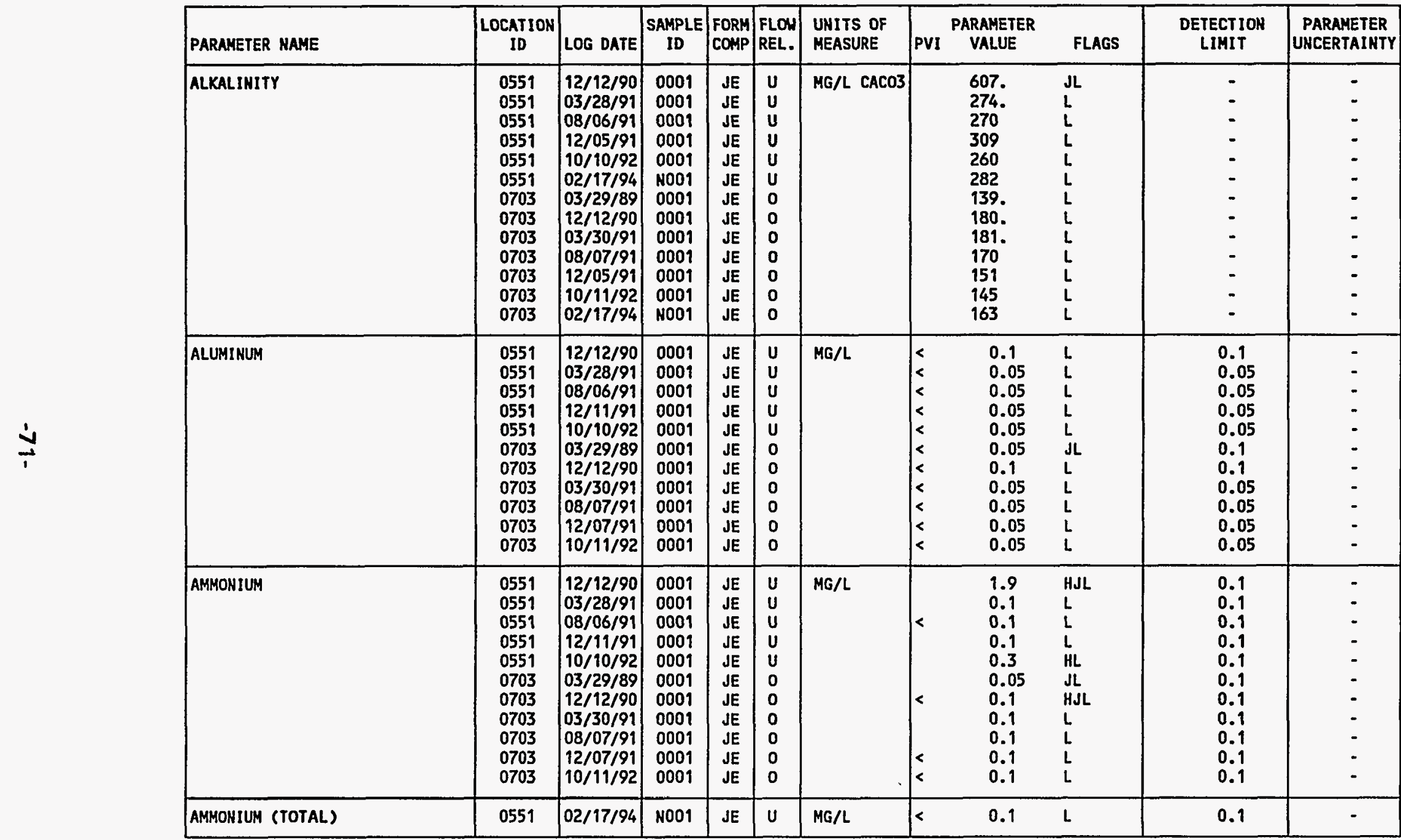

FORMATION OF COMPLETION CODE:

JE - JURASSIC ENTRADA SANDSTONE FORMATION

FLOH RELATIONSHIP COOE

U - UPGRADIENT

PARAMETER VALUE INDICATOR (PVI): < - LESS THAN DETECTION LIMIT

SAMPLE ID COOES:

0001 - FILTERED SAMPLE (.45 MICRONS)

OTHER PARAMETER VALUE FLAGS:

N001 - UNFILTERED SAMPLE

H - HOLD TIME EXPIRED, VALUE SUSPECT

J - estimated VALUE

L - LESS THAN THREE BORE VOLUMES REMOVED BEFORE SAMPLIHG 
TABLE 3.11 BACKGROUND GROUND HATER QUALITY DATA BY PARAMETER FOR THE IALTEDA FORMATION, UC PROCESSIHG SITE, SLICK ROCK, COLORADO

SITE: SRKO1 SLICK ROCK (BOTH SITES)

$03 / 29 / 89$ TO $02 / 17 / 94$

REPORT DATE: $09 / 28 / 94$

\begin{tabular}{|c|c|c|c|c|c|c|c|c|c|c|c|}
\hline PARAMETER NAME & $\underset{\text { ID }}{\text { LOCATION }}$ & LOG DATE & $\begin{array}{c}\text { SAMPLE } \\
\text { ID }\end{array}$ & $\begin{array}{l}\text { FORH } \\
\text { COMP }\end{array}$ & $\begin{array}{l}\text { FLOW } \\
\text { REL. }\end{array}$ & $\begin{array}{l}\text { UNITS OF } \\
\text { MEASURE }\end{array}$ & PV! & $\begin{array}{l}\text { ZAMETER } \\
\text { /ALUE }\end{array}$ & FLAGS & $\begin{array}{l}\text { DETECTION } \\
\text { LIMIT }\end{array}$ & $\begin{array}{l}\text { PARAMETER } \\
\text { UNCERTAINTY }\end{array}$ \\
\hline AMMONIUM (TOTAL) & 0703 & $02 / 17 / 94$ & N001 & JE & 0 & $M G / L$ & $<$ & 0.1 & $\mathbf{L}$ & 0.1 & - \\
\hline ANTIMONY & $\begin{array}{l}0551 \\
0551 \\
0551 \\
0551 \\
0551 \\
0703 \\
0703 \\
0703 \\
0703 \\
0703 \\
0703\end{array}$ & $\begin{array}{l}12 / 12 / 90 \\
03 / 28 / 91 \\
08 / 06 / 91 \\
12 / 11 / 91 \\
10 / 10 / 92 \\
03 / 29 / 89 \\
12 / 12 / 90 \\
03 / 30 / 91 \\
08 / 07 / 91 \\
12 / 07 / 91 \\
10 / 11 / 92\end{array}$ & $\begin{array}{l}0001 \\
0001 \\
0001 \\
0001 \\
0001 \\
0001 \\
0001 \\
0001 \\
0001 \\
0001 \\
0001\end{array}$ & $\begin{array}{l}\mathrm{JE} \\
\mathrm{JE} \\
\mathrm{JE} \\
\mathrm{JE} \\
\mathrm{JE} \\
\mathrm{JE} \\
\mathrm{JE} \\
\mathrm{JE} \\
\mathrm{JE} \\
\mathrm{JE} \\
\mathrm{JE}\end{array}$ & $\begin{array}{l}U \\
U \\
U \\
U \\
U \\
0 \\
0 \\
0 \\
0 \\
0 \\
0\end{array}$ & $M G / L$ & $\begin{array}{l}< \\
< \\
< \\
< \\
< \\
< \\
< \\
< \\
< \\
< \\
< \\
<\end{array}$ & $\begin{array}{l}0.003 \\
0.003 \\
0.003 \\
0.003 \\
0.003 \\
0.001 \\
0.003 \\
0.003 \\
0.003 \\
0.003 \\
0.003\end{array}$ & $\begin{array}{l}L \\
L \\
L \\
L \\
L \\
J L \\
L \\
L \\
L \\
L \\
L\end{array}$ & $\begin{array}{l}0.003 \\
0.003 \\
0.003 \\
0.003 \\
0.003 \\
0.003 \\
0.003 \\
0.003 \\
0.003 \\
0.003 \\
0.003\end{array}$ & $\begin{array}{l}- \\
- \\
- \\
- \\
- \\
- \\
- \\
-\end{array}$ \\
\hline ARSENIC & $\begin{array}{l}0551 \\
0551 \\
0551 \\
0551 \\
0551 \\
0703 \\
0703 \\
0703 \\
0703 \\
0703 \\
0703\end{array}$ & $\begin{array}{l}12 / 12 / 90 \\
03 / 28 / 91 \\
08 / 06 / 91 \\
12 / 11 / 91 \\
10 / 10 / 92 \\
03 / 29 / 89 \\
12 / 12 / 90 \\
03 / 30 / 91 \\
08 / 07 / 91 \\
12 / 07 / 91 \\
10 / 11 / 92\end{array}$ & $\begin{array}{l}0001 \\
0001 \\
0001 \\
0001 \\
0001 \\
0001 \\
0001 \\
0001 \\
0001 \\
0001 \\
0001\end{array}$ & $\begin{array}{l}\text { JE } \\
\text { JE } \\
\text { JE } \\
\text { JE } \\
\text { JE } \\
\text { JE } \\
\text { JE } \\
\text { JE } \\
\text { JE } \\
\text { JE } \\
\text { JE }\end{array}$ & $\begin{array}{l}U \\
U \\
U \\
U \\
U \\
0 \\
0 \\
0 \\
0 \\
0 \\
0\end{array}$ & $\mathrm{MG} / \mathrm{L}$ & $\begin{array}{l}< \\
< \\
< \\
< \\
< \\
< \\
< \\
< \\
< \\
< \\
< \\
<\end{array}$ & $\begin{array}{l}0.01 \\
0.01 \\
0.01 \\
0.01 \\
0.005 \\
0.001 \\
0.01 \\
0.01 \\
0.01 \\
0.01 \\
0.005\end{array}$ & $\begin{array}{l}L \\
L \\
L \\
L \\
L \\
J L \\
L \\
L \\
L \\
L H \\
L\end{array}$ & $\begin{array}{l}0.01 \\
0.01 \\
0.01 \\
0.01 \\
0.005 \\
0.01 \\
0.01 \\
0.01 \\
0.01 \\
0.01 \\
0.005\end{array}$ & $\begin{array}{l}- \\
- \\
- \\
- \\
- \\
- \\
- \\
-\end{array}$ \\
\hline BARIUM & $\begin{array}{l}0551 \\
0551 \\
0551 \\
0551 \\
0551 \\
0551 \\
0703 \\
0703 \\
0703 \\
0703 \\
0703\end{array}$ & $\begin{array}{l}12 / 12 / 90 \\
03 / 28 / 91 \\
08 / 06 / 91 \\
12 / 11 / 91 \\
10 / 10 / 92 \\
02 / 17 / 94 \\
03 / 29 / 89 \\
12 / 12 / 90 \\
03 / 30 / 91 \\
08 / 07 / 91 \\
12 / 07 / 91\end{array}$ & $\begin{array}{l}0001 \\
0001 \\
0001 \\
0001 \\
0001 \\
0001 \\
0001 \\
0001 \\
0001 \\
0001 \\
0001\end{array}$ & $\begin{array}{l}\mathrm{JE} \\
\mathrm{JE} \\
\mathrm{JE} \\
\mathrm{JE} \\
\mathrm{JE} \\
\mathrm{JE} \\
\mathrm{JE} \\
\mathrm{JE} \\
\mathrm{JE} \\
\mathrm{JE} \\
\mathrm{JE}\end{array}$ & $\begin{array}{l}U \\
U \\
U \\
U \\
U \\
U \\
0 \\
0 \\
0 \\
0 \\
0\end{array}$ & $M G / L$ & $<$ & $\begin{array}{l}0.1 \\
0.05 \\
0.06 \\
0.07 \\
0.07 \\
0.1 \\
0.12 \\
0.2 \\
0.13 \\
0.14 \\
0.31\end{array}$ & $\begin{array}{l}L \\
L \\
L \\
L \\
L \\
L \\
L \\
L \\
L \\
L \\
L\end{array}$ & $\begin{array}{l}0.1 \\
0.01 \\
0.01 \\
0.01 \\
0.01 \\
0.1 \\
0.1 \\
0.1 \\
0.01 \\
0.01 \\
0.01\end{array}$ & $\begin{array}{l}- \\
- \\
- \\
- \\
- \\
- \\
- \\
- \\
-\end{array}$ \\
\hline
\end{tabular}

FORMATION OF COMPLETION CODE:

JE - JURASSIC ENTRADA SANDSTONE FORMATION

FLOW RELATIONSHIP CODE:

O - ON-SITE

U - UPGRADIENT

PARAMETER VALUE INDICATOR (PVI): < - LESS THAN DETECTION LIMIT

SAMPLE ID CODES:

0001 - FILTERED SAMPLE (.45 MICRONS)

OTHER PARAMETER VALUE FLAGS:

MO01 - UMFILTERED SAMPLE

J - ESTIMATED VALUE

- LESS THAN THREE BORE VOLUMES REMOVEd BEFORE SAMPLING

$H$ - POST-DIGEST SPIKE OUT OF CNTR LIM HHILE SAMP ABS < 50\% SPIKE 
TABLE 3.11 BACKGROUND GROUHD HATER QUALITY DATA BY PARAMETER FOR THE

ENTRADA FORMATION, UC PROCESSING SITE, SLICK ROCK, COLORADO

SITE: SRKO1 SLICK ROCK (BOTH SITES)

03/29/89 TO 02/17/94

REPORT DATE: $09 / 28 / 94$

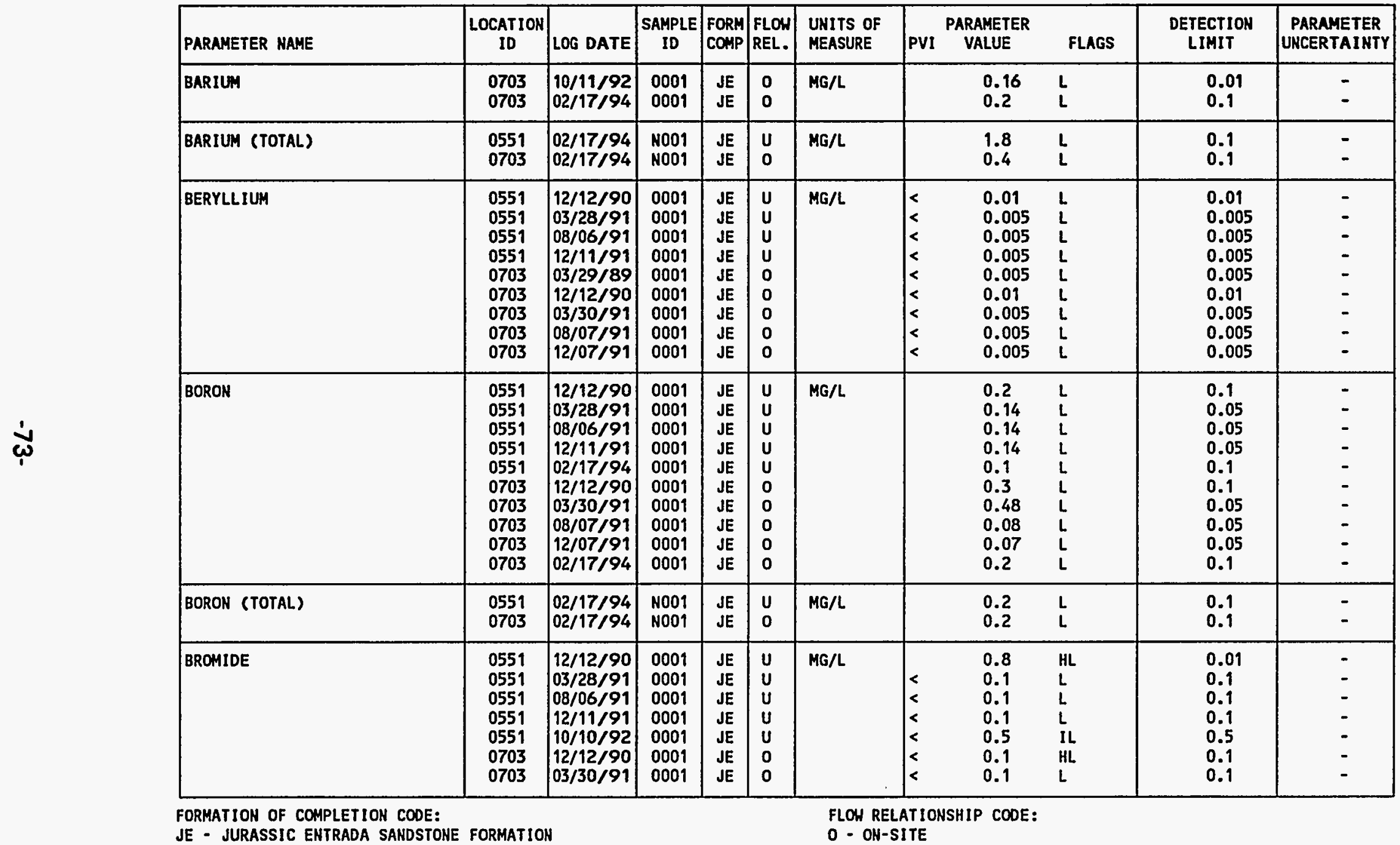

JE - JURASSIC ENTRADA SANDSTONE FORMATION

$U$ - UPGRADIENT

PARAMETER VALUE INDICATOR (PVI): < - LESS THAN DETECTION LIMIT

SAMPLE ID CODES:

0001 - FILTERED SAMPLE (.45 MICRONS)

OTHER PARAMETER VALUE FLAGS:

HOO1 - UNFILTERED SAMPLE

H - HOLD TIME EXPIRED, VALUE SUSPECT

I - INCREASED DETECTIÓN LIMIT DUE TO REQUIRED DILUTION

L - LESS THAN THREE BORE VOLUMES REMOVED BEFORE SAMPLING 
TABLE 3.11 BACKGROUHD GROUND HATER QUALITY DATA BY PARAMETER FOR THE ENTRADA FORMATION, UC PROCESSING SITE, SLICK ROCK, COLORADO

SITE: SRK01 SLICK ROCK (BOTH SITES)

$03 / 29 / 89$ TO $02 / 17 / 94$

\begin{tabular}{|c|c|c|c|c|c|c|c|c|c|c|c|}
\hline PARAMETER NAME & $\underset{\text { ID }}{\text { LOCATION }}$ & LOG DATE & $\begin{array}{c}\text { SAMPLE } \\
10\end{array}$ & $\begin{array}{l}\text { FORM } \\
\text { COMP }\end{array}$ & $\begin{array}{l}\text { FLOW } \\
\text { REL. }\end{array}$ & $\begin{array}{l}\text { UNITS OF } \\
\text { MEASURE }\end{array}$ & PVI & $\begin{array}{l}\text { ARAMETER } \\
\text { VALUE }\end{array}$ & FLAGS & $\begin{array}{l}\text { DETECTION } \\
\text { LIMIT }\end{array}$ & $\begin{array}{l}\text { PARAMETER } \\
\text { UNCERTAINTY }\end{array}$ \\
\hline BROMIDE & $\begin{array}{l}0703 \\
0703 \\
0703\end{array}$ & $\begin{array}{l}08 / 07 / 91 \\
12 / 07 / 91 \\
10 / 11 / 92\end{array}$ & $\begin{array}{l}0001 \\
0001 \\
0001\end{array}$ & $\begin{array}{l}J E \\
J E \\
J E\end{array}$ & $\begin{array}{l}0 \\
0 \\
0\end{array}$ & $M G / L$ & $<<$ & $\begin{array}{l}0.1 \\
0.1 \\
0.1\end{array}$ & $\begin{array}{l}L \\
L \\
L\end{array}$ & $\begin{array}{l}0.1 \\
0.1 \\
0.1\end{array}$ & $\begin{array}{l}- \\
-\end{array}$ \\
\hline CADMIUM & $\begin{array}{l}0551 \\
0551 \\
0551 \\
0551 \\
0551 \\
0551 \\
0703 \\
0703 \\
0703 \\
0703 \\
0703 \\
0703 \\
0703\end{array}$ & \begin{tabular}{|l|}
$12 / 12 / 90$ \\
$03 / 28 / 91$ \\
$08 / 06 / 91$ \\
$12 / 11 / 91$ \\
$10 / 10 / 92$ \\
$02 / 17 / 94$ \\
$03 / 29 / 89$ \\
$12 / 12 / 90$ \\
$03 / 30 / 91$ \\
$08 / 07 / 91$ \\
$12 / 07 / 91$ \\
$10 / 11 / 92$ \\
$02 / 17 / 94$
\end{tabular} & $\begin{array}{l}0001 \\
0001 \\
0001 \\
0001 \\
0001 \\
0001 \\
0001 \\
0001 \\
0001 \\
0001 \\
0001 \\
0001 \\
0001\end{array}$ & $\begin{array}{l}\text { JE } \\
\text { JE } \\
\text { JE } \\
\text { JE } \\
\text { JE } \\
\text { JE } \\
\text { JE } \\
\text { JE } \\
\text { JE } \\
\text { JE } \\
\text { JE } \\
\text { JE } \\
\text { JE }\end{array}$ & $\begin{array}{l}U \\
U \\
U \\
U \\
U \\
U \\
0 \\
0 \\
0 \\
0 \\
0 \\
0 \\
0\end{array}$ & $M G / L$ & $\begin{array}{l}< \\
< \\
< \\
< \\
< \\
< \\
< \\
< \\
< \\
< \\
< \\
< \\
< \\
<\end{array}$ & $\begin{array}{l}0.001 \\
0.001 \\
0.001 \\
0.001 \\
0.001 \\
0.001 \\
0.0001 \\
0.001 \\
0.001 \\
0.001 \\
0.005 \\
0.005 \\
0.001\end{array}$ & $\begin{array}{l}L \\
L \\
L \\
L \\
L \\
L \\
J L \\
L \\
L \\
L \\
I L \\
I L\end{array}$ & $\begin{array}{l}0.001 \\
0.001 \\
0.001 \\
0.001 \\
0.001 \\
0.001 \\
0.001 \\
0.001 \\
0.001 \\
0.001 \\
0.005 \\
0.005 \\
0.001\end{array}$ & $\begin{array}{l}- \\
- \\
- \\
- \\
- \\
- \\
- \\
- \\
- \\
-\end{array}$ \\
\hline CADMIUM (TOTAL) & $\begin{array}{l}0551 \\
0703\end{array}$ & $\left|\begin{array}{l}02 / 17 / 94 \\
02 / 17 / 94\end{array}\right|$ & $\begin{array}{l}\text { N001 } \\
\text { N001 }\end{array}$ & $\begin{array}{l}\mathrm{JE} \\
\mathrm{JE}\end{array}$ & $\begin{array}{l}U \\
0\end{array}$ & $M G / L$ & $<$ & $\begin{array}{l}0.002 \\
0.001\end{array}$ & $\begin{array}{l}L \\
L\end{array}$ & $\begin{array}{l}0.001 \\
0.001\end{array}$ & - \\
\hline CALCIUM & $\begin{array}{l}0551 \\
0551 \\
0551 \\
0551 \\
0551 \\
0551 \\
0703 \\
0703 \\
0703 \\
0703 \\
0703 \\
0703 \\
0703\end{array}$ & $\begin{array}{l}12 / 12 / 90 \\
03 / 28 / 91 \\
08 / 06 / 91 \\
12 / 11 / 91 \\
10 / 10 / 92 \\
02 / 17 / 94 \\
03 / 29 / 89 \\
12 / 12 / 90 \\
03 / 30 / 91 \\
08 / 07 / 91 \\
12 / 07 / 91 \\
10 / 11 / 92 \\
02 / 17 / 94\end{array}$ & $\begin{array}{l}0001 \\
0001 \\
0001 \\
0001 \\
0001 \\
0001 \\
0001 \\
0001 \\
0001 \\
0001 \\
0001 \\
0001 \\
0001\end{array}$ & $\begin{array}{l}\mathrm{JE} \\
\mathrm{JE} \\
\mathrm{JE} \\
\mathrm{JE} \\
\mathrm{JE} \\
\mathrm{JE} \\
\mathrm{JE} \\
\mathrm{JE} \\
\mathrm{JE} \\
\mathrm{JE} \\
\mathrm{JE} \\
\mathrm{JE} \\
\mathrm{JE}\end{array}$ & $\begin{array}{l}U \\
U \\
U \\
U \\
U \\
U \\
0 \\
0 \\
0 \\
0 \\
0 \\
0 \\
0\end{array}$ & $M G / L$ & & $\begin{array}{l}54.2 \\
28.3 \\
26.2 \\
24.4 \\
27.9 \\
29.5 \\
26 . \\
25.3 \\
27.5 \\
22.3 \\
18.5 \\
22.4 \\
21.9\end{array}$ & $\begin{array}{l}L \\
L \\
L \\
L \\
L \\
L \\
L \\
L \\
L \\
L \\
L \\
L \\
L\end{array}$ & $\begin{array}{l}0.01 \\
0.5 \\
0.5 \\
0.5 \\
0.5 \\
0.5 \\
0.01 \\
0.01 \\
0.5 \\
0.5 \\
0.1 \\
0.5 \\
0.5\end{array}$ & $\begin{array}{l}- \\
- \\
- \\
- \\
- \\
- \\
- \\
- \\
- \\
-\end{array}$ \\
\hline CALCIUM (TOTAL) & $\begin{array}{l}0551 \\
0703\end{array}$ & $\begin{array}{l}02 / 17 / 94 \\
02 / 17 / 94\end{array}$ & $\begin{array}{l}\text { N001 } \\
\text { N001 }\end{array}$ & $\begin{array}{l}\text { JE } \\
\text { JE }\end{array}$ & $\begin{array}{l}U \\
0\end{array}$ & $M G / L$ & & $\begin{array}{l}145 \\
48.7\end{array}$ & $L$ & $\begin{array}{l}0.5 \\
0.5\end{array}$ & - \\
\hline
\end{tabular}

FORMATION OF COMPLETIOH CODE:

JE - JURASSIC ENTRADA SANDSTONE FORMATION

PARAMETER VALUE INDICATOR (PVI): < - LESS THAN DETECTION LIMIT

OTHER PARAMETER VALUE FLAGS:

I - INCREASED DETECTION LIMIT DUE TO REQUIRED DILUTION

$J$ - ESTIMATED VALUE

L - LESS THAN THREE BORE VOLUMES REMOVED BEFORE SAMPLING
FLOW RELATIONSHIP CODE:

O - ON-SITE

U - UPGRADIENT

SAMPLE ID COOES:

0001 - FILTERED SAMPLE (.45 MICRONS)

NO01 - UNFILTERED SAMPLE 
TABLE 3.11 BACKGROUND GROUND WATER QUALITY DATA BY PARAMETER FOR THE ENTRADA FORMATIOH, UC PROCESSING SITE, SLICK ROCK, COLORADO

SITE: SRKO1 SLICK ROCK (BOTH SITES)

03/29/89 TO 02/17/94

\begin{tabular}{|c|c|c|c|c|c|c|c|c|c|c|c|}
\hline PARAMETER NAME & $\underset{\text { ID }}{\text { LOCATION }}$ & LOG DATE & $\underset{\text { ID }}{\text { SAMPLE }}$ & $\begin{array}{l}\text { FORM } \\
\text { COMP }\end{array}$ & $\begin{array}{l}\text { FLOW } \\
\text { REL. }\end{array}$ & $\begin{array}{l}\text { UNITS OF } \\
\text { MEASURE }\end{array}$ & PVI & $\begin{array}{l}\text { ARAMETER } \\
\text { VALUE }\end{array}$ & FLAGS & $\begin{array}{l}\text { DETECTIOH } \\
\text { LIMIT }\end{array}$ & $\begin{array}{l}\text { PARAMETER } \\
\text { UNCERTAINTY }\end{array}$ \\
\hline CHLORIDE & $\begin{array}{l}0551 \\
0551 \\
0551 \\
0551 \\
0551 \\
0551 \\
0703 \\
0703 \\
0703 \\
0703 \\
0703 \\
0703 \\
0703\end{array}$ & $\begin{array}{l}12 / 12 / 90 \\
03 / 28 / 91 \\
08 / 06 / 91 \\
12 / 11 / 91 \\
10 / 10 / 92 \\
02 / 17 / 94 \\
03 / 29 / 89 \\
12 / 12 / 90 \\
03 / 30 / 91 \\
08 / 07 / 91 \\
12 / 07 / 91 \\
10 / 11 / 92 \\
02 / 17 / 94\end{array}$ & $\begin{array}{l}0001 \\
0001 \\
0001 \\
0001 \\
0001 \\
0001 \\
0001 \\
0001 \\
0001 \\
0001 \\
0001 \\
0001 \\
0001\end{array}$ & $\begin{array}{l}\text { JE } \\
\text { JE } \\
\text { JE } \\
\text { JE } \\
\text { JE } \\
\text { JE } \\
\text { JE } \\
\text { JE } \\
\text { JE } \\
\text { JE } \\
\text { JE } \\
\text { JE } \\
\text { JE }\end{array}$ & $\begin{array}{l}U \\
U \\
U \\
U \\
U \\
U \\
0 \\
0 \\
0 \\
0 \\
0 \\
0 \\
0\end{array}$ & MG/L & & $\begin{array}{c}696 . \\
133 . \\
103 . \\
164 . \\
77 . \\
69.3 \\
4 . \\
4 . \\
4.3 \\
4.8 \\
4.6 \\
4.4 \\
4.2\end{array}$ & $\begin{array}{l}L \\
L \\
L \\
L \\
L \\
L \\
L \\
L \\
L \\
L \\
L \\
L \\
L\end{array}$ & $\begin{array}{l}1 . \\
0.5 \\
1 . \\
1 . \\
1 . \\
0.5 \\
1 . \\
1 . \\
0.5 \\
0.5 \\
0.5 \\
0.5 \\
0.5\end{array}$ & $\begin{array}{l}- \\
- \\
- \\
- \\
- \\
- \\
- \\
- \\
-\end{array}$ \\
\hline CHROMIUM & $\begin{array}{l}0551 \\
0551 \\
0551 \\
0551 \\
0551 \\
0551 \\
0703 \\
0703 \\
0703 \\
0703 \\
0703 \\
0703 \\
0703\end{array}$ & $\begin{array}{l}12 / 12 / 90 \\
03 / 28 / 91 \\
08 / 06 / 91 \\
12 / 11 / 91 \\
10 / 10 / 92 \\
02 / 17 / 94 \\
03 / 29 / 89 \\
12 / 12 / 90 \\
03 / 30 / 91 \\
08 / 07 / 91 \\
12 / 07 / 91 \\
10 / 11 / 92 \\
02 / 17 / 94\end{array}$ & $\begin{array}{l}0001 \\
0001 \\
0001 \\
0001 \\
0001 \\
0001 \\
0001 \\
0001 \\
0001 \\
0001 \\
0001 \\
0001 \\
0001\end{array}$ & $\begin{array}{l}\text { JE } \\
\text { JE } \\
\text { JE } \\
\text { JE } \\
\text { JE } \\
\text { JE } \\
\text { JE } \\
\text { JE } \\
\text { JE } \\
\text { JE } \\
\text { JE } \\
\text { JE } \\
\text { JE }\end{array}$ & $\begin{array}{l}U \\
U \\
U \\
U \\
U \\
U \\
0 \\
0 \\
0 \\
0 \\
0 \\
0 \\
0\end{array}$ & $M G / L$ & $\begin{array}{l}< \\
< \\
< \\
< \\
< \\
< \\
< \\
< \\
< \\
< \\
< \\
<\end{array}$ & $\begin{array}{l}0.01 \\
0.01 \\
0.01 \\
0.01 \\
0.01 \\
0.01 \\
0.01 \\
0.01 \\
0.01 \\
0.01 \\
0.01 \\
0.01 \\
0.01\end{array}$ & $\begin{array}{l}L \\
L \\
L \\
L \\
L \\
L \\
L \\
L \\
L \\
L \\
L \\
L \\
L\end{array}$ & $\begin{array}{l}0.01 \\
0.01 \\
0.01 \\
0.01 \\
0.01 \\
0.01 \\
0.01 \\
0.01 \\
0.01 \\
0.01 \\
0.01 \\
0.01 \\
0.01\end{array}$ & $\begin{array}{l}- \\
- \\
- \\
- \\
- \\
- \\
- \\
- \\
- \\
-\end{array}$ \\
\hline CHRONIUM (TOTAL) & $\begin{array}{l}0551 \\
0703\end{array}$ & $\begin{array}{l}02 / 17 / 94 \\
02 / 17 / 94\end{array}$ & $\begin{array}{l}\text { N001 } \\
\text { N001 }\end{array}$ & $\begin{array}{l}\text { JE } \\
\text { JE }\end{array}$ & $\begin{array}{l}U \\
0\end{array}$ & MG/L & & $\begin{array}{l}0.16 \\
0.02\end{array}$ & $L$ & $\begin{array}{l}0.01 \\
0.01\end{array}$ & $\dot{-}$ \\
\hline COBALT & $\begin{array}{l}0551 \\
0551 \\
0551 \\
0551 \\
0703 \\
0703 \\
0703\end{array}$ & $\begin{array}{l}12 / 12 / 90 \\
03 / 28 / 91 \\
08 / 06 / 91 \\
12 / 11 / 91 \\
03 / 29 / 89 \\
12 / 12 / 90 \\
03 / 30 / 91\end{array}$ & $\begin{array}{l}0001 \\
0001 \\
0001 \\
0001 \\
0001 \\
0001 \\
0001\end{array}$ & $\begin{array}{l}\mathrm{JE} \\
\mathrm{JE} \\
\mathrm{JE} \\
\mathrm{JE} \\
\mathrm{JE} \\
\mathrm{JE} \\
\mathrm{JE}\end{array}$ & $\begin{array}{l}U \\
U \\
U \\
U \\
0 \\
0 \\
0\end{array}$ & MG/L & $\begin{array}{l}< \\
< \\
< \\
< \\
< \\
< \\
<\end{array}$ & $\begin{array}{l}0.05 \\
0.03 \\
0.03 \\
0.03 \\
0.02 \\
0.05 \\
0.03\end{array}$ & $\begin{array}{l}L \\
L \\
L \\
L \\
J L \\
L \\
L\end{array}$ & $\begin{array}{l}0.05 \\
0.03 \\
0.03 \\
0.03 \\
0.05 \\
0.05 \\
0.03\end{array}$ & $\begin{array}{l}- \\
- \\
- \\
-\end{array}$ \\
\hline
\end{tabular}

FORMATIOH OF COHPLETIOH CODE:

JE - JURASSIC ENTRADA SANDSTONE FORMATION

FLOH RELATIONSHIP COOE:

- UPGRADIENT

PARAMETER VALUE INDICATOR (PVI): < - LESS THAN DETECTION LIMIT

SAMPLE ID CODES:

OTHER PARAMETER VALUE FLAGS:

0001 - FILTERED SAMPLE (.45 MICRONS)

J - ESTIMATED VALUE

L - LESS THAN THREE BORE VOLUMES REMOVED BEFORE SAMPLING

NOO - UNFILTERED SAMPLE 
TABLE 3.11 BACKGROUHD GROUND WATER QUALITY DATA BY PARAMETER FOR THE

ENTRADA FORMATION, UC PROCESSING SITE, SLICK ROCK, COLORADO

SITE: SRK01 SLICK ROCK (BOTH SITES)

03/29/89 TO 02/17/94

REPORT DATE : $09 / 28 / 94$

\begin{tabular}{|c|c|c|c|c|c|c|c|c|c|c|c|}
\hline PARAMETER NAME & $\begin{array}{c}\text { LOCATION } \\
\text { ID }\end{array}$ & LOG DATE & $\begin{array}{c}\text { SAMPLE } \\
\text { ID }\end{array}$ & FORM & $\begin{array}{l}\text { FLOW } \\
\text { REL. }\end{array}$ & $\begin{array}{l}\text { UNITS OF } \\
\text { MEASURE }\end{array}$ & PVI & $\begin{array}{l}\text { PRAMETER } \\
\text { VALUE }\end{array}$ & FLAGS & $\begin{array}{l}\text { DETECTION } \\
\text { LIMIT }\end{array}$ & $\begin{array}{l}\text { PARAMETER } \\
\text { UNCERTAINTY }\end{array}$ \\
\hline COBALT & $\begin{array}{l}0703 \\
0703\end{array}$ & $\begin{array}{l}08 / 07 / 91 \\
12 / 07 / 91\end{array}$ & $\begin{array}{l}0001 \\
0001\end{array}$ & $\begin{array}{l}\text { JE } \\
\text { JE }\end{array}$ & $\begin{array}{l}0 \\
0\end{array}$ & MG/L & $<$ & $\begin{array}{l}0.03 \\
0.03\end{array}$ & $L$ & $\begin{array}{l}0.03 \\
0.03\end{array}$ & - \\
\hline COPPER & $\begin{array}{l}0551 \\
0551 \\
0551 \\
0551 \\
0551 \\
0703 \\
0703 \\
0703 \\
0703 \\
0703 \\
0703\end{array}$ & $\begin{array}{l}12 / 12 / 90 \\
03 / 28 / 91 \\
08 / 06 / 91 \\
12 / 11 / 91 \\
10 / 10 / 92 \\
03 / 29 / 89 \\
12 / 12 / 90 \\
03 / 30 / 91 \\
08 / 07 / 91 \\
12 / 07 / 91 \\
10 / 11 / 92\end{array}$ & $\begin{array}{l}0001 \\
0001 \\
0001 \\
0001 \\
0001 \\
0001 \\
0001 \\
0001 \\
0001 \\
0001 \\
0001\end{array}$ & $\begin{array}{l}\text { JE } \\
\text { JE } \\
\text { JE } \\
\text { JE } \\
\text { JE } \\
\text { JE } \\
\text { JE } \\
\text { JE } \\
\text { JE } \\
\text { JE } \\
\text { JE }\end{array}$ & $\begin{array}{l}U \\
U \\
U \\
U \\
U \\
0 \\
0 \\
0 \\
0 \\
0 \\
0\end{array}$ & $M G / L$ & $\begin{array}{l}< \\
< \\
< \\
< \\
< \\
< \\
< \\
< \\
< \\
< \\
<\end{array}$ & $\begin{array}{l}0.02 \\
0.01 \\
0.01 \\
0.01 \\
0.01 \\
0.01 \\
0.02 \\
0.01 \\
0.01 \\
0.01 \\
0.01\end{array}$ & $\begin{array}{l}L \\
L \\
L \\
L \\
L \\
J L \\
L \\
L \\
L \\
L \\
L\end{array}$ & $\begin{array}{l}0.02 \\
0.01 \\
0.01 \\
0.01 \\
0.01 \\
0.02 \\
0.02 \\
0.01 \\
0.01 \\
0.01 \\
0.01\end{array}$ & $\begin{array}{l}- \\
- \\
- \\
- \\
- \\
- \\
- \\
- \\
-\end{array}$ \\
\hline CYANIDE & $\begin{array}{l}0551 \\
0551 \\
0551 \\
0551 \\
0703 \\
0703 \\
0703 \\
0703 \\
0703\end{array}$ & $\begin{array}{l}12 / 12 / 90 \\
03 / 28 / 91 \\
08 / 06 / 91 \\
12 / 11 / 91 \\
03 / 29 / 89 \\
12 / 12 / 90 \\
03 / 30 / 91 \\
08 / 07 / 91 \\
12 / 07 / 91\end{array}$ & $\begin{array}{l}0001 \\
0001 \\
0001 \\
0001 \\
0001 \\
0001 \\
0001 \\
0001 \\
0001\end{array}$ & $\begin{array}{l}\text { JE } \\
\text { JE } \\
\text { JE } \\
\text { JE } \\
\text { JE } \\
\text { JE } \\
\text { JE } \\
\text { JE } \\
\text { JE }\end{array}$ & $\begin{array}{l}U \\
U \\
U \\
U \\
0 \\
0 \\
0 \\
0 \\
0\end{array}$ & $M G / L$ & $\begin{array}{l}< \\
< \\
< \\
< \\
< \\
< \\
< \\
< \\
< \\
<\end{array}$ & $\begin{array}{l}0.01 \\
0.01 \\
0.01 \\
0.01 \\
0.002 \\
0.01 \\
0.01 \\
0.01 \\
0.01\end{array}$ & $\begin{array}{l}L \\
L \\
L \\
L \\
J L \\
L \\
L \\
L \\
L\end{array}$ & $\begin{array}{l}0.01 \\
0.01 \\
0.01 \\
0.01 \\
0.01 \\
0.01 \\
0.01 \\
0.01 \\
0.01\end{array}$ & $\begin{array}{l}: \\
: \\
: \\
: \\
-\end{array}$ \\
\hline DISSOLVED ORGANIC CARBON & $\begin{array}{l}0551 \\
0703\end{array}$ & $\begin{array}{l}02 / 17 / 94 \\
02 / 17 / 94\end{array}$ & $\begin{array}{l}0001 \\
0001\end{array}$ & $\begin{array}{l}\text { JE } \\
\text { JE }\end{array}$ & $\begin{array}{l}U \\
0\end{array}$ & MG/L & & $\begin{array}{l}4 \\
4\end{array}$ & $\begin{array}{l}L \\
L\end{array}$ & $\begin{array}{l}1 \\
1\end{array}$ & $\dot{-}$ \\
\hline FLUORIDE & $\begin{array}{l}0551 \\
0551 \\
0551 \\
0551 \\
0551 \\
0703 \\
0703 \\
0703 \\
0703\end{array}$ & $\begin{array}{l}12 / 12 / 90 \\
03 / 28 / 91 \\
08 / 06 / 91 \\
12 / 11 / 91 \\
10 / 10 / 92 \\
03 / 29 / 89 \\
12 / 12 / 90 \\
03 / 30 / 91 \\
08 / 07 / 91\end{array}$ & $\begin{array}{l}0001 \\
0001 \\
0001 \\
0001 \\
0001 \\
0001 \\
0001 \\
0001 \\
0001\end{array}$ & $\begin{array}{l}\text { JE } \\
\text { JE } \\
\text { JE } \\
\text { JE } \\
\text { JE } \\
\text { JE } \\
\text { JE } \\
\text { JE } \\
\text { JE }\end{array}$ & $\begin{array}{l}U \\
U \\
U \\
U \\
U \\
0 \\
0 \\
0 \\
0\end{array}$ & MG/L & & $\begin{array}{l}0.6 \\
0.6 \\
0.7 \\
0.6 \\
0.7 \\
0.3 \\
0.6 \\
0.6 \\
0.4\end{array}$ & $\begin{array}{l}H L \\
L \\
L \\
L \\
L \\
L \\
L \\
L \\
L\end{array}$ & $\begin{array}{l}0.1 \\
0.1 \\
0.1 \\
0.1 \\
0.1 \\
0.1 \\
0.1 \\
0.1 \\
0.1\end{array}$ & $\begin{array}{l}- \\
- \\
- \\
- \\
- \\
- \\
-\end{array}$ \\
\hline
\end{tabular}

FORMATION OF COMPLETION COOE:

JE - JURASSIC ENTRADA SANDSTONE FORMATION

FLOW RELATIONSHIP CODE:

O - ON-SITE

PARAMETER VALUE INDICATOR (PVI): < - LESS THAN DETECTION LIMIT

SAMPLE ID CODES:

0001 - FILTERED SAMPLE (.45 MICRONS)

OTHER PARAMETER VALUE FLAGS:

H - HOLD TIME EXPIREd, VALUE SUSPECT

$J$ - ESTIMATED VALUE

L - LESS thAH THREE BORE VOLUMES REMOVED BEFORE SAMPLING 
TABLE 3.11 BACKGROUND GROUND WATER QUALITY DATA BY PARAMETER FOR THE

ENTRADA FORYATIOH, UC PROCESSING SITE, SLICK ROCK, COLORAD

SITE: SRKOI SLICK ROCK (BOTH SITES)

$03 / 29 / 89$ TO $02 / 17 / 94$

REPORT DATE: 09/28/94

\begin{tabular}{|c|c|c|c|c|c|c|c|c|c|c|c|}
\hline PARAMETER NAME & $\underset{\text { ID }}{\text { LOCATIOH }}$ & LOG DATE & $\begin{array}{c}\text { SAMPLE } \\
\text { ID }\end{array}$ & $\begin{array}{l}\text { FORM } \\
\text { CONP }\end{array}$ & $\begin{array}{l}\text { FLOW } \\
\text { REL. }\end{array}$ & $\begin{array}{l}\text { UNITS OF } \\
\text { MEASURE }\end{array}$ & PVI & $\begin{array}{l}\text { ARAMETER } \\
\text { VALUE }\end{array}$ & FLAGS & $\begin{array}{l}\text { DETECTION } \\
\text { LIMIT }\end{array}$ & $\begin{array}{l}\text { PARAMETER } \\
\text { UNCERTAINTY }\end{array}$ \\
\hline FLUORIDE & $\begin{array}{l}0703 \\
0703\end{array}$ & $\begin{array}{l}12 / 07 / 91 \\
10 / 11 / 92\end{array}$ & $\begin{array}{l}0001 \\
0001\end{array}$ & $\begin{array}{l}\text { JE } \\
\text { JE }\end{array}$ & $\begin{array}{l}0 \\
0\end{array}$ & MG/L & & $\begin{array}{l}0.3 \\
0.5\end{array}$ & $\mathrm{~L}$ & $\begin{array}{l}0.1 \\
0.1\end{array}$ & - \\
\hline GROSS ALPHA & $\begin{array}{l}0551 \\
0551 \\
0551 \\
0551 \\
0551 \\
0551 \\
0703 \\
0703 \\
0703 \\
0703 \\
0703 \\
0703 \\
0703\end{array}$ & $\begin{array}{l}12 / 12 / 90 \\
03 / 28 / 91 \\
08 / 06 / 91 \\
12 / 05 / 91 \\
10 / 10 / 92 \\
02 / 17 / 94 \\
03 / 29 / 89 \\
12 / 12 / 90 \\
03 / 30 / 91 \\
08 / 07 / 91 \\
12 / 05 / 91 \\
10 / 11 / 92 \\
02 / 17 / 94\end{array}$ & $\begin{array}{l}0001 \\
0001 \\
0001 \\
0001 \\
0001 \\
0001 \\
0001 \\
0001 \\
0001 \\
0001 \\
0001 \\
0001 \\
0001\end{array}$ & $\begin{array}{l}\text { JE } \\
\text { JE } \\
\text { JE } \\
\text { JE } \\
\text { JE } \\
\text { JE } \\
\text { JE } \\
\text { JE } \\
\text { JE } \\
\text { JE } \\
\text { JE } \\
\text { JE } \\
\text { JE }\end{array}$ & $\begin{array}{l}U \\
U \\
U \\
U \\
U \\
U \\
0 \\
0 \\
0 \\
0 \\
0 \\
0 \\
0\end{array}$ & $\mathrm{PCl} / \mathrm{L}$ & & $\begin{array}{l}5 . \\
7.7 \\
0.0 \\
0.0 \\
0.0 \\
0.0 \\
5.11 \\
6.3 \\
4.5 \\
3.0 \\
0.0 \\
0.9 \\
4.4\end{array}$ & $\begin{array}{l}L \\
L \\
L \\
L \\
L K \\
L \\
J L \\
L \\
L \\
L \\
L \\
L N \\
L\end{array}$ & $\begin{array}{l}1 . \\
1 . \\
1 . \\
1 . \\
7.6 \\
3.1 \\
1 . \\
1 . \\
1 . \\
1 . \\
1 . \\
4.5 \\
1.2\end{array}$ & $\begin{array}{l}23 . \\
9.6 \\
5.1 \\
9.1 \\
4.2 \\
2.3 \\
3.76 \\
3.0 \\
3.3 \\
2.8 \\
4.2 \\
2.8 \\
0.9\end{array}$ \\
\hline GROSS ALPHA (TOTAL) & $\begin{array}{l}0551 \\
0703\end{array}$ & $\begin{array}{l}02 / 17 / 94 \\
02 / 17 / 94\end{array}$ & $\begin{array}{l}\text { No01 } \\
\text { N001 }\end{array}$ & $\begin{array}{l}\text { JE } \\
\text { JE }\end{array}$ & $\begin{array}{l}U \\
0\end{array}$ & $\mathrm{PCI} / \mathrm{L}$ & & $\begin{array}{l}38.0 \\
15.0\end{array}$ & $L$ & $\begin{array}{l}8.6 \\
2.0\end{array}$ & $\begin{array}{l}7.0 \\
2.0\end{array}$ \\
\hline GROSS BETA & $\begin{array}{l}0551 \\
0551 \\
0551 \\
0551 \\
0551 \\
0703 \\
0703 \\
0703 \\
0703 \\
0703 \\
0703\end{array}$ & $\begin{array}{l}12 / 12 / 90 \\
03 / 28 / 91 \\
08 / 06 / 91 \\
12 / 05 / 91 \\
10 / 10 / 92 \\
03 / 29 / 89 \\
12 / 12 / 90 \\
03 / 30 / 91 \\
08 / 07 / 91 \\
12 / 05 / 91 \\
10 / 11 / 92\end{array}$ & $\begin{array}{l}0001 \\
0001 \\
0001 \\
0001 \\
0001 \\
0001 \\
0001 \\
0001 \\
0001 \\
0001 \\
0001\end{array}$ & $\begin{array}{l}J E \\
\text { JE } \\
\text { JE } \\
\text { JE } \\
\text { JE } \\
\text { JE } \\
\text { JE } \\
\text { JE } \\
\text { JE } \\
\text { JE } \\
\text { JE }\end{array}$ & $\begin{array}{l}U \\
U \\
U \\
U \\
U \\
0 \\
0 \\
0 \\
0 \\
0 \\
0\end{array}$ & $\mathrm{PCI} / \mathrm{L}$ & & $\begin{array}{r}24 . \\
10.8 \\
4.4 \\
0.0 \\
4.5 \\
11.0 \\
5.9 \\
7.4 \\
6.0 \\
0.0 \\
7.5\end{array}$ & $\begin{array}{l}L \\
L \\
L \\
L \\
* L N \\
L \\
L \\
L \\
L \\
L \\
* L N\end{array}$ & $\begin{array}{l}0.5 \\
0.5 \\
0.5 \\
0.5 \\
7.1 \\
0.5 \\
0.5 \\
0.5 \\
0.5 \\
0.5 \\
4.5\end{array}$ & $\begin{array}{l}18 . \\
6.7 \\
3.3 \\
5.3 \\
4.4 \\
4.80 \\
1.8 \\
2.1 \\
2.0 \\
3.6 \\
3.0\end{array}$ \\
\hline IRON & $\begin{array}{l}0551 \\
0551 \\
0551 \\
0551\end{array}$ & $\begin{array}{l}12 / 12 / 90 \\
03 / 28 / 91 \\
08 / 06 / 91 \\
12 / 11 / 91\end{array}$ & $\begin{array}{l}0001 \\
0001 \\
0001 \\
0001\end{array}$ & $\begin{array}{l}\text { JE } \\
\text { JE } \\
\text { JE } \\
\text { JE }\end{array}$ & $\begin{array}{l}U \\
U \\
U \\
U\end{array}$ & MG/L & $\begin{array}{l}< \\
< \\
< \\
<\end{array}$ & $\begin{array}{l}0.03 \\
0.03 \\
0.03 \\
0.03\end{array}$ & $\begin{array}{l}L \\
L \\
L \\
L\end{array}$ & $\begin{array}{l}0.03 \\
0.03 \\
0.03 \\
0.03\end{array}$ & - \\
\hline
\end{tabular}

FORMATION OF COAPLETION CODE:

JE - JURASSIC ENTRADA SANDSTONE FORMATION

FLOW RELATIONSHIP CODE:

O - ON-SITE

U - UPGRADIENT

PARAMETER VALUE INDICATOR (PVI): < - LESS THAN DETECTION LIMIT

SAMPLE ID CODES:

0001 - FILTERED SAMPLE (.45 MICRONS)

OTHER PARAMETER VAlue flags:

NO01 - UNFILTERED SAMPLE

* - DUPLICATE ANALYSIS NOT yithIN CONTROL LIMITS

- ESTIMATED VALUE

- LESS THAN THREE BORE VOLUMES REMOVED BEFORE SAMPLING

H - SPIKE SAMPLE RECOVERY HOT HITHIN CONTROL LIMITS 
TABLE 3.11 BACKGROUND GROUND HATER QUALITY DATA BY PARAMETER FOR THE ENTRADA FORMATION, UC PROCESSING SITE, SLICK ROCK, COLORADO

SITE: SRK01 SLICK ROCK (BOTH SITES)

03/29/89 TO 02/17/94

REPORT DATE: $09 / 28 / 94$

\begin{tabular}{|c|c|c|c|c|c|c|c|c|c|c|c|}
\hline PARAMETER HAME & $\underset{\text { ID }}{\text { LOCATION }}$ & LOG DATE & $\begin{array}{c}\text { SAMPLE } \\
\text { ID }\end{array}$ & $\begin{array}{l}\text { FORM } \\
\text { COMP }\end{array}$ & $\begin{array}{l}\text { FLOW } \\
\text { REL. }\end{array}$ & $\begin{array}{l}\text { UNI TS OF } \\
\text { MEASURE }\end{array}$ & PVI & $\begin{array}{l}\text { PARAMETER } \\
\text { VALUE }\end{array}$ & FLAGS & $\begin{array}{l}\text { DETECTION } \\
\text { LIMIT }\end{array}$ & $\begin{array}{l}\text { PARAMETER } \\
\text { UNCERTAINTY }\end{array}$ \\
\hline IRON & $\begin{array}{l}0551 \\
0551 \\
0703 \\
0703 \\
0703 \\
0703 \\
0703 \\
0703 \\
0703\end{array}$ & $\begin{array}{l}10 / 10 / 92 \\
02 / 17 / 94 \\
03 / 29 / 89 \\
12 / 12 / 90 \\
03 / 30 / 91 \\
08 / 07 / 91 \\
12 / 07 / 91 \\
10 / 11 / 92 \\
02 / 17 / 94\end{array}$ & $\begin{array}{l}0001 \\
0001 \\
0001 \\
0001 \\
0001 \\
0001 \\
0001 \\
0001 \\
0001\end{array}$ & $\begin{array}{l}\text { JE } \\
\text { JE } \\
\text { JE } \\
\text { JE } \\
\text { JE } \\
\text { JE } \\
\text { JE } \\
\text { JE } \\
\text { JE }\end{array}$ & $\begin{array}{l}U \\
U \\
0 \\
0 \\
0 \\
0 \\
0 \\
0 \\
0\end{array}$ & $M G / L$ & $\begin{array}{l}< \\
< \\
< \\
< \\
< \\
< \\
< \\
< \\
<\end{array}$ & $\begin{array}{l}0.03 \\
0.03 \\
0.02 \\
0.03 \\
0.03 \\
0.03 \\
0.03 \\
0.03 \\
0.03\end{array}$ & $\begin{array}{l}L \\
L \\
J L \\
L \\
L \\
L \\
L \\
L \\
L\end{array}$ & $\begin{array}{l}0.03 \\
0.03 \\
0.03 \\
0.03 \\
0.03 \\
0.03 \\
0.03 \\
0.03 \\
0.03\end{array}$ & $\begin{array}{l}- \\
- \\
- \\
- \\
- \\
- \\
-\end{array}$ \\
\hline IRON (TOTAL) & $\begin{array}{l}0551 \\
0703\end{array}$ & $\begin{array}{l}02 / 17 / 94 \\
02 / 17 / 94\end{array}$ & $\begin{array}{l}\text { N001 } \\
\text { N001 }\end{array}$ & $\begin{array}{l}\text { JE } \\
\text { JE }\end{array}$ & $\begin{array}{l}U \\
0\end{array}$ & $M G / L$ & & $\begin{array}{l}64.1 \\
14.8\end{array}$ & $\begin{array}{l}L \\
L\end{array}$ & $\begin{array}{l}0.03 \\
0.03\end{array}$ & - \\
\hline LEAD & $\begin{array}{l}0551 \\
0551 \\
0551 \\
0551 \\
0551 \\
0703 \\
0703 \\
0703 \\
0703 \\
0703 \\
0703\end{array}$ & $\begin{array}{l}12 / 12 / 90 \\
03 / 28 / 91 \\
08 / 06 / 91 \\
12 / 11 / 91 \\
10 / 10 / 92 \\
03 / 29 / 89 \\
12 / 12 / 90 \\
03 / 30 / 91 \\
08 / 07 / 91 \\
12 / 07 / 91 \\
10 / 11 / 92\end{array}$ & $\begin{array}{l}0001 \\
0001 \\
0001 \\
0001 \\
0001 \\
0001 \\
0001 \\
0001 \\
0001 \\
0001 \\
0001\end{array}$ & $\begin{array}{l}\text { JE } \\
\text { JE } \\
\text { JE } \\
\text { JE } \\
\text { JE } \\
\text { JE } \\
\text { JE } \\
\text { JE } \\
\text { JE } \\
\text { JE } \\
\text { JE }\end{array}$ & $\begin{array}{l}U \\
U \\
U \\
U \\
U \\
0 \\
0 \\
0 \\
0 \\
0 \\
0\end{array}$ & MG/L & $\begin{array}{l}< \\
< \\
< \\
< \\
< \\
< \\
< \\
< \\
< \\
< \\
<\end{array}$ & $\begin{array}{l}0.01 \\
0.005 \\
0.005 \\
0.005 \\
0.003 \\
0.003 \\
0.01 \\
0.005 \\
0.005 \\
0.005 \\
0.02\end{array}$ & $\begin{array}{l}L \\
L \\
L \\
L \\
L \\
J L \\
L \\
L \\
L \\
L \\
\text { IL }\end{array}$ & $\begin{array}{l}0.01 \\
0.005 \\
0.005 \\
0.005 \\
0.003 \\
0.01 \\
0.01 \\
0.005 \\
0.005 \\
0.005 \\
0.02\end{array}$ & $\begin{array}{l}- \\
- \\
- \\
- \\
- \\
- \\
- \\
- \\
-\end{array}$ \\
\hline LEAD-210 & $\begin{array}{l}0551 \\
0551 \\
0551 \\
0703 \\
0703 \\
0703\end{array}$ & $\begin{array}{l}08 / 06 / 91 \\
12 / 05 / 91 \\
02 / 17 / 94 \\
08 / 07 / 91 \\
12 / 05 / 91 \\
02 / 17 / 94\end{array}$ & $\begin{array}{l}0001 \\
0001 \\
0001 \\
0001 \\
0001 \\
0001\end{array}$ & $\begin{array}{l}\text { JE } \\
\text { JE } \\
\text { JE } \\
\text { JE } \\
\text { JE } \\
\text { JE }\end{array}$ & $\begin{array}{l}U \\
U \\
U \\
0 \\
0 \\
0\end{array}$ & $\mathrm{PCI} / \mathrm{L}$ & & $\begin{array}{l}0.7 \\
0.3 \\
3.2 \\
0.4 \\
0.0 \\
1.7\end{array}$ & $\begin{array}{l}L \\
L \\
L \\
L \\
L \\
L\end{array}$ & $\begin{array}{l}1.5 \\
1.5 \\
1.8 \\
1.5 \\
1.5 \\
1.7\end{array}$ & $\begin{array}{l}0.9 \\
1.3 \\
1.1 \\
0.9 \\
0.8 \\
1.0\end{array}$ \\
\hline LEAD-210 (TOTAL) & $\begin{array}{l}0551 \\
0703\end{array}$ & $\begin{array}{l}02 / 17 / 94 \\
02 / 17 / 94\end{array}$ & $\begin{array}{l}\text { N001 } \\
\text { N001 }\end{array}$ & $\begin{array}{l}\mathrm{JE} \\
\mathrm{JE}\end{array}$ & $\begin{array}{l}U \\
0\end{array}$ & $\mathrm{PCl} / \mathrm{L}$ & & $\begin{array}{l}3.2 \\
2.4\end{array}$ & $\begin{array}{l}L \\
L\end{array}$ & $\begin{array}{l}1.7 \\
1.8\end{array}$ & $\begin{array}{l}1.1 \\
1.2\end{array}$ \\
\hline MAGNESIUH & $\begin{array}{l}0551 \\
0551\end{array}$ & $\begin{array}{l}12 / 12 / 90 \\
03 / 28 / 91\end{array}$ & $\begin{array}{l}0001 \\
0001\end{array}$ & $\begin{array}{l}\mathrm{JE} \\
\mathrm{JE}\end{array}$ & $\begin{array}{l}U \\
U\end{array}$ & HG/L & & $\begin{array}{l}81.4 \\
46.8\end{array}$ & $\begin{array}{l}L \\
L\end{array}$ & $\begin{array}{l}0.001 \\
0.1\end{array}$ & : \\
\hline
\end{tabular}

FORMATION OF COMPLETION COOE:

JE - JURASSIC ENTRADA SANDSTONE FORMATION

PARAMETER VALUE IHDICATOR (PVI): < - LESS THAN DETECTION LIMIT

OTHER PARAMETER VALUE FLAGS:

I - INCREASED DETECTION LIMIT DUE TO REQUIRED DILUTION

$J$ - ESTIMATED VALUE

L - LESS THAN THREE BORE VOLUMES REMOVED BEFORE SAMPLING
FLOW RELATIONSHIP CODE:

$U$ - UPGRADIENT

O - ON-SITE

SAMPLE ID CODES:

0001 - FILTERED SAMPLE (.45 MICRONS)

HOOI - UNFILTERED SAMPLE 
TABLE 3.11 BACKGROUND GROUND HATER QUALITY DATA BY PARAMETER FOR THE

ENTRADA FORMATION, UC PROCESSING SITE, SLICK ROCK, COLORADO

SITE: SRKO1 SLICK ROCK (BOTH SITES)

03/29/89 TO $02 / 17 / 94$

REPORT DATE: $09 / 28 / 94$

\begin{tabular}{|c|c|c|c|c|c|c|c|c|c|c|c|}
\hline PARAMETER NAME & $\underset{\text { ID }}{\text { LOCATION }}$ & LOG DATE & $\begin{array}{c}\text { SAMPLE } \\
\text { ID }\end{array}$ & $\begin{array}{l}\text { FORM } \\
\text { COMP }\end{array}$ & $\begin{array}{l}\text { FLOW } \\
\text { REL. }\end{array}$ & $\begin{array}{l}\text { UNITS OF } \\
\text { MEASURE }\end{array}$ & PVI & $\begin{array}{l}\text { PARAMETER } \\
\text { VALUE }\end{array}$ & FLAGS & $\begin{array}{l}\text { DETECTION } \\
\text { LIMIT }\end{array}$ & $\begin{array}{l}\text { PARANETER } \\
\text { UNCERTAINTY }\end{array}$ \\
\hline MAGNESIUM & $\begin{array}{l}0551 \\
0551 \\
0551 \\
0551 \\
0703 \\
0703 \\
0703 \\
0703 \\
0703 \\
0703 \\
0703\end{array}$ & $\begin{array}{l}08 / 06 / 91 \\
12 / 11 / 91 \\
10 / 10 / 92 \\
02 / 17 / 94 \\
03 / 29 / 89 \\
12 / 12 / 90 \\
03 / 30 / 91 \\
08 / 07 / 91 \\
12 / 07 / 91 \\
10 / 11 / 92 \\
02 / 17 / 94\end{array}$ & $\begin{array}{l}0001 \\
0001 \\
0001 \\
0001 \\
0001 \\
0001 \\
0001 \\
0001 \\
0001 \\
0001 \\
0001\end{array}$ & $\begin{array}{l}\text { JE } \\
\text { JE } \\
\text { JE } \\
\text { JE } \\
\text { JE } \\
\text { JE } \\
\text { JE } \\
\text { JE } \\
\text { JE } \\
\text { JE } \\
\text { JE }\end{array}$ & $\begin{array}{l}U \\
U \\
U \\
U \\
0 \\
0 \\
0 \\
0 \\
0 \\
0 \\
0\end{array}$ & $M G / L$ & & $\begin{array}{l}46.0 \\
45.3 \\
47.5 \\
49.1 \\
18 . \\
26.4 \\
27.9 \\
22.5 \\
19.7 \\
21.7 \\
22.2\end{array}$ & $\begin{array}{l}L \\
L \\
L \\
L \\
L \\
L \\
L \\
L \\
L \\
L \\
L\end{array}$ & $\begin{array}{l}0.1 \\
0.1 \\
0.1 \\
0.1 \\
0.001 \\
0.001 \\
0.1 \\
0.1 \\
0.1 \\
0.1 \\
0.1\end{array}$ & $\begin{array}{l}- \\
- \\
- \\
- \\
- \\
- \\
- \\
-\end{array}$ \\
\hline MAGNESIUM (TOTAL) & $\begin{array}{l}0551 \\
0703\end{array}$ & $\begin{array}{l}02 / 17 / 94 \\
02 / 17 / 94\end{array}$ & $\begin{array}{l}\text { N001 } \\
\text { N001 }\end{array}$ & $\begin{array}{l}\text { JE } \\
\text { JE }\end{array}$ & $\begin{array}{l}\text { U } \\
0\end{array}$ & $M G / L$ & & $\begin{array}{l}92.1 \\
33.4\end{array}$ & $L$ & $\begin{array}{l}0.1 \\
0.1\end{array}$ & $\dot{-}$ \\
\hline MANGANESE & $\begin{array}{l}0551 \\
0551 \\
0551 \\
0551 \\
0551 \\
0551 \\
0703 \\
0703 \\
0703 \\
0703 \\
0703 \\
0703 \\
0703\end{array}$ & $\begin{array}{l}12 / 12 / 90 \\
03 / 28 / 91 \\
08 / 06 / 91 \\
12 / 11 / 91 \\
10 / 10 / 92 \\
02 / 17 / 94 \\
03 / 29 / 89 \\
12 / 12 / 90 \\
03 / 30 / 91 \\
08 / 07 / 91 \\
12 / 07 / 91 \\
10 / 11 / 92 \\
02 / 17 / 94\end{array}$ & $\begin{array}{l}0001 \\
0001 \\
0001 \\
0009 \\
0001 \\
0001 \\
0001 \\
0009 \\
0001 \\
0001 \\
0001 \\
0001 \\
0001\end{array}$ & $\begin{array}{l}\mathrm{JE} \\
\mathrm{JE} \\
\mathrm{JE} \\
\mathrm{JE} \\
\mathrm{JE} \\
\mathrm{JE} \\
\mathrm{JE} \\
\mathrm{JE} \\
\mathrm{JE} \\
\mathrm{JE} \\
\mathrm{JE} \\
\mathrm{JE} \\
\mathrm{JE}\end{array}$ & $\begin{array}{l}U \\
U \\
U \\
U \\
U \\
U \\
0 \\
0 \\
0 \\
0 \\
0 \\
0 \\
0\end{array}$ & $M G / L$ & $\begin{array}{l}< \\
< \\
< \\
< \\
< \\
< \\
< \\
< \\
<\end{array}$ & $\begin{array}{l}0.02 \\
0.01 \\
0.01 \\
0.01 \\
0.01 \\
0.01 \\
0.02 \\
0.03 \\
0.08 \\
0.01 \\
0.01 \\
0.01 \\
0.01\end{array}$ & $\begin{array}{l}L \\
L \\
L \\
L \\
L \\
L \\
L \\
L \\
L \\
L \\
L \\
L \\
L\end{array}$ & $\begin{array}{l}0.01 \\
0.01 \\
0.01 \\
0.01 \\
0.01 \\
0.01 \\
0.01 \\
0.01 \\
0.01 \\
0.01 \\
0.01 \\
0.01 \\
0.01\end{array}$ & $\begin{array}{l}- \\
- \\
- \\
- \\
- \\
- \\
- \\
- \\
-\end{array}$ \\
\hline MANGANESE (TOTAL) & $\begin{array}{l}0551 \\
0703\end{array}$ & $\begin{array}{l}02 / 17 / 94 \\
02 / 17 / 94\end{array}$ & $\begin{array}{l}\text { N001 } \\
\text { N001 }\end{array}$ & $\begin{array}{l}\text { JE } \\
\text { JE }\end{array}$ & $\begin{array}{l}U \\
0\end{array}$ & $M G / L$ & & $\begin{array}{l}4.10 \\
0.57\end{array}$ & $\begin{array}{l}L \\
L\end{array}$ & $\begin{array}{l}0.01 \\
0.01\end{array}$ & $\dot{-}$ \\
\hline MERCURY & $\begin{array}{l}0551 \\
0551 \\
0551 \\
0551 \\
0703 \\
0703\end{array}$ & $\begin{array}{l}12 / 12 / 90 \\
03 / 28 / 91 \\
08 / 06 / 91 \\
12 / 11 / 91 \\
03 / 29 / 89 \\
12 / 12 / 90\end{array}$ & $\begin{array}{l}0001 \\
0001 \\
0001 \\
0001 \\
0001 \\
0001\end{array}$ & $\begin{array}{l}\text { JE } \\
\text { JE } \\
\text { JE } \\
\text { JE } \\
\text { JE } \\
\text { JE }\end{array}$ & $\begin{array}{l}U \\
U \\
U \\
U \\
0 \\
0\end{array}$ & $M G / L$ & $\begin{array}{l}< \\
< \\
< \\
< \\
< \\
<\end{array}$ & $\begin{array}{l}0.0002 \\
0.0002 \\
0.0002 \\
0.0002 \\
0.0001 \\
0.0002\end{array}$ & $\begin{array}{l}L \\
L \\
L \\
L \\
J L \\
L\end{array}$ & $\begin{array}{l}0.0002 \\
0.0002 \\
0.0002 \\
0.0002 \\
0.0002 \\
0.0002\end{array}$ & $\begin{array}{l}- \\
- \\
- \\
-\end{array}$ \\
\hline
\end{tabular}

FORMATION OF COMPLETION CODE:

JE - JURASSIC ENTRADA SANDSTONE FORMATION

FLOH RELATIONSHIP CODE:

U - UPGRADIENT

PARAMETER VALUE INDICATOR (PVI): < - LESS THAN DETECTIOM LIMIT

\section{SAMPLE ID COOES:}

0001 - FILTERED SAMPLE (.45 MICRONS)

OTHER PARAMETER VALUE FLAGS:

0001 - FILTERED SAMPLE $~$
N001 - UNFILTERED SAMPLE

$J$ - ESTIMATED VALUE

L - LESS THAN THREE BORE VOLUMES REMOVED BEFORE SAMPLING 
TABLE 3.11 BACKGROUND GROUND HATER QUALITY DATA BY PARAMETER FOR THE ENTRADA FORMATION, UC PROCESSING SITE, SLICK ROCK, COLORADO

SITE: SRK01 SLICK ROCK (BOTH SITES)

$03 / 29 / 89$ TO $02 / 17 / 94$

REPORT DATE: 09/28/94

\begin{tabular}{|c|c|c|c|c|c|c|c|c|c|c|c|}
\hline PARAMETER NAME & $\underset{\text { ID }}{\text { LOCATION }}$ & LOG DATE & $\begin{array}{c}\text { SAMPLE } \\
\text { ID }\end{array}$ & $\begin{array}{l}\text { FORM } \\
\text { COMP }\end{array}$ & $\begin{array}{l}\text { FLOW } \\
\text { REL. }\end{array}$ & $\begin{array}{l}\text { UNITS OF } \\
\text { MEASURE }\end{array}$ & PVI & $\begin{array}{l}\text { PARAMETER } \\
\text { VALUE }\end{array}$ & FLAGS & $\begin{array}{l}\text { DETECT ION } \\
\text { LIMIT }\end{array}$ & $\begin{array}{l}\text { PARAMETER } \\
\text { UHCERTAINTY }\end{array}$ \\
\hline MERCURY & $\begin{array}{l}0703 \\
0703 \\
0703\end{array}$ & $\begin{array}{l}03 / 30 / 91 \\
08 / 07 / 91 \\
12 / 07 / 91\end{array} \mid$ & $\begin{array}{l}0001 \\
0001 \\
0001\end{array}$ & $\begin{array}{l}\text { JE } \\
\text { JE } \\
\text { JE }\end{array}$ & $\begin{array}{l}0 \\
0 \\
0\end{array}$ & MG/L & $\left\{\begin{array}{l}< \\
<\end{array}\right.$ & $\begin{array}{l}0.0002 \\
0.0002 \\
0.0002\end{array}$ & $\begin{array}{l}L \\
L \\
L\end{array}$ & $\begin{array}{l}0.0002 \\
0.0002 \\
0.0002\end{array}$ & - \\
\hline MOLYYBDENUM & $\begin{array}{l}0551 \\
0551 \\
0551 \\
0551 \\
0551 \\
0551 \\
0703 \\
0703 \\
0703 \\
0703 \\
0703 \\
0703 \\
0703\end{array}$ & $\begin{array}{l}12 / 12 / 90 \\
03 / 28 / 91 \\
08 / 06 / 91 \\
12 / 11 / 91 \\
10 / 10 / 92 \\
02 / 17 / 94 \\
03 / 29 / 89 \\
12 / 12 / 90 \\
03 / 30 / 91 \\
08 / 07 / 91 \\
12 / 07 / 91 \\
10 / 11 / 92 \\
02 / 17 / 94\end{array}$ & $\begin{array}{l}0001 \\
0001 \\
0001 \\
0001 \\
0001 \\
0001 \\
0001 \\
0001 \\
0001 \\
0001 \\
0001 \\
0001 \\
0001\end{array}$ & $\begin{array}{l}\text { JE } \\
\text { JE } \\
\text { JE } \\
\text { JE } \\
\text { JE } \\
\text { JE } \\
\text { JE } \\
\text { JE } \\
\text { JE } \\
\text { JE } \\
\text { JE } \\
\text { JE } \\
\text { JE }\end{array}$ & $\begin{array}{l}U \\
U \\
U \\
U \\
U \\
U \\
0 \\
0 \\
0 \\
0 \\
0 \\
0 \\
0\end{array}$ & $M G / L$ & $\begin{array}{l}< \\
< \\
< \\
< \\
<\end{array}$ & $\begin{array}{l}0.07 \\
0.02 \\
0.01 \\
0.01 \\
0.01 \\
0.02 \\
0.002 \\
0.03 \\
0.01 \\
0.01 \\
0.01 \\
0.01 \\
0.01\end{array}$ & $\begin{array}{l}L \\
L \\
L \\
L \\
L \\
L \\
J L \\
L \\
L \\
L \\
L \\
L \\
L\end{array}$ & $\begin{array}{l}0.01 \\
0.01 \\
0.01 \\
0.01 \\
0.01 \\
0.01 \\
0.01 \\
0.01 \\
0.01 \\
0.01 \\
0.01 \\
0.01 \\
0.01\end{array}$ & $\begin{array}{l}- \\
- \\
- \\
- \\
- \\
- \\
- \\
- \\
- \\
-\end{array}$ \\
\hline MOLYBDENUM (TOTAL) & $\begin{array}{l}0551 \\
0703\end{array}$ & $\left|\begin{array}{l}02 / 17 / 94 \\
02 / 17 / 94\end{array}\right|$ & $\begin{array}{l}\text { N001 } \\
\text { N001 }\end{array}$ & $\begin{array}{l}\text { JE } \\
\text { JE }\end{array}$ & $\begin{array}{l}U \\
0\end{array}$ & $\mathrm{MG} / \mathrm{L}$ & $<$ & $\begin{array}{l}0.02 \\
0.01\end{array}$ & $\begin{array}{l}L \\
L\end{array}$ & $\begin{array}{l}0.01 \\
0.01\end{array}$ & - \\
\hline NET GROSS ALPHA * & $\begin{array}{l}0551 \\
0551 \\
0551 \\
0551 \\
0551 \\
0551 \\
0703 \\
0703 \\
0703 \\
0703 \\
0703 \\
0703 \\
0703\end{array}$ & $\begin{array}{l}12 / 12 / 90 \\
03 / 28 / 91 \\
08 / 06 / 91 \\
12 / 05 / 91 \\
10 / 10 / 92 \\
02 / 17 / 94 \\
03 / 29 / 89 \\
12 / 12 / 90 \\
03 / 30 / 91 \\
08 / 07 / 91 \\
12 / 05 / 91 \\
10 / 11 / 92 \\
02 / 17 / 94\end{array}$ & $\begin{array}{l}0001 \\
0001 \\
0001 \\
0001 \\
0001 \\
0001 \\
0001 \\
0001 \\
0001 \\
0001 \\
0001 \\
0001 \\
0001\end{array}$ & $\begin{array}{l}\text { JE } \\
\text { JE } \\
\text { JE } \\
\text { JE } \\
\text { JE } \\
\text { JE } \\
\text { JE } \\
\text { JE } \\
\text { JE } \\
\text { JE } \\
\text { JE } \\
\text { JE } \\
\text { JE }\end{array}$ & $\begin{array}{l}U \\
U \\
U \\
U \\
U \\
U \\
0 \\
0 \\
0 \\
0 \\
0 \\
0 \\
0\end{array}$ & $\mathrm{PCI} / \mathrm{L}$ & & $\begin{array}{r}-6.25 \\
4.27 \\
-0.34 \\
-4.12 \\
-1.37 \\
-6.17 \\
0.31 \\
4.10 \\
1.76 \\
0.94 \\
-0.69 \\
-1.16 \\
2.34\end{array}$ & & $\begin{array}{l}- \\
- \\
- \\
- \\
- \\
- \\
- \\
- \\
-\end{array}$ & $\begin{array}{l}- \\
- \\
- \\
- \\
- \\
- \\
- \\
- \\
- \\
- \\
-\end{array}$ \\
\hline NET GROSS ALPHA (TOTAL) ** & 0551 & $02 / 17 / 94$ & N001 & JE & $u$ & $\mathrm{PCI} / \mathrm{L}$ & & 35.94 & & - & - \\
\hline
\end{tabular}

* NET GROSS ALPHA (GROSS ALPHA - URANIUM) WITH 1 MG URANIUM = 686 PCI ** NET GROSS ALPHA (TOTAL) (TOTAL GROSS ALPHA - TOTAL URANIUM)

FORMATION OF CONPLETION CODE:

JE - JURASSIC ENTRADA SANDSTONE FORMATION

PARAMETER VALUE INDICATOR (PVI): < - LESS THAN DETECTION LIMIT

OTHER PARAMETER VALUE FLAGS:

$J$ - ESTIMATED VALUE
L - LESS THAN THREE BORE VOLUMES REMOVED BEFORE SAMPLING
FLOW RELATIONSHIP CODE:

O - ON-SITE

U - UPGRADIENT

SAMPLE ID CODES:

0001 - FILTERED SAMPLE (.45 MICRONS)

NO01 - UNFILTERED SAMPLE 
TABLE 3.11 BACKGROUND GROUND WATER QUALITY DATA BY PARAMETER FOR THE ENTRADA FORMATION, UC PROCESSING SITE, SLICK ROCK, COLORADO

SITE: SRKO1 SLICK ROCK (BOTH SITES)

$03 / 29 / 89$ TO $02 / 17 / 94$

REPORT DATE: 09/28/94

\begin{tabular}{|c|c|c|c|c|c|c|c|c|c|c|c|}
\hline PARAMETER NAME & $\underset{\text { ID }}{\text { LOCATION }}$ & LOG DATE & $\underset{\text { ID }}{\text { SAMPLE }}$ & $\begin{array}{l}\text { FORM } \\
\text { COMP }\end{array}$ & $\begin{array}{l}\text { FLOU } \\
\text { REL. }\end{array}$ & $\begin{array}{l}\text { UNITS OF } \\
\text { MEASURE }\end{array}$ & PVI & $\begin{array}{l}\text { RAMETER } \\
\text { JALUE }\end{array}$ & FLAGS & $\begin{array}{l}\text { DETECTIOH } \\
\text { LIMIT }\end{array}$ & $\begin{array}{l}\text { PARAMETER } \\
\text { UHCERTAINTY }\end{array}$ \\
\hline HET GROSS ALPHA (TOTAL) ** & 0703 & $02 / 17 / 94$ & NOOI & JE & 0 & $\mathrm{PCI} / \mathrm{L}$ & & 13.63 & & - & - \\
\hline HICKEL & $\begin{array}{l}0551 \\
0551 \\
0551 \\
0551 \\
0551 \\
0703 \\
0703 \\
0703 \\
0703 \\
0703 \\
0703\end{array}$ & $\begin{array}{l}12 / 12 / 90 \\
03 / 28 / 91 \\
08 / 06 / 91 \\
12 / 11 / 91 \\
10 / 10 / 92 \\
03 / 29 / 89 \\
12 / 12 / 90 \\
03 / 30 / 91 \\
08 / 07 / 91 \\
12 / 07 / 91 \\
10 / 11 / 92\end{array}$ & $\begin{array}{l}0001 \\
0001 \\
0001 \\
0001 \\
0001 \\
0001 \\
0001 \\
0001 \\
0001 \\
0001 \\
0001\end{array}$ & $\begin{array}{l}\text { JE } \\
\text { JE } \\
\text { JE } \\
\text { JE } \\
\text { JE } \\
\text { JE } \\
\text { JE } \\
\text { JE } \\
\text { JE } \\
\text { JE } \\
\text { JE }\end{array}$ & $\begin{array}{l}U \\
U \\
U \\
U \\
U \\
0 \\
0 \\
0 \\
0 \\
0 \\
0\end{array}$ & $M G / L$ & $\begin{array}{l}< \\
< \\
< \\
< \\
< \\
< \\
< \\
< \\
< \\
< \\
<\end{array}$ & $\begin{array}{l}0.04 \\
0.04 \\
0.04 \\
0.04 \\
0.04 \\
0.02 \\
0.04 \\
0.04 \\
0.04 \\
0.04 \\
0.04\end{array}$ & $\begin{array}{l}L \\
L \\
L \\
L \\
L \\
J L \\
L \\
L \\
L \\
L \\
L\end{array}$ & $\begin{array}{l}0.04 \\
0.04 \\
0.04 \\
0.04 \\
0.04 \\
0.04 \\
0.04 \\
0.04 \\
0.04 \\
0.04 \\
0.04\end{array}$ & $\begin{array}{l}- \\
- \\
- \\
- \\
- \\
- \\
- \\
-\end{array}$ \\
\hline NITRATE & $\begin{array}{l}0551 \\
0551 \\
0551 \\
0551 \\
0551 \\
0703 \\
0703 \\
0703 \\
0703 \\
0703 \\
0703\end{array}$ & $\begin{array}{l}12 / 12 / 90 \\
03 / 28 / 91 \\
08 / 06 / 91 \\
12 / 11 / 91 \\
10 / 10 / 92 \\
03 / 29 / 89 \\
12 / 12 / 90 \\
03 / 30 / 91 \\
08 / 07 / 91 \\
12 / 07 / 91 \\
10 / 11 / 92\end{array}$ & $\begin{array}{l}0001 \\
0001 \\
0001 \\
0001 \\
0001 \\
0001 \\
0001 \\
0001 \\
0001 \\
0001 \\
0001\end{array}$ & $\begin{array}{l}\mathrm{JE} \\
\mathrm{JE} \\
\mathrm{JE} \\
\mathrm{JE} \\
\mathrm{JE} \\
\mathrm{JE} \\
\mathrm{JE} \\
\mathrm{JE} \\
\mathrm{JE} \\
\mathrm{JE} \\
\mathrm{JE}\end{array}$ & $\begin{array}{l}U \\
U \\
U \\
U \\
U \\
0 \\
0 \\
0 \\
0 \\
0 \\
0\end{array}$ & $M G / L$ & & $\begin{array}{l}1 . \\
5.5 \\
3.5 \\
1.8 \\
8.5 \\
7.4 \\
3.9 \\
7.3 \\
8.9 \\
6.2 \\
5.7\end{array}$ & $\begin{array}{l}H L \\
L \\
L \\
L \\
L \\
L \\
L \\
L \\
L \\
L \\
L\end{array}$ & $\begin{array}{l}1 . \\
1 . \\
1 . \\
1.0 \\
1.0 \\
1 . \\
1 . \\
1 . \\
1.0\end{array}$ & $\begin{array}{l}- \\
: \\
: \\
: \\
: \\
: \\
-\end{array}$ \\
\hline NITRATE (TOTAL) & $\begin{array}{l}0551 \\
0703\end{array}$ & $\begin{array}{l}02 / 17 / 94 \\
02 / 17 / 94\end{array}$ & $\begin{array}{l}\text { N001 } \\
\text { HOO1 }\end{array}$ & $\begin{array}{l}\text { JE } \\
\text { JE }\end{array}$ & $\begin{array}{l}U \\
0\end{array}$ & MG/L & $<$ & $\begin{array}{l}1 \\
1\end{array}$ & $\begin{array}{l}\mathrm{L} \\
\mathrm{L}\end{array}$ & $\begin{array}{l}1 \\
1\end{array}$ & $\overline{-}$ \\
\hline NITRITE AND NITRATE & $\begin{array}{l}0551 \\
0551 \\
0551 \\
0703 \\
0703 \\
0703\end{array}$ & $\begin{array}{l}12 / 12 / 90 \\
03 / 28 / 91 \\
08 / 06 / 91 \\
12 / 12 / 90 \\
03 / 30 / 91 \\
08 / 07 / 91\end{array}$ & $\begin{array}{l}0001 \\
0001 \\
0001 \\
0001 \\
0001 \\
0001\end{array}$ & $\begin{array}{l}\text { JE } \\
\text { JE } \\
\text { JE } \\
\text { JE } \\
\text { JE } \\
\text { JE }\end{array}$ & $\begin{array}{l}U \\
U \\
U \\
0 \\
0 \\
0\end{array}$ & MG/L & & $\begin{array}{l}1 . \\
1.24 \\
0.82 \\
3 . \\
1.67 \\
1.98\end{array}$ & $\begin{array}{l}J L \\
L \\
L \\
J L \\
L \\
L\end{array}$ & $\begin{array}{l}1 . \\
0.05 \\
0.05 \\
1.0 \\
0.05 \\
0.05\end{array}$ & $\begin{array}{l}- \\
- \\
- \\
-\end{array}$ \\
\hline
\end{tabular}

** NET GROSS ALPHA (TOTAL)

(TOTAL GROSS ALPHA - TOTAL URANIUM)

FORMATION OF COMPLETION COOE:

JE - JURASSIC ENTRADA SANDSTONE FORMATION

PARAMETER VALUE INDICATOR (PVI): < - LESS THAN DETECTION LIMIT

OTHER PARAMETER VALUE FLAGS:

H - HOLD TIME EXPIRED, VALUE SUSPECT

$J$ - ESTIMATED VALUE

L - LESS THAN THREE BORE VOLUMES REMOVED BEFORE SAMPLING
FLOH RELATIONSHIP CODE:

O - ON-SITE

$U$ - UPGRADIENT

SAMPLE ID CODES:

DOO1 - FILTERED SAMPLE (.45 MICRONS)

NO01 - UNFILTERED SAMPLE 
TABLE 3.11 BACKGROUND GROUND WATER QUALITY DATA BY PARAMETER FOR THE ENTRADA FORMATION, UC PROCESSING SITE, SLICK ROCK, COLORADO

SITE: SRK01 SLICK ROCK (BOTH SITES)

03/29/89 TO $02 / 17 / 94$

REPORT DATE: $09 / 28 / 94$

\begin{tabular}{|c|c|c|c|c|c|c|c|c|c|c|c|}
\hline PARAMETER NAME & $\underset{\text { ID }}{\text { LOCATION }}$ & LOG DATE & $\begin{array}{c}\text { SAMPLE } \\
\text { ID }\end{array}$ & $\begin{array}{l}\text { FORM } \\
\text { COMP }\end{array}$ & $\begin{array}{l}\text { FLOW } \\
\text { REL. }\end{array}$ & $\begin{array}{l}\text { UNITS OF } \\
\text { MEASURE }\end{array}$ & PVI & $\begin{array}{l}\text { ARAMETER } \\
\text { VALLUE }\end{array}$ & FLAGS & $\begin{array}{l}\text { DETECTION } \\
\text { LIMIT }\end{array}$ & $\begin{array}{l}\text { PARAMETER } \\
\text { UNCERTAINTY }\end{array}$ \\
\hline PH & $\begin{array}{l}0551 \\
0551 \\
0551 \\
0551 \\
0551 \\
0551 \\
0703 \\
0703 \\
0703 \\
0703 \\
0703 \\
0703 \\
0703\end{array}$ & $\begin{array}{l}12 / 12 / 90 \\
03 / 28 / 91 \\
08 / 06 / 91 \\
12 / 05 / 91 \\
10 / 10 / 92 \\
02 / 17 / 94 \\
03 / 29 / 89 \\
12 / 12 / 90 \\
03 / 30 / 91 \\
08 / 07 / 91 \\
12 / 05 / 91 \\
10 / 11 / 92 \\
02 / 17 / 94\end{array}$ & $\begin{array}{l}0001 \\
0001 \\
0001 \\
0001 \\
0001 \\
N 001 \\
0001 \\
0001 \\
0001 \\
0001 \\
0001 \\
0001 \\
N 001\end{array}$ & $\begin{array}{l}\text { JE } \\
\text { JE } \\
\text { JE } \\
\text { JE } \\
\text { JE } \\
\text { JE } \\
\text { JE } \\
\text { JE } \\
\text { JE } \\
\text { JE } \\
\text { JE } \\
\text { JE } \\
\text { JE }\end{array}$ & $\begin{array}{l}U \\
U \\
U \\
U \\
U \\
U \\
0 \\
0 \\
0 \\
0 \\
0 \\
0 \\
0\end{array}$ & su & & $\begin{array}{l}7.82 \\
7.86 \\
7.77 \\
8.01 \\
7.99 \\
7.81 \\
7.93 \\
8.04 \\
7.78 \\
7.98 \\
7.93 \\
8.02 \\
7.98\end{array}$ & $\begin{array}{l}L \\
L \\
L \\
L \\
L \\
L \\
L \\
L \\
L \\
L \\
L \\
L \\
L\end{array}$ & $\begin{array}{l}- \\
- \\
- \\
- \\
- \\
- \\
- \\
- \\
- \\
-\end{array}$ & $\begin{array}{l}- \\
- \\
- \\
- \\
- \\
- \\
- \\
- \\
- \\
-\end{array}$ \\
\hline PHOSPHATE & $\begin{array}{l}0551 \\
0551 \\
0551 \\
0551 \\
0551 \\
0703 \\
0703 \\
0703 \\
0703 \\
0703 \\
0703\end{array}$ & $\begin{array}{l}12 / 12 / 90 \\
03 / 28 / 91 \\
08 / 06 / 91 \\
12 / 11 / 91 \\
10 / 10 / 92 \\
03 / 29 / 89 \\
12 / 12 / 90 \\
03 / 30 / 91 \\
08 / 07 / 91 \\
12 / 07 / 91 \\
10 / 11 / 92\end{array}$ & $\begin{array}{l}0001 \\
0001 \\
0001 \\
0001 \\
0001 \\
0001 \\
0001 \\
0001 \\
0001 \\
0001 \\
0001\end{array}$ & $\begin{array}{l}\text { JE } \\
\text { JE } \\
\text { JE } \\
\text { JE } \\
\text { JE } \\
\text { JE } \\
\text { JE } \\
\text { JE } \\
\text { JE } \\
\text { JE } \\
\text { JE }\end{array}$ & $\begin{array}{l}U \\
U \\
U \\
U \\
U \\
0 \\
0 \\
0 \\
0 \\
0 \\
0\end{array}$ & MG/L & $<$ & $\begin{array}{l}0.1 \\
0.1 \\
0.1 \\
0.9 \\
0.6 \\
0.1 \\
0.1 \\
0.1 \\
0.1 \\
0.1 \\
0.5\end{array}$ & $\begin{array}{l}H L \\
L \\
L \\
L \\
J L \\
L \\
H L \\
L \\
L \\
L \\
J L\end{array}$ & $\begin{array}{l}0.1 \\
0.1 \\
0.1 \\
0.1 \\
0.1 \\
0.1 \\
0.1 \\
0.1 \\
0.1 \\
0.01 \\
0.1\end{array}$ & $\begin{array}{l}\dot{-} \\
\dot{-} \\
\dot{-} \\
\dot{-} \\
\dot{-} \\
-\end{array}$ \\
\hline POLONIUM-210 & $\begin{array}{l}0551 \\
0551 \\
0551 \\
0703 \\
0703 \\
0703\end{array}$ & $\begin{array}{l}08 / 06 / 91 \\
12 / 05 / 91 \\
02 / 17 / 94 \\
08 / 07 / 91 \\
12 / 05 / 91 \\
02 / 17 / 94\end{array}$ & $\begin{array}{l}0001 \\
0001 \\
0001 \\
0001 \\
0001 \\
0001\end{array}$ & $\begin{array}{l}\text { JE } \\
\text { JE } \\
\text { JE } \\
\text { JE } \\
\text { JE } \\
\text { JE }\end{array}$ & $\begin{array}{l}U \\
U \\
U \\
0 \\
0 \\
0\end{array}$ & PCI/L & & $\begin{array}{l}0.1 \\
0.1 \\
0.0 \\
0.1 \\
0.0 \\
0.0\end{array}$ & $\begin{array}{l}L \\
L \\
L \\
L \\
L \\
L\end{array}$ & $\begin{array}{l}1 . \\
1 . \\
0.1 \\
1 . \\
1 . \\
0.1\end{array}$ & $\begin{array}{l}0.4 \\
0.5 \\
0.0 \\
0.3 \\
0.6 \\
0.1\end{array}$ \\
\hline POLONIUM-210 (TOTAL) & $\begin{array}{l}0551 \\
0703\end{array}$ & $\begin{array}{l}02 / 17 / 94 \\
02 / 17 / 94\end{array}$ & $\begin{array}{l}\text { N001 } \\
\text { N001 }\end{array}$ & $\begin{array}{l}\text { JE } \\
\text { JE }\end{array}$ & $\begin{array}{l}U \\
0\end{array}$ & $\mathrm{PCI} / \mathrm{L}$ & & $\begin{array}{l}0.2 \\
0.1\end{array}$ & $\begin{array}{l}L \\
L\end{array}$ & $\begin{array}{l}0.1 \\
0.1\end{array}$ & $\begin{array}{l}0.1 \\
0.1\end{array}$ \\
\hline POTASSIUH & 0551 & $12 / 12 / 90$ & 0001 & JE & U & MG/L & & 12.5 & L & 0.01 & - \\
\hline
\end{tabular}

FORMATION OF COMPLETION COOE:

JE - JURASSIC ENTRADA SANDSTONE FORMATION

PARAMETER VALUE INDICATOR (PVI): < - LESS THAN DETECTION LIMIT

OtHeR PARAMETER VALUE fLAGS:

H - HOLD TIME EXPIRED, VALUE SUSPECT

$J$ - ESTIMATED VALUE

L - LESS THAN THREE BORE VOLUMES REMOVED BEFORE SAMPLING
FLOW RELATIONSHIP CODE:

$$
\begin{aligned}
& \text { U - UPGRADIEN } \\
& \text { O - ON-SITE }
\end{aligned}
$$

SAMPLE ID COOES:

0001 - FILTERED SAMPLE (.45 MICRONS)

N001 - UNFILTERED SAMPLE 
37dwYS 098917IAN - $100 \mathrm{H}$

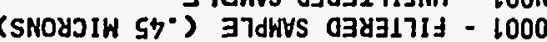
:s $\exists 003$ al $\exists$-1WWS

31 IS-No -0

LNGIOYZOdn - n

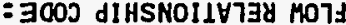

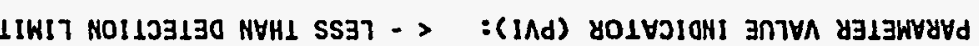

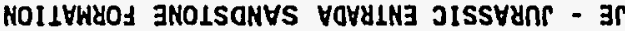
:300J NOIL37dkOJ tO NOILWYO

\begin{tabular}{|c|c|c|c|c|c|c|c|c|c|c|}
\hline $\begin{array}{l}- \\
- \\
- \\
- \\
- \\
-\end{array}$ & $\begin{array}{l}- \\
- \\
- \\
- \\
-\end{array}$ & & $\begin{array}{l}0 L \cdot 2 \\
01 \cdot 7 \\
0 L \cdot ? \\
0 E^{\circ} \cdot 0 \\
0 L^{\circ} \cdot 0 \\
07^{\circ} \cdot 2 \\
0 S^{\circ} \cdot 1\end{array}$ & $7 / 10 d$ & $\begin{array}{l}0 \\
n \\
n \\
n \\
n \\
n \\
n\end{array}$ & $\begin{array}{l}\exists r \\
\exists r \\
\exists r \\
\exists r \\
\exists r \\
\exists r \\
\exists r\end{array}$ & $\begin{array}{l}1000 \\
1000 \\
1000 \\
1000 \\
1000 \\
1000 \\
1000\end{array}$ & $\begin{array}{l}06 / 21 / 21 \\
76 / 2 b / 20 \\
26 / 01 / 01 \\
16 / 50 / 2 l \\
16 / 90 / 80 \\
16 / 82 / 80 \\
06 / 2 l / 2 l\end{array}$ & $\begin{array}{l}150 \angle 0 \\
1550 \\
1550 \\
1550 \\
1550 \\
1550 \\
1550\end{array}$ & 8Z2-wnI OYy + 9Z2-wnI O४y \\
\hline $\begin{array}{l}\varepsilon \cdot 0 \\
Z^{*} \cdot 0\end{array}$ & $\begin{array}{l}l \cdot 0 \\
l \cdot 0\end{array}$ & $\begin{array}{l}7 \\
7\end{array}$ & $\begin{array}{l}8.1 \\
7.1\end{array}$ & $7 / 10 d$ & $\begin{array}{l}0 \\
\text { n }\end{array}$ & $\begin{array}{l}\exists r \\
\exists r\end{array}$ & $\begin{array}{l}\text { LOON } \\
\text { LOON }\end{array}$ & $\begin{array}{l}76 / 2 L / 20 \\
76 / 21 / 20\end{array} \mid$ & $\begin{array}{l}\text { EOLO } \\
\text { ISSO }\end{array}$ & $(7 \forall 101) 922-$ wniayy \\
\hline $\begin{array}{l}l \cdot 0 \\
2 \cdot 0 \\
\Sigma \cdot 0 \\
2 \cdot 0 \\
2 \cdot 0 \\
7 \cdot 0 \\
1 \cdot 0 \\
9 \cdot 0 \\
2 \cdot 0 \\
2 \cdot 0 \\
2 \cdot 0 \\
2 \cdot 0\end{array}$ & 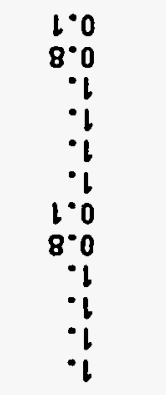 & $\begin{array}{l}7 \\
7 \\
7 \\
7 \\
7 \\
7 \\
7 \\
7 \\
7 \\
7 \\
7 \\
7\end{array}$ & 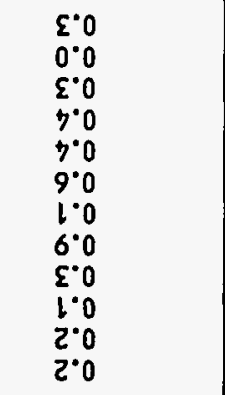 & $7 / 10 d$ & $\begin{array}{l}0 \\
0 \\
0 \\
0 \\
0 \\
0 \\
n \\
n \\
n \\
n \\
n \\
n\end{array}$ & $\begin{array}{l}\exists r \\
\exists r \\
\exists r \\
\exists r \\
\exists r \\
\exists r \\
\exists r \\
3 r \\
\exists r \\
\exists r \\
\exists r \\
\exists r\end{array}$ & $\begin{array}{l}1000 \\
1000 \\
1000 \\
1000 \\
1000 \\
1000 \\
1000 \\
1000 \\
1000 \\
1000 \\
1000 \\
1000\end{array}$ & $\begin{array}{l}76 / 2 l / 20 \\
26 / 11 / 01 \\
16 / 50 / 2 l \\
16 / 20 / 80 \\
16 / 0 \varepsilon / 20 \\
06 / 21 / 21 \\
76 / 21 / 20 \\
26 / 01 / 01 \\
16 / 50 / 21 \\
16 / 90 / 80 \\
16 / 82 / 50 \\
06 / 21 / 21\end{array}$ & 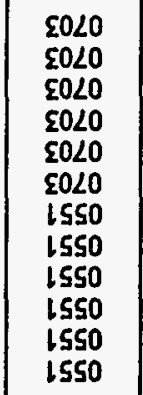 & gzz-wnioyy \\
\hline- & $\begin{array}{l}l \cdot 0 \\
l \cdot 0\end{array}$ & $\begin{array}{l}7 \\
7\end{array}$ & $\begin{array}{l}2.91 \\
0 . \varepsilon \varepsilon\end{array}$ & $7 / 9 W$ & $\begin{array}{l}0 \\
n\end{array}$ & $\begin{array}{l}\exists r \\
\exists r\end{array}$ & $\begin{array}{l}\text { LOON } \\
\text { LOON }\end{array}$ & $\begin{array}{l}76 / 2 l / 20 \\
76 / 2 l / 20\end{array}$ & $\begin{array}{l}\text { EOLO } \\
\text { ISSO }\end{array}$ & (7V101) WnISSY10d \\
\hline $\begin{array}{l}- \\
- \\
- \\
- \\
- \\
- \\
- \\
- \\
-\end{array}$ & $\begin{array}{l}1 \% 0 \\
10 \% 0 \\
10 \% 0 \\
10 \% 0 \\
10 \% 0 \\
10 \% 0 \\
10 \% 0 \\
1 \% 0 \\
10 \% 0 \\
10 \% 0 \\
10 \% 0 \\
10 \% 0\end{array}$ & $\begin{array}{l}7 \\
7 \\
7 \\
7 \\
7 \\
7 \\
7 \\
7 \\
7 \\
7 \\
7 \\
7\end{array}$ & 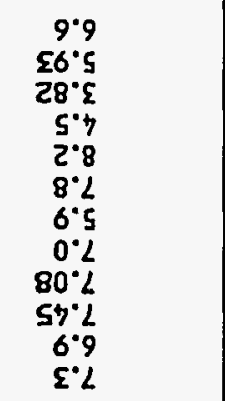 & . & $\begin{array}{l}0 \\
0 \\
0 \\
0 \\
0 \\
0 \\
0 \\
n \\
n \\
n \\
n \\
n\end{array}$ & $\begin{array}{l}\exists r \\
\exists r \\
\exists r \\
\exists r \\
\exists r \\
\exists r \\
\exists r \\
\exists r \\
\exists r \\
\exists r \\
\exists r \\
\exists r\end{array}$ & $\begin{array}{l}1000 \\
1000 \\
1000 \\
1000 \\
1000 \\
1000 \\
1000 \\
1000 \\
1000 \\
1000 \\
1000 \\
1000\end{array}$ & $\begin{array}{l}76 / 2 l / 20 \\
26 / 11 / 01 \\
16 / 20 / 2 L \\
16 / 20 / 80 \\
16 / 0 \varepsilon / \varepsilon 0 \\
06 / 21 / 2 l \\
68 / 62 / \varepsilon 0 \\
76 / 21 / 20 \\
26 / 01 / 01 \\
16 / 11 / 2 L \\
16 / 90 / 80 \\
16 / 82 / \varepsilon 0\end{array}$ & $\begin{array}{l}\text { EOLO } \\
\text { EOLO } \\
\text { EOLO } \\
\Sigma 0 L O \\
\varepsilon 0 L O \\
\text { EOLO } \\
\text { SOLO } \\
\text { ISSO } \\
\text { ISSO } \\
\text { ISSO } \\
\text { ISSO } \\
\text { ISSO }\end{array}$ & wnissviod \\
\hline 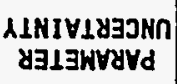 & $\begin{array}{c}\text { 1INI7 } \\
\text { NoI1J3130 }\end{array}$ & SפYרA & 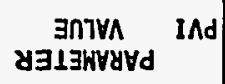 & $\begin{array}{l}\text { Jynsvak } \\
\text { Jo SIIKn }\end{array}$ & - $73 y$ & $\mid \begin{array}{l}\text { dWOJ } \\
\text { WYOS }\end{array}$ & $\begin{array}{c}\text { OI } \\
\text { 37dWYs }\end{array}$ & ヨ170 907) & $\begin{array}{c}\text { al } \\
\text { КoIIVรO7 }\end{array}$ & 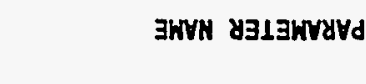 \\
\hline
\end{tabular}

$76 / 82 / 60$ : 3170 180dヨy

$76 / 21 / 200168 / 62 / 20$

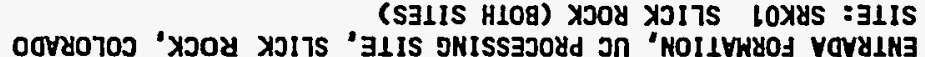

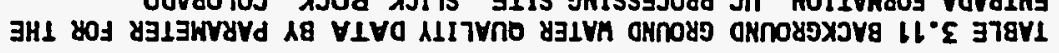


TABLE 3.11 BACKGROUND GROUND HATER QUALITY DATA BY PARAMETER FOR THE ENTRADA FORMATION, UC PROCESSING SITE, SLICK ROCK, COLORADO

SITE: SRK01 SLICK ROCK (BOTH SITES)

$03 / 29 / 89$ TO $02 / 17 / 94$

PEPORT DATE: $09 / 28 / 94$

\begin{tabular}{|c|c|c|c|c|c|c|c|c|c|c|c|}
\hline PARAMETER NAME & $\underset{\text { ID }}{\text { LOCATION }}$ & LOG DATE & $\begin{array}{l}\text { SAMPLE } \\
\text { ID }\end{array}$ & $\begin{array}{l}\text { FORM } \\
\text { COMP }\end{array}$ & $\begin{array}{l}\text { FLOW } \\
\text { REL. }\end{array}$ & $\begin{array}{l}\text { UNITS OF } \\
\text { MEASURE }\end{array}$ & PVI & $\begin{array}{l}\text { ARAMETER } \\
\text { VALUE }\end{array}$ & FLAGS & $\begin{array}{l}\text { DETECTION } \\
\text { LIMIT }\end{array}$ & $\begin{array}{l}\text { PARAMETER } \\
\text { UNCERTAINTY }\end{array}$ \\
\hline RADIUM-226 + RADIUM-228 & $\begin{array}{l}0703 \\
0703 \\
0703 \\
0703 \\
0703\end{array}$ & $\begin{array}{l}03 / 30 / 91 \\
08 / 07 / 91 \\
12 / 05 / 91 \\
10 / 11 / 92 \\
02 / 17 / 94\end{array}$ & $\begin{array}{l}0001 \\
0001 \\
0001 \\
0001 \\
0001\end{array}$ & $\begin{array}{l}\text { JE } \\
\text { JE } \\
\text { JE } \\
\text { JE } \\
\text { JE }\end{array}$ & $\begin{array}{l}0 \\
0 \\
0 \\
0 \\
0\end{array}$ & PCI/L & & $\begin{array}{l}0.40 \\
6.30 \\
1.10 \\
0.70 \\
1.70\end{array}$ & & $\begin{array}{l}- \\
- \\
- \\
-\end{array}$ & $\begin{array}{l}- \\
- \\
-\end{array}$ \\
\hline RADIUM-226 + RADIUM-228 TOTAL & $\begin{array}{l}0551 \\
0703\end{array}$ & $\begin{array}{l}02 / 17 / 94 \\
02 / 17 / 94\end{array}$ & $\begin{array}{l}\text { N001 } \\
\text { N001 }\end{array}$ & $\begin{array}{l}\mathrm{JE} \\
\mathrm{JE}\end{array}$ & $\begin{array}{l}U \\
0\end{array}$ & $\mathrm{PCI} / \mathrm{L}$ & & $\begin{array}{l}3.70 \\
6.20\end{array}$ & & $\dot{-}$ & $\begin{array}{l}- \\
-\end{array}$ \\
\hline RADIUM-228 & $\begin{array}{l}0551 \\
0551 \\
0551 \\
0551 \\
0551 \\
0551 \\
0703 \\
0703 \\
0703 \\
0703 \\
0703 \\
0703\end{array}$ & $\begin{array}{l}12 / 12 / 90 \\
03 / 28 / 91 \\
08 / 06 / 91 \\
12 / 05 / 91 \\
10 / 10 / 92 \\
02 / 17 / 94 \\
12 / 12 / 90 \\
03 / 30 / 91 \\
08 / 07 / 91 \\
12 / 05 / 91 \\
10 / 11 / 92 \\
02 / 17 / 94\end{array}$ & $\begin{array}{l}0001 \\
0001 \\
0001 \\
0001 \\
0001 \\
0001 \\
0001 \\
0001 \\
0001 \\
0001 \\
0001 \\
0001\end{array}$ & $\begin{array}{l}\text { JE } \\
\text { JE } \\
\text { JE } \\
J E \\
\text { JE } \\
\text { JE } \\
\text { JE } \\
\text { JE } \\
\text { JE } \\
\text { JE } \\
\text { JE } \\
\text { JE }\end{array}$ & $\begin{array}{l}U \\
U \\
U \\
U \\
U \\
U \\
0 \\
0 \\
0 \\
0 \\
0 \\
0\end{array}$ & $\mathrm{PCI} / \mathrm{L}$ & & $\begin{array}{l}1.3 \\
2.2 \\
0.0 \\
0.0 \\
1.8 \\
4.0 \\
2.1 \\
0.0 \\
5.9 \\
0.8 \\
0.7 \\
1.4\end{array}$ & $\begin{array}{l}L \\
L \\
L \\
L \\
L \\
L \\
L \\
L \\
L \\
L \\
L N \\
L\end{array}$ & $\begin{array}{l}1 . \\
1 . \\
1 . \\
1 . \\
2.4 \\
1.9 \\
1 . \\
1 . \\
1 . \\
1 . \\
2.6 \\
1.8\end{array}$ & $\begin{array}{l}0.9 \\
1.2 \\
1.5 \\
0.7 \\
1.6 \\
1.3 \\
1.0 \\
1.0 \\
2.3 \\
1.1 \\
1.6 \\
0.9\end{array}$ \\
\hline RADIUM-228 (TOTAL) & $\begin{array}{l}0551 \\
0703\end{array}$ & $\begin{array}{l}02 / 17 / 94 \\
02 / 17 / 94\end{array}$ & $\begin{array}{l}\text { N001 } \\
\text { N001 }\end{array}$ & $\begin{array}{l}\text { JE } \\
\text { JE }\end{array}$ & $\begin{array}{l}u \\
0\end{array}$ & PCI/L & & $\begin{array}{l}2.3 \\
4.4\end{array}$ & $\begin{array}{l}L \\
L\end{array}$ & $\begin{array}{l}2.1 \\
1.8\end{array}$ & $\begin{array}{l}1.2 \\
1.3\end{array}$ \\
\hline REDOX POTENTIAL & $\begin{array}{l}0551 \\
0551 \\
0703 \\
0703\end{array}$ & $\begin{array}{l}12 / 12 / 90 \\
10 / 10 / 92 \\
12 / 12 / 90 \\
10 / 11 / 92\end{array}$ & $\begin{array}{l}0001 \\
0001 \\
0001 \\
0001\end{array}$ & $\begin{array}{l}\text { JE } \\
\text { JE } \\
\text { JE } \\
\text { JE }\end{array}$ & $\begin{array}{l}U \\
U \\
0 \\
0\end{array}$ & mVOLTS & & $\begin{array}{l}434.3 \\
456.1 \\
368.3 \\
444.8\end{array}$ & $\begin{array}{l}L \\
L \\
L \\
L\end{array}$ & $\begin{array}{l}- \\
-\end{array}$ & : \\
\hline SELENIUM & $\begin{array}{l}0551 \\
0551 \\
0551 \\
0551 \\
0551 \\
0551\end{array}$ & $\begin{array}{l}12 / 12 / 90 \\
03 / 28 / 91 \\
08 / 06 / 91 \\
12 / 11 / 91 \\
10 / 10 / 92 \\
02 / 17 / 94\end{array}$ & $\begin{array}{l}0001 \\
0001 \\
0001 \\
0001 \\
0001 \\
0001\end{array}$ & $\begin{array}{l}\text { JE } \\
\text { JE } \\
\text { JE } \\
\text { JE } \\
\text { JE } \\
\text { JE }\end{array}$ & $\begin{array}{l}U \\
U \\
U \\
U \\
U \\
U\end{array}$ & $M G / L$ & $<$ & $\begin{array}{l}0.021 \\
0.013 \\
0.005 \\
0.005 \\
0.005 \\
0.005\end{array}$ & $\begin{array}{l}L \\
J L \\
L W \\
L \\
L \\
L\end{array}$ & $\begin{array}{l}0.005 \\
0.005 \\
0.005 \\
0.005 \\
0.005 \\
0.005\end{array}$ & $\begin{array}{l}- \\
- \\
- \\
-\end{array}$ \\
\hline
\end{tabular}

FORMATION OF COMPLETION CODE:

JE - JURASSIC ENTRADA SANDSTONE FORMATION

FLOW RELATIONSHIP CODE:

O - ON-SITE

$U$ - UPGRADIENT

PARAMETER VALUE INDICATOR (PVI): < - LESS THAN DETECTION LIMIT

ID CODES:

0001 - FILTERED SAMPLE (.45 MICRONS)

OTHER PARAMETER VALUE FLAGS:

MO01 - UNFILTERED SAMPLE

$J$ - ESTIMATED VALUE

L - LESS THAN THREE BORE VOLUMES REMOVED BEFORE SAMPLING

N - SPIKE SAMPLE RECOVERY NOT HITHIN CONTROL LIMITS

$H$ - POST-DIGEST SPIKE OUT OF CNTR LIM WHILE SAMP ABS < 50\% SPIKE 


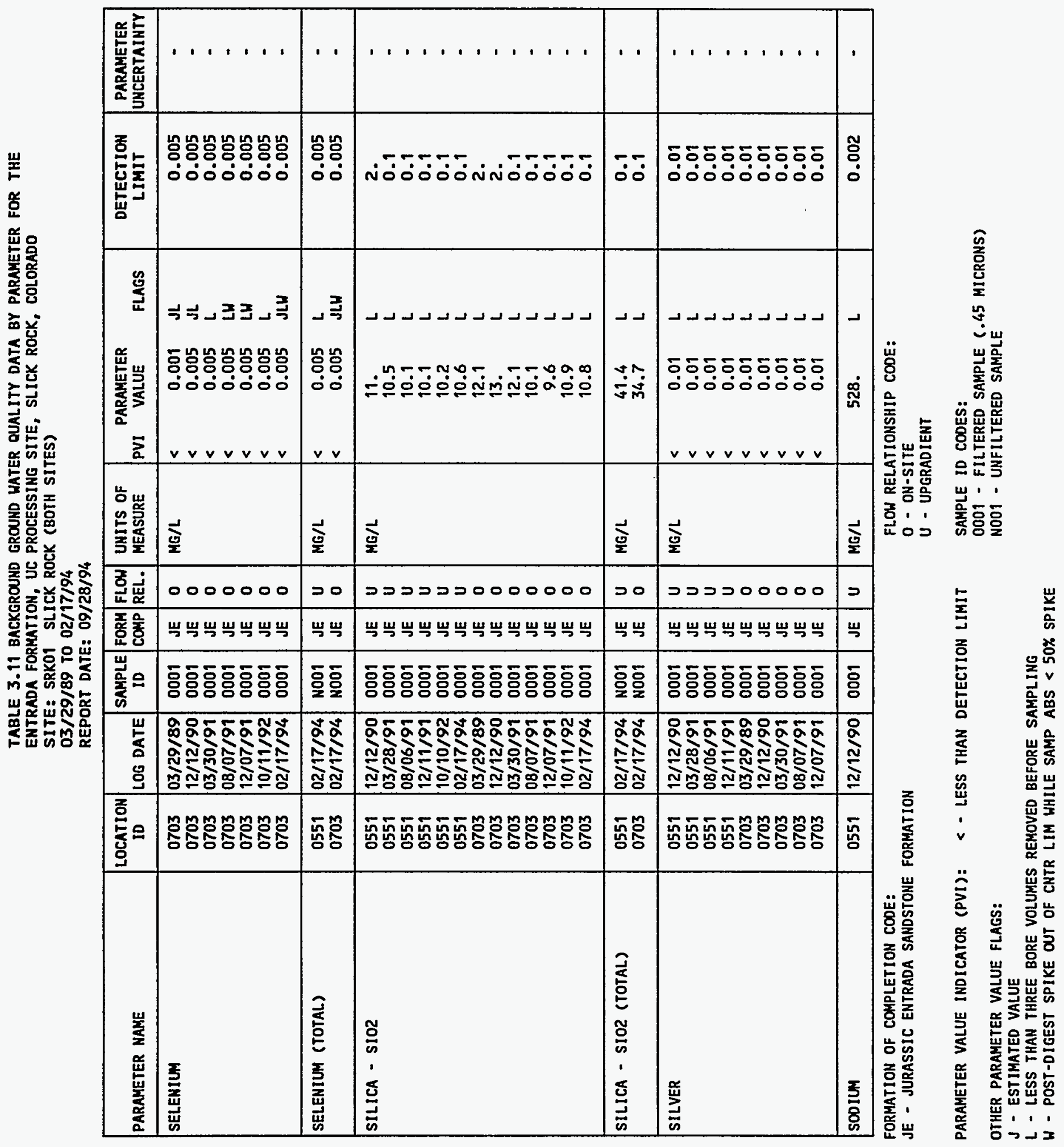


TABLE 3.11 BACKGROUND GROUND HATER QUALITY DATA BY PARAMETER FOR THE ENTRADA FORMATION, UC PROCESSING SITE, SLICK ROCK, COLORADO

SITE: SRKO1 SLICK ROCK (BOTH SITES)

03/29/89 TO 02/17/94

REPORT DATE: 09/28/94

\begin{tabular}{|c|c|c|c|c|c|c|c|c|c|c|c|}
\hline PARAMETER MAME & $\mid \begin{array}{c}\text { LOCATION } \\
\text { ID }\end{array}$ & LOG DATE & $\begin{array}{c}\text { SAMPLE } \\
\text { ID }\end{array}$ & $\begin{array}{l}\text { FORM } \\
\text { COMP }\end{array}$ & $\begin{array}{l}\text { FLOW } \\
\text { REL. }\end{array}$ & $\begin{array}{l}\text { UNITS OF } \\
\text { MEASURE }\end{array}$ & PVI & $\begin{array}{l}\text { PARAMETER } \\
\text { VALUE }\end{array}$ & FLAGS & $\begin{array}{l}\text { DETECTION } \\
\text { LIMIT }\end{array}$ & $\begin{array}{c}\text { PARAMETER } \\
\text { UNCERTAINTY }\end{array}$ \\
\hline SOD IUM & $\begin{array}{l}0551 \\
0551 \\
0551 \\
0551 \\
0551 \\
0703 \\
0703 \\
0703 \\
0703 \\
0703 \\
0703 \\
0703\end{array}$ & $\begin{array}{l}03 / 28 / 91 \\
08 / 06 / 91 \\
12 / 11 / 91 \\
10 / 10 / 92 \\
02 / 17 / 94 \\
03 / 29 / 89 \\
12 / 12 / 90 \\
03 / 30 / 91 \\
08 / 07 / 91 \\
12 / 07 / 91 \\
10 / 11 / 92 \\
02 / 17 / 94\end{array}$ & $\begin{array}{l}0001 \\
0001 \\
0001 \\
0001 \\
0001 \\
0001 \\
0001 \\
0001 \\
0001 \\
0001 \\
0001 \\
0001\end{array}$ & $\begin{array}{l}J E \\
J E \\
J E \\
J E \\
J E \\
J E \\
J E \\
J E \\
J E \\
J E \\
J E \\
J E\end{array}$ & $\begin{array}{l}U \\
U \\
U \\
U \\
U \\
0 \\
0 \\
0 \\
0 \\
0 \\
0 \\
0\end{array}$ & $M G / L$ & & $\begin{array}{l}204 . \\
135 . \\
76 . \\
83 . \\
70 \\
2 . \\
5.52 \\
5.8 \\
2.6 \\
2.27 \\
4.77 \\
4\end{array}$ & $\begin{array}{l}L \\
L \\
L \\
L \\
L \\
L \\
L \\
L \\
L \\
L \\
L \\
L\end{array}$ & $\begin{array}{l}5 . \\
5 . \\
i . \\
1 . \\
i \\
0.002 \\
0.002 \\
0.01 \\
0.01 \\
0.01 \\
0.01 \\
1\end{array}$ & $\begin{array}{l}- \\
- \\
- \\
- \\
- \\
- \\
- \\
-\end{array}$ \\
\hline SODIUM (TOTAL) & $\begin{array}{l}0551 \\
0703\end{array}$ & $\begin{array}{l}02 / 17 / 94 \\
02 / 17 / 94\end{array}$ & $\begin{array}{l}\text { N001 } \\
\text { N001 }\end{array}$ & $\begin{array}{l}\mathrm{JE} \\
\mathrm{JE}\end{array}$ & $\begin{array}{l}U \\
0\end{array}$ & MG/L & & $\begin{array}{r}69 \\
4\end{array}$ & $L$ & $\begin{array}{l}1 \\
1\end{array}$ & - \\
\hline SPECIFIC CONDUCTAMCE & $\begin{array}{l}0551 \\
0551 \\
0551 \\
0551 \\
0551 \\
0703 \\
0703 \\
0703 \\
0703 \\
0703 \\
0703\end{array}$ & $\begin{array}{l}12 / 12 / 90 \\
08 / 06 / 91 \\
12 / 05 / 91 \\
10 / 10 / 92 \\
02 / 17 / 94 \\
03 / 29 / 89 \\
12 / 12 / 90 \\
08 / 07 / 91 \\
12 / 05 / 91 \\
10 / 11 / 92 \\
02 / 17 / 94\end{array}$ & $\begin{array}{l}0001 \\
0001 \\
0001 \\
0001 \\
N 001 \\
0001 \\
0001 \\
0001 \\
0001 \\
0001 \\
N 001\end{array}$ & $\begin{array}{l}\mathrm{JE} \\
\mathrm{JE} \\
\mathrm{JE} \\
\mathrm{JE} \\
\mathrm{JE} \\
\mathrm{JE} \\
\mathrm{JE} \\
\mathrm{JE} \\
\mathrm{JE} \\
\mathrm{JE} \\
\mathrm{JE}\end{array}$ & $\begin{array}{l}U \\
U \\
U \\
U \\
U \\
0 \\
0 \\
0 \\
0 \\
0 \\
0\end{array}$ & UMHO/CM & & $\begin{array}{c}3650 . \\
12020 \\
1400 \\
725 \\
638 \\
230 . \\
350 . \\
298 \\
296 \\
248 \\
244\end{array}$ & $\begin{array}{l}L \\
L \\
L \\
L \\
L \\
L \\
L \\
L \\
L \\
L \\
L\end{array}$ & $\begin{array}{l}: \\
: \\
- \\
- \\
- \\
- \\
- \\
-\end{array}$ & $\begin{array}{l}- \\
- \\
- \\
- \\
- \\
- \\
-\end{array}$ \\
\hline STRONTIUM & $\begin{array}{l}0551 \\
0551 \\
0551 \\
0551 \\
0551 \\
0551 \\
0703 \\
0703 \\
0703 \\
0703 \\
0703\end{array}$ & $\begin{array}{l}12 / 12 / 90 \\
03 / 28 / 91 \\
08 / 06 / 91 \\
12 / 11 / 91 \\
10 / 10 / 92 \\
02 / 17 / 94 \\
12 / 12 / 90 \\
03 / 30 / 91 \\
08 / 07 / 91 \\
12 / 07 / 91 \\
10 / 11 / 92\end{array}$ & $\begin{array}{l}0001 \\
0001 \\
0001 \\
0001 \\
0001 \\
0001 \\
0001 \\
0001 \\
0001 \\
0001 \\
0001\end{array}$ & $\begin{array}{l}\mathrm{JE} \\
\mathrm{JE} \\
\mathrm{JE} \\
\mathrm{JE} \\
\mathrm{JE} \\
\mathrm{JE} \\
\mathrm{JE} \\
\mathrm{JE} \\
\mathrm{JE} \\
\mathrm{JE} \\
\mathrm{JE}\end{array}$ & $\begin{array}{l}U \\
U \\
U \\
U \\
U \\
U \\
0 \\
0 \\
0 \\
0 \\
0\end{array}$ & MG/L & & $\begin{array}{l}1.1 \\
0.62 \\
0.54 \\
0.53 \\
0.56 \\
0.60 \\
0.6 \\
0.72 \\
0.44 \\
0.33 \\
0.47\end{array}$ & $\begin{array}{l}L \\
L \\
L \\
L \\
L \\
L \\
L \\
L \\
L \\
L \\
L\end{array}$ & $\begin{array}{l}0.1 \\
0.01 \\
0.01 \\
0.01 \\
0.01 \\
0.01 \\
0.1 \\
0.01 \\
0.01 \\
0.01 \\
0.01\end{array}$ & $\begin{array}{l}- \\
- \\
- \\
- \\
- \\
- \\
- \\
-\end{array}$ \\
\hline
\end{tabular}

FORMATION OF COMPLETION CODE:

JE - JURASSIC ENTRADA SANDSTONE FORMATION

FLOW RELATIONSHIP CODE

U - UPGRADIENT

PARAMETER VALUE INDICATOR (PVI): < - LESS THAN DETECTION LIMIT

SAMPLE ID COOES:

0001 - FILTERED SAMPLE (.45 MICRONS)

OTHER PARAMETER VALUE FLAGS

NO01 - UNFILTERED SAMPLE

L - LESS THAN THREE BORE VOLUMES REMOVED BEFORE SAMPLING 
TABLE 3.11 BACKGROUND GROUND HATER QUALITY DATA BY PARAMETER FOR THE

ENTRADA FORMATIOH, UC PROCESSING SITE, SLICK ROCK, COLORADO

SITE: SRKOI SLICK ROCK (BOTH SITES)

03/29/89 TO 02/17/94

REPORT DATE: 09/28/94

\begin{tabular}{|c|c|c|c|c|c|c|c|c|c|c|c|}
\hline PARAMETER NAME & $\underset{\text { ID }}{\text { LOCATIOH }}$ & LOG DATE & $\underset{\text { ID }}{\text { SAMPLE }}$ & $\begin{array}{l}\text { FORM } \\
\text { COMP }\end{array}$ & FLOH & $\begin{array}{l}\text { UNITS OF } \\
\text { MEASURE }\end{array}$ & PVI & $\begin{array}{l}\text { ARAMETER } \\
\text { VALUE }\end{array}$ & FLAGS & $\begin{array}{l}\text { DETECTION } \\
\text { LIMIT }\end{array}$ & $\begin{array}{l}\text { PARAMETER } \\
\text { UNCERTAIHTY }\end{array}$ \\
\hline STRONTIUH & 0703 & $02 / 17 / 94$ & 0001 & JE & 0 & MG/L & & 0.54 & $\mathbf{L}$ & 0.01 & - \\
\hline STRONTIUM (TOTAL) & $\begin{array}{l}0551 \\
0703\end{array}$ & $\begin{array}{l}02 / 17 / 94 \\
02 / 17 / 94\end{array}$ & $\begin{array}{l}\text { N001 } \\
\text { N001 }\end{array}$ & $\begin{array}{l}\text { JE } \\
\text { JE }\end{array}$ & $\begin{array}{l}U \\
0\end{array}$ & $M G / L$ & & $\begin{array}{l}0.94 \\
0.60\end{array}$ & $L$ & $\begin{array}{l}0.01 \\
0.01\end{array}$ & - \\
\hline SULFATE & $\begin{array}{l}0551 \\
0551 \\
0551 \\
0551 \\
0551 \\
0551 \\
0703 \\
0703 \\
0703 \\
0703 \\
0703 \\
0703 \\
0703\end{array}$ & $\begin{array}{l}12 / 12 / 90 \\
03 / 28 / 91 \\
08 / 06 / 91 \\
12 / 11 / 91 \\
10 / 10 / 92 \\
02 / 17 / 94 \\
03 / 29 / 89 \\
12 / 12 / 90 \\
03 / 30 / 91 \\
08 / 07 / 91 \\
12 / 07 / 91 \\
10 / 11 / 92 \\
02 / 17 / 94\end{array}$ & $\begin{array}{l}0001 \\
0001 \\
0001 \\
0001 \\
0001 \\
0001 \\
0001 \\
0001 \\
0001 \\
0001 \\
0001 \\
0001 \\
0001\end{array}$ & $\begin{array}{l}\text { JE } \\
\text { JE } \\
\text { JE } \\
\text { JE } \\
\text { JE } \\
\text { JE } \\
\text { JE } \\
\text { JE } \\
\text { JE } \\
\text { JE } \\
\text { JE } \\
\text { JE } \\
\text { JE }\end{array}$ & $\begin{array}{l}U \\
U \\
U \\
U \\
U \\
U \\
0 \\
0 \\
0 \\
0 \\
0 \\
0 \\
0\end{array}$ & MG/L & $<$ & $\begin{array}{c}539 . \\
96.7 \\
71 . \\
133 . \\
68 . \\
68 \\
8 . \\
7.4 \\
5.4 \\
6.2 \\
10 . \\
5 . \\
4\end{array}$ & $\begin{array}{l}L \\
L \\
L \\
L \\
L \\
L \\
L \\
L \\
L \\
L \\
L \\
L \\
L\end{array}$ & $\begin{array}{c}0.1 \\
0.1 \\
0.1 \\
20 . \\
1 . \\
1 \\
0.1 \\
0.1 \\
0.1 \\
0.1 \\
10.1 \\
1 . \\
1\end{array}$ & $\begin{array}{l}- \\
- \\
- \\
- \\
- \\
- \\
- \\
- \\
-\end{array}$ \\
\hline SULFIDE & $\begin{array}{l}0551 \\
0551 \\
0551 \\
0551 \\
0551 \\
0703 \\
0703 \\
0703 \\
0703 \\
0703\end{array}$ & $\begin{array}{l}12 / 12 / 90 \\
03 / 28 / 91 \\
08 / 06 / 91 \\
12 / 11 / 91 \\
10 / 10 / 92 \\
12 / 12 / 90 \\
03 / 30 / 91 \\
08 / 07 / 91 \\
12 / 07 / 91 \\
10 / 11 / 92\end{array}$ & $\begin{array}{l}0001 \\
0001 \\
0001 \\
0001 \\
0001 \\
0001 \\
0001 \\
0001 \\
0001 \\
0001\end{array}$ & $\begin{array}{l}\text { JE } \\
\text { JE } \\
\text { JE } \\
\text { JE } \\
\text { JE } \\
\text { JE } \\
\text { JE } \\
\text { JE } \\
\text { JE } \\
\text { JE }\end{array}$ & $\begin{array}{l}U \\
U \\
U \\
U \\
U \\
0 \\
0 \\
0 \\
0 \\
0\end{array}$ & $M G / L$ & $\mid \begin{array}{l}< \\
< \\
<\end{array}$ & $\begin{array}{r}0.1 \\
42.0 \\
0.4 \\
0.3 \\
0.1 \\
0.1 \\
0.6 \\
0.1 \\
0.3 \\
0.2\end{array}$ & $\begin{array}{l}J L \\
L \\
L \\
L \\
L \\
J L \\
L \\
L \\
L \\
L\end{array}$ & $\begin{array}{l}0.1 \\
0.1 \\
0.1 \\
0.1 \\
0.1 \\
0.1 \\
0.1 \\
0.1 \\
0.1 \\
0.1\end{array}$ & $\begin{array}{l}- \\
- \\
- \\
- \\
- \\
- \\
-\end{array}$ \\
\hline TEMPERATURE & $\begin{array}{l}0551 \\
0551 \\
0551 \\
0551 \\
0551 \\
0551 \\
0703 \\
0703\end{array}$ & $\begin{array}{l}12 / 12 / 90 \\
03 / 28 / 91 \\
08 / 06 / 91 \\
12 / 05 / 91 \\
10 / 10 / 92 \\
02 / 17 / 94 \\
03 / 29 / 89 \\
12 / 12 / 90\end{array}$ & $\begin{array}{l}0001 \\
0001 \\
0001 \\
0001 \\
0001 \\
N 001 \\
0001 \\
0001\end{array}$ & $\begin{array}{l}\text { JE } \\
\text { JE } \\
\text { JE } \\
\text { JE } \\
\text { JE } \\
\text { JE } \\
\text { JE } \\
\text { JE }\end{array}$ & $\begin{array}{l}U \\
U \\
U \\
U \\
U \\
U \\
0 \\
0\end{array}$ & C - DEGREE & & $\begin{array}{l}12.2 \\
11.8 \\
15.1 \\
12.4 \\
17.5 \\
12.8 \\
15.0 \\
14.3\end{array}$ & $\begin{array}{l}L \\
L \\
L \\
L \\
L \\
L \\
L \\
L\end{array}$ & $\begin{array}{l}- \\
- \\
- \\
- \\
-\end{array}$ & $\begin{array}{l}- \\
- \\
- \\
- \\
- \\
-\end{array}$ \\
\hline
\end{tabular}

FORMATION OF COMPLETION CODE:

JE - JURASSIC ENTRADA SANDSTONE FORMATION

PARAMETER VALUE INDICATOR (PVI): < - LESS THAN DETECTION LIMIT

OTHER PARAMETER VALUE FLAGS:

$J$ - ESTIMATED VALUE

L - LESS tHAN THREE BORE VOLUMES REMOVED BEFORE SAMPLING
FLOH RELATIONSHIP CODE:

O - ON-SITE

- UPGRADIENT

SAMPLE IO CODES:

0001 - FILTERED SAMPLE (.45 MICRONS)

NO01 - UNFILTERED SAMPLE 
TABLE 3.11 BACKGROUND GROUND WATER QUALITY DATA BY PARAMETER FOR THE

ENTRADA FORMATIOH, UC PROCESSING SITE, SLICK ROCK, COLORADO

SITE: SRKO1 SLICK ROCK (BOTH SITES)

03/29/89 TO 02/17/94

REPORT DATE: $09 / 28 / 94$

\begin{tabular}{|c|c|c|c|c|c|c|c|c|c|c|c|}
\hline PARAMETER NAME & $\underset{\text { ID }}{\text { LOCATION }}$ & LOG DATE & $\begin{array}{c}\text { SAMPLE } \\
\text { ID }\end{array}$ & $\begin{array}{l}\text { FORM } \\
\text { COMP }\end{array}$ & $\begin{array}{l}\text { FLOW } \\
\text { REL. }\end{array}$ & $\begin{array}{l}\text { UNITS OF } \\
\text { MEASURE }\end{array}$ & PVI & $\begin{array}{l}\text { PARAMETER } \\
\text { VALUE }\end{array}$ & FLAGS & $\begin{array}{l}\text { DETECTION } \\
\text { LIMIT }\end{array}$ & $\begin{array}{l}\text { PARAMETER } \\
\text { UHCERTAINTY }\end{array}$ \\
\hline TEMPERATURE & $\begin{array}{l}0703 \\
0703 \\
0703 \\
0703 \\
0703\end{array}$ & $\begin{array}{l}03 / 30 / 91 \\
08 / 07 / 91 \\
12 / 05 / 91 \\
10 / 11 / 92 \\
02 / 17 / 94\end{array}$ & $\begin{array}{l}0001 \\
0001 \\
0001 \\
0001 \\
\text { N001 }\end{array}$ & $\begin{array}{l}\mathrm{JE} \\
\mathrm{JE} \\
\mathrm{JE} \\
\mathrm{JE} \\
\mathrm{JE}\end{array}$ & $\begin{array}{l}0 \\
0 \\
0 \\
0 \\
0\end{array}$ & C - DEGREE & & $\begin{array}{l}13.4 \\
15.0 \\
13.9 \\
16.4 \\
13.9\end{array}$ & $\begin{array}{l}L \\
L \\
L \\
L \\
L\end{array}$ & $\begin{array}{l}- \\
- \\
- \\
-\end{array}$ & $\begin{array}{l}- \\
- \\
-\end{array}$ \\
\hline THALLIUM & $\begin{array}{l}0551 \\
0551 \\
0551 \\
0551 \\
0551 \\
0703 \\
0703 \\
0703 \\
0703 \\
0703 \\
0703\end{array}$ & $\begin{array}{l}12 / 12 / 90 \\
03 / 28 / 91 \\
08 / 06 / 91 \\
12 / 11 / 91 \\
10 / 10 / 92 \\
03 / 29 / 89 \\
12 / 12 / 90 \\
03 / 30 / 91 \\
08 / 07 / 91 \\
12 / 07 / 91 \\
10 / 11 / 92\end{array}$ & $\begin{array}{l}0001 \\
0001 \\
0001 \\
0001 \\
0001 \\
0001 \\
0001 \\
0001 \\
0001 \\
0001 \\
0001\end{array}$ & $\begin{array}{l}\text { JE } \\
\text { JE } \\
\text { JE } \\
\text { JE } \\
\text { JE } \\
\text { JE } \\
\text { JE } \\
\text { JE } \\
\text { JE } \\
\text { JE } \\
\text { JE }\end{array}$ & $\begin{array}{l}U \\
U \\
U \\
U \\
U \\
0 \\
0 \\
0 \\
0 \\
0 \\
0\end{array}$ & MG/L & $\begin{array}{l}< \\
< \\
< \\
< \\
< \\
< \\
< \\
< \\
< \\
< \\
< \\
<\end{array}$ & $\begin{array}{l}0.01 \\
0.01 \\
0.1 \\
0.01 \\
0.005 \\
0.001 \\
0.01 \\
0.01 \\
0.01 \\
0.01 \\
0.005\end{array}$ & $\begin{array}{l}L \\
L \\
I L \\
L \\
L \\
L \\
L \\
L \\
L \\
L \\
L\end{array}$ & $\begin{array}{l}0.01 \\
0.01 \\
0.1 \\
0.01 \\
0.005 \\
0.001 \\
0.01 \\
0.01 \\
0.01 \\
0.01 \\
0.005\end{array}$ & $\begin{array}{l}- \\
- \\
- \\
- \\
- \\
- \\
- \\
-\end{array}$ \\
\hline THORIUM-230 & $\begin{array}{l}0551 \\
0551 \\
0551 \\
0703 \\
0703 \\
0703\end{array}$ & $\begin{array}{l}08 / 06 / 91 \\
12 / 05 / 91 \\
02 / 17 / 94 \\
08 / 07 / 91 \\
12 / 05 / 91 \\
02 / 17 / 94\end{array}$ & $\begin{array}{l}0001 \\
0001 \\
0001 \\
0001 \\
0001 \\
0001\end{array}$ & $\begin{array}{l}\text { JE } \\
\text { JE } \\
\text { JE } \\
\text { JE } \\
\text { JE } \\
\text { JE }\end{array}$ & $\begin{array}{l}u \\
U \\
U \\
0 \\
0 \\
0\end{array}$ & $\mathrm{PCI} / \mathrm{L}$ & & $\begin{array}{l}0.3 \\
0.5 \\
0.4 \\
1.1 \\
0.7 \\
0.2\end{array}$ & $\begin{array}{l}L \\
L \\
L \\
L \\
L \\
L\end{array}$ & $\begin{array}{l}1 . \\
1.0 \\
0.3 \\
1 . \\
1 . \\
0.2\end{array}$ & $\begin{array}{l}0.6 \\
0.7 \\
0.1 \\
0.7 \\
0.6 \\
0.1\end{array}$ \\
\hline THORIUM-230 (TOTAL) & $\begin{array}{l}0551 \\
0703\end{array}$ & $\left|\begin{array}{l}02 / 17 / 94 \\
02 / 17 / 94\end{array}\right|$ & $\begin{array}{l}\text { N001 } \\
\text { N001 }\end{array}$ & $\begin{array}{l}\text { JE } \\
\text { JE }\end{array}$ & $\begin{array}{l}\mathbf{u} \\
\mathbf{0}\end{array}$ & $\mathrm{PCI} / \mathrm{L}$ & & $\begin{array}{l}0.4 \\
0.3\end{array}$ & $\begin{array}{l}L \\
L\end{array}$ & $\begin{array}{l}0.3 \\
0.2\end{array}$ & $\begin{array}{l}0.1 \\
0.1\end{array}$ \\
\hline TIN & $\begin{array}{l}0551 \\
0551 \\
0551 \\
0551 \\
0551 \\
0703 \\
0703 \\
0703\end{array}$ & $\begin{array}{l}12 / 12 / 90 \\
03 / 28 / 91 \\
08 / 06 / 91 \\
12 / 11 / 91 \\
10 / 10 / 92 \\
03 / 29 / 89 \\
12 / 12 / 90 \\
03 / 30 / 91\end{array}$ & $\begin{array}{l}0001 \\
0001 \\
0001 \\
0001 \\
0001 \\
0001 \\
0001 \\
0001\end{array}$ & $\begin{array}{l}\text { JE } \\
\text { JE } \\
\text { JE } \\
\text { JE } \\
\text { JE } \\
\text { JE } \\
\text { JE } \\
\text { JE }\end{array}$ & $\begin{array}{l}U \\
U \\
U \\
U \\
U \\
0 \\
0 \\
0\end{array}$ & MG/L & $\begin{array}{l}< \\
< \\
< \\
< \\
< \\
<\end{array}$ & $\begin{array}{l}0.005 \\
0.005 \\
0.005 \\
0.005 \\
0.005 \\
0.001 \\
0.005 \\
0.005\end{array}$ & $\begin{array}{l}L \\
L \\
L W \\
L \\
L \\
J L \\
L \\
L\end{array}$ & $\begin{array}{l}0.005 \\
0.005 \\
0.005 \\
0.005 \\
0.005 \\
0.005 \\
0.005 \\
0.005\end{array}$ & $\begin{array}{l}- \\
- \\
- \\
- \\
- \\
-\end{array}$ \\
\hline
\end{tabular}

FORMATION OF COMPLETION CODE:

JE - JURASSIC ENTRADA SANDSTONE FORMATION

PARAMETER VALUE INDICATOR (PVI): < - LESS THAN DETECTION LIMIT

OTHER PARAMETER VALUE FLAGS:

I - IHCREASED DETECTION LIMIT DUE TO REQUIRED DILUTION

$J$ - estimated VALUE

L - LESS THAN THREE BORE VOLUMES REMOVED BEFORE SAMPLING

W - POST-DIGEST SPIKE OUT OF CNTR LIM HHILE SAMP ABS < 50\% SPIKE
FLOW RELATIONSHIP CODE:

O- ON-SITE

SAMPLE ID CODES:

0001 - FILTERED SAMPLE (.45 MICRONS)

NO01 - UNFILTERED SAMPLE 
TABLE 3.11 BACKGROUND GROUND MATER QUALITY DATA BY PARAMETER FOR THE ENTRADA FORMATIOH, UC PROCESSING SITE, SLICK ROCK, COLORADO SITE: SRKO1 SLICK ROCK (BOTH SITES)

03/29/89 TO 02/17/94

REPORT DATE: $09 / 28 / 94$

\begin{tabular}{|c|c|c|c|c|c|c|c|c|c|c|c|}
\hline PARAMETER NAME & $\left|\begin{array}{c}\text { LOCATION } \\
\text { ID }\end{array}\right|$ & LOG DATE & $\begin{array}{c}\text { SAMPLE } \\
\text { ID }\end{array}$ & $\begin{array}{l}\text { FORM } \\
\text { COMP }\end{array}$ & $\begin{array}{l}\text { FLOW } \\
\text { REL. }\end{array}$ & $\begin{array}{l}\text { UHITS OF } \\
\text { MEASURE }\end{array}$ & PVI & $\begin{array}{l}\text { PARAMETER } \\
\text { VALUE }\end{array}$ & FLAGS & $\begin{array}{l}\text { DETECTION } \\
\text { LIMIT }\end{array}$ & $\begin{array}{l}\text { PARAMETER } \\
\text { UNCERTAINTY }\end{array}$ \\
\hline TIN & $\begin{array}{l}0703 \\
0703 \\
0703\end{array}$ & $\begin{array}{l}08 / 07 / 91 \\
12 / 07 / 91 \\
10 / 11 / 92\end{array}$ & $\begin{array}{l}0001 \\
0001 \\
0001\end{array}$ & $\begin{array}{l}\text { JE } \\
\text { JE } \\
\text { JE }\end{array}$ & $\begin{array}{l}0 \\
0 \\
0\end{array}$ & MG/L & $\mid \begin{array}{l}< \\
<\end{array}$ & $\begin{array}{l}0.005 \\
0.005 \\
0.005\end{array}$ & $\begin{array}{l}L \\
L \\
L\end{array}$ & $\begin{array}{l}0.005 \\
0.005 \\
0.005\end{array}$ & $\begin{array}{l}- \\
-\end{array}$ \\
\hline TOTAL DISSOLVED SOLIDS & $\begin{array}{l}0551 \\
0551 \\
0551 \\
0551 \\
0551 \\
0551 \\
0703 \\
0703 \\
0703 \\
0703 \\
0703 \\
0703 \\
0703\end{array}$ & $\begin{array}{l}12 / 12 / 90 \\
03 / 28 / 91 \\
08 / 06 / 91 \\
12 / 11 / 91 \\
10 / 10 / 92 \\
02 / 17 / 94 \\
03 / 29 / 89 \\
12 / 12 / 90 \\
03 / 30 / 91 \\
08 / 07 / 91 \\
12 / 07 / 91 \\
10 / 11 / 92 \\
02 / 17 / 94\end{array}$ & $\begin{array}{l}0001 \\
0001 \\
0001 \\
0001 \\
0001 \\
0001 \\
0001 \\
0001 \\
0001 \\
0001 \\
0001 \\
0001 \\
0001\end{array}$ & $\begin{array}{l}\text { JE } \\
\text { JE } \\
\text { JE } \\
\text { JE } \\
\text { JE } \\
\text { JE } \\
\text { JE } \\
\text { JE } \\
\text { JE } \\
\text { JE } \\
\text { JE } \\
\text { JE } \\
\text { JE }\end{array}$ & $\begin{array}{l}U \\
U \\
U \\
U \\
U \\
U \\
0 \\
0 \\
0 \\
0 \\
0 \\
0 \\
0\end{array}$ & MG/L & & $\begin{array}{l}1990 . \\
612 . \\
532 . \\
472 . \\
484 . \\
450 \\
158 . \\
156 . \\
188 . \\
160 . \\
147 . \\
158 . \\
160\end{array}$ & $\begin{array}{l}L \\
L \\
L \\
L \\
L \\
L \\
L \\
L \\
L \\
L \\
H L \\
L \\
L\end{array}$ & $\begin{array}{l}10 . \\
10 . \\
10 . \\
10 . \\
10 . \\
10 \\
10 . \\
10 . \\
10 . \\
10 . \\
10 . \\
10 . \\
10\end{array}$ & $\begin{array}{l}- \\
- \\
- \\
- \\
- \\
- \\
- \\
- \\
- \\
-\end{array}$ \\
\hline TOTAL KJELDAHL NITROGEN & $\begin{array}{l}0551 \\
0551 \\
0551 \\
0551 \\
0703 \\
0703 \\
0703 \\
0703\end{array}$ & $\begin{array}{l}12 / 12 / 90 \\
03 / 28 / 91 \\
08 / 06 / 91 \\
12 / 11 / 91 \\
12 / 12 / 90 \\
03 / 30 / 91 \\
08 / 07 / 91 \\
12 / 07 / 91\end{array}$ & $\begin{array}{l}0001 \\
0001 \\
0001 \\
0001 \\
0001 \\
0001 \\
0001 \\
0001\end{array}$ & $\begin{array}{l}\text { JE } \\
\text { JE } \\
\text { JE } \\
\text { JE } \\
\text { JE } \\
\text { JE } \\
\text { JE } \\
\text { JE }\end{array}$ & $\begin{array}{l}U \\
U \\
U \\
U \\
0 \\
0 \\
0 \\
0\end{array}$ & MG/L & $\begin{array}{l}< \\
< \\
< \\
< \\
< \\
<\end{array}$ & $\begin{array}{l}1 . \\
1 . \\
1 . \\
2 . \\
4 . \\
1 . \\
1 . \\
2 .\end{array}$ & $\begin{array}{l}J L \\
L \\
L \\
I L \\
J L \\
L \\
L \\
I L\end{array}$ & $\begin{array}{l}1 . \\
1 . \\
1 . \\
2 . \\
1 . \\
1 . \\
1 . \\
2 .\end{array}$ & $\begin{array}{l}- \\
- \\
- \\
- \\
- \\
-\end{array}$ \\
\hline TOTAL ORGANIC CARBON & $\begin{array}{l}0551 \\
0551 \\
0551 \\
0551 \\
0551 \\
0551 \\
0703 \\
0703 \\
0703\end{array}$ & $\begin{array}{l}12 / 12 / 90 \\
03 / 28 / 91 \\
08 / 06 / 91 \\
12 / 11 / 91 \\
10 / 10 / 92 \\
02 / 17 / 94 \\
12 / 12 / 90 \\
03 / 30 / 91 \\
08 / 07 / 91\end{array}$ & $\begin{array}{l}0001 \\
0001 \\
0001 \\
0001 \\
0001 \\
N 001 \\
0001 \\
0001 \\
0001\end{array}$ & $\begin{array}{l}\text { JE } \\
\text { JE } \\
\text { JE } \\
\text { JE } \\
\text { JE } \\
\text { JE } \\
\text { JE } \\
\text { JE } \\
\text { JE }\end{array}$ & $\begin{array}{l}U \\
U \\
U \\
U \\
U \\
U \\
0 \\
0 \\
0\end{array}$ & $M G / L$ & $<$ & $\begin{array}{c}247 . \\
1 . \\
1 . \\
1 . \\
2 . \\
6 \\
40 . \\
1 . \\
1 .\end{array}$ & $\begin{array}{l}J L \\
L \\
L \\
L \\
L \\
L \\
J L \\
L \\
L\end{array}$ & $\begin{array}{l}1 . \\
1 . \\
1 . \\
1 . \\
1 . \\
1 . \\
1 . \\
1 .\end{array}$ & $\begin{array}{l}- \\
- \\
- \\
- \\
- \\
- \\
-\end{array}$ \\
\hline
\end{tabular}

FORMATION OF COMPLETION CODE:

JE - JURASSIC ENTRADA SANDSTONE FORMATION

FLOW RELATIONSHIP COOE:

O- ON-SITE

U - UPGRADIENT

PARAMETER VALUE INDICATOR (PVI): < - LESS THAN DETECTION LIMIT

SAMPLE ID CODES:

0001 - FILTERED SAMPLE (.45 MICRONS)

OTHER PARAMETER VALUE FLAGS:

N001 - UNFILTERED SAMPLE

H - HOLD TIME EXPIRED VALUE SUSPECT

1 - INCREASED DETECTION LIMIT DUE TO REQUIRED DILUTION

$J$ - ESTIMATED VALUE

L - LESS THAN THREE BORE VOLUMES REMOVEd BEFORE SAMPLING 
TABLE 3.11 BACKGROUND GROUND HATER QUALITY DATA BY PARAMETER FOR THE

ENTRADA FORMATION, UC PROCESSING SITE, SLICK ROCK, COLORADO

SITE: SRKO1 SLICK ROCK (BOTH SITES)

03/29/89 TO $02 / 17 / 94$

REPORT DATE : $09 / 28 / 94$

\begin{tabular}{|c|c|c|c|c|c|c|c|c|c|c|c|}
\hline PARAMETER HAME & $\underset{\text { ID }}{\text { LOCATION }}$ & LOG DATE & $\begin{array}{c}\text { SAMPLE } \\
\text { ID }\end{array}$ & $\begin{array}{l}\text { FORM } \\
\text { COMP }\end{array}$ & $\begin{array}{l}\text { FLOW } \\
\text { REL. }\end{array}$ & $\begin{array}{l}\text { UNITS OF } \\
\text { HEASURE }\end{array}$ & PVI & $\begin{array}{l}\text { ARAMETER } \\
\text { VALUE }\end{array}$ & FLAGS & $\begin{array}{l}\text { DETECTION } \\
\text { LIHIT }\end{array}$ & $\begin{array}{l}\text { PARAMETER } \\
\text { UNCERTAINTY }\end{array}$ \\
\hline TOTAL ORGANIC CARBON & $\begin{array}{l}0703 \\
0703 \\
0703\end{array}$ & $\begin{array}{l}12 / 07 / 91 \\
10 / 11 / 92 \\
02 / 17 / 94\end{array}$ & $\begin{array}{l}0001 \\
0001 \\
\text { N001 }\end{array}$ & $\begin{array}{l}\text { JE } \\
\text { JE } \\
\text { JE }\end{array}$ & $\begin{array}{l}0 \\
0 \\
0\end{array}$ & $M G / L$ & & $\begin{array}{l}1 . \\
4 .\end{array}$ & $\begin{array}{l}L \\
L \\
L\end{array}$ & $\begin{array}{l}1 . \\
1 .\end{array}$ & - \\
\hline URANIUM & $\begin{array}{l}0551 \\
0551 \\
0551 \\
0551 \\
0551 \\
0551 \\
0703 \\
0703 \\
0703 \\
0703 \\
0703 \\
0703 \\
0703\end{array}$ & $\begin{array}{l}12 / 12 / 90 \\
03 / 28 / 91 \\
08 / 06 / 91 \\
12 / 05 / 91 \\
10 / 10 / 92 \\
02 / 17 / 94 \\
03 / 29 / 89 \\
12 / 12 / 90 \\
03 / 30 / 91 \\
08 / 07 / 91 \\
12 / 05 / 91 \\
10 / 11 / 92 \\
02 / 17 / 94\end{array}$ & $\begin{array}{l}0001 \\
0001 \\
0001 \\
0001 \\
0001 \\
0001 \\
0001 \\
0001 \\
0001 \\
0001 \\
0001 \\
0001 \\
0001\end{array}$ & $\begin{array}{l}\text { JE } \\
\text { JE } \\
\text { JE } \\
\text { JE } \\
\text { JE } \\
\text { JE } \\
\text { JE } \\
\text { JE } \\
\text { JE } \\
\text { JE } \\
\text { JE } \\
\text { JE } \\
\text { JE }\end{array}$ & $\begin{array}{l}U \\
U \\
U \\
U \\
U \\
U \\
0 \\
0 \\
0 \\
0 \\
0 \\
0 \\
0\end{array}$ & $M G / L$ & $<$ & $\begin{array}{l}0.0164 \\
0.005 \\
0.001 \\
0.006 \\
0.002 \\
0.009 \\
0.007 \\
0.0032 \\
0.004 \\
0.003 \\
0.001 \\
0.003 \\
0.003\end{array}$ & $\begin{array}{l}L \\
L \\
L \\
L \\
L \\
L \\
L \\
L \\
L \\
L \\
L \\
L \\
L\end{array}$ & $\begin{array}{l}0.0003 \\
0.001 \\
0.001 \\
0.001 \\
0.001 \\
0.001 \\
0.003 \\
0.0003 \\
0.001 \\
0.001 \\
0.001 \\
0.001 \\
0.001\end{array}$ & $\begin{array}{c}- \\
- \\
- \\
- \\
- \\
0.002 \\
- \\
- \\
- \\
- \\
-\end{array}$ \\
\hline URANIUM (TOTAL) & $\begin{array}{l}0551 \\
0703\end{array}$ & $\begin{array}{l}02 / 17 / 94 \\
02 / 17 / 94\end{array}$ & $\begin{array}{l}\text { N001 } \\
\text { N001 }\end{array}$ & $\begin{array}{l}\text { JE } \\
\text { JE }\end{array}$ & $\begin{array}{l}U \\
0\end{array}$ & MG/L & & $\begin{array}{l}0.003 \\
0.002\end{array}$ & $\begin{array}{l}L \\
L\end{array}$ & $\begin{array}{l}0.001 \\
0.001\end{array}$ & - \\
\hline VANADIUM & $\begin{array}{l}0551 \\
0551 \\
0551 \\
0551 \\
0551 \\
0551 \\
0703 \\
0703 \\
0703 \\
0703 \\
0703 \\
0703 \\
0703\end{array}$ & $\begin{array}{l}12 / 12 / 90 \\
03 / 28 / 91 \\
08 / 06 / 91 \\
12 / 11 / 91 \\
10 / 10 / 92 \\
02 / 17 / 94 \\
03 / 29 / 89 \\
12 / 12 / 90 \\
03 / 30 / 91 \\
08 / 07 / 91 \\
12 / 07 / 91 \\
10 / 11 / 92 \\
02 / 17 / 94\end{array}$ & $\begin{array}{l}0001 \\
0001 \\
0001 \\
0001 \\
0001 \\
0001 \\
0001 \\
0001 \\
0001 \\
0001 \\
0001 \\
0001 \\
0001\end{array}$ & $\begin{array}{l}J E \\
J E \\
\text { JE } \\
J E \\
\text { JE } \\
J E \\
\text { JE } \\
\text { JE } \\
\text { JE } \\
\text { JE } \\
\text { JE } \\
\text { JE } \\
\text { JE }\end{array}$ & $\begin{array}{l}U \\
U \\
U \\
U \\
U \\
U \\
0 \\
0 \\
0 \\
0 \\
0 \\
0 \\
0\end{array}$ & $M G / L$ & $\begin{array}{l}< \\
< \\
< \\
< \\
< \\
< \\
< \\
< \\
< \\
< \\
< \\
< \\
<\end{array}$ & $\begin{array}{l}0.03 \\
0.01 \\
0.01 \\
0.01 \\
0.01 \\
0.01 \\
0.01 \\
0.02 \\
0.01 \\
0.01 \\
0.01 \\
0.01 \\
0.01\end{array}$ & $\begin{array}{l}L \\
L \\
L \\
L \\
L \\
L \\
L \\
L \\
L \\
L \\
L \\
L \\
L\end{array}$ & $\begin{array}{l}0.01 \\
0.01 \\
0.01 \\
0.01 \\
0.01 \\
0.01 \\
0.01 \\
0.01 \\
0.01 \\
0.01 \\
0.01 \\
0.01 \\
0.01\end{array}$ & $\begin{array}{l}- \\
- \\
- \\
- \\
- \\
- \\
- \\
- \\
- \\
-\end{array}$ \\
\hline VANADIUM (TOTAL) & $\begin{array}{l}0551 \\
0703\end{array}$ & $\begin{array}{l}02 / 17 / 94 \\
02 / 17 / 94\end{array}$ & $\begin{array}{l}\text { N001 } \\
\text { N001 }\end{array}$ & $\begin{array}{l}\mathrm{JE} \\
\mathrm{JE}\end{array}$ & $\begin{array}{l}\mathrm{U} \\
0\end{array}$ & $M G / L$ & & $\begin{array}{l}0.13 \\
0.02\end{array}$ & $\begin{array}{l}\mathrm{L} \\
\mathrm{L}\end{array}$ & $\begin{array}{l}0.01 \\
0.01\end{array}$ & - \\
\hline ZINC & 0551 & $12 / 12 / 90$ & 0001 & JE & u & $M G / L$ & $<$ & 0.005 & L & 0.005 & - \\
\hline
\end{tabular}

FORMATION OF COMPLETION CODE:

JE - JURASSIC ENTRADA SANDSTONE FORMATION

FLOH RELATIONSHIP CODE:

O - ON-SITE

$U$ - UPGRADIENT

PARAMETER VALUE INDICATOR (PVI): < - LESS THAN DETECTION LIMIT

0001 - FILTERED SAMPLE (.45 MICRONS)

OTHER PARAMETER VALUE FLAGS:

NO01 - UNFILTERED SAMPLE

L - LESS THAN THREE BORE VOLUMES REMOVED BEFORE SAMPLING 
TABLE 3.11 BACKGROUND GROUND UATER QUALITY DATA BY PARAMETER FOR THE

ENTRADA FORMATION, UC PROCESSING SITE, SLICK ROCK, COLORADO

SITE: SRKO1 SLICK ROCK (BOTH SITES)

$03 / 29 / 89$ TO $02 / 17 / 94$

REPORT DATE: $09 / 28 / 94$

\begin{tabular}{|c|c|c|c|c|c|c|c|c|c|c|c|}
\hline PARAMETER KAME & $\begin{array}{c}\text { LOCATIOH } \\
\text { ID }\end{array}$ & LOG DATE & $\begin{array}{c}\text { SAMPLE } \\
\text { ID }\end{array}$ & $\begin{array}{l}\text { FORM } \\
\text { COMP }\end{array}$ & $\begin{array}{l}\text { FLOW } \\
\text { REL. }\end{array}$ & $\begin{array}{l}\text { UHITS OF } \\
\text { MEASURE }\end{array}$ & PVI & $\begin{array}{l}\text { PARAMETER } \\
\text { VALUE }\end{array}$ & FLAGS & $\begin{array}{l}\text { DETECTION } \\
\text { LIMIT }\end{array}$ & $\begin{array}{l}\text { PARAMETER } \\
\text { UNCERTAINTY }\end{array}$ \\
\hline ZINC & $\begin{array}{l}0551 \\
0551 \\
0551 \\
0551 \\
0551 \\
0703 \\
0703 \\
0703 \\
0703 \\
0703 \\
0703 \\
0703\end{array}$ & $\begin{array}{l}03 / 28 / 91 \\
08 / 06 / 91 \\
12 / 11 / 91 \\
10 / 10 / 92 \\
02 / 17 / 94 \\
03 / 29 / 89 \\
12 / 12 / 90 \\
03 / 30 / 91 \\
08 / 07 / 91 \\
12 / 07 / 91 \\
10 / 11 / 92 \\
02 / 17 / 94\end{array}$ & $\begin{array}{l}0001 \\
0001 \\
0001 \\
0001 \\
0001 \\
0001 \\
0001 \\
0001 \\
0001 \\
0001 \\
0001 \\
0001\end{array}$ & $\begin{array}{l}\text { JE } \\
\text { JE } \\
\text { JE } \\
\text { JE } \\
\text { JE } \\
\text { JE } \\
\text { JE } \\
\text { JE } \\
\text { JE } \\
\text { JE } \\
\text { JE } \\
\text { JE }\end{array}$ & $\begin{array}{l}U \\
U \\
U \\
U \\
U \\
0 \\
0 \\
0 \\
0 \\
0 \\
0 \\
0\end{array}$ & MG/L & $\begin{array}{l}< \\
< \\
< \\
< \\
< \\
< \\
< \\
< \\
< \\
< \\
< \\
<\end{array}$ & $\begin{array}{l}0.009 \\
0.005 \\
0.005 \\
0.005 \\
0.05 \\
0.01 \\
0.005 \\
0.005 \\
0.005 \\
0.005 \\
0.005 \\
0.05\end{array}$ & $\begin{array}{l}L \\
L \\
L \\
L \\
L \\
L \\
L \\
L \\
L \\
L \\
L \\
L\end{array}$ & $\begin{array}{l}0.005 \\
0.005 \\
0.005 \\
0.005 \\
0.05 \\
0.01 \\
0.005 \\
0.005 \\
0.005 \\
0.005 \\
0.005 \\
0.05\end{array}$ & $\begin{array}{l}- \\
- \\
- \\
- \\
- \\
- \\
- \\
-\end{array}$ \\
\hline ZINC (TOTAL) & $\begin{array}{l}0551 \\
0703\end{array}$ & $\begin{array}{l}02 / 17 / 94 \\
02 / 17 / 94\end{array}$ & $\begin{array}{l}\text { No01 } \\
\text { N001 }\end{array}$ & $\begin{array}{l}\mathrm{JE} \\
\mathrm{JE}\end{array}$ & $\begin{array}{l}U \\
0\end{array}$ & MG/L & & $\begin{array}{l}0.22 \\
0.07\end{array}$ & $\begin{array}{l}\mathbf{L} \\
\mathbf{L}\end{array}$ & $\begin{array}{l}0.05 \\
0.05\end{array}$ & - \\
\hline
\end{tabular}

FORMATION OF COMPLETION COOE:

JE - JURASSIC ENTRADA SANDSTONE FORMATION

FLOW RELATIONSHIP CODE:

$U$ - UPGRADIENT

O - ON-SITE

PARAMETER VALUE INDICATOR (PVI): < - LESS THAN DETECTION LIMIT

CODES:

0001 - FILTERED SAMPLE (.45 MICRONS)

OTHER PARAMETER VALUE FLAGS:

L. - LESS THAN THREE BORE VOLUMES REMOVED BEFORE SAMPLING

N001 - UNFILTERED SAMPLE

DATA FILE NAME: IDARTISRKOIIGHQ10035.DAT 
TABLE 3.12 BACKGROUND GROUND WATER QUALITY STATISTICS BY PARAMETER FOR THE ENTRADA FORMATION, UC PROCESSING SITE, SLICK ROCK, COLORADO

SITE: SRKO1 SLICK ROCK (BOTH SITES)

03/29/89 TO 02/17/94

REPORT DATE: $09 / 28 / 94$

\begin{tabular}{|c|c|c|c|c|c|c|c|c|c|c|c|c|}
\hline \multicolumn{3}{|c|}{ PARAMETER NAME } & UNITS & \multirow[b]{2}{*}{ MEAN } & \multirow{2}{*}{$\begin{array}{l}\text { STANDARD } \\
\text { DEVIATION }\end{array}$} & \multirow{2}{*}{$\begin{array}{c}\text { COEFF. } \\
\text { OF } \\
\text { VARIATION }\end{array}$} & \multirow{2}{*}{$\mid \begin{array}{c}\% \text { OF } \\
\text { NON } \\
\text { DETECTS }\end{array}$} & \multirow{2}{*}{\multicolumn{3}{|c|}{ 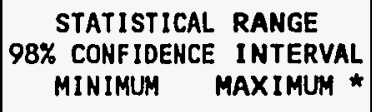 }} & \multirow{2}{*}{$\begin{array}{c}\text { DISTRIBUTION } \\
\text { TYPE }\end{array}$} & \multirow{2}{*}{$\begin{array}{l}\text { FOOT } \\
\text { NOTE }\end{array}$} \\
\hline \# OF SAMP & MINIMUN & MAXIMUM & MEDIAN & & & & & & & & & \\
\hline \multicolumn{3}{|l|}{ ALKALINITY } & MG/L CACO & \multirow[b]{2}{*}{240.8462} & \multirow[b]{2}{*}{125.4052} & \multirow[b]{2}{*}{0.5207} & \multirow[b]{2}{*}{0.0} & \multirow{2}{*}{\multicolumn{2}{|c|}{147.5979}} & \multirow[b]{2}{*}{334.0944} & \multirow[b]{2}{*}{ NORMAL. } & \\
\hline 13 & 139.0000 & 607.0000 & 181.0000 & & & & & & & & & \\
\hline \multicolumn{3}{|l|}{ ALUMINUM } & $\mathrm{MG} / \mathrm{L}$ & \multirow[b]{2}{*}{ NA } & \multirow[b]{2}{*}{ NA } & \multirow[b]{2}{*}{ NA } & \multirow[b]{2}{*}{100.0} & \multirow[b]{2}{*}{ ** } & \multirow[b]{2}{*}{0.0500} & \multirow[b]{2}{*}{0.0500} & \multirow[b]{2}{*}{ NONPARAMETRIC } & \multirow[b]{2}{*}{2} \\
\hline 11 & * $\quad 0.0500$ & 0.0500 & 0.0500 & & & & & & & & & \\
\hline \multicolumn{3}{|l|}{ AMMONIUM } & $\mathrm{MG} / \mathrm{L}$ & \multirow[b]{2}{*}{$\mathrm{NA}$} & \multirow[b]{2}{*}{ NA } & \multirow[b]{2}{*}{ NA } & & & & & & \\
\hline 11 & $\begin{array}{ll}* & 0.1000\end{array}$ & 1.9000 & 0.1000 & & & & 36.4 & $\star \star *$ & 0.1000 & 0.3000 & NONPARAMETRIC & 2 \\
\hline AMMONIUM & (TOTAL) & & $M G / L$ & & & & & & & & & \\
\hline 2 & $\begin{array}{ll}* & 0.1000\end{array}$ & 0.1000 & 0.1000 & NA & NA & NA & 100.0 & & NA & NA & UNKNOWN & 1 \\
\hline ANT IMONY & & & $M G / L$ & & & & & & & & & \\
\hline 11 & ** $\quad 0.0030$ & 0.0030 & 0.0030 & NA & NA & NA & 100.0 & ** & 0.0030 & 0.0030 & NONPARAMETRIC & 2 \\
\hline ARSENIC & & & $M G / L$ & & & & & & & & & \\
\hline 11 & ** $\quad 0.0050$ & 0.0050 & 0.0050 & NA & NA & NA & 100.0 & ** & 0.0050 & 0.0050 & NONPARAMETRIC & 2 \\
\hline BARIUM & & & $M G / L$ & & & & & & & & & \\
\hline 13 & 0.0500 & 0.3100 & 0.1200 & NA & NA & NA & 15.4 & & 0.0500 & 0.2000 & NONPARAMETRIC & 2 \\
\hline BARIUM CTO & OTAL) & & $M G / L$ & & & & & & & & & \\
\hline 2 & 0.4000 & 1.8000 & 1.1000 & NA & NA & NA & 0.0 & & NA & NA & UNKNOWN & 1 \\
\hline BERYLLIUM & & & $M G / L$ & & & & & & & & & \\
\hline 9 & 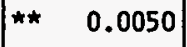 & 0.0050 & 0.0050 & NA & NA & NA & 100.0 & \#* & 0.0050 & 0.0050 & NONPARAMETRIC & 2 \\
\hline BORON & & & $M G / L$ & & & & & & & & & \\
\hline 10 & 0.0700 & 0.4800 & 0.1400 & 0.1850 & 0.1239 & 0.6699 & 0.0 & & 0.0744 & 0.2956 & NORMAL & \\
\hline
\end{tabular}

** The reported value is the minimum detection limit of the data set

+ The sample size is even, so the median value is the arithmetic average of the two middle values

* The statistical maximum is the 99 percent one sided confidence interval, $\alpha=0.01$

1) A minimum of 4 samples must be available for the statistical analysis.

2) The nonparametric distribution was used because the nondetected values comprise more than $15 \%$ of the samples. 
TABLE 3.12 BACKGROUND GROUND HATER QUALITY STATISTICS BY PARAMETER

FOR THE ENTRADA FORMATION, UC PROCESSING SITE, SLICK ROCK, COLORADO SITE: SRKOI SLICK ROCK (BOTH SITES)

$03 / 29 / 89$ TO $02 / 17 / 94$

REPORT DATE: $09 / 28 / 94$

\begin{tabular}{|c|c|c|c|c|c|c|c|c|c|c|c|}
\hline \multicolumn{3}{|c|}{ PARAMETER NAME } & UNITS & \multirow[b]{2}{*}{ MEAN } & \multirow{2}{*}{$\begin{array}{r}\text { STANDARD } \\
\text { DEVIATION }\end{array}$} & \multirow{2}{*}{$\begin{array}{c}\text { COEFF. } \\
\text { OF } \\
\text { VARIATION }\end{array}$} & \multirow{2}{*}{$\mid \begin{array}{c}x \text { OF } \\
\text { NON } \\
\text { DETECTS }\end{array}$} & \multirow{2}{*}{\multicolumn{2}{|c|}{$\begin{array}{l}\text { STATISTICAL RAHGE } \\
\text { 98\% CONFIDENCE INTERVAL } \\
\text { MINIMUM }\end{array}$}} & \multirow{2}{*}{$\begin{array}{l}\text { DISTRIBUTION } \\
\text { TYPE }\end{array}$} & \multirow{2}{*}{$\begin{array}{l}\text { FOOT } \\
\text { NOTE }\end{array}$} \\
\hline \# OF SAMP & MINIMUN & MAXIMUM & MED I AN & & & & & & & & \\
\hline \multicolumn{3}{|c|}{ BORON (TOTAL) } & MG/L & \multirow[b]{2}{*}{ NA } & \multirow[b]{2}{*}{ NA } & \multirow[b]{2}{*}{ NA } & \multirow[b]{2}{*}{0.0} & \multirow[b]{2}{*}{ NA } & \multirow[b]{2}{*}{ NA. } & \multirow[b]{2}{*}{ UNKNOWN } & \multirow[b]{2}{*}{1} \\
\hline 2 & 0.2000 & 0.2000 & 0.2000 & & & & & & & & \\
\hline \multicolumn{3}{|l|}{ BROMIDE } & MG/L & \multirow[b]{2}{*}{ NA } & \multirow[b]{2}{*}{ NA } & \multirow[b]{2}{*}{ NA } & \multirow[b]{2}{*}{90.0} & \multirow[b]{2}{*}{0.0500} & \multirow[b]{2}{*}{0.2500} & \multirow[b]{2}{*}{ HONPARAMETRIC } & \multirow[b]{2}{*}{2} \\
\hline 10 & 0.0500 & 0.8000 & 0.0500 & & & & & & & & \\
\hline \multicolumn{3}{|l|}{ CADMIUM } & $M G / L$ & \multirow[b]{2}{*}{ NA } & \multirow[b]{2}{*}{ NA } & \multirow[b]{2}{*}{ NA } & \multirow[b]{2}{*}{100.0} & \multirow[b]{2}{*}{0.0010} & & & \\
\hline 13 & ** $\quad 0.0010$ & 0.0025 & 0.0010 & & & & & & 0.0025 & NOMPARAMETRIC & 2 \\
\hline CADMIUM C & TOTAL) & & $M G / L$ & & & & & & & & \\
\hline 2 & $\begin{array}{ll}* * & 0.0010\end{array}$ & 0.0020 & 0.0013 & NA & NA & NA & 50.0 & NA & NA & UNKNOWN & 1 \\
\hline CALCIUM & & & $M G / L$ & & & & & & & & \\
\hline 13 & 18.5000 & 54.2000 & 26.0000 & 27.2615 & 8.6639 & 0.3178 & 0.0 & 20.8193 & 33.7038 & NORMAL & \\
\hline CALCIUM $(T$ & TOTAL) & & MG/L & & & & & & & & \\
\hline 2 & 48.7000 & 145.0000 & 96.8500 & NA & NA & NA & 0.0 & NA & NA & UNKNOWN & 1 \\
\hline CHLORIDE & & & $M G / L$ & & & & & & & & \\
\hline 13 & 4.0000 & 696.0000 & 4.8000 & 21.6834 & 6.6461 & NA & 0.0 & 5.3026 & 88.6678 & LOGHORMAL & 7,8 \\
\hline CHROMIUM & & & $M G / L$ & & & & & & & & \\
\hline 13 & ** $\quad 0.0100$ & 0.0100 & 0.0100 & NA & NA & NA & 92.3 & 0.0100 & 0.0100 & NOMPARAMETRIC & 2 \\
\hline CHROMIUM & (TOTAL) & & $M G / L$ & & & & & & & & \\
\hline 2 & 0.0200 & 0.1600 & 0.0900 & NA & HA & NA & 0.0 & NA & NA. & UNKNOWN & 1 \\
\hline
\end{tabular}

** The reported value is the minimum detection limit of the data set

+ The sample size is even, so the median value is the arithmetic average of the two middle values

* The statistical maximum is the 99 percent one sided confidence interval, $\alpha=0.01$

1) A minimum of 4 samples must be available for the statistical analysis.

2) The nonparametric distribution was used because the nondetected values comprise more than 15\% of the sarmples.

7) The lognormal distribution was used because the data failed the normal distribution test.

8) The mean is geometric. The standard deviation is the value to divide or multiply with the geometric mean. 
TABLE 3.12 BACKGROUND GROUND WATER QUALITY STATISTICS BY PARAMETER

FOR THE ENTRADA FORMATION, UC PROCESSING SITE, SLICK ROCK, COLORADO

SITE: SRKO1 SLICK ROCK (BOTH SITES)

03/29/89 TO 02/17/94

REPORT DATE : $09 / 28 / 94$

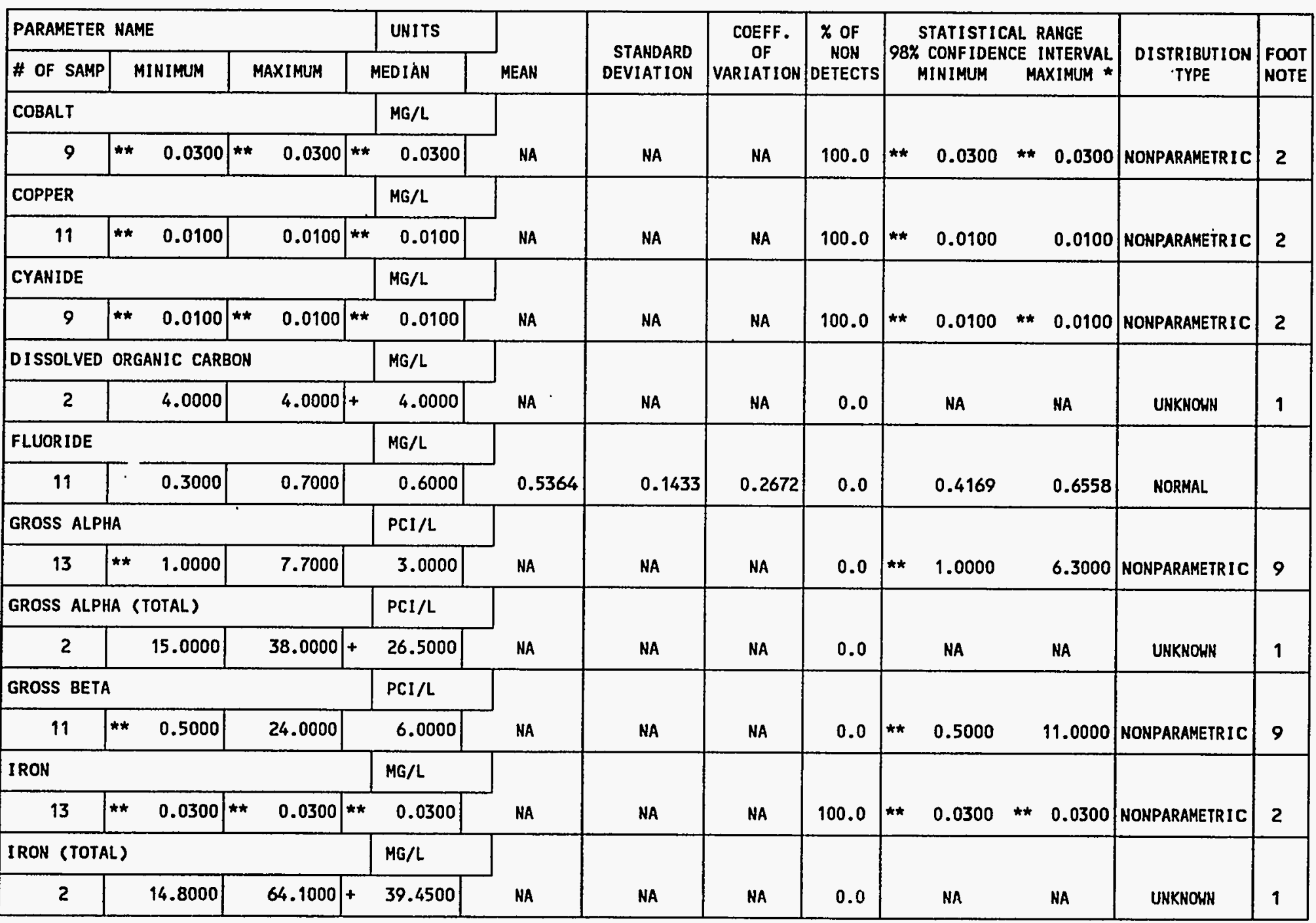

** The reported value is the minimum detection limit of the data set

+ The sample size is even, so the median value is the arithmetic average of the two middle values

* The statistical maximum is the 99 percent one sided confidence interval, $\alpha=0.01$

1) A minimum of 4 samples must be available for the statistical analysis.

2) The nonparametric distribution was used because the nondetected values comprise more than $15 \%$ of the samples.

9) The nonparametic distribution was used because the data failed the normal distribution test and includes values $\leq 0$. 
TABLE 3.12 BACKGROUND GROUND WATER QUALITY STATISTICS BY PARAMETER

FOR THE EHTRADA FORMATION, UC PROCESSING SITE, SLICK ROCK, COLORADO

SITE: SRKO1 SLICK ROCK (BOTH SITES)

03/29/89 TO 02/17/94

REPORT DATE: 09/28/94

\begin{tabular}{|c|c|c|c|c|c|c|c|c|c|c|c|c|c|c|}
\hline \multicolumn{5}{|c|}{ PARAMETER NAME } & UNITS & \multirow[b]{2}{*}{ MEAN } & \multirow{2}{*}{$\begin{array}{r}\text { STANDARD } \\
\text { DEVIATION }\end{array}$} & \multirow{2}{*}{$\begin{array}{c}\text { COEFF. } \\
\text { OF } \\
\text { VARIATION }\end{array}$} & \multirow{2}{*}{$\left|\begin{array}{c}x \text { OF } \\
\text { NON } \\
\text { DETECTS }\end{array}\right|$} & \multirow{2}{*}{\multicolumn{3}{|c|}{$\begin{array}{cc}\text { STATISTICAL } & \text { RANGE } \\
\text { 98\% CONFIDENCE } & \text { INTERVAL } \\
\text { MINIMUM } & \text { MAXIMUH * }\end{array}$}} & \multirow{2}{*}{$\begin{array}{l}\text { DISTRIBUTION } \\
\text { TYPE }\end{array}$} & \multirow{2}{*}{$\begin{array}{l}\text { FOOT } \\
\text { NOTE }\end{array}$} \\
\hline \# OF SAMP & & INIMUM & MAXINUM & \multicolumn{2}{|c|}{ MED IAN } & & & & & & & & & \\
\hline \multicolumn{5}{|l|}{ LEAD } & $M G / L$ & \multirow[b]{2}{*}{ NA } & \multirow[b]{2}{*}{ NA } & \multirow[b]{2}{*}{ NA } & \multirow[b]{2}{*}{90.9} & \multirow[b]{2}{*}{$\star \star$} & \multirow[b]{2}{*}{0.0030} & \multirow[b]{2}{*}{0.0050} & \multirow[b]{2}{*}{ NONPARAMETRIC } & \multirow[b]{2}{*}{2} \\
\hline 11 & ** & 0.0030 & 0.0100 & $\star \star$ & 0.0030 & & & & & & & & & \\
\hline \multicolumn{5}{|l|}{ LEAD-210 } & PCI/L & \multirow[b]{2}{*}{ NA } & \multirow[b]{2}{*}{ NA } & \multirow[b]{2}{*}{ NA } & \multirow[b]{2}{*}{0.0} & \multirow[b]{2}{*}{$\star \star$} & \multirow[b]{2}{*}{1.5000} & \multirow[b]{2}{*}{3.2000} & \multirow[b]{2}{*}{ NONPARAMETRIC } & \multirow[b]{2}{*}{9,6} \\
\hline 6 & $\star \star$ & 1.5000 & 3.2000 & $\star \star \star$ & 1.5000 & & & & & & & & & \\
\hline \multicolumn{5}{|c|}{ LEAD-210 (TOTAL) } & PCI/L & \multirow[b]{2}{*}{ NA } & \multirow[b]{2}{*}{ MA } & & & & & & & \\
\hline 2 & & 2.4000 & 3.2000 & + & 2.8000 & & & NA & 0.0 & & NA & NA & UNKNOWH & 1 \\
\hline MAGNESIUM & & & & & $M G / L$ & & & & & & & & & \\
\hline 13 & & 18.0000 & 81.4000 & & 27.9000 & 36.5000 & 18.2335 & 0.4995 & 0.0 & & 22.9420 & 50.0580 & NORMAL & \\
\hline MAGNESIUM & ८TOT & (AL) & & & $M G / L$ & & & & & & & & & \\
\hline 2. & & 33.4000 & 92.1000 & + & 62.7500 & NA & NA & NA & 0.0 & & NA & NA & UNKNOWH & 1 \\
\hline MANGANESE & & & & & $M G / L$ & & & & & & & & & \\
\hline 13 & $\star \star$ & 0.0100 & 0.0800 & $\star \star$ & 0.0100 & NA & NA & NA & 69.2 & ** & 0.0100 & 0.0300 & NONPARAMETRIC & 2 \\
\hline MANGANESE & STOT & (AL) & & & $M G / L$ & & & & & & & & & \\
\hline 2 & & 0.5700 & 4.1000 & + & 2.3350 & NA & NA & NA & 0.0 & & NA & NA & UNKNOWN & 1 \\
\hline MERCURY & & & & & $M G / L$ & & & & & & & & & \\
\hline 9 & ** & 0.0002 & 0.0002 & ** & 0.0002 & NA & NA & NA & 100.0 & ** & 0.0002 & 0.0002 & NONPARAMETRIC & 2 \\
\hline MOL YBDENUM & & & & & MG/L & & & & & & & & & \\
\hline 13 & $\star \star$ & 0.0100 & 0.0700 & \#* & 0.0100 & NA & NA & $N A$ & 46.2 & ** & 0.0100 & 0.0300 & NONPARAMETRIC & 2 \\
\hline
\end{tabular}

** The reported value is the minimum detection limit of the data set

+ The sample size is even, so the median value is the arithmetic average of the two middle values

* The statistical maximum is the 99 percent one sided confidence interval, $\alpha=0.01$

1) A minimum of 4 samples must be available for the statistical analysis.

2) The nonparametric distribution was used because the nondetected values comprise more than $15 \%$ of the samples.

6) The stat. range is the $96.9 \%$ confidence interval due to a sample size of 6 . The maximu is the $98.5 \%$ one sided confidence int.

9) The nonparametic distribution was used because the data failed the normal distribution test and includes values $\leq 0$. 
TABLE 3.12 BACKGROUND GROUND HATER QUALITY STATISTICS BY PARAMETER FOR THE ENTRADA FORMATION, UC PROCESSING SITE, SLICK ROCK, COLORADO SITE: SRKO1 SLICK ROCK (BOTH SITES)

03/29/89 TO 02/17/94

REPORT DATE: $09 / 28 / 94$

\begin{tabular}{|c|c|c|c|c|c|c|c|c|c|c|c|c|}
\hline \multicolumn{4}{|c|}{ PARAMETER NAME } & UNITS & \multirow[b]{2}{*}{ MEAN } & \multirow{2}{*}{$\begin{array}{r}\text { STANDARD } \\
\text { DEVIATION }\end{array}$} & \multirow{2}{*}{$\begin{array}{c}\text { COEFF. } \\
\text { OF } \\
\text { VARIATION }\end{array}$} & \multirow{2}{*}{$\begin{array}{c}\% \text { OF } \\
\text { NOH } \\
\text { DETECTS }\end{array}$} & \multirow{2}{*}{\multicolumn{2}{|c|}{$\begin{array}{c}\text { STATISTICAL RANGE } \\
\text { 98\% CONFIDENCE INTERVAL } \\
\text { MINIMUM }\end{array}$}} & \multirow{2}{*}{$\begin{array}{c}\text { DISTRIBUTION } \\
\text { TYPE }\end{array}$} & \multirow{2}{*}{$\begin{array}{l}\text { FOOT } \\
\text { NOTE }\end{array}$} \\
\hline \# OF SAMP & MINIMUM & & IAXIMUM & MEDIAN & & & & & & & & \\
\hline \multicolumn{4}{|c|}{ MOLYBDENUM (TOTAL) } & $M G / L$ & \multirow[b]{2}{*}{ NA } & \multirow[b]{2}{*}{ NA } & \multirow[b]{2}{*}{ NA } & \multirow[b]{2}{*}{50.0} & \multirow[b]{2}{*}{ NA } & \multirow[b]{2}{*}{ NA } & \multirow[b]{2}{*}{ UNKNOWN } & \multirow[b]{2}{*}{1} \\
\hline 2 & ** $\quad 0.0100$ & & 0.0200 & 0.0125 & & & & & & & & \\
\hline \multicolumn{4}{|c|}{ 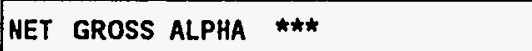 } & PCI/L & \multirow[b]{2}{*}{ NA } & \multirow[b]{2}{*}{ NA } & \multirow[b]{2}{*}{ NA } & \multirow[b]{2}{*}{0.0} & \multirow[b]{2}{*}{-6.1700} & \multirow[b]{2}{*}{4.1000} & \multirow[b]{2}{*}{ MONPARAMETRIC } & \multirow[b]{2}{*}{9} \\
\hline 13 & -6.2500 & & 4.2700 & -0.3400 & & & & & & & & \\
\hline \multicolumn{3}{|c|}{ NET GROSS ALPHA (TOTAL) } & $* \star *$ & $\mathrm{PCl} / \mathrm{L}$ & \multirow[b]{2}{*}{ NA } & \multirow[b]{2}{*}{ NA } & \multirow[b]{2}{*}{ NA } & \multirow[b]{2}{*}{0.0} & \multirow[b]{2}{*}{ NA } & & & \\
\hline 2 & 13.6300 & & 35.9400 & 24.7850 & & & & & & NA & UNKHOWH & 1 \\
\hline NICKEL & & & & MG/L & & & & & & & & \\
\hline 11 & $\star * \quad 0.0400$ & $\star \star$ & 0.0400 & 0.0400 & NA & NA & NA & 100.0 & 0.0400 & $* * 0.0400$ & NONPARAMETRIC & 2 \\
\hline NITRATE & & & & $M G / L$ & & & & & & & & \\
\hline 11 & 1.0000 & & 8.9000 & 5.7000 & 5.3455 & 2.6808 & 0.5015 & 0.0 & 3.1113 & 7.5796 & NORMAL & \\
\hline NITRATE & TOTAL) & & & $M G / L$ & & & & & & & & \\
\hline 2 & ** $\quad 1.0000$ & $\star \star$ & 1.0000 & 1.0000 & NA & NA & NA & 100.0 & NA & NA & UNKNOWN & 1 \\
\hline NITRITE AN & VD NITRATE & & & MG/L & & & & & & & & \\
\hline 6 & 0.8200 & & 3.0000 & 1.4550 & 1.6183 & 0.8007 & 0.4947 & 0.0 & 0.5184 & 2.7182 & NORMAL. & \\
\hline PH & & & & su & & & & & & & & \\
\hline 13 & 7.7700 & & 8.0400 & 7.9300 & NA & NA & NA & 0.0 & NA & NA & UNKNOWN & \\
\hline PHOSPHATE & & & & $M G / L$ & & & & & & & & \\
\hline 11 & 0.0500 & & 0.9000 & 0.1000 & NA & NA & NA & 36.4 & 0.0500 & 0.6000 & NONPARAMETRIC & 2 \\
\hline
\end{tabular}

*** NET GROSS ALPHA (GROSS ALPHA - URANIUM) WITH 1 MG URAN IUM = 686 PCI

**** NET GROSS ALPHA (TOTAL) (TOTAL GROSS ALPHA - TOTAL URANIUM)

** The reported value is the minimum detection limit of the data set

+ The sample size is even, so the median value is the arithmetic average of the two middle values

* The statistical maximum is the 99 percent one sided confidence interval, $\alpha=0.01$

1) A minimum of 4 samples must be available for the statistical analysis.

2) The nonparametric distribution was used because the nondetected values comprise more than $15 \%$ of the samples.

9) The nonparametic distribution was used because the data failed the normal distribution test and includes values $\leq 0$. 
TABLE 3.12 BACKGROUND GROUND HATER OUALITY STATISTICS BY PARAMETER

FOR THE ENTRADA FORMATION, UC PROCESSING SITE, SLICK ROCK, COLORADO

SITE: SRKO1 SLICK ROCK (BOTH SITES)

03/29/89 TO 02/17/94

REPORT DATE: $09 / 28 / 94$

\begin{tabular}{|c|c|c|c|c|c|c|c|c|c|c|c|c|c|}
\hline \multicolumn{4}{|c|}{ PARAMETER NAME } & UHITS & \multirow[b]{2}{*}{ MEAN } & \multirow{2}{*}{$\begin{array}{l}\text { STANDARD } \\
\text { DEVIATION }\end{array}$} & \multirow{2}{*}{$\begin{array}{l}\text { COEFF. } \\
\text { OF } \\
\text { VARIATION }\end{array}$} & \multirow{2}{*}{ 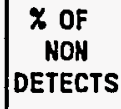 } & \multirow{2}{*}{\multicolumn{3}{|c|}{$\begin{array}{l}\text { STATISTICAL RANGE } \\
\text { 98\% CONFIDENCE INTERVAL } \\
\text { MINIMUM MAXIMUM * }\end{array}$}} & \multirow{2}{*}{$\begin{array}{l}\text { DISTRIBUT IOH } \\
\text { TYPE }\end{array}$} & \multirow{2}{*}{$\begin{array}{l}\text { FOOT } \\
\text { NOTE }\end{array}$} \\
\hline \# OF SAMP & MINIMUM & MAXIMUM & & MED IAN & & & & & & & & & \\
\hline \multicolumn{4}{|c|}{ POLONIUM-210 } & $\mathrm{PCI} / \mathrm{L}$ & \multirow[b]{2}{*}{ NA } & \multirow[b]{2}{*}{ MA } & \multirow[b]{2}{*}{ NA } & \multirow[b]{2}{*}{0.0} & \multirow[b]{2}{*}{$\star \star *$} & \multirow[b]{2}{*}{0.1000} & \multirow[b]{2}{*}{0.1000} & \multirow[b]{2}{*}{ NONPARAMETRIC } & \multirow[b]{2}{*}{9,6} \\
\hline 6 & ** $\quad 0.1000$ & 0.1000 & ** & 0.1000 & & & & & & & & & \\
\hline \multicolumn{4}{|c|}{ POLONIUN-210 (TOTAL) } & PCI/L & \multirow[b]{2}{*}{ NA } & \multirow[b]{2}{*}{ NA } & \multirow[b]{2}{*}{ HA } & \multirow[b]{2}{*}{0.0} & \multirow{2}{*}{\multicolumn{2}{|c|}{ NA }} & \multirow[b]{2}{*}{ NA } & \multirow[b]{2}{*}{ UNKNOWN } & \multirow[b]{2}{*}{1} \\
\hline 2 & 0.1000 & 0.2000 & + & 0.1500 & & & & & & & & & \\
\hline \multicolumn{4}{|l|}{ POTASSIUA } & MG/L & \multirow[b]{2}{*}{6.9985} & \multirow[b]{2}{*}{2.0720} & \multirow[b]{2}{*}{0.2961} & & & & & & \\
\hline 13 & 3.8200 & 12.5000 & & 7.0000 & & & & 0.0 & & 5.4578 & 8.5391 & NORMAL & \\
\hline POTASSIUM & (TOTAL) & & & MG/L & & & & & & & & & \\
\hline 2 & 16.2000 & 33.0000 & + & 24.6000 & NA & NA & NA & 0.0 & & NA & NA & UNKNOWN & 1 \\
\hline RADIUM-226 & & & & $\mathrm{PCI} / \mathrm{L}$ & & & & & & & & & \\
\hline 12 & ** $\quad 0.1000$ & 0.9000 & + & 0.3000 & NA & NA & NA & 0.0 & & 0.1000 & 0.6000 & NONPARAMETRIC & 9 \\
\hline RADIUH-226 & $S$ (TOTAL) & & & PCI/L & & & & & & & & & \\
\hline 2 & 1.4000 & 1.8000 & + & 1.6000 & NA & NA & NA & 0.0 & & NA & NA & UNKNOWN & 1 \\
\hline RADIUM-226 & $3+$ RADIUM-22 & & & $\mathrm{PCI} / \mathrm{L}$ & & & & & & & & & \\
\hline 12 & 0.1000 & 6.3000 & + & 1.6000 & 2.0000 & 1.8076 & 0.9038 & 0.0 & & 0.5818 & 3.4182 & NORMAL & \\
\hline RADIUM-226 & S + RADIUM-22 & (TOTAL) & & $\mathrm{PCI} / \mathrm{L}$ & & & & & & & & & \\
\hline 2 & 3.7000 & 6.2000 & + & 4.9500 & NA & HA & NA & 0.0 & & NA & NA & UNKNOWN & 1 \\
\hline RADIUM-228 & & & & $\mathrm{PCI} / \mathrm{L}$ & & & & & & & & & \\
\hline 12 & ** $\quad 1.0000$ & 5.9000 & + & 1.3500 & NA & HA & NA & 0.0 & $* \star$ & 1.0000 & 4.0000 & NONPARAMETRIC & 9 \\
\hline RADIUM-228 & 3 (TOTAL) & & & $\mathrm{PCI} / \mathrm{L}$ & & & & & & & & & \\
\hline 2 & 2.3000 & 4.4000 & + & 3.3500 & NA & NA & NA & 0.0 & & NA & NA & UNKNOWN & 1 \\
\hline
\end{tabular}

** The reported value is the minimum detection limit of the data set

+ The sample size is even, so the median value is the arithmetic average of the two middle values

* The statistical maximum is the 99 percent one sided confidence interval, $\alpha=0.01$

1) A minimum of 4 samples must be available for the statistical analysis.

6) The stat. range is the $96.9 \%$ confidence interval due to a sample size of 6 . The maximum is the $98.5 \%$ one sided confidence int.

9) The nonparametic distribution was used because the data failed the normal distribution test and includes values $\leq 0$. 
TABLE 3.12 BACKGROUND GROUND HATER QUALITY STATISTICS BY PARAMETER FOR THE ENTRADA FORMATION, UC PROCESSING SITE, SLICK ROCK, COLORADO SITE: SRKO1 SLICK ROCK (BOTH SITES)

$03 / 29 / 89$ TO $02 / 17 / 94$

REPORT DATE : $09 / 28 / 94$

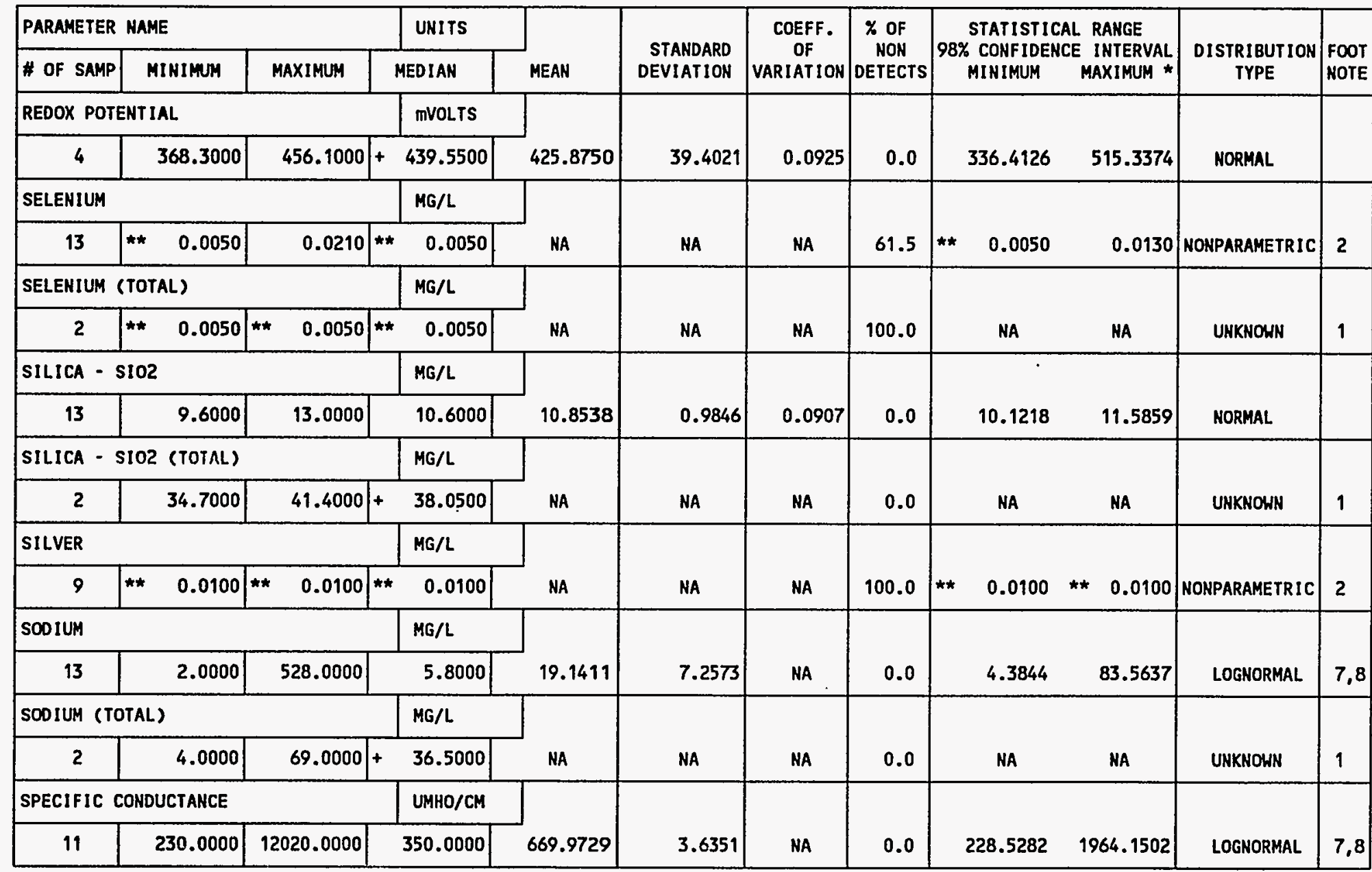

** The reported value is the minimu detection limit of the data set

+ The sample size is even, so the median value is the arithmetic average of the two middle values

* The statistical maximum is the 99 percent one sided confidence interval, $\alpha=0.01$

1) A minimm of 4 samples must be available for the statistical analysis.

2) The nonparametric distribution was used because the nondetected values comprise more than $15 \%$ of the samples.

7) The lognormal distribution was used because the data failed the normal distribution test.

8) The mean is geometric. The standard deviation is the value to divide or multiply with the geometric mean. 
TABLE 3.12 BACKGROUND GROUND UATER QUALITY STATISTICS BY PARAMETER

FOR THE ENTRADA FORMATION, UC PROCESSING SITE, SLICK ROCK, COLORADO

SITE: SRKO1 SLICK ROCK (BOTH SITES)

$03 / 29 / 89$ TO $02 / 17 / 94$

REPORT DATE: 09/28/94

\begin{tabular}{|c|c|c|c|c|c|c|c|c|c|c|c|c|}
\hline \multicolumn{3}{|c|}{ PARAMETER NAME } & UNITS & \multirow[b]{2}{*}{ MEAN } & \multirow{2}{*}{$\begin{array}{r}\text { STANDARD } \\
\text { DEVIATION }\end{array}$} & \multirow{2}{*}{$\begin{array}{c}\text { COEFF. } \\
\text { OF } \\
\text { VARIATION }\end{array}$} & \multirow{2}{*}{$\begin{array}{c}x \text { OF } \\
\text { NON } \\
\text { DETECTS }\end{array}$} & \multirow{2}{*}{\multicolumn{3}{|c|}{$\begin{array}{l}\text { STATISTICAL RANGE } \\
\text { 98\% CONFIDENCE INTERVAL } \\
\text { MINIMUM MAXIMUM * }\end{array}$}} & \multirow{2}{*}{$\begin{array}{l}\text { DISTRIBUTION } \\
\text { TYPE }\end{array}$} & \multirow{2}{*}{ FOOI } \\
\hline \# OF SAMP & MINIMU & MAXIMUA & MEDIAN & & & & & & & & & \\
\hline \multicolumn{3}{|l|}{ STRONTIUH } & $M G / L$ & \multirow[b]{2}{*}{0.5875} & \multirow[b]{2}{*}{0.1888} & \multirow[b]{2}{*}{0.3213} & \multirow[b]{2}{*}{0.0} & \multirow{2}{*}{\multicolumn{2}{|c|}{0.4394}} & \multirow[b]{2}{*}{0.7356} & \multirow[b]{2}{*}{ NORMAL } & \multirow{2}{*}{$0^{2}$} \\
\hline 12 & 0.3300 & 1.1000 & 0.5500 & & & & & & & & & \\
\hline \multicolumn{3}{|c|}{ STRONTIUM (TOTAL) } & $M G / L$ & \multirow[b]{2}{*}{ NA } & \multirow[b]{2}{*}{ NA } & \multirow[b]{2}{*}{ NA } & \multirow[b]{2}{*}{0.0} & \multirow{2}{*}{\multicolumn{2}{|c|}{ NA }} & \multirow[b]{2}{*}{ NA } & \multirow[b]{2}{*}{ UNKNOWN } & \multirow[b]{2}{*}{1} \\
\hline 2 & 0.6000 & 0.9400 & 0.7700 & & & & & & & & & \\
\hline \multicolumn{3}{|l|}{ SULFATE } & $M G / L$ & \multirow[b]{2}{*}{22.8044} & \multirow[b]{2}{*}{5.2041} & \multirow[b]{2}{*}{ NA } & \multirow[b]{2}{*}{7.7} & \multirow{2}{*}{\multicolumn{2}{|c|}{6.6890}} & \multirow[b]{2}{*}{77.7454} & & \\
\hline 13 & 4.0000 & 539.0000 & 8.0000 & & & & & & & & LOGNORMAL & 7,8 \\
\hline SULFIDE & & & MG/L & & & & & & & & & \\
\hline 10 & ** $\quad 0.1000$ & 42.0000 & 0.2500 & NA & NA & NA & 30.0 & \#* & 0.1000 & 0.6000 & NONPARAMETRIC & 2 \\
\hline TEMPERATUR & & & C - DEG & & & & & & & & & \\
\hline 13 & 11.8000 & 17.5000 & 13.9000 & 14.1308 & 1.6720 & 0.1183 & 0.0 & & 12.8875 & 15.3740 & NORMAL & \\
\hline THALLIUM & & & $M G / L$ & & & & & & & & & \\
\hline 11 & $\star \star \quad 0.0010$ & 0.0500 & 0.0050 & NA & NA & NA & 100.0 & & 0.0025 & 0.0050 & NONPARAMETRIC & 2 \\
\hline THORIUM-23 & & & $\mathrm{PCI} / \mathrm{L}$ & & & & & & & & & \\
\hline 6 & 0.2000 & 1.1000 & 0.4500 & 0.5333 & 0.3266 & 0.6124 & 0.0 & \#* & 0.2000 & 0.9820 & NORMAL & \\
\hline THORIUM-23 & 30 (TOTAL) & & $\mathrm{PCI} / \mathrm{L}$ & & & & & & & & & \\
\hline 2 & 0.3000 & 0.4000 & 0.3500 & NA & NA & NA & 0.0 & & NA & NA & UNKNOWN & 1 \\
\hline TIN & & & MG/L & & & & & & & & & \\
\hline 11 & 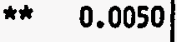 & 0.0050 & 0.0050 & HA & NA & NA & 90.9 & ** & 0.0050 & 0.0050 & NONPARAMETRIC & 2 \\
\hline
\end{tabular}

** The reported value is the minimum detection limit of the data set

+ The sample size is even, so the median value is the arithmetic average of the two middle values

* The statistical maximum is the 99 percent one sided confidence interval, $\alpha=0.01$

1) A minimum of 4 samples must be available for the statistical analysis.

2) The nonparametric distribution was used because the nondetected values comprise more than $15 \%$ of the samples.

7) The lognormal distribution was used because the data failed the normal distribution test.

8) The mean is geometric. The standard deviation is the value to divide or multiply with the geometric mean. 
TABLE 3.12 BACKGROUND GROUND HATER QUALITY STATISTICS BY PARAMETER FOR THE ENTRADA FORMATION, UC PROCESSING SITE, SLICK ROCK, COLORADO

SITE: SRK01 SLICK ROCK (BOTH SITES)

$03 / 29 / 89$ TO $02 / 17 / 94$

REPORT DATE: $09 / 28 / 94$

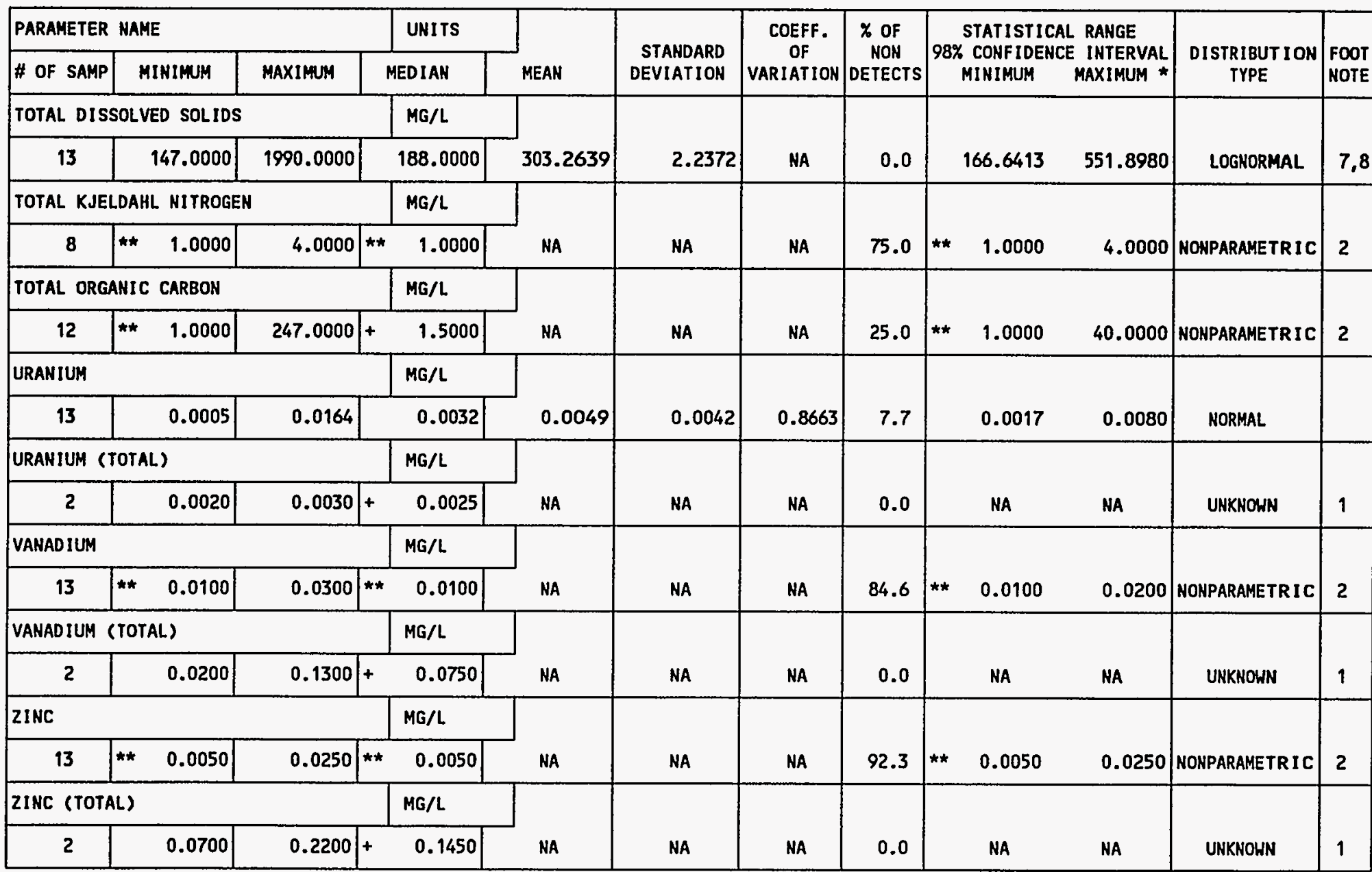

** The reported value is the minimum detection limit of the data set

+ The sample size is even, so the median value is the arithmetic average of the two middle values

* The statistical maximum is the 99 percent one sided confidence interval, $\alpha=0.01$

1) A minimum of 4 samples must be available for the statistical analysis.

2) The nonparametric distribution was used because the nondetected values comprise more than $15 \%$ of the samples.

7) The lognormal distribution was used because the data failed the normal distribution test.

8) The mean is geometric. The standard deviation is the value to divide or multiply with the geometric mean. 
TABLE 3.12 BACKGROUND GROUND WATER QUALITY STATISTICS BY PARAMETER

FOR THE ENTRADA FORMATION, UC PROCESSING SITE, SLICK ROCK, COLORADO

SITE: SRKO1 SLICK ROCK (BOTH SITES)

03/29/89 TO $02 / 17 / 94$

REPORT DATE: 09/28/94

\begin{tabular}{|c|c|c|c|c|c|c|c|c|c|c|}
\hline \multicolumn{3}{|c|}{ PARAMETER NAME } & UNITS & \multirow[b]{2}{*}{ MEAN } & \multirow[b]{2}{*}{$\begin{array}{r}\text { STANDARD } \\
\text { DEVIATIION }\end{array}$} & \multirow{2}{*}{$\begin{array}{c}\text { COEFF. } \\
\text { OF } \\
\text { VARIATION }\end{array}$} & \multirow{2}{*}{ 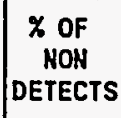 } & \multirow{2}{*}{$\begin{array}{l}\text { STATISTICAL RANGE } \\
\text { 98\% CONFIDENCE IHTERVAL } \\
\text { MINIMUM }\end{array}$} & \multirow[b]{2}{*}{$\begin{array}{c}\text { DISTRIBUTIOH } \\
\text { TYPE }\end{array}$} & \multirow[b]{2}{*}{$\begin{array}{l}\text { FOOT } \\
\text { HOTE }\end{array}$} \\
\hline \# OF SAMP & MINIMUN & MAXIMUM & MEDIAN & & & & & & & \\
\hline & & & 1 & $T$ & & & & & & \\
\hline
\end{tabular}

* The statistical maximum is the 99 percent one sided confidence interval, $a=0.01$

IMPUT DATA FILENAME: IDARTISRKO1IGHQ10038.DAT 
Table 3.13 Summary of regulated constituents in the Entrada Formation background ground water, UC processing site, Slick Rock, Colorado

\begin{tabular}{lccc}
\hline \multicolumn{4}{c}{ Constituents with MCLs } \\
\hline Parameter & MCLs & Mean or median & Statistical maximum \\
\hline Arsenic & 0.05 & $0.01^{\mathrm{e}}$ & $0.01^{\mathrm{e}}$ \\
Barium & 1.00 & 0.12 & 0.20 \\
Cadmium & 0.01 & $0.001^{\mathrm{e}}$ & 0.003 \\
Chromium & 0.05 & $0.01^{\mathrm{e}}$ & $0.01^{\mathrm{e}}$ \\
Net gross alphab & 15.0 & $-0.34^{\mathrm{a}}$ & 4.10 \\
Lead & 0.05 & $0.01^{\mathrm{e}}$ & $0.01^{\mathrm{e}}$ \\
Mercury & 0.002 & $0.0002^{\mathrm{e}}$ & $0.0002^{\mathrm{e}}$ \\
Molybdenum & 0.10 & $0.01^{\mathrm{e}}$ & 0.03 \\
Nitrate & 44.0 & $5.35^{\mathrm{d}}$ & 7.58 \\
Radium-226 and $-228^{\mathrm{b}}$ & 5.00 & $2.00^{\mathrm{d}}$ & $3.42^{\mathrm{d}}$ \\
Selenium & 0.01 & $0.005^{\mathrm{e}}$ & 0.013 \\
Silver & 0.05 & $0.01^{\mathrm{e}}$ & $0.01^{\mathrm{e}}$ \\
Uranium & 0.044 & $0.005^{\mathrm{d}}$ & $0.008^{\mathrm{d}}$ \\
\hline
\end{tabular}


Table 3.13 Summary of regulated constituents in the Entrada Formation background ground water, UC processing site, Slick Rock, Colorado (Concluded)

\begin{tabular}{lcc}
\hline \multicolumn{3}{c}{ Constituents without MCLs } \\
\hline Parameter & Mean or median & Statistical maximum \\
\hline Antimony & $0.003^{\mathrm{e}}$ & $0.003^{\mathrm{e}}$ \\
Beryllium & $0.01^{\mathrm{e}}$ & $0 . \mathrm{C}^{\mathrm{e}}$ \\
Cobalt & $0.05^{\mathrm{e}}$ & $0.05^{\mathrm{e}}$ \\
Copper & $0.02^{\mathrm{e}}$ & $0.02^{\mathrm{e}}$ \\
Cyanide & $0.01^{\mathrm{e}}$ & $0.01^{\mathrm{e}}$ \\
Nickel & $0.04^{\mathrm{e}}$ & $0.03^{\mathrm{e}}$ \\
Sulfide & $0.25^{\mathrm{e}}$ & 0.60 \\
Thallium & $0.01^{\mathrm{e}}$ & $0.01^{\mathrm{e}}$ \\
Tin & $0.005^{\mathrm{e}}$ & $0.005^{\mathrm{e}}$ \\
Vanadium & $0.01^{\mathrm{e}}$ & 0.02 \\
Zinc & $0.005^{\mathrm{e}}$ & 0.025 \\
\hline
\end{tabular}

${ }^{a}$ All units are $\mathrm{mg} / \mathrm{L}$ unless otherwise noted.

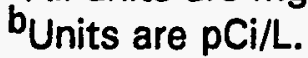

CMean value, Lognormal distribution, mean is geometric.

dMean value, Normal distribution, mean is arithmetic.

'Statistical values are below laboratory detection limits in Table 8.1 of the Technical Approach Document (DOE, 1989). 
TABLE 3.14 GROUND WATER QUALITY MEASUREMENTS EXCEEDING MCLS IN ENTRADA

FORMATION BACKGROUND GROUND WATER, UC SITE, SLICK ROCK, COLORADO

SITE: SRK01 SLICK ROCK (BOTH SITES)

03/29/89 TO 02/17/94

REPORT DATE: 09/29/94

\begin{tabular}{|c|c|c|c|c|c|c|c|c|c|c|c|}
\hline PARAMETER NAME & $\begin{array}{l}\text { TOTAL } \\
\# \text { OF } \\
\text { SAMP. }\end{array}$ & $\begin{array}{c}\text { UNITS } \\
\text { OF } \\
\text { MEASURE }\end{array}$ & $\begin{array}{l}\text { MAXIMUM } \\
\text { CONC. } \\
\text { LIMIT }\end{array}$ & $\underset{\text { ID }}{\operatorname{LOC}}$ & LOG DATE & $\begin{array}{c}\text { SAMP } \\
10\end{array}$ & $\begin{array}{c}\text { FORM } \\
\text { OF } \\
\text { COMP }\end{array}$ & $\begin{array}{l}\text { HYDR } \\
\text { FLOW } \\
\text { REL. }\end{array}$ & $\begin{array}{l}\text { RESULT EXCEEDING MAX. } \\
\text { CONCENTRATION LIMIT } \\
\text { VALUE FLAGS }\end{array}$ & $\begin{array}{l}\text { DETECTION } \\
\text { LIMIT }\end{array}$ & $\begin{array}{l}\text { PARAMETER } \\
\text { UNCERT. }\end{array}$ \\
\hline ARSENIC & 11 & $M G / L$ & 0.0500 & - & - & - & - & - & - & - & - \\
\hline ARSENIC (TOTAL) & 0 & $M G / L$ & 0.0500 & - & - & - & - & - & - & - & - \\
\hline BARIUM & 13 & $M G / L$ & 1.0000 & - & - & - & - & - & - & - & - \\
\hline BARIUM (TOTAL) & 2 & $M G / L$ & 1.0000 & 0551 & $02 / 17 / 94$ & N001 & JE & $u$ & 1.8 & 0.1 & - \\
\hline CADMIUM & 13 & $M G / L$ & 0.0100 & - & - & - & - & - & - & - & - \\
\hline CADMIUM (TOTAL) & 2 & MG/L & 0.0100 & - & - & - & - & - & - & - & - \\
\hline CHROMIUM & 13 & $M G / L$ & 0.0500 & - & - & - & - & - & - & - & - \\
\hline CHROMIUM (TOTAL) & 2 & $M G / L$ & 0.0500 & 0551 & $02 / 17 / 94$ & N001 & JE & $\mathrm{u}$ & $0.16 \quad \mathrm{~L}$ & 0.01 & - \\
\hline GROSS ALPHA & 13 & $\mathrm{PCI} / \mathrm{L}$ & 15.0000 & - & - & - & - & - & - & - & - \\
\hline GROSS ALPHA (TOTAL) & 2 & $\mathrm{PCI} / \mathrm{L}$ & 15.0000 & $\begin{array}{l}0551 \\
0703\end{array}$ & $\begin{array}{l}02 / 17 / 94 \\
02 / 17 / 94\end{array}$ & $\begin{array}{l}\text { NO01 } \\
\text { NO01 }\end{array}$ & $\begin{array}{l}\text { JE } \\
\text { JE }\end{array}$ & $\begin{array}{l}U \\
0\end{array}$ & $\begin{array}{ll}38.0 & \mathrm{~L} \\
15.0 & \mathrm{~L}\end{array}$ & $\begin{array}{l}8.6 \\
2.0\end{array}$ & $\begin{array}{l}7.0 \\
2.0\end{array}$ \\
\hline LEAD & 11 & MG/L & 0.0500 & - & - & - & - & - & - & $\cdot$ & - \\
\hline LEAD (TOTAL) & 0 & $M G / L$ & 0.0500 & - & - & - & - & - & - & - & - \\
\hline MERCURY & 9 & $M G / L$ & 0.0020 & - & - & - & - & - & - & - & - \\
\hline MERCURY (TOTAL) & 0 & $M G / L$ & 0.0020 & - & - & - & - & $\cdot$ & - & - & - \\
\hline MOLYBDENUM & 13 & $M G / L$ & 0.1000 & - & - & - & - & $\cdot$ & $\cdot$ & - & - \\
\hline MOLYBDENUM (TOTAL) & 2 & $M G / L$ & 0.1000 & - & - & - & - & $\cdot$ & - & - & - \\
\hline NET GROSS ALPHA * & 13 & PCI /L & 15.0000 & - & - & - & - & - & - & - & - \\
\hline NET GROSS ALPHA (TOTAL) ** & 2 & $\mathrm{PCI} / \mathrm{L}$ & 15.0000 & 0551 & $02 / 17 / 94$ & NOO1 & JE & u & 35.9 & - & - \\
\hline
\end{tabular}

* NET gRoss ALPHA (GROSS ALPHA - URANIUM) WITH 1 MG URANIUM = 686 PCI

** TOTAL NET GROSS ALPHA (TOTAL GROSS ALPHA - TOTAL URANIUM)

FORMATION OF COMPLETION CODE

JE - JURASSIC ENTRADA SANDSTONE FORMATION

FLOW RELATIONSHIP CODE:

U - UPGRADIENT

O - ON-SITE

OTHER PARAMETER VALUE FLAGS:

L - LESS THAN THREE BORE VOLUMES REMOVED BEFORE SAMPLING

SAMPLE ID CODES:

NO01 - UNFILTERED SAMPLE 
TABLE 3.14 GROUND HATER QUALITY MEASUREMENTS EXCEEDING MCLS IN ENTRADA FORMATION BACKGROUND GROUND WATER, UC SITE, SLICK ROCK, COLORADO

SITE: SRKO1 SLICK ROCK (BOTH SITES)

$03 / 29 / 89$ TO $02 / 17 / 94$

REPORT DATE: 09/29/94

\begin{tabular}{|c|c|c|c|c|c|c|c|c|c|c|c|}
\hline PARAMETER NAME & $\begin{array}{l}\text { TOTAL } \\
\text { \# OF } \\
\text { SAMP. }\end{array}$ & $\begin{array}{l}\text { UNITS } \\
\text { OF } \\
\text { MEASURE }\end{array}$ & $\begin{array}{l}\text { MAXIMUM } \\
\text { CONC. } \\
\text { LIMIT }\end{array}$ & LOC. & LOG DATE & $\underset{\text { SAMP }}{\operatorname{SO}}$ & $\begin{array}{c}\text { FORM } \\
\text { OF } \\
\text { COMP }\end{array}$ & $\begin{array}{l}\text { HYDR } \\
\text { FLOW } \\
\text { REL. }\end{array}$ & $\begin{array}{l}\text { RESULT EXCEEDING MAX. } \\
\text { CONCENTRATION LIMIT } \\
\text { VALUE FLAGS }\end{array}$ & $\begin{array}{l}\text { DETECTION } \\
\text { LIMIT }\end{array}$ & $\begin{array}{l}\text { PARAMETER } \\
\text { UNCERT. }\end{array}$ \\
\hline NITRATE & 11 & $M G / L$ & 44.0000 & - & - & - & - & - & - & - & - \\
\hline NITRATE (TOTAL) & 2 & $M G / L$ & 44.0000 & - & - & - & - & - & - & - & - \\
\hline$R A-226 \& R A-228$ & 12 & $\mathrm{PCI} / \mathrm{L}$ & 5.0000 & 0703 & $08 / 07 / 91$ & 0001 & JE & 0 & 6.3 & - & - \\
\hline RA-226 \& RA-228 (TOTAL) & 2 & $\mathrm{PCI} / \mathrm{L}$ & 5.0000 & 0703 & $02 / 17 / 94$ & N001 & JE & 0 & 6.2 & - & - \\
\hline SELENIUM & 13 & MG/L & 0.0100 & $\begin{array}{l}0551 \\
0551\end{array}$ & $\begin{array}{l}12 / 12 / 90 \\
03 / 28 / 91\end{array}$ & $\left|\begin{array}{l}0001 \\
0001\end{array}\right|$ & $\begin{array}{l}\text { JE } \\
\text { JE }\end{array}$ & $\begin{array}{l}U \\
U\end{array}$ & $\begin{array}{ll}0.021 & \mathrm{~L} \\
0.013 & \mathrm{JL}\end{array}$ & $\begin{array}{l}0.005 \\
0.005\end{array}$ & - \\
\hline SELENIUM (TOTAL) & 2 & MG/L & 0.0100 & - & - & - & - & - & - & - & - \\
\hline SILVER & 9 & $M G / L$ & 0.0500 & - & - & - & - & - & - & - & - \\
\hline SILVER (TOTAL) & 0 & $M G / L$ & 0.0500 & - & - & - & - & - & - & - & - \\
\hline URANIUM & 13 & MG/L & 0.0440 & - & - & - & - & - & - & - & - \\
\hline URANIUM (TOTAL) & 2 & $M G / L$ & 0.0440 & - & - & - & - & - & - & - & - \\
\hline
\end{tabular}

** TOTAL NET GROSS ALPHA (TOTAL GROSS ALPHA - TOTAL URANIUM)

WITH 1 MG DISSOLVED URANIUM $=686 \mathrm{PCI}$

\section{FORMATION OF COMPLETION CODE:}

JE - JURASSIC ENTRADA SANDSTONE FORMATION

OTHER PARAMETER VALUE FLAGS:

$J$ - ESTIMATED VALUE

L - LESS THAN THREE BORE VOLUMES REMOVED BEFORE SAMPLING

DATA FILE NAME: IDARTISRK01\GWQ10057.DAT
FLOW RELATIONSHIP CODE:

O - ON-SITE

U - UPGRADIENT

SAMPLE ID CODES:

0001 - FILTERED SAMPLE (.45 MICRONS)

N001 - UNFILTERED SAMPLE 
TABLE 3.15 BACKGROUND GROUND WATER QUALITY DATA BY PARAMETER FOR THE NAVAJO SANDSTONE, NC AND UC PROCESSING SITES, SLICK ROCK, COLORADO SITE: SRKO1 SLICK ROCK (BOTH SITES)

02/02/86 TO 02/19/94

REPORT DATE : $09 / 29 / 94$

\begin{tabular}{|c|c|c|c|c|c|c|c|c|c|c|c|}
\hline PARAMETER NAME & $\underset{\text { ID }}{\text { LOCATION }}$ & LOG DATE & $\underset{\text { ID }}{\text { SAMPLE }}$ & $\begin{array}{l}\text { FORM } \\
\text { COMP }\end{array}$ & $\begin{array}{l}\text { FLOW } \\
\text { REL. }\end{array}$ & $\begin{array}{l}\text { UNITS OF } \\
\text { MEASURE }\end{array}$ & PVI & $\begin{array}{l}\text { ARAMETER } \\
\text { VALUE }\end{array}$ & FLAGS & $\begin{array}{l}\text { DETECTION } \\
\text { LIMIT }\end{array}$ & $\begin{array}{l}\text { PARAMETER } \\
\text { UNCERTAINTY }\end{array}$ \\
\hline ALKAL INITY & $\begin{array}{l}0558 \\
0558 \\
0558 \\
0558 \\
0558 \\
0558 \\
0668 \\
0668 \\
0668 \\
0668 \\
0668 \\
0668 \\
0668 \\
0668 \\
0687 \\
0687 \\
0687 \\
0687 \\
0687 \\
0687 \\
0687 \\
0687 \\
0687 \\
0687\end{array}$ & $\begin{array}{l}12 / 15 / 90 \\
03 / 30 / 91 \\
08 / 07 / 91 \\
12 / 05 / 91 \\
10 / 12 / 92 \\
02 / 18 / 94 \\
02 / 02 / 86 \\
06 / 30 / 86 \\
10 / 14 / 87 \\
02 / 19 / 88 \\
12 / 15 / 90 \\
11 / 18 / 91 \\
10 / 11 / 92 \\
02 / 18 / 94 \\
07 / 18 / 86 \\
04 / 08 / 87 \\
10 / 15 / 87 \\
02 / 19 / 88 \\
12 / 15 / 90 \\
04 / 03 / 91 \\
08 / 27 / 91 \\
12 / 05 / 91 \\
10 / 07 / 92 \\
02 / 19 / 94\end{array}$ & $\begin{array}{l}0001 \\
0001 \\
0001 \\
0001 \\
0001 \\
\text { N001 } \\
0001 \\
0001 \\
0001 \\
0001 \\
0001 \\
0001 \\
0001 \\
\text { N001 } \\
0001 \\
0001 \\
0001 \\
0001 \\
0001 \\
0001 \\
0001 \\
0001 \\
0001 \\
\text { N001 }\end{array}$ & $\begin{array}{l}\text { NA } \\
\text { NA } \\
\text { NA } \\
\text { NA } \\
\text { NA } \\
\text { NA } \\
\text { NA } \\
\text { NA } \\
\text { NA } \\
\text { NA } \\
\text { NA } \\
\text { NA } \\
\text { NA } \\
\text { NA } \\
\text { NA } \\
\text { NA } \\
\text { NA } \\
\text { NA } \\
\text { NA } \\
\text { NA } \\
\text { NA } \\
\text { NA } \\
\text { NA } \\
\text { NA }\end{array}$ & $\begin{array}{l}U \\
U \\
U \\
U \\
U \\
U \\
U \\
U \\
U \\
U \\
U \\
U \\
U \\
U \\
U \\
U \\
U \\
U \\
U \\
U \\
U \\
U \\
U \\
U\end{array}$ & MG $/ L \quad C A C O 3$ & & $\begin{array}{l}348 . \\
368 . \\
330 \\
357 \\
344 \\
334 \\
268 . \\
261 . \\
256 . \\
292 . \\
310 . \\
267 \\
263 \\
266 \\
418 . \\
436 . \\
407 . \\
445 . \\
410 . \\
404 . \\
415 \\
398 \\
394 \\
407\end{array}$ & $\begin{array}{l}L \\
L \\
L \\
L \\
L \\
L \\
L \\
\\
\\
L \\
L \\
L \\
J \\
L\end{array}$ & $\begin{array}{l}- \\
- \\
- \\
- \\
- \\
- \\
- \\
- \\
- \\
- \\
- \\
- \\
- \\
- \\
- \\
- \\
- \\
-\end{array}$ & $\begin{array}{l}- \\
- \\
- \\
- \\
- \\
- \\
- \\
- \\
- \\
- \\
- \\
- \\
- \\
- \\
- \\
- \\
- \\
- \\
-\end{array}$ \\
\hline ALUM I NUM & $\begin{array}{l}0558 \\
0558 \\
0558 \\
0558 \\
0558 \\
0668 \\
0668 \\
0668 \\
0668 \\
0668 \\
0668 \\
0687 \\
0687 \\
0687\end{array}$ & $\begin{array}{l}12 / 15 / 90 \\
03 / 30 / 91 \\
08 / 07 / 91 \\
12 / 11 / 91 \\
10 / 12 / 92 \\
06 / 30 / 86 \\
10 / 14 / 87 \\
02 / 19 / 88 \\
12 / 15 / 90 \\
11 / 18 / 91 \\
10 / 11 / 92 \\
07 / 18 / 86 \\
04 / 08 / 87 \\
10 / 15 / 87\end{array}$ & $\begin{array}{l}0001 \\
0001 \\
0001 \\
0001 \\
0001 \\
0001 \\
0001 \\
0001 \\
0001 \\
0001 \\
0001 \\
0001 \\
0001 \\
0001\end{array}$ & $\begin{array}{l}\text { NA } \\
\text { NA } \\
\text { NA } \\
\text { NA } \\
\text { NA } \\
\text { NA } \\
\text { NA } \\
\text { NA } \\
\text { NA } \\
\text { NA } \\
\text { NA } \\
\text { NA } \\
\text { NA } \\
\text { NA }\end{array}$ & $\begin{array}{l}U \\
U \\
U \\
U \\
U \\
U \\
U \\
U \\
U \\
U \\
U \\
U \\
U \\
U\end{array}$ & MG/L & $\begin{array}{l}< \\
< \\
< \\
< \\
< \\
< \\
< \\
< \\
< \\
<\end{array}$ & $\begin{array}{l}0.1 \\
0.05 \\
0.05 \\
0.05 \\
0.05 \\
0.3 \\
0.1 \\
0.10 \\
0.1 \\
0.05 \\
0.05 \\
0.3 \\
0.1 \\
0.1\end{array}$ & $\begin{array}{l}L \\
L \\
L \\
L \\
L \\
L\end{array}$ & $\begin{array}{l}0.1 \\
0.05 \\
0.05 \\
0.05 \\
0.05 \\
0.1 \\
0.1 \\
0.1 \\
0.1 \\
0.05 \\
0.05 \\
0.1 \\
0.1 \\
0.1\end{array}$ & $\begin{array}{l}- \\
: \\
- \\
- \\
- \\
- \\
- \\
- \\
- \\
-\end{array}$ \\
\hline
\end{tabular}

FORMATION OF COMPLETION CODE:

NA - NAVAJO SANDSTONE

PARAMETER VALUE INDICATOR (PVI): < - LESS THAN DETECTION LIMIT

OTHER PARAMETER VALUE FLAGS:

$J$ - ESTIMATED VALUE

L - LESS THAN THREE BORE VOLUMES REMOVED BEFORE SAMPLING
FLOW RELATIONSHIP CODE:

$U$ - UPGRADIENT

SAMPLE ID CODES:

0001 - FILTERED SAMPLE (.45 MICRONS)

NO01 - UNFILTERED SAMPLE 


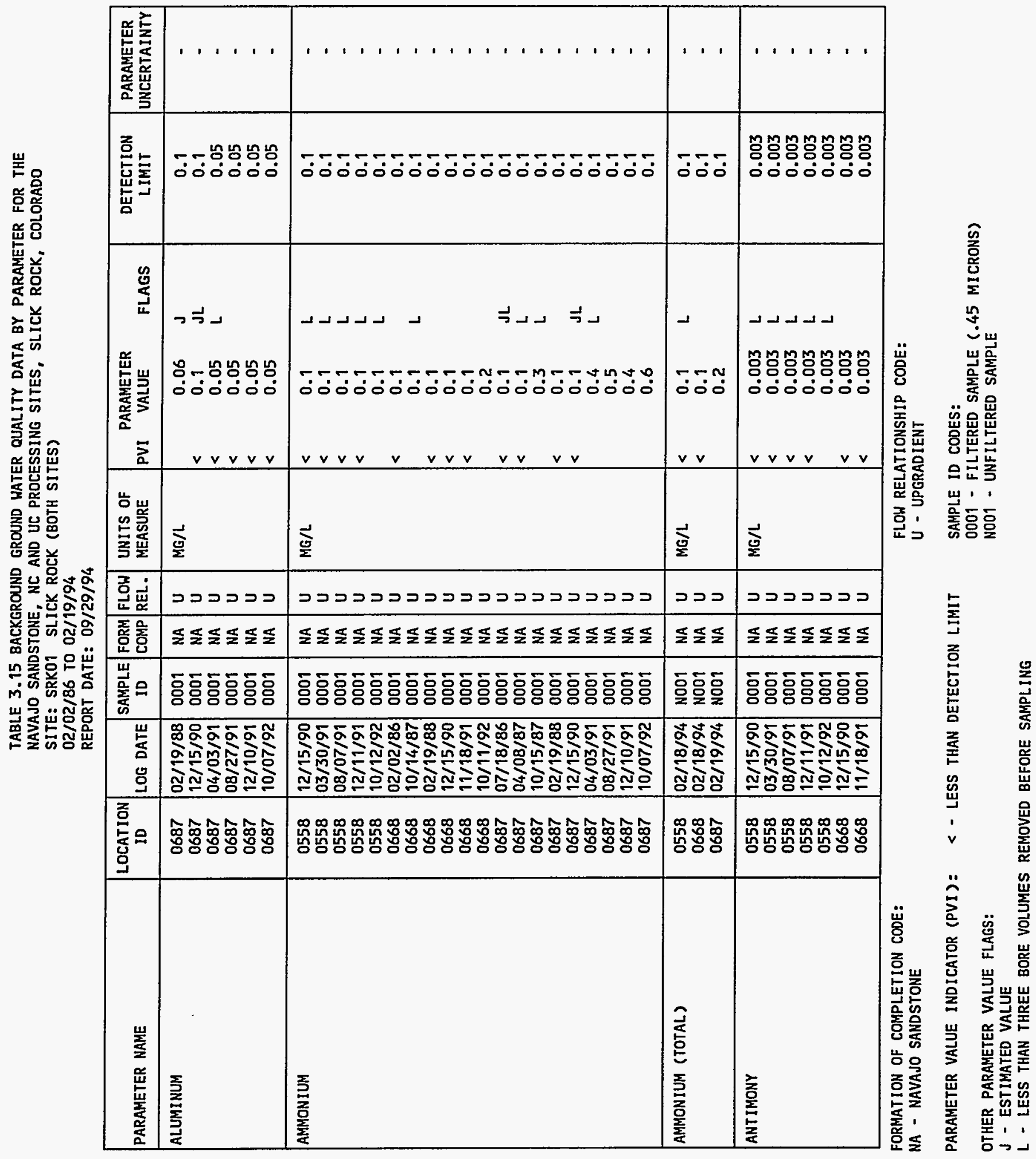


TABLE 3.15 BACKGROUND GROUND WATER QUALITY DATA BY PARAMETER FOR THE NAVAJO SANDSTONE, NC AND UC PROCESSING SITES, SLICK ROCK, COLORADO SITE: SRKO1 SLICK ROCK (BOTH SITES)

$02 / 02 / 86$ TO $02 / 19 / 94$

REPORT DATE: $09 / 29 / 94$

\begin{tabular}{|c|c|c|c|c|c|c|c|c|c|c|c|}
\hline PARAMETER NAME & $\begin{array}{c}\text { LOCATION } \\
\text { ID }\end{array}$ & LOG DATE & $\underset{\text { ID }}{\text { SAMPLE }}$ & $\begin{array}{l}\text { FORM } \\
\text { COMP }\end{array}$ & $\begin{array}{l}\text { FLOW } \\
\text { REL. }\end{array}$ & $\begin{array}{l}\text { UNITS OF } \\
\text { MEASURE }\end{array}$ & PVI & $\begin{array}{l}\text { PARAMETER } \\
\text { VALUEE }\end{array}$ & FLAGS & $\begin{array}{l}\text { DETECTION } \\
\text { LIMIT }\end{array}$ & $\begin{array}{l}\text { PARAMETER } \\
\text { UNCERTAINTY }\end{array}$ \\
\hline ANT IMONY & $\begin{array}{l}0668 \\
0687 \\
0687 \\
0687 \\
0687 \\
0687 \\
0687 \\
0687\end{array}$ & $\begin{array}{l}10 / 11 / 92 \\
07 / 18 / 86 \\
04 / 08 / 87 \\
12 / 15 / 90 \\
04 / 03 / 91 \\
08 / 27 / 91 \\
12 / 10 / 91 \\
10 / 07 / 92\end{array}$ & $\begin{array}{l}0001 \\
0001 \\
0001 \\
0001 \\
0001 \\
0001 \\
0001 \\
0001\end{array}$ & $\begin{array}{l}\text { NA } \\
\text { NA } \\
\text { NA } \\
\text { NA } \\
\text { NA } \\
\text { NA } \\
\text { NA } \\
\text { NA }\end{array}$ & $\begin{array}{l}U \\
U \\
U \\
U \\
U \\
U \\
U \\
U\end{array}$ & $M G / L$ & $\begin{array}{l}< \\
< \\
< \\
< \\
< \\
< \\
< \\
<\end{array}$ & $\begin{array}{l}0.003 \\
0.003 \\
0.003 \\
0.003 \\
0.003 \\
0.003 \\
0.003 \\
0.003\end{array}$ & $\begin{array}{l}L \\
L \\
J L \\
L\end{array}$ & $\begin{array}{l}0.003 \\
0.003 \\
0.003 \\
0.003 \\
0.003 \\
0.003 \\
0.003 \\
0.003\end{array}$ & $\begin{array}{l}- \\
- \\
- \\
- \\
- \\
- \\
-\end{array}$ \\
\hline ARSENIC & $\begin{array}{l}0558 \\
0558 \\
0558 \\
0558 \\
0558 \\
0668 \\
0668 \\
0668 \\
0668 \\
0668 \\
0668 \\
0687 \\
0687 \\
0687 \\
0687 \\
0687 \\
0687 \\
0687 \\
0687\end{array}$ & $\begin{array}{l}12 / 15 / 90 \\
03 / 30 / 91 \\
08 / 07 / 91 \\
12 / 11 / 91 \\
10 / 12 / 92 \\
02 / 02 / 86 \\
06 / 30 / 86 \\
10 / 14 / 87 \\
12 / 15 / 90 \\
11 / 18 / 91 \\
10 / 11 / 92 \\
07 / 18 / 86 \\
04 / 08 / 87 \\
10 / 15 / 87 \\
12 / 15 / 90 \\
04 / 03 / 91 \\
08 / 27 / 91 \\
12 / 10 / 91 \\
10 / 07 / 92\end{array}$ & $\begin{array}{l}0001 \\
0001 \\
0001 \\
0001 \\
0001 \\
0001 \\
0001 \\
0001 \\
0001 \\
0001 \\
0001 \\
0001 \\
0001 \\
0001 \\
0001 \\
0001 \\
0001 \\
0001 \\
0001\end{array}$ & $\begin{array}{l}\text { NA } \\
\text { NA } \\
\text { NA } \\
\text { NA } \\
\text { NA } \\
\text { NA } \\
\text { NA } \\
\text { NA } \\
\text { NA } \\
\text { NA } \\
\text { NA } \\
\text { NA } \\
\text { NA } \\
\text { NA } \\
\text { NA } \\
\text { NA } \\
\text { NA } \\
\text { NA } \\
\text { NA }\end{array}$ & $\begin{array}{l}U \\
U \\
U \\
U \\
U \\
U \\
U \\
U \\
U \\
U \\
U \\
U \\
U \\
U \\
U \\
U \\
U \\
U \\
U\end{array}$ & $M G / L$ & $\begin{array}{l}< \\
< \\
< \\
< \\
< \\
< \\
< \\
< \\
<\end{array}$ & $\begin{array}{l}0.001 \\
0.01 \\
0.01 \\
0.01 \\
0.005 \\
0.01 \\
0.01 \\
0.01 \\
0.005 \\
0.01 \\
0.007 \\
0.01 \\
0.017 \\
0.02 \\
0.022 \\
0.02 \\
0.018 \\
0.05 \\
0.019\end{array}$ & $\begin{array}{l}J L \\
L \\
L W \\
L \\
L \\
L \\
J \\
L \\
L \\
L \\
J L \\
L \\
I W\end{array}$ & $\begin{array}{l}0.01 \\
0.01 \\
0.01 \\
0.01 \\
0.005 \\
0.01 \\
0.01 \\
0.01 \\
0.01 \\
0.01 \\
0.005 \\
0.01 \\
0.01 \\
0.01 \\
0.01 \\
0.01 \\
0.01 \\
0.05 \\
0.005\end{array}$ & $\begin{array}{l}- \\
- \\
- \\
- \\
- \\
- \\
- \\
- \\
- \\
- \\
- \\
- \\
- \\
- \\
- \\
- \\
-\end{array}$ \\
\hline BARIUM & $\begin{array}{l}0558 \\
0558 \\
0558 \\
0558 \\
0558 \\
0558 \\
0668 \\
0668\end{array}$ & $\begin{array}{l}12 / 15 / 90 \\
03 / 30 / 91 \\
08 / 07 / 91 \\
12 / 11 / 91 \\
10 / 12 / 92 \\
02 / 18 / 94 \\
10 / 14 / 87 \\
12 / 15 / 90\end{array}$ & $\begin{array}{l}0001 \\
0001 \\
0001 \\
0001 \\
0001 \\
0001 \\
0001 \\
0001\end{array}$ & $\begin{array}{l}\text { NA } \\
\text { NA } \\
\text { NA } \\
\text { NA } \\
\text { NA } \\
\text { NA } \\
\text { NA } \\
\text { NA }\end{array}$ & $\begin{array}{l}U \\
U \\
U \\
U \\
U \\
U \\
U \\
U\end{array}$ & MG/L & 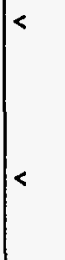 & $\begin{array}{l}0.1 \\
0.04 \\
0.03 \\
0.05 \\
0.03 \\
0.1 \\
0.2 \\
0.2\end{array}$ & $\begin{array}{l}L \\
L \\
L \\
L \\
L \\
L \\
L\end{array}$ & $\begin{array}{l}0.1 \\
0.01 \\
0.01 \\
0.01 \\
0.01 \\
0.1 \\
0.1 \\
0.1\end{array}$ & $\begin{array}{l}- \\
- \\
- \\
- \\
- \\
- \\
-\end{array}$ \\
\hline
\end{tabular}

FORMATION OF COMPLETION CODE:

NA - NAVAJO SANDSTONE

PARAMETER VALUE INDICATOR (PVI): < - LESS THAN DETECTION LIMIT
FLOW RELATIONSHIP CODE:

$U$ - UPGRADIENT

SAMPLE ID CODES:

0001 - FILTERED SAMPLE (.45 MICRONS)

OTHER PARAMETER VALUE FLAGS:

I - INCREASED DETECTION LIMIT DUE TO REQUIRED DILUTION

$J$ - ESTIMATED VALUE

L - LESS THAN THREE BORE VOLUMES REMOVED BEFORE SAMPLING

$W$ - POST-DIGEST SPIKE OUT OF CNTR LIM WHILE SAMP ABS < $50 \%$ SPIKE 
TABLE 3.15 BACKGROUND GROUND WATER QUALITY DATA BY PARAMETER FOR THE

NAVAJO SANDSTONE, NC AND UC PROCESSING SITES, SLICK ROCK, COLORADO

SITE: SRKOI SLICK ROCK (BOTH SITES)

02/02/86 TO 02/19/94

\begin{tabular}{|c|c|c|c|c|c|c|c|c|c|c|c|}
\hline PARAMETER NAME & $\begin{array}{c}\text { LOCATION } \\
\text { ID }\end{array}$ & LOG DATE & $\begin{array}{c}\text { SAMPLE } \\
\text { ID }\end{array}$ & $\begin{array}{l}\text { FORM } \\
\text { COMP }\end{array}$ & $\begin{array}{l}\text { FLOW } \\
\text { REL. }\end{array}$ & $\begin{array}{l}\text { UNITS OF } \\
\text { MEASURE }\end{array}$ & PVI & $\begin{array}{l}\text { PARAMETER } \\
\text { VALUE }\end{array}$ & FLAGS & $\begin{array}{l}\text { DETECTION } \\
\text { LIMIT }\end{array}$ & $\begin{array}{l}\text { PARAMETER } \\
\text { UNCERTAINTY }\end{array}$ \\
\hline BARIUM & $\begin{array}{l}0668 \\
0668 \\
0668 \\
0687 \\
0687 \\
0687 \\
0687 \\
0687 \\
0687 \\
0687 \\
0687 \\
0687\end{array}$ & $\begin{array}{l}11 / 18 / 91 \\
10 / 11 / 92 \\
02 / 18 / 94 \\
07 / 18 / 86 \\
04 / 08 / 87 \\
10 / 15 / 87 \\
12 / 15 / 90 \\
04 / 03 / 91 \\
08 / 27 / 91 \\
12 / 10 / 91 \\
10 / 07 / 92 \\
02 / 19 / 94\end{array}$ & $\begin{array}{l}0001 \\
0001 \\
0001 \\
0001 \\
0001 \\
0001 \\
0001 \\
0001 \\
0001 \\
0001 \\
0001 \\
0001\end{array}$ & $\begin{array}{l}\text { NA } \\
\text { NA } \\
\text { NA } \\
\text { NA } \\
\text { NA } \\
\text { NA } \\
\text { NA } \\
\text { NA } \\
\text { NA } \\
\text { NA } \\
\text { NA } \\
\text { NA }\end{array}$ & $\begin{array}{l}U \\
U \\
U \\
U \\
U \\
U \\
U \\
U \\
U \\
U \\
U \\
U\end{array}$ & MG/L & $<$ & $\begin{array}{l}0.16 \\
0.18 \\
0.2 \\
0.2 \\
0.1 \\
0.1 \\
0.1 \\
0.04 \\
0.04 \\
0.04 \\
0.04 \\
0.1\end{array}$ & $\begin{array}{l}\mathrm{L} \\
\mathrm{L} \\
\mathrm{L} \\
\mathrm{JL} \\
\mathrm{L}\end{array}$ & $\begin{array}{l}0.01 \\
0.01 \\
0.1 \\
0.1 \\
0.1 \\
0.1 \\
0.1 \\
0.01 \\
0.01 \\
0.01 \\
0.01 \\
0.1\end{array}$ & $\begin{array}{l}- \\
- \\
- \\
- \\
- \\
- \\
- \\
- \\
-\end{array}$ \\
\hline BARIUM (TOTAL) & $\begin{array}{l}0558 \\
0668 \\
0687\end{array}$ & $\begin{array}{l}02 / 18 / 94 \\
02 / 18 / 94 \\
02 / 19 / 94\end{array} \mid$ & $\begin{array}{l}\text { N001 } \\
\text { N001 } \\
\text { N001 }\end{array}$ & $\begin{array}{l}\text { NA } \\
\text { NA } \\
\text { NA }\end{array}$ & $\begin{array}{l}U \\
U \\
U\end{array}$ & $M G / L$ & $<$ & $\begin{array}{l}0.5 \\
0.2 \\
0.1\end{array}$ & L & $\begin{array}{l}0.1 \\
0.1 \\
0.1\end{array}$ & - \\
\hline BERYLLIUM & $\begin{array}{l}0558 \\
0558 \\
0558 \\
0558 \\
0668 \\
0668 \\
0687 \\
0687 \\
0687 \\
0687\end{array}$ & $\begin{array}{l}12 / 15 / 90 \\
03 / 30 / 91 \\
08 / 07 / 91 \\
12 / 11 / 91 \\
12 / 15 / 90 \\
11 / 18 / 91 \\
12 / 15 / 90 \\
04 / 03 / 91 \\
08 / 27 / 91 \\
12 / 10 / 91\end{array}$ & $\begin{array}{l}0001 \\
0001 \\
0001 \\
0001 \\
0001 \\
0001 \\
0001 \\
0001 \\
0001 \\
0001\end{array}$ & $\begin{array}{l}\text { NA } \\
\text { NA } \\
\text { NA } \\
\text { NA } \\
\text { NA } \\
\text { NA } \\
\text { NA } \\
\text { NA } \\
\text { NA } \\
\text { NA }\end{array}$ & $\begin{array}{l}U \\
U \\
U \\
U \\
U \\
U \\
U \\
U \\
U \\
U\end{array}$ & $M G / L$ & $\begin{array}{l}< \\
< \\
< \\
< \\
< \\
< \\
< \\
< \\
< \\
<\end{array}$ & $\begin{array}{l}0.01 \\
0.005 \\
0.005 \\
0.005 \\
0.01 \\
0.005 \\
0.01 \\
0.005 \\
0.005 \\
0.005\end{array}$ & $\begin{array}{l}\mathrm{L} \\
\mathrm{L} \\
\mathrm{L} \\
\mathrm{L} \\
\mathrm{JL} \\
\mathrm{L}\end{array}$ & $\begin{array}{l}0.01 \\
0.005 \\
0.005 \\
0.005 \\
0.01 \\
0.005 \\
0.01 \\
0.005 \\
0.005 \\
0.005\end{array}$ & $\begin{array}{l}- \\
- \\
- \\
- \\
- \\
- \\
-\end{array}$ \\
\hline BORON & $\begin{array}{l}0558 \\
0558 \\
0558 \\
0558 \\
0558 \\
0668 \\
0668 \\
0668 \\
0668 \\
0687 \\
0687\end{array}$ & $\begin{array}{l}12 / 15 / 90 \\
03 / 30 / 91 \\
08 / 07 / 91 \\
12 / 11 / 91 \\
02 / 18 / 94 \\
10 / 14 / 87 \\
12 / 15 / 90 \\
11 / 18 / 91 \\
02 / 18 / 94 \\
07 / 18 / 86 \\
10 / 15 / 87\end{array}$ & $\begin{array}{l}0001 \\
0001 \\
0001 \\
0001 \\
0001 \\
0001 \\
0001 \\
0001 \\
0001 \\
0001 \\
0001\end{array}$ & $\begin{array}{l}\text { NA } \\
\text { NA } \\
\text { NA } \\
\text { NA } \\
\text { NA } \\
\text { NA } \\
\text { NA } \\
\text { NA } \\
\text { NA } \\
\text { NA } \\
\text { NA }\end{array}$ & $\begin{array}{l}U \\
U \\
U \\
U \\
U \\
U \\
U \\
U \\
U \\
U \\
U\end{array}$ & $M G / L$ & 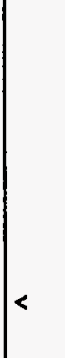 & $\begin{array}{l}0.3 \\
0.38 \\
0.48 \\
0.66 \\
0.5 \\
0.1 \\
0.1 \\
0.13 \\
0.1 \\
0.1 \\
1.6\end{array}$ & $\begin{array}{l}L \\
L \\
L \\
L \\
L \\
L\end{array}$ & $\begin{array}{l}0.1 \\
0.05 \\
0.05 \\
0.05 \\
0.1 \\
0.1 \\
0.1 \\
0.05 \\
0.1 \\
0.1 \\
0.1\end{array}$ & $\begin{array}{l}- \\
- \\
- \\
- \\
- \\
- \\
- \\
-\end{array}$ \\
\hline
\end{tabular}

FORMATION OF COMPLETION CODE:

NA - NAVAJO SANDSTONE

PARAMETER VALUE INDICATOR (PVI): < - LESS THAN DETECTION LIMIT

OTHER PARAMETER VALUE FLAGS:

$J$ - ESTIMATED VALUE

L - LESS THAN THREE BORE VOLUMES REMOVED BEFORE SAMPLING
FLOW RELATIONSHIP CODE:

$U$ - UPGRADIENT

SAMPLE ID CODES:

0001 - FILTERED SAMPLE (.45 MICRONS)

N001 - UNFILTERED SAMPLE 
TABLE 3.15 BACKGROUND GROUND HATER QUALITY DATA BY PARAMETER FOR THE NAVAJO SANDSTONE, NC AND UC PROCESSING SITES, SLICK ROCK, COLORADO

SITE: SRKO1 SLICK ROCK (BOTH SITES)

02/02/86 TO $02 / 19 / 94$

\begin{tabular}{|c|c|c|c|c|c|c|c|c|c|c|c|}
\hline PARAMETER NAME & $\begin{array}{c}\text { LOCATION } \\
\text { ID }\end{array}$ & LOG DATE & $\begin{array}{c}\text { SAMPLE } \\
10\end{array}$ & $\begin{array}{l}\text { FORM } \\
\text { COMP }\end{array}$ & $\begin{array}{l}\text { FLOW } \\
\text { REL. }\end{array}$ & $\begin{array}{l}\text { UNITS OF } \\
\text { MEASURE }\end{array}$ & PVI & $\begin{array}{l}\text { ARAMETER } \\
\text { VALUE }\end{array}$ & FLAGS & $\begin{array}{l}\text { DETECTION } \\
\text { LIMIT }\end{array}$ & $\begin{array}{l}\text { PARAMETER } \\
\text { UNCERTAINTY }\end{array}$ \\
\hline BORON & $\begin{array}{l}0687 \\
0687 \\
0687 \\
0687 \\
0687\end{array}$ & $\begin{array}{l}12 / 15 / 90 \\
04 / 03 / 91 \\
08 / 27 / 91 \\
12 / 10 / 91 \\
02 / 19 / 94\end{array}$ & $\begin{array}{l}0001 \\
0001 \\
0001 \\
0001 \\
0001\end{array}$ & $\begin{array}{l}\text { NA } \\
\text { NA } \\
\text { NA } \\
\text { NA } \\
\text { NA }\end{array}$ & $\begin{array}{l}U \\
U \\
U \\
U \\
U\end{array}$ & $M G / L$ & & $\begin{array}{l}1.6 \\
1.56 \\
1.63 \\
1.62 \\
1.6\end{array}$ & $\begin{array}{l}J L \\
L\end{array}$ & $\begin{array}{l}0.1 \\
0.05 \\
0.05 \\
0.05 \\
0.1\end{array}$ & $\begin{array}{l}- \\
- \\
-\end{array}$ \\
\hline BORON (TOTAL) & $\begin{array}{l}0558 \\
0668 \\
0687\end{array}$ & $\begin{array}{l}02 / 18 / 94 \\
02 / 18 / 94 \\
02 / 19 / 94\end{array}$ & $\begin{array}{l}\text { N001 } \\
\text { N001 } \\
\text { N001 }\end{array}$ & $\begin{array}{l}\text { NA } \\
\text { NA } \\
\text { NA }\end{array}$ & $\begin{array}{l}U \\
U \\
U\end{array}$ & $M G / L$ & & $\begin{array}{l}0.5 \\
0.2 \\
1.5\end{array}$ & $L$ & $\begin{array}{l}0.1 \\
0.1 \\
0.1\end{array}$ & $\begin{array}{l}- \\
-\end{array}$ \\
\hline BROMIDE & $\begin{array}{l}0558 \\
0558 \\
0558 \\
0558 \\
0558 \\
0668 \\
0668 \\
0668 \\
0687 \\
0687 \\
0687 \\
0687 \\
0687\end{array}$ & \begin{tabular}{|l|}
$12 / 15 / 90$ \\
$03 / 30 / 91$ \\
$08 / 07 / 91$ \\
$12 / 11 / 91$ \\
$10 / 12 / 92$ \\
$12 / 15 / 90$ \\
$11 / 18 / 91$ \\
$10 / 11 / 92$ \\
$12 / 15 / 90$ \\
$04 / 03 / 91$ \\
$08 / 27 / 91$ \\
$12 / 10 / 91$ \\
$10 / 07 / 92$
\end{tabular} & $\begin{array}{l}0001 \\
0001 \\
0001 \\
0001 \\
0001 \\
0001 \\
0001 \\
0001 \\
0001 \\
0001 \\
0001 \\
0001 \\
0001\end{array}$ & $\begin{array}{l}\text { NA } \\
\text { NA } \\
\text { NA } \\
\text { NA } \\
\text { NA } \\
\text { NA } \\
\text { NA } \\
\text { NA } \\
\text { NA } \\
\text { NA } \\
\text { NA } \\
\text { NA } \\
\text { NA }\end{array}$ & $\begin{array}{l}U \\
U \\
U \\
U \\
U \\
U \\
U \\
U \\
U \\
U \\
U \\
U \\
U\end{array}$ & $M G / L$ & $\begin{array}{l}\mid \\
< \\
< \\
< \\
< \\
< \\
< \\
< \\
< \\
<\end{array}$ & $\begin{array}{l}0.1 \\
0.4 \\
0.4 \\
0.5 \\
0.3 \\
0.1 \\
0.1 \\
0.1 \\
0.1 \\
0.1 \\
0.1 \\
0.2 \\
0.1\end{array}$ & $\begin{array}{l}L \\
L \\
L \\
L \\
I L\end{array}$ & $\begin{array}{l}0.1 \\
0.1 \\
0.4 \\
0.1 \\
0.3 \\
0.1 \\
0.1 \\
0.1 \\
0.1 \\
0.1 \\
0.1 \\
0.1 \\
0.1\end{array}$ & $\begin{array}{l}- \\
- \\
- \\
- \\
- \\
- \\
- \\
- \\
- \\
-\end{array}$ \\
\hline CADMIUM & $\begin{array}{l}0558 \\
0558 \\
0558 \\
0558 \\
0558 \\
0558 \\
0668 \\
0668 \\
0668 \\
0668 \\
0668 \\
0668 \\
0687 \\
0687\end{array}$ & $\begin{array}{l}12 / 15 / 90 \\
03 / 30 / 91 \\
08 / 07 / 91 \\
12 / 11 / 91 \\
10 / 12 / 92 \\
02 / 18 / 94 \\
02 / 02 / 86 \\
10 / 14 / 87 \\
12 / 15 / 90 \\
11 / 18 / 91 \\
10 / 11 / 92 \\
02 / 18 / 94 \\
07 / 18 / 86 \\
04 / 08 / 87\end{array}$ & $\begin{array}{l}0001 \\
0001 \\
0001 \\
0001 \\
0001 \\
0001 \\
0001 \\
0001 \\
0001 \\
0001 \\
0001 \\
0001 \\
0001 \\
0001\end{array}$ & $\begin{array}{l}\text { NA } \\
\text { NA } \\
\text { NA } \\
\text { NA } \\
\text { NA } \\
\text { NA } \\
\text { NA } \\
\text { NA } \\
\text { NA } \\
\text { NA } \\
\text { NA } \\
\text { NA } \\
\text { NA } \\
\text { NA }\end{array}$ & $\begin{array}{l}U \\
U \\
U \\
U \\
U \\
U \\
U \\
U \\
U \\
U \\
U \\
U \\
U \\
U\end{array}$ & MG/L. & $\begin{array}{l}< \\
< \\
< \\
< \\
< \\
< \\
< \\
< \\
< \\
< \\
< \\
< \\
< \\
< \\
<\end{array}$ & $\begin{array}{l}0.001 \\
0.001 \\
0.001 \\
0.001 \\
0.001 \\
0.001 \\
0.001 \\
0.001 \\
0.001 \\
0.001 \\
0.001 \\
0.001 \\
0.001 \\
0.001\end{array}$ & $\begin{array}{l}L \\
L W \\
L \\
L \\
L \\
L \\
L\end{array}$ & $\begin{array}{l}0.001 \\
0.001 \\
0.001 \\
0.001 \\
0.001 \\
0.001 \\
0.001 \\
0.001 \\
0.001 \\
0.001 \\
0.001 \\
0.001 \\
0.001 \\
0.001\end{array}$ & $\begin{array}{l}- \\
- \\
- \\
- \\
- \\
- \\
- \\
- \\
- \\
- \\
- \\
-\end{array}$ \\
\hline
\end{tabular}

FORMATION OF COMPLETION CODE:

NA - NAVAJO SANDSTONE

PARAMETER VALUE INDICATOR (PVI): < - LESS THAN DETECTION LIMIT

OTHER PARAMETER VALUE FLAGS:

I - INCREASED DETECTION LIMIT DUE TO REQUIRED DILUTION

$J$ - ESTIMATED VALUE

L - LESS THAN THREE BORE VOLUMES REMOVED BEFORE SAMPLING

$H$ - POST-DIGEST SPIKE OUT OF CNTR LIM WHILE SAMP ABS < $50 \%$ SPIKE
FLOW RELATIONSHIP CODE:

$U$ - UPGRADIENT

SAMPLE ID CODES:

0001 - FILTERED SAMPLE (.45 MICRONS)

NOO1 - UNFILTERED SAMPLE 
TABLE 3.15 BACKGROUND GROUND WATER QUALITY DATA BY PARAMETER FOR THE

SITE: SRKO1 SLICK ROCK (BOTH SITES)

02/02/86 TO $02 / 19 / 94$

REPORT DATE: $09 / 29 / 94$

\begin{tabular}{|c|c|c|c|c|c|c|c|c|c|c|c|}
\hline PARAMETER NAME & $\left|\begin{array}{c}\text { LOCATION } \\
\text { ID }\end{array}\right|$ & LOG DATE & $\begin{array}{c}\text { SAMPLE } \\
\text { ID }\end{array}$ & $\begin{array}{l}\text { FORM } \\
\text { COMP }\end{array}$ & $\begin{array}{l}\text { FLOW } \\
\text { REL. }\end{array}$ & $\begin{array}{l}\text { UNITS OF } \\
\text { MEASURE }\end{array}$ & PVI & $\begin{array}{l}\text { ARAMETER } \\
\text { VALUE }\end{array}$ & FLAGS & $\begin{array}{l}\text { DETECTION } \\
\text { LIMIT }\end{array}$ & $\begin{array}{l}\text { PARAMETER } \\
\text { UNCERTAINTY }\end{array}$ \\
\hline CADMIUM & $\begin{array}{l}0687 \\
0687 \\
0687 \\
0687 \\
0687 \\
0687 \\
0687\end{array}$ & $\begin{array}{l}10 / 15 / 87 \\
12 / 15 / 90 \\
04 / 03 / 91 \\
08 / 27 / 91 \\
12 / 10 / 91 \\
10 / 07 / 92 \\
02 / 19 / 94\end{array}$ & $\begin{array}{l}0001 \\
0001 \\
0001 \\
0001 \\
0001 \\
0001 \\
0001\end{array}$ & $\begin{array}{l}\text { NA } \\
\text { NA } \\
\text { NA } \\
\text { NA } \\
\text { NA } \\
\text { NA } \\
\text { NA }\end{array}$ & $\begin{array}{l}U \\
U \\
U \\
U \\
U \\
U \\
U\end{array}$ & MG/L & $\begin{array}{l}< \\
< \\
< \\
< \\
< \\
< \\
< \\
<\end{array}$ & $\begin{array}{l}0.001 \\
0.001 \\
0.0005 \\
0.001 \\
0.001 \\
0.001 \\
0.001\end{array}$ & $\begin{array}{l}\mathrm{L} \\
\mathrm{JL} \\
\mathrm{L}\end{array}$ & $\begin{array}{l}0.001 \\
0.001 \\
0.0005 \\
0.001 \\
0.001 \\
0.001 \\
0.001\end{array}$ & $\begin{array}{l}- \\
- \\
- \\
- \\
-\end{array}$ \\
\hline CADMIUM (TOTAL) & $\begin{array}{l}0558 \\
0668 \\
0687\end{array}$ & $\begin{array}{l}02 / 18 / 94 \\
02 / 18 / 94 \\
02 / 19 / 94\end{array}$ & $\begin{array}{l}\text { N001 } \\
\text { N001 } \\
\text { N001 }\end{array}$ & $\begin{array}{l}\text { NA } \\
\text { NA } \\
\text { NA }\end{array}$ & $\begin{array}{l}U \\
U \\
U\end{array}$ & $\mathrm{MG} / \mathrm{L}$ & $<$ & $\begin{array}{l}0.001 \\
0.001 \\
0.001\end{array}$ & L & $\begin{array}{l}0.001 \\
0.001 \\
0.001\end{array}$ & : \\
\hline CALCIUM & $\begin{array}{l}0558 \\
0558 \\
0558 \\
0558 \\
0558 \\
0558 \\
0668 \\
0668 \\
0668 \\
0668 \\
0668 \\
0668 \\
0668 \\
0668 \\
0687 \\
0687 \\
0687 \\
0687 \\
0687 \\
0687 \\
0687 \\
0687 \\
0687 \\
0687\end{array}$ & $\begin{array}{l}12 / 15 / 90 \\
03 / 30 / 91 \\
08 / 07 / 91 \\
12 / 11 / 91 \\
10 / 12 / 92 \\
02 / 18 / 94 \\
02 / 02 / 86 \\
06 / 30 / 86 \\
10 / 14 / 87 \\
02 / 19 / 88 \\
12 / 15 / 90 \\
11 / 18 / 91 \\
10 / 11 / 92 \\
02 / 18 / 94 \\
07 / 18 / 86 \\
04 / 08 / 87 \\
10 / 15 / 87 \\
02 / 19 / 88 \\
12 / 15 / 90 \\
04 / 03 / 91 \\
08 / 27 / 91 \\
12 / 10 / 91 \\
10 / 07 / 92 \\
02 / 19 / 94\end{array}$ & $\begin{array}{l}0001 \\
0001 \\
0001 \\
0001 \\
0001 \\
0001 \\
0001 \\
0001 \\
0001 \\
0001 \\
0001 \\
0001 \\
0001 \\
0001 \\
0001 \\
0001 \\
0001 \\
0001 \\
0001 \\
0001 \\
0001 \\
0001 \\
0001 \\
0001\end{array}$ & $\begin{array}{l}\text { NA } \\
\text { NA } \\
\text { NA } \\
\text { NA } \\
\text { NA } \\
\text { NA } \\
\text { NA } \\
\text { NA } \\
\text { NA } \\
\text { NA } \\
\text { NA } \\
\text { NA } \\
\text { NA } \\
\text { NA } \\
\text { NA } \\
\text { NA } \\
\text { NA } \\
\text { NA } \\
\text { NA } \\
\text { NA } \\
\text { NA } \\
\text { NA } \\
\text { NA } \\
\text { NA }\end{array}$ & $\begin{array}{l}U \\
U \\
U \\
U \\
U \\
U \\
U \\
U \\
U \\
U \\
U \\
U \\
U \\
U \\
U \\
U \\
U \\
U \\
U \\
U \\
U \\
U \\
U \\
U\end{array}$ & MG/L & & $\begin{array}{l}48.1 \\
50.8 \\
59.9 \\
72.6 \\
78.9 \\
44.7 \\
26.7 \\
28.1 \\
30 . \\
28.1 \\
29.3 \\
29.3 \\
31.3 \\
27.9 \\
28.1 \\
28.3 \\
26 . \\
24.3 \\
24.3 \\
24.3 \\
24.5 \\
23.6 \\
24.5 \\
24.0\end{array}$ & $\begin{array}{l}L \\
L \\
L \\
L \\
L \\
L \\
L\end{array}$ & $\begin{array}{l}0.01 \\
0.5 \\
0.5 \\
0.5 \\
0.5 \\
0.5 \\
0.01 \\
0.01 \\
0.01 \\
0.01 \\
0.01 \\
0.5 \\
0.5 \\
0.5 \\
0.01 \\
0.01 \\
0.01 \\
0.01 \\
0.01 \\
0.5 \\
0.5 \\
0.5 \\
0.5 \\
0.5\end{array}$ & $\begin{array}{l}: \\
: \\
: \\
: \\
: \\
: \\
: \\
: \\
- \\
- \\
- \\
- \\
- \\
- \\
- \\
-\end{array}$ \\
\hline CALCIUM (TOTAL) & $\begin{array}{l}0558 \\
0668\end{array}$ & $\mid \begin{array}{l}02 / 18 / 94 \\
02 / 18 / 94\end{array}$ & $\begin{array}{l}\text { N001 } \\
\text { N001 }\end{array}$ & $\begin{array}{l}\text { NA } \\
\text { NA }\end{array}$ & $\begin{array}{l}U \\
U\end{array}$ & MG/L & & $\begin{array}{l}77.8 \\
31.5\end{array}$ & $L$ & $\begin{array}{l}0.5 \\
0.5\end{array}$ & - \\
\hline
\end{tabular}

FORMATION OF COMPLETION CODE:

NA - NAVAJO SANDSTONE

PARAMETER VALUE INDICATOR (PVI): < - LESS THAN DETECTION LIMIT

OTHER PARAMETER VALUE FLAGS:

$J$ - ESTIMATED VALUE
FLOW RELATIONSHIP CODE:

$U$ - UPGRADIENT

SAMPLE ID CODES:

0001 - FILTERED SAMPLE (.45 MICRONS)

NO01 - UNFILTERED SAMPLE 
TABLE 3.15 BACKGROUND GROUND WATER QUALITY DATA BY PARAMETER FOR THE NAVAJO SANDSTONE, NC AND UC PROCESSING SITES, SLICK ROCK, COLORADO SITE: SRKO1 SLICK ROCK (BOTH SITES)

02/02/86 TO 02/19/94

REPORT DATE: $09 / 29 / 94$

\begin{tabular}{|c|c|c|c|c|c|c|c|c|c|c|c|}
\hline PARAMETER NAME & $\underset{\text { ID }}{\text { LOCATION }}$ & LOG DATE & $\begin{array}{c}\text { SAMPLE } \\
\text { ID }\end{array}$ & $\begin{array}{l}\text { FORM } \\
\text { COMP }\end{array}$ & $\begin{array}{l}\text { FLOW } \\
\text { REL. }\end{array}$ & $\begin{array}{l}\text { UNITS OF } \\
\text { MEASURE }\end{array}$ & PVI & $\begin{array}{l}\text { ARAMETER } \\
\text { VALUE }\end{array}$ & FLAGS & $\begin{array}{l}\text { DETECT ION } \\
\text { LIMIT }\end{array}$ & $\begin{array}{l}\text { PARAMETER } \\
\text { UNCERTAINTY }\end{array}$ \\
\hline CALCIUM (TOTAL) & 0687 & $02 / 19 / 94$ & N001 & NA & $\mathrm{u}$ & $M G / L$ & \multicolumn{3}{|c|}{24.1} & 0.5 & - \\
\hline CHLORIDE & $\begin{array}{l}0558 \\
0558 \\
0558 \\
0558 \\
0558 \\
0558 \\
0668 \\
0668 \\
0668 \\
0668 \\
0668 \\
0668 \\
0668 \\
0668 \\
0687 \\
0687 \\
0687 \\
0687 \\
0687 \\
0687 \\
0687 \\
0687 \\
0687 \\
0687\end{array}$ & $\begin{array}{l}12 / 15 / 90 \\
03 / 30 / 91 \\
08 / 07 / 91 \\
12 / 11 / 91 \\
10 / 12 / 92 \\
02 / 18 / 94 \\
02 / 02 / 86 \\
06 / 30 / 86 \\
10 / 14 / 87 \\
02 / 19 / 88 \\
12 / 15 / 90 \\
11 / 18 / 91 \\
10 / 11 / 92 \\
02 / 18 / 94 \\
07 / 18 / 86 \\
04 / 08 / 87 \\
10 / 15 / 87 \\
02 / 19 / 88 \\
12 / 15 / 90 \\
04 / 03 / 91 \\
08 / 27 / 91 \\
12 / 10 / 91 \\
10 / 07 / 92 \\
02 / 19 / 94\end{array}$ & $\begin{array}{l}0001 \\
0001 \\
0001 \\
0001 \\
0001 \\
0001 \\
0001 \\
0001 \\
0001 \\
0001 \\
0001 \\
0001 \\
0001 \\
0001 \\
0001 \\
0001 \\
0001 \\
0001 \\
0001 \\
0001 \\
0001 \\
0001 \\
0001 \\
0001\end{array}$ & $\begin{array}{l}\text { NA } \\
\text { NA } \\
\text { NA } \\
\text { NA } \\
\text { NA } \\
\text { NA } \\
\text { NA } \\
\text { NA } \\
\text { NA } \\
\text { NA } \\
\text { NA } \\
\text { NA } \\
\text { NA } \\
\text { NA } \\
\text { NA } \\
\text { NA } \\
\text { NA } \\
\text { NA } \\
\text { NA } \\
\text { NA } \\
\text { NA } \\
\text { NA } \\
\text { NA } \\
\text { NA }\end{array}$ & $\begin{array}{l}U \\
U \\
U \\
U \\
U \\
U \\
U \\
U \\
U \\
U \\
U \\
U \\
U \\
U \\
U \\
U \\
U \\
U \\
U \\
U \\
U \\
U \\
U \\
U\end{array}$ & $M G / L$ & & $\begin{array}{c}43 . \\
42 . \\
49 . \\
44 . \\
67 . \\
39.8 \\
18 . \\
15 . \\
8.9 \\
5.1 \\
8 . \\
8.7 \\
8.8 \\
7.9 \\
45 . \\
9.4 \\
15.4 \\
7.4 \\
8 . \\
9.3 \\
9.6 \\
9.4 \\
14 . \\
8.8\end{array}$ & $\begin{array}{l}\mathrm{L} \\
\mathrm{L} \\
\mathrm{L} \\
\mathrm{L} \\
\mathrm{L} \\
\mathrm{L} \\
\mathrm{L}\end{array}$ & $\begin{array}{l}1 . \\
0.5 \\
1 . \\
1 . \\
1 . \\
0.5 \\
1 . \\
1 . \\
1 . \\
1 . \\
1 . \\
0.5 \\
0.5 \\
0.5 \\
1 . \\
1 . \\
1.5 \\
1 . \\
1.5 \\
0.5 \\
0.5 \\
1.5 \\
0.5\end{array}$ & $\begin{array}{l}- \\
- \\
- \\
- \\
- \\
- \\
- \\
- \\
- \\
- \\
- \\
- \\
- \\
- \\
- \\
- \\
- \\
- \\
- \\
- \\
-\end{array}$ \\
\hline CHROMIUM & $\begin{array}{l}0558 \\
0558 \\
0558 \\
0558 \\
0558 \\
0558 \\
0668 \\
0668 \\
0668 \\
0668 \\
0668 \\
0687\end{array}$ & $\begin{array}{l}12 / 15 / 90 \\
03 / 30 / 91 \\
08 / 07 / 91 \\
12 / 11 / 91 \\
10 / 12 / 92 \\
02 / 18 / 94 \\
10 / 14 / 87 \\
12 / 15 / 90 \\
11 / 18 / 91 \\
10 / 11 / 92 \\
02 / 18 / 94 \\
07 / 18 / 86\end{array}$ & $\begin{array}{l}0001 \\
0001 \\
0001 \\
0001 \\
0001 \\
0001 \\
0001 \\
0001 \\
0001 \\
0001 \\
0001 \\
0001\end{array}$ & $\begin{array}{l}\text { NA } \\
\text { NA } \\
\text { NA } \\
\text { NA } \\
\text { NA } \\
\text { NA } \\
\text { NA } \\
\text { NA } \\
\text { NA } \\
\text { NA } \\
\text { NA } \\
\text { NA }\end{array}$ & $\begin{array}{l}U \\
U \\
U \\
U \\
U \\
U \\
U \\
U \\
U \\
U \\
U \\
U\end{array}$ & $M G / L$ & $\begin{array}{l}< \\
< \\
< \\
< \\
< \\
< \\
< \\
< \\
< \\
< \\
< \\
<\end{array}$ & $\begin{array}{l}0.01 \\
0.01 \\
0.01 \\
0.01 \\
0.01 \\
0.01 \\
0.01 \\
0.01 \\
0.01 \\
0.01 \\
0.01 \\
0.05\end{array}$ & $\begin{array}{l}L \\
L \\
L \\
L \\
L \\
L \\
L\end{array}$ & $\begin{array}{l}0.01 \\
0.01 \\
0.01 \\
0.01 \\
0.01 \\
0.01 \\
0.01 \\
0.01 \\
0.01 \\
0.01 \\
0.01 \\
0.01\end{array}$ & $\begin{array}{l}- \\
- \\
- \\
- \\
- \\
- \\
- \\
- \\
- \\
-\end{array}$ \\
\hline
\end{tabular}

FORMATION OF COMPLETION CODE: NA - NAVAJO SANDSTONE

PARAMETER VALUE INDICATOR (PVI):

OTHER PARAMETER VALUE FLAGS:

$J$ - ESTIMATED VALUE

$L$ - LESS THAN THREE BORE VOLUMES REMOVED BEFORE SAMPLING
FLOW RELATIONSHIP CODE:

U - UPGRADIENT

SAMPLE ID CODES:

0001 - FILTERED SAMPLE (.45 MICRONS)

N001 - UNFILTERED SAMPLE 
TABLE 3.15 BACKGROUND GROUND HATER QUALITY DATA BY PARAMETER FOR THE NAVAJO SANDSTONE, NC AND UC PROCESSING SITES, SLICK ROCK, COLORADO SITE: SRKOI SLICK ROCK (BOTH SITES)

$02 / 02 / 86$ TO 02/19/94

REPORT DATE: 09/29/94

\begin{tabular}{|c|c|c|c|c|c|c|c|c|c|c|c|}
\hline PARAMETER NAME & $\underset{\text { ID }}{\text { LOCATION }}$ & LOG DATE & $\begin{array}{l}\text { SAMPLE } \\
\text { ID }\end{array}$ & $\begin{array}{l}\text { FORM } \\
\text { COMP }\end{array}$ & $\begin{array}{l}\text { FLOW } \\
\text { REL. }\end{array}$ & $\begin{array}{l}\text { UNITS OF } \\
\text { MEASURE }\end{array}$ & PVI & $\begin{array}{l}\text { PARAMETER } \\
\text { VALUE }\end{array}$ & FLAGS & $\begin{array}{l}\text { DETECTION } \\
\text { LIMIT }\end{array}$ & $\begin{array}{l}\text { PARAMETER } \\
\text { UNCERTAINTY }\end{array}$ \\
\hline CHRONIUM & $\begin{array}{l}0687 \\
0687 \\
0687 \\
0687 \\
0687 \\
0687 \\
0687 \\
0687\end{array}$ & $\begin{array}{l}04 / 08 / 87 \\
10 / 15 / 87 \\
12 / 15 / 90 \\
04 / 03 / 91 \\
08 / 27 / 91 \\
12 / 10 / 91 \\
10 / 07 / 92 \\
02 / 19 / 94\end{array}$ & $\begin{array}{l}0001 \\
0001 \\
0001 \\
0001 \\
0001 \\
0001 \\
0001 \\
0001\end{array}$ & $\begin{array}{l}\text { NA } \\
\text { NA } \\
\text { NA } \\
\text { NA } \\
\text { NA } \\
\text { NA } \\
\text { NA } \\
\text { NA }\end{array}$ & $\begin{array}{l}U \\
U \\
U \\
U \\
U \\
U \\
U \\
U\end{array}$ & MG/L & $\begin{array}{l}< \\
< \\
< \\
< \\
< \\
< \\
< \\
<\end{array}$ & $\begin{array}{l}0.01 \\
0.01 \\
0.01 \\
0.01 \\
0.01 \\
0.01 \\
0.01 \\
0.01\end{array}$ & $\begin{array}{l}L \\
L \\
J L \\
L\end{array}$ & $\begin{array}{l}0.01 \\
0.01 \\
0.01 \\
0.01 \\
0.01 \\
0.01 \\
0.01 \\
0.01\end{array}$ & $\begin{array}{l}- \\
- \\
- \\
- \\
- \\
- \\
-\end{array}$ \\
\hline CHROMIUM (TOTAL) & $\begin{array}{l}0558 \\
0668 \\
0687\end{array}$ & $\begin{array}{l}02 / 18 / 94 \\
02 / 18 / 94 \\
02 / 19 / 94\end{array}$ & $\begin{array}{l}\text { N001 } \\
\text { N001 } \\
\text { N001 }\end{array}$ & $\begin{array}{l}\text { NA } \\
\text { NA } \\
\text { NA }\end{array}$ & $\begin{array}{l}U \\
U \\
U\end{array}$ & $M G / L$ & $<$ & $\begin{array}{l}0.02 \\
0.01 \\
0.01\end{array}$ & $\mathbf{L}$ & $\begin{array}{l}0.01 \\
0.01 \\
0.01\end{array}$ & - \\
\hline COBALT & $\begin{array}{l}0558 \\
0558 \\
0558 \\
0558 \\
0668 \\
0668 \\
0687 \\
0687 \\
0687 \\
0687\end{array}$ & $\begin{array}{l}12 / 15 / 90 \\
03 / 30 / 91 \\
08 / 07 / 91 \\
12 / 11 / 91 \\
12 / 15 / 90 \\
11 / 18 / 91 \\
12 / 15 / 90 \\
04 / 03 / 91 \\
08 / 27 / 91 \\
12 / 10 / 91\end{array}$ & $\begin{array}{l}0001 \\
0001 \\
0001 \\
0001 \\
0001 \\
0001 \\
0001 \\
0001 \\
0001 \\
0001\end{array}$ & $\begin{array}{l}\text { NA } \\
\text { NA } \\
\text { NA } \\
\text { NA } \\
\text { NA } \\
\text { NA } \\
\text { NA } \\
\text { NA } \\
\text { NA } \\
\text { NA }\end{array}$ & $\begin{array}{l}U \\
U \\
U \\
U \\
U \\
U \\
U \\
U \\
U \\
U\end{array}$ & $M G / L$ & $\begin{array}{l}< \\
< \\
< \\
< \\
< \\
< \\
< \\
< \\
< \\
< \\
<\end{array}$ & $\begin{array}{l}0.05 \\
0.03 \\
0.03 \\
0.03 \\
0.05 \\
0.03 \\
0.05 \\
0.03 \\
0.03 \\
0.03\end{array}$ & $\begin{array}{l}L \\
L \\
L \\
L \\
J L \\
L\end{array}$ & $\begin{array}{l}0.05 \\
0.03 \\
0.03 \\
0.03 \\
0.05 \\
0.03 \\
0.05 \\
0.03 \\
0.03 \\
0.03\end{array}$ & $\begin{array}{l}- \\
- \\
- \\
- \\
- \\
- \\
- \\
- \\
-\end{array}$ \\
\hline COPPER & $\begin{array}{l}0558 \\
0558 \\
0558 \\
0558 \\
0558 \\
0668 \\
0668 \\
0668 \\
0668 \\
0687 \\
0687 \\
0687 \\
0687 \\
0687 \\
0687\end{array}$ & $\begin{array}{l}12 / 15 / 90 \\
03 / 30 / 91 \\
08 / 07 / 91 \\
12 / 11 / 91 \\
10 / 12 / 92 \\
10 / 14 / 87 \\
12 / 15 / 90 \\
11 / 18 / 91 \\
10 / 11 / 92 \\
07 / 18 / 86 \\
04 / 08 / 87 \\
10 / 15 / 87 \\
12 / 15 / 90 \\
04 / 03 / 91 \\
08 / 27 / 91\end{array}$ & $\begin{array}{l}0001 \\
0001 \\
0001 \\
0001 \\
0001 \\
0001 \\
0001 \\
0001 \\
0001 \\
0001 \\
0001 \\
0001 \\
0001 \\
0001 \\
0001\end{array}$ & $\begin{array}{l}\text { NA } \\
\text { NA } \\
\text { NA } \\
\text { NA } \\
\text { NA } \\
\text { NA } \\
\text { NA } \\
\text { NA } \\
\text { NA } \\
\text { NA } \\
\text { NA } \\
\text { NA } \\
\text { NA } \\
\text { NA } \\
\text { NA }\end{array}$ & $\begin{array}{l}U \\
U \\
U \\
U \\
U \\
U \\
U \\
U \\
U \\
U \\
U \\
U \\
U \\
U \\
U\end{array}$ & $M G / L$ & $\begin{array}{l}< \\
< \\
< \\
< \\
< \\
< \\
< \\
< \\
< \\
< \\
< \\
< \\
< \\
< \\
< \\
<\end{array}$ & $\begin{array}{l}0.02 \\
0.01 \\
0.01 \\
0.01 \\
0.01 \\
0.02 \\
0.02 \\
0.01 \\
0.01 \\
0.03 \\
0.01 \\
0.02 \\
0.02 \\
0.01 \\
0.01\end{array}$ & $\begin{array}{l}L \\
L \\
L \\
L \\
L \\
L \\
L \\
L \\
J L \\
L \\
J L \\
L\end{array}$ & $\begin{array}{l}0.02 \\
0.01 \\
0.01 \\
0.01 \\
0.01 \\
0.02 \\
0.02 \\
0.01 \\
0.01 \\
0.02 \\
0.02 \\
0.02 \\
0.02 \\
0.01 \\
0.01\end{array}$ & $\begin{array}{l}- \\
- \\
- \\
- \\
- \\
- \\
- \\
- \\
- \\
- \\
- \\
-\end{array}$ \\
\hline
\end{tabular}

FORMATION OF COMPLETION CODE: NA - NAVAJO SANDSTONE

PARAMETER VALUE INDICATOR (PVI): < - LESS THAN DETECTION LIMIT OTHER PARAMETER VALUE FLAGS:

$J$ - ESTIMATED VALUE

L - LESS THAN THREE BORE VOLUMES REMOVED BEFORE SAMPLING
FLOW RELATIONSHIP CODE:

$U$ - UPGRADIENT

SAMPLE ID CODES:

0001 - FILTERED SAMPLE (.45 MICRONS)

N001 - UNFILTERED SAMPLE 
TABLE 3.15 BACKGROUND GROUND WATER QUALITY DATA BY PARAMETER FOR THE NAVAJO SANDSTONE, NC AND UC PROCESSING SITES, SLICK ROCK, COLORADO

SITE: SRKO1 SLICK ROCK (BOTH SITES)

02/02/86 TO 02/19/94

REPORT DATE : 09/29/94

\begin{tabular}{|c|c|c|c|c|c|c|c|c|c|c|c|}
\hline PARAMETER NAME & ${ }_{\text {ID }}^{\text {LOCATION }}$ & LOG DATE & $\begin{array}{c}\text { SAMPLE } \\
\text { ID }\end{array}$ & $\begin{array}{l}\text { FORM } \\
\text { COMP }\end{array}$ & $\begin{array}{l}\text { FLOW } \\
\text { REL. }\end{array}$ & $\begin{array}{l}\text { UNITS OF } \\
\text { MEASURE }\end{array}$ & PVI & $\begin{array}{l}\text { ARAMETER } \\
\text { VALUE }\end{array}$ & FLAGS & $\begin{array}{l}\text { DETECTION } \\
\text { LIMIT }\end{array}$ & $\begin{array}{l}\text { PARAMETER } \\
\text { UNCERTAINTY }\end{array}$ \\
\hline COPPER & $\begin{array}{l}0687 \\
0687\end{array}$ & $\begin{array}{l}12 / 10 / 91 \\
10 / 07 / 92\end{array} \mid$ & $\begin{array}{l}0001 \\
0001\end{array}$ & $\begin{array}{l}\text { NA } \\
\text { NA }\end{array}$ & $\begin{array}{l}U \\
U\end{array}$ & $M G / L$ & $<$ & $\begin{array}{l}0.01 \\
0.01\end{array}$ & & $\begin{array}{l}0.01 \\
0.01\end{array}$ & - \\
\hline CYANIDE & $\begin{array}{l}0558 \\
0558 \\
0558 \\
0558 \\
0668 \\
0668 \\
0687 \\
0687 \\
0687 \\
0687\end{array}$ & $\begin{array}{l}12 / 15 / 90 \\
03 / 30 / 91 \\
08 / 07 / 91 \\
12 / 11 / 91 \\
12 / 15 / 90 \\
11 / 18 / 91 \\
12 / 15 / 90 \\
04 / 03 / 91 \\
08 / 27 / 91 \\
12 / 10 / 91\end{array}$ & $\begin{array}{l}0001 \\
0001 \\
0001 \\
0001 \\
0001 \\
0001 \\
0001 \\
0001 \\
0001 \\
0001\end{array}$ & $\begin{array}{l}\text { NA } \\
\text { NA } \\
\text { NA } \\
\text { NA } \\
\text { NA } \\
\text { NA } \\
\text { NA } \\
\text { NA } \\
\text { NA } \\
\text { NA }\end{array}$ & $\begin{array}{l}U \\
U \\
U \\
U \\
U \\
U \\
U \\
U \\
U \\
U\end{array}$ & $M G / L$ & $\begin{array}{l}< \\
< \\
< \\
< \\
< \\
< \\
< \\
< \\
< \\
< \\
<\end{array}$ & $\begin{array}{l}0.01 \\
0.01 \\
0.01 \\
0.01 \\
0.01 \\
0.01 \\
0.01 \\
0.01 \\
0.01 \\
0.01\end{array}$ & $\begin{array}{l}\mathrm{L} \\
\mathrm{L} \\
\mathrm{L} \\
\mathrm{L} \\
\mathrm{JL} \\
\mathrm{L}\end{array}$ & $\begin{array}{l}0.01 \\
0.01 \\
0.01 \\
0.01 \\
0.01 \\
0.01 \\
0.01 \\
0.01 \\
0.01 \\
0.01\end{array}$ & $\begin{array}{l}- \\
- \\
- \\
- \\
- \\
- \\
-\end{array}$ \\
\hline DISSOLVED OXYGEN & $\begin{array}{l}0558 \\
0668 \\
0668 \\
0687 \\
0687\end{array}$ & $\begin{array}{l}02 / 18 / 94 \\
10 / 11 / 92 \\
02 / 18 / 94 \\
10 / 07 / 92 \\
02 / 19 / 94\end{array}$ & $\begin{array}{l}\text { N001 } \\
0001 \\
\text { N001 } \\
0001 \\
\text { N001 }\end{array}$ & $\begin{array}{l}\text { NA } \\
\text { NA } \\
\text { NA } \\
\text { NA } \\
\text { NA }\end{array}$ & $\begin{array}{l}u \\
U \\
U \\
U \\
U\end{array}$ & $M G / L$ & $<$ & $\begin{array}{l}0.6 \\
0.3 \\
4.2 \\
0.9 \\
0.6\end{array}$ & L & $\begin{array}{l}- \\
- \\
- \\
-\end{array}$ & $\begin{array}{l}- \\
- \\
-\end{array}$ \\
\hline FIELD FE (2+) & $\begin{array}{l}0668 \\
0687\end{array}$ & $\left|\begin{array}{l}10 / 11 / 92 \\
10 / 07 / 92\end{array}\right|$ & $\begin{array}{l}0001 \\
0001\end{array}$ & $\begin{array}{l}\text { NA } \\
\text { NA }\end{array}$ & $\begin{array}{l}U \\
U\end{array}$ & $M G / L$ & & $\begin{array}{l}0.06 \\
0.05\end{array}$ & & - & - \\
\hline FIELD FE (TOTAL) & 0668 & $10 / 11 / 92$ & 0001 & NA & U & $M G / L$ & & 0.07 & & - & - \\
\hline FLUORIDE & $\begin{array}{l}0558 \\
0558 \\
0558 \\
0558 \\
0558 \\
0668 \\
0668 \\
0668 \\
0668 \\
0668 \\
0687 \\
0687 \\
0687\end{array}$ & $\begin{array}{l}12 / 15 / 90 \\
03 / 30 / 91 \\
08 / 07 / 91 \\
12 / 11 / 91 \\
10 / 12 / 92 \\
10 / 14 / 87 \\
02 / 19 / 88 \\
12 / 15 / 90 \\
11 / 18 / 91 \\
10 / 11 / 92 \\
07 / 18 / 86 \\
04 / 08 / 87 \\
10 / 15 / 87\end{array}$ & $\begin{array}{l}0001 \\
0001 \\
0001 \\
0001 \\
0001 \\
0001 \\
0001 \\
0001 \\
0001 \\
0001 \\
0001 \\
0001 \\
0001\end{array}$ & $\begin{array}{l}\text { NA } \\
\text { NA } \\
\text { NA } \\
\text { NA } \\
\text { NA } \\
\text { NA } \\
\text { NA } \\
\text { NA } \\
\text { NA } \\
\text { NA } \\
\text { NA } \\
\text { NA } \\
\text { NA }\end{array}$ & $\begin{array}{l}U \\
U \\
U \\
U \\
U \\
U \\
U \\
U \\
U \\
U \\
U \\
U \\
U\end{array}$ & $M G / L$ & & $\begin{array}{l}0.6 \\
0.5 \\
0.7 \\
0.6 \\
0.6 \\
0.7 \\
0.74 \\
0.7 \\
0.7 \\
0.8 \\
0.7 \\
0.87 \\
0.8\end{array}$ & $\begin{array}{l}\mathrm{L} \\
\mathrm{L} \\
\mathrm{L} \\
\mathrm{L} \\
\mathrm{L} \\
\mathrm{L} \\
\mathrm{H}\end{array}$ & $\begin{array}{l}0.1 \\
0.1 \\
0.1 \\
0.1 \\
0.1 \\
0.1 \\
0.1 \\
0.1 \\
0.1 \\
0.1 \\
0.1 \\
0.1 \\
0.1\end{array}$ & $\begin{array}{l}- \\
- \\
- \\
- \\
- \\
- \\
- \\
- \\
-\end{array}$ \\
\hline
\end{tabular}

FORMATION OF COMPLETION CODE:

NA - NAVAJO SANDSTONE

PARAMETER VALUE INDICATOR (PVI): < - LESS THAN DETECTION LIMIT

OTHER PARAMETER VALUE FLAGS:

H - HOLD TIME EXPIRED, VALUE SUSPECT

$J$ - ESTIMATED VALUE

L - LESS THAN THREE BORE VOLUMES REMOVED BEFORE SAMPLING
FLOW RELATIONSHIP CODE:

$U$ - UPGRADIENT

SAMPLE ID CODES

0001 - FILTERED SAMPLE (.45 HICRONS)

N001 - UNFILTERED SAMPLE 
TABLE 3.15 BACKGROUND GROUND WATER QUALITY DATA BY PARAMETER FOR THE

SITE: SRKO1 SLICK ROCK (BOTH SITES)

O2/02/86 TO 02/19/94

REPORT DATE: $09 / 29 / 94$

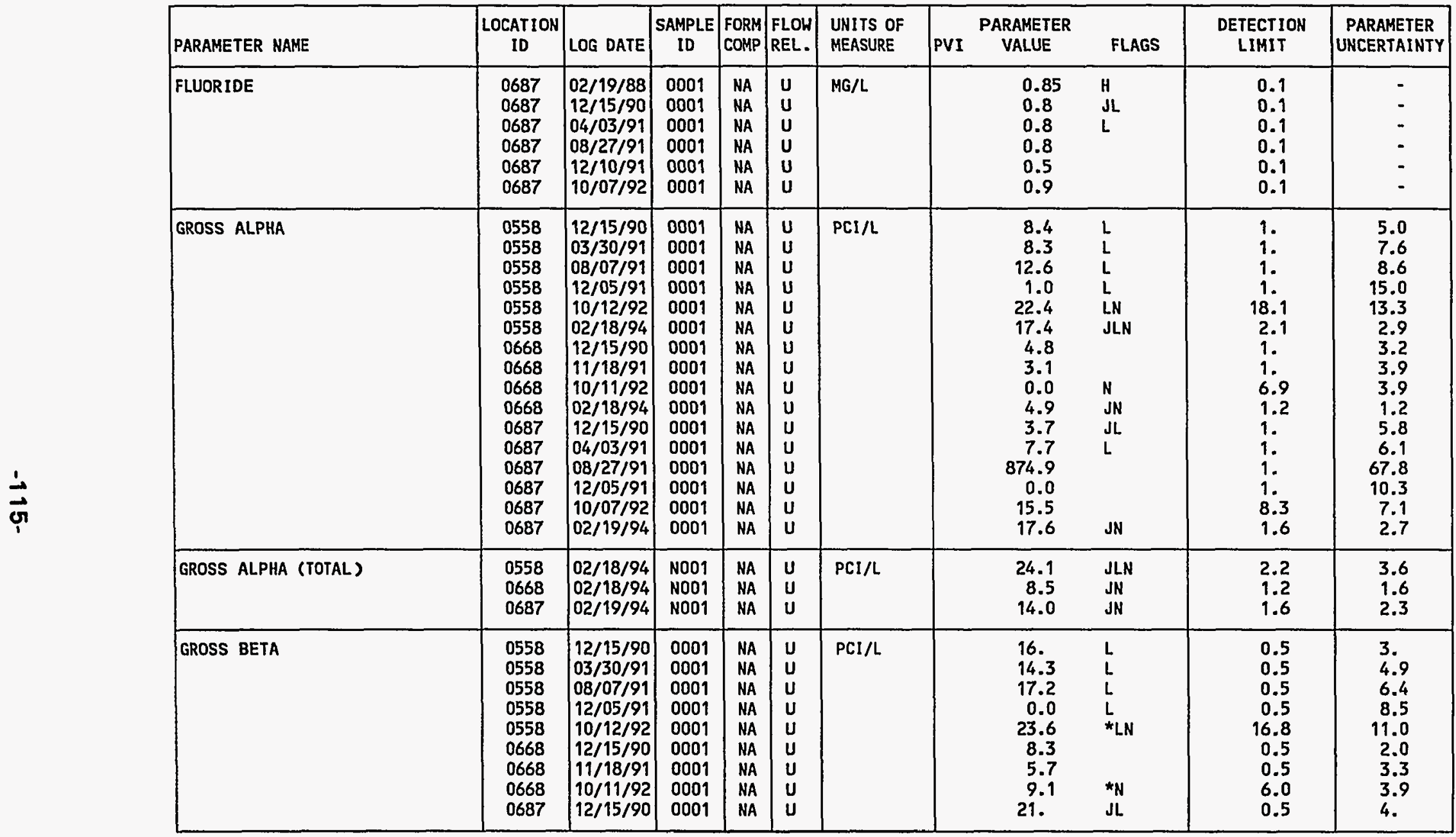

FORMATION OF COMPLETION CODE:

NA - NAVAJO SANDSTONE

PARAMETER VALUE INDICATOR (PVI): < - LESS THAN DETECTION LIMIT

\section{OTHER PARAMETER VALUE FLAGS:}

* - DUPLICATE AHALYSIS NOT WITHIN CONTROL LIMITS

H - HOLD TIME EXPIRED, VALUE SUSPECT

$J$ - ESTIMATED VALUE

- LESS THAN THREE BORE VOLUMES REMOVED BEFORE SAMPLING

N - SPIKE SAMPLE RECOVERY NOT HITHIN CONTROL LIMITS
FLOW RELATIONSHIP CODE:

- UPGRADIENT

SAMPLE ID CODES:

0001 - FILTERED SAMPLE (.45 MICRONS)

N001 - UNFILTERED SAMPLE 


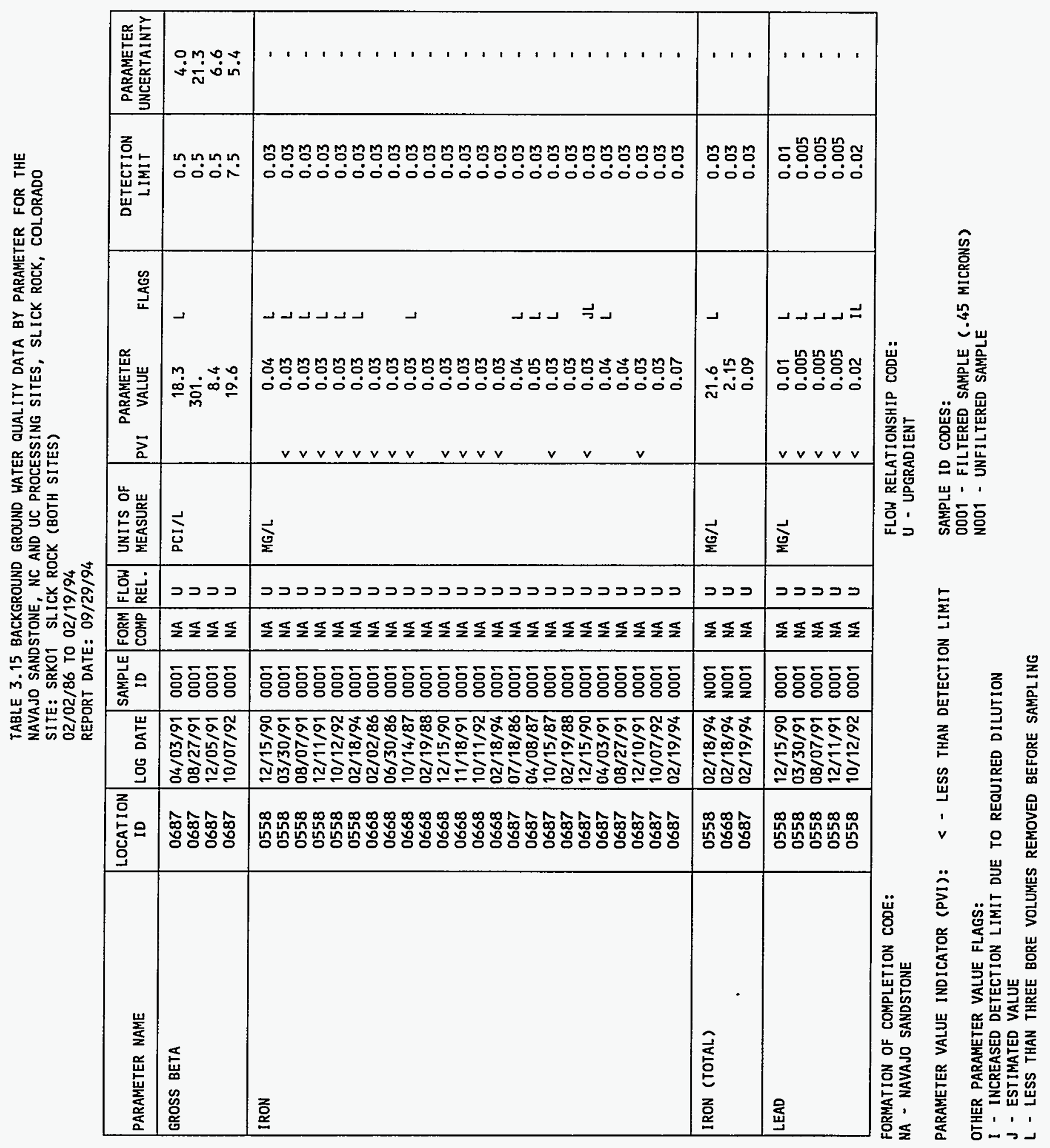


TABLE 3.15 BACKGROUND GROUND HATER QUALITY DATA BY PARAMETER FOR THE NAVAJO SANDSTONE, NC AND UC PROCESSING SITES, SLICK ROCK, COLORADO SITE: SRKO1 SLICK ROCK (BOTH SITES)

02/02/86 TO 02/19/94

REPORT DATE: $09 / 29 / 94$

\begin{tabular}{|c|c|c|c|c|c|c|c|c|c|c|c|c|}
\hline & PARAMETER NAME & $\underset{\text { LOCATION }}{\text { ID }}$ & LOG DATE & $\underset{\text { ID }}{\text { SAMPLE }}$ & $\begin{array}{l}\text { FORM } \\
\text { COMP }\end{array}$ & $\begin{array}{l}\text { FLOH } \\
\text { REL. }\end{array}$ & $\begin{array}{l}\text { UNITS OF } \\
\text { MEASURE }\end{array}$ & PVI & $\begin{array}{l}\text { PARAMETER } \\
\text { VALUE }\end{array}$ & FLAGS & $\begin{array}{l}\text { DETECTION } \\
\text { LIMIT }\end{array}$ & $\begin{array}{l}\text { PARAMETER } \\
\text { UNCERTAINTY }\end{array}$ \\
\hline & LEAD & $\begin{array}{l}0668 \\
0668 \\
0668 \\
0668 \\
0687 \\
0687 \\
0687 \\
0687 \\
0687 \\
0687 \\
0687 \\
0687\end{array}$ & $\begin{array}{l}10 / 14 / 87 \\
12 / 15 / 90 \\
11 / 18 / 91 \\
10 / 11 / 92 \\
07 / 18 / 86 \\
04 / 08 / 87 \\
10 / 15 / 87 \\
12 / 15 / 90 \\
04 / 03 / 91 \\
08 / 27 / 91 \\
12 / 10 / 91 \\
10 / 07 / 92\end{array}$ & $\begin{array}{l}0001 \\
0001 \\
0001 \\
0001 \\
0001 \\
0001 \\
0001 \\
0001 \\
0001 \\
0001 \\
0001 \\
0001\end{array}$ & $\begin{array}{l}\text { NA } \\
\text { NA } \\
\text { NA } \\
\text { NA } \\
\text { NA } \\
\text { NA } \\
\text { NA } \\
\text { NA } \\
\text { NA } \\
\text { NA } \\
\text { NA } \\
\text { NA }\end{array}$ & $\begin{array}{l}\mathbf{U} \\
\mathbf{U} \\
\mathbf{U} \\
\mathbf{U} \\
\mathbf{U} \\
\mathbf{U} \\
\mathbf{U} \\
\mathbf{U} \\
\mathbf{U} \\
\mathbf{U} \\
\mathbf{U} \\
\mathbf{U}\end{array}$ & MG/L & $\begin{array}{l}< \\
< \\
< \\
< \\
< \\
< \\
< \\
< \\
< \\
< \\
< \\
< \\
< \\
<\end{array}$ & $\begin{array}{l}0.01 \\
0.01 \\
0.005 \\
0.003 \\
0.01 \\
0.001 \\
0.01 \\
0.01 \\
0.005 \\
0.005 \\
0.005 \\
0.02\end{array}$ & $\begin{array}{l}L \\
L \\
J L \\
L \\
J L \\
L \\
I\end{array}$ & $\begin{array}{l}0.01 \\
0.01 \\
0.005 \\
0.003 \\
0.01 \\
0.01 \\
0.01 \\
0.01 \\
0.005 \\
0.005 \\
0.005 \\
0.02\end{array}$ & $\begin{array}{l}- \\
- \\
- \\
- \\
- \\
- \\
- \\
- \\
-\end{array}$ \\
\hline & LEAD-210 & $\begin{array}{l}0558 \\
0558 \\
0558 \\
0668 \\
0668 \\
0687 \\
0687 \\
0687 \\
0687\end{array}$ & $\begin{array}{l}08 / 07 / 91 \\
12 / 05 / 91 \\
02 / 18 / 94 \\
11 / 18 / 91 \\
02 / 18 / 94 \\
07 / 18 / 86 \\
08 / 27 / 91 \\
12 / 05 / 91 \\
02 / 19 / 94\end{array}$ & $\begin{array}{l}0001 \\
0001 \\
0001 \\
0001 \\
0001 \\
0001 \\
0001 \\
0001 \\
0001\end{array}$ & $\begin{array}{l}\text { NA } \\
\text { NA } \\
\text { NA } \\
\text { NA } \\
\text { NA } \\
\text { NA } \\
\text { NA } \\
\text { NA } \\
\text { NA }\end{array}$ & $\begin{array}{l}U \\
U \\
U \\
U \\
U \\
U \\
U \\
U \\
U\end{array}$ & $\mathrm{PCI} / \mathrm{L}$ & & $\begin{array}{l}1.3 \\
0.6 \\
0.0 \\
0.0 \\
0.9 \\
0.4 \\
0.3 \\
0.0 \\
0.0\end{array}$ & $\begin{array}{l}L \\
L \\
L \\
\text { JL }\end{array}$ & $\begin{array}{l}1.5 \\
1.5 \\
3.0 \\
1.5 \\
2.7 \\
1.5 \\
1.5 \\
1.5 \\
2.5\end{array}$ & $\begin{array}{l}0.9 \\
1.3 \\
1.1 \\
0.8 \\
0.9 \\
0.9 \\
1.0 \\
1.3 \\
0.8\end{array}$ \\
\hline & LEAD-210 (TOTAL) & $\begin{array}{l}0558 \\
0668 \\
0687\end{array}$ & $\begin{array}{l}02 / 18 / 94 \\
02 / 18 / 94 \\
02 / 19 / 94\end{array}$ & $\begin{array}{l}\text { N001 } \\
\text { N001 } \\
\text { N001 }\end{array}$ & $\begin{array}{l}\text { NA } \\
\text { NA } \\
\text { NA }\end{array}$ & $\begin{array}{l}U \\
U \\
U\end{array}$ & $\mathrm{PCI} / \mathrm{L}$ & & $\begin{array}{l}2.2 \\
0.0 \\
2.7\end{array}$ & L & $\begin{array}{l}2.7 \\
2.5 \\
2.1\end{array}$ & $\begin{array}{l}1.0 \\
0.9 \\
0.9\end{array}$ \\
\hline & MAGNESIUM & $\begin{array}{l}0558 \\
0558 \\
0558 \\
0558 \\
0558 \\
0558 \\
0668 \\
0668 \\
0668 \\
0668 \\
0668\end{array}$ & $\begin{array}{l}12 / 15 / 90 \\
03 / 30 / 91 \\
08 / 07 / 91 \\
12 / 11 / 91 \\
10 / 12 / 92 \\
02 / 18 / 94 \\
02 / 02 / 86 \\
06 / 30 / 86 \\
10 / 14 / 87 \\
02 / 19 / 88 \\
12 / 15 / 90\end{array}$ & $\begin{array}{l}0001 \\
0001 \\
0001 \\
0001 \\
0001 \\
0001 \\
0001 \\
0001 \\
0001 \\
0001 \\
0001\end{array}$ & $\begin{array}{l}\text { NA } \\
\text { NA } \\
\text { NA } \\
\text { NA } \\
\text { NA } \\
\text { NA } \\
\text { NA } \\
\text { NA } \\
\text { NA } \\
\text { NA } \\
\text { NA }\end{array}$ & $\begin{array}{l}U \\
U \\
U \\
U \\
U \\
U \\
U \\
U \\
U \\
U \\
U\end{array}$ & $\mathrm{MG} / \mathrm{L}$ & & $\begin{array}{c}66.7 \\
74.1 \\
91.4 \\
99.1 \\
109 . \\
63.5 \\
50.4 \\
44.4 \\
45 . \\
44.8 \\
45.9\end{array}$ & $\begin{array}{l}L \\
L \\
L \\
L \\
L \\
L\end{array}$ & $\begin{array}{l}0.001 \\
0.5 \\
0.5 \\
0.5 \\
0.5 \\
0.1 \\
0.001 \\
0.001 \\
0.001 \\
0.001 \\
0.001\end{array}$ & $\begin{array}{l}- \\
- \\
- \\
- \\
- \\
- \\
- \\
- \\
-\end{array}$ \\
\hline
\end{tabular}

FORMATION OF COMPLETION CODE:

NA - NAVAJO SANDSTONE

PARAMETER VALUE INDICATOR (PVI): < - LESS THAN DETECTION LIMIT

OTHER PARAMETER VALUE FLAGS:

I - INCREASED DETECTION LIMIT DUE TO REQUIRED DILUTION

$J$ - ESTIMATED VALUE

L - LESS THAN THREE BORE VOLUMES REMOVED BEFORE SAMPLING
FLOW RELATIONSHIP CODE:

$\checkmark$ - UPGRADIENT

SAMPLE ID CODES:

0001 - FILTERED SAMPLE (.45 MICRONS)

NO01 - UNFILTERED SAMPLE 


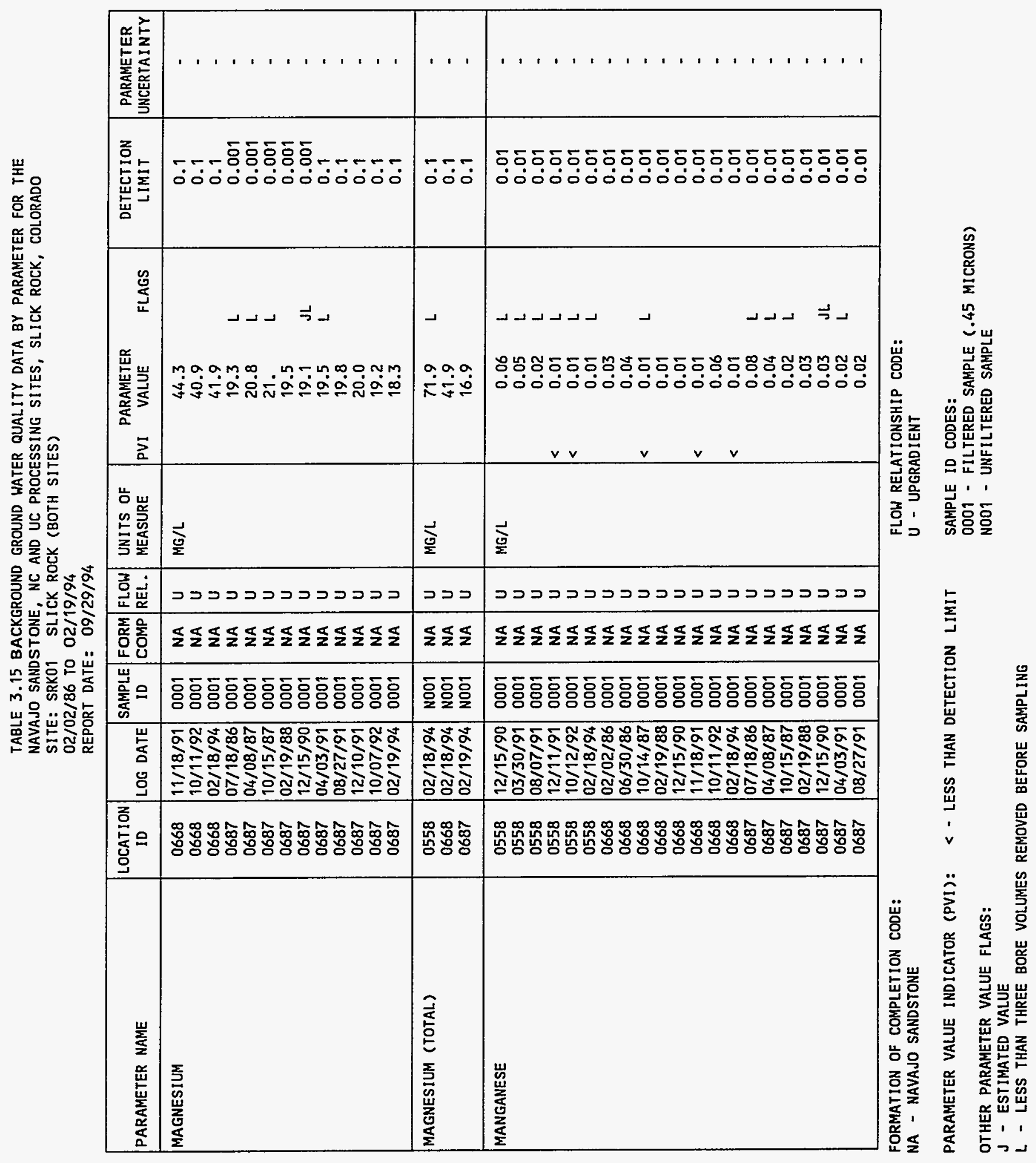




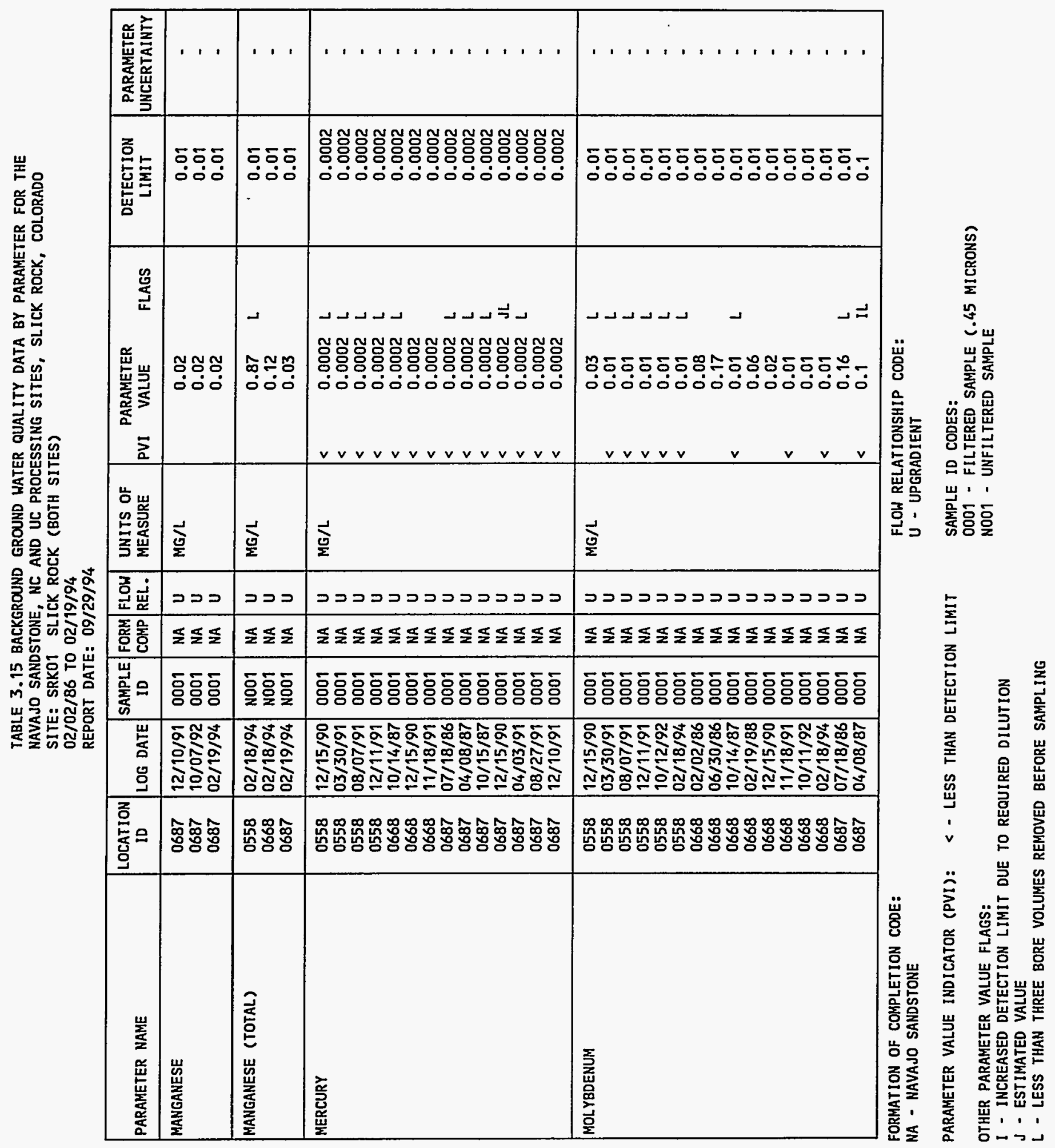


TABLE 3.15 BACKGROUND GROUND WATER QUALITY DATA BY PARAMETER FOR THE NAVAJO SANDSTONE, NC AND UC PROCESSING SITES, SLICK ROCK, COLORADO

SITE: SRK01 SLICK ROCK (BOTH SITES)

02/02/86 TO 02/19/94

REPORT DATE : $09 / 29 / 94$

\begin{tabular}{|c|c|c|c|c|c|c|c|c|c|c|c|}
\hline PARAMETER NAME & $\underset{\text { ID }}{\text { LOCATION }}$ & LOG DATE & $\begin{array}{c}\text { SAMPLE } \\
\text { ID }\end{array}$ & $\begin{array}{l}\text { FORM } \\
\text { COMP }\end{array}$ & $\begin{array}{l}\text { FLOW } \\
\text { REL. }\end{array}$ & $\begin{array}{l}\text { UNITS OF } \\
\text { MEASURE }\end{array}$ & PVI & $\begin{array}{l}\text { ARAMETER } \\
\text { VALUE }\end{array}$ & FLAGS & $\begin{array}{l}\text { DETECTION } \\
\text { LIMIT }\end{array}$ & $\begin{array}{l}\text { PARAMETER } \\
\text { UNCERTAINTY }\end{array}$ \\
\hline MOL YBDENUM & $\begin{array}{l}0687 \\
0687 \\
0687 \\
0687 \\
0687 \\
0687 \\
0687 \\
0687\end{array}$ & $\begin{array}{l}10 / 15 / 87 \\
02 / 19 / 88 \\
12 / 15 / 90 \\
04 / 03 / 91 \\
08 / 27 / 91 \\
12 / 10 / 91 \\
10 / 07 / 92 \\
02 / 19 / 94\end{array}$ & $\begin{array}{l}0001 \\
0001 \\
0001 \\
0001 \\
0001 \\
0001 \\
0001 \\
0001\end{array}$ & $\begin{array}{l}\text { NA } \\
\text { NA } \\
\text { NA } \\
\text { NA } \\
\text { NA } \\
\text { NA } \\
\text { NA } \\
\text { NA }\end{array}$ & $\begin{array}{l}U \\
U \\
U \\
U \\
U \\
U \\
U \\
U\end{array}$ & $M G / L$ & $\begin{array}{l}< \\
< \\
< \\
< \\
< \\
<\end{array}$ & $\begin{array}{l}0.01 \\
0.02 \\
0.01 \\
0.01 \\
0.01 \\
0.01 \\
0.01 \\
0.01\end{array}$ & $\begin{array}{l}\mathrm{L} \\
\mathrm{JL} \\
\mathrm{L}\end{array}$ & $\begin{array}{l}0.01 \\
0.01 \\
0.01 \\
0.01 \\
0.01 \\
0.01 \\
0.01 \\
0.01\end{array}$ & $\begin{array}{l}- \\
- \\
- \\
- \\
- \\
-\end{array}$ \\
\hline MOLYBDENUM (TOTAL) & $\begin{array}{l}0558 \\
0668 \\
0687\end{array}$ & $\begin{array}{l}02 / 18 / 94 \\
02 / 18 / 94 \\
02 / 19 / 94\end{array}$ & $\begin{array}{l}\text { N001 } \\
\text { N001 } \\
\text { N001 }\end{array}$ & $\begin{array}{l}\text { NA } \\
\text { NA } \\
\text { NA }\end{array}$ & $\begin{array}{l}U \\
U \\
U\end{array}$ & $M G / L$ & $\begin{array}{l}< \\
<\end{array}$ & $\begin{array}{l}0.01 \\
0.01 \\
0.01\end{array}$ & $L$ & $\begin{array}{l}0.01 \\
0.01 \\
0.01\end{array}$ & - \\
\hline NET GROSS ALPHA * & $\begin{array}{l}0558 \\
0558 \\
0558 \\
0558 \\
0558 \\
0558 \\
0668 \\
0668 \\
0668 \\
0668 \\
0687 \\
0687 \\
0687 \\
0687 \\
0687 \\
0687\end{array}$ & $\begin{array}{l}12 / 15 / 90 \\
03 / 30 / 91 \\
08 / 07 / 91 \\
12 / 05 / 91 \\
10 / 12 / 92 \\
02 / 18 / 94 \\
12 / 15 / 90 \\
11 / 18 / 91 \\
10 / 11 / 92 \\
02 / 18 / 94 \\
12 / 15 / 90 \\
04 / 03 / 91 \\
08 / 27 / 91 \\
12 / 05 / 91 \\
10 / 07 / 92 \\
02 / 19 / 94\end{array}$ & $\begin{array}{l}0001 \\
0001 \\
0001 \\
0001 \\
0001 \\
0001 \\
0001 \\
0001 \\
0001 \\
0001 \\
0001 \\
0001 \\
0001 \\
0001 \\
0001 \\
0001\end{array}$ & $\begin{array}{l}\text { NA } \\
\text { NA } \\
\text { NA } \\
\text { NA } \\
\text { NA } \\
\text { NA } \\
\text { NA } \\
\text { NA } \\
\text { NA } \\
\text { NA } \\
\text { NA } \\
\text { NA } \\
\text { NA } \\
\text { NA } \\
\text { NA } \\
\text { NA }\end{array}$ & $\begin{array}{l}U \\
U \\
U \\
U \\
U \\
U \\
U \\
U \\
U \\
U \\
U \\
U \\
U \\
U \\
U \\
U\end{array}$ & $\mathrm{PCI} / \mathrm{L}$ & & $\begin{array}{r}-1.20 \\
0.75 \\
0.25 \\
-7.92 \\
1.13 \\
1.62 \\
2.54 \\
0.36 \\
-0.69 \\
2.84 \\
2.88 \\
6.33 \\
-36.11 \\
-0.69 \\
13.44 \\
16.23\end{array}$ & & $\begin{array}{l}- \\
- \\
- \\
- \\
- \\
- \\
- \\
- \\
- \\
- \\
- \\
-\end{array}$ & $\begin{array}{l}- \\
- \\
- \\
- \\
- \\
- \\
- \\
- \\
- \\
- \\
- \\
- \\
-\end{array}$ \\
\hline NET GROSS ALPHA (TOTAL) ** & $\begin{array}{l}0558 \\
0668 \\
0687\end{array}$ & $\begin{array}{l}02 / 18 / 94 \\
02 / 18 / 94 \\
02 / 19 / 94\end{array}$ & $\begin{array}{l}\text { N001 } \\
\text { N001 } \\
\text { N001 }\end{array}$ & $\begin{array}{l}\text { NA } \\
\text { NA } \\
\text { NA }\end{array}$ & $\begin{array}{l}u \\
U \\
U\end{array}$ & $\mathrm{PCI} / \mathrm{L}$ & & $\begin{array}{r}13.12 \\
5.76 \\
12.63\end{array}$ & & $\begin{array}{l}- \\
-\end{array}$ & - \\
\hline NICKEL & 0558 & $12 / 15 / 90$ & 0001 & NA & $u$ & $M G / L$ & $<$ & 0.05 & L & 0.05 & - \\
\hline
\end{tabular}

* NET GROSS ALPHA (GROSS ALPHA - URANIUM) WITH 1 MG URANIUM $=686$ PCI

** NET GROSS ALPHA (TOTAL) (TOTAL GROSS ALPHA - TOTAL URANIUM)

FORMATION OF COMPLETION CODE:

NA - NAVAJO SANDSTONE

PARAMETER VALUE INDICATOR (PVI): < - LESS THAN DETECTION LIMIT

OTHER PARAMETER VALUE FLAGS:

$J$ - ESTIMATED VALUE

$L$ - LESS THAN THREE BORE VOLUMES REMOVED BEFORE SAMPLING
FLOW RELATIONSHIP CODE:

$U$ - UPGRADIENT

SAMPLE ID CODES:

0001 - FILTERED SAMPLE (.45 MICRONS)

NO01 - UNFILTERED SAMPLE 
TABLE 3.15 BACKGROUND GROUND HATER QUALITY DATA BY PARAMETER FOR THE NAVAJO SANDSTONE, NC AND UC PROCESSING SITES, SLICK ROCK, COLORADO SITE: SRKO1 SLICK ROCK (BOTH SITES)

$02 / 02 / 86$ TO $02 / 19 / 94$

REPORT DATE: 09/29/94

\begin{tabular}{|c|c|c|c|c|c|c|c|c|c|c|c|c|}
\hline & PARAMETER NAME & $\begin{array}{l}\text { LOCAT ION } \\
\text { ID }\end{array}$ & LOG DATE & $\begin{array}{c}\text { SAMPLE } \\
\text { ID }\end{array}$ & $\begin{array}{l}\text { FORM } \\
\text { COMP }\end{array}$ & $\begin{array}{l}\text { FLOW } \\
\text { REL. }\end{array}$ & $\begin{array}{l}\text { UNITS OF } \\
\text { MEASURE }\end{array}$ & PVI & $\begin{array}{l}\text { PARAMETER } \\
\text { VALUE }\end{array}$ & FLAGS & $\begin{array}{l}\text { DETECTION } \\
\text { LIMIT }\end{array}$ & \begin{tabular}{|l} 
PARAMETER \\
UNCERTAINTY
\end{tabular} \\
\hline & NICKEL & $\begin{array}{l}0558 \\
0558 \\
0558 \\
0558 \\
0668 \\
0668 \\
0668 \\
0668 \\
0668 \\
0687 \\
0687 \\
0687 \\
0687 \\
0687 \\
0687 \\
0687 \\
0687 \\
0687\end{array}$ & $\begin{array}{l}03 / 30 / 91 \\
08 / 07 / 91 \\
12 / 11 / 91 \\
10 / 12 / 92 \\
10 / 14 / 87 \\
02 / 19 / 88 \\
12 / 15 / 90 \\
11 / 18 / 91 \\
10 / 11 / 92 \\
07 / 18 / 86 \\
04 / 08 / 87 \\
10 / 15 / 87 \\
02 / 19 / 88 \\
12 / 15 / 90 \\
04 / 03 / 91 \\
08 / 27 / 91 \\
12 / 10 / 91 \\
10 / 07 / 92\end{array}$ & $\begin{array}{l}0001 \\
0001 \\
0001 \\
0001 \\
0001 \\
0001 \\
0001 \\
0001 \\
0001 \\
0001 \\
0001 \\
0001 \\
0001 \\
0001 \\
0001 \\
0001 \\
0001 \\
0001\end{array}$ & $\begin{array}{l}\text { NA } \\
\text { NA } \\
\text { NA } \\
\text { NA } \\
\text { NA } \\
\text { NA } \\
\text { NA } \\
\text { NA } \\
\text { NA } \\
\text { NA } \\
\text { NA } \\
\text { NA } \\
\text { NA } \\
\text { NA } \\
\text { NA } \\
\text { NA } \\
\text { NA } \\
\text { NA }\end{array}$ & $\begin{array}{l}U \\
U \\
U \\
U \\
U \\
U \\
U \\
U \\
U \\
U \\
U \\
U \\
U \\
U \\
U \\
U \\
U \\
U\end{array}$ & $M G / L$ & $\begin{array}{l}< \\
< \\
< \\
< \\
< \\
< \\
< \\
< \\
\\
< \\
< \\
< \\
< \\
< \\
< \\
< \\
<\end{array}$ & $\begin{array}{l}0.04 \\
0.04 \\
0.04 \\
0.04 \\
0.04 \\
0.01 \\
0.05 \\
0.04 \\
0.04 \\
0.06 \\
0.02 \\
0.04 \\
0.01 \\
0.05 \\
0.04 \\
0.04 \\
0.04 \\
0.04\end{array}$ & $\begin{array}{l}L \\
L \\
L \\
L \\
L \\
J\end{array}$ & $\begin{array}{r}0.04 \\
0.04 \\
0.04 \\
0.04 \\
-0.04 \\
0.04 \\
0.05 \\
0.04 \\
0.04 \\
0.04 \\
0.04 \\
0.04 \\
0.04 \\
0.05 \\
0.04 \\
0.04 \\
0.04 \\
0.04\end{array}$ & $\begin{array}{l}- \\
- \\
- \\
- \\
- \\
- \\
- \\
- \\
- \\
- \\
- \\
- \\
- \\
- \\
-\end{array}$ \\
\hline$\stackrel{N}{\rightarrow}$ & NITRATE & $\begin{array}{l}0558 \\
0558 \\
0558 \\
0558 \\
0558 \\
0668 \\
0668 \\
0668 \\
0668 \\
0668 \\
0668 \\
0668 \\
0687 \\
0687 \\
0687 \\
0687 \\
0687 \\
0687 \\
0687 \\
0687\end{array}$ & $\begin{array}{l}12 / 15 / 90 \\
03 / 30 / 91 \\
08 / 07 / 91 \\
12 / 11 / 91 \\
10 / 12 / 92 \\
02 / 02 / 86 \\
06 / 30 / 86 \\
10 / 14 / 87 \\
02 / 19 / 88 \\
12 / 15 / 90 \\
11 / 18 / 91 \\
10 / 11 / 92 \\
07 / 18 / 86 \\
04 / 08 / 87 \\
10 / 15 / 87 \\
02 / 19 / 88 \\
12 / 15 / 90 \\
04 / 03 / 91 \\
08 / 27 / 91 \\
12 / 10 / 91\end{array}$ & $\begin{array}{l}0001 \\
0001 \\
0001 \\
0001 \\
0001 \\
0001 \\
0001 \\
0001 \\
0001 \\
0001 \\
0001 \\
0001 \\
0001 \\
0001 \\
0001 \\
0001 \\
0001 \\
0001 \\
0001 \\
0001\end{array}$ & $\begin{array}{l}\text { NA } \\
N A \\
N A \\
N A \\
N A \\
N A \\
N A \\
N A \\
N A \\
N A \\
N A \\
N A \\
N A \\
N A \\
N A \\
N A \\
N A \\
N A \\
N A \\
N A\end{array}$ & $\begin{array}{l}U \\
U \\
U \\
U \\
U \\
U \\
U \\
U \\
U \\
U \\
U \\
U \\
U \\
U \\
U \\
U \\
U \\
U \\
U \\
U\end{array}$ & $M G / L$ & $\begin{array}{l}< \\
< \\
< \\
< \\
< \\
< \\
< \\
< \\
<\end{array}$ & $\begin{array}{c}2 . \\
5.6 \\
4.0 \\
5.7 \\
11.3 \\
1 . \\
1 . \\
1.0 \\
0.3 \\
1 . \\
1.0 \\
2.4 \\
80.0 \\
1.4 \\
1.0 \\
0.1 \\
1 . \\
3 . \\
6.9 \\
1.0\end{array}$ & $\begin{array}{l}J L \\
L \\
L \\
L \\
L \\
L \\
J \\
J \\
L \\
L \\
L \\
J \\
J L \\
L\end{array}$ & $\begin{array}{l}1 . \\
1 . \\
1 . \\
1.0 \\
1.0 \\
1 . \\
1 . \\
1 . \\
1 . \\
1.0 \\
1.0 \\
1 . \\
1 . \\
1 . \\
1 . \\
1 . \\
1 . \\
1 .\end{array}$ & $\begin{array}{l}- \\
- \\
- \\
- \\
- \\
- \\
- \\
- \\
- \\
- \\
- \\
- \\
- \\
- \\
-\end{array}$ \\
\hline
\end{tabular}

FORMATION OF COMPLETION CODE:

NA - NAVAJO SANDSTONE

PARAMETER VALUE INDICATOR (PVI): < - LESS THAN DETECTION LIMIT
FLOW RELATIONSHIP CODE:

U - UPGRADIENT

SAMPLE ID CODES:

0001 - FILTERED SAMPLE (.45 MICRONS)

OTHER PARAMETER VALUE FLAGS:

$J$ - ESTIMATED VALUE

$L$ - LESS THAN THREE BORE VOLUMES REMOVED BEFORE SAMPLING 
TABLE 3.15 BACKGROUND GROUND WATER QUALITY DATA BY PARAMETER FOR THE

NAVAJO SANDSTONE, NC AND UC PROCESSING SITES, SLICK ROCK, COLORADO

SITE: SRK01 SLICK ROCK (BOTH SITES)

$02 / 02 / 86$ TO $02 / 19 / 94$

REPORT DATE: $09 / 29 / 94$

\begin{tabular}{|c|c|c|c|c|c|c|c|c|c|c|c|}
\hline PARAMETER NAME & $\mid \begin{array}{c}\text { LOCAT ION } \\
\text { ID }\end{array}$ & LOG DATE & $\begin{array}{c}\text { SAMPLE } \\
\text { ID }\end{array}$ & $\mid \begin{array}{l}\text { FORM } \\
\text { COMP }\end{array}$ & $\begin{array}{l}\text { FLOW } \\
\text { REL. }\end{array}$ & $\begin{array}{l}\text { UNITS OF } \\
\text { MEASURE }\end{array}$ & PVI & $\begin{array}{l}\text { PARAMETER } \\
\text { VALLUE }\end{array}$ & FLAGS & $\begin{array}{l}\text { DETECTION } \\
\text { LIMIT }\end{array}$ & $\begin{array}{l}\text { PARAMETER } \\
\text { UNCERTAINTY }\end{array}$ \\
\hline NITRATE & 0687 & $10 / 07 / 92$ & 0001 & NA & $u$ & $\mathrm{MG} / \mathrm{L}$ & \multicolumn{3}{|c|}{6.5} & 1.0 & - \\
\hline NITRATE (TOTAL) & $\begin{array}{l}0558 \\
0668 \\
0687\end{array}$ & $\begin{array}{l}02 / 18 / 94 \\
02 / 18 / 94 \\
02 / 19 / 94\end{array}$ & $\begin{array}{l}\text { N001 } \\
\text { N001 } \\
\text { N001 }\end{array}$ & $\begin{array}{l}\text { NA } \\
\text { NA } \\
\text { NA }\end{array}$ & $\begin{array}{l}U \\
U \\
U\end{array}$ & $M G / L$ & $<$ & $\begin{array}{l}2 \\
1 \\
1\end{array}$ & $L$ & $\begin{array}{l}1 \\
1 \\
1\end{array}$ & - \\
\hline NITRITE AND NITRATE & $\begin{array}{l}0558 \\
0558 \\
0558 \\
0668 \\
0668 \\
0687 \\
0687 \\
0687 \\
0687\end{array}$ & $\begin{array}{l}12 / 15 / 90 \\
03 / 30 / 91 \\
08 / 07 / 91 \\
02 / 19 / 88 \\
12 / 15 / 90 \\
02 / 19 / 88 \\
12 / 15 / 90 \\
04 / 03 / 91 \\
08 / 27 / 91\end{array}$ & $\begin{array}{l}0001 \\
0001 \\
0001 \\
0001 \\
0001 \\
0001 \\
0001 \\
0001 \\
0001\end{array}$ & $\begin{array}{l}\text { NA } \\
\text { NA } \\
\text { NA } \\
\text { NA } \\
\text { NA } \\
\text { NA } \\
\text { NA } \\
\text { NA } \\
\text { NA }\end{array}$ & $\begin{array}{l}U \\
U \\
U \\
U \\
U \\
U \\
U \\
U \\
U\end{array}$ & MG/L & $\mid<$ & $\begin{array}{l}2 . \\
1.27 \\
0.87 \\
0.3 \\
1 . \\
0.1 \\
1 . \\
0.61 \\
1.56\end{array}$ & $\begin{array}{l}L \\
L \\
L \\
J \\
J \\
J L \\
L\end{array}$ & $\begin{array}{l}1 . \\
0.05 \\
0.05 \\
1 . \\
1 . \\
1 . \\
1 . \\
0.05 \\
0.05\end{array}$ & $\begin{array}{l}- \\
- \\
- \\
- \\
- \\
- \\
- \\
-\end{array}$ \\
\hline $\mathrm{PH}$ & $\begin{array}{l}0558 \\
0558 \\
0558 \\
0558 \\
0558 \\
0558 \\
0668 \\
0668 \\
0668 \\
0668 \\
0668 \\
0668 \\
0668 \\
0668 \\
0668 \\
0687 \\
0687 \\
0687 \\
0687 \\
0687 \\
0687 \\
0687 \\
0687\end{array}$ & $\begin{array}{l}12 / 15 / 90 \\
03 / 30 / 91 \\
08 / 07 / 91 \\
12 / 05 / 91 \\
10 / 12 / 92 \\
02 / 18 / 94 \\
02 / 02 / 86 \\
06 / 30 / 86 \\
10 / 14 / 87 \\
02 / 19 / 88 \\
12 / 15 / 90 \\
03 / 27 / 91 \\
11 / 18 / 91 \\
10 / 11 / 92 \\
02 / 18 / 94 \\
07 / 18 / 86 \\
04 / 08 / 87 \\
10 / 15 / 87 \\
02 / 19 / 88 \\
12 / 15 / 90 \\
04 / 03 / 91 \\
08 / 27 / 91 \\
12 / 05 / 91\end{array}$ & $\begin{array}{l}0001 \\
0001 \\
0001 \\
0001 \\
0001 \\
N 001 \\
0001 \\
0001 \\
0001 \\
0001 \\
0001 \\
0001 \\
0001 \\
0001 \\
N 001 \\
0001 \\
0001 \\
0001 \\
0001 \\
0001 \\
0001 \\
0001 \\
0001\end{array}$ & $\begin{array}{l}\text { NA } \\
\text { NA } \\
\text { NA } \\
\text { NA } \\
\text { NA } \\
\text { NA } \\
\text { NA } \\
\text { NA } \\
\text { NA } \\
\text { NA } \\
\text { NA } \\
\text { NA } \\
\text { NA } \\
\text { NA } \\
\text { NA } \\
\text { NA } \\
\text { NA } \\
\text { NA } \\
\text { NA } \\
\text { NA } \\
\text { NA } \\
\text { NA } \\
\text { NA }\end{array}$ & $\begin{array}{l}U \\
U \\
U \\
U \\
U \\
U \\
U \\
U \\
U \\
U \\
U \\
U \\
U \\
U \\
U \\
U \\
U \\
U \\
U \\
U \\
U \\
U \\
U\end{array}$ & SU & & $\begin{array}{l}7.80 \\
7.49 \\
7.58 \\
7.59 \\
7.47 \\
7.61 \\
8.22 \\
7.47 \\
7.43 \\
7.41 \\
7.65 \\
7.69 \\
7.82 \\
7.64 \\
7.69 \\
7.24 \\
7.51 \\
7.18 \\
7.34 \\
7.47 \\
7.37 \\
7.41 \\
7.64\end{array}$ & $\begin{array}{l}L \\
L \\
L \\
L \\
L \\
L \\
L\end{array}$ & $\begin{array}{l}- \\
- \\
- \\
- \\
- \\
- \\
- \\
- \\
- \\
- \\
- \\
- \\
- \\
- \\
- \\
- \\
-\end{array}$ & $\begin{array}{l}- \\
- \\
- \\
- \\
- \\
- \\
- \\
- \\
- \\
- \\
- \\
- \\
- \\
- \\
- \\
- \\
- \\
- \\
- \\
-\end{array}$ \\
\hline
\end{tabular}

FORMATION OF COMPLETION CODE:

NA - NAVAJO SANDSTONE

PARAMETER VALUE INDICATOR (PVI): < - LESS THAN DETECTION LIMIT

OTHER PARAMETER VALUE FLAGS:

$J$ - ESTIMATED VALUE

L - LESS THAN THREE BORE VOLUMES REMOVED BEFORE SAMPLING
FLOW RELATIONSHIP CODE:

U - UPGRADIENT

SAMPLE ID CODES:

0001 - FILTERED SAMPLE (.45 MICRONS)

NO01 - UNFILTERED SAMPLE 
TABLE 3.15 BACKGROUND GROUND WATER QUALITY DATA BY PARAMETER FOR THE NAVAJO SANDSTONE, NC AND UC PROCESSING SITES, SLICK ROCK, COLORADO SITE: SRKOI SLICK ROCK (BOTH SITES)

02/02/86 TO $02 / 19 / 94$

REPORT DATE: $09 / 29 / 94$

\begin{tabular}{|c|c|c|c|c|c|c|c|c|c|c|c|}
\hline PARAMETER NAME & $\underset{\text { ID }}{\text { LOCAT ION }}$ & LOG DATE & $\underset{10}{\text { SAMPLE }}$ & $\begin{array}{l}\text { FORM } \\
\text { COMP }\end{array}$ & $\begin{array}{l}\text { FLOW } \\
\text { REL. }\end{array}$ & $\begin{array}{l}\text { UNITS OF } \\
\text { MEASURE }\end{array}$ & PVI & $\begin{array}{l}\text { PARAMETER } \\
\text { VALUE }\end{array}$ & FLAGS & $\begin{array}{l}\text { DETECTION } \\
\text { LIMIT }\end{array}$ & $\begin{array}{l}\text { PARAMETER } \\
\text { UNCERTAINTY }\end{array}$ \\
\hline PH & $\begin{array}{l}0687 \\
0687\end{array}$ & $\left|\begin{array}{l}10 / 07 / 92 \\
02 / 19 / 94\end{array}\right|$ & $\begin{array}{l}0001 \\
\text { N001 }\end{array}$ & $\begin{array}{l}\text { NA } \\
\text { NA }\end{array}$ & $\begin{array}{l}U \\
U\end{array}$ & SU & & $\begin{array}{l}7.41 \\
7.50\end{array}$ & & - & - \\
\hline PHOSPHATE & $\begin{array}{l}0558 \\
0558 \\
0558 \\
0558 \\
0558 \\
0668 \\
0668 \\
0668 \\
0668 \\
0687 \\
0687 \\
0687 \\
0687 \\
0687 \\
0687 \\
0687 \\
0687\end{array}$ & $\begin{array}{l}12 / 15 / 90 \\
03 / 30 / 91 \\
08 / 07 / 91 \\
12 / 11 / 91 \\
10 / 12 / 92 \\
10 / 14 / 87 \\
12 / 15 / 90 \\
11 / 18 / 91 \\
10 / 11 / 92 \\
07 / 18 / 86 \\
04 / 08 / 87 \\
10 / 15 / 87 \\
12 / 15 / 90 \\
04 / 03 / 91 \\
08 / 27 / 91 \\
12 / 10 / 91 \\
10 / 07 / 92\end{array}$ & $\begin{array}{l}0001 \\
0001 \\
0001 \\
0001 \\
0001 \\
0001 \\
0001 \\
0001 \\
0001 \\
0001 \\
0001 \\
0001 \\
0001 \\
0001 \\
0001 \\
0001 \\
0001\end{array}$ & $\begin{array}{l}\text { NA } \\
\text { NA } \\
\text { NA } \\
\text { NA } \\
\text { NA } \\
\text { NA } \\
\text { NA } \\
\text { NA } \\
\text { NA } \\
\text { NA } \\
\text { NA } \\
\text { NA } \\
\text { NA } \\
\text { NA } \\
\text { NA } \\
\text { NA } \\
\text { NA }\end{array}$ & $\begin{array}{l}U \\
U \\
U \\
U \\
U \\
U \\
U \\
U \\
U \\
U \\
U \\
U \\
U \\
U \\
U \\
U \\
U\end{array}$ & MG/L & $\begin{array}{l}< \\
< \\
< \\
< \\
< \\
< \\
< \\
< \\
< \\
< \\
< \\
< \\
< \\
<\end{array}$ & $\begin{array}{l}0.1 \\
0.1 \\
0.1 \\
0.2 \\
0.8 \\
0.1 \\
0.1 \\
0.2 \\
0.1 \\
0.1 \\
0.1 \\
0.1 \\
0.1 \\
0.1 \\
0.1 \\
0.2 \\
0.1\end{array}$ & $\begin{array}{l}L \\
L \\
L \\
L \\
J L \\
L \\
H \\
J \\
J L \\
L \\
L \\
J L \\
L\end{array}$ & $\begin{array}{l}0.1 \\
0.1 \\
0.1 \\
0.1 \\
0.1 \\
0.1 \\
0.1 \\
0.1 \\
0.1 \\
0.1 \\
0.1 \\
0.1 \\
0.1 \\
0.1 \\
0.1 \\
0.1 \\
0.1\end{array}$ & $\begin{array}{l}- \\
- \\
- \\
- \\
- \\
- \\
- \\
- \\
- \\
- \\
- \\
- \\
-\end{array}$ \\
\hline POLONIUM-210 & $\begin{array}{l}0558 \\
0558 \\
0668 \\
0668 \\
0687 \\
0687 \\
0687 \\
0687\end{array}$ & $\begin{array}{l}08 / 07 / 91 \\
12 / 05 / 91 \\
11 / 18 / 91 \\
02 / 18 / 94 \\
07 / 18 / 86 \\
08 / 27 / 91 \\
12 / 05 / 91 \\
02 / 19 / 94\end{array}$ & $\begin{array}{l}0001 \\
0001 \\
0001 \\
0001 \\
0001 \\
0001 \\
0001 \\
0001\end{array}$ & $\begin{array}{l}\text { NA } \\
\text { NA } \\
\text { NA } \\
\text { NA } \\
\text { NA } \\
\text { NA } \\
\text { NA } \\
\text { NA }\end{array}$ & $\begin{array}{l}U \\
U \\
U \\
U \\
U \\
U \\
U \\
U\end{array}$ & $\mathrm{PCI} / \mathrm{L}$ & & $\begin{array}{l}0.3 \\
0.1 \\
0.0 \\
0.1 \\
0.1 \\
0.1 \\
0.0 \\
0.1\end{array}$ & $\begin{array}{l}\mathrm{L} \\
\mathrm{L} \\
\mathrm{L}\end{array}$ & $\begin{array}{l}1 . \\
1 . \\
1 . \\
0.1 \\
1 . \\
1 . \\
1 . \\
0.1\end{array}$ & $\begin{array}{l}0.4 \\
0.4 \\
0.4 \\
0.1 \\
0.5 \\
0.3 \\
0.2 \\
0.1\end{array}$ \\
\hline POLONIUM-210 (TOTAL) & $\begin{array}{l}0558 \\
0668 \\
0687\end{array}$ & $\begin{array}{l}02 / 18 / 94 \\
02 / 18 / 94 \\
02 / 19 / 94\end{array}$ & $\begin{array}{l}\text { N001 } \\
\text { N001 } \\
\text { N001 }\end{array}$ & $\begin{array}{l}\text { NA } \\
\text { NA } \\
\text { NA }\end{array}$ & $\begin{array}{l}U \\
U \\
U\end{array}$ & $\mathrm{PCl} / \mathrm{L}$ & & $\begin{array}{l}0.0 \\
0.1 \\
0.0\end{array}$ & $L$ & $\begin{array}{l}0.1 \\
0.1 \\
0.0\end{array}$ & $\begin{array}{l}0.0 \\
0.1 \\
0.1\end{array}$ \\
\hline POTASSIUM & $\begin{array}{l}0558 \\
0558 \\
0558 \\
0558\end{array}$ & $\begin{array}{l}12 / 15 / 90 \\
03 / 30 / 91 \\
08 / 07 / 91 \\
12 / 11 / 91\end{array}$ & $\begin{array}{l}0001 \\
0001 \\
0001 \\
0001\end{array}$ & $\begin{array}{l}\text { NA } \\
\text { NA } \\
\text { NA } \\
\text { NA }\end{array}$ & $\begin{array}{l}\mathbf{U} \\
\mathbf{U} \\
\mathbf{U} \\
\mathbf{U}\end{array}$ & $M G / L$ & & $\begin{array}{r}14.5 \\
9.4 \\
10.9 \\
12 .\end{array}$ & $\begin{array}{l}J L \\
L \\
L \\
L\end{array}$ & $\begin{array}{l}0.01 \\
0.01 \\
0.01 \\
5 .\end{array}$ & $\begin{array}{l}- \\
- \\
-\end{array}$ \\
\hline
\end{tabular}

FORMATION OF COMPLETION CODE:

NA - NAVAJO SANDSTONE

FLOW RELATIONSHIP CODE:

PARAMETER VALUE INDICATOR (PVI): < - LESS THAN DETECTION LIMIT

SAMPLE ID CODES:

0001 - FILTERED SAMPLE (.45 MICRONS)

OTHER PARAMETER VALUE FLAGS:

NOO1 - UNFILTERED SAMPLE

H - HOLD TIME EXPIRED, VALUE SUSPECT

$J$ - ESTIMATED VALUE

L - LESS THAN THREE BORE VOLUMES REMOVED BEFORE SAMPLING 
TABLE 3.15 BACKGROUND GROUND WATER QUALITY DATA BY PARAMETER FOR THE NAVAJO SANDSTONE, NC AND UC PROCESSING SITES, SLICK ROCK, COLORADO SITE: SRKO1 SLICK ROCK (BOTH SITES)

OL2/86 TO 02/19/94

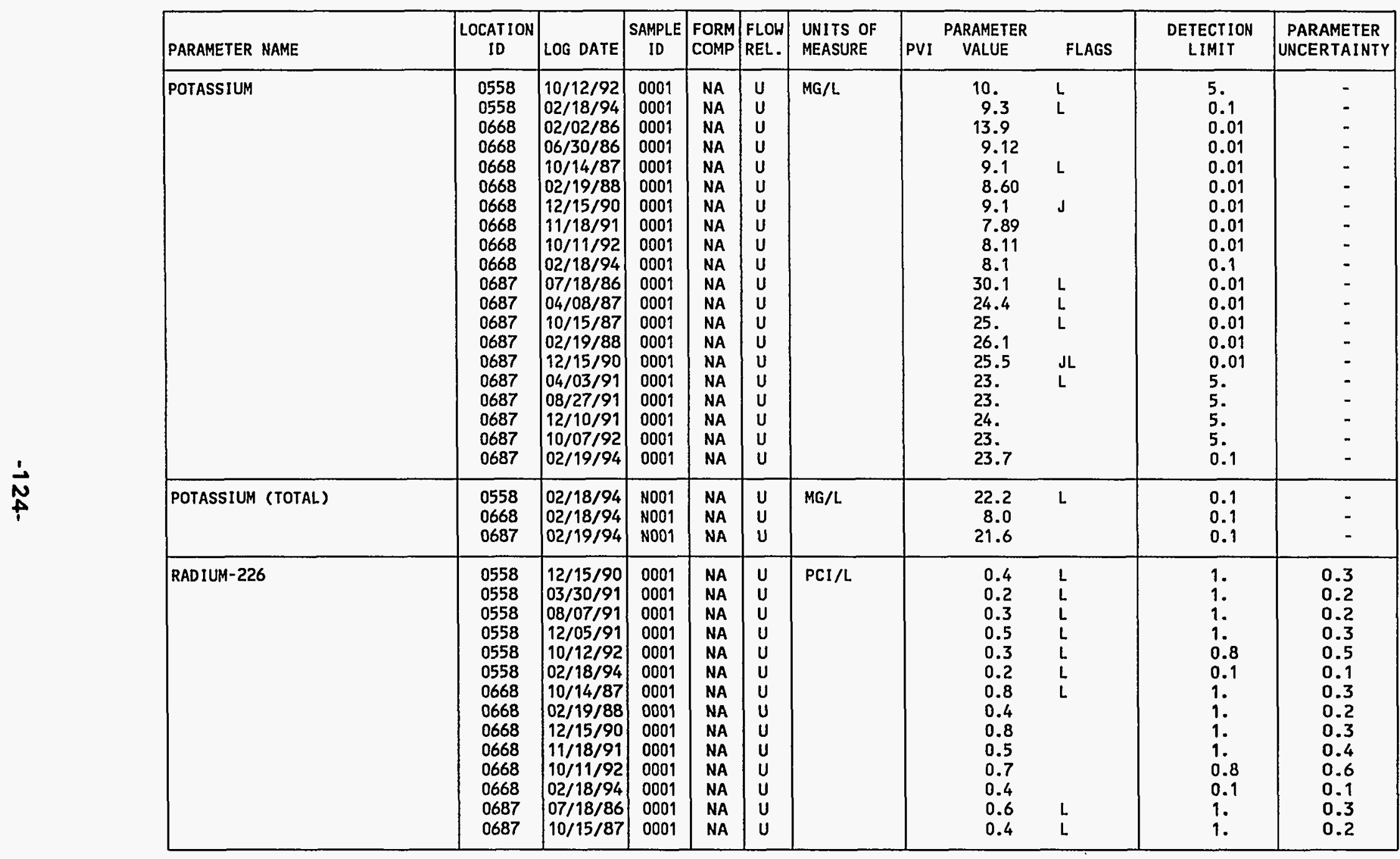

FORMATION OF COMPLETION CODE:

NA - NAVAJO SANDSTONE

PARAMETER VALUE INDICATOR (PVI):

OTHER PARAMETER VALUE FLAGS:

$J$ - ESTIMATED VALUE

L - LESS THAN THREE BORE VOLUMES REMOVED BEFORE SAMPLING
FLOW RELATIONSHIP CODE:

- UPGRADIENT

SAMPLE ID CODES

0001 - FILTERED SAMPLE (.45 MICRONS)

N001 - UNFILTERED SAMPLE 
TABLE 3.15 BACKGROUND GROUND WATER QUALITY DATA BY PARAMETER FOR THE NAVAJO SANDSTONE, NC AND UC PROCESSING SITES, SLICK ROCK, COLORADO

SITE: SRKO1 SLICK ROCK (BOTH SITES)

02/02/86 TO 02/19/94

REPORT DATE: $09 / 29 / 94$

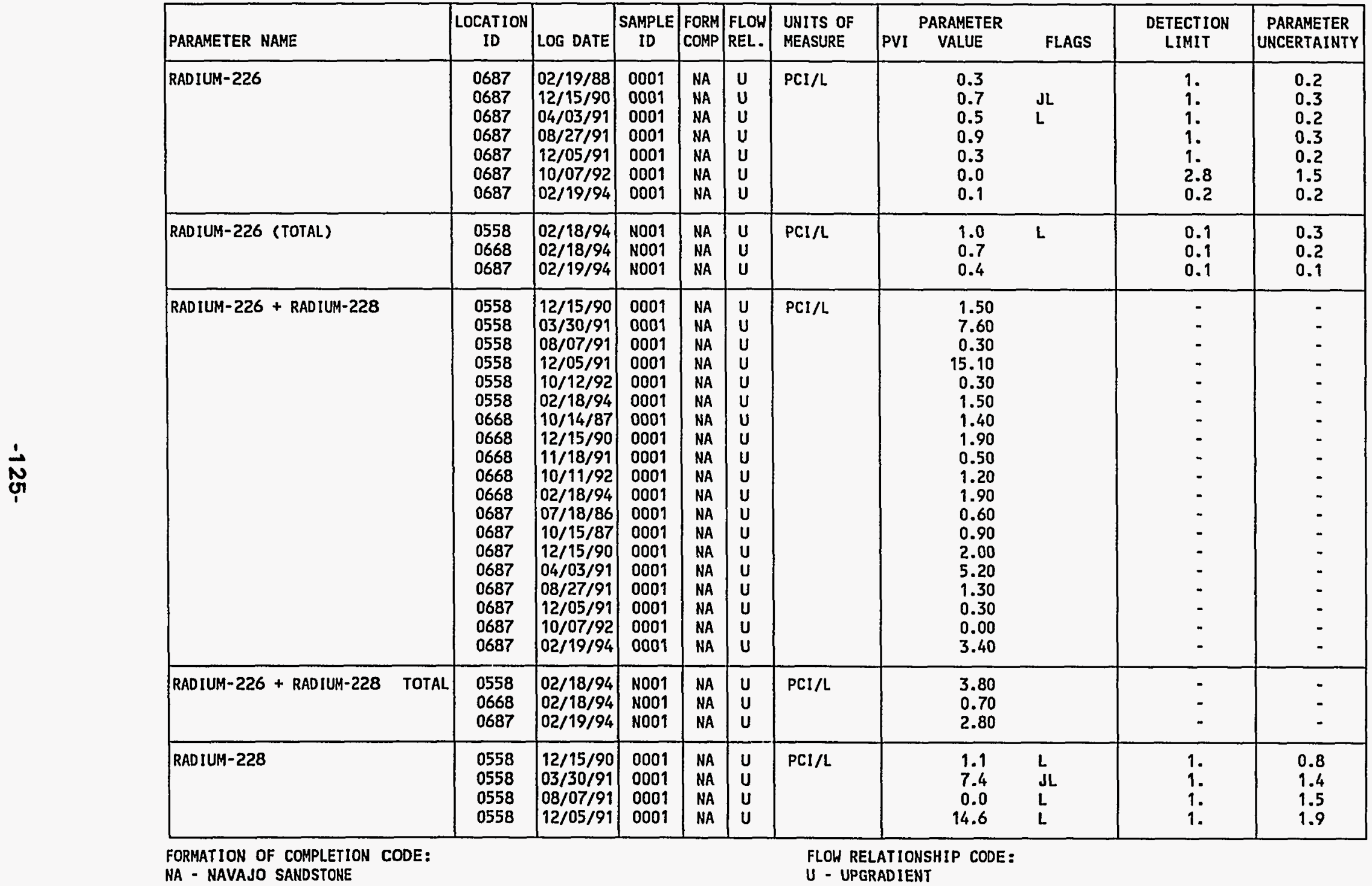

PARAMETER VALUE INDICATOR (PVI): < - LESS THAN DETECTION LIMIT

OTHER PARAMETER VALUE FLAGS:

SAMPLE ID CODES:

$J$ - ESTIMATED VALUE

0001 - FILTERED SAMPLE (.45 MICRONS)

N001 - UNFILTERED SAMPLE 
TABLE 3.15 BACKGROUND GROUND HATER QUALITY DATA BY PARAMETER FOR THE NAVAJO SANDSTONE, NC AND UC PROCESSING SITES, SLICK ROCK, COLORADO

SITE: SRKO1 SLICK ROCK (BOTH SI

$02 / 02 / 86$ TO $02 / 19 / 94$

REPORT DATE: $09 / 29 / 94$

\begin{tabular}{|c|c|c|c|c|c|c|c|c|c|c|c|}
\hline PARAMETER NAME & $\begin{array}{c}\text { LOCATION } \\
\text { ID }\end{array}$ & LOG DATE & $\begin{array}{c}\text { SAMPLEE } \\
\text { ID }\end{array}$ & $\begin{array}{l}\text { FORM } \\
\text { COMP }\end{array}$ & $\begin{array}{l}\text { FLOW } \\
\text { REL. }\end{array}$ & $\begin{array}{l}\text { UNITS OF } \\
\text { MEASURE }\end{array}$ & PVI & $\begin{array}{l}\text { ARAMETER } \\
\text { VALUE }\end{array}$ & FLAGS & $\begin{array}{l}\text { DETECTION } \\
\text { LIMIT }\end{array}$ & $\begin{array}{l}\text { PARAMETER } \\
\text { UNCERTAINTY }\end{array}$ \\
\hline RADIUM-228 & $\begin{array}{l}0558 \\
0558 \\
0668 \\
0668 \\
0668 \\
0668 \\
0668 \\
0687 \\
0687 \\
0687 \\
0687 \\
0687 \\
0687 \\
0687 \\
0687\end{array}$ & $\begin{array}{l}10 / 12 / 92 \\
02 / 18 / 94 \\
10 / 14 / 87 \\
12 / 15 / 90 \\
11 / 18 / 91 \\
10 / 11 / 92 \\
02 / 18 / 94 \\
07 / 18 / 86 \\
10 / 15 / 87 \\
12 / 15 / 90 \\
04 / 03 / 91 \\
08 / 27 / 91 \\
12 / 05 / 91 \\
10 / 07 / 92 \\
02 / 19 / 94\end{array}$ & $\begin{array}{l}0001 \\
0001 \\
0001 \\
0001 \\
0001 \\
0001 \\
0001 \\
0001 \\
0001 \\
0001 \\
0001 \\
0001 \\
0001 \\
0001 \\
0001\end{array}$ & $\begin{array}{l}\text { NA } \\
\text { NA } \\
\text { NA } \\
\text { NA } \\
\text { NA } \\
\text { NA } \\
\text { NA } \\
\text { NA } \\
\text { NA } \\
\text { NA } \\
\text { NA } \\
\text { NA } \\
\text { NA } \\
\text { NA } \\
\text { NA }\end{array}$ & $\begin{array}{l}U \\
U \\
U \\
U \\
U \\
U \\
U \\
U \\
U \\
U \\
U \\
U \\
U \\
U \\
U\end{array}$ & $\mathrm{PCI} / \mathrm{L}$ & & $\begin{array}{l}0.0 \\
1.3 \\
0.6 \\
1.1 \\
0.0 \\
0.5 \\
1.5 \\
0 . \\
0.5 \\
1.3 \\
4.7 \\
0.4 \\
0.0 \\
0.0 \\
3.3\end{array}$ & $\begin{array}{l}N \\
\mathrm{JL} \\
\mathrm{L} \\
\mathrm{JL} \\
\mathrm{L}\end{array}$ & $\begin{array}{l}2.7 \\
2.5 \\
1 . \\
1 . \\
1 . \\
2.4 \\
3.0 \\
1 . \\
1 . \\
1 . \\
1 . \\
1 . \\
1 . \\
2.5 \\
2.9\end{array}$ & $\begin{array}{l}1.6 \\
1.2 \\
0.8 \\
0.8 \\
1.0 \\
1.5 \\
1.2 \\
1.3 \\
1.3 \\
0.9 \\
1.1 \\
1.9 \\
0.7 \\
1.5 \\
1.5\end{array}$ \\
\hline RADIUM-228 (TOTAL) & $\begin{array}{l}0558 \\
0668 \\
0687\end{array}$ & $\begin{array}{l}02 / 18 / 94 \\
02 / 18 / 94 \\
02 / 19 / 94\end{array}$ & $\begin{array}{l}\text { NOO1 } \\
\text { NOO1 } \\
\text { N001 }\end{array}$ & $\begin{array}{l}\text { NA } \\
\text { NA } \\
\text { NA }\end{array}$ & $\begin{array}{l}u \\
u \\
u\end{array}$ & PCI/L & & $\begin{array}{l}2.8 \\
0.0 \\
2.4\end{array}$ & $\begin{array}{l}\text { LN } \\
N \\
N\end{array}$ & $\begin{array}{l}3.0 \\
2.6 \\
2.8\end{array}$ & $\begin{array}{l}1.4 \\
1.0 \\
1.2\end{array}$ \\
\hline REDOX POTENTIAL & $\begin{array}{l}0558 \\
0558 \\
0558 \\
0668 \\
0668 \\
0668 \\
0687 \\
0687 \\
0687\end{array}$ & $\begin{array}{l}12 / 15 / 90 \\
10 / 12 / 92 \\
02 / 18 / 94 \\
12 / 15 / 90 \\
10 / 11 / 92 \\
02 / 18 / 94 \\
12 / 15 / 90 \\
10 / 07 / 92 \\
02 / 19 / 94\end{array}$ & $\begin{array}{l}0001 \\
0001 \\
\text { N001 } \\
0001 \\
0001 \\
\text { N001 } \\
0001 \\
0001 \\
\text { N001 }\end{array}$ & $\begin{array}{l}\text { NA } \\
\text { NA } \\
\text { NA } \\
\text { NA } \\
\text { NA } \\
\text { NA } \\
\text { NA } \\
\text { NA } \\
\text { NA }\end{array}$ & $\begin{array}{l}U \\
U \\
U \\
U \\
U \\
U \\
U \\
U \\
U\end{array}$ & mVOLTS & & $\begin{array}{l}419 . \\
402.5 \\
396 \\
362.8 \\
427.8 \\
74 \\
336.4 \\
393.4 \\
230\end{array}$ & $\begin{array}{l}L \\
L \\
L\end{array}$ & $\begin{array}{l}- \\
- \\
- \\
- \\
- \\
- \\
-\end{array}$ & $\begin{array}{l}- \\
- \\
- \\
- \\
- \\
- \\
-\end{array}$ \\
\hline SELENIUM & $\begin{array}{l}0558 \\
0558 \\
0558 \\
0558 \\
0558 \\
0558 \\
0668\end{array}$ & $\begin{array}{l}12 / 15 / 90 \\
03 / 30 / 91 \\
08 / 07 / 91 \\
12 / 11 / 91 \\
10 / 12 / 92 \\
02 / 18 / 94 \\
02 / 02 / 86\end{array}$ & $\begin{array}{l}0001 \\
0001 \\
0001 \\
0001 \\
0001 \\
0001 \\
0001\end{array}$ & $\begin{array}{l}\text { NA } \\
\text { NA } \\
\text { NA } \\
\text { NA } \\
\text { NA } \\
\text { NA } \\
\text { NA }\end{array}$ & $\begin{array}{l}U \\
U \\
U \\
U \\
U \\
U \\
U\end{array}$ & $M G / L$ & $<$ & $\begin{array}{l}0.008 \\
0.005 \\
0.05 \\
0.04 \\
0.020 \\
0.006 \\
0.005\end{array}$ & $\begin{array}{l}L \\
J L \\
\text { IL } \\
L \\
L \\
L\end{array}$ & $\begin{array}{l}0.005 \\
0.005 \\
0.05 \\
0.03 \\
0.005 \\
0.005 \\
0.005\end{array}$ & $\begin{array}{l}- \\
- \\
- \\
- \\
-\end{array}$ \\
\hline
\end{tabular}

FORMATION OF COMPLETION CODE:

NA - NAVAJO SANDSTONE

PARAMETER VALUE INDICATOR (PVI): < - LESS THAN DETECTION LIMIT

OTHER PARAMETER VALUE FLAGS:

1 - INCREASED DETECTION LIMIT DUE TO REQUIRED DILUTION

$J$ - ESTIMATED VALUE

L - LESS THAN THREE BORE VOLUMES REMOVED BEFORE SAMPLING

N - SPIKE SAMPLE RECOVERY NOT WITHIN CONTROL LIMITS
FLOW RELATIONSHIP CODE:

$U$ - UPGRADIENT

SAMPLE ID CODES:

0001 - FILTERED SAMPLE (.45 MICRONS)

NOO1 - UNFILTERED SAMPLE 


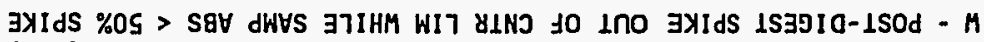

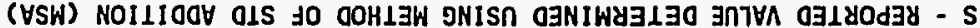

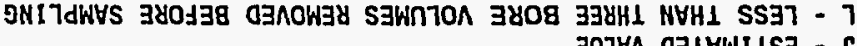

77dWHS 098 $171 \mathrm{INN}$ - 100N (SNOYJIW St.) :sज00J oI כ7dWHS

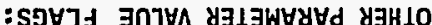

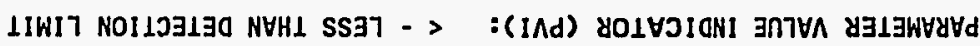

LNaI OYYOSO - n

: $\exists 000$ dIHSNOILV7ヨY M07

BNOISANYS ORYAYN - ZN : $\exists 000$ NOII37dWOJ to NOIIVWHOA

\begin{tabular}{|c|c|c|c|c|c|c|c|c|c|c|c|}
\hline $\begin{array}{l}- \\
- \\
- \\
- \\
- \\
- \\
- \\
- \\
- \\
- \\
- \\
- \\
- \\
-\end{array}$ & $\begin{array}{l}\cdot 2 \\
\cdot 2 \\
\cdot 2 \\
\cdot 2 \\
\cdot 2 \\
l \cdot 0 \\
l \cdot 0 \\
l \cdot 0 \\
\cdot 2 \\
\cdot 2 \\
\cdot 2 \\
l \cdot 0 \\
l=0 \\
l \cdot 0 \\
l \cdot 0 \\
l \cdot 0 \\
\cdot 2\end{array}$ & $\begin{array}{l}7 \\
7 \\
7 \\
7 \\
7 \\
7 \\
7\end{array}$ & $\begin{array}{l}\cdot 6 \\
5 \cdot 2 \\
9 \cdot 8 \\
9 \cdot 01 \\
\cdot 7 \\
1 \cdot 8 \\
8 \cdot 11 \\
6 \cdot 2 \\
\cdot 8 \\
2 \cdot 9 \\
8 \cdot 2 \\
8 \cdot 51 \\
8 \cdot 71 \\
2 \cdot 71 \\
2 \cdot 71 \\
9 \cdot 11 \\
=71\end{array}$ & & $7 / 9 W$ & $\begin{array}{l}n \\
n \\
n \\
n \\
n \\
n \\
n \\
n \\
n \\
n \\
n \\
n \\
n \\
n \\
n \\
n \\
n\end{array}$ & $\begin{array}{l}\forall N \\
\forall N \\
\forall N \\
\forall N \\
\forall N \\
\forall N \\
\forall N \\
\forall N \\
\forall N \\
\forall N \\
\forall N \\
\forall N \\
\forall N \\
\forall N \\
\forall N \\
\forall N \\
\forall N\end{array}$ & $\begin{array}{l}1000 \\
1000 \\
1000 \\
1000 \\
1000 \\
1000 \\
1000 \\
1000 \\
1000 \\
1000 \\
1000 \\
1000 \\
1000 \\
1000 \\
1000 \\
1000 \\
1000\end{array}$ & 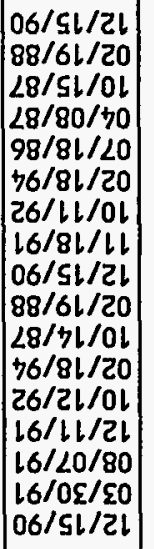 & $\begin{array}{l}\angle 890 \\
\angle 890 \\
\angle 890 \\
\angle 890 \\
\angle 890 \\
8990 \\
8990 \\
8990 \\
8990 \\
8990 \\
8990 \\
8550 \\
8550 \\
8550 \\
8550 \\
8550 \\
8950\end{array}$ & 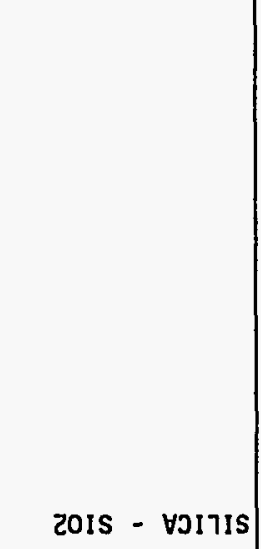 \\
\hline - & $\begin{array}{l}500^{\circ} 0 \\
500^{\circ} 0 \\
500^{\circ} 0\end{array}$ & $\begin{array}{l}M \Gamma \\
\text { S7 }\end{array}$ & $\begin{array}{l}500^{\circ} 0 \\
500^{\circ} 0 \\
800^{\circ} 0\end{array}$ & $\begin{array}{l}> \\
>\end{array}$ & $7 / 9 \mathrm{~W}$ & $\begin{array}{l}n \\
n \\
n\end{array}$ & $\begin{array}{l}\forall N \\
\forall N \\
\forall N\end{array}$ & $\begin{array}{l}\text { LOON } \\
\text { LOON } \\
\text { LOON }\end{array}$ & $\begin{array}{l}76 / 6 L / 20 \\
76 / 8 L / 20 \\
76 / 8 L / 20\end{array}$ & $\begin{array}{l}\angle 890 \\
8990 \\
8 S 50\end{array}$ & (7ษ101) WกIN3า \\
\hline $\begin{array}{l}- \\
- \\
- \\
- \\
- \\
- \\
- \\
- \\
- \\
- \\
-\end{array}$ & $\begin{array}{l}500^{\circ} 0 \\
500^{\circ} 0 \\
500^{\circ} 0 \\
500^{\circ} 0 \\
500^{\circ} 0 \\
500^{\circ} 0 \\
500^{\circ} 0 \\
500^{\circ} 0 \\
500^{\circ} 0 \\
500^{\circ} 0 \\
500^{\circ} 0 \\
500^{\circ} 0 \\
500^{\circ} 0 \\
500^{\circ} 0 \\
500^{\circ} 0\end{array}$ & $\begin{array}{r}M \\
M \\
7 \\
7 \Gamma \\
7 \\
7 \Gamma \\
7 \\
M \Gamma \\
M \\
M \\
7\end{array}$ & $\begin{array}{l}500^{\circ} 0 \\
500^{\circ} 0 \\
500^{\circ} 0 \\
500^{\circ} 0 \\
500^{\circ} 0 \\
500^{\circ} 0 \\
500^{\circ} 0 \\
200^{\circ} 0 \\
500^{\circ} 0 \\
500^{\circ} 0 \\
500^{\circ} 0 \\
500^{\circ} 0 \\
500^{\circ} 0 \\
500^{\circ} 0 \\
500^{\circ} 0\end{array}$ & $\begin{array}{l}> \\
> \\
> \\
> \\
> \\
> \\
> \\
> \\
> \\
> \\
> \\
> \\
> \\
> \\
>\end{array}$ & . & $\begin{array}{l}n \\
n \\
n \\
n \\
n \\
n \\
n \\
n \\
n \\
n \\
n \\
n \\
n \\
n \\
n\end{array}$ & $\begin{array}{l}\forall N \\
\forall N \\
\forall N \\
\forall N \\
\forall N \\
\forall N \\
\forall N \\
\forall N \\
\forall N \\
\forall N \\
\forall N \\
\forall N \\
\forall N \\
\forall N \\
\forall N\end{array}$ & $\begin{array}{l}1000 \\
1000 \\
1000 \\
1000 \\
1000 \\
1000 \\
1000 \\
1000 \\
1000 \\
1000 \\
1000 \\
1000 \\
1000 \\
1000 \\
1000\end{array}$ & 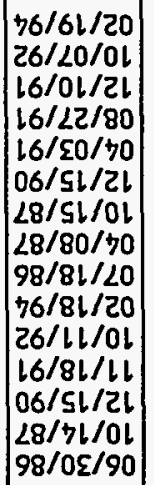 & $\begin{array}{l}\angle 890 \\
\angle 890 \\
\angle 890 \\
\angle 890 \\
\angle 890 \\
\angle 890 \\
\angle 890 \\
\angle 890 \\
\angle 890 \\
8990 \\
8990 \\
8990 \\
8990 \\
8990 \\
8990\end{array}$ & WกINヨา \\
\hline 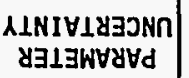 & 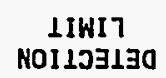 & Sפษาง & 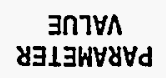 & Ind & 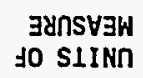 & $\begin{array}{l}-7 y \\
\text { M07t }\end{array}$ & $\begin{array}{l}\text { dWOJ } \\
\text { WYOS }\end{array}$ & aI & 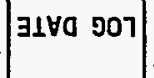 & 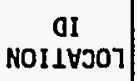 & 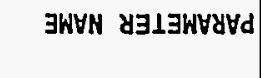 \\
\hline
\end{tabular}

$76 / 62 / 60$ : $: 140180 \mathrm{~d} 38$

$76 / 6 \mathrm{l} / 200198 / 20 / 20$

(S3IIS H108) X X308 X

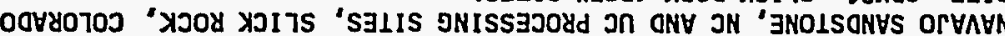

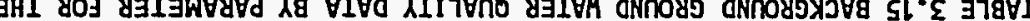


TABLE 3.15 BACKGROUND GROUND HATER QUALITY DATA BY PARAMETER FOR THE NAVAJO SANDSTONE, NC AND UC PROCESSING SITES, SLICK ROCK, COLORADO SITE: SRKO1 SLICK ROCK (BOTH SITES)

02/02/86 TO 02/19/94

REPORT DATE: $09 / 29 / 94$

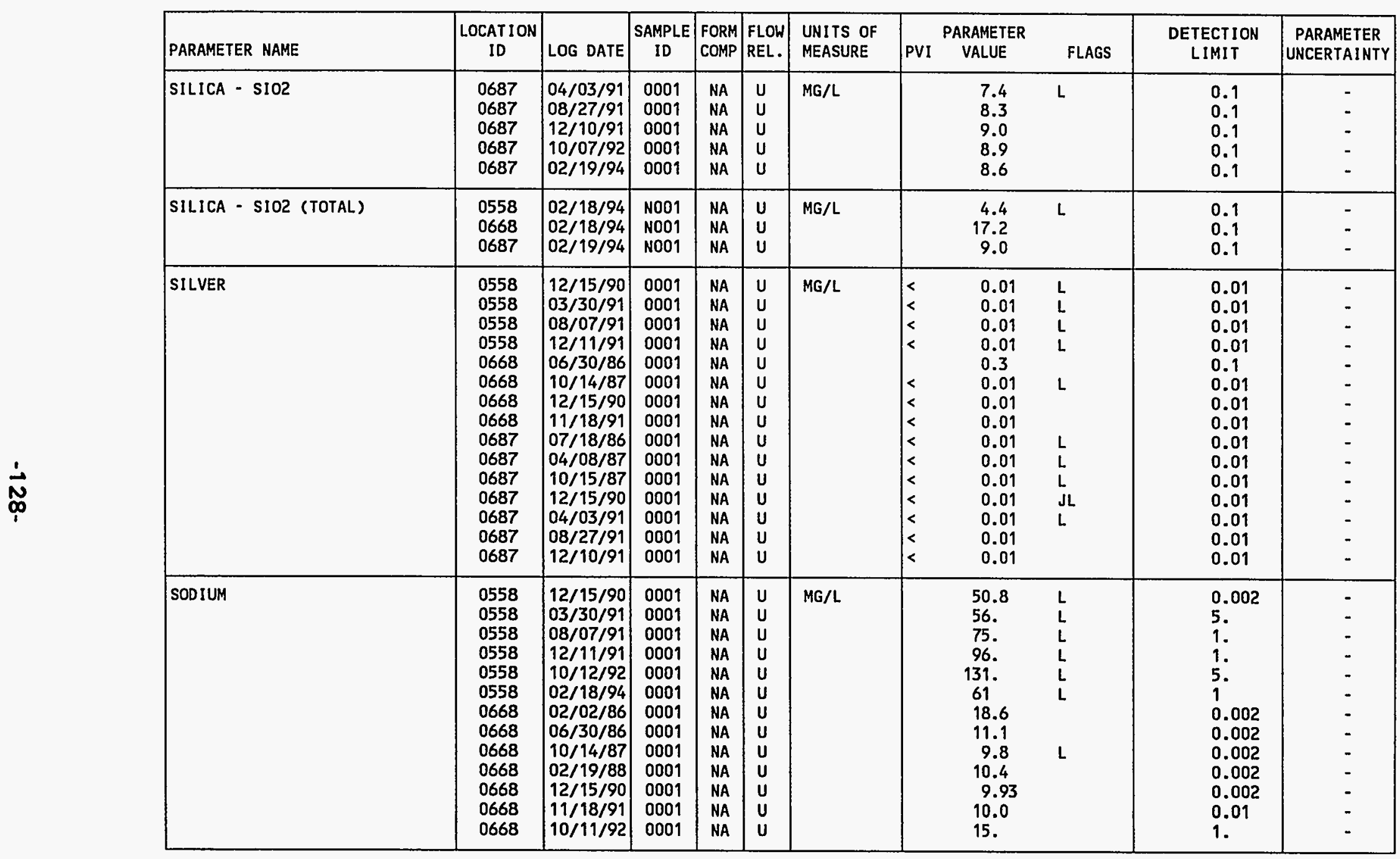

FORMATION OF COMPLETION CODE:

NA - NAVAJO SANDSTONE

PARAMETER VALUE INDICATOR (PVI): < - LESS THAN DETECTION LIMIT

OTHER PARAMETER VALUE FLAGS:

$J$ - ESTIMATED VALUE

L - LESS THAN THREE BORE VOLUMES REMOVED BEFORE SAMPLING
FLOW RELATIONSHIP CODE:

U - UPGRADIENT

SAMPLE ID CODES:

0001 - FILTERED SAMPLE (.45 MICRONS)

N001 - UNFILTERED SAMPLE 
TABLE 3.15 BACKGROUND GROUND WATER QUALITY DATA BY PARAMETER FOR THE NAVA 3 . SA BACKGRONE NC AND UC PROCESSING SITTS, SLICK ROCK, COLORADD

SITE: SRKO 9 SLICK ROCK (BOTH SITES)

$02 / 02 / 86$ TO $02 / 19 / 94$

REPORT DATE: $09 / 29 / 94$

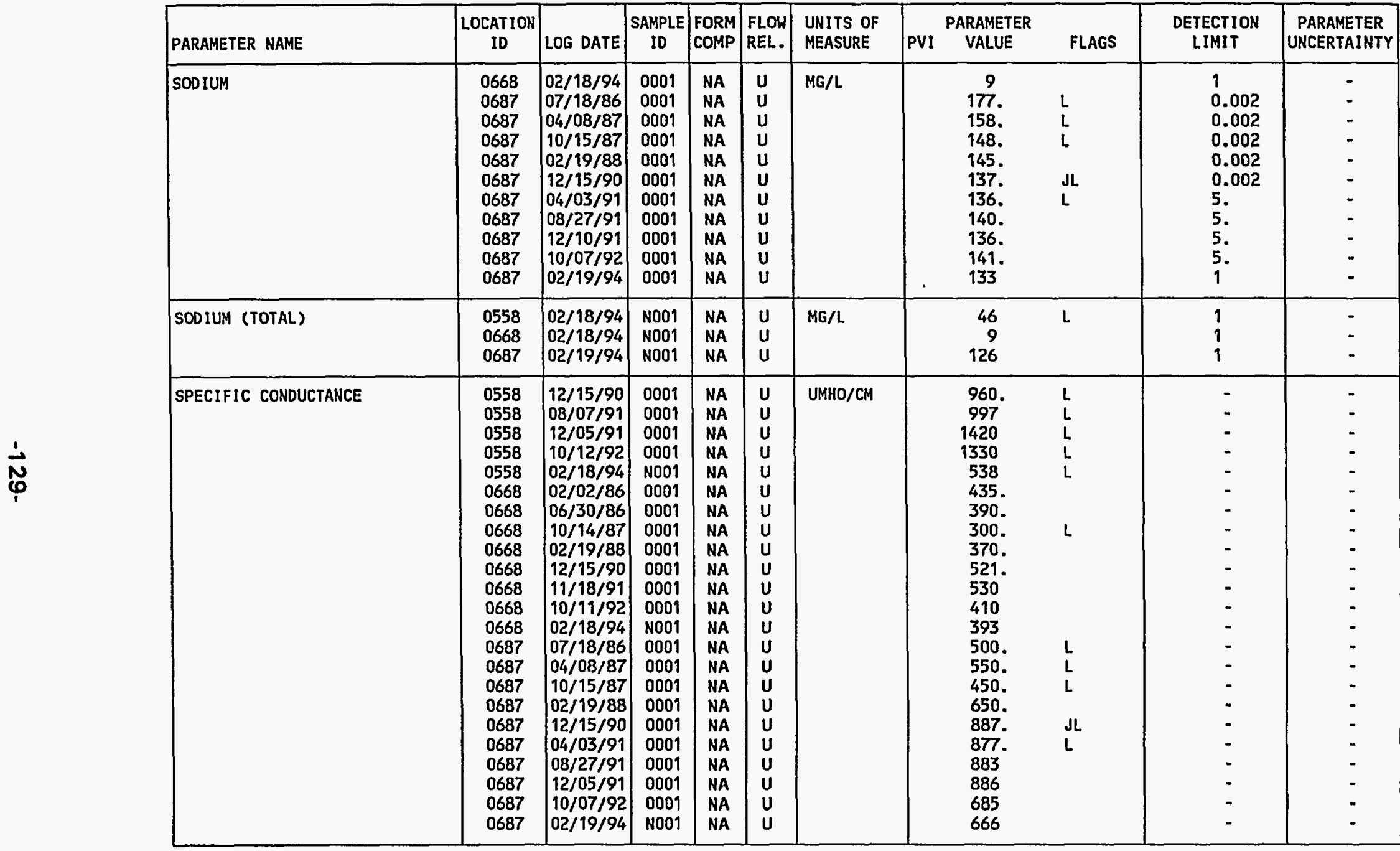

FORMATION OF COMPLETION CODE: NA - NAVAJO SANDSTONE

FLOW RELATIONSHIP CODE:

PARAMETER VALUE INDICATOR (PVI): < - LESS THAN DETECTION LIMIT

SAMPLE ID CODES:

000 - FILTERED SAMPLE (.45 MICRONS)

OTHER PARAMETER VALUE FLAGS:

N001 - UNFILTERED SAMPLE

L - LESS THAN THREE BORE VOLUMES REMOVED BEFORE SAMPLING 
TABLE 3.15 BACKGROUND GROUND HATER QUALITY DATA BY PARAMETER FOR THE NAVAJO SANDSTONE, NC AND UC PROCESSING SITES, SLICK ROCK, COLORADO SITE: SRKO1 SLICK ROCK (BOTH SITES)

02/02/86 TO $02 / 19 / 94$

REPORT DATE: $09 / 29 / 9$

\begin{tabular}{|c|c|c|c|c|c|c|c|c|c|c|c|}
\hline PARAMETER NAME & $\underset{\text { ID }}{\text { LOCATION }}$ & LOG DATE & $\begin{array}{c}\text { SAMPLE } \\
\text { ID }\end{array}$ & $\begin{array}{l}\text { FORM } \\
\text { COMP }\end{array}$ & $\begin{array}{l}\text { FLOW } \\
\text { REL. }\end{array}$ & $\begin{array}{l}\text { UNITS OF } \\
\text { MEASURE }\end{array}$ & PVI & $\begin{array}{l}\text { PARAMETER } \\
\text { VALUE }\end{array}$ & FLAGS & $\begin{array}{l}\text { DETECTION } \\
\text { LIMIT }\end{array}$ & $\begin{array}{l}\text { PARAMETER } \\
\text { UNCERTAINTY }\end{array}$ \\
\hline STRONTIUM & $\begin{array}{l}0558 \\
0558 \\
0558 \\
0558 \\
0558 \\
0558 \\
0668 \\
0668 \\
0668 \\
0668 \\
0687 \\
0687 \\
0687 \\
0687 \\
0687 \\
0687\end{array}$ & $\begin{array}{l}12 / 15 / 90 \\
03 / 30 / 91 \\
08 / 07 / 91 \\
12 / 11 / 91 \\
10 / 12 / 92 \\
02 / 18 / 94 \\
12 / 15 / 90 \\
11 / 18 / 91 \\
10 / 11 / 92 \\
02 / 18 / 94 \\
12 / 15 / 90 \\
04 / 03 / 91 \\
08 / 27 / 91 \\
12 / 10 / 91 \\
10 / 07 / 92 \\
02 / 19 / 94\end{array}$ & $\begin{array}{l}0001 \\
0001 \\
0001 \\
0001 \\
0001 \\
0001 \\
0001 \\
0001 \\
0001 \\
0001 \\
0001 \\
0001 \\
0001 \\
0001 \\
0001 \\
0001\end{array}$ & $\begin{array}{l}\text { NA } \\
\text { NA } \\
\text { NA } \\
\text { NA } \\
\text { NA } \\
\text { NA } \\
\text { NA } \\
\text { NA } \\
\text { NA } \\
\text { NA } \\
\text { NA } \\
\text { NA } \\
\text { NA } \\
\text { NA } \\
\text { NA } \\
\text { NA }\end{array}$ & $\begin{array}{l}U \\
U \\
U \\
U \\
U \\
U \\
U \\
U \\
U \\
U \\
U \\
U \\
U \\
U \\
U \\
U\end{array}$ & $M G / L$ & & $\begin{array}{l}0.9 \\
0.93 \\
1.13 \\
1.29 \\
1.27 \\
0.85 \\
0.9 \\
0.89 \\
0.91 \\
0.84 \\
1.1 \\
1.04 \\
1.17 \\
1.10 \\
1.07 \\
1.05\end{array}$ & $\begin{array}{l}L \\
L \\
L \\
L \\
L \\
L \\
\\
\mathrm{~J} L\end{array}$ & $\begin{array}{l}0.1 \\
0.01 \\
0.01 \\
0.01 \\
0.01 \\
0.01 \\
0.1 \\
0.01 \\
0.01 \\
0.01 \\
0.1 \\
0.01 \\
0.01 \\
0.01 \\
0.01 \\
0.01\end{array}$ & $\begin{array}{l}- \\
- \\
- \\
- \\
- \\
- \\
- \\
- \\
- \\
- \\
- \\
- \\
-\end{array}$ \\
\hline STRONTIUM (TOTAL) & $\begin{array}{l}0558 \\
0668 \\
0687\end{array}$ & $\begin{array}{l}02 / 18 / 94 \\
02 / 18 / 94 \\
02 / 19 / 94\end{array} \mid$ & $\begin{array}{l}\text { N001 } \\
\text { N001 } \\
\text { N001 }\end{array}$ & $\begin{array}{l}\text { NA } \\
\text { NA } \\
\text { NA }\end{array}$ & $\begin{array}{l}U \\
U \\
U\end{array}$ & $M G / L$ & & $\begin{array}{l}0.87 \\
0.87 \\
0.99\end{array}$ & $L$ & $\begin{array}{l}0.01 \\
0.01 \\
0.01\end{array}$ & - \\
\hline SULFATE & $\begin{array}{l}0558 \\
0558 \\
0558 \\
0558 \\
0558 \\
0558 \\
0668 \\
0668 \\
0668 \\
0668 \\
0668 \\
0668 \\
0668 \\
0668 \\
0687 \\
0687 \\
0687 \\
0687\end{array}$ & $\begin{array}{l}12 / 15 / 90 \\
03 / 30 / 91 \\
08 / 07 / 91 \\
12 / 11 / 91 \\
10 / 12 / 92 \\
02 / 18 / 94 \\
02 / 02 / 86 \\
06 / 30 / 86 \\
10 / 14 / 87 \\
02 / 19 / 88 \\
12 / 15 / 90 \\
11 / 18 / 91 \\
10 / 11 / 92 \\
02 / 18 / 94 \\
07 / 18 / 86 \\
04 / 08 / 87 \\
10 / 15 / 87 \\
02 / 19 / 88\end{array}$ & $\begin{array}{l}0001 \\
0001 \\
0001 \\
0001 \\
0001 \\
0001 \\
0001 \\
0001 \\
0001 \\
0001 \\
0001 \\
0001 \\
0001 \\
0001 \\
0001 \\
0001 \\
0001 \\
0001\end{array}$ & $\begin{array}{l}\text { NA } \\
\text { NA } \\
\text { NA } \\
\text { NA } \\
\text { NA } \\
\text { NA } \\
\text { NA } \\
\text { NA } \\
\text { NA } \\
\text { NA } \\
\text { NA } \\
\text { NA } \\
\text { NA } \\
\text { NA } \\
\text { NA } \\
\text { NA } \\
\text { NA } \\
\text { NA }\end{array}$ & $\begin{array}{l}U \\
U \\
U \\
U \\
U \\
U \\
U \\
U \\
U \\
U \\
U \\
U \\
U \\
U \\
U \\
U \\
U \\
U\end{array}$ & $M G / L$ & & $\begin{array}{l}143 . \\
181 . \\
343 . \\
206 . \\
432 . \\
153 \\
55 . \\
14.8 \\
11 . \\
13 . \\
11.9 \\
17 . \\
14 . \\
13 \\
63.8 \\
32.9 \\
57 . \\
59 .\end{array}$ & $\begin{array}{l}L \\
L \\
L \\
L \\
L \\
L \\
L \\
L \\
L \\
L\end{array}$ & $\begin{array}{c}0.1 \\
0.1 \\
0.1 \\
20 . \\
30 . \\
1 \\
0.1 \\
0.1 \\
0.1 \\
0.1 \\
0.1 \\
10 . \\
1 . \\
1 \\
0.1 \\
0.1 \\
0.1 \\
0.1\end{array}$ & $\begin{array}{l}- \\
- \\
- \\
- \\
- \\
- \\
- \\
- \\
- \\
- \\
- \\
- \\
-\end{array}$ \\
\hline
\end{tabular}

FORMATION OF COMPLETION CODE:

NA - NAVAJO SANDSTONE

PARAMETER VALUE INDICATOR (PVI): < - LESS THAN DETECTION LIMIT

OTHER PARAMETER VALUE FLAGS:

$J$ - ESTIMATED VALUE

FLOW RELATIONSHIP CODE:

$U$ - UPGRADIENT

SAMPLE ID CODES:

0001 - FILTERED SAMPLE (.45 MICRONS)

N001 - UNFILTERED SAMPLE 


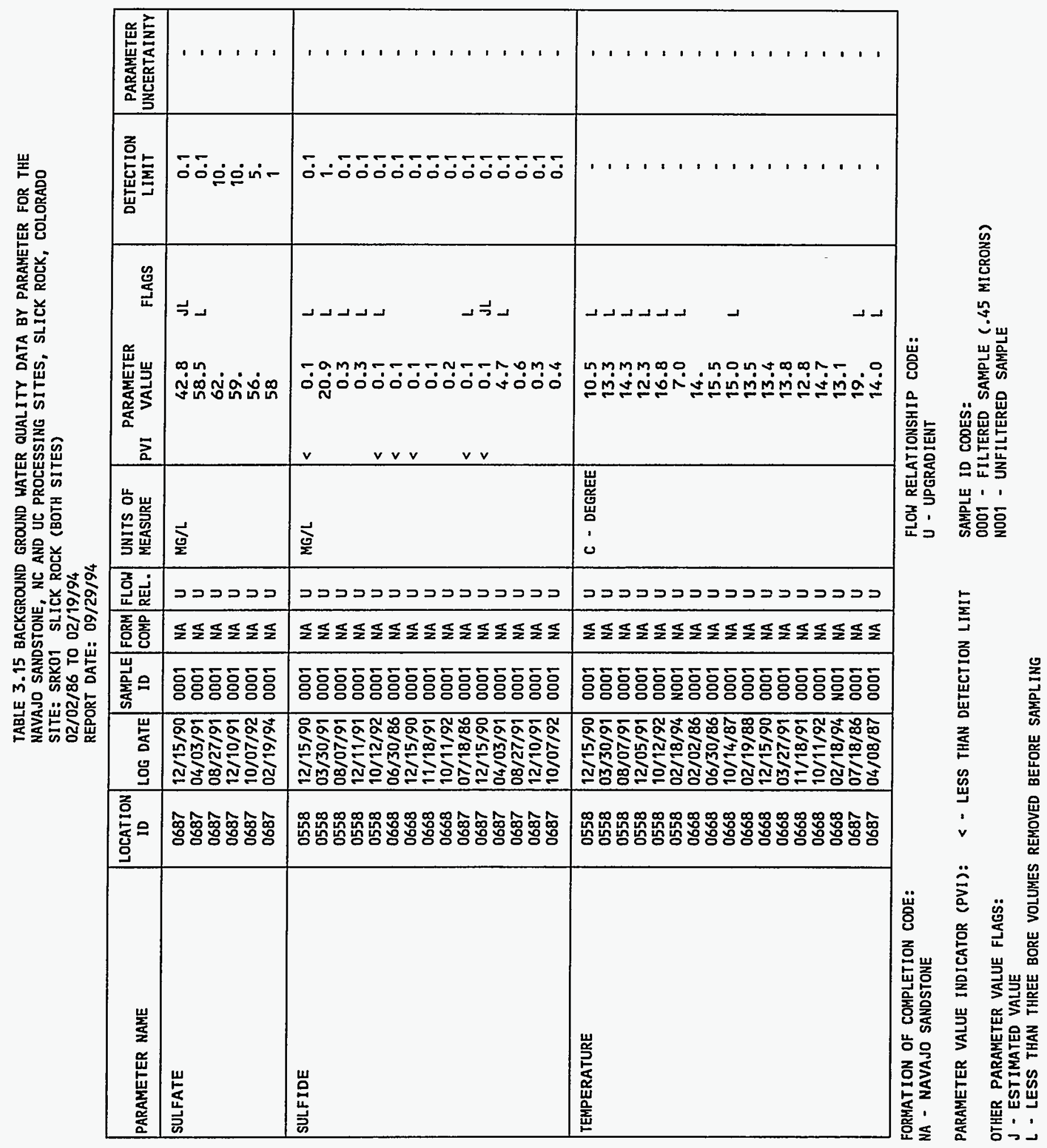


TABLE 3.15 BACKGROUND GROUND WATER QUALITY DATA BY PARAMETER FOR THE NAVAJO SANDSTONE, NC AND UC PROCESSING SITES, SLICK ROCK, COLORADO SITE: SRKO1 SLICK ROCK (BOTH SITES)

$02 / 02 / 86$ TO $02 / 19 / 94$

REPORT DATE: $09 / 29 / 94$

\begin{tabular}{|c|c|c|c|c|c|c|c|c|c|c|c|}
\hline PARAMETER NAME & $\begin{array}{c}\text { LOCATION } \\
\text { ID }\end{array}$ & LOG DATE & $\begin{array}{c}\text { SAMPLE } \\
\text { ID }\end{array}$ & $\begin{array}{l}\text { FORM } \\
\text { COMP }\end{array}$ & 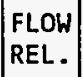 & $\begin{array}{l}\text { UNITS OF } \\
\text { MEASURE }\end{array}$ & PVI & $\begin{array}{l}\text { ARAMETER } \\
\text { VALUE }\end{array}$ & FLAGS & $\begin{array}{l}\text { DETECTION } \\
\text { LIMIT }\end{array}$ & $\begin{array}{l}\text { PARAMETER } \\
\text { UNCERTAINTY }\end{array}$ \\
\hline TEMPERATURE & $\begin{array}{l}0687 \\
0687 \\
0687 \\
0687 \\
0687 \\
0687 \\
0687 \\
0687\end{array}$ & $\begin{array}{l}10 / 15 / 87 \\
02 / 19 / 88 \\
12 / 15 / 90 \\
04 / 03 / 91 \\
08 / 27 / 91 \\
12 / 05 / 91 \\
10 / 07 / 92 \\
02 / 19 / 94\end{array}$ & $\begin{array}{l}0001 \\
0001 \\
0001 \\
0001 \\
0001 \\
0001 \\
0001 \\
\text { N001 }\end{array}$ & $\begin{array}{l}\text { NA } \\
\text { NA } \\
\text { NA } \\
\text { NA } \\
\text { NA } \\
\text { NA } \\
\text { NA } \\
\text { NA }\end{array}$ & $\begin{array}{l}U \\
U \\
U \\
U \\
U \\
U \\
U \\
U\end{array}$ & C - DEGREE & & $\begin{array}{l}15.0 \\
13.0 \\
12.4 \\
13.7 \\
14.4 \\
12.6 \\
13.5 \\
12.9\end{array}$ & $\begin{array}{l}L \\
L \\
J L \\
L\end{array}$ & $\begin{array}{l}- \\
- \\
- \\
- \\
- \\
-\end{array}$ & $\begin{array}{l}- \\
- \\
- \\
- \\
- \\
- \\
-\end{array}$ \\
\hline THALLIUM & $\begin{array}{l}0558 \\
0558 \\
0558 \\
0558 \\
0558 \\
0668 \\
0668 \\
0668 \\
0687 \\
0687 \\
0687 \\
0687 \\
0687\end{array}$ & $\begin{array}{l}12 / 15 / 90 \\
03 / 30 / 91 \\
08 / 07 / 91 \\
12 / 11 / 91 \\
10 / 12 / 92 \\
12 / 15 / 90 \\
11 / 18 / 91 \\
10 / 11 / 92 \\
12 / 15 / 90 \\
04 / 03 / 91 \\
08 / 27 / 91 \\
12 / 10 / 91 \\
10 / 07 / 92\end{array}$ & $\begin{array}{l}0001 \\
0001 \\
0001 \\
0001 \\
0001 \\
0001 \\
0001 \\
0001 \\
0001 \\
0001 \\
0001 \\
0001 \\
0001\end{array}$ & $\begin{array}{l}\text { NA } \\
\text { NA } \\
\text { NA } \\
\text { NA } \\
\text { NA } \\
\text { NA } \\
\text { NA } \\
\text { NA } \\
\text { NA } \\
\text { NA } \\
\text { NA } \\
\text { NA } \\
\text { NA }\end{array}$ & $\begin{array}{l}U \\
U \\
U \\
U \\
U \\
U \\
U \\
U \\
U \\
U \\
U \\
U \\
U\end{array}$ & $M G / L$ & $\begin{array}{l}< \\
< \\
< \\
< \\
< \\
< \\
< \\
< \\
< \\
< \\
< \\
< \\
<\end{array}$ & $\begin{array}{l}0.01 \\
0.01 \\
0.01 \\
0.01 \\
0.005 \\
0.01 \\
0.01 \\
0.005 \\
0.01 \\
0.01 \\
0.01 \\
0.01 \\
0.005\end{array}$ & $\begin{array}{l}L \\
L \\
L \\
L \\
L\end{array}$ & $\begin{array}{l}0.01 \\
0.01 \\
0.01 \\
0.01 \\
0.005 \\
0.01 \\
0.01 \\
0.005 \\
0.01 \\
0.01 \\
0.01 \\
0.01 \\
0.005\end{array}$ & $\begin{array}{l}- \\
- \\
- \\
- \\
- \\
- \\
- \\
- \\
- \\
- \\
-\end{array}$ \\
\hline THORIUM-230 & $\begin{array}{l}0558 \\
0558 \\
0668 \\
0668 \\
0687 \\
0687 \\
0687 \\
0687\end{array}$ & $\begin{array}{l}08 / 07 / 91 \\
12 / 05 / 91 \\
11 / 18 / 91 \\
02 / 18 / 94 \\
07 / 18 / 86 \\
08 / 27 / 91 \\
12 / 05 / 91 \\
02 / 19 / 94\end{array}$ & $\begin{array}{l}0001 \\
0001 \\
0001 \\
0001 \\
0001 \\
0001 \\
0001 \\
0001\end{array}$ & $\begin{array}{l}\text { NA } \\
\text { NA } \\
\text { NA } \\
\text { NA } \\
\text { NA } \\
\text { NA } \\
\text { NA } \\
\text { NA }\end{array}$ & $\begin{array}{l}U \\
U \\
U \\
U \\
U \\
U \\
U \\
U\end{array}$ & $\mathrm{PCI} / \mathrm{L}$ & & $\begin{array}{l}0.5 \\
0.9 \\
1.2 \\
0.1 \\
0 . \\
0.0 \\
0.4 \\
0.1\end{array}$ & $\begin{array}{l}\mathbf{L} \\
\mathbf{L} \\
\mathbf{L}\end{array}$ & $\begin{array}{l}1 . \\
1 . \\
1 . \\
0.2 \\
1 . \\
1 . \\
1 . \\
0.2\end{array}$ & $\begin{array}{l}0.6 \\
0.7 \\
1.0 \\
0.1 \\
0.1 \\
0.3 \\
0.8 \\
0.1\end{array}$ \\
\hline THORIUM-230 (TOTAL) & $\begin{array}{l}0558 \\
0668 \\
0687\end{array}$ & $\begin{array}{l}02 / 18 / 94 \\
02 / 18 / 94 \\
02 / 19 / 94\end{array} \mid$ & $\begin{array}{l}\text { NO01 } \\
\text { N001 } \\
\text { N001 }\end{array}$ & $\begin{array}{l}\text { NA } \\
\text { NA } \\
\text { NA }\end{array}$ & $\begin{array}{l}U \\
U \\
U\end{array}$ & $\mathrm{PCI} / \mathrm{L}$ & & $\begin{array}{l}0.5 \\
0.3 \\
0.2\end{array}$ & $L$ & $\begin{array}{l}0.2 \\
0.2 \\
0.2\end{array}$ & $\begin{array}{l}0.1 \\
0.1 \\
0.1\end{array}$ \\
\hline TIN & $\begin{array}{l}0558 \\
0558 \\
0558\end{array}$ & $\begin{array}{l}12 / 15 / 90 \\
03 / 30 / 91 \\
08 / 07 / 91\end{array}$ & $\begin{array}{l}0001 \\
0001 \\
0001\end{array}$ & $\begin{array}{l}\text { NA } \\
\text { NA } \\
\text { NA }\end{array}$ & $\begin{array}{l}U \\
U \\
U\end{array}$ & $\mathrm{MG} / \mathrm{L}$ & $<<$ & $\begin{array}{l}0.005 \\
0.005 \\
0.05\end{array}$ & $\begin{array}{l}\text { L } \\
\text { L } \\
\text { IL. }\end{array}$ & $\begin{array}{l}0.005 \\
0.005 \\
0.05\end{array}$ & - \\
\hline
\end{tabular}

FORMATION OF COMPLETION CODE:

NA - NAVAJO SANDSTONE

PARAMETER VALUE INDICATOR (PVI): < - LESS THAN DETECTION LIMIT

OTHER PARAMETER VALUE FLAGS:

I - INCREASED DETECTION LIMIT DUE TO REQUIRED DILUTION

$J$ - ESTIMATED VALUE

L - LESS THAN THREEj:BORE VOLUMES REMOVED BEFORE SAMPLING
FLOW RELATIONSHIP CODE :

- UPGRADIENT

\section{SAMPLE ID CODES:}

0001 - FILTERED SAMPLE (.45 MICRONS)

NOO - UNFILTERED SAMPLE 
TABLE 3.15 BACKGROUND GROUND HATER QUALITY DATA BY PARAMETER FOR THE NAVAJO SANDSTONE, NC AND UC PROCESSING SITES, SLICK ROCK, COLORADO SITE: SRK01 SLICK ROCK (BOTH SITES)

$02 / 02 / 86$ TO $02 / 19 / 94$

REPORT DATE: $09 / 29 / 94$

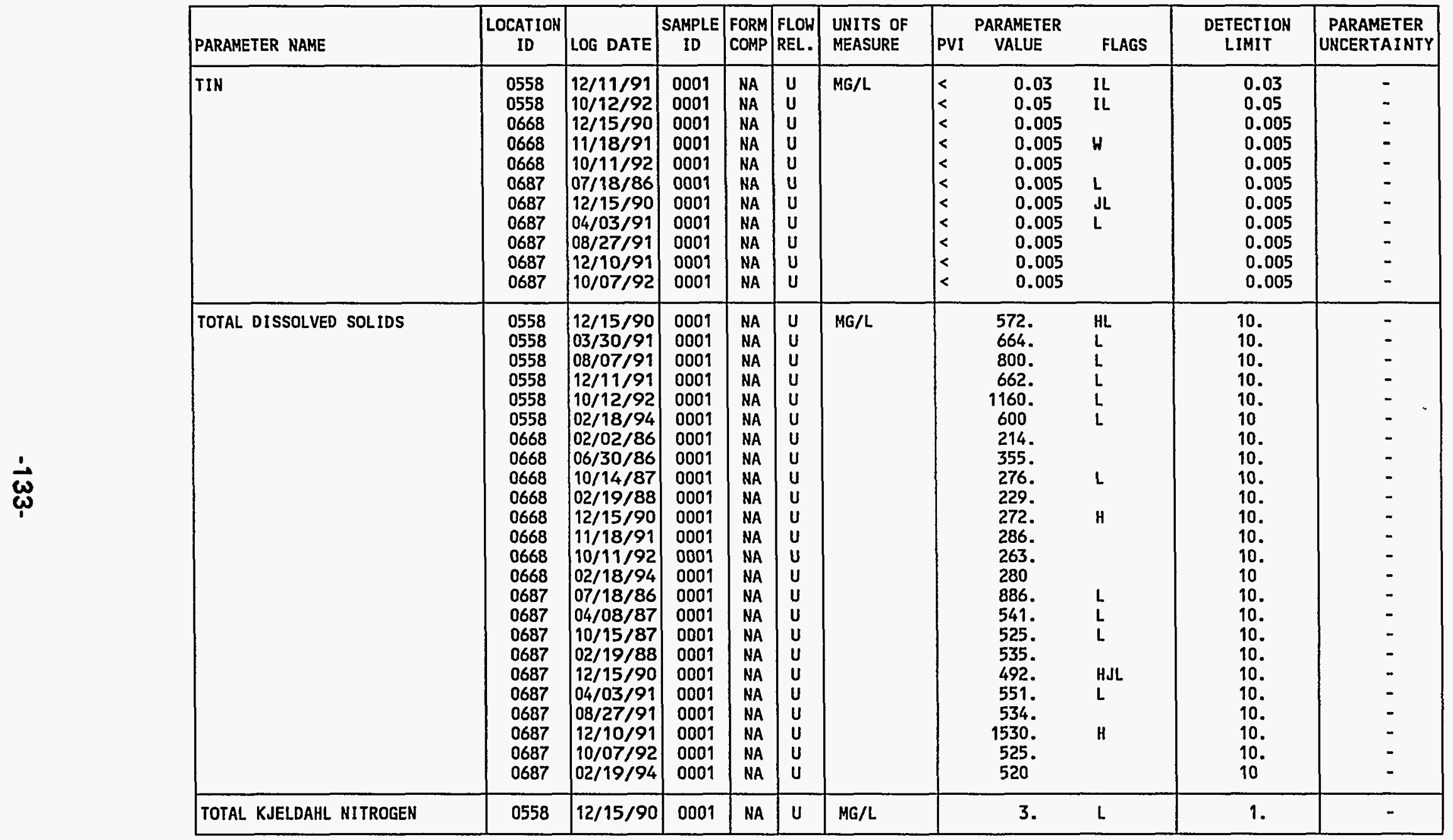

FORHATION OF COMPLETION CODE:

NA - NAVAJO SANDSTONE

PARAMETER VALUE INDICATOR (PVI): < - LESS THAN DETECTION LIMIT

OTHER PARAMETER VALUE FLAGS:

H - HOLD TIME EXPIRED, VALUE SUSPECT

I - INCREASED DETECTION LIMIT DUE TO REQUIRED DILUTION

J - ESTIMATED VALUE

L - LESS THAN THREE BORE VOLUMES REMOVED BEFORE SAMPLING

$W$ - POST-DIGEST SPIKE OUT OF CNTR LIM WHILE SAMP ABS $<50 \%$ SPIKE
FLOW RELATIONSHIP CODE:

$U$ - UPGRADIENT 
TABLE 3.15 BACKGROUND GROUND WATER QUALITY DATA BY PARAMETER FOR THE NAVAJO SANDSTONE, NC AND UC PROCESSING SITES, SLICK ROCK, COLORADO SITE: SRKO1 SLICK ROCK (BOTH SITES)

02/02/86 TO 02/19/94

REPORT DATE: $09 / 29 / 94$

\begin{tabular}{|c|c|c|c|c|c|c|c|c|c|c|c|}
\hline PARAMETER NAME & $\underset{\text { ID }}{\text { LOCATION }}$ & LOG DATE & $\begin{array}{l}\text { SAMPLE } \\
\text { ID }\end{array}$ & $\begin{array}{l}\text { FORM } \\
\text { COMP }\end{array}$ & $\begin{array}{l}\text { FLOW } \\
\text { REL. }\end{array}$ & $\begin{array}{l}\text { UNITS OF } \\
\text { MEASURE }\end{array}$ & PVI & $\begin{array}{l}\text { ARAMETER } \\
\text { VALUE }\end{array}$ & FLAGS & $\begin{array}{l}\text { DETECTION } \\
\text { LIMIT }\end{array}$ & $\begin{array}{l}\text { PARAMETER } \\
\text { UNCERTAINTY }\end{array}$ \\
\hline TOTAL KJELDAHL NITROGEN & $\begin{array}{l}0558 \\
0558 \\
0558 \\
0668 \\
0668 \\
0687 \\
0687 \\
0687 \\
0687\end{array}$ & $\begin{array}{l}03 / 30 / 91 \\
08 / 07 / 91 \\
12 / 11 / 91 \\
12 / 15 / 90 \\
11 / 18 / 91 \\
12 / 15 / 90 \\
04 / 03 / 91 \\
08 / 27 / 91 \\
12 / 10 / 91\end{array}$ & $\begin{array}{l}0001 \\
0001 \\
0001 \\
0001 \\
0001 \\
0001 \\
0001 \\
0001 \\
0001\end{array}$ & $\begin{array}{l}\text { NA } \\
\text { NA } \\
\text { NA } \\
\text { NA } \\
\text { NA } \\
\text { NA } \\
\text { NA } \\
\text { NA } \\
\text { NA }\end{array}$ & $\begin{array}{l}U \\
U \\
U \\
U \\
U \\
U \\
U \\
U \\
U\end{array}$ & $M G / L$ & $\begin{array}{l}< \\
< \\
< \\
< \\
< \\
< \\
<\end{array}$ & $\begin{array}{l}1 . \\
1 . \\
2 . \\
1 . \\
2 . \\
1 . \\
1 . \\
1 . \\
1 .\end{array}$ & $\begin{array}{l}\mathrm{L} \\
\mathrm{L} \\
\mathrm{IL} \\
\mathrm{I} \\
\mathrm{JL} \\
\mathrm{L}\end{array}$ & $\begin{array}{l}1 . \\
1 . \\
2 . \\
1 . \\
2 . \\
1 . \\
1 . \\
1 . \\
1 .\end{array}$ & $\begin{array}{l}- \\
- \\
- \\
- \\
- \\
-\end{array}$ \\
\hline TOTAL ORGANIC CARBON & $\begin{array}{l}0558 \\
0558 \\
0558 \\
0558 \\
0558 \\
0558 \\
0668 \\
0668 \\
0668 \\
0668 \\
0668 \\
0687 \\
0687 \\
0687 \\
0687 \\
0687 \\
0687 \\
0687\end{array}$ & \begin{tabular}{|l|}
$12 / 15 / 90$ \\
$03 / 30 / 91$ \\
$08 / 07 / 91$ \\
$12 / 11 / 91$ \\
$10 / 12 / 92$ \\
$02 / 18 / 94$ \\
$12 / 15 / 90$ \\
$11 / 18 / 91$ \\
$10 / 11 / 92$ \\
$02 / 18 / 94$ \\
$02 / 18 / 94$ \\
$12 / 15 / 90$ \\
$04 / 03 / 91$ \\
$08 / 27 / 91$ \\
$12 / 10 / 91$ \\
$10 / 07 / 92$ \\
$02 / 19 / 94$ \\
$02 / 19 / 94$
\end{tabular} & $\begin{array}{l}0001 \\
0001 \\
0001 \\
0001 \\
0001 \\
N 001 \\
0001 \\
0001 \\
0001 \\
0001 \\
N 001 \\
0001 \\
0001 \\
0001 \\
0001 \\
0001 \\
0001 \\
N 001\end{array}$ & $\begin{array}{l}\text { NA } \\
\text { NA } \\
\text { NA } \\
\text { NA } \\
\text { NA } \\
\text { NA } \\
\text { NA } \\
\text { NA } \\
\text { NA } \\
\text { NA } \\
\text { NA } \\
\text { NA } \\
\text { NA } \\
\text { NA } \\
\text { NA } \\
\text { NA } \\
\text { NA } \\
\text { NA }\end{array}$ & $\begin{array}{l}U \\
U \\
U \\
U \\
U \\
U \\
U \\
U \\
U \\
U \\
U \\
U \\
U \\
U \\
U \\
U \\
U \\
U\end{array}$ & $M G / L$ & $\mid<$ & $\begin{array}{r}162 . \\
1 . \\
2 . \\
2 . \\
4 . \\
3 \\
59 . \\
2 . \\
1 . \\
1 \\
1 \\
100 . \\
11 . \\
2 . \\
1 . \\
2 . \\
1 \\
2\end{array}$ & $\begin{array}{l}\mathrm{L} \\
\mathbf{L} \\
\mathbf{L} \\
\mathrm{L} \\
\mathrm{L} \\
\mathrm{L} \\
\\
\mathrm{JL} \\
\mathrm{L}\end{array}$ & $\begin{array}{l}1 . \\
1 . \\
1 . \\
1 . \\
1 . \\
1 . \\
1 . \\
1 . \\
1 . \\
1 \\
1 . \\
1 . \\
1 . \\
1 . \\
1 . \\
1 .\end{array}$ & $\begin{array}{l}- \\
- \\
- \\
- \\
- \\
- \\
- \\
- \\
- \\
- \\
- \\
- \\
- \\
-\end{array}$ \\
\hline TURBIDITY & 0668 & $02 / 18 / 94$ & N001 & NA & U & NTU & & 3.0 & & - & - \\
\hline URANIUM & $\begin{array}{l}0558 \\
0558 \\
0558 \\
0558 \\
0558 \\
0558 \\
0668\end{array}$ & $\begin{array}{l}12 / 15 / 90 \\
03 / 30 / 91 \\
08 / 07 / 91 \\
12 / 05 / 91 \\
10 / 12 / 92 \\
02 / 18 / 94 \\
02 / 02 / 86\end{array}$ & $\begin{array}{l}0001 \\
0001 \\
0001 \\
0001 \\
0001 \\
0001 \\
0001\end{array}$ & $\begin{array}{l}\text { NA } \\
\text { NA } \\
\text { NA } \\
\text { NA } \\
\text { NA } \\
\text { NA } \\
\text { NA }\end{array}$ & $\begin{array}{l}U \\
U \\
U \\
U \\
U \\
U \\
U\end{array}$ & $M G / L$ & & $\begin{array}{l}0.0140 \\
0.011 \\
0.018 \\
0.013 \\
0.031 \\
0.023 \\
0.0078\end{array}$ & $\begin{array}{l}L \\
L \\
L \\
L \\
L \\
L\end{array}$ & $\begin{array}{l}0.0003 \\
0.001 \\
0.001 \\
0.001 \\
0.001 \\
0.001 \\
0.003\end{array}$ & $\begin{array}{l}- \\
- \\
- \\
- \\
-\end{array}$ \\
\hline
\end{tabular}

FORMATION OF COMPLETION CODE:

NA - NAVAJO SANDSTONE

PARAMETER VALUE INDICATOR (PVI): < - LESS THAN DETECTION LIMIT

OTHER PARAMETER VALUE FLAGS:

I - INCREASED DETECTION LIMIT DUE TO REQUIRED DILUTION

$J$ - ESTIMATED VALUE

L - LESS THAN THREE BORE VOLUMES REMOVED BEFORE SAMPLING
FLOW RELATIONSHIP CODE:

$U$ - UPGRADIENT

SAMPLE ID CODES

0001 - FILTERED SAMPLE (.45 MICRONS)

N001 - UNFILTERED SAMPLE 
TABLE 3.15 BACKGROUND GROUND WATER QUALITY DATA BY PARAMETER FOR THE NAVAJO SANDSTONE, NC AND UC PROCESSING SITES, SLICK ROCK, COLORADO

SITE: SRKO1 SLICK ROCK (BOTH SITES)

TITE: 02/19/94

REPORT DATE: $09 / 29 / 94$

\begin{tabular}{|c|c|c|c|c|c|c|c|c|c|c|c|}
\hline PARAMETER NAME & $\left|\begin{array}{c}\text { LOCATION } \\
\text { ID }\end{array}\right|$ & LOG DATE & $\begin{array}{c}\text { SAMPLE } \\
\text { ID }\end{array}$ & $\begin{array}{l}\text { FORM } \\
\text { COMP }\end{array}$ & $\begin{array}{l}\text { FLOH } \\
\text { REL. }\end{array}$ & $\begin{array}{l}\text { UNITS OF } \\
\text { MEASURE }\end{array}$ & PVI & $\begin{array}{l}\text { PARAMETER } \\
\text { VALUE }\end{array}$ & FLAGS & $\begin{array}{l}\text { DETECTION } \\
\text { LIMIT }\end{array}$ & $\begin{array}{l}\text { PARAMETER } \\
\text { UNCERTAINTY }\end{array}$ \\
\hline URANIUM & $\begin{array}{l}0668 \\
0668 \\
0668 \\
0668 \\
0668 \\
0668 \\
0668 \\
0687 \\
0687 \\
0687 \\
0687 \\
0687 \\
0687 \\
0687 \\
0687 \\
0687 \\
0687\end{array}$ & $\begin{array}{l}06 / 30 / 86 \\
10 / 14 / 87 \\
02 / 19 / 88 \\
12 / 15 / 90 \\
11 / 18 / 91 \\
10 / 11 / 92 \\
02 / 18 / 94 \\
07 / 18 / 86 \\
04 / 08 / 87 \\
10 / 15 / 87 \\
02 / 19 / 88 \\
12 / 15 / 90 \\
04 / 03 / 91 \\
08 / 27 / 91 \\
12 / 05 / 91 \\
10 / 07 / 92 \\
02 / 19 / 94\end{array}$ & $\begin{array}{l}0001 \\
0001 \\
0001 \\
0001 \\
0001 \\
0001 \\
0001 \\
0001 \\
0001 \\
0001 \\
0001 \\
0001 \\
0001 \\
0001 \\
0001 \\
0001 \\
0001\end{array}$ & $\begin{array}{l}\text { NA } \\
\text { NA } \\
\text { NA } \\
\text { NA } \\
\text { NA } \\
\text { NA } \\
\text { NA } \\
\text { NA } \\
\text { NA } \\
\text { NA } \\
\text { NA } \\
\text { NA } \\
\text { NA } \\
\text { NA } \\
\text { NA } \\
\text { NA } \\
\text { NA }\end{array}$ & $\begin{array}{l}U \\
U \\
U \\
U \\
U \\
U \\
U \\
U \\
U \\
U \\
U \\
U \\
U \\
U \\
U \\
U \\
U\end{array}$ & $M G / L$ & & $\begin{array}{l}0.0028 \\
0.003 \\
0.0028 \\
0.0033 \\
0.004 \\
0.001 \\
0.003 \\
0.003 \\
0.0022 \\
0.005 \\
0.0021 \\
0.0012 \\
0.002 \\
1.328 \\
0.001 \\
0.003 \\
0.002\end{array}$ & $\begin{array}{l}\mathrm{L} \\
\mathrm{JL} \\
\mathrm{L} \\
\mathrm{J} \\
\mathrm{J} L \\
\mathrm{~L}\end{array}$ & $\begin{array}{l}0.003 \\
0.003 \\
0.003 \\
0.0003 \\
0.001 \\
0.001 \\
0.001 \\
0.003 \\
0.003 \\
0.003 \\
0.003 \\
0.0003 \\
0.001 \\
0.001 \\
0.001 \\
0.001 \\
0.001\end{array}$ & $\begin{array}{l}- \\
- \\
- \\
- \\
- \\
- \\
- \\
- \\
- \\
- \\
- \\
- \\
-\end{array}$ \\
\hline URANIUM (TOTAL) & $\begin{array}{l}0558 \\
0668 \\
0687\end{array}$ & $\begin{array}{l}02 / 18 / 94 \\
02 / 18 / 94 \\
02 / 19 / 94\end{array}$ & $\begin{array}{l}\text { N001 } \\
\text { N001 } \\
\text { N001 }\end{array}$ & $\begin{array}{l}\text { NA } \\
\text { NA } \\
\text { NA }\end{array}$ & $\begin{array}{l}U \\
U \\
U\end{array}$ & $M G / L$ & & $\begin{array}{l}0.016 \\
0.004 \\
0.002\end{array}$ & $L$ & $\begin{array}{l}0.001 \\
0.001 \\
0.001\end{array}$ & - \\
\hline VANADIUM & $\begin{array}{l}0558 \\
0558 \\
0558 \\
0558 \\
0558 \\
0558 \\
0668 \\
0668 \\
0668 \\
0668 \\
0668 \\
0668 \\
0687 \\
0687 \\
0687 \\
0687 \\
0687\end{array}$ & $\begin{array}{l}12 / 15 / 90 \\
03 / 30 / 91 \\
08 / 07 / 91 \\
12 / 11 / 91 \\
10 / 12 / 92 \\
02 / 18 / 94 \\
06 / 30 / 86 \\
10 / 14 / 87 \\
12 / 15 / 90 \\
11 / 18 / 91 \\
10 / 11 / 92 \\
02 / 18 / 94 \\
07 / 18 / 86 \\
04 / 08 / 87 \\
10 / 15 / 87 \\
12 / 15 / 90 \\
04 / 03 / 91\end{array}$ & $\begin{array}{l}0001 \\
0001 \\
0001 \\
0001 \\
0001 \\
0001 \\
0001 \\
0001 \\
0001 \\
0001 \\
0001 \\
0001 \\
0001 \\
0001 \\
0001 \\
0001 \\
0001\end{array}$ & $\begin{array}{l}\text { NA } \\
\text { NA } \\
\text { NA } \\
\text { NA } \\
\text { NA } \\
\text { NA } \\
\text { NA } \\
\text { NA } \\
\text { NA } \\
\text { NA } \\
\text { NA } \\
\text { NA } \\
\text { NA } \\
\text { NA } \\
\text { NA } \\
\text { NA } \\
\text { NA }\end{array}$ & $\begin{array}{l}U \\
U \\
U \\
U \\
U \\
U \\
U \\
U \\
U \\
U \\
U \\
U \\
U \\
U \\
U \\
U \\
U\end{array}$ & MG/L & $\begin{array}{l}< \\
< \\
< \\
< \\
< \\
< \\
< \\
< \\
< \\
< \\
< \\
< \\
< \\
< \\
< \\
< \\
<\end{array}$ & $\begin{array}{l}0.01 \\
0.01 \\
0.01 \\
0.01 \\
0.01 \\
0.01 \\
0.44 \\
0.01 \\
0.01 \\
0.01 \\
0.01 \\
0.01 \\
0.43 \\
0.2 \\
0.01 \\
0.01 \\
0.01\end{array}$ & $\begin{array}{l}L \\
L \\
L \\
L \\
L \\
L \\
L\end{array}$ & $\begin{array}{l}0.01 \\
0.01 \\
0.01 \\
0.01 \\
0.01 \\
0.01 \\
0.01 \\
0.01 \\
0.01 \\
0.01 \\
0.01 \\
0.01 \\
0.01 \\
0.2 \\
0.01 \\
0.01 \\
0.01\end{array}$ & $\begin{array}{l}- \\
- \\
- \\
- \\
- \\
- \\
- \\
- \\
- \\
- \\
- \\
- \\
- \\
- \\
-\end{array}$ \\
\hline
\end{tabular}

FORMATION OF COMPLETION CODE:

NA - NAVAJO SANDSTONE

PARAMETER VALUE INDICATOR (PVI)

< - LESS THAN DETECTION LIMIT

OTHER PARAMETER VALUE FLAGS

$J$ - ESTIMATED VALUE

L - LESS THAN THREE BORE VOLUMES REMOVED BEFORE SAMPLING
FLOH RELATIONSHIP CODE:

$U$ - UPGRADIENT

SAMPLE ID CODES

0001 - FILTERED SAMPLE (.45 MICRONS)

NOO1 - UNFILTERED SAMPLE 
TABLE 3.15 BACKGROUND GROUND WATER QUALITY DATA BY PARAMETER FOR THE NAVAJO SANDSTONE, NC AND UC PROCESSING SITES, SLICK ROCK, COLORADO

SITE: SRKO1 SLICK ROCK (BOTH SITES)

REPORT

\begin{tabular}{|c|c|c|c|c|c|c|c|c|c|c|c|}
\hline PARAMETER NAME & $\begin{array}{c}\text { LOCATION } \\
\text { ID }\end{array}$ & LOG DATE & $\begin{array}{c}\text { SAMPLE } \\
\text { ID }\end{array}$ & $\begin{array}{l}\text { FORM } \\
\text { COMP }\end{array}$ & $\begin{array}{l}\text { FLOW } \\
\text { REL. }\end{array}$ & $\begin{array}{l}\text { UNITS OF } \\
\text { MEASURE }\end{array}$ & PVI & $\begin{array}{l}\text { ARAMETER } \\
\text { VALUE }\end{array}$ & FLAGS & $\begin{array}{l}\text { DETECTION } \\
\text { LIMIT }\end{array}$ & $\begin{array}{l}\text { PARAMETER } \\
\text { UNCERTAINTY }\end{array}$ \\
\hline VANADIUM & $\begin{array}{l}0687 \\
0687 \\
0687 \\
0687\end{array}$ & $\begin{array}{l}08 / 27 / 91 \\
12 / 10 / 91 \\
10 / 07 / 92 \\
02 / 19 / 94\end{array}$ & $\begin{array}{l}0001 \\
0001 \\
0001 \\
0001\end{array}$ & $\begin{array}{l}\text { NA } \\
\text { NA } \\
\text { NA } \\
\text { NA }\end{array}$ & $\begin{array}{l}U \\
U \\
U \\
U\end{array}$ & $M G / L$ & $\begin{array}{l}< \\
< \\
< \\
<\end{array}$ & $\begin{array}{l}0.01 \\
0.01 \\
0.01 \\
0.01\end{array}$ & & $\begin{array}{l}0.01 \\
0.01 \\
0.01 \\
0.01\end{array}$ & $\begin{array}{l}- \\
- \\
-\end{array}$ \\
\hline VANADIUM (TOTAL) & $\begin{array}{l}0558 \\
0668 \\
0687\end{array}$ & $\begin{array}{l}02 / 18 / 94 \\
02 / 18 / 94 \\
02 / 19 / 94\end{array}$ & $\begin{array}{l}\text { N001 } \\
\text { N001 } \\
\text { N001 }\end{array}$ & $\begin{array}{l}\text { NA } \\
\text { NA } \\
\text { NA }\end{array}$ & $\begin{array}{l}U \\
U \\
U\end{array}$ & $M G / L$ & $<$ & $\begin{array}{l}0.03 \\
0.01 \\
0.01\end{array}$ & L & $\begin{array}{l}0.01 \\
0.01 \\
0.01\end{array}$ & $\overline{-}$ \\
\hline ZINC & $\begin{array}{l}0558 \\
0558 \\
0558 \\
0558 \\
0558 \\
0558 \\
0668 \\
0668 \\
0668 \\
0668 \\
0668 \\
0687 \\
0687 \\
0687 \\
0687 \\
0687 \\
0687 \\
0687 \\
0687 \\
0687\end{array}$ & $\begin{array}{l}12 / 15 / 90 \\
03 / 30 / 91 \\
08 / 07 / 91 \\
12 / 11 / 91 \\
10 / 12 / 92 \\
02 / 18 / 94 \\
10 / 14 / 87 \\
12 / 15 / 90 \\
11 / 18 / 91 \\
10 / 11 / 92 \\
02 / 18 / 94 \\
07 / 18 / 86 \\
04 / 08 / 87 \\
10 / 15 / 87 \\
12 / 15 / 90 \\
04 / 03 / 91 \\
08 / 27 / 91 \\
12 / 10 / 91 \\
10 / 07 / 92 \\
02 / 19 / 94\end{array}$ & $\begin{array}{l}0001 \\
0001 \\
0001 \\
0001 \\
0001 \\
0001 \\
0001 \\
0001 \\
0001 \\
0001 \\
0001 \\
0001 \\
0001 \\
0001 \\
0001 \\
0001 \\
0001 \\
0001 \\
0001 \\
0001\end{array}$ & $\begin{array}{l}\text { NA } \\
\text { NA } \\
\text { NA } \\
\text { NA } \\
\text { NA } \\
\text { NA } \\
\text { NA } \\
\text { NA } \\
\text { NA } \\
\text { NA } \\
\text { NA } \\
\text { NA } \\
\text { NA } \\
\text { NA } \\
\text { NA } \\
\text { NA } \\
\text { NA } \\
\text { NA } \\
\text { NA } \\
\text { NA }\end{array}$ & $\begin{array}{l}U \\
U \\
U \\
U \\
U \\
U \\
U \\
U \\
U \\
U \\
U \\
U \\
U \\
U \\
U \\
U \\
U \\
U \\
U \\
U\end{array}$ & $M G / L$ & $\begin{array}{l}< \\
< \\
< \\
< \\
< \\
< \\
< \\
< \\
< \\
< \\
< \\
< \\
< \\
< \\
< \\
< \\
< \\
< \\
<\end{array}$ & $\begin{array}{l}0.005 \\
0.005 \\
0.005 \\
0.007 \\
0.005 \\
0.05 \\
0.005 \\
0.005 \\
0.005 \\
0.005 \\
0.05 \\
0.021 \\
0.242 \\
0.005 \\
0.012 \\
0.005 \\
0.005 \\
0.005 \\
0.005 \\
0.05\end{array}$ & $\begin{array}{l}\mathrm{L} \\
\mathrm{L} \\
\mathrm{L} \\
\mathrm{L} \\
\mathrm{L} \\
\mathrm{L} \\
\mathrm{L} \\
\\
\mathrm{L} \\
\mathrm{LN} \\
\mathrm{L} \\
\mathrm{JL} \\
\mathrm{L}\end{array}$ & $\begin{array}{l}0.005 \\
0.005 \\
0.005 \\
0.005 \\
0.005 \\
0.05 \\
0.005 \\
0.005 \\
0.005 \\
0.005 \\
0.05 \\
0.005 \\
0.005 \\
0.005 \\
0.005 \\
0.005 \\
0.005 \\
0.005 \\
0.005 \\
0.05\end{array}$ & $\begin{array}{l}- \\
- \\
- \\
- \\
- \\
- \\
- \\
- \\
- \\
- \\
- \\
- \\
- \\
- \\
- \\
-\end{array}$ \\
\hline ZINC (TOTAL) & $\begin{array}{l}0558 \\
0668 \\
0687\end{array}$ & $\begin{array}{l}02 / 18 / 94 \\
02 / 18 / 94 \\
02 / 19 / 94\end{array}$ & $\begin{array}{l}\text { N001 } \\
\text { N001 } \\
\text { N001 }\end{array}$ & $\begin{array}{l}\text { NA } \\
\text { NA } \\
\text { NA }\end{array}$ & $\begin{array}{l}u \\
u \\
U\end{array}$ & $M G / L$ & $<$ & $\begin{array}{l}0.09 \\
0.05 \\
0.05\end{array}$ & $L$ & $\begin{array}{l}0.05 \\
0.05 \\
0.05\end{array}$ & - \\
\hline
\end{tabular}

FORMATION OF COMPLETION CODE:

NA - NAVAJO SANDSTONE

FLOW RELATIONSHIP CODE:

$U$ - UPGRADIENT

PARAMETER VALUE INDICATOR (PVI): < - LESS THAN DETECTION LIMIT

SAMPLE ID CODES:

0001 - FILTERED SAMPLE (.45 MICRONS)

OTHER PARAMETER VALUE FLAGS:

NO01 - UNFILTERED SAMPLE

$J$ - ESTIMATED VALUE

L - LESS THAN THREE BORE VOLUMES REMOVED BEFORE SAMPLING

N - SPIKE SAMPLE RECOVERY NOT WITHIN CONTROL LIMITS

DATA FILE NAME: IDARTISRK01\GWQ10058.DAT 
TABLE 3.16 BACKGROUND GROUND HATER QUALITY STATISTICS BY PARAMETER FOR THE NAVAJO SANDSTONE, NC PROCESSING SITE, SLICK ROCK, COLORADO

SITE: SRKO1 SLICK ROCK (BOTH SITES)

$07 / 18 / 86$ TO $02 / 19 / 94$

REPORT DATE: 09/29/94

\begin{tabular}{|c|c|c|c|c|c|c|c|c|c|c|c|c|}
\hline \multicolumn{3}{|c|}{ PARAMETER NAME } & UNITS & \multirow[b]{2}{*}{ MEAN } & \multirow{2}{*}{$\begin{array}{r}\text { STANDARD } \\
\text { DEVIATION }\end{array}$} & \multirow{2}{*}{$\begin{array}{c}\text { COEFF. } \\
\text { OF } \\
\text { VARIATION }\end{array}$} & \multirow{2}{*}{$\begin{array}{c}\% \text { OF } \\
\text { NON } \\
\text { DETECTS }\end{array}$} & \multirow{2}{*}{\multicolumn{3}{|c|}{$\begin{array}{cc}\text { STATISTICAL } & \text { RANGE } \\
98 \% \text { CONFIDENCE INTERVAL } \\
\text { MINIMUM } & \text { MAXIMUM * }\end{array}$}} & \multirow{2}{*}{$\begin{array}{l}\text { DISTRIBUTION } \\
\text { TYPE }\end{array}$} & \multirow{2}{*}{$\begin{array}{l}\text { FOOT } \\
\text { NOTE }\end{array}$} \\
\hline \# OF SAMP & MINIMUM & MAXIMUM & MEDIAN & & & & & & & & & \\
\hline \multicolumn{3}{|l|}{ ALKALINITY } & $\mathrm{MG} / \mathrm{L}$ CACO & \multirow[b]{2}{*}{413.4000} & \multirow[b]{2}{*}{16.0845} & \multirow[b]{2}{*}{0.0389} & \multirow[b]{2}{*}{0.0} & \multirow{2}{*}{\multicolumn{2}{|c|}{399.0514}} & \multirow[b]{2}{*}{427.7486} & \multirow[b]{2}{*}{ NORMAL } & \\
\hline 10 & 394.0000 & $445.0000+$ & +408.5000 & & & & & & & & & \\
\hline \multicolumn{3}{|l|}{ ALUMINUM } & $M G / L$ & \multirow[b]{2}{*}{ NA } & \multirow[b]{2}{*}{ NA } & \multirow[b]{2}{*}{ NA } & \multirow[b]{2}{*}{66.7} & \multirow[b]{2}{*}{$\star \star$} & \multirow[b]{2}{*}{0.0500} & \multirow[b]{2}{*}{0.3000} & \multirow[b]{2}{*}{ NONPARAMETRIC } & \multirow[b]{2}{*}{2} \\
\hline 9 & 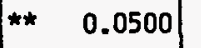 & 0.3000 & 0.0500 & & & & & & & & & \\
\hline \multicolumn{3}{|l|}{ AMMONIUM } & $M G / L$ & \multirow[b]{2}{*}{ NA } & \multirow[b]{2}{*}{ NA } & \multirow[b]{2}{*}{ NA } & \multirow[b]{2}{*}{44.4} & \multirow[b]{2}{*}{ ** } & & & & \\
\hline 9 & ** $\quad 0.1000$ & 0.6000 & 0.3000 & & & & & & 0.1000 & 0.6000 & NONPARAMETRIC & 2 \\
\hline AMMONIUM ( & (TOTAL) & & $M G / L$ & & & & & & & & & \\
\hline 1 & 0.2000 & 0.2000 & 0.2000 & NA & NA & NA & 0.0 & & NA & NA & UNKNOWN & 1 \\
\hline ANT IMONY & & & $M G / L$ & & & & & & & & & \\
\hline 7 & 0.0030 & $0.0030 *$ & 0.0030 & NA & NA & NA & 100.0 & ** & 0.0030 & 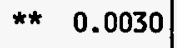 & NONPARAMETRIC & 2 \\
\hline ARSENIC & & & $M G / L$ & & & & & & & & & \\
\hline 8 & 0.0100 & $0.0250+$ & 0.0195 & 0.0189 & 0.0044 & 0.2308 & 12.5 & & 0.0143 & 0.0235 & NORMAL & \\
\hline BARIUM & & & $M G / L$ & & & & & & & & & \\
\hline 9 & 0.0400 & 0.2000 & 0.0500 & NA & NA & NA & 33.3 & & 0.0400 & 0.2000 & NONPARAMETRIC & 2 \\
\hline BARIUM (TO & OTAL) & & $M G / L$ & & & & & & & & & \\
\hline 1 & ** $\quad 0.1000$ & 0.1000 & 0.1000 & NA & NA & NA & 100.0 & & NA & NA & UNKNOWN & 1 \\
\hline BERYLLIUM & & & $M G / L$ & & & & & & & & & \\
\hline 4 & ** $\quad 0.0050$ & 0.0050 & 0.0050 & NA & NA & NA & 100.0 & ** & 0.0050 & 0.0050 & NONPARAMETRIC & 2,4 \\
\hline BORON & & & $M G / L$ & & & & & & & & & \\
\hline 7 & 0.0500 & 1.6300 & 1.6000 & 1.3800 & 0.5869 & 0.4253 & 14.3 & & 0.6828 & 2.0772 & NORMAL & \\
\hline
\end{tabular}

** The reported value is the minimum detection limit of the data set

+ The sample size is even, so the median value is the arithmetic average of the two middle values

* The statistical maximum is the 99 percent one sided confidence interval, $\alpha=0.01$

1) A minimum of 4 samples must be available for the statistical analysis.

2) The nonparametric distribution was used because the nondetected values comprise more than $15 \%$ of the samples.

4) The stat. range is the $87.5 \%$ confidence interval due to a sample size of 4 . The maxima is the $93.8 \%$ one sided confidence int. 
TABLE 3.16 BACKGROUND GROUND WATER QUALITY STATISTICS BY PARAMETER FOR THE NAVAJO SANDSTONE, NC PROCESSING SITE, SLICK ROCK, COLORADO SITE: SRKO1 SLICK ROCK (BOTH SITES)

$07 / 18 / 86$ TO $02 / 19 / 94$

REPORT DATE: $09 / 29 / 94$

\begin{tabular}{|c|c|c|c|c|c|c|c|c|c|c|c|c|}
\hline \multicolumn{3}{|c|}{ PARAMETER NAME } & UNITS & \multirow[b]{2}{*}{ MEAN } & \multirow{2}{*}{$\begin{array}{r}\text { STANDARD } \\
\text { DEVIATION }\end{array}$} & \multirow{2}{*}{$\begin{array}{c}\text { COEFF. } \\
\text { OF } \\
\text { VARIATION }\end{array}$} & \multirow{2}{*}{$\begin{array}{l}\% \text { OF } \\
\text { NON } \\
\text { DETECTS }\end{array}$} & \multirow{2}{*}{\multicolumn{3}{|c|}{$\begin{array}{c}\text { STATISTICAL RANGE } \\
\text { 98\% CONFIDENCE } \\
\text { INTERVAL } \\
\text { MINIMUM } \\
\text { MAXIMUM * }\end{array}$}} & \multirow{2}{*}{$\begin{array}{c}\text { DISTRIBUTION } \\
\text { TYPE }\end{array}$} & \multirow{2}{*}{$\begin{array}{l}\text { FOOT } \\
\text { NOTE }\end{array}$} \\
\hline \# OF SAMP & MINIMUM & MAXIMUM & MEDIAN & & & & & & & & & \\
\hline \multicolumn{3}{|c|}{ BORON (TOTAL) } & $\mathrm{MG} / \mathrm{L}$ & \multirow[b]{2}{*}{ NA } & \multirow[b]{2}{*}{ NA } & \multirow[b]{2}{*}{ NA } & \multirow[b]{2}{*}{0.0} & \multirow{2}{*}{\multicolumn{2}{|c|}{ NA }} & \multirow[b]{2}{*}{ NA } & \multirow[b]{2}{*}{ UNKNOWN } & \multirow[b]{2}{*}{1} \\
\hline 1 & 1.5000 & 1.5000 & 1.5000 & & & & & & & & & \\
\hline \multicolumn{3}{|l|}{ BROMIDE } & $M G / L$ & \multirow[b]{2}{*}{ NA } & \multirow[b]{2}{*}{ NA } & \multirow[b]{2}{*}{ NA } & \multirow[b]{2}{*}{80.0} & \multirow[b]{2}{*}{$\star *$} & \multirow[b]{2}{*}{0.1000} & \multirow[b]{2}{*}{0.2000} & \multirow[b]{2}{*}{ NONPARAMETRIC } & \multirow[b]{2}{*}{2,5} \\
\hline 5 & ** $\quad 0.1000$ & 0.2000 * & 0.1000 & & & & & & & & & \\
\hline \multicolumn{3}{|l|}{ CADMIUM } & $M G / L$ & \multirow[b]{2}{*}{ NA } & \multirow[b]{2}{*}{ NA } & \multirow[b]{2}{*}{ NA } & \multirow[b]{2}{*}{100.0} & & & & & \\
\hline 9 & ** 0.0005 & 0.0005 & 0.0005 & & & & & ** & 0.0005 & 0.0005 & NONPARAMETRIC & 2 \\
\hline CADMIUM ( $T$ & TOTAL) & & $M G / L$ & & & & & & & & & \\
\hline 1 & 0.0010 & ** $\quad 0.0010 \mid$ * & 0.0010 & NA & NA & NA & 100.0 & & NA & NA & UNKNOWN & 1 \\
\hline CALCIUM & & & $M G / L$ & & & & & & & & & \\
\hline 10 & 23.6000 & $28.3000+$ & 24.4000 & 25.1900 & 1.7019 & 0.0676 & 0.0 & & 23.6717 & 26.7083 & NORMAL & \\
\hline CALCIUM CT & TOTAL) & & $M G / L$ & & & & & & & & & \\
\hline 1 & 24.1000 & 24.1000 & 24.1000 & NA & NA & NA & 0.0 & & NA & NA & UNKNOWN & 1 \\
\hline CHLORIDE & & & $M G / L$ & & & & & & & & & \\
\hline 10 & 7.4000 & $45.0000+$ & 9.4000 & 13.6300 & 11.3135 & 0.8300 & 0.0 & & 3.5375 & 23.7225 & NORMAL & \\
\hline CHROMIUM & & & $M G / L$ & & & & & & & & & \\
\hline 9 & 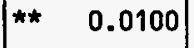 & $0.0500 \times$ & 0.0100 & NA & NA & NA & 88.9 & ** & 0.0100 & 0.0500 & NONPARAMETRIC & 2 \\
\hline CHROMIUM & (TOTAL) & & MG/L & & & & & & & & & \\
\hline 1 & 0.0100 & 0.0100 & 0.0100 & NA & NA & NA & 100.0 & & NA & NA & UNKNOWN & 1 \\
\hline COBALT & & & $M G / L$ & & & & & & & & & \\
\hline 4 & 0.0300 & 0.0300 & 0.0300 & NA & NA & NA & 100.0 & $\star \star$ & 0.0300 & 0.0300 & NONPARAMETRIC & 2,4 \\
\hline
\end{tabular}

** The reported value is the minimum detection limit of the data set

+ The sample size is even, so the median value is the arithmetic average of the two middle values

* The statistical maximum is the 99 percent one sided confidence interval, $\alpha=0.01$

1) A minimum of 4 samples must be available for the statistical analysis.

2) The nonparametric distribution was used because the nondetected values comprise more than $15 \%$ of the samples.

4) The stat. range is the $87.5 \%$ confidence interval due to a sample size of 4 . The maximum is the $93.8 \%$ one sided confidence int.

5) The stat. range is the $93.8 \%$ confidence interval due to a sample size of 5 . The maximum is the $96.9 \%$ one sided confidence int. 
TABLE 3.16 BACKGROUND GROUND WATER QUALITY STATISTICS BY PARAMETER

SITE: SRKO1 SLICK ROCK (BOTH SITES)

$07 / 18 / 86$ TO $02 / 19 / 94$

REPORT DATE: $09 / 29 / 94$

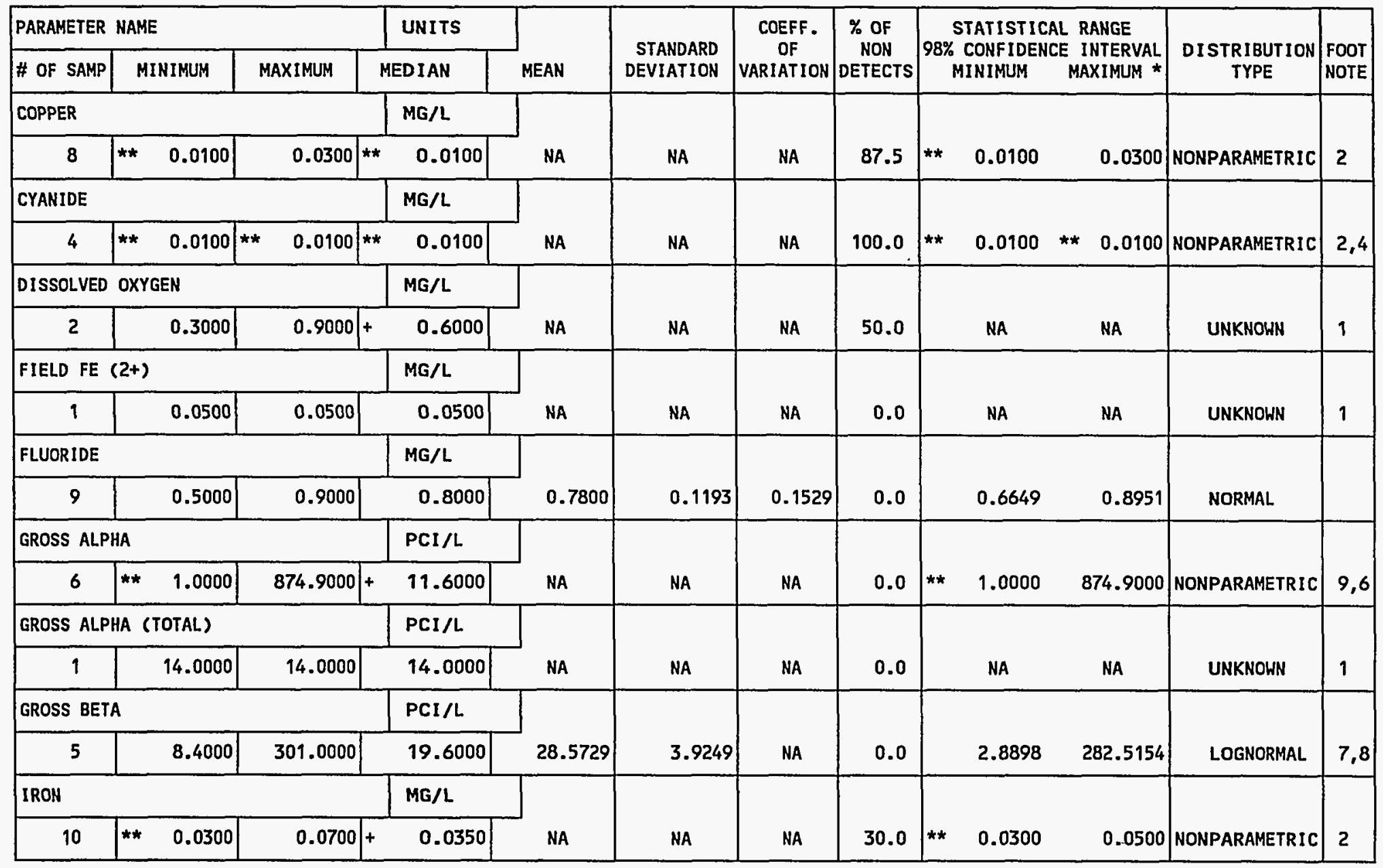

** The reported value is the minimum detection limit of the data set

+ The sample size is even, so the median value is the arithmetic average of the two middle values

* The statistical maximum is the 99 percent one sided confidence interval, $\alpha=0.01$

1) A minimum of 4 samples must be available for the statistical analysis.

2) The nonparametric distribution was used because the nondetected values comprise more than $15 \%$ of the samples.

4) The stat. range is the $87.5 \%$ confidence interval due to a sample size of 4 . The maximum is the $93.8 \%$ one sided confidence int.

6) The stat. range is the $96.9 \%$ confidence interval due to a sample size of 6 . The maximum is the $98.5 \%$ one sided confidence int.

7) The lognormal distribution was used because the data failed the normal distribution test.

8) The mean is geometric. The standard deviation is the value to divide or multiply with the geometric mean.

9) The nonparametic distribution was used because the data failed the normal distribution test and includes values $\leq 0$. 
TABLE 3.16 BACKGROUND GROUND HATER QUALITY STATISTICS BY PARAMETER FOR THE NAVAJO SANDSTONE, NC PROCESSING SITE, SLICK ROCK, COLORADO SITE: SRKO1 SLICK ROCK (BOTH SITES)

$07 / 18 / 86$ TO $02 / 19 / 94$

REPORT DATE: 09/29/94

\begin{tabular}{|c|c|c|c|c|c|c|c|c|c|c|c|c|c|c|c|c|}
\hline \multicolumn{6}{|c|}{ PARAMETER NAME } & UNITS & \multirow[b]{2}{*}{ MEAN } & \multirow{2}{*}{$\begin{array}{l}\text { STANDARD } \\
\text { DEVI I I I ON }\end{array}$} & \multirow{2}{*}{$\begin{array}{c}\text { COEFF. } \\
\text { OF } \\
\text { VARIATION }\end{array}$} & \multirow{2}{*}{$\begin{array}{c}\% \text { OF } \\
\text { NON } \\
\text { DETECTS }\end{array}$} & \multirow{2}{*}{\multicolumn{4}{|c|}{$\begin{array}{|cc|}\text { STATISTICAL } & \text { RANGE } \\
\text { 98\% CONF IDENCE } & \text { INTERVAL } \\
\text { MINIMUM } & \text { MAXIMUM * }\end{array}$}} & \multirow{2}{*}{$\begin{array}{c}\text { DISTRIBUTION } \\
\text { TYPE }\end{array}$} & \multirow{2}{*}{$\begin{array}{l}\text { FOOT } \\
\text { NOTE }\end{array}$} \\
\hline \# OF SAMP & & NIMUM & & AAXIMUM & & IEDIAN & & & & & & & & & & \\
\hline \multicolumn{5}{|c|}{ IRON (TOTAL) } & & $M G / L$ & \multirow[b]{2}{*}{ NA } & \multirow[b]{2}{*}{ NA } & \multirow[b]{2}{*}{ NA } & \multirow[b]{2}{*}{0.0} & \multirow{2}{*}{\multicolumn{2}{|c|}{ NA }} & \multirow{2}{*}{\multicolumn{2}{|c|}{ NA }} & \multirow[b]{2}{*}{ UNKNOWN } & \multirow[b]{2}{*}{1} \\
\hline 1 & & 0.0900 & & 0.0900 & & 0.0900 & & & & & & & & & & \\
\hline \multicolumn{5}{|l|}{ LEAD } & & $M G / L$ & \multirow[b]{2}{*}{ NA } & \multirow[b]{2}{*}{ NA } & \multirow[b]{2}{*}{ NA } & \multirow[b]{2}{*}{100.0} & \multirow[b]{2}{*}{ ** } & \multirow[b]{2}{*}{0.0050} & \multirow{2}{*}{\multicolumn{2}{|c|}{0.0100}} & \multirow[b]{2}{*}{ NONPARAMETRIC } & \multirow[b]{2}{*}{2} \\
\hline 8 & $\star \star$ & 0.0050 & & 0.0100 & + & 0.0050 & & & & & & & & & & \\
\hline \multicolumn{6}{|l|}{ LEAD-210 } & $\mathrm{PCI} / \mathrm{L}$ & \multirow[b]{2}{*}{ NA } & \multirow[b]{2}{*}{ NA } & \multirow[b]{2}{*}{ NA } & & & & & & & \\
\hline 4 & $\star \star$ & 1.5000 & ** & 1.5000 & 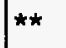 & 1.5000 & & & & 0.0 & ** & 1.5000 & $\star *$ & 1.5000 & NONPARAMETR IC & 9,4 \\
\hline LEAD - 210 & (TOT) & & & & & $\mathrm{PCI} / \mathrm{L}$ & & & & & & & & & & \\
\hline 1 & & 2.7000 & & 2.7000 & & 2.7000 & NA & NA & NA & 0.0 & & NA & & NA & UNKNOWN & 1 \\
\hline MAGNESIUM & & & & & & $M G / L$ & & & & & & & & & & \\
\hline 10 & & 18.3000 & & 21.0000 & + & 19.5000 & 19.6500 & 0.8017 & 0.0408 & 0.0 & & 18.9348 & & 20.3652 & NORMAL & \\
\hline MAGNESIUM & (TO & TAL) & & & & $M G / L$ & & & & & & & & & & \\
\hline 1 & & 16.9000 & & 16.9000 & & 16.9000 & NA & NA & NA & 0.0 & & NA & & NA & UNKNOWN & 1 \\
\hline MANGANESE & & & & & & MG/L & & & & & & & & & & \\
\hline 10 & & 0.0200 & & 0.0800 & + & 0.0200 & 0.0300 & 0.0189 & 0.6285 & 0.0 & & 0.0132 & & 0.0468 & NORMAL & \\
\hline MANGANESE & (TO & (AL) & & & & MG/L & & & & & & & & & & \\
\hline 1 & & 0.0300 & & 0.0300 & & 0.0300 & NA & NA & NA & 0.0 & & NA & & NA & UNKNOWN & 1 \\
\hline MERCURY & & & & & & $M G / L$ & & & & & & & & & & \\
\hline 7 & ** & 0.0002 & ** & 0.0002 & ** & 0.0002 & NA & NA & NA & 100.0 & ** & 0.0002 & $\star \star$ & 0.0002 & NONPARAMETR I C & 2 \\
\hline
\end{tabular}

** The reported value is the minimum detection limit of the data set

+ The sample size is even, so the median value is the arithmetic average of the two middle values

* The statistical maximum is the 99 percent one sided confidence interval, $\alpha=0.01$

1) A minimum of 4 samples must be available for the statistical analysis.

2) The nonparametric distribution was used because the nondetected values comprise more than $15 \%$ of the samples.

4) The stat. range is the $87.5 \%$ confidence interval due to a sample size of 4 . The maximum is the $93.8 \%$ one sided confidence int.

9) The nonparametic distribution was used because the data failed the normal distribution test and includes values $\leq 0$. 
TABLE 3.16 BACKGROUND GROUND HATER QUALITY STATISTICS BY PARAMETER FOR THE NAVAJO SANDSTONE, NC PROCESSING SITE, SLICK ROCK, COLORADO SITE: SRKO1 SLICK ROCK (BOTH SITES)

$07 / 18 / 86$ TO $02 / 19 / 94$

REPORT DATE: 09/29/94

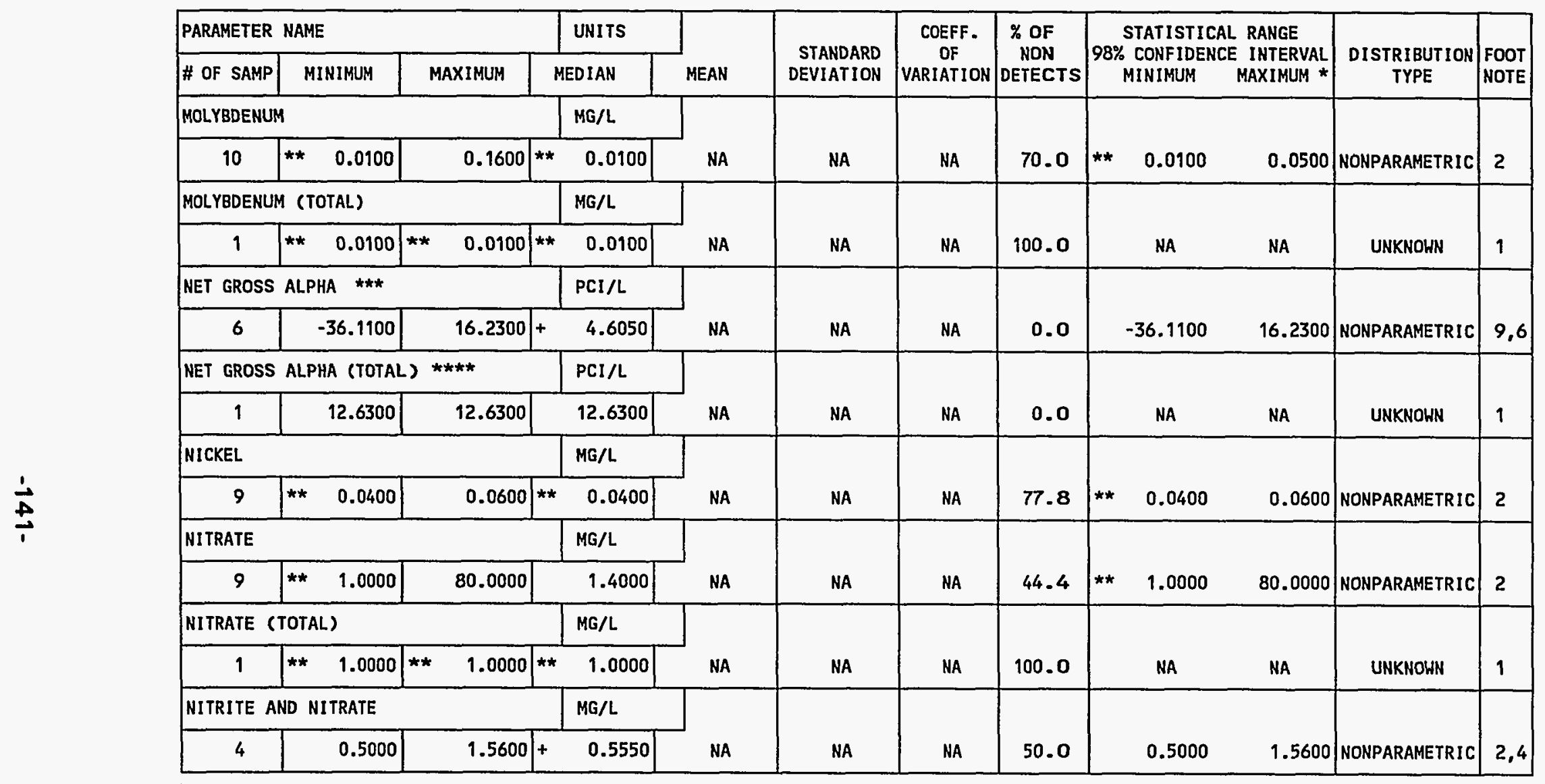

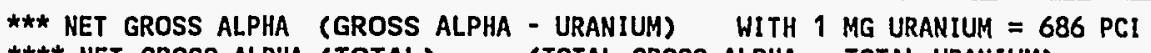

**** NET GROSS ALPHA (TOTAL) (TOTAL GROSS ALPHA - TOTAL URANIUM)

** The reported value is the minimum detection limit of the data set

+ The sample size is even, so the median value is the arithmetic average of the two middle values

* The statistical maximum is the 99 percent one sided confidence interval, $\alpha=0.01$

1) A minimum of 4 samples must be available for the statistical analysis.

2) The nonparametric distribution was used because the nondetected values comprise more than $15 \%$ of the samples.

4) The stat. range is the $87.5 \%$ confidence interval due to a sample size of 4 . The maximum is the $93.8 \%$ one sided confidence int.

6) The stat. range is the $96.9 \%$ confidence interval due to a sample size of 6 . The maximum is the $98.5 \%$ one sided confidence int.

9) The nonparametic distribution was used because the data failed the normal distribution test and includes values $\leq 0$. 
TABLE 3.16 BACKGROUND GROUND WATER QUALITY STATISTICS BY PARAMETER FOR THE NAVAJO SANDSTONE, NC PROCESSING SITE, SLICK ROCK, COLORADO SITE: SRKO1 SLICK ROCK (BOTH SITES)

07/18/86 TO 02/19/94

REPORT DATE : 09/29/94

\begin{tabular}{|c|c|c|c|c|c|c|c|c|c|c|c|c|}
\hline \multicolumn{3}{|c|}{ PARAMETER NAME } & UNITS & \multirow[b]{2}{*}{ MEAN } & \multirow{2}{*}{$\begin{array}{r}\text { STANDARD } \\
\text { DEVIATION }\end{array}$} & \multirow{2}{*}{$\begin{array}{c}\text { COEFF. } \\
\text { OF } \\
\text { VARIATION }\end{array}$} & \multirow{2}{*}{$\begin{array}{l}\% \text { OF } \\
\text { NON } \\
\text { DETECTS }\end{array}$} & \multirow{2}{*}{\multicolumn{3}{|c|}{$\begin{array}{c}\text { STATISTICAL RANGE } \\
98 \% \text { CONFIDENCE INTERVAL } \\
\text { MINIMUM } \\
\text { MAXIMUM * }\end{array}$}} & \multirow{2}{*}{$\begin{array}{c}\text { DISTRIBUTION } \\
\text { TYPE }\end{array}$} & \multirow{2}{*}{$\begin{array}{l}\text { FOOT } \\
\text { NOTE }\end{array}$} \\
\hline \# OF SAMP & MINIMUM & MAXIMUM & MED I AN & & & & & & & & & \\
\hline \multicolumn{3}{|l|}{ PH } & su & \multirow[b]{2}{*}{ NA } & \multirow[b]{2}{*}{ NA } & \multirow[b]{2}{*}{ NA } & \multirow[b]{2}{*}{0.0} & \multirow{2}{*}{\multicolumn{2}{|c|}{ NA }} & \multirow[b]{2}{*}{ NA } & \multirow[b]{2}{*}{ UNKNOWN } & \\
\hline 10 & 7.1800 & 7.6400 & 7.4100 & & & & & & & & & \\
\hline \multicolumn{3}{|l|}{ PHOSPHATE } & MG/L & \multirow[b]{2}{*}{ NA } & \multirow[b]{2}{*}{ NA } & \multirow[b]{2}{*}{ NA } & \multirow[b]{2}{*}{62.5} & \multirow[b]{2}{*}{ ** } & \multirow[b]{2}{*}{0.1000} & \multirow[b]{2}{*}{0.2000} & \multirow[b]{2}{*}{ NONPARAMETRIC } & \multirow[b]{2}{*}{2} \\
\hline 8 & 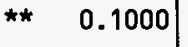 & 0.2000 & 0.1000 & & & & & & & & & \\
\hline \multicolumn{3}{|c|}{ POLONIUM-210 } & $\mathrm{PCI} / \mathrm{L}$ & \multirow[b]{2}{*}{ NA } & \multirow[b]{2}{*}{ NA } & \multirow[b]{2}{*}{ NA } & \multirow[b]{2}{*}{0.0} & \multirow[b]{2}{*}{$\star \star *$} & & & & \\
\hline 4 & 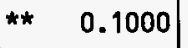 & 0.1000 & 0.1000 & & & & & & 0.1000 & 0.1000 & NONPARAMETRIC & 9,4 \\
\hline POLONIUM-2 & 210 (TOTAL) & & $\mathrm{PCI} / \mathrm{L}$ & & & & & & & & & \\
\hline 1 & 0.0000 & 0.0000 & 0.0000 & NA & NA & NA & 0.0 & & NA & NA & UNKNOWN & 1 \\
\hline POTASSIUM & & & $M G / L$ & & & & & & & & & \\
\hline 10 & 23.0000 & 30.1000 & 24.2000 & 24.7800 & 2.1612 & 0.0872 & 0.0 & & 22.8521 & 26.7079 & NORMAL & \\
\hline POTASSIUM & (TOTAL) & & MG/L & & & & & & & & & \\
\hline 1 & 21.6000 & 21.6000 & 21.6000 & NA & NA & NA & 0.0 & & NA & NA & UNKNOWN & 1 \\
\hline RADIUM-226 & & & PCI/L & & & & & & & & & \\
\hline 9 & $\begin{array}{ll}* & 0.2000\end{array}$ & 0.9000 & 0.4000 & NA & NA & NA & 0.0 & $\star \star$ & 0.2000 & 0.9000 & NONPARAMETRIC & 9 \\
\hline RADIUM-226 & 6 (TOTAL) & & $\mathrm{PCI} / \mathrm{L}$ & & & & & & & & & \\
\hline 1 & 0.4000 & 0.4000 & 0.4000 & NA & NA & NA & 0.0 & & NA & NA & UNKNOWN & 1 \\
\hline RADIUM-226 & $6+$ RADIUM-22 & & $\mathrm{PCI} / \mathrm{L}$ & & & & & & & & & \\
\hline 8 & 0.0000 & 5.2000 & 1.1000 & NA & NA & NA & 0.0 & & 0.0000 & 5.2000 & NONPARAMETRIC & 9 \\
\hline
\end{tabular}

** The reported value is the minimum detection limit of the data set

+ The sample size is even, so the median value is the arithmetic average of the two middle values

* The statistical maximum is the 99 percent one sided confidence interval, $\alpha=0.01$

1) A minimum of 4 samples must be available for the statistical analysis.

2) The nonparametric distribution was used because the nondetected values comprise more than $15 \%$ of the samples.

4) The stat. range is the $87.5 \%$ confidence interval due to a sample size of 4 . The maximum is the $93.8 \%$ one sided confidence int.

9) The nonparametic distribution was used because the data failed the normal distribution test and includes values $\leq 0$. 
TABLE 3.16 BACKGROUND GROUND HATER QUALITY STATISTICS BY PARAMETER

FOR THE NAVAJO SANDSTONE, NC PROCESSING SITE, SLICK ROCK, COLORADO

SITE: SRKO1 SLICK ROCK (BOTH SITES)

07/18/86 TO 02/19/94

REPORT DATE: 09/29/94

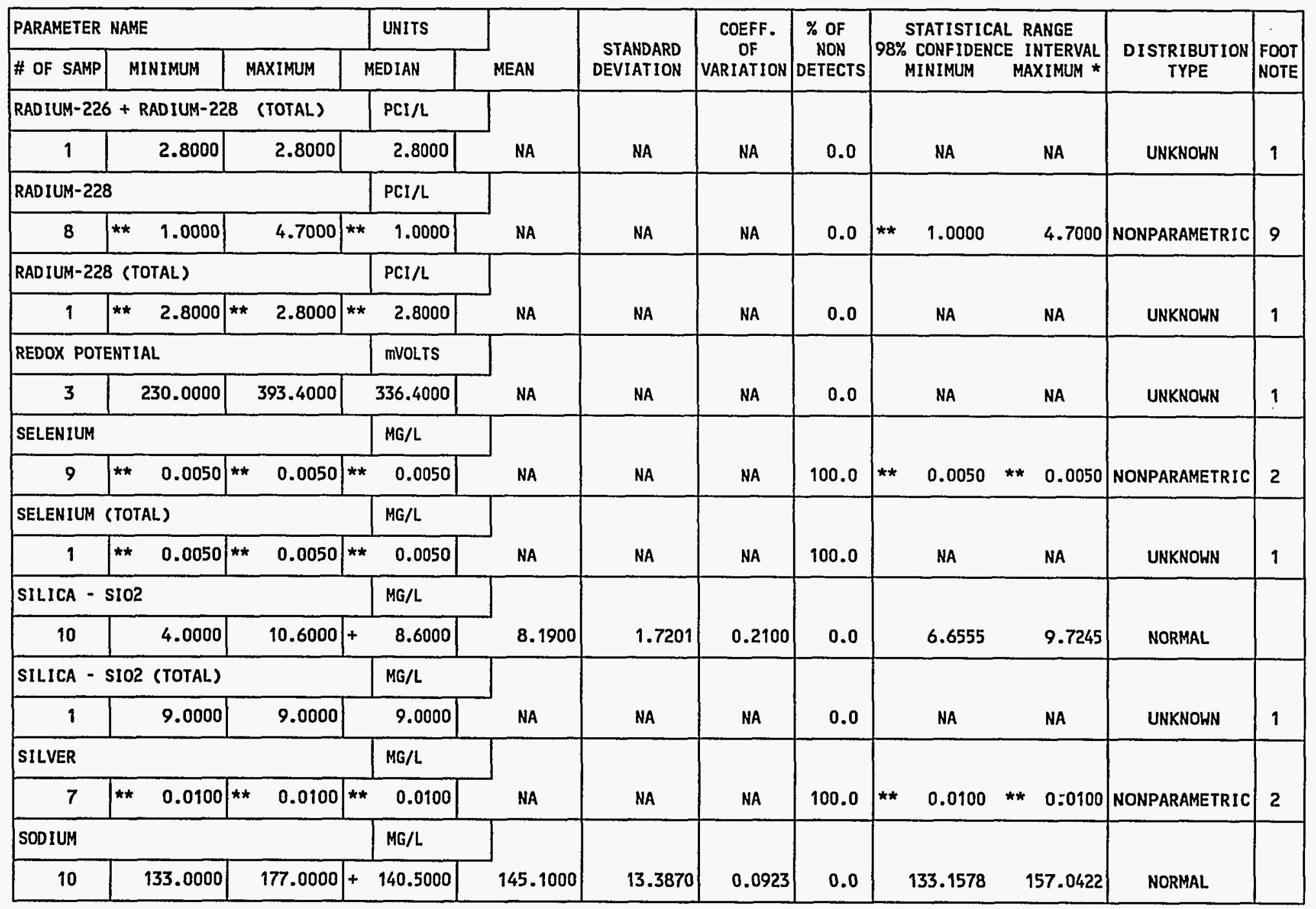

** The reported value is the minimum detection limit of the data set

+ The sample size is even, so the median value is the arithmetic average of the two middle values

* The statistical maximum is the 99 percent one sided confidence interval, $\alpha=0.01$

1) A minimum of 4 samples must be available for the statistical analysis.

2) The nonparametric distribution was used because the nondetected values comprise more than $15 \%$ of the samples.

9) The nonparametic distribution was used because the data failed the normal distribution test and includes values $\leq 0$. 
TABLE 3.16 BACKGROUND GROUND WATER QUALITY STATISTICS BY PARAMETER FOR THE NAVAJO SANDSTONE, NC PROCESSING SITE, SLICK ROCK, COLORADO SITE: SRKO1 SLICK ROCK (BOTH SITES)

$07 / 18 / 86$ TO $02 / 19 / 94$

REPORT DATE: $09 / 29 / 94$

\begin{tabular}{|c|c|c|c|c|c|c|c|c|c|c|c|}
\hline \multicolumn{3}{|c|}{ PARAMETER NAME } & UNITS & \multirow[b]{2}{*}{ MEAN } & \multirow{2}{*}{$\begin{array}{r}\text { STANDARD } \\
\text { DEVIATION }\end{array}$} & \multirow{2}{*}{$\begin{array}{c}\text { COEFF. } \\
\text { OF } \\
\text { VARIATION }\end{array}$} & \multirow{2}{*}{$\begin{array}{l}\% \text { OF } \\
\text { NON } \\
\text { DETECTS }\end{array}$} & \multirow{2}{*}{\multicolumn{2}{|c|}{ 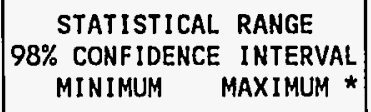 }} & \multirow{2}{*}{$\begin{array}{c}\text { DISTRIBUTION } \\
\text { TYPE }\end{array}$} & \multirow{2}{*}{$\begin{array}{l}\text { FOOT } \\
\text { NOTE }\end{array}$} \\
\hline \# OF SAMP & MINIMUM & MAXIMUM & MEDIAN & & & & & & & & \\
\hline \multicolumn{3}{|c|}{ SODIUM (TOTAL) } & $M G / L$ & \multirow[b]{2}{*}{ NA } & \multirow[b]{2}{*}{ NA } & \multirow[b]{2}{*}{ NA } & \multirow[b]{2}{*}{0.0} & \multirow[b]{2}{*}{ NA } & \multirow[b]{2}{*}{ NA } & \multirow[b]{2}{*}{ UNKNOWN } & \multirow[b]{2}{*}{1} \\
\hline 1 & 126.0000 & 126.0000 & 126.0000 & & & & & & & & \\
\hline \multicolumn{3}{|c|}{ SPECIFIC CONDUCTANCE } & UMHO/CM & \multirow[b]{2}{*}{703.4000} & \multirow[b]{2}{*}{170.9933} & \multirow[b]{2}{*}{0.2431} & \multirow[b]{2}{*}{0.0} & \multirow[b]{2}{*}{550.8605} & \multirow[b]{2}{*}{855.9395} & \multirow[b]{2}{*}{ NORMAL } & \\
\hline 10 & 450.0000 & 887.0000 & +675.5000 & & & & & & & & \\
\hline \multicolumn{3}{|l|}{ STRONTIUM } & $M G / L$ & \multirow[b]{2}{*}{1.0883} & \multirow[b]{2}{*}{0.0471} & \multirow[b]{2}{*}{0.0433} & \multirow[b]{2}{*}{0.0} & \multirow[b]{2}{*}{1.0237} & \multirow[b]{2}{*}{1.1530} & & \\
\hline 6 & 1.0400 & 1.1700 & 1.0850 & & & & & & & NORMAL & \\
\hline STRONT IUM & (TOTAL) & & $M G / L$ & & & & & & & & \\
\hline 1 & 0.9900 & 0.9900 & 0.9900 & NA & NA & NA & 0.0 & NA & NA & UNKNOWN & 1 \\
\hline SULFATE & & & $\mathrm{MG} / \mathrm{L}$ & & & & & & & & \\
\hline 10 & 32.9000 & 63.8000 & 58.2500 & 54.9000 & 9.5559 & 0.1741 & 0.0 & 46.3754 & 63.4246 & NORMAL & \\
\hline SULF IDE & & & $M G / L$ & & & & & & & & \\
\hline 6 & ** $\quad 0.1000$ & 4.7000 & 0.3500 & NA & NA & NA & 33.3 & 0.1000 & 4.7000 & NONPARAMETRIC & 2,6 \\
\hline TEMPERATU & & & C - DEGR & & & & & & & & \\
\hline 10 & 12.4000 & 19.0000 & 13.6000 & 14.0500 & 1.9208 & 0.1367 & 0.0 & 12.3365 & 15.7635 & NORMAL & \\
\hline THALLIUM & & & $M G / L$ & & & & & & & & \\
\hline 5 & ** $\quad 0.0050$ & 0.0050 & 0.0050 & NA & NA & NA & 100.0 & 0.0050 & 0.0050 & NONPARAMETRIC & 2,5 \\
\hline THOR IUM - 2 & & & $\mathrm{PCl} / \mathrm{L}$ & & & & & & & & \\
\hline 4 & ** $\quad 0.2000$ & 0.4000 & 0.2000 & NA & NA & NA & 0.0 & 0.2000 & 0.4000 & NONPARAMETRIC & 9,4 \\
\hline
\end{tabular}

** The reported value is the minimum detection limit of the data set

+ The sample size is even, so the median value is the arithmetic average of the two middle values

* The statistical maximum is the 99 percent one sided confidence interval, $\alpha=0.01$

1) A minimum of 4 samples must be available for the statistical analysis.

2) The nonparametric distribution was used because the nondetected values comprise more than $15 \%$ of the samples.

4) The stat. range is the $87.5 \%$ confidence interval due to a sample size of 4 . The maximum is the $93.8 \%$ one sided confidence int.

5) The stat. range is the $93.8 \%$ confidence interval due to a sample size of 5 . The maximum is the $96.9 \%$ one sided confidence int.

6) The stat. range is the $96.9 \%$ confidence interval due to a sample size of 6 . The maximum is the $98.5 \%$ one sided confidence int.

9) The nonparametic distribution was used because the data failed the normal distribution test and includes values $\leq 0$. 
TABLE 3.16 BACKGROUND GROUND WATER QUALITY STATISTICS BY PARAMETER FOR THE NAVAJO SANDSTONE, NC PROCESSING SITE, SLICK ROCK, COLORADO SITE: SRKO1 SLICK ROCK (BOTH SITES)

$07 / 18 / 86$ TO $02 / 19 / 94$

REPORT DATE: $09 / 29 / 94$

\begin{tabular}{|c|c|c|c|c|c|c|c|c|c|c|c|c|}
\hline \multicolumn{3}{|c|}{ PARAMETER NAME } & UNITS & \multirow[b]{2}{*}{ MEAN } & \multirow{2}{*}{$\begin{array}{r}\text { STANDARD } \\
\text { DEVIATION }\end{array}$} & \multirow{2}{*}{$\begin{array}{c}\text { COEFF. } \\
\text { OF } \\
\text { VARIATION }\end{array}$} & \multirow{2}{*}{$\begin{array}{l}\% \text { OF } \\
\text { NON } \\
\text { DETECTS }\end{array}$} & \multirow{2}{*}{\multicolumn{3}{|c|}{$\begin{array}{l}\text { STATISTICAL RANGE } \\
98 \% \text { CONFIDENCE INTERVAL } \\
\text { MINIMUM MAXIMUM * }\end{array}$}} & \multirow{2}{*}{$\begin{array}{c}\text { DISTRIBUTION } \\
\text { TYPE }\end{array}$} & \multirow{2}{*}{$\begin{array}{l}\text { FOOT } \\
\text { NOTE }\end{array}$} \\
\hline \# OF SAMP & MINIMUM & MAXIMUM & MEDIAN & & & & & & & & & \\
\hline \multicolumn{3}{|c|}{ THORIUM-230 (TOTAL) } & $\mathrm{PCI} / \mathrm{L}$ & \multirow[b]{2}{*}{ NA } & \multirow[b]{2}{*}{ NA } & \multirow[b]{2}{*}{ NA } & \multirow[b]{2}{*}{0.0} & \multirow{2}{*}{\multicolumn{2}{|c|}{ NA }} & \multirow[b]{2}{*}{ NA. } & \multirow[b]{2}{*}{ UNKNOWN } & \multirow[b]{2}{*}{1} \\
\hline 1 & 0.2000 & 0.2000 & 0.2000 & & & & & & & & & \\
\hline \multicolumn{3}{|l|}{ TIN } & $M G / L$ & \multirow[b]{2}{*}{ NA } & \multirow[b]{2}{*}{ NA } & \multirow[b]{2}{*}{ NA } & \multirow[b]{2}{*}{100.0} & \multirow[b]{2}{*}{ ** } & \multirow[b]{2}{*}{0.0050} & \multirow[b]{2}{*}{ ** 0.0050} & \multirow[b]{2}{*}{ NONPARAMETRIC } & \multirow[b]{2}{*}{2,6} \\
\hline 6 & 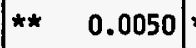 & 0.0050 & 0.0050 & & & & & & & & & \\
\hline \multicolumn{3}{|c|}{ TOTAL DISSOLVED SOLIDS } & $M G / L$ & \multirow[b]{2}{*}{663.9000} & \multirow[b]{2}{*}{324.8317} & \multirow[b]{2}{*}{0.4893} & \multirow[b]{2}{*}{0.0} & \multirow{2}{*}{\multicolumn{2}{|c|}{374.1246}} & & & \\
\hline 10 & 492.0000 & $1530.0000++$ & 534.5000 & & & & & & & 953.6754 & NORMAL & \\
\hline TOTAL KJE & LDAHL NITROGE & & $M G / L$ & & & & & & & & & \\
\hline 4 & ** $\quad 1.0000$ & 1.0000 * & 1.0000 & NA & NA & NA & 75.0 & ** & 1.0000 & 1.0000 & NONPARAMETRIC & 2,4 \\
\hline TOTAL ORG & ANIC CARBON & & $M G / L$ & & & & & & & & & \\
\hline 6 & $* \star \quad 1.0000$ & $100.0000 \mid+$ & 2.0000 & NA & NA & NA & 16.7 & ** & 1.0000 & 100.0000 & NONPARAMETRIC & 2,6 \\
\hline URANIUM & & & $M G / L$ & & & & & & & & & \\
\hline 10 & 0.0010 & $1.3280 \mid+$ & 0.0022 & 0.0041 & 8.0209 & NA & 0.0 & & 0.0006 & 0.0262 & LOGNORMAL & 7,8 \\
\hline URANIUM & TOTAL) & & $M G / L$ & & & & & & & & & \\
\hline 1 & 0.0020 & 0.0020 & 0.0020 & NA & NA & NA & 0.0 & & NA & NA & UNKNOWN & 1 \\
\hline VANADIUM & & & MG/L & & & & & & & & & \\
\hline 9 & ** $\quad 0.0100$ & 0.4300 * & 0.0100 & NA & NA & NA & 88.9 & ** & 0.0100 & 0.4300 & NONPARAMETRIC & 2 \\
\hline VANADIUM & (TOTAL) & & $M G / L$ & & & & & & & & & \\
\hline 1 & $\begin{array}{ll}* & 0.0100\end{array}$ & 0.0100 * & 0.0100 & $N A$ & NA & NA & 100.0 & & NA & NA & UNKNOWN & 1 \\
\hline
\end{tabular}

** The reported value is the minimum detection limit of the data set

+ The sample size is even, so the median value is the arithmetic average of the two middle values

* The statistical maximum is the 99 percent one sided confidence interval, $\alpha=0.01$

1) A minimum of 4 samples must be available for the statistical analysis.

2) The nonparametric distribution was used because the nondetected values comprise more than $15 \%$ of the samples.

4) The stat. range is the $87.5 \%$ confidence interval due to a sample size of 4 . The maximum is the $93.8 \%$ one sided confidence int.

6) The stat. range is the $96.9 \%$ confidence interval due to a sample size of 6 . The maximum is the $98.5 \%$ one sided confidence int.

7) The lognormal distribution was used because the data failed the normal distribution test.

8) The mean is geometric. The standard deviation is the value to divide or multiply with the geometric mean. 
TABLE 3.16 BACKGROUND GROUND WATER QUALITY STATISTICS BY PARAMETER FOR THE NAVAJO SANDSTONE, NC PROCESSING SITE, SLICK ROCK, COLORADO SITE: SRKO1 SLICK ROCK (BOTH SITES)

$07 / 18 / 86$ TO $02 / 19 / 94$

REPORT DATE: $09 / 29 / 94$

\begin{tabular}{|c|c|c|c|c|c|c|c|c|c|c|c|}
\hline \multicolumn{3}{|c|}{ PARAMETER NAME } & UNITS & \multirow[b]{2}{*}{ MEAN } & \multirow{2}{*}{$\begin{array}{r}\text { STANDARD } \\
\text { DEVIAT ION }\end{array}$} & \multirow{2}{*}{\begin{tabular}{|} 
COEFF. \\
OF \\
VARIATION
\end{tabular}} & \multirow{2}{*}{$\begin{array}{c}\% \text { OF } \\
\text { NON } \\
\text { DETECTS }\end{array}$} & \multirow{2}{*}{\multicolumn{2}{|c|}{$\begin{array}{l}\text { STATISTICAL RANGE } \\
\text { 98\% CONF IDENCE INTERVAL. } \\
\text { MINIMUM } \\
\text { MAXIMUM * }\end{array}$}} & \multirow{2}{*}{$\begin{array}{l}\text { DISTRIBUTION } \\
\text { TYPE }\end{array}$} & \multirow{2}{*}{$\begin{array}{l}\text { FOOT } \\
\text { NOTE }\end{array}$} \\
\hline \# OF SAMP & MINIMUM & MAXIMUM & MEDIAN & & & & & & & & \\
\hline \multicolumn{3}{|l|}{ ZINC } & $\mathrm{MG} / \mathrm{L}$ & \multirow[b]{2}{*}{ NA } & \multirow[b]{2}{*}{ NA } & \multirow[b]{2}{*}{ NA } & \multirow[b]{2}{*}{66.7} & \multirow[b]{2}{*}{0.0050} & \multirow[b]{2}{*}{0.2420} & \multirow[b]{2}{*}{ NONPARAMETRIC } & \multirow[b]{2}{*}{2} \\
\hline 9 & 0.0050 & 0.2420 & 0.0050 & & & & & & & & \\
\hline \multicolumn{3}{|c|}{ ZINC (TOTAL) } & MG/L & & & & & & & & \\
\hline 1 & 0.0500 & 0.0500 & 0.0500 & NA & NA & NA & 100.0 & NA & NA & UNKNOWN & 1 \\
\hline
\end{tabular}

** The reported value is the minimum detection limit of the data set

* The statistical maximum is the 99 percent one sided confidence interval, $\alpha=0.01$

1) A minimum of 4 samples must be available for the statistical analysis.

2) The nonparametric distribution was used because the nondetected values comprise more than $15 \%$ of the samples.

INPUT DATA FILENAME: IDARTISRK0IIGWQ10060.DAT 
Table 3.17 Summary of regulated constituents in the Navajo Sandstone background ground water, NC processing site, Slick Rock, Colorado

\begin{tabular}{|c|c|c|c|}
\hline \multicolumn{4}{|c|}{ Constituents with MCLs ${ }^{a}$} \\
\hline Parameter & MCLS & Mean or median & Statistical maximum \\
\hline Arsenic & 0.05 & $0.019^{d}$ & $0.024^{d}$ \\
\hline Barium & 1.00 & $0.10^{e}$ & 0.200 \\
\hline Cadmium & 0.01 & $0.001^{e}$ & $0.001^{e}$ \\
\hline Chromium & 0.05 & $0.01^{e}$ & 0.05 \\
\hline Net gross alphab & 15.0 & 4.61 & 16.23 \\
\hline Lead & 0.05 & $0.01^{e}$ & $0.01^{e}$ \\
\hline Mercury & 0.002 & $0.0002^{e}$ & $0.0002^{e}$ \\
\hline Molybdenum & 0.10 & $0.01^{e}$ & 0.05 \\
\hline Nitrate & 44.0 & 1.40 & 80.0 \\
\hline Radium-226 and $-228^{b}$ & 5.00 & 1.10 & 5.20 \\
\hline Selenium & 0.01 & $0.005^{e}$ & $0.005^{e}$ \\
\hline Silver & 0.05 & $0.01^{e}$ & $0.01^{e}$ \\
\hline Uranium & 0.044 & $0.004^{c}$ & 0.026 \\
\hline
\end{tabular}


Table 3.17 Summary of regulated constituents in the Navajo Sandstone background ground water, NC processing site, Slick Rock, Colorado (Concluded)

\begin{tabular}{lcc}
\hline \multicolumn{3}{c}{ Constituents without MCLs } \\
\hline Parameter & Mean or median & Statistical maximum \\
\hline Antimony & $0.003^{\mathrm{e}}$ & $0.003^{\mathrm{e}}$ \\
Beryllium & $0.01^{\mathrm{e}}$ & $0.01^{\mathrm{e}}$ \\
Cobalt & $0.05^{\mathrm{e}}$ & $0.05^{\mathrm{e}}$ \\
Copper & $0.02^{\mathrm{e}}$ & 0.03 \\
Cyanide & $0.01^{\mathrm{e}}$ & $0.01^{\mathrm{e}}$ \\
Nickel & $0.04^{\mathrm{e}}$ & 0.06 \\
Sulfide & $0.35^{\mathrm{N}}$ & 4.70 \\
Thallium & $0.01^{\mathrm{e}}$ & $0.01^{\mathrm{e}}$ \\
Tin & $0.005^{\mathrm{e}}$ & $0.005^{\mathrm{e}}$ \\
Vanadium & $0.01^{\mathrm{e}}$ & 0.43 \\
Zinc & $0.005^{\mathrm{e}}$ & 0.242 \\
\hline
\end{tabular}

${ }^{a}$ All units are $\mathrm{mg} / \mathrm{L}$ unless otherwise noted.

bunits are $\mathrm{pCi}$.

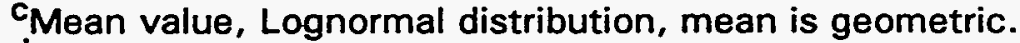

dMean value, Normal distribution, mean is arithmetic.

eStatistical values are below laboratory detection limits in Table 8.1 of the Technical Approach Document (DOE, 1989). 
TABLE 3.18 GROUND HATER QUALITY MEASUREMENTS EXCEEDING MCLS IN NAVAJO

SANDSTONE BACKGROUND GROUND HATER, NC AND UC SITES, SLICK ROCK, COLORADO

SITE: SRKO1 SLICK ROCK (BOTH SITES)

O2/02/86 TO 02/19/94

REPORT DATE: 09/29/94

\begin{tabular}{|c|c|c|c|c|c|c|c|c|c|c|c|c|}
\hline PARAMETER NAME & $\begin{array}{l}\text { TOTAL } \\
\text { \# OF } \\
\text { SAMP. }\end{array}$ & $\begin{array}{l}\text { UNITS } \\
\text { OF } \\
\text { MEASURE }\end{array}$ & $\begin{array}{l}\text { MAXIMUM } \\
\text { CONC. } \\
\text { LIMIT }\end{array}$ & LOC. & LOG DATE & SAMP & $\begin{array}{l}\text { FORM } \\
\text { OF } \\
\text { COMP }\end{array}$ & $\begin{array}{l}\text { HYDR } \\
\text { FLOW } \\
\text { REL. }\end{array}$ & $\begin{array}{c}\text { RESULT EXCEE } \\
\text { CONCENTRATIO } \\
\text { VALUE }\end{array}$ & $\begin{array}{l}\text { ING MAX. } \\
\text { LIMIT } \\
\text { FLAGS }\end{array}$ & $\begin{array}{l}\text { DETECTION } \\
\text { LIMIT }\end{array}$ & $\begin{array}{l}\text { PARAMETER } \\
\text { UNCERT. }\end{array}$ \\
\hline ARSENIC & 18 & $M G / L$ & 0.0500 & 0687 & $12 / 10 / 91$ & 0001 & NA & $\mathbf{u}$ & 0.05 & IW & 0.05 & - \\
\hline ARSENIC (TOTAL) & 0 & $M G / L$ & 0.0500 & - & $=$ & - & - & - & - & & - & - \\
\hline BARIUM & 20 & $M G / L$ & 1.0000 & - & - & - & - & - & - & & - & - \\
\hline BARIUM (TOTAL) & 3 & $M G / L$ & 1.0000 & - & - & - & - & - & - & & - & - \\
\hline CADMIUM & 20 & $M G / L$ & 0.0100 & - & - & - & - & - & - & & - & - \\
\hline CADMIUM (TOTAL) & 3 & $M G / L$ & 0.0100 & - & - & - & - & - & - & & - & - \\
\hline CHROMIUM & 20 & MG/L & 0.0500 & 0687 & $07 / 18 / 86$ & 0001 & NA & $\mathbf{u}$ & 0.05 & $L$ & 0.01 & - \\
\hline CHROMIUM (TOTAL) & 3 & MG/L & 0.0500 & - & - & - & - & - & - & & - & - \\
\hline GROSS ALPHA & 16 & $\mathrm{PCI} / \mathrm{L}$ & 15.0000 & $\left|\begin{array}{l}0558 \\
0558 \\
0687 \\
0687 \\
0687\end{array}\right|$ & $\begin{array}{l}10 / 12 / 92 \\
02 / 18 / 94 \\
08 / 27 / 91 \\
10 / 07 / 92 \\
02 / 19 / 94\end{array}$ & $\left|\begin{array}{l}0001 \\
0001 \\
0001 \\
0001 \\
0001\end{array}\right|$ & $\begin{array}{l}\text { NA } \\
\text { NA } \\
\text { NA } \\
\text { NA } \\
\text { NA }\end{array}$ & $\begin{array}{l}U \\
U \\
U \\
U \\
U\end{array}$ & $\begin{array}{r}22.4 \\
17.4 \\
874.9 \\
15.5 \\
17.6\end{array}$ & $\begin{array}{l}\text { LN } \\
\text { JLN } \\
\text { JN }\end{array}$ & $\begin{array}{c}18.1 \\
2.1 \\
1 . \\
8.3 \\
1.6\end{array}$ & $\begin{array}{r}13.3 \\
2.9 \\
67.8 \\
7.1 \\
2.7\end{array}$ \\
\hline GROSS ALPHA (TOTAL) & 3 & $\mathrm{PCI} / \mathrm{L}$ & 15.0000 & 0558 & $02 / 18 / 94$ & NoO1 & NA & $u$ & 24.1 & JL.N & 2.2 & 3.6 \\
\hline LEAD & 17 & $M G / L$ & 0.0500 & - & - & - & - & - & - & & - & - \\
\hline LEAD (TOTAL) & 0 & $M G / L$ & 0.0500 & - & - & $\cdot$ & - & - & - & & - & - \\
\hline MERCURY & 14 & MG/L & 0.0020 & $\cdot$ & - & - & - & - & - & & - & - \\
\hline MERCURY (TOTAL) & 0 & $M G / L$ & 0.0020 & - & - & - & - & - & - & & - & - \\
\hline MOLYBDDENUM & 23 & $M G / L$ & 0.1000 & 0668 & $06 / 30 / 86$ & 0001 & $N A$ & $u$ & 0.17 & & 0.01 & - \\
\hline
\end{tabular}

< - the DATA IS flagGed AS A NON-DETECT, SO THE RESULT IS AN ESTIMATED VALUE OR THE DETECTION LIMIT

FORMATION OF COMPLETION CODE:

NA - NAVAJO SANDSTONE

OTHER PARAMETER VALUE FLAGS:

I - INCREASED DETECTION LIMIT DUE TO REQUIRED DILUTION

$J$ - ESTIMATED VALUE

L - LESS THAN THREE BORE VOLUMES REMOVED BEFORE SAMPLING

$N$ - SPIKE SAMPLE RECOVERY NOT HITHIN CONTROL LIMITS

$W$ - POST-DIGEST SPIKE OUT OF CNTR LIM WHILE SAMP ABS < 50\% SPIKE
FLOH RELATIONSHIP CODE:

$$
U \text { - UPGRADIENT }
$$

SAMPLE ID CODES:

0001 - FILTERED SAMPLE (.45 MICRONS)

NO01 - UNFILTERED SAMPLE 
TABLE 3.18 GROUND WATER QUALITY MEASUREMENTS EXCEEDING MCLS IN NAVAJO SANDSTONE BACKGROUND GROUND WATER, NC AND UC SITES, SLICK ROCK, COLORADO SITE: SRKO1 SLICK ROCK (BOTH SITES)

02/02/86 TO 02/19/94

REPORT DATE: 09/29/94

\begin{tabular}{|c|c|c|c|c|c|c|c|c|c|c|c|c|}
\hline PARAMETER NAME & $\begin{array}{l}\text { TOTAL } \\
\# \text { OF } \\
\text { SAMP. }\end{array}$ & $\begin{array}{c}\text { UNITS } \\
\text { OF } \\
\text { MEASURE }\end{array}$ & $\begin{array}{l}\text { MAXIMUM } \\
\text { CONC. } \\
\text { LIMIT }\end{array}$ & LOC. & LOG DATE & $\begin{array}{c}\text { SAMP } \\
\text { ID }\end{array}$ & $\begin{array}{l}\text { FORM } \\
\text { OF } \\
\text { COMP }\end{array}$ & $\begin{array}{l}\text { HYDR } \\
\text { FL.OW } \\
\text { REL. }\end{array}$ & $\begin{array}{c}\text { RESULT EXCEEO } \\
\text { CONCENTRATION } \\
\text { VALUE }\end{array}$ & $\begin{array}{l}\text { DING MAX. } \\
\text { N LIMIT } \\
\text { FLAGS }\end{array}$ & $\begin{array}{l}\text { DETECTION } \\
\text { LIMIT }\end{array}$ & $\begin{array}{l}\text { PARAMETER } \\
\text { UNCERT. }\end{array}$ \\
\hline MOLYBDEENUM & 23 & $M G / L$ & 0.1000 & $\begin{array}{l}0687 \\
0687\end{array}$ & $\begin{array}{l}07 / 18 / 86 \\
04 / 08 / 87\end{array}$ & $\begin{array}{l}0001 \\
0001\end{array}$ & $\begin{array}{l}\text { NA } \\
\text { NA }\end{array}$ & $\begin{array}{l}u \\
\mathbf{u}\end{array}$ & $\begin{array}{l}0.16 \\
0.1\end{array}$ & $\begin{array}{l}\mathrm{L} \\
\mathrm{IL}\end{array}$ & $\begin{array}{l}0.01 \\
0.1\end{array}$ & $\overline{-}$ \\
\hline MOLYBDENUM (TOTAL) & 3 & $M G / L$ & 0.1000 & - & - & - & - & - & - & & - & - \\
\hline NET GROSS ALPHA * & 16 & $\mathrm{PCI} / \mathrm{L}$ & 15.0000 & 0687 & $02 / 19 / 94$ & 0001 & NA & $\mathbf{u}$ & 16.2 & & - & - \\
\hline NET GROSS ALPHA (TOTAL) ** & 3 & $\mathrm{PCl} / \mathrm{L}$ & 15.0000 & - & - & - & - & - & - & & - & - \\
\hline NITRATE & 20 & $M G / L$ & 44.0000 & 0687 & $07 / 18 / 86$ & 0001 & NA & $u$ & 80.0 & L & 1. & - \\
\hline NITRATE (TOTAL) & 3 & $M G / L$ & 44.0000 & - & - & - & - & - & - & & - & - \\
\hline$R A-226 \& R A-228$ & 19 & $\mathrm{PCI} / \mathrm{L}$ & 5.0000 & $\begin{array}{l}0558 \\
0558 \\
0687\end{array}$ & $\begin{array}{l}03 / 30 / 91 \\
12 / 05 / 91 \\
04 / 03 / 91\end{array} \mid$ & $\left|\begin{array}{l}0001 \\
0001 \\
0001\end{array}\right|$ & $\begin{array}{l}\text { NA } \\
\text { NA } \\
\text { NA }\end{array}$ & $\begin{array}{l}U \\
U \\
U\end{array}$ & $\begin{array}{r}7.6 \\
15.1 \\
5.2\end{array}$ & & - & $\begin{array}{l}- \\
-\end{array}$ \\
\hline$R A-226 \& R A-228$ (TOTAL) & 3 & $\mathrm{PCI} / \mathrm{L}$ & 5.0000 & - & - & - & - & - & - & & - & - \\
\hline SELENIUM & 21 & $M G / L$ & 0.0100 & $\begin{array}{l}0558 \\
0558 \\
0558\end{array}$ & $\begin{array}{l}08 / 07 / 91 \\
12 / 11 / 91 \\
10 / 12 / 92\end{array}$ & $\begin{array}{l}0001 \\
0001 \\
0001\end{array} \mid$ & $\begin{array}{l}\text { NA } \\
\text { NA } \\
\text { NA }\end{array}$ & $\begin{array}{l}U \\
U \\
U\end{array}$ & $\begin{array}{l}0.05 \\
0.04 \\
0.020\end{array}$ & $\begin{array}{l}\text { IL } \\
\text { L } \\
\text { L }\end{array}$ & $\begin{array}{l}0.05 \\
0.03 \\
0.005\end{array}$ & $\begin{array}{l}- \\
-\end{array}$ \\
\hline SELENIUM (TOTAL) & 3 & $M G / L$ & 0.0100 & - & - & - & - & - & - & & - & - \\
\hline SILVER & 15 & $M G / L$ & 0.0500 & 0668 & $06 / 30 / 86$ & 0001 & NA & $\mathbf{u}$ & 0.3 & & 0.1 & - \\
\hline SILVER (TOTAL) & 0 & $M G / L$ & 0.0500 & - & - & - & - & - & - & & - & - \\
\hline URANIUM & 23 & $M G / L$ & 0.0440 & 0687 & $08 / 27 / 91$ & 0001 & NA & U & 1.328 & & 0.001 & - \\
\hline URANIUM (TOTAL) & 3 & $M G / L$ & 0.0440 & - & - & - & - & - & - & & - & - \\
\hline
\end{tabular}

* NET GROSS ALPHA (GROSS ALPHA - URANIUM) WITH 1 MG URANIUM = 686 PCI

** TOTAL NET GROSS ALPHA (TOTAL GROSS ALPHA - TOTAL URANIUM)

FORMATION OF COMPLETION CODE:

NA - NAVAJO SANDSTONE

FLOW RELATIONSHIP CODE:

FARMATION - NAVAS

OTHER PARAMETER VALUE FLAGS:

I - INCREASED DETECTION LIMIT DUE TO REQUIRED DILUTION

$U$ - UPGRADIENT

L. - LESS THAN THREE BORE VOLUMES REMOVED BEFORE SAMPLING

SAMPLE ID CODES:

0001 - FILTERED SAMPLE (.45 MICRONS)

DATA FILE NAME: IDARTISRK01\GWQ10061.DAT 
TABLE 3.19 BACKGROUND GROUND WATER QUALITY STATISTICS BY PARAMETER FOR THE NAVAJO SANDSTONE, UC PROCESSING SITE, SLICK ROCK, COLORADO

SITE: SRK01 SLICK ROCK (BOTH SITES)

02/02/86 TO 02/18/94

REPORT DATE: 09/29/94

\begin{tabular}{|c|c|c|c|c|c|c|c|c|c|c|c|c|}
\hline \multicolumn{3}{|c|}{ PARAMETER NAME } & UNITS & \multirow[b]{2}{*}{ MEAN } & \multirow{2}{*}{$\begin{array}{r}\text { STANDARD } \\
\text { DEVIATION }\end{array}$} & \multirow{2}{*}{$\begin{array}{c}\text { COEFF. } \\
\text { OF } \\
\text { VARIATION }\end{array}$} & \multirow{2}{*}{$\begin{array}{l}\% \text { OF } \\
\text { NON } \\
\text { DETECTS }\end{array}$} & \multirow{2}{*}{\multicolumn{3}{|c|}{ 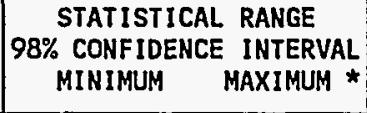 }} & \multirow{2}{*}{$\begin{array}{l}\text { DISTRIBUTION } \\
\text { TYPE }\end{array}$} & \multirow{2}{*}{$\begin{array}{l}\text { FOOT } \\
\text { NOTE }\end{array}$} \\
\hline \# OF SAMP & MINIMUM & MAXIMUM & MEDIAN & & & & & & & & & \\
\hline \multicolumn{3}{|l|}{ ALKALINITY } & $M G / L$ CACC & \multirow[b]{2}{*}{307.3846} & \multirow[b]{2}{*}{41.5282} & \multirow[b]{2}{*}{0.1351} & \multirow[b]{2}{*}{0.0} & \multirow{2}{*}{\multicolumn{2}{|c|}{276.5053}} & \multirow[b]{2}{*}{338.2640} & \multirow[b]{2}{*}{ NORMAL } & \\
\hline 13 & 256.0000 & 368.0000 & 310.0000 & & & & & & & & & \\
\hline \multicolumn{3}{|l|}{ ALUMINUM } & $M G / L$ & \multirow[b]{2}{*}{ NA } & \multirow[b]{2}{*}{ NA } & \multirow[b]{2}{*}{ NA } & \multirow[b]{2}{*}{72.7} & \multirow[b]{2}{*}{ ** } & \multirow[b]{2}{*}{0.0500} & \multirow[b]{2}{*}{0.1000} & \multirow[b]{2}{*}{ NONPARAMETRIC) } & \multirow[b]{2}{*}{2} \\
\hline 11 & $\begin{array}{ll}* & 0.0500\end{array}$ & 0.3000 & 0.0500 & & & & & & & & & \\
\hline \multicolumn{3}{|l|}{ AMMONIUM } & MG/L & \multirow[b]{2}{*}{ NA } & \multirow[b]{2}{*}{ NA } & \multirow[b]{2}{*}{ NA } & \multirow[b]{2}{*}{70.0} & \multirow[b]{2}{*}{ ** } & & & & \\
\hline 10 & $\begin{array}{ll}* * & 0.1000\end{array}$ & 0.2000 & 0.1000 & & & & & & 0.1000 & 0.1000 & NONPARAMETRIC & 2 \\
\hline AMMONIUM ( & (TOTAL) & & $M G / L$ & & & & & & & & & \\
\hline 2 & ** 0.1000 * & 0.1000 & 0.1000 & NA & NA & NA & 100.0 & & NA & NA & UNKNOWN & 1 \\
\hline ANTIMONY & & & $M G / L$ & & & & & & & & & \\
\hline 8 & ** $\quad 0.0030$ & 0.0030 & 0.0030 & NA & NA & NA & 87.5 & ** & 0.0030 & 0.0030 & NONPARAMETRIC & 2 \\
\hline ARSENIC & & & MG/L & & & & & & & & & \\
\hline 10 & $\begin{array}{ll}* * & 0.0050\end{array}$ & $0.0070+$ & 0.0050 & NA & NA & NA & 80.0 & & 0.0050 & 0.0050 & NONPARAMETRIC & 2 \\
\hline BARIUM & & & $M G / L$ & & & & & & & & & \\
\hline 11 & 0.0300 & 0.2000 & 0.0500 & NA & NA & NA & 18.2 & & 0.0300 & 0.2000 & NONPARAMETRIC & 2 \\
\hline BARIUH CTO & DTAL) & & $M G / L$ & & & & & & & & & \\
\hline 2 & 0.2000 & 0.5000 & 0.3500 & NA & NA & NA & 0.0 & & NA & NA & UNKNOWN & 1 \\
\hline BERYLLIUM & & & $M G / L$ & & & & & & & & & \\
\hline 6 & $\begin{array}{ll}* * & 0.0050\end{array}$ & 0.0050 & 0.0050 & NA & NA & NA & 100.0 & ** & 0.0050 & 0.0050 & NONPARAMETRIC & 2,6 \\
\hline BORON & & & $M G / L$ & & & & & & & & & \\
\hline 9 & 0.1000 & 0.6600 & 0.3000 & 0.3056 & 0.2113 & 0.6914 & 0.0 & & 0.1016 & 0.5095 & NORMAL & \\
\hline
\end{tabular}

** The reported value is the minimum detection limit of the data set

+ The sample size is even, so the median value is the arithmetic average of the two middle values

* The statistical maximum is the 99 percent one sided confidence interval, $\alpha=0.01$

1) A minimum of 4 samples must be available for the statistical analysis.

2) The nonparametric distribution was used because the nondetected values comprise more than $15 \%$ of the samples.

6) The stat. range is the $96.9 \%$ confidence interval due to a sample size of 6 . The maximum is the $98.5 \%$ one sided confidence int. 
TABLE 3.19 BACKGROUND GROUND WATER QUALITY STATISTICS BY PARAMETER FOR THE NAVAJO SANDSTONE, UC PROCESSING SITE, SLICK ROCK, COLORADO

SITE: SRK01 SLICK ROCK (BOTH SITES)

02/02/86 TO 02/18/94

REPORT DATE : 09/29/94

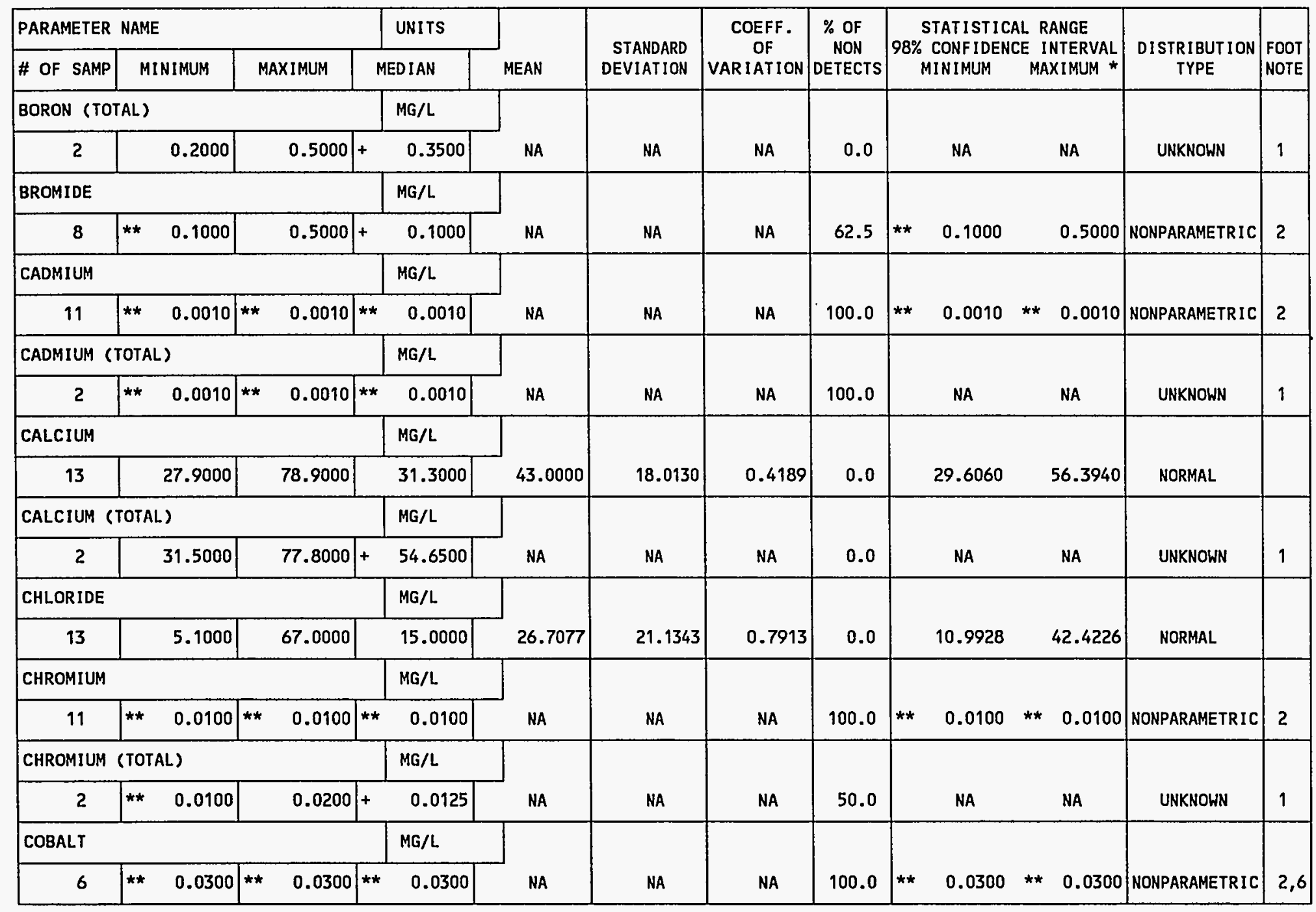

** The reported value is the minimum detection limit of the data set

+ The sample size is even, so the median value is the arithmetic average of the two middle values

* The statistical maximum is the 99 percent one sided confidence interval, $\alpha=0.01$

1) A minimum of 4 samples must be available for the statistical analysis.

2) The nonparametric distribution was used because the nondetected values comprise more than $15 \%$ of the samples.

6) The stat. range is the $96.9 \%$ confidence interval due to a sample size of 6 . The maximum is the $98.5 \%$ one sided confidence int. 
TABLE 3.19 BACKGROUND GROUND WATER QUALITY STATISTICS BY PARAMETER FOR THE NAVAJO SANDSTONE, UC PROCESSING SITE, SLICK ROCK, COLORADO

SITE: SRKO1 SLICK ROCK (BOTH SITES)

02/02/86 TO 02/18/94

REPORT DATE: $09 / 29 / 94$

\begin{tabular}{|c|c|c|c|c|c|c|c|c|c|c|c|c|c|}
\hline \multicolumn{4}{|c|}{ PARAMETER NAME } & UNITS & \multirow[b]{2}{*}{ MEAN } & \multirow{2}{*}{$\begin{array}{r}\text { STANDARD } \\
\text { DEVIATION }\end{array}$} & \multirow{2}{*}{$\begin{array}{c}\text { COEFF. } \\
\text { OF } \\
\text { VARIATION }\end{array}$} & \multirow{2}{*}{$\begin{array}{c}\% \text { OF } \\
\text { NON } \\
\text { DETECTS }\end{array}$} & \multirow{2}{*}{\multicolumn{3}{|c|}{ 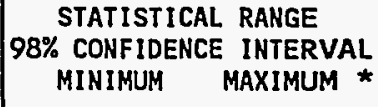 }} & \multirow{2}{*}{$\begin{array}{l}\text { DISTRIBUTION } \\
\text { TYPE }\end{array}$} & \multirow{2}{*}{$\begin{array}{l}\text { FOOT } \\
\text { NOTE }\end{array}$} \\
\hline \# OF SAMP & & NIMUM & MAXIMUM & MED IAN & & & & & & & & & \\
\hline \multicolumn{4}{|l|}{ COPPER } & MG/L & \multirow[b]{2}{*}{ NA } & \multirow[b]{2}{*}{ NA } & \multirow[b]{2}{*}{ NA } & \multirow[b]{2}{*}{100.0} & \multirow[b]{2}{*}{ ** } & \multirow[b]{2}{*}{0.0100} & \multirow[b]{2}{*}{0.0100} & \multirow[b]{2}{*}{ NONPARAMETRIC } & \multirow[b]{2}{*}{2} \\
\hline 9 & $\star \star *$ & 0.0100 & 0.0100 & 0.0100 & & & & & & & & & \\
\hline \multicolumn{4}{|l|}{ CYANIDE } & $M G / L$ & \multirow[b]{2}{*}{ NA } & \multirow[b]{2}{*}{ NA } & \multirow[b]{2}{*}{ NA } & \multirow[b]{2}{*}{100.0} & \multirow[b]{2}{*}{ ** } & \multirow[b]{2}{*}{0.0100} & \multirow[b]{2}{*}{ ** 0.0100} & \multirow[b]{2}{*}{ NONPARAMETRIC } & \multirow[b]{2}{*}{2,6} \\
\hline 6 & ** & 0.0100 & 0.0100 & 0.0100 & & & & & & & & & \\
\hline \multicolumn{4}{|c|}{ DISSOLVED OXYGEN } & MG/L & \multirow[b]{2}{*}{ NA } & \multirow[b]{2}{*}{ NA } & \multirow[b]{2}{*}{ NA } & & & & & & \\
\hline 3 & & 0.3000 & 4.2000 & 0.3000 & & & & 33.3 & & NA & NA & UNKNOWN & 1 \\
\hline FIELD FE & $(2+)$ & & & $M G / L$ & & & & & & & & & \\
\hline 1 & & 0.0600 & 0.0600 & 0.0600 & NA & NA & NA & 0.0 & & NA & NA & UNKNOWN & 1 \\
\hline FIELD FE & CTOTA & & & $M G / L$ & & & & & & & & & \\
\hline 1 & & 0.0700 & 0.0700 & 0.0700 & NA & NA & NA & 0.0 & & NA & NA & UNKNOWN & १- \\
\hline FLUORIDE & & & & $M G / L$ & & & & & & & & & \\
\hline 10 & & 0.5000 & 0.8000 & 0.7000 & 0.6640 & 0.0873 & 0.1315 & 0.0 & & 0.5861 & 0.7419 & NORMAL & \\
\hline GROSS ALPI & & & & PCI/L & & & & & & & & & \\
\hline 10 & ** & 1.0000 & 22.4000 & 6.6000 & NA & NA & NA & 0.0 & & 1.0000 & 17.4000 & NONPARAMETRIC & 9 \\
\hline GROSS ALPI & HACT & OTAL) & & $\mathrm{PCI} / \mathrm{L}$ & & & & & & & & & \\
\hline 2 & & 8.5000 & 24.1000 & 16.3000 & NA & NA & NA & 0.0 & & NA & NA & UNKNOWN & 1 \\
\hline GROSS BET & & & & $\mathrm{PCI} / \mathrm{L}$ & & & & & & & & & \\
\hline 8 & ** & 0.5000 & 23.6000 & 11.7000 & NA & NA & NA & 0.0 & ** & 0.5000 & 23.6000 & NONPARAMETRIC & 9 \\
\hline
\end{tabular}

** The reported value is the minimum detection limit of the data set

+ The sample size is even, so the median value is the arithmetic average of the two middle values

* The statistical maximum is the 99 percent one sided confidence interval, $\alpha=0.01$

1) A minimum of 4 samples must be avai lable for the statistical analysis.

2) The nonparametric distribution was used because the nondetected values comprise more than $15 \%$ of the samples.

6) The stat. range is the $96.9 \%$ confidence interval due to a sample size of 6 . The maximum is the $98.5 \%$ one sided confidence int.

9) The nonparametic distribution was used because the data failed the normal distribution test and includes values $\leq 0$. 
TABLE 3.19 BACKGROUND GROUND WATER QUALITY STATISTICS BY PARAMETER FOR THE NAVAJO SANDSTONE, UC PROCESSING SITE, SLICK ROCK, COLORADO

SITE: SRKO1 SLICK ROCK (BOTH SITES)

$02 / 02 / 86$ TO $02 / 18 / 94$

REPORT DATE: $09 / 29 / 94$

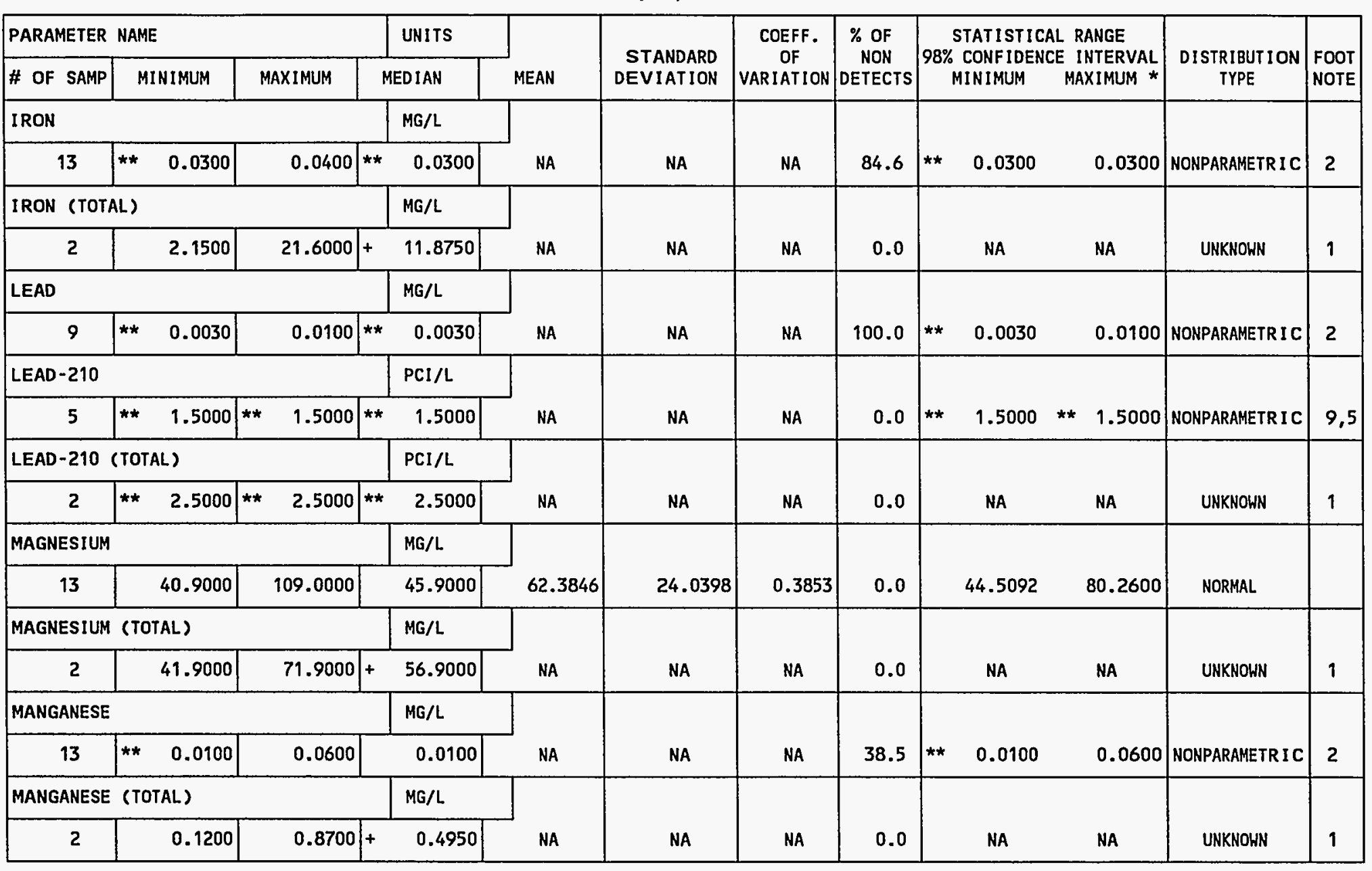

** The reported value is the minimum detection limit of the data set

+ The sample size is even, so the median value is the arithmetic average of the two middle values

* The statistical maximum is the 99 percent one sided confidence interval, $\alpha=0.01$

1) A minimum of 4 samples must be available for the statistical analysis.

2) The nonparametric distribution was used because the nondetected values comprise more than $15 \%$ of the samples.

5) The stat. range is the $93.8 \%$ confidence interval due to a sample size of 5 . The maximum is the $96.9 \%$ one sided confidence int.

9) The nonparametic distribution was used because the data failed the normal distribution test and includes values $\leq 0$. 
TABLE 3.19 BACKGROUND GROUND HATER QUALITY STATISTICS BY PARAMETER FOR THE NAVAJO SANDSTONE, UC PROCESSING SITE, SLICK ROCK, COLORADO

SITE: SRKO1 SLICK ROCK (BOTH SITES)

02/02/86 TO 02/18/94

REPORT DATE: 09/29/94

\begin{tabular}{|c|c|c|c|c|c|c|c|c|c|c|c|c|c|c|}
\hline \multicolumn{4}{|c|}{ PARAMETER NAME } & UNITS & \multirow[b]{2}{*}{ MEAN } & \multirow[b]{2}{*}{$\begin{array}{r}\text { STANDARD } \\
\text { DEVIATION }\end{array}$} & \multirow{2}{*}{$\begin{array}{c}\text { COEFF. } \\
\text { OF } \\
\text { VARIATION }\end{array}$} & \multirow{2}{*}{$\begin{array}{c}\% \text { OF } \\
\text { NON } \\
\text { DETECTS }\end{array}$} & \multirow{2}{*}{\multicolumn{4}{|c|}{$\begin{array}{l}\text { STATISTICAL RANGE } \\
\text { 98\% CONFIDENCE INTERVAL } \\
\text { MINIMUM } \\
\text { MAXIMUM * }\end{array}$}} & \multirow[b]{2}{*}{$\begin{array}{c}\text { DISTRIBUTION } \\
\text { TYPE }\end{array}$} & \multirow[b]{2}{*}{$\begin{array}{l}\text { FOOT } \\
\text { NOTE }\end{array}$} \\
\hline \# OF SAMP & MINIMUM & MAXIMUM & & IEDIAN & & & & & & & & & & \\
\hline \multicolumn{4}{|l|}{ MERCURY } & $M G / L$ & \multirow[b]{2}{*}{ NA } & \multirow[b]{2}{*}{ NA } & \multirow[b]{2}{*}{ NA } & \multirow[b]{2}{*}{100.0} & \multirow[b]{2}{*}{$\star \star *$} & \multirow[b]{2}{*}{0.0002} & \multirow[b]{2}{*}{ ** } & \multirow[b]{2}{*}{0.0002} & \multirow[b]{2}{*}{ NONPARAMETRIC } & \multirow[b]{2}{*}{2} \\
\hline 7 & ** $\quad 0.0002$ & 0.0002 & ** & 0.0002 & & & & & & & & & & \\
\hline \multicolumn{4}{|l|}{ MOLYYBDENUM } & $M G / L$ & \multirow[b]{2}{*}{ NA } & \multirow[b]{2}{*}{ NA } & \multirow[b]{2}{*}{ NA } & \multirow[b]{2}{*}{61.5} & \multirow[b]{2}{*}{ ** } & \multirow{2}{*}{\multicolumn{2}{|c|}{0.0100}} & \multirow[b]{2}{*}{0.0600} & \multirow[b]{2}{*}{ NONPARAMETRIC } & \multirow[b]{2}{*}{2} \\
\hline 13 & $* * \quad 0.0100$ & 0.1700 & ** & 0.0100 & & & & & & & & & & \\
\hline \multicolumn{4}{|c|}{ MOLYBDENUM (TOTAL) } & $M G / L$ & \multirow[b]{2}{*}{ NA } & \multirow[b]{2}{*}{ NA } & & & & & & & & \\
\hline 2 & ** $\quad 0.0100$ & ** $\quad 0.0100$ & $\star \star$ & 0.0100 & & & NA & 100.0 & & NA & & NA & UNKNOWN & 1 \\
\hline NET GROSS & ALPHA $* * *$ & & & $\mathrm{PCl} / \mathrm{L}$ & & & & & & & & & & \\
\hline 10 & -7.9200 & 2.8400 & + & 0.5550 & NA & NA & NA & 0.0 & & -1.2000 & & 2.5400 & NONPARAMETRIC & 9 \\
\hline NET GROSS & ALPHA (TOTAL & L) $* * * *$ & & $\mathrm{PCI} / \mathrm{L}$ & & & & & & & & & & \\
\hline 2 & 5.7600 & 13.1200 & + & 9.4400 & NA & NA & NA & 0.0 & & NA & & NA & UNKNOWN & 1 \\
\hline NICKEL & & & & $M G / L$ & & & & & & & & & & \\
\hline 10 & ** $\quad 0.0400$ & 0.0400 & ** & 0.0400 & NA & NA & NA & 80.0 & $\star \star$ & 0.0400 & ** & 0.0400 & NONPARAMETRIC & 2 \\
\hline NITRATE & & & & $M G / L$ & & & & & & & & & & \\
\hline 11 & $\begin{array}{ll}* * & 1.0000\end{array}$ & 11.3000 & & 2.0000 & NA & NA & NA & 36.4 & ** & 1.0000 & & 5.7000 & NONPARAMETRIC & 2 \\
\hline NITRATE $(1$ & TOTAL) & & & $M G / L$ & & & & & & & & & & \\
\hline 2 & $\begin{array}{ll}* & 1.0000\end{array}$ & 2.0000 & + & 1.2500 & NA & NA & NA & 50.0 & & NA & & NA & UNKNOWN & 1 \\
\hline NITRITE AI & ND NITRATE & & & MG/L & & & & & & & & & & \\
\hline 5 & 0.3000 & 2.0000 & & 0.8700 & NA & NA & NA & 20.0 & & 0.3000 & & 2.0000 & NONPARAMETRIC & 2,5 \\
\hline
\end{tabular}

*** NET GROSS ALPHA (GROSS ALPHA - URANIUM) HITH 1 MG URANIUM = 686 PCI

**** NET GROSS ALPHA (TOTAL) (TOTAL GROSS ALPHA - TOTAL URANIUM)

** The reported value is the minimum detection limit of the data set

+ The sample size is even, so the median value is the arithmetic average of the two middle values

* The statistical maximum is the 99 percent one sided confidence interval, $\alpha=0.01$

1) A minimum of 4 samples must be available for the statistical analysis.

2) The nonparametric distribution was used because the nondetected values comprise more than $15 \%$ of the samples.

5) The stat. range is the $93.8 \%$ confidence interval due to a sample size of 5 . The maximum is the $96.9 \%$ one sided confidence int.

9) The nonparametic distribution was used because the data failed the normal distribution test and includes values $\leq 0$. 
TABLE 3.19 BACKGROUND GROUND WATER QUALITY STATISTICS BY PARAMETER FOR THE NAVAJO SANDSTONE, UC PROCESSING SITE, SLICK ROCK, COLORADO

SITE: SRK01 SLICK ROCK (BOTH SITES)

$02 / 02 / 86$ TO $02 / 18 / 94$

REPORT DATE : $09 / 29 / 94$

\begin{tabular}{|c|c|c|c|c|c|c|c|c|c|c|c|}
\hline \multicolumn{3}{|c|}{ PARAMETER NAME } & UNITS & \multirow[b]{2}{*}{ MEAN } & \multirow{2}{*}{$\begin{array}{r}\text { STANDARD } \\
\text { DEVIAT I ON }\end{array}$} & \multirow{2}{*}{$\begin{array}{c}\text { COEFF. } \\
\text { OF } \\
\text { VARIATION }\end{array}$} & \multirow{2}{*}{$\begin{array}{l}\% \text { OF } \\
\text { NON } \\
\text { DETECTS }\end{array}$} & \multirow{2}{*}{\multicolumn{2}{|c|}{$\begin{array}{l}\text { STATISTICAL RANGE } \\
\text { 98\% CONFIDENCE INTERVAL } \\
\text { MINIMUM } \\
\text { MAXIMUM * }\end{array}$}} & \multirow{2}{*}{$\begin{array}{c}\text { DISTRIBUT ION } \\
\text { TYPE }\end{array}$} & \multirow{2}{*}{$\begin{array}{l}\text { FOOT } \\
\text { NOTE }\end{array}$} \\
\hline \# OF SAMP & MINIMUM & MAXIMUM & MEDIAN & & & & & & & & \\
\hline \multicolumn{3}{|l|}{ PH } & SU & \multirow[b]{2}{*}{ NA } & \multirow[b]{2}{*}{ NA } & \multirow[b]{2}{*}{ NA } & \multirow[b]{2}{*}{0.0} & \multirow[b]{2}{*}{ NA } & \multirow[b]{2}{*}{ NA } & \multirow[b]{2}{*}{ UNKNOWN } & \\
\hline 14 & 7.4100 & 7.8200 & 7.5999 & & & & & & & & \\
\hline \multicolumn{3}{|l|}{ PHOSPHATE } & MG/L & \multirow[b]{2}{*}{ NA } & \multirow[b]{2}{*}{ NA } & \multirow[b]{2}{*}{ NA } & \multirow[b]{2}{*}{55.6} & \multirow[b]{2}{*}{0.1000} & \multirow[b]{2}{*}{0.8000} & \multirow[b]{2}{*}{ NONPARAMETRIC } & \multirow[b]{2}{*}{2} \\
\hline 9 & ** $\quad 0.1000$ & 0.8000 & 0.1000 & & & & & & & & \\
\hline \multicolumn{3}{|c|}{ POL.ONIUM-210 } & $\mathrm{PCI} / \mathrm{L}$ & \multirow[b]{2}{*}{ NA } & \multirow[b]{2}{*}{ NA } & \multirow[b]{2}{*}{ NA } & \multirow[b]{2}{*}{0.0} & \multirow[b]{2}{*}{0.1000} & & & \\
\hline 4 & ** $\quad 0.1000$ & 0.3000 & 0.1000 & & & & & & 0.3000 & NONPARAMETRIC & 9,4 \\
\hline POLONIUM- & 210 (TOTAL) & & $\mathrm{PCI} / \mathrm{L}$ & & & & & & & & \\
\hline 2 & ** $\quad 0.1000$ & 0.1000 & 0.1000 & NA & NA & NA & 0.0 & NA & NA & UNKNOWN & 1 \\
\hline POTASSIUM & & & MG/L & & & & & & & & \\
\hline 13 & 7.8900 & 14.5000 & 9.1200 & 9.7015 & 1.8426 & 0.1899 & 0.0 & 8.3315 & 11.0716 & NORMAL & \\
\hline POTASSIUM & (TOTAL) & & $M G / L$ & & & & & & & & \\
\hline 2 & 8.0000 & 22.2000 & 15.1000 & NA & NA & NA & 0.0 & NA & NA & UNKNOWN & 1 \\
\hline RADIUM-22 & & & $\mathrm{PCI} / \mathrm{L}$ & & & & & & & & \\
\hline 12 & 0.2000 & 0.8000 & 0.4000 & 0.4583 & 0.2109 & 0.4601 & 0.0 & 0.2929 & 0.6238 & NORMAL. & \\
\hline RADIUM-22 & 6 (TOTAL) & & $\mathrm{PCI} / \mathrm{L}$ & & & & & & & & \\
\hline 2 & 0.7000 & 1.0000 & 0.8500 & NA & NA & NA & 0.0 & NA & NA & UNKNOWN & 1 \\
\hline RADIUM-22 & $6+$ RADIUM -2 & & $\mathrm{PCI} / \mathrm{L}$ & & & & & & & & \\
\hline 11 & 0.3000 & 15.1000 & 1.5000 & 1.4723 & 3.3361 & NA & 0.0 & 0.5394 & 4.0184 & LOGNORMAL & 7,8 \\
\hline
\end{tabular}

** The reported value is the minimum detection limit of the data set

+ The sample size is even, so the median value is the arithmetic average of the two middle values

* The statistical maximum is the 99 percent one sided confidence interval, $\alpha=0.01$

1) A minimum of 4 samples must be available for the statistical analysis.

2) The nonparametric distribution was used because the nondetected values comprise more than $15 \%$ of the samples.

4) The stat. range is the $87.5 \%$ confidence interval due to a sample size of 4 . The maximum is the $93.8 \%$ one sided confidence int.

7) The lognormal distribution was used because the data failed the normal distribution test.

8) The mean is geometric. The standard deviation is the value to divide or multiply with the geometric mean.

9) The nonparametic distribution was used because the data failed the normal distribution test and includes values $\leq 0$. 
TABLE 3.19 BACKGROUND GROUND WATER QUALITY STATISTICS BY PARAMETER FOR THE NAVAJO SANDSTONE, UC PROCESSING SITE, SLICK ROCK, COLORADD

SITE: SRK01 SLICK ROCK (BOTH SITES)

02/02/86 TO 02/18/94

REPORT DATE: 09/29/94

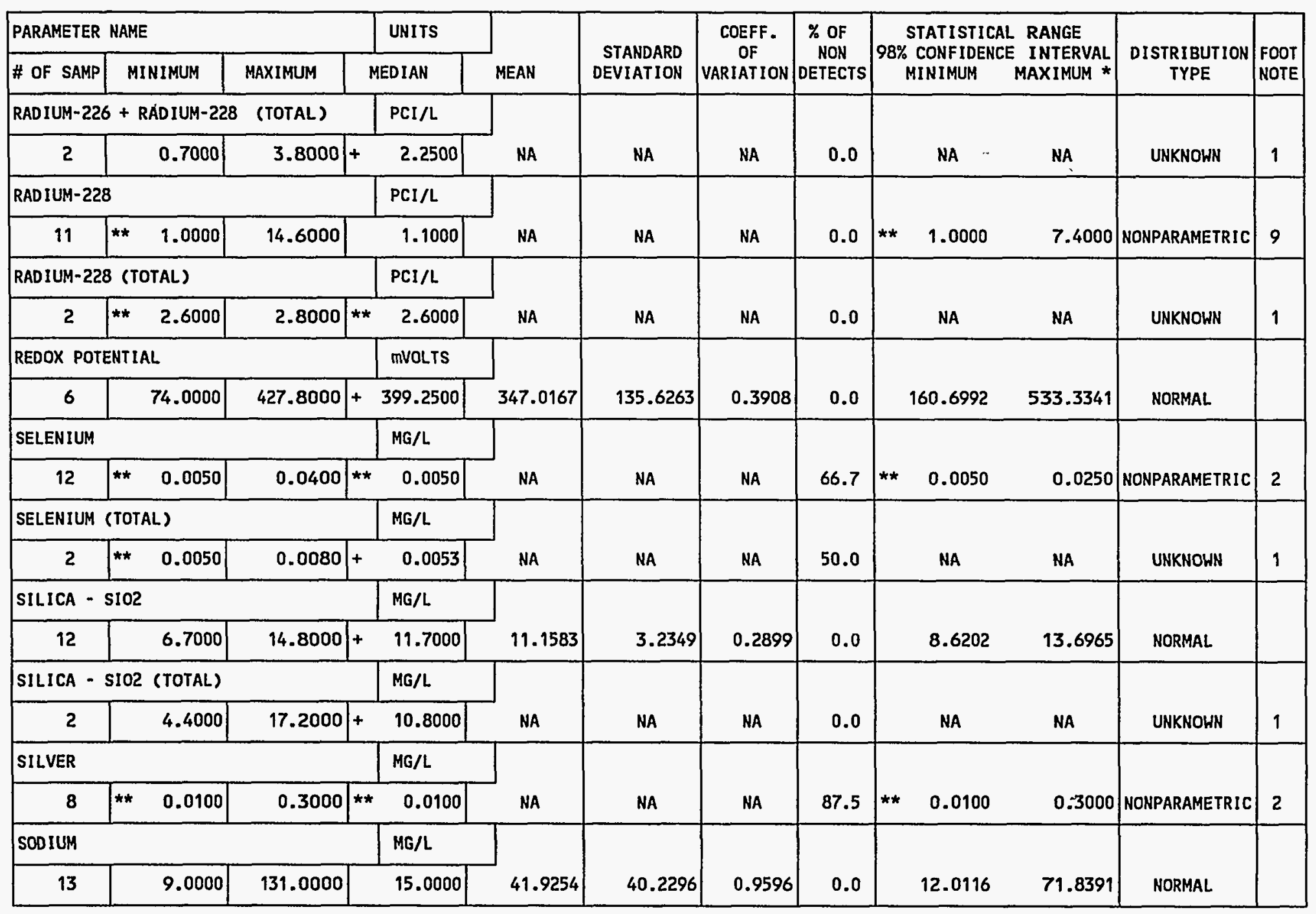

** The reported value is the minimum detection limit of the data set

+ The sample size is even, so the median value is the arithmetic average of the two middle values

* The statistical maximum is the 99 percent one sided confidence interval, $\alpha=0.01$

1) A minimum of 4 samples must be available for the statistical analysis.

2) The nonparametric distribution was used because the nondetected values comprise more than $15 \%$ of the samples.

9) The nonparametic distribution was used because the data failed the normal distribution test and includes values $\leq 0$. 
TABLE 3.19 BACKGROUND GROUND WATER QUALITY STATISTICS BY PARAMETER FOR THE NAVAJO SANDSTONE, UC PROCESSING SITE, SLICK ROCK, COLORADO

SITE: SRK01 SLICK ROCK (BOTH SITES)

02/02/86 TO $02 / 18 / 94$

REPORT DATE : $09 / 29 / 94$

\begin{tabular}{|c|c|c|c|c|c|c|c|c|c|c|c|}
\hline \multicolumn{3}{|c|}{ PARAMETER NAME } & UNITS & \multirow[b]{2}{*}{ MEAN } & \multirow{2}{*}{$\begin{array}{r}\text { STANDARD } \\
\text { DEVIATION }\end{array}$} & \multirow{2}{*}{$\begin{array}{c}\text { COEFF. } \\
\text { OF } \\
\text { VARIATION }\end{array}$} & \multirow{2}{*}{$\begin{array}{l}\% \text { OF } \\
\text { NON } \\
\text { DETECTS }\end{array}$} & \multirow{2}{*}{\multicolumn{2}{|c|}{ 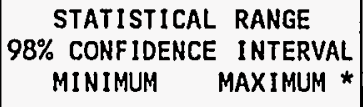 }} & \multirow{2}{*}{$\begin{array}{c}\text { DISTRIBUTION } \\
\text { TYPE }\end{array}$} & \multirow{2}{*}{$\begin{array}{l}\text { FOOT } \\
\text { NOTE }\end{array}$} \\
\hline \# OF SAMP & MINIMUM & MAXIMUM & MEDIAN & & & & & & & & \\
\hline \multicolumn{3}{|c|}{ SODIUM (TOTAL) } & $M G / L$ & \multirow[b]{2}{*}{ NA } & \multirow[b]{2}{*}{ NA } & \multirow[b]{2}{*}{ NA } & \multirow[b]{2}{*}{0.0} & \multirow[b]{2}{*}{ NA } & \multirow[b]{2}{*}{ NA } & \multirow[b]{2}{*}{ UNKNOWN } & \multirow[b]{2}{*}{1} \\
\hline 2 & 9.0000 & 46.0000 & 27.5000 & & & & & & & & \\
\hline \multicolumn{3}{|c|}{ SPECIFIC CONDUCTANCE } & UMHO/CM & \multirow[b]{2}{*}{679.9167} & \multirow[b]{2}{*}{392.7529} & \multirow[b]{2}{*}{0.5776} & \multirow[b]{2}{*}{0.0} & \multirow[b]{2}{*}{371.7553} & \multirow[b]{2}{*}{988.0780} & \multirow[b]{2}{*}{ NORMAL } & \\
\hline 12 & 300.0000 & 1420.0000 & 525.5000 & & & & & & & & \\
\hline \multicolumn{3}{|l|}{ STRONT IUM } & MG/L & \multirow[b]{2}{*}{0.9910} & \multirow[b]{2}{*}{0.1720} & \multirow[b]{2}{*}{0.1736} & \multirow[b]{2}{*}{0.0} & \multirow[b]{2}{*}{0.8376} & \multirow[b]{2}{*}{1.1444} & \multirow[b]{2}{*}{ NORMAL } & \\
\hline 10 & 0.8400 & 1.2900 & 0.9050 & & & & & & & & \\
\hline STRONTIUM & (TOTAL) & & MG/L & & & & & & & & \\
\hline 2 & 0.8700 & 0.8700 & 0.8700 & NA & NA & NA & 0.0 & NA & NA & UNKNOWN & 1 \\
\hline SULFATE & & & $M G / L$ & & & & & & & & \\
\hline 13 & 11.0000 & 432.0000 & 17.0000 & 49.0127 & 4.4341 & NA & 0.0 & 16.1943 & 148.3388 & LOGNORMAL & 7,8 \\
\hline SULFIDE & & & MG/L & & & & & & & & \\
\hline 9 & ** 0.1000 & 20.9000 & 0.1000 & NA & NA & NA & 44.4 & 0.1000 & 20.9000 & NONPARAMETRIC & 2 \\
\hline TEMPERATU & & & $C$ - DEG & & & & & & & & \\
\hline 14 & 7.0000 & 16.8000 & 13.4500 & 13.2857 & 2.3543 & 0.1772 & 0.0 & 11.6183 & 14.9531 & NORMAL & \\
\hline THALLIUM & & & MG/L & & & & & & & & \\
\hline 8 & $\begin{array}{ll}* & 0.0050\end{array}$ & 0.0050 & 0.0050 & NA & NA & NA & 100.0 & 0.0050 & 0.0050 & NONPARAMETRIC & 2 \\
\hline THORIUM-2. & & & $\mathrm{PCI} / \mathrm{L}$ & & & & & & & & \\
\hline 4 & ** $\quad 0.2000$ & 1.2000 & $+\quad 0.7000$ & 0.6750 & 0.4787 & 0.7092 & 0.0 & 0.2000 & 1.7619 & NORMAL & \\
\hline
\end{tabular}

** The reported value is the minimum detection limit of the data set

+ The sample size is even, so the median value is the ari thmetic average of the two middle values

* The statistical maximum is the 99 percent one sided confidence interval, $\alpha=0.01$

1) A minimum of 4 samples must be available for the statistical analysis.

2) The nonparametric distribution was used because the nondetected values comprise more than $15 \%$ of the samples.

7) The lognormal distribution was used because the data failed the normal distribution test.

8) The mean is geometric. The standard deviation is the value to divide or multiply with the geometric mean. 
TABLE 3.19 BACKGROUND GROUND WATER QUALITY STATISTICS BY PARAMETER FOR THE

NAVAJO SANDSTONE, UC PROCESSING SITE, SLICK ROCK, COLORADO

SITE: SRKO1 SLICK ROCK (BOTH SITES)

$02 / 02 / 86$ TO $02 / 18 / 94$

REPORT DATE: $09 / 29 / 94$

\begin{tabular}{|c|c|c|c|c|c|c|c|c|c|c|c|c|}
\hline \multicolumn{3}{|c|}{ PARAMETER NAME } & UNITS & \multirow[b]{2}{*}{ MEAN } & \multirow{2}{*}{$\begin{array}{r}\text { STANDARD } \\
\text { DEVIATION }\end{array}$} & \multirow{2}{*}{$\begin{array}{c}\text { COEFF. } \\
\text { OF } \\
\text { VARIATION }\end{array}$} & \multirow{2}{*}{$\mid \begin{array}{c}\% \text { OF } \\
\text { NON } \\
\text { DETECTS }\end{array}$} & \multirow{2}{*}{\multicolumn{3}{|c|}{ 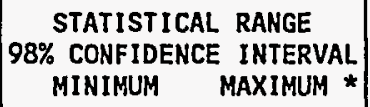 }} & \multirow{2}{*}{$\begin{array}{c}\text { DISTRIBUTION } \\
\text { TYPE }\end{array}$} & \multirow{2}{*}{$\begin{array}{l}\text { FOOT } \\
\text { NOTE }\end{array}$} \\
\hline \# OF SAMP & MINIMUM & MAXIMUN & MEDIAN & & & & & & & & & \\
\hline THORIUM-23 & 30 (TOTAL) & & $\mathrm{PCI} / \mathrm{L}$ & \multirow[b]{2}{*}{ NA } & \multirow[b]{2}{*}{ NA } & \multirow[b]{2}{*}{ NA } & \multirow[b]{2}{*}{0.0} & \multirow{2}{*}{\multicolumn{2}{|c|}{ NA }} & \multirow[b]{2}{*}{$\mathrm{NA}^{-}$} & \multirow[b]{2}{*}{ UNKNOWN } & \multirow[b]{2}{*}{1} \\
\hline 2 & 0.3000 & 0.5000 & 0.4000 & & & & & & & & & \\
\hline \multicolumn{3}{|l|}{ TIN } & $M G / L$ & \multirow[b]{2}{*}{ NA } & \multirow[b]{2}{*}{ NA } & \multirow[b]{2}{*}{ NA } & \multirow[b]{2}{*}{100.0} & \multirow[b]{2}{*}{ ** } & \multirow[b]{2}{*}{0.0050} & \multirow[b]{2}{*}{0.0250} & \multirow[b]{2}{*}{ NONPARAMETRIC } & \multirow[b]{2}{*}{2} \\
\hline 8 & ** $\quad 0.0050$ & 0.0250 & 0.0050 & & & & & & & & & \\
\hline \multicolumn{3}{|c|}{ TOTAL DISSOLVED SOLIDS } & $M G / L$ & \multirow[b]{2}{*}{493.7692} & \multirow[b]{2}{*}{279.9420} & \multirow[b]{2}{*}{0.5669} & \multirow[b]{2}{*}{0.0} & & & & & \\
\hline 13 & 229.0000 & 1160.0000 & 355.0000 & & & & & & 285.6112 & 701.9273 & NORMAL. & \\
\hline TOTAL KJEL & LDAHL NITROGE & & $M G / L$ & & & & & & & & & \\
\hline 6 & ** $\quad 1.0000$ & 3.0000 & 1.0000 & NA & NA & NA & 83.3 & ** & 1.0000 & 3.0000 & NONPARAMETRIC & 2,6 \\
\hline TOTAL ORGA & ANIC CARBON & & $M G / L$ & & & & & & & & & \\
\hline 10 & ** $\quad 1.0000$ & 162.0000 & 2.0000 & NA & NA & NA & 20.0 & ** & 1.0000 & 59.0000 & NONPARAMETRIC & 2 \\
\hline TURBIDITY & & & NTU & & & & & & & & & \\
\hline 1 & 3.0000 & 3.0000 & 3.0000 & NA & NA & NA & 0.0 & & NA & NA & UNKNOWN & 1 \\
\hline URANIUM & & & $M G / L$ & & & & & & & & & \\
\hline 13 & 0.0010 & 0.0310 & 0.0040 & 0.0100 & 0.0094 & 0.9422 & 0.0 & & 0.0030 & 0.0170 & NORMAL & \\
\hline URANIUM $\angle T$ & TOTAL) & & $M G / L$ & & & & & & & & & \\
\hline 2 & 0.0040 & 0.0160 & 0.0100 & NA & NA & NA & 0.0 & & NA & NA & UNKNOHN & 1 \\
\hline VANADIUM & & & MG/L & & & & & & & & & \\
\hline 12 & $\begin{array}{ll}* & 0.0100\end{array}$ & 0.4400 & 0.0100 & NA & NA & NA & 91.7 & ** & 0.0100 & 0.0100 & NONPARAMETRIC & 2 \\
\hline VANADIUM & (TOTAL) & & $M G / L$ & & & & & & & & & \\
\hline 2 & ** $\quad 0.0100$ & 0.0300 & 0.0175 & NA & NA & NA & 50.0 & & NA & NA & UNKNOWN & 1 \\
\hline
\end{tabular}

** The reported value is the minimum detection limit of the data set

+ The sample size is even, so the median value is the arithmetic average of the two middle values

* The statistical maximum is the 99 percent one sided confidence interval, $\alpha=0.01$

1) A minimu of 4 samples must be available for the statistical analysis.

2) The nonparametric distribution was used because the nondetected values comprise more than $15 \%$ of the samples.

6) The stat. range is the $96.9 \%$ confidence interval due to a sample size of 6 . The maximum is the $98.5 \%$ one sided confidence int. 
TABLE 3.19 BACKGROUND GROUND WATER QUALITY STATISTICS BY PARAMETER FOR THE

NAVAJO SANDSTONE, UC PROCESSING SITE, SLICK ROCK, COLORADO

SITE: SRK01 SLICK ROCK (BOTH SITES)

$02 / 02 / 86$ TO $02 / 18 / 94$

REPORT DATE: $09 / 29 / 94$

\begin{tabular}{|c|c|c|c|c|c|c|c|c|c|c|c|}
\hline \multicolumn{3}{|c|}{ PARAMETER NAME } & UNITS & \multirow[b]{2}{*}{ MEAN } & \multirow{2}{*}{$\begin{array}{r}\text { STANDARD } \\
\text { DEVIATION }\end{array}$} & \multirow{2}{*}{$\begin{array}{c}\text { COEFF. } \\
\text { OF } \\
\text { VARIATION }\end{array}$} & \multirow{2}{*}{$\begin{array}{c}\% \text { OF } \\
\text { NON } \\
\text { DETECTS }\end{array}$} & \multirow{2}{*}{\multicolumn{2}{|c|}{$\begin{array}{c}\text { STATISTICAL RANGE } \\
\text { 98\% CONFIDENCE } \\
\begin{array}{cc}\text { INTERVAL } \\
\text { MINIMUM } & \text { MAXIMUM * }\end{array}\end{array}$}} & \multirow{2}{*}{$\begin{array}{c}\text { DISTRIBUTION } \\
\text { TYPE }\end{array}$} & \multirow{2}{*}{$\begin{array}{l}\text { FOOT } \\
\text { NOTE }\end{array}$} \\
\hline \# OF SAMP & MINIMUM & MAXIMUM & MEDIAN & & & & & & & & \\
\hline \multicolumn{3}{|l|}{ ZINC } & $M G / L$ & \multirow[b]{2}{*}{ NA } & \multirow[b]{2}{*}{ NA } & \multirow[b]{2}{*}{ NA } & \multirow[b]{2}{*}{90.9} & \multirow[b]{2}{*}{0.0050} & \multirow[b]{2}{*}{0.0250} & \multirow[b]{2}{*}{ NONPARAMETRIC } & \multirow[b]{2}{*}{2} \\
\hline 11 & 0.0050 & 0.0250 & 0.0050 & & & & & & & & \\
\hline \multicolumn{3}{|c|}{ ZINC (TOTAL) } & $M G / L$ & & & & & & & & \\
\hline 2 & ** $\quad 0.0500$ & 0.0900 & 0.0575 & NA & NA & NA & 50.0 & NA & NA & UNKNOWN & 1 \\
\hline
\end{tabular}

** The reported value is the minimum detection limit of the data set

+ The sample size is even, so the median value is the arithmetic average of the two middle values

* The statistical maximum is the 99 percent one sided confidence interval, $\alpha=0.01$

1) A minimum of 4 samples must be available for the statistical analysis.

2) The nonparanetric distribution was used because the nondetected values comprise more than $15 \%$ of the samples.

INPUT DATA FILENAME: IDARTISRK01YGWQ10063.DAT 
Table 3.20 Summary of regulated constituents in the Navajo Sandstone background ground water, UC processing site, Slick Rock, Colorado

\begin{tabular}{lccc}
\hline \multicolumn{4}{c}{ Constituents with MCLs } \\
\hline \multicolumn{1}{c}{ Parameter } & MCLs & Mean or median & Statistical maximum \\
\hline Arsenic & 0.05 & $0.01^{\mathrm{e}}$ & $0.01^{\mathrm{e}}$ \\
Barium & 1.00 & $0.10^{\mathrm{e}}$ & 0.20 \\
Cadmium & 0.01 & $0.001^{\mathrm{e}}$ & $0.001^{\mathrm{e}}$ \\
Chromium & 0.05 & $0.01^{\mathrm{e}}$ & $0.01^{\mathrm{e}}$ \\
Net gross alpha & 15.0 & 0.56 & 2.54 \\
Lead & 0.05 & $0.01^{\mathrm{e}}$ & $0.01^{\mathrm{e}}$ \\
Mercury & 0.002 & $0.0002^{\mathrm{e}}$ & $0.0002^{\mathrm{e}}$ \\
Molybdenum & 0.10 & $0.01^{\mathrm{e}}$ & 0.06 \\
Nitrate & 44.0 & 2.00 & 5.70 \\
Radium-226 and $-228^{\mathrm{b}}$ & 5.00 & $1.47^{\mathrm{c}}$ & $4.02^{\mathrm{c}}$ \\
Selenium & 0.01 & $0.005^{\mathrm{e}}$ & 0.025 \\
Silver & 0.05 & $0.01^{\mathrm{e}}$ & 0.30 \\
Uranium & 0.044 & $0.010^{\mathrm{d}}$ & $0.017^{\mathrm{d}}$ \\
\hline
\end{tabular}


Table 3.20 Summary of regulated constituents in the Navajo Sandstone background ground water, UC processing site, Slick Rock, Colorado (Concluded)

\begin{tabular}{lcc}
\hline \multicolumn{3}{c}{ Constituents without MCLs } \\
\hline Antimony & Mean or median & Statistical maximum \\
\hline Beryllium & $0.003^{\mathrm{e}}$ & $0.003^{\mathrm{e}}$ \\
Cobalt & $0.01^{\mathrm{e}}$ & $0.01^{\mathrm{e}}$ \\
Copper & $0.05^{\mathrm{e}}$ & $0.05^{\mathrm{e}}$ \\
Cyanide & $0.02^{\mathrm{e}}$ & $0.02^{\mathrm{e}}$ \\
Nickel & $0.01^{\mathrm{e}}$ & $0.01^{\mathrm{e}}$ \\
Sulfide & $0.04^{\mathrm{e}}$ & $0.04^{\mathrm{e}}$ \\
Thallium & $0.10^{\mathrm{e}}$ & 20.90 \\
Tin & $0.01^{\mathrm{e}}$ & $0.01^{\mathrm{e}}$ \\
Vanadium & $0.005^{\mathrm{e}}$ & 0.025 \\
Zinc & $0.01^{\mathrm{e}}$ & $0.01^{\mathrm{e}}$ \\
\hline
\end{tabular}

${ }^{a}$ All units are $\mathrm{mg} / \mathrm{L}$ unless otherwise noted.

bunits are $\mathrm{pCi} / \mathrm{L}$.

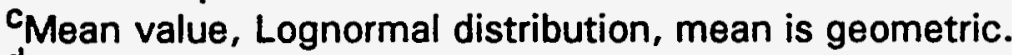

${ }^{d}$ Mean value, Normal distribution, mean is arithmetic.

eStatistical values are below laboratory detection limits in Table 8.1 of the Technical Approach Document (DOE, 1989). 
TABLE 3.21 TAILINGS PORE FLUID HATER QUALITY DATA BY PARAMETER, NC AND UC PROCESSING SITES, SLICK ROCK, COLORADO

SITE: SRKOI SLICK

$01 / 12 / 89$ TO $10 / 14 / 92$

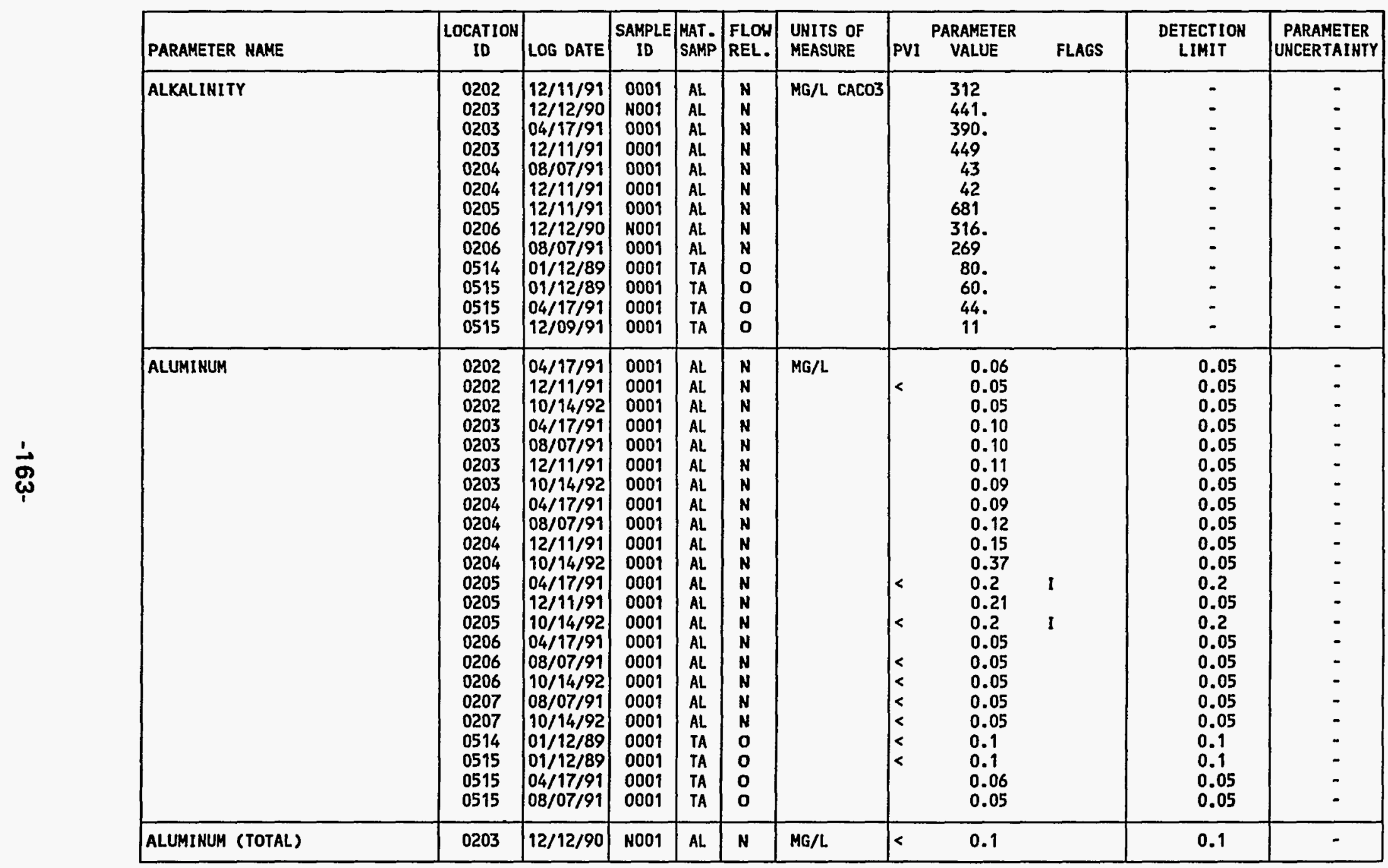

MATERIAL OF SAMPLING CODE: AL - ALLUVIUM

TA - URANIUM MILL TAILINGS

PARAMETER VALUE INDICATOR (PVI): < - LESS THAN DETECTION LIMIT OTHER PARAMETER VALUE FLAGS:

I - INCREASED DETECTION LIMIT DUE TO REQUIRED DILUTION
FLOW RELATIONSHIP CODE:

N - UNKNOWN

SAMPLE ID CODES:

0001 - FILTERED SAMPLE (.45 MICRONS)

NO01 - UNFILTERED SAMPLE 


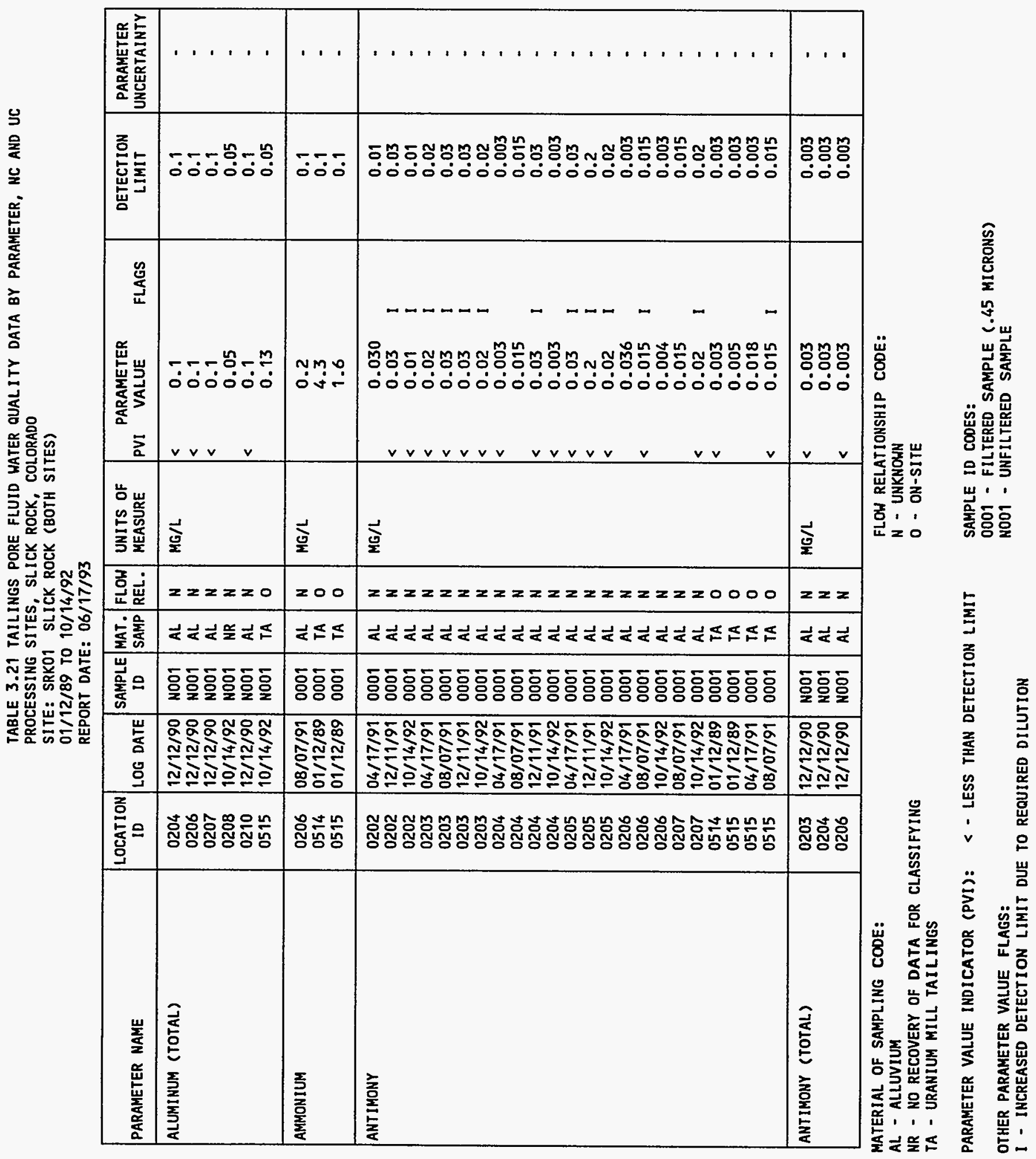


TABLE 3.21 TAILINGS PORE FLUID HATER QUALITY DATA BY PARAMETER, KC AND UC PROCESSING SITES, SLICK ROCK, COLORADO

SITE: SRKO1 SLICK ROCK (BOTH SITES)

01/12/89 TO $10 / 14 / 92$

REPORT DATE: 06/17/93

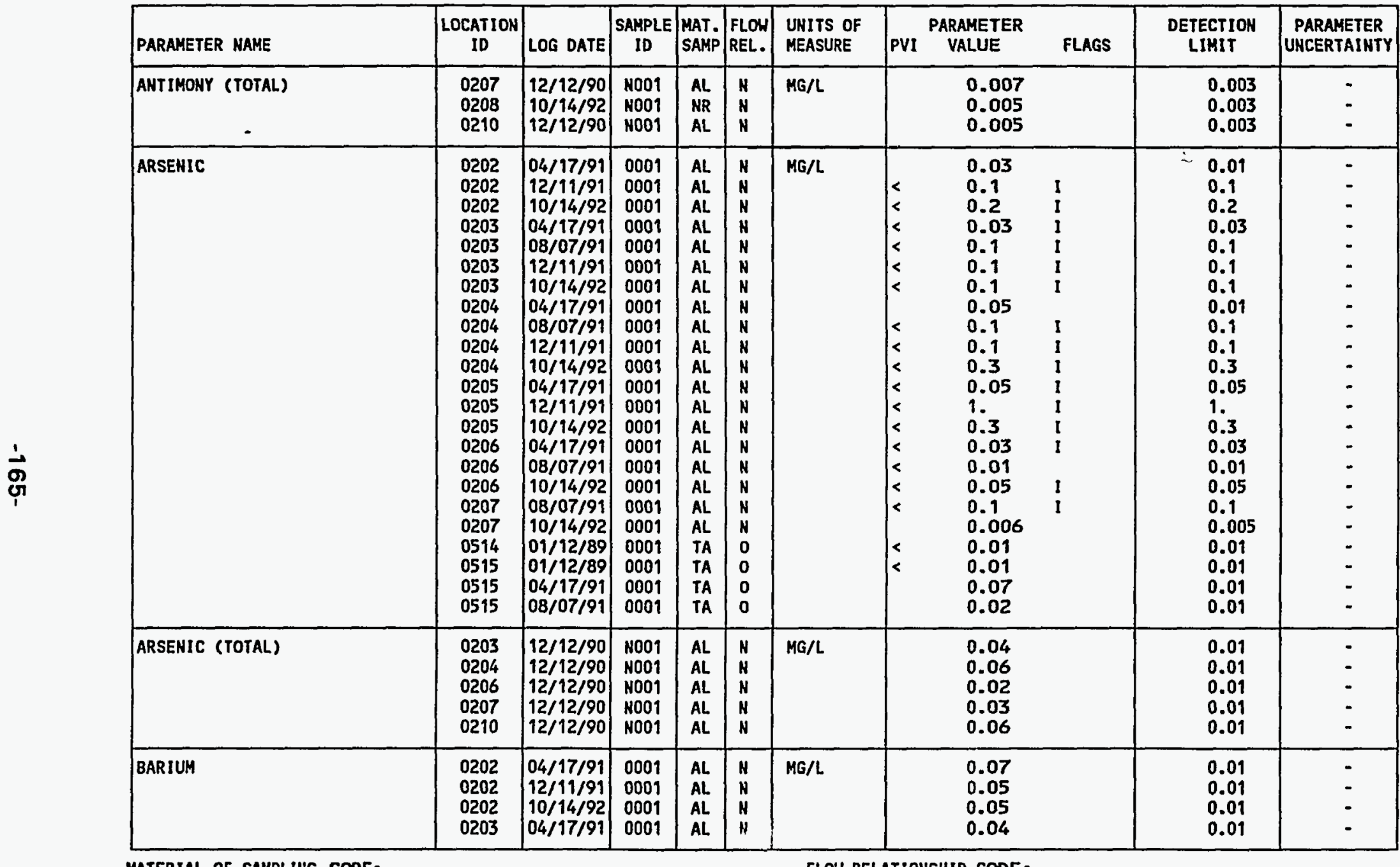

MATERIAL OF SAMPLIHG CODE:

AL - ALLUVIUN

NR - NO RECOVERY OF DATA FOR CLASSIFYING

TA - URANIUM HILL TAILINGS

FLOH RELATIONSHIP CODE:

D. UNKNOWH

PARAMETER VALUE INDICATOR (PVI): < - LESS THAN DETECTION LIMIT

SAMPLE ID CODES:

0001 - FILTERED SAMPLE (.45 MICRONS)

OTHER PARAMETER VALUE FLAGS:

NO01 - UNFILTERED SAMPLE

I - INCREASED DETECTION LIMIT DUE TO REQUIRED DILUTION 
TABLE 3.21 TAILINGS PORE FLUID HATER QUALITY DATA BY PARAMETER, NC AND UC PROCESSING SITES, SLICK ROCK, COLORADO

SITE: SRKO1 SLICK ROCK (BOTH SITES)

$01 / 12 / 89$ TO $10 / 14 / 92$

REPORT DATE: $06 / 17 / 93$

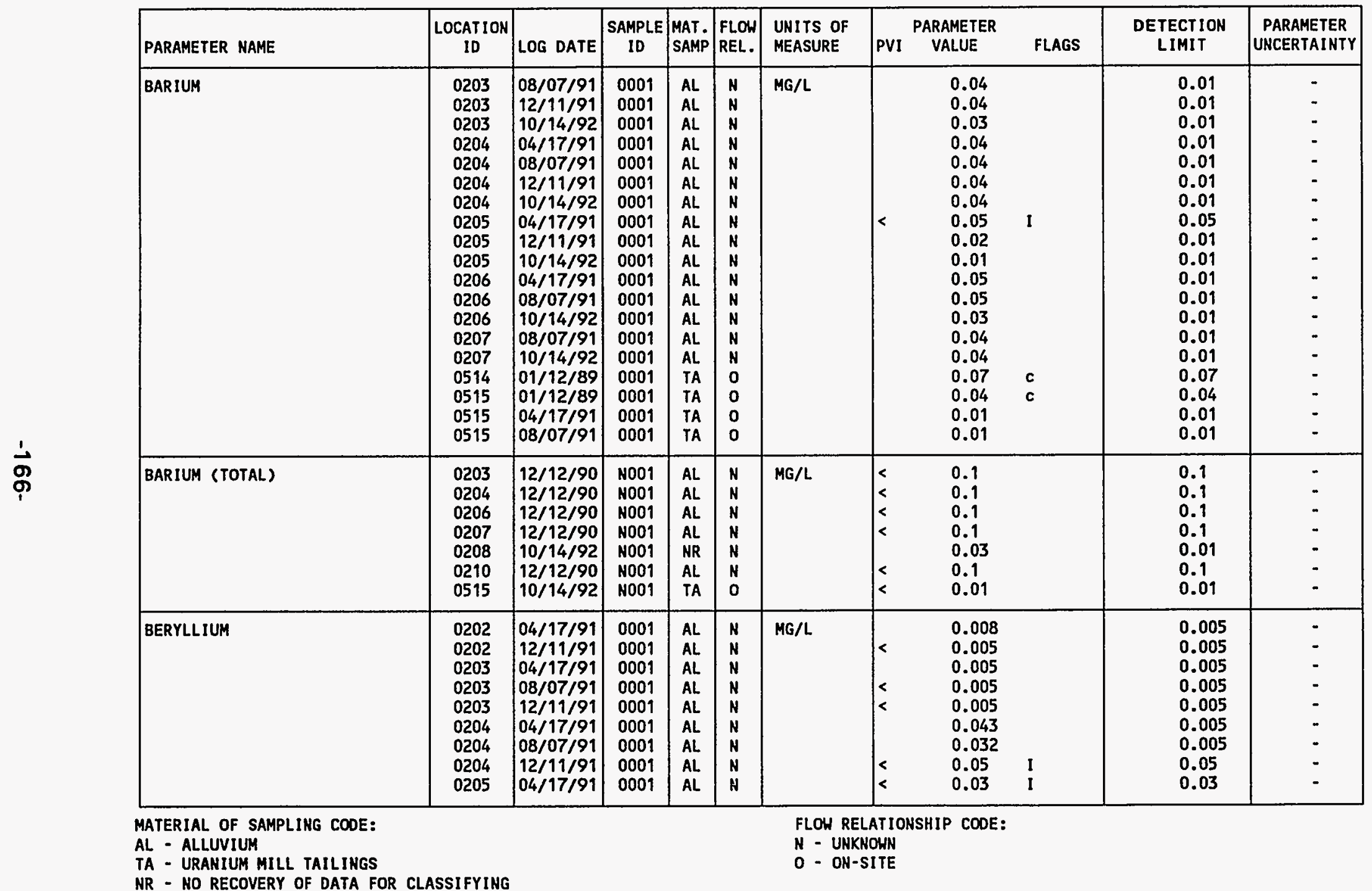

PARAMETER VALUE IMDICATOR (PVI): < - LESS THAN DETECTION LIMIT

SAMPLE ID CODES:

O001 - FILTERED SAMPLE ( 45 MICRONS)

OTHER PARAMETER VALUE FLAGS:

NO01 - UNFILTERED SAMPLE

I - INCPEASED DETECTION LIMIT DUE TO REQUIRED DILUTION

c - CHANGED DETECTION LIMIT 
TABLE 3.21 TAILINGS PORE FLUID WATER QUALITY DATA BY PARAMETER, NC AND UC PROCESSING SITES, SLICK ROCK, COLORADO

SITE: SRKO1 SLICK ROCK (BOTH SITES)

01/12/89 TO 10/14/92

REPORT DATE: $06 / 17 / 93$

\begin{tabular}{|c|c|c|c|c|c|c|c|c|c|c|c|c|}
\hline & PARAMETER NAME & $\begin{array}{c}\text { LOCATION } \\
\text { ID }\end{array}$ & LOG DATE & $\begin{array}{c}\text { SAMPLE } \\
\text { ID }\end{array}$ & $\begin{array}{l}\text { MAT. } \\
\text { SAMP }\end{array}$ & $\begin{array}{l}\text { FLOW } \\
\text { REL. }\end{array}$ & $\begin{array}{l}\text { UNITS OF } \\
\text { MEASURE }\end{array}$ & PVI & $\begin{array}{l}\text { PARAMETER } \\
\text { VALUE }\end{array}$ & FLAGS & $\begin{array}{l}\text { DETECTION } \\
\text { LIMIT }\end{array}$ & $\begin{array}{l}\text { PARAMETER } \\
\text { UNCERTAINTY }\end{array}$ \\
\hline & BERYLLIUM & $\begin{array}{l}0205 \\
0206 \\
0206 \\
0207 \\
0514 \\
0515 \\
0515 \\
0515\end{array}$ & $\begin{array}{l}12 / 11 / 91 \\
04 / 17 / 91 \\
08 / 07 / 91 \\
08 / 07 / 91 \\
01 / 12 / 89 \\
01 / 12 / 89 \\
04 / 17 / 91 \\
08 / 07 / 91\end{array}$ & $\begin{array}{l}0009 \\
0001 \\
0001 \\
0001 \\
0001 \\
0001 \\
0001 \\
0001\end{array}$ & $\begin{array}{l}A L \\
A L \\
A L \\
A L \\
T A \\
T A \\
T A \\
T A\end{array}$ & $\begin{array}{l}N \\
N \\
N \\
N \\
0 \\
0 \\
0 \\
0\end{array}$ & $M G / L$ & $\begin{array}{l}< \\
< \\
< \\
< \\
< \\
< \\
< \\
<\end{array}$ & $\begin{array}{l}0.005 \\
0.005 \\
0.005 \\
0.005 \\
0.01 \\
0.01 \\
0.005 \\
0.005\end{array}$ & & $\begin{array}{l}0.005 \\
0.005 \\
0.005 \\
0.005 \\
0.01 \\
0.01 \\
0.005 \\
0.005\end{array}$ & $\begin{array}{l}- \\
- \\
- \\
- \\
- \\
-\end{array}$ \\
\hline & BERYLLIUM (TOTAL) & $\begin{array}{l}0203 \\
0204 \\
0206 \\
0207 \\
0210\end{array}$ & $\mid \begin{array}{l}12 / 12 / 90 \\
12 / 12 / 90 \\
12 / 12 / 90 \\
12 / 12 / 90 \\
12 / 12 / 90\end{array}$ & $\begin{array}{l}\text { N001 } \\
\text { N001 } \\
\text { N001 } \\
\text { N001 } \\
\text { N001 }\end{array}$ & $\begin{array}{l}A L \\
A L \\
A L \\
A L \\
A L\end{array}$ & $\begin{array}{l}N \\
N \\
N \\
N \\
N\end{array}$ & $\mathrm{MG} / \mathrm{L}$ & $\begin{array}{l}< \\
< \\
<\end{array}$ & $\begin{array}{l}0.02 \\
0.05 \\
0.01 \\
0.01 \\
0.01\end{array}$ & & $\begin{array}{l}0.01 \\
0.01 \\
0.01 \\
0.01 \\
0.01\end{array}$ & $\begin{array}{l}- \\
- \\
- \\
-\end{array}$ \\
\hline$\stackrel{\vec{\sigma}}{\vec{\sigma}}$ & BORON & $\begin{array}{l}0202 \\
0202 \\
0203 \\
0203 \\
0204 \\
0204 \\
0205 \\
0205 \\
0206 \\
0514 \\
0515 \\
0515\end{array}$ & $\begin{array}{l}04 / 17 / 91 \\
12 / 11 / 91 \\
04 / 17 / 91 \\
12 / 11 / 91 \\
04 / 17 / 91 \\
12 / 11 / 91 \\
04 / 17 / 91 \\
12 / 11 / 91 \\
04 / 17 / 91 \\
01 / 12 / 89 \\
01 / 12 / 89 \\
04 / 17 / 91\end{array}$ & $\begin{array}{l}0001 \\
0001 \\
0001 \\
0001 \\
0001 \\
0001 \\
0001 \\
0001 \\
0001 \\
0001 \\
0001 \\
0001\end{array}$ & $\begin{array}{l}A L \\
A L \\
A L \\
A L \\
A L \\
A L \\
A L \\
A L \\
A L \\
T A \\
T A \\
T A\end{array}$ & $\begin{array}{l}N \\
N \\
N \\
N \\
N \\
N \\
N \\
N \\
N \\
0 \\
0 \\
0\end{array}$ & $\mathrm{MG} / \mathrm{L}$ & & $\begin{array}{l}0.81 \\
0.87 \\
1.52 \\
1.95 \\
0.06 \\
0.31 \\
1.3 \\
1.50 \\
0.43 \\
0.5 \\
0.2 \\
0.33\end{array}$ & & $\begin{array}{l}0.05 \\
0.05 \\
0.05 \\
0.05 \\
0.05 \\
0.05 \\
0.2 \\
0.05 \\
0.05 \\
0.1 \\
0.1 \\
0.05\end{array}$ & $\begin{array}{l}- \\
- \\
- \\
- \\
- \\
- \\
- \\
- \\
-\end{array}$ \\
\hline & BORON (TOTAL) & $\begin{array}{l}0203 \\
0204 \\
0206 \\
0207 \\
0210\end{array}$ & $\begin{array}{l}12 / 12 / 90 \\
12 / 12 / 90 \\
12 / 12 / 90 \\
12 / 12 / 90 \\
12 / 12 / 90\end{array}$ & $\begin{array}{l}\text { N001 } \\
\text { N001 } \\
\text { N001 } \\
\text { N001 } \\
\text { N001 }\end{array}$ & $\begin{array}{l}\text { AL } \\
\text { AL } \\
\text { AL } \\
\text { AL } \\
\text { AL }\end{array}$ & $\begin{array}{l}\mathbf{N} \\
\mathbf{N} \\
\mathbf{N} \\
\mathbf{N} \\
\mathbf{N}\end{array}$ & $M G / L$ & & $\begin{array}{l}1.7 \\
0.1 \\
0.5 \\
0.5 \\
0.2\end{array}$ & & $\begin{array}{l}0.1 \\
0.1 \\
0.1 \\
0.1 \\
0.1\end{array}$ & $\begin{array}{l}- \\
- \\
-\end{array}$ \\
\hline & BROMIDE & $\begin{array}{l}0202 \\
0203 \\
0204 \\
0205 \\
0206\end{array}$ & $\begin{array}{l}10 / 14 / 92 \\
10 / 14 / 92 \\
10 / 14 / 92 \\
10 / 14 / 92 \\
10 / 14 / 92\end{array}$ & $\begin{array}{l}0001 \\
0001 \\
0001 \\
0001 \\
0001\end{array}$ & $\begin{array}{l}\text { AL } \\
\text { AL } \\
\text { AL } \\
\text { AL. } \\
\text { AL }\end{array}$ & $\begin{array}{l}\mathbf{N} \\
\mathbf{N} \\
\mathbf{N} \\
\mathbf{N} \\
\mathbf{N}\end{array}$ & $M G / L$ & $\begin{array}{l}< \\
< \\
< \\
<\end{array}$ & $\begin{array}{c}7 . \\
15 . \\
0.3 \\
30 . \\
1 .\end{array}$ & $\begin{array}{l}I \\
I \\
I \\
I \\
I\end{array}$ & $\begin{array}{c}7 . \\
15 \\
0.3 \\
30 . \\
1 .\end{array}$ & - \\
\hline
\end{tabular}

MATERIAL OF SAMPLING CODE: AL - ALLUVIUM

TA - URANIUH MILL TAILINGS

FLOH RELATIONSHIP CODE:

N - UNKNOWN

PARAMETER VALUE INDICATOR (PVI): < - LESS THAN DETECTION LIMIT

SAMPLE ID CODES:

0001 - FILTERED SAMPLE (.45 MICRONS)

OTHER PARAMETER VALUE FLAGS:

I - INCREASED DETECTION LIMIT DUE TO REQUIRED DILUTION

N001 - UNFILTERED SAMPLE 
TABLE 3.21 TAILINGS PORE FLUID HATER QUALITY DATA BY PARAMETER, NC AND UC PROCESSING SITES, SLICK ROCK, COLORADO

SITE: SRKO1 SLICK ROCK (BOTH SITES)

01/12/89 TO $10 / 14 / 92$

REPORT DATE: $06 / 17 / 93$

\begin{tabular}{|c|c|c|c|c|c|c|c|c|c|c|c|}
\hline PARAMETER NAME & $\underset{\text { ID }}{\text { LOCATION }}$ & LOG DATE & $\begin{array}{c}\text { SAMPLE } \\
10\end{array}$ & $\begin{array}{l}\text { MAT. } \\
\text { SAMP }\end{array}$ & $\begin{array}{l}\text { FLOW } \\
\text { REL. }\end{array}$ & $\begin{array}{l}\text { UNITS OF } \\
\text { MEASURE }\end{array}$ & PVI & $\begin{array}{l}\text { ARAMETER } \\
\text { VALUE }\end{array}$ & FLAGS & $\begin{array}{l}\text { DETECTION } \\
\text { LIMIT }\end{array}$ & $\begin{array}{l}\text { PARAMETER } \\
\text { UNCERTAINTY }\end{array}$ \\
\hline BROMIDE & $\begin{array}{l}0207 \\
0514 \\
0515\end{array}$ & $\begin{array}{l}10 / 14 / 92 \\
01 / 12 / 89 \\
01 / 12 / 89\end{array}$ & $\begin{array}{l}0001 \\
0001 \\
0001\end{array}$ & $\begin{array}{l}\text { AL } \\
\text { TA } \\
\text { TA }\end{array}$ & $\begin{array}{l}N \\
0 \\
0\end{array}$ & $M G / L$ & $\begin{array}{l}< \\
< \\
<\end{array}$ & $\begin{array}{l}0.5 \\
0.1 \\
0.1\end{array}$ & I & $\begin{array}{l}0.5 \\
0.1 \\
0.1\end{array}$ & - \\
\hline BROMIDE (TOTAL) & $\begin{array}{l}0202 \\
0203 \\
0204 \\
0205 \\
0206 \\
0210\end{array}$ & $\begin{array}{l}12 / 12 / 90 \\
12 / 12 / 90 \\
12 / 12 / 90 \\
12 / 12 / 90 \\
12 / 12 / 90 \\
12 / 12 / 90\end{array}$ & $\begin{array}{l}\text { N001 } \\
\text { N001 } \\
\text { N001 } \\
\text { N001 } \\
\text { N001 } \\
\text { N001 }\end{array}$ & $\begin{array}{l}A L \\
A L \\
A L \\
A L \\
A L \\
A L\end{array}$ & $\begin{array}{l}\mathbf{N} \\
\mathbf{N} \\
\mathbf{N} \\
\mathbf{N} \\
\mathbf{N} \\
\mathbf{N}\end{array}$ & $M G / L$ & $\mid<$ & $\begin{array}{l}1.4 \\
3.2 \\
0.1 \\
3.3 \\
0.1 \\
0.1\end{array}$ & $\begin{array}{l}\text { c } \\
\text { c } \\
\text { c }\end{array}$ & $\begin{array}{l}0.01 \\
0.01 \\
0.1 \\
0.01 \\
0.1 \\
0.1\end{array}$ & $\begin{array}{l}- \\
- \\
- \\
- \\
-\end{array}$ \\
\hline CADMIUM & $\begin{array}{l}0202 \\
0202 \\
0202 \\
0203 \\
0203 \\
0203 \\
0203 \\
0204 \\
0204 \\
0204 \\
0204 \\
0205 \\
0205 \\
0205 \\
0206 \\
0206 \\
0206 \\
0207 \\
0207 \\
0514 \\
0515 \\
0515 \\
0515\end{array}$ & $\begin{array}{l}04 / 17 / 91 \\
12 / 11 / 91 \\
10 / 14 / 92 \\
04 / 17 / 91 \\
08 / 07 / 91 \\
12 / 11 / 91 \\
10 / 14 / 92 \\
04 / 17 / 91 \\
08 / 07 / 91 \\
12 / 11 / 91 \\
10 / 14 / 92 \\
04 / 17 / 91 \\
12 / 11 / 91 \\
10 / 14 / 92 \\
04 / 17 / 91 \\
08 / 07 / 91 \\
10 / 14 / 92 \\
08 / 07 / 91 \\
10 / 14 / 92 \\
01 / 12 / 89 \\
01 / 12 / 89 \\
04 / 17 / 91 \\
08 / 07 / 91\end{array}$ & $\begin{array}{l}0001 \\
0001 \\
0001 \\
0001 \\
0001 \\
0001 \\
0001 \\
0001 \\
0001 \\
0001 \\
0001 \\
0001 \\
0001 \\
0001 \\
0001 \\
0001 \\
0001 \\
0001 \\
0001 \\
0001 \\
0001 \\
0001 \\
0001\end{array}$ & $\begin{array}{l}A L \\
A L \\
A L \\
A L \\
A L \\
A L \\
A L \\
A L \\
A L \\
A L \\
A L \\
A L \\
A L \\
A L \\
A L \\
A L \\
A L \\
A L \\
A L \\
T A \\
T A \\
T A \\
T A\end{array}$ & $\begin{array}{l}N \\
N \\
N \\
N \\
N \\
N \\
N \\
N \\
N \\
N \\
N \\
N \\
N \\
N \\
N \\
N \\
N \\
N \\
N \\
0 \\
0 \\
0 \\
0\end{array}$ & $\mathrm{MG} / \mathrm{L}$ & $\begin{array}{l}< \\
< \\
< \\
< \\
< \\
< \\
< \\
< \\
< \\
< \\
< \\
< \\
<\end{array}$ & $\begin{array}{l}0.006 \\
0.01 \\
0.12 \\
0.001 \\
0.001 \\
0.01 \\
0.18 \\
0.008 \\
0.03 \\
0.01 \\
0.02 \\
0.003 \\
0.01 \\
0.23 \\
0.002 \\
0.001 \\
0.001 \\
0.001 \\
0.005 \\
0.652 \\
0.207 \\
0.194 \\
0.1\end{array}$ & $\begin{array}{l}\text { I } \\
1 \\
1 \\
1 \\
1\end{array}$ & $\begin{array}{l}0.001 \\
0.01 \\
0.03 \\
0.001 \\
0.001 \\
0.01 \\
0.03 \\
0.001 \\
0.03 \\
0.01 \\
0.02 \\
0.001 \\
0.01 \\
0.03 \\
0.001 \\
0.001 \\
0.001 \\
0.001 \\
0.005 \\
0.001 \\
0.001 \\
0.005 \\
0.1\end{array}$ & $\begin{array}{l}- \\
- \\
- \\
- \\
- \\
- \\
- \\
- \\
- \\
- \\
- \\
- \\
- \\
- \\
- \\
- \\
-\end{array}$ \\
\hline CADMIUH (TOTAL) & $\begin{array}{l}0203 \\
0204 \\
0206\end{array}$ & $\left|\begin{array}{l}12 / 12 / 90 \\
12 / 12 / 90 \\
12 / 12 / 90\end{array}\right|$ & $\begin{array}{l}\text { N001 } \\
\text { N001 } \\
\text { N001 }\end{array}$ & $\begin{array}{l}A L \\
A L \\
A L\end{array}$ & $\begin{array}{l}N \\
N \\
N\end{array}$ & $M G / L$ & $<$ & $\begin{array}{l}0.001 \\
0.002 \\
0.001\end{array}$ & & $\begin{array}{l}0.001 \\
0.001 \\
0.001\end{array}$ & - \\
\hline
\end{tabular}

MATERIAL OF SAMPLING CODE:

AL - ALLUVIUM

FLOW RELATIONSHIP CODE:

TA - URANIUM MILL TAILINGS

N - UNKNOWN

PARAMETER VALUE INDICATOR (PVI): < - LESS THAN DETECTION LIMIT

SAMPLE ID CODES:

0001 - FILTERED SAMPLE (.45 MICRONS)

OTHER PARAMETER VALUE FLAGS:

NOO1 - UNFILTERED SAMPLE

I - INCREASED DETECTION LIMIT DUE TO REQUIRED DILUTION

C - CHANGED DETECTION LIMIT 
TABLE 3.21 TAILINGS PORE FLUID MATER QUALITY DATA BY PARAMETER, NC AND UC PROCESSING SITES, SLICK ROCK, COLORADO

SITE: SRK01 SLICK ROCK (BOTH SITES)

$01 / 12 / 89$ TO $10 / 14 / 92$

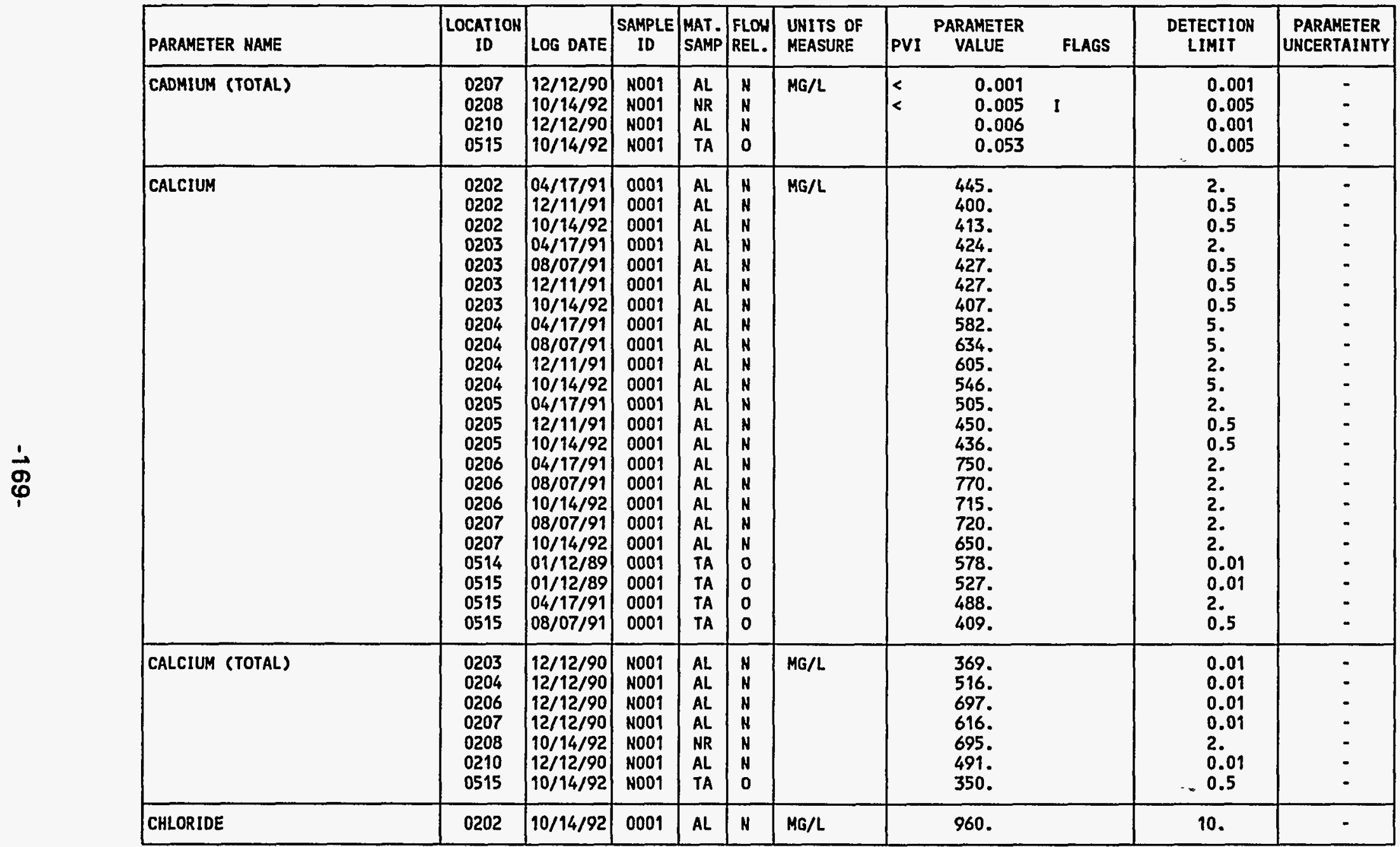

MATERIAL OF SAMPLIHG CODE:

AL. - ALLUVIUM

NR - NO RECOVERY OF DATA FOR CLASSIFYING

FLOH RELATIONSHIP CODE:

TA - URANIUM MILL TAILINGS

N - UNKHOWH

PARAMETER VALUE INDICATOR (PVI): < - LESS THAN DETECTION LIMIT

SAMPLE ID CODES:

0001 - FILTERED SAMPLE (.45 MICRONS)

OTHER PARAMETER VALUE FLAGS:

NO01 - UHFILTERED SAMPLE

I - INCREASED DETECTION LIMIT DUE TO REQUIRED DILUTION 
TABLE 3.21 TAILINGS PORE FLUID HATER QUALITY DATA BY PARAMETER, NC AND UC PROCESSING SITES, SLICK ROCK, COLORADO

SITE: SRKO1 SLICK ROCK (BOTH SITES)

$01 / 12 / 89$ TO $10 / 14 / 92$

REPORT DATE: $06 / 17 / 93$

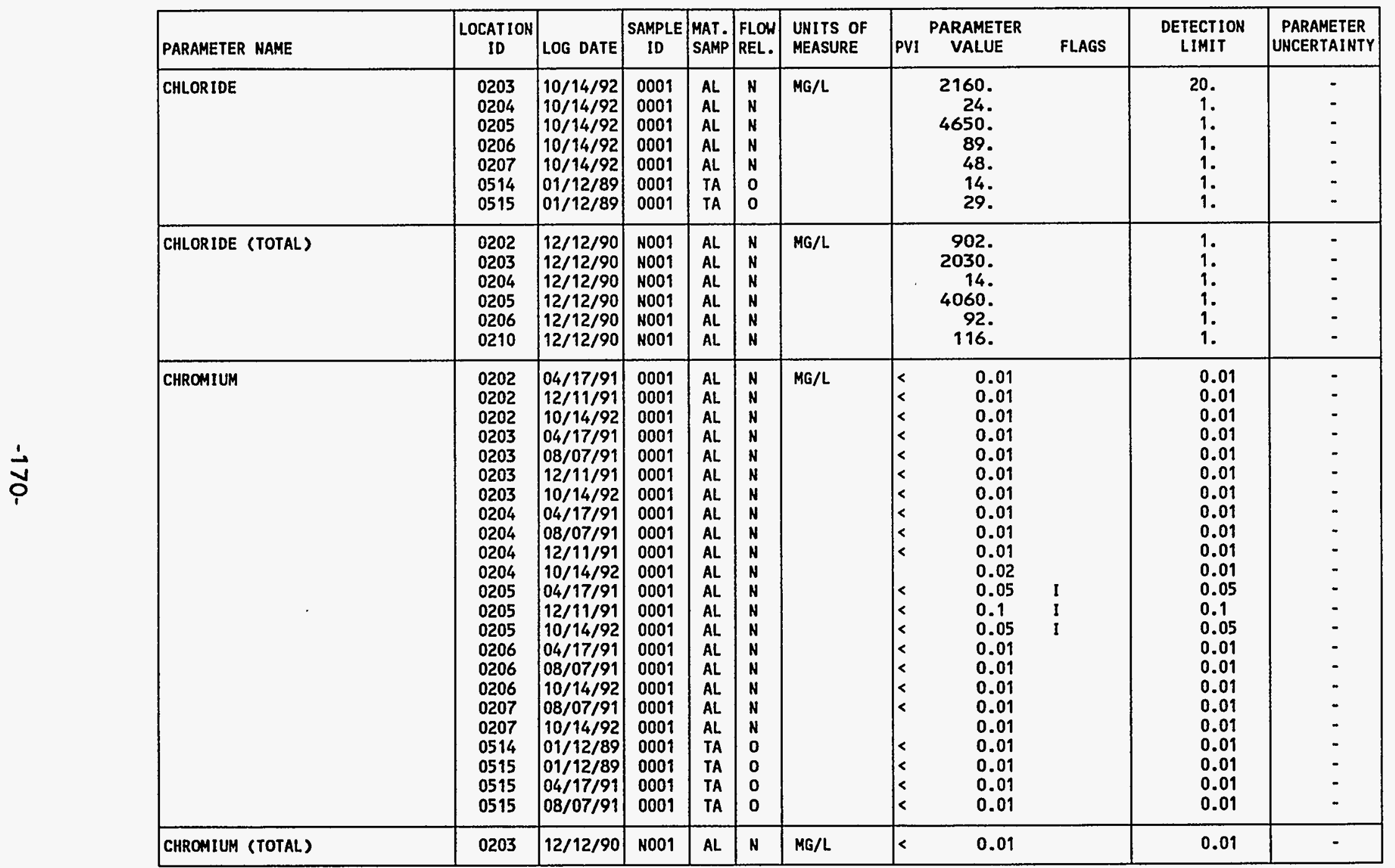

\section{MATERIAL OF SAMPLING CODE:}

AL - ALLUVIUM

TA - URANIUM MILL TAILINGS

PARAMETER VALUE INDICATOR (PVI): < - LESS THAN DETECTION LIMIT

OTHER PARAMETER VALUE FLAGS:

1 - INCREASED DETECTION LIMIT DUE TO REQUIRED DILUTION
FLOW RELATIOHSHIP COOE:

$$
\text { O - ON-SITE }
$$

SAMPLE ID CODES:

0001 - FILTERED SAMPLE (.45 MICRONS)

NO01 - UNFILTERED SAMPLE 
TABLE 3.21 TAILINGS PORE FLUID HATER QUALITY DATA BY PARAMETER, NC AND UC PROCESSING SITES, SLICK ROCK, COLORADO

SITE: SRKO1 SLICK ROCK (BOTH SITES)

$01 / 12 / 89$ TO $10 / 14 / 92$

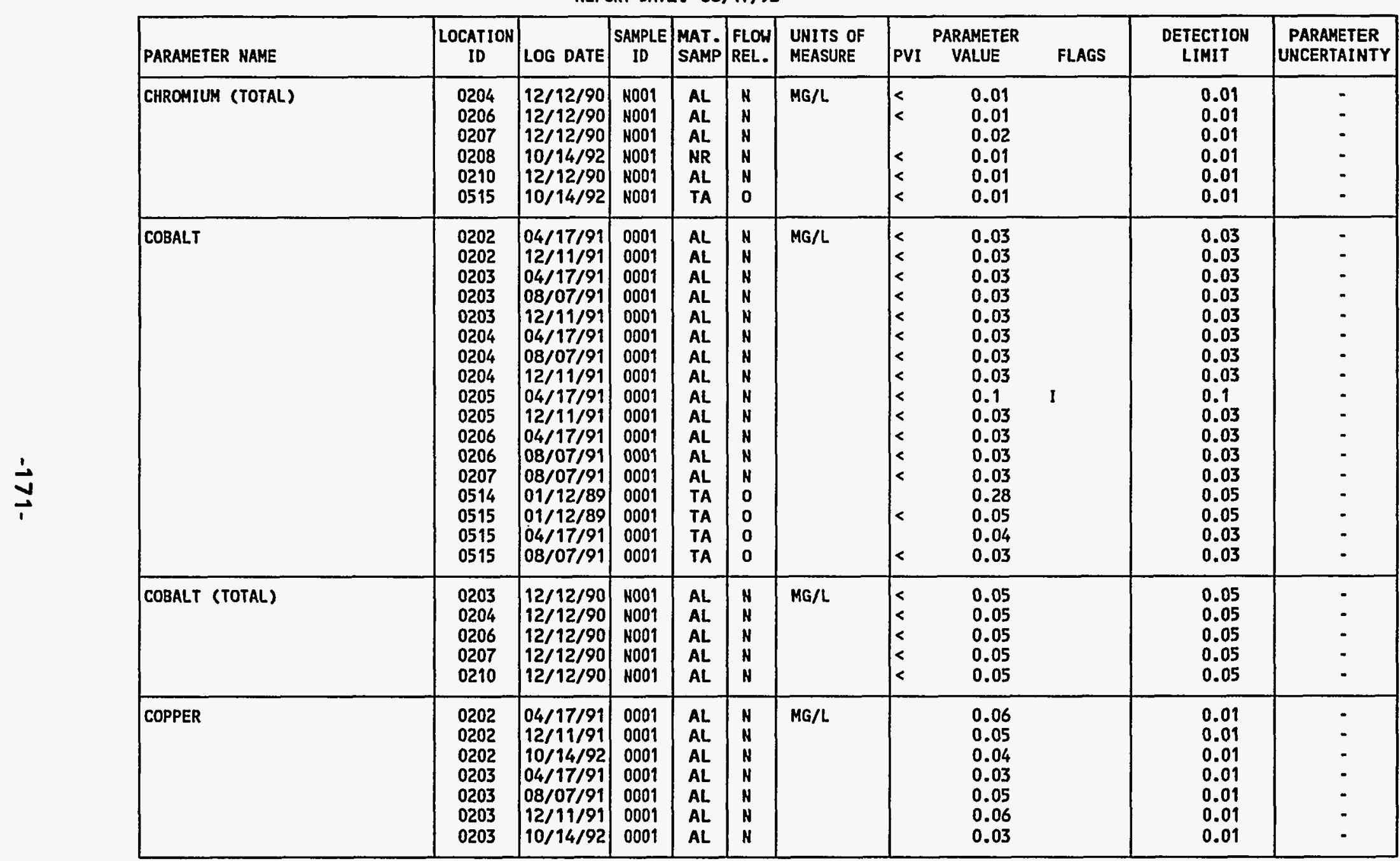

MATERIAL OF SAMPLING COOE:

\section{AL - ALLUVIUH}

HR - NO RECOVERY OF DATA FOR CLASSIFYING

TA - URAHIUM MILL TAILINGS

PARAMETER VALUE INDICATOR (PVI): < - LESS THAN DETECTION LIMIT

OTHER PARAMETER VALUE FLAGS:

I - INCREASED DETECTION LIMIT DUE TO REQUIRED DILUTIOH
FLOH RELATIONSHIP CODE:

N - UNKNOWN

O - ON-SITE

SAMPLE ID COOES:

0001 - FILTERED SAMPLE (.45 MICRONS)

NO01 - UNFILTERED SAMPLE 
TABLE 3.21 TAILINGS PORE FLUID HATER QUALITY DATA BY PARAMETER, NC AND UC PROCESSING SITES, SLICK ROCK, COLORADO

SITE: SRKO1 SLICK ROCK (BOTH SITES)

01/12/89 TO 10/14/92

REPORT DATE: 06/17/93

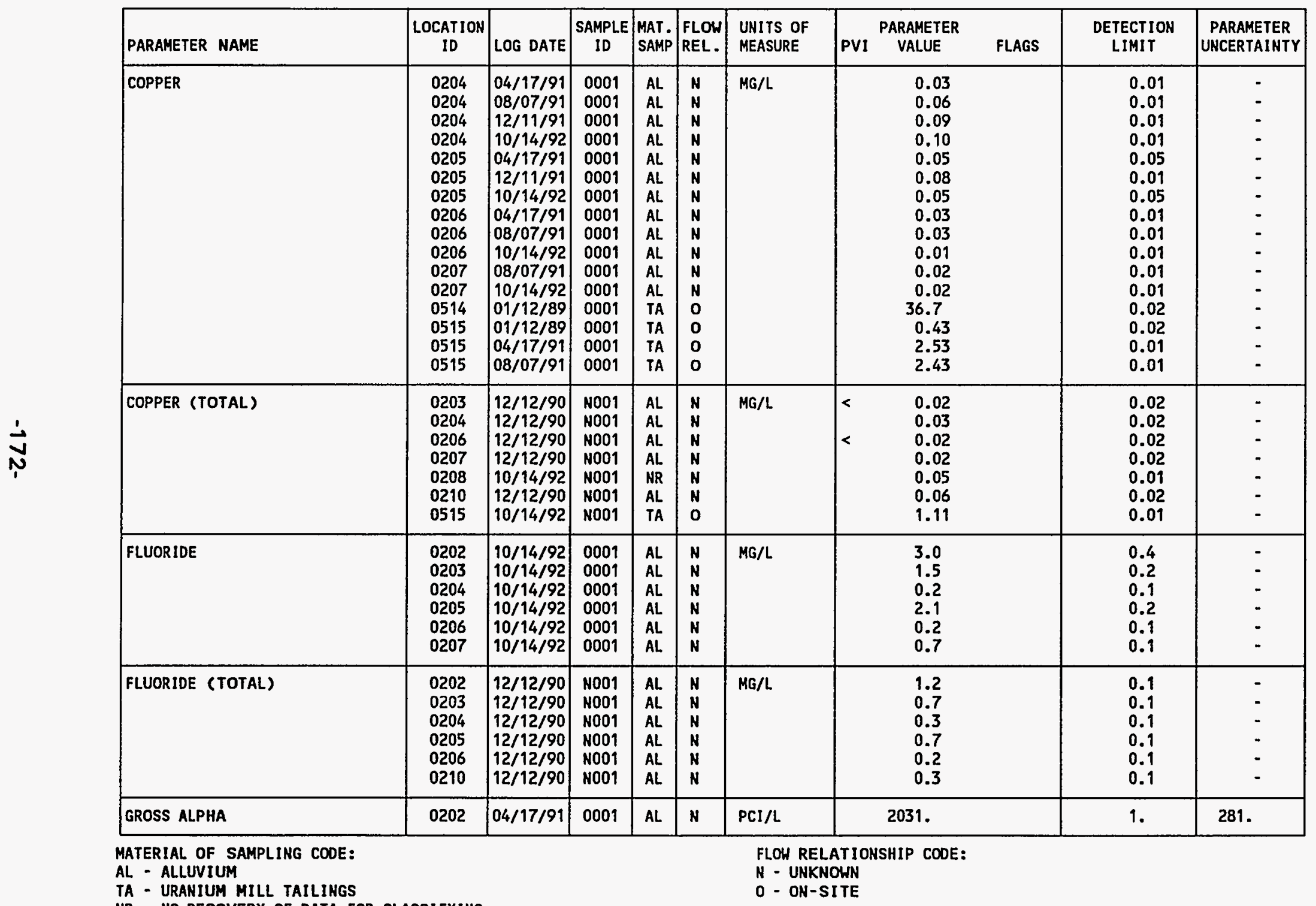

NR - NO RECOVERY OF DATA FOR CLASSIFYING

PARAMETER VALUE INDICATOR (PVI): < - LESS THAN DETECTION LIMIT

SAMPLE ID CODES:

0001 - FILTERED SAMPLE (.45 MICRONS)

N001 - UNFILTERED SAMPLE 
TABLE 3.21 TAILINGS PORE FLUID MATER QUALITY DATA BY PARAMETER, NC AND UC PROCESSING SITES, SLICK ROCK, COLORADO

SITE: SRKO1 SLICK ROCK (BOTH SITES)

01/12/89 TO $10 / 14 / 92$

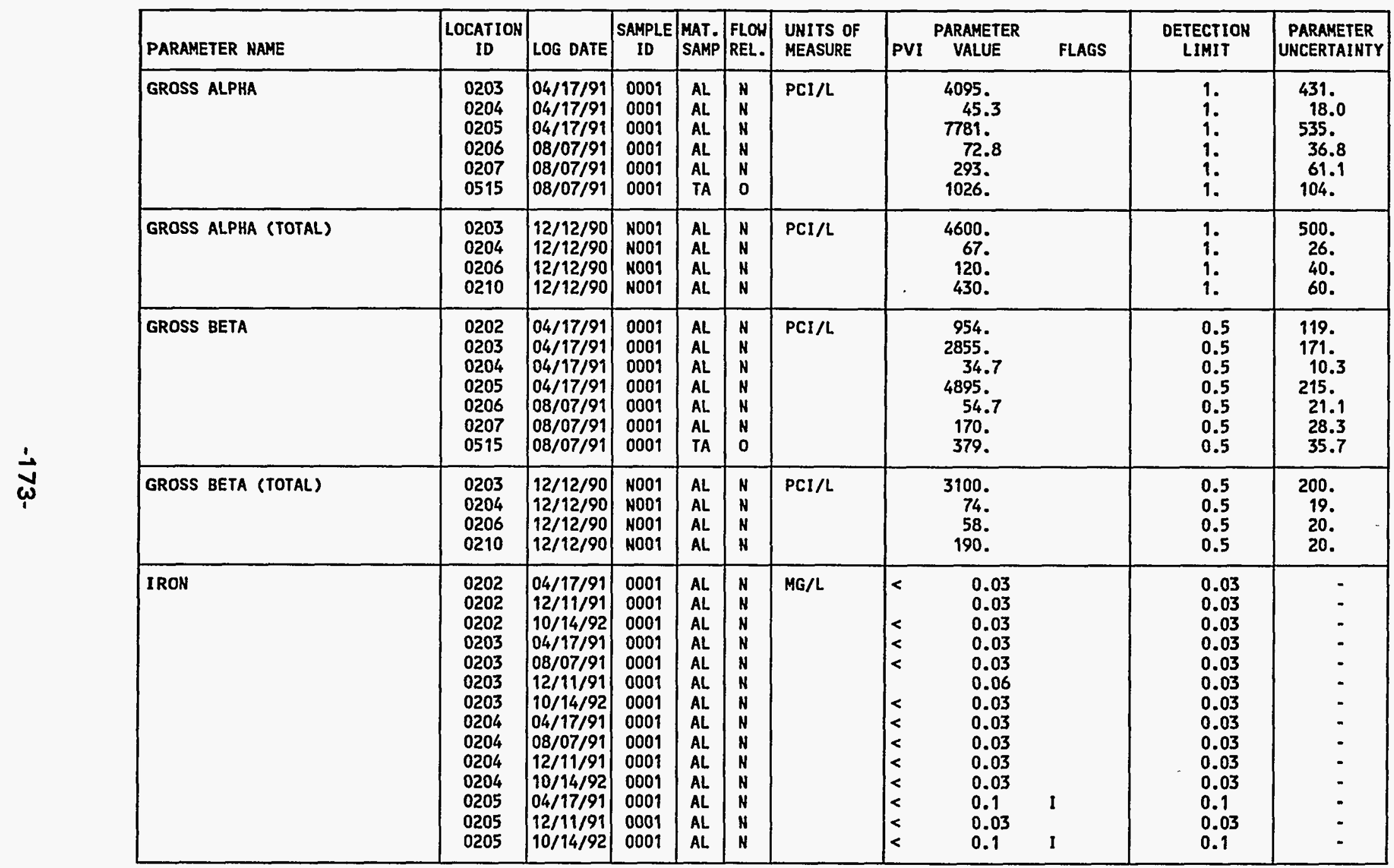

MATERIAL OF SAMPLING COOE:

AL - ALLUVIUM

TA - URANIUM MILL TAILINGS

FLOH RELATIONSHIP CODE:

PARAMETER VALUE INDICATOR (PVI): < - LESS THAN DETECTION LIMIT

N - UNKNOWN

O - ON-SITE

OTHER PARAMETER VALUE FLAGS:

I - INCREASED DETECTION LIMIT DUE TO REQUIRED DILUTIOH

SAMPLE ID CODES:

0001 - FILTERED SAMPLE (.45 MICRONS)

N001 - UNFILTERED SAMPLE 
TABLE 3.21 TAILINGS PORE FLUID HATER QUAL ITY DATA BY PARAMETER, NC AND UC PROCESSING SITES, SLICK ROCK, COLORADO

SITE: SRKOI SLICK ROCK (BOTH SITES)

$01 / 12 / 89$ TO $10 / 14 / 92$

\begin{tabular}{|c|c|c|c|c|c|c|c|c|c|c|c|}
\hline PARAMETER HAME & $\underset{\text { LOCATION }}{\text { ID }}$ & LOG DATE & $\underset{\text { ID }}{\text { SAMPLE }}$ & $\begin{array}{l}\text { MAT. } \\
\text { SAMP }\end{array}$ & $\begin{array}{l}\text { FLOW } \\
\text { REL. }\end{array}$ & $\begin{array}{l}\text { UNITS OF } \\
\text { MEASURE }\end{array}$ & PVI & $\begin{array}{l}\text { ARAMETER } \\
\text { VALUE }\end{array}$ & FLAGS & $\begin{array}{l}\text { DETECTION } \\
\text { LIMIT }\end{array}$ & $\begin{array}{l}\text { PARAMETER } \\
\text { UNCERTAINTY }\end{array}$ \\
\hline IROH & $\begin{array}{l}0206 \\
0206 \\
0206 \\
0207 \\
0207 \\
0514 \\
0515 \\
0515 \\
0515\end{array}$ & $\begin{array}{l}04 / 17 / 91 \\
08 / 07 / 91 \\
10 / 14 / 92 \\
08 / 07 / 91 \\
10 / 14 / 92 \\
01 / 12 / 89 \\
01 / 12 / 89 \\
04 / 17 / 91 \\
08 / 07 / 91\end{array}$ & $\begin{array}{l}0001 \\
0001 \\
0001 \\
0001 \\
0001 \\
0001 \\
0001 \\
0001 \\
0001\end{array}$ & $\begin{array}{l}A L \\
A L \\
A L \\
A L \\
A L \\
T A \\
T A \\
T A \\
T A\end{array}$ & $\begin{array}{l}N \\
N \\
N \\
N \\
N \\
0 \\
0 \\
0 \\
0\end{array}$ & $M G / L$ & $\mid \begin{array}{l}< \\
< \\
< \\
< \\
< \\
< \\
< \\
<\end{array}$ & $\begin{array}{l}0.03 \\
0.03 \\
0.03 \\
0.03 \\
0.03 \\
0.08 \\
0.10 \\
0.03 \\
0.03\end{array}$ & & $\begin{array}{l}0.03 \\
0.03 \\
0.03 \\
0.03 \\
0.03 \\
0.03 \\
0.03 \\
0.03 \\
0.03\end{array}$ & $\begin{array}{l}- \\
: \\
- \\
- \\
- \\
-\end{array}$ \\
\hline IRON (TOTAL) & $\begin{array}{l}0203 \\
0204 \\
0206 \\
0207 \\
0208 \\
0210 \\
0515\end{array}$ & $\begin{array}{l}12 / 12 / 90 \\
12 / 12 / 90 \\
12 / 12 / 90 \\
12 / 12 / 90 \\
10 / 14 / 92 \\
12 / 12 / 90 \\
10 / 14 / 92\end{array}$ & $\begin{array}{l}\text { N001 } \\
\text { N001 } \\
\text { N001 } \\
\text { N001 } \\
\text { N001 } \\
\text { N001 } \\
\text { N001 }\end{array}$ & $\begin{array}{l}A L \\
A L \\
A L \\
A L \\
N R \\
A L \\
T A\end{array}$ & $\begin{array}{l}N \\
N \\
N \\
N \\
N \\
N \\
0\end{array}$ & MG/L & & $\begin{array}{l}0.78 \\
0.09 \\
0.27 \\
0.19 \\
0.05 \\
0.11 \\
0.04\end{array}$ & & $\begin{array}{l}0.03 \\
0.03 \\
0.03 \\
0.03 \\
0.03 \\
0.03 \\
0.03\end{array}$ & $\begin{array}{l}- \\
- \\
- \\
-\end{array}$ \\
\hline LEAD & $\begin{array}{l}0202 \\
0202 \\
0202 \\
0203 \\
0203 \\
0203 \\
0203 \\
0204 \\
0204 \\
0204 \\
0204 \\
0205 \\
0205 \\
0205 \\
0206 \\
0206 \\
0206 \\
0207 \\
0207 \\
0514\end{array}$ & $\begin{array}{l}04 / 17 / 91 \\
12 / 11 / 91 \\
10 / 14 / 92 \\
04 / 17 / 91 \\
08 / 07 / 91 \\
12 / 11 / 91 \\
10 / 14 / 92 \\
04 / 17 / 91 \\
08 / 07 / 91 \\
12 / 11 / 91 \\
10 / 14 / 92 \\
04 / 17 / 91 \\
12 / 11 / 91 \\
10 / 14 / 92 \\
04 / 17 / 91 \\
08 / 07 / 91 \\
10 / 14 / 92 \\
08 / 07 / 91 \\
10 / 14 / 92 \\
01 / 12 / 89\end{array}$ & $\begin{array}{l}0001 \\
0001 \\
0001 \\
0001 \\
0001 \\
0001 \\
0001 \\
0001 \\
0001 \\
0001 \\
0001 \\
0001 \\
0001 \\
0001 \\
0001 \\
0001 \\
0001 \\
0001 \\
0001 \\
0001\end{array}$ & $\begin{array}{l}A L \\
A L \\
A L \\
A L \\
A L \\
A L \\
A L \\
A L \\
A L \\
A L \\
A L \\
A L \\
A L \\
A L \\
A L \\
A L \\
A L \\
A L \\
A L \\
T A\end{array}$ & $\begin{array}{l}N \\
N \\
N \\
N \\
N \\
N \\
N \\
N \\
N \\
N \\
N \\
N \\
N \\
N \\
N \\
N \\
N \\
N \\
N \\
0\end{array}$ & $\mathrm{MG} / \mathrm{L}$ & $\begin{array}{l}< \\
< \\
< \\
< \\
< \\
< \\
< \\
< \\
< \\
< \\
< \\
< \\
< \\
< \\
< \\
< \\
< \\
< \\
< \\
<\end{array}$ & $\begin{array}{l}0.03 \\
0.3 \\
0.02 \\
0.03 \\
0.3 \\
0.05 \\
0.02 \\
0.03 \\
0.03 \\
0.05 \\
0.003 \\
0.03 \\
0.05 \\
0.02 \\
0.03 \\
0.005 \\
0.003 \\
0.03 \\
0.003 \\
0.01\end{array}$ & $\begin{array}{l}1 \\
1 \\
1 \\
1 \\
I \\
1 \\
1 \\
1 \\
1 \\
1 \\
1 \\
I \\
I \\
1 \\
I \\
I\end{array}$ & $\begin{array}{l}0.03 \\
0.3 \\
0.02 \\
0.03 \\
0.3 \\
0.05 \\
0.02 \\
0.03 \\
0.03 \\
0.05 \\
0.003 \\
0.03 \\
0.05 \\
0.02 \\
0.03 \\
0.005 \\
0.003 \\
0.03 \\
0.003 \\
0.01\end{array}$ & $\begin{array}{l}- \\
- \\
: \\
- \\
- \\
- \\
- \\
- \\
- \\
- \\
- \\
- \\
- \\
-\end{array}$ \\
\hline
\end{tabular}

MATERIAL OF SAMPLING CODE:

AL - ALLUVIUM

TA - URANIUM MILL TAILINGS

NR - NO RECOVERY OF DATA FOR CLASSIFYING

FLOW RELATIONSHIP CODE:

PARAMETER VALUE INDICATOR (PVI): < - LESS THAN DETECTION LIMIT

- UNKNOWN

- ON-SITE

OTHER PARAMETER VALUE FLAGS:

I - INCREASED DETECTION LIMIT DUE TO REQUIRED DILUTION

SAMPLE ID COOES:

0001 - FILTERED SAMPLE (.45 MICRONS)

N001 - UNFILTERED SAMPLE 
TABLE 3.21 TAILINGS PORE FLUID WATER QUALITY DATA 8Y PARAMETER, NC AND UC PROCESSING SITES, SLICK ROCK, COLORADO

SITE: SRKOI SLICK ROCK (BOTH SITES)

01/12/89 TO 10/14/92

REPORT DATE: 06/17/93

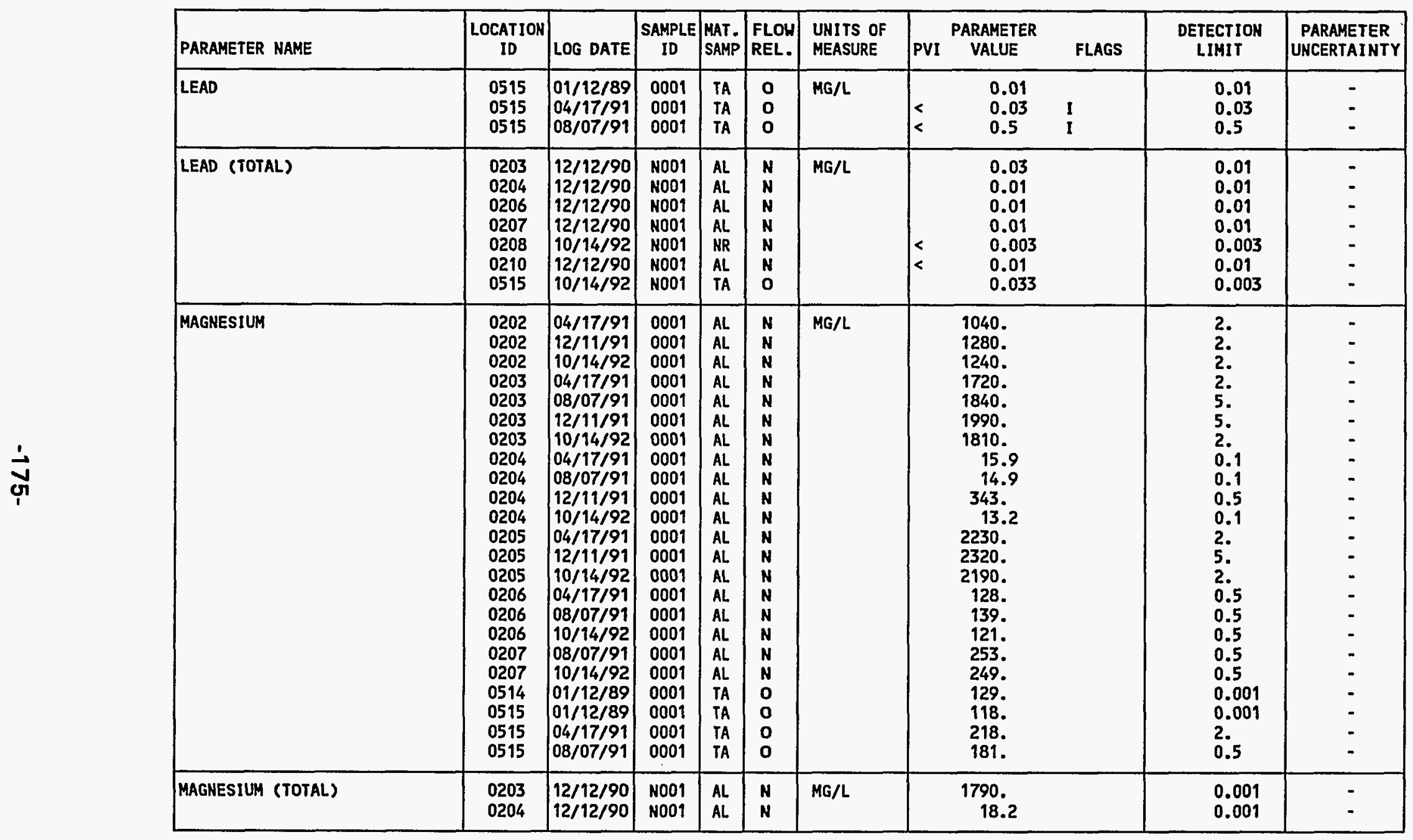

MATERIAL OF SAMPLIHG CODE:

TA - URANIUM MILL TAILINGS

AL - ALLUVIUM

NR - NO RECOVERY OF DATA FOR CLASSIFYING

PARAMETER VALUE INDICATOR (PVI): < - LESS THAN DETECTION LIMIT

OTHER PARAMETER VALUE FLAGS:

I - INCREASED DETECTION LIMIT DUE TO REQUIRED DILUTION
FLOW RELATIONSHIP CODE:

O - ON-SITE

SAMPLE ID CODES:

0001 - FILTERED SAMPLE (.45 MICRONS)

H001 - UMFILTERED SAMPLE 
TABLE 3.21 TAILINGS PORE FLUID HATER QUALITY DATA BY PARAMETER, NC AND UC PROCESSING SITES, SLICK ROCK, COLORADO

SITE: SRKOI SLICK ROCK (BOTH SITES)

$01 / 12 / 89$ TO $10 / 14 / 92$

REPORT DATE: 06/17/93

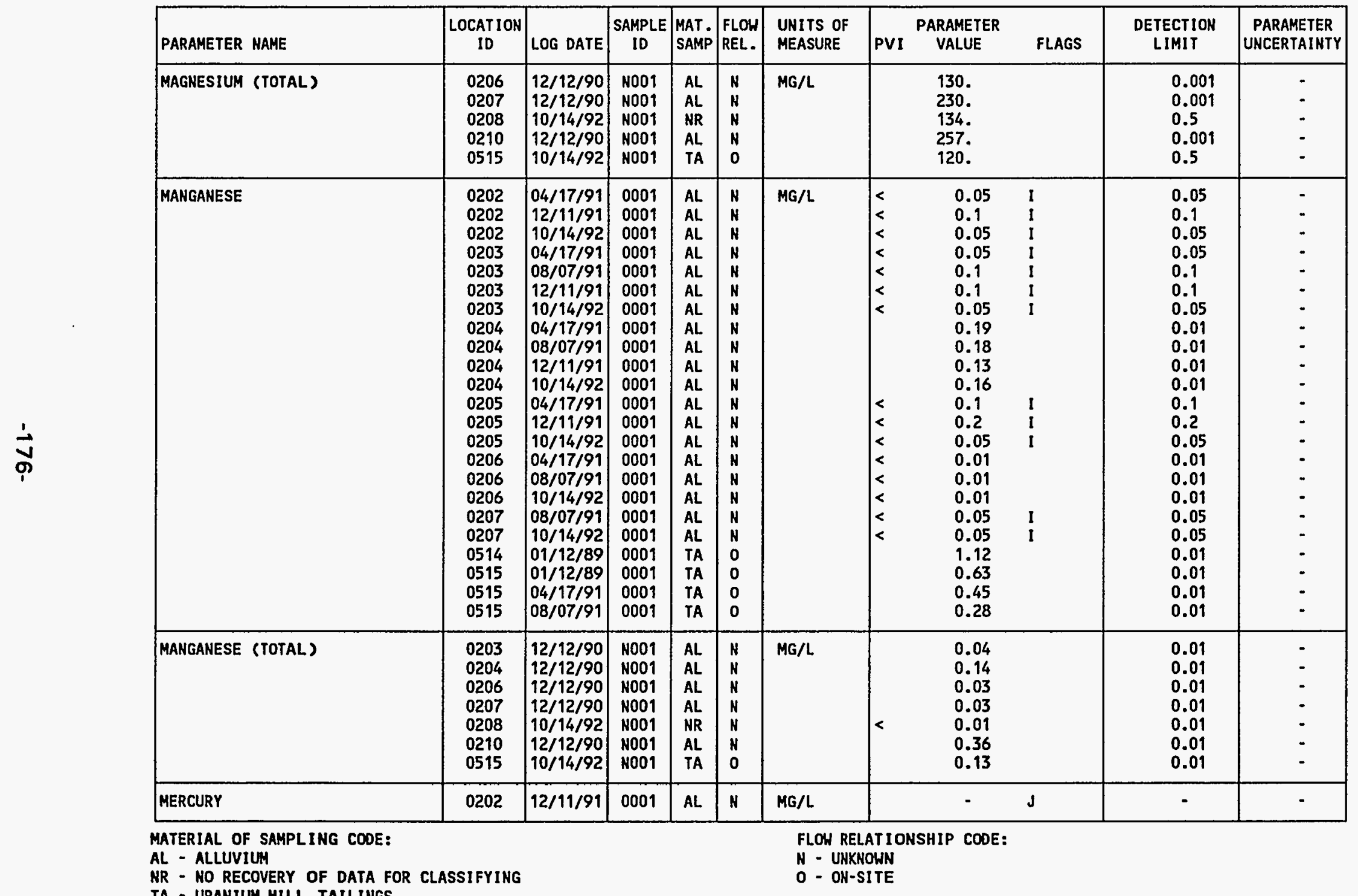

TA - URANIUM MILL TAILINGS

PARAMETER VALUE INDICATOR (PVI): < - LESS THAN DETECTION LIMIT

OTHER PARAMETER VALUE FLAGS:

SAMPLE ID CODES:

I - INCREASED DETECTION LIMIT DUE TO REQUIRED DILUTION

0001 - FILTERED SAMPLE (.45 MICRONS)

NO01 - UNFILTERED SAMPLE 
TABLE 3.21 TAILINGS PORE FLUID WATER QUALITY DATA BY PARAMETER, NC AND UC PROCESSING SITES, SLICK ROCK, COLORADO

SITE: SRKOI SLICK ROCK (BOTH SITES)

01/12/89 TO $10 / 14 / 92$

REPORT DATE: 06/17/93

\begin{tabular}{|c|c|c|c|c|c|c|c|c|c|c|}
\hline PARAMETER NAME & $\begin{array}{c}\text { LOCATION } \\
\text { ID }\end{array}$ & LOG DATE & $\begin{array}{c}\text { SAMPLE } \\
\text { ID }\end{array}$ & $\begin{array}{l}\text { MAT. } \\
\text { SAMP }\end{array}$ & $\begin{array}{l}\text { FLOW } \\
\text { REL. }\end{array}$ & $\begin{array}{l}\text { UNITS OF } \\
\text { MEASURE }\end{array}$ & PVI & $\begin{array}{l}\text { PARAMETER } \\
\text { VALUE }\end{array}$ & $\begin{array}{l}\text { DETECTION } \\
\text { LIMIT }\end{array}$ & $\begin{array}{l}\text { PARAMETER } \\
\text { UNCERTAINTY }\end{array}$ \\
\hline MERCURY & $\begin{array}{l}0203 \\
0204 \\
0205 \\
0514 \\
0515\end{array}$ & $\begin{array}{l}12 / 11 / 91 \\
12 / 11 / 91 \\
12 / 11 / 91 \\
01 / 12 / 89 \\
01 / 12 / 89\end{array}$ & $\begin{array}{l}0001 \\
0001 \\
0001 \\
0001 \\
0001\end{array}$ & $\begin{array}{l}A L \\
A L \\
A L \\
T A \\
T A\end{array}$ & $\begin{array}{l}N \\
N \\
N \\
0 \\
0\end{array}$ & $M G / L$ & $<$ & $\begin{array}{cc}- & J \\
- & J \\
- & J \\
0.0002 & \\
0.0002 & \end{array}$ & $\begin{array}{c}- \\
- \\
0.0002 \\
0.0002\end{array}$ & $\begin{array}{l}- \\
- \\
-\end{array}$ \\
\hline MERCURY (TOTAL) & $\begin{array}{l}0203 \\
0206 \\
0207 \\
0210\end{array}$ & $\begin{array}{l}12 / 12 / 90 \\
12 / 12 / 90 \\
12 / 12 / 90 \\
12 / 12 / 90\end{array}$ & $\begin{array}{l}\text { NO01 } \\
\text { N001 } \\
\text { N001 } \\
\text { N001 }\end{array}$ & $\begin{array}{l}A L \\
A L \\
A L \\
A L\end{array}$ & $\begin{array}{l}N \\
N \\
N \\
N\end{array}$ & $M G / L$ & $<$ & $\begin{array}{l}0.0002 \\
0.0002 \\
0.0002 \\
0.0002\end{array}$ & $\begin{array}{l}0.0002 \\
0.0002 \\
0.0002 \\
0.0002\end{array}$ & $\begin{array}{l}- \\
- \\
-\end{array}$ \\
\hline MOLYBDENUM & $\begin{array}{l}0202 \\
0202 \\
0202 \\
0203 \\
0203 \\
0203 \\
0203 \\
0204 \\
0204 \\
0204 \\
0204 \\
0205 \\
0205 \\
0205 \\
0206 \\
0206 \\
0206 \\
0207 \\
0207 \\
0514 \\
0515 \\
0515 \\
0515\end{array}$ & $\begin{array}{l}04 / 17 / 91 \\
12 / 11 / 91 \\
10 / 14 / 92 \\
04 / 17 / 91 \\
08 / 07 / 91 \\
12 / 11 / 91 \\
10 / 14 / 92 \\
04 / 17 / 91 \\
08 / 07 / 91 \\
12 / 11 / 91 \\
10 / 14 / 92 \\
04 / 17 / 91 \\
12 / 11 / 91 \\
10 / 14 / 92 \\
04 / 17 / 91 \\
08 / 07 / 91 \\
10 / 14 / 92 \\
08 / 07 / 91 \\
10 / 14 / 92 \\
01 / 12 / 89 \\
01 / 12 / 89 \\
04 / 17 / 91 \\
08 / 07 / 91\end{array}$ & $\begin{array}{l}0001 \\
0001 \\
0001 \\
0001 \\
0001 \\
0001 \\
0001 \\
0001 \\
0001 \\
0001 \\
0001 \\
0001 \\
0001 \\
0001 \\
0001 \\
0001 \\
0001 \\
0001 \\
0001 \\
0001 \\
0001 \\
0001 \\
0001\end{array}$ & $\begin{array}{l}A L \\
A L \\
A L \\
A L \\
A L \\
A L \\
A L \\
A L \\
A L \\
A L \\
A L \\
A L \\
A L \\
A L \\
A L \\
A L \\
A L \\
A L \\
A L \\
T A \\
T A \\
T A \\
T A\end{array}$ & $\begin{array}{l}N \\
N \\
N \\
N \\
N \\
N \\
N \\
N \\
N \\
N \\
N \\
N \\
N \\
N \\
N \\
N \\
N \\
N \\
N \\
0 \\
0 \\
0 \\
0\end{array}$ & $M G / L$ & & $\begin{array}{c}0.33 \\
0.29 \\
0.31 \\
0.21 \\
0.22 \\
0.19 \\
0.16 \\
0.50 \\
0.55 \\
0.50 \\
0.56 \\
0.30 \\
0.23 \\
0.15 \\
0.22 \\
0.20 \\
0.16 \\
13.5 \\
11.6 \\
3.46 \\
18.0 \\
23.1 \\
21.1\end{array}$ & $\begin{array}{l}0.01 \\
0.01 \\
0.01 \\
0.01 \\
0.01 \\
0.01 \\
0.01 \\
0.01 \\
0.01 \\
0.01 \\
0.01 \\
0.05 \\
0.01 \\
0.05 \\
0.01 \\
0.01 \\
0.01 \\
0.05 \\
0.05 \\
0.01 \\
0.01 \\
0.05 \\
0.05\end{array}$ & $\begin{array}{l}- \\
- \\
- \\
- \\
- \\
- \\
- \\
- \\
- \\
- \\
- \\
- \\
- \\
- \\
- \\
- \\
= \\
-\end{array}$ \\
\hline MOLYBDENUM (TOTAL) & $\begin{array}{l}0203 \\
0204 \\
0206 \\
0207\end{array}$ & $\begin{array}{l}12 / 12 / 90 \\
12 / 12 / 90 \\
12 / 12 / 90 \\
12 / 12 / 90\end{array}$ & $\begin{array}{l}\text { NO01 } \\
\text { N001 } \\
\text { N001 } \\
\text { N001 }\end{array}$ & $\begin{array}{l}A L \\
A L \\
A L \\
A L\end{array}$ & $\begin{array}{l}N \\
N \\
N \\
N\end{array}$ & MG/L & & $\begin{array}{c}0.42 \\
0.50 \\
0.49 \\
30.6\end{array}$ & $\begin{array}{l}0.01 \\
0.01 \\
0.01 \\
0.01\end{array}$ & $\begin{array}{l}- \\
-\end{array}$ \\
\hline
\end{tabular}

MATERIAL OF SAMPLING CODE:

AL - ALLUVIUH

TA - URANIUM MILL TAILINGS

PARAMETER VALUE INDICATOR (PVI): < - LESS THAN DETECTION LIMIT OTHER PARAMETER VALUE FLAGS: J - ESTIMATED VALUE
FLOW RELATIONSHIP CODE

N - UNKNOWN

SAMPLE IO CODES:

0001 - FILTERED SAMPLE (.45 MICRONS)

NOO1 - UNFILTERED SAMPLE 
TABLE 3.21 TAILINGS PORE FLUID HATER QUALITY DATA BY PARAMETER, NC AND UC PROCESSING SITES, SLICK ROCK, COLORADO

SITE: SRK01 SLICK ROCK (BOTH SITES)

$01 / 12 / 89$ TO $10 / 14 / 92$

REPORT DATE: $06 / 17 / 93$

\begin{tabular}{|c|c|c|c|c|c|c|c|c|c|c|c|}
\hline PARAMETER NAME & $\underset{\text { ID }}{\text { LOCAT ION }}$ & LOG DATE & $\underset{\text { ID }}{\text { SAMPLE }}$ & $\begin{array}{l}\text { MAT. } \\
\text { SAMP }\end{array}$ & $\begin{array}{l}\text { FLOW } \\
\text { REL. }\end{array}$ & $\begin{array}{l}\text { UNITS OF } \\
\text { MEASURE }\end{array}$ & PVI & $\begin{array}{l}\text { PARAMETER } \\
\text { VALUE }\end{array}$ & FLAGS & $\begin{array}{l}\text { DETECTION } \\
\text { LIMIT }\end{array}$ & $\begin{array}{l}\text { PARAMETER } \\
\text { UNCERTAINTY }\end{array}$ \\
\hline MOLYBDENUM (TOTAL) & $\begin{array}{l}0208 \\
0210 \\
0515\end{array}$ & $\begin{array}{l}10 / 14 / 92 \\
12 / 12 / 90 \\
10 / 14 / 92\end{array} \mid$ & $\begin{array}{l}\text { N001 } \\
\text { N001 } \\
\text { N001 }\end{array}$ & $\begin{array}{l}\text { NR } \\
\text { AL } \\
\text { TA }\end{array}$ & $\begin{array}{l}N \\
H \\
0\end{array}$ & $M G / L$ & & $\begin{array}{l}9.45 \\
13.6 \\
14.2\end{array}$ & & $\begin{array}{l}0.05 \\
0.01 \\
0.05\end{array}$ & : \\
\hline NET GROSS ALPHA * & $\begin{array}{l}0202 \\
0203 \\
0204 \\
0205 \\
0206 \\
0207 \\
0515\end{array}$ & $\begin{array}{l}04 / 17 / 91 \\
04 / 17 / 91 \\
04 / 17 / 91 \\
04 / 17 / 91 \\
08 / 07 / 91 \\
08 / 07 / 91 \\
08 / 07 / 91\end{array}$ & $\begin{array}{l}0001 \\
0001 \\
0001 \\
0001 \\
0001 \\
0001 \\
0001\end{array}$ & $\begin{array}{l}A L \\
A L \\
A L \\
A L \\
A L \\
A L \\
T A\end{array}$ & $\begin{array}{l}N \\
N \\
N \\
N \\
N \\
N \\
0\end{array}$ & $\mathrm{PCI} / \mathrm{L}$ & & $\begin{array}{r}21.02 \\
-2305.38 \\
29.52 \\
-6213.40 \\
-31.47 \\
-21.19 \\
1022.57\end{array}$ & & $\begin{array}{l}: \\
: \\
: \\
-\end{array}$ & $\begin{array}{l}- \\
- \\
- \\
- \\
-\end{array}$ \\
\hline NET GROSS ALPHA (TOTAL) ** & $\begin{array}{l}0203 \\
0204 \\
0206 \\
0210\end{array}$ & $\begin{array}{l}12 / 12 / 90 \\
12 / 12 / 90 \\
12 / 12 / 90 \\
12 / 12 / 90\end{array} \mid$ & $\begin{array}{l}\text { N001 } \\
\text { N001 } \\
\text { N001 } \\
\text { N001 }\end{array}$ & $\begin{array}{l}A L \\
A L \\
A L \\
A L\end{array}$ & $\begin{array}{l}\mathbf{H} \\
\mathbf{N} \\
\mathbf{N} \\
\mathbf{N}\end{array}$ & $\mathrm{PCI} / \mathrm{L}$ & & $\begin{array}{r}-2397.20 \\
-7.77 \\
27.39 \\
-9.73\end{array}$ & & $\begin{array}{l}- \\
- \\
-\end{array}$ & $\begin{array}{l}- \\
- \\
-\end{array}$ \\
\hline$\frac{1}{\infty}$ & $\begin{array}{l}0202 \\
0202 \\
0202 \\
0203 \\
0203 \\
0203 \\
0203 \\
0204 \\
0204 \\
0204 \\
0204 \\
0205 \\
0205 \\
0205 \\
0206 \\
0206 \\
0206\end{array}$ & $\begin{array}{l}04 / 17 / 91 \\
12 / 11 / 91 \\
10 / 14 / 92 \\
04 / 17 / 91 \\
08 / 07 / 91 \\
12 / 11 / 91 \\
10 / 14 / 92 \\
04 / 17 / 91 \\
08 / 07 / 91 \\
12 / 11 / 91 \\
10 / 14 / 92 \\
04 / 17 / 91 \\
12 / 11 / 91 \\
10 / 14 / 92 \\
04 / 17 / 91 \\
08 / 07 / 91 \\
10 / 14 / 92\end{array}$ & $\begin{array}{l}0001 \\
0001 \\
0001 \\
0001 \\
0001 \\
0001 \\
0001 \\
0001 \\
0001 \\
0001 \\
0001 \\
0001 \\
0001 \\
0001 \\
0001 \\
0001 \\
0001\end{array}$ & $\begin{array}{l}A L \\
A L \\
A L \\
A L \\
A L \\
A L \\
A L \\
A L \\
A L \\
A L \\
A L \\
A L \\
A L \\
A L \\
A L \\
A L \\
A L\end{array}$ & $\begin{array}{l}N \\
N \\
N \\
N \\
N \\
N \\
N \\
N \\
N \\
N \\
N \\
N \\
N \\
N \\
N \\
N \\
N\end{array}$ & $M G / L$ & $\begin{array}{l}< \\
< \\
< \\
< \\
< \\
< \\
< \\
< \\
< \\
< \\
< \\
< \\
< \\
< \\
< \\
< \\
<\end{array}$ & $\begin{array}{l}0.04 \\
0.04 \\
0.04 \\
0.04 \\
0.04 \\
0.04 \\
0.04 \\
0.04 \\
0.04 \\
0.04 \\
0.04 \\
0.2 \\
0.04 \\
0.2 \\
0.04 \\
0.04 \\
0.04\end{array}$ & $\begin{array}{l}1 \\
1\end{array}$ & $\begin{array}{l}0.04 \\
0.04 \\
0.04 \\
0.04 \\
0.04 \\
0.04 \\
0.04 \\
0.04 \\
0.04 \\
0.04 \\
0.04 \\
0.2 \\
0.04 \\
0.2 \\
0.04 \\
0.04 \\
0.04\end{array}$ & $\begin{array}{l}- \\
: \\
- \\
- \\
- \\
- \\
- \\
- \\
- \\
- \\
- \\
-\end{array}$ \\
\hline
\end{tabular}

* NET GROSS ALPHA (GROSS ALPHA - URANIUM) HITH 1 MG URANIUM = 686 PCI

** NET GROSS ALPHA (TOTAL) (TOTAL GROSS ALPHA - TOTAL URANIUM)

MATERIAL OF SAMPLING CODE:

NR - NO RECOVERY OF DATA FOR CLASSIFYING

FLOH RELATIONSHIP CODE:

AL - ALLUVIUM

N - UNKNOWN

TA - URANIUM MILL TAILINGS

O - ON-SITE

PARAMETER VALUE INDICATOR (PVI): < - LESS THAN DETECTION LIMIT

OTHER PARAMETER VALUE FLAGS:

I - INCREASED DETECTION LIMIT DUE TO REQUIRED DILUTION

SAMPLE ID CODES:

0001 - FILTERED SAMPLE (.45 MICRONS)

N001 - UNF I LTERED SAMPLE 
TABLE 3.21 TAILINGS PORE FLUID WATER QUALITY DATA BY PARAMETER, HC AND UC PROCESSING SITES, SLICK ROCK, COLORADO

SITE: SRKO1 SLICK ROCK (BOTH SITES)

01/12/89 TO $10 / 14 / 92$

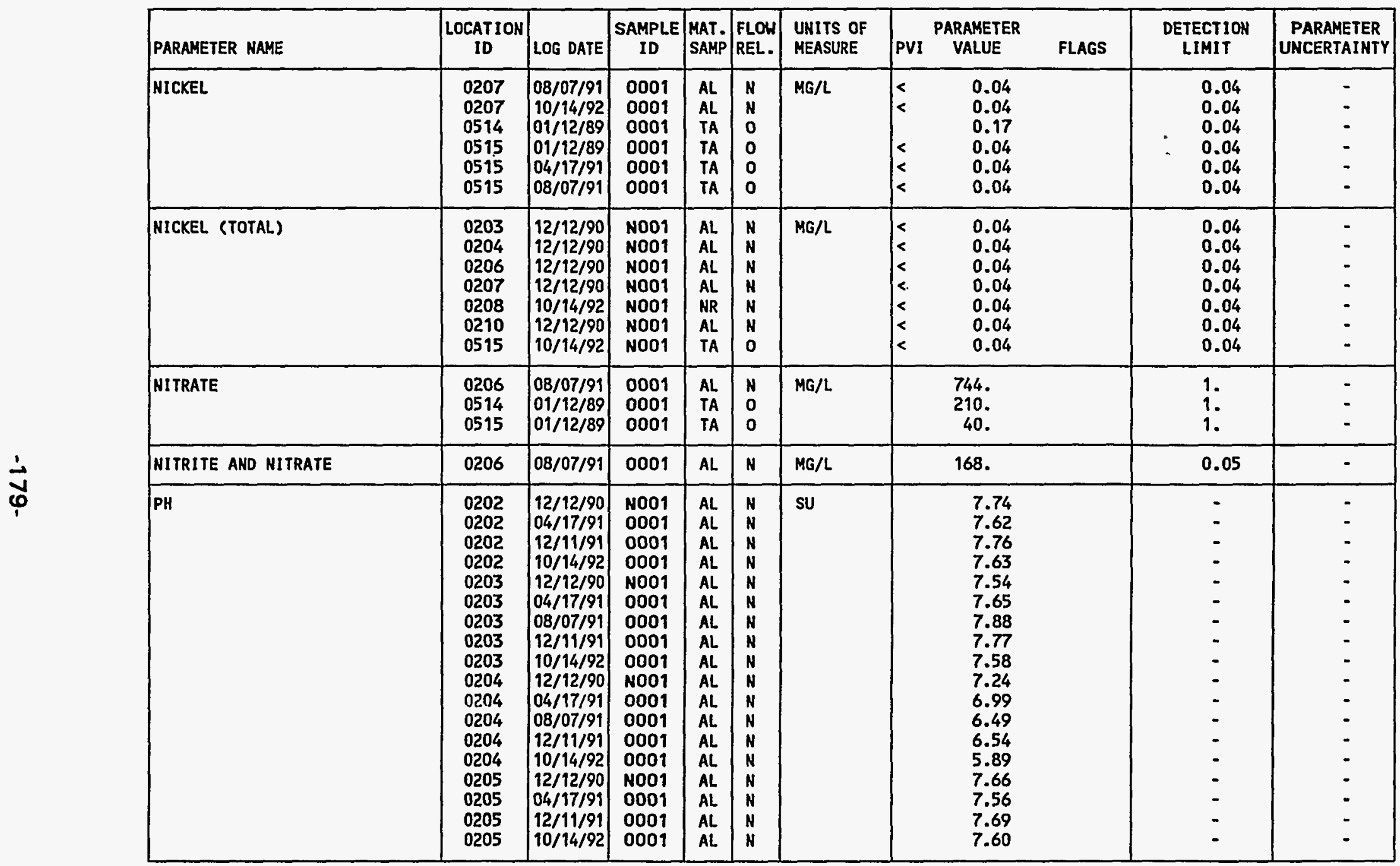

\section{MATERIAL OF SAMPLING CODE:}

\section{$A L$ - ALLUVIUM}

TA - URANIUM MILL TAILINGS

NR - NO RECOVERY OF DATA FOR CLASSIFYING

PARAMETER VALUE INDICATOR (PVI): < - LESS THAN DETECTION LIMIT

FLOW RELATIONSHIP COOE:

N - UNKNOWN
0 - ON-SITE

SAMPLE ID CODES:

0001 - FILTERED SAMPLE (.45 MICRONS)

HOO1 - UNFILTERED SAMPLE 
TABLE 3.21 TAILINGS PORE FLUID HATER QUALITY DATA BY PARAMETER, NC AND UC PROCESSING SITES, SLICK ROCK, COLORADO

SITE: SRKO1 SLICK ROCK (BOTH SITES)

01/12/89 TO $10 / 14 / 92$

REPORT DATE: $06 / 17 / 93$

\begin{tabular}{|c|c|c|c|c|c|c|c|c|c|c|}
\hline PARAMETER NAME & $\underset{\text { ID }}{\text { LOCATION }}$ & LOG DATE & $\begin{array}{c}\text { SAMPLE } \\
\text { ID }\end{array}$ & $\begin{array}{l}\text { MAT. } \\
\text { SAMP }\end{array}$ & $\begin{array}{l}\text { FLOW } \\
\text { REL. }\end{array}$ & $\begin{array}{l}\text { UNITS OF } \\
\text { MEASURE }\end{array}$ & PVI & $\begin{array}{l}\text { PARAMETER } \\
\text { VALUE }\end{array}$ & $\begin{array}{l}\text { DETECTION } \\
\text { LIMIT }\end{array}$ & $\begin{array}{l}\text { PARAMETER } \\
\text { UNCERTAINTY }\end{array}$ \\
\hline PH & $\begin{array}{l}0206 \\
0206 \\
0206 \\
0206 \\
0207 \\
0207 \\
0207 \\
0208 \\
0210 \\
0514 \\
0515 \\
0515 \\
0515 \\
0515\end{array}$ & \begin{tabular}{|l|}
$12 / 12 / 90$ \\
$04 / 17 / 91$ \\
$08 / 07 / 91$ \\
$10 / 14 / 92$ \\
$12 / 12 / 90$ \\
$08 / 07 / 91$ \\
$10 / 14 / 92$ \\
$10 / 14 / 92$ \\
$12 / 12 / 90$ \\
$01 / 12 / 89$ \\
$01 / 12 / 89$ \\
$04 / 17 / 91$ \\
$12 / 09 / 91$ \\
$10 / 14 / 92$
\end{tabular} & $\begin{array}{l}\text { N001 } \\
0001 \\
0001 \\
0001 \\
N 001 \\
0001 \\
0001 \\
\text { N001 } \\
\text { N001 } \\
0001 \\
0001 \\
0001 \\
0001 \\
\text { N001 }\end{array}$ & $\begin{array}{l}A L \\
A L \\
A L \\
A L \\
A L \\
A L \\
A L \\
\text { NR } \\
A L \\
T A \\
T A \\
T A \\
T A \\
T A\end{array}$ & $\begin{array}{l}N \\
N \\
N \\
N \\
N \\
N \\
N \\
N \\
N \\
0 \\
0 \\
0 \\
0 \\
0\end{array}$ & su & & $\begin{array}{l}7.16 \\
7.47 \\
7.02 \\
7.11 \\
7.8 \\
7.66 \\
7.39 \\
7.69 \\
7.81 \\
6.21 \\
7.04 \\
6.43 \\
6.62 \\
6.00\end{array}$ & $\begin{array}{l}- \\
- \\
- \\
- \\
- \\
- \\
- \\
- \\
- \\
-\end{array}$ & $\begin{array}{l}- \\
- \\
- \\
- \\
- \\
- \\
- \\
- \\
- \\
- \\
-\end{array}$ \\
\hline PHOSPHATE & $\begin{array}{l}0514 \\
0515\end{array}$ & $\mid \begin{array}{l}01 / 12 / 89 \\
01 / 12 / 89\end{array}$ & $\begin{array}{l}0001 \\
0001\end{array}$ & $\begin{array}{l}\text { TA } \\
\text { TA }\end{array}$ & $\begin{array}{l}0 \\
0\end{array}$ & MG/L & $<$ & $\begin{array}{l}0.1 \\
0.1\end{array}$ & $\begin{array}{l}0.1 \\
0.1\end{array}$ & $\overline{-}$ \\
\hline PHOSPHATE (TOTAL) & $\begin{array}{l}0202 \\
0203 \\
0204 \\
0205 \\
0206 \\
0210\end{array}$ & $\begin{array}{l}12 / 12 / 90 \\
12 / 12 / 90 \\
12 / 12 / 90 \\
12 / 12 / 90 \\
12 / 12 / 90 \\
12 / 12 / 90\end{array}$ & $\begin{array}{l}\text { N001 } \\
\text { N001 } \\
\text { N001 } \\
\text { N001 } \\
\text { N001 } \\
\text { N001 }\end{array}$ & $\begin{array}{l}A L \\
A L \\
A L \\
A L \\
A L \\
A L\end{array}$ & $\begin{array}{l}\mathbf{N} \\
\mathbf{N} \\
\mathbf{N} \\
\mathbf{N} \\
\mathbf{N} \\
\mathbf{N}\end{array}$ & $M G / L$ & $<$ & $\begin{array}{l}1.3 \\
0.9 \\
0.9 \\
1.3 \\
0.1 \\
0.1\end{array}$ & $\begin{array}{l}0.1 \\
0.1 \\
0.1 \\
0.1 \\
0.1 \\
0.1\end{array}$ & $\begin{array}{l}- \\
- \\
- \\
- \\
-\end{array}$ \\
\hline POTASSIUM & $\begin{array}{l}0202 \\
0202 \\
0202 \\
0203 \\
0203 \\
0203 \\
0203 \\
0204 \\
0204 \\
0204 \\
0204 \\
0205 \\
0205 \\
0205\end{array}$ & $\begin{array}{l}04 / 17 / 91 \\
12 / 11 / 91 \\
10 / 14 / 92 \\
04 / 17 / 91 \\
08 / 07 / 91 \\
12 / 11 / 91 \\
10 / 14 / 92 \\
04 / 17 / 91 \\
08 / 07 / 91 \\
12 / 11 / 91 \\
10 / 14 / 92 \\
04 / 17 / 91 \\
12 / 11 / 91 \\
10 / 14 / 92\end{array}$ & $\begin{array}{l}0001 \\
0001 \\
0001 \\
0001 \\
0001 \\
0001 \\
0001 \\
0001 \\
0001 \\
0001 \\
0001 \\
0001 \\
0001 \\
0001\end{array}$ & $\begin{array}{l}A L \\
A L \\
A L \\
A L \\
A L \\
A L \\
A L \\
A L \\
A L \\
A L \\
A L \\
A L \\
A L \\
A L\end{array}$ & $\begin{array}{l}N \\
N \\
N \\
N \\
N \\
N \\
N \\
N \\
N \\
N \\
N \\
N \\
N \\
N\end{array}$ & $M G / L$ & & $\begin{array}{c}86 . \\
69 . \\
72 . \\
121 . \\
139 . \\
124 . \\
115 . \\
5 . \\
6.3 \\
16 . \\
5.52 \\
110 . \\
71 . \\
52 .\end{array}$ & $\begin{array}{l}5 . \\
5 . \\
5 . \\
5 . \\
5 . \\
5 . \\
5 . \\
5 . \\
0.01 \\
5 . \\
0.01 \\
20 . \\
5 . \\
5 .\end{array}$ & $\begin{array}{l}- \\
- \\
- \\
- \\
- \\
- \\
- \\
- \\
- \\
- \\
-\end{array}$ \\
\hline
\end{tabular}

MATERIAL OF SAMPLING CODE:

AL - ALLUVIUH

NR - NO RECOVERY OF DATA FOR CLASSIFYING

FLOW RELATIONSHIP CODE:

TA - URANIUM MILL. TAILINGS

N - UNKNOWN

O - ON-SITE

PARAMETER VALUE INDICATOR (PVI): < - LESS THAN DETECTION LIMIT

SAMPLE ID CODES:

0001 - FILTERED SAMPLE (.45 MICRONS)

NO01 - UNFILTERED SAMPLE 
TABLE 3.21 TAILINGS PORE FLUID HATER QUALITY DATA BY PARAMETER, HC AND UC PROCESSING SITES, SLICK ROCK, COLORADO

SITE: SRKOI SLICK ROCK (BOTH SITES)

01/12/89 TO $10 / 14 / 92$

\begin{tabular}{|c|c|c|c|c|c|c|c|c|c|c|}
\hline PARAMETER NAME & $\underset{\text { ID }}{\text { LOCATION }}$ & LOG DATE & $\begin{array}{c}\text { SAMPLE } \\
\text { ID }\end{array}$ & $\begin{array}{l}\text { MAT. } \\
\text { SAMP }\end{array}$ & $\begin{array}{l}\text { FLOW } \\
\text { REL. }\end{array}$ & $\begin{array}{l}\text { UNITS OF } \\
\text { MEASURE }\end{array}$ & $\begin{array}{ll} & \text { PARAMETER } \\
\text { PVI } & \text { VALUE }\end{array}$ & FLAGS & $\begin{array}{l}\text { DETECTIOH } \\
\text { LIMIT }\end{array}$ & $\begin{array}{l}\text { PARAMETER } \\
\text { UNCERTAINTY }\end{array}$ \\
\hline POTASSIUM & $\begin{array}{l}0206 \\
0206 \\
0206 \\
0207 \\
0207 \\
0514 \\
0515 \\
0515 \\
0515\end{array}$ & $\begin{array}{l}04 / 17 / 91 \\
08 / 07 / 91 \\
10 / 14 / 92 \\
08 / 07 / 91 \\
10 / 14 / 92 \\
01 / 12 / 89 \\
01 / 12 / 89 \\
04 / 17 / 91 \\
08 / 07 / 91\end{array}$ & $\begin{array}{l}0001 \\
0001 \\
0001 \\
0001 \\
0001 \\
0001 \\
0001 \\
0001 \\
0001\end{array}$ & $\begin{array}{l}A L \\
A L \\
A L \\
A L \\
A L \\
T A \\
T A \\
T A \\
T A\end{array}$ & $\begin{array}{l}N \\
N \\
N \\
N \\
N \\
0 \\
0 \\
0 \\
0\end{array}$ & MG/L & $\begin{array}{l}5.2 \\
4.7 \\
3.61 \\
4.8 \\
3.34 \\
6.3 \\
2.1 \\
4.1 \\
4.7\end{array}$ & & $\begin{array}{l}0.1 \\
0.01 \\
0.01 \\
0.01 \\
0.01 \\
0.01 \\
0.01 \\
0.1 \\
0.01\end{array}$ & $\begin{array}{l}- \\
- \\
- \\
- \\
- \\
- \\
-\end{array}$ \\
\hline POTASSIUM (TOTAL) & $\begin{array}{l}0203 \\
0204 \\
0206 \\
0207 \\
0210\end{array}$ & $\begin{array}{l}12 / 12 / 90 \\
12 / 12 / 90 \\
12 / 12 / 90 \\
12 / 12 / 90 \\
12 / 12 / 90\end{array}$ & $\begin{array}{l}\text { N001 } \\
\text { N001 } \\
\text { N001 } \\
\text { N001 } \\
\text { N001 }\end{array}$ & $\begin{array}{l}A L \\
A L \\
A L \\
A L \\
A L\end{array}$ & $\begin{array}{l}N \\
N \\
N \\
N \\
N\end{array}$ & MG/L & $\begin{array}{r}175 . \\
7.2 \\
8.2 \\
28.4 \\
10.6\end{array}$ & & $\begin{array}{l}0.01 \\
0.01 \\
0.01 \\
0.01 \\
0.01\end{array}$ & $\begin{array}{l}- \\
: \\
-\end{array}$ \\
\hline RADIUM-228 & $\begin{array}{l}0202 \\
0203 \\
0204\end{array}$ & $\begin{array}{l}10 / 14 / 92 \\
10 / 14 / 92 \\
10 / 14 / 92\end{array}$ & $\begin{array}{l}0001 \\
0001 \\
0001\end{array}$ & $\begin{array}{l}A L \\
A L \\
A L\end{array}$ & $\begin{array}{l}N \\
N \\
N\end{array}$ & $\mathrm{PCI} / \mathrm{L}$ & $\begin{array}{l}5.8 \\
0.0 \\
0.0\end{array}$ & & $\begin{array}{l}4.4 \\
4.4 \\
4.4\end{array}$ & $\begin{array}{l}2.8 \\
2.5 \\
2.5\end{array}$ \\
\hline SELENIUH & $\begin{array}{l}0202 \\
0202 \\
0202 \\
0203 \\
0203 \\
0203 \\
0203 \\
0204 \\
0204 \\
0204 \\
0204 \\
0205 \\
0205\end{array}$ & $\begin{array}{l}04 / 17 / 91 \\
12 / 11 / 91 \\
10 / 14 / 92 \\
04 / 17 / 91 \\
08 / 07 / 91 \\
12 / 11 / 91 \\
10 / 14 / 92 \\
04 / 17 / 91 \\
08 / 07 / 91 \\
12 / 11 / 91 \\
10 / 14 / 92 \\
04 / 17 / 91 \\
12 / 11 / 91\end{array}$ & $\begin{array}{l}0001 \\
0001 \\
0001 \\
0001 \\
0001 \\
0001 \\
0001 \\
0001 \\
0001 \\
0001 \\
0001 \\
0001 \\
0001\end{array}$ & $\begin{array}{l}A L \\
A L \\
A L \\
A L \\
A L \\
A L \\
A L \\
A L \\
A L \\
A L \\
A L \\
A L \\
A L\end{array}$ & $\begin{array}{l}N \\
N \\
N \\
N \\
N \\
N \\
N \\
N \\
N \\
N \\
N \\
N \\
N\end{array}$ & MG/L & $\begin{array}{c}6.0 \\
10 . \\
7.0 \\
6.0 \\
6.5 \\
13 . \\
6.0 \\
1.3 \\
1.5 \\
2.4 \\
3 . \\
0.140 \\
2.6\end{array}$ & & $\begin{array}{l}0.5 \\
5 . \\
0.5 \\
0.5 \\
0.5 \\
5 . \\
0.5 \\
0.1 \\
0.1 \\
0.5 \\
1.9 \\
0.005 \\
0.5\end{array}$ & $\begin{array}{l}: \\
: \\
: \\
: \\
: \\
- \\
- \\
- \\
- \\
-\end{array}$ \\
\hline
\end{tabular}

MATERIAL OF SAMPLING COOE:

AL - ALLUVIUM

TA - URANIUM MILL TAILINGS

FLOH RELATIONSHIP CODE:

N - UNKNOWN

PARAMETER VALUE INDICATOR (PVI): < - LESS THAN DETECTION LIMIT

SAMPLE ID CODES:

0001 - FILTERED SAMPLE (.45 MICRONS)

NOOI - UNFILTERED SAMPLE 
TABLE 3.21 TAILINGS PORE FLUID WATER QUALITY DATA BY PARAMETER, NC AND UC PROCESSING SITES, SLICK ROCK, COLORADO

SITE: SRKO1 SLICK ROCK (BOTH SITES)

SITE SRKO1 SLICK ROCK

REPORT DATE: $06 / 17 / 93$

\begin{tabular}{|c|c|c|c|c|c|c|c|c|c|c|}
\hline PARAMETER NAME & $\underset{\text { ID }}{\text { LOCATION }}$ & LOG DATE & $\begin{array}{c}\text { SAMPLE } \\
\text { ID }\end{array}$ & $\begin{array}{l}\text { MAT. } \\
\text { SAMP }\end{array}$ & $\begin{array}{l}\text { FLOW } \\
\text { REL. }\end{array}$ & $\begin{array}{l}\text { UNITS OF } \\
\text { MEASURE }\end{array}$ & PVI & $\begin{array}{l}\text { ARAMETER } \\
\text { VALUE }\end{array}$ & $\begin{array}{l}\text { DETECTION } \\
\text { LIMIT }\end{array}$ & $\begin{array}{l}\text { PARAMETER } \\
\text { UNCERTAINTY }\end{array}$ \\
\hline SELENIUM & $\begin{array}{l}0205 \\
0206 \\
0206 \\
0206 \\
0207 \\
0207 \\
0514 \\
0515 \\
0515 \\
0515\end{array}$ & $\begin{array}{l}10 / 14 / 92 \\
04 / 17 / 91 \\
08 / 07 / 91 \\
10 / 14 / 92 \\
08 / 07 / 91 \\
10 / 14 / 92 \\
01 / 12 / 89 \\
01 / 12 / 89 \\
04 / 17 / 91 \\
08 / 07 / 91\end{array}$ & $\begin{array}{l}0001 \\
0001 \\
0001 \\
0001 \\
0001 \\
0001 \\
0001 \\
0001 \\
0001 \\
0001\end{array}$ & $\begin{array}{l}A L \\
A L \\
A L \\
A L \\
A L \\
A L \\
T A \\
T A \\
T A \\
T A\end{array}$ & $\begin{array}{l}N \\
N \\
N \\
N \\
N \\
N \\
0 \\
0 \\
0 \\
0\end{array}$ & $M G / L$ & & $\begin{array}{c}1.3 \\
1.00 \\
0.150 \\
0.09 \\
16.0 \\
16 . \\
1.64 \\
1.54 \\
8.0 \\
7.0\end{array}$ & $\begin{array}{l}0.3 \\
0.005 \\
0.03 \\
0.05 \\
0.5 \\
5 . \\
0.005 \\
0.005 \\
0.5 \\
0.5\end{array}$ & $\begin{array}{l}- \\
- \\
- \\
- \\
- \\
- \\
-\end{array}$ \\
\hline SELENIUM (TOTAL) & $\begin{array}{l}0203 \\
0204 \\
0206 \\
0207 \\
0208 \\
0210 \\
0515\end{array}$ & $\begin{array}{l}12 / 12 / 90 \\
12 / 12 / 90 \\
12 / 12 / 90 \\
12 / 12 / 90 \\
10 / 14 / 92 \\
12 / 12 / 90 \\
10 / 14 / 92\end{array}$ & $\begin{array}{l}\text { N001 } \\
\text { N001 } \\
\text { N001 } \\
\text { N001 } \\
\text { N001 } \\
\text { N001 } \\
\text { N001 }\end{array}$ & $\begin{array}{l}A L \\
A L \\
A L \\
A L \\
N R \\
A L \\
T A\end{array}$ & $\begin{array}{l}N \\
N \\
N \\
N \\
N \\
N \\
0\end{array}$ & MG/L & & $\begin{array}{l}8.5 \\
1.64 \\
0.39 \\
21.6 \\
14.0 \\
1.48 \\
7.0\end{array}$ & $\begin{array}{l}0.005 \\
0.005 \\
0.005 \\
0.005 \\
0.5 \\
0.005 \\
0.5\end{array}$ & $\begin{array}{l}- \\
- \\
- \\
- \\
-\end{array}$ \\
\hline SILICA - SIO2 & $\begin{array}{l}0202 \\
0203 \\
0204 \\
0205 \\
0206 \\
0207 \\
0514 \\
0515\end{array}$ & $\begin{array}{l}10 / 14 / 92 \\
10 / 14 / 92 \\
10 / 14 / 92 \\
10 / 14 / 92 \\
10 / 14 / 92 \\
10 / 14 / 92 \\
01 / 12 / 89 \\
01 / 12 / 89\end{array}$ & $\begin{array}{l}0001 \\
0001 \\
0001 \\
0001 \\
0001 \\
0001 \\
0001 \\
0001\end{array}$ & $\begin{array}{l}A L \\
A L \\
A L \\
A L \\
A L \\
A L \\
T A \\
T A\end{array}$ & $\begin{array}{l}N \\
N \\
N \\
N \\
N \\
N \\
0 \\
0\end{array}$ & $M G / L$ & & $\begin{array}{l}74.7 \\
67.4 \\
59.8 \\
68.5 \\
61.5 \\
70.4 \\
49 . \\
48 .\end{array}$ & $\begin{array}{l}0.1 \\
0.1 \\
0.1 \\
0.5 \\
0.1 \\
0.1 \\
2 . \\
2 .\end{array}$ & $\begin{array}{l}- \\
- \\
- \\
- \\
- \\
-\end{array}$ \\
\hline SILICA - SIOZ (TOTAL) & $\begin{array}{l}0203 \\
0204 \\
0206 \\
0207 \\
0208 \\
0210 \\
0515\end{array}$ & $\begin{array}{l}12 / 12 / 90 \\
12 / 12 / 90 \\
12 / 12 / 90 \\
12 / 12 / 90 \\
10 / 14 / 92 \\
12 / 12 / 90 \\
10 / 14 / 92\end{array}$ & $\begin{array}{l}\text { N001 } \\
\text { N001 } \\
\text { N001 } \\
\text { N001 } \\
\text { N001 } \\
\text { N001 } \\
\text { N001 }\end{array}$ & $\begin{array}{l}\text { AL } \\
\text { AL } \\
\text { AL } \\
\text { AL } \\
\text { NR } \\
\text { AL } \\
\text { TA }\end{array}$ & $\begin{array}{l}\mathbf{N} \\
\mathbf{N} \\
\mathbf{N} \\
\mathbf{N} \\
\mathbf{N} \\
\mathbf{N} \\
\mathbf{O}\end{array}$ & MG/L & & $\begin{array}{l}59 . \\
59 . \\
52 . \\
48 . \\
70.7 \\
65 . \\
55.9\end{array}$ & $\begin{array}{l}2 . \\
2 . \\
2 . \\
2 . \\
0.1 \\
2 . \\
0.1\end{array}$ & $\begin{array}{l}- \\
: \\
- \\
-\end{array}$ \\
\hline SILVER & $\begin{array}{l}0202 \\
0202 \\
0203\end{array}$ & $\begin{array}{l}04 / 17 / 91 \\
12 / 11 / 91 \\
04 / 17 / 91\end{array}$ & $\begin{array}{l}0001 \\
0001 \\
0001\end{array}$ & $\begin{array}{l}A L \\
A L \\
A L\end{array}$ & $\begin{array}{l}\mathbf{H} \\
\mathrm{N} \\
\mathrm{N}\end{array}$ & MG/L & $\begin{array}{l}< \\
< \\
<\end{array}$ & $\begin{array}{l}0.01 \\
0.01 \\
0.01\end{array}$ & $\begin{array}{l}0.01 \\
0.01 \\
0.01\end{array}$ & : \\
\hline
\end{tabular}

MATERIAL OF SAMPLING CODE:

AL - ALLUVIUM

TA - URANIUM MILL TAILINGS

NR - NO RECOVERY OF DATA FOR CLASSIFYING

PARAMETER VALUE INDICATOR (PVI): < - LESS THAN DETECTION LIMIT
FLOH RELATIOHSHIP CODE:

N - UNKNOWN
O - ON-SITE

SAMPLE ID CODES:

0001 - FILTERED SAMPLE (.45 MICRONS)

NOOI - UNFILTERED SAMPLE 
TABLE 3.21 TAILINGS PORE FLUID WATER QUALITY DATA BY PARAMETER, NC AND UC PROCESSING SITES, SLICK ROCK, COLORADO

SITE: SRKOI SLICK ROCK (BOTH SITES)

01/12/89 TO 10/14/92

REPORT DATE: 06/17/93

\begin{tabular}{|c|c|c|c|c|c|c|c|c|c|c|c|}
\hline PARAMETER NAME & $\begin{array}{c}\text { LOCATION } \\
\text { ID }\end{array}$ & LOG DATE & $\begin{array}{c}\text { SAMPLE } \\
\text { ID }\end{array}$ & $\begin{array}{l}\text { MAT. } \\
\text { SAMP }\end{array}$ & $\begin{array}{l}\text { FLOW } \\
\text { REL. }\end{array}$ & $\begin{array}{l}\text { UNITS OF } \\
\text { MEASURE }\end{array}$ & PVI & $\begin{array}{l}\text { PARAMETER } \\
\text { VALUE }\end{array}$ & FLAGS & $\begin{array}{l}\text { DETECTION } \\
\text { LIMIT }\end{array}$ & $\begin{array}{l}\text { PARAMETER } \\
\text { UNCERTAINTY }\end{array}$ \\
\hline SILVER & $\begin{array}{l}0203 \\
0203 \\
0204 \\
0204 \\
0204 \\
0205 \\
0205 \\
0206 \\
0206 \\
0207 \\
0514 \\
0515 \\
0515 \\
0515\end{array}$ & $\begin{array}{l}08 / 07 / 91 \\
12 / 11 / 91 \\
04 / 17 / 91 \\
08 / 07 / 91 \\
12 / 11 / 91 \\
04 / 17 / 91 \\
12 / 11 / 91 \\
04 / 17 / 91 \\
08 / 07 / 91 \\
08 / 07 / 91 \\
01 / 12 / 89 \\
01 / 12 / 89 \\
04 / 17 / 91 \\
08 / 07 / 91\end{array}$ & $\begin{array}{l}0001 \\
0001 \\
0001 \\
0001 \\
0001 \\
0001 \\
0001 \\
0001 \\
0001 \\
0001 \\
0001 \\
0001 \\
0001 \\
0001\end{array}$ & $\begin{array}{l}A L \\
A L \\
A L \\
A L \\
A L \\
A L \\
A L \\
A L \\
A L \\
A L \\
T A \\
T A \\
T A \\
T A\end{array}$ & $\begin{array}{l}N \\
N \\
N \\
N \\
N \\
N \\
N \\
N \\
N \\
N \\
0 \\
0 \\
0 \\
0\end{array}$ & $M G / L$ & $\begin{array}{l}< \\
< \\
< \\
< \\
< \\
< \\
< \\
< \\
< \\
< \\
< \\
< \\
< \\
<\end{array}$ & $\begin{array}{l}0.01 \\
0.01 \\
0.01 \\
0.01 \\
0.01 \\
0.05 \\
0.01 \\
0.01 \\
0.01 \\
0.01 \\
0.01 \\
0.01 \\
0.01 \\
0.01\end{array}$ & 1 & $\begin{array}{c}0.01 \\
0.01 \\
0.01 \\
0.01 \\
0.01 \\
0.05 \\
0.01 \\
0.01 \\
0.01 \\
0.01 \\
0.01 \\
0.01 \\
0.01 \\
0.01\end{array}$ & $\begin{array}{l}- \\
- \\
- \\
- \\
- \\
- \\
- \\
- \\
-\end{array}$ \\
\hline SILVER (TOTAL) & $\begin{array}{l}0203 \\
0204 \\
0206 \\
0207 \\
0210\end{array}$ & $\begin{array}{l}12 / 12 / 90 \\
12 / 12 / 90 \\
12 / 12 / 90 \\
12 / 12 / 90 \\
12 / 12 / 90\end{array}$ & $\begin{array}{l}\text { N001 } \\
\text { N001 } \\
\text { N001 } \\
\text { N001 } \\
\text { N001 }\end{array}$ & $\begin{array}{l}A L \\
A L \\
A L \\
A L \\
A L\end{array}$ & $\begin{array}{l}N \\
N \\
N \\
N \\
N\end{array}$ & $\mathrm{MG} / \mathrm{L}$ & $\begin{array}{l}< \\
< \\
< \\
< \\
<\end{array}$ & $\begin{array}{l}0.01 \\
0.01 \\
0.01 \\
0.01 \\
0.01\end{array}$ & & $\begin{array}{l}0.01 \\
0.01 \\
0.01 \\
0.01 \\
0.01\end{array}$ & $:$ \\
\hline SODIUM & $\begin{array}{l}0202 \\
0202 \\
0202 \\
0203 \\
0203 \\
0203 \\
0203 \\
0204 \\
0204 \\
0204 \\
0204 \\
0205 \\
0205 \\
0205 \\
0206 \\
0206 \\
0206 \\
0207\end{array}$ & $\begin{array}{l}04 / 17 / 91 \\
12 / 11 / 91 \\
10 / 14 / 92 \\
04 / 17 / 91 \\
08 / 07 / 91 \\
12 / 11 / 91 \\
10 / 14 / 92 \\
04 / 17 / 91 \\
08 / 07 / 91 \\
12 / 11 / 91 \\
10 / 14 / 92 \\
04 / 17 / 91 \\
12 / 11 / 91 \\
10 / 14 / 92 \\
04 / 17 / 91 \\
08 / 07 / 91 \\
10 / 14 / 92 \\
08 / 07 / 91\end{array}$ & $\begin{array}{l}0001 \\
0001 \\
0001 \\
0001 \\
0001 \\
0001 \\
0001 \\
0001 \\
0001 \\
0001 \\
0001 \\
0001 \\
0001 \\
0001 \\
0001 \\
0001 \\
0001 \\
0001\end{array}$ & $\begin{array}{l}A L \\
A L \\
A L \\
A L \\
A L \\
A L \\
A L \\
A L \\
A L \\
A L \\
A L \\
A L \\
A L \\
A L \\
A L \\
A L \\
A L \\
A L\end{array}$ & $\begin{array}{l}N \\
N \\
N \\
N \\
N \\
N \\
N \\
N \\
N \\
N \\
N \\
N \\
N \\
N \\
N \\
N \\
N \\
N\end{array}$ & $M G / L$ & & $\begin{array}{r}2140 . \\
2680 . \\
2480 . \\
3230 . \\
3510 . \\
3910 . \\
3540 . \\
51 . \\
53 . \\
1140 . \\
50 . \\
6360 . \\
7020 . \\
6700 . \\
149 . \\
160 . \\
161 . \\
54 .\end{array}$ & & $\begin{array}{r}20 . \\
20 . \\
20 . \\
20 . \\
50 . \\
50 . \\
20 . \\
1 . \\
1 . \\
20 . \\
10 . \\
50 . \\
50 . \\
100 . \\
5 . \\
5 . \\
5 . \\
1 .\end{array}$ & $\begin{array}{l}- \\
= \\
= \\
- \\
- \\
= \\
- \\
- \\
- \\
- \\
- \\
- \\
-\end{array}$ \\
\hline
\end{tabular}

MATERIAL OF SAMPLING CODE:

AL - ALLUVIUM

TA - URANIUM MILL TAILINGS

PARAMETER VALUE INDICATOR (PVI): < - LESS THAN DETECTION LIMIT

OTHER PARAMETER VALUE FLAGS:

I - INCREASED DETECTION LIMIT DUE TO REQUIRED DILUTIOH
FLOW RELATIONSHIP CODE:

N - UNKNOWN

SAMPLE ID CODES:

0001 - FILTERED SAMPLE (.45 MICRONS)

HOO1 - UNFILTERED SAMPLE 
TABLE 3.21 TAILINGS PORE FLUID HATER QUALITY DATA BY PARAMETER, NC AND UC PROCESSING SITES, SLICK ROCK, COLORADO

SITE: SRKO1 SLICK ROCK (BOTH SITES)

01/12/89 TO $10 / 14 / 92$

\begin{tabular}{|c|c|c|c|c|c|c|c|c|c|c|}
\hline PARAMETER NAME & $\begin{array}{c}\text { LOCAT ION } \\
\text { ID }\end{array}$ & LOG DATE & $\underset{\text { SD }}{\text { SAMPLE }}$ & $\begin{array}{l}\text { MAT. } \\
\text { SAMP }\end{array}$ & $\begin{array}{l}\text { FLOW } \\
\text { REL. }\end{array}$ & $\begin{array}{l}\text { UNITS OF } \\
\text { MEASURE }\end{array}$ & $\begin{array}{c}\text { PARAMETER } \\
\text { PVI VALUE }\end{array}$ & FLAGS & $\begin{array}{l}\text { DETECTION } \\
\text { LIMIT }\end{array}$ & $\begin{array}{l}\text { PARAMETER } \\
\text { UNCERTAINTY }\end{array}$ \\
\hline SODIUM & $\begin{array}{l}0207 \\
0514 \\
0515 \\
0515 \\
0515\end{array}$ & $\begin{array}{l}10 / 14 / 92 \\
01 / 12 / 89 \\
01 / 12 / 89 \\
04 / 17 / 91 \\
08 / 07 / 91\end{array}$ & $\begin{array}{l}0001 \\
0001 \\
0001 \\
0001 \\
0001\end{array}$ & $\begin{array}{l}\text { AL } \\
\text { TA } \\
\text { TA } \\
\text { TA } \\
\text { TA }\end{array}$ & $\begin{array}{l}N \\
0 \\
0 \\
0 \\
0\end{array}$ & $M G / L$ & $\begin{array}{l}55 . \\
25.2 \\
44.7 \\
695 . \\
591 .\end{array}$ & & $\begin{array}{l}1 . \\
0.002 \\
0.002 \\
20 . \\
5 .\end{array}$ & $\begin{array}{l}- \\
- \\
-\end{array}$ \\
\hline SOOIUM (TOTAL) & $\begin{array}{l}0203 \\
0204 \\
0206 \\
0207 \\
0208 \\
0210 \\
0515\end{array}$ & $\begin{array}{l}12 / 12 / 90 \\
12 / 12 / 90 \\
12 / 12 / 90 \\
12 / 12 / 90 \\
10 / 14 / 92 \\
12 / 12 / 90 \\
10 / 14 / 92\end{array}$ & $\begin{array}{l}\text { N001 } \\
\text { N001 } \\
\text { N001 } \\
\text { N001 } \\
\text { N001 } \\
\text { N001 } \\
\text { H001 }\end{array}$ & $\begin{array}{l}A L \\
A L \\
A L \\
A L \\
A R \\
A L \\
T A\end{array}$ & $\begin{array}{l}N \\
N \\
N \\
N \\
N \\
N \\
0\end{array}$ & MG/L & $\begin{array}{c}3370 . \\
54.4 \\
149 . \\
63.1 \\
88 . \\
189 . \\
510 .\end{array}$ & & $\begin{array}{l}0.002 \\
0.002 \\
0.002 \\
0.002 \\
1 . \\
0.002 \\
5 .\end{array}$ & $\begin{array}{l}- \\
- \\
- \\
- \\
-\end{array}$ \\
\hline SPECIFIC CONDUCTANCE & $\begin{array}{l}0202 \\
0202 \\
0202 \\
0203 \\
0203 \\
0203 \\
0204 \\
0204 \\
0204 \\
0204 \\
0205 \\
0205 \\
0205 \\
0206 \\
0206 \\
0206 \\
0207 \\
0210 \\
0514 \\
0515 \\
0515 \\
0515\end{array}$ & $\begin{array}{l}12 / 12 / 90 \\
04 / 17 / 91 \\
12 / 11 / 91 \\
12 / 12 / 90 \\
04 / 17 / 91 \\
12 / 11 / 91 \\
12 / 12 / 90 \\
04 / 17 / 91 \\
08 / 07 / 91 \\
12 / 11 / 91 \\
12 / 12 / 90 \\
04 / 17 / 91 \\
12 / 11 / 91 \\
12 / 12 / 90 \\
04 / 17 / 91 \\
08 / 07 / 91 \\
08 / 07 / 91 \\
12 / 12 / 90 \\
01 / 12 / 89 \\
01 / 12 / 89 \\
04 / 17 / 91 \\
12 / 09 / 91\end{array}$ & $\begin{array}{l}\text { NO01 } \\
0001 \\
0001 \\
\text { N001 } \\
0001 \\
0001 \\
\text { N001 } \\
0001 \\
0001 \\
0001 \\
\text { N001 } \\
0001 \\
0001 \\
\text { N001 } \\
0001 \\
0001 \\
0001 \\
\text { N001 } \\
0001 \\
0001 \\
0001 \\
0001\end{array}$ & $\begin{array}{l}A L \\
A L \\
A L \\
A L \\
A L \\
A L \\
A L \\
A L \\
A L \\
A L \\
A L \\
A L \\
A L \\
A L \\
A L \\
A L \\
A L \\
A L \\
T A \\
T A \\
T A \\
T A\end{array}$ & $\begin{array}{l}N \\
N \\
N \\
N \\
N \\
N \\
N \\
N \\
N \\
N \\
N \\
N \\
N \\
N \\
N \\
N \\
N \\
N \\
0 \\
0 \\
0 \\
0\end{array}$ & UMHO/CM & $\begin{array}{c}6400 . \\
13950 . \\
15900 \\
17700 . \\
15550 . \\
21200 \\
2510 . \\
1986 . \\
2310 \\
2450 \\
27300 . \\
20700 . \\
36000 \\
3380 . \\
4410 . \\
3960 \\
4100 \\
2950 . \\
1825 . \\
1500 . \\
4850 . \\
5570\end{array}$ & & $\begin{array}{l}- \\
- \\
- \\
- \\
- \\
- \\
- \\
- \\
- \\
- \\
- \\
- \\
- \\
- \\
- \\
- \\
-\end{array}$ & $\begin{array}{l}- \\
- \\
- \\
- \\
- \\
- \\
- \\
- \\
- \\
- \\
- \\
- \\
- \\
- \\
- \\
- \\
- \\
-\end{array}$ \\
\hline STRONTIUM & $\begin{array}{l}0202 \\
0202\end{array}$ & $\begin{array}{l}04 / 17 / 91 \\
12 / 11 / 91\end{array}$ & $\begin{array}{l}0001 \\
0001\end{array}$ & $\begin{array}{l}A L \\
A L\end{array}$ & $\begin{array}{l}\mathbf{N} \\
\mathbf{N}\end{array}$ & MG/L & $\begin{array}{l}12.7 \\
13.5\end{array}$ & & $\begin{array}{l}0.05 \\
0.01\end{array}$ & - \\
\hline
\end{tabular}

\section{MATERIAL OF SAMPLING CODE:}

AL - ALLUVIUM

URANIUM MILL TALLINGS

NR - NO RECOVERY OF DATA FOR CLASSIFYING

PARAMETER VALUE INDICATOR (PVI): < - LESS THAN DETECTION LIMIT
FLOH RELATIONSHIP CODE:

N - UNKHOWN

O - ON-SITE

SAMPLE IO CODES:

0001 - FILTERED SAMPLE (.45 MICRONS)

NOO1 - UMFILTERED SAMPLE 
TABLE 3.21 TAILINGS PORE FLUID MATER QUALITY DATA BY PARAMETER, NC AND UC PROCESSING SITES, SLICK ROCK, COLORADO

SITE: SRKO1 SLICK ROCK (BOTH SITES)

01/12/89 TO $10 / 14 / 92$

REPORT DATE: $06 / 17 / 93$

\begin{tabular}{|c|c|c|c|c|c|c|c|c|c|c|c|c|}
\hline & PARAMETER NAME & $\begin{array}{c}\text { LOCATION } \\
\text { ID }\end{array}$ & LOG DATE & $\begin{array}{c}\text { SAMPLE } \\
\text { ID }\end{array}$ & $\begin{array}{l}\text { MAT. } \\
\text { SAMP }\end{array}$ & $\begin{array}{l}\text { FLOW } \\
\text { REL. }\end{array}$ & $\begin{array}{l}\text { UNITS OF } \\
\text { MEASURE }\end{array}$ & PVI & $\begin{array}{l}\text { PARAMETER } \\
\text { VALUE }\end{array}$ & FLAGS & $\begin{array}{l}\text { DETECTION } \\
\text { LIMIT }\end{array}$ & $\begin{array}{l}\text { PARAMETER } \\
\text { UNCERTAINTY }\end{array}$ \\
\hline & STRONTIUM & $\begin{array}{l}0202 \\
0203 \\
0203 \\
0203 \\
0203 \\
0204 \\
0204 \\
0204 \\
0204 \\
0205 \\
0205 \\
0205 \\
0206 \\
0206 \\
0206 \\
0207 \\
0207 \\
0514 \\
0515 \\
0515 \\
0515\end{array}$ & $\begin{array}{l}10 / 14 / 92 \\
04 / 17 / 91 \\
08 / 07 / 91 \\
12 / 11 / 91 \\
10 / 14 / 92 \\
04 / 17 / 91 \\
08 / 07 / 91 \\
12 / 11 / 91 \\
10 / 14 / 92 \\
04 / 17 / 91 \\
12 / 11 / 91 \\
10 / 14 / 92 \\
04 / 17 / 91 \\
08 / 07 / 91 \\
10 / 14 / 92 \\
08 / 07 / 91 \\
10 / 14 / 92 \\
01 / 12 / 89 \\
01 / 12 / 89 \\
04 / 17 / 91 \\
08 / 07 / 91\end{array}$ & $\begin{array}{l}0001 \\
0001 \\
0001 \\
0001 \\
0001 \\
0001 \\
0001 \\
0001 \\
0001 \\
0001 \\
0001 \\
0001 \\
0001 \\
0001 \\
0001 \\
0001 \\
0001 \\
0001 \\
0001 \\
0001 \\
0001\end{array}$ & $\begin{array}{l}A L \\
A L \\
A L \\
A L \\
A L \\
A L \\
A L \\
A L \\
A L \\
A L \\
A L \\
A L \\
A L \\
A L \\
A L \\
A L \\
A L \\
T A \\
T A \\
T A \\
T A\end{array}$ & $\begin{array}{l}N \\
N \\
N \\
N \\
N \\
N \\
N \\
N \\
N \\
N \\
N \\
N \\
N \\
N \\
N \\
N \\
N \\
0 \\
0 \\
0 \\
0\end{array}$ & $M G / L$ & & $\begin{array}{l}14.0 \\
19.0 \\
19.0 \\
21.5 \\
19.6 \\
3.60 \\
3.76 \\
6.89 \\
3.6 \\
22.2 \\
22.0 \\
21.0 \\
4.65 \\
4.89 \\
4.30 \\
6.07 \\
6.37 \\
3.8 \\
3.7 \\
7.25 \\
6.11\end{array}$ & & $\begin{array}{l}0.01 \\
0.05 \\
0.01 \\
0.01 \\
0.01 \\
0.05 \\
0.01 \\
0.01 \\
0.1 \\
0.05 \\
0.01 \\
0.01 \\
0.05 \\
0.01 \\
0.01 \\
0.01 \\
0.01 \\
0.1 \\
0.1 \\
0.05 \\
0.01\end{array}$ & $\begin{array}{l}- \\
- \\
- \\
- \\
- \\
- \\
- \\
- \\
- \\
- \\
- \\
- \\
- \\
- \\
- \\
-\end{array}$ \\
\hline & STRONTIUM (TOTAL) & $\begin{array}{l}0203 \\
0204 \\
0206 \\
0207 \\
0208 \\
0210 \\
0515\end{array}$ & $\begin{array}{l}12 / 12 / 90 \\
12 / 12 / 90 \\
12 / 12 / 90 \\
12 / 12 / 90 \\
10 / 14 / 92 \\
12 / 12 / 90 \\
10 / 14 / 92\end{array}$ & $\begin{array}{l}\text { N001 } \\
\text { N001 } \\
\text { N001 } \\
\text { NO01 } \\
\text { NO01 } \\
\text { N001 } \\
\text { N001 }\end{array}$ & $\begin{array}{l}A L \\
A L \\
A L \\
A L \\
N R \\
A L \\
T A\end{array}$ & $\begin{array}{l}N \\
N \\
N \\
N \\
N \\
N \\
0\end{array}$ & $M G / L$ & & $\begin{array}{l}23.7 \\
3.8 \\
5.3 \\
6.4 \\
6.31 \\
5.7 \\
5.30\end{array}$ & & $\begin{array}{l}0.1 \\
0.1 \\
0.1 \\
0.1 \\
0.01 \\
0.1 \\
0.01\end{array}$ & $\begin{array}{l}: \\
: \\
: \\
-\end{array}$ \\
\hline & SULFATE & $\begin{array}{l}0202 \\
0203 \\
0204 \\
0205 \\
0206 \\
0207 \\
0514 \\
0515\end{array}$ & $\begin{array}{l}10 / 14 / 92 \\
10 / 14 / 92 \\
10 / 14 / 92 \\
10 / 14 / 92 \\
10 / 14 / 92 \\
10 / 14 / 92 \\
01 / 12 / 89 \\
01 / 12 / 89\end{array}$ & $\begin{array}{l}0001 \\
0001 \\
0001 \\
0001 \\
0001 \\
0001 \\
0001 \\
0001\end{array}$ & $\begin{array}{l}A L \\
A L \\
A L \\
A L \\
A L \\
A L \\
T A \\
T A\end{array}$ & $\begin{array}{l}N \\
N \\
N \\
N \\
N \\
N \\
0 \\
0\end{array}$ & $M G / L$ & & $\begin{array}{c}9490 . \\
12500 . \\
1450 . \\
18800 . \\
1500 . \\
1840 . \\
2030 . \\
1870 .\end{array}$ & & $\begin{array}{l}10 . \\
10 . \\
10 . \\
10 . \\
10 . \\
10 . \\
0.1 \\
0.1\end{array}$ & $\begin{array}{l}- \\
- \\
- \\
- \\
- \\
-\end{array}$ \\
\hline & SULFATE (TOTAL) & 0202 & $12 / 12 / 90$ & N001 & AL & $\mathbf{N}$ & MG/L & & 7950. & & 0.1 & - \\
\hline
\end{tabular}

MATERIAL OF SAMPLING COOE:

AL - ALLUVIUM

TA - URAHIUM MILL TAILINGS

NR - NO RECOVERY OF DATA FOR CLASSIFYING

PARAMETER VALUE INDICATOR (PVI): < - LESS THAH DETECTION LIMIT
FLOH RELATIONSHIP CODE:

H - UNKHOWH

SAMPLE ID CODES

0001 - FILTERED SAMPLE (.45 MICRONS)

NOO1 - UNFILTERED SAMPLE 
TABLE 3.21 TAILINGS PORE FLUID HATER QUALITY DATA BY PARAMETER, NC AND UC PROCESSING SITES, SLICK ROCK, COLORADO

SITE: SRKO1 SLICK ROCK (BOTH SITES)

$01 / 12 / 8$

REPORT DATE: $06 / 17 / 93$

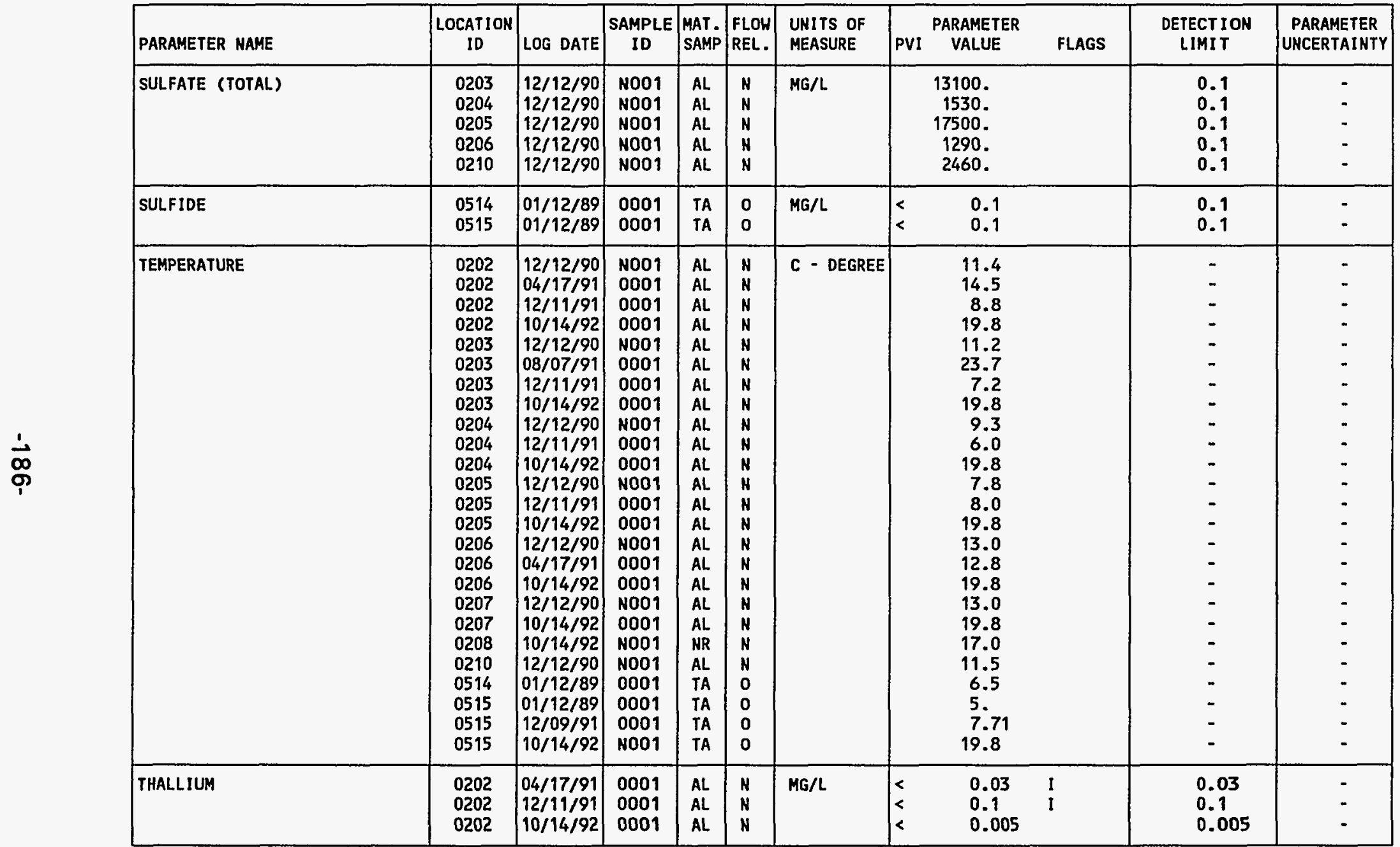

\section{MATERIAL OF SAMPLIHG COOE:}

AL - ALLUVIUM

TA - URANIUM MILL TAILINGS

NR - NO RECOVERY OF DATA FOR CLASSIFYING

PARAMETER VALUE INDICATOR (PVI): < - LESS THAN DETECTION LIMIT

OTHER PARAMETER VALUE FLAGS:

I - INCREASED DETECTION LIMIT DUE TO REQUIRED DILUTION
FLOW RELATIONSHIP COOE:

N - UNKNOWN
O - ON-SITE

SAMPLE ID COOES:

0001 - FILTERED SAMPLE (.45 MICRONS)

NO01 - UNFILTERED SAMPLE 
TABLE 3.21 TAILINGS PORE FLUID HATER QUALITY DATA BY PARAMETER, NC AND UC PROCESSING SITES, SLICK ROCK, COLORADO

SITE: SRKO1 SLICK ROCK (BOTH SITES)

01/12/89 TO $10 / 14 / 92$

\begin{tabular}{|c|c|c|c|c|c|c|c|c|c|c|c|}
\hline PARAMETER NAME & $\underset{\text { ID }}{\text { LOCATION }}$ & LOG DATE & $\begin{array}{c}\text { SAMPLE } \\
\text { ID }\end{array}$ & $\begin{array}{l}\text { MAT. } \\
\text { SAMP }\end{array}$ & $\begin{array}{l}\text { FLOH } \\
\text { REL. }\end{array}$ & $\begin{array}{l}\text { UNITS OF } \\
\text { MEASURE }\end{array}$ & PVI & $\begin{array}{l}\text { PARAMETER } \\
\text { VALUE }\end{array}$ & FLAGS & $\begin{array}{l}\text { DETECT ION } \\
\text { LIMIT }\end{array}$ & $\begin{array}{l}\text { PARAMETER } \\
\text { UNCERTAINTY }\end{array}$ \\
\hline THALLIUM & $\begin{array}{l}0203 \\
0203 \\
0203 \\
0203 \\
0204 \\
0204 \\
0204 \\
0204 \\
0205 \\
0205 \\
0205 \\
0206 \\
0206 \\
0206 \\
0207 \\
0207 \\
0514 \\
0515 \\
0515 \\
0515\end{array}$ & $\begin{array}{l}04 / 17 / 91 \\
08 / 07 / 91 \\
12 / 111 / 91 \\
10 / 14 / 92 \\
04 / 17 / 91 \\
08 / 07 / 91 \\
12 / 11 / 91 \\
10 / 14 / 92 \\
04 / 17 / 91 \\
12 / 11 / 91 \\
10 / 14 / 92 \\
04 / 17 / 91 \\
08 / 07 / 91 \\
10 / 14 / 92 \\
08 / 07 / 91 \\
10 / 14 / 92 \\
01 / 12 / 89 \\
01 / 12 / 89 \\
04 / 17 / 91 \\
08 / 07 / 91\end{array}$ & $\begin{array}{l}0001 \\
0001 \\
0001 \\
0001 \\
0001 \\
0001 \\
0001 \\
0001 \\
0001 \\
0001 \\
0001 \\
0001 \\
0001 \\
0001 \\
0001 \\
0001 \\
0001 \\
0001 \\
0001 \\
0001\end{array}$ & $\begin{array}{l}A L \\
A L \\
A L \\
A L \\
A L \\
A L \\
A L \\
A L \\
A L \\
A L \\
A L \\
A L \\
A L \\
A L \\
A L \\
A L \\
T A \\
T A \\
T A \\
T A\end{array}$ & $\begin{array}{l}N \\
N \\
N \\
N \\
N \\
N \\
N \\
N \\
N \\
N \\
N \\
N \\
N \\
N \\
N \\
N \\
0 \\
0 \\
0 \\
0\end{array}$ & $M G / L$ & $\begin{array}{l}< \\
< \\
< \\
< \\
< \\
< \\
< \\
< \\
< \\
< \\
< \\
< \\
< \\
< \\
< \\
< \\
< \\
< \\
< \\
< \\
< \\
<\end{array}$ & $\begin{array}{l}0.03 \\
0.01 \\
0.1 \\
0.02 \\
0.01 \\
0.01 \\
0.1 \\
0.005 \\
0.1 \\
0.1 \\
0.02 \\
0.01 \\
0.05 \\
0.005 \\
0.01 \\
0.005 \\
0.01 \\
0.01 \\
0.01 \\
0.01\end{array}$ & $\begin{array}{l}I \\
I \\
I \\
I \\
I \\
I \\
I \\
I\end{array}$ & $\begin{array}{l}0.03 \\
0.01 \\
0.1 \\
0.02 \\
0.01 \\
0.01 \\
0.1 \\
0.005 \\
0.1 \\
0.1 \\
0.02 \\
0.01 \\
0.05 \\
0.005 \\
0.01 \\
0.005 \\
0.01 \\
0.01 \\
0.01 \\
0.01\end{array}$ & $\begin{array}{l}- \\
- \\
- \\
- \\
- \\
- \\
- \\
- \\
- \\
- \\
- \\
- \\
-\end{array}$ \\
\hline THALLIUM (TOTAL) & $\begin{array}{l}0203 \\
0204 \\
0206 \\
0207 \\
0208 \\
0210\end{array}$ & $\begin{array}{l}12 / 12 / 90 \\
12 / 12 / 90 \\
12 / 12 / 90 \\
12 / 12 / 90 \\
10 / 14 / 92 \\
12 / 12 / 90\end{array}$ & $\begin{array}{l}\text { N001 } \\
\text { N001 } \\
\text { N001 } \\
\text { N001 } \\
\text { N001 } \\
\text { N001 }\end{array}$ & $\begin{array}{l}A L \\
A L \\
A L \\
A L \\
N R \\
A L\end{array}$ & $\begin{array}{l}N \\
N \\
N \\
N \\
N \\
N\end{array}$ & $M G / L$ & $\begin{array}{l}< \\
< \\
< \\
< \\
< \\
<\end{array}$ & $\begin{array}{l}0.01 \\
0.01 \\
0.01 \\
0.01 \\
0.005 \\
0.01\end{array}$ & & $\begin{array}{l}0.01 \\
0.01 \\
0.01 \\
0.01 \\
0.005 \\
0.01\end{array}$ & $\begin{array}{l}- \\
- \\
- \\
- \\
-\end{array}$ \\
\hline TIN & $\begin{array}{l}0202 \\
0202 \\
0202 \\
0203 \\
0203 \\
0203 \\
0203 \\
0204 \\
0204 \\
0204\end{array}$ & $\begin{array}{l}04 / 17 / 91 \\
12 / 11 / 91 \\
10 / 14 / 92 \\
04 / 17 / 91 \\
08 / 07 / 91 \\
12 / 11 / 91 \\
10 / 14 / 92 \\
04 / 17 / 91 \\
08 / 07 / 91 \\
12 / 11 / 91\end{array}$ & $\begin{array}{l}0001 \\
0001 \\
0001 \\
0001 \\
0001 \\
0001 \\
0001 \\
0001 \\
0001 \\
0001\end{array}$ & $\begin{array}{l}A L \\
A L \\
A L \\
A L \\
A L \\
A L \\
A L \\
A L \\
A L \\
A L\end{array}$ & $\begin{array}{l}N \\
N \\
N \\
N \\
N \\
N \\
N \\
N \\
N \\
N\end{array}$ & $M G / L$ & $\begin{array}{l}< \\
< \\
< \\
< \\
< \\
< \\
< \\
< \\
< \\
<\end{array}$ & $\begin{array}{l}0.05 \\
0.5 \\
0.2 \\
0.05 \\
0.3 \\
0.03 \\
0.2 \\
0.01 \\
0.005 \\
0.03\end{array}$ & $\begin{array}{l}1 \\
I \\
1 \\
I \\
1 \\
1 \\
1 \\
1 \\
1 \\
1\end{array}$ & $\begin{array}{l}0.05 \\
0.5 \\
0.2 \\
0.05 \\
0.3 \\
0.03 \\
0.2 \\
0.01 \\
0.005 \\
0.03\end{array}$ & $\begin{array}{l}- \\
- \\
- \\
- \\
- \\
- \\
-\end{array}$ \\
\hline
\end{tabular}

MATERIAL OF SAMPLING CODE:

AL - ALLUVIUM

TA - URANIUM MILL TAILIHGS

NR - NO RECOVERY OF DATA FOR CLASSIFYING

PARAMETER VALUE INDICATOR (PVI): < - LESS THAN DETECTION LIMIT

FLOH RELATIONSHIP CODE:

H - UNKNOWN

SAMPLE ID CODES:

OTHER PARAMETER VALUE FLAGS:

0001 - FILTERED SAMPLE (.45 MICRONS)

I - IHCREASED DETECTION LIMIT DUE TO REQUIRED DILUTION

HOO1 - UNFILTERED SAMPLE 
TABLE 3.21 TAILINGS PORE FLUID WATER QUALITY DATA BY PARAMETER, NC AND UC PROCESSING SITES, SLICK ROCK, COLORADO

SITE: SRKO1 SLICK ROCK (BOTH SITES)

01/12/89 TO $10 / 14 / 92$

REPORT DATE: $06 / 17 / 93$

\begin{tabular}{|c|c|c|c|c|c|c|c|c|c|c|c|c|}
\hline & PARAMETER NAME & $\begin{array}{c}\text { LOCATION } \\
\text { ID }\end{array}$ & LOG DATE & $\begin{array}{c}\text { SAMPLE } \\
\text { ID }\end{array}$ & $\begin{array}{l}\text { MAT. } \\
\text { SAMP }\end{array}$ & $\begin{array}{l}\text { FLOW } \\
\text { REL. }\end{array}$ & $\begin{array}{l}\text { UNITS OF } \\
\text { MEASURE }\end{array}$ & PVI & $\begin{array}{l}\text { PARAMETER } \\
\text { VALUE }\end{array}$ & FLAGS & $\begin{array}{l}\text { DETECTION } \\
\text { LIMIT }\end{array}$ & $\begin{array}{l}\text { PARAMETER } \\
\text { UNCERTAINTY }\end{array}$ \\
\hline & TIN & $\begin{array}{l}0204 \\
0205 \\
0205 \\
0205 \\
0206 \\
0206 \\
0206 \\
0207 \\
0207 \\
0514 \\
0515 \\
0515 \\
0515\end{array}$ & $\begin{array}{l}10 / 14 / 92 \\
04 / 17 / 91 \\
12 / 11 / 91 \\
10 / 14 / 92 \\
04 / 17 / 91 \\
08 / 07 / 91 \\
10 / 14 / 92 \\
08 / 07 / 91 \\
10 / 14 / 92 \\
01 / 12 / 89 \\
01 / 12 / 89 \\
04 / 17 / 91 \\
08 / 07 / 91\end{array}$ & $\begin{array}{l}0001 \\
0001 \\
0001 \\
0001 \\
0001 \\
0001 \\
0001 \\
0001 \\
0001 \\
0001 \\
0001 \\
0001 \\
0001\end{array}$ & $\begin{array}{l}A L \\
A L \\
A L \\
A L \\
A L \\
A L \\
A L \\
A L \\
A L \\
T A \\
T A \\
T A \\
T A\end{array}$ & $\begin{array}{l}N \\
N \\
N \\
N \\
N \\
N \\
N \\
N \\
N \\
0 \\
0 \\
0 \\
0\end{array}$ & $M G / L$ & $\begin{array}{l}< \\
< \\
< \\
< \\
< \\
< \\
< \\
< \\
< \\
< \\
< \\
< \\
<\end{array}$ & $\begin{array}{l}0.005 \\
0.05 \\
0.5 \\
0.2 \\
0.01 \\
0.01 \\
0.005 \\
0.005 \\
0.05 \\
0.006 \\
0.008 \\
0.01 \\
0.05\end{array}$ & $\begin{array}{l}1 \\
1 \\
1 \\
1 \\
1 \\
1 \\
1 \\
1\end{array}$ & $\begin{array}{l}0.005 \\
0.05 \\
0.5 \\
0.2 \\
0.01 \\
0.01 \\
0.005 \\
0.005 \\
0.05 \\
0.005 \\
0.005 \\
0.01 \\
0.05\end{array}$ & $\begin{array}{l}- \\
- \\
- \\
- \\
- \\
- \\
- \\
- \\
-\end{array}$ \\
\hline & TIN (TOTAL) & $\begin{array}{l}0203 \\
0204 \\
0206 \\
0207 \\
0210\end{array}$ & $\begin{array}{l}12 / 12 / 90 \\
12 / 12 / 90 \\
12 / 12 / 90 \\
12 / 12 / 90 \\
12 / 12 / 90\end{array}$ & $\begin{array}{l}\text { No01 } \\
\text { No01 } \\
\text { N001 } \\
\text { N001 } \\
\text { N001 }\end{array}$ & $\begin{array}{l}\text { AL } \\
\text { AL } \\
\text { AL } \\
\text { AL } \\
\text { AL }\end{array}$ & $\begin{array}{l}N \\
N \\
N \\
N \\
N\end{array}$ & $M G / L$ & $<$ & $\begin{array}{l}0.012 \\
0.012 \\
0.005 \\
0.005 \\
0.15\end{array}$ & & $\begin{array}{l}0.005 \\
0.005 \\
0.005 \\
0.005 \\
0.005\end{array}$ & $\begin{array}{l}- \\
: \\
-\end{array}$ \\
\hline & TOTAL KJELDAHL NITROGEN & 0206 & 08/07/91 & 0001 & AL & $\mathbf{N}$ & $M G / L$ & & 1. & & 1. & - \\
\hline & URANIUM & $\begin{array}{l}0202 \\
0202 \\
0203 \\
0203 \\
0204 \\
0204 \\
0205\end{array}$ & $\begin{array}{l}04 / 17 / 91 \\
10 / 14 / 92 \\
04 / 17 / 91 \\
10 / 14 / 92 \\
04 / 17 / 91 \\
10 / 14 / 92 \\
04 / 17 / 91\end{array}$ & $\begin{array}{l}0001 \\
0001 \\
0001 \\
0001 \\
0001 \\
0001 \\
0001\end{array}$ & $\begin{array}{l}\text { AL } \\
\text { AL } \\
\text { AL } \\
\text { AL } \\
\text { AL } \\
\text { AL } \\
\text { AL }\end{array}$ & $\begin{array}{l}\mathbf{N} \\
\mathbf{N} \\
\mathbf{N} \\
\mathbf{N} \\
\mathbf{N} \\
\mathbf{N} \\
\mathbf{N}\end{array}$ & $M G / L$ & $<$ & $\begin{array}{c}2.93 \\
5.19 \\
9.33 \\
10.7 \\
0.023 \\
0.001 \\
20.4\end{array}$ & & $\begin{array}{l}0.001 \\
0.001 \\
0.001 \\
0.001 \\
0.001 \\
0.001 \\
0.001\end{array}$ & $\begin{array}{l}- \\
- \\
- \\
- \\
-\end{array}$ \\
\hline
\end{tabular}

MATERIAL OF SAMPLING CODE:

AL - ALLUVIUM

TA - URANIUM MILL TAILINGS

PARAMETER VALUE INDICATOR (PVI): < - LESS THAN DETECTION LIMIT

OTHER PARAMETER VALUE FLAGS:

H - HOLD TIME EXPIRED, VALUE SUSPECT

1 - INCREASED DETECTION LIMIT DUE TO REQUIRED DILUTION
FLOW RELATIONSHIP COOE:

$$
\begin{aligned}
& \text { N - UNKNOWN } \\
& \text { O - ON-SITE }
\end{aligned}
$$

SAMPLE ID CODES:

0001 - FILTERED SAMPLE (.45 MICRONS)

N001 - UNFILTERED SAMPLE 
TABLE 3.21 TAILINGS PORE FLUID WATER QUALITY DATA BY PARAMETER, NC AND UC

PROCESSING SITES, SLICK ROCK, COLORADO

SITE: SRKOI SLICK ROCK (BOTH SITES)

REPORT DATE: $06 / 17 / 93$

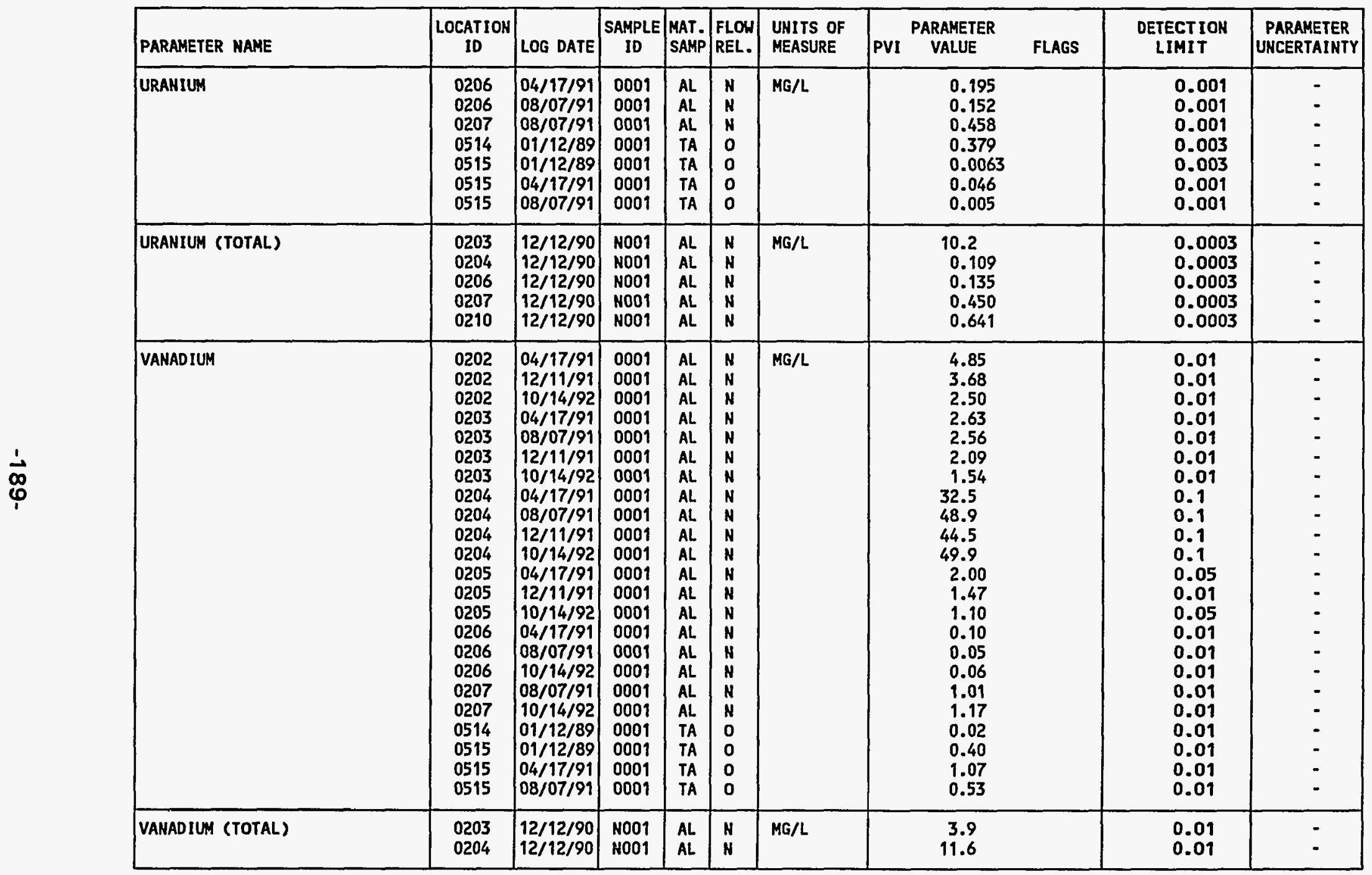

MATERIAL OF SAMPLING CODE:

AL - ALLLUVIUH

TA - URANIUM MILL TAILIHGS

PARAMETER VALUE IHDICATOR (PVI): < - LESS THAN DETECTION LIMIT
FLOW RELATIONSHIP CODE:

- UNKNOWN

SAMPLE ID CODES:

0001 - FILTERED SAMPLE (.45 MICRONS)

N001 - UNFILTERED SAMPLE 
TABLE 3.21 TAILIMGS PORE FLUID HATER QUALITY DATA BY PARAMETER, NC AND UC PROCESSING SITES, SLICK ROCK, COLORADO

SITE: SRKO1 SLICK ROCK (BOTH SITES)

$01 / 12 / 89$ TO $10 / 14 / 92$

REPORT DATE: $06 / 17 / 93$



MATERIAL OF SAMPLING CODE:

\section{AL. - ALLUVIUM}

NR - NO RECOVERY OF DATA FOR CLASSIFYING

TA - URANIUM MILL TAILINGS

PARAMETER VALUE INDICATOR (PVI): < - LESS THAN DETECTION LIMIT

FLOW RELATIONSHIP CODE:

N - UNKNOWN

SAMPLE ID COOES:

0001 - FILTERED SAMPLE (.45 MICRONS)

OTHER PARAMETER VALUE FLAGS:

I - INCREASED DETECTION LIMIT DUE TO REQUIRED DILUTIOH

H001 - UNFILTERED SAMPLE

DATA FILE NAME: M: DDARTISRKOIILYS10006.DAT 
TABLE 3.22 TAILINGS PORE FLUID HATER QUALITY STATISTICS BY PARAMETER,

NC PROCESSING SITE, SLICK ROCK, COLORADO

SITE: SRKO1 SLICK ROCK (BOTH SITES)

$12 / 12 / 90$ TO $10 / 14 / 92$

REPORT DATE: 07/26/93

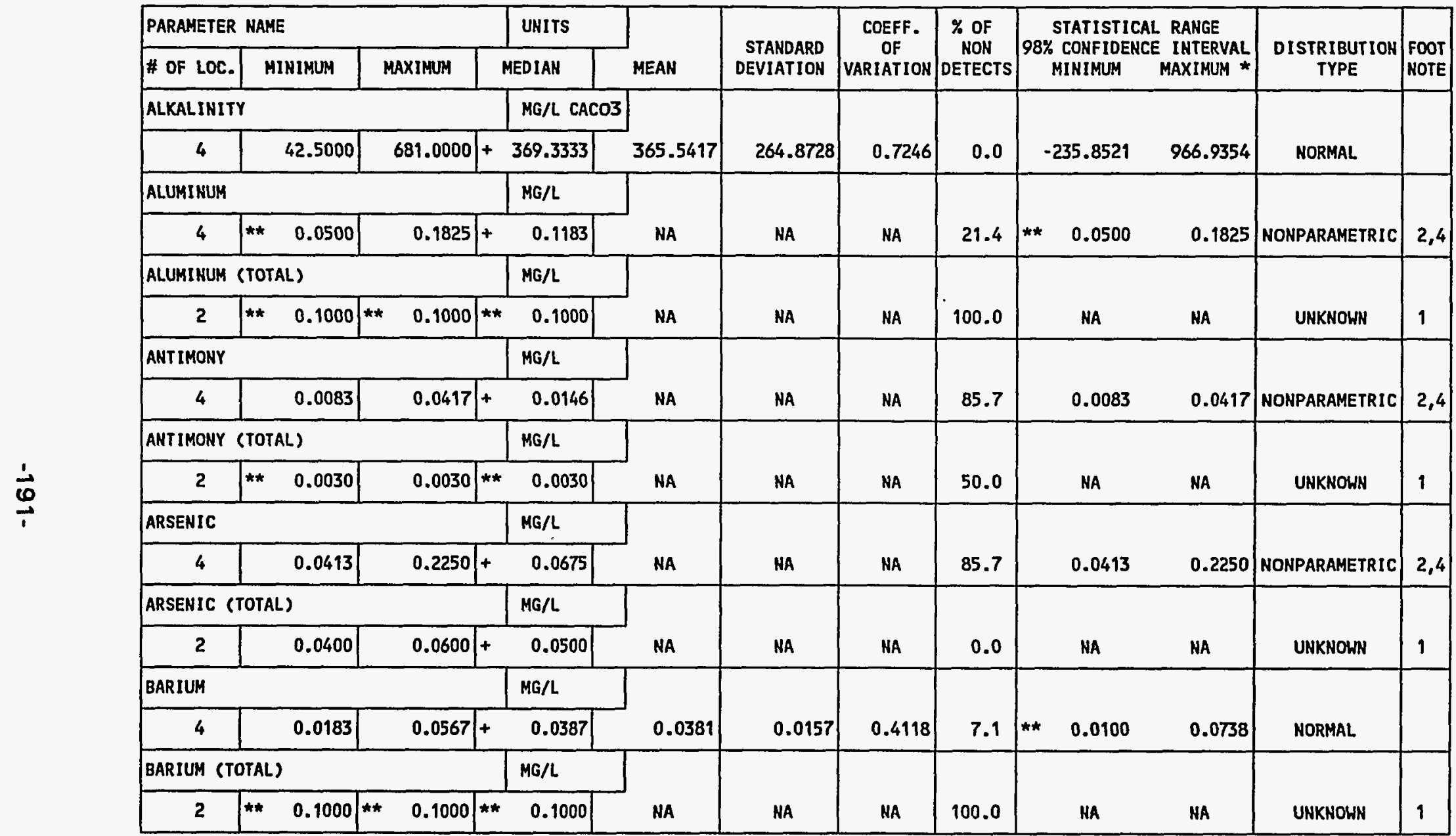

** The reported value is the minimum detection limit of the data set

+ The sample size is even, so the median value is the arithmetic average of the two middle values

* The statistical maximum is the 99 percent one sided confidence interval, $\alpha=0.01$

1) Data from a minimum of 4 locations must be available for the statistical analysis.

2) The nonparametric distribution was used because the nondetected values comprise more than $15 \%$ of the samples.

4) The stat. range is the $87.5 \%$ confidence interval due to a sample size of 4 . The maximum is the $93.8 \%$ one sided confidence int.

Note the data at each location was averaged before the statistical calculations were performed 
TABLE 3.22 TAILINGS PORE FLUID HATER QUALITY STATISTICS BY PARAMETER,

NC PROCESSING SITE, SLICK ROCK, COLORADO

SITE: SRKO1 SLICK ROCK (BOTH SITES)

$12 / 12 / 90$ TO $10 / 14 / 92$

REPORT DATE: $07 / 26 / 93$

\begin{tabular}{|c|c|c|c|c|c|c|c|c|c|c|c|}
\hline \multicolumn{3}{|c|}{ PARAMETER NAME } & UNITS & \multirow[b]{2}{*}{ MEAN } & \multirow{2}{*}{$\begin{array}{r}\text { STANDARD } \\
\text { DEVIAT ION }\end{array}$} & \multirow{2}{*}{$\begin{array}{c}\text { COEFF. } \\
\text { OF } \\
\text { VARIATION }\end{array}$} & \multirow{2}{*}{$\begin{array}{c}\% \text { OF } \\
\text { NON } \\
\text { DETECTS }\end{array}$} & \multirow{2}{*}{\multicolumn{2}{|c|}{$\begin{array}{l}\text { STATISTICAL RANGE } \\
\text { 98\% CONFIDENCE INTERVAL } \\
\text { MINIMUM MAXIMUM * }\end{array}$}} & \multirow{2}{*}{$\begin{array}{l}\text { DISTRIBUTION } \\
\text { TYPE }\end{array}$} & \multirow{2}{*}{$\begin{array}{l}\text { FOOT } \\
\text { NOTE }\end{array}$} \\
\hline \# OF LOC. & MINIMUM & MAXIMUM & MEDIAN & & & & & & & & \\
\hline \multicolumn{3}{|l|}{ BERYLLIUM } & MG/L & & \multirow[b]{2}{*}{ NA } & \multirow[b]{2}{*}{ NA } & \multirow[b]{2}{*}{60.0} & \multirow[b]{2}{*}{0.0050} & \multirow[b]{2}{*}{0.0333} & \multirow[b]{2}{*}{ NONPARAMETRIC } & \multirow[b]{2}{*}{2,4} \\
\hline 4 & $\begin{array}{ll}* * & 0.0050\end{array}$ & 0.0333 & 0.0070 & NA & & & & & & & \\
\hline \multicolumn{3}{|c|}{ BERYLLIUM (TOTAL) } & $M G / L$ & \multirow[b]{2}{*}{ NA } & \multirow[b]{2}{*}{ NA } & \multirow[b]{2}{*}{ NA } & \multirow[b]{2}{*}{0.0} & \multirow[b]{2}{*}{ NA } & \multirow[b]{2}{*}{ NA } & \multirow[b]{2}{*}{ UNKNOWN } & \multirow[b]{2}{*}{1} \\
\hline 2 & 0.0200 & 0.0500 & 0.0350 & & & & & & & & \\
\hline \multicolumn{3}{|l|}{ BORON } & $M G / L$ & \multirow[b]{2}{*}{1.0400} & \multirow[b]{2}{*}{0.6791} & \multirow[b]{2}{*}{0.6530} & \multirow[b]{2}{*}{0.0} & \multirow[b]{2}{*}{0.0500} & & & \\
\hline 4 & 0.1850 & 1.7350 & 1.1200 & & & & & & 2.5820 & NORMAL & \\
\hline BORON (TO & TAL) & & $M G / L$ & & & & & & & & \\
\hline 2 & 0.1000 & 1.7000 & 0.9000 & NA & NA & NA & 0.0 & NA & NA & UNKNOHN & 1 \\
\hline BROMIDE & & & MG/L & & & & & & & & \\
\hline BROMIDE ( & rotAL) & & $M G / L$ & & & & & & & & \\
\hline 4 & 0.0500 & 3.3000 & 2.3000 & NA & NA & NA & 25.0 & 0.0500 & 3.3000 & NONPARAMETRIC & 2,4 \\
\hline CADMIUM & & & $M G / L$ & & & & & & & & \\
\hline 4 & 0.0095 & 0.0793 & 0.0452 & NA & NA & NA & 42.9 & 0.0095 & 0.0793 & NONPARAMETRIC & 2,4 \\
\hline CADMIUM ( & TOTAL) & & $M G / L$ & & & & & & & & \\
\hline 2 & ** $\quad 0.0010$ & 0.0020 & 0.0013 & NA & NA & NA & 50.0 & NA & NA & UNKNOWN & 1 \\
\hline CALCIUM & & & $M G / L$ & & & & & & & & \\
\hline 4 & 419.3333 & 591.7500 & +442.4583 & 474.0000 & 81.1230 & 0.1711 & 0.0 & 289.8101 & 658.1899 & NORMAL & \\
\hline
\end{tabular}

** The reported value is the minimum detection limit of the data set

+ The sample size is even, so the median value is the arithmetic average of the two middle values

* The statistical maximum is the 99 percent one sided confidence interval, $\alpha=0.01$

1) Data from a minimum of 4 locations must be available for the statistical analysis.

2) The nonparametric distribution was used because the nondetected values comprise more than $15 \%$ of the samples.

4) The stat. range is the $\mathbf{8 7 . 5 \%}$ confidence interval due to a sample size of 4 . The maximum is the $93.8 \%$ one sided confidence int.

Note the data at each location was averaged before the statistical calculations were performed 
TABLE 3.22 TAILINGS PORE FLUID HATER QUALITY STATISTICS BY PARAMETER,

IC PROCESSING SITE, SLICK ROCK, COLORADO

SITE: SRKO1 SLICK ROCK (BOTH SITES)

12/12/90 TO $10 / 14 / 92$

REPORT DATE: 07/26/93

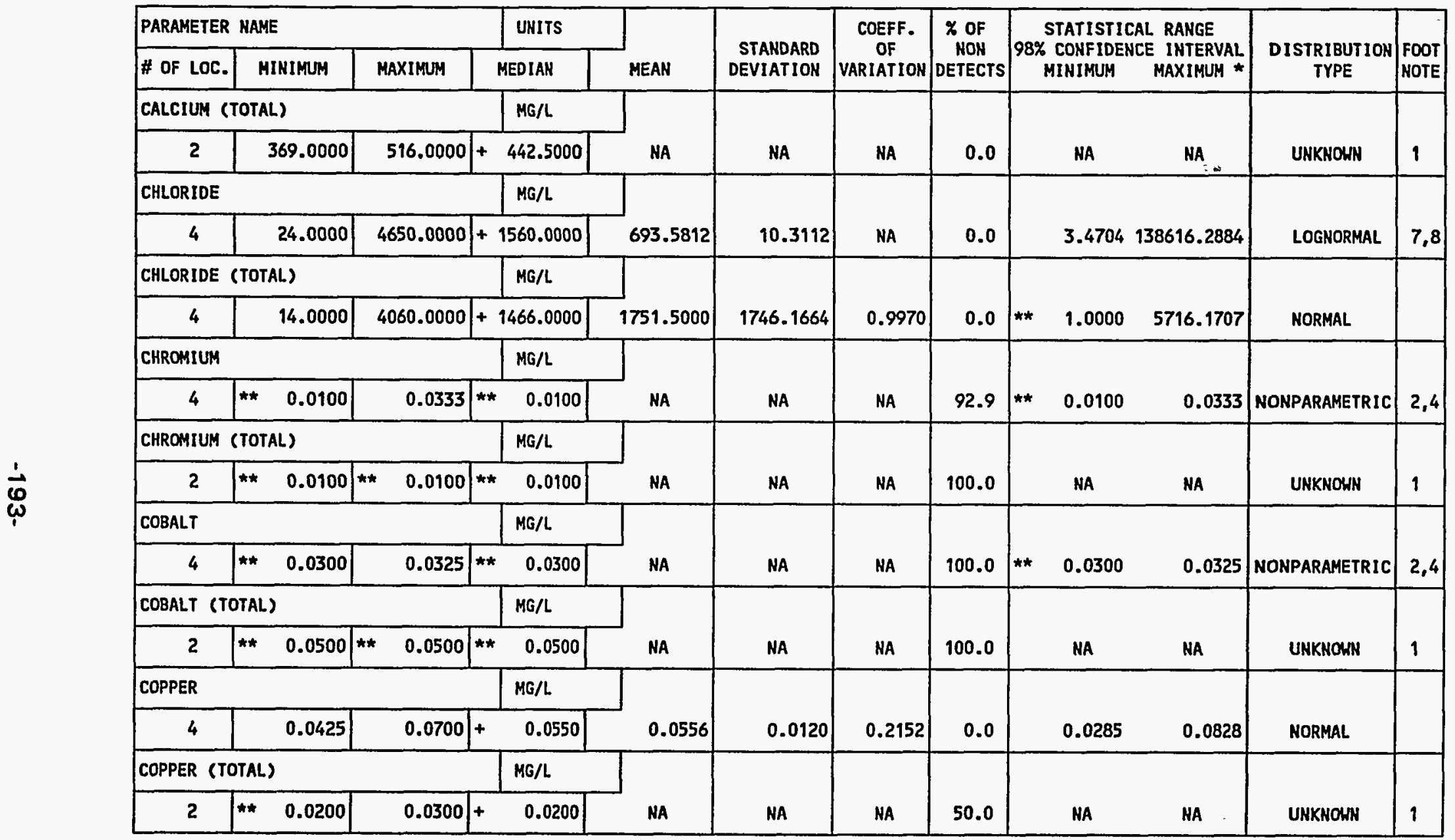

** The reported value is the minimm detection limit of the data set

+ The sample size is even, so the median value is the arithmetic average of the two middle values

* The statistical maximum is the 99 percent one sided confidence interval, $\alpha=0.01$

1) Data from a minimum of 4 locations must be available for the statistical analysis.

2) The nonparametric distribution was used because the nondetected values comprise more than $15 \%$ of the samples.

4) The stat. range is the $87.5 \%$ confidence interval due to a sample size of 4 . The maximum is the $93.8 \%$ one sided confidence int.

7) The lognormal distribution was used because the data failed the normal distribution test.

8) The mean is geometric. The standard deviation is the value to divide or multiply with the geometric mean.

Note the data at each location was averaged before the statistical calculations were performed 
TABLE 3.22 TAILINGS PORE FLUID WATER QUALITY STATISTICS BY PARAMETER,

NC PROCESSING SITE, SLICK ROCK, COLORADO

SITE: SRKO1 SLICK ROCK (BOTH SITES)

$12 / 12 / 90$ TO 10/14/92

REPORT DATE: $07 / 26 / 93$

\begin{tabular}{|c|c|c|c|c|c|c|c|c|c|c|c|c|}
\hline PARAMETER & NAME & & UNITS & & & COEFF. & & & STATISTIC & AL RANGE & & \\
\hline \# OF LOC. & MINIMUM & MAXIMUM & MEDIAN & MEAN & DEVIATION & VARIATION & DETECTS & & AINIMUM & MAXIMUM * & TYPE & $\begin{array}{l}\text { FUOI } \\
\text { NOTE }\end{array}$ \\
\hline FLUORIDE & & & $M G / L$ & & & & & & & & & \\
\hline 4 & 0.2000 & 3.0000 & 1.8000 & 1.7000 & 1.1747 & 0.6910 & 0.0 & ** & 0.1000 & 4.3672 & MORMAL & \\
\hline FLUORIDE & (TOTAL) & & MG/L & & & & & & & & & \\
\hline 4 & 0.3000 & 1.2000 & 0.7000 & 0.7250 & 0.3686 & 0.5084 & 0.0 & ** & 0.1000 & 1.5618 & NORMAL & \\
\hline GROSS ALPI & & & $\mathrm{PCI} / \mathrm{L}$ & & & & & & & & & \\
\hline 4 & 45.3000 & 7781.0000 & +3063.0000 & 3488.0750 & 3305.2146 & 0.9476 & 0.0 & ** & 1.0000 & 10992.5647 & HORMAL & \\
\hline GROSS ALPI & HA (TOTAL) & & PCI/L & & & & & & & & & \\
\hline 2 & 67.0000 & 4600.0000 & +2333.5000 & NA & NA & NA & 0.0 & & NA & NA & UNKNOWN & 1 \\
\hline GROSS BET & & & PCI/L & & & & & & & & & \\
\hline 4 & 34.7000 & 4895.0000 & +1904.5000 & 2184.6750 & 2155.0059 & 0.9864 & 0.0 & ** & 0.5000 & 7077.6158 & NORMAL & \\
\hline GROSS BETA & (TOTAL) & & $\mathrm{PCI} / \mathrm{L}$ & & & & & & & & & \\
\hline 2 & 74.0000 & 3100.0000 & +1587.0000 & NA & NA & NA & 0.0 & & NA & NA & UNKNOWN & 1 \\
\hline IRON & & & $M G / L$ & & & & & & & & & \\
\hline 4 & $\begin{array}{ll}* & 0.0300\end{array}$ & 0.0383 & 0.0300 & NA & NA & NA & 85.7 & ** & 0.0300 & 0.0383 & NONPARAMETRIC & 2,4 \\
\hline IRON (TOTA & & & $M G / L$ & & & & & & & & & \\
\hline 2 & 0.0900 & 0.7800 & 0.4350 & NA & NA & NA & 0.0 & & NA & NA & UNKNOWN & 1 \\
\hline LEAD & & & $M G / L$ & & & & & & & & & \\
\hline 4 & 0.0141 & 0.0583 & 0.0333 & NA & NA & NA & 100.0 & & 0.0141 & 0.0583 & NONPARAMETRIC & 2,4 \\
\hline
\end{tabular}

** The reported value is the minimum detection limit of the data set

+ The sample size is even, so the median value is the arithmetic average of the two middle values

* The statistical maximum is the 99 percent one sided confidence interval $\alpha=0.01$

1) Data from a minimum of 4 locations must be available for the statistical analysis.

2) The nonparametric distribution was used because the nondetected values comprise more than 15\% of the samples.

4) The stat. range is the $87.5 \%$ confidence interval due to a sample size of 4 . The maximum is the $93.8 \%$ one sided confidence int.

Note the data at each location was averaged before the statistical calculations were performed 
TABLE 3.22 TAILINGS PORE FLUID HATER QUALITY STATISTICS BY PARAMETER,

MC PROCESSING SITE, SLICK ROCK, COLORADO

SITE: SRKO1 SLICK ROCK (BOTH SITES)

$12 / 12 / 90$ TO $10 / 14 / 92$

REPORT DATE: $07 / 26 / 93$

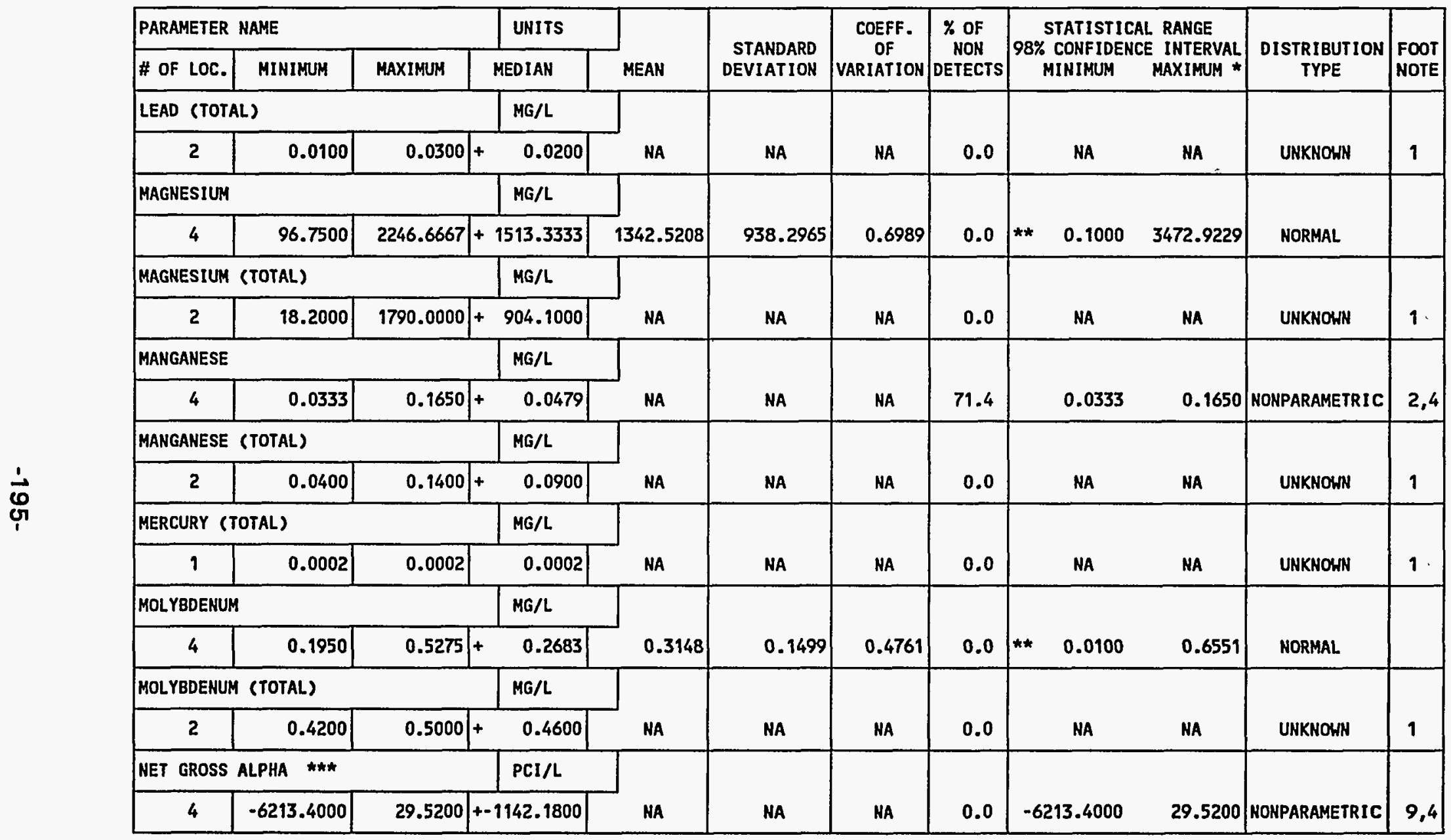

t** HET GROSS ALPHA (GROSS ALPHA - URANIUN) WITH 1 MG URANIUM = $686 \mathrm{PCI}$

** The reported value is the minimum detection limit of the data set

+ The sample size is even, so the median value is the arithmetic average of the two middle values

* The statistical maximum is the 99 percent one sided confidence interval, $\alpha=0.01$

1) Data from a minimum of 4 locations must be available for the statistical analysis.

2) The nonparametric distribution was used because the nondetected values comprise more than $15 \%$ of the samples.

4) The stat. range is the $87.5 \%$ confidence interval due to a sample size of 4 . The maximum is the $93.8 \%$ one sided confidence int.

9) The nonparametic distribution was used because the data failed the normal distribution test and includes values $\leq 0$.

Note the data at each location was averaged before the statistical calculations were performed 
TABLE 3.22 TAILINGS PORE FLUID WATER QUALITY STATISTICS BY PARAMETER, NC PROCESSING SITE, SLICK ROCK, COLORADO

SITE: SRK01 SLICK ROCK (BOTH SITES)

$12 / 12 / 90$ TO $10 / 14 / 92$

REPORT DATE: $07 / 26 / 93$

\begin{tabular}{|c|c|c|c|c|c|c|c|c|c|c|c|}
\hline \multicolumn{3}{|c|}{ PARAMETER NAME } & UNITS & \multirow[b]{2}{*}{ MEAN } & \multirow{2}{*}{$\begin{array}{r}\text { STANDARD } \\
\text { DEVIATION }\end{array}$} & \multirow{2}{*}{$\begin{array}{c}\text { COEFF. } \\
\text { OF } \\
\text { VARIATION }\end{array}$} & \multirow{2}{*}{$\begin{array}{l}\% \text { OF } \\
\text { NON } \\
\text { DETECTS }\end{array}$} & \multirow{2}{*}{\multicolumn{2}{|c|}{$\begin{array}{l}\text { STATISTICAL RANGE } \\
98 \% \text { CONFIDENCE INTERVAL } \\
\text { MINIMUM MAXIMUM * }\end{array}$}} & \multirow{2}{*}{$\begin{array}{l}\text { DISTRIBUTION } \\
\text { TYPE }\end{array}$} & \multirow{2}{*}{$\begin{array}{l}\text { FOOT } \\
\text { NOTE }\end{array}$} \\
\hline \# OF LOC. & MINIMUM & MAXIMUM & MEDIAN & & & & & & & & \\
\hline \multicolumn{3}{|c|}{ NET GROSS ALPHA (TOTAL) **** } & $\mathrm{PCI} / \mathrm{L}$ & \multirow[b]{2}{*}{ NA } & \multirow[b]{2}{*}{ NA } & \multirow[b]{2}{*}{ NA } & \multirow[b]{2}{*}{0.0} & \multirow[b]{2}{*}{ NA } & \multirow[b]{2}{*}{ NA } & \multirow[b]{2}{*}{ UNKNOWN } & \multirow[b]{2}{*}{1} \\
\hline 2 & -2397.2000 & -7.7700 & +-1202.4850 & & & & & & & & \\
\hline \multicolumn{3}{|l|}{ NICKEL } & $M G / L$ & \multirow[b]{2}{*}{ NA } & \multirow[b]{2}{*}{ NA } & \multirow[b]{2}{*}{ NA } & \multirow[b]{2}{*}{100.0} & \multirow[b]{2}{*}{0.0400} & \multirow[b]{2}{*}{0.0733} & \multirow[b]{2}{*}{ NONPARAMETRIC } & \multirow[b]{2}{*}{2,4} \\
\hline 4 & ** $\quad 0.0400$ & 0.0733 & ** $\quad 0.0400$ & & & & & & & & \\
\hline \multicolumn{3}{|c|}{ NICKEL. (TOTAL) } & $M G / L$ & \multirow[b]{2}{*}{ NA } & \multirow[b]{2}{*}{ NA } & \multirow[b]{2}{*}{ NA } & \multirow[b]{2}{*}{100.0} & & & & \\
\hline 2 & ** $\quad 0.0400$ & 0.0400 & 0.0400 & & & & & NA & NA & UNKNOWN & 1 \\
\hline PH & & & su & & & & & & & & \\
\hline 4 & 6.3851 & 7.6830 & 7.6451 & NA & NA & NA & 0.0 & NA & NA & UNKNOWN & \\
\hline PHOSPHATE & (TOTAL) & & $M G / L$ & & & & & & & & \\
\hline 4 & 0.9000 & 1.3000 & 1.1000 & 1.1000 & 0.2309 & 0.2099 & 0.0 & 0.5757 & 1.6243 & NORMAL & \\
\hline POTASSIUM & & & $\mathrm{MG} / \mathrm{L}$ & & & & & & & & \\
\hline 4 & 8.2050 & 124.7500 & 76.6667 & 71.5721 & 47.9485 & 0.6699 & 0.0 & 0.0100 & 180.4392 & NORMAL & \\
\hline POTASSIUM & (TOTAL) & & $M G / L$ & & & & & & & & \\
\hline 2 & 7.2000 & 175.0000 & 91.1000 & NA & NA & NA & 0.0 & NA & NA & UNKNOHN & 1 \\
\hline RADIUM-228 & & & $\mathrm{PCI} / \mathrm{L}$ & & & & & & & & \\
\hline 3 & ** $\quad 4.4000$ & 5.8000 & $\begin{array}{ll}* & 4.4000\end{array}$ & NA & NA & NA & 0.0 & NA & NA & UNKNOWN & 1 \\
\hline REDOX POTE & NTIAL & & mVOLTS & & & & & & & & \\
\hline 4 & 420.5000 & 487.8000 & $+\quad 437.4000$ & 445.7750 & 29.4471 & 0.0661 & 0.0 & 378.9155 & 512.6345 & NORMAL & \\
\hline
\end{tabular}

\section{**** NET GROSS ALPHA (TOTAL)}

(TOTAL GROSS ALPHA - TOTAL URANIUM)

** The reported value is the minimum detection limit of the data set

+ The sample size is even, so the median value is the arithmetic average of the two middle values

* The statistical maximum is the 99 percent one sided confidence interval, $\alpha=0.01$

1) Data from a minimum of 4 locations must be available for the statistical analysis.

2) The nonparametric distribution was used because the nondetected values comprise more than $15 \%$ of the samples.

4) The stat. range is the $87.5 \%$ confidence interval due to a sample size of 4 . The maximum is the $93.8 \%$ one sided confidence int.

Note the data at each location was averaged before the statistical calculations were performed 
TABLE 3.22 TAILIHGS PORE FLUID MATER QUALITY STATISTICS BY PARAMETER,

NC PROCESSIHG SITE, SLICK ROCK, COLORADO

SITE: SRKO1 SLICK ROCK (BOTH SITES)

$12 / 12 / 90$ To $10 / 14 / 92$

REPORT DATE: $07 / 26 / 93$

\begin{tabular}{|c|c|c|c|c|c|c|c|c|c|c|c|c|}
\hline \multicolumn{3}{|c|}{ PARAMETER NAME } & UNITS & \multirow[b]{2}{*}{ MEAH } & \multirow{2}{*}{$\begin{array}{r}\text { STANDARD } \\
\text { DEVIATION }\end{array}$} & \multirow{2}{*}{$\begin{array}{c}\text { COEFF. } \\
\text { OF } \\
\text { VARIATION }\end{array}$} & \multirow{2}{*}{$\begin{array}{c}\% \text { OF } \\
\text { NON } \\
\text { DETECTS }\end{array}$} & \multirow{2}{*}{\multicolumn{3}{|c|}{$\begin{array}{c}\text { STATISTICAL RANGE } \\
\text { 98\% CONFIDENCE INTERVAL } \\
\text { MINIMUM MAXIMUH * }\end{array}$}} & \multirow{2}{*}{$\begin{array}{c}\text { DISTRIBUTION } \\
\text { TYPE }\end{array}$} & \multirow{2}{*}{$\begin{array}{l}\text { FOOT } \\
\text { NOTE }\end{array}$} \\
\hline \# OF LOC. & MINIMUM & MAXIMUM & MEDIAN & & & & & & & & & \\
\hline \multicolumn{3}{|l|}{ SELENIUM } & $M G / L$ & \multirow[b]{2}{*}{4.7346} & \multirow[b]{2}{*}{3.5187} & \multirow[b]{2}{*}{0.7432} & \multirow[b]{2}{*}{0.0} & \multirow[b]{2}{*}{$* *$} & \multirow[b]{2}{*}{0.0050} & \multirow[b]{2}{*}{12.7239} & \multirow[b]{2}{*}{ NORMAL } & \\
\hline 4 & 1.3467 & 7.8750 & 4.8583 & & & & & & & & & \\
\hline \multicolumn{3}{|c|}{ SELENIUM (TOTAL) } & $M G / L$ & \multirow[b]{2}{*}{ NA } & \multirow[b]{2}{*}{ NA } & \multirow[b]{2}{*}{ NA } & \multirow[b]{2}{*}{0.0} & \multirow{2}{*}{\multicolumn{2}{|c|}{ NA }} & \multirow[b]{2}{*}{ NA } & \multirow[b]{2}{*}{ UNKNOWN } & \multirow[b]{2}{*}{1} \\
\hline 2 & 1.6400 & 8.5000 & 5.0700 & & & & & & & & & \\
\hline \multicolumn{3}{|c|}{ SILICA - SIO2 } & $M G / L$ & \multirow[b]{2}{*}{67.6000} & \multirow[b]{2}{*}{6.1128} & \multirow[b]{2}{*}{0.0904} & \multirow[b]{2}{*}{0.0} & \multirow{2}{*}{\multicolumn{2}{|c|}{53.7208}} & \multirow[b]{2}{*}{81.4792} & & \\
\hline 4 & 59.8000 & 74.7000 & 67.9500 & & & & & & & & NORMAL & \\
\hline SILICA - S & $\$ 102$ (TOTAL) & & $M G / L$ & & & & & & & & & \\
\hline 2 & 59.0000 & 59.0000 & 59.0000 & NA & NA & NA & 0.0 & & NA & HA & UNKNOWH & 1 \\
\hline SILVER & & & $M G / L$ & & & & & & & & & \\
\hline 4 & ** $\quad 0.0100$ & 0.0175 & $\begin{array}{ll}* \star & 0.0100\end{array}$ & NA & NA & NA & 90.0 & $\star \star$ & 0.0100 & 0.0175 & NONPARAMETRIC & 2,4 \\
\hline SILVER (TC & DTAL) & & $M G / L$ & & & & & & & & & \\
\hline 2 & $* \quad 0.0100$ & 0.0100 & $* * \quad 0.0100$ & NA & NA & NA & 100.0 & & NA & NA & UNKNOWN & 1 \\
\hline SOD IUM & & & MG/L & & & & & & & & & \\
\hline 4 & 323.5000 & 6693.3333 & +2990.4167 & 3249.4167 & 2656.8400 & 0.8176 & 0.0 & ** & 1.0000 & 9281.7718 & NORMAL & \\
\hline SODIUN (TO & JTAL) & & $M G / L$ & & & & & & & & & \\
\hline 2 & 54.4000 & 3370.0000 & +1712.2000 & NA & NA & NA & 0.0 & & NA & NA & UNKNOHN & 1 \\
\hline SPECIFIC C & CONDUCTANCE & & UMHO/CM & & & & & & & & & \\
\hline 4 & 2314.0000 & 28000.0000 & +15116.6667 & 15136.8333 & 10774.8031 & 0.7118 & 0.0 & & 327.3572 & 39601.0238 & NORMAL & \\
\hline
\end{tabular}

** The reported value is the minimum detection limit of the data set

+ The sample size is even, so the median value is the arithmetic average of the two middle values

* The statistical maximum is the 99 percent one sided confidence interval, $\alpha=0.01$

1) Dato from a minimum of 4 locations must be available for the statistical analysis.

2) The nonparametric distribution was used because the nondetected values comprise more than $15 \%$ of the samples.

4) The stat. range is the $\mathbf{8 7 . 5 \%}$ confidence interval due to a sample size of 4 . The maximum is the $93.8 \%$ one sided confidence int.

Note the data at each location was averaged before the statistical calculations were performed 
TABLE 3.22 TAILINGS PORE FLUID WATER QUALITY STATISTICS BY PARAMETER, NC PROCESSING SITE, SLICK ROCK, COLORADO

SITE: SRKO1 SLICK ROCK (BOTH SITES)

$12 / 12 / 90$ TO $10 / 14 / 92$

REPORT DATE : $07 / 26 / 93$

\begin{tabular}{|c|c|c|c|c|c|c|c|c|c|c|c|c|}
\hline \multicolumn{3}{|c|}{ PARAMETER NAME } & UNITS & \multirow[b]{2}{*}{ MEAH } & \multirow{2}{*}{$\begin{array}{r}\text { STANDARD } \\
\text { DEVIATION }\end{array}$} & \multirow{2}{*}{$\begin{array}{c}\text { COEFF. } \\
\text { OF } \\
\text { VARIATION }\end{array}$} & \multirow{2}{*}{$\mid \begin{array}{c}\% \text { OF } \\
\text { NON } \\
\text { DETECTS }\end{array}$} & \multirow{2}{*}{\multicolumn{3}{|c|}{$\begin{array}{l}\text { STATISTICAL RANGE } \\
\text { 98\% CONFIDENCE INTERVAL } \\
\text { MINIMUM MAXIMUM * }\end{array}$}} & \multirow{2}{*}{$\begin{array}{l}\text { DISTRIBUT ION } \\
\text { TYPE }\end{array}$} & \multirow{2}{*}{$\begin{array}{l}\text { FOOT } \\
\text { NOTE }\end{array}$} \\
\hline \# OF LOC. & MINIMUM & MAXIMUM & MEDIAN & & & & & & & & & \\
\hline \multicolumn{3}{|l|}{ STRONTIUM } & $M G / L$ & \multirow[b]{2}{*}{14.8427} & \multirow[b]{2}{*}{7.7811} & \multirow[b]{2}{*}{0.5242} & \multirow[b]{2}{*}{0.0} & \multirow[b]{2}{*}{ ** } & \multirow[b]{2}{*}{0.0100} & \multirow[b]{2}{*}{32.5098} & \multirow[b]{2}{*}{ NORMAL } & \\
\hline 4 & 4.4625 & 21.7333 & 16.5875 & & & & & & & & & \\
\hline \multicolumn{3}{|c|}{ STRONTIUM (TOTAL) } & $M G / L$ & \multirow[b]{2}{*}{ NA } & \multirow[b]{2}{*}{ NA } & \multirow[b]{2}{*}{ NA } & \multirow[b]{2}{*}{0.0} & \multirow{2}{*}{\multicolumn{2}{|c|}{ NA }} & \multirow[b]{2}{*}{ NA } & \multirow[b]{2}{*}{ UNKNOWN } & \multirow[b]{2}{*}{1} \\
\hline 2 & 3.8000 & 23.7000 & 13.7500 & & & & & & & & & \\
\hline \multicolumn{3}{|l|}{ SULFATE } & MG/L & & \multirow[b]{2}{*}{7206.4369} & \multirow[b]{2}{*}{0.6824} & \multirow[b]{2}{*}{0.0} & \multirow[b]{2}{*}{ ** } & & \multirow[b]{2}{*}{26922.2151} & & \\
\hline 4 & 1450.0000 & 18800.0000 & +10995.0000 & 10560.0000 & & & & & 10.0000 & & NORMAL & \\
\hline SULFATE & (OTAL) & & $M G / L$ & & & & & & & & & \\
\hline 4 & 1530.0000 & 17500.0000 & +10525.0000 & 10020.0000 & 6875.1194 & 0.6861 & 0.0 & ** & 0.1000 & 25629.9586 & NORMAL & \\
\hline TEMPERATUR & & & $C-D E G R$ & & & & & & & & & \\
\hline 4 & 11.7000 & 15.4750 & 12.7458 & 13.1667 & 1.7682 & 0.1343 & 0.0 & & 9.1520 & 17.1814 & NORMAL & \\
\hline THALLIUM & & & MG/L & & & & & & & & & \\
\hline 4 & 0.0156 & 0.0367 & 0.0213 & NA & NA & NA & 100.0 & & 0.0156 & 0.0367 & NONPARAMETRIC & 2,4 \\
\hline THALLIUM & TOTAL) & & $M G / L$ & & & & & & & & & \\
\hline 2 & 0.0100 & ** $\quad 0.0100$ & 0.0100 & NA & NA & NA & 100.0 & & NA & NA & UNKNOWN & 1 \\
\hline TIN & & & $M G / L$ & & & & & & & & & \\
\hline 4 & 0.0062 & 0.1250 & 0.0988 & NA & NA & NA & 100.0 & & 0.0062 & 0.1250 & NONPARAMETRIC & 2,4 \\
\hline TIN (TOTAL & & & $M G / L$ & & & & & & & & & \\
\hline 2 & 0.0120 & 0.0120 & 0.0120 & NA & NA & NA & 0.0 & & NA & NA & UNKHOWN & 1 \\
\hline
\end{tabular}

** The reported value is the minimum detection limit of the data set

+ The sample size is even, so the median value is the arithmetic average of the two middle values

* The statistical maximum is the 99 percent one sided confidence interval, $a=0.01$

1) Data from a minimum of 4 locations must be avai lable for the statistical analysis.

2) The nonparametric distribution was used because the nondetected values comprise more than $15 \%$ of the samples.

4) The stat. range is the $\mathbf{8 7 . 5 \%}$ confidence interval due to a sample size of 4 . The maximu is the $93.8 \%$ one sided confidence int.

Note the data at each location was averaged before the statistical calculations were performed 
TABLE 3.22 TAILINGS PORE FLUID HATER QUALITY STATISTICS BY PARAMETER,

NC PROCESSING SITE, SLICK ROCK, COLORADO

SITE: SRKO1 SLICK ROCK (BOTH SITES)

$12 / 12 / 90$ TO $10 / 14 / 92$

REPORT DATE: 07/26/93

\begin{tabular}{|c|c|c|c|c|c|c|c|c|c|c|c|c|}
\hline \multicolumn{3}{|c|}{ PARAMETER NAME } & UNITS & \multirow[b]{2}{*}{ MEAN } & \multirow{2}{*}{$\begin{array}{l}\text { STANDARD } \\
\text { DEVIATION }\end{array}$} & \multirow{2}{*}{$\begin{array}{c}\text { COEFF. } \\
\text { OF } \\
\text { VARIATION }\end{array}$} & \multirow{2}{*}{$\begin{array}{c}\% \text { OF } \\
\text { NON } \\
\text { DETECTS }\end{array}$} & \multirow{2}{*}{\multicolumn{3}{|c|}{ 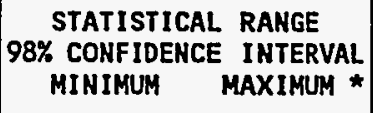 }} & \multirow{2}{*}{$\begin{array}{c}\text { DISTRIBUTION } \\
\text { TYPE }\end{array}$} & \multirow{2}{*}{$\begin{array}{l}\text { FOOT } \\
\text { NOTE }\end{array}$} \\
\hline \# OF LOC. & MINIMUM & MAXIMUM & MEDIAN & & & & & & & & & \\
\hline \multicolumn{3}{|c|}{ TOTAL DISSOLVED SOLIDS } & $M G / L$ & \multirow[b]{2}{*}{18732.5000} & \multirow[b]{2}{*}{13095.4022} & \multirow[b]{2}{*}{0.6991} & \multirow[b]{2}{*}{0.0} & \multirow[b]{2}{*}{ ** } & \multirow[b]{2}{*}{10.0000} & \multirow[b]{2}{*}{48465.6107} & \multirow[b]{2}{*}{ NORMAL } & \\
\hline 4 & 2430.0000 & 33900.0000 & +19300.0000 & & & & & & & & & \\
\hline \multicolumn{3}{|l|}{ URANIUM } & MG/L & \multirow[b]{2}{*}{1.7669} & \multirow[b]{2}{*}{30.1669} & \multirow[b]{2}{*}{ NA } & \multirow[b]{2}{*}{14.3} & \multirow[b]{2}{*}{ ** } & \multirow[b]{2}{*}{0.0010} & \multirow[b]{2}{*}{4040.9812} & \multirow[b]{2}{*}{ LOGNORMAL. } & \multirow[b]{2}{*}{7,8} \\
\hline 4 & 0.0118 & 20.4000 & 7.0375 & & & & & & & & & \\
\hline \multicolumn{2}{|c|}{ URANIUM (TOTAL) } & & $M G / L$ & \multirow[b]{2}{*}{ NA } & \multirow[b]{2}{*}{ NA } & \multirow[b]{2}{*}{ NA } & \multirow[b]{2}{*}{0.0} & & & & & \\
\hline 2 & 0.1090 & 10.2000 & 5.1545 & & & & & & NA & NA & UNKNOWN & 1 \\
\hline VANADIUM & & & $M G / L$ & & & & & & & & & \\
\hline 4 & 1.5233 & 43.9500 & 2.9408 & 4.8267 & 4.5551 & NA & 0.0 & & 0.1544 & 150.9304 & LOGNORMAL. & 7,8 \\
\hline VANADIUM ( & OTAL) & & $M G / L$ & & & & & & & & & \\
\hline ZINC & & & $M G / L$ & & & & & & & & & \\
\hline 4 & 0.0148 & 0.1857 & 0.0383 & NA & NA & HA & 42.9 & & 0.0148 & 0.1857 & NONPARAMETRIC & 2,4 \\
\hline ZINC (TOTA & & & $M G / L$ & & & & & & & & & \\
\hline 2 & 0.0400 & 0.0900 & 0.0650 & NA & HA & NA & 0.0 & & NA & NA & UNKNOWN & 1 \\
\hline
\end{tabular}

** The reported value is the minimum detection limit of the data set

+ The sample size is even, so the median value is the arithmetic average of the two middle values

* The statistical maximum is the 99 percent one sided confidence interval, $\alpha=0.01$

1) Data from a minimum of 4 locations must be available for the statistical analysis.

2) The nonparametric distribution Has used because the nondetected values comprise more than 15\% of the samples.

4) The stat. range is the $87.5 \%$ confidence interval due to a sample size of 4 . The maximum is the $93.8 \%$ one sided confidence int.

7) The lognormal distribution was used because the data failed the normal distribution test.

8) The mean is geometric. The standard deviation is the value to divide or multiply with the geometric mean

Hote the data at each location was averaged before the statistical calculations Hare performed

INPUT DATA FILENAME: M: IDARTISRKO1YLYS10004.DAT 
Table 3.23 Summary of regulated constituents in tailings pore fluid samples, NC processing site, Slick Rock, Colorado

\begin{tabular}{|c|c|c|c|c|}
\hline \multicolumn{5}{|c|}{ Constituents with MCLs ${ }^{a}$} \\
\hline Parameter & Median & MCL & Background $^{\mathbf{b}}$ & Exceed \\
\hline Arsenic & $0.07^{e}$ & 0.05 & $0.01^{g}$ & $1.4 x$ \\
\hline Barium & $0.04^{d}$ & 1.00 & $0.05^{e}$ & -- \\
\hline Cadmium & $0.04^{e}$ & 0.01 & $0.001^{g}$ & $4 x$ \\
\hline Chromium & $0.01^{9}$ & 0.05 & $0.01^{g}$ & -- \\
\hline Net gross alpha ${ }^{f}$ & $-1142.18^{e}$ & 15.00 & $6.96^{e}$ & -- \\
\hline Lead & $0.03^{e}$ & 0.05 & $0.01^{g}$ & -- \\
\hline Mercury & - & 0.002 & $0.0002^{g}$ & - \\
\hline Molybdenum & $0.31^{d}$ & 0.10 & $0.02^{g}$ & $3 x$ \\
\hline Nitrate & - & 44.0 & $4.4^{e}$ & - \\
\hline Radium-226 and $-228^{f}$ & -- & 5.0 & $1.80^{d}$ & -- \\
\hline Selenium & $4.73^{d}$ & 0.01 & $0.012^{g}$ & $473 x$ \\
\hline Silver & $0.01^{g}$ & 0.05 & $0.01^{g}$ & -- \\
\hline Uranium & $1.77^{c}$ & 0.044 & $0.019^{e}$ & $40 x$ \\
\hline
\end{tabular}


Table 3.23 Summary of regulated constituents in tailings pore fluid samples, NC processing site, Slick Rock, Colorado (Concluded)

\begin{tabular}{lcccc}
\hline \multicolumn{5}{c}{ Constituents without MCLs } \\
\hline Parameter & Median & MCL & Background $^{\mathrm{b}}$ & Exceed \\
\hline Antimony & $0.015^{\mathrm{e}}$ & None & $0.003^{\mathrm{g}}$ & $5 \mathrm{x}$ \\
Beryllium & $0.007^{\mathrm{e}}$ & None & $0.01^{\mathrm{g}}$ & -- \\
Cobalt & $0.05^{\mathrm{g}}$ & None & $0.05^{\mathrm{g}}$ & -- \\
Copper & $0.06^{\mathrm{d}}$ & None & $0.02^{\mathrm{g}}$ & $3 \mathrm{x}$ \\
Cyanide & -- & None & $0.01^{\mathrm{g}}$ & - \\
Nickel & $0.04^{\mathrm{g}}$ & None & $0.04^{\mathrm{g}}$ & -- \\
Sulfide & -- & None & $1.0^{\mathrm{e}}$ & -- \\
Thallium & $0.02^{\mathrm{e}}$ & None & $0.01^{\mathrm{g}}$ & $2 \mathrm{x}$ \\
Tin & $0.099^{\mathrm{e}}$ & None & $0.005^{\mathrm{g}}$ & $20 \mathrm{x}$ \\
Vanadium & $4.83^{\mathrm{c}}$ & None & $0.02^{\mathrm{e}}$ & $242 \mathrm{x}$ \\
Zinc & $0.03^{\mathrm{e}}$ & None & $0.01^{\mathrm{e}}$ & $4 \mathrm{x}$ \\
\hline
\end{tabular}

a All units are $\mathrm{mg} / \mathrm{L}$ unless otherwise noted.

bisposal site background groundwater statistical maximum (upper sandstone unit).

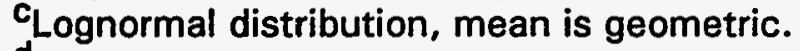

$d_{\text {Normal distribution, mean is arithmetic. }}$

ENonparametric distribution

Units are $\mathrm{pCi} / \mathrm{L}$.

IStatistical values are below laboratory detection limits in Table 8.1 of the Technical Approach Document (DOE, 1989) 
TABLE 3.24 TAILINGS PORE FLUID MEASUREMENTS EXCEEDING MAXIMUM CONCENTRATION

LIMITS, NC AND UC PROCESSING SITES, SLICK ROCK, COLORADO

SITE: SRKO1 SLICK ROCK (BOTH SITES)

REPORT DATE: $06 / 17 / 93$

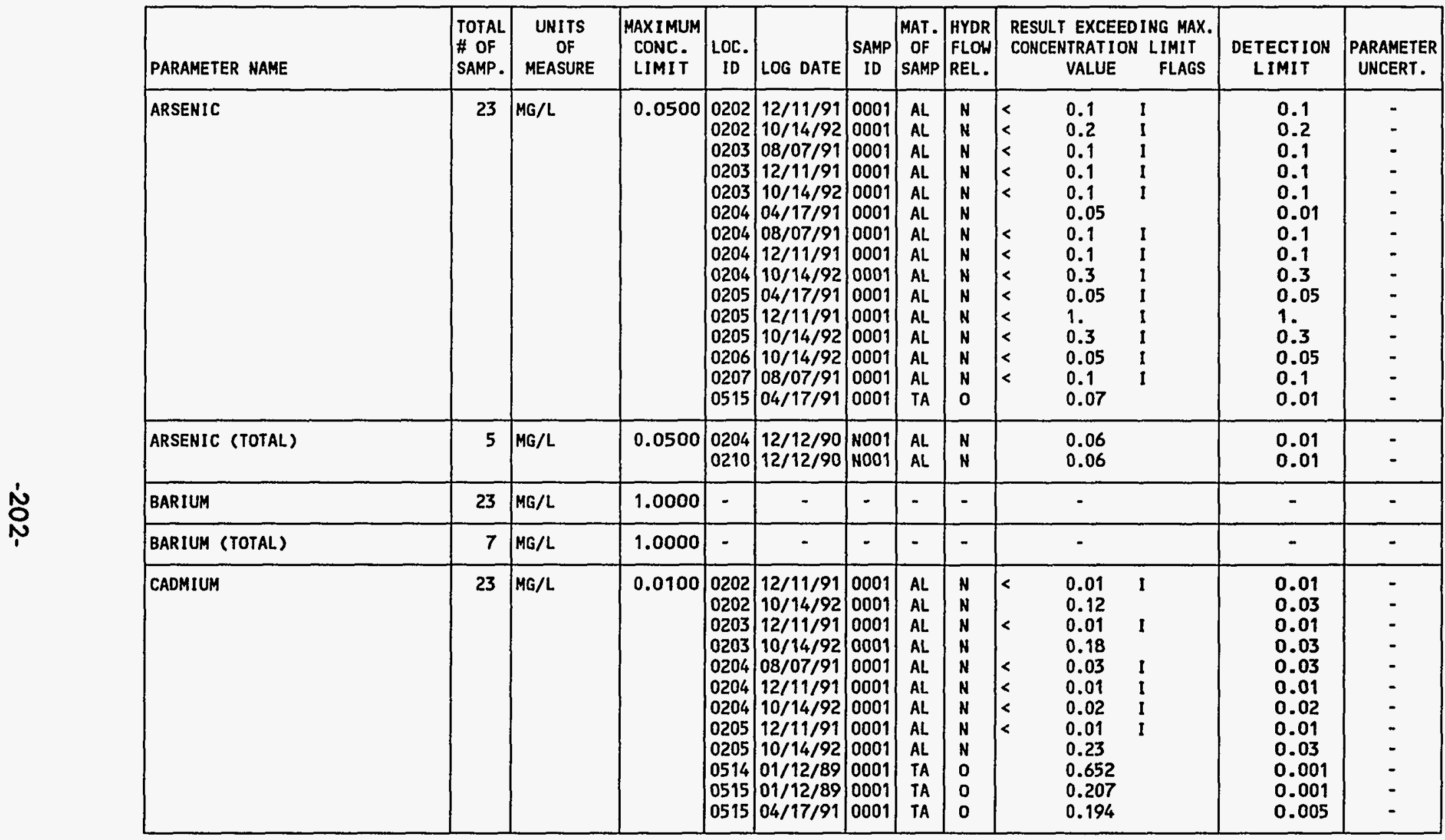

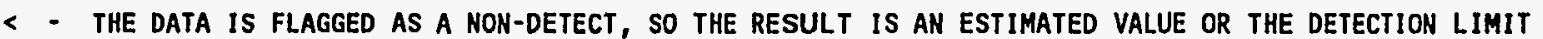

\section{MATERIAL OF SAMPLING CODE:}

AL - ALLUVIUH

TA - URANIUM MILL TAILINGS

OTHER PARAMETER VALUE FLAGS:

1 - INCREASED DETECTION LIMIT DUE TO REQUIRED DILUTION
FLOW RELATIONSHIP CODE:

N - UNKNOWN

O - ON-SITE

SAMPLE ID COOES:

0001 - FILTERED SAMPLE (.45 MICRONS)

NOO1 - UNFILTERED SAMPLE 
TABLE 3.24 TAILINGS PORE FLUID MEASUREMENTS EXCEEDING MAXIMUM CONCENTRATION LIMITS, NC AND UC PROCESSING SITES, SLICK ROCK, COLORADO

SITE: SRKO1 SLICK ROCK (BOTH SITES)

$01 / 12 / 89$ TO $10 / 14 / 92$

REPORT DATE: $06 / 17 / 93$

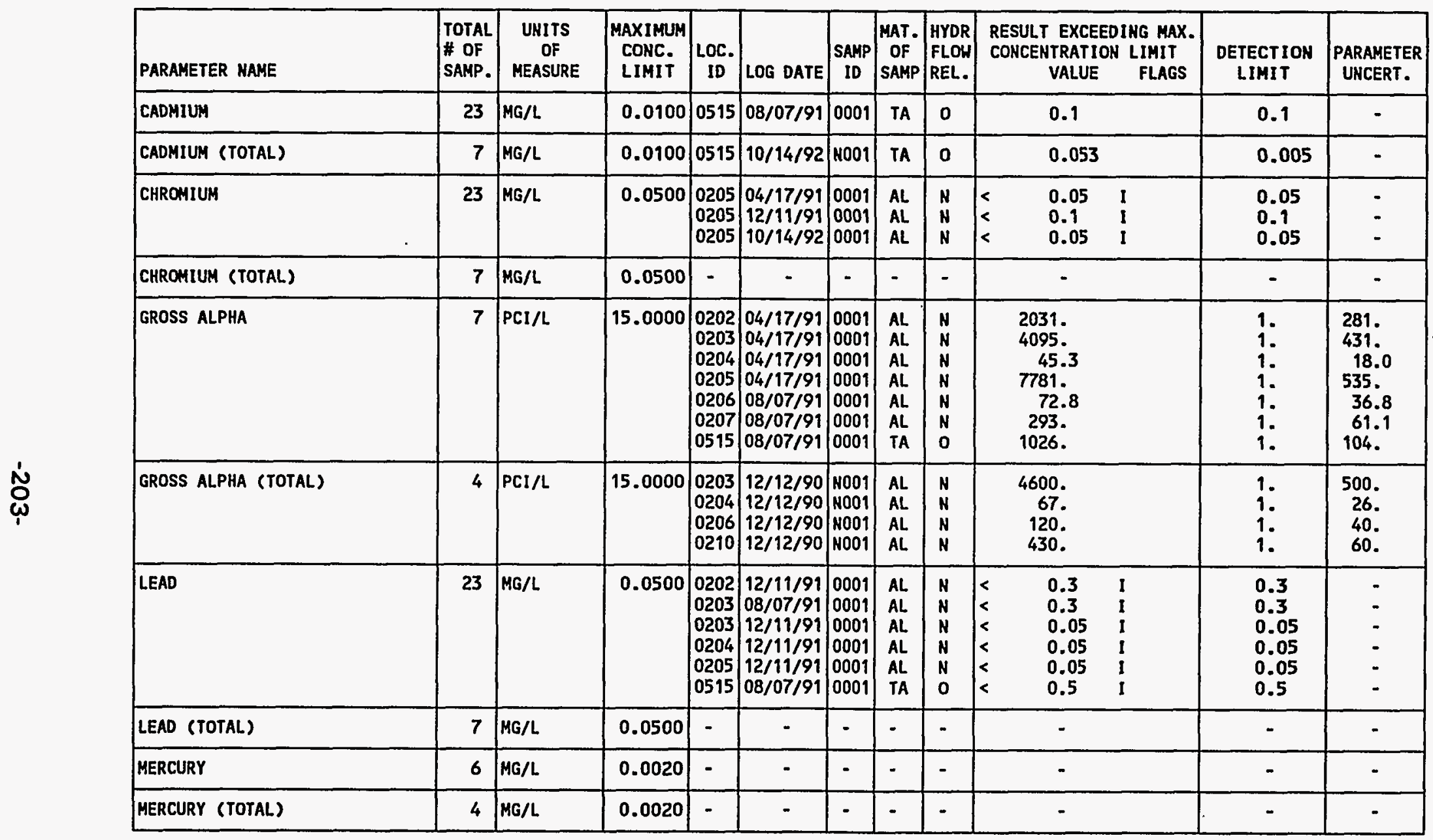

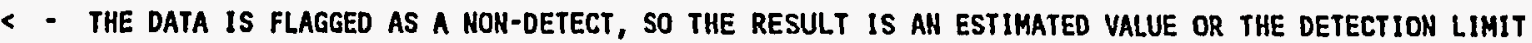

MATERIAL OF SAMPLING COUE:

TA - URAMIUM MILL TAILINGS

AL - ALLUUVIUM

OTHER PARAMETER VALUE FLAGS:

I - INCREASED DETECTION LIMIT DUE TO REQUIRED DILUTION
FLOH RELATIONSHIP COOE:

O - ON-SITE

N - UNKNOWN

SAMPLE ID CODES:

0001 - FILTERED SAMPLE (.45 MICRONS)

N001 - UNFILTERED SAMPLE 
TABLE 3.24 TAILINGS PORE FLUID MEASUREMENTS EXCEEDING MAXIMUM CONCENTRATION LIMITS, NC AND UC PROCESSING SITES, SLICK ROCK, COLORADO

SITE: SRK01 SLICK ROCK (BOTH SITES)

REPORT DATE: $06 / 17 / 93$

\begin{tabular}{|c|c|c|c|c|c|c|c|c|c|c|c|}
\hline PARAMETER NAME & $\begin{array}{l}\text { TOTAL } \\
\text { \# OF } \\
\text { SAMP. }\end{array}$ & $\begin{array}{l}\text { UNITS } \\
\text { OF } \\
\text { MEASURE }\end{array}$ & $\begin{array}{l}\text { MAXIMUM } \\
\text { CONC. } \\
\text { LIMIT }\end{array}$ & Loc. & LOG DATE & $\begin{array}{c}\text { SAMP } \\
\text { ID }\end{array}$ & $\begin{array}{l}\text { MAT. } \\
\text { OF } \\
\text { SAMP }\end{array}$ & $\begin{array}{l}\text { HYDR } \\
\text { FLOW } \\
\text { REL. }\end{array}$ & $\begin{array}{l}\text { RESULT EXCEEDING MAX. } \\
\text { CONCENTRATION LIMIT } \\
\text { VALUE FLAGS }\end{array}$ & $\begin{array}{l}\text { DETECTION } \\
\text { LIMIT }\end{array}$ & $\begin{array}{l}\text { PARAMETER } \\
\text { UNCERT. }\end{array}$ \\
\hline MOL YBDENUM & 23 & $M G / L$ & 0.1000 & $\begin{array}{l}0202 \\
0202 \\
0202 \\
0203 \\
0203 \\
0203 \\
0203 \\
0204 \\
0204 \\
0204 \\
0204 \\
0205 \\
0205 \\
0205 \\
0206 \\
0206 \\
0206 \\
0207 \\
0207 \\
0514 \\
0515 \\
0515 \\
0515\end{array}$ & $\begin{array}{l}04 / 17 / 91 \\
12 / 11 / 91 \\
10 / 14 / 92 \\
04 / 17 / 91 \\
08 / 07 / 91 \\
12 / 11 / 91 \\
10 / 14 / 92 \\
04 / 17 / 91 \\
08 / 07 / 91 \\
12 / 11 / 91 \\
10 / 14 / 92 \\
04 / 17 / 91 \\
12 / 11 / 91 \\
10 / 14 / 92 \\
04 / 17 / 91 \\
08 / 07 / 91 \\
10 / 14 / 92 \\
08 / 07 / 91 \\
10 / 14 / 92 \\
01 / 12 / 89 \\
01 / 12 / 89 \\
04 / 17 / 91 \\
08 / 07 / 91\end{array}$ & $\begin{array}{l}0001 \\
0001 \\
0001 \\
0001 \\
0001 \\
0001 \\
0001 \\
0001 \\
0001 \\
0001 \\
0001 \\
0001 \\
0001 \\
0001 \\
0001 \\
0001 \\
0001 \\
0001 \\
0001 \\
0001 \\
0001 \\
0001 \\
0001\end{array} \mid$ & $\begin{array}{l}A L \\
A L \\
A L \\
A L \\
A L \\
A L \\
A L \\
A L \\
A L \\
A L \\
A L \\
A L \\
A L \\
A L \\
A L \\
A L \\
A L \\
A L \\
A L \\
T A \\
T A \\
T A \\
T A\end{array}$ & $\begin{array}{l}N \\
N \\
N \\
N \\
N \\
N \\
N \\
N \\
N \\
N \\
N \\
N \\
N \\
N \\
N \\
N \\
N \\
N \\
N \\
0 \\
0 \\
0 \\
0\end{array}$ & $\begin{array}{c}0.33 \\
0.29 \\
0.31 \\
0.21 \\
0.22 \\
0.19 \\
0.16 \\
0.50 \\
0.55 \\
0.50 \\
0.56 \\
0.30 \\
0.23 \\
0.15 \\
0.22 \\
0.20 \\
0.16 \\
13.5 \\
11.6 \\
3.46 \\
18.0 \\
23.1 \\
21.1\end{array}$ & $\begin{array}{l}0.01 \\
0.01 \\
0.01 \\
0.01 \\
0.01 \\
0.01 \\
0.01 \\
0.01 \\
0.01 \\
0.01 \\
0.01 \\
0.05 \\
0.01 \\
0.05 \\
0.01 \\
0.01 \\
0.01 \\
0.05 \\
0.05 \\
0.01 \\
0.01 \\
0.05 \\
0.05\end{array}$ & $\begin{array}{l}- \\
- \\
- \\
- \\
- \\
- \\
- \\
- \\
- \\
- \\
- \\
- \\
- \\
- \\
- \\
- \\
- \\
- \\
-\end{array}$ \\
\hline MOLYYBDENUM (TOTAL) & 7 & $M G / L$ & 0.1000 & $\begin{array}{l}0203 \\
0204 \\
0206 \\
0207 \\
0208 \\
0210 \\
0515\end{array}$ & $\begin{array}{l}12 / 12 / 90 \\
12 / 12 / 90 \\
12 / 12 / 90 \\
12 / 12 / 90 \\
10 / 14 / 92 \\
12 / 12 / 90 \\
10 / 14 / 92\end{array}$ & $\begin{array}{l}\text { N001 } \\
\text { N001 } \\
\text { N001 } \\
\text { N001 } \\
\text { N001 } \\
\text { N001 } \\
\text { N001 }\end{array}$ & $\begin{array}{l}\text { AL } \\
\text { AL } \\
\text { AL } \\
\text { AL } \\
\text { NR } \\
\text { AL } \\
\text { TA }\end{array}$ & $\begin{array}{l}N \\
N \\
N \\
N \\
N \\
N \\
0\end{array}$ & $\begin{array}{c}0.42 \\
0.50 \\
0.49 \\
30.6 \\
9.45 \\
13.6 \\
14.2\end{array}$ & $\begin{array}{l}0.01 \\
0.01 \\
0.01 \\
0.01 \\
0.05 \\
0.01 \\
0.05\end{array}$ & $\begin{array}{l}- \\
- \\
- \\
- \\
-\end{array}$ \\
\hline NET GROSS ALPHA * & 7 & $\mathrm{PCI} / \mathrm{L}$ & 15.0000 & 0202 & $04 / 17 / 91 \mid$ & 0001 & AL & N & 21.0 & - & - \\
\hline
\end{tabular}

* Net gRoss aLPHA (GROSS ALPHA - URANIUM) HITH 1 MG URANIUM = 686 PCI

\section{MATERIAL OF SAMPLING CODE:}

\section{AL - ALLUVIUM}

TA - URANIUM MILL TAILINGS

NR - NO RECOVERY OF DATA FOR CLASSIFYING
FLOW RELATIONSHIP CODE:

N - UNKNOWN

O - ON-SITE

SAMPLE ID CODES:

0001 - FILTERED SAMPLE (.45 MICRONS)

N001 - UNFILTERED SAMPLE 
TABLE 3.24 TAILINGS PORE FLUID MEASUREMENTS EXCEEDING MAXIMUM CONCENTRATION LIMITS, NC AND UC PROCESSING SITES, SLICK ROCK, COLORADO

SITE: SRKO1 SLICK ROCK (BOTH SITES)

TO 10/14/92

\begin{tabular}{|c|c|c|c|c|c|c|c|c|c|c|c|}
\hline PARAMETER NAME & $\begin{array}{l}\text { TOTAL } \\
\text { \# OF } \\
\text { SAMP. }\end{array}$ & $\begin{array}{c}\text { UNITS } \\
\text { OF } \\
\text { MEASURE }\end{array}$ & $\begin{array}{l}\text { MAXIMUM } \\
\text { CONC. } \\
\text { LIMIT }\end{array}$ & Loc. & LOG DATE & $\begin{array}{l}\text { SAMP } \\
\text { ID }\end{array}$ & $\begin{array}{l}\text { MAT. } \\
\text { OF } \\
\text { SAMP }\end{array}$ & $\begin{array}{l}\text { HYDR } \\
\text { FLOW } \\
\text { REL. }\end{array}$ & $\begin{array}{c}\text { RESULT EXCEEDING MAX. } \\
\text { CONCENTRATION LIMIT } \\
\text { VALUE FLAGS }\end{array}$ & $\begin{array}{l}\text { DETECTION } \\
\text { LIMIT }\end{array}$ & $\begin{array}{l}\text { PARAMETER } \\
\text { UNCERT. }\end{array}$ \\
\hline HET GROSS ALPHA * & 7 & $\mathrm{PCI} / \mathrm{L}$ & 15.0000 & $\begin{array}{l}0204 \\
0515\end{array} \mid$ & $\begin{array}{l}04 / 17 / 91 \\
08 / 07 / 91\end{array}$ & $\begin{array}{l}0001 \\
0001\end{array} \mid$ & AL & $\begin{array}{l}\mathbf{N} \\
\mathbf{0}\end{array}$ & $\begin{array}{r}29.5 \\
1022.6\end{array}$ & - & - \\
\hline HET GROSS ALPHA (TOTAL) ** & 4 & $\mathrm{PCI} / \mathrm{L}$ & 15.0000 & 0206 & $12 / 12 / 90$ & N001 & AL & N & 27.4 & - & - \\
\hline NITRATE & 3 & MG/L & 44.0000 & $\begin{array}{l}0206 \\
0514\end{array} \mid$ & $\begin{array}{l}08 / 07 / 91 \\
01 / 12 / 89\end{array}$ & $\begin{array}{l}0001 \\
0001\end{array} \mid$ & AL & $\begin{array}{l}N \\
0\end{array}$ & $\begin{array}{l}744 . \\
210 .\end{array}$ & 1. & - \\
\hline NITRATE (TOTAL) & 0 & MG/L & 44.0000 & - & - & - & - & - & - & - & - \\
\hline$R A-226 \& R A-228$ & 0 & $\mathrm{PCI} / \mathrm{L}$ & 5.0000 & - & - & - & - & - & - & - & - \\
\hline RA-226 \& RA-228 (TOTAL) & 0 & $\mathrm{PCl} / \mathrm{L}$ & 5.0000 & - & - & - & - & - & - & - & - \\
\hline SELENIUM & 23 & $M G / L$ & 0.0100 & $\begin{array}{l}0202 \\
0202 \\
0202 \\
0203 \\
0203 \\
0203 \\
0203 \\
0204 \\
0204 \\
0204 \\
0204 \\
0205 \\
0205 \\
0205 \\
0206 \\
0206 \\
0206 \\
0207\end{array}$ & $\begin{array}{l}04 / 17 / 91 \\
12 / 11 / 91 \\
10 / 14 / 92 \\
04 / 17 / 91 \\
08 / 07 / 91 \\
12 / 11 / 91 \\
10 / 14 / 92 \\
04 / 17 / 91 \\
08 / 07 / 91 \\
12 / 11 / 91 \\
10 / 14 / 92 \\
04 / 17 / 91 \\
12 / 11 / 91 \\
10 / 14 / 92 \\
04 / 17 / 91 \\
08 / 07 / 91 \\
10 / 14 / 92 \\
08 / 07 / 91\end{array}$ & $\begin{array}{l}0001 \\
0001 \\
0001 \\
0001 \\
0001 \\
0001 \\
0001 \\
0001 \\
0001 \\
0001 \\
0001 \\
0001 \\
0001 \\
0001 \\
0001 \\
0001 \\
0001 \\
0001\end{array}$ & $\begin{array}{l}A L \\
A L \\
A L \\
A L \\
A L \\
A L \\
A L \\
A L \\
A L \\
A L \\
A L \\
A L \\
A L \\
A L \\
A L \\
A L \\
A L \\
A L\end{array}$ & $\begin{array}{l}N \\
N \\
N \\
N \\
N \\
N \\
N \\
N \\
N \\
N \\
N \\
N \\
N \\
N \\
N \\
N \\
N \\
N\end{array}$ & $\begin{array}{c}6.0 \\
10 . \\
7.0 \\
6.0 \\
6.5 \\
13 . \\
6.0 \\
1.3 \\
1.5 \\
2.4 \\
3 . \\
0.140 \\
2.6 \\
1.3 \\
1.00 \\
0.150 \\
0.09 \\
16.0\end{array}$ & $\begin{array}{l}0.5 \\
5 . \\
0.5 \\
0.5 \\
0.5 \\
5.5 \\
0.5 \\
0.1 \\
0.1 \\
0.5 \\
1 . \\
0.005 \\
0.5 \\
0.3 \\
0.005 \\
0.03 \\
0.05 \\
0.5\end{array}$ & $\begin{array}{l}- \\
- \\
= \\
- \\
- \\
- \\
- \\
- \\
- \\
- \\
- \\
- \\
- \\
-\end{array}$ \\
\hline
\end{tabular}

* NET GROSS ALPHA (GROSS ALPHA - URANIUH)

WITH 1 MG URANIUN $=686 \mathrm{PCI}$

** TOTAL NET GROSS ALPHA (TOTAL GROSS ALPHA - TOTAL URANIUM)

MATERIAL OF SAMPLIHG CODE:

AL - ALLUVIUM

TA - URANIUM MILL TAILINGS

\section{FLOW RELATIONSHIP COOE:}

N - UNKNOWN

O - ON-SITE

SAMPLE ID CODES:

0001 - FILTERED SAMPLE (.45 MICRONS)

N001 - UNFILTERED SAMPLE 
TABLE 3.24 TAILINGS PORE FLUID MEASUREMENTS EXCEEOING MAXIMUM CONCENTRATION

LIMITS, NC AND UC PROCESSING SITES, SLICK ROCK, COLORADO

SITE: SRKO1 SLICK ROCK (BOTH SITES)

$01 / 12 / 89$ TO $10 / 14 / 92$

\begin{tabular}{|c|c|c|c|c|c|c|c|c|c|c|c|c|}
\hline & PARAMETER NAME & $\begin{array}{l}\text { TOTAL } \\
\# \text { OF } \\
\text { SAMP. }\end{array}$ & $\begin{array}{l}\text { UNITS } \\
\text { OF } \\
\text { MEASURE }\end{array}$ & $\begin{array}{l}\text { MAXIMUM } \\
\text { CONC. } \\
\text { LIMIT }\end{array}$ & Loc. & LOG DATE & $\begin{array}{c}\text { SAMP } \\
\text { ID }\end{array}$ & $\begin{array}{c}\text { MAT. } \\
\text { OF } \\
\text { SAMP }\end{array}$ & $\begin{array}{l}\text { HYDR } \\
\text { FLOW } \\
\text { REL. }\end{array}$ & $\begin{array}{l}\text { RESULT EXCEEDING MAX. } \\
\text { CONCENTRATION LIMIT } \\
\text { VALUE FLAGS }\end{array}$ & $\begin{array}{l}\text { DETECTION } \\
\text { LIMIT }\end{array}$ & $\begin{array}{l}\text { PARAMETER } \\
\text { UNCERT. }\end{array}$ \\
\hline & SELENIUM & 23 & $M G / L$ & 0.0100 & $\begin{array}{l}0207 \\
0514 \\
0515 \\
0515 \\
0515\end{array}$ & $\begin{array}{l}10 / 14 / 92 \\
01 / 12 / 89 \\
01 / 12 / 89 \\
04 / 17 / 91 \\
08 / 07 / 91\end{array}$ & $\begin{array}{l}0001 \\
0001 \\
0001 \\
0001 \\
0001\end{array}$ & $\begin{array}{l}\text { AL } \\
\text { TA } \\
\text { TA } \\
\text { TA } \\
\text { TA }\end{array}$ & $\begin{array}{l}H \\
0 \\
0 \\
0 \\
0\end{array}$ & $\begin{array}{l}16 . \\
1.64 \\
1.54 \\
8.0 \\
7.0\end{array}$ & $\begin{array}{l}5 . \\
0.005 \\
0.005 \\
0.5 \\
0.5\end{array}$ & $\begin{array}{l}- \\
- \\
-\end{array}$ \\
\hline & SELENIUM (TOTAL) & 7 & $M G / L$ & 0.0100 & $\begin{array}{l}0203 \\
0204 \\
0206 \\
0207 \\
0208 \\
0210 \\
0515\end{array}$ & \begin{tabular}{|l|}
$12 / 12 / 90$ \\
$12 / 12 / 90$ \\
$12 / 12 / 90$ \\
$12 / 12 / 90$ \\
$10 / 14 / 92$ \\
$12 / 12 / 90$ \\
$10 / 14 / 92$
\end{tabular} & $\begin{array}{l}\text { NO01 } \\
\text { NO01 } \\
\text { NO01 } \\
\text { NO01 } \\
\text { NO01 } \\
\text { NO01 } \\
\text { NO01 }\end{array}$ & $\begin{array}{l}\text { AL } \\
\text { AL } \\
\text { AL } \\
\text { AL } \\
\text { NR } \\
\text { AL } \\
\text { TA }\end{array}$ & $\begin{array}{l}N \\
N \\
N \\
N \\
N \\
N \\
0\end{array}$ & $\begin{array}{c}8.5 \\
1.64 \\
0.39 \\
21.6 \\
14.0 \\
1.48 \\
7.0\end{array}$ & $\begin{array}{l}0.005 \\
0.005 \\
0.005 \\
0.005 \\
0.5 \\
0.005 \\
0.5\end{array}$ & $\begin{array}{l}- \\
- \\
- \\
-\end{array}$ \\
\hline & SILVER & 17 & $M G / L$ & 0.0500 & 0205 & $04 / 17 / 91$ & 0001 & AL & $N$ & 0.05 & 0.05 & - \\
\hline & SILVER (TOTAL) & 5 & $M G / L$ & 0.0500 & - & - & - & - & - & - & - & - \\
\hline & URANIUM (TOTAL) & 5 & $M G / L$ & 0.0440 & $\begin{array}{l}0203 \\
0204 \\
0206 \\
0207 \\
0210\end{array}$ & $\begin{array}{l}12 / 12 / 90 \\
12 / 12 / 90 \\
12 / 12 / 90 \\
12 / 12 / 90 \\
12 / 12 / 90\end{array}$ & $\begin{array}{l}\text { NO01 } \\
\text { NO01 } \\
\text { NO01 } \\
\text { NO01 } \\
\text { NO01 }\end{array}$ & $\begin{array}{l}A L \\
A L \\
A L \\
A L \\
A L\end{array}$ & $\begin{array}{l}N \\
N \\
N \\
N \\
N\end{array}$ & $\begin{array}{c}10.2 \\
0.109 \\
0.135 \\
0.450 \\
0.641\end{array}$ & $\begin{array}{l}0.0003 \\
0.0003 \\
0.0003 \\
0.0003 \\
0.0003\end{array}$ & $\begin{array}{l}- \\
- \\
- \\
-\end{array}$ \\
\hline
\end{tabular}

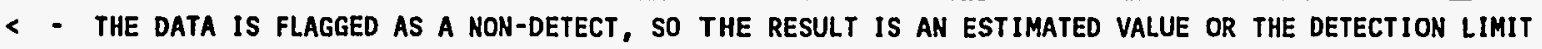

MATERIAL OF SAMPLING CODE:

TA - URANIUM MILL TAILINGS

AL - ALLUVIUM

NR - NO RECOVERY OF DATA FOR CLASSIFYING

OTHER PARAMETER VALUE FLAGS:

I - INCREASED DETECTION LIMIT DUE TO REQUIRED DILUTION
FLOW RELATIONSHIP CODE:

O - ON-SITE

N - UNKNOWN

SAMPLE ID COOES:

0001 - FILTERED SAMPLE (.45 MICRONS)

NOO1 - UNFILTERED SAMPLE 
TABLE 3.25 TAILINGS PORE FLUID MATER QUALITY STATISTICS BY PARAMETER, UC

PROCESSING SITE, SLICK ROCK, COLORADO

SITE: SRKO1 SLICK ROCK (BOTH SITES)

01/12/89 TO $10 / 14 / 92$

REPORT DATE: $06 / 17 / 93$

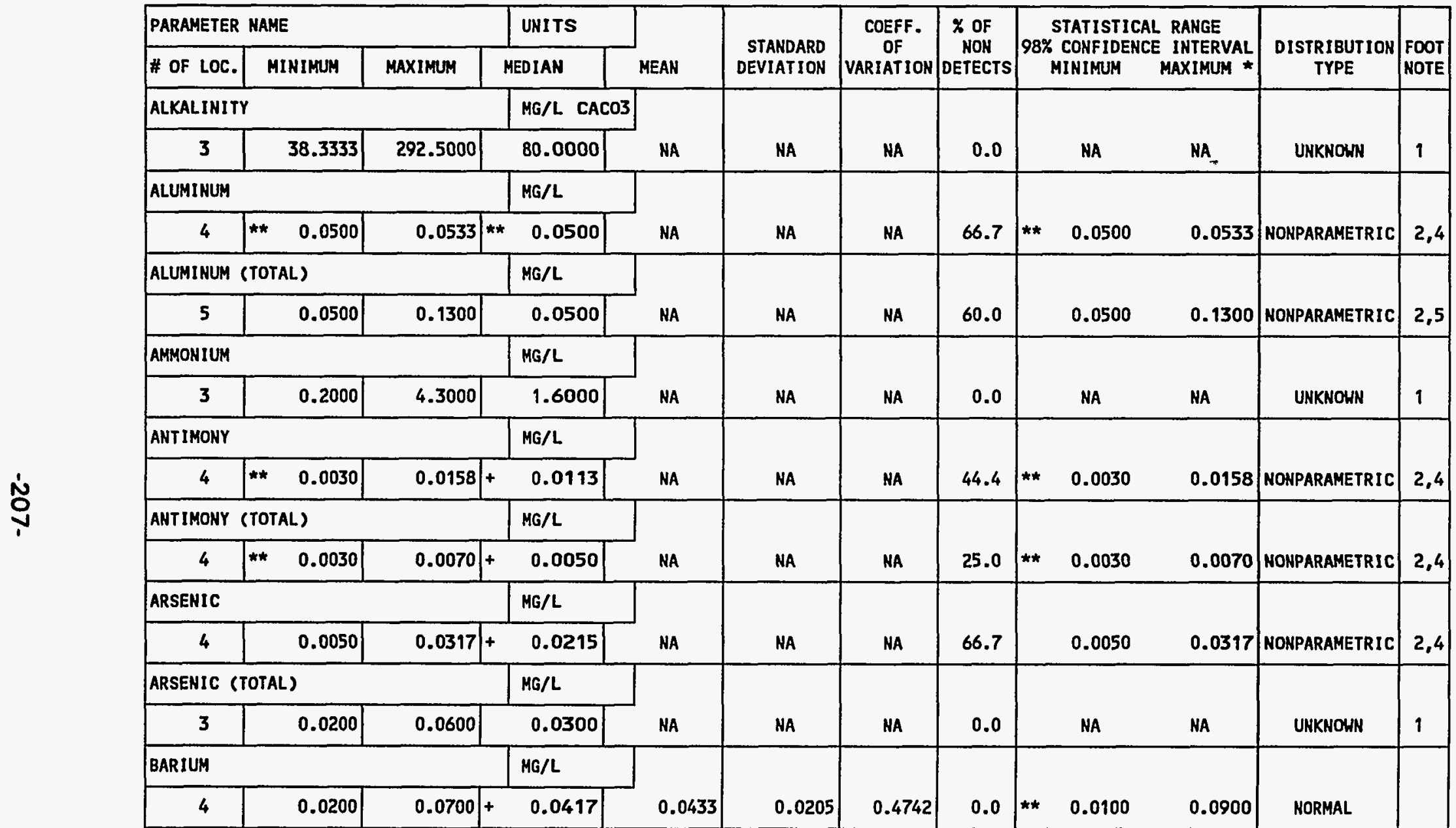

** The reported value is the minimum detection limit of the data set

+ The sample size is even, so the median value is the arithmetic average of the two middle values

* The statistical maximum is the 99 percent one sided confidence interval, $\alpha=0.01$

1) Data from a minimum of 4 locations must be available for the statistical analysis.

2) The nonparametric distribution was used because the nondetected values comprise more than 15\% of the samples.

4) The stat. range is the $87.5 \%$ confidence interval due to a sample size of 4 . The maximum is the $93.8 \%$ one sided confidence int.

5) The stat. range is the $93.8 \%$ confidence interval due to a sample size of 5 . The maximum is the $96.9 \%$ one sided confidence int.

Hote the data at each location was averaged before the statistical calculations were performed 
TABLE 3.25 TAILINGS PORE FLUIO NATER QUALITY STATISTICS BY PARAMETER, UC PROCESSING SITE, SLICK ROCK, COLORADO

SITE: SRKO1 SLICK ROCK (BOTH

$01 / 12 / 89$ TO $10 / 14 / 92$

REPORT DATE: $06 / 17 / 93$

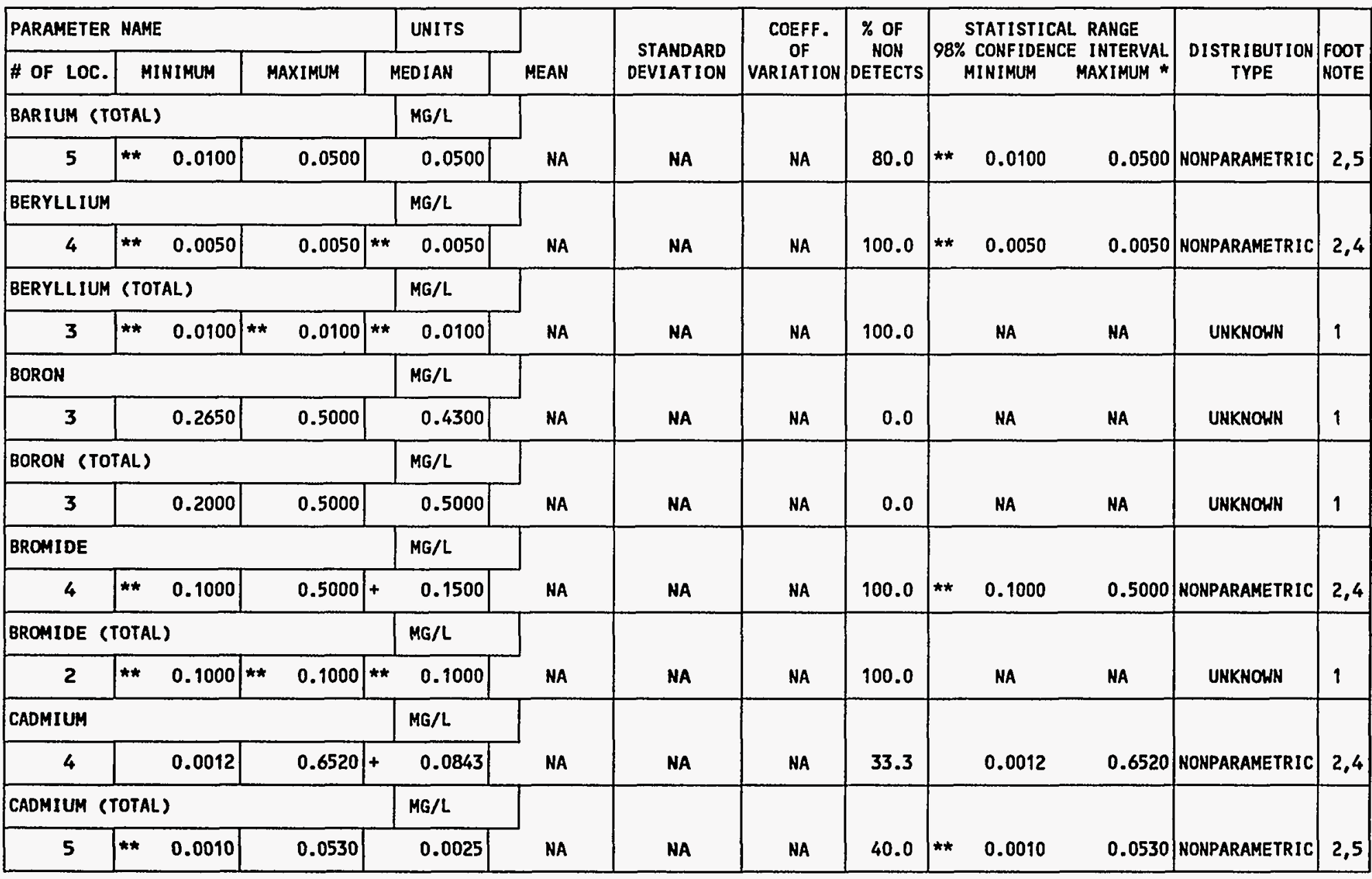

** The reported value is the minimum detection limit of the data set

+ The sample size is even, so the median value is the arithmetic average of the two middle values

* The statistical maximum is the 99 percent one sided confidence interval $\alpha=0.01$

1) Data from a minimum of 4 locations must be available for the statistical analysis.

2) The nonparametric distribution was used because the nondetected values comprise more than $15 \%$ of the samples.

4) The stat. range is the $87.5 \%$ confidence interval due to a sample size of 4 . The maximum is the $93.8 \%$ one sided confidence int.

5) The stat. range is the $93.8 \%$ confidence interval due to a sample size of 5 . The maximum is the $96.9 \%$ one sided confidence int.

Note the data at each location was averaged before the statistical calculations were performed 
TABLE 3.25 TAILINGS PORE FLUID WATER QUALITY STATISTICS BY PARAMETER, UC PROCESSING SITE, SLICK ROCK, COLORADO

SITE: SRKO1 SLICK ROCK (BOTH SITES)

01/12/89 TO $10 / 14 / 92$

REPORT DATE: 06/17/93

\begin{tabular}{|c|c|c|c|c|c|c|c|c|c|c|c|}
\hline \multicolumn{3}{|c|}{ PARAMETER NAME } & UNITS & \multirow[b]{2}{*}{ MEAN } & \multirow{2}{*}{$\begin{array}{r}\text { STANDARD } \\
\text { DEVIATION }\end{array}$} & \multirow{2}{*}{$\begin{array}{l}\text { COEFF. } \\
\text { OF } \\
\text { VARIATION }\end{array}$} & \multirow{2}{*}{$\begin{array}{c}* \text { OF } \\
\text { NOH } \\
\text { DETECTS }\end{array}$} & \multirow{2}{*}{\multicolumn{2}{|c|}{$\begin{array}{c}\text { STATISTICAL RANGE } \\
\text { 98\% CONFIDENCE IHTERVAL } \\
\text { MINIMUM MAXIMUM * }\end{array}$}} & \multirow{2}{*}{$\begin{array}{l}\text { DISTRIBUTION } \\
\text { TYPE }\end{array}$} & \multirow{2}{*}{$\begin{array}{l}\text { FOOT } \\
\text { NOTE }\end{array}$} \\
\hline \# OF LOC. & MINIMUM & MAXIMUM & MEDIAN & & & & & & & & \\
\hline \multicolumn{3}{|l|}{ CALCIUM } & MG/L & \multirow[b]{2}{*}{620.6667} & \multirow[b]{2}{*}{119.3510} & \multirow[b]{2}{*}{0.1923} & \multirow[b]{2}{*}{0.0} & \multirow[b]{2}{*}{349.6802} & \multirow[b]{2}{*}{891.6532} & \multirow[b]{2}{*}{ NORMAL } & \\
\hline 4 & 474.6667 & 745.0000 & 631.5000 & & & & & & & & \\
\hline \multicolumn{3}{|c|}{ CALCIUM (TOTAL) } & MG/L & \multirow[b]{2}{*}{569.8000} & \multirow[b]{2}{*}{148.7538} & \multirow[b]{2}{*}{0.2611} & \multirow[b]{2}{*}{0.0} & \multirow[b]{2}{*}{320.5318} & \multirow[b]{2}{*}{819.0682} & \multirow[b]{2}{*}{ NORMAL } & \\
\hline 5 & 350.0000 & 697.0000 & 616.0000 & & & & & & & & \\
\hline \multicolumn{3}{|l|}{ CHLORIDE } & MG/L & \multirow[b]{2}{*}{45.0000} & \multirow[b]{2}{*}{32.4654} & \multirow[b]{2}{*}{0.7215} & \multirow[b]{2}{*}{0.0} & \multirow[b]{2}{*}{1.0000} & \multirow[b]{2}{*}{118.7126} & \multirow[b]{2}{*}{ KORMAL } & \\
\hline 4 & 14.0000 & 89.0000 & 38.5000 & & & & & & & & \\
\hline CHLORIDE & (TOTAL) & & MG/L & & & & & & & & \\
\hline 2 & 92.0000 & 116.0000 & 104.0000 & NA & NA & NA & 0.0 & NA & NA & UNKNOWN & 1 \\
\hline CHROMIUM & & & $M G / L$ & & & & & & & & \\
\hline 4 & 0.0100 & 0.0100 & 0.0100 & NA & NA & NA & 88.9 & 0.0100 & ** 0.0100 & NONPARAMETRIC & 2,4 \\
\hline CHROMIUM & (TOTAL) & & $M G / L$ & & & & & & & & \\
\hline 5 & ** $\quad 0.0100$ & 0.0200 & 0.0100 & NA & NA & NA & 80.0 & 0.0100 & 0.0200 & NONPARAMETRIC & 2,5 \\
\hline COBALT & & & MG/L & & & & & & & & \\
\hline 4 & ** $\quad 0.0300$ & 0.2800 & 0.0300 & NA & NA & NA & 71.4 & 0.0300 & 0.2800 & NONPARAMETRIC & 2,4 \\
\hline COBALT $\angle T$ & DTAL) & & $M G / L$ & & & & & & & & \\
\hline 3 & 0.0500 & 0.0500 & 0.0500 & NA & NA & NA & 100.0 & NA & NA & UNKHOWN & 1 \\
\hline COPPER & & & $M G / L$ & & & & & & & & \\
\hline 4 & 0.0200 & 36.7000 & 0.9100 & 0.4188 & 38.0402 & NA & 0.0 & 0.0100 & 1621.7224 & LOGNORMAL & 7,8 \\
\hline
\end{tabular}

** The reported value is the minimum detection limit of the data set

+ The sample size is even, so the median value is the arithmetic average of the two middle values

* The statistical maximum is the 99 percent one sided confidence interval, $\alpha=0.01$

1) Data from a minimum of 4 locations must be available for the statistical analysis.

2) The nonparametric distribution was used because the nondetected values comprise more than $15 \%$ of the samples.

4) The stat. range is the $87.5 \%$ confidence interval due to a sample size of 4 . The maximum is the $93.8 \%$ one sided confidence int

5) The stat. range is the $93.8 \%$ confidence interval due to a sample size of 5 . The maximum is the $96.9 \%$ one sided confidence int.

7) The lognormal distribution was used because the data failed the normal distribution test.

8) The mean is geometric. The standard deviation is the value to divide or multiply with the geometric mean.

Note the data at each location was averaged before the statistical calculations were performed 
TABLE 3.25 TAILINGS PORE FLUID HATER QUALITY STATISTICS BY PARAMETER, UC PROCESSING SITE, SLICK ROCK, COLORADO

SITE: SRKO1 SLICK ROCK (BOTH SITES)

01/12/89 TO $10 / 14 / 92$

REPORT DATE: $06 / 17 / 93$

\begin{tabular}{|c|c|c|c|c|c|c|c|c|c|c|c|}
\hline \multicolumn{3}{|c|}{ PARAMETER NAME } & UNITS & \multirow[b]{2}{*}{ MEAN } & \multirow{2}{*}{$\begin{array}{l}\text { STANDARD } \\
\text { DEVIATION }\end{array}$} & \multirow{2}{*}{$\begin{array}{c}\text { COEFF. } \\
\text { OF } \\
\text { VARIATION }\end{array}$} & \multirow{2}{*}{$\begin{array}{c}\% \text { OF } \\
\text { NON } \\
\text { DETECTS }\end{array}$} & \multirow{2}{*}{\multicolumn{2}{|c|}{$\begin{array}{l}\text { STATISTICAL RANGE } \\
\text { 98\% CONFIDENCE INTERVAL } \\
\text { MINIMUM }\end{array}$}} & \multirow{2}{*}{$\underset{\substack{\text { DISTRIBUTION } \\
\text { TYPE }}}{\text { DiOn }}$} & \multirow{2}{*}{$\begin{array}{l}\text { FOOT } \\
\text { NOTE }\end{array}$} \\
\hline \# OF LOC. & MINIMUM & MAXIMUN & MEDIAN & & & & & & & & \\
\hline \multicolumn{3}{|c|}{ COPPER (TOTAL) } & $M G / L$ & \multirow[b]{2}{*}{ NA } & \multirow[b]{2}{*}{ NA } & \multirow[b]{2}{*}{ NA } & \multirow[b]{2}{*}{20.0} & \multirow[b]{2}{*}{0.0100} & \multirow[b]{2}{*}{1.1100} & \multirow[b]{2}{*}{ NONPARAMETRIC } & \multirow[b]{2}{*}{2,5} \\
\hline 5 & 0.0100 & 1.1100 & 0.0500 & & & & & & & & \\
\hline \multicolumn{3}{|l|}{ FLUORIDE } & $M G / L$ & \multirow[b]{2}{*}{ NA } & \multirow[b]{2}{*}{ NA } & \multirow[b]{2}{*}{ NA } & \multirow[b]{2}{*}{0.0} & \multirow[b]{2}{*}{ NA } & \multirow[b]{2}{*}{ NA } & \multirow[b]{2}{*}{ UNKNOWH } & \multirow[b]{2}{*}{1} \\
\hline 2 & 0.2000 & 0.7000 & 0.4500 & & & & & & & & \\
\hline \multicolumn{3}{|c|}{ FLUORIDE (TOTAL) } & $M G / L$ & \multirow[b]{2}{*}{ NA } & \multirow[b]{2}{*}{ NA } & \multirow[b]{2}{*}{ NA } & \multirow[b]{2}{*}{0.0} & \multirow[b]{2}{*}{ NA } & \multirow[b]{2}{*}{ HA } & & \\
\hline 2 & 0.2000 & 0.3000 & 0.2500 & & & & & & & UNKNOWN & 1 \\
\hline GROSS ALPh & & & $\mathrm{PCI} / \mathrm{L}$ & & & & & & & & \\
\hline 3 & 72.8000 & 1026.0000 & 293.0000 & HA & NA & NA & 0.0 & NA & NA & UNKNOWN & 1 \\
\hline GROSS ALPH & A (TOTAL) & & $\mathrm{PCl} / \mathrm{L}$ & & & & & & & & \\
\hline 2 & 120.0000 & 430.0000 & +275.0000 & NA & NA & NA & 0.0 & NA & HA & UNKNOWH & 1 \\
\hline GROSS BETA & & & $\mathrm{PCI} / \mathrm{L}$ & & & & & & & & \\
\hline 3 & 54.7000 & 379.0000 & 170.0000 & NA & NA & NA & 0.0 & NA & NA & UNKNOWN & 1 \\
\hline GROSS BETA & (TOTAL) & & PCI/L & & & & & & & & \\
\hline 2 & 58.0000 & 190.0000 & +124.0000 & NA & NA & NA & 0.0 & NA & NA & UNKNOWN & 1 \\
\hline IRON & & & MG/L & & & & & & & & \\
\hline 4 & $\star \quad 0.0300$ & 0.0800 & 0.0300 & NA & NA & NA & 77.8 & 0.0300 & 0.0800 & NONPARAMETRIC & 2,4 \\
\hline IRON (TOTA & & & MG/L & & & & & & & & \\
\hline 5 & 0.0400 & 0.2700 & 0.1100 & 0.1320 & 0.0976 & 0.7392 & 0.0 & 0.0300 & 0.2955 & NORMAL & \\
\hline
\end{tabular}

** The reported value is the minimum detection limit of the data set

- The sample size is even, so the median value is the arithmet ic average of the two middle values

* The statistical maximum is the 99 percent one sided confidence interval $a=0.01$

1) Data from a minimm of 4 locations must be available for the statistical analysis.

2) The nonparametric distribution was used because the nondetected values comprise more than $15 \%$ of the samples.

4) The stat. range is the $87.5 \%$ confidence interval due to a sample size of 4 . The maximm is the $93.8 \%$ one sided confidence int.

5) The stat. range is the $93.8 \%$ confidence interval due to a sample size of 5 . The maximum is the $96.9 \%$ one sided confidence int.

Note the data at each location was averaged before the statistical calculations were performed 
TABLE 3.25 TAILINGS PORE FLUID HATER QUALITY STATISTICS BY PARAMETER, UC PROCESSING SITE, SLICK ROCK, COLORADO

SITE: SRKO1 SLICK ROCK (BOTH SITES)

$01 / 12 / 89$ TO $10 / 14 / 92$

REPORT DATE: 06/17/93

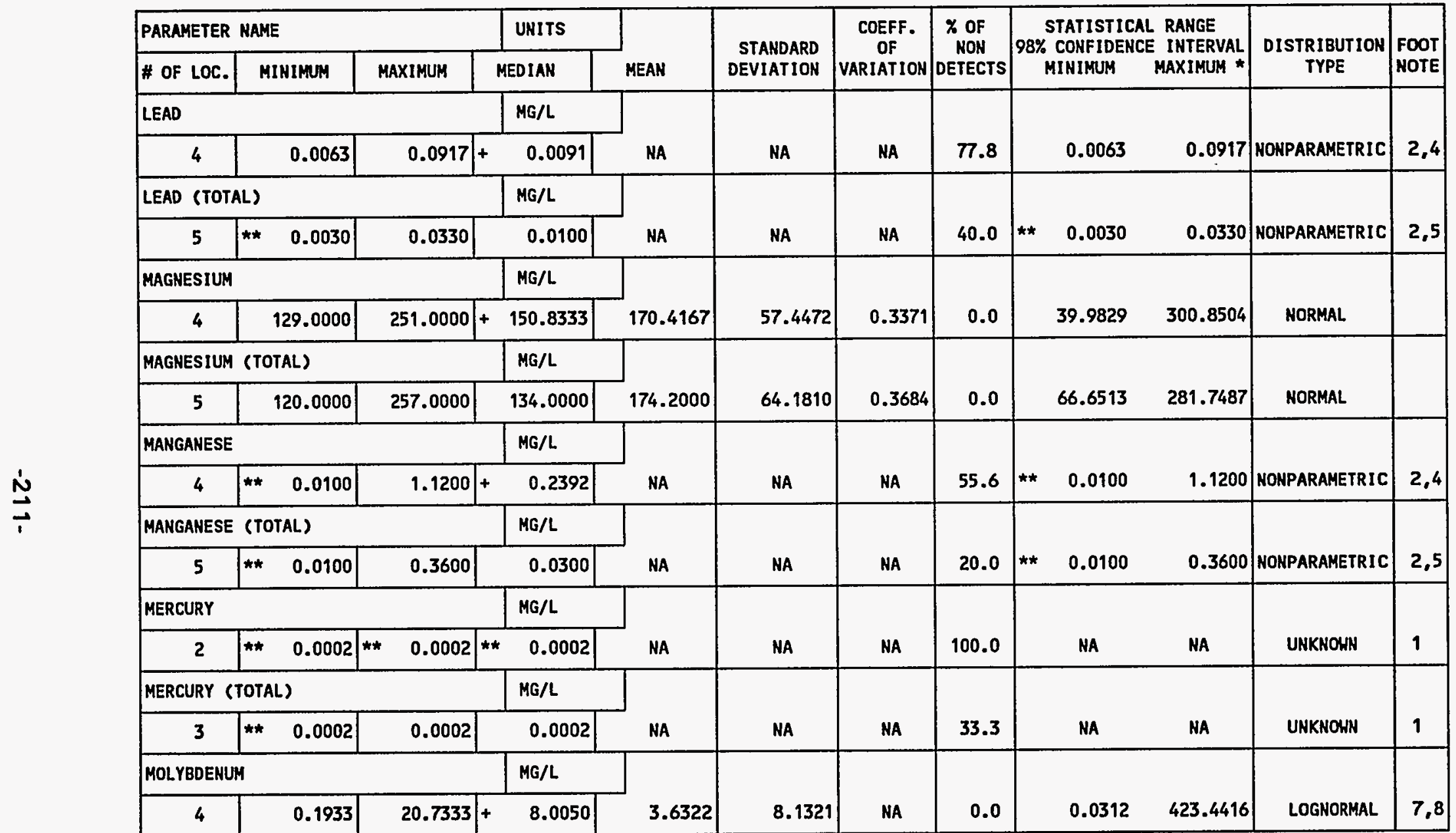

** The reported value is the minimum detection limit of the data set

+ The sample size is even, so the median value is the arithmetic average of the two middle values

* The statistical maximum is the 99 percent one sided confidence interval, $\alpha=0.01$

1) Data from a minimum of 4 locations must be available for the statistical analysis.

2) The nomparametric distribution was used because the nondetected values comprise more than $15 \%$ of the samples.

4) The stat. renged

5) The stat. range is the $93.8 \%$ confidence interval due to a sample size of 5 . The maximum is the $96.9 \%$ one sided confidence int.

7) The lognormal distribution was used because the data failed the normal distribution test.

8) The mean is geometric. The standard deviation is the value to divide or multiply with the geometric mean.

Hote the data at each location was averaged before the statistical calculations Here performed 
TABLE 3.25 TAILINGS PORE FLUID HATER QUALITY STATISTICS BY PARAMETER, UC PROCESSING SITE, SLICK ROCK, COLORADO

SITE: SRKO1 SLICK ROCK (BOTH SITES)

$01 / 12 / 89$ TO $10 / 14 / 92$

REPORT DATE: 06/17/93

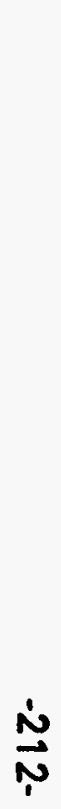

\begin{tabular}{|c|c|c|c|c|c|c|c|c|c|c|c|c|}
\hline \multicolumn{3}{|c|}{ PARAMETER NAME } & UNITS & \multirow[b]{2}{*}{ MEAN } & \multirow{2}{*}{$\begin{array}{l}\text { STANDARD } \\
\text { DEVIATION }\end{array}$} & \multirow{2}{*}{$\begin{array}{c}\text { COEFF. } \\
\text { OF } \\
\text { VARIATION }\end{array}$} & \multirow{2}{*}{$\begin{array}{c}\% \text { OF } \\
\text { NON } \\
\text { DETECTS }\end{array}$} & \multirow{2}{*}{\multicolumn{3}{|c|}{$\begin{array}{l}\text { STATISTICAL RANGE } \\
\text { 98\% CONFIDENCE INTERVAL } \\
\text { MINIMUM MAXIMUM * }\end{array}$}} & \multirow{2}{*}{$\begin{array}{l}\text { DISTRIBUTION } \\
\text { TYPE }\end{array}$} & \multirow{2}{*}{$\begin{array}{l}\text { FOOT } \\
\text { NOTE }\end{array}$} \\
\hline \# OF LOC. & MINIMUM & MAXIMUM & MEDIAN & & & & & & & & & \\
\hline MOLYBDENUT & 4 (TOTAL) & & $M G / L$ & \multirow[b]{2}{*}{13.6680} & \multirow[b]{2}{*}{10.9365} & \multirow[b]{2}{*}{0.8002} & \multirow[b]{2}{*}{0.0} & \multirow[b]{2}{*}{ ** } & \multirow[b]{2}{*}{0.0100} & \multirow[b]{2}{*}{31.9945} & \multirow[b]{2}{*}{ NORMAL } & \\
\hline 5 & 0.4900 & 30.6000 & 13.6000 & & & & & & & & & \\
\hline \multicolumn{3}{|c|}{ NET GROSS ALPHA $* * \star$} & $\mathrm{PCI} / \mathrm{L}$ & \multirow[b]{2}{*}{ NA } & \multirow[b]{2}{*}{ NA } & \multirow[b]{2}{*}{ NA } & \multirow[b]{2}{*}{0.0} & \multirow{2}{*}{\multicolumn{2}{|c|}{ NA }} & \multirow[b]{2}{*}{ NA } & \multirow[b]{2}{*}{ UNKNOHN } & \multirow[b]{2}{*}{1} \\
\hline 3 & -31.4700 & 1022.5700 & -21.1900 & & & & & & & & & \\
\hline \multicolumn{2}{|c|}{ NET GROSS ALPHA (TOTAL) } & L) $* * \star *$ & PCI/L & \multirow[b]{2}{*}{ NA } & \multirow[b]{2}{*}{ NA } & \multirow[b]{2}{*}{ NA } & \multirow[b]{2}{*}{0.0} & \multirow{2}{*}{\multicolumn{2}{|c|}{ NA }} & \multirow[b]{2}{*}{ NA } & \multirow[b]{2}{*}{ UNKNOWN } & \\
\hline 2 & -9.7300 & 27.3900 & 8.8300 & & & & & & & & & 1 \\
\hline NICKEL. & & & $M G / L$ & & & & & & & & & \\
\hline 4 & $* * \quad 0.0400$ & 0.1700 & 0.0400 & NA & NA & NA & 88.9 & ** & 0.0400 & 0.1700 & NONPARAMETRIC & 2,4 \\
\hline NICKEL (T & OTAL) & & $M G / L$ & & & & & & & & & \\
\hline 5 & $* * \quad 0.0400$ & 0.0400 & 0.0400 & NA & NA & NA & 100.0 & ** & 0.0400 & 0.0400 & NONPARAMETRIC & 2,5 \\
\hline NITRATE & & & $M G / L$ & & & & & & & & & \\
\hline 3 & 40.0000 & 744.0000 & 210.0000 & NA & NA & NA & 0.0 & & NA & NA & UNKHONN & 1 \\
\hline NITRITE A & ND NITRATE & & $M G / L$ & & & & & & & & & \\
\hline 1 & 168.0000 & 168.0000 & 168.0000 & NA & NA & NA & 0.0 & & NA & NA & UNKHOWN & 1 \\
\hline $\mathrm{PH}$ & & & su & & & & & & & & & \\
\hline 6 & 6.2100 & 7.8100 & 7.3224 & NA & NA & NA & 0.0 & & NA & NA & UNKNOWN & \\
\hline
\end{tabular}

*** NET GROSS ALPHA (GROSS ALPHA - URANIUM) HITH 1 MG URANIUM = 686 PCI

**** NET GROSS ALPHA (TOTAL) (TOTAL GROSS ALPHA - TOTAL URANIUM)

** The reported value is the minimum detection limit of the data set

+ The sample size is even, so the median value is the arithmetic average of the two middle values

* The statistical maximum is the 99 percent one sided confidence interval, $a=0.01$

1) Data from a minimum of 4 locations must be available for the statistical analysis.

2) The nonparametric distribution was used because the nondetected values comprise more than $15 \%$ of the samples.

4) The stat. range is the $87.5 \%$ confidence interval due to a sample size of 4 . The maximum is the $93.8 \%$ one sided confidence int.

5) The stat. range is the $93.8 \%$ confidence interval due to a sample size of 5 . The maximum is the $96.9 \%$ one sided confidence int.

Note the data at each location was averaged before the statistical calculations were performed 
TABLE 3.25 TAILIMGS PORE FLUID HATER QUALITY STATISTICS BY PARAMETER, UC PROCESSIHG SITE, SLICK ROCK, COLORADO

SITE: SRKO1 SLICK ROCK (BOTH SITES)

01/12/89 TO $10 / 14 / 92$

REPORT DATE: $06 / 17 / 93$

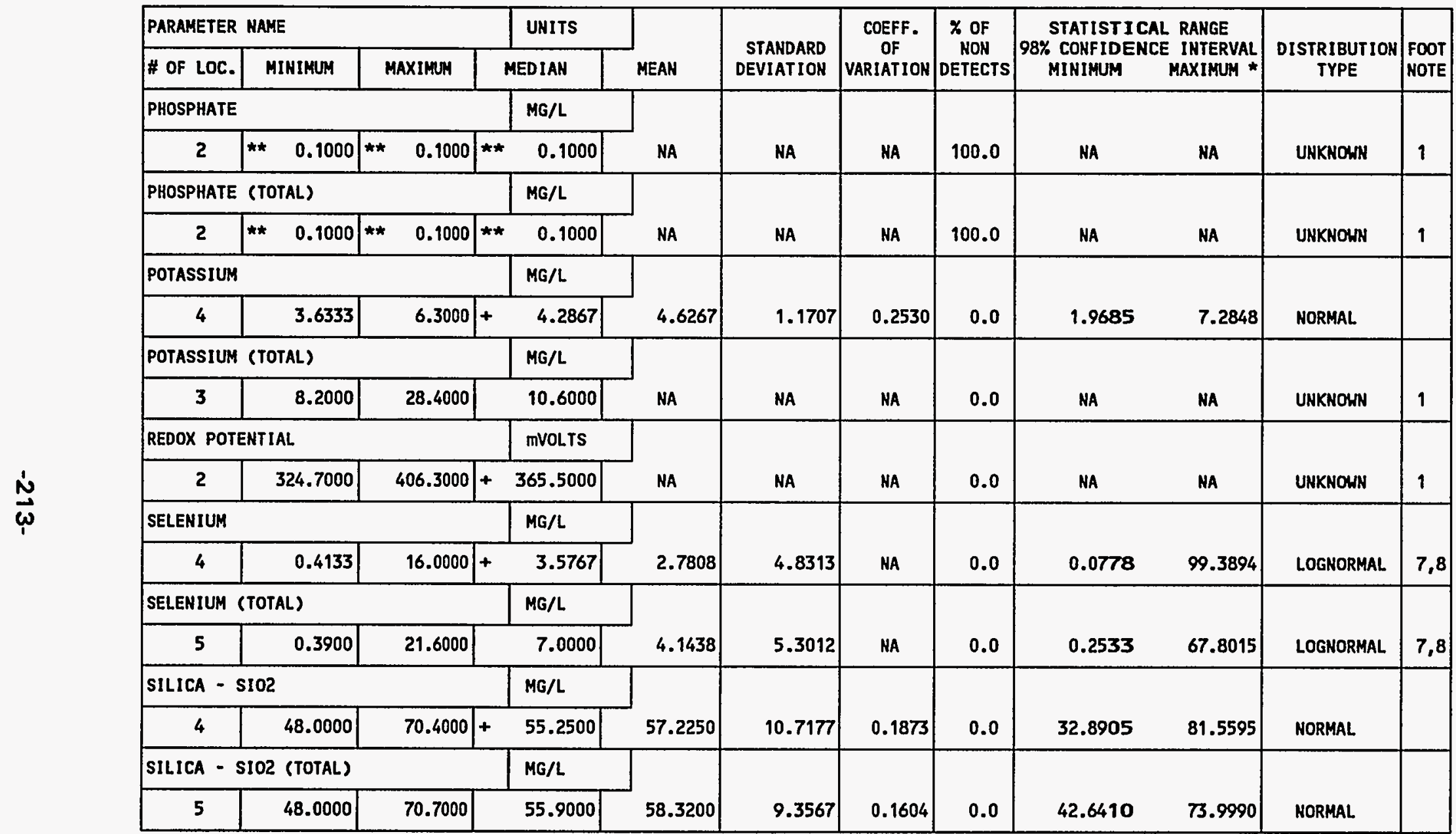

** The reported value is the minimum detection limit of the data set

+ The sample size is even, so the median value is the arithmetic average of the two middle values

* The statistical maximum is the 99 percent one sided confidence interval, $\alpha=0.01$

1) Data from a minimum of 4 locations must be available for the statistical analysis.

7) The lognormal distribution was used because the data failed the normal distribution test.

8) The mean is geometric. The standard deviation is the value to divide or multiply with the geometric mean.

Hote the data at each location was averaged before the statistical calculations were performed 
TABLE 3.25 TAILINGS PORE FLUID HATER QUALITY STATISTICS BY PARAMETER, UC PROCESSING SITE, SLICK ROCK, COLORADO

SITE: SRK01 SLICK ROCK (BOTH SITES)

$01 / 12 / 89$ TO $10 / 14 / 92$

REPORT DATE: $06 / 17 / 93$

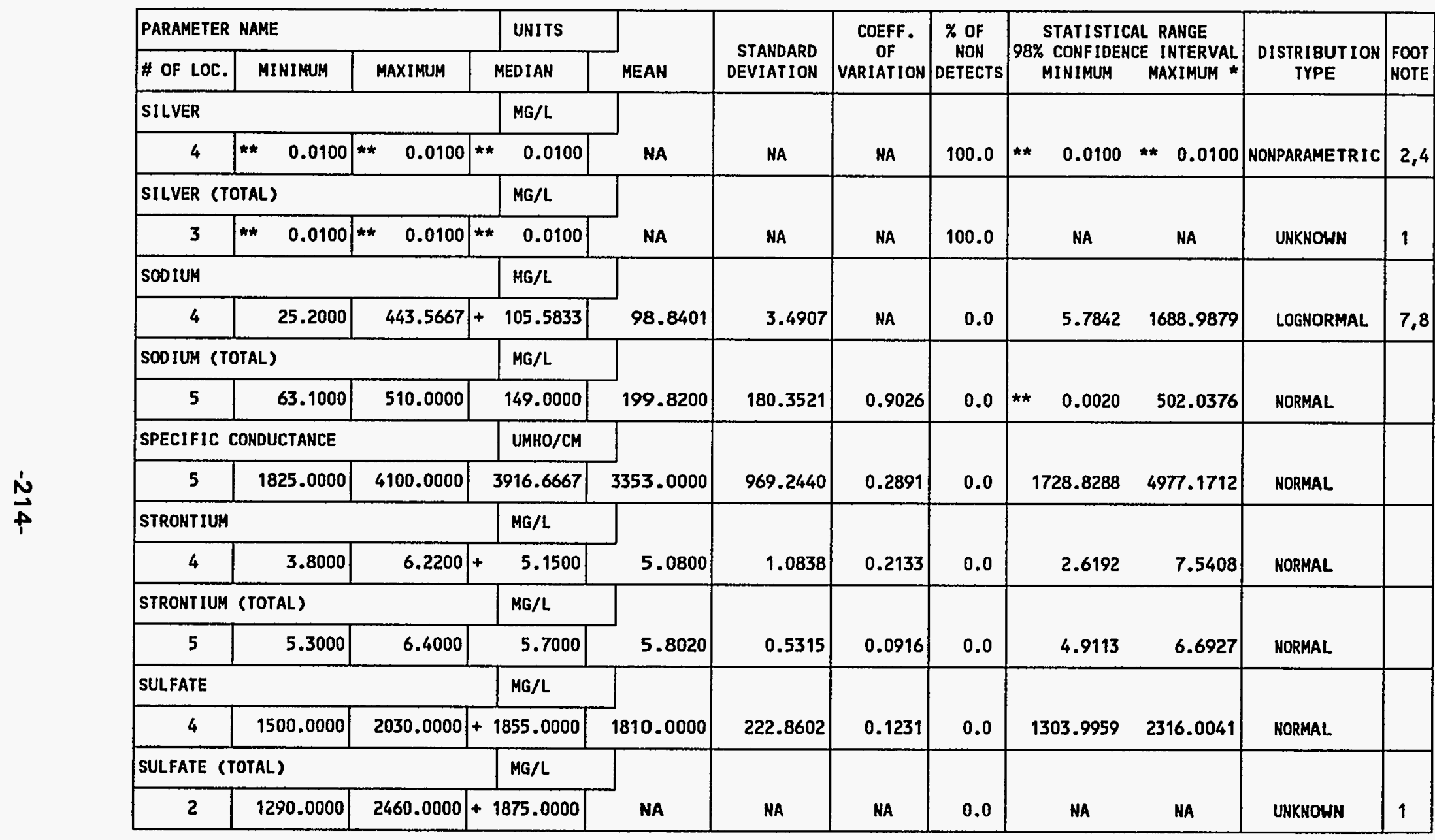

** The reported value is the minimum detection limit of the data set

+ The sample size is even, so the median value is the arithmetic svirage of the two middle values

* The statistical maximum is the 99 percent one sided confidence interval, $\alpha=0.01$

1) Data from a minimum of 4 locations must be available for the statistical analysis.

2) The nonparametric distribution was used because the nondetected values comprise more than $15 \%$ of the samples.

4) The stat. range is the $87.5 \%$ confidence interval due to a sample size of 4 . The maximum is the $93.8 \%$ one sided confidence int.

7) The lognormal distribution was used because the data failed the normal distribution test.

8) The mean is geometric. The standard deviation is the value to divide or multiply with the geometric mean.

Note the data at each location was averaged before the statistical calculations were performed 
TABLE 3.25 TAILINGS PORE FLUID MATER QUALITY STATISTICS BY PARAMETER, UC PROCESSING SITE, SLICK ROCK, COLORADO

SITE: SRKOI SLICK ROCK (BOTH SITES)

01/12/89 TO 10/14/92

REPORT DATE: 06/17/93

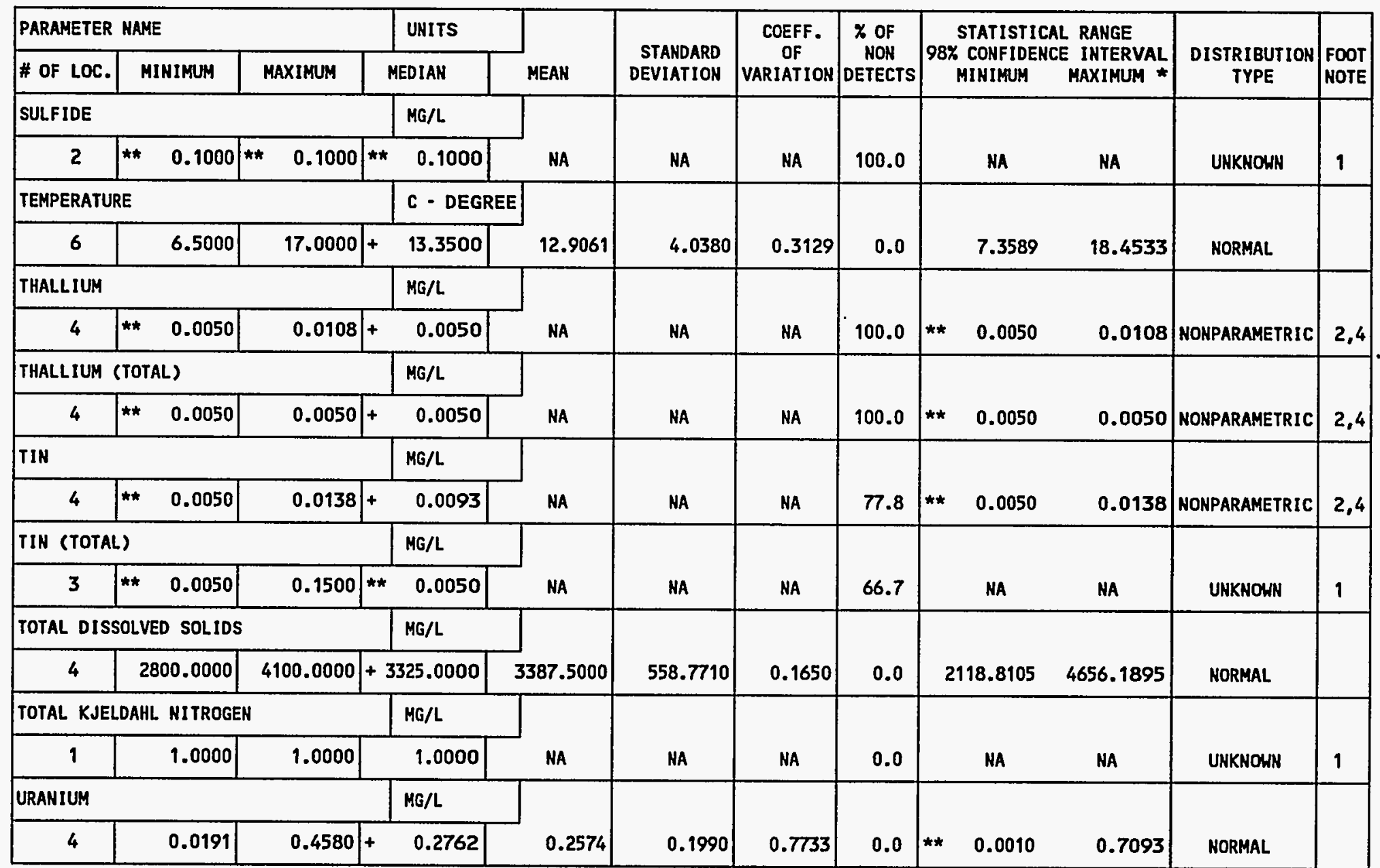

** The reported value is the minimum detection limit of the data set

+ The sample size is even, so the median value is the arithmetic average of the two middle values

* The statistical maximum is the 99 percent one sided confidence interval, $\alpha=0.01$

1) Data from a minimum of 4 locations must be available for the statistical analysis.

2) The nonparametric distribution was used because the nondetected values comprise more than $15 \%$ of the samples.

4) The stat. range is the $87.5 \%$ confidence interval due to a sample size of 4 . The maximum is the $93.8 \%$ one sided confidence int.

Note the data at each location was averaged before the statistical calculations were performed 
TABLE 3.25 TAILINGS PORE FLUID HATER QUALITY STATISTICS BY PARAMETER, UC

PROCESSING SITE, SLICK ROCK, COLORADO

SITE: SRKO1 SLICK ROCK (BOTH SITES)

01/12/89 TO $10 / 14 / 92$

REPORT DATE : $06 / 17 / 93$

\begin{tabular}{|c|c|c|c|c|c|c|c|c|c|c|c|c|}
\hline \multicolumn{3}{|c|}{ PARAMETER NAME } & UNITS & \multirow[b]{2}{*}{ MEAN } & \multirow{2}{*}{$\begin{array}{r}\text { STANDARD } \\
\text { DEVIATION }\end{array}$} & \multirow{2}{*}{$\begin{array}{c}\text { COEFF. } \\
\text { OF } \\
\text { VARIATION }\end{array}$} & \multirow{2}{*}{$\begin{array}{c}\% \text { OF } \\
\text { NON } \\
\text { DETECTS }\end{array}$} & \multirow{2}{*}{\multicolumn{3}{|c|}{$\begin{array}{l}\text { STATISTICAL RANGE } \\
\text { 98\% CONFIDENCE INTERVAL } \\
\text { MINIMUM }\end{array}$}} & \multirow{2}{*}{$\begin{array}{c}\text { DISTRIBUTION } \\
\text { TYPE }\end{array}$} & \multirow{2}{*}{$\begin{array}{l}\text { FOOT } \\
\text { NOTE }\end{array}$} \\
\hline \# OF LOC. & MINIMUM & MAXIMUM & MEDIAN & & & & & & & & & \\
\hline \multicolumn{3}{|c|}{ URANIUM (TOTAL) } & $M G / L$ & \multirow[b]{2}{*}{ NA } & \multirow[b]{2}{*}{ NA } & \multirow[b]{2}{*}{ NA } & \multirow[b]{2}{*}{0.0} & \multirow{2}{*}{\multicolumn{2}{|c|}{ NA }} & \multirow[b]{2}{*}{ NA } & \multirow[b]{2}{*}{ UNKNOWN } & \multirow[b]{2}{*}{1} \\
\hline 3 & 0.1350 & 0.6410 & 0.4500 & & & & & & & & & \\
\hline \multicolumn{3}{|l|}{ VANADIUH } & $\mathrm{MG} / \mathrm{L}$ & \multirow[b]{2}{*}{0.1786} & \multirow[b]{2}{*}{6.5967} & \multirow[b]{2}{*}{ NA } & \multirow[b]{2}{*}{0.0} & \multirow[b]{2}{*}{ ** } & \multirow[b]{2}{*}{0.0100} & \multirow[b]{2}{*}{12.9463} & \multirow[b]{2}{*}{ LOGNORMAL } & \multirow[b]{2}{*}{7,8} \\
\hline 4 & 0.0200 & 1.0900 & 0.3683 & & & & & & & & & \\
\hline \multicolumn{3}{|c|}{ VANADIUM (TOTAL) } & $M G / L$ & \multirow[b]{2}{*}{0.7820} & \multirow[b]{2}{*}{0.5270} & \multirow[b]{2}{*}{0.6739} & \multirow[b]{2}{*}{0.0} & \multirow[b]{2}{*}{ ** } & & \multirow[b]{2}{*}{1.6651} & \multirow[b]{2}{*}{ NORMAL } & \\
\hline 5 & 0.2300 & 1.6500 & 0.6300 & & & & & & 0.0100 & & & \\
\hline \multicolumn{3}{|l|}{ ZINC } & $M G / L$ & \multirow[b]{2}{*}{0.2358} & & & & & & & & \\
\hline 4 & 0.0240 & 4.4900 & 0.3173 & & 10.9618 & NA & 0.0 & ** & 0.0050 & 54.1540 & LOGNORMAL & 7,8 \\
\hline ZINC (TOTA & & & $M G / L$ & & & & & & & & & \\
\hline 5 & 0.0570 & 0.2900 & 0.0900 & 0.1234 & 0.0966 & 0.7827 & 0.0 & ** & 0.0050 & 0.2852 & NORMAL & \\
\hline
\end{tabular}

** The reported value is the minimum detection limit of the data set

+ The sample size is even, so the median value is the arithmetic average of the two middle values

* The statistical maximum is the 99 percent one sided confidence interval, $\alpha=0.01$

1) Data from a minimum of 4 locations must be available for the statistical analysis.

7) The lognormal distribution was used because the data failed the normal distribution test.

8) The mean is geometric. The standard deviation is the value to divide or multiply with the geometric mean.

Note the data at each location was averaged before the statistical calculations were performed

INPUT DATA FILENAME: M: IDARTISRKO1YLYS10005.DAT 
Table 3.26 Summary of regulated constituents in tailings pore fluid samples, UC processing site, Slick Rock, Colorado

\begin{tabular}{|c|c|c|c|c|}
\hline \multicolumn{5}{|c|}{ Constituents with MCLs ${ }^{\mathrm{a}}$} \\
\hline Parameter & Median & MCL & Backgroundb & Exceed \\
\hline Arsenic & $0.02^{e}$ & 0.05 & $0.01^{g}$ & -- \\
\hline Barium & $0.04^{d}$ & 1.00 & $0.05^{e}$ & - \\
\hline Cadmium & $0.08^{e}$ & 0.01 & $0.001^{g}$ & $8 x$ \\
\hline Chromium & $0.01^{g}$ & 0.05 & $0.01^{9}$ & -- \\
\hline Net gross alpha $f$ & -21.19 & 15.00 & $6.96^{\mathrm{e}}$ & - \\
\hline Lead & $0.009^{e}$ & 0.05 & 0.019 & -- \\
\hline Mercury & $0.0002^{g}$ & 0.002 & $0.0002^{g}$ & - \\
\hline Molybdenum & $3.63^{C}$ & 0.10 & $0.02^{e}$ & $36 x$ \\
\hline Nitrate & 210.0 & 44.0 & $4.4^{e}$ & $5 x$ \\
\hline Radium-226 and $-228^{f}$ & -- & 5.0 & $1.80^{d}$ & - \\
\hline Selenium & $2.78^{\mathrm{C}}$ & 0.01 & $0.012^{g}$ & $278 x$ \\
\hline Silver & $0.01^{g}$ & 0.05 & $0.01^{g}$ & - \\
\hline Uranium & $0.26^{d}$ & 0.044 & $0.019^{e}$ & $6 x$ \\
\hline
\end{tabular}


Table 3.26 Summary of regulated constituents in tailings pore fluid samples, UC processing site, Slick Rock, Colorado (Concluded)

\begin{tabular}{lcccc}
\hline \multicolumn{5}{c}{ Constituents without MCLs } \\
\hline Parameter & Median & MCL & Background & Exceed \\
\hline Antimony & $0.011^{\mathrm{e}}$ & None & $0.003^{\mathrm{g}}$ & $4 \mathrm{x}$ \\
Beryllium & $0.01^{\mathrm{g}}$ & None & $0.01^{\mathrm{g}}$ & $\ldots$ \\
Cobalt & $0.03^{\mathrm{e}}$ & None & $0.05^{\mathrm{g}}$ & - \\
Copper & $0.42^{\mathrm{c}}$ & None & $0.02^{\mathrm{g}}$ & $21 \mathrm{x}$ \\
Cyanide & -- & None & $0.01^{\mathrm{g}}$ & - \\
Nickel & $0.04^{\mathrm{g}}$ & None & $0.04^{\mathrm{g}}$ & -- \\
Sulfide & $0.1^{\mathrm{g}}$ & None & $1.0^{\mathrm{e}}$ & - \\
Thallium & $0.01^{\mathrm{g}}$ & None & $0.01^{\mathrm{g}}$ & - \\
Tin & $0.009^{\mathrm{e}}$ & None & $0.005^{\mathrm{g}}$ & $2 \mathrm{x}$ \\
Vanadium & $0.18^{\mathrm{c}}$ & None & $0.02^{\mathrm{e}}$ & $9 \mathrm{x}$ \\
Zinc & $0.236^{\mathrm{c}}$ & None & $0.01^{\mathrm{e}}$ & $24 \mathrm{x}$ \\
\hline
\end{tabular}

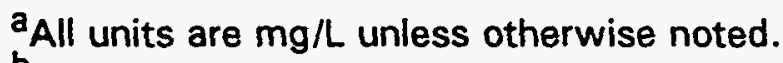

bisposal site background groundwater statistical maximum (upper sandstone unit).

CLognormal distribution, mean is geometric.

dNormal distribution, mean is arithmetic.

enonparametric distribution

Units are $\mathrm{pCi} / \mathrm{L}$.

IStatistical values are below laboratory detection limits in Table 8.1 of the Technical Approach Document (DOE, 1989) 
TABLE 3.27 BASELINE GROUND HATER QUALITY DATA BY PARAMETER FOR THE ALLUVIUM, NC AND UC PROCESSING SITES, SLICK ROCK, COLORADO

SITE: SRKO1 SLICK ROCK (BOTH SITES)

$09 / 07 / 82$ TO $02 / 22 / 94$

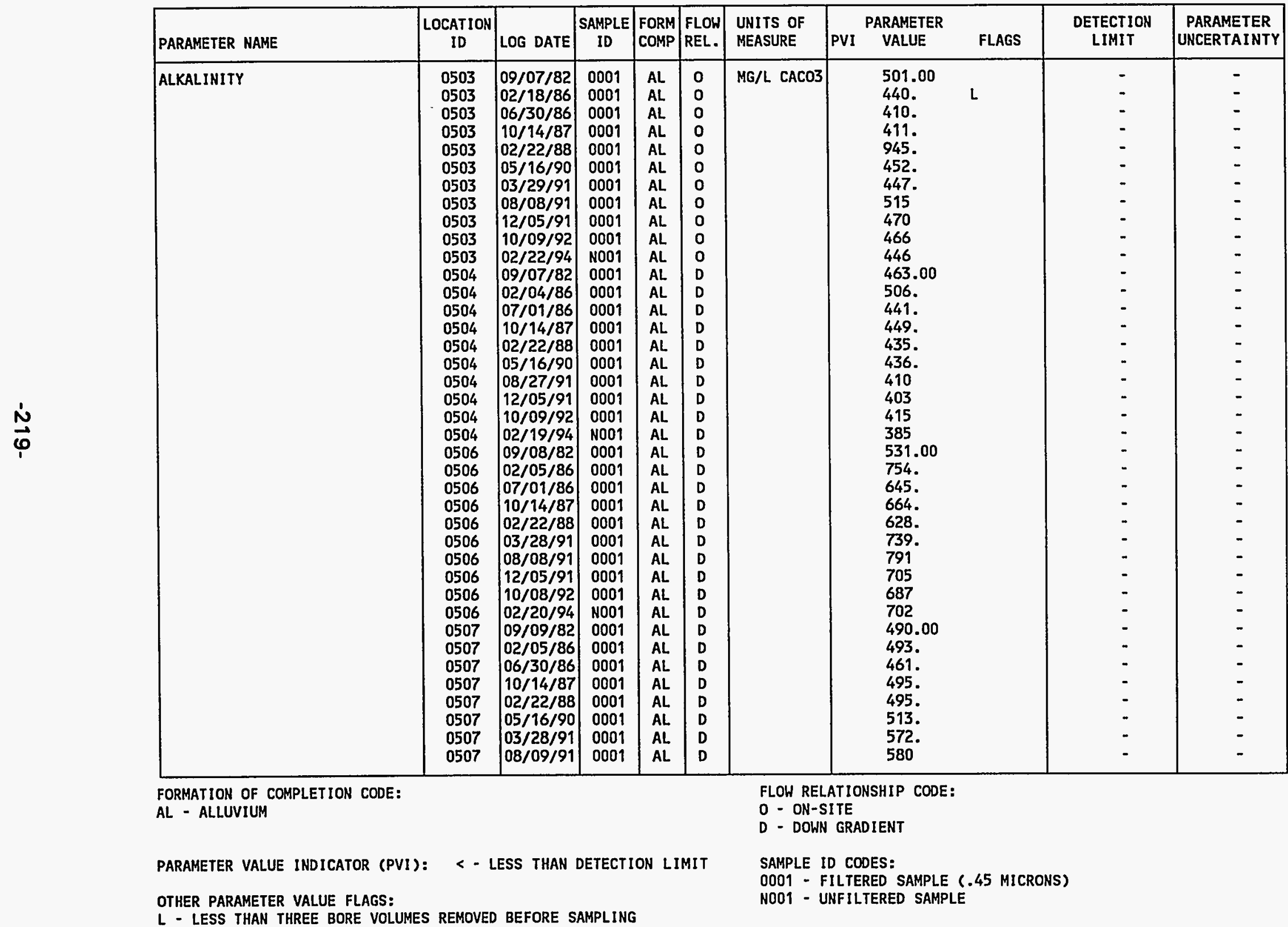




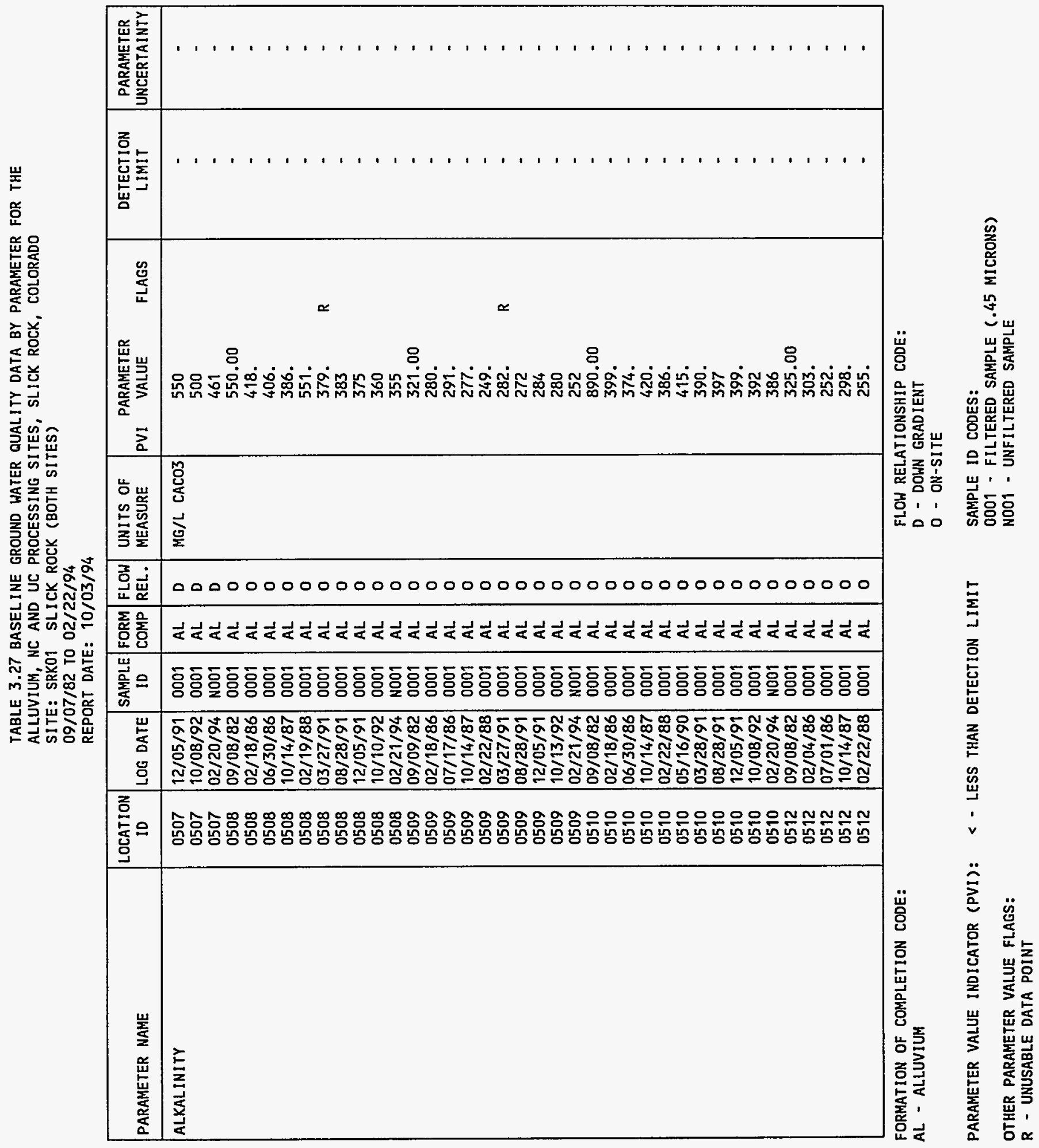


TABLE 3.27 BASELINE GROUND HATER QUALITY DATA BY PARAMETER FOR THE ALLUVIUM, NC AND UC PROCESSING SITES, SLICK ROCK, COLORADO

SITE: SRKO1 SLICK ROCK (BOTH SITES)

O9/07/82 TO 02/22/94

REPORT DATE: $10 / 03 / 94$

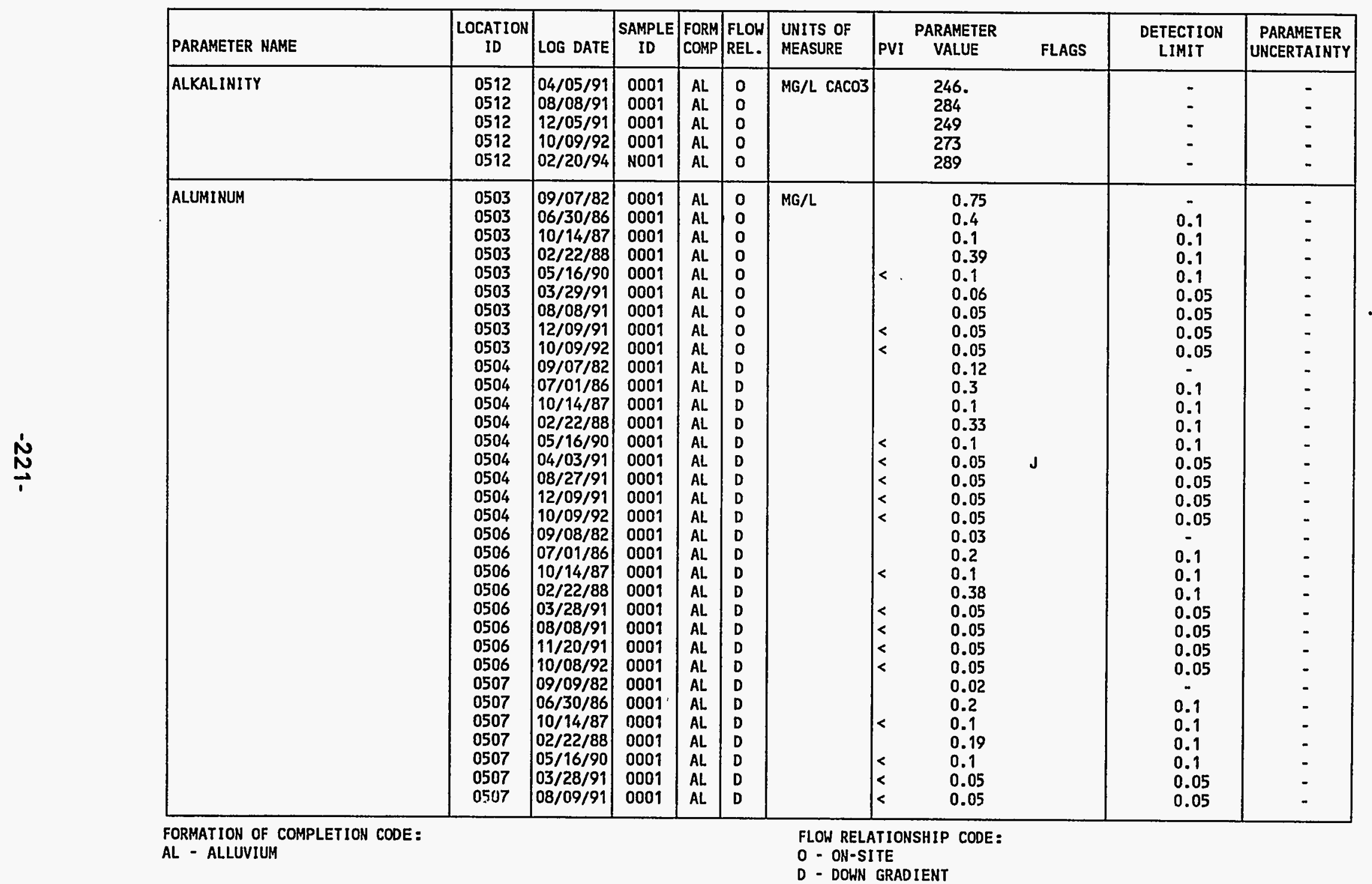

PARAMETER VALUE INDICATOR (PVI): < - LESS THAN DETECTION LIMIT

OTHER PARAMETER VALUE FLAGS:

J - ESTIMATED VALUE
SAMPLE ID CODES:

0001 - FILTERED SAMPLE (. 45 MICRONS)

N001 - UNFILTERED SAMPLE 


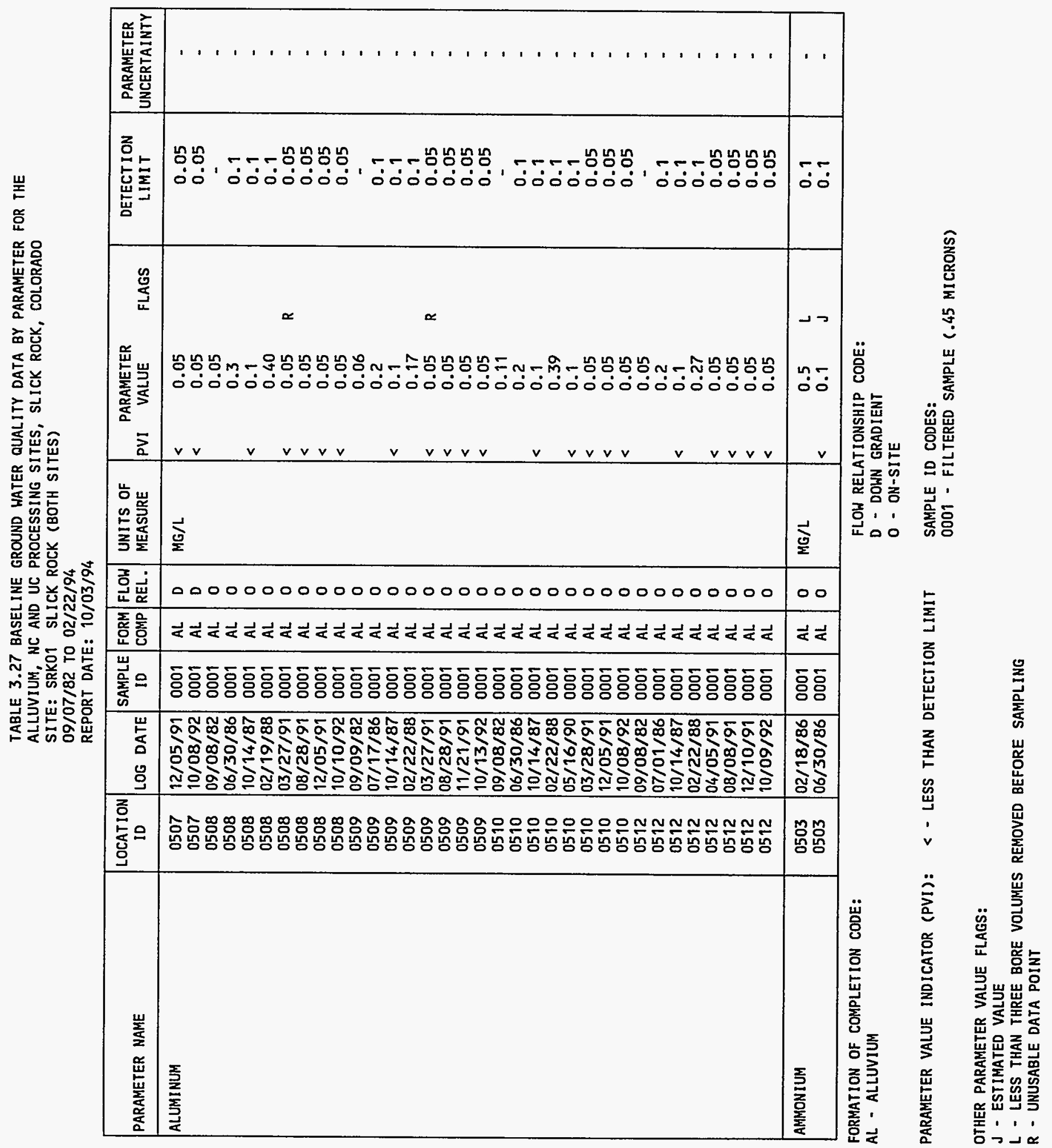


TABLE 3.27 BASELINE GROUND HATER QUALITY DATA BY PARAMETER FOR THE ALLUVIUM, NC AND UC PROCESSING SITES, SLICK ROCK, COLORADO

SITE: SRKO1 SLICK ROCK (BOTH SITES)

$09 / 07 / 82$ TO $02 / 23 / 94$

REPORT DATE: $10 / 03 / 94$

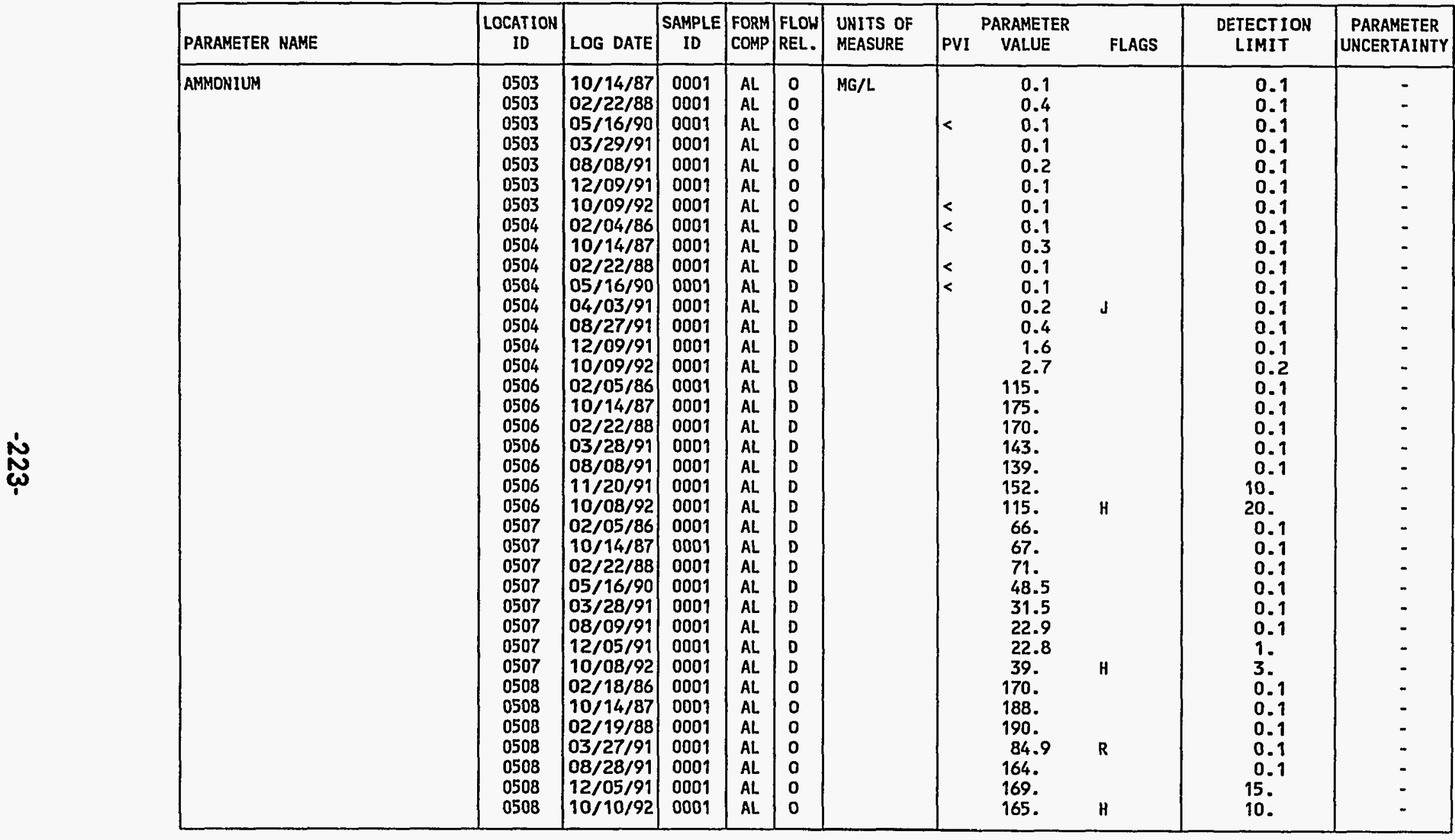

FORMATION OF COMPLETION CODE:

$A L$ - ALLUVIUM

PARAMETER VALUE INDICATOR (PVI): < - LESS THAN DETECTION LIMIT
FLOW RELATIONSHIP CODE:

O - ON-SITE

- DOWN GRADIENT

SAMPLE ID CODES

0001 - FILTERED SAMPLE (.45 MICRONS)

OTHER PARAMETER VALUE FLAGS:

$H$ - HOLD TIME EXPIRED, VALUE SUSPEC

$J$ - ESTIMATED VALUE

R - UNUSABLE DATA POINT 


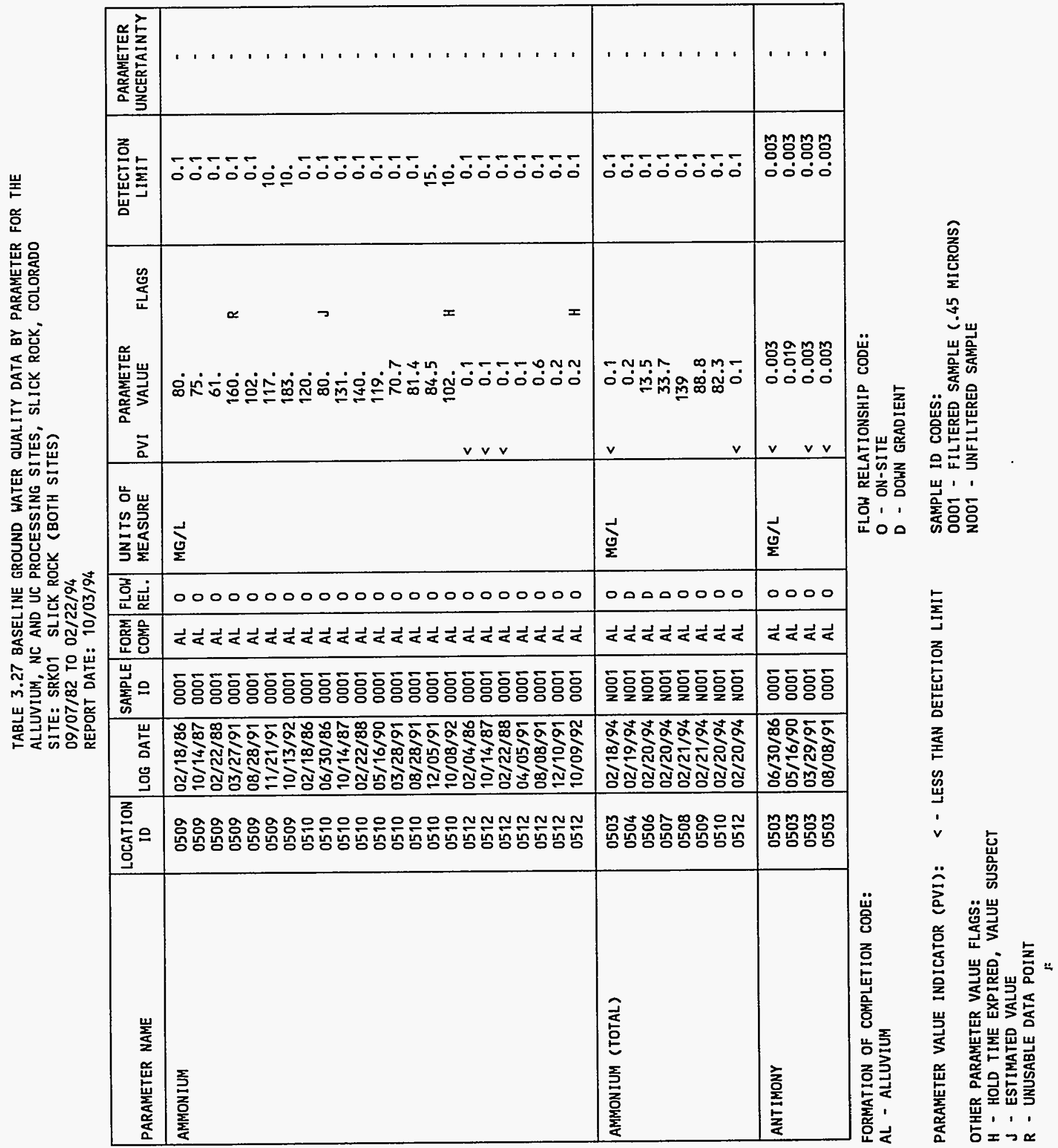




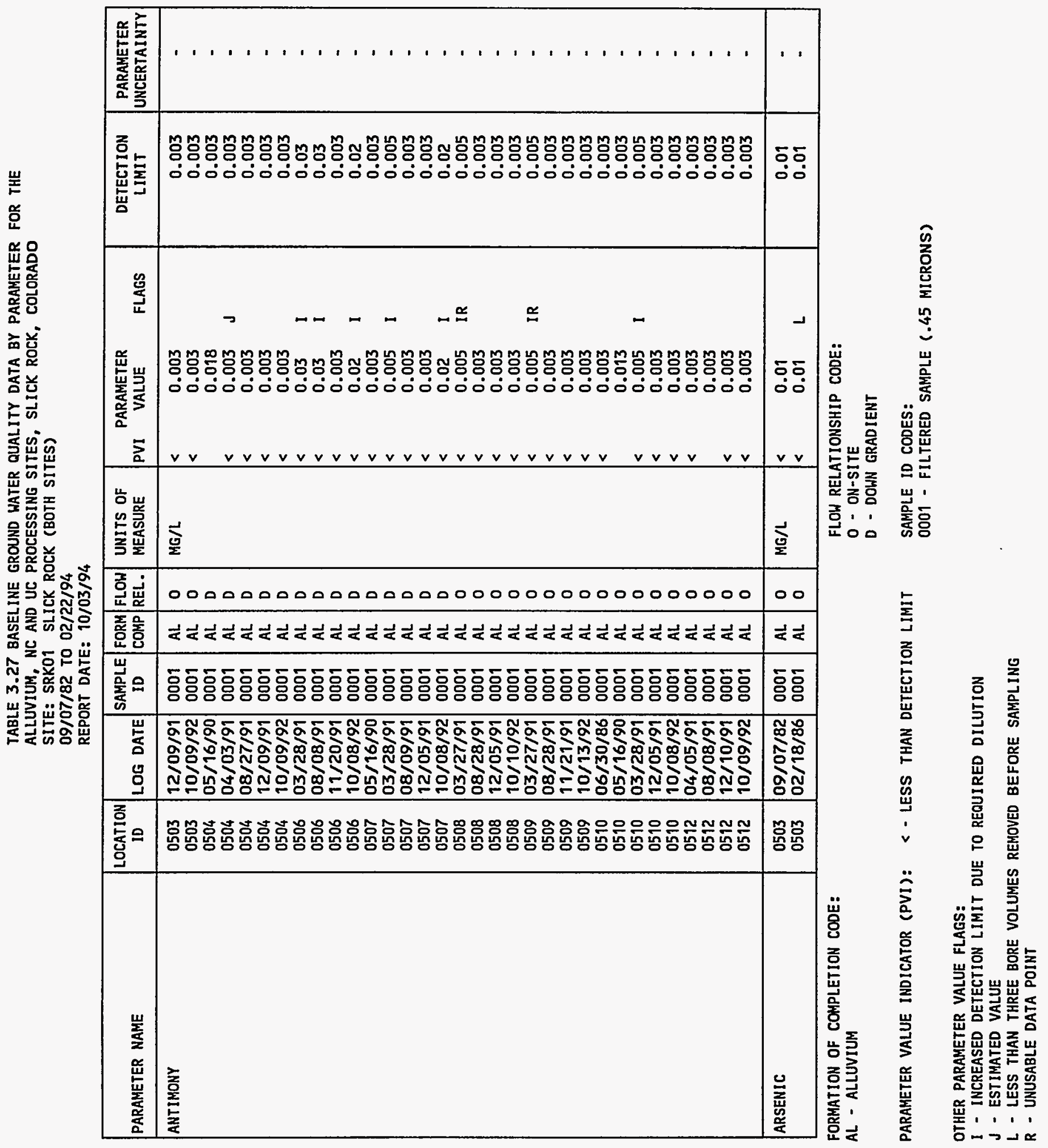




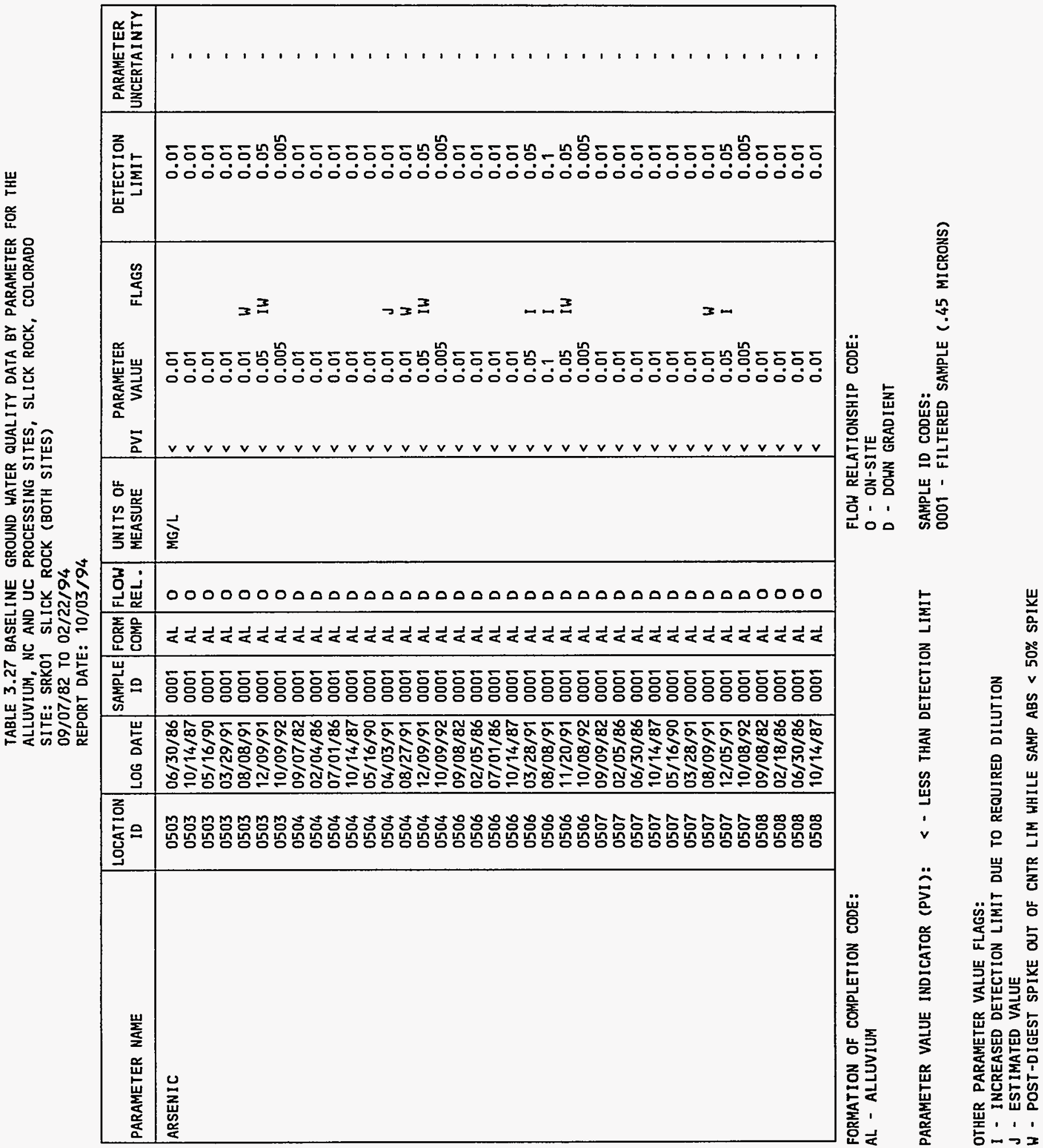


TABLE 3.27 BASELINE GROUND HATER QUALITY DATA BY PARAMETER FOR THE ALLUVIUM, NC AND UC PROCESSING SITES, SLICK ROCK, COLORADO

SITE: SRKO1 SLICK ROCK (BOTH SITES)

DQ/07/82 TO 05123194

REPORT DATE: $10 / 03 / 94$

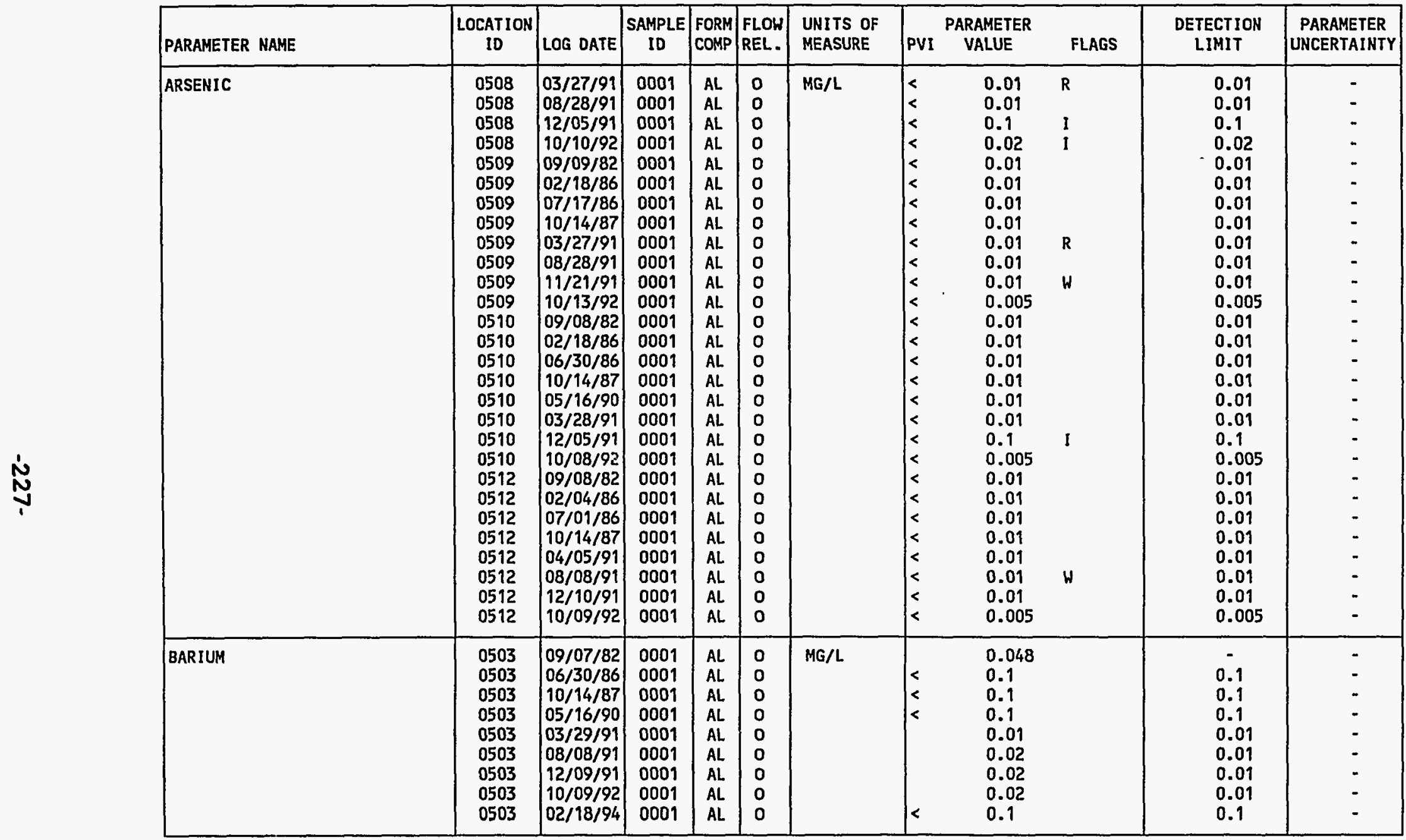

FORMATION OF COMPLETION CODE:

AL - ALLUVIUM

FLOW RELATIONSHIP CODE:

PARAMETER VALUE INDICATOR (PVI): < - LESS THAN DETECTION LIMIT

SAMPLE ID CODES:

0001 - FILTERED SAMPLE (.45 MICRONS)

OTHER PARAMETER VALUE FLAGS:

I - INCREASED DETECTION LIMIT DUE TO REQUIRED DILUTION

I - INCREASED DETECTION
R - UNUSABLE DATA POINT

$H$ - POST-DIGEST SPIKE OUT OF CNTR LIM WHILE SAMP ABS < 50\% SPIKE 
TABLE 3.27 BASELINE GROUND WATER QUALITY DATA BY PARAMETER FOR THE ALLUVIUM, NC AND UC PROCESSING SITES, SLICK ROCK, COLORADO

SITE: SRK01 SLICK ROCK (BOTH SITES)

09/07/82 TO 02/22/94

REPORT DATE: $10 / 03 / 94$

\begin{tabular}{|c|c|c|c|c|c|c|c|c|c|c|c|}
\hline PARAMETER NAME & $\mid \begin{array}{c}\text { LOCATION } \\
\text { ID }\end{array}$ & LOG DATE & $\begin{array}{c}\text { SAMPLE } \\
10\end{array}$ & $\begin{array}{l}\text { FORM } \\
\text { COMP }\end{array}$ & $\begin{array}{l}\text { FLOW } \\
\text { REL. }\end{array}$ & $\begin{array}{l}\text { UNITS OF } \\
\text { MEASURE }\end{array}$ & PVI & $\begin{array}{l}\text { PARAMETER } \\
\text { VALUE }\end{array}$ & FLAGS & $\begin{array}{l}\text { DETECTION } \\
\text { LIMIT }\end{array}$ & $\begin{array}{l}\text { PARAMETER } \\
\text { UNCERTAINTY }\end{array}$ \\
\hline BARIUM & $\begin{array}{l}0504 \\
0504 \\
0504 \\
0504 \\
0504 \\
0504 \\
0504 \\
0504 \\
0506 \\
0506 \\
0506 \\
0506 \\
0506 \\
0506 \\
0507 \\
0507 \\
0507 \\
0507 \\
0507 \\
0507 \\
0507 \\
0507 \\
0508 \\
0508 \\
0508 \\
0508 \\
0508 \\
0508 \\
0509 \\
0509 \\
0509 \\
0509 \\
0509 \\
0509 \\
0509 \\
0510 \\
0510 \\
0510\end{array}$ & $\begin{array}{l}09 / 07 / 82 \\
10 / 14 / 87 \\
05 / 16 / 90 \\
04 / 03 / 91 \\
08 / 27 / 91 \\
12 / 09 / 91 \\
10 / 09 / 92 \\
02 / 19 / 94 \\
10 / 14 / 87 \\
03 / 28 / 91 \\
08 / 08 / 91 \\
11 / 20 / 91 \\
10 / 08 / 92 \\
02 / 20 / 94 \\
09 / 09 / 82 \\
10 / 14 / 87 \\
05 / 16 / 90 \\
03 / 28 / 91 \\
08 / 09 / 91 \\
12 / 05 / 91 \\
10 / 08 / 92 \\
02 / 20 / 94 \\
10 / 14 / 87 \\
03 / 27 / 91 \\
08 / 28 / 91 \\
12 / 05 / 91 \\
10 / 10 / 92 \\
02 / 21 / 94 \\
09 / 09 / 82 \\
10 / 14 / 87 \\
03 / 27 / 91 \\
08 / 28 / 91 \\
11 / 21 / 91 \\
10 / 13 / 92 \\
02 / 21 / 94 \\
09 / 08 / 82 \\
06 / 30 / 86 \\
10 / 14 / 87\end{array}$ & $\begin{array}{l}0001 \\
0001 \\
0001 \\
0001 \\
0001 \\
0001 \\
0001 \\
0001 \\
0001 \\
0001 \\
0001 \\
0001 \\
0001 \\
0001 \\
0001 \\
0001 \\
0001 \\
0001 \\
0001 \\
0001 \\
0001 \\
0001 \\
0001 \\
0001 \\
0001 \\
0001 \\
0001 \\
0001 \\
0001 \\
0001 \\
0001 \\
0001 \\
0001 \\
0001 \\
0001 \\
0001 \\
0001 \\
0001\end{array}$ & $\begin{array}{l}A L \\
A L \\
A L \\
A L \\
A L \\
A L \\
A L \\
A L \\
A L \\
A L \\
A L \\
A L \\
A L \\
A L \\
A L \\
A L \\
A L \\
A L \\
A L \\
A L \\
A L \\
A L \\
A L \\
A L \\
A L \\
A L \\
A L \\
A L \\
A L \\
A L \\
A L \\
A L \\
A L \\
A L \\
A L \\
A L \\
A L \\
A L\end{array}$ & $\begin{array}{l}D \\
D \\
D \\
D \\
D \\
D \\
D \\
D \\
D \\
D \\
D \\
D \\
D \\
D \\
D \\
D \\
D \\
D \\
D \\
D \\
D \\
D \\
0 \\
D \\
D \\
D \\
0 \\
0 \\
0 \\
D \\
0 \\
0 \\
0 \\
D \\
0 \\
0 \\
0 \\
0\end{array}$ & MG/L & $\begin{array}{l}< \\
< \\
< \\
< \\
< \\
< \\
< \\
< \\
< \\
< \\
< \\
< \\
<\end{array}$ & $\begin{array}{l}0.028 \\
0.1 \\
0.1 \\
0.01 \\
0.02 \\
0.02 \\
0.02 \\
0.1 \\
0.1 \\
0.03 \\
0.03 \\
0.02 \\
0.02 \\
0.1 \\
0.053 \\
0.1 \\
0.1 \\
0.06 \\
0.06 \\
0.06 \\
0.07 \\
0.1 \\
0.1 \\
0.01 \\
0.03 \\
0.03 \\
0.03 \\
0.1 \\
0.027 \\
0.1 \\
0.03 \\
0.01 \\
0.01 \\
0.01 \\
0.1 \\
0.043 \\
0.1 \\
0.1\end{array}$ & $R$ & $\begin{array}{l}- \\
0.1 \\
0.1 \\
0.01 \\
0.01 \\
0.01 \\
0.01 \\
0.1 \\
0.1 \\
0.01 \\
0.01 \\
0.01 \\
0.01 \\
0.1 \\
- \\
0.1 \\
0.1 \\
0.01 \\
0.01 \\
0.01 \\
0.01 \\
0.1 \\
0.1 \\
0.01 \\
0.01 \\
0.01 \\
0.01 \\
0.1 \\
- \\
0.1 \\
0.01 \\
0.01 \\
0.01 \\
0.01 \\
0.1 \\
- \\
0.1 \\
0.1\end{array}$ & $\begin{array}{l}- \\
- \\
- \\
- \\
- \\
- \\
- \\
- \\
- \\
- \\
- \\
- \\
- \\
- \\
- \\
- \\
- \\
- \\
- \\
- \\
- \\
- \\
- \\
- \\
- \\
- \\
- \\
- \\
- \\
- \\
- \\
- \\
- \\
- \\
- \\
- \\
-\end{array}$ \\
\hline
\end{tabular}

FORMATION OF COMPLETION CODE:

AL - ALLUVIUM

FLOW RELATIONSHIP CODE:

D - DOWN GRADIENT

O - ON-SITE

PARAMETER VALUE INDICATOR (PVI): < - LESS THAN DETECTION LIMIT

SAMPLE ID CODES:

0001 - FILTERED SAMPLE (.45 MICRONS)

OTHER PARAMETER VALUE FLAGS:

$J$ - ESTIMATED VALUE

$R$ - UNUSABLE DATA POINT 
TABLE 3.27 BASELINE GROUND HATER QUALITY DATA BY PARAMETER FOR THE

ALLUVIUM, NC AND UC PROCESSING SITES, SLICK ROCK, COLORADO

SITE: SRKO1 SLICK ROCK CBOTH SITES

$09 / 07 / 82$ TO $02 / 22 / 94$

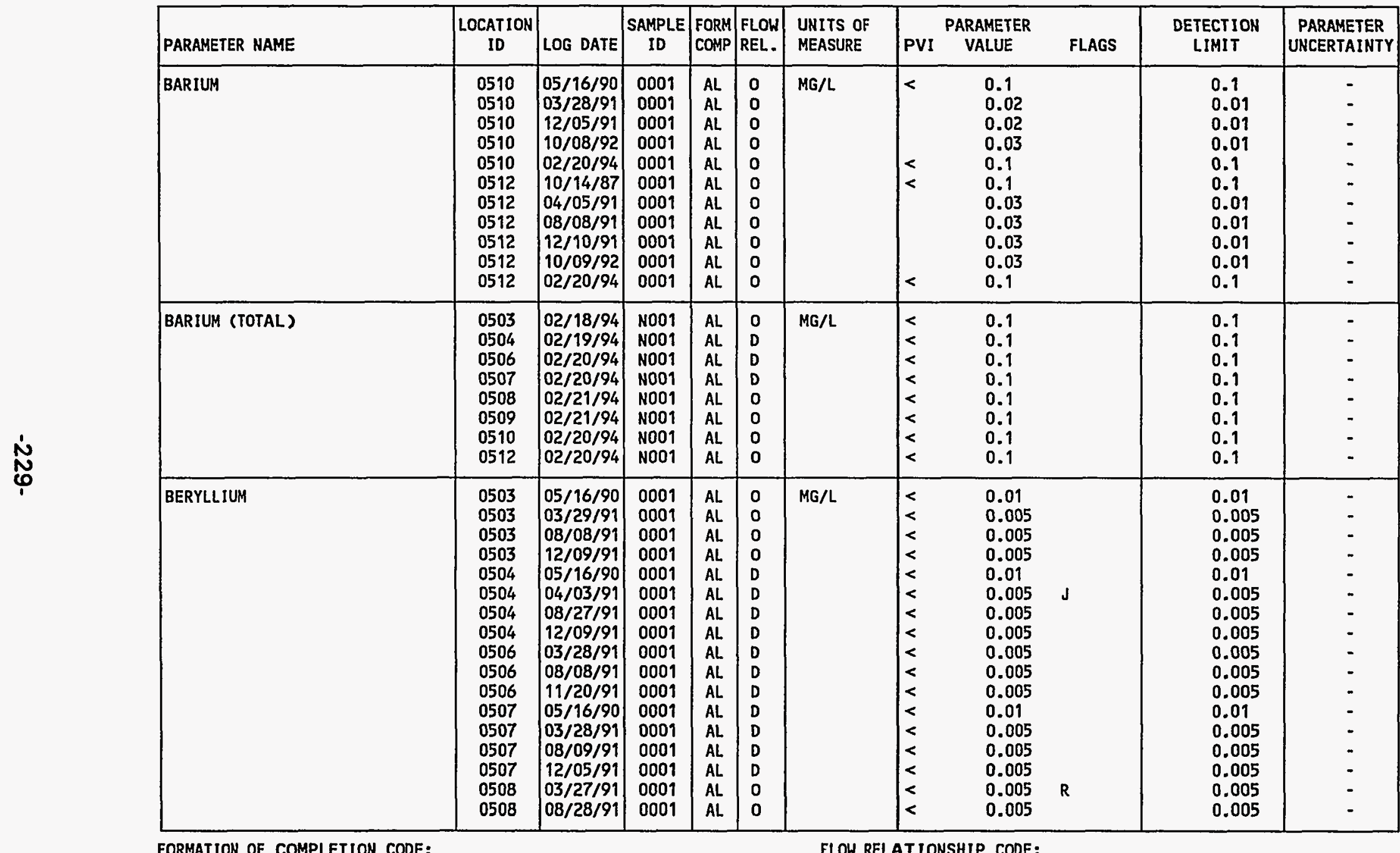

FORMATION OF COMPLETION CODE:

FLOH RELATIONSHIP CODE:

AL - ALLUVIUH

O - ON-SITE

D - DOWN GRADIENT

PARAMETER VALUE INDICATOR (PVI): < - LESS THAN DETECTION LIMIT OTHER PARAMETER VALUE FLAGS:

SAMPLE ID CODES:

0001 - FILTERED SAMPLE (.45 MICRONS)

$J$ - ESTIMATED VALUE

NO01 - UNFILTERED SAMPLE

$R$ - UNUSABLE DATA POINT 
TABLE 3.27 BASELINE GROUND WATER QUALITY DATA BY PARAMETER FOR THE ALLUVIUM, NC AND UC PROCESSING SITES, SLICK ROCK, COLORADO

SITE: SRK01 SLICK ROCK (BOTH SITES)

$09 / 07 / 82$ TO $02 / 22 / 94$

REPORT DATE: $10 / 03 / 94$

\begin{tabular}{|c|c|c|c|c|c|c|c|c|c|c|c|}
\hline PARAMETER NAME & $\underset{\text { ID }}{\text { LOCATION }}$ & LOG DATE & $\begin{array}{c}\text { SAMPLE } \\
\text { ID }\end{array}$ & $\begin{array}{l}\text { FORM } \\
\text { COMP }\end{array}$ & $\begin{array}{l}\text { FLOW } \\
\text { REL. }\end{array}$ & $\begin{array}{l}\text { UNITS OF } \\
\text { MEASURE }\end{array}$ & PVI & $\begin{array}{l}\text { ARAMETER } \\
\text { VALUE }\end{array}$ & FLAGS & $\begin{array}{l}\text { DETECTION } \\
\text { LIMIT }\end{array}$ & $\begin{array}{l}\text { PARAMETER } \\
\text { UNCERTAINTY }\end{array}$ \\
\hline BERYLLIUM & $\begin{array}{l}0508 \\
0509 \\
0509 \\
0509 \\
0510 \\
0510 \\
0510 \\
0512 \\
0512 \\
0512\end{array}$ & $\begin{array}{l}12 / 05 / 91 \\
03 / 27 / 91 \\
08 / 28 / 91 \\
11 / 21 / 91 \\
05 / 16 / 90 \\
03 / 28 / 91 \\
12 / 05 / 91 \\
04 / 05 / 91 \\
08 / 08 / 91 \\
12 / 10 / 91\end{array}$ & $\begin{array}{l}0001 \\
0001 \\
0001 \\
0001 \\
0001 \\
0001 \\
0001 \\
0001 \\
0001 \\
0001\end{array}$ & $\begin{array}{l}A L \\
A L \\
A L \\
A L \\
A L \\
A L \\
A L \\
A L \\
A L \\
A L\end{array}$ & $\begin{array}{l}0 \\
0 \\
0 \\
0 \\
0 \\
0 \\
0 \\
0 \\
0 \\
0\end{array}$ & $M G / L$ & $\begin{array}{l}< \\
< \\
< \\
< \\
< \\
< \\
< \\
< \\
< \\
< \\
<\end{array}$ & $\begin{array}{l}0.005 \\
0.005 \\
0.005 \\
0.005 \\
0.01 \\
0.005 \\
0.005 \\
0.005 \\
0.005 \\
0.005\end{array}$ & $\mathbf{R}$ & $\begin{array}{l}0.005 \\
0.005 \\
0.005 \\
0.005 \\
0.01 \\
0.005 \\
0.005 \\
0.005 \\
0.005 \\
0.005\end{array}$ & $\begin{array}{l}- \\
- \\
- \\
- \\
- \\
- \\
- \\
-\end{array}$ \\
\hline BICARBONATE - HCO3 & $\begin{array}{l}0503 \\
0504 \\
0506 \\
0507 \\
0508 \\
0509 \\
0510 \\
0512\end{array}$ & $\begin{array}{l}09 / 07 / 82 \\
09 / 07 / 82 \\
09 / 08 / 82 \\
09 / 09 / 82 \\
09 / 08 / 82 \\
09 / 09 / 82 \\
09 / 08 / 82 \\
09 / 08 / 82\end{array}$ & $\begin{array}{l}0001 \\
0001 \\
0001 \\
0001 \\
0001 \\
0001 \\
0001 \\
0001\end{array}$ & $\begin{array}{l}A L \\
A L \\
A L \\
A L \\
A L \\
A L \\
A L \\
A L\end{array}$ & $\begin{array}{l}0 \\
D \\
D \\
D \\
0 \\
0 \\
0 \\
0\end{array}$ & $M G / L$ & & $\begin{array}{r}611.00 \\
565.00 \\
648.00 \\
598.00 \\
671.00 \\
392.00 \\
1090.00 \\
396.00\end{array}$ & & $\begin{array}{l}- \\
- \\
- \\
- \\
-\end{array}$ & $\begin{array}{l}- \\
- \\
- \\
- \\
- \\
- \\
-\end{array}$ \\
\hline BORON & $\begin{array}{l}0503 \\
0503 \\
0503 \\
0503 \\
0503 \\
0503 \\
0503 \\
0504 \\
0504 \\
0504 \\
0504 \\
0504 \\
0504 \\
0506 \\
0506 \\
0506 \\
0506 \\
0506\end{array}$ & $\begin{array}{l}06 / 30 / 86 \\
10 / 14 / 87 \\
05 / 16 / 90 \\
03 / 29 / 91 \\
08 / 08 / 91 \\
12 / 09 / 91 \\
02 / 18 / 94 \\
10 / 14 / 87 \\
05 / 16 / 90 \\
04 / 03 / 91 \\
08 / 27 / 91 \\
12 / 09 / 91 \\
02 / 19 / 94 \\
10 / 14 / 87 \\
03 / 28 / 91 \\
08 / 08 / 91 \\
11 / 20 / 91 \\
02 / 20 / 94\end{array}$ & $\begin{array}{l}0001 \\
0001 \\
0001 \\
0001 \\
0001 \\
0001 \\
0001 \\
0001 \\
0001 \\
0001 \\
0001 \\
0001 \\
0001 \\
0001 \\
0001 \\
0001 \\
0001 \\
0001\end{array}$ & $\begin{array}{l}A L \\
A L \\
A L \\
A L \\
A L \\
A L \\
A L \\
A L \\
A L \\
A L \\
A L \\
A L \\
A L \\
A L \\
A L \\
A L \\
A L \\
A L\end{array}$ & $\begin{array}{l}0 \\
0 \\
0 \\
0 \\
0 \\
0 \\
0 \\
D \\
D \\
D \\
D \\
D \\
D \\
D \\
D \\
D \\
D \\
D\end{array}$ & $M G / L$ & $<$ & $\begin{array}{l}0.1 \\
0.4 \\
0.4 \\
0.35 \\
0.34 \\
0.35 \\
0.3 \\
0.6 \\
0.4 \\
0.31 \\
0.36 \\
0.32 \\
0.3 \\
0.5 \\
0.40 \\
0.47 \\
0.46 \\
0.4\end{array}$ & J & $\begin{array}{l}0.1 \\
0.1 \\
0.1 \\
0.05 \\
0.05 \\
0.05 \\
0.1 \\
0.1 \\
0.1 \\
0.05 \\
0.05 \\
0.05 \\
0.1 \\
0.1 \\
0.05 \\
0.05 \\
0.05 \\
0.1\end{array}$ & $\begin{array}{l}- \\
- \\
- \\
- \\
- \\
- \\
- \\
- \\
- \\
- \\
- \\
- \\
- \\
-\end{array}$ \\
\hline
\end{tabular}

FORMATION OF COMPLETION CODE:

AL - ALLUVIUM

PARAMETER VALUE INDICATOR (PVI): < - LESS THAN DETECTION LIMIT
FLOW RELATIONSHIP CODE:

O - ON-SITE

- DOWN GRADIENT

0001 - FILTERED SAMPLE (.45 MICRONS)

OTHER PARAMETER VALUE FLAGS:

$J$ - ESTIMATED VALUE

$R$ - UNUSABLE DATA POINT 
TABLE 3.27 BASELINE GROUND WATER QUALITY DATA BY PARAMETER FOR THE ALLUVIUM, NC AND UC PROCESSING SITES, SLICK ROCK, COLORADO

SITE: SRKO1 SLICK ROCK (8OTH SITES)

$09 / 07 / 82$ TO $02 / 22 / 94$

REPORT DATE: $10 / 03 / 94$

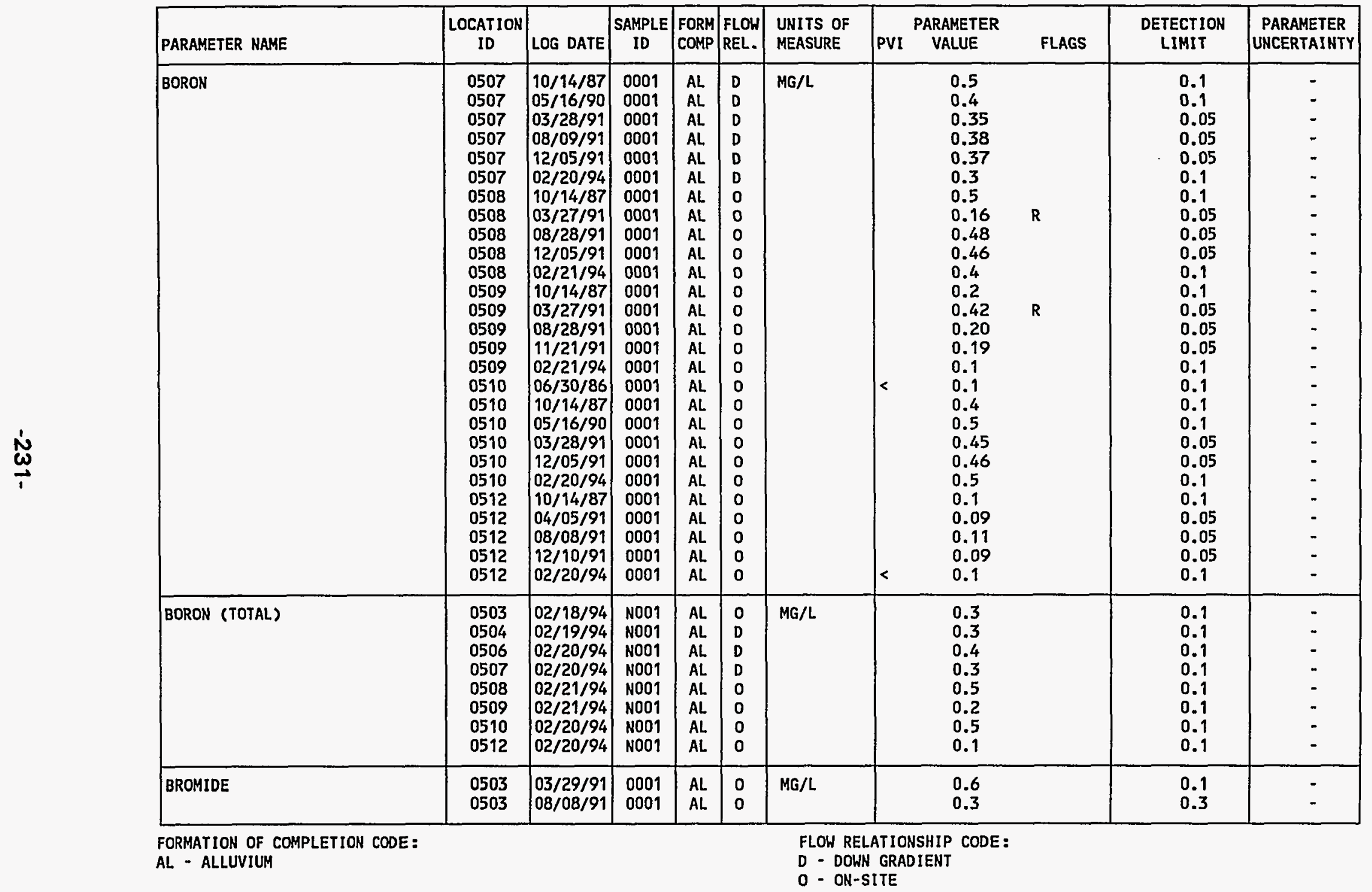

PARAMETER VALUE INDICATOR (PVI): < - LESS THAN DETECTION LIMIT

SAMPLE ID CODES:

0001 - FILTERED SAMPLE ( .45 MICRONS)

OTHER PARAMETER VALUE FLAGS

NO01 - UNFILTERED SAMPLE

$R$ - UNUSABLE DATA POINT 
TABLE 3.27 BASELINE GROUND WATER QUALITY DATA BY PARAMETER FOR THE ALLUVIUM, NC AND UC PROCESSING SITES, SLICK ROCK, COLORADO SITE: SRKO1 SLICK ROCK (BOTH SITES)

$09 / 07 / 82$ TO $02 / 22 / 94$

REPORT DATE: $10 / 03 / 94$

\begin{tabular}{|c|c|c|c|c|c|c|c|c|c|c|c|}
\hline PARAMETER NAME & $\begin{array}{l}\text { LOCATION } \\
\text { ID }\end{array}$ & LOG DATE & $\begin{array}{c}\text { SAMPLE } \\
\text { ID }\end{array}$ & $\begin{array}{l}\text { FORM } \\
\text { COMP }\end{array}$ & $\begin{array}{l}\text { FLOW } \\
\text { REL. }\end{array}$ & $\begin{array}{l}\text { UNITS OF } \\
\text { MEASURE }\end{array}$ & PVI & $\begin{array}{l}\text { ARAMETER } \\
\text { VALUE }\end{array}$ & FLAGS & $\begin{array}{l}\text { DETECT ION } \\
\text { LIMIT }\end{array}$ & $\begin{array}{l}\text { PARAMETER } \\
\text { UNCERTAINTY }\end{array}$ \\
\hline BROMIDE & $\begin{array}{l}0503 \\
0503 \\
0504 \\
0504 \\
0504 \\
0504 \\
0506 \\
0506 \\
0506 \\
0506 \\
0507 \\
0507 \\
0507 \\
0507 \\
0508 \\
0508 \\
0508 \\
0508 \\
0509 \\
0509 \\
0509 \\
0509 \\
0510 \\
0510 \\
0510 \\
0510 \\
0512 \\
0512 \\
0512 \\
0512\end{array}$ & $\begin{array}{l}12 / 09 / 91 \\
10 / 09 / 92 \\
04 / 03 / 91 \\
08 / 27 / 91 \\
12 / 09 / 91 \\
10 / 09 / 92 \\
03 / 28 / 91 \\
08 / 08 / 91 \\
11 / 20 / 91 \\
10 / 08 / 92 \\
03 / 28 / 91 \\
08 / 09 / 91 \\
12 / 05 / 91 \\
10 / 08 / 92 \\
03 / 27 / 91 \\
08 / 28 / 91 \\
12 / 05 / 91 \\
10 / 10 / 92 \\
03 / 27 / 91 \\
08 / 28 / 91 \\
11 / 21 / 91 \\
10 / 13 / 92 \\
03 / 28 / 91 \\
08 / 28 / 91 \\
12 / 05 / 91 \\
10 / 08 / 92 \\
04 / 05 / 91 \\
08 / 08 / 91 \\
12 / 10 / 91 \\
10 / 09 / 92\end{array}$ & $\begin{array}{l}0001 \\
0001 \\
0001 \\
0001 \\
0001 \\
0001 \\
0001 \\
0001 \\
0001 \\
0001 \\
0001 \\
0001 \\
0001 \\
0001 \\
0001 \\
0001 \\
0001 \\
0001 \\
0001 \\
0001 \\
0001 \\
0001 \\
0001 \\
0001 \\
0001 \\
0001 \\
0001 \\
0001 \\
0001 \\
0001\end{array}$ & $\begin{array}{l}A L \\
A L \\
A L \\
A L \\
A L \\
A L \\
A L \\
A L \\
A L \\
A L \\
A L \\
A L \\
A L \\
A L \\
A L \\
A L \\
A L \\
A L \\
A L \\
A L \\
A L \\
A L \\
A L \\
A L \\
A L \\
A L \\
A L \\
A L \\
A L \\
A L\end{array}$ & $\begin{array}{l}0 \\
0 \\
0 \\
0 \\
0 \\
D \\
0 \\
D \\
0 \\
D \\
D \\
0 \\
D \\
D \\
0 \\
0 \\
0 \\
0 \\
0 \\
0 \\
0 \\
0 \\
0 \\
0 \\
0 \\
0 \\
0 \\
0 \\
0 \\
0\end{array}$ & MG/L & $\begin{array}{l}< \\
< \\
< \\
< \\
< \\
< \\
< \\
< \\
< \\
< \\
< \\
< \\
< \\
< \\
< \\
< \\
< \\
<\end{array}$ & $\begin{array}{c}0.5 \\
2 . \\
0.4 \\
1.0 \\
0.2 \\
1 . \\
9.1 \\
5.7 \\
3.9 \\
10 . \\
0.8 \\
0.5 \\
0.6 \\
0.6 \\
0.3 \\
5.0 \\
5.0 \\
0.1 \\
3.2 \\
1.0 \\
0.1 \\
1 . \\
4.0 \\
5.0 \\
4.0 \\
0.8 \\
0.2 \\
0.2 \\
0.1 \\
0.5\end{array}$ & $\begin{array}{l}I \\
J \\
I \\
I \\
I \\
I \\
\\
I \\
R \\
I \\
I \\
R \\
I \\
I \\
I \\
I \\
I\end{array}$ & $\begin{array}{l}0.4 \\
2.1 \\
0.1 \\
1 . \\
0.2 \\
1 . \\
0.1 \\
2 . \\
1 . \\
10 . \\
0.1 \\
0.5 \\
0.1 \\
0.6 \\
0.1 \\
5 . \\
5.1 \\
0.1 \\
0.1 \\
1 . \\
0.1 \\
1 . \\
0.1 \\
5 . \\
4 . \\
0.8 \\
0.1 \\
0.2 \\
0.1 \\
0.5\end{array}$ & $\begin{array}{l}- \\
- \\
- \\
- \\
- \\
- \\
- \\
- \\
- \\
- \\
- \\
- \\
- \\
- \\
- \\
- \\
- \\
- \\
- \\
- \\
- \\
- \\
- \\
-\end{array}$ \\
\hline CADMIUM & $\begin{array}{l}0503 \\
0503 \\
0503 \\
0503 \\
0503\end{array}$ & $\begin{array}{l}09 / 07 / 82 \\
02 / 18 / 86 \\
06 / 30 / 86 \\
10 / 14 / 87 \\
05 / 16 / 90\end{array}$ & $\begin{array}{l}0001 \\
0001 \\
0001 \\
0001 \\
0001\end{array}$ & $\begin{array}{l}A L \\
A L \\
A L \\
A L \\
A L\end{array}$ & $\begin{array}{l}0 \\
0 \\
0 \\
0 \\
0\end{array}$ & MG/L & $\begin{array}{l}< \\
< \\
< \\
< \\
<\end{array}$ & $\begin{array}{l}0.01 \\
0.001 \\
0.001 \\
0.001 \\
0.001\end{array}$ & L & $\begin{array}{l}0.01 \\
0.001 \\
0.001 \\
0.001 \\
0.001\end{array}$ & $\begin{array}{l}- \\
- \\
-\end{array}$ \\
\hline
\end{tabular}

FORMATION OF COMPLETION CODE:

AL - ALLUVIUM

FLOW RELATIONSHIP CODE:

- DOWN GRADIENT

PARAMETER VALUE INDICATOR (PVI): < - LESS THAN DETECTION LIMIT

0001 - FILTERED SAMPLE (.45 MICRONS)

OTHER PARAMETER VALUE FLAGS:

1 - INCREASED DETECTION LIMIT DUE TO REQUIRED DILUTION

$J$ - ESTIMATED VALUE

L - LESS THAN THREE BORE VOLUMES REMOVED BEFORE SAMPLING

$R$ - UNUSABLE DATA POINT 
TABLE 3.27 BASELINE GROUND HATER QUALITY DATA BY PARAMETER FOR THE ALLUVIUM, NC AND UC PROCESSING SITES, SLICK ROCK, COLORADD

SITE: SRKO1 SLICK ROCK (BOTH SITES)

09/07/82 TO 02/22/94

REPORT DATE: $10 / 03 / 94$

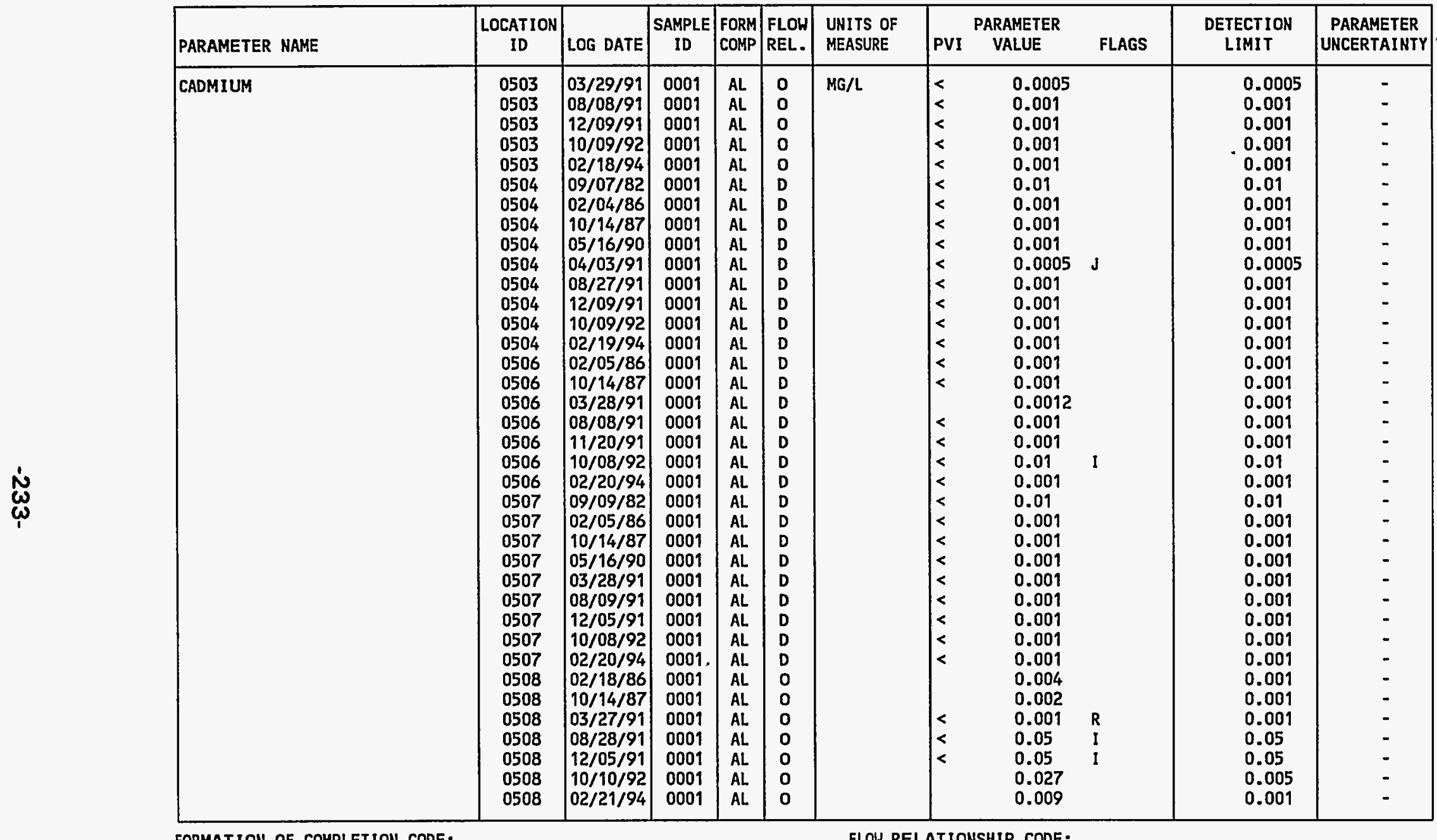

FORMATION OF COMPLETION CODE:

AL - ALLUVIUM

FLOW RELATIONSHIP CODE

D - DOWN GRADIENT

PARAMETER VALUE INDICATOR (PVI): < - LESS THAN DETECTION LIMIT

0001 - FILTERED SAMPLE (.45 MICRONS)

OTHER PARAMETER VALUE FLAGS:

I - INCREASED DETECTION LIMIT DUE TO REQUIRED DILUTION

$J$ - ESTIMATED VALUE

$R$ - UNUSABLE DATA POINT 
TABLE 3.27 BASELINE GROUND HATER QUALITY DATA BY PARAMETER FOR THE ALLUVIUM, NC AND UC PROCESSING SITES, SLICK ROCK, COLORADO

SITE: SRKO1 SLICK ROCK (BOTH SITES)

09/07/82 TO 02/22/94

REPORT DATE: $10 / 03 / 9$

\begin{tabular}{|c|c|c|c|c|c|c|c|c|c|c|c|}
\hline PARAMETER NAME & $\underset{\text { ID }}{\text { LOCATION }}$ & LOG DATE & $\begin{array}{c}\text { SAMPLE } \\
\text { ID }\end{array}$ & $\begin{array}{l}\text { FORM } \\
\text { COMP }\end{array}$ & $\begin{array}{l}\text { FLOW } \\
\text { REL. }\end{array}$ & $\begin{array}{l}\text { UNITS OF } \\
\text { MEASURE }\end{array}$ & PVI & $\begin{array}{l}\text { PARAMETER } \\
\text { VALUE }\end{array}$ & FLAGS & $\begin{array}{l}\text { DETECTION } \\
\text { LIMIT }\end{array}$ & $\begin{array}{l}\text { PARAMETER } \\
\text { UNCERTAINTY }\end{array}$ \\
\hline CADMIUM & $\begin{array}{l}0509 \\
0509 \\
0509 \\
0509 \\
0509 \\
0509 \\
0509 \\
0509 \\
0510 \\
0510 \\
0510 \\
0510 \\
0510 \\
0510 \\
0510 \\
0510 \\
0510 \\
0512 \\
0512 \\
0512 \\
0512 \\
0512 \\
0512 \\
0512\end{array}$ & $\begin{array}{l}09 / 09 / 82 \\
02 / 18 / 86 \\
10 / 14 / 87 \\
03 / 27 / 91 \\
08 / 28 / 91 \\
11 / 21 / 91 \\
10 / 13 / 92 \\
02 / 21 / 94 \\
09 / 08 / 82 \\
02 / 18 / 86 \\
06 / 30 / 86 \\
10 / 14 / 87 \\
05 / 16 / 90 \\
03 / 28 / 91 \\
12 / 05 / 91 \\
10 / 08 / 92 \\
02 / 20 / 94 \\
02 / 04 / 86 \\
10 / 14 / 87 \\
04 / 05 / 91 \\
08 / 08 / 91 \\
12 / 10 / 91 \\
10 / 09 / 92 \\
02 / 20 / 94\end{array}$ & $\begin{array}{l}0001 \\
0001 \\
0001 \\
0001 \\
0001 \\
0001 \\
0001 \\
0001 \\
0001 \\
0001 \\
0001 \\
0001 \\
0001 \\
0001 \\
0001 \\
0001 \\
0001 \\
0001 \\
0001 \\
0001 \\
0001 \\
0001 \\
0001 \\
0001\end{array}$ & $\begin{array}{l}A L \\
A L \\
A L \\
A L \\
A L \\
A L \\
A L \\
A L \\
A L \\
A L \\
A L \\
A L \\
A L \\
A L \\
A L \\
A L \\
A L \\
A L \\
A L \\
A L \\
A L \\
A L \\
A L \\
A L\end{array}$ & $\begin{array}{l}0 \\
0 \\
0 \\
0 \\
0 \\
0 \\
0 \\
0 \\
0 \\
0 \\
0 \\
0 \\
0 \\
0 \\
0 \\
0 \\
0 \\
0 \\
0 \\
0 \\
0 \\
0 \\
0 \\
0\end{array}$ & $M G / L$ & $\begin{array}{l}< \\
< \\
< \\
< \\
< \\
< \\
< \\
< \\
< \\
< \\
< \\
< \\
<\end{array}$ & $\begin{array}{l}0.01 \\
0.001 \\
0.001 \\
0.0080 \\
0.001 \\
0.001 \\
0.001 \\
0.001 \\
0.01 \\
0.001 \\
0.001 \\
0.001 \\
0.001 \\
0.0010 \\
0.001 \\
0.001 \\
0.002 \\
0.001 \\
0.001 \\
0.0005 \\
0.001 \\
0.001 \\
0.001 \\
0.001\end{array}$ & $\mathbf{R}$ & 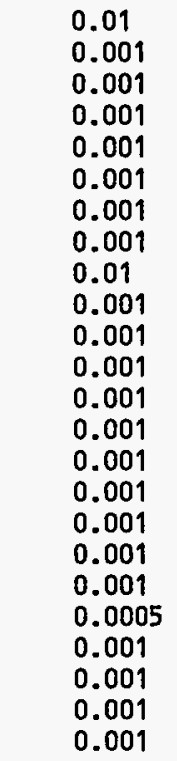 & $\begin{array}{l}- \\
- \\
- \\
- \\
- \\
- \\
- \\
- \\
- \\
- \\
- \\
- \\
- \\
- \\
- \\
- \\
- \\
- \\
- \\
-\end{array}$ \\
\hline CADMIUM (TOTAL) & $\begin{array}{l}0503 \\
0504 \\
0506 \\
0507 \\
0508 \\
0509 \\
0510 \\
0512\end{array}$ & $\begin{array}{l}02 / 18 / 94 \\
02 / 19 / 94 \\
02 / 20 / 94 \\
02 / 20 / 94 \\
02 / 21 / 94 \\
02 / 21 / 94 \\
02 / 20 / 94 \\
02 / 20 / 94\end{array}$ & $\begin{array}{l}\text { NO01 } \\
\text { N001 } \\
\text { N001 } \\
\text { N001 } \\
\text { N001 } \\
\text { N001 } \\
\text { N001 } \\
\text { N001 }\end{array}$ & $\begin{array}{l}A L \\
A L \\
A L \\
A L \\
A L \\
A L \\
A L \\
A L\end{array}$ & $\begin{array}{l}0 \\
D \\
D \\
D \\
0 \\
0 \\
0 \\
0\end{array}$ & $M G / L$ & $\begin{array}{l}< \\
< \\
< \\
<\end{array}$ & $\begin{array}{l}0.001 \\
0.001 \\
0.001 \\
0.001 \\
0.009 \\
0.001 \\
0.002 \\
0.001\end{array}$ & & $\begin{array}{l}0.001 \\
0.001 \\
0.001 \\
0.001 \\
0.001 \\
0.001 \\
0.001 \\
0.001\end{array}$ & $\begin{array}{l}- \\
- \\
- \\
- \\
- \\
-\end{array}$ \\
\hline CALCIUM & $\begin{array}{l}0503 \\
0503 \\
0503 \\
0503\end{array}$ & $\begin{array}{l}09 / 07 / 82 \\
02 / 18 / 86 \\
06 / 30 / 86 \\
10 / 14 / 87\end{array}$ & $\begin{array}{l}0001 \\
0001 \\
0001 \\
0001\end{array}$ & $\begin{array}{l}A L \\
A L \\
A L \\
A L\end{array}$ & $\begin{array}{l}0 \\
0 \\
0 \\
0\end{array}$ & $M G / L$ & & $\begin{array}{l}300.00 \\
225 . \\
264 . \\
237 .\end{array}$ & L & $\begin{array}{l}- \\
0.01 \\
0.01 \\
0.01\end{array}$ & $\begin{array}{l}- \\
-\end{array}$ \\
\hline
\end{tabular}

FORMATION OF COMPLETION CODE:

AL - ALLUVIUM

PARAMETER VALUE INDICATOR (PVI):

< - LESS THAN DETECTION LIMIT

OTHER PARAMETER VALUE FLAGS:

$L$ - LESS THAN THREE BORE VOLUMES REMOVED BEFORE SAMPLING

$R$ - UNUSABLE DATA POINT
FLOW RELATIONSHIP CODE:

- DOWN GRADIENT

SAMPLE ID CODES:

0001 - FILTERED SAMPLE (.45 MICRONS)

NO01 - UNFILTERED SAMPLE 
TABLE 3.27 BASELINE GROUND HATER QUALITY DATA BY PARAMETER FOR THE ALLUVIUM, NC AND UC PROCESSING SITES, SLICK ROCK, COLORADO

SITE: SRKO1 SLICK ROCK (BOTH SITES)

09/07/82 TO 02/22/94

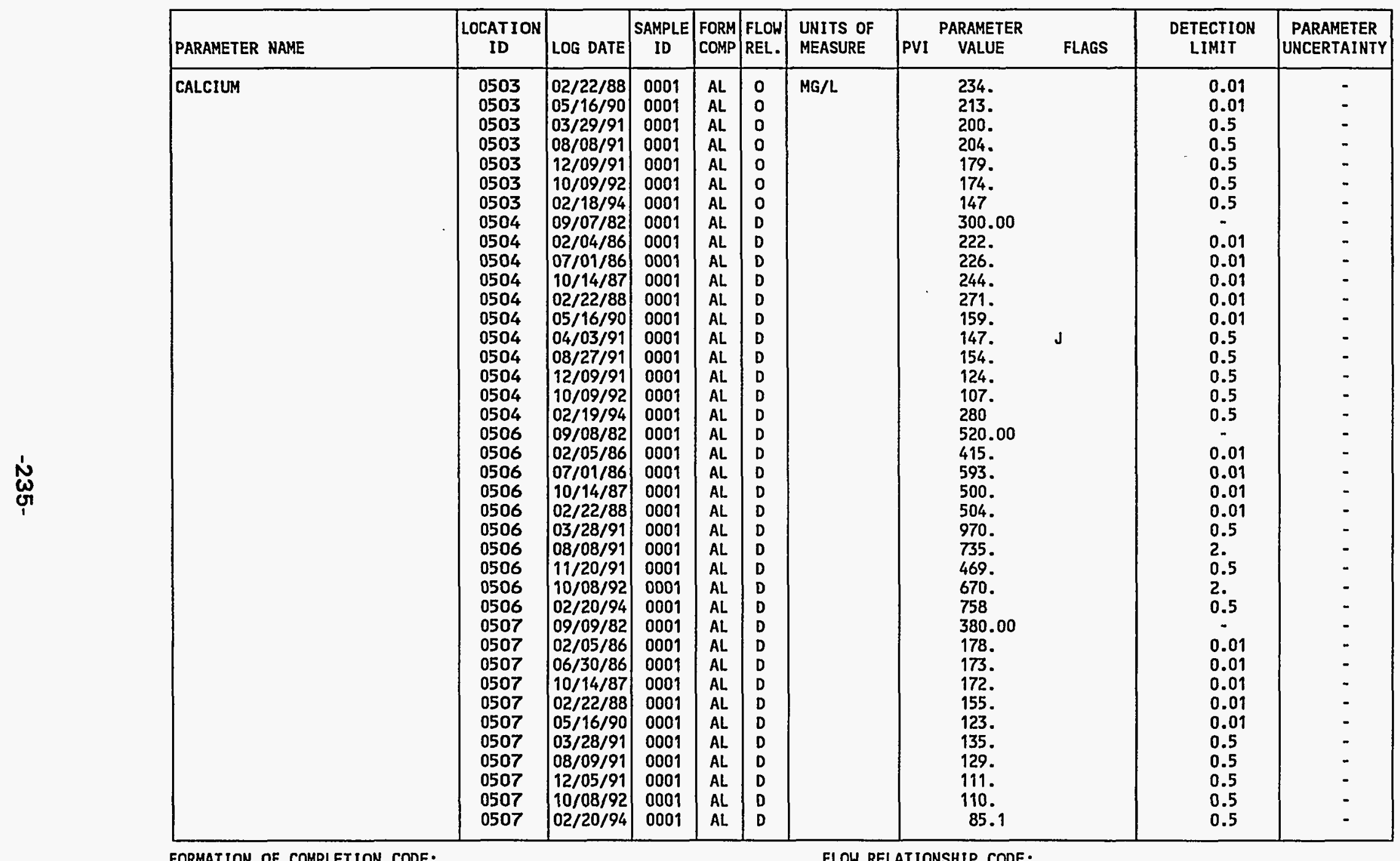

FORHATION OF COMPLETION CODE:

AL - ALLUVIUM

PARAMETER VALUE INDICATOR (PVI): < - LESS THAN DETECTION LIMIT
FLOW RELATIONSHIP CODE:

O - ON-SITE

D - DOWN GRADIENT

SAMPLE ID CODES:

0001 - FILTERED SAMPLE (.45 MICRONS)

OTHER PARAMETER VALUE FLAGS:

$J$ - ESTIMATED VALUE 
TABLE 3.27 BASELINE GROUND WATER QUALITY DATA BY PARAMETER FOR THE ALLUVIUM, NC AND UC PROCESSING SITES, SLICK ROCK, COLORADO

SITE: SRKO1 SLICK ROCK (BOTH SITES)

$09 / 07 / 82$ TO $02 / 22 / 94$

REPORT DATE: $10 / 03 / 94$

\begin{tabular}{|c|c|c|c|c|c|c|c|c|c|c|c|}
\hline PARAMETER NAME & $\underbrace{\text { LOCATION }}_{\text {ID }}$ & LOG DATE & $\begin{array}{c}\text { SAMPLE } \\
\text { ID }\end{array}$ & $\begin{array}{l}\text { FORM } \\
\text { COMP }\end{array}$ & $\begin{array}{l}\text { FLOW } \\
\text { REL. }\end{array}$ & $\begin{array}{l}\text { UNITS OF } \\
\text { MEASURE }\end{array}$ & PVI & $\begin{array}{l}\text { PARAMETER } \\
\text { VALUEE }\end{array}$ & FLAGS & $\begin{array}{l}\text { DETECTION } \\
\text { LIMIT }\end{array}$ & $\begin{array}{l}\text { PARAMETER } \\
\text { UNCERTAINTY }\end{array}$ \\
\hline CALCIUM & $\begin{array}{l}0508 \\
0508 \\
0508 \\
0508 \\
0508 \\
0508 \\
0508 \\
0508 \\
0508 \\
0508 \\
0509 \\
0509 \\
0509 \\
0509 \\
0509 \\
0509 \\
0509 \\
0509 \\
0509 \\
0509 \\
0510 \\
0510 \\
0510 \\
0510 \\
0510 \\
0510 \\
0510 \\
0510 \\
0510 \\
0510 \\
0512 \\
0512 \\
0512 \\
0512 \\
0512 \\
0512 \\
0512 \\
0512 \\
0512 \\
0512\end{array}$ & $\begin{array}{l}09 / 08 / 82 \\
02 / 18 / 86 \\
06 / 30 / 86 \\
10 / 14 / 87 \\
02 / 19 / 88 \\
03 / 27 / 91 \\
08 / 28 / 91 \\
12 / 05 / 91 \\
10 / 10 / 92 \\
02 / 21 / 94 \\
09 / 09 / 82 \\
02 / 18 / 86 \\
07 / 17 / 86 \\
10 / 14 / 87 \\
02 / 22 / 88 \\
03 / 27 / 91 \\
08 / 28 / 91 \\
11 / 21 / 91 \\
10 / 13 / 92 \\
02 / 21 / 94 \\
09 / 08 / 82 \\
02 / 18 / 86 \\
06 / 30 / 86 \\
10 / 14 / 87 \\
02 / 22 / 88 \\
05 / 16 / 90 \\
03 / 28 / 91 \\
12 / 05 / 91 \\
10 / 08 / 92 \\
02 / 20 / 94 \\
09 / 08 / 82 \\
02 / 04 / 86 \\
07 / 01 / 86 \\
10 / 14 / 87 \\
02 / 22 / 88 \\
04 / 05 / 91 \\
08 / 08 / 91 \\
12 / 10 / 91 \\
10 / 09 / 92 \\
02 / 20 / 94\end{array}$ & $\begin{array}{l}0001 \\
0001 \\
0001 \\
0001 \\
0001 \\
0001 \\
0001 \\
0001 \\
0001 \\
0001 \\
0001 \\
0001 \\
0001 \\
0001 \\
0001 \\
0001 \\
0001 \\
0001 \\
0001 \\
0001 \\
0001 \\
0001 \\
0001 \\
0001 \\
0001 \\
0001 \\
0001 \\
0001 \\
0001 \\
0001 \\
0001 \\
0001 \\
0001 \\
0001 \\
0001 \\
0001 \\
0001 \\
0001 \\
0001 \\
0001\end{array}$ & $\begin{array}{l}A L \\
A L \\
A L \\
A L \\
A L \\
A L \\
A L \\
A L \\
A L \\
A L \\
A L \\
A L \\
A L \\
A L \\
A L \\
A L \\
A L \\
A L \\
A L \\
A L \\
A L \\
A L \\
A L \\
A L \\
A L \\
A L \\
A L \\
A L \\
A L \\
A L \\
A L \\
A L \\
A L \\
A L \\
A L \\
A L \\
A L \\
A L \\
A L \\
A L\end{array}$ & $\begin{array}{l}0 \\
0 \\
0 \\
0 \\
0 \\
0 \\
0 \\
0 \\
0 \\
0 \\
0 \\
0 \\
0 \\
0 \\
0 \\
0 \\
0 \\
0 \\
0 \\
0 \\
0 \\
0 \\
0 \\
0 \\
0 \\
0 \\
0 \\
0 \\
0 \\
0 \\
0 \\
0 \\
0 \\
0 \\
0 \\
0 \\
0 \\
0 \\
0 \\
0\end{array}$ & $M G / L$ & & $\begin{array}{l}540.00 \\
383 . \\
541 . \\
500 . \\
520 . \\
134 . \\
443 . \\
401 . \\
470 . \\
471 \\
270.00 \\
182 . \\
138 . \\
168 . \\
145 . \\
426 . \\
153 . \\
149 . \\
155 . \\
117 \\
710.00 \\
453 . \\
590 . \\
660 . \\
541 . \\
524 . \\
590 . \\
520 . \\
520 . \\
636 \\
230.00 \\
232 . \\
210 . \\
295 . \\
196 . \\
191 . \\
194 . \\
146 . \\
254 . \\
221 .\end{array}$ & $\mathbf{R}$ & $\begin{array}{l}- \\
0.01 \\
0.01 \\
0.01 \\
0.01 \\
0.5 \\
0.5 \\
0.5 \\
0.5 \\
0.5 \\
- \\
0.01 \\
0.01 \\
0.01 \\
0.01 \\
0.5 \\
0.5 \\
0.5 \\
0.5 \\
0.5 \\
0 . \\
0.01 \\
0.01 \\
0.01 \\
0.01 \\
0.01 \\
0.5 \\
2 . \\
2 . \\
0.5 \\
- \\
0.01 \\
0.01 \\
0.01 \\
0.01 \\
0.5 \\
0.5 \\
0.5 \\
0.5 \\
0.5\end{array}$ & $\begin{array}{l}- \\
- \\
- \\
- \\
- \\
- \\
- \\
- \\
- \\
- \\
- \\
- \\
- \\
- \\
- \\
- \\
- \\
- \\
- \\
- \\
- \\
- \\
- \\
- \\
- \\
- \\
- \\
- \\
- \\
- \\
- \\
- \\
- \\
- \\
- \\
- \\
- \\
-\end{array}$ \\
\hline
\end{tabular}

FORMATION OF COMPLETION CODE: AL - ALLUUIUM

PARAMETER VALUE INDICATOR (PVI): < - LESS THAN DETECTION LIMIT
FLOW RELATIONSHIP CODE:

O - ON-SITE

SAMPLE ID CODES:

0001 - FILTERED SAMPLE (.45 MICRONS)

OTHER PARAMETER VALUE FLAGS:

$R$ - UNUSABLE DATA POINT 
TABLE 3.27 BASELINE GROUND HATER QUALITY DATA BY PARAMETER FOR THE ALLUVIUM, NC AND UC PROCESSING SITES, SLICK ROCK, COLORADO

SITE: SRKO1 SLICK ROCK (BOTH SITES)

107/82 TO 02/22/94

REPORT DATE: $10 / 03 / 94$

\begin{tabular}{|c|c|c|c|c|c|c|c|c|c|c|c|}
\hline PARAMETER NAME & $\begin{array}{c}\text { LOCATION } \\
\text { ID }\end{array}$ & LOG DATE & $\begin{array}{c}\text { SAMPLE } \\
\text { ID }\end{array}$ & $\begin{array}{l}\text { FORM } \\
\text { COMP }\end{array}$ & $\begin{array}{l}\text { FLOW } \\
\text { REL. }\end{array}$ & $\begin{array}{l}\text { UNITS OF } \\
\text { MEASURE }\end{array}$ & PVI & $\begin{array}{l}\text { PARAMETER } \\
\text { VALUE }\end{array}$ & FLAGS & $\begin{array}{l}\text { DETECTION } \\
\text { LIMIT }\end{array}$ & $\begin{array}{l}\text { PARAMETER } \\
\text { UNCERTAINTY }\end{array}$ \\
\hline CALCIUM (TOTAL) & $\begin{array}{l}0503 \\
0504 \\
0506 \\
0507 \\
0508 \\
0509 \\
0510 \\
0512\end{array}$ & $\begin{array}{l}02 / 18 / 94 \\
02 / 19 / 94 \\
02 / 20 / 94 \\
02 / 20 / 94 \\
02 / 21 / 94 \\
02 / 21 / 94 \\
02 / 20 / 94 \\
02 / 20 / 94\end{array}$ & $\begin{array}{l}\text { N001 } \\
\text { N001 } \\
\text { N001 } \\
\text { N001 } \\
\text { N001 } \\
\text { N001 } \\
\text { N001 } \\
\text { N001 }\end{array}$ & $\begin{array}{l}A L \\
A L \\
A L \\
A L \\
A L \\
A L \\
A L \\
A L\end{array}$ & $\begin{array}{l}\text { O } \\
\text { D } \\
D \\
D \\
0 \\
0 \\
0 \\
0\end{array}$ & MG/L & & $\begin{array}{l}145 \\
269 \\
717 \\
80.0 \\
509 \\
123 \\
641 \\
220\end{array}$ & & $\begin{array}{l}0.5 \\
0.5 \\
0.5 \\
0.5 \\
0.5 \\
0.5 \\
0.5 \\
0.5\end{array}$ & $\begin{array}{l}- \\
- \\
- \\
- \\
- \\
-\end{array}$ \\
\hline CHLORIDE & $\begin{array}{l}0503 \\
0503 \\
0503 \\
0503 \\
0503 \\
0503 \\
0503 \\
0503 \\
0503 \\
0503 \\
0503 \\
0504 \\
0504 \\
0504 \\
0504 \\
0504 \\
0504 \\
0504 \\
0504 \\
0504 \\
0504 \\
0504 \\
0506 \\
0506 \\
0506 \\
0506 \\
0506 \\
0506 \\
0506\end{array}$ & $\begin{array}{l}09 / 07 / 82 \\
02 / 18 / 86 \\
06 / 30 / 86 \\
10 / 14 / 87 \\
02 / 22 / 88 \\
05 / 16 / 90 \\
03 / 29 / 91 \\
08 / 08 / 91 \\
12 / 09 / 91 \\
10 / 09 / 92 \\
02 / 18 / 94 \\
09 / 07 / 82 \\
02 / 04 / 86 \\
07 / 01 / 86 \\
10 / 14 / 87 \\
02 / 22 / 88 \\
05 / 16 / 90 \\
04 / 03 / 91 \\
08 / 27 / 91 \\
12 / 09 / 91 \\
10 / 09 / 92 \\
02 / 19 / 94 \\
09 / 08 / 82 \\
02 / 05 / 86 \\
07 / 01 / 86 \\
10 / 14 / 87 \\
02 / 22 / 88 \\
03 / 28 / 91 \\
08 / 08 / 91\end{array}$ & $\begin{array}{l}0001 \\
0001 \\
0001 \\
0001 \\
0001 \\
0001 \\
0001 \\
0001 \\
0001 \\
0001 \\
0001 \\
0001 \\
0001 \\
0001 \\
0001 \\
0001 \\
0001 \\
0001 \\
0001 \\
0001 \\
0001 \\
0001 \\
0001 \\
0001 \\
0001 \\
0001 \\
0001 \\
0001 \\
0001\end{array}$ & $\begin{array}{l}A L \\
A L \\
A L \\
A L \\
A L \\
A L \\
A L \\
A L \\
A L \\
A L \\
A L \\
A L \\
A L \\
A L \\
A L \\
A L \\
A L \\
A L \\
A L \\
A L \\
A L \\
A L \\
A L \\
A L \\
A L \\
A L \\
A L \\
A L \\
A L\end{array}$ & $\begin{array}{l}\text { O } \\
0 \\
0 \\
0 \\
0 \\
0 \\
0 \\
0 \\
0 \\
0 \\
0 \\
D \\
D \\
D \\
D \\
D \\
D \\
D \\
D \\
D \\
D \\
D \\
D \\
D \\
D \\
D \\
D \\
D \\
D\end{array}$ & $M G / L$ & & $\begin{array}{l}293.00 \\
310 . \\
380 . \\
296 . \\
342 . \\
325 . \\
324 . \\
354 . \\
331 . \\
325 . \\
274 \\
323.00 \\
360 . \\
360 . \\
315 . \\
380 . \\
227 . \\
520 . \\
189 . \\
172 . \\
145 . \\
325 \\
271.00 \\
430 . \\
810 . \\
500 . \\
500 . \\
3400 . \\
2660 .\end{array}$ & L & $\begin{array}{l}1 . \\
1 . \\
1 . \\
1 . \\
1 . \\
0.5 \\
1 . \\
4 . \\
5 . \\
0.5 \\
i . \\
1 . \\
1 . \\
1 . \\
1 . \\
0.5 \\
1 . \\
1 . \\
1 . \\
0.5 \\
1 . \\
1 . \\
1 . \\
1 . \\
1 . \\
1 .\end{array}$ & $\begin{array}{l}- \\
- \\
- \\
- \\
- \\
- \\
- \\
- \\
- \\
- \\
- \\
- \\
- \\
- \\
- \\
- \\
- \\
- \\
- \\
- \\
-\end{array}$ \\
\hline
\end{tabular}

FORMATION OF COMPLETION CODE:

AL - ALLUVIUM

PARAMETER VALUE INDICATOR (PVI):

< - LESS THAN DETECTION LIMIT

OTHER PARAMETER VALUE FLAGS:

$J$ - ESTIMATED VALUE

L - LESS THAN THREE BORE VOLUMES REMOVED BEFORE SAMPLING
FLOH RELATIONSHIP CODE:

O - ON-SITE

D - DOWN GRADIENT

SAMPLE ID CODES:

0001 - FILTERED SAMPLE (.45 MICRONS)

N001 - UNFILTERED SAMPLE 


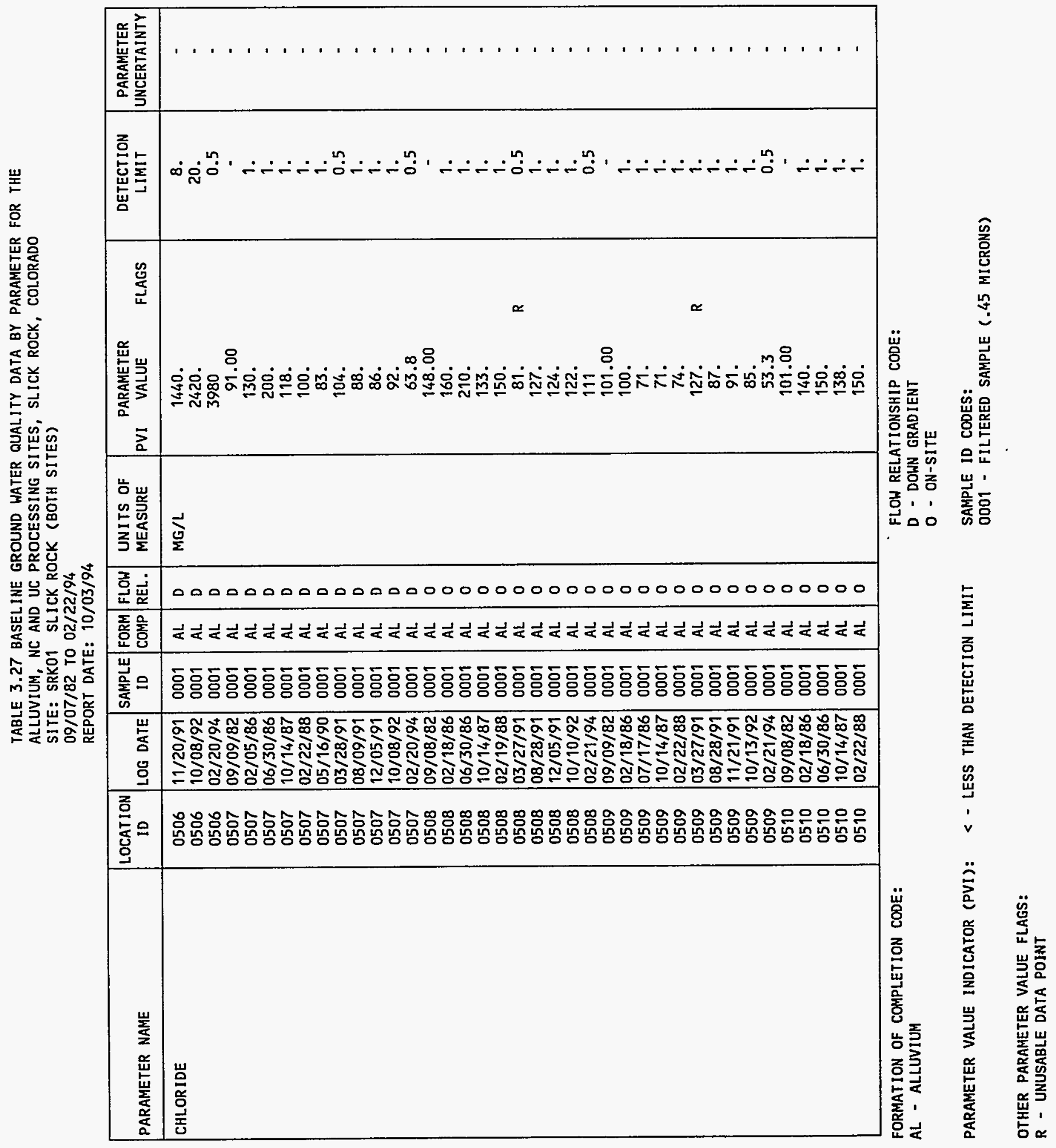




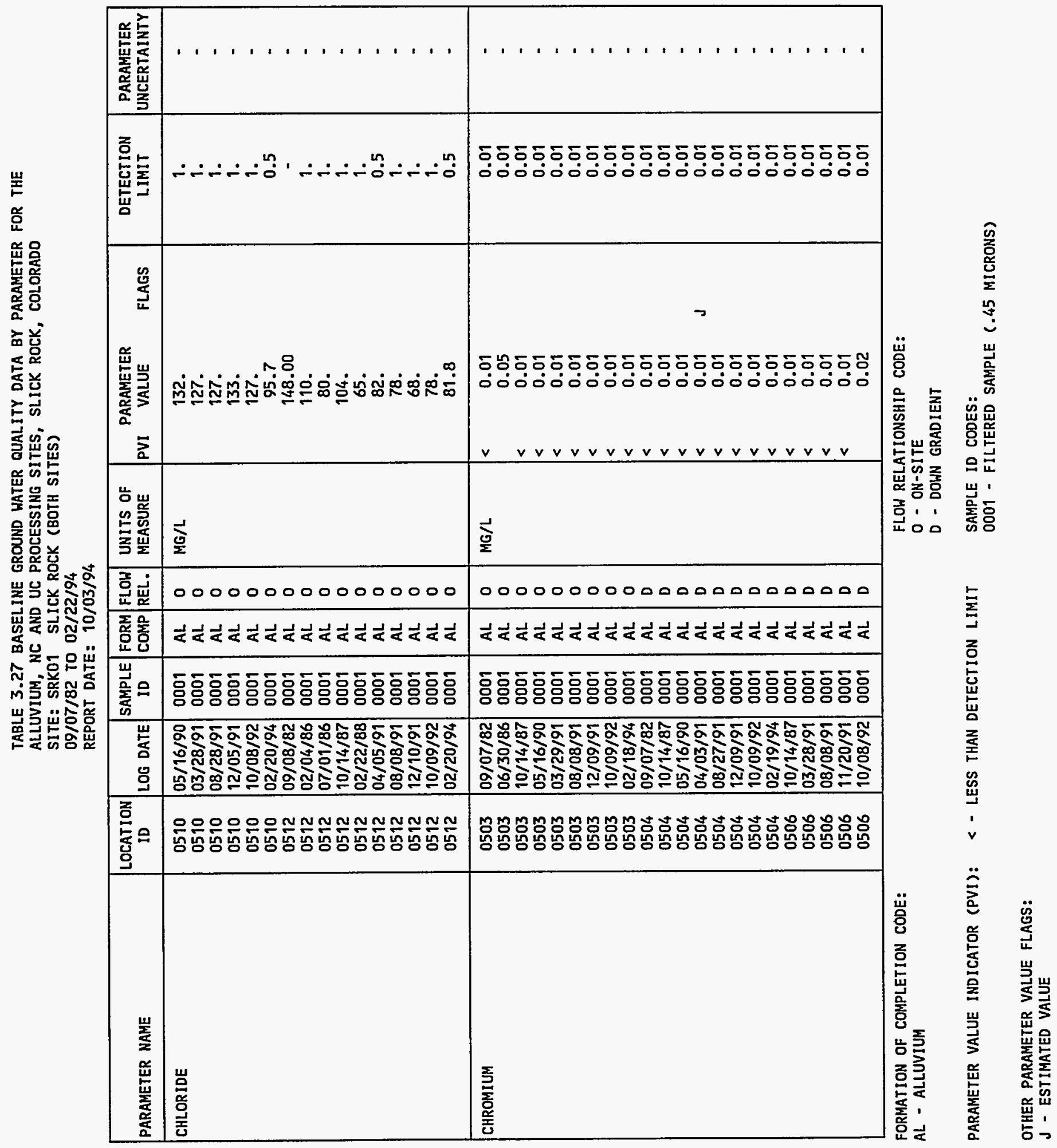




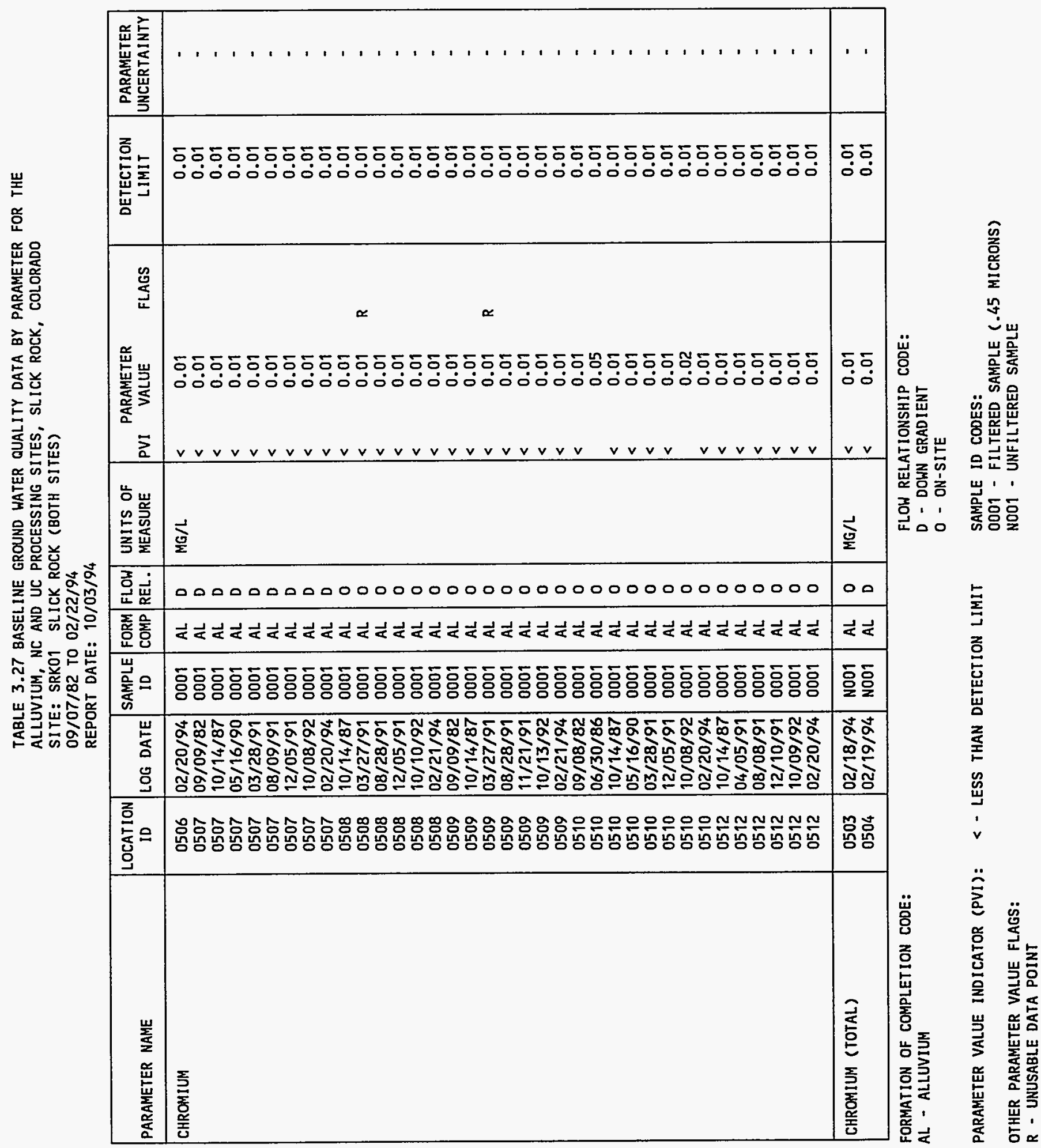


TABLE 3.27 BASELINE GROUND HATER QUALITY DATA BY PARAMETER FOR THE ALLUVIUM, NC AND UC PROCESSING SITES, SLICK ROCK, COLORADO

SITE: SRKOI SLICK ROCK (BOTH SITES)

09/07/82 TO 02/22/94

REPORT DATE: $10 / 03 / 94$

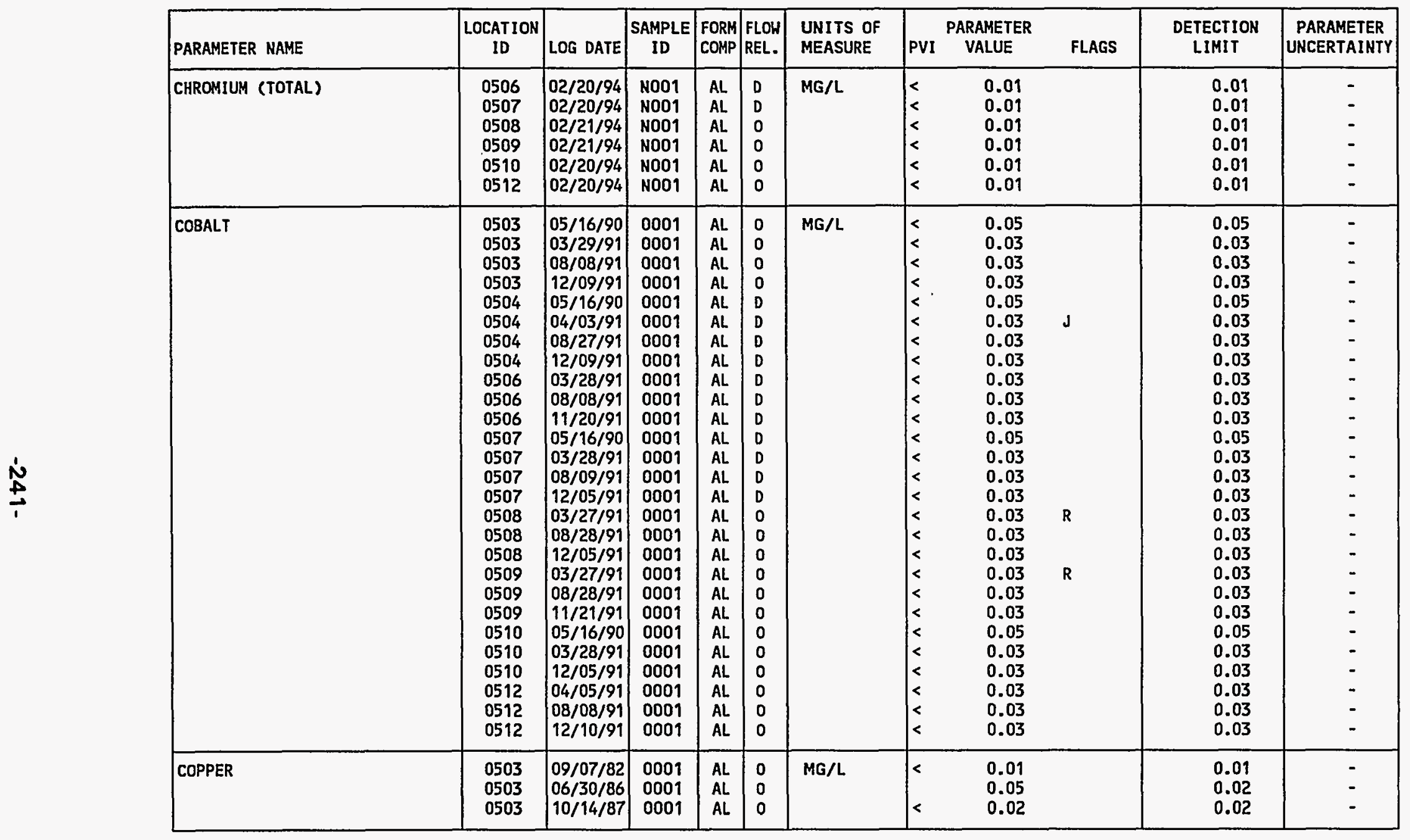

\section{FORMATION OF COMPLETION CODE:}

AL - ALLUVIUM

PARAMETER VALUE INDICATOR (PVI): < - LESS THAN DETECTION LIMIT

FLOW RELATIONSHIP CODE:

D - DOWN GRADIENT

O - ON-SITE

\section{SAMPLE ID CODES:}

0001 - FILTERED SAMPLE (.45 MICRONS)

NOO1 - UNFILTERED SAMPLE

$J$ - ESTIMATED VALUE

$R$ - UNUSABLE DATA POINT 
TABLE 3.27 BASELINE GROUND HATER QUAL.ITY DATA BY PARAMETER FOR THE ALLUVIUM, NC AND UC PROCESSING SITES, SLICK ROCK, COLORADO

SITE: SRKO1 SLICK ROCK (BOTH SITES)

09/07/82 TO 02/22/94

REPORT DATE : $10 / 03 / 94$

\begin{tabular}{|c|c|c|c|c|c|c|c|c|c|c|c|}
\hline PARAMETER NAME & ${ }_{\text {ID }}^{\text {LOCATION }}$ & LOG DATE & $\begin{array}{c}\text { SAMPLE } \\
\text { ID }\end{array}$ & $\begin{array}{l}\text { FORM } \\
\text { COMP }\end{array}$ & $\begin{array}{l}\text { FLOW } \\
\text { REL. }\end{array}$ & $\begin{array}{l}\text { UNITS OF } \\
\text { MEASURE }\end{array}$ & PVI & $\begin{array}{l}\text { PARAMETER } \\
\text { VALUE }\end{array}$ & FLAGS & $\begin{array}{l}\text { DETECTION } \\
\text { LIMIT }\end{array}$ & $\begin{array}{l}\text { PARAMETER } \\
\text { UNCERTAINTY }\end{array}$ \\
\hline COPPER & $\begin{array}{l}0503 \\
0503 \\
0503 \\
0503 \\
0503 \\
0504 \\
0504 \\
0504 \\
0504 \\
0504 \\
0504 \\
0504 \\
0506 \\
0506 \\
0506 \\
0506 \\
0506 \\
0507 \\
0507 \\
0507 \\
0507 \\
0507 \\
0507 \\
0507 \\
0508 \\
0508 \\
0508 \\
0508 \\
0508 \\
0509 \\
0509 \\
0509 \\
0509 \\
0509 \\
0509 \\
0510 \\
0510 \\
0510\end{array}$ & $\begin{array}{l}05 / 16 / 90 \\
03 / 29 / 91 \\
08 / 08 / 91 \\
12 / 09 / 91 \\
10 / 09 / 92 \\
09 / 07 / 82 \\
10 / 14 / 87 \\
05 / 16 / 90 \\
04 / 03 / 91 \\
08 / 27 / 91 \\
12 / 09 / 91 \\
10 / 09 / 92 \\
10 / 14 / 87 \\
03 / 28 / 91 \\
08 / 08 / 91 \\
11 / 20 / 91 \\
10 / 08 / 92 \\
09 / 09 / 82 \\
10 / 14 / 87 \\
05 / 16 / 90 \\
03 / 28 / 91 \\
08 / 09 / 91 \\
12 / 05 / 91 \\
10 / 08 / 92 \\
10 / 14 / 87 \\
03 / 27 / 91 \\
08 / 28 / 91 \\
12 / 05 / 91 \\
10 / 10 / 92 \\
09 / 09 / 82 \\
10 / 14 / 87 \\
03 / 27 / 91 \\
08 / 28 / 91 \\
11 / 21 / 91 \\
10 / 13 / 92 \\
09 / 08 / 82 \\
06 / 30 / 86 \\
10 / 14 / 87\end{array}$ & $\begin{array}{l}0001 \\
0001 \\
0001 \\
0001 \\
0001 \\
0001 \\
0001 \\
0001 \\
0001 \\
0001 \\
0001 \\
0001 \\
0001 \\
0001 \\
0001 \\
0001 \\
0001 \\
0001 \\
0001 \\
0001 \\
0001 \\
0001 \\
0001 \\
0001 \\
0001 \\
0001 \\
0001 \\
0001 \\
0001 \\
0001 \\
0001 \\
0001 \\
0001 \\
0001 \\
0001 \\
0001 \\
0001 \\
0001\end{array}$ & $\begin{array}{l}A L \\
A L \\
A L \\
A L \\
A L \\
A L \\
A L \\
A L \\
A L \\
A L \\
A L \\
A L \\
A L \\
A L \\
A L \\
A L \\
A L \\
A L \\
A L \\
A L \\
A L \\
A L \\
A L \\
A L \\
A L \\
A L \\
A L \\
A L \\
A L \\
A L \\
A L \\
A L \\
A L \\
A L \\
A L \\
A L \\
A L \\
A L\end{array}$ & $\begin{array}{l}\text { D } \\
0 \\
0 \\
0 \\
0 \\
D \\
D \\
D \\
D \\
D \\
D \\
D \\
D \\
D \\
D \\
D \\
D \\
D \\
D \\
D \\
D \\
D \\
D \\
D \\
0 \\
0 \\
0 \\
0 \\
D \\
0 \\
0 \\
0 \\
0 \\
0 \\
0 \\
0 \\
0 \\
0\end{array}$ & $\mathrm{MG} / \mathrm{L}$ & 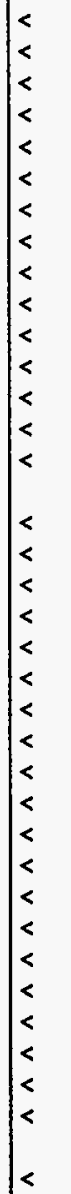 & $\begin{array}{l}0.02 \\
0.01 \\
0.01 \\
0.01 \\
0.01 \\
0.01 \\
0.02 \\
0.02 \\
0.01 \\
0.01 \\
0.01 \\
0.01 \\
0.02 \\
0.01 \\
0.01 \\
0.01 \\
0.01 \\
0.01 \\
0.02 \\
0.02 \\
0.01 \\
0.01 \\
0.01 \\
0.01 \\
0.02 \\
0.01 \\
0.01 \\
0.01 \\
0.01 \\
0.01 \\
0.02 \\
0.01 \\
0.01 \\
0.01 \\
0.01 \\
0.01 \\
0.06 \\
0.02\end{array}$ & $\mathbf{R}$ & $\begin{array}{l}0.02 \\
0.01 \\
0.01 \\
0.01 \\
0.01 \\
0.01 \\
0.02 \\
0.02 \\
0.01 \\
0.01 \\
0.01 \\
0.01 \\
0.02 \\
0.01 \\
0.01 \\
0.01 \\
0.01 \\
0.01 \\
0.02 \\
0.02 \\
0.01 \\
0.01 \\
0.01 \\
0.01 \\
0.02 \\
0.01 \\
0.01 \\
0.01 \\
0.01 \\
0.01 \\
0.02 \\
0.01 \\
0.01 \\
0.01 \\
0.01 \\
0.01 \\
0.02 \\
0.02\end{array}$ & $\begin{array}{l}- \\
- \\
- \\
- \\
- \\
- \\
- \\
- \\
- \\
- \\
- \\
- \\
- \\
- \\
- \\
- \\
- \\
- \\
- \\
- \\
- \\
- \\
- \\
- \\
- \\
- \\
- \\
- \\
- \\
- \\
- \\
-\end{array}$ \\
\hline
\end{tabular}

FORMATION OF COMPLETION CODE:

AL - ALLUVIUM

PARAMETER VALUE INDICATOR (PVI)

< - LESS THAN DETECTION LIMIT
FLOW RELATIONSHIP CODE:

- DOWN GRADIENT

0001 - FILTERED SAMPLE (.45 MICRONS)

OTHER PARAMETER VALUE FLAGS:

$J$ - ESTIMATED VALUE

$R$ - UNUSABLE DATA POINT 
TABLE 3.27 BASELINE GROUND HATER QUALITY DATA BY PARAMETER FOR THE ALLUVIUM, NC AND UC PROCESSING SITES, SLICK ROCK, COLORADO

SITE: SRKO1 SLICK ROCK (BOTH SITES)

09/07/82 TO 02/22/94

\begin{tabular}{|c|c|c|c|c|c|c|c|c|c|c|c|c|}
\hline & PARAMETER NAME & $\begin{array}{c}\text { LOCATION } \\
\text { ID }\end{array}$ & LOG DATE & $\begin{array}{c}\text { SAMPLE } \\
\text { ID }\end{array}$ & $\begin{array}{l}\text { FORM } \\
\text { COMP }\end{array}$ & $\begin{array}{l}\text { FLOW } \\
\text { REL. }\end{array}$ & $\begin{array}{l}\text { UNITS OF } \\
\text { MEASURE }\end{array}$ & PVI & $\begin{array}{l}\text { ARAMETER } \\
\text { VALUE }\end{array}$ & FLAGS & $\begin{array}{l}\text { DETECTION } \\
\text { LIMIT }\end{array}$ & $\begin{array}{l}\text { PARAMETER } \\
\text { UNCERTAINTY }\end{array}$ \\
\hline & COPPER & $\begin{array}{l}0510 \\
0510 \\
0510 \\
0510 \\
0512 \\
0512 \\
0512 \\
0512 \\
0512\end{array}$ & $\begin{array}{l}05 / 16 / 90 \\
03 / 28 / 91 \\
12 / 05 / 91 \\
10 / 08 / 92 \\
10 / 14 / 87 \\
04 / 05 / 91 \\
08 / 08 / 91 \\
12 / 10 / 91 \\
10 / 09 / 92\end{array}$ & $\begin{array}{l}0001 \\
0001 \\
0001 \\
0001 \\
0001 \\
0001 \\
0001 \\
0001 \\
0001\end{array}$ & $\begin{array}{l}A L \\
A L \\
A L \\
A L \\
A L \\
A L \\
A L \\
A L \\
A L\end{array}$ & $\begin{array}{l}0 \\
0 \\
0 \\
0 \\
0 \\
0 \\
0 \\
0 \\
0\end{array}$ & MG/L & $\begin{array}{l}< \\
< \\
< \\
< \\
< \\
< \\
< \\
< \\
< \\
<\end{array}$ & $\begin{array}{l}0.02 \\
0.01 \\
0.01 \\
0.01 \\
0.02 \\
0.01 \\
0.01 \\
0.01 \\
0.01\end{array}$ & & $\begin{array}{l}0.02 \\
0.01 \\
0.01 \\
0.01 \\
0.02 \\
0.01 \\
0.01 \\
0.01 \\
0.01\end{array}$ & $\begin{array}{l}- \\
- \\
- \\
- \\
- \\
- \\
-\end{array}$ \\
\hline & CYANIDE & $\begin{array}{l}0503 \\
0503 \\
0503 \\
0504 \\
0504 \\
0504 \\
0506 \\
0506 \\
0506 \\
0507 \\
0507 \\
0507 \\
0508 \\
0508 \\
0508 \\
0509 \\
0509 \\
0509 \\
0510 \\
0510 \\
0510 \\
0512 \\
0512 \\
0512\end{array}$ & $\begin{array}{l}03 / 29 / 91 \\
08 / 08 / 91 \\
12 / 09 / 91 \\
04 / 03 / 91 \\
08 / 27 / 91 \\
12 / 09 / 91 \\
03 / 28 / 91 \\
08 / 08 / 91 \\
11 / 20 / 91 \\
03 / 28 / 91 \\
08 / 09 / 91 \\
12 / 05 / 91 \\
03 / 27 / 91 \\
08 / 28 / 91 \\
12 / 05 / 91 \\
03 / 27 / 91 \\
08 / 28 / 91 \\
11 / 21 / 91 \\
03 / 28 / 91 \\
08 / 28 / 91 \\
12 / 05 / 91 \\
04 / 05 / 91 \\
08 / 08 / 91 \\
12 / 10 / 91\end{array}$ & $\begin{array}{l}0001 \\
0001 \\
0001 \\
0001 \\
0001 \\
0001 \\
0001 \\
0001 \\
0001 \\
0001 \\
0001 \\
0001 \\
0001 \\
0001 \\
0001 \\
0001 \\
0001 \\
0001 \\
0001 \\
0001 \\
0001 \\
0001 \\
0001 \\
0001\end{array}$ & $\begin{array}{l}A L \\
A L \\
A L \\
A L \\
A L \\
A L \\
A L \\
A L \\
A L \\
A L \\
A L \\
A L \\
A L \\
A L \\
A L \\
A L \\
A L \\
A L \\
A L \\
A L \\
A L \\
A L \\
A L \\
A L\end{array}$ & $\begin{array}{l}0 \\
0 \\
0 \\
D \\
D \\
D \\
D \\
D \\
D \\
D \\
D \\
D \\
0 \\
0 \\
0 \\
0 \\
0 \\
0 \\
0 \\
0 \\
0 \\
0 \\
0 \\
0\end{array}$ & MG/L & $\begin{array}{l}< \\
< \\
< \\
< \\
< \\
< \\
< \\
< \\
< \\
< \\
< \\
< \\
< \\
< \\
< \\
< \\
< \\
< \\
< \\
< \\
< \\
< \\
< \\
< \\
< \\
<\end{array}$ & $\begin{array}{l}0.01 \\
0.01 \\
0.01 \\
0.01 \\
0.01 \\
0.01 \\
0.01 \\
0.01 \\
0.01 \\
0.01 \\
0.01 \\
0.01 \\
0.01 \\
0.01 \\
0.01 \\
0.01 \\
0.01 \\
0.01 \\
0.01 \\
0.01 \\
0.01 \\
0.01 \\
0.02 \\
0.01\end{array}$ & $\begin{array}{l}\mathbf{R} \\
\mathbf{R}\end{array}$ & $\begin{array}{l}0.01 \\
0.01 \\
0.01 \\
0.01 \\
0.01 \\
0.01 \\
0.01 \\
0.01 \\
0.01 \\
0.01 \\
0.01 \\
0.01 \\
0.01 \\
0.01 \\
0.01 \\
0.01 \\
0.01 \\
0.01 \\
0.01 \\
0.01 \\
0.01 \\
0.01 \\
0.01 \\
0.01\end{array}$ & $\begin{array}{l}- \\
- \\
- \\
- \\
- \\
- \\
- \\
- \\
- \\
- \\
- \\
- \\
- \\
- \\
- \\
- \\
- \\
- \\
-\end{array}$ \\
\hline & DISSOLVED ORGANIC CARBON & $\begin{array}{l}0503 \\
0504 \\
0506\end{array}$ & $\begin{array}{l}02 / 18 / 94 \\
02 / 19 / 94 \\
02 / 20 / 94\end{array}$ & $\begin{array}{l}0001 \\
0001 \\
0001\end{array}$ & $\begin{array}{l}A L \\
A L \\
A L\end{array}$ & $\begin{array}{l}0 \\
D \\
D\end{array}$ & $M G / L$ & & $\begin{array}{r}5 \\
5 \\
48\end{array}$ & & $\begin{array}{l}1 \\
1 \\
1\end{array}$ & $=$ \\
\hline & $\begin{array}{l}\text { FORMATION OF COMPLETION CO } \\
\text { AL - ALLUVIUM }\end{array}$ & & & & & & $\begin{array}{l}\text { FLOW R } \\
D-D N \\
D-D O\end{array}$ & GRA & $\begin{array}{l}\text { SHIP COD } \\
\text { ENT }\end{array}$ & & & \\
\hline
\end{tabular}

PARAMETER VALUE INDICATOR (PVI): < - LESS THAN DETECTION LIMIT

SAMPLE ID CODES:

0001 - FILTERED SAMPLE (.45 MICRONS)

OTHER PARAMETER VALUE FLAGS:

$J$ - ESTIMATED VALUE

R - UNUSABLE DATA POINT 
TABLE 3.27 BASELINE GROUND WATER QUALITY DATA BY PARAMETER FOR THE

ALLUVIUM, NC AND UC PROCESSING SITES, SLICK ROCK, COLORADO

SITE: SRKO1 SLICK ROCK (BOTH SITES)

$09 / 07 / 82$ TO $02 / 22 / 94$

REPORT DATE: $10 / 03 / 94$

\begin{tabular}{|c|c|c|c|c|c|c|c|c|c|c|}
\hline PARAMETER NAME & $\begin{array}{l}\text { LOCATION } \\
\text { ID }\end{array}$ & LOG DATE & $\begin{array}{c}\text { SAMPLE } \\
\text { ID }\end{array}$ & $\begin{array}{l}\text { FORM } \\
\text { COMP }\end{array}$ & $\begin{array}{l}\text { FLOW } \\
\text { REL. }\end{array}$ & $\begin{array}{l}\text { UNITS OF } \\
\text { MEASURE }\end{array}$ & PVI & $\begin{array}{l}\text { PARAMETER } \\
\text { VALUE }\end{array}$ & $\begin{array}{l}\text { DETECTION } \\
\text { LIMIT }\end{array}$ & $\begin{array}{l}\text { PARAMETER } \\
\text { UNCERTAINTY }\end{array}$ \\
\hline DISSOLVED ORGANIC CARBON & $\begin{array}{l}0507 \\
0508 \\
0509\end{array}$ & $\begin{array}{l}02 / 20 / 94 \\
02 / 21 / 94 \\
02 / 21 / 94\end{array} \mid$ & $\begin{array}{l}0001 \\
0001 \\
0001\end{array}$ & $\begin{array}{l}\mathrm{AL} \\
\mathrm{AL} \\
\mathrm{AL}\end{array}$ & $\begin{array}{l}0 \\
0 \\
0\end{array}$ & MG/L & & $\begin{array}{l}7 \\
8 \\
3\end{array}$ & $\begin{array}{l}1 \\
1 \\
1\end{array}$ & : \\
\hline DISSOLVED OXYGEN & $\begin{array}{l}0503 \\
0503 \\
0504 \\
0504 \\
0506 \\
0506 \\
0507 \\
0507 \\
0508 \\
0508 \\
0509 \\
0509 \\
0510 \\
0510 \\
0512 \\
0512\end{array}$ & $\begin{array}{l}10 / 09 / 92 \\
02 / 22 / 94 \\
10 / 09 / 92 \\
02 / 19 / 94 \\
10 / 08 / 92 \\
02 / 20 / 94 \\
10 / 08 / 92 \\
02 / 20 / 94 \\
10 / 10 / 92 \\
02 / 21 / 94 \\
10 / 13 / 92 \\
02 / 21 / 94 \\
10 / 08 / 92 \\
02 / 20 / 94 \\
10 / 09 / 92 \\
02 / 20 / 94\end{array}$ & $\begin{array}{l}0001 \\
\text { N001 } \\
0001 \\
\text { N001 } \\
0001 \\
\text { N001 } \\
0001 \\
\text { N001 } \\
0001 \\
\text { N001 } \\
0001 \\
\text { N001 } \\
0001 \\
\text { N001 } \\
\text { O001 } \\
\text { N001 }\end{array}$ & $\begin{array}{l}A L \\
A L \\
A L \\
A L \\
A L \\
A L \\
A L \\
A L \\
A L \\
A L \\
A L \\
A L \\
A L \\
A L \\
A L \\
A L\end{array}$ & $\begin{array}{l}0 \\
0 \\
D \\
D \\
D \\
D \\
D \\
D \\
0 \\
0 \\
0 \\
0 \\
0 \\
0 \\
0 \\
0\end{array}$ & $M G / L$ & $<$ & $\begin{array}{l}0.1 \\
0.13 \\
0.1 \\
0.26 \\
0.2 \\
0.20 \\
0.0 \\
0.07 \\
0.0 \\
0.6 \\
0.0 \\
0.6 \\
0.2 \\
0.15 \\
1.1 \\
0.65\end{array}$ & $\begin{array}{l}- \\
- \\
- \\
- \\
- \\
- \\
- \\
- \\
- \\
- \\
- \\
-\end{array}$ & $\begin{array}{l}- \\
- \\
- \\
- \\
- \\
- \\
- \\
- \\
- \\
- \\
- \\
- \\
-\end{array}$ \\
\hline FIELD FE (2+) & $\begin{array}{l}0503 \\
0503 \\
0504 \\
0504 \\
0506 \\
0506 \\
0507 \\
0507 \\
0508 \\
0508 \\
0509 \\
0509 \\
0510 \\
0512\end{array}$ & $\begin{array}{l}10 / 09 / 92 \\
02 / 22 / 94 \\
10 / 09 / 92 \\
02 / 19 / 94 \\
10 / 08 / 92 \\
02 / 20 / 94 \\
10 / 08 / 92 \\
02 / 20 / 94 \\
10 / 10 / 92 \\
02 / 21 / 94 \\
10 / 13 / 92 \\
02 / 21 / 94 \\
02 / 20 / 94 \\
10 / 09 / 92\end{array}$ & $\begin{array}{l}\text { O001 } \\
\text { NO01 } \\
0001 \\
\text { N001 } \\
0001 \\
\text { N001 } \\
0001 \\
\text { NO01 } \\
\text { O001 } \\
\text { N001 } \\
0001 \\
\text { N001 } \\
\text { NO01 } \\
0001\end{array}$ & $\begin{array}{l}A L \\
A L \\
A L \\
A L \\
A L \\
A L \\
A L \\
A L \\
A L \\
A L \\
A L \\
A L \\
A L \\
A L\end{array}$ & $\begin{array}{l}0 \\
0 \\
D \\
D \\
D \\
D \\
D \\
D \\
0 \\
0 \\
0 \\
0 \\
0 \\
0\end{array}$ & $M G / L$ & 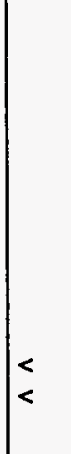 & $\begin{array}{l}2.34 \\
1.9 \\
3.58 \\
8.1 \\
3.37 \\
10 . \\
2.43 \\
2.4 \\
0.01 \\
0.02 \\
0.0 \\
0.02 \\
0.02 \\
0.75\end{array}$ & $\begin{array}{l}- \\
- \\
- \\
- \\
- \\
- \\
- \\
- \\
- \\
- \\
- \\
-\end{array}$ & $\begin{array}{l}- \\
- \\
- \\
- \\
- \\
- \\
- \\
- \\
- \\
- \\
-\end{array}$ \\
\hline FIELD FE (TOTAL) & $\begin{array}{l}0503 \\
0503 \\
0504 \\
0506\end{array}$ & $\begin{array}{l}10 / 09 / 92 \\
02 / 22 / 94 \\
02 / 19 / 94 \\
10 / 08 / 92\end{array}$ & $\begin{array}{l}0001 \\
\text { N001 } \\
\text { N001 } \\
0001\end{array}$ & $\begin{array}{l}A L \\
A L \\
A L \\
A L\end{array}$ & $\begin{array}{l}0 \\
0 \\
D \\
D\end{array}$ & $M G / L$ & & $\begin{array}{l}2.42 \\
2.0 \\
8.8 \\
5.42\end{array}$ & $\begin{array}{l}- \\
- \\
-\end{array}$ & $\begin{array}{l}- \\
- \\
-\end{array}$ \\
\hline
\end{tabular}

FORMATION OF COMPLETION CODE:

FLOH RELATIONSHIP CODE:

AL - ALLUVIUM

D - DOWN GRADIENT

O - ON-SITE

PARAMETER VALUE INDICATOR (PVI): < - LESS THAN DETECTION LIMIT

SAMPLE ID CODES:

0001 - FILTERED SAMPLE (.45 MICRONS)

N001 - UNF I LTERED SAMPLE 
TABLE 3.27 BASELINE GROUND HATER QUALITY DATA BY PARAMETER FOR THE

ALLUVIUM, NC AND UC PROCESSING SITES, SLICK ROCK, COLORADO

SITE: SRKO1 SLICK ROCK (BOTH SITES)

09/07/82 TO 02/22/94

REPORT DATE: $10 / 03 / 94$

\begin{tabular}{|c|c|c|c|c|c|c|c|c|c|c|c|}
\hline PARAMETER NAME & $\underset{\text { ID }}{\text { LOCATION }}$ & LOG DATE & $\underset{\text { ID }}{\text { SAMPLE }}$ & $\begin{array}{l}\text { FORM } \\
\text { COMP }\end{array}$ & $\begin{array}{l}\text { FLOW } \\
\text { REL. }\end{array}$ & $\begin{array}{l}\text { UNITS OF } \\
\text { MEASURE }\end{array}$ & PVI & $\begin{array}{l}\text { PARAMETER } \\
\text { VALUE }\end{array}$ & FLAGS & $\begin{array}{l}\text { DETECTION } \\
\text { LIMIT }\end{array}$ & $\begin{array}{l}\text { PARAMETER } \\
\text { UNCERTAI NTY }\end{array}$ \\
\hline FIELD FE (TOTAL) & $\begin{array}{l}0506 \\
0507 \\
0508 \\
0509 \\
0509 \\
0510 \\
0512\end{array}$ & $\begin{array}{l}02 / 20 / 94 \\
02 / 20 / 94 \\
02 / 21 / 94 \\
10 / 13 / 92 \\
02 / 21 / 94 \\
02 / 20 / 94 \\
10 / 09 / 92\end{array}$ & $\begin{array}{l}\text { N001 } \\
\text { N001 } \\
\text { N001 } \\
\text { O001 } \\
\text { N001 } \\
\text { N001 } \\
0001\end{array}$ & $\begin{array}{l}A L \\
A L \\
A L \\
A L \\
A L \\
A L \\
A L\end{array}$ & $\begin{array}{l}D \\
D \\
0 \\
0 \\
0 \\
0 \\
0\end{array}$ & MG/L & $<$ & $\begin{array}{l}9.9 \\
2.4 \\
0.08 \\
0.1 \\
0.02 \\
0.03 \\
85\end{array}$ & & $\begin{array}{l}- \\
- \\
- \\
- \\
-\end{array}$ & $\begin{array}{l}- \\
- \\
- \\
- \\
-\end{array}$ \\
\hline FLUORIDE & $\begin{array}{l}0503 \\
0503 \\
0503 \\
0503 \\
0503 \\
0503 \\
0503 \\
0503 \\
0503 \\
0504 \\
0504 \\
0504 \\
0504 \\
0504 \\
0504 \\
0504 \\
0504 \\
0506 \\
0506 \\
0506 \\
0506 \\
0506 \\
0506 \\
0506 \\
0507 \\
0507 \\
0507 \\
0507 \\
0507 \\
0507 \\
0507\end{array}$ & $\begin{array}{l}09 / 07 / 82 \\
06 / 30 / 86 \\
10 / 14 / 87 \\
02 / 22 / 88 \\
05 / 16 / 90 \\
03 / 29 / 91 \\
08 / 08 / 91 \\
12 / 09 / 91 \\
10 / 09 / 92 \\
09 / 07 / 82 \\
10 / 14 / 87 \\
02 / 22 / 88 \\
05 / 16 / 90 \\
04 / 03 / 91 \\
08 / 27 / 91 \\
12 / 09 / 91 \\
10 / 09 / 92 \\
09 / 08 / 82 \\
10 / 14 / 87 \\
02 / 22 / 88 \\
03 / 28 / 91 \\
08 / 08 / 91 \\
11 / 20 / 91 \\
10 / 08 / 92 \\
09 / 09 / 82 \\
10 / 14 / 87 \\
02 / 22 / 88 \\
05 / 16 / 90 \\
03 / 28 / 91 \\
08 / 09 / 91 \\
12 / 05 / 91\end{array}$ & $\begin{array}{l}0001 \\
0001 \\
0001 \\
0001 \\
0001 \\
0001 \\
0001 \\
0001 \\
0001 \\
0001 \\
0001 \\
0001 \\
0001 \\
0001 \\
0001 \\
0001 \\
0001 \\
0001 \\
0001 \\
0001 \\
0001 \\
0001 \\
0001 \\
0001 \\
0001 \\
0001 \\
0001 \\
0001 \\
0001 \\
0001 \\
0001\end{array}$ & $\begin{array}{l}A L \\
A L \\
A L \\
A L \\
A L \\
A L \\
A L \\
A L \\
A L \\
A L \\
A L \\
A L \\
A L \\
A L \\
A L \\
A L \\
A L \\
A L \\
A L \\
A L \\
A L \\
A L \\
A L \\
A L \\
A L \\
A L \\
A L \\
A L \\
A L \\
A L \\
A L\end{array}$ & $\begin{array}{l}0 \\
0 \\
0 \\
0 \\
0 \\
0 \\
0 \\
0 \\
0 \\
D \\
D \\
D \\
D \\
D \\
D \\
D \\
D \\
D \\
D \\
D \\
D \\
D \\
D \\
D \\
D \\
D \\
D \\
D \\
D \\
D \\
D\end{array}$ & MG/L & $<$ & $\begin{array}{l}1.00 \\
0.3 \\
0.1 \\
0.24 \\
0.2 \\
0.3 \\
0.4 \\
0.2 \\
0.3 \\
1.00 \\
0.1 \\
0.15 \\
0.2 \\
0.1 \\
0.1 \\
0.1 \\
0.1 \\
1.00 \\
0.2 \\
0.19 \\
0.7 \\
0.3 \\
0.2 \\
0.2 \\
1.00 \\
0.4 \\
0.45 \\
0.6 \\
0.6 \\
0.7 \\
0.6\end{array}$ & $\sqrt{ }$ & $\begin{array}{l}1 . \\
0.1 \\
0.1 \\
0.1 \\
0.1 \\
0.1 \\
0.1 \\
0.1 \\
0.1 \\
1.1 \\
0.1 \\
0.1 \\
0.1 \\
0.1 \\
0.1 \\
0.1 \\
0.1 \\
1.1 \\
0.1 \\
0.1 \\
0.1 \\
0.1 \\
0.1 \\
0.1 \\
1.1 \\
0.1 \\
0.1 \\
0.1 \\
0.1 \\
0.1 \\
0.1\end{array}$ & $\begin{array}{l}- \\
- \\
- \\
- \\
- \\
- \\
- \\
- \\
- \\
- \\
- \\
- \\
- \\
- \\
- \\
- \\
- \\
- \\
- \\
- \\
- \\
- \\
- \\
-\end{array}$ \\
\hline
\end{tabular}

FORMATION OF COMPLETION CODE:

FLOW RELATIONSHIP CODE:

AL - ALLUVIUM

D - DOWN GRADIENT

PARAMETER VALUE INDICATOR (PVI): < - LESS THAN DETECTION LIMIT

SAMPLE ID CODES:

OTHER PARAMETER VALUE FLAGS:

0001 - FILTERED SAMPLE (.45 MICRONS)

$J$ - ESTIMATED VALUE

N001 - UNFILTERED SAMPLE 
TABLE 3.27 BASELINE GROUND WATER QUALITY DATA BY PARAMETER FOR THE ALLUVIUM, NC AND UC PROCESSING SITES, SLICK ROCK, COLORADO

SITE: SRKO1 SLICK ROCK (BOTH SITES)

REPORT DATE: $10 / 03 / 94$

\begin{tabular}{|c|c|c|c|c|c|c|c|c|c|c|c|}
\hline PARAMETER NAME & $\underset{\text { ID }}{\text { LOCATION }}$ & LOG DATE & $\begin{array}{c}\text { SAMPLE } \\
\text { ID }\end{array}$ & $\begin{array}{l}\text { FORM } \\
\text { COMP }\end{array}$ & $\begin{array}{l}\text { FLOW } \\
\text { REL. }\end{array}$ & $\begin{array}{l}\text { UNITS OF } \\
\text { MEASURE }\end{array}$ & PVI & $\begin{array}{l}\text { PARAMETER } \\
\text { VALUE }\end{array}$ & FLAGS & $\begin{array}{l}\text { DETECTION } \\
\text { LIMIT }\end{array}$ & $\begin{array}{l}\text { PARAMETER } \\
\text { UNCERTAINTY }\end{array}$ \\
\hline FLUORIDE & $\begin{array}{l}0507 \\
0508 \\
0508 \\
0508 \\
0508 \\
0508 \\
0508 \\
0508 \\
0509 \\
0509 \\
0509 \\
0509 \\
0509 \\
0509 \\
0509 \\
0510 \\
0510 \\
0510 \\
0510 \\
0510 \\
0510 \\
0510 \\
0510 \\
0510 \\
0512 \\
0512 \\
0512 \\
0512 \\
0512 \\
0512 \\
0512\end{array}$ & $\begin{array}{l}10 / 08 / 92 \\
09 / 08 / 82 \\
10 / 14 / 87 \\
02 / 19 / 88 \\
03 / 27 / 91 \\
08 / 28 / 91 \\
12 / 05 / 91 \\
10 / 10 / 92 \\
09 / 09 / 82 \\
10 / 14 / 87 \\
02 / 22 / 88 \\
03 / 27 / 91 \\
08 / 28 / 91 \\
11 / 21 / 91 \\
10 / 13 / 92 \\
09 / 08 / 82 \\
06 / 30 / 86 \\
10 / 14 / 87 \\
02 / 22 / 88 \\
05 / 16 / 90 \\
03 / 28 / 91 \\
08 / 28 / 91 \\
12 / 05 / 91 \\
10 / 08 / 92 \\
09 / 08 / 82 \\
10 / 14 / 87 \\
02 / 22 / 88 \\
04 / 05 / 91 \\
08 / 08 / 91 \\
12 / 10 / 91 \\
10 / 09 / 92\end{array}$ & $\begin{array}{l}0001 \\
0001 \\
0001 \\
0001 \\
0001 \\
0001 \\
0001 \\
0001 \\
0001 \\
0001 \\
0001 \\
0001 \\
0001 \\
0001 \\
0001 \\
0001 \\
0001 \\
0001 \\
0001 \\
0001 \\
0001 \\
0001 \\
0001 \\
0001 \\
0001 \\
0001 \\
0001 \\
0001 \\
0001 \\
0001 \\
0001\end{array}$ & $\begin{array}{l}A L \\
A L \\
A L \\
A L \\
A L \\
A L \\
A L \\
A L \\
A L \\
A L \\
A L \\
A L \\
A L \\
A L \\
A L \\
A L \\
A L \\
A L \\
A L \\
A L \\
A L \\
A L \\
A L \\
A L \\
A L \\
A L \\
A L \\
A L \\
A L \\
A L \\
A L\end{array}$ & $\begin{array}{l}D \\
0 \\
0 \\
0 \\
0 \\
0 \\
0 \\
0 \\
0 \\
0 \\
0 \\
0 \\
0 \\
0 \\
0 \\
0 \\
0 \\
0 \\
0 \\
0 \\
0 \\
0 \\
0 \\
0 \\
0 \\
0 \\
0 \\
0 \\
0 \\
0 \\
0\end{array}$ & $M G / L$ & . & $\begin{array}{l}0.7 \\
1.00 \\
0.4 \\
0.38 \\
0.2 \\
0.4 \\
0.4 \\
0.5 \\
1.00 \\
0.2 \\
0.28 \\
0.4 \\
0.3 \\
0.2 \\
0.3 \\
1.00 \\
0.4 \\
0.3 \\
0.34 \\
0.3 \\
0.3 \\
0.3 \\
0.4 \\
0.4 \\
1.00 \\
0.3 \\
0.32 \\
0.3 \\
0.3 \\
0.3 \\
0.3\end{array}$ & $R$ & $\begin{array}{l}0.1 \\
1 . \\
0.1 \\
0.1 \\
0.1 \\
0.1 \\
0.1 \\
0.1 \\
1.1 \\
0.1 \\
0.1 \\
0.1 \\
0.1 \\
0.1 \\
0.1 \\
1.1 \\
0.1 \\
0.1 \\
0.1 \\
0.1 \\
0.1 \\
0.1 \\
0.1 \\
0.1 \\
1.1 \\
0.1 \\
0.1 \\
0.1 \\
0.1 \\
0.1 \\
0.1\end{array}$ & $\begin{array}{l}- \\
- \\
- \\
- \\
- \\
- \\
- \\
- \\
- \\
- \\
- \\
- \\
- \\
- \\
- \\
- \\
- \\
- \\
- \\
- \\
- \\
- \\
-\end{array}$ \\
\hline GROSS ALPHA & $\begin{array}{l}0503 \\
0503 \\
0503 \\
0503 \\
0503 \\
0503\end{array}$ & $\begin{array}{l}09 / 07 / 82 \\
03 / 29 / 91 \\
08 / 08 / 91 \\
12 / 05 / 91 \\
10 / 09 / 92 \\
02 / 18 / 94\end{array}$ & $\begin{array}{l}0001 \\
0001 \\
0001 \\
0001 \\
0001 \\
0001\end{array}$ & $\begin{array}{l}A L \\
A L \\
A L \\
A L \\
A L \\
A L\end{array}$ & $\begin{array}{l}0 \\
0 \\
0 \\
0 \\
0 \\
0\end{array}$ & $\mathrm{PCI} / \mathrm{L}$ & & $\begin{array}{l}2366.00 \\
2299 . \\
1821 . \\
2175 . \\
1610 . \\
1920\end{array}$ & $\begin{array}{l}N \\
*\end{array}$ & $\begin{array}{c}- \\
1 . \\
1 . \\
1 . \\
37.8 \\
10.4\end{array}$ & $\begin{array}{l}11 .- \\
118 . \\
108 . \\
165 . \\
99.3 \\
46.1\end{array}$ \\
\hline
\end{tabular}

FORMATION OF COMPLETION CODE:

AL - ALLUVIUM

PARAMETER VALUE INDICATOR (PVI): < - LESS THAN DETECTION LIMIT
FLOW RELATIONSHIP CODE:

D - DOWN GRADIENT

O - ON-SITE

0001 - FILTERED SAMPLE (.45 MICRONS)

OTHER PARAMETER VALUE FLAGS:

* - DUPLICATE ANALYSIS NOT WITHIN CONTROL LIMITS

N - SPIKE SAMPLE RECOVERY NOT HITHIN CONTROL LIMITS

$R$ - UNUSABLE DATA POINT 
TABLE 3.27 BASELINE GROUND HATER QUALITY DATA BY PARAMETER FOR THE ALLUVIUM, NC AND UC PROCESSING SITES, SLICK ROCK, COLORADO

SITE: SRKO1 SLICK ROCK (BOTH SITES)

09/07/82 TO 02/22/94

REPORT DATE: $10 / 03 / 94$

\begin{tabular}{|c|c|c|c|c|c|c|c|c|c|c|c|}
\hline PARAMETER NAME & $\mid \begin{array}{c}\text { LOCATION } \\
\text { ID }\end{array}$ & LOG DATE & $\begin{array}{c}\text { SAMPLE } \\
\text { ID }\end{array}$ & $\begin{array}{l}\text { FORM } \\
\text { COMP }\end{array}$ & $\begin{array}{l}\text { FLOW } \\
\text { REL. }\end{array}$ & $\begin{array}{l}\text { UNITS OF } \\
\text { MEASURE }\end{array}$ & PVI & $\begin{array}{l}\text { PARAMETER } \\
\text { VALUE }\end{array}$ & FLAGS & $\begin{array}{l}\text { DETECTION } \\
\text { LIMIT }\end{array}$ & $\begin{array}{l}\text { PARAMETER } \\
\text { UNCERTAINTY }\end{array}$ \\
\hline GROSS ALPHA & $\begin{array}{l}0504 \\
0504 \\
0504 \\
0504 \\
0504 \\
0504 \\
0506 \\
0506 \\
0506 \\
0506 \\
0506 \\
0507 \\
0507 \\
0507 \\
0507 \\
0507 \\
0507 \\
0508 \\
0508 \\
0508 \\
0508 \\
0508 \\
0509 \\
0509 \\
0509 \\
0509 \\
0509 \\
0509 \\
0510 \\
0510 \\
0510 \\
0510 \\
0510 \\
0510 \\
0512 \\
0512\end{array}$ & $\begin{array}{l}09 / 07 / 82 \\
04 / 03 / 91 \\
08 / 27 / 91 \\
12 / 05 / 91 \\
10 / 09 / 92 \\
02 / 19 / 94 \\
03 / 28 / 91 \\
08 / 08 / 91 \\
12 / 05 / 91 \\
10 / 08 / 92 \\
02 / 20 / 94 \\
09 / 09 / 82 \\
03 / 28 / 91 \\
08 / 09 / 91 \\
12 / 05 / 91 \\
10 / 08 / 92 \\
02 / 20 / 94 \\
03 / 27 / 91 \\
08 / 28 / 91 \\
12 / 05 / 91 \\
10 / 10 / 92 \\
02 / 21 / 94 \\
09 / 09 / 82 \\
03 / 27 / 91 \\
08 / 28 / 91 \\
12 / 05 / 91 \\
10 / 13 / 92 \\
02 / 21 / 94 \\
09 / 08 / 82 \\
03 / 28 / 91 \\
08 / 28 / 91 \\
12 / 05 / 91 \\
10 / 08 / 92 \\
02 / 20 / 94 \\
04 / 05 / 91 \\
08 / 08 / 91\end{array}$ & $\begin{array}{l}0001 \\
0001 \\
0001 \\
0001 \\
0001 \\
0001 \\
0001 \\
0001 \\
0001 \\
0001 \\
0001 \\
0001 \\
0001 \\
0001 \\
0001 \\
0001 \\
0001 \\
0001 \\
0001 \\
0001 \\
0001 \\
0001 \\
0001 \\
0001 \\
0001 \\
0001 \\
0001 \\
0001 \\
0001 \\
0001 \\
0001 \\
0001 \\
0001 \\
0001 \\
0001 \\
0001\end{array}$ & $\begin{array}{l}A L \\
A L \\
A L \\
A L \\
A L \\
A L \\
A L \\
A L \\
A L \\
A L \\
A L \\
A L \\
A L \\
A L \\
A L \\
A L \\
A L \\
A L \\
A L \\
A L \\
A L \\
A L \\
A L \\
A L \\
A L \\
A L \\
A L \\
A L \\
A L \\
A L \\
A L \\
A L \\
A L \\
A L \\
A L \\
A L\end{array}$ & $\begin{array}{l}D \\
D \\
D \\
D \\
D \\
D \\
D \\
D \\
D \\
D \\
D \\
D \\
D \\
D \\
D \\
D \\
D \\
0 \\
0 \\
0 \\
0 \\
0 \\
0 \\
0 \\
0 \\
0 \\
0 \\
0 \\
0 \\
0 \\
0 \\
0 \\
0 \\
0 \\
0 \\
0\end{array}$ & $\mathrm{PCI} / \mathrm{L}$ & 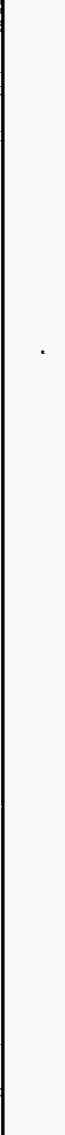 & $\begin{array}{c}964.00 \\
1177 . \\
768.3 \\
718 . \\
641 . \\
2220 \\
191 . \\
23.0 \\
0.0 \\
189 . \\
136 \\
56.00 \\
41.0 \\
30.6 \\
19.3 \\
5.0 \\
13.4 \\
63.2 \\
67.2 \\
0.0 \\
23.1 \\
32.6 \\
39.00 \\
111 . \\
23.5 \\
19.0 \\
16.1 \\
25.4 \\
156.00 \\
132 . \\
84.2 \\
0.0 \\
118 . \\
95.5 \\
1222 . \\
916 .\end{array}$ & $\begin{array}{l}\mathrm{R} \\
\mathrm{N} \\
\star \\
\mathrm{R} \\
\mathrm{N} \\
\text { * }\end{array}$ & $\begin{array}{c}- \\
1 . \\
1 . \\
1 . \\
25.0 \\
16.1 \\
1 . \\
1 . \\
1 . \\
82.4 \\
46.7 \\
- \\
1 . \\
1 . \\
1 . \\
6.4 \\
5.1 \\
1 . \\
1 . \\
1 . \\
48.4 \\
24.3 \\
1 . \\
1 . \\
1 . \\
20.2 \\
5.4 \\
1 . \\
1 . \\
1 . \\
41.2 \\
21.4 \\
1 . \\
1 .\end{array}$ & $\begin{array}{c}85.7 \\
63.7 \\
80.4 \\
51.7 \\
61.7 \\
140 . \\
71.2 \\
116 . . \\
74.3 \\
30.4 \\
17.0 \\
13.6 \\
26.0 \\
4.6 \\
3.2 \\
23.2 \\
34.2 \\
62.4 \\
31.6 \\
19.1 \\
70.5 \\
12.0 \\
23.8 \\
13.9 \\
4.1 \\
73.1 \\
37.6 \\
57.9 \\
40.0 \\
16.6 \\
58.2 \\
51.1\end{array}$ \\
\hline
\end{tabular}

FORMATION OF COMPLETION CODE:

AL - ALLUVIUM

PARAMETER VALUE INDICATOR (PVI): < - LESS THAN DETECTION LIMIT
FLOW RELATIONSHIP CODE:

D - DOWN GRADIENT

O - ON-SITE

SAMPLE ID CODES:

0001 - FILTERED SAMPLE (.45 MICRONS)

OTHER PARAMETER VALUE FLAGS:

* - DUPLICATE aNALYSIS NOT WITHIN CONTROL LIMITS

$J$ - ESTIMATED VALUE

N - SPIKE SAMPLE RECOVERY NOT WITHIN CONTROL LIMITS

$R$ - UNUSABLE DATA POINT 
TABLE 3.27 BASEL INE GROUND WATER QUALITY DATA BY PARAMETER FOR THE ALLUVIUM, NC AND UC PROCESSING SITES, SLICK ROCK, COLORADO

SITE: SRKO1 SLICK ROCK (BOTH SITES)

$09 / 07 / 82$ TO 02/22/94

REPORT DATE: $10 / 03 / 94$

\begin{tabular}{|c|c|c|c|c|c|c|c|c|c|c|c|}
\hline PARAMETER NAME & $\begin{array}{c}\text { LOCATION } \\
\text { ID }\end{array}$ & LOG DATE & $\begin{array}{c}\text { SAMPLE } \\
\text { ID }\end{array}$ & $\begin{array}{l}\text { FORM } \\
\text { COMP }\end{array}$ & $\begin{array}{l}\text { FLOW } \\
\text { REL. }\end{array}$ & $\begin{array}{l}\text { UNITS OF } \\
\text { MEASURE }\end{array}$ & PVI & $\begin{array}{l}\text { PARAMETER } \\
\text { VALUE }\end{array}$ & FLAGS & $\begin{array}{l}\text { DETECTION } \\
\text { LIMIT }\end{array}$ & $\begin{array}{l}\text { PARAMETER } \\
\text { UNCERTAINTY }\end{array}$ \\
\hline GROSS ALPHA & $\begin{array}{l}0512 \\
0512 \\
0512\end{array}$ & $\begin{array}{l}12 / 05 / 91 \\
10 / 09 / 92 \\
02 / 20 / 94\end{array} \mid$ & $\begin{array}{l}0001 \\
0001 \\
0001\end{array}$ & $\begin{array}{l}\mathrm{AL} \\
\mathrm{AL} \\
\mathrm{AL}\end{array}$ & $\begin{array}{l}0 \\
0 \\
0\end{array}$ & $\mathrm{PCI} / \mathrm{L}$ & & $\begin{array}{l}870 \\
1460 \\
2680\end{array}$ & $\begin{array}{l}N \\
*\end{array}$ & $\begin{array}{r}1 . \\
22.5 \\
7.2\end{array}$ & $\begin{array}{l}66.1 \\
72.3 \\
46.1\end{array}$ \\
\hline GROSS ALPHA (TOTAL) & $\begin{array}{l}0503 \\
0504 \\
0506 \\
0507 \\
0508 \\
0509 \\
0510 \\
0512\end{array}$ & $\begin{array}{l}02 / 18 / 94 \\
02 / 19 / 94 \\
02 / 20 / 94 \\
02 / 20 / 94 \\
02 / 21 / 94 \\
02 / 21 / 94 \\
02 / 20 / 94 \\
02 / 20 / 94\end{array}$ & $\begin{array}{l}\text { N001 } \\
\text { N001 } \\
\text { N001 } \\
\text { N001 } \\
\text { N001 } \\
\text { N001 } \\
\text { N001 } \\
\text { N001 }\end{array}$ & $\begin{array}{l}A L \\
A L \\
A L \\
A L \\
A L \\
A L \\
A L \\
A L\end{array}$ & $\begin{array}{l}0 \\
D \\
D \\
D \\
0 \\
0 \\
0 \\
0\end{array}$ & $\mathrm{PCI} / \mathrm{L}$ & & $\begin{array}{c}2180 \\
1770 \\
84.0 \\
15.5 \\
59.0 \\
27.5 \\
103 \\
1590\end{array}$ & $\begin{array}{l}\text { * } \\
\text { * } \\
\text { * } \\
\text { * } \\
\text { * }\end{array}$ & $\begin{array}{r}9.7 \\
16.3 \\
48.1 \\
4.5 \\
19.9 \\
4.9 \\
19.9 \\
5.4\end{array}$ & $\begin{array}{r}47.7 \\
55.2 \\
29.0 \\
3.1 \\
12.6 \\
4.2 \\
17.9 \\
30.4\end{array}$ \\
\hline GROSS BETA & $\begin{array}{l}0503 \\
0503 \\
0503 \\
0503 \\
0504 \\
0504 \\
0504 \\
0504 \\
0506 \\
0506 \\
0506 \\
0506 \\
0507 \\
0507 \\
0507 \\
0507 \\
0508 \\
0508 \\
0508 \\
0508 \\
0509 \\
0509 \\
0509\end{array}$ & $\begin{array}{l}03 / 29 / 91 \\
08 / 08 / 91 \\
12 / 05 / 91 \\
10 / 09 / 92 \\
04 / 03 / 91 \\
08 / 27 / 91 \\
12 / 05 / 91 \\
10 / 09 / 92 \\
03 / 28 / 91 \\
08 / 08 / 91 \\
12 / 05 / 91 \\
10 / 08 / 92 \\
03 / 28 / 91 \\
08 / 09 / 91 \\
12 / 05 / 91 \\
10 / 08 / 92 \\
03 / 27 / 91 \\
08 / 28 / 91 \\
12 / 05 / 91 \\
10 / 10 / 92 \\
03 / 27 / 91 \\
08 / 28 / 91 \\
12 / 05 / 91\end{array}$ & $\begin{array}{l}0001 \\
0001 \\
0001 \\
0001 \\
0001 \\
0001 \\
0001 \\
0001 \\
0001 \\
0001 \\
0001 \\
0001 \\
0001 \\
0001 \\
0001 \\
0001 \\
0001 \\
0001 \\
0001 \\
0001 \\
0001 \\
0001 \\
0001\end{array}$ & $\begin{array}{l}A L \\
A L \\
A L \\
A L \\
A L \\
A L \\
A L \\
A L \\
A L \\
A L \\
A L \\
A L \\
A L \\
A L \\
A L \\
A L \\
A L \\
A L \\
A L \\
A L \\
A L \\
A L \\
A L\end{array}$ & $\begin{array}{l}0 \\
0 \\
0 \\
0 \\
D \\
D \\
D \\
D \\
D \\
D \\
D \\
D \\
D \\
D \\
D \\
D \\
0 \\
0 \\
0 \\
0 \\
0 \\
0 \\
0\end{array}$ & PCI/L & & $\begin{array}{r}875 . \\
984 . \\
885 . \\
577 . \\
340 . \\
319 . \\
264 . \\
188 . \\
165 . \\
16.1 \\
0.0 \\
145 . \\
23.4 \\
19.8 \\
0.0 \\
11.8 \\
42.8 \\
54.1 \\
0.0 \\
25.1 \\
87.7 \\
23.6 \\
4.9\end{array}$ & $\begin{array}{l}{ }_{\mathrm{N}} \\
\mathrm{J} \\
{ }_{\mathrm{N}}\end{array}$ & $\begin{array}{r}0.5 \\
0.5 \\
0.5 \\
33.7 \\
0.5 \\
0.5 \\
0.5 \\
22.8 \\
0.5 \\
0.5 \\
0.5 \\
63.8 \\
0.5 \\
0.5 \\
0.5 \\
7.8 \\
0.5 \\
0.5 \\
0.5 \\
41.0 \\
0.5 \\
0.5 \\
0.5\end{array}$ & $\begin{array}{r}37.3 \\
44.0 \\
55.6 \\
37.9 \\
25.6 \\
21.7 \\
27.9 \\
20.3 \\
84.5 \\
55.5 \\
79.1 \\
45.1 \\
8.6 \\
8.7 \\
15.3 \\
5.2 \\
11.6 \\
19.4 \\
40.4 \\
25.5 \\
45.5 \\
6.9 \\
15.0\end{array}$ \\
\hline
\end{tabular}

FORMATION OF COMPLETION CODE:

AL - ALLUVIUM

PARAMETER VALUE INDICATOR (PVI): < - LESS THAN DETECTION LIMIT

OTHER PARAMETER VALUE FLAGS:

* - DUPLICATE ANALYSIS NOt WITHIN CONTROL limits

J - ESTIMATED VALUE

N - SPIKE SAMPLE RECOVERY NOT WITHIN CONTROL LIMITS

$R$ - UNUSABLE DATA POINT
FLOW RELATIONSHIP CODE:

O - ON-SITE

D - DOWN GRADIENT

\section{SAMPLE ID CODES:}

0001 - FILTERED SAMPLE (.45 MICRONS)

N001 - UNFILTERED SAMPLE 
TABLE 3.27 BASELINE GROUND HATER QUALITY DATA BY PARAMETER FOR THE ALLUVIUM, NC AND UC PROCESSING SITES, SLICK ROCK, COLORADO

SITE: SRKO 1 SLICK ROCK (BOTH SITES)

$09 / 07 / 82$ TO $02 / 22 / 94$

REPORT DATE: $10 / 03 / 94$

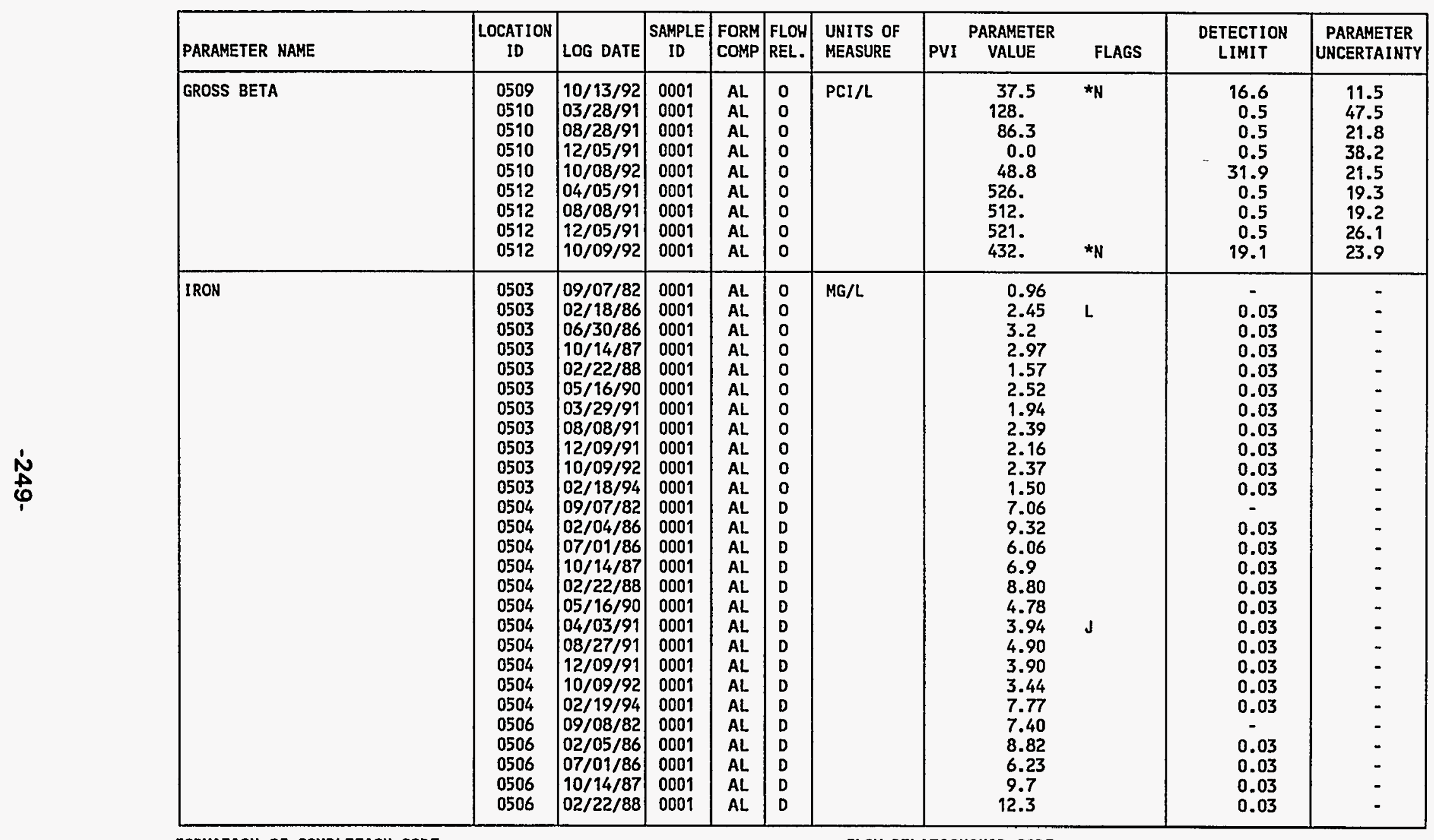

FORMATION OF COMPLETION CODE:

AL - ALLUVIUM

PARAMETER VALUE INDICATOR (PVI): < - LESS THAN DETECTION LIMIT
FLOW RELATIONSHIP CODE:

O - ON-SITE

- DOWN GRADIENT

SAMPLE ID CODES:

0001 - FILTERED SAMPLE (.45 MICRONS)

OTHER PARAMETER VALUE FLAGS:

* - DUPLICATE ANALYSIS NOT WITHIN CONTROL LIMITS

J - ESTIMATED VALUE

$L$ - LESS THAN THREE BORE VOLUMES REMOVED BEFORE SAMPLING

N - SPIKE SAMPLE RECOVERY NOT WITHIN CONTROL LIMITS 
TABLE 3.27 BASELINE GROUND WATER QUALITY DATA BY PARAMETER FOR THE ALLUVIUM, NC AND UC PROCESSING SITES, SLICK ROCK, COLORADO

SITE: SRKO1 SLICK ROCK (BOTH SITES)

09/07/82 TO 02/22/94

\begin{tabular}{|c|c|c|c|c|c|c|c|c|c|c|c|}
\hline PARAMETER NAME & $\begin{array}{c}\text { LOCATION } \\
\text { ID }\end{array}$ & LOG DATE & $\begin{array}{c}\text { SAMPLE } \\
\text { ID }\end{array}$ & $\begin{array}{l}\text { FORM } \\
\text { COMP }\end{array}$ & $\begin{array}{l}\text { FLOW } \\
\text { REL. }\end{array}$ & $\begin{array}{l}\text { UNITS OF } \\
\text { MEASURE }\end{array}$ & PVI & $\begin{array}{l}\text { PARAMETER } \\
\text { VALUE }\end{array}$ & FLAGS & $\begin{array}{l}\text { DETECTION } \\
\text { LIMIT }\end{array}$ & $\begin{array}{l}\text { PARAMETER } \\
\text { UNCERTAINTY }\end{array}$ \\
\hline IRON & $\begin{array}{l}0506 \\
0506 \\
0506 \\
0506 \\
0506 \\
0507 \\
0507 \\
0507 \\
0507 \\
0507 \\
0507 \\
0507 \\
0507 \\
0507 \\
0507 \\
0507 \\
0508 \\
0508 \\
0508 \\
0508 \\
0508 \\
0508 \\
0508 \\
0508 \\
0508 \\
0508 \\
0509 \\
0509 \\
0509 \\
0509 \\
0509 \\
0509 \\
0509 \\
0509 \\
0509 \\
0509 \\
0510 \\
0510 \\
0510\end{array}$ & $\begin{array}{l}03 / 28 / 91 \\
08 / 08 / 91 \\
11 / 20 / 91 \\
10 / 08 / 92 \\
02 / 20 / 94 \\
09 / 09 / 82 \\
02 / 05 / 86 \\
06 / 30 / 86 \\
10 / 14 / 87 \\
02 / 22 / 88 \\
05 / 16 / 90 \\
03 / 28 / 91 \\
08 / 09 / 91 \\
12 / 05 / 91 \\
10 / 08 / 92 \\
02 / 20 / 94 \\
09 / 08 / 82 \\
02 / 18 / 86 \\
06 / 30 / 86 \\
10 / 14 / 87 \\
02 / 19 / 88 \\
03 / 27 / 91 \\
08 / 28 / 91 \\
12 / 05 / 91 \\
10 / 10 / 92 \\
02 / 21 / 94 \\
09 / 09 / 82 \\
02 / 18 / 86 \\
07 / 17 / 86 \\
10 / 14 / 87 \\
02 / 22 / 88 \\
03 / 27 / 91 \\
08 / 28 / 91 \\
11 / 21 / 91 \\
10 / 13 / 92 \\
02 / 21 / 94 \\
09 / 08 / 82 \\
02 / 18 / 86 \\
06 / 30 / 86\end{array}$ & \begin{tabular}{|l}
0001 \\
0001 \\
0001 \\
0001 \\
0001 \\
0001 \\
0001 \\
0001 \\
0001 \\
0001 \\
0001 \\
0001 \\
0001 \\
0001 \\
0001 \\
0001 \\
0001 \\
0001 \\
0001 \\
0001 \\
0001 \\
0001 \\
0001 \\
0001 \\
0001 \\
0001 \\
0001 \\
0001 \\
0001 \\
0001 \\
0001 \\
0001 \\
0001 \\
0001 \\
0001 \\
0001 \\
0001 \\
0001 \\
0001
\end{tabular} & $\begin{array}{l}A L \\
A L \\
A L \\
A L \\
A L \\
A L \\
A L \\
A L \\
A L \\
A L \\
A L \\
A L \\
A L \\
A L \\
A L \\
A L \\
A L \\
A L \\
A L \\
A L \\
A L \\
A L \\
A L \\
A L \\
A L \\
A L \\
A L \\
A L \\
A L \\
A L \\
A L \\
A L \\
A L \\
A L \\
A L \\
A L \\
A L \\
A L \\
A L\end{array}$ & $\begin{array}{l}D \\
D \\
D \\
D \\
D \\
D \\
D \\
D \\
D \\
D \\
D \\
D \\
D \\
D \\
D \\
D \\
0 \\
0 \\
0 \\
0 \\
0 \\
0 \\
0 \\
0 \\
0 \\
0 \\
0 \\
0 \\
0 \\
0 \\
0 \\
0 \\
0 \\
0 \\
0 \\
0 \\
0 \\
0 \\
0\end{array}$ & $M G / L$ & $\mid \begin{array}{l}< \\
< \\
< \\
< \\
< \\
<\end{array}$ & $\begin{array}{c}4.17 \\
14.2 \\
12.6 \\
3.21 \\
2.35 \\
0.22 \\
2.28 \\
2.11 \\
2.71 \\
2.43 \\
2.44 \\
2.46 \\
2.89 \\
2.68 \\
2.62 \\
2.33 \\
0.18 \\
0.27 \\
0.08 \\
0.03 \\
0.16 \\
0.03 \\
0.03 \\
0.03 \\
0.03 \\
0.03 \\
0.06 \\
0.07 \\
0.05 \\
0.03 \\
0.05 \\
0.03 \\
0.03 \\
0.03 \\
0.03 \\
0.03 \\
0.20 \\
0.12 \\
0.07\end{array}$ & $\mathbf{R}$ & $\begin{array}{l}0.03 \\
0.03 \\
0.03 \\
0.03 \\
0.03 \\
-. \\
0.03 \\
0.03 \\
0.03 \\
0.03 \\
0.03 \\
0.03 \\
0.03 \\
0.03 \\
0.03 \\
0.03 \\
- \\
0.03 \\
0.03 \\
0.03 \\
0.03 \\
0.03 \\
0.03 \\
0.03 \\
0.03 \\
0.03 \\
- \\
0.03 \\
0.03 \\
0.03 \\
0.03 \\
0.03 \\
0.03 \\
0.03 \\
0.03 \\
0.03 \\
- \\
0.03 \\
0.03\end{array}$ & $\begin{array}{l}- \\
- \\
- \\
- \\
- \\
- \\
- \\
- \\
- \\
- \\
- \\
- \\
- \\
- \\
- \\
- \\
- \\
- \\
- \\
- \\
- \\
- \\
- \\
- \\
- \\
- \\
- \\
- \\
- \\
- \\
- \\
- \\
- \\
- \\
- \\
- \\
- \\
-\end{array}$ \\
\hline
\end{tabular}

FORMATION OF COMPLETION CODE:

AL - ALLUVIUM

PARAMETER VALUE INDICATOR (PVI)
FLOW RELATIONSHIP CODE:

D - DOWN GRADIENT

O - ON-SITE

0001 - FILTERED SAMPLE (.45 MICRONS)

OTHER PARAMETER VALUE FLAGS:

$R$ - UNUSABLE DATA PQIINT 
TABLE 3.27 BASELINE GROUND HATER QUALITY DATA BY PARAMETER FOR THE ALLUVIUM, NC AND UC PROCESSING SITES, SLICK ROCK, COLORADO

SITE: SRKO1 SLICK ROCK (BOTH SITES)

07/82 TO 02/22/94

REPORT DATE: $10 / 03 / 94$

\begin{tabular}{|c|c|c|c|c|c|c|c|c|c|c|c|}
\hline PARAMETER NAME & $\underset{\text { ID }}{\text { LOCATION }}$ & LOG DATE & $\begin{array}{c}\text { SAMPLE } \\
\text { ID }\end{array}$ & $\begin{array}{l}\text { FORM } \\
\text { COMP }\end{array}$ & $\begin{array}{l}\text { FLOW } \\
\text { REL. }\end{array}$ & $\begin{array}{l}\text { UNITS OF } \\
\text { MEASURE }\end{array}$ & PVI & $\begin{array}{l}\text { PARAMETER } \\
\text { VALUE }\end{array}$ & FLAGS & $\begin{array}{l}\text { DETECTION } \\
\text { LIMIT }\end{array}$ & $\begin{array}{l}\text { PARAMETER } \\
\text { UNCERTAINTY }\end{array}$ \\
\hline IRON & $\begin{array}{l}0510 \\
0510 \\
0510 \\
0510 \\
0510 \\
0510 \\
0510 \\
0512 \\
0512 \\
0512 \\
0512 \\
0512 \\
0512 \\
0512 \\
0512 \\
0512 \\
0512\end{array}$ & \begin{tabular}{|l|}
$10 / 14 / 87$ \\
$02 / 22 / 88$ \\
$05 / 16 / 90$ \\
$03 / 28 / 91$ \\
$12 / 05 / 91$ \\
$10 / 08 / 92$ \\
$02 / 20 / 94$ \\
$09 / 08 / 82$ \\
$02 / 04 / 86$ \\
$07 / 01 / 86$ \\
$10 / 14 / 87$ \\
$02 / 22 / 88$ \\
$04 / 05 / 91$ \\
$08 / 08 / 91$ \\
$12 / 10 / 91$ \\
$10 / 09 / 92$ \\
$02 / 20 / 94$
\end{tabular} & $\begin{array}{l}0001 \\
0001 \\
0001 \\
0001 \\
0001 \\
0001 \\
0001 \\
0001 \\
0001 \\
0001 \\
0001 \\
0001 \\
0001 \\
0001 \\
0001 \\
0001 \\
0001\end{array}$ & $\begin{array}{l}A L \\
A L \\
A L \\
A L \\
A L \\
A L \\
A L \\
A L \\
A L \\
A L \\
A L \\
A L \\
A L \\
A L \\
A L \\
A L \\
A L\end{array}$ & $\begin{array}{l}0 \\
0 \\
0 \\
0 \\
0 \\
0 \\
0 \\
0 \\
0 \\
0 \\
0 \\
0 \\
0 \\
0 \\
0 \\
0 \\
0\end{array}$ & $M G / L$ & $\begin{array}{l}< \\
< \\
< \\
< \\
<\end{array}$ & $\begin{array}{l}0.03 \\
0.14 \\
0.11 \\
0.03 \\
0.03 \\
0.03 \\
0.03 \\
1.76 \\
0.3 \\
0.07 \\
0.20 \\
0.18 \\
0.69 \\
0.34 \\
0.72 \\
0.65 \\
0.10\end{array}$ & & $\begin{array}{l}0.03 \\
0.03 \\
0.03 \\
0.03 \\
0.03 \\
0.03 \\
0.03 \\
- \\
0.03 \\
0.03 \\
0.03 \\
0.03 \\
0.03 \\
0.03 \\
0.03 \\
0.03 \\
0.03\end{array}$ & $\begin{array}{l}- \\
- \\
- \\
- \\
- \\
- \\
- \\
- \\
- \\
- \\
- \\
- \\
- \\
-\end{array}$ \\
\hline IRON (TOTAL) & $\begin{array}{l}0503 \\
0504 \\
0506 \\
0507 \\
0508 \\
0509 \\
0510 \\
0512\end{array}$ & \begin{tabular}{|l|}
$02 / 18 / 94$ \\
$02 / 19 / 94$ \\
$02 / 20 / 94$ \\
$02 / 20 / 94$ \\
$02 / 21 / 94$ \\
$02 / 21 / 94$ \\
$02 / 20 / 94$ \\
$02 / 20 / 94$
\end{tabular} \mid & $\begin{array}{l}\text { N001 } \\
\text { N001 } \\
\text { N001 } \\
\text { N001 } \\
\text { N001 } \\
\text { N001 } \\
\text { N001 } \\
\text { N001 }\end{array}$ & $\begin{array}{l}A L \\
A L \\
A L \\
A L \\
A L \\
A L \\
A L \\
A L\end{array}$ & $\begin{array}{l}0 \\
D \\
D \\
D \\
0 \\
0 \\
0 \\
0\end{array}$ & $M G / L$ & & $\begin{array}{l}2.29 \\
8.19 \\
3.66 \\
2.56 \\
0.06 \\
0.11 \\
0.07 \\
0.12\end{array}$ & & $\begin{array}{l}0.03 \\
0.03 \\
0.03 \\
0.03 \\
0.03 \\
0.03 \\
0.03 \\
0.03\end{array}$ & $\begin{array}{l}- \\
- \\
- \\
- \\
- \\
-\end{array}$ \\
\hline LEAD & $\begin{array}{l}0503 \\
0503 \\
0503 \\
0503 \\
0503 \\
0503 \\
0503 \\
0503 \\
0504 \\
0504 \\
0504 \\
0504\end{array}$ & $\begin{array}{l}09 / 07 / 82 \\
06 / 30 / 86 \\
10 / 14 / 87 \\
05 / 16 / 90 \\
03 / 29 / 91 \\
08 / 08 / 91 \\
12 / 09 / 91 \\
10 / 09 / 92 \\
09 / 07 / 82 \\
10 / 14 / 87 \\
05 / 16 / 90 \\
04 / 03 / 91\end{array}$ & $\begin{array}{l}0001 \\
0001 \\
0001 \\
0001 \\
0001 \\
0001 \\
0001 \\
0001 \\
0001 \\
0001 \\
0001 \\
0001\end{array}$ & $\begin{array}{l}A L \\
A L \\
A L \\
A L \\
A L \\
A L \\
A L \\
A L \\
A L \\
A L \\
A L \\
A L\end{array}$ & $\begin{array}{l}\text { O } \\
0 \\
0 \\
0 \\
0 \\
0 \\
0 \\
0 \\
D \\
D \\
D \\
D\end{array}$ & $M G / L$ & $\begin{array}{l}< \\
< \\
< \\
< \\
< \\
< \\
< \\
< \\
< \\
< \\
< \\
< \\
<\end{array}$ & $\begin{array}{l}0.01 \\
0.01 \\
0.01 \\
0.01 \\
0.005 \\
0.005 \\
0.005 \\
0.003 \\
0.01 \\
0.01 \\
0.01 \\
0.005\end{array}$ & $\downarrow$ & $\begin{array}{l}0.01 \\
0.01 \\
0.01 \\
0.01 \\
0.005 \\
0.005 \\
0.005 \\
0.003 \\
0.01 \\
0.01 \\
0.01 \\
0.005\end{array}$ & $\begin{array}{l}- \\
- \\
- \\
- \\
- \\
- \\
- \\
-\end{array}$ \\
\hline
\end{tabular}

FORMATION OF COMPLETION CODE: AL - ALLUVIUM

PARAMETER VALUE INDICATOR (PVI): < - LESS THAN DETECTION LIMIT

OTHER PARAMETER VALUE FLAGS:

$J$ - ESTIMATED VALUE
FLOW RELATIONSHIP CODE:

O - ON-SITE

D - DOWN GRADIENT

SAMPLE ID CODES:

0001 - FILTERED SAMPLE (.45 MICRONS)

NOO1 - UNFILTERED SAMPLE 


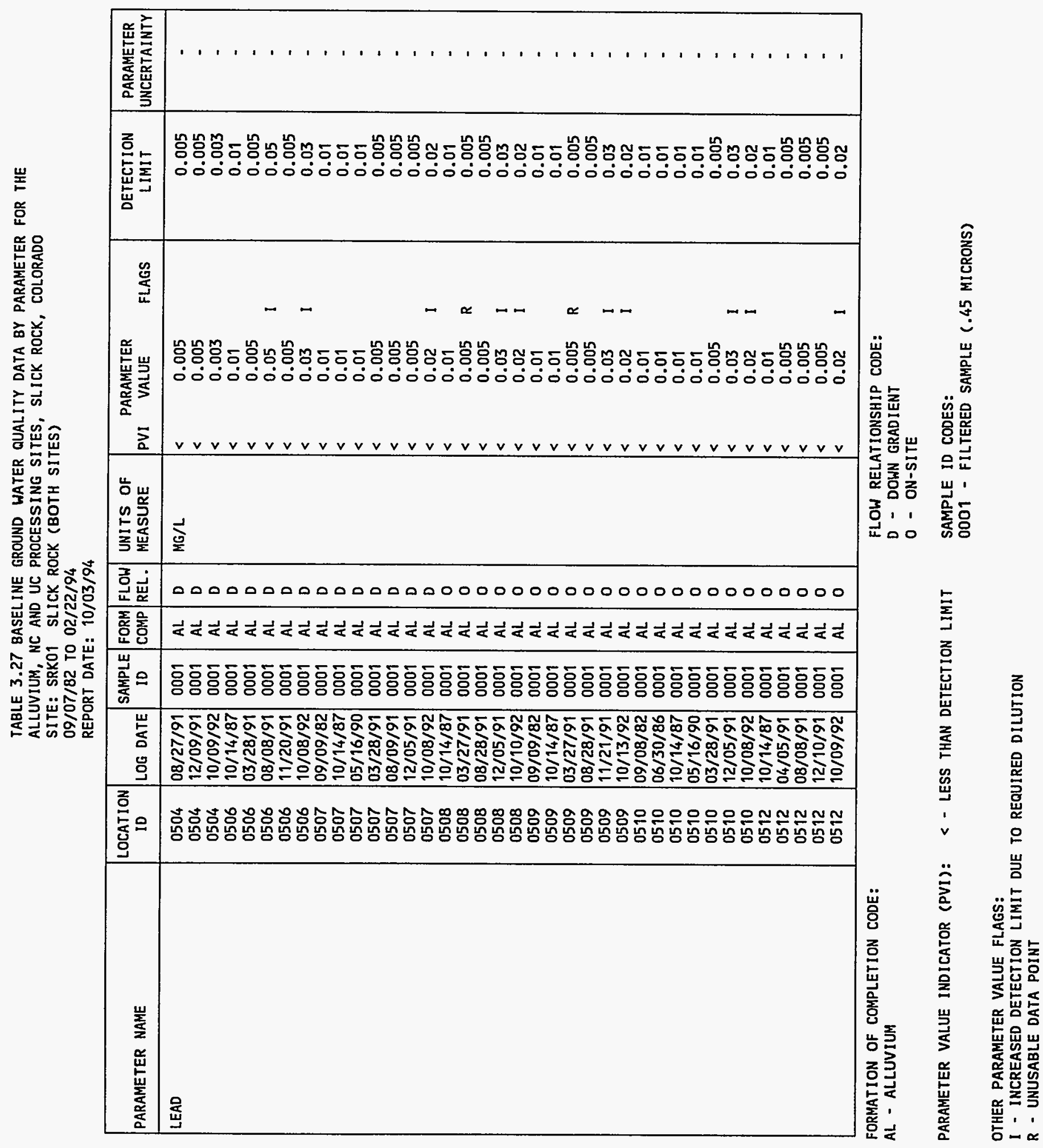


TABLE 3.27 BASELINE GROUND HATER QUALITY DATA BY PARAMETER FOR THE ALLUVIUM, NC AND UC PROCESSING SITES, SLICK ROCK, COLORADO

SITE: SRK01 SLICK ROCK (BOTH SITES)

$09 / 07 / 82$ TO 02/22/94

REPORT DATE: 10/03/94

\begin{tabular}{|c|c|c|c|c|c|c|c|c|c|c|c|}
\hline PARAMETER NAME & $\underset{\text { ID }}{\text { LOCATION }}$ & LOG DATE & $\begin{array}{c}\text { SAMPLE } \\
\text { ID }\end{array}$ & $\mid \begin{array}{l}\text { FORM } \\
\text { COMP }\end{array}$ & $\begin{array}{l}\text { FLOW } \\
\text { REL. }\end{array}$ & $\begin{array}{l}\text { UNITS OF } \\
\text { MEASURE }\end{array}$ & PVI & $\begin{array}{l}\text { PARAMETER } \\
\text { VALUE }\end{array}$ & FLAGS & $\begin{array}{l}\text { DETECTION } \\
\text { LIMIT }\end{array}$ & $\begin{array}{l}\text { PARAMETER } \\
\text { UNCERTAINTY }\end{array}$ \\
\hline LEAD-210 & $\begin{array}{l}0503 \\
0503 \\
0503 \\
0503 \\
0504 \\
0504 \\
0504 \\
0506 \\
0506 \\
0506 \\
0507 \\
0507 \\
0507 \\
0508 \\
0508 \\
0508 \\
0509 \\
0509 \\
0509 \\
0510 \\
0510 \\
0510 \\
0510 \\
0512 \\
0512 \\
0512\end{array}$ & $\begin{array}{l}06 / 30 / 86 \\
08 / 08 / 91 \\
12 / 05 / 91 \\
02 / 18 / 94 \\
08 / 27 / 91 \\
12 / 05 / 91 \\
02 / 19 / 94 \\
08 / 08 / 91 \\
12 / 05 / 91 \\
02 / 20 / 94 \\
08 / 09 / 91 \\
12 / 05 / 91 \\
02 / 20 / 94 \\
08 / 28 / 91 \\
12 / 05 / 91 \\
02 / 21 / 94 \\
08 / 28 / 91 \\
12 / 05 / 91 \\
02 / 21 / 94 \\
06 / 30 / 86 \\
08 / 28 / 91 \\
12 / 05 / 91 \\
02 / 20 / 94 \\
08 / 08 / 91 \\
12 / 05 / 91 \\
02 / 20 / 94\end{array}$ & $\begin{array}{l}0001 \\
0001 \\
0001 \\
0001 \\
0001 \\
0001 \\
0001 \\
0001 \\
0001 \\
0001 \\
0001 \\
0001 \\
0001 \\
0001 \\
0001 \\
0001 \\
0001 \\
0001 \\
0001 \\
0001 \\
0001 \\
0001 \\
0001 \\
0001 \\
0001 \\
0001\end{array}$ & $\begin{array}{l}A L \\
A L \\
A L \\
A L \\
A L \\
A L \\
A L \\
A L \\
A L \\
A L \\
A L \\
A L \\
A L \\
A L \\
A L \\
A L \\
A L \\
A L \\
A L \\
A L \\
A L \\
A L \\
A L \\
A L \\
A L \\
A L\end{array}$ & $\begin{array}{l}0 \\
0 \\
0 \\
0 \\
D \\
D \\
D \\
D \\
D \\
D \\
D \\
0 \\
D \\
0 \\
0 \\
0 \\
0 \\
0 \\
0 \\
0 \\
0 \\
0 \\
0 \\
0 \\
0 \\
0\end{array}$ & $\mathrm{PCI} / \mathrm{L}$ & & $\begin{array}{r}33 . \\
157 . \\
216 . \\
0.2 \\
40.5 \\
65.5 \\
1.6 \\
3.5 \\
2.9 \\
0.0 \\
2.3 \\
2.8 \\
0.0 \\
2.7 \\
5.5 \\
0.0 \\
0.7 \\
1.4 \\
0.0 \\
1.9 \\
5.0 \\
6.5 \\
0.4 \\
105 . \\
119 . \\
6.1\end{array}$ & $\mathbf{J}$ & $\begin{array}{l}1.5 \\
1.5 \\
1.5 \\
1.4 \\
1.5 \\
1.5 \\
1.5 \\
1.5 \\
1.5 \\
1.7 \\
1.5 \\
1.5 \\
1.8 \\
1.5 \\
1.5 \\
2.2 \\
1.5 \\
1.5 \\
1.6 \\
1.5 \\
1.5 \\
1.5 \\
1.4 \\
1.5 \\
1.5 \\
1.6\end{array}$ & $\begin{array}{l}2 . \\
3.6 \\
6.0 \\
0.7 \\
2.1 \\
3.5 \\
0.8 \\
1.0 \\
1.0 \\
0.8 \\
0.9 \\
1.0 \\
0.8 \\
1.1 \\
1.1 \\
1.4 \\
1.0 \\
0.9 \\
0.8 \\
1.1 \\
1.2 \\
1.1 \\
0.7 \\
3.0 \\
4.5 \\
1.2\end{array}$ \\
\hline LEAD-210 (TOTAL) & $\begin{array}{l}0503 \\
0504 \\
0506 \\
0507 \\
0508 \\
0509 \\
0510 \\
0512\end{array}$ & $\begin{array}{l}02 / 18 / 94 \\
02 / 19 / 94 \\
02 / 20 / 94 \\
02 / 20 / 94 \\
02 / 21 / 94 \\
02 / 21 / 94 \\
02 / 20 / 94 \\
02 / 20 / 94\end{array}$ & $\begin{array}{l}\text { N001 } \\
\text { N001 } \\
\text { N001 } \\
\text { N001 } \\
\text { N001 } \\
\text { N001 } \\
\text { N001 } \\
\text { N001 }\end{array}$ & $\begin{array}{l}A L \\
A L \\
A L \\
A L \\
A L \\
A L \\
A L \\
A L\end{array}$ & $\begin{array}{l}0 \\
D \\
D \\
D \\
0 \\
0 \\
0 \\
0\end{array}$ & PCI/L & & $\begin{array}{l}1.0 \\
0.0 \\
0.0 \\
1.4 \\
1.0 \\
1.0 \\
1.4 \\
0.3\end{array}$ & & $\begin{array}{l}1.5 \\
1.9 \\
1.9 \\
1.6 \\
1.4 \\
1.6 \\
1.9 \\
1.8\end{array}$ & $\begin{array}{l}0.9 \\
1.0 \\
1.0 \\
0.9 \\
0.8 \\
0.9 \\
1.0 \\
0.9\end{array}$ \\
\hline MAGNESIUM & $\begin{array}{l}0503 \\
0503\end{array}$ & $\begin{array}{l}09 / 07 / 82 \\
02 / 18 / 86\end{array}$ & $\begin{array}{l}0001 \\
0001\end{array}$ & $\begin{array}{l}A L \\
A L\end{array}$ & $\begin{array}{l}0 \\
0\end{array}$ & $M G / L$ & & $\begin{array}{l}120.00 \\
126 .\end{array}$ & L & 0.001 & - \\
\hline
\end{tabular}

FORMATION OF COMPLETION CODE:

AL - ALLUVIUM

FLOW RELATIONSHIP CODE

O - ON-SITE

D - DOWN GRADIENT

PARAMETER VALUE INDICATOR (PVI): < - LESS THAN DETECTION LIMIT

LLE ID CODES:

0001 - FILTERED SAMPLE (.45 MICRONS)

RARAMETER VALUE FLA

N001 - UNFILTERED SAMPLE

* DUPLICATE ANALYSIS NOT WITHIN CONTROL LIMITS

J - ESTIMATED VALUE

L - LESS THAN THREE BORE VOLUMES REMOVED BEFORE SAMPLING 
TABLE 3.27 BASELINE GROUND WATER QUALITY DATA BY PARAMETER FOR THE ALLUVIUM, NC AND UC PROCESSING SITES, SLICK ROCK, COLORADO

SITE: SRKO1 SLICK ROCK (BOTH SITES)

REPORT DATE: $10 / 03 / 94$

\begin{tabular}{|c|c|c|c|c|c|c|c|c|c|c|c|}
\hline PARAMETER NAME & $\begin{array}{c}\text { LOCAT ION } \\
\text { ID }\end{array}$ & LOG DATE & $\begin{array}{c}\text { SAMPLE } \\
\text { ID }\end{array}$ & $\begin{array}{l}\text { FORM } \\
\text { COMP }\end{array}$ & $\begin{array}{l}\text { FLOW } \\
\text { REL. }\end{array}$ & $\begin{array}{l}\text { UNITS OF } \\
\text { MEASURE }\end{array}$ & PVI & $\begin{array}{l}\text { PARAMETER } \\
\text { VALUE }\end{array}$ & FLAGS & $\begin{array}{l}\text { DETECTION } \\
\text { LIMIT }\end{array}$ & $\begin{array}{l}\text { PARAMETER } \\
\text { UNCERTAINTY }\end{array}$ \\
\hline MAGNESIUM & $\begin{array}{l}0503 \\
0503 \\
0503 \\
0503 \\
0503 \\
0503 \\
0503 \\
0503 \\
0503 \\
0504 \\
0504 \\
0504 \\
0504 \\
0504 \\
0504 \\
0504 \\
0504 \\
0504 \\
0504 \\
0504 \\
0506 \\
0506 \\
0506 \\
0506 \\
0506 \\
0506 \\
0506 \\
0506 \\
0506 \\
0506 \\
0507 \\
0507 \\
0507 \\
0507 \\
0507 \\
0507 \\
0507 \\
0507 \\
0507\end{array}$ & $\begin{array}{l}06 / 30 / 86 \\
10 / 14 / 87 \\
02 / 22 / 88 \\
05 / 16 / 90 \\
03 / 29 / 91 \\
08 / 08 / 91 \\
12 / 09 / 91 \\
10 / 09 / 92 \\
02 / 18 / 94 \\
09 / 07 / 82 \\
02 / 04 / 86 \\
07 / 01 / 86 \\
10 / 14 / 87 \\
02 / 22 / 88 \\
05 / 16 / 90 \\
04 / 03 / 91 \\
08 / 27 / 91 \\
12 / 09 / 91 \\
10 / 09 / 92 \\
02 / 19 / 94 \\
09 / 08 / 82 \\
02 / 05 / 86 \\
07 / 01 / 86 \\
10 / 14 / 87 \\
02 / 22 / 88 \\
03 / 28 / 91 \\
08 / 08 / 91 \\
11 / 20 / 91 \\
10 / 08 / 92 \\
02 / 20 / 94 \\
09 / 09 / 82 \\
02 / 05 / 86 \\
06 / 30 / 86 \\
10 / 14 / 87 \\
02 / 22 / 88 \\
05 / 16 / 90 \\
03 / 28 / 91 \\
08 / 09 / 91 \\
12 / 05 / 91\end{array}$ & $\begin{array}{l}0001 \\
0001 \\
0001 \\
0001 \\
0001 \\
0001 \\
0001 \\
0001 \\
0001 \\
0001 \\
0001 \\
0001 \\
0001 \\
0001 \\
0001 \\
0001 \\
0001 \\
0001 \\
0001 \\
0001 \\
0001 \\
0001 \\
0001 \\
0001 \\
0001 \\
0001 \\
0001 \\
0001 \\
0001 \\
0001 \\
0001 \\
0001 \\
0001 \\
0001 \\
0001 \\
0001 \\
0001 \\
0001 \\
0001\end{array}$ & $\begin{array}{l}A L \\
A L \\
A L \\
A L \\
A L \\
A L \\
A L \\
A L \\
A L \\
A L \\
A L \\
A L \\
A L \\
A L \\
A L \\
A L \\
A L \\
A L \\
A L \\
A L \\
A L \\
A L \\
A L \\
A L \\
A L \\
A L \\
A L \\
A L \\
A L \\
A L \\
A L \\
A L \\
A L \\
A L \\
A L \\
A L \\
A L \\
A L \\
A L\end{array}$ & $\begin{array}{l}\text { O } \\
0 \\
D \\
D \\
D \\
D \\
D \\
D \\
D \\
D \\
D \\
D \\
D \\
D \\
D \\
D \\
D \\
D \\
D \\
D \\
D \\
D \\
D \\
D \\
D \\
D \\
D \\
D \\
D \\
D \\
D \\
D \\
D \\
D \\
D \\
D \\
D \\
D \\
D\end{array}$ & MG/L & & $\begin{array}{c}127 . \\
114 . \\
110 . \\
99.6 \\
97.3 \\
99.3 \\
87.8 \\
84.8 \\
70.9 \\
160.00 \\
218 . \\
161 . \\
199 . \\
200 . \\
98.4 \\
86.9 \\
89.7 \\
71.2 \\
63.0 \\
191 \\
250.00 \\
363 . \\
339 . \\
360 . \\
368 . \\
625 . \\
535 . \\
327 . \\
434 . \\
579 \\
140.00 \\
84.5 \\
81.4 \\
88 . \\
79.6 \\
68.0 \\
86.4 \\
83.5 \\
74.7\end{array}$ & $J$ & $\begin{array}{l}0.001 \\
0.001 \\
0.001 \\
0.001 \\
0.5 \\
0.5 \\
0.5 \\
0.5 \\
0.1 \\
- \\
0.001 \\
0.001 \\
0.001 \\
0.001 \\
0.001 \\
0.5 \\
0.5 \\
0.5 \\
0.5 \\
0.1 \\
- \\
0.001 \\
0.001 \\
0.001 \\
0.001 \\
0.5 \\
2 . \\
0.5 \\
0.5 \\
0.1 \\
- \\
0.001 \\
0.001 \\
0.001 \\
0.001 \\
0.001 \\
0.5 \\
0.5 \\
0.5\end{array}$ & $\begin{array}{l}- \\
- \\
- \\
- \\
- \\
- \\
- \\
- \\
- \\
- \\
- \\
- \\
- \\
- \\
- \\
- \\
- \\
- \\
- \\
- \\
- \\
- \\
- \\
- \\
- \\
- \\
- \\
- \\
- \\
- \\
- \\
- \\
- \\
- \\
- \\
- \\
- \\
-\end{array}$ \\
\hline
\end{tabular}

\section{FORMATION OF COMPLETION CODE:}

AL - ALLUVIUM

PARAMETER VALUE INDICATOR (PVI): < - LESS THAN DETECTION LIMIT
FLOW RELATIONSHIP CODE:

O - ON-SITE

D - DOWN GRADIENT

SAMPLE ID CODES:

0001 - FILTERED SAMPLE (.45 MICRONS)

OTHER PARAMETER VALUE FLAGS:

$J$ - ESTIMATED VALUE 
TABLE 3.27 BASELINE GROUND WATER QUALITY DATA BY PARAMETER FOR THE ALLUVIUM, NC AND UC PROCESSING SITES, SLICK ROCK, COLORADD

SITE: SRKO1 SLICK ROCK (BOTH SITES)

09/07/82 TO 02/22/94

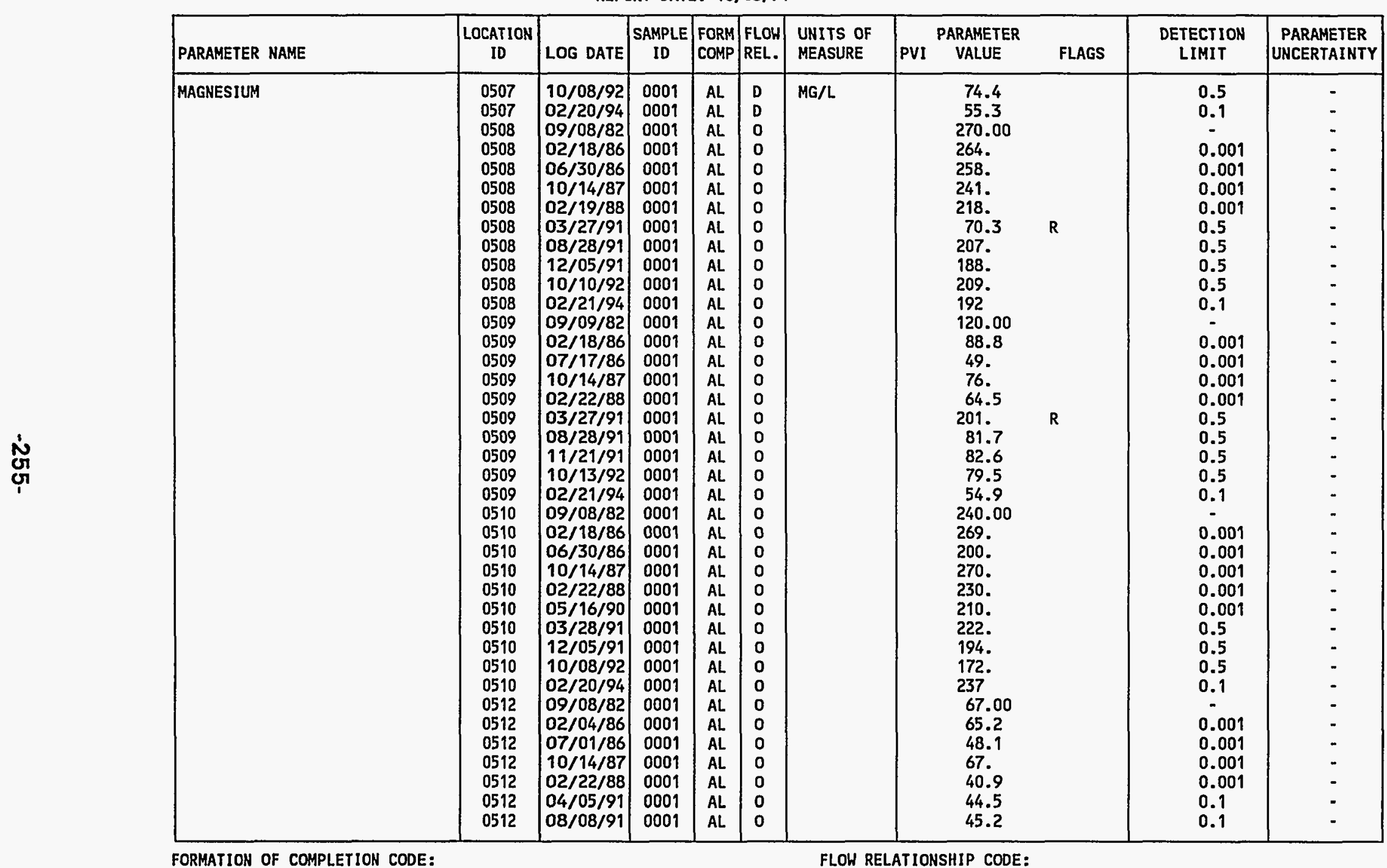

FORMATION OF COMPLETION CODE:

FLOW RELATIONSHIP CODE:

AL - ALLUVIUM

D - DOWN GRADIENT

O - ON-SITE

PARAMETER VALUE INDICATOR (PVI): < - LESS THAN DETECTION LIMIT SAMPLE ID CODES:

0001 - FILTERED SAMPLE (.45 MICRONS)

OTHER PARAMETER VALUE FLAGS:

$R$ - UNUSABLE DATA POINT 
TABLE 3.27 BASELINE GROUND WATER QUALITY DATA BY PARAMETER FOR THE ALLUVIUM, NC AND UC PROCESSING SITES, SLICK ROCK, COLORADO

SITE: SRKO1 SLICK ROCK (BOTH SITES)

$09 / 07 / 82$ TO $02 / 22 / 94$

REPORT DATE: $10 / 03 / 94$

\begin{tabular}{|c|c|c|c|c|c|c|c|c|c|c|c|}
\hline PARAMETER NAME & $\underset{\text { LOCATION }}{\text { LOC }}$ & LOG DATE & $\begin{array}{c}\text { SAMPLE } \\
\text { ID }\end{array}$ & $\begin{array}{l}\text { FORM } \\
\text { COMP }\end{array}$ & $\begin{array}{l}\text { FLOW } \\
\text { REL. }\end{array}$ & $\begin{array}{l}\text { UNITS OF } \\
\text { MEASURE }\end{array}$ & PVI & $\begin{array}{l}\text { PARAMETER } \\
\text { VALUE }\end{array}$ & FLAGS & $\begin{array}{l}\text { DETECTION } \\
\text { LIMIT }\end{array}$ & $\begin{array}{l}\text { PARAMETER } \\
\text { UNCERTAINTY }\end{array}$ \\
\hline MAGNESIUM & $\begin{array}{l}0512 \\
0512 \\
0512\end{array}$ & $\begin{array}{l}12 / 10 / 91 \\
10 / 09 / 92 \\
02 / 20 / 94\end{array}$ & $\begin{array}{l}0001 \\
0001 \\
0001\end{array}$ & $\begin{array}{l}A L \\
A L \\
A L\end{array}$ & $\begin{array}{l}0 \\
0 \\
0\end{array}$ & $M G / L$ & & $\begin{array}{l}36.8 \\
60.0 \\
45.8\end{array}$ & & $\begin{array}{l}0.1 \\
0.5 \\
0.1\end{array}$ & - \\
\hline MAGNESIUM (TOTAL) & $\begin{array}{l}0503 \\
0504 \\
0506 \\
0507 \\
0508 \\
0509 \\
0510 \\
0512\end{array}$ & $\begin{array}{l}02 / 18 / 94 \\
02 / 19 / 94 \\
02 / 20 / 94 \\
02 / 20 / 94 \\
02 / 21 / 94 \\
02 / 21 / 94 \\
02 / 20 / 94 \\
02 / 20 / 94\end{array}$ & $\begin{array}{l}\text { N001 } \\
\text { N001 } \\
\text { N001 } \\
\text { NO01 } \\
\text { N001 } \\
\text { N001 } \\
\text { N001 } \\
\text { N001 }\end{array}$ & $\begin{array}{l}A L \\
A L \\
A L \\
A L \\
A L \\
A L \\
A L \\
A L\end{array}$ & $\begin{array}{l}0 \\
D \\
D \\
D \\
0 \\
0 \\
0 \\
0\end{array}$ & $M G / L$ & & $\begin{array}{c}70.9 \\
185 \\
542 \\
52.9 \\
204 \\
57.0 \\
236 \\
43.9\end{array}$ & & $\begin{array}{l}0.1 \\
0.1 \\
0.1 \\
0.1 \\
0.1 \\
0.1 \\
0.1 \\
0.1\end{array}$ & $\begin{array}{l}. \\
: \\
- \\
- \\
-\end{array}$ \\
\hline MANGANESE & $\begin{array}{l}0503 \\
0503 \\
0503 \\
0503 \\
0503 \\
0503 \\
0503 \\
0503 \\
0503 \\
0503 \\
0504 \\
0504 \\
0504 \\
0504 \\
0504 \\
0504 \\
0504 \\
0504 \\
0504 \\
0504 \\
0506 \\
0506 \\
0506 \\
0506 \\
0506\end{array}$ & $\begin{array}{l}02 / 18 / 86 \\
06 / 30 / 86 \\
10 / 14 / 87 \\
02 / 22 / 88 \\
05 / 16 / 90 \\
03 / 29 / 91 \\
08 / 08 / 91 \\
12 / 09 / 91 \\
10 / 09 / 92 \\
02 / 18 / 94 \\
02 / 04 / 86 \\
07 / 01 / 86 \\
10 / 14 / 87 \\
02 / 22 / 88 \\
05 / 16 / 90 \\
04 / 03 / 91 \\
08 / 27 / 91 \\
12 / 09 / 91 \\
10 / 09 / 92 \\
02 / 19 / 94 \\
02 / 05 / 86 \\
07 / 01 / 86 \\
10 / 14 / 87 \\
02 / 22 / 88 \\
03 / 28 / 91\end{array}$ & $\begin{array}{l}0001 \\
0001 \\
0001 \\
0001 \\
0001 \\
0001 \\
0001 \\
0001 \\
0001 \\
0001 \\
0001 \\
0001 \\
0001 \\
0001 \\
0001 \\
0001 \\
0001 \\
0001 \\
0001 \\
0001 \\
0001 \\
0001 \\
0001 \\
0001 \\
0001\end{array}$ & $\begin{array}{l}A L \\
A L \\
A L \\
A L \\
A L \\
A L \\
A L \\
A L \\
A L \\
A L \\
A L \\
A L \\
A L \\
A L \\
A L \\
A L \\
A L \\
A L \\
A L \\
A L \\
A L \\
A L \\
A L \\
A L \\
A L\end{array}$ & $\begin{array}{l}0 \\
0 \\
0 \\
0 \\
0 \\
0 \\
0 \\
0 \\
0 \\
0 \\
D \\
D \\
D \\
D \\
D \\
D \\
D \\
D \\
D \\
D \\
D \\
D \\
D \\
D \\
D\end{array}$ & $M G / L$ & & $\begin{array}{l}0.75 \\
0.68 \\
0.55 \\
0.62 \\
0.47 \\
0.37 \\
0.46 \\
0.40 \\
0.38 \\
0.29 \\
0.8 \\
0.83 \\
0.67 \\
0.86 \\
0.54 \\
0.54 \\
0.55 \\
0.45 \\
0.39 \\
0.90 \\
4.73 \\
6.12 \\
4.66 \\
4.97 \\
5.37\end{array}$ & J & $\begin{array}{l}0.01 \\
0.01 \\
0.01 \\
0.01 \\
0.01 \\
0.01 \\
0.01 \\
0.01 \\
0.01 \\
0.01 \\
0.01 \\
0.01 \\
0.01 \\
0.01 \\
0.01 \\
0.01 \\
0.01 \\
0.01 \\
0.01 \\
0.01 \\
0.01 \\
0.01 \\
0.01 \\
0.01 \\
0.01\end{array}$ & $\begin{array}{l}- \\
- \\
: \\
- \\
- \\
- \\
- \\
- \\
- \\
- \\
- \\
- \\
- \\
- \\
- \\
- \\
- \\
- \\
- \\
-\end{array}$ \\
\hline
\end{tabular}

FORMATION OF COMPLETION CODE:

AL - ALLUVIUM

PARAMETER VALUE INDICATOR (PVI): < - LESS THAN DETECTION LIMIT OTHER PARAMETER VALUE FLAGS:

$J$ - ESTIMATED VALUE

L - LESS THAN THREE BORE VOLUMES REMOVED BEFORE SAMPLING
FLOW RELATIONSHIP CODE:

O - ON-SITE

D - DOWN GRADIENT

SAMPLE ID CODES:

0001 - FILTERED SAMPLE (.45 MICRONS)

NO01 - UNFILTERED SAMPLE 
TABLE 3.27 BASELINE GROUND HATER QUALITY DATA BY PARAMETER FOR THE ALLUVIUM, NC AND UC PROCESSING SITES, SLICK ROCK, COLORADO

SITE: SRKOI SLICK ROCK (BOTH SITES)

09/07/82 TO 02/22/94

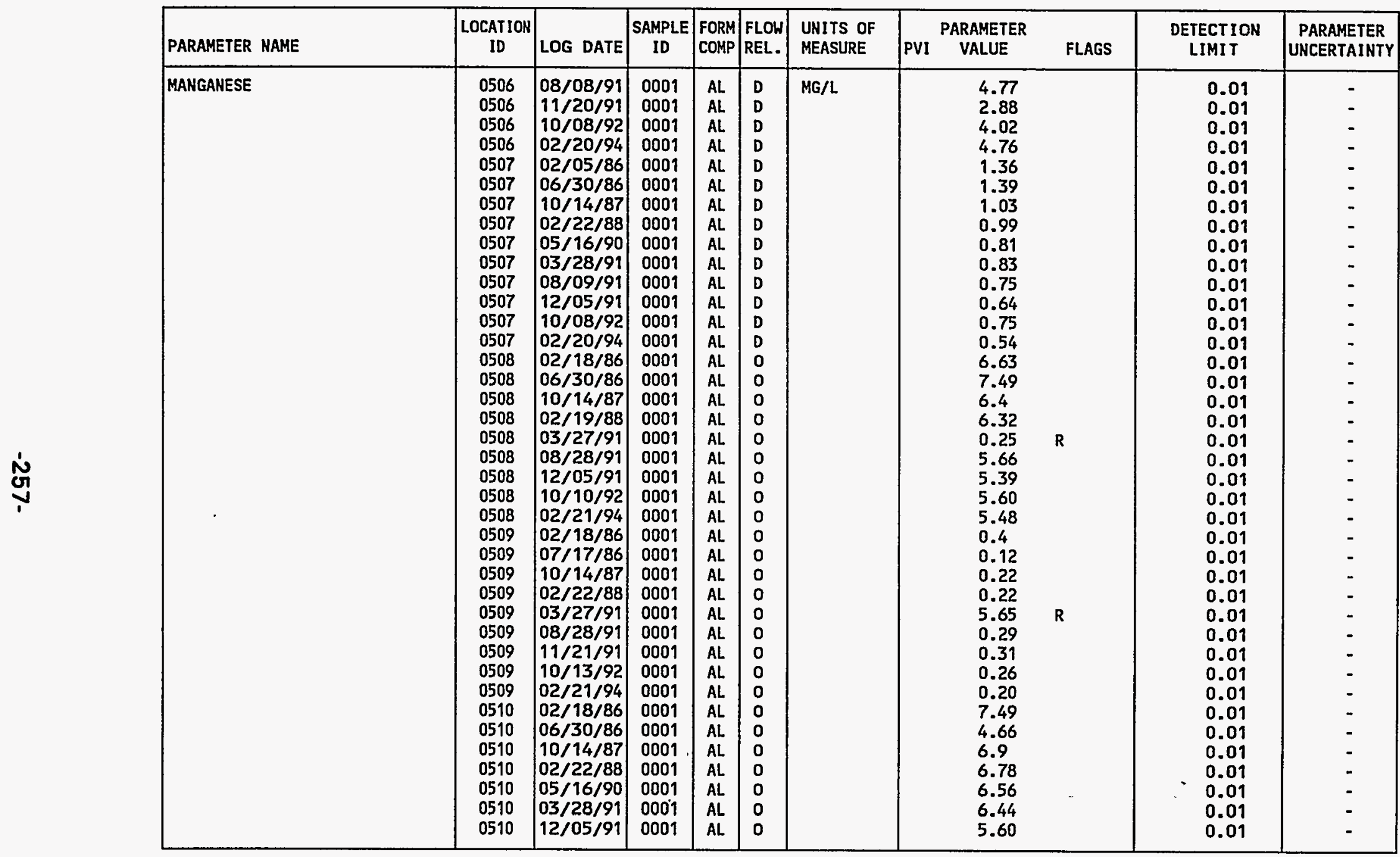

FORMATION OF COMPLETION CODE:

AL - ALLUVIUM

PARAMETER VALUE INDICATOR (PVI): < - LESS THAN DETECTION LIMIT
FLOW RELATIONSHIP CODE:

D - DOWN GRADIENT

O - ON-SITE

0001 - FILTERED SAMPLE (.45 MICRONS)

OTHER PARAMETER VALUE FLAGS

$R$ - UNUSABLE DATA POINT 
TABLE 3.27 BASELINE GROUND WATER QUALITY DATA BY PARAMETER FOR THE ALLUVIUM, NC AND UC PROCESSING SITES, SLICK ROCK, COLORADO

SITE: SRK01 SLICK ROCK (BOTH SITES)

09/07/82 TO 02/22/94

REPORT DATE: $10 / 03 / 94$

\begin{tabular}{|c|c|c|c|c|c|c|c|c|c|c|c|}
\hline PARAMETER NAME & $\underset{\text { LOCATION }}{\text { ID }}$ & LOG DATE & $\begin{array}{c}\text { SAMPLE } \\
\text { ID }\end{array}$ & $\begin{array}{l}\text { FORM } \\
\text { COMP }\end{array}$ & $\begin{array}{l}\text { FLOW } \\
\text { REL. }\end{array}$ & $\begin{array}{l}\text { UNITS OF } \\
\text { MEASURE }\end{array}$ & PVI & $\begin{array}{l}\text { ARAMETER } \\
\text { VALUE }\end{array}$ & FLAGS & $\begin{array}{l}\text { DETECTION } \\
\text { LIMIT }\end{array}$ & $\begin{array}{l}\text { PARAMETER } \\
\text { UNCERTAINTY }\end{array}$ \\
\hline MANGANESE & $\begin{array}{l}0510 \\
0510 \\
0512 \\
0512 \\
0512 \\
0512 \\
0512 \\
0512 \\
0512 \\
0512 \\
0512\end{array}$ & $\begin{array}{l}10 / 08 / 92 \\
02 / 20 / 94 \\
02 / 04 / 86 \\
07 / 01 / 86 \\
10 / 14 / 87 \\
02 / 22 / 88 \\
04 / 05 / 91 \\
08 / 08 / 91 \\
12 / 10 / 91 \\
10 / 09 / 92 \\
02 / 20 / 94\end{array}$ & $\begin{array}{l}0001 \\
0001 \\
0001 \\
0001 \\
0001 \\
0001 \\
0001 \\
0001 \\
0001 \\
0001 \\
0001\end{array}$ & $\begin{array}{l}A L \\
A L \\
A L \\
A L \\
A L \\
A L \\
A L \\
A L \\
A L \\
A L \\
A L\end{array}$ & $\begin{array}{l}0 \\
0 \\
0 \\
0 \\
0 \\
0 \\
0 \\
0 \\
0 \\
0 \\
0\end{array}$ & $M G / L$ & & $\begin{array}{l}5.68 \\
6.64 \\
0.25 \\
0.09 \\
0.32 \\
0.13 \\
0.25 \\
0.40 \\
0.38 \\
0.44 \\
0.48\end{array}$ & & $\begin{array}{l}0.01 \\
0.01 \\
0.01 \\
0.01 \\
0.01 \\
0.01 \\
0.01 \\
0.01 \\
0.01 \\
0.01 \\
0.01\end{array}$ & $\begin{array}{l}- \\
- \\
- \\
- \\
- \\
- \\
- \\
- \\
-\end{array}$ \\
\hline MANGANESE (TOTAL) & $\begin{array}{l}0503 \\
0504 \\
0506 \\
0507 \\
0508 \\
0509 \\
0510 \\
0512\end{array}$ & $\begin{array}{l}02 / 18 / 94 \\
02 / 19 / 94 \\
02 / 20 / 94 \\
02 / 20 / 94 \\
02 / 21 / 94 \\
02 / 21 / 94 \\
02 / 20 / 94 \\
02 / 20 / 94\end{array}$ & $\begin{array}{l}\text { N001 } \\
\text { N001 } \\
\text { N001 } \\
\text { N001 } \\
\text { N001 } \\
\text { N001 } \\
\text { N001 } \\
\text { N001 }\end{array}$ & $\begin{array}{l}A L \\
A L \\
A L \\
A L \\
A L \\
A L \\
A L \\
A L\end{array}$ & $\begin{array}{l}0 \\
D \\
D \\
D \\
0 \\
0 \\
0 \\
0\end{array}$ & $M G / L$ & & $\begin{array}{l}0.33 \\
0.87 \\
4.54 \\
0.51 \\
6.11 \\
0.21 \\
6.73 \\
0.43\end{array}$ & & $\begin{array}{l}0.01 \\
0.01 \\
0.01 \\
0.01 \\
0.01 \\
0.01 \\
0.01 \\
0.01\end{array}$ & $\begin{array}{l}- \\
- \\
- \\
- \\
-\end{array}$ \\
\hline MERCURY & $\begin{array}{l}0503 \\
0503 \\
0503 \\
0503 \\
0503 \\
0503 \\
0503 \\
0504 \\
0504 \\
0504 \\
0504 \\
0504 \\
0504 \\
0506 \\
0506 \\
0506 \\
0506 \\
0507\end{array}$ & $\begin{array}{l}09 / 07 / 82 \\
06 / 30 / 86 \\
10 / 14 / 87 \\
05 / 16 / 90 \\
03 / 29 / 91 \\
08 / 08 / 91 \\
12 / 09 / 91 \\
09 / 07 / 82 \\
10 / 14 / 87 \\
05 / 16 / 90 \\
04 / 03 / 91 \\
08 / 27 / 91 \\
12 / 09 / 91 \\
10 / 14 / 87 \\
03 / 28 / 91 \\
08 / 08 / 91 \\
11 / 20 / 91 \\
09 / 09 / 82\end{array}$ & $\begin{array}{l}0001 \\
0001 \\
0001 \\
0001 \\
0001 \\
0001 \\
0001 \\
0001 \\
0001 \\
0001 \\
0001 \\
0001 \\
0001 \\
0001 \\
0001 \\
0001 \\
0001 \\
0001\end{array}$ & $\begin{array}{l}A L \\
A L \\
A L \\
A L \\
A L \\
A L \\
A L \\
A L \\
A L \\
A L \\
A L \\
A L \\
A L \\
A L \\
A L \\
A L \\
A L \\
A L\end{array}$ & $\begin{array}{l}0 \\
0 \\
0 \\
0 \\
0 \\
0 \\
0 \\
D \\
D \\
D \\
D \\
D \\
D \\
D \\
D \\
D \\
D \\
D\end{array}$ & MG/L. & $\begin{array}{l}< \\
< \\
< \\
< \\
< \\
< \\
< \\
< \\
< \\
< \\
< \\
< \\
< \\
< \\
< \\
< \\
< \\
< \\
< \\
<\end{array}$ & $\begin{array}{l}0.002 \\
0.0002 \\
0.0002 \\
0.0002 \\
0.0002 \\
0.0002 \\
0.0002 \\
0.002 \\
0.0002 \\
0.0002 \\
0.0002 \\
0.0002 \\
0.0002 \\
0.0002 \\
0.0002 \\
0.0002 \\
0.0002 \\
0.002\end{array}$ & $J$ & $\begin{array}{l}0.002 \\
0.0002 \\
0.0002 \\
0.0002 \\
0.0002 \\
0.0002 \\
0.0002 \\
0.002 \\
0.0002 \\
0.0002 \\
0.0002 \\
0.0002 \\
0.0002 \\
0.0002 \\
0.0002 \\
0.0002 \\
0.0002 \\
0.002\end{array}$ & $\begin{array}{l}- \\
- \\
- \\
- \\
- \\
- \\
- \\
- \\
- \\
- \\
- \\
- \\
- \\
-\end{array}$ \\
\hline
\end{tabular}

FORMATION OF COMPLETION CODE:

AL - ALLUVIUM

PARAMETER VALUE INDICATOR (PVI): < - LESS THAN DETECTION LIMIT OTHER PARAMETER VALUE FLAGS:

$J$ - ESTIMATED VALUE
FLOW RELATIONSHIP CODE:

O - ON-SITE

D - DOWN GRADIENT

SAMPLE ID CODES:

0001 - FILTERED SAMPLE (.45 MICRONS)

N001 - UNFILTERED SAMPLE 


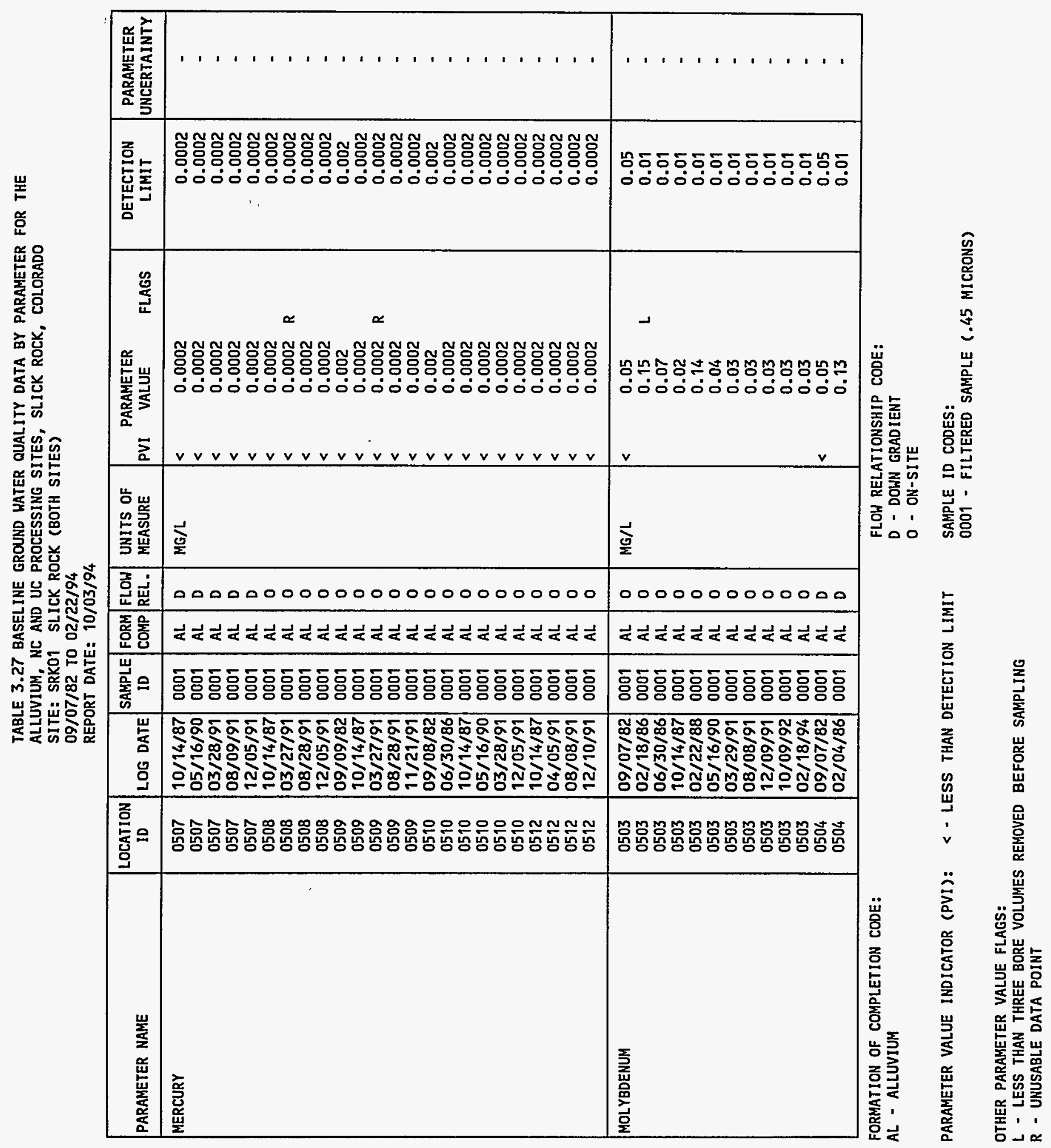




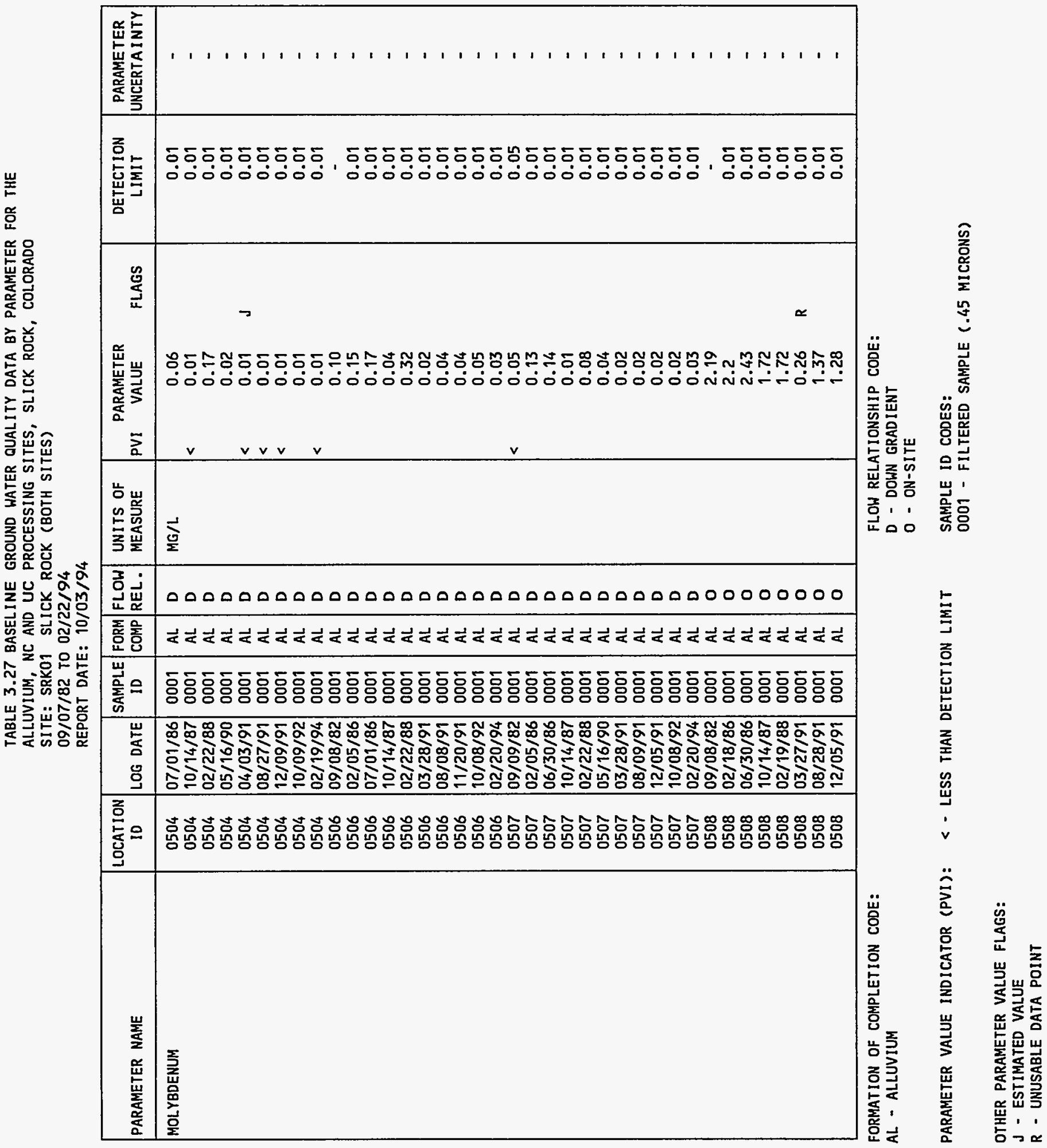


TABLE 3.27 BASELINE GROUND HATER QUALITY DATA BY PARAMETER FOR THE ALLUVIUM, NC AND UC PROCESSING SITES, SLICK ROCK, COLORADD

SITE: SRKO1 SLICK ROCK (BOTH SITES)

09/07/82 TO 02/22/94

REPORT DATE: $10 / 03 / 94$

\begin{tabular}{|c|c|c|c|c|c|c|c|c|c|c|c|c|}
\hline & PARAMETER NAME & $\begin{array}{c}\text { LOCATION } \\
\text { ID }\end{array}$ & LOG DATE & $\underset{\text { ID }}{\text { SAMPLE }}$ & $\mid \begin{array}{l}\text { FORM } \\
\text { COMP }\end{array}$ & $\begin{array}{l}\text { FLOW } \\
\text { REL. }\end{array}$ & $\begin{array}{l}\text { UNITS OF } \\
\text { MEASURE }\end{array}$ & PVI & $\begin{array}{l}\text { PARAMETER } \\
\text { VALUE }\end{array}$ & FLAGS & $\begin{array}{l}\text { DETECTION } \\
\text { LIMIT }\end{array}$ & $\begin{array}{l}\text { PARAMETER } \\
\text { UNCERTAINTY }\end{array}$ \\
\hline Nీ & MOL YBDENUM & $\begin{array}{l}0508 \\
0508 \\
0509 \\
0509 \\
0509 \\
0509 \\
0509 \\
0509 \\
0509 \\
0509 \\
0509 \\
0509 \\
0510 \\
0510 \\
0510 \\
0510 \\
0510 \\
0510 \\
0510 \\
0510 \\
0510 \\
0510 \\
0512 \\
0512 \\
0512 \\
0512 \\
0512 \\
0512 \\
0512 \\
0512 \\
0512 \\
0512\end{array}$ & $\begin{array}{l}10 / 10 / 92 \\
02 / 21 / 94 \\
09 / 09 / 82 \\
02 / 18 / 86 \\
07 / 17 / 86 \\
10 / 14 / 87 \\
02 / 22 / 88 \\
03 / 27 / 91 \\
08 / 28 / 91 \\
11 / 21 / 91 \\
10 / 13 / 92 \\
02 / 21 / 94 \\
09 / 08 / 82 \\
02 / 18 / 86 \\
06 / 30 / 86 \\
10 / 14 / 87 \\
02 / 22 / 88 \\
05 / 16 / 90 \\
03 / 28 / 91 \\
12 / 05 / 91 \\
10 / 08 / 92 \\
02 / 20 / 94 \\
09 / 08 / 82 \\
02 / 04 / 86 \\
07 / 01 / 86 \\
10 / 14 / 87 \\
02 / 22 / 88 \\
04 / 05 / 91 \\
08 / 08 / 91 \\
12 / 10 / 91 \\
10 / 09 / 92 \\
02 / 20 / 94\end{array}$ & $\begin{array}{l}0001 \\
0001 \\
0001 \\
0001 \\
0001 \\
0001 \\
0001 \\
0001 \\
0001 \\
0001 \\
0001 \\
0001 \\
0001 \\
0001 \\
0001 \\
0001 \\
0001 \\
0001 \\
0001 \\
0001 \\
0001 \\
0001 \\
0001 \\
0001 \\
0001 \\
0001 \\
0001 \\
0001 \\
0001 \\
0001 \\
0001 \\
0001\end{array}$ & $\begin{array}{l}A L \\
A L \\
A L \\
A L \\
A L \\
A L \\
A L \\
A L \\
A L \\
A L \\
A L \\
A L \\
A L \\
A L \\
A L \\
A L \\
A L \\
A L \\
A L \\
A L \\
A L \\
A L \\
A L \\
A L \\
A L \\
A L \\
A L \\
A L \\
A L \\
A L \\
A L \\
A L\end{array}$ & $\begin{array}{l}0 \\
0 \\
0 \\
0 \\
0 \\
0 \\
0 \\
0 \\
0 \\
0 \\
0 \\
0 \\
0 \\
0 \\
0 \\
0 \\
0 \\
0 \\
0 \\
0 \\
0 \\
0 \\
0 \\
0 \\
0 \\
0 \\
0 \\
0 \\
0 \\
0 \\
0 \\
0\end{array}$ & MG/L & 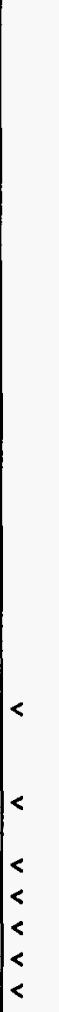 & $\begin{array}{l}1.33 \\
1.10 \\
0.30 \\
0.44 \\
0.38 \\
0.27 \\
0.33 \\
1.28 \\
0.28 \\
0.29 \\
0.26 \\
0.28 \\
0.85 \\
1.22 \\
1.09 \\
1.00 \\
1.38 \\
0.99 \\
0.81 \\
0.67 \\
0.88 \\
0.88 \\
0.05 \\
0.08 \\
0.11 \\
0.01 \\
0.02 \\
0.01 \\
0.01 \\
0.01 \\
0.01 \\
0.01\end{array}$ & $\mathbf{R}$ & $\begin{array}{l}0.01 \\
0.01 \\
- \\
0.01 \\
0.01 \\
0.01 \\
0.01 \\
0.01 \\
0.01 \\
0.01 \\
0.01 \\
0.01 \\
0.01 \\
0.01 \\
0.01 \\
0.01 \\
0.01 \\
0.01 \\
0.01 \\
0.01 \\
0.01 \\
0.01 \\
0.05 \\
0.01 \\
0.01 \\
0.01 \\
0.01 \\
0.01 \\
0.01 \\
0.01 \\
0.01 \\
0.01\end{array}$ & $\begin{array}{l}- \\
- \\
- \\
- \\
- \\
- \\
- \\
- \\
- \\
- \\
- \\
- \\
- \\
- \\
- \\
- \\
- \\
- \\
- \\
- \\
- \\
- \\
- \\
- \\
- \\
-\end{array}$ \\
\hline & MOLYBDENUM (TOTAL) & $\begin{array}{l}0503 \\
0504 \\
0506 \\
0507 \\
0508 \\
0509\end{array}$ & $\begin{array}{l}02 / 18 / 94 \\
02 / 19 / 94 \\
02 / 20 / 94 \\
02 / 20 / 94 \\
02 / 21 / 94 \\
02 / 21 / 94\end{array}$ & $\begin{array}{l}\text { No01 } \\
\text { N001 } \\
\text { N001 } \\
\text { N001 } \\
\text { N001 } \\
\text { N001 }\end{array}$ & $\begin{array}{l}A L \\
A L \\
A L \\
A L \\
A L \\
A L\end{array}$ & $\begin{array}{l}0 \\
D \\
D \\
D \\
0 \\
0\end{array}$ & $M G / L$ & $<$ & $\begin{array}{l}0.03 \\
0.01 \\
0.03 \\
0.03 \\
1.19 \\
0.29\end{array}$ & & $\begin{array}{l}0.01 \\
0.01 \\
0.01 \\
0.01 \\
0.01 \\
0.01\end{array}$ & $\begin{array}{l}- \\
- \\
- \\
-\end{array}$ \\
\hline
\end{tabular}

FORMATION OF COMPLETION CODE: AL - ALLUVIUM

PARAMETER VALUE INDICATOR (PVI): OTHER PARAMETER VALUE FLAGS: $R$ - UNUSABLE DATA POINT
FLOW RELATIONSHIP CODE: O - ON-SITE

D - DOWN GRADIENT

SAMPLE ID CODES:

0001 - FILTERED SAMPLE (.45 MICRONS)

N001 - UNFILTERED SAMPLE 
TABLE 3.27 BASEL I NE GROUND WATER QUALITY DATA BY PARAMETER FOR THE ALLUVIUM, NC AND UC PROCESSING SITES, SLICK ROCK, COLORADO

SITE: SRKO1 SLICK ROCK (BOTH SITES)

$09 / 07 / 82$ TO 02/22/94

REPORT DATE: $10 / 03 / 94$

\begin{tabular}{|c|c|c|c|c|c|c|c|c|c|c|}
\hline PARAMETER NAME & $\mid \begin{array}{c}\text { LOCATION } \\
\text { ID }\end{array}$ & LOG DATE & $\begin{array}{c}\text { SAMPLE } \\
\text { ID }\end{array}$ & $\begin{array}{l}\text { FORM } \\
\text { COMP }\end{array}$ & $\begin{array}{l}\text { FLOW } \\
\text { REL. }\end{array}$ & $\begin{array}{l}\text { UNITS OF } \\
\text { MEASURE }\end{array}$ & PVI & $\begin{array}{l}\text { PARAMETER } \\
\text { VAL.UE }\end{array}$ & $\begin{array}{l}\text { DETECTION } \\
\text { LIMIT }\end{array}$ & $\begin{array}{l}\text { PARAMETER } \\
\text { UNCERTAINTY }\end{array}$ \\
\hline MOLYBDENUM (TOTAL) & $\begin{array}{l}0510 \\
0512\end{array}$ & $\begin{array}{l}02 / 20 / 94 \\
02 / 20 / 94\end{array}$ & $\begin{array}{l}\text { N001 } \\
\text { N001 }\end{array}$ & $\begin{array}{l}A L \\
A L\end{array}$ & $\begin{array}{l}0 \\
0\end{array}$ & $M G / L$ & $<$ & $\begin{array}{l}0.87 \\
0.01\end{array}$ & $\begin{array}{l}0.01 \\
0.01\end{array}$ & $\overline{-}$ \\
\hline NET GROSS ALPHA * & $\begin{array}{l}0503 \\
0503 \\
0503 \\
0503 \\
0503 \\
0503 \\
0504 \\
0504 \\
0504 \\
0504 \\
0504 \\
0504 \\
0506 \\
0506 \\
0506 \\
0506 \\
0506 \\
0507 \\
0507 \\
0507 \\
0507 \\
0507 \\
0507 \\
0508 \\
0508 \\
0508 \\
0508 \\
0508 \\
0509 \\
0509 \\
0509 \\
0509 \\
0509 \\
0509 \\
0510\end{array}$ & $\begin{array}{l}09 / 07 / 82 \\
03 / 29 / 91 \\
08 / 08 / 91 \\
12 / 05 / 91 \\
10 / 09 / 92 \\
02 / 18 / 94 \\
09 / 07 / 82 \\
04 / 03 / 91 \\
08 / 27 / 91 \\
12 / 05 / 91 \\
10 / 09 / 92 \\
02 / 19 / 94 \\
03 / 28 / 91 \\
08 / 08 / 91 \\
12 / 05 / 91 \\
10 / 08 / 92 \\
02 / 20 / 94 \\
09 / 09 / 82 \\
03 / 28 / 91 \\
08 / 09 / 91 \\
12 / 05 / 91 \\
10 / 08 / 92 \\
02 / 20 / 94 \\
03 / 27 / 91 \\
08 / 28 / 91 \\
12 / 05 / 91 \\
10 / 10 / 92 \\
02 / 21 / 94 \\
09 / 09 / 82 \\
03 / 27 / 91 \\
08 / 28 / 91 \\
12 / 05 / 91 \\
10 / 13 / 92 \\
02 / 21 / 94 \\
09 / 08 / 82\end{array}$ & $\begin{array}{l}0001 \\
0001 \\
0001 \\
0001 \\
0001 \\
0001 \\
0001 \\
0001 \\
0001 \\
0001 \\
0001 \\
0001 \\
0001 \\
0001 \\
0001 \\
0001 \\
0001 \\
0001 \\
0001 \\
0001 \\
0001 \\
0001 \\
0001 \\
0001 \\
0001 \\
0001 \\
0001 \\
0001 \\
0001 \\
0001 \\
0001 \\
0001 \\
0001 \\
0001 \\
0001\end{array}$ & $\begin{array}{l}A L \\
A L \\
A L \\
A L \\
A L \\
A L \\
A L \\
A L \\
A L \\
A L \\
A L \\
A L \\
A L \\
A L \\
A L \\
A L \\
A L \\
A L \\
A L \\
A L \\
A L \\
A L \\
A L \\
A L \\
A L \\
A L \\
A L \\
A L \\
A L \\
A L \\
A L \\
A L \\
A L \\
A L \\
A L\end{array}$ & 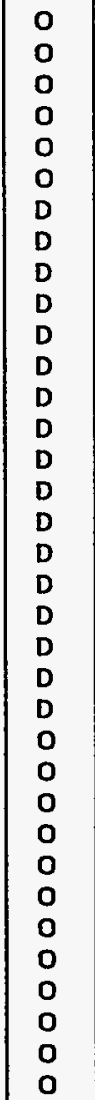 & $\mathrm{PCI} / \mathrm{L}$ & & $\begin{array}{r}513.80 \\
-26.54 \\
-136.84 \\
123.86 \\
-399.98 \\
-727.96 \\
278.00 \\
99.98 \\
139.92 \\
121.18 \\
33.20 \\
-64.38 \\
149.84 \\
-4.44 \\
-21.27 \\
133.43 \\
-27.27 \\
18.27 \\
21.11 \\
7.28 \\
0.78 \\
-14.21 \\
3.11 \\
48.79 \\
17.12 \\
-70.66 \\
-48.24 \\
-58.64 \\
10.87 \\
57.49 \\
4.98 \\
3.91 \\
-0.36 \\
8.25 \\
-8.64\end{array}$ & $\begin{array}{l}- \\
\\
- \\
- \\
- \\
- \\
- \\
- \\
- \\
- \\
- \\
- \\
- \\
- \\
- \\
- \\
- \\
- \\
- \\
- \\
- \\
- \\
- \\
- \\
- \\
-\end{array}$ & $\begin{array}{l}- \\
- \\
- \\
- \\
- \\
- \\
- \\
- \\
- \\
- \\
- \\
- \\
- \\
- \\
- \\
- \\
- \\
- \\
- \\
- \\
- \\
- \\
- \\
- \\
- \\
- \\
- \\
-\end{array}$ \\
\hline
\end{tabular}

* Net GROSS ALPHA (GROSS ALPHA - URANIUM) WITH 1 MG URANIUM $=686$ PCI

FORMATION OF COMPLETION CODE: AL - ALLUVIUM

PARAMETER VALUE INDICATOR (PVI): < - LESS THAN DETECTION LIMIT
FLOW RELATIONSHIP CODE:

O - ON-SITE

D - DOWN GRADIENT

SAMPLE ID CODES:

0001 - .FILTERED SAMPLE (.45 MICRONS)

N001 - UNFILTERED SAMPLE 
TABLE 3.27 BASELINE GROUND HATER QUALITY DATA BY PARAMETER FOR THE ALLUVIUM, NC AND UC PROCESSING SITES, SLICK ROCK, COLORADO

SITE = SRKO1 SLICK ROCK (BOTH SITES)

$09 / 07 / 82$ TO 02/22/94

REPORT DATE: $10 / 03 / 94$

\begin{tabular}{|c|c|c|c|c|c|c|c|c|c|c|c|}
\hline PARAMETER NAME & $\underset{\text { ID }}{\text { LOCATION }}$ & LOG DATE & $\underset{\text { ID }}{\text { SAMPLE }}$ & $\begin{array}{l}\text { FORM } \\
\text { COMP }\end{array}$ & $\begin{array}{l}\text { FLOW } \\
\text { REL. }\end{array}$ & $\begin{array}{l}\text { UNITS OF } \\
\text { MEASURE }\end{array}$ & PVI & $\begin{array}{l}\text { PARAMETER } \\
\text { VALUE }\end{array}$ & FLAGS & $\begin{array}{l}\text { DETECTION } \\
\text { LIMIT }\end{array}$ & $\begin{array}{l}\text { PARAMETER } \\
\text { UNCERTAINTY }\end{array}$ \\
\hline NET GROSS ALPHA * & $\begin{array}{l}0510 \\
0510 \\
0510 \\
0510 \\
0510 \\
0512 \\
0512 \\
0512 \\
0512 \\
0512\end{array}$ & $\begin{array}{l}03 / 28 / 91 \\
08 / 28 / 91 \\
12 / 05 / 91 \\
10 / 08 / 92 \\
02 / 20 / 94 \\
04 / 05 / 91 \\
08 / 08 / 91 \\
12 / 05 / 91 \\
10 / 09 / 92 \\
02 / 20 / 94\end{array}$ & $\begin{array}{l}0001 \\
0001 \\
0001 \\
0001 \\
0001 \\
0001 \\
0001 \\
0001 \\
0001 \\
0001\end{array}$ & $\begin{array}{l}A L \\
A L \\
A L \\
A L \\
A L \\
A L \\
A L \\
A L \\
A L \\
A L\end{array}$ & $\begin{array}{l}0 \\
0 \\
0 \\
0 \\
0 \\
0 \\
0 \\
0 \\
0 \\
0\end{array}$ & $\mathrm{PCI} / \mathrm{L}$ & & $\begin{array}{r}68.89 \\
7.37 \\
-90.55 \\
14.41 \\
-19.06 \\
-493.00 \\
-622.70 \\
-296.20 \\
-440.22 \\
2520.85\end{array}$ & & $\begin{array}{l}- \\
- \\
- \\
- \\
- \\
- \\
- \\
-\end{array}$ & $\begin{array}{l}- \\
- \\
- \\
- \\
- \\
- \\
- \\
-\end{array}$ \\
\hline NET GROSS ALPHA (TOTAL) ** & $\begin{array}{l}0503 \\
0504 \\
0506 \\
0507 \\
0508 \\
0509 \\
0510 \\
0512\end{array}$ & $\begin{array}{l}02 / 18 / 94 \\
02 / 19 / 94 \\
02 / 20 / 94 \\
02 / 20 / 94 \\
02 / 21 / 94 \\
02 / 21 / 94 \\
02 / 20 / 94 \\
02 / 20 / 94\end{array}$ & $\begin{array}{l}\text { N001 } \\
\text { N001 } \\
\text { N001 } \\
\text { N001 } \\
\text { N001 } \\
\text { N001 } \\
\text { N001 } \\
\text { N001 }\end{array}$ & $\begin{array}{l}A L \\
A L \\
A L \\
A L \\
A L \\
A L \\
A L \\
A L\end{array}$ & $\begin{array}{l}\text { O } \\
D \\
D \\
D \\
0 \\
0 \\
0 \\
0\end{array}$ & $\mathrm{PCI} / \mathrm{L}$ & & $\begin{array}{r}-406.22 \\
-260.56 \\
-77.90 \\
4.52 \\
-32.24 \\
10.35 \\
-6.07 \\
-907.04\end{array}$ & & $\begin{array}{l}- \\
- \\
- \\
- \\
- \\
- \\
-\end{array}$ & $\begin{array}{l}- \\
- \\
- \\
- \\
-\end{array}$ \\
\hline NICKEL & $\begin{array}{l}0503 \\
0503 \\
0503 \\
0503 \\
0503 \\
0503 \\
0503 \\
0503 \\
0504 \\
0504 \\
0504 \\
0504 \\
0504 \\
0504 \\
0504\end{array}$ & \begin{tabular}{|l|}
$06 / 30 / 86$ \\
$10 / 14 / 87$ \\
$02 / 22 / 88$ \\
$05 / 16 / 90$ \\
$03 / 29 / 91$ \\
$08 / 08 / 91$ \\
$12 / 09 / 91$ \\
$10 / 09 / 92$ \\
$10 / 14 / 87$ \\
$02 / 22 / 88$ \\
$05 / 16 / 90$ \\
$04 / 03 / 91$ \\
$08 / 27 / 91$ \\
$12 / 09 / 91$ \\
$10 / 09 / 92$
\end{tabular} & $\begin{array}{l}0001 \\
0001 \\
0001 \\
0001 \\
0001 \\
0001 \\
0001 \\
0001 \\
0001 \\
0001 \\
0001 \\
0001 \\
0001 \\
0001 \\
0001\end{array}$ & $\begin{array}{l}A L \\
A L \\
A L \\
A L \\
A L \\
A L \\
A L \\
A L \\
A L \\
A L \\
A L \\
A L \\
A L \\
A L \\
A L\end{array}$ & $\begin{array}{l}0 \\
0 \\
0 \\
0 \\
0 \\
0 \\
0 \\
0 \\
D \\
D \\
D \\
D \\
D \\
D \\
D\end{array}$ & $M G / L$ & $\begin{array}{l}< \\
< \\
< \\
< \\
< \\
< \\
< \\
< \\
< \\
< \\
< \\
< \\
< \\
<\end{array}$ & $\begin{array}{l}0.04 \\
0.04 \\
0.04 \\
0.04 \\
0.04 \\
0.04 \\
0.04 \\
0.04 \\
0.04 \\
0.07 \\
0.04 \\
0.04 \\
0.04 \\
0.04 \\
0.04\end{array}$ & J & $\begin{array}{l}0.04 \\
0.04 \\
0.04 \\
0.04 \\
0.04 \\
0.04 \\
0.04 \\
0.04 \\
0.04 \\
0.04 \\
0.04 \\
0.04 \\
0.04 \\
0.04 \\
0.04\end{array}$ & $\begin{array}{l}- \\
- \\
- \\
- \\
- \\
- \\
- \\
- \\
- \\
- \\
- \\
-\end{array}$ \\
\hline
\end{tabular}

* Net gRoss alPHa (GROSS ALPHA - URANIUM) HITH 1 MG URANIUM = 686 PCI

** NET GROSS ALPHA (TOTAL) (TOTAL GROSS ALPHA - TOTAL URANIUM)

FORMATION OF COMPLETION CODE:

AL - ALLUVIUM

PARAMETER VALUE INDICATOR (PVI)

OTHER PARAMETER VALUE FLAGS:

$J$ - ESTIMATEI VALUE
FLOH RELATIONSHIP CODE:

O - ON-SITE

D - DOWN GRADIENT

SAMPLE ID CODES

0001 - FILTERED SAMPLE (.45 MICRONS)

NO01 - UNFILTERED SAMPLE 
TABLE 3.27 BASELINE GROUND WATER QUALITY DATA BY PARAMETER FOR THE ALLUVIUM, NC AND UC PROCESSING SITES, SLICK ROCK, COLORADO

SITE: SRKO1 SLICK ROCK (BOTH SITES)

$09 / 07 / 82$ TO $02 / 22 / 94$

REPORT DATE : $10 / 03 / 94$

\begin{tabular}{|c|c|c|c|c|c|c|c|c|c|c|c|}
\hline PARAMETER NAME & $\begin{array}{c}\text { LOCATION } \\
10\end{array}$ & LOG DATE & $\begin{array}{c}\text { SAMPLE } \\
\text { ID }\end{array}$ & $\begin{array}{l}\text { FORM } \\
\text { COMP }\end{array}$ & $\begin{array}{l}\text { FLOW } \\
\text { REL. }\end{array}$ & $\begin{array}{l}\text { UNITS OF } \\
\text { MEASURE }\end{array}$ & PVI & $\begin{array}{l}\text { PARAMETER } \\
\text { VALUE }\end{array}$ & FLAGS & $\begin{array}{l}\text { DETECTION } \\
\text { LIMIT }\end{array}$ & $\begin{array}{l}\text { PARAMETER } \\
\text { UNCERTAINTY }\end{array}$ \\
\hline NICKEL & $\begin{array}{l}0506 \\
0506 \\
0506 \\
0506 \\
0506 \\
0506 \\
0507 \\
0507 \\
0507 \\
0507 \\
0507 \\
0507 \\
0507 \\
0508 \\
0508 \\
0508 \\
0508 \\
0508 \\
0508 \\
0509 \\
0509 \\
0509 \\
0509 \\
0509 \\
0509 \\
0510 \\
0510 \\
0510 \\
0510 \\
0510 \\
0510 \\
0510 \\
0512 \\
0512 \\
0512 \\
0512 \\
0512 \\
0512\end{array}$ & $\begin{array}{l}10 / 14 / 87 \\
02 / 22 / 88 \\
03 / 28 / 91 \\
08 / 08 / 91 \\
11 / 20 / 91 \\
10 / 08 / 92 \\
10 / 14 / 87 \\
02 / 22 / 88 \\
05 / 16 / 90 \\
03 / 28 / 91 \\
08 / 09 / 91 \\
12 / 05 / 91 \\
10 / 08 / 92 \\
10 / 14 / 87 \\
02 / 19 / 88 \\
03 / 27 / 91 \\
08 / 28 / 91 \\
12 / 05 / 91 \\
10 / 10 / 92 \\
10 / 14 / 87 \\
02 / 22 / 88 \\
03 / 27 / 91 \\
08 / 28 / 91 \\
11 / 21 / 91 \\
10 / 13 / 92 \\
06 / 30 / 86 \\
10 / 14 / 87 \\
02 / 22 / 88 \\
05 / 16 / 90 \\
03 / 28 / 91 \\
12 / 05 / 91 \\
10 / 08 / 92 \\
10 / 14 / 87 \\
02 / 22 / 88 \\
04 / 05 / 91 \\
08 / 08 / 91 \\
12 / 10 / 91 \\
10 / 09 / 92\end{array}$ & $\begin{array}{l}0001 \\
0001 \\
0001 \\
0001 \\
0001 \\
0001 \\
0001 \\
0001 \\
0001 \\
0001 \\
0001 \\
0001 \\
0001 \\
0001 \\
0001 \\
0001 \\
0001 \\
0001 \\
0001 \\
0001 \\
0001 \\
0001 \\
0001 \\
0001 \\
0001 \\
0001 \\
0001 \\
0001 \\
0001 \\
0001 \\
0001 \\
0001 \\
0001 \\
0001 \\
0001 \\
0001 \\
0001 \\
0001\end{array}$ & $\begin{array}{l}A L \\
A L \\
A L \\
A L \\
A L \\
A L \\
A L \\
A L \\
A L \\
A L \\
A L \\
A L \\
A L \\
A L \\
A L \\
A L \\
A L \\
A L \\
A L \\
A L \\
A L \\
A L \\
A L \\
A L \\
A L \\
A L \\
A L \\
A L \\
A L \\
A L \\
A L \\
A L \\
A L \\
A L \\
A L \\
A L \\
A L \\
A L\end{array}$ & $\begin{array}{l}D \\
D \\
D \\
D \\
D \\
D \\
D \\
D \\
D \\
D \\
D \\
D \\
D \\
0 \\
0 \\
0 \\
0 \\
0 \\
0 \\
0 \\
0 \\
0 \\
0 \\
0 \\
0 \\
0 \\
0 \\
0 \\
0 \\
0 \\
0 \\
0 \\
0 \\
0 \\
0 \\
0 \\
0 \\
0\end{array}$ & $M G / L$ & $\begin{array}{l}< \\
< \\
< \\
< \\
< \\
< \\
< \\
< \\
< \\
< \\
< \\
< \\
< \\
< \\
< \\
< \\
< \\
< \\
< \\
< \\
< \\
< \\
< \\
< \\
< \\
< \\
< \\
< \\
< \\
< \\
< \\
< \\
<\end{array}$ & $\begin{array}{l}0.04 \\
0.11 \\
0.04 \\
0.04 \\
0.04 \\
0.04 \\
0.04 \\
0.03 \\
0.04 \\
0.04 \\
0.04 \\
0.04 \\
0.04 \\
0.04 \\
0.09 \\
0.04 \\
0.04 \\
0.04 \\
0.04 \\
0.04 \\
0.03 \\
0.04 \\
0.04 \\
0.04 \\
0.04 \\
0.09 \\
0.04 \\
0.10 \\
0.04 \\
0.04 \\
0.04 \\
0.04 \\
0.04 \\
0.02 \\
0.04 \\
0.04 \\
0.04 \\
0.04\end{array}$ & $\mathbf{R}$ & $\begin{array}{l}0.04 \\
0.04 \\
0.04 \\
0.04 \\
0.04 \\
0.04 \\
0.04 \\
0.04 \\
0.04 \\
0.04 \\
0.04 \\
0.04 \\
0.04 \\
0.04 \\
0.04 \\
0.04 \\
0.04 \\
0.04 \\
0.04 \\
0.04 \\
0.04 \\
0.04 \\
0.04 \\
0.04 \\
0.04 \\
0.04 \\
0.04 \\
0.04 \\
0.04 \\
0.04 \\
0.04 \\
0.04 \\
0.04 \\
0.04 \\
0.04 \\
0.04 \\
0.04 \\
0.04\end{array}$ & $\begin{array}{l}- \\
- \\
- \\
- \\
- \\
- \\
- \\
- \\
- \\
- \\
- \\
- \\
- \\
- \\
- \\
- \\
- \\
- \\
- \\
- \\
- \\
- \\
- \\
- \\
- \\
- \\
- \\
- \\
-\end{array}$ \\
\hline
\end{tabular}

FORMATION OF COMPLETION CODE:

AL - ALLUVIUM

PARAMETER VALUE INDICATOR (PVI): < - LESS THAN DETECTION LIMIT
FLOW RELATIONSHIP CODE:

D - DOWN GRADIENT

O - ON-SITE

SAMPLE ID CODES:

0001 - FILTERED SAMPLE (.45 MICRONS)

OTHER PARAMETER VALUE FLAGS:

$J$ - ESTIMATED VALUE

R - UNUSABLE DATA POINT 
TABLE 3.27 BASELINE GROUND HATER QUALITY DATA BY PARAMETER FOR THE ALLUVIUM, NC AND UC PROCESSING SITES, SLICK ROCK, COLORADO

SITE: SRKO1 SLICK ROCK (BOTH SITES)

09/07/82 TO 02/22/94

REPORT DATE: $10 / 03 / 94$

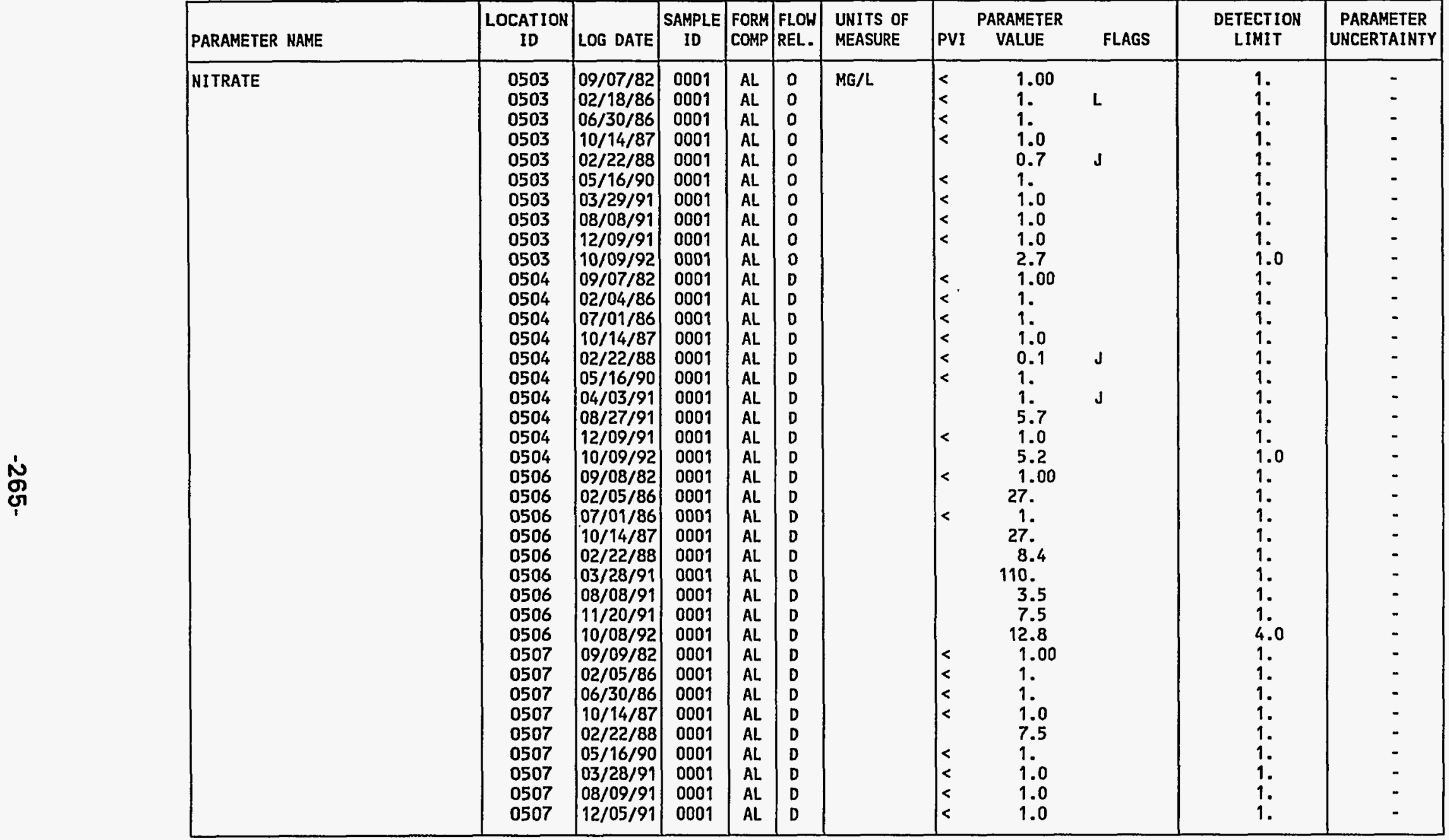

FORMATION OF COMPLETION CODE:

AL - ALLUVIUM

FLOW RELATIONSHIP CODE

O - ON-SITE

D - DOWN GRADIENT

PARAMETER VALUE INDICATOR (PVI): < - LESS THAN DETECTION LIMIT

0001 - FILTERED SAMPLE (.45 MICRONS)

OTHER PARAMETER VALUE FLAGS:

$J$ - ESTIMATED VALUE

$\checkmark$ - LESS THAN THREE BORE VOLUMES REMOVED BEFORE SAMPLING 
TABLE 3.27 BASELINE GROUND WATER QUALITY DATA BY PARAMETER FOR THE ALLUVIUM, NC AND UC PROCESSING SITES, SLICK ROCK, COLORADO

SITE: SRK01 SLICK ROCK (BOTH SITES)

$09 / 07 / 82$ TO $02 / 22 / 94$

\begin{tabular}{|c|c|c|c|c|c|c|c|c|c|c|c|}
\hline PARAMETER NAME & $\begin{array}{c}\text { LOCATION } \\
\text { ID }\end{array}$ & LOG DATE & $\begin{array}{c}\text { SAMPLE } \\
\text { ID }\end{array}$ & $\begin{array}{l}\text { FORM } \\
\text { COMP }\end{array}$ & $\begin{array}{l}\text { FLOW } \\
\text { REL. }\end{array}$ & $\begin{array}{l}\text { UNITS OF } \\
\text { MEASURE }\end{array}$ & PVI & $\begin{array}{l}\text { PARAMETER } \\
\text { VALUE }\end{array}$ & FLAGS & $\begin{array}{l}\text { OETECTION } \\
\text { LIMIT }\end{array}$ & $\begin{array}{l}\text { PARAMETER } \\
\text { UNCERTAINTY }\end{array}$ \\
\hline NITRATE & $\begin{array}{l}0507 \\
0508 \\
0508 \\
0508 \\
0508 \\
0508 \\
0508 \\
0508 \\
0508 \\
0508 \\
0509 \\
0509 \\
0509 \\
0509 \\
0509 \\
0509 \\
0509 \\
0509 \\
0509 \\
0510 \\
0510 \\
0510 \\
0510 \\
0510 \\
0510 \\
0510 \\
0510 \\
0510 \\
0510 \\
0512 \\
0512 \\
0512 \\
0512 \\
0512 \\
0512 \\
0512 \\
0512 \\
0512\end{array}$ & $\begin{array}{l}10 / 08 / 92 \\
09 / 08 / 82 \\
02 / 18 / 86 \\
06 / 30 / 86 \\
10 / 14 / 87 \\
02 / 19 / 88 \\
03 / 27 / 91 \\
08 / 28 / 91 \\
12 / 05 / 91 \\
10 / 10 / 92 \\
09 / 09 / 82 \\
02 / 18 / 86 \\
07 / 17 / 86 \\
10 / 14 / 87 \\
02 / 22 / 88 \\
03 / 27 / 91 \\
08 / 28 / 91 \\
11 / 21 / 91 \\
10 / 13 / 92 \\
09 / 08 / 82 \\
02 / 18 / 86 \\
06 / 30 / 86 \\
10 / 14 / 87 \\
02 / 22 / 88 \\
05 / 16 / 90 \\
03 / 28 / 91 \\
08 / 28 / 91 \\
12 / 05 / 91 \\
10 / 08 / 92 \\
09 / 08 / 82 \\
02 / 04 / 86 \\
07 / 01 / 86 \\
10 / 14 / 87 \\
02 / 22 / 88 \\
04 / 05 / 91 \\
08 / 08 / 91 \\
12 / 10 / 91 \\
10 / 09 / 92\end{array}$ & $\begin{array}{l}0001 \\
0001 \\
0001 \\
0001 \\
0001 \\
0001 \\
0001 \\
0001 \\
0001 \\
0001 \\
0001 \\
0001 \\
0001 \\
0001 \\
0001 \\
0001 \\
0001 \\
0001 \\
0001 \\
0001 \\
0001 \\
0001 \\
0001 \\
0001 \\
0001 \\
0001 \\
0001 \\
0001 \\
0001 \\
0001 \\
0001 \\
0001 \\
0001 \\
0001 \\
0001 \\
0001 \\
0001 \\
0001\end{array}$ & $\begin{array}{l}A L \\
A L \\
A L \\
A L \\
A L \\
A L \\
A L \\
A L \\
A L \\
A L \\
A L \\
A L \\
A L \\
A L \\
A L \\
A L \\
A L \\
A L \\
A L \\
A L \\
A L \\
A L \\
A L \\
A L \\
A L \\
A L \\
A L \\
A L \\
A L \\
A L \\
A L \\
A L \\
A L \\
A L \\
A L \\
A L \\
A L \\
A L\end{array}$ & $\begin{array}{l}D \\
0 \\
0 \\
0 \\
0 \\
0 \\
0 \\
0 \\
0 \\
0 \\
0 \\
0 \\
0 \\
0 \\
0 \\
0 \\
0 \\
0 \\
0 \\
0 \\
0 \\
0 \\
0 \\
0 \\
0 \\
0 \\
0 \\
0 \\
0 \\
0 \\
0 \\
0 \\
0 \\
0 \\
0 \\
0 \\
0 \\
0\end{array}$ & $M G / L$ & 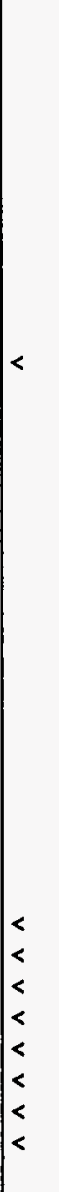 & $\begin{array}{c}6.8 \\
323.00 \\
800 . \\
290 . \\
1250 . \\
1220 . \\
32.9 \\
1040 . \\
1200 . \\
1360 . \\
13.00 \\
1 . \\
5 . \\
42 . \\
35 . \\
1050 . \\
28.3 \\
19.5 \\
34 . \\
284.00 \\
610 . \\
1000 . \\
1620 . \\
1190 . \\
1000 . \\
943 . \\
947 . \\
837 . \\
257 . \\
1.00 \\
1 . \\
1 . \\
1.0 \\
0.1 \\
1.0 \\
1.0 \\
1.0 \\
6.5\end{array}$ & R & $\begin{array}{c}1.0 \\
1 . \\
1 . \\
1 . \\
1 . \\
1 . \\
75 . \\
125 . \\
150 . \\
i . \\
1 . \\
1 . \\
1 . \\
1 . \\
1 . \\
5 . \\
1 . \\
5 . \\
1 . \\
1 . \\
1 . \\
1 . \\
1 . \\
1 . \\
75 . \\
125 . \\
10 . \\
1 . \\
1 . \\
1 . \\
1 . \\
1 . \\
1 . \\
1 . \\
1 . \\
1.0\end{array}$ & $\begin{array}{l}- \\
- \\
- \\
- \\
- \\
- \\
- \\
- \\
- \\
- \\
- \\
- \\
- \\
- \\
- \\
- \\
- \\
- \\
- \\
- \\
- \\
- \\
- \\
- \\
- \\
- \\
- \\
- \\
- \\
- \\
- \\
- \\
- \\
- \\
- \\
- \\
- \\
-\end{array}$ \\
\hline
\end{tabular}

FORMATION OF COMPLETION CODE:

AL - ALLUVIUM

PARAMETER VALUE INDICATOR (PVI)
FLOW RELATIONSHIP CODE:

D - DOWN GRADIENT

O - ON-SITE

SAMPLE ID CODES:

0001 - FILTERED SAMPLE (.45 MICRONS)

OTHER PARAMETER VALUE FLAGS:

$J$ - ESTIMATED VALUE

R - UNUSABLE DATA POINT 
TABLE 3.27 BASELINE GROUND WATER QUALITY DATA BY PARAMETER FOR THE ALLUVIUM, NC AND UC PROCESSING SITES, SLICK ROCK, COLORADO

SITE: SRKO1 SLICK ROCK (BOTH SITES)

09/07/82 TO 02/22/94

REPORT DATE: $10 / 03 / 94$

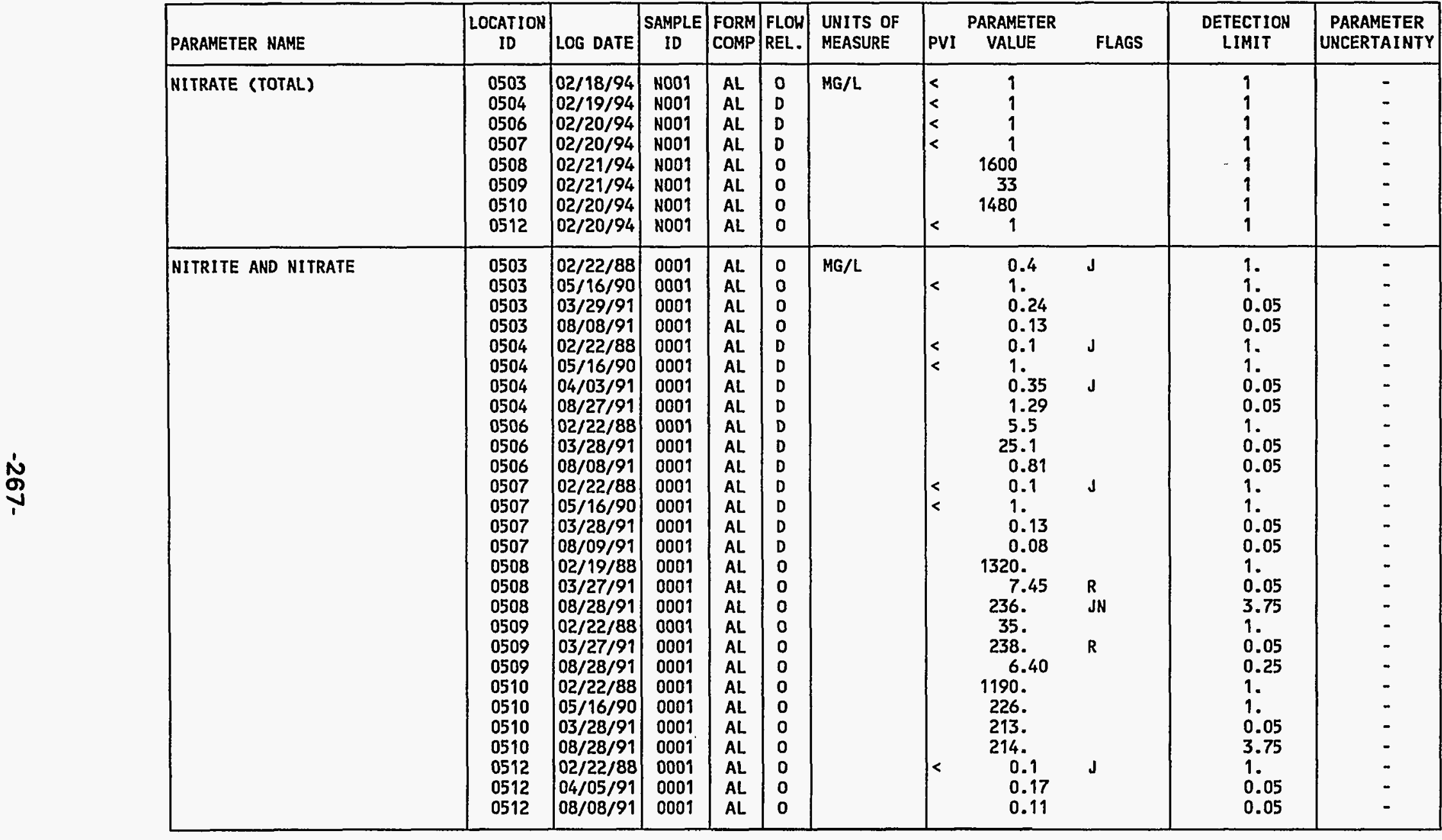

FORMATION OF COMPLETION CODE:

AL. - ALLUVIUM

FLOW RELATIONSHIP CODE:

O - ON-SITE

D - DOWN GRADIENT

PARAMETER VALUE INDICATOR (PVI): < - LESS THAN DETECTION LIMI

OTHER PARAMETER VALUE FLAGS:

SAMPLE ID CODES:

0001 - FILTERED SAMPLE (.45 MICRONS)

NO01 - UNFILTERED SAMPLE

$\mathrm{J}$ - ESTIMATED VALUE

N - SPIKE SAMPLE RECOVERY NOT WITHIN CONTROL LIMITS

$R$ - UNUSABLE DATA POINT 
TABLE 3.27 BASELINE GROUND WATER QUALITY DATA BY PARAMETER FOR THE ALLUVIUM NC AND UC PROCESSING SITES, SLICK ROCK, COLORADO

SITE: SRKO1 SLICK ROCK (BOTH SITES)

09/07/82 TO 02/22/94

REPORT DATE : $10 / 03 / 94$

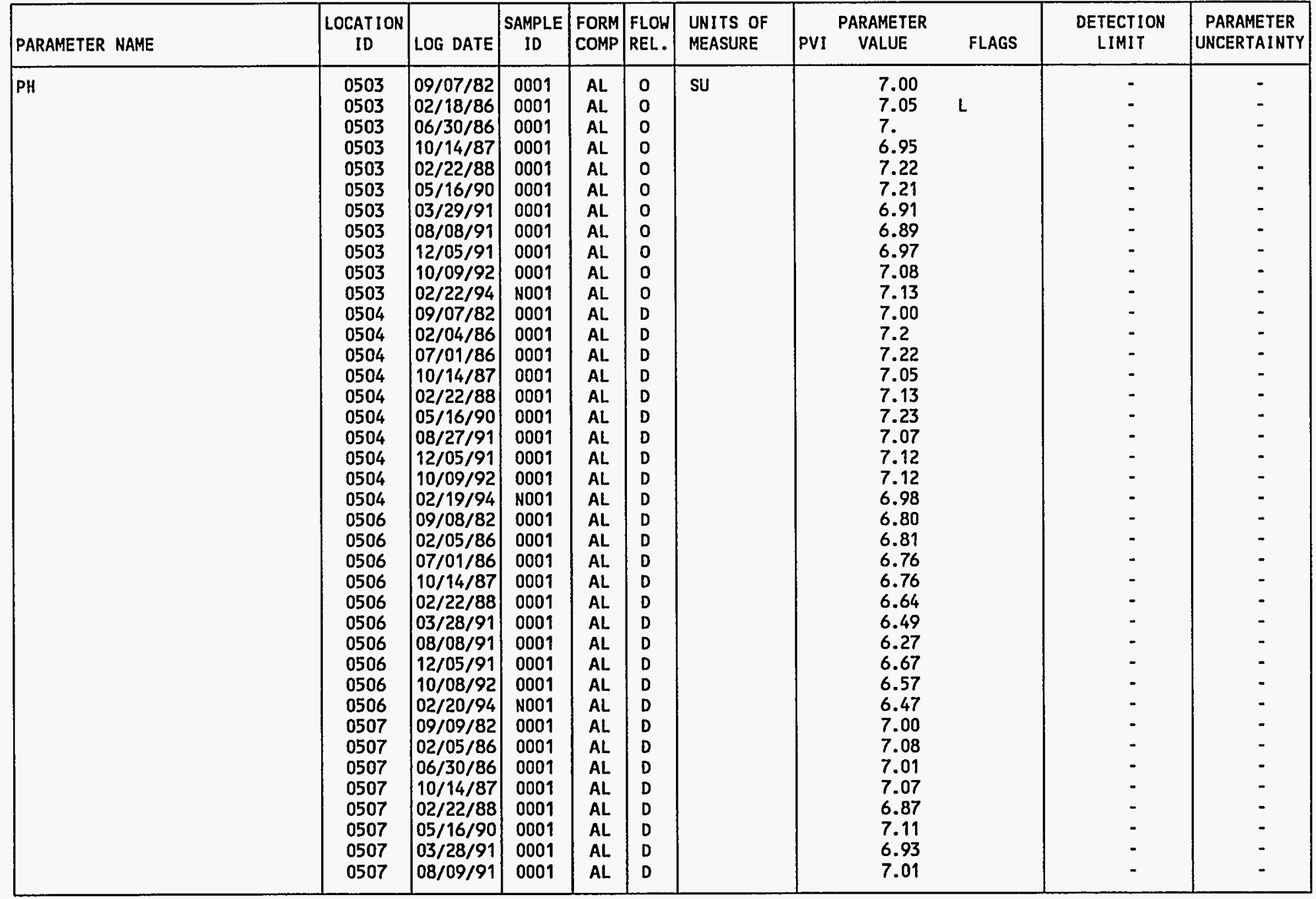

FORMATION OF COMPLETION CODE:

AL - ALLUVIUM

PARAMETER VALUE INDICATOR (PVI): < - LESS THAN DETECTION LIMIT

OTHER PARAMETER VALUE FLAGS:

$L$ - LESS THAN THREE BORE VOLUMES REMOVED BEFORE SAMPLING
FLOW RELATIONSHIP CODE:

O - ON-SITE

D - DOWN GRADIENT

SAMPLE ID CODES:

0001 - FILTERED SAMPLE (.45 MICRONS)

NOO1 - UNFILTERED SAMPLE 
TABLE 3.27 BASELINE GROUND HATER QUALITY DATA BY PARAMETER FOR THE

ALLUVIUM, NC AND UC PROCESSING SITES, SLICK ROCK, COLORADO

SITE: SRKO1 SLICK ROCK (BOTH SITES)

$09 / 07 / 82$ TO $02 / 22 / 94$

REPORT DATE: $10 / 03 / 94$

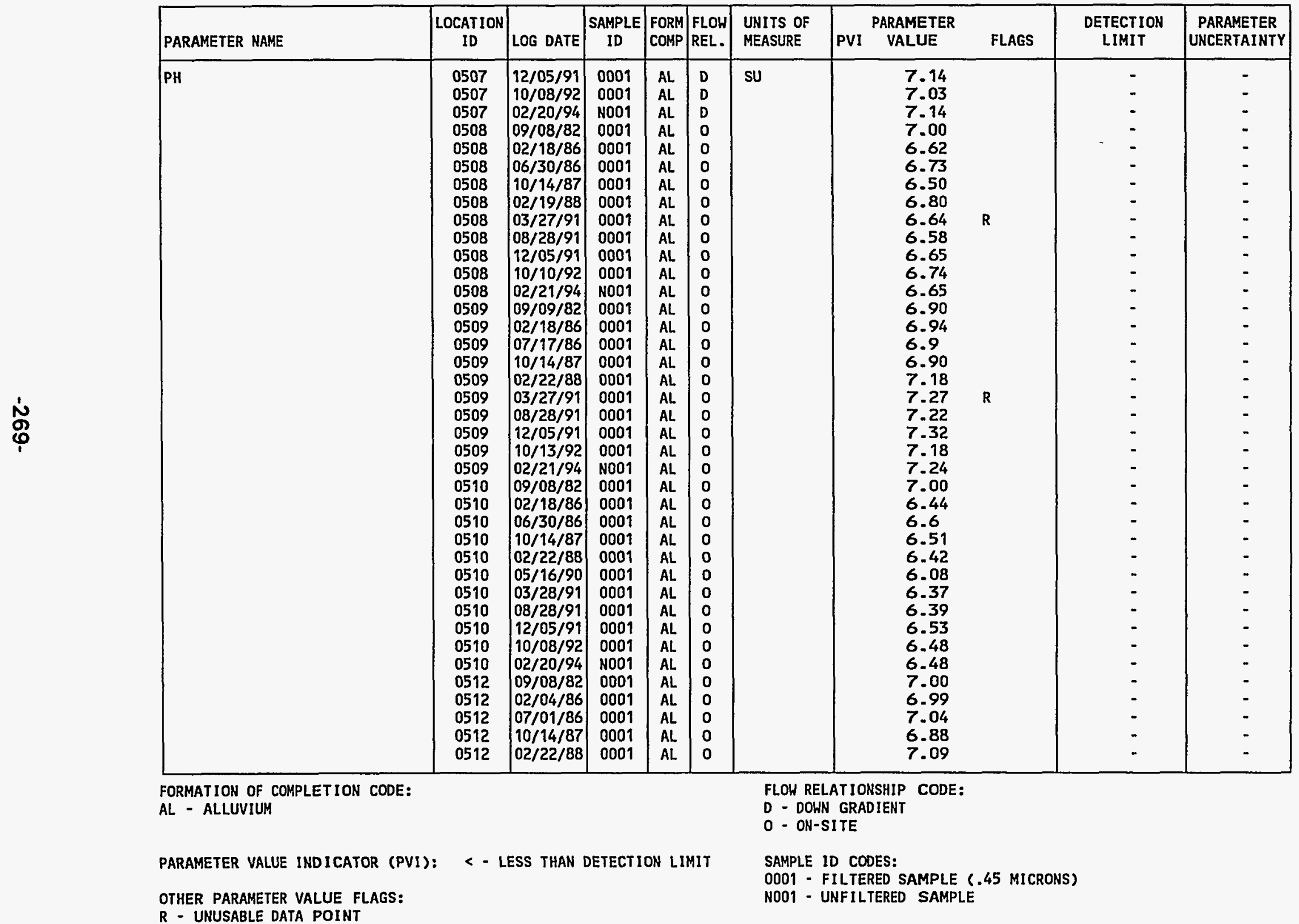


TABLE 3.27 BASELINE GROUND WATER QUALITY DATA BY PARAMETER FOR THE ALLUVIUM, NC AND UC PROCESSING SITES, SLICK ROCK, COLORADO

SITE : SRKO1 SLICK ROCK (BOTH SITES)

$09 / 07 / 82$ TO $02 / 22 / 94$

REPORT DATE: $10 / 03 / 94$

\begin{tabular}{|c|c|c|c|c|c|c|c|c|c|c|c|}
\hline PARAMETER NAME & $\begin{array}{c}\text { LOCATION } \\
\text { ID }\end{array}$ & LOG DATE & $\begin{array}{c}\text { SAMPLE } \\
\text { ID }\end{array}$ & $\begin{array}{l}\text { FORM } \\
\text { COMP }\end{array}$ & $\begin{array}{l}\text { FLOW } \\
\text { REL. }\end{array}$ & $\begin{array}{l}\text { UNITS OF } \\
\text { MEASURE }\end{array}$ & PVI & $\begin{array}{l}\text { ARAMETE } \\
\text { VALUE }\end{array}$ & FLAGS & $\begin{array}{l}\text { DETECTION } \\
\text { LIMIT }\end{array}$ & $\begin{array}{l}\text { PARAMETER } \\
\text { UNCERTAINTY }\end{array}$ \\
\hline PH & $\begin{array}{l}0512 \\
0512 \\
0512 \\
0512 \\
0512\end{array}$ & $\begin{array}{l}04 / 05 / 91 \\
08 / 08 / 91 \\
12 / 05 / 91 \\
10 / 09 / 92 \\
02 / 20 / 94\end{array}$ & $\begin{array}{l}0001 \\
0001 \\
0001 \\
0001 \\
\text { N001 }\end{array}$ & $\begin{array}{l}A L \\
A L \\
A L \\
A L \\
A L\end{array}$ & $\begin{array}{l}0 \\
0 \\
0 \\
0 \\
0\end{array}$ & su & & $\begin{array}{l}6.96 \\
7.01 \\
7.14 \\
6.85 \\
7.00\end{array}$ & & $\begin{array}{l}- \\
- \\
-\end{array}$ & $\begin{array}{l}- \\
- \\
- \\
-\end{array}$ \\
\hline PHOSPHATE & $\begin{array}{l}0503 \\
0503 \\
0503 \\
0503 \\
0503 \\
0503 \\
0503 \\
0504 \\
0504 \\
0504 \\
0504 \\
0504 \\
0504 \\
0506 \\
0506 \\
0506 \\
0506 \\
0506 \\
0507 \\
0507 \\
0507 \\
0507 \\
0507 \\
0507 \\
0508 \\
0508 \\
0508 \\
0508 \\
0508 \\
0509 \\
0509 \\
0509\end{array}$ & $\begin{array}{l}06 / 30 / 86 \\
10 / 14 / 87 \\
05 / 16 / 90 \\
03 / 29 / 91 \\
08 / 08 / 91 \\
12 / 09 / 91 \\
10 / 09 / 92 \\
10 / 14 / 87 \\
05 / 16 / 90 \\
04 / 03 / 91 \\
08 / 27 / 91 \\
12 / 09 / 91 \\
10 / 09 / 92 \\
10 / 14 / 87 \\
03 / 28 / 91 \\
08 / 08 / 91 \\
11 / 20 / 91 \\
10 / 08 / 92 \\
10 / 14 / 87 \\
05 / 16 / 90 \\
03 / 28 / 91 \\
08 / 09 / 91 \\
12 / 05 / 91 \\
10 / 08 / 92 \\
10 / 14 / 87 \\
03 / 27 / 91 \\
08 / 28 / 91 \\
12 / 05 / 91 \\
10 / 10 / 92 \\
10 / 14 / 87 \\
03 / 27 / 91 \\
08 / 28 / 91\end{array}$ & $\begin{array}{l}0001 \\
0001 \\
0001 \\
0001 \\
0001 \\
0001 \\
0001 \\
0001 \\
0001 \\
0001 \\
0001 \\
0001 \\
0001 \\
0001 \\
0001 \\
0001 \\
0001 \\
0001 \\
0001 \\
0001 \\
0001 \\
0001 \\
0001 \\
0001 \\
0001 \\
0001 \\
0001 \\
0001 \\
0001 \\
0001 \\
0001 \\
0001\end{array}$ & $\begin{array}{l}A L \\
A L \\
A L \\
A L \\
A L \\
A L \\
A L \\
A L \\
A L \\
A L \\
A L \\
A L \\
A L \\
A L \\
A L \\
A L \\
A L \\
A L \\
A L \\
A L \\
A L \\
A L \\
A L \\
A L \\
A L \\
A L \\
A L \\
A L \\
A L \\
A L \\
A L \\
A L\end{array}$ & $\begin{array}{l}0 \\
0 \\
0 \\
0 \\
0 \\
D \\
0 \\
D \\
D \\
D \\
D \\
D \\
D \\
D \\
D \\
D \\
D \\
D \\
D \\
D \\
D \\
D \\
D \\
D \\
0 \\
0 \\
0 \\
0 \\
0 \\
0 \\
0 \\
0\end{array}$ & MG/L & $\begin{array}{l}< \\
< \\
< \\
< \\
< \\
< \\
< \\
< \\
< \\
< \\
< \\
< \\
< \\
< \\
< \\
< \\
<\end{array}$ & $\begin{array}{l}0.1 \\
0.1 \\
0.1 \\
0.1 \\
0.1 \\
0.2 \\
0.1 \\
0.1 \\
0.1 \\
0.1 \\
0.1 \\
0.1 \\
0.3 \\
0.1 \\
0.1 \\
0.1 \\
0.1 \\
0.1 \\
0.1 \\
0.1 \\
0.1 \\
0.1 \\
0.1 \\
0.1 \\
0.1 \\
0.1 \\
0.1 \\
0.1 \\
0.1 \\
0.1 \\
0.1 \\
0.1\end{array}$ & $\begin{array}{l}J \\
J \\
J\end{array}$ & $\begin{array}{l}0.1 \\
0.1 \\
0.1 \\
0.1 \\
0.1 \\
0.1 \\
0.1 \\
0.1 \\
0.1 \\
0.1 \\
0.1 \\
0.1 \\
0.1 \\
0.1 \\
0.1 \\
0.1 \\
0.1 \\
0.1 \\
0.1 \\
0.1 \\
0.1 \\
0.1 \\
0.01 \\
0.1 \\
0.1 \\
0.1 \\
0.1 \\
0.01 \\
0.1 \\
0.1 \\
0.1 \\
0.1\end{array}$ & $\begin{array}{l}- \\
- \\
- \\
- \\
- \\
- \\
- \\
- \\
- \\
- \\
- \\
- \\
- \\
- \\
- \\
- \\
- \\
- \\
- \\
- \\
- \\
- \\
- \\
- \\
- \\
-\end{array}$ \\
\hline
\end{tabular}

FORMATION OF COMPLETION CODE: AL - ALLUVIUM

PARAMETER VALUE INDICATOR (PVI)
FLOW RELATIONSHIP CODE:

O - ON-SITE

D - DOWN GRADIENT

SAMPLE ID CODES:

0001 - FILTERED SAMPLE (.45 MICRONS)

NO01 - UNFILTERED SAMPLE

OTHER PARAMETER VALUE FLAGS:

$J$ - ESTIMATED VALUE

$R$ - UNUSABLE DATA POINT 
TABLE 3.27 BASELINE GROUND WATER QUALITY DATA BY PARAMETER FOR THE ALLUVIUM, NC AND UC PROCESSING SITES, SLICK ROCK, COLORADO

SITE: SRKO1 SLICK ROCK (BOTH SITES)

REPORT DATE: $10 / 03 / 94$

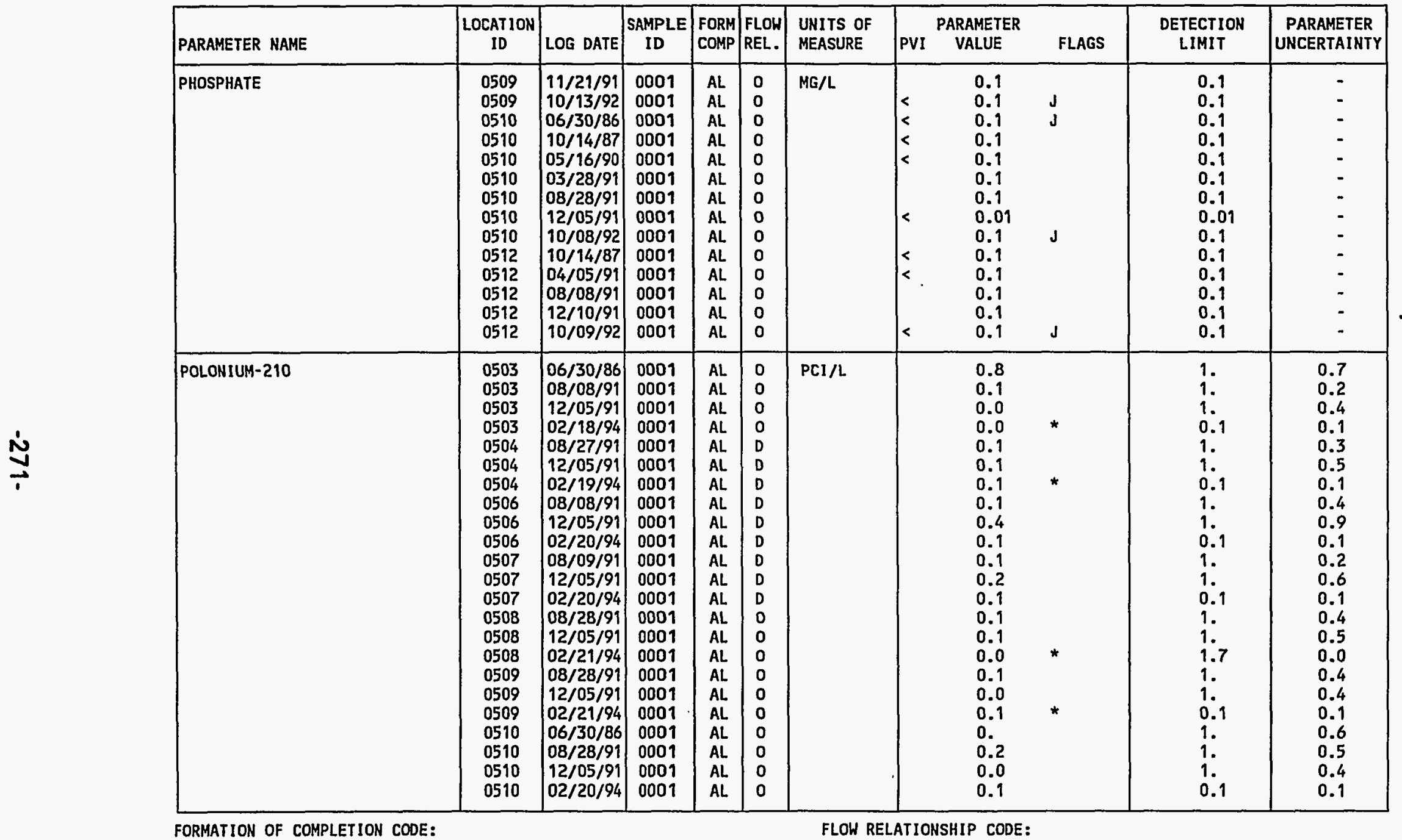

FORMATION OF COMPLETION CODE:

FLOW RELATIONSHIP CODE:

D - DOWN GRADIENT

PARAMETER VALUE INDICATOR (PVI): < - LESS THAN DETECTIION LIMIT

SAMPLE ID CODES

0001 - FILTERED SAMPLE (.45 MICRONS)

OTHER PARAMETER VALUE FLAGS:

* - DUPLICATE ANALYSIS NOT WITHIN CONTROL LIMITS

$J$ - ESTIMATED VALUE 
TABLE 3.27 BASELINE GROUND HATER QUALITY DATA BY PARAMETER FOR THE ALLUVIUM, NC AND UC PROCESSING SITES, SLICK ROCK, COLORADO

SITE: SRKO1 SLICK ROCK (BOTH SITES)

09/07/82 TO $02 / 23 / 94$

REPORT DATE: $10 / 03 / 94$

\begin{tabular}{|c|c|c|c|c|c|c|c|c|c|c|}
\hline PARAMETER NAME & $\underset{\text { ID }}{\text { LOCATION }}$ & LOG DATE & $\begin{array}{c}\text { SAMPLE } \\
\text { ID }\end{array}$ & $\begin{array}{l}\text { FORM } \\
\text { COMP }\end{array}$ & $\begin{array}{l}\text { FLOW } \\
\text { REL. }\end{array}$ & $\begin{array}{l}\text { UNITS OF } \\
\text { MEASURE }\end{array}$ & $\begin{array}{cc}\text { PARAMETER } \\
\text { PVI } \\
\text { VALUE }\end{array}$ & FLAGS & $\begin{array}{l}\text { DETECTION } \\
\text { LIMIT }\end{array}$ & $\begin{array}{l}\text { PARAMETER } \\
\text { UNCERTAINTY }\end{array}$ \\
\hline POLONIUM-210 & $\begin{array}{l}0512 \\
0512 \\
0512\end{array}$ & $\begin{array}{l}08 / 08 / 91 \\
12 / 05 / 91 \\
02 / 20 / 94\end{array}$ & $\begin{array}{l}0001 \\
0001 \\
0001\end{array}$ & $\begin{array}{l}A L \\
A L \\
A L\end{array}$ & $\begin{array}{l}0 \\
0 \\
0\end{array}$ & $\mathrm{PCI} / \mathrm{L}$ & $\begin{array}{l}0.3 \\
0.0 \\
0.1\end{array}$ & * & $\begin{array}{l}1 . \\
1 . \\
0.2\end{array}$ & $\begin{array}{l}0.4 \\
0.3 \\
0.1\end{array}$ \\
\hline POLONIUM-210 (TOTAL) & $\begin{array}{l}0503 \\
0504 \\
0506 \\
0507 \\
0508 \\
0509 \\
0510 \\
0512\end{array}$ & $\begin{array}{l}02 / 18 / 94 \\
02 / 19 / 94 \\
02 / 20 / 94 \\
02 / 20 / 94 \\
02 / 21 / 94 \\
02 / 21 / 94 \\
02 / 20 / 94 \\
02 / 20 / 94\end{array}$ & $\begin{array}{l}\text { N001 } \\
\text { N001 } \\
\text { N001 } \\
\text { N001 } \\
\text { N001 } \\
\text { N001 } \\
\text { N001 } \\
\text { N001 }\end{array}$ & $\begin{array}{l}A L \\
A L \\
A L \\
A L \\
A L \\
A L \\
A L \\
A L\end{array}$ & $\begin{array}{l}0 \\
D \\
D \\
D \\
0 \\
0 \\
0 \\
0\end{array}$ & PCI/L & $\begin{array}{l}0.7 \\
0.2 \\
0.2 \\
0.1 \\
0.3 \\
0.0 \\
0.1 \\
0.1\end{array}$ & $\begin{array}{l}* \\
* \\
* \\
* \\
*\end{array}$ & $\begin{array}{l}0.1 \\
0.1 \\
0.1 \\
0.1 \\
2.0 \\
0.2 \\
0.5 \\
0.1\end{array}$ & $\begin{array}{l}0.2 \\
0.1 \\
0.1 \\
0.1 \\
1.1 \\
0.1 \\
0.3 \\
0.1\end{array}$ \\
\hline POTASSIUM & $\begin{array}{l}0503 \\
0503 \\
0503 \\
0503 \\
0503 \\
0503 \\
0503 \\
0503 \\
0503 \\
0503 \\
0503 \\
0504 \\
0504 \\
0504 \\
0504 \\
0504 \\
0504 \\
0504 \\
0504 \\
0504 \\
0504 \\
0504 \\
0506 \\
0506\end{array}$ & $\begin{array}{l}09 / 07 / 82 \\
02 / 18 / 86 \\
06 / 30 / 86 \\
10 / 14 / 87 \\
02 / 22 / 88 \\
05 / 16 / 90 \\
03 / 29 / 91 \\
08 / 08 / 91 \\
12 / 09 / 91 \\
10 / 09 / 92 \\
02 / 18 / 94 \\
09 / 07 / 82 \\
02 / 04 / 86 \\
07 / 01 / 86 \\
10 / 14 / 87 \\
02 / 22 / 88 \\
05 / 16 / 90 \\
04 / 03 / 91 \\
08 / 27 / 91 \\
12 / 09 / 91 \\
10 / 09 / 92 \\
02 / 19 / 94 \\
09 / 08 / 82 \\
02 / 05 / 86\end{array}$ & $\begin{array}{l}0001 \\
0001 \\
0001 \\
0001 \\
0001 \\
0001 \\
0001 \\
0001 \\
0001 \\
0001 \\
0001 \\
0001 \\
0001 \\
0001 \\
0001 \\
0001 \\
0001 \\
0001 \\
0001 \\
0001 \\
0001 \\
0001 \\
0001 \\
0001\end{array}$ & $\begin{array}{l}A L \\
A L \\
A L \\
A L \\
A L \\
A L \\
A L \\
A L \\
A L \\
A L \\
A L \\
A L \\
A L \\
A L \\
A L \\
A L \\
A L \\
A L \\
A L \\
A L \\
A L \\
A L \\
A L \\
A L\end{array}$ & $\begin{array}{l}0 \\
0 \\
0 \\
0 \\
0 \\
0 \\
0 \\
0 \\
0 \\
0 \\
0 \\
D \\
D \\
D \\
D \\
D \\
D \\
D \\
D \\
D \\
D \\
D \\
D \\
D\end{array}$ & $M G / L$ & $\begin{array}{l}42.00 \\
54.1 \\
44.7 \\
41 . \\
49.1 \\
41.7 \\
35 . \\
38 . \\
32 . \\
32 . \\
34.9 \\
11.00 \\
13.3 \\
12.4 \\
12.6 \\
14.0 \\
10.6 \\
9.0 \\
8.3 \\
8.11 \\
8.15 \\
14.0 \\
33.00 \\
39.2\end{array}$ & L & $\begin{array}{l}0.01 \\
0.01 \\
0.01 \\
0.01 \\
0.01 \\
5 . \\
5 . \\
5 . \\
5 . \\
0.1 \\
- \\
0.01 \\
0.01 \\
0.01 \\
0.01 \\
0.01 \\
0.01 \\
0.01 \\
0.01 \\
0.01 \\
0.1 \\
- \\
0.01\end{array}$ & $\begin{array}{l}- \\
- \\
- \\
- \\
- \\
- \\
- \\
- \\
- \\
- \\
- \\
- \\
- \\
- \\
- \\
- \\
- \\
- \\
- \\
- \\
-\end{array}$ \\
\hline
\end{tabular}

FORMATION OF COMPLETION CODE:

FLOW RELATIONSHIP CODE:

AL - ALLUVIUM

O - ON-SITE

D - DOHN GRADIENT

PARAMETER VALUE INDICATOR (PVI): < - LESS THAN DETECTION LIMIT

SAMPLE ID CODES:

0001 - FILTERED SAMPLE (.45 MICRONS)

OTHER PARAMETER VALUE FLAGS:

NOO1 - UNFILTERED SAMPLE

* - DUPLICATE ANALYSIS NOT WITHIN CONTROL LIMITS

$J$ - ESTIMATED VALUE

L - LESS THAN THREE BORE VOLUMES REMOVED BEFORE SAMPLING 
TABLE 3.27 BASELINE GROUND WATER QUALITY DATA BY PARAMETER FOR THE ALLUVIUM, NC AND UC PROCESSING SITES, SLICK ROCK, COLORADO

SITE: SRKO1 SLICK ROCK (BOTH SITES)

$09 / 07 / 82$ TO 02/22/94

REPORT DATE: $10 / 03 / 94$

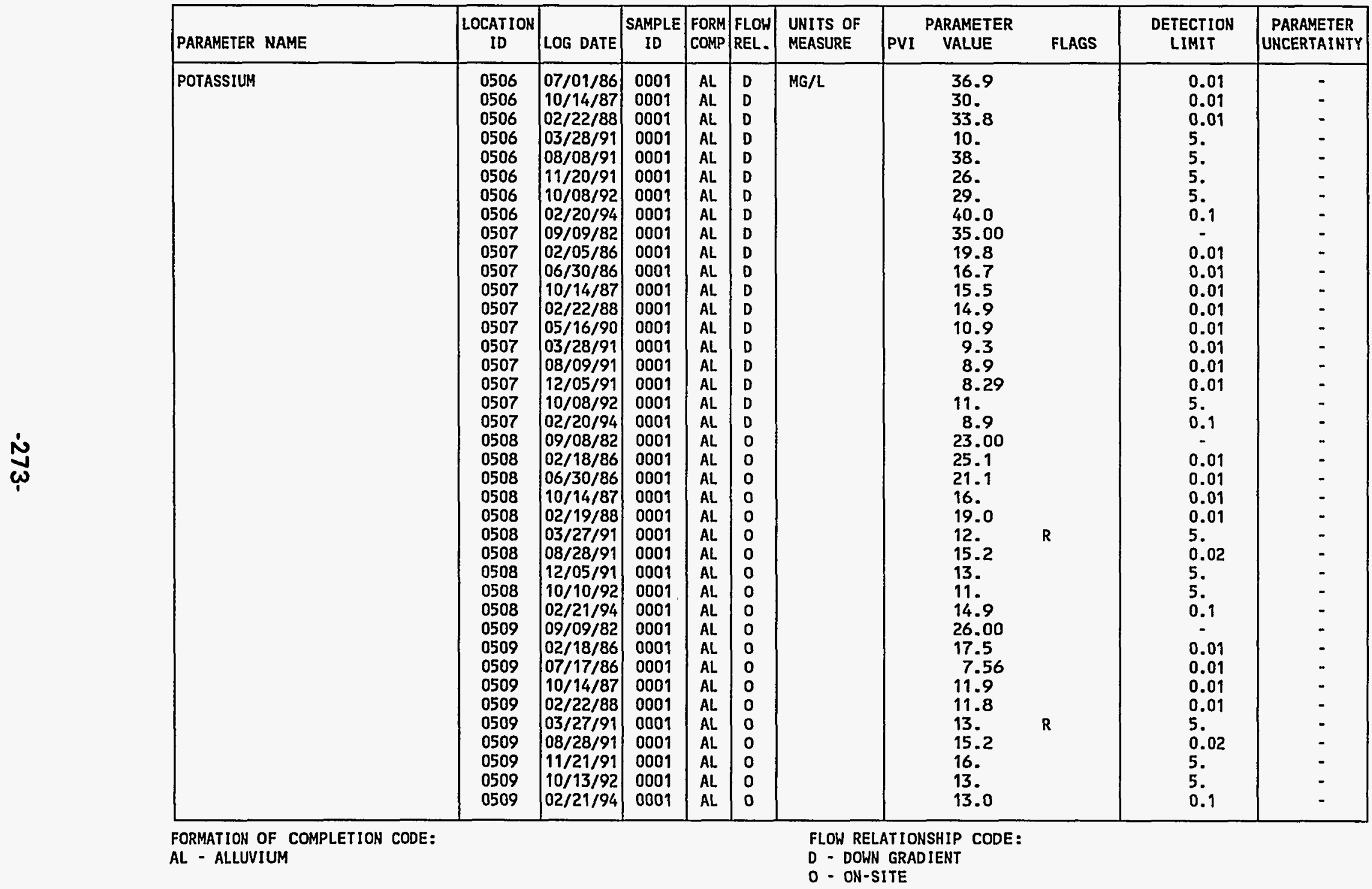

PARAMETER VALUE INDICATOR (PVI): < - LESS THAN DETECTION LIMIT

0001 - FILTERED SAMPLE (.45 MICRONS)

OTHER PARAMETER VALUE FLAGS:

$R$ - UNUSABLE DATA POINT 


\begin{tabular}{|c|c|c|c|c|c|}
\hline \multirow{10}{*}{ 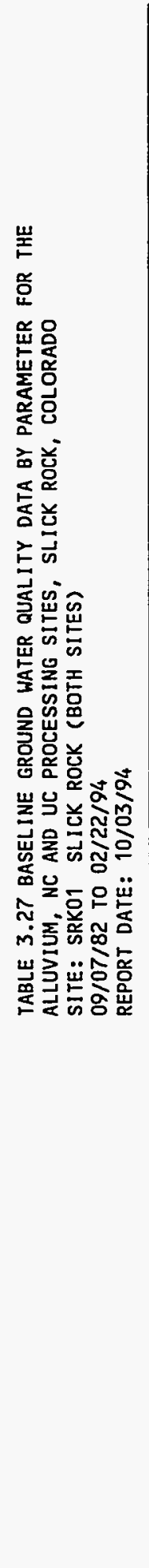 } & ', & 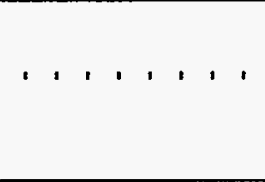 & ' & \multirow{10}{*}{ 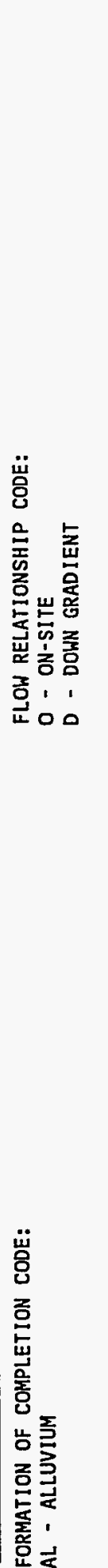 } & \multirow{4}{*}{ 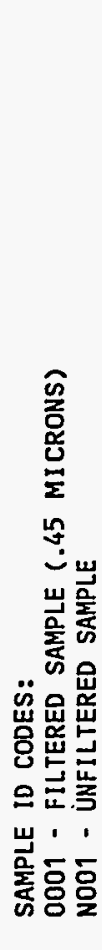 } \\
\hline & 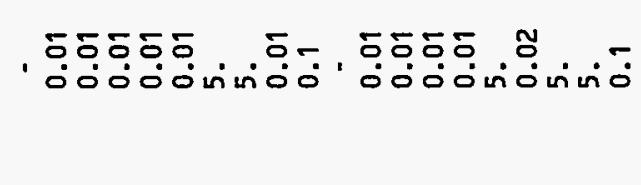 & 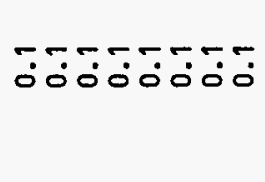 & 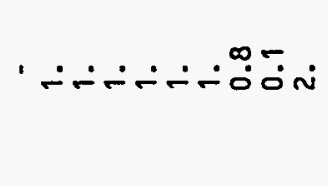 & & \\
\hline & 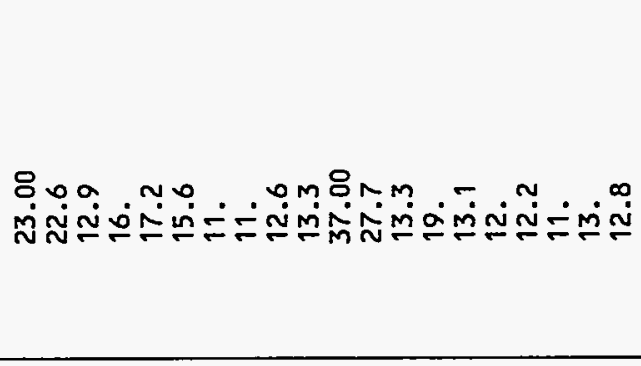 & 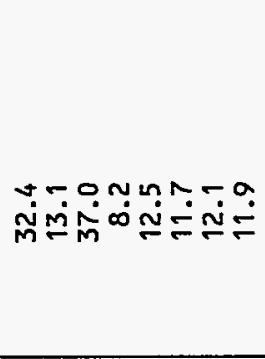 & 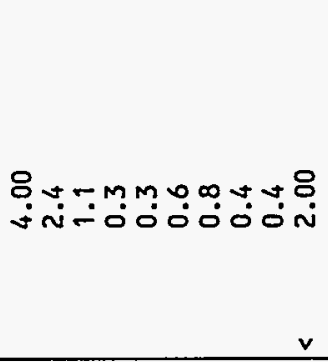 & & \\
\hline & 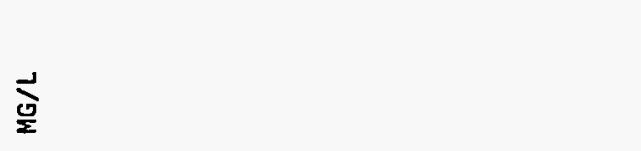 & ङ & $\stackrel{5}{\grave{0}}$ & & \\
\hline & 00000000000000000000 & 00000000 & 0000000000 & & \multirow{5}{*}{ 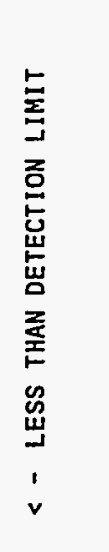 } \\
\hline & 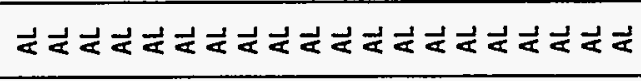 & 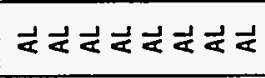 & 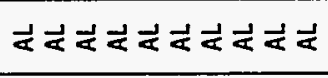 & & \\
\hline & 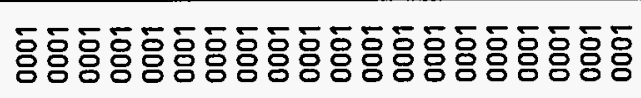 & 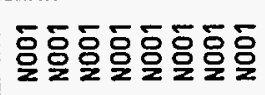 & 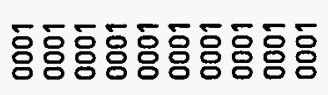 & & \\
\hline & 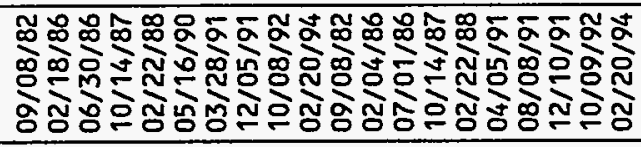 & 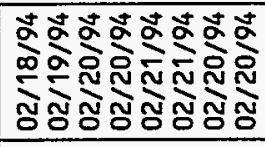 & 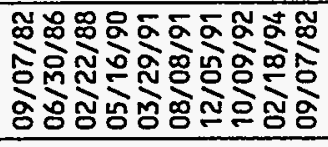 & & \\
\hline & 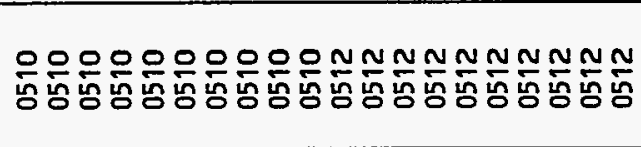 & 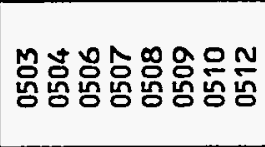 & 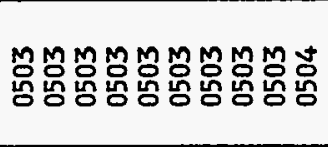 & & \\
\hline & 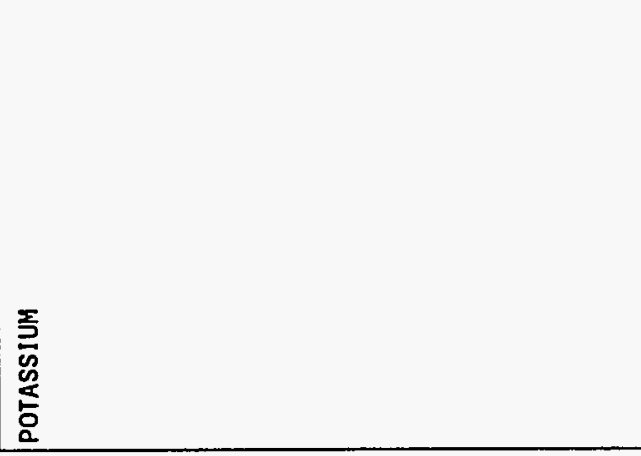 & 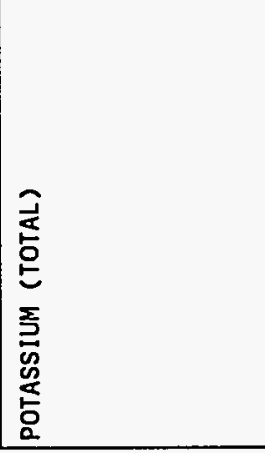 & 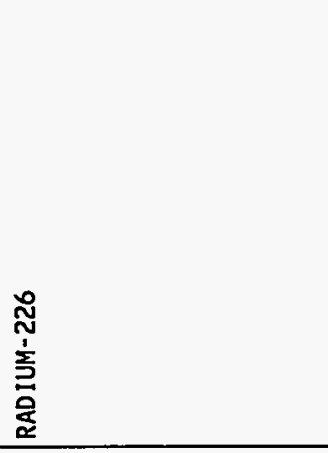 & & 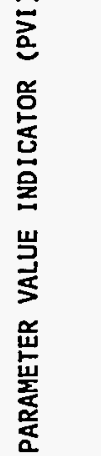 \\
\hline
\end{tabular}


TABLE 3.27 BASELINE GROUND HATER QUALITY DATA BY PARAMETER FOR THE ALLUVIUM, NC AND UC PROCESSING SITES, SLICK ROCK, COLORADO

SITE: SRKO1 SLICK ROCK (BOTH SITES)

$09 / 07 / 82$ TO $02 / 22 / 94$

REPORT DATE: $10 / 03 / 94$

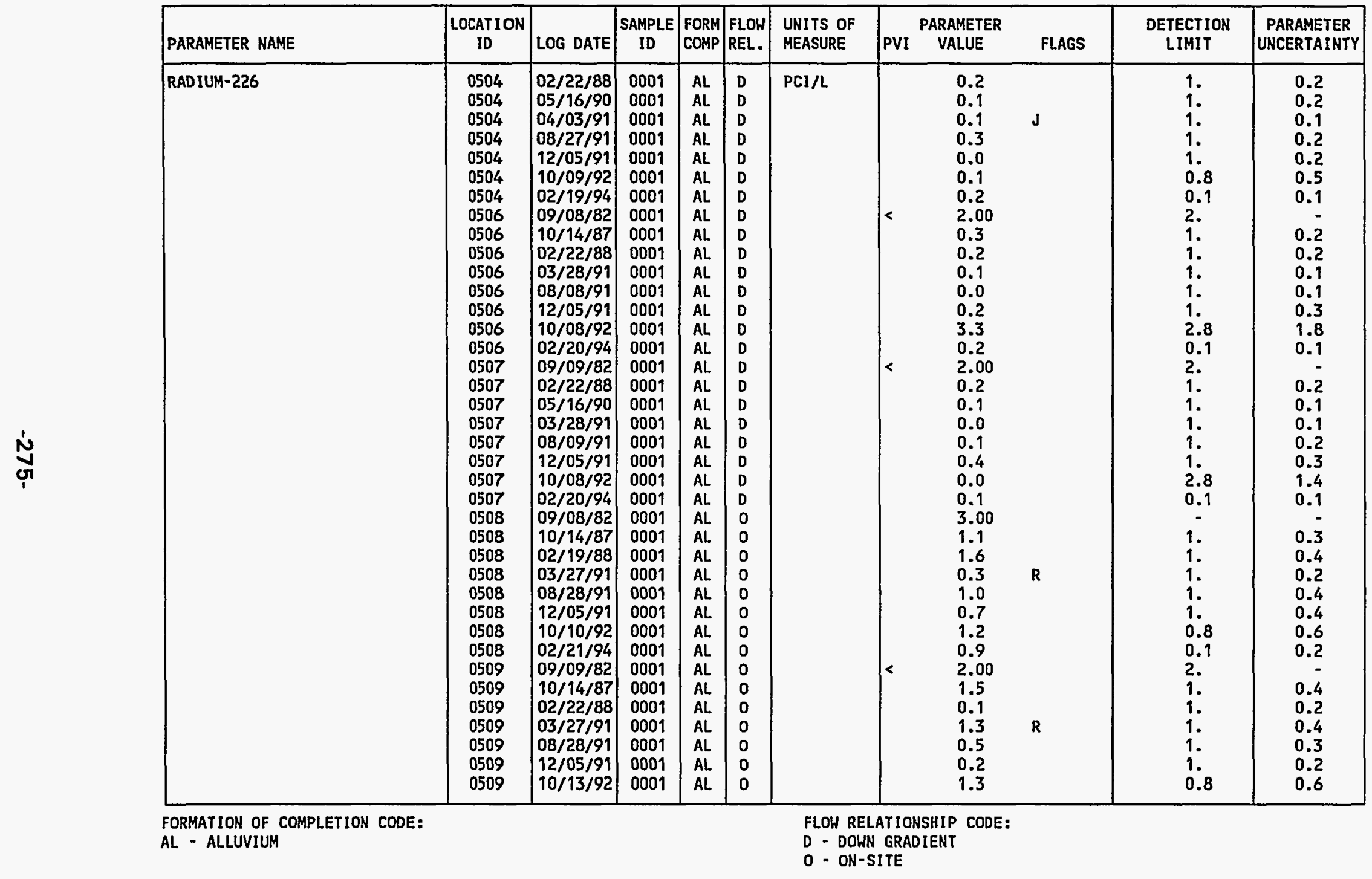

PARAMETER VALUE INDICATOR (PVI): < - LESS THAN DETECTION LIMIT

SAMPLE ID CODES:

0001 - FILTERED SAMPLE (.45 MICRONS)

OTHER PARAMETER VALUE FLAGS:

$J$ - ESTIMATED VALUE

$R$ - UNUSABLE DATA POINT 
TABLE 3.27 BASELINE GROUND HATER QUALITY DATA BY PARAMETER FOR THE ALLUVIUM, NC AND UC PROCESSING SITES, SLICK ROCK, COLORADO

SITE: SRK01 SLICK ROCK (BOTH SITES)

09/07/82 TO $02 / 22 / 94$

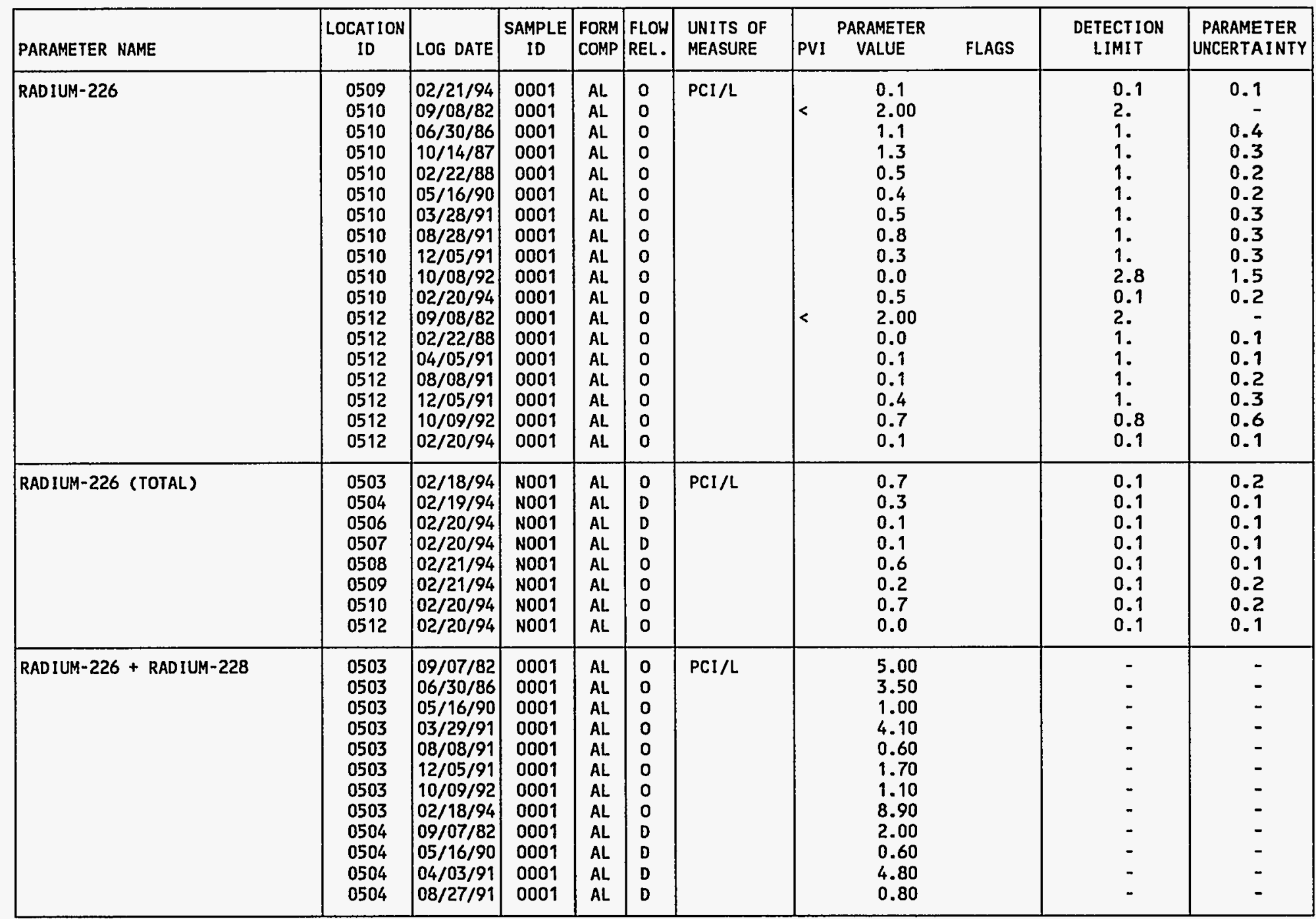

FORMATION OF COMPLETION CODE: AL - ALLUVIUM
FLOW RELATIONSHIP CODE:

O - ON-SITE

D - DOHN GRADIENT

PARAMETER VALUE INDICATOR (PVI): < - LESS THAN DETECTION LIMIT

SAMPLE IO CODES:

0001 - FILTERED SAMPLE (.45 MICRONS)

NO01 - UNFILTERED SAMPLE 
TABLE 3.27 BASELINE GROUND WATER QUALITY DATA BY PARAMETER FOR THE ALLUVIUH, NC AND UC PROCESSING SITES, SLICK ROCK, COLORADD

SITE: SRKOI SLICK ROCK (BOTH SITES)

$09 / 07 / 82$ TO $02 / 22 / 94$

REPORT DATE: $10 / 03 / 94$

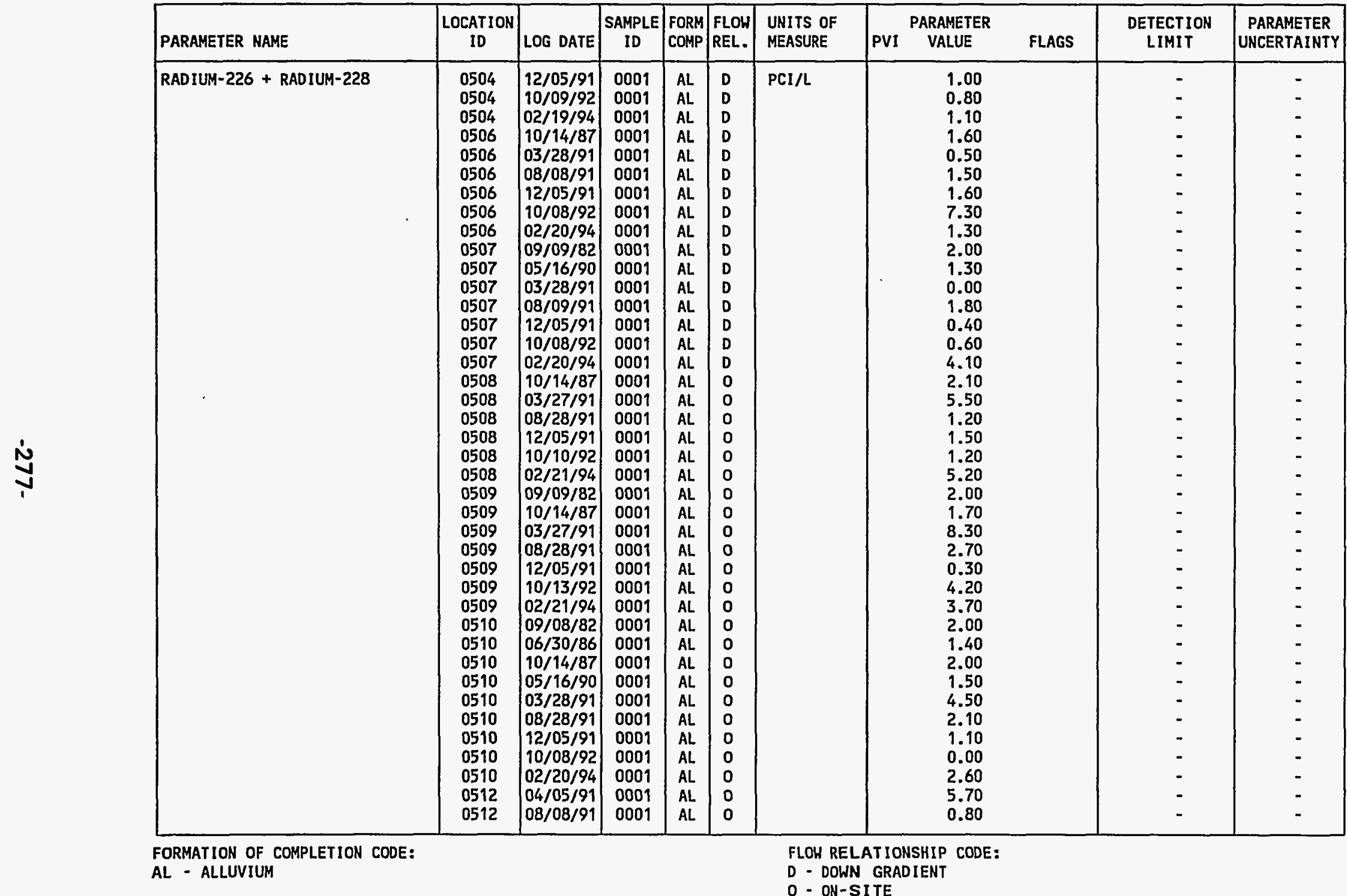

PARAMETER VALUE INDICATOR (PVI): < - LESS THAN DETECTION LIMIT SAMPLE ID CODES:

0001 - FILTERED SAMPLE (.45 MICRONS) 
TABLE 3.27 BASELINE GROUND WATER QUALITY DATA BY PARAMETER FOR THE ALIUVIUM NC AND UC PROCESSING SITES, SLICK ROCK, COLORADO

SITE: SRKO1 SLICK ROCK (BOTH SITES)

$09 / 07 / 82$ TO $02 / 22 / 94$

REPORT DATE: $10 / 03 / 94$

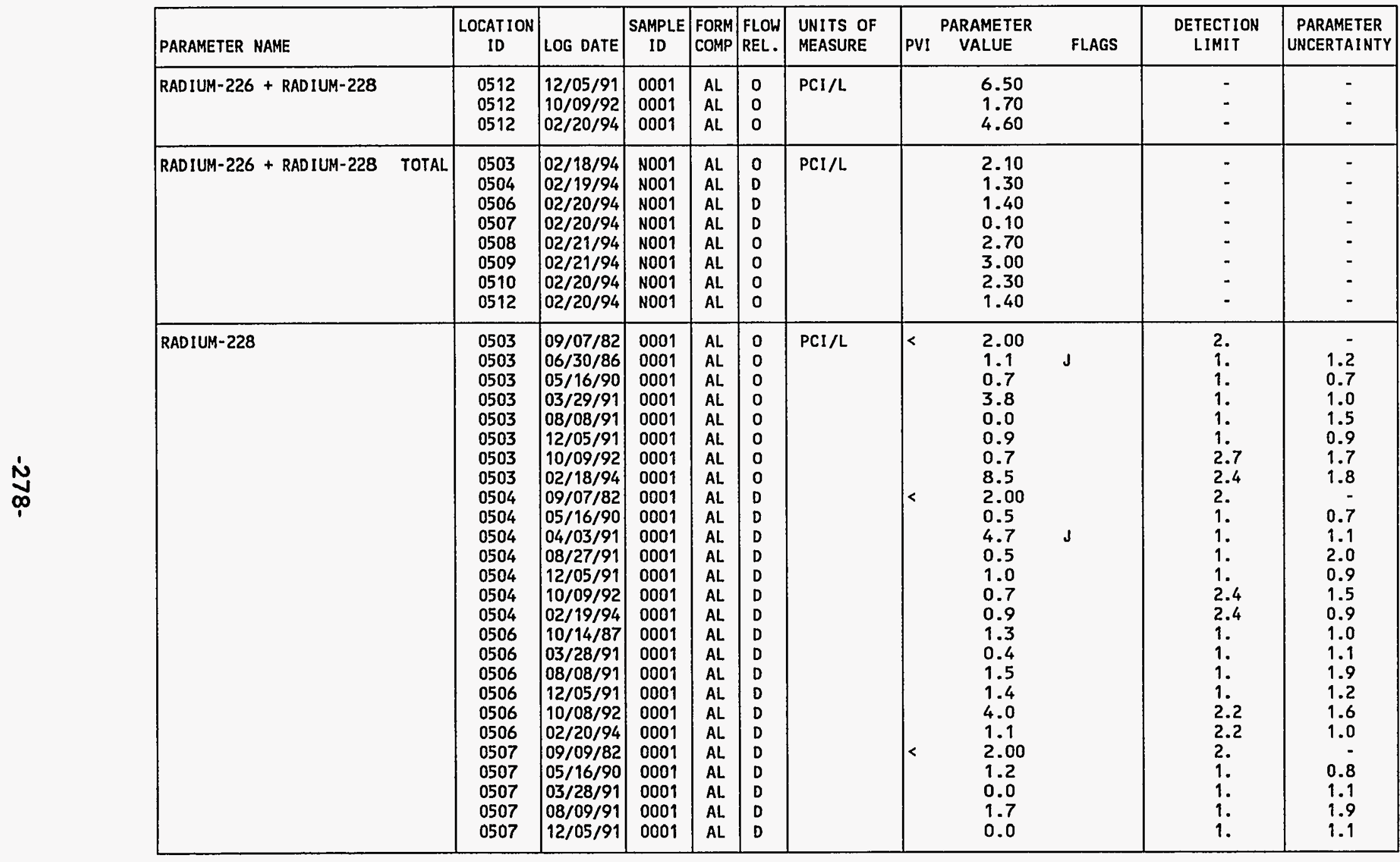

FORMATION OF COMPLETION CODE:

AL - ALLUVIUM

PARAMETER VALUE INDICATOR (PVI): < - LESS THAN DETECTION LIMIT

OTHER PARAMETER VALUE FLAGS:

$J$ - ESTIMATED VALUE
FLOW RELATIONSHIP CODE:

D - DOWN GRADIENT

SAMPLE ID CODES:

0001 - FILTERED SAMPLE (.45 MICRONS)

NOO1 - UNFILTERED SAMPLE 


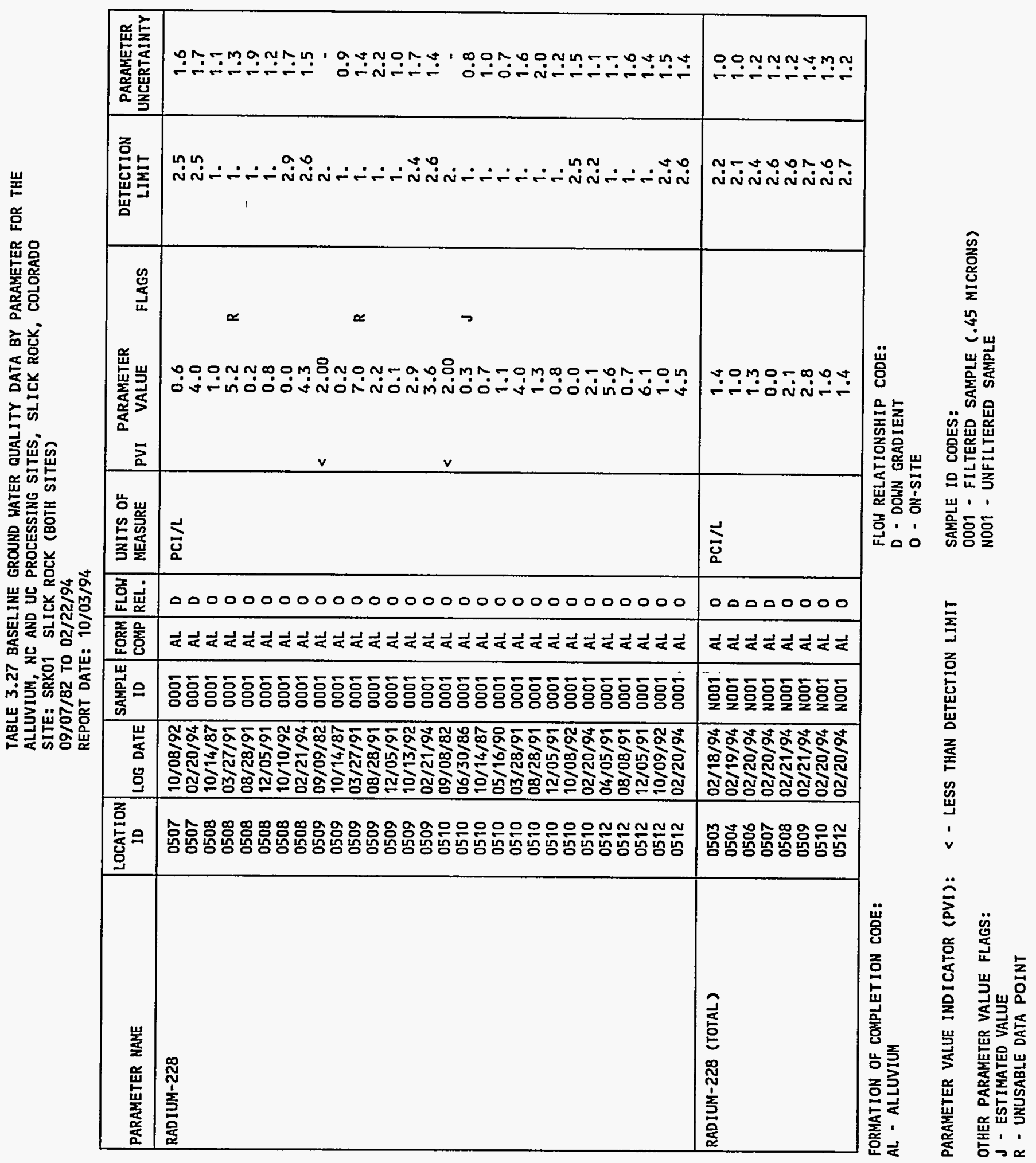


TABLE 3.27 BASELINE GROUND WATER QUALITY DATA BY PARAMETER FOR THE ALLUVIUM, NC AND UC PROCESSING SITES, SLICK ROCK, COLORADO

SITE: SRKOT SLICK ROCK (BOTH SITES)

$09 / 07 / 82$ TO $02 / 22 / 94$

REPORT DATE: $10 / 03 / 94$

\begin{tabular}{|c|c|c|c|c|c|c|c|c|c|c|c|c|}
\hline & PARAMETER NAME & $\begin{array}{c}\text { LOCATION } \\
\text { ID }\end{array}$ & LOG DATE & $\begin{array}{c}\text { SAMPLE } \\
\text { ID }\end{array}$ & $\begin{array}{l}\text { FORM } \\
\text { COMP }\end{array}$ & $\begin{array}{l}\text { FLOW } \\
\text { REL. }\end{array}$ & $\begin{array}{l}\text { UNITS OF } \\
\text { MEASURE }\end{array}$ & PVI & $\begin{array}{l}\text { ARAMETER } \\
\text { VALUE }\end{array}$ & FLAGS & $\begin{array}{l}\text { DETECTION } \\
\text { LIMIT }\end{array}$ & $\begin{array}{l}\text { PARAMETER } \\
\text { UNCERTAINTY }\end{array}$ \\
\hline & REDOX POTENTIAL. & $\begin{array}{l}0503 \\
0503 \\
0504 \\
0504 \\
0506 \\
0506 \\
0507 \\
0507 \\
0508 \\
0508 \\
0509 \\
0509 \\
0510 \\
0510 \\
0512 \\
0512\end{array}$ & $\begin{array}{l}10 / 09 / 92 \\
02 / 22 / 94 \\
10 / 09 / 92 \\
02 / 19 / 94 \\
10 / 08 / 92 \\
02 / 20 / 94 \\
10 / 08 / 92 \\
02 / 20 / 94 \\
10 / 10 / 92 \\
02 / 21 / 94 \\
10 / 13 / 92 \\
02 / 21 / 94 \\
10 / 08 / 92 \\
02 / 20 / 94 \\
10 / 09 / 92 \\
02 / 20 / 94\end{array}$ & $\begin{array}{l}0001 \\
\text { N001 } \\
0001 \\
\text { N001 } \\
0001 \\
\text { N001 } \\
0001 \\
\text { N001 } \\
0001 \\
\text { N001 } \\
0001 \\
\text { N001 } \\
0001 \\
\text { N001 } \\
0001 \\
\text { N001 }\end{array}$ & $\begin{array}{l}A L \\
A L \\
A L \\
A L \\
A L \\
A L \\
A L \\
A L \\
A L \\
A L \\
A L \\
A L \\
A L \\
A L \\
A L \\
A L\end{array}$ & $\begin{array}{l}0 \\
0 \\
D \\
D \\
D \\
D \\
D \\
D \\
0 \\
0 \\
0 \\
0 \\
0 \\
0 \\
0 \\
0\end{array}$ & mVOLTS & & $\begin{array}{l}252.8 \\
216 \\
77.8 \\
161 \\
431.6 \\
370 \\
323.8 \\
158 \\
417.8 \\
494 \\
469.5 \\
479 \\
543.8 \\
480 \\
455.3 \\
322\end{array}$ & & $\begin{array}{l}- \\
- \\
- \\
- \\
- \\
- \\
- \\
- \\
- \\
- \\
- \\
-\end{array}$ & $\begin{array}{l}- \\
- \\
- \\
- \\
- \\
- \\
- \\
- \\
- \\
- \\
- \\
-\end{array}$ \\
\hline$\stackrel{\leftrightarrow}{\infty}$ & SELENIUM & $\begin{array}{l}0503 \\
0503 \\
0503 \\
0503 \\
0503 \\
0503 \\
0503 \\
0503 \\
0503 \\
0503 \\
0504 \\
0504 \\
0504 \\
0504 \\
0504 \\
0504 \\
0504 \\
0504 \\
0504\end{array}$ & $\begin{array}{l}09 / 07 / 82 \\
02 / 18 / 86 \\
06 / 30 / 86 \\
10 / 14 / 87 \\
05 / 16 / 90 \\
03 / 29 / 91 \\
08 / 08 / 91 \\
12 / 09 / 91 \\
10 / 09 / 92 \\
02 / 18 / 94 \\
09 / 07 / 82 \\
02 / 04 / 86 \\
07 / 01 / 86 \\
10 / 14 / 87 \\
05 / 16 / 90 \\
04 / 03 / 91 \\
08 / 27 / 91 \\
12 / 09 / 91 \\
10 / 09 / 92\end{array}$ & $\begin{array}{l}0001 \\
0001 \\
0001 \\
0001 \\
0001 \\
0001 \\
0001 \\
0001 \\
0001 \\
0001 \\
0001 \\
0001 \\
0001 \\
0001 \\
0001 \\
0001 \\
0001 \\
0001 \\
0001\end{array}$ & $\begin{array}{l}A L \\
A L \\
A L \\
A L \\
A L \\
A L \\
A L \\
A L \\
A L \\
A L \\
A L \\
A L \\
A L \\
A L \\
A L \\
A L \\
A L \\
A L \\
A L\end{array}$ & $\begin{array}{l}0 \\
0 \\
0 \\
0 \\
0 \\
0 \\
0 \\
0 \\
0 \\
0 \\
D \\
D \\
D \\
D \\
D \\
D \\
D \\
D \\
D\end{array}$ & $M G / L$ & $\begin{array}{l}< \\
< \\
< \\
< \\
< \\
< \\
< \\
< \\
< \\
< \\
< \\
< \\
< \\
< \\
< \\
< \\
< \\
< \\
<\end{array}$ & $\begin{array}{l}0.01 \\
0.005 \\
0.005 \\
0.005 \\
0.015 \\
0.03 \\
0.005 \\
0.03 \\
0.005 \\
0.005 \\
0.01 \\
0.005 \\
0.005 \\
0.005 \\
0.015 \\
0.03 \\
0.005 \\
0.03 \\
0.005\end{array}$ & $\begin{array}{l}\text { L. } \\
I \\
W \\
I\end{array}$ & $\begin{array}{l}0.01 \\
0.005 \\
0.005 \\
0.005 \\
0.005 \\
0.03 \\
0.005 \\
0.03 \\
0.005 \\
0.005 \\
0.01 \\
0.005 \\
0.005 \\
0.005 \\
0.005 \\
0.03 \\
0.005 \\
0.03 \\
0.005\end{array}$ & $\begin{array}{l}- \\
- \\
- \\
- \\
- \\
- \\
- \\
- \\
- \\
- \\
- \\
- \\
- \\
- \\
- \\
-\end{array}$ \\
\hline
\end{tabular}

FORMATION OF COMPLETION CODE:

AL - ALLUVIUM

PARAMETER VALUE INDICATOR (PVI): < - LESS THAN DETECTION LIMIT

OTHER PARAMETER VALUE FLAGS:

1 - INCREASED DETECTION LIMIT DUE TO REQUIRED DILUTION

$J$ - ESTIMATED VALUE

L - LESS THAN THREE BORE VOLUMES REMOVED BEFORE SAMPLING

$W$ - POST-DIGEST SPIKE OUT OF CNTR LIM WHILE SAMP ABS < 50\% SPIKE
FLOW RELATIONSHIP CODE:

O - ON-SITE

D - DOWN GRADIENT

\section{SAMPLE ID CODES:}

0001 - FILTERED SAMPLE (.45 MICRONS)

NO01 - UNFILTERED SAMPLE 
TABLE 3.27 BASELINE GROUND HATER QUALITY DATA BY PARAMETER FOR THE ALLUVIUN, NC AND UC PROCESSING SITES, SLICK ROCK, COLORADO

SITE: SRKO1 SLICK ROCK (BOTH SITES)

09/07/82 TO 02/22/94

REPORT DATE: $10 / 03 / 94$

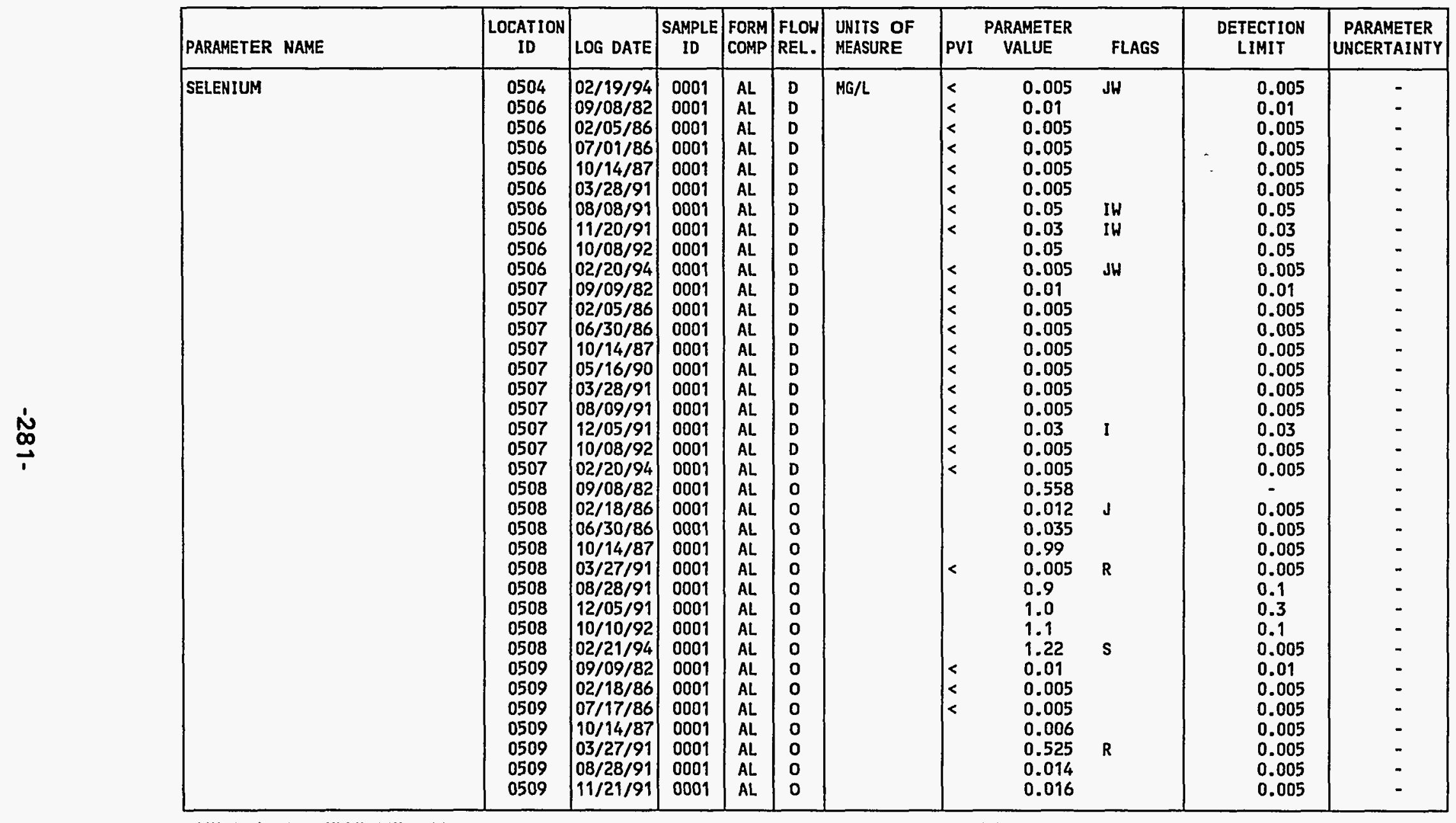

FORMATION OF COMPLETION CODE:

AL - ALLUVIUM

PARAMETER VALUE INDICATOR (PVI): < - LESS THAN DETECTION LIMIT
FLOW RELATIONSHIP CODE:

D - DOWN GRADIENT

O - ON-SITE

SAMPLE ID CODES:

0001 - FILTERED SAMPLE (.45 MICRONS)

OTHER PARAMETER VALUE FLAGS:

I - INCREASED DETECTION LIMIT DUE TO REQUIRED DILUTION

$J$ - ESTIMATED VALUE

R - UNUSABLE DATA POINT

$S$ - REPORTED VALUE DETERMINED USING METHOD OF STD ADDITION (MSA)

$H$ - POST-DIGEST SPIKE OUT OF CNTR LIM WHILE SAMP ABS $<50 \%$ SPIKE 
TABLE 3.27 BASELINE GROUND HATER QUALITY DATA BY PARAMETER FOR THE ALLUVIUM, NC AND UC PROCESSING SITES, SLICK ROCK, COLORADO

SITE: SRKO1 SLICK ROCK (BOTH SITES)

$09 / 07 / 82$ TO $02 / 22 / 94$

REPORT DATE: $10 / 03 / 94$

\begin{tabular}{|c|c|c|c|c|c|c|c|c|c|c|c|}
\hline PARAMETER NAME & $\begin{array}{c}\text { LOCATION } \\
\text { ID }\end{array}$ & LOG DATE & $\begin{array}{c}\text { SAMPLE } \\
\text { ID }\end{array}$ & $\begin{array}{l}\text { FORM } \\
\text { COMP }\end{array}$ & $\begin{array}{l}\text { FLOH } \\
\text { REL. }\end{array}$ & $\begin{array}{l}\text { UNITS OF } \\
\text { MEASURE }\end{array}$ & PVI & $\begin{array}{l}\text { PARAMETER } \\
\text { VALUE }\end{array}$ & FLAGS & $\begin{array}{l}\text { DETECTION } \\
\text { LIMIT }\end{array}$ & $\begin{array}{l}\text { PARAMETER } \\
\text { UNCERTAINTY }\end{array}$ \\
\hline SELENIUM & $\begin{array}{l}0509 \\
0509 \\
0510 \\
0510 \\
0510 \\
0510 \\
0510 \\
0510 \\
0510 \\
0510 \\
0510 \\
0512 \\
0512 \\
0512 \\
0512 \\
0512 \\
0512 \\
0512 \\
0512 \\
0512\end{array}$ & \begin{tabular}{|l|}
$10 / 13 / 92$ \\
$02 / 21 / 94$ \\
$09 / 08 / 82$ \\
$02 / 18 / 86$ \\
$06 / 30 / 86$ \\
$10 / 14 / 87$ \\
$05 / 16 / 90$ \\
$03 / 28 / 91$ \\
$12 / 05 / 91$ \\
$10 / 08 / 92$ \\
$02 / 20 / 94$ \\
$09 / 08 / 82$ \\
$02 / 04 / 86$ \\
$07 / 01 / 86$ \\
$10 / 14 / 87$ \\
$04 / 05 / 91$ \\
$08 / 08 / 91$ \\
$12 / 10 / 91$ \\
$10 / 09 / 92$ \\
$02 / 20 / 94$
\end{tabular} & $\begin{array}{l}0001 \\
0001 \\
0001 \\
0001 \\
0001 \\
0001 \\
0001 \\
0001 \\
0001 \\
0001 \\
0001 \\
0001 \\
0001 \\
0001 \\
0001 \\
0001 \\
0001 \\
0001 \\
0001 \\
0001\end{array}$ & $\begin{array}{l}A L \\
A L \\
A L \\
A L \\
A L \\
A L \\
A L \\
A L \\
A L \\
A L \\
A L \\
A L \\
A L \\
A L \\
A L \\
A L \\
A L \\
A L \\
A L \\
A L\end{array}$ & $\begin{array}{l}0 \\
0 \\
0 \\
0 \\
0 \\
0 \\
0 \\
0 \\
0 \\
0 \\
0 \\
0 \\
0 \\
0 \\
0 \\
0 \\
0 \\
0 \\
0 \\
0\end{array}$ & $M G / L$ & $\mid \begin{array}{l}< \\
< \\
< \\
< \\
< \\
< \\
< \\
< \\
< \\
< \\
< \\
< \\
< \\
< \\
<\end{array}$ & $\begin{array}{l}0.009 \\
0.006 \\
0.063 \\
0.005 \\
0.005 \\
0.17 \\
0.016 \\
0.065 \\
0.10 \\
0.2 \\
0.640 \\
0.01 \\
0.005 \\
0.005 \\
0.005 \\
0.03 \\
0.005 \\
0.005 \\
0.005 \\
0.005\end{array}$ & $\begin{array}{l}\text { S } \\
\text { I } \\
\text { W } \\
\text { JW }\end{array}$ & $\begin{array}{l}0.005 \\
0.005 \\
- \\
0.005 \\
0.005 \\
0.005 \\
0.005 \\
0.005 \\
0.05 \\
0.2 \\
0.005 \\
0.01 \\
0.005 \\
0.005 \\
0.005 \\
0.03 \\
0.005 \\
0.005 \\
0.005 \\
0.005\end{array}$ & $\begin{array}{l}- \\
- \\
- \\
- \\
- \\
- \\
- \\
- \\
- \\
- \\
- \\
- \\
- \\
- \\
- \\
- \\
-\end{array}$ \\
\hline SELENIUM (TOTAL) & $\begin{array}{l}0503 \\
0504 \\
0506 \\
0507 \\
0508 \\
0509 \\
0510 \\
0512\end{array}$ & $\begin{array}{l}02 / 18 / 94 \\
02 / 19 / 94 \\
02 / 20 / 94 \\
02 / 20 / 94 \\
02 / 21 / 94 \\
02 / 21 / 94 \\
02 / 20 / 94 \\
02 / 20 / 94\end{array}$ & $\begin{array}{l}\text { N001 } \\
\text { N001 } \\
\text { N001 } \\
\text { N001 } \\
\text { N001 } \\
\text { N001 } \\
\text { N001 } \\
\text { N001 }\end{array}$ & $\begin{array}{l}A L \\
A L \\
A L \\
A L \\
A L \\
A L \\
A L \\
A L\end{array}$ & $\begin{array}{l}0 \\
D \\
D \\
D \\
0 \\
0 \\
0 \\
0\end{array}$ & MG/L & $\mid \begin{array}{l}< \\
< \\
< \\
<\end{array}$ & $\begin{array}{l}0.005 \\
0.005 \\
0.005 \\
0.005 \\
1.09 \\
0.005 \\
0.585 \\
0.005\end{array}$ & $\begin{array}{l}\text { JW } \\
\text { JW } \\
s \\
s\end{array}$ & $\begin{array}{l}0.005 \\
0.005 \\
0.005 \\
0.005 \\
0.005 \\
0.005 \\
0.005 \\
0.005\end{array}$ & $\begin{array}{l}- \\
: \\
- \\
- \\
-\end{array}$ \\
\hline SILICA - SIOZ & $\begin{array}{l}0503 \\
0503 \\
0503 \\
0503 \\
0503 \\
0503\end{array}$ & $\begin{array}{l}09 / 07 / 82 \\
06 / 30 / 86 \\
10 / 14 / 87 \\
02 / 22 / 88 \\
05 / 16 / 90 \\
03 / 29 / 91\end{array}$ & $\begin{array}{l}0001 \\
0001 \\
0001 \\
0001 \\
0001 \\
0001\end{array}$ & $\begin{array}{l}A L \\
A L \\
A L \\
A L \\
A L \\
A L\end{array}$ & $\begin{array}{l}0 \\
0 \\
0 \\
0 \\
0 \\
0\end{array}$ & $M G / L$ & & $\begin{array}{l}7.92 \\
7 . \\
13.9 \\
13.4 \\
15 . \\
12.2\end{array}$ & & $\begin{array}{l}- \\
2 . \\
2 . \\
2 . \\
2 . \\
0.1\end{array}$ & $\begin{array}{l}- \\
- \\
- \\
-\end{array}$ \\
\hline
\end{tabular}

FORMATION OF COMPLETION CODE:

AL - ALLUVIUM

PARAMETER VALUE INDICATOR (PVI): < - LESS THAN DETECTION LIMIT

OTHER PARAMETER VALUE FLAGS:

I - INCREASED DETECTION LIMIT DUE TO REQUIRED DILUTION

$J$ - ESTIMATED VALUE

$S$ - REPORTED VALUE DETERMINED USING METHOD OF STD ADDITION (MSA)

$W$ - POST-DIGEST SPIKE OUT OF CNTR LIM WHILE SAMP ABS < 50\% SPIKE
FLOW RELATIONSHIP CODE:

D - DOWN GRADIENT

SAMPLE ID CODES:

0001 - FILTERED SAMPLE (.45 MICRONS)

NO01 - UNFILTERED SAMPLE 


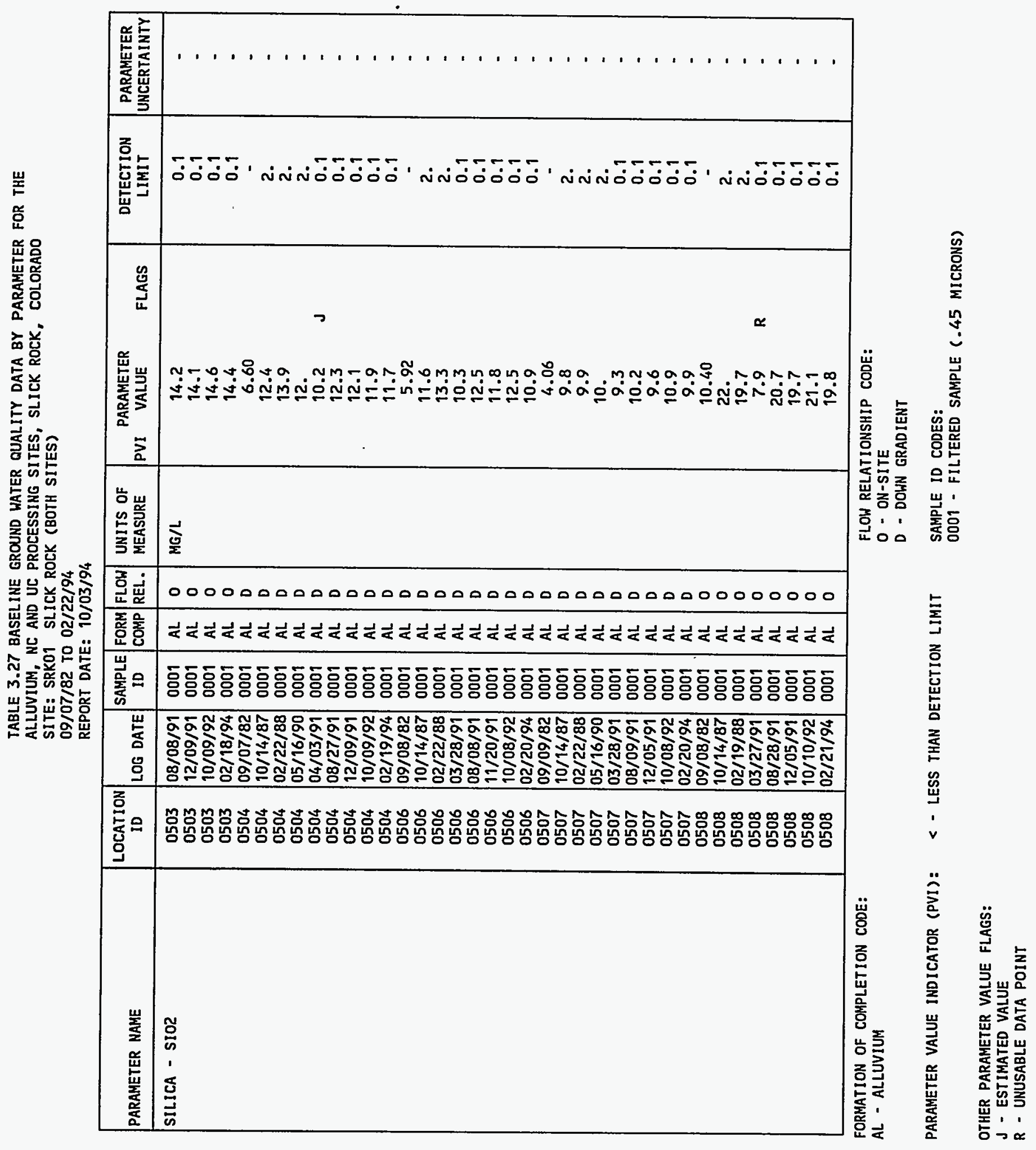


TABLE 3.27 BASELINE GROUND HATER QUALITY DATA BY PARAMETER FOR THE ALLUVIUM, NC AND UC PROCESSING SITES, SLICK ROCK, COLORADO

SITE: SRKO1 SLICK ROCK (BOTH SITES)

$09 / 07 / 82$ TO $02 / 22 / 94$

REPORT DATE: $10 / 03 / 94$

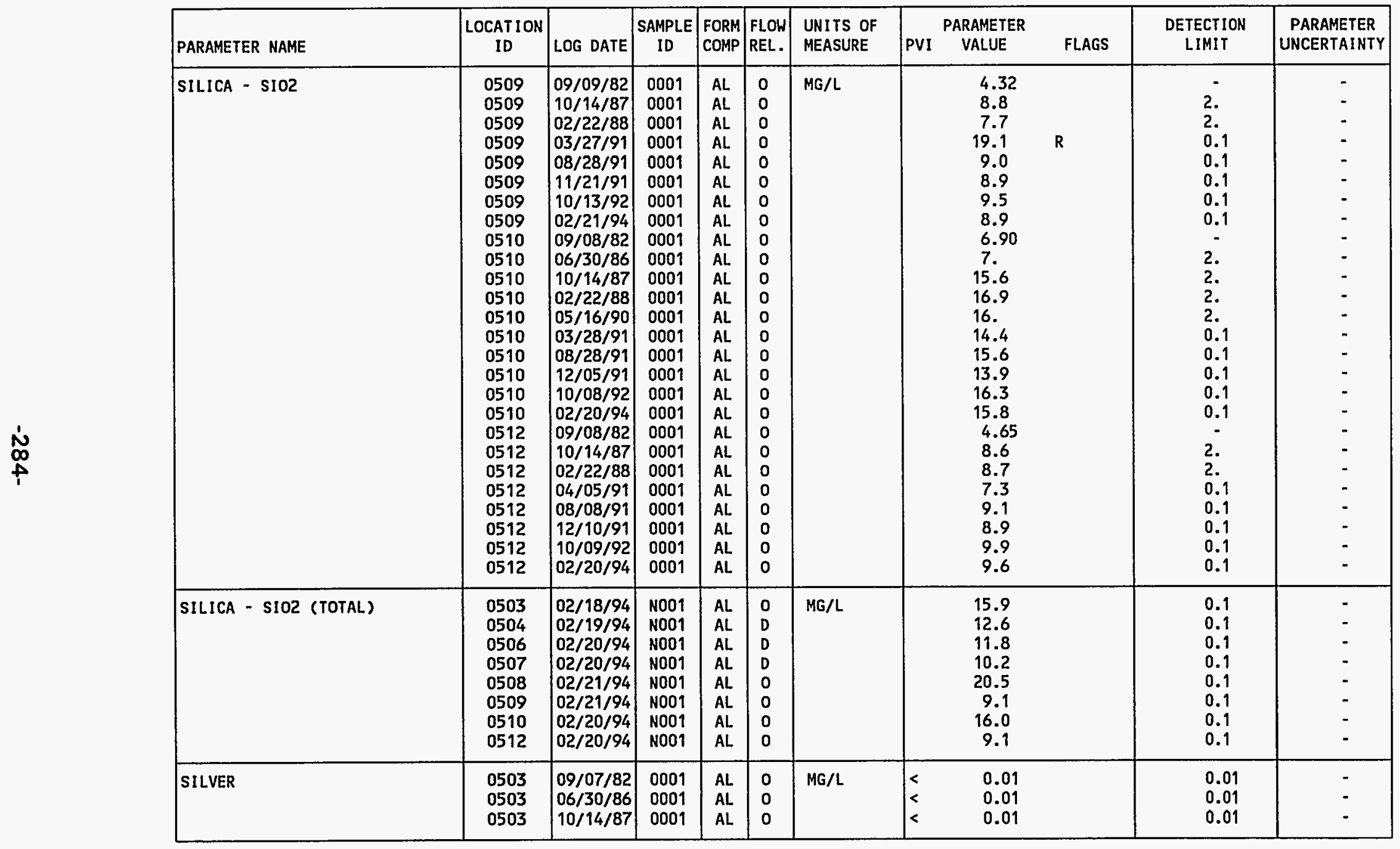

FORMATION OF COMPLETION CODE:

AL - ALLUVIUM

PARAMETER VALUE INDICATOR (PVI)

OTHER PARAMETER VALUE FLAGS:

$R$ - UNUSABLE DATA POINT
FLOW RELATIONSHIP CODE:

- ON-SITE

D - DOWN GRADIENT

SAMPLE ID CODES

0001 - FILTERED SAMPLE (.45 MICRONS)

N001 - UNFILTERED SAMPLE 


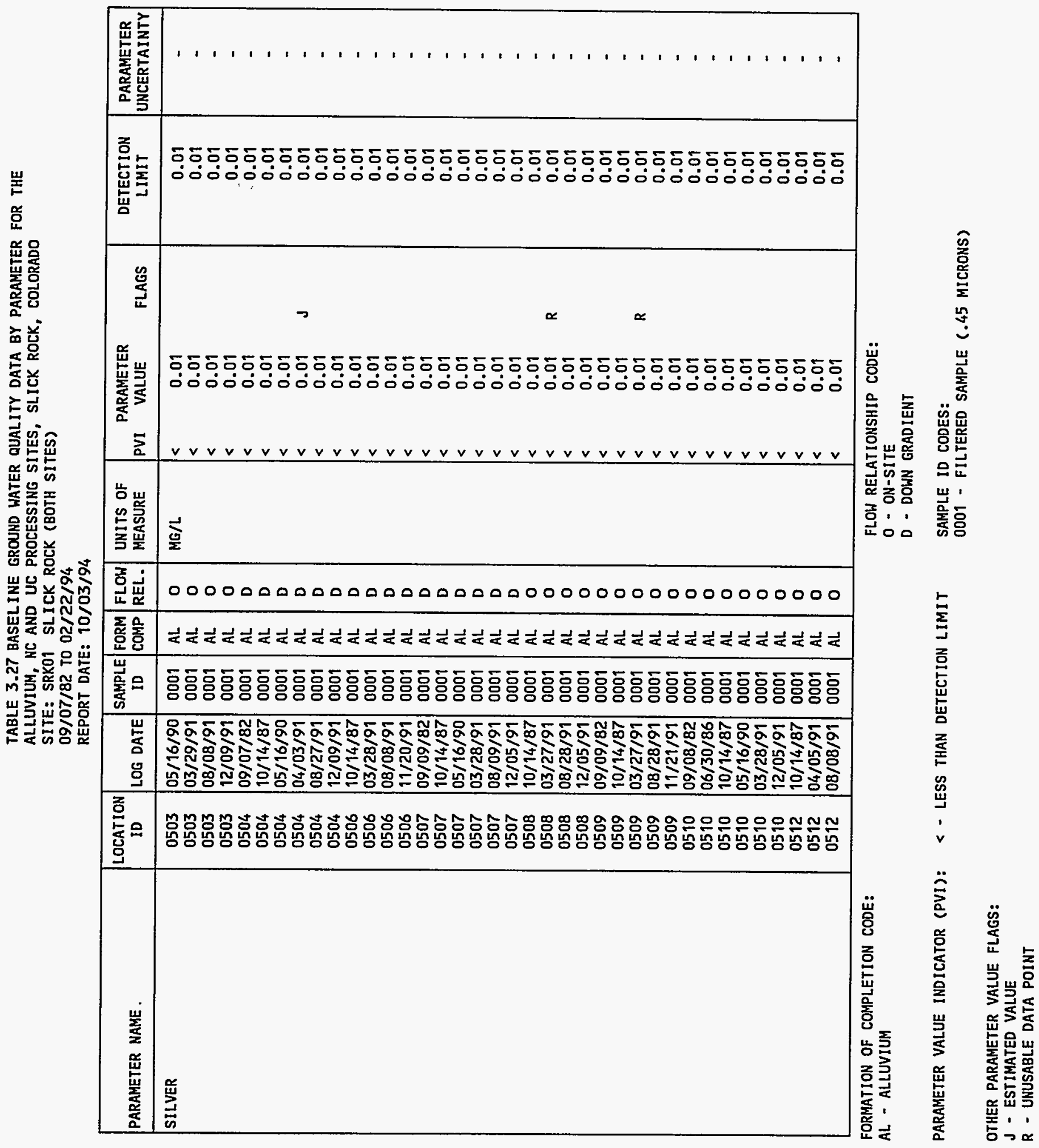


TABLE 3.27 BASELINE GROUND WATER QUALITY DATA BY PARAMETER FOR THE ALLUVIUM, NC AND UC PROCESSING SITES, SLICK ROCK, COLORADO

SITE: SRKO1 SLICK ROCK (BOTH SITES)

$09 / 07 / 82$ TO 02/22/94

REPORT DATE: $10 / 03 / 94$

\begin{tabular}{|c|c|c|c|c|c|c|c|c|c|c|c|}
\hline PARAMETER NAME & $\underset{\text { ID }}{\text { LOCATION }}$ & LOG DATE & $\begin{array}{c}\text { SAMPLE } \\
10\end{array}$ & $\begin{array}{l}\text { FORM } \\
\text { COMP }\end{array}$ & $\begin{array}{l}\text { FLOW } \\
\text { REL. }\end{array}$ & $\begin{array}{l}\text { UNITS OF } \\
\text { MEASURE }\end{array}$ & PVI & $\begin{array}{l}\text { ARAMETE } \\
\text { VALUE }\end{array}$ & FLAGS & $\begin{array}{l}\text { DETECTION } \\
\text { LIMIT }\end{array}$ & $\begin{array}{l}\text { PARAMETER } \\
\text { UNCERTAINTY }\end{array}$ \\
\hline SILVER & 0512 & $12 / 10 / 91$ & 0001 & $A L$ & 0 & $M G / L$ & $<$ & 0.01 & & 0.01 & - \\
\hline SODIUM & $\begin{array}{l}0503 \\
0503 \\
0503 \\
0503 \\
0503 \\
0503 \\
0503 \\
0503 \\
0503 \\
0503 \\
0503 \\
0504 \\
0504 \\
0504 \\
0504 \\
0504 \\
0504 \\
0504 \\
0504 \\
0504 \\
0504 \\
0504 \\
0506 \\
0506 \\
0506 \\
0506 \\
0506 \\
0506 \\
0506 \\
0506 \\
0506 \\
0506 \\
0507 \\
0507 \\
0507 \\
0507\end{array}$ & $\begin{array}{l}09 / 07 / 82 \\
02 / 18 / 86 \\
06 / 30 / 86 \\
10 / 14 / 87 \\
02 / 22 / 88 \\
05 / 16 / 90 \\
03 / 29 / 91 \\
08 / 08 / 91 \\
12 / 09 / 91 \\
10 / 09 / 92 \\
02 / 18 / 94 \\
09 / 07 / 82 \\
02 / 04 / 86 \\
07 / 01 / 86 \\
10 / 14 / 87 \\
02 / 22 / 88 \\
05 / 16 / 90 \\
04 / 03 / 91 \\
08 / 27 / 91 \\
12 / 09 / 91 \\
10 / 09 / 92 \\
02 / 19 / 94 \\
09 / 08 / 82 \\
02 / 05 / 86 \\
07 / 01 / 86 \\
10 / 14 / 87 \\
02 / 22 / 88 \\
03 / 28 / 91 \\
08 / 08 / 91 \\
11 / 20 / 91 \\
10 / 08 / 92 \\
02 / 20 / 94 \\
09 / 09 / 82 \\
02 / 05 / 86 \\
06 / 30 / 86 \\
10 / 14 / 87\end{array}$ & $\begin{array}{l}0001 \\
0001 \\
0001 \\
0001 \\
0001 \\
0001 \\
0001 \\
0001 \\
0001 \\
0001 \\
0001 \\
0001 \\
0001 \\
0001 \\
0001 \\
0001 \\
0001 \\
0001 \\
0001 \\
0001 \\
0001 \\
0001 \\
0001 \\
0001 \\
0001 \\
0001 \\
0001 \\
0001 \\
0001 \\
0001 \\
0001 \\
0001 \\
0001 \\
0001 \\
0001 \\
0001\end{array}$ & $\begin{array}{l}A L \\
A L \\
A L \\
A L \\
A L \\
A L \\
A L \\
A L \\
A L \\
A L \\
A L \\
A L \\
A L \\
A L \\
A L \\
A L \\
A L \\
A L \\
A L \\
A L \\
A L \\
A L \\
A L \\
A L \\
A L \\
A L \\
A L \\
A L \\
A L \\
A L \\
A L \\
A L \\
A L \\
A L \\
A L \\
A L\end{array}$ & $\begin{array}{l}0 \\
0 \\
0 \\
0 \\
0 \\
0 \\
0 \\
0 \\
0 \\
0 \\
0 \\
D \\
D \\
D \\
D \\
D \\
D \\
D \\
D \\
D \\
D \\
D \\
D \\
D \\
D \\
D \\
D \\
D \\
D \\
D \\
D \\
D \\
D \\
D \\
D \\
D\end{array}$ & $M G / L$ & & $\begin{array}{l}600.00 \\
646 . \\
637 . \\
590 . \\
555 . \\
537 . \\
541 . \\
584 . \\
536 . \\
552 . \\
513 \\
827.00 \\
933 . \\
774 . \\
830 . \\
736 . \\
501 . \\
480 . \\
478 . \\
416 . \\
351 . \\
561 \\
249.00 \\
608 . \\
970 . \\
490 . \\
479 . \\
1280 . \\
1220 . \\
827 . \\
1240 . \\
1580 \\
155.00 \\
172 . \\
322 . \\
135 .\end{array}$ & J & $\begin{array}{l}0 . \\
0.002 \\
0.002 \\
0.002 \\
0.002 \\
0.002 \\
5 . \\
5 . \\
5 . \\
5 . \\
1 \\
0 . \\
0.002 \\
0.002 \\
0.002 \\
0.002 \\
0.002 \\
5 . \\
5 . \\
5 . \\
5 . \\
1 \\
- \\
0.002 \\
0.002 \\
0.002 \\
0.002 \\
5 . \\
20 . \\
5 . \\
20 . \\
1 \\
- \\
0.002 \\
0.002 \\
0.002\end{array}$ & $\begin{array}{l}- \\
- \\
- \\
- \\
- \\
- \\
- \\
- \\
- \\
- \\
- \\
- \\
- \\
- \\
- \\
- \\
- \\
- \\
- \\
- \\
- \\
- \\
- \\
- \\
- \\
- \\
- \\
- \\
- \\
- \\
-\end{array}$ \\
\hline
\end{tabular}

FORMATION OF COMPLETION CODE:

AL - ALLUVIUM

PARAMETER VALUE INDICATOR (PVI): < - LESS THAN DETECTION LIMIT
FLOW RELATIONSHIP CODE:

O - ON-SITE

D - DOWN GRADIENT

SAMPLE ID CODES:

0001 - FILTERED SAMPLE (.45 MICRONS)

OTHER PARAMETER VALUE FLAGS:

$J$ - ESTIMATED VALUE

L - LESS THAN THREE; BORE VOLUMES REMOVED BEFORE SAMPLING 
TABLE 3.27 BASELINE GROUND WATER QUALITY DATA BY PARAMETER FOR THE ALLUVIUM, NC AND UC PROCESSING SITES, SLICK ROCK, COLORADD

SITE: SRKO1 SLICK ROCK (BOTH SITES)

09/07/82 TO 02/22/94

REPORT DATE: $10 / 03 / 94$

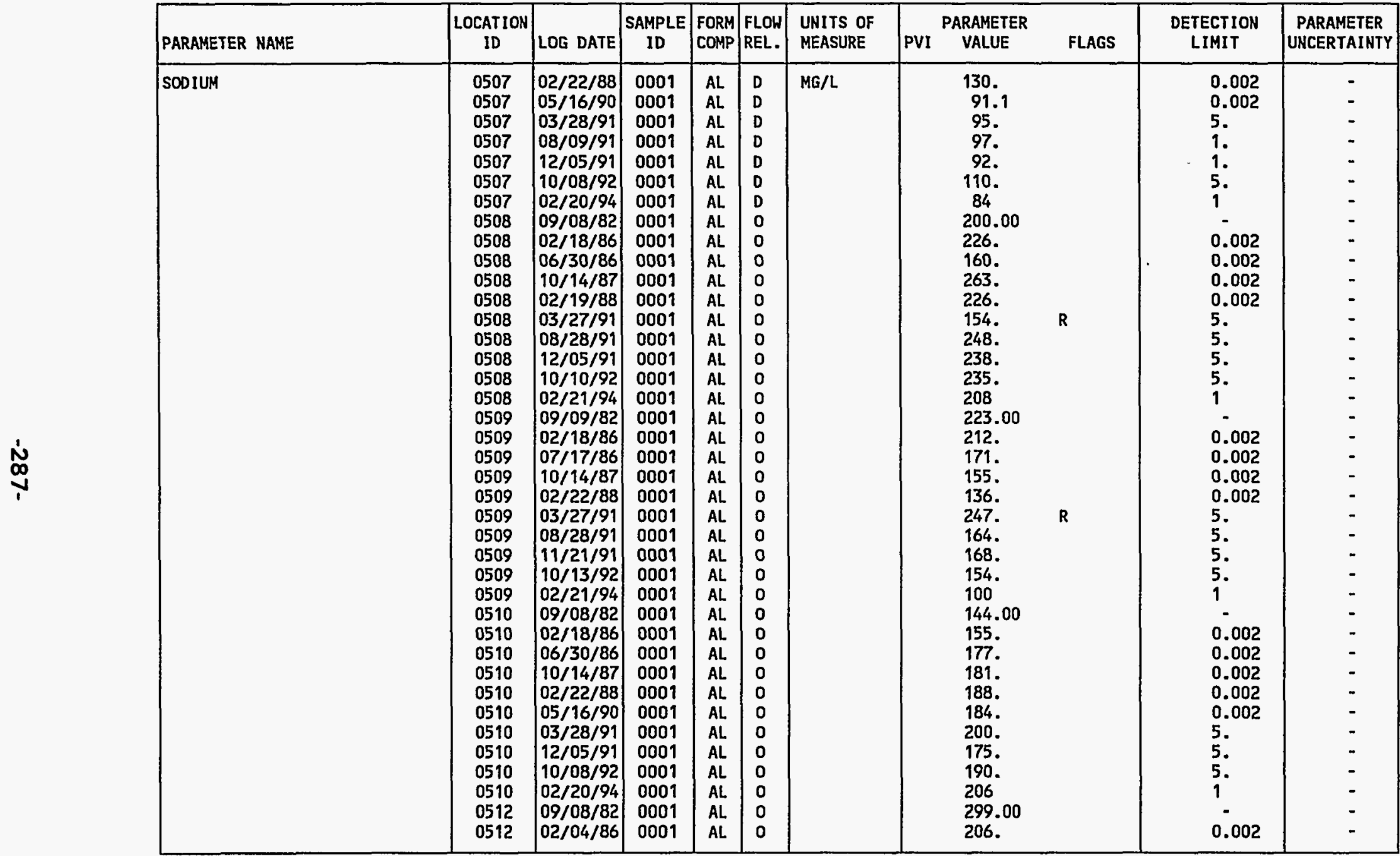

FORMATION OF COMPLETION CODE:

$A L$ - ALLUVIUM

PARAMETER VALUE INDICATOR (PVI): < - LESS THAN DETECTION LIMIT
FLOW RELATIONSHIP CODE:

D- DOWN GRADIENT

O - ON-SITE

SAMPLE ID CODES:

0001 - FILTERED SAMPLE (.45 MICRONS)

OTHER PARAMETER VALUE FLAGS:

$R$ - UNUSABLE DATA POINT 





TABLE 3.27 BASELINE GROUND HATER QUALITY DATA BY PARAMETER FOR THE ALLUVIUM, NC AND UC PROCESSING SITES, SLICK ROCK, COLORADO

SITE: SRKO1 SLICK ROCK (BOTH SITES)

$09 / 07 / 82$ TO $02 / 22 / 94$

REPORT DATE: $10 / 03 / 94$

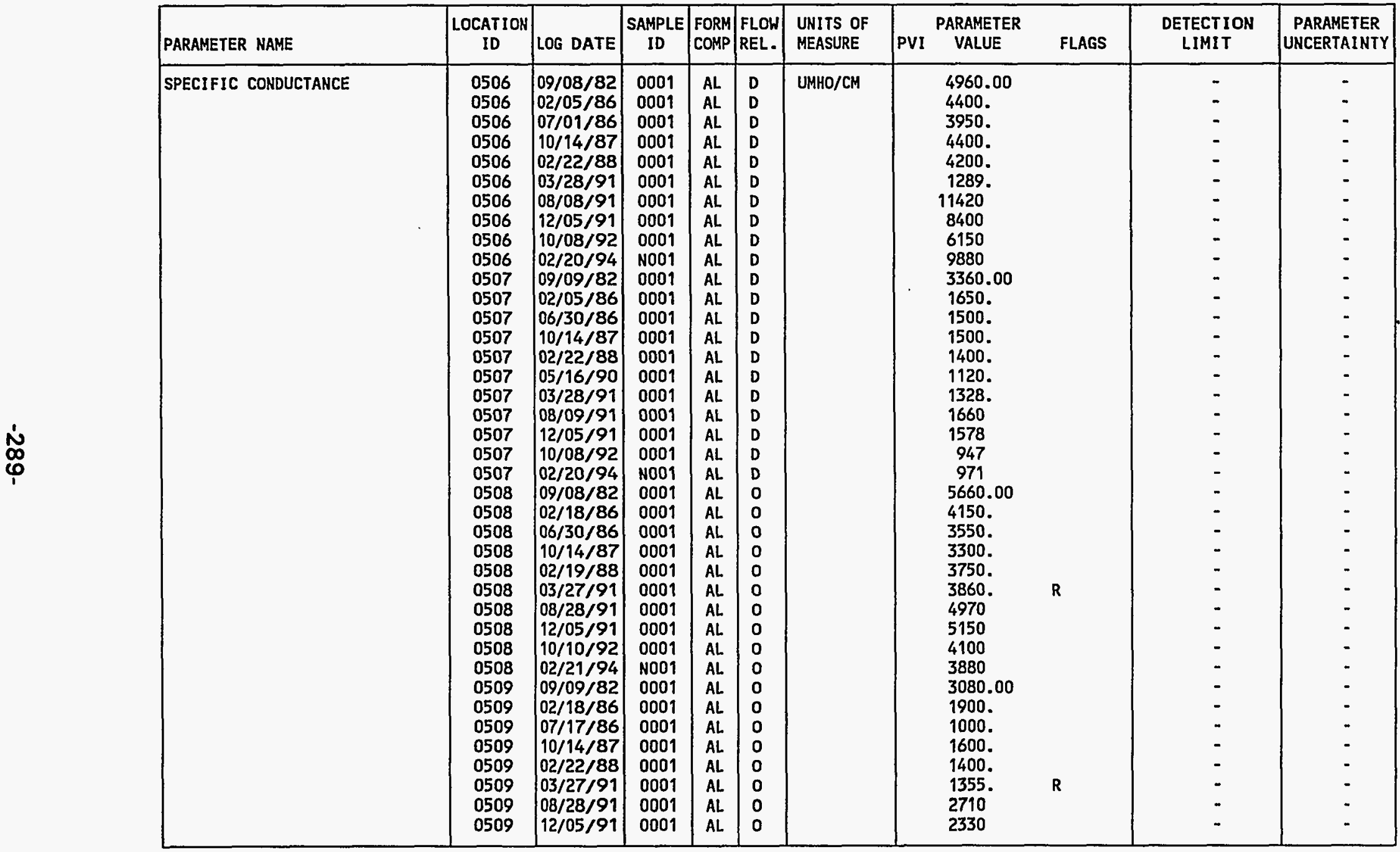

FORMATION OF COMPLETION CODE:

AL - ALLUVIUM

PARAMETER VALUE INDICATOR (PVI): < - LESS THAN DETECTION LIMIT
FLOW RELATIONSHIP CODE:

D - DOWN GRADIENT

$O$ - ON-SITE

SAMPLE ID CODES:

0001 - FILTERED SAMPLE (.45 MICRONS)

NO01 - UNFILTERED SAMPLE

OTHER PARAMETER VALUE FLAGS:

$R$ - UNUSABLE DATA POINT 


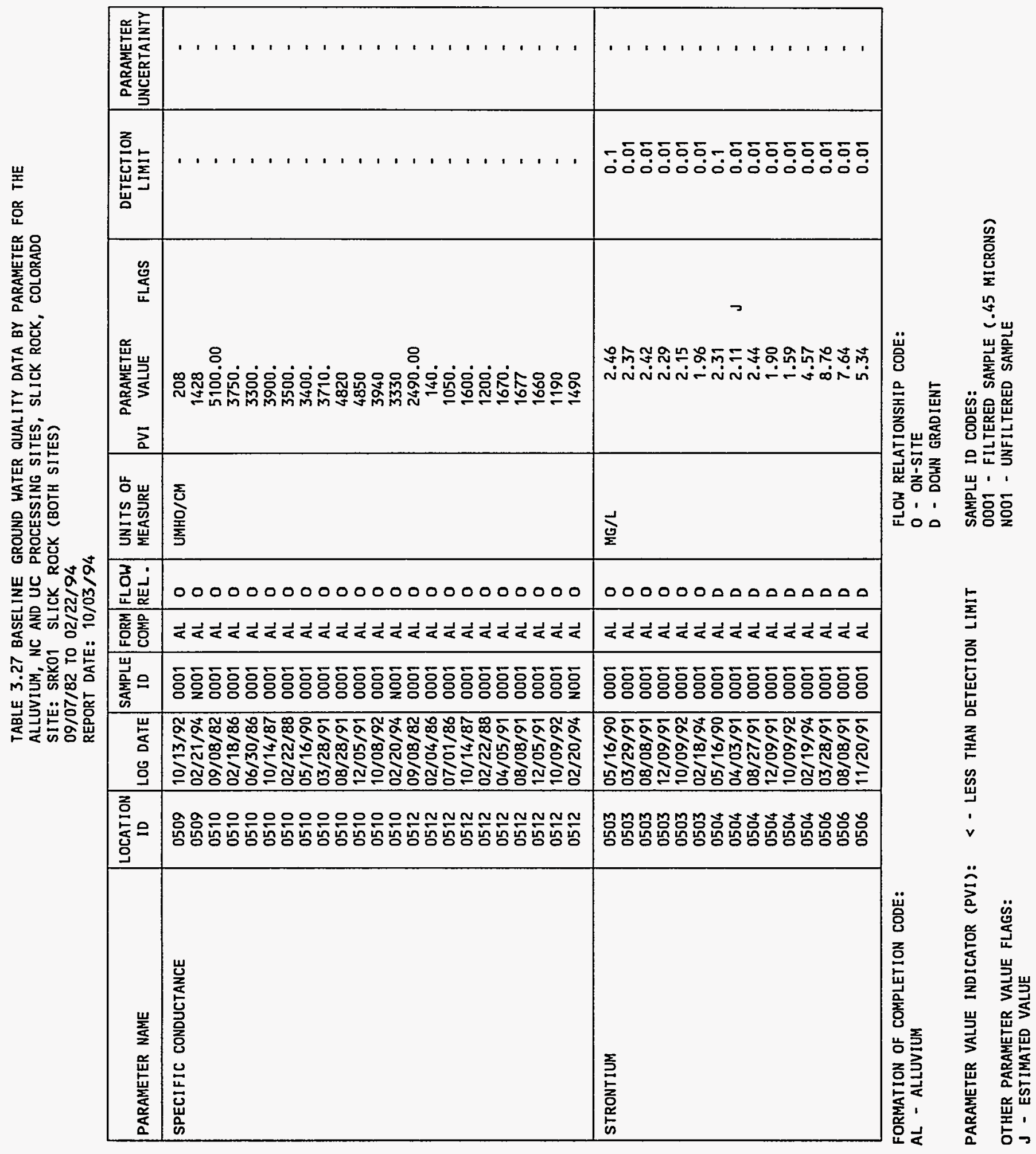


TABLE 3.27 BASELINE GROUND WATER QUALITY DATA BY PARAMETER FOR THE ALLUVIUM, NC AND UC PROCESSING SITES, SLICK ROCK, COLORADO

SITE: SRKOI SLICK ROCK (BOTH SITES)

02/22/94

REPORT DATE: $10 / 03 / 94$

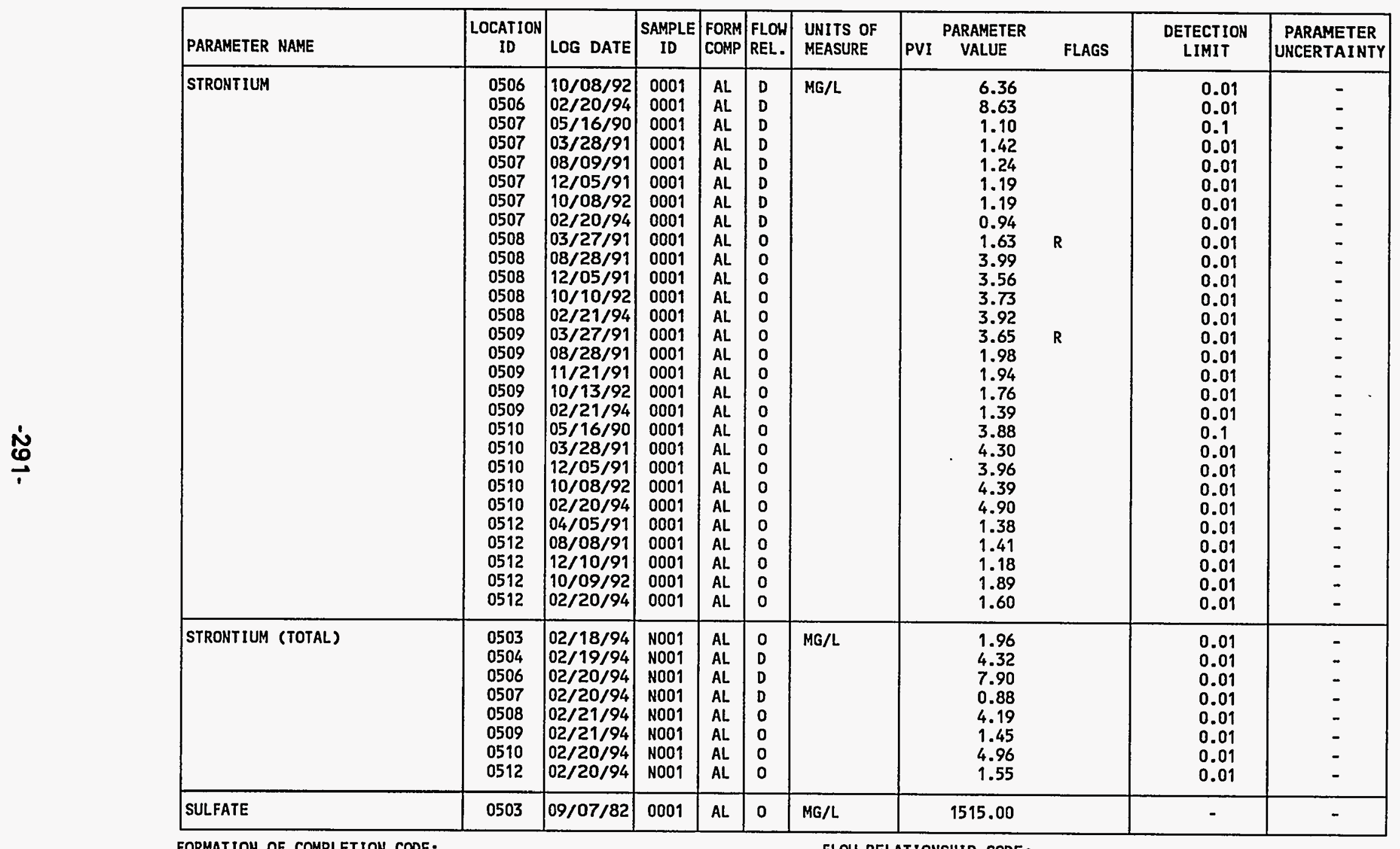

FORMATION OF COMPLETION CODE:

AL. - ALLUVIUM

FLOW RELATIONSHIP CODE:

D - DOWN GRADIENT

O - ON-SITE

PARAMETER VALUE INDICATOR (PVI): < - LESS THAN DETECTION LIMIT

OTHER PARAMETER VALUE FLAGS:

SAMPLE ID CODES:

0001 - FILTERED SAMPLE (.45 MICRONS)

NO01 - UNFILTERED SAMPLE 
TABLE 3.27 BASELINE GROUND WATER QUALITY DATA BY PARAMETER FOR THE ALLUVIUM, NC AND UC PROCESSING SITES, SLICK ROCK, COLORADO

SITE: SRKO1 SLICK ROCK (BOTH SITES)

09/07/82 TO $02 / 22 / 94$

REPORT DATE: $10 / 03 / 94$

\begin{tabular}{|c|c|c|c|c|c|c|c|c|c|c|c|}
\hline PARAMETER NAME & $\underset{\text { ID }}{\text { LOCATION }}$ & LOG DATE & $\begin{array}{c}\text { SAMPLE } \\
\text { ID }\end{array}$ & $\begin{array}{l}\text { FORM } \\
\text { COMP }\end{array}$ & $\begin{array}{l}\text { FLOW } \\
\text { REL. }\end{array}$ & $\begin{array}{l}\text { UNITS OF } \\
\text { MEASURE }\end{array}$ & PVI & $\begin{array}{l}\text { PARAMETER } \\
\text { VALUE }\end{array}$ & FLAGS & $\begin{array}{l}\text { DETECTION } \\
\text { LIMIT }\end{array}$ & $\begin{array}{l}\text { PARAMETER } \\
\text { UNCERTAINTY }\end{array}$ \\
\hline SULFATE & $\begin{array}{l}0503 \\
0503 \\
0503 \\
0503 \\
0503 \\
0503 \\
0503 \\
0503 \\
0503 \\
0503 \\
0504 \\
0504 \\
0504 \\
0504 \\
0504 \\
0504 \\
0504 \\
0504 \\
0504 \\
0504 \\
0504 \\
0506 \\
0506 \\
0506 \\
0506 \\
0506 \\
0506 \\
0506 \\
0506 \\
0506 \\
0506 \\
0507 \\
0507 \\
0507 \\
0507 \\
0507 \\
0507\end{array}$ & $\begin{array}{l}02 / 18 / 86 \\
06 / 30 / 86 \\
10 / 14 / 87 \\
02 / 22 / 88 \\
05 / 16 / 90 \\
03 / 29 / 91 \\
08 / 08 / 91 \\
12 / 09 / 91 \\
10 / 09 / 92 \\
02 / 18 / 94 \\
09 / 07 / 82 \\
02 / 04 / 86 \\
07 / 01 / 86 \\
10 / 14 / 87 \\
02 / 22 / 88 \\
05 / 16 / 90 \\
04 / 03 / 91 \\
08 / 27 / 91 \\
12 / 09 / 91 \\
10 / 09 / 92 \\
02 / 19 / 94 \\
09 / 08 / 82 \\
02 / 05 / 86 \\
07 / 01 / 86 \\
10 / 14 / 87 \\
02 / 22 / 88 \\
03 / 28 / 91 \\
08 / 08 / 91 \\
11 / 20 / 91 \\
10 / 08 / 92 \\
02 / 20 / 94 \\
09 / 09 / 82 \\
02 / 05 / 86 \\
06 / 30 / 86 \\
10 / 14 / 87 \\
02 / 22 / 88 \\
05 / 16 / 90\end{array}$ & $\begin{array}{l}0001 \\
0001 \\
0001 \\
0001 \\
0001 \\
0001 \\
0001 \\
0001 \\
0001 \\
0001 \\
0001 \\
0001 \\
0001 \\
0001 \\
0001 \\
0001 \\
0001 \\
0001 \\
0001 \\
0001 \\
0001 \\
0001 \\
0001 \\
0001 \\
0001 \\
0001 \\
0001 \\
0001 \\
0001 \\
0001 \\
0001 \\
0001 \\
0001 \\
0001 \\
0001 \\
0001 \\
0001\end{array}$ & $\begin{array}{l}A L \\
A L \\
A L \\
A L \\
A L \\
A L \\
A L \\
A L \\
A L \\
A L \\
A L \\
A L \\
A L \\
A L \\
A L \\
A L \\
A L \\
A L \\
A L \\
A L \\
A L \\
A L \\
A L \\
A L \\
A L \\
A L \\
A L \\
A L \\
A L \\
A L \\
A L \\
A L \\
A L \\
A L \\
A L \\
A L \\
A L\end{array}$ & $\begin{array}{l}0 \\
0 \\
0 \\
0 \\
0 \\
0 \\
0 \\
0 \\
0 \\
0 \\
D \\
D \\
D \\
D \\
D \\
D \\
D \\
D \\
D \\
D \\
D \\
D \\
D \\
D \\
D \\
D \\
D \\
D \\
D \\
D \\
D \\
D \\
D \\
D \\
D \\
D \\
D\end{array}$ & $M G / L$ & & $\begin{array}{c}1600 . \\
1650 . \\
1450 . \\
1500 . \\
1380 . \\
1280 . \\
1160 . \\
1200 . \\
1100 . \\
945 \\
1878.0 \\
2470 . \\
2130 . \\
2340 . \\
2140 . \\
1280 . \\
1090 . \\
1020 . \\
942 . \\
744 . \\
2070 \\
2651.00 \\
2930 . \\
3160 . \\
2940 . \\
2800 . \\
2260 . \\
2080 . \\
2100 . \\
2450 . \\
2450 \\
1454.00 \\
808 . \\
733 . \\
630 . \\
535 . \\
315 .\end{array}$ & $\begin{array}{l}\mathrm{H} \\
\mathrm{J}\end{array}$ & $\begin{array}{c}0.1 \\
0.1 \\
0.1 \\
0.1 \\
0.1 \\
10 . \\
10 . \\
10 . \\
10 . \\
1 \\
- \\
0.1 \\
0.1 \\
0.1 \\
0.1 \\
0.1 \\
10 . \\
10 . \\
10 . \\
80 . \\
1 \\
- \\
0.1 \\
0.1 \\
0.1 \\
0.1 \\
10 . \\
10 . \\
10 . \\
10 . \\
1 \\
- \\
0.1 \\
0.1 \\
0.1 \\
0.1 \\
0.1\end{array}$ & $\begin{array}{l}- \\
- \\
- \\
- \\
- \\
- \\
- \\
- \\
- \\
- \\
- \\
- \\
- \\
- \\
- \\
- \\
- \\
- \\
- \\
- \\
- \\
- \\
- \\
- \\
- \\
- \\
- \\
- \\
-\end{array}$ \\
\hline
\end{tabular}

FORMATION OF COMPLETION CODE:

AL - ALLUVIUN

PARAMETER VALUE INDICATOR (PVI): < - LESS THAN DETECTION LIMIT
FLOW RELATIONSHIP CODE:

O - ON-SITE

D - DOWN GRADIENT

\section{SAMPLE ID CODES:}

0001 - FILTERED SAMPLE (.45 MICRONS)

OTHER PARAMETER VALUE FLAGS

H - HOLD TIME EXPIRED, VALUE SUSPECT

$J$ - ESTIMATED VALUE

L - LESS THAN THREE BORE VOLUMES REMOVED BEFORE SAMPLING 
TABLE 3.27 BASELINE GROUND HATER QUALITY DATA BY PARAMETER FOR THE ALLUVIUM, NC AND UC PROCESSING SITES, SLICK ROCK, COLORADO

SITE: SRKO1 SLICK ROCK (BOTH SITES)

$09 / 07 / 85$ TO $05 / 25 / 94$

REPORT DATE: $10 / 03 / 94$

\begin{tabular}{|c|c|c|c|c|c|c|c|c|c|c|c|}
\hline PARAMETER NAME & $\begin{array}{c}\text { LOCATION } \\
\text { ID }\end{array}$ & LOG DATE & $\begin{array}{c}\text { SAMPLE } \\
\text { ID }\end{array}$ & $\mid \begin{array}{l}\text { FORM } \\
\text { COMP }\end{array}$ & $\begin{array}{l}\text { FLOW } \\
\text { REL. }\end{array}$ & $\begin{array}{l}\text { UNITS OF } \\
\text { MEASURE }\end{array}$ & PVI & $\begin{array}{l}\text { PARAMETER } \\
\text { VALUE }\end{array}$ & FLAGS & $\begin{array}{l}\text { DETECTION } \\
\text { LIMIT }\end{array}$ & $\begin{array}{c}\text { PARAMETER } \\
\text { UNCERTAINTY }\end{array}$ \\
\hline SULFATE & $\begin{array}{l}0507 \\
0507 \\
0507 \\
0507 \\
0507 \\
0508 \\
0508 \\
0508 \\
0508 \\
0508 \\
0508 \\
0508 \\
0508 \\
0508 \\
0508 \\
0509 \\
0509 \\
0509 \\
0509 \\
0509 \\
0509 \\
0509 \\
0509 \\
0509 \\
0509 \\
0510 \\
0510 \\
0510 \\
0510 \\
0510 \\
0510 \\
0510 \\
0510 \\
0510 \\
0510 \\
0510 \\
0512 \\
0512\end{array}$ & $\begin{array}{l}03 / 28 / 91 \\
08 / 09 / 91 \\
12 / 05 / 91 \\
10 / 08 / 92 \\
02 / 20 / 94 \\
09 / 08 / 82 \\
02 / 18 / 86 \\
06 / 30 / 86 \\
10 / 14 / 87 \\
02 / 19 / 88 \\
03 / 27 / 91 \\
08 / 28 / 91 \\
12 / 05 / 91 \\
10 / 10 / 92 \\
02 / 21 / 94 \\
09 / 09 / 82 \\
02 / 18 / 86 \\
07 / 17 / 86 \\
10 / 14 / 87 \\
02 / 22 / 88 \\
03 / 27 / 91 \\
08 / 28 / 91 \\
11 / 21 / 91 \\
10 / 13 / 92 \\
02 / 21 / 94 \\
09 / 08 / 82 \\
02 / 18 / 86 \\
06 / 30 / 86 \\
10 / 114 / 87 \\
02 / 22 / 88 \\
05 / 16 / 90 \\
03 / 28 / 91 \\
08 / 28 / 91 \\
12 / 05 / 91 \\
10 / 08 / 92 \\
02 / 20 / 94 \\
09 / 08 / 82 \\
02 / 04 / 86\end{array}$ & $\begin{array}{l}0001 \\
0001 \\
0001 \\
0001 \\
0001 \\
0001 \\
0001 \\
0001 \\
0001 \\
0001 \\
0001 \\
0001 \\
0001 \\
0001 \\
0001 \\
0001 \\
0001 \\
0001 \\
0001 \\
0001 \\
0001 \\
0001 \\
0001 \\
0001 \\
0001 \\
0001 \\
0001 \\
0001 \\
0001 \\
0001 \\
0001 \\
0001 \\
0001 \\
0001 \\
0001 \\
0001 \\
0001 \\
0001\end{array}$ & $\begin{array}{l}A L \\
A L \\
A L \\
A L \\
A L \\
A L \\
A L \\
A L \\
A L \\
A L \\
A L \\
A L \\
A L \\
A L \\
A L \\
A L \\
A L \\
A L \\
A L \\
A L \\
A L \\
A L \\
A L \\
A L \\
A L \\
A L \\
A L \\
A L \\
A L \\
A L \\
A L \\
A L \\
A L \\
A L \\
A L \\
A L \\
A L \\
A L\end{array}$ & $\begin{array}{l}0 \\
0 \\
0 \\
0 \\
0 \\
0 \\
0 \\
0 \\
0 \\
0 \\
0 \\
0 \\
0 \\
0 \\
0 \\
0 \\
0 \\
0 \\
0 \\
0 \\
0 \\
0 \\
0 \\
0 \\
0 \\
0 \\
0 \\
0 \\
0 \\
0 \\
0 \\
0 \\
0 \\
0 \\
0 \\
0 \\
0 \\
0\end{array}$ & $M G / L$ & & $\begin{array}{c}253 . \\
213 . \\
198 . \\
243 . \\
182 \\
1768.00 \\
1700 . \\
1920 . \\
1680 . \\
1480 . \\
835 . \\
1430 . \\
1490 . \\
1520 . \\
1240 \\
1212.00 \\
1160 . \\
532 . \\
790 . \\
694 . \\
1490 . \\
938 . \\
1040 . \\
868 . \\
610 \\
1576.00 \\
1730 . \\
1540 . \\
1840 . \\
1670 . \\
1670 . \\
1620 . \\
1600 . \\
1570 . \\
1670 . \\
1430 \\
1080.00 \\
916 .\end{array}$ & $\mathbf{R}$ & $\begin{array}{c}0.1 \\
0.1 \\
40 . \\
25 . \\
1 \\
0.1 \\
0.1 \\
0.1 \\
0.1 \\
10 . \\
10 . \\
10 . \\
10 . \\
1 \\
. \\
0.1 \\
0.1 \\
0.1 \\
0.1 \\
10 . \\
10 . \\
10 . \\
90 . \\
1 \\
- \\
0.1 \\
0.1 \\
0.1 \\
0.1 \\
0.1 \\
10 . \\
10 . \\
10 . \\
10 . \\
1 \\
0.1 \\
0.1\end{array}$ & $\begin{array}{l}- \\
- \\
- \\
- \\
- \\
- \\
- \\
- \\
- \\
- \\
- \\
- \\
- \\
- \\
- \\
- \\
- \\
- \\
- \\
- \\
- \\
- \\
- \\
- \\
- \\
- \\
- \\
- \\
- \\
- \\
-\end{array}$ \\
\hline
\end{tabular}

FOPMATION OF COMPLETION CODE:

AL - ALLUVIUM

PARAMETER VALUE INDICATOR (PVI): < - LESS THAN DETECTION LIMIT
FLOH RELATIONSHIP CODE:

D - DOWN GRADIENT

O - ON-SITE

SAMPLE ID CODES:

0001 - FILTERED SAMPLE (.45 MICRONS)

OTHER PARAMETER VALUE FLAGS:

H - HOLD TIME EXPIRED, VALUE SUSPECT

R - UNUSABLE DATA POIŃT 


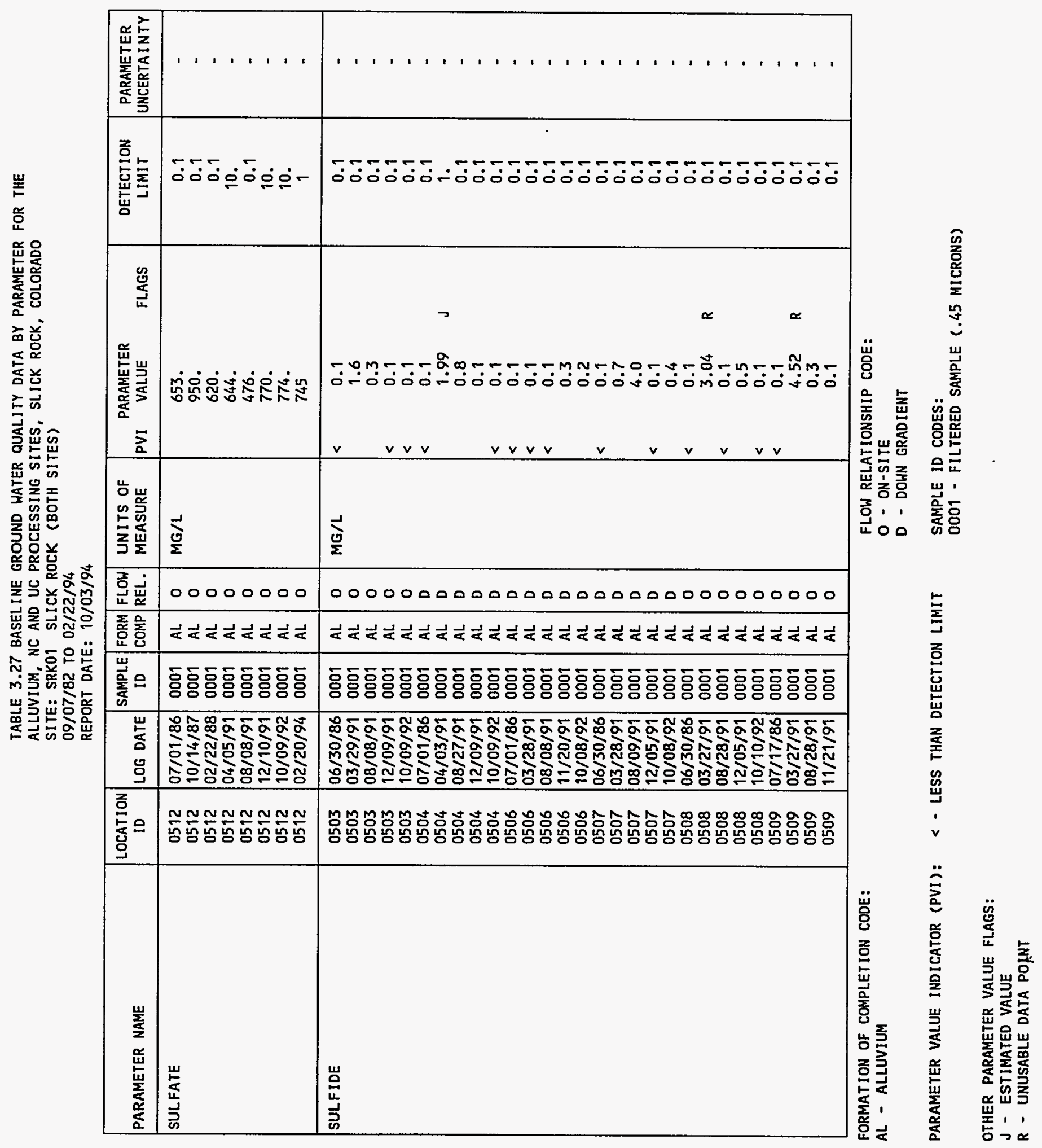


TABLE 3.27 BASELINE GROUND WATER QUALITY DATA BY PARAMETER FOR THE ALLUVIUM, NC AND UC PROCESSING SITES, SLICK ROCK, COLORADO

SITE: SRKO1 SLICK ROCK (BOTH SITES)

\begin{tabular}{|c|c|c|c|c|c|c|c|c|c|}
\hline PARAMETER NAME & $\underset{\text { ID }}{\text { LOCATION }} \mid$ LOG DATE & $\begin{array}{c}\text { SAMPLE } \\
\text { ID }\end{array}$ & $\mid \begin{array}{l}\text { FORM } \\
\text { COMP }\end{array}$ & $\begin{array}{l}\text { FLOH } \\
\text { REL. }\end{array}$ & $\begin{array}{l}\text { UNITS OF } \\
\text { MEASURE }\end{array}$ & \begin{tabular}{|c} 
PARAMETER \\
PVI \\
VALUE
\end{tabular} & FLAGS & $\begin{array}{l}\text { DETECTION } \\
\text { LIMIT }\end{array}$ & $\begin{array}{l}\text { PARAMETER } \\
\text { UNCERTAINTY }\end{array}$ \\
\hline SULFIDE & $\begin{array}{l}10 / 13 / 92 \\
06 / 30 / 86 \\
03 / 28 / 91 \\
08 / 28 / 91 \\
12 / 05 / 91 \\
10 / 08 / 92 \\
07 / 01 / 86 \\
04 / 05 / 91 \\
08 / 08 / 91 \\
12 / 10 / 91 \\
10 / 09 / 92\end{array}$ & $\begin{array}{l}0001 \\
0001 \\
0001 \\
0001 \\
0001 \\
0001 \\
0001 \\
0001 \\
0001 \\
0001 \\
0001\end{array}$ & $\begin{array}{l}A L \\
A L \\
A L \\
A L \\
A L \\
A L \\
A L \\
A L \\
A L \\
A L \\
A L\end{array}$ & $\begin{array}{l}0 \\
0 \\
0 \\
0 \\
0 \\
0 \\
0 \\
0 \\
0 \\
0 \\
0\end{array}$ & $M G / L$ & $\begin{array}{r}0.1 \\
0.1 \\
0.3 \\
0.1 \\
0.1 \\
0.1 \\
0.1 \\
32.9 \\
1.1 \\
0.3 \\
0.2\end{array}$ & & $\begin{array}{l}0.1 \\
0.1 \\
0.1 \\
0.1 \\
0.1 \\
0.1 \\
0.1 \\
0.1 \\
0.2 \\
0.1 \\
0.1\end{array}$ & $\begin{array}{l}- \\
- \\
= \\
- \\
- \\
- \\
- \\
-\end{array}$ \\
\hline TEMPERATURE & $\begin{array}{l}09 / 07 / 82 \\
02 / 18 / 86 \\
06 / 30 / 86 \\
10 / 14 / 87 \\
02 / 22 / 88 \\
05 / 16 / 90 \\
03 / 29 / 91 \\
08 / 08 / 91 \\
12 / 05 / 91 \\
10 / 09 / 92 \\
02 / 22 / 94 \\
09 / 07 / 82 \\
02 / 04 / 86 \\
07 / 01 / 86 \\
10 / 14 / 87 \\
02 / 22 / 88 \\
05 / 16 / 90 \\
08 / 27 / 91 \\
12 / 05 / 91 \\
10 / 09 / 92 \\
02 / 19 / 94 \\
09 / 08 / 82 \\
02 / 05 / 86 \\
07 / 01 / 86 \\
10 / 14 / 87 \\
02 / 22 / 88 \\
03 / 28 / 91\end{array}$ & $\begin{array}{l}0001 \\
0001 \\
0001 \\
0001 \\
0001 \\
0001 \\
0001 \\
0001 \\
0001 \\
0001 \\
N 001 \\
0001 \\
0001 \\
0001 \\
0001 \\
0001 \\
0001 \\
0001 \\
0001 \\
0001 \\
N 001 \\
0001 \\
0001 \\
0001 \\
0001 \\
0001 \\
0001\end{array}$ & $\begin{array}{l}A L \\
A L \\
A L \\
A L \\
A L \\
A L \\
A L \\
A L \\
A L \\
A L \\
A L \\
A L \\
A L \\
A L \\
A L \\
A L \\
A L \\
A L \\
A L \\
A L \\
A L \\
A L \\
A L \\
A L \\
A L \\
A L \\
A L\end{array}$ & $\begin{array}{l}0 \\
D \\
0 \\
0 \\
0 \\
0 \\
0 \\
0 \\
0 \\
0 \\
0 \\
D \\
D \\
D \\
D \\
D \\
D \\
D \\
D \\
D \\
D \\
D \\
D \\
D \\
D \\
D \\
D\end{array}$ & C - DEGREE & $\begin{array}{l}14.00 \\
12 . \\
15 . \\
14.5 \\
13.0 \\
13.5 \\
13.1 \\
14.2 \\
14.0 \\
14.7 \\
13.5 \\
15.00 \\
11 . . \\
12 . \\
13.0 \\
11.0 \\
12.2 \\
14.0 \\
12.7 \\
15.2 \\
11.2 \\
19.00 \\
10.5 \\
13 . \\
14.5 \\
10.0 \\
9.8\end{array}$ & $\mathbf{L}$ & $\begin{array}{l}- \\
- \\
- \\
- \\
- \\
- \\
- \\
- \\
- \\
- \\
- \\
- \\
- \\
- \\
- \\
- \\
- \\
- \\
- \\
-\end{array}$ & $\begin{array}{l}- \\
- \\
- \\
- \\
- \\
- \\
- \\
- \\
- \\
- \\
- \\
- \\
- \\
- \\
- \\
- \\
- \\
- \\
- \\
- \\
-\end{array}$ \\
\hline
\end{tabular}

FOPHATION OF COMPLETION CODE:

AL - ALLUVIUM

FLOW RELATIONSHIP CODE

D - DOWN GRADIENT

PARAMETER VALUE INDICATOR (PVI): < - LESS THAN DETECTION LIMIT

SAMPLE ID CODES:

0001 - FILTERED SAMPLE (.45 MICRONS)

OTHER PARAMETER VALUE FLAGS

N001 - UNFILTERED SAMPLE

L - LESS THAN THREE BORE VOLUMES REMOVED BEFORE SAMPLING 


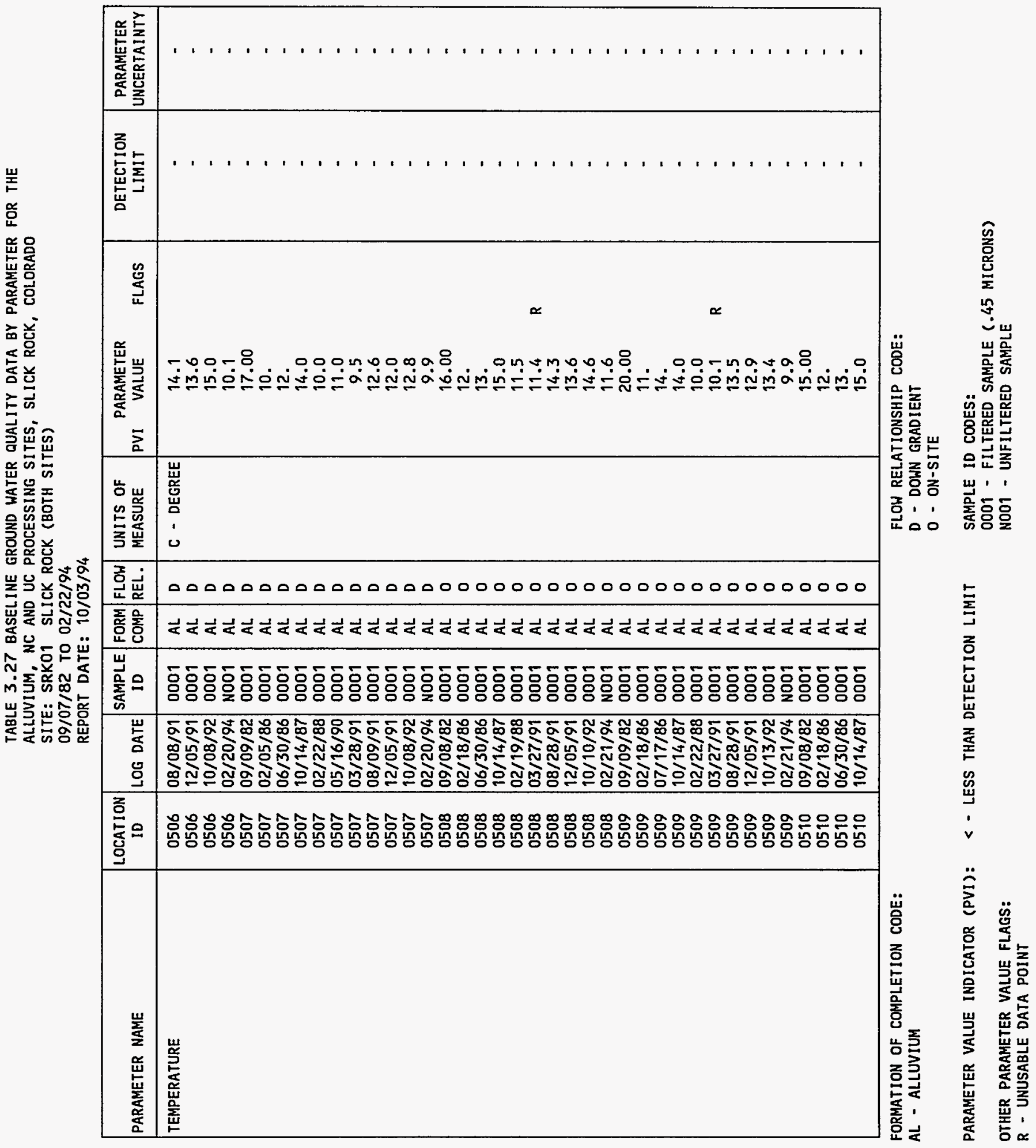


TABLE 3.27 BASELINE GROUND HATER QUALITY DATA BY PARAMETER FOR THE ALLUVIUM, NC AND UC PROCESSING SITES, SLICK ROCK, COLORADO

SITE: SRKO1 SLICK ROCK (BOTH SITES)

SIET/82 TO $02 / 23 / 94$

REPORT DATE : $10 / 03 / 94$

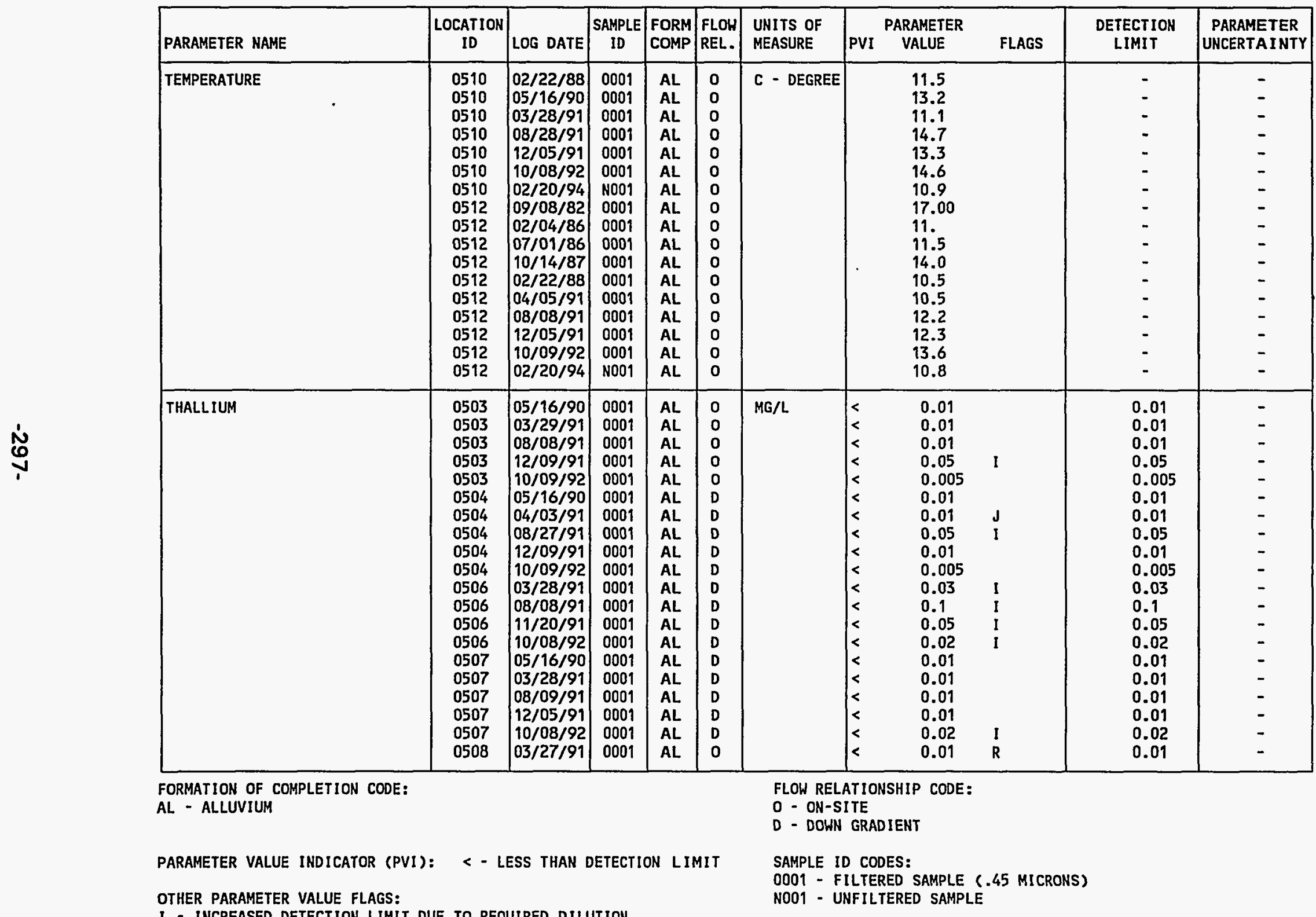

I - INCREASED DETECTION LIMIT DUE TO REQUIRED DILUTION

NO01 - UNFILTERED SAMPLE

$J$ - ESTIMATED VALUE

$R$ - UNUSABLE DATA POINT 


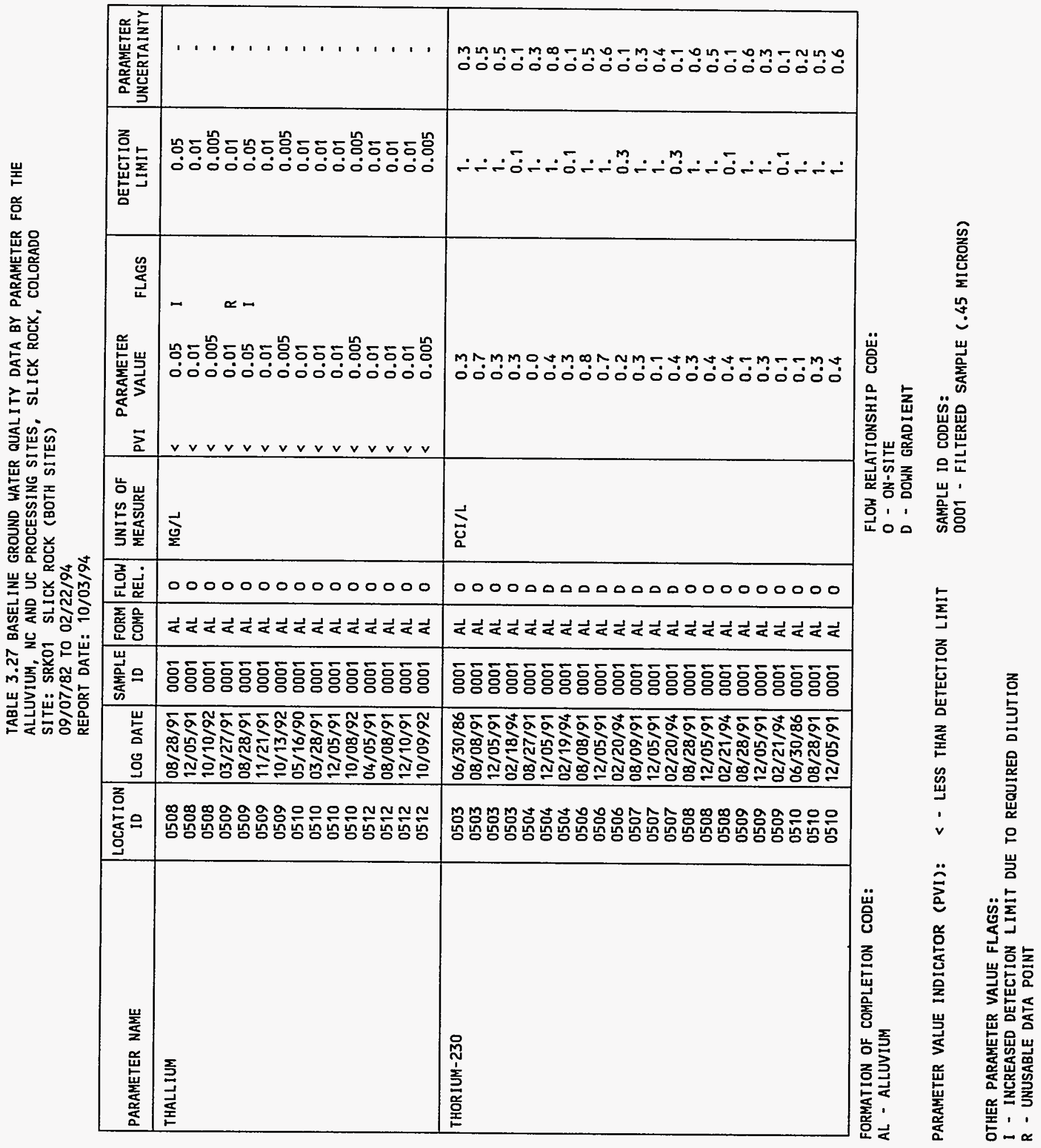


TABLE 3.27 BASELINE GROUND WATER QUALITY DATA BY PARAMETER FOR THE ALLUVIUM, NC AND UC PROCESSING SITES, SLICK ROCK, COLORADO

SITE: SRKOI SLICK ROCK (BOTH SITES)

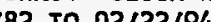

REPORT DATE: $10 / 03 / 94$

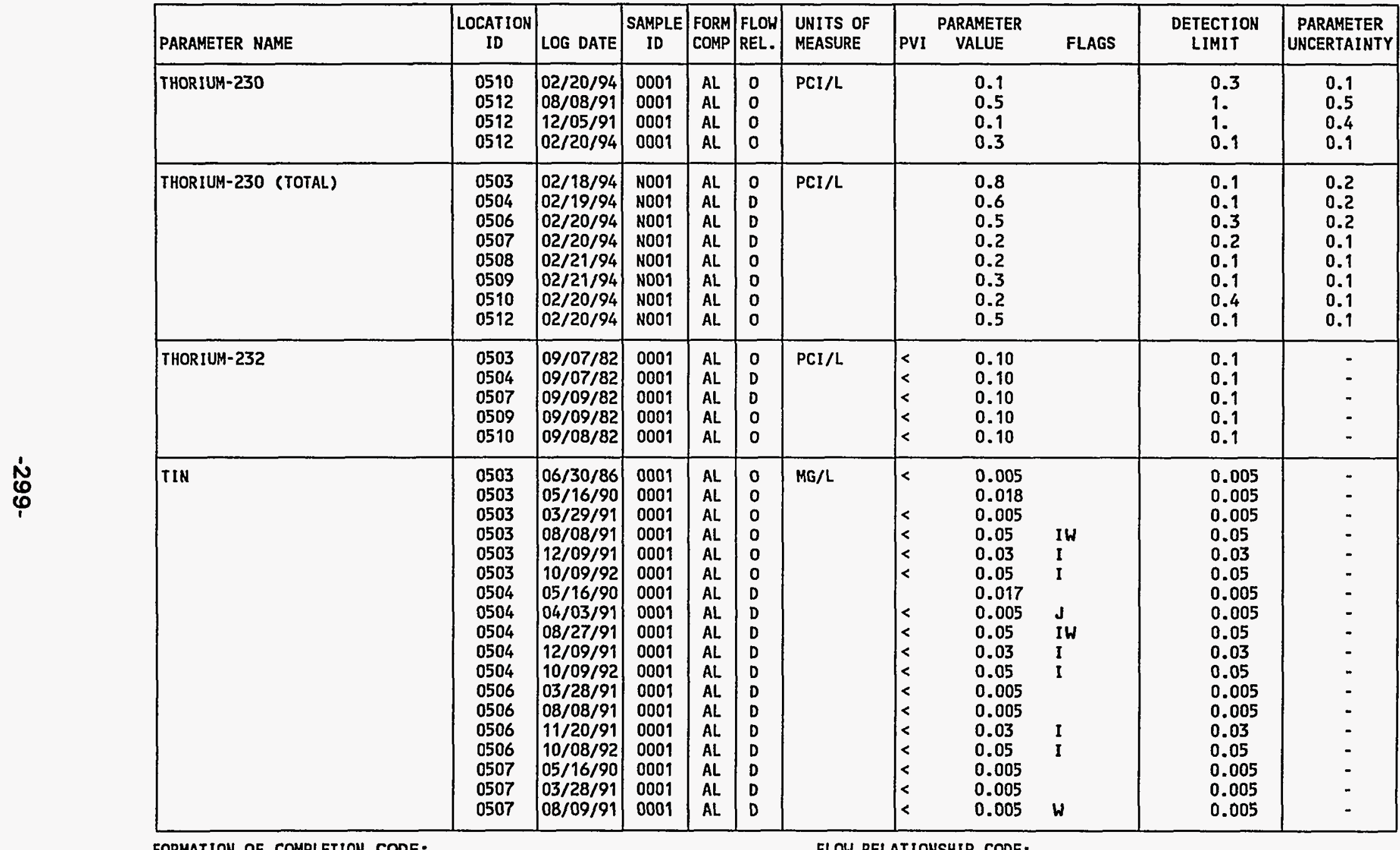

FORMATION OF COMPLETION CODE:

FLOW RELATIONSHIP CODE:

AL. - ALLUVIUM

D - DOWN GRADIENT

PARAMETER VALUE INDICATOR (PVI): < - LESS THAN DETECTION LIMIT

CODES

OTHER PARAMETER VALUE FLAGS:

0001 - FILTERED SAMPLE (. 45 MICRONS)

I - INCREASED DETECTION LIMIT DUE TO REQUIRED DILUTION

N001 - UNFILTERED SAMPLE

$J$ - ESTIMATED VALUE

H - POST-DIGEST SPIKE OUT OF CNTR LIM WHILE SAMP ABS < $50 \%$ SPIKE 
TABLE 3.27 BASELINE GROUND HATER QUALITY DATA BY PARAMETER FOR THE ALLUVIUM, NC AND UC PROCESSING SITES, SLICK ROCK, COLORADO

SITE: SRKOI SLICK ROCK (BOTH SITES)

RITE:

REPORT DATE: $10 / 03 / 94$

\begin{tabular}{|c|c|c|c|c|c|c|c|c|c|c|c|}
\hline PARAMETER NAME & ${ }_{\text {ID }}^{\text {LOCATION }}$ & LOG DATE & $\begin{array}{c}\text { SAMPLE } \\
\text { ID }\end{array}$ & $\begin{array}{l}\text { FORM } \\
\text { COMP }\end{array}$ & $\begin{array}{l}\text { FLOW } \\
\text { REL. }\end{array}$ & $\begin{array}{l}\text { UNITS OF } \\
\text { MEASURE }\end{array}$ & PVI & $\begin{array}{l}\text { PARAMETER } \\
\text { VALUE }\end{array}$ & FLAGS & $\begin{array}{l}\text { DETECTION } \\
\text { LIMIT }\end{array}$ & $\begin{array}{l}\text { PARAMETER } \\
\text { UNCERTAINTY }\end{array}$ \\
\hline TIN & $\begin{array}{l}0507 \\
0507 \\
0508 \\
0508 \\
0508 \\
0508 \\
0509 \\
0509 \\
0509 \\
0509 \\
0510 \\
0510 \\
0510 \\
0510 \\
0510 \\
0512 \\
0512 \\
0512 \\
0512\end{array}$ & \begin{tabular}{|l|}
$12 / 05 / 91$ \\
$10 / 08 / 92$ \\
$03 / 27 / 91$ \\
$08 / 28 / 91$ \\
$12 / 05 / 91$ \\
$10 / 10 / 92$ \\
$03 / 27 / 91$ \\
$08 / 28 / 91$ \\
$11 / 21 / 91$ \\
$10 / 13 / 92$ \\
$06 / 30 / 86$ \\
$05 / 16 / 90$ \\
$03 / 28 / 91$ \\
$12 / 05 / 91$ \\
$10 / 08 / 92$ \\
$04 / 05 / 91$ \\
$08 / 08 / 91$ \\
$12 / 10 / 91$ \\
$10 / 09 / 92$
\end{tabular} & $\begin{array}{l}0001 \\
0001 \\
0001 \\
0001 \\
0001 \\
0001 \\
0001 \\
0001 \\
0001 \\
0001 \\
0001 \\
0001 \\
0001 \\
0001 \\
0001 \\
0001 \\
0001 \\
0001 \\
0001\end{array}$ & $\begin{array}{l}A L \\
A L \\
A L \\
A L \\
A L \\
A L \\
A L \\
A L \\
A L \\
A L \\
A L \\
A L \\
A L \\
A L \\
A L \\
A L \\
A L \\
A L \\
A L\end{array}$ & $\begin{array}{l}D \\
D \\
0 \\
0 \\
0 \\
0 \\
0 \\
0 \\
0 \\
0 \\
0 \\
0 \\
0 \\
0 \\
0 \\
0 \\
0 \\
0 \\
0\end{array}$ & $M G / L$ & $\begin{array}{l}< \\
< \\
< \\
< \\
< \\
< \\
< \\
< \\
< \\
< \\
< \\
< \\
< \\
< \\
< \\
< \\
< \\
< \\
< \\
< \\
<\end{array}$ & $\begin{array}{l}0.005 \\
0.05 \\
0.005 \\
0.05 \\
0.005 \\
0.05 \\
0.005 \\
0.05 \\
0.03 \\
0.005 \\
0.005 \\
0.005 \\
0.005 \\
0.005 \\
0.05 \\
0.005 \\
0.05 \\
0.005 \\
0.005\end{array}$ & $\begin{array}{l}W \\
I \\
R \\
\text { IW } \\
I \\
\text { R } \\
\text { IW } \\
I \\
\text { I } \\
\text { I } \\
\text { IW }\end{array}$ & $\begin{array}{l}0.005 \\
0.05 \\
0.005 \\
0.05 \\
0.005 \\
0.05 \\
0.005 \\
0.05 \\
0.03 \\
0.005 \\
0.005 \\
0.005 \\
0.005 \\
0.005 \\
0.05 \\
0.005 \\
0.05 \\
0.005 \\
0.005\end{array}$ & $\begin{array}{l}- \\
- \\
- \\
- \\
- \\
- \\
- \\
- \\
- \\
- \\
- \\
- \\
- \\
- \\
- \\
-\end{array}$ \\
\hline TOTAL. DISSOLVED SOLIDS & $\begin{array}{l}0503 \\
0503 \\
0503 \\
0503 \\
0503 \\
0503 \\
0503 \\
0503 \\
0503 \\
0503 \\
0503 \\
0504 \\
0504 \\
0504 \\
0504\end{array}$ & $\begin{array}{l}09 / 07 / 82 \\
02 / 18 / 86 \\
06 / 30 / 86 \\
10 / 14 / 87 \\
02 / 22 / 88 \\
05 / 16 / 90 \\
03 / 29 / 91 \\
08 / 08 / 91 \\
12 / 09 / 91 \\
10 / 09 / 92 \\
02 / 18 / 94 \\
09 / 07 / 82 \\
02 / 04 / 86 \\
07 / 01 / 86 \\
10 / 14 / 87\end{array}$ & $\begin{array}{l}0001 \\
0001 \\
0001 \\
0001 \\
0001 \\
0001 \\
0001 \\
0001 \\
0001 \\
0001 \\
0001 \\
0001 \\
0001 \\
0001 \\
0001\end{array}$ & $\begin{array}{l}A L \\
A L \\
A L \\
A L \\
A L . \\
A L \\
A L \\
A L \\
A L \\
A L \\
A L \\
A L \\
A L \\
A L \\
A L\end{array}$ & $\begin{array}{l}0 \\
0 \\
0 \\
0 \\
0 \\
0 \\
0 \\
0 \\
0 \\
0 \\
0 \\
D \\
0 \\
D \\
D\end{array}$ & $M G / L$ & & $\begin{array}{l}3190.00 \\
3330 . \\
3400 . \\
3130 . \\
3130 . \\
2770 . \\
2830 . \\
1060 . \\
2640 . \\
2520 . \\
2430 \\
3800.00 \\
4770 . \\
3950 . \\
4300 .\end{array}$ & $\begin{array}{l}\text { L } \\
\text { H }\end{array}$ & $\begin{array}{l}10 . \\
10 . \\
10 . \\
10 . \\
10 . \\
10 . \\
10 . \\
10 . \\
10 . \\
10 . \\
10 . \\
10 . \\
10 .\end{array}$ & $\begin{array}{l}- \\
- \\
- \\
- \\
- \\
- \\
- \\
- \\
- \\
- \\
- \\
-\end{array}$ \\
\hline
\end{tabular}

FORMATION OF COMPLETION CODE:

$A L$ - ALLUVIUM

PARAMETER VALUE INDICATOR (PVI): < - LESS THAN DETECTION LIMIT
FLOH RELATIONSHIP CODE:

D - DOWN GRADIENT

O - ON-SITE

SAMPLE ID CODES:

0001 - FILTEREO SAMPLE (.45 MICRONS)

OTHER PARAMETER VALUE FLAGS:

H - HOLD TIME EXPIRED, VALUE SUSPECT

I - INCREASED DETECTION LIMIT DUE TO REQUIRED DILUTION

$L$ - LESS THAN THREE BORE VOLUMES REMOVED BEFORE SAMPLING

$R$ - UNUSABLE DATA POINT

W - POST-DIGEST SAIKE OUT OF CNTR LIM WHILE SAMP ABS < 50\% SPIKE 
TABLE 3.27 BASELINE GROUND WATER QUALITY DATA BY PARAMETER FOR THE ALLUVIUM, NC AND UC PROCESSING SITES, SLICK ROCK, COLORADO

SITE: SRKO1 SLICK ROCK (BOTH SITES)

$09 / 07 / 82$ TO $02 / 22 / 94$

REPORT DATE: $10 / 03 / 94$

\begin{tabular}{|c|c|c|c|c|c|c|c|c|c|c|c|c|}
\hline & PARAMETER NAME & $\underset{\text { ID }}{\text { LOCATION }}$ & LOG DATE & $\begin{array}{c}\text { SAMPLE } \\
\text { ID }\end{array}$ & $\begin{array}{l}\text { FORM } \\
\text { COMP }\end{array}$ & $\begin{array}{l}\text { FLOW } \\
\text { REL. }\end{array}$ & $\begin{array}{l}\text { UNITS OF } \\
\text { MEASURE }\end{array}$ & PVI & $\begin{array}{l}\text { PARAMETER } \\
\text { VALUE }\end{array}$ & FLAGS & $\begin{array}{l}\text { DETECTION } \\
\text { LIMIT }\end{array}$ & $\begin{array}{l}\text { PARAMETER } \\
\text { UNCERTAINTY }\end{array}$ \\
\hline & TOTAL DISSOLVED SOLIDS & $\begin{array}{l}0504 \\
0504 \\
0504 \\
0504 \\
0504 \\
0504 \\
0504 \\
0506 \\
0506 \\
0506 \\
0506 \\
0506 \\
0506 \\
0506 \\
0506 \\
0506 \\
0506 \\
0507 \\
0507 \\
0507 \\
0507 \\
0507 \\
0507 \\
0507 \\
0507 \\
0507 \\
0507 \\
0507 \\
0508 \\
0508 \\
0508 \\
0508 \\
0508 \\
0508 \\
0508 \\
0508 \\
0508\end{array}$ & $\begin{array}{l}02 / 22 / 88 \\
05 / 16 / 90 \\
04 / 03 / 91 \\
08 / 27 / 91 \\
12 / 09 / 91 \\
10 / 09 / 92 \\
02 / 19 / 94 \\
09 / 08 / 82 \\
02 / 05 / 86 \\
07 / 01 / 86 \\
10 / 14 / 87 \\
02 / 22 / 88 \\
03 / 28 / 91 \\
08 / 08 / 91 \\
11 / 20 / 91 \\
10 / 08 / 92 \\
02 / 20 / 94 \\
09 / 09 / 82 \\
02 / 05 / 86 \\
06 / 30 / 86 \\
10 / 14 / 87 \\
02 / 22 / 88 \\
05 / 16 / 90 \\
03 / 28 / 91 \\
08 / 09 / 91 \\
12 / 05 / 91 \\
10 / 08 / 92 \\
02 / 20 / 94 \\
09 / 08 / 82 \\
02 / 18 / 86 \\
06 / 30 / 86 \\
10 / 14 / 87 \\
02 / 19 / 88 \\
03 / 27 / 91 \\
08 / 28 / 91 \\
12 / 05 / 91 \\
10 / 10 / 92\end{array}$ & $\begin{array}{l}0001 \\
0001 \\
0001 \\
0001 \\
0001 \\
0001 \\
0001 \\
0001 \\
0001 \\
0001 \\
0001 \\
0001 \\
0001 \\
0001 \\
0001 \\
0001 \\
0001 \\
0001 \\
0001 \\
0001 \\
0001 \\
0001 \\
0001 \\
0001 \\
0001 \\
0001 \\
0001 \\
0001 \\
0001 \\
0001 \\
0001 \\
0001 \\
0001 \\
0001 \\
0001 \\
0001 \\
0001\end{array}$ & $\begin{array}{l}A L \\
A L \\
A L \\
A L \\
A L \\
A L \\
A L \\
A L \\
A L \\
A L \\
A L \\
A L \\
A L \\
A L \\
A L \\
A L \\
A L \\
A L \\
A L \\
A L \\
A L \\
A L \\
A L \\
A L \\
A L \\
A L \\
A L \\
A L \\
A L \\
A L \\
A L \\
A L \\
A L \\
A L \\
A L \\
A L \\
A L\end{array}$ & $\begin{array}{l}D \\
D \\
D \\
D \\
D \\
D \\
D \\
D \\
D \\
D \\
D \\
D \\
D \\
D \\
D \\
D \\
D \\
D \\
D \\
D \\
D \\
D \\
D \\
D \\
D \\
D \\
D \\
D \\
D \\
0 \\
0 \\
0 \\
0 \\
D \\
D \\
0 \\
0\end{array}$ & MG/L & & $\begin{array}{l}4080 . \\
2470 . \\
2350 . \\
2160 . \\
1970 . \\
1670 . \\
4010 \\
4310.00 \\
5630 . \\
5370 . \\
5220 . \\
5170 . \\
9560 . \\
2780 . \\
5840 . \\
7560 . \\
190 \\
2560.00 \\
1460 . \\
1520 . \\
1413 . \\
1260 . \\
892 . \\
259 . \\
863 . \\
911 . \\
928 . \\
780 \\
3620.00 \\
4790 . \\
4420 . \\
4210 . \\
3870 . \\
1320 . \\
3620 . \\
3620 . \\
3640 .\end{array}$ & $\begin{array}{l}H \\
\text { R } \\
\text { H } \\
\\
H \\
\\
\text { H } \\
\text { R } \\
H \\
H\end{array}$ & $\begin{array}{c}10 . \\
10 . \\
10 . \\
10 . \\
10 . \\
10 . \\
10 \\
10 . \\
10 . \\
10 . \\
10 . \\
10 . \\
10 . \\
10 . \\
10 . \\
10 \\
10 . \\
10 . \\
10 . \\
10 . \\
10 . \\
10 . \\
10 . \\
10 . \\
10 . \\
10 \\
10 . \\
10 . \\
10 . \\
10 . \\
10 . \\
10 . \\
10 . \\
10 .\end{array}$ & $\begin{array}{l}- \\
- \\
- \\
- \\
- \\
- \\
- \\
- \\
- \\
- \\
- \\
- \\
- \\
- \\
- \\
- \\
- \\
- \\
- \\
- \\
- \\
- \\
- \\
- \\
- \\
- \\
-\end{array}$ \\
\hline & $\begin{array}{l}\text { FORMATION OF COMPLETION CODE: } \\
\text { AL - ALLUVIUM }\end{array}$ & & & & & & $\begin{array}{l}\text { FLOW R } \\
D-D O \\
O-O N\end{array}$ & & $\begin{array}{l}\text { SHIP CODE } \\
\text { IENT }\end{array}$ & & & \\
\hline & PARAMETER VALUE INDICATOR (PVI): & $<-$ LE & ESS THAN D & DETECTIC & ON LIM & & $\begin{array}{l}\text { SAMPLE } \\
0001\end{array}$ & & $\begin{array}{l}\text { S: } \\
\text { O SAMPL }\end{array}$ & & & \\
\hline
\end{tabular}

OTHER PARAMETER VALUE FLAGS:

H - HOLD TIME EXPIRED, VALUE SUSPECT

$J$ - ESTIMATED VALUE

$R$ - UNUSABLE DATA POINT 
TABLE 3.27 BASELINE GROUND WATER QUALITY DATA BY PARAMETER FOR THE ALLUVIUM, NC AND UC PROCESSING SITES, SLICK ROCK, COLORADO

SITE: SRKO1 SLICK ROCK (BOTH SITES)

DEPT/82 TO 02/22/94

\begin{tabular}{|c|c|c|c|c|c|c|c|c|c|c|c|}
\hline PARAMETER NAME & $\begin{array}{c}\text { LOCATION } \\
\text { ID }\end{array}$ & LOG DATE & $\begin{array}{c}\text { SAMPLE } \\
\text { ID }\end{array}$ & $\begin{array}{l}\text { FORM } \\
\text { COMP }\end{array}$ & $\begin{array}{l}\text { FLOW } \\
\text { REL. }\end{array}$ & $\begin{array}{l}\text { UNITS OF } \\
\text { MEASURE }\end{array}$ & PVI & $\begin{array}{l}\text { PARAMETER } \\
\text { VALUE }\end{array}$ & FLAGS & $\begin{array}{l}\text { DETECTION } \\
\text { LIMIT }\end{array}$ & $\begin{array}{l}\text { PARAMETER } \\
\text { UNCERTAINTY }\end{array}$ \\
\hline TOTAL DISSOLVED SOLIDS & $\begin{array}{l}0508 \\
0509 \\
0509 \\
0509 \\
0509 \\
0509 \\
0509 \\
0509 \\
0509 \\
0509 \\
0509 \\
0510 \\
0510 \\
0510 \\
0510 \\
0510 \\
0510 \\
0510 \\
0510 \\
0510 \\
0510 \\
0510 \\
0512 \\
0512 \\
0512 \\
0512 \\
0512 \\
0512 \\
0512 \\
0512 \\
0512 \\
0512\end{array}$ & $\begin{array}{l}02 / 21 / 94 \\
09 / 09 / 82 \\
02 / 18 / 86 \\
07 / 17 / 86 \\
10 / 14 / 87 \\
02 / 22 / 88 \\
03 / 27 / 91 \\
08 / 28 / 91 \\
11 / 21 / 91 \\
10 / 13 / 92 \\
02 / 21 / 94 \\
09 / 08 / 82 \\
02 / 18 / 86 \\
06 / 30 / 86 \\
10 / 14 / 87 \\
02 / 22 / 88 \\
05 / 16 / 90 \\
03 / 28 / 91 \\
08 / 28 / 91 \\
12 / 05 / 91 \\
10 / 08 / 92 \\
02 / 20 / 94 \\
09 / 08 / 82 \\
02 / 04 / 86 \\
07 / 01 / 86 \\
10 / 14 / 87 \\
02 / 22 / 88 \\
04 / 05 / 91 \\
08 / 08 / 91 \\
12 / 10 / 91 \\
10 / 09 / 92 \\
02 / 20 / 94\end{array}$ & $\begin{array}{l}0001 \\
0001 \\
0001 \\
0001 \\
0001 \\
0001 \\
0001 \\
0001 \\
0001 \\
0001 \\
0001 \\
0001 \\
0001 \\
0001 \\
0001 \\
0001 \\
0001 \\
0001 \\
0001 \\
0001 \\
0001 \\
0001 \\
0001 \\
0001 \\
0001 \\
0001 \\
0001 \\
0001 \\
0001 \\
0001 \\
0001 \\
0001\end{array}$ & $\begin{array}{l}A L \\
A L \\
A L \\
A L \\
A L \\
A L \\
A L \\
A L \\
A L \\
A L \\
A L \\
A L \\
A L \\
A L \\
A L \\
A L \\
A L \\
A L \\
A L \\
A L \\
A L \\
A L \\
A L \\
A L \\
A L \\
A L \\
A L \\
A L \\
A L \\
A L \\
A L \\
A L\end{array}$ & $\begin{array}{l}0 \\
0 \\
0 \\
0 \\
0 \\
0 \\
0 \\
0 \\
0 \\
0 \\
0 \\
0 \\
0 \\
0 \\
0 \\
0 \\
0 \\
0 \\
0 \\
0 \\
0 \\
0 \\
0 \\
0 \\
0 \\
0 \\
0 \\
0 \\
0 \\
0 \\
0 \\
0\end{array}$ & MG/L & & $\begin{array}{l}3890 \\
2170.00 \\
1940 . \\
1140 . \\
1450 . \\
1300 . \\
3440 . \\
1572 . \\
1520 . \\
1510 . \\
1070 \\
3630.00 \\
4780 . \\
4180 . \\
4370 . \\
4000 . \\
3750 . \\
3710 . \\
4300 . \\
3760 . \\
4090 . \\
4220 \\
2070.00 \\
1850 . \\
1310 . \\
1890 . \\
1260 . \\
1330 . \\
1250 . \\
1130 . \\
1580 . \\
1600\end{array}$ & $\begin{array}{l}\mathrm{H} \\
\mathrm{H}\end{array}$ & $\begin{array}{l}10 . \\
10 . \\
10 . \\
10 . \\
10 . \\
10 . \\
10 . \\
10 . \\
10 . \\
10 . \\
10 . \\
10 . \\
10 . \\
10 . \\
10 . \\
10 . \\
10 . \\
10 . \\
10 . \\
10 \\
10 . \\
10 . \\
10 . \\
10 . \\
10 . \\
10 . \\
10 . \\
10 . \\
10\end{array}$ & $\begin{array}{l}- \\
- \\
- \\
- \\
- \\
- \\
- \\
- \\
- \\
- \\
- \\
- \\
- \\
- \\
- \\
- \\
- \\
- \\
- \\
- \\
- \\
- \\
- \\
- \\
- \\
- \\
- \\
-\end{array}$ \\
\hline TOTAL KJELDAHL NITROGEN & $\begin{array}{l}0503 \\
0503 \\
0503 \\
0504\end{array}$ & $\begin{array}{l}03 / 29 / 91 \\
08 / 08 / 91 \\
12 / 09 / 91 \\
04 / 03 / 91\end{array}$ & $\begin{array}{l}0001 \\
0001 \\
0001 \\
0001\end{array}$ & $\begin{array}{l}A L \\
A L \\
A L \\
A L\end{array}$ & $\begin{array}{l}0 \\
0 \\
0 \\
0\end{array}$ & $M G / L$ & $\mid<$ & $\begin{array}{l}1 . \\
1 . \\
2 . \\
1 .\end{array}$ & $\begin{array}{l}\text { I } \\
\text { J }\end{array}$ & $\begin{array}{l}1 . \\
1 . \\
2 . \\
1 .\end{array}$ & $\begin{array}{l}- \\
- \\
-\end{array}$ \\
\hline
\end{tabular}

FORMATION OF COMPLETION CODE:

AL - ALLUVIUM

PARAMETER VALUE INDICATOR (PVI):
FLOW RELATIONSHIP CODE:

O - ON-SITE

D - DOWN GRADIENT

\section{SAMPLE ID CODES:}

0001 - FILTERED SAMPLE (.45 MICRONS)

OTHER PARAMETER VALUE FLAGS:

H - HOLD TIME EXPIRED, VALUE SUSPEC

I - INCREASED DETECTION LIMIT DUE TO REQUIRED DILUTION

$J$ - ESTIMATED VALUE

R - UNUSABLE DATA POINT 
TABLE 3.27 BASELINE GROUND HATER QUALITY DATA BY PARANETER FOR THE ALLUVIUN, NC AND UC PROCESSING SITES, SLICK ROCK, COLORADO

SITE: SRKO1 SLICK ROCK (BOTH SITES)

O9/07/82 To 02/22/94

REPORT DATE: $10 / 03 / 94$

\begin{tabular}{|c|c|c|c|c|c|c|c|c|c|c|c|}
\hline PARAMETER NAME & $\begin{array}{c}\text { LOCATION } \\
\text { ID }\end{array}$ & LOG DATE & $\begin{array}{c}\text { SAMPLE } \\
\text { ID }\end{array}$ & $\begin{array}{l}\text { FORM } \\
\text { COMP }\end{array}$ & $\begin{array}{l}\text { FLOW } \\
\text { REL. }\end{array}$ & $\begin{array}{l}\text { UNITS OF } \\
\text { MEASURE }\end{array}$ & PVI & $\begin{array}{l}\text { PARAMETER } \\
\text { VALUE }\end{array}$ & FLAGS & $\begin{array}{l}\text { DETECTION } \\
\text { LIMIT }\end{array}$ & $\begin{array}{l}\text { PARAMETER } \\
\text { UNCERTAINTY }\end{array}$ \\
\hline TOTAL KJELDAHL NITROGEN & $\begin{array}{l}0504 \\
0504 \\
0506 \\
0506 \\
0506 \\
0507 \\
0507 \\
0507 \\
0508 \\
0508 \\
0508 \\
0509 \\
0509 \\
0509 \\
0510 \\
0510 \\
0510 \\
0512 \\
0512 \\
0512\end{array}$ & $\begin{array}{l}08 / 27 / 91 \\
12 / 09 / 91 \\
03 / 28 / 91 \\
08 / 08 / 91 \\
11 / 20 / 91 \\
03 / 28 / 91 \\
08 / 09 / 91 \\
12 / 05 / 91 \\
03 / 27 / 91 \\
08 / 28 / 91 \\
12 / 05 / 91 \\
03 / 27 / 91 \\
08 / 28 / 91 \\
11 / 21 / 91 \\
03 / 28 / 91 \\
08 / 28 / 91 \\
12 / 05 / 91 \\
04 / 05 / 91 \\
08 / 08 / 91 \\
12 / 10 / 91\end{array}$ & $\begin{array}{l}0001 \\
0001 \\
0001 \\
0001 \\
0001 \\
0001 \\
0001 \\
0001 \\
0001 \\
0001 \\
0001 \\
0001 \\
0001 \\
0001 \\
0001 \\
0001 \\
0001 \\
0001 \\
0001 \\
0001\end{array}$ & $\begin{array}{l}A L \\
A L \\
A L \\
A L \\
A L \\
A L \\
A L \\
A L \\
A L \\
A L \\
A L \\
A L \\
A L \\
A L \\
A L \\
A L \\
A L \\
A L \\
A L \\
A L\end{array}$ & $\begin{array}{l}D \\
D \\
D \\
D \\
D \\
D \\
D \\
D \\
0 \\
0 \\
0 \\
0 \\
0 \\
0 \\
0 \\
0 \\
0 \\
0 \\
0 \\
0\end{array}$ & MG/L & 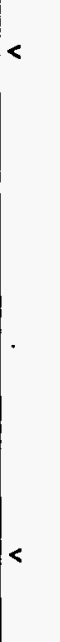 & $\begin{array}{r}1 . \\
2 . \\
113 . \\
130 . \\
116 . \\
25 . \\
22 . \\
20 . \\
72 . \\
112 . \\
111 . \\
110 . \\
84 . \\
98 . \\
59 . \\
24 . \\
51 . \\
1 . \\
2 . \\
5 .\end{array}$ & $\begin{array}{l}\mathbf{R} \\
\mathbf{R}\end{array}$ & $\begin{array}{l}1 . \\
2 . \\
1 . \\
1 . \\
2 . \\
1 . \\
1 . \\
2 . \\
1 . \\
1 . \\
2 . \\
1 . \\
1 . \\
2 . \\
1 . \\
1 . \\
2 . \\
1 . \\
1 . \\
2 .\end{array}$ & $\begin{array}{l}- \\
- \\
- \\
- \\
- \\
- \\
- \\
- \\
- \\
- \\
- \\
- \\
- \\
- \\
- \\
-\end{array}$ \\
\hline TOTAL ORGANIC CARBON & $\begin{array}{l}0503 \\
0503 \\
0503 \\
0503 \\
0503 \\
0504 \\
0504 \\
0504 \\
0504 \\
0504 \\
0506 \\
0506 \\
0506 \\
0506 \\
0506 \\
0507\end{array}$ & $\begin{array}{l}03 / 29 / 91 \\
08 / 08 / 91 \\
12 / 09 / 91 \\
10 / 09 / 92 \\
02 / 18 / 94 \\
04 / 03 / 91 \\
08 / 27 / 91 \\
12 / 09 / 91 \\
10 / 09 / 92 \\
02 / 19 / 94 \\
03 / 28 / 91 \\
08 / 08 / 91 \\
11 / 20 / 91 \\
10 / 08 / 92 \\
02 / 20 / 94 \\
03 / 28 / 91\end{array}$ & $\begin{array}{l}0001 \\
0001 \\
0001 \\
0001 \\
\text { No01 } \\
0001 \\
0001 \\
0001 \\
0001 \\
\text { N001 } \\
0001 \\
0001 \\
0001 \\
0001 \\
\text { N001 } \\
0001\end{array}$ & $\begin{array}{l}A L \\
A L \\
A L \\
A L \\
A L \\
A L \\
A L \\
A L \\
A L \\
A L \\
A L \\
A L \\
A L \\
A L \\
A L \\
A L\end{array}$ & $\begin{array}{l}\text { O } \\
0 \\
0 \\
0 \\
0 \\
D \\
D \\
D \\
D \\
D \\
D \\
D \\
D \\
D \\
D \\
D\end{array}$ & MG/L & & $\begin{array}{c}3 . \\
3 . \\
2 . \\
3 . \\
4 \\
10 . \\
3 . \\
2 . \\
5 . \\
5 \\
33 . \\
38 . \\
24 . \\
39 . \\
45 \\
7 .\end{array}$ & 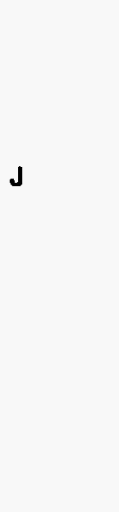 & $\begin{array}{l}1 . \\
1 . \\
1 . \\
1 . \\
1 \\
1 . \\
1 . \\
1 . \\
1 . \\
1 . \\
1 . \\
1 . \\
1 . \\
1 . \\
1 .\end{array}$ & $\begin{array}{l}- \\
- \\
- \\
- \\
- \\
- \\
- \\
- \\
- \\
- \\
- \\
- \\
-\end{array}$ \\
\hline
\end{tabular}

FORMATION OF COMPLETION CODE:

AL - ALLUVIUH

PARAMETER VALUE INDICATOR (PVI): < - LESS THAN DETECTION LIMIT

OTHER PARAMETER VALUE FLAGS:

I - INCREASED DETECTION LIMIT DUE TO REQUIRED DILUTION

J - ESTIMATED VALUE

$R$ - UNUSABLE DATA POINT
FLOW RELATIONSHIP CODE:

D - DOWN GRADIENT

O - ON-SITE

SAMPLE ID CODES:

SAMPLE ID CODES: SAMPLE ( 45 MICRONS)

N001 - UNFILTERED SAMPLE 
TABLE 3.27 BASELINE GROUND WATER QUALITY DATA BY PARAMETER FOR THE ALLUVIUM, NC AND UC PROCESSING SITES, SLICK ROCK, COLORADO

SITE: SRKO1 SLICK ROCK (BOTH SITES)

$09 / 07 / 82$ TO $02 / 22 / 94$

REPORT DATE: $10 / 03 / 94$

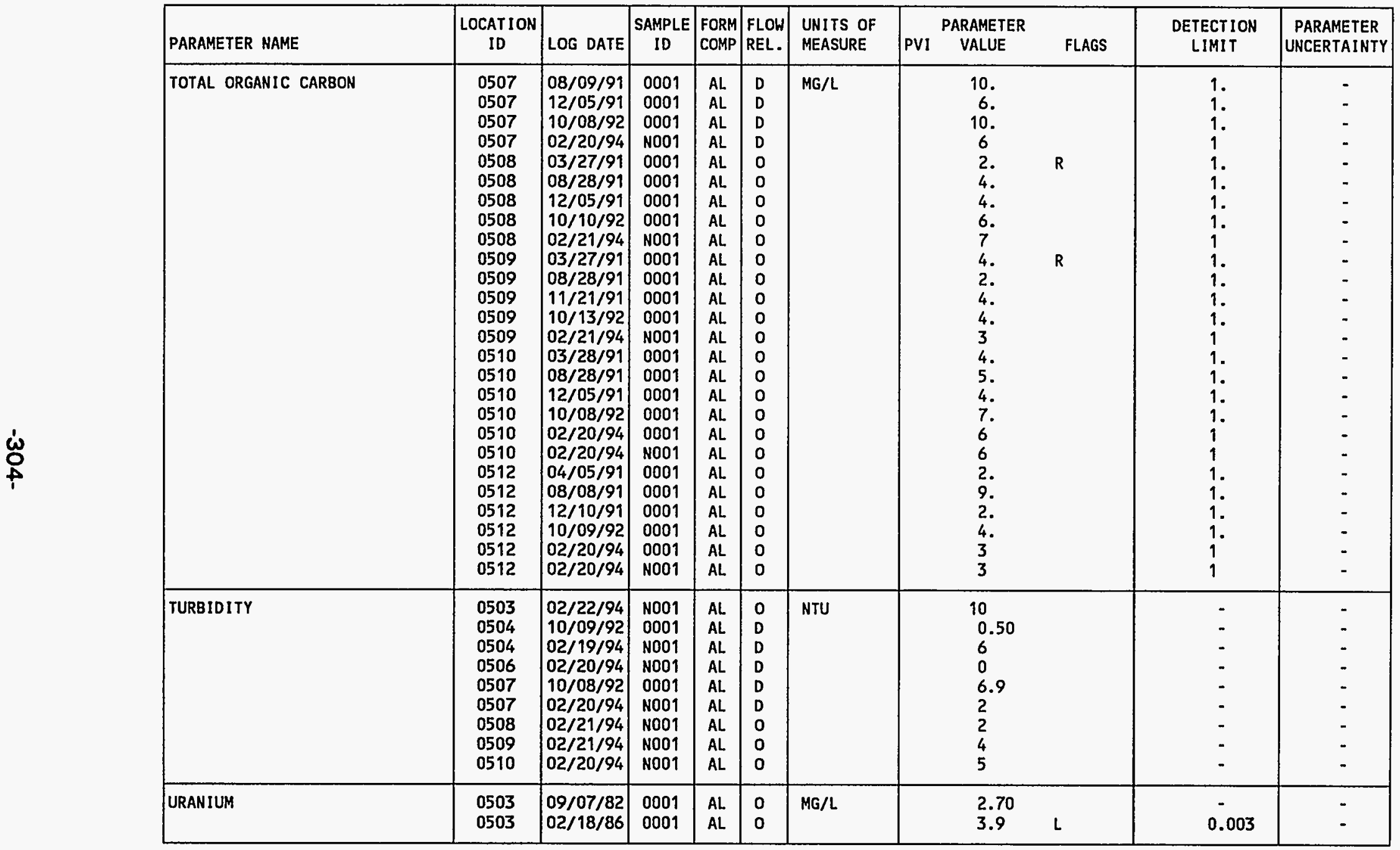

FORMATION OF COMPLETION CODE:

AL - ALLUVIUH

PARAMETER VALUE INDICATOR (PVI): < - LESS THAN DETECTION LIMIT

OTHER PARAMETER VALUE FLAGS:

L - LESS THAN THREE GORE VOLUIIES REMOVED BEFORE SAMPLING

$R$ - UNUSABLE DATA POINT
FLOW RELATIONSHIP CODE:

D - DOHN GRADIENT

O - ON-SITE

SAMPLE ID CODES

0001 - FILTERED SAMPLE (.45 MICRONS)

N001 - UNFILTERED SAMPLE 
TABLE 3.27 BASELINE GROUND WATER QUALITY DATA BY PARAMETER FOR THE ALLUVIUM, NC AND UC PROCESSING SITES, SLICK ROCK, COLORADO

SITE: SRKO1 SLICK ROCK (BOTH SITES)

$09 / 07 / 82$ 10 $02 / 22 / 94$

REPORT DATE: $10 / 03 / 9$

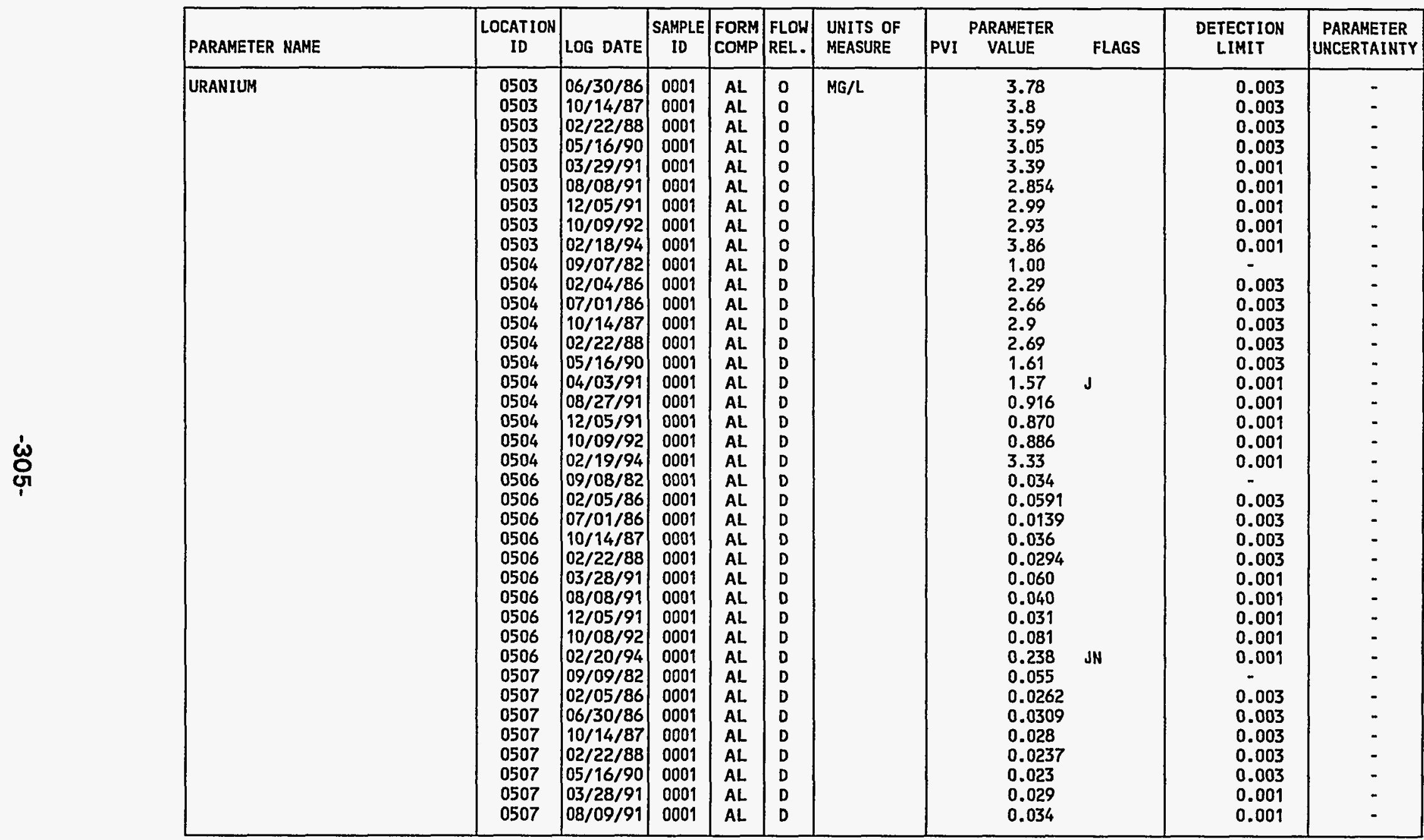

FORMATION OF COMPLETION CODE:

AL - ALLUVIUM

FLOW RELATIONSHIP CODE:

O - ON-SITE

D - DOWN GRADIENT

PARAMETER VALUE INDICATOR (PVI): < - LESS THAN DETECTION LIMIT

0001 - FILTERED SAMPLE (.45 MICRONS)

OTHER PARAMETER VALUE FLAGS:

$J$ - ESTIMATED VALUE

N - SPIKE SAMPLE RECOVERY NOT HITHIN CONTROL LIMITS 
TABLE 3.27 BASELINE GROUND WATER QUAL ITY DATA BY PARAMETER FOR THE ALLUVIUM, NC AND UC PROCESSING SITES, SLICK ROCK, COLORADO

SITE: SRKO1 SLICK ROCK (BOTH SITES)

$09 / 07 / 82$ TO 02/22/94

REPORT DATE: $10 / 03 / 94$

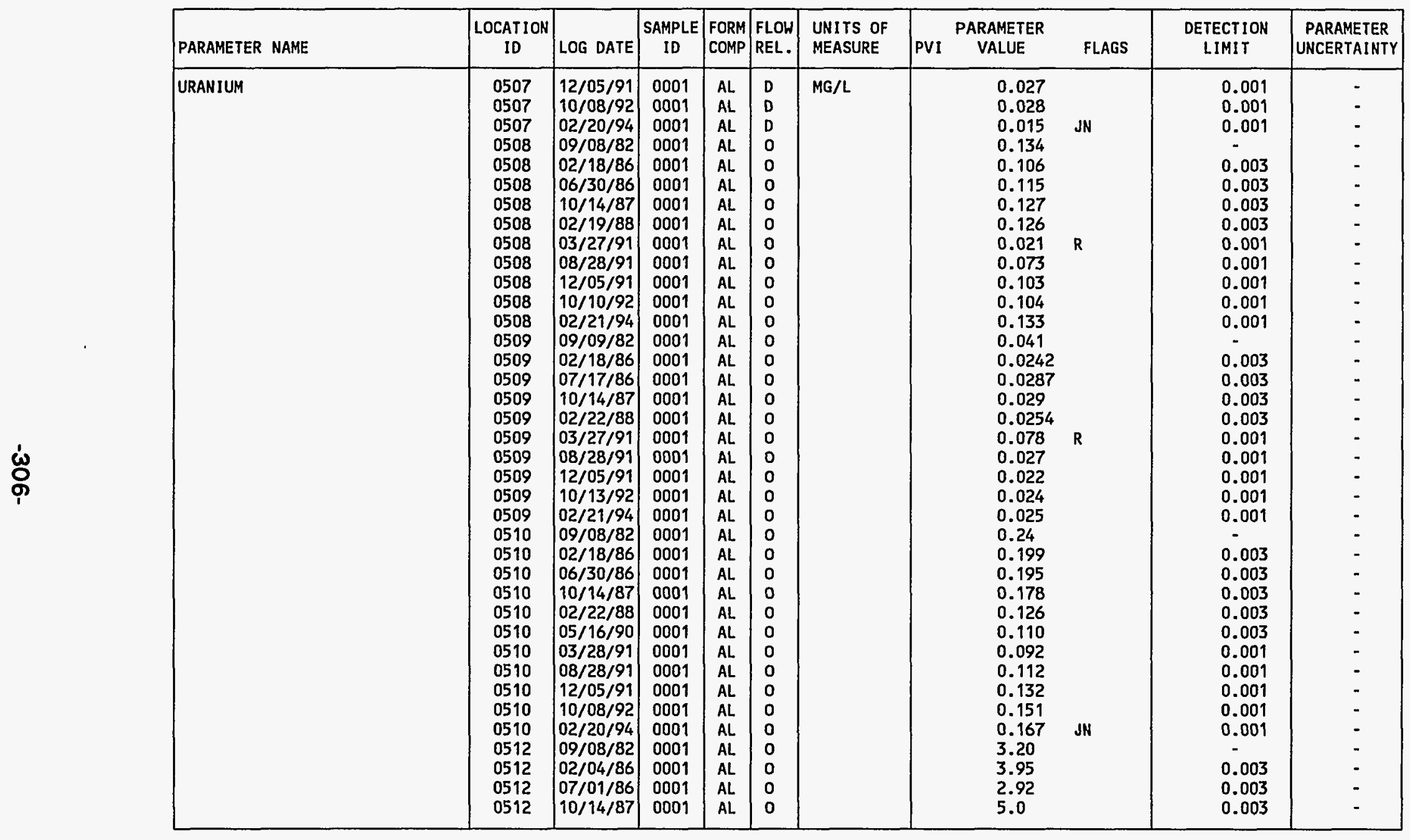

FORMATION OF COMPLETION CODE:

AL - ALLUVIUM
FLOW RELATIONSHIP CODE:

- DOWN GRADIENT

O - ON-SITE

PARAMETER VALUE INDICATOR (PVI): < - LESS THAN DETECTION LIMIT

SAMPLE ID CODES:

0001 - FILTERED SAMPLE (.45 MICRONS)

OTHER PARAMETER VALUE FLAGS:

$J$ - ESTIMATED VALUE

N - SPIKE SAMPLE REÇOVERY NOT WITHIN CONTROL LIMITS

$R$ - UNUSABLE DATA POINT 
TABLE 3.27 BASELINE GROUND WATER QUALITY DATA BY PARAMETER FOR THE ALLUVIUM, NC AND UC PROCESSING SITES, SLICK ROCK, COLORADO SITE: SRKO1 SLICK ROCK (BOTH SITES)

REPORT DATE: $10 / 03 / 94$

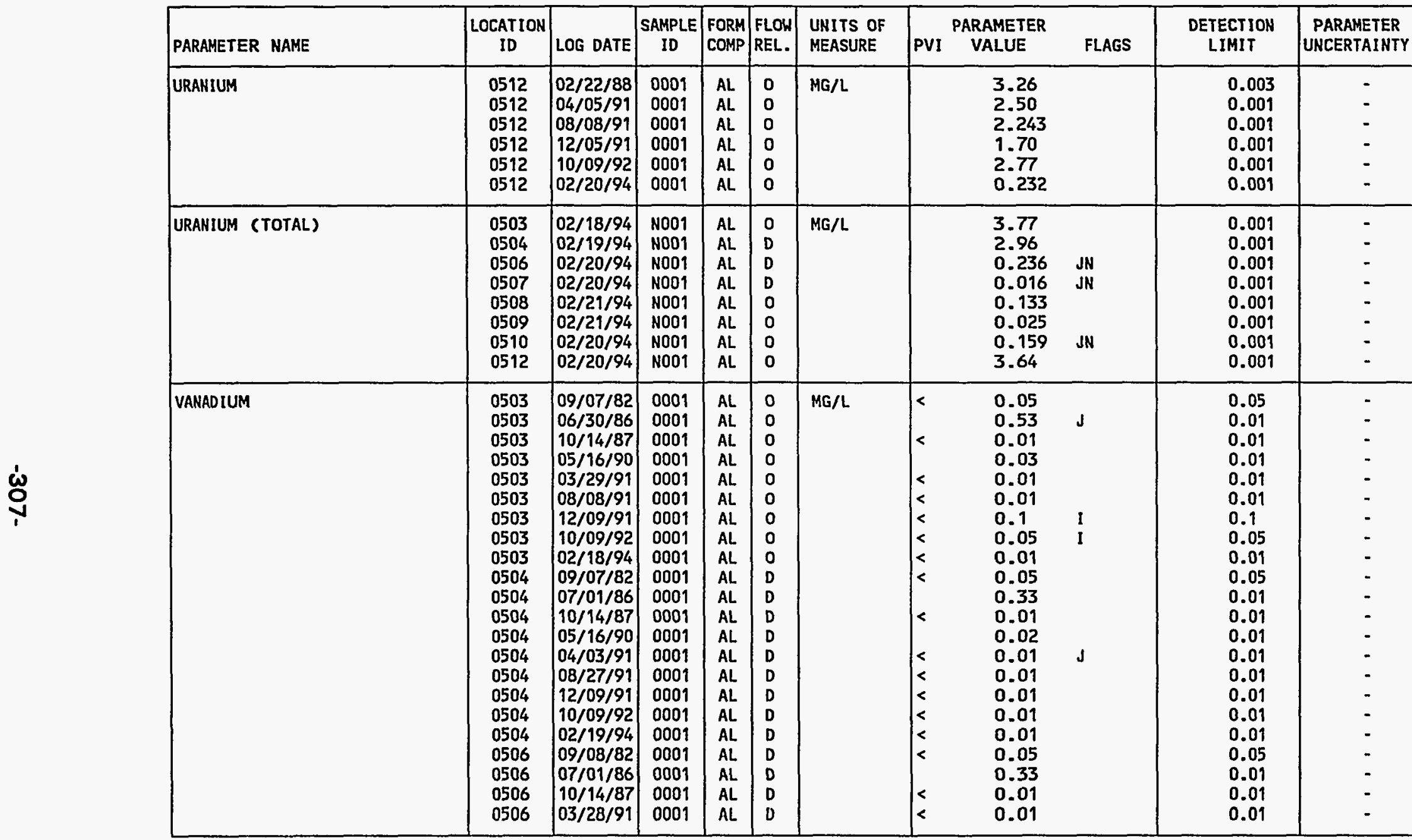

FORHATION OF COMPLETION CODE:

AL - ALLUVIUM

PARAMETER VALUE INDICATOR (PVI): < - LESS THAN DETECTION LIMIT

OTHER PARAMETER VALUE FLAGS:

I - INCREASED DETECTION LIMIT DUE TO REQUIRED DILUTION

$J$ - ESTIMATED VALUE

N - SPIKE SAMPLE RECOVERY NOT WITHIN CONTROL LIMITS
FLOW RELATIONSHIP CODE:

O - ON-SITE

D - DOWN GRADIENT

SAMPLE ID CODES:

0001 - FILTERED SAMPLE (.45 MICRONS)

N001 - UNFILTERED SAMPLE 


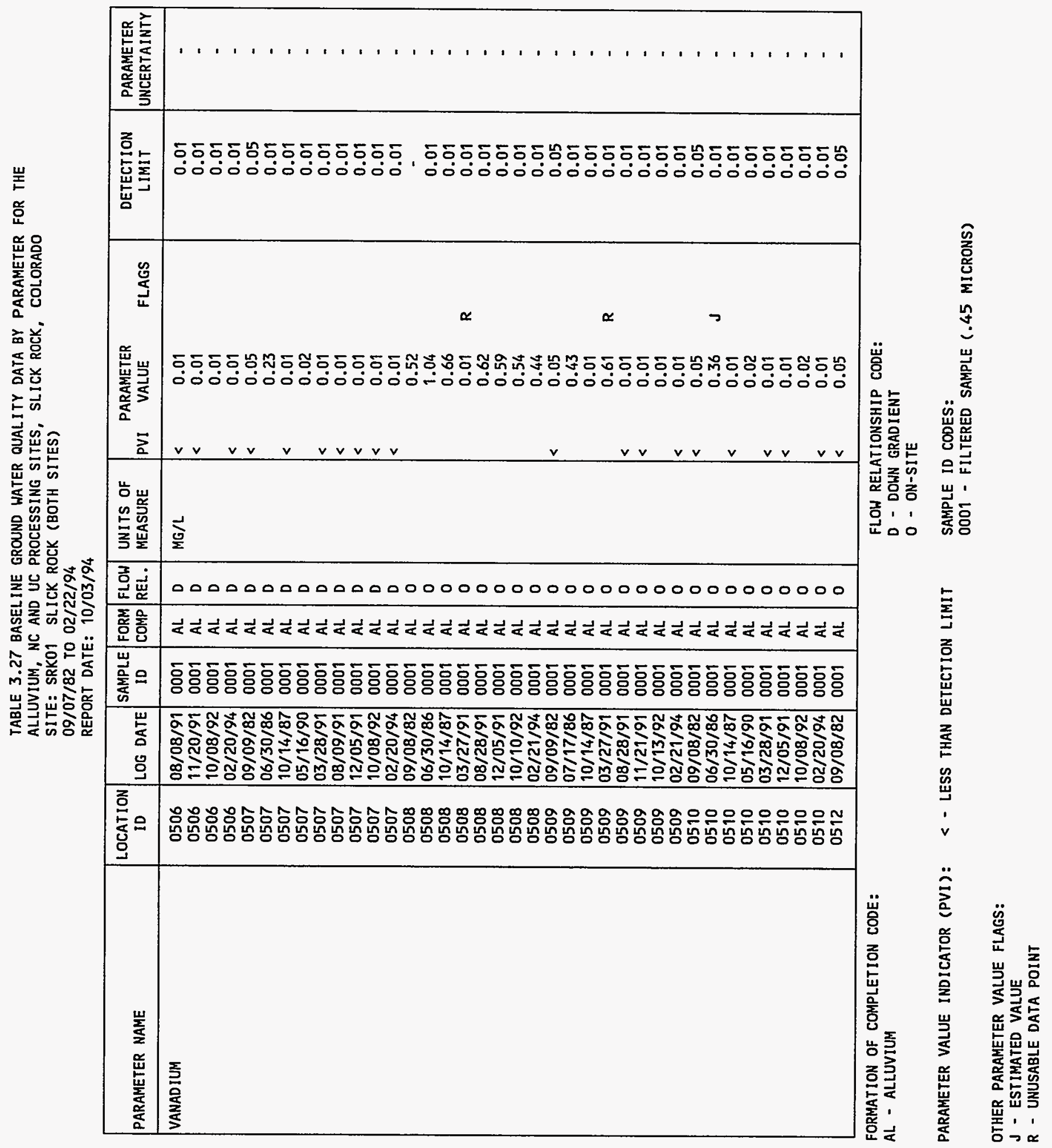


TABLE 3.27 BASELINE GROUND WATER QUALITY DATA BY PARAMETER FOR THE

ALLUVIUM, NC AND UC PROCESSING SITES, SLICK ROCK, COLORADO

SITE: SRK01 SLICK ROCK (BOTH SITES)

$09 / 07 / 82$ TO $02 / 22 / 94$

REPORT DATE: $10 / 03 / 94$

\begin{tabular}{|c|c|c|c|c|c|c|c|c|c|c|c|}
\hline PARAMETER NAME & $\begin{array}{l}\text { LOCATION } \\
\text { ID }\end{array}$ & LOG DATE & $\begin{array}{c}\text { SAMPLE } \\
\text { ID }\end{array}$ & $\begin{array}{l}\text { FORM } \\
\text { COMP }\end{array}$ & $\begin{array}{l}\text { FLOH } \\
\text { REL. }\end{array}$ & $\begin{array}{l}\text { UNITS OF } \\
\text { MEASURE }\end{array}$ & PVI & $\begin{array}{l}\text { PARAMETER } \\
\text { VALUE }\end{array}$ & FLAGS & $\begin{array}{l}\text { DETECTION } \\
\text { LIMIT }\end{array}$ & $\begin{array}{l}\text { PARAMETER } \\
\text { UNCERTAINTY }\end{array}$ \\
\hline VANADIUM & $\begin{array}{l}0512 \\
0512 \\
0512 \\
0512 \\
0512 \\
0512 \\
0512\end{array}$ & $\begin{array}{l}07 / 01 / 86 \\
10 / 14 / 87 \\
04 / 05 / 91 \\
08 / 08 / 91 \\
12 / 10 / 91 \\
10 / 09 / 92 \\
02 / 20 / 94\end{array}$ & $\begin{array}{l}0001 \\
0001 \\
0001 \\
0001 \\
0001 \\
0001 \\
0001\end{array}$ & $\begin{array}{l}A L \\
A L \\
A L \\
A L \\
A L \\
A L \\
A L\end{array}$ & $\begin{array}{l}0 \\
0 \\
0 \\
0 \\
0 \\
0 \\
0\end{array}$ & MG/L & $\begin{array}{l}< \\
< \\
< \\
< \\
< \\
<\end{array}$ & $\begin{array}{l}0.53 \\
0.01 \\
0.01 \\
0.01 \\
0.05 \\
0.05 \\
0.01\end{array}$ & $\begin{array}{l}1 \\
l\end{array}$ & $\begin{array}{l}0.01 \\
0.01 \\
0.01 \\
0.01 \\
0.05 \\
0.05 \\
0.01\end{array}$ & $\begin{array}{l}- \\
- \\
- \\
-\end{array}$ \\
\hline VANADIUM (TOTAL) & $\begin{array}{l}0503 \\
0504 \\
0506 \\
0507 \\
0508 \\
0509 \\
0510 \\
0512\end{array}$ & $\begin{array}{l}02 / 18 / 94 \\
02 / 19 / 94 \\
02 / 20 / 94 \\
02 / 20 / 94 \\
02 / 21 / 94 \\
02 / 21 / 94 \\
02 / 20 / 94 \\
02 / 20 / 94\end{array}$ & $\begin{array}{l}\text { N001 } \\
\text { N001 } \\
\text { N001 } \\
\text { N001 } \\
\text { N001 } \\
\text { N001 } \\
\text { N001 } \\
\text { N001 }\end{array}$ & $\begin{array}{l}A L \\
A L \\
A L \\
A L \\
A L \\
A L \\
A L \\
A L\end{array}$ & $\begin{array}{l}D \\
D \\
D \\
D \\
0 \\
0 \\
0 \\
0\end{array}$ & $M G / L$ & $\begin{array}{l}< \\
< \\
< \\
< \\
< \\
< \\
<\end{array}$ & $\begin{array}{l}0.01 \\
0.01 \\
0.01 \\
0.01 \\
0.52 \\
0.01 \\
0.01 \\
0.01\end{array}$ & & $\begin{array}{l}0.01 \\
0.01 \\
0.01 \\
0.01 \\
0.01 \\
0.01 \\
0.01 \\
0.01\end{array}$ & $\begin{array}{l}- \\
- \\
- \\
- \\
-\end{array}$ \\
\hline ZINC & $\begin{array}{l}0503 \\
0503 \\
0503 \\
0503 \\
0503 \\
0503 \\
0503 \\
0503 \\
0504 \\
0504 \\
0504 \\
0504 \\
0504 \\
0504 \\
0504 \\
0506 \\
0506 \\
0506 \\
0506 \\
0506 \\
0506\end{array}$ & $\begin{array}{l}06 / 30 / 86 \\
10 / 14 / 87 \\
05 / 16 / 90 \\
03 / 29 / 91 \\
08 / 08 / 91 \\
12 / 09 / 91 \\
10 / 09 / 92 \\
02 / 18 / 94 \\
10 / 14 / 87 \\
05 / 16 / 90 \\
04 / 03 / 91 \\
08 / 27 / 91 \\
12 / 09 / 91 \\
10 / 09 / 92 \\
02 / 19 / 94 \\
10 / 14 / 87 \\
03 / 28 / 91 \\
08 / 08 / 91 \\
11 / 20 / 91 \\
10 / 08 / 92 \\
02 / 20 / 94\end{array}$ & $\begin{array}{l}0001 \\
0001 \\
0001 \\
0001 \\
0001 \\
0001 \\
0001 \\
0001 \\
0001 \\
0001 \\
0001 \\
0001 \\
0001 \\
0001 \\
0001 \\
0001 \\
0001 \\
0001 \\
0001 \\
0001 \\
0001\end{array}$ & $\begin{array}{l}A L \\
A L \\
A L \\
A L \\
A L \\
A L \\
A L \\
A L \\
A L \\
A L \\
A L \\
A L \\
A L \\
A L \\
A L \\
A L \\
A L \\
A L \\
A L \\
A L \\
A L\end{array}$ & $\begin{array}{l}0 \\
0 \\
0 \\
0 \\
0 \\
0 \\
0 \\
0 \\
D \\
D \\
D \\
D \\
D \\
D \\
D \\
D \\
D \\
D \\
D \\
D \\
D\end{array}$ & $M G / L$ & $\begin{array}{l}< \\
< \\
< \\
< \\
< \\
< \\
< \\
< \\
< \\
< \\
< \\
< \\
< \\
< \\
< \\
< \\
< \\
< \\
< \\
< \\
< \\
< \\
< \\
< \\
<\end{array}$ & $\begin{array}{l}0.028 \\
0.005 \\
0.005 \\
0.005 \\
0.005 \\
0.005 \\
0.005 \\
0.05 \\
0.005 \\
0.005 \\
0.005 \\
0.005 \\
0.005 \\
0.005 \\
0.05 \\
0.005 \\
0.03 \\
0.005 \\
0.005 \\
0.03 \\
0.05\end{array}$ & I & $\begin{array}{l}0.005 \\
0.005 \\
0.005 \\
0.005 \\
0.005 \\
0.005 \\
0.005 \\
0.05 \\
0.005 \\
0.005 \\
0.005 \\
0.005 \\
0.005 \\
0.005 \\
0.05 \\
0.005 \\
0.03 \\
0.005 \\
0.005 \\
0.03 \\
0.05\end{array}$ & $\begin{array}{l}- \\
- \\
- \\
- \\
- \\
- \\
- \\
- \\
- \\
- \\
- \\
- \\
- \\
- \\
- \\
- \\
-\end{array}$ \\
\hline
\end{tabular}

FORMATION OF COMPLETION CODE:

AL - ALLUVIUM

PARAMETER VALUE INDICATOR (PVI): < - LESS THAN DETECTION LIMIT

OTHER PARAMETER VALUE FLAGS

I - INCREASED DETECTION LIMIT DUE TO REQUIRED DILUTION

$J$ - ESTIMATED VALUE
FLOH RELATIONSHIP CODE:

D - DOWN GRADIENT

\section{SAMPLE ID CODES:}

0001 - FILTERED SAMPLE (.45 MICRONS)

NOO1 - UNFILTERED SAMPLE 


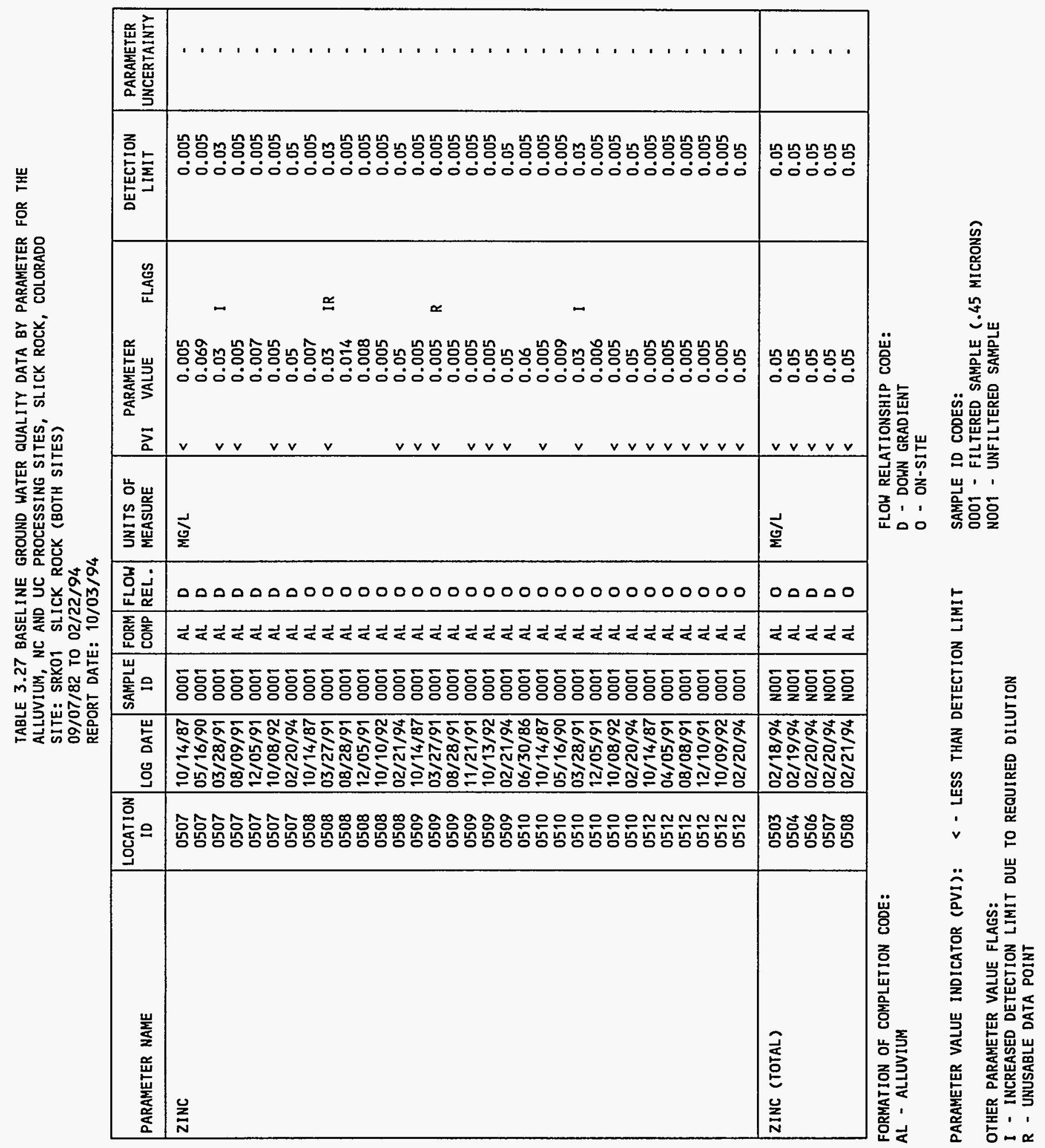


TABLE 3.27 BASELINE GROUND WATER QUALITY DATA BY PARAMETER FOR THE

ALLUVIUM, NC AND UC PROCESSING SITES, SLICK ROCK, COLORADO

SITE: SRKOI SLICK ROCK (BOTH SITES)

09/07/82 TO 02/22/94

REPORT DATE: $10 / 03 / 94$

\begin{tabular}{|c|c|c|c|c|c|c|c|c|c|c|c|}
\hline PARAMETER NAME & $\underset{\text { ID }}{\text { LOCATION }}$ & LOG DATE & $\underset{\text { ID }}{\text { SAMPLE }}$ & $\begin{array}{l}\text { FORM } \\
\text { COMP }\end{array}$ & $\begin{array}{l}\text { FLOW } \\
\text { REL. }\end{array}$ & $\begin{array}{l}\text { UNITS OF } \\
\text { MEASURE }\end{array}$ & PVI & $\begin{array}{l}\text { PARAMETER } \\
\text { VALUE }\end{array}$ & FLAGS & $\begin{array}{l}\text { DETECTION } \\
\text { LIMIT }\end{array}$ & $\begin{array}{l}\text { PARAMETER } \\
\text { UNCERTAINTY }\end{array}$ \\
\hline ZINC (TOTAL) & $\begin{array}{l}0509 \\
0510 \\
0512\end{array}$ & $\begin{array}{l}02 / 21 / 94 \\
02 / 20 / 94 \\
02 / 20 / 94\end{array}$ & $\begin{array}{l}\text { N001 } \\
\text { N001 } \\
\text { N001 }\end{array}$ & $\begin{array}{l}A L \\
A L \\
A L\end{array}$ & $\begin{array}{l}0 \\
0 \\
0\end{array}$ & MG/L & $<$ & $\begin{array}{l}0.05 \\
0.05 \\
0.05\end{array}$ & & $\begin{array}{l}0.05 \\
0.05 \\
0.05\end{array}$ & - \\
\hline
\end{tabular}

FORMATION OF COMPLETION CODE:

FLOW RELATIONSHIP CODE:

$$
\text { AL - ALLUVIUM }
$$

O - ON-SITE

PARAMETER VALUE INDICATOR (PVI): < - LESS THAN DETECTION LIMIT

SAMPLE ID CODES:

NOO1 - UNFILTERED SAMPLE

DATA FILE NAME: IDART \SRK01\GWQ10067.DAT 
TABLE 3.28 BASELINE GROUND WATER QUALITY STATISTICS BY PARAMETER FOR

THE ALLUVIUM, NC PROCESSING SITE, SLICK ROCK, COLORADO

SITE: SRKO1 SLICK ROCK (BOTH SITES)

$09 / 07 / 82$ TO $02 / 22 / 94$

REPORT DATE: $09 / 30 / 94$

\begin{tabular}{|c|c|c|c|c|c|c|c|c|c|c|c|c|c|}
\hline \multicolumn{4}{|c|}{ PARAMETER NAME } & UNITS & \multirow[b]{2}{*}{ MEAN } & \multirow{2}{*}{$\begin{array}{r}\text { STANDARD } \\
\text { DEVIATION }\end{array}$} & \multirow{2}{*}{$\begin{array}{l}\text { COEFF. } \\
\text { OF } \\
\text { VARIATION }\end{array}$} & \multirow{2}{*}{$\begin{array}{l}\% \text { OF } \\
\text { NON } \\
\text { DETECTS }\end{array}$} & \multirow{2}{*}{\multicolumn{3}{|c|}{ 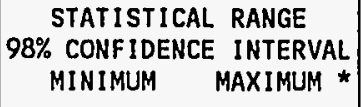 }} & \multirow{2}{*}{$\begin{array}{c}\text { DISTRIBUTION } \\
\text { TYPE }\end{array}$} & \multirow{2}{*}{$\begin{array}{l}\text { FOOT } \\
\text { NOTE }\end{array}$} \\
\hline \# OF SAMP & MINIMUM & MAXIMUM & & MEDIAN & & & & & & & & & \\
\hline \multicolumn{3}{|l|}{ ALKALINITY } & & $M G / L \quad C A C$ & \multirow[b]{2}{*}{403.2800} & \multirow[b]{2}{*}{140.7428} & \multirow[b]{2}{*}{0.3490} & \multirow[b]{2}{*}{0.0} & \multirow{2}{*}{\multicolumn{2}{|c|}{333.1338}} & \multirow[b]{2}{*}{473.4262} & \multirow[b]{2}{*}{ NORMAL } & \\
\hline 25 & 246.0000 & 945.0000 & & 411.0000 & & & & & & & & & \\
\hline \multicolumn{3}{|l|}{ ALUMINUM } & & $M G / L$ & \multirow[b]{2}{*}{ NA } & \multirow[b]{2}{*}{ NA } & \multirow[b]{2}{*}{ NA } & \multirow[b]{2}{*}{56.5} & \multirow[b]{2}{*}{ ** } & \multirow[b]{2}{*}{0.0500} & \multirow[b]{2}{*}{0.2000} & \multirow[b]{2}{*}{ NONPARAMETRIC } & \multirow[b]{2}{*}{2} \\
\hline 23 & ** $\quad 0.0500$ & 0.4000 & & 0.0500 & & & & & & & & & \\
\hline \multicolumn{3}{|l|}{ AMMONIUM } & & $M G / L$ & \multirow[b]{2}{*}{ NA } & \multirow[b]{2}{*}{ NA } & \multirow[b]{2}{*}{ NA } & \multirow[b]{2}{*}{33.3} & & & & & \\
\hline 21 & ** $\quad 0.1000$ & 2.7000 & & 0.1000 & & & & & ** & 0.1000 & 0.4000 & NONPARAMETRIC & 2 \\
\hline AMMONIUM ( & (TOTAL) & & & $M G / L$ & & & & & & & & & \\
\hline 3 & ** $\quad 0.1000$ & 0.2000 & ** & 0.1000 & NA & NA & NA & 66.7 & & NA & NA & UNKNOWN & 1 \\
\hline ANT IMONY & & & & $M G / L$ & & & & & & & & & \\
\hline 15 & 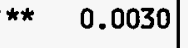 & 0.0190 & ** & 0.0030 & NA & NA & NA & 80.0 & ** & 0.0030 & 0.0030 & NONPARAMETRIC & 2 \\
\hline ARSENIC & & & & MG/L & & & & & & & & & \\
\hline 20 & 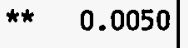 & 0.0250 & + & 0.0050 & NA & NA & NA & 100.0 & & 0.0050 & 0.0050 & NONPARAMETRIC & 2 \\
\hline BARIUM & & & & $M G / L$ & & & & & & & & & \\
\hline 21 & 0.0100 & 0.0500 & & 0.0300 & NA & NA & NA & 42.9 & & 0.0200 & 0.0500 & NONPARAMETRIC & 2 \\
\hline BARIUM (TO & JTAL) & & & $M G / L$ & & & & & & & & & \\
\hline 3 & ** $\quad 0.1000$ & 0.1000 & ** & 0.1000 & NA & NA & NA & 100.0 & & NA & NA & UNKNOWN & 1 \\
\hline BERYLLIUM & & & & $M G / L$ & & & & & & & & & \\
\hline 11 & $\begin{array}{ll}* * & 0.0050\end{array}$ & 0.0050 & ** & 0.0050 & NA & NA & NA & 100.0 & ** & 0.0050 & 0.0050 & NONPARAMETRIC & 2 \\
\hline BORON & & & & $M G / L$ & & & & & & & & & \\
\hline 18 & 0.0500 & 0.6000 & + & 0.3150 & 0.2733 & 0.1548 & 0.5662 & 11.1 & & 0.1797 & 0.3670 & NORMAL & \\
\hline
\end{tabular}

** The reported value is the minimum detection limit of the data set

+ The sample size is even, so the median value is the arithmetic average of the two middle values

* The statistical maximum is the 99 percent one sided confidence interval, $\alpha=0.01$

1) A minimum of 4 samples must be available for the statistical analysis.

2) The nonparametric distribution was used because the nondetected values comprise more than $15 \%$ of the samples. 
TABLE 3.28 BASELINE GROUND WATER QUALITY STATISTICS BY PARAMETER FOR

THE ALLUVIUM, NC PROCESSING SITE, SLICK ROCK, COLORADD

SITE: SRKO1 SLICK ROCK (BOTH SITES)

$09 / 07 / 82$ TO $02 / 22 / 94$

REPORT DATE: $09 / 30 / 9$

\begin{tabular}{|c|c|c|c|c|c|c|c|c|c|c|c|}
\hline \multicolumn{3}{|c|}{ PARAMETER NAME } & UNITS & \multirow[b]{2}{*}{ MEAN } & \multirow{2}{*}{$\begin{array}{r}\text { STANDARD } \\
\text { DEVIATION }\end{array}$} & \multirow{2}{*}{$\begin{array}{c}\text { COEFF. } \\
\text { OF } \\
\text { VARIATION }\end{array}$} & \multirow{2}{*}{$\left|\begin{array}{c}\% \text { OF } \\
\text { NON } \\
\text { DETECTS }\end{array}\right|$} & \multirow{2}{*}{\multicolumn{2}{|c|}{$\begin{array}{l}\text { STATISTICAL RANGE } \\
\text { 98\% CONFIDENCE INTERVAL } \\
\text { MINIMUM MAXIMUM * }\end{array}$}} & \multirow{2}{*}{$\begin{array}{l}\text { DISTRIBUTION } \\
\text { TYPE }\end{array}$} & \multirow{2}{*}{$\begin{array}{l}\text { FOOT } \\
\text { NOTE }\end{array}$} \\
\hline \# OF SAMP & MINIMUM & MAXIMUM & MEDIAN & & & & & & & & \\
\hline \multicolumn{3}{|c|}{ BORON (TOTAL) } & $\mathrm{MG} / \mathrm{L}$ & \multirow[b]{2}{*}{ NA } & \multirow[b]{2}{*}{ NA } & \multirow[b]{2}{*}{ NA } & \multirow[b]{2}{*}{0.0} & \multirow[b]{2}{*}{ NA } & \multirow[b]{2}{*}{ NA } & \multirow[b]{2}{*}{ UNKNOWN } & \multirow[b]{2}{*}{1} \\
\hline 3 & 0.1000 & 0.3000 & 0.3000 & & & & & & & & \\
\hline \multicolumn{3}{|l|}{ BROMIDE } & $\mathrm{MG} / \mathrm{L}$ & \multirow[b]{2}{*}{ NA } & \multirow[b]{2}{*}{ NA } & \multirow[b]{2}{*}{ NA } & \multirow[b]{2}{*}{33.3} & \multirow[b]{2}{*}{0.2000} & \multirow[b]{2}{*}{0.6000} & \multirow[b]{2}{*}{ NONPARAMETRIC } & \multirow[b]{2}{*}{2} \\
\hline 12 & 0.1000 & 1.0000 & 0.3500 & & & & & & & & \\
\hline \multicolumn{3}{|l|}{ CADMIUM } & $M G / L$ & \multirow[b]{2}{*}{ NA } & \multirow[b]{2}{*}{ NA } & \multirow[b]{2}{*}{ NA } & \multirow[b]{2}{*}{100.0} & \multirow[b]{2}{*}{0.0005} & & & \\
\hline 21 & ** $\quad 0.0005$ & 0.0005 & 0.0005 & & & & & & 0.0005 & NONPARAMETRIC & 2 \\
\hline CADMIUM $C T$ & TOTAL) & & $M G / L$ & & & & & & & & \\
\hline 3 & $\begin{array}{ll}* & 0.0010\end{array}$ & ** $\quad 0.0010$ & 0.0010 & NA & NA & NA & 100.0 & NA & NA & UNKNOWN & 1 \\
\hline CALCIUM & & & $M G / L$ & & & & & & & & \\
\hline 26 & 107.0000 & 295.0000 & 202.0000 & 202.7308 & 49.4583 & 0.2440 & 0.0 & 178.6273 & 226.8342 & NORMAL & \\
\hline CALCIUM $C T$ & (OTAL) & & MG/L & & & & & & & & \\
\hline 3 & 145.0000 & 269.0000 & 220.0000 & NA & NA & NA & 0.0 & NA & NA & UNKNOWN & 1 \\
\hline CHLORIDE & & & $M G / L$ & & & & & & & & \\
\hline 26 & 65.0000 & 520.0000 & 285.0000 & 239.2615 & 130.4635 & 0.5453 & 0.0 & 175.6803 & 302.8427 & NORMAL & \\
\hline CHROMIUN & & & $M G / L$ & & & & & & & & \\
\hline 21 & ** $\quad 0.0100$ & 0.0500 & 0.0100 & NA & NA & NA & 95.2 & 0.0100 & ** 0.0100 & NONPARAMETRIC & 2 \\
\hline CHROMIUM & TOTAL) & & $M G / L$ & & & & & & & & \\
\hline 3 & ** $\quad 0.0100$ & 0.0100 & 0.0100 & NA & NA & NA & 100.0 & NA & $N A-$ & UNKNOWN & 1 \\
\hline COBALT & & & $M G / L$ & & & & & & & & \\
\hline 11 & ** $\quad 0.0300$ & 0.0300 & 0.0300 & NA & NA & NA & 100.0 & 0.0300 & ** 0.0300 & NONPARAMETRIC & 2 \\
\hline
\end{tabular}

** The reported value is the minimum detection limit of the data set

+ The sample size is even, so the median value is the arithmetic average of the two middle values

* The statistical maximum is the 99 percent one sided confidence interval, $\alpha=0.01$

1) A minimum of 4 samples must be available for the statistical analysis.

2) The nonparametric distribution was used because the nondetected values comprise more than $15 \%$ of the samples. 
TABLE 3.28 BASELINE GROUND WATER QUALITY STATISTICS BY PARAMETER FOR THE ALLUVIUM, NC PROCESSING SITE, SLICK ROCK, COLORADO

SITE: SRKO1 SLICK ROCK (BOTH SITES)

09/07/82 TO 02/22/94

REPORT DATE: $09 / 30 / 94$

\begin{tabular}{|c|c|c|c|c|c|c|c|c|c|c|c|}
\hline \multicolumn{3}{|c|}{ PARAMETER NAME } & UNITS & \multirow[b]{2}{*}{ MEAN } & \multirow{2}{*}{$\begin{array}{r}\text { STANDARD } \\
\text { DEVIATION }\end{array}$} & \multirow{2}{*}{$\begin{array}{c}\text { COEFF. } \\
\text { OF } \\
\text { VARIATION }\end{array}$} & \multirow{2}{*}{$\begin{array}{c}\% \text { OF } \\
\text { NON } \\
\text { DETECTS }\end{array}$} & \multirow{2}{*}{\multicolumn{2}{|c|}{ 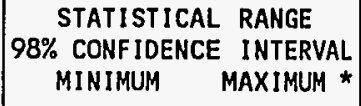 }} & \multirow{2}{*}{$\begin{array}{c}\text { DISTRIBUTION } \\
\text { TYPE }\end{array}$} & \multirow{2}{*}{$\begin{array}{l}\text { FOOT } \\
\text { NOTE }\end{array}$} \\
\hline \# OF SAMP & MINIMUM & MAXIMUM & MEDIAN & & & & & & & & \\
\hline \multicolumn{3}{|l|}{ COPPER } & MG/L & \multirow[b]{2}{*}{ NA } & \multirow[b]{2}{*}{ NA } & \multirow[b]{2}{*}{ NA } & \multirow[b]{2}{*}{94.4} & \multirow[b]{2}{*}{0.0100} & \multirow[b]{2}{*}{0.0100} & \multirow[b]{2}{*}{ NONPARAMETRIC } & \multirow[b]{2}{*}{2} \\
\hline 18 & $\begin{array}{ll}* * & 0.0100\end{array}$ & 0.0500 & 0.0100 & & & & & & & & \\
\hline \multicolumn{3}{|l|}{ CYANIDE } & $M G / L$ & \multirow[b]{2}{*}{ NA } & \multirow[b]{2}{*}{ NA } & \multirow[b]{2}{*}{ NA } & \multirow[b]{2}{*}{88.9} & \multirow[b]{2}{*}{0.0100} & \multirow[b]{2}{*}{0.0200} & \multirow[b]{2}{*}{ NONPARAMETRIC } & \multirow[b]{2}{*}{2} \\
\hline 9 & ** $\quad 0.0100$ & 0.0200 & 0.0100 & & & & & & & & \\
\hline \multicolumn{3}{|c|}{ DISSOLVED ORGANIC CARBON } & $M G / L$ & \multirow[b]{2}{*}{ NA } & \multirow[b]{2}{*}{ NA } & \multirow[b]{2}{*}{ NA } & \multirow[b]{2}{*}{0.0} & \multirow[b]{2}{*}{ NA } & & & \\
\hline 2 & 5.0000 & 5.0000 & 5.0000 & & & & & & NA & UNKNOWN & 1 \\
\hline DISSOLVED & OXYGEN & & $M G / L$ & & & & & & & & \\
\hline 6 & 0.1000 & 1.1000 & 0.1950 & 0.2496 & 2.7771 & NA & 0.0 & 0.0613 & 1.0153 & LOGNORMAL & 7,8 \\
\hline FIELD FE & $(2+)$ & & $M G / L$ & & & & & & & & \\
\hline 5 & 0.7500 & 8.1000 & 2.3400 & 3.3340 & 2.8503 & 0.8549 & 0.0 & -1.4423 & 8.1103 & NORMAL & \\
\hline FIELD FE & (TOTAL) & & $M G / L$ & & & & & & & & \\
\hline 4 & 2.0000 & 85.0000 & 5.6100 & 7.7569 & 5.6204 & NA & 0.0 & 0.1539 & 390.8779 & LOGNORMAL & 7,8 \\
\hline FLUORIDE & & & $M G / L$ & & & & & & & & \\
\hline 21 & ** $\quad 0.1000$ & 0.4000 & 0.2400 & 0.2219 & 0.1002 & 0.4517 & 4.8 & 0.1666 & 0.2772 & NORMAL & \\
\hline GROSS ALPH & & & $\mathrm{PCl} / \mathrm{L}$ & & & & & & & & \\
\hline 15 & 641.0000 & 2680.0000 & 1460.0000 & 1499.8200 & 660.2124 & 0.4402 & 0.0 & 1052.5170 & 1947.1230 & NORMAL & \\
\hline GROSS ALPH & IA (TOTAL) & & $\mathrm{PCI} / \mathrm{L}$ & & & & & & & & \\
\hline 3 & 1590.0000 & 2180.0000 & 1770.0000 & NA & NA & NA & 0.0 & NA & NA & UNKNOWN & 1 \\
\hline
\end{tabular}

** The reported value is the minimum detection limit of the data set

+ The sample size is even, so the median value is the arithmetic average of the two middle values

* The statistical maximum is the 99 percent one sided confidence interval, $\alpha=0.01$

1) A minimum of 4 samples must be available for the statistical analysis.

2) The nonparametric distribution was used because the nondetected values comprise more than $15 \%$ of the samples.

7) The lognormal distribution was used because the data failed the normal distribution test.

8) The mean is geometric. The standard deviation is the value to divide or multiply with the geometric mean. 
TABLE 3.28 BASELINE GROUND HATER QUALITY STATISTICS BY PARAMETER FOR THE ALLUVIUM, NC PROCESSING SITE, SLICK ROCK, COLORADO

SITE: SRKO1 SLICK ROCK (BOTH SITES)

$09 / 07 / 82$ TO 02/22/94

REPORT DATE: 09/30/94

\begin{tabular}{|c|c|c|c|c|c|c|c|c|c|c|c|}
\hline \multicolumn{3}{|c|}{ PARAMETER NAME } & UNITS & \multirow[b]{2}{*}{ MEAN } & \multirow{2}{*}{$\begin{array}{r}\text { STANDARD } \\
\text { DEVIATION }\end{array}$} & \multirow{2}{*}{$\begin{array}{c}\text { COEFF. } \\
\text { OF } \\
\text { VARIATION }\end{array}$} & \multirow{2}{*}{$\begin{array}{c}\% \text { OF } \\
\text { NON } \\
\text { DETECTS }\end{array}$} & \multirow{2}{*}{\multicolumn{2}{|c|}{$\begin{array}{l}\text { STATISTICAL RANGE } \\
\text { 98\% CONFIDENCE INTERVAL } \\
\text { MINIMUM } \\
\text { MAXIMUM * }\end{array}$}} & \multirow{2}{*}{$\begin{array}{c}\text { DISTRIBUTION } \\
\text { TYPE }\end{array}$} & \multirow{2}{*}{$\begin{array}{l}\text { FOOT } \\
\text { NOTE }\end{array}$} \\
\hline \# OF SAMP & MINIMUM & MAXIMUM & MEDIAN & & & & & & & & \\
\hline \multicolumn{3}{|l|}{ GROSS BETA } & $\mathrm{PCI} / \mathrm{L}$ & \multirow[b]{2}{*}{535.2500} & \multirow[b]{2}{*}{257.8601} & \multirow[b]{2}{*}{0.4818} & \multirow[b]{2}{*}{0.0} & \multirow[b]{2}{*}{332.9280} & \multirow[b]{2}{*}{737.5720} & \multirow[b]{2}{*}{ NORMAL } & \\
\hline 12 & 188.0000 & 984.0000 & +516.5000 & & & & & & & & \\
\hline \multicolumn{3}{|l|}{ IRON } & $M G / L$ & \multirow[b]{2}{*}{2.8485} & \multirow[b]{2}{*}{2.4667} & \multirow[b]{2}{*}{0.8660} & \multirow[b]{2}{*}{0.0} & \multirow[b]{2}{*}{1.6463} & \multirow[b]{2}{*}{4.0506} & \multirow[b]{2}{*}{ NORMAL } & \\
\hline 26 & 0.0700 & 8.8000 & 2.3800 & & & & & & & & \\
\hline \multicolumn{3}{|c|}{ IRON (TOTAL) } & $M G / L$ & \multirow[b]{2}{*}{ NA } & \multirow[b]{2}{*}{ NA } & \multirow[b]{2}{*}{ NA } & \multirow[b]{2}{*}{0.0} & \multirow[b]{2}{*}{ NA } & \multirow[b]{2}{*}{ NA } & \multirow[b]{2}{*}{ UNKNOWN } & \\
\hline 3 & 0.1200 & 8.1100 & 2.2900 & & & & & & & & 1 \\
\hline LEAD & & & $M G / L$ & & & & & & & & \\
\hline 18 & 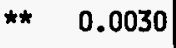 & 0.0100 & 0.0030 & NA & NA & NA & 100.0 & 0.0030 & 0.0050 & NONPARAMETRIC & 2 \\
\hline LEAD-210 & & & $\mathrm{PCI} / \mathrm{L}$ & & & & & & & & \\
\hline 10 & 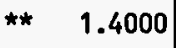 & 216.0000 & 53.0000 & 74.3900 & 73.1905 & 0.9839 & 0.0 & 9.0984 & 139.6816 & NORMAL & \\
\hline LEAD-210 & (TOTAL) & & $\mathrm{PCI} / \mathrm{L}$ & & & & & & & & \\
\hline 3 & ** $\quad 1.5000$ & ** 1.5000 & 1.5000 & NA & NA & NA & 0.0 & NA & NA & UNKNOWN & 1 \\
\hline MAGNESIUM & & & MG/L & & & & & & & & \\
\hline 26 & 36.8000 & 200.0000 & B7.3500 & 93.8154 & 47.9322 & 0.5109 & 0.0 & 70.4557 & 117.1751 & NORMAL & \\
\hline MAGNESIUM & (TOTAL) & & $M G / L$ & & & & & & & & \\
\hline 3 & 43.9000 & 185.0000 & 70.9000 & NA & NA & NA & 0.0 & NA & NA & UNKNOWN & 1 \\
\hline MANGANESE & & & $M G / L$ & & & & & & & & \\
\hline 26 & 0.0900 & 0.9000 & 0.4550 & 0.4785 & 0.2001 & 0.4182 & 0.0 & 0.3809 & 0.5760 & NORMAL & \\
\hline MANGANESE & (TOTAL) & & $M G / L$ & & & & & & & & \\
\hline 3 & 0.3300 & 0.8700 & 0.4300 & NA & NA & NA & 0.0 & NA & NA & UNKNOWN & 1 \\
\hline
\end{tabular}

** The reported value is the minimum detection limit of the data set

+ The sample size is even, so the median value is the arithmetic average of the two middle values

* The statistical maximum is the 99 percent one sided confidence interval, $\alpha=0.01$

1) A minimum of 4 samples must be available for the statistical analysis.

2) The nonparametric distribution was used because the nondetected values comprise more than $15 \%$ of the samples. 
TABLE 3.28 BASELINE GROUND WATER QUALITY STATISTICS BY PARAMETER FOR

THE ALLUVIUM, NC PROCESSING SITE, SLICK ROCK, COLORADO

SITE: SRKO1 SLICK ROCK (BOTH SITES)

$09 / 07 / 82$ TO 02/22/94

REPORT DATE: 09/30/94

\begin{tabular}{|c|c|c|c|c|c|c|c|c|c|c|c|c|c|}
\hline \multicolumn{4}{|c|}{ PARAMETER NAME } & UNITS & \multirow[b]{2}{*}{ MEAN } & \multirow{2}{*}{$\begin{array}{r}\text { STANDARD } \\
\text { DEVIATION }\end{array}$} & \multirow{2}{*}{$\begin{array}{c}\text { COEFF. } \\
\text { OF } \\
\text { VARIATION }\end{array}$} & \multirow{2}{*}{$\begin{array}{c}\% \text { OF } \\
\text { NON } \\
\text { DETECTS }\end{array}$} & \multirow{2}{*}{\multicolumn{3}{|c|}{ 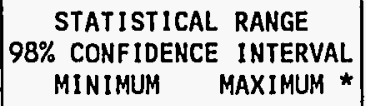 }} & \multirow{2}{*}{$\begin{array}{c}\text { DISTRIBUTION } \\
\text { TYPE }\end{array}$} & \multirow{2}{*}{$\begin{array}{l}\text { FOOT } \\
\text { NOTE }\end{array}$} \\
\hline \# OF SAMP & MINIMUM & & AXIMUM & MEDIAN & & & & & & & & & \\
\hline \multicolumn{4}{|l|}{ MERCURY } & $M G / L$ & \multirow[b]{2}{*}{ NA } & \multirow[b]{2}{*}{ NA } & \multirow[b]{2}{*}{ NA } & \multirow[b]{2}{*}{100.0} & \multirow[b]{2}{*}{ ** } & \multirow[b]{2}{*}{0.0002} & \multirow[b]{2}{*}{0.0002} & \multirow[b]{2}{*}{ NONPARAMETRIC } & \multirow[b]{2}{*}{2} \\
\hline 15 & ** $\quad 0.0002$ & ** & 0.0002 & 0.0002 & & & & & & & & & \\
\hline \multicolumn{4}{|l|}{ MOLYBDEENUM } & $M G / L$ & \multirow[b]{2}{*}{ NA } & \multirow[b]{2}{*}{ NA } & \multirow[b]{2}{*}{ NA } & \multirow[b]{2}{*}{42.3} & \multirow[b]{2}{*}{ ** } & \multirow[b]{2}{*}{0.0100} & \multirow[b]{2}{*}{0.0300} & \multirow[b]{2}{*}{ NONPARAMETRIC } & \multirow[b]{2}{*}{2} \\
\hline 26 & ** $\quad 0.0100$ & & 0.1700 & 0.0200 & & & & & & & & & \\
\hline \multicolumn{4}{|c|}{ MOLYBDENUM (TOTAL) } & $M G / L$ & \multirow[b]{2}{*}{ NA } & \multirow[b]{2}{*}{ NA } & & & & & & & \\
\hline 3 & ** $\quad 0.0100$ & & 0.0300 & 0.0100 & & & NA & 66.7 & & NA & NA & UNKNOWN & 1 \\
\hline NET GROSS & ALPHA $\quad \star * \star$ & & & $\mathrm{PCI} / \mathrm{L}$ & & & & & & & & & \\
\hline 15 & -727.9600 & & 520.8500 & -64.3800 & NA & NA & NA & 0.0 & & 493.0000 & 123.8600 & NONPARAMETRIC & 9 \\
\hline NET GROSS & ALPHA (TOTAL & L) $* *$ & $* * *$ & $\mathrm{PCI} / \mathrm{L}$ & & & & & & & & & \\
\hline 3 & -907.0400 & & 260.5600 & -406.2200 & NA & NA & NA & 0.0 & & NA & NA & UNKNOHN & 1 \\
\hline NICKEL & & & & $\mathrm{MG} / \mathrm{L}$ & & & & & & & & & \\
\hline 21 & $\begin{array}{ll}* * & 0.0400\end{array}$ & & 0.0700 & 0.0400 & NA & NA & NA & 85.7 & ** & 0.0400 & 0.0400 & NONPARAMETRIC & 2 \\
\hline NI TRATE & & & & $M G / L$ & & & & & & & & & \\
\hline 23 & ** $\quad 1.0000$ & & 6.5000 & 1.0000 & NA & NA & NA & 73.9 & ** & 1.0000 & 1.0000 & NONPARAMETRIC & 2 \\
\hline NITRATE & TOTAL) & & & $M G / L$ & & & & & & & & & \\
\hline 3 & ** $\quad 1.0000$ & $* *$ & 1.0000 & 1.0000 & NA & NA & NA & 100.0 & & NA & NA & UNKNOWN & 1 \\
\hline NITRITE Al & ND NITRATE & & & $\mathrm{MG} / \mathrm{L}$ & & & & & & & & & \\
\hline 11 & 0.1100 & & 1.2900 & 0.4000 & NA & NA & NA & 36.4 & & 0.1300 & 0.5000 & NONPARAMETRIC & 2 \\
\hline
\end{tabular}

*** NET GROSS ALPHA (GROSS ALPHA - URANIUM) WITH 1 MG URANIUM = 686 PCI

**** NET GROSS ALPHA (TOTAL) (TOTAL GROSS ALPHA - TOTAL URANIUM)

** The reported value is the minimum detection limit of the data set

+ The sample size is even, so the median value is the arithmetic average of the two middle values

* The statistical maximum is the 99 percent one sided confidence interval, $\alpha=0.01$

1) A minimum of 4 samples must be available for the statistical analysis.

2) The nonparametric distribution was used because the nondetected values comprise more than $15 \%$ of the samples.

9) The nonparametic distribution was used because the data failed the normal distribution test and includes values $\leq 0$. 
TABLE 3.28 BASELINE GROUND HATER QUALITY STATISTICS BY PARAMETER FOR THE ALLUVIUM, NC PROCESSING SITE, SLICK ROCK, COLORADO

SITE: SRKO1 SLICK ROCK (BOTH SITES)

09/07/82 TO 02/22/94

REPORT DATE: 09/30/94

\begin{tabular}{|c|c|c|c|c|c|c|c|c|c|c|c|}
\hline \multicolumn{3}{|c|}{ PARAMETER NAME } & UNITS & \multirow[b]{2}{*}{ MEAN } & \multirow[b]{2}{*}{$\begin{array}{r}\text { STANDARD } \\
\text { DEVIATION }\end{array}$} & \multirow{2}{*}{$\begin{array}{c}\text { COEFF. } \\
\text { OF } \\
\text { VARIATION }\end{array}$} & \multirow{2}{*}{$\begin{array}{l}\% \text { OF } \\
\text { NON } \\
\text { DETECTS }\end{array}$} & \multirow{2}{*}{\multicolumn{2}{|c|}{ 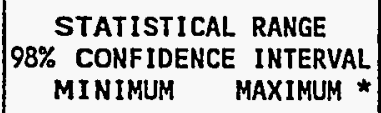 }} & \multirow[b]{2}{*}{$\begin{array}{c}\text { DISTRIBUTION } \\
\text { TYPE }\end{array}$} & \multirow[b]{2}{*}{$\begin{array}{l}\text { FOOT } \\
\text { NOTE }\end{array}$} \\
\hline \# OF SAMP & MINIMUM & MAXIMUM & MEDIAN & & & & & & & & \\
\hline \multicolumn{3}{|l|}{ PH } & SU & \multirow[b]{2}{*}{ NA } & \multirow[b]{2}{*}{ NA } & \multirow[b]{2}{*}{ NA } & \multirow[b]{2}{*}{0.0} & \multirow[b]{2}{*}{ NA } & \multirow[b]{2}{*}{ NA } & \multirow[b]{2}{*}{ UNKNOWN } & \multirow{2}{*}{ 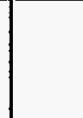 } \\
\hline 25 & 6.8500 & 7.2300 & 7.0500 & & & & & & & & \\
\hline \multicolumn{3}{|l|}{ PHOSPHATE } & $M G / L$ & \multirow[b]{2}{*}{ NA } & \multirow[b]{2}{*}{ NA } & \multirow[b]{2}{*}{ NA } & \multirow[b]{2}{*}{61.1} & \multirow[b]{2}{*}{0.1000} & \multirow[b]{2}{*}{0.1000} & \multirow[b]{2}{*}{ NONPARAMETRIC } & \multirow[b]{2}{*}{2} \\
\hline 18 & ** 0.1000 & 0.3000 & 0.1000 & & & & & & & & \\
\hline \multicolumn{3}{|c|}{ POLONIUM-210 } & $\mathrm{PCI} / \mathrm{L}$ & \multirow[b]{2}{*}{ NA } & \multirow[b]{2}{*}{ NA } & \multirow[b]{2}{*}{ NA } & \multirow[b]{2}{*}{0.0} & & & & \\
\hline 10 & ** $\quad 0.1000$ & 0.8000 & 0.1000 & & & & & 0.1000 & 0.3000 & NONPARAMETRIC & 9 \\
\hline POLONIUM-2 & 210 (TOTAL) & & PCI/L & & & & & & & & \\
\hline 3 & 0.1000 & 0.7000 & 0.2000 & NA & NA & NA & 0.0 & NA & NA & UNKNOWN & 1 \\
\hline POTASSIUH & & & $\mathrm{MG} / \mathrm{L}$ & & & & & & & & \\
\hline 26 & 8.1100 & 49.1000 & 13.2000 & 21.2292 & 13.5665 & 0.6390 & 0.0 & 14.6176 & 27.8409 & NORMAL & \\
\hline POTASSIUM & (TOTAL) & & MG/L & & & & & & & & \\
\hline 3 & 11.9000 & 32.4000 & 13.1000 & NA & NA & NA & 0.0 & NA & NA & UNKNOWN & 1 \\
\hline RADIUM-226 & & & $\mathrm{PCI} / \mathrm{L}$ & & & & & & & & \\
\hline 21 & ** 0.1000 & 2.4000 & 0.3000 & NA & NA & NA & 0.0 & 0.1000 & 0.6000 & NONPARAMETRIC & 9 \\
\hline RADIUM-226 & 3 (TOTAL) & & $\mathrm{PCI} / \mathrm{L}$ & & & & & & & & \\
\hline 3 & ** 0.1000 & 0.7000 & 0.3000 & NA & NA & NA & 0.0 & NA & NA & UNKNOWN & 1 \\
\hline RADIUM-226 & + RADIUM-2Z & & $\mathrm{PCI} / \mathrm{L}$ & & & & & & & & \\
\hline 18 & 0.6000 & 8.9000 & 1.4000 & 2.7389 & 2.4855 & 0.9075 & 0.0 & 1.2350 & 4.2427 & NORMAL & \\
\hline RADIUM-226 & + RADIUM-2Z & (TOTAL) & $\mathrm{PCI} / \mathrm{L}$ & & & & & & & & \\
\hline 3 & 1.3000 & 2.1000 & 1.4000 & NA & NA & NA & 0.0 & NA & NA & UNKNOWN & 1 \\
\hline
\end{tabular}

** The reported value is the minimum detection limit of the data set

+ The sample size is even, so the median value is the arithmetic average of the two middle values

* The statistical maximum is the 99 percent one sided confidence interval, $\alpha=0.01$

1) A minimum of 4 samples must be available for the statistical analysis.

2) The nonparametric distribution was used because the nondetected values comprise more than $15 \%$ of the samples.

9) The nonparametic distribution was used because the data failed the normal distribution test and includes values $\leq 0$. 
TABLE 3.28 BASELINE GROUND WATER QUALITY STATISTICS BY PARAMETER FOR

THE ALLUVIUM, NC PROCESSING SITE, SLICK ROCK, COLORADO

SITE: SRKO1 SLICK ROCK (BOTH SITES)

$09 / 07 / 82$ TO $02 / 22 / 94$

REPORT DATE: $09 / 30 / 9$

\begin{tabular}{|c|c|c|c|c|c|c|c|c|c|c|c|}
\hline \multicolumn{3}{|c|}{ PARAMETER NAME } & UNITS & \multirow[b]{2}{*}{ MEAN } & \multirow{2}{*}{$\begin{array}{r}\text { STANDARD } \\
\text { DEVIATION }\end{array}$} & \multirow{2}{*}{$\begin{array}{c}\text { COEFF. } \\
\text { OF } \\
\text { VARIATION }\end{array}$} & \multirow{2}{*}{$\begin{array}{c}\% \text { OF } \\
\text { NON } \\
\text { DETECTS }\end{array}$} & \multirow{2}{*}{\multicolumn{2}{|c|}{ 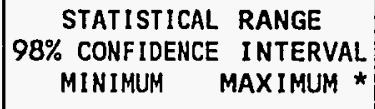 }} & \multirow{2}{*}{$\begin{array}{c}\text { DISTRIBUTION } \\
\text { TYPE }\end{array}$} & \multirow{2}{*}{$\begin{array}{l}\text { FOOT } \\
\text { NOTE }\end{array}$} \\
\hline \# OF SAMP & MINIMUM & MAXIMUM & MEDIAN & & & & & & & & \\
\hline \multicolumn{3}{|l|}{ RADIUM-228 } & $\mathrm{PCI} / \mathrm{L}$ & \multirow[b]{2}{*}{ NA } & \multirow[b]{2}{*}{ NA } & \multirow[b]{2}{*}{ NA } & \multirow[b]{2}{*}{0.0} & \multirow[b]{2}{*}{1.0000} & \multirow[b]{2}{*}{4.7000} & \multirow[b]{2}{*}{ NONPARAMETRIC } & \multirow[b]{2}{*}{9} \\
\hline 18 & ** $\quad 1.0000$ & 8.5000 & 1.0000 & & & & & & & & \\
\hline \multicolumn{3}{|c|}{ RADIUM-228 (TOTAL) } & $\mathrm{PCI} / \mathrm{L}$ & \multirow[b]{2}{*}{ NA } & \multirow[b]{2}{*}{ NA } & \multirow[b]{2}{*}{ NA } & \multirow[b]{2}{*}{0.0} & \multirow[b]{2}{*}{ NA } & \multirow[b]{2}{*}{ NA } & \multirow[b]{2}{*}{ UNKNOWN } & \multirow[b]{2}{*}{1} \\
\hline 3 & ** 2.1000 & ** 2.1000 & 2.1000 & & & & & & & & \\
\hline \multicolumn{3}{|c|}{ REDOX POTENTIAL } & mVOLTS & \multirow[b]{2}{*}{247.4833} & \multirow[b]{2}{*}{131.1730} & \multirow[b]{2}{*}{0.5300} & \multirow[b]{2}{*}{0.0} & & & & \\
\hline 6 & 77.8000 & 455.3000 & +234.4000 & & & & & 67.2837 & 427.6829 & NORMAL & \\
\hline SELENIUM & & & $M G / L$ & & & & & & & & \\
\hline 23 & ** $\quad 0.0050$ & 0.0150 & 0.0050 & NA & NA & NA & 91.3 & 0.0050 & 0.0150 & NONPARAMETRIC & 2 \\
\hline SELENIUM ( & (TOTAL) & & $M G / L$ & & & & & & & & \\
\hline 3 & ** $\quad 0.0050$ & $* * \quad 0.0050$ & 0.0050 & NA & NA & NA & 100.0 & NA & NA & UNKNOWN & 1 \\
\hline SILICA - S & 5102 & & $M G / L$ & & & & & & & & \\
\hline 24 & 7.0000 & 15.0000 & 12.0500 & 11.5583 & 2.4374 & 0.2109 & 0.0 & 10.3145 & 12.8022 & NORMAL & \\
\hline SILICA - S & SIO2 (TOTAL) & & $M G / L$ & & & & & & & & \\
\hline 3 & 9.1000 & 15.9000 & 12.6000 & NA & NA & NA & 0.0 & NA & NA & UNKNOWN & 1 \\
\hline SILVER & & & $M G / L$ & & & & & & & & \\
\hline 15 & ** $\quad 0.0100$ & 0.0100 & 0.0100 & NA & NA & NA & 100.0 & $0.0100 \times$ & 0.0100 & NONPARAMETRIC & 2 \\
\hline SODIUM & & & $M G / L$ & & & & & & & & \\
\hline 26 & 135.0000 & 830.0000 & 507.0000 & 441.4231 & 213.7513 & 0.4842 & 0.0 & 337.2517 & 545.5945 & NORMAL & \\
\hline SODIUM <TO & DTAL) & & MG/L & & & & & & & & \\
\hline 3 & 185.0000 & 543.0000 & 512.0000 & NA & NA & NA & 0.0 & NA & NA & UNKNOWN & 1 \\
\hline
\end{tabular}

** The reported value is the minimum detection limit of the data set

+ The sample size is even, so the median value is the arithmetic average of the two middle values

* The statistical maximum is the 99 percent one sided confidence interval, $\alpha=0.01$

1) A minimum of 4 samples must be available for the statistical analysis.

2) The nonparametric distribution was used because the nondetected values comprise more than $15 \%$ of the samples.

9) The nonparametic distribution was used because the data failed the normal distribution test and includes values $\leq 0$. 
TABLE 3.28 BASELINE GROUND HATER QUALITY STATISTICS BY PARAMETER FOR

THE ALLUVIUM, NC PROCESSING SITE, SLICK ROCK, COLORADD

SITE: SRKO1 SLICK ROCK (BOTH SITES)

$09 / 07 / 82$ TO $02 / 22 / 94$

REPORT DATE: $09 / 30 / 94$

\begin{tabular}{|c|c|c|c|c|c|c|c|c|c|c|c|}
\hline \multicolumn{3}{|c|}{ PARAMETER NAME } & UNITS & \multirow[b]{2}{*}{ MEAN } & \multirow{2}{*}{$\begin{array}{l}\text { STANDARD } \\
\text { DEVIATION }\end{array}$} & \multirow{2}{*}{$\begin{array}{c}\text { COEFF. } \\
\text { OF } \\
\text { VARIATION }\end{array}$} & \multirow{2}{*}{$\begin{array}{l}\% \text { OF } \\
\text { NON } \\
\text { DETECTS }\end{array}$} & \multirow{2}{*}{\multicolumn{2}{|c|}{$\begin{array}{l}\text { STATISTICAL RANGE } \\
\text { 98\% CONFIDENCE INTERVAL } \\
\text { MINIMUM MAXIMUM * }\end{array}$}} & \multirow{2}{*}{$\begin{array}{c}\text { DISTRIBUTION } \\
\text { TYPE }\end{array}$} & \multirow{2}{*}{$\begin{array}{l}\text { FOOT } \\
\text { NOTE }\end{array}$} \\
\hline \# OF SAMP & MINIMUM & MAXIMUM & MEDIAN & & & & & & & & \\
\hline \multicolumn{3}{|c|}{ SPECIFIC CONDUCTANCE } & UMHO/CM & \multirow[b]{2}{*}{2479.1200} & \multirow[b]{2}{*}{839.4961} & \multirow[b]{2}{*}{0.3386} & \multirow[b]{2}{*}{0.0} & \multirow[b]{2}{*}{2060.7151} & \multirow[b]{2}{*}{2897.5249} & \multirow[b]{2}{*}{ NORMAL } & \\
\hline 25 & 1050.0000 & 3840.0000 & 2656.0000 & & & & & & & & \\
\hline \multicolumn{3}{|l|}{ STRONTIUM } & MG/L & \multirow[b]{2}{*}{2.1194} & \multirow[b]{2}{*}{0.7522} & \multirow[b]{2}{*}{0.3549} & \multirow[b]{2}{*}{0.0} & \multirow[b]{2}{*}{1.6482} & \multirow[b]{2}{*}{2.5906} & \multirow[b]{2}{*}{ NORMAL } & \\
\hline 17 & 1.1800 & 4.5700 & 2.1100 & & & & & & & & \\
\hline \multicolumn{3}{|c|}{ STRONTIUM (TOTAL) } & $M G / L$ & \multirow[b]{2}{*}{ NA } & \multirow[b]{2}{*}{ NA } & \multirow[b]{2}{*}{ NA } & \multirow[b]{2}{*}{0.0} & \multirow[b]{2}{*}{ NA } & \multirow[b]{2}{*}{ NA } & \multirow[b]{2}{*}{ UNKNOWN } & \\
\hline 3 & 1.5500 & 4.3200 & 1.9600 & & & & & & & & 1 \\
\hline SULFATE & & & MG/L & & & & & & & & \\
\hline 26 & 476.0000 & 2340.0000 & +1095.0000 & 1194.3462 & 517.8732 & 0.4336 & 0.0 & 941.9614 & 1446.7309 & NORMAL & \\
\hline SULFIDE & & & MG/L & & & & & & & & \\
\hline 15 & $\begin{array}{ll}* & 0.1000\end{array}$ & 32.9000 & 0.2000 & NA & NA & NA & 40.0 & 0.1000 & 1.6000 & NONPARAMETRIC & 2 \\
\hline TEMPERATU & & & $C$ - DEGR & & & & & & & & \\
\hline 25 & 10.5000 & 15.2000 & 13.0000 & 12.8880 & 1.4240 & 0.1105 & 0.0 & 12.1783 & 13.5977 & NORMAL & \\
\hline THALLIUM & & & MG/L & & & & & & & & \\
\hline 14 & $\begin{array}{ll}* & 0.0050\end{array}$ & 0.0250 & 0.0050 & NA & NA & NA & 100.0 & 0.0050 & 0.0050 & NONPARAMETRIC & 2 \\
\hline THORIUM - 2? & & & $\mathrm{PCI} / \mathrm{L}$ & & & & & & & & \\
\hline 10 & $\begin{array}{ll}* * & 0.1000\end{array}$ & 0.7000 & 0.3000 & NA & NA & NA & 0.0 & 0.1000 & 0.5000 & NONPARAMETRIC & 9 \\
\hline THORIUM-2 & 30 (TOTAL) & & $\mathrm{PCI} / \mathrm{L}$ & & & & & & & & \\
\hline 3 & 0.5000 & 0.8000 & 0.6000 & NA & NA & NA & 0.0 & NA & NA & UNKNOWN & 1 \\
\hline TIN & & & $M G / L$ & & & & & & & & \\
\hline 15 & ** $\quad 0.0050$ & 0.0250 & 0.0150 & NA & NA & NA & 86.7 & 0.0050 & 0.0250 & NONPARAMETRIC & 2 \\
\hline
\end{tabular}

** The reported value is the minimum detection limit of the data set

+ The sample size is even, so the median value is the arithmetic average of the two middle values

* The statistical maximum is the 99 percent one sided confidence interval, $\alpha=0.01$

1) A minimum of 4 samples must be available for the statistical analysis.

2) The nonparametric distribution was used because the nondetected values comprise more than $15 \%$ of the samples.

9) The nonparametic distribution was used because the data failed the normal distribution test and includes values $\leq 0$. 
TABLE 3.28 BASELINE GROUND WATER QUALITY STATISTICS BY PARAMETER FOR

THE ALLUVIUM, NC PROCESSING SITE, SLICK ROCK, COLORADO

SITE: SRKO1 SLICK ROCK (BOTH SITES)

$09 / 07 / 82$ TO $02 / 22 / 94$

REPORT DATE : 09/30/94

\begin{tabular}{|c|c|c|c|c|c|c|c|c|c|c|c|c|}
\hline \multicolumn{3}{|c|}{ PARAMETER NAME } & UNITS & \multirow[b]{2}{*}{ MEAN } & \multirow{2}{*}{$\begin{array}{r}\text { STANDARD } \\
\text { DEVIATION }\end{array}$} & \multirow{2}{*}{$\begin{array}{c}\text { COEFF. } \\
\text { OF } \\
\text { VARIATION }\end{array}$} & \multirow{2}{*}{$\begin{array}{c}\% \text { OF } \\
\text { NON } \\
\text { DETECTS }\end{array}$} & \multirow{2}{*}{\multicolumn{3}{|c|}{$\begin{array}{c}\text { STATISTICAL RANGE } \\
\text { 98\% CONFIDENCE INTERVAL } \\
\text { MINIMUM MAXIMUM * }\end{array}$}} & \multirow{2}{*}{$\begin{array}{l}\text { DISTRIBUTION } \\
\text { TYPE }\end{array}$} & \multirow{2}{*}{$\begin{array}{l}\text { FOOT } \\
\text { NOTE }\end{array}$} \\
\hline \# OF SAMP & MINIMUM & MAXIMUM & MEDIAN & & & & & & & & & \\
\hline \multicolumn{3}{|c|}{ TOTAL DISSOLVED SOLIDS } & MG/L. & & \multirow[b]{2}{*}{992.0716} & \multirow[b]{2}{*}{0.4146} & \multirow[b]{2}{*}{0.0} & \multirow{2}{*}{\multicolumn{2}{|c|}{1909.5922}} & \multirow[b]{2}{*}{2876.5616} & \multirow[b]{2}{*}{ NORMAL } & \\
\hline 26 & 1060.0000 & 4300.0000 & +2390.0000 & 2393.0769 & & & & & & & & \\
\hline \multicolumn{3}{|c|}{ TOTAL KJELDAHL NITROGEN } & $M G / L$ & \multirow[b]{2}{*}{ NA } & \multirow[b]{2}{*}{ NA } & \multirow[b]{2}{*}{ NA } & \multirow[b]{2}{*}{44.4} & \multirow[b]{2}{*}{ ** } & \multirow[b]{2}{*}{1.0000} & \multirow[b]{2}{*}{5.0000} & \multirow[b]{2}{*}{ NONPARAMETRIC } & \multirow[b]{2}{*}{2} \\
\hline 9 & $* * \quad 1.0000$ & 5.0000 & 1.0000 & & & & & & & & & \\
\hline \multicolumn{3}{|c|}{ TOTAL ORGANIC CARBON } & MG/L & \multirow[b]{2}{*}{4.0000} & \multirow[b]{2}{*}{2.4495} & \multirow[b]{2}{*}{0.6124} & \multirow[b]{2}{*}{0.0} & \multirow{2}{*}{\multicolumn{2}{|c|}{2.3404}} & \multirow[b]{2}{*}{5.6596} & & \\
\hline 15 & 2.0000 & 10.0000 & 3.0000 & & & & & & & & NORMAL & \\
\hline TURBIDI TY & & & NTU & & & & & & & & & \\
\hline 3 & 0.5000 & 10.0000 & 6.0000 & NA & NA & NA & 0.0 & & NA & NA & UNKNOWN & 1 \\
\hline URANIUM & & & $M G / L$ & & & & & & & & & \\
\hline 26 & 0.2320 & 5.0000 & 2.8770 & 2.6270 & 1.1110 & 0.4229 & 0.0 & & 2.0855 & 3.1684 & NORMAL. & \\
\hline URANIUM $C T$ & TOTAL) & & $M G / L$ & & & & & & & & & \\
\hline 3 & 2.9600 & 3.7700 & 3.6400 & NA & NA & NA & 0.0 & & NA & NA & UNKNOWN & 1 \\
\hline VANADIUM & & & $M G / L$ & & & & & & & & & \\
\hline 23 & ** $\quad 0.0100$ & 0.5300 & $\begin{array}{ll}* & 0.0100\end{array}$ & NA & NA & NA & 78.3 & ** & 0.0100 & 0.0250 & NONPARAMETRIC & 2 \\
\hline VANADIUM & (TOTAL) & & MG/L & & & & & & & & & \\
\hline 3 & 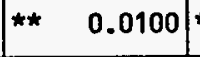 & 0.0100 & 0.0100 & NA & NA & NA & 100.0 & & NA & NA & UNKNOWN & 1 \\
\hline ZINC & & & $M G / L$ & & & & & & & & & \\
\hline 21 & ** $\quad 0.0050$ & 0.0280 & 0.0050 & NA & NA & NA & 95.2 & ** & 0.0050 & 0.0050 & NONPARAMETRIC & 2 \\
\hline ZINC (TOTA & $A L)$ & & $M G / L$ & & & & & & & & & \\
\hline 3 & $\star \star \quad 0.0500$ & 0.0500 & 0.0500 & NA & NA & NA & 100.0 & & NA & NA & UNKNOWN & 1 \\
\hline
\end{tabular}

** The reported value is the minimum detection limit of the data set

+ The sample size is even, so the median value is the arithmetic average of the two middle values

* The statistical maximum is the 99 percent one sided confidence interval, $\alpha=0.01$

1) A minimum of 4 samples must be available for the statistical analysis.

2) The nonparametric distribution was used because the nondetected values comprise more than $15 \%$ of the samples. 
TABLE 3.28 BASELINE GROUND WATER QUALITY STATISTICS BY PARAMETER FOR

THE ALLUVIUM, NC PROCESSING SITE, SLICK ROCK, COLORADO

SITE: SRKO1 SLICK ROCK (BOTH SITES)

$09 / 07 / 82$ TO $02 / 22 / 94$

REPORT DATE: 09/30/94

\begin{tabular}{|c|c|c|c|c|c|c|c|c|c|c|}
\hline \multicolumn{3}{|c|}{ PARAMETER NAME } & UNITS & \multirow[b]{2}{*}{ MEAN } & \multirow{2}{*}{$\begin{array}{l}\text { STANDARD } \\
\text { DEVIATION }\end{array}$} & \multirow{2}{*}{$\begin{array}{c}\text { COEFF. } \\
\text { OF } \\
\text { VARIATION }\end{array}$} & \multirow{2}{*}{$\begin{array}{c}\% \text { OF } \\
\text { NON } \\
\text { DETECTS }\end{array}$} & \multirow{2}{*}{$\begin{array}{c}\text { STATISTICAL RANGE } \\
\text { 98\% CONFIDENCE INTERVAL } \\
\text { MINIMUM } \\
\text { MAXIMUM * }\end{array}$} & \multirow{2}{*}{$\begin{array}{l}\text { DISTRIBUT ION } \\
\text { TYPE }\end{array}$} & \multirow{2}{*}{$\begin{array}{l}\text { FOOT } \\
\text { NOTE }\end{array}$} \\
\hline \# OF SAMP & MINIMUM & MAXIMUM & MEDIAN & & & & & & & \\
\hline
\end{tabular}

* The statistical maximum is the 99 percent one sided confidence interval, $\alpha=0.01$

INPUT DATA FILENAME: IDARTISRK01IGWQ10069.DAT 
Table 3.29 Summary of regulated constituents in alluvial baseline ground water, NC processing site, Slick Rock, Colorado

\begin{tabular}{|c|c|c|c|c|}
\hline \multicolumn{5}{|c|}{ Constituents with MCLs } \\
\hline Parameter & $\begin{array}{l}\text { Baseline } \\
\text { median }\end{array}$ & $\begin{array}{l}\text { Baseline } \\
\text { stat max }\end{array}$ & $\begin{array}{l}\text { Background } \\
\text { stat max }\end{array}$ & MCL \\
\hline Arsenic & $0.01^{g}$ & $0.01^{g}$ & $0.01^{9}$ & 0.05 \\
\hline Barium & $0.10^{g}$ & $0.10^{9}$ & $0.10^{9}$ & 1.00 \\
\hline Cadmium & $0.001^{9}$ & $0.001^{9}$ & $0.001^{g}$ & 0.01 \\
\hline Chromium & $0.01^{g}$ & 0.019 & $0.01^{g}$ & 0.05 \\
\hline Net gross alpha ${ }^{f}$ & $-64.38^{e}$ & $123.86^{\mathrm{e}}$ & $4.72^{e}$ & 15.00 \\
\hline Lead & $0.01^{g}$ & 0.019 & $0.01^{g}$ & 0.05 \\
\hline Mercury & $0.0002^{g}$ & $0.0002^{g}$ & $0.0002^{g}$ & 0.002 \\
\hline Molybdenum & $0.02^{e}$ & $0.03^{e}$ & $0.12^{d}$ & 0.10 \\
\hline Nitrate & $1.0^{9}$ & $1.0^{g}$ & $1.6^{\mathrm{e}}$ & 44.0 \\
\hline Radium-226,-228 & $2.74^{d}$ & $4.24^{d}$ & $7.80^{e}$ & 5.0 \\
\hline Selenium & $0.005^{9}$ & $0.015^{e}$ & $0.005^{g}$ & 0.01 \\
\hline Silver & $0.01^{g}$ & $0.01^{g}$ & $0.01^{g}$ & 0.05 \\
\hline Uranium & $2.627^{d}$ & $3.168^{d}$ & $0.045^{d}$ & 0.044 \\
\hline
\end{tabular}


Table 3.29 Summary of regulated constituents in alluvial baseline ground water, NC processing site, Slick Rock, Colorado (Concluded)

\begin{tabular}{llcll}
\hline \multicolumn{5}{c}{ Constituents without MCLs } \\
\hline Parameter & $\begin{array}{l}\text { Baseline } \\
\text { median }\end{array}$ & $\begin{array}{c}\text { Baseline } \\
\text { stat max }\end{array}$ & $\begin{array}{c}\text { Background } \\
\text { stat. max }\end{array}$ & MCL \\
\hline Antimony & $0.003^{\mathrm{g}}$ & $0.003^{\mathrm{g}}$ & $0.003^{\mathrm{g}}$ & None \\
Beryllium & $0.01^{\mathrm{g}}$ & $0.01^{\mathrm{g}}$ & $0.01^{\mathrm{g}}$ & None \\
Cobalt & $0.05^{\mathrm{g}}$ & $0.05^{\mathrm{g}}$ & $0.05^{\mathrm{g}}$ & None \\
Copper & $0.02^{\mathrm{g}}$ & $0.02^{\mathrm{g}}$ & $0.05^{\mathrm{e}}$ & None \\
Cyanide & $0.01^{\mathrm{g}}$ & $0.02^{\mathrm{e}}$ & $0.01^{\mathrm{g}, \mathrm{h}}$ & None \\
Nickel & $0.04^{\mathrm{g}}$ & $0.04^{\mathrm{g}}$ & $0.04^{\mathrm{g}}$ & None \\
Sulfide & $0.2^{\mathrm{e}}$ & $1.6^{\mathrm{e}}$ & $1.0^{\mathrm{e}}$ & None \\
Thallium & $0.01^{\mathrm{g}}$ & $0.01^{\mathrm{g}}$ & $0.01^{\mathrm{g}}$ & None \\
Tin & $0.015^{\mathrm{e}}$ & $0.025^{\mathrm{e}}$ & $0.005^{\mathrm{g}}$ & None \\
Vanadium & $0.01^{\mathrm{g}}$ & $0.03^{\mathrm{e}}$ & $0.23^{\mathrm{e}}$ & None \\
Zinc & $0.005^{\mathrm{g}}$ & $0.005^{\mathrm{g}}$ & $0.015^{\mathrm{e}}$ & None \\
\hline
\end{tabular}

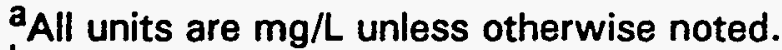

bNC Processing site background groundwater statistical maximum.

CLognormal distribution, mean is geometric.

dNormal distribution, mean is arithmetic.

ONonparametric distribution

Units are $\mathrm{pCi} / \mathrm{L}$.

9Statistical values are below laboratory detection limits in Table 8.1 of the Technical Approach Document (DOE, 1989).

hValue is an observed maximum, rather than a statistical maximum, because less than four samples were available for statistical analysis. 
TABLE 3.30 GROUND WATER QUALITY MEASUREMENTS EXCEEDING MCLS IN ALLUVIAL

BASELINE GROUND WATER, NC AND UC SITES, SLICK ROCK, COLORADO

SITE: SRKO1 SLICK ROCK (BOTH SITES)

$09 / 07 / 82$ TO 02/22/94

REPORT DATE: $09 / 30 / 94$

\begin{tabular}{|c|c|c|c|c|c|c|c|c|c|c|c|c|}
\hline PARAMETER NAME & $\begin{array}{l}\text { TOTAL } \\
\text { \# OF } \\
\text { SAMP. }\end{array}$ & $\begin{array}{c}\text { UNITS } \\
\text { OF } \\
\text { MEASURE }\end{array}$ & $\begin{array}{l}\text { MAXIMUM } \\
\text { CONC. } \\
\text { LIMIT }\end{array}$ & LOC. & LOG DATE & $\begin{array}{l}\text { SAMP } \\
\text { ID }\end{array}$ & $\begin{array}{l}\text { FORM } \\
\text { OF } \\
\text { COMP }\end{array}$ & $\begin{array}{l}\text { HYOR } \\
\text { FLOW } \\
\text { REL. }\end{array}$ & $\begin{array}{c}\text { RESULT EXCEEL } \\
\text { CONCENTRATIOI } \\
\text { VALUE }\end{array}$ & $\begin{array}{l}\text { DING MAX. } \\
\text { N LIMIT } \\
\text { FLAGS }\end{array}$ & $\begin{array}{l}\text { DETECTION } \\
\text { LIMIT }\end{array}$ & $\begin{array}{l}\text { PARAMETER } \\
\text { UNCERT. }\end{array}$ \\
\hline ARSENIC & 51 & $M G / L$ & 0.0500 & $\left|\begin{array}{l}0503 \\
0504 \\
0506 \\
0506 \\
0506 \\
0507 \\
0508 \\
0510\end{array}\right|$ & $\begin{array}{l}12 / 09 / 91 \\
12 / 09 / 91 \\
03 / 28 / 91 \\
08 / 08 / 91 \\
11 / 20 / 91 \\
12 / 05 / 91 \\
12 / 05 / 91 \\
12 / 05 / 91\end{array}$ & $\begin{array}{l}0001 \\
0001 \\
0001 \\
0001 \\
0001 \\
0001 \\
0001 \\
0001\end{array}$ & $\begin{array}{l}A L \\
A L \\
A L \\
A L \\
A L \\
A L \\
A L \\
A L\end{array}$ & $\begin{array}{l}0 \\
0 \\
D \\
D \\
D \\
D \\
0 \\
0\end{array}$ & $\begin{array}{l}0.05 \\
0.05 \\
0.05 \\
0.1 \\
0.05 \\
0.05 \\
0.1 \\
0.1\end{array}$ & $\begin{array}{l}\text { IW } \\
\text { IW } \\
I \\
I \\
\text { IW } \\
\text { I } \\
I \\
I\end{array}$ & $\begin{array}{l}0.05 \\
0.05 \\
0.05 \\
0.1 \\
0.05 \\
0.05 \\
0.1 \\
0.1\end{array}$ & $\begin{array}{l}- \\
- \\
- \\
- \\
- \\
-\end{array}$ \\
\hline ARSENIC (TOTAL) & 0 & MG/L & 0.0500 & - & - & - & - & - & - & & - & - \\
\hline BARIUM & 53 & MG/L & 1.0000 & - & - & - & - & - & - & & - & - \\
\hline BARIUM (TOTAL) & 8 & $M G / L$ & 1.0000 & - & - & - & - & - & - & & - & - \\
\hline CADMIUM & 53 & MG/L. & 0.0100 & $\begin{array}{l}0506 \\
0508 \\
0508 \\
0508\end{array}$ & $\begin{array}{l}10 / 08 / 92 \\
08 / 28 / 91 \\
12 / 05 / 91 \\
10 / 10 / 92\end{array}$ & $\begin{array}{l}0001 \\
0001 \\
0001 \\
0001\end{array}$ & $\begin{array}{l}A L \\
A L \\
A L \\
A L\end{array}$ & $\begin{array}{l}0 \\
0 \\
0 \\
0\end{array}$ & $\begin{array}{l}0.01 \\
0.05 \\
0.05 \\
0.027\end{array}$ & $\begin{array}{l}I \\
I \\
I\end{array}$ & $\begin{array}{l}0.01 \\
0.05 \\
0.05 \\
0.005\end{array}$ & $\begin{array}{l}- \\
-\end{array}$ \\
\hline CADMIUM (TOTAL) & 8 & $M G / L$ & 0.0100 & - & - & - & - & - & - & & - & - \\
\hline CHROMIUM & 53 & MG/L & 0.0500 & $\mid \begin{array}{l}0503 \\
0510\end{array}$ & $\begin{array}{l}06 / 30 / 86 \\
06 / 30 / 86\end{array}$ & $\begin{array}{l}0001 \\
0001\end{array}$ & $\begin{array}{l}A L \\
A L\end{array}$ & $\begin{array}{l}0 \\
0\end{array}$ & $\begin{array}{l}0.05 \\
0.05\end{array}$ & & $\begin{array}{l}0.01 \\
0.01\end{array}$ & $\begin{array}{l}\overline{-} \\
\end{array}$ \\
\hline CHROMIUM (TOTAL) & 8 & $M G / L$ & 0.0500 & - & - & - & - & - & - & & - & - \\
\hline GROSS ALPHA & 40 & $\mathrm{PCI} / \mathrm{L}$ & 15.0000 & $\begin{array}{l}0503 \\
0503 \\
0503 \\
0503 \\
0503 \\
0504\end{array}$ & $\begin{array}{l}03 / 29 / 91 \\
08 / 08 / 91 \\
12 / 05 / 91 \\
10 / 09 / 92 \\
02 / 18 / 94 \\
04 / 03 / 91\end{array}$ & $\begin{array}{l}0001 \\
0001 \\
0001 \\
0001 \\
0001 \\
0001\end{array}$ & $\begin{array}{l}A L \\
A L \\
A L \\
A L \\
A L \\
A L\end{array}$ & $\begin{array}{l}0 \\
0 \\
0 \\
0 \\
0 \\
0\end{array}$ & $\begin{array}{l}2299 . \\
1821 . \\
2175 . \\
1610 . \\
1920 . \\
1177 .\end{array}$ & $\begin{array}{l}N \\
\star \\
J\end{array}$ & $\begin{array}{c}1 . \\
1 . \\
1 . \\
37.8 \\
10.4 \\
1 .\end{array}$ & $\begin{array}{c}118 . \\
108 . \\
165 . \\
99.3 \\
46.1 \\
85.7\end{array}$ \\
\hline
\end{tabular}

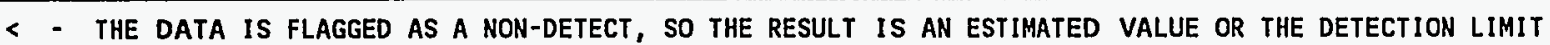

FORMATION OF COMPLETION CODE:

AL - ALLUVIUM

OTHER PARAMETER VALUE FLAGS:

* - DUPLICATE ANALYSIS NOT HITHIN CONTROL LIMITS

I - INCREASED DETECTION LIMIT DUE TO REQUIRED DILUTION

$J$ - ESTIMATED VALUE

N - SPIKE SAMPLE RECOVERY NOT WITHIN CONTROL LIMITS

$W$ - POST-DIGEST SPIKE OUT OF CNTR LIM WHILE SAMP ABS < $50 \%$ SPIKE
FLOW RELATIONSHIP CODE:

O - ON-SITE

D - DOWN GRADIENT

SAMPLE ID CODES:

0001 - FILTERED SAMPLE (.45 MICRONS) 
TABLE 3.30 GROUND WATER QUALITY MEASUREMENTS EXCEEDING MCLS IN ALLUVIAL BASELINE GROUND HATER, NC AND UC SITES, SLICK ROCK, COLORADO

SITE: SRKO1 SLICK ROCK (BOTH SITES)

09/07/82 TO 02/22/94

\begin{tabular}{|c|c|c|c|c|c|c|c|}
\hline & PARAMETER NAME & $\begin{array}{l}\text { TOTAL } \\
\text { \# OF } \\
\text { SAMP. }\end{array}$ & $\begin{array}{c}\text { UNITS } \\
\text { OF } \\
\text { MEASURE }\end{array}$ & $\begin{array}{l}\text { MAXIMUM } \\
\text { CONC. } \\
\text { LIMIT }\end{array}$ & LOC. & LOG DATE & $\begin{array}{l}\text { SAMP } \\
\text { ID }\end{array}$ \\
\hline & GROSS ALPHA & 40 & $\mathrm{PCI} / \mathrm{L}$ & 15.0000 & $\begin{array}{l}0504 \\
0504 \\
0504 \\
0504 \\
0506 \\
0506 \\
0506 \\
0506 \\
0507 \\
0507 \\
0507 \\
0508 \\
0508 \\
0508 \\
0508 \\
0509 \\
0509 \\
0509 \\
0509 \\
0509 \\
0510 \\
0510 \\
0510 \\
0510 \\
0512 \\
0512 \\
0512 \\
0512 \\
0512\end{array}$ & $\begin{array}{l}08 / 27 / 91 \\
12 / 05 / 91 \\
10 / 09 / 92 \\
02 / 19 / 94 \\
03 / 28 / 91 \\
08 / 08 / 91 \\
10 / 08 / 92 \\
02 / 20 / 94 \\
03 / 28 / 91 \\
08 / 09 / 91 \\
12 / 05 / 91 \\
03 / 27 / 91 \\
08 / 28 / 91 \\
10 / 10 / 92 \\
02 / 21 / 94 \\
03 / 27 / 91 \\
08 / 28 / 91 \\
12 / 05 / 91 \\
10 / 13 / 92 \\
02 / 21 / 94 \\
03 / 28 / 91 \\
08 / 28 / 91 \\
10 / 08 / 92 \\
02 / 20 / 94 \\
04 / 05 / 91 \\
08 / 08 / 91 \\
12 / 05 / 91 \\
10 / 09 / 92 \\
02 / 20 / 94\end{array}$ & $\begin{array}{l}0001 \\
0001 \\
0001 \\
0001 \\
0001 \\
0001 \\
0001 \\
0001 \\
0001 \\
0001 \\
0001 \\
0001 \\
0001 \\
0001 \\
0001 \\
0001 \\
0001 \\
0001 \\
0001 \\
0001 \\
0001 \\
0001 \\
0001 \\
0001 \\
0001 \\
0001 \\
0001 \\
0001 \\
0001\end{array}$ \\
\hline & GROSS ALPHA (TOTAL) & 8 & $\mathrm{PCI} / \mathrm{L}$ & 15.0000 & $\begin{array}{l}0503 \\
0504 \\
0506 \\
0507 \\
0508\end{array}$ & $\begin{array}{l}02 / 18 / 94 \\
02 / 19 / 94 \\
02 / 20 / 94 \\
02 / 20 / 94 \\
02 / 21 / 94\end{array}$ & $\begin{array}{l}\text { N001 } \\
\text { NO01 } \\
\text { N001 } \\
\text { N001 } \\
\text { N001 }\end{array}$ \\
\hline
\end{tabular}

\begin{tabular}{|c|c|c|c|c|c|}
\hline $\begin{array}{l}\text { FORM } \\
\text { OF } \\
\text { COMP }\end{array}$ & $\begin{array}{l}\text { HYDR } \\
\text { FLOW } \\
\text { REL. }\end{array}$ & $\begin{array}{c}\text { RESULT EXCEEI } \\
\text { CONCENTRATIO } \\
\text { VALUE }\end{array}$ & $\begin{array}{l}\text { DIHG MAX. } \\
\text { N LIMIT } \\
\text { FLAGS }\end{array}$ & $\begin{array}{l}\text { DETECTION } \\
\text { LIMIT }\end{array}$ & $\begin{array}{l}\text { PARAMETER } \\
\text { UNCERT. }\end{array}$ \\
\hline $\begin{array}{l}A L \\
A L \\
A L \\
A L \\
A L \\
A L \\
A L \\
A L \\
A L \\
A L \\
A L \\
A L \\
A L \\
A L \\
A L \\
A L \\
A L \\
A L \\
A L \\
A L \\
A L \\
A L \\
A L \\
A L \\
A L \\
A L \\
A L \\
A L \\
A L\end{array}$ & $\begin{array}{l}D \\
D \\
D \\
D \\
D \\
D \\
D \\
D \\
D \\
D \\
D \\
0 \\
0 \\
0 \\
D \\
0 \\
0 \\
0 \\
0 \\
0 \\
0 \\
0 \\
0 \\
0 \\
0 \\
0 \\
0 \\
0 \\
0\end{array}$ & $\begin{array}{c}768.3 \\
718 . \\
641 . \\
2220 . \\
191 . \\
23.0 \\
189 . \\
136 . \\
41.0 \\
30.6 \\
19.3 \\
63.2 \\
67.2 \\
23.1 \\
32.6 \\
111 . \\
23.5 \\
19.0 \\
16.1 \\
25.4 \\
132 . \\
84.2 \\
118 . \\
95.5 \\
1222 . \\
916 . \\
870 . \\
1460 . \\
2680 .\end{array}$ & $\begin{array}{l}R \\
N \\
* \\
R\end{array}$ & $\begin{array}{c}1 . \\
1 . \\
25.0 \\
16.1 \\
1 . \\
1 . \\
82.4 \\
46.7 \\
1 . \\
1 . \\
1 . \\
1 . \\
1 . \\
48.4 \\
24.3 \\
1 . \\
1 . \\
1 . \\
20.2 \\
5.4 \\
1 . \\
1 . \\
41.2 \\
21.4 \\
1 . \\
1 . \\
1 . \\
22.5 \\
7.2\end{array}$ & $\begin{array}{c}63.7 \\
80.4 \\
51.7 \\
61.7 \\
140 . \\
71.2 \\
74.3 \\
30.4 \\
17.0 \\
13.6 \\
26.0 \\
23.2 \\
34.2 \\
31.6 \\
19.1 \\
70.7 \\
12.0 \\
23.8 \\
13.9 \\
4.1 \\
73.1 \\
37.6 \\
40.0 \\
16.6 \\
58.2 \\
51.1 \\
66.1 \\
72.3 \\
46.1\end{array}$ \\
\hline $\begin{array}{l}A L \\
A L \\
A L \\
A L \\
A L\end{array}$ & $\begin{array}{l}0 \\
D \\
D \\
D \\
0\end{array}$ & $\begin{array}{r}2180 . \\
1770 . \\
84.0 \\
15.5 \\
59.0\end{array}$ & * & $\begin{array}{r}9.7 \\
16.3 \\
48.1 \\
4.5 \\
19.9\end{array}$ & $\begin{array}{r}47.7 \\
55.2 \\
29.0 \\
3.1 \\
12.6\end{array}$ \\
\hline
\end{tabular}

FORMATION OF COMPLETION CODE:

FLOW RELATIONSHIP CODE

AL - ALLUVIUM

D - DOWN GRADIENT

O - ON-SITE

OTHER PARAMETER VALUE FLAGS:

* - DUPLICATE ANALYSIS NOT HITHIN CONTROL LIMITS

SAMPLE ID CODES:

N - SPIKE SAMPLE RECOVERY NOT WITHIN CONTROL LIMITS

0001 - FILTERED SAMPLE (.45 MICRONS)

$R$ - UNUSABLE DATA POINT 
TABLE 3.30 GROUND WATER QUALITY MEASUREMENTS EXCEEDING MCLS IN ALLUVIAL

BASELINE GROUND WATER, NC AND UC SITES, SLICK ROCK, COLORADO

SITE: SRKO1 SLICK ROCK (BOTH SITES)

$09 / 07 / 82$ TO 02/22/94

REPORT DATE : 09/30/94

\begin{tabular}{|c|c|c|c|c|c|c|c|c|c|c|c|c|}
\hline PARAMETER NAME & $\begin{array}{l}\text { TOTAL } \\
\text { \# OF } \\
\text { SAMP. }\end{array}$ & $\begin{array}{c}\text { UNITS } \\
\text { OF } \\
\text { MEASURE }\end{array}$ & $\begin{array}{l}\text { MAXIMUM } \\
\text { CONC. } \\
\text { LIMIT }\end{array}$ & LOC. & LOG DATE & $\begin{array}{c}\text { SAMP } \\
\text { ID }\end{array}$ & $\begin{array}{c}\text { FORM } \\
\text { OF } \\
\text { COMP }\end{array}$ & $\begin{array}{l}\text { HYDR } \\
\text { FLOW } \\
\text { REL. }\end{array}$ & $\begin{array}{c}\text { RESULT EXCEE } \\
\text { CONCENTRATIO } \\
\text { VALUE }\end{array}$ & $\begin{array}{l}\text { DING MAX. } \\
\text { N LIMIT } \\
\text { FLAGS }\end{array}$ & $\begin{array}{l}\text { DETECTION } \\
\text { LIMIT }\end{array}$ & $\begin{array}{l}\text { PARAME TER } \\
\text { UNCERT. }\end{array}$ \\
\hline GROSS ALPHA (TOTAL) & 8 & PCI/L & 15.0000 & $\begin{array}{l}0509 \\
0510 \\
0512\end{array}$ & $\begin{array}{l}02 / 21 / 94 \\
02 / 20 / 94 \\
02 / 20 / 94\end{array}$ & $\begin{array}{l}\text { NO01 } \\
\text { NO01 } \\
\text { NO01 }\end{array}$ & $\begin{array}{l}A L \\
A L \\
A L\end{array}$ & $\begin{array}{l}0 \\
0 \\
0\end{array}$ & $\begin{array}{l}27.5 \\
103 . \\
1590 .\end{array}$ & * & $\begin{array}{r}4.9 \\
19.9 \\
5.4\end{array}$ & $\begin{array}{r}4.2 \\
17.9 \\
30.4\end{array}$ \\
\hline LEAD & 45 & MG/L & 0.0500 & 0506 & 08/08/91 & 0001 & AL & D & 0.05 & I & 0.05 & - \\
\hline LEAD (TOTAL) & 0 & $M G / L$ & 0.0500 & - & - & - & - & - & - & & - & - \\
\hline MERCURY & 37 & HG/L & 0.0020 & - & - & - & - & - & - & & - & - \\
\hline MERCURY (TOTAL) & 0 & MG/L & 0.0020 & - & - & - & - & - & - & & - & - \\
\hline MOLYYDDENUM & 67 & $M G / L$ & 0.1000 & $\begin{array}{l}0503 \\
0504 \\
0506 \\
0506 \\
0507 \\
0508 \\
0508 \\
0508 \\
0508 \\
0508 \\
0508 \\
0508 \\
0508 \\
0509 \\
0509 \\
0509 \\
0509 \\
0509 \\
0509 \\
0509 \\
0509 \\
0510\end{array}$ & $\begin{array}{l}02 / 22 / 88 \\
02 / 22 / 88 \\
07 / 01 / 86 \\
02 / 22 / 88 \\
06 / 30 / 86 \\
06 / 30 / 86 \\
10 / 14 / 87 \\
02 / 19 / 88 \\
03 / 27 / 91 \\
08 / 28 / 91 \\
12 / 05 / 91 \\
10 / 10 / 92 \\
02 / 21 / 94 \\
07 / 17 / 86 \\
10 / 14 / 87 \\
02 / 22 / 88 \\
03 / 27 / 91 \\
08 / 28 / 91 \\
11 / 21 / 91 \\
10 / 13 / 92 \\
02 / 21 / 94 \\
06 / 30 / 86\end{array}$ & $\begin{array}{l}0001 \\
0001 \\
0001 \\
0001 \\
0001 \\
0001 \\
0001 \\
0001 \\
0001 \\
0001 \\
0001 \\
0001 \\
0001 \\
0001 \\
0001 \\
0001 \\
0001 \\
0001 \\
0001 \\
0001 \\
0001 \\
0001\end{array}$ & $\begin{array}{l}A L \\
A L \\
A L \\
A L \\
A L \\
A L \\
A L \\
A L \\
A L \\
A L \\
A L \\
A L \\
A L \\
A L \\
A L \\
A L \\
A L \\
A L \\
A L \\
A L \\
A L \\
A L\end{array}$ & $\begin{array}{l}0 \\
D \\
D \\
0 \\
D \\
0 \\
0 \\
0 \\
0 \\
0 \\
0 \\
0 \\
0 \\
0 \\
0 \\
0 \\
0 \\
0 \\
0 \\
0 \\
0 \\
0\end{array}$ & $\begin{array}{l}0.14 \\
0.17 \\
0.17 \\
0.32 \\
0.14 \\
2.43 \\
1.72 \\
1.72 \\
0.26 \\
1.37 \\
1.28 \\
1.33 \\
1.10 \\
0.38 \\
0.27 \\
0.33 \\
1.28 \\
0.28 \\
0.29 \\
0.26 \\
0.28 \\
1.09\end{array}$ & $\mathbf{R}$ & $\begin{array}{l}0.01 \\
0.01 \\
0.01 \\
0.01 \\
0.01 \\
0.01 \\
0.01 \\
0.01 \\
0.01 \\
0.01 \\
0.01 \\
0.01 \\
0.01 \\
0.01 \\
0.01 \\
0.01 \\
0.01 \\
0.01 \\
0.01 \\
0.01 \\
0.01 \\
0.01\end{array}$ & $\begin{array}{l}- \\
- \\
- \\
- \\
- \\
- \\
- \\
- \\
- \\
- \\
- \\
- \\
- \\
- \\
- \\
- \\
-\end{array}$ \\
\hline
\end{tabular}

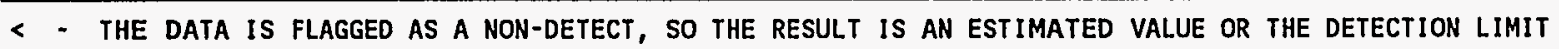

\section{FORMATION OF COMPLETION CODE:}

AL - ALLUVIUM

OTHER PARAMETER VALUE FLAGS:

* - DUPLICATE ANALYSIS NOT WITHIN CONTROL LIMITS

I - INCREASED DETECTION LIMIT DUE TO REQUIRED DILUTION

R - UNUSABLE DATA POINT
FLOW RELATIONSHIP CODE:

$$
\text { O - ON-SITE }
$$

D - DOWN GRADIENT

\section{SAMPLE ID CODES}

0001 - FILTERED SAMPLE (.45 MICRONS)

N001 - UNFILTERED SAMPLE 
TABLE 3.30 GROUND WATER QUALITY MEASUREMENTS EXCEEDING MCLS IN ALLUVIAL

BASELINE GROUND HATER, NC AND UC SITES, SLICK ROCK, COLORADO

SITE: SRKO1 SLICK ROCK (BOTH SITES)

REPORT

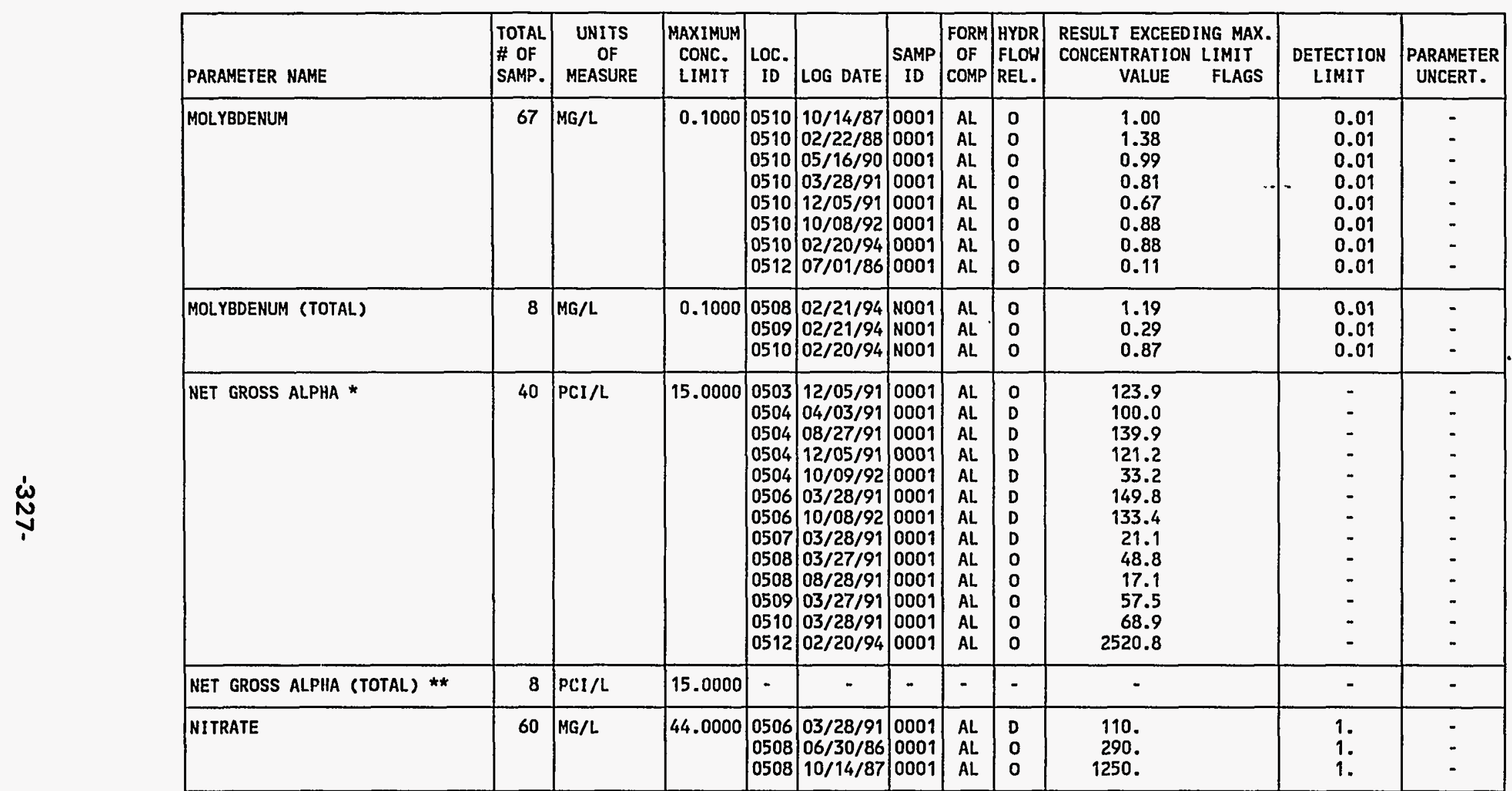

* NET gROSS aLPHA (GROSS ALPHA - URANIUM)

WITH 1 MG URANIUM $=686 \mathrm{PC}$

** TOTAL NET GROSS ALPHA (TOTAL GROSS ALPHA - TOTAL URANIUM)

FORMATION OF COMPLETION CODE:

AL - ALLUVIUM

FLOW RELATIONSHIP CODE:

O - ON-SITE

D - DOWN GRADIENT

SAMPLE ID CODES:

0001 - FILTERED SAMPLE (.45 MICRONS)

NOO1 - UNFILTERED SAMPLE 
TABLE 3.30 GROUND WATER QUALITY MEASUREMENTS EXCEEDING MCLS IN ALLUVIAL

BASELINE GROUND WATER, NC AND UC SITES, SLICK ROCK, COLORADO

SITE: SRKO1 SLICK ROCK (BOTH SITES)

$09 / 07 / 82$ TO 02/22/94

REPORT DATE: $09 / 30 / 94$

\begin{tabular}{|c|c|c|c|c|c|c|c|c|c|c|c|c|}
\hline PARAMETER NAME & $\begin{array}{l}\text { TOTAL. } \\
\# \text { OF } \\
\text { SAMP. }\end{array}$ & $\begin{array}{c}\text { UNITS } \\
\text { OF } \\
\text { MEASURE }\end{array}$ & $\begin{array}{l}\text { MAXIMUM } \\
\text { CONC. } \\
\text { LIMIT }\end{array}$ & $\underset{10}{\operatorname{LOC} .}$ & LOG DATE & $\begin{array}{c}\text { SAMP } \\
\text { ID }\end{array}$ & $\mid \begin{array}{c}\text { FORM } \\
\text { OF } \\
\text { COMP }\end{array}$ & $\begin{array}{l}\text { HYDR } \\
\text { FLOW } \\
\text { REL. }\end{array}$ & $\begin{array}{c}\text { RESULT EXCEE } \\
\text { CONCENTRATIO } \\
\text { VALUE }\end{array}$ & $\begin{array}{l}\text { DING MAX. } \\
\text { N LIMIT } \\
\text { FLAGS }\end{array}$ & $\begin{array}{l}\text { DETECTION } \\
\text { LIMIT }\end{array}$ & $\begin{array}{l}\text { PARAMETER } \\
\text { UNCERT. }\end{array}$ \\
\hline NITRATE & 60 & $M G / L$ & 44.0000 & $\begin{array}{l}0508 \\
0508 \\
0508 \\
0508 \\
0509 \\
0510 \\
0510 \\
0510 \\
0510 \\
0510 \\
0510 \\
0510 \\
0510\end{array}$ & $\begin{array}{l}02 / 19 / 88 \\
08 / 28 / 91 \\
12 / 05 / 91 \\
10 / 10 / 92 \\
03 / 27 / 91 \\
06 / 30 / 86 \\
10 / 14 / 87 \\
02 / 22 / 88 \\
05 / 16 / 90 \\
03 / 28 / 91 \\
08 / 28 / 91 \\
12 / 05 / 91 \\
10 / 08 / 92\end{array}$ & $\left|\begin{array}{l}0001 \\
0001 \\
0001 \\
0001 \\
0001 \\
0001 \\
0001 \\
0001 \\
0001 \\
0001 \\
0001 \\
0001 \\
0001\end{array}\right|$ & $\begin{array}{l}A L \\
A L \\
A L \\
A L \\
A L \\
A L \\
A L \\
A L \\
A L \\
A L \\
A L \\
A L \\
A L\end{array}$ & $\begin{array}{l}0 \\
0 \\
0 \\
0 \\
0 \\
0 \\
0 \\
0 \\
0 \\
0 \\
0 \\
0 \\
0\end{array}$ & $\begin{array}{l}1220 . \\
1040 . \\
1200 . \\
1360 . \\
1050 . \\
1000 . \\
1620 . \\
1190 . \\
1000 . \\
943 . \\
947 . \\
837 . \\
257 .\end{array}$ & $\mathbf{R}$ & $\begin{array}{r}1 . \\
75 . \\
125 . \\
150 . \\
1 . \\
1 . \\
1 . \\
1 . \\
1 . \\
1 . \\
75 . \\
125 . \\
10 .\end{array}$ & $\begin{array}{l}- \\
- \\
- \\
- \\
- \\
- \\
- \\
- \\
- \\
-\end{array}$ \\
\hline NITRATE (TOTAL) & 8 & $M G / L$ & 44.0000 & $\begin{array}{l}0508 \\
0510\end{array}$ & $\begin{array}{l}02 / 21 / 94 \\
02 / 20 / 94\end{array} \mid$ & $\begin{array}{l}\text { N001 } \\
\text { N001 }\end{array}$ & $\begin{array}{l}A L \\
A L\end{array}$ & $\begin{array}{l}0 \\
0\end{array}$ & $\begin{array}{l}1600 \\
1480\end{array}$ & & 1 & - \\
\hline$R A-226 \& R A-228$ & 50 & $\mathrm{PCl} / \mathrm{L}$ & 5.0000 & $\begin{array}{l}0503 \\
0506 \\
0508 \\
0508 \\
0509 \\
0512 \\
0512\end{array}$ & $\begin{array}{l}02 / 18 / 94 \\
10 / 08 / 92 \\
03 / 27 / 91 \\
02 / 21 / 94 \\
03 / 27 / 91 \\
04 / 05 / 91 \\
12 / 05 / 91\end{array}$ & $\left|\begin{array}{l}0001 \\
0001 \\
0001 \\
0001 \\
0001 \\
0001 \\
0001\end{array}\right|$ & $\begin{array}{l}A L \\
A L \\
A L \\
A L \\
A L \\
A L \\
A L\end{array}$ & $\begin{array}{l}0 \\
D \\
0 \\
0 \\
0 \\
0 \\
0\end{array}$ & $\begin{array}{l}8.9 \\
7.3 \\
5.5 \\
5.2 \\
8.3 \\
5.7 \\
6.5\end{array}$ & & $\begin{array}{l}- \\
- \\
- \\
- \\
-\end{array}$ & $\begin{array}{l}- \\
- \\
- \\
- \\
-\end{array}$ \\
\hline RA-226 \& RA-228 (TOTAL) & 8 & $\mathrm{PCl} / \mathrm{L}$ & 5.0000 & - & - & - & - & - & - & & - & - \\
\hline SELENIUM & 59 & $M G / L$ & 0.0100 & $\begin{array}{l}0503 \\
0503 \\
0503 \\
0504 \\
0504 \\
0504 \\
0506\end{array}$ & $\begin{array}{l}05 / 16 / 90 \\
03 / 29 / 91 \\
12 / 09 / 91 \\
05 / 16 / 90 \\
04 / 03 / 91 \\
12 / 09 / 91 \\
08 / 08 / 91\end{array}$ & $\left|\begin{array}{l}0001 \\
0001 \\
0001 \\
0001 \\
0001 \\
0001 \\
0001\end{array}\right|$ & $\begin{array}{l}A L \\
A L \\
A L \\
A L \\
A L \\
A L \\
A L\end{array}$ & $\begin{array}{l}\text { D } \\
0 \\
0 \\
D \\
D \\
D \\
D\end{array}$ & $\begin{array}{l}0.015 \\
0.03 \\
0.03 \\
0.015 \\
0.03 \\
0.03 \\
0.05\end{array}$ & $\begin{array}{l}\text { I } \\
\text { I } \\
\text { IJ } \\
\text { IH }\end{array}$ & $\begin{array}{l}0.005 \\
0.03 \\
0.03 \\
0.005 \\
0.03 \\
0.03 \\
0.05\end{array}$ & $\begin{array}{l}- \\
- \\
- \\
- \\
-\end{array}$ \\
\hline
\end{tabular}

$<$ - the dATA IS FLAGged AS A NON-DETECT, SO THE RESULT IS AN ESTIMATED VALUE OR THE DETECTION LIMIT

\section{FORMATION OF COMPLETION CODE:}

AL - ALLUVIUM

OTHER PARAMETER VALUE FLAGS:

I - INCREASED DETECTION LIMIT DUE TO REQUIRED DILUTION

J - ESTIMATED VALUE

$R$ - UNUSABLE DATA POINT

$W$ - POST-DIGEST SPIKE OUT OF CNTR LIM WHILE SAMP ABS < 50\% SPIKE
FLOW RELATIONSHIP CODE:

O - ON-SITE

D - DOWN GRADIENT

SAMPLE ID CODES:

0001 - FILTERED SAMPLE (.45 MICRONS)

NOD1 - UNFILTERED SAMPLE 
TABLE 3.30 GROUND HATER QUALITY MEASUREMENTS EXCEEDING MCLS IN ALLUVIAL BASELINE GROUND HATER, NC AND UC SITES, SLICK ROCK, COLORADO

SITE: SRK01 SLICK ROCK (BOTH SITES)

O9/T/OT/82 TO 02/22/94

REPORT DATE: 09/30/94

\begin{tabular}{|c|c|c|c|c|c|c|c|c|c|c|c|c|}
\hline PARAMETER NAME & $\begin{array}{l}\text { TOTAL } \\
\# \text { OF } \\
\text { SAMP. }\end{array}$ & $\begin{array}{c}\text { UNITS } \\
\text { OF } \\
\text { MEASURE }\end{array}$ & $\begin{array}{l}\text { MAXIMUM } \\
\text { CONC. } \\
\text { LIMIT }\end{array}$ & LOC. & LOG DATE & $\begin{array}{c}\text { SAMP } \\
\text { ID }\end{array}$ & $\mid \begin{array}{c}\text { FORM } \\
\text { OF } \\
\text { COMP }\end{array}$ & $\begin{array}{l}\text { HYDR } \\
\text { FLOW } \\
\text { REL. }\end{array}$ & $\begin{array}{c}\text { RESULT EXCEED } \\
\text { CONCENTRATIO } \\
\text { VALUE }\end{array}$ & $\begin{array}{l}\text { DING MAX. } \\
\text { N LIMIT } \\
\text { FLAGS }\end{array}$ & $\begin{array}{l}\text { DETECTION } \\
\text { LIMIT }\end{array}$ & $\begin{array}{l}\text { PARAMETER } \\
\text { UNCERT. }\end{array}$ \\
\hline SELENIUM & 59 & $M G / L$ & 0.0100 & $\begin{array}{l}0506 \\
0506 \\
0507 \\
0508 \\
0508 \\
0508 \\
0508 \\
0508 \\
0508 \\
0509 \\
0509 \\
0509 \\
0510 \\
0510 \\
0510 \\
0510 \\
0510 \\
0510 \\
0512\end{array}$ & $\begin{array}{l}11 / 20 / 91 \\
10 / 08 / 92 \\
12 / 05 / 91 \\
06 / 30 / 86 \\
10 / 14 / 87 \\
08 / 28 / 91 \\
12 / 05 / 91 \\
10 / 10 / 92 \\
02 / 21 / 94 \\
03 / 27 / 91 \\
08 / 28 / 91 \\
11 / 21 / 91 \\
10 / 14 / 87 \\
05 / 16 / 90 \\
03 / 28 / 91 \\
12 / 05 / 91 \\
10 / 08 / 92 \\
02 / 20 / 94 \\
04 / 05 / 91\end{array}$ & $\begin{array}{l}0001 \\
0001 \\
0001 \\
0001 \\
0001 \\
0001 \\
0001 \\
0001 \\
0001 \\
0001 \\
0001 \\
0001 \\
0001 \\
0001 \\
0001 \\
0001 \\
0001 \\
0001 \\
0001\end{array}$ & $\begin{array}{l}A L \\
A L \\
A L \\
A L \\
A L \\
A L \\
A L \\
A L \\
A L \\
A L \\
A L \\
A L \\
A L \\
A L \\
A L \\
A L \\
A L \\
A L \\
A L\end{array}$ & $\begin{array}{l}D \\
D \\
D \\
0 \\
0 \\
0 \\
0 \\
0 \\
0 \\
0 \\
0 \\
0 \\
0 \\
0 \\
0 \\
0 \\
0 \\
0 \\
0\end{array}$ & $\begin{array}{l}0.03 \\
0.05 \\
0.03 \\
0.035 \\
0.99 \\
0.9 \\
1.0 \\
1.1 \\
1.22 \\
0.525 \\
0.014 \\
0.016 \\
0.17 \\
0.016 \\
0.065 \\
0.10 \\
0.2 \\
0.640 \\
0.03\end{array}$ & $\begin{array}{l}\text { IW } \\
\text { I }\end{array}$ & $\begin{array}{l}0.03 \\
0.05 \\
0.03 \\
0.005 \\
0.005 \\
0.1 \\
0.3 \\
0.1 \\
0.005 \\
0.005 \\
0.005 \\
0.005 \\
0.005 \\
0.005 \\
0.005 \\
0.05 \\
0.2 \\
0.005 \\
0.03\end{array}$ & $\begin{array}{l}- \\
\overline{-} \\
- \\
- \\
- \\
- \\
- \\
- \\
- \\
- \\
- \\
- \\
- \\
- \\
- \\
-\end{array}$ \\
\hline SELENIUM (TOTAL) & 8 & MG/L & 0.0100 & $\mid \begin{array}{l}0508 \\
0510\end{array}$ & $\begin{array}{l}02 / 21 / 94 \\
02 / 20 / 94\end{array}$ & $\begin{array}{l}\text { N001 } \\
\text { N001 }\end{array}$ & $\begin{array}{l}A L \\
A L\end{array}$ & $\begin{array}{l}0 \\
0\end{array}$ & $\begin{array}{l}1.09 \\
0.585\end{array}$ & & $\begin{array}{l}0.005 \\
0.005\end{array}$ & - \\
\hline SILVER & 37 & $M G / L$ & 0.0500 & - & - & - & - & - & - & & - & - \\
\hline SILVER (TOTAL) & 0 & $M G / L$ & 0.0500 & - & - & - & - & - & - & & - & - \\
\hline URANIUM & 68 & $M G / L$ & 0.0440 & $\begin{array}{l}0503 \\
0503 \\
0503 \\
0503 \\
0503 \\
0503\end{array}$ & $\begin{array}{l}06 / 30 / 86 \\
10 / 14 / 87 \\
02 / 22 / 88 \\
05 / 16 / 90 \\
03 / 29 / 91 \\
08 / 08 / 91\end{array}$ & $\left|\begin{array}{l}0001 \\
0001 \\
0001 \\
0001 \\
0001 \\
0001\end{array}\right|$ & $\begin{array}{l}A L \\
A L \\
A L \\
A L \\
A L \\
A L\end{array}$ & $\begin{array}{l}0 \\
0 \\
0 \\
0 \\
0 \\
0\end{array}$ & $\begin{array}{l}3.78 \\
3.8 \\
3.59 \\
3.05 \\
3.39 \\
2.854\end{array}$ & & $\begin{array}{l}0.003 \\
0.003 \\
0.003 \\
0.003 \\
0.001 \\
0.001\end{array}$ & $\begin{array}{l}- \\
- \\
- \\
-\end{array}$ \\
\hline
\end{tabular}

< - THE DATA IS FLAGged AS A NON-DETECT, SO THE RESULT IS AN ESTIMATED VALUE OR THE DETECTION LIMIT

FORMATION OF COMPLETION CODE:

AL - ALLUVIUM

OTHER PARAMETER VALUE FLAGS:

I - INCREASED DETECTION LIMIT DUE TO REQUIRED DILUTION

R - UNUSABLE DATA POINT

$S$ - REPORTED VALUE DETERMINED USING METHOD OF STD ADDITION (MSA)

$H$ - POST-DIGEST SPIKE OUT OF CNTR LIM WHILE SAMP ABS < 50\% SPIKE
FLOH RELATIONSHIP CODE:

D - DOWN GRADIENT

$$
\text { O - ON-SITE }
$$

SAMPLE ID CODES:

0001 - FILTERED SAMPLE (.45 MICRONS)

NOO1 - UNFILTERED SAMPLE 


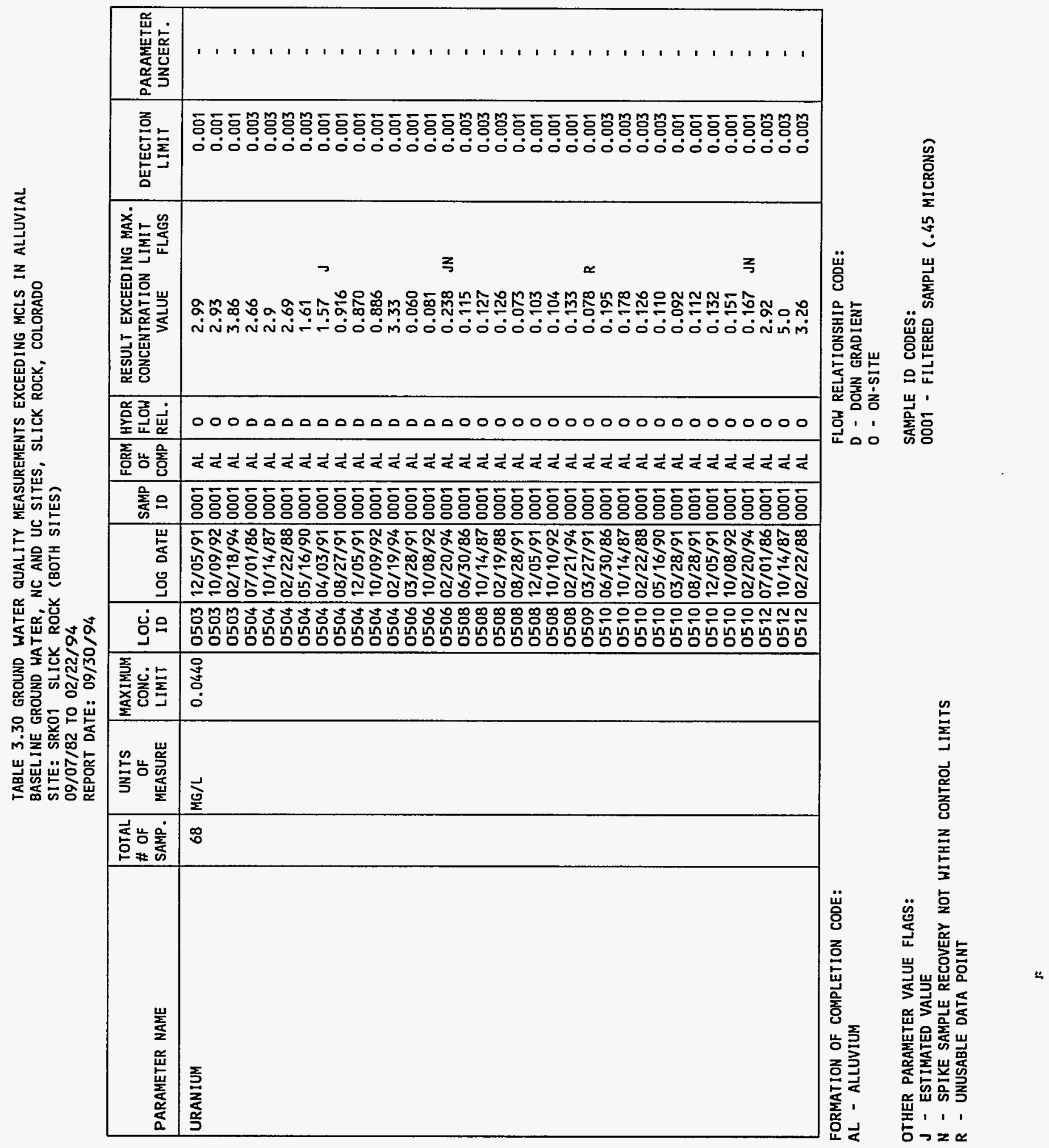


TABLE 3.30 GROUND WATER QUALITY MEASUREMENTS EXCEEDING MCLS IN ALLUVIAL BASELINE GROUND WATER, NC AND UC SITES, SLICK ROCK, COLORADO

SITE: SRKOI SLICK ROCK (BOTH SITES)

09/07/82 TO 02/22/94

REPORT DATE: 09/30/94

\begin{tabular}{|c|c|c|c|c|c|c|c|c|c|c|c|}
\hline PARAMETER NAME & $\begin{array}{l}\text { TOTAL } \\
\text { \# OF } \\
\text { SAMP. }\end{array}$ & $\begin{array}{l}\text { UNITS } \\
\text { OF } \\
\text { MEASURE }\end{array}$ & $\begin{array}{l}\text { MAXIMUM } \\
\text { CONC. } \\
\text { LIMIT }\end{array}$ & LOC. & LOG DATE & $\begin{array}{c}\text { SAMP } \\
\text { ID }\end{array}$ & $\mid \begin{array}{c}\text { FORM } \\
\text { OF } \\
\text { COMP }\end{array}$ & $\begin{array}{l}\text { HYDR } \\
\text { FLOH } \\
\text { REL. }\end{array}$ & $\begin{array}{l}\text { RESULT EXCEEDING MAX. } \\
\text { CONCENTRATION LIMIT } \\
\text { VALUE FLAGS }\end{array}$ & $\begin{array}{l}\text { DETECTION } \\
\text { LIMIT }\end{array}$ & $\begin{array}{l}\text { PARAMETER } \\
\text { UNCERT. }\end{array}$ \\
\hline URANIUM & 68 & MG/L & 0.0440 & $\mid \begin{array}{l}0512 \\
0512 \\
0512 \\
0512 \\
0512\end{array}$ & $\mid \begin{array}{l}04 / 05 / 91 \\
08 / 08 / 91 \\
12 / 05 / 91 \\
10 / 09 / 92 \\
02 / 20 / 94\end{array}$ & $\begin{array}{l}0001 \\
0001 \\
0001 \\
0001 \\
0001\end{array}$ & $\begin{array}{l}A L \\
A L \\
A L \\
A L \\
A L\end{array}$ & $\begin{array}{l}0 \\
0 \\
0 \\
0 \\
0\end{array}$ & $\begin{array}{l}2.50 \\
2.243 \\
1.70 \\
2.77 \\
0.232\end{array}$ & $\begin{array}{l}0.001 \\
0.001 \\
0.001 \\
0.001 \\
0.001\end{array}$ & $\begin{array}{l}\overline{-} \\
\overline{-} \\
-\end{array}$ \\
\hline URANIUM (TOTAL) & 8 & $M G / L$ & 0.0440 & $\mid \begin{array}{l}0503 \\
0504 \\
0506 \\
0508 \\
0510 \\
0512\end{array}$ & $\begin{array}{l}02 / 18 / 94 \\
02 / 19 / 94 \\
02 / 20 / 94 \\
02 / 21 / 94 \\
02 / 20 / 94 \\
02 / 20 / 94\end{array}$ & $\begin{array}{l}\text { NO01 } \\
\text { NO01 } \\
\text { NO01 } \\
\text { NO01 } \\
\text { NO01 } \\
\text { NO01 }\end{array}$ & $\begin{array}{l}A L \\
A L \\
A L \\
A L \\
A L \\
A L\end{array}$ & $\begin{array}{l}0 \\
D \\
D \\
0 \\
0 \\
0\end{array}$ & $\begin{array}{l}3.77 \\
2.96 \\
0.236 \quad \mathrm{JN} \\
0.133 \\
0.159 \quad \mathrm{JN} \\
3.64\end{array}$ & $\begin{array}{l}0.001 \\
0.001 \\
0.001 \\
0.001 \\
0.001 \\
0.001\end{array}$ & $\begin{array}{l}- \\
- \\
- \\
-\end{array}$ \\
\hline
\end{tabular}

FORMATION OF COMPLETION CODE:

FLOW RELATIONSHIP CODE:

AL - ALLUVIUM

O - ON-SITE

D - DOWN GRADIENT

OTHER PARAMETER VALUE FLAGS:

$J$ - ESTIMATED VALUE

SAMPLE ID CODES:

N - SPIKE SAMPLE RECOVERY NOT HITHIN CONTROL LIMITS

0001 - FILTERED SAMPLE ( 45 MICRONS)

N001 - UNFILTERED SAMPLE

DATA FILE NAME: IDARTISRK01\GWQ10073.DAT 
TABLE 3.31 BASELINE GROUND WATER QUALITY STATISTICS BY PARAMETER FOR THE ALLUVIUM, UC PROCESSING SITE, SLICK ROCK, COLORADO

SITE: SRK01 SLICK ROCK (BOTH SITES)

$09 / 08 / 82$ TO $02 / 21 / 94$

REPORT DATE: $09 / 30 / 94$

\begin{tabular}{|c|c|c|c|c|c|c|c|c|c|c|c|}
\hline \multicolumn{3}{|c|}{ PARAMETER NAME } & UNITS & \multirow[b]{2}{*}{ MEAN } & \multirow{2}{*}{$\begin{array}{r}\text { STANDARD } \\
\text { DEVIATION }\end{array}$} & \multirow{2}{*}{$\begin{array}{c}\text { COEFF. } \\
\text { OF } \\
\text { VARIATION }\end{array}$} & \multirow{2}{*}{$\begin{array}{l}\% \text { OF } \\
\text { NON } \\
\text { DETECTS }\end{array}$} & \multirow{2}{*}{\multicolumn{2}{|c|}{$\begin{array}{l}\text { STATISTICAL RANGE } \\
\text { 98\% CONF IDENCE INTERVAL } \\
\text { MINIMUM } \\
\text { MAXIMUM * }\end{array}$}} & \multirow{2}{*}{$\begin{array}{c}\text { DISTRIBUTION } \\
\text { TYPE }\end{array}$} & \multirow{2}{*}{$\begin{array}{l}\text { FOOT } \\
\text { NOTE }\end{array}$} \\
\hline \# OF SAMP & MINIMUM & MAXIMUM & MEDIAN & & & & & & & & \\
\hline \multicolumn{3}{|l|}{ ALKALINITY } & $M G / L \quad C A C$ & \multirow[b]{2}{*}{455.4524} & \multirow[b]{2}{*}{146.4591} & \multirow[b]{2}{*}{0.3216} & \multirow[b]{2}{*}{0.0} & \multirow[b]{2}{*}{400.7399} & \multirow[b]{2}{*}{510.1649} & \multirow[b]{2}{*}{ NORMAL } & \\
\hline 42 & 249.0000 & 791.0000 & $+\quad 402.5000$ & & & & & & & & \\
\hline \multicolumn{3}{|l|}{ ALUMINUM } & $M G / L$ & \multirow[b]{2}{*}{ NA } & \multirow[b]{2}{*}{ NA } & \multirow[b]{2}{*}{ NA } & \multirow[b]{2}{*}{72.2} & \multirow[b]{2}{*}{0.0500} & \multirow[b]{2}{*}{0.0500} & \multirow[b]{2}{*}{ NONPARAMETRIC } & \multirow[b]{2}{*}{2} \\
\hline 36 & ** $\quad 0.0500$ & 0.4000 & 0.0500 & & & & & & & & \\
\hline \multicolumn{3}{|l|}{ AMMONIUM } & $M G / L$ & \multirow[b]{2}{*}{111.0364} & \multirow[b]{2}{*}{51.4043} & \multirow[b]{2}{*}{0.4630} & \multirow[b]{2}{*}{0.0} & \multirow[b]{2}{*}{89.1308} & & & \\
\hline 33 & 22.8000 & 190.0000 & 115.0000 & & & & & & 132.9419 & NORMAL & \\
\hline AMMONIUM ( & (TOTAL) & & $M G / L$ & & & & & & & & \\
\hline 5 & 13.5000 & 139.0000 & 82.3000 & 71.4600 & 49.4090 & 0.6914 & 0.0 & 0.1000 & 154.2552 & NORMAL. & \\
\hline ANT IMONY & & & $M G / L$ & & & & & & & & \\
\hline 22 & ** $\quad 0.0030$ & 0.0150 & 0.0030 & NA & NA & NA & 95.5 & 0.0030 & $\star * * 0.0030$ & NONPARAMETRIC & 2 \\
\hline ARSENIC & & & $M G / L$ & & & & & & & & \\
\hline 31 & ** $\quad 0.0050$ & 0.0500 & 0.0050 & NA & NA & NA & 100.0 & 0.0050 & 0.0050 & NONPARAMETRIC & 2 \\
\hline BARIUM & & & $M G / L$ & & & & & & & & \\
\hline 32 & 0.0100 & 0.1000 & 0.0500 & NA & NA & NA & 37.5 & 0.0300 & 0.0500 & NONPARAMETRIC & 2 \\
\hline BARIUM (TO & OTAL) & & $M G / L$ & & & & & & & & \\
\hline 5 & ** $\quad 0.1000$ & 0.1000 & 0.1000 & NA & NA & NA & 100.0 & 0.1000 & $\star * \quad 0.1000$ & NONPARAMETRIC & 2,5 \\
\hline BERYLLIUM & & & $M G / L$ & & & & & & & & \\
\hline 16 & ** $\quad 0.0050$ & 0.0050 & 0.0050 & NA & NA & NA & 100.0 & 0.0050 & ** 0.0050 & NONPARAMETRIC & 2 \\
\hline BORON & & & $M G / L$ & & & & & & & & \\
\hline 27 & 0.0500 & 0.5000 & 0.4000 & 0.3704 & 0.1329 & 0.3589 & 3.7 & 0.3070 & 0.4338 & NORMAL & \\
\hline
\end{tabular}

** The reported value is the minimum detection limit of the data set

+ The sample size is even, so the median value is the arithmetic average of the two middle values

* The statistical maximum is the 99 percent one sided confidence interval, $a=0.01$

2) The nonparametric distribution was used because the nondetected values comprise more than $15 \%$ of the samples.

5) The stat. range is the $93.8 \%$ confidence interval due to a sample size of 5 . The maximum is the $96.9 \%$ one sided confidence int. 
TABLE 3.31 BASELINE GROUND WATER QUALITY STATISTICS BY PARAMETER FOR

THE ALLUVIUM, UC PROCESSING SITE, SLICK ROCK, COLORADO

SITE: SRK01 SLICK ROCK (BOTH SITES)

$09 / 08 / 82$ TO $02 / 21 / 94$

REPORT DATE: 09/30/94

\begin{tabular}{|c|c|c|c|c|c|c|c|c|c|c|c|c|}
\hline \multicolumn{4}{|c|}{ PARAMETER NAME } & UNITS & \multirow[b]{2}{*}{ MEAN } & \multirow{2}{*}{$\begin{array}{r}\text { STANDARD } \\
\text { DEVIATION }\end{array}$} & \multirow{2}{*}{$\begin{array}{l}\text { COEFF. } \\
\text { OF } \\
\text { VARIATION }\end{array}$} & \multirow{2}{*}{$\begin{array}{l}\% \text { OF } \\
\text { NON } \\
\text { DETECTS }\end{array}$} & \multirow{2}{*}{\multicolumn{2}{|c|}{$\begin{array}{c}\text { STATISTICAL RANGE } \\
\text { 98\% CONFIDENCE INTERVAL } \\
\text { MINIMUM } \\
\text { MAXIMUM * }\end{array}$}} & \multirow{2}{*}{$\begin{array}{c}\text { DISTRIBUTION } \\
\text { TYPE }\end{array}$} & \multirow{2}{*}{$\begin{array}{l}\text { FOOT } \\
\text { NOTE }\end{array}$} \\
\hline \# OF SAMP & MINIMUM & MAXIMUM & & MEDIAN & & & & & & & & \\
\hline \multicolumn{4}{|c|}{ BORON (TOTAL) } & MG/L & \multirow[b]{2}{*}{0.3800} & \multirow[b]{2}{*}{0.1304} & \multirow[b]{2}{*}{0.3431} & \multirow[b]{2}{*}{0.0} & \multirow[b]{2}{*}{0.1615} & \multirow[b]{2}{*}{0.5985} & \multirow[b]{2}{*}{ NORMAL } & \\
\hline 5 & 0.2000 & 0.5000 & & 0.4000 & & & & & & & & \\
\hline \multicolumn{4}{|l|}{ BROMIDE } & $M G / L$ & \multirow[b]{2}{*}{ NA } & \multirow[b]{2}{*}{ NA } & \multirow[b]{2}{*}{ NA } & \multirow[b]{2}{*}{50.0} & \multirow[b]{2}{*}{0.4000} & \multirow[b]{2}{*}{3.9000} & \multirow[b]{2}{*}{ NONPARAMETRIC } & \multirow[b]{2}{*}{2} \\
\hline 20 & ** $\quad 0.1000$ & .9 .1000 & + & 1.4000 & & & & & & & & \\
\hline \multicolumn{4}{|l|}{ CADMIUM } & $M G / L$ & \multirow[b]{2}{*}{ NA } & \multirow[b]{2}{*}{ NA } & \multirow[b]{2}{*}{ NA } & \multirow[b]{2}{*}{68.8} & \multirow[b]{2}{*}{0.0010} & \multirow[b]{2}{*}{0.0012} & & \\
\hline 32 & $* * \quad 0.0010$ & 0.0270 & ** & 0.0010 & & & & & & & |NONPARAMETRIC & 2 \\
\hline CADMIUM (T & (OTAL) & & & MG/L & & & & & & & & \\
\hline 5 & ** $\quad 0.0010$ & 0.0090 & $\star \star$ & 0.0010 & NA & NA & NA & 60.0 & 0.0010 & 0.0090 & NONPARAMETRIC & 2,5 \\
\hline CALCIUM & & & & $M G / L$ & & & & & & & & \\
\hline 41 & 85.1000 & 970.0000 & & 469.0000 & 387.9049 & 233.6882 & 0.6024 & 0.0 & 299.4752 & 476.3346 & NORMAL & \\
\hline CALCIUM (T & TOTAL) & & & MG/L & & & & & & & & \\
\hline 5 & 80.0000 & 717.0000 & & 509.0000 & 414.0000 & 295.2118 & 0.7131 & 0.0 & 0.5000 & 908.6891 & NORMAL & \\
\hline CHLORIDE & & & & MG/L & & & & & & & & \\
\hline 42 & 53.3000 & 3980.0000 & + & 127.0000 & 177.6339 & 3.1211 & NA & 0.0 & 116.1101 & 271.7576 & LOGNORMAL & 7,8 \\
\hline CHROMIUM & & & & MG/L & & & & & & & & \\
\hline 32 & $\begin{array}{ll}* & 0.0100\end{array}$ & 0.0500 & $\star \star *$ & 0.0100 & NA & NA & NA & 90.6 & 0.0100 & 0.0100 & NONPARAMETRIC & 2 \\
\hline CHROMIUM & (TOTAL) & & & $M G / L$ & & & & & & & & \\
\hline 5 & $\begin{array}{ll}* & 0.0100\end{array}$ & ** $\quad 0.0100$ & $\star \star *$ & 0.0100 & NA & NA & NA & 100.0 & 0.0100 & ** 0.0100 & NONPARAMETRIC & 2,5 \\
\hline
\end{tabular}

** The reported value is the minimum detection limit of the data set

+ The sample size is even, so the median value is the arithmetic average of the two middle values

* The statistical maximum is the 99 percent one sided confidence interval, $\alpha=0.01$

2) The nonparametric distribution was used because the nondetected values comprise more than $15 \%$ of the samples.

5) The stat. range is the $93.8 \%$ confidence interval due to a sample size of 5 . The maximum is the $96.9 \%$ one sided confidence int.

7) The lognormal distribution was used because the data failed the normal distribution test.

8) The mean is geometric. The standard deviation is the value to divide or multiply with the geometric mean. 
TABLE 3.31 BASELINE GROUND WATER QUALITY STATISTICS BY PARAMETER FOR

THE ALLUVIUM, UC PROCESSING SITE, SLICK ROCK, COLORADO

SITE: SRKO1 SLICK ROCK (BOTH SITES)

$09 / 08 / 82$ TO 02/21/94

REPORT DATE: 09/30/94

\begin{tabular}{|c|c|c|c|c|c|c|c|c|c|c|c|c|c|}
\hline \multicolumn{4}{|c|}{ PARAMETER NAME } & UNITS & \multirow[b]{2}{*}{ MEAN } & \multirow{2}{*}{$\begin{array}{l}\text { STANDARD } \\
\text { DEVIATION }\end{array}$} & \multirow{2}{*}{$\begin{array}{c}\text { COEFF. } \\
\text { OF } \\
\text { VARIATION }\end{array}$} & \multirow{2}{*}{$\begin{array}{l}\% \text { OF } \\
\text { NON } \\
\text { DETECTS }\end{array}$} & \multirow{2}{*}{\multicolumn{3}{|c|}{$\begin{array}{c}\text { STATISTICAL RANGE } \\
98 \% \text { CONFIDENCE INTERVAL } \\
\text { MINIMUM } \\
\text { MAXIMUM * }\end{array}$}} & \multirow{2}{*}{$\begin{array}{c}\text { DISTRIBUT ION } \\
\text { TYPE }\end{array}$} & \multirow{2}{*}{$\begin{array}{l}\text { FOOT } \\
\text { NOTE }\end{array}$} \\
\hline \# OF SAMP & & NIMUM & MAXIMUM & MEDIAN & & & & & & & & & \\
\hline \multicolumn{4}{|l|}{ COBALT } & MG/L & \multirow[b]{2}{*}{ NA } & \multirow[b]{2}{*}{ NA } & \multirow[b]{2}{*}{ NA } & \multirow[b]{2}{*}{100.0} & \multirow[b]{2}{*}{ ** } & \multirow[b]{2}{*}{0.0300} & \multirow[b]{2}{*}{ ** 0.0300} & \multirow[b]{2}{*}{ NONPARAMETRIC } & \multirow[b]{2}{*}{2} \\
\hline 16 & \#* & 0.0300 & 0.0300 & 0.0300 & & & & & & & & & \\
\hline \multicolumn{4}{|l|}{ COPPER } & $M G / L$ & \multirow[b]{2}{*}{ NA } & \multirow[b]{2}{*}{ NA } & \multirow[b]{2}{*}{ NA } & \multirow[b]{2}{*}{92.6} & \multirow[b]{2}{*}{ ** } & \multirow[b]{2}{*}{0.0100} & \multirow[b]{2}{*}{0.0100} & \multirow[b]{2}{*}{ NONPARAMETRIC } & \multirow[b]{2}{*}{2} \\
\hline 27 & ** & 0.0100 & 0.0600 & 0.0100 & & & & & & & & & \\
\hline \multicolumn{4}{|l|}{ CYANIDE } & $\mathrm{MG} / \mathrm{L}$ & \multirow[b]{2}{*}{ NA } & \multirow[b]{2}{*}{ NA } & \multirow[b]{2}{*}{ NA } & & & & & & \\
\hline 15 & ** & 0.0100 & 0.0100 & 0.0100 & & & & 100.0 & ** & 0.0100 & ** 0.0100 & NONPARAMETRIC & 2 \\
\hline DISSOLVED & ORG & NIC CARE & BON & $M G / L$ & & & & & & & & & \\
\hline 4 & & 3.0000 & 48.0000 & 7.5000 & 9.4763 & 3.2077 & NA & 0.0 & $\star \star$ & 1.0000 & 133.6440 & LOGNORMAL & 7,8 \\
\hline DISSOLVED & OXY & & & MG/L & & & & & & & & & \\
\hline 10 & & 0.0000 & 0.3000 & 0.1750 & NA & NA & NA & 20.0 & & 0.0000 & 0.3000 & NONPARAMETRIC & 2 \\
\hline FIELD FE & $(2+)$ & & & $M G / L$ & & & & & & & & & \\
\hline 9 & & 0.0000 & 10.0000 & 0.0200 & NA & NA & NA & 22.2 & & 0.0000 & 10.0000 & NONPARAMETRIC & 2 \\
\hline FIELD FE & (TOT & & & $M G / L$ & & & & & & & & & \\
\hline 7 & & 0.0100 & 9.9000 & 0.1000 & 0.3152 & 15.3398 & NA & 14.3 & & 0.0123 & 8.0773 & LOGNORMAL & 7,8 \\
\hline FLUORIDE & & & & MG/L & & & & & & & & & \\
\hline 33 & & 0.1900 & 0.7000 & 0.3800 & 0.3800 & 0.1543 & 0.4060 & 0.0 & & 0.3142 & 0.4458 & NORMAL & \\
\hline GROSS ALPH & & & & $\mathrm{PCI} / \mathrm{L}$ & & & & & & & & & \\
\hline 25 & ** & 1.0000 & 191.0000 & 30.6000 & NA & NA & NA & 0.0 & & 19.0000 & 95.5000 & NONPARAMETR I C & 9 \\
\hline
\end{tabular}

** The reported value is the minimum detection limit of the data set

+ The sample size is even, so the median value is the arithmetic average of the two middle values

* The statistical maximum is the 99 percent one sided confidence interval, $\alpha=0.01$

2) The nonparametric distribution was used because the nondetected values comprise more than $15 \%$ of the samples.

7) The lognormal distribution was used because the data failed the normal distribution test.

8) The mean is geometric. The standard deviation is the value to divide or multiply with the geometric mean.

9) The nonparametic distribution was used because the data failed the normal distribution test and includes values $\leq 0$. 
TABLE 3.31 BASELINE GROUND HATER QUALITY STATISTICS BY PARAMETER FOR

THE ALLUVIUM, UC PROCESSING SITE, SLICK ROCK, COLORADD

SITE: SRKO1 SLICK ROCK (BOTH SITES)

$09 / 08 / 82$ TO 02/21/94

REPORT DATE: 09/30/94

\begin{tabular}{|c|c|c|c|c|c|c|c|c|c|c|c|c|}
\hline \multicolumn{3}{|c|}{ PARAMETER NAME } & UNITS & \multirow[b]{2}{*}{ MEAN } & \multirow{2}{*}{$\begin{array}{r}\text { STANDARD } \\
\text { DEVIATION }\end{array}$} & \multirow{2}{*}{$\begin{array}{c}\text { COEFF. } \\
\text { OF } \\
\text { VARIATION }\end{array}$} & \multirow{2}{*}{$\mid \begin{array}{c}\% \text { OF } \\
\text { NON } \\
\text { DETECTS }\end{array}$} & \multirow{2}{*}{\multicolumn{3}{|c|}{$\begin{array}{l}\text { STATISTICAL RANGE } \\
\text { 98\% CONFIDENCE INTERVAL } \\
\text { MINIMUM } \\
\text { MAXIMUM * }\end{array}$}} & \multirow{2}{*}{$\begin{array}{c}\text { DISTRIBUTION } \\
\text { TYPE }\end{array}$} & \multirow{2}{*}{$\begin{array}{l}\text { FOOT } \\
\text { NOTE }\end{array}$} \\
\hline \# OF SAMP & MINIMUM & MAXIMUM & MEDIAN & & & & & & & & & \\
\hline \multicolumn{3}{|c|}{ GROSS ALPHA (TOTAL) } & PCI /L & \multirow[b]{2}{*}{57.8000} & \multirow[b]{2}{*}{36.8724} & \multirow[b]{2}{*}{0.6379} & \multirow[b]{2}{*}{0.0} & \multirow[b]{2}{*}{ ** } & \multirow[b]{2}{*}{4.5000} & \multirow[b]{2}{*}{119.5874} & \multirow[b]{2}{*}{ NORMAL } & \\
\hline 5 & 15.5000 & 103.0000 & 59.0000 & & & & & & & & & \\
\hline \multicolumn{3}{|l|}{ GROSS BETA } & $\mathrm{PCI} / \mathrm{L}$ & \multirow[b]{2}{*}{ NA } & \multirow[b]{2}{*}{ NA } & \multirow[b]{2}{*}{ NA } & \multirow[b]{2}{*}{0.0} & \multirow{2}{*}{\multicolumn{2}{|c|}{4.9000}} & \multirow[b]{2}{*}{86.3000} & \multirow[b]{2}{*}{ NONPARAMETRIC } & \multirow[b]{2}{*}{9} \\
\hline 20 & $\begin{array}{ll}* * & 0.5000\end{array}$ & 165.0000 & 24.3500 & & & & & & & & & \\
\hline \multicolumn{3}{|l|}{ IRON } & $M G / L$ & \multirow[b]{2}{*}{ NA } & \multirow[b]{2}{*}{ NA } & \multirow[b]{2}{*}{ NA } & \multirow[b]{2}{*}{39.0} & \multirow[b]{2}{*}{ ** } & \multirow[b]{2}{*}{0.0300} & & & \\
\hline 41 & ** $\quad 0.0300$ & 14.2000 & 0.0800 & & & & & & & 2.4400 & NONPARAMETRIC & 2 \\
\hline IRON (TOTA & & & $M G / L$ & & & & & & & & & \\
\hline 5 & 0.0600 & 3.6600 & 0.1100 & 0.3367 & 7.6227 & NA & 0.0 & ** & 0.0300 & 10.1258 & LOGNORMAL & 7,8 \\
\hline LEAD & & & $M G / L$ & & & & & & & & & \\
\hline 27 & $\begin{array}{ll}* & 0.0050\end{array}$ & 0.0250 & 0.0050 & NA & NA & NA & 100.0 & ** & 0.0050 & 0.0100 & NONPARAMETRIC & 2 \\
\hline LEAD-210 & & & $\mathrm{PCI} / \mathrm{L}$ & & & & & & & & & \\
\hline 16 & ** $\quad 1.4000$ & 6.5000 & 2.1000 & NA & NA & NA & 0.0 & ** & 1.4000 & 5.0000 & NONPARAMETRIC & 9 \\
\hline LEAD-210 & (TOTAL) & & $\mathrm{PCI} / \mathrm{L}$ & & & & & & & & & \\
\hline 5 & ** $\quad 1.4000$ & 1.4000 & 1.4000 & NA & NA & NA & 0.0 & ** & 1.4000 & 1.4000 & NONPARAMETRIC & 9,5 \\
\hline MAGNESIUM & & & $M G / L$ & & & & & & & & & \\
\hline 41 & 49.0000 & 625.0000 & 194.0000 & 201.6049 & 147.3795 & 0.7310 & 0.0 & & 145.8352 & 257.3746 & NORMAL & \\
\hline MAGNESIUM & (TOTAL) & & $M G / L$ & & & & & & & & & \\
\hline 5 & 52.9000 & 542.0000 & 204.0000 & 218.3800 & 199.1697 & 0.9120 & 0.0 & ** & 0.1000 & 552.1305 & NORMAL & \\
\hline
\end{tabular}

** The reported value is the minimum detection limit of the data set

+ The sample size is even, so the median value is the arithmetic average of the two middle values

* The statistical maximum is the 99 percent one sided confidence interval, $\alpha=0.01$

2) The nonparametric distribution was used because the nondetected values comprise more than $15 \%$ of the samples.

5) The stat. range is the $93.8 \%$ confidence interval due to a sample size of 5 . The maximum is the $96.9 \%$ one sided confidence int.

7) The lognormal distribution was used because the data failed the normal distribution test.

8) The mean is geometric. The standard deviation is the value to divide or multiply with the geometric mean.

9) The nonparametic distribution was used because the data failed the normal distribution test and includes values $\leq 0$. 
TABLE 3.31 BASELINE GROUND WATER QUALITY STATISTICS BY PARAMETER FOR

THE ALLUVIUM, UC PROCESSING SITE, SLICK ROCK, COLORADO

SITE: SRKO1 SLICK ROCK (BOTH SITES)

$09 / 08 / 82$ TO $02 / 21 / 94$

REPORT DATE: $09 / 30 / 94$

\begin{tabular}{|c|c|c|c|c|c|c|c|c|c|c|c|c|c|}
\hline \multicolumn{3}{|c|}{ PARAMETER NAME } & UNITS & \multirow[b]{2}{*}{ MEAN } & \multirow{2}{*}{$\begin{array}{l}\text { STANDARD } \\
\text { DEVIATION }\end{array}$} & \multirow{2}{*}{$\begin{array}{c}\text { COEFF. } \\
\text { OF } \\
\text { VARIATION }\end{array}$} & \multirow{2}{*}{$\begin{array}{l}\% \text { OF } \\
\text { NON } \\
\text { DETECTS }\end{array}$} & \multirow{2}{*}{\multicolumn{4}{|c|}{$\begin{array}{c}\text { STATISTICAL RANGE } \\
\text { 98\% CONFIDENCE INTERVAL } \\
\text { MINIMUM } \\
\text { MAXIMUM * }\end{array}$}} & \multirow{2}{*}{$\begin{array}{c}\text { DISTRIBUTION } \\
\text { TYPE }\end{array}$} & \multirow{2}{*}{$\begin{array}{l}\text { FOOT } \\
\text { NOTE }\end{array}$} \\
\hline \# OF SAMP & MINIMUM & MAXIMUM & MEDIAN & & & & & & & & & & \\
\hline \multicolumn{3}{|l|}{ MANGANESE } & $\mathrm{MG} / \mathrm{L}$ & \multirow[b]{2}{*}{3.5220} & \multirow[b]{2}{*}{2.6482} & \multirow[b]{2}{*}{0.7519} & \multirow[b]{2}{*}{0.0} & \multirow{2}{*}{\multicolumn{3}{|c|}{2.5198}} & & \multirow[b]{2}{*}{ NORMAL } & \\
\hline 41 & 0.1200 & 7.4900 & 4.6600 & & & & & & & & & & \\
\hline \multicolumn{3}{|c|}{ MANGANESE (TOTAL) } & $M G / L$ & \multirow[b]{2}{*}{3.6200} & \multirow[b]{2}{*}{3.0830} & \multirow[b]{2}{*}{0.8516} & \multirow[b]{2}{*}{0.0} & \multirow[b]{2}{*}{ *夫 } & \multirow[b]{2}{*}{0.0100} & \multirow{2}{*}{\multicolumn{2}{|c|}{8.7862}} & \multirow[b]{2}{*}{ NORMAL } & \\
\hline 5 & 0.2100 & 6.7300 & 4.5400 & & & & & & & & & & \\
\hline \multicolumn{3}{|l|}{ MERCURY } & $M G / L$ & \multirow[b]{2}{*}{ NA } & \multirow[b]{2}{*}{ NA } & \multirow[b]{2}{*}{ NA } & \multirow[b]{2}{*}{100.0} & \multirow[b]{2}{*}{ \#* } & \multirow[b]{2}{*}{0.0002} & \multirow{2}{*}{\multicolumn{2}{|c|}{ ** 0.0002}} & & \\
\hline 22 & ** $\quad 0.0002$ & 0.0002 & 0.0002 & & & & & & & & & NONPARAMETRIC & 2 \\
\hline MOLYBDENUI & & & $M G / L$ & & & & & & & & & & \\
\hline 41 & 0.0100 & 2.4300 & 0.2800 & 0.2225 & 5.2156 & NA & 0.0 & & 0.1191 & & 0.4156 & LOGNORMAL & 7,8 \\
\hline MOLYBDENUI & N (TOTAL) & & $M G / L$ & & & & & & & & & & \\
\hline 5 & 0.0300 & 1.1900 & 0.2900 & 0.1933 & 5.9293 & NA & 0.0 & ** & 0.0100 & & 3.8166 & LOGNORMAL & 7,8 \\
\hline NET GROSS & ALPHA & & $\mathrm{PCI} / \mathrm{L}$ & & & & & & & & & & \\
\hline 25 & -90.5500 & 149.8400 & 3.9100 & NA & NA & NA & 0.0 & & -19.0600 & & 17.1200 & NONPARAMETRIC & 9 \\
\hline NET GROSS & ALPHA CTOTAL & 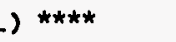 & $\mathrm{PCI} / \mathrm{L}$ & & & & & & & & & & \\
\hline 5 & -77.9000 & 10.3500 & -6.0700 & NA & NA & NA & 0.0 & & -77.9000 & & 10.3500 & NONPARAMETRIC & 9,5 \\
\hline NICKEL & & & $M G / L$ & & & & & & & & & & \\
\hline 32 & $* * \quad 0.0400$ & 0.1100 & 0.0400 & NA & NA & NA & 78.1 & ** & 0.0400 & ** & 0.0400 & NONPARAMETRIC & 2 \\
\hline
\end{tabular}

*** NET GROSS ALPHA (GROSS ALPHA - URANIUM) HITH 1 MG URANIUM = 686 PCI

**** NET GROSS ALPHA (TOTAL) (TOTAL GROSS ALPHA - TOTAL URANIUM)

** The reported value is the minimum detection limit of the data set

* The statistical maximum is the 99 percent one sided confidence interval, $\alpha=0.01$

2) The nonparametric distribution was used because the nondetected values comprise more than $15 \%$ of the samples.

5) The stat. range is the $93.8 \%$ confidence interval due to a sample size of 5 . The maximum is the $96.9 \%$ one sided confidence int.

7) The lognormal distribution was used because the data failed the normal distribution test.

8) The mean is geometric. The standard deviation is the value to divide or multiply with the geometric mean.

9) The nonparametic distribution was used because the data failed the normal distribution test and includes values $\leq 0$. 
TABLE 3.31 BASELINE GROUND WATER QUALITY STATISTICS BY PARAMETER FOR THE ALLUVIUM, UC PROCESSING SITE, SLICK ROCK, COLORADO

SITE: SRKO1 SLICK ROCK (BOTH SITES)

$09 / 08 / 82$ TO 02/21/94

REPORT DATE: 09/30/94

\begin{tabular}{|c|c|c|c|c|c|c|c|c|c|c|c|c|}
\hline \multicolumn{3}{|c|}{ PARAMETER NAME } & UNITS & \multirow[b]{2}{*}{ MEAN } & \multirow{2}{*}{$\begin{array}{r}\text { STANDARD } \\
\text { DEVIATION }\end{array}$} & \multirow{2}{*}{$\begin{array}{c}\text { COEFF. } \\
\text { OF } \\
\text { VARIATION }\end{array}$} & \multirow{2}{*}{$\left|\begin{array}{c}\% \text { OF } \\
\text { NON } \\
\text { DETECTS }\end{array}\right|$} & \multirow{2}{*}{\multicolumn{3}{|c|}{$\begin{array}{cc}\text { STATISTICAL RANGE } \\
\text { 98\% CONFIDENCE INTERVAL } \\
\text { MINIMUM } & \text { MAXIMUM * }\end{array}$}} & \multirow{2}{*}{$\begin{array}{l}\text { DISTRIBUTION } \\
\text { TYPE }\end{array}$} & \multirow[b]{2}{*}{$\begin{array}{l}\text { FOOT } \\
\text { NOTE }\end{array}$} \\
\hline \# OF SAMP & MINIMUM & MAXIMUM & MEDIAN & & & & & & & & & \\
\hline \multicolumn{3}{|l|}{ NITRATE } & MG/L & \multirow[b]{2}{*}{ NA } & \multirow[b]{2}{*}{ NA } & \multirow[b]{2}{*}{ NA } & \multirow[b]{2}{*}{18.9} & \multirow{2}{*}{\multicolumn{2}{|c|}{7.5000}} & \multirow[b]{2}{*}{947.0000} & \multirow[b]{2}{*}{ NONPARAMETRIC } & \multirow[b]{2}{*}{2} \\
\hline 37 & $* * \quad 1.0000$ & 1620.0000 & 34.0000 & & & & & & & & & \\
\hline \multicolumn{3}{|c|}{ NITRATE (TOTAL) } & MG/L & \multirow[b]{2}{*}{ NA } & \multirow[b]{2}{*}{ NA } & \multirow[b]{2}{*}{ NA } & \multirow[b]{2}{*}{40.0} & \multirow[b]{2}{*}{ ** } & \multirow[b]{2}{*}{1.0000} & \multirow[b]{2}{*}{1600.0000} & \multirow[b]{2}{*}{ NONPARAMETRIC } & \multirow[b]{2}{*}{2,5} \\
\hline 5 & $* * \quad 1.0000$ & 1600.0000 & 33.0000 & & & & & & & & & \\
\hline \multicolumn{3}{|c|}{ NITRITE AND NITRATE } & $M G / L$ & \multirow[b]{2}{*}{16.3824} & \multirow[b]{2}{*}{23.7505} & \multirow[b]{2}{*}{ NA } & \multirow[b]{2}{*}{11.8} & \multirow{2}{*}{\multicolumn{2}{|c|}{2.2520}} & & & \\
\hline 17 & 0.0800 & 1320.0000 & 25.1000 & & & & & & & 119.1774 & LOGNORMAL & 7,8 \\
\hline PH & & & su & & & & & & & & & \\
\hline 42 & 6.0800 & 7.3200 & 6.7350 & NA & NA & NA & 0.0 & & NA & NA & UNKNOWN & \\
\hline PHOSPHATE & & & $M G / L$ & & & & & & & & & \\
\hline 28 & $\star * \quad 0.0100$ & 0.1000 & 0.0500 & NA & NA & NA & 53.6 & & 0.0500 & 0.1000 & NONPARAMETRIC & 2 \\
\hline POLONIUM-2 & & & $\mathrm{PCI} / \mathrm{L}$ & & & & & & & & & \\
\hline 16 & ** 0.1000 & 0.4000 & 0.1000 & NA & NA & NA & 0.0 & ** & 0.1000 & 0.2000 & NONPARAMETRIC & 9 \\
\hline POLONIUM-2 & 210 (TOTAL) & & $\mathrm{PCl} / \mathrm{L}$ & & & & & & & & & \\
\hline 5 & ** $\quad 0.1000$ & 0.3000 & 0.1000 & NA & NA & NA & 0.0 & ** & 0.1000 & 0.3000 & NONPARAMETRIC & 9,5 \\
\hline POTASSIUM & & & $M G / L$ & & & & & & & & & \\
\hline 41 & 7.5600 & 40.0000 & 13.3000 & 16.6183 & 8.4518 & 0.5086 & 0.0 & & 13.4200 & 19.8165 & NORMAL & \\
\hline POTASSIUM & (TOTAL) & & $M G / L$ & & & & & & & & & \\
\hline 5 & 8.2000 & 37.0000 & 12.1000 & 16.3000 & 11.6976 & 0.7176 & 0.0 & ** & 0.1000 & 35.9019 & NORMAL & \\
\hline
\end{tabular}

** The reported value is the minimum detection limit of the data set

+ The sample size is even, so the median value is the arithmetic average of the two middle values

* The statistical maximum is the 99 percent one sided confidence interval, $\alpha=0.01$

1) A minimum of 4 samples must be available for the statistical analysis.

2) The nonparametric distribution was used because the nondetected values comprise more than $15 \%$ of the samples.

5) The stat. range is the $93.8 \%$ confidence interval due to a sample size of 5 . The maximum is the $96.9 \%$ one sided confidence int.

7) The lognormal distribution was used because the data failed the normal distribution test.

8) The mean is geometric. The standard deviation is the value to divide or multiply with the geometric mean.

9) The nonparametic distribution was used because the data failed the normal distribution test and includes values $\leq 0$. 
TABLE 3.31 BASELINE GROUND HATER QUALITY STATISTICS BY PARAMETER FOR

THE ALLUVIUM, UC PROCESSING SITE, SLICK ROCK, COLORADO

SITE: SRKO1' SLICK ROCK (BOTH SITES)

$09 / 08 / 82$ TO $02 / 21 / 94$

REPORT DATE: 09/30/94

\begin{tabular}{|c|c|c|c|c|c|c|c|c|c|c|c|c|}
\hline \multicolumn{3}{|c|}{ PARAMETER NAME } & UNITS & \multirow[b]{2}{*}{ MEAN } & \multirow{2}{*}{$\begin{array}{r}\text { STANDARD } \\
\text { DEVIATION }\end{array}$} & \multirow{2}{*}{$\begin{array}{c}\text { COEFF. } \\
\text { OF } \\
\text { VARIATION }\end{array}$} & \multirow{2}{*}{$\begin{array}{c}\% \text { OF } \\
\text { NON } \\
\text { DETECTS }\end{array}$} & \multirow{2}{*}{\multicolumn{3}{|c|}{$\begin{array}{l}\text { STATISTICAL RANGE } \\
\text { 98\% CONFIDENCE INTERVAL } \\
\text { MINIMUM }\end{array}$}} & \multirow{2}{*}{$\begin{array}{c}\text { DISTRIBUT ION } \\
\text { TYPE }\end{array}$} & \multirow{2}{*}{$\begin{array}{l}\text { FOOT } \\
\text { NOTE }\end{array}$} \\
\hline \# OF SAMP & MINIMUM & MAXIMUM & MEDIAN & & & & & & & & & \\
\hline \multicolumn{3}{|l|}{ RADIUM-226 } & $\mathrm{PCI} / \mathrm{L}$ & \multirow[b]{2}{*}{ NA } & \multirow[b]{2}{*}{ NA } & \multirow[b]{2}{*}{ NA } & \multirow[b]{2}{*}{0.0} & \multirow{2}{*}{\multicolumn{2}{|c|}{0.2000}} & \multirow[b]{2}{*}{0.9000} & \multirow[b]{2}{*}{ NONPARAMETR I C } & \multirow[b]{2}{*}{9} \\
\hline 37 & ** 0.1000 & 3.3000 & 0.4000 & & & & & & & & & \\
\hline \multicolumn{3}{|c|}{ RADIUM-226 (TOTAL) } & $\mathrm{PCI} / \mathrm{L}$ & \multirow[b]{2}{*}{0.3400} & \multirow[b]{2}{*}{0.2881} & \multirow[b]{2}{*}{0.8473} & \multirow[b]{2}{*}{0.0} & \multirow[b]{2}{*}{ ** } & \multirow[b]{2}{*}{0.1000} & \multirow[b]{2}{*}{0.8228} & \multirow[b]{2}{*}{ NORMAL } & \\
\hline 5 & 0.1000 & 0.7000 & 0.2000 & & & & & & & & & \\
\hline \multicolumn{3}{|c|}{ RADIUM-226 + RADIUM-228 } & $\mathrm{PCI} / \mathrm{L}$ & \multirow[b]{2}{*}{ NA } & \multirow[b]{2}{*}{ NA } & \multirow[b]{2}{*}{ NA } & \multirow[b]{2}{*}{0.0} & \multirow{2}{*}{\multicolumn{2}{|c|}{1.2000}} & & & \\
\hline 32 & 0.0000 & 8.3000 & 1.6000 & & & & & & & 2.7000 & NONPARAMETR I C & 9 \\
\hline RADIUM-226 & 6 + RADIUM-22 & (TOTAL) & $\mathrm{PCI} / \mathrm{L}$ & & & & & & & & & \\
\hline 5 & 0.1000 & 3.0000 & 2.3000 & 1.9000 & 1.1726 & 0.6172 & 0.0 & & -0.0649 & 3.8649 & NORMAL & \\
\hline RADIUN-228 & & & $\mathrm{PCI} / \mathrm{L}$ & & & & & & & & & \\
\hline 32 & $* * \quad 1.0000$ & 7.0000 & 1.1500 & NA & NA & NA & 0.0 & ** & 1.0000 & 2.2000 & NONPARAMETR IC & 9 \\
\hline RADIUM-228 & 8 (TOTAL) & & $\mathrm{PCl} / \mathrm{L}$ & & & & & & & & & \\
\hline 5 & $\begin{array}{ll}* & 2.4000\end{array}$ & 2.8000 & 2.4000 & NA & NA & NA & 0.0 & $* *$ & 2.4000 & 2.8000 & NONPARAMETR I C & 9,5 \\
\hline REDOX POTE & ENTIAL & & mVOLTS & & & & & & & & & \\
\hline 10 & 158.0000 & 543.8000 & +450.5500 & 416.7500 & 110.9384 & 0.2662 & 0.0 & & 317.7843 & 515.7157 & NORMAL & \\
\hline SELENIUM & & & MG/L & & & & & & & & & \\
\hline 36 & ** $\quad 0.0050$ & 1.2200 & 0.0145 & NA & NA & NA & 47.2 & ** & 0.0050 & 0.0650 & NONPARAMETR I C & 2 \\
\hline SELENIUM ( & (TOTAL) & & $M G / L$ & & & & & & & & & \\
\hline 5 & $\begin{array}{ll}* * & 0.0050\end{array}$ & 1.0900 & 0.0050 & NA & NA & NA & 40.0 & ** & 0.0050 & 1.0900 & NONPARAMETR IC & 2,5 \\
\hline SILICA - S & SIOZ & & $M G / L$ & & & & & & & & & \\
\hline 38 & 7.0000 & 22.0000 & 11.7000 & 13.0737 & 4.3478 & 0.3326 & 0.0 & & 11.3591 & 14.7883 & NORMAL & \\
\hline
\end{tabular}

** The reported value is the minimum detection limit of the data set

+ The sample size is even, so the median value is the arithmetic average of the two middle values

* The statistical maximum is the 99 percent one sided confidence interval, $\alpha=0.01$

2) The nonparametric distribution was used because the nondetected values comprise more than $15 \%$ of the samples.

5) The stat. range is the $93.8 \%$ confidence interval due to a sample size of 5 . The maximum is the $96.9 \%$ one sided confidence int.

9) The nonparametic distribution was used because the data failed the normal distribution test and includes values $\leq 0$. 
TABLE 3.31 BASELINE GROUND HATER QUALITY STATISTICS BY PARAMETER FOR

THE ALLUVIUM, UC PROCESSING SITE, SLICK ROCK, COLORADO

SITE: SRKO1 SLICK ROCK (BOTH SITES)

$09 / 08 / 82$ TO 02/21/94

REPORT DATE: $09 / 30 / 94$



** The reported value is the minimum detection limit of the data set

+ The sample size is even, so the median value is the arithmetic average of the two middle values

* The statistical maximum is the 99 percent one sided confidence interval, $\alpha=0.01$

2) The nonparametric distribution was used because the nondetected values comprise more than $15 \%$ of the samples.

7) The lognormal distribution was used because the data failed the normal distribution test.

8) The mean is geometric. The standard deviation is the value to divide or multiply with the geometric mean. 
TABLE 3.31 BASELINE GROUND WATER QUALITY STATISTICS BY PARAMETER FOR

THE ALLUVIUM, UC PROCESSING SITE, SLICK ROCK, COLORADO

SITE: SRK01 SLICK ROCK (BOTH SITES)

$09 / 08 / 82$ TO $02 / 21 / 94$

REPORT DATE: $09 / 30 / 94$

\begin{tabular}{|c|c|c|c|c|c|c|c|c|c|c|c|}
\hline \multicolumn{3}{|c|}{ PARAMETER NAME } & UNITS & \multirow[b]{2}{*}{ MEAN } & \multirow{2}{*}{$\begin{array}{l}\text { STANDARD } \\
\text { DEVIATION }\end{array}$} & \multirow{2}{*}{\begin{tabular}{|} 
COEFF. \\
OF \\
VARIATION
\end{tabular}} & \multirow{2}{*}{$\begin{array}{l}\% \text { OF } \\
\text { NON } \\
\text { DETECTS }\end{array}$} & \multirow{2}{*}{\multicolumn{2}{|c|}{$\begin{array}{c}\text { STATISTICAL RANGE } \\
\text { 98\% CONFIDENCE INTERVAL } \\
\text { MINIMUM }\end{array}$}} & \multirow{2}{*}{$\begin{array}{l}\text { DISTRIBUTION } \\
\text { TYPE }\end{array}$} & \multirow{2}{*}{$\begin{array}{l}\text { FOOT } \\
\text { NOTE }\end{array}$} \\
\hline \# OF SAMP & MINIMUM & MAXIMUM & MEDIAN & & & & & & & & \\
\hline \multicolumn{3}{|l|}{ THALLIUM } & $\mathrm{MG} / \mathrm{L}$ & \multirow[b]{2}{*}{ NA } & \multirow[b]{2}{*}{ NA } & \multirow[b]{2}{*}{ NA } & \multirow[b]{2}{*}{100.0} & \multirow[b]{2}{*}{0.0050} & \multirow[b]{2}{*}{0.0150} & \multirow[b]{2}{*}{ NONPARAMETRIC } & \multirow[b]{2}{*}{2} \\
\hline 21 & ** 0.0050 & 0.0500 & 0.0050 & & & & & & & & \\
\hline \multicolumn{3}{|c|}{ THOR IUM-230 } & $\mathrm{PCI} / \mathrm{L}$ & \multirow[b]{2}{*}{0.3125} & \multirow[b]{2}{*}{0.2094} & \multirow[b]{2}{*}{0.6700} & \multirow[b]{2}{*}{0.0} & \multirow[b]{2}{*}{0.1763} & \multirow[b]{2}{*}{0.4487} & \multirow[b]{2}{*}{ NORMAL } & \\
\hline 16 & 0.1000 & 0.8000 & 0.3000 & & & & & & & & \\
\hline \multicolumn{3}{|c|}{ THORIUM-230 (TOTAL) } & $\mathrm{PCI} / \mathrm{L}$ & \multirow[b]{2}{*}{0.2800} & \multirow[b]{2}{*}{0.1304} & \multirow[b]{2}{*}{0.4657} & \multirow[b]{2}{*}{0.0} & \multirow[b]{2}{*}{0.1000} & \multirow[b]{2}{*}{0.4985} & \multirow[b]{2}{*}{ NORMAL } & \\
\hline 5 & 0.2000 & 0.5000 & 0.2000 & & & & & & & & \\
\hline TIN & & & $M G / L$ & & & & & & & & \\
\hline 22 & ** $\quad 0.0050$ & 0.0250 & 0.0050 & NA & NA & NA & 100.0 & 0.0050 & 0.0250 & NONPARAMETRIC & 2 \\
\hline TOTAL DISS & SOLVED SOLIDS & & $M G / L$ & & & & & & & & \\
\hline 42 & 190.0000 & 9560.0000 & +3620.0000 & 3059.2381 & 2043.5520 & 0.6680 & 0.0 & 2295.8316 & 3822.6446 & NORMAL & \\
\hline TOTAL. KJEI & LDAHL NITROGE & & $M G / L$ & & & & & & & & \\
\hline 15 & 20.0000 & 130.0000 & 84.0000 & 76.4667 & 39.9944 & 0.5230 & 0.0 & 49.3699 & 103.5634 & NORMAL & \\
\hline TOTAL ORG & ANIC CARBON & & $M G / L$ & & & & & & & & \\
\hline 25 & 2.0000 & 45.0000 & 6.0000 & 7.1537 & 2.4742 & NA & 0.0 & 4.5545 & 11.2362 & LOGNORMAL & 7,8 \\
\hline TURB IDI TY & & & NTU & & & & & & & & \\
\hline 6 & 0.0000 & 6.9000 & 3.0000 & NA & NA & NA & 0.0 & 0.0000 & 6.9000 & NONPARAMETRIC & 9,6 \\
\hline URANIUM & & & $M G / L$ & & & & & & & & \\
\hline 42 & 0.0139 & 0.2380 & 0.0380 & 0.0736 & 0.0581 & 0.7891 & 0.0 & 0.0519 & 0.0953 & NORMAL & \\
\hline
\end{tabular}

** The reported value is the minimum detection limit of the data set

+ The sample size is even, so the median value is the arithmetir overage of the two middle values

* The statistical maximum is the 99 percent one sided confidence interval, $\alpha=0.01$

2) The nonparametric distribution was used because the nondetected values comprise more than $15 \%$ of the samples.

6) The stat. range is the $96.9 \%$ confidence interval due to a sample size of 6 . The maximum is the $98.5 \%$ one sided confidence int.

7) The lognormal distribution was used because the data failed the normal distribution test.

8) The mean is geometric. The standard deviation is the value to divide or multiply with the geometric mean.

9) The nonparametic distribution was used because the data failed the normal distribution test and includes values $\leq 0$. 
TABLE 3.31 BASELINE GROUND WATER QUALITY STATISTICS BY PARAMETER FOR

THE ALLUVIUM, UC PROCESSING SITE, SLICK ROCK, COLORADO

SITE: SRKO1 SLICK ROCK (BOTH SITES)

$09 / 08 / 82$ TO $02 / 21 / 94$

REPORT DATE: 09/30/94

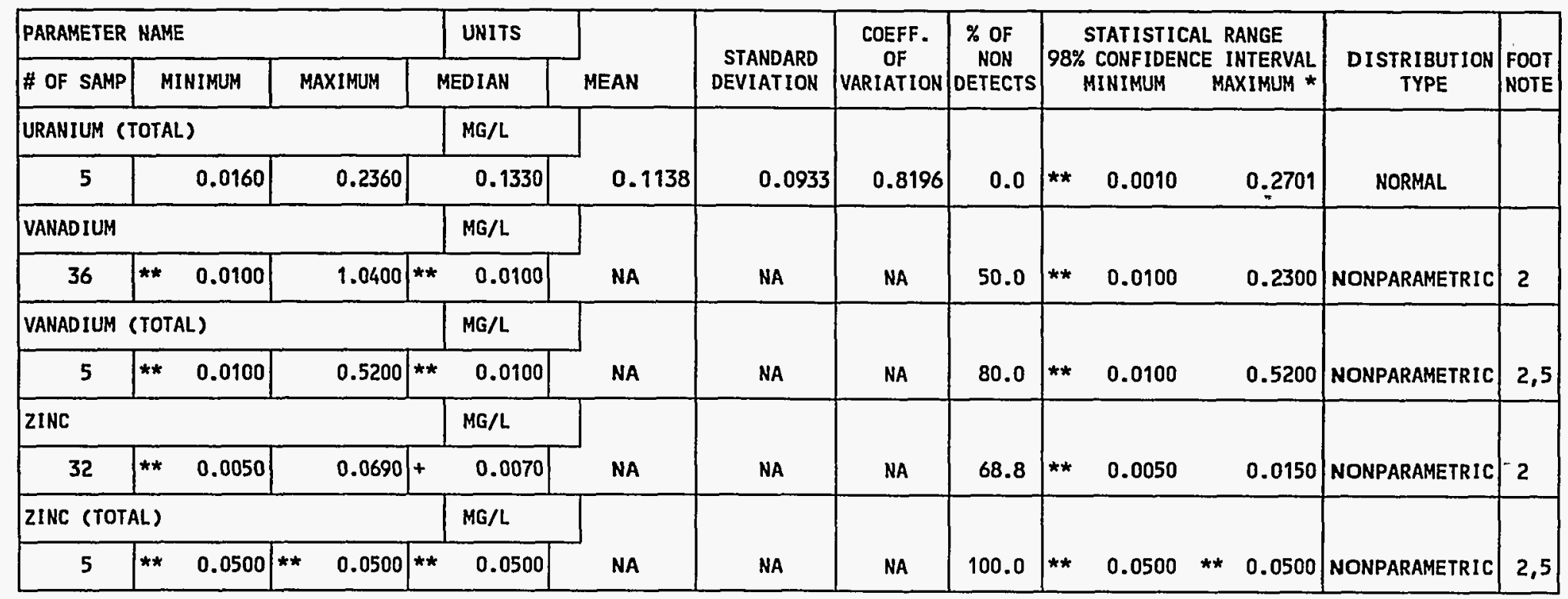

** The reported value is the minimum detection limit of the data set

+ The sample size is even, so the median value is the arithmetic average of the two middle values

* The statistical maximum is the 99 percent one sided confidence interval, $\alpha=0.01$

2) The nonparametric distribution was used because the nondetected values comprise more than $15 \%$ of the samples.

5) The stat. range is the $93.8 \%$ confidence interval due to a sample size of 5 . The maximum is the $96.9 \%$ one sided confidence int.

INPUT DATA FILENAME: IDARTISRK0IIGWQ10074.DAT 
Table 3.32 Summary of regulated constituents in alluvial baseline ground water, UC processing site, Slick Rock, Colorado

\begin{tabular}{lcccc}
\hline \multicolumn{4}{c}{ Constituents with MCLs } \\
\hline \multicolumn{1}{c}{ Parameter } & $\begin{array}{c}\text { Baseline } \\
\text { median }\end{array}$ & $\begin{array}{c}\text { Baseline } \\
\text { stat max }\end{array}$ & $\begin{array}{c}\text { Background } \\
\text { stat max }\end{array}$ & MCL \\
\hline Arsenic & $0.01^{\mathrm{g}}$ & $0.01^{\mathrm{g}}$ & $0.01^{\mathrm{g}}$ & 0.05 \\
Barium & $0.10^{\mathrm{g}}$ & $0.10^{\mathrm{g}}$ & $0.10^{\mathrm{g}}$ & 1.00 \\
Cadmium & $0.001^{\mathrm{g}}$ & $0.001^{\mathrm{g}}$ & $0.001^{\mathrm{g}}$ & 0.01 \\
Chromium & $0.01^{\mathrm{g}}$ & $0.01^{\mathrm{g}}$ & $0.07^{\mathrm{e}}$ & 0.05 \\
Net gross alpha & $3.91^{\mathrm{e}}$ & $17.12^{\mathrm{e}}$ & $-3.45^{\mathrm{h}}$ & 15.00 \\
Lead & $0.01^{\mathrm{g}}$ & $0.01^{\mathrm{g}}$ & $0.01^{\mathrm{g}}$ & 0.05 \\
Mercury & $0.0002^{\mathrm{g}}$ & $0.0002^{\mathrm{g}}$ & $0.0002^{\mathrm{g}}$ & 0.002 \\
Molybdenum & $0.22^{\mathrm{c}}$ & $0.42^{\mathrm{c}}$ & $0.11^{\mathrm{d}}$ & 0.10 \\
Nitrate & $34.0^{\mathrm{e}}$ & $947.0^{\mathrm{e}}$ & $2.00^{\mathrm{e}}$ & 44.0 \\
Radium-226,-228 & $1.60^{\mathrm{e}}$ & $2.70^{\mathrm{e}}$ & $2.52^{\mathrm{d}}$ & 5.0 \\
Selenium & $0.015^{\mathrm{e}}$ & $0.065^{\mathrm{e}}$ & $0.007^{\mathrm{e}}$ & 0.01 \\
Silver & $0.01^{\mathrm{g}}$ & $0.01^{\mathrm{g}}$ & $0.01^{\mathrm{g}}$ & 0.05 \\
Uranium & $0.04^{\mathrm{d}}$ & $0.095^{\mathrm{d}}$ & $0.033^{\mathrm{d}}$ & 0.044 \\
\hline
\end{tabular}


Table 3.32 Summary of regulated constituents in alluvial baseline ground water, UC processing site, Slick Rock, Colorado (Concluded)

\begin{tabular}{lllll}
\hline \multicolumn{4}{c}{ Constituents without MCLs } & \\
\hline \multicolumn{1}{c}{ Parameter } & $\begin{array}{c}\text { Baseline } \\
\text { median }\end{array}$ & $\begin{array}{c}\text { Baseline } \\
\text { stat max }\end{array}$ & $\begin{array}{c}\text { Background } \\
\text { stat. max }\end{array}$ & MCL \\
\hline Antimony & $0.003^{\mathrm{g}}$ & $0.003^{\mathrm{g}}$ & $0.003^{\mathrm{e}, \mathrm{g}}$ & None \\
Beryllium & $0.01^{\mathrm{g}}$ & $0.01^{\mathrm{g}}$ & $0.01^{\mathrm{g}, \mathrm{h}}$ & None \\
Cobalt & $0.05^{\mathrm{g}}$ & $0.05^{\mathrm{g}}$ & $0.05^{\mathrm{g}, \mathrm{h}}$ & None \\
Copper & $0.02^{\mathrm{g}}$ & $0.02^{\mathrm{g}}$ & $0.03^{\mathrm{e}}$ & None \\
Cyanide & $0.01^{\mathrm{g}}$ & $0.01^{\mathrm{g}}$ & $0.01^{\mathrm{g}, \mathrm{h}}$ & None \\
Nickel & $0.04^{\mathrm{g}}$ & $0.04^{\mathrm{g}}$ & $0.04^{\mathrm{g}}$ & None \\
Sulfide & $0.1^{\mathrm{g}}$ & $0.3^{\mathrm{e}}$ & $0.3^{\mathrm{h}}$ & None \\
Thallium & $0.01^{\mathrm{g}}$ & $0.015^{\mathrm{e}}$ & $0.01^{\mathrm{g}, \mathrm{h}}$ & None \\
Tin & $0.005^{\mathrm{g}}$ & $0.025^{\mathrm{e}}$ & $0.025^{\mathrm{e}}$ & None \\
Vanadium & $0.01^{\mathrm{g}}$ & $0.23^{\mathrm{e}}$ & $0.24^{\mathrm{e}}$ & None \\
Zinc & $0.007^{\mathrm{e}}$ & $0.015^{\mathrm{e}}$ & $0.025^{\mathrm{e}}$ & None \\
& & & & \\
\hline
\end{tabular}

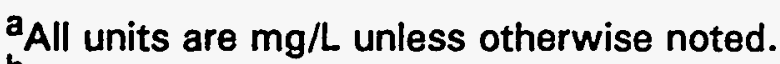

bNC Processing site background groundwater statistical maximum.

Lognormal distribution, mean is geometric.

$\mathrm{d}_{\text {Normal distribution, mean is arithmetic. }}$

ONonparametric distribution

Units are $\mathrm{pCi} / \mathrm{L}$.

IStatistical values are below laboratory detection limits in Table 8.1 of the Technical Approach Document (DOE, 1989).

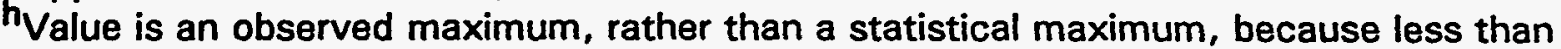
four samples were available for statistical analysis. 
TABLE 3.33 BASELINE GROUND HATER DATA BY PARAMETER FOR THE ENTRADA

FORMATION, UC PROCESSING SITE, SLICK ROCK, COLORADO

SITE: SRKO1 SLICK ROCK (BOTH SITES)

$03 / 29 / 89$ TO $02 / 21 / 94$

\begin{tabular}{|c|c|c|c|c|c|c|c|c|c|c|c|}
\hline PARAMETER NAME & $\begin{array}{c}\text { LOCATION } \\
\text { ID }\end{array}$ & LOG DATE & $\begin{array}{c}\text { SAMPLEE } \\
\text { ID }\end{array}$ & $\begin{array}{l}\text { FORM } \\
\text { COMP }\end{array}$ & $\begin{array}{l}\text { FLOW } \\
\text { REL. }\end{array}$ & $\begin{array}{l}\text { UNITS OF } \\
\text { MEASURE }\end{array}$ & PVI & $\begin{array}{l}\text { PARAMETER } \\
\text { VALUE }\end{array}$ & FLAGS & $\begin{array}{l}\text { DETECTION } \\
\text { LIMIT }\end{array}$ & $\begin{array}{l}\text { PARAMETER } \\
\text { UNCERTAINTY }\end{array}$ \\
\hline ALKALINITY & $\begin{array}{l}0554 \\
0554 \\
0554 \\
0554 \\
0554 \\
0554 \\
0702 \\
0702 \\
0702 \\
0702 \\
0702 \\
0702 \\
0702 \\
0704 \\
0704 \\
0704 \\
0704 \\
0704 \\
0704 \\
0704\end{array}$ & $\begin{array}{l}12 / 12 / 90 \\
03 / 28 / 91 \\
08 / 05 / 91 \\
12 / 05 / 91 \\
10 / 15 / 92 \\
02 / 17 / 94 \\
03 / 29 / 89 \\
12 / 12 / 90 \\
03 / 31 / 91 \\
08 / 07 / 91 \\
12 / 05 / 91 \\
10 / 11 / 92 \\
02 / 21 / 94 \\
03 / 29 / 89 \\
12 / 12 / 90 \\
04 / 01 / 91 \\
08 / 24 / 91 \\
12 / 05 / 91 \\
10 / 12 / 92 \\
02 / 17 / 94\end{array}$ & $\begin{array}{l}0001 \\
0001 \\
0001 \\
0001 \\
0001 \\
\text { N001 } \\
0001 \\
0001 \\
0001 \\
0001 \\
0001 \\
0001 \\
\text { N001 } \\
0001 \\
0001 \\
0001 \\
0001 \\
0001 \\
0001 \\
\text { N001 }\end{array}$ & $\begin{array}{l}\mathrm{JE} \\
\mathrm{JE} \\
\mathrm{JE} \\
\mathrm{JE} \\
\mathrm{JE} \\
\mathrm{JE} \\
\mathrm{JE} \\
\mathrm{JE} \\
\mathrm{JE} \\
\mathrm{JE} \\
\mathrm{JE} \\
\mathrm{JE} \\
\mathrm{JE} \\
\mathrm{JE} \\
\mathrm{JE} \\
\mathrm{JE} \\
\mathrm{JE} \\
\mathrm{JE} \\
\mathrm{JE} \\
\mathrm{JE}\end{array}$ & $\begin{array}{l}U \\
U \\
U \\
U \\
U \\
U \\
0 \\
0 \\
0 \\
0 \\
0 \\
0 \\
0 \\
0 \\
0 \\
0 \\
0 \\
0 \\
0 \\
0\end{array}$ & MG/L CACO3 & & $\begin{array}{l}574 . \\
550 . \\
524 \\
552 \\
623 \\
584 \\
156 . \\
174 . \\
169 . \\
178 \\
160 \\
149 \\
152 \\
186 . \\
202 . \\
203 . \\
187 \\
200 \\
223 \\
214\end{array}$ & $\begin{array}{l}L \\
L \\
L \\
L \\
L \\
L \\
L \\
L \\
L \\
L \\
L \\
L \\
L \\
L\end{array}$ & $\begin{array}{l}- \\
- \\
- \\
- \\
- \\
- \\
- \\
- \\
- \\
- \\
- \\
- \\
- \\
- \\
- \\
-\end{array}$ & $\begin{array}{l}- \\
- \\
- \\
- \\
- \\
- \\
- \\
- \\
- \\
- \\
- \\
- \\
- \\
- \\
- \\
- \\
-\end{array}$ \\
\hline ALUMINUM & $\begin{array}{l}0554 \\
0554 \\
0554 \\
0554 \\
0554 \\
0702 \\
0702 \\
0702 \\
0702 \\
0702 \\
0702 \\
0704 \\
0704 \\
0704 \\
0704 \\
0704 \\
0704\end{array}$ & $\begin{array}{l}12 / 12 / 90 \\
03 / 28 / 91 \\
08 / 05 / 91 \\
12 / 06 / 91 \\
10 / 15 / 92 \\
03 / 29 / 89 \\
12 / 12 / 90 \\
03 / 31 / 91 \\
08 / 07 / 91 \\
12 / 07 / 91 \\
10 / 11 / 92 \\
03 / 29 / 89 \\
12 / 12 / 90 \\
04 / 01 / 91 \\
08 / 24 / 91 \\
12 / 12 / 91 \\
10 / 12 / 92\end{array}$ & $\begin{array}{l}0001 \\
0001 \\
0001 \\
0001 \\
0001 \\
0001 \\
0001 \\
0001 \\
0001 \\
0001 \\
0001 \\
0001 \\
0001 \\
0001 \\
0001 \\
0001 \\
0001\end{array}$ & $\begin{array}{l}\mathrm{JE} \\
\mathrm{JE} \\
\mathrm{JE} \\
\mathrm{JE} \\
\mathrm{JE} \\
\mathrm{JE} \\
\mathrm{JE} \\
\mathrm{JE} \\
\mathrm{JE} \\
\mathrm{JE} \\
\mathrm{JE} \\
\mathrm{JE} \\
\mathrm{JE} \\
\mathrm{JE} \\
\mathrm{JE} \\
\mathrm{JE} \\
\mathrm{JE}\end{array}$ & $\begin{array}{l}U \\
U \\
U \\
U \\
U \\
0 \\
0 \\
0 \\
0 \\
0 \\
0 \\
0 \\
0 \\
0 \\
0 \\
0 \\
0\end{array}$ & MG/L & $\begin{array}{l}< \\
< \\
< \\
< \\
< \\
< \\
< \\
< \\
< \\
< \\
< \\
< \\
< \\
< \\
< \\
< \\
< \\
<\end{array}$ & $\begin{array}{l}0.1 \\
0.05 \\
0.05 \\
0.05 \\
0.05 \\
0.05 \\
0.1 \\
0.05 \\
0.05 \\
0.05 \\
0.05 \\
0.05 \\
0.1 \\
0.05 \\
0.05 \\
0.05 \\
0.05\end{array}$ & $\begin{array}{l}\mathrm{JL} \\
\mathrm{L} \\
\mathrm{L} \\
\mathrm{L} \\
\mathrm{L} \\
\mathrm{L} \\
\mathrm{J} L \\
\mathrm{~L} \\
\mathrm{~L} \\
\mathrm{~L} \\
\mathrm{~L} \\
\mathrm{~L}\end{array}$ & $\begin{array}{l}0.1 \\
0.05 \\
0.05 \\
0.05 \\
0.05 \\
0.1 \\
0.1 \\
0.05 \\
0.05 \\
0.05 \\
0.05 \\
0.1 \\
0.1 \\
0.05 \\
0.05 \\
0.05 \\
0.05\end{array}$ & $\begin{array}{l}- \\
- \\
- \\
- \\
- \\
- \\
- \\
- \\
- \\
- \\
- \\
- \\
- \\
- \\
-\end{array}$ \\
\hline
\end{tabular}

FORMATION OF COMPLETION CODE:

JE - JURASSIC ENTRADA SANDSTONE FORMATION

PARAMETER VALUE INDICATOR (PVI): < - LESS THAN DETECTION LIMIT

OTHER PARAMETER VALUE FLAGS:

$J$ - ESTIMATED VALUE

L - LESS THAN THREE BORE VOLUMES REMOVED BEFORE SAMPLING
FLOW RELATIONSHIP CODE:

$$
\text { U - UPGRADIENT }
$$

O - ON-SITE

SAMPLE ID CODES

0001 - FILTERED SAMPLE (.45 MICRONS)

NO01 - UNFILTERED SAMPLE 
TABLE 3.33 BASELINE GROUND HATER DATA BY PARAMETER FOR THE ENTRADA

FORMATION UC PROCESSING SITE SLICK ROCK, COLORADD

SITE: SRKO1 SLICK ROCK (BOTH SITES)

03/29/89 TO 02/21/94

REPORT DATE: $09 / 30 / 94$

\begin{tabular}{|c|c|c|c|c|c|c|c|c|c|c|c|}
\hline PARAMETER NAME & $\begin{array}{c}\text { LOCATION } \\
\text { ID }\end{array}$ & LOG DATE & $\begin{array}{l}\text { SAMPLE } \\
\text { ID }\end{array}$ & $\begin{array}{l}\text { FORM } \\
\text { COMP }\end{array}$ & $\begin{array}{l}\text { FLOW } \\
\text { REL. }\end{array}$ & $\begin{array}{l}\text { UNITS OF } \\
\text { MEASURE }\end{array}$ & PVI & $\begin{array}{l}\text { PARAMETER } \\
\text { VALUE }\end{array}$ & FLAGS & $\begin{array}{l}\text { DETECTION } \\
\text { LIMIT }\end{array}$ & $\begin{array}{l}\text { PARAMETER } \\
\text { UNCERTAI NTY }\end{array}$ \\
\hline AMMONIUM & $\begin{array}{l}0554 \\
0554 \\
0554 \\
0554 \\
0554 \\
0702 \\
0702 \\
0702 \\
0702 \\
0702 \\
0702 \\
0704 \\
0704 \\
0704 \\
0704 \\
0704 \\
0704\end{array}$ & \begin{tabular}{|l|}
$12 / 12 / 90$ \\
$03 / 28 / 91$ \\
$08 / 05 / 91$ \\
$12 / 06 / 91$ \\
$10 / 15 / 92$ \\
$03 / 29 / 89$ \\
$12 / 12 / 90$ \\
$03 / 31 / 91$ \\
$08 / 07 / 91$ \\
$12 / 07 / 91$ \\
$10 / 11 / 92$ \\
$03 / 29 / 89$ \\
$12 / 12 / 90$ \\
$04 / 01 / 91$ \\
$08 / 24 / 91$ \\
$12 / 12 / 91$ \\
$10 / 12 / 92$
\end{tabular} & $\begin{array}{l}0001 \\
0001 \\
0001 \\
0001 \\
0001 \\
0001 \\
0001 \\
0001 \\
0001 \\
0001 \\
0001 \\
0001 \\
0001 \\
0001 \\
0001 \\
0001 \\
0001\end{array}$ & $\begin{array}{l}\mathrm{JE} \\
\mathrm{JE} \\
\mathrm{JE} \\
\mathrm{JE} \\
\mathrm{JE} \\
\mathrm{JE} \\
\mathrm{JE} \\
\mathrm{JE} \\
\mathrm{JE} \\
\mathrm{JE} \\
\mathrm{JE} \\
\mathrm{JE} \\
\mathrm{JE} \\
\mathrm{JE} \\
\mathrm{JE} \\
\mathrm{JE} \\
\mathrm{JE}\end{array}$ & $\begin{array}{l}U \\
U \\
U \\
U \\
U \\
0 \\
0 \\
0 \\
0 \\
0 \\
0 \\
0 \\
0 \\
0 \\
0 \\
0 \\
0\end{array}$ & $M G / L$ & $\mid \begin{array}{l}< \\
< \\
< \\
<\end{array}$ & $\begin{array}{l}0.1 \\
0.3 \\
0.2 \\
0.1 \\
0.4 \\
0.04 \\
0.1 \\
0.1 \\
0.1 \\
0.2 \\
0.1 \\
0.05 \\
0.1 \\
0.1 \\
0.1 \\
0.2 \\
0.6\end{array}$ & $\begin{array}{l}J \\
\\
J L \\
H J L \\
L \\
L \\
L \\
L \\
J L \\
H J L \\
L \\
L \\
L \\
L\end{array}$ & $\begin{array}{l}0.1 \\
0.1 \\
0.1 \\
0.1 \\
0.1 \\
0.1 \\
0.1 \\
0.1 \\
0.1 \\
0.1 \\
0.1 \\
0.1 \\
0.1 \\
0.1 \\
0.1 \\
0.1 \\
0.1\end{array}$ & $\begin{array}{l}- \\
- \\
- \\
- \\
- \\
- \\
- \\
- \\
- \\
- \\
- \\
- \\
- \\
- \\
-\end{array}$ \\
\hline AMMONIUM (TOTAL) & $\begin{array}{l}0554 \\
0702 \\
0704\end{array}$ & $\begin{array}{l}02 / 17 / 94 \\
02 / 21 / 94 \\
02 / 17 / 94\end{array} \mid$ & $\begin{array}{l}\text { No01 } \\
\text { N001 } \\
\text { N001 }\end{array}$ & $\begin{array}{l}\mathrm{JE} \\
\mathrm{JE} \\
\mathrm{JE}\end{array}$ & $\begin{array}{l}U \\
0 \\
0\end{array}$ & MG/L & $<$ & $\begin{array}{l}0.1 \\
0.1 \\
0.1\end{array}$ & $\begin{array}{l}L \\
L\end{array}$ & $\begin{array}{l}0.1 \\
0.1 \\
0.1\end{array}$ & - \\
\hline ANT IMONY & $\begin{array}{l}0554 \\
0554 \\
0554 \\
0554 \\
0554 \\
0702 \\
0702 \\
0702 \\
0702 \\
0702 \\
0702 \\
0704 \\
0704 \\
0704 \\
0704\end{array}$ & $\begin{array}{l}12 / 12 / 90 \\
03 / 28 / 91 \\
08 / 05 / 91 \\
12 / 06 / 91 \\
10 / 15 / 92 \\
03 / 29 / 89 \\
12 / 12 / 90 \\
03 / 31 / 91 \\
08 / 07 / 91 \\
12 / 07 / 91 \\
10 / 11 / 92 \\
03 / 29 / 89 \\
12 / 12 / 90 \\
016 / 01 / 91 \\
08 / 24 / 91\end{array}$ & $\begin{array}{l}0001 \\
0001 \\
0001 \\
0001 \\
0001 \\
0001 \\
0001 \\
0001 \\
0001 \\
0001 \\
0001 \\
0001 \\
0001 \\
0001 \\
0001\end{array}$ & $\begin{array}{l}\mathrm{JE} \\
\mathrm{JE} \\
\mathrm{JE} \\
\mathrm{JE} \\
\mathrm{JE} \\
\mathrm{JE} \\
\mathrm{JE} \\
\mathrm{JE} \\
\mathrm{JE} \\
\mathrm{JE} \\
\mathrm{JE} \\
\mathrm{JE} \\
\mathrm{JE} \\
\mathrm{JE} \\
\mathrm{JE}\end{array}$ & $\begin{array}{l}U \\
U \\
U \\
U \\
U \\
0 \\
0 \\
0 \\
0 \\
0 \\
0 \\
0 \\
0 \\
0 \\
0\end{array}$ & $M G / L$ & $\begin{array}{l}< \\
< \\
< \\
< \\
< \\
< \\
< \\
< \\
< \\
< \\
< \\
< \\
< \\
<\end{array}$ & $\begin{array}{l}0.003 \\
0.003 \\
0.003 \\
0.003 \\
0.003 \\
0.001 \\
0.003 \\
0.006 \\
0.003 \\
0.003 \\
0.004 \\
0.001 \\
0.003 \\
0.003 \\
0.003\end{array}$ & $\begin{array}{l}J L \\
L \\
L \\
L \\
L \\
L \\
J L \\
L \\
L \\
L\end{array}$ & $\begin{array}{l}0.003 \\
0.003 \\
0.003 \\
0.003 \\
0.003 \\
0.003 \\
0.003 \\
0.003 \\
0.003 \\
0.003 \\
0.003 \\
0.003 \\
0.003 \\
0.003 \\
0.003\end{array}$ & $\begin{array}{l}- \\
- \\
- \\
- \\
- \\
- \\
= \\
- \\
- \\
- \\
- \\
-\end{array}$ \\
\hline
\end{tabular}

FORHATION OF COMPLETIOH CODE:

JE - JURASSIC EHTRADA SANDSTONE FORMATION

PARAMETER VALUE INDICATOR (PVI): < - LESS THAN DETECTION LIMIT

OTHER PARAMETER VALUE FLAGS:

$H$ - HOLD TIME EXPIRED, VALUE SUSPECT

$J$ - ESTIMATED VALUE

L - LESS THAN THREE BORE VOLUMES REMOVED BEFORE SAMPLING
FLOW RELATIONSHIP CODE:

$U$ - UPGRADIEHT

O - ON-SITE

SAMPLE ID CODES:

O001 - FILTERED SAMPLE (.45 MICRONS)

N001 - UNFILTERED SAMPLE 
TABLE 3.33 BASELINE GROUND WATER DATA BY PARAMETER FOR THE ENTRADA

FORMATION, UC PROCESSING SITE, SLICK ROCK, COLORADO

SITE: SRKO1 SLICK ROCK (BOTH SITES)

REPORT DATE: $09 / 30 / 94$

\begin{tabular}{|c|c|c|c|c|c|c|c|c|c|c|c|}
\hline PARAMETER NAME & $\begin{array}{c}\text { LOCATION } \\
\text { ID }\end{array}$ & LOG DATE & $\begin{array}{c}\text { SAMPLE } \\
\text { ID }\end{array}$ & $\mid \begin{array}{l}\text { FORM } \\
\text { COMP }\end{array}$ & $\begin{array}{l}\text { FLOW } \\
\text { REL . }\end{array}$ & $\begin{array}{l}\text { UNITS OF } \\
\text { MEASURE }\end{array}$ & PVI & $\begin{array}{l}\text { PARAMETER } \\
\text { VALUE }\end{array}$ & FLAGS & $\begin{array}{l}\text { DETECTION } \\
\text { LIMIT }\end{array}$ & $\begin{array}{l}\text { PARAMETER } \\
\text { UNCERTAINTY }\end{array}$ \\
\hline ANT IMONY & $\begin{array}{l}0704 \\
0704\end{array}$ & $\begin{array}{l}12 / 12 / 91 \\
10 / 12 / 92\end{array}$ & $\begin{array}{l}0001 \\
0001\end{array}$ & $\begin{array}{l}\text { JE } \\
\text { JE }\end{array}$ & $\begin{array}{l}0 \\
0\end{array}$ & $M G / L$ & $<$ & $\begin{array}{l}0.003 \\
0.003\end{array}$ & $L$ & $\begin{array}{l}0.003 \\
0.003\end{array}$ & - \\
\hline ARSENIC & $\begin{array}{l}0554 \\
0554 \\
0554 \\
0554 \\
0554 \\
0702 \\
0702 \\
0702 \\
0702 \\
0702 \\
0702 \\
0704 \\
0704 \\
0704 \\
0704 \\
0704 \\
0704\end{array}$ & $\begin{array}{l}12 / 12 / 90 \\
03 / 28 / 91 \\
08 / 05 / 91 \\
12 / 06 / 91 \\
10 / 15 / 92 \\
03 / 29 / 89 \\
12 / 12 / 90 \\
03 / 31 / 91 \\
08 / 07 / 91 \\
12 / 07 / 91 \\
10 / 11 / 92 \\
03 / 29 / 89 \\
12 / 12 / 90 \\
04 / 01 / 91 \\
08 / 24 / 91 \\
12 / 12 / 91 \\
10 / 12 / 92\end{array}$ & $\begin{array}{l}0001 \\
0001 \\
0001 \\
0001 \\
0001 \\
0001 \\
0001 \\
0001 \\
0001 \\
0001 \\
0001 \\
0001 \\
0001 \\
0001 \\
0001 \\
0001 \\
0001\end{array}$ & $\begin{array}{l}\text { JE } \\
\text { JE } \\
\text { JE } \\
\text { JE } \\
\text { JE } \\
\text { JE } \\
\text { JE } \\
\text { JE } \\
\text { JE } \\
\text { JE } \\
\mathrm{JE} \\
\mathrm{JE} \\
\mathrm{JE} \\
\mathrm{JE} \\
\mathrm{JE} \\
\mathrm{JE} \\
\mathrm{JE}\end{array}$ & $\begin{array}{l}U \\
U \\
U \\
U \\
U \\
0 \\
0 \\
0 \\
0 \\
0 \\
0 \\
0 \\
0 \\
0 \\
0 \\
0 \\
0\end{array}$ & $M G / L$ & $\begin{array}{l}< \\
< \\
< \\
< \\
< \\
< \\
< \\
< \\
< \\
< \\
< \\
< \\
< \\
< \\
<\end{array}$ & $\begin{array}{l}0.01 \\
0.01 \\
0.01 \\
0.01 \\
0.006 \\
0.001 \\
0.01 \\
0.01 \\
0.01 \\
0.01 \\
0.005 \\
0.001 \\
0.01 \\
0.01 \\
0.01 \\
0.01 \\
0.005\end{array}$ & $\begin{array}{l}H \\
J L \\
L \\
L \\
L \\
L \\
L \\
J L \\
L \\
L \\
L \\
L \\
L\end{array}$ & $\begin{array}{l}0.01 \\
0.01 \\
0.01 \\
0.01 \\
0.005 \\
0.01 \\
0.01 \\
0.01 \\
0.01 \\
0.01 \\
0.005 \\
0.01 \\
0.01 \\
0.01 \\
0.01 \\
0.01 \\
0.005\end{array}$ & $\begin{array}{l}- \\
- \\
- \\
- \\
- \\
- \\
- \\
- \\
- \\
- \\
- \\
- \\
- \\
-\end{array}$ \\
\hline BARIUM & $\begin{array}{l}0554 \\
0554 \\
0554 \\
0554 \\
0554 \\
0554 \\
0702 \\
0702 \\
0702 \\
0702 \\
0702 \\
0702 \\
0702 \\
0704 \\
0704 \\
0704\end{array}$ & $\begin{array}{l}12 / 12 / 90 \\
03 / 28 / 91 \\
08 / 05 / 91 \\
12 / 06 / 91 \\
10 / 15 / 92 \\
02 / 17 / 94 \\
03 / 29 / 89 \\
12 / 12 / 90 \\
03 / 31 / 91 \\
08 / 07 / 91 \\
12 / 07 / 91 \\
10 / 11 / 92 \\
02 / 21 / 94 \\
03 / 29 / 89 \\
12 / 12 / 90 \\
04 / 01 / 91\end{array}$ & $\begin{array}{l}0001 \\
0001 \\
0001 \\
0001 \\
0001 \\
0001 \\
0001 \\
0001 \\
0001 \\
0001 \\
0001 \\
0001 \\
0001 \\
0001 \\
0001 \\
0001\end{array}$ & $\begin{array}{l}\mathrm{JE} \\
\mathrm{JE} \\
\mathrm{JE} \\
\mathrm{JE} \\
\mathrm{JE} \\
\mathrm{JE} \\
\mathrm{JE} \\
\mathrm{JE} \\
\mathrm{JE} \\
\mathrm{JE} \\
\mathrm{JE} \\
\mathrm{JE} \\
\mathrm{JE} \\
\mathrm{JE} \\
\mathrm{JE} \\
\mathrm{JE}\end{array}$ & $\begin{array}{l}U \\
U \\
U \\
U \\
U \\
U \\
0 \\
0 \\
0 \\
0 \\
0 \\
0 \\
0 \\
0 \\
0 \\
0\end{array}$ & MG/L & $\begin{array}{l}< \\
< \\
< \\
<\end{array}$ & $\begin{array}{l}0.5 \\
0.42 \\
0.42 \\
0.48 \\
1.34 \\
2.3 \\
0.38 \\
0.1 \\
0.05 \\
0.05 \\
0.05 \\
0.15 \\
0.1 \\
0.12 \\
0.1 \\
0.07\end{array}$ & $\begin{array}{l}\mathrm{L} \\
\mathrm{L} \\
\mathrm{L} \\
\mathrm{L} \\
\mathrm{L} \\
\mathrm{L} \\
\mathrm{L} \\
\mathrm{L} \\
\mathrm{L} \\
\mathrm{L}\end{array}$ & $\begin{array}{l}0.1 \\
0.01 \\
0.01 \\
0.01 \\
0.01 \\
0.1 \\
0.1 \\
0.1 \\
0.01 \\
0.01 \\
0.01 \\
0.01 \\
0.1 \\
0.1 \\
0.1 \\
0.01\end{array}$ & $\begin{array}{l}- \\
- \\
- \\
- \\
- \\
- \\
- \\
- \\
- \\
- \\
- \\
-\end{array}$ \\
\hline
\end{tabular}

FORMATION OF COMPLETION CODE:

JE - JURASSIC ENTRADA SANDSTONE FORMATION

FLOW RELATIONSHIP CODE:

O - ON-SITE

PARAMETER VALUE INDICATOR (PVI): < - LESS THAN DETECTION LIMIT

SAMPLE ID CODES:

0001 - FILTERED SAMPLE (.45 MICRONS)

OTHER PARAMETER VALUE FLAGS:

$J$ - ESTIMATED VALUE

L - LESS THAN THREE BORE VOLUMES REMOVED BEFORE SAMPLING

$W$ - POST-DIGEST SPIKE OUT OF CNTR LIM WHILE SAMP ABS < $50 \%$ SPIKE 
TABLE 3.33 BASELINE GROUND HATER DATA BY PARAMETER FOR THE ENTRADA FORMATION, UC PROCESSING SITE, SLICK ROCK, COLORADD

SITE: SRKO1 SLICK ROCK (BOTH SITES)

O3/29/89 TO 02/21/94

REPORT DATE: 09/30/94

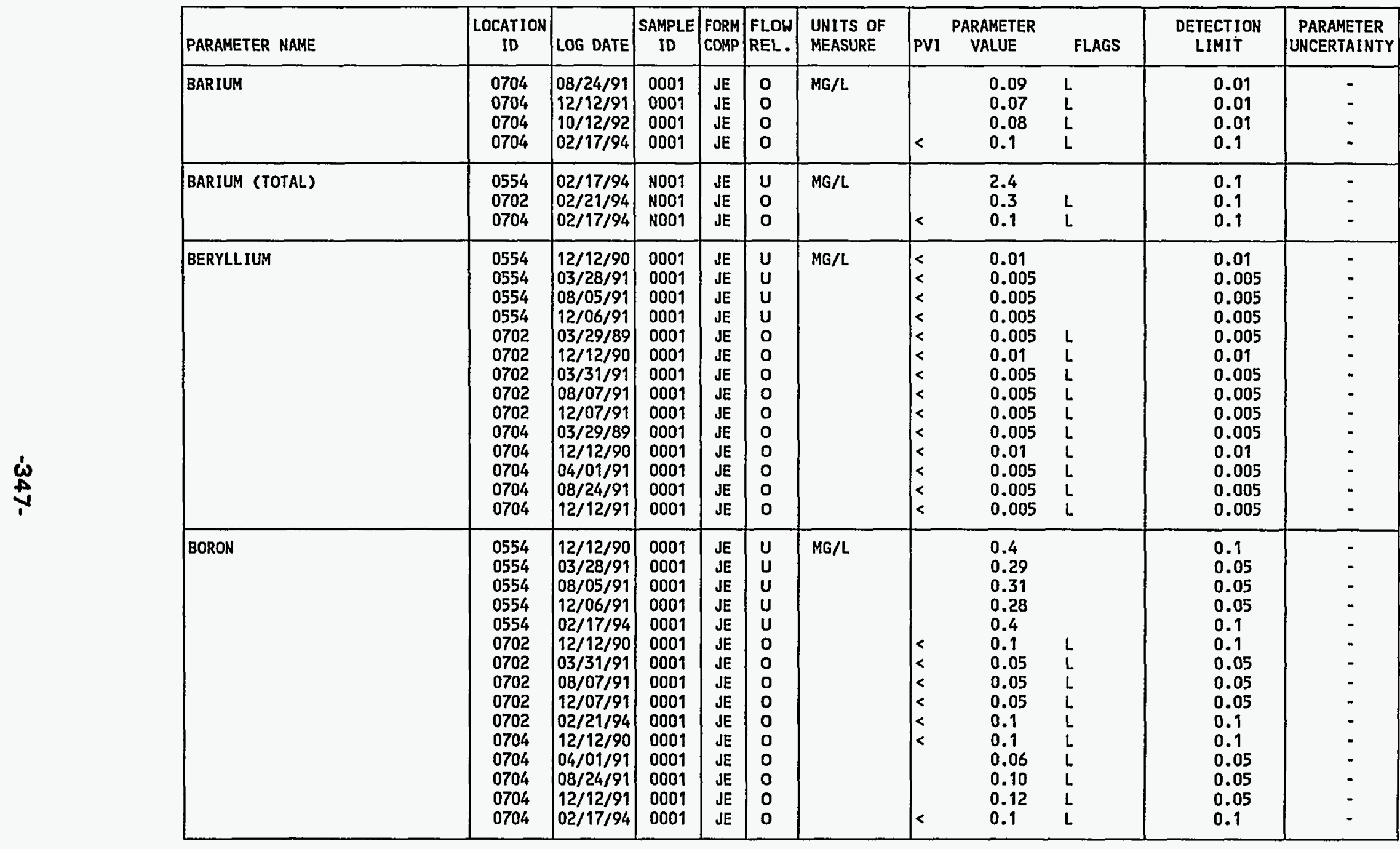

FORMATION OF COMPLETION CODE:

JE - JURASSIC ENTRADA SANDSTONE FORMATION

FLOW RELATIONSHIP CODE:

O - ON-SITE

$U$ - UPGRADIENT

PARAMETER VALUE INDICATOR (PVI): < - LESS THAN DETECTION LIMIT

OTHER PARAMETER VALUE FLAGS:

L - LESS THAN THREE BORE VOLUMES REMOVED BEFORE SAMPLING

SAMPLE ID CODES:

0001 - FILTERED SAMPLE (.45 MICRONS)

N001 - UNFILTERED SAMPLE 


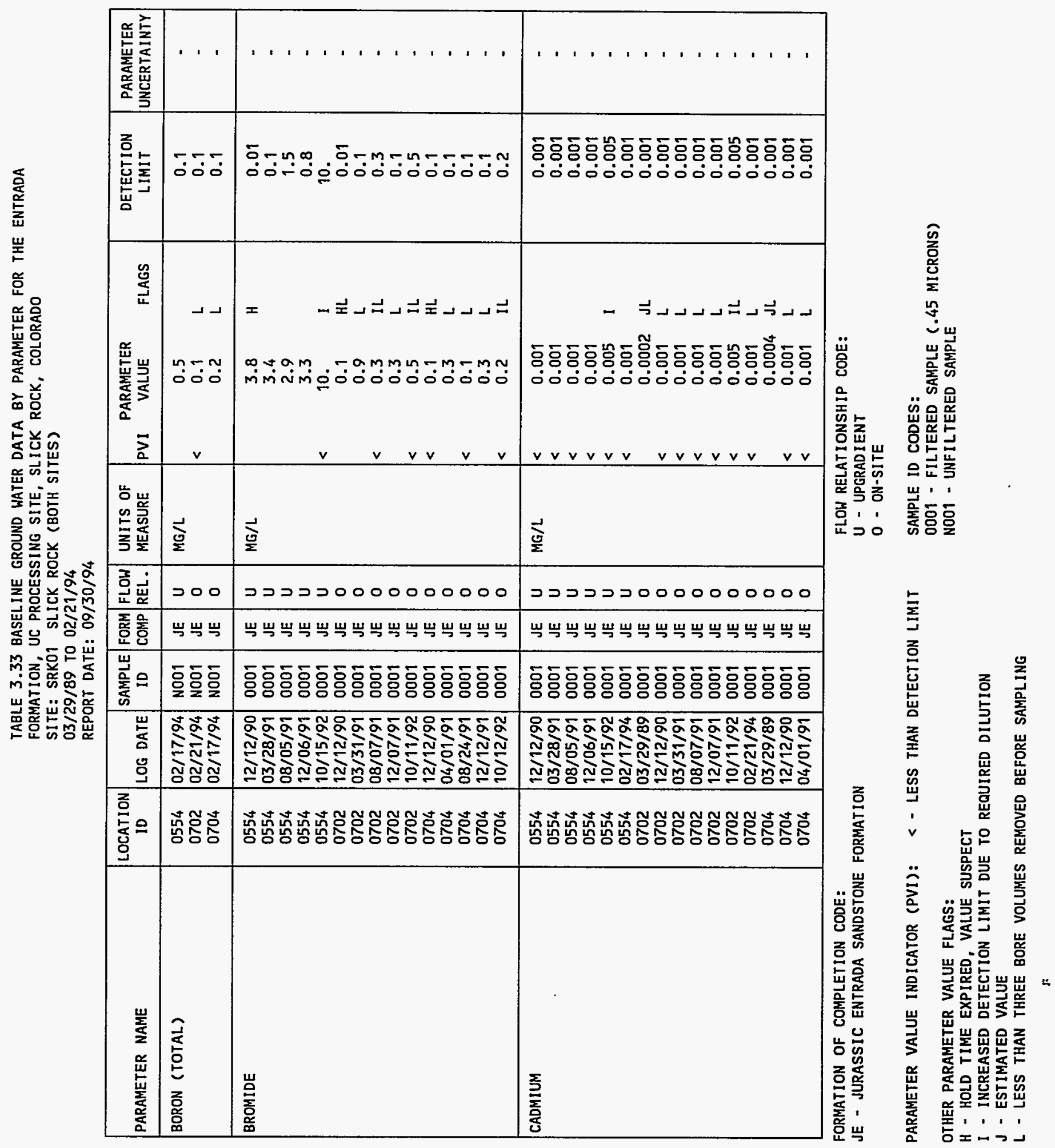


TABLE 3.33 BASELINE GROUND HATER DATA BY PARAMETER FOR THE ENTRADA FDRMATION, UC PROCESSING SITE, SLICK ROCK, COLORADO

SITE: SRKO 1 SLICK ROCK (BOTH SITES)

$03 / 29 / 89$ TO $02 / 21 / 94$

REPORT DATE: $09 / 30 / 94$

\begin{tabular}{|c|c|c|c|c|c|c|c|c|c|c|c|}
\hline PARAMETER NAME & $\mid \begin{array}{c}\text { LOCATION } \\
\text { ID }\end{array}$ & LOG DATE & $\begin{array}{c}\text { SAMPLE } \\
\text { ID }\end{array}$ & $\begin{array}{l}\text { FORM } \\
\text { COMP }\end{array}$ & $\begin{array}{l}\text { FLOW } \\
\text { REL. }\end{array}$ & $\begin{array}{l}\text { UNITS OF } \\
\text { MEASURE }\end{array}$ & PVI & $\begin{array}{l}\text { ARAMETER } \\
\text { VALUE }\end{array}$ & FLAGS & $\begin{array}{l}\text { DETECTION } \\
\text { LINIT }\end{array}$ & $\begin{array}{l}\text { PARAMETER } \\
\text { UNCERTAINTY }\end{array}$ \\
\hline CADMIUH & $\begin{array}{l}0704 \\
0704 \\
0704 \\
0704\end{array}$ & $\begin{array}{l}08 / 24 / 91 \\
12 / 12 / 91 \\
10 / 12 / 92 \\
02 / 17 / 94\end{array}$ & $\begin{array}{l}0001 \\
0001 \\
0001 \\
0001\end{array}$ & $\begin{array}{l}J E \\
J E \\
J E \\
J E\end{array}$ & $\begin{array}{l}0 \\
0 \\
0 \\
0\end{array}$ & $\mathrm{MG} / \mathrm{L}$ & $\begin{array}{l}< \\
< \\
<\end{array}$ & $\begin{array}{l}0.001 \\
0.001 \\
0.005 \\
0.001\end{array}$ & $\begin{array}{l}L \\
L \\
I L\end{array}$ & $\begin{array}{l}0.001 \\
0.001 \\
0.005 \\
0.001\end{array}$ & $\begin{array}{l}- \\
-\end{array}$ \\
\hline CADMIUM (TOTAL) & $\begin{array}{l}0554 \\
0702 \\
0704\end{array}$ & $\begin{array}{l}02 / 17 / 94 \\
02 / 21 / 94 \\
02 / 17 / 94\end{array} \mid$ & $\begin{array}{l}\text { No01 } \\
\text { N001 } \\
\text { N001 }\end{array}$ & $\begin{array}{l}\text { JE } \\
\text { JE } \\
\text { JE }\end{array}$ & $\begin{array}{l}\text { U } \\
0 \\
0\end{array}$ & MG/L & $\begin{array}{l}< \\
< \\
<\end{array}$ & $\begin{array}{l}0.001 \\
0.001 \\
0.001\end{array}$ & $\begin{array}{l}L \\
L\end{array}$ & $\begin{array}{l}0.001 \\
0.001 \\
0.001\end{array}$ & - \\
\hline CALCIUM & $\begin{array}{l}0554 \\
0554 \\
0554 \\
0554 \\
0554 \\
0554 \\
0702 \\
0702 \\
0702 \\
0702 \\
0702 \\
0702 \\
0702 \\
0704 \\
0704 \\
0704 \\
0704 \\
0704 \\
0704 \\
0704\end{array}$ & $\begin{array}{l}12 / 12 / 90 \\
03 / 28 / 91 \\
08 / 05 / 91 \\
12 / 06 / 91 \\
10 / 15 / 92 \\
02 / 17 / 94 \\
03 / 29 / 89 \\
12 / 12 / 90 \\
03 / 31 / 91 \\
08 / 07 / 91 \\
12 / 07 / 91 \\
10 / 11 / 92 \\
02 / 21 / 94 \\
03 / 29 / 89 \\
12 / 12 / 90 \\
04 / 01 / 91 \\
08 / 24 / 91 \\
12 / 12 / 91 \\
10 / 12 / 92 \\
02 / 17 / 94\end{array}$ & $\begin{array}{l}0001 \\
0001 \\
0001 \\
0001 \\
0001 \\
0001 \\
0001 \\
0001 \\
0001 \\
0001 \\
0001 \\
0001 \\
0001 \\
0001 \\
0001 \\
0001 \\
0001 \\
0001 \\
0001 \\
0001\end{array}$ & $\begin{array}{l}\mathrm{JE} \\
\mathrm{JE} \\
\mathrm{JE} \\
\mathrm{JE} \\
\mathrm{JE} \\
\mathrm{JE} \\
\mathrm{JE} \\
\mathrm{JE} \\
\mathrm{JE} \\
\mathrm{JE} \\
\mathrm{JE} \\
\mathrm{JE} \\
\mathrm{JE} \\
\mathrm{JE} \\
\mathrm{JE} \\
\mathrm{JE} \\
\mathrm{JE} \\
\mathrm{JE} \\
\mathrm{JE} \\
\mathrm{JE}\end{array}$ & $\begin{array}{l}U \\
U \\
U \\
U \\
U \\
U \\
0 \\
0 \\
0 \\
0 \\
0 \\
0 \\
0 \\
0 \\
0 \\
0 \\
0 \\
0 \\
0 \\
0\end{array}$ & MG/L & & $\begin{array}{c}138 . \\
134 . \\
140 . \\
125 . \\
203 . \\
195 \\
72 . \\
65.2 \\
50.5 \\
57.8 \\
40.9 \\
66.5 \\
61.7 \\
54 . \\
51.0 \\
51.2 \\
52.2 \\
53.1 \\
46.7 \\
42.1\end{array}$ & $\begin{array}{l}L \\
L \\
L \\
L \\
L \\
L \\
L \\
L \\
L \\
L \\
L \\
L \\
L \\
L\end{array}$ & $\begin{array}{l}0.01 \\
0.5 \\
0.5 \\
0.5 \\
0.5 \\
0.5 \\
0.01 \\
0.01 \\
0.5 \\
0.5 \\
0.5 \\
0.5 \\
0.5 \\
0.01 \\
0.01 \\
0.5 \\
0.5 \\
0.5 \\
0.5 \\
0.5\end{array}$ & $\begin{array}{l}- \\
- \\
- \\
- \\
- \\
- \\
- \\
- \\
- \\
- \\
- \\
- \\
- \\
- \\
- \\
- \\
-\end{array}$ \\
\hline CALCIUM (TOTAL) & $\begin{array}{l}0554 \\
0702 \\
0704\end{array}$ & $\begin{array}{l}02 / 17 / 94 \\
02 / 21 / 94 \\
02 / 17 / 94\end{array}$ & $\begin{array}{l}\text { N001 } \\
\text { N001 } \\
\text { N001 }\end{array}$ & $\begin{array}{l}\text { JE } \\
\text { JE } \\
\text { JE }\end{array}$ & $\begin{array}{l}\mathbf{U} \\
\mathbf{0} \\
\mathbf{0}\end{array}$ & $M G / L$ & & $\begin{array}{r}223 \\
87.7 \\
48.9\end{array}$ & $L$ & $\begin{array}{l}0.5 \\
0.5 \\
0.5\end{array}$ & - \\
\hline CHLORIDE & $\begin{array}{l}0554 \\
0554 \\
0554 \\
0554\end{array}$ & $\begin{array}{l}12 / 12 / 90 \\
03 / 28 / 91 \\
08 / 05 / 91 \\
12 / 06 / 91\end{array}$ & $\begin{array}{l}0001 \\
0001 \\
0001 \\
0001\end{array}$ & $\begin{array}{l}\text { JE } \\
\text { JE } \\
\text { JE } \\
\text { JE }\end{array}$ & $\begin{array}{l}\mathbf{U} \\
\mathbf{U} \\
\mathbf{U} \\
\mathbf{U}\end{array}$ & $\mathrm{MG} / \mathrm{L}$ & & $\begin{array}{l}741 . \\
582 . \\
592 . \\
660 .\end{array}$ & & $\begin{array}{l}1 . \\
0.5 \\
1 . \\
1 .\end{array}$ & $\begin{array}{l}- \\
- \\
-\end{array}$ \\
\hline
\end{tabular}

FORMATION OF COMPLETIOY CODE:

JE - JURASSIC ENTRADA SANDSTONE FORMATION
FLOH RELATIONSHIP CODE:

O - ON-SITE

U - UPGRADIENT

SAMPLE ID CODES:

0001 - FILTERED SAMPLE (.45 MICRONS)

N001 - UNFILTERED SAMPLE

OTHER PARAMETER VALUE FLAGS:

I - INCREASED DETECTION LIMIT DUE TO REQUIRED DILUTION

$L$ - LESS THAN THREE BORE VOLUMES REMOVED BEFORE SAMPLING 
TABLE 3.33 BASELINE GROUND WATER DATA BY PARAMETER FOR THE ENTRADA

FORMATION, UC PROCESSING SITE, SLICK ROCK, COLORADO

SITE: SRKO1 SLICK ROCK (BOTH SITES)

$03 / 29 / 89$ TO $02 / 21 / 94$

REPORT DATE: $09 / 30 / 94$

\begin{tabular}{|c|c|c|c|c|c|c|c|c|c|c|c|}
\hline PARAMETER NAME & $\underset{\text { LOCATION }}{\text { ID }}$ & LOG DATE & $\begin{array}{c}\text { SAMPLE } \\
\text { ID }\end{array}$ & $\begin{array}{l}\text { FORM } \\
\text { COMP }\end{array}$ & $\begin{array}{l}\text { FLOW } \\
\text { REL. }\end{array}$ & $\begin{array}{l}\text { UNITS OF } \\
\text { MEASURE }\end{array}$ & PVI & $\begin{array}{l}\text { PARAMETER } \\
\text { VALUE }\end{array}$ & FLAGS & $\begin{array}{l}\text { DETECTION } \\
\text { LIMIT }\end{array}$ & $\begin{array}{l}\text { PARAMETER } \\
\text { UNCERTAINTY }\end{array}$ \\
\hline CHLORIDE & $\begin{array}{l}0554 \\
0554 \\
0702 \\
0702 \\
0702 \\
0702 \\
0702 \\
0702 \\
0702 \\
0704 \\
0704 \\
0704 \\
0704 \\
0704 \\
0704 \\
0704\end{array}$ & $\begin{array}{l}10 / 15 / 92 \\
02 / 17 / 94 \\
03 / 29 / 89 \\
12 / 12 / 90 \\
03 / 31 / 91 \\
08 / 07 / 91 \\
12 / 07 / 91 \\
10 / 11 / 92 \\
02 / 21 / 94 \\
03 / 29 / 89 \\
12 / 12 / 90 \\
04 / 01 / 91 \\
08 / 24 / 91 \\
12 / 12 / 91 \\
10 / 12 / 92 \\
02 / 17 / 94\end{array}$ & $\begin{array}{l}0001 \\
0001 \\
0001 \\
0001 \\
0001 \\
0001 \\
0001 \\
0001 \\
0001 \\
0001 \\
0001 \\
0001 \\
0001 \\
0001 \\
0001 \\
0001\end{array}$ & $\begin{array}{l}\mathrm{JE} \\
\mathrm{JE} \\
\mathrm{JE} \\
\mathrm{JE} \\
\mathrm{JE} \\
\mathrm{JE} \\
\mathrm{JE} \\
\mathrm{JE} \\
\mathrm{JE} \\
\mathrm{JE} \\
\mathrm{JE} \\
\mathrm{JE} \\
\mathrm{JE} \\
\mathrm{JE} \\
\mathrm{JE} \\
\mathrm{JE}\end{array}$ & $\begin{array}{l}U \\
U \\
0 \\
0 \\
0 \\
0 \\
0 \\
0 \\
0 \\
0 \\
0 \\
0 \\
0 \\
0 \\
0 \\
0\end{array}$ & $\mathrm{MG} / \mathrm{L}$ & & $\begin{array}{c}1180 . \\
1330 \\
340 . \\
92 . \\
53 . \\
66 . \\
44 . \\
73 . \\
68.6 \\
30 . \\
30 . \\
27 . \\
26 . \\
26 . \\
24 . \\
22.1\end{array}$ & $\begin{array}{l}L \\
L \\
L \\
L \\
L \\
L \\
L \\
L \\
L \\
L \\
L \\
L \\
L \\
L\end{array}$ & $\begin{array}{l}10 . \\
0.5 \\
1 . \\
1 . \\
0.5 \\
1 . \\
1 . \\
1 . \\
0.5 \\
1 . \\
1 . \\
0.5 \\
1 . \\
1 . \\
1 . \\
0.5\end{array}$ & $\begin{array}{l}- \\
: \\
: \\
: \\
- \\
: \\
- \\
- \\
- \\
-\end{array}$ \\
\hline CHROMIUM & $\begin{array}{l}0554 \\
0554 \\
0554 \\
0554 \\
0554 \\
0554 \\
0702 \\
0702 \\
0702 \\
0702 \\
0702 \\
0702 \\
0702 \\
0704 \\
0704 \\
0704 \\
0704 \\
0704 \\
0704 \\
0704\end{array}$ & \begin{tabular}{|l|}
$12 / 12 / 90$ \\
$03 / 28 / 91$ \\
$08 / 05 / 91$ \\
$12 / 06 / 91$ \\
$10 / 15 / 92$ \\
$02 / 17 / 94$ \\
$03 / 29 / 89$ \\
$12 / 12 / 90$ \\
$03 / 31 / 91$ \\
$08 / 07 / 91$ \\
$12 / 07 / 91$ \\
$10 / 11 / 92$ \\
$02 / 21 / 94$ \\
$03 / 29 / 89$ \\
$12 / 12 / 90$ \\
$04 / 01 / 91$ \\
$08 / 24 / 91$ \\
$12 / 12 / 91$ \\
$10 / 12 / 92$ \\
$02 / 17 / 94$
\end{tabular} & $\begin{array}{l}0001 \\
0001 \\
0001 \\
0001 \\
0001 \\
0001 \\
0001 \\
0001 \\
0001 \\
0001 \\
0001 \\
0001 \\
0001 \\
0001 \\
0001 \\
0001 \\
0001 \\
0001 \\
0001 \\
0001\end{array}$ & $\begin{array}{l}\mathrm{JE} \\
\mathrm{JE} \\
\mathrm{JE} \\
\mathrm{JE} \\
\mathrm{JE} \\
\mathrm{JE} \\
\mathrm{JE} \\
\mathrm{JE} \\
\mathrm{JE} \\
\mathrm{JE} \\
\mathrm{JE} \\
\mathrm{JE} \\
\mathrm{JE} \\
\mathrm{JE} \\
\mathrm{JE} \\
\mathrm{JE} \\
\mathrm{JE} \\
\mathrm{JE} \\
\mathrm{JE} \\
\mathrm{JE}\end{array}$ & $\begin{array}{l}U \\
U \\
U \\
U \\
U \\
U \\
0 \\
0 \\
0 \\
0 \\
0 \\
0 \\
0 \\
0 \\
0 \\
0 \\
0 \\
0 \\
0 \\
0\end{array}$ & MG/L & $\begin{array}{l}< \\
< \\
< \\
< \\
< \\
< \\
< \\
< \\
< \\
< \\
< \\
< \\
< \\
< \\
< \\
< \\
< \\
< \\
< \\
< \\
<\end{array}$ & $\begin{array}{l}0.01 \\
0.01 \\
0.01 \\
0.01 \\
0.01 \\
0.01 \\
0.01 \\
0.01 \\
0.01 \\
0.01 \\
0.01 \\
0.01 \\
0.01 \\
0.01 \\
0.01 \\
0.01 \\
0.01 \\
0.01 \\
0.01 \\
0.01\end{array}$ & $\begin{array}{l}L \\
L \\
L \\
L \\
L \\
L \\
L \\
L \\
L \\
L \\
L \\
L \\
L \\
L\end{array}$ & $\begin{array}{l}0.01 \\
0.01 \\
0.01 \\
0.01 \\
0.01 \\
0.01 \\
0.01 \\
0.01 \\
0.01 \\
0.01 \\
0.01 \\
0.01 \\
0.01 \\
0.01 \\
0.01 \\
0.01 \\
0.01 \\
0.01 \\
0.01 \\
0.01\end{array}$ & $\begin{array}{l}- \\
: \\
: \\
: \\
: \\
: \\
: \\
: \\
- \\
- \\
- \\
- \\
- \\
-\end{array}$ \\
\hline CHROMIUN (TOTAL) & 0554 & $02 / 17 / 94$ & N001 & JE & $u$ & $M G / L$ & & 0.01 & & 0.01 & - \\
\hline
\end{tabular}

FORMATION OF COMPLETION CODE:

JE - JURASSIC ENTRADA SANDSTONE FORMATION

PARAMETER VALUE INDICATOR (PVI): < - LESS THAN DETECTION LIMIT

OTHER PARAMETER VALUE FLAGS:

$L$ - LESS THAN THREE BORE VOLUMES REMOVED BEFORE SAMPLING
FLOW RELATIONSHIP CODE:

- UPGRADIENT

\section{SAMPLE ID CODES:}

0001 - FILTERED SAMPLE (.45 MICRONS)

NOO1 - UNFILTERED SAMPLE 
TABLE 3.33 BASELINE GROUND HATER DATA BY PARAMETER FOR THE ENTRADA

FORMATION, UC PROCESSING SITE, SLICK ROCK, COLORADO

SITE: SRKO1 SLICK ROCK (BOTH SITES)

$03 / 29 / 89$ TO $02 / 21 / 94$

\begin{tabular}{|c|c|c|c|c|c|c|c|c|c|c|c|c|}
\hline & PARAMETER NAME & $\begin{array}{l}\text { LOCATION } \\
\text { ID }\end{array}$ & LOG DATE & \begin{tabular}{|} 
SAMPLE \\
ID
\end{tabular} & $\begin{array}{l}\text { FORH } \\
\text { COMP }\end{array}$ & $\begin{array}{l}\text { FLOW } \\
\text { REL. }\end{array}$ & $\begin{array}{l}\text { UNITS OF } \\
\text { MEASURE }\end{array}$ & PVI & $\begin{array}{l}\text { RAMETEI } \\
\text { VALUE }\end{array}$ & FLAGS & $\begin{array}{l}\text { DETECTION } \\
\text { LIMIT }\end{array}$ & $\begin{array}{l}\text { PARAMETER } \\
\text { UNCERTAINTY }\end{array}$ \\
\hline & CHROMIUH (TOTAL) & $\begin{array}{l}0702 \\
0704\end{array}$ & $\left|\begin{array}{l}02 / 21 / 94 \\
02 / 17 / 94\end{array}\right|$ & $\begin{array}{l}\text { N001 } \\
\text { N001 }\end{array}$ & $\begin{array}{l}\mathrm{JE} \\
\mathrm{JE}\end{array}$ & $\begin{array}{l}0 \\
0\end{array}$ & MG/L & $<$ & $\begin{array}{l}0.01 \\
0.01\end{array}$ & $L$ & $\begin{array}{l}0.01 \\
0.01\end{array}$ & - \\
\hline & COBALT & $\begin{array}{l}0554 \\
0554 \\
0554 \\
0554 \\
0702 \\
0702 \\
0702 \\
0702 \\
0702 \\
0704 \\
0704 \\
0704 \\
0704 \\
0704\end{array}$ & \begin{tabular}{|l|}
$12 / 12 / 90$ \\
$03 / 28 / 91$ \\
$08 / 05 / 91$ \\
$12 / 06 / 91$ \\
$03 / 29 / 89$ \\
$12 / 12 / 90$ \\
$03 / 31 / 91$ \\
$08 / 07 / 91$ \\
$12 / 07 / 91$ \\
$03 / 29 / 89$ \\
$12 / 12 / 90$ \\
$04 / 01 / 91$ \\
$08 / 24 / 91$ \\
$12 / 12 / 91$
\end{tabular} & $\begin{array}{l}0001 \\
0001 \\
0001 \\
0001 \\
0001 \\
0001 \\
0001 \\
0001 \\
0001 \\
0001 \\
0001 \\
0001 \\
0001 \\
0001\end{array}$ & $\begin{array}{l}\mathrm{JE} \\
\mathrm{JE} \\
\mathrm{JE} \\
\mathrm{JE} \\
\mathrm{JE} \\
\mathrm{JE} \\
\mathrm{JE} \\
\mathrm{JE} \\
\mathrm{JE} \\
\mathrm{JE} \\
\mathrm{JE} \\
\mathrm{JE} \\
\mathrm{JE} \\
\mathrm{JE}\end{array}$ & $\begin{array}{l}U \\
U \\
U \\
U \\
0 \\
0 \\
0 \\
0 \\
0 \\
0 \\
0 \\
0 \\
0 \\
0\end{array}$ & MG/L & $\begin{array}{l}< \\
< \\
< \\
< \\
< \\
< \\
< \\
< \\
< \\
< \\
< \\
< \\
< \\
< \\
< \\
<\end{array}$ & $\begin{array}{l}0.05 \\
0.03 \\
0.03 \\
0.03 \\
0.02 \\
0.05 \\
0.03 \\
0.03 \\
0.03 \\
0.02 \\
0.05 \\
0.03 \\
0.03 \\
0.03\end{array}$ & $\begin{array}{l}J L \\
L \\
L \\
L \\
L \\
J L \\
L \\
L \\
L \\
L\end{array}$ & $\begin{array}{l}0.05 \\
0.03 \\
0.03 \\
0.03 \\
0.05 \\
0.05 \\
0.03 \\
0.03 \\
0.03 \\
0.05 \\
0.05 \\
0.03 \\
0.03 \\
0.03\end{array}$ & $\begin{array}{l}- \\
- \\
- \\
- \\
- \\
- \\
- \\
- \\
- \\
- \\
-\end{array}$ \\
\hline$\dot{\omega}$ & COPPER & $\begin{array}{l}0554 \\
0554 \\
0554 \\
0554 \\
0554 \\
0702 \\
0702 \\
0702 \\
0702 \\
0702 \\
0702 \\
0704 \\
0704 \\
0704 \\
0704 \\
0704 \\
0704\end{array}$ & $\begin{array}{l}12 / 12 / 90 \\
03 / 28 / 91 \\
08 / 05 / 91 \\
12 / 06 / 91 \\
10 / 15 / 92 \\
03 / 29 / 89 \\
12 / 12 / 90 \\
03 / 31 / 91 \\
08 / 07 / 91 \\
12 / 07 / 91 \\
10 / 11 / 92 \\
03 / 29 / 89 \\
12 / 12 / 90 \\
04 / 01 / 91 \\
08 / 24 / 91 \\
12 / 12 / 91 \\
10 / 12 / 92\end{array}$ & $\begin{array}{l}0001 \\
0001 \\
0001 \\
0001 \\
0001 \\
0001 \\
0001 \\
0001 \\
0001 \\
0001 \\
0001 \\
0001 \\
0001 \\
0001 \\
0001 \\
0001 \\
0001\end{array}$ & $\begin{array}{l}J E \\
J E \\
J E \\
J E \\
J E \\
J E \\
J E \\
J E \\
J E \\
J E \\
J E \\
J E \\
J E \\
J E \\
J E \\
J E \\
J E\end{array}$ & $\begin{array}{l}U \\
U \\
U \\
U \\
U \\
0 \\
0 \\
0 \\
0 \\
0 \\
0 \\
0 \\
0 \\
0 \\
0 \\
0 \\
0\end{array}$ & $M G / L$ & $\begin{array}{l}< \\
< \\
< \\
< \\
< \\
< \\
< \\
< \\
< \\
< \\
< \\
< \\
< \\
< \\
< \\
< \\
< \\
<\end{array}$ & $\begin{array}{l}0.02 \\
0.01 \\
0.01 \\
0.01 \\
0.01 \\
0.01 \\
0.02 \\
0.01 \\
0.01 \\
0.01 \\
0.01 \\
0.01 \\
0.02 \\
0.01 \\
0.01 \\
0.01 \\
0.01\end{array}$ & $\begin{array}{l}J L \\
L \\
L \\
L \\
L \\
L \\
J L \\
L \\
L \\
L \\
L \\
L\end{array}$ & $\begin{array}{l}0.02 \\
0.01 \\
0.01 \\
0.01 \\
0.01 \\
0.02 \\
0.02 \\
0.01 \\
0.01 \\
0.01 \\
0.01 \\
0.02 \\
0.02 \\
0.01 \\
0.01 \\
0.01 \\
0.01\end{array}$ & $\begin{array}{l}- \\
- \\
- \\
- \\
- \\
- \\
- \\
- \\
- \\
- \\
- \\
- \\
- \\
-\end{array}$ \\
\hline & CYANIDE & $\begin{array}{l}0554 \\
0554\end{array}$ & $\begin{array}{l}12 / 12 / 90 \\
03 / 28 / 91\end{array}$ & $\begin{array}{l}0001 \\
0001\end{array}$ & $\begin{array}{l}\text { JE } \\
\text { JE }\end{array}$ & $\begin{array}{l}U \\
U\end{array}$ & $M G / L$ & $k$ & $\begin{array}{l}0.01 \\
0.01\end{array}$ & & $\begin{array}{l}0.01 \\
0.01\end{array}$ & - \\
\hline
\end{tabular}

FORMATION OF CONPLETION CODE:

JE - JURASSIC ENTRADA SANDSTONE FORMATION

PARAMETER VALUE INDICATOR (PVI): < - LESS THAN DETECTION LIMIT

OTHER PARAMETER VALUE FLAGS:

$J$ - ESTIMATED VALUE

L - LESS THAN THREE BORE VOLUMES REMOVED BEFORE SAMPLING
FLON RELATIONSHIP CODE:

O- ON-SITE

$U$ - UPGRADIENT

SAMPLE ID CODES:

0001 - FILTERED SAMPLE (.45 MICRONS)

N001 - UNFILTERED SAMPLE 
TABLE 3.33 BASELINE GROUND WATER DATA BY PARAMETER FOR THE ENTRADA FORMATION, UC PROCESSING SITE, SLICK ROCK, COLORADO

SITE: SRKO1 SLICK ROCK (BOTH SITES)

03/29/89 TO 02/21/94

REPORT DATE: $09 / 30 / 94$

\begin{tabular}{|c|c|c|c|c|c|c|c|c|c|c|c|}
\hline PARAMETER NAME & $\underset{\text { ID }}{\text { LOCATION }}$ & LOG DATE & $\underset{\text { ID }}{\text { SAMPLE }}$ & $\begin{array}{l}\text { FORM } \\
\text { COMP }\end{array}$ & $\begin{array}{l}\text { FLOW } \\
\text { REL. }\end{array}$ & $\begin{array}{l}\text { UNITS OF } \\
\text { MEASURE }\end{array}$ & PVI & $\begin{array}{l}\text { ARAMETER } \\
\text { VALUE }\end{array}$ & FLAGS & $\begin{array}{l}\text { DETECTION } \\
\text { LIMIT }\end{array}$ & $\begin{array}{l}\text { PARAMETER } \\
\text { UNCERTAINTY }\end{array}$ \\
\hline CYANIDE & $\begin{array}{l}0554 \\
0554 \\
0702 \\
0702 \\
0702 \\
0702 \\
0702 \\
0704 \\
0704 \\
0704 \\
0704 \\
0704\end{array}$ & $\begin{array}{l}08 / 05 / 91 \\
12 / 06 / 91 \\
03 / 29 / 89 \\
12 / 12 / 90 \\
03 / 31 / 91 \\
08 / 07 / 91 \\
12 / 07 / 91 \\
03 / 29 / 89 \\
12 / 12 / 90 \\
04 / 01 / 91 \\
08 / 24 / 91 \\
12 / 12 / 91\end{array}$ & $\begin{array}{l}0001 \\
0001 \\
0001 \\
0001 \\
0001 \\
0001 \\
0001 \\
0001 \\
0001 \\
0001 \\
0001 \\
0001\end{array}$ & $\begin{array}{l}\mathrm{JE} \\
\mathrm{JE} \\
\mathrm{JE} \\
\mathrm{JE} \\
\mathrm{JE} \\
\mathrm{JE} \\
\mathrm{JE} \\
\mathrm{JE} \\
\mathrm{JE} \\
\mathrm{JE} \\
\mathrm{JE} \\
\mathrm{JE}\end{array}$ & $\begin{array}{l}U \\
U \\
0 \\
0 \\
0 \\
0 \\
0 \\
0 \\
0 \\
0 \\
0 \\
0\end{array}$ & $M G / L$ & $\begin{array}{l}< \\
< \\
< \\
< \\
< \\
< \\
< \\
< \\
< \\
< \\
< \\
<\end{array}$ & $\begin{array}{l}0.01 \\
0.01 \\
0.007 \\
0.01 \\
0.01 \\
0.01 \\
0.01 \\
0.002 \\
0.01 \\
0.01 \\
0.01 \\
0.01\end{array}$ & $\begin{array}{l}\mathrm{JL} \\
\mathrm{L} \\
\mathrm{L} \\
\mathrm{L} \\
\mathrm{L} \\
\mathrm{L} \\
\mathrm{JL} \\
\mathrm{L} \\
\mathrm{L} \\
\mathrm{L} \\
\mathrm{L}\end{array}$ & $\begin{array}{l}0.01 \\
0.01 \\
0.01 \\
0.01 \\
0.01 \\
0.01 \\
0.01 \\
0.01 \\
0.01 \\
0.01 \\
0.01 \\
0.01\end{array}$ & $\begin{array}{l}- \\
- \\
- \\
- \\
- \\
- \\
- \\
-\end{array}$ \\
\hline DISSOLVED ORGANIC CARBON & $\begin{array}{l}0554 \\
0704\end{array}$ & $\begin{array}{l}02 / 17 / 94 \\
02 / 17 / 94\end{array}$ & $\begin{array}{l}0001 \\
0001\end{array}$ & $\begin{array}{l}\mathrm{JE} \\
\mathrm{JE}\end{array}$ & $\begin{array}{l}u \\
0\end{array}$ & $M G / L$ & & $\begin{array}{r}26 \\
3\end{array}$ & L & $\begin{array}{l}1 \\
1\end{array}$ & . \\
\hline DISSOLVED OXYGEN & $\begin{array}{l}0554 \\
0702 \\
0702 \\
0704\end{array}$ & $\begin{array}{l}10 / 15 / 92 \\
10 / 11 / 92 \\
02 / 21 / 94 \\
10 / 12 / 92\end{array}$ & $\begin{array}{l}0001 \\
0001 \\
\text { N001 } \\
0001\end{array}$ & $\begin{array}{l}\mathrm{JE} \\
\mathrm{JE} \\
\mathrm{JE} \\
\mathrm{JE}\end{array}$ & $\begin{array}{l}U \\
0 \\
0 \\
0\end{array}$ & $\mathrm{MG} / \mathrm{L}$ & & $\begin{array}{l}0.0 \\
9.6 \\
7.7 \\
5.0\end{array}$ & $\begin{array}{l}\mathbf{L} \\
\mathbf{L} \\
\mathrm{L}\end{array}$ & : & $\dot{-}$ \\
\hline FIELD FE (2+) & 0554 & $10 / 15 / 92$ & 0001 & JE & $u$ & $M G / L$ & & 1.84 & & - & - \\
\hline FIELD FE (TOTAL) & 0554 & $10 / 15 / 92$ & 0001 & JE & $\mathrm{U}$ & $M G / L$ & & 1.98 & & - & - \\
\hline FLUORIDE & $\begin{array}{l}0554 \\
0554 \\
0554 \\
0554 \\
0554 \\
0702 \\
0702 \\
0702 \\
0702 \\
0702 \\
0702 \\
0704 \\
0704\end{array}$ & $\begin{array}{l}12 / 12 / 90 \\
03 / 28 / 91 \\
08 / 05 / 91 \\
12 / 06 / 91 \\
10 / 15 / 92 \\
03 / 29 / 89 \\
12 / 12 / 90 \\
03 / 31 / 91 \\
08 / 07 / 91 \\
12 / 07 / 91 \\
10 / 11 / 92 \\
03 / 29 / 89 \\
12 / 12 / 90\end{array}$ & $\begin{array}{l}0001 \\
0001 \\
0001 \\
0001 \\
0001 \\
0001 \\
0001 \\
0001 \\
0001 \\
0001 \\
0001 \\
0001 \\
0001\end{array}$ & $\begin{array}{l}\mathrm{JE} \\
\mathrm{JE} \\
\mathrm{JE} \\
\mathrm{JE} \\
\mathrm{JE} \\
\mathrm{JE} \\
\mathrm{JE} \\
\mathrm{JE} \\
\mathrm{JE} \\
\mathrm{JE} \\
\mathrm{JE} \\
\mathrm{JE} \\
\mathrm{JE}\end{array}$ & $\begin{array}{l}U \\
U \\
U \\
U \\
U \\
0 \\
0 \\
0 \\
0 \\
0 \\
0 \\
0 \\
0\end{array}$ & $M G / L$ & $<$ & $\begin{array}{l}0.3 \\
0.1 \\
0.2 \\
0.1 \\
0.2 \\
0.3 \\
0.2 \\
0.2 \\
0.2 \\
0.2 \\
0.2 \\
0.4 \\
0.4\end{array}$ & $\begin{array}{l}\mathrm{L} \\
\mathrm{L} \\
\mathrm{L} \\
\mathrm{L} \\
\mathrm{L} \\
\mathrm{L} \\
\mathrm{L} \\
\mathrm{HL}\end{array}$ & $\begin{array}{l}0.1 \\
0.1 \\
0.1 \\
0.1 \\
0.1 \\
0.1 \\
0.1 \\
0.1 \\
0.1 \\
0.1 \\
0.1 \\
0.1 \\
0.1\end{array}$ & $\begin{array}{l}- \\
\vdots \\
\vdots \\
: \\
- \\
- \\
-\end{array}$ \\
\hline
\end{tabular}

FORMATION OF COMPLETION CODE:

JE - JURASSIC ENTRADA SANDSTONE FORMATION

FLOW RELATIONSHIP CODE:

$U$ - UPGRADIENT

O - ON-SITE

PARAMETER VALUE INDICATOR (PVI): < - LESS THAN DETECTION LIMIT

MAPLE ID CODES:

0001 - FILTERED SAMPLE (.45 MICRONS)

OTHER PARAMETER VALUE FLAGS:

H - HOLD TIME EXPIRED, VALUE SUSPECT

NO01 - UNFILTERED SAMPLE

$J$ - ESTIMATED VALUE

L - LESS THAN THREE BORE VOLUMES REMOVED BEFORE SAMPLING 
TABLE 3.33 BASELINE GROUND HATER DATA BY PARAMETER FOR THE ENTRADA FORMATION, UC PROCESSING SITE, SLICK ROCK, COLORADD

SITE: SRKO1 SLICK ROCK (BOTH SITES)

$03 / 29 / 89$ TO $02 / 21 / 94$

REPORT DATE: $09 / 30 / 94$

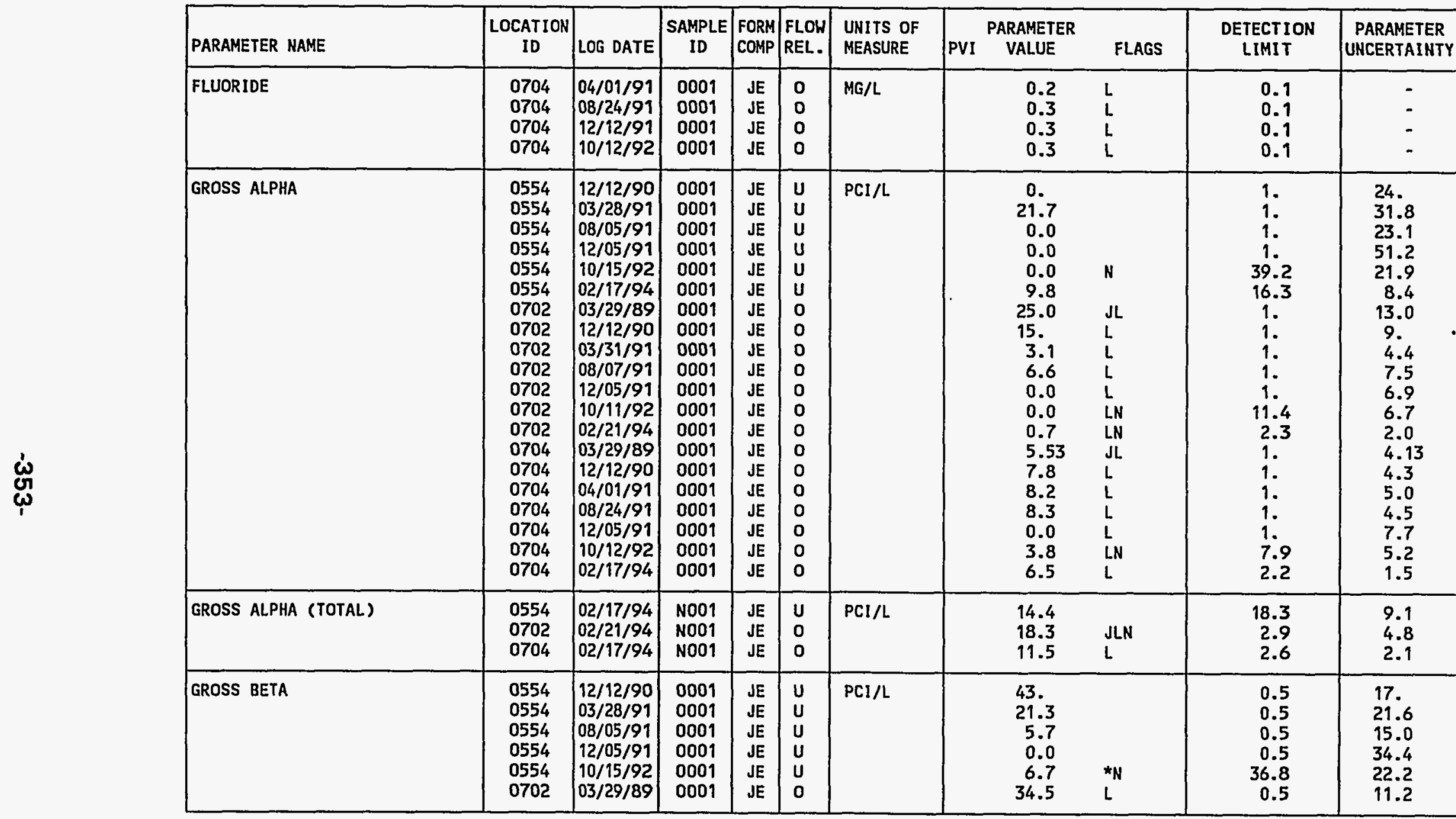

FORMATION OF COMPLETION CODE:

JE - JURASSIC ENTRADA SANDSTONE FORMATION

PARAMETER VALUE INDICATOR (PVI): < - LESS THAN DETECTION LIMIT

OTHER PARAMETER VALUE FLAGS:

* - DUPLICATE ANALYSIS NOT WITHIN CONTROL LIMITS

$J$ - ESTIMATED VALUE

L - LESS THAN THREE BORE VOLUMES REMOVED BEFORE SAMPLING

$N$ - SPIKE SAMPLE RECOVERY NOT WITHIN CONTROL LIMITS
FLOW RELATIONSHIP CODE:

O - ON-SITE

$U$ - UPGRADIENT

SAMPLE ID CODES:

0001 - FILTERED SAMPLE (.45 MICRONS)

N001 - UNFILTERED SAMPLE 
TABLE 3.33 BASELINE GROUND HATER DATA BY PARAMETER FOR THE ENTRADA

FORMATION, UC PROCESSING SITE, SLICK ROCK, COLORADO

SITE: SRK01 SLICK ROCK (BOTH SITES)

03/29/89 TO $02 / 21 / 94$

REPORT DATE: $09 / 30 / 94$

\begin{tabular}{|c|c|c|c|c|c|c|c|c|c|c|c|}
\hline PARAMETER NAME & $\underset{\text { ID }}{\text { LOCATION }}$ & LOG DATE & $\begin{array}{c}\text { SAMPLE } \\
\text { ID }\end{array}$ & $\begin{array}{l}\text { FORM } \\
\text { COMP }\end{array}$ & $\begin{array}{l}\text { FLOW } \\
\text { REL. }\end{array}$ & $\begin{array}{l}\text { UNITS OF } \\
\text { MEASURE }\end{array}$ & PVI & $\begin{array}{l}\text { ARAMETER } \\
\text { VALUE }\end{array}$ & FLAGS & $\begin{array}{l}\text { DETECTION } \\
\text { LIMIT }\end{array}$ & $\begin{array}{l}\text { PARAMETER } \\
\text { UNCERTAINTY }\end{array}$ \\
\hline GROSS BETA & $\begin{array}{l}0702 \\
0702 \\
0702 \\
0702 \\
0702 \\
0704 \\
0704 \\
0704 \\
0704 \\
0704 \\
0704\end{array}$ & $\begin{array}{l}12 / 12 / 90 \\
03 / 31 / 91 \\
08 / 07 / 91 \\
12 / 05 / 91 \\
10 / 11 / 92 \\
03 / 29 / 89 \\
12 / 12 / 90 \\
04 / 01 / 91 \\
08 / 24 / 91 \\
12 / 05 / 91 \\
10 / 12 / 92\end{array}$ & $\begin{array}{l}0001 \\
0001 \\
0001 \\
0001 \\
0001 \\
0001 \\
0001 \\
0001 \\
0001 \\
0001 \\
0001\end{array}$ & $\begin{array}{l}\text { JE } \\
\text { JE } \\
\text { JE } \\
\text { JE } \\
\text { JE } \\
\text { JE } \\
\text { JE } \\
\text { JE } \\
\text { JE } \\
\text { JE } \\
\text { JE }\end{array}$ & $\begin{array}{l}0 \\
0 \\
0 \\
0 \\
0 \\
0 \\
0 \\
0 \\
0 \\
0 \\
0\end{array}$ & $\mathrm{PCI} / \mathrm{L}$ & & $\begin{array}{r}8.6 \\
4.6 \\
10.5 \\
0.0 \\
9.3 \\
16.1 \\
6.2 \\
8.3 \\
11.1 \\
0.0 \\
5.3\end{array}$ & $\begin{array}{l}L \\
L \\
L \\
L \\
{ }^{*} L N \\
L \\
L \\
L \\
L \\
L \\
{ }^{*} L N\end{array}$ & $\begin{array}{r}0.5 \\
0.5 \\
0.5 \\
0.5 \\
10.0 \\
0.5 \\
0.5 \\
0.5 \\
0.5 \\
0.5 \\
7.0\end{array}$ & $\begin{array}{l}4.2 \\
4.2 \\
5.7 \\
5.4 \\
6.4 \\
5.20 \\
2.2 \\
2.8 \\
3.2 \\
4.9 \\
4.4\end{array}$ \\
\hline IRON & $\begin{array}{l}0554 \\
0554 \\
0554 \\
0554 \\
0554 \\
0554 \\
0702 \\
0702 \\
0702 \\
0702 \\
0702 \\
0702 \\
0702 \\
0704 \\
0704 \\
0704 \\
0704 \\
0704 \\
0704 \\
0704\end{array}$ & \begin{tabular}{|l|}
$12 / 12 / 90$ \\
$03 / 28 / 91$ \\
$08 / 05 / 91$ \\
$12 / 06 / 91$ \\
$10 / 15 / 92$ \\
$02 / 17 / 94$ \\
$03 / 29 / 89$ \\
$12 / 12 / 90$ \\
$03 / 31 / 91$ \\
$08 / 07 / 91$ \\
$12 / 07 / 91$ \\
$10 / 11 / 92$ \\
$02 / 21 / 94$ \\
$03 / 29 / 89$ \\
$12 / 12 / 90$ \\
$04 / 01 / 91$ \\
$08 / 24 / 91$ \\
$12 / 12 / 91$ \\
$10 / 12 / 92$ \\
$02 / 17 / 94$
\end{tabular} & $\begin{array}{l}0001 \\
0001 \\
0001 \\
0001 \\
0001 \\
0001 \\
0001 \\
0001 \\
0001 \\
0001 \\
0001 \\
0001 \\
0001 \\
0001 \\
0001 \\
0001 \\
0001 \\
0001 \\
0001 \\
0001\end{array}$ & $\begin{array}{l}\mathrm{JE} \\
\mathrm{JE} \\
\mathrm{JE} \\
\mathrm{JE} \\
\mathrm{JE} \\
\mathrm{JE} \\
\mathrm{JE} \\
\mathrm{JE} \\
\mathrm{JE} \\
\mathrm{JE} \\
\mathrm{JE} \\
\mathrm{JE} \\
\mathrm{JE} \\
\mathrm{JE} \\
\mathrm{JE} \\
\mathrm{JE} \\
\mathrm{JE} \\
\mathrm{JE} \\
\mathrm{JE} \\
\mathrm{JE}\end{array}$ & $\begin{array}{l}U \\
U \\
U \\
U \\
U \\
U \\
0 \\
0 \\
0 \\
0 \\
0 \\
0 \\
0 \\
0 \\
0 \\
0 \\
0 \\
0 \\
0 \\
0\end{array}$ & $M G / L$ & $\begin{array}{l}< \\
< \\
< \\
< \\
< \\
<\end{array}$ & $\begin{array}{l}0.73 \\
0.61 \\
0.75 \\
0.91 \\
2.33 \\
3.19 \\
0.02 \\
0.03 \\
0.03 \\
0.03 \\
0.03 \\
0.04 \\
0.11 \\
0.02 \\
0.03 \\
0.03 \\
0.03 \\
0.03 \\
0.03 \\
0.03\end{array}$ & $\begin{array}{l}J L \\
L \\
L \\
L \\
L \\
L \\
L \\
d L \\
L \\
L \\
L \\
L \\
L \\
L\end{array}$ & $\begin{array}{l}0.03 \\
0.03 \\
0.03 \\
0.03 \\
0.03 \\
0.03 \\
0.03 \\
0.03 \\
0.03 \\
0.03 \\
0.03 \\
0.03 \\
0.03 \\
0.03 \\
0.03 \\
0.03 \\
0.03 \\
0.03 \\
0.03 \\
0.03\end{array}$ & $\begin{array}{l}- \\
- \\
- \\
- \\
- \\
- \\
- \\
- \\
- \\
- \\
- \\
- \\
- \\
- \\
- \\
- \\
-\end{array}$ \\
\hline IRON (TOTAL) & $\begin{array}{l}0554 \\
0702 \\
0704\end{array}$ & $\begin{array}{l}02 / 17 / 94 \\
02 / 21 / 94 \\
02 / 17 / 94\end{array}$ & $\begin{array}{l}\text { N001 } \\
\text { N001 } \\
\text { N001 }\end{array}$ & $\begin{array}{l}\mathrm{JE} \\
\mathrm{JE} \\
\mathrm{JE}\end{array}$ & $\begin{array}{l}U \\
0 \\
0\end{array}$ & $M G / L$ & & $\begin{array}{c}13.6 \\
10.9 \\
2.31\end{array}$ & $\stackrel{L}{L}$ & $\begin{array}{l}0.03 \\
0.03 \\
0.03\end{array}$ & - \\
\hline LEAD & 0554 & $12 / 12 / 90$ & 0001 & JE & $u$ & MG/L & $<$ & 0.01 & & 0.01 & - \\
\hline
\end{tabular}

FORMATION OF COMPLETION CODE:

JE - JURASSIC ENTRADA SANDSTONE FORMATION

FLOH RELATIONSHIP CODE:

O - ON-SITE

$U$ - UPGRADIENT

PARAMETER VALUE INDICATOR (PVI): < - LESS THAN DETECTION LIMIT

SAMPLE ID CODES:

0001 - FILTERED SAMPLE (.45 MICRONS)

OTHER PARAMETER VALUE FLAGS:

* - DUPLICATE ANALYSIS NOT WITHIN CONTROL LIMITS

N001 - UNFILTERED SAMPLE

$J$ - ESTIMATED VALUE

L - LESS THAN THREE BORE VOLUMES REMOVED BEFORE SAMPLING

N - SPIKE SAMPLE RECOVERY NOT WITHIN CONTROL LIMITS 
TABLE 3.33 BASELINE GROUND WATER DATA BY PARAMETER FOR THE ENTRADA FORMATION, UC PROCESSING SITE, SLICK ROCK, COLORADO

SITE: SRKO1 SLICK ROCK (BOTH SITES)

03/29/89 TO 02/21/94

REPORT DATE: $09 / 30 / 9$

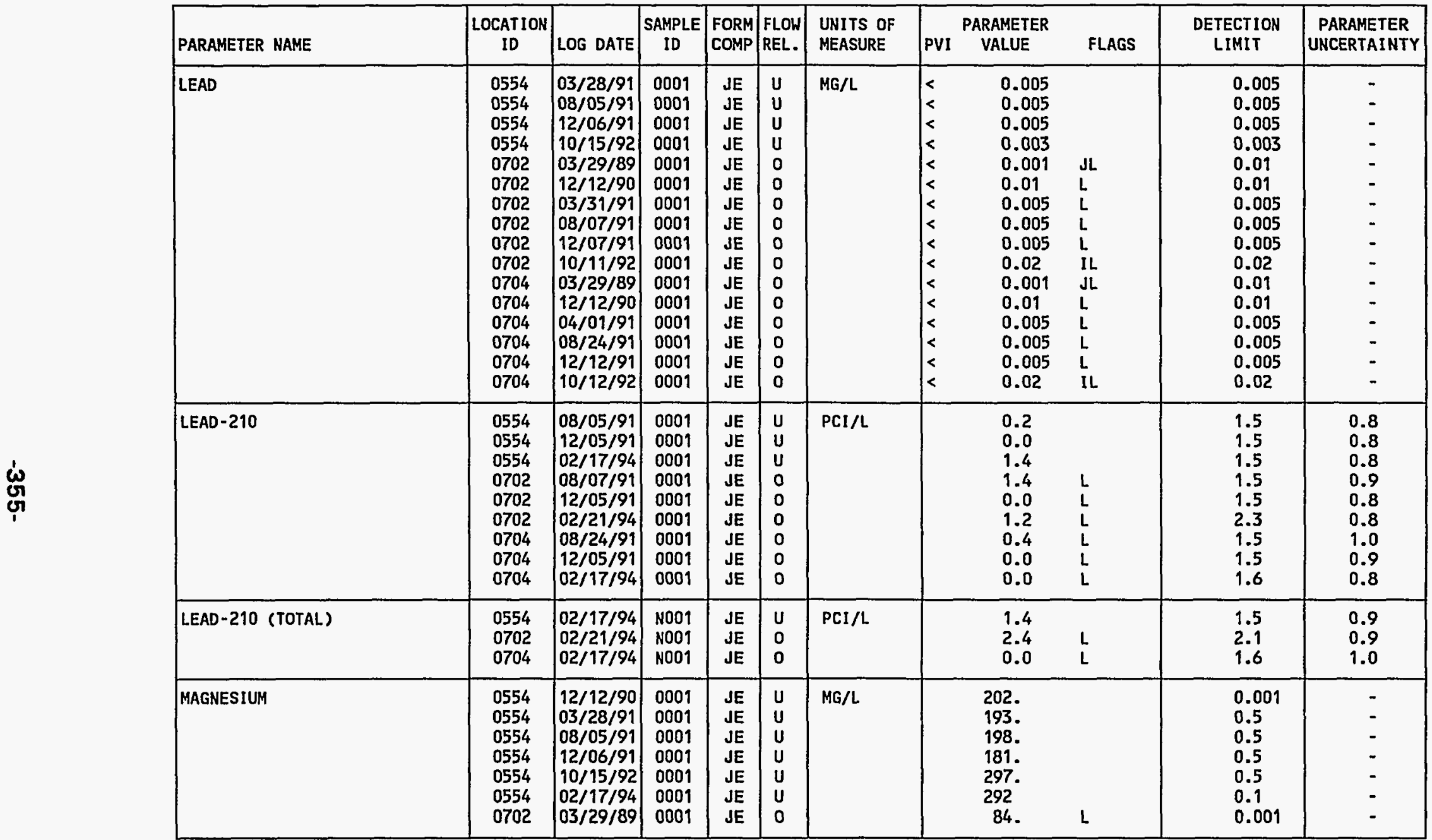

FORMATION OF COMPLETION CODE:

JE - JURASSIC ENTRADA SANDSTONE FORMATION

FLOW RELATIONSHIP CODE:

U - UPGRADIENT

O - ON-SITE

PARAMETER VALUE INDICATOR (PVI): < - LESS THAN DETECTION LIMIT

SAMPLE ID CODES:

ODO1 - FILTERED SAMPLE (.45 MICRONS)

OTHER PARAMETER VALUE FLAGS:

I - INCREASED DETECTION LIMIT DUE TO REQUIRED DILUTION

NO01 - UNFILTERED SAMPLE

STIMATED VALUE

L - LESS THAN THREE BORE VOLUMES REMOVED BEFORE SAMPLING 
TABLE 3.33 BASELINE GROUND WATER DATA BY PARAMETER FOR THE ENTRADA

FORMATION, UC PROCESSING SITE, SLICK ROCK, COLORADO

SITE: SRKO1 SLICK ROCK (BOTH SITES)

03/29/89 TO 02/21/94

REPORT DATE : $09 / 30 / 94$

\begin{tabular}{|c|c|c|c|c|c|c|c|c|c|c|c|c|}
\hline & PARAMETER NAME & $\underbrace{\text { LOCATION }}_{\text {ID }}$ & LOG DATE & $\underset{10}{\text { SAMPLE }}$ & $\begin{array}{l}\text { FORM } \\
\text { COMP }\end{array}$ & $\begin{array}{l}\text { FLOW } \\
\text { REL. }\end{array}$ & $\begin{array}{l}\text { UNITS OF } \\
\text { MEASURE }\end{array}$ & PVI & $\begin{array}{l}\text { PARAMETER } \\
\text { VALUE }\end{array}$ & FLAGS & $\begin{array}{l}\text { DETECTION } \\
\text { LIMIT }\end{array}$ & $\begin{array}{l}\text { PARAMETER } \\
\text { UNCERTAINTY }\end{array}$ \\
\hline & MAGNESIUM & $\begin{array}{l}0702 \\
0702 \\
0702 \\
0702 \\
0702 \\
0702 \\
0704 \\
0704 \\
0704 \\
0704 \\
0704 \\
0704 \\
0704\end{array}$ & $\begin{array}{l}12 / 12 / 90 \\
03 / 31 / 91 \\
08 / 07 / 91 \\
12 / 07 / 91 \\
10 / 11 / 92 \\
02 / 21 / 94 \\
03 / 29 / 89 \\
12 / 12 / 90 \\
04 / 01 / 91 \\
08 / 24 / 91 \\
12 / 12 / 91 \\
10 / 12 / 92 \\
02 / 17 / 94\end{array}$ & $\begin{array}{l}0001 \\
0001 \\
0001 \\
0001 \\
0001 \\
0001 \\
0001 \\
0001 \\
0001 \\
0001 \\
0001 \\
0001 \\
0001\end{array}$ & $\begin{array}{l}\text { JE } \\
\text { JE } \\
\text { JE } \\
\text { JE } \\
\text { JE } \\
\text { JE } \\
\text { JE } \\
\text { JE } \\
\text { JE } \\
\text { JE } \\
\text { JE } \\
\text { JE } \\
\text { JE }\end{array}$ & $\begin{array}{l}0 \\
0 \\
0 \\
0 \\
0 \\
0 \\
0 \\
0 \\
0 \\
0 \\
0 \\
0 \\
0\end{array}$ & $M G / L$ & & $\begin{array}{c}105 . \\
86.0 \\
94.4 \\
64.8 \\
108 . \\
98.2 \\
42 . \\
44.3 \\
45.4 \\
47.5 \\
44.1 \\
39.5 \\
32.2\end{array}$ & $\begin{array}{l}L \\
L \\
L \\
L \\
L \\
L \\
L \\
L \\
L \\
L \\
L \\
L \\
L\end{array}$ & $\begin{array}{l}0.001 \\
0.5 \\
0.5 \\
0.5 \\
0.5 \\
0.1 \\
0.001 \\
0.001 \\
0.1 \\
0.1 \\
0.1 \\
0.1 \\
0.1\end{array}$ & $\begin{array}{l}- \\
- \\
- \\
- \\
- \\
- \\
- \\
- \\
- \\
- \\
-\end{array}$ \\
\hline & MAGNESIUM (TOTAL) & $\begin{array}{l}0554 \\
0702 \\
0704\end{array}$ & $\begin{array}{l}02 / 17 / 94 \\
02 / 21 / 94 \\
02 / 17 / 94\end{array}$ & $\begin{array}{l}\text { N001 } \\
\text { N001 } \\
\text { N001 }\end{array}$ & $\begin{array}{l}\text { JE } \\
\text { JE } \\
\text { JE }\end{array}$ & $\begin{array}{l}U \\
0 \\
0\end{array}$ & $M G / L$ & & $\begin{array}{c}312 \\
103 \\
38.0\end{array}$ & $\begin{array}{l}L \\
L\end{array}$ & $\begin{array}{l}0.1 \\
0.1 \\
0.1\end{array}$ & $\begin{array}{l}- \\
-\end{array}$ \\
\hline \begin{tabular}{l}
$\dot{\omega}$ \\
\multirow{\sigma}{*}{} \\
$\sigma_{1}$
\end{tabular} & MANGANESE & $\begin{array}{l}0554 \\
0554 \\
0554 \\
0554 \\
0554 \\
0554 \\
0702 \\
0702 \\
0702 \\
0702 \\
0702 \\
0702 \\
0702 \\
0704 \\
0704 \\
0704 \\
0704 \\
0704 \\
0704 \\
0704\end{array}$ & $\begin{array}{l}12 / 12 / 90 \\
03 / 28 / 91 \\
08 / 05 / 91 \\
12 / 06 / 91 \\
10 / 15 / 92 \\
02 / 17 / 94 \\
03 / 29 / 89 \\
12 / 12 / 90 \\
03 / 31 / 91 \\
08 / 07 / 91 \\
12 / 07 / 91 \\
10 / 11 / 92 \\
02 / 21 / 94 \\
03 / 29 / 89 \\
12 / 12 / 90 \\
04 / 01 / 91 \\
08 / 24 / 91 \\
12 / 12 / 91 \\
10 / 12 / 92 \\
02 / 17 / 94\end{array}$ & $\begin{array}{l}0001 \\
0001 \\
0001 \\
0001 \\
0001 \\
0001 \\
0001 \\
0001 \\
0001 \\
0001 \\
0001 \\
0001 \\
0001 \\
0001 \\
0001 \\
0001 \\
0001 \\
0001 \\
0001 \\
0001\end{array}$ & $\begin{array}{l}\mathrm{JE} \\
\mathrm{JE} \\
\mathrm{JE} \\
\mathrm{JE} \\
\mathrm{JE} \\
\mathrm{JE} \\
\mathrm{JE} \\
\mathrm{JE} \\
\mathrm{JE} \\
\mathrm{JE} \\
\mathrm{JE} \\
\mathrm{JE} \\
\mathrm{JE} \\
\mathrm{JE} \\
\mathrm{JE} \\
\mathrm{JE} \\
\mathrm{JE} \\
\mathrm{JE} \\
\mathrm{JE} \\
\mathrm{JE}\end{array}$ & $\begin{array}{l}U \\
U \\
U \\
U \\
U \\
U \\
0 \\
0 \\
0 \\
0 \\
0 \\
0 \\
0 \\
0 \\
0 \\
0 \\
0 \\
0 \\
0 \\
0\end{array}$ & $M G / L$ & $\begin{array}{l}< \\
< \\
< \\
< \\
< \\
< \\
< \\
< \\
< \\
< \\
< \\
<\end{array}$ & $\begin{array}{l}0.71 \\
0.62 \\
0.62 \\
0.55 \\
0.85 \\
0.79 \\
0.05 \\
0.02 \\
0.01 \\
0.01 \\
0.01 \\
0.02 \\
0.01 \\
0.05 \\
0.01 \\
0.01 \\
0.01 \\
0.01 \\
0.01 \\
0.01\end{array}$ & $\begin{array}{l}L \\
L \\
L \\
L \\
L \\
L \\
L \\
L \\
L \\
L \\
L \\
L \\
L \\
L\end{array}$ & $\begin{array}{l}0.01 \\
0.01 \\
0.01 \\
0.01 \\
0.01 \\
0.01 \\
0.01 \\
0.01 \\
0.01 \\
0.01 \\
0.01 \\
0.01 \\
0.01 \\
0.01 \\
0.01 \\
0.01 \\
0.01 \\
0.01 \\
0.01 \\
0.01\end{array}$ & $\begin{array}{l}- \\
- \\
- \\
- \\
- \\
- \\
- \\
- \\
- \\
- \\
- \\
- \\
- \\
- \\
- \\
-\end{array}$ \\
\hline & MANGANESE (TOTAL) & 0554 & $02 / 17 / 94$ & N001 & JE & U & $M G / L$ & & 1.26 & & 0.01 & - \\
\hline
\end{tabular}

FORMATION OF COMPLETION CODE:

JE - JURASSIC ENTRADA SANDSTONE FORMATION

FLOW RELATIONSHIP CODE:

O - ON-SITE

PARAMETER VALUE INDICATOR (PVI): < - LESS THAN DETECTION LIMIT

\section{SAMPLE ID CODES:}

0001 - FILTERED SAMPLE (.45 MICRONS)

OTHER PARAMETER VALUE FLAGS:

NOO1 - UNFILTERED SAMPLE

L - LESS THAN THREE BORE VOLUMES REMOVED BEFORE SAMPLING 
TABLE 3.33 BASEL INE GROUND HATER DATA BY PARAMETER FOR THE ENTRADA FORMATION, UC PROCESSING SITE, SLICK ROCK, COLORADO

SITE: SRKO1 SLICK ROCK (BOTH SITES)

03/29/89 TO $02 / 21 / 94$

\begin{tabular}{|c|c|c|c|c|c|c|c|c|c|c|c|c|}
\hline & PARAMETER NAME & $\underset{\text { ID }}{\text { LOCATION }}$ & LOG DATE & $\underset{\text { SD }}{\text { SAMPLE }}$ & $\begin{array}{l}\text { FORM } \\
\text { COMP }\end{array}$ & $\begin{array}{l}\text { FLOH } \\
\text { REL. }\end{array}$ & $\begin{array}{l}\text { UNITS OF } \\
\text { MEASURE }\end{array}$ & PVI & $\begin{array}{l}\text { PARAMETER } \\
\text { VALUE }\end{array}$ & FLAGS & $\begin{array}{l}\text { DETECT ION } \\
\text { LIMIT }\end{array}$ & $\begin{array}{l}\text { PARAMETER } \\
\text { UNCERTAINTY }\end{array}$ \\
\hline & MANGANESE (TOTAL) & $\begin{array}{l}0702 \\
0704\end{array}$ & $\begin{array}{l}02 / 21 / 94 \\
02 / 17 / 94\end{array}$ & $\begin{array}{l}\text { N001 } \\
\text { N001 }\end{array}$ & $\begin{array}{l}\text { JE } \\
\text { JE }\end{array}$ & $\begin{array}{l}\mathbf{0} \\
\mathbf{0}\end{array}$ & MG/L & & $\begin{array}{l}0.49 \\
0.08\end{array}$ & $\begin{array}{l}L \\
L\end{array}$ & $\begin{array}{l}0.01 \\
0.01\end{array}$ & $\dot{-}$ \\
\hline & MERCURY & $\begin{array}{l}0554 \\
0554 \\
0554 \\
0554 \\
0702 \\
0702 \\
0702 \\
0702 \\
0702 \\
0704 \\
0704 \\
0704 \\
0704 \\
0704\end{array}$ & $\begin{array}{l}12 / 12 / 90 \\
03 / 28 / 91 \\
08 / 05 / 91 \\
12 / 06 / 91 \\
03 / 29 / 89 \\
12 / 12 / 90 \\
03 / 31 / 91 \\
08 / 07 / 91 \\
12 / 07 / 91 \\
03 / 29 / 89 \\
12 / 12 / 90 \\
04 / 01 / 91 \\
08 / 24 / 91 \\
12 / 12 / 91\end{array}$ & $\begin{array}{l}0001 \\
0001 \\
0001 \\
0001 \\
0001 \\
0001 \\
0001 \\
0001 \\
0001 \\
0001 \\
0001 \\
0001 \\
0001 \\
0001\end{array}$ & $\begin{array}{l}\mathrm{JE} \\
\mathrm{JE} \\
\mathrm{JE} \\
\mathrm{JE} \\
\mathrm{JE} \\
\mathrm{JE} \\
\mathrm{JE} \\
\mathrm{JE} \\
\mathrm{JE} \\
\mathrm{JE} \\
\mathrm{JE} \\
\mathrm{JE} \\
\mathrm{JE} \\
\mathrm{JE}\end{array}$ & $\begin{array}{l}U \\
U \\
U \\
U \\
0 \\
0 \\
0 \\
0 \\
0 \\
0 \\
0 \\
0 \\
0 \\
0\end{array}$ & $M G / L$ & $\begin{array}{l}< \\
< \\
< \\
< \\
< \\
< \\
< \\
< \\
< \\
< \\
< \\
< \\
< \\
< \\
<\end{array}$ & $\begin{array}{l}0.0002 \\
0.0002 \\
0.0002 \\
0.0002 \\
0.0001 \\
0.0002 \\
0.0002 \\
0.0002 \\
0.0002 \\
0.0001 \\
0.0002 \\
0.0002 \\
0.0002 \\
0.0002\end{array}$ & $\begin{array}{l}\mathrm{JL} \\
\mathrm{L} \\
\mathrm{L} \\
\mathrm{L} \\
\mathrm{L} \\
\mathrm{J} \mathrm{L} \\
\mathrm{L} \\
\mathrm{L} \\
\mathrm{L} \\
\mathrm{L}\end{array}$ & $\begin{array}{l}0.0002 \\
0.0002 \\
0.0002 \\
0.0002 \\
0.0002 \\
0.0002 \\
0.0002 \\
0.0002 \\
0.0002 \\
0.0002 \\
0.0002 \\
0.0002 \\
0.0002 \\
0.0002\end{array}$ & $\begin{array}{l}- \\
- \\
- \\
- \\
- \\
- \\
- \\
- \\
- \\
- \\
-\end{array}$ \\
\hline $\begin{array}{c}\dot{\omega} \\
\tilde{\sigma}\end{array}$ & MOLYBDENUM & $\begin{array}{l}0554 \\
0554 \\
0554 \\
0554 \\
0554 \\
0554 \\
0702 \\
0702 \\
0702 \\
0702 \\
0702 \\
0702 \\
0702 \\
0704 \\
0704 \\
0704 \\
0704 \\
0704 \\
0704 \\
0704\end{array}$ & $\begin{array}{l}12 / 12 / 90 \\
03 / 28 / 91 \\
08 / 05 / 91 \\
12 / 06 / 91 \\
10 / 15 / 92 \\
02 / 17 / 94 \\
03 / 29 / 89 \\
12 / 12 / 90 \\
03 / 31 / 91 \\
08 / 07 / 91 \\
12 / 07 / 91 \\
10 / 11 / 92 \\
02 / 21 / 94 \\
03 / 29 / 89 \\
12 / 12 / 90 \\
04 / 01 / 91 \\
08 / 24 / 91 \\
12 / 12 / 91 \\
10 / 12 / 92 \\
02 / 17 / 94\end{array}$ & $\begin{array}{l}0001 \\
0001 \\
0001 \\
0001 \\
0001 \\
0001 \\
0001 \\
0001 \\
0001 \\
0001 \\
0001 \\
0001 \\
0001 \\
0001 \\
0001 \\
0001 \\
0001 \\
0001 \\
0001 \\
0001\end{array}$ & $\begin{array}{l}\mathrm{JE} \\
\mathrm{JE} \\
\mathrm{JE} \\
\mathrm{JE} \\
\mathrm{JE} \\
\mathrm{JE} \\
\mathrm{JE} \\
\mathrm{JE} \\
\mathrm{JE} \\
\mathrm{JE} \\
\mathrm{JE} \\
\mathrm{JE} \\
\mathrm{JE} \\
\mathrm{JE} \\
\mathrm{JE} \\
\mathrm{JE} \\
\mathrm{JE} \\
\mathrm{JE} \\
\mathrm{JE} \\
\mathrm{JE}\end{array}$ & $\begin{array}{l}U \\
U \\
U \\
U \\
U \\
U \\
0 \\
0 \\
0 \\
0 \\
0 \\
0 \\
0 \\
0 \\
0 \\
0 \\
0 \\
0 \\
0 \\
0\end{array}$ & MG/L & $\begin{array}{l}< \\
< \\
< \\
< \\
< \\
< \\
< \\
< \\
< \\
< \\
< \\
< \\
< \\
< \\
< \\
< \\
<\end{array}$ & $\begin{array}{l}0.06 \\
0.01 \\
0.01 \\
0.01 \\
0.01 \\
0.01 \\
0.017 \\
0.04 \\
0.01 \\
0.01 \\
0.01 \\
0.01 \\
0.01 \\
0.003 \\
0.02 \\
0.01 \\
0.01 \\
0.01 \\
0.01 \\
0.01\end{array}$ & $\begin{array}{l}L \\
L \\
L \\
L \\
L \\
L \\
L \\
J L \\
L \\
L \\
L \\
L \\
L \\
L\end{array}$ & $\begin{array}{l}0.01 \\
0.01 \\
0.01 \\
0.01 \\
0.01 \\
0.01 \\
0.01 \\
0.01 \\
0.01 \\
0.01 \\
0.01 \\
0.01 \\
0.01 \\
0.01 \\
0.01 \\
0.01 \\
0.01 \\
0.01 \\
0.01 \\
0.01\end{array}$ & $\begin{array}{l}- \\
- \\
- \\
- \\
- \\
- \\
- \\
- \\
- \\
- \\
- \\
- \\
- \\
- \\
- \\
-\end{array}$ \\
\hline & \multicolumn{6}{|c|}{$\begin{array}{l}\text { FORMATION OF COMPLETION CODE: } \\
\text { JE - JURASSIC ENTRADA SANDSTONE FORMATION }\end{array}$} & \multicolumn{4}{|c|}{$\begin{array}{l}\text { FLOW RELATIONSHIP CODE: } \\
0 \text { - ON-SITE } \\
\text { U - UPGRADIENT }\end{array}$} & & \\
\hline & $\begin{array}{l}\text { PARAMETER VALUE INDICATOR (PVI): } \\
\text { OTHER PARAMETER VALUE FLAGS: }\end{array}$ & \multicolumn{2}{|c|}{$<$ - LESS THAN } & \multicolumn{3}{|c|}{ DETECTION LIMIT } & \multicolumn{5}{|c|}{$\begin{array}{l}\text { SAMPLE ID CODES: } \\
\text { O001 - FILTERED SAMPLE (.45 MICRONS) } \\
\text { NO01 - UNFILTERED SAMPLE }\end{array}$} & \\
\hline
\end{tabular}

OTHER PARAMETER VALUE FLAGS:

OOO1 - FILTERED SAMPLE

L - LESS THAN THREE BORE VOLUMES REMOVED BEFORE SAMPLING 
TABLE 3.33 BASELINE GROUND HATER DATA BY PARAMETER FOR THE ENTRADA FORMATION, UC PROCESSING SITE, SLICK ROCK, COLORADO

SITE: SRKO1 SLICK ROCK (BOTH SITES)

$03 / 29 / 89$ TO $02 / 21 / 94$

REPORT DATE: $09 / 30 / 94$

\begin{tabular}{|c|c|c|c|c|c|c|c|c|c|c|c|}
\hline PARAMETER NAME & $\left|\begin{array}{c}\text { LOCATION } \\
\text { ID }\end{array}\right|$ & LOG DATE & $\begin{array}{c}\text { SAMPLE } \\
\text { ID }\end{array}$ & $\begin{array}{l}\text { FORM } \\
\text { COMP }\end{array}$ & $\begin{array}{l}\text { FLOW } \\
\text { REL. }\end{array}$ & $\begin{array}{l}\text { UNITS OF } \\
\text { MEASURE }\end{array}$ & PVI & $\begin{array}{l}\text { ARAMETER } \\
\text { VALUE }\end{array}$ & FLAGS & $\begin{array}{l}\text { DETECTION } \\
\text { LIMIT }\end{array}$ & $\begin{array}{l}\text { PARAMETER } \\
\text { UNCERTAINTY }\end{array}$ \\
\hline MOLYBDENUM (TOTAL) & $\begin{array}{l}0554 \\
0702 \\
0704\end{array}$ & $\left|\begin{array}{l}02 / 17 / 94 \\
02 / 21 / 94 \\
02 / 17 / 94\end{array}\right|$ & $\begin{array}{l}\text { N001 } \\
\text { N001 } \\
\text { N001 }\end{array}$ & $\begin{array}{l}\text { JE } \\
\text { JE } \\
\text { JE }\end{array}$ & $\begin{array}{l}U \\
0 \\
0\end{array}$ & $M G / L$ & $<$ & $\begin{array}{l}0.01 \\
0.01 \\
0.01\end{array}$ & $\begin{array}{l}L \\
L\end{array}$ & $\begin{array}{l}0.01 \\
0.01 \\
0.01\end{array}$ & - \\
\hline NET GROSS ALPHA * & $\begin{array}{l}0554 \\
0554 \\
0554 \\
0554 \\
0554 \\
0554 \\
0702 \\
0702 \\
0702 \\
0702 \\
0702 \\
0702 \\
0702 \\
0704 \\
0704 \\
0704 \\
0704 \\
0704 \\
0704 \\
0704\end{array}$ & $\begin{array}{l}12 / 12 / 90 \\
03 / 28 / 91 \\
08 / 05 / 91 \\
12 / 05 / 91 \\
10 / 15 / 92 \\
02 / 17 / 94 \\
03 / 29 / 89 \\
12 / 12 / 90 \\
03 / 31 / 91 \\
08 / 07 / 91 \\
12 / 05 / 91 \\
10 / 11 / 92 \\
02 / 21 / 94 \\
03 / 29 / 89 \\
12 / 12 / 90 \\
04 / 01 / 91 \\
08 / 24 / 91 \\
12 / 05 / 91 \\
10 / 12 / 92 \\
02 / 17 / 94\end{array}$ & $\begin{array}{l}0001 \\
0001 \\
0001 \\
0001 \\
0001 \\
0001 \\
0001 \\
0001 \\
0001 \\
0001 \\
0001 \\
0001 \\
0001 \\
0001 \\
0001 \\
0001 \\
0001 \\
0001 \\
0001 \\
0001\end{array}$ & $\begin{array}{l}\mathrm{JE} \\
\mathrm{JE} \\
\mathrm{JE} \\
\mathrm{JE} \\
\mathrm{JE} \\
\mathrm{JE} \\
\mathrm{JE} \\
\mathrm{JE} \\
\mathrm{JE} \\
\mathrm{JE} \\
\mathrm{JE} \\
\mathrm{JE} \\
\mathrm{JE} \\
\mathrm{JE} \\
\mathrm{JE} \\
\mathrm{JE} \\
\mathrm{JE} \\
\mathrm{JE} \\
\mathrm{JE} \\
\mathrm{JE}\end{array}$ & $\begin{array}{l}U \\
U \\
U \\
U \\
U \\
U \\
0 \\
0 \\
0 \\
0 \\
0 \\
0 \\
0 \\
0 \\
0 \\
0 \\
0 \\
0 \\
0 \\
0\end{array}$ & $\mathrm{PCI} / \mathrm{L}$ & & $\begin{array}{r}-1.17 \\
21.01 \\
-0.34 \\
-1.37 \\
-0.34 \\
8.43 \\
-7.24 \\
2.79 \\
0.36 \\
-0.26 \\
-2.74 \\
-10.29 \\
-1.36 \\
1.41 \\
5.88 \\
7.51 \\
7.61 \\
-2.74 \\
1.74 \\
3.76\end{array}$ & & $\begin{array}{l}- \\
- \\
- \\
- \\
- \\
- \\
- \\
- \\
- \\
- \\
- \\
- \\
- \\
- \\
- \\
-\end{array}$ & $\begin{array}{l}- \\
- \\
- \\
- \\
- \\
- \\
- \\
- \\
- \\
- \\
- \\
- \\
- \\
- \\
- \\
- \\
- \\
-\end{array}$ \\
\hline NET GROSS ALPHA (TOTAL) ** & $\begin{array}{l}0554 \\
0702 \\
0704\end{array}$ & $\begin{array}{l}02 / 17 / 94 \\
02 / 21 / 94 \\
02 / 17 / 94\end{array}$ & $\begin{array}{l}\text { N001 } \\
\text { N001 } \\
\text { N001 }\end{array}$ & $\begin{array}{l}\mathrm{JE} \\
\mathrm{JE} \\
\mathrm{JE}\end{array}$ & $\begin{array}{l}U \\
0 \\
0\end{array}$ & $\mathrm{PCI} / \mathrm{L}$ & & $\begin{array}{r}11.66 \\
16.24 \\
8.76\end{array}$ & & - & : \\
\hline NICKEL & $\begin{array}{l}0554 \\
0554 \\
0554 \\
0554 \\
0554 \\
0702\end{array}$ & $\begin{array}{l}12 / 12 / 90 \\
03 / 28 / 91 \\
08 / 05 / 91 \\
12 / 06 / 91 \\
10 / 15 / 92 \\
03 / 29 / 89\end{array}$ & $\begin{array}{l}0001 \\
0001 \\
0001 \\
0001 \\
0001 \\
0001\end{array}$ & $\begin{array}{l}\mathrm{JE} \\
\mathrm{JE} \\
\mathrm{JE} \\
\mathrm{JE} \\
\mathrm{JE} \\
\mathrm{JE}\end{array}$ & $\begin{array}{l}U \\
U \\
U \\
U \\
U \\
0\end{array}$ & $M G / L$ & $\begin{array}{l}< \\
< \\
< \\
< \\
< \\
<\end{array}$ & $\begin{array}{l}0.04 \\
0.04 \\
0.04 \\
0.04 \\
0.04 \\
0.02\end{array}$ & JL & $\begin{array}{l}0.04 \\
0.04 \\
0.04 \\
0.04 \\
0.04 \\
0.04\end{array}$ & $\begin{array}{l}- \\
- \\
- \\
-\end{array}$ \\
\hline
\end{tabular}

* NET GROSS ALPHA (GROSS ALPHA - URANIUM) WITH 1 MG URANIUM = 686 PCI

** NET GROSS ALPHA (TOTAL) (TOTAL GROSS ALPHA - TOTAL URANIUM)

FORMATION OF COMPLETION CODE:

JE - JURASSIC ENTRADA SANDSTONE FORMATION

PARAMETER VALUE INDICATOR (PVI): < - LESS THAN DETECTION LIMIT

OTHER PARAMETER VALUE FLAGS:

$J$ - ESTIMATED VALUE

L - LESS THAN THREE BORE VOLUMES REMOVED BEFORE SAMPLING
FLOW RELATIONSHIP CODE:

$U$ - UPGRADIENT

O - ON-SITE

SAMPLE ID CODES:

0001 - FILTERED SAMPLE (.45 MICRONS)

NOO1 - UNFILTERED SAMPLE 
TABLE 3.33 BASELINE GROUND WATER DATA BY PARAMETER FOR THE ENTRADA

FORMATION, UC PROCESSING SITE, SLICK ROCK, COLORADD

SITE: SRKO1 SLICK ROCK (BOTH SITES)

$03 / 29 / 89$ TO $02 / 21 / 94$

\begin{tabular}{|c|c|c|c|c|c|c|c|c|c|c|c|c|}
\hline & PARAMETER NAME & $\underset{\text { ID }}{\text { LOCATION }}$ & LOG DATE & $\begin{array}{c}\text { SAMPLE } \\
\text { ID }\end{array}$ & $\begin{array}{l}\text { FORM } \\
\text { COMP }\end{array}$ & $\begin{array}{l}\text { FLOH } \\
\text { REL. }\end{array}$ & $\begin{array}{l}\text { UNITS OF } \\
\text { MEASURE }\end{array}$ & PVI & $\begin{array}{l}\text { ARAMETER } \\
\text { VALUE }\end{array}$ & FLAGS & $\begin{array}{l}\text { DETECTION } \\
\text { LIMIT }\end{array}$ & $\begin{array}{l}\text { PARAMETER } \\
\text { UNCERTAINTY }\end{array}$ \\
\hline & NICKEL. & $\begin{array}{l}0702 \\
0702 \\
0702 \\
0702 \\
0702 \\
0704 \\
0704 \\
0704 \\
0704 \\
0704 \\
0704\end{array}$ & $\begin{array}{l}12 / 12 / 90 \\
03 / 31 / 91 \\
08 / 07 / 91 \\
12 / 07 / 91 \\
10 / 11 / 92 \\
03 / 29 / 89 \\
12 / 12 / 90 \\
04 / 01 / 91 \\
08 / 24 / 91 \\
12 / 12 / 91 \\
10 / 12 / 92\end{array}$ & $\begin{array}{l}0001 \\
0001 \\
0001 \\
0001 \\
0001 \\
0001 \\
0001 \\
0001 \\
0001 \\
0001 \\
0001\end{array}$ & $\begin{array}{l}\text { JE } \\
\text { JE } \\
\text { JE } \\
\text { JE } \\
J E \\
\text { JE } \\
\text { JE } \\
\text { JE } \\
\text { JE } \\
\text { JE } \\
\text { JE }\end{array}$ & $\begin{array}{l}0 \\
0 \\
0 \\
0 \\
0 \\
0 \\
0 \\
0 \\
0 \\
0 \\
0\end{array}$ & $M G / L$ & $\begin{array}{l}< \\
< \\
< \\
< \\
< \\
< \\
< \\
< \\
< \\
< \\
< \\
< \\
<.\end{array}$ & $\begin{array}{l}0.04 \\
0.04 \\
0.04 \\
0.04 \\
0.04 \\
0.02 \\
0.04 \\
0.04 \\
0.04 \\
0.04 \\
0.04\end{array}$ & $\begin{array}{l}L \\
L \\
L \\
L \\
L \\
J L \\
L \\
L \\
L \\
L \\
L\end{array}$ & $\begin{array}{l}0.04 \\
0.04 \\
0.04 \\
0.04 \\
0.04 \\
0.04 \\
0.04 \\
0.04 \\
0.04 \\
0.04 \\
0.04\end{array}$ & $\begin{array}{l}- \\
- \\
- \\
- \\
= \\
- \\
- \\
-\end{array}$ \\
\hline 、 & NITRATE & $\begin{array}{l}0554 \\
0554 \\
0554 \\
0554 \\
0554 \\
0702 \\
0702 \\
0702 \\
0702 \\
0702 \\
0702 \\
0704 \\
0704 \\
0704 \\
0704 \\
0704 \\
0704\end{array}$ & $\begin{array}{l}12 / 12 / 90 \\
03 / 28 / 91 \\
08 / 05 / 91 \\
12 / 06 / 91 \\
10 / 15 / 92 \\
03 / 29 / 89 \\
12 / 12 / 90 \\
03 / 31 / 91 \\
08 / 07 / 91 \\
12 / 07 / 91 \\
10 / 11 / 92 \\
03 / 29 / 89 \\
12 / 12 / 90 \\
04 / 01 / 91 \\
08 / 24 / 91 \\
12 / 12 / 91 \\
10 / 12 / 92\end{array}$ & $\begin{array}{l}0001 \\
0001 \\
0001 \\
0001 \\
0001 \\
0001 \\
0001 \\
0001 \\
0001 \\
0001 \\
0001 \\
0001 \\
0001 \\
0001 \\
0001 \\
0001 \\
0001\end{array}$ & $\begin{array}{l}J E \\
J E \\
J E \\
J E \\
J E \\
J E \\
J E \\
J E \\
J E \\
J E \\
J E \\
J E \\
J E \\
J E \\
J E \\
J E \\
J E\end{array}$ & $\begin{array}{l}U \\
U \\
U \\
U \\
U \\
0 \\
0 \\
0 \\
0 \\
0 \\
0 \\
0 \\
0 \\
0 \\
0 \\
0 \\
0\end{array}$ & MG/L & $\mid<$ & $\begin{array}{c}1 . \\
2.9 \\
1.0 \\
1.0 \\
1.9 \\
85.6 \\
126 . \\
66 . \\
79.2 \\
46.0 \\
105 . \\
10.8 \\
11 . \\
10.2 \\
12.5 \\
8.0 \\
7.8\end{array}$ & $\begin{array}{l}L \\
L \\
L \\
L \\
L \\
L \\
L \\
H L \\
L \\
L \\
L \\
L\end{array}$ & $\begin{array}{l}1 . \\
1 . \\
1 . \\
1 . \\
0.1 \\
1 . \\
1 . \\
1 . \\
1 . \\
7 . \\
10 . \\
1 . \\
1 . \\
1 . \\
1 . \\
1 . \\
1.0\end{array}$ & $\begin{array}{l}= \\
= \\
= \\
= \\
= \\
= \\
= \\
= \\
= \\
- \\
-\end{array}$ \\
\hline & NITRATE (TOTAL) & $\begin{array}{l}0554 \\
0702 \\
0704\end{array}$ & $\begin{array}{l}02 / 17 / 94 \\
02 / 21 / 94 \\
02 / 17 / 94\end{array}$ & $\begin{array}{l}\text { N001 } \\
\text { N001 } \\
\text { N001 }\end{array}$ & $\begin{array}{l}\mathrm{JE} \\
\mathrm{JE} \\
\mathrm{JE}\end{array}$ & $\begin{array}{l}U \\
0 \\
0\end{array}$ & $M G / L$ & $<$ & $\begin{array}{r}1 \\
96 \\
1\end{array}$ & $\begin{array}{l}L \\
L\end{array}$ & $\begin{array}{l}1 \\
1 \\
1\end{array}$ & - \\
\hline & NITRITE AND NITRATE & $\begin{array}{l}0554 \\
0554 \\
0554\end{array}$ & $\begin{array}{l}12 / 12 / 90 \\
03 / 28 / 91 \\
08 / 05 / 91\end{array}$ & $\begin{array}{l}0001 \\
0001 \\
0001\end{array}$ & $\begin{array}{l}J E \\
\text { JE } \\
\text { JE }\end{array}$ & $\begin{array}{l}U \\
U \\
U\end{array}$ & $M G / L$ & $<$ & $\begin{array}{l}1 . \\
0.66 \\
0.23\end{array}$ & $J$ & $\begin{array}{l}1 . \\
0.05 \\
0.05\end{array}$ & $\overline{-}$ \\
\hline
\end{tabular}

FORMATION OF COMPLETION CODE:

JE - JURASSIC ENTRADA SANDSTONE FORMATION

FLOW RELATIONSHIP CODE:

O - ON-SITE

PARAMETER VALUE INDICATOR (PVI): < - LESS thAN DETECTION LIMIT

OTHER PARAMETER VALUE FLAGS:

$U$ - UPGRADIENT

H - HOLD TIME EXPIRED, VALUE SUSPECT

SAMPLE ID CODES:

0001 - FILTERED SAMPLE (.45 MICRONS)

NOO1 - UNFILTEREE SAMPLE

$J$ - estimitied VALUE

L - LESS THAN THREE BORE VOLUMES REMOVED BEFORE SAMPLING 
TABLE 3.33 BASELINE GROUND WATER DATA BY PARAMETER FOR THE ENTRADA

FORMATION, UC PROCESSING SITE, SLICK ROCK, COLORADO

SITE: SRKO1 SLICK ROCK (BOTH SITES)

$03 / 29 / 89$ TO $02 / 21 / 94$

REPORT DATE: $09 / 30 / 94$

\begin{tabular}{|c|c|c|c|c|c|c|c|c|c|c|c|}
\hline PARAMETER NAME & $\begin{array}{c}\text { LOCATION } \\
\text { ID }\end{array}$ & LOG DATE & $\begin{array}{c}\text { SAMPLE } \\
\text { ID }\end{array}$ & $\begin{array}{l}\text { FORM } \\
\text { COMP }\end{array}$ & $\begin{array}{l}\text { FLOW } \\
\text { REL. }\end{array}$ & $\begin{array}{l}\text { UNITS OF } \\
\text { MEASURE }\end{array}$ & PVI & $\begin{array}{l}\text { ARAMETER } \\
\text { VALUE }\end{array}$ & FLAGS & $\begin{array}{l}\text { DETECTION } \\
\text { LIMIT }\end{array}$ & $\begin{array}{l}\text { PARAMETER } \\
\text { UNCERTAINTY }\end{array}$ \\
\hline NITRITE AND NITRATE & $\begin{array}{l}0702 \\
0702 \\
0702 \\
0704 \\
0704 \\
0704\end{array}$ & $\begin{array}{l}12 / 12 / 90 \\
03 / 31 / 91 \\
08 / 07 / 91 \\
12 / 12 / 90 \\
04 / 01 / 91 \\
08 / 24 / 91\end{array}$ & $\begin{array}{l}0001 \\
0001 \\
0001 \\
0001 \\
0001 \\
0001\end{array}$ & $\begin{array}{l}\mathrm{JE} \\
\mathrm{JE} \\
\mathrm{JE} \\
\mathrm{JE} \\
\mathrm{JE} \\
\mathrm{JE}\end{array}$ & $\begin{array}{l}0 \\
0 \\
0 \\
0 \\
0 \\
0\end{array}$ & $M G / L$ & & $\begin{array}{c}126 . \\
15.0 \\
17.9 \\
11 . \\
2.31 \\
2.82\end{array}$ & $\begin{array}{l}J L \\
L \\
L \\
J L \\
L \\
L\end{array}$ & $\begin{array}{l}1 . \\
0.05 \\
0.05 \\
1 . \\
0.05 \\
0.05\end{array}$ & : \\
\hline PH & $\begin{array}{l}0554 \\
0554 \\
0554 \\
0554 \\
0554 \\
0554 \\
0702 \\
0702 \\
0702 \\
0702 \\
0702 \\
0702 \\
0702 \\
0704 \\
0704 \\
0704 \\
0704 \\
0704 \\
0704 \\
0704\end{array}$ & $\begin{array}{l}12 / 12 / 90 \\
03 / 28 / 91 \\
08 / 05 / 91 \\
12 / 05 / 91 \\
10 / 15 / 92 \\
02 / 17 / 94 \\
03 / 29 / 89 \\
12 / 12 / 90 \\
03 / 31 / 91 \\
08 / 07 / 91 \\
12 / 05 / 91 \\
10 / 11 / 92 \\
02 / 21 / 94 \\
03 / 29 / 89 \\
12 / 12 / 90 \\
04 / 01 / 91 \\
08 / 24 / 91 \\
12 / 05 / 91 \\
10 / 12 / 92 \\
02 / 17 / 94\end{array}$ & $\begin{array}{l}0001 \\
0001 \\
0001 \\
0001 \\
0001 \\
N 001 \\
0001 \\
0001 \\
0001 \\
0001 \\
0001 \\
0001 \\
N 001 \\
0001 \\
0001 \\
0001 \\
0001 \\
0001 \\
0001 \\
\text { N001 }\end{array}$ & $\begin{array}{l}\mathrm{JE} \\
\mathrm{JE} \\
\mathrm{JE} \\
\mathrm{JE} \\
\mathrm{JE} \\
\mathrm{JE} \\
\mathrm{JE} \\
\mathrm{JE} \\
\mathrm{JE} \\
\mathrm{JE} \\
\mathrm{JE} \\
\mathrm{JE} \\
\mathrm{JE} \\
\mathrm{JE} \\
\mathrm{JE} \\
\mathrm{JE} \\
\mathrm{JE} \\
\mathrm{JE} \\
\mathrm{JE} \\
\mathrm{JE}\end{array}$ & $\begin{array}{l}U \\
U \\
U \\
U \\
U \\
U \\
0 \\
0 \\
0 \\
0 \\
0 \\
0 \\
0 \\
0 \\
0 \\
0 \\
0 \\
0 \\
0 \\
0\end{array}$ & su & & $\begin{array}{l}6.98 \\
7.06 \\
6.93 \\
7.09 \\
6.96 \\
7.00 \\
7.97 \\
7.79 \\
7.71 \\
7.83 \\
7.79 \\
7.90 \\
7.86 \\
7.74 \\
7.51 \\
7.79 \\
7.63 \\
7.84 \\
7.76 \\
7.77\end{array}$ & $\begin{array}{l}\mathrm{L} \\
\mathrm{L} \\
\mathrm{L} \\
\mathrm{L} \\
\mathrm{L} \\
\mathrm{L} \\
\mathrm{L} \\
\mathrm{L} \\
\mathrm{L} \\
\mathrm{L} \\
\mathrm{L} \\
\mathrm{L} \\
\mathrm{L} \\
\mathrm{L}\end{array}$ & $\begin{array}{l}- \\
- \\
- \\
- \\
- \\
- \\
- \\
- \\
- \\
- \\
- \\
- \\
- \\
- \\
- \\
-\end{array}$ & $\begin{array}{l}- \\
- \\
- \\
- \\
- \\
- \\
- \\
- \\
- \\
- \\
- \\
- \\
- \\
- \\
- \\
-\end{array}$ \\
\hline PHOSPHATE & $\begin{array}{l}0554 \\
0554 \\
0554 \\
0554 \\
0554 \\
0702 \\
0702 \\
0702 \\
0702 \\
0702\end{array}$ & $\begin{array}{l}12 / 12 / 90 \\
03 / 28 / 91 \\
08 / 05 / 91 \\
12 / 06 / 91 \\
10 / 15 / 92 \\
03 / 29 / 89 \\
12 / 12 / 90 \\
03 / 31 / 91 \\
08 / 07 / 91 \\
12 / 07 / 91\end{array}$ & $\begin{array}{l}0001 \\
0001 \\
0001 \\
0001 \\
0001 \\
0001 \\
0001 \\
0001 \\
0001 \\
0001\end{array}$ & $\begin{array}{l}\mathrm{JE} \\
\mathrm{JE} \\
\mathrm{JE} \\
\mathrm{JE} \\
\mathrm{JE} \\
\mathrm{JE} \\
\mathrm{JE} \\
\mathrm{JE} \\
\mathrm{JE} \\
\mathrm{JE}\end{array}$ & $\begin{array}{l}U \\
U \\
U \\
U \\
U \\
0 \\
0 \\
0 \\
0 \\
0\end{array}$ & $M G / L$ & $\mid<$ & $\begin{array}{l}0.1 \\
0.2 \\
0.2 \\
0.2 \\
0.1 \\
0.1 \\
0.1 \\
0.1 \\
0.1 \\
0.1\end{array}$ & $\begin{array}{l}H \\
J \\
L \\
H L \\
L \\
L \\
L\end{array}$ & $\begin{array}{l}0.1 \\
0.1 \\
0.1 \\
0.01 \\
0.1 \\
0.1 \\
0.1 \\
0.1 \\
0.1 \\
0.1\end{array}$ & $\begin{array}{l}- \\
- \\
- \\
- \\
- \\
- \\
- \\
-\end{array}$ \\
\hline
\end{tabular}

FORMATION OF COMPLETION CODE:

JE - JURASSIC ENTRADA SANDSTONE FORMATION

PARAMETER VALUE INDICATOR (PVI): < - LESS THAN DETECTION LIMIT

OTHER PARAMETER VALUE FLAGS:

H - HOLD TIME EXPIRED, VALUE SUSPECT

$J$ - ESTIMATED VALUE

L - LESS THAN THREE BORE VOLUMES REMOVED BEFORE SAMPLING
FLOW RELATIONSHIP CODE:

O - ON-SITE

$U$ - UPGRADIENT

SAMPLE ID CODES:

0001 - FILTERED SAMPLE (.45 MICRONS)

NO01 - UNFILTERED SAMPLE 
TABLE 3.33 BASELINE GROUND WATER DATA BY PARAMETER FOR THE ENTRADA

FORMATION, UC PROCESSING SITE, SLICK ROCK, COLORADO

SITE: SRKO1 SLICK ROCK (BOTH SITES)

$03 / 29 / 89$ TO $02 / 21 / 94$

REPORT DATE: 09/30/94

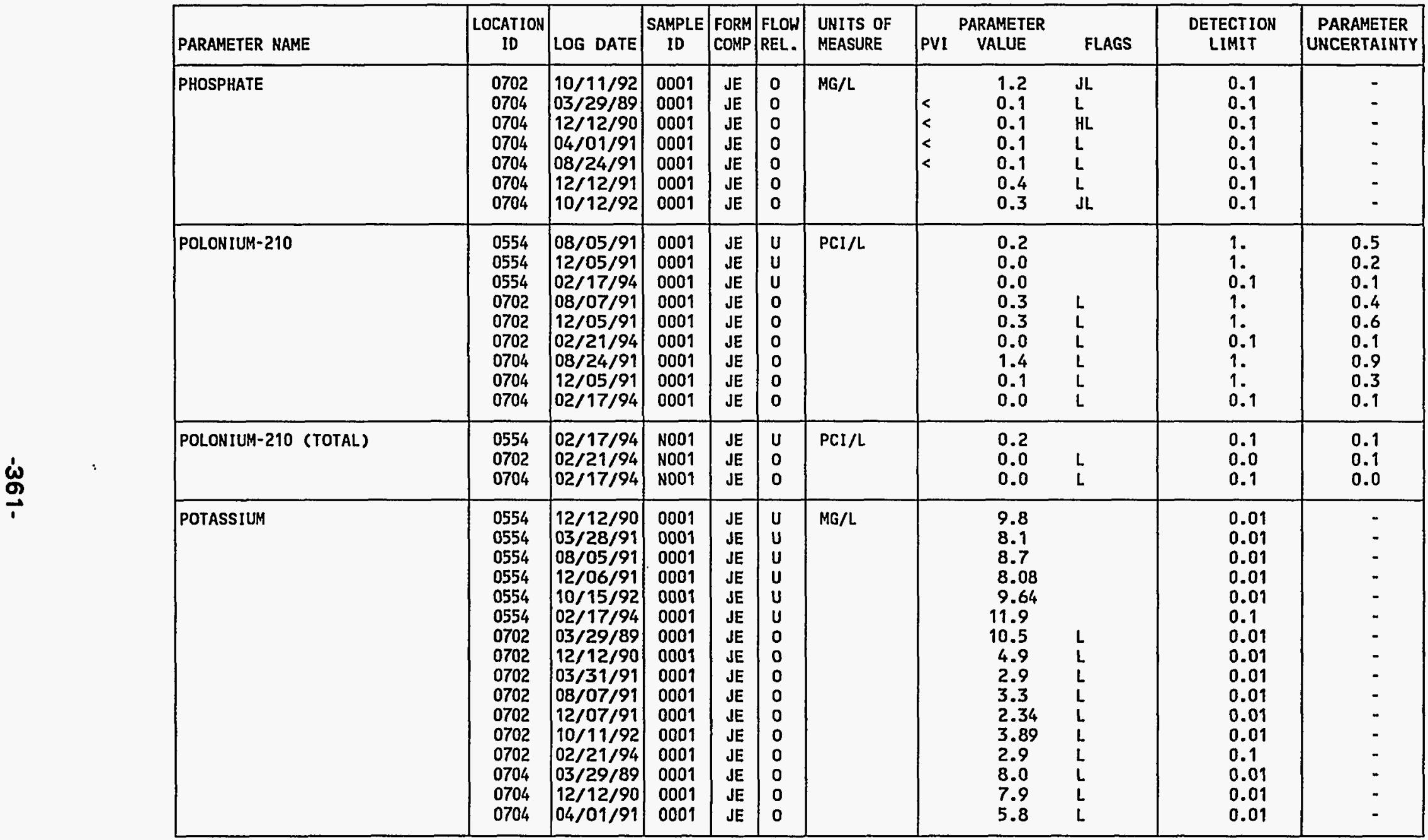

FORMATION OF COMPLETION CODE:

JE - JURASSIC ENTRADA SANDSTONE FORMATION

PARAMETER VALUE INDICATOR (PVI): < - LESS THAN DETECTION LIMIT

OTHER PARAMETER VALUE FLAGS:

H - HOLD TIME EXPIRED, VALUE SUSPECT

$J$ - ESTIMATED VALUE

L - LESS THAN THREE BORE VOLUMES REMOVED BEFORE SAMPLING
FLOW RELATIONSHIP CODE:

O - ON-SITE

$U$ - UPGRADIENT

SAMPLE ID CODES:

0001 - FILTERED SAMPLE (.45 MICRONS)

NOO1 - UNFILTERED SAMPLE 
TABLE 3.33 BASELINE GROUND WATER DATA BY PARAMETER FOR THE ENTRADA

FORMATION, UC PROCESSING SITE, SLICK ROCK, COLORADO

SITE: SRKO1 SLICK ROCK (BOTH SITES)

$03 / 29 / 89$ TO $02 / 21 / 94$

REPORT DATE: $09 / 30 / 94$

\begin{tabular}{|c|c|c|c|c|c|c|c|c|c|c|c|}
\hline PARAMETER NAME & $\begin{array}{c}\text { LOCAT ION } \\
\text { ID }\end{array}$ & LOG DATE & $\begin{array}{c}\text { SAMPLE } \\
\text { ID }\end{array}$ & $\begin{array}{l}\text { FORM } \\
\text { COMP }\end{array}$ & $\begin{array}{l}\text { FLOW } \\
\text { REL. }\end{array}$ & $\begin{array}{l}\text { UNITS OF } \\
\text { MEASURE }\end{array}$ & PVI & $\begin{array}{l}\text { PARAMETER } \\
\text { VALUE }\end{array}$ & FLAGS & $\begin{array}{l}\text { DETECTION } \\
\text { LIMIT }\end{array}$ & $\begin{array}{l}\text { PARAMETER } \\
\text { UNCERTAINTY }\end{array}$ \\
\hline POTASSIUM & $\begin{array}{l}0704 \\
0704 \\
0704 \\
0704\end{array}$ & $\left|\begin{array}{l}08 / 24 / 91 \\
12 / 12 / 91 \\
10 / 12 / 92 \\
02 / 17 / 94\end{array}\right|$ & $\begin{array}{l}0001 \\
0001 \\
0001 \\
0001\end{array}$ & $\begin{array}{l}\mathrm{JE} \\
\mathrm{JE} \\
\mathrm{JE} \\
\mathrm{JE}\end{array}$ & $\begin{array}{l}0 \\
0 \\
0 \\
0\end{array}$ & MG/L & & $\begin{array}{l}7.6 \\
8.39 \\
6.70 \\
8.9\end{array}$ & $\begin{array}{l}L \\
L \\
L \\
L\end{array}$ & $\begin{array}{l}0.01 \\
0.01 \\
0.01 \\
0.1\end{array}$ & $\begin{array}{l}- \\
- \\
-\end{array}$ \\
\hline POTASSIUM (TOTAL) & $\begin{array}{l}0554 \\
0702 \\
0704\end{array}$ & $\left|\begin{array}{l}02 / 17 / 94 \\
02 / 21 / 94 \\
02 / 17 / 94\end{array}\right|$ & $\begin{array}{l}\text { N001 } \\
\text { N001 } \\
\text { N001 }\end{array}$ & $\begin{array}{l}\mathrm{JE} \\
\mathrm{JE} \\
\mathrm{JE}\end{array}$ & $\begin{array}{l}U \\
0 \\
0\end{array}$ & MG/L & & $\begin{array}{r}16.1 \\
9.7 \\
11.1\end{array}$ & $\begin{array}{l}L \\
L\end{array}$ & $\begin{array}{l}0.1 \\
0.1 \\
0.1\end{array}$ & : \\
\hline RADIUM-226 & $\begin{array}{l}0554 \\
0554 \\
0554 \\
0554 \\
0554 \\
0554 \\
0702 \\
0702 \\
0702 \\
0702 \\
0702 \\
0702 \\
0704 \\
0704 \\
0704 \\
0704 \\
0704 \\
0704\end{array}$ & $\begin{array}{l}12 / 12 / 90 \\
03 / 28 / 91 \\
08 / 05 / 91 \\
12 / 05 / 91 \\
10 / 15 / 92 \\
02 / 17 / 94 \\
12 / 12 / 90 \\
03 / 31 / 91 \\
08 / 07 / 91 \\
12 / 05 / 91 \\
10 / 11 / 92 \\
02 / 21 / 94 \\
12 / 12 / 90 \\
04 / 01 / 91 \\
08 / 24 / 91 \\
12 / 05 / 91 \\
10 / 12 / 92 \\
02 / 17 / 94\end{array}$ & $\begin{array}{l}0001 \\
0001 \\
0001 \\
0001 \\
0001 \\
0001 \\
0001 \\
0001 \\
0001 \\
0001 \\
0001 \\
0001 \\
0001 \\
0001 \\
0001 \\
0001 \\
0001 \\
0001\end{array}$ & $\begin{array}{l}\mathrm{JE} \\
\mathrm{JE} \\
\mathrm{JE} \\
\mathrm{JE} \\
\mathrm{JE} \\
\mathrm{JE} \\
\mathrm{JE} \\
\mathrm{JE} \\
\mathrm{JE} \\
\mathrm{JE} \\
\mathrm{JE} \\
\mathrm{JE} \\
\mathrm{JE} \\
\mathrm{JE} \\
\mathrm{JE} \\
\mathrm{JE} \\
\mathrm{JE} \\
\mathrm{JE}\end{array}$ & $\begin{array}{l}U \\
U \\
U \\
U \\
U \\
U \\
0 \\
0 \\
0 \\
0 \\
0 \\
0 \\
0 \\
0 \\
0 \\
0 \\
0 \\
0\end{array}$ & $\mathrm{PCI} / \mathrm{L}$ & & $\begin{array}{l}0.6 \\
0.6 \\
0.5 \\
1.0 \\
1.0 \\
2.7 \\
0.3 \\
0.3 \\
0.4 \\
0.3 \\
0.8 \\
0.1 \\
0.2 \\
0.2 \\
0.5 \\
0.7 \\
0.5 \\
0.2\end{array}$ & $\begin{array}{l}\mathrm{L} \\
\mathrm{L} \\
\mathrm{L} \\
\mathrm{L} \\
\mathrm{L} \\
\mathrm{L} \\
\mathrm{L} \\
\mathrm{L} \\
\mathrm{L} \\
\mathrm{L} \\
\mathrm{L} \\
\mathrm{L}\end{array}$ & $\begin{array}{l}1 . \\
1 . \\
1 . \\
1 . \\
0.8 \\
0.1 \\
1 . \\
1 . \\
1 . \\
1 . \\
0.8 \\
0.1 \\
1 . \\
1 . \\
1 . \\
1 . \\
0.8 \\
0.1\end{array}$ & $\begin{array}{l}0.3 \\
0.3 \\
0.3 \\
0.5 \\
0.6 \\
0.4 \\
0.2 \\
0.2 \\
0.2 \\
0.3 \\
0.6 \\
0.1 \\
0.3 \\
0.2 \\
0.3 \\
0.4 \\
0.5 \\
0.1\end{array}$ \\
\hline RADIUM-226 (TOTAL) & $\begin{array}{l}0554 \\
0702 \\
0704\end{array}$ & $\begin{array}{l}02 / 17 / 94 \\
02 / 21 / 94 \\
02 / 17 / 94\end{array}$ & $\begin{array}{l}\text { N001 } \\
\text { N001 } \\
\text { N001 }\end{array}$ & $\begin{array}{l}\mathrm{JE} \\
\mathrm{JE} \\
\mathrm{JE}\end{array}$ & $\begin{array}{l}U \\
0 \\
0\end{array}$ & $\mathrm{PCI} / \mathrm{L}$ & & $\begin{array}{l}2.7 \\
0.7 \\
0.6\end{array}$ & $\begin{array}{l}L \\
L\end{array}$ & $\begin{array}{l}0.1 \\
0.2 \\
0.1\end{array}$ & $\begin{array}{l}0.4 \\
0.3 \\
0.2\end{array}$ \\
\hline RADIUM-226 + RADIUM-228 & $\begin{array}{l}0554 \\
0554 \\
0554 \\
0554 \\
0554 \\
0554 \\
0702\end{array}$ & $\begin{array}{l}12 / 12 / 90 \\
03 / 28 / 91 \\
08 / 05 / 91 \\
12 / 05 / 91 \\
10 / 15 / 92 \\
02 / 17 / 94 \\
12 / 12 / 90\end{array}$ & $\begin{array}{l}0001 \\
0001 \\
0001 \\
0001 \\
0001 \\
0001 \\
0001\end{array}$ & $\begin{array}{l}\mathrm{JE} \\
\mathrm{JE} \\
\mathrm{JE} \\
\mathrm{JE} \\
\mathrm{JE} \\
\mathrm{JE} \\
\mathrm{JE}\end{array}$ & $\begin{array}{l}\mathbf{U} \\
\mathbf{U} \\
\mathbf{U} \\
\mathbf{U} \\
\mathbf{U} \\
\mathbf{U} \\
\mathbf{O}\end{array}$ & $\mathrm{PCl} / \mathrm{L}$ & & $\begin{array}{l}2.10 \\
1.10 \\
0.50 \\
2.50 \\
1.10 \\
5.30 \\
2.10\end{array}$ & & $\begin{array}{l}- \\
- \\
- \\
-\end{array}$ & $\begin{array}{l}- \\
- \\
- \\
- \\
-\end{array}$ \\
\hline
\end{tabular}

FORMATION OF COMPLETION CODE:

JE - JURASSIC ENTRADA SANDSTONE FORMATION

PARAMETER VALUE INDICATOR (PVI): < - LESS THAN DETECTION LIMIT

OTHER PARAMETER VALUE FLAGS:

L - LESS THAN THREE BORE VOLUMES REMOVED BEFORE SAMPLING
FLOW RELATIONSHIP CODE:

O - ON-SITE

SAMPLE ID CODES:

0001 - FILTERED SAMPLE (.45 MICRONS)

NO01 - UNFILTERED SAMPLE 
TABLE 3.33 BASELINE GROUND HATER DATA BY PARAMETER FOR THE ENTRADA

FOPMATIOH UC PROCESSING SITE, SLICK ROCK, COLORADD

SITE: SRKO1 SLICK ROCK (BOTH SITES)

$03 / 29 / 89$ TO $02 / 21 / 94$

REPORT DATE: $09 / 30 / 94$

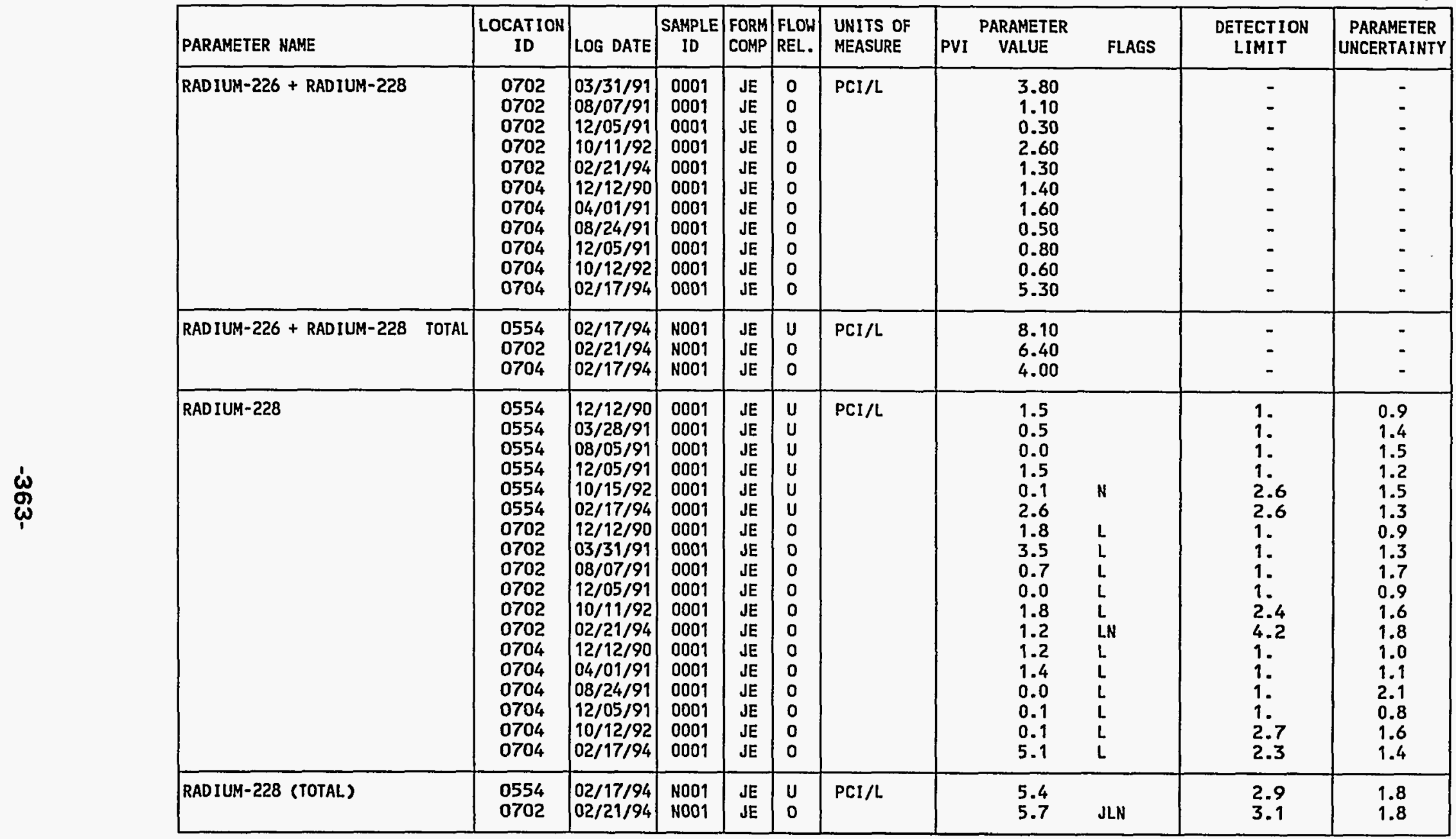

FORMATION OF COMPLETION CODE:

JE - JURASSIC ENTRADA SANDSTONE FORMATION

PARAMETER VALUE INDICATOR (PVI): < - LESS THAN DETECTION LIMIT

OTHER PARAMETER VALUE FLAGS:

$J$ - ESTIMATED VALUE

L - LESS THAN THREE BORE VOLUMES REMOVED BEFORE SAMPLING

N - SPIKE SAMPLE RECOVERY NOT HITHIN CONTROL LIMITS
FLOW RELATIONSHIP CODE:

O - ON-SITE

U - UPGRADIENT

SAMPLE ID CODES:

0001 - FILTERED SAMPLE (.45 MICRONS)

N001 - UNFILTERED SAMPLE 
TABLE 3.33 BASELINE GROUND HATER DATA BY PARAMETER FOR THE ENTRADA

FORMATION, UC PROCESSING SITE, SLICK ROCK, COLORADO

SITE: SRKO1 SLICK ROCK (BOTH SITES)

03/29/89 TO 02/21/94

REPORT DATE : 09/30/94

\begin{tabular}{|c|c|c|c|c|c|c|c|c|c|c|c|}
\hline PARAMETER NAME & $\underset{\text { ID }}{\text { LOCATION }}$ & LOG DATE & $\begin{array}{c}\text { SAMPLE } \\
\text { ID }\end{array}$ & $\begin{array}{l}\text { FORM } \\
\text { COMP }\end{array}$ & $\begin{array}{l}\text { FLOW } \\
\text { REL. }\end{array}$ & $\begin{array}{l}\text { UNITS OF } \\
\text { MEASURE }\end{array}$ & PVI & $\begin{array}{l}\text { ARAMETER } \\
\text { VALUE }\end{array}$ & FLAGS & $\begin{array}{l}\text { DETECTION } \\
\text { LIMIT }\end{array}$ & $\begin{array}{l}\text { PARAMETER } \\
\text { UNCERTAINTY }\end{array}$ \\
\hline RADIUM-228 (TOTAL) & 0704 & $02 / 17 / 94$ & N001 & JE & 0 & $\mathrm{PCl} / \mathrm{L}$ & & 3.4 & $L$ & 2.4 & 1.4 \\
\hline REDOX POTENTIAL & $\begin{array}{l}0554 \\
0554 \\
0702 \\
0702 \\
0702 \\
0704 \\
0704 \\
0704\end{array}$ & $\begin{array}{l}12 / 12 / 90 \\
10 / 15 / 92 \\
12 / 12 / 90 \\
10 / 11 / 92 \\
02 / 21 / 94 \\
12 / 12 / 90 \\
10 / 12 / 92 \\
02 / 17 / 94\end{array}$ & $\begin{array}{l}0001 \\
0001 \\
0001 \\
0001 \\
\text { N001 } \\
0001 \\
0001 \\
\text { N001 }\end{array}$ & $\begin{array}{l}\text { JE } \\
\text { JE } \\
\text { JE } \\
\text { JE } \\
\text { JE } \\
\text { JE } \\
\text { JE } \\
\text { JE }\end{array}$ & $\begin{array}{l}U \\
U \\
0 \\
0 \\
0 \\
0 \\
0 \\
0\end{array}$ & mVOLTS & & $\begin{array}{l}80.5 \\
81.8 \\
412.5 \\
409.5 \\
438 \\
431.7 \\
436.5 \\
400\end{array}$ & $\begin{array}{l}L \\
L \\
L \\
L \\
L \\
L\end{array}$ & $\begin{array}{l}- \\
- \\
- \\
- \\
- \\
-\end{array}$ & $\begin{array}{l}- \\
- \\
- \\
- \\
- \\
-\end{array}$ \\
\hline SELENIUM & $\begin{array}{l}0554 \\
0554 \\
0554 \\
0554 \\
0554 \\
0554 \\
0702 \\
0702 \\
0702 \\
0702 \\
0702 \\
0702 \\
0702 \\
0704 \\
0704 \\
0704 \\
0704 \\
0704 \\
0704 \\
0704\end{array}$ & $\begin{array}{l}12 / 12 / 90 \\
03 / 28 / 91 \\
08 / 05 / 91 \\
12 / 06 / 91 \\
10 / 15 / 92 \\
02 / 17 / 94 \\
03 / 29 / 89 \\
12 / 12 / 90 \\
03 / 31 / 91 \\
08 / 07 / 91 \\
12 / 07 / 91 \\
10 / 11 / 92 \\
02 / 21 / 94 \\
03 / 29 / 89 \\
12 / 12 / 90 \\
04 / 01 / 91 \\
08 / 24 / 91 \\
12 / 12 / 91 \\
10 / 12 / 92 \\
02 / 17 / 94\end{array}$ & $\begin{array}{l}0001 \\
0001 \\
0001 \\
0001 \\
0001 \\
0001 \\
0001 \\
0001 \\
0001 \\
0001 \\
0001 \\
0001 \\
0001 \\
0001 \\
0001 \\
0001 \\
0001 \\
0001 \\
0001 \\
0001\end{array}$ & $\begin{array}{l}\mathrm{JE} \\
\mathrm{JE} \\
\mathrm{JE} \\
\mathrm{JE} \\
\mathrm{JE} \\
\mathrm{JE} \\
\mathrm{JE} \\
\mathrm{JE} \\
\mathrm{JE} \\
\mathrm{JE} \\
\mathrm{JE} \\
\mathrm{JE} \\
\mathrm{JE} \\
\mathrm{JE} \\
\mathrm{JE} \\
\mathrm{JE} \\
\mathrm{JE} \\
\mathrm{JE} \\
\mathrm{JE} \\
\mathrm{JE}\end{array}$ & $\begin{array}{l}U \\
U \\
U \\
U \\
U \\
U \\
0 \\
0 \\
0 \\
0 \\
0 \\
0 \\
0 \\
0 \\
0 \\
0 \\
0 \\
0 \\
0 \\
0\end{array}$ & $M G / L$ & $\begin{array}{l}< \\
< \\
< \\
< \\
< \\
<\end{array}$ & $\begin{array}{l}0.005 \\
0.04 \\
0.005 \\
0.005 \\
0.005 \\
0.005 \\
0.023 \\
0.042 \\
0.020 \\
0.05 \\
0.026 \\
0.007 \\
0.035 \\
0.012 \\
0.017 \\
0.010 \\
0.017 \\
0.026 \\
0.006 \\
0.011\end{array}$ & $\begin{array}{l}J \\
W \\
L \\
L \\
J L \\
L \\
I L H \\
L \\
L \\
L S \\
L \\
J L \\
L \\
L \\
L \\
L \\
L\end{array}$ & $\begin{array}{l}0.005 \\
0.03 \\
0.005 \\
0.005 \\
0.005 \\
0.005 \\
0.005 \\
0.005 \\
0.005 \\
0.05 \\
0.005 \\
0.005 \\
0.005 \\
0.005 \\
0.005 \\
0.005 \\
0.005 \\
0.005 \\
0.005 \\
0.005\end{array}$ & $\begin{array}{l}- \\
- \\
- \\
- \\
- \\
- \\
- \\
- \\
- \\
- \\
- \\
- \\
- \\
- \\
- \\
-\end{array}$ \\
\hline SELENIUM (TOTAL) & $\begin{array}{l}0554 \\
0702 \\
0704\end{array}$ & $\begin{array}{l}02 / 17 / 94 \\
02 / 21 / 94 \\
02 / 17 / 94\end{array}$ & $\begin{array}{l}\text { NOO1 } \\
\text { NOO1 } \\
\text { N001 }\end{array}$ & $\begin{array}{l}\text { JE } \\
\text { JE } \\
\text { JE }\end{array}$ & $\begin{array}{l}U \\
0 \\
0\end{array}$ & $M G / L$ & $<$ & $\begin{array}{l}0.005 \\
0.029 \\
0.010\end{array}$ & $\begin{array}{l}\text { JW } \\
\text { LS } \\
\text { L }\end{array}$ & $\begin{array}{l}0.005 \\
0.005 \\
0.005\end{array}$ & $\begin{array}{l}- \\
-\end{array}$ \\
\hline
\end{tabular}

FORMATION OF COMPLETION CODE:

JE - JURASSIC ENTRADA SANDSTONE FORMATION

PARAMETER VALUE INDICATOR (PVI): < - LESS THAN DETECTION LIMIT

\section{OTHER PARAMETER VALUE FLAGS:}

I - INCREASED DETECTION LIMIT DUE TO REQUIRED DILUTION

J - ESTIMATED VALUE

L - LESS THAN THREE BORE VOLUMES REMOVED BEFORE SAMPLING

S - REPORTED VALUE DETERMINED USING METHOD OF STD ADDITION (MSA)

H - POST-DIGEST SPIKE OUT OF CNTR LIM WHILE SAMP ABS < 50\% SPIKE
FLOW RELATIONSHIP CODE:

O - ON-SITE

SAMPLE IO CODES:

0001 - FILTERED SAMPLE (.45 MICRONS)

NO01 - UNFILTERED SAMPLE 


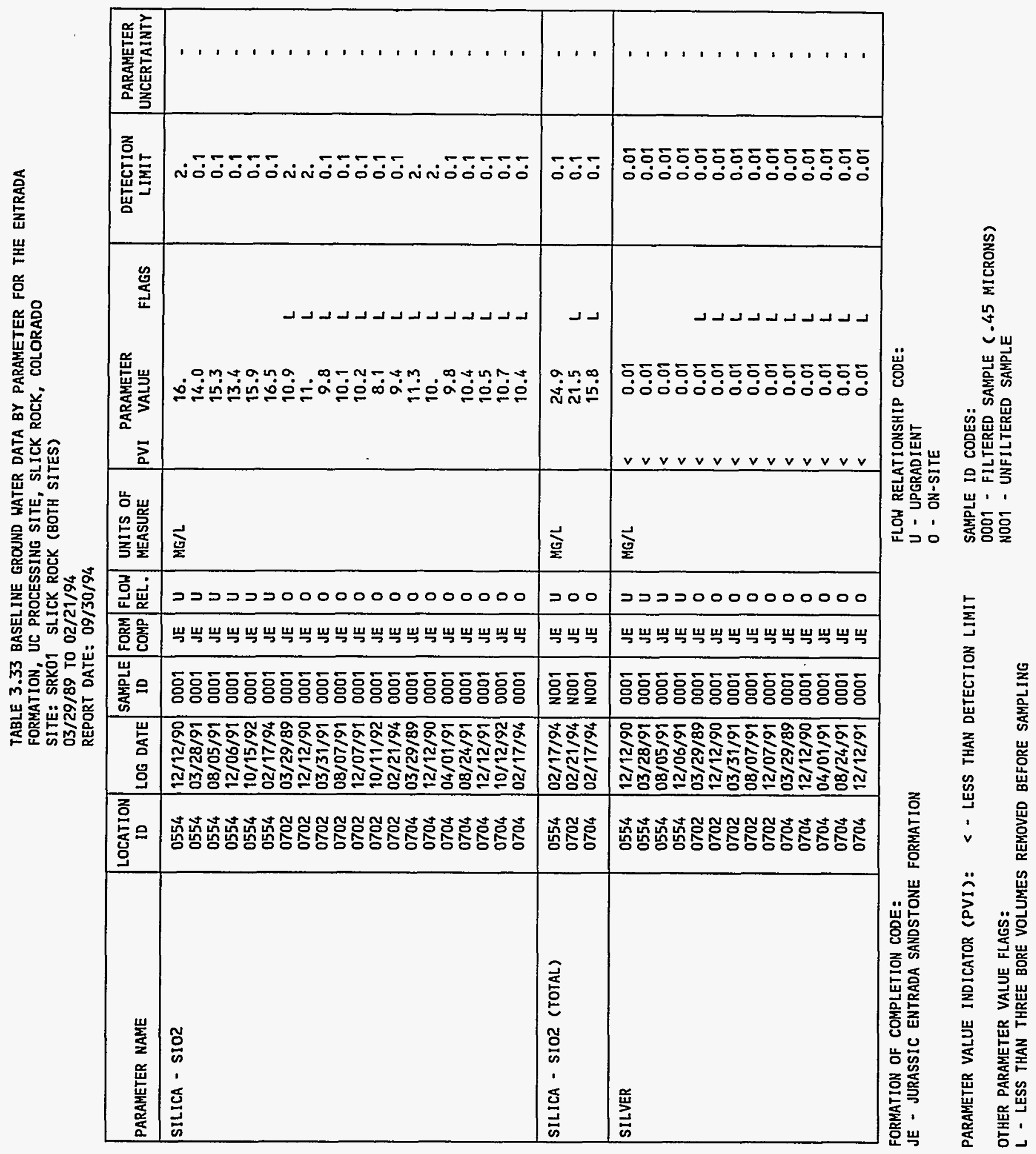


TABLE 3.33 BASELINE GROUND WATER DATA BY PARAMETER FOR THE ENTRADA FORMATION, UC PROCESSING SITE, SLICK ROCK, COLORADO

SITE: SRKOI SLICK ROCK (BOTH SITES)

$03 / 29 / 89$ TO $02 / 21 / 94$

REPORT DATE: $09 / 30 / 94$

\begin{tabular}{|c|c|c|c|c|c|c|c|c|c|c|c|}
\hline PARAMETER NAME & $\underset{\text { LOCATION }}{\text { LOD }}$ & LOG DATE & $\begin{array}{c}\text { SAMPLE } \\
\text { ID }\end{array}$ & $\begin{array}{l}\text { FORM } \\
\text { COMP }\end{array}$ & $\begin{array}{l}\text { FLOW } \\
\text { REL. }\end{array}$ & $\begin{array}{l}\text { UNITS OF } \\
\text { MEASURE }\end{array}$ & PVI & $\begin{array}{l}\text { ARAMETER } \\
\text { VALUE }\end{array}$ & FLAGS & $\begin{array}{l}\text { DETECT ION } \\
\text { LIMIT }\end{array}$ & $\begin{array}{l}\text { PARAMETER } \\
\text { UNCERTAINTY }\end{array}$ \\
\hline SODIUM & $\begin{array}{l}0554 \\
0554 \\
0554 \\
0554 \\
0554 \\
0554 \\
0702 \\
0702 \\
0702 \\
0702 \\
0702 \\
0702 \\
0702 \\
0704 \\
0704 \\
0704 \\
0704 \\
0704 \\
0704 \\
0704\end{array}$ & $\begin{array}{l}12 / 12 / 90 \\
03 / 28 / 91 \\
08 / 05 / 91 \\
12 / 06 / 91 \\
10 / 15 / 92 \\
02 / 17 / 94 \\
03 / 29 / 89 \\
12 / 12 / 90 \\
03 / 31 / 91 \\
08 / 07 / 91 \\
12 / 07 / 91 \\
10 / 11 / 92 \\
02 / 21 / 94 \\
03 / 29 / 89 \\
12 / 12 / 90 \\
04 / 01 / 91 \\
08 / 24 / 91 \\
12 / 12 / 91 \\
10 / 12 / 92 \\
02 / 17 / 94\end{array}$ & $\begin{array}{l}0001 \\
0001 \\
0001 \\
0001 \\
0001 \\
0001 \\
0001 \\
0001 \\
0001 \\
0001 \\
0001 \\
0001 \\
0001 \\
0001 \\
0001 \\
0001 \\
0001 \\
0001 \\
0001 \\
0001\end{array}$ & $\begin{array}{l}\mathrm{JE} \\
\mathrm{JE} \\
\mathrm{JE} \\
\mathrm{JE} \\
\mathrm{JE} \\
\mathrm{JE} \\
\mathrm{JE} \\
\mathrm{JE} \\
\mathrm{JE} \\
\mathrm{JE} \\
\mathrm{JE} \\
\mathrm{JE} \\
\mathrm{JE} \\
\mathrm{JE} \\
\mathrm{JE} \\
\mathrm{JE} \\
\mathrm{JE} \\
\mathrm{JE} \\
\mathrm{JE} \\
\mathrm{JE}\end{array}$ & $\begin{array}{l}U \\
U \\
U \\
U \\
U \\
U \\
0 \\
0 \\
0 \\
0 \\
0 \\
0 \\
0 \\
0 \\
0 \\
0 \\
0 \\
0 \\
0 \\
0\end{array}$ & MG/L & & $\begin{array}{l}191 . \\
167 . \\
166 . \\
158 . \\
258 . \\
296 \\
280 . \\
71.1 \\
30 . \\
32 . \\
20 . \\
10 . \\
39 \\
24 . \\
30.2 \\
29 . \\
27 . \\
24 . \\
39 . \\
31\end{array}$ & $\begin{array}{l}\text { L } \\
\text { L } \\
L \\
L \\
L \\
L \\
L \\
L \\
L \\
L \\
L \\
L \\
L \\
L\end{array}$ & $\begin{array}{l}0.002 \\
5 . \\
2 . \\
5 . \\
5 . \\
1 \\
0.002 \\
0.002 \\
5 . \\
1 . \\
1 . \\
1 . \\
1 \\
0.002 \\
0.002 \\
5 . \\
1 . \\
1 . \\
1 . \\
1\end{array}$ & $\begin{array}{l}- \\
- \\
- \\
- \\
- \\
- \\
- \\
- \\
- \\
- \\
- \\
- \\
- \\
- \\
- \\
-\end{array}$ \\
\hline SODIUM (TOTAL) & $\begin{array}{l}0554 \\
0702 \\
0704\end{array}$ & $\begin{array}{l}02 / 17 / 94 \\
02 / 21 / 94 \\
02 / 17 / 94\end{array}$ & $\begin{array}{l}\text { N001 } \\
\text { N001 } \\
\text { N001 }\end{array}$ & $\begin{array}{l}\mathrm{JE} \\
\mathrm{JE} \\
\mathrm{JE}\end{array}$ & $\begin{array}{l}\text { U } \\
0 \\
0\end{array}$ & $\mathrm{MG} / \mathrm{L}$ & & $\begin{array}{r}307 \\
36 \\
29\end{array}$ & 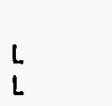 & $\begin{array}{l}1 \\
1 \\
1\end{array}$ & - \\
\hline SPECIFIC CONDUCTANCE & $\begin{array}{l}0554 \\
0554 \\
0554 \\
0554 \\
0554 \\
0702 \\
0702 \\
0702 \\
0702 \\
0702 \\
0702 \\
0704 \\
0704 \\
0704\end{array}$ & $\begin{array}{l}12 / 12 / 90 \\
08 / 05 / 91 \\
12 / 05 / 91 \\
10 / 15 / 92 \\
02 / 17 / 94 \\
03 / 29 / 89 \\
12 / 12 / 90 \\
08 / 07 / 91 \\
12 / 05 / 91 \\
10 / 11 / 92 \\
02 / 21 / 94 \\
03 / 29 / 89 \\
12 / 12 / 90 \\
08 / 24 / 91\end{array}$ & $\begin{array}{l}0001 \\
0001 \\
0001 \\
0001 \\
\text { N001 } \\
0001 \\
0001 \\
0001 \\
0001 \\
0001 \\
N 001 \\
0001 \\
0001 \\
0001\end{array}$ & $\begin{array}{l}\text { JE } \\
\text { JE } \\
\text { JE } \\
\text { JE } \\
\text { JE } \\
\text { JE } \\
\text { JE } \\
\text { JE } \\
\text { JE } \\
\text { JE } \\
\text { JE } \\
\text { JE } \\
\text { JE } \\
\text { JE }\end{array}$ & $\begin{array}{l}U \\
U \\
U \\
U \\
U \\
0 \\
0 \\
0 \\
0 \\
0 \\
0 \\
0 \\
0 \\
0\end{array}$ & UMHO/CM & & $\begin{array}{c}3230 . \\
2780 \\
2960 \\
3340 \\
3540 \\
1550 . \\
685 . \\
1085 \\
1130 \\
945 \\
804 \\
400 . \\
823 . \\
716\end{array}$ & $\begin{array}{l}\mathrm{L} \\
\mathrm{L} \\
\mathrm{L} \\
\mathrm{L} \\
\mathrm{L} \\
\mathrm{L} \\
\mathrm{L} \\
\mathrm{L} \\
\mathrm{L}\end{array}$ & $\begin{array}{l}- \\
- \\
- \\
- \\
- \\
- \\
- \\
- \\
- \\
- \\
-\end{array}$ & $\begin{array}{l}- \\
- \\
- \\
- \\
- \\
- \\
- \\
- \\
- \\
- \\
-\end{array}$ \\
\hline
\end{tabular}

FORMATION OF COMPLETION CODE:

JE - JURASSIC ENTRADA SANDSTONE FORMATION

PARAMETER VALUE INDICATOR (PVI):

OTHER PARAMETER VALUE FLAGS

$L$ - LESS THAN THREE BORE VOLUMES REMOVED BEFORE SAMPLING
FLOW RELATIONSHIP CODE:

U - UPGRADIENT

SAMPLE ID CODES:

0001 - FILTERED SAMPLE (.45 MICRONS)

N001 - UNFILTERED SAMPLE 
TABLE 3.33 BASELINE GROUND HATER DATA BY PARAMETER FOR THE ENTRADA FORMATION, UC PROCESSING SITE, SLICK ROCK, COLORADO

SITE: SRKO 1 SLICK ROCK (BOTH SITES)

TO $02 / 21 / 94$

REPORT DATE: 09/30/94

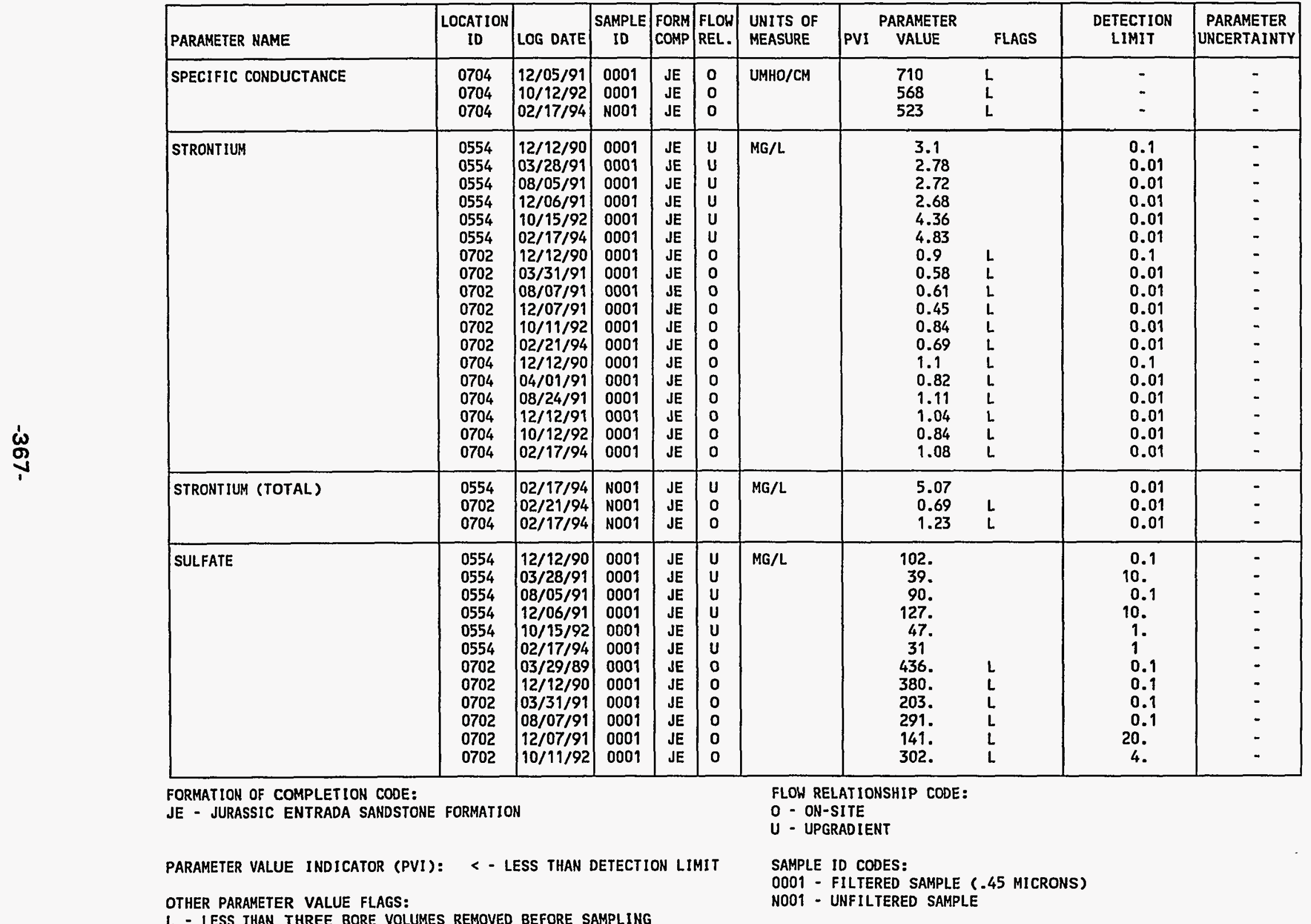


TABLE 3.33 BASELINE GROUND HATER DATA BY PARAMETER FOR THE ENTRADA FORMATION, UC PROCESSING SITE, SLICK ROCK, COLORADO

SITE: SRKO1 SLICK ROCK (BOTH SITES)

$03 / 29 / 89$ TO $02 / 21 / 94$

REPORT DATE: $09 / 30 / 94$

\begin{tabular}{|c|c|c|c|c|c|c|c|c|c|c|c|}
\hline PARAMETER NAME & $\begin{array}{c}\text { LOCATION } \\
\text { ID }\end{array}$ & LOG DATE & $\begin{array}{c}\text { SAMPLE } \\
\text { ID }\end{array}$ & $\begin{array}{l}\text { FORM } \\
\text { COMP }\end{array}$ & $\begin{array}{l}\text { FLOW } \\
\text { REL. }\end{array}$ & $\begin{array}{l}\text { UNITS OF } \\
\text { MEASURE }\end{array}$ & PVI & $\begin{array}{l}\text { ARAMETER } \\
\text { VALUE }\end{array}$ & FLAGS & $\begin{array}{l}\text { DETECTION } \\
\text { LIMIT }\end{array}$ & $\begin{array}{l}\text { PARAMETER } \\
\text { UNCERTAINTY }\end{array}$ \\
\hline SULFATE & $\begin{array}{l}0702 \\
0704 \\
0704 \\
0704 \\
0704 \\
0704 \\
0704 \\
0704\end{array}$ & $\begin{array}{l}02 / 21 / 94 \\
03 / 29 / 89 \\
12 / 12 / 90 \\
04 / 01 / 91 \\
08 / 24 / 91 \\
12 / 12 / 91 \\
10 / 12 / 92 \\
02 / 17 / 94\end{array}$ & $\begin{array}{l}0001 \\
0001 \\
0001 \\
0001 \\
0001 \\
0001 \\
0001 \\
0001\end{array}$ & $\begin{array}{l}\mathrm{JE} \\
\mathrm{JE} \\
\mathrm{JE} \\
\mathrm{JE} \\
\mathrm{JE} \\
\mathrm{JE} \\
\mathrm{JE} \\
\mathrm{JE}\end{array}$ & $\begin{array}{l}0 \\
0 \\
0 \\
0 \\
0 \\
0 \\
0 \\
0\end{array}$ & $M G / L$ & & $\begin{array}{c}325 \\
144 . \\
135 \\
131 \\
132 \\
127 \\
109 \\
84\end{array}$ & $\begin{array}{l}L \\
L \\
L \\
L \\
L \\
L \\
L \\
L\end{array}$ & $\begin{array}{l}1 \\
0.1 \\
0.1 \\
0.1 \\
10 . \\
20 . \\
20 . \\
1\end{array}$ & $\begin{array}{l}- \\
- \\
- \\
- \\
- \\
-\end{array}$ \\
\hline SULFIDE & $\begin{array}{l}0554 \\
0554 \\
0554 \\
0554 \\
0554 \\
0702 \\
0702 \\
0702 \\
0702 \\
0702 \\
0704 \\
0704 \\
0704 \\
0704 \\
0704\end{array}$ & $\begin{array}{l}12 / 12 / 90 \\
03 / 28 / 91 \\
08 / 05 / 91 \\
12 / 06 / 91 \\
10 / 15 / 92 \\
12 / 12 / 90 \\
03 / 31 / 91 \\
08 / 07 / 91 \\
12 / 07 / 91 \\
10 / 11 / 92 \\
12 / 12 / 90 \\
04 / 01 / 91 \\
08 / 24 / 91 \\
12 / 12 / 91 \\
10 / 12 / 92\end{array}$ & $\begin{array}{l}0001 \\
0001 \\
0001 \\
0001 \\
0001 \\
0001 \\
0001 \\
0001 \\
0001 \\
0001 \\
0001 \\
0001 \\
0001 \\
0001 \\
0001\end{array}$ & $\begin{array}{l}J E \\
J E \\
J E \\
J E \\
J E \\
J E \\
J E \\
J E \\
J E \\
J E \\
J E \\
J E \\
J E \\
J E \\
J E\end{array}$ & $\begin{array}{l}U \\
U \\
U \\
U \\
U \\
0 \\
0 \\
0 \\
0 \\
0 \\
0 \\
0 \\
0 \\
0 \\
0\end{array}$ & $M G / L$ & $<$ & $\begin{array}{r}3.5 \\
16.3 \\
9.8 \\
6.2 \\
0.6 \\
0.1 \\
12.8 \\
0.3 \\
0.1 \\
0.2 \\
0.1 \\
42.3 \\
0.6 \\
0.5 \\
0.1\end{array}$ & $\begin{array}{l}J \\
\\
J L \\
L \\
L \\
L \\
L \\
J L \\
L \\
L \\
L \\
L\end{array}$ & $\begin{array}{l}0.1 \\
0.1 \\
0.1 \\
0.1 \\
0.1 \\
0.1 \\
0.1 \\
0.1 \\
0.1 \\
0.1 \\
0.1 \\
0.1 \\
0.1 \\
0.1 \\
0.1\end{array}$ & $\begin{array}{l}- \\
- \\
- \\
- \\
- \\
- \\
- \\
- \\
- \\
- \\
- \\
- \\
-\end{array}$ \\
\hline TEMPERATURE & $\begin{array}{l}0554 \\
0554 \\
0554 \\
0554 \\
0554 \\
0554 \\
0702 \\
0702 \\
0702 \\
0702 \\
0702 \\
0702 \\
0702\end{array}$ & $\begin{array}{l}12 / 12 / 90 \\
03 / 28 / 91 \\
08 / 05 / 91 \\
12 / 05 / 91 \\
10 / 15 / 92 \\
02 / 17 / 94 \\
03 / 29 / 89 \\
12 / 12 / 90 \\
03 / 31 / 91 \\
08 / 07 / 91 \\
12 / 05 / 91 \\
10 / 11 / 92 \\
02 / 21 / 94\end{array}$ & $\begin{array}{l}0001 \\
0001 \\
0001 \\
0001 \\
0001 \\
N 001 \\
0001 \\
0001 \\
0001 \\
0001 \\
0001 \\
0001 \\
N 001\end{array}$ & $\begin{array}{l}\mathrm{JE} \\
\mathrm{JE} \\
\mathrm{JE} \\
\mathrm{JE} \\
\mathrm{JE} \\
\mathrm{JE} \\
\mathrm{JE} \\
\mathrm{JE} \\
\mathrm{JE} \\
\mathrm{JE} \\
\mathrm{JE} \\
\mathrm{JE} \\
\mathrm{JE}\end{array}$ & $\begin{array}{l}U \\
U \\
U \\
U \\
U \\
U \\
0 \\
0 \\
0 \\
0 \\
0 \\
0 \\
0\end{array}$ & C - DEGREE & & $\begin{array}{l}13.6 \\
13.6 \\
14.2 \\
13.9 \\
14.7 \\
13.8 \\
14.0 \\
13.4 \\
13.9 \\
14.7 \\
13.5 \\
15.1 \\
11.3\end{array}$ & $\begin{array}{l}L \\
L \\
L \\
L \\
L \\
L \\
L\end{array}$ & $\begin{array}{l}- \\
- \\
- \\
- \\
- \\
- \\
- \\
- \\
-\end{array}$ & $\begin{array}{l}- \\
- \\
- \\
- \\
- \\
- \\
- \\
- \\
-\end{array}$ \\
\hline
\end{tabular}

FORMATION OF COMPLETION CODE:

JE - JURASSIC ENTRADA SANDSTONE FORMATION

FLOW RELATIONSHIP CODE:

- ON-SITE

PARAMETER VALUE INDICATOR (PVI): < - LESS THAN DETECTION LIMIT

SAMPLE ID CODES:

0001 - FILTERED SAMPLE (.45 MICRONS)

OTHER PARAMETER VALUE FLAGS:

NO01 - UNFILTERED SAMPLE

$J$ - ESTIMATED VALUE

L - LESS THAN THREE BORE VOLUMES REMOVEd BEFORE SAMPLING 
TABLE 3.33 BASELINE GROUND UATER DATA BY PARAMETER FOR THE ENTRADA FORMATION, UC PROCESSING SITE, SLICK ROCK, COLORADO

SITE: SRKO1 SLICK ROCK (BOTH SITES)

$02 / 21 / 94$

REPORT DATE: $09 / 30 / 94$

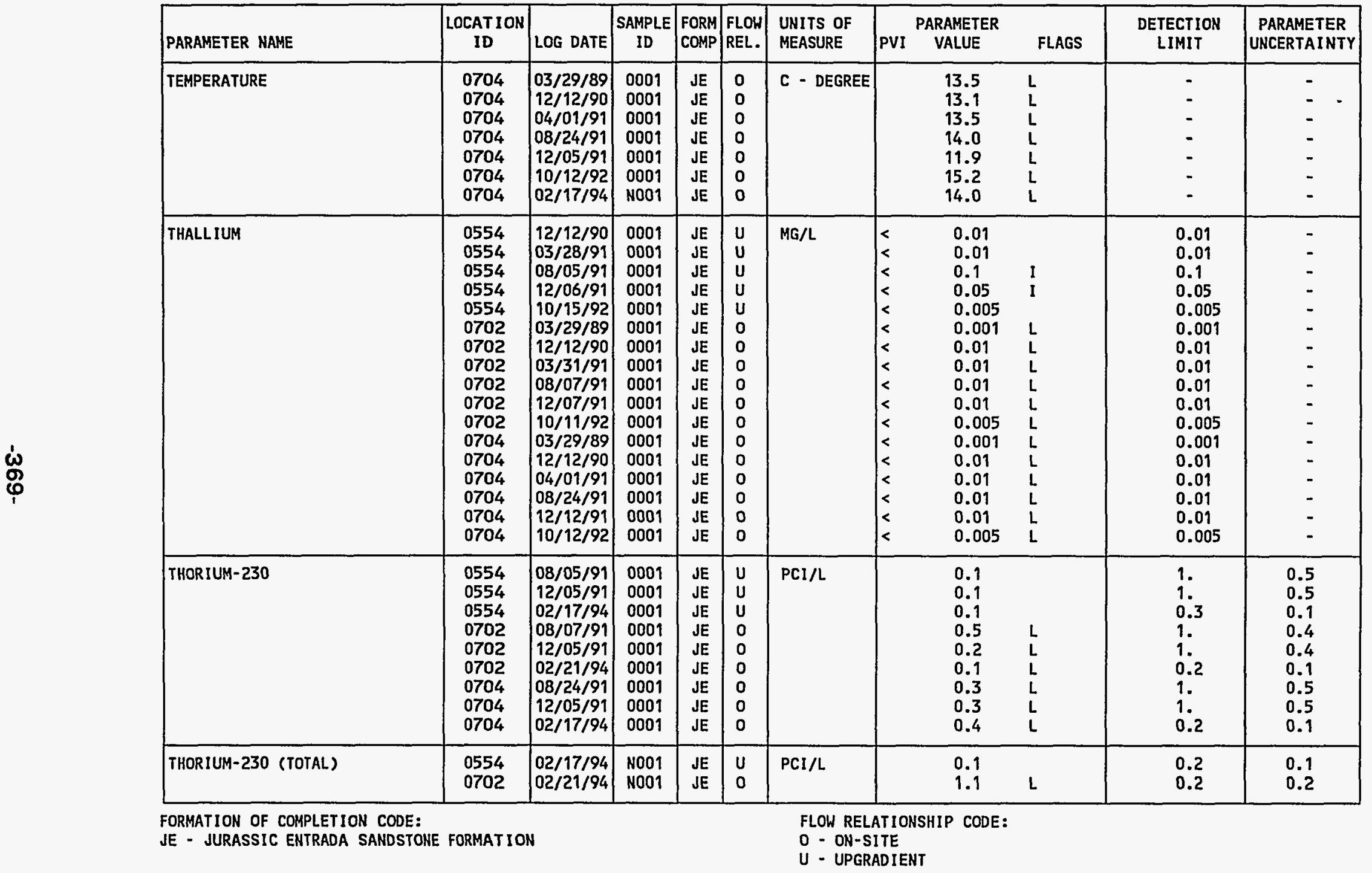

PARAMETER VALUE INDICATOR (PVI): < - LESS THAN DETECTION LIMIT

OTHER PARAMETER VALUE FLAGS:

SAMPLE ID CODES:

1 - INCREASED DETECTION LIMIT DUE TO REQUIRED DILUTION

0001 - FILTERED SAMPLE (.45 MICRONS)

N001 - UNFILTERED SAMPLE

L - LESS THAN THREE BORE VOLUMES REMOVED BEFORE SAMPLING 
TABLE 3.33 BASELINE GROUND WATER DATA BY PARAMETER FOR THE ENTRADA

FORMATIOH UC PROCESSING SITE SLICK ROCK, COLORADO

SITE: SRKO1 SLICK ROCK (BOTH SITES)

$03 / 29 / 89$ TO $02 / 21 / 94$

REPORT DATE : $09 / 30 / 94$

\begin{tabular}{|c|c|c|c|c|c|c|c|c|c|c|c|}
\hline PARAMETER NAME & $\underset{\text { ID }}{\text { LOCATION }}$ & LOG DATE & $\begin{array}{c}\text { SAMPLE } \\
\text { ID }\end{array}$ & $\begin{array}{l}\text { FORM } \\
\text { COMP }\end{array}$ & $\begin{array}{l}\text { FLOW } \\
\text { REL. }\end{array}$ & $\begin{array}{l}\text { UNITS OF } \\
\text { MEASURE }\end{array}$ & PVI & $\begin{array}{l}\text { PARAMETER } \\
\text { VALUE }\end{array}$ & FLAGS & $\begin{array}{l}\text { DETECTION } \\
\text { LIMIT }\end{array}$ & $\begin{array}{l}\text { PARAMETER } \\
\text { UNCERTAINTY }\end{array}$ \\
\hline THOR IUM-230 (TOTAL) & 0704 & $02 / 17 / 94$ & N001 & JE & $\mathbf{0}$ & $\mathrm{PCI} / \mathrm{L}$ & & 0.4 & L & 0.3 & 0.1 \\
\hline TIN & $\begin{array}{l}0554 \\
0554 \\
0554 \\
0554 \\
0554 \\
0702 \\
0702 \\
0702 \\
0702 \\
0702 \\
0702 \\
0704 \\
0704 \\
0704 \\
0704 \\
0704 \\
0704\end{array}$ & $\begin{array}{l}12 / 12 / 90 \\
03 / 28 / 91 \\
08 / 05 / 91 \\
12 / 06 / 91 \\
10 / 15 / 92 \\
03 / 29 / 89 \\
12 / 12 / 90 \\
03 / 31 / 91 \\
08 / 07 / 91 \\
12 / 07 / 91 \\
10 / 11 / 92 \\
03 / 29 / 89 \\
12 / 12 / 90 \\
04 / 01 / 91 \\
08 / 24 / 91 \\
12 / 12 / 91 \\
10 / 12 / 92\end{array}$ & $\begin{array}{l}0001 \\
0001 \\
0001 \\
0001 \\
0001 \\
0001 \\
0001 \\
0001 \\
0001 \\
0001 \\
0001 \\
0001 \\
0001 \\
0001 \\
0001 \\
0001 \\
0001\end{array}$ & $\begin{array}{l}\mathrm{JE} \\
\mathrm{JE} \\
\mathrm{JE} \\
\mathrm{JE} \\
\mathrm{JE} \\
\mathrm{JE} \\
\mathrm{JE} \\
\mathrm{JE} \\
\mathrm{JE} \\
\mathrm{JE} \\
\mathrm{JE} \\
\mathrm{JE} \\
\mathrm{JE} \\
\mathrm{JE} \\
\mathrm{JE} \\
\mathrm{JE} \\
\mathrm{JE}\end{array}$ & $\begin{array}{l}U \\
U \\
U \\
U \\
U \\
0 \\
0 \\
0 \\
0 \\
0 \\
0 \\
0 \\
0 \\
0 \\
0 \\
0 \\
0\end{array}$ & $M G / L$ & $\begin{array}{l}< \\
< \\
< \\
< \\
< \\
< \\
< \\
< \\
< \\
< \\
< \\
< \\
< \\
< \\
< \\
< \\
< \\
<\end{array}$ & $\begin{array}{l}0.005 \\
0.005 \\
0.05 \\
0.005 \\
0.05 \\
0.001 \\
0.005 \\
0.005 \\
0.05 \\
0.005 \\
0.05 \\
0.001 \\
0.005 \\
0.005 \\
0.005 \\
0.005 \\
0.005\end{array}$ & $\begin{array}{l}I \\
W \\
I \\
J L \\
L \\
L \\
I L \\
L \\
I L \\
J L \\
L \\
L \\
L W \\
L \\
L\end{array}$ & $\begin{array}{l}0.005 \\
0.005 \\
0.05 \\
0.005 \\
0.05 \\
0.005 \\
0.005 \\
0.005 \\
0.05 \\
0.005 \\
0.05 \\
0.005 \\
0.005 \\
0.005 \\
0.005 \\
0.005 \\
0.005\end{array}$ & $\begin{array}{l}- \\
- \\
- \\
- \\
- \\
- \\
- \\
- \\
- \\
- \\
- \\
- \\
- \\
- \\
-\end{array}$ \\
\hline TOTAL DISSOLVED SOLIDS & $\begin{array}{l}0554 \\
0554 \\
0554 \\
0554 \\
0554 \\
0554 \\
0702 \\
0702 \\
0702 \\
0702 \\
0702 \\
0702 \\
0702 \\
0704 \\
0704\end{array}$ & $\begin{array}{l}12 / 12 / 90 \\
03 / 28 / 91 \\
08 / 05 / 91 \\
12 / 06 / 91 \\
10 / 15 / 92 \\
02 / 17 / 94 \\
03 / 29 / 89 \\
12 / 12 / 90 \\
03 / 31 / 91 \\
08 / 07 / 91 \\
12 / 07 / 91 \\
10 / 11 / 92 \\
02 / 21 / 94 \\
03 / 29 / 89 \\
12 / 12 / 90\end{array}$ & $\begin{array}{l}0001 \\
0001 \\
0001 \\
0001 \\
0001 \\
0001 \\
0001 \\
0001 \\
0001 \\
0001 \\
0001 \\
0001 \\
0001 \\
0001 \\
0001\end{array}$ & $\begin{array}{l}\mathrm{JE} \\
\mathrm{JE} \\
\mathrm{JE} \\
\mathrm{JE} \\
\mathrm{JE} \\
\mathrm{JE} \\
\mathrm{JE} \\
\mathrm{JE} \\
\mathrm{JE} \\
\mathrm{JE} \\
\mathrm{JE} \\
\mathrm{JE} \\
\mathrm{JE} \\
\mathrm{JE} \\
\mathrm{JE}\end{array}$ & $\begin{array}{l}U \\
U \\
U \\
U \\
U \\
U \\
0 \\
0 \\
0 \\
0 \\
0 \\
0 \\
0 \\
0 \\
0\end{array}$ & $M G / L$ & & $\begin{array}{c}1980 . \\
1740 . \\
1880 . \\
1740 . \\
2650 . \\
2680 \\
1432 . \\
960 . \\
607 . \\
724 . \\
478 . \\
794 . \\
790 \\
428 . \\
412 .\end{array}$ & $\begin{array}{l}L \\
L \\
L \\
L \\
H L \\
L \\
L \\
L \\
L\end{array}$ & $\begin{array}{l}10 . \\
10 . \\
10 . \\
10 . \\
10 . \\
10 \\
10 . \\
10 . \\
10 . \\
10 . \\
10 . \\
10 . \\
10 \\
10 . \\
10 .\end{array}$ & $\begin{array}{l}- \\
- \\
- \\
- \\
- \\
- \\
- \\
- \\
- \\
- \\
-\end{array}$ \\
\hline
\end{tabular}

FORMATION OF COMPLETION CODE:

JE - JURASSIC ENTRADA SANDSTONE FORMATION

FLOW RELATIONSHIP CODE:

O - ON-SITE

- UPGRADIENT

PARAMETER VALUE INDICATOR (PVI): < - LESS THAN DETECTION LIMIT

SAMPLE ID CODES:

0001 - FILTERED SAMPLE (.45 MICRONS)

N001 - UNFILTERED SAMPLE

OTHER PARAMETER VALUE FLAGS:

H - HOLD TIME EXPIRED, VALUE SUSPECT

I - INCREASED DETECTION LIMIT DUE TO REQUIRED DILUTION

$J$ - ESTIMATED VALUE

L - LESS THAN THREE BORE VOLUMES REMOVED BEFORE SAMPLING

$W$ - POST-DIGEST SPIKE OUT OF CNTR LIM WHILE SAMP ABS < $50 \%$ SPIKE 
TABLE 3.33 BASELINE GROUND HATER DATA BY PARAMETER FOR THE ENTRADA FORMATION, UC PROCESSING SITE, SLICK ROCK, COLORADO

SITE: SRKO 1 SLICK ROCK (BOTH SITES)

03/29/89 TO 02/21/94

REPORT DATE: 09/30/94

\begin{tabular}{|c|c|c|c|c|c|c|c|c|c|c|c|}
\hline PARAMETER NAME & $\begin{array}{c}\text { LOCATION } \\
\text { ID }\end{array}$ & LOG DATE & $\underset{\text { ID }}{\text { SAMPLE }}$ & $\begin{array}{l}\text { FORM } \\
\text { COMP }\end{array}$ & $\begin{array}{l}\text { FLOW } \\
\text { REL. }\end{array}$ & $\begin{array}{l}\text { UNITS OF } \\
\text { MEASURE }\end{array}$ & PVI & $\begin{array}{l}\text { ARAMETER } \\
\text { VALUE }\end{array}$ & FLAGS & $\begin{array}{l}\text { DETECTION } \\
\text { LIMIT }\end{array}$ & $\begin{array}{l}\text { PARAMETER } \\
\text { UNCERTAINTY }\end{array}$ \\
\hline TOTAL DISSOLVED SOLIDS & $\begin{array}{l}0704 \\
0704 \\
0704 \\
0704 \\
0704\end{array}$ & $\begin{array}{l}04 / 01 / 91 \\
08 / 24 / 91 \\
12 / 12 / 91 \\
10 / 12 / 92 \\
02 / 17 / 94\end{array}$ & $\begin{array}{l}0001 \\
0001 \\
0001 \\
0001 \\
0001\end{array}$ & $\begin{array}{l}\mathrm{JE} \\
\mathrm{JE} \\
\mathrm{JE} \\
\mathrm{JE} \\
\mathrm{JE}\end{array}$ & $\begin{array}{l}0 \\
0 \\
0 \\
0 \\
0\end{array}$ & MG/L & & $\begin{array}{l}445 . \\
435 . \\
425 . \\
443 . \\
360\end{array}$ & $\begin{array}{l}L \\
L \\
L \\
L \\
L\end{array}$ & $\begin{array}{l}10 . \\
10 . \\
10 . \\
10 . \\
10\end{array}$ & $\begin{array}{l}- \\
- \\
-\end{array}$ \\
\hline TOTAL KJELDAHL NITROGEN & $\begin{array}{l}0554 \\
0554 \\
0554 \\
0554 \\
0702 \\
0702 \\
0702 \\
0702 \\
0704 \\
0704 \\
0704 \\
0704\end{array}$ & $\begin{array}{l}12 / 12 / 90 \\
03 / 28 / 91 \\
08 / 05 / 91 \\
12 / 06 / 91 \\
12 / 12 / 90 \\
03 / 31 / 91 \\
08 / 07 / 91 \\
12 / 07 / 91 \\
12 / 12 / 90 \\
04 / 01 / 91 \\
08 / 24 / 91 \\
12 / 12 / 91\end{array}$ & $\begin{array}{l}0001 \\
0001 \\
0001 \\
0001 \\
0001 \\
0001 \\
0001 \\
0001 \\
0001 \\
0001 \\
0001 \\
0001\end{array}$ & $\begin{array}{l}\text { JE } \\
\text { JE } \\
\text { JE } \\
\text { JE } \\
J E \\
\text { JE } \\
\text { JE } \\
\text { JE } \\
\text { JE } \\
\text { JE } \\
\text { JE } \\
\text { JE }\end{array}$ & $\begin{array}{l}U \\
U \\
U \\
U \\
0 \\
0 \\
0 \\
0 \\
0 \\
0 \\
0 \\
0\end{array}$ & $M G / L$ & $\begin{array}{l}< \\
< \\
< \\
< \\
< \\
< \\
< \\
<\end{array}$ & $\begin{array}{r}1 . \\
1 . \\
1 . \\
2 . \\
191 . \\
1 . \\
1 . \\
2 . \\
13 . \\
1 . \\
1 . \\
2 .\end{array}$ & $\begin{array}{l}J \\
I \\
J L \\
L \\
L \\
I L \\
J L \\
L \\
L \\
I L\end{array}$ & $\begin{array}{l}1 . \\
1 . \\
1 . \\
2 . \\
1 . \\
1 . \\
1 . \\
2 . \\
1 . \\
1 . \\
1 . \\
2 .\end{array}$ & $\begin{array}{l}- \\
- \\
- \\
- \\
- \\
- \\
- \\
- \\
-\end{array}$ \\
\hline TOTAL ORGANIC CARBON & $\begin{array}{l}0554 \\
0554 \\
0554 \\
0554 \\
0554 \\
0554 \\
0702 \\
0702 \\
0702 \\
0702 \\
0702 \\
0702 \\
0702 \\
0704 \\
0704 \\
0704 \\
0704 \\
0704\end{array}$ & $\begin{array}{l}12 / 12 / 90 \\
03 / 28 / 91 \\
08 / 05 / 91 \\
12 / 06 / 91 \\
10 / 15 / 92 \\
02 / 17 / 94 \\
12 / 12 / 90 \\
03 / 31 / 91 \\
08 / 07 / 91 \\
12 / 07 / 91 \\
10 / 11 / 92 \\
02 / 21 / 94 \\
02 / 21 / 94 \\
12 / 12 / 90 \\
04 / 01 / 91 \\
08 / 24 / 91 \\
12 / 12 / 91 \\
10 / 12 / 92\end{array}$ & $\begin{array}{l}0001 \\
0001 \\
0001 \\
0001 \\
0001 \\
\text { N001 } \\
0001 \\
0001 \\
0001 \\
0001 \\
0001 \\
0001 \\
N 001 \\
0001 \\
0001 \\
0001 \\
0001 \\
0001\end{array}$ & $\begin{array}{l}\mathrm{JE} \\
\mathrm{JE} \\
\mathrm{JE} \\
\mathrm{JE} \\
\mathrm{JE} \\
\mathrm{JE} \\
\mathrm{JE} \\
\mathrm{JE} \\
\mathrm{JE} \\
\mathrm{JE} \\
\mathrm{JE} \\
\mathrm{JE} \\
\mathrm{JE} \\
\mathrm{JE} \\
\mathrm{JE} \\
\mathrm{JE} \\
\mathrm{JE} \\
\mathrm{JE}\end{array}$ & $\begin{array}{l}U \\
U \\
U \\
U \\
U \\
U \\
0 \\
0 \\
0 \\
0 \\
0 \\
0 \\
0 \\
0 \\
0 \\
0 \\
0 \\
0\end{array}$ & $M G / L$ & $<$ & $\begin{array}{c}127 . \\
14 . \\
18 . \\
20 . \\
74 . \\
29 \\
44 . \\
1 . \\
1 . \\
1 . \\
3 . \\
1 \\
2 \\
35 . \\
1 . \\
2 . \\
2 . \\
2 .\end{array}$ & $\begin{array}{l}J \\
J \\
J L \\
L \\
L \\
L \\
L \\
L \\
L \\
J L \\
L \\
L \\
L \\
L\end{array}$ & $\begin{array}{l}1 . \\
1 . \\
1 . \\
1 . \\
1 . \\
1 . \\
1 . \\
1 . \\
1 . \\
1 . \\
1 . \\
1 . \\
1 . \\
1 . \\
1 . \\
1 .\end{array}$ & $\begin{array}{l}- \\
- \\
- \\
- \\
- \\
- \\
- \\
- \\
- \\
- \\
- \\
- \\
-\end{array}$ \\
\hline
\end{tabular}

FORMATION OF COMPLETION CODE:

JE - JURASSIC ENTRADA SANDSTONE FORMATION

PARAMETER VALUE INDICATOR (PVI): < - LESS THAN DETECTION LIMIT

OTHER PARAMETER VALUE FLAGS:

1 - INCREASED DETECTION LIMIT DUE TO REQUIRED DILUTION

FLOW RELATIONSHIP CODE:

O - ON-SITE

U - UPGRADIENT

SAMPLE ID CODES:

0001 - FILTERED SAMPLE (.45 MICRONS)

N001 - UNFILTERED SAMPLE

$J$ - ESTIMATED VALUE

L - LESS THAN THREE BORE VOLUMES REMOVED BEFORE SAMPLING 
TABLE 3.33 BASELINE GROUND WATER DATA BY PARAMETER FOR THE ENTRADA

FORMATION, UC PROCESSING SITE, SLICK ROCK, COLORADO

SITE: SRKO1 SLICK ROCK (BOTH SITES)

$03 / 29 / 89$ TO $02 / 21 / 94$

REPORT DATE. 09/30/94

\begin{tabular}{|c|c|c|c|c|c|c|c|c|c|c|c|}
\hline PARAMETER NAME & $\begin{array}{c}\text { LOCATION } \\
\text { ID }\end{array}$ & LOG DATE & $\begin{array}{c}\text { SAMPLE } \\
\text { ID }\end{array}$ & $\begin{array}{l}\text { FORM } \\
\text { COMP }\end{array}$ & $\begin{array}{l}\text { FL.OW } \\
\text { REL. }\end{array}$ & $\begin{array}{l}\text { UNITS OF } \\
\text { MEASURE }\end{array}$ & PVI & $\begin{array}{l}\text { IRAMETER } \\
\text { VALUE }\end{array}$ & FLAGS & $\begin{array}{l}\text { DETECTION } \\
\text { LIMIT }\end{array}$ & $\begin{array}{l}\text { PARAMETER } \\
\text { UNCERTAINTY }\end{array}$ \\
\hline TOTAL. ORGANIC CARBON & 0704 & $02 / 17 / 94$ & N001 & JE & 0 & MG/L & & 2 & $\mathbf{L}$ & 1 & - \\
\hline TURBIDITY & $\begin{array}{l}0702 \\
0704\end{array}$ & $\begin{array}{l}02 / 21 / 94 \\
02 / 17 / 94\end{array}$ & $\begin{array}{l}\text { N001 } \\
\text { N001 }\end{array}$ & $\begin{array}{l}\text { JE } \\
\text { JE }\end{array}$ & $\begin{array}{l}0 \\
0\end{array}$ & NTU & & $\begin{array}{r}4 \\
61\end{array}$ & $\begin{array}{l}\mathrm{L} \\
\mathrm{L}\end{array}$ & 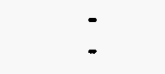 & - \\
\hline URANIUM & $\begin{array}{l}0554 \\
0554 \\
0554 \\
0554 \\
0554 \\
0554 \\
0702 \\
0702 \\
0702 \\
0702 \\
0702 \\
0702 \\
0702 \\
0704 \\
0704 \\
0704 \\
0704 \\
0704 \\
0704 \\
0704\end{array}$ & $\begin{array}{l}12 / 12 / 90 \\
03 / 28 / 91 \\
08 / 05 / 91 \\
12 / 05 / 91 \\
10 / 15 / 92 \\
02 / 17 / 94 \\
03 / 29 / 89 \\
12 / 12 / 90 \\
03 / 31 / 91 \\
08 / 07 / 91 \\
12 / 05 / 91 \\
10 / 11 / 92 \\
02 / 21 / 94 \\
03 / 29 / 89 \\
12 / 12 / 90 \\
04 / 01 / 91 \\
08 / 24 / 91 \\
12 / 05 / 91 \\
10 / 12 / 92 \\
02 / 17 / 94\end{array}$ & $\begin{array}{l}0001 \\
0001 \\
0001 \\
0001 \\
0001 \\
0001 \\
0001 \\
0001 \\
0001 \\
0001 \\
0001 \\
0001 \\
0001 \\
0001 \\
0001 \\
0001 \\
0001 \\
0001 \\
0001 \\
0001\end{array}$ & $\begin{array}{l}\mathrm{JE} \\
\mathrm{JE} \\
\mathrm{JE} \\
\mathrm{JE} \\
\mathrm{JE} \\
\mathrm{JE} \\
\mathrm{JE} \\
\mathrm{JE} \\
\mathrm{JE} \\
\mathrm{JE} \\
\mathrm{JE} \\
\mathrm{JE} \\
\mathrm{JE} \\
\mathrm{JE} \\
\mathrm{JE} \\
\mathrm{JE} \\
\mathrm{JE} \\
\mathrm{JE} \\
\mathrm{JE} \\
\mathrm{JE}\end{array}$ & $\begin{array}{l}U \\
U \\
U \\
U \\
U \\
U \\
0 \\
0 \\
0 \\
0 \\
0 \\
0 \\
0 \\
0 \\
0 \\
0 \\
0 \\
0 \\
0 \\
0\end{array}$ & $M G / L$ & $<$ & $\begin{array}{l}0.0017 \\
0.001 \\
0.001 \\
0.002 \\
0.001 \\
0.002 \\
0.047 \\
0.0178 \\
0.004 \\
0.010 \\
0.004 \\
0.015 \\
0.003 \\
0.006 \\
0.0028 \\
0.001 \\
0.001 \\
0.004 \\
0.003 \\
0.004\end{array}$ & $\begin{array}{l}L \\
L \\
L \\
L \\
L \\
L \\
L \\
L \\
L \\
L \\
L \\
L \\
L \\
L \\
J L N\end{array}$ & $\begin{array}{l}0.0003 \\
0.001 \\
0.001 \\
0.001 \\
0.001 \\
0.001 \\
0.003 \\
0.0003 \\
0.001 \\
0.001 \\
0.001 \\
0.001 \\
0.001 \\
0.003 \\
0.0003 \\
0.001 \\
0.001 \\
0.001 \\
0.001 \\
0.001\end{array}$ & $\begin{array}{c}- \\
- \\
- \\
- \\
- \\
0.010 \\
- \\
- \\
- \\
- \\
- \\
0.001 \\
- \\
- \\
- \\
- \\
-\end{array}$ \\
\hline URANIUM (TOTAL) & $\begin{array}{l}0554 \\
0702 \\
0704\end{array}$ & $\begin{array}{l}02 / 17 / 94 \\
02 / 21 / 94 \\
02 / 17 / 94\end{array}$ & $\begin{array}{l}\text { N001 } \\
\text { N001 } \\
\text { N001 }\end{array}$ & $\begin{array}{l}\mathrm{JE} \\
\mathrm{JE} \\
\mathrm{JE}\end{array}$ & $\begin{array}{l}U \\
0 \\
0\end{array}$ & $M G / L$ & & $\begin{array}{l}0.004 \\
0.003 \\
0.004\end{array}$ & L JLN & $\begin{array}{l}0.001 \\
0.001 \\
0.001\end{array}$ & - \\
\hline VANADIUM & $\begin{array}{l}0554 \\
0554 \\
0554 \\
0554 \\
0554 \\
0554 \\
0702 \\
0702\end{array}$ & $\begin{array}{l}12 / 12 / 90 \\
03 / 28 / 91 \\
08 / 05 / 91 \\
12 / 06 / 91 \\
10 / 15 / 92 \\
02 / 17 / 94 \\
03 / 29 / 89 \\
12 / 12 / 90\end{array}$ & $\begin{array}{l}0001 \\
0001 \\
0001 \\
0001 \\
0001 \\
0001 \\
0001 \\
0001\end{array}$ & $\begin{array}{l}\mathrm{JE} \\
\mathrm{JE} \\
\mathrm{JE} \\
\mathrm{JE} \\
\mathrm{JE} \\
\mathrm{JE} \\
\mathrm{JE} \\
\mathrm{JE}\end{array}$ & $\begin{array}{l}U \\
U \\
U \\
U \\
U \\
U \\
0 \\
0\end{array}$ & $M G / L$ & $\begin{array}{l}< \\
< \\
< \\
< \\
<\end{array}$ & $\begin{array}{l}0.03 \\
0.01 \\
0.01 \\
0.01 \\
0.01 \\
0.01 \\
0.01 \\
0.03\end{array}$ & $L$ & $\begin{array}{l}0.01 \\
0.01 \\
0.01 \\
0.01 \\
0.01 \\
0.01 \\
0.01 \\
0.01\end{array}$ & $\begin{array}{l}- \\
- \\
- \\
- \\
- \\
-\end{array}$ \\
\hline
\end{tabular}

FORMATION OF COMPLETION CODE:

JE - JURASSIC ENTRADA SANDSTONE FORMATION

FLOW RELATIONSHIP CODE:

O - ON-SITE

$U$ - UPGRADIENT

PARAMETER VALUE INDICATOR (PVI): < - LESS THAN DETECTION LIMIT

SAMPLE ID CODES:

0001 - FILTERED SAMPLE (.45 MICRONS)

OTHER PARAMETER VALUE FLAGS:

NOO1 - UNFILTERED SAMPLE

J - ESTIMATED VALUE

L - LESS THAN THREE BORE VOLUMES REMOVED BEFORE SAMPLING

N - SPIKE SAMPLE RECOVERY NOT HITHIN CONTROL LIMITS 


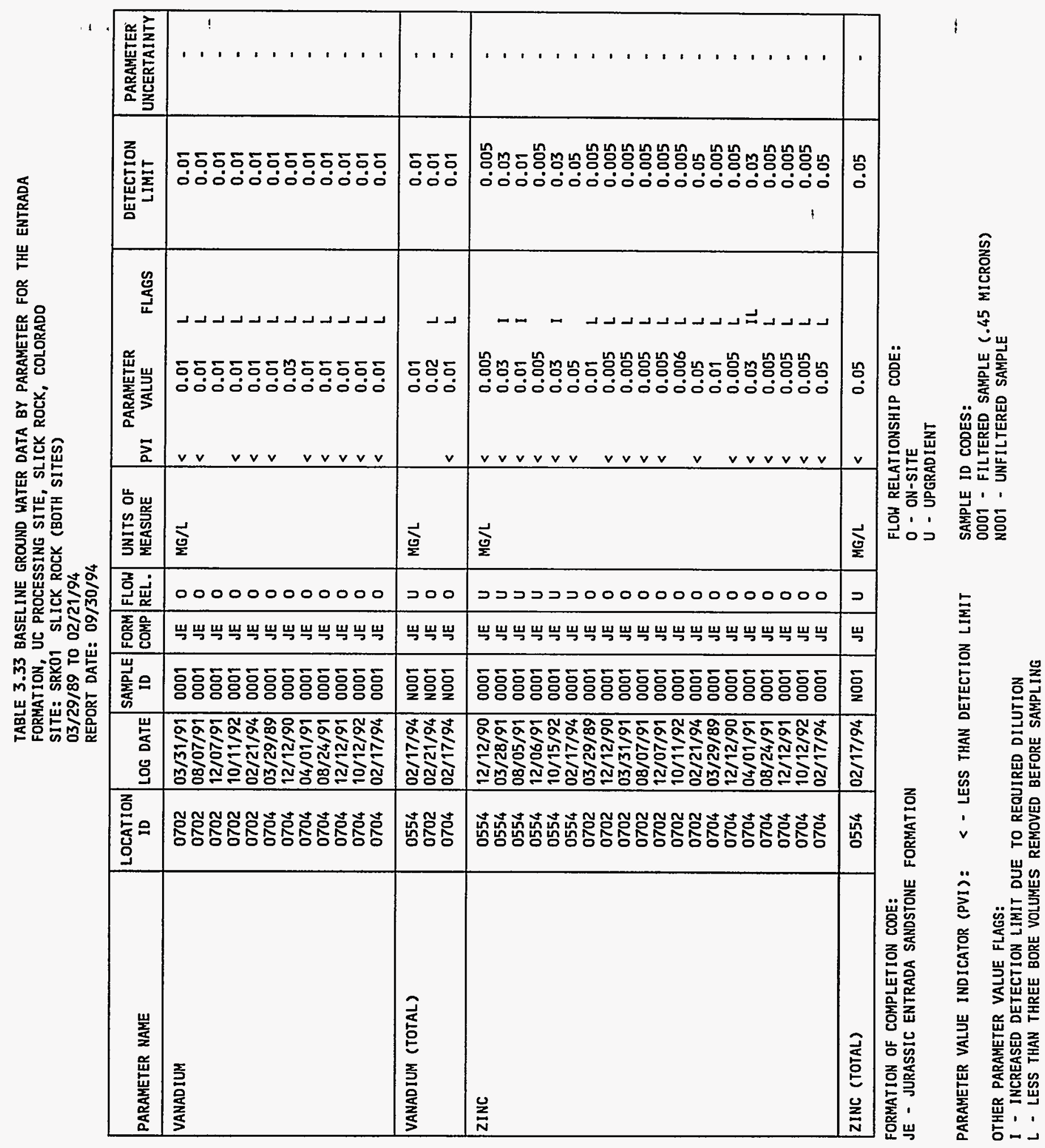


TABLE 3.33 BASELINE GROUND WATER DATA BY PARAMETER FOR THE ENTRADA

FORMATION, UC PROCESSING SITE, SLICK ROCK, COLORADO

SITE: SRKO1 SLICK ROCK (BOTH SITES)

03/29/89 TO 02/21/94

REPORT DATE: $09 / 30 / 94$

\begin{tabular}{|c|c|c|c|c|c|c|c|c|c|c|c|}
\hline PARAMETER NAME & $\underset{\text { ID }}{\text { LOCATION }}$ & LOG DATE & $\begin{array}{c}\text { SAMPLE } \\
\text { ID }\end{array}$ & $\begin{array}{l}\text { FORM } \\
\text { COMP }\end{array}$ & $\begin{array}{l}\text { FLOW } \\
\text { REL. }\end{array}$ & $\begin{array}{l}\text { UNITS OF } \\
\text { MEASURE }\end{array}$ & PVI & $\begin{array}{l}\text { PARAMETER } \\
\text { VALUE }\end{array}$ & FLAGS & $\begin{array}{l}\text { DETECTION } \\
\text { LIMIT }\end{array}$ & $\begin{array}{l}\text { PARAMETER } \\
\text { UNCERTAINTY }\end{array}$ \\
\hline ZINC (TOTAL) & $\begin{array}{l}0702 \\
0704\end{array}$ & $\left|\begin{array}{l}02 / 21 / 94 \\
02 / 17 / 94\end{array}\right|$ & $\begin{array}{l}\text { N001 } \\
\text { N001 }\end{array}$ & $\begin{array}{l}\text { JE } \\
\text { JE }\end{array}$ & $\begin{array}{l}0 \\
0\end{array}$ & MG/L & $<<$ & $\begin{array}{l}0.06 \\
0.05\end{array}$ & $\begin{array}{l}\mathrm{L} \\
\mathrm{L}\end{array}$ & $\begin{array}{l}0.05 \\
0.05\end{array}$ & - \\
\hline
\end{tabular}

FORMATION OF COMPLETION CODE:

JE - JURASSIC ENTRADA SANDSTONE FORMATION

FLOW RELATIONSHIP CODE:

PARAMETER VALUE INDICATOR (PVI): < - LESS THAN DETECTION LIMIT

SAMPLE ID CODES:

NO01 - UNFILTERED SAMPLE

OTHER PARAMETER VALUE FLAGS:

L - LESS THAN THREE BORE VOLUMES REMOVED BEFORE SAMPLING

DATA FILE NAME: IDARTISRKO1\GWQ10075.DAT 
TABLE 3.34 BASELINE GROUND MATER QUALITY STATISTICS BY PARAMETER FOR THE ENTRADA FORMATION, UC PROCESSING SITE, SLICK ROCK, COLORADO

SITE: SRKOI SLICK ROCK (BOTH SITES)

$03 / 29 / 89$ TO $02 / 21 / 94$

REPORT DATE: $10 / 03 / 94$

\begin{tabular}{|c|c|c|c|c|c|c|c|c|c|c|c|c|}
\hline \multicolumn{3}{|c|}{ PARAMETER NAME } & UNITS & \multirow[b]{2}{*}{ MEAN } & \multirow{2}{*}{$\begin{array}{r}\text { STANDARD } \\
\text { DEVIATION }\end{array}$} & \multirow{2}{*}{$\begin{array}{l}\text { COEFF. } \\
\text { OF } \\
\text { VARIATION }\end{array}$} & \multirow{2}{*}{$\mid \begin{array}{c}x \text { OF } \\
\text { NON } \\
\text { DETECTS }\end{array}$} & \multirow{2}{*}{\multicolumn{3}{|c|}{$\begin{array}{c}\text { STATISTICAL RANGE } \\
\text { 98\% CONFIDENCE INTERVAL } \\
\text { MINIMUM } \\
\text { MAXIMUM * }\end{array}$}} & \multirow{2}{*}{$\begin{array}{l}\text { DISTRIBUT ION } \\
\text { TYPE }\end{array}$} & \multirow{2}{*}{$\begin{array}{l}\text { FOOT } \\
\text { HOTE }\end{array}$} \\
\hline \# OF SAMP & MINIMUM & MAXIMUM & MEDIAN & & & & & & & & & \\
\hline \multicolumn{3}{|c|}{ ALKALINITY } & MG/L CAC & \multirow[b]{2}{*}{298.0000} & \multirow[b]{2}{*}{183.1344} & \multirow[b]{2}{*}{0.6145} & \multirow[b]{2}{*}{0.0} & \multirow{2}{*}{\multicolumn{2}{|c|}{194.0277}} & \multirow[b]{2}{*}{401.9723} & \multirow[b]{2}{*}{ NORMAL } & \\
\hline 20 & 149.0000 & 623.0000 & +201.0000 & & & & & & & & & \\
\hline \multicolumn{3}{|l|}{ ALUMINUM } & MG/L & \multirow[b]{2}{*}{ NA } & \multirow[b]{2}{*}{ NA } & \multirow[b]{2}{*}{ NA } & \multirow[b]{2}{*}{100.0} & \multirow[b]{2}{*}{ ** } & \multirow[b]{2}{*}{0.0500} & \multirow[b]{2}{*}{0.0500} & \multirow[b]{2}{*}{ NONPARAMETRIC } & \multirow[b]{2}{*}{2} \\
\hline 17 & ** $\quad 0.0500$ & 0.0500 & 0.0500 & & & & & & & & & \\
\hline \multicolumn{3}{|l|}{ AMMONIUM } & $M G / L$ & \multirow[b]{2}{*}{ NA } & \multirow[b]{2}{*}{ NA } & \multirow[b]{2}{*}{ NA } & \multirow[b]{2}{*}{41.2} & & & & & \\
\hline 17 & ** $\quad 0.1000$ & 0.6000 & ** $\quad 0.1000$ & & & & & ** & 0.1000 & 0.2000 & NONPARAMETRIC & 2 \\
\hline AMMONIUM & (TOTAL) & & MG/L & & & & & & & & & \\
\hline 3 & $\begin{array}{ll}* & 0.1000\end{array}$ & 0.1000 & 0.1000 & NA & NA & NA & 100.0 & & NA & NA & UNKNOWN & 1 \\
\hline ANT IMONY & & & MG/L & & & & & & & & & \\
\hline 17 & $\begin{array}{ll}* & 0.0030\end{array}$ & 0.0060 & 0.0030 & NA & NA & NA & 82.4 & ** & 0.0030 & $\star \quad 0.0030$ & MONPARAMETR IC & 2 \\
\hline ARSENIC & & & $M G / L$ & & & & & & & & & \\
\hline 17 & $\begin{array}{ll}* & 0.0050\end{array}$ & 0.0100 & 0.0050 & NA & NA & NA & 76.5 & $\star *$ & 0.0050 & 0.0050 & NONPARAMETRIC & 2 \\
\hline BARIUM & & & $M G / L$ & & & & & & & & & \\
\hline 20 & 0.0500 & 2.3000 & 0.0850 & NA & NA & NA & 20.0 & & 0.0500 & 0.4200 & NONPARAMETR IC & 2 \\
\hline BARIUM (TO & DTAL) & & MG/L & & & & & & & & & \\
\hline 3 & $\begin{array}{ll}* & 0.1000\end{array}$ & 2.4000 & 0.3000 & NA & NA & NA & 33.3 & & NA & NA & UNKNOWN & 1 \\
\hline BERYLLIUM & & & $M G / L$ & & & & & & & & & \\
\hline 14 & ** $\quad 0.0050$ & 0.0050 & 0.0050 & NA & NA & HA & 100.0 & $\star \star$ & 0.0050 & 0.0050 & NONPARAMETRIC & 2 \\
\hline BORON & & & $M G / L$ & & & & & & & & & \\
\hline 15 & $\begin{array}{ll}* & 0.0500\end{array}$ & 0.4000 & 0.0600 & NA & NA & HA & 46.7 & ** & 0.0500 & 0.3100 & NONPARAMETRIC & 2 \\
\hline
\end{tabular}

** The reported value is the minimum detection limit of the data set

+ The sample size is even, so the median value is the arithmetic average of the two middle values

* The statistical maximum is the 99 percent one sided confidence interval, $a=0.01$

1) A minimum of 4 samples must be available for the statistical analysis.

2) The nonparametric distribution was used because the nondetected values comprise more than $15 \%$ of the samples. 
TABLE 3,34 BASEL INE GROUND HATER QUALITY STATISTICS BY PARAMETER FOR THE ENTRADA FORMATION, UC PROCESSING SITE, SLICK ROCK, COLORADO

SITE: SPKO1 SLICK ROCK (BOTH S:

$03 / 29 / 89$ TO $02 / 21 / 94$

REPORT DATE: $10 / 03 / 94$

\begin{tabular}{|c|c|c|c|c|c|c|c|c|c|c|c|}
\hline \multicolumn{3}{|c|}{ PARAMETER NAME } & UNITS & \multirow[b]{2}{*}{ MEAN } & \multirow{2}{*}{$\begin{array}{r}\text { STANDARD } \\
\text { DEVIATION }\end{array}$} & \multirow{2}{*}{$\begin{array}{c}\text { COEFF. } \\
\text { OF } \\
\text { VARIATION }\end{array}$} & \multirow{2}{*}{ 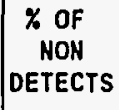 } & \multirow{2}{*}{\multicolumn{2}{|c|}{$\begin{array}{c}\text { STATISTICAL RANGE } \\
\text { 98\% CONFIDENCE INTERVAL } \\
\text { MINIMUM }\end{array}$}} & \multirow{2}{*}{$\begin{array}{l}\text { DISTRIBUTION } \\
\text { TYPE }\end{array}$} & \multirow{2}{*}{$\begin{array}{l}\text { FOOT } \\
\text { NOTE }\end{array}$} \\
\hline \# OF SAMP & MINIMUM & MAXIMUM & MEDIAN & & & & & & & & \\
\hline \multicolumn{3}{|c|}{ BORON (TOTAL) } & $M G / L$ & \multirow[b]{2}{*}{ NA } & \multirow[b]{2}{*}{ NA } & \multirow[b]{2}{*}{ NA } & \multirow[b]{2}{*}{33.3} & \multirow[b]{2}{*}{ HA } & \multirow[b]{2}{*}{ NA } & \multirow[b]{2}{*}{ UNKNOWH } & \multirow[b]{2}{*}{1} \\
\hline 3 & ** 0.1000 & 0.5000 & 0.2000 & & & & & & & & \\
\hline \multicolumn{3}{|l|}{ BROMIDE } & $M G / L$ & \multirow[b]{2}{*}{ NA } & \multirow[b]{2}{*}{ NA } & \multirow[b]{2}{*}{ NA } & \multirow[b]{2}{*}{40.0} & \multirow[b]{2}{*}{0.1000} & \multirow[b]{2}{*}{3.4000} & \multirow[b]{2}{*}{ NONPARAMETRIC } & \multirow[b]{2}{*}{2} \\
\hline 15 & 0.0500 & 5.0000 & 0.3000 & & & & & & & & \\
\hline \multicolumn{3}{|l|}{ CADMIUM } & $M G / L$ & \multirow[b]{2}{*}{ NA } & \multirow[b]{2}{*}{ NA } & \multirow[b]{2}{*}{ NA } & \multirow[b]{2}{*}{90.0} & & & & \\
\hline 20 & $\star * \quad 0.0010$ & 0.0025 & ** $\quad 0.0010$ & & & & & 0.0010 & 0.0010 & NONPARAMETRIC & 2 \\
\hline CADMIUM (T & TOTAL) & & $M G / L$ & & & & & & & & \\
\hline 3 & $\star * \quad 0.0010$ & ** $\quad 0.0010$ & ** $\quad 0.0010$ & NA & NA & NA & 100.0 & NA & NA & UNKNOWN & 1 \\
\hline CALCIUM & & & $\mathrm{MG} / \mathrm{L}$ & & & & & & & & \\
\hline 20 & 40.9000 & 203.0000 & 59.7500 & 84.9950 & 51.2169 & 0.6026 & 0.0 & 55.9172 & 114.0728 & NORMAL & \\
\hline CALCIUN (T & TOTAL) & & MG/L & & & & & & & & \\
\hline 3 & 48.9000 & 223.0000 & 87.7000 & NA & NA & NA & 0.0 & NA & NA & UNKNOWN & 1 \\
\hline CHLORIDE & & & $M G / L$ & & & & & & & & \\
\hline 20 & 22.1000 & 1330.0000 & 67.3000 & 108.9517 & 4.4253 & NA & 0.0 & 46.8281 & 253.4904 & LOGNORMAL & 7,8 \\
\hline CHROMIUM & & & $M G / L$ & & & & & & & & \\
\hline 20 & 0.0100 & 0.0100 & 0.0100 & NA & NA & NA & 100.0 & 0.0100 & 0.0100 & NONPARAMETRIC & 2 \\
\hline CHROMIUM ( & (TOTAL) & & $M G / L$ & & & & & & & & \\
\hline 3 & ** $\quad 0.0100$ & 0.0100 & 0.0100 & NA & NA & NA & 33.3 & NA & NA & UNKNOWN & 1 \\
\hline
\end{tabular}

** The reported value is the minimum detection limit of the data set

+ The sample size is even, so the median value is the arithmetic average of the two middle values

* The statistical maximum is the 99 percent one sided confidence interval, $\alpha=0.01$

1) A minimum of 4 samples must be available for the statistical analysis.

2) The nonparametric distribution was used because the nondetected values comprise more than $15 \%$ of the samples.

7) The lognormal distribution was used because the data failed the normal distribution test.

8) The mean is geometric. The standard deviation is the value to divide or multiply with the geometric mean. 
TABLE 3.34 BASELINE GROUND MATER QUALITY STATISTICS BY PARAMETER FOR THE

ENTRADA FORMATIOH, UC PROCESSING SITE, SLICK ROCK, COLORADO

SITE: SRKO1 SLICK ROCK (BOTH SITES)

$03 / 29 / 89$ TO $02 / 21 / 94$

REPORT DATE: $10 / 03 / 94$

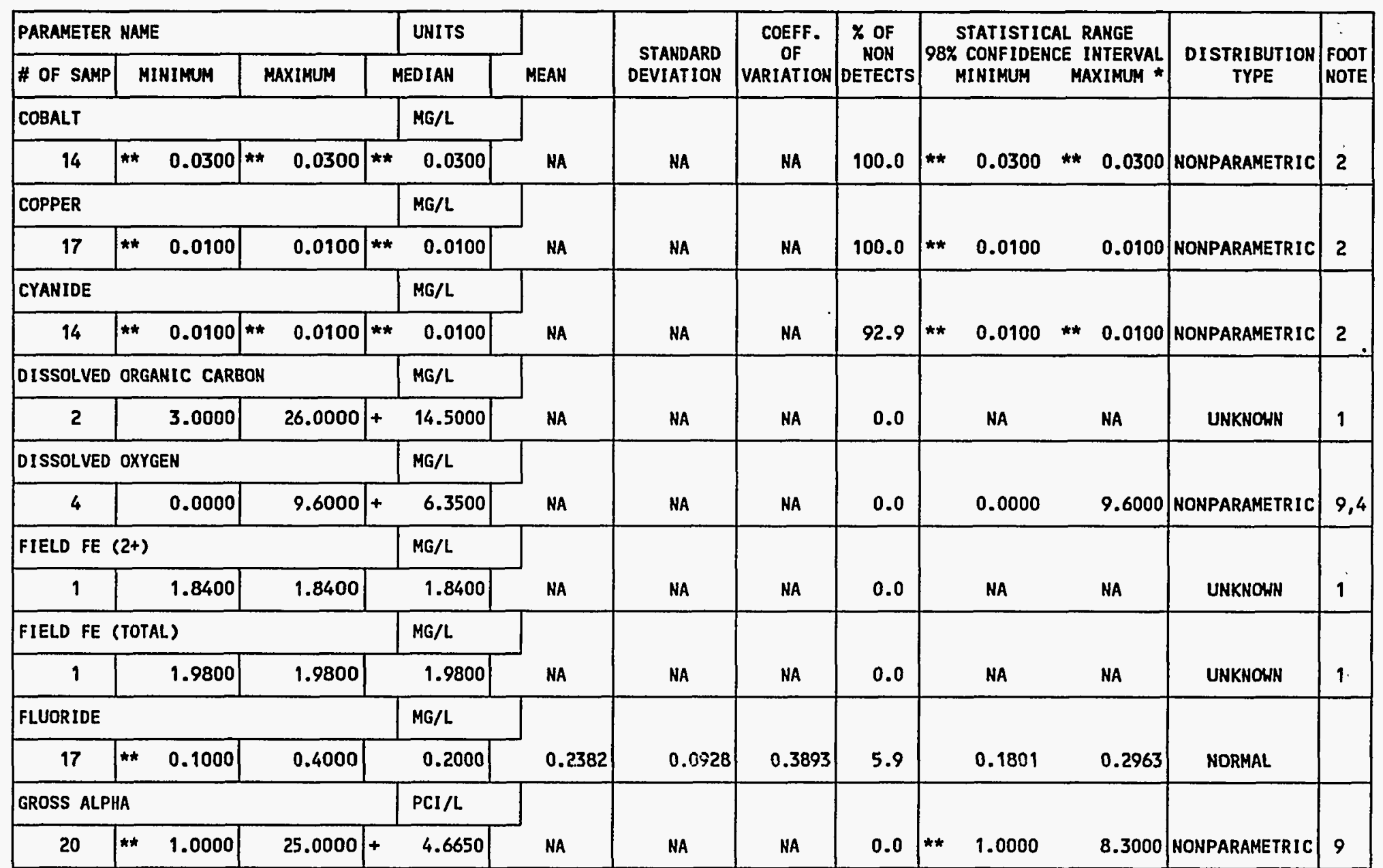

** The reported value is the minimum detection limit of the data set

+ The sample size is even, so the median value is the arithmetic average of the two middle values

* The statistical maximum is the 99 percent one sided confidence interval, $\alpha=0.01$

1) A minimum of 4 samples must be available for the statistical analysis.

2) The nonparametric distribution was used because the nondetected values comprise more than $15 \%$ of the samples.

4) The stat. range is the $87.5 \%$ confidence interval due to a sample size of 4 . The maximum is the $93.8 \%$ one sided confidence int

9) The nonparametic distribution was used because the data failed the normal distribution test and includes values $\leq 0$. 
TABLE 3.34 BASELINE GROUND MATER QUALITY STATISTICS BY PARAMETER FOR THE ENTRADA FORMATION, UC PROCESSING SITE, SLICK ROCK, COLORADO

SITE: SRKO1 SLICK ROCK (BOTH SITES)

$03 / 29 / 89$ TO $02 / 21 / 94$

REPORT DATE: $10 / 03 / 94$

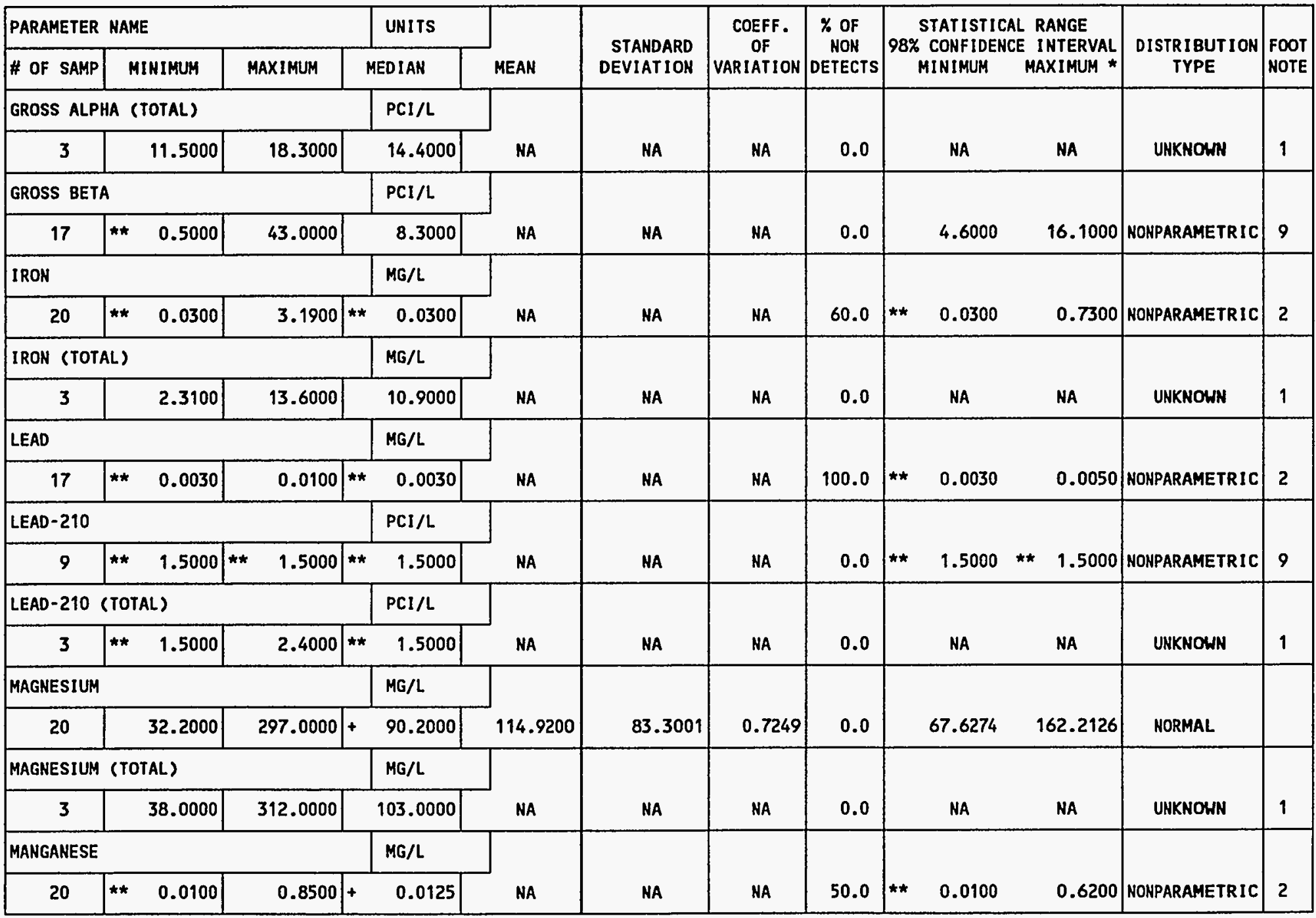

** The reported value is the minimum detection limit of the data set

- The sample size is even, so the median value is the arithmetic average of the two middle values

* The statistical maximum is the 99 percent one sided confidence interval, $\alpha=0.01$

1) A minimum of 4 samples must be available for the statistical analysis.

2) The nonparametric distribution was used because the nondetected values comprise more than $15 \%$ of the samples.

9) The nonparametic distribution was used because the data failed the normal distribution test and includes values $\leq 0$. 
TABLE 3.34 BASELINE GROUND WATER QUALITY STATISTICS BY PARAMETER FOR THE ENTRADA FORMATION, UC PROCESSIHG SITE, SLICK ROCK, COLORADO

SITE: SRKOI SLICK ROCK (BOTH SITES)

$03 / 29 / 89$ TO $02 / 21 / 94$

REPORT DATE: $10 / 03 / 94$

\begin{tabular}{|c|c|c|c|c|c|c|c|c|c|c|c|c|c|}
\hline \multicolumn{3}{|c|}{ PARAMETER NAME } & UNITS & \multirow[b]{2}{*}{ MEAN } & \multirow{2}{*}{$\begin{array}{l}\text { STANDARD } \\
\text { DEVIATION }\end{array}$} & \multirow{2}{*}{$\begin{array}{c}\text { COEFF. } \\
\text { OF } \\
\text { VARIATION }\end{array}$} & \multirow{2}{*}{$\begin{array}{c}x \text { OF } \\
\text { HON } \\
\text { DETECTS }\end{array}$} & \multirow{2}{*}{\multicolumn{4}{|c|}{$\begin{array}{c}\text { STATISTICAL RANGE } \\
\text { 98\% CONFIDENCE INTERVAL } \\
\text { MINIMUM }\end{array}$}} & \multirow{2}{*}{$\begin{array}{c}\text { DISTRIBUTION } \\
\text { TYPE }\end{array}$} & \multirow{2}{*}{ FOOT } \\
\hline \# OF SAMP & MIHIMUN & MAXIMUM & MEDIAN & & & & & & & & & & \\
\hline \multicolumn{3}{|c|}{ MANGAMESE (TOTAL) } & MG/L. & \multirow[b]{2}{*}{ NA } & \multirow[b]{2}{*}{ NA } & \multirow[b]{2}{*}{ NA } & \multirow[b]{2}{*}{0.0} & \multirow{2}{*}{\multicolumn{2}{|c|}{ MA }} & \multirow{2}{*}{\multicolumn{2}{|c|}{ MA }} & \multirow[b]{2}{*}{ UNKNOWN } & \multirow{2}{*}{ i } \\
\hline 3 & 0.0800 & 1.2600 & 0.4900 & & & & & & & & & & \\
\hline \multicolumn{3}{|l|}{ MERCURY } & MG/L & \multirow[b]{2}{*}{ NA } & \multirow[b]{2}{*}{ NA } & \multirow[b]{2}{*}{ NA } & \multirow[b]{2}{*}{100.0} & \multirow[b]{2}{*}{ ** } & \multirow[b]{2}{*}{0.0002} & \multirow[b]{2}{*}{ * } & \multirow[b]{2}{*}{0.0002} & \multirow[b]{2}{*}{ NONPARAMETRIC } & \multirow[b]{2}{*}{2} \\
\hline 14 & ** $\quad 0.0002$ & 0.0002 & 0.0002 & & & & & & & & & & \\
\hline \multicolumn{3}{|l|}{ MOLYBDENUM } & MG/L & \multirow[b]{2}{*}{ NA } & \multirow[b]{2}{*}{ NA } & \multirow[b]{2}{*}{ NA } & & & & & & & \\
\hline 20 & ** 0.0100 & 0.0600 & 0.0100 & & & & 75.0 & ** & 0.0100 & ** & 0.0100 & NONPARAMETRIC & 2 \\
\hline MOLYBDENUY & (TOTAL) & & MG/L & & & & & & & & & & \\
\hline 3 & ** 0.0100 & 0.0100 & 0.0100 & NA & NA & NA & 66.7 & & NA & & NA & UNKNOWN & 1 \\
\hline NET GROSS & ALPHA $\star \star * \star$ & & $\mathrm{PCl} / \mathrm{L}$ & & & & & & & & & & \\
\hline 20 & -10.2900 & 21.0100 & 0.0500 & NA & NA & NA & 0.0 & & -1.3700 & & 5.8800 & NONPARAMETRIC & 9 \\
\hline NET GROSS & ALPHA CTOTAL & L) $* * * *$ & $\mathrm{PCI} / \mathrm{L}$ & & & & & & & & & & \\
\hline 3 & 8.7600 & 16.2400 & 11.6600 & NA & NA & NA & 0.0 & & NA & & NA & UNKNOWN & 1 \\
\hline NICKEL & & & $M G / L$ & & & & & & & & & & \\
\hline 17 & $\begin{array}{ll}* * & 0.0400\end{array}$ & $* * \quad 0.0400$ & 0.0400 & NA & NA & NA & 100.0 & ** & 0.0400 & ** & 0.0400 & NONPARAMETRIC & 2 \\
\hline NITRATE & & & $M G / L$ & & & & & & & & & & \\
\hline 17 & 0.5000 & 126.0000 & 10.8000 & NA & NA & HA & 17.6 & & 1.9000 & & 79.2000 & NONPARAMETRIC & 2 \\
\hline NITRATE (T & TOTAL) & & $M G / L$ & & & & - & & & & & & \\
\hline 3 & ** $\quad 1.0000$ & 96.0000 & 1.0000 & NA & NA & NA & 33.3 & & NA & & NA & UNKNOWN & 1 \\
\hline
\end{tabular}

*** NET GROSS ALPHA (GROSS ALPHA - URANIUM) WITH 1 MG URANIUM = $686 \mathrm{PCI}$

**** NET GROSS ALPHA (TOTAL) (TOTAL GROSS ALPHA - TOTAL URANIUH)

** The reported value is the minimum detection limit of the data set

+ The sample size is even, so the median value is the arithmetic average of the two middle values

* The statistical maximum is the 99 percent one sided confidence interval, $\alpha=0.01$

1) A minimum of 4 samples must be available for the statistical analysis.

2) The nonparametric distribution was used because the nondetected values comprise more than $15 \%$ of the samples.

9) The nonparametic distribution was used because the data failed the normal distribution test and includes values $\leq 0$. 
TABLE 3.34 BASELINE GROUND HATER QUALITY STATISTICS BY PARAMETER FOR THE ENTRADA FORMATION, UC PROCESSING SITE, SLICK ROCK, COLORADO

SITE: SRKO1 SLICK ROCK (BOTH SITES)

03/29/89 TO 02/21/94

REPORT DATE: $10 / 03 / 94$

\begin{tabular}{|c|c|c|c|c|c|c|c|c|c|c|c|}
\hline \multicolumn{3}{|c|}{ PARAMETER NAME } & UNITS & \multirow[b]{2}{*}{ MEAN } & \multirow{2}{*}{$\begin{array}{l}\text { STANDARD } \\
\text { DEVIATION }\end{array}$} & \multirow{2}{*}{\begin{tabular}{|c} 
COEFF. \\
OF \\
VARIATION
\end{tabular}} & \multirow{2}{*}{$\begin{array}{c}x \text { OF } \\
\text { NON } \\
\text { DETECTS }\end{array}$} & \multirow{2}{*}{\multicolumn{2}{|c|}{ 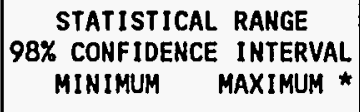 }} & \multirow{2}{*}{$\begin{array}{c}\text { DISTRIBUTION } \\
\text { TYPE }\end{array}$} & \multirow{2}{*}{$\begin{array}{l}\text { FOOT } \\
\text { NOTE }\end{array}$} \\
\hline \# OF SAMP & MINIMUM & MAXIMUM & MEDIAN & & & & & & & & \\
\hline \multicolumn{3}{|c|}{ NITRITE AND NITRATE } & $M G / L$ & \multirow[b]{2}{*}{3.8457} & \multirow[b]{2}{*}{7.6347} & \multirow[b]{2}{*}{ NA } & \multirow[b]{2}{*}{11.1} & \multirow[b]{2}{*}{0.5405} & \multirow[b]{2}{*}{27.3633} & \multirow[b]{2}{*}{ LOGNORMAL } & \multirow[b]{2}{*}{7,8} \\
\hline 9 & 0.2300 & 126.0000 & 2.8200 & & & & & & & & \\
\hline \multicolumn{3}{|l|}{$\mathrm{PH}$} & su & \multirow[b]{2}{*}{ NA } & \multirow[b]{2}{*}{ NA } & \multirow[b]{2}{*}{ NA } & \multirow[b]{2}{*}{0.0} & \multirow[b]{2}{*}{ NA } & \multirow[b]{2}{*}{ NA } & \multirow[b]{2}{*}{ UNKNOWN } & \\
\hline 20 & 6.9300 & 7.9700 & 7.7499 & & & & & & & & \\
\hline \multicolumn{3}{|l|}{ PHOSPHATE } & $M G / L$ & \multirow[b]{2}{*}{ NA } & \multirow[b]{2}{*}{ NA } & \multirow[b]{2}{*}{ NA } & \multirow[b]{2}{*}{47.1} & \multirow[b]{2}{*}{0.0500} & \multirow[b]{2}{*}{0.2000} & \multirow[b]{2}{*}{ NONPARAMETRIC } & \\
\hline 17 & 0.0500 & 1.2000 & 0.1000 & & & & & & & & 2 \\
\hline POLONIUM-Z & 10 & & $\mathrm{PCI} / \mathrm{L}$ & & & & & & & & \\
\hline 9 & $* * \quad 0.1000$ & 1.4000 & 0.1000 & NA & NA & NA & 0.0 & 0.1000 & 1.4000 & NONPARAMETRIC & 9 \\
\hline POLONIUM-2 & 10 (TOTAL) & & $\mathrm{PCl} / \mathrm{L}$ & & & & & & & & \\
\hline 3 & 0.0000 & 0.2000 & 0.0000 & NA & NA & NA & 0.0 & NA & NA & UNKNOWN & 1 \\
\hline POTASSIUM & & & $M G / L$ & & & & & & & & \\
\hline 20 & 2.3400 & 11.9000 & 7.9500 & 7.0120 & 2.7974 & 0.3989 & 0.0 & 5.4238 & 8.6002 & NORMAL & \\
\hline POTASSIUM & (TOTAL) & & $M G / L$ & & & & & & & & \\
\hline 3 & 9.7000 & 16.1000 & 11.1000 & NA & NA & NA & 0.0 & NA & NA & UNKNOWN & 1 \\
\hline RADIUM-220 & & & $\mathrm{PCI} / \mathrm{L}$ & & & & & & & & \\
\hline 18 & 0.1000 & 2.7000 & 0.5000 & 0.6056 & 0.5866 & 0.9687 & 0.0 & 0.2506 & 0.9605 & NORMAL & \\
\hline RADIUM-220 & (TOTAL) & & $\mathrm{PCl} / \mathrm{L}$ & & & & & & & & \\
\hline 3 & 0.6000 & 2.7000 & 0.7000 & NA & NA & NA & 0.0 & NA & NA & UNKNOWN & 1 \\
\hline
\end{tabular}

** The reported value is the minimum detection limit of the data set

+ The sample size is even, so the median value is the arithmetic average of the two middle values

* The statistical maximum is the 99 percent one sided confidence interval, $a=0.01$

1) A minimum of 4 samples must be available for the statistical analys is.

2) The nonparametric distribution was used because the nondetected values comprise more than $15 \%$ of the samples.

7) The lognormal distribution was used because the data failed the normal distribution test.

8) The mean is geometric. The standard deviation is the value to divide or multiply with the geometric mean.

9) The nonparametic distribution was used because the data failed the normal distribution test and includes values $\leq 0$. 
TABLE 3.34 BASELINE GROUHD HATER QUALITY STATISTICS BY PARAMETER FOR THE ENTRADA FORMATION, UC PROCESSING SITE, SLICK ROCK, COLORADO

SITE: SRKO1 SLICK ROCK (BOTH SITES)

$03 / 29 / 89$ TO $02 / 21 / 94$

REPORT DATE $=10 / 03 / 94$

\begin{tabular}{|c|c|c|c|c|c|c|c|c|c|c|c|c|}
\hline \multicolumn{4}{|c|}{ PARAMETER NAME } & UNITS & \multirow[b]{2}{*}{ MEAN } & \multirow{2}{*}{$\begin{array}{r}\text { STANDARD } \\
\text { DEVIATION }\end{array}$} & \multirow{2}{*}{$\begin{array}{c}\text { COEFF. } \\
\text { OF } \\
\text { VARIATION }\end{array}$} & \multirow{2}{*}{$\mid \begin{array}{c}\% \text { OF } \\
\text { NON } \\
\text { DETECTS }\end{array}$} & \multirow{2}{*}{\multicolumn{2}{|c|}{$\begin{array}{l}\text { STATISTICAL RANGE } \\
\text { 98\% CONFIDENCE INTERVAL } \\
\text { NINIMUM }\end{array}$}} & \multirow{2}{*}{$\begin{array}{l}\text { DISTRIBUTION } \\
\text { TYPE }\end{array}$} & \multirow{2}{*}{$\begin{array}{l}= \\
\text { FOOT } \\
\text { HOTE }\end{array}$} \\
\hline \# OF SAMP & MINIMUN & MAXIMUM & & MEDIAN & & & & & & & & \\
\hline \multicolumn{4}{|c|}{ RADIUH-226 + RADIUM-228 } & $\mathrm{PCI} / \mathrm{L}$ & \multirow[b]{2}{*}{1.8889} & \multirow[b]{2}{*}{1.5274} & \multirow[b]{2}{*}{0.8086} & \multirow[b]{2}{*}{0.0} & \multirow[b]{2}{*}{0.9648} & \multirow[b]{2}{*}{2.8130} & \multirow[b]{2}{*}{ NORMAL } & \\
\hline 18 & 0.3000 & 5.3000 & + & 1.3500 & & & & & & & & \\
\hline \multicolumn{2}{|c|}{ RADIUH-226 + RADIUM-228 } & (TOTAL) & & $\mathrm{PCI} / \mathrm{L}$ & \multirow[b]{2}{*}{ NA } & \multirow[b]{2}{*}{ NA } & \multirow[b]{2}{*}{ NA } & \multirow[b]{2}{*}{0.0} & \multirow[b]{2}{*}{ NA } & \multirow[b]{2}{*}{ HA } & \multirow[b]{2}{*}{ UNKNOWN } & \multirow[b]{2}{*}{1} \\
\hline 3 & 4.0000 & 8.1000 & & 6.4000 & & & & & & & & \\
\hline \multicolumn{4}{|l|}{ RADILA-228 } & $\mathrm{PCI} / \mathrm{L}$ & \multirow[b]{2}{*}{ NA } & \multirow[b]{2}{*}{ NA } & \multirow[b]{2}{*}{ NA } & \multirow[b]{2}{*}{0.0} & \multirow[b]{2}{*}{1.0000} & \multirow[b]{2}{*}{1.8000} & & \\
\hline 18 & $* * \quad 1.0000$ & 5.1000 & + & 1.2000 & & & & & & & NONPARAMETRIC & 9 \\
\hline RADIUM-228 & 8 (TOTAL) & & & $\mathrm{PCl} / \mathrm{L}$ & & & & & & & & \\
\hline 3 & 3.4000 & 5.7000 & & 5.4000 & NA & NA & NA & 0.0 & NA & NA & UNKNOWN & 1 \\
\hline REDOX POTE & ENTIAL & & & mVOLTS & & & & & & & & \\
\hline 8 & 80.5000 & 438.0000 & + & 411.0000 & 336.3125 & 158.0734 & 0.4700 & 0.0 & 168.7621 & 503.8629 & NORMAL & \\
\hline SELEHIUM & & & & $M G / L$ & & & & & & & & \\
\hline 20 & $\begin{array}{ll}* * & 0.0050\end{array}$ & 0.0420 & + & 0.0145 & NA & NA & HA & 30.0 & 0.0050 & 0.0260 & NONPARAMETRIC & 2 \\
\hline SELENIUM & (TOTAL) & & & $M G / L$ & & & & & & & & \\
\hline 3 & $\begin{array}{ll}* * & 0.0050\end{array}$ & 0.0290 & & 0.0100 & NA & NA & NA & 33.3 & NA & NA & UHKNOWN & 1 \\
\hline SILICA - S & s102 & & & $M G / L$ & & & & & & & & \\
\hline 20 & 8.1000 & 16.5000 & + & 10.6000 & 11.6850 & 2.5192 & 0.2156 & 0.0 & 10.2547 & 13.1153 & NORMAL & \\
\hline SILICA - S & SIO2 (TOTAL) & & & $M G / L$ & & & & & & & & \\
\hline 3 & 15.8000 & 24.9000 & & 21.5000 & NA & NA & NA & 0.0 & NA & NA & UNKNOWN & 1 \\
\hline SILVER & & & & $M G / L$ & & & & & & & & \\
\hline 14 & $* \star \quad 0.0100$ & 0.0100 & 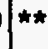 & 0.0100 & $N A$ & NA & HA & 100.0 & 0.0100 & ** 0.0100 & NONPARAMETRIC & 2 \\
\hline
\end{tabular}

** The reported value is the minimum detection limit of the data set

+ The sample size is even, so the median value is the arithmetic average of the tro middle values

* The statistical maximum is the 99 percent one sided confidence interval, $\alpha=0.01$

1) A minimu of 4 samples must be available for the statistical analysis.

2) The nonparametric distribution was used because the nondetected values comprise more than $15 \%$ of the samples.

9) The nonparametic distribution was used because the data failed the normal distribution test and includes values $\leq 0$. 
TABLE 3.34 BASELINE GROUND WATER QUALITY STATISTICS BY PARAMETER FOR THE ENTRADA FORMATION, UC PROCESSIHG SITE, SLICK ROCK, COLORADO

SITE: SRKO1 SLICK ROCK (BOTH SITES)

03/29/89 TO 02/21/94

REPORT DATE: $10 / 03 / 94$

\begin{tabular}{|c|c|c|c|c|c|c|c|c|c|c|c|}
\hline \multicolumn{3}{|c|}{ PARAMETER NAME } & UNITS & \multirow[b]{2}{*}{ MEAN } & \multirow{2}{*}{$\begin{array}{r}\text { STANDARD } \\
\text { DEVIATION }\end{array}$} & \multirow{2}{*}{$\begin{array}{c}\text { COEFF. } \\
\text { OF } \\
\text { VARIATIOH }\end{array}$} & \multirow{2}{*}{$\begin{array}{c}* \text { OF } \\
\text { NON } \\
\text { DETECTS }\end{array}$} & \multirow{2}{*}{\multicolumn{2}{|c|}{$\begin{array}{l}\text { STATISTICAL RANGE } \\
\text { 98\% CONFIDENCE INTERVAL } \\
\text { MINIMUM } \\
\text { MAXIMUM * }\end{array}$}} & \multirow{2}{*}{$\begin{array}{l}\text { DISTRIBUTION } \\
\text { TYPE }\end{array}$} & \multirow{2}{*}{$\begin{array}{l}\text { FOOT } \\
\text { NOTE }\end{array}$} \\
\hline \# OF SAMP & MINIMUM & MAXIMUM & MEDIAN & & & & & & & & \\
\hline \multicolumn{3}{|l|}{ SOO IUM } & $M G / L$ & \multirow[b]{2}{*}{57.5138} & \multirow[b]{2}{*}{2.8485} & \multirow[b]{2}{*}{ NA } & \multirow[b]{2}{*}{0.0} & \multirow[b]{2}{*}{31.7447} & \multirow[b]{2}{*}{104.2012} & \multirow[b]{2}{*}{ LOGMORMAL } & \multirow[b]{2}{*}{7,8} \\
\hline 20 & 10.0000 & 296.0000 & 35.5000 & & & & & & & & \\
\hline \multicolumn{3}{|c|}{ SODIUM (TOTAL) } & $M G / L$ & \multirow[b]{2}{*}{ NA } & \multirow[b]{2}{*}{ NA } & \multirow[b]{2}{*}{ NA } & \multirow[b]{2}{*}{0.0} & \multirow[b]{2}{*}{ NA } & \multirow[b]{2}{*}{ NA } & \multirow[b]{2}{*}{ UNKNOWN } & \multirow[b]{2}{*}{1} \\
\hline 3 & 29.0000 & 307.0000 & 36.0000 & & & & & & & & \\
\hline \multicolumn{3}{|c|}{ SPECIFIC CONDUCTANCE } & $\mathrm{UMHO} / \mathrm{CM}$ & \multirow[b]{2}{*}{1517.0000} & \multirow[b]{2}{*}{1140.2773} & \multirow[b]{2}{*}{0.7517} & \multirow[b]{2}{*}{0.0} & \multirow[b]{2}{*}{802.6510} & \multirow[b]{2}{*}{2231.3490} & & \\
\hline 17 & 400.0000 & 3540.0000 & 945.0000 & & & & & & & NORMAL & \\
\hline STRONTIUM & & & $M G / L$ & & & & & & & & \\
\hline 18 & 0.4500 & 4.8300 & 1.0600 & 1.6961 & 1.3601 & 0.8019 & 0.0 & 0.8732 & 2.5190 & NORMAL & \\
\hline STRONTIUM & (TOTAL) & & $M G / L$ & & & & & & & & \\
\hline 3 & 0.6900 & 5.0700 & 1.2300 & NA & NA & NA & 0.0 & NA & NA & UNKNOWH & 1 \\
\hline SULFATE & & & $M G / L$ & & & & & & & & \\
\hline 20 & 31.0000 & 436.0000 & +131.5000 & 168.8000 & 115.8863 & 0.6865 & 0.0 & 103.0070 & 234.5930 & NORMAL & \\
\hline SULFIDE & & & $M G / L$ & & & & & & & & \\
\hline 15 & 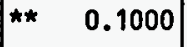 & 42.3000 & 0.6000 & 0.9557 & 9.6558 & NA & 13.3 & 0.2056 & 4.4415 & LOGNORMAL & 7,8 \\
\hline TEMPERATUF & & & C - DEG & & & & & & & & \\
\hline 20 & 11.3000 & 15.2000 & 13.8500 & 13.7450 & 0.9282 & 0.0675 & 0.0 & 13.2180 & 14.2720 & NORMAL & \\
\hline THALLIUM & & & MG/L & & & & & & & & \\
\hline 17 & $\left|\begin{array}{ll}* * & 0.0010\end{array}\right|$ & 0.0500 & 0.0050 & NA & NA & NA & 100.0 & 0.0025 & 0.0050 & | NONPARAMETRIC & 2 \\
\hline
\end{tabular}

** The reported value is the minimun detection limit of the data set

+ The sample size is even, so the median value is the arithmetic average of the two middle values

* The statistical maximum is the 99 percent one sided confidence interval, $\alpha=0.01$

1) A minimum of 4 samples must be available for the statistical analysis.

2) The nonparametric distribution was used because the nondetected values comprise more than $15 \%$ of the samples.

7) The lognormal distribution was used because the data failed the normal distribution test.

8) The mean is geometric. The standard deviation is the value to divide or multiply with the geometric mean. 
TABLE 3.34 BASELINE GROUND MATER OUALITY STATISTICS BY PARAMETER FOR THE ENTRADA FORMATION, UC PROCESSING SITE, SLICK ROCK, COLORADO

SITE: SRKOI SLICK ROCK (BOTH SITES)

03/29/89 TO 02/21/94

REPORT DATE: $10 / 03 / 94$

\begin{tabular}{|c|c|c|c|c|c|c|c|c|c|c|c|c|}
\hline \multicolumn{3}{|c|}{ PARAMETER NAME } & UNITS & \multirow[b]{2}{*}{ MEAN } & \multirow{2}{*}{$\begin{array}{l}\text { STANDARD } \\
\text { DEVIATION }\end{array}$} & \multirow{2}{*}{$\begin{array}{c}\text { COEFF. } \\
\text { OF } \\
\text { VARIATION }\end{array}$} & \multirow{2}{*}{$\begin{array}{c}x \text { OF } \\
\text { NON } \\
\text { DETECTS }\end{array}$} & \multirow{2}{*}{\multicolumn{3}{|c|}{$\begin{array}{c}\text { STATISTICAL RANGE } \\
\text { 98\% CONFIDENCE INTERVAL } \\
\text { MINIMUM }\end{array}$}} & \multirow{2}{*}{$\begin{array}{l}\text { DISTRIBUTION } \\
\text { TYPE }\end{array}$} & \multirow{2}{*}{$\begin{array}{l}- \\
\text { FOOT } \\
\text { HOTE }\end{array}$} \\
\hline \# OF SAMP & MINIMUM & MAXIMUN & MEDIAN & & & & & & & & & \\
\hline \multicolumn{3}{|c|}{ THORIUH-230 } & PCI /L & \multirow[b]{2}{*}{0.2333} & \multirow[b]{2}{*}{0.1500} & \multirow[b]{2}{*}{0.6429} & \multirow[b]{2}{*}{0.0} & \multirow[b]{2}{*}{ ** } & \multirow[b]{2}{*}{0.2000} & \multirow[b]{2}{*}{0.3781} & \multirow[b]{2}{*}{ HORMAL } & - \\
\hline 9 & $\star \star \quad 0.2000$ & 0.5000 & 0.2000 & & & & & & & & & \\
\hline \multicolumn{3}{|c|}{ THORIUM-230 (TOTAL) } & $\mathrm{PCI} / \mathrm{L}$ & \multirow[b]{2}{*}{ NA } & \multirow[b]{2}{*}{ NA } & \multirow[b]{2}{*}{ NA } & \multirow[b]{2}{*}{0.0} & \multirow{2}{*}{\multicolumn{2}{|c|}{ NA }} & \multirow[b]{2}{*}{ NA } & \multirow[b]{2}{*}{ UNKNOWN } & \multirow[b]{2}{*}{1} \\
\hline 3 & $\star \star * \quad 0.2000$ & 1.1000 & 0.4000 & & & & & & & & & \\
\hline \multicolumn{3}{|l|}{ TIN } & MG/L & \multirow[b]{2}{*}{ NA } & \multirow[b]{2}{*}{ NA } & \multirow[b]{2}{*}{ NA } & \multirow[b]{2}{*}{100.0} & \multirow[b]{2}{*}{$\star \star \star$} & \multirow[b]{2}{*}{0.0050} & & & \\
\hline 17 & $\begin{array}{ll}* * & 0.0050\end{array}$ & 0.0250 & 0.0050 & & & & & & & 0.0250 & NONPARAMETRIC & 2 \\
\hline TOTAL DIS & SOLVED SOLIDS & & $M G / L$ & & & & & & & & & \\
\hline 20 & 360.0000 & 2680.0000 & 757.0000 & 1070.1500 & 774.7665 & 0.7240 & 0.0 & & 630.2859 & 1510.0141 & NORMAL & \\
\hline TOTAL KJE & LDAHL. NITROGE & & MG/L & & & & & & & & & \\
\hline 12 & ** 1.0000 & 191.0000 & 1.0000 & NA & NA & NA & 58.3 & ** & 1.0000 & 13.0000 & NONPARAMETRIC & 2 \\
\hline TOTAL ORG & ANIC CARBON & & $M G / L$ & & & & & & & & & \\
\hline 18 & ** $\quad 1.0000$ & 127.0000 & 2.5000 & 5.7733 & 5.8323 & NA & 5.6 & & 1.9863 & 16.7800 & LOGNORMAL & 7,8 \\
\hline TURBIDITY & & & NTU & & & & & & & & & \\
\hline 2 & 4.0000 & 61.0000 & 32.5000 & NA & NA & NA & 0.0 & & NA & NA & UNKNOWN & 1 \\
\hline URANIUM & & & $M G / L$ & & & & & & & & & \\
\hline 20 & 0.0005 & 0.0470 & 0.0030 & 0.0031 & 3.2397 & NA & 10.0 & & 0.0016 & 0.0061 & LOGNORMAL & 7,8 \\
\hline URANIUM (1 & TOTAL) & & MG/L. & & & & & & & & & \\
\hline 3 & 0.0030 & 0.0040 & 0.0040 & NA & NA & HA & 0.0 & & NA & NA & UNKNOWN & 1 \\
\hline
\end{tabular}

** The reported value is the minimun detection limit of the data set

- The sample size is even, so the median value is the arithmetic average of the two middle values

* The statistical maximum is the 99 percent one sided confidence interval, $a=0.01$

1) A minimum of 4 samples must be available for the statistical analysis.

2) The nonparametric distribution was used because the nondetected values comprise more than $15 \%$ of the samples.

7) The lognormal distribution was used because the data failed the normal distribution test.

8) The mean is geometric. The standard deviation is the value to divide or multiply with the geometric mean. 
TABLE 3.34 BASELINE GROUND HATER QUALITY STATISTICS BY PARAMETER FOR THE ENTRADA FORMATION, UC PROCESSING SITE, SLICK ROCK, COLORADO

SITE: SRKO1 SLICK ROCK (BOTH SITES)

(SI/29/89 TO 02/21/94

REPORT DATE: $10 / 03 / 94$

\begin{tabular}{|c|c|c|c|c|c|c|c|c|c|c|c|}
\hline \multicolumn{3}{|c|}{ PARAMETER NAME } & UNITS & \multirow[b]{2}{*}{ MEAN } & \multirow{2}{*}{$\begin{array}{r}\text { STANDARD } \\
\text { DEVIATION }\end{array}$} & \multirow{2}{*}{$\begin{array}{c}\text { COEFF. } \\
\text { OF } \\
\text { VARIATION }\end{array}$} & \multirow{2}{*}{$\mid \begin{array}{c}\% \text { OF } \\
\text { NON } \\
\text { DETECTS }\end{array}$} & \multirow{2}{*}{\multicolumn{2}{|c|}{ 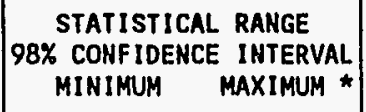 }} & \multirow{2}{*}{$\begin{array}{l}\text { OISTRIBUTION } \\
\text { TYPE }\end{array}$} & \multirow{2}{*}{$\begin{array}{l}\text { FOOT } \\
\text { NOTE }\end{array}$} \\
\hline \# OF SAMP & MINIMUN & MAXIMUM & MEDIAN & & & & & & & & \\
\hline \multicolumn{3}{|l|}{ VANAD IUPA } & $M G / L$ & \multirow[b]{2}{*}{ NA } & \multirow[b]{2}{*}{ NA } & \multirow[b]{2}{*}{ NA } & \multirow[b]{2}{*}{80.0} & \multirow[b]{2}{*}{0.0100} & \multirow[b]{2}{*}{0.0100} & \multirow[b]{2}{*}{ NONPARAMETRIC } & \multirow[b]{2}{*}{2} \\
\hline 20 & ** $\quad 0.0100$ & 0.0300 & 0.0100 & & & & & & & & \\
\hline \multicolumn{3}{|c|}{ VANADIUM (TOTAL) } & $M G / L$ & \multirow[b]{2}{*}{ NA } & \multirow[b]{2}{*}{ NA } & \multirow[b]{2}{*}{ HA } & \multirow[b]{2}{*}{33.3} & \multirow[b]{2}{*}{$\mathrm{HA}$} & \multirow[b]{2}{*}{ NA } & \multirow[b]{2}{*}{ UNKHOWN } & \multirow[b]{2}{*}{1} \\
\hline 3 & ** $\quad 0.0100$ & 0.0200 & 0.0100 & & & & & & & & \\
\hline \multicolumn{3}{|l|}{ ZINC } & MG/L & \multirow[b]{2}{*}{ NA } & \multirow[b]{2}{*}{ NA } & \multirow[b]{2}{*}{ NA } & \multirow[b]{2}{*}{85.0} & \multirow[b]{2}{*}{0.0050} & \multirow[b]{2}{*}{0.0150} & \multirow[b]{2}{*}{ NONPARAMETRIC } & \multirow[b]{2}{*}{2} \\
\hline 20 & ** $\quad 0.0050$ & 0.0250 & 0.0050 & & & & & & & & \\
\hline ZINC CTOTA & $A()$ & & MG/L & & & & & & & & \\
\hline 3 & $\begin{array}{ll}* & 0.0500\end{array}$ & 0.0600 & 0.0500 & NA & NA & HA & 66.7 & NA & NA & UNKNOWN & 1 \\
\hline
\end{tabular}

** The reported value is the minimum detection limit of the data set

* The statistical maximum is the 99 percent one sided confidence interval, $\alpha=0.01$

1) A minimum of 4 samples must be available for the statistical analysis.

2) The nonparametric distribution was used because the nondetected values comprise more than $15 \%$ of the samples.

INPUT DATA FILENAME: IDARTISRK01\GHQ10075.DAT 
Table 3.35 Summary of regulated constituents in the Entrada Formation baseline ground water, UC processing site, Slick Rock, Colorado

\begin{tabular}{lcccc}
\hline \multicolumn{4}{c}{ Constituents with MCLs } \\
\hline \multicolumn{1}{c}{ Parameter } & $\begin{array}{c}\text { Baseline } \\
\text { median }\end{array}$ & $\begin{array}{c}\text { Baseline } \\
\text { stat max }\end{array}$ & $\begin{array}{c}\text { Background } \\
\text { stat max }\end{array}$ & MCL \\
\hline Arsenic & $0.01^{\mathrm{g}}$ & $0.01^{\mathrm{g}}$ & $0.01^{\mathrm{g}}$ & 0.05 \\
Barium & $0.085^{\mathrm{e}}$ & $0.42^{\mathrm{e}}$ & $0.20^{\mathrm{e}}$ & 1.00 \\
Cadmium & $0.001^{\mathrm{g}}$ & $0.001^{\mathrm{g}}$ & $0.003^{\mathrm{e}}$ & 0.01 \\
Chromium & $0.01^{\mathrm{g}}$ & $0.01^{\mathrm{g}}$ & $0.01^{\mathrm{g}}$ & 0.05 \\
Net gross alpha & $0.05^{\mathrm{e}}$ & $5.88^{\mathrm{e}}$ & $4.10^{\mathrm{e}}$ & 15.00 \\
Lead & $0.01^{\mathrm{g}}$ & $0.01^{\mathrm{g}}$ & $0.01^{\mathrm{g}}$ & 0.05 \\
Mercury & $0.0002^{\mathrm{g}}$ & $0.0002^{\mathrm{g}}$ & $0.0002^{\mathrm{g}}$ & 0.002 \\
Molybdenum & $0.01^{\mathrm{g}}$ & $0.01^{\mathrm{g}}$ & $0.03^{\mathrm{e}}$ & 0.10 \\
Nitrate & $10.8^{\mathrm{e}}$ & $79.2^{\mathrm{e}}$ & $7.6^{\mathrm{d}}$ & 44.0 \\
Radium-226,-228 & $1.89^{\mathrm{d}}$ & $2.81^{\mathrm{d}}$ & $3.42^{\mathrm{d}}$ & 5.0 \\
Selenium & $0.01^{\mathrm{e}}$ & $0.026^{\mathrm{e}}$ & $0.013^{\mathrm{e}}$ & 0.01 \\
Silver & $0.01^{\mathrm{g}}$ & $0.01^{\mathrm{g}}$ & $0.01^{\mathrm{g}}$ & 0.05 \\
Uranium & $0.003^{\mathrm{c}}$ & $0.006^{\mathrm{c}}$ & $0.008^{\mathrm{d}}$ & 0.044 \\
\hline
\end{tabular}


Table 3.35 Summary of regulated constituents in the Entrada Formation baseline ground water, UC processing site, Slick Rock, Colorado (Concluded)

\begin{tabular}{llcll}
\hline \multicolumn{1}{c}{ Constituents without MCLs } & \\
\hline \multicolumn{1}{c}{ Parameter } & $\begin{array}{l}\text { Baseline } \\
\text { median }\end{array}$ & $\begin{array}{c}\text { Baseline } \\
\text { stat max }\end{array}$ & $\begin{array}{c}\text { Background } \\
\text { stat. max }\end{array}$ & MCL \\
\hline Antimony & $0.003^{\mathrm{g}}$ & $0.003^{\mathrm{g}}$ & $0.003^{\mathrm{g}}$ & None \\
Beryllium & $0.01^{\mathrm{g}}$ & $0.01^{\mathrm{g}}$ & $0.01^{\mathrm{g}}$ & None \\
Cobalt & $0.05^{\mathrm{g}}$ & $0.05^{\mathrm{g}}$ & $0.05^{\mathrm{g}}$ & None \\
Copper & $0.02^{\mathrm{g}}$ & $0.02^{\mathrm{g}}$ & $0.02^{\mathrm{g}}$ & None \\
Cyanide & $0.01^{\mathrm{g}}$ & $0.01^{\mathrm{g}}$ & $0.01^{\mathrm{g}}$ & None \\
Nickel & $0.04^{\mathrm{g}}$ & $0.04^{\mathrm{g}}$ & $0.04^{\mathrm{g}}$ & None \\
Sulfide & $0.96^{\mathrm{c}}$ & $4.44^{\mathrm{c}}$ & $0.60^{\mathrm{e}}$ & None \\
Thallium & $0.01^{\mathrm{g}}$ & $0.01^{\mathrm{g}}$ & $0.01^{\mathrm{g}}$ & None \\
Tin & $0.005^{\mathrm{g}}$ & $0.025^{\mathrm{e}}$ & $0.005^{\mathrm{g}}$ & None \\
Vanadium & $0.01^{\mathrm{g}}$ & $0.01^{\mathrm{g}}$ & $0.02^{\mathrm{g}}$ & None \\
Zinc & $0.005^{\mathrm{g}}$ & $0.05^{\mathrm{e}}$ & $0.025^{\mathrm{g}}$ & None \\
\hline
\end{tabular}

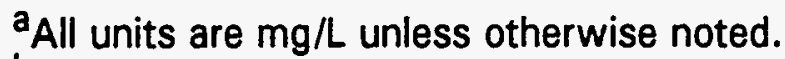

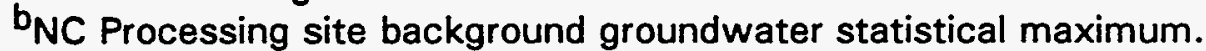

CLognormal distribution, mean is geometric.

$\mathrm{d}_{\text {Normal distribution, mean is arithmetic. }}$

enonparametric distribution

Units are $\mathrm{pCi} / \mathrm{L}$.

IStatistical values are below laboratory detection limits in Table 8.1 of the Technical Approach Document (DOE, 1989). 
TABLE 3.36 GROUND WATER QUALITY MEASUREMENTS EXCEEDING MCLS IN ENTRADA

FORMATION BASELINE GROUND WATER, UC SITE, SLICK ROCK, COLORADO

SITE: SRKO1 SLICK ROCK (BOTH SITES)

$03 / 29 / 89$ TO $02 / 21 / 94$

REPORT DATE: 09/30/94

\begin{tabular}{|c|c|c|c|c|c|c|c|c|c|c|c|}
\hline PARAMETER NAME & $\begin{array}{l}\text { TOTAL } \\
\text { \# OF } \\
\text { SAMP. }\end{array}$ & $\begin{array}{l}\text { UNITS } \\
\text { OF } \\
\text { MEASURE }\end{array}$ & $\begin{array}{l}\text { MAXIMUM } \\
\text { CONC. } \\
\text { LIMIT }\end{array}$ & LOC. & LOG DATE & $\underset{10}{\text { SAMP }}$ & $\begin{array}{l}\text { FORM } \\
\text { OF } \\
\text { COMP }\end{array}$ & $\begin{array}{l}\text { HYDR } \\
\text { FLOH } \\
\text { REL. }\end{array}$ & $\begin{array}{l}\text { RESULT EXCEEDING MAX. } \\
\text { CONCENTRATION LIMIT } \\
\text { VALUE FLAGS }\end{array}$ & $\begin{array}{l}\text { DETECTION } \\
\text { LIMIT }\end{array}$ & $\begin{array}{l}\text { PARAMETER } \\
\text { UNCERT. }\end{array}$ \\
\hline ARSENIC & 17 & $M G / L$ & 0.0500 & - & - & - & - & - & - & - & - \\
\hline ARSENIC (TOTAL) & 0 & $M G / L$ & 0.0500 & - & - & - & $=$ & - & - & - & - \\
\hline BARIUM & 20 & $M G / L$ & 1.0000 & $\begin{array}{l}0554 \\
0554\end{array}$ & $\begin{array}{l}10 / 15 / 92 \\
02 / 17 / 94\end{array}$ & $\begin{array}{l}0001 \\
0001\end{array}$ & $\begin{array}{l}\text { JE } \\
\text { JE }\end{array}$ & $\begin{array}{l}\text { u } \\
\text { u }\end{array}$ & $\begin{array}{l}1.34 \\
2.3\end{array}$ & $\begin{array}{l}0.01 \\
0.1\end{array}$ & - \\
\hline BARIUM (TOTAL) & 3 & $M G / L$ & 1.0000 & 0554 & $02 / 17 / 94$ & NOO1 & JE & $\mathbf{u}$ & 2.4 & 0.1 & - \\
\hline CADMIUM & 20 & $M G / L$ & 0.0100 & - & - & - & - & - & - & - & - \\
\hline CADMIUM (TOTAL) & 3 & $M G / L$ & 0.0100 & - & - & - & - & - & - & - & - \\
\hline CHROMIUM & 20 & $M G / L$ & 0.0500 & - & - & - & - & - & - & - & - \\
\hline CHROMIUM (TOTAL) & 3 & MG/L & 0.0500 & - & - & - & - & - & - & - & - \\
\hline GROSS ALPHA & 20 & PCI/L & 15.0000 & $\begin{array}{l}0554 \\
0702 \\
0702\end{array}$ & $\begin{array}{l}03 / 28 / 91 \\
03 / 29 / 89 \\
12 / 12 / 90\end{array}$ & $\begin{array}{l}0001 \\
0001 \\
0001\end{array}$ & $\begin{array}{l}\mathrm{JE} \\
\mathrm{JE} \\
\mathrm{JE}\end{array}$ & $\begin{array}{l}U \\
0 \\
0\end{array}$ & $\begin{array}{ll}21.7 \\
25.0 \\
15 . & \mathrm{JL} \\
\end{array}$ & $\begin{array}{l}1 . \\
1 . \\
1 .\end{array}$ & $\begin{array}{l}31.8 \\
13.0 \\
9 .\end{array}$ \\
\hline GROSS ALPHA (TOTAL) & 3 & PCI/L & 15.0000 & 0702 & $02 / 21 / 94$ & N001 & JE & 0 & 18.3 & 2.9 & 4.8 \\
\hline LEAD & 17 & $M G / L$ & 0.0500 & - & - & - & - & - & - & - & - \\
\hline LEAD (TOTAL) & 0 & $M G / L$ & 0.0500 & - & - & - & - & - & - & - & - \\
\hline MERCURY & 14 & $M G / L$ & 0.0020 & - & - & - & - & - & - & - & - \\
\hline MERCURY (TOTAL) & 0 & $M G / L$ & 0.0020 & - & - & - & - & - & - & - & - \\
\hline MOLYYBDENUM & 20 & $M G / L$ & 0.1000 & - & - & - & - & - & - & - & - \\
\hline MOLYBDENUM (TOTAL) & 3 & $M G / L$ & 0.1000 & - & - & - & - & - & - & - & - \\
\hline NET GROSS ALPHA * & 20 & PCI/L & 15.0000 & 0554 & $03 / 28 / 91$ & 0001 & JE & u & 21.0 & - & - \\
\hline
\end{tabular}

* net gross alpha (GRoss alpha - URANium)

HITH 1 MG URANIUM $=686 \mathrm{PCI}$

FORMATION OF COHPLETION COOE:

JE - JURASSIC ENTRADA SANDSTONE FORMATION

OTHER PARAMETER VALUE FLAGS:

$J$ - ESTIMATED VALUE

$L$ - LESS THAN THREE BORE VOLUMES REMOVED BEFORE SAMPLING

N - SPIKE SAMPLE RECOVERY NOT WITHIN CONTROL LIMITS
FI.OH RELATIONSHIP CODE:

4 - UPGRADIENT

O - ON-SITE

SAMPLE ID CODES:

0001 - FILTERED SAMPLE (.45 MICRONS)

NO01 - UNFILTERED SAMPLE 
TABLE 3.36 GROUND WATER QUALITY MEASUREMENTS EXCEEDING MCLS IN ENTRADA

FORMATION BASELINE GROUND WATER, UC SITE, SLICK ROCK, COLORADO

SITE: SRKO1 SLICK ROCK (BOTH SITES)

03/29/89 TO $02 / 21 / 94$

REPORT DATE: $09 / 30 / 94$

\begin{tabular}{|c|c|c|c|c|c|c|c|c|c|c|c|c|}
\hline PARAMETER NAME & $\begin{array}{l}\text { TOTAL } \\
\text { \# OF } \\
\text { SAMP. }\end{array}$ & $\begin{array}{c}\text { UNITS } \\
\text { OF } \\
\text { MEASURE }\end{array}$ & $\begin{array}{l}\text { MAXIMUM } \\
\text { CONC. } \\
\text { LIMIT }\end{array}$ & IOC. & LOG DATE & $\begin{array}{l}\text { SAMP } \\
\text { ID }\end{array}$ & $\begin{array}{c}\text { FORM } \\
\text { OF } \\
\text { COMP }\end{array}$ & $\begin{array}{l}\text { HYDR } \\
\text { FLOW } \\
\text { REL. }\end{array}$ & $\begin{array}{c}\text { RESULT EXCEED } \\
\text { CONCENTRATIO } \\
\text { VALUE }\end{array}$ & $\begin{array}{l}\text { DING MAX. } \\
\text { N LIMIT } \\
\text { FLAGS }\end{array}$ & $\begin{array}{l}\text { DETECTION } \\
\text { LIMIT }\end{array}$ & $\begin{array}{l}\text { PARAMETER } \\
\text { UNCERT. }\end{array}$ \\
\hline NET GROSS ALPHA (TOTAL) ** & 3 & $\mathrm{PCI} / \mathrm{L}$ & 15.0000 & 0702 & $02 / 21 / 94$ & N001 & JE & 0 & 16.2 & & - & - \\
\hline NITRATE & 17 & $M G / L$ & 44.0000 & $\begin{array}{l}0702 \\
0702 \\
0702 \\
0702 \\
0702 \\
0702\end{array}$ & $\begin{array}{l}03 / 29 / 89 \\
12 / 12 / 90 \\
03 / 31 / 91 \\
08 / 07 / 91 \\
12 / 07 / 91 \\
10 / 11 / 92\end{array}$ & $\begin{array}{l}0001 \\
0001 \\
0001 \\
0001 \\
0001 \\
0001\end{array}$ & $\begin{array}{l}\mathrm{JE} \\
\mathrm{JE} \\
\mathrm{JE} \\
\mathrm{JE} \\
\mathrm{JE} \\
\mathrm{JE}\end{array}$ & $\begin{array}{l}0 \\
0 \\
0 \\
0 \\
0 \\
0\end{array}$ & $\begin{array}{c}85.6 \\
126 . \\
66 . \\
79.2 \\
46.0 \\
105 .\end{array}$ & $\begin{array}{l}L \\
L \\
L \\
L \\
L \\
L\end{array}$ & $\begin{array}{l}1 . \\
1 . \\
1 . \\
1 . \\
7 . \\
10 .\end{array}$ & $\begin{array}{l}- \\
- \\
- \\
-\end{array}$ \\
\hline NITRATE (TOTAL) & 3 & $M G / L$ & 44.0000 & 0702 & $02 / 21 / 94$ & N001 & JE & 0 & 96. & L & 1 & - \\
\hline$R A-226 \& R A-228$ & 18 & $\mathrm{PCI} / \mathrm{L}$ & 5.0000 & $\begin{array}{l}0554 \\
0704\end{array}$ & $\begin{array}{l}02 / 17 / 94 \\
02 / 17 / 94\end{array}$ & $\begin{array}{l}0001 \\
0001\end{array}$ & $\begin{array}{l}\mathrm{JE} \\
\mathrm{JE}\end{array}$ & $\begin{array}{l}U \\
0\end{array}$ & $\begin{array}{l}5.3 \\
5.3\end{array}$ & & - & - \\
\hline RA-226\& RA-228 (TOTAL) & 3 & $\mathrm{PCI} / \mathrm{L}$ & 5.0000 & $\begin{array}{l}0554 \\
0702\end{array}$ & $\begin{array}{l}02 / 17 / 94 \\
02 / 21 / 94\end{array} \mid$ & $\begin{array}{l}\text { N001 } \\
\text { N001 }\end{array}$ & $\begin{array}{l}\mathrm{JE} \\
\mathrm{JE}\end{array}$ & $\begin{array}{l}u \\
0\end{array}$ & $\begin{array}{l}8.1 \\
6.4\end{array}$ & & - & - \\
\hline SELENIUM & 20 & MG/L & 0.0100 & $\begin{array}{l}0554 \\
0702 \\
0702 \\
0702 \\
0702 \\
0702 \\
0702 \\
0704 \\
0704 \\
0704 \\
0704 \\
0704\end{array}$ & $\begin{array}{l}03 / 28 / 91 \\
03 / 29 / 89 \\
12 / 12 / 90 \\
03 / 31 / 91 \\
08 / 07 / 91 \\
12 / 07 / 91 \\
02 / 21 / 94 \\
03 / 29 / 89 \\
12 / 12 / 90 \\
04 / 01 / 91 \\
08 / 24 / 91 \\
12 / 12 / 91\end{array}$ & $\begin{array}{l}0001 \\
0001 \\
0001 \\
0001 \\
0001 \\
0001 \\
0001 \\
0001 \\
0001 \\
0001 \\
0001 \\
0001\end{array}$ & $\begin{array}{l}\mathrm{JE} \\
\mathrm{JE} \\
\mathrm{JE} \\
\mathrm{JE} \\
\mathrm{JE} \\
\mathrm{JE} \\
\mathrm{JE} \\
\mathrm{JE} \\
\mathrm{JE} \\
\mathrm{JE} \\
\mathrm{JE} \\
\mathrm{JE}\end{array}$ & $\begin{array}{l}U \\
0 \\
0 \\
0 \\
0 \\
0 \\
0 \\
0 \\
0 \\
0 \\
0 \\
0\end{array}$ & $\begin{array}{l}0.04 \\
0.023 \\
0.042 \\
0.020 \\
0.05 \\
0.026 \\
0.035 \\
0.012 \\
0.017 \\
0.010 \\
0.017 \\
0.026\end{array}$ & $\begin{array}{l}J \\
L \\
J L \\
L \\
I L W \\
L \\
L S \\
L \\
J L \\
L \\
L \\
L\end{array}$ & $\begin{array}{l}0.03 \\
0.005 \\
0.005 \\
0.005 \\
0.05 \\
0.005 \\
0.005 \\
0.005 \\
0.005 \\
0.005 \\
0.005 \\
0.005\end{array}$ & $\begin{array}{l}- \\
- \\
- \\
- \\
- \\
- \\
- \\
- \\
-\end{array}$ \\
\hline
\end{tabular}

< - the dATA IS fLAGged AS a nON-DETECT, SO the RESULt IS AN ESTIMATEd VALUE OR THE DETECTION LIMIT

* Net gRoss alPHa (GROSS alPHa - URANIUM)

WITH 1 MG URANIUM $=686 \mathrm{PCI}$

** TOTAL NET GROSS ALPHA (TOTAL GROSS ALPHA - TOTAL URANIUM)

\section{FORMATION OF COMPLETION CODE:}

JE - JURASSIC ENTRADA SANDSTONE FORMATION

OTHER PARAMETER VALUE FLAGS:

I - INCREASED DETECTION LIMIT DUE TO REQUIRED DILUTION

$J$ - ESTIMATED VALUE

L - LESS THAN THREE BORE VOLUMES REMOVED BEFORE SAMPLING

$S$ - REPORTED VALUE DETERMINED USING METHOD OF STD ADDITION (MSA)

$W$ - POST-DIGEST SPIKE OUT OF CNTR LIM WHILE SAMP ABS < 50\% SPIKE

FLOW RELATIONSHIP CODE:

O - ON-SITE

$U$ - UPGRADIENT

SAMPLE ID CODES:

O001 - FILTERED SAMPLE ( .45 MICRONS)

NOO1 - UNFILTERED SAMPLE 
TABLE 3.36 GROUND WATER QUALITY MEASUREMENTS EXCEEDING MCLS IN ENTRADA FORMATION BASELINE GROUND WATER, UC SITE, SLICK ROCK, COLORADO

SITE: SRKO1 SLICK ROCK (BOTH SITES)

$03 / 29 / 89$ TO $02 / 21 / 94$

REPORT DATE: $09 / 30 / 94$

\begin{tabular}{|c|c|c|c|c|c|c|c|c|c|c|c|}
\hline PARAMETER NAME & $\begin{array}{l}\text { TOTAL } \\
\text { \# OF } \\
\text { SAMP. }\end{array}$ & $\begin{array}{l}\text { UNITS } \\
\text { OF } \\
\text { MEASURE }\end{array}$ & $\begin{array}{l}\text { MAXIMUM } \\
\text { CONC. } \\
\text { LIMIT }\end{array}$ & $\underset{\text { ID }}{\operatorname{Loc} .}$ & LOG DATE & $\underset{\text { ID }}{\text { SAMP }}$ & $\begin{array}{c}\text { FORM } \\
\text { OF } \\
\text { COMP }\end{array}$ & $\begin{array}{l}\text { HYDR } \\
\text { FLOW } \\
\text { REL. }\end{array}$ & $\begin{array}{c}\text { RESULT EXCEEDING MAX. } \\
\text { CONCENTRATION LIMIT } \\
\text { VALUE FLAGS }\end{array}$ & $\begin{array}{l}\text { DETECTION } \\
\text { LIMIT }\end{array}$ & $\begin{array}{l}\text { PARAMETER } \\
\text { UNCERT. }\end{array}$ \\
\hline SELENIUM & 20 & $M G / L$ & 0.0100 & 0704 & $02 / 17 / 94$ & 0001 & JE & 0 & $0.011 \mathrm{~L}$ & 0.005 & - \\
\hline SELENIUM (TOTAL) & 3 & $M G / L$ & 0.0100 & $\left|\begin{array}{l}0702 \\
0704\end{array}\right|$ & $\begin{array}{l}02 / 21 / 94 \\
02 / 17 / 94\end{array}$ & $\begin{array}{l}\text { NOD1 } \\
\text { NO01 }\end{array}$ & $\begin{array}{l}\mathrm{JE} \\
\mathrm{JE}\end{array}$ & $\begin{array}{l}0 \\
0\end{array}$ & $\begin{array}{l}0.029 \text { LS } \\
0.010 ~ L\end{array}$ & $\begin{array}{l}0.005 \\
0.005\end{array}$ & - \\
\hline SILVER & 14 & $M G / L$ & 0.0500 & - & - & - & - & - & - & - & - \\
\hline SILVER (TOTAL) & 0 & $M G / L$ & 0.0500 & - & - & - & - & - & - & - & - \\
\hline URANIUM & 20 & $M G / L$ & 0.0440 & 0702 & $03 / 29 / 89$ & 0001 & JE & 0 & $0.047 \mathrm{~L}$ & 0.003 & 0.010 \\
\hline URANIUM (TOTAL) & 3 & $M G / L$ & 0.0440 & - & - & - & - & - & - & - & - \\
\hline
\end{tabular}

FORMATION OF COMPLETION CODE:

JE - JURASSIC ENTRADA SANDSTONE FORMATION

FLOW RELATIONSHIP CODE:

\section{OTHER PARAMETER VALUE FLAGS}

L - LESS THAN THREE BORE VOLUMES REMOVEd BEFORE SAMPLING

DATA FILE NAME: IDARTISRK01 IGWQ10077.DAT

\section{SAMPLE ID CODES:}

O001 - FILTERED SAMPLE (.45 MICRONS)

NO01 - UNFILTERED SAMPLE 
TABLE 3.37 BASELINE GROUND WATER QUALITY DATA BY PARAMETER FOR THE NAVAJO SANDSTONE, UC PROCESSING SITE, SLICK ROCK, COLORADO

SITE: SRK01 SLICK ROCK (BOTH SITES)

$02 / 02 / 86$ TO $02 / 21 / 94$

REPORT DATE: $09 / 30 / 94$

\begin{tabular}{|c|c|c|c|c|c|c|c|c|c|c|c|}
\hline PARAMETER NAME & $\begin{array}{c}\text { LOCATION } \\
\text { ID }\end{array}$ & LOG DATE & $\begin{array}{c}\text { SAMPLE } \\
\text { ID }\end{array}$ & $\begin{array}{l}\text { FORM } \\
\text { COMP }\end{array}$ & $\begin{array}{l}\text { FLOW } \\
\text { REL. }\end{array}$ & $\begin{array}{l}\text { UNITS OF } \\
\text { MEASURE }\end{array}$ & PVI & $\begin{array}{l}\text { PARAMETER } \\
\text { VALUE }\end{array}$ & FLAGS & $\begin{array}{l}\text { DETECTION } \\
\text { LIMIT }\end{array}$ & $\begin{array}{l}\text { PARAMETER } \\
\text { UNCERTAINTY }\end{array}$ \\
\hline ALKAL IN I TY & $\begin{array}{l}0668 \\
0668 \\
0668 \\
0668 \\
0668 \\
0668 \\
0668 \\
0668 \\
0669 \\
0669 \\
0669 \\
0669 \\
0669 \\
0669 \\
0669 \\
0669 \\
0669 \\
0669 \\
0670 \\
0670 \\
0670 \\
0670 \\
0670 \\
0670 \\
0670 \\
0670 \\
0670\end{array}$ & $\begin{array}{l}02 / 02 / 86 \\
06 / 30 / 86 \\
10 / 14 / 87 \\
02 / 19 / 88 \\
12 / 15 / 90 \\
11 / 18 / 91 \\
10 / 11 / 92 \\
02 / 18 / 94 \\
02 / 04 / 86 \\
06 / 30 / 86 \\
10 / 14 / 87 \\
02 / 19 / 88 \\
12 / 15 / 90 \\
03 / 31 / 91 \\
08 / 24 / 91 \\
11 / 19 / 91 \\
10 / 12 / 92 \\
02 / 20 / 94 \\
02 / 03 / 86 \\
07 / 19 / 86 \\
10 / 15 / 87 \\
02 / 19 / 88 \\
12 / 15 / 90 \\
04 / 01 / 91 \\
08 / 24 / 91 \\
12 / 05 / 91 \\
10 / 14 / 92\end{array}$ & $\begin{array}{l}0001 \\
0001 \\
0001 \\
0001 \\
0001 \\
0001 \\
0001 \\
\text { N001 } \\
0001 \\
0001 \\
0001 \\
0001 \\
0001 \\
0001 \\
0001 \\
0001 \\
0001 \\
N 001 \\
0001 \\
0001 \\
0001 \\
0001 \\
0001 \\
0001 \\
0001 \\
0001 \\
0001\end{array}$ & $\begin{array}{l}\text { NA } \\
\text { NA } \\
\text { NA } \\
\text { NA } \\
\text { NA } \\
\text { NA } \\
\text { NA } \\
\text { NA } \\
\text { NA } \\
\text { NA } \\
\text { NA } \\
\text { NA } \\
\text { NA } \\
\text { NA } \\
\text { NA } \\
\text { NA } \\
\text { NA } \\
\text { NA } \\
\text { NA } \\
\text { NA } \\
\text { NA } \\
\text { NA } \\
\text { NA } \\
\text { NA } \\
\text { NA } \\
\text { NA } \\
\text { NA }\end{array}$ & $\begin{array}{l}U \\
U \\
U \\
U \\
U \\
U \\
U \\
U \\
U \\
U \\
U \\
U \\
U \\
U \\
U \\
U \\
U \\
U \\
U \\
U \\
U \\
U \\
U \\
U \\
U \\
U \\
U\end{array}$ & MG/L CACO3 & & $\begin{array}{l}268 . \\
261 . \\
256 . \\
292 . \\
310 . \\
267 \\
263 \\
266 \\
140 . \\
205 . \\
236 . \\
185 . \\
274 . \\
267 . \\
243 \\
227 \\
238 \\
259 \\
184 . \\
225 . \\
266 . \\
360 . \\
279 . \\
262 . \\
271 \\
272 \\
207\end{array}$ & $\begin{array}{l}\text { L } \\
\\
\text { GL. } \\
L \\
L \\
L \\
L \\
L \\
L \\
L \\
L \\
L \\
G L \\
L \\
L \\
J L \\
L \\
L \\
L \\
L \\
L\end{array}$ & $\begin{array}{l}- \\
- \\
- \\
- \\
- \\
- \\
- \\
- \\
- \\
- \\
- \\
- \\
- \\
- \\
- \\
- \\
- \\
- \\
- \\
- \\
- \\
- \\
-\end{array}$ & $\begin{array}{l}- \\
- \\
- \\
- \\
- \\
- \\
- \\
- \\
- \\
- \\
- \\
- \\
- \\
- \\
- \\
- \\
- \\
- \\
- \\
-\end{array}$ \\
\hline ALUMINUM & $\begin{array}{l}0668 \\
0668 \\
0668 \\
0668 \\
0668 \\
0668 \\
0669 \\
0669 \\
0669 \\
0669\end{array}$ & \begin{tabular}{|l|}
$06 / 30 / 86$ \\
$10 / 14 / 87$ \\
$02 / 19 / 88$ \\
$12 / 15 / 90$ \\
$11 / 18 / 91$ \\
$10 / 11 / 92$ \\
$06 / 30 / 86$ \\
$10 / 14 / 87$ \\
$02 / 19 / 88$ \\
$12 / 15 / 90$
\end{tabular} & $\begin{array}{l}0001 \\
0001 \\
0001 \\
0001 \\
0001 \\
0001 \\
0001 \\
0001 \\
0001 \\
0001\end{array}$ & $\begin{array}{l}\text { NA } \\
\text { NA } \\
\text { NA } \\
\text { NA } \\
\text { NA } \\
\text { NA } \\
\text { NA } \\
\text { NA } \\
\text { NA } \\
\text { NA }\end{array}$ & $\begin{array}{l}U \\
U \\
U \\
U \\
U \\
U \\
U \\
U \\
U \\
U\end{array}$ & $M G / L$ & $\mid \begin{array}{l}< \\
< \\
< \\
< \\
< \\
<\end{array}$ & $\begin{array}{l}0.3 \\
0.1 \\
0.10 \\
0.1 \\
0.05 \\
0.05 \\
0.4 \\
0.1 \\
0.10 \\
0.1\end{array}$ & $\begin{array}{l}\mathbf{L} \\
\mathbf{L} \\
\mathbf{L} \\
\mathbf{L}\end{array}$ & $\begin{array}{l}0.1 \\
0.1 \\
0.1 \\
0.1 \\
0.05 \\
0.05 \\
0.1 \\
0.1 \\
0.1 \\
0.1\end{array}$ & $\begin{array}{l}- \\
- \\
- \\
- \\
- \\
-\end{array}$ \\
\hline
\end{tabular}

FORMATION OF COMPLETION CODE:

NA - NAVAJO SANDSTONE

FLOW RELATIONSHIP CODE

PARAMETER VALUE INDICATOR (PVI): < - LESS THAN DETECTION LIMIT

OTHER PARAMETER VALUE FLAGS:

$U$ - UPGRADIENT

$G$ - PH > 9, POSSIBLE GROUT CONTAMINATION

SAMPLE ID CODES:

0001 - FILTERED SAMPLE (.45 MICRONS)

$\mathrm{J}$ - ESTIMATED VALUE

L - LESS THAN THREE BORE VOLUMES REMOVED BEFORE SAMPLING 
TABLE 3.37 BASELINE GROUND WATER QUALITY DATA BY PARAMETER FOR THE NAVAJO SANDSTONE, UC PROCESSING SITE, SLICK ROCK, COLORADO

SITE: SRKO1 SLICK ROCK (BOTH SITES)

$02 / 02 / 86$ TO $02 / 21 / 94$

REPORT DATE: $09 / 30 / 9$

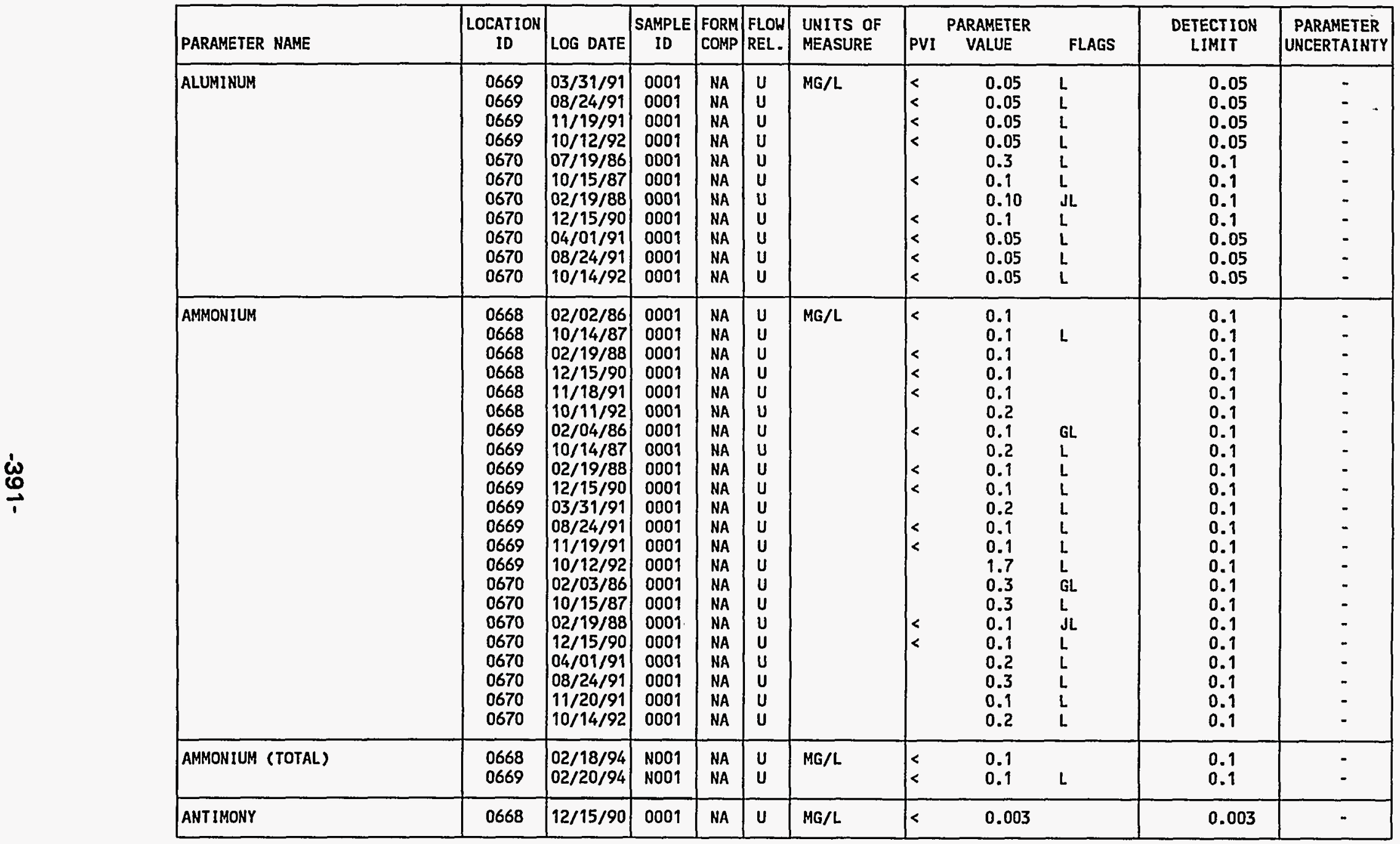

FORMATION OF COMPLETION CODE:

NA - MAVAJO SANDSTONE

FLOW RELATIONSHIP CODE:

PARAMETER VALUE INDICATOR (PVI): < - LESS THAN DETECTION LIMIT

SAMPLE ID CODES:

OTHER PARAMETER VALUE FLAGS:

0001 - FILTERED SAMPLE (.45 MICRONS)

$G$ - PH > 9, POSSIBLE GROUT CONTAMINATION

N001 - UNFILTERED SAMPLE

- ESTIMATED VALUE

L - LESS THAN THREE BORE VOLUMES REMOVED BEFORE SAMPLING 
TABLE 3.37 BASELINE GROUND WATER QUALITY DATA BY PARAMETER FOR THE NAVAJO SANDSTONE, UC PROCESSING SITE, SLICK ROCK, COLORADO

SITE: SRKO1 SLICK ROCK (BOTH SITES)

02/02/86 TO $02 / 21 / 94$

REPORT DATE: 09/30/94

\begin{tabular}{|c|c|c|c|c|c|c|c|c|c|c|c|}
\hline PARAMETER NAME & $\underset{\text { ID }}{\text { LOCATION }}$ & LOG DATE & $\begin{array}{c}\text { SAMPLE } \\
\text { ID }\end{array}$ & $\begin{array}{l}\text { FORM } \\
\text { COMP }\end{array}$ & $\begin{array}{l}\text { FLOW } \\
\text { REL. }\end{array}$ & $\begin{array}{l}\text { UNITS OF } \\
\text { MEASURE }\end{array}$ & PVI & $\begin{array}{l}\text { ARAMETER } \\
\text { VALUE }\end{array}$ & FLAGS & $\begin{array}{l}\text { DETECTION } \\
\text { LIMIT }\end{array}$ & $\begin{array}{l}\text { PARAMETER } \\
\text { UNCERTAINTY }\end{array}$ \\
\hline ANT IMONY & $\begin{array}{l}0668 \\
0668 \\
0669 \\
0669 \\
0669 \\
0669 \\
0669 \\
0670 \\
0670 \\
0670 \\
0670\end{array}$ & $\begin{array}{l}11 / 18 / 91 \\
10 / 11 / 92 \\
12 / 15 / 90 \\
03 / 31 / 91 \\
08 / 24 / 91 \\
11 / 19 / 91 \\
10 / 12 / 92 \\
12 / 15 / 90 \\
04 / 01 / 91 \\
08 / 24 / 91 \\
10 / 14 / 92\end{array}$ & $\begin{array}{l}0001 \\
0001 \\
0001 \\
0001 \\
0001 \\
0001 \\
0001 \\
0001 \\
0001 \\
0001 \\
0001\end{array}$ & $\begin{array}{l}\text { NA } \\
\text { NA } \\
\text { NA } \\
\text { NA } \\
\text { NA } \\
\text { NA } \\
\text { NA } \\
\text { NA } \\
\text { NA } \\
\text { NA } \\
\text { NA }\end{array}$ & $\begin{array}{l}U \\
U \\
U \\
U \\
U \\
U \\
U \\
U \\
U \\
U \\
U\end{array}$ & $M G / L$ & $\begin{array}{l}< \\
< \\
< \\
< \\
< \\
< \\
< \\
< \\
< \\
< \\
<\end{array}$ & $\begin{array}{l}0.003 \\
0.003 \\
0.003 \\
0.003 \\
0.003 \\
0.003 \\
0.009 \\
0.003 \\
0.003 \\
0.003 \\
0.003\end{array}$ & $\begin{array}{l}\mathrm{L} \\
\mathrm{L} \\
\mathrm{L} \\
\mathrm{L} \\
\mathrm{L} \\
\mathrm{L} \\
\mathrm{L} \\
\mathrm{L} \\
\mathrm{L}\end{array}$ & $\begin{array}{l}0.003 \\
0.003 \\
0.003 \\
0.003 \\
0.003 \\
0.003 \\
0.003 \\
0.003 \\
0.003 \\
0.003 \\
0.003\end{array}$ & $\begin{array}{l}- \\
- \\
- \\
- \\
- \\
- \\
- \\
- \\
-\end{array}$ \\
\hline ARSENIC & $\begin{array}{l}0668 \\
0668 \\
0668 \\
0668 \\
0668 \\
0668 \\
0669 \\
0669 \\
0669 \\
0669 \\
0669 \\
0669 \\
0669 \\
0669 \\
0670 \\
0670 \\
0670 \\
0670 \\
0670 \\
0670 \\
0670\end{array}$ & $\begin{array}{l}02 / 02 / 86 \\
06 / 30 / 86 \\
10 / 14 / 87 \\
12 / 15 / 90 \\
11 / 18 / 91 \\
10 / 11 / 92 \\
02 / 04 / 86 \\
06 / 30 / 86 \\
10 / 14 / 87 \\
12 / 15 / 90 \\
03 / 31 / 91 \\
08 / 24 / 91 \\
11 / 19 / 91 \\
10 / 12 / 92 \\
02 / 03 / 86 \\
07 / 19 / 86 \\
10 / 15 / 87 \\
12 / 15 / 90 \\
04 / 01 / 91 \\
08 / 24 / 91 \\
10 / 14 / 92\end{array}$ & $\begin{array}{l}0001 \\
0001 \\
0001 \\
0001 \\
0001 \\
0001 \\
0001 \\
0001 \\
0001 \\
0001 \\
0001 \\
0001 \\
0001 \\
0001 \\
0001 \\
0001 \\
0001 \\
0001 \\
0001 \\
0001 \\
0001\end{array}$ & $\begin{array}{l}\text { NA } \\
\text { NA } \\
\text { NA } \\
\text { NA } \\
\text { NA } \\
\text { NA } \\
\text { NA } \\
\text { NA } \\
\text { NA } \\
\text { NA } \\
\text { NA } \\
\text { NA } \\
\text { NA } \\
\text { NA } \\
\text { NA } \\
\text { NA } \\
\text { NA } \\
\text { NA } \\
\text { NA } \\
\text { NA } \\
\text { NA }\end{array}$ & $\begin{array}{l}U \\
U \\
U \\
U \\
U \\
U \\
U \\
U \\
U \\
U \\
U \\
U \\
U \\
U \\
U \\
U \\
U \\
U \\
U \\
U \\
U\end{array}$ & MG/L. & $\begin{array}{l}< \\
< \\
< \\
<\end{array}$ & $\begin{array}{l}0.01 \\
0.01 \\
0.01 \\
0.005 \\
0.01 \\
0.007 \\
0.01 \\
0.01 \\
0.02 \\
0.014 \\
0.01 \\
0.01 \\
0.01 \\
0.010 \\
0.01 \\
0.01 \\
0.02 \\
0.025 \\
0.01 \\
0.01 \\
0.013\end{array}$ & $\begin{array}{l}\text { L } \\
J \\
G L \\
L \\
L \\
L \\
L \\
L \\
L \\
L \\
G L \\
L \\
L \\
L \\
L \\
L \\
L\end{array}$ & $\begin{array}{l}0.01 \\
0.01 \\
0.01 \\
0.01 \\
0.01 \\
0.005 \\
0.01 \\
0.01 \\
0.01 \\
0.01 \\
0.01 \\
0.01 \\
0.01 \\
0.005 \\
0.01 \\
0.01 \\
0.01 \\
0.01 \\
0.01 \\
0.01 \\
0.005\end{array}$ & $\begin{array}{l}- \\
- \\
- \\
- \\
- \\
- \\
- \\
- \\
- \\
- \\
- \\
- \\
- \\
- \\
- \\
- \\
-\end{array}$ \\
\hline BARIUM & $\begin{array}{l}0668 \\
0668 \\
0668 \\
0668\end{array}$ & $\begin{array}{l}10 / 14 / 87 \\
12 / 15 / 90 \\
11 / 18 / 91 \\
10 / 11 / 92\end{array}$ & $\begin{array}{l}0001 \\
0001 \\
0001 \\
0001\end{array}$ & $\begin{array}{l}\text { NA } \\
\text { NA } \\
\text { NA } \\
\text { NA }\end{array}$ & $\begin{array}{l}U \\
U \\
U \\
U\end{array}$ & $M G / L$ & & $\begin{array}{l}0.2 \\
0.2 \\
0.16 \\
0.18\end{array}$ & L & $\begin{array}{l}0.1 \\
0.1 \\
0.01 \\
0.01\end{array}$ & $\begin{array}{l}- \\
- \\
-\end{array}$ \\
\hline
\end{tabular}

FORMATION OF COMPLETION CODE:

NA - NAVAJO SANDSTONE

PARAMETER VALUE INDICATOR (PVI): < - LESS THAN DETECTION LIMIT

\section{FLOW RELATIONSHIP CODE:}

$U$ - UPGRADIENT

0001 - FILTERED SAMPLE (.45 MICRONS)

OTHER PARAMETER VALUE FLAGS:

G - PH > 9, POSSIBLE GROUT CONTAMINATION

$J$ - ESTIMATED VALUE

L - LESS THAN THREE: BORE VOLUMES REMOVED BEFORE SAMPLING 
TABLE 3.37 BASELINE GROUND HATER QUALITY DATA BY PARAMETER FOR THE NAVAJO SANDSTONE, UC PROCESSING SITE, SLICK ROCK, COLORADO

SITE: SRKOI SLICK ROCK (BOTH SITES)

$02 / 02 / 86$ TO $02 / 21 / 94$

REPORT DATE: 09/30/94

\begin{tabular}{|c|c|c|c|c|c|c|c|c|c|c|c|}
\hline PARAMETER NAME & $\begin{array}{c}\text { LOCATION } \\
\text { ID }\end{array}$ & LOG DATE & $\begin{array}{c}\text { SAMPLE } \\
\text { ID }\end{array}$ & $\begin{array}{l}\text { FORM } \\
\text { COMP }\end{array}$ & $\begin{array}{l}\text { FLOW } \\
\text { REL. }\end{array}$ & $\begin{array}{l}\text { UNITS OF } \\
\text { MEASURE }\end{array}$ & PVI & $\begin{array}{l}\text { PARAMETER } \\
\text { VALUE }\end{array}$ & FLAGS & $\begin{array}{l}\text { DETECTION } \\
\text { LIMIT }\end{array}$ & $\begin{array}{l}\text { PARAMETER } \\
\text { UNCERTAINTY }\end{array}$ \\
\hline BARIUM & $\begin{array}{l}0668 \\
0669 \\
0669 \\
0669 \\
0669 \\
0669 \\
0669 \\
0669 \\
0670 \\
0670 \\
0670 \\
0670 \\
0670\end{array}$ & $\begin{array}{l}02 / 18 / 94 \\
10 / 14 / 87 \\
12 / 15 / 90 \\
03 / 31 / 91 \\
08 / 24 / 91 \\
11 / 19 / 91 \\
10 / 12 / 92 \\
02 / 20 / 94 \\
10 / 15 / 87 \\
12 / 15 / 90 \\
04 / 01 / 91 \\
08 / 24 / 91 \\
10 / 14 / 92\end{array}$ & $\begin{array}{l}0001 \\
0001 \\
0001 \\
0001 \\
0001 \\
0001 \\
0001 \\
0001 \\
0001 \\
0001 \\
0001 \\
0001 \\
0001\end{array}$ & $\begin{array}{l}\text { NA } \\
\text { NA } \\
\text { NA } \\
\text { NA } \\
\text { NA } \\
\text { NA } \\
\text { NA } \\
\text { NA } \\
\text { NA } \\
\text { NA } \\
\text { NA } \\
\text { NA } \\
\text { NA }\end{array}$ & $\begin{array}{l}U \\
U \\
U \\
U \\
U \\
U \\
U \\
U \\
U \\
U \\
U \\
U \\
U\end{array}$ & $M G / L$ & & $\begin{array}{l}0.2 \\
0.2 \\
0.1 \\
0.15 \\
0.12 \\
0.11 \\
0.08 \\
0.1 \\
0.1 \\
0.1 \\
0.16 \\
0.15 \\
0.06\end{array}$ & $\begin{array}{l}\mathrm{L} \\
\mathrm{L} \\
\mathrm{L} \\
\mathrm{L} \\
\mathrm{L} \\
\mathrm{L} \\
\mathrm{L} \\
\mathrm{L} \\
\mathrm{L} \\
\mathrm{L} \\
\mathrm{L} \\
\mathrm{L}\end{array}$ & $\begin{array}{l}0.1 \\
0.1 \\
0.1 \\
0.01 \\
0.01 \\
0.01 \\
0.01 \\
0.1 \\
0.1 \\
0.1 \\
0.01 \\
0.01 \\
0.01\end{array}$ & $\begin{array}{l}- \\
- \\
- \\
- \\
- \\
- \\
- \\
- \\
- \\
- \\
-\end{array}$ \\
\hline BARIUM (TOTAL) & $\begin{array}{l}0668 \\
0669\end{array}$ & $\left|\begin{array}{l}02 / 18 / 94 \\
02 / 20 / 94\end{array}\right|$ & $\begin{array}{l}\text { No01 } \\
\text { No01 }\end{array}$ & $\begin{array}{l}\text { NA } \\
\text { NA }\end{array}$ & $\begin{array}{l}\mathbf{U} \\
\mathbf{U}\end{array}$ & MG/L & & $\begin{array}{l}0.2 \\
0.4\end{array}$ & L. & $\begin{array}{l}0.1 \\
0.1\end{array}$ & . \\
\hline BERYLLIUM & $\begin{array}{l}0668 \\
0668 \\
0669 \\
0669 \\
0669 \\
0669 \\
0670 \\
0670 \\
0670\end{array}$ & $\begin{array}{l}12 / 15 / 90 \\
11 / 18 / 91 \\
12 / 15 / 90 \\
03 / 31 / 91 \\
08 / 24 / 91 \\
11 / 19 / 91 \\
12 / 15 / 90 \\
04 / 01 / 91 \\
08 / 24 / 91\end{array}$ & $\begin{array}{l}0001 \\
0001 \\
0001 \\
0001 \\
0001 \\
0001 \\
0001 \\
0001 \\
0001\end{array}$ & $\begin{array}{l}\text { NA } \\
\text { NA } \\
\text { NA } \\
\text { NA } \\
\text { NA } \\
\text { NA } \\
\text { NA } \\
\text { NA } \\
\text { NA }\end{array}$ & $\begin{array}{l}U \\
U \\
U \\
U \\
U \\
U \\
U \\
U \\
U\end{array}$ & $M G / L$ & $\begin{array}{l}< \\
< \\
< \\
< \\
< \\
< \\
< \\
< \\
< \\
<\end{array}$ & $\begin{array}{l}0.01 \\
0.005 \\
0.01 \\
0.005 \\
0.005 \\
0.005 \\
0.01 \\
0.005 \\
0.005\end{array}$ & $\begin{array}{l}\mathbf{L} \\
\mathbf{L} \\
\mathrm{L} \\
\mathrm{L} \\
\mathrm{L} \\
\mathrm{L} \\
\mathrm{L}\end{array}$ & $\begin{array}{l}0.01 \\
0.005 \\
0.01 \\
0.005 \\
0.005 \\
0.005 \\
0.01 \\
0.005 \\
0.005\end{array}$ & $\begin{array}{l}- \\
- \\
- \\
- \\
- \\
-\end{array}$ \\
\hline BORON & $\begin{array}{l}0668 \\
0668 \\
0668 \\
0668 \\
0669 \\
0669 \\
0669 \\
0669 \\
0669 \\
0669 \\
0670 \\
0670 \\
0670\end{array}$ & $\begin{array}{l}10 / 14 / 87 \\
12 / 15 / 90 \\
11 / 18 / 91 \\
02 / 18 / 94 \\
10 / 14 / 87 \\
12 / 15 / 90 \\
03 / 31 / 91 \\
08 / 24 / 91 \\
11 / 19 / 91 \\
02 / 20 / 94 \\
10 / 15 / 87 \\
12 / 15 / 90 \\
04 / 01 / 91\end{array}$ & $\begin{array}{l}0001 \\
0001 \\
0001 \\
0001 \\
0001 \\
0001 \\
0001 \\
0001 \\
0001 \\
0001 \\
0001 \\
0001 \\
0001\end{array}$ & $\begin{array}{l}\text { NA } \\
\text { NA } \\
\text { NA } \\
\text { NA } \\
\text { NA } \\
\text { NA } \\
\text { NA } \\
\text { NA } \\
\text { NA } \\
\text { NA } \\
\text { NA } \\
\text { NA } \\
\text { NA }\end{array}$ & $\begin{array}{l}U \\
U \\
U \\
U \\
U \\
U \\
U \\
U \\
U \\
U \\
U \\
U \\
U\end{array}$ & $M G / L$ & & $\begin{array}{l}0.1 \\
0.1 \\
0.13 \\
0.1 \\
0.4 \\
0.5 \\
0.48 \\
0.53 \\
0.55 \\
0.5 \\
0.3 \\
0.3 \\
0.25\end{array}$ & $\begin{array}{l}L \\
L \\
L \\
L \\
L \\
L \\
L \\
L \\
L \\
L\end{array}$ & $\begin{array}{l}0.1 \\
0.1 \\
0.05 \\
0.1 \\
0.1 \\
0.1 \\
0.05 \\
0.05 \\
0.05 \\
0.1 \\
0.1 \\
0.1 \\
0.05\end{array}$ & $\begin{array}{l}- \\
- \\
- \\
- \\
- \\
- \\
- \\
- \\
-\end{array}$ \\
\hline
\end{tabular}

FORMATION OF COMPLETION CODE:

NA - NAVAJO SANDSTONE

FLOH RELATIONSHIP CODE:

PARAMETER VALUE INDICATOR (PVI): < - LESS THAN DETECTION LIMIT

SAMPLE ID CODES:

OTHER PARAMETER VALUE FLAGS:

0001 - FILTERED SAMPLE (.45 MICRONS)

$L$ - LESS THAN THREE BORE VOLUMES REMOVED BEFORE SAMPLING

NOO1 - UNFILTERED SAMPLE 
TABLE 3.37 BASELINE GROUND WATER QUALITY DATA BY PARAMETER FOR THE NAVAJO SANDSTONE, UC PROCESSING SITE, SLICK ROCK, COLORADO

SITE: SRKO1 SLICK ROCK (BOTH SITES)

$02 / 02 / 86$ TO $02 / 21 / 94$

REPORT DATE : 09/30/94

\begin{tabular}{|c|c|c|c|c|c|c|c|c|c|c|c|}
\hline PARAMETER NAME & $\underset{\text { ID }}{\text { LOCATION }}$ & LOG DATE & $\begin{array}{c}\text { SAMPLE } \\
\text { ID }\end{array}$ & $\begin{array}{l}\text { FORM } \\
\text { COMP }\end{array}$ & $\begin{array}{l}\text { FLOW } \\
\text { REL. }\end{array}$ & $\begin{array}{l}\text { UNITS OF } \\
\text { MEASURE }\end{array}$ & PVI & $\begin{array}{l}\text { PARAMETER } \\
\text { VALUE }\end{array}$ & FLAGS & $\begin{array}{l}\text { DETECTION } \\
\text { LIMIT }\end{array}$ & $\begin{array}{l}\text { PARAMETER } \\
\text { UNCERTAINTY }\end{array}$ \\
\hline BORON & 0670 & $08 / 24 / 91$ & 0001 & NA & $\mathbf{u}$ & $M G / L$ & & 0.32 & $\mathbf{L}$ & 0.05 & - \\
\hline BORON (TOTAL) & $\begin{array}{l}0668 \\
0669\end{array}$ & $\begin{array}{l}02 / 18 / 94 \\
02 / 20 / 94\end{array}$ & $\begin{array}{l}\text { N001 } \\
\text { N001 }\end{array}$ & $\begin{array}{l}\text { NA } \\
\text { NA }\end{array}$ & $\mathbf{U}$ & $M G / L$ & & $\begin{array}{l}0.2 \\
0.5\end{array}$ & $\mathbf{L}$ & $\begin{array}{l}0.1 \\
0.1\end{array}$ & - \\
\hline BROMIDE & $\begin{array}{l}0668 \\
0668 \\
0668 \\
0669 \\
0669 \\
0669 \\
0669 \\
0669 \\
0670 \\
0670 \\
0670 \\
0670 \\
0670\end{array}$ & $\begin{array}{l}12 / 15 / 90 \\
11 / 18 / 91 \\
10 / 11 / 92 \\
12 / 15 / 90 \\
03 / 31 / 91 \\
08 / 24 / 91 \\
11 / 19 / 91 \\
10 / 12 / 92 \\
12 / 15 / 90 \\
04 / 01 / 91 \\
08 / 24 / 91 \\
11 / 20 / 91 \\
10 / 14 / 92\end{array}$ & $\begin{array}{l}0001 \\
0001 \\
0001 \\
0001 \\
0001 \\
0001 \\
0001 \\
0001 \\
0001 \\
0001 \\
0001 \\
0001 \\
0001\end{array}$ & $\begin{array}{l}\text { NA } \\
\text { NA } \\
\text { NA } \\
\text { NA } \\
\text { NA } \\
\text { NA } \\
\text { NA } \\
\text { NA } \\
\text { NA } \\
\text { NA } \\
\text { NA } \\
\text { NA } \\
\text { NA }\end{array}$ & $\begin{array}{l}U \\
U \\
U \\
U \\
U \\
U \\
U \\
U \\
U \\
U \\
U \\
\mathbf{U} \\
\mathbf{U}\end{array}$ & $M G / L$ & $\begin{array}{l}< \\
< \\
< \\
< \\
< \\
< \\
< \\
< \\
< \\
< \\
< \\
< \\
< \\
<\end{array}$ & $\begin{array}{l}0.1 \\
0.1 \\
0.1 \\
0.1 \\
0.1 \\
0.1 \\
0.1 \\
0.1 \\
0.1 \\
0.1 \\
0.1 \\
0.1 \\
0.1\end{array}$ & $\begin{array}{l}\mathrm{L} \\
\mathrm{L} \\
\mathrm{L} \\
\mathrm{L} \\
\mathrm{L} \\
\mathrm{L} \\
\mathrm{L} \\
\mathrm{L} \\
\mathrm{L} \\
\mathrm{L}\end{array}$ & $\begin{array}{l}0.1 \\
0.1 \\
0.1 \\
0.1 \\
0.1 \\
0.1 \\
0.1 \\
0.1 \\
0.1 \\
0.1 \\
0.1 \\
0.1 \\
0.1\end{array}$ & $\begin{array}{l}- \\
- \\
- \\
- \\
- \\
- \\
- \\
- \\
- \\
-\end{array}$ \\
\hline CADMIUM & $\begin{array}{l}0668 \\
0668 \\
0668 \\
0668 \\
0668 \\
0668 \\
0669 \\
0669 \\
0669 \\
0669 \\
0669 \\
0669 \\
0669 \\
0669 \\
0670 \\
0670 \\
0670 \\
0670 \\
0670\end{array}$ & $\begin{array}{l}02 / 02 / 86 \\
10 / 14 / 87 \\
12 / 15 / 90 \\
11 / 18 / 91 \\
10 / 11 / 92 \\
02 / 18 / 94 \\
02 / 04 / 86 \\
10 / 14 / 87 \\
12 / 15 / 90 \\
03 / 31 / 91 \\
08 / 24 / 91 \\
11 / 19 / 91 \\
10 / 12 / 92 \\
02 / 20 / 94 \\
02 / 03 / 86 \\
10 / 15 / 87 \\
12 / 15 / 90 \\
04 / 01 / 91 \\
08 / 24 / 91\end{array}$ & $\begin{array}{l}0001 \\
0001 \\
0001 \\
0001 \\
0001 \\
0001 \\
0001 \\
0001 \\
0001 \\
0001 \\
0001 \\
0001 \\
0001 \\
0001 \\
0001 \\
0001 \\
0001 \\
0001 \\
0001\end{array}$ & $\begin{array}{l}\text { NA } \\
\text { NA } \\
\text { NA } \\
\text { NA } \\
\text { NA } \\
\text { NA } \\
\text { NA } \\
\text { NA } \\
\text { NA } \\
\text { NA } \\
\text { NA } \\
\text { NA } \\
\text { NA } \\
\text { NA } \\
\text { NA } \\
\text { NA } \\
\text { NA } \\
\text { NA } \\
\text { NA }\end{array}$ & $\begin{array}{l}U \\
U \\
U \\
U \\
U \\
U \\
U \\
U \\
U \\
U \\
U \\
U \\
U \\
U \\
U \\
U \\
U \\
U \\
U\end{array}$ & $M G / L$ & $\begin{array}{l}< \\
< \\
< \\
< \\
< \\
< \\
< \\
< \\
< \\
< \\
< \\
< \\
< \\
< \\
< \\
< \\
< \\
< \\
<\end{array}$ & $\begin{array}{l}0.001 \\
0.001 \\
0.001 \\
0.001 \\
0.001 \\
0.001 \\
0.001 \\
0.001 \\
0.001 \\
0.001 \\
0.001 \\
0.001 \\
0.005 \\
0.001 \\
0.001 \\
0.001 \\
0.001 \\
0.001 \\
0.001\end{array}$ & $\begin{array}{l}L \\
\\
G L \\
L \\
L \\
L \\
L \\
L \\
I L \\
L \\
G L \\
L \\
L \\
L \\
L\end{array}$ & $\begin{array}{l}0.001 \\
0.001 \\
0.001 \\
0.001 \\
0.001 \\
0.001 \\
0.001 \\
0.001 \\
0.001 \\
0.001 \\
0.001 \\
0.001 \\
0.005 \\
0.001 \\
0.001 \\
0.001 \\
0.001 \\
0.001 \\
0.001\end{array}$ & $\begin{array}{l}- \\
- \\
- \\
- \\
- \\
- \\
- \\
- \\
- \\
- \\
- \\
- \\
- \\
- \\
-\end{array}$ \\
\hline
\end{tabular}

FORMATION OF COMPLETION CODE:

NA - NAVAJO SANDSTONE

PARAMETER VALUE INDICATOR (PVI): < - LESS THAN DETECTION LIMIT

OTHER PARAMETER VALUE FLAGS:

G - PH $>9$, POSSIBLE GROUT CONTAMINATION

I - INCREASED DETECTION LIMIT DUE TO REQUIRED DILUTION

L - LESS THAN THREE BORE VOLUMES REMOVED BEFORE SAMPLING
FLOW RELATIONSHIP CODE:

$U$ - UPGRADIENT

\section{SAMPLE ID CODES:}

0001 - FILTERED SAMPLE (.45 MICRONS)

NOO1 - UNFILTERED SAMPLE 
TABLE 3.37 BASELINE GROUND HATER QUALITY DATA BY PARAMETER FOR THE NAVAJO SANDSTONE, UC PROCESSING SITE, SLICK ROCK, COLORADO

SITE: SRKO1 SLICK ROCK (BOTH SITES)

REPORT DATE: $09 / 30 / 94$

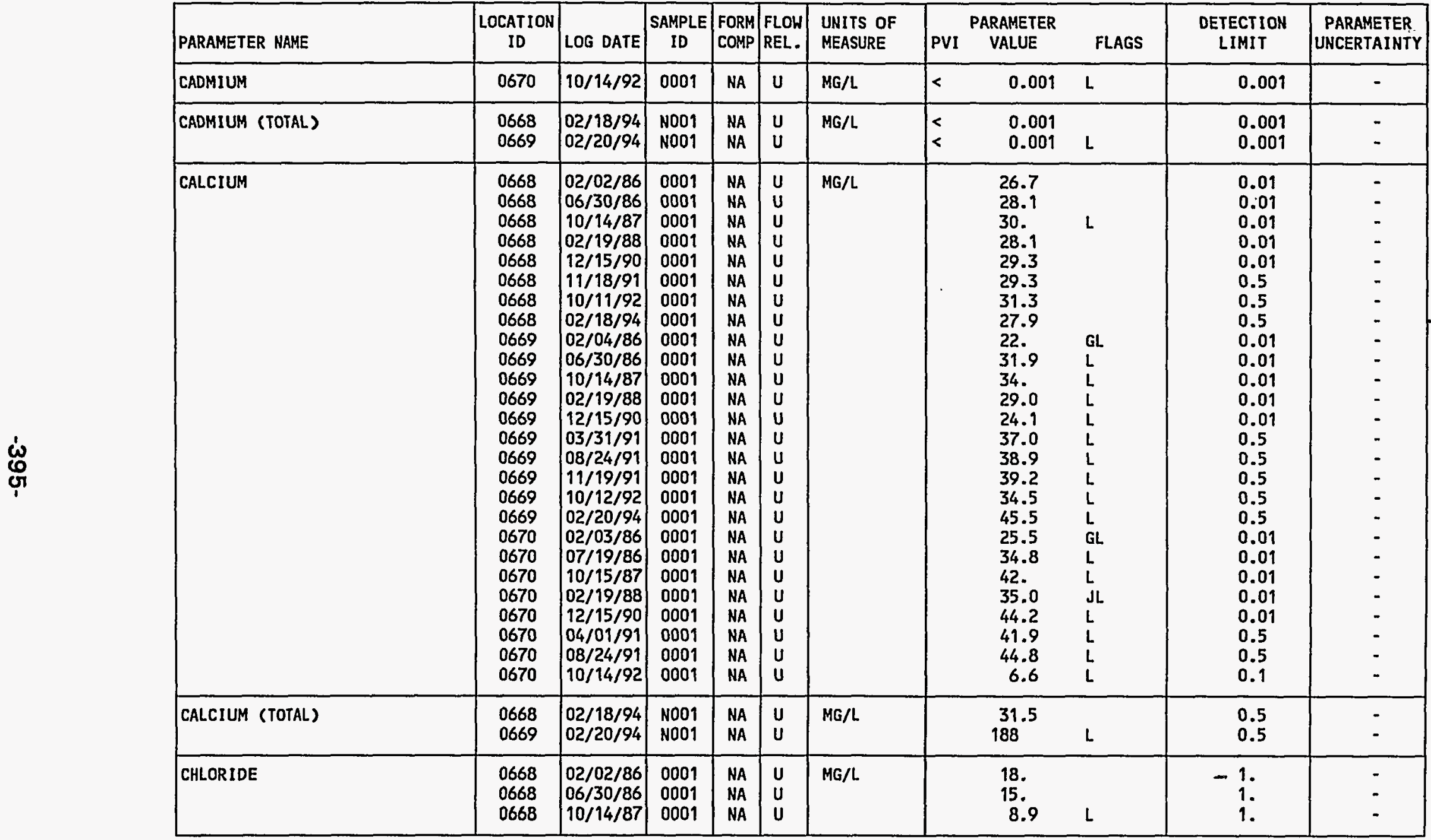

FOPMATION OF COMPLETION CODE:

NA - NAVAJO SAMDSTONE

PARAMETER VALUE INDICATOR (PVI): < - LESS THAN DETECTION LIMIT

OTHER PARAMETER VALUE FLAGS:

G - PH > 9, POSSIBLE GROUT CONTAMINATION

ESTIMATED VALUE

L - LESS THAN THREE BORE VOLUMES REMOVED BEFORE SAMPLING
FLOW RELATIONSHIP CODE:

$U$ - UPGRADIENT

SAMPLE ID CODES:

O001 - FILTERED SAMPLE (.45 MICRONS)

NOO - UNFILTERED SAMPLE 
TABLE 3.37 BASELINE GROUND HATER QUALITY DATA BY PARAMETER FOR THE NAVAJO SANDSTONE, UC PROCESSING SITE, SLICK ROCK, COLORADO

SITE: SRKO1 SLICK ROCK (BOTH SITES)

$02 / 02 / 86$ TO $02 / 21 / 94$

REPORT DATE: $09 / 30 / 94$

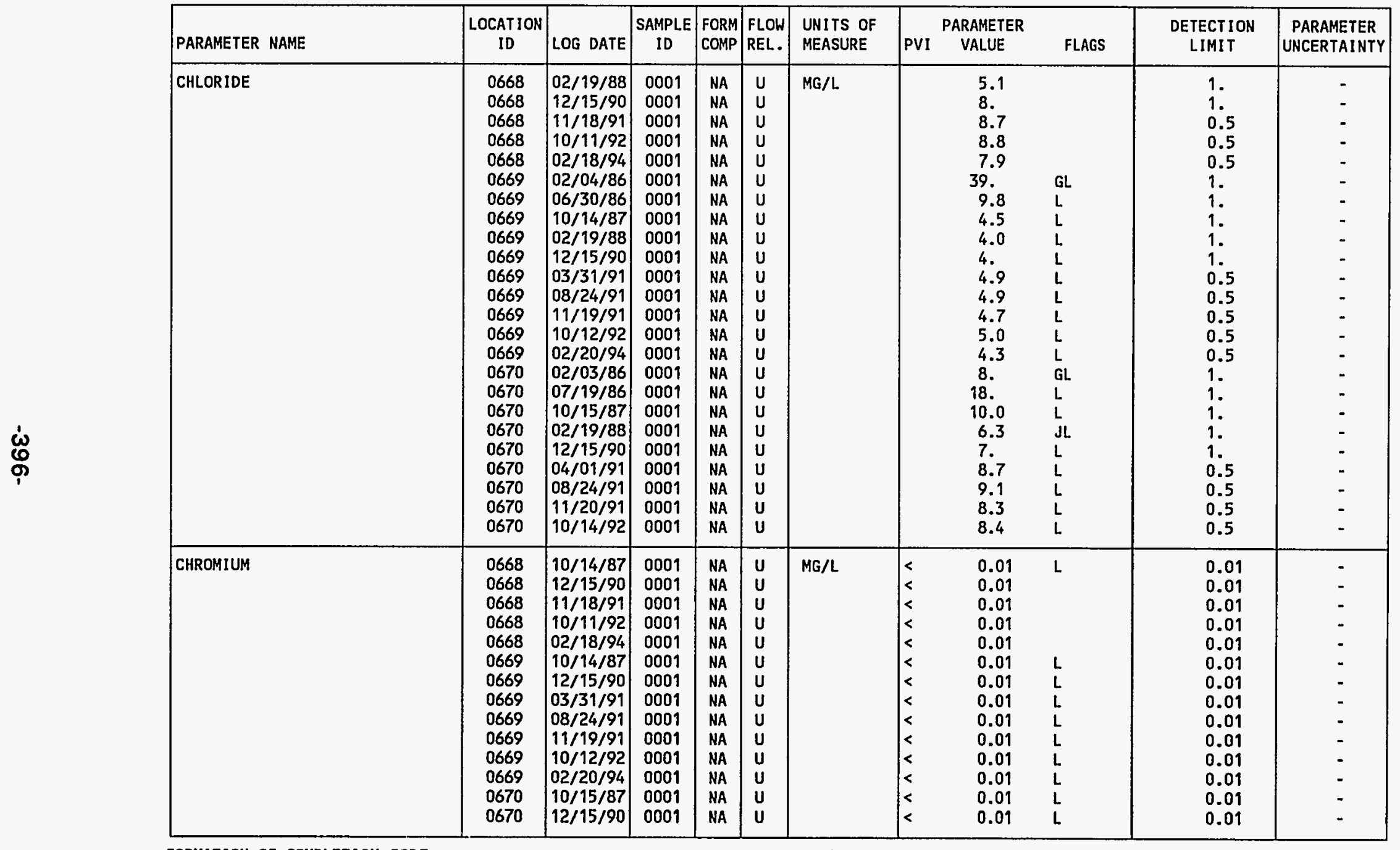

FORMATION OF COMPLETION CODE:

NA - NAVAJO SANDSTONE

FLOH RELATIONSHIP CODE:

PARAMETER VALUE INDICATOR (PVI): < - LESS THAN DETECTION LIMIT

SAMPLE ID CODES:

0001 - FILTERED SAMPLE (.45 MICRONS)

OTHER PARAMETER VALUE FLAGS

G - PH > 9, POSSIBLE GROUT CONTAMINATION

$J$ - estimated VALUE

L - LESS THAN THREE BORE VOLUMES REMOVED BEFORE SAMPLING 
TABLE 3.37 BASELINE GROUND WATER QUALITY DATA BY PARAMETER FOR THE NAVAJO SANDSTONE, UC PROCESSING SITE, SLICK ROCK, COLORADO

SITE: SRKO1 SLICK ROCK (BOTH SITES)

$02 / 02 / 86$ TO $02 / 21 / 94$

REPORT DATE: $09 / 30 / 94$

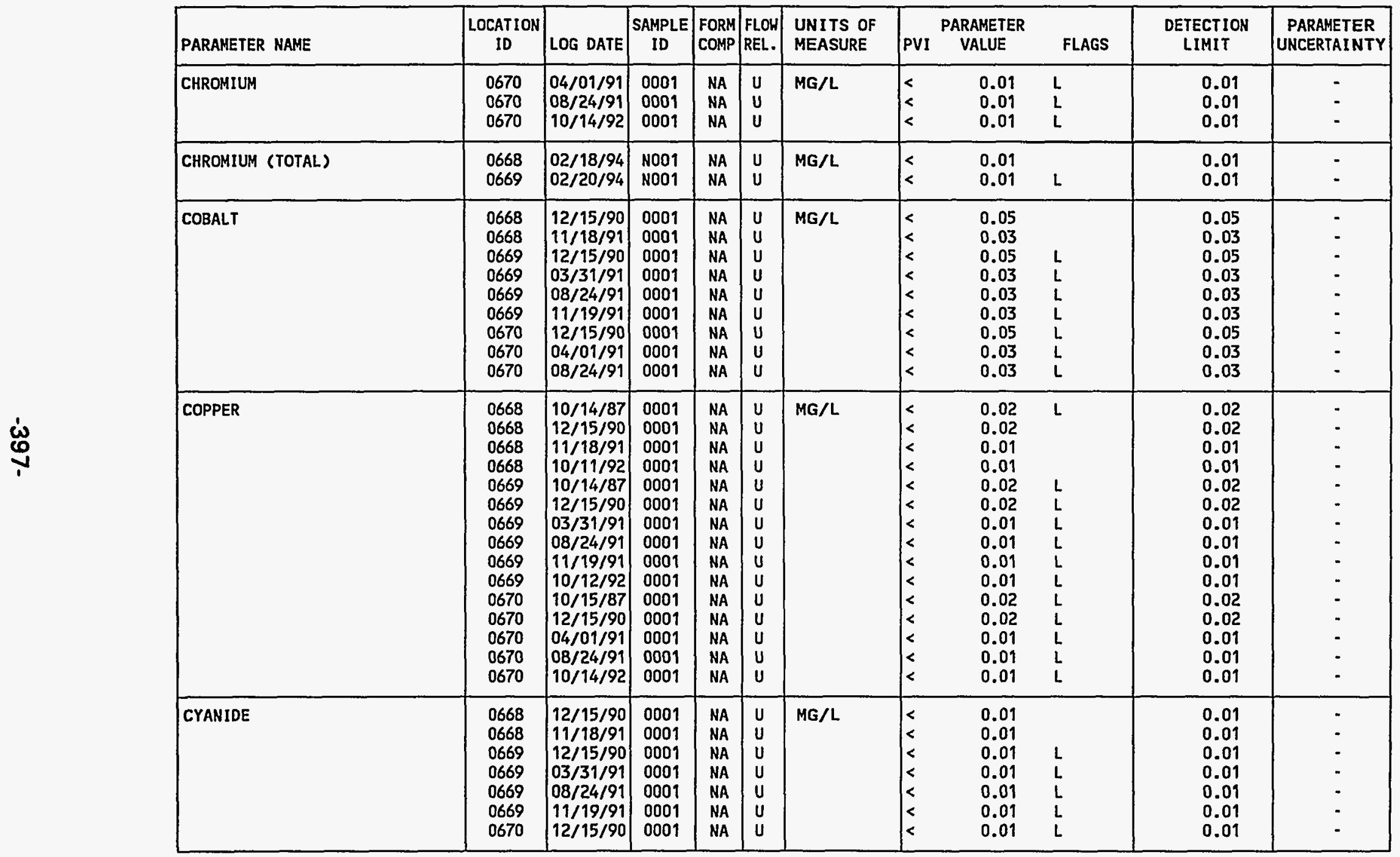

FORMATION OF COMPLETION CODE:

NA - NAVAJO SANDSTONE

FLOW RELATIONSHIP CODE:

PARAMETER VALUE INDICATOR (PVI): < - LESS THAN DETECTION LIMIT

OTHER PARAMETER VALUE FLAGS

$L$ - LESS THAN THREE BORE VOLUMES REMOVED BEFORE SAMPLING

SAMPLE ID CODES:

O001 - FILTERED SAMPLE (.45 MICRONS)

N001 - UNFILTERED SAMPLE 
TABLE 3.37 BASELINE GROUND WATER QUALITY DATA BY PARAMETER FOR THE

NAVAJO SANDSTONE, UC PROCESSING SITE, SLICK ROCK, COLORADO

SITE: SRKO1 SLICK ROCK (BOTH SITES)

$02 / 02 / 86$ TO $02 / 21 / 94$

REPORT DATE : $09 / 30 / 94$

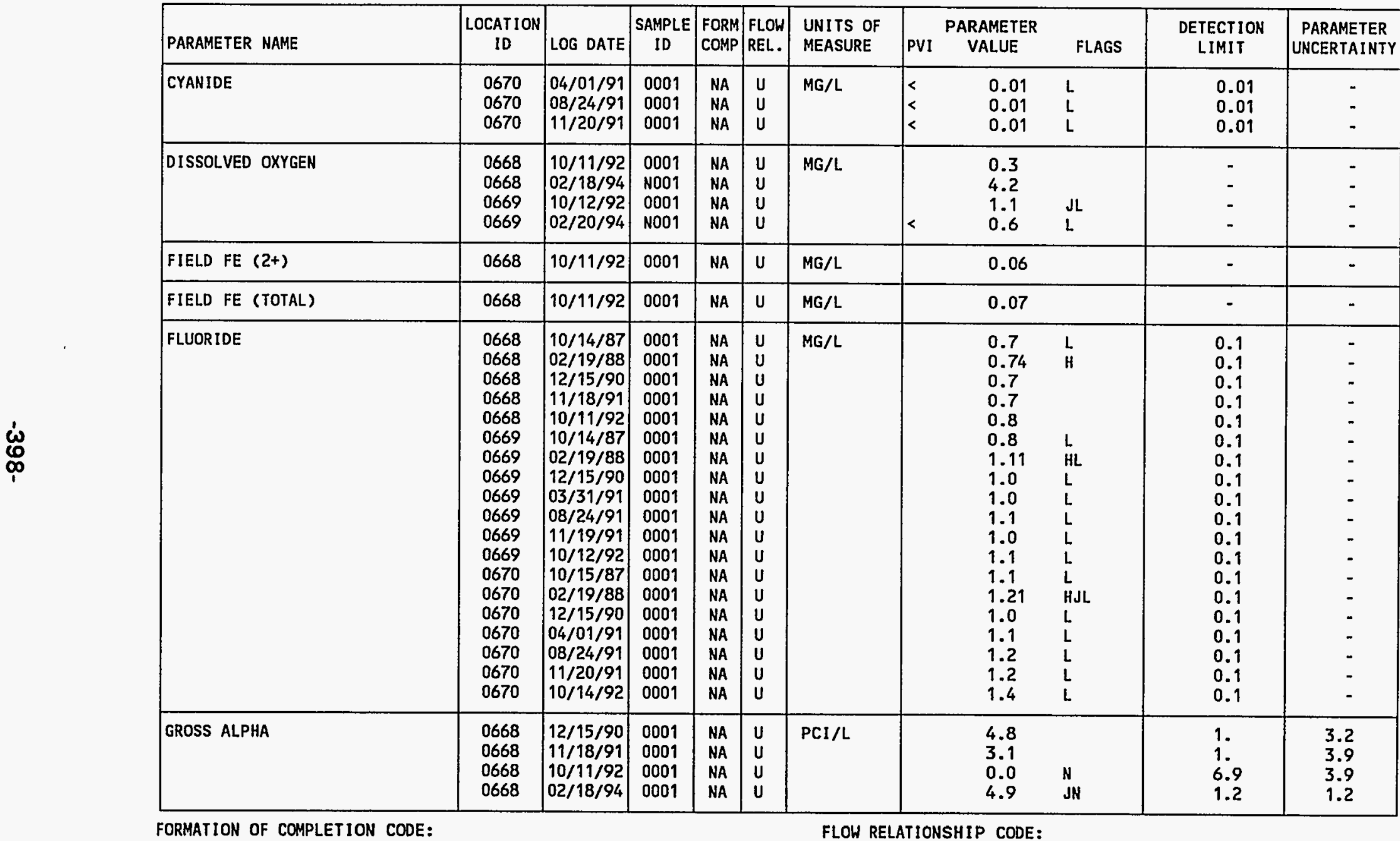

FORMATION OF COMPLETION CODE:

NA - NAVAJO SANDSTONE

FLOW RELATIONSHIP CODE:

PARAMETER VALUE INDICATOR (PVI): < - LESS THAN DETECTION LIMIT

SAMPLE ID CODES:

OTHER PARAMETER VALUE FLAGS:

0001 - FILTERED SAMPLE (.45 MICRONS)

H - HOLD TIME EXPIRED, VALUE SUSPECT

NOO1 - UNFILTERED SAMPLE

$\mathrm{J}$ - ESTIMATED VALUE

L - LESS THAN THREE BORE VOLUMES REMOVED BEFORE SAMPLING

$N$ - SPIKE SAMPLE RECOVERY NOT WITHIN CONTROL LIMITS 
TABLE 3.37 BASELINE GROUND HATER QUALITY DATA BY PARAMETER FOR THE NAVAJO SANDSTONE, UC PROCESSING SITE, SLICK ROCK, COLORADO

SITE: SRKO1 SLICK ROCK (BOTH SITES)

$02 / 02 / 86$ TO $02 / 21 / 94$

REPORT DATE: 09/30/94

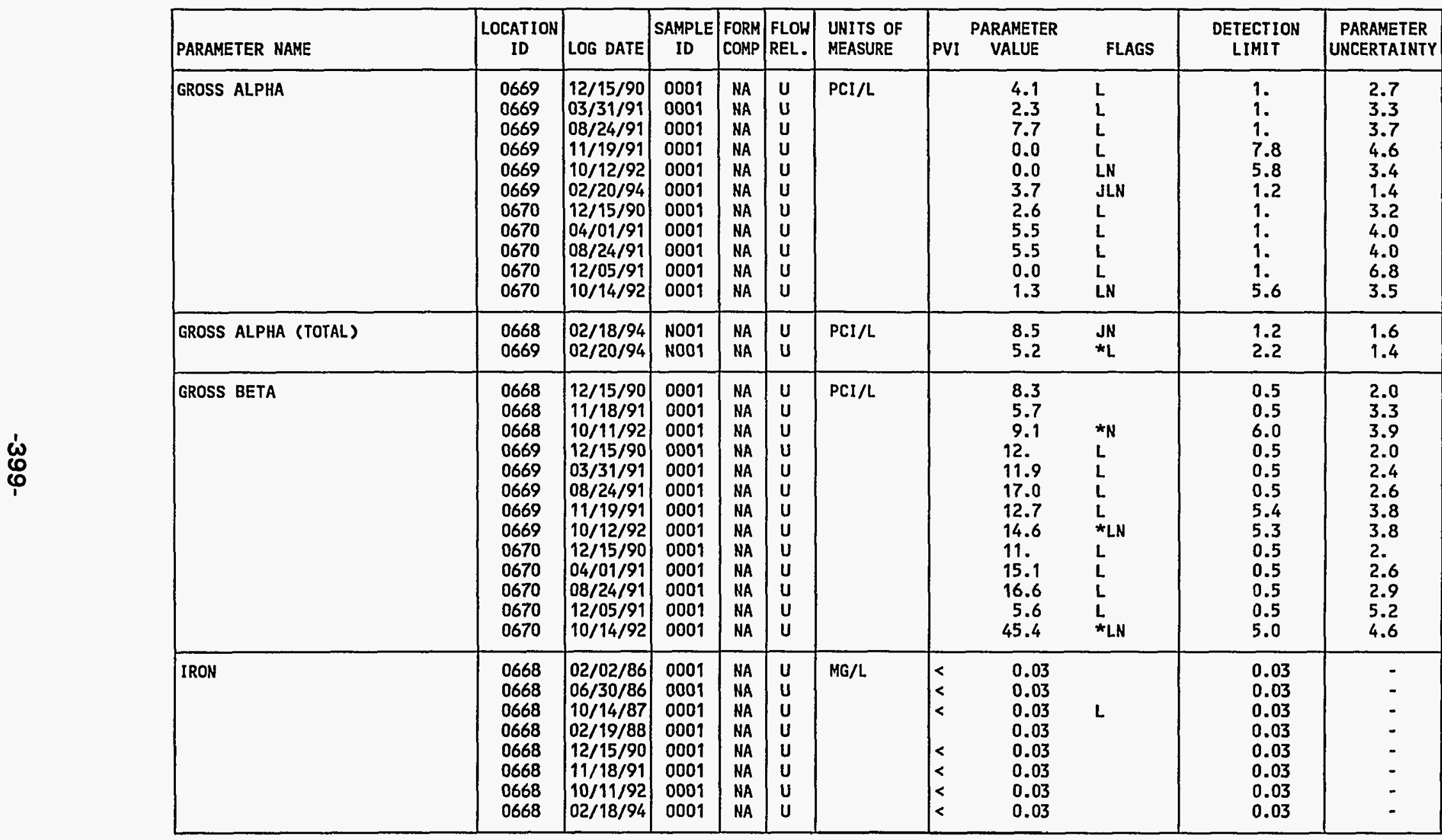

FORMATION OF COMPLETION CODE:

NA - NAVAJO SANDSTONE

PARAMETER VALUE INDICATOR (PVI): < - LESS THAN DETECTION LIMIT

OTHER PARAMETER VALUE FLAGS:

* - DUPLICATE ANALYSIS NOT HITHIN CONTROL LIMITS

$J$ - ESTIMATED VALUE

L - LESS THAN THREE BORE VOLUMES REMOVED BEFORE SAMPLING

$N$ - SPIKE SAMPLE RECOVERY NOT HITHIN CONTROL LIMITS
FLOH RELATIONSHIP CODE:

$U$ - UPGRADIENT

SAMPLE ID CODES

0001 - FILTERED SAMPLE (.45 MICRONS)

N001 - UNFILTERED SAMPLE 
TABLE 3.37 BASELINE GROUND HATER QUALITY DATA BY PARAMETER FOR THE

NAVAJO SANDSTONE, UC PROCESSING SITE, SLICK ROCK, COLORADO

SITE : SRKO1 SLICK ROCK (BOTH SITES)

$02 / 02 / 86$ TO 02/21/94

\begin{tabular}{|c|c|c|c|c|c|c|c|c|c|c|c|}
\hline PARAMETER NAME & $\mid \begin{array}{c}\text { LOCAT ION } \\
\text { ID }\end{array}$ & LOG DATE & $\begin{array}{c}\text { SAMPLE } \\
\text { ID }\end{array}$ & $\left|\begin{array}{l}\text { FORM } \\
\text { COMP }\end{array}\right|$ & $\begin{array}{l}\text { FLOW } \\
\text { REL. }\end{array}$ & $\begin{array}{l}\text { UNITS OF } \\
\text { MEASURE }\end{array}$ & PVI & $\begin{array}{l}\text { ARAMETER } \\
\text { VALUE }\end{array}$ & FLAGS & $\begin{array}{l}\text { DETECTION } \\
\text { LIMIT }\end{array}$ & $\begin{array}{l}\text { PARAMETER } \\
\text { UNCERTAINTY }\end{array}$ \\
\hline IRON & $\begin{array}{l}0669 \\
0669 \\
0669 \\
0669 \\
0669 \\
0669 \\
0669 \\
0669 \\
0669 \\
0669 \\
0670 \\
0670 \\
0670 \\
0670 \\
0670 \\
0670 \\
0670 \\
0670\end{array}$ & $\begin{array}{l}02 / 04 / 86 \\
06 / 30 / 86 \\
10 / 14 / 87 \\
02 / 19 / 88 \\
12 / 15 / 90 \\
03 / 31 / 91 \\
08 / 24 / 91 \\
11 / 19 / 91 \\
10 / 12 / 92 \\
02 / 20 / 94 \\
02 / 03 / 86 \\
07 / 19 / 86 \\
10 / 15 / 87 \\
02 / 19 / 88 \\
12 / 15 / 90 \\
04 / 01 / 91 \\
08 / 24 / 91 \\
10 / 14 / 92\end{array}$ & $\begin{array}{l}0001 \\
0001 \\
0001 \\
0001 \\
0001 \\
0001 \\
0001 \\
0001 \\
0001 \\
0001 \\
0001 \\
0001 \\
0001 \\
0001 \\
0001 \\
0001 \\
0001 \\
0001\end{array}$ & $\begin{array}{l}\text { NA } \\
\text { NA } \\
\text { NA } \\
\text { NA } \\
\text { NA } \\
\text { NA } \\
\text { NA } \\
\text { NA } \\
\text { NA } \\
\text { NA } \\
\text { NA } \\
\text { NA } \\
\text { NA } \\
\text { NA } \\
\text { NA } \\
\text { NA } \\
\text { NA } \\
\text { NA }\end{array}$ & $\begin{array}{l}U \\
U \\
U \\
U \\
U \\
U \\
U \\
U \\
U \\
U \\
U \\
U \\
U \\
U \\
U \\
U \\
U \\
U\end{array}$ & $\mathrm{MG} / \mathrm{L}$ & $\begin{array}{l}< \\
< \\
< \\
< \\
< \\
< \\
<\end{array}$ & $\begin{array}{l}0.03 \\
0.06 \\
0.03 \\
0.08 \\
0.03 \\
0.03 \\
0.03 \\
0.04 \\
0.03 \\
0.03 \\
0.06 \\
0.03 \\
0.12 \\
0.22 \\
0.74 \\
0.04 \\
0.08 \\
0.03\end{array}$ & $\begin{array}{l}G L \\
L \\
L \\
L \\
L \\
L \\
L \\
L \\
L \\
L \\
G L \\
L \\
L \\
J L \\
L \\
L \\
L \\
L\end{array}$ & $\begin{array}{l}0.03 \\
0.03 \\
0.03 \\
0.03 \\
0.03 \\
0.03 \\
0.03 \\
0.03 \\
0.03 \\
0.03 \\
0.03 \\
0.03 \\
0.03 \\
0.03 \\
0.03 \\
0.03 \\
0.03 \\
0.03\end{array}$ & $\begin{array}{l}- \\
- \\
- \\
- \\
- \\
- \\
- \\
- \\
- \\
- \\
- \\
- \\
- \\
- \\
-\end{array}$ \\
\hline IRON (TOTAL) & $\begin{array}{l}0668 \\
0669\end{array}$ & $\begin{array}{l}02 / 18 / 94 \\
02 / 20 / 94\end{array}$ & $\begin{array}{l}\text { N001 } \\
\text { N001 }\end{array}$ & $\begin{array}{l}\text { NA } \\
\text { NA }\end{array}$ & $\begin{array}{l}U \\
U\end{array}$ & $M G / L$ & & $\begin{array}{l}2.15 \\
8.25\end{array}$ & L & $\begin{array}{l}0.03 \\
0.03\end{array}$ & - \\
\hline LEAD & $\begin{array}{l}0668 \\
0668 \\
0668 \\
0668 \\
0669 \\
0669 \\
0669 \\
0669 \\
0669 \\
0669 \\
0670 \\
0670 \\
0670 \\
0670 \\
0670\end{array}$ & $\begin{array}{l}10 / 14 / 87 \\
12 / 15 / 90 \\
11 / 18 / 91 \\
10 / 11 / 92 \\
10 / 14 / 87 \\
12 / 15 / 90 \\
03 / 31 / 91 \\
08 / 24 / 91 \\
11 / 19 / 91 \\
10 / 12 / 92 \\
10 / 15 / 87 \\
12 / 15 / 90 \\
04 / 01 / 91 \\
08 / 24 / 91 \\
10 / 14 / 92\end{array}$ & $\begin{array}{l}0001 \\
0001 \\
0001 \\
0001 \\
0001 \\
0001 \\
0001 \\
0001 \\
0001 \\
0001 \\
0001 \\
0001 \\
0001 \\
0001 \\
0001\end{array}$ & $\begin{array}{l}\text { NA } \\
\text { NA } \\
\text { NA } \\
\text { NA } \\
\text { NA } \\
\text { NA } \\
\text { NA } \\
\text { NA } \\
\text { NA } \\
\text { NA } \\
\text { NA } \\
\text { NA } \\
\text { NA } \\
\text { NA } \\
\text { NA }\end{array}$ & $\begin{array}{l}u \\
U \\
U \\
U \\
U \\
U \\
U \\
U \\
U \\
U \\
U \\
U \\
U \\
U \\
U\end{array}$ & MG/L & $\begin{array}{l}< \\
< \\
< \\
< \\
< \\
< \\
< \\
< \\
< \\
< \\
< \\
< \\
< \\
< \\
<\end{array}$ & $\begin{array}{l}0.01 \\
0.01 \\
0.005 \\
0.003 \\
0.01 \\
0.01 \\
0.005 \\
0.005 \\
0.005 \\
0.02 \\
0.01 \\
0.01 \\
0.005 \\
0.005 \\
0.003\end{array}$ & $\begin{array}{l}\text { L } \\
L \\
L \\
L \\
L \\
I L \\
L \\
L \\
L \\
L \\
L\end{array}$ & $\begin{array}{l}0.01 \\
0.01 \\
0.005 \\
0.003 \\
0.01 \\
0.01 \\
0.005 \\
0.005 \\
0.005 \\
0.02 \\
0.01 \\
0.01 \\
0.005 \\
0.005 \\
0.003\end{array}$ & $\begin{array}{l}- \\
- \\
- \\
- \\
- \\
- \\
- \\
- \\
- \\
- \\
- \\
- \\
-\end{array}$ \\
\hline LEAD-210 & 0668 & $11 / 18 / 91$ & 0001 & NA & U & $\mathrm{PCI} / \mathrm{L}$ & & 0.0 & & 1.5 & 0.8 \\
\hline
\end{tabular}

FORMATION OF COMPLETION CODE:

NA - NAVAJO SANDSTONE

FLOW RELATIONSHIP CODE:

PARAMETER VALUE INDICATOR (PVI): < - LESS THAN DETECTION LIMIT

$U$ - UPGRADIENT

OTHER PARAMETER VALUE FLAGS:

SAMPLE ID CODES:

O001 - FILTERED SAMPLE (.45 MICRONS)

$G$ - PH > 9, POSSIBLE GROUT CONTAMINATION

N001 - UNFILTERED SAMPLE

I - INCREASED DETECTION LIMIT DUE TO REQUIRED DILUTION

$J$ - ESTIMATED VALUE

L - LESS THAN THREE BORE VOLUMES REMOVED BEFORE SAMPLING 
TABLE 3.37 BASELINE GROUND HATER QUALITY DATA BY PARAMETER FOR THE

NAVAJO SANDSTONE, UC PROCESSING SITE, SLICK RDCK, COLORADO

SITE: SRKO1 SLICK ROCK (BOTH SITES)

02/02/86 TO 02/21/94

REPORT DATE: 09/30/94

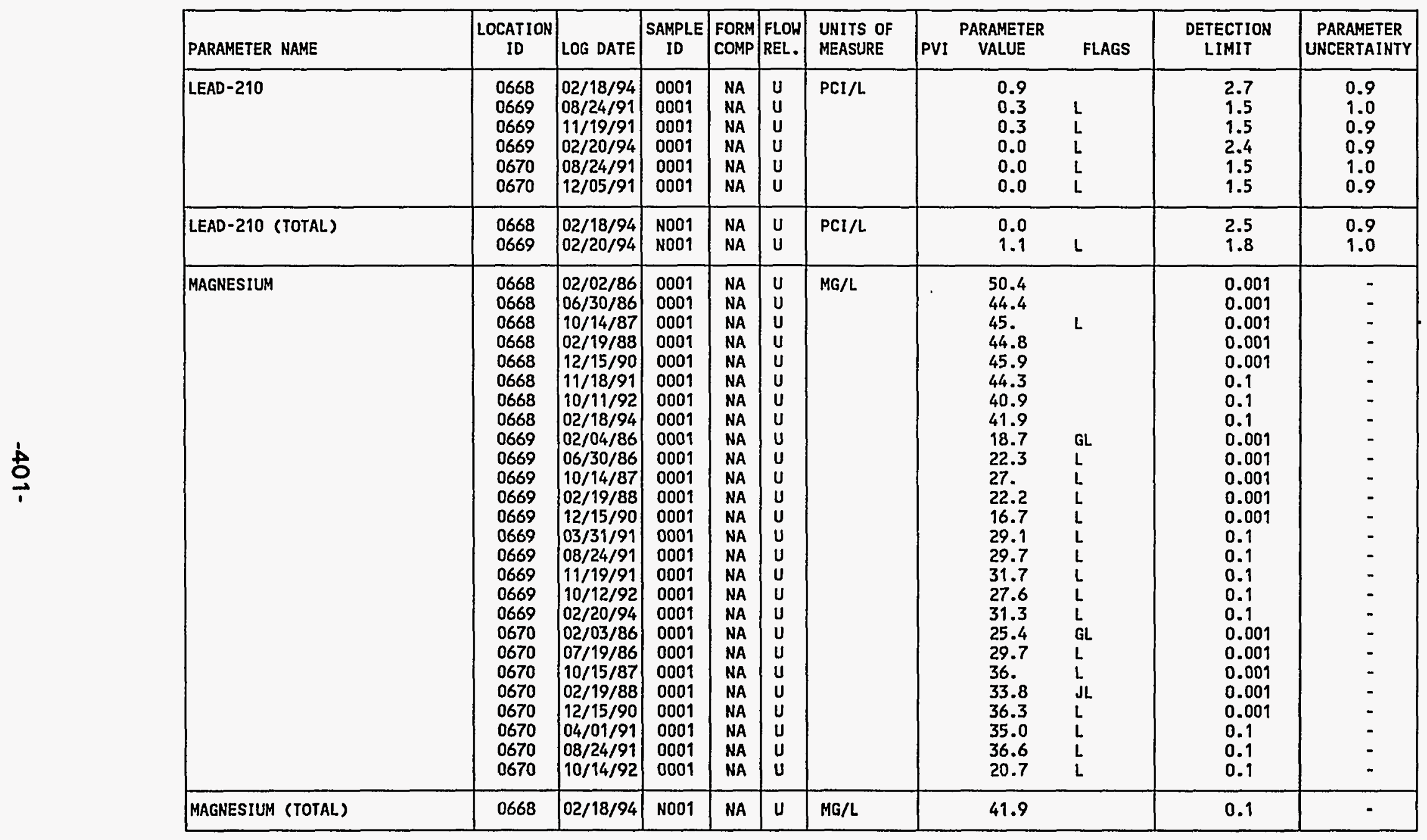

FORMATION OF COMPLETION CODE

NA - NAVAJO SANDSTONE

PARAMETER VALUE INDICATOR (PVI): < - LESS THAN DETECTION LIMIT

OTHER PARAMETER VALUE FLAGS:

$G$ - PH > 9, POSSIBLE GROUT CONTAMINATION

$J$ - ESTIMATED VALUE

L - LESS THAI: IIIREE BORE VOLLMES RTHOVED BEFCRE SAMPLING
FLOW RELATIONSHIP CODE:

U - UPGRADIENT

SAMPLE ID CODES:

0001 - FILTERED SAMPLE (.45 MICRONS)

N001 - UNFILTERED SAMPLE 
TABLE 3.37 BASELINE GROUND WATER QUALITY DATA BY PARAMETER FOR THE

NAVAJO SANDSTONE, UC PROCESSING SITE, SLICK ROCK, COLORADO

SITE: SRKO1 SLICK ROCK (BOTH SITES)

$02 / 02 / 86$ TO $02 / 21 / 94$

REPORT DATE: $09 / 30 / 94$

\begin{tabular}{|c|c|c|c|c|c|c|c|c|c|c|c|}
\hline PARAMETER NAME & $\begin{array}{c}\text { LOCATION } \\
\text { ID }\end{array}$ & LOG DATE & $\begin{array}{c}\text { SAMPLE } \\
\text { ID }\end{array}$ & $\begin{array}{l}\text { FORM } \\
\text { COMP }\end{array}$ & $\begin{array}{l}\text { FLOW } \\
\text { REL. }\end{array}$ & $\begin{array}{l}\text { UNITS OF } \\
\text { MEASURE }\end{array}$ & PV! & $\begin{array}{l}\text { ARAMETER } \\
\text { VALUE }\end{array}$ & FLAGS & $\begin{array}{l}\text { DETECTION } \\
\text { LIMIT }\end{array}$ & $\begin{array}{l}\text { PARAMETER } \\
\text { UNCERTAINTY }\end{array}$ \\
\hline MAGNESIUM (TOTAL) & 0669 & $02 / 20 / 94$ & N001 & NA & $u$ & $M G / L$ & & 42.5 & $\mathbf{L}$ & 0.1 & - \\
\hline MANGANESE & $\begin{array}{l}0668 \\
0668 \\
0668 \\
0668 \\
0668 \\
0668 \\
0668 \\
0668 \\
0669 \\
0669 \\
0669 \\
0669 \\
0669 \\
0669 \\
0669 \\
0669 \\
0669 \\
0669 \\
0670 \\
0670 \\
0670 \\
0670 \\
0670 \\
0670 \\
0670 \\
0670\end{array}$ & $\begin{array}{l}02 / 02 / 86 \\
06 / 30 / 86 \\
10 / 14 / 87 \\
02 / 19 / 88 \\
12 / 15 / 90 \\
11 / 18 / 91 \\
10 / 11 / 92 \\
02 / 18 / 94 \\
02 / 04 / 86 \\
06 / 30 / 86 \\
10 / 14 / 87 \\
02 / 19 / 88 \\
12 / 15 / 90 \\
03 / 31 / 91 \\
08 / 24 / 91 \\
11 / 19 / 91 \\
10 / 12 / 92 \\
02 / 20 / 94 \\
02 / 03 / 86 \\
07 / 19 / 86 \\
10 / 15 / 87 \\
02 / 19 / 88 \\
12 / 15 / 90 \\
04 / 01 / 91 \\
08 / 24 / 91 \\
10 / 14 / 92\end{array}$ & $\begin{array}{l}0001 \\
0001 \\
0001 \\
0001 \\
0001 \\
0001 \\
0001 \\
0001 \\
0001 \\
0001 \\
0001 \\
0001 \\
0001 \\
0001 \\
0001 \\
0001 \\
0001 \\
0001 \\
0001 \\
0001 \\
0001 \\
0001 \\
0001 \\
0001 \\
0001 \\
0001\end{array}$ & $\begin{array}{l}\text { NA } \\
\text { NA } \\
\text { NA } \\
\text { NA } \\
\text { NA } \\
\text { NA } \\
\text { NA } \\
\text { NA } \\
\text { NA } \\
\text { NA } \\
\text { NA } \\
\text { NA } \\
\text { NA } \\
\text { NA } \\
\text { NA } \\
\text { NA } \\
\text { NA } \\
\text { NA } \\
\text { NA } \\
\text { NA } \\
\text { NA } \\
\text { NA } \\
\text { NA } \\
\text { NA } \\
\text { NA } \\
\text { NA }\end{array}$ & $\begin{array}{l}U \\
U \\
U \\
U \\
U \\
U \\
U \\
U \\
U \\
U \\
U \\
U \\
U \\
U \\
U \\
U \\
U \\
U \\
U \\
U \\
U \\
U \\
U \\
U \\
U \\
U\end{array}$ & $M G / L$ & $\begin{array}{l}< \\
<\end{array}$ & $\begin{array}{l}0.03 \\
0.04 \\
0.01 \\
0.01 \\
0.01 \\
0.01 \\
0.06 \\
0.01 \\
0.02 \\
0.13 \\
0.06 \\
0.07 \\
0.02 \\
0.03 \\
0.02 \\
0.04 \\
0.03 \\
0.04 \\
0.02 \\
0.12 \\
0.18 \\
0.15 \\
0.11 \\
0.08 \\
0.07 \\
0.01\end{array}$ & $\begin{array}{l}G L \\
L \\
L \\
L \\
L \\
L \\
L \\
L \\
L \\
L \\
G L \\
L \\
L \\
J L \\
L \\
L \\
L \\
L\end{array}$ & $\begin{array}{l}0.01 \\
0.01 \\
0.01 \\
0.01 \\
0.01 \\
0.01 \\
0.01 \\
0.01 \\
0.01 \\
0.01 \\
0.01 \\
0.01 \\
0.01 \\
0.01 \\
0.01 \\
0.01 \\
0.01 \\
0.01 \\
0.01 \\
0.01 \\
0.01 \\
0.01 \\
0.01 \\
0.01 \\
0.01 \\
0.01\end{array}$ & $\begin{array}{l}- \\
- \\
- \\
- \\
- \\
- \\
- \\
- \\
- \\
- \\
- \\
- \\
- \\
- \\
- \\
- \\
- \\
- \\
-\end{array}$ \\
\hline MANGANESE (TOTAL) & $\begin{array}{l}0668 \\
0669\end{array}$ & $\begin{array}{l}02 / 18 / 94 \\
02 / 20 / 94\end{array}$ & $\begin{array}{l}\text { N001 } \\
\text { N001 }\end{array}$ & $\begin{array}{l}N A \\
\text { NA }\end{array}$ & $\begin{array}{l}\mathbf{U} \\
\mathbf{u}\end{array}$ & $M G / L$ & & $\begin{array}{l}0.12 \\
0.32\end{array}$ & L & $\begin{array}{l}0.01 \\
0.01\end{array}$ & - \\
\hline MERCURY & $\begin{array}{l}0668 \\
0668 \\
0668 \\
0669 \\
0669 \\
0669\end{array}$ & $\begin{array}{l}10 / 14 / 87 \\
12 / 15 / 90 \\
11 / 18 / 91 \\
10 / 14 / 87 \\
12 / 15 / 90 \\
03 / 31 / 91\end{array}$ & $\begin{array}{l}0001 \\
0001 \\
0001 \\
0001 \\
0001 \\
0001\end{array}$ & $\begin{array}{l}\text { NA } \\
\text { NA } \\
\text { NA } \\
\text { NA } \\
\text { NA } \\
\text { NA }\end{array}$ & $\begin{array}{l}U \\
U \\
U \\
U \\
U \\
U\end{array}$ & MG/L & $\begin{array}{l}< \\
< \\
< \\
< \\
< \\
<\end{array}$ & $\begin{array}{l}0.0002 \\
0.0002 \\
0.0002 \\
0.0002 \\
0.0002 \\
0.0002\end{array}$ & $\begin{array}{l}L \\
L \\
L \\
L\end{array}$ & $\begin{array}{l}0.0002 \\
0.0002 \\
0.0002 \\
0.0002 \\
0.0002 \\
0.0002\end{array}$ & $\begin{array}{l}- \\
: \\
- \\
-\end{array}$ \\
\hline
\end{tabular}

FORMATION OF COMPLETION CODE:

NA - NAVAJO SANDSTONE

PARAMETER VALUE INDICATOR (PVI): < - LESS THAN DETECTION LIMIT

OTHER PARAMETER VALUE FLAGS:

$G$ - PH $>9$, POSSIBLE GROUT CONTAMINATION

$J$ - ESTIMATED VALUE

L - LESS THAN THREE BORE VOLUMES REMOVED BEFORE SAMPLING
FLOW RELATIONSHIP CODE:

U - UPGRADIENT

SAMPLE ID CODES:

0001 - FILTERED SAMPLE (.45 MICRONS)

N001 - UNFILTERED SAMPLE 
TABLE 3.37 BASELINE GROUND HATER QUALITY DATA BY PARAMETER FOR THE NAVAJO SANDSTONE, UC PROCESSING SITE, SLICK ROCK, COLORADO

SITE: SRKO1 SLICK ROCK (BOTH SITES)

02/02/86 TO 02/21/94

REPORT DATE: $09 / 30 / 94$

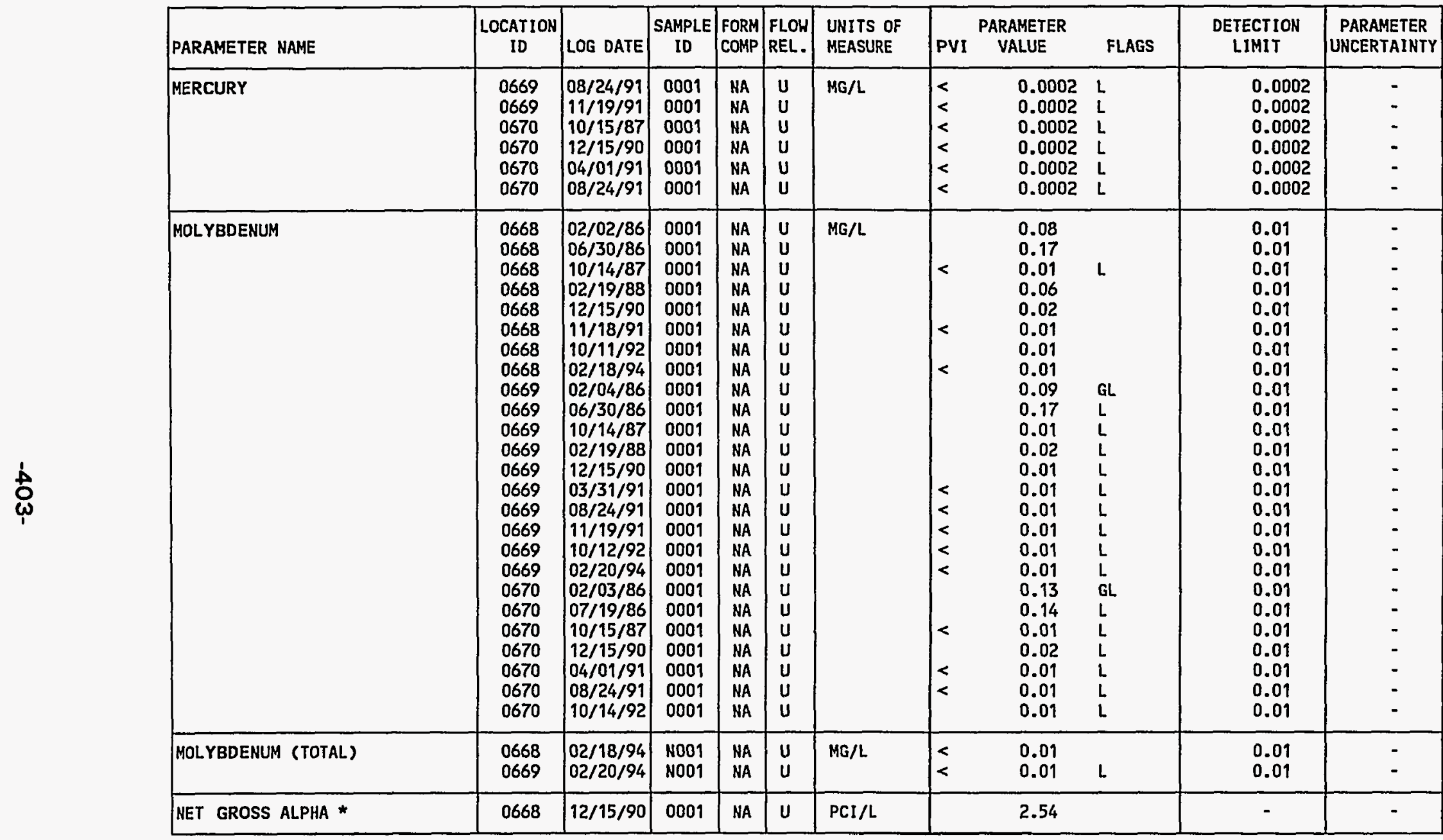

* NET GROSS ALPHA (GROSS ALPHA - URANIUM) WITH 1 MG URANIUM $=686 \mathrm{PCI}$

FOPMATION OF COMPLETION CODE:

NA - NAVAJO SANDSTONE

PARAMETER VALUE INDICATOR (PVI): < - LESS THAN DETECTION LIMIT

OTHER PARAMETER VALUE FLAGS:

$G$ - $P H>9$, POSSIBLE GROUT CONTAMINATION

L - LESS THAN THREE BORE VOLUMES REMOVED BEFORE SAMPLING
FLOH RELATIONSHIP CODE:

\section{$U$ - UPGRADIENT}

SAMPLE ID CODES:

0001 - FILTERED SAMPLE (.45 MICRONS) N001 - UNF ILTERED SAMPLE 
TABLE 3.37 BASELINE GROUND HATER QUALITY DATA BY PARAMETER FOR THE

NAVAJO SANDSTONE, UC PROCESSING SITE, SLICK ROCK, COLORADO

SITE: SRKO1 SLICK ROCK (BOTH SITES)

02/02/86 TO $02 / 21 / 94$

REPORT DATE: $09 / 30 / 94$

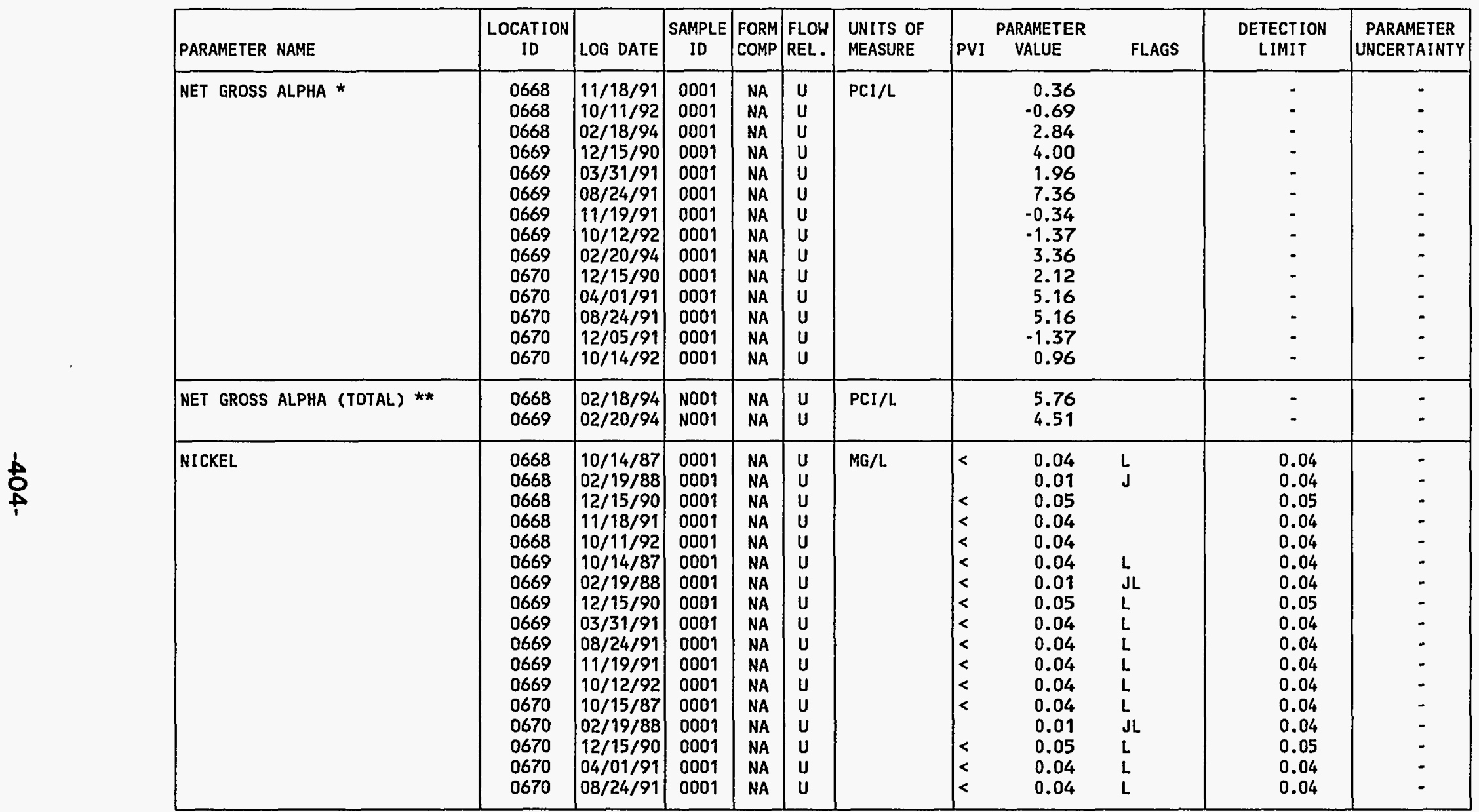

* NET GROSS ALPHA (GROSS ALPHA - URANIUM) WITH 1 MG URANIUM = 686 PCI

** NET GROSS ALPHA (TOTAL) (TOTAL GROSS ALPHA - TOTAL URANIUM)

FORMATION OF COMPLETION CODE:

NA - NAVAJO SANDSTONE

PARAMETER VALUE INDICATOR (PVI): < - LESS THAN DETECTION LIMIT

OTHER PARAMETER VALUE FLAGS:

$J$ - ESTIMATED VALUE

L - LESS THAN THREE BORE VOLUMES REMOVED BEFORE SAMPLING
FLOW RELATIONSHIP CODE:

$U$ - UPGRADIENT

SAMPLE ID CODES:

0001 - FILTERED SAMPLE (.45 MICRONS)

NO01 - UNFILTERED SAMPLE 
TABLE 3.37 BASELINE GROUND WATER QUALITY DATA BY PARAMETER FOR THE NAVAJO SANDSTONE, UC PROCESSING SITE, SLICK ROCK, COLORADO

SITE: SRKOI SLICK ROCK (BOTH SITES)

DEPORT TO 02/21/94

\begin{tabular}{|c|c|c|c|c|c|c|c|c|c|c|c|}
\hline PARAMETER NAME & $\underset{\text { ID }}{\text { LOCATION }}$ & LOG DATE & $\begin{array}{c}\text { SAMPLE } \\
\text { ID }\end{array}$ & $\begin{array}{l}\text { FORM } \\
\text { COMP }\end{array}$ & $\begin{array}{l}\text { FLOH } \\
\text { REL. }\end{array}$ & $\begin{array}{l}\text { UNITS OF } \\
\text { MEASURE }\end{array}$ & PVI & $\begin{array}{l}\text { ARAMETER } \\
\text { VALUE }\end{array}$ & FLAGS & $\begin{array}{l}\text { DETECTION } \\
\text { LIMIT }\end{array}$ & $\begin{array}{l}\text { PARAMETER } \\
\text { UNCERTAINTY }\end{array}$ \\
\hline NICKEL & 0670 & $10 / 14 / 92$ & 0001 & NA & $\mathbf{U}$ & $M G / L$ & $<$ & 0.04 & L & 0.04 & - \\
\hline NITRATE & $\begin{array}{l}0668 \\
0668 \\
0668 \\
0668 \\
0668 \\
0668 \\
0668 \\
0669 \\
0669 \\
0669 \\
0669 \\
0669 \\
0669 \\
0669 \\
0669 \\
0669 \\
0670 \\
0670 \\
0670 \\
0670 \\
0670 \\
0670 \\
0670 \\
0670\end{array}$ & $\begin{array}{l}02 / 02 / 86 \\
06 / 30 / 86 \\
10 / 14 / 87 \\
02 / 19 / 88 \\
12 / 15 / 90 \\
11 / 18 / 91 \\
10 / 11 / 92 \\
02 / 04 / 86 \\
06 / 30 / 86 \\
10 / 14 / 87 \\
02 / 19 / 88 \\
12 / 15 / 90 \\
03 / 31 / 91 \\
08 / 24 / 91 \\
11 / 19 / 91 \\
10 / 12 / 92 \\
02 / 03 / 86 \\
07 / 19 / 86 \\
10 / 15 / 87 \\
12 / 15 / 90 \\
04 / 01 / 91 \\
08 / 24 / 91 \\
11 / 20 / 91 \\
10 / 14 / 92\end{array}$ & $\begin{array}{l}0001 \\
0001 \\
0001 \\
0001 \\
0001 \\
0001 \\
0001 \\
0001 \\
0001 \\
0001 \\
0001 \\
0001 \\
0001 \\
0001 \\
0001 \\
0001 \\
0001 \\
0001 \\
0001 \\
0001 \\
0001 \\
0001 \\
0001 \\
0001\end{array}$ & $\begin{array}{l}\text { NA } \\
\text { NA } \\
\text { NA } \\
\text { NA } \\
\text { NA } \\
\text { NA } \\
\text { NA } \\
\text { NA } \\
\text { NA } \\
\text { NA } \\
\text { NA } \\
\text { NA } \\
\text { NA } \\
\text { NA } \\
\text { NA } \\
\text { NA } \\
\text { NA } \\
\text { NA } \\
\text { NA } \\
\text { NA } \\
\text { NA } \\
\text { NA } \\
\text { NA } \\
\text { NA }\end{array}$ & $\begin{array}{l}U \\
U \\
U \\
U \\
U \\
U \\
U \\
U \\
U \\
U \\
U \\
U \\
U \\
U \\
U \\
U \\
U \\
U \\
U \\
U \\
U \\
U \\
U \\
U\end{array}$ & MG/L & $\begin{array}{l}< \\
< \\
< \\
< \\
< \\
< \\
< \\
< \\
< \\
< \\
< \\
<\end{array}$ & $\begin{array}{l}1 . \\
1.0 \\
1.0 \\
0.3 \\
1.0 \\
1.0 \\
2.4 \\
1 . \\
1.0 \\
1.0 \\
0.4 \\
1.0 \\
2.9 \\
1.2 \\
1.0 \\
7.9 \\
1.9 \\
1.9 \\
1.0 \\
1.0 \\
2.5 \\
4.2 \\
1.0 \\
1.7\end{array}$ & $\begin{array}{l}L \\
J \\
J \\
G L \\
L \\
L \\
L \\
J L \\
J L \\
L \\
L \\
L \\
L \\
G L \\
L \\
L \\
J L \\
L \\
L \\
L \\
L \\
L\end{array}$ & 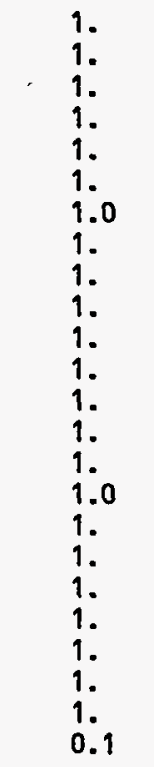 & $\begin{array}{l}- \\
- \\
- \\
- \\
- \\
- \\
- \\
- \\
- \\
- \\
- \\
- \\
- \\
- \\
- \\
- \\
- \\
- \\
-\end{array}$ \\
\hline NITRATE (TOTAL) & $\begin{array}{l}0668 \\
0669\end{array}$ & $\left|\begin{array}{l}02 / 18 / 94 \\
02 / 20 / 94\end{array}\right|$ & $\begin{array}{l}\text { No01 } \\
\text { N001 }\end{array}$ & $\begin{array}{l}\text { NA } \\
\text { NA }\end{array}$ & $\begin{array}{l}U \\
U\end{array}$ & MG/L & $\mid<$ & $\begin{array}{l}1 \\
1\end{array}$ & $L$ & $\begin{array}{l}1 \\
1\end{array}$ & 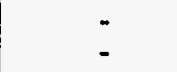 \\
\hline NITRITE AND NITRATE & $\begin{array}{l}0668 \\
0668 \\
0669 \\
0669 \\
0669 \\
0669 \\
0670 \\
0670\end{array}$ & $\begin{array}{l}02 / 19 / 88 \\
12 / 15 / 90 \\
02 / 19 / 88 \\
12 / 15 / 90 \\
03 / 31 / 91 \\
08 / 24 / 91 \\
02 / 19 / 88 \\
12 / 15 / 90\end{array}$ & $\begin{array}{l}0001 \\
0001 \\
0001 \\
0001 \\
0001 \\
0001 \\
0001 \\
0001\end{array}$ & $\begin{array}{l}\text { NA } \\
\text { NA } \\
\text { NA } \\
\text { NA } \\
\text { NA } \\
\text { NA } \\
\text { NA } \\
\text { NA }\end{array}$ & $\begin{array}{l}U \\
U \\
U \\
U \\
U \\
U \\
U \\
U\end{array}$ & MG/L & $\mid \begin{array}{l}< \\
< \\
<\end{array}$ & $\begin{array}{l}0.3 \\
1 . \\
0.4 \\
1 . \\
0.68 \\
0.27 \\
0.1 \\
1 .\end{array}$ & $\begin{array}{l}J \\
J L \\
L \\
L \\
L \\
J L \\
L\end{array}$ & $\begin{array}{l}1 . \\
1 . \\
1 . \\
1 . \\
0.05 \\
0.05 \\
1 . \\
1 .\end{array}$ & $\begin{array}{l}- \\
- \\
- \\
- \\
- \\
-\end{array}$ \\
\hline
\end{tabular}

FORMATION OF CGMPLETION CODE:

NA - NAVAJO SANDSTONE

PARAMETER VALUE INDICATOR (PVI): < - LESS THAN DETECTION LIMIT

OTHER PARAMETER VALUE FLAGS:

$G-$ PH $>9$, POSSIBLE GROUT CONTAMINATION

$J$ - ESTIMATED VALUE

L - LESS THAN THREE BORE VOLUMES REMOVED BEFORE SAMPLING
FLOW RELATIONSHIP CODE:

$U$ - UPGRADIENT

SAMPLE ID CODES:

0001 - FILTERED SAMPLE (.45 MICRONS)

NOO1 - UNFILTERED SAMPLE 
TABLE 3.37 BASELINE GROUND WATER QUALITY DATA BY PARAMETER FOR THE NAVAJO SANDSTONE, UC PROCESSING SITE, SLICK ROCK, COLORADO

SITE: SRKO1 SLICK ROCK (BOTH SITES)

02/02/86 TO 02/21/94

REPORT DATE: $09 / 30 / 94$

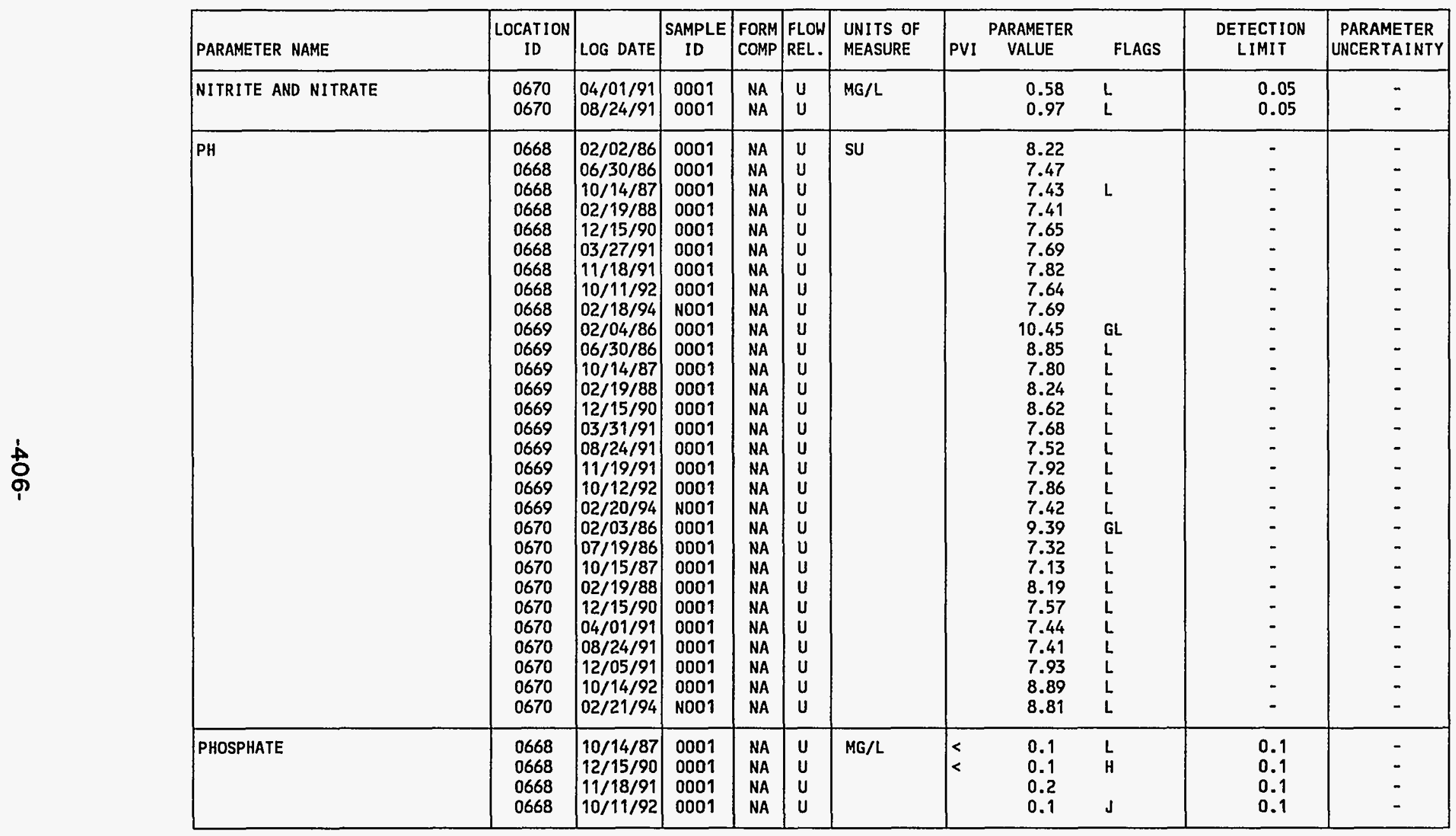

FORMATION OF COMPLETION CODE:

NA - NAVAJO SANDSTONE

PARAMETER VALUE INDICATOR (PVI): < - LESS THAN DETECTION LIMIT

OTHER PARAMETER VALUE FLAGS:

G - PH > 9, POSSIBLE GROUT CONTAMINATION

H - HOLD TIME EXPIRED, VALUE SUSPECT

$J$ - ESTIMATED VALUE

L - LESS THAN THREE BORE VOLUMES REMOVED BEFORE SAMPLING
FLOW RELAT IONSHIP CODE:

\section{SAMPLE ID CODES:}

0001 - FILTERED SAMPLE (.45 MICRONS)

N001 - UNFILTERED SAMPLE 
TABLE 3.37 BASELINE GROUND WATER QUALITY DATA BY PARAMETER FOR THE NAVAJO SANDSTONE, UC PROCESSING SITE, SLICK ROCK, COLORADO

SITE: SRKO1 SLICK ROCK (BOTH SITES)

02/02/86 TO 02/21/94

REPORT DATE: 09/30/94

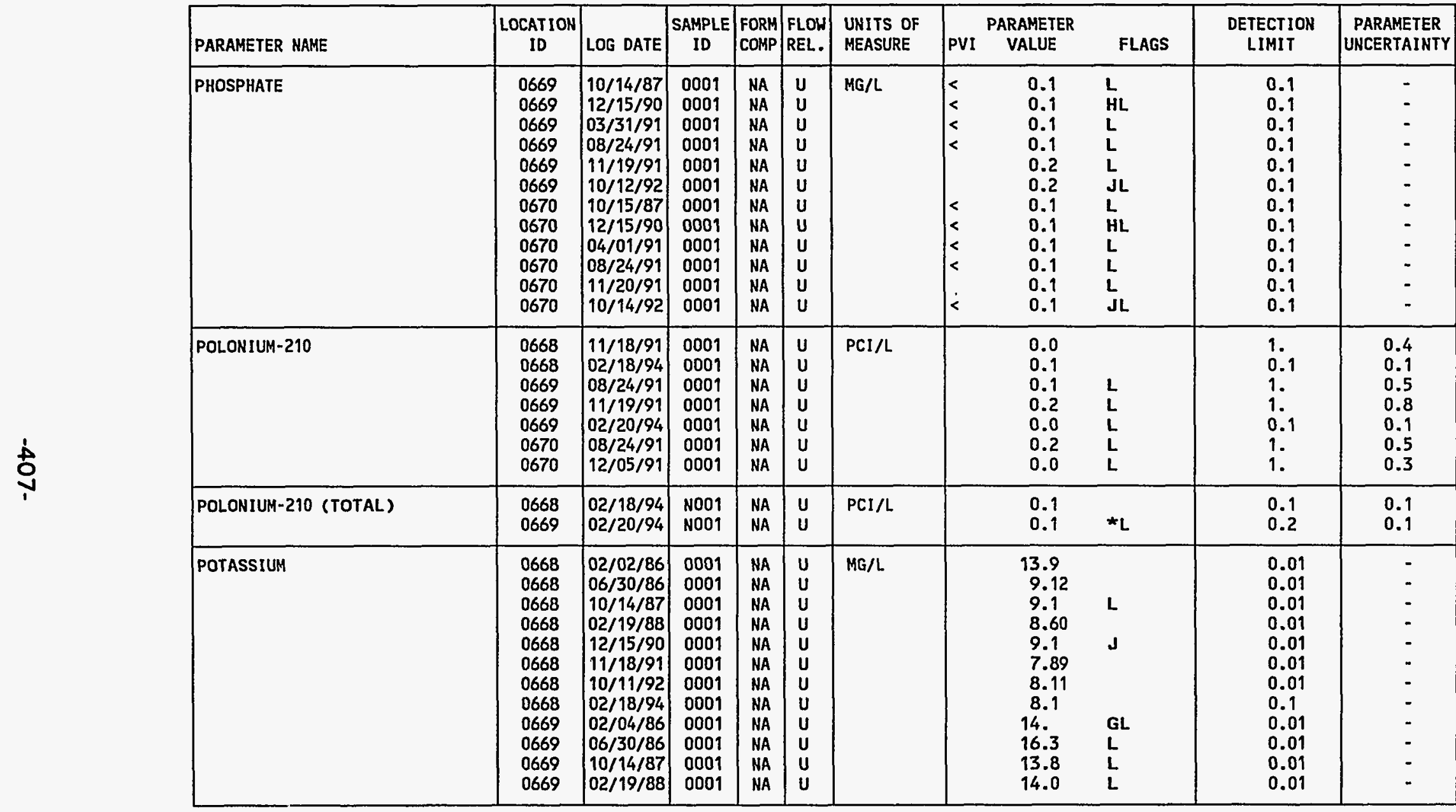

FORMATION OF COMPLETION CODE:

NA - NAVAJO SANDSTONE

PARAMETER VALUE INDICATOR (PVI): < - LESS THAN DETECTION LIMIT

OTHER PARAMETER VALUE FLAGS:

* - DUPLICATE ANALYSIS NOT WITHIN CONTROL LIMITS

G - PH > 9, POSSIBLE GROUT CONTAMINATION

H - HOLD TIME EXPIRED, VALUE SUSPECT

$J$ - ESTIMATED VALUE

L - LESS THAN THREE BORE VOLUMES REMOVED BEFORE SAMPLING
FLOW RELATIONSHIP CODE:

$U$ - UPGRADIENT

\section{SAMPLE ID CODES:}

0001 - FILTERED SAMPLE (.45 MICRONS)

N001 - UNFILTERED SAMPLE 
TABLE 3.37 BASELINE GROUND WATER QUALITY DATA BY PARAMETER FOR THE NAVAJO SANDSTONE, UC PROCESSING SITE, SLICK ROCK, COLORADO

SITE: SRKO1 SLICK ROCK (BOTH SITES)

02/02/86 TO 02/21/94

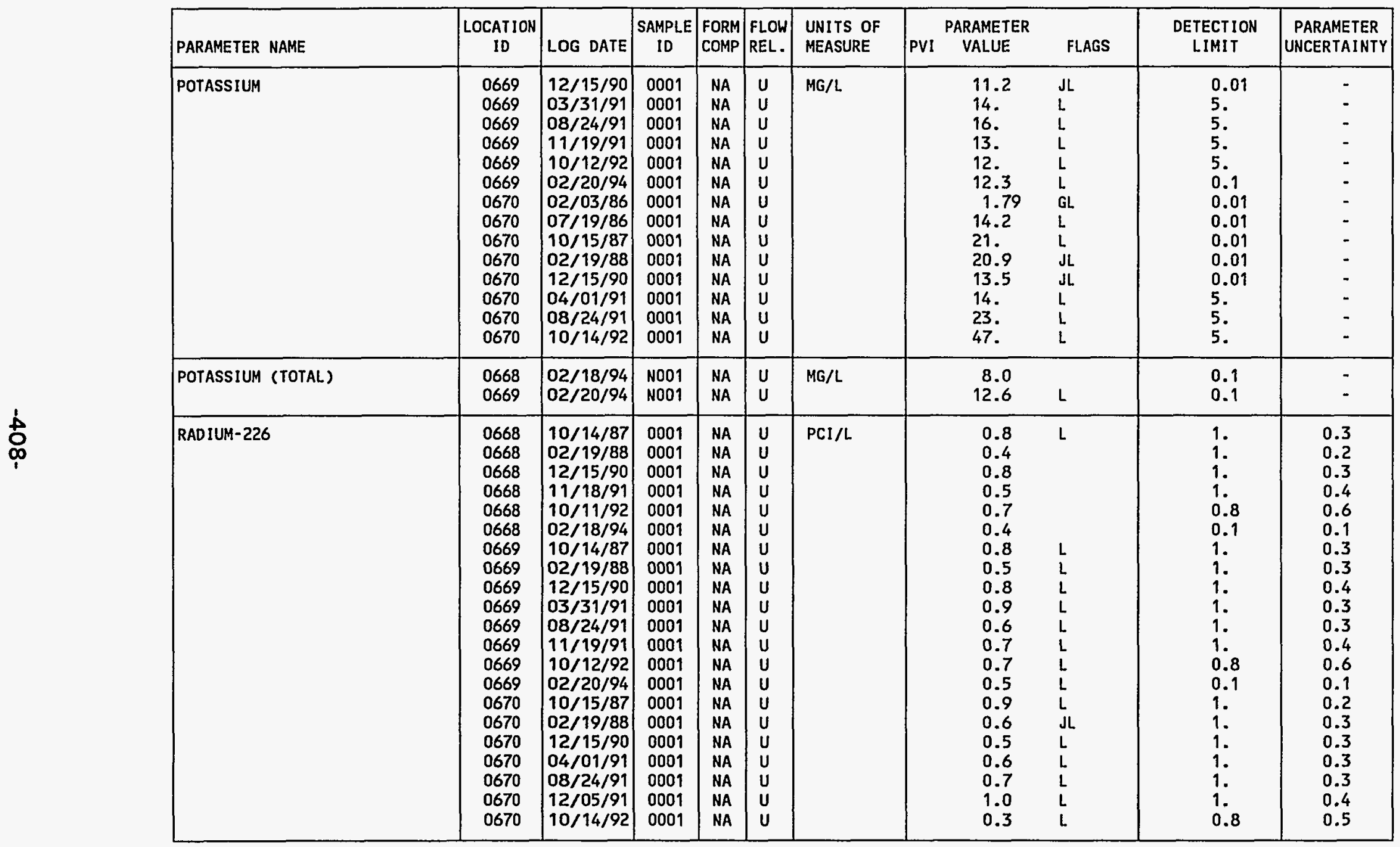

FORMATION OF COMPLETION CODE:

NA - NAVAJO SANDSTONE

PARAMETER VALUE INDICATOR (PVI): < - LESS THAN DETECTION LIMIT

OTHER PAPAMETER VALUE FLAGS:

$G$ - PH > 9, POSSIBLE GROUT CONTAMINATION

$J$ - ESTIMATED VALUE

L - LESS THAN THREE BORE VOLUMES REMOVED BEFORE SAMPLING
FLOW RELATIONSHIP CODE:

- UPGRADIENT

SAMPLE ID CODES

0001 - FILTERED SAMPLE (.45 MICRONS)

N001 - UNFILTERED SAMPLE 
TABLE 3.37 BASELINE GROUND HATER QUALITY DATA BY PARAMETER FOR THE NAVAJO SANDSTONE, UC PROCESSING SITE, SLICK ROCK, COLORADO

SITE: SRKD1 SLICK ROCK (BOTH SITES)

02/02/86 TO 02/21/94

REPORT DATE: $09 / 30 / 94$

\begin{tabular}{|c|c|c|c|c|c|c|c|c|c|c|c|}
\hline PARAMETER NAME & $\underset{\text { ID }}{\text { LOCATION }}$ & LOG DATE & $\underset{\text { ID }}{\text { SAMPLE }}$ & $\begin{array}{l}\text { FORM } \\
\text { COMP }\end{array}$ & $\begin{array}{l}\text { FLOW } \\
\text { REL. }\end{array}$ & $\begin{array}{l}\text { UNITS OF } \\
\text { MEASURE }\end{array}$ & PVI & $\begin{array}{l}\text { PARAMETEF } \\
\text { VALUE }\end{array}$ & FLAGS & $\begin{array}{l}\text { DETECTION } \\
\text { LIMIT }\end{array}$ & $\begin{array}{l}\text { PARAMETER } \\
\text { UNCERTAINTY }\end{array}$ \\
\hline RADIUM-226 (TOTAL) & $\begin{array}{l}0668 \\
0669\end{array}$ & $\begin{array}{l}02 / 18 / 94 \\
02 / 20 / 94\end{array}$ & $\begin{array}{l}\text { N001 } \\
\text { N001 }\end{array}$ & $\begin{array}{l}\text { NA } \\
\text { NA }\end{array}$ & $\begin{array}{l}\mathrm{U} \\
\mathrm{U}\end{array}$ & $\mathrm{PCI} / \mathrm{L}$ & & $\begin{array}{l}0.7 \\
1.3\end{array}$ & $\mathbf{L}$ & $\begin{array}{l}0.1 \\
0.1\end{array}$ & $\begin{array}{l}0.2 \\
0.2\end{array}$ \\
\hline RADIUM-226 + RADIUM-228 & $\begin{array}{l}0668 \\
0668 \\
0668 \\
0668 \\
0668 \\
0669 \\
0669 \\
0669 \\
0669 \\
0669 \\
0669 \\
0669 \\
0670 \\
0670 \\
0670 \\
0670 \\
0670 \\
0670\end{array}$ & $\begin{array}{l}10 / 14 / 87 \\
12 / 15 / 90 \\
11 / 18 / 91 \\
10 / 11 / 92 \\
02 / 18 / 94 \\
10 / 14 / 87 \\
12 / 15 / 90 \\
03 / 31 / 91 \\
08 / 24 / 91 \\
11 / 19 / 91 \\
10 / 12 / 92 \\
02 / 20 / 94 \\
10 / 15 / 87 \\
12 / 15 / 90 \\
04 / 01 / 91 \\
08 / 24 / 91 \\
12 / 05 / 91 \\
10 / 14 / 92\end{array}$ & $\begin{array}{l}0001 \\
0001 \\
0001 \\
0001 \\
0001 \\
0001 \\
0001 \\
0001 \\
0001 \\
0001 \\
0001 \\
0001 \\
0001 \\
0001 \\
0001 \\
0001 \\
0001 \\
0001\end{array}$ & $\begin{array}{l}\text { NA } \\
\text { NA } \\
\text { NA } \\
\text { NA } \\
\text { NA } \\
\text { NA } \\
\text { NA } \\
\text { NA } \\
\text { NA } \\
\text { NA } \\
\text { NA } \\
\text { NA } \\
\text { NA } \\
\text { NA } \\
\text { NA } \\
\text { NA } \\
\text { NA } \\
\text { NA }\end{array}$ & $\begin{array}{l}U \\
U \\
U \\
U \\
U \\
U \\
U \\
U \\
U \\
U \\
U \\
U \\
U \\
U \\
U \\
U \\
U \\
U\end{array}$ & $\mathrm{PCl} / \mathrm{L}$ & & $\begin{array}{l}1.40 \\
1.90 \\
0.50 \\
1.20 \\
1.90 \\
0.90 \\
2.40 \\
8.30 \\
0.60 \\
0.70 \\
1.10 \\
5.70 \\
1.70 \\
2.20 \\
4.10 \\
3.10 \\
2.80 \\
1.40\end{array}$ & & $\begin{array}{l}- \\
- \\
- \\
- \\
- \\
- \\
- \\
- \\
- \\
- \\
- \\
- \\
-\end{array}$ & $\begin{array}{l}- \\
- \\
- \\
- \\
- \\
- \\
= \\
- \\
- \\
- \\
- \\
- \\
- \\
-\end{array}$ \\
\hline RADIUM-226 + RADIUM-228 TOTAL & $\begin{array}{l}0668 \\
0669\end{array}$ & $\begin{array}{l}02 / 18 / 94 \\
02 / 20 / 94\end{array}$ & $\begin{array}{l}\text { N001 } \\
\text { N001 }\end{array}$ & $\begin{array}{l}\text { NA } \\
\text { NA }\end{array}$ & $\begin{array}{l}\mathbf{U} \\
\mathbf{U}\end{array}$ & $\mathrm{PCI} / \mathrm{L}$ & & $\begin{array}{l}0.70 \\
4.40\end{array}$ & & - & $\overline{-}$ \\
\hline RADIUM-228 & $\begin{array}{l}0668 \\
0668 \\
0668 \\
0668 \\
0668 \\
0669 \\
0669 \\
0669 \\
0669 \\
0669 \\
0669 \\
0669 \\
0670\end{array}$ & $\begin{array}{l}10 / 14 / 87 \\
12 / 15 / 90 \\
11 / 18 / 91 \\
10 / 11 / 92 \\
02 / 18 / 94 \\
10 / 14 / 87 \\
12 / 15 / 90 \\
03 / 31 / 91 \\
08 / 24 / 91 \\
11 / 19 / 91 \\
10 / 12 / 92 \\
02 / 20 / 94 \\
10 / 15 / 87\end{array}$ & $\begin{array}{l}0001 \\
0001 \\
0001 \\
0001 \\
0001 \\
0001 \\
0001 \\
0001 \\
0001 \\
0001 \\
0001 \\
0001 \\
0001\end{array}$ & $\begin{array}{l}\text { NA } \\
\text { NA } \\
\text { NA } \\
\text { NA } \\
\text { NA } \\
\text { NA } \\
\text { NA } \\
\text { NA } \\
\text { NA } \\
\text { NA } \\
\text { NA } \\
\text { NA } \\
\text { NA }\end{array}$ & $\begin{array}{l}\mathbf{U} \\
\mathbf{U} \\
\mathbf{U} \\
\mathbf{U} \\
\mathbf{U} \\
\mathbf{U} \\
\mathbf{U} \\
\mathbf{U} \\
\mathbf{U} \\
\mathbf{U} \\
\mathbf{U} \\
\mathbf{U} \\
\mathbf{U}\end{array}$ & $\mathrm{PCI} / \mathrm{L}$ & & $\begin{array}{l}0.6 \\
1.1 \\
0.0 \\
0.5 \\
1.5 \\
0.1 \\
1.6 \\
7.4 \\
0.0 \\
0.0 \\
0.4 \\
5.2 \\
0.8\end{array}$ & $\begin{array}{l}L \\
N \\
N \\
L \\
L \\
J L \\
L \\
L \\
L \\
J L N \\
L\end{array}$ & $\begin{array}{l}1 . \\
1 . \\
1 . \\
2.4 \\
3.0 \\
1 . \\
1 . \\
1 . \\
1 . \\
1 . \\
2.7 \\
2.3 \\
1 .\end{array}$ & $\begin{array}{l}0.8 \\
0.8 \\
1.0 \\
1.5 \\
1.2 \\
0.9 \\
0.9 \\
1.5 \\
2.0 \\
1.1 \\
1.6 \\
1.5 \\
1.2\end{array}$ \\
\hline
\end{tabular}

FORMATION OF COMPLETION CODE:

NA - NAVAJO SANDSTONE

PARAMETER VALUE INDICATOR (PVI): < - LESS THAN DETECTION LIMIT

\section{OTHER PARAMETER VALUE FLAGS:}

$J$ - ESTIMATED VALUE

L - LESS THAN THREE BORE VOLUMES REMOVED BEFORE SAMPLING

N - SPIKE SAMPLE RECOVERY NOT WITHIN CONTROL LIMITS
FLOW RELATIONSHIP CODE:

U - UPGRADIENT

SAMPLE ID CODES

0001 - FILTERED SAMPLE (.45 MICRONS)

N001 - UNFILTERED SAMPLE 
TABLE 3.37 BASELINE GROUND HATER QUALITY DATA BY PARAMETER FOR THE NAVAJO SANDSTONE, UC PROCESSING SITE, SLICK ROCK, COLORADO

SITE: SRKO1 SLICK ROCK (BOTH SITES)

REPORT DATE $02 / 21 / 94$

\begin{tabular}{|c|c|c|c|c|c|c|c|c|c|c|c|}
\hline PARAMETER NAME & $\begin{array}{c}\text { LOCATION } \\
\text { ID }\end{array}$ & LOG DATE & $\underset{\text { ID }}{\text { SAMPLE }}$ & $\begin{array}{l}\text { FORM } \\
\text { COMP }\end{array}$ & $\begin{array}{l}\text { FLOW } \\
\text { REL. }\end{array}$ & $\begin{array}{l}\text { UNITS OF } \\
\text { MEASURE }\end{array}$ & PVI & $\begin{array}{l}\text { PARAMETER } \\
\text { VALLUE }\end{array}$ & FLAGS & $\begin{array}{l}\text { DETECTION } \\
\text { LIMIT }\end{array}$ & $\begin{array}{l}\text { PARAMETER } \\
\text { UNCERTAINTY }\end{array}$ \\
\hline RADIUM-228 & $\begin{array}{l}0670 \\
0670 \\
0670 \\
0670 \\
0670\end{array}$ & $\begin{array}{l}12 / 15 / 90 \\
04 / 01 / 91 \\
08 / 24 / 91 \\
12 / 05 / 91 \\
10 / 14 / 92\end{array}$ & $\begin{array}{l}0001 \\
0001 \\
0001 \\
0001 \\
0001\end{array}$ & $\begin{array}{l}\text { NA } \\
\text { NA } \\
\text { NA } \\
\text { NA } \\
\text { NA }\end{array}$ & $\begin{array}{l}u \\
u \\
u \\
u \\
u\end{array}$ & $\mathrm{PCI} / \mathrm{L}$ & & $\begin{array}{l}1.7 \\
3.5 \\
2.4 \\
1.8 \\
1.1\end{array}$ & $\begin{array}{l}L \\
L \\
L \\
L \\
L N\end{array}$ & $\begin{array}{l}1 . \\
1 . \\
1 . \\
1 . \\
2.6\end{array}$ & $\begin{array}{l}0.9 \\
1.3 \\
2.2 \\
1.0 \\
1.6\end{array}$ \\
\hline RADIUM-228 (TOTAL) & $\begin{array}{l}0668 \\
0669\end{array}$ & $\begin{array}{l}02 / 18 / 94 \\
02 / 20 / 94\end{array}$ & $\begin{array}{l}\text { N001 } \\
\text { N001 }\end{array}$ & $\begin{array}{l}\text { NA } \\
\text { NA }\end{array}$ & $\begin{array}{l}u \\
U\end{array}$ & $\mathrm{PCI} / \mathrm{L}$ & & $\begin{array}{l}0.0 \\
3.1\end{array}$ & $\begin{array}{l}N \\
L\end{array}$ & $\begin{array}{l}2.6 \\
2.8\end{array}$ & $\begin{array}{l}1.0 \\
1.6\end{array}$ \\
\hline REDOX POTENTIAL & $\begin{array}{l}0668 \\
0668 \\
0668 \\
0669 \\
0669 \\
0669 \\
0670 \\
0670 \\
0670\end{array}$ & $\begin{array}{l}12 / 15 / 90 \\
10 / 11 / 92 \\
02 / 18 / 94 \\
12 / 15 / 90 \\
10 / 12 / 92 \\
02 / 20 / 94 \\
12 / 15 / 90 \\
10 / 14 / 92 \\
02 / 21 / 94\end{array}$ & $\begin{array}{l}0001 \\
0001 \\
\text { N001 } \\
0001 \\
0001 \\
\text { N001 } \\
0001 \\
0001 \\
\text { N001 }\end{array}$ & $\begin{array}{l}\text { NA } \\
\text { NA } \\
\text { NA } \\
\text { NA } \\
\text { NA } \\
\text { NA } \\
\text { NA } \\
\text { NA } \\
\text { NA }\end{array}$ & $\begin{array}{l}U \\
U \\
U \\
U \\
U \\
U \\
U \\
U \\
U\end{array}$ & mVOLTS & & $\begin{array}{l}362.8 \\
427.8 \\
74 \\
285.5 \\
438.5 \\
395 \\
189 . \\
437.9 \\
226\end{array}$ & $\begin{array}{l}\mathrm{L} \\
\mathrm{L} \\
\mathrm{L} \\
\mathrm{L} \\
\mathrm{L} \\
\mathrm{L}\end{array}$ & $\begin{array}{l}- \\
- \\
- \\
- \\
- \\
-\end{array}$ & $\begin{array}{l}- \\
: \\
- \\
- \\
- \\
-\end{array}$ \\
\hline SELENIUM & $\begin{array}{l}0668 \\
0668 \\
0668 \\
0668 \\
0668 \\
0668 \\
0668 \\
0669 \\
0669 \\
0669 \\
0669 \\
0669 \\
0669 \\
0669 \\
0669 \\
0669\end{array}$ & $\begin{array}{l}02 / 02 / 86 \\
06 / 30 / 86 \\
10 / 14 / 87 \\
12 / 15 / 90 \\
11 / 18 / 91 \\
10 / 11 / 92 \\
02 / 18 / 94 \\
02 / 04 / 86 \\
06 / 30 / 86 \\
10 / 14 / 87 \\
12 / 15 / 90 \\
03 / 31 / 91 \\
08 / 24 / 91 \\
11 / 19 / 91 \\
10 / 12 / 92 \\
02 / 20 / 94\end{array}$ & $\begin{array}{l}0001 \\
0001 \\
0001 \\
0001 \\
0001 \\
0001 \\
0001 \\
0001 \\
0001 \\
0001 \\
0001 \\
0001 \\
0001 \\
0001 \\
0001 \\
0001\end{array}$ & $\begin{array}{l}\text { NA } \\
\text { NA } \\
\text { NA } \\
\text { NA } \\
\text { NA } \\
\text { NA } \\
\text { NA } \\
\text { NA } \\
\text { NA } \\
\text { NA } \\
\text { NA } \\
\text { NA } \\
\text { NA } \\
\text { NA } \\
\text { NA } \\
\text { NA }\end{array}$ & $\begin{array}{l}U \\
U \\
U \\
U \\
U \\
U \\
U \\
U \\
U \\
U \\
U \\
U \\
U \\
U \\
U \\
U\end{array}$ & $M G / L$ & $\begin{array}{l}< \\
< \\
< \\
< \\
< \\
< \\
< \\
< \\
< \\
< \\
< \\
< \\
< \\
< \\
<\end{array}$ & $\begin{array}{l}0.005 \\
0.005 \\
0.005 \\
0.005 \\
0.005 \\
0.005 \\
0.005 \\
0.005 \\
0.005 \\
0.005 \\
0.005 \\
0.03 \\
0.005 \\
0.005 \\
0.006 \\
0.005\end{array}$ & $\begin{array}{l}L \\
W \\
J W \\
G L \\
L \\
L \\
L \\
\text { IJL } \\
\text { LW } \\
\text { LW } \\
L \\
L\end{array}$ & $\begin{array}{l}0.005 \\
0.005 \\
0.005 \\
0.005 \\
0.005 \\
0.005 \\
0.005 \\
0.005 \\
0.005 \\
0.005 \\
0.005 \\
0.03 \\
0.005 \\
0.005 \\
0.005 \\
0.005\end{array}$ & $\begin{array}{l}- \\
- \\
- \\
- \\
- \\
- \\
- \\
- \\
- \\
- \\
- \\
- \\
-\end{array}$ \\
\hline
\end{tabular}

FORMATION OF COMPLETION CODE:

NA - NAVAJO SANDSTONE

PARAMETER VALUE INDICATOR (PVI): < - LESS THAN DETECTION LIMIT

OTHER PARAMETER VALUE FLAGS:

G - PH $>$ 9, POSSIBLE GROUT CONTAMINATION

I - INCREASED DETECTION LIMIT DUE TO REQUIRED DILUTION

$J$ - ESTIMATED VALUE

L - LESS THAN THREE BORE VOLUMES REMOVED BEFORE SAMPLING

N - SPIKE SAMPLE RECOVERY NOT WITHIN CONTROL LIMITS

W - POST-DIGEST SPIKE OUT OF CNTR LIM WHILE SAMP ABS < 50\% SPIKE
FLOW RELATIONSHIP CODE:

$U$ - UPGRADIENT

SAMPLE ID CODES:

D001 - FILTERED SAMPLE (.45 MICRONS)

N001 - UNFILTERED SAMPLE 
TABLE 3.37 BASELINE GROUND WATER QUALITY DATA BY PARAMETER FOR THE NAVAJO SANDSTONE, UC PROCESSING SITE, SLICK ROCK, COLORADO

SITE: SRKO1 SLICK ROCK (BOTH SITES)

D2/02/86 TO 02/21/94

REPORT DATE: $09 / 30 / 94$

\begin{tabular}{|c|c|c|c|c|c|c|c|c|c|c|c|}
\hline PARAMETER NAME & $\begin{array}{c}\text { LOCATION } \\
\text { ID }\end{array}$ & LOG DATE & $\underset{\text { ID }}{\text { SAMPLE }}$ & $\begin{array}{l}\text { FORM } \\
\text { COMP }\end{array}$ & $\begin{array}{l}\text { FLOW } \\
\text { REL. }\end{array}$ & $\begin{array}{l}\text { UNITS OF } \\
\text { MEASURE }\end{array}$ & PVI & $\begin{array}{l}\text { ARAMETER } \\
\text { VALUE }\end{array}$ & FLAGS & $\begin{array}{l}\text { DETECTION } \\
\text { LIMIT }\end{array}$ & $\begin{array}{l}\text { PARAMETER } \\
\text { UNCERTAINTY }\end{array}$ \\
\hline SELENIUM & $\begin{array}{l}0670 \\
0670 \\
0670 \\
0670 \\
0670 \\
0670 \\
0670\end{array}$ & $\begin{array}{l}02 / 03 / 86 \\
07 / 19 / 86 \\
10 / 15 / 87 \\
12 / 15 / 90 \\
04 / 01 / 91 \\
08 / 24 / 91 \\
10 / 14 / 92\end{array}$ & $\begin{array}{l}0001 \\
0001 \\
0001 \\
0001 \\
0001 \\
0001 \\
0001\end{array}$ & $\begin{array}{l}\text { NA } \\
\text { NA } \\
\text { NA } \\
\text { NA } \\
\text { NA } \\
\text { NA } \\
\text { NA }\end{array}$ & $\begin{array}{l}U \\
U \\
U \\
U \\
U \\
U \\
U\end{array}$ & $\mathrm{MG} / \mathrm{L}$ & $\begin{array}{l}< \\
< \\
< \\
< \\
< \\
< \\
< \\
<\end{array}$ & $\begin{array}{l}0.005 \\
0.005 \\
0.005 \\
0.005 \\
0.03 \\
0.005 \\
0.005\end{array}$ & $\begin{array}{l}\text { GL } \\
L \\
L \\
L \\
\text { IJL } \\
\text { LW } \\
L\end{array}$ & $\begin{array}{r}0.005 \\
0.005 \\
0.005 \\
0.005 \\
-\quad 0.03 \\
0.005 \\
0.005\end{array}$ & $\begin{array}{l}: \\
: \\
: \\
-\end{array}$ \\
\hline SELENIUM (TOTAL) & $\begin{array}{l}0668 \\
0669\end{array}$ & $\begin{array}{l}02 / 18 / 94 \\
02 / 20 / 94\end{array}$ & $\begin{array}{l}\text { N001 } \\
\text { N001 }\end{array}$ & $\begin{array}{l}\text { NA } \\
\text { NA }\end{array}$ & $\begin{array}{l}U \\
U\end{array}$ & $M G / L$ & k & $\begin{array}{l}0.005 \\
0.005\end{array}$ & $\begin{array}{l}\mathrm{JW} \\
\mathrm{L}\end{array}$ & $\begin{array}{l}0.005 \\
0.005\end{array}$ & - \\
\hline SILICA - SIOZ & $\begin{array}{l}0668 \\
0668 \\
0668 \\
0668 \\
0668 \\
0668 \\
0669 \\
0669 \\
0669 \\
0669 \\
0669 \\
0669 \\
0669 \\
0669 \\
0670 \\
0670 \\
0670 \\
0670 \\
0670 \\
0670\end{array}$ & $\begin{array}{l}10 / 14 / 87 \\
02 / 19 / 88 \\
12 / 15 / 90 \\
11 / 18 / 91 \\
10 / 11 / 92 \\
02 / 18 / 94 \\
10 / 14 / 87 \\
02 / 19 / 88 \\
12 / 15 / 90 \\
03 / 31 / 91 \\
08 / 24 / 91 \\
11 / 19 / 91 \\
10 / 12 / 92 \\
02 / 20 / 94 \\
10 / 15 / 87 \\
02 / 19 / 88 \\
12 / 15 / 90 \\
04 / 01 / 91 \\
08 / 24 / 91 \\
10 / 14 / 92\end{array}$ & $\begin{array}{l}0001 \\
0001 \\
0001 \\
0001 \\
0001 \\
0001 \\
0001 \\
0001 \\
0001 \\
0001 \\
0001 \\
0001 \\
0001 \\
0001 \\
0001 \\
0001 \\
0001 \\
0001 \\
0001 \\
0001\end{array}$ & $\begin{array}{l}\text { NA } \\
\text { NA } \\
\text { NA } \\
\text { NA } \\
\text { NA } \\
\text { NA } \\
\text { NA } \\
\text { NA } \\
\text { NA } \\
\text { NA } \\
\text { NA } \\
\text { NA } \\
\text { NA } \\
\text { NA } \\
\text { NA } \\
\text { NA } \\
\text { NA } \\
\text { NA } \\
\text { NA } \\
\text { NA }\end{array}$ & $\begin{array}{l}U \\
U \\
U \\
U \\
U \\
U \\
U \\
U \\
U \\
U \\
U \\
U \\
U \\
U \\
U \\
U \\
U \\
U \\
U \\
U\end{array}$ & $M G / L$ & & $\begin{array}{c}7.8 \\
6.7 \\
8 . \\
7.9 \\
11.8 \\
8.1 \\
11.8 \\
10.2 \\
13 . \\
11.0 \\
12.2 \\
12.1 \\
14.8 \\
11.5 \\
8.9 \\
8.4 \\
10 . \\
8.2 \\
9.6 \\
5.9\end{array}$ & $\begin{array}{l}L \\
\\
L \\
L \\
L \\
L \\
L \\
L \\
L \\
L \\
L \\
J L \\
L \\
L \\
L\end{array}$ & $\begin{array}{l}2 . \\
2 . \\
2 . \\
0.1 \\
0.1 \\
0.1 \\
2 . \\
2 . \\
2 . \\
0.1 \\
0.1 \\
0.1 \\
0.1 \\
0.1 \\
2 . \\
2 . \\
2 . \\
0.1 \\
0.1 \\
0.1\end{array}$ & $\begin{array}{l}- \\
- \\
- \\
= \\
- \\
- \\
- \\
- \\
- \\
- \\
- \\
- \\
- \\
- \\
-\end{array}$ \\
\hline SILICA - SIO2 (TOTAL) & $\begin{array}{l}0668 \\
0669\end{array}$ & $\mid \begin{array}{l}02 / 18 / 94 \\
02 / 20 / 94\end{array}$ & $\begin{array}{l}\text { N001 } \\
\text { N001 }\end{array}$ & $\begin{array}{l}\text { NA } \\
\text { NA }\end{array}$ & $u$ & $M G / L$ & & $\begin{array}{r}17.2 \\
0.3\end{array}$ & $L$ & $\begin{array}{l}0.1 \\
0.1\end{array}$ & - \\
\hline SILVER & $\begin{array}{l}0668 \\
0668 \\
0668\end{array}$ & $\begin{array}{l}06 / 30 / 86 \\
10 / 14 / 87 \\
12 / 15 / 90\end{array} \mid$ & $\begin{array}{l}0001 \\
0001 \\
0001\end{array}$ & $\begin{array}{l}\text { NA } \\
\text { NA } \\
\text { NA }\end{array}$ & $\begin{array}{l}U \\
U \\
U\end{array}$ & $M G / L$ & $<$ & $\begin{array}{l}0.3 \\
0.01 \\
0.01\end{array}$ & $\mathbf{L}$ & $\begin{array}{l}0.1 \\
0.01 \\
0.01\end{array}$ & : \\
\hline
\end{tabular}

FORMATION OF COMPLETION CODE

NA - NAVAJO SANDSTONE

PARAMETER VALUE IHDICATOR (PVI): < - LESS THAN DETECTION LIMIT

OTHER PARAMETER VALUE FLAGS:

G - PH > 9, POSSIBLE GROUT CONTAMINATION

1 - INCREASED DETECTION LIMIT DUE TO REQUIRED DILUTION

$J$ - ESTIMATED VALUE

L - LESS THAN THREE BORE VOLUMES REMOVED BEFORE SAMPLING

$H$ - POST-DIGEST SPIKE OUT OF CNTR LIM WHILE SAMP ABS < $50 \%$ SPIKE
FLOW RELATIONSHIP CODE:

U - UPGRADIENT

SAMPLE ID CODES:

0001 - FILTERED SAMPLE (.45 MICRONS)

N001 - UNFILTERED SAMPLE 
TABLE 3.37 BASELINE GROUND HATER QUALITY DATA BY PARAMETER FOR THE NAVAJO SANDSTONE, UC PROCESSING SITE, SLICK ROCK, COLORADO

SITE: SRKOI SLICK ROCK (BOTH SITES)

02/02/86 TO 02/21/94

REPORT DATE : $09 / 30 / 94$

\begin{tabular}{|c|c|c|c|c|c|c|c|c|c|c|c|}
\hline PARAMETER NAME & $\begin{array}{c}\text { LOCATION } \\
\text { ID }\end{array}$ & LOG DATE & $\begin{array}{c}\text { SAMPLE } \\
\text { ID }\end{array}$ & $\begin{array}{l}\text { FORM } \\
\text { COMP }\end{array}$ & $\begin{array}{l}\text { FLOW } \\
\text { REL. }\end{array}$ & $\begin{array}{l}\text { UNITS OF } \\
\text { MEASURE }\end{array}$ & PVI & $\begin{array}{l}\text { ARAMETER } \\
\text { VALUE }\end{array}$ & FLAGS & $\begin{array}{l}\text { DETECT ION } \\
\text { LIMIT }\end{array}$ & $\begin{array}{l}\text { PARAMETER } \\
\text { UNCERTAINTY }\end{array}$ \\
\hline SILVER & $\begin{array}{l}0668 \\
0669 \\
0669 \\
0669 \\
0669 \\
0669 \\
0670 \\
0670 \\
0670 \\
0670\end{array}$ & $\begin{array}{l}11 / 18 / 91 \\
10 / 14 / 87 \\
12 / 15 / 90 \\
03 / 31 / 91 \\
08 / 24 / 91 \\
11 / 19 / 91 \\
10 / 15 / 87 \\
12 / 15 / 90 \\
04 / 01 / 91 \\
08 / 24 / 91\end{array}$ & $\begin{array}{l}0001 \\
0001 \\
0001 \\
0001 \\
0001 \\
0001 \\
0001 \\
0001 \\
0001 \\
0001\end{array}$ & $\begin{array}{l}\text { NA } \\
\text { NA } \\
\text { NA } \\
\text { NA } \\
\text { NA } \\
\text { NA } \\
\text { NA } \\
\text { NA } \\
\text { NA } \\
\text { NA }\end{array}$ & $\begin{array}{l}U \\
U \\
U \\
U \\
U \\
U \\
U \\
U \\
U \\
U\end{array}$ & $M G / L$ & $\begin{array}{l}< \\
< \\
< \\
< \\
< \\
< \\
< \\
< \\
< \\
<\end{array}$ & $\begin{array}{l}0.01 \\
0.01 \\
0.01 \\
0.01 \\
0.01 \\
0.01 \\
0.01 \\
0.01 \\
0.01 \\
0.01\end{array}$ & $\begin{array}{l}L \\
L \\
L \\
L \\
L \\
L \\
L \\
L \\
L\end{array}$ & $\begin{array}{l}0.01 \\
0.01 \\
0.01 \\
0.01 \\
0.01 \\
0.01 \\
0.01 \\
0.01 \\
0.01 \\
0.01\end{array}$ & $\begin{array}{l}- \\
- \\
- \\
- \\
- \\
- \\
- \\
-\end{array}$ \\
\hline SODIUM & $\begin{array}{l}0668 \\
0668 \\
0668 \\
0668 \\
0668 \\
0668 \\
0668 \\
0668 \\
0669 \\
0669 \\
0669 \\
0669 \\
0669 \\
0669 \\
0669 \\
0669 \\
0669 \\
0669 \\
0670 \\
0670 \\
0670 \\
0670 \\
0670 \\
0670 \\
0670 \\
0670\end{array}$ & $\begin{array}{l}02 / 02 / 86 \\
06 / 30 / 86 \\
10 / 14 / 87 \\
02 / 19 / 88 \\
12 / 15 / 90 \\
11 / 18 / 91 \\
10 / 11 / 92 \\
02 / 18 / 94 \\
02 / 04 / 86 \\
06 / 30 / 86 \\
10 / 14 / 87 \\
02 / 19 / 88 \\
12 / 15 / 90 \\
03 / 31 / 91 \\
08 / 24 / 91 \\
11 / 19 / 91 \\
10 / 12 / 92 \\
02 / 20 / 94 \\
02 / 03 / 86 \\
07 / 19 / 86 \\
10 / 15 / 87 \\
02 / 19 / 88 \\
12 / 15 / 90 \\
04 / 01 / 91 \\
08 / 24 / 91 \\
10 / 14 / 92\end{array}$ & $\begin{array}{l}0001 \\
0001 \\
0001 \\
0001 \\
0001 \\
0001 \\
0001 \\
0001 \\
0001 \\
0001 \\
0001 \\
0001 \\
0001 \\
0001 \\
0001 \\
0001 \\
0001 \\
0001 \\
0001 \\
0001 \\
0001 \\
0001 \\
0001 \\
0001 \\
0001 \\
0001\end{array}$ & $\begin{array}{l}\text { NA } \\
\text { NA } \\
\text { NA } \\
\text { NA } \\
\text { NA } \\
\text { NA } \\
\text { NA } \\
\text { NA } \\
\text { NA } \\
\text { NA } \\
\text { NA } \\
\text { NA } \\
\text { NA } \\
\text { NA } \\
\text { NA } \\
\text { NA } \\
\text { NA } \\
\text { NA } \\
\text { NA } \\
\text { NA } \\
\text { NA } \\
\text { NA } \\
\text { NA } \\
\text { NA } \\
\text { NA } \\
\text { NA }\end{array}$ & $\begin{array}{l}U \\
U \\
U \\
U \\
U \\
U \\
U \\
U \\
U \\
U \\
U \\
U \\
U \\
U \\
U \\
U \\
U \\
U \\
U \\
U \\
U \\
U \\
U \\
U \\
U \\
U\end{array}$ & $M G / L$ & & $\begin{array}{c}18.6 \\
11.1 \\
9.8 \\
10.4 \\
9.93 \\
10.0 \\
15 . \\
9 \\
20.5 \\
9.38 \\
16 . \\
15.1 \\
14.9 \\
15 . \\
17 . \\
16 . \\
17 . \\
14 \\
14 . \\
15.5 \\
13.6 \\
14.9 \\
12.2 \\
11 . \\
16 . \\
34 .\end{array}$ & $\begin{array}{l}L \\
\\
\\
G L \\
L \\
L \\
L \\
L \\
L \\
L \\
L \\
L \\
L \\
G L \\
L \\
L \\
J L \\
L \\
L \\
L \\
L\end{array}$ & $\begin{array}{l}0.002 \\
0.002 \\
0.002 \\
0.002 \\
0.002 \\
0.01 \\
1 . \\
1 \\
0.002 \\
0.002 \\
0.002 \\
0.002 \\
0.002 \\
5 . \\
1 . \\
1 . \\
1 . \\
1 \\
0.002 \\
0.002 \\
0.002 \\
0.002 \\
0.002 \\
5 . \\
1 . \\
1 .\end{array}$ & $\begin{array}{l}- \\
- \\
- \\
- \\
- \\
- \\
- \\
- \\
- \\
- \\
- \\
- \\
- \\
- \\
- \\
- \\
- \\
- \\
- \\
- \\
- \\
-\end{array}$ \\
\hline SODIUM (TOTAL) & 0668 & $02 / 18 / 94$ & N001 & NA & U & $M G / L$ & & 9 & & 1 & - \\
\hline
\end{tabular}

FORMATION OF COMPLETION CODE :

NA - NAVAJO SANDSTONE

PARAMETER VALUE INDICATOR (PVI): < - LESS THAN DETECTION LIMIT

OTHER PARAMETER VALUE FLAGS:

G - PH > 9, POSSIBLE GROUT CONTAMINATION

J - ESTIMATED VALUE

L - LESS THAN THREE BORE VOLUMES REMOVED BEFORE SAMPLING
FLOW RELATIONSHIP CODE:

SAMPLE ID CODES

0001 - FILTERED SAMPLE (.45 MICRONS)

NOD1 - UNFILTERED SAMPLE 
TABLE 3.37 BASELINE GROUND WATER QUALITY DATA BY PARAMETER FOR THE

NAVAJO SANDSTONE, UC PROCESSING SITE, SLICK ROCK, COLORADD

SITE: SRKOI SLICK ROCK (BOTH SITES)

02/02/86 TO 02/21/94

REPORT DATE: $09 / 30 / 94$

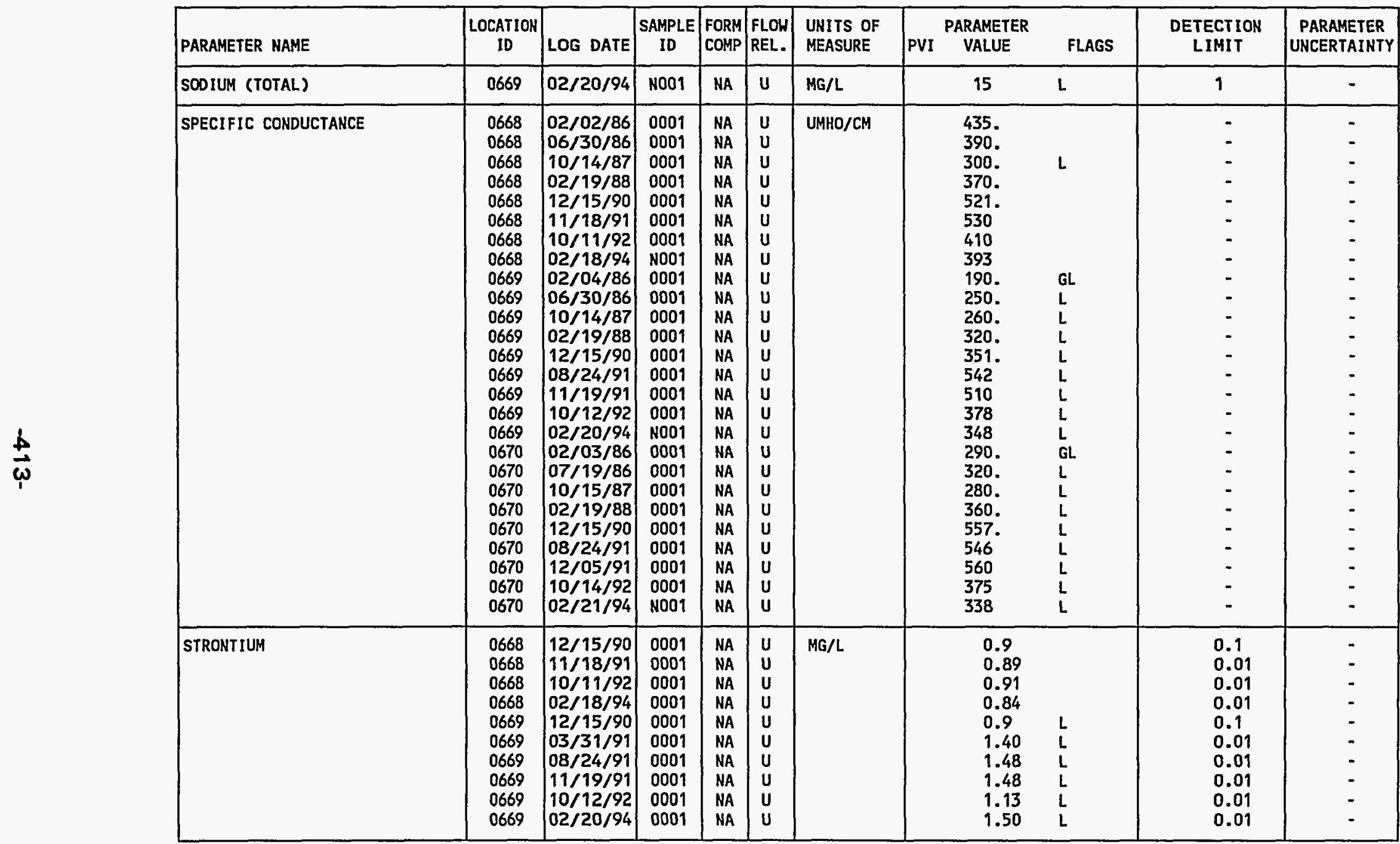

FORMATION OF COMPLETION CODE: NA - NAVAJO SANDSTONE

FLOW RELATIONSHIP CODE:

PARAMETER VALUE INDICATOR (PVI): < - LESS THAN DETECTION LIMI

0001 - FILTERED SAMPLE (.45 MICRONS)

OTHER PARAMETER VALUE FLAGS:

NOO1 - UNFILTERED SAMPLE

G - PH > 9, POSSIBLE GROUT CONTAMINATION

L - LESS THAN THREE BORE VOLUMES REMOVED BEFORE SAMPLING 
TABLE 3.37 BASELINE GROUND WATER QUALITY DATA BY PARAMETER FOR THE NAVAJO SANDSTONE, UC PROCESSING SITE, SLICK ROCK, COLORADO

SITE: SRKOI SLICK ROCK (BOTH SITES)

02/02/86 TO 02/21/94

REPORT DATE : 09/30/94

\begin{tabular}{|c|c|c|c|c|c|c|c|c|c|c|c|}
\hline PARAMETER NAME & $\begin{array}{c}\text { LOCATION } \\
\text { ID }\end{array}$ & LOG DATE & $\begin{array}{c}\text { SAMPLE } \\
\text { ID }\end{array}$ & $\begin{array}{l}\text { FORM } \\
\text { COMP }\end{array}$ & $\begin{array}{l}\text { FLOW } \\
\text { REL. }\end{array}$ & $\begin{array}{l}\text { UNITS OF } \\
\text { MEASURE }\end{array}$ & PVI & $\begin{array}{l}\text { ARAMETER } \\
\text { VALUE }\end{array}$ & FLAGS & $\begin{array}{l}\text { DETECTION } \\
\text { LIMIT }\end{array}$ & $\begin{array}{l}\text { PARAMETER } \\
\text { UNCERTAINTY }\end{array}$ \\
\hline STRONT IUM & $\begin{array}{l}0670 \\
0670 \\
0670 \\
0670\end{array}$ & $\left|\begin{array}{l}12 / 15 / 90 \\
04 / 01 / 91 \\
08 / 24 / 91 \\
10 / 14 / 92\end{array}\right|$ & $\begin{array}{l}0001 \\
0001 \\
0001 \\
0001\end{array}$ & $\begin{array}{l}\text { NA } \\
\text { NA } \\
\text { NA } \\
\text { NA }\end{array}$ & $\begin{array}{l}U \\
U \\
U \\
U\end{array}$ & $M G / L$ & & $\begin{array}{l}1.6 \\
1.54 \\
1.77 \\
0.66\end{array}$ & $\begin{array}{l}L \\
L \\
L \\
L\end{array}$ & $\begin{array}{l}0.1 \\
0.01 \\
0.01 \\
0.01\end{array}$ & $\begin{array}{l}: \\
:\end{array}$ \\
\hline STRONTIUM (TOTAL) & $\begin{array}{l}0668 \\
0669\end{array}$ & $\begin{array}{l}02 / 18 / 94 \\
02 / 20 / 94\end{array}$ & $\begin{array}{l}\text { N001 } \\
\text { N001 }\end{array}$ & $\begin{array}{l}\text { NA } \\
\text { NA }\end{array}$ & $\begin{array}{l}U \\
U\end{array}$ & $M G / L$ & & $\begin{array}{l}0.87 \\
2.74\end{array}$ & L & $\begin{array}{l}0.01 \\
0.01\end{array}$ & $\dot{-}$ \\
\hline SULFATE & $\begin{array}{l}0668 \\
0668 \\
0668 \\
0668 \\
0668 \\
0668 \\
0668 \\
0668 \\
0669 \\
0669 \\
0669 \\
0669 \\
0669 \\
0669 \\
0669 \\
0669 \\
0669 \\
0669 \\
0670 \\
0670 \\
0670 \\
0670 \\
0670 \\
0670 \\
0670 \\
0670 \\
0670\end{array}$ & $\begin{array}{l}02 / 02 / 86 \\
06 / 30 / 86 \\
10 / 14 / 87 \\
02 / 19 / 88 \\
12 / 15 / 90 \\
11 / 18 / 91 \\
10 / 11 / 92 \\
02 / 18 / 94 \\
02 / 04 / 86 \\
06 / 30 / 86 \\
10 / 14 / 87 \\
02 / 19 / 88 \\
12 / 15 / 90 \\
03 / 31 / 91 \\
08 / 24 / 91 \\
11 / 19 / 91 \\
10 / 12 / 92 \\
02 / 20 / 94 \\
02 / 03 / 86 \\
07 / 19 / 86 \\
10 / 15 / 87 \\
02 / 19 / 88 \\
12 / 15 / 90 \\
04 / 01 / 91 \\
08 / 24 / 91 \\
11 / 20 / 91 \\
10 / 14 / 92\end{array}$ & $\begin{array}{l}0001 \\
0001 \\
0001 \\
0001 \\
0001 \\
0001 \\
0001 \\
0001 \\
0001 \\
0001 \\
0001 \\
0001 \\
0001 \\
0001 \\
0001 \\
0001 \\
0001 \\
0001 \\
0001 \\
0001 \\
0001 \\
0001 \\
0001 \\
0001 \\
0001 \\
0001 \\
0001\end{array}$ & $\begin{array}{l}\text { NA } \\
\text { NA } \\
\text { NA } \\
\text { NA } \\
\text { NA } \\
\text { NA } \\
\text { NA } \\
\text { NA } \\
\text { NA } \\
\text { NA } \\
\text { NA } \\
\text { NA } \\
\text { NA } \\
\text { NA } \\
\text { NA } \\
\text { NA } \\
\text { NA } \\
\text { NA } \\
\text { NA } \\
\text { NA } \\
\text { NA } \\
\text { NA } \\
\text { NA } \\
\text { NA } \\
\text { NA } \\
\text { NA } \\
\text { NA }\end{array}$ & $\begin{array}{l}U \\
U \\
U \\
U \\
U \\
U \\
U \\
U \\
U \\
U \\
U \\
U \\
U \\
U \\
U \\
U \\
U \\
U \\
U \\
U \\
U \\
U \\
U \\
U \\
U \\
U \\
U\end{array}$ & $M G / L$ & & $\begin{array}{l}55 . \\
14.8 \\
11 . \\
13 . \\
11.9 \\
17 . \\
14 . \\
13 \\
34 . \\
19.3 \\
23 . \\
29 . \\
20.2 \\
24.4 \\
33 . \\
28 . \\
24 . \\
21 \\
23 . \\
16.5 \\
22 . \\
37 . \\
12.3 \\
15.8 \\
17 . \\
20 . \\
16 .\end{array}$ & $\begin{array}{l}\text { GL } \\
\mathrm{L} \\
\mathrm{L} \\
\mathrm{L} \\
\mathrm{L} \\
\mathrm{L} \\
\mathrm{L} \\
\mathrm{L} \\
\mathrm{L} \\
\mathrm{L} \\
\mathrm{L} \\
\mathrm{GL} \\
\mathrm{L} \\
\mathrm{L} \\
\mathrm{J} \\
\mathrm{J} \\
\mathrm{L} \\
\mathrm{L} \\
\mathrm{L} \\
\mathrm{L} \\
\mathrm{L}\end{array}$ & $\begin{array}{c}0.1 \\
0.1 \\
0.1 \\
0.1 \\
0.1 \\
10.1 \\
1 . \\
1 \\
0.1 \\
0.1 \\
0.1 \\
0.1 \\
0.1 \\
0.1 \\
10 . \\
10 . \\
10 . \\
1 \\
0.1 \\
0.1 \\
0.1 \\
0.1 \\
0.1 \\
0.1 \\
10 . \\
10 . \\
1 .\end{array}$ & $\begin{array}{l}- \\
: \\
: \\
- \\
- \\
- \\
- \\
- \\
- \\
- \\
- \\
- \\
- \\
- \\
- \\
- \\
- \\
- \\
- \\
-\end{array}$ \\
\hline SULFIDE & $\begin{array}{l}0668 \\
0668\end{array}$ & $\begin{array}{l}06 / 30 / 86 \\
12 / 15 / 90\end{array}$ & $\begin{array}{l}0001 \\
0001\end{array}$ & $\begin{array}{l}\text { NA } \\
\text { NA }\end{array}$ & $\begin{array}{l}\mathbf{U} \\
\mathbf{U}\end{array}$ & MG/L & $<$ & $\begin{array}{l}0.1 \\
0.1\end{array}$ & & $\begin{array}{l}0.1 \\
0.1\end{array}$ & - \\
\hline
\end{tabular}

FORMATION OF COMPLETION CODE:

NA - NAVAJO SANDSTONE

PARAMETER VALUE INDICATOR (PVI): < - LESS THAN DETECTION LIMIT

OTHER PARAMETER VALUE FLAGS:

G - PH > 9, POSSIBLE GROUT CONTAMINATION

$J$ - ESTIMATED VALUE

$L$ - LESS THAN THREE BORE VOLUMES REMOVED BEFORE SAMPLING
FLOW RELATIONSHIP CODE:

- UPGRADIENT

SAMPLE ID CODES

0001 - FILTERED SAMPLE (.45 MICRONS)

NO01 - UNFILTERED SAMPLE 
TABLE 3.37 BASELINE GROUND HATER QUALITY DATA BY PARAMETER FOR THE NAVAJO SANDSTONE, UC PROCESSING SITE, SLICK ROCK, COLORADO

SITE: SRKO1 SLICK ROCK (BOTH SITES)

$02 / 05 / 86$ TO $02 / 21 / 94$

REPORT DATE: $00 / 30 / 94$

\begin{tabular}{|c|c|c|c|c|c|c|c|c|c|c|c|}
\hline PARAMETER NAME & $\underset{\text { ID }}{\text { LOCATION }}$ & LOG DATE & $\begin{array}{c}\text { SAMPLE } \\
\text { ID }\end{array}$ & $\begin{array}{l}\text { FORM } \\
\text { COMP }\end{array}$ & $\begin{array}{l}\text { FLOW } \\
\text { REL. }\end{array}$ & $\begin{array}{l}\text { UNITS OF } \\
\text { MEASURE }\end{array}$ & PVI & $\begin{array}{l}\text { ARAMETE } \\
\text { VALUE }\end{array}$ & FLAGS & $\begin{array}{l}\text { DETECTION } \\
\text { LIMIT }\end{array}$ & $\begin{array}{l}\text { PARAMETER } \\
\text { UNCERTAINTY }\end{array}$ \\
\hline SULFIDE & $\begin{array}{l}0668 \\
0668 \\
0669 \\
0669 \\
0669 \\
0669 \\
0669 \\
0669 \\
0670 \\
0670 \\
0670 \\
0670 \\
0670 \\
0670\end{array}$ & $\begin{array}{l}11 / 18 / 91 \\
10 / 11 / 92 \\
06 / 30 / 86 \\
12 / 15 / 90 \\
03 / 31 / 91 \\
08 / 24 / 91 \\
11 / 19 / 91 \\
10 / 12 / 92 \\
07 / 19 / 86 \\
12 / 15 / 90 \\
04 / 01 / 91 \\
08 / 24 / 91 \\
11 / 20 / 91 \\
10 / 14 / 92\end{array}$ & $\begin{array}{l}0001 \\
0001 \\
0001 \\
0001 \\
0001 \\
0001 \\
0001 \\
0001 \\
0001 \\
0001 \\
0001 \\
0001 \\
0001 \\
0001\end{array}$ & $\begin{array}{l}\text { NA } \\
\text { NA } \\
\text { NA } \\
\text { NA } \\
\text { NA } \\
\text { NA } \\
\text { NA } \\
\text { NA } \\
\text { NA } \\
\text { NA } \\
\text { NA } \\
\text { NA } \\
\text { NA } \\
\text { NA }\end{array}$ & $\begin{array}{l}U \\
U \\
U \\
U \\
U \\
U \\
U \\
U \\
U \\
U \\
U \\
U \\
U \\
U\end{array}$ & $M G / L$ & $\begin{array}{l}< \\
< \\
< \\
< \\
< \\
<\end{array}$ & $\begin{array}{l}0.1 \\
0.2 \\
0.1 \\
0.1 \\
6.7 \\
0.6 \\
0.3 \\
0.1 \\
0.1 \\
0.1 \\
5.8 \\
0.3 \\
0.3 \\
0.1\end{array}$ & $\begin{array}{l}\mathrm{L} \\
\mathrm{L} \\
\mathrm{L} \\
\mathrm{L} \\
\mathrm{L} \\
\mathrm{L} \\
\mathrm{L} \\
\mathrm{L} \\
\mathrm{L} \\
\mathrm{L} \\
\mathrm{L} \\
\mathrm{L} \\
\mathrm{L}\end{array}$ & $\begin{array}{l}0.1 \\
0.1 \\
0.1 \\
0.1 \\
-0.1 \\
0.1 \\
0.1 \\
0.1 \\
0.1 \\
0.1 \\
0.1 \\
0.1 \\
0.1 \\
0.1\end{array}$ & $\begin{array}{l}- \\
- \\
= \\
- \\
- \\
- \\
- \\
- \\
- \\
-\end{array}$ \\
\hline TEMPERATURE & $\begin{array}{l}0668 \\
0668 \\
0668 \\
0668 \\
0668 \\
0668 \\
0668 \\
0668 \\
0668 \\
0669 \\
0669 \\
0669 \\
0669 \\
0669 \\
0669 \\
0669 \\
0669 \\
0669 \\
0669 \\
0670 \\
0670 \\
0670 \\
0670 \\
0670\end{array}$ & $\begin{array}{l}02 / 02 / 86 \\
06 / 30 / 86 \\
10 / 14 / 87 \\
02 / 19 / 88 \\
12 / 15 / 90 \\
03 / 27 / 91 \\
11 / 18 / 91 \\
10 / 11 / 92 \\
02 / 18 / 94 \\
02 / 04 / 86 \\
06 / 30 / 86 \\
10 / 14 / 87 \\
02 / 19 / 88 \\
12 / 15 / 90 \\
03 / 31 / 91 \\
08 / 24 / 91 \\
11 / 19 / 91 \\
10 / 12 / 92 \\
02 / 20 / 94 \\
02 / 03 / 86 \\
07 / 19 / 86 \\
10 / 15 / 87 \\
02 / 19 / 88 \\
12 / 15 / 90\end{array}$ & $\begin{array}{l}0001 \\
0001 \\
0001 \\
0001 \\
0001 \\
0001 \\
0001 \\
0001 \\
N 001 \\
0001 \\
0001 \\
0001 \\
0001 \\
0001 \\
0001 \\
0001 \\
0001 \\
0001 \\
N 001 \\
0001 \\
0001 \\
0001 \\
0001 \\
0001\end{array}$ & $\begin{array}{l}\text { NA } \\
\text { NA } \\
\text { NA } \\
\text { NA } \\
\text { NA } \\
\text { NA } \\
\text { NA } \\
\text { NA } \\
\text { NA } \\
\text { NA } \\
\text { NA } \\
\text { NA } \\
\text { NA } \\
\text { NA } \\
\text { NA } \\
\text { NA } \\
\text { NA } \\
\text { NA } \\
\text { NA } \\
\text { NA } \\
\text { NA } \\
\text { NA } \\
\text { NA } \\
\text { NA }\end{array}$ & $\begin{array}{l}U \\
U \\
U \\
U \\
U \\
U \\
U \\
U \\
U \\
U \\
U \\
U \\
U \\
U \\
U \\
U \\
U \\
U \\
U \\
U \\
U \\
U \\
U \\
U\end{array}$ & C - DEGREE & & $\begin{array}{l}14 . \\
15.5 \\
15.0 \\
13.5 \\
13.4 \\
13.8 \\
12.8 \\
14.7 \\
13.1 \\
12 . \\
13.5 \\
15.0 \\
12.0 \\
11.5 \\
12.3 \\
14.2 \\
11.9 \\
14.5 \\
7.3 \\
11.5 \\
13.5 \\
13.0 \\
12.0 \\
10.6\end{array}$ & 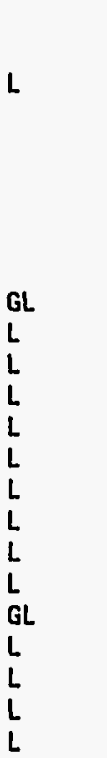 & $\begin{array}{l}- \\
- \\
- \\
- \\
- \\
- \\
- \\
- \\
- \\
- \\
- \\
- \\
- \\
- \\
- \\
- \\
- \\
- \\
-\end{array}$ & $\begin{array}{l}- \\
: \\
- \\
- \\
- \\
- \\
- \\
- \\
- \\
- \\
- \\
- \\
- \\
- \\
- \\
- \\
-\end{array}$ \\
\hline
\end{tabular}

FORMATION OF COMPLETION CODE:

NA - NAVAJO SANDSTONE

PARAMETER VALUE INDICATOR (PVI): < - LESS THAN DETECTION LIMIT

OTHER PARAMETER VALUE FLAGS:

G - PH > 9, POSSIBLE GROUT CONTAMINATION

$L$ - LESS THAN THREE BORE VOLUMES REMOVED BEFORE SAMPLING
FLOW RELATIONSHIP CODE:

SAMPLE ID CODES

O001 - FILTERED SAMPLE (.45 MICRONS)

NO01 - UNFILTERED SAMPLE 
TABLE 3.37 BASELINE GROUND WATER QUALITY DATA BY PARAMETER FOR THE NAVAJO SANDSTONE, UC PROCESSING SITE, SLICK ROCK, COLORADO

SITE: SRK01 SLICK ROCK (BOTH SITES)

02/02/86 TO 02/21/94

REPORT DATE: $09 / 30 / 94$

\begin{tabular}{|c|c|c|c|c|c|c|c|c|c|c|c|}
\hline PARAMETER NAME & $\underset{\text { ID }}{\text { LOCATION }}$ & LOG DATE & $\begin{array}{c}\text { SAMPLE } \\
\text { ID }\end{array}$ & $\begin{array}{l}\text { FORM } \\
\text { COMP }\end{array}$ & $\begin{array}{l}\text { FLOW } \\
\text { REL. }\end{array}$ & $\begin{array}{l}\text { UNITS OF } \\
\text { MEASURE }\end{array}$ & PVI & $\begin{array}{l}\text { ARAMETER } \\
\text { VALUE }\end{array}$ & FLAGS & $\begin{array}{l}\text { DETECTION } \\
\text { LIMIT }\end{array}$ & $\begin{array}{l}\text { PARAMETER } \\
\text { UNCERTAINTY }\end{array}$ \\
\hline TEMPERATURE & $\begin{array}{l}0670 \\
0670 \\
0670 \\
0670 \\
0670\end{array}$ & $\begin{array}{l}04 / 01 / 91 \\
08 / 24 / 91 \\
12 / 05 / 91 \\
10 / 14 / 92 \\
02 / 21 / 94\end{array}$ & $\begin{array}{l}0001 \\
0001 \\
0001 \\
0001 \\
\text { N001 }\end{array}$ & $\begin{array}{l}\text { NA } \\
\text { NA } \\
\text { NA } \\
\text { NA } \\
\text { NA }\end{array}$ & $\begin{array}{l}U \\
U \\
U \\
U \\
U\end{array}$ & C - DEGREE & & $\begin{array}{l}12.3 \\
13.7 \\
10.7 \\
14.5 \\
10.8\end{array}$ & $\begin{array}{l}L \\
L \\
L \\
L \\
L\end{array}$ & $\begin{array}{l}- \\
- \\
- \\
-\end{array}$ & $\begin{array}{l}- \\
- \\
- \\
-\end{array}$ \\
\hline THALLIUM & $\begin{array}{l}0668 \\
0668 \\
0668 \\
0669 \\
0669 \\
0669 \\
0669 \\
0669 \\
0670 \\
0670 \\
0670 \\
0670\end{array}$ & $\begin{array}{l}12 / 15 / 90 \\
11 / 18 / 91 \\
10 / 11 / 92 \\
12 / 15 / 90 \\
03 / 31 / 91 \\
08 / 24 / 91 \\
11 / 19 / 91 \\
10 / 12 / 92 \\
12 / 15 / 90 \\
04 / 01 / 91 \\
08 / 24 / 91 \\
10 / 14 / 92\end{array}$ & $\begin{array}{l}0001 \\
0001 \\
0001 \\
0001 \\
0001 \\
0001 \\
0001 \\
0001 \\
0001 \\
0001 \\
0001 \\
0001\end{array}$ & $\begin{array}{l}\text { NA } \\
\text { NA } \\
\text { NA } \\
\text { NA } \\
\text { NA } \\
\text { NA } \\
\text { NA } \\
\text { NA } \\
\text { NA } \\
\text { NA } \\
\text { NA } \\
\text { NA }\end{array}$ & $\begin{array}{l}U \\
U \\
U \\
U \\
U \\
U \\
U \\
U \\
U \\
U \\
U \\
U\end{array}$ & $M G / L$ & $\begin{array}{l}< \\
< \\
< \\
< \\
< \\
< \\
< \\
< \\
< \\
< \\
< \\
< \\
<\end{array}$ & $\begin{array}{l}0.01 \\
0.01 \\
0.005 \\
0.01 \\
0.01 \\
0.01 \\
0.01 \\
0.005 \\
0.01 \\
0.01 \\
0.01 \\
0.005\end{array}$ & $\begin{array}{l}L \\
L \\
L \\
L \\
L \\
L \\
L \\
L \\
L\end{array}$ & $\begin{array}{l}0.01 \\
0.01 \\
0.005 \\
0.01 \\
0.01 \\
0.01 \\
0.01 \\
0.005 \\
0.01 \\
0.01 \\
0.01 \\
0.005\end{array}$ & $\begin{array}{l}- \\
- \\
- \\
- \\
- \\
- \\
- \\
- \\
-\end{array}$ \\
\hline THORIUM-230 & $\begin{array}{l}0668 \\
0668 \\
0669 \\
0669 \\
0669 \\
0670 \\
0670\end{array}$ & $\begin{array}{l}11 / 18 / 91 \\
02 / 18 / 94 \\
08 / 24 / 91 \\
11 / 19 / 91 \\
02 / 20 / 94 \\
08 / 24 / 91 \\
12 / 05 / 91\end{array}$ & $\begin{array}{l}0001 \\
0001 \\
0001 \\
0001 \\
0001 \\
0001 \\
0001\end{array}$ & $\begin{array}{l}\text { NA } \\
\text { NA } \\
\text { NA } \\
\text { NA } \\
\text { NA } \\
\text { NA } \\
\text { NA }\end{array}$ & $\begin{array}{l}U \\
U \\
U \\
U \\
U \\
U \\
U\end{array}$ & $\mathrm{PCI} / \mathrm{L}$ & & $\begin{array}{l}1.2 \\
0.1 \\
0.8 \\
0.4 \\
0.1 \\
0.0 \\
0.3\end{array}$ & $\begin{array}{l}L \\
L \\
L \\
L \\
L\end{array}$ & $\begin{array}{l}1 . \\
0.2 \\
1 . \\
1 . \\
0.2 \\
1 . \\
1 .\end{array}$ & $\begin{array}{l}1.0 \\
0.1 \\
0.9 \\
0.5 \\
0.1 \\
0.4 \\
0.5\end{array}$ \\
\hline THORIUM-230 (TOTAL) & $\begin{array}{l}0668 \\
0669\end{array}$ & $\begin{array}{l}02 / 18 / 94 \\
02 / 20 / 94\end{array}$ & $\begin{array}{l}\text { N001 } \\
\text { N001 }\end{array}$ & $\begin{array}{l}\text { NA } \\
\text { NA }\end{array}$ & $\begin{array}{l}u \\
U\end{array}$ & $\mathrm{PCI} / \mathrm{L}$ & & $\begin{array}{l}0.3 \\
0.3\end{array}$ & $\mathbf{L}$ & $\begin{array}{l}0.2 \\
0.1\end{array}$ & $\begin{array}{l}0.1 \\
0.1\end{array}$ \\
\hline TIN & $\begin{array}{l}0668 \\
0668 \\
0668 \\
0669 \\
0669 \\
0669 \\
0669 \\
0669 \\
0670\end{array}$ & $\begin{array}{l}12 / 15 / 90 \\
11 / 18 / 91 \\
10 / 11 / 92 \\
12 / 15 / 90 \\
03 / 31 / 91 \\
08 / 24 / 91 \\
11 / 19 / 91 \\
10 / 12 / 92 \\
12 / 15 / 90\end{array}$ & $\begin{array}{l}0001 \\
0001 \\
0001 \\
0001 \\
0001 \\
0001 \\
0001 \\
0001 \\
0001\end{array}$ & $\begin{array}{l}\text { NA } \\
\text { NA } \\
\text { NA } \\
\text { NA } \\
\text { NA } \\
\text { NA } \\
\text { NA } \\
\text { NA } \\
\text { NA }\end{array}$ & $\begin{array}{l}U \\
U \\
U \\
U \\
U \\
U \\
U \\
U \\
U\end{array}$ & $M G / L$ & $\begin{array}{l}< \\
< \\
< \\
< \\
< \\
< \\
< \\
< \\
< \\
<\end{array}$ & $\begin{array}{l}0.005 \\
0.005 \\
0.005 \\
0.005 \\
0.005 \\
0.005 \\
0.005 \\
0.005 \\
0.005\end{array}$ & $\begin{array}{l}H \\
L \\
L \\
L H \\
L W \\
L \\
L\end{array}$ & $\begin{array}{l}0.005 \\
0.005 \\
0.005 \\
0.005 \\
0.005 \\
0.005 \\
0.005 \\
0.005 \\
0.005\end{array}$ & $\begin{array}{l}- \\
- \\
- \\
- \\
- \\
- \\
-\end{array}$ \\
\hline
\end{tabular}

FORMATION OF COMPLETION CODE:

NA - NAVAJO SANDSTONE

PARAMETER VALUE INDICATOR (PVI): < - LESS THAN DETECTION LIMIT

OTHER PARAMETER VALUE FLAGS:

L - LESS THAN THREE BORE VOLUMES REMOVED BEFORE SAMPLING

H - POST-DIGEST SPIKE OUT OF CNTR LIM WHILE SAMP ABS $<50 \%$ SPIKE
FLOW RELATIONSHIP CODE:

$U$ - UPGRADIENT

\section{SAMPLE ID CODES:}

0001 - FILTERED SAMPLE (.45 MICRONS)

NOO1 - UNFILTERED SAMPLE 
TABLE 3.37 BASELINE GROUND HATER QUALITY DATA BY PARAMETER FOR THE NAVA S SANDSTOKE, UC PROCESSING SITE, SLICK

SITE: SRKO1 SLICK ROCK (BOTH SITES)

02/02/86 TO 02/21/94

REPORT DATE: $09 / 30 / 94$

\begin{tabular}{|c|c|c|c|}
\hline PARAMETER NAME & $\begin{array}{l}\text { LOCATION } \\
\text { ID }\end{array}$ & LOG DATE & $\begin{array}{c}\text { SAMPL } \\
\text { ID }\end{array}$ \\
\hline TIN & $\begin{array}{l}0670 \\
0670 \\
0670\end{array}$ & $\begin{array}{l}04 / 01 / 91 \\
08 / 24 / 91 \\
10 / 14 / 92\end{array}$ & $\begin{array}{l}0001 \\
0001 \\
0001\end{array}$ \\
\hline TOTAL DISSOLVED SOLIDS & $\begin{array}{l}0668 \\
0668 \\
0668 \\
0668 \\
0668 \\
0668 \\
0668 \\
0668 \\
0669 \\
0669 \\
0669 \\
0669 \\
0669 \\
0669 \\
0669 \\
0669 \\
0669 \\
0669 \\
0670 \\
0670 \\
0670 \\
0670 \\
0670 \\
0670 \\
0670 \\
0670 \\
0670\end{array}$ & $\begin{array}{l}02 / 02 / 86 \\
06 / 30 / 86 \\
10 / 14 / 87 \\
02 / 19 / 88 \\
12 / 15 / 90 \\
11 / 18 / 91 \\
10 / 11 / 92 \\
02 / 18 / 94 \\
02 / 04 / 86 \\
06 / 30 / 86 \\
10 / 14 / 87 \\
02 / 19 / 88 \\
12 / 15 / 90 \\
03 / 31 / 91 \\
08 / 24 / 91 \\
11 / 19 / 91 \\
10 / 12 / 92 \\
02 / 20 / 94 \\
02 / 03 / 86 \\
07 / 19 / 86 \\
10 / 15 / 87 \\
02 / 19 / 88 \\
12 / 15 / 90 \\
04 / 01 / 91 \\
08 / 24 / 91 \\
11 / 20 / 91 \\
10 / 14 / 92\end{array}$ & $\begin{array}{l}0001 \\
0001 \\
0001 \\
0001 \\
0001 \\
0001 \\
0001 \\
0001 \\
0001 \\
0001 \\
0001 \\
0001 \\
0001 \\
0001 \\
0001 \\
0001 \\
0001 \\
0001 \\
0001 \\
0001 \\
0001 \\
0001 \\
0001 \\
0001 \\
0001 \\
0001 \\
0001\end{array}$ \\
\hline TOTAL KJELDAHL NITROGEN & $\begin{array}{l}0668 \\
0668 \\
0669 \\
0669\end{array}$ & $\begin{array}{l}12 / 15 / 90 \\
11 / 18 / 91 \\
12 / 15 / 90 \\
03 / 31 / 91\end{array}$ & $\begin{array}{l}0001 \\
0001 \\
0001 \\
0001\end{array}$ \\
\hline
\end{tabular}

FORMATION OF COMPLETION CODE:

NA - NAVAJO SANDSTONE

PARAMETER VALUE INDICATOR (PVI): < - LESS THAN DETECTION LIMIT

\begin{tabular}{|c|c|c|c|c|c|c|c|}
\hline $\begin{array}{l}\text { FORM } \\
\text { COMP }\end{array}$ & $\begin{array}{l}\text { FLOW } \\
\text { REL. }\end{array}$ & $\begin{array}{l}\text { UNITS OF } \\
\text { MEASURE }\end{array}$ & PVI & $\begin{array}{l}\text { ARAMETER } \\
\text { VALUE }\end{array}$ & FLAGS & $\begin{array}{l}\text { DETECTION } \\
\text { LIMIT }\end{array}$ & $\begin{array}{l}\text { PARAMETER } \\
\text { UNCERTAINTY }\end{array}$ \\
\hline $\begin{array}{l}\text { NA } \\
\text { NA } \\
\text { NA }\end{array}$ & $\begin{array}{l}U \\
U \\
U\end{array}$ & $M G / L$ & $<<$ & $\begin{array}{l}0.005 \\
0.005 \\
0.005\end{array}$ & $\begin{array}{l}L \\
L \\
L\end{array}$ & $\begin{array}{l}0.005 \\
0.005 \\
0.005\end{array}$ & - \\
\hline $\begin{array}{l}\text { NA } \\
\text { NA } \\
\text { NA } \\
\text { NA } \\
\text { NA } \\
\text { NA } \\
\text { NA } \\
\text { NA } \\
\text { NA } \\
\text { NA } \\
\text { NA } \\
\text { NA } \\
\text { NA } \\
\text { NA } \\
\text { NA } \\
\text { NA } \\
\text { NA } \\
\text { NA } \\
\text { NA } \\
\text { NA } \\
\text { NA } \\
\text { NA } \\
\text { NA } \\
\text { NA } \\
\text { NA } \\
\text { NA } \\
\text { NA }\end{array}$ & $\begin{array}{l}U \\
U \\
U \\
U \\
U U \\
U U \\
U \\
U \\
U \\
U \\
U \\
U \\
U \\
U \\
U \\
U \\
U \\
U \\
U \\
U \\
U \\
U \\
U \\
U \\
U \\
U \\
U \\
U \\
U\end{array}$ & MG/L & & $\begin{array}{l}214 . \\
355 . \\
276 . \\
229 . \\
272 . \\
286 . \\
263 . \\
280 \\
162 . \\
288 . \\
273 . \\
222 . \\
280 . \\
273 . \\
291 . \\
288 . \\
243 . \\
310 \\
201 . \\
322 . \\
313 . \\
255 . \\
296 . \\
293 . \\
318 . \\
307 . \\
262 .\end{array}$ & $\begin{array}{l}G L \\
L \\
L \\
L \\
H L \\
L \\
L \\
L \\
L \\
L \\
G L \\
L \\
L \\
J L \\
H L \\
L \\
L \\
L \\
L\end{array}$ & $\begin{array}{l}10 . \\
10 . \\
10 . \\
10 . \\
10 . \\
10 . \\
10 . \\
10 \\
10 . \\
10 . \\
10 . \\
10 . \\
10 . \\
10 . \\
10 . \\
10 . \\
10 . \\
10 \\
10 . \\
10 . \\
10 . \\
10 . \\
10 . \\
10 . \\
10 . \\
10 . \\
10 .\end{array}$ & $\begin{array}{l}- \\
- \\
- \\
- \\
- \\
- \\
- \\
- \\
- \\
- \\
- \\
- \\
- \\
- \\
- \\
- \\
- \\
- \\
- \\
- \\
-\end{array}$ \\
\hline $\begin{array}{l}\text { NA } \\
\text { NA } \\
\text { NA } \\
\text { NA }\end{array}$ & $\begin{array}{l}\mathbf{U} \\
\mathbf{U} \\
\mathbf{U} \\
\mathbf{U}\end{array}$ & $M G / L$ & $<<$ & $\begin{array}{l}1 . \\
2 . \\
1 .\end{array}$ & $\begin{array}{l}\text { I } \\
\text { L } \\
\text { L }\end{array}$ & $\begin{array}{l}1 . \\
2 . \\
1 . \\
1 .\end{array}$ & $\begin{array}{l}- \\
-\end{array}$ \\
\hline
\end{tabular}

FLOW RELATIONSHIP CODE:

$U$ - UPGRADIENT

SAMPLE ID CODES:

0001 - FILTERED SAMPLE (.45 MICRONS)

OTHER PARAMETER VALUE FLAGS:

$G$ - PH > 9, POSSIBLE GROUT CONTAMINATION

H - HOLD TIME EXPIRED, VALUE SUSPECT

- INCREASED DETECTION LIMIT DUE TO REQUIRED DILUTION

J - ESTIMATED VALUE

$L$ - LESS THAN THREE BORE VOLUMES REMOVED BEFORE SAMPLING 
TABLE 3.37 BASELINE GROUND WATER QUALITY DATA BY PARAMETER FOR THE

NAVAJO SANDSTONE, UC PROCESSING SITE, SLICK ROCK, COLORADO

SITE: SRKO1 SLICK ROCK (BOTH SITES)

02/02/86 TO 02/21/94

REPORT DATE: $09 / 30 / 94$

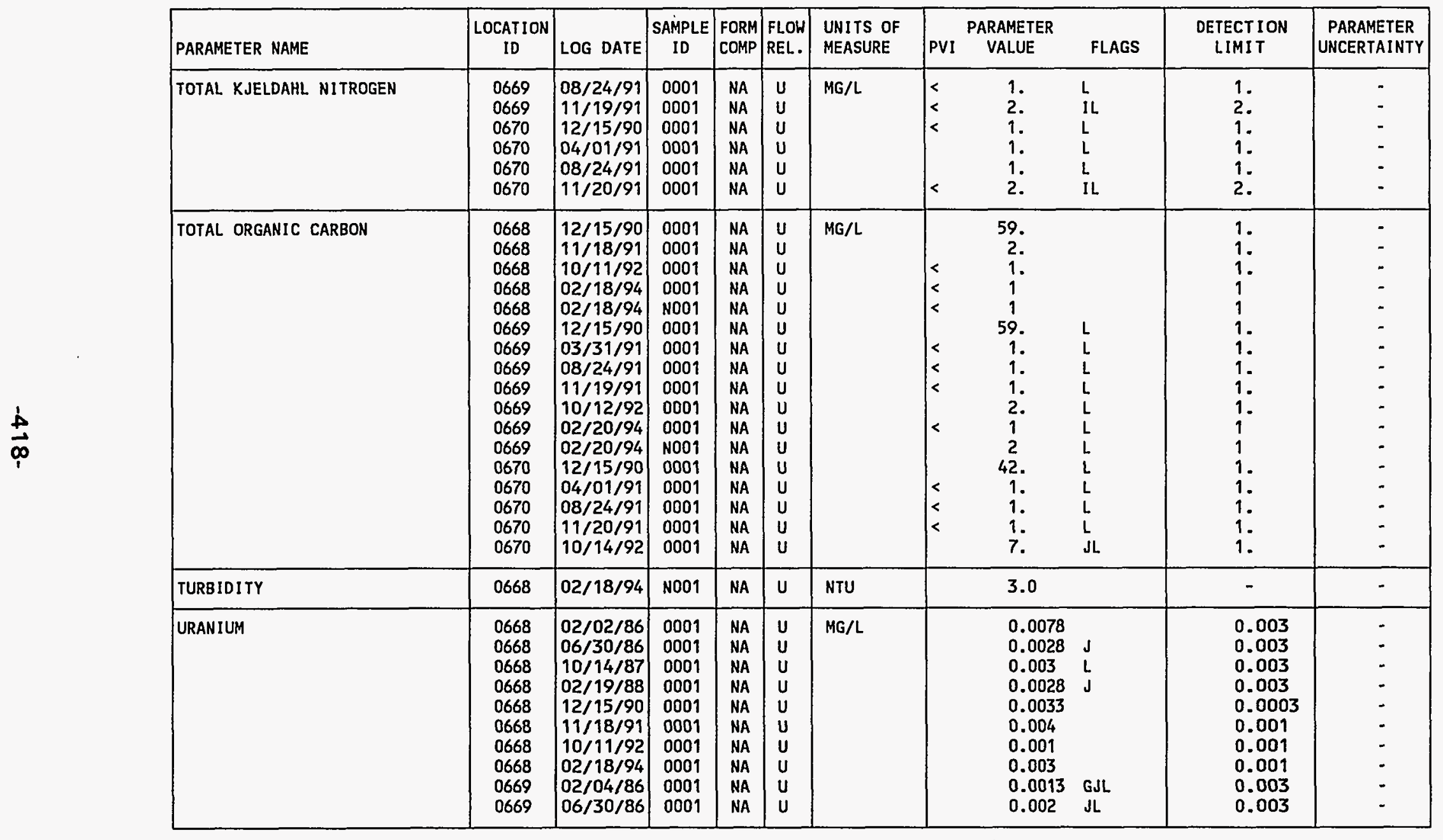

FORMATION OF COMPLETION CODE:

NA - NAVAJO SANDSTONE

PARAMETER VALUE INDICATOR (PVI): < - LESS THAN DETECTION LIMIT

OTHER PARAMETER VALUE FLAGS:

$G$ - PH > 9, POSSIBLE GROUT CONTAMINATION

I - INCREASED DETECTION LIMIT DUE TO REQUIRED DILUTION

$J$ - ESTIMATED VALUE

L - LESS THAN THREE BORE VOLUMES REMOVED BEFORE SAMPLING
FLOW RELATIONSHIP CODE:

- UPGRADIENT

SAMPLE ID CODES:

0001 - FILTERED SAMPLE (.45 MICRONS)

NO01 - UNFILTERED SAMPLE 
TABLE 3.37 BASELINE GROUND WATER QUALITY DATA BY PARAMETER FOR THE NAVAJO SANDSTONE, UC PROCESSING SITE, SLICK ROCK, COLORADO

SITE: SRKO1 SLICK ROCK (BOTH SITES)

02/02/86 TO 02/21/94

REPORT DATE: $09 / 30 / 94$

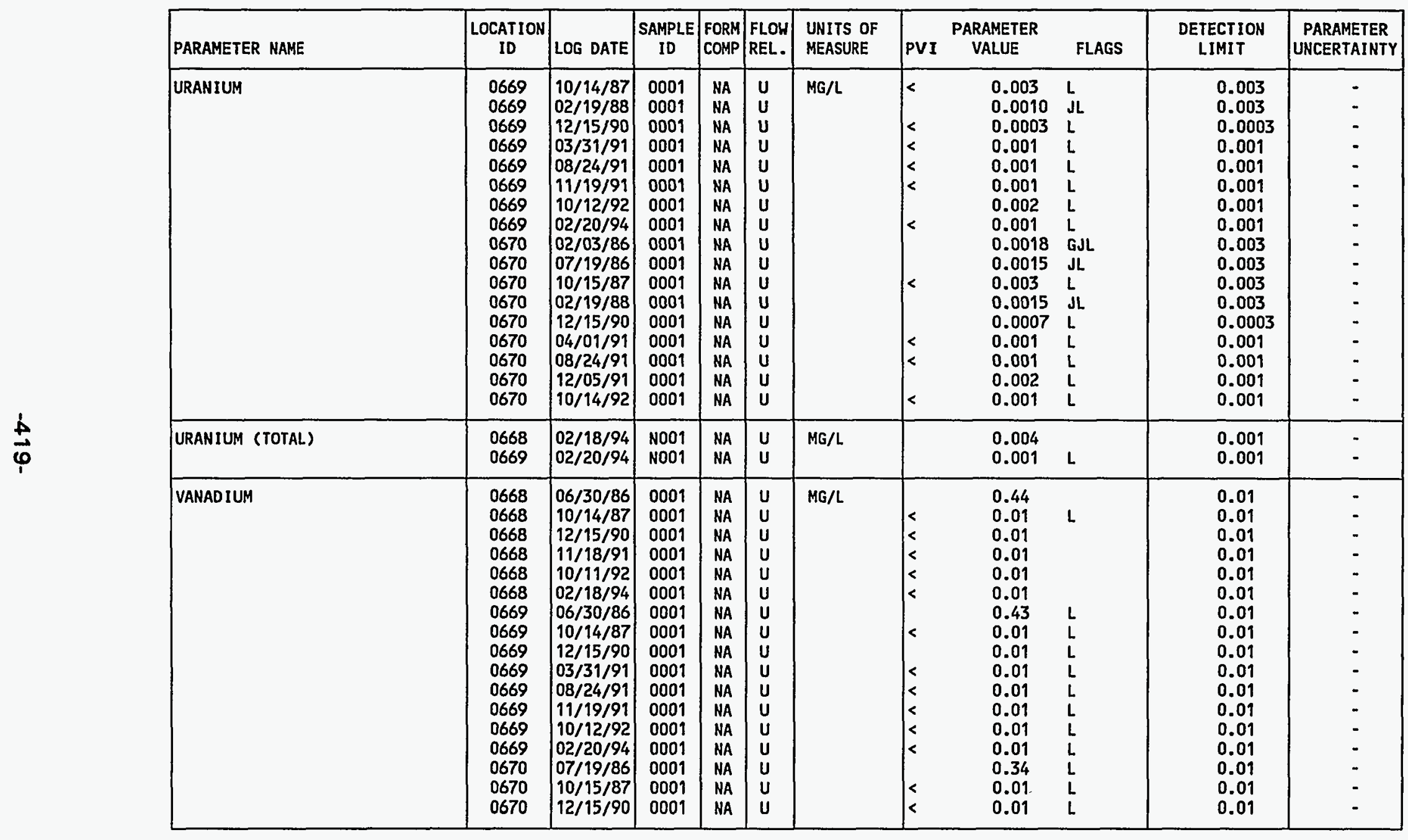

FORMATION OF COMPLETION CODE:

NA - NAVAJO SANDSTONE

PARAMETER VALUE INDICATOR (PVI): < - LESS THAN DETECTION LIMIT

OTHER PARAMETER VALUE FLAGS:

$G$ - PH > 9, POSSIBLE GROUT CONTAMINATION

J - ESTIMATED VALUE

L - LESS THAN THREE BORE VOLUMES REMOVED BEFORE SAMPLING
FLOH RELATIONSHIP CODE:

$U$ - UPGRADIENT

SAMPLE ID CODES:

0001 - FILTERED SAMPLE (.45 MICRONS)

NOD1 - UNFILTERED SAMPLE 
TABLE 3.37 BASELINE GROUND WATER QUALITY DATA BY PARAMETER FOR THE NAVAJO SANDSTONE, UC PROCESSING SITE, SLICK ROCK, COLORADO

SITE: SRKO1 SLICK ROCK (BOTH SITES)

02/02/86 TO $02 / 21 / 94$

REPORT DATE: $09 / 30 / 94$

\begin{tabular}{|c|c|c|c|c|c|c|c|c|c|c|c|}
\hline PARAMETER NAME & $\underset{\text { ID }}{\text { LOCATION }}$ & LOG DATE & $\begin{array}{c}\text { SAMPLE } \\
\text { ID }\end{array}$ & $\begin{array}{l}\text { FORM } \\
\text { COMP }\end{array}$ & $\begin{array}{l}\text { FLOW } \\
\text { REL. }\end{array}$ & $\begin{array}{l}\text { UNITS OF } \\
\text { MEASURE }\end{array}$ & PV1 & $\begin{array}{l}\text { ARAMETER } \\
\text { VALUE }\end{array}$ & FLAGS & $\begin{array}{l}\text { DETECTION } \\
\text { LIMIT }\end{array}$ & $\begin{array}{c}\text { PARAMETER } \\
\text { UNCERTAINTY }\end{array}$ \\
\hline VANADIUM & $\begin{array}{l}0670 \\
0670 \\
0670\end{array}$ & $\begin{array}{l}04 / 01 / 91 \\
08 / 24 / 91 \\
10 / 14 / 92\end{array}$ & $\begin{array}{l}0001 \\
0001 \\
0001\end{array}$ & $\begin{array}{l}\text { NA } \\
\text { NA } \\
\text { NA }\end{array}$ & $\begin{array}{l}U \\
U \\
U\end{array}$ & $M G / L$ & $\begin{array}{l}< \\
< \\
<\end{array}$ & $\begin{array}{l}0.01 \\
0.01 \\
0.01\end{array}$ & $\begin{array}{l}L \\
L\end{array}$ & $\begin{array}{l}0.01 \\
0.01 \\
0.01\end{array}$ & - \\
\hline VANADIUM (TOTAL) & $\begin{array}{l}0668 \\
0669\end{array}$ & $\begin{array}{l}02 / 18 / 94 \\
02 / 20 / 94\end{array}$ & $\begin{array}{l}\text { No01 } \\
\text { N001 }\end{array}$ & $\begin{array}{l}\text { NA } \\
\text { NA }\end{array}$ & $\begin{array}{l}U \\
U\end{array}$ & $M G / L$ & $<$ & $\begin{array}{l}0.01 \\
0.01\end{array}$ & L & $\begin{array}{l}0.01 \\
0.01\end{array}$ & - \\
\hline ZINC & $\begin{array}{l}0668 \\
0668 \\
0668 \\
0668 \\
0668 \\
0669 \\
0669 \\
0669 \\
0669 \\
0669 \\
0669 \\
0669 \\
0670 \\
0670 \\
0670 \\
0670 \\
0670\end{array}$ & $\begin{array}{l}10 / 14 / 87 \\
12 / 15 / 90 \\
11 / 18 / 91 \\
10 / 11 / 92 \\
02 / 18 / 94 \\
10 / 14 / 87 \\
12 / 15 / 90 \\
03 / 31 / 91 \\
08 / 24 / 91 \\
11 / 19 / 91 \\
10 / 12 / 92 \\
02 / 20 / 94 \\
10 / 15 / 87 \\
12 / 15 / 90 \\
04 / 01 / 91 \\
08 / 24 / 91 \\
10 / 14 / 92\end{array}$ & $\begin{array}{l}0001 \\
0001 \\
0001 \\
0001 \\
0001 \\
0001 \\
0001 \\
0001 \\
0001 \\
0001 \\
0001 \\
0001 \\
0001 \\
0001 \\
0001 \\
0001 \\
0001\end{array}$ & $\begin{array}{l}\text { NA } \\
\text { NA } \\
\text { NA } \\
\text { NA } \\
\text { NA } \\
\text { NA } \\
\text { NA } \\
\text { NA } \\
\text { NA } \\
\text { NA } \\
\text { NA } \\
\text { NA } \\
\text { NA } \\
\text { NA } \\
\text { NA } \\
\text { NA } \\
\text { NA }\end{array}$ & $\begin{array}{l}U \\
U \\
U \\
U \\
U \\
U \\
U \\
U \\
U \\
U \\
U \\
U \\
U \\
U \\
U \\
U \\
U\end{array}$ & $M G / L$ & $\begin{array}{l}< \\
< \\
< \\
< \\
< \\
< \\
< \\
< \\
< \\
< \\
< \\
< \\
< \\
< \\
< \\
< \\
<\end{array}$ & $\begin{array}{l}0.005 \\
0.005 \\
0.005 \\
0.005 \\
0.05 \\
0.005 \\
0.005 \\
0.005 \\
0.011 \\
0.005 \\
0.005 \\
0.05 \\
0.034 \\
0.005 \\
0.005 \\
0.005 \\
0.036\end{array}$ & $\begin{array}{l}\mathrm{L} \\
\mathrm{L} \\
\mathrm{L} \\
\mathrm{L} \\
\mathrm{L} \\
\mathrm{L} \\
\mathrm{L} \\
\mathrm{L} \\
\mathrm{L} \\
\mathrm{L} \\
\mathrm{L} \\
\mathrm{L} \\
\mathrm{L}\end{array}$ & $\begin{array}{l}0.005 \\
0.005 \\
0.005 \\
0.005 \\
0.05 \\
0.005 \\
0.005 \\
0.005 \\
0.005 \\
0.005 \\
0.005 \\
0.05 \\
0.005 \\
0.005 \\
0.005 \\
0.005 \\
0.005\end{array}$ & $\begin{array}{l}- \\
- \\
- \\
- \\
- \\
- \\
- \\
- \\
- \\
- \\
- \\
- \\
- \\
-\end{array}$ \\
\hline ZINC (TOTAL) & $\begin{array}{l}0668 \\
0669\end{array}$ & $\begin{array}{l}02 / 18 / 94 \\
02 / 20 / 94\end{array}$ & $\begin{array}{l}\text { N001 } \\
\text { N001 }\end{array}$ & $\begin{array}{l}\text { NA } \\
\text { NA }\end{array}$ & $\begin{array}{l}U \\
U\end{array}$ & $M G / L$ & $<$ & $\begin{array}{l}0.05 \\
0.05\end{array}$ & L. & $\begin{array}{l}0.05 \\
0.05\end{array}$ & - \\
\hline
\end{tabular}

FORMATION OF COMPLETION CODE:

NA - NAVAJO SANDSTONE

PARAMETER VALUE INDICATOR (PVI): < - LESS THAN DETECTION LIMIT

OTHER PARAMETER VALUE FLAGS:

L - LESS THAN THREE BORE VOLUMES REMOVED BEFORE SAMPLING
FLOW RELATIONSHIP CODE:

U - UPGRADIENT

\section{SAMPLE ID CODES:}

0001 - FILTERED SAMPLE (.45 MICRONS)

N001 - UNFILTERED SAMPLE

DATA FILE NAME: IDARTISRK01\GWQ10078.DAT 
TABLE 3.38 BASELINE GROUND HATER QUALITY STATISTICS BY PARAMETER FOR THE NAVAJO SANDSTONE, UC PROCESSING SITE, SLICK ROCK, COLORADO

SITE: SRKO1 SLICK ROCK (BOTH SITES)

02/03/86 TO 02/21/94

REPORT DATE: 09/30/94

\begin{tabular}{|c|c|c|c|c|c|c|c|c|c|c|c|c|c|}
\hline \multicolumn{4}{|c|}{ PARAMETER NAME } & UNITS & \multirow[b]{2}{*}{ MEAN } & \multirow{2}{*}{$\begin{array}{r}\text { STANDARD } \\
\text { DEVIATION }\end{array}$} & \multirow{2}{*}{$\begin{array}{c}\text { COEFF. } \\
\text { OF } \\
\text { VARIATION }\end{array}$} & \multirow{2}{*}{$\mid \begin{array}{c}\% \text { OF } \\
\text { NON } \\
\text { DETECTS }\end{array}$} & \multirow{2}{*}{\multicolumn{3}{|c|}{$\begin{array}{c}\text { STATISTICAL RANGE } \\
\text { 98\% CONFIDENCE INTERVAL } \\
\text { MINIMUM } \\
\text { MAXIMUM * }\end{array}$}} & \multirow{2}{*}{$\begin{array}{c}\text { DISTRIBUTION } \\
\text { TYPE }\end{array}$} & \multirow{2}{*}{$\begin{array}{l}\text { FOOT } \\
\text { NOTE }\end{array}$} \\
\hline \# OF SAMP & MINIMUM & MAXIMUM & \multicolumn{2}{|c|}{ MEDIAN } & & & & & & & & & \\
\hline \multicolumn{4}{|l|}{ ALKALINITY } & MG/L CAC & \multirow[b]{2}{*}{273.6296} & \multirow[b]{2}{*}{43.9301} & \multirow[b]{2}{*}{0.1605} & \multirow[b]{2}{*}{0.0} & \multirow{2}{*}{\multicolumn{2}{|c|}{252.6713}} & \multirow[b]{2}{*}{294.5880} & \multirow[b]{2}{*}{ NORMAL } & \\
\hline 27 & 185.0000 & 360.0000 & & 272.0000 & & & & & & & & & \\
\hline \multicolumn{4}{|l|}{ ALUMINUM } & $M G / L$ & \multirow[b]{2}{*}{ NA } & \multirow[b]{2}{*}{ NA } & \multirow[b]{2}{*}{ NA } & \multirow[b]{2}{*}{70.8} & \multirow[b]{2}{*}{ ** } & \multirow[b]{2}{*}{0.0500} & \multirow[b]{2}{*}{0.1000} & \multirow[b]{2}{*}{ NONPARAMETRIC } & \multirow[b]{2}{*}{2} \\
\hline 24 & ** $\quad 0.0500$ & 0.4000 & + & 0.0500 & & & & & & & & & \\
\hline \multicolumn{4}{|l|}{ AMMONIUM } & $M G / L$ & \multirow[b]{2}{*}{ NA } & \multirow[b]{2}{*}{ NA } & \multirow[b]{2}{*}{ NA } & & & & & & \\
\hline 22 & $\begin{array}{ll}* * & 0.1000\end{array}$ & 1.7000 & ** & 0.1000 & & & & 59.1 & ** & 0.1000 & 0.2000 & NONPARAMETRIC & 2 \\
\hline AMMONIUM ( & (TOTAL) & & & $M G / L$ & & & & & & & & & \\
\hline 2 & $\begin{array}{ll}* & 0.1000\end{array}$ & 0.1000 & $* *$ & 0.1000 & NA & NA & NA & 100.0 & & NA & NA & UNKNOWN & 1 \\
\hline ANT IMONY & & & & $M G / L$ & & & & & & & & & \\
\hline 15 & $\begin{array}{ll}* & 0.0030\end{array}$ & 0.0090 & $\star *$ & 0.0030 & NA & NA & NA & 93.3 & ** & 0.0030 & 0.0030 & NONPARAMETRIC & 2 \\
\hline ARSENIC & & & & $M G / L$ & & & & & & & & & \\
\hline 21 & $\begin{array}{ll}* & 0.0050\end{array}$ & 0.0250 & & 0.0050 & NA & NA & NA & 52.4 & & 0.0050 & 0.0130 & NONPARAMETRIC & 2 \\
\hline BARIUM & & & & $M G / L$ & & & & & & & & & \\
\hline 20 & 0.0600 & 0.2000 & + & 0.1500 & 0.1440 & 0.0478 & 0.3322 & 0.0 & & 0.1168 & 0.1712 & NORMAL & \\
\hline BARIUM CTO & DTAL) & & & $M G / L$ & & & & & & & & & \\
\hline 2 & 0.2000 & 0.4000 & + & 0.3000 & NA & NA & NA & 0.0 & & NA & NA & UNKNOWN & 1 \\
\hline BERYLLIUM & & & & MG/L & & & & & & & & & \\
\hline 11 & $\begin{array}{ll}* * & 0.0050\end{array}$ & 0.0050 & ** & 0.0050 & NA & NA & NA & 100.0 & ** & 0.0050 & 0.0050 & NONPARAMETRIC & 2 \\
\hline BORON & & & & $M G / L$ & & & & & & & & & \\
\hline 16 & 0.1000 & 0.5500 & + & 0.3000 & 0.3006 & 0.1735 & 0.5770 & 0.0 & & 0.1878 & 0.4135 & NORMAL & \\
\hline
\end{tabular}

** The reported value is the minimum detection limit of the data set

* The sample size is even, so the median value is the arithmetic average of the two middle values

* The statistical maximum is the 99 percent one sided confidence interval, $\alpha=0.01$

1) A minimum of 4 samples must be available for the statistical analysis.

2) The nonparametric distribution was used because the nondetected values comprise more than $15 \%$ of the samples. 
TABLE 3.38 BASELINE GROUND WATER QUALITY STATISTICS BY PARAMETER FOR THE NAVAJO SANDSTONE, UC PROCESSING SITE, SLICK ROCK, COLORADO

SITE: SRKO1 SLICK ROCK (BOTH SITES)

02/03/86 TO $02 / 21 / 94$

REPORT DATE : 09/30/94

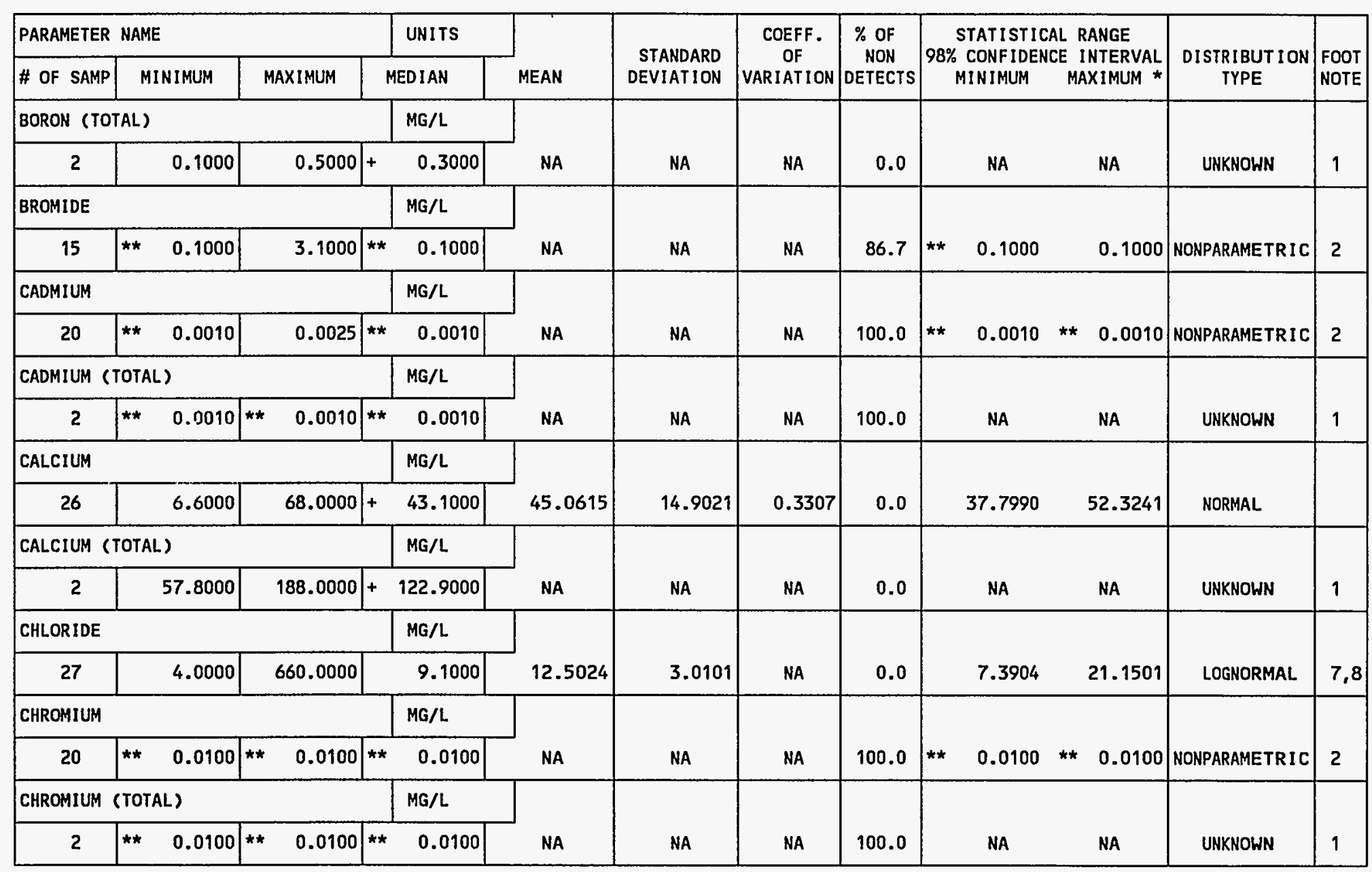

** The reported value is the minimum detection limit of the data set

+ The sample size is even, so the median value is the arithmetic average of the two middle values

* The statistical maximum is the 99 percent one sided confidence interval, $\alpha=0.01$

1) A minimum of 4 samples must be available for the statistical analysis.

2) The nonparametric distribution was used because the nondetected values comprise more than $15 \%$ of the samples.

7) The lognormal distribution was used because the data failed the normal distribution test.

8) The mean is geometric. The standard deviation is the value to divide or multiply with the geometric mean. 
TABLE 3.38 BASELINE GROUND HATER QUALITY STATISTICS BY PARAMETER FOR

THE NAVAJO SANDSTONE, UC PROCESSING SITE, SLICK ROCK, COLORADO

SITE: SRK01 SLICK ROCK (BOTH SITES)

02/03/86 TO 02/21/94

REPORT DATE: 09/30/94

\begin{tabular}{|c|c|c|c|c|c|c|c|c|c|c|c|c|c|c|c|c|}
\hline \multicolumn{6}{|c|}{ PARAMETER NAME } & UNITS & \multirow[b]{2}{*}{ MEAN } & \multirow{2}{*}{$\begin{array}{r}\text { STANDARD } \\
\text { DEVIATION }\end{array}$} & \multirow{2}{*}{$\begin{array}{c}\text { COEFF. } \\
\text { OF } \\
\text { VARIATION }\end{array}$} & \multirow{2}{*}{$\begin{array}{c}\% \text { OF } \\
\text { NON } \\
\text { DETECTS }\end{array}$} & \multirow{2}{*}{\multicolumn{4}{|c|}{$\begin{array}{l}\text { STATISTICAL RANGE } \\
\text { 98\% CONFIDENCE INTERVAL } \\
\text { MINIMUM }\end{array}$}} & \multirow{2}{*}{$\begin{array}{c}\text { DISTRIBUTION } \\
\text { TYPE }\end{array}$} & \multirow{2}{*}{$\begin{array}{l}\text { FOOT } \\
\text { NOTE }\end{array}$} \\
\hline \# OF SAMP & & NIMUM & & AXIMUM & \multicolumn{2}{|c|}{ MEDIAN } & & & & & & & & & & \\
\hline COBALT & & & & & & MG/L & \multirow[b]{2}{*}{ NA } & \multirow[b]{2}{*}{ NA } & \multirow[b]{2}{*}{ NA } & \multirow[b]{2}{*}{100.0} & \multirow[b]{2}{*}{ ** } & \multirow[b]{2}{*}{0.0300} & \multirow[b]{2}{*}{ ** } & \multirow[b]{2}{*}{0.0300} & \multirow[b]{2}{*}{ NONPARAMETRIC } & \multirow[b]{2}{*}{2} \\
\hline 11 & ** & 0.0300 & ** & 0.0300 & ** & 0.0300 & & & & & & & & & & \\
\hline \multicolumn{6}{|l|}{ COPPER } & $M G / L$ & \multirow[b]{2}{*}{ NA } & \multirow[b]{2}{*}{ NA } & \multirow[b]{2}{*}{ NA } & \multirow[b]{2}{*}{100.0} & \multirow[b]{2}{*}{ ** } & \multirow[b]{2}{*}{0.0100} & \multirow{2}{*}{\multicolumn{2}{|c|}{0.0100}} & \multirow[b]{2}{*}{ NONPARAMETRIC } & \multirow[b]{2}{*}{2} \\
\hline 18 & **. & 0.0100 & & 0.0100 & ** & 0.0100 & & & & & & & & & & \\
\hline \multicolumn{6}{|l|}{ CYANIDE } & $M G / L$ & \multirow[b]{2}{*}{ NA } & & & & & & & & & \\
\hline 12 & \#* & 0.0100 & ** & 0.0100 & ** & 0.0100 & & NA & NA & 100.0 & ** & 0.0100 & ** & 0.0100 & NONPARAMETRIC & 2 \\
\hline DISSOLVED & OXYG & & & & & MG/L & & & & & & & & & & \\
\hline 4 & & 0.3000 & & 5.4000 & + & 2.6500 & NA & NA & NA & 25.0 & & 0.3000 & & 5.4000 & NONPARAMETRIC & 2,4 \\
\hline FIELD FE & $(2+)$ & & & & & $M G / L$ & & & & & & & & & & \\
\hline 1 & & 0.0300 & & 0.0300 & & 0.0300 & NA & NA & NA & 0.0 & & NA & & NA & UNKNOWN & 1 \\
\hline FLUORIDE & & & & & & $M G / L$ & & & & & & & & & & \\
\hline 22 & & 0.2000 & & 1.4000 & + & 1.0000 & 0.8600 & 0.3412 & 0.3968 & 0.0 & & 0.6768 & & 1.0432 & NORMAL & \\
\hline GROSS ALP & & & & & & $\mathrm{PCI} / \mathrm{L}$ & & & & & & & & & & \\
\hline 17 & ** & 1.0000 & & 12.8000 & & 3.2000 & NA & NA & NA & 0.0 & ** & 1.0000 & & 5.8000 & NONPARAMETRIC & 9 \\
\hline GROSS ALP & HA $C T$ & OTAL) & & & & $\mathrm{PCI} / \mathrm{L}$ & & & & & & & & & & \\
\hline 2 & & 2.1000 & & 5.2000 & + & 3.6500 & NA & NA & NA & 0.0 & & NA & & NA & UNKNOWN & 1 \\
\hline GROSS BET & & & & & & PCI/L & & & & & & & & & & \\
\hline 15 & ** & 0.5000 & & 45.4000 & & 11.9000 & NA & NA & NA & 0.0 & & 5.6000 & & 16.6000 & NONPARAMETRIC & 9 \\
\hline
\end{tabular}

** The reported value is the minimum detection limit of the data se?

+ The sample size is even, so the median value is the arithmetic average of the two middle values

* The statistical maximum is the 99 percent one sided confidence interval, $\alpha=0.01$

1) A minimum of 4 samples must be available for the statistical analysis.

2) The nomparametric distribution was used because the nondetected values comprise more than $15 \%$ of the samples.

4) The stat. range is the $87.5 \%$ confidence interval due to a sample size of 4 . The maximum is the $93.8 \%$ one sided confidence int.

9) The nonparametic distribution was used because the data failed the normal distribution test and includes values $\leq 0$. 
TABLE 3.38 BASELINE GROUND HATER QUALITY STATISTICS BY PARAMETER FOR THE NAVAJO SANDSTONE, UC PROCESSING SITE, SLICK ROCK, COLORADO

SITE: SRKO1 SLICK ROCK (BOTH SITES)

02/03/86 TO 02/21/94

REPORT DATE: $09 / 30 / 94$

\begin{tabular}{|c|c|c|c|c|c|c|c|c|c|c|c|c|c|}
\hline \multicolumn{3}{|c|}{ PARAMETER NAME } & UNITS & \multirow[b]{2}{*}{ MEAN } & \multirow{2}{*}{$\begin{array}{r}\text { STANDARD } \\
\text { DEVIATION }\end{array}$} & \multirow{2}{*}{$\begin{array}{c}\text { COEFF. } \\
\text { OF } \\
\text { VARIATION }\end{array}$} & \multirow{2}{*}{$\begin{array}{c}\% \text { OF } \\
\text { NON } \\
\text { DETECTS }\end{array}$} & \multirow{2}{*}{\multicolumn{4}{|c|}{$\begin{array}{c}\text { STATISTICAL RANGE } \\
\text { 98\% CONFIDENCE } \\
\begin{array}{cc}\text { INTERVAL } \\
\text { MINIMUM } & \text { MAXIMUM * }\end{array}\end{array}$}} & \multirow{2}{*}{$\begin{array}{c}\text { DISTRIBUTION } \\
\text { TYPE }\end{array}$} & \multirow{2}{*}{$\begin{array}{l}\text { FOOT } \\
\text { NOTE }\end{array}$} \\
\hline \# OF SAMP & MINIMUM & MAXIMUM & MEDIAN & & & & & & & & & & \\
\hline \multicolumn{3}{|l|}{ IRON } & $\mathrm{MG} / \mathrm{L}$ & \multirow[b]{2}{*}{ NA } & \multirow[b]{2}{*}{ NA } & \multirow[b]{2}{*}{ NA } & \multirow[b]{2}{*}{53.8} & \multirow[b]{2}{*}{ ** } & \multirow[b]{2}{*}{0.0300} & \multirow{2}{*}{\multicolumn{2}{|c|}{0.0500}} & \multirow[b]{2}{*}{ NONPARAMETRIC } & \multirow[b]{2}{*}{2} \\
\hline 26 & $\begin{array}{ll}* \star & 0.0300\end{array}$ & 0.7400 & 0.0300 & & & & & & & & & & \\
\hline \multicolumn{3}{|c|}{ IRON (TOTAL) } & $\mathrm{MG} / \mathrm{L}$ & \multirow[b]{2}{*}{ NA } & \multirow[b]{2}{*}{ NA } & \multirow[b]{2}{*}{ NA } & \multirow[b]{2}{*}{50.0} & \multirow{2}{*}{\multicolumn{2}{|c|}{ NA }} & \multirow{2}{*}{\multicolumn{2}{|c|}{ NA }} & \multirow[b]{2}{*}{ UNKNOWN } & \multirow[b]{2}{*}{1} \\
\hline 2 & ** $\quad 0.0300$ & 8.2500 & 4.1325 & & & & & & & & & & \\
\hline \multicolumn{3}{|l|}{ LEAD } & $M G / L$ & \multirow[b]{2}{*}{ NA } & \multirow[b]{2}{*}{ NA } & & & & & & & & \\
\hline 18 & ** $\quad 0.0030$ & 0.0100 & $\begin{array}{ll}* & 0.0030\end{array}$ & & & NA & 100.0 & ** & 0.0030 & & 0.0050 & NONPARAMETRIC & 2 \\
\hline LEAD-210 & & & $\mathrm{PCI} / \mathrm{L}$ & & & & & & & & & & \\
\hline 8 & $\begin{array}{ll}* & 1.5000\end{array}$ & 1.5000 & 1.5000 & NA & NA & NA & 0.0 & ** & 1.5000 & $\star *$ & 1.5000 & NONPARAMETRIC & 9 \\
\hline LEAD-210 & (TOTAL) & & $\mathrm{PCI} / \mathrm{L}$ & & & & & & & & & & \\
\hline 2 & ** $\quad 1.8000$ & ** $\quad 1.8000$ & 1.8000 & NA & NA & NA & 0.0 & & NA & & NA & UNKNOWN & 1 \\
\hline MAGNESIUM & & & $\mathrm{MG} / \mathrm{L}$ & & & & & & & & & & \\
\hline 26 & 16.7000 & 41.1000 & $+\quad 35.0000$ & 32.7885 & 6.7611 & 0.2062 & 0.0 & & 29.4935 & & 36.0835 & NORMAL. & \\
\hline MAGNESIUM & (TOTAL) & & $M G / L$ & & & & & & & & & & \\
\hline 2 & 35.2000 & 42.5000 & 38.8500 & NA & NA & NA & 0.0 & & NA & & NA & UNKNOWN & 1 \\
\hline MANGANESE & & & $M G / L$ & & & & & & & & & & \\
\hline 26 & $\begin{array}{ll}* * & 0.0100\end{array}$ & 0.1800 & 0.0250 & NA & NA & NA & 38.5 & ** & 0.0100 & & 0.0700 & NONPARAMETRIC & 2 \\
\hline MANGANESE & (TOTAL) & & $M G / L$ & & & & & & & & & & \\
\hline 2 & $\star * \quad 0.0100$ & 0.3200 & 0.1625 & NA & NA & NA & 50.0 & & NA & & NA & UNKNOWN & 1 \\
\hline MERCURY & & & MG/L & & & & & & & & & & \\
\hline 15 & ** $\quad 0.0002$ & ** $\quad 0.0002$ & 0.0002 & NA & NA & NA & 100.0 & $* *$ & 0.0002 & $\star \star$ & 0.0002 & NONPARAMETRIC & 2 \\
\hline
\end{tabular}

** The reported value is the minimum detection limit of the data set

+ The sample size is even, so the median value is the arithmetic average of the two middle values

* The statistical maximum is the 99 percent one sided confidence interval, $\alpha=0.01$

1) A minimum of 4 samples must be available for the statistical analysis.

2) The nonparametric distribution was used because the nondetected values comprise more than $15 \%$ of the samples.

9) The nonparametic distribution was used because the data failed the normal. distribution test and includes values $\leq 0$. 
TABLE 3.38 BASELINE GROUND HATER QUALITY STATISTICS BY PARAMETER FOR THE NAVAJO SANDSTONE, UC PROCESSING SITE, SLICK ROCK, COLORADO

SITE: SRKOI SLICK ROCK (BOTH SITES)

02/03/86 TO 02/21/94

REPORT DATE: 09/30/94

\begin{tabular}{|c|c|c|c|c|c|c|c|c|c|c|c|c|c|c|c|}
\hline \multicolumn{5}{|c|}{ PARAMETER NAME } & UNITS & \multirow[b]{2}{*}{ MEAN } & \multirow{2}{*}{$\begin{array}{l}\text { STANDARD } \\
\text { DEVIATION }\end{array}$} & \multirow{2}{*}{$\begin{array}{c}\text { COEFF. } \\
\text { OF } \\
\text { VARIATION }\end{array}$} & \multirow{2}{*}{$\left|\begin{array}{c}\% \text { OF } \\
\text { NON } \\
\text { DETECTS }\end{array}\right|$} & \multirow{2}{*}{\multicolumn{4}{|c|}{$\begin{array}{c}\text { STATISTICAL RANGE } \\
\text { 98\% CONFIDENCE INTERVAL } \\
\text { MINIMUM }\end{array}$}} & \multirow{2}{*}{$\begin{array}{l}\text { DISTRIBUTION } \\
\text { TYPE }\end{array}$} & \multirow{2}{*}{$\begin{array}{l}\text { FOOT } \\
\text { NOTE }\end{array}$} \\
\hline \# OF SAMP & MINIMUM & & XIMUM & \multicolumn{2}{|c|}{ MEDIAN } & & & & & & & & & & \\
\hline MOLYBDENUM & & & & & MG/L & \multirow[b]{2}{*}{ NA } & \multirow[b]{2}{*}{ NA } & \multirow[b]{2}{*}{ NA } & \multirow[b]{2}{*}{60.0} & \multirow[b]{2}{*}{$\star \star *$} & \multirow[b]{2}{*}{0.0100} & \multirow{2}{*}{\multicolumn{2}{|c|}{0.0200}} & \multirow[b]{2}{*}{ NONPARAMETRIC } & \multirow[b]{2}{*}{2} \\
\hline 25 & ** $\quad 0.0100$ & & 0.1700 & $\star \star$ & 0.0100 & & & & & & & & & & \\
\hline \multicolumn{5}{|c|}{ MOLYYBDENUM (TOTAL) } & $M G / L$ & \multirow[b]{2}{*}{ NA } & \multirow[b]{2}{*}{ NA } & \multirow[b]{2}{*}{ NA } & \multirow[b]{2}{*}{100.0} & \multirow{2}{*}{\multicolumn{2}{|c|}{ NA }} & \multirow{2}{*}{\multicolumn{2}{|c|}{ NA }} & \multirow[b]{2}{*}{ UNKNOWN } & \multirow[b]{2}{*}{1} \\
\hline 2 & ** $\quad 0.0100$ & $* *$ & 0.0100 & ** & 0.0100 & & & & & & & & & & \\
\hline \multicolumn{5}{|c|}{ NET GROSS ALPHA $\quad * \star \star$} & PCI/L & \multirow[b]{2}{*}{ NA } & \multirow[b]{2}{*}{ NA } & \multirow[b]{2}{*}{ NA } & & & & & & & \\
\hline 17 & -4.8700 & & 7.3600 & & 0.9600 & & & & 0.0 & & -1.3700 & & 5.1600 & NONPARAMETRIC & 9 \\
\hline NET GROSS & ALPHA (TOTAL & L) * & & & $\mathrm{PCI} / \mathrm{L}$ & & & & & & & & & & \\
\hline 2 & -4.0700 & & 4.5100 & + & 0.2200 & NA & NA & NA & 0.0 & & NA & & NA & UNKNOWN & 1 \\
\hline NICKELL & & & & & $\mathrm{MG} / \mathrm{L}$ & & & & & & & & & & \\
\hline 21 & ** $\quad 0.0400$ & ** & 0.0400 & $\star \star$ & 0.0400 & NA & NA & NA & 85.7 & ** & 0.0400 & $\star *$ & 0.0400 & NONPARAMETRIC & 2 \\
\hline NITRATE & & & & & $\mathrm{MG} / \mathrm{L}$ & & & & & & & & & & \\
\hline 24 & 0.4000 & & 7.9000 & + & 1.0000 & NA & NA & NA & 33.3 & & 0.5000 & & 2.5000 & NONPARAMETRIC & 2 \\
\hline NITRATE (T & TOTAL) & & & & $\mathrm{MG} / \mathrm{L}$ & & & & & & & & & & \\
\hline 2 & ** $\quad 1.0000$ & & 2.0000 & + & 1.2500 & NA & NA & NA & 50.0 & & NA & & NA & UNKNOWN & 1 \\
\hline NITRITE AN & ND NITRATE & & & & MG/L & & & & & & & & & & \\
\hline 12 & 0.2700 & & 1.0000 & + & 0.5400 & NA & NA & NA & 25.0 & & 0.3800 & & 0.9700 & NONPARAMETRIC & 2 \\
\hline PH & & & & & SU & & & & & & & & & & \\
\hline 28 & 6.9800 & & 8.8900 & + & 7.4299 & NA & NA & NA & 0.0 & & NA & & NA & UNKNOWN & \\
\hline
\end{tabular}

*** NET GROSS ALPHA (GROSS ALPHA - URANIUM) WITH 1 MG URANIUM $\square 686$ PCI

**** NET GROSS ALPHA (TOTAL) (TOTAL GROSS ALPHA - TOTAL URANIUM)

** The reported value is the minimum detection limit of the data set

+ The sample size is even, so the median value is the arithmetic average of the two middle values

* The statistical maximum is the 99 percent one sided confidence interval, $\alpha=0.01$

1) A minimum of 4 samples must be available for the statistical analysis.

2) The nonparametric distribution was used because the nondetected values comprise more than $15 \%$ of the samples.

9) The nonparametic distribution was used because the data failed the normal distribution test and includes values $\leq 0$. 
TABLE 3.38 BASELINE GROUND WATER QUALITY STATISTICS BY PARAMETER FOR THE NAVAJO SANDSTONE, UC PROCESSING SITE, SLICK ROCK, COLORADO

SITE: SRKO1 SLICK ROCK

$02 / 03 / 86$ TO $02 / 21 / 94$

REPORT DATE : 09/30/94

\begin{tabular}{|c|c|c|c|c|c|c|c|c|c|c|c|c|c|}
\hline \multicolumn{4}{|c|}{ PARAMETER NAME } & UNITS & \multirow[b]{2}{*}{ MEAN } & \multirow{2}{*}{$\begin{array}{r}\text { STANDARD } \\
\text { DEVIATION }\end{array}$} & \multirow{2}{*}{$\begin{array}{c}\text { COEFF. } \\
\text { OF } \\
\text { VARIATION }\end{array}$} & \multirow{2}{*}{$\begin{array}{c}\% \text { OF } \\
\text { NON } \\
\text { DETECTS }\end{array}$} & \multirow{2}{*}{\multicolumn{3}{|c|}{$\begin{array}{c}\text { STATISTICAL RANGE } \\
\text { 98\% CONFIDENCE INTERVAL } \\
\text { MINIMUM } \\
\text { MAXIMUM * }\end{array}$}} & \multirow{2}{*}{$\begin{array}{l}\text { DISTRIBUTION } \\
\text { TYPE }\end{array}$} & \multirow{2}{*}{$\begin{array}{l}\text { FOOT } \\
\text { NOTE }\end{array}$} \\
\hline \# OF SAMP & MINIMUM & MAXIMUM & & MEDIAN & & & & & & & & & \\
\hline \multicolumn{4}{|l|}{ PHOSPHATE } & $M G / L$ & \multirow[b]{2}{*}{ NA } & \multirow[b]{2}{*}{ NA } & \multirow[b]{2}{*}{ NA } & \multirow[b]{2}{*}{84.2} & \multirow{2}{*}{\multicolumn{2}{|c|}{0.0500}} & \multirow[b]{2}{*}{0.0500} & \multirow[b]{2}{*}{ NONPARAMETRIC } & \multirow[b]{2}{*}{2} \\
\hline 19 & ** $\quad 0.0100$ & 0.2000 & & 0.0500 & & & & & & & & & \\
\hline \multicolumn{4}{|c|}{ POLONIUM-210 } & $\mathrm{PCI} / \mathrm{L}$ & \multirow[b]{2}{*}{ NA } & \multirow[b]{2}{*}{$N A$} & \multirow[b]{2}{*}{ NA } & \multirow[b]{2}{*}{0.0} & \multirow[b]{2}{*}{ ** } & \multirow[b]{2}{*}{0.1000} & \multirow[b]{2}{*}{0.4000} & \multirow[b]{2}{*}{ NONPARAMETRIC } & \multirow[b]{2}{*}{9} \\
\hline 8 & ** 0.1000 & 0.4000 & + & 0.1500 & & & & & & & & & \\
\hline \multicolumn{4}{|c|}{ POLONIUM-210 (TOTAL) } & $\mathrm{PCl} / \mathrm{L}$ & \multirow[b]{2}{*}{ NA } & \multirow[b]{2}{*}{ NA } & \multirow[b]{2}{*}{ NA } & & & & & & \\
\hline 2 & 0.1000 & 0.1000 & + & 0.1000 & & & & 0.0 & & NA & NA & UNKNOWN & 1 \\
\hline POTASSIUM & & & & $M G / L$ & & & & & & & & & \\
\hline 26 & 4.6100 & 47.0000 & + & 12.6500 & 12.6304 & 8.9792 & 0.7109 & 0.0 & & 8.2544 & 17.0064 & NORMAL & \\
\hline POTASSIUM & (TOTAL) & & & $M G / L$ & & & & & & & & & \\
\hline 2 & 4.9000 & 12.6000 & + & 8.7500 & NA & NA & NA & 0.0 & & NA & NA & UNKNOWN & 1 \\
\hline RADIUM-22C & & & & $\mathrm{PCI} / \mathrm{L}$ & & & & & & & & & \\
\hline 23 & 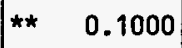 & 1.0000 & & 0.5000 & NA & NA & NA & 0.0 & & 0.1000 & 0.7000 & NONPARAMETRIC & 9 \\
\hline RADIUM-22 & 6 (TOTAL) & & & $\mathrm{PCI} / \mathrm{L}$ & & & & & & & & & \\
\hline 2 & 0.1000 & 1.3000 & + & 0.7000 & NA & NA & NA & 0.0 & & NA & NA & UNKNOWN & 1 \\
\hline RADIUM-22 & $6+$ RADIUM -2 & & & $\mathrm{PCI} / \mathrm{L}$ & & & & & & & & & \\
\hline 20 & 0.0000 & 8.3000 & + & 1.5500 & NA & NA & NA & 0.0 & & 1.0000 & 3.3000 & NONPARAMETRIC & 9 \\
\hline RADIUM-22 & $6+$ RADIUM-2 & (TOTAL) & & $\mathrm{PCl} / \mathrm{L}$ & & & & & & & & & \\
\hline 2 & 1.4000 & 4.4000 & + & 2.9000 & NA & NA & NA & 0.0 & & NA & NA & UNKNOWN & 1 \\
\hline RADIUM-22 & & & & $\mathrm{PCI} / \mathrm{L}$ & & & & & & & & & \\
\hline 20 & ** $\quad 1.0000$ & 7.4000 & t+ & 1.2500 & NA & NA & NA & 0.0 & 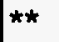 & 1.0000 & 3.2000 & NONPARAMETRIC & 9 \\
\hline
\end{tabular}

** The reported value is the minimum detection limit of the data set

+ The sample size is even, so the median value is the arithmetic average of the two middle values

* The statistical maximum is the 99 percent one sided confidence interval, $\alpha=0.01$

1) A minimum of 4 samples must be available for the statistical analysis.

2) The nonparametric distribution was used because the nondetected values comprise more than $15 \%$ of the samples.

9) The nonparametic distribution was used because the data fajled the normal distribution test and includes values $\leq 0$. 
TABLE 3.38 BASELINE GROUND WATER QUALITY STATISTICS BY PARAMETER FOR THE NAVAJO SANDSTONE, UC PROCESSING SITE, SLICK ROCK, COLORADO

SITE: SRKO1 SLICK ROCK (BOTH SITES)

$02 / 03 / 86$ TO 02/21/94

REPORT DATE: $09 / 30 / 94$

\begin{tabular}{|c|c|c|c|c|c|c|c|c|c|c|c|}
\hline \multicolumn{3}{|c|}{ PARAMETER NAME } & UNITS & \multirow[b]{2}{*}{ MEAN } & \multirow{2}{*}{$\begin{array}{r}\text { STANDARD } \\
\text { DEVIATION }\end{array}$} & \multirow{2}{*}{$\begin{array}{c}\text { COEFF. } \\
\text { OF } \\
\text { VARIATION }\end{array}$} & \multirow{2}{*}{$\begin{array}{l}\% \text { OF } \\
\text { NON } \\
\text { DETECTS }\end{array}$} & \multirow{2}{*}{\multicolumn{2}{|c|}{$\begin{array}{l}\text { STATISTICAL RANGE } \\
\text { 98\% CONFIDENCE INTERVAL } \\
\text { MINIMUM } \\
\text { MAXIMUM * }\end{array}$}} & \multirow{2}{*}{$\begin{array}{c}\text { DISTRIBUTION } \\
\text { TYPE }\end{array}$} & \multirow{2}{*}{$\begin{array}{l}\text { FOOT } \\
\text { NOTE }\end{array}$} \\
\hline \# OF SAMP & MINIMUM & MAXIMUM & MEDIAN & & & & & & & & \\
\hline \multicolumn{3}{|c|}{ RADIUM-228 (TOTAL) } & $\mathrm{PCI} / \mathrm{L}$ & \multirow[b]{2}{*}{ NA } & \multirow[b]{2}{*}{ NA } & \multirow[b]{2}{*}{ NA } & \multirow[b]{2}{*}{0.0} & \multirow[b]{2}{*}{ NA } & \multirow[b]{2}{*}{ NA } & \multirow[b]{2}{*}{ UNKNOWN } & \multirow[b]{2}{*}{1} \\
\hline 2 & ** $\quad 2.8000$ & 3.1000 & 2.8000 & & & & & & & & \\
\hline \multicolumn{3}{|c|}{ REDOX POTENTIAL } & mVOLTS & \multirow[b]{2}{*}{358.2667} & \multirow[b]{2}{*}{97.8578} & \multirow[b]{2}{*}{0.2731} & \multirow[b]{2}{*}{0.0} & \multirow[b]{2}{*}{263.8013} & \multirow[b]{2}{*}{452.7320} & \multirow[b]{2}{*}{ NORMAL } & \\
\hline 9 & 189.0000 & 438.5000 & 400.0000 & & & & & & & & \\
\hline \multicolumn{3}{|l|}{ SELENIUM } & $M G / L$ & \multirow[b]{2}{*}{ NA } & \multirow[b]{2}{*}{ NA } & \multirow[b]{2}{*}{ NA } & \multirow[b]{2}{*}{95.7} & \multirow[b]{2}{*}{0.0050} & & & \\
\hline 23 & ** $\quad 0.0050$ & 0.0150 & 0.0050 & & & & & & ** 0.0050 & NONPARAMETRIC & 2 \\
\hline SELENIUM ( & (TOTAL) & & MG/L & & & & & & & & \\
\hline 2 & ** $\quad 0.0050$ & $* \quad 0.0050$ & 0.0050 & NA & NA & NA & 100.0 & NA & NA & UNKNOWN & 1 \\
\hline SILICA - S & $\$ 102$ & & MG/L & & & & & & & & \\
\hline 23 & 5.9000 & 14.8000 & 10.8000 & 10.5870 & 1.8555 & 0.1753 & 0.0 & 9.6166 & 11.5573 & NORMAL & \\
\hline SILICA - S & SIO2 (TOTAL) & & MG/L & & & & & & & & \\
\hline 2 & 0.3000 & 10.9000 & 5.6000 & NA & NA & NA & 0.0 & NA & NA & UNKNOWN & 1 \\
\hline SILVER & & & $M G / L$ & & & & & & & & \\
\hline 15 & 0.0100 & ** $\quad 0.0100$ & 0.0100 & NA & NA & NA & 100.0 & 0.0100 & 0.0100 & NONPARAMETRIC & 2 \\
\hline SODIUM & & & $M G / L$ & & & & & & & & \\
\hline 26 & 9.3800 & 52.1000 & 16.5000 & 22.6569 & 10.7824 & 0.4759 & 0.0 & 17.4021 & 27.9117 & NORMAL & \\
\hline SODIUM (TO & DTAL) & & MG/L & & & & & & & & \\
\hline 2 & 15.0000 & 28.0000 & 21.5000 & NA & NA & NA & 0.0 & NA & NA. & UNKNOWN & 1 \\
\hline SPECIFIC C & CONDUCTANCE & & UMHO/CH & & & & & & & & \\
\hline 25 & 250.0000 & 713.0000 & 390.0000 & 447.1600 & 137.7748 & 0.3081 & 0.0 & 378.4930 & 515.8270 & NORMAL & \\
\hline
\end{tabular}

** The reported value is the minimum detection limit of the data set

+ The sample size is even, so the median value is the arithmetic average of the two middle values

* The statistical maximum is the 99 percent one sided confidence interval, $\alpha=0.01$

1) A minimum of 4 samples must be available for the statistical analysis.

2) The nonparametric distribution was used because the nondetected values comprise more than $15 \%$ of the samples. 
TABLE 3.38 BASELINE GROUND WATER QUALITY STATISTICS BY PARAMETER FOR THE NAVAJO SANDSTONE, UC PROCESSING SITE, SLICK ROCK, COL.ORADO

SITE: SRK01 SLICK ROCK (BOTH SITES)

02/03/86 TO 02/21/94

REPORT DATE: $09 / 30 / 94$

\begin{tabular}{|c|c|c|c|c|c|c|c|c|c|c|c|}
\hline \multicolumn{3}{|c|}{ PARAMETER NAME } & UNITS & \multirow[b]{2}{*}{ MEAN } & \multirow{2}{*}{$\begin{array}{l}\text { STANDARD } \\
\text { DEVIATION }\end{array}$} & \multirow{2}{*}{$\begin{array}{c}\text { COEFF. } \\
\text { OF } \\
\text { VARIATION }\end{array}$} & \multirow{2}{*}{$\begin{array}{l}\% \text { OF } \\
\text { NON } \\
\text { DETECTS }\end{array}$} & \multirow{2}{*}{\multicolumn{2}{|c|}{ 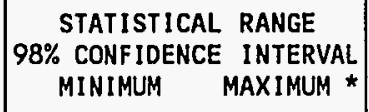 }} & \multirow{2}{*}{$\begin{array}{l}\text { DISTRIBUTION } \\
\text { TYPE }\end{array}$} & \multirow{2}{*}{$\begin{array}{l}\text { FOOT } \\
\text { NOTE }\end{array}$} \\
\hline \# OF SAMP & MINIMUM & MAXIMUM & MEDIAN & & & & & & & & \\
\hline \multicolumn{3}{|l|}{ STRONTIUM } & $M G / L$ & \multirow[b]{2}{*}{1.1038} & \multirow[b]{2}{*}{0.4186} & \multirow[b]{2}{*}{0.3793} & \multirow[b]{2}{*}{0.0} & \multirow[b]{2}{*}{0.8314} & \multirow[b]{2}{*}{1.3761} & \multirow[b]{2}{*}{ NORMAL } & \\
\hline 16 & 0.6500 & 1.7700 & 1.0150 & & & & & & & & \\
\hline \multicolumn{3}{|c|}{ STRONTIUM (TOTAL) } & $M G / L$ & \multirow[b]{2}{*}{ NA } & \multirow[b]{2}{*}{ NA } & \multirow[b]{2}{*}{ NA } & \multirow[b]{2}{*}{0.0} & \multirow[b]{2}{*}{ NA } & \multirow[b]{2}{*}{ NA } & \multirow[b]{2}{*}{ UNKNOWN } & \multirow[b]{2}{*}{1} \\
\hline 2 & 0.6700 & 2.7400 & 1.7050 & & & & & & & & \\
\hline \multicolumn{3}{|l|}{ SULFATE } & MG/L & \multirow[b]{2}{*}{30.1000} & \multirow[b]{2}{*}{17.4361} & \multirow[b]{2}{*}{0.5793} & \multirow[b]{2}{*}{0.0} & \multirow[b]{2}{*}{21.7815} & \multirow[b]{2}{*}{38.4185} & & \\
\hline 27 & 12.3000 & 100.0000 & 24.3000 & & & & & & & NORMAL & \\
\hline SULFIDE & & & $M G / L$ & & & & & & & & \\
\hline 18 & $* * \quad 0.1000$ & 6.7000 & 0.2000 & NA & NA & NA & 44.4 & 0.1000 & 0.8000 & NONPARAMETRIC & 2 \\
\hline TEMPERATUR & & & C - DEGRE & & & & & & & & \\
\hline 28 & 7.3000 & 15.0000 & 13.0000 & 12.6786 & 1.5673 & 0.1236 & 0.0 & 11.9461 & 13.4111 & NORMAL & \\
\hline THALLIUM & & & $M G / L$ & & & & & & & & \\
\hline 14 & $\star \star \quad 0.0050$ & 0.0050 & 0.0050 & NA & NA & NA & 100.0 & 0.0050 & 0.0050 & NONPARAMETRIC & 2 \\
\hline THORIUM-23 & & & $\mathrm{PCI} / \mathrm{L}$ & & & & & & & & \\
\hline 8 & $\begin{array}{ll}* & 0.2000\end{array}$ & 0.8000 & 0.3500 & NA & NA & NA & 0.0 & 0.2000 & 0.8000 & NONPARAMETRIC & 9 \\
\hline THORIUM-23 & 30 (TOTAL) & & $\mathrm{PCI} / \mathrm{L}$ & & & & & & & & \\
\hline 2 & 0.2000 & 0.3000 & 0.2500 & NA & NA & NA & 0.0 & NA & NA & UNKNOWN & 1 \\
\hline TIN & & & $M G / L$ & & & & & & & & \\
\hline 14 & $\begin{array}{ll}* * & 0.0050\end{array}$ & 0.0050 & 0.0050 & NA & NA & NA & 100.0 & 0.0050 & 0.0050 & NONPARAMETRIC & 2 \\
\hline TOTAL DISS & SOLVED SOLIDS & & MG/L & & & & & & & & \\
\hline 27 & 222.0000 & 1760.0000 & 310.0000 & 374.1111 & 282.4415 & 0.7550 & 0.0 & 239.3629 & 508.8594 & NORMAL & \\
\hline
\end{tabular}

** The reported value is the minimum detection Limit of the data set

+ The sample size is even, so the median value is the arithmetic average of the two middle values

* The statistical maximum is the 99 percent one sided confidence interval, $\alpha=0.01$

1) A minimum of 4 samples must be available for the statistical analysis.

2) The nonparametric distribution was used because the nondetected values comprise more than $15 \%$ of the samples.

9) The nonparametic distribution was used because the data failed the normal distribution test and includes values $\leq 0$. 
TABLE 3.38 BASELINE GROUND WATER QUALITY STATISTICS BY PARAMETER FOR

THE NAVAJO SANDSTONE, UC PROCESSING SITE, SLICK ROCK, COLORADO

SITE: SRKO1 SLICK ROCK (BOTH SITES)

$02 / 03 / 86$ TO $02 / 21 / 94$

REPORT DATE: 09/30/94

\begin{tabular}{|c|c|c|c|c|c|c|c|c|c|c|c|c|}
\hline \multicolumn{3}{|c|}{ PARAMETER NAME } & UNITS & \multirow[b]{2}{*}{ MEAN } & \multirow{2}{*}{$\begin{array}{r}\text { STANDARD } \\
\text { DEVIATION }\end{array}$} & \multirow{2}{*}{$\begin{array}{c}\text { COEFF. } \\
\text { OF } \\
\text { VARIATION }\end{array}$} & \multirow{2}{*}{$\begin{array}{l}\% \text { OF } \\
\text { NON } \\
\text { DETECTS }\end{array}$} & \multirow{2}{*}{\multicolumn{3}{|c|}{$\begin{array}{l}\text { STATISTICAL RANGE } \\
\text { 98\% CONFIDENCE INTERVAL } \\
\text { MINIMUM }\end{array}$}} & \multirow{2}{*}{$\begin{array}{c}\text { DISTRIBUTION } \\
\text { TYPE }\end{array}$} & \multirow{2}{*}{$\begin{array}{l}\text { FOOT } \\
\text { NOTE }\end{array}$} \\
\hline \# OF SAMP & HINIMUM & MAXIMUM & MED IAN & & & & & & & & & \\
\hline \multicolumn{3}{|c|}{ TOTAL KJELDAHL NITROGEN } & $M G / L$ & \multirow[b]{2}{*}{ NA } & \multirow[b]{2}{*}{ NA } & \multirow[b]{2}{*}{ NA } & \multirow[b]{2}{*}{66.7} & \multirow[b]{2}{*}{ ** } & \multirow[b]{2}{*}{1.0000} & \multirow[b]{2}{*}{1.0000} & \multirow[b]{2}{*}{ NONPARAMETRIC } & \multirow[b]{2}{*}{2} \\
\hline 12 & ** $\quad 1.0000$ & 1.0000 & 1.0000 & & & & & & & & & \\
\hline \multicolumn{3}{|c|}{ TOTAL ORGANIC CARBON } & $M G / L$ & \multirow[b]{2}{*}{ NA } & \multirow[b]{2}{*}{ NA } & \multirow[b]{2}{*}{ NA } & \multirow[b]{2}{*}{52.9} & \multirow[b]{2}{*}{ ** } & \multirow[b]{2}{*}{1.0000} & \multirow[b]{2}{*}{7.0000} & \multirow[b]{2}{*}{ NONPARAMETRIC } & \multirow[b]{2}{*}{2} \\
\hline 17 & 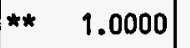 & 66.0000 & 1.0000 & & & & & & & & & \\
\hline \multicolumn{3}{|l|}{ TURBIDITY } & NTU & \multirow[b]{2}{*}{ NA } & \multirow[b]{2}{*}{ NA } & \multirow[b]{2}{*}{ NA } & & & & & & \\
\hline 1 & 0.0000 & 0.0000 & 0.0000 & & & & 0.0 & & NA & NA & UNKNOWN & 1 \\
\hline URANIUM & & & MG/L & & & & & & & & & \\
\hline 27 & ** $\quad 0.0003$ & 0.1000 & 0.0015 & NA & NA & NA & 37.0 & & 0.0005 & 0.0083 & NONPARAMETRIC & 2 \\
\hline URANIUM (T & (OTAL) & & MG/L & & & & & & & & & \\
\hline 2 & 0.0010 & 0.0090 & 0.0050 & NA & NA & NA & 0.0 & & NA & NA & UNKNOWN & 1 \\
\hline VANADIUM & & & $M G / L$ & & & & & & & & & \\
\hline 23 & ** $\quad 0.0100$ & 0.4300 & 0.0100 & NA & NA & NA & 78.3 & ** & 0.0100 & 0.0100 & NONPARAMETRIC & 2 \\
\hline VANADIUM & (TOTAL) & & $M G / L$ & & & & & & & & & \\
\hline 2 & ** $\quad 0.0100$ & 0.0100 & 0.0100 & NA & NA & NA & 50.0 & & NA & NA & UNKNOWN & 1 \\
\hline ZINC & & & $M G / L$ & & & & & & & & & \\
\hline 20 & $\begin{array}{ll}* & 0.0050\end{array}$ & 0.0360 & 0.0050 & NA & NA & NA & 75.0 & ** & 0.0050 & 0.0160 & NONPARAMETRIC & 2 \\
\hline ZINC (TOTI & AL) & & MG/L & & & & & & & & & \\
\hline 2 & $\begin{array}{ll}* & 0.0500\end{array}$ & 0.0500 & 0.0500 & NA & NA & NA & 100.0 & & NA & NA & UNKNOWN & 1 \\
\hline
\end{tabular}

** The reported value is the minimum detection limit of the data set

+ The sample size is even, so the median value is the arithmetic average of the two middle values

* The statistical maximum is the 99 percent one sided confidence interval, $\alpha=0.01$

1) A minimum of 4 samples must be available for the statistical analysis.

2) The nonparametric distribution was used because the nondetected values comprise more than $15 \%$ of the samples.

INPUT DATA FILENAME: IDARTISRKOI \GWQ10079.DAT 
Table 3.39 Summary of regulated constituents in the Navajo Sandstone baseline ground water, UC processing site, Slick Rock, Colorado

\begin{tabular}{llccc}
\hline \multicolumn{4}{c}{ Constituents with MCLs } \\
\hline \multicolumn{1}{c}{ Parameter } & $\begin{array}{l}\text { Baseline } \\
\text { median }\end{array}$ & $\begin{array}{c}\text { Baseline } \\
\text { stat max }\end{array}$ & $\begin{array}{c}\text { Background } \\
\text { stat max }\end{array}$ & MCL \\
\hline Arsenic & $0.01^{\mathrm{g}}$ & $0.013^{\mathrm{e}}$ & $0.01^{\mathrm{e}}$ & 0.05 \\
Barium & $0.14^{\mathrm{d}}$ & $0.17^{\mathrm{d}}$ & $0.20^{\mathrm{e}}$ & 1.00 \\
Cadmium & $0.001^{\mathrm{g}}$ & $0.001^{\mathrm{g}}$ & $0.001^{\mathrm{g}}$ & 0.01 \\
Chromium & $0.01^{\mathrm{g}}$ & $0.01^{\mathrm{g}}$ & $0.01^{\mathrm{g}}$ & 0.05 \\
Net gross alpha & $0.96^{\mathrm{f}}$ & $5.16^{\mathrm{e}}$ & $2.54^{\mathrm{e}}$ & 15.00 \\
Lead & $0.01^{\mathrm{g}}$ & $0.01^{\mathrm{g}}$ & $0.01^{\mathrm{g}}$ & 0.05 \\
Mercury & $0.0002^{\mathrm{g}}$ & $0.0002^{\mathrm{g}}$ & $0.0002^{\mathrm{g}}$ & 0.002 \\
Molybdenum & $0.01^{\mathrm{e}}$ & $0.02^{\mathrm{e}}$ & $0.06^{\mathrm{e}}$ & 0.10 \\
Nitrate & $1.0^{\mathrm{g}}$ & $2.5^{\mathrm{e}}$ & $5.7^{\mathrm{e}}$ & 44.0 \\
Radium-226,-228 & $1.55^{\mathrm{e}}$ & $3.30^{\mathrm{e}}$ & $4.02^{\mathrm{c}}$ & 5.0 \\
Selenium & $0.005^{\mathrm{g}}$ & $0.005^{\mathrm{g}}$ & $0.025^{\mathrm{e}}$ & 0.01 \\
Silver & $0.01^{\mathrm{g}}$ & $0.01^{\mathrm{g}}$ & $0.30^{\mathrm{e}}$ & 0.05 \\
Uranium & $0.002^{\mathrm{e}}$ & $0.008^{\mathrm{e}}$ & $0.017^{\mathrm{c}}$ & 0.044 \\
\hline
\end{tabular}


Table 3.39 Summary of regulated constituents in the Navajo Sandstone baseline ground water, UC processing site, Slick Rock, Colorado (Concluded)

\begin{tabular}{llccc}
\hline \multicolumn{4}{c}{ Constituents without MCLs } & \\
\hline \multicolumn{1}{c}{ Parameter } & $\begin{array}{l}\text { Baseline } \\
\text { median }\end{array}$ & $\begin{array}{c}\text { Baseline } \\
\text { stat max }\end{array}$ & $\begin{array}{c}\text { Background } \\
\text { stat. max }\end{array}$ & MCL \\
\hline Antimony & $0.003^{g}$ & $0.003^{g}$ & $0.003^{g}$ & None \\
Beryllium & $0.01^{g}$ & $0.01^{g}$ & $0.01^{g}$ & None \\
Cobalt & $0.05^{g}$ & $0.05^{g}$ & $0.05^{g}$ & None \\
Copper & $0.02^{g}$ & $0.02^{g}$ & $0.02^{g}$ & None \\
Cyanide & $0.01^{g}$ & $0.01^{g}$ & $0.01^{g}$ & None \\
Nickel & $0.04^{g}$ & $0.04^{g}$ & $0.04^{g}$ & None \\
Sulfide & $0.2^{\mathrm{e}}$ & $0.8^{\mathrm{e}}$ & $20.9^{\mathrm{g}}$ & None \\
Thallium & $0.01^{\mathrm{g}}$ & $0.01^{\mathrm{g}}$ & $0.01^{\mathrm{g}}$ & None \\
Tin & $0.005^{\mathrm{g}}$ & $0.005^{\mathrm{g}}$ & $0.025^{\mathrm{e}}$ & None \\
Vanadium & $0.01^{\mathrm{g}}$ & $0.01^{\mathrm{g}}$ & $0.01^{\mathrm{g}}$ & None \\
Zinc & $0.005^{\mathrm{g}}$ & $0.06^{\mathrm{g}}$ & $0.025^{\mathrm{g}}$ & None \\
\hline
\end{tabular}

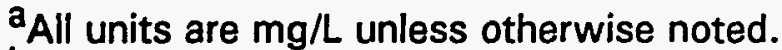

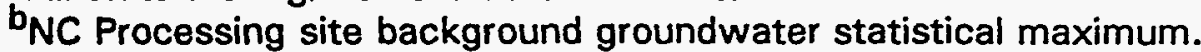

CLognormal distribution, mean is geometric.

${ }^{d}$ Normal distribution, mean is arithmetic.

ONonparametric distribution

Units are $\mathrm{pCi} / \mathrm{L}$.

9Statistical values are below laboratory detection limits in Table 8.1 of the Technical Approach Document (DOE, 1989). 
TABLE 3.40 GROUND HATER QUAL ITY MEASUREMENTS EXCEEDING MCLS IN NAVAJO

SANDSTONE BASELINE GROUND WATER, UC SITE, SLICK ROCK, COLORADO

SITE: SRKO1 SLICK ROCK (BOTH SITES)

02/03/86 TO 02/21/94

REPORT DATE: $09 / 30 / 94$

\begin{tabular}{|c|c|c|c|c|c|c|c|c|c|c|c|}
\hline PARAMETER NAME & $\begin{array}{l}\text { TOTAL } \\
\text { \# OF } \\
\text { SAMP. }\end{array}$ & $\begin{array}{l}\text { UNITS } \\
\text { OF } \\
\text { MEASURE }\end{array}$ & $\begin{array}{c}\text { MAXIMUM } \\
\text { CONC. } \\
\text { LIMIT }\end{array}$ & Loc. & LOG DATE & SAMP & $\begin{array}{l}\text { FORM } \\
\text { OF } \\
\text { COMP }\end{array}$ & $\begin{array}{l}\text { HYDR } \\
\text { FLOH } \\
\text { REL. }\end{array}$ & $\begin{array}{l}\text { RESULT EXCEEDING MAX. } \\
\text { CONCENTRATION LIMIT } \\
\text { VALUE FLAGS }\end{array}$ & $\begin{array}{l}\text { DETECTION } \\
\text { LIMIT }\end{array}$ & $\begin{array}{l}\text { PARAMETER } \\
\text { UNCERT. }\end{array}$ \\
\hline ARSENIC & 21 & $M G / L$ & 0.0500 & - & - & - & - & - & - & - & - \\
\hline ARSENIC (TOTAL) & 0 & $M G / L$ & 0.0500 & - & - & - & - & - & - & - & - \\
\hline BARIUM & 20 & $M G / L$ & 1.0000 & - & - & - & - & - & - & - & - \\
\hline BARIUM (TOTAL) & 2 & $M G / L$ & 1.0000 & - & - & - & - & - & - & - & - \\
\hline CADMIUM & 20 & $M G / L$ & 0.0100 & - & - & - & - & - & - & - & - \\
\hline CADMIUM (TOTAL) & 2 & $M G / L$ & 0.0100 & - & - & - & - & - & - & - & - \\
\hline CHROMIUM & 20 & $M G / L$ & 0.0500 & - & - & - & - & - & - & - & - \\
\hline CHROMIUM (TOTAL) & 2 & $M G / L$ & 0.0500 & - & - & - & - & - & - & - & - \\
\hline GROSS ALPHA & 17 & PCI/L & 15.0000 & - & - & - & - & - & - & - & - \\
\hline GROSS ALPHA (TOTAL) & 2 & $\mathrm{PCI} / \mathrm{L}$ & 15.0000 & - & - & - & - & - & - & - & - \\
\hline LEAD & 18 & $M G / L$ & 0.0500 & - & - & - & - & - & - & - & - \\
\hline LEAD (TOTAL) & 0 & $M G / L$ & 0.0500 & - & - & - & - & - & - & - & - \\
\hline MERCURY & 15 & MG/L & 0.0020 & - & - & $\cdot$ & - & - & - & - & - \\
\hline MERCURY (TOTAL) & 0 & $M G / L$ & 0.0020 & - & - & - & - & - & - & - & - \\
\hline MOLYBDENUM & 25 & MG $/ L$ & 0.1000 & $\begin{array}{l}0669 \\
0670 \\
0688 \\
0688\end{array} \mid$ & $\mid \begin{array}{l}06 / 30 / 86 \\
07 / 19 / 86 \\
07 / 17 / 86 \\
04 / 08 / 87\end{array}$ & $\left|\begin{array}{l}0001 \\
0001 \\
0001 \\
0001\end{array}\right|$ & $\begin{array}{l}\text { NA } \\
\text { NA } \\
\text { NA } \\
\text { NA }\end{array}$ & $\begin{array}{l}U \\
U \\
U \\
U\end{array}$ & $\begin{array}{ll}0.17 & L \\
0.14 & L \\
0.15 & \\
0.1 & \end{array}$ & $\begin{array}{l}0.01 \\
0.01 \\
0.01 \\
0.1\end{array}$ & $\begin{array}{l}- \\
- \\
-\end{array}$ \\
\hline MOLYBDENUM (TOTAL) & 2 & $M G / L$ & 0.1000 & - & - & - & - & - & - & - & - \\
\hline NET GROSS ALPHA * & 17 & PCI/L & 15.0000 & - & - & - & - & - & - & - & - \\
\hline
\end{tabular}

< - THE dATA IS FLAGged AS a NON-DETECT, SO THE RESULt IS AN ESTIMATED VALUE OR THE DETECTION LIMIT
* Net GROSS alPHA (GROSS ALPHA - URANIUM)
HITH 1 MG URANIUM $=686 \mathrm{PCI}$

FORMATION OF COMPLETION CODE:

NA - NAVAJO SANDSTONE

FLOW RELATIONSHIP CODE:

$L$ - LESS THAN THREE BORE VOLUMES REMOVED BEFORE SAMPLING $U$ - UPGRADIENT

SAMPLE ID CODES:

0001 - FILTERED SAMPLE (.45 MICRONS) 
TABLE 3.40 GROUND HATER QUALITY MEASUREMENTS EXCEEDIHG MCLS IN NAVAJO

SANDSTONE BASELINE GROUND HATER, UC SITE, SLICK ROCK, COLORADO

SITE: SRK01 SLICK ROCK (BOTH SITES)

02/03/86 TO 02/21/94

REPORT DATE: $09 / 30 / 94$

\begin{tabular}{|c|c|c|c|c|c|c|c|c|c|c|c|}
\hline PARAMETER NAME & $\begin{array}{l}\text { TOTAL } \\
\# \text { OF } \\
\text { SAMP. }\end{array}$ & $\begin{array}{c}\text { UNITS } \\
\text { OF } \\
\text { MEASURE }\end{array}$ & \begin{tabular}{|} 
MAXIMUM \\
CONC. \\
LIMIT
\end{tabular} & Loc. & LOG DATE & $\underset{\text { ID }}{\text { SAMP }}$ & $\begin{array}{l}\text { FORM } \\
\text { OF } \\
\text { COMP }\end{array}$ & $\begin{array}{l}\text { HYDR } \\
\text { FLOW } \\
\text { REL. }\end{array}$ & $\begin{array}{c}\text { RESULT EXCEEDING MAX. } \\
\text { CONCENTRATION LIMIT } \\
\text { VALUE FLAGS }\end{array}$ & $\begin{array}{l}\text { DETECTION } \\
\text { LIMIT }\end{array}$ & $\begin{array}{l}\text { PARAMETER } \\
\text { UNCERT. }\end{array}$ \\
\hline NET GROSS ALPHA (TOTAL) ** & 2 & PCI/L & 15.0000 & - & - & - & - & - & - & - & - \\
\hline NITRATE & 24 & MG/L & 44.0000 & - & - & - & - & - & - & - & - \\
\hline NITRATE (TOTAL) & 2 & MG/L & 44.0000 & - & - & - & - & - & - & - & - \\
\hline$R A-226 \& R A-228$ & 20 & PCI/L & 5.0000 & $\begin{array}{l}0669 \\
0669\end{array}$ & $\begin{array}{l}03 / 31 / 91 \\
02 / 20 / 94\end{array}$ & $\begin{array}{l}0001 \\
0001\end{array} \mid$ & $\begin{array}{l}\text { NA } \\
\text { NA }\end{array}$ & $\begin{array}{l}u \\
u\end{array}$ & $\begin{array}{l}8.3 \\
5.7\end{array}$ & 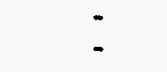 & - \\
\hline RA-226 \& RA-228 (TOTAL) & 2 & $\mathrm{PCI} / \mathrm{L}$ & 5.0000 & - & - & - & - & - & - & - & - \\
\hline SELENIUM & 23 & $M G / L$ & 0.0100 & $\mid \begin{array}{l}0669 \\
0670\end{array}$ & $\begin{array}{l}03 / 31 / 91 \\
04 / 01 / 91\end{array}$ & $\begin{array}{l}0001 \\
0001\end{array}$ & $\begin{array}{l}\text { NA } \\
\text { NA }\end{array}$ & $\begin{array}{l}u \\
u\end{array}$ & $\begin{array}{ll}0.03 & \text { IJL } \\
0.03 & \text { I JL }\end{array}$ & $\begin{array}{l}0.03 \\
0.03\end{array}$ & $\overline{-}$ \\
\hline SELENIUM (TOTAL) & 2 & MG/L & 0.0100 & $=$ & - & - & - & - & - & - & - \\
\hline SILVER & 15 & MG/L & 0.0500 & $=$ & - & - & - & - & - & - & - \\
\hline SILVER (TOTAL) & 0 & $M G / L$ & 0.0500 & - & - & - & - & - & - & - & - \\
\hline URANIUM & 27 & $M G / L$ & 0.0440 & 0688 & $10 / 14 / 87$ & 0001 & NA & $\mathbf{U}$ & 0.10 & 0.003 & - \\
\hline URANIUM (TOTAL) & 2 & $M G / L$ & 0.0440 & - & - & - & - & - & - & - & - \\
\hline
\end{tabular}

** TOTAL NET GROSS ALPHA (TOTAL GROSS ALPHA - TOTAL URANIUM)

WITH 1 MG DISSOLVED URANIUM $=686 \mathrm{PCI}$

FORMATION OF COMPLETION CODE:

NA - NAVAJO SANDSTONE

FLOW RELATIONSHIP CODE:

OTHER PARAMETER VALUE FLAGS:

I - INCREASED DETECTION LIMIT DUE TO REQUIRED DILUTION $U$ - UPGRADIENT

$J$ - ESTIMATED VALUE

SAMPLE ID CODES:

L - LESS THAN THREE BORE VOLUMES REMOVED BEFORE SAMPLING

0001 - FILTERED SAMPLE (.45 MICRONS)

DATA FILE NAME: IDARTISRK01\GHQ10080.DAT 
Table 3.41 Information for Private Wells Located in the Vicinity of the Slick Rock Processing Sites

\begin{tabular}{|c|c|c|c|c|c|c|}
\hline $\begin{array}{l}\text { Permit } \\
\quad \text { No. } \\
\end{array}$ & $\begin{array}{l}\text { TAf } \\
\text { ID }\end{array}$ & $\begin{array}{l}\text { Date(s) } \\
\text { Sampled }\end{array}$ & $\begin{array}{c}\text { Total/Casing } \\
\text { Depth (ft) }\end{array}$ & Aquifer & Well Status & Water Use \\
\hline $25342 \mathrm{~F}$ & 672 & $\begin{array}{l}7 / 86 \\
4 / 91 \\
2 / 94 \\
\end{array}$ & Unknown & Unknown & Active & $\begin{array}{l}\text { Domestic } \\
\text { Stock }\end{array}$ \\
\hline $2135 F$ & 635 & $6 / 86$ & $80 / 20-60$ & Morrison & Inactive & $\begin{array}{l}\text { Industrial } \\
\text { Domestic }\end{array}$ \\
\hline $15805 \mathrm{~F}$ & 805 & $\begin{array}{l}4 / 91 \\
2 / 94 \\
\end{array}$ & 200/Unknown & Unknown & Active & $\begin{array}{l}\text { Industrial } \\
\text { Domestic }\end{array}$ \\
\hline $4483 \mathrm{~F}$ & NA & NA & Unknown & Unknown & Unknown & Industrial \\
\hline $2164 \mathrm{~F}$ & NA & NA & $202 / 10-202$ & $\begin{array}{l}\text { Alluvial, } \\
\text { Entrada, } \\
\text { Navajo }\end{array}$ & Inactive & $\begin{array}{l}\text { Industrial } \\
\text { Domestic }\end{array}$ \\
\hline $2165 \mathrm{~F}$ & NA & NA & $152 / 10-152$ & $\begin{array}{l}\text { Alluvial, } \\
\text { Entrada }\end{array}$ & Inactive & $\begin{array}{l}\text { Industrial } \\
\text { Domestic }\end{array}$ \\
\hline $2166 \mathrm{~F}$ & NA & NA & $150 / 10-150$ & $\begin{array}{l}\text { Alluvial, } \\
\text { Entrada }\end{array}$ & Inactive & $\begin{array}{l}\text { Industrial } \\
\text { Domestic }\end{array}$ \\
\hline $2163 F$ & NA & NA & $152 / 12-152$ & $\begin{array}{l}\text { Alluvial, } \\
\text { Entrada } \\
\end{array}$ & Inactive & $\begin{array}{l}\text { Industrial } \\
\text { Domestic }\end{array}$ \\
\hline $2134 \mathrm{~F}$ & 634 & $\begin{array}{r}6 / 86 \\
10 / 87 \\
2 / 88 \\
\end{array}$ & $125 / 20-125$ & $\begin{array}{l}\text { Alluvial, } \\
\text { Entrada, } \\
\text { Navajo }\end{array}$ & Inactive? & $\begin{array}{l}\text { Industrial } \\
\text { Domestic }\end{array}$ \\
\hline $2133 F$ & NA & NA & $40 / 20-40$ & Entrada & Inactive & $\begin{array}{l}\text { Industrial } \\
\text { Domestic }\end{array}$ \\
\hline $2167 F$ & NA & NA & $200 / 5-200$ & $\begin{array}{l}\text { Entrada, } \\
\text { Navajo }\end{array}$ & Inactive & $\begin{array}{l}\text { Industrial } \\
\text { Domestic }\end{array}$ \\
\hline $2168 \mathrm{~F}$ & NA & NA & $106 / 43-106$ & $\begin{array}{l}\text { Entrada, } \\
\text { Navajo }\end{array}$ & Sealed? & $\begin{array}{l}\text { Industrial } \\
\text { Domestic }\end{array}$ \\
\hline $15806 \mathrm{~F}$ & 806 & NA & 125/Unknown & Unknown & Inactive? & $\begin{array}{l}\text { Industrial } \\
\text { Domestic }\end{array}$ \\
\hline 142293 & NA & NA & 800/Unknown & Unknown & Unknown & Unknown \\
\hline NA & NA & NA & Unknown & Unknown & Inactive? & Unknown \\
\hline NA & NA & NA & Unknown & Unknown & Sealed? & Unknown \\
\hline NA & NA & NA & Unknown & Unknown & Sealed? & Unknown \\
\hline NA & 675 & $6 / 86$ & Unknown & Unknown & Inactive $^{2}$ & $\begin{array}{l}\text { Domestic } \\
\text { Stock }\end{array}$ \\
\hline NA & 807 & $2 / 94$ & Surface seep & Entrada & Active & Stock \\
\hline
\end{tabular}

${ }^{1}$ Location ID nos. as shown in Figure 3.1.

2 Well was inactive in June 1986 but was inactive in February 1994.

NA - Information not available. 
TABLE 3.42. MONITORING HELL INFORMATION FOR THE

BURRO CAHYON DISPOSAL SITE, SLICK ROCK, COLORADO

SITE: SRKO2 BORROW SITE 1 (BURRO CANYON)

REPORT DATE: 03/07/94

\begin{tabular}{|c|c|c|c|c|c|c|c|c|c|c|c|c|}
\hline$\underset{\text { ID }}{\text { LOCATION }}$ & $\begin{array}{c}\text { NORTH } \\
\text { COORDINATE } \\
\text { (FT) }\end{array}$ & $\begin{array}{c}\text { EAST } \\
\text { COORDINATE } \\
\text { (FT) }\end{array}$ & $\begin{array}{c}\text { GROUND } \\
\text { ELEVATION } \\
\text { (FT MSL) }\end{array}$ & $\begin{array}{l}\text { BOREHOLE } \\
\text { DEPTH } \\
\text { (FT) }\end{array}$ & $\begin{array}{l}\text { BOREHOLE } \\
\text { DIAMETER } \\
\text { (INCHES) }\end{array}$ & $\begin{array}{l}\text { CASING } \\
\text { ELEVATION } \\
\text { (FT MSL) }\end{array}$ & $\begin{array}{l}\text { CASING } \\
\text { DEPTH } \\
\text { (FT) }\end{array}$ & $\begin{array}{l}\text { CASING } \\
\text { DIAMETER } \\
\text { (INCHES) }\end{array}$ & $\begin{array}{c}\text { SCREEN } \\
\text { BEGINNING } \\
\text { DEPTH (FT) }\end{array}$ & $\begin{array}{l}\text { SCREEN } \\
\text { LENGTH } \\
\text { (FT) }\end{array}$ & $\begin{array}{l}\text { FLOH } \\
\text { CODE }\end{array}$ & $\begin{array}{l}\text { FORMATION } \\
\text { OF } \\
\text { COMPLETION }\end{array}$ \\
\hline $\begin{array}{l}0516 \\
0517 \\
0518 \\
0519 \\
0520 \\
0521 \\
0522 \\
0523 \\
0524 \\
0525 \\
0526 \\
0527 \\
0528 \\
0529 \\
0551 \\
0552\end{array}$ & $\begin{array}{l}19099.00 \\
19217.00 \\
19959.00 \\
19960.00 \\
19974.00 \\
19621.00 \\
19670.00 \\
19620.00 \\
19012.06 \\
19023.44 \\
18859.00 \\
18873.00 \\
20137.00 \\
20126.00 \\
18590 \\
18920\end{array}$ & $\begin{array}{l}21931.00 \\
22547.00 \\
21745.00 \\
21758.00 \\
21748.00 \\
22459.00 \\
22470.00 \\
22476.00 \\
21702.85 \\
21712.23 \\
22153.00 \\
22141.00 \\
22121.00 \\
22114.00 \\
22770 \\
22830\end{array}$ & $\begin{array}{l}5862.4 \\
5870.2 \\
5897.0 \\
5897.1 \\
5897.8 \\
5875.0 \\
5874.6 \\
5875.0 \\
5848.9 \\
5849.1 \\
5833.8 \\
\mathbf{5 8 3 4 . 6} \\
5896.8 \\
5896.6 \\
\mathbf{5 8 2 3 . 0} \\
\mathbf{5 8 4 3}\end{array}$ & $\begin{array}{l}225 . \\
340 . \\
109 . \\
338 . \\
240.5 \\
353 . \\
235 . \\
125 . \\
295.5 \\
203 . \\
207 . \\
81 . \\
223 . \\
119 . \\
112 \\
179\end{array}$ & $\begin{array}{l}6.13 \\
6.13 \\
8 . \\
8 . \\
8 . \\
8 . \\
8 . \\
8 . \\
8 . \\
8 . \\
8 . \\
8 . \\
8 . \\
8 . \\
5.875 \\
7.25\end{array}$ & $\begin{array}{l}5864.36 \\
5871.80 \\
5898.03 \\
5898.12 \\
5899.49 \\
5876.05 \\
5876.50 \\
5876.39 \\
5850.72 \\
5850.89 \\
5835.42 \\
5836.51 \\
5898.37 \\
5898.51 \\
5824.5 \\
5844.5\end{array}$ & $\begin{array}{l}225 . \\
340 . \\
109 . \\
338 . \\
240.5 \\
352 . \\
235 . \\
125 . \\
295.5 \\
203 . \\
207 . \\
81 . \\
223 . \\
119 . \\
112 \\
100.5\end{array}$ & $\begin{array}{l}2 . \\
2 . \\
4 . \\
4 . \\
4 . \\
4 . \\
4 . \\
4 . \\
4 . \\
4 . \\
4 . \\
4 . \\
4 . \\
4 . \\
2 \\
2\end{array}$ & $\begin{array}{c}213 . \\
328 . \\
97 . \\
316 . \\
218.5 \\
330 \\
203 . \\
103 . \\
273.5 \\
171 . \\
175 . \\
59 . \\
201 . \\
107 . \\
90 \\
78.15\end{array}$ & $\begin{array}{l}10 . \\
10 . \\
10 \\
20 . \\
20 . \\
20 \\
30 . \\
20 . \\
20 . \\
30 . \\
30 . \\
20 . \\
20 . \\
10 . \\
20 \\
20\end{array}$ & $\begin{array}{l}0 \\
0 \\
0 \\
0 \\
0 \\
0 \\
0 \\
0 \\
0 \\
0 \\
0 \\
0 \\
0 \\
0 \\
0 \\
0\end{array}$ & $\begin{array}{l}\text { MB } \\
\text { LB } \\
\text { UB } \\
\text { LB } \\
\text { MB } \\
\text { LB } \\
\text { MB } \\
\text { UB } \\
\text { LB } \\
\text { MB } \\
\text { MB } \\
\text { UB } \\
\text { MB } \\
\text { UB } \\
\text { UB } \\
\text { UB }\end{array}$ \\
\hline
\end{tabular}

FORMATION OF COMPLETION CODE:

MB - MIDDLE BURRO CANYON

FLOW RELATIONSHIP CODE:

LB - LOWER BUPRO CANYON

O - ON-SITE

UB - UPPER BURRO CANYON

DATA FILE: M: \DART \SRK02 \MWI 10006.DAT 
TABLE 3.43 STATIC GROUND HATER LEVELS FOR THE BURRO CANYON

DISPOSAL SI TE, SLICK ROCK, COLORADO

SITE: SRKO2 BORROW SITE ?' (BURRO CANYON)

REPORT DATE : 09/30/94

\begin{tabular}{|c|c|c|c|c|c|c|c|c|c|c|c|}
\hline$\underset{10}{\text { LOCATION }}$ & $\begin{array}{l}\text { NORTH } \\
\text { COORDINATE } \\
\text { (FT) }\end{array}$ & $\begin{array}{l}\text { EAST } \\
\text { COORDINATE } \\
\text { (FT) }\end{array}$ & $\begin{array}{l}\text { FORMATION } \\
\text { OF } \\
\text { COMPLETION }\end{array}$ & $\begin{array}{l}\text { FLOW } \\
\text { CODE }\end{array}$ & $\begin{array}{l}\text { CASING } \\
\text { ELEVATION } \\
\text { (FT MSL) }\end{array}$ & $\begin{array}{l}\text { GROUND } \\
\text { ELEVATION } \\
\text { (FT MSL) }\end{array}$ & LOG DATE & $\begin{array}{l}\text { LOG } \\
\text { TIME }\end{array}$ & $\begin{array}{l}\text { OEPTH FROM } \\
\text { TOP OF } \\
\text { CASING (FT) }\end{array}$ & $\begin{array}{c}\text { DEPTH FROM } \\
\text { GROUND } \\
\text { (FT) }\end{array}$ & $\begin{array}{l}\text { GROUNDWATER } \\
\text { ELEVATION } \\
\text { (FT MSL) }\end{array}$ \\
\hline 0516 & 19099.00 & 21931.00 & MB & 0 & 5864.36 & 5862.4 & $\begin{array}{l}02 / 12 / 90 \\
04 / 13 / 90 \\
05 / 05 / 90 \\
12 / 02 / 90 \\
12 / 07 / 90 \\
04 / 02 / 91 \\
08 / 25 / 91 \\
10 / 14 / 92 \\
02 / 21 / 94 \\
04 / 05 / 94 \\
04 / 20 / 94\end{array}$ & $\begin{array}{l}15: 05 \\
08: 30 \\
09: 05 \\
10: 10 \\
10: 00 \\
15: 21 \\
09: 00 \\
10: 52 \\
17: 01 \\
13: 30 \\
10: 54\end{array}$ & $\begin{array}{l}215 . \\
125.75 \\
124.9 \\
127.01 \\
127.73 \\
127.42 \\
127.64 \\
127.71 \\
127.25 \\
127.35 \\
127.56\end{array}$ & $\begin{array}{l}213.04 \\
123.79 \\
122.94 \\
125.05 \\
125.77 \\
125.46 \\
125.68 \\
125.75 \\
125.29 \\
125.39 \\
125.60\end{array}$ & $\begin{array}{l}5649.36 \\
5738.61 \\
5739.46 \\
5737.35 \\
5736.63 \\
5736.94 \\
5736.72 \\
5736.65 \\
5737.11 \\
5737.01 \\
5736.80\end{array}$ \\
\hline 0517 & 19217.00 & 22547.00 & LB & 0 & 5871.80 & 5870.2 & $\begin{array}{l}04 / 13 / 90 \\
05 / 05 / 90 \\
12 / 02 / 90 \\
12 / 07 / 90 \\
04 / 02 / 91 \\
08 / 25 / 91 \\
10 / 14 / 92 \\
02 / 21 / 94 \\
04 / 05 / 94 \\
04 / 20 / 94\end{array}$ & $\begin{array}{l}08: 40 \\
09: 10 \\
10: 54 \\
14: 30 \\
16: 09 \\
10: 30 \\
15: 11 \\
16: 40 \\
13: 35 \\
10: 06\end{array}$ & $\begin{array}{l}102.6 \\
102.8 \\
103.11 \\
103.15 \\
103.52 \\
103.09 \\
102.64 \\
102.89 \\
102.92 \\
103.75\end{array}$ & $\begin{array}{l}101.00 \\
101.20 \\
101.51 \\
101.55 \\
101.92 \\
101.49 \\
101.04 \\
101.29 \\
101.32 \\
102.15\end{array}$ & $\begin{array}{l}5769.20 \\
5769.00 \\
5768.69 \\
5768.65 \\
5768.28 \\
5768.71 \\
5769.16 \\
5768.91 \\
5768.88 \\
5768.05\end{array}$ \\
\hline 0518 & 19959.00 & 21745.00 & UB & 0 & 5898.03 & 5897.0 & $\begin{array}{l}03 / 31 / 90 \\
04 / 03 / 90 \\
04 / 13 / 90 \\
05 / 05 / 90 \\
12 / 02 / 90 \\
12 / 12 / 90 \\
03 / 31 / 91 \\
08 / 23 / 91 \\
10 / 11 / 92 \\
02 / 21 / 94 \\
04 / 04 / 94 \\
04 / 20 / 94\end{array}$ & $\begin{array}{l}10: 00 \\
08: 00 \\
08: 50 \\
09: 20 \\
10: 24 \\
15: 10 \\
13: 05 \\
14: 25 \\
10: 34 \\
17: 00 \\
15: 35 \\
10: 46\end{array}$ & $\begin{array}{l}103.5 \\
102.5 \\
102.1 \\
101.2 \\
102.70 \\
102.25 \\
103.55 \\
102.78 \\
102.80 \\
102.49 \\
102.35 \\
102.64\end{array}$ & $\begin{array}{l}102.47 \\
101.47 \\
101.07 \\
100.17 \\
101.67 \\
101.22 \\
102.52 \\
101.75 \\
101.77 \\
101.46 \\
101.32 \\
101.61\end{array}$ & $\begin{array}{l}5794.53 \\
5795.53 \\
5795.93 \\
5796.83 \\
5795.33 \\
5795.78 \\
5794.48 \\
5795.25 \\
5795.23 \\
5795.54 \\
5795.68 \\
5795.39\end{array}$ \\
\hline 0519 & 19960.00 & 21758.00 & L.B & 0 & 5898.12 & 5897.1 & $\begin{array}{l}03 / 31 / 90 \\
04 / 01 / 90 \\
04 / 03 / 90 \\
04 / 13 / 90\end{array}$ & $\begin{array}{l}07: 50 \\
10: 50 \\
08: 05 \\
09: 00\end{array}$ & $\begin{array}{l}160 . \\
112 . \\
91 . \\
84.75\end{array}$ & $\begin{array}{r}158.98 \\
110.98 \\
89.98 \\
83.73\end{array}$ & $\begin{array}{l}5738.12 \\
5786.12 \\
5807.12 \\
5813.37\end{array}$ \\
\hline
\end{tabular}

FORMATION OF COHPLETION CODE:

MB - MIDDLE BURRO CANYON

FLOW RELATIONSHIP CODE:

LB - LOHER BURRO CANYON

O - ON-SITE

UB - UPPER BURRO CAYYON 
TABLE 3.43 STATIC GROUND HATER LEVELS FOR THE BURRO CANYON

DISPOSAL SITE, SLICK ROCK, COLORADO

SITE: SRKO2 BORROW SITE I (BURRO CANYON)

REPORT DATE: 09/30/94

\begin{tabular}{|c|c|c|c|c|c|c|c|c|c|c|c|}
\hline$\underset{\text { ID }}{\text { LOCATION }}$ & $\begin{array}{c}\text { NORTH } \\
\text { COORDINATE } \\
\text { (FT) }\end{array}$ & $\begin{array}{c}\text { EAST } \\
\text { COORDINATE } \\
\text { (FT) }\end{array}$ & \begin{tabular}{|} 
FORMATION \\
OF \\
COMPLETION
\end{tabular} & $\begin{array}{l}\text { FLOW } \\
\text { CODE }\end{array}$ & $\begin{array}{l}\text { CASING } \\
\text { ELEVATION } \\
\text { (FT MSL) }\end{array}$ & $\begin{array}{l}\text { GROUND } \\
\text { ELEVATION } \\
\text { (FT MSL) }\end{array}$ & LOG DATE & $\begin{array}{l}\text { LOG } \\
\text { TIME }\end{array}$ & $\begin{array}{c}\text { DEPTH FROH } \\
\text { TOP OF } \\
\text { CASING (FT) }\end{array}$ & $\begin{array}{l}\text { DEPTH FROM } \\
\text { GROUND } \\
\text { (FT) }\end{array}$ & $\begin{array}{l}\text { GROUNDWATER } \\
\text { ELEVATION } \\
\text { (FT MSL) }\end{array}$ \\
\hline 0519 & 19960.00 & 21758.00 & LB & 0 & 5898.12 & 5897.1 & $\begin{array}{l}05 / 05 / 90 \\
12 / 02 / 90 \\
12 / 12 / 90 \\
03 / 31 / 91 \\
08 / 22 / 91 \\
10 / 11 / 92 \\
02 / 21 / 94 \\
04 / 04 / 94 \\
04 / 20 / 94\end{array}$ & $\begin{array}{l}09: 25 \\
10: 27 \\
11: 00 \\
11: 15 \\
09: 15 \\
08: 58 \\
16: 58 \\
15: 38 \\
10: 44\end{array}$ & $\begin{array}{l}82.3 \\
81.91 \\
81.75 \\
82.55 \\
81.95 \times \\
80.63 \\
81.37 \\
81.35 \\
82.72\end{array}$ & $\begin{array}{l}81.28 \\
80.89 \\
80.73 \\
81.53 \\
80.93 \\
79.61 \\
80.35 \\
80.33 \\
81.70\end{array}$ & $\begin{array}{l}5815.82 \\
5816.21 \\
5816.37 \\
5815.57 \\
5816.17 \\
5817.49 \\
5816.75 \\
5816.77 \\
5815.40\end{array}$ \\
\hline 0520 & 19974.00 & 21748.00 & MB & 0 & 5899.49 & 5897.8 & $\begin{array}{l}04 / 03 / 90 \\
04 / 13 / 90 \\
05 / 05 / 90 \\
12 / 02 / 90 \\
12 / 11 / 90 \\
03 / 31 / 91 \\
08 / 22 / 91 \\
10 / 11 / 92 \\
02 / 21 / 94 \\
04 / 04 / 94 \\
04 / 20 / 94\end{array}$ & $\begin{array}{l}08: 10 \\
09: 10 \\
09: 30 \\
10: 22 \\
13: 00 \\
10: 41 \\
10: 47 \\
11: 42 \\
16: 57 \\
15: 39 \\
10: 49\end{array}$ & $\begin{array}{l}151 . \\
150.2 \\
149.9 \\
151.15 \\
150.75 \\
151.75 \\
151.85 \\
151.26 \\
151.39 \\
151.42 \\
151.68\end{array}$ & $\begin{array}{l}149.31 \\
148.51 \\
148.21 \\
149.46 \\
149.06 \\
150.06 \\
150.16 \\
149.57 \\
149.70 \\
149.73 \\
149.99\end{array}$ & $\begin{array}{l}5748.49 \\
5749.29 \\
5749.59 \\
5748.34 \\
5748.74 \\
5747.74 \\
5747.64 \\
5748.23 \\
5748.10 \\
5748.07 \\
5747.81\end{array}$ \\
\hline 0521 & 19621.00 & 22459.00 & LB & 0 & 5876.05 & 5875.0 & $\begin{array}{l}04 / 04 / 90 \\
04 / 10 / 90 \\
04 / 13 / 90 \\
05 / 05 / 90 \\
12 / 02 / 90 \\
12 / 05 / 90 \\
03 / 31 / 91 \\
08 / 25 / 91 \\
10 / 12 / 92 \\
02 / 21 / 94 \\
04 / 05 / 94 \\
04 / 20 / 94\end{array}$ & $\begin{array}{l}11: 15 \\
16: 35 \\
09: 20 \\
09: 35 \\
10: 46 \\
09: 30 \\
13: 58 \\
14: 40 \\
11: 16 \\
16: 45 \\
13: 40 \\
10: 25\end{array}$ & $\begin{array}{c}160 . \\
80.5 \\
89.5 \\
82.8 \\
76.94 \\
77.02 \\
77.46 \\
76.74 \\
76.39 \\
76.43 \\
76.43 \\
78.15\end{array}$ & $\begin{array}{r}158.95 \\
79.45 \\
88.45 \\
81.75 \\
75.89 \\
75.97 \\
76.41 \\
75.69 \\
75.34 \\
75.38 \\
75.38 \\
77.10\end{array}$ & $\begin{array}{l}5716.05 \\
5795.55 \\
5786.55 \\
5793.25 \\
5799.11 \\
5799.03 \\
5798.59 \\
5799.31 \\
5799.66 \\
5799.62 \\
5799.62 \\
5797.90\end{array}$ \\
\hline 0522 & 19670.00 & 22470.00 & MB & 0 & 5876.50 & 5874.6 & $\begin{array}{l}04 / 13 / 90 \\
05 / 05 / 90 \\
12 / 02 / 90 \\
12 / 05 / 90 \\
03 / 31 / 91 \\
08 / 22 / 91\end{array}$ & $\begin{array}{l}09: 30 \\
09: 40 \\
10: 42 \\
14: 20 \\
15: 00 \\
17: 20\end{array}$ & $\begin{array}{l}135.0 \\
134.8 \\
136.19 \\
136.26 \\
136.81 \\
137.76\end{array}$ & $\begin{array}{l}133.10 \\
132.90 \\
134.29 \\
134.36 \\
134.91 \\
135.86\end{array}$ & $\begin{array}{l}5741.50 \\
5741.70 \\
5740.31 \\
5740.24 \\
5739.69 \\
5738.74\end{array}$ \\
\hline
\end{tabular}

FORMATION OF COMPLETION CODE:

LB - LOWER BURRO CANYON

MB - MIDDLE BURRO CANYON
FLOW RELATIONSHIP CODE:

O - ON-SITE 
TABLE 3.43 STATIC GROUND WATER LEVELS FOR THE BURRO CANYON

DISPOSAL SITE, SLICK ROCK, COLORADO

SITE: SRKO2 BORROW SITE 1 (BURRO CANYON)

REPORT DATE : 09/30/94

\begin{tabular}{|c|c|c|c|c|c|c|c|c|c|c|c|}
\hline$\underset{\text { ID }}{\text { LOCATION }}$ & $\begin{array}{l}\text { NORTH } \\
\text { COORDINATE } \\
\text { (FT) }\end{array}$ & $\begin{array}{c}\text { EAST } \\
\text { COORDINATE } \\
\text { (FT) }\end{array}$ & $\begin{array}{l}\text { FORMATION } \\
\text { OF } \\
\text { COMPLETION }\end{array}$ & $\begin{array}{l}\text { FLOW } \\
\text { CODE }\end{array}$ & $\begin{array}{l}\text { CASING } \\
\text { ELEVATION } \\
\text { (FT MSL) }\end{array}$ & $\begin{array}{l}\text { GROUND } \\
\text { ELEVATION } \\
\text { (FT MSL) }\end{array}$ & LOG DATE & $\begin{array}{l}\text { LOG } \\
\text { TIME }\end{array}$ & $\begin{array}{l}\text { DEPTH FROM } \\
\text { TOP OF } \\
\text { CASING (FT) }\end{array}$ & $\begin{array}{l}\text { DEPTH FROM } \\
\text { GROUND } \\
\text { (FT) }\end{array}$ & $\begin{array}{l}\text { GROUNDWATER } \\
\text { ELEVATION } \\
\text { (FT MSL) }\end{array}$ \\
\hline 0522 & 19670.00 & 22470.00 & MB & 0 & 5876.50 & 5874.6 & $\begin{array}{l}10 / 12 / 92 \\
02 / 21 / 94 \\
04 / 05 / 94 \\
04 / 20 / 94\end{array}$ & $\begin{array}{l}08: 46 \\
16: 47 \\
13: 42 \\
10: 15\end{array}$ & $\begin{array}{l}136.36 \\
136.56 \\
136.65 \\
136.87\end{array}$ & $\begin{array}{l}134.46 \\
134.66 \\
134.75 \\
134.97\end{array}$ & $\begin{array}{l}5740.14 \\
5739.94 \\
5739.85 \\
5739.63\end{array}$ \\
\hline 0523 & 19620.00 & 22476.00 & UB & 0 & 5876.39 & 5875.0 & $\begin{array}{l}04 / 13 / 90 \\
05 / 05 / 90 \\
12 / 02 / 90 \\
12 / 11 / 90 \\
03 / 31 / 91 \\
08 / 23 / 91 \\
10 / 12 / 92 \\
02 / 21 / 94 \\
04 / 05 / 94 \\
04 / 20 / 94\end{array}$ & $\begin{array}{l}09: 40 \\
09: 45 \\
10: 40 \\
14: 05 \\
13: 03 \\
12: 15 \\
12: 39 \\
16: 44 \\
13: 44 \\
10: 12\end{array}$ & $\begin{array}{l}111.25 \\
109.6 \\
108.25 \\
107.78 \\
108.53 \\
107.94 \\
108.19 \\
108.25 \\
108.35 \\
108.69\end{array}$ & $\begin{array}{l}109.86 \\
108.21 \\
106.86 \\
106.39 \\
107.14 \\
106.55 \\
106.80 \\
106.86 \\
106.96 \\
107.30\end{array}$ & $\begin{array}{l}5765.14 \\
5766.79 \\
5768.14 \\
5768.61 \\
5767.86 \\
5768.45 \\
5768.20 \\
5768.14 \\
5768.04 \\
5767.70\end{array}$ \\
\hline 0524 & 19012.06 & 21702.85 & LB & 0 & 5850.72 & 5848.9 & $\begin{array}{l}04 / 16 / 90 \\
04 / 18 / 90 \\
05 / 05 / 90 \\
12 / 02 / 90 \\
12 / 06 / 90 \\
03 / 30 / 91 \\
08 / 26 / 91 \\
10 / 13 / 92 \\
02 / 21 / 94 \\
04 / 05 / 94 \\
04 / 20 / 94\end{array}$ & $\begin{array}{l}09: 21 \\
09: 15 \\
09: 48 \\
09: 55 \\
09: 00 \\
13: 47 \\
10: 10 \\
15: 23 \\
17: 10 \\
13: 50 \\
11: 01\end{array}$ & $\begin{array}{l}113.4 \\
97 . \\
89.7 \\
82.58 \\
82.62 \\
83.73 \\
83.53 \\
82.90 \\
82.82 \\
82.78 \\
85.10\end{array}$ & $\begin{array}{r}111.58 \\
95.18 \\
87.88 \\
80.76 \\
80.80 \\
81.91 \\
81.71 \\
81.08 \\
81.00 \\
80.96 \\
83.28\end{array}$ & $\begin{array}{l}5737.32 \\
5753.72 \\
5761.02 \\
5768.14 \\
5768.10 \\
5766.99 \\
5767.19 \\
5767.82 \\
5767.90 \\
5767.94 \\
5765.62\end{array}$ \\
\hline 0525 & 19023.44 & 21712.23 & MB & 0 & 5850.89 & 5849.1 & $\begin{array}{l}04 / 16 / 90 \\
04 / 18 / 90 \\
05 / 05 / 90 \\
12 / 02 / 90 \\
12 / 06 / 90 \\
04 / 02 / 91 \\
08 / 26 / 91 \\
10 / 14 / 92 \\
02 / 21 / 94 \\
04 / 05 / 94 \\
04 / 20 / 94\end{array}$ & $\begin{array}{l}09: 28 \\
09: 30 \\
09: 50 \\
09: 53 \\
12: 00 \\
13: 43 \\
12: 35 \\
08: 30 \\
17: 08 \\
13: 52 \\
11: 04\end{array}$ & $\begin{array}{l}115.0 \\
115.1 \\
112.7 \\
114.47 \\
114.72 \\
115.10 \\
115.08 \\
114.55 \\
114.66 \\
114.73 \\
114.97\end{array}$ & $\begin{array}{l}113.21 \\
113.31 \\
110.91 \\
112.68 \\
112.93 \\
113.31 \\
113.29 \\
112.76 \\
112.87 \\
112.94 \\
113.18\end{array}$ & $\begin{array}{l}5735.89 \\
5735.79 \\
5738.19 \\
5736.42 \\
5736.17 \\
5735.79 \\
5735.81 \\
5736.34 \\
5736.23 \\
5736.16 \\
5735.92\end{array}$ \\
\hline 0526 & 18859.00 & 22153.00 & MB & 0 & 5835.42 & 5833.8 & $04 / 18 / 90$ & $08: 00$ & 98.0 & 96.38 & 5737.42 \\
\hline
\end{tabular}

FORMATION OF COMPLETION CODE:

MB - MIDDLE BURRO CANYON

FLOW RELATIONSHIP CODE:

UB - UPPER BURRO CANYON

O - ON-SITE

LB - LOWER BURRO CANYON 
TABLE 3.43 STATIC GROUND HATER LEVELS FOR THE BURRO CANYON

DISPOSAL SITE, SLICK ROCK, COLORADO

SITE: SRKO2 BORROH SITE I (BURRO CANYON)

REPORT DATE: 09/30/94

\begin{tabular}{|c|c|c|c|c|c|c|c|c|c|c|c|}
\hline $\begin{array}{l}\text { LOCATION } \\
\text { ID }\end{array}$ & $\begin{array}{c}\text { HORTH } \\
\text { COORDINATE } \\
\text { (FT) }\end{array}$ & $\begin{array}{c}\text { EAST } \\
\text { COORD INATE } \\
\text { (FT) }\end{array}$ & $\begin{array}{l}\text { FORMATION } \\
\text { OF } \\
\text { COMPLETION }\end{array}$ & $\begin{array}{l}\text { FLOH } \\
\text { CODE }\end{array}$ & $\begin{array}{l}\text { CASING } \\
\text { ELEVATION } \\
\text { (FT MSL) }\end{array}$ & $\begin{array}{l}\text { GROUND } \\
\text { ELEVATION } \\
\text { (FT MSL) }\end{array}$ & LOG DATE & $\begin{array}{l}\text { LOG } \\
\text { TIME }\end{array}$ & $\begin{array}{c}\text { DEPTH FROM } \\
\text { TOP OF } \\
\text { CASING (FT) }\end{array}$ & $\begin{array}{l}\text { DEPTH FROM } \\
\text { GROUND } \\
\text { (FT) }\end{array}$ & $\begin{array}{l}\text { GROUNDWATER } \\
\text { ELEVATION } \\
\text { (FT MSL) }\end{array}$ \\
\hline 0526 & 18859.00 & 22153.00 & MB & 0 & 5835.42 & 5833.8 & $\begin{array}{l}04 / 26 / 90 \\
05 / 05 / 90 \\
12 / 02 / 90 \\
12 / 11 / 90 \\
03 / 30 / 91 \\
08 / 21 / 91 \\
10 / 14 / 92 \\
02 / 21 / 94 \\
04 / 04 / 94 \\
04 / 20 / 94\end{array}$ & $\begin{array}{l}16=30 \\
09=55 \\
09=40 \\
10=00 \\
15=03 \\
10=10 \\
12=32 \\
16=34 \\
15=22 \\
09=54\end{array}$ & $\begin{array}{l}101.25 \\
100.7 \\
101.85 \\
101.73 \\
102.43 \\
102.58 \\
101.65 \\
102.23 \\
102.20 \\
102.53\end{array}$ & $\begin{array}{r}99.63 \\
99.08 \\
100.23 \\
100.11 \\
100.81 \\
100.96 \\
100.03 \\
100.61 \\
100.58 \\
100.91\end{array}$ & $\begin{array}{l}5734.17 \\
5734.72 \\
5733.57 \\
5733.69 \\
5732.99 \\
5732.84 \\
5733.77 \\
5733.19 \\
5733.22 \\
5732.89\end{array}$ \\
\hline 0527 & 18873.00 & 22141.00 & UB & 0 & 5836.51 & 5834.6 & $\begin{array}{l}04 / 25 / 90 \\
04 / 26 / 90 \\
05 / 05 / 90 \\
12 / 02 / 90 \\
12 / 13 / 90 \\
03 / 30 / 91 \\
08 / 23 / 91 \\
10 / 12 / 92 \\
02 / 21 / 94 \\
04 / 04 / 94 \\
04 / 20 / 94\end{array}$ & $\begin{array}{l}08=00 \\
16=40 \\
09: 57 \\
09=37 \\
13=00 \\
15=58 \\
15=30 \\
15=22 \\
16=35 \\
13=53 \\
09=49\end{array}$ & $\begin{array}{r}\text { DRY } \\
\text { DRY } \\
\text { DRY } \\
77.22 \\
76.91 \\
77.62 \\
77.39 \\
77.15 \\
76.93 \\
77.06 \\
77.37\end{array}$ & $\begin{array}{r}\text { DRY } \\
\text { DRY } \\
\text { DRY } \\
75.31 \\
75.00 \\
75.71 \\
75.48 \\
75.24 \\
75.02 \\
75.15 \\
75.46\end{array}$ & $\begin{array}{c}- \\
- \\
- \\
5759.29 \\
5759.60 \\
5758.89 \\
5759.12 \\
5759.36 \\
5759.58 \\
5759.45 \\
5759.14\end{array}$ \\
\hline 0528 & 20137.00 & 22121.00 & MB & 0 & 5898.37 & 5896.8 & $\begin{array}{l}04 / 27 / 90 \\
05 / 05 / 90 \\
12 / 02 / 90 \\
12 / 13 / 90 \\
03 / 31 / 91 \\
08 / 21 / 91 \\
10 / 13 / 92 \\
02 / 21 / 94 \\
04 / 04 / 94 \\
04 / 20 / 94\end{array}$ & $\begin{array}{l}09=20 \\
10=00 \\
11=04 \\
09=30 \\
16=57 \\
15=00 \\
12=13 \\
16=52 \\
17=03 \\
10=29\end{array}$ & $\begin{array}{l}146.3 \\
144.5 \\
145.64 \\
145.45 \\
146.25 \\
145.82 \\
146.0 \\
146.00 \\
146.00 \\
146.31\end{array}$ & $\begin{array}{l}144.73 \\
142.93 \\
144.07 \\
143.88 \\
144.68 \\
144.25 \\
144.43 \\
144.43 \\
144.43 \\
144.74\end{array}$ & $\begin{array}{l}5752.07 \\
5753.87 \\
5752.73 \\
5752.92 \\
5752.12 \\
5752.55 \\
5752.37 \\
5752.37 \\
5752.37 \\
5752.06\end{array}$ \\
\hline 0529 & 20126.00 & 22114.00 & UB & 0 & .5898 .51 & 5896.6 & $\begin{array}{l}04 / 27 / 90 \\
05 / 05 / 90 \\
12 / 02 / 90 \\
12 / 06 / 90 \\
03 / 31 / 91 \\
08 / 23 / 91 \\
10 / 12 / 92\end{array}$ & $\begin{array}{l}09=10 \\
10=05 \\
11=08 \\
15=15 \\
16=10 \\
10=45 \\
13=59\end{array}$ & $\begin{array}{l}114.4 \\
106.1 \\
106.39 \\
106.65 \\
107.15 \\
106.78 \\
106.99\end{array}$ & $\begin{array}{l}112.49 \\
104.19 \\
104.48 \\
104.74 \\
105.24 \\
104.87 \\
105.08\end{array}$ & $\begin{array}{l}5784.11 \\
5792.41 \\
5792.12 \\
5791.86 \\
5791.36 \\
5791.73 \\
5791.52\end{array}$ \\
\hline
\end{tabular}

FORMATION OF COMPLETION CODE:

MB - MIDDLE BURRO CANYON

FLOW RELATIONSHIP CODE:

UB - UPPER BURRO CANYON

O- ON-SITE 
TABLE 3.43 STATIC GROUND HATER LEVELS FOR THE BURRO CANYON

DISPOSAL SITE, SLICK ROCK, COLORADO

SITE: SRKO2 BORROW SITE 1 (BURRO CANYON)

REPORT DATE: $09 / 30 / 94$

\begin{tabular}{|c|c|c|c|c|c|c|c|c|c|c|c|}
\hline$\underset{10}{\text { LOCATION }}$ & $\begin{array}{c}\text { NORTH } \\
\text { COORDINATE } \\
\text { (FT) }\end{array}$ & $\begin{array}{c}\text { EAST } \\
\text { COORDINATE } \\
\text { (FT) }\end{array}$ & $\begin{array}{l}\text { FORMATION } \\
\text { OF } \\
\text { COMPLETION }\end{array}$ & $\begin{array}{l}\text { FLOW } \\
\text { CODE }\end{array}$ & $\begin{array}{l}\text { CASING } \\
\text { ELEVATION } \\
\text { (FT MSL) }\end{array}$ & $\begin{array}{l}\text { GROUND } \\
\text { ELEVATION } \\
\text { (FT MSL) }\end{array}$ & LOG DATE & $\begin{array}{l}\text { LOG } \\
\text { TIME }\end{array}$ & $\mid \begin{array}{l}\text { DEPTH FROM } \\
\text { TOP OF } \\
\text { CASING (FT) }\end{array}$ & $\begin{array}{l}\text { DEPTH FROM } \\
\text { GROUND } \\
\text { (FT) }\end{array}$ & $\begin{array}{l}\text { GROUNDWATER } \\
\text { ELEVATION } \\
\text { (FT MSL) }\end{array}$ \\
\hline 0529 & 20126.00 & 22114.00 & UB & 0 & 5898.51 & 5896.6 & $\begin{array}{l}02 / 21 / 94 \\
04 / 04 / 94 \\
04 / 20 / 94\end{array}$ & $\begin{array}{l}16: 50 \\
17: 04 \\
10: 40\end{array}$ & $\begin{array}{l}106.97 \\
107.00 \\
107.40\end{array}$ & $\begin{array}{l}105.06 \\
105.09 \\
105.49\end{array}$ & $\begin{array}{l}5791.54 \\
5791.51 \\
5791.11\end{array}$ \\
\hline
\end{tabular}

FORMATION OF COMPLETION CODE:

UB - UPPER BURRO CANYON

FLOW RELATIONSHIP CODE:

DATA FILE: IDARTISRK02\GWL10000.DAT

FIELDS DISPLAYED WITH A DASH INDICATE THE DATA IS UNAVAILABLE 
Table 3.44 Hydraulic parameters for the Burro Canyon disposal site, Slick Rock, Colorado

\begin{tabular}{lcccccc}
\hline \multirow{2}{*}{$\begin{array}{c}\text { Hydraulic } \\
\text { property }\end{array}$} & $\begin{array}{c}\text { Dakota } \\
\text { Sandstone }\end{array}$ & $\begin{array}{c}\text { Burro } \\
\text { Canyon } \\
\text { mudstone }\end{array}$ & \multicolumn{2}{c}{ Burro Canyon Formation sandstone units } \\
\cline { 6 - 7 } \cline { 5 - 6 } $\begin{array}{l}\text { Average hydraulic } \\
\text { Cond. }\end{array}$ & $\begin{array}{c}4 \times 10^{-1} \mathrm{ft} / \mathrm{d} \\
1 \times 10^{-4} \mathrm{~cm} / \mathrm{s}\end{array}$ & $\begin{array}{c}6 \times 10^{-3} \mathrm{ft} / \mathrm{d} \\
2 \times 10^{-6} \mathrm{~cm} / \mathrm{s}\end{array}$ & $\begin{array}{c}4 \times 10^{-2} \mathrm{ft} / \mathrm{d} \\
1 \times 10^{-5} \mathrm{~cm} / \mathrm{s}\end{array}$ & $\begin{array}{c}9 \times 10^{-2} \mathrm{ft} / \mathrm{d} \\
3 \times 10^{-5} \mathrm{~cm} / \mathrm{s}\end{array}$ & $\begin{array}{c}5 \times 10^{-3} \mathrm{ft} / \mathrm{d} \\
2 \times 10^{-6} \mathrm{~cm} / \mathrm{s}\end{array}$ \\
\hline $\begin{array}{l}\text { Average hydraulic } \\
\text { gradient }\end{array}$ & $\mathrm{NA}$ & $\mathrm{NA}$ & 0.04 & 0.02 & 0.06 \\
\hline $\begin{array}{l}\text { Average linear } \\
\text { groundwater } \\
\text { velocity }\end{array}$ & $\mathrm{NA}$ & $\mathrm{NA}$ & $\begin{array}{c}6 \mathrm{ft} / \mathrm{yr} \\
6 \times 10^{-6} \mathrm{~cm} / \mathrm{s}\end{array}$ & $\begin{array}{c}2 \times 10^{-6} \mathrm{~cm} / \mathrm{sr} \\
2 \times 1 \times 10^{-6} \mathrm{~cm} / \mathrm{s}\end{array}$ \\
\hline
\end{tabular}


TABLE 3.45 BACKGROUND GROUND WATER QUALITY BY PARAMETER FOR THE UPPER SANDSTONE UNIT BURRO CANYON DISPOSAL SITE, SLICK ROCK, COLORADO SITE: SRKO2 BORROW SITE 1 (BURRO CANYON)

06/04/90 TO 04/27/94

REPORT DATE. $09 / 30 / 94$

\begin{tabular}{|c|c|c|c|c|c|c|c|c|c|c|c|}
\hline PARAMETER NAME & $\underbrace{\text { LOCATION }}_{\text {ID }}$ & LOG DATE & $\underset{I D}{\text { SAMPLEE }}$ & $\begin{array}{l}\text { FORM } \\
\text { COMP }\end{array}$ & $\begin{array}{l}\text { FLOH } \\
\text { REL. }\end{array}$ & $\begin{array}{l}\text { UNI IS OF } \\
\text { MEASURE }\end{array}$ & PVI & $\begin{array}{l}\text { ARAMETER } \\
\text { VALUE }\end{array}$ & FLAGS & $\begin{array}{l}\text { DETECTION } \\
\text { LIMIT }\end{array}$ & $\begin{array}{l}\text { PARAMETER } \\
\text { UNCERTAINTY }\end{array}$ \\
\hline ALKALINITY & $\begin{array}{l}0518 \\
0518 \\
0518 \\
0518 \\
0518 \\
0518 \\
0518 \\
0518 \\
0523 \\
0523 \\
0523 \\
0523 \\
0523 \\
0523 \\
0523 \\
0527 \\
0527 \\
0527 \\
0527 \\
0527 \\
0527 \\
0529 \\
0529 \\
0529 \\
0529 \\
0529 \\
0529 \\
0529 \\
0529\end{array}$ & $\begin{array}{l}06 / 04 / 90 \\
12 / 15 / 90 \\
04 / 01 / 91 \\
08 / 23 / 91 \\
10 / 11 / 92 \\
02 / 24 / 94 \\
04 / 04 / 94 \\
04 / 27 / 94 \\
06 / 04 / 90 \\
12 / 12 / 90 \\
04 / 01 / 91 \\
08 / 23 / 91 \\
10 / 12 / 92 \\
02 / 24 / 94 \\
04 / 20 / 94 \\
06 / 06 / 90 \\
12 / 15 / 90 \\
04 / 04 / 91 \\
08 / 23 / 91 \\
10 / 12 / 92 \\
02 / 23 / 94 \\
06 / 06 / 90 \\
12 / 08 / 90 \\
04 / 02 / 91 \\
08 / 23 / 91 \\
10 / 12 / 92 \\
02 / 24 / 94 \\
04 / 04 / 94 \\
04 / 26 / 94\end{array}$ & $\begin{array}{l}0001 \\
0001 \\
0001 \\
0001 \\
0001 \\
0001 \\
0001 \\
0001 \\
0001 \\
0001 \\
0001 \\
0001 \\
0001 \\
0001 \\
0001 \\
0001 \\
0001 \\
0001 \\
0001 \\
0001 \\
0001 \\
0001 \\
0001 \\
0001 \\
0001 \\
0001 \\
0001 \\
0001 \\
0001\end{array}$ & $\begin{array}{l}\text { UB } \\
\text { UB } \\
\text { UB } \\
\text { UB } \\
\text { UB } \\
\text { UB } \\
\text { UB } \\
\text { UB } \\
\text { UB } \\
\text { UB } \\
\text { UB } \\
\text { UB } \\
\text { UB } \\
\text { UB } \\
\text { UB } \\
\text { UB } \\
\text { UB } \\
\text { UB } \\
\text { UB } \\
\text { UB } \\
\text { UB } \\
\text { UB } \\
\text { UB } \\
\text { UB } \\
\text { UB } \\
\text { UB } \\
\text { UB } \\
\text { UB } \\
\text { UB }\end{array}$ & $\begin{array}{l}0 \\
0 \\
0 \\
0 \\
0 \\
0 \\
0 \\
0 \\
0 \\
0 \\
0 \\
0 \\
0 \\
0 \\
0 \\
0 \\
0 \\
0 \\
0 \\
0 \\
0 \\
0 \\
0 \\
0 \\
0 \\
0 \\
0 \\
0 \\
0\end{array}$ & MG/L CACO3 & & $\begin{array}{l}268 . \\
230 . \\
200 . \\
249 \\
189 \\
239 \\
230 \\
198 \\
354 . \\
445 . \\
607 . \\
409 \\
362 \\
369 \\
259 \\
292 . \\
283 . \\
304 . \\
266 \\
283 \\
550 \\
230 . \\
394 . \\
233 . \\
277 \\
270 \\
421 \\
148 \\
257\end{array}$ & $\begin{array}{l}L \\
L \\
L \\
J \\
L \\
L \\
L \\
J \\
J \\
L \\
L\end{array}$ & $\begin{array}{l}- \\
- \\
- \\
- \\
- \\
- \\
- \\
- \\
- \\
- \\
- \\
- \\
- \\
- \\
- \\
- \\
- \\
- \\
- \\
- \\
- \\
- \\
- \\
- \\
-\end{array}$ & $\begin{array}{l}- \\
- \\
- \\
- \\
- \\
- \\
- \\
- \\
- \\
- \\
- \\
- \\
- \\
- \\
- \\
- \\
- \\
- \\
- \\
- \\
- \\
-\end{array}$ \\
\hline ALUMINUM & $\begin{array}{l}0518 \\
0518 \\
0518 \\
0518 \\
0518 \\
0523 \\
0523 \\
0523 \\
0523\end{array}$ & $\begin{array}{l}06 / 04 / 90 \\
12 / 15 / 90 \\
04 / 01 / 91 \\
08 / 23 / 91 \\
10 / 11 / 92 \\
06 / 04 / 90 \\
12 / 12 / 90 \\
04 / 01 / 91 \\
08 / 23 / 91\end{array}$ & $\begin{array}{l}0001 \\
0001 \\
0001 \\
0001 \\
0001 \\
0001 \\
0001 \\
0001 \\
0001\end{array}$ & $\begin{array}{l}\text { UB } \\
\text { UB } \\
\text { UB } \\
\text { UB } \\
\text { UB } \\
\text { UB } \\
\text { UB } \\
\text { UB } \\
\text { UB }\end{array}$ & $\begin{array}{l}0 \\
0 \\
0 \\
0 \\
0 \\
0 \\
0 \\
0 \\
0\end{array}$ & $M G / L$ & $\begin{array}{l}< \\
< \\
< \\
< \\
<\end{array}$ & $\begin{array}{l}0.1 \\
0.1 \\
0.05 \\
0.05 \\
0.05 \\
0.2 \\
0.1 \\
0.07 \\
0.14\end{array}$ & 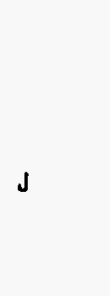 & $\begin{array}{l}0.1 \\
0.1 \\
0.05 \\
0.05 \\
0.05 \\
0.1 \\
0.1 \\
0.05 \\
0.05\end{array}$ & $\begin{array}{l}- \\
- \\
- \\
- \\
- \\
-\end{array}$ \\
\hline
\end{tabular}

FORMATION OF COMPLETION CODE: UB - UPPER BURRO CANYON

PARAMETER VALUE INDICATOR (PVI): < - LESS THAN DETECTION LIMIT

OTHER PARAMETER VALUE FLAGS:

$J$ - ESTIMATED VALUE

L - LESS THAN THREE: BORE VOLUMES REMOVED BEFORE SAMPLING
FLOW RELATIONSHIP CODE:

$$
\text { O - ON-SITE }
$$

SAMPLE ID CODES

0001 - FILTERED SAMPLE (.45 MICRONS) 
TABLE 3.45 BACKGROUND GROUND WATER QUALITY BY PARAMETER FOR THE UPPER SANDSTONE UNIT, BURRO CANYON DISPOSAL SITE, SLICK ROCK, COLORADO SITE: SRKO2 BORROH SITE 1 (BURRO CANYON)

$06 / 04 / 90$ TO $04 / 27 / 94$

REPORT DATE: 09/30/94

\begin{tabular}{|c|c|c|c|c|c|c|c|c|c|c|c|}
\hline PARAMETER NAME & $\underset{\text { ID }}{\text { LOCAT ION }}$ & LOG DATE & $\underset{\text { SAMPLE }}{\text { ID }}$ & $\begin{array}{l}\text { FORM } \\
\text { COMP }\end{array}$ & $\begin{array}{l}\text { FLOW } \\
\text { REL. }\end{array}$ & $\begin{array}{l}\text { UNITS OF } \\
\text { MEASURE }\end{array}$ & PVI & $\begin{array}{l}\text { PARAMETER } \\
\text { VALUE }\end{array}$ & FLAGS & $\begin{array}{l}\text { DETECTION } \\
\text { LIMIT }\end{array}$ & $\begin{array}{l}\text { PARAMETER } \\
\text { UNCERTAINTY }\end{array}$ \\
\hline ALUMINUM & $\begin{array}{l}0523 \\
0527 \\
0527 \\
0527 \\
0527 \\
0527 \\
0529 \\
0529 \\
0529 \\
0529 \\
0529\end{array}$ & $\begin{array}{l}10 / 12 / 92 \\
06 / 06 / 90 \\
12 / 15 / 90 \\
04 / 04 / 91 \\
08 / 23 / 91 \\
10 / 12 / 92 \\
06 / 06 / 90 \\
12 / 08 / 90 \\
04 / 02 / 91 \\
08 / 23 / 91 \\
10 / 12 / 92\end{array}$ & $\begin{array}{l}0001 \\
0001 \\
0001 \\
0001 \\
0001 \\
0001 \\
0001 \\
0001 \\
0001 \\
0001 \\
0001\end{array}$ & $\begin{array}{l}\text { UB } \\
\text { UB } \\
\text { UB } \\
\text { UB } \\
\text { UB } \\
\text { UB } \\
\text { UB } \\
\text { UB } \\
\text { UB } \\
\text { UB } \\
\text { UB }\end{array}$ & $\begin{array}{l}0 \\
0 \\
0 \\
0 \\
0 \\
0 \\
0 \\
0 \\
0 \\
0 \\
0\end{array}$ & MG/L & $\begin{array}{l}< \\
< \\
< \\
< \\
< \\
<\end{array}$ & $\begin{array}{l}0.16 \\
0.1 \\
0.1 \\
0.07 \\
0.05 \\
0.05 \\
0.1 \\
0.1 \\
0.14 \\
0.05 \\
0.07\end{array}$ & J & $\begin{array}{l}0.05 \\
0.1 \\
0.1 \\
0.05 \\
0.05 \\
0.05 \\
0.1 \\
0.1 \\
0.05 \\
0.05 \\
0.05\end{array}$ & $\begin{array}{l}- \\
- \\
- \\
- \\
- \\
- \\
- \\
- \\
-\end{array}$ \\
\hline AMMONIUM & $\begin{array}{l}0518 \\
0518 \\
0518 \\
0518 \\
0518 \\
0523 \\
0523 \\
0523 \\
0523 \\
0523 \\
0527 \\
0527 \\
0527 \\
0527 \\
0527 \\
0529 \\
0529 \\
0529 \\
0529 \\
0529\end{array}$ & $\begin{array}{l}06 / 04 / 90 \\
12 / 15 / 90 \\
04 / 01 / 91 \\
08 / 23 / 91 \\
10 / 11 / 92 \\
06 / 04 / 90 \\
12 / 12 / 90 \\
04 / 01 / 91 \\
08 / 23 / 91 \\
10 / 12 / 92 \\
06 / 06 / 90 \\
12 / 15 / 90 \\
04 / 04 / 91 \\
08 / 23 / 91 \\
10 / 12 / 92 \\
06 / 06 / 90 \\
12 / 08 / 90 \\
04 / 02 / 91 \\
08 / 23 / 91 \\
10 / 12 / 92\end{array}$ & $\begin{array}{l}0001 \\
0001 \\
0001 \\
0001 \\
0001 \\
0001 \\
0001 \\
0001 \\
0001 \\
0001 \\
0001 \\
0001 \\
0001 . \\
0001 \\
0001 \\
0001 \\
0001 \\
0001 \\
0001 \\
0001\end{array}$ & $\begin{array}{l}\text { UB } \\
\text { UB } \\
\text { UB } \\
\text { UB } \\
\text { UB } \\
\text { UB } \\
\text { UB } \\
\text { UB } \\
\text { UB } \\
\text { UB } \\
\text { UB } \\
\text { UB } \\
\text { UB } \\
\text { UB } \\
\text { UB } \\
\text { UB } \\
\text { UB } \\
\text { UB } \\
\text { UB } \\
\text { UB }\end{array}$ & $\begin{array}{l}0 \\
0 \\
0 \\
0 \\
0 \\
0 \\
0 \\
0 \\
0 \\
0 \\
0 \\
0 \\
0 \\
0 \\
0 \\
0 \\
0 \\
0 \\
0 \\
0\end{array}$ & MG/L & $<<$ & $\begin{array}{l}0.1 \\
0.1 \\
0.1 \\
0.3 \\
0.3 \\
0.3 \\
0.1 \\
0.3 \\
0.1 \\
0.2 \\
0.3 \\
0.1 \\
0.4 \\
0.1 \\
0.3 \\
0.3 \\
0.2 \\
0.4 \\
0.3 \\
0.2\end{array}$ & $J$ & $\begin{array}{l}0.1 \\
0.1 \\
0.1 \\
0.1 \\
0.1 \\
0.1 \\
0.1 \\
0.1 \\
0.1 \\
0.1 \\
0.1 \\
0.1 \\
0.1 \\
0.1 \\
0.1 \\
0.1 \\
0.1 \\
0.1 \\
0.1 \\
0.1\end{array}$ & $\begin{array}{l}- \\
- \\
- \\
- \\
- \\
- \\
- \\
- \\
- \\
- \\
- \\
- \\
- \\
- \\
- \\
-\end{array}$ \\
\hline ANT IMONY & $\begin{array}{l}0518 \\
0518 \\
0518 \\
0518 \\
0518 \\
0523\end{array}$ & $\begin{array}{l}06 / 04 / 90 \\
12 / 15 / 90 \\
04 / 01 / 91 \\
08 / 23 / 91 \\
10 / 11 / 92 \\
06 / 04 / 90\end{array}$ & $\begin{array}{l}0001 \\
0001 \\
0001 \\
0001 \\
0001 \\
0001\end{array}$ & $\begin{array}{l}\text { UB } \\
\text { UB } \\
\text { UB } \\
\text { UB } \\
\text { UB } \\
\text { UB }\end{array}$ & $\begin{array}{l}0 \\
0 \\
0 \\
0 \\
0 \\
0\end{array}$ & $M G / L$ & $\begin{array}{l}< \\
< \\
< \\
<\end{array}$ & $\begin{array}{l}0.003 \\
0.003 \\
0.005 \\
0.003 \\
0.004 \\
0.008\end{array}$ & $\begin{array}{l}\mathbf{I} \\
\mathbf{J}\end{array}$ & $\begin{array}{l}0.003 \\
0.003 \\
0.005 \\
0.003 \\
0.003 \\
0.003\end{array}$ & $\begin{array}{l}- \\
- \\
- \\
-\end{array}$ \\
\hline
\end{tabular}

FORMATION OF COMPLETION CODE:

UB - UPPER BURRO CANYON

PARAMETER VALUE INDICATOR (PVI): < - LESS THAN DETECTION LIMIT
FLOH RELATIONSHIP CODE:

O - ON-SITE

0001 - FILTERED SAMPLE (.45 MICRONS)

OTHER PARAMETER VALUE FLAGS:

I - INCREASED DETECTION LIMIT DUE TO REQUIRED DILUTION

$J$ - ESTIMATED VALUE 
TABLE 3.45 BACKGROUND GROUND HATER QUALITY BY PARAMETER FOR THE UPPER

SANDSTONE UNIT, BURRO CANYON DISPOSAL SITE, SLICK ROCK, COLORADO

SITE: SRKO2 BORROW SITE 1 (BURRO CANYON)

06/04/90 TO 04/27/94

REPORT DATE : $09 / 30 / 94$

\begin{tabular}{|c|c|c|c|c|c|c|c|c|c|c|c|}
\hline PARAMETER NAME & $\mid \begin{array}{c}\text { LOCATION } \\
\text { ID }\end{array}$ & LOG DATE & $\begin{array}{c}\text { SAMPLE } \\
\text { ID }\end{array}$ & $\begin{array}{l}\text { FORM } \\
\text { COMP }\end{array}$ & $\begin{array}{l}\text { FLOW } \\
\text { REL. }\end{array}$ & $\begin{array}{l}\text { UNITS OF } \\
\text { MEASURE }\end{array}$ & PVI & $\begin{array}{l}\text { PARAMETER } \\
\text { VALUEE }\end{array}$ & FLAGS & $\begin{array}{l}\text { DETECTION } \\
\text { LIMIT }\end{array}$ & $\begin{array}{l}\text { PARAMETER } \\
\text { UNCERTAINTY }\end{array}$ \\
\hline ANTIMONY & $\begin{array}{l}0523 \\
0523 \\
0523 \\
0523 \\
0527 \\
0527 \\
0527 \\
0527 \\
0527 \\
0529 \\
0529 \\
0529 \\
0529 \\
0529\end{array}$ & $\begin{array}{l}12 / 12 / 90 \\
04 / 01 / 91 \\
08 / 23 / 91 \\
10 / 12 / 92 \\
06 / 06 / 90 \\
12 / 15 / 90 \\
04 / 04 / 91 \\
08 / 23 / 91 \\
10 / 12 / 92 \\
06 / 06 / 90 \\
12 / 08 / 90 \\
04 / 02 / 91 \\
08 / 23 / 91 \\
10 / 12 / 92\end{array}$ & $\begin{array}{l}0001 \\
0001 \\
0001 \\
0001 \\
0001 \\
0001 \\
0001 \\
0001 \\
0001 \\
0001 \\
0001 \\
0001 \\
0001 \\
0001\end{array}$ & $\begin{array}{l}\text { UB } \\
\text { UB } \\
\text { UB } \\
\text { UB } \\
\text { UB } \\
\text { UB } \\
\text { UB } \\
\text { UB } \\
\text { UB } \\
\text { UB } \\
\text { UB } \\
\text { UB } \\
\text { UB } \\
\text { UB }\end{array}$ & $\begin{array}{l}0 \\
0 \\
0 \\
0 \\
0 \\
0 \\
0 \\
0 \\
0 \\
0 \\
0 \\
0 \\
0 \\
0\end{array}$ & $M G / L$ & $\begin{array}{l}< \\
< \\
< \\
< \\
< \\
< \\
< \\
< \\
< \\
< \\
< \\
< \\
< \\
<\end{array}$ & $\begin{array}{l}0.003 \\
0.005 \\
0.003 \\
0.003 \\
0.008 \\
0.003 \\
0.005 \\
0.003 \\
0.003 \\
0.004 \\
0.003 \\
0.005 \\
0.003 \\
0.003\end{array}$ & $\begin{array}{l}\text { I } \\
\text { J } \\
I\end{array}$ & $\begin{array}{l}0.003 \\
0.005 \\
0.003 \\
0.003 \\
0.003 \\
0.003 \\
0.005 \\
0.003 \\
0.003 \\
0.003 \\
0.003 \\
0.005 \\
0.003 \\
0.003\end{array}$ & $\begin{array}{l}- \\
- \\
- \\
- \\
- \\
- \\
- \\
- \\
- \\
- \\
-\end{array}$ \\
\hline ARSENIC & $\begin{array}{l}0518 \\
0518 \\
0518 \\
0518 \\
0518 \\
0523 \\
0523 \\
0523 \\
0523 \\
0523 \\
0527 \\
0527 \\
0527 \\
0527 \\
0527 \\
0529 \\
0529 \\
0529 \\
0529 \\
0529\end{array}$ & \begin{tabular}{|l|}
$06 / 04 / 90$ \\
$12 / 15 / 90$ \\
$04 / 01 / 91$ \\
$08 / 23 / 91$ \\
$10 / 11 / 92$ \\
$06 / 04 / 90$ \\
$12 / 12 / 90$ \\
$04 / 01 / 91$ \\
$08 / 23 / 91$ \\
$10 / 12 / 92$ \\
$06 / 06 / 90$ \\
$12 / 15 / 90$ \\
$04 / 04 / 91$ \\
$08 / 23 / 91$ \\
$10 / 12 / 92$ \\
$06 / 06 / 90$ \\
$12 / 08 / 90$ \\
$04 / 02 / 91$ \\
$08 / 23 / 91$ \\
$10 / 12 / 92$
\end{tabular} & $\begin{array}{l}0001 \\
0001 \\
0001 \\
0001 \\
0001 \\
0001 \\
0001 \\
0001 \\
0001 \\
0001 \\
0001 \\
0001 \\
0001 \\
0001 \\
0001 \\
0001 \\
0001 \\
0001 \\
0001 \\
0001\end{array}$ & $\begin{array}{l}\text { UB } \\
\text { UB } \\
\text { UB } \\
\text { UB } \\
\text { UB } \\
\text { UB } \\
\text { UB } \\
\text { UB } \\
\text { UB } \\
\text { UB } \\
\text { UB } \\
\text { UB } \\
\text { UB } \\
\text { UB } \\
\text { UB } \\
\text { UB } \\
\text { UB } \\
\text { UB } \\
\text { UB } \\
\text { UB }\end{array}$ & $\begin{array}{l}0 \\
0 \\
0 \\
0 \\
0 \\
0 \\
0 \\
0 \\
0 \\
0 \\
0 \\
0 \\
0 \\
0 \\
0 \\
0 \\
0 \\
0 \\
0 \\
0\end{array}$ & $M G / L$ & $\begin{array}{l}< \\
< \\
< \\
< \\
< \\
< \\
< \\
< \\
< \\
< \\
< \\
< \\
< \\
< \\
< \\
< \\
< \\
< \\
< \\
< \\
<\end{array}$ & $\begin{array}{l}0.01 \\
0.01 \\
0.01 \\
0.01 \\
0.005 \\
0.01 \\
0.01 \\
0.01 \\
0.01 \\
0.005 \\
0.01 \\
0.01 \\
0.01 \\
0.05 \\
0.005 \\
0.01 \\
0.01 \\
0.01 \\
0.05 \\
0.005\end{array}$ & $\begin{array}{l}\text { I } \\
\text { J } \\
\text { I }\end{array}$ & $\begin{array}{l}0.01 \\
0.01 \\
0.01 \\
0.01 \\
0.005 \\
0.01 \\
0.01 \\
0.01 \\
0.01 \\
0.005 \\
0.01 \\
0.01 \\
0.01 \\
0.05 \\
0.005 \\
0.01 \\
0.01 \\
0.01 \\
0.05 \\
0.005\end{array}$ & $\begin{array}{l}- \\
- \\
- \\
- \\
- \\
- \\
- \\
- \\
- \\
- \\
- \\
- \\
- \\
- \\
- \\
-\end{array}$ \\
\hline BARIUM & $\begin{array}{l}0518 \\
0518 \\
0518\end{array}$ & $\begin{array}{l}06 / 04 / 90 \\
12 / 15 / 90 \\
04 / 01 / 91\end{array}$ & $\begin{array}{l}0001 \\
0001 \\
0001\end{array}$ & $\begin{array}{l}\text { UB } \\
\text { UB } \\
\text { UB }\end{array}$ & $\begin{array}{l}0 \\
0 \\
0\end{array}$ & $\mathrm{MG} / \mathrm{L}$ & $<$ & $\begin{array}{l}0.1 \\
0.1 \\
0.03\end{array}$ & & $\begin{array}{l}0.1 \\
0.1 \\
0.01\end{array}$ & - \\
\hline
\end{tabular}

FORMATION OF COMPLETION CODE:

UB - UPPER BURRO CANYON

PARAMETER VALUE INDICATOR (PVI): < - LESS THAN DETECTION LIMIT
FLOW RELATIONSHIP CODE:

O - ON-SITE

SAMPLE ID CODES

0001 - FILTERED SAMPLE (.45 MICRONS)

OTHER PARAMETER VALUE FLAGS:

I - INCREASED DETECTION LIMIT DUE TO REQUIRED DILUTION

$J$ - ESTIMATED VALUE 
TABLE 3.45 BACKGROUND GROUND WATER QUALITY BY PARAMETER FOR THE UPPER SANDSTONE UNIT, BURRO CANYON DISPOSAL SITE, SLICK ROCK, COLORADO SITE: SRKO2 BORROH SITE 1 (BURRO CANYON)

06/04/90 TO $04 / 27 / 94$

REPORT DATE: $09 / 30 / 94$

\begin{tabular}{|c|c|c|c|c|c|c|c|c|c|c|c|}
\hline PARAMETER NAME & $\begin{array}{c}\text { LOCATION } \\
\text { ID }\end{array}$ & LOG DATE & $\begin{array}{c}\text { SAMPLE } \\
\text { ID }\end{array}$ & $\begin{array}{l}\text { FORM } \\
\text { COMP }\end{array}$ & $\begin{array}{l}\text { FLOW } \\
\text { REL. }\end{array}$ & $\begin{array}{l}\text { UNITS OF } \\
\text { MEASURE }\end{array}$ & PVI & $\begin{array}{l}\text { ARAMETER } \\
\text { VALUE }\end{array}$ & FLAGS & $\begin{array}{l}\text { DETECTION } \\
\text { LIMIT }\end{array}$ & $\begin{array}{l}\text { PARAMETER } \\
\text { UNCERTAINTY }\end{array}$ \\
\hline BARIUM & $\begin{array}{l}0518 \\
0518 \\
0518 \\
0518 \\
0523 \\
0523 \\
0523 \\
0523 \\
0523 \\
0523 \\
0523 \\
0527 \\
0527 \\
0527 \\
0527 \\
0527 \\
0527 \\
0527 \\
0529 \\
0529 \\
0529 \\
0529 \\
0529 \\
0529 \\
0529\end{array}$ & $\begin{array}{l}08 / 23 / 91 \\
10 / 11 / 92 \\
02 / 24 / 94 \\
04 / 27 / 94 \\
06 / 04 / 90 \\
12 / 12 / 90 \\
04 / 01 / 91 \\
08 / 23 / 91 \\
10 / 12 / 92 \\
02 / 23 / 94 \\
04 / 20 / 94 \\
06 / 06 / 90 \\
12 / 15 / 90 \\
04 / 04 / 91 \\
08 / 23 / 91 \\
10 / 12 / 92 \\
02 / 23 / 94 \\
04 / 26 / 94 \\
06 / 06 / 90 \\
12 / 08 / 90 \\
04 / 02 / 91 \\
08 / 23 / 91 \\
10 / 12 / 92 \\
02 / 24 / 94 \\
04 / 26 / 94\end{array}$ & $\begin{array}{l}0001 \\
0001 \\
0001 \\
0001 \\
0001 \\
0001 \\
0001 \\
0001 \\
0001 \\
0001 \\
0001 \\
0001 \\
0001 \\
0001 \\
0001 \\
0001 \\
0001 \\
0001 \\
0001 \\
0001 \\
0001 \\
0001 \\
0001 \\
0001 \\
0001 .\end{array}$ & $\begin{array}{l}\text { UB } \\
\text { UB } \\
\text { UB } \\
\text { UB } \\
\text { UB } \\
\text { UB } \\
\text { UB } \\
\text { UB } \\
\text { UB } \\
\text { UB } \\
\text { UB } \\
\text { UB } \\
\text { UB } \\
\text { UB } \\
\text { UB } \\
\text { UB } \\
\text { UB } \\
\text { UB } \\
\text { UB } \\
\text { UB } \\
\text { UB } \\
\text { UB } \\
\text { UB } \\
\text { UB } \\
\text { UB }\end{array}$ & $\begin{array}{l}0 \\
0 \\
0 \\
0 \\
0 \\
0 \\
0 \\
0 \\
0 \\
0 \\
0 \\
0 \\
0 \\
0 \\
0 \\
0 \\
0 \\
0 \\
0 \\
0 \\
0 \\
0 \\
0 \\
0 \\
0\end{array}$ & MG/L & $\begin{array}{l}< \\
< \\
< \\
< \\
< \\
\\
< \\
< \\
< \\
< \\
< \\
< \\
< \\
< \\
< \\
< \\
<\end{array}$ & $\begin{array}{l}0.03 \\
0.03 \\
0.1 \\
0.1 \\
0.1 \\
0.1 \\
0.03 \\
0.02 \\
0.02 \\
0.1 \\
0.1 \\
0.1 \\
0.1 \\
0.04 \\
0.03 \\
0.04 \\
0.1 \\
0.1 \\
0.1 \\
0.1 \\
0.02 \\
0.02 \\
0.02 \\
0.1 \\
0.1\end{array}$ & $\begin{array}{l}\mathbf{L} \\
\mathbf{L} \\
\mathbf{J}\end{array}$ & $\begin{array}{l}0.01 \\
0.01 \\
0.1 \\
0.1 \\
0.1 \\
0.1 \\
0.1 \\
0.01 \\
0.01 \\
0.01 \\
0.1 \\
0.1 \\
0.1 \\
0.1 \\
0.01 \\
0.01 \\
0.01 \\
0.1 \\
0.1 \\
0.1 \\
0.1 \\
0.01 \\
0.01 \\
0.01 \\
0.1 \\
0.1\end{array}$ & $\begin{array}{l}- \\
- \\
- \\
- \\
- \\
- \\
- \\
- \\
- \\
- \\
- \\
- \\
- \\
- \\
- \\
- \\
- \\
- \\
- \\
-\end{array}$ \\
\hline BERYLLIUM & $\begin{array}{l}0518 \\
0518 \\
0518 \\
0518 \\
0523 \\
0523 \\
0523 \\
0523 \\
0527 \\
0527 \\
0527 \\
0527 \\
0529\end{array}$ & $\begin{array}{l}06 / 04 / 90 \\
12 / 15 / 90 \\
04 / 01 / 91 \\
08 / 23 / 91 \\
06 / 04 / 90 \\
12 / 12 / 90 \\
04 / 01 / 91 \\
08 / 23 / 91 \\
06 / 06 / 90 \\
12 / 15 / 90 \\
04 / 04 / 91 \\
08 / 23 / 91 \\
06 / 06 / 90\end{array}$ & $\begin{array}{l}0001 \\
0001 \\
0001 \\
0001 \\
0001 \\
0001 \\
0001 \\
0001 \\
0001 \\
0001 \\
0001 \\
0001 \\
0001\end{array}$ & $\begin{array}{l}\text { UB } \\
\text { UB } \\
\text { UB } \\
\text { UB } \\
\text { UB } \\
\text { UB } \\
\text { UB } \\
\text { UB } \\
\text { UB } \\
\text { UB } \\
\text { UB } \\
\text { UB } \\
\text { UB }\end{array}$ & $\begin{array}{l}0 \\
0 \\
0 \\
0 \\
0 \\
0 \\
0 \\
0 \\
0 \\
0 \\
0 \\
0 \\
0\end{array}$ & $M G / L$ & $\begin{array}{l}< \\
< \\
< \\
< \\
< \\
< \\
< \\
< \\
< \\
< \\
< \\
< \\
<\end{array}$ & $\begin{array}{l}0.01 \\
0.01 \\
0.005 \\
0.005 \\
0.01 \\
0.01 \\
0.005 \\
0.005 \\
0.01 \\
0.01 \\
0.005 \\
0.005 \\
0.01\end{array}$ & J & $\begin{array}{l}0.01 \\
0.01 \\
0.005 \\
0.005 \\
0.01 \\
0.01 \\
0.005 \\
0.005 \\
0.01 \\
0.01 \\
0.005 \\
0.005 \\
0.01\end{array}$ & $\begin{array}{l}- \\
- \\
- \\
- \\
- \\
- \\
- \\
- \\
- \\
-\end{array}$ \\
\hline
\end{tabular}

FORMATION OF COMPLETION CODE:

UB - UPPER BURRO CANYON

FLOW RELATIONSHIP CODE:

O - ON-SITE

PARAMETER VALUE INDICATOR (PVI): < - LESS THAN DETECTION LIMIT

CODES:

0001 - FILTERED SAMPLE (.45 MICRONS)

OTHER PARAMETER VALUE FLAGS:

J - ESTIMATED VALUE

L - LESS THAN THREE BORE VOLUMES REMOVED BEFORE SAMPLING 
TABLE 3.45 BACKGROUND GROUND HATER QUALITY BY PARAMETER FOR THE UPPER SANDSTONE UNIT, BURRO CANYON DISPOSAL SITE, SLICK ROCK, COLORADO

SITE: SRKO2 BORROW SITE I (BURRO CANYON)

$06 / 04 / 90$ TO 04/27/94

REPORT DATE: $09 / 30 / 94$

\begin{tabular}{|c|c|c|c|c|c|c|c|c|c|c|c|}
\hline PARAMETER NAME & $\begin{array}{c}\text { LOCATION } \\
\text { ID }\end{array}$ & LOG DATE & $\begin{array}{c}\text { SAMPLE } \\
\text { ID }\end{array}$ & $\begin{array}{l}\text { FORM } \\
\text { COMP }\end{array}$ & $\begin{array}{l}\text { FLOW } \\
\text { REL. }\end{array}$ & $\begin{array}{l}\text { UNITS OF } \\
\text { MEASURE }\end{array}$ & PVI & $\begin{array}{l}\text { RAMETER } \\
\text { VALUE }\end{array}$ & FLAGS & $\begin{array}{l}\text { OETECTION } \\
\text { LIMIT }\end{array}$ & $\begin{array}{l}\text { PARAMETER } \\
\text { UNCERTAINTY }\end{array}$ \\
\hline BERYLLIUM & $\begin{array}{l}0529 \\
0529 \\
0529\end{array}$ & $\begin{array}{l}12 / 08 / 90 \\
04 / 02 / 91 \\
08 / 23 / 91\end{array}$ & $\begin{array}{l}0001 \\
0001 \\
0001\end{array}$ & $\begin{array}{l}\text { UB } \\
\text { UB } \\
\text { UB }\end{array}$ & $\begin{array}{l}0 \\
0 \\
0\end{array}$ & $M G / L$ & $\mid \begin{array}{l}< \\
<\end{array}$ & $\begin{array}{l}0.01 \\
0.005 \\
0.005\end{array}$ & & $\begin{array}{l}0.01 \\
0.005 \\
0.005\end{array}$ & - \\
\hline BORON & $\begin{array}{l}0518 \\
0518 \\
0518 \\
0518 \\
0518 \\
0518 \\
0523 \\
0523 \\
0523 \\
0523 \\
0523 \\
0523 \\
0527 \\
0527 \\
0527 \\
0527 \\
0527 \\
0527 \\
0529 \\
0529 \\
0529 \\
0529 \\
0529 \\
0529\end{array}$ & $\begin{array}{l}06 / 04 / 90 \\
12 / 15 / 90 \\
04 / 01 / 91 \\
08 / 23 / 91 \\
02 / 24 / 94 \\
04 / 27 / 94 \\
06 / 04 / 90 \\
12 / 12 / 90 \\
04 / 01 / 91 \\
08 / 23 / 91 \\
02 / 23 / 94 \\
04 / 20 / 94 \\
06 / 06 / 90 \\
12 / 15 / 90 \\
04 / 04 / 91 \\
08 / 23 / 91 \\
02 / 23 / 94 \\
04 / 26 / 94 \\
06 / 06 / 90 \\
12 / 08 / 90 \\
04 / 02 / 91 \\
08 / 23 / 91 \\
02 / 24 / 94 \\
04 / 26 / 94\end{array}$ & $\begin{array}{l}0001 \\
0001 \\
0001 \\
0001 \\
0001 \\
0001 \\
0001 \\
0001 \\
0001 \\
0001 \\
0001 \\
0001 \\
0001 \\
0001 \\
0001 \\
0001 \\
0001 \\
0001 \\
0001 \\
0001 \\
0001 \\
0001 \\
0001 \\
0001\end{array}$ & $\begin{array}{l}\text { UB } \\
\text { UB } \\
\text { UB } \\
\text { UB } \\
\text { UB } \\
\text { UB } \\
\text { UB } \\
\text { UB } \\
\text { UB } \\
\text { UB } \\
\text { UB } \\
\text { UB } \\
\text { UB } \\
\text { UB } \\
\text { UB } \\
\text { UB } \\
\text { UB } \\
\text { UB } \\
\text { UB } \\
\text { UB } \\
\text { UB } \\
\text { UB } \\
\text { UB } \\
\text { UB }\end{array}$ & $\begin{array}{l}0 \\
0 \\
0 \\
0 \\
0 \\
0 \\
0 \\
0 \\
0 \\
0 \\
0 \\
0 \\
0 \\
0 \\
0 \\
0 \\
0 \\
0 \\
0 \\
0 \\
0 \\
0 \\
0 \\
0\end{array}$ & $M G / L$ & & $\begin{array}{l}0.2 \\
0.2 \\
0.24 \\
0.23 \\
0.3 \\
0.2 \\
0.2 \\
0.1 \\
0.18 \\
0.18 \\
0.2 \\
0.2 \\
0.2 \\
0.2 \\
0.20 \\
0.21 \\
0.2 \\
0.1 \\
0.3 \\
0.2 \\
0.27 \\
0.25 \\
0.3 \\
0.2\end{array}$ & $\begin{array}{l}L \\
L \\
J\end{array}$ & $\begin{array}{l}0.1 \\
0.1 \\
0.05 \\
0.05 \\
0.1 \\
0.1 \\
0.1 \\
0.1 \\
0.05 \\
0.05 \\
0.1 \\
0.1 \\
0.1 \\
0.1 \\
0.05 \\
0.05 \\
0.1 \\
0.1 \\
0.1 \\
0.1 \\
0.05 \\
0.05 \\
0.1 \\
0.1\end{array}$ & $\begin{array}{l}: \\
: \\
: \\
- \\
: \\
: \\
- \\
- \\
- \\
- \\
- \\
- \\
- \\
- \\
- \\
- \\
-\end{array}$ \\
\hline BROMIDE & $\begin{array}{l}0518 \\
0518 \\
0518 \\
0518 \\
0523 \\
0523 \\
0523 \\
0523 \\
0527\end{array}$ & $\begin{array}{l}12 / 15 / 90 \\
04 / 01 / 91 \\
08 / 23 / 91 \\
10 / 11 / 92 \\
12 / 12 / 90 \\
04 / 01 / 91 \\
08 / 23 / 91 \\
10 / 12 / 92 \\
12 / 15 / 90\end{array}$ & $\begin{array}{l}0001 \\
0001 \\
0001 \\
0001 \\
0001 \\
0001 \\
0001 \\
0001 \\
0001\end{array}$ & $\begin{array}{l}\text { UB } \\
\text { UB } \\
\text { UB } \\
\text { UB } \\
\text { UB } \\
\text { UB } \\
\text { UB } \\
\text { UB } \\
\text { UB }\end{array}$ & $\begin{array}{l}0 \\
0 \\
0 \\
0 \\
0 \\
0 \\
0 \\
0 \\
0\end{array}$ & $M G / L$ & $\mid \begin{array}{l}< \\
< \\
< \\
< \\
<\end{array}$ & $\begin{array}{l}0.1 \\
0.2 \\
0.2 \\
0.1 \\
0.1 \\
0.2 \\
0.1 \\
0.2 \\
0.1\end{array}$ & $\begin{array}{l}\text { J } \\
\text { J }\end{array}$ & $\begin{array}{l}0.1 \\
0.1 \\
0.1 \\
0.1 \\
0.1 \\
0.1 \\
0.1 \\
0.2 \\
0.1\end{array}$ & $\begin{array}{l}- \\
: \\
: \\
- \\
- \\
-\end{array}$ \\
\hline
\end{tabular}

FORMATION OF COMPLETION CODE:

UB - UPPER BURRO CANYON

PARAMETER VALUE INDICATOR (PVI): < - LESS THAN DETECTION LIMIT
FLOW RELATIONSHIP CODE:

O - ON-SITE

SAMPLE ID CODES:

0001 - FILTERED SAMPLE (.45 MICRONS)

OTHER PARAMETER VALUE FLAGS:

I - INCREASED DETECTION LIMIT DUE TO REQUIRED DILUTION

$J$ - ESTIMATED VALUE

L - LESS THAN THREE BORE VOLUMES REMOVED BEFORE SAMPLING 
TABLE 3.45 BACKGROUND GROUND WATER QUALITY BY PARAMETER FOR THE UPPER SANDSTONE UNIT, BURRO CANYON DISPOSAL SITE, SLICK ROCK, COLORADD SITE: SRKO2 BORROW SITE 1 (BURRO CANYON)

06/04/90 TO 04/27/94

REPORT DATE: 09/30/94

\begin{tabular}{|c|c|c|c|c|c|c|c|c|c|c|c|}
\hline PARAMETER NAME & $\underset{\text { LOCAT ION }}{\text { ID }}$ & LOG DATE & $\begin{array}{c}\text { SAMPLE } \\
\text { ID }\end{array}$ & $\begin{array}{l}\text { FORM } \\
\text { COMP }\end{array}$ & $\begin{array}{l}\text { FLOW } \\
\text { REL. }\end{array}$ & $\begin{array}{l}\text { UNITS OF } \\
\text { MEASURE }\end{array}$ & PVI & $\begin{array}{l}\text { ARAMETER } \\
\text { VALUE }\end{array}$ & FLAGS & $\begin{array}{l}\text { DETECTION } \\
\text { LIHIT }\end{array}$ & $\begin{array}{l}\text { PARAMETER } \\
\text { UNCERTAINTY }\end{array}$ \\
\hline BROMIDE & $\begin{array}{l}0527 \\
0527 \\
0527 \\
0529 \\
0529 \\
0529 \\
0529\end{array}$ & $\begin{array}{l}04 / 04 / 91 \\
08 / 23 / 91 \\
10 / 12 / 92 \\
12 / 08 / 90 \\
04 / 02 / 91 \\
08 / 23 / 91 \\
10 / 12 / 92\end{array}$ & $\begin{array}{l}0001 \\
0001 \\
0001 \\
0001 \\
0001 \\
0001 \\
0001\end{array}$ & $\begin{array}{l}\text { UB } \\
\text { UB } \\
\text { UB } \\
\text { UB } \\
\text { UB } \\
\text { UB } \\
\text { UB }\end{array}$ & $\begin{array}{l}0 \\
0 \\
0 \\
0 \\
0 \\
0 \\
0\end{array}$ & $M G / L$ & $<$ & $\begin{array}{l}0.3 \\
0.3 \\
0.3 \\
0.1 \\
0.5 \\
0.4 \\
0.2\end{array}$ & $\begin{array}{l}\text { I } \\
\text { J }\end{array}$ & $\begin{array}{l}0.1 \\
0.1 \\
0.3 \\
0.01 \\
0.1 \\
0.1 \\
0.2\end{array}$ & $\begin{array}{l}- \\
- \\
- \\
- \\
-\end{array}$ \\
\hline CADMIUM & $\begin{array}{l}0518 \\
0518 \\
0518 \\
0518 \\
0518 \\
0518 \\
0518 \\
0523 \\
0523 \\
0523 \\
0523 \\
0523 \\
0523 \\
0523 \\
0527 \\
0527 \\
0527 \\
0527 \\
0527 \\
0527 \\
0527 \\
0529 \\
0529 \\
0529 \\
0529 \\
0529 \\
0529 \\
0529\end{array}$ & $\begin{array}{l}06 / 04 / 90 \\
12 / 15 / 90 \\
04 / 01 / 91 \\
08 / 23 / 91 \\
10 / 11 / 92 \\
02 / 24 / 94 \\
04 / 27 / 94 \\
06 / 04 / 90 \\
12 / 12 / 90 \\
04 / 01 / 91 \\
08 / 23 / 91 \\
10 / 12 / 92 \\
02 / 23 / 94 \\
04 / 20 / 94 \\
06 / 06 / 90 \\
12 / 15 / 90 \\
04 / 04 / 91 \\
08 / 23 / 91 \\
10 / 12 / 92 \\
02 / 23 / 94 \\
04 / 26 / 94 \\
06 / 06 / 90 \\
12 / 08 / 90 \\
04 / 02 / 91 \\
08 / 23 / 91 \\
10 / 12 / 92 \\
02 / 24 / 94 \\
04 / 26 / 94\end{array}$ & $\begin{array}{l}0001 \\
0001 \\
0001 \\
0001 \\
0001 \\
0001 \\
0001 \\
0001 \\
0001 \\
0001 \\
0001 \\
0001 \\
0001 \\
0001 \\
0001 \\
0001 \\
0001 \\
0001 \\
0001 \\
0001 \\
0001 \\
0001 \\
0001 \\
0001 \\
0001 \\
0001 \\
0001 \\
0001\end{array}$ & $\begin{array}{l}\text { UB } \\
\text { UB } \\
\text { UB } \\
\text { UB } \\
\text { UB } \\
\text { UB } \\
\text { UB } \\
\text { UB } \\
\text { UB } \\
\text { UB } \\
\text { UB } \\
\text { UB } \\
\text { UB } \\
\text { UB } \\
\text { UB } \\
\text { UB } \\
\text { UB } \\
\text { UB } \\
\text { UB } \\
\text { UB } \\
\text { UB } \\
\text { UB } \\
\text { UB } \\
\text { UB } \\
\text { UB } \\
\text { UB } \\
\text { UB } \\
\text { UB }\end{array}$ & $\begin{array}{l}0 \\
0 \\
0 \\
0 \\
0 \\
0 \\
0 \\
0 \\
0 \\
0 \\
0 \\
0 \\
0 \\
0 \\
0 \\
0 \\
0 \\
0 \\
0 \\
0 \\
0 \\
0 \\
0 \\
0 \\
0 \\
0 \\
0 \\
0\end{array}$ & $M G / L$ & $\begin{array}{l}< \\
< \\
< \\
< \\
< \\
< \\
< \\
< \\
< \\
< \\
< \\
< \\
< \\
< \\
< \\
< \\
< \\
< \\
< \\
< \\
< \\
< \\
< \\
< \\
< \\
< \\
<\end{array}$ & $\begin{array}{l}0.001 \\
0.001 \\
0.0006 \\
0.001 \\
0.02 \\
0.001 \\
0.001 \\
0.001 \\
0.001 \\
0.0005 \\
0.001 \\
0.001 \\
0.001 \\
0.001 \\
0.001 \\
0.001 \\
0.0005 \\
0.001 \\
0.001 \\
0.003 \\
0.001 \\
0.001 \\
0.001 \\
0.0005 \\
0.001 \\
0.001 \\
0.001 \\
0.001\end{array}$ & $\begin{array}{l}\mathbf{I} \\
\mathbf{L} \\
\mathbf{L} \\
\mathbf{J}\end{array}$ & $\begin{array}{l}0.001 \\
0.001 \\
0.0005 \\
0.001 \\
0.02 \\
0.001 \\
0.001 \\
0.001 \\
0.001 \\
0.0005 \\
0.001 \\
0.001 \\
0.001 \\
0.001 \\
0.001 \\
0.001 \\
0.0005 \\
0.001 \\
0.001 \\
0.001 \\
0.001 \\
0.001 \\
0.001 \\
0.0005 \\
0.001 \\
0.001 \\
0.001 \\
0.001\end{array}$ & $\begin{array}{l}- \\
- \\
- \\
- \\
- \\
- \\
- \\
- \\
- \\
- \\
- \\
- \\
- \\
- \\
- \\
- \\
- \\
- \\
- \\
- \\
- \\
- \\
- \\
-\end{array}$ \\
\hline CALCIUM & 0518 & $06 / 04 / 90$ & 0001 & UB & 0 & MG/L & \multicolumn{3}{|c|}{118.} & 0.01 & - \\
\hline
\end{tabular}

FORMATION OF COMPLETION CODE:

UB - UPPER BURRO CANYON

PARAMETER VALUE INDICATOR (PVI): < - LESS THAN DETECTION LIMIT
FLOW RELATIONSHIP CODE:

O - ON-SITE

0001 - FILTERED SAMPLE (.45 MICRONS)

OTHER PARAMETER VALUE FLAGS

I - INCREASED DETECTION LIMIT DUE TO REQUIRED DILUTION

$J$ - ESTIMATED VALUE

L - LESS THAN THREE BORE VOLUMES REMOVED BEFORE SAMPLING 
TABLE 3.45 BACKGROUND GROUND WATER QUALITY BY PARAMETER FOR THE UPPER SANDSTONE UNIT, BURRO CANYON DISPOSAL SITE, SLICK ROCK, COLORADO

SITE: SRKO2 BORROW SITE 1 (BURRO CANYON)

06/04/90 TO $04 / 27 / 94$

REPORT DATE : 09/30/94

\begin{tabular}{|c|c|c|c|c|c|c|c|c|c|c|c|}
\hline PARAMETER NAME & $\underset{\text { ID }}{\text { LOCATION }}$ & LOG DATE & $\begin{array}{c}\text { SAMPLE } \\
\text { ID }\end{array}$ & $\begin{array}{l}\text { FORM } \\
\text { COMP }\end{array}$ & $\begin{array}{l}\text { FLOW } \\
\text { REL. }\end{array}$ & $\begin{array}{l}\text { UNITS OF } \\
\text { MEASURE }\end{array}$ & PVI & $\begin{array}{l}\text { PARAMETER } \\
\text { VALUEE }\end{array}$ & FLAGS & $\begin{array}{l}\text { DETECTION } \\
\text { LIMIT }\end{array}$ & $\begin{array}{l}\text { PARAMETER } \\
\text { UNCERTAINTY }\end{array}$ \\
\hline CALCIUM & $\begin{array}{l}0518 \\
0518 \\
0518 \\
0518 \\
0518 \\
0518 \\
0523 \\
0523 \\
0523 \\
0523 \\
0523 \\
0523 \\
0523 \\
0527 \\
0527 \\
0527 \\
0527 \\
0527 \\
0527 \\
0527 \\
0529 \\
0529 \\
0529 \\
0529 \\
0529 \\
0529 \\
0529\end{array}$ & \begin{tabular}{|l|}
$12 / 15 / 90$ \\
$04 / 01 / 91$ \\
$08 / 23 / 91$ \\
$10 / 11 / 92$ \\
$02 / 24 / 94$ \\
$04 / 27 / 94$ \\
$06 / 04 / 90$ \\
$12 / 12 / 90$ \\
$04 / 01 / 91$ \\
$08 / 23 / 91$ \\
$10 / 12 / 92$ \\
$02 / 23 / 94$ \\
$04 / 20 / 94$ \\
$06 / 06 / 90$ \\
$12 / 15 / 90$ \\
$04 / 04 / 91$ \\
$08 / 23 / 91$ \\
$10 / 12 / 92$ \\
$02 / 23 / 94$ \\
$04 / 26 / 94$ \\
$06 / 06 / 90$ \\
$12 / 08 / 90$ \\
$04 / 02 / 91$ \\
$08 / 23 / 91$ \\
$10 / 12 / 92$ \\
$02 / 24 / 94$ \\
$04 / 26 / 94$
\end{tabular} & $\begin{array}{l}0001 \\
0001 \\
0001 \\
0001 \\
0001 \\
0001 \\
0001 \\
0001 \\
0001 \\
0001 \\
0001 \\
0001 \\
0001 \\
0001 \\
0001 \\
0001 \\
0001 \\
0001 \\
0001 \\
0001 \\
0001 \\
0001 \\
0001 \\
0001 \\
0001 \\
0001 \\
0001\end{array}$ & $\begin{array}{l}\text { UB } \\
\text { UB } \\
\text { UB } \\
\text { UB } \\
\text { UB } \\
\text { UB } \\
\text { UB } \\
\text { UB } \\
\text { UB } \\
\text { UB } \\
\text { UB } \\
\text { UB } \\
\text { UB } \\
\text { UB } \\
\text { UB } \\
\text { UB } \\
\text { UB } \\
\text { UB } \\
\text { UB } \\
\text { UB } \\
\text { UB } \\
\text { UB } \\
\text { UB } \\
\text { UB } \\
\text { UB } \\
\text { UB } \\
\text { UB }\end{array}$ & $\begin{array}{l}0 \\
0 \\
0 \\
0 \\
0 \\
0 \\
0 \\
0 \\
0 \\
0 \\
0 \\
0 \\
0 \\
0 \\
0 \\
0 \\
0 \\
0 \\
0 \\
0 \\
0 \\
0 \\
0 \\
0 \\
0 \\
0 \\
0\end{array}$ & $M G / L$ & & $\begin{array}{c}105 . \\
112 . \\
108 . \\
105 . \\
108 \\
105 \\
3.67 \\
4.54 \\
5.1 \\
3.7 \\
4.8 \\
6.0 \\
5.7 \\
18.7 \\
17.7 \\
20.1 \\
18.5 \\
15.9 \\
16.3 \\
17.6 \\
11.1 \\
6.96 \\
7.5 \\
7.3 \\
6.8 \\
10.8 \\
8.6\end{array}$ & $\begin{array}{l}\mathrm{L} \\
\mathrm{L} \\
\mathrm{J}\end{array}$ & $\begin{array}{l}0.01 \\
0.5 \\
0.5 \\
0.5 \\
0.5 \\
0.5 \\
0.01 \\
0.01 \\
0.1 \\
0.1 \\
0.1 \\
0.5 \\
0.5 \\
0.01 \\
0.01 \\
0.5 \\
0.1 \\
0.1 \\
0.5 \\
0.5 \\
0.01 \\
0.01 \\
0.1 \\
0.1 \\
0.1 \\
0.5 \\
0.5\end{array}$ & $\begin{array}{l}- \\
- \\
- \\
- \\
- \\
- \\
- \\
- \\
- \\
- \\
- \\
- \\
- \\
- \\
- \\
- \\
- \\
- \\
- \\
- \\
-\end{array}$ \\
\hline CHLORIDE & $\begin{array}{l}0518 \\
0518 \\
0518 \\
0518 \\
0518 \\
0518 \\
0518 \\
0523 \\
0523 \\
0523 \\
0523\end{array}$ & $\begin{array}{l}06 / 04 / 90 \\
12 / 15 / 90 \\
04 / 01 / 91 \\
08 / 23 / 91 \\
10 / 11 / 92 \\
02 / 24 / 94 \\
04 / 27 / 94 \\
06 / 04 / 90 \\
12 / 12 / 90 \\
04 / 01 / 91 \\
08 / 23 / 91\end{array}$ & $\begin{array}{l}0001 \\
0001 \\
0001 \\
0001 \\
0001 \\
0001 \\
0001 \\
0001 \\
0001 \\
0001 \\
0001\end{array}$ & $\begin{array}{l}\text { UB } \\
\text { UB } \\
\text { UB } \\
\text { UB } \\
\text { UB } \\
\text { UB } \\
\text { UB } \\
\text { UB } \\
\text { UB } \\
\text { UB } \\
\text { UB }\end{array}$ & $\begin{array}{l}0 \\
0 \\
0 \\
0 \\
0 \\
0 \\
0 \\
0 \\
0 \\
0 \\
0\end{array}$ & $M G / L$ & & $\begin{array}{l}13 . \\
14 . \\
15.7 \\
15.6 \\
16.3 \\
17.0 \\
14.2 \\
21 . \\
19 . \\
20 . \\
22 .\end{array}$ & $\begin{array}{l}\mathrm{L} \\
\mathrm{L}\end{array}$ & $\begin{array}{l}1 . \\
1 . \\
0.5 \\
0.5 \\
0.5 \\
0.5 \\
0.5 \\
1 . \\
1 . \\
0.5 \\
0.5\end{array}$ & $\begin{array}{l}- \\
- \\
- \\
- \\
- \\
- \\
- \\
- \\
-\end{array}$ \\
\hline
\end{tabular}

FORMATION OF COMPLETION CODE:

UB - UPPER BURRO CANYON

PARAMETER VALUE INDICATOR (PVI): < - LESS THAN DETECTION LIMIT
FLOW RELATIONSHIP CODE:

O - ON-SITE

AMPLE ID CODES:

0001 - FILTERED SAMPLE (.45 MICRONS)

\section{OTHER PARAMETER VALUE FLAGS:}

$J$ - ESTIMATED VALUE

L - LESS THAN THREE „BORE VOLUMES REMOVED BEFORE SAMPLING 
TABLE 3.45 BACKGROUND GROUND WATER QUALITY BY PARAMETER FOR THE UPPER SANDSTONE UNIT, BURRO CANYON DISPOSAL SITE, SLICK ROCK, COLORADO SITE: SRKO2 BORROW SITE 1 (BURRO CANYON)

06/04/90 TO 04/27/94

REPORT DATE: $09 / 30 / 94$

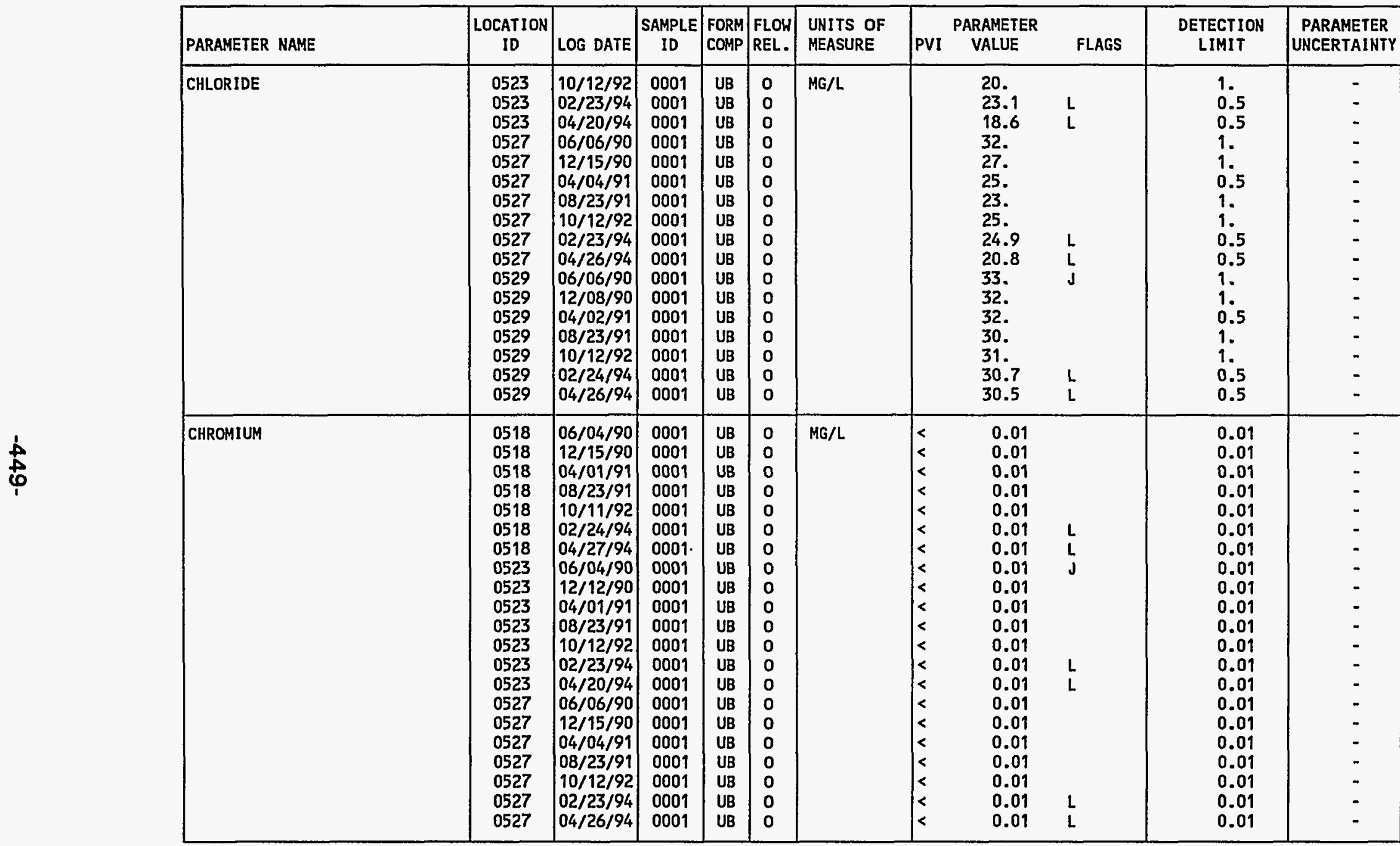

FORMATION OF COMPLETION CODE:

UB - UPPER BURRO CANYON

FLOW RELATIONSHIP CODE

PARAMETER VALUE INDICATOR (PVI): < - LESS THAN DETECTION LIMIT

OTHER PARAMETER VALUE FLAGS:

$\mathrm{J}$ - ESTIMATED VALUE

L - LESS tHAN THREE BORE VOLUMES REMOVED BEFORE SAMPLING 
TABLE 3.45 BACKGROUND GROUND WATER QUALITY BY PARAMETER FOR THE UPPER SANDSTONE UNIT BURRO CANYON DISPOSAL SITE, SLICK ROCK, COLORADO

$06 / 04 / 90$ TO 04/27/94

PEPORT DATE: $09 / 30 / 94$

\begin{tabular}{|c|c|c|c|c|c|c|c|c|c|c|c|}
\hline PARAMETER NAME & $\begin{array}{c}\text { LOCATION } \\
\text { ID }\end{array}$ & LOG DATE & $\begin{array}{c}\text { SAMPLE } \\
\text { ID }\end{array}$ & $\begin{array}{l}\text { FORM } \\
\text { COMP }\end{array}$ & $\begin{array}{l}\text { FLOW } \\
\text { REL. }\end{array}$ & $\begin{array}{l}\text { UNITS OF } \\
\text { MEASURE }\end{array}$ & PVI & $\begin{array}{l}\text { AMETER } \\
\text { ALLUE }\end{array}$ & FLAGS & $\begin{array}{l}\text { DETECTION } \\
\text { LIMIT }\end{array}$ & $\begin{array}{l}\text { PARAMETER } \\
\text { UNCERTAINTY }\end{array}$ \\
\hline CHROMIUM & $\begin{array}{l}0529 \\
0529 \\
0529 \\
0529 \\
0529 \\
0529 \\
0529\end{array}$ & $\begin{array}{l}06 / 06 / 90 \\
12 / 08 / 90 \\
04 / 02 / 91 \\
08 / 23 / 91 \\
10 / 12 / 92 \\
02 / 24 / 94 \\
04 / 26 / 94\end{array}$ & $\begin{array}{l}0001 \\
0001 \\
0001 \\
0001 \\
0001 \\
0001 \\
0001\end{array}$ & $\begin{array}{l}\text { UB } \\
\text { UB } \\
\text { UB } \\
\text { UB } \\
\text { UB } \\
\text { UB } \\
\text { UB }\end{array}$ & $\begin{array}{l}0 \\
0 \\
0 \\
0 \\
0 \\
0 \\
0\end{array}$ & $M G / L$ & $\begin{array}{l}< \\
< \\
< \\
< \\
< \\
<\end{array}$ & $\begin{array}{l}0.01 \\
0.01 \\
0.01 \\
0.01 \\
0.01 \\
0.01 \\
0.01\end{array}$ & $\begin{array}{l}L \\
L\end{array}$ & $\begin{array}{l}0.01 \\
0.01 \\
0.01 \\
0.01 \\
0.01 \\
0.01 \\
0.01\end{array}$ & $\begin{array}{l}- \\
- \\
- \\
- \\
-\end{array}$ \\
\hline COBALT & $\begin{array}{l}0518 \\
0518 \\
0518 \\
0518 \\
0523 \\
0523 \\
0523 \\
0523 \\
0527 \\
0527 \\
0527 \\
0527 \\
0529 \\
0529 \\
0529 \\
0529\end{array}$ & $\begin{array}{l}06 / 04 / 90 \\
12 / 15 / 90 \\
04 / 01 / 91 \\
08 / 23 / 91 \\
06 / 04 / 90 \\
12 / 12 / 90 \\
04 / 01 / 91 \\
08 / 23 / 91 \\
06 / 06 / 90 \\
12 / 15 / 90 \\
04 / 04 / 91 \\
08 / 23 / 91 \\
06 / 06 / 90 \\
12 / 08 / 90 \\
04 / 02 / 91 \\
08 / 23 / 91\end{array}$ & $\begin{array}{l}0001 \\
0001 \\
0001 \\
0001 \\
0001 \\
0001 \\
0001 \\
0001 \\
0001 \\
0001 \\
0001 \\
0001 \\
0001 \\
0001 \\
0001 \\
0001\end{array}$ & $\begin{array}{l}\text { UB } \\
\text { UB } \\
\text { UB } \\
\text { UB } \\
\text { UB } \\
\text { UB } \\
\text { UB } \\
\text { UB } \\
\text { UB } \\
\text { UB } \\
\text { UB } \\
\text { UB } \\
\text { UB } \\
\text { UB } \\
\text { UB } \\
\text { UB }\end{array}$ & $\begin{array}{l}0 \\
0 \\
0 \\
0 \\
0 \\
0 \\
0 \\
0 \\
0 \\
0 \\
0 \\
0 \\
0 \\
0 \\
0 \\
0\end{array}$ & MG/L & $\begin{array}{l}< \\
< \\
< \\
< \\
< \\
< \\
< \\
< \\
< \\
< \\
< \\
< \\
< \\
< \\
< \\
< \\
< \\
<\end{array}$ & $\begin{array}{l}0.05 \\
0.05 \\
0.03 \\
0.03 \\
0.05 \\
0.05 \\
0.03 \\
0.03 \\
0.05 \\
0.05 \\
0.03 \\
0.03 \\
0.05 \\
0.05 \\
0.03 \\
0.03\end{array}$ & J & $\begin{array}{l}0.05 \\
0.05 \\
0.03 \\
0.03 \\
0.05 \\
0.05 \\
0.03 \\
0.03 \\
0.05 \\
0.05 \\
0.03 \\
0.03 \\
0.05 \\
0.05 \\
0.03 \\
0.03\end{array}$ & $\begin{array}{l}- \\
- \\
- \\
- \\
- \\
- \\
- \\
- \\
- \\
- \\
- \\
-\end{array}$ \\
\hline COPPER & $\begin{array}{l}0518 \\
0518 \\
0518 \\
0518 \\
0518 \\
0523 \\
0523 \\
0523 \\
0523 \\
0523 \\
0527 \\
0527 \\
0527 \\
0527\end{array}$ & $\begin{array}{l}06 / 04 / 90 \\
12 / 15 / 90 \\
04 / 01 / 91 \\
08 / 23 / 91 \\
10 / 11 / 92 \\
06 / 04 / 90 \\
12 / 12 / 90 \\
04 / 01 / 91 \\
08 / 23 / 91 \\
10 / 12 / 92 \\
06 / 06 / 90 \\
12 / 15 / 90 \\
04 / 04 / 91 \\
08 / 23 / 91\end{array}$ & $\begin{array}{l}0001 \\
0001 \\
0001 \\
0001 \\
0001 \\
0001 \\
0001 \\
0001 \\
0001 \\
0001 \\
0001 \\
0001 \\
0001 \\
0001\end{array}$ & $\begin{array}{l}\text { UB } \\
\text { UB } \\
\text { UB } \\
\text { UB } \\
\text { UB } \\
\text { UB } \\
\text { UB } \\
\text { UB } \\
\text { UB } \\
\text { UB } \\
\text { UB } \\
\text { UB } \\
\text { UB } \\
\text { UB }\end{array}$ & $\begin{array}{l}0 \\
0 \\
0 \\
0 \\
0 \\
0 \\
0 \\
0 \\
0 \\
0 \\
0 \\
0 \\
0 \\
0\end{array}$ & $M G / L$ & $\begin{array}{l}< \\
< \\
< \\
< \\
< \\
< \\
< \\
< \\
< \\
< \\
< \\
< \\
< \\
< \\
< \\
<\end{array}$ & $\begin{array}{l}0.02 \\
0.02 \\
0.01 \\
0.01 \\
0.01 \\
0.02 \\
0.02 \\
0.01 \\
0.01 \\
0.01 \\
0.02 \\
0.02 \\
0.01 \\
0.01\end{array}$ & J & $\begin{array}{l}0.02 \\
0.02 \\
0.01 \\
0.01 \\
0.01 \\
0.02 \\
0.02 \\
0.01 \\
0.01 \\
0.01 \\
0.02 \\
0.02 \\
0.01 \\
0.01\end{array}$ & $\begin{array}{l}- \\
- \\
- \\
- \\
- \\
- \\
- \\
- \\
- \\
- \\
-\end{array}$ \\
\hline
\end{tabular}

FORMATION OF COMPLETION CODE:

UB - UPPER BURRO CANYON

PARAMETER VALUE INDICATOR (PVI): < - LESS THAN DETECTION LIMIT

OTHER PARAMETER VALUE FLAGS:

$J$ - ESTIMATED VALUE

L - LESS THAN THREE BORE VOLUMES REMOVED BEFORE SAMPLING
FLOW RELATIONSHIP CODE:

O- ON-SITE

SAMPLE ID CODES:

0001 - FILTERED SAMPLE (.45 MICRONS) 
TABLE 3.45 BACKGROUND GROUND WATER QUALITY BY PARAMETER FOR THE UPPER

SANDSTONE UNIT, BURRD CANYON DISPOSAL SITE, SLICK ROCK, COLORADD

SITE: SRKO2 BORROW SITE 1 (BURRO CANYON)

06/04/90 TO 04/27/94

REPORT DATE: $09 / 30 / 94$

\begin{tabular}{|c|c|c|c|c|c|c|c|c|c|c|c|}
\hline PARAMETER NAME & $\begin{array}{c}\text { LOCATION } \\
\text { ID }\end{array}$ & LOG DATE & $\begin{array}{l}\text { SAMPLE } \\
\text { ID }\end{array}$ & $\begin{array}{l}\text { FORM } \\
\text { COMP }\end{array}$ & $\begin{array}{l}\text { FLOH } \\
\text { REL. }\end{array}$ & $\begin{array}{l}\text { UNITS OF } \\
\text { MEASURE }\end{array}$ & PVI & $\begin{array}{l}\text { PARAMETER } \\
\text { VALUE }\end{array}$ & FLAGS & $\begin{array}{l}\text { DETECTION } \\
\text { LIHIT }\end{array}$ & $\begin{array}{l}\text { PARAMETER } \\
\text { UNCERTAINTY }\end{array}$ \\
\hline COPPER & $\begin{array}{l}0527 \\
0529 \\
0529 \\
0529 \\
0529 \\
0529\end{array}$ & $\begin{array}{l}10 / 12 / 92 \\
06 / 06 / 90 \\
12 / 08 / 90 \\
04 / 02 / 91 \\
08 / 23 / 91 \\
10 / 12 / 92\end{array}$ & $\begin{array}{l}0001 \\
0001 \\
0001 \\
0001 \\
0001 \\
0001\end{array}$ & $\begin{array}{l}\text { UB } \\
\text { UB } \\
\text { UB } \\
\text { UB } \\
\text { UB } \\
\text { UB }\end{array}$ & $\begin{array}{l}0 \\
0 \\
0 \\
0 \\
0 \\
0\end{array}$ & MG/L & $\begin{array}{l}< \\
< \\
< \\
< \\
< \\
<\end{array}$ & $\begin{array}{l}0.01 \\
0.02 \\
0.02 \\
0.01 \\
0.01 \\
0.01\end{array}$ & 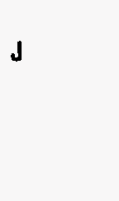 & $\begin{array}{l}0.01 \\
0.02 \\
0.02 \\
0.01 \\
0.01 \\
0.01\end{array}$ & $\begin{array}{l}- \\
- \\
- \\
-\end{array}$ \\
\hline CYANIDE & $\begin{array}{l}0518 \\
0518 \\
0518 \\
0523 \\
0523 \\
0523 \\
0527 \\
0527 \\
0527 \\
0529 \\
0529 \\
0529\end{array}$ & $\begin{array}{l}12 / 15 / 90 \\
04 / 01 / 91 \\
08 / 23 / 91 \\
12 / 12 / 90 \\
04 / 01 / 91 \\
08 / 23 / 91 \\
12 / 15 / 90 \\
04 / 04 / 91 \\
08 / 23 / 91 \\
12 / 08 / 90 \\
04 / 02 / 91 \\
08 / 23 / 91\end{array}$ & $\begin{array}{l}0001 \\
0001 \\
0001 \\
0001 \\
0001 \\
0001 \\
0001 \\
0001 \\
0001 \\
0001 \\
0001 \\
0001\end{array}$ & $\begin{array}{l}\text { UB } \\
\text { UB } \\
\text { UB } \\
\text { UB } \\
\text { UB } \\
\text { UB } \\
\text { UB } \\
\text { UB } \\
\text { UB } \\
\text { UB } \\
\text { UB } \\
\text { UB }\end{array}$ & $\begin{array}{l}0 \\
0 \\
0 \\
0 \\
0 \\
0 \\
0 \\
0 \\
0 \\
0 \\
0 \\
0\end{array}$ & $\mathrm{HG} / \mathrm{L}$ & $\begin{array}{l}< \\
< \\
< \\
< \\
< \\
< \\
< \\
< \\
< \\
< \\
< \\
< \\
< \\
<\end{array}$ & $\begin{array}{l}0.01 \\
0.01 \\
0.01 \\
0.01 \\
0.01 \\
0.01 \\
0.01 \\
0.01 \\
0.01 \\
0.01 \\
0.01 \\
0.01\end{array}$ & & $\begin{array}{l}0.01 \\
0.01 \\
0.01 \\
0.01 \\
0.01 \\
0.01 \\
0.01 \\
0.01 \\
0.01 \\
0.01 \\
0.01 \\
0.01\end{array}$ & $\begin{array}{l}- \\
- \\
- \\
- \\
- \\
- \\
- \\
- \\
-\end{array}$ \\
\hline DISSOLVED ORGANIC CARBON & $\begin{array}{l}0518 \\
0523 \\
0527 \\
0529\end{array}$ & $\begin{array}{l}04 / 27 / 94 \\
04 / 20 / 94 \\
04 / 26 / 94 \\
04 / 26 / 94\end{array}$ & $\begin{array}{l}0001 \\
0001 \\
0001 \\
0001\end{array}$ & $\begin{array}{l}\text { UB } \\
\text { UB } \\
\text { UB } \\
\text { UB }\end{array}$ & $\begin{array}{l}0 \\
0 \\
0 \\
0\end{array}$ & $\mathrm{MG} / \mathrm{L}$ & $<$ & $\begin{array}{r}1 \\
2 \\
10 \\
3\end{array}$ & $\begin{array}{l}L \\
L \\
L \\
L\end{array}$ & $\begin{array}{l}1 \\
1 \\
1 \\
1\end{array}$ & $\begin{array}{l}- \\
- \\
-\end{array}$ \\
\hline DISSOLVED OXYGEN & 0523 & $04 / 05 / 94$ & 0001 & UB & 0 & $\mathrm{MG} / \mathrm{L}$ & & 2.0 & & - & - \\
\hline FLUDRIDE & $\begin{array}{l}0518 \\
0518 \\
0518 \\
0518 \\
0518 \\
0523 \\
0523 \\
0523 \\
0523 \\
0523 \\
0527 \\
0527\end{array}$ & $\begin{array}{l}06 / 04 / 90 \\
12 / 15 / 90 \\
04 / 01 / 91 \\
08 / 23 / 91 \\
10 / 11 / 92 \\
06 / 04 / 90 \\
12 / 12 / 90 \\
04 / 01 / 91 \\
08 / 23 / 91 \\
10 / 12 / 92 \\
06 / 06 / 90 \\
12 / 15 / 90\end{array}$ & $\begin{array}{l}0001 \\
0001 \\
0001 \\
0001 \\
0001 \\
0001 \\
0001 \\
0001 \\
0001 \\
0001 \\
0001 \\
0001\end{array}$ & $\begin{array}{l}\text { UB } \\
\text { UB } \\
\text { UB } \\
\text { UB } \\
\text { UB } \\
\text { UB } \\
\text { UB } \\
\text { UB } \\
\text { UB } \\
\text { UB } \\
\text { UB } \\
\text { UB }\end{array}$ & $\begin{array}{l}0 \\
0 \\
0 \\
0 \\
0 \\
0 \\
0 \\
0 \\
0 \\
0 \\
0 \\
0\end{array}$ & $M G / L$ & & $\begin{array}{l}0.7 \\
0.8 \\
0.6 \\
0.7 \\
0.8 \\
1.1 \\
1.1 \\
0.9 \\
0.9 \\
1.1 \\
0.8 \\
0.8\end{array}$ & J & $\begin{array}{l}0.1 \\
0.1 \\
0.1 \\
0.1 \\
0.1 \\
0.1 \\
0.1 \\
0.1 \\
0.1 \\
0.1 \\
0.1 \\
0.1\end{array}$ & $\begin{array}{l}- \\
- \\
- \\
- \\
- \\
- \\
- \\
- \\
-\end{array}$ \\
\hline
\end{tabular}

FORMATION OF COMPLETION CODE:

UB - UPPER BURRO CANYON

PARAMETER VALUE INDICATOR (PVI): < - LESS THAN DETECTION LIMIT

OTHER PARAMETER VALUE FLAGS:

$J$ - ESTIMATED VALUE

L. - LESS THAN THREE BORE VOLUMES REMOVED BEFORE SAMPLING

\section{FLOW RELATIONSHIP CODE:}

$$
0 \text { - ON-SITE }
$$

0001 - FILTERED SAMPLE (.45 MICRONS) 
TABLE 3.45 BACKGROUND GROUND WATER QUALITY BY PARAMETER FOR THE UPPER SANDSTONE UNIT, BURRO CANYON DISPOSAL SITE, SLICK ROCK, COLORADO

SITE: SRKO2 BORROW SITE 1 (BURRO CANYON)

66/04/90 TO 04/27/94

\begin{tabular}{|c|c|c|c|c|c|c|c|c|c|c|c|}
\hline PARAMETER NAME & $\begin{array}{c}\text { LOCATION } \\
\text { IO }\end{array}$ & LOG DATE & $\begin{array}{c}\text { SAMPLE } \\
\text { ID }\end{array}$ & $\begin{array}{l}\text { FORM } \\
\text { COMP }\end{array}$ & $\begin{array}{l}\text { FLOW } \\
\text { REL. }\end{array}$ & $\begin{array}{l}\text { UNITS OF } \\
\text { MEASURE }\end{array}$ & PVI & $\begin{array}{l}\text { ARAMETER } \\
\text { VALUE }\end{array}$ & FLAGS & $\begin{array}{l}\text { DETECTION } \\
\text { LIMIT }\end{array}$ & $\begin{array}{l}\text { PARAMETER } \\
\text { UNCERTAINTY }\end{array}$ \\
\hline FLUORIDE & $\begin{array}{l}0527 \\
0527 \\
0527 \\
0529 \\
0529 \\
0529 \\
0529 \\
0529\end{array}$ & $\begin{array}{l}04 / 04 / 91 \\
08 / 23 / 91 \\
10 / 12 / 92 \\
06 / 06 / 90 \\
12 / 08 / 90 \\
04 / 02 / 91 \\
08 / 23 / 91 \\
10 / 12 / 92\end{array}$ & $\begin{array}{l}0001 \\
0001 \\
0001 \\
0001 \\
0001 \\
0001 \\
0001 \\
0001\end{array}$ & $\begin{array}{l}\text { UB } \\
\text { UB } \\
\text { UB } \\
\text { UB } \\
\text { UB } \\
\text { UB } \\
\text { UB } \\
\text { UB }\end{array}$ & $\begin{array}{l}0 \\
0 \\
0 \\
0 \\
0 \\
0 \\
0 \\
0\end{array}$ & $M G / L$ & & $\begin{array}{l}0.7 \\
0.7 \\
0.8 \\
0.9 \\
0.8 \\
0.7 \\
0.6 \\
0.8\end{array}$ & $J$ & $\begin{array}{l}0.1 \\
0.1 \\
0.1 \\
0.1 \\
0.1 \\
0.1 \\
0.1 \\
0.1\end{array}$ & $\begin{array}{l}- \\
- \\
- \\
- \\
- \\
-\end{array}$ \\
\hline GROSS ALPHA & $\begin{array}{l}0518 \\
0518 \\
0518 \\
0518 \\
0518 \\
0518 \\
0523 \\
0523 \\
0523 \\
0523 \\
0523 \\
0523 \\
0527 \\
0527 \\
0527 \\
0527 \\
0527 \\
0527 \\
0529 \\
0529 \\
0529 \\
0529 \\
0529 \\
0529\end{array}$ & $\begin{array}{l}12 / 15 / 90 \\
04 / 01 / 91 \\
08 / 23 / 91 \\
10 / 11 / 92 \\
02 / 24 / 94 \\
04 / 04 / 94 \\
12 / 12 / 90 \\
04 / 01 / 91 \\
08 / 23 / 91 \\
10 / 12 / 92 \\
02 / 23 / 94 \\
04 / 05 / 94 \\
12 / 15 / 90 \\
04 / 04 / 91 \\
08 / 23 / 91 \\
10 / 12 / 92 \\
02 / 23 / 94 \\
04 / 04 / 94 \\
12 / 08 / 90 \\
04 / 02 / 91 \\
08 / 23 / 91 \\
10 / 12 / 92 \\
02 / 24 / 94 \\
04 / 05 / 94\end{array}$ & $\begin{array}{l}0001 \\
0001 \\
0001 \\
0001 \\
0001 \\
0001 \\
0001 \\
0001 \\
0001 \\
0001 \\
0001 \\
0001 \\
0001 \\
0001 \\
0001 \\
0001 \\
0001 \\
0001 \\
0001 \\
0001 \\
0001 \\
0001 \\
0001 \\
0001\end{array}$ & $\begin{array}{l}\text { UB } \\
\text { UB } \\
\text { UB } \\
\text { UB } \\
\text { UB } \\
\text { UB } \\
\text { UB } \\
\text { UB } \\
\text { UB } \\
\text { UB } \\
\text { UB } \\
\text { UB } \\
\text { UB } \\
\text { UB } \\
\text { UB } \\
\text { UB } \\
\text { UB } \\
\text { UB } \\
\text { UB } \\
\text { UB } \\
\text { UB } \\
\text { UB } \\
\text { UB } \\
\text { UB }\end{array}$ & $\begin{array}{l}0 \\
0 \\
0 \\
0 \\
0 \\
0 \\
0 \\
0 \\
0 \\
0 \\
0 \\
0 \\
0 \\
0 \\
0 \\
0 \\
0 \\
0 \\
0 \\
0 \\
0 \\
0 \\
0 \\
0\end{array}$ & $\mathrm{PCI} / \mathrm{L}$ & & $\begin{array}{c}18 . \\
12.6 \\
12.6 \\
11.9 \\
17.2 \\
17.0 \\
1.3 \\
0.0 \\
0.0 \\
0.0 \\
3.0 \\
0.7 \\
10 . \\
2.4 \\
7.3 \\
0.0 \\
9.9 \\
0.8 \\
1.7 \\
1.6 \\
10.2 \\
0.0 \\
1.3 \\
0.0\end{array}$ & $\begin{array}{l}N \\
\text { JLN } \\
\text { N } \\
L \\
N\end{array}$ & $\begin{array}{c}1 . \\
1 . \\
1 . \\
11.5 \\
3.1 \\
3.7 \\
1 . \\
1 . \\
1 . \\
11.9 \\
2.6 \\
2.6 \\
1 . \\
1 . \\
1 . \\
14.3 \\
3.6 \\
3.5 \\
1 . \\
1 . \\
1 . \\
11.1 \\
2.7 \\
2.5\end{array}$ & $\begin{array}{r}7 . \\
8.9 \\
14.0 \\
8.2 \\
2.8 \\
3.5 \\
4.3 \\
5.0 \\
8.2 \\
6.3 \\
1.6 \\
1.4 \\
7 . \\
7.3 \\
12.6 \\
7.6 \\
2.7 \\
2.2 \\
4.0 \\
4.8 \\
10.5 \\
5.7 \\
1.3 \\
1.6\end{array}$ \\
\hline GROSS BETA & $\begin{array}{l}0518 \\
0518 \\
0518 \\
0518\end{array}$ & $\begin{array}{l}12 / 15 / 90 \\
04 / 01 / 91 \\
08 / 23 / 91 \\
10 / 11 / 92\end{array}$ & $\begin{array}{l}0001 \\
0001 \\
0001 \\
0001\end{array}$ & $\begin{array}{l}\text { UB } \\
\text { UB } \\
\text { UB } \\
\text { UB }\end{array}$ & $\begin{array}{l}0 \\
0 \\
0 \\
0\end{array}$ & $\mathrm{PCI} / \mathrm{L}$ & & $\begin{array}{r}11 . \\
7.3 \\
3.8 \\
39.2\end{array}$ & $\star N$ & $\begin{array}{r}0.5 \\
0.5 \\
0.5 \\
10.2\end{array}$ & $\begin{array}{l}4 . \\
4.9 \\
9.3 \\
7.7\end{array}$ \\
\hline
\end{tabular}

FORMATION OF COMPLETION CODE:

UB - UPPER BURRO CANYON

PARAMETER VALUE INDICATOR (PVI): < - LESS THAN DETECTION LIMIT
FLOW RELATIONSHIP CODE:

O - ON-SITE

0001 - FILTERED SAMPLE (.45 MICRONS)

OTHER PARAMETER VALUE FLAGS:

* - DUPLICATE ANALYSIS NOT HITHIN CONTROL LIMITS

$J$ - ESTIMATED VALUE

L - LESS THAN THREE BORE VOLUMES REMOVED BEFORE SAMPLING

$N$ - SPIKE SAMPLE RECOVERY NOT WITHIN CONTROL LIMITS 


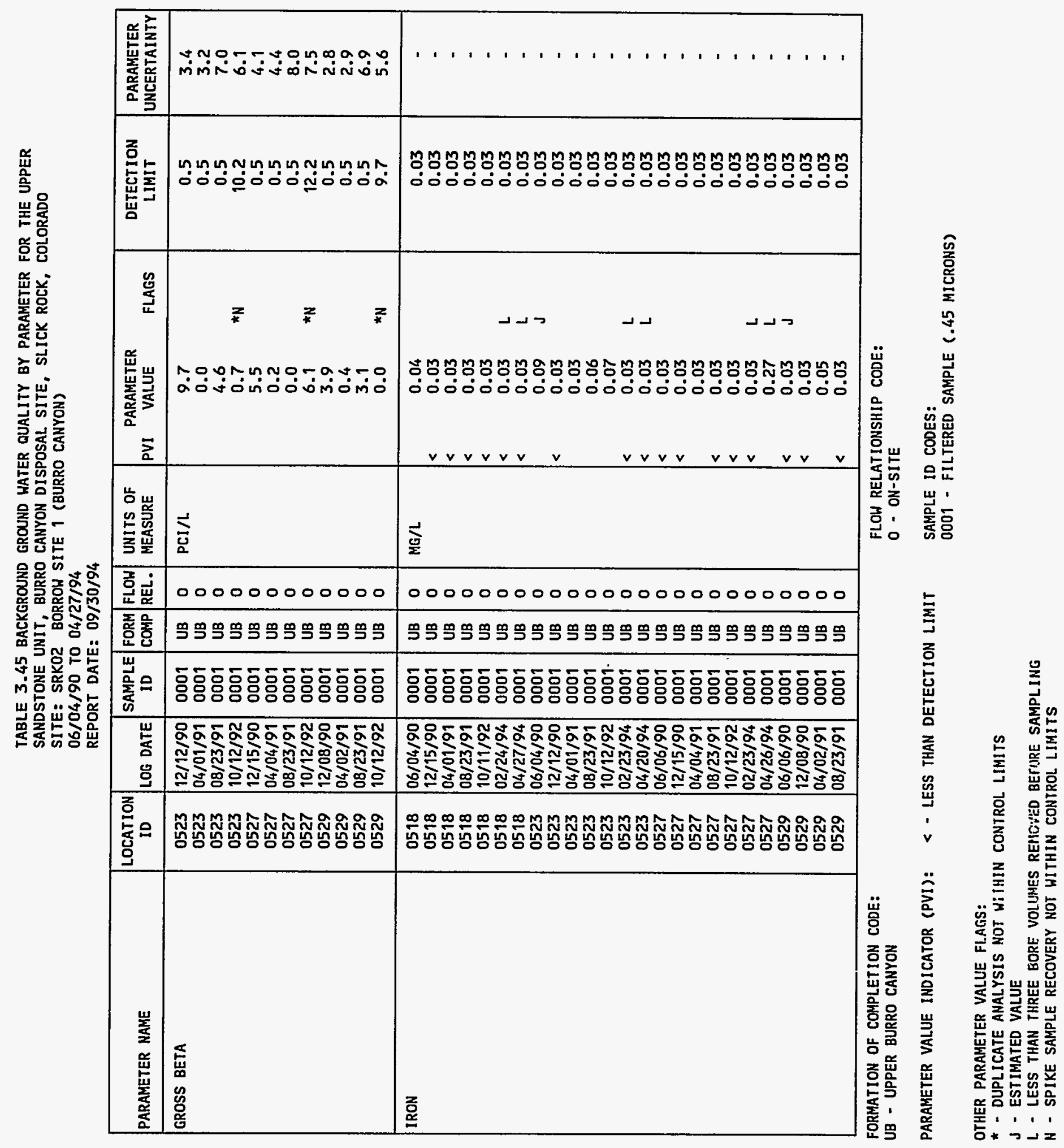


TABLE 3.45 BACKGROUND GROUND WATER QUALITY BY PARAMETER FOR THE UPPER SANDSTONE UNIT, BURRO CANYON DISPOSAL SITE, SLICK ROCK, COLORADO

SITE: SRKO2 BORROW SITE 1 (BURRO CANYON)

06/04/90 TO $04 / 27 / 94$

REPORT DATE : 09/30/94

\begin{tabular}{|c|c|c|c|c|c|c|c|c|c|c|c|}
\hline PARAMETER NAME & $\mid \begin{array}{c}\text { LOCATION } \\
10\end{array}$ & LOG DATE & $\begin{array}{c}\text { SAMPLE } \\
\text { ID }\end{array}$ & $\begin{array}{l}\text { FORM } \\
\text { COMP }\end{array}$ & $\begin{array}{l}\text { FLOW } \\
\text { REL. }\end{array}$ & $\begin{array}{l}\text { UNITS OF } \\
\text { MEASURE }\end{array}$ & PVI & $\begin{array}{l}\text { RAMETER } \\
\text { VALUE }\end{array}$ & FLAGS & $\begin{array}{l}\text { DETECTION } \\
\text { LIMIT }\end{array}$ & $\begin{array}{l}\text { PARAMETER } \\
\text { UNCERTAINTY }\end{array}$ \\
\hline IRON & $\begin{array}{l}0529 \\
0529 \\
0529\end{array}$ & $\left|\begin{array}{l}10 / 12 / 92 \\
02 / 24 / 94 \\
04 / 26 / 94\end{array}\right|$ & $\begin{array}{l}0001 \\
0001 \\
0001\end{array}$ & $\begin{array}{l}\text { UB } \\
\text { UB } \\
\text { UB }\end{array}$ & $\begin{array}{l}0 \\
0 \\
0\end{array}$ & $M G / L$ & $<$ & $\begin{array}{l}0.03 \\
0.59 \\
0.09\end{array}$ & $\begin{array}{l}\mathrm{L} \\
\mathrm{L}\end{array}$ & $\begin{array}{l}0.03 \\
0.03 \\
0.03\end{array}$ & - \\
\hline LEAD & $\begin{array}{l}0518 \\
0518 \\
0518 \\
0518 \\
0518 \\
0523 \\
0523 \\
0523 \\
0523 \\
0523 \\
0527 \\
0527 \\
0527 \\
0527 \\
0527 \\
0529 \\
0529 \\
0529 \\
0529 \\
0529\end{array}$ & $\begin{array}{l}06 / 04 / 90 \\
12 / 15 / 90 \\
04 / 01 / 91 \\
08 / 23 / 91 \\
10 / 11 / 92 \\
06 / 04 / 90 \\
12 / 12 / 90 \\
04 / 01 / 91 \\
08 / 23 / 91 \\
10 / 12 / 92 \\
06 / 06 / 90 \\
12 / 15 / 90 \\
04 / 04 / 91 \\
08 / 23 / 91 \\
10 / 12 / 92 \\
06 / 06 / 90 \\
12 / 08 / 90 \\
04 / 02 / 91 \\
08 / 23 / 91 \\
10 / 12 / 92\end{array}$ & $\begin{array}{l}0001 \\
0001 \\
0001 \\
0001 \\
0001 \\
0001 \\
0001 \\
0001 \\
0001 \\
0001 \\
0001 \\
0001 \\
0001 \\
0001 \\
0001 \\
0001 \\
0001 \\
0001 \\
0001 \\
0001\end{array}$ & $\begin{array}{l}\text { UB } \\
\text { UB } \\
\text { UB } \\
\text { UB } \\
\text { UB } \\
\text { UB } \\
\text { UB } \\
\text { UB } \\
\text { UB } \\
\text { UB } \\
\text { UB } \\
\text { UB } \\
\text { UB } \\
\text { UB } \\
\text { UB } \\
\text { UB } \\
\text { UB } \\
\text { UB } \\
\text { UB } \\
\text { UB }\end{array}$ & $\begin{array}{l}0 \\
0 \\
0 \\
0 \\
0 \\
0 \\
0 \\
0 \\
0 \\
0 \\
0 \\
0 \\
0 \\
0 \\
0 \\
0 \\
0 \\
0 \\
0 \\
0\end{array}$ & $M G / L$ & $\begin{array}{l}< \\
< \\
< \\
< \\
< \\
< \\
< \\
< \\
< \\
< \\
< \\
< \\
< \\
< \\
< \\
< \\
< \\
< \\
< \\
< \\
< \\
<\end{array}$ & $\begin{array}{l}0.01 \\
0.01 \\
0.005 \\
0.03 \\
0.02 \\
0.01 \\
0.01 \\
0.005 \\
0.005 \\
0.02 \\
0.01 \\
0.01 \\
0.005 \\
0.005 \\
0.02 \\
0.01 \\
0.01 \\
0.005 \\
0.005 \\
0.02\end{array}$ & $\begin{array}{l}1 \\
1 \\
J \\
1 \\
I \\
J \\
I \\
I\end{array}$ & $\begin{array}{l}0.01 \\
0.01 \\
0.005 \\
0.03 \\
0.02 \\
0.01 \\
0.01 \\
0.005 \\
0.005 \\
0.02 \\
0.01 \\
0.01 \\
0.005 \\
0.005 \\
0.02 \\
0.01 \\
0.01 \\
0.005 \\
0.005 \\
0.02\end{array}$ & $\begin{array}{l}- \\
- \\
- \\
- \\
- \\
- \\
- \\
- \\
- \\
- \\
- \\
- \\
- \\
- \\
- \\
-\end{array}$ \\
\hline LEAD-210 & $\begin{array}{l}0518 \\
0518 \\
0518 \\
0523 \\
0523 \\
0523 \\
0527 \\
0527 \\
0527 \\
0529 \\
0529 \\
0529\end{array}$ & $\begin{array}{l}12 / 15 / 90 \\
04 / 01 / 91 \\
08 / 23 / 91 \\
12 / 12 / 90 \\
04 / 01 / 91 \\
08 / 23 / 91 \\
12 / 15 / 90 \\
04 / 04 / 91 \\
08 / 23 / 91 \\
12 / 08 / 90 \\
04 / 02 / 91 \\
08 / 23 / 91\end{array}$ & $\begin{array}{l}0001 \\
0001 \\
0001 \\
0001 \\
0001 \\
0001 \\
0001 \\
0001 \\
0001 \\
0001 \\
0001 \\
0001\end{array}$ & $\begin{array}{l}\text { UB } \\
\text { UB } \\
\text { UB } \\
\text { UB } \\
\text { UB } \\
\text { UB } \\
\text { UB } \\
\text { UB } \\
\text { UB } \\
\text { UB } \\
\text { UB } \\
\text { UB }\end{array}$ & $\begin{array}{l}0 \\
0 \\
0 \\
0 \\
0 \\
0 \\
0 \\
0 \\
0 \\
0 \\
0 \\
0\end{array}$ & PCI/L & & $\begin{array}{l}0.2 \\
0.3 \\
0.9 \\
0.7 \\
0.0 \\
0.0 \\
0.0 \\
0.0 \\
0.0 \\
0.0 \\
0.0 \\
0.0\end{array}$ & & $\begin{array}{l}1.5 \\
1.5 \\
1.5 \\
1.5 \\
1.5 \\
1.5 \\
1.5 \\
1.5 \\
1.5 \\
1.5 \\
1.5 \\
1.5\end{array}$ & $\begin{array}{l}1.2 \\
1.4 \\
1.0 \\
0.9 \\
1.3 \\
0.9 \\
0.9 \\
1.3 \\
0.9 \\
0.9 \\
1.3 \\
0.9\end{array}$ \\
\hline MAGNESIUM & 0518 & $06 / 04 / 90$ & 0001 & UB & 0 & $M G / L$ & & 32.2 & & 0.001 & - \\
\hline
\end{tabular}

FORMATION OF COMPLETION CODE:

UB - UPPER BURRO CANYON

PARAMETER VALUE INDICATOR (PVI):
FLOW RELATIONSHIP CODE:

\section{SAMPLE ID CODES:}

0001 - FILTERED SAMPLE (.45 MICRONS)

OTHER PARAMETER VALUE FLAGS:

I - INCREASED DETECTION LIMIT DUE TO REQUIRED DILUTION

J - ESTIMATED VALUE

L - LESS THAN THREE BORE VOLUMES REMOVED BEFORE SAMPLING 


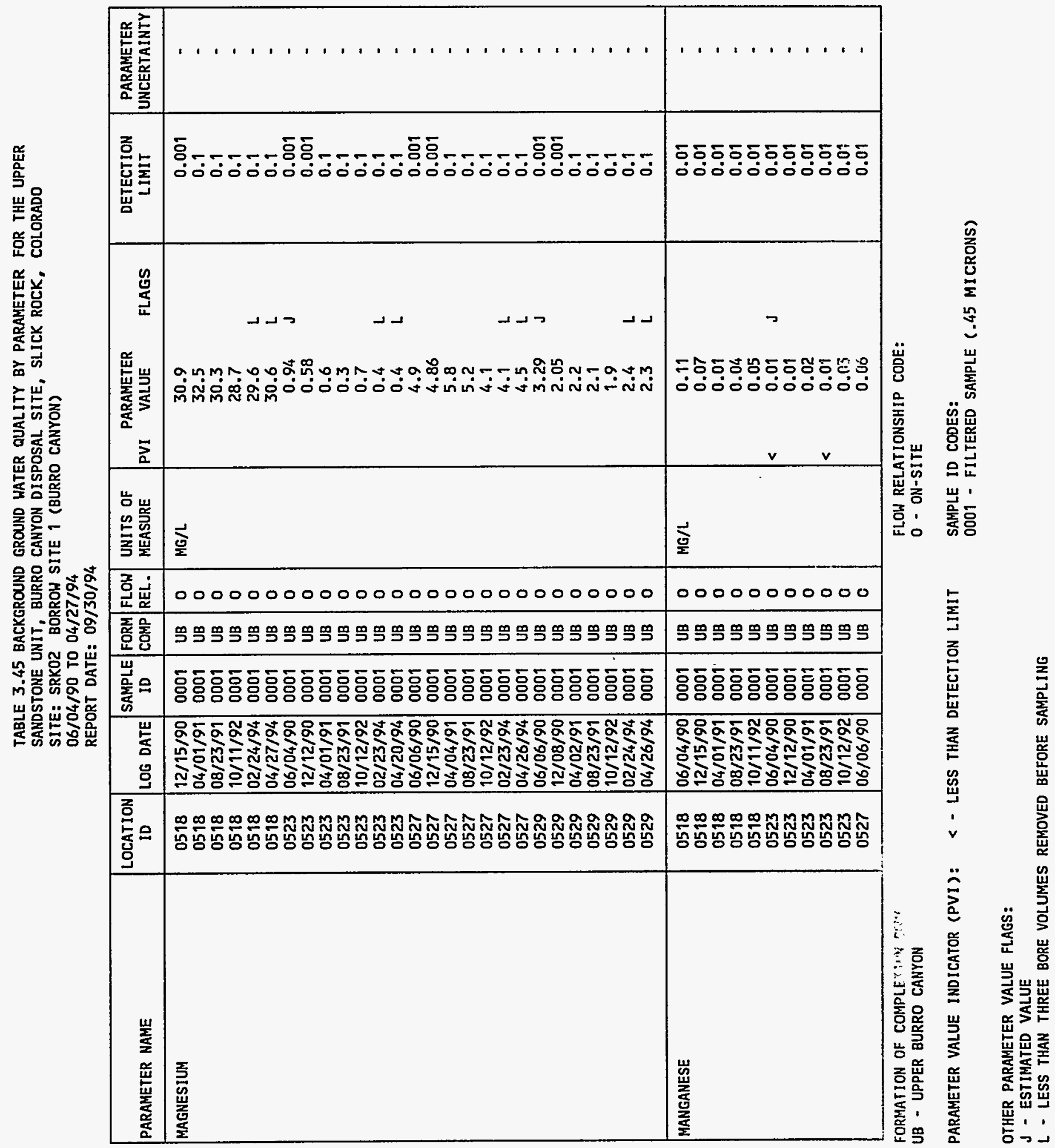




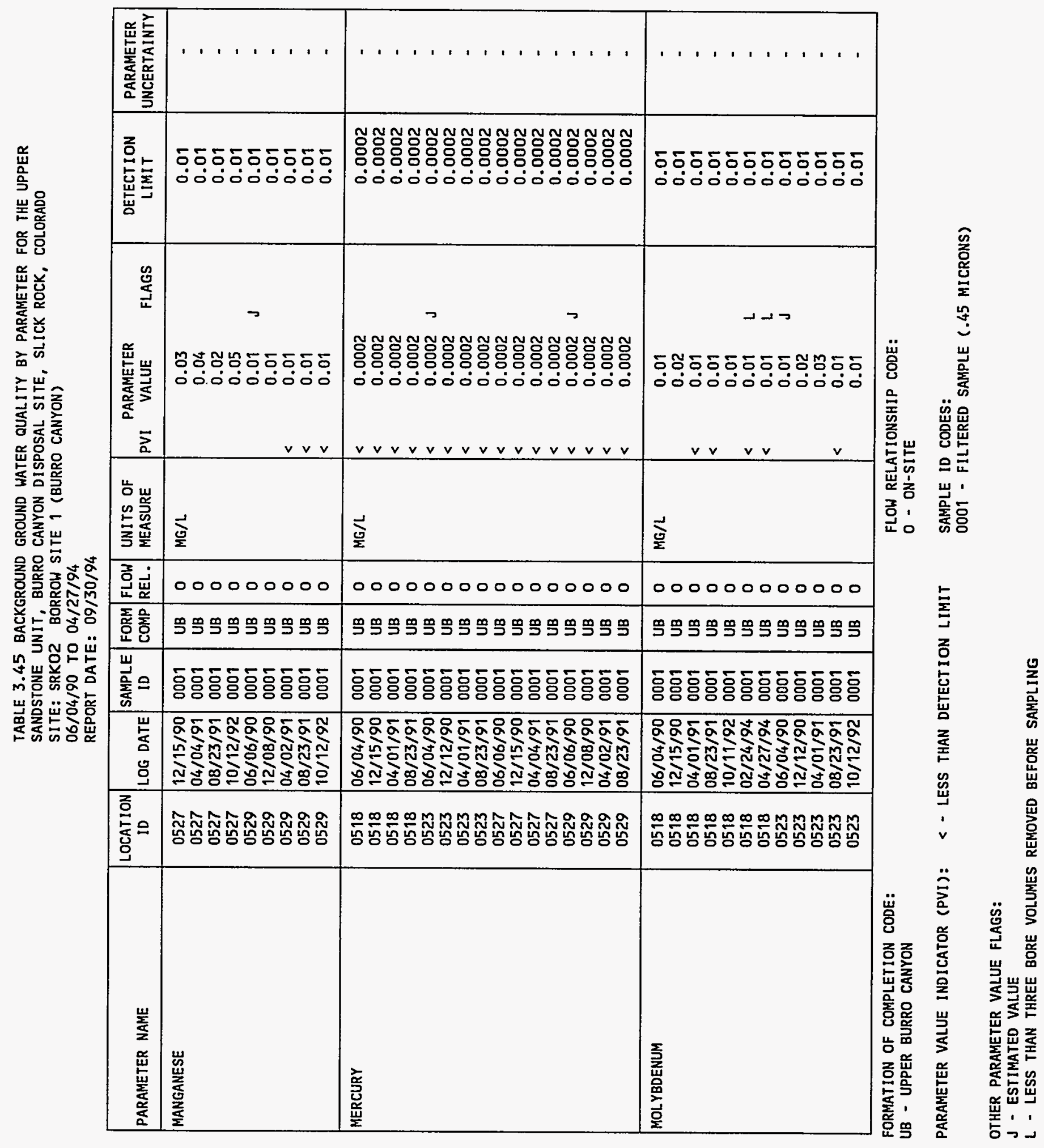




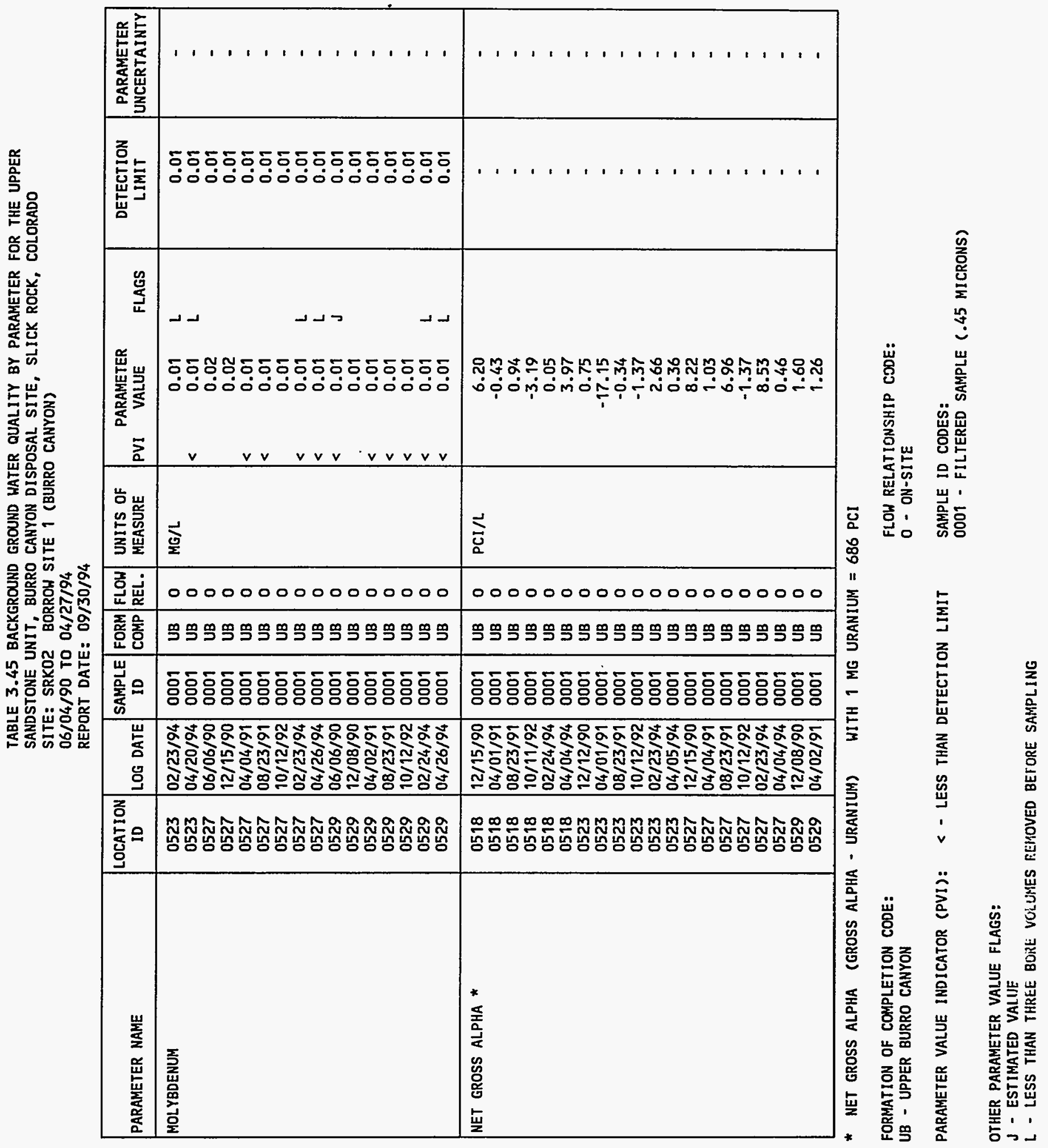


TABLE 3.45 BACKGROUND GROUND WATER QUALITY BY PARAMETER FOR THE UPPER SANDSTONE UNIT, BURRO CANYON DISPOSAL SITE, SLICK ROCK, COLORADO

SITE: SRKO2 BORROW SITE 1 (BURRO CANYON)

06/04/90 TO 04/27/94

REPORT DATE: $09 / 30 / 94$

\begin{tabular}{|c|c|c|c|c|c|c|c|c|c|c|c|}
\hline PARAMETER NAME & $\mid \begin{array}{c}\text { LOCATION } \\
\text { ID }\end{array}$ & LOG DATE & $\begin{array}{c}\text { SAMPLE } \\
\text { ID }\end{array}$ & $\begin{array}{l}\text { FORM } \\
\text { COMP }\end{array}$ & $\begin{array}{l}\text { FLOW } \\
\text { REL. }\end{array}$ & $\begin{array}{l}\text { UNITS OF } \\
\text { MEASURE }\end{array}$ & PVI & $\begin{array}{l}\text { ARAMETER } \\
\text { VALUE }\end{array}$ & FLAGS & $\begin{array}{l}\text { DETECTION } \\
\text { LIMIT }\end{array}$ & $\begin{array}{l}\text { PARAMETER } \\
\text { UNCERTAINTY }\end{array}$ \\
\hline NET GROSS ALPHA * & $\begin{array}{l}0529 \\
0529 \\
0529 \\
0529\end{array}$ & $\begin{array}{l}08 / 23 / 91 \\
10 / 12 / 92 \\
02 / 24 / 94 \\
04 / 05 / 94\end{array}$ & $\begin{array}{l}0001 \\
0001 \\
0001 \\
0001\end{array}$ & $\begin{array}{l}\text { UB } \\
\text { UB } \\
\text { UB } \\
\text { UB }\end{array}$ & $\begin{array}{l}0 \\
0 \\
0 \\
0\end{array}$ & $\mathrm{PCI} / \mathrm{L}$ & & $\begin{array}{r}9.86 \\
-1.37 \\
0.96 \\
-0.34\end{array}$ & & - & $\begin{array}{l}- \\
- \\
-\end{array}$ \\
\hline NICKEL & $\begin{array}{l}0518 \\
0518 \\
0518 \\
0518 \\
0518 \\
0523 \\
0523 \\
0523 \\
0523 \\
0523 \\
0527 \\
0527 \\
0527 \\
0527 \\
0527 \\
0529 \\
0529 \\
0529 \\
0529 \\
0529\end{array}$ & $\begin{array}{l}06 / 04 / 90 \\
12 / 15 / 90 \\
04 / 01 / 91 \\
08 / 23 / 91 \\
10 / 11 / 92 \\
06 / 04 / 90 \\
12 / 12 / 90 \\
04 / 01 / 91 \\
08 / 23 / 91 \\
10 / 12 / 92 \\
06 / 06 / 90 \\
12 / 15 / 90 \\
04 / 04 / 91 \\
08 / 23 / 91 \\
10 / 12 / 92 \\
06 / 06 / 90 \\
12 / 08 / 90 \\
04 / 02 / 91 \\
08 / 23 / 91 \\
10 / 12 / 92\end{array}$ & $\begin{array}{l}0001 \\
0001 \\
0001 \\
0001 \\
0001 \\
0001 \\
0001 \\
0001 \\
0001 \\
0001 \\
0001 \\
0001 \\
0001 \\
0001 \\
0001 \\
0001 \\
0001 \\
0001 \\
0001 \\
0001\end{array}$ & $\begin{array}{l}\text { UB } \\
\text { UB } \\
\text { UB } \\
\text { UB } \\
\text { UB } \\
\text { UB } \\
\text { UB } \\
\text { UB } \\
\text { UB } \\
\text { UB } \\
\text { UB } \\
\text { UB } \\
\text { UB } \\
\text { UB } \\
\text { UB } \\
\text { UB } \\
\text { UB } \\
\text { UB } \\
\text { UB } \\
\text { UB }\end{array}$ & $\begin{array}{l}0 \\
0 \\
0 \\
0 \\
0 \\
0 \\
0 \\
0 \\
0 \\
0 \\
0 \\
0 \\
0 \\
0 \\
0 \\
0 \\
0 \\
0 \\
0 \\
0\end{array}$ & MG/L & $\begin{array}{l}< \\
< \\
< \\
< \\
< \\
< \\
< \\
< \\
< \\
< \\
< \\
< \\
< \\
< \\
< \\
< \\
< \\
< \\
< \\
< \\
< \\
< \\
<\end{array}$ & $\begin{array}{l}0.04 \\
0.04 \\
0.04 \\
0.04 \\
0.04 \\
0.04 \\
0.04 \\
0.04 \\
0.04 \\
0.04 \\
0.04 \\
0.04 \\
0.04 \\
0.04 \\
0.04 \\
0.04 \\
0.04 \\
0.04 \\
0.04 \\
0.04\end{array}$ & $\mathbf{J}$ & $\begin{array}{l}0.04 \\
0.04 \\
0.04 \\
0.04 \\
0.04 \\
0.04 \\
0.04 \\
0.04 \\
0.04 \\
0.04 \\
0.04 \\
0.04 \\
0.04 \\
0.04 \\
0.04 \\
0.04 \\
0.04 \\
0.04 \\
0.04 \\
0.04\end{array}$ & $\begin{array}{l}- \\
- \\
- \\
- \\
- \\
- \\
- \\
- \\
- \\
- \\
- \\
- \\
- \\
- \\
- \\
-\end{array}$ \\
\hline NITRATE & $\begin{array}{l}0518 \\
0518 \\
0518 \\
0518 \\
0518 \\
0523 \\
0523 \\
0523 \\
0523 \\
0523 \\
0527 \\
0527\end{array}$ & $\begin{array}{l}06 / 04 / 90 \\
12 / 15 / 90 \\
04 / 01 / 91 \\
08 / 23 / 91 \\
10 / 11 / 92 \\
06 / 04 / 90 \\
12 / 12 / 90 \\
04 / 01 / 91 \\
08 / 23 / 91 \\
10 / 12 / 92 \\
06 / 06 / 90 \\
12 / 15 / 90\end{array}$ & $\begin{array}{l}0001 \\
0001 \\
0001 \\
0001 \\
0001 \\
0001 \\
0001 \\
0001 \\
0001 \\
0001 \\
0001 \\
0001\end{array}$ & $\begin{array}{l}\text { UB } \\
\text { UB } \\
\text { UB } \\
\text { UB } \\
\text { UB } \\
\text { UB } \\
\text { UB } \\
\text { UB } \\
\text { UB } \\
\text { UB } \\
\text { UB } \\
\text { UB }\end{array}$ & $\begin{array}{l}0 \\
0 \\
0 \\
0 \\
0 \\
0 \\
0 \\
0 \\
0 \\
0 \\
0 \\
0\end{array}$ & $M G / L$ & 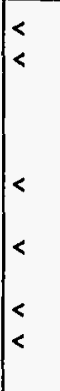 & $\begin{array}{l}1 . \\
1 . \\
2 . \\
4.4 \\
1.6 \\
1 . \\
4 . \\
1.0 \\
5.8 \\
1.0 \\
1 . \\
2 .\end{array}$ & $\begin{array}{l}\text { J } \\
\text { J }\end{array}$ & $\begin{array}{l}1 . \\
1 . \\
1 . \\
1.0 \\
1.0 \\
1 . \\
1 . \\
1 . \\
1.0 \\
1.0 \\
1 .\end{array}$ & $\begin{array}{l}- \\
- \\
- \\
- \\
- \\
- \\
- \\
- \\
- \\
-\end{array}$ \\
\hline
\end{tabular}

\footnotetext{
* NeT GROSS ALPHA (GROSS ALPHA - URANIUM) WITH 1 MG URANIUM = 686 PCI
}

FORMATION OF COMPLETION CODE:

UB - UPPER BURRO CANYON

PARAMETER VALUE INDICATOR (PVI): < - LESS THAN DETECTION LIMIT
FLOW RELATIONSHIP CODE:

O - ON-SITE

SAMPLE ID CODES:

0001 - FILTERED SAMPLE (.45 MICRONS)

OTHER PARAMETER VALUE FLAGS:

J - ESTIMATED VALUE 
TABLE 3.45 BACKGROUND GROUND WATER QUALITY BY PARAMETER FOR THE UPPER SANDSTONE UNIT, BURRO CANYON DISPOSAL SITE, SLICK ROCK, COLORADO SITE: SRKO2 BORROH SITE 1 (BURRO CANYON)

06/04/90 TO 04/27/94

REPORT DATE: 09/30/94

\begin{tabular}{|c|c|c|c|c|c|c|c|c|c|c|c|}
\hline PARAMETER NAME & $\underset{\text { ID }}{\text { LOCATION }}$ & LOG DATE & $\begin{array}{c}\text { SAMPLE } \\
\text { ID }\end{array}$ & $\begin{array}{l}\text { FORM } \\
\text { COMP }\end{array}$ & $\begin{array}{l}\text { FLOW } \\
\text { REL. }\end{array}$ & $\begin{array}{l}\text { UNITS OF } \\
\text { MEASURE }\end{array}$ & PVI & $\begin{array}{l}\text { PARAMETER } \\
\text { VALUE }\end{array}$ & FLAGS & $\begin{array}{l}\text { DETECTION } \\
\text { LIMIT }\end{array}$ & $\begin{array}{l}\text { PARAMETER } \\
\text { UNCERTAINT }\end{array}$ \\
\hline NITRATE & $\begin{array}{l}0527 \\
0527 \\
0527 \\
0529 \\
0529 \\
0529 \\
0529 \\
0529\end{array}$ & $\begin{array}{l}04 / 04 / 91 \\
08 / 23 / 91 \\
10 / 12 / 92 \\
06 / 06 / 90 \\
12 / 08 / 90 \\
04 / 02 / 91 \\
08 / 23 / 91 \\
10 / 12 / 92\end{array}$ & $\begin{array}{l}0001 \\
0001 \\
0001 \\
0001 \\
0001 \\
0001 \\
0001 \\
0001\end{array}$ & $\begin{array}{l}\text { UB } \\
\text { UB } \\
\text { UB } \\
\text { UB } \\
\text { UB } \\
\text { UB } \\
\text { UB } \\
\text { UB }\end{array}$ & $\begin{array}{l}0 \\
0 \\
0 \\
0 \\
0 \\
0 \\
0 \\
0\end{array}$ & MG/L & $\mid \begin{array}{l}< \\
< \\
<\end{array}$ & $\begin{array}{l}3 . \\
4.4 \\
1.4 \\
1 . \\
1 . \\
1.0 \\
24.3 \\
1.6\end{array}$ & $\begin{array}{l}\mathrm{J} \\
\mathrm{J}\end{array}$ & $\begin{array}{l}1 . \\
1.0 \\
1.0 \\
1 . \\
1 . \\
1 . \\
1.0\end{array}$ & $\begin{array}{l}- \\
- \\
- \\
- \\
- \\
- \\
-\end{array}$ \\
\hline NITRITE AND NITRATE & $\begin{array}{l}0518 \\
0518 \\
0518 \\
0518 \\
0523 \\
0523 \\
0523 \\
0523 \\
0527 \\
0527 \\
0527 \\
0527 \\
0529 \\
0529 \\
0529 \\
0529\end{array}$ & $\begin{array}{l}06 / 04 / 90 \\
12 / 15 / 90 \\
04 / 01 / 91 \\
08 / 23 / 91 \\
06 / 04 / 90 \\
12 / 12 / 90 \\
04 / 01 / 91 \\
08 / 23 / 91 \\
06 / 06 / 90 \\
12 / 15 / 90 \\
04 / 04 / 91 \\
08 / 23 / 91 \\
06 / 06 / 90 \\
12 / 08 / 90 \\
04 / 02 / 91 \\
08 / 23 / 91\end{array}$ & $\begin{array}{l}0001 \\
0001 \\
0001 \\
0001 \\
0001 \\
0001 \\
0001 \\
0001 \\
0001 \\
0001 \\
0001 \\
0001 \\
0001 \\
0001 \\
0001 \\
0001 .\end{array}$ & $\begin{array}{l}\text { UB } \\
\text { UB } \\
\text { UB } \\
\text { UB } \\
\text { UB } \\
\text { UB } \\
\text { UB } \\
\text { UB } \\
\text { UB } \\
\text { UB } \\
\text { UB } \\
\text { UB } \\
\text { UB } \\
\text { UB } \\
\text { UB } \\
\text { UB }\end{array}$ & $\begin{array}{l}0 \\
0 \\
0 \\
0 \\
0 \\
0 \\
0 \\
0 \\
0 \\
0 \\
0 \\
0 \\
0 \\
0 \\
0 \\
0\end{array}$ & $M G / L$ & $\mid<$ & $\begin{array}{l}1 . \\
1 . \\
0.39 \\
0.98 \\
1 . \\
4 . \\
0.12 \\
1.31 \\
1 . \\
2 . \\
0.70 \\
1.08 \\
1 . \\
1 . \\
0.26 \\
5.54\end{array}$ & $\begin{array}{l}J \\
J \\
J \\
J \\
J \\
J\end{array}$ & $\begin{array}{l}1 . \\
1 . \\
0.05 \\
0.05 \\
1 . \\
1 . \\
0.05 \\
0.05 \\
1 . \\
1 . \\
0.05 \\
0.05 \\
1 . \\
1 . \\
0.05 \\
0.05\end{array}$ & $\begin{array}{l}- \\
- \\
- \\
- \\
- \\
- \\
- \\
- \\
- \\
- \\
- \\
-\end{array}$ \\
\hline $\mathrm{PH}$ & $\begin{array}{l}0518 \\
0518 \\
0518 \\
0518 \\
0518 \\
0518 \\
0518 \\
0518 \\
0523 \\
0523 \\
0523 \\
0523 \\
0523\end{array}$ & $\begin{array}{l}06 / 04 / 90 \\
12 / 15 / 90 \\
04 / 01 / 91 \\
08 / 23 / 91 \\
10 / 11 / 92 \\
02 / 24 / 94 \\
04 / 04 / 94 \\
04 / 27 / 94 \\
06 / 04 / 90 \\
12 / 12 / 90 \\
04 / 01 / 91 \\
08 / 23 / 91 \\
10 / 12 / 92\end{array}$ & $\begin{array}{l}0001 \\
0001 \\
0001 \\
0001 \\
0001 \\
0001 \\
0001 \\
0001 \\
0001 \\
0001 \\
0001 \\
0001 \\
0001\end{array}$ & $\begin{array}{l}\text { UB } \\
\text { UB } \\
\text { UB } \\
\text { UB } \\
\text { UB } \\
\text { UB } \\
\text { UB } \\
\text { UB } \\
\text { UB } \\
\text { UB } \\
\text { UB } \\
\text { UB } \\
\text { UB }\end{array}$ & $\begin{array}{l}0 \\
0 \\
0 \\
0 \\
0 \\
0 \\
0 \\
0 \\
0 \\
0 \\
0 \\
0 \\
0\end{array}$ & sU & & $\begin{array}{l}7.58 \\
7.69 \\
7.58 \\
7.56 \\
7.46 \\
7.46 \\
7.25 \\
7.42 \\
8.72 \\
8.28 \\
8.25 \\
8.27 \\
8.22\end{array}$ & $\begin{array}{l}\mathbf{L} \\
\mathbf{L} \\
\mathbf{L}\end{array}$ & $\begin{array}{l}- \\
- \\
- \\
- \\
- \\
- \\
- \\
- \\
- \\
- \\
-\end{array}$ & $\begin{array}{l}- \\
- \\
- \\
- \\
- \\
- \\
- \\
- \\
- \\
-\end{array}$ \\
\hline
\end{tabular}

UB - UPPER BURRO CANYON

O- ON-SITE

PARAMETER VALUE INDICATOR (PVI): < - LESS THAN DETECTION LIMIT

SAMPLE ID CODES:

0001 - FILTERED SAMPLE (.45 MICRONS)

OTHER PARAMETER VALUE FLAGS:

$J$ - ESTIMATED VALUE

L - LESS THAN THREE BORE VOLUMES REMOVED BEFORE SAMPLING 
TABLE 3.45 BACKGROUND GROUND WATER QUALITY BY PARAMETER FOR THE UPPER

SANDSTONE UNIT, BURRO CANYON DISPOSAL SITE, SLICK ROCK, COLORADO

SITE: SRKO2 BORROW SITE 1 (BURRO CANYON)

06/04/90 TO 04/27/94

REPORT DATE: $09 / 30 / 94$

\begin{tabular}{|c|c|c|c|c|c|c|c|c|c|c|c|}
\hline PARAMETER NAME & $\underset{\text { ID }}{\text { LOCATION }}$ & LOG DATE & $\begin{array}{l}\text { SAMPLE } \\
\text { ID }\end{array}$ & $\begin{array}{l}\text { FORM } \\
\text { COMP }\end{array}$ & $\begin{array}{l}\text { FLOH } \\
\text { REL. }\end{array}$ & $\begin{array}{l}\text { UNITS OF } \\
\text { MEASURE }\end{array}$ & PVI & $\begin{array}{l}\text { PARAMETER } \\
\text { VALUE }\end{array}$ & FLAGS & $\begin{array}{l}\text { DETECTION } \\
\text { LIMIT }\end{array}$ & $\begin{array}{l}\text { PARAMETER } \\
\text { UNCERTAINTY }\end{array}$ \\
\hline PH & $\begin{array}{l}0523 \\
0523 \\
0523 \\
0527 \\
0527 \\
0527 \\
0527 \\
0527 \\
0527 \\
0527 \\
0527 \\
0529 \\
0529 \\
0529 \\
0529 \\
0529 \\
0529 \\
0529 \\
0529\end{array}$ & $\begin{array}{l}02 / 24 / 94 \\
04 / 05 / 94 \\
04 / 20 / 94 \\
06 / 06 / 90 \\
12 / 15 / 90 \\
04 / 04 / 91 \\
08 / 23 / 91 \\
10 / 12 / 92 \\
02 / 23 / 94 \\
04 / 04 / 94 \\
04 / 26 / 94 \\
06 / 06 / 90 \\
12 / 08 / 90 \\
04 / 02 / 91 \\
08 / 23 / 91 \\
10 / 12 / 92 \\
02 / 24 / 94 \\
04 / 04 / 94 \\
04 / 26 / 94\end{array}$ & $\begin{array}{l}0001 \\
0001 \\
0001 \\
0001 \\
0001 \\
0001 \\
0001 \\
0001 \\
0001 \\
0001 \\
0001 \\
0001 \\
0001 \\
0001 \\
0001 \\
0001 \\
0001 \\
0001 \\
0001\end{array}$ & $\begin{array}{l}\text { UB } \\
\text { UB } \\
\text { UB } \\
\text { UB } \\
\text { UB } \\
\text { UB } \\
\text { UB } \\
\text { UB } \\
\text { UB } \\
\text { UB } \\
\text { UB } \\
\text { UB } \\
\text { UB } \\
\text { UB } \\
\text { UB } \\
\text { UB } \\
\text { UB } \\
\text { UB } \\
\text { UB }\end{array}$ & $\begin{array}{l}0 \\
0 \\
0 \\
0 \\
0 \\
0 \\
0 \\
0 \\
0 \\
0 \\
0 \\
0 \\
0 \\
0 \\
0 \\
0 \\
0 \\
0 \\
0\end{array}$ & SU & & $\begin{array}{l}8.08 \\
8.41 \\
8.37 \\
8.19 \\
8.00 \\
7.98 \\
7.94 \\
7.96 \\
7.88 \\
7.99 \\
8.01 \\
9.09 \\
8.86 \\
8.94 \\
8.93 \\
8.90 \\
8.82 \\
8.80 \\
8.94\end{array}$ & $\begin{array}{l}\mathrm{L} \\
\mathrm{L} \\
\mathrm{L}\end{array}$ & $\begin{array}{l}- \\
- \\
- \\
- \\
- \\
- \\
- \\
- \\
- \\
- \\
- \\
- \\
- \\
- \\
- \\
- \\
- \\
-\end{array}$ & $\begin{array}{l}- \\
- \\
- \\
- \\
- \\
- \\
- \\
- \\
- \\
- \\
- \\
- \\
- \\
- \\
- \\
-\end{array}$ \\
\hline PHOSPHATE & $\begin{array}{l}0518 \\
0518 \\
0518 \\
0518 \\
0518 \\
0523 \\
0523 \\
0523 \\
0523 \\
0523 \\
0527 \\
0527 \\
0527 \\
0527 \\
0527 \\
0529 \\
0529 \\
0529 \\
0529\end{array}$ & $\begin{array}{l}06 / 04 / 90 \\
12 / 15 / 90 \\
04 / 01 / 91 \\
08 / 23 / 91 \\
10 / 11 / 92 \\
06 / 04 / 90 \\
12 / 12 / 90 \\
04 / 01 / 91 \\
08 / 23 / 91 \\
10 / 12 / 92 \\
06 / 06 / 90 \\
12 / 15 / 90 \\
04 / 04 / 91 \\
08 / 23 / 91 \\
10 / 12 / 92 \\
06 / 06 / 90 \\
12 / 08 / 90 \\
04 / 02 / 91 \\
08 / 23 / 91\end{array}$ & $\begin{array}{l}0001 \\
0001 \\
0001 \\
0001 \\
0001 \\
0001 \\
0001 \\
0001 \\
0001 \\
0001 \\
0001 \\
0001 \\
0001 \\
0001 \\
0001 \\
0001 \\
0001 \\
0001 \\
0001\end{array}$ & $\begin{array}{l}\text { UB } \\
\text { UB } \\
\text { UB } \\
\text { UB } \\
\text { UB } \\
\text { UB } \\
\text { UB } \\
\text { UB } \\
\text { UB } \\
\text { UB } \\
\text { UB } \\
\text { UB } \\
\text { UB } \\
\text { UB } \\
\text { UB } \\
\text { UB } \\
\text { UB } \\
\text { UB } \\
\text { UB }\end{array}$ & $\begin{array}{l}0 \\
0 \\
0 \\
0 \\
0 \\
0 \\
0 \\
0 \\
0 \\
0 \\
0 \\
0 \\
0 \\
0 \\
0 \\
0 \\
0 \\
0 \\
0\end{array}$ & $M G / L$ & $\begin{array}{l}< \\
< \\
<\end{array}$ & $\begin{array}{l}0.1 \\
0.1 \\
0.1 \\
0.1 \\
0.4 \\
0.8 \\
0.1 \\
0.1 \\
0.1 \\
1.6 \\
0.1 \\
0.1 \\
0.1 \\
0.2 \\
0.5 \\
0.1 \\
0.1 \\
0.1 \\
0.1\end{array}$ & $\begin{array}{l}J \\
J \\
J \\
J \\
J \\
J\end{array}$ & $\begin{array}{l}0.1 \\
0.1 \\
0.1 \\
0.1 \\
0.1 \\
0.1 \\
0.1 \\
0.1 \\
0.1 \\
0.1 \\
0.1 \\
0.1 \\
0.1 \\
0.1 \\
0.1 \\
0.1 \\
0.1 \\
0.1 \\
0.1\end{array}$ & $\begin{array}{l}- \\
- \\
- \\
- \\
- \\
- \\
- \\
- \\
- \\
- \\
- \\
- \\
- \\
- \\
- \\
-\end{array}$ \\
\hline
\end{tabular}

FORMATION OF COMPLETION CODE:

UB - UPPER BURRO CANYON

PARAMETER VALUE INDICATOR (PVI): < - LESS THAN DETECTION LIMIT
FLOH RELATIONSHIP CODE:

O - ON-SITE

0001 - FILTERED SAMPLE (.45 MICRONS)

OTHER PARAMETER VALUE FLAGS:

$J$ - ESTIMATED VALUE

L - LESS THAN THREE: BORE VOLUMES REMOVED BEFORE SAMPLING 
TABLE 3.45 BACKGROUND GROUND HATER QUALITY BY PARAMETER FOR THE UPPER SANDSTONE UNIT, BURRO CANYON DISPOSAL SITE, SLICK ROCK, COLORADO SITE: SRKO2 BORROH SITE I (BURRO CANYON)

$06 / 04 / 90$ TO $04 / 27 / 94$

REPORT DATE: $09 / 30 / 94$

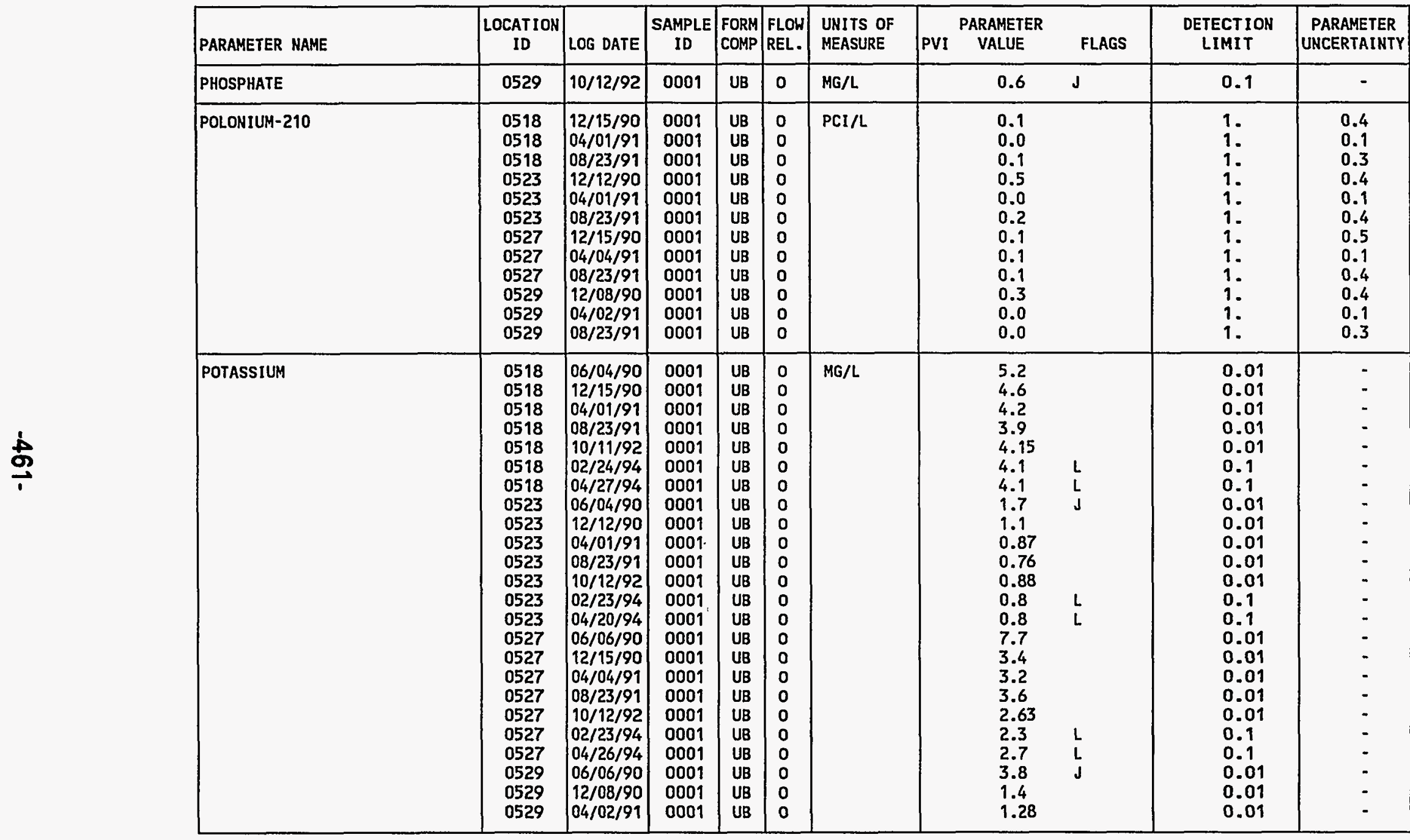

FORMATION OF COMPLETION CODE:

UB - UPPER BURRO CANYON

FLOW RELATIONSHIP CODE:

O - ON-SITE

PARAMETER VALUE INDICATOR (PVI): < - LESS THAN DETECTION LIMIT

ID CODES:

0001 - FILTERED SAMPLE (.45 MICRONS)

OTHER PARAMETER VALUE FLAGS:

$J$ - ESTIMATED VALUE

- LESS THAN THREE BORE VOLUMES REMOVED BEFORE SAMPLING 
TABLE 3.45 BACKGROUND GROUND WATER QUALITY BY PARAMETER FOR THE UPPER SANDSTONE UNIT, BURRO CANYON DISPOSAL SITE, SLICK ROCK, COLORADO

SITE: SRKO2 BORROH SITE 1 (BURRO CANYON)

$06 / 04 / 90$ TO $04 / 27 / 94$

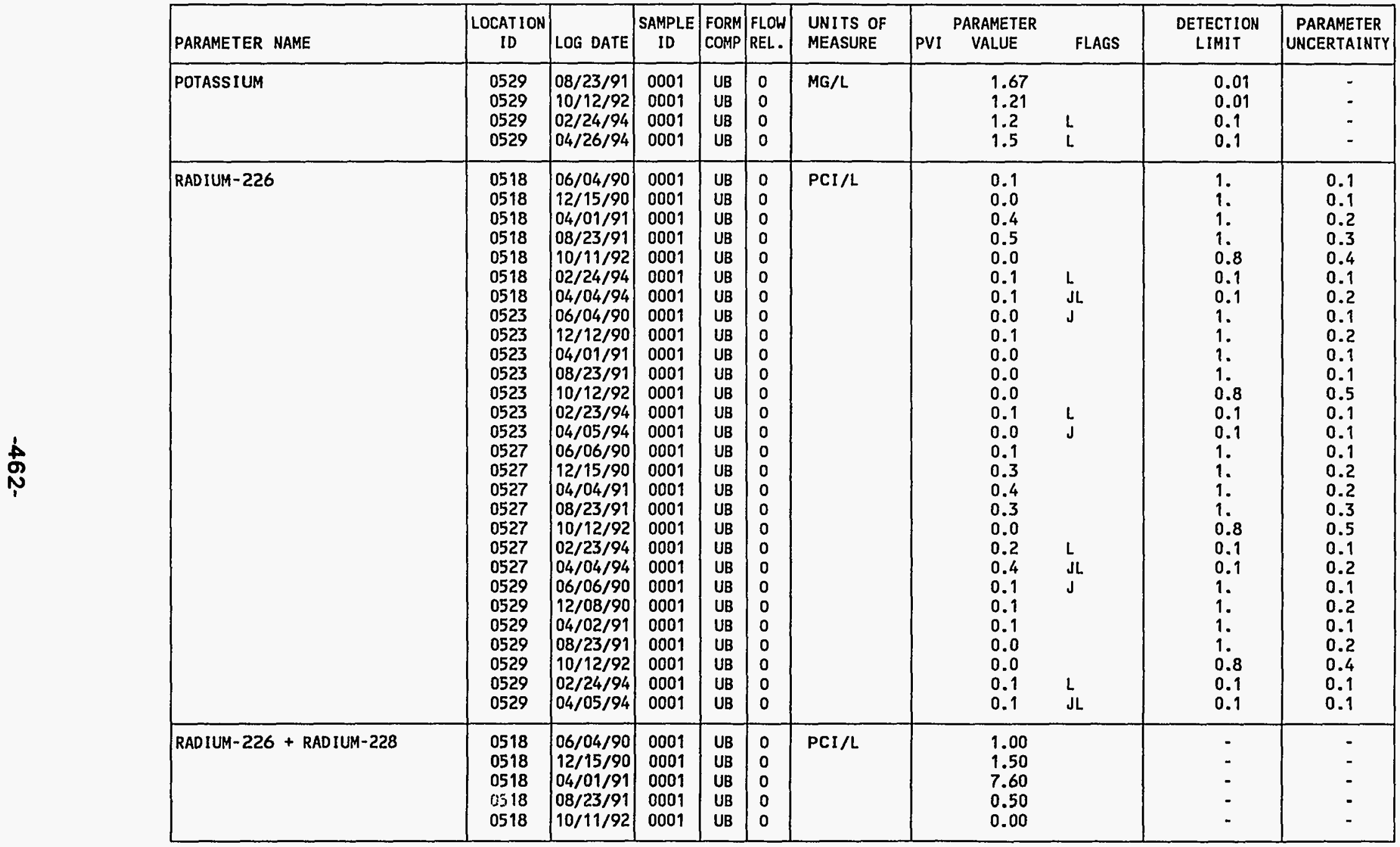

FORMATION OF COMPLETION CODE:

UB - UPPER BURRO CANYON

PARAMETER VALUE INDICATOR (PVI): < - LESS THAN DETECTION LIMIT

OTHER PARAMETER VALUE FLAGS

$J$ - ESTIMATED VALUE

L - LESS THAN THREE BORE VOLUMES REMOVED BEFORE SAMPLING
FL.OW RELATIONSHIP CODE:

O - ON-SITE

SAMPLE ID CODES

0001 - FILTERED SAMPLE (.45 MICRONS) 
TABLE 3.45 BACKGROUND GROUND WATER QUALITY BY PARAMETER FOR THE UPPER SANDSTONE UNIT, BURRO CANYON DISPOSAL SITE, SLICK ROCK, COLORADO

SITE: SRKO2 BORROH SITE 1 (BURRO CANYON)

06/04/90 TO 04/27/94

REPORT DATE: $09 / 30 / 94$

\begin{tabular}{|c|c|c|c|c|c|c|c|c|c|c|c|}
\hline PARAMETER NAME & $\begin{array}{c}\text { LOCATION } \\
\text { ID }\end{array}$ & LOG DATE & $\begin{array}{c}\text { SAMPLE } \\
\text { ID }\end{array}$ & $\begin{array}{l}\text { FORM } \\
\text { COMP }\end{array}$ & $\begin{array}{l}\text { FLOH } \\
\text { REL. }\end{array}$ & $\begin{array}{l}\text { UNITS OF } \\
\text { MEASURE }\end{array}$ & PVI & $\begin{array}{l}\text { ARAMETE } \\
\text { VALUE }\end{array}$ & FLAGS & $\begin{array}{l}\text { DETECTION } \\
\text { LIMIT }\end{array}$ & $\begin{array}{l}\text { PARAMETER } \\
\text { UNCERTAINTY }\end{array}$ \\
\hline RADIUM-226 + RADIUM-228 & $\begin{array}{l}0518 \\
0518 \\
0523 \\
0523 \\
0523 \\
0523 \\
0523 \\
0523 \\
0523 \\
0527 \\
0527 \\
0527 \\
0527 \\
0527 \\
0527 \\
0527 \\
0529 \\
0529 \\
0529 \\
0529 \\
0529 \\
0529 \\
0529\end{array}$ & $\begin{array}{l}02 / 24 / 94 \\
04 / 04 / 94 \\
06 / 04 / 90 \\
12 / 12 / 90 \\
04 / 01 / 91 \\
08 / 23 / 91 \\
10 / 12 / 92 \\
02 / 23 / 94 \\
04 / 05 / 94 \\
06 / 06 / 90 \\
12 / 15 / 90 \\
04 / 04 / 91 \\
08 / 23 / 91 \\
10 / 12 / 92 \\
02 / 23 / 94 \\
04 / 04 / 94 \\
06 / 06 / 90 \\
12 / 08 / 90 \\
04 / 02 / 91 \\
08 / 23 / 91 \\
10 / 12 / 92 \\
02 / 24 / 94 \\
04 / 05 / 94\end{array}$ & $\begin{array}{l}0001 \\
0001 \\
0001 \\
0001 \\
0001 \\
0001 \\
0001 \\
0001 \\
0001 \\
0001 \\
0001 \\
0001 \\
0001 \\
0001 \\
0001 \\
0001 \\
0001 \\
0001 \\
0001 \\
0001 \\
0001 \\
0001 \\
0001\end{array}$ & $\begin{array}{l}\text { UB } \\
\text { UB } \\
\text { UB } \\
\text { UB } \\
\text { UB } \\
\text { UB } \\
\text { UB } \\
\text { UB } \\
\text { UB } \\
\text { UB } \\
\text { UB } \\
\text { UB } \\
\text { UB } \\
\text { UB } \\
\text { UB } \\
\text { UB } \\
\text { UB } \\
\text { UB } \\
\text { UB } \\
\text { UB } \\
\text { UB } \\
\text { UB } \\
\text { UB }\end{array}$ & $\begin{array}{l}0 \\
0 \\
0 \\
0 \\
0 \\
0 \\
0 \\
0 \\
0 \\
0 \\
0 \\
0 \\
0 \\
0 \\
0 \\
0 \\
0 \\
0 \\
0 \\
0 \\
0 \\
0 \\
0\end{array}$ & PCI/L & & $\begin{array}{l}0.80 \\
1.20 \\
1.10 \\
0.70 \\
3.30 \\
0.50 \\
0.60 \\
0.70 \\
0.70 \\
1.30 \\
1.80 \\
0.90 \\
1.70 \\
0.60 \\
0.60 \\
1.20 \\
1.10 \\
0.90 \\
5.00 \\
1.10 \\
0.00 \\
0.20 \\
0.30\end{array}$ & & $\begin{array}{l}- \\
- \\
- \\
- \\
- \\
- \\
- \\
- \\
- \\
- \\
- \\
- \\
- \\
- \\
- \\
- \\
- \\
- \\
- \\
-\end{array}$ & $\begin{array}{l}- \\
- \\
- \\
- \\
- \\
- \\
- \\
- \\
- \\
- \\
- \\
- \\
- \\
- \\
- \\
- \\
- \\
- \\
-\end{array}$ \\
\hline RADIUM-228 & $\begin{array}{l}0518 \\
0518 \\
0518 \\
0518 \\
0518 \\
0518 \\
0518 \\
0523 \\
0523 \\
0523 \\
0523 \\
0523 \\
0523 \\
0523\end{array}$ & $\begin{array}{l}06 / 04 / 90 \\
12 / 15 / 90 \\
04 / 01 / 91 \\
08 / 23 / 91 \\
10 / 11 / 92 \\
02 / 24 / 94 \\
04 / 04 / 94 \\
06 / 04 / 90 \\
12 / 12 / 90 \\
04 / 01 / 91 \\
08 / 23 / 91 \\
10 / 12 / 92 \\
02 / 23 / 94 \\
04 / 05 / 94\end{array}$ & $\begin{array}{l}0001 \\
0001 \\
0001 \\
0001 \\
0001 \\
0001 \\
0001 \\
0001 \\
0001 \\
0001 \\
0001 \\
0001 \\
0001 \\
0001\end{array}$ & $\begin{array}{l}\text { UB } \\
\text { UB } \\
\text { UB } \\
\text { UB } \\
\text { UB } \\
\text { UB } \\
\text { UB } \\
\text { UB } \\
\text { UB } \\
\text { UB } \\
\text { UB } \\
\text { UB } \\
\text { UB } \\
\text { UB }\end{array}$ & $\begin{array}{l}0 \\
0 \\
0 \\
0 \\
0 \\
0 \\
0 \\
0 \\
0 \\
0 \\
0 \\
0 \\
0 \\
0\end{array}$ & PCI/L & & $\begin{array}{l}0.9 \\
1.5 \\
7.2 \\
0.0 \\
0.0 \\
0.7 \\
1.1 \\
1.1 \\
0.6 \\
3.3 \\
0.5 \\
0.6 \\
0.6 \\
0.7\end{array}$ & $\begin{array}{l}N \\
L \\
L \\
J\end{array}$ & $\begin{array}{l}1 . \\
1 . \\
1 . \\
1 . \\
4.1 \\
3.5 \\
3.0 \\
1 . \\
1 . \\
1 . \\
1 . \\
2.9 \\
5.3 \\
4.2\end{array}$ & $\begin{array}{l}0.7 \\
0.8 \\
1.2 \\
2.0 \\
2.3 \\
1.0 \\
1.0 \\
0.8 \\
0.8 \\
1.1 \\
2.1 \\
1.8 \\
1.5 \\
1.6\end{array}$ \\
\hline
\end{tabular}

FORMATION OF COMPLETION CODE:

UB - UPPER BURRO CANYON

FLON RELATIONSHIP CODE:

PARAMETER VALUE INDICATOR (PVI): < - LESS THAN DETECTION LIMIT

OTHER PARAMETER VALUE FLAGS:

$J$ - ESTIMATED VALUE

- LESS THAN THREE BORE VOLUMES REMOVED BEFORE SAMPLING

N - SPIKE SAMPLE RECOVERY NOT HITHIN CONTROL LIMITS 
TABLE 3.45 BACKGROUND GROUND WATER QUALITY BY PARAMETER FOR THE UPPER

SANDSTONE UNIT, BURRO CANYON DISPOSAL SITE, SLICK ROCK, COLORADO

SITE: SRKO2 BORROW SITE 1 (BURRO CANYON)

06/04/90 TO $04 / 27 / 94$

REPORT DATE: $09 / 30 / 94$

\begin{tabular}{|c|c|c|c|c|c|c|c|c|c|c|c|}
\hline PARAMETER NAME & $\underset{\text { ID }}{\text { LOCATION }}$ & LOG DATE & $\underset{\text { ID }}{\text { SAMPLE }}$ & $\begin{array}{l}\text { FORM } \\
\text { COMP }\end{array}$ & $\begin{array}{l}\text { FLOW } \\
\text { REL. }\end{array}$ & $\begin{array}{l}\text { UNITS OF } \\
\text { MEASURE }\end{array}$ & PVI & $\begin{array}{l}\text { PARAMETER } \\
\text { VALUEE }\end{array}$ & FLAGS & $\begin{array}{l}\text { DETECTION } \\
\text { LIMIT }\end{array}$ & $\begin{array}{l}\text { PARAMETER } \\
\text { UNCERTAINTY }\end{array}$ \\
\hline RADIUM-228 & $\begin{array}{l}0527 \\
0527 \\
0527 \\
0527 \\
0527 \\
0527 \\
0527 \\
0529 \\
0529 \\
0529 \\
0529 \\
0529 \\
0529 \\
0529\end{array}$ & $\begin{array}{l}06 / 06 / 90 \\
12 / 15 / 90 \\
04 / 04 / 91 \\
08 / 23 / 91 \\
10 / 12 / 92 \\
02 / 23 / 94 \\
04 / 04 / 94 \\
06 / 06 / 90 \\
12 / 08 / 90 \\
04 / 02 / 91 \\
08 / 23 / 91 \\
10 / 12 / 92 \\
02 / 24 / 94 \\
04 / 05 / 94\end{array}$ & $\begin{array}{l}0001 \\
0001 \\
0001 \\
0001 \\
0001 \\
0001 \\
0001 \\
0001 \\
0001 \\
0001 \\
0001 \\
0001 \\
0001 \\
0001\end{array}$ & $\begin{array}{l}\text { UB } \\
\text { UB } \\
\text { UB } \\
\text { UB } \\
\text { UB } \\
\text { UB } \\
\text { UB } \\
\text { UB } \\
\text { UB } \\
\text { UB } \\
\text { UB } \\
\text { UB } \\
\text { UB } \\
\text { UB }\end{array}$ & $\begin{array}{l}0 \\
0 \\
0 \\
0 \\
0 \\
0 \\
0 \\
0 \\
0 \\
0 \\
0 \\
0 \\
0 \\
0\end{array}$ & $\mathrm{PCI} / \mathrm{L}$ & & $\begin{array}{l}1.2 \\
1.5 \\
0.5 \\
1.4 \\
0.6 \\
0.4 \\
0.8 \\
1.0 \\
0.8 \\
4.9 \\
1.1 \\
0.0 \\
0.1 \\
0.2\end{array}$ & $\begin{array}{l}L \\
L \\
J\end{array}$ & $\begin{array}{l}1 . \\
1 . \\
1 . \\
1 . \\
2.9 \\
2.9 \\
3.1 \\
1 . \\
1 . \\
1 . \\
1 . \\
2.9 \\
3.2 \\
3.1\end{array}$ & $\begin{array}{l}0.9 \\
0.8 \\
1.2 \\
2.2 \\
1.8 \\
0.9 \\
1.2 \\
0.8 \\
0.7 \\
1.4 \\
2.2 \\
1.7 \\
1.0 \\
0.9\end{array}$ \\
\hline REDOX POTENTIAL & $\begin{array}{l}0518 \\
0523 \\
0523 \\
0527 \\
0529\end{array}$ & $\begin{array}{l}12 / 15 / 90 \\
12 / 12 / 90 \\
04 / 05 / 94 \\
12 / 15 / 90 \\
12 / 08 / 90\end{array}$ & $\begin{array}{l}0001 \\
0001 \\
0001 \\
0001 \\
0001\end{array}$ & $\begin{array}{l}\text { UB } \\
\text { UB } \\
\text { UB } \\
\text { UB } \\
\text { UB }\end{array}$ & $\begin{array}{l}0 \\
0 \\
0 \\
0 \\
0\end{array}$ & mVOLTS & & $\begin{array}{l}264 . \\
276.7 \\
262 \\
368.7 \\
194.1\end{array}$ & & $\begin{array}{l}- \\
- \\
- \\
-\end{array}$ & $\begin{array}{l}- \\
- \\
-\end{array}$ \\
\hline SELENIUM & $\begin{array}{l}0518 \\
0518 \\
0518 \\
0518 \\
0518 \\
0518 \\
0518 \\
0523 \\
0523 \\
0523 \\
0523 \\
0523 \\
0523 \\
0523 \\
0527 \\
0527\end{array}$ & $\begin{array}{l}06 / 04 / 90 \\
12 / 15 / 90 \\
04 / 01 / 91 \\
08 / 23 / 91 \\
10 / 11 / 92 \\
02 / 24 / 94 \\
04 / 27 / 94 \\
06 / 04 / 90 \\
12 / 12 / 90 \\
04 / 01 / 91 \\
08 / 23 / 91 \\
10 / 12 / 92 \\
02 / 23 / 94 \\
04 / 20 / 94 \\
06 / 06 / 90 \\
12 / 15 / 90\end{array}$ & $\begin{array}{l}0001 \\
0001 \\
0001 \\
0001 \\
0001 \\
0001 \\
0001 \\
0001 \\
0001 \\
0001 \\
0001 \\
0001 \\
0001 \\
0001 \\
0001 \\
0001\end{array}$ & $\begin{array}{l}\text { UB } \\
\text { UB } \\
\text { UB } \\
\text { UB } \\
\text { UB } \\
\text { UB } \\
\text { UB } \\
\text { UB } \\
\text { UB } \\
\text { UB } \\
\text { UB } \\
\text { UB } \\
\text { UB } \\
\text { UB } \\
\text { UB } \\
\text { UB }\end{array}$ & $\begin{array}{l}0 \\
0 \\
0 \\
0 \\
0 \\
0 \\
0 \\
0 \\
0 \\
0 \\
0 \\
0 \\
0 \\
0 \\
0 \\
0\end{array}$ & $M G / L$ & $\begin{array}{l}< \\
< \\
< \\
< \\
< \\
< \\
< \\
< \\
< \\
<\end{array}$ & $\begin{array}{l}0.012 \\
0.015 \\
0.011 \\
0.04 \\
0.02 \\
0.023 \\
0.044 \\
0.005 \\
0.005 \\
0.005 \\
0.005 \\
0.02 \\
0.005 \\
0.005 \\
0.005 \\
0.005\end{array}$ & $\begin{array}{l}\text { LS } \\
\text { LS } \\
J\end{array}$ & $\begin{array}{l}0.005 \\
0.005 \\
0.005 \\
0.03 \\
0.02 \\
0.005 \\
0.005 \\
0.005 \\
0.005 \\
0.005 \\
0.005 \\
0.02 \\
0.005 \\
0.005 \\
0.005 \\
0.005\end{array}$ & $\begin{array}{l}- \\
- \\
- \\
- \\
- \\
- \\
- \\
- \\
- \\
- \\
-\end{array}$ \\
\hline
\end{tabular}

FORMATION OF COMPLETION CODE:

UB - UPPER BURRO CANYON

PARAMETER VALUE INDICATOR (PVI): < - LESS THAN DETECTION LIMIT
FLOW RELATIONSHIP CODE:

O - ON-SITE

SAMPLE ID CODES:

0001 - FILTERED SAMPLE (.45 MICRONS)

OTHER PARAMETER VALUE FLAGS:

I - INCREASED DETECTION LIMIT DUE TO REQUIRED DILUTION

$J$ - ESTIMATED VALUE

L - LESS THAN THREE BORE VOLUMES REMOVED BEFORE SAMPLING

S - REPORTED VALUE DETERMINED USING METHOD OF STD ADDITION (MSA) 
TABLE 3.45 BACKGROUND GROUND HATER QUALITY BY PARAMETER FOR THE UPPER SANDSTONE UNIT, BURRO CANYON DISPOSAL SITE, SLICK ROCK, COLORADO SITE: SRKO2 BORROH SITE 1 (18

06/04/90 TO 04/27/94

REPORT DATE: $09 / 30 / 94$

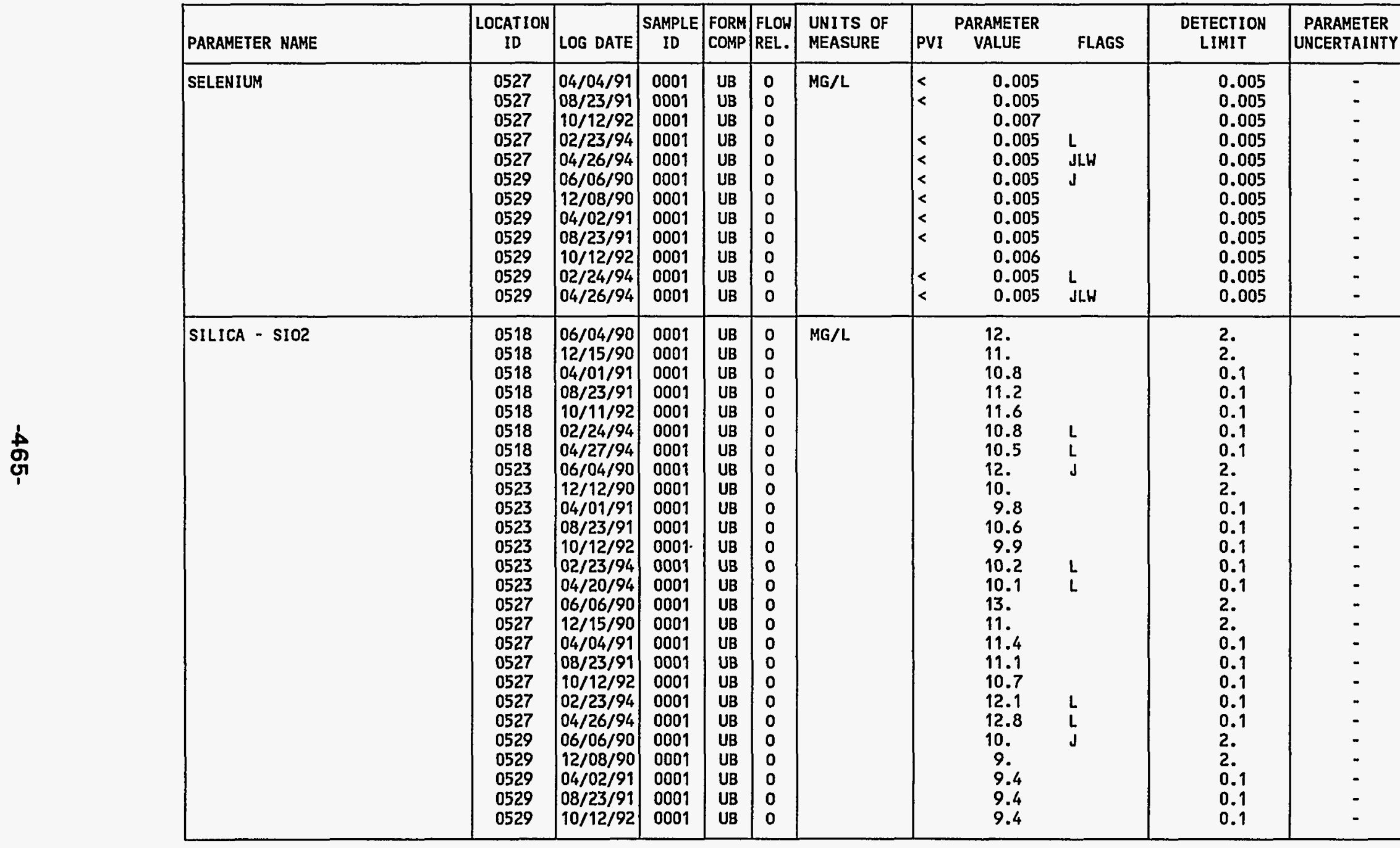

FORMATION OF COMPLETION CODE:

UB - UPPER BURRO CANYON

PARAMETER VALUE INDICATOR (PVI): < - LESS THAN DETECTION LIMIT

OTHER PARAMETER VALUE FLAGS:

$J$ - ESTIMATED VALUE

L - LESS IHAN THREE BORE VOLUMES REMOVED BEFORE SAMPLING

$H$ - POST-DIGEST SPIKE OUT OF CNTR LIM WHILE SAMP ABS < 50\% SPIKE
FLOW RELATIONSHIP CODE:

O - ON-SITE

SAMPLE ID CODES:

0001 - FILTERED SAMPLE (.45 MICRONS) 


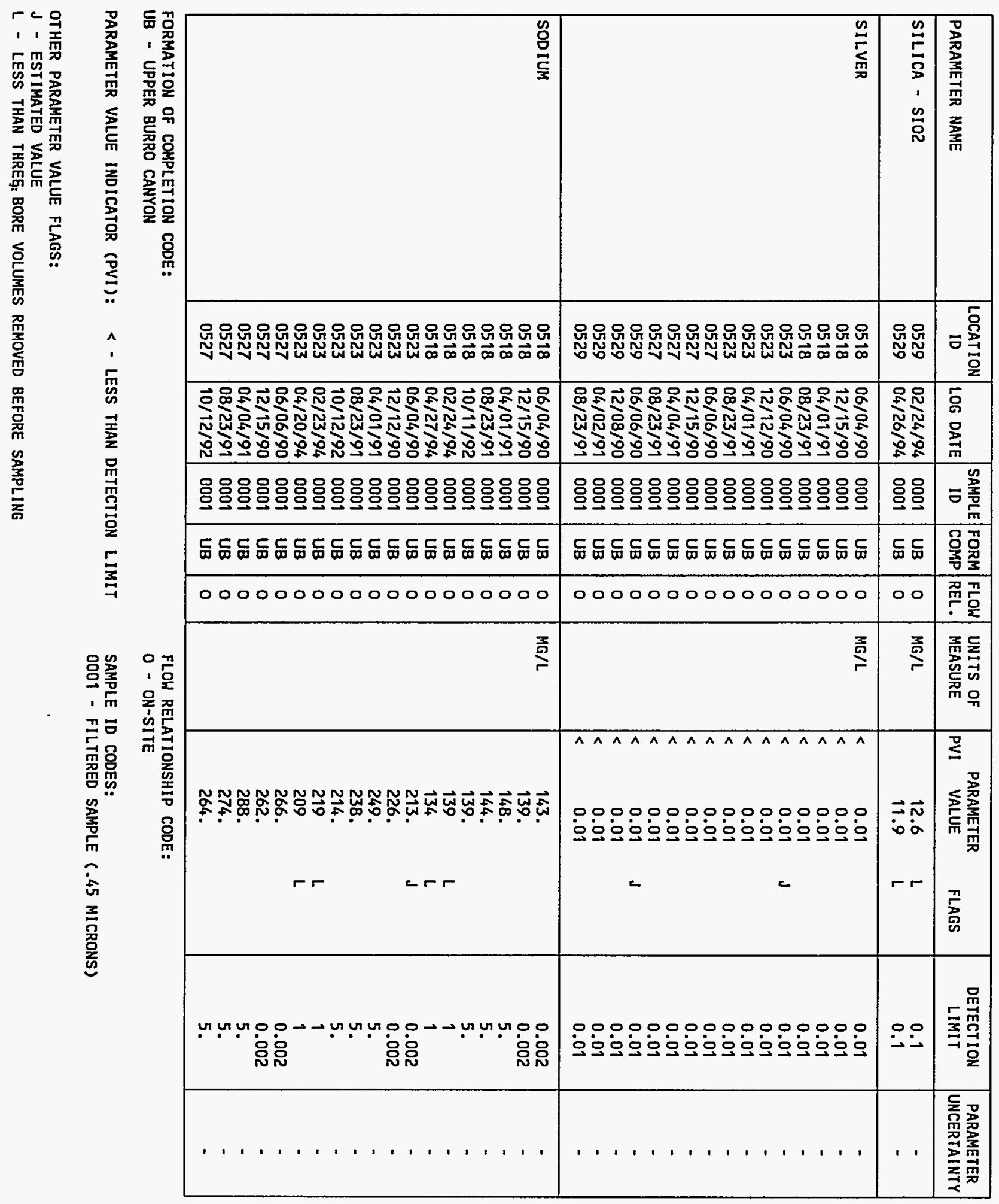

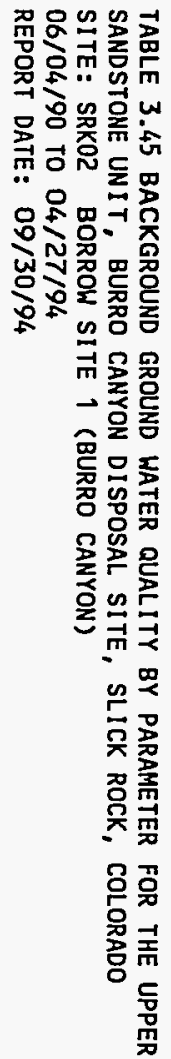


TABLE 3.45 BACKGROUND GROUND HATER QUALITY BY PARAMETER FOR THE UPPER SANDSTONE UNIT, BURRO CANYON DISPOSAL SITE, SLICK ROCK, COLORADO SITE: SRKO2 BORROW SITE 1 (BURRO CANYON)

06/04/90 TO 04/27/94

REPORT DATE: $09 / 30 / 94$

\begin{tabular}{|c|c|c|c|c|c|c|c|c|c|c|c|}
\hline PARAMETER NAME & $\begin{array}{c}\text { LOCATION } \\
\text { ID }\end{array}$ & LOG DATE & $\begin{array}{c}\text { SAMPLE } \\
\text { ID }\end{array}$ & $\begin{array}{l}\text { FORM } \\
\text { COMP }\end{array}$ & $\mid \begin{array}{l}\text { FLOH } \\
\text { REL. }\end{array}$ & $\begin{array}{l}\text { UNITS OF } \\
\text { MEASURE }\end{array}$ & PVI & $\begin{array}{l}\text { PARAMETER } \\
\text { VALUE }\end{array}$ & FLAGS & $\begin{array}{l}\text { DETECTION } \\
\text { LIMIT }\end{array}$ & \begin{tabular}{|l} 
PARAMETER \\
UNCERTAINTY
\end{tabular} \\
\hline SODIUM & $\begin{array}{l}0527 \\
0527 \\
0529 \\
0529 \\
0529 \\
0529 \\
0529 \\
0529 \\
0529\end{array}$ & $\begin{array}{l}02 / 23 / 94 \\
04 / 26 / 94 \\
06 / 06 / 90 \\
12 / 08 / 90 \\
04 / 02 / 91 \\
08 / 23 / 91 \\
10 / 12 / 92 \\
02 / 24 / 94 \\
04 / 26 / 94\end{array}$ & $\begin{array}{l}0001 \\
0001 \\
0001 \\
0001 \\
0001 \\
0001 \\
0001 \\
0001 \\
0001\end{array}$ & $\begin{array}{l}\text { UB } \\
\text { UB } \\
\text { UB } \\
\text { UB } \\
\text { UB } \\
\text { UB } \\
\text { UB } \\
\text { UB } \\
\text { UB }\end{array}$ & $\begin{array}{l}0 \\
0 \\
0 \\
0 \\
0 \\
0 \\
0 \\
0 \\
0\end{array}$ & MG/L & & $\begin{array}{l}261 \\
255 \\
211 . \\
213 . \\
229 . \\
221 . \\
218 . \\
209 \\
202\end{array}$ & L & $\begin{array}{l}9 \\
1 \\
0.002 \\
0.002 \\
5 . \\
5 . \\
5 . \\
1 \\
1\end{array}$ & $\begin{array}{l}- \\
- \\
- \\
- \\
- \\
-\end{array}$ \\
\hline SPECIFIC CONDUCTANCE & $\begin{array}{l}0518 \\
0518 \\
0518 \\
0518 \\
0518 \\
0518 \\
0518 \\
0518 \\
0523 \\
0523 \\
0523 \\
0523 \\
0523 \\
0523 \\
0523 \\
0523 \\
0527 \\
0527 \\
0527 \\
0527 \\
0527 \\
0527 \\
0527 \\
0527 \\
0529 \\
0529 \\
0529 \\
0529 \\
0529\end{array}$ & $\begin{array}{l}06 / 04 / 90 \\
12 / 15 / 90 \\
04 / 01 / 91 \\
08 / 23 / 91 \\
10 / 11 / 92 \\
02 / 24 / 94 \\
04 / 04 / 94 \\
04 / 27 / 94 \\
06 / 04 / 90 \\
12 / 12 / 90 \\
04 / 01 / 91 \\
08 / 23 / 91 \\
10 / 12 / 92 \\
02 / 24 / 94 \\
04 / 05 / 94 \\
04 / 20 / 94 \\
06 / 06 / 90 \\
12 / 15 / 90 \\
04 / 04 / 91 \\
08 / 23 / 91 \\
10 / 12 / 92 \\
02 / 23 / 94 \\
04 / 04 / 94 \\
04 / 26 / 94 \\
06 / 06 / 90 \\
04 / 02 / 91 \\
08 / 23 / 91 \\
10 / 12 / 92 \\
02 / 24 / 94\end{array}$ & $\begin{array}{l}0001 \\
0001 \\
0001 \\
0001 \\
0001 \\
0001 \\
0001 \\
0001 \\
0001 \\
0001 \\
0001 \\
0001 \\
0001 \\
0001 \\
0001 \\
0001 \\
0001 \\
0001 \\
0001 \\
0001 \\
0001 \\
0001 \\
0001 \\
0001 \\
0001 \\
0001 \\
0001 \\
0001 \\
0001\end{array}$ & $\begin{array}{l}\text { UB } \\
\text { UB } \\
\text { UB } \\
\text { UB } \\
\text { UB } \\
\text { UB } \\
\text { UB } \\
\text { UB } \\
\text { UB } \\
\text { UB } \\
\text { UB } \\
\text { UB } \\
\text { UB } \\
\text { UB } \\
\text { UB } \\
\text { UB } \\
\text { UB } \\
\text { UB } \\
\text { UB } \\
\text { UB } \\
\text { UB } \\
\text { UB } \\
\text { UB } \\
\text { UB } \\
\text { UB } \\
\text { UB } \\
\text { UB } \\
\text { UB } \\
\text { UB }\end{array}$ & $\begin{array}{l}0 \\
0 \\
0 \\
0 \\
0 \\
0 \\
0 \\
0 \\
0 \\
0 \\
0 \\
0 \\
0 \\
0 \\
0 \\
0 \\
0 \\
0 \\
0 \\
0 \\
0 \\
0 \\
0 \\
0 \\
0 \\
0 \\
0 \\
0 \\
0\end{array}$ & UMHO/CM & & $\begin{array}{c}1000 . \\
1307 . \\
1324 . \\
1298 \\
970 \\
964 \\
1003 \\
1004 \\
950 . \\
1010 . \\
1022 . \\
990 \\
730 \\
727 \\
722 \\
755 \\
1000 . \\
1321 . \\
1326 . \\
1322 \\
1032 \\
945 \\
1007 \\
936 \\
850 . \\
1065 . \\
1057 \\
828 \\
790\end{array}$ & $\begin{array}{l}\mathrm{L} \\
\mathrm{L}\end{array}$ & $\begin{array}{l}- \\
- \\
= \\
- \\
- \\
- \\
- \\
- \\
- \\
- \\
- \\
- \\
- \\
- \\
- \\
- \\
- \\
- \\
- \\
- \\
-\end{array}$ & $\begin{array}{l}- \\
- \\
- \\
- \\
- \\
- \\
- \\
- \\
- \\
- \\
- \\
- \\
- \\
- \\
- \\
- \\
- \\
- \\
- \\
- \\
-\end{array}$ \\
\hline
\end{tabular}

FORMATION OF COMPLETION CODE: UB - UPPER BURRO CANYON

FLOW RELATIONSHIP CODE

PARAMETER VALUE INDICATOR (PVI): < - LESS THAN DETECTION LIMIT

SAMPLE ID CODES:

0001 - FILTERED SAMPLE (.45 MICRONS)

OTHER PARAMETER VALLE FLAGS:

$J$ - ESTIMATED VALUE

L - LESS THAN THREE BORE VOLUMES REMOVED BEFORE SAMPLING 
TABLE 3.45 BACKGROUND GROUND HATER QUALITY BY PARAMETER FOR THE UPPER SANDSTONE UNIT, BURRO CANYON DISPOSAL SITE, SLICK ROCK, COLORADO

SITE: SRKO2 BORROW SITE 1 (BURRO CANYON)

06/04/90 TO 04/27/94

\begin{tabular}{|c|c|c|c|c|c|c|c|c|c|c|c|}
\hline PARAMETER NAME & $\begin{array}{c}\text { LOCATION } \\
\text { ID }\end{array}$ & LOG DATE & $\underset{\text { ID }}{\text { SAMPLE }}$ & $\begin{array}{l}\text { FORM } \\
\text { COMP }\end{array}$ & $\begin{array}{l}\text { FLOW } \\
\text { REL. }\end{array}$ & $\begin{array}{l}\text { UNITS OF } \\
\text { MEASURE }\end{array}$ & PVI & $\begin{array}{l}\text { ARAMETER } \\
\text { VALUE }\end{array}$ & FLAGS & $\begin{array}{l}\text { DETECTION } \\
\text { LIMIT }\end{array}$ & $\begin{array}{l}\text { PARAMETER } \\
\text { UNCERTAINTY }\end{array}$ \\
\hline SPECIFIC CONDUCTANCE & $\begin{array}{l}0529 \\
0529\end{array}$ & $\begin{array}{l}04 / 04 / 94 \\
04 / 26 / 94\end{array}$ & $\begin{array}{l}0001 \\
0001\end{array}$ & $\begin{array}{l}\text { UB } \\
\text { UB }\end{array}$ & $\begin{array}{l}0 \\
0\end{array}$ & UMHO/CM & & $\begin{array}{l}812 \\
802\end{array}$ & $\begin{array}{l}L \\
L\end{array}$ & $\overline{-}$ & $\overline{-}$ \\
\hline STRONTIUM & $\begin{array}{l}0518 \\
0518 \\
0518 \\
0518 \\
0518 \\
0518 \\
0518 \\
0523 \\
0523 \\
0523 \\
0523 \\
0523 \\
0523 \\
0523 \\
0527 \\
0527 \\
0527 \\
0527 \\
0527 \\
0527 \\
0527 \\
0529 \\
0529 \\
0529 \\
0529 \\
0529 \\
0529 \\
0529\end{array}$ & $\begin{array}{l}06 / 04 / 90 \\
12 / 15 / 90 \\
04 / 01 / 91 \\
08 / 23 / 91 \\
10 / 11 / 92 \\
02 / 24 / 94 \\
04 / 27 / 94 \\
06 / 04 / 90 \\
12 / 12 / 90 \\
04 / 01 / 91 \\
08 / 23 / 91 \\
10 / 12 / 92 \\
02 / 23 / 94 \\
04 / 20 / 94 \\
06 / 06 / 90 \\
12 / 15 / 90 \\
04 / 04 / 91 \\
08 / 23 / 91 \\
10 / 12 / 92 \\
02 / 23 / 94 \\
04 / 26 / 94 \\
06 / 06 / 90 \\
12 / 08 / 90 \\
04 / 02 / 91 \\
08 / 23 / 91 \\
10 / 12 / 92 \\
02 / 24 / 94 \\
04 / 26 / 94\end{array}$ & $\begin{array}{l}0001 \\
0001 \\
0001 \\
0001 \\
0001 \\
0001 \\
0001 \\
0001 \\
0001 \\
0001 \\
0001 \\
0001 \\
0001 \\
0001 \\
0001 \\
0001 \\
0001 \\
0001 \\
0001 \\
0001 \\
0001 \\
0001 \\
0001 \\
0001 \\
0001 \\
0001 \\
0001 \\
0001\end{array}$ & $\begin{array}{l}\text { UB } \\
\text { UB } \\
\text { UB } \\
\text { UB } \\
\text { UB } \\
\text { UB } \\
\text { UB } \\
\text { UB } \\
\text { UB } \\
\text { UB } \\
\text { UB } \\
\text { UB } \\
\text { UB } \\
\text { UB } \\
\text { UB } \\
\text { UB } \\
\text { UB } \\
\text { UB } \\
\text { UB } \\
\text { UB } \\
\text { UB } \\
\text { UB } \\
\text { UB } \\
\text { UB } \\
\text { UB } \\
\text { UB } \\
\text { UB } \\
\text { UB }\end{array}$ & $\begin{array}{l}0 \\
0 \\
0 \\
0 \\
0 \\
0 \\
0 \\
0 \\
0 \\
0 \\
0 \\
0 \\
0 \\
0 \\
0 \\
0 \\
0 \\
0 \\
0 \\
0 \\
0 \\
0 \\
0 \\
0 \\
0 \\
0 \\
0 \\
0\end{array}$ & MG/L & & $\begin{array}{l}14.8 \\
15.0 \\
14.8 \\
13.8 \\
13.3 \\
14.0 \\
14.0 \\
0.26 \\
0.4 \\
0.53 \\
0.35 \\
0.48 \\
0.53 \\
0.56 \\
1.62 \\
3.0 \\
3.83 \\
3.57 \\
3.24 \\
3.48 \\
3.39 \\
1.34 \\
1.2 \\
1.44 \\
1.43 \\
1.34 \\
1.69 \\
1.54\end{array}$ & $\begin{array}{l}\mathrm{L} \\
\mathrm{L}\end{array}$ & $\begin{array}{l}0.1 \\
0.1 \\
0.01 \\
0.01 \\
0.01 \\
0.01 \\
0.01 \\
0.1 \\
0.1 \\
0.01 \\
0.01 \\
0.01 \\
0.01 \\
0.01 \\
0.1 \\
0.1 \\
0.01 \\
0.01 \\
0.01 \\
0.01 \\
0.01 \\
0.1 \\
0.1 \\
0.01 \\
0.01 \\
0.01 \\
0.01 \\
0.01\end{array}$ & $\begin{array}{l}- \\
- \\
- \\
- \\
- \\
- \\
- \\
- \\
- \\
- \\
- \\
- \\
- \\
- \\
- \\
- \\
- \\
- \\
- \\
- \\
- \\
-\end{array}$ \\
\hline SULFATE & $\begin{array}{l}0518 \\
0518 \\
0518 \\
0518 \\
0518 \\
0518 \\
0518\end{array}$ & $\begin{array}{l}06 / 04 / 90 \\
12 / 15 / 90 \\
04 / 01 / 91 \\
08 / 23 / 91 \\
10 / 11 / 92 \\
02 / 24 / 94 \\
04 / 27 / 94\end{array}$ & $\begin{array}{l}0001 \\
0001 \\
0001 \\
0001 \\
0001 \\
0001 \\
0001\end{array}$ & $\begin{array}{l}\text { UB } \\
\text { UB } \\
\text { UB } \\
\text { UB } \\
\text { UB } \\
\text { UB } \\
\text { UB }\end{array}$ & $\begin{array}{l}0 \\
0 \\
0 \\
0 \\
0 \\
0 \\
0\end{array}$ & $M G / L$ & & $\begin{array}{l}535 . \\
519 . \\
498 . \\
468 . \\
477 . \\
469 \\
486\end{array}$ & $L$ & $\begin{array}{c}0.1 \\
0.1 \\
10 . \\
10 . \\
6 . \\
1 \\
1\end{array}$ & $\begin{array}{l}- \\
- \\
- \\
- \\
-\end{array}$ \\
\hline
\end{tabular}

FORMATION OF COMPLETION CODE:

UB - UPPER BURRO CANYON

PARAMETER VALUE INDICATOR (PVI): < - LESS THAN DETECTION LIMIT
FLOW RELATIONSHIP CODE

O- ON-SITE

SAMPLE ID CODES:

0001 - FILTERED SAMPLE (.45 MICRONS)

OTHER PARAMETER VALUE FLAGS:

$J$ - EST IMATED VALUE

$L$ - LESS THAN THREE BORE VOLUMES REMOVED BEFORE SAMPLING 


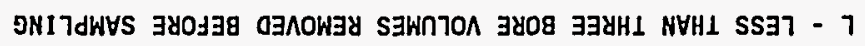

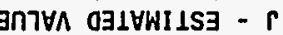

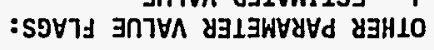

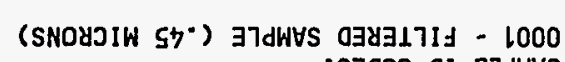
:s 3000 aI $37 d W \forall S$

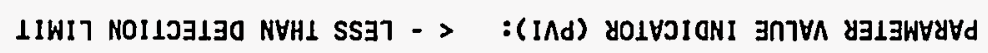

JIIS-NO - O

: $\exists 000$ dIHSNOIL

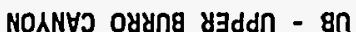
: 3000 NO1137dWOJ to NOILVWYOS

\begin{tabular}{|c|c|c|c|c|c|c|c|c|c|c|c|}
\hline- & - & & $\varsigma^{\bullet} \Sigma l$ & & $\exists \exists \triangle 930-5$ & 0 & gn & 1000 & $06 / 70 / 90$ & 8LSO & $\exists y \cap \forall y \exists d \omega \exists \perp$ \\
\hline $\begin{array}{l}- \\
- \\
- \\
- \\
- \\
- \\
- \\
- \\
- \\
- \\
- \\
-\end{array}$ & $\begin{array}{l}l \cdot 0 \\
l \cdot 0 \\
l=0 \\
l=0 \\
l=0 \\
l=0 \\
l=0 \\
l=0 \\
l=0 \\
l \cdot 0 \\
l=0 \\
l=0 \\
l \cdot 0 \\
l=0 \\
l=0\end{array}$ & & 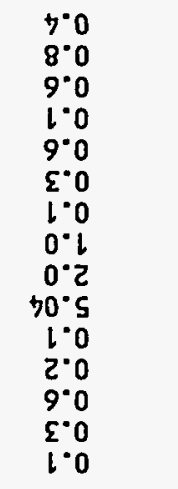 & $\begin{array}{l}> \\
> \\
> \\
>\end{array}$ & . & $\begin{array}{l}0 \\
0 \\
0 \\
0 \\
0 \\
0 \\
0 \\
0 \\
0 \\
0 \\
0 \\
0 \\
0 \\
0 \\
0\end{array}$ & $\begin{array}{l}\text { 8n } \\
\text { 8n } \\
\text { 8n } \\
\text { gn } \\
\text { gn } \\
\text { gn } \\
\text { घn } \\
\text { 8n } \\
\text { 8n } \\
\text { gn } \\
\text { 8n } \\
\text { 8n } \\
\text { 8n } \\
\text { 8n } \\
\text { 8n }\end{array}$ & $\begin{array}{l}1000 \\
1000 \\
1000 \\
1000 \\
1000 \\
1000 \\
1000 \\
1000 \\
1000 \\
1000 \\
1000 \\
1000 \\
1000 \\
1000 \\
1000\end{array}$ & $\begin{array}{l}26 / 21 / 01 \\
16 / 22 / 80 \\
16 / 20 / 70 \\
06 / 80 / 2 L \\
26 / 2 L / 01 \\
16 / 70 / 70 \\
06 / 51 / 2 L \\
26 / 21 / 01 \\
16 / \varepsilon 2 / 80 \\
16 / 10 / 70 \\
06 / 21 / 21 \\
26 / 11 / 01 \\
16 / \varepsilon 2 / 80 \\
16 / 10 / 70 \\
06 / 51 / 21\end{array}$ & 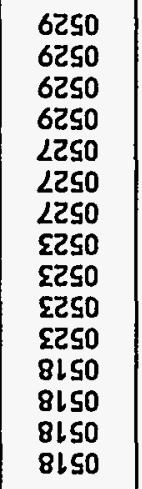 & בดIงากร \\
\hline $\begin{array}{l}- \\
- \\
- \\
- \\
- \\
- \\
- \\
- \\
- \\
- \\
- \\
- \\
- \\
- \\
- \\
- \\
- \\
- \\
- \\
-\end{array}$ & 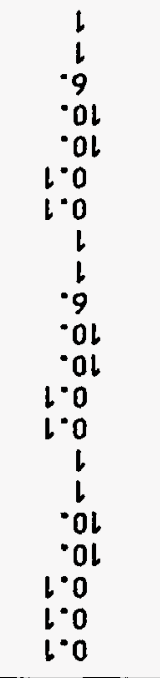 & 1 & 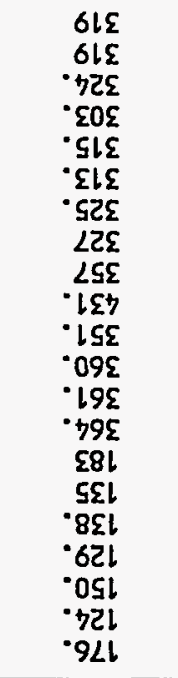 & & 7/5W & $\begin{array}{l}0 \\
0 \\
0 \\
0 \\
0 \\
0 \\
0 \\
0 \\
0 \\
0 \\
0 \\
0 \\
0 \\
0 \\
0 \\
0 \\
0 \\
0 \\
0 \\
0 \\
0\end{array}$ & $\begin{array}{l}8 n \\
8 n \\
8 n \\
8 n \\
8 n \\
8 n \\
8 n \\
8 n \\
8 n \\
8 n \\
8 n \\
8 n \\
8 n \\
8 n \\
8 n \\
8 n \\
\text { gn } \\
8 n \\
8 n \\
8 n \\
8 n\end{array}$ & $\begin{array}{l}1000 \\
1000 \\
1000 \\
1000 \\
1000 \\
1000 \\
1000 \\
1000 \\
1000 \\
1000 \\
1000 \\
1000 \\
1000 \\
1000 \\
1000 \\
1000 \\
1000 \\
1000 \\
1000 \\
1000 \\
1000\end{array}$ & $\begin{array}{l}76 / 92 / 70 \\
76 / 72 / 20 \\
26 / 21 / 01 \\
16 / \varepsilon 2 / 80 \\
16 / 20 / 70 \\
06 / 80 / 2 l \\
06 / 90 / 90 \\
76 / 92 / 70 \\
76 / \varepsilon 2 / 20 \\
26 / 21 / 01 \\
16 / \varepsilon 2 / 80 \\
16 / 70 / 70 \\
06 / 51 / 21 \\
06 / 90 / 90 \\
76 / 02 / 70 \\
76 / \varepsilon 2 / 20 \\
26 / 21 / 01 \\
16 / \varepsilon 2 / 80 \\
16 / 10 / 70 \\
06 / 21 / 21 \\
06 / 70 / 90\end{array}$ & 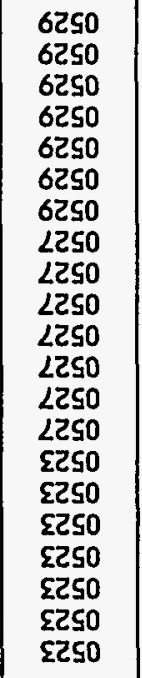 & כเทยากร \\
\hline 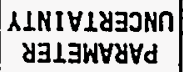 & $\begin{array}{c}\text { 1IWI7 } \\
\text { NoIIJङ130 }\end{array}$ & Sפษาย & 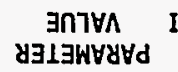 & $I \wedge d$ & $\begin{array}{l}\text { JynSHבW } \\
\text { to SLINn }\end{array}$ & $\mid \begin{array}{c}738 \\
\text { M07y }\end{array}$ & $\begin{array}{l}\text { dWOJ } \\
\text { WYOS }\end{array}$ & $\left|\begin{array}{c}\text { OI } \\
\text { aาdWGS }\end{array}\right|$ & J180 907] & $\mid \begin{array}{c}\text { OI } \\
\text { NOILYวO] }\end{array}$ & $\exists W Y N \quad$ X $\exists \perp \exists W Y Y Y d$ \\
\hline
\end{tabular}

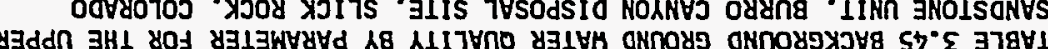




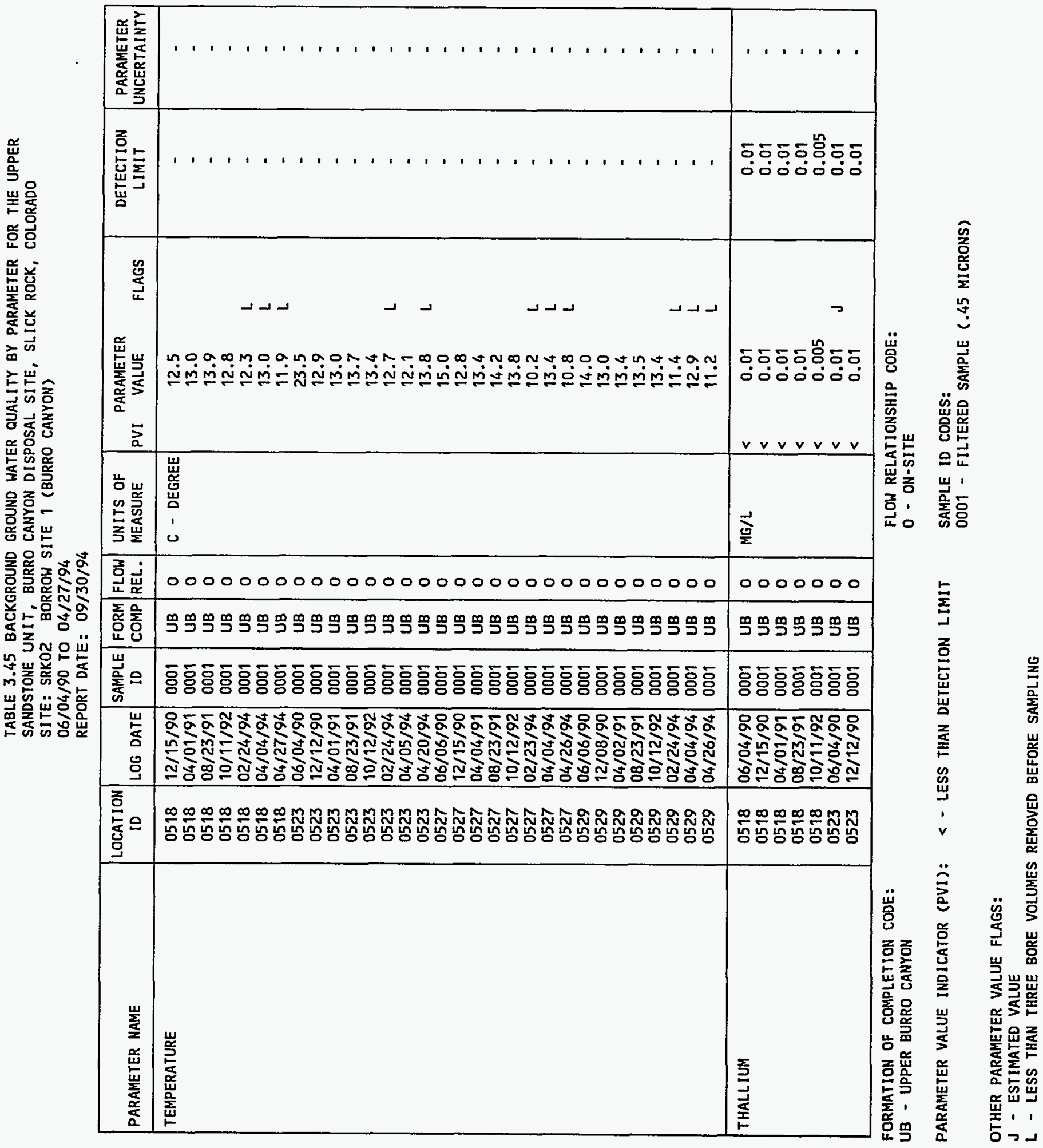




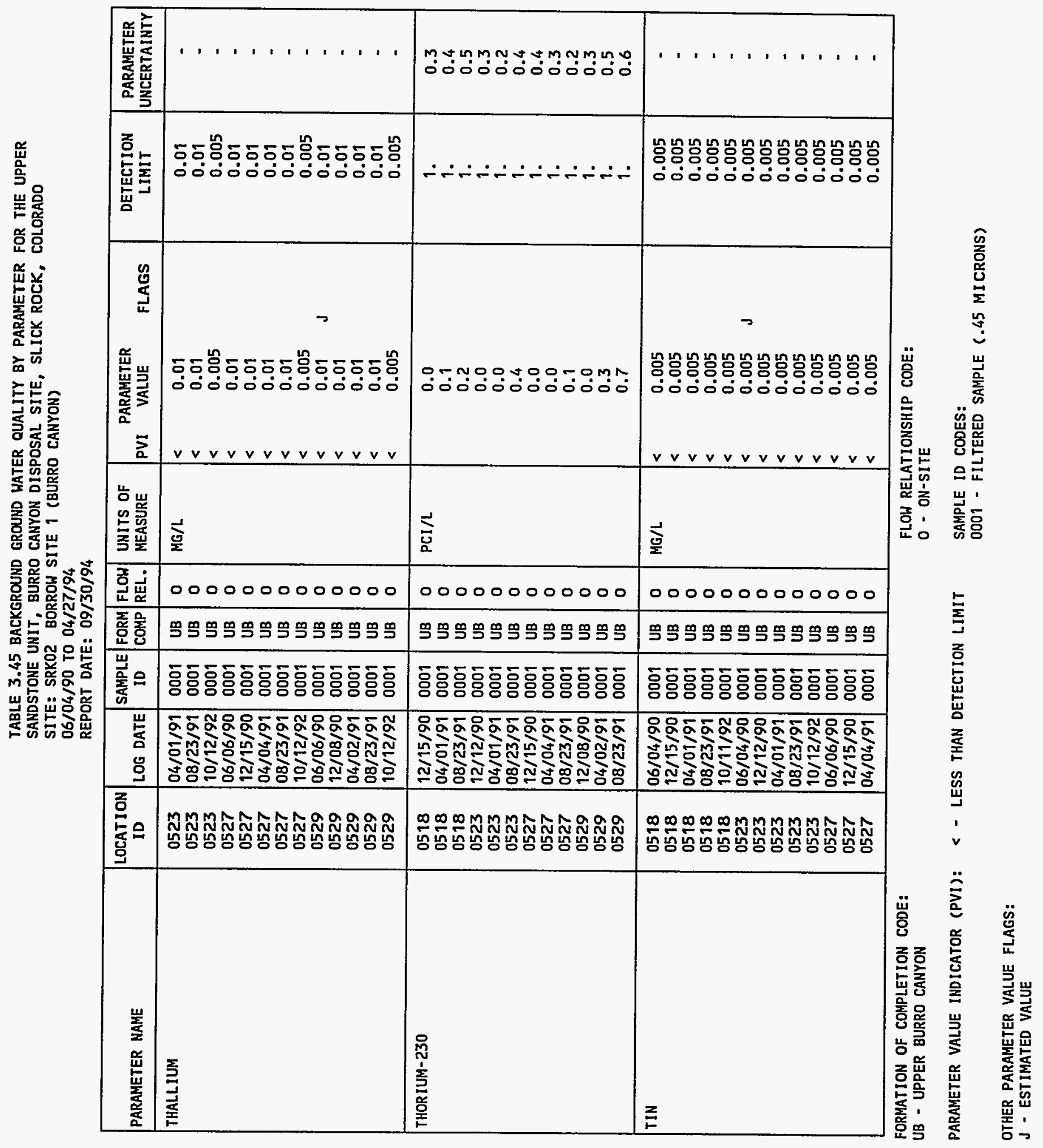


TABLE 3.45 BACKGROUND GROUND WATER QUALITY BY PARAMETER FOR THE UPPER SANDSTONE UNIT, BURRO CANYON DISPOSAL SITE, SLICK ROCK, COLORADO SITE: SRKO2 BORROW SITE 1 (BURRO CANYON)

06/04/90 TO 04/27/94

REPORT DATE : 09/30/94

\begin{tabular}{|c|c|c|c|c|c|c|c|c|c|c|c|}
\hline PARAMETER NAME & $\begin{array}{c}\text { LOCATION } \\
\text { ID }\end{array}$ & LOG DATE & $\underset{\text { ID }}{\text { SAMPLE }}$ & $\begin{array}{l}\text { FORM } \\
\text { COMP }\end{array}$ & $\begin{array}{l}\text { FLOW } \\
\text { REL. }\end{array}$ & $\begin{array}{l}\text { UNITS OF } \\
\text { MEASURE }\end{array}$ & PVI & $\begin{array}{l}\text { PARAMETER } \\
\text { VALUE }\end{array}$ & FLAGS & $\begin{array}{l}\text { DETECTION } \\
\text { LIMIT }\end{array}$ & $\begin{array}{l}\text { PARAMETER } \\
\text { UNCERTAINTY }\end{array}$ \\
\hline TIN & $\begin{array}{l}0527 \\
0527 \\
0529 \\
0529 \\
0529 \\
0529 \\
0529\end{array}$ & $\begin{array}{l}08 / 23 / 91 \\
10 / 12 / 92 \\
06 / 06 / 90 \\
12 / 08 / 90 \\
04 / 02 / 91 \\
08 / 23 / 91 \\
10 / 12 / 92\end{array}$ & $\begin{array}{l}0001 \\
0001 \\
0001 \\
0001 \\
0001 \\
0001 \\
0001\end{array}$ & $\begin{array}{l}\text { UB } \\
\text { UB } \\
\text { UB } \\
\text { UB } \\
\text { UB } \\
\text { UB } \\
\text { UB }\end{array}$ & $\begin{array}{l}0 \\
0 \\
0 \\
0 \\
0 \\
0 \\
0\end{array}$ & MG/L & $\mid \begin{array}{l}< \\
< \\
< \\
< \\
< \\
<\end{array}$ & $\begin{array}{l}0.005 \\
0.005 \\
0.006 \\
0.005 \\
0.005 \\
0.005 \\
0.05\end{array}$ & $\mathbf{J}$ & $\begin{array}{l}0.005 \\
0.005 \\
0.005 \\
0.005 \\
0.005 \\
0.005 \\
0.05\end{array}$ & $\begin{array}{l}- \\
- \\
- \\
- \\
-\end{array}$ \\
\hline TOTAL DISSOLVED SOLIDS & $\begin{array}{l}0518 \\
0518 \\
0518 \\
0518 \\
0518 \\
0518 \\
0518 \\
0523 \\
0523 \\
0523 \\
0523 \\
0523 \\
0523 \\
0523 \\
0527 \\
0527 \\
0527 \\
0527 \\
0527 \\
0527 \\
0527 \\
0529 \\
0529 \\
0529 \\
0529 \\
0529 \\
0529 \\
0529\end{array}$ & $\begin{array}{l}06 / 04 / 90 \\
12 / 15 / 90 \\
04 / 01 / 91 \\
08 / 23 / 91 \\
10 / 11 / 92 \\
02 / 24 / 94 \\
04 / 27 / 94 \\
06 / 04 / 90 \\
12 / 12 / 90 \\
04 / 01 / 91 \\
08 / 23 / 91 \\
10 / 12 / 92 \\
02 / 23 / 94 \\
04 / 20 / 94 \\
06 / 06 / 90 \\
12 / 15 / 90 \\
04 / 04 / 91 \\
08 / 23 / 91 \\
10 / 12 / 92 \\
02 / 23 / 94 \\
04 / 26 / 94 \\
06 / 06 / 90 \\
12 / 08 / 90 \\
04 / 02 / 91 \\
08 / 23 / 91 \\
10 / 12 / 92 \\
02 / 24 / 94 \\
04 / 26 / 94\end{array}$ & $\begin{array}{l}0001 \\
0001 \\
0001 \\
0001 \\
0001 \\
0001 \\
0001 \\
0001 \\
0001 \\
0001 \\
0001 \\
0001 \\
0001 \\
0001 \\
0001 \\
0001 \\
0001 \\
0001 \\
0001 \\
0001 \\
0001 \\
0001 \\
0001 \\
0001 \\
0001 \\
0001 \\
0001 \\
0001\end{array}$ & $\begin{array}{l}\text { UB } \\
\text { UB } \\
\text { UB } \\
\text { UB } \\
\text { UB } \\
\text { UB } \\
\text { UB } \\
\text { UB } \\
\text { UB } \\
\text { UB } \\
\text { UB } \\
\text { UB } \\
\text { UB } \\
\text { UB } \\
\text { UB } \\
\text { UB } \\
\text { UB } \\
\text { UB } \\
\text { UB } \\
\text { UB } \\
\text { UB } \\
\text { UB } \\
\text { UB } \\
\text { UB } \\
\text { UB } \\
\text { UB } \\
\text { UB } \\
\text { UB }\end{array}$ & $\begin{array}{l}0 \\
0 \\
0 \\
0 \\
0 \\
0 \\
0 \\
0 \\
0 \\
0 \\
0 \\
0 \\
0 \\
0 \\
0 \\
0 \\
0 \\
0 \\
0 \\
0 \\
0 \\
0 \\
0 \\
0 \\
0 \\
0 \\
0 \\
0\end{array}$ & $M G / L$ & & $\begin{array}{l}966 . \\
928 . \\
973 . \\
951 . \\
906 . \\
920 \\
950 \\
556 . \\
556 . \\
636 . \\
615 . \\
587 . \\
600 \\
610 \\
762 . \\
760 . \\
854 . \\
843 . \\
840 . \\
850 \\
770 \\
620 . \\
600 . \\
664 . \\
662 . \\
676 . \\
680 \\
690\end{array}$ & $\begin{array}{l}L \\
L \\
J\end{array}$ & $\begin{array}{l}10 . \\
10 . \\
10 . \\
10 . \\
10 . \\
10 \\
10 \\
10 . \\
10 . \\
10 . \\
10 . \\
10 . \\
10 \\
10 \\
10 . \\
10 . \\
10 . \\
10 . \\
10 . \\
10 \\
10 \\
10 . \\
10 . \\
10 . \\
10 . \\
10 . \\
10 \\
10\end{array}$ & $\begin{array}{l}- \\
- \\
- \\
- \\
- \\
- \\
- \\
- \\
- \\
- \\
- \\
- \\
- \\
- \\
- \\
- \\
- \\
- \\
- \\
- \\
- \\
- \\
-\end{array}$ \\
\hline TOTAL KJELDAHL NITROGEN & 0518 & $12 / 15 / 90$ & 0001 & UB & 0 & $\mathrm{MG} / \mathrm{L}$ & $<<$ & 1. & & 1. & - \\
\hline
\end{tabular}

FORMATION OF COMPLETION CODE:

UB - UPPER BURRO CANYON

PARAMETER VALUE INDICATOR (PVI):
- LESS THAN DETECTION LIMIT

OTHER PARAMETER VALUE FLAGS:

I - INCREASED DETECTION LIMIT DUE TO REQUIRED DILUTION

$J$ - ESTIMATED VALUE

L - LESS THAN THREE BORE VOLUMES REMOVED BEFORE SAMPLING
FLOW RELATIONSHIP CODE:

O- ON-SITE

\section{SAMPLE ID CODES:}

0001 - FILTERED SAMPLE (.45 MICRONS) 
TABLE 3.45 BACKGROUND GROUND HATER QUALITY BY PARAMETER FOR THE UPPER

SANDSTONE UNIT, BURRO CANYON DISPOSAL SITE, SLICK ROCK, COLORADO

SITE: SRKO2 BORROH SITE 1 (BURRO CANYON)

06/04/90 TO $04 / 27 / 94$

REPORT DATE: 09/30/94

\begin{tabular}{|c|c|c|c|c|c|c|c|c|c|c|c|}
\hline PARAMETER NAME & $\begin{array}{c}\text { LOCATION } \\
\text { ID }\end{array}$ & LOG DATE & $\begin{array}{c}\text { SAMPLE } \\
\text { ID }\end{array}$ & $\left|\begin{array}{l}\text { FORM } \\
\text { COMP }\end{array}\right|$ & $\begin{array}{l}\text { FLOW } \\
\text { REL. }\end{array}$ & $\begin{array}{l}\text { UNITS OF } \\
\text { MEASURE }\end{array}$ & PVI & $\begin{array}{l}\text { PARAMETE } \\
\text { VALUE }\end{array}$ & FLAGS & $\begin{array}{l}\text { DETECTION } \\
\text { LIMIT }\end{array}$ & $\begin{array}{l}\text { PARAMETER } \\
\text { UNCERTAINTY }\end{array}$ \\
\hline TOTAL KJELDAHL NITROGEN & $\begin{array}{l}0518 \\
0518 \\
0523 \\
0523 \\
0523 \\
0527 \\
0527 \\
0527 \\
0529 \\
0529 \\
0529\end{array}$ & $\begin{array}{l}04 / 01 / 91 \\
08 / 23 / 91 \\
12 / 12 / 90 \\
04 / 01 / 91 \\
08 / 23 / 91 \\
12 / 15 / 90 \\
04 / 04 / 91 \\
08 / 23 / 91 \\
12 / 08 / 90 \\
04 / 02 / 91 \\
08 / 23 / 91\end{array}$ & $\begin{array}{l}0001 \\
0001 \\
0001 \\
0001 \\
0001 \\
0001 \\
0001 \\
0001 \\
0001 \\
0001 \\
0001\end{array}$ & $\begin{array}{l}\text { UB } \\
\text { UB } \\
\text { UB } \\
\text { UB } \\
\text { UB } \\
\text { UB } \\
\text { UB } \\
\text { UB } \\
\text { UB } \\
\text { UB } \\
\text { UB }\end{array}$ & $\begin{array}{l}0 \\
0 \\
0 \\
0 \\
0 \\
0 \\
0 \\
0 \\
0 \\
0 \\
0\end{array}$ & MG/L & $\mid \begin{array}{l}< \\
< \\
< \\
< \\
<\end{array}$ & $\begin{array}{l}1 . \\
1 . \\
1 . \\
1 . \\
1 . \\
1 . \\
2 . \\
1 . \\
1 . \\
1 . \\
1 .\end{array}$ & & $\begin{array}{l}1 . \\
1 . \\
1 . \\
1 . \\
1 . \\
1 . \\
1 . \\
1 . \\
1 . \\
1 .\end{array}$ & $\begin{array}{l}- \\
- \\
- \\
- \\
- \\
- \\
- \\
- \\
-\end{array}$ \\
\hline TOTAL ORGANIC CARBON & $\begin{array}{l}0518 \\
0518 \\
0518 \\
0518 \\
0523 \\
0523 \\
0523 \\
0523 \\
0523 \\
0527 \\
0527 \\
0527 \\
0527 \\
0527 \\
0529 \\
0529 \\
0529 \\
0529 \\
0529\end{array}$ & $\begin{array}{l}04 / 01 / 91 \\
08 / 23 / 91 \\
10 / 11 / 92 \\
02 / 24 / 94 \\
12 / 12 / 90 \\
04 / 01 / 91 \\
08 / 23 / 91 \\
10 / 12 / 92 \\
02 / 23 / 94 \\
12 / 15 / 90 \\
04 / 04 / 91 \\
08 / 23 / 91 \\
10 / 12 / 92 \\
02 / 23 / 94 \\
12 / 08 / 90 \\
04 / 02 / 91 \\
08 / 23 / 91 \\
10 / 12 / 92 \\
02 / 24 / 94\end{array}$ & $\begin{array}{l}0001 \\
0001 \\
0001 \\
0001 \\
0001 \\
0001 \\
0001 \\
0001 \\
0001 \\
0001 \\
0001 \\
0001 \\
0001 \\
0001 \\
0001 \\
0001 \\
0001 \\
0001 \\
0001\end{array}$ & $\begin{array}{l}\text { UB } \\
\text { UB } \\
\text { UB } \\
\text { UB } \\
\text { UB } \\
\text { UB } \\
\text { UB } \\
\text { UB } \\
\text { UB } \\
\text { UB } \\
\text { UB } \\
\text { UB } \\
\text { UB } \\
\text { UB } \\
\text { UB } \\
\text { UB } \\
\text { UB } \\
\text { UB } \\
\text { UB }\end{array}$ & $\begin{array}{l}0 \\
0 \\
0 \\
0 \\
0 \\
0 \\
0 \\
0 \\
0 \\
0 \\
0 \\
0 \\
0 \\
0 \\
0 \\
0 \\
0 \\
0 \\
0\end{array}$ & $M G / L$ & $<$ & $\begin{array}{c}1 . \\
2 . \\
2 . \\
2 \\
103 . \\
1 . \\
2 . \\
3 . \\
6 \\
38 . \\
1 . \\
4 . \\
3 . \\
11 \\
41 . \\
1 . \\
3 . \\
3 . \\
3\end{array}$ & $\begin{array}{l}\mathrm{L} \\
\mathrm{J} \\
\mathrm{L} \\
\mathrm{J}\end{array}$ & $\begin{array}{l}1 . \\
1 . \\
1 . \\
1 \\
1 . \\
1 . \\
1 . \\
1 \\
1 . \\
1 . \\
1 . \\
1 . \\
1 . \\
1 . \\
1 . \\
1 .\end{array}$ & $\begin{array}{l}- \\
- \\
- \\
- \\
- \\
- \\
- \\
- \\
- \\
- \\
- \\
- \\
- \\
- \\
-\end{array}$ \\
\hline TURBIDITY & 0523 & $04 / 05 / 94$ & 0001 & UB & 0 & NTU & & 23 & & - & - \\
\hline URANIUM & $\begin{array}{l}0518 \\
0518 \\
0518 \\
0518 \\
0518\end{array}$ & $\begin{array}{l}06 / 04 / 90 \\
12 / 15 / 90 \\
04 / 01 / 91 \\
08 / 23 / 91 \\
10 / 11 / 92\end{array}$ & $\begin{array}{l}0001 \\
0001 \\
0001 \\
0001 \\
0001\end{array}$ & $\begin{array}{l}\text { UB } \\
\text { UB } \\
\text { UB } \\
\text { UB } \\
\text { UB }\end{array}$ & $\begin{array}{l}0 \\
0 \\
0 \\
0 \\
0\end{array}$ & $M G / L$ & \multicolumn{3}{|c|}{$\begin{array}{l}0.020 \\
0.0172 \\
0.019 \\
0.017 \\
0.022\end{array}$} & $\begin{array}{l}0.003 \\
0.0003 \\
0.001 \\
0.001 \\
0.001\end{array}$ & $\begin{array}{l}- \\
- \\
- \\
-\end{array}$ \\
\hline
\end{tabular}

FORMATION OF COMPLETION CODE:

UB - UPPER BURRO CANYON

PARAMETER VALUE INDICATOR (PVI): < - LESS THAN DETECTION LIMIT
FLOW RELATIONSHIP CODE:

SAMPLE ID CODES:

0001 - FILTERED SAMPLE (.45 MICRONS)

OTHER PARAMETER VALUE FLAGS:

J - ESTIMATED VALUE

L - LESS THAN THREE BORE VOLUMES REMOVED BEFORE SAMPLING 
TABLE 3.45 BACKGROUND GROUND WATER QUALITY BY PARAMETER FOR THE UPPER SANDSTONE UNIT, BURRO CANYON DISPOSAL SITE, SLICK ROCK, COLORADO

SITE: SRKO2 BORROW SITE 1 (BURRO CANYON)

06/04/90 TO 04/27/94

\begin{tabular}{|c|c|c|c|c|c|c|c|c|c|c|c|}
\hline PARAMETER NAME & $\begin{array}{c}\text { LOCATION } \\
\text { ID }\end{array}$ & LOG DATE & $\begin{array}{c}\text { SAMPLE } \\
\text { ID }\end{array}$ & $\mid \begin{array}{l}\text { FORM } \\
\text { COMP }\end{array}$ & $\begin{array}{l}\text { FL.OW } \\
\text { REL. . }\end{array}$ & $\begin{array}{l}\text { UNITS OF } \\
\text { MEASURE }\end{array}$ & PVI & $\begin{array}{l}\text { PARAMETER } \\
\text { VALUE }\end{array}$ & FLAGS & $\begin{array}{l}\text { OETECTION } \\
\text { LIMIT }\end{array}$ & $\begin{array}{l}\text { PARAMETER } \\
\text { UNCERTAINTY }\end{array}$ \\
\hline URANIUM & $\begin{array}{l}0518 \\
0518 \\
0523 \\
0523 \\
0523 \\
0523 \\
0523 \\
0523 \\
0523 \\
0527 \\
0527 \\
0527 \\
0527 \\
0527 \\
0527 \\
0527 \\
0529 \\
0529 \\
0529 \\
0529 \\
0529 \\
0529 \\
0529\end{array}$ & $\begin{array}{l}02 / 24 / 94 \\
04 / 04 / 94 \\
06 / 04 / 90 \\
12 / 12 / 90 \\
04 / 01 / 91 \\
08 / 23 / 91 \\
10 / 12 / 92 \\
02 / 23 / 94 \\
04 / 05 / 94 \\
06 / 06 / 90 \\
12 / 15 / 90 \\
04 / 04 / 91 \\
08 / 23 / 91 \\
10 / 12 / 92 \\
02 / 23 / 94 \\
04 / 04 / 94 \\
06 / 06 / 90 \\
12 / 08 / 90 \\
04 / 02 / 91 \\
08 / 23 / 91 \\
10 / 12 / 92 \\
02 / 24 / 94 \\
04 / 05 / 94\end{array}$ & $\begin{array}{l}0001 \\
0001 \\
0001 \\
0001 \\
0001 \\
0001 \\
0001 \\
0001 \\
0001 \\
0001 \\
0001 \\
0001 \\
0001 \\
0001 \\
0001 \\
0001 \\
0001 \\
0001 \\
0001 \\
0001 \\
0001 \\
0001 \\
0001\end{array}$ & $\begin{array}{l}\text { UB } \\
\text { UB } \\
\text { UB } \\
\text { UB } \\
\text { UB } \\
\text { UB } \\
\text { UB } \\
\text { UB } \\
\text { UB } \\
\text { UB } \\
\text { UB } \\
\text { UB } \\
\text { UB } \\
\text { UB } \\
\text { UB } \\
\text { UB } \\
\text { UB } \\
\text { UB } \\
\text { UB } \\
\text { UB } \\
\text { UB } \\
\text { UB } \\
\text { UB }\end{array}$ & $\begin{array}{l}0 \\
0 \\
0 \\
0 \\
0 \\
0 \\
0 \\
0 \\
0 \\
0 \\
0 \\
0 \\
0 \\
0 \\
0 \\
0 \\
0 \\
0 \\
0 \\
0 \\
0 \\
0 \\
0\end{array}$ & $M G / L$ & 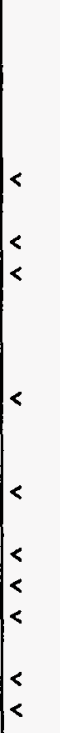 & $\begin{array}{l}0.025 \\
0.019 \\
0.0028 \\
0.0008 \\
0.025 \\
0.001 \\
0.002 \\
0.001 \\
0.001 \\
0.0066 \\
0.0026 \\
0.002 \\
0.001 \\
0.002 \\
0.002 \\
0.001 \\
0.0012 \\
0.0003 \\
0.001 \\
0.001 \\
0.002 \\
0.001 \\
0.001\end{array}$ & $\begin{array}{l}\text { LN } \\
\\
J L N \\
L \\
J \\
L N \\
L\end{array}$ & $\begin{array}{l}0.001 \\
0.001 \\
0.003 \\
0.0003 \\
0.001 \\
0.001 \\
0.001 \\
0.001 \\
0.001 \\
0.003 \\
0.0003 \\
0.001 \\
0.001 \\
0.001 \\
0.001 \\
0.001 \\
0.003 \\
0.0003 \\
0.001 \\
0.001 \\
0.001 \\
0.001 \\
0.001\end{array}$ & $\begin{array}{l}- \\
- \\
- \\
- \\
- \\
- \\
- \\
- \\
- \\
- \\
- \\
- \\
- \\
- \\
- \\
- \\
- \\
- \\
- \\
- \\
-\end{array}$ \\
\hline VANADIUM & $\begin{array}{l}0518 \\
0518 \\
0518 \\
0518 \\
0518 \\
0518 \\
0518 \\
0523 \\
0523 \\
0523 \\
0523 \\
0523 \\
0523 \\
0523 \\
0527 \\
0527\end{array}$ & $\begin{array}{l}06 / 04 / 90 \\
12 / 15 / 90 \\
04 / 01 / 91 \\
08 / 23 / 91 \\
10 / 11 / 92 \\
02 / 24 / 94 \\
04 / 27 / 94 \\
06 / 04 / 90 \\
12 / 12 / 90 \\
04 / 01 / 91 \\
08 / 23 / 91 \\
10 / 12 / 92 \\
02 / 23 / 94 \\
04 / 20 / 94 \\
06 / 06 / 90 \\
12 / 15 / 90\end{array}$ & $\begin{array}{l}0001 \\
0001 \\
0001 \\
0001 \\
0001 \\
0001 \\
0001 \\
0001 \\
0001 \\
0001 \\
0001 \\
0001 \\
0001 \\
0001 \\
0001 \\
0001\end{array}$ & $\begin{array}{l}\text { UB } \\
\text { UB } \\
\text { UB } \\
\text { UB } \\
\text { UB } \\
\text { UB } \\
\text { UB } \\
\text { UB } \\
\text { UB } \\
\text { UB } \\
\text { UB } \\
\text { UB } \\
\text { UB } \\
\text { UB } \\
\text { UB } \\
\text { UB }\end{array}$ & $\begin{array}{l}0 \\
0 \\
0 \\
0 \\
0 \\
0 \\
0 \\
0 \\
0 \\
0 \\
0 \\
0 \\
0 \\
0 \\
0 \\
0\end{array}$ & MG/L & $\begin{array}{l}< \\
< \\
< \\
< \\
< \\
< \\
< \\
< \\
< \\
< \\
< \\
< \\
< \\
< \\
< \\
<\end{array}$ & $\begin{array}{l}0.02 \\
0.03 \\
0.01 \\
0.01 \\
0.01 \\
0.01 \\
0.01 \\
0.01 \\
0.02 \\
0.01 \\
0.01 \\
0.01 \\
0.01 \\
0.01 \\
0.01 \\
0.02\end{array}$ & $\begin{array}{l}\mathrm{L} \\
\mathrm{L} \\
\mathrm{J}\end{array}$ & $\begin{array}{l}0.01 \\
0.01 \\
0.01 \\
0.01 \\
0.01 \\
0.01 \\
0.01 \\
0.01 \\
0.01 \\
0.01 \\
0.01 \\
0.01 \\
0.01 \\
0.01 \\
0.01 \\
0.01\end{array}$ & $\begin{array}{l}- \\
- \\
- \\
- \\
- \\
- \\
- \\
- \\
- \\
- \\
-\end{array}$ \\
\hline
\end{tabular}

FORMATION OF COMPLETION CODE:

UB - UPPER BURRO CANYON

PARAMETER VALUE INDICATOR (PVI):

OTHER PARAMETER VALUE FLAGS:

J - ESTIMATED VALUE

L - LESS THAN THREE BORE VOLUMES REMOVED BEFORE SAMPLING

N - SPIKE SAMPLE RECOVERY NOT WITHIN CONTROL LIMITS
FLOW RELATIONSHIP CODE:

O - ON-SITE

SAMPLE ID CODES:

0001 - FILTERED SAMPLE (.45 MICRONS) 


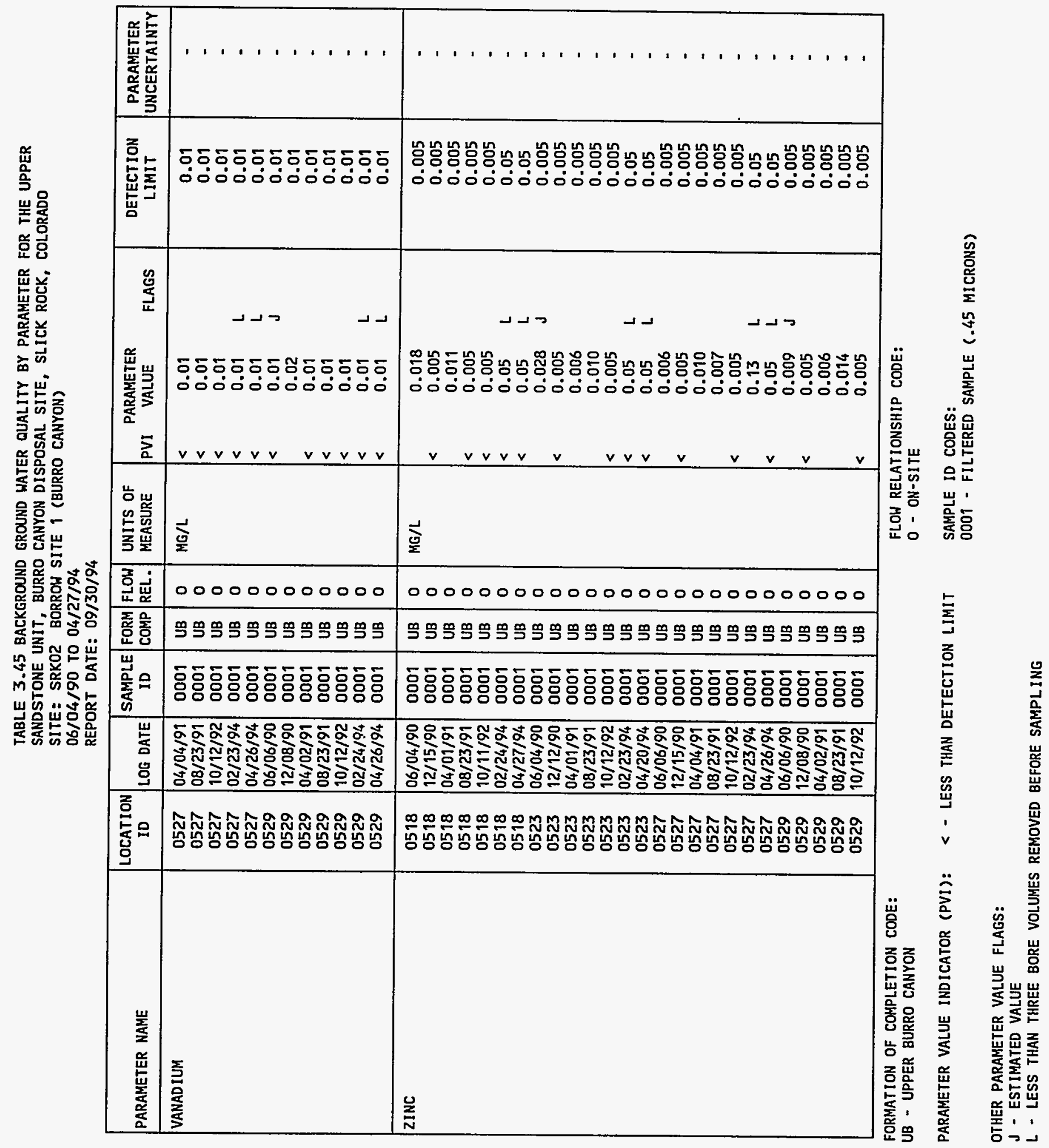


TABLE 3.45 BACKGROUND GROUND WATER QUALITY BY PARAMETER FOR THE UPPER

SANDSTONE UNIT, BURRO CANYON DISPOSAL SITE, SLICK ROCK, COLORADO

SITE: SRKOZ BORROW SITE 1 (BURRO CANYON)

06/04/90 TO 04/27/94

REPORT DATE: $09 / 30 / 94$

\begin{tabular}{|c|c|c|c|c|c|c|c|c|c|c|c|}
\hline PARAMETER NAME & $\underset{10}{\text { LOCATION }}$ & LOG DATE & $\begin{array}{c}\text { SAMPLE } \\
\text { ID }\end{array}$ & $\begin{array}{l}\text { FORM } \\
\text { COMP }\end{array}$ & $\begin{array}{l}\text { FLOW } \\
\text { REL. }\end{array}$ & $\begin{array}{l}\text { UNITS OF } \\
\text { MEASURE }\end{array}$ & PVI & $\begin{array}{l}\text { PARAMETEF } \\
\text { VALUE }\end{array}$ & FLAGS & $\begin{array}{l}\text { DETECTION } \\
\text { LIMIT }\end{array}$ & $\begin{array}{l}\text { PARAMETER } \\
\text { UNCERTAINTY }\end{array}$ \\
\hline ZINC & $\begin{array}{l}0529 \\
0529\end{array}$ & $\begin{array}{l}02 / 24 / 94 \\
04 / 26 / 94\end{array}$ & $\begin{array}{l}0001 \\
0001\end{array}$ & $\begin{array}{l}\text { UB } \\
\text { UB }\end{array}$ & $\begin{array}{l}0 \\
0\end{array}$ & $M G / L$ & $<<$ & $\begin{array}{l}0.05 \\
0.05\end{array}$ & $L$ & $\begin{array}{l}0.05 \\
0.05\end{array}$ & - \\
\hline
\end{tabular}

FORMATION OF COMPLETION CODE:

FLOW RELATIONSHIP CODE:

UB - UPPER BURRO CANYON

O- ON-SITE

PARAMETER VALUE INDICATOR (PVI): < - LESS THAN DETECTION LIMIT

SAMPLE ID CODES:

0001 - FILTERED SAMPLE (.45 MICRONS)

OTHER PARAMETER VALUE FLAGS:

L - LESS THAN THREE BORE VOLUMES REMOVED BEFORE SAMPLING

DATA FILE NAME: IOARTISRK02\GWQ10002.DAT 
TABLE 3.46 BACKGROUND GROUND HATER QUALITY STATISTICS BY PARAMETER FOR

THE UPPER SANDSTONE UNIT, BURRO CANYON DISPOSAL SITE, SLICK ROCK, COLORADO

SITE: SRKO2 BORROH SITE 1 (BURRO CANYON)

$06 / 04 / 90$ TO 04/27/94

REPORT DATE: $09 / 30 / 94$

\begin{tabular}{|c|c|c|c|c|c|c|c|c|c|c|c|}
\hline \multicolumn{3}{|c|}{ PARAMETER NAME } & UNITS & \multirow[b]{2}{*}{ MEAN } & \multirow{2}{*}{$\begin{array}{r}\text { STANDARD } \\
\text { DEVIATION }\end{array}$} & \multirow{2}{*}{$\begin{array}{c}\text { COEFF. } \\
\text { OF } \\
\text { VARIATION }\end{array}$} & \multirow{2}{*}{$\begin{array}{l}\% \text { OF } \\
\text { NON } \\
\text { DETECTS }\end{array}$} & \multirow{2}{*}{\multicolumn{2}{|c|}{$\begin{array}{c}\text { STATISTICAL RANGE } \\
\text { 98\% CONFIDENCE INTERVAL } \\
\text { MINIMUM } \\
\text { MAXIMUM * }\end{array}$}} & \multirow{2}{*}{$\begin{array}{c}\text { DISTRIBUTION } \\
\text { TYPE }\end{array}$} & \multirow{2}{*}{$\begin{array}{l}\text { FOOT } \\
\text { NOTE }\end{array}$} \\
\hline \# OF SAMP & MINIMUM & MAXIMUM & MEDIAN & & & & & & & & \\
\hline \multicolumn{3}{|l|}{ ALKALINITY } & $M G / L C A$ & \multirow[b]{2}{*}{304.0000} & \multirow[b]{2}{*}{105.7838} & \multirow[b]{2}{*}{0.3480} & \multirow[b]{2}{*}{0.0} & \multirow[b]{2}{*}{255.5393} & \multirow[b]{2}{*}{352.4607} & \multirow[b]{2}{*}{ NORMAL } & \\
\hline 29 & 148.0000 & 607.0000 & 270.0000 & & & & & & & & \\
\hline \multicolumn{3}{|l|}{ ALUMINUM } & $M G / L$ & \multirow[b]{2}{*}{ NA } & \multirow[b]{2}{*}{ NA } & \multirow[b]{2}{*}{ NA } & \multirow[b]{2}{*}{55.0} & \multirow[b]{2}{*}{0.0500} & \multirow[b]{2}{*}{0.1000} & \multirow[b]{2}{*}{ NONPARAMETRIC } & \multirow[b]{2}{*}{2} \\
\hline 20 & 0.0500 & 0.2000 & 0.0500 & & & & & & & & \\
\hline \multicolumn{3}{|l|}{ AMMONIUM } & $M G / L$ & \multirow[b]{2}{*}{ NA } & \multirow[b]{2}{*}{ NA } & \multirow[b]{2}{*}{ NA } & \multirow[b]{2}{*}{20.0} & \multirow[b]{2}{*}{0.1000} & & & \\
\hline 20 & ** $\quad 0.1000$ & 0.4000 & 0.2500 & & & & & & 0.3000 & NONPARAMETRIC & 2 \\
\hline ANT IMONY & & & $M G / L$ & & & & & & & & \\
\hline 20 & $\begin{array}{ll}* & 0.0030\end{array}$ & 0.0080 & 0.0030 & NA & NA & NA & 80.0 & 0.0030 & 0.0030 & NONPARAMETRIC & 2 \\
\hline ARSENIC & & & $M G / L$ & & & & & & & & \\
\hline 20 & ** $\quad 0.0050$ & 0.0250 & 0.0050 & NA & NA & NA & 100.0 & 0.0050 & 0.0050 & NONPARAMETRIC & 2 \\
\hline BARIUM & & & $M G / L$ & & & & & & & & \\
\hline 28 & 0.0200 & 0.1000 & 0.0500 & NA & NA & NA & 53.6 & 0.0300 & 0.0500 & NONPARAMETRIC & 2 \\
\hline BERYLLIUM & & & MG/L & & & & & & & & \\
\hline 16 & $\begin{array}{ll}* & 0.0050\end{array}$ & 0.0050 & 0.0050 & NA & NA & NA & 100.0 & 0.0050 & 0.0050 & NONPARAMETRIC & 2 \\
\hline BORON & & & $M G / L$ & & & & & & & & \\
\hline 24 & 0.1000 & 0.3000 & 0.2000 & 0.2108 & 0.0502 & 0.2381 & 0.0 & 0.1852 & 0.2365 & NORMAL & \\
\hline BROMIDE & & & $M G / L$ & & & & & & & & \\
\hline 16 & 0.0500 & 0.5000 & 0.1250 & NA & NA & NA & 43.8 & 0.0500 & 0.3000 & NONPARAMETRIC & 2 \\
\hline CADMIUM & & & $M G / L$ & & & & & & & & \\
\hline 28 & ** $\quad 0.0005$ & 0.0100 & 0.0005 & NA & NA & NA & 92.9 & 0.0005 & 0.0005 & NONPARAMETRIC & 2 \\
\hline
\end{tabular}

** The reported value is the minimum detection limit of the data set

+ The sample size is even, so the median value is the arithmetic average of the two middle values

* The statistical maximum is the 99 percent one sided confidence interval, $\alpha=0.01$

2) The nonparametric distribution was used because the nondetected values comprise more than $15 \%$ of the samples. 
TABLE 3.46 BACKGROUND GROUND WATER QUALITY STATISTICS BY PARAMETER FOR THE UPPER SANDSTONE UNIT, BURRO CANYON DISPOSAL SITE, SLICK ROCK, COLORADO SITE: SRKO2 BORROW SITE 1 (BURRO CANYON)

06/04/90 TO 04/27/94

REPORT DATE: $09 / 30 / 94$

\begin{tabular}{|c|c|c|c|c|c|c|c|c|c|c|c|c|}
\hline \multicolumn{3}{|c|}{ PARAMETER NAME } & UNITS & \multirow[b]{2}{*}{ MEAN } & \multirow{2}{*}{$\begin{array}{r}\text { STANDARD } \\
\text { DEVIATION }\end{array}$} & \multirow{2}{*}{$\begin{array}{c}\text { COEFF. } \\
\text { OF } \\
\text { VARIATION }\end{array}$} & \multirow{2}{*}{$\begin{array}{c}\% \text { OF } \\
\text { NON } \\
\text { DETECTS }\end{array}$} & \multirow{2}{*}{\multicolumn{3}{|c|}{$\begin{array}{c}\text { STATISTICAL RANGE } \\
\text { 98\% CONFIDENCE INTERVAL } \\
\text { MINIMUM } \\
\text { MAXIMUM * }\end{array}$}} & \multirow{2}{*}{$\begin{array}{c}\text { DISTRIBUTION } \\
\text { TYPE }\end{array}$} & \multirow{2}{*}{$\begin{array}{l}\text { FOOT } \\
\text { NOTE }\end{array}$} \\
\hline \# OF SAMP & MINIMUH & MAXIMUM & MEDIAN & & & & & & & & & \\
\hline \multicolumn{3}{|l|}{ CALCIUM } & MG/L & \multirow[b]{2}{*}{16.5690} & \multirow[b]{2}{*}{3.3645} & \multirow[b]{2}{*}{ NA } & \multirow[b]{2}{*}{0.0} & \multirow{2}{*}{\multicolumn{2}{|c|}{9.3981}} & \multirow[b]{2}{*}{29.2114} & \multirow[b]{2}{*}{ LOGNORMAL } & \multirow[b]{2}{*}{7,8} \\
\hline 28 & 3.6700 & 118.0000 & 13.5000 & & & & & & & & & \\
\hline \multicolumn{3}{|l|}{ CHLORIDE } & $M G / L$ & \multirow[b]{2}{*}{23.0857} & \multirow[b]{2}{*}{6.4104} & \multirow[b]{2}{*}{0.2777} & \multirow[b]{2}{*}{0.0} & \multirow{2}{*}{\multicolumn{2}{|c|}{20.0898}} & \multirow[b]{2}{*}{26.0817} & \multirow[b]{2}{*}{ NORMAL } & \\
\hline 28 & 13.0000 & 33.0000 & 22.5000 & & & & & & & & & \\
\hline \multicolumn{3}{|l|}{ CHROMI UM } & $M G / L$ & \multirow[b]{2}{*}{ NA } & \multirow[b]{2}{*}{ NA } & \multirow[b]{2}{*}{ NA } & \multirow[b]{2}{*}{100.0} & \multirow[b]{2}{*}{$\star \star \star$} & \multirow[b]{2}{*}{0.0100} & & & \\
\hline 28 & 0.0100 & 0.0100 & 0.0100 & & & & & & & 0.0100 & NONPARAMETRIC & 2 \\
\hline COBALT & & & $M G / L$ & & & & & & & & & \\
\hline 16 & 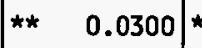 & 0.0300 & 0.0300 & NA & NA & NA & 100.0 & ** & 0.0300 & 0.0300 & NONPARAMETRIC & 2 \\
\hline COPPER & & & MG/L & & & & & & & & & \\
\hline 20 & ** $\quad 0.0100$ & 0.0100 & 0.0100 & NA & NA & NA & 100.0 & $\star *$ & 0.0100 & 0.0100 & NONPARAMETRIC & 2 \\
\hline CYANIDE & & & $M G / L$ & & & & & & & & & \\
\hline 12 & $\begin{array}{ll}* * & 0.0100\end{array} *$ & 0.0100 & ** $\quad 0.0100$ & NA & NA & NA & 100.0 & $\star \star$ & 0.0100 & 0.0100 & NONPARAMETRIC & 2 \\
\hline DISSOLVED & ORGANIC CARBO & & $M G / L$ & & & & & & & & & \\
\hline 4 & $\begin{array}{ll}* * & 1.0000\end{array}$ & 10.0000 & 2.5000 & NA & $n A$ & NA & 25.0 & $\star \star$ & 1.0000 & 10.0000 & NONPARAMETRIC & 2,4 \\
\hline DISSULVED & DXYGEN & & $M G / L$ & & & & & & & & & \\
\hline 1 & 2.0000 & 2.0000 & 2.0000 & NA & NA & NA & 0.0 & & NA & NA & UNKNOWN & 1 \\
\hline FLUOR IDE & & & $M G / L$ & & & & & & & & & \\
\hline 20 & 0.6000 & 1.1000 & 0.8000 & 0.8150 & 0.1496 & 0.1836 & 0.0 & & 0.7300 & 0.9000 & NORMAL & \\
\hline
\end{tabular}

** The reported value is the minimum detection limit of the data set

+ The sample size is even, so the median value is the arithmetic average of the two middle values

* The statistical maximum is the 99 percent one sided confidence interval, $\alpha \quad 0.01$

1) A minimum of 4 samples must be available for the statistical analysis.

2) The nonparametric distribution was used because the nondetected values comprise more than $15 \%$ of the samples.

4) The stat. range is the $\mathbf{8 7 . 5 \%}$ confidence interval due to a sample size of 4 . The maximum is the $93.8 \%$ one sided confidence int.

7) The lognormal distribution was used because the data failed the normal distribution test.

8) The mean is geometric. The standard deviation is the value to divide or multiply with the geometric mean. 
TABLE 3.46 BACKGROUND GROUND WATER QUALITY STATISTICS BY PARAMETER FOR

THE UPPER SANDSTONE UNIT, BURRO CANYON DISPOSAL SITE, SLICK ROCK, COLORADO

SITE: SRKO2 BORROW SITE 1 (BURRO CAN

06/04/90 TO 04/27/94

REPORT DATE: 09/30/94

\begin{tabular}{|c|c|c|c|c|c|c|c|c|c|c|c|c|c|c|c|}
\hline \multicolumn{5}{|c|}{ PARAMETER NAME } & UNITS & \multirow[b]{2}{*}{ MEAN } & \multirow{2}{*}{$\begin{array}{r}\text { STANDARD } \\
\text { DEVIATION }\end{array}$} & \multirow{2}{*}{$\begin{array}{l}\text { COEFF. } \\
\text { OF } \\
\text { VARIATION }\end{array}$} & \multirow{2}{*}{$\mid \begin{array}{c}\% \text { OF } \\
\text { NON } \\
\text { DETECTS }\end{array}$} & \multirow{2}{*}{\multicolumn{4}{|c|}{ 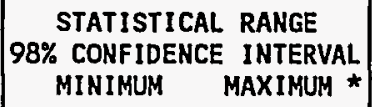 }} & \multirow{2}{*}{$\begin{array}{c}\text { DISTRIBUTION } \\
\text { TYPE }\end{array}$} & \multirow{2}{*}{$\begin{array}{l}\text { FOOT } \\
\text { NOTE }\end{array}$} \\
\hline \# OF SAMP & & INIMUM & MAXIMUM & & IEDIAN & & & & & & & & & & \\
\hline \multicolumn{5}{|c|}{ GROSS ALPHA } & $\mathrm{PCI} / \mathrm{L}$ & \multirow[b]{2}{*}{ NA } & \multirow[b]{2}{*}{ NA } & \multirow[b]{2}{*}{ NA } & \multirow[b]{2}{*}{0.0} & \multirow[b]{2}{*}{ ** } & \multirow[b]{2}{*}{1.0000} & \multirow{2}{*}{\multicolumn{2}{|c|}{11.9000}} & \multirow[b]{2}{*}{ NONPARAMETRIC } & \multirow[b]{2}{*}{9} \\
\hline 24 & ** & 1.0000 & 18.0000 & + & 2.0500 & & & & & & & & & & \\
\hline \multicolumn{5}{|l|}{ GROSS BETA } & $\mathrm{PCI} / \mathrm{L}$ & \multirow[b]{2}{*}{ NA } & \multirow[b]{2}{*}{ NA } & \multirow[b]{2}{*}{ NA } & \multirow[b]{2}{*}{0.0} & \multirow[b]{2}{*}{$\star \star \star$} & \multirow{2}{*}{\multicolumn{2}{|c|}{0.5000}} & & \multirow[b]{2}{*}{ NONPARAMETRIC } & \multirow[b]{2}{*}{9} \\
\hline 16 & ** & 0.5000 & 39.2000 & + & 3.8500 & & & & & & & & & & \\
\hline \multicolumn{5}{|l|}{ IRON } & MG/L & \multirow[b]{2}{*}{ NA } & \multirow[b]{2}{*}{ NA } & & & & & & & & \\
\hline 28 & ** & 0.0300 & 0.5900 & ** & 0.0300 & & & NA & 64.3 & $\star \star$ & 0.0300 & & 0.0400 & NONPARAMETRIC & 2 \\
\hline LEAD & & & & & $M G / L$ & & & & & & & & & & \\
\hline 20 & ** & 0.0050 & 0.0150 & + & 0.0050 & NA & NA & NA & 100.0 & ** & 0.0050 & & 0.0100 & NONPARAMETRIC & 2 \\
\hline LEAD-210 & & & & & $\mathrm{PCl} / \mathrm{L}$ & & & & & & & & & & \\
\hline 12 & ** & 1.5000 & 1.5000 & ** & 1.5000 & NA & NA & NA & 0.0 & ** & 1.5000 & ** & 1.5000 & NONPARAMETRIC & 9 \\
\hline MAGNESIUM & & & & & $\mathrm{MG} / \mathrm{L}$ & & & & & & & & & & \\
\hline 28 & & 0.3000 & 32.5000 & + & 3.6950 & 3.6357 & 4.5093 & NA & 0.0 & & 1.7984 & & 7.3500 & LOGNORMAL & 7,8 \\
\hline MANGANESE & & & & & $M G / L$ & & & & & & & & & & \\
\hline 20 & & 0.0100 & 0.1100 & + & 0.0200 & NA & NA & NA & 25.0 & ** & 0.0100 & & 0.0500 & NONPARAMETRIC & 2 \\
\hline MERCURY & & & & & MG/L & & & & & & & & & & \\
\hline 16 & $\star \star$ & 0.0002 & 0.0002 & ** & 0.0002 & NA & NA & NA & 100.0 & ** & 0.0002 & ** & 0.0002 & NONPARAMETRIC & 2 \\
\hline MOLYBDENUI & & & & & $M G / L$ & & & & & & & & & & \\
\hline 28 & ** & 0.0100 & 0.0300 & ** & 0.0100 & NA & NA & NA & 57.1 & ** & 0.0100 & & 0.0100 & NONPARAMETRIC & 2 \\
\hline
\end{tabular}

** The reported value is the minimum detection limit of the data set

+ The sample size is even, so the median value is the arithmetic average of the two middle values

* The statistical maximum is the 99 percent one sided confidence interval, $\alpha=0.01$

2) The nonparametric distribution was used because the nondetected values comprise more than $15 \%$ of the samples.

7) The lognormal distribution was used because the data failed the normal distribution test.

B) The mean is geometric. The standard deviation is the value to divide or multiply with the geometric mean.

9) The nonparametic distribution was used because the data failed the normal distribution test and includes values $\leq 0$. 
TABLE 3.46 BACKGROUND GROUND WATER QUALITY STATISTICS BY PARAMETER FOR THE UPPER SANDSTONE UNIT, BURRO CANYON DISPOSAL SITE, SLICK ROCK, COLORADO SITE: SRKO2 BORROW SITE 1 (BURRO CANYON)

$06 / 04 / 90$ TO $04 / 27 / 94$

REPORT DATE : 09/30/94

\begin{tabular}{|c|c|c|c|c|c|c|c|c|c|c|c|c|c|}
\hline \multicolumn{3}{|c|}{ PARAMETER NAME } & UNITS & \multirow[b]{2}{*}{ MEAN } & \multirow{2}{*}{$\begin{array}{l}\text { STANDARD } \\
\text { DEVIATION }\end{array}$} & \multirow{2}{*}{$\begin{array}{c}\text { COEFF. } \\
\text { OF } \\
\text { VARIATION }\end{array}$} & \multirow{2}{*}{$\mid \begin{array}{c}\% \text { OF } \\
\text { NON } \\
\text { DETECTS }\end{array}$} & \multirow{2}{*}{\multicolumn{4}{|c|}{$\begin{array}{l}\text { STATISTICAL RANGE } \\
\text { 98\% CONFIDENCE INTERVAL } \\
\text { MINIMUM } \\
\text { MAXIMUM * }\end{array}$}} & \multirow{2}{*}{$\begin{array}{l}\text { DISTRIBUTION } \\
\text { TYPE }\end{array}$} & \multirow{2}{*}{$\begin{array}{l}\text { FOOT } \\
\text { NOTE }\end{array}$} \\
\hline \# OF SAMP & MINIMUM & MAXIMUM & MEDIAN & & & & & & & & & & \\
\hline NET GROSS & ALPHA $\quad \star \star \star$ & & $\mathrm{PCl} / \mathrm{L}$ & \multirow[b]{2}{*}{ NA } & \multirow[b]{2}{*}{ NA } & \multirow[b]{2}{*}{ NA } & \multirow[b]{2}{*}{0.0} & \multirow{2}{*}{\multicolumn{2}{|c|}{-0.4300}} & \multirow{2}{*}{\multicolumn{2}{|c|}{3.9700}} & \multirow[b]{2}{*}{ NONPARAMETRIC } & \multirow[b]{2}{*}{9} \\
\hline 24 & -17.1500 & 9.8600 & 0.8450 & & & & & & & & & & \\
\hline \multicolumn{3}{|l|}{ NICKEL. } & $M G / L$ & \multirow[b]{2}{*}{ NA } & \multirow[b]{2}{*}{ NA } & \multirow[b]{2}{*}{ NA } & \multirow[b]{2}{*}{100.0} & \multirow[b]{2}{*}{$\star \star *$} & \multirow[b]{2}{*}{0.0400} & \multirow[b]{2}{*}{ ** } & \multirow[b]{2}{*}{0.0400} & \multirow[b]{2}{*}{ NONPARAMETRIC } & \multirow[b]{2}{*}{2} \\
\hline 20 & $\begin{array}{ll}* * & 0.0400\end{array}$ & 0.0400 & 0.0400 & & & & & & & & & & \\
\hline \multicolumn{3}{|l|}{ NI TRATE } & MG/L & \multirow[b]{2}{*}{ NA } & \multirow[b]{2}{*}{ NA } & \multirow[b]{2}{*}{ NA } & & & & & & & \\
\hline 20 & $\begin{array}{ll}* & 1.0000\end{array}$ & 24.3000 & 1.5000 & & & & 45.0 & ** & 1.0000 & & 4.0000 & NONPARAMETRIC & 2 \\
\hline NITRITE Al & ND NITRATE & & $\mathrm{MG} / \mathrm{L}$ & & & & & & & & & & \\
\hline 16 & 0.1200 & 5.5400 & 0.5000 & NA & NA & NA & 37.5 & & 0.3900 & & 2.0000 & NONPARAMETRIC & 2 \\
\hline PH & & & su & & & & & & & & & & \\
\hline 32 & 7.2500 & 9.0900 & 8.1315 & NA & NA & NA & 0.0 & & NA & & NA & UNKNOWN & \\
\hline PHOSPHATE & & & MG/L & & & & & & & & & & \\
\hline 20 & ** $\quad 0.1000$ & 1.6000 & 0.1000 & NA & NA & NA & 50.0 & $\star \star$ & 0.1000 & & 0.4000 & NONPARAMETRIC & 2 \\
\hline POLONIUM-? & 210 & & $\mathrm{PCI} / \mathrm{L}$ & & & & & & & & & & \\
\hline 12 & ** $\quad 1.0000$ & 1.0000 & 1.0000 & NA & NA & NA & 0.0 & ** & 1.0000 & ** & 1.0000 & NONPARAMETRIC & 9 \\
\hline POTASSIUN & & & $M G / L$ & & & & & & & & & & \\
\hline 28 & 0.7600 & 7.7000 & 2.4650 & 2.6696 & 1.7144 & 0.6422 & 0.0 & & 1.8684 & & 3.4709 & NORMAL & \\
\hline RADIUM-22C & & & $\mathrm{PCI} / \mathrm{L}$ & & & & & & & & & & \\
\hline 28 & ** $\quad 0.1000$ & 0.5000 & 0.1000 & NA & NA & NA & 0.0 & ** & 0.1000 & & 0.1000 & NONPARAMETRIC & 9 \\
\hline
\end{tabular}

** NET GROSS ALPHA (GROSS ALPHA - URANIUM) WITH 1 MG URANIUM = 686 PCI

** The reported value is the minimum detection limit of the data set

+ The sample size is even, so the median value is the arithmetic average of the two middle values

* The statistical maximum is the 99 percent one sided confidence interval, $\alpha=0.01$

1) A minimum of 4 samples must be available for the statistical analysis.

2) The nonparametric distribution was used because the nondetected values comprise more than $15 \%$ of the samples.

9) The nonparametic distribution was used because the data failed the normal distribution test and includes values $\leq 0$. 
TABLE 3.46 BACKGROUND GROUND WATER QUALITY STATISTICS BY PARAMETER FOR THE UPPER SANDSTONE UNIT, BURRO CANYON DISPOSAL SITE, SLICK ROCK, COLORADO SITE: SRKO2 BORROH SITE 1 (BURRO CANYON)

OS/04/90 TO $04 / 27 / 94$

REPORT DATE: $09 / 30 / 94$

\begin{tabular}{|c|c|c|c|c|c|c|c|c|c|c|c|c|}
\hline \multicolumn{4}{|c|}{ PARAMETER NAME } & UNITS & \multirow[b]{2}{*}{ MEAN } & \multirow{2}{*}{$\begin{array}{r}\text { STANDARD } \\
\text { DEVIATION }\end{array}$} & \multirow{2}{*}{$\begin{array}{c}\text { COEFF. } \\
\text { OF } \\
\text { VARIATION }\end{array}$} & \multirow{2}{*}{$\begin{array}{c}\% \text { OF } \\
\text { NON } \\
\text { DETECTS }\end{array}$} & \multirow{2}{*}{\multicolumn{2}{|c|}{ 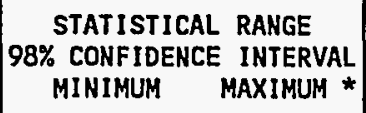 }} & \multirow{2}{*}{$\begin{array}{l}\text { DISTRIBUTION } \\
\text { TYPE }\end{array}$} & \multirow{2}{*}{$\begin{array}{l}\text { FOOT } \\
\text { NOTE }\end{array}$} \\
\hline \# OF SAMP & MINIMUM & MAXIMUM & & MEDIAN & & & & & & & & \\
\hline \multicolumn{4}{|c|}{ RADIUM-226 + RADIUM-228 } & $\mathrm{PCI} / \mathrm{L}$ & \multirow[b]{2}{*}{ NA } & \multirow[b]{2}{*}{ NA } & \multirow[b]{2}{*}{ NA } & \multirow[b]{2}{*}{0.0} & \multirow[b]{2}{*}{0.6000} & \multirow[b]{2}{*}{1.2000} & \multirow[b]{2}{*}{ NONPARAMETRIC } & \multirow[b]{2}{*}{9} \\
\hline 28 & 0.0000 & 7.6000 & + & 0.9000 & & & & & & & & \\
\hline \multicolumn{4}{|c|}{ RADIUM-2228 } & PCI/L & \multirow[b]{2}{*}{ NA } & \multirow[b]{2}{*}{ NA } & \multirow[b]{2}{*}{ NA } & \multirow[b]{2}{*}{0.0} & \multirow[b]{2}{*}{1.0000} & \multirow[b]{2}{*}{1.1000} & \multirow[b]{2}{*}{ NONPARAMETRIC } & \multirow[b]{2}{*}{9} \\
\hline 28 & ** 1.0000 & 7.2000 & ** & 1.0000 & & & & & & & & \\
\hline \multicolumn{4}{|c|}{ REDOX POTENTIAL } & mVOLTS & \multirow[b]{2}{*}{273.1000} & \multirow[b]{2}{*}{62.4487} & \multirow[b]{2}{*}{0.2287} & \multirow[b]{2}{*}{0.0} & \multirow[b]{2}{*}{168.4542} & & & \\
\hline 5 & 194.1000 & 368.7000 & & 264.0000 & & & & & & 377.7458 & NORMAL & \\
\hline SELENILIM & & & & $M G / L$ & & & & & & & & \\
\hline 28 & ** $\quad 0.0050$ & 0.0440 & $\star *$ & 0.0050 & NA & NA & NA & 67.9 & 0.0050 & 0.0100 & NONPARAMETRIC & 2 \\
\hline SILICA - S & 5102 & & & $M G / L$ & & & & & & & & \\
\hline 28 & 9.0000 & 13.0000 & + & 10.8000 & 10.8679 & 1.0931 & 0.1006 & 0.0 & 10.3570 & 11.3787 & NORMAL & \\
\hline SILVER & & & & $M G / L$ & & & & & & & & \\
\hline 16 & $\begin{array}{ll}* & 0.0100\end{array}$ & ** $\quad 0.0100$ & $\star * *$ & 0.0100 & NA & NA & NA & 100.0 & 0.0100 & ** 0.0100 & NONPARAMETRIC & 2 \\
\hline SODIUM & & & & $\mathrm{MG} / \mathrm{L}$ & & & & & & & & \\
\hline 28 & 134.0000 & 288.0000 & + & 216.0000 & 211.6786 & 47.2817 & 0.2234 & 0.0 & 189.5813 & 233.7758 & NORMAL & \\
\hline SPECIFIC & CONDUCTANCE & & & UMHO/CM & & & & & & & & \\
\hline 31 & 722.0000 & 1326.0000 & & 1000.0000 & 995.7742 & 189.4747 & 0.1903 & 0.0 & 912.1609 & 1079.3875 & NORMAL & \\
\hline STRONTIUM & & & & $M G / L$ & & & & & & & & \\
\hline 28 & 0.2600 & 15.0000 & + & 1.6550 & 2.2719 & 3.6975 & NA & 0.0 & 1.2330 & 4.1861 & LOGNORHAL & 7,8 \\
\hline
\end{tabular}

** The reported value is the minimum detection limit of the data set

+ The sample size is even, so the median value is the arithmetic average of the two middle values

* The statistical maximum is the 99 percent one sided confidence interval, $\alpha=0.01$

2) The nonparametric distribution was used because the nondetected values comprise more than $15 \%$ of the samples.

7) The lognormal distribution was used because the data failed the normal distribution test.

8) The mean is geometric. The standard deviation is the value to divide or multiply with the geometric mean.

9) The nonparametic distribution was used because the data failed the normal distribution test and includes values $\leq 0$. 
TABLE 3.46 BACKGROUND GROUND WATER QUALITY STATISTICS BY PARAMETER FOR THE UPPER SANDSTONE UNIT, BURRO CANYON DISPOSAL SITE, SLICK ROCK, COLORADO SITE: SRKO2 BORROW SITE 1 (BURRO CANYON)

$06 / 04 / 90$ TO $04 / 27 / 94$

REPORT DATE : 09/30/94

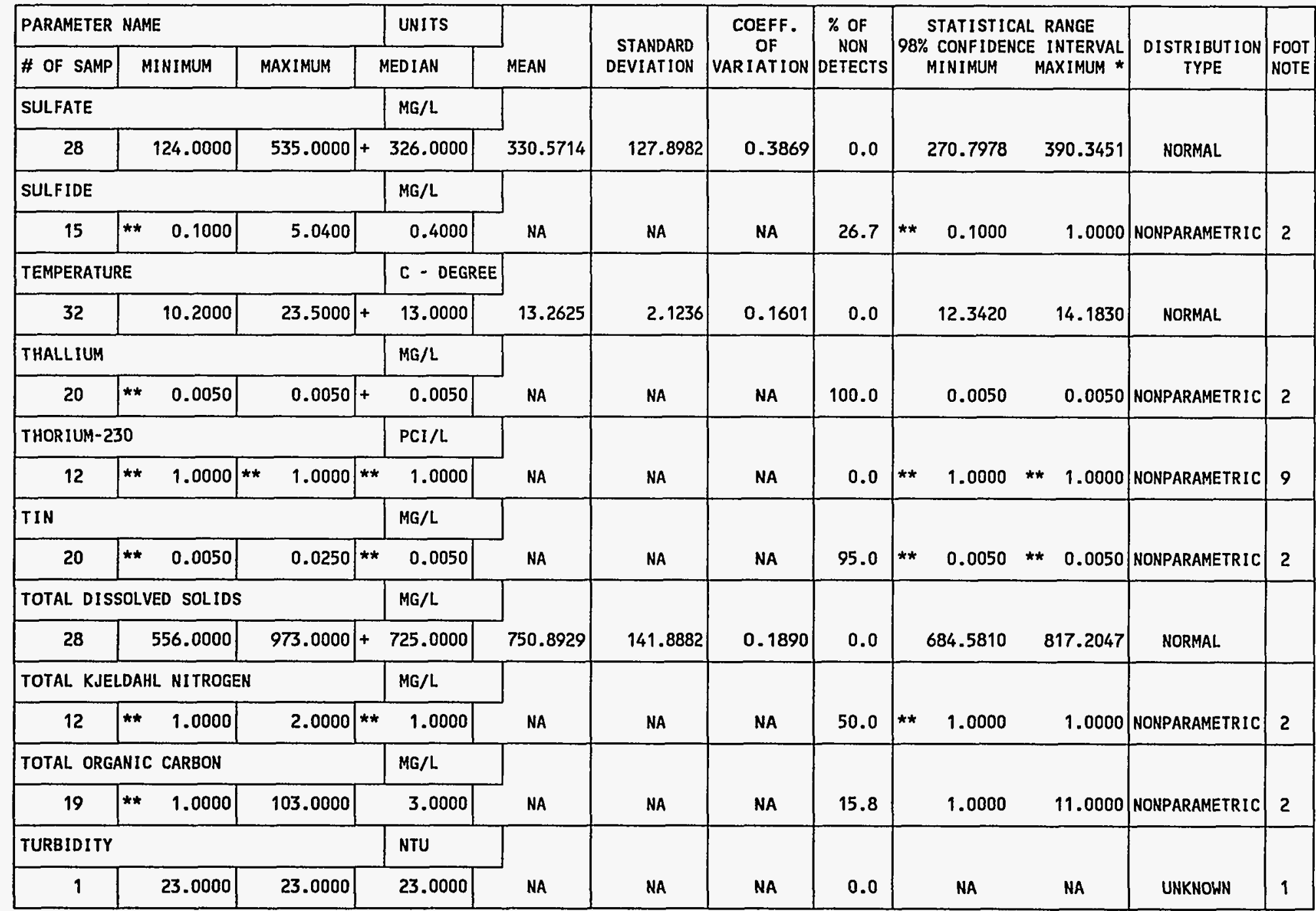

** The reported value is the minimum detection limit of the data set

+ The sample size is even, so the median value is the arithmetic average of the two middle values

* The statistical maximum is the 99 percent one sided confidence interval, $\alpha=0.01$

1) A minimum of 4 samples must be available for the statistical analysis.

2) The nonparametric distribution was used because the nondetected values comprise more than $15 \%$ of the samples.

9) The nonparametic distribution was used because the data failed the normal distribution test and includes values $\leq 0$. 
TABLE 3.46 BACKGROUND GROUND WATER QUALITY STATISTICS BY PARAMETER FOR

THE UPPER SANDSTONE UNIT, BURRO CANYON DISPOSAL SITE, SLICK ROCK, COLORADO

SITE: SRKO2 BORROW SITE 1 (BURRO CANYON)

06/04/90 TO $04 / 27 / 94$

REPORT DATE: $09 / 30 / 94$

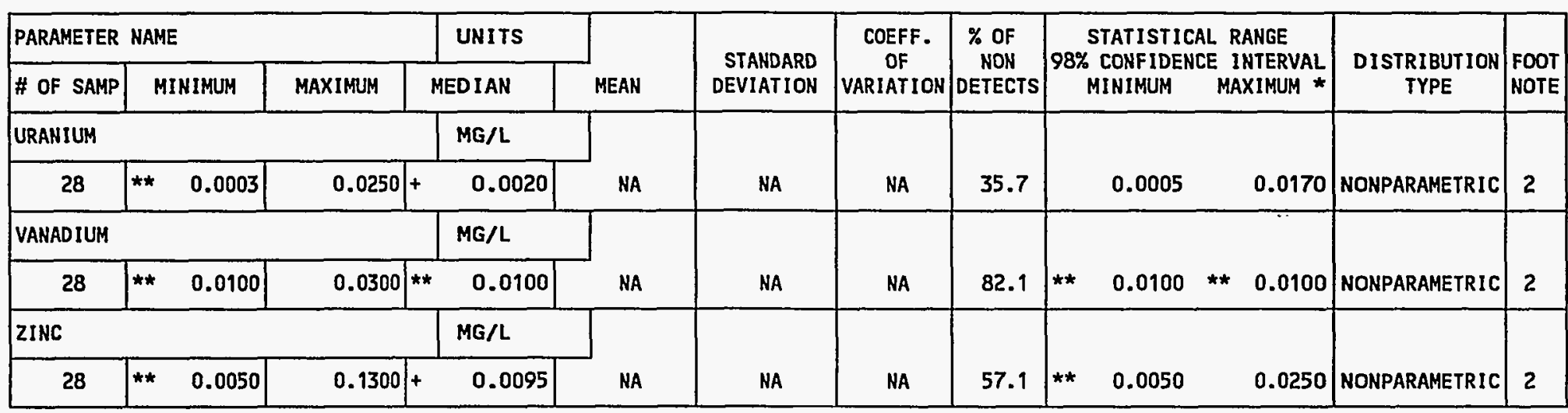

** The reported value is the minimum detection limit of the data set

+ The sample size is even, so the median value is the arithmetic average of the two middle values

* The statistical maximum is the 99 percent one sided confidence interval, $\alpha=0.01$

2) The nonparametric distribution was used because the nondetected values comprise more than $15 \%$ of the samples.

INPUT DATA FILENAME: IDART\SRKO2\GWQ10003.DAT 
Table 3.47 Summary of regulated constituents in the upper sandstone unit, Burro Canyon disposal site ${ }^{a}$, Slick Rock, Colorado

\begin{tabular}{lcll}
\hline & \multicolumn{2}{c}{ Constituents with MCLs } \\
\hline \multicolumn{1}{c}{ Parameter } & \multicolumn{2}{c}{ Background $^{\mathrm{b}}$} \\
\cline { 3 - 4 } Arsenic & 0.05 & Average & Stat. Max. \\
Barium & 1.0 & $0.01^{\mathrm{g}}$ & $0.01^{\mathrm{g}}$ \\
Cadmium & 0.01 & $0.10^{\mathrm{g}}$ & $0.10^{\mathrm{g}}$ \\
Chromium & 0.05 & $0.001^{\mathrm{g}}$ & $0.001^{\mathrm{g}}$ \\
Net gross alpha & 15.0 & $0.01^{\mathrm{g}}$ & $0.01^{\mathrm{g}}$ \\
Lead & 0.05 & $0.845^{\mathrm{e}}$ & $3.97^{\mathrm{e}}$ \\
Mercury & 0.002 & $0.01^{\mathrm{g}}$ & $0.01^{\mathrm{g}}$ \\
Molybdenum & 0.1 & $0.0002^{\mathrm{g}}$ & $0.0002^{\mathrm{g}}$ \\
Nitrate & 44.0 & $0.01^{\mathrm{g}}$ & $0.01^{\mathrm{g}}$ \\
Radium-226,-228 & 5.0 & $1.50^{\mathrm{e}}$ & $4.00^{\mathrm{e}}$ \\
Selenium & 0.01 & $0.9^{\mathrm{e}}$ & $1.2^{\mathrm{e}}$ \\
Silver & 0.05 & $0.005^{\mathrm{g}}$ & $0.01^{\mathrm{e}}$ \\
Uranium & 0.044 & $0.01^{\mathrm{g}}$ & $0.01^{\mathrm{g}}$ \\
\hline
\end{tabular}

${ }^{a}$ All units are $\mathrm{mg} / \mathrm{L}$ unless otherwise noted.

buppermost aquifer.

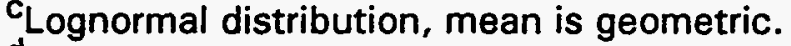

${ }^{d}$ Normal distribution, mean is arithmetic.

enonparametric distribution

fUnits are $\mathrm{pCi} / \mathrm{L}$.

IStatistical values are below laboratory detection limits in Table 8.1 of the Technical Approach Document (DOE, 1989). 
Table 3.47 Summary of regulated constituents in the upper sandstone unit, Burro Canyon disposal site ${ }^{a}$, Slick Rock, Colorado (Concluded)

\begin{tabular}{|c|c|c|}
\hline \multicolumn{3}{|c|}{ Constituents without MCLs } \\
\hline \multirow[b]{2}{*}{ Parameter } & \multicolumn{2}{|c|}{ Background $^{b}$} \\
\hline & Average & Stat. max. \\
\hline Antimony & $0.003^{9}$ & $0.003^{g}$ \\
\hline Beryllium & $0.01^{g}$ & 0.019 \\
\hline Cobalt & $0.05^{g}$ & $0.05^{g}$ \\
\hline Copper & $0.02^{g}$ & $0.02^{g}$ \\
\hline Cyanide & $0.01^{g}$ & $0.01^{g}$ \\
\hline Nickel & $0.04^{g}$ & $0.04^{g}$ \\
\hline Sulfide & $0.4^{e}$ & $1.0^{\mathrm{e}}$ \\
\hline Thallium & $0.01^{9}$ & $0.01^{g}$ \\
\hline Tin & $0.005^{g}$ & $0.005^{9}$ \\
\hline Vanadium & $0.01^{\mathrm{g}}$ & $0.01^{g}$ \\
\hline Zinc & $0.010^{e}$ & $0.025^{e}$ \\
\hline
\end{tabular}

${ }^{\mathrm{a}}$ All units are $\mathrm{mg} / \mathrm{L}$ unless otherwise noted.

buppermost aquifer.

CLognormal distribution, mean is geometric.

dNormal distribution, mean is arithmetic.

ENonparametric distribution

funits are $\mathrm{pCi} / \mathrm{L}$.

IStatistical values are below laboratory detection limits in Table 8.1 of the Technical Approach Document (DOE, 1989). 
TABLE 3.48 GROUND WATER QUALITY MEASUREMENTS EXCEEDING MCLS IN THE UPPER SANDSTONE UNIT, BURRO CANYON DISPOSAL SITE, SLICK ROCK, COLORADO

SITE: SRKO2 BORROW SITE 1 (BURRO CANYON)

$06 / 04 / 90$ TO $04 / 27 / 94$

\begin{tabular}{|c|c|c|c|c|c|c|c|c|c|c|c|c|}
\hline PARAMETER NAME & $\begin{array}{l}\text { TOTAL } \\
\text { \# OF } \\
\text { SAMP. }\end{array}$ & $\begin{array}{c}\text { UNITS } \\
\text { OF } \\
\text { MEASURE }\end{array}$ & $\begin{array}{l}\text { MAXIMUM } \\
\text { CONC. } \\
\text { LIMIT }\end{array}$ & LOC. & LOG DATE & $\begin{array}{c}\text { SAMP } \\
\text { ID }\end{array}$ & $\begin{array}{l}\text { FORM } \\
\text { OF } \\
\text { COMP }\end{array}$ & $\begin{array}{l}\text { HYDR } \\
\text { FLOW } \\
\text { REL. }\end{array}$ & $\begin{array}{c}\text { RESULT EXCEE } \\
\text { CONCENTRATIO } \\
\text { VALUE }\end{array}$ & $\begin{array}{l}\text { DING MAX. } \\
\text { N LIMIT } \\
\text { FLAGS }\end{array}$ & $\begin{array}{l}\text { DETECTION } \\
\text { LIMIT }\end{array}$ & $\begin{array}{l}\text { PARAMETER } \\
\text { UNCERT. }\end{array}$ \\
\hline ARSENIC & 20 & $M G / L$ & 0.0500 & $\begin{array}{l}0527 \\
0529\end{array}$ & $\begin{array}{l}08 / 23 / 91 \\
08 / 23 / 91\end{array}$ & $\begin{array}{l}0001 \\
0001\end{array}$ & $\begin{array}{l}\text { UB } \\
\text { UB }\end{array}$ & $\begin{array}{l}0 \\
0\end{array}$ & $\begin{array}{l}0.05 \\
0.05\end{array}$ & I & $\begin{array}{l}0.05 \\
0.05\end{array}$ & - \\
\hline ARSENIC (TOTAL) & 0 & MG/L & 0.0500 & - & - & - & - & - & - & & - & - \\
\hline BARIUM & 28 & $M G / L$ & 1.0000 & - & - & - & - & - & - & & - & - \\
\hline BARIUM (TOTAL) & 0 & MG/L & 1.0000 & - & - & - & - & - & - & & - & - \\
\hline CADMIUM & 28 & $M G / L$ & 0.0100 & 0518 & $10 / 11 / 92$ & 0001 & UB & 0 & 0.02 & $I$ & 0.02 & - \\
\hline CADMIUM (TOTAL) & 0 & $M G / L$ & 0.0100 & - & - & - & - & - & - & & - & - \\
\hline CHROMIUM & 28 & $M G / L$ & 0.0500 & - & - & - & - & - & - & & - & - \\
\hline CHROMIUM (TOTAL) & 0 & $M G / L$ & 0.0500 & - & - & - & - & - & - & & - & - \\
\hline GROSS ALPHA & 24 & $\mathrm{PCI} / \mathrm{L}$ & 15.0000 & $\begin{array}{l}0518 \\
0518 \\
0518\end{array}$ & $\begin{array}{l}12 / 15 / 90 \\
02 / 24 / 94 \\
04 / 04 / 94\end{array}$ & $\begin{array}{l}0001 \\
0001 \\
0001\end{array}$ & $\begin{array}{l}\text { UB } \\
\text { UB } \\
\text { UB }\end{array}$ & $\begin{array}{l}0 \\
0 \\
0\end{array}$ & $\begin{array}{l}18 . \\
17.2 \\
17.0\end{array}$ & $\stackrel{\mathrm{L}}{\mathrm{JLN}}$ & $\begin{array}{l}1 . \\
3.1 \\
3.7\end{array}$ & $\begin{array}{l}7 . \\
2.8 \\
3.5\end{array}$ \\
\hline GROSS ALPHA (TOTAL) & 0 & $\mathrm{PCl} / \mathrm{L}$ & 15.0000 & - & - & - & - & - & - & & - & - \\
\hline LEAD & 20 & $M G / L$ & 0.0500 & - & - & - & $\cdot$ & - & - & & - & - \\
\hline LEAD (TOTAL) & 0 & $M G / L$ & 0.0500 & - & - & - & - & - & - & & - & - \\
\hline MERCURY & 16 & $M G / L$ & 0.0020 & - & - & - & - & - & - & & - & - \\
\hline MERCURY (TOTAL) & 0 & $M G / L$ & 0.0020 & - & - & - & - & - & - & & - & - \\
\hline MOLYBDENUM & 28 & $M G / L$ & 0.1000 & - & - & - & - & - & - & & - & - \\
\hline MOLYBDENUM (TOTAL) & 0 & $M G / L$ & 0.1000 & - & - & - & - & - & - & & - & - \\
\hline NET GROSS ALPHA * & 24 & $\mathrm{PCl} / \mathrm{L}$ & 15.0000 & - & - & - & $\cdot$ & - & - & & - & - \\
\hline
\end{tabular}

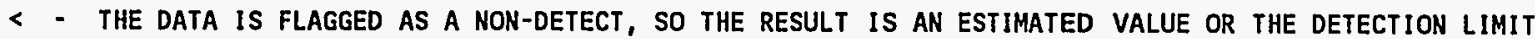

* net gross alpha (Gross alpha - URanium)

HITH 1 MG URANIUM $=686 \mathrm{PCI}$

FORMATION OF COMPLETION CODE:

UB - UPPER BURRO CANYON

OTHER PARAMETER VALUE FLAGS:

I - INCREASED DETECTION LIMIT DUE TO REQUIRED DILUTION

$J$ - ESTIMATED VALUE

L - LESS THAN THREE BORE VOLUMES REMOVED BEFORE SAMPLING

N - SPIKE SAMPLE RECOVERY NOT WITHIN CONTROL LIMITS
FLOW RELATIONSHIP CODE:

O - ON-SITE

SAMPLE ID CODES:

0001 - FILTERED SAMPLE (.45 MICRONS) 
TABLE 3.48 GROUND WATER QUALITY MEASUREMENTS EXCEEDING MCLS IN THE UPPER SANDSTONE UNIT, BURRO CANYON DISPOSAL SITE, SLICK ROCK, COLORADO

SITE: SRKO2 BORROH SITE 1 (BURRO CANYON)

06/04/90 TO 04/27/94

REPORT DATE: $09 / 30 / 94$

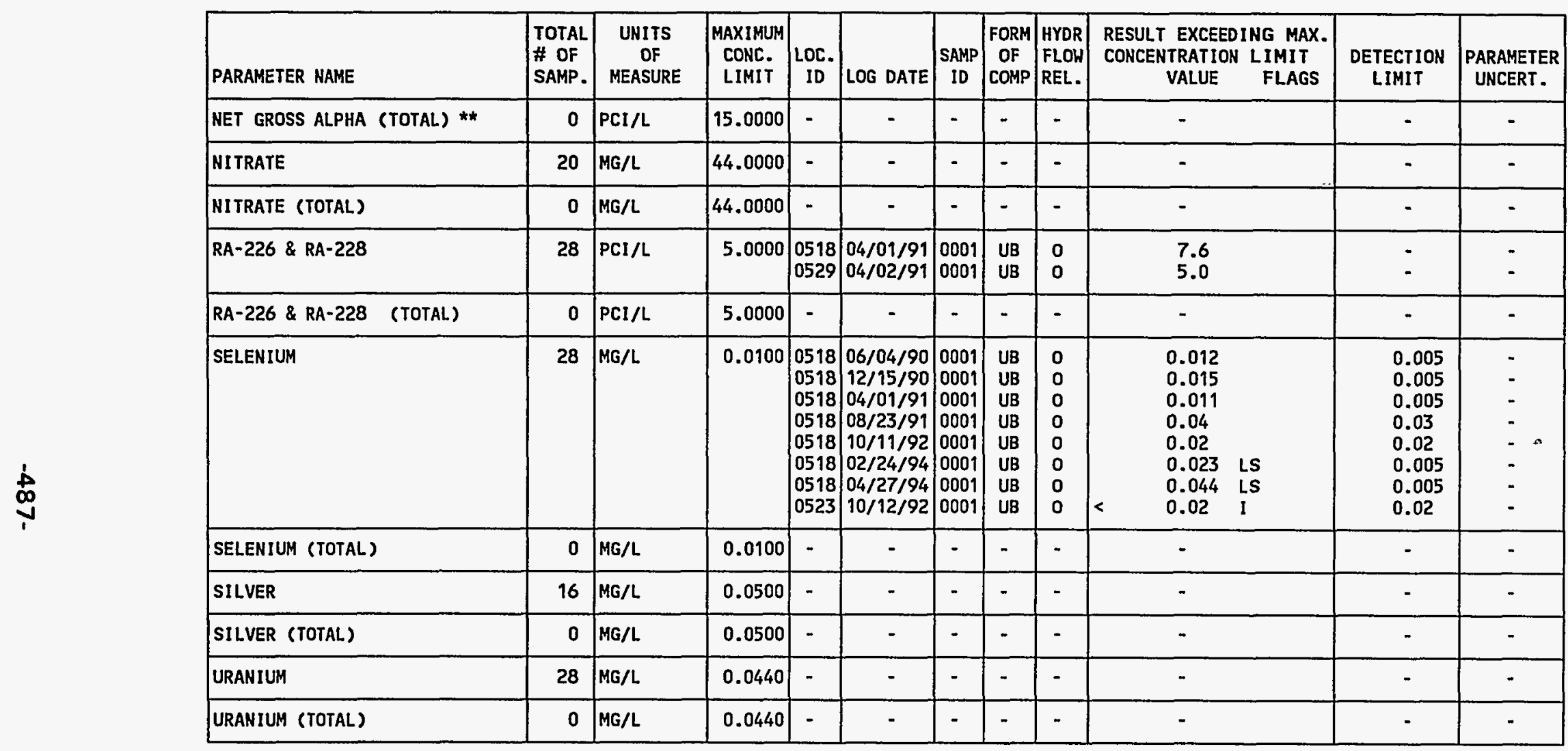

** TOTAL NET GROSS ALPHA (TOTAL GROSS ALPHA - TOTAL URANIUM)

WITH 1 MG DISSOLVED URANIUM $=686 \mathrm{PCI}$

FORMATION OF COMPLETION CODE:

UB - UPPER BURRO CANYON

OTHER PARAMETER VALUE FLAGS:

1 - INCREASED DETECTION LIMIT DUE TO REQUIRED DILUTION

L - LESS THAN THREE BORE VOLUMES REMOVED BEFORE SAMPLING

$S$ - REPORTED VALUE DETERMINED USING METHOD OF STD ADDITION (MSA)

DATA FILE NAME: IDARTISRK02\GWQ10004.DAT
FLOH RELATIONSHIP CODE:

O - ON-SITE

SAMPLE ID CODES:

0001 - FILTERED SAMPLE (.45 MICRONS) 


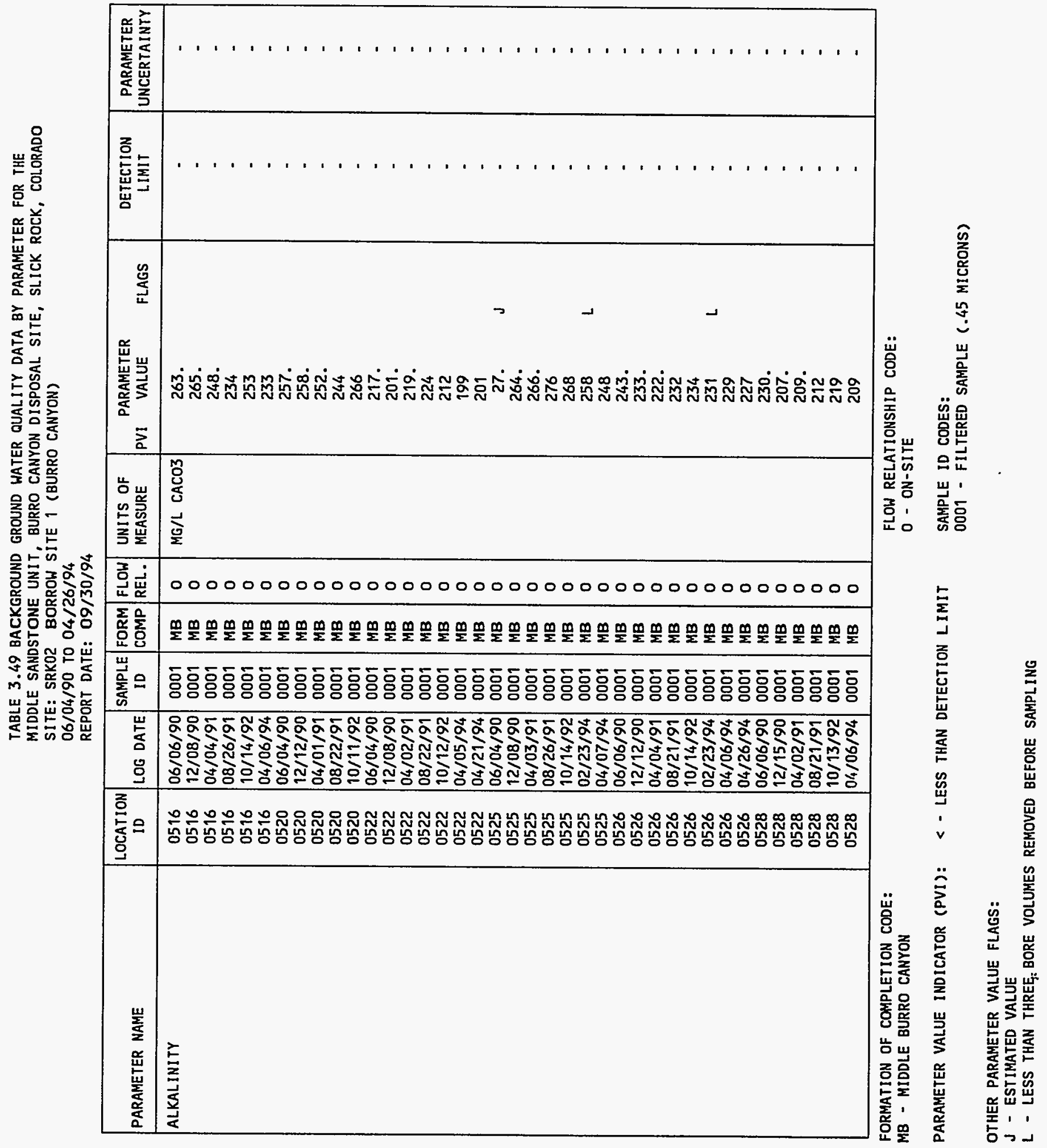


TABLE 3.49 BACKGROUND GROUND WATER QUALITY DATA BY PARAMETER FOR THE MIDDLE SANDSTONE UNIT, BURRO CANYON DISPOSAL SITE, SLICK ROCK, COLORADO SITE: SRKO2 BORROH SITE 1 (BURRO CANYON)

06/04/90 TO 04/26/94

REPORT DATE: $09 / 30 / 94$

\begin{tabular}{|c|c|c|c|c|c|c|c|c|c|c|c|c|}
\hline & PARAMETER NAME & $\begin{array}{c}\text { LOCATION } \\
\text { ID }\end{array}$ & LOG DATE & $\underset{\text { ID }}{\text { SAMPLE }}$ & $\begin{array}{l}\text { FORM } \\
\text { COMP }\end{array}$ & $\begin{array}{l}\text { FLOH } \\
\text { REL. }\end{array}$ & $\begin{array}{l}\text { UNITS OF } \\
\text { MEASURE }\end{array}$ & PVI & $\begin{array}{l}\text { ARAMETER } \\
\text { VALUE }\end{array}$ & FLAGS & $\begin{array}{l}\text { DETECTION } \\
\text { LIMIT }\end{array}$ & $\begin{array}{l}\text { PARAMETER } \\
\text { UNCERTAINTY }\end{array}$ \\
\hline & ALKALINITY & 0528 & $04 / 26 / 94$ & 0001 & MB & 0 & MG/L CACO3 & & 217 & & - & - \\
\hline & ALUMINUM & $\begin{array}{l}0516 \\
0516 \\
0516 \\
0516 \\
0516 \\
0520 \\
0520 \\
0520 \\
0520 \\
0520 \\
0522 \\
0522 \\
0522 \\
0522 \\
0522 \\
0525 \\
0525 \\
0525 \\
0525 \\
0525 \\
0526 \\
0526 \\
0526 \\
0526 \\
0526 \\
0528 \\
0528 \\
0528 \\
0528 \\
0528\end{array}$ & $\begin{array}{l}06 / 06 / 90 \\
12 / 08 / 90 \\
04 / 04 / 91 \\
08 / 26 / 91 \\
10 / 14 / 92 \\
06 / 04 / 90 \\
12 / 12 / 90 \\
04 / 01 / 91 \\
08 / 22 / 91 \\
10 / 11 / 92 \\
06 / 04 / 90 \\
12 / 08 / 90 \\
04 / 02 / 91 \\
08 / 22 / 91 \\
10 / 12 / 92 \\
06 / 04 / 90 \\
12 / 08 / 90 \\
04 / 03 / 91 \\
08 / 26 / 91 \\
10 / 14 / 92 \\
06 / 06 / 90 \\
12 / 12 / 90 \\
04 / 04 / 91 \\
08 / 21 / 91 \\
10 / 14 / 92 \\
06 / 06 / 90 \\
12 / 15 / 90 \\
04 / 02 / 91 \\
08 / 21 / 91 \\
10 / 13 / 92\end{array}$ & $\begin{array}{l}0001 \\
0001 \\
0001 \\
0001 \\
0001 \\
0001 \\
0001 \\
0001 \\
0001 \\
0001 \\
0001 \\
0001 \\
0001 \\
0001 \\
0001 \\
0001 \\
0001 \\
0001 \\
0001 \\
0001 \\
0001 \\
0001 \\
0001 \\
0001 \\
0001 \\
0001 \\
0001 \\
0001 \\
0001 \\
0001\end{array}$ & $\begin{array}{l}M B \\
M B \\
M B \\
M B \\
M B \\
M B \\
M B \\
M B \\
M B \\
M B \\
M B \\
M B \\
M B \\
M B \\
M B \\
M B \\
M B \\
M B \\
M B \\
M B \\
M B \\
M B \\
M B \\
M B \\
M B \\
M B \\
M B \\
M B \\
M B \\
M B\end{array}$ & $\begin{array}{l}0 \\
0 \\
0 \\
0 \\
0 \\
0 \\
0 \\
0 \\
0 \\
0 \\
0 \\
0 \\
0 \\
0 \\
0 \\
0 \\
0 \\
0 \\
0 \\
0 \\
0 \\
0 \\
0 \\
0 \\
0 \\
0 \\
0 \\
0 \\
0 \\
0\end{array}$ & $M G / L$ & $\begin{array}{l}< \\
< \\
< \\
< \\
< \\
< \\
< \\
< \\
< \\
< \\
< \\
< \\
< \\
< \\
< \\
< \\
< \\
< \\
< \\
< \\
< \\
< \\
< \\
< \\
< \\
< \\
< \\
< \\
< \\
< \\
<\end{array}$ & $\begin{array}{l}0.1 \\
0.1 \\
0.05 \\
0.05 \\
0.05 \\
0.1 \\
0.1 \\
0.05 \\
0.05 \\
0.05 \\
0.1 \\
0.1 \\
0.05 \\
0.05 \\
0.05 \\
0.1 \\
0.1 \\
0.05 \\
0.05 \\
0.05 \\
0.1 \\
0.1 \\
0.05 \\
0.05 \\
0.05 \\
0.1 \\
0.1 \\
0.05 \\
0.05 \\
0.05\end{array}$ & J & $\begin{array}{l}0.1 \\
0.1 \\
0.05 \\
0.05 \\
0.05 \\
0.1 \\
0.1 \\
0.05 \\
0.05 \\
0.05 \\
0.1 \\
0.1 \\
0.05 \\
0.05 \\
0.05 \\
0.1 \\
0.1 \\
0.05 \\
0.05 \\
0.05 \\
0.1 \\
0.1 \\
0.05 \\
0.05 \\
0.05 \\
0.1 \\
0.1 \\
0.05 \\
0.05 \\
0.05\end{array}$ & $\begin{array}{l}- \\
- \\
- \\
- \\
- \\
- \\
- \\
- \\
- \\
- \\
- \\
- \\
- \\
- \\
- \\
- \\
- \\
- \\
- \\
- \\
- \\
- \\
-\end{array}$ \\
\hline & AMMONIUM & $\begin{array}{l}0516 \\
0516 \\
0516 \\
0516 \\
0520 \\
0520 \\
0520\end{array}$ & $\begin{array}{l}06 / 06 / 90 \\
12 / 08 / 90 \\
04 / 04 / 91 \\
08 / 26 / 91 \\
06 / 04 / 90 \\
12 / 12 / 90 \\
04 / 01 / 91\end{array}$ & $\begin{array}{l}0001 \\
0001 \\
0001 \\
0001 \\
0001 \\
0001 \\
0001\end{array}$ & $\begin{array}{l}\text { MB } \\
\text { MB } \\
\text { MB } \\
\text { MB } \\
\text { MB } \\
\text { MB } \\
\text { MB }\end{array}$ & $\begin{array}{l}0 \\
0 \\
0 \\
0 \\
0 \\
0 \\
0\end{array}$ & $M G / L$ & $<$ & $\begin{array}{l}0.1 \\
0.1 \\
0.3 \\
0.4 \\
0.1 \\
0.1 \\
0.3\end{array}$ & & $\begin{array}{l}0.1 \\
0.1 \\
0.1 \\
0.1 \\
0.1 \\
0.1 \\
0.1\end{array}$ & $\begin{array}{l}- \\
- \\
- \\
- \\
-\end{array}$ \\
\hline
\end{tabular}

FORMATION OF COMPLETION CODE:

MB - MIDDLE BURRO CANYON

PARAMETER VALUE INDICATOR (PVI): < - LESS THAN DETECTION LIMIT
FLOW RELATIONSHIP CODE:

0001 - FILTERED SAMPLE (.45 MICRONS)

OTHER PARAMETER VALUE FLAGS:

$J$ - ESTIMATED VALUE 


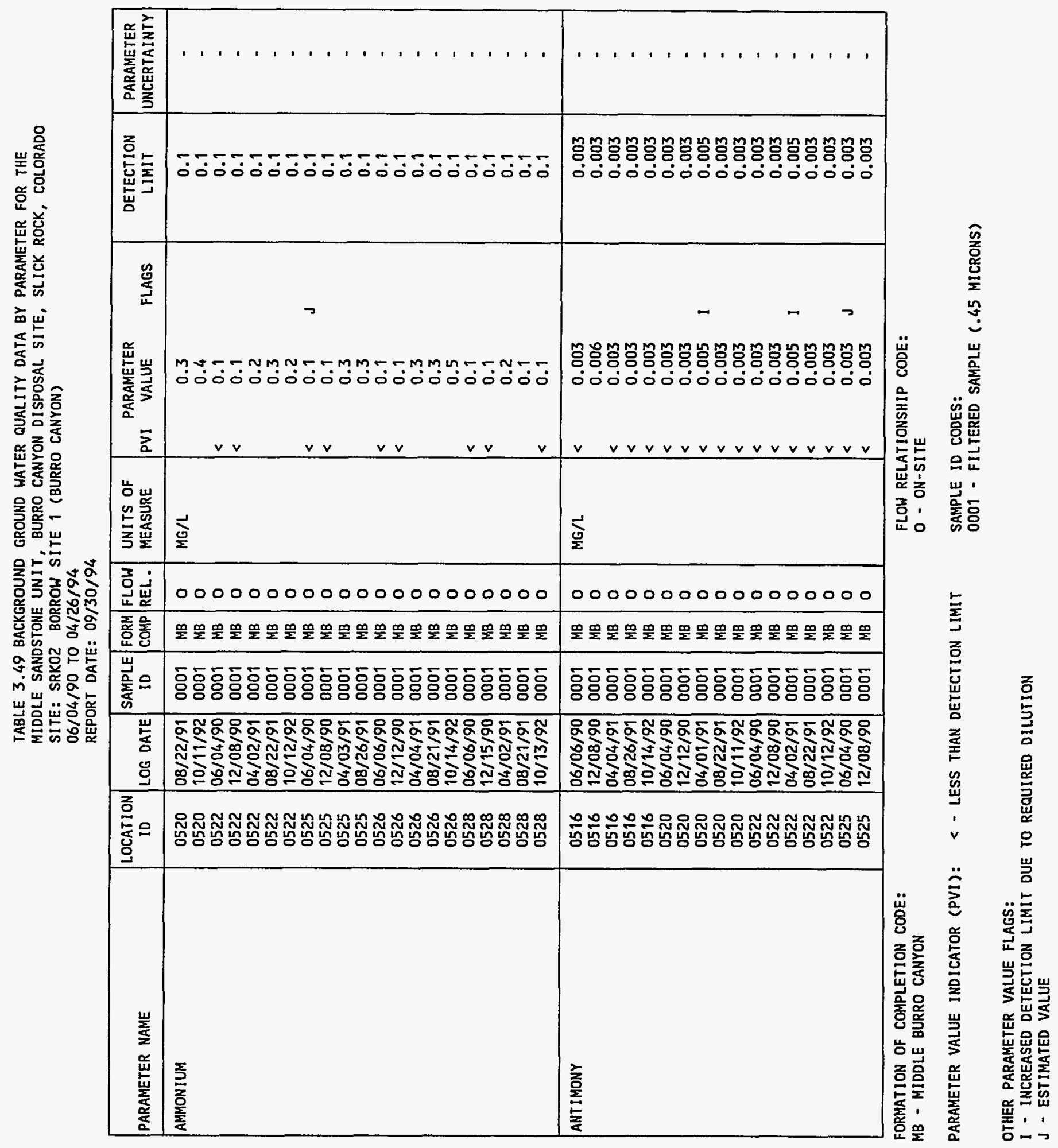


TABLE 3.49 BACKGROUND GROUND WATER QUALITY DATA BY PARAMETER FOR THE MIDDLE SANDSTONE UNIT, BURRO CANYON DISPOSAL SITE, SLICK ROCK, COLORADO SITE: SRKO2 BORROW SITE 1 (BURRO CANYON)

06/04/90 TO 04/26/94

REPORT DATE: $09 / 30 / 94$

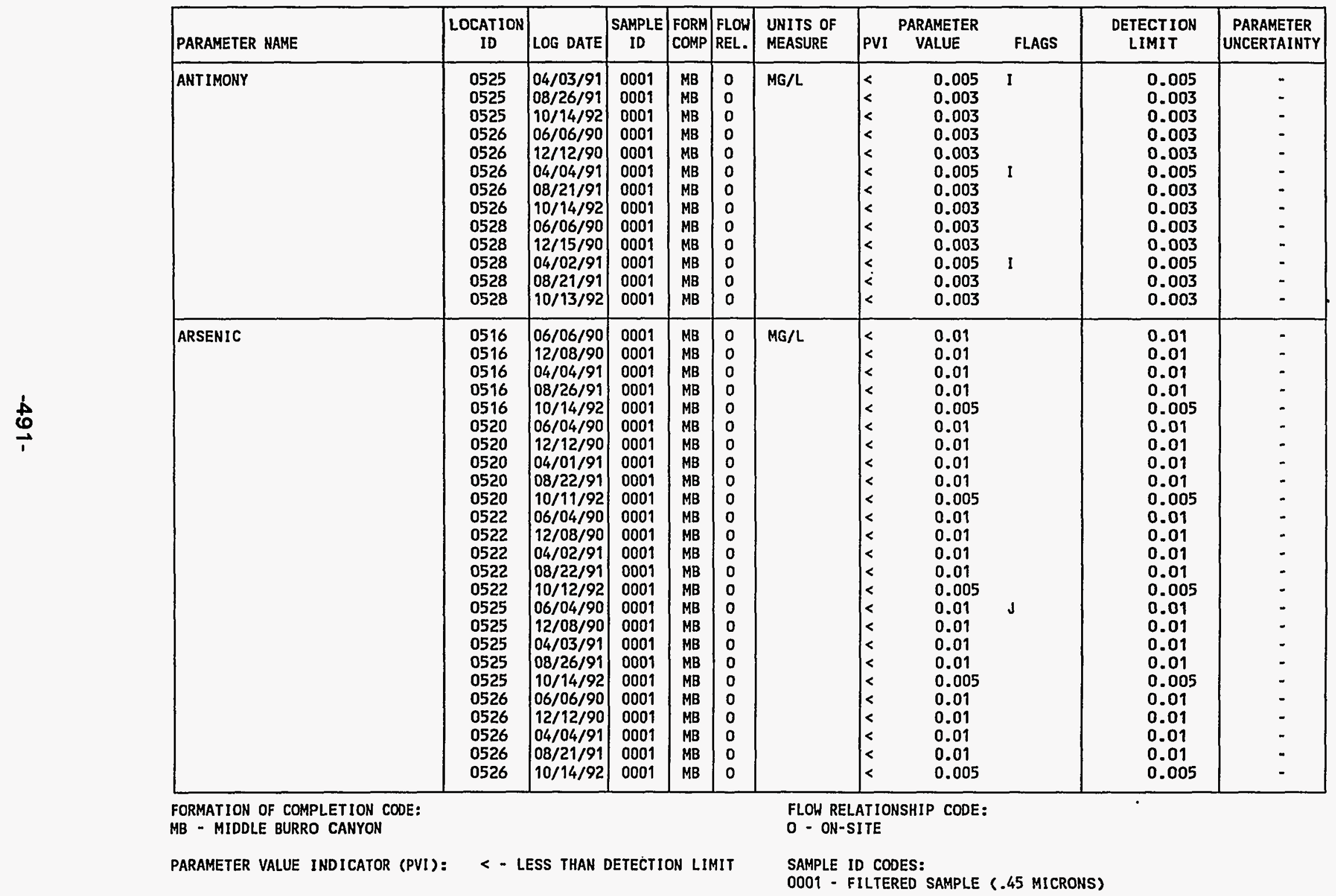

OTHER PARAMETER VALUE FLAGS:

1 - INCREASED DETECTION LIMIT DUE TO REQUIRED DILUTION

J - ESTIMATED VALUE 
TABLE 3.49 BACKGROUND GROUND HATER QUAL.ITY DATA BY PARAMETER FOR THE MIDDLE SANDSTONE UNIT, BURRO CANYON DISPOSAL SITE, SLICK ROCK, COLORADO SITE: SRKO2 BORROW SITE 1 (BURRO CANYOH)

06/04/90 TO 04/26/94

REPORT DATE $=09 / 30 / 94$

\begin{tabular}{|c|c|c|c|c|c|c|c|c|c|c|c|}
\hline PARAMETER NAME & $\underset{\text { ID }}{\text { LOCATION }}$ & LOG DATE & $\underset{\text { ID }}{\text { SAMPLE }}$ & $\begin{array}{l}\text { FORM } \\
\text { COMP }\end{array}$ & $\begin{array}{l}\text { FLOW } \\
\text { REL. }\end{array}$ & $\begin{array}{l}\text { UNITS OF } \\
\text { MEASURE }\end{array}$ & PVI & $\begin{array}{l}\text { ARAMETER } \\
\text { VALUE }\end{array}$ & FLAGS & $\begin{array}{l}\text { DETECTION } \\
\text { LIMIT }\end{array}$ & $\begin{array}{l}\text { PARAMETER } \\
\text { UNCERTAINTY }\end{array}$ \\
\hline ARSENIC & $\begin{array}{l}0528 \\
0528 \\
0528 \\
0528 \\
0528\end{array}$ & $\left|\begin{array}{l}06 / 06 / 90 \\
12 / 15 / 90 \\
04 / 02 / 91 \\
08 / 21 / 91 \\
10 / 13 / 92\end{array}\right|$ & $\begin{array}{l}0001 \\
0001 \\
0001 \\
0001 \\
0001\end{array}$ & $\begin{array}{l}\text { MB } \\
\text { MB } \\
\text { MB } \\
\text { MB } \\
\text { MB }\end{array}$ & $\begin{array}{l}0 \\
0 \\
0 \\
0 \\
0\end{array}$ & MG/L & $\begin{array}{l}< \\
< \\
< \\
< \\
<\end{array}$ & $\begin{array}{l}0.01 \\
0.01 \\
0.01 \\
0.01 \\
0.005\end{array}$ & & $\begin{array}{l}0.01 \\
0.01 \\
0.01 \\
0.01 \\
0.005\end{array}$ & $\begin{array}{l}- \\
- \\
- \\
-\end{array}$ \\
\hline BARIUM & $\begin{array}{l}0516 \\
0516 \\
0516 \\
0516 \\
0516 \\
0516 \\
0520 \\
0520 \\
0520 \\
0520 \\
0520 \\
0522 \\
0522 \\
0522 \\
0522 \\
0522 \\
0522 \\
0525 \\
0525 \\
0525 \\
0525 \\
0525 \\
0525 \\
0525 \\
0526 \\
0526 \\
0526 \\
0526 \\
0526 \\
0526 \\
0526 \\
0528 \\
0528\end{array}$ & $\begin{array}{l}06 / 06 / 90 \\
12 / 08 / 90 \\
04 / 04 / 91 \\
08 / 26 / 91 \\
10 / 14 / 92 \\
04 / 26 / 94 \\
06 / 04 / 90 \\
12 / 12 / 90 \\
04 / 01 / 91 \\
08 / 22 / 91 \\
10 / 11 / 92 \\
06 / 04 / 90 \\
12 / 08 / 90 \\
04 / 02 / 91 \\
08 / 22 / 91 \\
10 / 12 / 92 \\
04 / 21 / 94 \\
06 / 04 / 90 \\
12 / 08 / 90 \\
04 / 03 / 91 \\
08 / 26 / 91 \\
10 / 14 / 92 \\
02 / 23 / 94 \\
04 / 26 / 94 \\
06 / 06 / 90 \\
12 / 12 / 90 \\
04 / 04 / 91 \\
08 / 21 / 91 \\
10 / 14 / 92 \\
02 / 23 / 94 \\
04 / 26 / 94 \\
06 / 06 / 90 \\
12 / 15 / 90\end{array}$ & $\begin{array}{l}0001 \\
0001 \\
0001 \\
0001 \\
0001 \\
0001 \\
0001 \\
0001 \\
0001 \\
0001 \\
0001 \\
0001 \\
0001 \\
0001 \\
0001 \\
0001 \\
0001 \\
0001 \\
0001 \\
0001 \\
0001 \\
0001 \\
0001 \\
0001 \\
0001 \\
0001 \\
0001 \\
0001 \\
0001 \\
0001 \\
0001 \\
0001 \\
0001\end{array}$ & $\begin{array}{l}M B \\
M B \\
M B \\
M B \\
M B \\
M B \\
M B \\
M B \\
M B \\
M B \\
M B \\
M B \\
M B \\
M B \\
M B \\
M B \\
M B \\
M B \\
M B \\
M B \\
M B \\
M B \\
M B \\
M B \\
M B \\
M B \\
M B \\
M B \\
M B \\
M B \\
M B \\
M B \\
M B\end{array}$ & $\begin{array}{l}0 \\
0 \\
0 \\
0 \\
0 \\
0 \\
0 \\
0 \\
0 \\
0 \\
0 \\
0 \\
0 \\
0 \\
0 \\
0 \\
0 \\
0 \\
0 \\
0 \\
0 \\
0 \\
0 \\
0 \\
0 \\
0 \\
0 \\
0 \\
0 \\
0 \\
0 \\
0 \\
0\end{array}$ & $M G / L$ & $\mid \begin{array}{l}< \\
< \\
< \\
< \\
< \\
< \\
< \\
< \\
< \\
< \\
<\end{array}$ & $\begin{array}{l}0.1 \\
0.1 \\
0.02 \\
0.04 \\
0.02 \\
0.1 \\
0.1 \\
0.1 \\
0.02 \\
0.02 \\
0.03 \\
0.1 \\
0.1 \\
0.02 \\
0.02 \\
0.01 \\
0.1 \\
0.1 \\
0.1 \\
0.02 \\
0.02 \\
0.02 \\
0.1 \\
0.1 \\
0.1 \\
0.1 \\
0.02 \\
0.02 \\
0.01 \\
0.1 \\
0.1 \\
0.1 \\
0.1\end{array}$ & $\begin{array}{l}L \\
L\end{array}$ & $\begin{array}{l}0.1 \\
0.1 \\
0.01 \\
0.01 \\
0.01 \\
0.1 \\
0.1 \\
0.1 \\
0.01 \\
0.01 \\
0.01 \\
0.1 \\
0.1 \\
0.01 \\
0.01 \\
0.01 \\
0.1 \\
0.1 \\
0.1 \\
0.01 \\
0.01 \\
0.01 \\
0.1 \\
0.1 \\
0.1 \\
0.1 \\
0.01 \\
0.01 \\
0.01 \\
0.1 \\
0.1 \\
0.1 \\
0.1\end{array}$ & $\begin{array}{l}- \\
- \\
- \\
- \\
- \\
- \\
- \\
- \\
- \\
- \\
- \\
- \\
- \\
- \\
- \\
- \\
- \\
- \\
- \\
- \\
- \\
- \\
- \\
- \\
- \\
-\end{array}$ \\
\hline
\end{tabular}

FORMATIOH OF COMPLETION CODE:

MB - MIDDLE BURRO CANYON

PARAMETER VALUE INDICATOR (PVI):
FLOH RELATIONSHIP CODE:

O - ON-SITE

SAMPLE ID CODES:

0001 - FILTERED SAMPLE (.45 MICRONS)

OTHER PARAMETER VALUE FLAGS:

$J$ - ESTIMATED VALUE

L - LESS THAN THREE BORE VOLUMES REMOVED BEFORE SAMPLING 


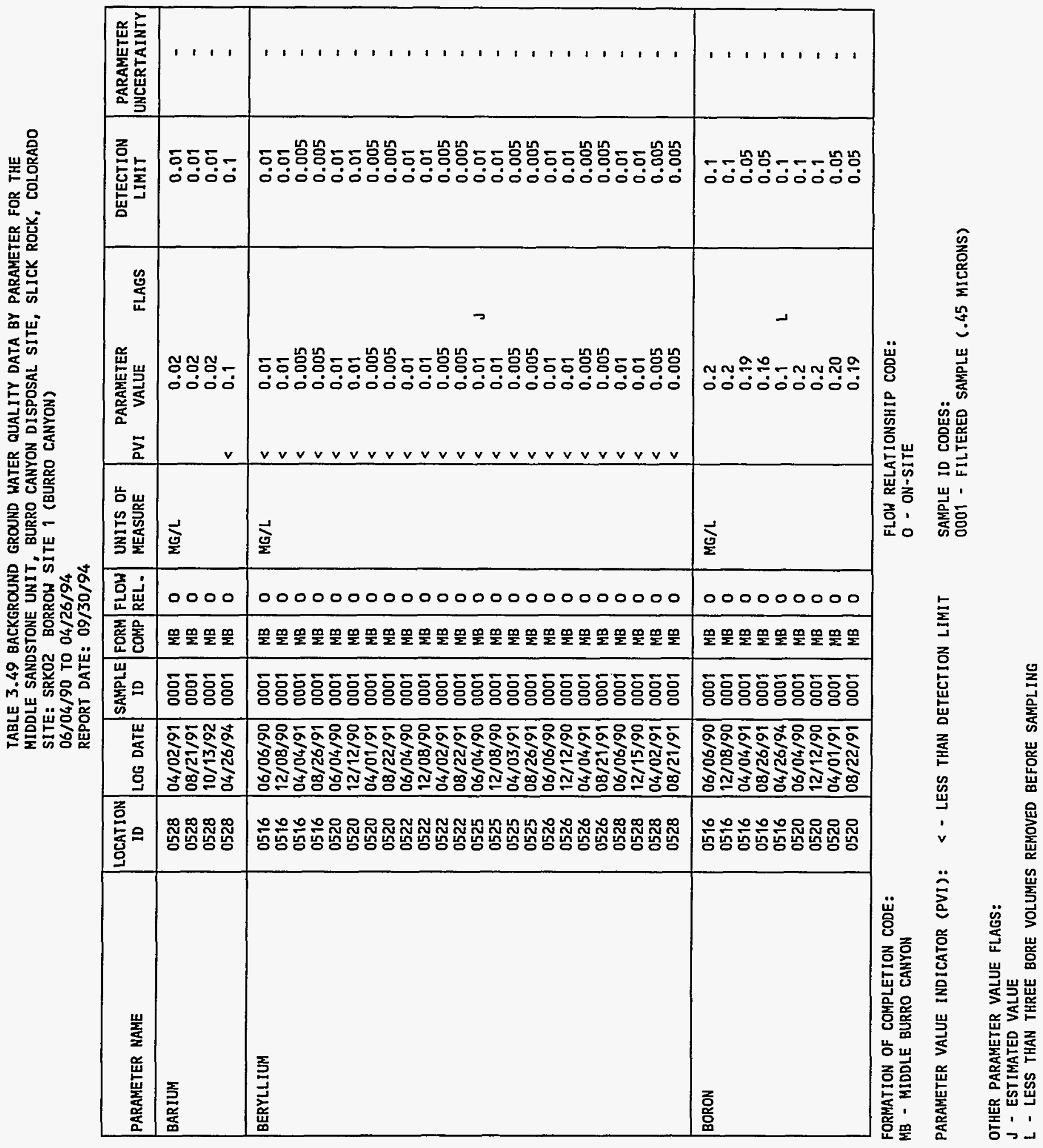




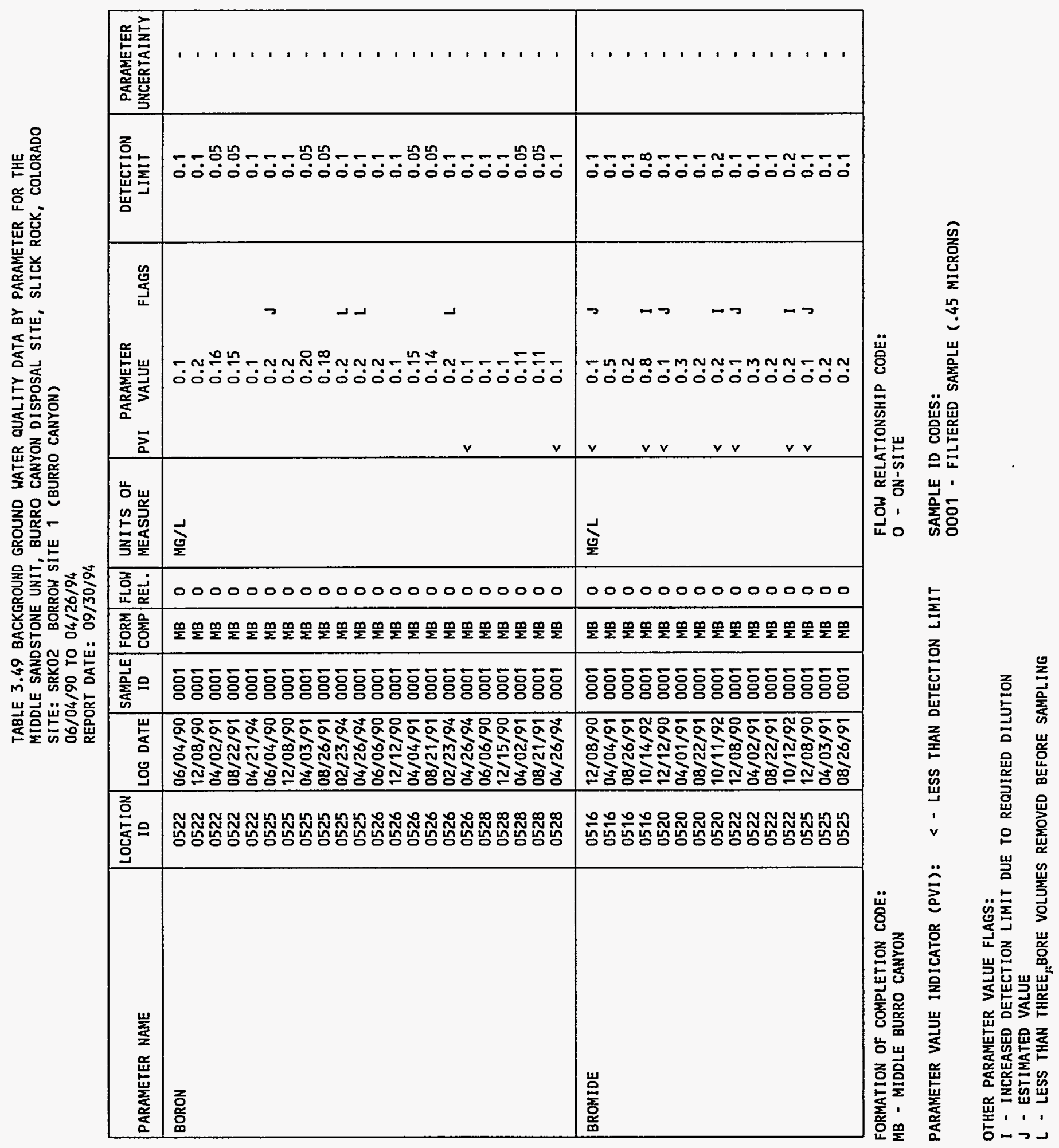


TABLE 3.49 BACKGROUND GROUND HATER QUALITY DATA BY PARAMETER FOR THE

MIDDLE SANDSTONE UNIT, BURRO CANYON DISPOSAL SITE, SLICK ROCK, COLORADO SITE: SRKO2 BORROH SITE 1 (BURRO CANYON)

06/04/90 TO 04/26/94

REPORT DATE: 09/30/94

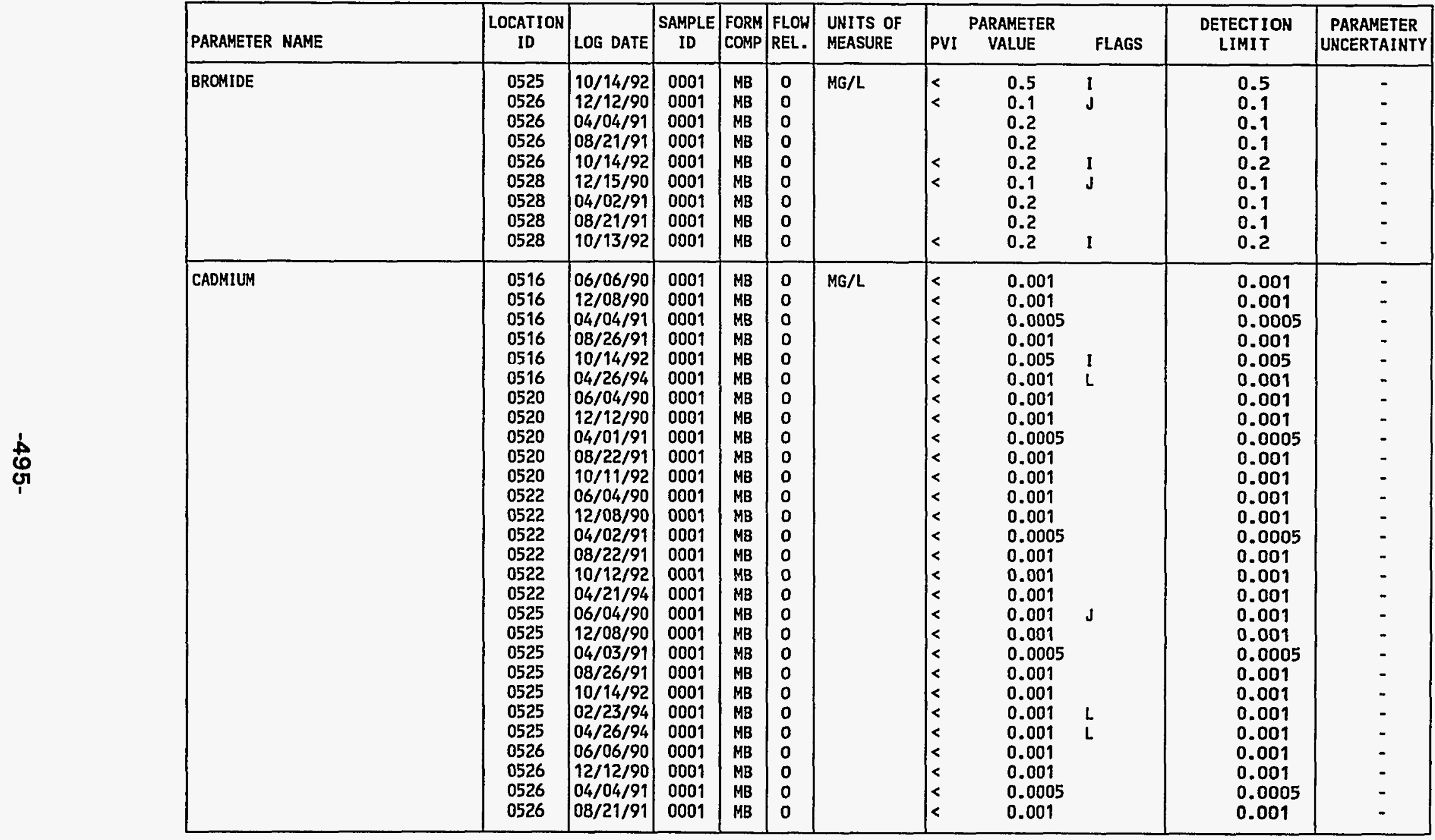

FOPMATION OF COMPLETION CODE:

MB - MIDDLE BURRO CANYOH

PARAMETER VALUE INDICATOR (PVI): < - LESS THAN DETECTION LIMIT

\section{FLOW RELATIONSHIP CODE}

O - ON-SITE

OTHER PARAMETER VALUE FLAGS:

1 - INCREASED DETECTION LIMIT DUE TO REQUIRED DILUTION

$J$ - ESTIMATEd VALUE

L - LESS THAN THREE BORE VOLUMES REMOVED BEFORE SAMPLING 
TABLE 3.49 BACKGROUND GROUND WATER QUALITY DATA BY PARAMETER FOR THE

MIDDLE SANDSTONE UNIT, BURRO CANYON DISPOSAL SITE, SLICK ROCK, COLORADO SITE: SRKO2 BORROW SITE 1 (BURRO CANYON)

06/04/90 TO 04/26/94

REPORT DATE : $09 / 30 / 94$

\begin{tabular}{|c|c|c|c|c|c|c|c|c|c|c|c|}
\hline PARAMETER NAME & $\underset{\text { ID }}{\text { LOCATION }}$ & LOG DATE & $\begin{array}{c}\text { SAMPLE } \\
\text { ID }\end{array}$ & $\mid \begin{array}{l}\text { FORM } \\
\text { COMP }\end{array}$ & $\begin{array}{l}\text { FLOW } \\
\text { REL. }\end{array}$ & $\begin{array}{l}\text { UNITS OF } \\
\text { MEASURE }\end{array}$ & PVI & $\begin{array}{l}\text { ARAMETER } \\
\text { VALUE }\end{array}$ & FLAGS & $\begin{array}{l}\text { DETECTION } \\
\text { LIMIT }\end{array}$ & $\begin{array}{l}\text { PARAMETER } \\
\text { UNCERTAINTY }\end{array}$ \\
\hline CADMIUM & $\begin{array}{l}0526 \\
0526 \\
0526 \\
0528 \\
0528 \\
0528 \\
0528 \\
0528 \\
0528\end{array}$ & $\begin{array}{l}10 / 14 / 92 \\
02 / 23 / 94 \\
04 / 26 / 94 \\
06 / 06 / 90 \\
12 / 15 / 90 \\
04 / 02 / 91 \\
08 / 21 / 91 \\
10 / 13 / 92 \\
04 / 26 / 94\end{array}$ & $\begin{array}{l}0001 \\
0001 \\
0001 \\
0001 \\
0001 \\
0001 \\
0001 \\
0001 \\
0001\end{array}$ & $\begin{array}{l}M B \\
M B \\
M B \\
M B \\
M B \\
M B \\
M B \\
M B \\
M B\end{array}$ & $\begin{array}{l}0 \\
0 \\
0 \\
0 \\
0 \\
0 \\
0 \\
0 \\
0\end{array}$ & $M G / L$ & $\begin{array}{l}< \\
< \\
< \\
< \\
< \\
< \\
< \\
< \\
<\end{array}$ & $\begin{array}{l}0.001 \\
0.001 \\
0.001 \\
0.001 \\
0.001 \\
0.0005 \\
0.001 \\
0.001 \\
0.001\end{array}$ & $L$ & $\begin{array}{l}0.001 \\
0.001 \\
0.001 \\
0.001 \\
0.001 \\
0.0005 \\
0.001 \\
0.001 \\
0.001\end{array}$ & $\begin{array}{l}- \\
- \\
- \\
- \\
- \\
-\end{array}$ \\
\hline CALCIUM & $\begin{array}{l}0516 \\
0516 \\
0516 \\
0516 \\
0516 \\
0516 \\
0520 \\
0520 \\
0520 \\
0520 \\
0520 \\
0522 \\
0522 \\
0522 \\
0522 \\
0522 \\
0522 \\
0525 \\
0525 \\
0525 \\
0525 \\
0525 \\
0525 \\
0525 \\
0526 \\
0526 \\
0526 \\
0526 \\
0526\end{array}$ & $\begin{array}{l}06 / 06 / 90 \\
12 / 08 / 90 \\
04 / 04 / 91 \\
08 / 26 / 91 \\
10 / 14 / 92 \\
04 / 26 / 94 \\
06 / 04 / 90 \\
12 / 12 / 90 \\
04 / 01 / 91 \\
08 / 22 / 91 \\
10 / 11 / 92 \\
06 / 04 / 90 \\
12 / 08 / 90 \\
04 / 02 / 91 \\
08 / 22 / 91 \\
10 / 12 / 92 \\
04 / 21 / 94 \\
06 / 04 / 90 \\
12 / 08 / 90 \\
04 / 03 / 91 \\
08 / 26 / 91 \\
10 / 14 / 92 \\
02 / 23 / 94 \\
04 / 26 / 94 \\
06 / 06 / 90 \\
12 / 12 / 90 \\
04 / 04 / 91 \\
08 / 21 / 91 \\
10 / 14 / 92\end{array}$ & $\begin{array}{l}0001 \\
0001 \\
0001 \\
0001 \\
0001 \\
0001 \\
0001 \\
0001 \\
0001 \\
0001 \\
0001 \\
0001 \\
0001 \\
0001 \\
0001 \\
0001 \\
0001 \\
0001 \\
0001 \\
0001 \\
0001 \\
0001 \\
0001 \\
0001 \\
0001 \\
0001 \\
0001 \\
0001 \\
0001\end{array}$ & $\begin{array}{l}M B \\
M B \\
M B \\
M B \\
M B \\
M B \\
M B \\
M B \\
M B \\
M B \\
M B \\
M B \\
M B \\
M B \\
M B \\
M B \\
M B \\
M B \\
M B \\
M B \\
M B \\
M B \\
M B \\
M B \\
M B \\
M B \\
M B \\
M B \\
M B\end{array}$ & $\begin{array}{l}0 \\
0 \\
0 \\
0 \\
0 \\
0 \\
0 \\
0 \\
0 \\
0 \\
0 \\
0 \\
0 \\
0 \\
0 \\
0 \\
0 \\
0 \\
0 \\
0 \\
0 \\
0 \\
0 \\
0 \\
0 \\
0 \\
0 \\
0 \\
0\end{array}$ & MG/L & & $\begin{array}{l}47.7 \\
45.2 \\
45.7 \\
49.1 \\
44.5 \\
44.8 \\
82.5 \\
80.5 \\
85.5 \\
84.6 \\
73.1 \\
63.8 \\
60.4 \\
65.2 \\
62.9 \\
60.7 \\
57.6 \\
59.1 \\
53.4 \\
57.4 \\
56.1 \\
48.4 \\
55.4 \\
51.1 \\
53.2 \\
51.6 \\
57.2 \\
54.1 \\
53.4\end{array}$ & $\begin{array}{l}\mathrm{L} \\
\mathrm{L}\end{array}$ & $\begin{array}{l}0.01 \\
0.01 \\
0.5 \\
0.5 \\
0.5 \\
0.5 \\
0.01 \\
0.01 \\
0.5 \\
0.5 \\
0.5 \\
0.01 \\
0.01 \\
0.5 \\
0.5 \\
0.5 \\
0.5 \\
0.01 \\
0.01 \\
0.5 \\
0.5 \\
0.5 \\
0.5 \\
0.5 \\
0.01 \\
0.01 \\
0.5 \\
0.5 \\
0.5\end{array}$ & $\begin{array}{l}- \\
- \\
- \\
- \\
- \\
- \\
- \\
- \\
- \\
- \\
- \\
- \\
- \\
- \\
- \\
- \\
- \\
- \\
- \\
- \\
- \\
- \\
- \\
-\end{array}$ \\
\hline
\end{tabular}

FORMATION OF COMPLETION CODE:

MB - MIDDLE BURRO CANYON

PARAMETER VALUE INDICATOR (PVI): < - LESS THAN DETECTION LIMIT
FLOW RELATIONSHIP CODE:

O - ON-SITE

0001 - FILTERED SAMPLE (.45 MICRONS)

OTHER PARAMETER VALUE FLAGS:

$J$ - ESTIMATED VALUE

L - LESS THAN THREE BORE VOLUMES REMOVED BEFORE SAMPLING 
TABLE 3.49 BACKGROUND GROUND WATER QUALITY DATA BY PARAMETER FOR THE MIDDLE SANDSTONE UNIT, BURRO CANYON DISPOSAL SITE, SLICK ROCK, COLORADO SITE: SRKO2 BORROW SITE 1 (BURRO CANYON)

06/04/90 TO 04/26/94

REPORT DATE: $09 / 30 / 94$

\begin{tabular}{|c|c|c|c|c|c|c|c|c|c|c|c|}
\hline PARAMETER NAME & $\underset{\text { ID }}{\text { LOCATION }}$ & LOG DATE & $\begin{array}{c}\text { SAMPLE } \\
\text { ID }\end{array}$ & $\begin{array}{l}\text { FORM } \\
\text { COMP }\end{array}$ & $\begin{array}{l}\text { FLOW } \\
\text { REL. }\end{array}$ & $\begin{array}{l}\text { UNITS OF } \\
\text { MEASURE }\end{array}$ & PVI & $\begin{array}{l}\text { PARAMETER } \\
\text { VALUE }\end{array}$ & FLAGS & $\begin{array}{l}\text { DETECTION } \\
\text { LIMIT }\end{array}$ & $\begin{array}{l}\text { PARAMETER } \\
\text { UNCERTAINTY }\end{array}$ \\
\hline CALCIUM & $\begin{array}{l}0526 \\
0526 \\
0528 \\
0528 \\
0528 \\
0528 \\
0528 \\
0528\end{array}$ & $\begin{array}{l}02 / 23 / 94 \\
04 / 26 / 94 \\
06 / 06 / 90 \\
12 / 15 / 90 \\
04 / 02 / 91 \\
08 / 21 / 91 \\
10 / 13 / 92 \\
04 / 26 / 94\end{array}$ & $\begin{array}{l}0001 \\
0001 \\
0001 \\
0001 \\
0001 \\
0001 \\
0001 \\
0001\end{array}$ & $\begin{array}{l}M B \\
M B \\
M B \\
M B \\
M B \\
M B \\
M B \\
M B\end{array}$ & $\begin{array}{l}0 \\
0 \\
0 \\
0 \\
0 \\
0 \\
0 \\
0\end{array}$ & MG/L & & $\begin{array}{l}51.9 \\
52.9 \\
59.6 \\
58.3 \\
61.0 \\
61.2 \\
59.1 \\
57.6\end{array}$ & $L$ & $\begin{array}{l}0.5 \\
0.5 \\
0.01 \\
0.01 \\
0.5 \\
0.5 \\
0.5 \\
0.5\end{array}$ & $\begin{array}{l}- \\
- \\
- \\
- \\
- \\
-\end{array}$ \\
\hline CHLORIDE & $\begin{array}{l}0516 \\
0516 \\
0516 \\
0516 \\
0516 \\
0516 \\
0520 \\
0520 \\
0520 \\
0520 \\
0520 \\
0522 \\
0522 \\
0522 \\
0522 \\
0522 \\
0522 \\
0525 \\
0525 \\
0525 \\
0525 \\
0525 \\
0525 \\
0525 \\
0526 \\
0526 \\
0526 \\
0526 \\
0526 \\
0526\end{array}$ & $\begin{array}{l}06 / 06 / 90 \\
12 / 08 / 90 \\
04 / 04 / 91 \\
08 / 26 / 91 \\
10 / 14 / 92 \\
04 / 26 / 94 \\
06 / 04 / 90 \\
12 / 12 / 90 \\
04 / 01 / 91 \\
08 / 22 / 91 \\
10 / 11 / 92 \\
06 / 04 / 90 \\
12 / 08 / 90 \\
04 / 02 / 91 \\
08 / 22 / 91 \\
10 / 12 / 92 \\
04 / 21 / 94 \\
06 / 04 / 90 \\
12 / 08 / 90 \\
04 / 03 / 91 \\
08 / 26 / 91 \\
10 / 14 / 92 \\
02 / 23 / 94 \\
04 / 26 / 94 \\
06 / 06 / 90 \\
12 / 12 / 90 \\
04 / 04 / 91 \\
08 / 21 / 91 \\
10 / 14 / 92 \\
02 / 23 / 94\end{array}$ & $\begin{array}{l}0001 \\
0001 \\
0001 \\
0001 \\
0001 \\
0001 \\
0001 \\
0001 \\
0001 \\
0001 \\
0001 \\
0001 \\
0001 \\
0001 \\
0001 \\
0001 \\
0001 \\
0001 \\
0001 \\
0001 \\
0001 \\
0001 \\
0001 \\
0001 \\
0001 \\
0001 \\
0001 \\
0001 \\
0001 \\
0001\end{array}$ & $\begin{array}{l}M B \\
M B \\
M B \\
M B \\
M B \\
M B \\
M B \\
M B \\
M B \\
M B \\
M B \\
M B \\
M B \\
M B \\
M B \\
M B \\
M B \\
M B \\
M B \\
M B \\
M B \\
M B \\
M B \\
M B \\
M B \\
M B \\
M B \\
M B \\
M B \\
M B\end{array}$ & $\begin{array}{l}0 \\
0 \\
0 \\
0 \\
0 \\
0 \\
0 \\
0 \\
0 \\
0 \\
0 \\
0 \\
0 \\
0 \\
0 \\
0 \\
0 \\
0 \\
0 \\
0 \\
0 \\
0 \\
0 \\
0 \\
0 \\
0 \\
0 \\
0 \\
0 \\
0\end{array}$ & $M G / L$ & & $\begin{array}{l}27 . \\
28 . \\
28 . \\
21 . \\
25 . \\
26.2 \\
27 . \\
30 . \\
31 . \\
29 . \\
31 . \\
20 . \\
25 . \\
23 . \\
22 . \\
23 . \\
22.9 \\
37 . \\
44 . \\
40 . \\
40 . \\
59 . \\
36.7 \\
32.0 \\
24 . \\
23 . \\
21 . \\
20 . \\
21 . \\
22.7\end{array}$ & $\begin{array}{l}\mathbf{L} \\
\mathbf{L} \\
\mathbf{L}\end{array}$ & $\begin{array}{l}1 . \\
1 . \\
0.5 \\
1 . \\
1.05 \\
0.5 \\
1 . \\
1.5 \\
0.5 \\
1 . \\
1.5 \\
1 . \\
0.5 \\
1 . \\
1.5 \\
0.5 \\
1 . \\
1.5 \\
0.5 \\
1 . \\
1.5 \\
0.5 \\
0.5 \\
1 . \\
1 . \\
0.5 \\
1 . \\
1.5 \\
0.5\end{array}$ & $\begin{array}{l}- \\
- \\
- \\
- \\
- \\
- \\
- \\
- \\
- \\
- \\
- \\
- \\
- \\
- \\
- \\
- \\
- \\
- \\
- \\
- \\
- \\
- \\
-\end{array}$ \\
\hline
\end{tabular}

FORMATION OF COMPLETION CODE:

MB - MIDDLE BURRO CANYON

PARAMETER VALUE INDICATOR (PVI):

< - LESS THAN DETECTION LIMIT
FLOW RELATIONSHIP CODE:

O - ON-SITE

SAMPLE ID CODES:

0001 - FILTERED SAMPLE (.45 MICRONS)

OTHER PARAMETER VALUE FLAGS:

J - ESTIMATED VALUE

L - LESS THAN THREE BORE VOLUMES REMOVED BEFORE SAMPLING 


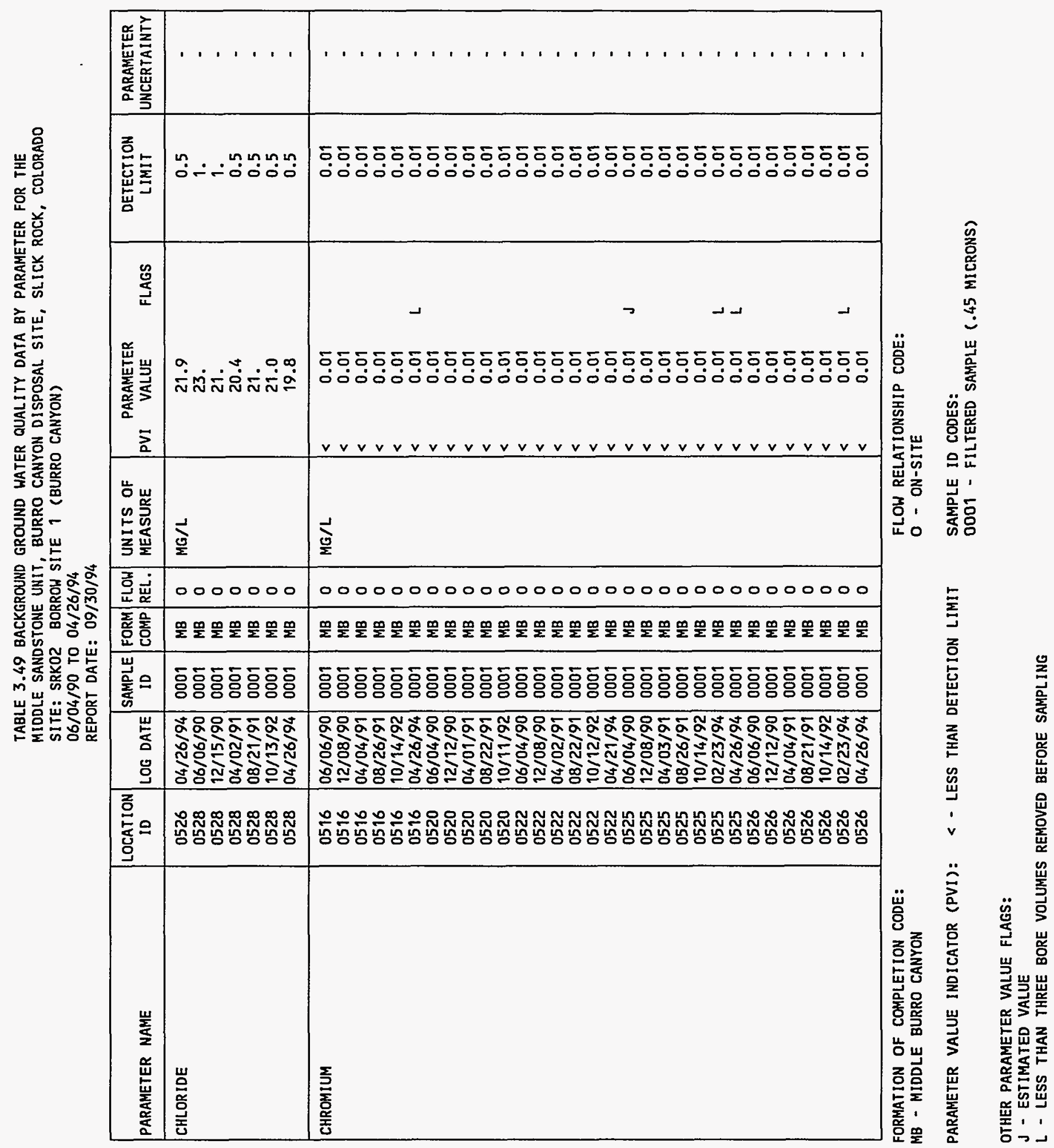


TABLE 3.49 BACKGROUND GROUND HATER QUALITY DATA BY PARAMETER FOR THE

MIDDLE SANDSTONE UNIT, BURRO CANYON DISPOSAL SITE, SLICK ROCK, COLORADO

SITE: SRKO2 BORROW SITE 1 (BURRO CANYON)

06/04/90 TO 04/26/94

PEPORT DATE: $09 / 30 / 94$

\begin{tabular}{|c|c|c|c|c|c|c|c|c|c|c|c|}
\hline PARAMETER NAME & $\begin{array}{c}\text { LOCATION } \\
\text { ID }\end{array}$ & LOG DATE & $\begin{array}{l}\text { SAMPLE } \\
\text { ID }\end{array}$ & $\begin{array}{l}\text { FORM } \\
\text { COMP }\end{array}$ & $\begin{array}{l}\text { FLOW } \\
\text { REL. }\end{array}$ & $\begin{array}{l}\text { UNITS OF } \\
\text { MEASURE }\end{array}$ & PVI & $\begin{array}{l}\text { ARAMETER } \\
\text { VALUE }\end{array}$ & FLAGS & $\begin{array}{l}\text { DETECTION } \\
\text { LIMIT }\end{array}$ & $\begin{array}{l}\text { PARAMETER } \\
\text { UNCERTAINTY }\end{array}$ \\
\hline CHRONIUH & $\begin{array}{l}0528 \\
0528 \\
0528 \\
0528 \\
0528 \\
0528\end{array}$ & $\begin{array}{l}06 / 06 / 90 \\
12 / 15 / 90 \\
04 / 02 / 91 \\
08 / 21 / 91 \\
10 / 13 / 92 \\
04 / 26 / 94\end{array}$ & $\begin{array}{l}0001 \\
0001 \\
0001 \\
0001 \\
0001 \\
0001\end{array}$ & $\begin{array}{l}M B \\
M B \\
M B \\
M B \\
M B \\
M B\end{array}$ & $\begin{array}{l}0 \\
0 \\
0 \\
0 \\
0 \\
0\end{array}$ & $M G / L$ & $\begin{array}{l}< \\
< \\
< \\
< \\
< \\
<\end{array}$ & $\begin{array}{l}0.01 \\
0.01 \\
0.01 \\
0.01 \\
0.01 \\
0.01\end{array}$ & & $\begin{array}{l}0.01 \\
0.01 \\
0.01 \\
0.01 \\
0.01 \\
0.01\end{array}$ & $\begin{array}{l}- \\
- \\
- \\
-\end{array}$ \\
\hline COBALT & $\begin{array}{l}0516 \\
0516 \\
0516 \\
0516 \\
0520 \\
0520 \\
0520 \\
0520 \\
0522 \\
0522 \\
0522 \\
0522 \\
0525 \\
0525 \\
0525 \\
0525 \\
0526 \\
0526 \\
0526 \\
0526 \\
0528 \\
0528 \\
0528 \\
0528\end{array}$ & $\begin{array}{l}06 / 06 / 90 \\
12 / 08 / 90 \\
04 / 04 / 91 \\
08 / 26 / 91 \\
06 / 04 / 90 \\
12 / 12 / 90 \\
04 / 01 / 91 \\
08 / 22 / 91 \\
06 / 04 / 90 \\
12 / 08 / 90 \\
04 / 02 / 91 \\
08 / 22 / 91 \\
06 / 04 / 90 \\
12 / 08 / 90 \\
04 / 03 / 91 \\
08 / 26 / 91 \\
06 / 06 / 90 \\
12 / 12 / 90 \\
04 / 04 / 91 \\
08 / 21 / 91 \\
06 / 06 / 90 \\
12 / 15 / 90 \\
04 / 02 / 91 \\
08 / 21 / 91\end{array}$ & $\begin{array}{l}0001 \\
0001 \\
0001 \\
0001 \\
0001 \\
0001 \\
0001 \\
0001 \\
0001 \\
0001 \\
0001 \\
0001 \\
0001 \\
0001 \\
0001 \\
0001 \\
0001 \\
0001 \\
0001 \\
0001 \\
0001 \\
0001 \\
0001 \\
0001\end{array}$ & $\begin{array}{l}M B \\
M B \\
M B \\
M B \\
M B \\
M B \\
M B \\
M B \\
M B \\
M B \\
M B \\
M B \\
M B \\
M B \\
M B \\
M B \\
M B \\
M B \\
M B \\
M B \\
M B \\
M B \\
M B \\
M B\end{array}$ & $\begin{array}{l}0 \\
0 \\
0 \\
0 \\
0 \\
0 \\
0 \\
0 \\
0 \\
0 \\
0 \\
0 \\
0 \\
0 \\
0 \\
0 \\
0 \\
0 \\
0 \\
0 \\
0 \\
0 \\
0 \\
0\end{array}$ & $M G / L$ & $\begin{array}{l}< \\
< \\
< \\
< \\
< \\
< \\
< \\
< \\
< \\
< \\
< \\
< \\
< \\
< \\
< \\
< \\
< \\
< \\
< \\
< \\
< \\
< \\
< \\
< \\
< \\
< \\
<\end{array}$ & $\begin{array}{l}0.05 \\
0.05 \\
0.03 \\
0.03 \\
0.05 \\
0.05 \\
0.03 \\
0.03 \\
0.05 \\
0.05 \\
0.03 \\
0.03 \\
0.05 \\
0.05 \\
0.03 \\
0.03 \\
0.05 \\
0.05 \\
0.03 \\
0.03 \\
0.05 \\
0.05 \\
0.03 \\
0.03\end{array}$ & J & $\begin{array}{l}0.05 \\
0.05 \\
0.03 \\
0.03 \\
0.05 \\
0.05 \\
0.03 \\
0.03 \\
0.05 \\
0.05 \\
0.03 \\
0.03 \\
0.05 \\
0.05 \\
0.03 \\
0.03 \\
0.05 \\
0.05 \\
0.03 \\
0.03 \\
0.05 \\
0.05 \\
0.03 \\
0.03\end{array}$ & $\begin{array}{l}- \\
- \\
- \\
- \\
- \\
- \\
- \\
- \\
- \\
- \\
- \\
- \\
- \\
- \\
- \\
- \\
- \\
- \\
- \\
- \\
-\end{array}$ \\
\hline COPPER & $\begin{array}{l}0516 \\
0516 \\
0516 \\
0516 \\
0516 \\
0520 \\
0520 \\
0520\end{array}$ & $\begin{array}{l}06 / 06 / 90 \\
12 / 08 / 90 \\
04 / 04 / 91 \\
08 / 26 / 91 \\
10 / 14 / 92 \\
06 / 04 / 90 \\
12 / 12 / 90 \\
04 / 01 / 91\end{array}$ & $\begin{array}{l}0001 \\
0001 \\
0001 \\
0001 \\
0001 \\
0001 \\
0001 \\
0001\end{array}$ & $\begin{array}{l}\text { MB } \\
M B \\
M B \\
M B \\
M B \\
M B \\
M B \\
M B\end{array}$ & $\begin{array}{l}0 \\
0 \\
0 \\
0 \\
0 \\
0 \\
0 \\
0\end{array}$ & $\mathrm{MG} / \mathrm{L}$ & $\begin{array}{l}< \\
< \\
< \\
< \\
< \\
< \\
< \\
<\end{array}$ & $\begin{array}{l}0.02 \\
0.02 \\
0.01 \\
0.01 \\
0.01 \\
0.02 \\
0.02 \\
0.01\end{array}$ & & $\begin{array}{l}0.02 \\
0.02 \\
0.01 \\
0.01 \\
0.01 \\
0.02 \\
0.02 \\
0.01\end{array}$ & $\begin{array}{l}- \\
- \\
- \\
- \\
-\end{array}$ \\
\hline
\end{tabular}

FORMATION OF COMPLETION CODE:

MB - MIDDLE BURRO CANYON

FLOW RELATIONSHIP CODE

PARAMETER VALUE INDICATOR (PVI): < - LESS THAN DETECTION LIMIT

SAMPLE ID CODES:

0001 - FILTERED SAMPLE (.45 MICRONS)

OTHER PARAMETER VALUE FLAGS:

$J$ - Est IMATED VALUE 


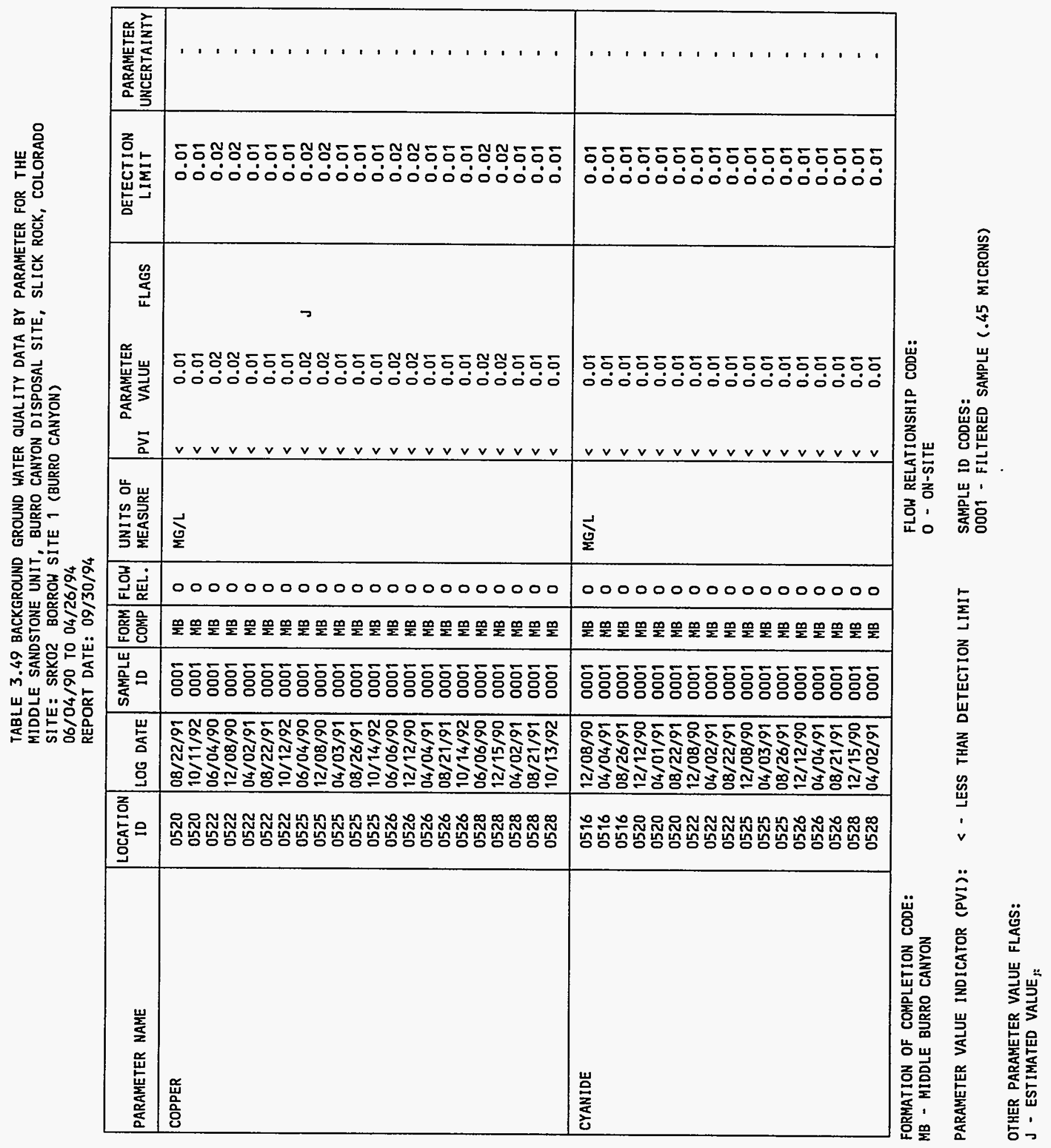


TABLE 3.49 BACKGROUND GROUND HATER QUALITY DATA BY PARAMETER FOR THE

MIDDLE SANDSTONE UNIT, BURRO CANYON DISPOSAL SITE, SLICK ROCK, COLORADO

SITE: SRKO2 BORROW SITE 1 (BURRO CANYON)

06/04/90 TO 04/26/94

REPORT DATE: 09/30/94

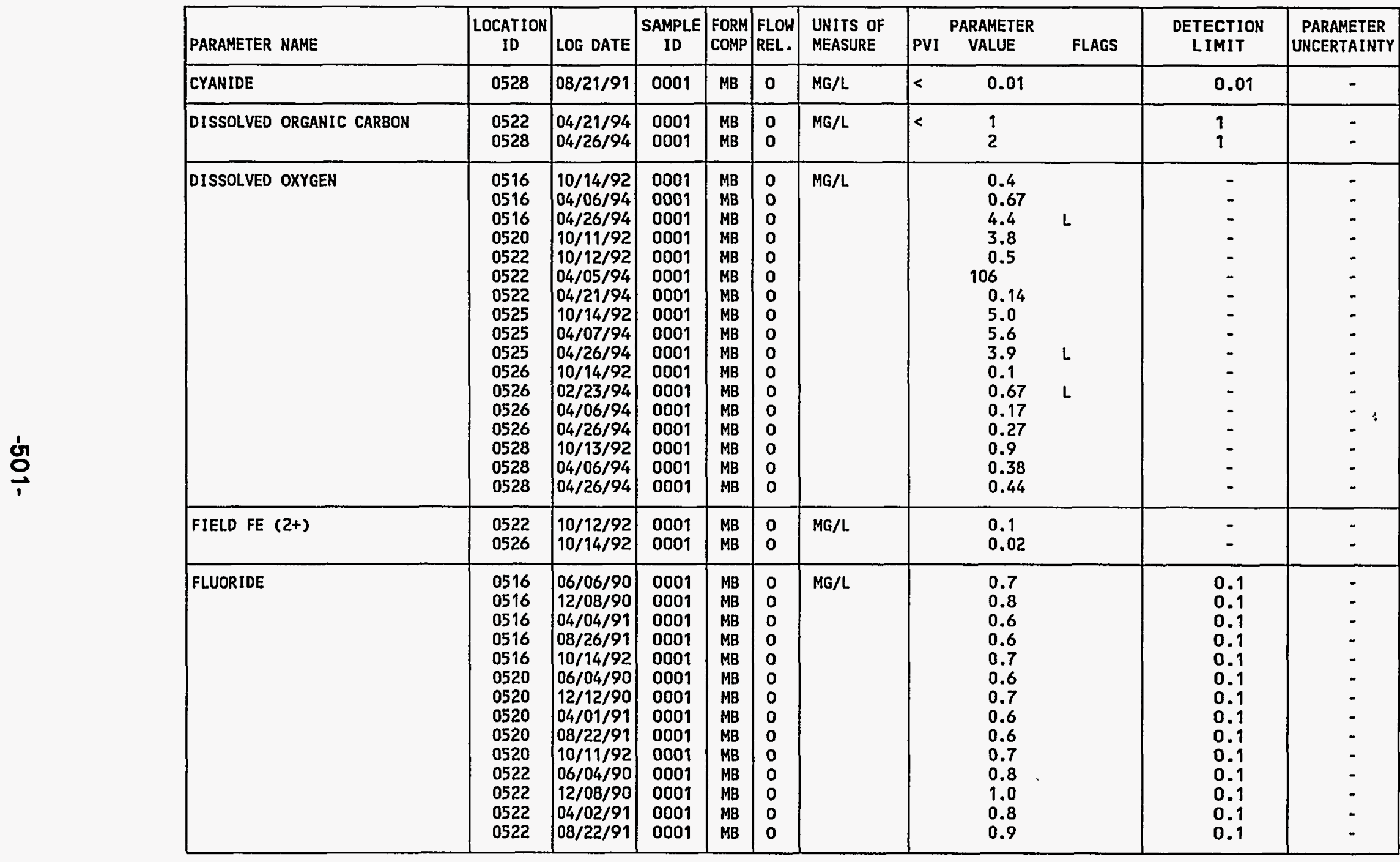

FORMATION OF COMPLETION CODE:

MB - MIDDLE BURRO CANYON

PARAMETER VALUE INDICATOR (PVI): < - LESS THAN DETECTION LIMIT
FLOW RELATIONSHIP CODE:

O - ON-SITE

SAMPLE ID CODES:

0001 - FILTERED SAMPLE (.45 MICRONS)

OTHER PARAMETER VALUE FLAGS:

L - LESS THAN THREE BORE VOLUMES REMOVED BEFORE SAMPLING 
TABLE 3.49 BACKGROUND GROUND HATER QUALITY DATA BY PARAMETER FOR THE MIDDLE SANDSTONE UNIT , BURRO CANYON DISPOSAL SITE, SLICK ROCK, COLORADO SITE: SRKO2 BORROW SITE 1 (BURRO CANYON)

06/04/90 TO 04/26/94

REPORT DATE: $09 / 30 / 94$

\begin{tabular}{|c|c|c|c|c|c|c|c|c|c|c|c|}
\hline PARAMETER NAME & $\begin{array}{c}\text { LOCATION } \\
\text { ID }\end{array}$ & LOG DATE & $\begin{array}{c}\text { SAMPLE } \\
\text { ID }\end{array}$ & $\begin{array}{l}\text { FORM } \\
\text { COMP }\end{array}$ & $\begin{array}{l}\text { FLOW } \\
\text { REL. }\end{array}$ & $\begin{array}{l}\text { UNITS OF } \\
\text { MEASURE }\end{array}$ & PVI & $\begin{array}{l}\text { ARAMETEF } \\
\text { VALUE }\end{array}$ & FLAGS & $\begin{array}{l}\text { DETECTION } \\
\text { LIMIT }\end{array}$ & $\begin{array}{l}\text { PARAMETER } \\
\text { UNCERTAINTY }\end{array}$ \\
\hline FLUORIDE & $\begin{array}{l}0522 \\
0525 \\
0525 \\
0525 \\
0525 \\
0525 \\
0526 \\
0526 \\
0526 \\
0526 \\
0526 \\
0528 \\
0528 \\
0528 \\
0528 \\
0528\end{array}$ & $\begin{array}{l}10 / 12 / 92 \\
06 / 04 / 90 \\
12 / 08 / 90 \\
04 / 03 / 91 \\
08 / 26 / 91 \\
10 / 14 / 92 \\
06 / 06 / 90 \\
12 / 12 / 90 \\
04 / 04 / 91 \\
08 / 21 / 91 \\
10 / 14 / 92 \\
06 / 06 / 90 \\
12 / 15 / 90 \\
04 / 02 / 91 \\
08 / 21 / 91 \\
10 / 13 / 92\end{array}$ & $\begin{array}{l}0001 \\
0001 \\
0001 \\
0001 \\
0001 \\
0001 \\
0001 \\
0001 \\
0001 \\
0001 \\
0001 \\
0001 \\
0001 \\
0001 \\
0001 \\
0001\end{array}$ & $\begin{array}{l}\text { MB } \\
\text { MB } \\
M B \\
M B \\
M B \\
M B \\
M B \\
M B \\
M B \\
M B \\
M B \\
M B \\
M B \\
M B \\
M B \\
M B\end{array}$ & $\begin{array}{l}0 \\
0 \\
0 \\
0 \\
0 \\
0 \\
0 \\
0 \\
0 \\
0 \\
0 \\
0 \\
0 \\
0 \\
0 \\
0\end{array}$ & $M G / L$ & & $\begin{array}{l}1.0 \\
0.6 \\
0.7 \\
0.6 \\
0.6 \\
0.7 \\
0.6 \\
0.6 \\
0.6 \\
0.6 \\
0.6 \\
0.5 \\
0.6 \\
0.6 \\
0.6 \\
0.6\end{array}$ & J & $\begin{array}{l}0.1 \\
0.1 \\
0.1 \\
0.1 \\
0.1 \\
0.1 \\
0.1 \\
0.1 \\
0.1 \\
0.1 \\
0.1 \\
0.1 \\
0.1 \\
0.1 \\
0.1 \\
0.1\end{array}$ & $\begin{array}{l}- \\
- \\
- \\
- \\
- \\
- \\
- \\
- \\
- \\
- \\
- \\
- \\
-\end{array}$ \\
\hline GROSS ALPHA & $\begin{array}{l}0516 \\
0516 \\
0516 \\
0516 \\
0516 \\
0520 \\
0520 \\
0520 \\
0520 \\
0522 \\
0522 \\
0522 \\
0522 \\
0522 \\
0525 \\
0525 \\
0525 \\
0525 \\
0525 \\
0525 \\
0526\end{array}$ & $\begin{array}{l}12 / 08 / 90 \\
04 / 04 / 91 \\
08 / 26 / 91 \\
10 / 14 / 92 \\
04 / 06 / 94 \\
12 / 12 / 90 \\
04 / 01 / 91 \\
08 / 22 / 91 \\
10 / 11 / 92 \\
12 / 08 / 90 \\
04 / 02 / 91 \\
08 / 22 / 91 \\
10 / 12 / 92 \\
04 / 05 / 94 \\
12 / 08 / 90 \\
04 / 03 / 91 \\
08 / 26 / 91 \\
10 / 14 / 92 \\
02 / 23 / 94 \\
04 / 07 / 94 \\
12 / 12 / 90\end{array}$ & $\begin{array}{l}0001 \\
0001 \\
0001 \\
0001 \\
0001 \\
0001 \\
0001 \\
0001 \\
0001 \\
0001 \\
0001 \\
0001 \\
0001 \\
0001 \\
0001 \\
0001 \\
0001 \\
0001 \\
0001 \\
0001 \\
0001\end{array}$ & $\begin{array}{l}\text { MB } \\
M B \\
M B \\
M B \\
M B \\
M B \\
M B \\
M B \\
M B \\
M B \\
M B \\
M B \\
M B \\
M B \\
\text { MB } \\
\text { MB } \\
\text { MB } \\
\text { MB } \\
\text { MB } \\
\text { MB } \\
\text { MB }\end{array}$ & $\begin{array}{l}0 \\
0 \\
0 \\
0 \\
0 \\
0 \\
0 \\
0 \\
0 \\
0 \\
0 \\
0 \\
0 \\
0 \\
0 \\
0 \\
0 \\
0 \\
0 \\
0 \\
0\end{array}$ & $\mathrm{PCI} / \mathrm{L}$ & & $\begin{array}{l}3.3 \\
3.6 \\
1.9 \\
0.0 \\
1.6 \\
3.8 \\
4.4 \\
2.2 \\
0.0 \\
1.9 \\
0.0 \\
4.0 \\
0.0 \\
1.4 \\
4.1 \\
0.0 \\
6.4 \\
0.0 \\
1.2 \\
2.8 \\
0.0\end{array}$ & $\begin{array}{l}N \\
L \\
N\end{array}$ & $\begin{array}{c}1 . \\
1 . \\
1 . \\
9.6 \\
2.7 \\
1 . \\
1 . \\
1 . \\
12.0 \\
1 . \\
1 . \\
1 . \\
11.1 \\
2.3 \\
1 . \\
1 . \\
1 . \\
12.2 \\
2.8 \\
2.5 \\
1 .\end{array}$ & $\begin{array}{r}4.0 \\
5.8 \\
9.2 \\
5.0 \\
1.7 \\
4.6 \\
6.4 \\
10.3 \\
6.6 \\
3.5 \\
4.5 \\
8.2 \\
5.9 \\
1.7 \\
5.8 \\
6.0 \\
11.1 \\
6.3 \\
1.5 \\
1.7 \\
3.4\end{array}$ \\
\hline
\end{tabular}

FORMATION OF COMPLETION CODE:

MB - MIDDLE BURRO CANYON

PARAMETER VALUE INDICATOR (PVI): < - LESS THAN DETECTION LIMIT
FLOW RELATIONSHIP CODE:

O - ON-SITE

SAMPLE ID CODES

OOO1 - FILTERED SAMPLE (.45 MICRONS)

OTHER PARAMETER VALUE FLAGS:

$J$ - ESTIMATED VALUE

$L$ - LESS THAN THREE BORE VOLUMES REMOVED BEFORE SAMPLING

$N$ - SPIKE SAMPLE RECOVERY NOT HITHIN CONTROL LIMITS 
TABLE 3.49 BACKGROUND GROUND HATER QUALITY DATA BY PARAMETER FOR THE

MIDDLE SANDSTONE UNIT, BURRO CANYON DISPOSAL SITE, SLICK ROCK, COLORADO SITE: SRKO2 BORROW SITE 1 (BURRO CANYON)

06/04/90 TO 04/26/94

REPORT DATE: $09 / 30 / 94$

\begin{tabular}{|c|c|c|c|c|c|c|c|c|c|c|c|}
\hline PARAMETER NAME & $\begin{array}{c}\text { LOCATION } \\
\text { ID }\end{array}$ & LOG DATE & $\begin{array}{c}\text { SAMPLE } \\
\text { ID }\end{array}$ & $\begin{array}{l}\text { FORM } \\
\text { COMP }\end{array}$ & $\begin{array}{l}\text { FLOW } \\
\text { REL. }\end{array}$ & $\begin{array}{l}\text { UNITS OF } \\
\text { MEASURE }\end{array}$ & PVI & $\begin{array}{l}\text { PARAMETER } \\
\text { VALUE }\end{array}$ & FLAGS & $\begin{array}{l}\text { DETECTION } \\
\text { LIMIT }\end{array}$ & $\begin{array}{l}\text { PARAMETER } \\
\text { UNCERTAINTY }\end{array}$ \\
\hline GROSS ALPHA & $\begin{array}{l}0526 \\
0526 \\
0526 \\
0526 \\
0526 \\
0528 \\
0528 \\
0528 \\
0528 \\
0528\end{array}$ & $\begin{array}{l}04 / 04 / 91 \\
08 / 21 / 91 \\
10 / 14 / 92 \\
02 / 23 / 94 \\
04 / 06 / 94 \\
12 / 15 / 90 \\
04 / 02 / 91 \\
08 / 21 / 91 \\
10 / 13 / 92 \\
04 / 06 / 94\end{array}$ & $\begin{array}{l}0001 \\
0001 \\
0001 \\
0001 \\
0001 \\
0001 \\
0001 \\
0001 \\
0001 \\
0001\end{array}$ & $\begin{array}{l}M B \\
M B \\
M B \\
M B \\
M B \\
M B \\
M B \\
M B \\
M B \\
M B\end{array}$ & $\begin{array}{l}0 \\
0 \\
0 \\
0 \\
0 \\
0 \\
0 \\
0 \\
0 \\
0\end{array}$ & $\mathrm{PCI} / \mathrm{L}$ & & $\begin{array}{l}1.4 \\
0.0 \\
0.0 \\
0.0 \\
4.4 \\
5.3 \\
0.3 \\
3.4 \\
0.0 \\
4.1\end{array}$ & $\begin{array}{l}\mathrm{N} \\
\mathrm{L} \\
\mathrm{JN}\end{array}$ & $\begin{array}{l}1 . \\
1 . \\
8.7 \\
2.6 \\
2.3 \\
1 . \\
1 . \\
1 . \\
8.5 \\
2.1\end{array}$ & $\begin{array}{l}5.1 \\
8.1 \\
4.7 \\
2.0 \\
1.8 \\
3.5 \\
4.1 \\
8.4 \\
4.8 \\
1.6\end{array}$ \\
\hline GROSS BETA & $\begin{array}{l}0516 \\
0516 \\
0516 \\
0516 \\
0520 \\
0520 \\
0520 \\
0520 \\
0522 \\
0522 \\
0522 \\
0522 \\
0525 \\
0525 \\
0525 \\
0525 \\
0526 \\
0526 \\
0526 \\
0526 \\
0528 \\
0528 \\
0528 \\
0528\end{array}$ & \begin{tabular}{|l|}
$12 / 08 / 90$ \\
$04 / 04 / 91$ \\
$08 / 26 / 91$ \\
$10 / 14 / 92$ \\
$12 / 12 / 90$ \\
$04 / 01 / 91$ \\
$08 / 22 / 91$ \\
$10 / 11 / 92$ \\
$12 / 08 / 90$ \\
$04 / 02 / 91$ \\
$08 / 22 / 91$ \\
$10 / 12 / 92$ \\
$12 / 08 / 90$ \\
$04 / 03 / 91$ \\
$08 / 26 / 91$ \\
$10 / 14 / 92$ \\
$12 / 12 / 90$ \\
$04 / 04 / 91$ \\
$08 / 21 / 91$ \\
$10 / 14 / 92$ \\
$12 / 15 / 90$ \\
$04 / 02 / 91$ \\
$08 / 21 / 91$ \\
$10 / 13 / 92$
\end{tabular} & $\begin{array}{l}0001 \\
0001 \\
0001 \\
0001 \\
0001 \\
0001 \\
0001 \\
0001 \\
0001 \\
0001 \\
0001 \\
0001 \\
0001 \\
0001 \\
0001 \\
0001 \\
0001 \\
0001 \\
0001 \\
0001 \\
0001 \\
0001 \\
0001 \\
0001\end{array}$ & $\begin{array}{l}\mathrm{MB} \\
\mathrm{MB} \\
\mathrm{MB} \\
\mathrm{MB} \\
\mathrm{MB} \\
\mathrm{MB} \\
\mathrm{MB} \\
\mathrm{MB} \\
\mathrm{MB} \\
\mathrm{MB} \\
\mathrm{MB} \\
\mathrm{MB} \\
\mathrm{MB} \\
\mathrm{MB} \\
\mathrm{MB} \\
\mathrm{MB} \\
\mathrm{MB} \\
\mathrm{MB} \\
\mathrm{MB} \\
\mathrm{MB} \\
\mathrm{MB} \\
\mathrm{MB} \\
\mathrm{MB} \\
\mathrm{MB}\end{array}$ & $\begin{array}{l}0 \\
0 \\
0 \\
0 \\
0 \\
0 \\
0 \\
0 \\
0 \\
0 \\
0 \\
0 \\
0 \\
0 \\
0 \\
0 \\
0 \\
0 \\
0 \\
0 \\
0 \\
0 \\
0 \\
0\end{array}$ & $\mathrm{PCI} / \mathrm{L}$ & & $\begin{array}{r}5.9 \\
3.6 \\
4.1 \\
5.2 \\
6.1 \\
0.8 \\
12.9 \\
0.0 \\
3.9 \\
1.3 \\
5.4 \\
0.0 \\
6.5 \\
3.1 \\
0.0 \\
0.0 \\
6.2 \\
1.4 \\
6.3 \\
0.5 \\
5.4 \\
1.6 \\
4.2 \\
0.0\end{array}$ & $\begin{array}{l}*_{N} \\
*_{N} \\
*_{N} \\
*_{N} \\
*_{N}\end{array}$ & $\begin{array}{r}0.5 \\
0.5 \\
0.5 \\
8.8 \\
0.5 \\
0.5 \\
0.5 \\
10.5 \\
0.5 \\
0.5 \\
0.5 \\
9.8 \\
0.5 \\
0.5 \\
0.5 \\
10.6 \\
0.5 \\
0.5 \\
0.5 \\
7.8 \\
0.5 \\
0.5 \\
0.5 \\
7.7\end{array}$ & $\begin{array}{l}2.9 \\
3.5 \\
6.5 \\
5.5 \\
2.9 \\
3.6 \\
7.8 \\
6.0 \\
2.4 \\
3.3 \\
6.2 \\
5.5 \\
3.2 \\
3.9 \\
7.6 \\
6.3 \\
2.7 \\
3.1 \\
6.8 \\
4.6 \\
2.3 \\
2.6 \\
6.3 \\
4.2\end{array}$ \\
\hline IRON & 0516 & $06 / 06 / 90$ & 0001 & MB & 0 & $M G / L$ & < & 0.03 & & 0.03 & - \\
\hline
\end{tabular}

FORMATIOH OF COMPLETION CODE:

MB - MIDDLE BURRO CANYON

PARAMETER VALUE INDICATOR (PVI): < - LESS THAN DETECTION LIMIT

OTHER PARAMETER VALUE FLAGS:

* - DUPLICATE ANALYSIS NOT WITHIN CONTROL LIMITS

J - ESTIMATED VALUE

L - LESS THAN THREE BORE VOLUMES REMOVED BEFORE SAMPLING

N - SPIKE SAMPLE RECOVERY NOT HITHIN CONTROL LIMITS
FLOW RELATIONSHIP CODE:

O - ON-SITE

SAMPLE ID CODES:

0001 - FILTERED SAMPLE (.45 MICRONS) 
TABLE 3.49 BACKGROUND GROUND HATER QUALITY DATA BY PARAMETER FOR THE

MIDDLE SANDSTONE UNIT, BURRO CANYON DISPOSAL SITE, SLICK ROCK, COLORADO SITE: SRKO2 BORROW SITE 1 (BURRO CANYON)

06/04/90 TO 04/26/94

REPORT DATE : 09/30/9

\begin{tabular}{|c|c|c|c|c|c|c|c|c|c|c|c|}
\hline PARAMETER NAME & $\mid \begin{array}{c}\text { LOCATION } \\
\text { ID }\end{array}$ & LOG DATE & $\underset{10}{\text { SAMPLE }}$ & $\begin{array}{l}\text { FORM } \\
\text { COMP }\end{array}$ & $\begin{array}{l}\text { FLOW } \\
\text { REL. }\end{array}$ & $\begin{array}{l}\text { UNI IS OF } \\
\text { MEASURE }\end{array}$ & PVI & $\begin{array}{l}\text { PARAMETER } \\
\text { VALUE }\end{array}$ & FLAGS & $\begin{array}{l}\text { DETECTION } \\
\text { LIMIT }\end{array}$ & $\begin{array}{l}\text { PARAMETER } \\
\text { UNCERTAINTY }\end{array}$ \\
\hline IRON & $\begin{array}{l}0516 \\
0516 \\
0516 \\
0516 \\
0516 \\
0520 \\
0520 \\
0520 \\
0520 \\
0520 \\
0522 \\
0522 \\
0522 \\
0522 \\
0522 \\
0522 \\
0525 \\
0525 \\
0525 \\
0525 \\
0525 \\
0525 \\
0525 \\
0526 \\
0526 \\
0526 \\
0526 \\
0526 \\
0526 \\
0526 \\
0528 \\
0528 \\
0528 \\
0528 \\
0528 \\
0528\end{array}$ & $\begin{array}{l}12 / 08 / 90 \\
04 / 04 / 91 \\
08 / 26 / 91 \\
10 / 14 / 92 \\
04 / 26 / 94 \\
06 / 04 / 90 \\
12 / 12 / 90 \\
04 / 01 / 91 \\
08 / 22 / 91 \\
10 / 11 / 92 \\
06 / 04 / 90 \\
12 / 08 / 90 \\
04 / 02 / 91 \\
08 / 22 / 91 \\
10 / 12 / 92 \\
04 / 21 / 94 \\
06 / 04 / 90 \\
12 / 08 / 90 \\
04 / 03 / 91 \\
08 / 26 / 91 \\
10 / 14 / 92 \\
02 / 23 / 94 \\
04 / 26 / 94 \\
06 / 06 / 90 \\
12 / 12 / 90 \\
04 / 04 / 91 \\
08 / 21 / 91 \\
10 / 14 / 92 \\
02 / 23 / 94 \\
04 / 26 / 94 \\
06 / 06 / 90 \\
12 / 15 / 90 \\
04 / 02 / 91 \\
08 / 21 / 91 \\
10 / 13 / 92 \\
04 / 26 / 94\end{array}$ & $\begin{array}{l}0001 \\
0001 \\
0001 \\
0001 \\
0001 \\
0001 \\
0001 \\
0001 \\
0001 \\
0001 \\
0001 \\
0001 \\
0001 \\
0001 \\
0001 \\
0001 \\
0001 \\
0001 \\
0001 \\
0001 \\
0001 \\
0001 \\
0001 \\
0001 \\
0001 \\
0001 \\
0001 \\
0001 \\
0001 \\
0001 \\
0001 \\
0001 \\
0001 \\
0001 \\
0001 \\
0001\end{array}$ & $\begin{array}{l}M B \\
M B \\
M B \\
M B \\
M B \\
M B \\
M B \\
M B \\
M B \\
M B \\
M B \\
M B \\
M B \\
M B \\
M B \\
M B \\
M B \\
M B \\
M B \\
M B \\
M B \\
M B \\
M B \\
M B \\
M B \\
M B \\
M B \\
M B \\
M B \\
M B \\
M B \\
M B \\
M B \\
M B \\
M B \\
M B\end{array}$ & $\begin{array}{l}0 \\
0 \\
0 \\
0 \\
0 \\
0 \\
0 \\
0 \\
0 \\
0 \\
0 \\
0 \\
0 \\
0 \\
0 \\
0 \\
0 \\
0 \\
0 \\
0 \\
0 \\
0 \\
0 \\
0 \\
0 \\
0 \\
0 \\
0 \\
0 \\
0 \\
0 \\
0 \\
0 \\
0 \\
0 \\
0\end{array}$ & MG/L. & $\begin{array}{l} \\
\\
< \\
< \\
< \\
< \\
< \\
< \\
< \\
< \\
< \\
< \\
< \\
< \\
<\end{array}$ & $\begin{array}{l}0.03 \\
0.05 \\
0.03 \\
0.03 \\
0.05 \\
0.05 \\
0.03 \\
0.03 \\
0.03 \\
0.03 \\
0.05 \\
0.06 \\
0.06 \\
0.05 \\
0.11 \\
0.08 \\
0.03 \\
0.03 \\
0.03 \\
0.03 \\
0.03 \\
0.03 \\
0.03 \\
0.03 \\
0.03 \\
0.03 \\
0.08 \\
0.03 \\
0.07 \\
0.04 \\
0.06 \\
0.09 \\
0.11 \\
0.12 \\
0.09 \\
0.10\end{array}$ & $\begin{array}{l}L \\
\\
J \\
L \\
L\end{array}$ & $\begin{array}{l}0.03 \\
0.03 \\
0.03 \\
0.03 \\
0.03 \\
0.03 \\
0.03 \\
0.03 \\
0.03 \\
0.03 \\
0.03 \\
0.03 \\
0.03 \\
0.03 \\
0.03 \\
0.03 \\
0.03 \\
0.03 \\
0.03 \\
0.03 \\
0.03 \\
0.03 \\
0.03 \\
0.03 \\
0.03 \\
0.03 \\
0.03 \\
0.03 \\
0.03 \\
0.03 \\
0.03 \\
0.03 \\
0.03 \\
0.03 \\
0.03 \\
0.03\end{array}$ & $\begin{array}{l}- \\
- \\
- \\
- \\
- \\
- \\
- \\
- \\
- \\
- \\
- \\
- \\
- \\
- \\
- \\
- \\
- \\
- \\
- \\
- \\
- \\
- \\
- \\
- \\
- \\
- \\
- \\
-\end{array}$ \\
\hline LEAD & $\begin{array}{l}0516 \\
0516\end{array}$ & $\begin{array}{l}06 / 06 / 90 \\
12 / 08 / 90\end{array}$ & $\begin{array}{l}0001 \\
0001\end{array}$ & $\begin{array}{l}\text { MB } \\
\text { MB }\end{array}$ & $\begin{array}{l}0 \\
0\end{array}$ & $M G / L$ & $<$ & $\begin{array}{l}0.01 \\
0.01\end{array}$ & & $\begin{array}{l}0.01 \\
0.01\end{array}$ & $\overline{-}$ \\
\hline
\end{tabular}

FORMATION OF COMPLETION CODE:

MB - MIDDLE BURRO CANYON

PARAMETER VALUE INDICATOR (PVI): < - LESS THAN DETECTION LIMIT
FLOW RELATIONSHIP CODE:

O - ON-SITE

SAMPLE ID CODES:

0001 - FILTERED SAMPLE (.45 MICRONS)

OTHER PARAMETER VALUE FLAGS:

$J$ - ESTIMATED VALUE

L - LESS THAN THREE BORE VOLUMES REMOVED BEFORE SAMPLING 


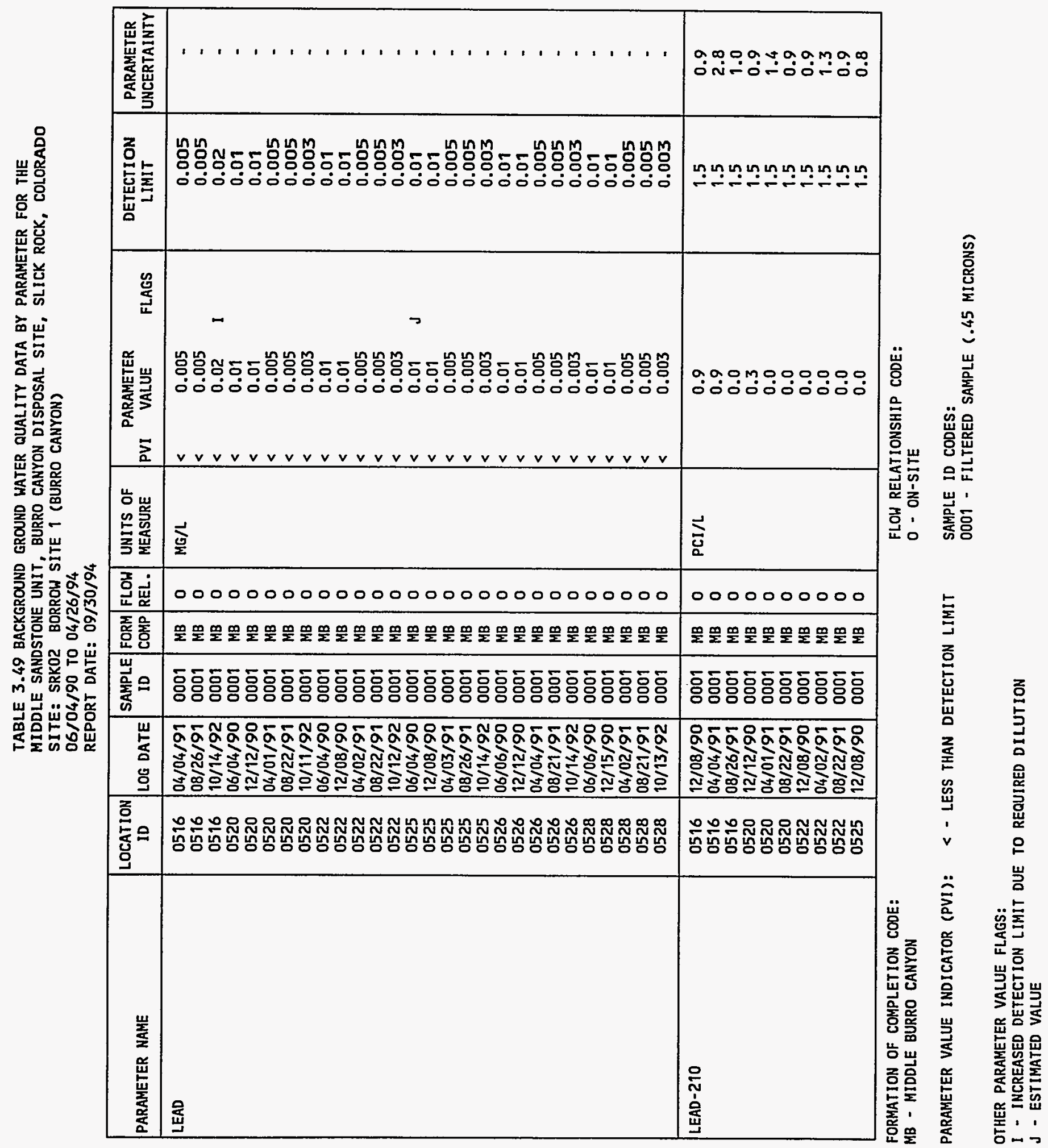


TABLE 3.49 BACKGROUND GROUND HATER QUALITY DATA BY PARAMETER FOR THE

MIDDLE SANDSTONE UNIT, BURRO CANYON DISPOSAL SITE, SLICK ROCK, COLORADO SITE: SRKO2 BORROW SITE 1 (BURRO CANYON)

06/04/90 TO 04/26/94

REPORT DATE: $09 / 30 / 94$

\begin{tabular}{|c|c|c|c|c|c|c|c|c|c|c|c|}
\hline PARAMETER NAME & $\begin{array}{c}\text { LOCATION } \\
\text { ID }\end{array}$ & LOG DATE & $\begin{array}{c}\text { SAMPLE } \\
\text { ID }\end{array}$ & $\begin{array}{l}\text { FORM } \\
\text { COMP }\end{array}$ & $\begin{array}{l}\text { FLOW } \\
\text { REL. }\end{array}$ & $\begin{array}{l}\text { UNITS OF } \\
\text { MEASURE }\end{array}$ & PVI & $\begin{array}{l}\text { PARAMETEI } \\
\text { VALUE }\end{array}$ & FLAGS & $\begin{array}{l}\text { DETECTION } \\
\text { LIMIT }\end{array}$ & $\begin{array}{l}\text { PARAMETER } \\
\text { UNCERTAINTY }\end{array}$ \\
\hline LEAD-210 & $\begin{array}{l}0525 \\
0525 \\
0526 \\
0526 \\
0526 \\
0528 \\
0528 \\
0528\end{array}$ & $\begin{array}{l}04 / 03 / 91 \\
08 / 26 / 91 \\
12 / 12 / 90 \\
04 / 04 / 91 \\
08 / 21 / 91 \\
12 / 15 / 90 \\
04 / 02 / 91 \\
08 / 21 / 91\end{array}$ & $\begin{array}{l}0001 \\
0001 \\
0001 \\
0001 \\
0001 \\
0001 \\
0001 \\
0001\end{array}$ & $\begin{array}{l}M B \\
M B \\
M B \\
M B \\
M B \\
M B \\
M B \\
M B\end{array}$ & $\begin{array}{l}0 \\
0 \\
0 \\
0 \\
0 \\
0 \\
0 \\
0\end{array}$ & $\mathrm{PCI} / \mathrm{L}$ & & $\begin{array}{l}1.4 \\
0.0 \\
0.0 \\
0.5 \\
0.0 \\
0.0 \\
0.4 \\
0.0\end{array}$ & & $\begin{array}{l}1.5 \\
1.5 \\
1.5 \\
1.5 \\
1.5 \\
1.5 \\
1.5 \\
1.5\end{array}$ & $\begin{array}{l}1.4 \\
1.0 \\
0.9 \\
1.4 \\
0.9 \\
0.9 \\
1.4 \\
0.9\end{array}$ \\
\hline MAGNESIUM & $\begin{array}{l}0516 \\
0516 \\
0516 \\
0516 \\
0516 \\
0516 \\
0520 \\
0520 \\
0520 \\
0520 \\
0520 \\
0522 \\
0522 \\
0522 \\
0522 \\
0522 \\
0522 \\
0525 \\
0525 \\
0525 \\
0525 \\
0525 \\
0525 \\
0525 \\
0526 \\
0526 \\
0526 \\
0526 \\
0526 \\
0526\end{array}$ & $\begin{array}{l}06 / 06 / 90 \\
12 / 08 / 90 \\
04 / 04 / 91 \\
08 / 26 / 91 \\
10 / 14 / 92 \\
04 / 26 / 94 \\
06 / 04 / 90 \\
12 / 12 / 90 \\
04 / 01 / 91 \\
08 / 22 / 91 \\
10 / 11 / 92 \\
06 / 04 / 90 \\
12 / 08 / 90 \\
04 / 02 / 91 \\
08 / 22 / 91 \\
10 / 12 / 92 \\
04 / 21 / 94 \\
06 / 04 / 90 \\
12 / 08 / 90 \\
04 / 03 / 91 \\
08 / 26 / 91 \\
10 / 14 / 92 \\
02 / 23 / 94 \\
04 / 26 / 94 \\
06 / 06 / 90 \\
12 / 12 / 90 \\
04 / 04 / 91 \\
08 / 21 / 91 \\
10 / 14 / 92 \\
02 / 23 / 94\end{array}$ & $\begin{array}{l}0001 \\
0001 \\
0001 \\
0001 \\
0001 \\
0001 \\
0001 \\
0001 \\
0001 \\
0001 \\
0001 \\
0001 \\
0001 \\
0001 \\
0001 \\
0001 \\
0001 \\
0001 \\
0001 \\
0001 \\
0001 \\
0001 \\
0001 \\
0001 \\
0001 \\
0001 \\
0001 \\
0001 \\
0001 \\
0001\end{array}$ & $\begin{array}{l}\text { MB } \\
\text { MB } \\
M B \\
\text { MB } \\
\text { MB } \\
\text { MB } \\
\text { MB } \\
\text { MB } \\
\text { MB } \\
\text { MB } \\
\text { MB } \\
\text { MB } \\
\text { MB } \\
\text { MB } \\
\text { MB } \\
\text { MB } \\
\text { MB } \\
\text { MB } \\
\text { MB } \\
\text { MB } \\
\text { MB } \\
\text { MB } \\
\text { MB } \\
\text { MB } \\
\text { MB } \\
\text { MB } \\
\text { MB } \\
\text { MB } \\
\text { MB } \\
\text { MB }\end{array}$ & $\begin{array}{l}0 \\
0 \\
0 \\
0 \\
0 \\
0 \\
0 \\
0 \\
0 \\
0 \\
0 \\
0 \\
0 \\
0 \\
0 \\
0 \\
0 \\
0 \\
0 \\
0 \\
0 \\
0 \\
0 \\
0 \\
0 \\
0 \\
0 \\
0 \\
0 \\
0\end{array}$ & $M G / L$ & & $\begin{array}{l}18.1 \\
17.2 \\
17.8 \\
16.8 \\
16.5 \\
17.1 \\
29.2 \\
28.5 \\
30.3 \\
29.0 \\
24.4 \\
23.1 \\
21.8 \\
24.0 \\
22.5 \\
20.3 \\
20.9 \\
21.4 \\
20.4 \\
22.3 \\
21.4 \\
18.0 \\
20.1 \\
19.2 \\
20.3 \\
19.1 \\
21.3 \\
19.8 \\
18.9 \\
19.1\end{array}$ & $\begin{array}{l}\mathrm{J} \\
\mathrm{L} \\
\mathrm{L}\end{array}$ & $\begin{array}{l}0.001 \\
0.001 \\
0.1 \\
0.1 \\
0.1 \\
0.1 \\
0.001 \\
0.001 \\
0.1 \\
0.1 \\
0.1 \\
0.001 \\
0.001 \\
0.1 \\
0.1 \\
0.1 \\
0.1 \\
0.001 \\
0.001 \\
0.1 \\
0.1 \\
0.1 \\
0.1 \\
0.1 \\
0.001 \\
0.001 \\
0.1 \\
0.1 \\
0.1 \\
0.1\end{array}$ & $\begin{array}{l}- \\
- \\
: \\
. \\
: \\
- \\
- \\
- \\
- \\
- \\
- \\
- \\
- \\
- \\
- \\
- \\
- \\
- \\
- \\
- \\
- \\
-\end{array}$ \\
\hline
\end{tabular}

FORMATION OF COMPLETION CODE:

MB - MIDDLE BURRO CANYON

PARAMETER VALUE INDICATOR (PVI): < - LESS THAN DETECTION LIMIT
FLOW RELATIONSHIP CODE:

O - ON-SITE

SAMPLE ID CODES:

0001 - FILTERED SAMPLE (.45 MICRONS)

OTHER PARAMETER VALUE FLAGS:

$J$ - ESTIMATED VALUE

L - LESS THAN THREE: BORE VOLUMES REMOVED BEFORE SAMPLING 
TABLE 3.49 BACKGROUND GROUND HATER QUALITY DATA BY PARAMETER FOR THE

MIDDLE SANDSTONE UNIT, BURRO CANYON DISPOSAL SITE, SLICK ROCK, COLORADO SITE: SRKO2 BORROW SITE 1 (BURRO CANYON)

06/04/90 TO 04/26/94

REPORT DATE: 09/30/94

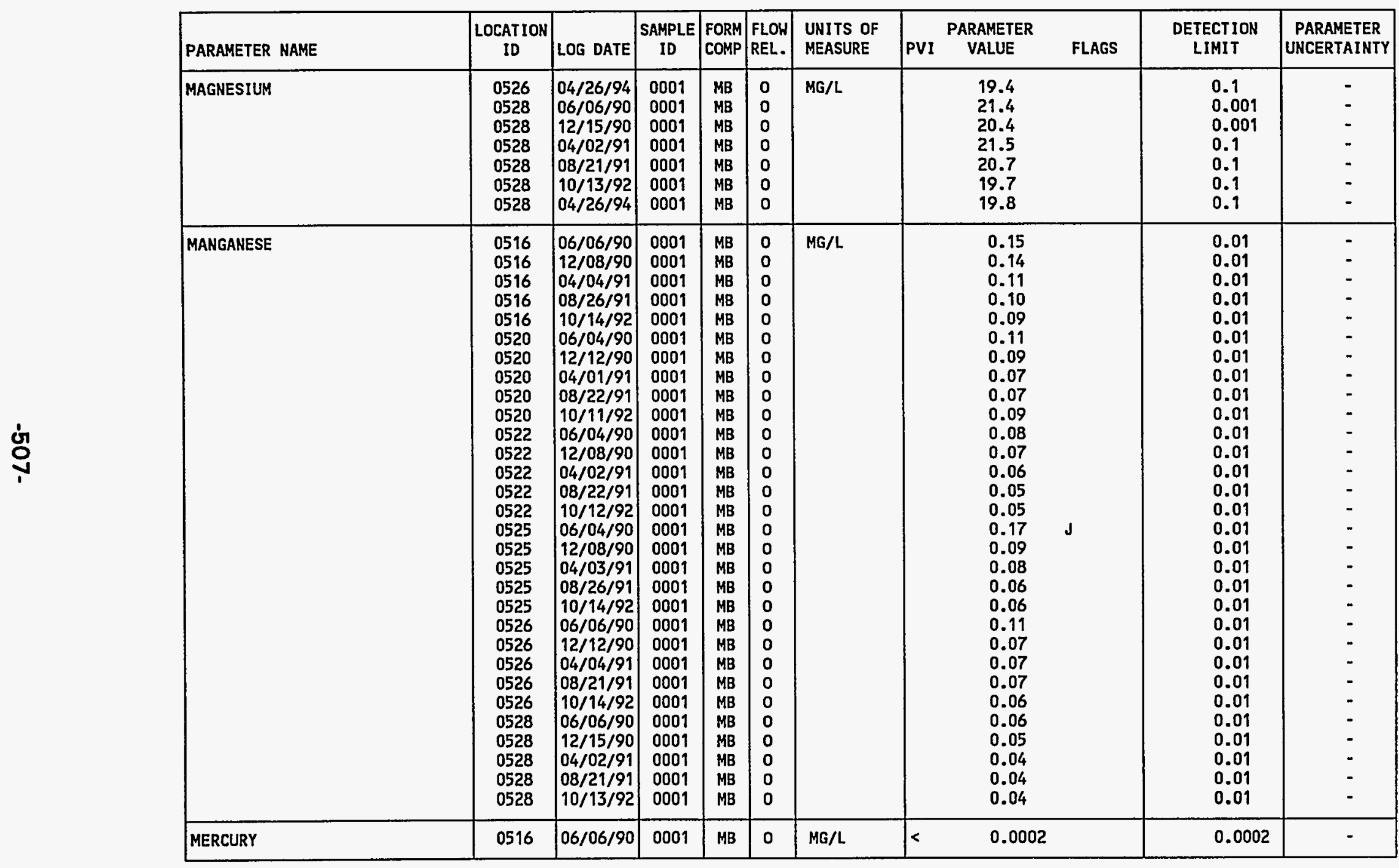

FORMATION OF COMPLETION CODE:

MB - MIDDLE BURRO CANYON

PARAMETER VALUE INDICATOR (PVI): < - LESS THAN DETECTION LIMIT
FLOW RELATIONSHIP CODE:

O- ON-SITE

0001 - FILTERED SAMPLE (.45 MICRONS)

OTHER PARAMETER VALUE FLAGS:

J - ESTIMATED VALUE 


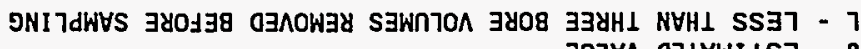
anT४ 03IVWILS -

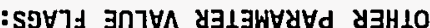

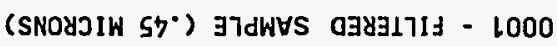
: $\$ 3000$ oI $\exists 7 d W \forall S$

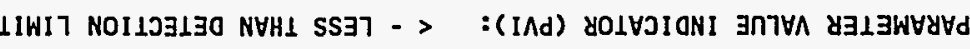

IIIS-NO - O

NOANGJ Oy\&ng כ700IW - 8h

: $\exists 000$ dIHSNOILV7ヨy MOTA : 3003 NOIIJ7d

\begin{tabular}{|c|c|c|c|c|c|c|c|c|c|c|c|}
\hline $\begin{array}{l}- \\
- \\
- \\
- \\
- \\
- \\
- \\
- \\
- \\
- \\
- \\
-\end{array}$ & $\begin{array}{l}10^{\circ} 0 \\
10^{\circ} 0 \\
10^{\circ} 0 \\
10^{\circ} 0 \\
10^{\circ} 0 \\
10^{\circ} 0 \\
10^{\circ} 0 \\
10^{\circ} 0 \\
10^{\circ} 0 \\
10^{\circ} 0 \\
10^{\circ} 0 \\
10^{\circ} 0 \\
10^{\circ} 0 \\
10^{\circ} 0 \\
10^{\circ} 0\end{array}$ & 7 & $\begin{array}{l}10^{\circ} 0 \\
10^{\circ} 0 \\
20^{\circ} 0 \\
10^{\circ} 0 \\
10^{\circ} 0 \\
10^{\circ} 0 \\
10^{\circ} 0 \\
20^{\circ} 0 \\
10^{\circ} 0 \\
10^{\circ} 0 \\
10^{\circ} 0 \\
10^{\circ} 0 \\
10^{\circ} 0 \\
20^{\circ} 0 \\
10^{\circ} 0\end{array}$ & $\begin{array}{l}> \\
> \\
> \\
>\end{array}$ & $7 / 9 W$ & $\begin{array}{l}0 \\
0 \\
0 \\
0 \\
0 \\
0 \\
0 \\
0 \\
0 \\
0 \\
0 \\
0 \\
0 \\
0 \\
0\end{array}$ & $\begin{array}{l}\text { gW } \\
\text { gW } \\
\text { gW } \\
\text { gw } \\
\text { gW } \\
\text { gW } \\
\text { gW } \\
\text { gW } \\
\text { gW } \\
\text { gW } \\
\text { gW } \\
\text { gW } \\
\text { gW } \\
\text { gW } \\
\text { gW }\end{array}$ & $\begin{array}{l}1000 \\
1000 \\
1000 \\
1000 \\
1000 \\
1000 \\
1000 \\
1000 \\
1000 \\
1000 \\
1000 \\
1000 \\
1000 \\
1000 \\
1000\end{array}$ & $\begin{array}{l}16 / 22 / 80 \\
16 / 20 / 70 \\
06 / 80 / 21 \\
06 / 70 / 90 \\
26 / 11 / 01 \\
16 / 22 / 80 \\
16 / 10 / 40 \\
06 / 21 / 21 \\
06 / 70 / 90 \\
76 / 92 / 40 \\
26 / 71 / 01 \\
16 / 92 / 80 \\
16 / 70 / 70 \\
06 / 80 / 21 \\
06 / 90 / 90\end{array}$ & $\begin{array}{l}2250 \\
2250 \\
2250 \\
2250 \\
0250 \\
0250 \\
0250 \\
0250 \\
0250 \\
9150 \\
9150 \\
9150 \\
9150 \\
9150 \\
9150\end{array}$ & 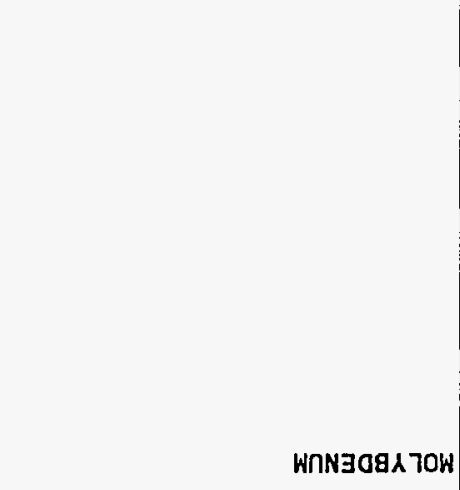 \\
\hline $\begin{array}{l}- \\
- \\
- \\
- \\
- \\
- \\
- \\
- \\
- \\
- \\
- \\
- \\
- \\
- \\
- \\
- \\
- \\
- \\
- \\
-\end{array}$ & $\begin{array}{l}2000^{\circ} 0 \\
2000^{\circ} 0 \\
2000^{\circ} 0 \\
2000^{\circ} 0 \\
2000^{\circ} 0 \\
2000^{\circ} 0 \\
2000^{\circ} 0 \\
2000^{\circ} 0 \\
2000^{\circ} 0 \\
2000^{\circ} 0 \\
2000^{\circ} 0 \\
2000^{\circ} 0 \\
2000^{\circ} 0 \\
2000^{\circ} 0 \\
2000^{\circ} 0 \\
2000^{\circ} 0 \\
2000^{\circ} 0 \\
2000^{\circ} 0 \\
2000^{\circ} 0 \\
2000^{\circ} 0 \\
2000^{\circ} 0 \\
2000^{\circ} 0 \\
2000^{\circ} 0\end{array}$ & $\boldsymbol{r}$ & $\begin{array}{l}2000^{\circ} 0 \\
2000^{\circ} 0 \\
2000^{\circ} 0 \\
2000^{\circ} 0 \\
2000^{\circ} 0 \\
2000^{\circ} 0 \\
2000^{\circ} 0 \\
2000^{\circ} 0 \\
2000^{\circ} 0 \\
2000^{\circ} 0 \\
2000^{\circ} 0 \\
2000^{\circ} 0 \\
2000^{\circ} 0 \\
2000^{\circ} 0 \\
2000^{\circ} 0 \\
2000^{\circ} 0 \\
2000^{\circ} 0 \\
2000^{\circ} 0 \\
2000^{\circ} 0 \\
2000^{\circ} 0 \\
2000^{\circ} 0 \\
2000^{\circ} 0 \\
2000^{\circ} 0\end{array}$ & $\begin{array}{l}> \\
> \\
> \\
> \\
> \\
> \\
> \\
> \\
> \\
> \\
> \\
> \\
> \\
> \\
> \\
> \\
> \\
> \\
> \\
> \\
> \\
> \\
>\end{array}$ & 列 & $\begin{array}{l}0 \\
0 \\
0 \\
0 \\
0 \\
0 \\
0 \\
0 \\
0 \\
0 \\
0 \\
0 \\
0 \\
0 \\
0 \\
0 \\
0 \\
0 \\
0 \\
0 \\
0 \\
0 \\
0\end{array}$ & 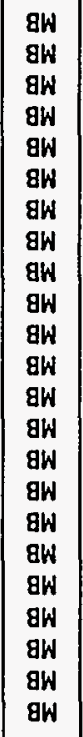 & $\begin{array}{l}1000 \\
1000 \\
1000 \\
1000 \\
1000 \\
1000 \\
1000 \\
1000 \\
1000 \\
1000 \\
1000 \\
1000 \\
1000 \\
1000 \\
1000 \\
1000 \\
1000 \\
1000 \\
1000 \\
1000 \\
1000 \\
1000 \\
1000\end{array}$ & $\begin{array}{l}16 / 12 / 80 \\
16 / 20 / 70 \\
06 / 51 / 21 \\
06 / 90 / 90 \\
16 / 12 / 80 \\
16 / 70 / 70 \\
06 / 21 / 21 \\
06 / 90 / 90 \\
16 / 92 / 80 \\
16 / 50 / 70 \\
06 / 80 / 21 \\
06 / 70 / 90 \\
16 / 22 / 80 \\
16 / 20 / 70 \\
06 / 80 / 21 \\
06 / 70 / 90 \\
16 / 22 / 80 \\
16 / 10 / 70 \\
06 / 21 / 21 \\
06 / 70 / 90 \\
16 / 92 / 80 \\
16 / 70 / 70 \\
06 / 80 / 21\end{array}$ & $\begin{array}{l}8250 \\
8250 \\
8250 \\
8250 \\
9250 \\
9250 \\
9250 \\
9250 \\
5250 \\
5250 \\
5250 \\
5250 \\
2250 \\
2250 \\
2250 \\
2250 \\
0250 \\
0250 \\
0250 \\
0250 \\
9150 \\
9150 \\
9150\end{array}$ & ㅅกำ \\
\hline 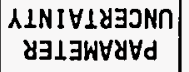 & $\begin{array}{c}\text { 11W17 } \\
\text { No1 } 15 \exists 1 \exists 0\end{array}$ & SפชาS & $\begin{array}{c}\exists \cap 7 \forall \wedge \\
\& \exists \perp \exists W \forall \& \forall d\end{array}$ & Ind & 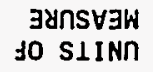 & M07t & $\begin{array}{l}\text { dWOJ } \\
\text { WYOS }\end{array}$ & $\begin{array}{c}\text { OI } \\
\text { 3าdWHS }\end{array}$ & 1ㅜ & $\begin{array}{c}\text { 01 } \\
\text { NoI1 }\end{array}$ & $\exists W \forall N \quad$ \& $\exists \perp \exists W \forall \forall d$ \\
\hline
\end{tabular}

$76 / 0 \varepsilon / 60$ : $\exists 170$ LYOdJy

(NONNGJ OYYng) । $\exists 11 \mathrm{~S} \mathrm{MOYYOB}$ zOXYS : $\exists 1 \mathrm{IS}$

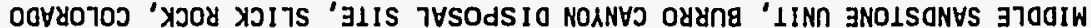

3H1 401 \& 
TABLE 3.49 BACKGROUND GROUND WATER QUALITY DATA BY PARAMETER FOR THE

MIDDLE SANDSTONE UNIT, BURRO CANYON DISPOSAL SITE, SLICK ROCK, COLORADO

SITE: SRKO2 BORROH SITE 1 (BURRO CANYON)

06/04/90 TO $04 / 26 / 94$

REPORT DATE: $09 / 30 / 94$

\begin{tabular}{|c|c|c|c|c|c|c|c|c|c|c|c|}
\hline PARAMETER NAME & $\underset{\text { LOCATION }}{\text { ID }}$ & LOG DATE & $\underset{\text { ID }}{\text { SAMPLE }}$ & $\begin{array}{l}\text { FORM } \\
\text { COMP }\end{array}$ & $\begin{array}{l}\text { FLOW } \\
\text { REL. }\end{array}$ & $\begin{array}{l}\text { UNITS OF } \\
\text { MEASURE }\end{array}$ & PVI & $\begin{array}{l}\text { PARAMETER } \\
\text { VALUE }\end{array}$ & FLAGS & $\begin{array}{l}\text { DETECTION } \\
\text { LIMIT }\end{array}$ & $\begin{array}{l}\text { PARAMETER } \\
\text { UNCERTAINTY }\end{array}$ \\
\hline MOLYBDENUM & $\begin{array}{l}0522 \\
0522 \\
0525 \\
0525 \\
0525 \\
0525 \\
0525 \\
0525 \\
0525 \\
0526 \\
0526 \\
0526 \\
0526 \\
0526 \\
0526 \\
0526 \\
0528 \\
0528 \\
0528 \\
0528 \\
0528 \\
0528\end{array}$ & $\begin{array}{l}10 / 12 / 92 \\
04 / 21 / 94 \\
06 / 04 / 90 \\
12 / 08 / 90 \\
04 / 03 / 91 \\
08 / 26 / 91 \\
10 / 14 / 92 \\
02 / 23 / 94 \\
04 / 26 / 94 \\
06 / 06 / 90 \\
12 / 12 / 90 \\
04 / 04 / 91 \\
08 / 21 / 91 \\
10 / 14 / 92 \\
02 / 23 / 94 \\
04 / 26 / 94 \\
06 / 06 / 90 \\
12 / 15 / 90 \\
04 / 02 / 91 \\
08 / 21 / 91 \\
10 / 13 / 92 \\
04 / 26 / 94\end{array}$ & $\begin{array}{l}0001 \\
0001 \\
0001 \\
0001 \\
0001 \\
0001 \\
0001 \\
0001 \\
0001 \\
0001 \\
0001 \\
0001 \\
0001 \\
0001 \\
0001 \\
0001 \\
0001 \\
0001 \\
0001 \\
0001 \\
0001 \\
0001\end{array}$ & $\begin{array}{l}\text { MB } \\
\text { MB } \\
\text { MB } \\
M B \\
M B \\
M B \\
M B \\
M B \\
\text { MB } \\
\text { MB } \\
\text { MB } \\
\text { MB } \\
\text { MB } \\
\text { MB } \\
\text { MB } \\
\text { MB } \\
\text { MB } \\
\text { MB } \\
\text { MB } \\
\text { MB } \\
\text { MB } \\
\text { MB }\end{array}$ & $\begin{array}{l}0 \\
0 \\
0 \\
0 \\
0 \\
0 \\
0 \\
0 \\
0 \\
0 \\
0 \\
0 \\
0 \\
0 \\
0 \\
0 \\
0 \\
0 \\
0 \\
0 \\
0 \\
0\end{array}$ & $\mathrm{MG} / \mathrm{L}$ & $\begin{array}{l}< \\
< \\
< \\
< \\
< \\
< \\
< \\
< \\
< \\
< \\
< \\
< \\
< \\
< \\
< \\
< \\
< \\
< \\
< \\
<\end{array}$ & $\begin{array}{l}0.02 \\
0.01 \\
0.01 \\
0.02 \\
0.01 \\
0.01 \\
0.01 \\
0.01 \\
0.01 \\
0.01 \\
0.02 \\
0.01 \\
0.01 \\
0.01 \\
0.01 \\
0.01 \\
0.01 \\
0.02 \\
0.01 \\
0.01 \\
0.01 \\
0.01\end{array}$ & $\begin{array}{l}\text { J } \\
\text { L } \\
\text { L } \\
\text { L }\end{array}$ & $\begin{array}{l}0.01 \\
0.01 \\
0.01 \\
0.01 \\
0.01 \\
0.01 \\
0.01 \\
0.01 \\
0.01 \\
0.01 \\
0.01 \\
0.01 \\
0.01 \\
0.01 \\
0.01 \\
0.01 \\
0.01 \\
0.01 \\
0.01 \\
0.01 \\
0.01 \\
0.01\end{array}$ & $\begin{array}{l}- \\
- \\
- \\
- \\
- \\
- \\
- \\
- \\
- \\
- \\
- \\
- \\
- \\
- \\
- \\
- \\
- \\
-\end{array}$ \\
\hline NET GROSS ALPHA * & $\begin{array}{l}0516 \\
0516 \\
0516 \\
0516 \\
0516 \\
0520 \\
0520 \\
0520 \\
0520 \\
0522 \\
0522 \\
0522 \\
0522 \\
0522\end{array}$ & $\begin{array}{l}12 / 08 / 90 \\
04 / 04 / 91 \\
08 / 26 / 91 \\
10 / 14 / 92 \\
04 / 06 / 94 \\
12 / 12 / 90 \\
04 / 01 / 91 \\
08 / 22 / 91 \\
10 / 11 / 92 \\
12 / 08 / 90 \\
04 / 02 / 91 \\
08 / 22 / 91 \\
10 / 12 / 92 \\
04 / 05 / 94\end{array}$ & $\begin{array}{l}0001 \\
0001 \\
0001 \\
0001 \\
0001 \\
0001 \\
0001 \\
0001 \\
0001 \\
0001 \\
0001 \\
0001 \\
0001 \\
0001\end{array}$ & $\begin{array}{l}M B \\
M B \\
M B \\
M B \\
M B \\
M B \\
M B \\
M B \\
M B \\
M B \\
M B \\
M B \\
M B \\
M B\end{array}$ & $\begin{array}{l}0 \\
0 \\
0 \\
0 \\
0 \\
0 \\
0 \\
0 \\
0 \\
0 \\
0 \\
0 \\
0 \\
0\end{array}$ & $\mathrm{PCI} / \mathrm{L}$ & & $\begin{array}{r}3.20 \\
3.26 \\
1.56 \\
-0.34 \\
1.26 \\
3.46 \\
4.06 \\
1.86 \\
-1.37 \\
1.15 \\
-0.34 \\
-0.12 \\
-1.37 \\
0.71\end{array}$ & & $\begin{array}{l}- \\
- \\
- \\
- \\
- \\
- \\
- \\
- \\
- \\
-\end{array}$ & $\begin{array}{l}- \\
- \\
- \\
- \\
- \\
- \\
- \\
- \\
- \\
- \\
-\end{array}$ \\
\hline
\end{tabular}

* Net gROSS ALPHA (GROSS ALPHA - URANIUH)

WITH १ MG URANIUM $=686 \mathrm{PCI}$

FORMATION OF COMPLETION CODE:

MB - MIDDLE BURRO CANYON

PARAMETER VALUE INDICATOR (PVI): < - LESS THAN DETECTION LIMIT

OTHER PARAMETER VALUE FLAGS:

$J$
L - ESTIMATED VALUE
- LESS THAN THREE BORE VOLUMES REMOVED BEFORE SAMPLING
FLOH RELATIONSHIP CODE: O - ON-SITE

SAMPLE ID CODES:

0001 - FILTERED SAMPLE (.45 MICRONS) 


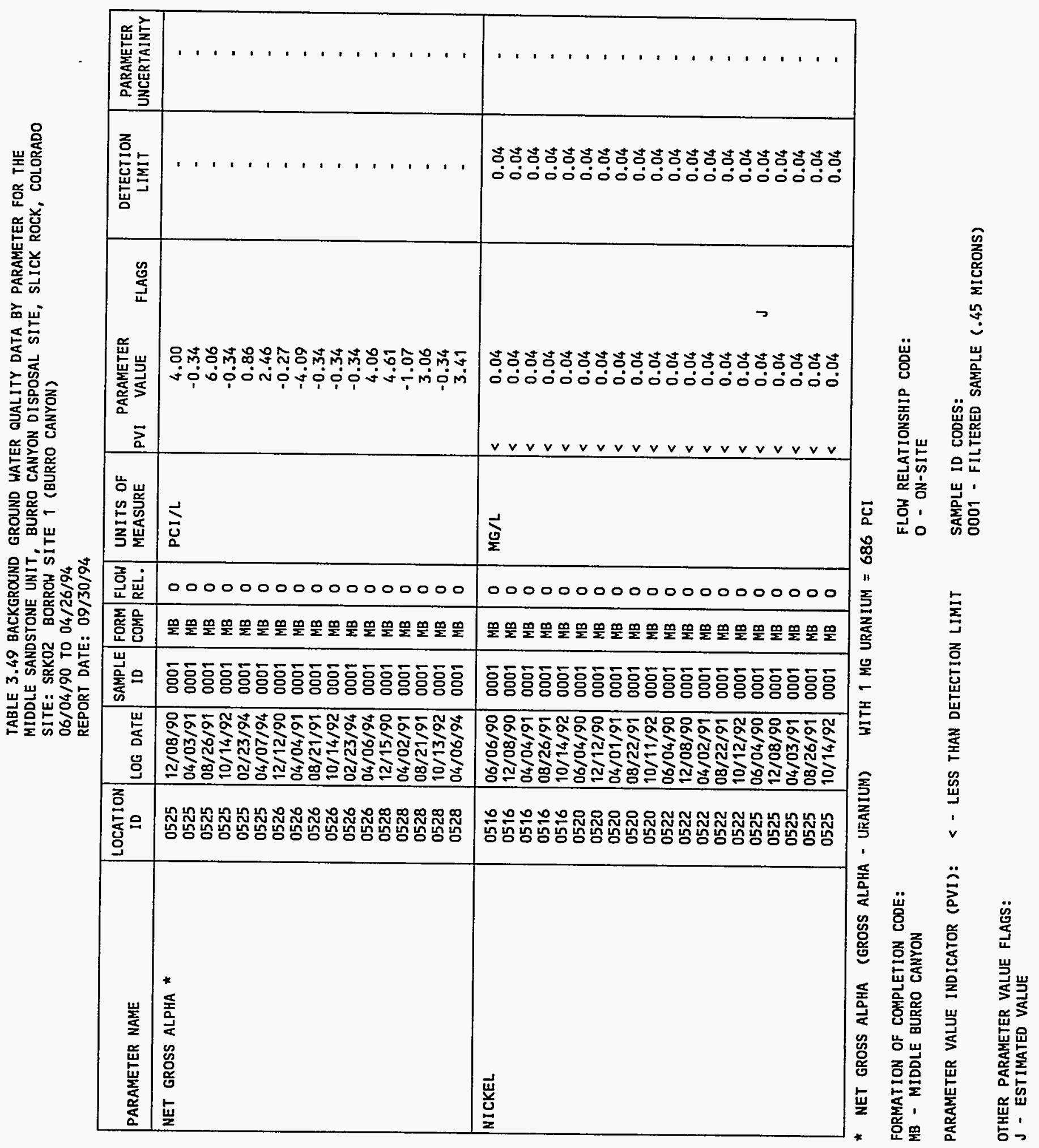


TABLE 3.49 BACKGROUND GROUND HATER QUALITY DATA BY PARAMETER FOR THE MIDDLE SANDSTONE UNIT, BURRO CANYON DISPOSAL SITE, SLICK ROCK, COLORADO SITE: SRKO2 BORROH SITE 1 (BURRO CANYON)

06/04/90 TO 04/26/94

REPORT DATE: $09 / 30 / 94$

\begin{tabular}{|c|c|c|c|c|c|c|c|c|c|c|c|}
\hline PARAMETER NAME & $\begin{array}{c}\text { LOCATION } \\
\text { ID }\end{array}$ & LOG DATE & $\begin{array}{c}\text { SAMPLE } \\
\text { ID }\end{array}$ & $\begin{array}{l}\text { FORM } \\
\text { COMP }\end{array}$ & $\begin{array}{l}\text { FLOW } \\
\text { REL. }\end{array}$ & $\begin{array}{l}\text { UNITS OF } \\
\text { MEASURE }\end{array}$ & PVI & $\begin{array}{l}\text { PARAMETER } \\
\text { VALUE }\end{array}$ & FLAGS & $\begin{array}{l}\text { DETECTION } \\
\text { LIMIT }\end{array}$ & \begin{tabular}{|} 
PARAMETER \\
UNCERTAINTY
\end{tabular} \\
\hline NICKEL & $\begin{array}{l}0526 \\
0526 \\
0526 \\
0526 \\
0526 \\
0528 \\
0528 \\
0528 \\
0528 \\
0528\end{array}$ & $\begin{array}{l}06 / 06 / 90 \\
12 / 12 / 90 \\
04 / 04 / 91 \\
08 / 21 / 91 \\
10 / 14 / 92 \\
06 / 06 / 90 \\
12 / 15 / 90 \\
04 / 02 / 91 \\
08 / 21 / 91 \\
10 / 13 / 92\end{array}$ & $\begin{array}{l}0001 \\
0001 \\
0001 \\
0001 \\
0001 \\
0001 \\
0001 \\
0001 \\
0001 \\
0001\end{array}$ & $\begin{array}{l}M B \\
M B \\
M B \\
M B \\
M B \\
M B \\
M B \\
M B \\
M B \\
M B\end{array}$ & $\begin{array}{l}0 \\
0 \\
0 \\
0 \\
0 \\
0 \\
0 \\
0 \\
0 \\
0\end{array}$ & MG/L & $\mid \begin{array}{l}< \\
< \\
< \\
< \\
< \\
< \\
< \\
< \\
< \\
<\end{array}$ & $\begin{array}{l}0.04 \\
0.04 \\
0.04 \\
0.04 \\
0.04 \\
0.04 \\
0.04 \\
0.04 \\
0.04 \\
0.04\end{array}$ & & $\begin{array}{l}0.04 \\
0.04 \\
0.04 \\
0.04 \\
0.04 \\
0.04 \\
0.04 \\
0.04 \\
0.04 \\
0.04\end{array}$ & $\begin{array}{l}- \\
- \\
- \\
- \\
- \\
- \\
-\end{array}$ \\
\hline NITRATE & $\begin{array}{l}0516 \\
0516 \\
0516 \\
0516 \\
0520 \\
0520 \\
0520 \\
0520 \\
0520 \\
0522 \\
0522 \\
0522 \\
0522 \\
0522 \\
0525 \\
0525 \\
0525 \\
0525 \\
0526 \\
0526 \\
0526 \\
0526 \\
0526 \\
0528 \\
0528 \\
0528 \\
0528 \\
0528\end{array}$ & $\begin{array}{l}06 / 06 / 90 \\
12 / 08 / 90 \\
04 / 04 / 91 \\
08 / 26 / 91 \\
06 / 04 / 90 \\
12 / 12 / 90 \\
04 / 01 / 91 \\
08 / 22 / 91 \\
10 / 11 / 92 \\
06 / 04 / 90 \\
12 / 08 / 90 \\
04 / 02 / 91 \\
08 / 22 / 91 \\
10 / 12 / 92 \\
06 / 04 / 90 \\
12 / 08 / 90 \\
04 / 03 / 91 \\
08 / 26 / 91 \\
06 / 06 / 90 \\
12 / 12 / 90 \\
04 / 04 / 91 \\
08 / 21 / 91 \\
10 / 14 / 92 \\
06 / 06 / 90 \\
12 / 15 / 90 \\
04 / 02 / 91 \\
08 / 21 / 91 \\
10 / 13 / 92\end{array}$ & $\begin{array}{l}0001 \\
0001 \\
0001 \\
0001 \\
0001 \\
0001 \\
0001 \\
0001 \\
0001 \\
0001 \\
0001 \\
0001 \\
0001 \\
0001 \\
0001 \\
0001 \\
0001 \\
0001 \\
0001 \\
0001 \\
0001 \\
0001 \\
0001 \\
0001 \\
0001 \\
0001 \\
0001 \\
0001\end{array}$ & $\begin{array}{l}M B \\
M B \\
M B \\
M B \\
M B \\
M B \\
M B \\
M B \\
M B \\
M B \\
M B \\
M B \\
M B \\
M B \\
M B \\
M B \\
M B \\
M B \\
M B \\
M B \\
M B \\
M B \\
M B \\
M B \\
M B \\
M B \\
M B \\
M B\end{array}$ & $\begin{array}{l}0 \\
0 \\
0 \\
0 \\
0 \\
0 \\
0 \\
0 \\
0 \\
0 \\
0 \\
0 \\
0 \\
0 \\
0 \\
0 \\
0 \\
0 \\
0 \\
0 \\
0 \\
0 \\
0 \\
0 \\
0 \\
0 \\
0 \\
0\end{array}$ & $M G / L$ & $\begin{array}{l}< \\
< \\
< \\
< \\
< \\
< \\
< \\
< \\
< \\
< \\
< \\
< \\
< \\
< \\
< \\
< \\
<\end{array}$ & $\begin{array}{c}1 . \\
1 . \\
2 . \\
4.0 \\
1.0 \\
1.0 \\
1.0 \\
17.7 \\
1.0 \\
1.0 \\
1.0 \\
1.0 \\
18.6 \\
1.0 \\
1.0 \\
1.0 \\
1 . \\
6.2 \\
1.0 \\
1.0 \\
2 . \\
15.5 \\
1.8 \\
1.5 \\
1.0 \\
2.0 \\
19.5 \\
1.5\end{array}$ & $\begin{array}{l}\text { J } \\
\text { J } \\
\text { J } \\
\text { J } \\
\text { J }\end{array}$ & $\begin{array}{l}1 . \\
1 . \\
1 . \\
1 . \\
1 . \\
1 . \\
1.0 \\
1.0 \\
1 . \\
1 . \\
1.0 \\
1.0 \\
1 . \\
1 . \\
1 . \\
1 . \\
1 . \\
1 . \\
1 . \\
0.1 \\
1 . \\
1 . \\
1 . \\
1 . \\
0.1\end{array}$ & $\begin{array}{l}- \\
- \\
- \\
- \\
- \\
- \\
- \\
- \\
- \\
- \\
- \\
- \\
- \\
- \\
- \\
- \\
- \\
- \\
- \\
- \\
- \\
-\end{array}$ \\
\hline NITRITE AND NITRATE & 0516 & $06 / 06 / 90$ & 0001 & MB & 0 & MG/L & $<$ & 1. & & 1. & - \\
\hline
\end{tabular}

FORMATION OF COMPLETION CODE:

MB - MIDDLE BURRO CANYON

PARAMETER VALUE INDICATOR (PVI):
FLOW RELATIONSHIP CODE:

O - ON-SITE

SAMPLE ID CODES:
0001 - FILTERED SAMPLE (.45 MICRONS)

OTHER PARAMETER VALUE FLAGS:

J - ESTIMATED VALUE 
TABLE 3.49 BACKGROUND GROUND WATER QUALITY DATA BY PARAMETER FOR THE MIDDLE SANDSTONE UNIT, BURRO CANYON DISPOSAL SITE, SLICK ROCK, COLORADO SITE: SRKO2 BORROW SITE 1 (BURRO CANYON)

06/04/90 TO $04 / 26 / 94$

REPORT DATE: $09 / 30 / 94$

\begin{tabular}{|c|c|c|c|c|c|c|c|c|c|c|c|}
\hline PARAMETER NAME & $\underset{10}{\text { LOCATION }}$ & LOG DATE & $\begin{array}{c}\text { SAMPLE } \\
\text { ID }\end{array}$ & $\begin{array}{l}\text { FORM } \\
\text { COMP }\end{array}$ & $\begin{array}{l}\text { FLOW } \\
\text { REL. }\end{array}$ & $\begin{array}{l}\text { UNI TS OF } \\
\text { MEASURE }\end{array}$ & PVI & $\begin{array}{l}\text { PARAMETER } \\
\text { VALUE }\end{array}$ & FLAGS & $\begin{array}{l}\text { DETECTION } \\
\text { LIMIT }\end{array}$ & $\begin{array}{l}\text { PARAMETER } \\
\text { UNCERTAINTY }\end{array}$ \\
\hline NITRITE AND NITRATE & $\begin{array}{l}0516 \\
0516 \\
0516 \\
0520 \\
0520 \\
0520 \\
0520 \\
0522 \\
0522 \\
0522 \\
0522 \\
0525 \\
0525 \\
0525 \\
0525 \\
0526 \\
0526 \\
0526 \\
0526 \\
0528 \\
0528 \\
0528 \\
0528\end{array}$ & $\begin{array}{l}12 / 08 / 90 \\
04 / 04 / 91 \\
08 / 26 / 91 \\
06 / 04 / 90 \\
12 / 12 / 90 \\
04 / 01 / 91 \\
08 / 22 / 91 \\
06 / 04 / 90 \\
12 / 08 / 90 \\
04 / 02 / 91 \\
08 / 22 / 91 \\
06 / 04 / 90 \\
12 / 08 / 90 \\
04 / 03 / 91 \\
08 / 26 / 91 \\
06 / 06 / 90 \\
12 / 12 / 90 \\
04 / 04 / 91 \\
08 / 21 / 91 \\
06 / 06 / 90 \\
12 / 15 / 90 \\
04 / 02 / 91 \\
08 / 21 / 91\end{array}$ & $\begin{array}{l}0001 \\
0001 \\
0001 \\
0001 \\
0001 \\
0001 \\
0001 \\
0001 \\
0001 \\
0001 \\
0001 \\
0001 \\
0001 \\
0001 \\
0001 \\
0001 \\
0001 \\
0001 \\
0001 \\
0001 \\
0001 \\
0001 \\
0001\end{array}$ & $\begin{array}{l}M B \\
M B \\
M B \\
M B \\
M B \\
M B \\
M B \\
M B \\
M B \\
M B \\
M B \\
M B \\
M B \\
M B \\
M B \\
M B \\
M B \\
M B \\
M B \\
M B \\
M B \\
M B \\
M B\end{array}$ & $\begin{array}{l}0 \\
0 \\
0 \\
0 \\
0 \\
0 \\
0 \\
0 \\
0 \\
0 \\
0 \\
0 \\
0 \\
0 \\
0 \\
0 \\
0 \\
0 \\
0 \\
0 \\
0 \\
0 \\
0\end{array}$ & $M G / L$ & $\begin{array}{l}< \\
< \\
< \\
< \\
< \\
< \\
< \\
< \\
< \\
< \\
< \\
<\end{array}$ & $\begin{array}{l}1 . \\
0.38 \\
0.93 \\
1 . \\
1 . \\
0.19 \\
4.04 \\
1 . \\
1 . \\
0.23 \\
4.24 \\
1 . \\
1 . \\
0.30 \\
1.38 \\
1 . \\
1 . \\
0.44 \\
3.49 \\
1 . \\
1 . \\
0.37 \\
4.41\end{array}$ & $\begin{array}{l}J \\
J \\
J \\
J\end{array}$ & $\begin{array}{l}1 . \\
0.05 \\
0.05 \\
1 . \\
1 . \\
0.05 \\
0.05 \\
1 . \\
1 . \\
0.05 \\
0.05 \\
1 . \\
1 . \\
0.05 \\
0.05 \\
1 . \\
1 . \\
0.05 \\
0.05 \\
1 . \\
1.05 \\
0.05 \\
0.05\end{array}$ & $\begin{array}{l}- \\
- \\
- \\
- \\
- \\
- \\
- \\
- \\
- \\
- \\
- \\
- \\
- \\
- \\
- \\
- \\
- \\
- \\
-\end{array}$ \\
\hline PH & $\begin{array}{l}0516 \\
0516 \\
0516 \\
0516 \\
0516 \\
0516 \\
0520 \\
0520 \\
0520 \\
0520 \\
0520 \\
0522 \\
0522 \\
0522 \\
0522 \\
0522\end{array}$ & $\begin{array}{l}06 / 06 / 90 \\
12 / 08 / 90 \\
04 / 04 / 91 \\
08 / 26 / 91 \\
10 / 14 / 92 \\
04 / 06 / 94 \\
06 / 04 / 90 \\
12 / 12 / 90 \\
04 / 01 / 91 \\
08 / 22 / 91 \\
10 / 11 / 92 \\
06 / 04 / 90 \\
12 / 08 / 90 \\
04 / 02 / 91 \\
08 / 22 / 91 \\
10 / 12 / 92\end{array}$ & $\begin{array}{l}0001 \\
0001 \\
0001 \\
0001 \\
0001 \\
0001 \\
0001 \\
0001 \\
0001 \\
0001 \\
0001 \\
0001 \\
0001 \\
0001 \\
0001 \\
0001\end{array}$ & $\begin{array}{l}M B \\
M B \\
M B \\
M B \\
M B \\
M B \\
M B \\
M B \\
M B \\
M B \\
M B \\
M B \\
M B \\
M B \\
M B \\
M B\end{array}$ & $\begin{array}{l}0 \\
0 \\
0 \\
0 \\
0 \\
0 \\
0 \\
0 \\
0 \\
0 \\
0 \\
0 \\
0 \\
0 \\
0 \\
0\end{array}$ & SU & & $\begin{array}{l}7.56 \\
7.5 \\
7.57 \\
7.53 \\
7.43 \\
7.48 \\
7.26 \\
7.19 \\
7.26 \\
7.27 \\
7.24 \\
7.28 \\
7.42 \\
7.38 \\
7.37 \\
7.47\end{array}$ & & $\begin{array}{l}- \\
- \\
- \\
- \\
- \\
- \\
- \\
- \\
- \\
- \\
- \\
- \\
-\end{array}$ & $\begin{array}{l}- \\
- \\
- \\
- \\
- \\
- \\
- \\
- \\
- \\
- \\
- \\
-\end{array}$ \\
\hline
\end{tabular}

FORMATION OF COMPLETION CODE:

MB - MIDDLE BURRO CANYON

PARAMETER VALUE INDICATOR (PVI):
FLOW RELATIONSHIP CODE:

O - ON-SITE 
TABLE 3.49 BACKGROUND GROUND WATER QUALITY DATA BY PARAMETER FOR THE

MIDDLE SANDSTONE UNIT, BURRO CANYON DISPOSAL SITE, SLICK ROCK, COLORADO

SITE: SRKO2 BORROW SITE 1 (BURRO CANYON)

06/04/90 TO 04/26/94

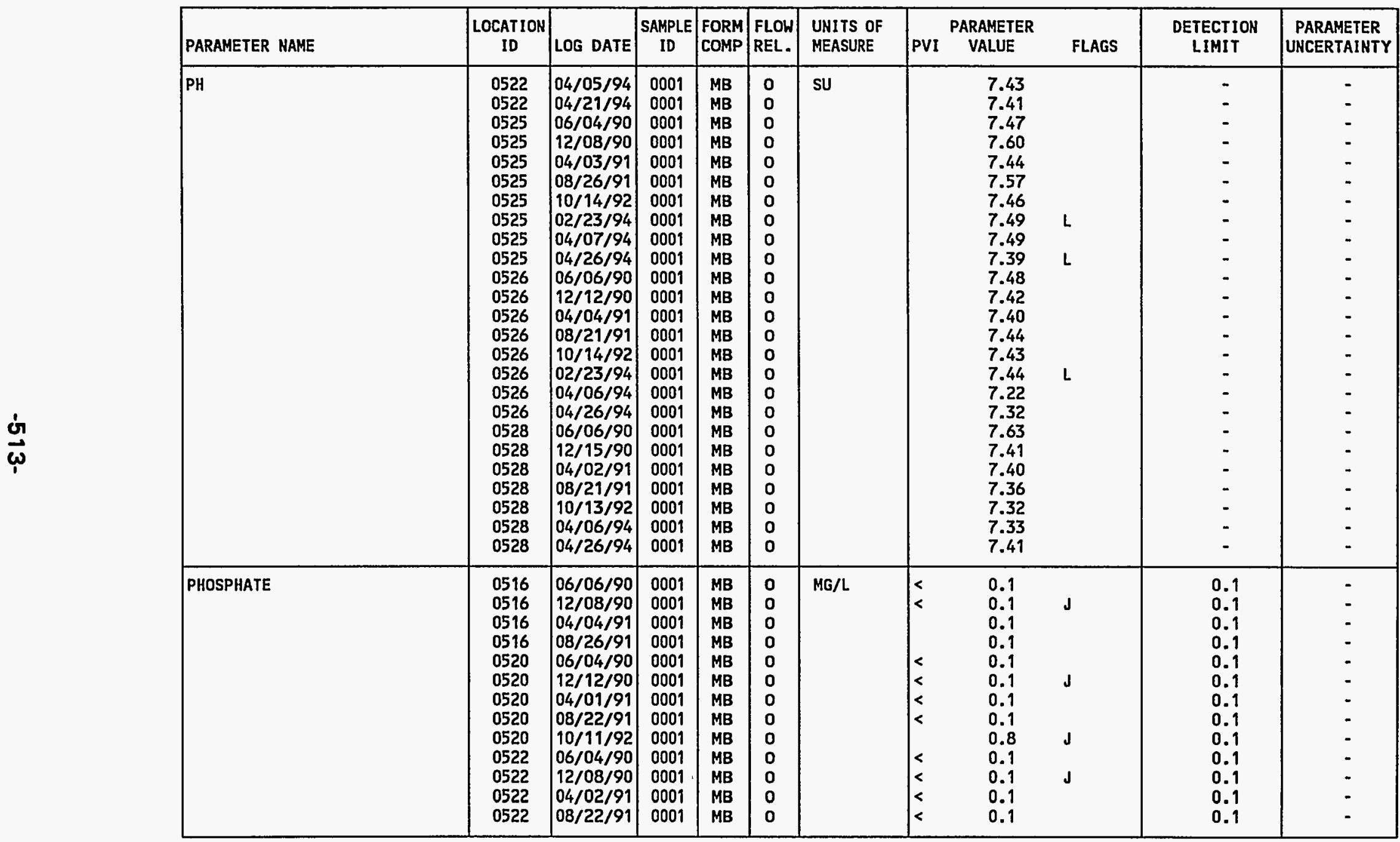

FOPMATION OF COMPLETION CODE:

MB - MIDDLE BURRO CANYON

PARAMETER VALUE INDICATOR (PVI): < - LESS THAN DETECTION LIMIT

OTHER PARAMETER VALUE FLAGS:

$J$ - ESTIMATED VALUE

L - LESS THAN THREE BORE VOLUMES REMOVED BEFORE SAMPLING
FLOH RELATIONSHIP CODE:

O- ON-SITE

SAMPLE ID CODES:

0001 - FILTERED SAMPLE (.45 MICRONS) 


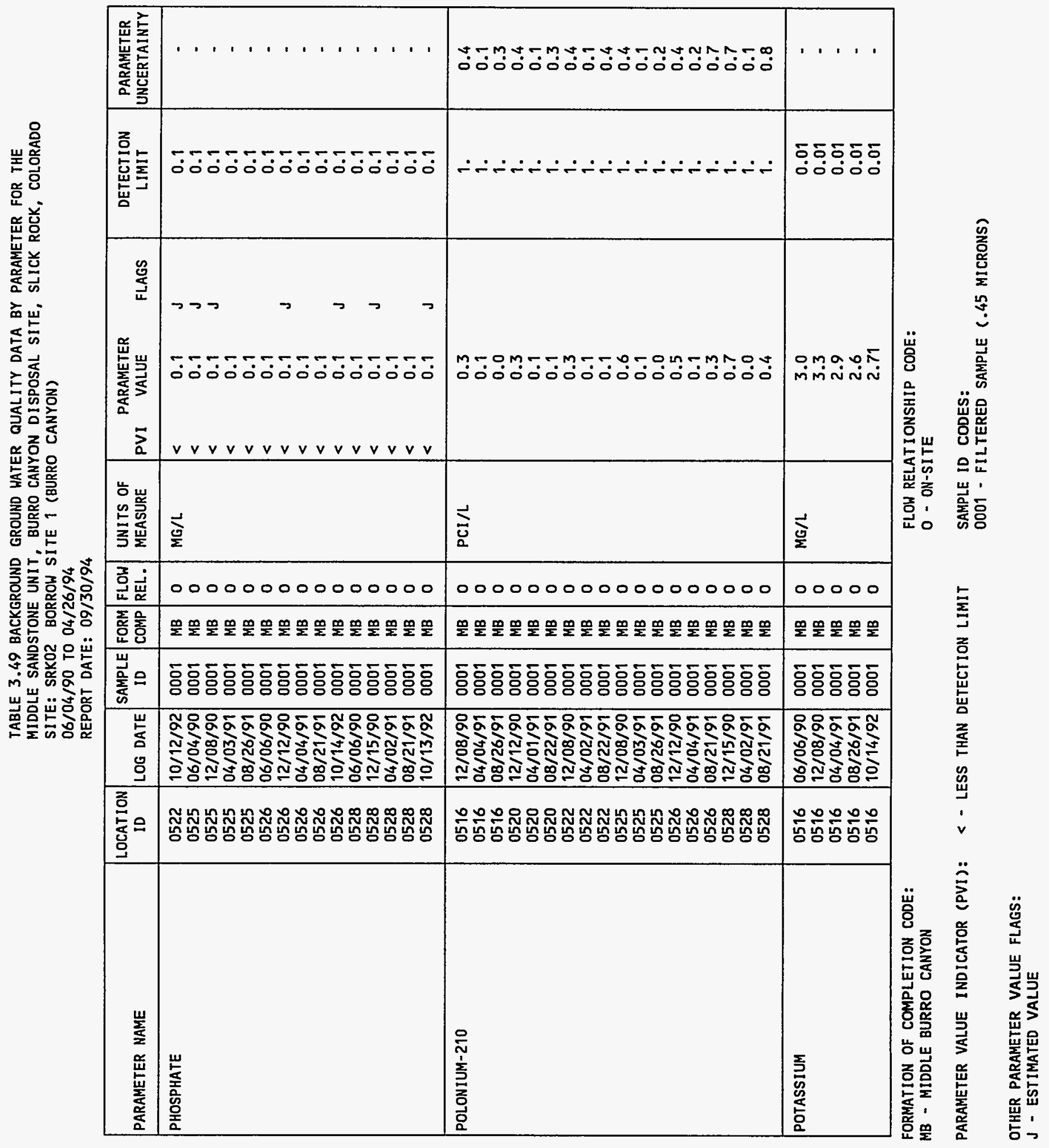




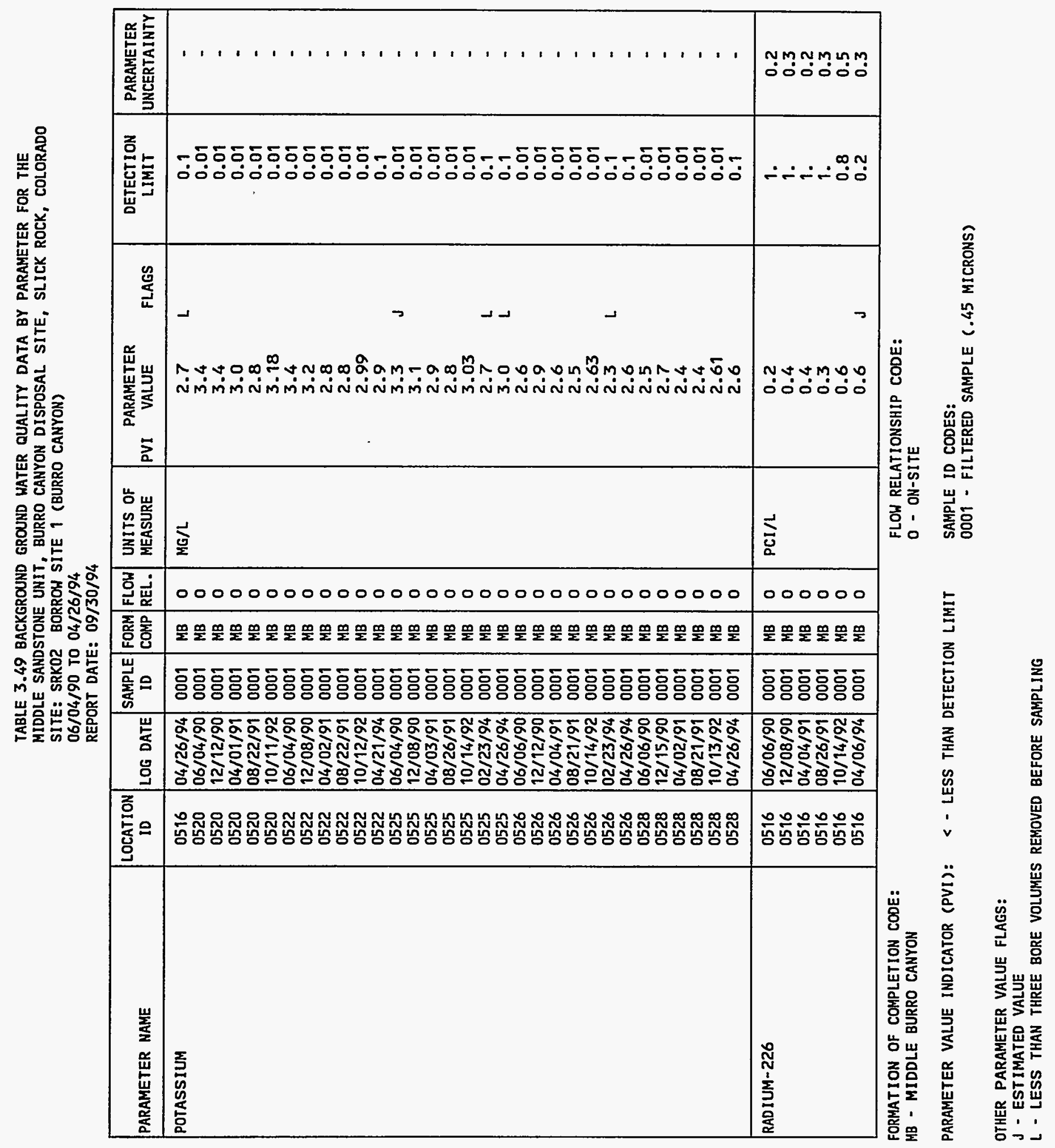


TABLE 3.49 BACKGROUND GROUND WATER QUALITY DATA BY PARAMETER FOR THE

MIDDLE SANDSTONE UNIT, BURRO CANYON DISPOSAL SITE, SLIICK ROCK, COLORADO SITE: SRKO2 BORROW SITE 1 (BURRO CANYON)

$06 / 04 / 90$ TO $04 / 26 / 94$

REPORT DATE : 09/30/94

\begin{tabular}{|c|c|c|c|c|c|c|c|c|c|c|c|}
\hline PARAMETER NAME & $\underset{\text { ID }}{\text { LOCATION }}$ & LOG DATE & $\underset{\text { ID }}{\text { SAMPLE }}$ & $\begin{array}{l}\text { FORM } \\
\text { COMP }\end{array}$ & $\begin{array}{l}\text { FLOW } \\
\text { REL. }\end{array}$ & $\begin{array}{l}\text { UNITS OF } \\
\text { MEASURE }\end{array}$ & PVI & $\begin{array}{l}\text { PARAMETE } \\
\text { VALUE }\end{array}$ & FLAGS & $\begin{array}{l}\text { DETECTION } \\
\text { LIMIT }\end{array}$ & $\begin{array}{l}\text { PARAMETER } \\
\text { UNCERTAINTYY }\end{array}$ \\
\hline RADIUM-226 & $\begin{array}{l}0520 \\
0520 \\
0520 \\
0520 \\
0520 \\
0522 \\
0522 \\
0522 \\
0522 \\
0522 \\
0522 \\
0525 \\
0525 \\
0525 \\
0525 \\
0525 \\
0525 \\
0525 \\
0526 \\
0526 \\
0526 \\
0526 \\
0526 \\
0526 \\
0526 \\
0528 \\
0528 \\
0528 \\
0528 \\
0528 \\
0528\end{array}$ & $\begin{array}{l}06 / 04 / 90 \\
12 / 12 / 90 \\
04 / 01 / 91 \\
08 / 22 / 91 \\
10 / 11 / 92 \\
06 / 04 / 90 \\
12 / 08 / 90 \\
04 / 02 / 91 \\
08 / 22 / 91 \\
10 / 12 / 92 \\
04 / 05 / 94 \\
06 / 04 / 90 \\
12 / 08 / 90 \\
04 / 03 / 91 \\
08 / 26 / 91 \\
10 / 14 / 92 \\
02 / 23 / 94 \\
04 / 07 / 94 \\
06 / 06 / 90 \\
12 / 12 / 90 \\
04 / 04 / 91 \\
08 / 21 / 91 \\
10 / 14 / 92 \\
02 / 23 / 94 \\
04 / 06 / 94 \\
06 / 06 / 90 \\
12 / 15 / 90 \\
04 / 02 / 91 \\
08 / 21 / 91 \\
10 / 13 / 92 \\
04 / 06 / 94\end{array}$ & $\begin{array}{l}0001 \\
0001 \\
0001 \\
0001 \\
0001 \\
0001 \\
0001 \\
0001 \\
0001 \\
0001 \\
0001 \\
0001 \\
0001 \\
0001 \\
0001 \\
0001 \\
0001 \\
0001 \\
0001 \\
0001 \\
0001 \\
0001 \\
0001 \\
0001 \\
0001 \\
0001 \\
0001 \\
0001 \\
0001 \\
0001 \\
0001\end{array}$ & $\begin{array}{l}\text { MB } \\
\text { MB } \\
\text { MB } \\
\text { MB } \\
\text { MB } \\
\text { MB } \\
\text { MB } \\
\text { MB } \\
\text { MB } \\
\text { MB } \\
\text { MB } \\
\text { MB } \\
\text { MB } \\
\text { MB } \\
\text { MB } \\
\text { MB } \\
\text { MB } \\
\text { MB } \\
\text { MB } \\
\text { MB } \\
\text { MB } \\
\text { MB } \\
\text { MB } \\
\text { MB } \\
\text { MB } \\
\text { MB } \\
\text { MB } \\
M B \\
M B \\
\text { MB } \\
\text { MB }\end{array}$ & $\begin{array}{l}0 \\
0 \\
0 \\
0 \\
0 \\
0 \\
0 \\
0 \\
0 \\
0 \\
0 \\
0 \\
0 \\
0 \\
0 \\
0 \\
0 \\
0 \\
0 \\
0 \\
0 \\
0 \\
0 \\
0 \\
0 \\
0 \\
0 \\
0 \\
0 \\
0 \\
0\end{array}$ & $\mathrm{PCI} / \mathrm{L}$ & & $\begin{array}{l}0.2 \\
0.4 \\
0.8 \\
0.6 \\
0.6 \\
0.5 \\
0.3 \\
0.6 \\
0.3 \\
0.9 \\
1.0 \\
0.5 \\
0.3 \\
0.4 \\
0.6 \\
0.0 \\
0.4 \\
0.2 \\
0.1 \\
0.2 \\
0.8 \\
0.9 \\
0.5 \\
0.6 \\
0.7 \\
0.2 \\
0.7 \\
0.8 \\
0.8 \\
1.0 \\
0.6\end{array}$ & $\begin{array}{l}J \\
J \\
J \\
J\end{array}$ & $\begin{array}{l}1 . \\
1 . \\
1 . \\
1.8 \\
1 . \\
1 . \\
1 . \\
1 . \\
0.8 \\
0.1 \\
1 . \\
1 . \\
1 . \\
1 . \\
0.8 \\
0.1 \\
0.1 \\
1 . \\
1 . \\
1 . \\
1 . \\
0.8 \\
0.1 \\
0.1 \\
1 . \\
1 . \\
1 . \\
1 . \\
0.8 \\
0.1\end{array}$ & $\begin{array}{l}0.3 \\
0.3 \\
0.3 \\
0.3 \\
0.6 \\
0.3 \\
0.2 \\
0.2 \\
0.3 \\
0.6 \\
0.2 \\
0.5 \\
0.2 \\
0.2 \\
0.3 \\
0.5 \\
0.1 \\
0.1 \\
0.2 \\
0.2 \\
0.3 \\
0.4 \\
0.5 \\
0.2 \\
0.2 \\
0.2 \\
0.3 \\
0.3 \\
0.4 \\
0.6 \\
0.2\end{array}$ \\
\hline RADIUM-226 + RADIUM-228 & $\begin{array}{l}0516 \\
0516 \\
0516 \\
0516 \\
0516 \\
0516 \\
0520\end{array}$ & $\begin{array}{l}06 / 06 / 90 \\
12 / 08 / 90 \\
04 / 04 / 91 \\
08 / 26 / 91 \\
10 / 14 / 92 \\
04 / 06 / 94 \\
06 / 04 / 90\end{array}$ & $\begin{array}{l}0001 \\
0001 \\
0001 \\
0001 \\
0001 \\
0001 \\
0001\end{array}$ & $\begin{array}{l}\text { MB } \\
\text { MB } \\
\text { MB } \\
\text { MB } \\
\text { MB } \\
\text { MB } \\
\text { MB }\end{array}$ & $\begin{array}{l}0 \\
0 \\
0 \\
0 \\
0 \\
0 \\
0\end{array}$ & $\mathrm{PCl} / \mathrm{L}$ & & $\begin{array}{l}2.40 \\
2.00 \\
8.20 \\
0.30 \\
0.60 \\
2.30 \\
0.70\end{array}$ & & $\begin{array}{l}- \\
- \\
- \\
- \\
-\end{array}$ & $\begin{array}{l}: \\
: \\
: \\
-\end{array}$ \\
\hline
\end{tabular}

FORMATION OF COMPLETION CODE:

MB - MIDDLE BURRO CANYON

PARAMETER VALUE INDICATOR (PVI): < - LESS THAN DETECTION LIMIT

OTHER PARAMETER VALUE FLAGS:

$J$ - ESTIMATED VALUE

L - LESS THAN THREE BORE VOLUMES REMOVED BEFORE SAMPLING
FLOW RELATIONSHIP CODE:

SAMPLE ID CODES:

0001 - FILTERED SAMPLE (.45 MICRONS) 
TABLE 3.49 BACKGROUND GROUND MATER QUALITY DATA BY PARAMETER FOR THE

MIDDLE SANDSTONE UNIT, BURRO CANYON DISPOSAL SITE, SLICK ROCK, COLORADO

SITE: SRKO2 BORROH SITE 1 (BURRO CANYON)

06/04/90 TO 04/26/94

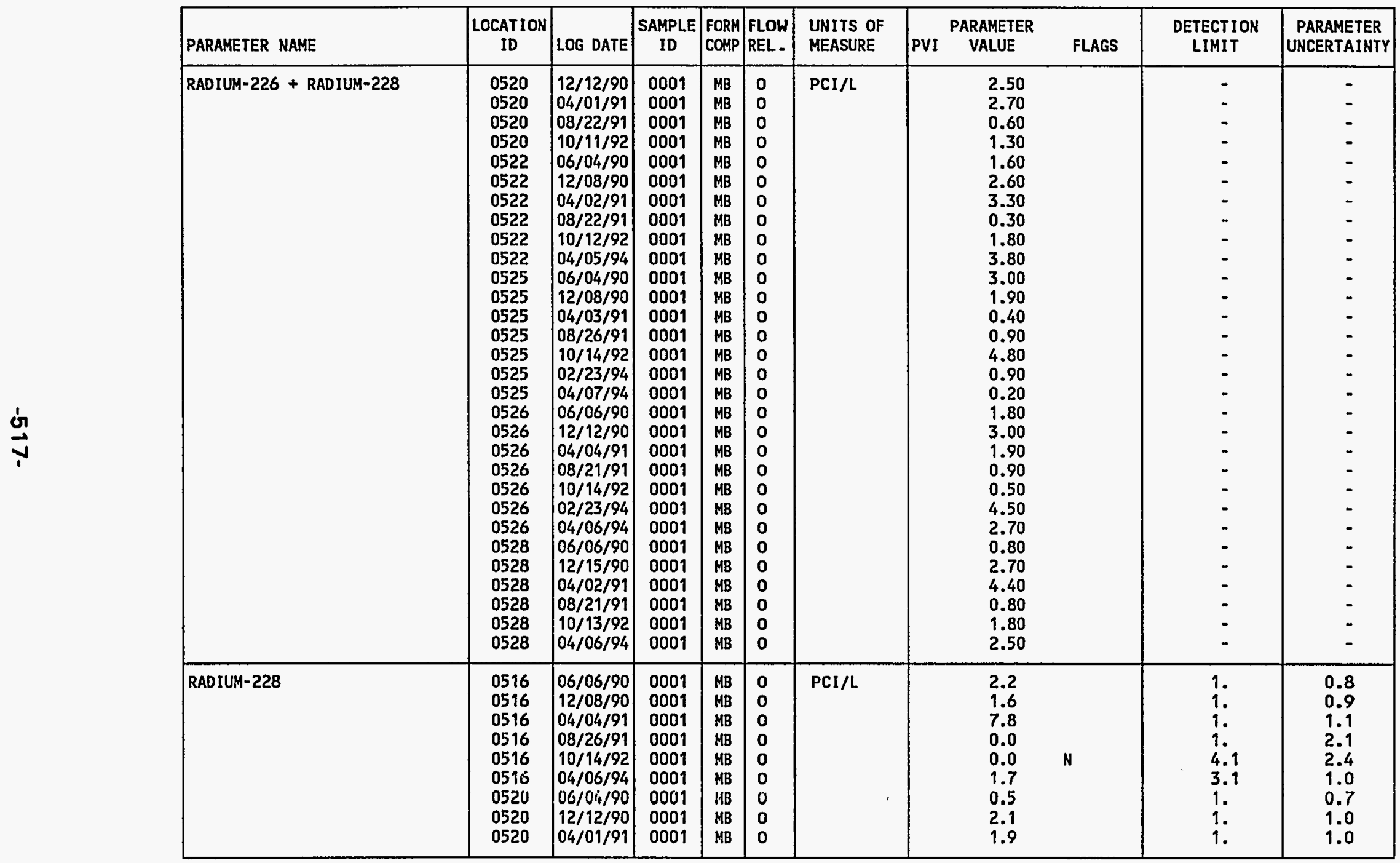

FORMATION OF COMPLETION CODE:

MB - MIDDLE BURRO CANYON

FLOH RELATIONSHIP CODE

PARAMETER VALUE INDICATOR (PVI): < - LESS THAN DETECTION LIMIT

SAMPLE ID CODES:

0001 - FILTERED SAMPLE (.45 MICRONS)

OTHER PARAMETER VALUE FLAGS

$N$ - SPIKE SAMPLE RECOVERY NOT WITHIN CONTROL LIMITS 
TABLE 3.49 BACKGROUND GROUND WATER QUALITY DATA BY PARAMETER FOR THE MIDDLE SANDSTONE UNIT, BURRO CANYON DISPOSAL SITE, SLICK ROCK, COLORADO SITE: SRKO2 BORROW SITE 1 (BURRO CANYON)

06/04/90 TO 04/26/94

REPORT DATE: $09 / 30 / 94$

\begin{tabular}{|c|c|c|c|c|c|c|c|c|c|c|c|}
\hline PARAMETER NAME & ${ }_{\text {IO }}^{\text {LOCATION }}$ & LOG DATE & $\begin{array}{c}\text { SAMPLE } \\
10\end{array}$ & $\begin{array}{l}\text { FORM } \\
\text { COMP }\end{array}$ & $\begin{array}{l}\text { FLOW } \\
\text { REL. }\end{array}$ & $\begin{array}{l}\text { UNITS OF } \\
\text { MEASURE }\end{array}$ & PVI & $\begin{array}{l}\text { PARAMETER } \\
\text { VALUE }\end{array}$ & FLAGS & $\begin{array}{l}\text { DETECTION } \\
\text { LIMIT }\end{array}$ & $\begin{array}{l}\text { PARAMETER } \\
\text { UNCERTAINTY }\end{array}$ \\
\hline RAD IUM-228 & $\begin{array}{l}0520 \\
0520 \\
0522 \\
0522 \\
0522 \\
0522 \\
0522 \\
0522 \\
0525 \\
0525 \\
0525 \\
0525 \\
0525 \\
0525 \\
0525 \\
0526 \\
0526 \\
0526 \\
0526 \\
0526 \\
0526 \\
0526 \\
0528 \\
0528 \\
0528 \\
0528 \\
0528 \\
0528\end{array}$ & $\begin{array}{l}08 / 22 / 91 \\
10 / 11 / 92 \\
06 / 04 / 90 \\
12 / 08 / 90 \\
04 / 02 / 91 \\
08 / 22 / 91 \\
10 / 12 / 92 \\
04 / 05 / 94 \\
06 / 04 / 90 \\
12 / 08 / 90 \\
04 / 03 / 91 \\
08 / 26 / 91 \\
10 / 14 / 92 \\
02 / 23 / 94 \\
04 / 07 / 94 \\
06 / 06 / 90 \\
12 / 12 / 90 \\
04 / 04 / 91 \\
08 / 21 / 91 \\
10 / 14 / 92 \\
02 / 23 / 94 \\
04 / 06 / 94 \\
06 / 06 / 90 \\
12 / 15 / 90 \\
04 / 02 / 91 \\
08 / 21 / 91 \\
10 / 13 / 92 \\
04 / 06 / 94\end{array}$ & $\begin{array}{l}0001 \\
0001 \\
0001 \\
0001 \\
0001 \\
0001 \\
0001 \\
0001 \\
0001 \\
0001 \\
0001 \\
0001 \\
0001 \\
0001 \\
0001 \\
0001 \\
0001 \\
0001 \\
0001 \\
0001 \\
0001 \\
0001 \\
0001 \\
0001 \\
0001 \\
0001 \\
0001 \\
0001\end{array}$ & $\begin{array}{l}\text { MB } \\
\text { MB } \\
M B \\
M B \\
M B \\
M B \\
M B \\
M B \\
M B \\
M B \\
M B \\
M B \\
M B \\
M B \\
M B \\
M B \\
M B \\
M B \\
M B \\
M B \\
M B \\
M B \\
M B \\
M B \\
M B \\
M B \\
M B \\
M B\end{array}$ & $\begin{array}{l}0 \\
0 \\
0 \\
0 \\
0 \\
0 \\
0 \\
0 \\
0 \\
0 \\
0 \\
0 \\
0 \\
0 \\
0 \\
0 \\
0 \\
0 \\
0 \\
0 \\
0 \\
0 \\
0 \\
0 \\
0 \\
0 \\
0 \\
0\end{array}$ & PCI/L & & $\begin{array}{l}0.0 \\
0.7 \\
1.1 \\
2.3 \\
2.7 \\
0.0 \\
0.9 \\
2.8 \\
2.5 \\
1.6 \\
0.0 \\
0.3 \\
4.8 \\
0.5 \\
0.0 \\
1.7 \\
2.8 \\
1.1 \\
0.0 \\
0.0 \\
3.9 \\
2.0 \\
0.6 \\
2.0 \\
3.6 \\
0.0 \\
0.8 \\
1.9\end{array}$ & $\begin{array}{l}\text { N } \\
\mathbf{L}\end{array}$ & $\begin{array}{l}1 . \\
2.9 \\
1 . \\
1 . \\
1 . \\
1 . \\
2.9 \\
3.1 \\
1 . \\
1 . \\
1 . \\
1 . \\
2.6 \\
2.9 \\
3.5 \\
1 . \\
1 . \\
1 . \\
1 . \\
4.1 \\
3.1 \\
3.2 \\
1 . \\
1 . \\
1 . \\
1 . \\
2.6 \\
2.8\end{array}$ & $\begin{array}{l}2.4 \\
1.8 \\
0.7 \\
0.9 \\
1.0 \\
2.6 \\
1.8 \\
1.1 \\
0.9 \\
0.8 \\
1.1 \\
2.1 \\
1.9 \\
0.8 \\
1.5 \\
0.9 \\
1.0 \\
1.2 \\
2.6 \\
2.4 \\
1.4 \\
1.1 \\
0.8 \\
0.8 \\
1.4 \\
2.5 \\
1.6 \\
1.3\end{array}$ \\
\hline REDOX POTENTIAL & $\begin{array}{l}0516 \\
0516 \\
0516 \\
0520 \\
0520 \\
0522 \\
0522 \\
0522 \\
0522\end{array}$ & $\begin{array}{l}12 / 08 / 90 \\
10 / 14 / 92 \\
04 / 06 / 94 \\
12 / 12 / 90 \\
10 / 11 / 92 \\
12 / 08 / 90 \\
10 / 12 / 92 \\
04 / 05 / 94 \\
04 / 21 / 94\end{array}$ & $\begin{array}{l}0001 \\
0001 \\
0001 \\
0001 \\
0001 \\
0001 \\
0001 \\
0001 \\
0001\end{array}$ & $\begin{array}{l}\text { MB } \\
M B \\
M B \\
M B \\
M B \\
M B \\
M B \\
M B \\
M B\end{array}$ & $\begin{array}{l}0 \\
0 \\
0 \\
0 \\
0 \\
0 \\
0 \\
0 \\
0\end{array}$ & mVOLTS & & $\begin{array}{l}242.5 \\
239.3 \\
383 \\
342.6 \\
322 \\
209.9 \\
246.3 \\
15.2 \\
-227\end{array}$ & & $\begin{array}{l}- \\
- \\
- \\
- \\
- \\
-\end{array}$ & $\begin{array}{l}- \\
- \\
- \\
- \\
- \\
-\end{array}$ \\
\hline
\end{tabular}

FORMATION OF COMPLETION CODE:

MB - MIDDLE BURRO CANYON

FLOW RELATIONSHIP CODE:

PARAMETER VALUE INDICATOR (PVI): < - LESS THAN DETECTION LIMIT

SAMPLE ID CODES:

0001 - FILTERED SAMPLE (.45 MICRONS)

OTHER PARAMETER VALUE FLAGS:

$J$ - ESTIMATED VALUE

L - LESS THAN THREE BORE VOLUMES REMOVED BEFORE SAMPLING

N - SPIKE SAMPLE RECONERY NOT HITHIN CONTROL LIMITS 


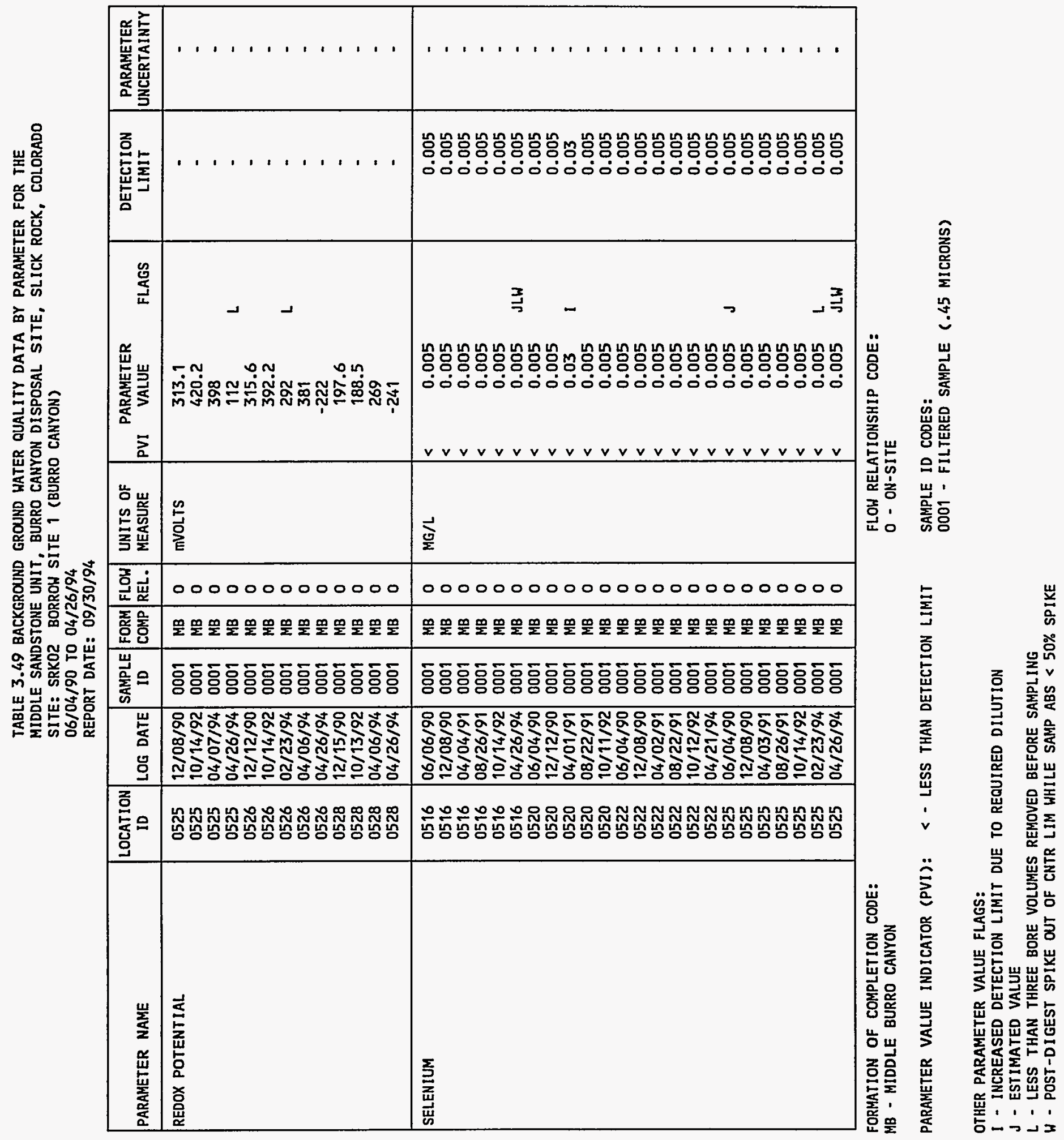


TABLE 3.49 BACKGROUND GROUND WATER QUALITY DATA BY PARAMETER FOR THE

MIDDLE SANDSTONE UNIT, BURRO CANYON DISPOSAL SITE, SLICK ROCK, COLORADO

SITE: SRKO2 BORROW SITE 1 (BURRO CANYON)

$06 / 04 / 90$ TO $04 / 26 / 94$

REPORT DATE: $09 / 30 / 94$

\begin{tabular}{|c|c|c|c|c|c|c|c|c|c|c|c|}
\hline PARAMETER NAME & $\begin{array}{c}\text { LOCATION } \\
\text { ID }\end{array}$ & LOG DATE & $\begin{array}{c}\text { SAMPLE } \\
\text { ID }\end{array}$ & $\begin{array}{l}\text { FORM } \\
\text { COMP }\end{array}$ & $\begin{array}{l}\text { FLOW } \\
\text { REL. }\end{array}$ & $\begin{array}{l}\text { UNITS OF } \\
\text { MEASURE }\end{array}$ & PVI & $\begin{array}{l}\text { PARAMETER } \\
\text { VALUE }\end{array}$ & FLAGS & $\begin{array}{l}\text { DETECTION } \\
\text { LIMIT }\end{array}$ & $\begin{array}{l}\text { PARAMETER } \\
\text { UNCERTAINTY }\end{array}$ \\
\hline SELENIUM & $\begin{array}{l}0526 \\
0526 \\
0526 \\
0526 \\
0526 \\
0526 \\
0526 \\
0528 \\
0528 \\
0528 \\
0528 \\
0528 \\
0528\end{array}$ & $\begin{array}{l}06 / 06 / 90 \\
12 / 12 / 90 \\
04 / 04 / 91 \\
08 / 21 / 91 \\
10 / 14 / 92 \\
02 / 23 / 94 \\
04 / 26 / 94 \\
06 / 06 / 90 \\
12 / 15 / 90 \\
04 / 02 / 91 \\
08 / 21 / 91 \\
10 / 13 / 92 \\
04 / 26 / 94\end{array}$ & $\begin{array}{l}0001 \\
0001 \\
0001 \\
0001 \\
0001 \\
0001 \\
0001 \\
0001 \\
0001 \\
0001 \\
0001 \\
0001 \\
0001\end{array}$ & $\begin{array}{l}\text { MB } \\
\text { MB } \\
\text { MB } \\
\text { MB } \\
\text { MB } \\
\text { MB } \\
\text { MB } \\
M B \\
M B \\
M B \\
\text { MB } \\
M B \\
M B\end{array}$ & $\begin{array}{l}0 \\
0 \\
0 \\
0 \\
0 \\
0 \\
0 \\
0 \\
0 \\
0 \\
0 \\
0 \\
0\end{array}$ & MG/L & $\begin{array}{l}< \\
< \\
< \\
< \\
< \\
< \\
< \\
< \\
< \\
< \\
< \\
< \\
< \\
< \\
<\end{array}$ & $\begin{array}{l}0.005 \\
0.005 \\
0.005 \\
0.005 \\
0.005 \\
0.005 \\
0.005 \\
0.005 \\
0.005 \\
0.005 \\
0.005 \\
0.005 \\
0.005\end{array}$ & JW & $\begin{array}{l}0.005 \\
0.005 \\
0.005 \\
0.005 \\
0.005 \\
0.005 \\
0.005 \\
0.005 \\
0.005 \\
0.005 \\
0.005 \\
0.005 \\
0.005\end{array}$ & $\begin{array}{l}- \\
- \\
- \\
- \\
- \\
- \\
- \\
- \\
- \\
-\end{array}$ \\
\hline SILICA - SIOZ & $\begin{array}{l}0516 \\
0516 \\
0516 \\
0516 \\
0516 \\
0516 \\
0520 \\
0520 \\
0520 \\
0520 \\
0520 \\
0522 \\
0522 \\
0522 \\
0522 \\
0522 \\
0522 \\
0525 \\
0525 \\
0525 \\
0525 \\
0525 \\
0525 \\
0525 \\
0526\end{array}$ & $\begin{array}{l}06 / 06 / 90 \\
12 / 08 / 90 \\
04 / 04 / 91 \\
08 / 26 / 91 \\
10 / 14 / 92 \\
04 / 26 / 94 \\
06 / 04 / 90 \\
12 / 12 / 90 \\
04 / 01 / 91 \\
08 / 22 / 91 \\
10 / 11 / 92 \\
06 / 04 / 90 \\
12 / 08 / 90 \\
04 / 02 / 91 \\
08 / 22 / 91 \\
10 / 12 / 92 \\
04 / 21 / 94 \\
06 / 04 / 90 \\
12 / 08 / 90 \\
04 / 03 / 91 \\
08 / 26 / 91 \\
10 / 14 / 92 \\
02 / 23 / 94 \\
04 / 26 / 94 \\
06 / 06 / 90\end{array}$ & $\begin{array}{l}0001 \\
0001 \\
0001 \\
0001 \\
0001 \\
0001 \\
0001 \\
0001 \\
0001 \\
0001 \\
0001 \\
0001 \\
0001 \\
0001 \\
0001 \\
0001 \\
0001 \\
0001 \\
0001 \\
0001 \\
0001 \\
0001 \\
0001 \\
0001 \\
0001\end{array}$ & $\begin{array}{l}\text { MB } \\
M B \\
M B \\
M B \\
M B \\
M B \\
M B \\
M B \\
M B \\
M B \\
M B \\
M B \\
M B \\
M B \\
M B \\
M B \\
M B \\
M B \\
M B \\
M B \\
M B \\
M B \\
M B \\
M B \\
M B\end{array}$ & $\begin{array}{l}0 \\
0 \\
0 \\
0 \\
0 \\
0 \\
0 \\
0 \\
0 \\
0 \\
0 \\
0 \\
0 \\
0 \\
0 \\
0 \\
0 \\
0 \\
0 \\
0 \\
0 \\
0 \\
0 \\
0 \\
0\end{array}$ & $M G / L$ & & $\begin{array}{l}14 . \\
14 . \\
12.6 \\
12.6 \\
13.3 \\
13.7 \\
14 . \\
14 . \\
13.5 \\
14.0 \\
14.2 \\
13 . \\
13 . \\
13.3 \\
13.4 \\
13.3 \\
13.6 \\
13 . \\
13 . \\
12.5 \\
12.8 \\
13.0 \\
13.1 \\
13.3 \\
14 .\end{array}$ & $\begin{array}{l}\mathrm{L} \\
\mathrm{L}\end{array}$ & $\begin{array}{l}2 . \\
2 . \\
0.1 \\
0.1 \\
0.1 \\
0.1 \\
2 . \\
2 . \\
0.1 \\
0.1 \\
0.1 \\
2 . \\
2 . \\
0.1 \\
0.1 \\
0.1 \\
0.1 \\
2 . \\
2 . \\
0.1 \\
0.1 \\
0.1 \\
0.1 \\
0.1 \\
2 .\end{array}$ & $\begin{array}{l}- \\
- \\
- \\
- \\
- \\
- \\
- \\
- \\
- \\
- \\
- \\
- \\
- \\
- \\
- \\
- \\
- \\
- \\
- \\
-\end{array}$ \\
\hline
\end{tabular}

FORMATION OF COMPLETION CODE:

MB - MIDDLE BURRO CANYON

PARAMETER VALUE INDICATOR (PVI): < - LESS THAN DETECTION LIMIT
FLOW RELATIONSHIP CODE:

O - ON-SITE

SAMPLE ID CODES

0001 - FILTERED SAMPLE (.45 MICRONS)

OTHER PARAMETER VALUE FLAGS:

$J$ - ESTIMATED VALUE

L - LESS THAN THREE BORE VOLUMES REMOVED BEFORE SAMPLING

$W$ - POST-DIGEST SPIKE OUT OF CNTR LIM HHILE SAMP ABS < 50\% SPIKE 
TABLE 3.49 BACKGROUND GROUND HATER QUALITY DATA BY PARAMETER FOR THE

MIDDLE SANDSTONE UNIT, BURRO CANYON DISPOSAL SITE, SLICK ROCK, COLORADO SITE: SRKO2 BDRROW SITE 1 (BURRO CANYON)

06/04/90 TO 04/26/94

\begin{tabular}{|c|c|c|c|c|c|c|c|c|c|c|c|}
\hline PARAMETER NAME & $\underset{\text { ID }}{\text { LOCATION }}$ & LOG DATE & $\begin{array}{c}\text { SAMPLE } \\
\text { ID }\end{array}$ & $\begin{array}{l}\text { FORM } \\
\text { COMP }\end{array}$ & $\begin{array}{l}\text { FLOW } \\
\text { REL. }\end{array}$ & $\begin{array}{l}\text { UNITS OF } \\
\text { MEASURE }\end{array}$ & PVI & $\begin{array}{l}\text { PARAMETER } \\
\text { VALUE }\end{array}$ & FLAGS & $\begin{array}{l}\text { DETECTION } \\
\text { LIMIT }\end{array}$ & $\begin{array}{l}\text { PARAMETER } \\
\text { UNCERTAINTY }\end{array}$ \\
\hline SILICA - SIO2 & $\begin{array}{l}0526 \\
0526 \\
0526 \\
0526 \\
0526 \\
0526 \\
0528 \\
0528 \\
0528 \\
0528 \\
0528 \\
0528\end{array}$ & $\begin{array}{l}12 / 12 / 90 \\
04 / 04 / 91 \\
08 / 21 / 91 \\
10 / 14 / 92 \\
02 / 23 / 94 \\
04 / 26 / 94 \\
06 / 06 / 90 \\
12 / 15 / 90 \\
04 / 02 / 91 \\
08 / 21 / 91 \\
10 / 13 / 92 \\
04 / 26 / 94\end{array}$ & $\begin{array}{l}0001 \\
0001 \\
0001 \\
0001 \\
0001 \\
0001 \\
0001 \\
0001 \\
0001 \\
0001 \\
0001 \\
0001\end{array}$ & $\begin{array}{l}\text { MB } \\
\text { MB } \\
\text { MB } \\
\text { MB } \\
\text { MB } \\
\text { MB } \\
\text { MB } \\
\text { MB } \\
\text { MB } \\
\text { MB } \\
\text { MB } \\
M B\end{array}$ & $\begin{array}{l}0 \\
0 \\
0 \\
0 \\
0 \\
0 \\
0 \\
0 \\
0 \\
0 \\
0 \\
0\end{array}$ & $\mathrm{MG} / \mathrm{L}$ & & $\begin{array}{l}13 . \\
13.2 \\
13.5 \\
13.6 \\
14.0 \\
13.7 \\
14 . \\
14 . \\
13.4 \\
13.7 \\
13.8 \\
14.1\end{array}$ & $L$ & $\begin{array}{l}2.1 \\
0.1 \\
0.1 \\
0.1 \\
0.1 \\
0.1 \\
2 . \\
2 . \\
0.1 \\
0.1 \\
0.1 \\
0.1\end{array}$ & $\begin{array}{l}- \\
- \\
- \\
- \\
- \\
- \\
- \\
- \\
- \\
-\end{array}$ \\
\hline SILVER & $\begin{array}{l}0516 \\
0516 \\
0516 \\
0516 \\
0520 \\
0520 \\
0520 \\
0520 \\
0522 \\
0522 \\
0522 \\
0522 \\
0525 \\
0525 \\
0525 \\
0525 \\
0526 \\
0526 \\
0526 \\
0526 \\
0528 \\
0528 \\
0528 \\
0528\end{array}$ & $\begin{array}{l}06 / 06 / 90 \\
12 / 08 / 90 \\
04 / 04 / 91 \\
08 / 26 / 91 \\
06 / 04 / 90 \\
12 / 12 / 90 \\
04 / 01 / 91 \\
08 / 22 / 91 \\
06 / 04 / 90 \\
12 / 08 / 90 \\
04 / 02 / 91 \\
08 / 22 / 91 \\
06 / 04 / 90 \\
12 / 08 / 90 \\
04 / 03 / 91 \\
08 / 26 / 91 \\
06 / 06 / 90 \\
12 / 12 / 90 \\
04 / 04 / 91 \\
08 / 21 / 91 \\
06 / 06 / 90 \\
12 / 15 / 90 \\
04 / 02 / 91 \\
08 / 21 / 91\end{array}$ & $\begin{array}{l}0001 \\
0001 \\
0001 \\
0001 \\
0001 \\
0001 \\
0001 \\
0001 \\
0001 \\
0001 \\
0001 \\
0001 \\
0001 \\
0001 \\
0001 \\
0001 \\
0001 \\
0001 \\
0001 \\
0001 \\
0001 \\
0001 \\
0001 \\
0001\end{array}$ & $\begin{array}{l}M B \\
M B \\
M B \\
M B \\
M B \\
M B \\
M B \\
M B \\
M B \\
M B \\
M B \\
M B \\
M B \\
M B \\
M B \\
M B \\
M B \\
M B \\
M B \\
M B \\
M B \\
M B \\
M B \\
M B\end{array}$ & $\begin{array}{l}0 \\
0 \\
0 \\
0 \\
0 \\
0 \\
0 \\
0 \\
0 \\
0 \\
0 \\
0 \\
0 \\
0 \\
0 \\
0 \\
0 \\
0 \\
0 \\
0 \\
0 \\
0 \\
0 \\
0\end{array}$ & $M G / L$ & $\begin{array}{l}< \\
< \\
< \\
< \\
< \\
< \\
< \\
< \\
< \\
< \\
< \\
< \\
< \\
< \\
< \\
< \\
< \\
< \\
< \\
< \\
< \\
< \\
< \\
< \\
< \\
<\end{array}$ & $\begin{array}{l}0.01 \\
0.01 \\
0.01 \\
0.01 \\
0.01 \\
0.01 \\
0.01 \\
0.01 \\
0.01 \\
0.01 \\
0.01 \\
0.01 \\
0.01 \\
0.01 \\
0.01 \\
0.01 \\
0.01 \\
0.01 \\
0.01 \\
0.01 \\
0.01 \\
0.01 \\
0.01 \\
0.01\end{array}$ & $J$ & $\begin{array}{l}0.01 \\
0.01 \\
0.01 \\
0.01 \\
0.01 \\
0.01 \\
0.01 \\
0.01 \\
0.01 \\
0.01 \\
0.01 \\
0.01 \\
0.01 \\
0.01 \\
0.01 \\
0.01 \\
0.01 \\
0.01 \\
0.01 \\
0.01 \\
0.01 \\
0.01 \\
0.01 \\
0.01\end{array}$ & $\begin{array}{l}- \\
- \\
- \\
- \\
- \\
- \\
- \\
- \\
- \\
- \\
- \\
- \\
- \\
- \\
- \\
- \\
- \\
- \\
-\end{array}$ \\
\hline SODIUM & 0516 & $06 / 06 / 90$ & 0001 & MB & 0 & $M G / L$ & & 145. & & 0.002 & - \\
\hline
\end{tabular}

FORMATION OF COMPLETION CODE:

MB - MIDDLE BURRO CANYON

PARAMETER VALUE INDICATOR (PVI):

FLOW RELATIONSHIP CODE:

O - ON-SITE

SAMPLE ID CODES:

0001 - FILTERED SAMPLE (.45 MICRONS)

OTHER PARAMETER VALUE FLAGS:

$J$ - ESTIMATED VALUE

L - LESS THAN THREE BORE VOLUMES REMOVED BEFOPE SAMPLING 
TABLE 3.49 BACKGROUND GROUND WATER QUALITY DATA BY PARAMETER FOR THE

MIDDLE SANDSTONE UNIT, BURRO CANYON DISPOSAL SITE, SLICK ROCK, COLORADO

SITE: SRKO2 BORROH SITE 1 (BURRO CANYON)

$06 / 04 / 90$ TO $04 / 26 / 94$

REPORT DATE: 09/30/94

\begin{tabular}{|c|c|c|c|c|c|c|c|c|c|c|c|}
\hline PARAMETER NAME & $\begin{array}{c}\text { LOCATION } \\
\text { ID }\end{array}$ & LOG DATE & $\begin{array}{c}\text { SAMPLE } \\
\text { ID }\end{array}$ & $\begin{array}{l}\text { FORM } \\
\text { COMP }\end{array}$ & $\begin{array}{l}\text { FLOW } \\
\text { REL. }\end{array}$ & $\begin{array}{l}\text { UNITS OF } \\
\text { MEASURE }\end{array}$ & PVI & $\begin{array}{l}\text { PARAMETER } \\
\text { VALUE }\end{array}$ & FLAGS & $\begin{array}{l}\text { DETECTION } \\
\text { LIMIT }\end{array}$ & \begin{tabular}{|} 
PARAMETER \\
UNCERTAINTY
\end{tabular} \\
\hline SODIUM & $\begin{array}{l}0516 \\
0516 \\
0516 \\
0516 \\
0516 \\
0520 \\
0520 \\
0520 \\
0520 \\
0520 \\
0522 \\
0522 \\
0522 \\
0522 \\
0522 \\
0522 \\
0525 \\
0525 \\
0525 \\
0525 \\
0525 \\
0525 \\
0525 \\
0526 \\
0526 \\
0526 \\
0526 \\
0526 \\
0526 \\
0526 \\
0528 \\
0528 \\
0528 \\
0528 \\
0528 \\
0528\end{array}$ & $\begin{array}{l}12 / 08 / 90 \\
04 / 04 / 91 \\
08 / 26 / 91 \\
10 / 14 / 92 \\
04 / 26 / 94 \\
06 / 04 / 90 \\
12 / 12 / 90 \\
04 / 01 / 91 \\
08 / 22 / 91 \\
10 / 11 / 92 \\
06 / 04 / 90 \\
12 / 08 / 90 \\
04 / 02 / 91 \\
08 / 22 / 91 \\
10 / 12 / 92 \\
04 / 21 / 94 \\
06 / 04 / 90 \\
12 / 08 / 90 \\
04 / 03 / 91 \\
08 / 26 / 91 \\
10 / 14 / 92 \\
02 / 23 / 94 \\
04 / 26 / 94 \\
06 / 06 / 90 \\
12 / 12 / 90 \\
04 / 04 / 91 \\
08 / 21 / 91 \\
10 / 14 / 92 \\
02 / 23 / 94 \\
04 / 26 / 94 \\
06 / 06 / 90 \\
12 / 15 / 90 \\
04 / 02 / 91 \\
08 / 21 / 91 \\
10 / 13 / 92 \\
04 / 26 / 94\end{array}$ & $\begin{array}{l}0001 \\
0001 \\
0001 \\
0001 \\
0001 \\
0001 \\
0001 \\
0001 \\
0001 \\
0001 \\
0001 \\
0001 \\
0001 \\
0001 \\
0001 \\
0001 \\
0001 \\
0001 \\
0001 \\
0001 \\
0001 \\
0001 \\
0001 \\
0001 \\
0001 \\
0001 \\
0001 \\
0001 \\
0001 \\
0001 \\
0001 \\
0001 \\
0001 \\
0001 \\
0001 \\
0001\end{array}$ & $\begin{array}{l}M B \\
M B \\
M B \\
M B \\
M B \\
M B \\
M B \\
M B \\
M B \\
M B \\
M B \\
M B \\
M B \\
M B \\
M B \\
M B \\
M B \\
M B \\
M B \\
M B \\
M B \\
M B \\
M B \\
M B \\
M B \\
M B \\
M B \\
M B \\
M B \\
M B \\
M B \\
M B \\
M B \\
M B \\
M B \\
M B\end{array}$ & $\begin{array}{l}0 \\
0 \\
0 \\
0 \\
0 \\
0 \\
0 \\
0 \\
0 \\
0 \\
0 \\
0 \\
0 \\
0 \\
0 \\
0 \\
0 \\
0 \\
0 \\
0 \\
0 \\
0 \\
0 \\
0 \\
0 \\
0 \\
0 \\
0 \\
0 \\
0 \\
0 \\
0 \\
0 \\
0 \\
0 \\
0\end{array}$ & $\mathrm{MG} / \mathrm{L}$ & & $\begin{array}{l}150 . \\
154 . \\
130 . \\
146 . \\
139 \\
102 . \\
100 . \\
107 . \\
100 . \\
120 . \\
109 . \\
107 . \\
115 . \\
112 . \\
111 . \\
106 \\
139 . \\
142 . \\
150 . \\
143 . \\
167 . \\
137 \\
132 \\
110 . \\
106 . \\
114 . \\
114 . \\
109 . \\
104 \\
103 \\
73.5 \\
73.5 \\
74 . \\
72 . \\
75 . \\
70\end{array}$ & $\begin{array}{l}L \\
L\end{array}$ & $\begin{array}{l}0.002 \\
5 . \\
5 . \\
5 . \\
1 \\
0.002 \\
0.002 \\
5 . \\
1 . \\
5 . \\
0.002 \\
0.002 \\
5 . \\
5 . \\
5 . \\
1 \\
0.002 \\
0.002 \\
5 . \\
5 . \\
5 . \\
1 \\
1 \\
0.002 \\
0.002 \\
5 . \\
5 . \\
5 . \\
1 \\
1 \\
0.002 \\
0.002 \\
5 . \\
1 . \\
1 . \\
1\end{array}$ & $\begin{array}{l}- \\
- \\
- \\
- \\
- \\
- \\
- \\
- \\
- \\
- \\
- \\
- \\
- \\
- \\
- \\
- \\
- \\
- \\
- \\
- \\
- \\
- \\
- \\
- \\
- \\
- \\
- \\
- \\
-\end{array}$ \\
\hline SPECIFIC CONDUCTANCE & $\begin{array}{l}0516 \\
0516\end{array}$ & $\left|\begin{array}{l}06 / 06 / 90 \\
04 / 04 / 91\end{array}\right|$ & $\begin{array}{l}0001 \\
0001\end{array}$ & $\begin{array}{l}\text { MB } \\
\text { MB }\end{array}$ & $\begin{array}{l}0 \\
0\end{array}$ & UMHO/CM & & $\begin{array}{l}780 . \\
984 .\end{array}$ & & - & - \\
\hline
\end{tabular}

FORMATION OF COMPLETION COOE:

MB - MIDDLE BURRO CANYON

PARAMETER VALUE INDICATOR (PVI): < - LESS THAN DETECTION LIMIT
FLOW RELATIONSHIP CODE:

- ON-SITE

SAMPLE ID CODES:

0001 - FILTERED SAMPLE (.45 MICRONS)

OTHER PARAMETER VALUE FLAGS:

$J$ - ESTIMATED VALUE

L - LESS THAN THREE BORE VOLUMES REMOVED BEFORE SAMPLING 
TABLE 3.49 BACKGROUND GROUND HATER QUALITY DATA BY PARAMETER FOR THE MIDDLE SANDSTONE UNIT, BURRO CANYON DISPOSAL SITE, SLICK ROCK, COLORADO SITE: SRKO2 BORROW SITE 1 (BURRO CANYON)

06/04/90 TO $04 / 26 / 94$

REPORT DATE: $09 / 30 / 94$

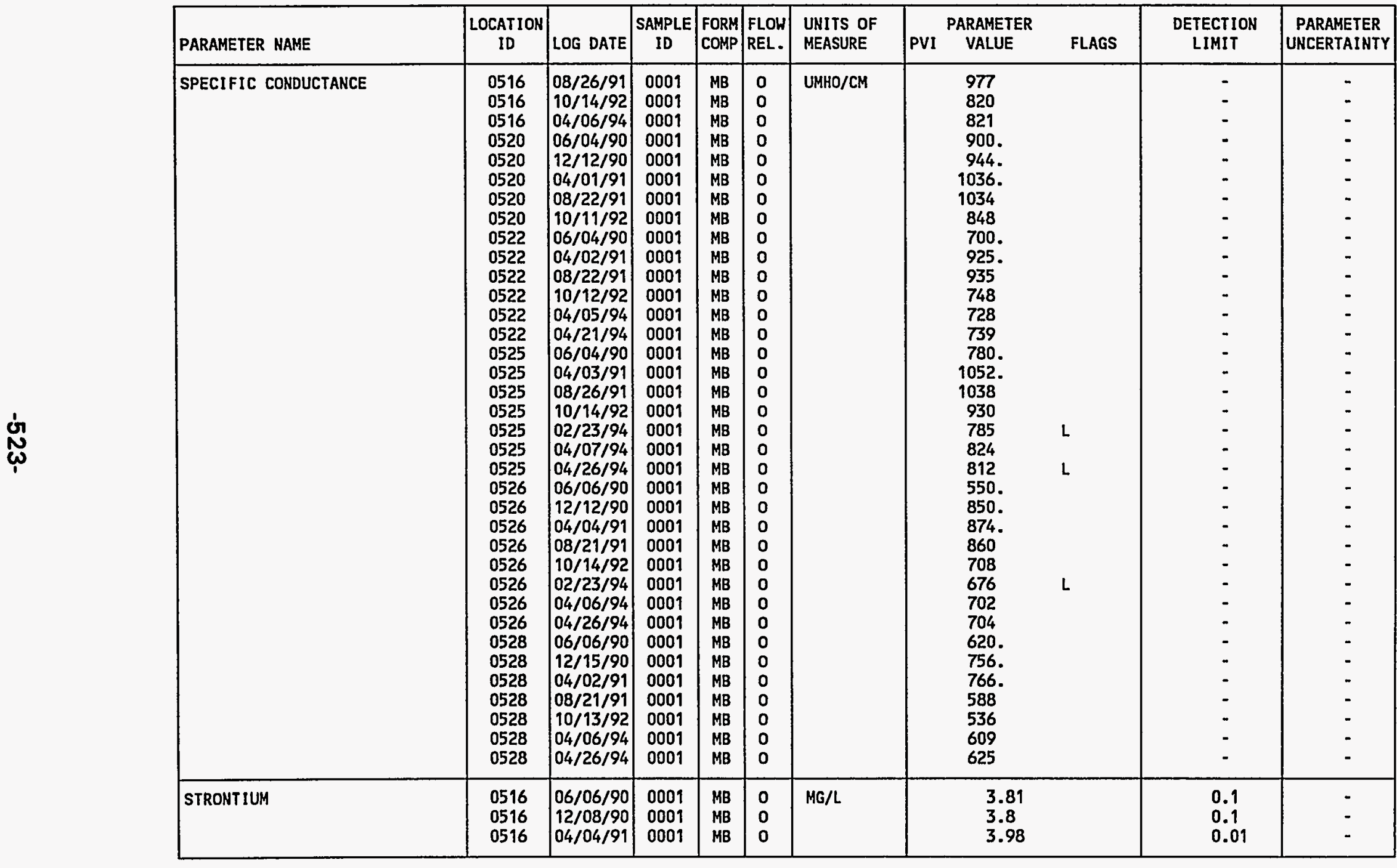

FORMATION OF COMPLETION CODE:

MB - MIDDLE BURRO CANYON

PARAMETER VALUE INDICATOR (PVI): < - LESS THAN DETECTION LIMIT
FLOW RELATIONSHIP CODE:

O - ON-SITE

SAMPLE ID CODES:

0001 - FILTERED SAMPLE (.45 MICRONS)

OTHER PARAMETER VALUE FLAGS:

L - LESS THAN THREE BORE VOLUMES REMOVED BEFORE SAMPLING 
TABLE 3.49 BACKGROUND GROUND HATER QUALITY DATA BY PARAMETER FOR THE MIDDLE SANDSTONE UNIT, BURRO CANYON DISPOSAL SITE, SLICK ROCK, COLORADO SITE: SRKO2 BORROW SITE 1 (BURRO CANYON)

06/04/90 TO 04/26/94

REPORT DATE: $09 / 30 / 94$

\begin{tabular}{|c|c|c|c|c|c|c|c|c|c|c|c|}
\hline PARAMETER NAME & $\begin{array}{l}\text { LOCATION } \\
\text { ID }\end{array}$ & LOG DATE & $\begin{array}{c}\text { SAMPLE } \\
\text { ID }\end{array}$ & $\begin{array}{l}\text { FORM } \\
\text { COMP }\end{array}$ & $\begin{array}{l}\text { FLOW } \\
\text { REL. }\end{array}$ & $\begin{array}{l}\text { UNITS OF } \\
\text { MEASURE }\end{array}$ & PVI & $\begin{array}{l}\text { PARAMETER } \\
\text { VALUE }\end{array}$ & FLAGS & $\begin{array}{l}\text { DETECTION } \\
\text { LIMIT }\end{array}$ & $\begin{array}{l}\text { PARAMETER } \\
\text { UNCERTAINTY }\end{array}$ \\
\hline STRONTIUM & $\begin{array}{l}0516 \\
0516 \\
0516 \\
0520 \\
0520 \\
0520 \\
0520 \\
0520 \\
0522 \\
0522 \\
0522 \\
0522 \\
0522 \\
0522 \\
0525 \\
0525 \\
0525 \\
0525 \\
0525 \\
0525 \\
0525 \\
0526 \\
0526 \\
0526 \\
0526 \\
0526 \\
0526 \\
0526 \\
0528 \\
0528 \\
0528 \\
0528 \\
0528 \\
0528\end{array}$ & $\begin{array}{l}08 / 26 / 91 \\
10 / 14 / 92 \\
04 / 26 / 94 \\
06 / 04 / 90 \\
12 / 12 / 90 \\
04 / 01 / 91 \\
08 / 22 / 91 \\
10 / 11 / 92 \\
06 / 04 / 90 \\
12 / 08 / 90 \\
04 / 02 / 91 \\
08 / 22 / 91 \\
10 / 12 / 92 \\
04 / 21 / 94 \\
06 / 04 / 90 \\
12 / 08 / 90 \\
04 / 03 / 91 \\
08 / 26 / 91 \\
10 / 14 / 92 \\
02 / 23 / 94 \\
04 / 26 / 94 \\
06 / 06 / 90 \\
12 / 12 / 90 \\
04 / 04 / 91 \\
08 / 21 / 91 \\
10 / 14 / 92 \\
02 / 23 / 94 \\
04 / 26 / 94 \\
06 / 06 / 90 \\
12 / 15 / 90 \\
04 / 02 / 91 \\
08 / 21 / 91 \\
10 / 13 / 92 \\
04 / 26 / 94\end{array}$ & $\begin{array}{l}0001 \\
0001 \\
0001 \\
0001 \\
0001 \\
0001 \\
0001 \\
0001 \\
0001 \\
0001 \\
0001 \\
0001 \\
0001 \\
0001 \\
0001 \\
0001 \\
0001 \\
0001 \\
0001 \\
0001 \\
0001 \\
0001 \\
0001 \\
0001 \\
0001 \\
0001 \\
0001 \\
0001 \\
0001 \\
0001 \\
0001 \\
0001 \\
0001 \\
0001\end{array}$ & $\begin{array}{l}M B \\
M B \\
M B \\
M B \\
M B \\
M B \\
M B \\
M B \\
M B \\
M B \\
M B \\
M B \\
M B \\
M B \\
M B \\
M B \\
M B \\
M B \\
M B \\
M B \\
M B \\
M B \\
M B \\
M B \\
M B \\
M B \\
M B \\
M B \\
M B \\
M B \\
M B \\
M B \\
M B \\
M B\end{array}$ & $\begin{array}{l}0 \\
0 \\
0 \\
0 \\
0 \\
0 \\
0 \\
0 \\
0 \\
0 \\
0 \\
0 \\
0 \\
0 \\
0 \\
0 \\
0 \\
0 \\
0 \\
0 \\
0 \\
0 \\
0 \\
0 \\
0 \\
0 \\
0 \\
0 \\
0 \\
0 \\
0 \\
0 \\
0 \\
0\end{array}$ & $M G / L$ & & $\begin{array}{l}3.43 \\
3.74 \\
3.92 \\
5.83 \\
5.7 \\
6.12 \\
5.81 \\
5.44 \\
3.12 \\
3.1 \\
3.49 \\
3.22 \\
2.98 \\
3.07 \\
5.03 \\
4.4 \\
4.95 \\
4.60 \\
5.41 \\
4.65 \\
4.72 \\
3.85 \\
3.4 \\
3.94 \\
3.68 \\
3.51 \\
3.79 \\
3.62 \\
3.11 \\
2.9 \\
3.16 \\
3.03 \\
2.94 \\
2.97\end{array}$ & . & $\begin{array}{l}0.01 \\
0.01 \\
0.01 \\
0.1 \\
0.1 \\
0.01 \\
0.01 \\
0.01 \\
0.1 \\
0.1 \\
0.01 \\
0.01 \\
0.01 \\
0.01 \\
0.1 \\
0.1 \\
0.01 \\
0.01 \\
0.01 \\
0.01 \\
0.01 \\
0.1 \\
0.1 \\
0.01 \\
0.01 \\
0.01 \\
0.01 \\
0.01 \\
0.1 \\
0.1 \\
0.01 \\
0.01 \\
0.01 \\
0.01\end{array}$ & $\begin{array}{l}- \\
- \\
- \\
- \\
- \\
- \\
- \\
- \\
- \\
- \\
- \\
- \\
- \\
- \\
- \\
- \\
- \\
- \\
- \\
- \\
- \\
- \\
- \\
- \\
- \\
- \\
- \\
- \\
- \\
-\end{array}$ \\
\hline SULFATE & $\begin{array}{l}0516 \\
0516 \\
0516 \\
0516\end{array}$ & $\begin{array}{l}06 / 06 / 90 \\
12 / 08 / 90 \\
04 / 04 / 91 \\
08 / 26 / 91\end{array}$ & $\begin{array}{l}0001 \\
0001 \\
0001 \\
0001\end{array}$ & $\begin{array}{l}\text { MB } \\
\text { MB } \\
\text { MB } \\
\text { MB }\end{array}$ & $\begin{array}{l}0 \\
0 \\
0 \\
0\end{array}$ & $M G / L$ & & $\begin{array}{l}214 . \\
211 . \\
209 . \\
195 .\end{array}$ & $\mathrm{J}$ & $\begin{array}{c}0.1 \\
0.1 \\
0.1 \\
10 .\end{array}$ & $\begin{array}{l}- \\
- \\
-\end{array}$ \\
\hline
\end{tabular}

FORMATION OF COMPLETION CODE:

MB - MIDDLE BURRO CANYON

PARAMETER VALUE INDICATOR (PVI): < - LESS THAN DETECTION LIMIT
FLOW RELATIONSHIP CODE

O - ON-SITE

SAMPLE ID CODES

0001 - FILTERED SAMPLE (.45 MICRONS)

\section{OTHER PARAMETER VALUE FLAGS:}

$J$ - ESTIMATED VALUE

L - LESS THAN THREE: BORE VOLUMES REMOVED BEFORE SAMPLING 
TABLE 3.49 BACKGROUND GROUND HATER QUALITY DATA BY PARAMETER FOR THE

MIDDLE SANDSTONE UNIT, BURRO CANYON DISPOSAL SITE, SLICK ROCK, COLORADO

SITE: SRKO2 BORROW SITE 1 (BURRO CANYON)

06/04/90 TO 04/26/94

REPORT DATE: $09 / 30 / 94$

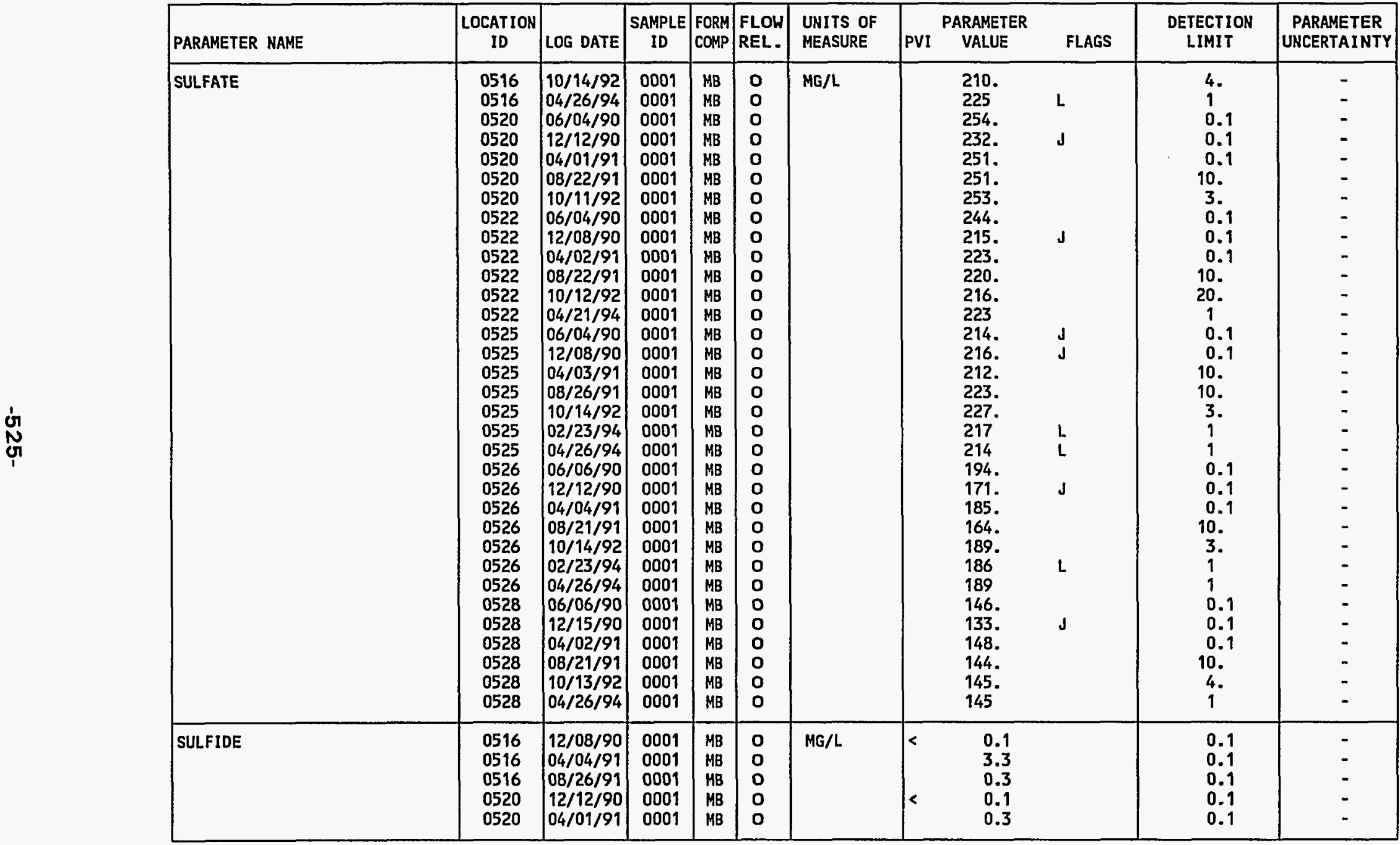

FORMATION OF COMPLETION CODE:

MB - MIDDLE BURRO CANYON

FLOW RELATIONSHIP CODE:

PARAMETER VALUE INDICATOR (PVI): < - LESS THAN DETECTION LIMIT

SAMPLE ID CODES:

0001 - FILTERED SAMPLE (.45 MICRONS)

OTHER PARAMETER VALUE FLAGS:

J - ESTIMATED VALUE

L - LESS THAN THREE BORE VOLUMES REMOVED BEFORE SAMPLING 
TABLE 3.49 BACKGROUND GROUND WATER QUALITY DATA BY PARAMETER FOR THE MIDOLE SANDSTONE UNIT, BURRO CANYON DISPOSAL SITE, SLICK ROCK, COLORADO SITE: SRKO2 BORROW SITE 1 (BURRO CANYON)

S/04/90 TO 04/26/94

\begin{tabular}{|c|c|c|c|c|c|c|c|c|c|c|}
\hline PARAMETER NAME & $\begin{array}{c}\text { LOCATION } \\
\text { ID }\end{array}$ & LOG DATE & $\begin{array}{c}\text { SAMPLE } \\
\text { ID }\end{array}$ & $\begin{array}{l}\text { FORM } \\
\text { COMP }\end{array}$ & $\begin{array}{l}\text { FLOW } \\
\text { REL. }\end{array}$ & $\begin{array}{l}\text { UNITS OF } \\
\text { MEASURE }\end{array}$ & PVI & $\begin{array}{l}\text { PARAMETER } \\
\text { VAL.UE }\end{array}$ & $\begin{array}{l}\text { DETECTION } \\
\text { LIMIT }\end{array}$ & $\begin{array}{l}\text { PARAMETER } \\
\text { UNCERTAINTY }\end{array}$ \\
\hline SULFIDE & $\begin{array}{l}0520 \\
0520 \\
0522 \\
0522 \\
0522 \\
0522 \\
0525 \\
0525 \\
0525 \\
0526 \\
0526 \\
0526 \\
0526 \\
0528 \\
0528 \\
0528 \\
0528\end{array}$ & $\begin{array}{l}08 / 22 / 91 \\
10 / 11 / 92 \\
12 / 08 / 90 \\
04 / 02 / 91 \\
08 / 22 / 91 \\
10 / 12 / 92 \\
12 / 08 / 90 \\
04 / 03 / 91 \\
08 / 26 / 91 \\
12 / 12 / 90 \\
04 / 04 / 91 \\
08 / 21 / 91 \\
10 / 14 / 92 \\
12 / 15 / 90 \\
04 / 02 / 91 \\
08 / 21 / 91 \\
10 / 13 / 92\end{array}$ & $\begin{array}{l}0001 \\
0001 \\
0001 \\
0001 \\
0001 \\
0001 \\
0001 \\
0001 \\
0001 \\
0001 \\
0001 \\
0001 \\
0001 \\
0001 \\
0001 \\
0001 \\
0001\end{array}$ & $\begin{array}{l}\text { MB } \\
M B \\
M B \\
M B \\
M B \\
M B \\
M B \\
M B \\
M B \\
M B \\
M B \\
M B \\
M B \\
M B \\
M B \\
M B \\
M B\end{array}$ & $\begin{array}{l}0 \\
0 \\
0 \\
0 \\
0 \\
0 \\
0 \\
0 \\
0 \\
0 \\
0 \\
0 \\
0 \\
0 \\
0 \\
0 \\
0\end{array}$ & $M G / L$ & $\begin{array}{l}< \\
< \\
< \\
< \\
<\end{array}$ & $\begin{array}{r}1.6 \\
1.2 \\
0.1 \\
17.9 \\
2.9 \\
0.4 \\
0.1 \\
0.5 \\
0.3 \\
0.1 \\
0.3 \\
0.1 \\
0.1 \\
0.1 \\
0.3 \\
0.6 \\
0.1\end{array}$ & $\begin{array}{l}0.1 \\
0.1 \\
0.1 \\
0.1 \\
0.1 \\
0.1 \\
0.1 \\
0.1 \\
0.1 \\
0.1 \\
0.1 \\
0.1 \\
0.1 \\
0.1 \\
0.1 \\
0.1 \\
0.1\end{array}$ & $\begin{array}{l}- \\
- \\
- \\
- \\
- \\
- \\
- \\
- \\
- \\
- \\
- \\
- \\
- \\
-\end{array}$ \\
\hline TEMPERATURE & $\begin{array}{l}0516 \\
0516 \\
0516 \\
0516 \\
0516 \\
0516 \\
0520 \\
0520 \\
0520 \\
0520 \\
0520 \\
0522 \\
0522 \\
0522 \\
0522 \\
0522 \\
0522 \\
0522 \\
0525 \\
0525 \\
0525 \\
0525 \\
0525\end{array}$ & $\begin{array}{l}06 / 06 / 90 \\
12 / 08 / 90 \\
04 / 04 / 91 \\
08 / 26 / 91 \\
10 / 14 / 92 \\
04 / 06 / 94 \\
06 / 04 / 90 \\
12 / 12 / 90 \\
04 / 01 / 91 \\
08 / 22 / 91 \\
10 / 11 / 92 \\
06 / 04 / 90 \\
12 / 08 / 90 \\
04 / 02 / 91 \\
08 / 22 / 91 \\
10 / 12 / 92 \\
04 / 05 / 94 \\
04 / 21 / 94 \\
06 / 04 / 90 \\
12 / 08 / 90 \\
04 / 03 / 91 \\
08 / 26 / 91 \\
10 / 14 / 92\end{array}$ & $\begin{array}{l}0001 \\
0001 \\
0001 \\
0001 \\
0001 \\
0001 \\
0001 \\
0001 \\
0001 \\
0001 \\
0001 \\
0001 \\
0001 \\
0001 \\
0001 \\
0001 \\
0001 \\
0001 \\
0001 \\
0001 \\
0001 \\
0001 \\
0001\end{array}$ & $\begin{array}{l}M B \\
M B \\
M B \\
M B \\
M B \\
M B \\
M B \\
M B \\
M B \\
M B \\
M B \\
M B \\
M B \\
M B \\
M B \\
M B \\
M B \\
M B \\
M B \\
M B \\
M B \\
M B \\
M B\end{array}$ & $\begin{array}{l}0 \\
0 \\
0 \\
0 \\
0 \\
0 \\
0 \\
0 \\
0 \\
0 \\
0 \\
0 \\
0 \\
0 \\
0 \\
0 \\
0 \\
0 \\
0 \\
0 \\
0 \\
0 \\
0\end{array}$ & C - DEGREE & & $\begin{array}{l}16.0 \\
14.0 \\
13.9 \\
16.9 \\
17.1 \\
17.3 \\
17.5 \\
18.6 \\
16.2 \\
15.5 \\
16.0 \\
17.6 \\
16.0 \\
15.7 \\
15.3 \\
15.5 \\
15.2 \\
15.8 \\
16.5 \\
17.0 \\
16.7 \\
17.1 \\
15.7\end{array}$ & $\begin{array}{l}- \\
- \\
- \\
- \\
- \\
- \\
- \\
- \\
- \\
- \\
- \\
- \\
- \\
- \\
- \\
- \\
- \\
- \\
-\end{array}$ & $\begin{array}{l}- \\
- \\
- \\
- \\
- \\
- \\
- \\
- \\
- \\
- \\
- \\
- \\
- \\
- \\
- \\
- \\
- \\
- \\
- \\
- \\
- \\
-\end{array}$ \\
\hline
\end{tabular}

FORMATION OF COMPLETION CODE:

MB - MIDDLE BURRO CANYON

PARAMETER VALUE INDICATOR (PVI): < - LESS thaN DETECTION LIMIT
FLOW RELATIONSHIP CODE:

O- ON-SITE

SAMPLE ID COOES:

0001 - FILTERED SAMPLE (.45 MICRONS) 
TABLE 3.49 BACKGROUND GROUHD HATER QUALITY DATA BY PARAMETER FOR THE MIDDLE SANDSTONE UNIT, BURRO CANYON DISPOSAL SITE, SLICK ROCK, COLORADO SITE: SRKO2 BORROW SITE 1 (BURRO CANYON)

06/04/90 TO 04/26/94

REPORT DATE: 09/30/94

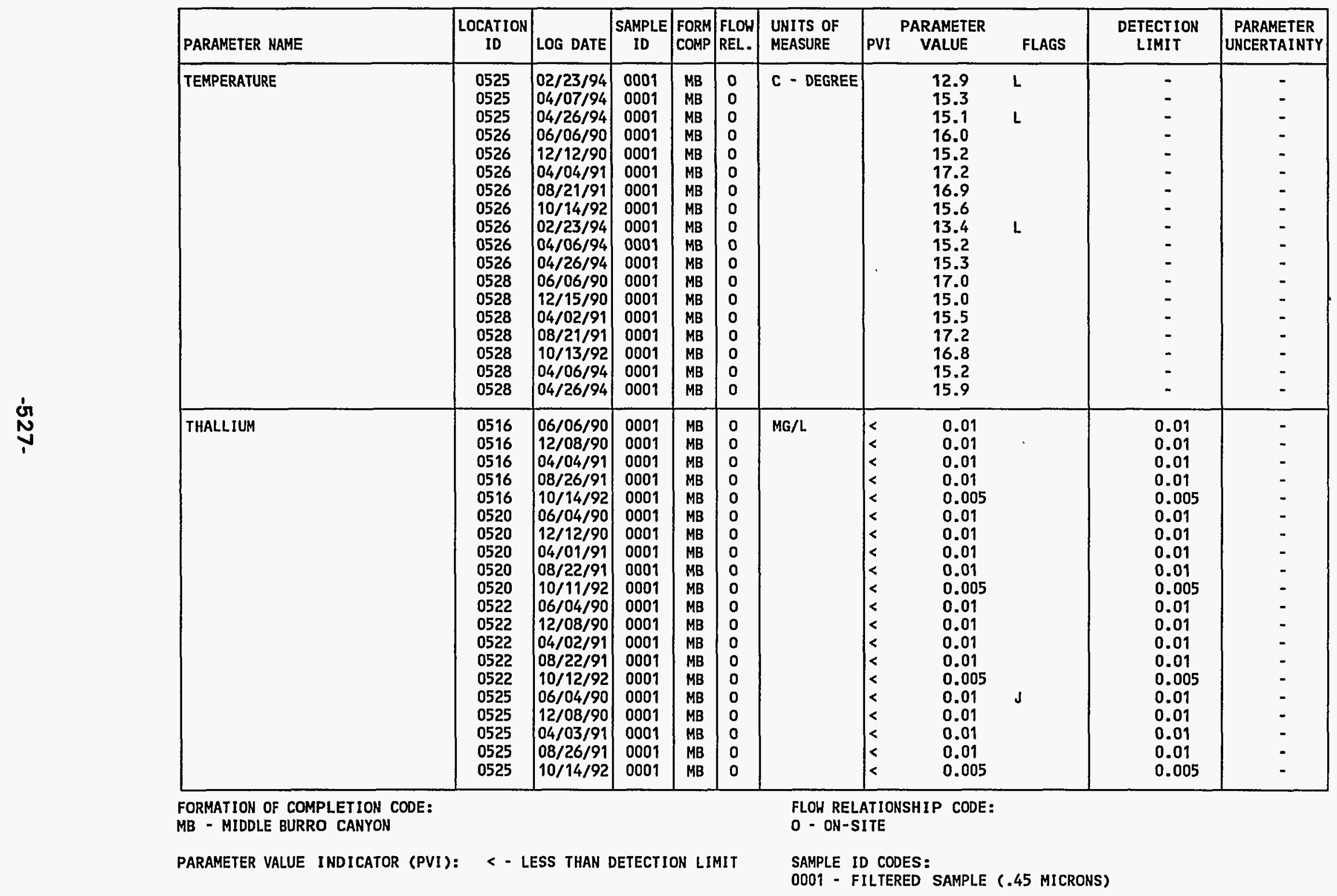

OTHER PARAMETER VALUE FLAGS:

$J$ - ESTIMATED VALUE

L - LESS THAN THREE bORE VOLUMES REMOVED BEFORE SAMPLING 
TABLE 3.49 BACKGROUND GROUND WATER QUALITY DATA BY PARAMETER FOR THE MIDDLE SANDSTONE UNIT, BURRO CANYON DISPOSAL SITE, SLICK ROCK, COLORADO SITE: SRKO2 BORROW SITE 1 (BURRO CANYON)

06/04/90 TO 04/26/94

REPORT DATE: $09 / 30 / 94$

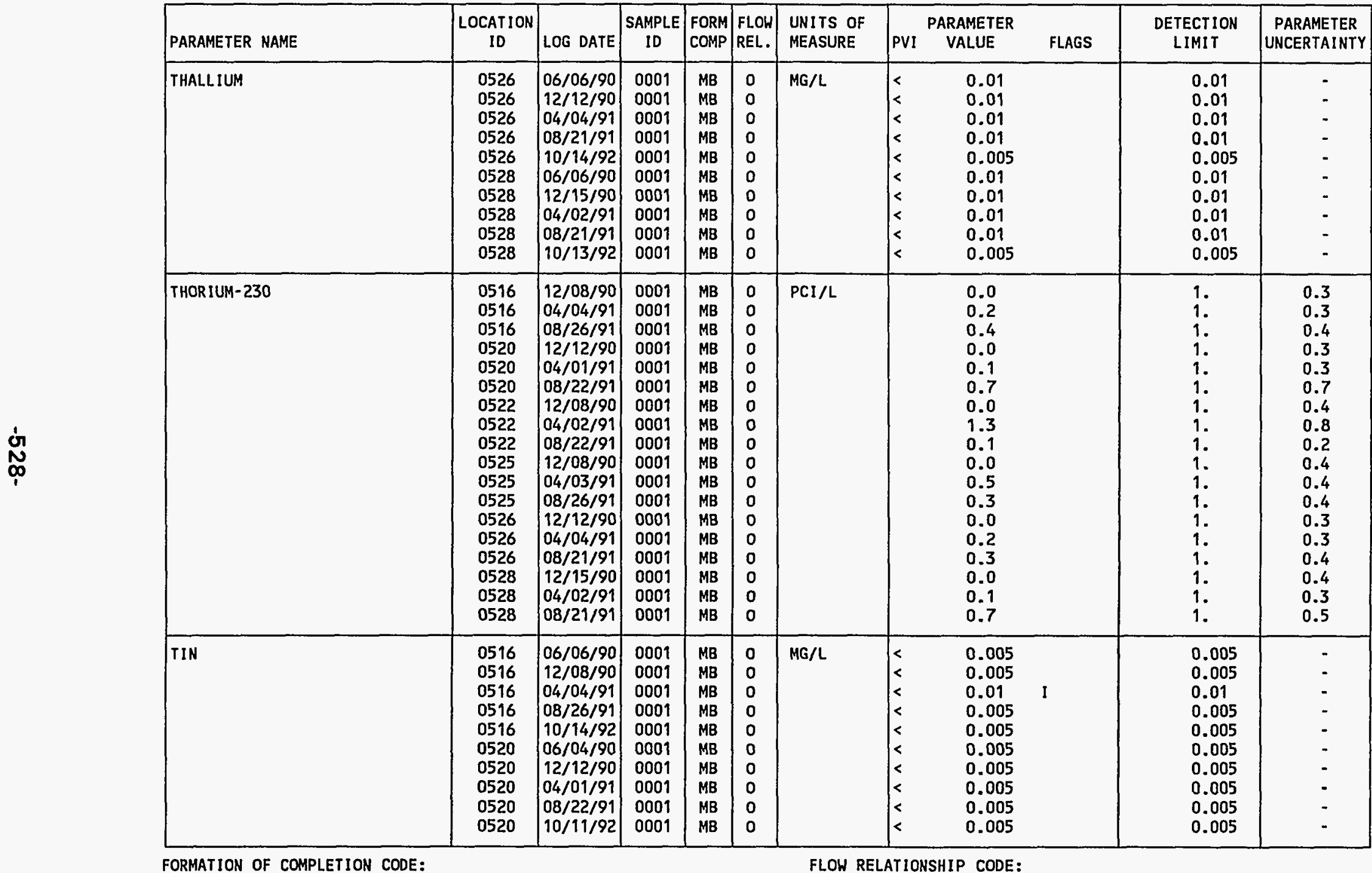

FORMATION OF COMPLETION CODE:

MB - MIDDLE BURRO CANYON

PARAMETER VALUE INDICATOR (PVI):

< - LESS THAN DETECTION LIMIT
FLOW RELATIONSHIP CODE:

SAMPLE ID CODES

0001 - FILTERED SAMPLE (.45 MICRONS)

OTHER PARAMETER VALUE FLAGS:

I - INCREASED DETECTION LIMIT DUE TO REQUIRED DILUTION 
TABLE 3.49 BACKGROUND GROUND HATER QUALITY DATA BY PARAMETER FOR THE

MIDDLE SANDSTONE UNIT, BURRO CANYON DISPOSAL SITE, SLICK ROCK, COLORADO SITE: SRKO2 BORROW SITE 1 (BURRO CANYON)

06/04/90 TO 04/26/94

REPORT DATE: 09/30/94

\begin{tabular}{|c|c|c|c|c|c|c|c|c|c|c|c|c|}
\hline & PARAMETER NAME & $\underset{\text { ID }}{\text { LOCATION }}$ & LOG DATE & $\begin{array}{c}\text { SAMPLE } \\
\text { ID }\end{array}$ & $\begin{array}{l}\text { FORM } \\
\text { COMP }\end{array}$ & $\begin{array}{l}\text { FLOW } \\
\text { REL. }\end{array}$ & $\begin{array}{l}\text { UNITS OF } \\
\text { MEASURE }\end{array}$ & PVI & $\begin{array}{l}\text { PARAMETER } \\
\text { VALUE }\end{array}$ & FLAGS & $\begin{array}{l}\text { DETECTION } \\
\text { LIMIT }\end{array}$ & $\begin{array}{l}\text { PARAMETER } \\
\text { UNCERTAINTY }\end{array}$ \\
\hline & TIN & $\begin{array}{l}0522 \\
0522 \\
0522 \\
0522 \\
0522 \\
0525 \\
0525 \\
0525 \\
0525 \\
0525 \\
0526 \\
0526 \\
0526 \\
0526 \\
0526 \\
0528 \\
0528 \\
0528 \\
0528 \\
0528\end{array}$ & $\begin{array}{l}06 / 04 / 90 \\
12 / 08 / 90 \\
04 / 02 / 91 \\
08 / 22 / 91 \\
10 / 12 / 92 \\
06 / 04 / 90 \\
12 / 08 / 90 \\
04 / 03 / 91 \\
08 / 26 / 91 \\
10 / 14 / 92 \\
06 / 06 / 90 \\
12 / 12 / 90 \\
04 / 04 / 91 \\
08 / 21 / 91 \\
10 / 14 / 92 \\
06 / 06 / 90 \\
12 / 15 / 90 \\
04 / 02 / 91 \\
08 / 21 / 91 \\
10 / 13 / 92\end{array}$ & $\begin{array}{l}0001 \\
0001 \\
0001 \\
0001 \\
0001 \\
0001 \\
0001 \\
0001 \\
0001 \\
0001 \\
0001 \\
0001 \\
0001 \\
0001 \\
0001 \\
0001 \\
0001 \\
0001 \\
0001 \\
0001\end{array}$ & $\begin{array}{l}M B \\
M B \\
M B \\
M B \\
M B \\
M B \\
M B \\
M B \\
M B \\
M B \\
M B \\
M B \\
M B \\
M B \\
M B \\
M B \\
M B \\
M B \\
M B \\
M B\end{array}$ & $\begin{array}{l}0 \\
0 \\
0 \\
0 \\
0 \\
0 \\
0 \\
0 \\
0 \\
0 \\
0 \\
0 \\
0 \\
0 \\
0 \\
0 \\
0 \\
0 \\
0 \\
0\end{array}$ & $M G / L$ & $\begin{array}{l}< \\
< \\
< \\
< \\
< \\
< \\
< \\
< \\
< \\
< \\
< \\
< \\
< \\
< \\
< \\
< \\
< \\
< \\
< \\
< \\
<\end{array}$ & $\begin{array}{l}0.005 \\
0.005 \\
0.005 \\
0.005 \\
0.005 \\
0.025 \\
0.005 \\
0.005 \\
0.005 \\
0.005 \\
0.005 \\
0.005 \\
0.005 \\
0.005 \\
0.005 \\
0.005 \\
0.005 \\
0.005 \\
0.005 \\
0.005\end{array}$ & 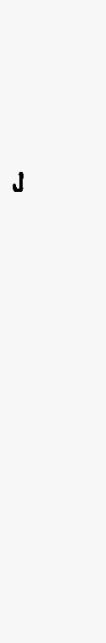 & $\begin{array}{l}0.005 \\
0.005 \\
0.005 \\
0.005 \\
0.005 \\
0.005 \\
0.005 \\
0.005 \\
0.005 \\
0.005 \\
0.005 \\
0.005 \\
0.005 \\
0.005 \\
0.005 \\
0.005 \\
0.005 \\
0.005 \\
0.005 \\
0.005\end{array}$ & $\begin{array}{l}- \\
- \\
- \\
- \\
- \\
- \\
- \\
- \\
- \\
- \\
- \\
- \\
- \\
- \\
- \\
-\end{array}$ \\
\hline & TOTAL DISSOLVED SOLIOS & $\begin{array}{l}0516 \\
0516 \\
0516 \\
0516 \\
0516 \\
0516 \\
0520 \\
0520 \\
0520 \\
0520 \\
0520 \\
0522 \\
0522 \\
0522 \\
0522 \\
0522 \\
0522 \\
0525\end{array}$ & \begin{tabular}{|l|}
$06 / 06 / 90$ \\
$12 / 08 / 90$ \\
$04 / 04 / 91$ \\
$08 / 26 / 91$ \\
$10 / 14 / 92$ \\
$04 / 26 / 94$ \\
$06 / 04 / 90$ \\
$12 / 12 / 90$ \\
$04 / 01 / 91$ \\
$08 / 22 / 91$ \\
$10 / 11 / 92$ \\
$06 / 04 / 90$ \\
$12 / 08 / 90$ \\
$04 / 02 / 91$ \\
$08 / 22 / 91$ \\
$10 / 12 / 92$ \\
$04 / 21 / 94$ \\
$06 / 04 / 90$
\end{tabular} & $\begin{array}{l}0001 \\
0001 \\
0001 \\
0001 \\
0001 \\
0001 \\
0001 \\
0001 \\
0001 \\
0001 \\
0001 \\
0001 \\
0001 \\
0001 \\
0001 \\
0001 \\
0001 \\
0001\end{array}$ & $\begin{array}{l}M B \\
M B \\
M B \\
M B \\
M B \\
M B \\
M B \\
M B \\
M B \\
M B \\
M B \\
M B \\
M B \\
M B \\
M B \\
M B \\
M B \\
M B\end{array}$ & $\begin{array}{l}0 \\
0 \\
0 \\
0 \\
0 \\
0 \\
0 \\
0 \\
0 \\
0 \\
0 \\
0 \\
0 \\
0 \\
0 \\
0 \\
0 \\
0\end{array}$ & MG/L & & $\begin{array}{l}568 . \\
584 . \\
641 . \\
576 . \\
621 . \\
630 \\
642 . \\
636 . \\
669 . \\
667 . \\
677 . \\
586 . \\
536 . \\
598 . \\
585 . \\
587 . \\
590 \\
580 .\end{array}$ & $\begin{array}{l}\text { L } \\
\\
J\end{array}$ & $\begin{array}{l}10 . \\
10 . \\
10 . \\
10 . \\
10 . \\
10 \\
10 . \\
10 . \\
10 . \\
10 . \\
10 . \\
10 . \\
10 . \\
10 . \\
10 . \\
10 . \\
10 \\
10 .\end{array}$ & $\begin{array}{l}- \\
- \\
- \\
- \\
- \\
- \\
- \\
- \\
- \\
- \\
- \\
- \\
- \\
-\end{array}$ \\
\hline
\end{tabular}

FORMATION OF COMPLETION CODE:

FLOW RELATIONSHIP CODE:

MB - MIDDLE BURRO CANYON

O- ON-SITE

PARAMETER VALUE INDICATOR (PVI): < - LESS THAN DETECTION LIMIT

D CODES:

0001 - FILTERED SAMPLE (.45 MICRONS)

OTHER PARAMETER VALUE FLAGS:

$J$ - EST IMATED VALUE

L - LESS THAN THREE BORE VOLUMES REMOVED BEFORE SAMPLING 
TABLE 3.49 BACKGROUND GROUND HATER QUALITY DATA BY PARAMETER FOR THE MIDDLE SANDSTONE UNIT, BURRO CANYON DISPOSAL SITE, SLICK ROCK, COLORADO SITE: SRKO2 BORROW SITE 1 (BURRO CANYON)

06/04/90 TO 04/26/94

REPORT DATE : $09 / 30 / 94$

\begin{tabular}{|c|c|c|c|c|c|c|c|c|c|c|c|}
\hline PARAMETER NAME & $\underset{\text { ID ION }}{\text { LOCATION }}$ & LOG DATE & $\begin{array}{c}\text { SAMPLE } \\
\text { ID }\end{array}$ & $\begin{array}{l}\text { FORM } \\
\text { COMP }\end{array}$ & $\begin{array}{l}\text { FLOW } \\
\text { REL. }\end{array}$ & $\begin{array}{l}\text { UNITS OF } \\
\text { MEASURE }\end{array}$ & PVI & $\begin{array}{l}\text { ARAMETER } \\
\text { VALUE }\end{array}$ & FLAGS & $\begin{array}{l}\text { DETECTION } \\
\text { LIMIT }\end{array}$ & $\begin{array}{l}\text { PARAMETER } \\
\text { UNCERTAINTY }\end{array}$ \\
\hline TOTAL DISSOLVED SOLIDS & $\begin{array}{l}0525 \\
0525 \\
0525 \\
0525 \\
0525 \\
0525 \\
0526 \\
0526 \\
0526 \\
0526 \\
0526 \\
0526 \\
0526 \\
0528 \\
0528 \\
0528 \\
0528 \\
0528 \\
0528\end{array}$ & $\begin{array}{l}12 / 08 / 90 \\
04 / 03 / 91 \\
08 / 26 / 91 \\
10 / 14 / 92 \\
02 / 23 / 94 \\
04 / 26 / 94 \\
06 / 06 / 90 \\
12 / 12 / 90 \\
04 / 04 / 91 \\
08 / 21 / 91 \\
10 / 14 / 92 \\
02 / 23 / 94 \\
04 / 26 / 94 \\
06 / 06 / 90 \\
12 / 15 / 90 \\
04 / 02 / 91 \\
08 / 21 / 91 \\
10 / 13 / 92 \\
04 / 26 / 94\end{array}$ & $\begin{array}{l}0001 \\
0001 \\
0001 \\
0001 \\
0001 \\
0001 \\
0001 \\
0001 \\
0001 \\
0001 \\
0001 \\
0001 \\
0001 \\
0001 \\
0001 \\
0001 \\
0001 \\
0001 \\
0001\end{array}$ & $\begin{array}{l}M B \\
M B \\
M B \\
M B \\
M B \\
M B \\
M B \\
M B \\
M B \\
M B \\
M B \\
M B \\
M B \\
M B \\
M B \\
M B \\
M B \\
M B \\
M B\end{array}$ & $\begin{array}{l}0 \\
0 \\
0 \\
0 \\
0 \\
0 \\
0 \\
0 \\
0 \\
0 \\
0 \\
0 \\
0 \\
0 \\
0 \\
0 \\
0 \\
0 \\
0\end{array}$ & $M G / L$ & & $\begin{array}{l}596 . \\
600 . \\
651 . \\
696 . \\
640 \\
670 \\
498 . \\
508 . \\
551 . \\
550 . \\
558 . \\
540 \\
580 \\
422 . \\
444 . \\
486 . \\
466 . \\
481 . \\
490\end{array}$ & $\dot{L}$ & $\begin{array}{l}10 . \\
10 . \\
10 . \\
10 . \\
10 \\
10 \\
10 . \\
10 . \\
10 . \\
10 . \\
10 . \\
10 \\
10 \\
10 . \\
10 . \\
10 . \\
10 . \\
10 . \\
10\end{array}$ & $\begin{array}{l}: \\
- \\
- \\
- \\
- \\
- \\
- \\
- \\
- \\
- \\
- \\
- \\
- \\
-\end{array}$ \\
\hline TOTAL KJELDAHL NITROGEN & $\begin{array}{l}0516 \\
0516 \\
0516 \\
0520 \\
0520 \\
0520 \\
0522 \\
0522 \\
0522 \\
0525 \\
0525 \\
0525 \\
0526 \\
0526 \\
0526 \\
0528 \\
0528 \\
0528\end{array}$ & $\begin{array}{l}12 / 08 / 90 \\
04 / 04 / 91 \\
08 / 26 / 91 \\
12 / 12 / 90 \\
04 / 01 / 91 \\
08 / 22 / 91 \\
12 / 08 / 90 \\
04 / 02 / 91 \\
08 / 22 / 91 \\
12 / 08 / 90 \\
04 / 03 / 91 \\
08 / 26 / 91 \\
12 / 12 / 90 \\
04 / 04 / 91 \\
08 / 21 / 91 \\
12 / 15 / 90 \\
04 / 02 / 91 \\
08 / 21 / 91\end{array}$ & $\begin{array}{l}0001 \\
0001 \\
0001 \\
0001 \\
0001 \\
0001 \\
0001 \\
0001 \\
0001 \\
0001 \\
0001 \\
0001 \\
0001 \\
0001 \\
0001 \\
0001 \\
0001 \\
0001\end{array}$ & $\begin{array}{l}\text { MB } \\
\text { MB } \\
\text { MB } \\
M B \\
\text { MB } \\
\text { MB } \\
M B \\
M B \\
M B \\
M B \\
M B \\
M B \\
M B \\
M B \\
\text { MB } \\
\text { MB } \\
M B \\
M B\end{array}$ & $\begin{array}{l}0 \\
0 \\
0 \\
0 \\
0 \\
0 \\
0 \\
0 \\
0 \\
0 \\
0 \\
0 \\
0 \\
0 \\
0 \\
0 \\
0 \\
0\end{array}$ & $M G / L$ & $\begin{array}{l}< \\
< \\
< \\
< \\
< \\
< \\
< \\
< \\
< \\
< \\
< \\
< \\
< \\
< \\
< \\
<\end{array}$ & $\begin{array}{l}1 . \\
1 . \\
1 . \\
1 . \\
1 . \\
1 . \\
1 . \\
1 . \\
1 . \\
1 . \\
1 . \\
1 . \\
1 . \\
1 . \\
1 . \\
1 .\end{array}$ & & $\begin{array}{l}1 . \\
1 . \\
1 . \\
1 . \\
1 . \\
1 . \\
1 . \\
1 . \\
1 . \\
1 . \\
1 . \\
1 . \\
1 . \\
1 .\end{array}$ & $\begin{array}{l}- \\
- \\
- \\
- \\
- \\
- \\
- \\
- \\
- \\
- \\
- \\
- \\
-\end{array}$ \\
\hline TOTAL ORGANIC CARBON & 0516 & $12 / 08 / 90$ & 0001 & MB & 0 & $M G / L$ & & 62. & $\mathbf{J}$ & 1. & - \\
\hline
\end{tabular}

FORMATION OF COMPLETION CODE:

MB - MIDDLE BURRO CANYON

PARAMETER VALUE INDICATOR (PVI): < - LESS THAN DETECTION LIMIT

OTHER PARAMETER VALUE FLAGS:

$J$ - ESTIMATED VALUE

L - LESS THAN THREE BORE VOLUMES REMOVED BEFORE SAMPLING
FLOW RELATIONSHIP CODE

O - ON-SITE

SAMPLE ID CODES:

OO01 - FILTERED SAMPLE (.45 MICRONS) 
TABLE 3.49 BACKGROUND GROUND WATER QUALITY DATA BY PARAMETER FOR THE

MIDDLE SANDSTONE UNIT, BURRO CANYON DISPOSAL SITE, SLICK ROCK, COLORADO

SITE: SRKO2 BORROW SITE 1 (BURRO CANYON)

$06 / 04 / 90$ TO $04 / 26 / 94$

REPORT DATE: 09/30/94

\begin{tabular}{|c|c|c|c|c|c|c|c|c|c|c|c|}
\hline PARAMETER NAME & $\begin{array}{c}\text { LOCATION } \\
\text { ID }\end{array}$ & LOG DATE & $\begin{array}{l}\text { SAMPLE } \\
\text { ID }\end{array}$ & $\begin{array}{l}\text { FORH } \\
\text { CONP }\end{array}$ & $\begin{array}{l}\text { FLOW } \\
\text { REL. }\end{array}$ & $\begin{array}{l}\text { UNITS OF } \\
\text { MEASURE }\end{array}$ & PVI & $\begin{array}{l}\text { PARAMETER } \\
\text { VALUE }\end{array}$ & FLAGS & $\begin{array}{l}\text { DETECTION } \\
\text { LIMIT }\end{array}$ & $\begin{array}{l}\text { PARAMETER } \\
\text { UNCERTAINTY }\end{array}$ \\
\hline TOTAL ORGANIC CARBON & $\begin{array}{l}0516 \\
0520 \\
0520 \\
0520 \\
0520 \\
0522 \\
0522 \\
0522 \\
0522 \\
0525 \\
0525 \\
0525 \\
0525 \\
0526 \\
0526 \\
0526 \\
0526 \\
0526 \\
0528 \\
0528 \\
0528 \\
0528\end{array}$ & $\begin{array}{l}04 / 04 / 91 \\
12 / 12 / 90 \\
04 / 01 / 91 \\
08 / 22 / 91 \\
10 / 11 / 92 \\
12 / 08 / 90 \\
04 / 02 / 91 \\
08 / 22 / 91 \\
10 / 12 / 92 \\
12 / 08 / 90 \\
04 / 03 / 91 \\
08 / 26 / 91 \\
02 / 23 / 94 \\
12 / 12 / 90 \\
04 / 04 / 91 \\
08 / 21 / 91 \\
10 / 14 / 92 \\
02 / 23 / 94 \\
12 / 15 / 90 \\
04 / 02 / 91 \\
08 / 21 / 91 \\
10 / 13 / 92\end{array}$ & $\begin{array}{l}0001 \\
0001 \\
0001 \\
0001 \\
0001 \\
0001 \\
0001 \\
0001 \\
0001 \\
0001 \\
0001 \\
0001 \\
0001 \\
0001 \\
0001 \\
0001 \\
0001 \\
0001 \\
0001 \\
0001 \\
0001 \\
0001\end{array}$ & $\begin{array}{l}\text { MB } \\
M B \\
M B \\
M B \\
M B \\
M B \\
M B \\
M B \\
M B \\
M B \\
M B \\
M B \\
M B \\
M B \\
M B \\
M B \\
M B \\
M B \\
M B \\
M B \\
M B \\
M B\end{array}$ & $\begin{array}{l}0 \\
0 \\
0 \\
0 \\
0 \\
0 \\
0 \\
0 \\
0 \\
0 \\
0 \\
0 \\
0 \\
0 \\
0 \\
0 \\
0 \\
0 \\
0 \\
0 \\
0 \\
0\end{array}$ & $M G / L$ & $\begin{array}{l} \\
< \\
< \\
< \\
<\end{array}$ & $\begin{array}{r}1 . \\
68 . \\
1 . \\
6 . \\
3 . \\
57 . \\
2 . \\
2 . \\
1 . \\
65 . \\
1 . \\
1 . \\
3 . \\
62 . \\
1 . \\
1 . \\
6 . \\
1 \\
65 . \\
1 . \\
1 . \\
7 .\end{array}$ & 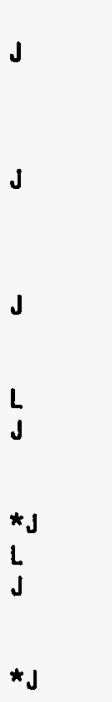 & $\begin{array}{l}1 . \\
1 . \\
1 . \\
1 . \\
1 . \\
1 . \\
1 . \\
1 . \\
1 . \\
1 . \\
1 . \\
1 . \\
1 . \\
1 . \\
1 . \\
1 . \\
1 . \\
1 .\end{array}$ & $\begin{array}{l}- \\
- \\
- \\
- \\
- \\
- \\
- \\
- \\
- \\
- \\
- \\
- \\
- \\
- \\
- \\
-\end{array}$ \\
\hline TURBIDITY & $\begin{array}{l}0516 \\
0516 \\
0522 \\
0522 \\
0525 \\
0525 \\
0526 \\
0526 \\
0526 \\
0528 \\
0528\end{array}$ & $\begin{array}{l}04 / 06 / 94 \\
04 / 26 / 94 \\
04 / 05 / 94 \\
04 / 21 / 94 \\
04 / 07 / 94 \\
04 / 26 / 94 \\
02 / 23 / 94 \\
04 / 06 / 94 \\
04 / 26 / 94 \\
04 / 06 / 94 \\
04 / 26 / 94\end{array}$ & $\begin{array}{l}0001 \\
0001 \\
0001 \\
0001 \\
0001 \\
0001 \\
0001 \\
0001 \\
0001 \\
0001 . \\
0001\end{array}$ & $\begin{array}{l}\text { MB } \\
M B \\
M B \\
M B \\
M B \\
M B \\
M B \\
M B \\
M B \\
M B \\
M B\end{array}$ & $\begin{array}{l}0 \\
0 \\
0 \\
0 \\
0 \\
0 \\
0 \\
0 \\
0 \\
0 \\
0\end{array}$ & NTU & & $\begin{array}{r}11 \\
174 \\
1 \\
0 \\
19 \\
19 \\
0 \\
0 \\
0 \\
4 \\
0\end{array}$ & $\begin{array}{l}L \\
L\end{array}$ & $\begin{array}{l}- \\
- \\
- \\
- \\
- \\
- \\
- \\
-\end{array}$ & $\begin{array}{l}- \\
- \\
- \\
- \\
- \\
- \\
- \\
-\end{array}$ \\
\hline URANIUM & $\begin{array}{l}0516 \\
0516 \\
0516\end{array}$ & $\begin{array}{l}06 / 06 / 90 \\
12 / 08 / 90 \\
04 / 04 / 91\end{array}$ & $\begin{array}{l}0001 \\
0001 \\
0001\end{array}$ & $\begin{array}{l}\text { MB } \\
\text { MB } \\
\text { MB }\end{array}$ & $\begin{array}{l}0 \\
0 \\
0\end{array}$ & MG/L & $<$ & $\begin{array}{l}0.0013 \\
0.0003 \\
0.001\end{array}$ & J & $\begin{array}{l}0.003 \\
0.0003 \\
0.001\end{array}$ & $\begin{array}{l}- \\
-\end{array}$ \\
\hline
\end{tabular}

FOPHATION OF COMPLETION CODE:

MB - MIDDLE BURRO CANYON

PARAMETER VALUE INDICATOR (PVI): < - LESS THAN DETECTION LIMIT
FLOW RELATIONSHIP CODE:

O - ON-SITE

SAMPLE ID CODES:

0001 - FILTERED SAMPLE (.45 MICRONS)

OTHER PARAMETER VALUE FLAGS:

* - DUPLICATE ANALYSIS NOT WITHIN CONTROL LIMITS

J - ESTIMATED VALUE

$L$ - LESS THAN THREE BORE VOLUMES REMOVED BEFORE SAMPLING 
TABLE 3.49 BACKGROUND GROUND WATER QUALITY DATA BY PARAMETER FOR THE MIDDLE SANDSTONE UNIT, BURRO CANYON DISPOSAL SITE, SLICK ROCK, COLORADO

SITE: SRKO2 BORROW SITE 1 (BURRO CANYON)

O6/04/90 TO 04/26/94

REPORT DATE : 09/30/94

\begin{tabular}{|c|c|c|c|c|c|c|c|c|c|c|c|}
\hline PARAMETER NAME & $\begin{array}{c}\text { LOCATION } \\
\text { ID }\end{array}$ & LOG DATE & $\underset{\text { ID }}{\text { SAMPLE }}$ & $\begin{array}{l}\text { FORM } \\
\text { COMP }\end{array}$ & $\begin{array}{l}\text { FLOW } \\
\text { REL. }\end{array}$ & $\begin{array}{l}\text { UNITS OF } \\
\text { MEASURE }\end{array}$ & PVI & $\begin{array}{l}\text { PARAMETER } \\
\text { VALUE }\end{array}$ & FLAGS & $\begin{array}{l}\text { DETECTION } \\
\text { LIMIT }\end{array}$ & $\begin{array}{l}\text { PARAMETER } \\
\text { UNCERTAINTY }\end{array}$ \\
\hline URANIUM & $\begin{array}{l}0516 \\
0516 \\
0516 \\
0520 \\
0520 \\
0520 \\
0520 \\
0520 \\
0522 \\
0522 \\
0522 \\
0522 \\
0522 \\
0522 \\
0525 \\
0525 \\
0525 \\
0525 \\
0525 \\
0525 \\
0525 \\
0526 \\
0526 \\
0526 \\
0526 \\
0526 \\
0526 \\
0526 \\
0528 \\
0528 \\
0528 \\
0528 \\
0523 \\
0528\end{array}$ & $\begin{array}{l}08 / 26 / 91 \\
10 / 14 / 92 \\
04 / 06 / 94 \\
06 / 04 / 90 \\
12 / 12 / 90 \\
04 / 01 / 91 \\
08 / 22 / 91 \\
10 / 11 / 92 \\
06 / 04 / 90 \\
12 / 08 / 90 \\
04 / 02 / 91 \\
08 / 22 / 91 \\
10 / 12 / 92 \\
04 / 05 / 94 \\
06 / 04 / 90 \\
12 / 08 / 90 \\
04 / 03 / 91 \\
08 / 26 / 91 \\
10 / 14 / 92 \\
02 / 23 / 94 \\
04 / 07 / 94 \\
06 / 06 / 90 \\
12 / 12 / 90 \\
04 / 04 / 91 \\
08 / 21 / 91 \\
10 / 14 / 92 \\
02 / 23 / 94 \\
04 / 06 / 94 \\
06 / 06 / 90 \\
12 / 15 / 90 \\
04 / 02 / 91 \\
08 / 21 / 91 \\
10 / 13 / 92 \\
04 / 06 / 94\end{array}$ & $\begin{array}{l}0001 \\
0001 \\
0001 \\
0001 \\
0001 \\
0001 \\
0001 \\
0001 \\
0001 \\
0001 \\
0001 \\
0001 \\
0001 \\
0001 \\
0001 \\
0001 \\
0001 \\
0001 \\
0001 \\
0001 \\
0001 \\
0001 \\
0001 \\
0001 \\
0001 \\
0001 \\
0001 \\
0001 \\
0001 \\
0001 \\
0001 \\
0001 \\
0001 \\
0001\end{array}$ & $\begin{array}{l}M B \\
M B \\
M B \\
M B \\
M B \\
M B \\
M B \\
M B \\
M B \\
M B \\
M B \\
M B \\
M B \\
M B \\
M B \\
M B \\
M B \\
M B \\
M B \\
M B \\
M B \\
M B \\
M B \\
M B \\
M B \\
M B \\
M B \\
M B \\
M B \\
M B \\
M B \\
M B \\
M B \\
M B\end{array}$ & $\begin{array}{l}0 \\
0 \\
0 \\
0 \\
0 \\
0 \\
0 \\
0 \\
0 \\
0 \\
0 \\
0 \\
0 \\
0 \\
0 \\
0 \\
0 \\
0 \\
0 \\
0 \\
0 \\
0 \\
0 \\
0 \\
0 \\
0 \\
0 \\
0 \\
0 \\
0 \\
0 \\
0 \\
0 \\
0\end{array}$ & $M G / L$ & $\begin{array}{l}< \\
< \\
< \\
< \\
< \\
< \\
< \\
< \\
< \\
< \\
< \\
< \\
< \\
<\end{array}$ & $\begin{array}{l}0.001 \\
0.001 \\
0.001 \\
0.0010 \\
0.0005 \\
0.001 \\
0.001 \\
0.002 \\
0.0018 \\
0.0011 \\
0.001 \\
0.006 \\
0.002 \\
0.001 \\
0.0009 \\
0.0003 \\
0.001 \\
0.001 \\
0.001 \\
0.001 \\
0.001 \\
0.0008 \\
0.0004 \\
0.008 \\
0.001 \\
0.001 \\
0.001 \\
0.001 \\
0.0013 \\
0.0010 \\
0.002 \\
0.001 \\
0.001 \\
0.001\end{array}$ & $\begin{array}{l}\text { J } \\
\text { J } \\
\text { J } \\
\text { L } \\
\text { J }\end{array}$ & $\begin{array}{l}0.001 \\
0.001 \\
0.001 \\
0.003 \\
0.0003 \\
0.001 \\
0.001 \\
0.001 \\
0.003 \\
0.0003 \\
0.001 \\
0.001 \\
0.001 \\
0.001 \\
0.003 \\
0.0003 \\
0.001 \\
0.001 \\
0.001 \\
0.001 \\
0.001 \\
0.003 \\
0.0003 \\
0.001 \\
0.001 \\
0.001 \\
0.001 \\
0.001 \\
0.003 \\
0.0003 \\
0.001 \\
0.001 \\
0.001 \\
0.001\end{array}$ & $\begin{array}{l}- \\
- \\
- \\
i \\
- \\
- \\
- \\
- \\
- \\
- \\
- \\
- \\
- \\
- \\
- \\
- \\
- \\
- \\
- \\
- \\
- \\
- \\
- \\
- \\
- \\
-\end{array}$ \\
\hline VANADIUM & $\begin{array}{l}0516 \\
0516 \\
0516\end{array}$ & $\begin{array}{l}06 / 06 / 90 \\
12 / 08 / 90 \\
04 / 04 / 91\end{array}$ & $\begin{array}{l}0001 \\
0001 \\
0001\end{array}$ & $\begin{array}{l}\text { MB } \\
\text { MB } \\
M B\end{array}$ & $\begin{array}{l}0 \\
0 \\
0\end{array}$ & $M G / L$ & $<$ & $\begin{array}{l}0.02 \\
0.03 \\
0.01\end{array}$ & & $\begin{array}{l}0.01 \\
0.01 \\
0.01\end{array}$ & - \\
\hline
\end{tabular}

FORMATION OF COMPLETION CODE:

MB - MIDOLE BURRO CANYON

PARAMETER VALUE INDICATOR (PVI): < - LESS THAN DETECTION LIMIT
FLOW RELATIONSHIP CODE:

O - ON-SITE

SAMPLE ID CODES:

0001 - FILTERED SAMPLE (.45 MICRONS)

OTHER PARAMETER VALUE FLAGS:

$J$ - ESTIMATED VALUE

L - LESS THAN THREE BORE VOLUMES REMOVED BEFORE SAMPLING

N - SPIKE SAMPLE RECOVERY NOT WITHIN CONTROL LIMITS 
TABLE 3.49 BACKGROUND GROUND HATER QUALITY DATA BY PARAMETER FOR THE MIDDLE SANDSTONE UNIT, BURRO CANYON DISPOSAL SITE, SLICK ROCK, COLORADO SITE: SRKO2 BORROW SITE 1 (BURRO CANYON)

06/04/90 TO 04/26/94

REPORT DATE: $09 / 30 / 94$

\begin{tabular}{|c|c|c|c|c|c|c|c|c|c|c|c|}
\hline PARAMETER NAME & $\begin{array}{c}\text { LOCATION } \\
\text { ID }\end{array}$ & LOG DATE & $\underset{\text { ID }}{\text { SAMPLE }}$ & $\begin{array}{l}\text { FORM } \\
\text { COMP }\end{array}$ & $\begin{array}{l}\text { FLOW } \\
\text { REL. }\end{array}$ & $\begin{array}{l}\text { UNITS OF } \\
\text { MEASURE }\end{array}$ & PVI & $\begin{array}{l}\text { PARAMETER } \\
\text { VALUE }\end{array}$ & FLAGS & $\begin{array}{l}\text { DETECTION } \\
\text { LIMIT }\end{array}$ & $\begin{array}{l}\text { PARAMETER } \\
\text { UNCERTAINTY }\end{array}$ \\
\hline VANADIUM & $\begin{array}{l}0516 \\
0516 \\
0516 \\
0520 \\
0520 \\
0520 \\
0520 \\
0520 \\
0522 \\
0522 \\
0522 \\
0522 \\
0522 \\
0522 \\
0525 \\
0525 \\
0525 \\
0525 \\
0525 \\
0525 \\
0525 \\
0526 \\
0526 \\
0526 \\
0526 \\
0526 \\
0526 \\
0526 \\
0528 \\
0528 \\
0528 \\
0528 \\
0528 \\
0528\end{array}$ & $\begin{array}{l}08 / 26 / 91 \\
10 / 14 / 92 \\
04 / 26 / 94 \\
06 / 04 / 90 \\
12 / 12 / 90 \\
04 / 01 / 91 \\
08 / 22 / 91 \\
10 / 11 / 92 \\
06 / 04 / 90 \\
12 / 08 / 90 \\
04 / 02 / 91 \\
08 / 22 / 91 \\
10 / 12 / 92 \\
04 / 21 / 94 \\
06 / 04 / 90 \\
12 / 08 / 90 \\
04 / 03 / 91 \\
08 / 26 / 91 \\
10 / 14 / 92 \\
02 / 23 / 94 \\
04 / 26 / 94 \\
06 / 06 / 90 \\
12 / 12 / 90 \\
04 / 04 / 91 \\
08 / 21 / 91 \\
10 / 14 / 92 \\
02 / 23 / 94 \\
04 / 26 / 94 \\
06 / 06 / 90 \\
12 / 15 / 90 \\
04 / 02 / 91 \\
08 / 21 / 91 \\
10 / 13 / 92 \\
04 / 26 / 94\end{array}$ & $\begin{array}{l}0001 \\
0001 \\
0001 \\
0001 \\
0001 \\
0001 \\
0001 \\
0001 \\
0001 \\
0001 \\
0001 \\
0001 \\
0001 \\
0001 \\
0001 \\
0001 \\
0001 \\
0001 \\
0001 \\
0001 \\
0001 \\
0001 \\
0001 \\
0001 \\
0001 \\
0001 \\
0001 \\
0001 \\
0001 \\
0001 \\
0001 \\
0001 \\
0001 \\
0001\end{array}$ & $\begin{array}{l}M B \\
M B \\
M B \\
M B \\
M B \\
M B \\
M B \\
M B \\
M B \\
M B \\
M B \\
M B \\
M B \\
M B \\
M B \\
M B \\
M B \\
M B \\
M B \\
M B \\
M B \\
M B \\
M B \\
M B \\
M B \\
M B \\
M B \\
M B \\
M B \\
M B \\
M B \\
M B \\
M B \\
M B\end{array}$ & $\begin{array}{l}0 \\
0 \\
0 \\
0 \\
0 \\
0 \\
0 \\
0 \\
0 \\
0 \\
0 \\
0 \\
0 \\
0 \\
0 \\
0 \\
0 \\
0 \\
0 \\
0 \\
0 \\
0 \\
0 \\
0 \\
0 \\
0 \\
0 \\
0 \\
0 \\
0 \\
0 \\
0 \\
0 \\
0\end{array}$ & $M G / L$ & $\begin{array}{l}< \\
< \\
< \\
< \\
< \\
< \\
< \\
< \\
< \\
< \\
< \\
< \\
< \\
< \\
< \\
< \\
< \\
< \\
< \\
< \\
< \\
< \\
< \\
< \\
< \\
< \\
< \\
< \\
< \\
< \\
\\
<\end{array}$ & $\begin{array}{l}0.01 \\
0.01 \\
0.01 \\
0.01 \\
0.03 \\
0.01 \\
0.01 \\
0.01 \\
0.02 \\
0.03 \\
0.01 \\
0.01 \\
0.01 \\
0.01 \\
0.01 \\
0.03 \\
0.01 \\
0.01 \\
0.01 \\
0.01 \\
0.01 \\
0.01 \\
0.03 \\
0.01 \\
0.01 \\
0.01 \\
0.01 \\
0.01 \\
0.01 \\
0.03 \\
0.01 \\
0.01 \\
0.01 \\
0.01\end{array}$ & $\begin{array}{l}\text { J } \\
\text { L } \\
\text { L }\end{array}$ & $\begin{array}{l}0.01 \\
0.01 \\
0.01 \\
0.01 \\
0.01 \\
0.01 \\
0.01 \\
0.01 \\
0.01 \\
0.01 \\
0.01 \\
0.01 \\
0.01 \\
0.01 \\
0.01 \\
0.01 \\
0.01 \\
0.01 \\
0.01 \\
0.01 \\
0.01 \\
0.01 \\
0.01 \\
0.01 \\
0.01 \\
0.01 \\
0.01 \\
0.01 \\
0.01 \\
0.01 \\
0.01 \\
0.01 \\
0.01 \\
0.01\end{array}$ & $\begin{array}{l}- \\
- \\
- \\
- \\
- \\
- \\
- \\
- \\
- \\
- \\
- \\
- \\
- \\
- \\
- \\
- \\
- \\
- \\
- \\
- \\
- \\
- \\
- \\
- \\
- \\
- \\
- \\
- \\
- \\
- \\
- \\
- \\
-\end{array}$ \\
\hline ZINC & $\begin{array}{l}0516 \\
0516 \\
0516 \\
0516\end{array}$ & $\begin{array}{l}06 / 06 / 90 \\
12 / 08 / 90 \\
04 / 04 / 91 \\
08 / 26 / 91\end{array}$ & $\begin{array}{l}0001 \\
0001 \\
0001 \\
0001\end{array}$ & $\begin{array}{l}\text { MB } \\
M B \\
M B \\
M B\end{array}$ & $\begin{array}{l}0 \\
0 \\
0 \\
0\end{array}$ & MG/L & $\mid<$ & $\begin{array}{l}0.053 \\
0.005 \\
0.017 \\
0.005\end{array}$ & & $\begin{array}{l}0.005 \\
0.005 \\
0.005 \\
0.005\end{array}$ & - \\
\hline
\end{tabular}

FORMATION OF COMPLETION CODE:

MB - MIDDLE BURRO CANYON

PARAMETER VALUE INDICATOR (PVI): < - LESS THAN DETECTION LIMIT

OTHER PARAMETER VALUE FLAGS:

$J$ - ESTIMATED VALUE

L - LESS THAN THREE , gORE VOLUMES REMOVED BEFORE SAMPLING
FLOW RELATIONSHIP CODE:

O - ON-SITE

SAMPLE ID CODES:

0001 - FILTERED SAMPLE (.45 MICRONS) 
TABLE 3.49 BACKGROUND GROUND WATER QUALITY DATA BY PARAMETER FOR THE MIDDLE SANDSTONE UNIT, BURRO CANYON DISPOSAL SITE, SLICK ROCK, COLORADO SITE: SRK02 BORROW SITE 1 (BURRO CANYON)

06/04/90 TO 04/26/94

REPORT DATE: 09/30/94

\begin{tabular}{|c|c|c|c|c|c|c|c|c|c|c|c|}
\hline PARAMETER NAME & $\begin{array}{c}\text { LOCAT ION } \\
\text { ID }\end{array}$ & LOG DATE & $\begin{array}{c}\text { SAMPLE } \\
\text { ID }\end{array}$ & $\begin{array}{l}\text { FORM } \\
\text { COMP }\end{array}$ & 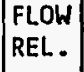 & $\begin{array}{l}\text { UNITS OF } \\
\text { MEASURE }\end{array}$ & PVI & $\begin{array}{l}\text { PARAMETER } \\
\text { VALUE }\end{array}$ & FLAGS & $\begin{array}{l}\text { DETECTION } \\
\text { LIMIT }\end{array}$ & $\begin{array}{l}\text { PARAMETER } \\
\text { UNCERTAINTY }\end{array}$ \\
\hline ZINC & $\begin{array}{l}0516 \\
0516 \\
0520 \\
0520 \\
0520 \\
0520 \\
0520 \\
0522 \\
0522 \\
0522 \\
0522 \\
0522 \\
0522 \\
0525 \\
0525 \\
0525 \\
0525 \\
0525 \\
0525 \\
0525 \\
0526 \\
0526 \\
0526 \\
0526 \\
0526 \\
0526 \\
0526 \\
0528 \\
0528 \\
0528 \\
0528 \\
0528 \\
0528\end{array}$ & $\begin{array}{l}10 / 14 / 92 \\
04 / 26 / 94 \\
06 / 04 / 90 \\
12 / 12 / 90 \\
04 / 01 / 91 \\
08 / 22 / 91 \\
10 / 11 / 92 \\
06 / 04 / 90 \\
12 / 08 / 90 \\
04 / 02 / 91 \\
08 / 22 / 91 \\
10 / 12 / 92 \\
04 / 21 / 94 \\
06 / 04 / 90 \\
12 / 08 / 90 \\
04 / 03 / 91 \\
08 / 26 / 91 \\
10 / 14 / 92 \\
02 / 23 / 94 \\
04 / 26 / 94 \\
06 / 06 / 90 \\
12 / 12 / 90 \\
04 / 04 / 91 \\
08 / 21 / 91 \\
10 / 14 / 92 \\
02 / 23 / 94 \\
04 / 26 / 94 \\
06 / 06 / 90 \\
12 / 15 / 90 \\
04 / 02 / 91 \\
08 / 21 / 91 \\
10 / 13 / 92 \\
04 / 26 / 94\end{array}$ & $\begin{array}{l}0001 \\
0001 \\
0001 \\
0001 \\
0001 \\
0001 \\
0001 \\
0001 \\
0001 \\
0001 \\
0001 \\
0001 \\
0001 \\
0001 \\
0001 \\
0001 \\
0001 \\
0001 \\
0001 \\
0001 \\
0001 \\
0001 \\
0001 \\
0001 \\
0001 \\
0001 \\
0001 \\
0001 \\
0001 \\
0001 \\
0001 \\
0001 \\
0001\end{array}$ & $\begin{array}{l}M B \\
M B \\
M B \\
M B \\
M B \\
M B \\
M B \\
M B \\
M B \\
M B \\
M B \\
M B \\
M B \\
M B \\
M B \\
M B \\
M B \\
M B \\
M B \\
M B \\
M B \\
M B \\
M B \\
M B \\
M B \\
M B \\
M B \\
M B \\
M B \\
M B \\
M B \\
M B \\
M B\end{array}$ & $\begin{array}{l}0 \\
0 \\
0 \\
0 \\
0 \\
0 \\
0 \\
0 \\
0 \\
0 \\
0 \\
0 \\
0 \\
0 \\
0 \\
0 \\
0 \\
0 \\
0 \\
0 \\
0 \\
0 \\
0 \\
0 \\
0 \\
0 \\
0 \\
0 \\
0 \\
0 \\
0 \\
0 \\
0\end{array}$ & $M G / L$ & $\begin{array}{l}< \\
< \\
< \\
< \\
< \\
< \\
< \\
< \\
< \\
< \\
< \\
< \\
< \\
< \\
< \\
< \\
<\end{array}$ & $\begin{array}{l}0.009 \\
0.05 \\
0.054 \\
0.077 \\
0.147 \\
0.078 \\
0.005 \\
0.080 \\
0.044 \\
0.057 \\
0.041 \\
0.005 \\
0.05 \\
0.048 \\
0.043 \\
0.033 \\
0.005 \\
0.005 \\
0.05 \\
0.05 \\
0.022 \\
0.020 \\
0.027 \\
0.005 \\
0.005 \\
0.05 \\
0.05 \\
0.095 \\
0.032 \\
0.033 \\
0.008 \\
0.005 \\
0.05\end{array}$ & $\begin{array}{l}J \\
\text { J } \\
\text { L } \\
\text { L }\end{array}$ & $\begin{array}{l}0.005 \\
0.05 \\
0.005 \\
0.005 \\
0.005 \\
0.005 \\
0.005 \\
0.005 \\
0.005 \\
0.005 \\
0.005 \\
0.005 \\
0.05 \\
0.005 \\
0.005 \\
0.005 \\
0.005 \\
0.005 \\
0.05 \\
0.05 \\
0.005 \\
0.005 \\
0.005 \\
0.005 \\
0.005 \\
0.05 \\
0.05 \\
0.005 \\
0.005 \\
0.005 \\
0.005 \\
0.005 \\
0.05\end{array}$ & $\begin{array}{l}- \\
- \\
- \\
- \\
- \\
- \\
- \\
- \\
- \\
- \\
- \\
- \\
- \\
- \\
- \\
- \\
- \\
- \\
- \\
- \\
- \\
- \\
- \\
- \\
- \\
-\end{array}$ \\
\hline
\end{tabular}

FORMATION OF COMPLETION CODE:

MB - MIDDLE BURRO CANYON

PARAMETER VALUE INDICATOR (PVI): < - LESS THAN DETECTION LIMIT

OTHER PARAMETER VALUE FLAGS:

$J$ - ESTIMATED VALUE

L - LESS THAN THREE BORE VOLUMES REMOVED BEFORE SAMPLING
FLOW RELATIONSHIP CODE:

O - ON-SITE

SAMPLE ID CODES:

0001 - FILTERED SAMPLE (.45 MICRONS)

DATA FILE NAME: IDARTISRK02\GWQ10006.DAT 
TABLE 3.50 BACKGROUND GROUND HATER QUALITY STATISTICS BY PARAMETER FOR THE MIDDLE SANDSTONE UNIT, BURRO CANYON DISPOSAL SITE, SLICK ROCK, COLORADD SITE: SRKO2 BORROW SITE 1 (BURRO CANYON)

06/04/90 TO 04/26/94

REPORT DATE: $09 / 30 / 94$

\begin{tabular}{|c|c|c|c|c|c|c|c|c|c|c|c|c|}
\hline \multicolumn{3}{|c|}{ PARAMETER NAME } & UNITS & \multirow[b]{2}{*}{ MEAN } & \multirow[b]{2}{*}{$\begin{array}{r}\text { STANDARD } \\
\text { DEVIATION }\end{array}$} & \multirow{2}{*}{$\begin{array}{c}\text { COEFF. } \\
\text { OF } \\
\text { VARIATION }\end{array}$} & \multirow{2}{*}{$\begin{array}{l}\% \text { OF } \\
\text { NON } \\
\text { DETECTS }\end{array}$} & \multirow{2}{*}{\multicolumn{3}{|c|}{$\begin{array}{c}\text { STATISTICAL RANGE } \\
\text { 98\% CONFIDENCE INTERVAL } \\
\text { MINIMUM }\end{array}$}} & \multirow[b]{2}{*}{$\begin{array}{l}\text { DISTRIBUTION } \\
\text { TYPE }\end{array}$} & \multirow[b]{2}{*}{$\begin{array}{l}\text { FOOT } \\
\text { NOTE }\end{array}$} \\
\hline \# OF SAMP & MINIMUM & MAXIMUM & MEDIAN & & & & & & & & & \\
\hline \multicolumn{3}{|l|}{ ALKALINITY } & MG/L CAC & \multirow[b]{2}{*}{230.1750} & \multirow[b]{2}{*}{39.4188} & \multirow[b]{2}{*}{0.1713} & \multirow[b]{2}{*}{0.0} & \multirow{2}{*}{\multicolumn{2}{|c|}{215.0608}} & \multirow[b]{2}{*}{245.2892} & \multirow[b]{2}{*}{ NORMAL } & \\
\hline 40 & 27.0000 & 276.0000 & +232.5000 & & & & & & & & & \\
\hline \multicolumn{3}{|l|}{ ALUMINUM } & $M G / L$ & \multirow[b]{2}{*}{ NA } & \multirow[b]{2}{*}{ NA } & \multirow[b]{2}{*}{ NA } & \multirow[b]{2}{*}{100.0} & \multirow[b]{2}{*}{ ** } & \multirow[b]{2}{*}{0.0500} & \multirow[b]{2}{*}{0.0500} & \multirow[b]{2}{*}{ NONPARAMETRIC } & \multirow[b]{2}{*}{2} \\
\hline 30 & 0.0500 & 0.0500 & 0.0500 & & & & & & & & & \\
\hline \multicolumn{3}{|l|}{ AMMON IUM } & $M G / L$ & \multirow[b]{2}{*}{ NA } & \multirow[b]{2}{*}{ NA } & \multirow[b]{2}{*}{ NA } & \multirow[b]{2}{*}{39.3} & \multirow[b]{2}{*}{ ** } & & & & \\
\hline 28 & $\star * \quad 0.1000$ & 0.5000 & 0.1500 & & & & & & 0.1000 & 0.3000 & NONPARAMETRIC & 2 \\
\hline ANT IMONY & & & $M G / L$ & & & & & & & & & \\
\hline 30 & ** $\quad 0.0030$ & 0.0060 & 0.0030 & NA & NA & NA & 96.7 & ** & 0.0030 & 0.0030 & NONPARAMETRIC & 2 \\
\hline ARSEN IC & & & $M G / L$ & & & & & & & & & \\
\hline 30 & ** $\quad 0.0050$ & 0.0050 & 0.0050 & NA & NA & NA & 100.0 & & 0.0050 & 0.0050 & NONPARAMETRIC & 2 \\
\hline BARIUM & & & $M G / L$ & & & & & & & & & \\
\hline 37 & 0.0100 & 0.0500 & 0.0500 & NA & NA & NA & 51.4 & & 0.0200 & 0.0500 & NONPARAMETRIC & 2 \\
\hline BERYLLIUM & & & $M G / L$ & & & & & & & & & \\
\hline 24 & ** $\quad 0.0050$ & 0.0050 & 0.0050 & NA & NA & NA & 100.0 & ** & 0.0050 & 0.0050 & NONPARAMETRIC & 2 \\
\hline BORON & & & $M G / L$ & & & & & & & & & \\
\hline 31 & 0.0500 & 0.2000 & 0.1800 & 0.1561 & 0.0496 & 0.3180 & 6.5 & & 0.1342 & 0.1780 & NORMAL & \\
\hline BROMIDE & & & MG/L & & & & & & & & & \\
\hline 24 & ** $\quad 0.1000$ & 0.5000 & 0.2000 & NA & NA & NA & 50.0 & ** & 0.1000 & 0.2000 & NONPARAMETRIC & 2 \\
\hline CADHIUM & & & $M G / L$ & & & & & & & & & \\
\hline 37 & ** $\quad 0.0005$ & 0.0025 & 0.0005 & NA & NA & NA & 100.0 & & 0.0005 & 0.0005 & NONPARAMETRIC & 2 \\
\hline
\end{tabular}

** The reported value is the minimum detection limit of the data set

+ The sample size is even, so the median value is the arithmetic average of the two middle values

* The statistical maximum is the 99 percent one sided confidence interval, $\alpha=0.01$

2) The nonparametric distribution was used because the nondetected values comprise more than $15 \%$ of the samples. 
REPORT DATE: 09/30/94

\begin{tabular}{|c|c|c|c|c|c|c|c|c|c|c|c|c|c|}
\hline \multicolumn{3}{|c|}{ PARAMETER NAME } & UNITS & \multirow[b]{2}{*}{ MEAN } & \multirow{2}{*}{$\begin{array}{l}\text { STANDARD } \\
\text { DEVIATION }\end{array}$} & \multirow{2}{*}{$\begin{array}{c}\text { COEFF. } \\
\text { OF } \\
\text { VARIATION }\end{array}$} & \multirow{2}{*}{$\begin{array}{l}\% \text { OF } \\
\text { NON } \\
\text { DETECTS }\end{array}$} & \multirow{2}{*}{\multicolumn{4}{|c|}{$\begin{array}{c}\text { STATISTICAL RANGE } \\
98 \% \text { CONFIDENCE INTERVAL } \\
\text { MINIMUM } \\
\text { MAXIMUM * }\end{array}$}} & \multirow{2}{*}{$\begin{array}{c}\text { OISTRIBUTION } \\
\text { TYPE }\end{array}$} & \multirow{2}{*}{$\begin{array}{l}\text { FOOT } \\
\text { NOTE }\end{array}$} \\
\hline \# OF SAMP & MINIMUM & MAXIMUM & MEDIAN & & & & & & & & & & \\
\hline CALCIUM & & & $M G / L$ & \multirow[b]{2}{*}{58.5351} & \multirow[b]{2}{*}{10.7079} & \multirow[b]{2}{*}{0.1829} & \multirow[b]{2}{*}{0.0} & \multirow{2}{*}{\multicolumn{2}{|c|}{54.2504}} & \multirow{2}{*}{\multicolumn{2}{|c|}{62.8199}} & \multirow[b]{2}{*}{ NORMAL } & \\
\hline 37 & 44.5000 & 85.5000 & 57.4000 & & & & & & & & & & \\
\hline \multicolumn{3}{|l|}{ CHLORIDE } & $M G / L$ & \multirow[b]{2}{*}{27.2324} & \multirow[b]{2}{*}{8.3207} & \multirow[b]{2}{*}{0.3055} & \multirow[b]{2}{*}{0.0} & \multirow{2}{*}{\multicolumn{2}{|c|}{23.9029}} & \multirow{2}{*}{\multicolumn{2}{|c|}{30.5619}} & \multirow[b]{2}{*}{ NORMAL } & \\
\hline 37 & 19.8000 & 59.0000 & 24.0000 & & & & & & & & & & \\
\hline \multicolumn{3}{|l|}{ CHROMIUM } & $M G / L$ & \multirow[b]{2}{*}{ NA } & \multirow[b]{2}{*}{ NA } & \multirow[b]{2}{*}{ NA } & \multirow[b]{2}{*}{100.0} & \multirow[b]{2}{*}{ ** } & \multirow[b]{2}{*}{0.0100} & \multirow[b]{2}{*}{ ** } & & & \\
\hline 37 & 0.0100 & 0.0100 & 0.0100 & & & & & & & & 0.0100 & NONPARAMETRIC & 2 \\
\hline COBALT & & & MG/L & & & & & & & & & & \\
\hline 24 & ** $\quad 0.0300$ & $\begin{array}{ll}* * & 0.0300\end{array}$ & 0.0300 & NA & NA & NA & 100.0 & *夫 & 0.0300 & ** & 0.0300 & NONPARAMETRIC & 2 \\
\hline COPPER & & & $\mathrm{MG} / \mathrm{L}$ & & & & & & & & & & \\
\hline 30 & ** $\quad 0.0100$ & 0.0100 & 0.0100 & NA & NA & NA & 100.0 & 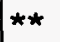 & 0.0100 & & 0.0100 & NONPARAMETRIC & 2 \\
\hline CYANIDE & & & $M G / L$ & & & & & & & & & & \\
\hline 18 & $\begin{array}{ll}* & 0.0100\end{array}$ & 0.0100 & 0.0100 & NA & NA & NA & 100.0 & ** & 0.0100 & ** & 0.0100 & NONPARAMETRIC & 2 \\
\hline DISSOLVED & ORGANIC CARB & $30 \mathrm{~N}$ & $M G / L$ & & & & & & & & & & \\
\hline 2 & ** $\quad 1.0000$ & 2.0000 & 1.2500 & NA & NA & NA & 50.0 & & NA & & NA & UNKNOWN & 1 \\
\hline DISSOLVED & OXYGEN & & $M G / L$ & & & & & & & & & & \\
\hline 17 & 0.1000 & 106.0000 & 0.6700 & 1.0310 & 5.8996 & NA & 0.0 & & 0.3391 & & 3.1344 & LOGNORMAL. & 7,8 \\
\hline FIELD FE ? & $2+1$ & & $\mathrm{MG} / \mathrm{L}$ & & & & & & & & & & \\
\hline 2 & 0.0200 & 0.1000 & 0.0600 & NA & NA & NA & 0.0 & & NA & & NA & UNKNOWN & 1 \\
\hline
\end{tabular}

** The reported value is the minimum detection limit of the data set

+ The sample size is even, so the median value is the arithmetic average of the two middle values

* The statistical maximum is the 99 percent one sided confidence interval, $\alpha=0.01$

1) A minimum of 4 samples must be available for the statistical analysis.

2) The nonparametric distribution was used because the nondetected values comprise more than $15 \%$ of the samples.

7) The lognormal distribution was used because the data failed the normal distribution test.

8) The mean is geometric. The standard deviation is the value to divide or multiply with the geometric mean. 
TABLE 3.50 BACKGROUND GROUND HATER QUALITY STATISTICS BY PARAMETER FOR THE MIDDLE SANDSTONE UNIT, BURRO CANYON DISPOSAL SITE, SLICK ROCK, COLORADO

SITE: SRKO2 BORROW SITE 1 (BURRO CANYON)

$06 / 04 / 90$ TO $04 / 26 / 94$

REPORT DATE : 09/30/94

\begin{tabular}{|c|c|c|c|c|c|c|c|c|c|c|c|c|c|c|c|}
\hline \multicolumn{6}{|c|}{ PARAMETER NAME } & UNITS & \multirow[b]{2}{*}{ MEAN } & \multirow{2}{*}{$\begin{array}{r}\text { STANDARD } \\
\text { DEVIATION }\end{array}$} & \multirow{2}{*}{$\begin{array}{c}\text { COEFF. } \\
\text { OF } \\
\text { VARIATION }\end{array}$} & \multirow{2}{*}{$\mid \begin{array}{c}\% \text { OF } \\
\text { NON } \\
\text { DETECTS }\end{array}$} & \multirow{2}{*}{\multicolumn{3}{|c|}{$\begin{array}{c}\text { STATISTICAL RANGE } \\
\text { 98\% CONFIDENCE INTERVAL } \\
\text { MINIMUM } \\
\text { MAXIMUM * }\end{array}$}} & \multirow{2}{*}{$\begin{array}{l}\text { DISTRIBUTION } \\
\text { TYPE }\end{array}$} & \multirow[b]{2}{*}{$\begin{array}{l}\text { FOOT } \\
\text { NOTE }\end{array}$} \\
\hline \# OF SAMP & & INIMUM & & IAXIMUM & & MED I AN & & & & & & & & & \\
\hline \multicolumn{6}{|l|}{ FLUORIDE } & MG/L & \multirow[b]{2}{*}{0.6733} & \multirow[b]{2}{*}{0.1230} & \multirow[b]{2}{*}{0.1827} & \multirow[b]{2}{*}{0.0} & \multirow{2}{*}{\multicolumn{2}{|c|}{0.6180}} & \multirow[b]{2}{*}{0.7286} & \multirow[b]{2}{*}{ NORMAL } & \\
\hline 30 & & 0.5000 & & 1.0000 & + & 0.6000 & & & & & & & & & \\
\hline \multicolumn{6}{|c|}{ GROSS ALPHA } & $\mathrm{PCI} / \mathrm{L}$ & \multirow[b]{2}{*}{ NA } & \multirow[b]{2}{*}{ NA } & \multirow[b]{2}{*}{ NA } & \multirow[b]{2}{*}{0.0} & \multirow[b]{2}{*}{ ** } & \multirow[b]{2}{*}{1.0000} & \multirow[b]{2}{*}{3.6000} & \multirow[b]{2}{*}{ NONPARAMETRIC } & \multirow[b]{2}{*}{9} \\
\hline 31 & ** & 1.0000 & & 6.4000 & & 1.6000 & & & & & & & & & \\
\hline \multicolumn{6}{|l|}{ GROSS BETA } & PCI/L & \multirow[b]{2}{*}{ NA } & \multirow[b]{2}{*}{ NA } & \multirow[b]{2}{*}{ NA } & & & & & & \\
\hline 24 & ** & 0.5000 & & 12.9000 & + & 3.7500 & & & & 0.0 & & 0.5000 & 5.9000 & NONPARAMETRI C & 9 \\
\hline IRON & & & & & & $M G / L$ & & & & & & & & & \\
\hline 37 & ** & 0.0300 & & 0.1200 & & 0.0300 & NA & NA & NA & 43.2 & $\star \star$ & 0.0300 & 0.0600 & NONPARAMETRIC & 2 \\
\hline LEAD & & & & & & $M G / L$ & & & & & & & & & \\
\hline 30 & $\star \star$ & 0.0030 & & 0.0100 & * & 0.0030 & NA & NA & NA & 100.0 & ** & 0.0030 & 0.0050 & NONPARAMETRIC & 2 \\
\hline LEAD-210 & & & & & & $\mathrm{PCI} / \mathrm{L}$ & & & & & & & & & \\
\hline 18 & ** & 1.5000 & $\star \star$ & 1.5000 & * & 1.5000 & NA & NA & NA & 0.0 & ** & 1.5000 & 1.5000 & NONPARAMETRIC & 9 \\
\hline MAGNESIUM & & & & & & $M G / L$ & & & & & & & & & \\
\hline 37 & & 16.5000 & & 30.3000 & & 20.4000 & 21.1270 & 3.4301 & 0.1624 & 0.0 & & 19.7545 & 22.4996 & NORMAL & \\
\hline MANGANESE & & & & & & $M G / L$ & & & & & & & & & \\
\hline 30 & & 0.0400 & & 0.1700 & + & 0.0700 & 0.0800 & 0.0323 & 0.4034 & 0.0 & & 0.0655 & 0.0945 & NORMAL & \\
\hline MERCURY & & & & & & $M G / L$ & & & & & & & & & \\
\hline 24 & ** & 0.0002 & ** & 0.0002 & * & 0.0002 & NA & NA & NA & 100.0 & $\star \star$ & 0.0002 & 0.0002 & NONPARAMETRIC & 2 \\
\hline MOLYBDENUM & & & & & & MG/L & & & & & & & & & \\
\hline 37 & ** & 0.0100 & & 0.0300 & * & 0.0100 & NA & NA & NA & 70.3 & $\star \star$ & 0.0100 & 0.0100 & NONPARAMETRIC & 2 \\
\hline
\end{tabular}

** The reported value is the minimum detection limit of the data set

+ The sample size is even, so the median value is the arithmetic average of the two middle values

* The statistical maximum is the 99 percent one sided confidence interval, $\alpha=0.01$

2) The nonparametric distribution was used because the nondetected values comprise more than $15 \%$ of the samples.

9) The nonparametic distribution was used because the data failed the normal distribution tort and includes values $\leq 0$. 
TABLE 3.50 BACKGROUND GROUND WATER QUALITY STATISTICS BY PARAMETER FOR THE MIDDLE SANDSTONE UNIT, BURRO CANYON DISPOSAL SITE, SLICK ROCK, COLORADO

SITE: SRKO2 BORROW SITE 1 (BURRO CANYON)

$06 / 04 / 90$ TO $04 / 26 / 94$

REPORT DATE: $09 / 30 / 94$

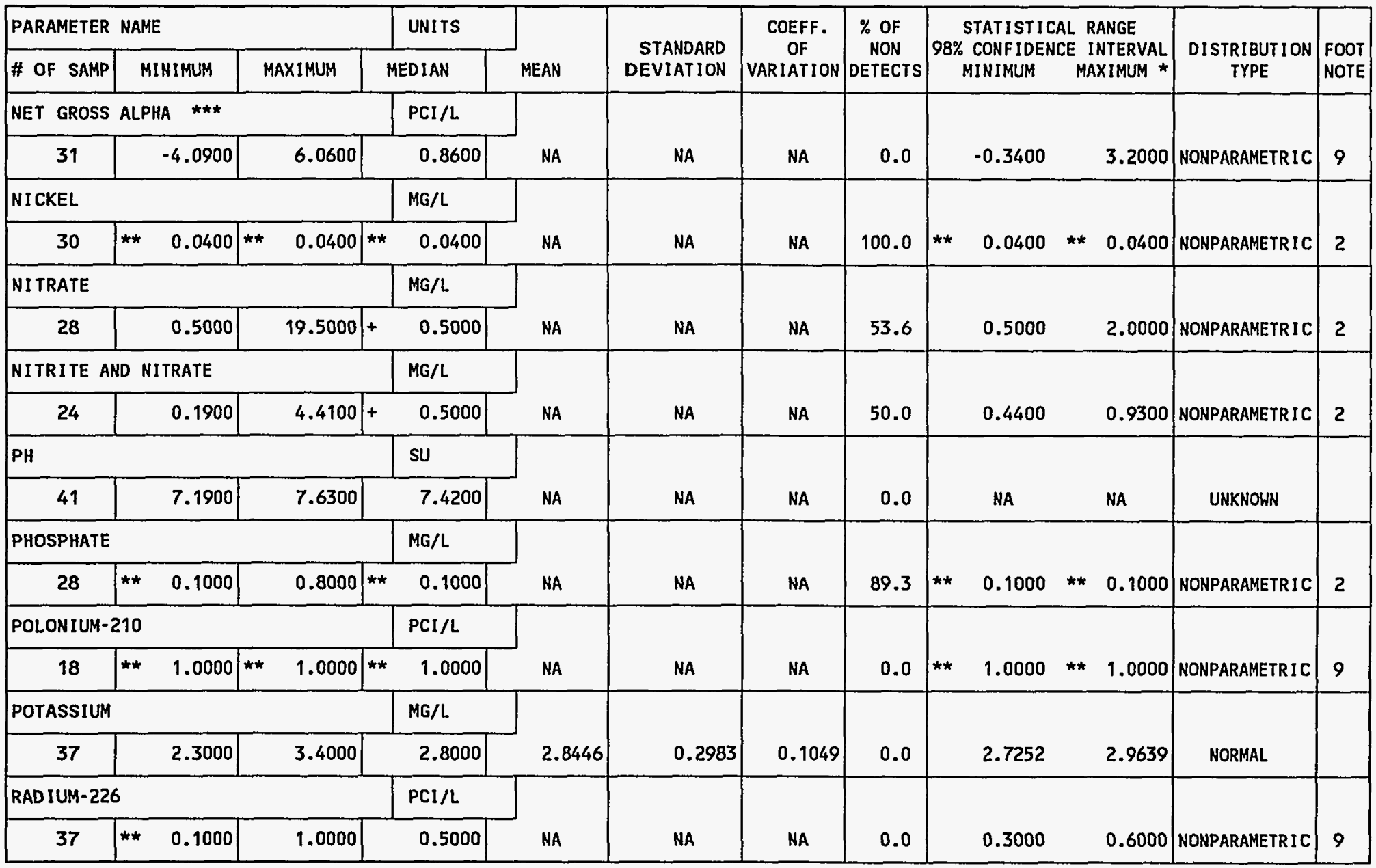

** NET GROSS ALPHA (GROSS ALPHA - URANIUM) HITH 1 MG URANIUM = $686 \mathrm{PCI}$

** The reported value is the minimum detection limit of the data set

+ The sample size is even, so the median value is the arithmetic average of the two middle values

* The statistical maximum is the 99 percent one sided confidence interval, $\alpha=0.01$

1) A minimum of 4 samples must be available for the statistical analysis.

2) The nonparametric distribution was used because the nondetected values comprise more than $15 \%$ of the samples.

9) The nonparametic distribution was used because the data failed the normal distribution test and includes values $\leq 0$. 
TABLE 3.50 BACKGROUND GROUND HATER QUALITY STATISTICS BY PARAMETER FOR THE MIDDLE SANDSTONE UNIT, BURRO CANYON DISPOSAL SITE, SLICK ROCK, COLORADO

SITE: SRKO2

$06 / 04 / 90$ TO $04 / 26 / 94$

REPORT DATE: $09 / 30 / 94$

\begin{tabular}{|c|c|c|c|c|c|c|c|c|c|c|c|}
\hline \multicolumn{3}{|c|}{ PARAMETER NAME } & UNITS & \multirow[b]{2}{*}{ MEAN } & \multirow{2}{*}{$\begin{array}{r}\text { STANDARD } \\
\text { DEVIATION }\end{array}$} & \multirow{2}{*}{$\begin{array}{c}\text { COEFF. } \\
\text { OF } \\
\text { VARIATION }\end{array}$} & \multirow{2}{*}{$\begin{array}{c}\% \text { OF } \\
\text { NON } \\
\text { DETECTS }\end{array}$} & \multirow{2}{*}{\multicolumn{2}{|c|}{$\begin{array}{l}\text { STATISTICAL RANGE } \\
\text { 98\% CONFIDENCE INTERVAL } \\
\text { MINIMUM }\end{array}$}} & \multirow{2}{*}{$\begin{array}{c}\text { DISTRIBUTION } \\
\text { TYPE }\end{array}$} & \multirow{2}{*}{$\begin{array}{l}\text { FOOT } \\
\text { NOTE }\end{array}$} \\
\hline \# OF SAMP & MINIMUM & MAXIMUM & MEDIAN & & & & & & & & \\
\hline \multicolumn{3}{|c|}{ RADIUM-226 + RADIUM-228 } & $\mathrm{PCI} / \mathrm{L}$ & \multirow[b]{2}{*}{2.0919} & \multirow[b]{2}{*}{1.6178} & \multirow[b]{2}{*}{0.7734} & \multirow[b]{2}{*}{0.0} & \multirow[b]{2}{*}{1.4445} & \multirow[b]{2}{*}{2.7393} & \multirow[b]{2}{*}{ NORMAL } & \\
\hline 37 & 0.2000 & 8.2000 & 1.9000 & & & & & & & & \\
\hline \multicolumn{3}{|l|}{ RADIUM-228 } & $\mathrm{PCI} / \mathrm{L}$ & \multirow[b]{2}{*}{ NA } & \multirow[b]{2}{*}{ NA } & \multirow[b]{2}{*}{ NA } & \multirow[b]{2}{*}{0.0} & \multirow[b]{2}{*}{1.0000} & \multirow[b]{2}{*}{2.1000} & \multirow[b]{2}{*}{ NONPARAMETRIC } & \multirow[b]{2}{*}{9} \\
\hline 37 & ** $\quad 1.0000$ & 7.8000 & 1.6000 & & & & & & & & \\
\hline \multicolumn{3}{|c|}{ REDOX POTENTIAL } & mVOLTS & \multirow[b]{2}{*}{ NA } & \multirow[b]{2}{*}{ NA } & \multirow[b]{2}{*}{ NA } & \multirow[b]{2}{*}{0.0} & \multirow[b]{2}{*}{188.5000} & & & \\
\hline 22 & -241.0000 & 420.2000 & 257.6500 & & & & & & 342.6000 & NONPARAMETRIC & 9 \\
\hline SELENIUM & & & $M G / L$ & & & & & & & & \\
\hline 37 & ** $\quad 0.0050$ & 0.0150 & 0.0050 & NA & NA & NA & 100.0 & 0.0050 & ** 0.0050 & NONPARAMETRIC & 2 \\
\hline SILICA - S & 102 & & $M G / L$ & & & & & & & & \\
\hline 37 & 12.5000 & 14.2000 & 13.5000 & 13.4649 & 0.4809 & 0.0357 & 0.0 & 13.2724 & 13.6573 & NORMAL & \\
\hline SILVER & & & $M G / L$ & & & & & & & & \\
\hline 24 & ** $\quad 0.0100$ & 0.0100 & $\begin{array}{ll}* * & 0.0100\end{array}$ & NA & NA & NA & 100.0 & 0.0100 & ** 0.0100 & NONPARAMETRIC & 2 \\
\hline SODIUM & & & MG/L & & & & & & & & \\
\hline 37 & 70.0000 & 167.0000 & 111.0000 & 115.1622 & 25.8846 & 0.2248 & 0.0 & 104.8045 & 125.5198 & NORMAL & \\
\hline SPECIFIC C & CONDUCTANCE & & UMHO/CM & & & & & & & & \\
\hline 38 & 536.0000 & 1052.0000 & 798.5000 & 804.3158 & 141.1379 & 0.1755 & 0.0 & 748.6566 & 859.9750 & NORMAL & \\
\hline STRONTIUM & & & $M G / L$ & & & & & & & & \\
\hline 37 & 2.9000 & 6.1200 & 3.7900 & 4.0059 & 0.9586 & 0.2393 & 0.0 & 3.6224 & 4.3895 & NORMAL & \\
\hline SULFATE & & & $M G / L$ & & & & & & & & \\
\hline 37 & 133.0000 & 254.0000 & 214.0000 & 202.9189 & 33.8004 & 0.1666 & 0.0 & 189.3938 & 216.4440 & NORMAL & \\
\hline
\end{tabular}

** The reported value is the minimum detection limit of the data set

+ The sample size is even, so the median value is the arithmetic average of the two middle values

* The statistical maximum is the 99 percent one sided confidence interval, $\alpha=0.01$

2) The nonparametric distribution was used because the nondetected values comprise more than $15 \%$ of the samples.

9) The nonparametic distribution was used because the data failed the normal distribution test and includes values $\leq 0$. 
TABLE 3.50 BACKGROUND GROUND WATER QUALITY STATISTICS BY PARAMETER FOR THE

MIDDLE SANDSTONE UNIT, BURRO CANYON DISPOSAL SITE, SLICK ROCK, COLORADO

SITE: SRKO2 BORROH SITE 1 (BURRO CANYON)

06/04/90 TO 04/26/94

REPORT DATE: $09 / 30 / 94$

\begin{tabular}{|c|c|c|c|c|c|c|c|c|c|c|c|}
\hline \multicolumn{3}{|c|}{ PARAMETER NAME } & UNITS & \multirow[b]{2}{*}{ MEAN } & \multirow{2}{*}{$\begin{array}{r}\text { STANDARD } \\
\text { DEVIATION }\end{array}$} & \multirow{2}{*}{$\begin{array}{c}\text { COEFF. } \\
\text { OF } \\
\text { VARIATION }\end{array}$} & \multirow{2}{*}{$\begin{array}{l}\% \text { OF } \\
\text { NON } \\
\text { DETECTS }\end{array}$} & \multirow{2}{*}{\multicolumn{2}{|c|}{$\begin{array}{c}\text { STATISTICAL RANGE } \\
98 \% \text { CONFIDENCE INTERVAL } \\
\text { MINIMUM MAXIMUM * }\end{array}$}} & \multirow{2}{*}{$\begin{array}{l}\text { DISTRIBUTION } \\
\text { TYPE }\end{array}$} & \multirow{2}{*}{$\begin{array}{l}\text { FOOT } \\
\text { NOTE }\end{array}$} \\
\hline \# OF SAMP & MINIMUM & MAXIMUM & MEDIAN & & & & & & & & \\
\hline \multicolumn{3}{|l|}{ SULFIDE } & $M G / L$ & \multirow[b]{2}{*}{ NA } & \multirow[b]{2}{*}{ NA } & \multirow[b]{2}{*}{ NA } & \multirow[b]{2}{*}{31.8} & \multirow[b]{2}{*}{0.1000} & \multirow[b]{2}{*}{0.6000} & \multirow[b]{2}{*}{ NONPARAMETRIC } & \multirow[b]{2}{*}{2} \\
\hline 22 & ** $\quad 0.1000$ & 17.9000 & 0.3000 & & & & & & & & \\
\hline \multicolumn{3}{|c|}{ TEMPERATURE } & C - DEGR & \multirow[b]{2}{*}{15.9463} & \multirow[b]{2}{*}{1.1752} & \multirow[b]{2}{*}{0.0737} & \multirow[b]{2}{*}{0.0} & \multirow[b]{2}{*}{15.5016} & \multirow[b]{2}{*}{16.3910} & \multirow[b]{2}{*}{ NORMAL } & \\
\hline 41 & 12.9000 & 18.6000 & 15.9000 & & & & & & & & \\
\hline \multicolumn{3}{|l|}{ THALLIUM } & MG/L & \multirow[b]{2}{*}{ NA } & \multirow[b]{2}{*}{ NA } & \multirow[b]{2}{*}{ NA } & \multirow[b]{2}{*}{100.0} & \multirow[b]{2}{*}{0.0050} & & & \\
\hline 30 & ** $\quad 0.0050$ & 0.0050 & 0.0050 & & & & & & 0.0050 & NONPARAMETRIC & 2 \\
\hline THORIUM-23 & & & $\mathrm{PCI} / \mathrm{L}$ & & & & & & & & \\
\hline 18 & $\begin{array}{ll}* & 1.0000\end{array}$ & 1.3000 & 1.0000 & NA & NA & NA & 0.0 & 1.0000 & 1.0000 & NONPARAMETRIC & 9 \\
\hline TIN & & & $M G / L$ & & & & & & & & \\
\hline 30 & $\begin{array}{ll}* & 0.0050\end{array}$ & 0.0250 & 0.0050 & NA & NA & NA & 96.7 & 0.0050 & 0.0050 & NONPARAMETRIC & 2 \\
\hline TOTAL DISS & SOLVED SOLIDS & & $M G / L$ & & & & & & & & \\
\hline 37 & 422.0000 & 696.0000 & 585.0000 & 578.3784 & 69.1433 & 0.1195 & 0.0 & 550.7109 & 606.0459 & NORMAL & \\
\hline TOTAL KJEL & LDAHL NITROGEI & & $M G / L$ & & & & & & & & \\
\hline 18 & 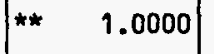 & 1.0000 & 1.0000 & NA & NA & NA & 72.2 & 1.0000 & 1.0000 & NONPARAMETRIC & 2 \\
\hline TOTAL ORGA & ANIC CARBON & & $M G / L$ & & & & & & & & \\
\hline 23 & $\begin{array}{ll}* * & 1.0000\end{array}$ & 68.0000 & 2.0000 & NA & NA & NA & 21.7 & 1.0000 & 57.0000 & NONPARAMETRIC & 2 \\
\hline TURBIDITY & & & NTU & & & & & & & & \\
\hline 11 & 0.0000 & 174.0000 & 1.0000 & NA & NA & NA & 0.0 & 0.0000 & 19.0000 & NONPARAMETRIC & 9 \\
\hline URANIUA & & & $M G / L$ & & & & & & & & \\
\hline 37 & 0.0003 & 0.0080 & 0.0005 & NA & NA & NA & 54.1 & 0.00 & 0.0010 & NONF" " "FTRICI & 2 \\
\hline
\end{tabular}

** The reported valu' is the minimum detection limit of the data set

+ The sample size is even, so the median value is the arithmetic average of the two middle values

* The statistical maximum is the 99 percent one sided confidence interval, $\alpha=0.01$

2) The nonparametric distribution was used because the nondetected values comprise more than $15 \%$ of the samples.

9) The nonparametic distribution was used because the data failed the normal distribution test and includes values $\leq 0$. 
TABLE 3.50 BACKGROUND GROUND HATER QUALITY STATISTICS BY PARAMETER FOR THE

MIDDLE SANDSTONE UNIT, BURRO CANYON DISPOSAL SITE, SLICK ROCK, COLORADD

SITE: SRKO2 BORROW SITE 1 (BURRO CANYON)

06/04/90 TO 04/26/94

REPORT DATE: $09 / 30 / 94$

\begin{tabular}{|c|c|c|c|c|c|c|c|c|c|c|c|c|}
\hline \multicolumn{3}{|c|}{ PARAMETER NAME } & UNITS & \multirow[b]{2}{*}{ MEAN } & \multirow[b]{2}{*}{$\begin{array}{r}\text { STANDARD } \\
\text { DEVIATION }\end{array}$} & \multirow{2}{*}{$\begin{array}{c}\text { COEFF. } \\
\text { OF } \\
\text { VARIATION }\end{array}$} & \multirow{2}{*}{$\begin{array}{l}\% \text { OF } \\
\text { NON } \\
\text { DETECTS }\end{array}$} & \multirow{2}{*}{\multicolumn{3}{|c|}{ 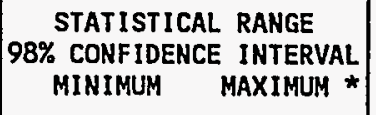 }} & \multirow[b]{2}{*}{$\begin{array}{l}\text { DISTRIBUTION } \\
\text { TYPE }\end{array}$} & \multirow[b]{2}{*}{$\begin{array}{l}\text { FOOT } \\
\text { NOTE }\end{array}$} \\
\hline \# OF SAMP & MINIMUM & MAXIMUM & MEDIAN & & & & & & & & & \\
\hline \multicolumn{3}{|l|}{ VANADIUM } & $M G / L$ & \multirow[b]{2}{*}{ NA } & \multirow[b]{2}{*}{ NA } & \multirow[b]{2}{*}{ NA } & \multirow[b]{2}{*}{75.7} & \multirow[b]{2}{*}{0.0100} & \multirow[b]{2}{*}{ ** } & \multirow[b]{2}{*}{0.0100} & \multirow[b]{2}{*}{ NONPARAMETRIC } & \multirow[b]{2}{*}{2} \\
\hline 37 & 0.0100 & 0.0300 & 0.0100 & & & & & & & & & \\
\hline \multicolumn{3}{|l|}{ ZINC } & $M G / L$ & \multirow[b]{2}{*}{ NA } & \multirow[b]{2}{*}{ NA } & \multirow[b]{2}{*}{ NA } & \multirow[b]{2}{*}{43.2} & \multirow[b]{2}{*}{0.0090} & & \multirow[b]{2}{*}{0.0430} & \multirow[b]{2}{*}{ NONPARAMETRIC } & \multirow[b]{2}{*}{2} \\
\hline 37 & 0.0050 & 0.1470 & 0.0250 & & & & & & & & & \\
\hline
\end{tabular}

** The reported value is the minimum detection limit of the data set

* The statistical maximum is the 99 percent one sided confidence interval, $\alpha=0.01$

2) The nonparametric distribution was used because the nondetected values comprise more than $15 \%$ of the samples.

INPUT DATA FILENAME: IDARTISRK02\GWQ10007.DAT 
TABLE 3.51 GROUND WATER QUALITY MEASUREMENTS EXCEEDING MCLS IN THE MIDDLE SANDSTONE UNIT, BURRO CANYON DISPOSAL SITE, SLICK ROCK, COLORADO

SITE: SRKO2 BORROW SITE 1 (BURRO CANYON)

$06 / 04 / 90$ TO 04/26/94

REPORT DATE: $09 / 30 /$

\begin{tabular}{|c|c|c|c|c|c|c|c|c|c|c|c|c|}
\hline PARAMETER NAME & $\begin{array}{l}\text { TOTAL } \\
\text { \# OF } \\
\text { SAMP. }\end{array}$ & $\begin{array}{l}\text { UNITS } \\
\text { OF } \\
\text { MEASURE }\end{array}$ & $\begin{array}{l}\text { MAXIMUM } \\
\text { CONC. } \\
\text { LIMIT }\end{array}$ & Loc. & LOG & DATE & $\begin{array}{c}\text { SAMP } \\
\text { ID }\end{array}$ & $\mid \begin{array}{c}\text { FORM } \\
\text { OF } \\
\text { COMP }\end{array}$ & $\begin{array}{l}\text { HYDR } \\
\text { FLOW } \\
\text { REL. }\end{array}$ & $\begin{array}{l}\text { RESULT EXCEEDING MAX. } \\
\text { CONCENTRATION LIMIT } \\
\text { VALUE FLAGS }\end{array}$ & $\begin{array}{l}\text { DETECTION } \\
\text { LIMIT }\end{array}$ & $\begin{array}{l}\text { PARAMETER } \\
\text { UNCERT. }\end{array}$ \\
\hline ARSENIC & 30 & MG/L & 0.0500 & - & & - & - & - & - & - & - & - \\
\hline ARSENIC (TOTAL) & 0 & $M G / L$ & 0.0500 & - & & - & - & $\cdot$ & - & - & - & - \\
\hline BARIUM & 37 & $M G / L$ & 1.0000 & - & & - & - & - & $\cdot$ & - & - & - \\
\hline BARIUM (TOTAL) & 0 & $M G / L$ & 1.0000 & - & & - & - & - & - & $\cdot$ & - & - \\
\hline CADMIUM & 37 & MG/L & 0.0100 & - & & - & - & - & - & $\cdot$ & - & - \\
\hline CADMIUM (TOTAL) & 0 & $M G / L$ & 0.0100 & - & & - & - & - & - & - & - & - \\
\hline CHROMIUM & 37 & $M G / L$ & 0.0500 & - & & - & - & - & - & $\cdot$ & - & - \\
\hline CHROMIUM (TOTAL) & 0 & $M G / L$ & 0.0500 & - & & - & - & - & - & - & - & - \\
\hline GROSS ALPHA & 31 & $\mathrm{PCI} / \mathrm{L}$ & 15.0000 & - & & - & - & $\cdot$ & - & - & - & - \\
\hline GROSS ALPHA (TOTAL) & 0 & $\mathrm{PCI} / \mathrm{L}$ & 15.0000 & - & & - & - & - & - & - & - & - \\
\hline LEAD & 30 & $M G / L$ & 0.0500 & - & & - & - & - & - & - & - & $\cdot$ \\
\hline LEAD (TOTAL) & 0 & $M G / L$ & 0.0500 & - & & - & $\cdot$ & $\cdot$ & - & - & - & $\cdot$ \\
\hline MERCURY & 24 & $M G / L$ & 0.0020 & - & & - & $\cdot$ & $\cdot$ & $\cdot$ & - & - & - \\
\hline MERCURY (TOTAL) & 0 & $M G / L$ & 0.0020 & - & & - & $\cdot$ & $\cdot$ & - & $\cdot$ & - & - \\
\hline MOLYBDENUM & 37 & MG/L & 0.1000 & - & & - & $\cdot$ & $\cdot$ & - & - & - & - \\
\hline MOLYBDENUM (TOTAL) & 0 & $M G / L$ & 0.1000 & - & & - & - & $\cdot$ & - & - & - & - \\
\hline NET GROSS ALPHA * & 31 & $\mathrm{PCI} / \mathrm{L}$ & 15.0000 & - & & - & - & $\cdot$ & - & $\cdot$ & - & - \\
\hline NET GROSS ALPHA (TOTAL) ** & 0 & $\mathrm{PCI} / \mathrm{L}$ & 15.0000 & - & & - & - & - & - & - & - & - \\
\hline NITRATE & 28 & $\mathrm{MG} / \mathrm{L}$ & 44.0000 & - & & - & - & - & - & - & - & - \\
\hline
\end{tabular}

* NET GROSS ALPHA (GROSS ALPHA - URANIUM)

WITH 1 MG URANIUM $=686 \mathrm{PCI}$

** TOTAL NET GROSS ALPHA (TOTAL GROSS ALPHA - TOTAL URANIUM) 
TABLE 3.51 GROUND WATER QUALITY MEASUREMENTS EXCEEDING MCLS IN THE MIDDLE SANDSTONE UNIT, BURRO CANYON DISPOSAL SITE, SLICK ROCK, COLORADO

SITE: SRKO2 BORROH SITE 1 (BURRO CANYON)

$06 / 04 / 90$ TO $04 / 26 / 94$

REPORT DATE: 09/30/94

\begin{tabular}{|c|c|c|c|c|c|c|c|c|c|c|c|}
\hline PARAMETER NAME & $\begin{array}{l}\text { TOTAL } \\
\text { \# OF } \\
\text { SAMP. }\end{array}$ & $\begin{array}{l}\text { UNITS } \\
\text { OF } \\
\text { MEASURE }\end{array}$ & $\begin{array}{l}\text { MAXIMUM } \\
\text { CONC. } \\
\text { LIMIT }\end{array}$ & LOC. & LOG DATE & $\begin{array}{c}\text { SAMP } \\
\text { ID }\end{array}$ & $\begin{array}{c}\text { FORM } \\
\text { OF } \\
\text { COMP }\end{array}$ & $\begin{array}{l}\text { HYDR } \\
\text { FLOW } \\
\text { REL. }\end{array}$ & $\begin{array}{l}\text { RESULT EXCEEDING MAX. } \\
\text { CONCENTRATION LIMIT } \\
\text { VALUE FLAGS }\end{array}$ & $\begin{array}{l}\text { DETECTION } \\
\text { LIMIT }\end{array}$ & $\begin{array}{l}\text { PARAMETER } \\
\text { UNCERT. }\end{array}$ \\
\hline NITRATE (TOTAL) & 0 & $M G / L$ & 44.0000 & - & - & - & - & - & - & - & - \\
\hline$R A-226 \&$ \&A-228 & 37 & $\mathrm{PCI} / \mathrm{L}$ & 5.0000 & 0516 & $04 / 04 / 91$ & 0001 & MB & 0 & 8.2 & - & - \\
\hline RA-226 \& RA-228 (TOTAL) & 0 & PCI/L & 5.0000 & - & - & - & - & - & - & - & - \\
\hline SELENIUM & 37 & HG/L & 0.0100 & 0520 & $04 / 01 / 91$ & 0001 & MB & 0 & 0.03 & 0.03 & - \\
\hline SELENIUM (TOTAL) & 0 & $M G / L$ & 0.0100 & - & - & - & - & - & - & - & - \\
\hline SILVER & 24 & $M G / L$ & 0.0500 & - & - & - & - & - & - & - & - \\
\hline SILVER (TOTAL) & 0 & MG/L & 0.0500 & - & - & - & - & - & - & - & - \\
\hline URANIUM & 37 & $M G / L$ & 0.0440 & - & - & - & - & - & - & - & - \\
\hline URANIUM (TOTAL) & 0 & MG/L & 0.0440 & - & - & - & - & - & - & - & - \\
\hline
\end{tabular}

FORMATION OF COMPLETION CODE:

MB - MIDDLE BURRO CANYON

FLOW RELATIONSHIP CODE:

O- ON-SITE

OTHER PARAMETER VALUE FLAGS:

SAMPLE ID CODES:

I - INCREASED DETECTION LIMIT DUE TO REQUIRED DILUTION

0001 - FILTERED SAMPLE (.45 MICRONS)

DATA FILE NAME: IDARTISRKO2\GWQ10008.DAT 
TABLE 3.52 BACKGROUND GROUND HATER QUALITY DATA BY PARAMETER FOR THE LOWER SANDSTONE UNIT, BURRO CANYON DISPOSAL SITE, SLICK ROCK, COLORADO SITE: SRKO2 BORROW SITE 1 (BURRO CANYON)

$06 / 04 / 90$ TO $04 / 21 / 94$

REPORT DATE: $09 / 30 / 94$

\begin{tabular}{|c|c|c|c|c|c|c|c|c|c|c|c|}
\hline PARAMETER NAME & $\begin{array}{l}\text { LOCATION } \\
\text { ID }\end{array}$ & LOG DATE & $\begin{array}{c}\text { SAMPLE } \\
\text { ID }\end{array}$ & $\begin{array}{l}\text { FORM } \\
\text { COMP }\end{array}$ & $\begin{array}{l}\text { FLOW } \\
\text { REL . }\end{array}$ & $\begin{array}{l}\text { UNITS OF } \\
\text { MEASURE }\end{array}$ & PVI & $\begin{array}{l}\text { ARAMETER } \\
\text { VALUE }\end{array}$ & FLAGS & $\begin{array}{l}\text { DETECT ION } \\
\text { LIMIT }\end{array}$ & $\begin{array}{l}\text { PARAMETER } \\
\text { UNCERTAINTY }\end{array}$ \\
\hline ALKALINITY & $\begin{array}{l}0517 \\
0517 \\
0517 \\
0517 \\
0517 \\
0517 \\
0517 \\
0519 \\
0519 \\
0519 \\
0519 \\
0519 \\
0519 \\
0521 \\
0521 \\
0521 \\
0521 \\
0521 \\
0524 \\
0524 \\
0524 \\
0524 \\
0524 \\
0524\end{array}$ & $\begin{array}{l}06 / 04 / 90 \\
12 / 08 / 90 \\
04 / 02 / 91 \\
08 / 25 / 91 \\
10 / 14 / 92 \\
04 / 06 / 94 \\
04 / 21 / 94 \\
06 / 04 / 90 \\
12 / 15 / 90 \\
04 / 01 / 91 \\
08 / 22 / 91 \\
10 / 11 / 92 \\
04 / 07 / 94 \\
06 / 04 / 90 \\
12 / 08 / 90 \\
04 / 02 / 91 \\
08 / 25 / 91 \\
10 / 13 / 92 \\
06 / 06 / 90 \\
12 / 08 / 90 \\
04 / 03 / 91 \\
08 / 26 / 91 \\
10 / 14 / 92 \\
04 / 07 / 94\end{array}$ & $\begin{array}{l}0001 \\
0001 \\
0001 \\
0001 \\
0001 \\
0001 \\
0001 \\
0001 \\
0001 \\
0001 \\
0001 \\
0001 \\
0001 \\
0001 \\
0001 \\
0001 \\
0001 \\
0001 \\
0001 \\
0001 \\
0001 \\
0001 \\
0001 \\
0001\end{array}$ & $\begin{array}{l}\text { LB } \\
\text { LB } \\
\text { LB } \\
\text { LB } \\
\text { LB } \\
\text { LB } \\
\text { LB } \\
\text { LB } \\
\text { LB } \\
\text { LB } \\
\text { LB } \\
\text { LB } \\
\text { LB } \\
\text { LB } \\
\text { LB } \\
\text { LB } \\
\text { LB } \\
\text { LB } \\
\text { LB } \\
\text { LB } \\
\text { LB } \\
\text { LB } \\
\text { LB } \\
\text { LB }\end{array}$ & $\begin{array}{l}0 \\
0 \\
0 \\
0 \\
0 \\
0 \\
0 \\
0 \\
0 \\
0 \\
0 \\
0 \\
0 \\
0 \\
0 \\
0 \\
0 \\
0 \\
0 \\
0 \\
0 \\
0 \\
0 \\
0\end{array}$ & MG/L CACO3 & & $\begin{array}{l}198 . \\
188 . \\
174 . \\
195 \\
185 \\
178 \\
177 \\
172 . \\
163 . \\
162 . \\
156 \\
157 \\
145 \\
215 . \\
187 . \\
192 . \\
191 \\
189 \\
222 . \\
184 . \\
152 . \\
206 \\
183 \\
174\end{array}$ & $\begin{array}{l}\text { L } \\
\text { G } \\
\text { G } \\
\text { J }\end{array}$ & $\begin{array}{l}- \\
- \\
- \\
- \\
- \\
- \\
- \\
- \\
- \\
- \\
- \\
- \\
- \\
- \\
- \\
- \\
- \\
-\end{array}$ & $\begin{array}{l}- \\
- \\
- \\
- \\
- \\
- \\
- \\
- \\
- \\
- \\
- \\
- \\
- \\
- \\
- \\
- \\
- \\
-\end{array}$ \\
\hline ALUMINUM & $\begin{array}{l}0517 \\
0517 \\
0517 \\
0517 \\
0517 \\
0519 \\
0519 \\
0519 \\
0519 \\
0519 \\
0521 \\
0521 \\
0521\end{array}$ & $\begin{array}{l}06 / 04 / 90 \\
12 / 08 / 90 \\
04 / 02 / 91 \\
08 / 25 / 91 \\
10 / 14 / 92 \\
06 / 04 / 90 \\
12 / 15 / 90 \\
04 / 01 / 91 \\
08 / 22 / 91 \\
10 / 11 / 92 \\
06 / 04 / 90 \\
12 / 08 / 90 \\
04 / 02 / 91\end{array}$ & $\begin{array}{l}0001 \\
0001 \\
0001 \\
0001 \\
0001 \\
0001 \\
0001 \\
0001 \\
0001 \\
0001 \\
0001 \\
0001 \\
0001\end{array}$ & $\begin{array}{l}\text { LB } \\
\text { LB } \\
\text { LB } \\
\text { LB } \\
\text { LB } \\
\text { LB } \\
\text { LB } \\
\text { LB } \\
\text { LB } \\
\text { LB } \\
\text { LB } \\
\text { LB } \\
\text { LB }\end{array}$ & $\begin{array}{l}0 \\
0 \\
0 \\
0 \\
0 \\
0 \\
0 \\
0 \\
0 \\
0 \\
0 \\
0 \\
0\end{array}$ & $M G / L$ & $\mid \begin{array}{l}< \\
< \\
< \\
< \\
< \\
< \\
<\end{array}$ & $\begin{array}{l}0.2 \\
0.1 \\
0.06 \\
0.12 \\
0.05 \\
0.1 \\
0.1 \\
0.05 \\
0.05 \\
0.05 \\
0.1 \\
0.1 \\
0.05\end{array}$ & $\begin{array}{l}G \\
G\end{array}$ & $\begin{array}{l}0.1 \\
0.1 \\
0.05 \\
0.05 \\
0.05 \\
0.1 \\
0.1 \\
0.05 \\
0.05 \\
0.05 \\
0.1 \\
0.1 \\
0.05\end{array}$ & $\begin{array}{l}- \\
- \\
- \\
- \\
- \\
- \\
- \\
- \\
- \\
- \\
-\end{array}$ \\
\hline
\end{tabular}

FORMATION OF COMPLETION CODE:

LB - LOWER BURRO CANYON

PARAMETER VALUE INDICATOR (PVI): < - LESS THAN DETECTION LIMIT
FLOW RELATIONSHIP CODE:

O - ON-SITE

0001 - FILTERED SAMPLE (.45 MICRONS)

OTHER PARAMETER VALUE FLAGS:

$G$ - PH $>$ 9, POSSIBLE GROUT CONTAMINATION

$J$ - ESTIMATED VALUE

L - LESS THAN THREE BORE VOLUMES REMOVED BEFORE SAMPLING 
TABLE 3.52 BACKGROUND GROUND YATER QUALITY DATA BY PARAMETER FOR THE

LOWER SANDSTONE UNIT, BURRO CANYON DISPOSAL SITE, SLICK ROCK, COLORADD

SITE: SRKO2 BORROW SITE 1 (BURRO CANYON)

06/04/90 TO 04/21/94

REPORT DATE: $09 / 30 / 94$

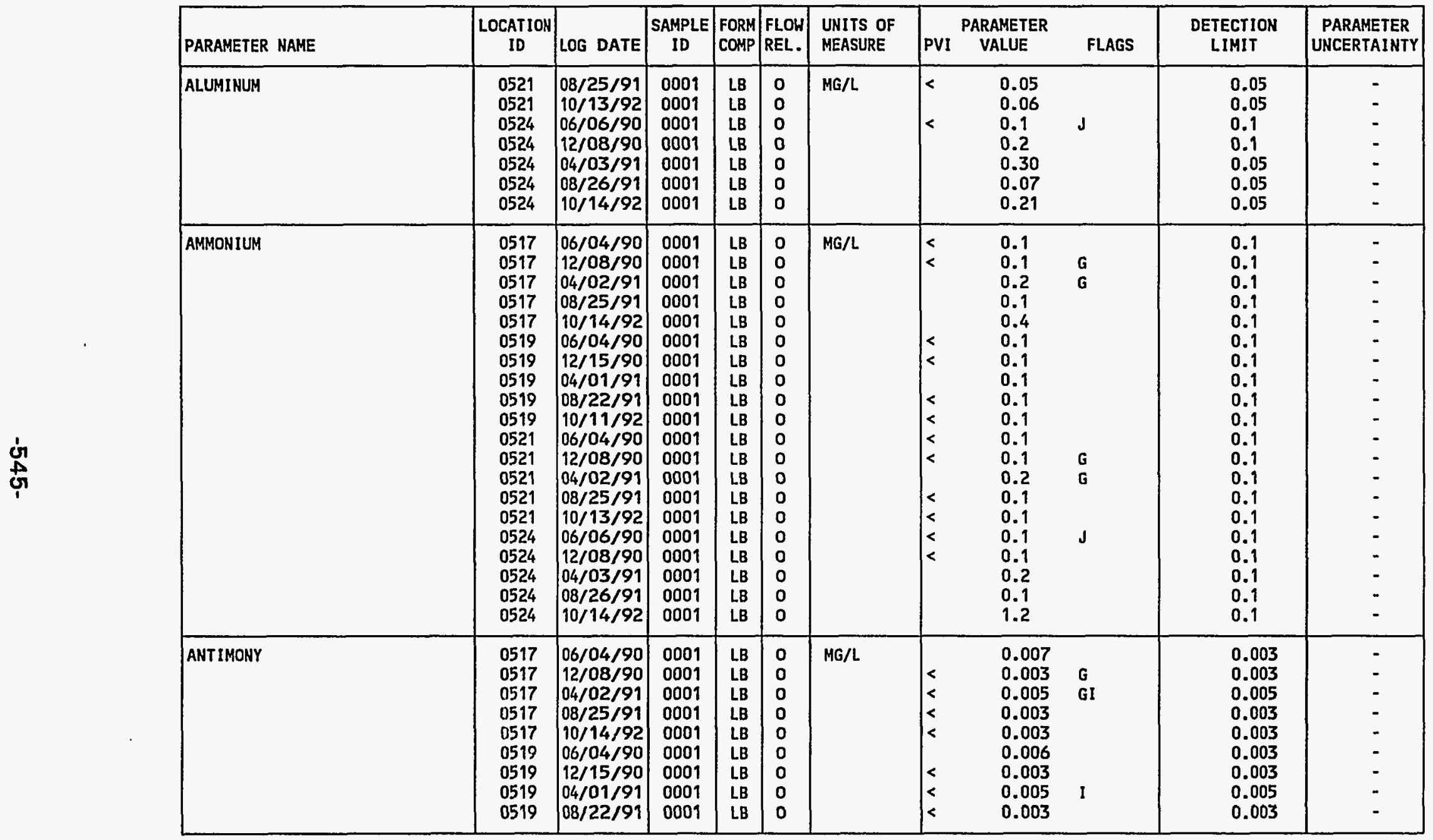

FORMATION OF COMPLETION CODE:

LB - LOHER BURRO CANYON

FLOH RELATIONSHIP CODE:

O - ON-SITE

PARAMETER VALUE INDICATOR (PVI): < - LESS THAN DETECTION LIMIT

SAMPLE ID CODES:

0001 - FILTERED SAMPLE (.45 MICRONS)

OTHER PARAMETER VALUE FLAGS:

- PH $>9$, POSSIBLE GROUT CONTAMINATION

1 - INCREASEd DETECTION LIMIT DUE TO REQUIRED DILUTION

J - ESTIMATED VALUE 
TABLE 3.52 BACKGROUND GROUND WATER QUALITY DATA BY PARAMETER FOR THE

LOWER SANDSTONE UNIT, BURRO CANYON DISPOSAL SITE, SLICK ROCK, COLORADO

SITE: SRKD2 BORROW SITE 1 (BURRO CAMYON)

06/04/90 TO 04/21/94

REPORT DATE: $09 / 30 / 94$

\begin{tabular}{|c|c|c|c|c|c|c|c|c|c|c|c|}
\hline PARAMETER NAME & $\underset{\text { ID }}{\text { LOCATION }}$ & LOG DATE & $\begin{array}{c}\text { SAMPLE } \\
\text { ID }\end{array}$ & $\mid \begin{array}{l}\text { FORM } \\
\text { COMP }\end{array}$ & $\begin{array}{l}\text { FLOW } \\
\text { REL. }\end{array}$ & $\begin{array}{l}\text { UNITS OF } \\
\text { MEASURE }\end{array}$ & PVI & $\begin{array}{l}\text { PARAMETER } \\
\text { VALUE }\end{array}$ & FLAGS & $\begin{array}{l}\text { DETECTION } \\
\text { LIMIT }\end{array}$ & $\begin{array}{l}\text { PARAMETER } \\
\text { UNCERTAINTY }\end{array}$ \\
\hline ANT IMONY & $\begin{array}{l}0519 \\
0521 \\
0521 \\
0521 \\
0521 \\
0521 \\
0524 \\
0524 \\
0524 \\
0524 \\
0524\end{array}$ & $\begin{array}{l}10 / 11 / 92 \\
06 / 04 / 90 \\
12 / 08 / 90 \\
04 / 02 / 91 \\
08 / 25 / 91 \\
10 / 13 / 92 \\
06 / 06 / 90 \\
12 / 08 / 90 \\
04 / 03 / 91 \\
08 / 26 / 91 \\
10 / 14 / 92\end{array}$ & $\begin{array}{l}0001 \\
0001 \\
0001 \\
0001 \\
0001 \\
0001 \\
0001 \\
0001 \\
0001 \\
0001 \\
0001\end{array}$ & $\begin{array}{l}\text { LB } \\
\text { LB } \\
\text { LB } \\
\text { LB } \\
\text { LB } \\
\text { LB } \\
\text { LB } \\
\text { LB } \\
\text { LB } \\
\text { LB } \\
\text { LB }\end{array}$ & $\begin{array}{l}0 \\
0 \\
0 \\
0 \\
0 \\
0 \\
0 \\
0 \\
0 \\
0 \\
0\end{array}$ & $\mathrm{MG} / \mathrm{L}$ & $\begin{array}{l}< \\
< \\
< \\
< \\
< \\
<\end{array}$ & $\begin{array}{l}0.003 \\
0.003 \\
0.003 \\
0.005 \\
0.003 \\
0.003 \\
0.009 \\
0.004 \\
0.005 \\
0.005 \\
0.003\end{array}$ & $\begin{array}{l}\text { J } \\
\text { I }\end{array}$ & $\begin{array}{l}0.003 \\
0.003 \\
0.003 \\
0.005 \\
0.003 \\
0.003 \\
0.003 \\
0.003 \\
0.005 \\
0.003 \\
0.003\end{array}$ & $\begin{array}{l}: \\
: \\
: \\
: \\
: \\
: \\
-\end{array}$ \\
\hline ARSENIC & $\begin{array}{l}0517 \\
0517 \\
0517 \\
0517 \\
0517 \\
0519 \\
0519 \\
0519 \\
0519 \\
0519 \\
0521 \\
0521 \\
0521 \\
0521 \\
0521 \\
0524 \\
0524 \\
0524 \\
0524 \\
0524\end{array}$ & $\begin{array}{l}06 / 04 / 90 \\
12 / 08 / 90 \\
04 / 02 / 91 \\
08 / 25 / 91 \\
10 / 14 / 92 \\
06 / 04 / 90 \\
12 / 15 / 90 \\
04 / 01 / 91 \\
08 / 22 / 91 \\
10 / 11 / 92 \\
06 / 04 / 90 \\
12 / 08 / 90 \\
04 / 02 / 91 \\
08 / 25 / 91 \\
10 / 13 / 92 \\
06 / 06 / 90 \\
12 / 08 / 90 \\
04 / 03 / 91 \\
08 / 26 / 91 \\
10 / 14 / 92\end{array}$ & $\begin{array}{l}0001 \\
0001 \\
0001 \\
0001 \\
0001 \\
0001 \\
0001 \\
0001 \\
0001 \\
0001 \\
0001 \\
0001 \\
0001 \\
0001 \\
0001 \\
0001 \\
0001 \\
0001 \\
0001 \\
0001\end{array}$ & $\begin{array}{l}\text { LB } \\
\text { LB } \\
\text { LB } \\
\text { LB } \\
\text { LB } \\
\text { LB } \\
\text { LB } \\
\text { LB } \\
\text { LB } \\
\text { LB } \\
\text { LB } \\
\text { LB } \\
\text { LB } \\
\text { LB } \\
\text { LB } \\
\text { LB } \\
\text { LB } \\
\text { LB } \\
\text { LB } \\
\text { LB }\end{array}$ & $\begin{array}{l}0 \\
0 \\
0 \\
0 \\
0 \\
0 \\
0 \\
0 \\
0 \\
0 \\
0 \\
0 \\
0 \\
0 \\
0 \\
0 \\
0 \\
0 \\
0 \\
0\end{array}$ & $\mathrm{MG} / \mathrm{L}$ & $\begin{array}{l}< \\
< \\
< \\
< \\
< \\
< \\
< \\
< \\
< \\
< \\
< \\
< \\
< \\
< \\
< \\
< \\
< \\
< \\
< \\
< \\
< \\
<\end{array}$ & $\begin{array}{l}0.01 \\
0.01 \\
0.01 \\
0.01 \\
0.005 \\
0.01 \\
0.01 \\
0.01 \\
0.01 \\
0.005 \\
0.01 \\
0.018 \\
0.01 \\
0.01 \\
0.005 \\
0.01 \\
0.01 \\
0.01 \\
0.01 \\
0.005\end{array}$ & $\begin{array}{l}G \\
G\end{array}$ & $\begin{array}{l}0.01 \\
0.01 \\
0.01 \\
0.01 \\
0.005 \\
0.01 \\
0.01 \\
0.01 \\
0.01 \\
0.005 \\
0.01 \\
0.01 \\
0.01 \\
0.01 \\
0.005 \\
0.01 \\
0.01 \\
0.01 \\
0.01 \\
0.005\end{array}$ & $\begin{array}{l}- \\
- \\
- \\
- \\
- \\
- \\
- \\
- \\
- \\
- \\
- \\
- \\
- \\
- \\
-\end{array}$ \\
\hline BARIUM & $\begin{array}{l}0517 \\
0517 \\
0517 \\
0517 \\
0517\end{array}$ & $\begin{array}{l}06 / 04 / 90 \\
12 / 08 / 90 \\
04 / 02 / 91 \\
08 / 25 / 91 \\
10 / 14 / 92\end{array}$ & $\begin{array}{l}0001 \\
0001 \\
0001 \\
0001 \\
0001\end{array}$ & $\begin{array}{l}\text { LB } \\
\text { LB } \\
\text { LB } \\
\text { LB } \\
\text { LB }\end{array}$ & $\begin{array}{l}0 \\
0 \\
0 \\
0 \\
0\end{array}$ & $M G / L$ & $\mid \begin{array}{l}< \\
<\end{array}$ & $\begin{array}{l}0.1 \\
0.1 \\
0.02 \\
0.01 \\
0.01\end{array}$ & $\begin{array}{l}\text { G } \\
\mathbf{G}\end{array}$ & $\begin{array}{l}0.1 \\
0.1 \\
0.09 \\
0.01 \\
0.01\end{array}$ & $\begin{array}{l}- \\
: \\
:\end{array}$ \\
\hline
\end{tabular}

FORMATION OF COMPLETION CODE:

LB - LOWER BURRO CANYON

PARAMETER VALUE INDICATOR (PVI): < - LESS THAN DETECTION LIMIT
FLOW RELATIONSHIP CODE:

O - ON-SITE

SAMPLE IO CODES:

0001 - FILTERED SAMPLE (.45 MICRONS)

OTHER PARAMETER VALUE FLAGS:

G - PH > 9, POSSIBLE GROUT CONTAMINATION

I - INCREASED DETECTION LIMIT DUE TO REQUIRED DILUTION

J - ESTIMATED VALUE 
TABLE 3.52 BACKGROUND GROUND HATER QUALITY DATA BY PARAMETER FOR THE LOHER SANDSTONE UNIT, BURRO CANYON DISPOSAL SITE, SLICK ROCK, COLORADO SITE: SRKO2 BORROW SITE 1 (BURRO CANYON)

06/04/90 TO 04/21/94

REPORT DATE: $09 / 30 / 94$

\begin{tabular}{|c|c|c|c|c|c|c|c|c|c|c|c|}
\hline PARAMETER NAME & $\underset{\text { ID }}{\text { LOCATION }}$ & LOG DATE & $\begin{array}{c}\text { SAMPLE } \\
\text { ID }\end{array}$ & $\mid \begin{array}{l}\text { FORM } \\
\text { COMP }\end{array}$ & $\begin{array}{l}\text { FLOW } \\
\text { REL. }\end{array}$ & $\begin{array}{l}\text { UNITS OF } \\
\text { MEASURE }\end{array}$ & PVI & $\begin{array}{l}\text { PARAMETER } \\
\text { VALUE }\end{array}$ & FLAGS & $\begin{array}{l}\text { DETECTION } \\
\text { LIMIT }\end{array}$ & $\begin{array}{l}\text { PARAMETER } \\
\text { UNCERTAINTY }\end{array}$ \\
\hline BARIUM & $\begin{array}{l}0517 \\
0519 \\
0519 \\
0519 \\
0519 \\
0519 \\
0519 \\
0521 \\
0521 \\
0521 \\
0521 \\
0521 \\
0524 \\
0524 \\
0524 \\
0524 \\
0524 \\
0524\end{array}$ & $\begin{array}{l}04 / 21 / 94 \\
06 / 04 / 90 \\
12 / 15 / 90 \\
04 / 01 / 91 \\
08 / 22 / 91 \\
10 / 11 / 92 \\
04 / 08 / 94 \\
06 / 04 / 90 \\
12 / 08 / 90 \\
04 / 02 / 91 \\
08 / 25 / 91 \\
10 / 13 / 92 \\
06 / 06 / 90 \\
12 / 08 / 90 \\
04 / 03 / 91 \\
08 / 26 / 91 \\
10 / 14 / 92 \\
04 / 08 / 94\end{array}$ & $\begin{array}{l}0001 \\
0001 \\
0001 \\
0001 \\
0001 \\
0001 \\
0001 \\
0001 \\
0001 \\
0001 \\
0001 \\
0001 \\
0001 \\
0001 \\
0001 \\
0001 \\
0001 \\
0001\end{array}$ & $\begin{array}{l}\text { LB } \\
\text { LB } \\
\text { LB } \\
\text { LB } \\
\text { LB } \\
\text { LB } \\
\text { LB } \\
\text { LB } \\
\text { LB } \\
\text { LB } \\
\text { LB } \\
\text { LB } \\
\text { LB } \\
\text { LB } \\
\text { LB } \\
\text { LB } \\
\text { LB } \\
\text { LB }\end{array}$ & $\begin{array}{l}0 \\
0 \\
0 \\
0 \\
0 \\
0 \\
0 \\
0 \\
0 \\
0 \\
0 \\
0 \\
0 \\
0 \\
0 \\
0 \\
0 \\
0\end{array}$ & $M G / L$ & $\begin{array}{l}< \\
< \\
< \\
< \\
< \\
< \\
< \\
< \\
<\end{array}$ & $\begin{array}{l}0.1 \\
0.1 \\
0.1 \\
0.01 \\
0.01 \\
0.01 \\
0.1 \\
0.1 \\
0.1 \\
0.01 \\
0.01 \\
0.02 \\
0.1 \\
0.1 \\
0.03 \\
0.01 \\
0.02 \\
0.1\end{array}$ & $\begin{array}{l}\mathbf{G} \\
\mathbf{G} \\
\mathbf{J}\end{array}$ & $\begin{array}{l}0.1 \\
0.1 \\
0.1 \\
0.01 \\
0.01 \\
0.01 \\
0.1 \\
0.1 \\
0.1 \\
0.01 \\
0.01 \\
0.01 \\
0.1 \\
0.1 \\
0.01 \\
0.01 \\
0.01 \\
0.1\end{array}$ & $\begin{array}{l}- \\
- \\
= \\
- \\
- \\
- \\
- \\
- \\
- \\
- \\
- \\
- \\
- \\
-\end{array}$ \\
\hline BERYLLIUM & $\begin{array}{l}0517 \\
0517 \\
0517 \\
0517 \\
0519 \\
0519 \\
0519 \\
0519 \\
0521 \\
0521 \\
0521 \\
0521 \\
0524 \\
0524 \\
0524 \\
0524\end{array}$ & $\begin{array}{l}06 / 04 / 90 \\
12 / 08 / 90 \\
04 / 02 / 91 \\
08 / 25 / 91 \\
06 / 04 / 90 \\
12 / 15 / 90 \\
04 / 01 / 91 \\
08 / 22 / 91 \\
06 / 04 / 90 \\
12 / 08 / 90 \\
04 / 02 / 91 \\
08 / 25 / 91 \\
06 / 06 / 90 \\
12 / 08 / 90 \\
04 / 03 / 91 \\
08 / 26 / 91\end{array}$ & $\begin{array}{l}0001 \\
0001 \\
0001 \\
0001 \\
0001 \\
0001 \\
0001 \\
0001 \\
0001 \\
0001 \\
0001 \\
0001 \\
0001 \\
0001 \\
0001 \\
0001\end{array}$ & $\begin{array}{l}\text { LB } \\
\text { LB } \\
\text { LB } \\
\text { LB } \\
\text { LB } \\
\text { LB } \\
\text { LB } \\
\text { LB } \\
\text { LB } \\
\text { LB } \\
\text { LB } \\
\text { LB } \\
\text { LB } \\
\text { LB } \\
\text { LB } \\
\text { LB }\end{array}$ & $\begin{array}{l}0 \\
0 \\
0 \\
0 \\
0 \\
0 \\
0 \\
0 \\
0 \\
0 \\
0 \\
0 \\
0 \\
0 \\
0 \\
0\end{array}$ & $M G / L$ & $\begin{array}{l}< \\
< \\
< \\
< \\
< \\
< \\
< \\
< \\
< \\
< \\
< \\
< \\
< \\
< \\
< \\
< \\
<\end{array}$ & $\begin{array}{l}0.01 \\
0.01 \\
0.005 \\
0.005 \\
0.01 \\
0.01 \\
0.005 \\
0.005 \\
0.01 \\
0.01 \\
0.005 \\
0.005 \\
0.01 \\
0.01 \\
0.005 \\
0.005\end{array}$ & $\begin{array}{l}\mathbf{G} \\
\mathbf{G} \\
\mathbf{J}\end{array}$ & $\begin{array}{l}0.01 \\
0.01 \\
0.005 \\
0.005 \\
0.01 \\
0.01 \\
0.005 \\
0.005 \\
0.01 \\
0.01 \\
0.005 \\
0.005 \\
0.01 \\
0.01 \\
0.005 \\
0.005\end{array}$ & $\begin{array}{l}- \\
- \\
- \\
- \\
- \\
- \\
- \\
- \\
- \\
- \\
- \\
-\end{array}$ \\
\hline BORON & $\begin{array}{l}0517 \\
0517 \\
0517\end{array}$ & $\begin{array}{l}06 / 04 / 90 \\
12 / 08 / 90 \\
04 / 02 / 91\end{array}$ & $\begin{array}{l}0001 \\
0001 \\
0001\end{array}$ & $\begin{array}{l}\text { LB } \\
\text { LB } \\
\text { LB }\end{array}$ & $\begin{array}{l}0 \\
0 \\
0\end{array}$ & MG/L & & $\begin{array}{l}0.1 \\
0.1 \\
0.11\end{array}$ & $\begin{array}{l}\text { G } \\
\text { G }\end{array}$ & $\begin{array}{l}0.1 \\
0.1 \\
0.05\end{array}$ & $\because$ \\
\hline
\end{tabular}

FORMATION OF COMPLETION CODE:

LB - LOHER BURRO CANYON

PARAMETER VALUE INDICATOR (PVI): < - LESS THAN DETECTION LIMIT
FLOH RELATIONSHIP CODE:

O - ON-SITE

SAMPLE ID CODES:

0001 - FILTERED SAMPLE (.45 MICRONS)

OTHER PARAMETER VALUE FLAGS:

G - PH $>9$, POSSIBLE GROUT CONTAMINATION

$J$ - ESTIMATED VALUE

L - LESS THAN THREE BORE VOLUMES REMOVED BEFORE SAMPLING 
TABLE 3.52 BACKGROUND GROUND WATER QUALITY DATA BY PARAMETER FOR THE LOWER SANDSTONE UNIT, BURRO CANYON DISPOSAL SITE, SLICK ROCK, COLORADO SITE: SRKO2 BORROW SITE 1 (BURRO CANYON)

$06 / 04 / 90$ TO $04 / 21 / 94$

REPORT DATE: $09 / 30 / 9$

\begin{tabular}{|c|c|c|c|c|c|c|c|c|c|c|c|c|}
\hline & PARAMETER NAME & $\underset{\text { ID }}{\text { LOCATION }}$ & LOG DATE & $\begin{array}{c}\text { SAMPLEE } \\
\text { ID }\end{array}$ & $\begin{array}{l}\text { FORM } \\
\text { COMP }\end{array}$ & $\begin{array}{l}\text { FLOW } \\
\text { REL. }\end{array}$ & $\begin{array}{l}\text { UNITS OF } \\
\text { MEASURE }\end{array}$ & PVI & $\begin{array}{l}\text { PARAMETER } \\
\text { VALUE }\end{array}$ & FLAGS & $\begin{array}{l}\text { DETECTION } \\
\text { LIMIT }\end{array}$ & $\begin{array}{l}\text { PARAMETER } \\
\text { UNCERTAINTY }\end{array}$ \\
\hline & BORON & $\begin{array}{l}0517 \\
0517 \\
0519 \\
0519 \\
0519 \\
0519 \\
0519 \\
0521 \\
0521 \\
0521 \\
0521 \\
0524 \\
0524 \\
0524 \\
0524 \\
0524\end{array}$ & $\begin{array}{l}08 / 25 / 91 \\
04 / 21 / 94 \\
06 / 04 / 90 \\
12 / 15 / 90 \\
04 / 01 / 91 \\
08 / 22 / 91 \\
04 / 08 / 94 \\
06 / 04 / 90 \\
12 / 08 / 90 \\
04 / 02 / 91 \\
08 / 25 / 91 \\
06 / 06 / 90 \\
12 / 08 / 90 \\
04 / 03 / 91 \\
08 / 26 / 91 \\
04 / 08 / 94\end{array}$ & $\begin{array}{l}0001 \\
0001 \\
0001 \\
0001 \\
0001 \\
0001 \\
0001 \\
0001 \\
0001 \\
0001 \\
0001 \\
0001 \\
0001 \\
0001 \\
0001 \\
0001\end{array}$ & $\begin{array}{l}\text { LB } \\
\text { LB } \\
\text { LB } \\
\text { LB } \\
\text { LB } \\
\text { LB } \\
\text { LB } \\
\text { LB } \\
\text { LB } \\
\text { LB } \\
\text { LB } \\
\text { LB } \\
\text { LB } \\
\text { LB } \\
\text { LB } \\
\text { LB }\end{array}$ & $\begin{array}{l}0 \\
0 \\
0 \\
0 \\
0 \\
0 \\
0 \\
0 \\
0 \\
0 \\
0 \\
0 \\
0 \\
0 \\
0 \\
0\end{array}$ & $M G / L$ & $\begin{array}{l}< \\
< \\
< \\
< \\
< \\
< \\
< \\
<\end{array}$ & $\begin{array}{l}0.10 \\
0.1 \\
0.1 \\
0.1 \\
0.07 \\
0.06 \\
0.1 \\
0.1 \\
0.1 \\
0.12 \\
0.10 \\
0.1 \\
0.1 \\
0.08 \\
0.08 \\
0.1\end{array}$ & $\begin{array}{l}\text { GL } \\
\\
\text { G } \\
\text { G } \\
\text { J }\end{array}$ & $\begin{array}{l}0.05 \\
0.1 \\
0.1 \\
0.1 \\
0.05 \\
0.05 \\
0.1 \\
0.1 \\
0.1 \\
0.05 \\
0.05 \\
0.1 \\
0.1 \\
0.05 \\
0.05 \\
0.1\end{array}$ & $\begin{array}{l}- \\
- \\
- \\
- \\
- \\
- \\
- \\
- \\
- \\
- \\
- \\
- \\
-\end{array}$ \\
\hline & BROMIDE & $\begin{array}{l}0517 \\
0517 \\
0517 \\
0517 \\
0519 \\
0519 \\
0519 \\
0519 \\
0521 \\
0521 \\
0521 \\
0521 \\
0524 \\
0524 \\
0524 \\
0524\end{array}$ & $\begin{array}{l}12 / 08 / 90 \\
04 / 02 / 91 \\
08 / 25 / 91 \\
10 / 14 / 92 \\
12 / 15 / 90 \\
04 / 01 / 91 \\
08 / 22 / 91 \\
10 / 11 / 92 \\
12 / 08 / 90 \\
04 / 02 / 91 \\
08 / 25 / 91 \\
10 / 13 / 92 \\
12 / 08 / 90 \\
04 / 03 / 91 \\
08 / 26 / 91 \\
10 / 14 / 92\end{array}$ & $\begin{array}{l}0001 \\
0001 \\
0001 \\
0001 \\
0001 \\
0001 \\
0001 \\
0001 \\
0001 \\
0001 \\
0001 \\
0001 \\
0001 \\
0001 \\
0001 \\
0001\end{array}$ & $\begin{array}{l}\text { LB } \\
\text { LB } \\
\text { LB } \\
\text { LB } \\
\text { LB } \\
\text { LB } \\
\text { LB } \\
\text { LB } \\
\text { LB } \\
\text { LB } \\
\text { LB } \\
\text { LB } \\
\text { LB } \\
\text { LB } \\
\text { LB } \\
\text { LB }\end{array}$ & $\begin{array}{l}0 \\
0 \\
0 \\
0 \\
0 \\
0 \\
0 \\
0 \\
0 \\
0 \\
0 \\
0 \\
0 \\
0 \\
0 \\
0\end{array}$ & $M G / L$ & $\begin{array}{l}< \\
< \\
< \\
< \\
< \\
< \\
< \\
< \\
< \\
< \\
< \\
<\end{array}$ & $\begin{array}{l}0.1 \\
0.1 \\
0.1 \\
0.2 \\
0.1 \\
0.2 \\
0.1 \\
0.1 \\
0.1 \\
0.1 \\
0.1 \\
0.5 \\
0.1 \\
0.2 \\
0.1 \\
0.5\end{array}$ & $\begin{array}{l}\text { GJ } \\
\text { G } \\
\text { I } \\
J \\
\text { GJ } \\
\text { G } \\
\text { I } \\
\text { J } \\
\text { I }\end{array}$ & $\begin{array}{l}0.1 \\
0.1 \\
0.1 \\
0.2 \\
0.1 \\
0.1 \\
0.1 \\
0.1 \\
0.1 \\
0.1 \\
0.1 \\
0.5 \\
0.1 \\
0.1 \\
0.1 \\
0.5\end{array}$ & $\begin{array}{l}- \\
- \\
- \\
- \\
- \\
- \\
- \\
- \\
- \\
- \\
- \\
- \\
- \\
- \\
-\end{array}$ \\
\hline & CADMIUM & $\begin{array}{l}0517 \\
0517 \\
0517 \\
0517\end{array}$ & $\begin{array}{l}06 / 04 / 90 \\
12 / 08 / 90 \\
04 / 02 / 91 \\
08 / 25 / 91\end{array}$ & $\begin{array}{l}0001 \\
0001 \\
0001 \\
0001\end{array}$ & $\begin{array}{l}\text { LB } \\
\text { LB } \\
\text { LB } \\
\text { LB }\end{array}$ & $\begin{array}{l}0 \\
0 \\
0 \\
0\end{array}$ & MG/L & $\begin{array}{l}< \\
< \\
< \\
<\end{array}$ & $\begin{array}{l}0.001 \\
0.001 \\
0.0005 \\
0.001\end{array}$ & $\begin{array}{l}\mathbf{G} \\
\mathbf{G}\end{array}$ & $\begin{array}{l}0.001 \\
0.001 \\
0.0005 \\
0.001\end{array}$ & $\begin{array}{l}- \\
-\end{array}$ \\
\hline
\end{tabular}

FORMATION OF COMPLETION CODE:

LB - LOWER BURRO CANYON

PARAMETER VALUE INDICATOR (PVI): < - LESS THAN DETECTION LIMIT
FLOW RELATIONSHIP CODE:

O - ON-SITE

0001 - FILTERED SAMPLE (.45 MICRONS)

OTHER PARAMETER VALUE FLAGS:

$G$ - PH $>9$, POSSIBLE GROUT CONTAMINATION

I - INCREASED DETECTION LIMIT DUE TO REQUIRED DILUTION

$J$ - ESTIMATED VALUE

L - LESS tHAN tHREE BORE VOLUMES REMOVED BEFORE SAMPLING 


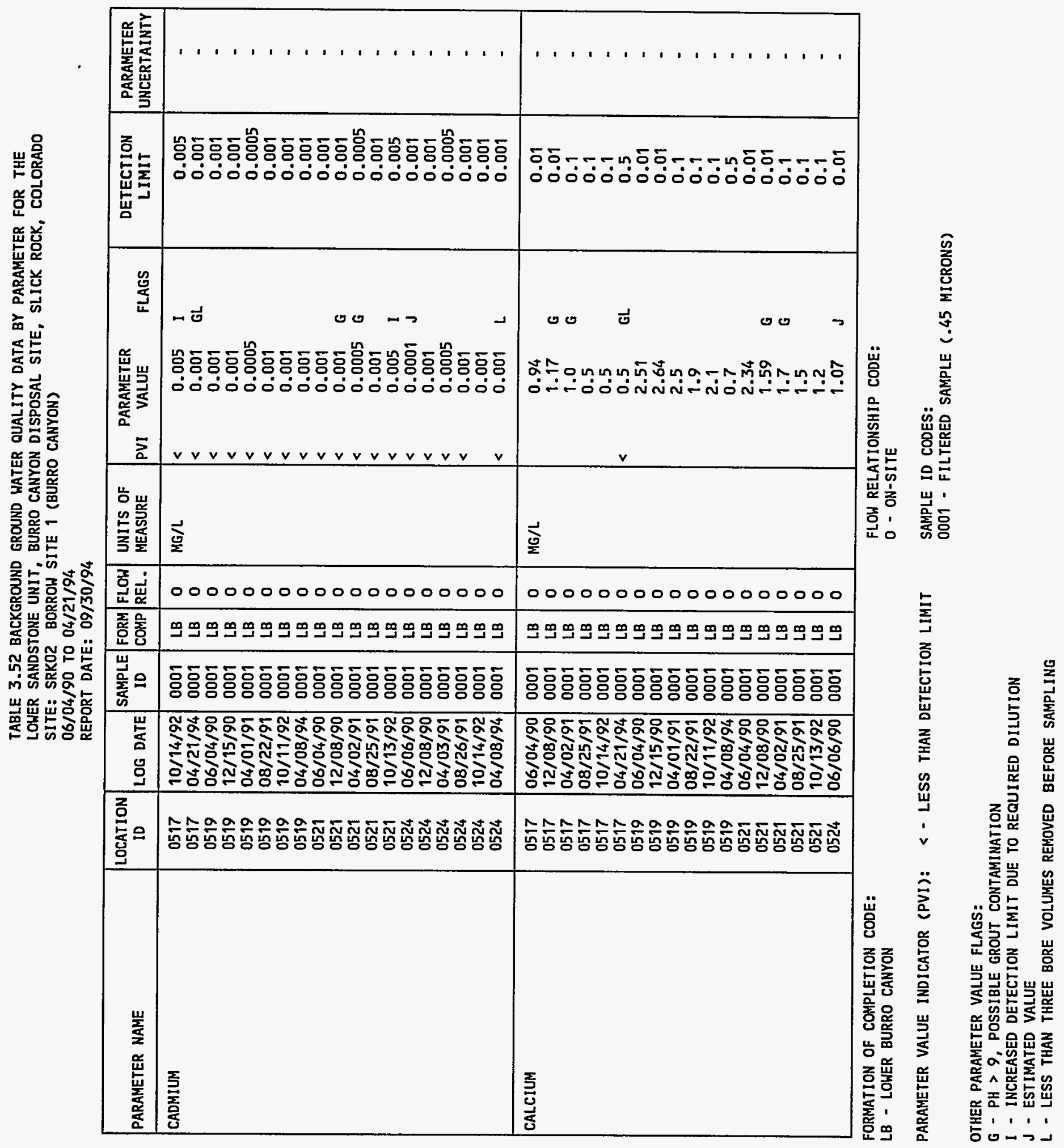


TABLE 3.52 BACKGROUND GROUND WATER QUALITY DATA BY PARAMETER FOR THE

LOWER SANDSTONE UNIT, BURRO CANYON DISPOSAL SITE, SLICK ROCK, COLORADO

SITE: SRKO2 BORROW SITE 1 (BURRO CANYON)

$06 / 04 / 90$ TO $04 / 21 / 94$

REPORT DATE: $09 / 30 / 9$

\begin{tabular}{|c|c|c|c|c|c|c|c|c|c|c|c|}
\hline PARAMETER NAME & $\begin{array}{c}\text { LOCATION } \\
\text { ID }\end{array}$ & LOG DATE & $\begin{array}{c}\text { SAMPLE } \\
\text { ID }\end{array}$ & $\begin{array}{l}\text { FORM } \\
\text { COMP }\end{array}$ & $\begin{array}{l}\text { FLOW } \\
\text { REL. }\end{array}$ & $\begin{array}{l}\text { UNITS OF } \\
\text { MEASURE }\end{array}$ & PVI & $\begin{array}{l}\text { PARAMETER } \\
\text { VALUE }\end{array}$ & FLAGS & $\begin{array}{l}\text { DETECTION } \\
\text { LIMIT }\end{array}$ & $\begin{array}{l}\text { PARAMETER } \\
\text { UNCERTA INTY }\end{array}$ \\
\hline CALCIUM & $\begin{array}{l}0524 \\
0524 \\
0524 \\
0524 \\
0524\end{array}$ & $\begin{array}{l}12 / 08 / 90 \\
04 / 03 / 91 \\
08 / 26 / 91 \\
10 / 14 / 92 \\
04 / 08 / 94\end{array}$ & $\begin{array}{l}0001 \\
0001 \\
0001 \\
0001 \\
0001\end{array}$ & $\begin{array}{l}\text { LB } \\
\text { LB } \\
\text { LB } \\
\text { LB } \\
\text { LB }\end{array}$ & $\begin{array}{l}0 \\
0 \\
0 \\
0 \\
0\end{array}$ & $M G / L$ & & $\begin{array}{l}2.16 \\
2.1 \\
1.8 \\
1.1 \\
0.9\end{array}$ & L & $\begin{array}{l}0.01 \\
0.1 \\
0.1 \\
0.1 \\
0.5\end{array}$ & $\begin{array}{l}- \\
- \\
- \\
-\end{array}$ \\
\hline CHLORIDE & $\begin{array}{l}0517 \\
0517 \\
0517 \\
0517 \\
0517 \\
0517 \\
0519 \\
0519 \\
0519 \\
0519 \\
0519 \\
0519 \\
0521 \\
0521 \\
0521 \\
0521 \\
0521 \\
0524 \\
0524 \\
0524 \\
0524 \\
0524 \\
0524\end{array}$ & $\begin{array}{l}06 / 04 / 90 \\
12 / 08 / 90 \\
04 / 02 / 91 \\
08 / 25 / 91 \\
10 / 14 / 92 \\
04 / 21 / 94 \\
06 / 04 / 90 \\
12 / 15 / 90 \\
04 / 01 / 91 \\
08 / 22 / 91 \\
10 / 11 / 92 \\
04 / 08 / 94 \\
06 / 04 / 90 \\
12 / 08 / 90 \\
04 / 02 / 91 \\
08 / 25 / 91 \\
10 / 13 / 92 \\
06 / 06 / 90 \\
12 / 08 / 90 \\
04 / 03 / 91 \\
08 / 26 / 91 \\
10 / 14 / 92 \\
04 / 08 / 94\end{array}$ & $\begin{array}{l}0001 \\
0001 \\
0001 \\
0001 \\
0001 \\
0001 \\
0001 \\
0001 \\
0001 \\
0001 \\
0001 \\
0001 \\
0001 \\
0001 \\
0001 \\
0001 \\
0001 \\
0001 \\
0001 \\
0001 \\
0001 \\
0001 \\
0001\end{array}$ & $\begin{array}{l}\text { LB } \\
\text { LB } \\
\text { LB } \\
\text { LB } \\
\text { LB } \\
\text { LB } \\
\text { LB } \\
\text { LB } \\
\text { LB } \\
\text { LB } \\
\text { LB } \\
\text { LB } \\
\text { LB } \\
\text { LB } \\
\text { LB } \\
\text { LB } \\
\text { LB } \\
\text { LB } \\
\text { LB } \\
\text { LB } \\
\text { LB } \\
\text { LB } \\
\text { LB }\end{array}$ & $\begin{array}{l}0 \\
0 \\
0 \\
0 \\
0 \\
0 \\
0 \\
0 \\
0 \\
0 \\
0 \\
0 \\
0 \\
0 \\
0 \\
0 \\
0 \\
0 \\
0 \\
0 \\
0 \\
0 \\
0\end{array}$ & MG/L & & $\begin{array}{l}15 . \\
14 . \\
15.8 \\
14.9 \\
15.0 \\
13.5 \\
8 . \\
11 . \\
13.3 \\
13.0 \\
13.2 \\
11.6 \\
12 . \\
16 . \\
16.5 \\
16.5 \\
16.6 \\
23 . \\
30 . \\
64 . \\
52 . \\
18.5 \\
13.3\end{array}$ & $\begin{array}{l}\text { G } \\
\text { G } \\
\text { GL } \\
\text { G } \\
\text { G } \\
\text { J } \\
\text { L }\end{array}$ & $\begin{array}{l}1 . \\
1 . \\
0.5 \\
0.5 \\
0.5 \\
0.5 \\
1 . \\
1 . \\
0.5 \\
0.5 \\
0.5 \\
0.5 \\
1.5 \\
1 . \\
0.5 \\
0.5 \\
0.5 \\
1 . \\
1.5 \\
0.5 \\
1 . \\
0.5 \\
0.5\end{array}$ & $\begin{array}{l}- \\
- \\
- \\
- \\
- \\
- \\
- \\
- \\
- \\
- \\
- \\
- \\
- \\
- \\
- \\
- \\
- \\
- \\
- \\
- \\
- \\
-\end{array}$ \\
\hline CHROMIUM & $\begin{array}{l}0517 \\
0517 \\
0517 \\
0517 \\
0517 \\
0517 \\
0519 \\
0519\end{array}$ & $\begin{array}{l}06 / 04 / 90 \\
12 / 08 / 90 \\
04 / 02 / 91 \\
08 / 25 / 91 \\
10 / 14 / 92 \\
04 / 21 / 94 \\
06 / 04 / 90 \\
12 / 15 / 90\end{array}$ & $\begin{array}{l}0001 \\
0001 \\
0001 \\
0001 \\
0001 \\
0001 \\
0001 \\
0001\end{array}$ & $\begin{array}{l}\text { LB } \\
\text { LB } \\
\text { LB } \\
\text { LB } \\
\text { LB } \\
\text { LB } \\
\text { LB } \\
\text { LB }\end{array}$ & $\begin{array}{l}0 \\
0 \\
0 \\
0 \\
0 \\
0 \\
0 \\
0\end{array}$ & MG/L & $\begin{array}{l}< \\
< \\
< \\
< \\
< \\
< \\
< \\
<\end{array}$ & $\begin{array}{l}0.01 \\
0.01 \\
0.01 \\
0.01 \\
0.01 \\
0.01 \\
0.01 \\
0.01\end{array}$ & $\begin{array}{l}\text { G } \\
\text { G } \\
\text { GL. }\end{array}$ & $\begin{array}{l}0.01 \\
0.01 \\
0.01 \\
0.01 \\
0.01 \\
0.01 \\
0.01 \\
0.01\end{array}$ & $\begin{array}{l}- \\
- \\
- \\
- \\
- \\
- \\
-\end{array}$ \\
\hline
\end{tabular}

FORMATION OF COMPLETION CODE:

LB - LOWER BURRO CANYON

PARAMETER VALUE INDICATOR (PVI): < - LESS THAN DETECTION LIMIT
FLOW RELATIONSHIP CODE:

O - ON-SITE

OTHER PARAMETER VALUE FLAGS:

G - PH > 9, POSSIBLE GROUT CONTAMINATION

J - ESTIMATED VALUE

L - LESS THAN THREE BORE VOLUMES REMOVEd BEFORE SAMPLING 
TABLE 3.52 BACKGROUND GROUND HATER QUALITY DATA BY PARAMETER FOR THE

LOUER SANDSTONE UNIT, BURRO CANYON DISPOSAL SITE, SLICK ROCK, COLORADO

SITE: SRKO2 BORROW SITE 1 (BURRO CANYON)

06/04/90 TO 04/21/94

REPORT DATE: $09 / 30 / 94$

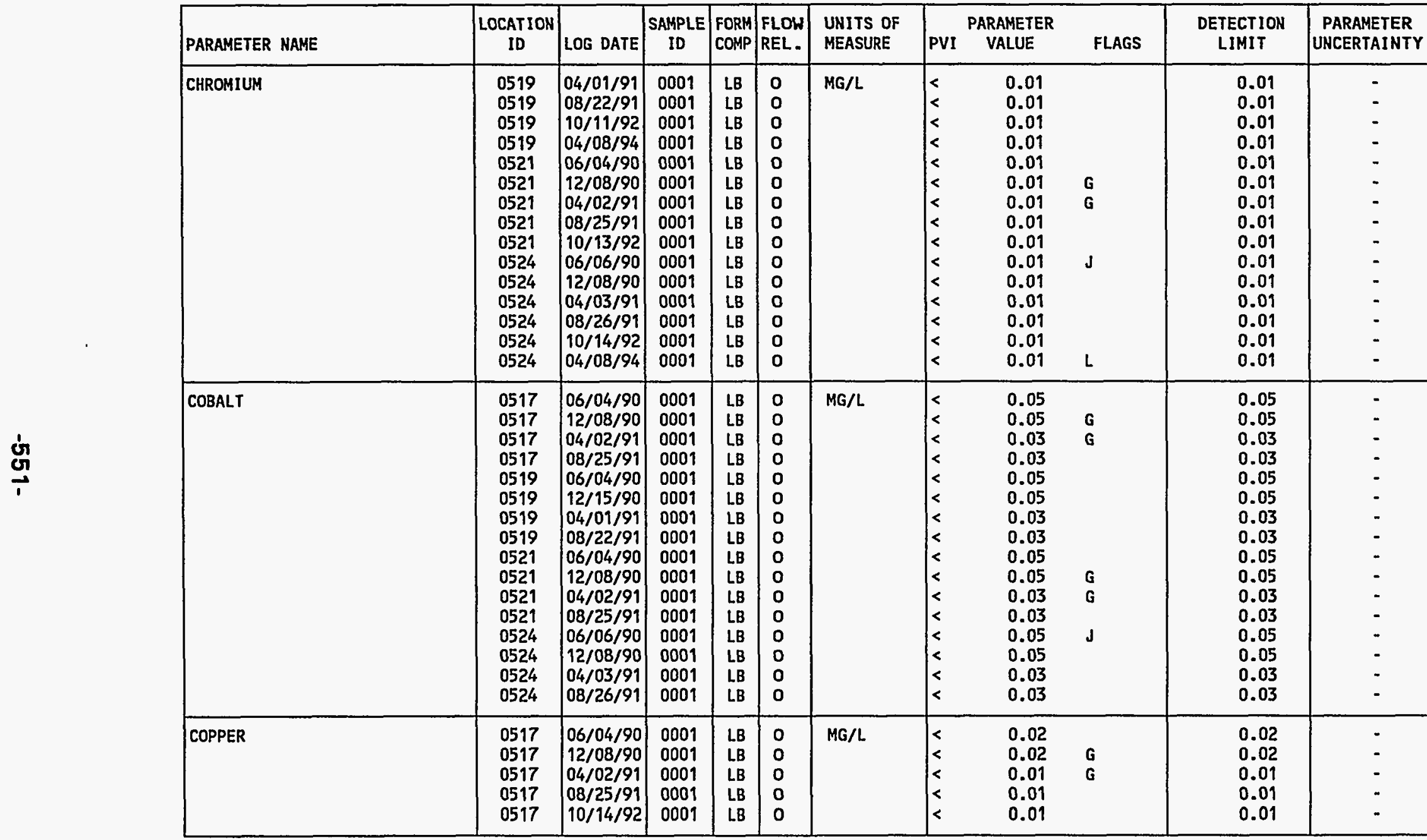

FORMATION OF COMPLETION CODE:

LB - LOWER BURRO CANYON

PARAMETER VALUE INDICATOR (PVI): < - LESS THAN DETECTION LIMIT
FLOW RELATIONSHIP CODE:

O - ON-SITE

SAMPLE ID CODES:

0001 - FILTERED SAMPLE (.45 MICRONS)

OTHER PARAMETER VALUE FLAGS:

$G$ - PH $>9$, POSSIBLE GROUT CONTAMINATION

$J$ - ESTIMATED VALUE

L - LESS THAN THREE, BORE VOLUMES REMOVED BEFORE SAMPLING 


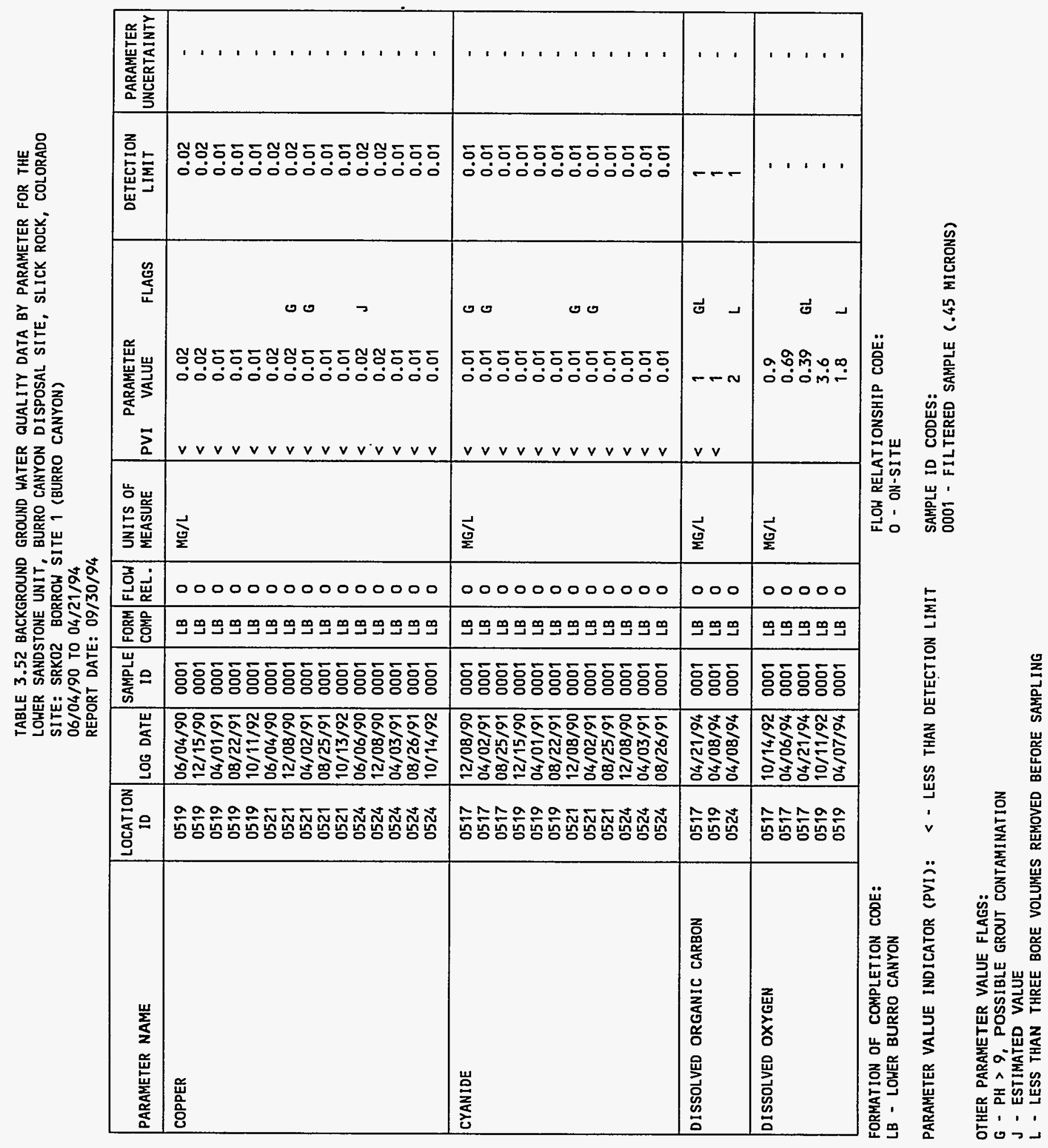


TABLE 3.52 BACKGROUND GROUND HATER QUALITY DATA BY PARAMETER FOR THE

LOWER SANDSTONE UNIT, BURRO CANYON DISPOSAL SITE, SLICK ROCK, COLORADO

SITE: SRKO2 BORROH SITE 1 (BURRO CANYON)

06/04/90 TO 04/21/4

REPORT DATE: $09 / 30 / 9$

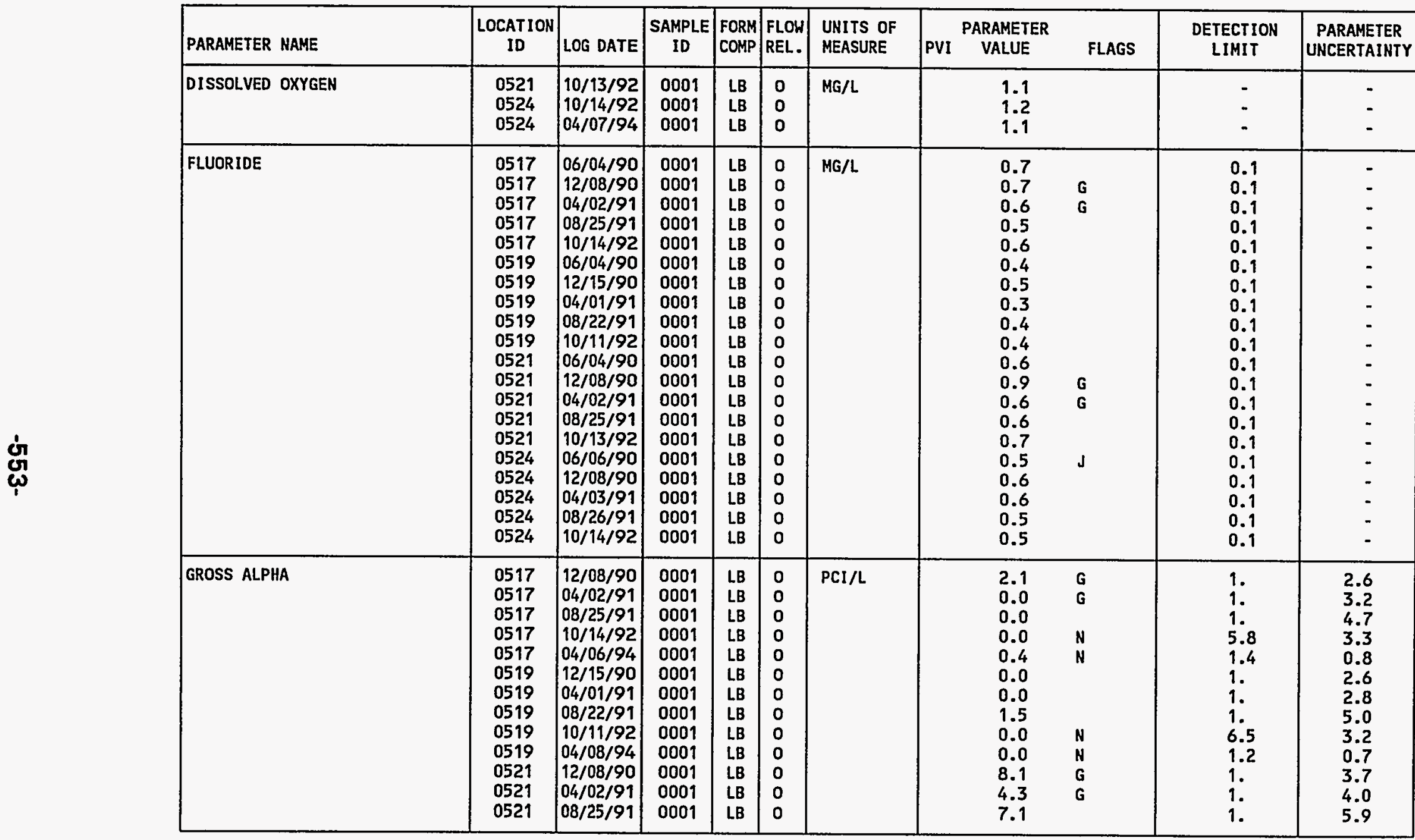

FORMATION OF COMPLETION CODE:

LB - LOWER BURRO CANYON

PARAMETER VALUE INDICATOR (PVI): < - LESS THAN DETECTION LIMIT
FLOW RELATIONSHIP CODE:

O - ON-SITE

0001 - FILTERED SAMPLE (.45 MICRONS)

OTHER PARAMETER VALUE FLAGS:

G - PH > 9, POSSIBLE GROUT CONTAMINATION

$J$ - ESTIMATED VALUE

N - SPIKE SAMPLE RECOVERY NOT HITHIN CONTROL LIMITS 
TABLE 3.52 BACKGROUND GROUND WATER QUALITY DATA BY PARAMETER FOR THE LOWER SANDSTONE UNIT BURRO CANYON DISPOSAL SITE, SLICK ROCK, COLORADO SITE: SRK02 BORROW SITE 1 (BURRO CANYON)

06/04/90 TO 04/21/94

REPORT DATE: $09 / 30 / 94$

\begin{tabular}{|c|c|c|c|c|c|c|c|c|c|c|c|}
\hline PARAMETER NAME & $\left|\begin{array}{c}\text { LOCATION } \\
\text { ID }\end{array}\right|$ & LOE DATE & $\begin{array}{c}\text { SAMPLE } \\
\text { ID }\end{array}$ & $\begin{array}{l}\text { FORM } \\
\text { COMP }\end{array}$ & $\begin{array}{l}\text { FLOW } \\
\text { REL. }\end{array}$ & $\begin{array}{l}\text { UNITS OF } \\
\text { MEASURE }\end{array}$ & PVI & $\begin{array}{l}\text { ARAMETER } \\
\text { VALUE }\end{array}$ & FLAGS & $\begin{array}{l}\text { DETECTION } \\
\text { L.IMIT }\end{array}$ & $\begin{array}{l}\text { PARAMETER } \\
\text { UNCERTAINTY }\end{array}$ \\
\hline GROSS ALPHA & $\begin{array}{l}0521 \\
0524 \\
0524 \\
0524 \\
0524 \\
0524\end{array}$ & $\begin{array}{l}10 / 13 / 92 \\
12 / 08 / 90 \\
04 / 03 / 91 \\
08 / 26 / 91 \\
10 / 14 / 92 \\
04 / 08 / 94\end{array}$ & $\begin{array}{l}0001 \\
0001 \\
0001 \\
0001 \\
0001 \\
0001\end{array}$ & $\begin{array}{l}\text { LB } \\
\text { LB } \\
\text { L.B } \\
\text { LB } \\
\text { LB } \\
\text { LB }\end{array}$ & $\begin{array}{l}0 \\
0 \\
0 \\
0 \\
0 \\
0\end{array}$ & $\mathrm{PCI} / \mathrm{L}$ & & $\begin{array}{l}0.0 \\
0.2 \\
0.0 \\
3.6 \\
1.0 \\
0.2\end{array}$ & $\begin{array}{l}\text { N } \\
\text { LN } \\
\text { LN }\end{array}$ & $\begin{array}{l}7.2 \\
1 . \\
1 . \\
1 . \\
6.1 \\
1.4\end{array}$ & $\begin{array}{l}3.6 \\
3.1 \\
4.1 \\
7.2 \\
3.7 \\
0.8\end{array}$ \\
\hline GROSS BETA & $\begin{array}{l}0517 \\
0517 \\
0517 \\
0517 \\
0519 \\
0519 \\
0519 \\
0519 \\
0521 \\
0521 \\
0521 \\
0521 \\
0524 \\
0524 \\
0524 \\
0524\end{array}$ & $\begin{array}{l}12 / 08 / 90 \\
04 / 02 / 91 \\
08 / 25 / 91 \\
10 / 14 / 92 \\
12 / 15 / 90 \\
04 / 01 / 91 \\
08 / 22 / 91 \\
10 / 11 / 92 \\
12 / 08 / 90 \\
04 / 02 / 91 \\
08 / 25 / 91 \\
10 / 13 / 92 \\
12 / 08 / 90 \\
04 / 03 / 91 \\
08 / 26 / 91 \\
10 / 14 / 92\end{array}$ & $\begin{array}{l}0001 \\
0001 \\
0001 \\
0001 \\
0001 \\
0001 \\
0001 \\
0001 \\
0001 \\
0001 \\
0001 \\
0001 \\
0001 \\
0001 \\
0001 \\
0001\end{array}$ & $\begin{array}{l}\text { LB } \\
\text { LB } \\
\text { LB } \\
\text { LB } \\
\text { LB } \\
\text { LB } \\
\text { LB } \\
\text { LB } \\
\text { LB } \\
\text { LB } \\
\text { LB } \\
\text { LB } \\
\text { LB } \\
\text { LB } \\
\text { LB } \\
\text { LB }\end{array}$ & $\begin{array}{l}0 \\
0 \\
0 \\
0 \\
0 \\
0 \\
0 \\
0 \\
0 \\
0 \\
0 \\
0 \\
0 \\
0 \\
0 \\
0\end{array}$ & $\mathrm{PCI} / \mathrm{L}$ & & $\begin{array}{l}1.9 \\
6.1 \\
0.0 \\
0.0 \\
0.6 \\
0.0 \\
1.6 \\
0.0 \\
4.0 \\
1.5 \\
1.6 \\
1.6 \\
1.9 \\
0.0 \\
2.6 \\
0.0\end{array}$ & $\begin{array}{l}G \\
G \\
*_{N} \\
*_{N} \\
G \\
G \\
*_{N} \\
*_{N}\end{array}$ & $\begin{array}{l}0.5 \\
0.5 \\
0.5 \\
5.2 \\
0.5 \\
0.5 \\
0.5 \\
6.3 \\
0.5 \\
0.5 \\
0.5 \\
6.2 \\
0.5 \\
0.5 \\
0.5 \\
5.1\end{array}$ & $\begin{array}{l}1.8 \\
2.3 \\
4.1 \\
3.0 \\
1.6 \\
2.2 \\
3.4 \\
3.7 \\
1.9 \\
2.2 \\
3.9 \\
3.8 \\
1.8 \\
2.6 \\
4.6 \\
3.0\end{array}$ \\
\hline I RON & $\begin{array}{l}0517 \\
0517 \\
0517 \\
0517 \\
0517 \\
0517 \\
0519 \\
0519 \\
0519 \\
0519 \\
0519 \\
0519 \\
0521\end{array}$ & $\begin{array}{l}06 / 04 / 90 \\
12 / 08 / 90 \\
04 / 02 / 91 \\
08 / 25 / 91 \\
10 / 14 / 92 \\
04 / 21 / 94 \\
06 / 04 / 90 \\
12 / 15 / 90 \\
04 / 01 / 91 \\
08 / 22 / 91 \\
10 / 11 / 92 \\
04 / 08 / 94 \\
06 / 04 / 90\end{array}$ & $\begin{array}{l}0001 \\
0001 \\
0001 \\
0001 \\
0001 \\
0001 \\
0001 \\
0001 \\
0001 \\
0001 \\
0001 \\
0001 \\
0001\end{array}$ & $\begin{array}{l}\text { LB } \\
\text { LB } \\
\text { LB } \\
\text { LB } \\
\text { LB } \\
\text { LB } \\
\text { LB } \\
\text { LB } \\
\text { LB } \\
\text { LB } \\
\text { LB } \\
\text { LB } \\
\text { LB }\end{array}$ & $\begin{array}{l}0 \\
0 \\
0 \\
0 \\
0 \\
0 \\
0 \\
0 \\
0 \\
0 \\
0 \\
0 \\
0\end{array}$ & MG/L & $\begin{array}{l}< \\
< \\
< \\
< \\
< \\
< \\
< \\
< \\
< \\
<\end{array}$ & $\begin{array}{l}0.06 \\
0.03 \\
0.03 \\
0.04 \\
0.03 \\
0.03 \\
0.03 \\
0.03 \\
0.03 \\
0.03 \\
0.03 \\
0.06 \\
0.05\end{array}$ & $\begin{array}{l}\mathbf{G} \\
\mathbf{G} \\
\mathbf{G L}\end{array}$ & $\begin{array}{l}0.03 \\
0.03 \\
0.03 \\
0.03 \\
0.03 \\
0.03 \\
0.03 \\
0.03 \\
0.03 \\
0.03 \\
0.03 \\
0.03 \\
0.03\end{array}$ & $\begin{array}{l}- \\
- \\
- \\
- \\
- \\
- \\
- \\
- \\
- \\
-\end{array}$ \\
\hline
\end{tabular}

FORMATION OF COMPLETION CODE:

LB - LOHER BURRO CANYON

PARAMETER VALUE INDICATOR (PVI): < - LESS THAN DETECTION LIMIT
FLOW RELATIONSHIP CODE:

0001 - FILTERED SAMPLE (.45 MICRONS)

OTHER PARAMETER VALUE FLAGS:

* - DUPLICATE ANALYSIS NOT HITHIN CONTROL LIMITS

G - PH > 9, POSSIBLE GROUT CONTAMINATION

L - LESS THAN THREE BORE VOLUMES REMOVED BEFORE SAMPLING

N - SPIKE SAMPLE RECOVERY NOT HITHIN CONTROL LIMITS 
TABLE 3.52 BACKGROUND GROUND HATER QUALITY DATA BY PARAMETER FOR THE LOHER SANDSTONE UNIT, BURRO CANYON DISPOSAL SITE, SLICK ROCK, COLORADO SITE: SRKO2 BORROH SITE 1 (BURRO CANYON)

06/04/90 TO 04/21/94

REPORT DATE: $09 / 30 / 94$

\begin{tabular}{|c|c|c|c|c|c|c|c|c|c|c|c|c|}
\hline & PARAMETER NAME & $\underset{\text { ID }}{\text { LOCATION }}$ & LOG DATE & $\begin{array}{c}\text { SAMPLE } \\
\text { ID }\end{array}$ & $\begin{array}{l}\text { FORM } \\
\text { COMP }\end{array}$ & $\begin{array}{l}\text { FLOH } \\
\text { REL. }\end{array}$ & $\begin{array}{l}\text { UNITS OF } \\
\text { MEASURE }\end{array}$ & PVI & $\begin{array}{l}\text { PARAMETER } \\
\text { VALUE }\end{array}$ & FLAGS & $\begin{array}{l}\text { DETECTION } \\
\text { LIMIT }\end{array}$ & $\begin{array}{l}\text { PARAMETER } \\
\text { UNCERTAINTY }\end{array}$ \\
\hline & IRON & $\begin{array}{l}0521 \\
0521 \\
0521 \\
0521 \\
0524 \\
0524 \\
0524 \\
0524 \\
0524 \\
0524\end{array}$ & $\begin{array}{l}12 / 08 / 90 \\
04 / 02 / 91 \\
08 / 25 / 91 \\
10 / 13 / 92 \\
06 / 06 / 90 \\
12 / 08 / 90 \\
04 / 03 / 91 \\
08 / 26 / 91 \\
10 / 14 / 92 \\
04 / 08 / 94\end{array}$ & $\begin{array}{l}0001 \\
0001 \\
0001 \\
0001 \\
0001 \\
0001 \\
0001 \\
0001 \\
0001 \\
0001\end{array}$ & $\begin{array}{l}\text { LB } \\
\text { LB } \\
\text { LB } \\
\text { LB } \\
\text { LB } \\
\text { LB } \\
\text { LB } \\
\text { LB } \\
\text { LB } \\
\text { LB }\end{array}$ & $\begin{array}{l}0 \\
0 \\
0 \\
0 \\
0 \\
0 \\
0 \\
0 \\
0 \\
0\end{array}$ & $M G / L$ & $\begin{array}{l}< \\
< \\
< \\
< \\
< \\
<\end{array}$ & $\begin{array}{l}0.03 \\
0.03 \\
0.03 \\
0.03 \\
0.03 \\
0.03 \\
0.23 \\
0.03 \\
0.05 \\
0.05\end{array}$ & $\begin{array}{l}G \\
G \\
J \\
\text { L }\end{array}$ & $\begin{array}{l}0.03 \\
0.03 \\
0.03 \\
0.03 \\
0.03 \\
0.03 \\
0.03 \\
0.03 \\
0.03 \\
0.03\end{array}$ & $\begin{array}{l}- \\
- \\
- \\
- \\
- \\
- \\
-\end{array}$ \\
\hline & LEAD & $\begin{array}{l}0517 \\
0517 \\
0517 \\
0517 \\
0517 \\
0519 \\
0519 \\
0519 \\
0519 \\
0519 \\
0521 \\
0521 \\
0521 \\
0521 \\
0521 \\
0524 \\
0524 \\
0524 \\
0524 \\
0524\end{array}$ & $\begin{array}{l}06 / 04 / 90 \\
12 / 08 / 90 \\
04 / 02 / 91 \\
08 / 25 / 91 \\
10 / 14 / 92 \\
06 / 04 / 90 \\
12 / 15 / 90 \\
04 / 01 / 91 \\
08 / 22 / 91 \\
10 / 11 / 92 \\
06 / 04 / 90 \\
12 / 08 / 90 \\
04 / 02 / 91 \\
08 / 25 / 91 \\
10 / 13 / 92 \\
06 / 06 / 90 \\
12 / 08 / 90 \\
04 / 03 / 91 \\
08 / 26 / 91 \\
10 / 14 / 92\end{array}$ & $\begin{array}{l}0001 \\
0001 \\
0001 \\
0001 \\
0001 \\
0001 \\
0001 \\
0001 \\
0001 \\
0001 \\
0001 \\
0001 \\
0001 \\
0001 \\
0001 \\
0001 \\
0001 \\
0001 \\
0001 \\
0001\end{array}$ & $\begin{array}{l}\text { LB } \\
\text { LB } \\
\text { LB } \\
\text { LB } \\
\text { LB } \\
\text { LB } \\
\text { LB } \\
\text { LB } \\
\text { LB } \\
\text { LB } \\
\text { LB } \\
\text { LB } \\
\text { LB } \\
\text { LB } \\
\text { LB } \\
\text { LB } \\
\text { LB } \\
\text { LB } \\
\text { LB } \\
\text { LB }\end{array}$ & $\begin{array}{l}0 \\
0 \\
0 \\
0 \\
0 \\
0 \\
0 \\
0 \\
0 \\
0 \\
0 \\
0 \\
0 \\
0 \\
0 \\
0 \\
0 \\
0 \\
0 \\
0\end{array}$ & $M G / L$ & $\begin{array}{l}< \\
< \\
< \\
< \\
< \\
< \\
< \\
< \\
< \\
< \\
< \\
< \\
< \\
< \\
< \\
< \\
< \\
< \\
< \\
< \\
< \\
< \\
<\end{array}$ & $\begin{array}{l}0.01 \\
0.01 \\
0.005 \\
0.005 \\
0.02 \\
0.01 \\
0.01 \\
0.005 \\
0.005 \\
0.003 \\
0.01 \\
0.01 \\
0.005 \\
0.005 \\
0.02 \\
0.01 \\
0.01 \\
0.005 \\
0.005 \\
0.003\end{array}$ & $\begin{array}{l}\text { G } \\
\mathbf{G} \\
\mathbf{I} \\
J\end{array}$ & $\begin{array}{l}0.01 \\
0.01 \\
0.005 \\
0.005 \\
0.02 \\
0.01 \\
0.01 \\
0.005 \\
0.005 \\
0.003 \\
0.01 \\
0.01 \\
0.005 \\
0.005 \\
0.02 \\
0.01 \\
0.01 \\
0.005 \\
0.005 \\
0.003\end{array}$ & $\begin{array}{l}- \\
- \\
- \\
- \\
- \\
- \\
- \\
- \\
- \\
- \\
- \\
- \\
- \\
- \\
- \\
-\end{array}$ \\
\hline & LEAD-210 & $\begin{array}{l}0517 \\
0517 \\
0517 \\
0519 \\
0519\end{array}$ & $\begin{array}{l}12 / 08 / 90 \\
04 / 02 / 91 \\
08 / 25 / 91 \\
12 / 15 / 90 \\
04 / 01 / 91\end{array}$ & $\begin{array}{l}0001 \\
0001 \\
0001 \\
0001 \\
0001\end{array}$ & $\begin{array}{l}\text { LB } \\
\text { LB } \\
\text { LB } \\
\text { LB } \\
\text { LB }\end{array}$ & $\begin{array}{l}0 \\
0 \\
0 \\
0 \\
0\end{array}$ & $\mathrm{PCI} / \mathrm{L}$ & & $\begin{array}{l}0.0 \\
0.4 \\
0.0 \\
0.0 \\
0.9\end{array}$ & $\begin{array}{l}\mathbf{G} \\
\mathbf{G}\end{array}$ & $\begin{array}{l}1.5 \\
1.5 \\
1.5 \\
1.5 \\
1.5\end{array}$ & $\begin{array}{l}0.8 \\
1.4 \\
1.0 \\
0.9 \\
1.4\end{array}$ \\
\hline
\end{tabular}

FORMATION OF COMPLETION CODE:

LB - LOWER BURRO CANYON

PARAMETER VALUE INDICATOR (PVI): < - LESS THAN DETECTION LIMIT
FLOW RELATIONSHIP CODE:

O - ON-SITE

0001 - FILTERED SAMPLE (.45 MICRONS)

OTHER PARAMETER VALUE FLAGS:

$G$ - PH > 9, POSSIBLE GROUT CONTAMINATION

I - INCREASED DETECTION LIMIT DUE TO REQUIRED DILUTION

J - ESTIMATED VALUE

L - LESS THAN THREE BORE VOLUMES REMOVED BEFORE SAMPLING 
TABLE 3.52 BACKGROUND GROUND WATER QUALITY DATA BY PARAMETER FOR THE

LOWER SANDSTONE UNIT, BURRO CANYON DISPOSAL SITE, SLICK ROCK, COLORADO

SITE: SRKO2 BORROW SITE 1 (BURRO CANYON)

06/04/90 TO 04/21/94

REPORT DATE: $09 / 30 / 94$

\begin{tabular}{|c|c|c|c|c|c|c|c|c|c|c|c|}
\hline PARAMETER NAME & $\underset{\text { ID }}{\text { LOCATION }}$ & LOG DATE & $\begin{array}{c}\text { SAMPLE } \\
\text { ID }\end{array}$ & $\begin{array}{l}\text { FORM } \\
\text { COMP }\end{array}$ & $\begin{array}{l}\text { FLOW } \\
\text { REL. }\end{array}$ & $\begin{array}{l}\text { UNITS OF } \\
\text { MEASURE }\end{array}$ & PVI & $\begin{array}{l}\text { PARAMETER } \\
\text { VALUE }\end{array}$ & FLAGS & $\begin{array}{l}\text { DETECTION } \\
\text { LIMIT }\end{array}$ & $\begin{array}{l}\text { PARAMETER } \\
\text { UNCERTAINTY }\end{array}$ \\
\hline LEAD-210 & $\begin{array}{l}0519 \\
0521 \\
0521 \\
0521 \\
0524 \\
0524 \\
0524\end{array}$ & $\begin{array}{l}08 / 22 / 91 \\
12 / 08 / 90 \\
04 / 02 / 91 \\
08 / 25 / 91 \\
12 / 08 / 90 \\
04 / 03 / 91 \\
08 / 26 / 91\end{array}$ & $\begin{array}{l}0001 \\
0001 \\
0001 \\
0001 \\
0001 \\
0001 \\
0001\end{array}$ & $\begin{array}{l}\text { LB } \\
\text { LB } \\
\text { LB } \\
\text { LB } \\
\text { LB } \\
\text { LB } \\
\text { L.B }\end{array}$ & $\begin{array}{l}0 \\
0 \\
0 \\
0 \\
0 \\
0 \\
0\end{array}$ & $\mathrm{PCI} / \mathrm{L}$ & & $\begin{array}{l}0.0 \\
0.0 \\
0.5 \\
0.5 \\
0.3 \\
0.0 \\
0.0\end{array}$ & $\begin{array}{l}\mathbf{G} \\
\mathbf{G}\end{array}$ & $\begin{array}{l}1.5 \\
1.5 \\
1.5 \\
1.5 \\
1.5 \\
1.5 \\
1.5\end{array}$ & $\begin{array}{l}0.9 \\
1.0 \\
1.4 \\
1.0 \\
0.8 \\
1.3 \\
0.9\end{array}$ \\
\hline MAGNESIUM & $\begin{array}{l}0517 \\
0517 \\
0517 \\
0517 \\
0517 \\
0517 \\
0519 \\
0519 \\
0519 \\
0519 \\
0519 \\
0519 \\
0521 \\
0521 \\
0521 \\
0521 \\
0521 \\
0524 \\
0524 \\
0524 \\
0524 \\
0524 \\
0524\end{array}$ & $\begin{array}{l}06 / 04 / 90 \\
12 / 08 / 90 \\
04 / 02 / 91 \\
08 / 25 / 91 \\
10 / 14 / 92 \\
04 / 21 / 94 \\
06 / 04 / 90 \\
12 / 15 / 90 \\
04 / 01 / 91 \\
08 / 22 / 91 \\
10 / 11 / 92 \\
04 / 08 / 94 \\
06 / 04 / 90 \\
12 / 08 / 90 \\
04 / 02 / 91 \\
08 / 25 / 91 \\
10 / 13 / 92 \\
06 / 06 / 90 \\
12 / 08 / 90 \\
04 / 03 / 91 \\
08 / 26 / 91 \\
10 / 14 / 92 \\
04 / 08 / 94\end{array}$ & $\begin{array}{l}0001 \\
0001 \\
0001 \\
0001 \\
0001 \\
0001 \\
0001 \\
0001 \\
0001 \\
0001 \\
0001 \\
0001 \\
0001 \\
0001 \\
0001 \\
0001 \\
0001 \\
0001 \\
0001 \\
0001 \\
0001 \\
0001 \\
0001\end{array}$ & $\begin{array}{l}\text { LB } \\
\text { LB } \\
\text { LB } \\
\text { LB } \\
\text { LB } \\
\text { LB } \\
\text { LB } \\
\text { LB } \\
\text { LB } \\
\text { LB } \\
\text { LB } \\
\text { LB } \\
\text { LB } \\
\text { LB } \\
\text { LB } \\
\text { LB } \\
\text { LB } \\
\text { LB } \\
\text { LB } \\
\text { LB } \\
\text { LB } \\
\text { LB } \\
\text { LB }\end{array}$ & $\begin{array}{l}0 \\
0 \\
0 \\
0 \\
0 \\
0 \\
0 \\
0 \\
0 \\
0 \\
0 \\
0 \\
0 \\
0 \\
0 \\
0 \\
0 \\
0 \\
0 \\
0 \\
0 \\
0 \\
0\end{array}$ & MG/L & $<$ & $\begin{array}{l}0.25 \\
0.14 \\
0.1 \\
0.1 \\
0.1 \\
0.1 \\
0.40 \\
0.27 \\
0.2 \\
0.1 \\
0.3 \\
0.1 \\
0.45 \\
0.31 \\
0.2 \\
0.1 \\
0.1 \\
0.30 \\
0.48 \\
0.6 \\
0.5 \\
0.2 \\
0.1\end{array}$ & $\begin{array}{l}G \\
G \\
G L \\
G \\
G \\
J \\
\text { J } \\
L\end{array}$ & $\begin{array}{l}0.001 \\
0.001 \\
0.1 \\
0.1 \\
0.1 \\
0.1 \\
0.001 \\
0.001 \\
0.1 \\
0.1 \\
0.1 \\
0.1 \\
0.001 \\
0.001 \\
0.1 \\
0.1 \\
0.1 \\
0.001 \\
0.001 \\
0.1 \\
0.1 \\
0.1 \\
0.1\end{array}$ & $\begin{array}{l}- \\
- \\
- \\
- \\
- \\
- \\
- \\
- \\
- \\
- \\
- \\
- \\
- \\
- \\
- \\
- \\
- \\
- \\
-\end{array}$ \\
\hline MANGANESE & $\begin{array}{l}0517 \\
0517 \\
0517 \\
0517 \\
0517 \\
0519\end{array}$ & $\begin{array}{l}06 / 04 / 90 \\
12 / 08 / 90 \\
04 / 02 / 91 \\
08 / 25 / 91 \\
10 / 14 / 92 \\
06 / 04 / 90\end{array}$ & $\begin{array}{l}0001 \\
0001 \\
0001 \\
0001 \\
0001 \\
0001\end{array}$ & $\begin{array}{l}\text { LB } \\
\text { LB } \\
\text { LB } \\
\text { LB } \\
\text { LB } \\
\text { LB }\end{array}$ & $\begin{array}{l}0 \\
0 \\
0 \\
0 \\
0 \\
0\end{array}$ & $M G / L$ & $\begin{array}{l}< \\
< \\
< \\
< \\
< \\
<\end{array}$ & $\begin{array}{l}0.01 \\
0.01 \\
0.01 \\
0.01 \\
0.01 \\
0.01\end{array}$ & $\begin{array}{l}\text { G } \\
G\end{array}$ & $\begin{array}{l}0.01 \\
0.01 \\
0.01 \\
0.01 \\
0.01 \\
0.01\end{array}$ & $\begin{array}{l}- \\
- \\
- \\
-\end{array}$ \\
\hline
\end{tabular}

FORMATION OF COMPLETION CODE:

LB - LOWER BURRO CANYON

FLOW RELATIONSHIP CODE:

PARAMETER VALUE INDICATOR (PVI): < - LESS THAN DETECTION LIMIT

O - ON-SITE

SAMPLE ID CODES:

0001 - FILTERED SAMPLE (.45 MICRONS)

OTHER PARAMETER VALUE FLAGS:

G - PH $>9$, POSSIBLE GROUT CONTAMINATION

J - ESTIMATED VALUE

$L$ - LESS THAN THREE BORE VOLUMES REMOVED BEFORE SAMPLING 


\begin{tabular}{|c|c|c|c|c|c|c|c|}
\hline \multirow{10}{*}{ 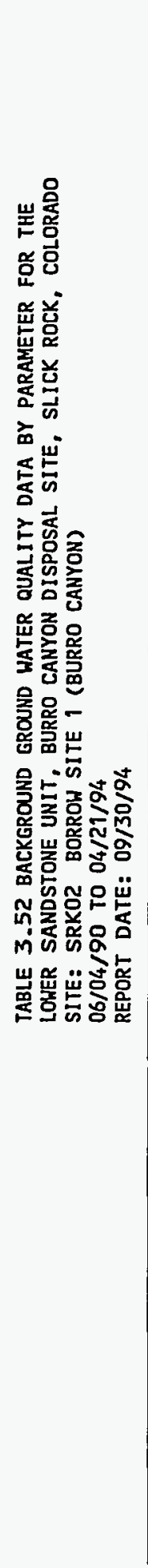 } & 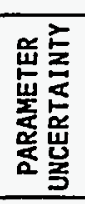 & $1,1,1,1,1,1$ & ' & 1,1 & & & \\
\hline & 总 & 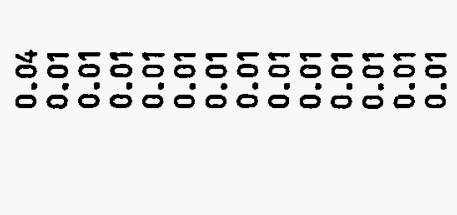 & 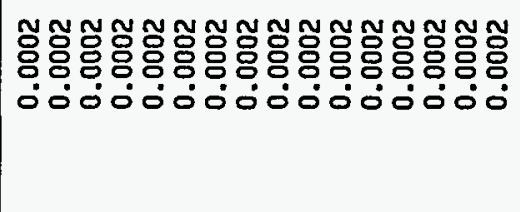 & 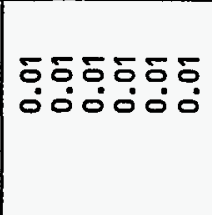 & & & \\
\hline & 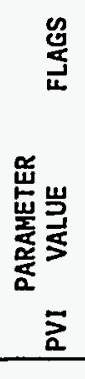 & 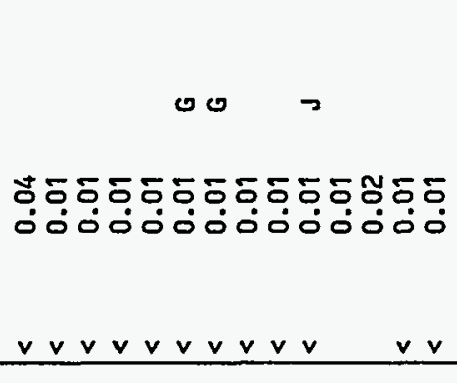 & 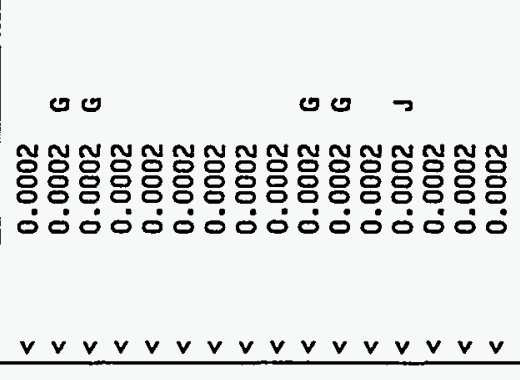 & 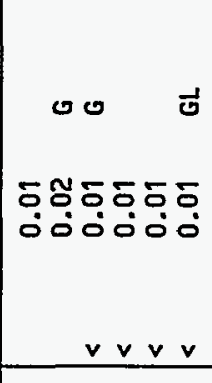 & 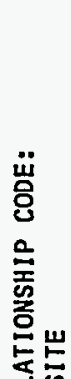 & 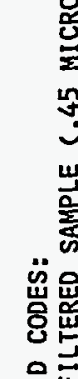 & \\
\hline & 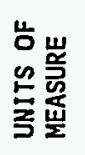 & 훌 & के & $\overrightarrow{\mathrm{o}}$ & 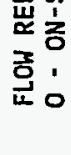 & 状 & \\
\hline & 䂞莡 & 00000000000000 & 0000000000000000 & 000000 & & 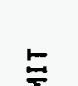 & \\
\hline & 焉高 & 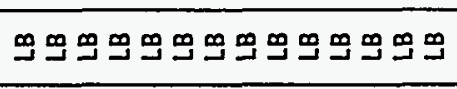 & 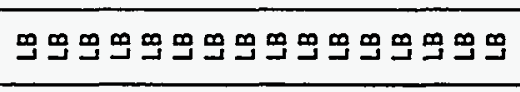 & פエ & & $\begin{array}{l}\frac{\Sigma}{3} \\
\bar{z}\end{array}$ & \\
\hline & 率 & 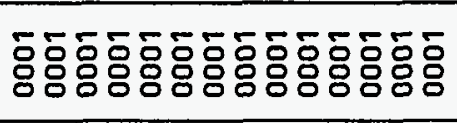 & 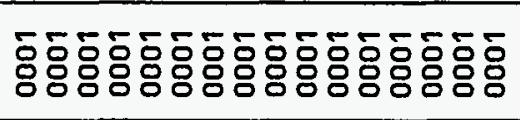 & 항ㅎㅇㅇㅎㅇㅇㅇㅇ & & 总 & \\
\hline & $\begin{array}{l}\text { 㟥 } \\
\Xi \\
\end{array}$ & 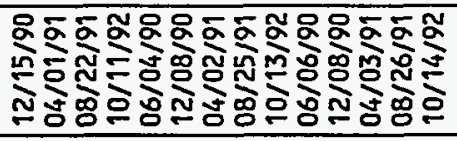 & 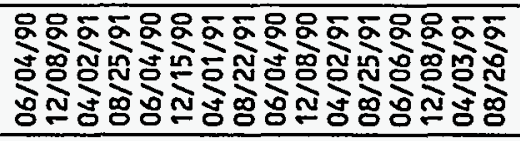 & 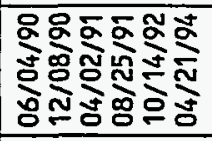 & & 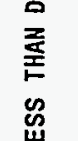 & \\
\hline & 密 & 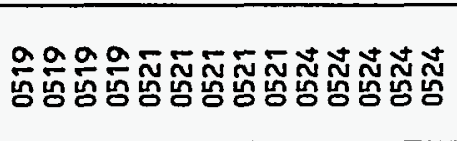 & 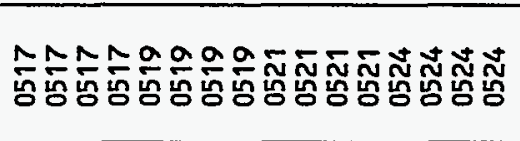 & 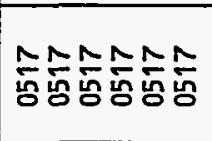 & & $\begin{array}{l}\text { ü } \\
\dot{v} \\
v\end{array}$ & 总 \\
\hline & 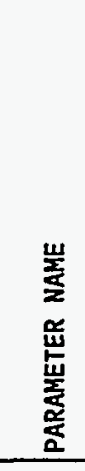 & 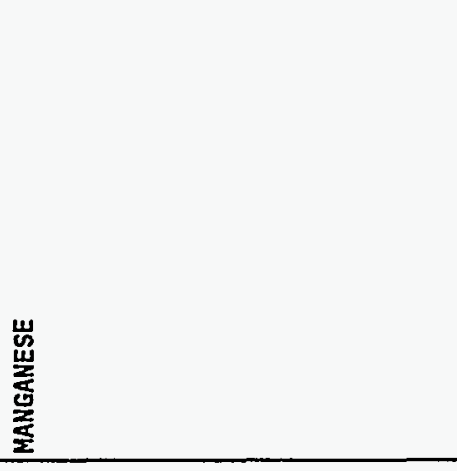 & 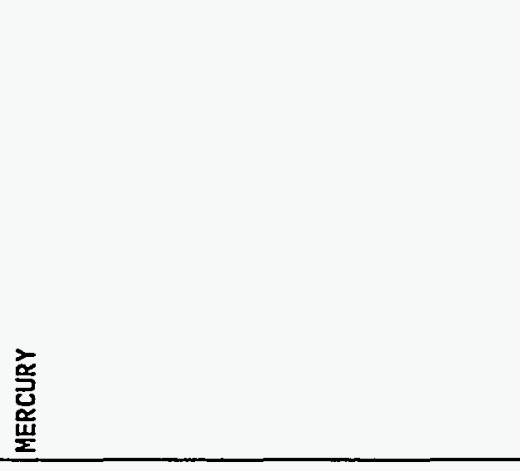 & 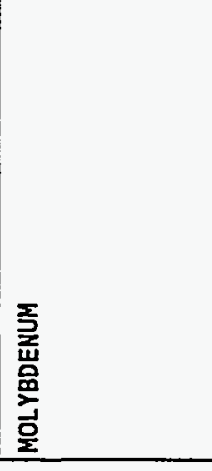 & 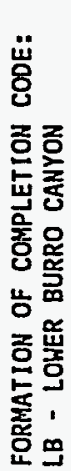 & 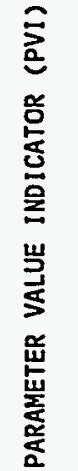 & 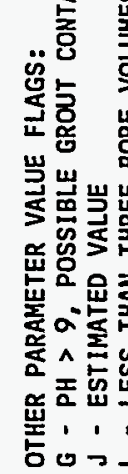 \\
\hline
\end{tabular}




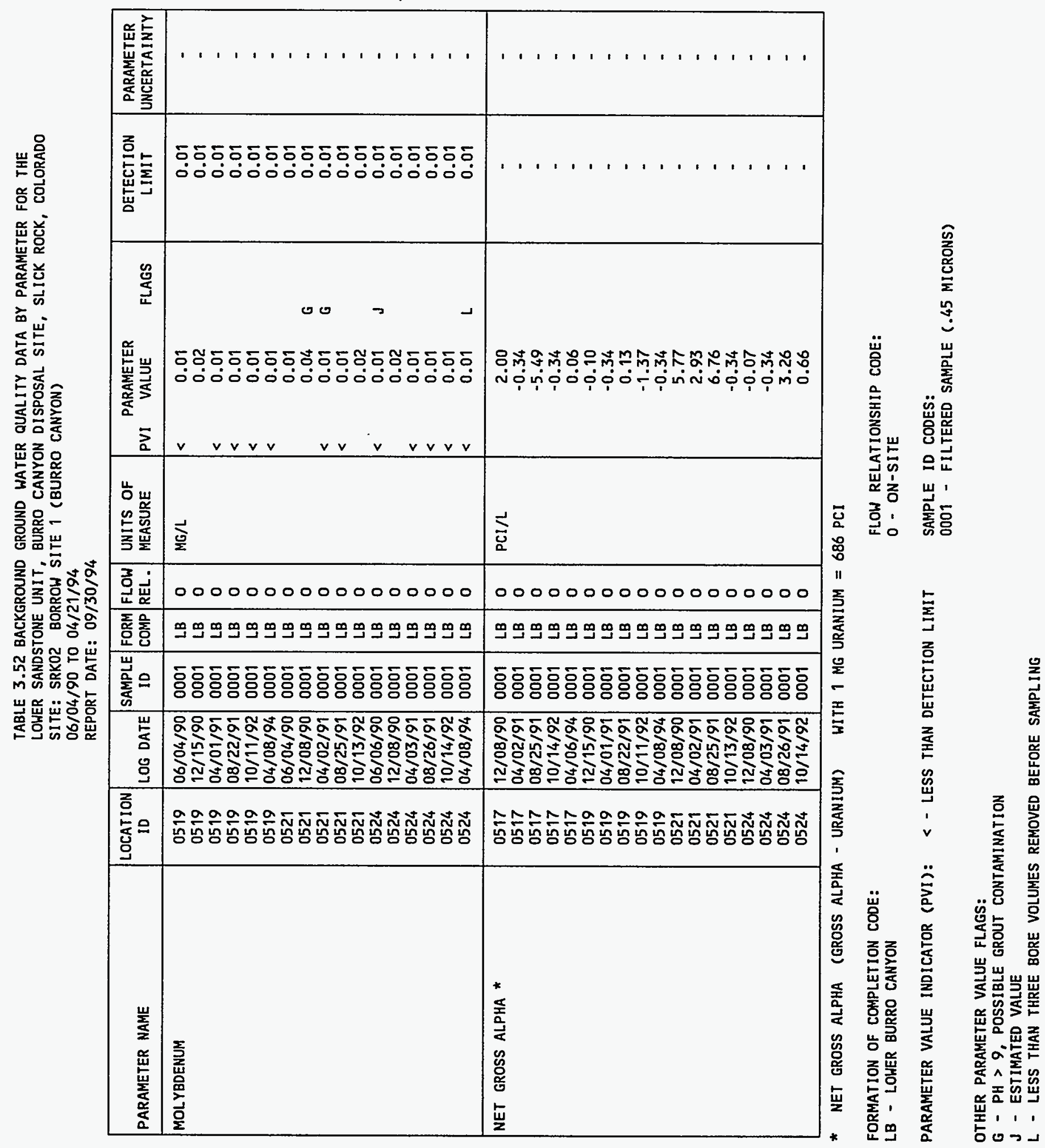


TABLE 3.52 BACKGROUND GROUND WATER QUALITY DATA BY PARAMETER FOR THE LOWER SANDSTONE UNIT, BURRO CANYON DISPOSAL SITE, SLICK ROCK, COLORADO SITE: SRKO2 BORROW SITE 1 (BURRO CANYON)

06/04/90 TO 04/21/94

REPORT DATE: 09/30/94

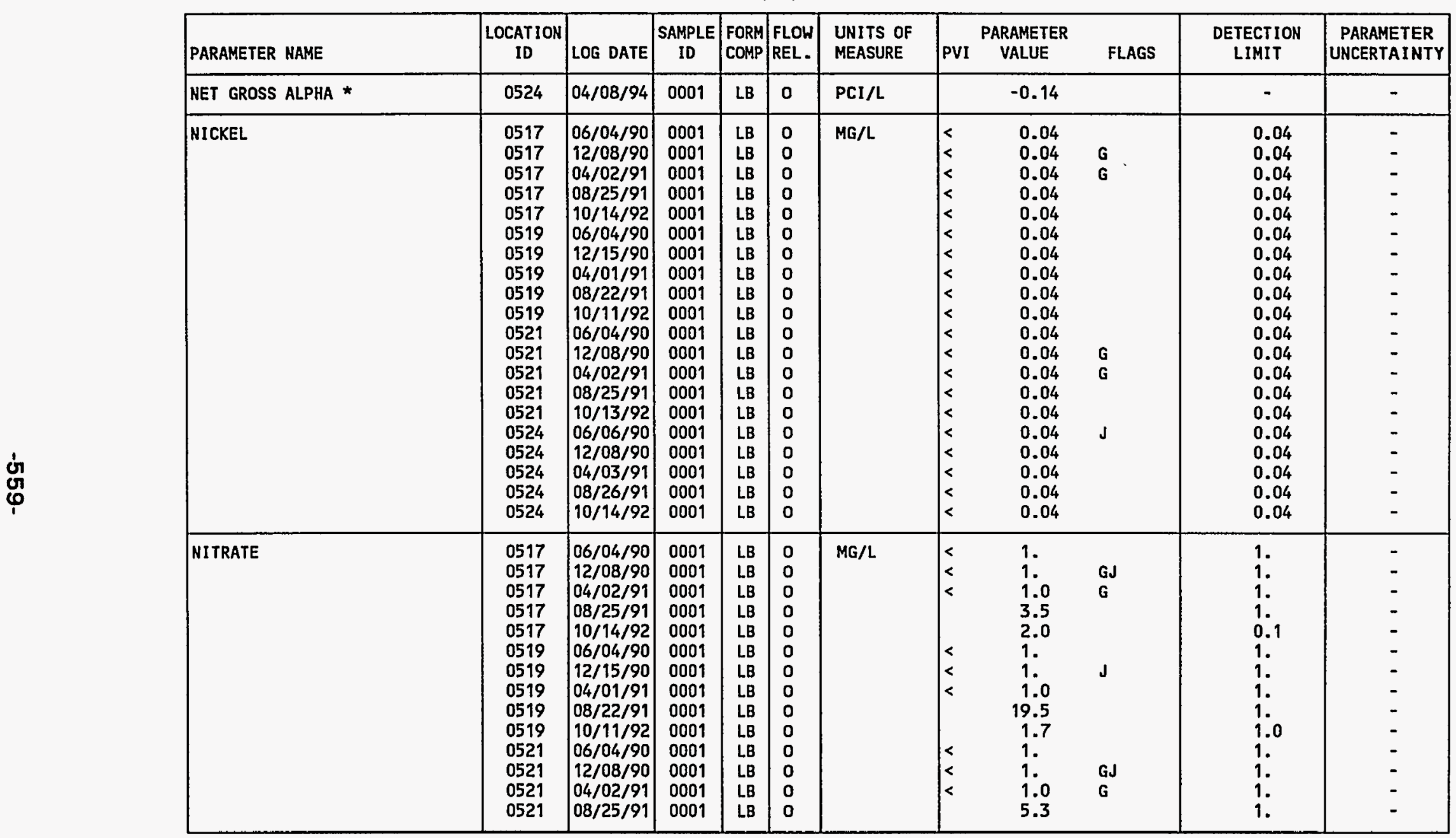

* Net gROSS ALPHA (GROSS ALPHA - URANIUM) HITH 1 MG URANIUM = 686 PCI

FORMATION OF COMPLETION CODE:

LB - LOWER BURRO CANYON

PARAMETER VALUE INDICATOR (PVI): < - LESS THAN DETECTION LIMIT
FLOH RELATIONSHIP CODE: O - ON-SITE

SAMPLE ID CODES:

0001 - FILTERED SAMPLE (.45 MICRONS)

OTHER PARAMETER VALUE FLAGS:

$G$ - PH $>9$, POSSIBLE GROUT CONTAMINATION

$\mathrm{J}$ - Estimated VALUE 
TABLE 3.52 BACKGROUND GROUND WATER QUALITY DATA BY PARAMETER FOR THE LOWER SANDSTONE UNIT, BURRO CANYON DISPOSAL SITE, SLICK ROCK, COLORADO SITE: SRKO2 BORROH SITE 1 (BURRO CANYON)

$06 / 04 / 90$ TO $04 / 21 / 94$

REPORT DATE: $09 / 30 / 94$

\begin{tabular}{|c|c|c|c|c|c|c|c|c|c|c|c|c|}
\hline & PARAMETER NAME & $\underset{\text { ID }}{\text { LOCATION }}$ & LOG DATE & $\begin{array}{c}\text { SAMPLE } \\
\text { ID }\end{array}$ & $\begin{array}{l}\text { FORM } \\
\text { COMP }\end{array}$ & $\begin{array}{l}\text { FLOW } \\
\text { REL. }\end{array}$ & $\begin{array}{l}\text { UNITS OF } \\
\text { MEASURE }\end{array}$ & PVI & $\begin{array}{l}\text { PARAMETER } \\
\text { VALUE }\end{array}$ & FLAGS & $\begin{array}{l}\text { DETECTION } \\
\text { LIMIT }\end{array}$ & $\begin{array}{l}\text { PARAMETER } \\
\text { UNCERTAINTY }\end{array}$ \\
\hline & NITRATE & $\begin{array}{l}0521 \\
0524 \\
0524 \\
0524 \\
0524 \\
0524\end{array}$ & $\begin{array}{l}10 / 13 / 92 \\
06 / 06 / 90 \\
12 / 08 / 90 \\
04 / 03 / 91 \\
08 / 26 / 91 \\
10 / 14 / 92\end{array}$ & $\begin{array}{l}0001 \\
0001 \\
0001 \\
0001 \\
0001 \\
0001\end{array}$ & $\begin{array}{l}\text { LB } \\
\text { LB } \\
\text { LBB } \\
\text { LB } \\
\text { LB } \\
\text { LB }\end{array}$ & $\begin{array}{l}0 \\
0 \\
0 \\
0 \\
0 \\
0\end{array}$ & $M G / L$ & $<$ & $\begin{array}{l}1.7 \\
1 . \\
1 . \\
1.0 \\
11.5 \\
1.6\end{array}$ & $\begin{array}{l}J \\
J\end{array}$ & $\begin{array}{l}0.1 \\
1 . \\
1 . \\
1 . \\
1 . \\
0.1\end{array}$ & $\begin{array}{l}- \\
- \\
- \\
- \\
-\end{array}$ \\
\hline $\begin{array}{l}\text { dr } \\
\text { ه̆ }\end{array}$ & NITRITE AND NITRATE & $\begin{array}{l}0517 \\
0517 \\
0517 \\
0517 \\
0519 \\
0519 \\
0519 \\
0519 \\
0521 \\
0521 \\
0521 \\
0521 \\
0524 \\
0524 \\
0524 \\
0524\end{array}$ & $\begin{array}{l}06 / 04 / 90 \\
12 / 08 / 90 \\
04 / 02 / 91 \\
08 / 25 / 91 \\
06 / 04 / 90 \\
12 / 15 / 90 \\
04 / 01 / 91 \\
08 / 22 / 91 \\
06 / 04 / 90 \\
12 / 08 / 90 \\
04 / 02 / 91 \\
08 / 25 / 91 \\
06 / 06 / 90 \\
12 / 08 / 90 \\
04 / 03 / 91 \\
08 / 26 / 91\end{array}$ & $\begin{array}{l}0001 \\
0001 \\
0001 \\
0001 \\
0001 \\
0001 \\
0001 \\
0001 \\
0001 \\
0001 \\
0001 \\
0001 \\
0001 \\
0001 \\
0001 \\
0001\end{array}$ & $\begin{array}{l}\text { LB } \\
\text { LB } \\
\text { LB } \\
\text { LB } \\
\text { LB } \\
\text { LB } \\
\text { LB } \\
\text { LB } \\
\text { LB } \\
\text { LB } \\
\text { LB } \\
\text { LB } \\
\text { LB } \\
\text { LB } \\
\text { LB } \\
\text { LB }\end{array}$ & $\begin{array}{l}0 \\
0 \\
0 \\
0 \\
0 \\
0 \\
0 \\
0 \\
0 \\
0 \\
0 \\
0 \\
0 \\
0 \\
0 \\
0\end{array}$ & $M G / L$ & $\begin{array}{l}< \\
< \\
< \\
< \\
< \\
< \\
<\end{array}$ & $\begin{array}{l}1 . \\
1 . \\
0.23 \\
0.76 \\
1 . \\
1 . \\
0.19 \\
4.37 \\
1 . \\
1 . \\
0.20 \\
1.23 \\
1 . \\
1 . \\
0.22 \\
2.62\end{array}$ & $\begin{array}{l}\text { GJ } \\
G \\
J \\
\text { GJ } \\
G \\
J \\
J\end{array}$ & $\begin{array}{l}1 . \\
1.05 \\
0.05 \\
0.05 \\
1 . \\
1 . \\
0.05 \\
0.05 \\
1 . \\
1 . \\
0.05 \\
0.05 \\
1 . \\
1 . \\
0.05 \\
0.05\end{array}$ & $\begin{array}{l}- \\
- \\
- \\
- \\
- \\
- \\
- \\
- \\
- \\
- \\
- \\
- \\
-\end{array}$ \\
\hline & $\mathrm{PH}$ & $\begin{array}{l}0517 \\
0517 \\
0517 \\
0517 \\
0517 \\
0517 \\
0517 \\
0519 \\
0519 \\
0519 \\
0519 \\
0519 \\
0519 \\
0521\end{array}$ & $\begin{array}{l}06 / 04 / 90 \\
12 / 08 / 90 \\
04 / 02 / 91 \\
08 / 25 / 91 \\
10 / 14 / 92 \\
04 / 06 / 94 \\
04 / 21 / 94 \\
06 / 04 / 90 \\
12 / 15 / 90 \\
04 / 01 / 91 \\
08 / 22 / 91 \\
10 / 11 / 92 \\
04 / 07 / 94 \\
06 / 04 / 90\end{array}$ & $\begin{array}{l}0001 \\
0001 \\
0001 \\
0001 \\
0001 \\
0001 \\
0001 \\
0001 \\
0001 \\
0001 \\
0001 \\
0001 \\
0001 \\
0001\end{array}$ & $\begin{array}{l}\text { LB } \\
\text { LB } \\
\text { LB } \\
\text { LB } \\
\text { LB } \\
\text { LB } \\
\text { LB } \\
\text { LB } \\
\text { LB } \\
\text { LB } \\
\text { LB } \\
\text { LB } \\
\text { LB } \\
\text { LB }\end{array}$ & $\begin{array}{l}0 \\
0 \\
0 \\
0 \\
0 \\
0 \\
0 \\
0 \\
0 \\
0 \\
0 \\
0 \\
0 \\
0\end{array}$ & sU & & $\begin{array}{l}9.13 \\
9.14 \\
9.22 \\
9.21 \\
9.24 \\
9.13 \\
9.28 \\
8.68 \\
8.57 \\
8.65 \\
8.76 \\
8.77 \\
8.68 \\
9.55\end{array}$ & $\begin{array}{l}\mathbf{G} \\
\mathbf{G} \\
\mathbf{G L}\end{array}$ & $\begin{array}{l}- \\
- \\
- \\
- \\
- \\
- \\
- \\
- \\
- \\
-\end{array}$ & $\begin{array}{l}- \\
- \\
- \\
- \\
- \\
- \\
- \\
- \\
- \\
-\end{array}$ \\
\hline
\end{tabular}

FORMATION OF COMPLETION CODE:

LB - LOWER BURRO CANYON

PARAMETER VALUE INDICATOR (PVI):

< - LESS THAN DETECTION LIMIT
FLOW RELATIONSHIP CODE:

O - ON-SITE

SAMPLE ID CODES:
0001 - FILTERED SAMPLE (.45 MICRONS)

OTHER PARAMETER VALUE FLAGS:

G - PH > 9, POSSIBLE GROUT CONTAMINATION

$J$ - ESTIMATED VALUE

L - LESS THAN THREE BORE VOLUMES REMOVED BEFORE SAMPLING 
TABLE 3.52 BACKGROUND GROUND HATER QUALITY DATA BY PARAMETER FOR THE

LOWER SANDSTONE UNIT, BURRO CANYON DISPOSAL SITE, SLICK ROCK, COLORADO

SITE: SRKO2 BORROW SITE 1 (BURRO CANYON)

06/04/90 TO 04/21/94

REPORT DATE : 09/30/94

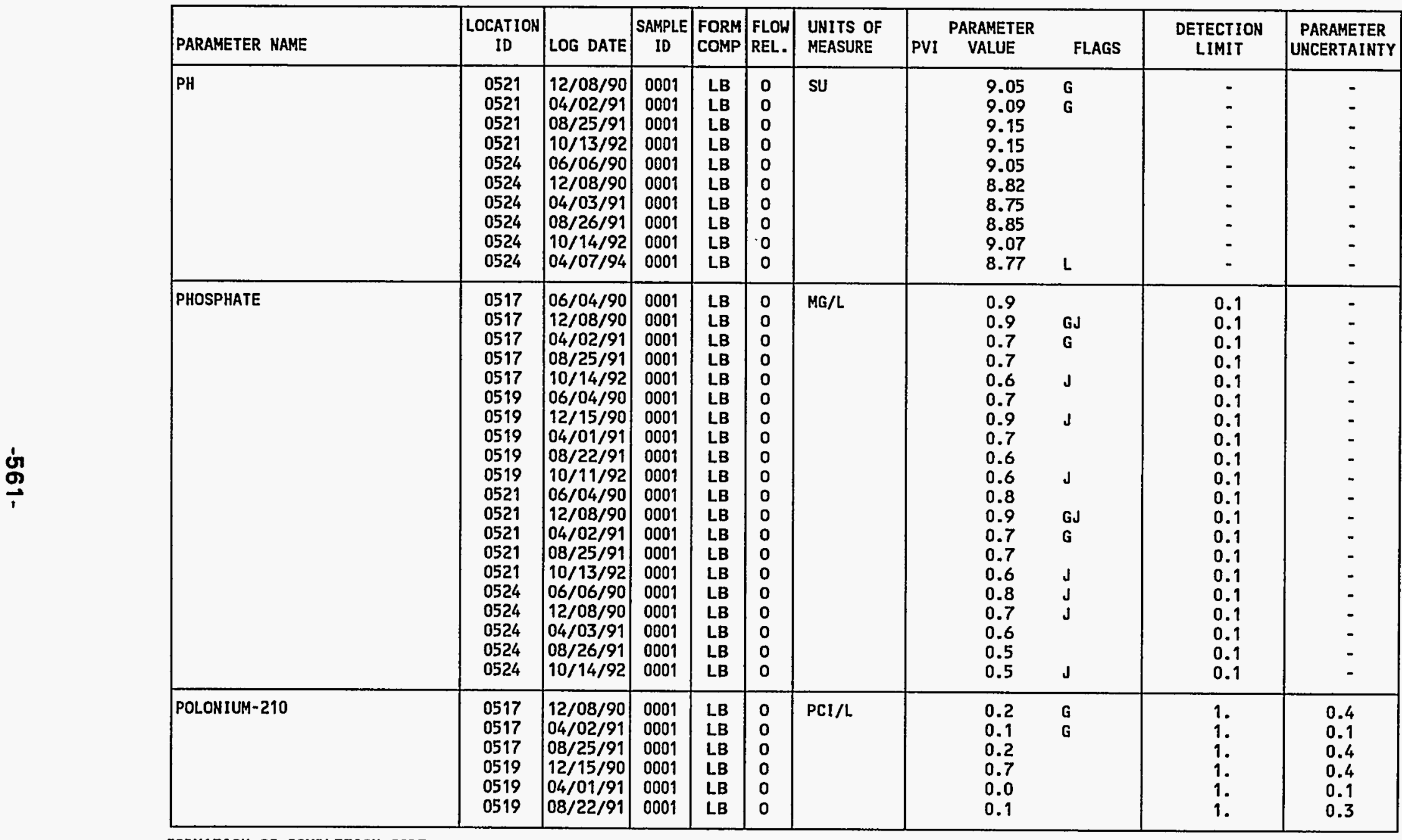

FORMATION OF COMPLETION CODE:

LB - LOWER BURRO CANYON

FLOW RELATIONSHIP CODE:

PARAMETER VALUE INDICATOR (PVI): < - LESS THAN DETECTION LIMIT

SAMPLE ID CODES:

0001 - FILTERED SAMPLE ( .45 MICRONS)

OTHER PARAMETER VALUE FLAGS:

$G$ - PH $>9$, POSSIBLE GROUT CONTAMINATION

$J$ - ESTIMATED VALUE

L - LESS THAN THREE BORE VOLUMES REMOVED BEFORE SAMPLING 
TABLE 3.52 BACKGROUND GROUND HATER QUALITY DATA BY PARAMETER FOR THE LOWER SANDSTONE UNIT, BURRO CANYON DISPOSAL SITE, SLICK ROCK, COLORADO SITE: SRKOZ BORROW SITE 1 (BURRO CANYON)

$06 / 04 / 90$ TO $04 / 21 / 94$

REPORT DATE: $09 / 30 / 94$

\begin{tabular}{|c|c|c|c|c|c|c|c|c|c|c|c|}
\hline PARAMETER NAME & $\begin{array}{c}\text { LOCAT ION } \\
10\end{array}$ & LOG DATE & $\begin{array}{c}\text { SAMPLE } \\
\text { ID }\end{array}$ & $\begin{array}{l}\text { FORM } \\
\text { COMP }\end{array}$ & $\begin{array}{l}\text { FLOW } \\
\text { REL. }\end{array}$ & $\begin{array}{l}\text { UNITS OF } \\
\text { MEASURE }\end{array}$ & PVI & $\begin{array}{l}\text { PARAMETEF } \\
\text { VALUE }\end{array}$ & FLAGS & $\begin{array}{l}\text { DETECTION } \\
\text { LIMIT }\end{array}$ & $\begin{array}{l}\text { PARAMETER } \\
\text { UNCERTAINTY }\end{array}$ \\
\hline POLONIUM-210 & $\begin{array}{l}0521 \\
0521 \\
0521 \\
0524 \\
0524 \\
0524\end{array}$ & $\begin{array}{l}12 / 08 / 90 \\
04 / 02 / 91 \\
08 / 25 / 91 \\
12 / 08 / 90 \\
04 / 03 / 91 \\
08 / 26 / 91\end{array}$ & $\begin{array}{l}0001 \\
0001 \\
0001 \\
0001 \\
0001 \\
0001\end{array}$ & $\begin{array}{l}\text { L8 } \\
\text { LB } \\
\text { LB } \\
\text { LB } \\
\text { LB } \\
\text { LB }\end{array}$ & $\begin{array}{l}0 \\
0 \\
0 \\
0 \\
0 \\
0\end{array}$ & $\mathrm{PCI} / \mathrm{L}$ & & $\begin{array}{l}0.9 \\
0.0 \\
0.1 \\
0.0 \\
0.1 \\
0.2\end{array}$ & $\begin{array}{l}\text { G } \\
\text { G }\end{array}$ & $\begin{array}{l}1 . \\
1 . \\
1 . \\
1 . \\
1 . \\
1 .\end{array}$ & $\begin{array}{l}0.5 \\
0.1 \\
0.3 \\
0.3 \\
0.1 \\
0.5\end{array}$ \\
\hline POTASSIUM & $\begin{array}{l}0517 \\
0517 \\
0517 \\
0517 \\
0517 \\
0517 \\
0519 \\
0519 \\
0519 \\
0519 \\
0519 \\
0519 \\
0521 \\
0521 \\
0521 \\
0521 \\
0521 \\
0524 \\
0524 \\
0524 \\
0524 \\
0524 \\
0524\end{array}$ & $\begin{array}{l}06 / 04 / 90 \\
12 / 08 / 90 \\
04 / 02 / 91 \\
08 / 25 / 91 \\
10 / 14 / 92 \\
04 / 21 / 94 \\
06 / 04 / 90 \\
12 / 15 / 90 \\
04 / 01 / 91 \\
08 / 22 / 91 \\
10 / 11 / 92 \\
04 / 08 / 94 \\
06 / 04 / 90 \\
12 / 08 / 90 \\
04 / 02 / 91 \\
08 / 25 / 91 \\
10 / 13 / 92 \\
06 / 06 / 90 \\
12 / 08 / 90 \\
04 / 03 / 91 \\
08 / 26 / 91 \\
10 / 14 / 92 \\
04 / 08 / 94\end{array}$ & $\begin{array}{l}0001 \\
0001 \\
0001 \\
0001 \\
0001 \\
0001 \\
0001 \\
0001 \\
0001 \\
0001 \\
0001 \\
0001 \\
0001 \\
0001 \\
0001 \\
0001 \\
0001 \\
0001 \\
0001 \\
0001 \\
0001 \\
0001 \\
0001\end{array}$ & $\begin{array}{l}\text { LB } \\
\text { LB } \\
\text { LB } \\
\text { LB } \\
\text { LB } \\
\text { LB } \\
\text { LB } \\
\text { LB } \\
\text { LB } \\
\text { LB } \\
\text { LB } \\
\text { LB } \\
\text { LB } \\
\text { LB } \\
L B \\
\text { LB } \\
\text { LB } \\
\text { LB } \\
\text { LB } \\
\text { LB } \\
\text { LB } \\
\text { LB } \\
\text { LB }\end{array}$ & $\begin{array}{l}0 \\
0 \\
0 \\
0 \\
0 \\
0 \\
0 \\
0 \\
0 \\
0 \\
0 \\
0 \\
0 \\
0 \\
0 \\
0 \\
0 \\
0 \\
0 \\
0 \\
0 \\
0 \\
0\end{array}$ & $M G / L$ & & $\begin{array}{l}0.7 \\
0.6 \\
0.69 \\
0.29 \\
0.52 \\
0.5 \\
1.0 \\
0.5 \\
0.92 \\
0.45 \\
0.50 \\
0.4 \\
13.4 \\
1.0 \\
3.1 \\
1.30 \\
2.16 \\
1.0 \\
1.5 \\
1.29 \\
1.14 \\
0.64 \\
0.7\end{array}$ & $\begin{array}{l}\text { G } \\
\text { G } \\
\text { GL. }\end{array}$ & $\begin{array}{l}0.01 \\
0.01 \\
0.01 \\
0.01 \\
0.01 \\
0.1 \\
0.01 \\
0.01 \\
0.01 \\
0.01 \\
0.01 \\
0.1 \\
0.01 \\
0.01 \\
0.01 \\
0.01 \\
0.01 \\
0.01 \\
0.01 \\
0.01 \\
0.01 \\
0.01 \\
0.1\end{array}$ & $\begin{array}{l}- \\
- \\
- \\
- \\
- \\
- \\
- \\
- \\
- \\
- \\
- \\
- \\
- \\
- \\
- \\
- \\
- \\
-\end{array}$ \\
\hline RADIUM-226 & $\begin{array}{l}0517 \\
0517 \\
0517 \\
0517 \\
0517 \\
0517 \\
0519\end{array}$ & $\begin{array}{l}06 / 04 / 90 \\
12 / 08 / 90 \\
04 / 02 / 91 \\
08 / 25 / 91 \\
10 / 14 / 92 \\
04 / 06 / 94 \\
06 / 04 / 90\end{array}$ & $\begin{array}{l}0001 \\
0001 \\
0001 \\
0001 \\
0001 \\
0001 \\
0001\end{array}$ & $\begin{array}{l}\text { LB } \\
\text { LB } \\
\text { LB } \\
\text { LB } \\
\text { LB } \\
\text { LB } \\
\text { LB }\end{array}$ & $\begin{array}{l}0 \\
0 \\
0 \\
0 \\
0 \\
0 \\
0\end{array}$ & $\mathrm{PCI} / \mathrm{L}$ & & $\begin{array}{l}0.0 \\
0.0 \\
0.1 \\
0.0 \\
0.0 \\
0.0 \\
0.0\end{array}$ & $\begin{array}{l}G \\
G \\
J\end{array}$ & $\begin{array}{l}1 . \\
1 . \\
1 . \\
1 . \\
0.8 \\
0.0 \\
1 .\end{array}$ & $\begin{array}{l}0.1 \\
0.1 \\
0.1 \\
0.2 \\
0.4 \\
0.1 \\
0.1\end{array}$ \\
\hline
\end{tabular}

FORMATION OF COMPLETION CODE:

LB - LOHER BURRO CANYON

PARAMETER VALUE INDICATOR (PVI):

FLOW RELATIONSHIP CODE:

0001 - FILTERED SAMPLE (.45 MICRONS)

OTHER PARAMETER VALUE FLAGS:

$G$ - PH > 9, POSSIBLE GROUT CONTAMINATION

$J$ - estimated VALUE

L - LESS THAN THREE BORE VOLUMES REMOVED BEFORE SAMPLING 


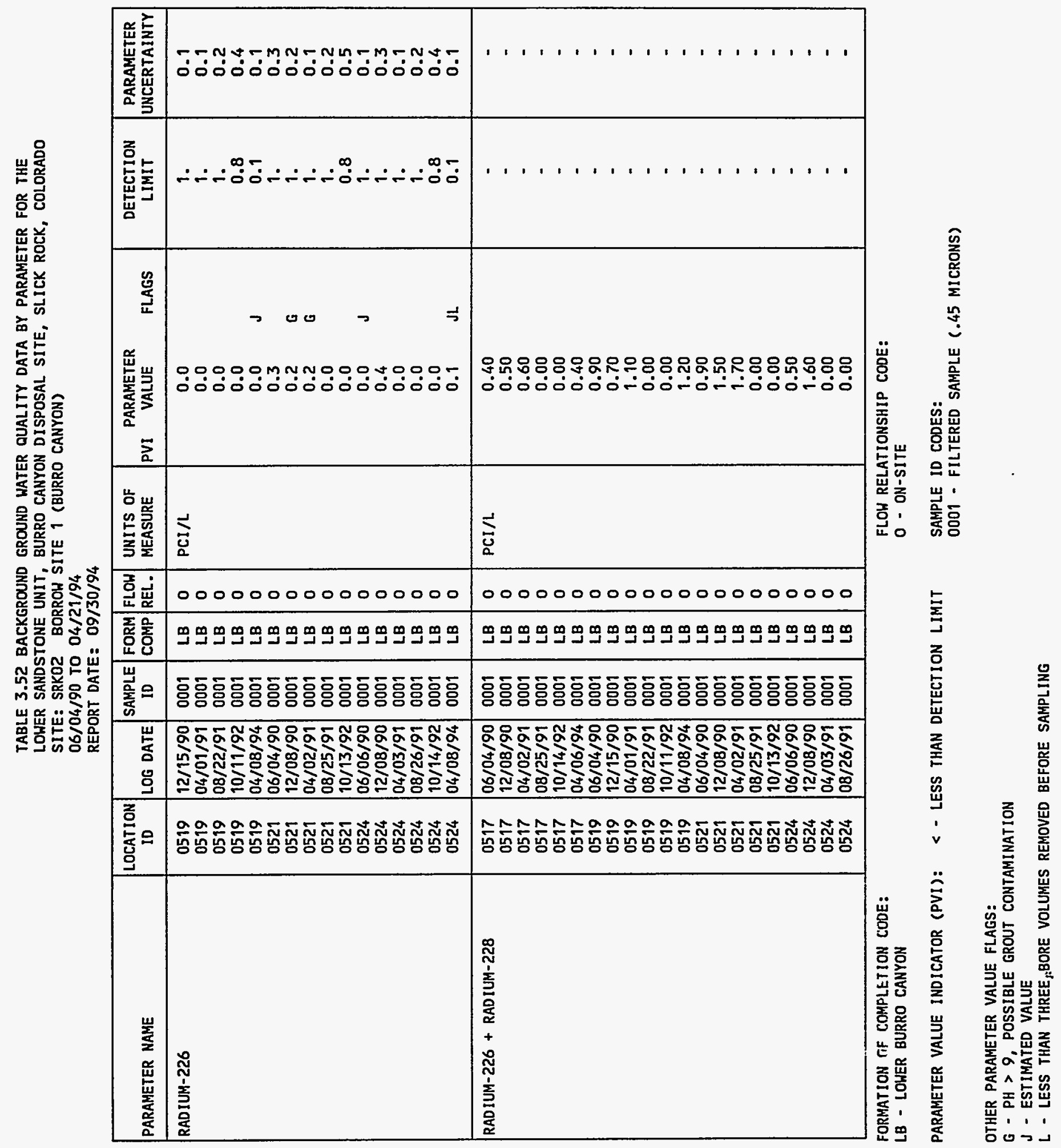


TABLE 3.52 BACKGROUND GROUND WATER QUALITY DATA BY PARAMETER FOR THE LOWER SANDSTONE UNIT, BURRO CANYON DISPOSAL SITE, SLICK ROCK, COLORADO SITE: SRKO2 BORROW SITE 1 (BURRO CANYON)

06/04/90 TO 04/21/94

REPORT DATE: $09 / 30 / 94$

\begin{tabular}{|c|c|c|c|c|c|c|c|c|c|c|c|}
\hline PARAMETER NAME & $\underset{\text { ID }}{\text { LOCATION }}$ & LOG DATE & $\begin{array}{c}\text { SAMPLE } \\
\text { ID }\end{array}$ & $\begin{array}{l}\text { FORM } \\
\text { COMP }\end{array}$ & $\begin{array}{l}\text { FL.OW } \\
\text { REL. }\end{array}$ & $\begin{array}{l}\text { UNITS OF } \\
\text { MEASURE }\end{array}$ & PVI & $\begin{array}{l}\text { ARAMETER } \\
\text { VALUE }\end{array}$ & FLAGS & $\begin{array}{l}\text { DETECTION } \\
\text { LIMIT }\end{array}$ & $\begin{array}{l}\text { PARAMETER } \\
\text { UNCERTAINTY }\end{array}$ \\
\hline RADIUM-226 + RADIUM-228 & $\begin{array}{l}0524 \\
0524\end{array}$ & $\begin{array}{l}10 / 14 / 92 \\
04 / 08 / 94\end{array}$ & $\begin{array}{l}0001 \\
0001\end{array}$ & $\begin{array}{l}\text { LB } \\
\text { LB }\end{array}$ & $\begin{array}{l}0 \\
0\end{array}$ & $\mathrm{PCI} / \mathrm{L}$ & & $\begin{array}{l}0.00 \\
2.20\end{array}$ & & - & - \\
\hline RADIUM-228 & $\begin{array}{l}0517 \\
0517 \\
0517 \\
0517 \\
0517 \\
0517 \\
0519 \\
0519 \\
0519 \\
0519 \\
0519 \\
0519 \\
0521 \\
0521 \\
0521 \\
0521 \\
0521 \\
0524 \\
0524 \\
0524 \\
0524 \\
0524 \\
0524\end{array}$ & $\begin{array}{l}06 / 04 / 90 \\
12 / 08 / 90 \\
04 / 02 / 91 \\
08 / 25 / 91 \\
10 / 14 / 92 \\
04 / 06 / 94 \\
06 / 04 / 90 \\
12 / 15 / 90 \\
04 / 01 / 91 \\
08 / 22 / 91 \\
10 / 11 / 92 \\
04 / 08 / 94 \\
06 / 04 / 90 \\
12 / 08 / 90 \\
04 / 02 / 91 \\
08 / 25 / 91 \\
10 / 13 / 92 \\
06 / 06 / 90 \\
12 / 08 / 90 \\
04 / 03 / 91 \\
08 / 26 / 91 \\
10 / 14 / 92 \\
04 / 08 / 94\end{array}$ & $\begin{array}{l}0001 \\
0001 \\
0001 \\
0001 \\
0001 \\
0001 \\
0001 \\
0001 \\
0001 \\
0001 \\
0001 \\
0001 \\
0001 \\
0001 \\
0001 \\
0001 \\
0001 \\
0001 \\
0001 \\
0001 \\
0001 \\
0001 \\
0001\end{array}$ & $\begin{array}{l}\text { LB } \\
\text { LB } \\
\text { LB } \\
\text { LB } \\
\text { LB } \\
\text { LB } \\
\text { LB } \\
\text { LB } \\
\text { LB } \\
\text { LB } \\
\text { LB } \\
\text { LB } \\
\text { LB } \\
\text { LB } \\
\text { LB } \\
\text { LB } \\
\text { LB } \\
\text { LB } \\
\text { LB } \\
\text { LB } \\
\text { LB } \\
\text { LB } \\
\text { LB }\end{array}$ & $\begin{array}{l}0 \\
0 \\
0 \\
0 \\
0 \\
0 \\
0 \\
0 \\
0 \\
0 \\
0 \\
0 \\
0 \\
0 \\
0 \\
0 \\
0 \\
0 \\
0 \\
0 \\
0 \\
0 \\
0\end{array}$ & $\mathrm{PCl} / \mathrm{L}$ & & $\begin{array}{l}0.4 \\
0.5 \\
0.5 \\
0.0 \\
0.0 \\
0.4 \\
0.9 \\
0.7 \\
1.1 \\
0.0 \\
0.0 \\
1.2 \\
0.6 \\
1.3 \\
1.5 \\
0.0 \\
0.0 \\
0.5 \\
1.2 \\
0.0 \\
0.0 \\
0.0 \\
2.1\end{array}$ & $\begin{array}{l}G \\
G \\
N \\
J \\
\text { N } \\
\text { L }\end{array}$ & $\begin{array}{l}1 . \\
1 . \\
1 . \\
1 . \\
4.1 \\
3.1 \\
1 . \\
1 . \\
1 . \\
1 . \\
2.9 \\
3.8 \\
1 . \\
1 . \\
1 . \\
4.1 \\
1 . \\
1 . \\
1 . \\
1 . \\
3.1 \\
3.5\end{array}$ & $\begin{array}{l}0.7 \\
0.9 \\
0.9 \\
2.0 \\
2.4 \\
1.0 \\
0.7 \\
0.7 \\
1.0 \\
2.5 \\
1.6 \\
1.8 \\
0.7 \\
0.8 \\
1.0 \\
2.0 \\
2.3 \\
0.8 \\
0.8 \\
1.2 \\
2.6 \\
2.3 \\
1.3\end{array}$ \\
\hline REDOX POTENTIAL & $\begin{array}{l}0517 \\
0517 \\
0517 \\
0517 \\
0519 \\
0519 \\
0519 \\
0521 \\
0524 \\
0524\end{array}$ & $\begin{array}{l}12 / 08 / 90 \\
10 / 14 / 92 \\
04 / 06 / 94 \\
04 / 21 / 94 \\
12 / 15 / 90 \\
10 / 11 / 92 \\
04 / 07 / 94 \\
10 / 13 / 92 \\
12 / 08 / 90 \\
10 / 14 / 92\end{array}$ & $\begin{array}{l}0001 \\
0001 \\
0001 \\
0001 \\
0001 \\
0001 \\
0001 \\
0001 \\
0001 \\
0001\end{array}$ & $\begin{array}{l}\text { LB } \\
\text { LB } \\
\text { LB } \\
\text { LB } \\
\text { LB } \\
\text { LB } \\
\text { LB } \\
\text { LB } \\
\text { LB } \\
\text { LB }\end{array}$ & $\begin{array}{l}0 \\
0 \\
0 \\
0 \\
0 \\
0 \\
0 \\
0 \\
0 \\
0\end{array}$ & mVOLTS & & $\begin{array}{l}342.3 \\
383.6 \\
433 \\
-189 \\
268.2 \\
395.1 \\
357 \\
393.1 \\
261.2 \\
402.0\end{array}$ & $\begin{array}{l}\text { G } \\
\text { GL } \\
\text { L }\end{array}$ & $\begin{array}{l}- \\
- \\
- \\
- \\
- \\
- \\
- \\
-\end{array}$ & $\begin{array}{l}- \\
- \\
- \\
- \\
- \\
- \\
-\end{array}$ \\
\hline
\end{tabular}

FORMATION OF COMPLETION CODE:

LB - LOWER BURRO CANYON

PARAMETER VALUE INDICATOR (PVI): < - LESS THAN DETECTION LIMIT
FLOW RELATIONSHIP CODE:

O - ON-SITE

SAMPLE ID CODES:

0001 - FILTERED SAMPLE (.45 MICRONS)

OTHER PARAMETER VALUE FLAGS:

G - PH > 9, POSSIBLE GROUT CONTAMINATION

J - ESTIMATED VALUE

L - LESS THAN THREE BORE VOLUMES REMOVED BEFORE SAMPLING

N - SPIKE SAMPLE RECOVERY NOT WITHIN CONTROL LIMITS 
TABLE 3.52 BACKGROUND GROUND HATER QUALITY DATA BY PARAMETER FOR THE LOWER SANDSTONE UNIT, BURRO CANYON DISPOSAL SITE, SLICK ROCK, COLORADO SITE: SRKO2 BORROW SITE 1 (BURRO CANYON)

06/04/90 TO 04/21/94

REPORT DATE: 09/30/94

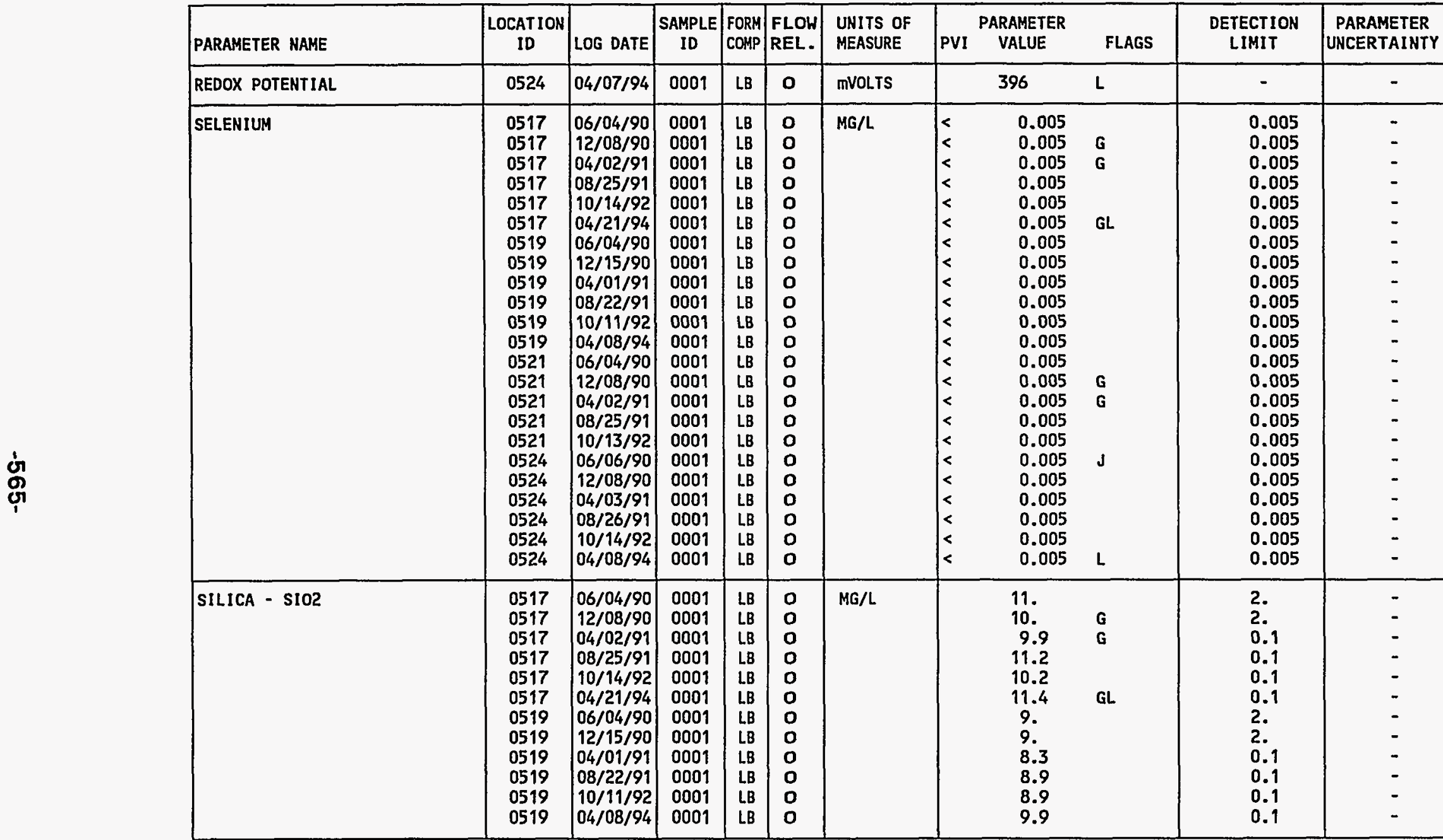

FORMATION OF COMPLETION CODE:

LB - LOWER BURRO CANYON

FLOW RELATIONSHIP CODE:

PARAMETER VALUE INDICATOR (PVI): < - LESS THAN DETECTION LIMIT SAMPLE ID CODES:

OOMPI - FILTERED SAMPLE (.45 MICRONS)

OTHER PARAMETER VALUE FLAGS:

G - PH $>9$, POSSIBLE GROUT CONTAMINATION

$\mathrm{J}$ - ESTIMATED VALUE

L - LESS THAN THREE BORE VOLUMES REMOVED BEFORE SAMPLING 
TABLE 3.52 BACKGROUND GROUND HATER QUALITY DATA BY PARAMETER FOR THE

LOWER SANDSTONE UNIT, BURRO CANYON DISPOSAL SITE, SLICK ROCK, COLORADO SITE: SRKO2 BORROW SITE 1 (BURRO CANYON)

06/04/90 TO 04/21/94

REPORT DATE: $09 / 30 / 94$

\begin{tabular}{|c|c|c|c|c|c|c|c|c|c|c|c|}
\hline PARAMETER NAME & $\underset{\text { ID }}{\text { LOCATION }}$ & LOG DATE & $\underset{\text { ID }}{\text { SAMPLE }}$ & $\begin{array}{l}\text { FORM } \\
\text { COMP }\end{array}$ & $\begin{array}{l}\text { FLOW } \\
\text { REL. }\end{array}$ & $\begin{array}{l}\text { UNITS OF } \\
\text { MEASURE }\end{array}$ & PVI & $\begin{array}{l}\text { PARAMETER } \\
\text { VALUE }\end{array}$ & FLAGS & $\begin{array}{l}\text { DETECTION } \\
\text { LIMIT }\end{array}$ & $\begin{array}{l}\text { PARAMETER } \\
\text { UNCERTAINTY }\end{array}$ \\
\hline SILICA - SIO2 & $\begin{array}{l}0521 \\
0521 \\
0521 \\
0521 \\
0521 \\
0524 \\
0524 \\
0524 \\
0524 \\
0524 \\
0524\end{array}$ & $\begin{array}{l}06 / 04 / 90 \\
12 / 08 / 90 \\
04 / 02 / 91 \\
08 / 25 / 91 \\
10 / 13 / 92 \\
06 / 06 / 90 \\
12 / 08 / 90 \\
04 / 03 / 91 \\
08 / 26 / 91 \\
10 / 14 / 92 \\
04 / 08 / 94\end{array}$ & $\begin{array}{l}0001 \\
0001 \\
0001 \\
0001 \\
0001 \\
0001 \\
0001 \\
0001 \\
0001 \\
0001 \\
0001\end{array}$ & $\begin{array}{l}\text { LB } \\
\text { LB } \\
\text { LB } \\
\text { LB } \\
\text { LB } \\
\text { LB } \\
\text { LB } \\
\text { LB } \\
\text { LB } \\
\text { LB } \\
\text { LB }\end{array}$ & $\begin{array}{l}0 \\
0 \\
0 \\
0 \\
0 \\
0 \\
0 \\
0 \\
0 \\
0 \\
0\end{array}$ & $M G / L$ & & $\begin{array}{l}10 . \\
10 . \\
9.6 \\
10.0 \\
9.4 \\
11 . \\
10 . \\
10.7 \\
10.6 \\
10.8 \\
11.9\end{array}$ & $\begin{array}{l}\text { G } \\
\text { G } \\
J\end{array}$ & $\begin{array}{l}2 . \\
2 . \\
0.1 \\
0.1 \\
0.1 \\
2 . \\
2 . \\
0.1 \\
0.1 \\
0.1 \\
0.1\end{array}$ & $\begin{array}{l}- \\
- \\
- \\
- \\
- \\
- \\
- \\
- \\
-\end{array}$ \\
\hline SILVER & $\begin{array}{l}0517 \\
0517 \\
0517 \\
0517 \\
0519 \\
0519 \\
0519 \\
0519 \\
0521 \\
0521 \\
0521 \\
0521 \\
0524 \\
0524 \\
0524 \\
0524\end{array}$ & $\begin{array}{l}06 / 04 / 90 \\
12 / 08 / 90 \\
04 / 02 / 91 \\
08 / 25 / 91 \\
06 / 04 / 90 \\
12 / 15 / 90 \\
04 / 01 / 91 \\
08 / 22 / 91 \\
06 / 04 / 90 \\
12 / 08 / 90 \\
04 / 02 / 91 \\
08 / 25 / 91 \\
06 / 06 / 90 \\
12 / 08 / 90 \\
04 / 03 / 91 \\
08 / 26 / 91\end{array}$ & $\begin{array}{l}0001 \\
0001 \\
0001 \\
0001 \\
0001 \\
0001 \\
0001 \\
0001 \\
0001 \\
0001 \\
0001 \\
0001 \\
0001 \\
0001 \\
0001 \\
0001\end{array}$ & $\begin{array}{l}\text { LB } \\
\text { LB } \\
\text { LB } \\
\text { LB } \\
\text { LB } \\
\text { LB } \\
\text { LB } \\
\text { LB } \\
\text { LB } \\
\text { LB } \\
\text { LB } \\
\text { LB } \\
\text { LB } \\
\text { LB } \\
\text { LB } \\
\text { LB }\end{array}$ & $\begin{array}{l}0 \\
0 \\
0 \\
0 \\
0 \\
0 \\
0 \\
0 \\
0 \\
0 \\
0 \\
0 \\
0 \\
0 \\
0 \\
0\end{array}$ & $M G / L$ & $\begin{array}{l}< \\
< \\
< \\
< \\
< \\
< \\
< \\
< \\
< \\
< \\
< \\
< \\
< \\
< \\
< \\
< \\
<\end{array}$ & $\begin{array}{l}0.01 \\
0.01 \\
0.01 \\
0.01 \\
0.01 \\
0.01 \\
0.01 \\
0.01 \\
0.01 \\
0.01 \\
0.01 \\
0.01 \\
0.01 \\
0.01 \\
0.01 \\
0.01\end{array}$ & $\begin{array}{l}\mathbf{G} \\
\mathbf{G} \\
\mathbf{J}\end{array}$ & $\begin{array}{l}0.01 \\
0.01 \\
0.01 \\
0.01 \\
0.01 \\
0.01 \\
0.01 \\
0.01 \\
0.01 \\
0.01 \\
0.01 \\
0.01 \\
0.01 \\
0.01 \\
0.01 \\
0.01\end{array}$ & $\begin{array}{l}- \\
- \\
- \\
- \\
- \\
- \\
- \\
- \\
- \\
- \\
- \\
-\end{array}$ \\
\hline SOD IUM & $\begin{array}{l}0517 \\
0517 \\
0517 \\
0517 \\
0517 \\
0517 \\
0519 \\
0519 \\
0519\end{array}$ & $\begin{array}{l}06 / 04 / 90 \\
12 / 08 / 90 \\
04 / 02 / 91 \\
08 / 25 / 91 \\
10 / 14 / 92 \\
04 / 21 / 94 \\
06 / 04 / 90 \\
12 / 15 / 90 \\
04 / 01 / 91\end{array}$ & $\begin{array}{l}0001 \\
0001 \\
0001 \\
0001 \\
0001 \\
0001 \\
0001 \\
0001 \\
0001\end{array}$ & $\begin{array}{l}\text { LB } \\
\text { LB } \\
\text { LB } \\
\text { LB } \\
\text { LB } \\
\text { LB } \\
\text { LB } \\
\text { LB } \\
\text { LB }\end{array}$ & $\begin{array}{l}0 \\
0 \\
0 \\
0 \\
0 \\
0 \\
0 \\
0 \\
0\end{array}$ & MG/L & & $\begin{array}{l}139 . \\
132 . \\
136 . \\
136 . \\
132 . \\
129 \\
112 . \\
108 . \\
115 .\end{array}$ & $\begin{array}{l}\text { G } \\
\text { G } \\
\text { GL }\end{array}$ & $\begin{array}{l}0.002 \\
0.002 \\
5 . \\
5 . \\
5 . \\
1 \\
0.002 \\
0.002 \\
5 .\end{array}$ & $\begin{array}{l}- \\
- \\
- \\
- \\
- \\
- \\
-\end{array}$ \\
\hline
\end{tabular}

FORMATION OF COMPLETION CODE:

LB - LOWER BURRO CANYON

PARAMETER VALUE INDICATOR (PVI): < - LESS THAN DETECTION LIMIT
FLOW RELATIONSHIP CODE:

O - ON-SITE

0001 - FILTERED SAMPLE (.45 MICRONS)

OTHER PARAMETER VALUE FLAGS:

$G$ - PH > 9, POSSIBLE GROUT CONTAMINATION

VALUE

L - LESS THAN THREE BORE VOLUMES REMOVED BEFORE SAMPLING 
TABLE 3.52 BACKGROUND GROUND WATER QUALITY DATA BY PARAMETER FOR THE

LOWER SANDSTONE UNIT, BURRO CANYON DISPOSAL SITE, SLICK ROCK, COLORADO SITE: SRKO2 BORROH SITE 1 (BURRO CANYON)

06/04/90 TO 04/21/94

REPORT DATE: $09 / 30 / 94$

\begin{tabular}{|c|c|c|c|c|c|c|c|c|c|c|c|c|}
\hline & PARAMETER NAME & $\begin{array}{l}\text { LOCATION } \\
\text { ID }\end{array}$ & LOG DATE & $\begin{array}{c}\text { SAMPLE } \\
\text { ID }\end{array}$ & $\begin{array}{l}\text { FORM } \\
\text { COMP }\end{array}$ & $\begin{array}{l}\text { FLOW } \\
\text { REL. }\end{array}$ & $\begin{array}{l}\text { UNITS OF } \\
\text { MEASURE }\end{array}$ & PVI & $\begin{array}{l}\text { PARAMETER } \\
\text { VALUE }\end{array}$ & FLAGS & $\begin{array}{l}\text { DETECTION } \\
\text { LIMIT }\end{array}$ & $\begin{array}{l}\text { PARAMETER } \\
\text { UNCERTAINTY }\end{array}$ \\
\hline & SODIUM & $\begin{array}{l}0519 \\
0519 \\
0519 \\
0521 \\
0521 \\
0521 \\
0521 \\
0521 \\
0524 \\
0524 \\
0524 \\
0524 \\
0524 \\
0524\end{array}$ & $\begin{array}{l}08 / 22 / 91 \\
10 / 11 / 92 \\
04 / 08 / 94 \\
06 / 04 / 90 \\
12 / 08 / 90 \\
04 / 02 / 91 \\
08 / 25 / 91 \\
10 / 13 / 92 \\
06 / 06 / 90 \\
12 / 08 / 90 \\
04 / 03 / 91 \\
08 / 26 / 91 \\
10 / 14 / 92 \\
04 / 08 / 94\end{array}$ & $\begin{array}{l}0001 \\
0001 \\
0001 \\
0001 \\
0001 \\
0001 \\
0001 \\
0001 \\
0001 \\
0001 \\
0001 \\
0001 \\
0001 \\
0001\end{array}$ & $\begin{array}{l}\text { LB } \\
\text { LB } \\
\text { LB } \\
\text { LB } \\
\text { LB } \\
\text { LB } \\
\text { LB } \\
\text { LB } \\
\text { LB } \\
\text { LB } \\
\text { LB } \\
\text { LB } \\
\text { LB } \\
\text { LB }\end{array}$ & $\begin{array}{l}0 \\
0 \\
0 \\
0 \\
0 \\
0 \\
0 \\
0 \\
0 \\
0 \\
0 \\
0 \\
0 \\
0\end{array}$ & $M G / L$ & & $\begin{array}{l}112 . \\
110 . \\
99 \\
142 . \\
161 . \\
148 . \\
140 . \\
129 . \\
130 . \\
133 . \\
182 . \\
158 . \\
124 . \\
117\end{array}$ & $\begin{array}{l}\mathbf{G} \\
\mathbf{G} \\
\mathbf{J}\end{array}$ & $\begin{array}{l}5 . \\
5 . \\
1 \\
0.002 \\
0.002 \\
5 . \\
5 . \\
5 . \\
0.002 \\
0.002 \\
5 . \\
5 . \\
5 . \\
1\end{array}$ & $\begin{array}{l}- \\
- \\
- \\
- \\
- \\
- \\
- \\
- \\
- \\
-\end{array}$ \\
\hline gُ & SPECIFIC CONDUCTANCE & $\begin{array}{l}0517 \\
0517 \\
0517 \\
0517 \\
0517 \\
0517 \\
0519 \\
0519 \\
0519 \\
0519 \\
0519 \\
0519 \\
0521 \\
0521 \\
0521 \\
0521 \\
0524 \\
0524 \\
0524 \\
0524 \\
0524\end{array}$ & $\begin{array}{l}06 / 04 / 90 \\
04 / 02 / 91 \\
08 / 25 / 91 \\
10 / 14 / 92 \\
04 / 06 / 94 \\
04 / 21 / 94 \\
06 / 04 / 90 \\
12 / 15 / 90 \\
04 / 01 / 91 \\
08 / 22 / 91 \\
10 / 11 / 92 \\
04 / 07 / 94 \\
06 / 04 / 90 \\
04 / 02 / 91 \\
08 / 25 / 91 \\
10 / 13 / 92 \\
06 / 06 / 90 \\
04 / 03 / 91 \\
08 / 26 / 91 \\
10 / 14 / 92 \\
04 / 07 / 94\end{array}$ & $\begin{array}{l}0001 \\
0001 \\
0001 \\
0001 \\
0001 \\
0001 \\
0001 \\
0001 \\
0001 \\
0001 \\
0001 \\
0001 \\
0001 \\
0001 \\
0001 \\
0001 \\
0001 \\
0001 \\
0001 \\
0001 \\
0001\end{array}$ & $\begin{array}{l}\text { LB } \\
\text { LB } \\
\text { LB } \\
\text { LB } \\
\text { LB } \\
\text { LB } \\
\text { LB } \\
\text { LB } \\
\text { LB } \\
\text { LB } \\
\text { LB } \\
\text { LB } \\
\text { LB } \\
\text { LB } \\
\text { LB } \\
\text { LB } \\
\text { LB } \\
\text { LB } \\
\text { LB } \\
\text { LB } \\
\text { LB }\end{array}$ & $\begin{array}{l}0 \\
0 \\
0 \\
0 \\
0 \\
0 \\
0 \\
0 \\
0 \\
0 \\
0 \\
0 \\
0 \\
0 \\
0 \\
0 \\
0 \\
0 \\
0 \\
0 \\
0\end{array}$ & UMHO/CM & & $\begin{array}{l}465 . \\
599 . \\
585 \\
489 \\
463 \\
508 \\
380 . \\
407 . \\
501 . \\
410 \\
381 \\
380 \\
520 . \\
649 . \\
534 \\
536 \\
495 . \\
790 . \\
691 \\
454 \\
459\end{array}$ & $\begin{array}{l}\text { G } \\
\text { GL } \\
\text { L } \\
\text { G }\end{array}$ & $\begin{array}{l}- \\
- \\
- \\
- \\
- \\
- \\
- \\
- \\
- \\
- \\
- \\
- \\
- \\
- \\
- \\
-\end{array}$ & $\begin{array}{l}- \\
- \\
- \\
- \\
- \\
- \\
- \\
- \\
- \\
- \\
- \\
- \\
- \\
- \\
- \\
- \\
-\end{array}$ \\
\hline & STRONTIUM & 0517 & $06 / 04 / 90$ & 0001 & LB & 0 & MG/L & & 0.06 & J & 0.1 & - \\
\hline
\end{tabular}

FORMATION OF COMPLETION CODE:

LB - LOWER BURRO CANYON

PARAMETER VALUE INDICATOR (PVI): < - LESS THAN DETECTION LIMIT
FLOW RELATIONSHIP CODE:

O - ON-SITE

SAMPLE ID CODES:

0001 - FILTERED SAMPLE (.45 MICRONS)

OTHER PARAMETER VALUE FLAGS:

G - PH > 9, POSSIBLE GROUT CONTAMINATION

J - ESTIMATED VALUE

L - LESS THAN THREE BORE VOLUMES REMOVED BEFORE SAMPLING 
TABLE 3.52 BACKGROUND GROUND WATER QUALITY DATA BY PARAMETER FOR THE LOWER SANDSTONE UNIT, BURRO CANYON DISPOSAL SITE, SLICK ROCK, COLORADO SITE: SRKO2 BORROW SITE 1 (BURRO CANYON)

06/04/90 TO 04/21/94

REPORT DATE: $09 / 30 / 94$

\begin{tabular}{|c|c|c|c|c|c|c|c|c|c|c|c|}
\hline PARAMETER NAME & $\begin{array}{c}\text { LOCATION } \\
\text { ID }\end{array}$ & LOG DATE & $\begin{array}{c}\text { SAMPLE } \\
\text { ID }\end{array}$ & $\begin{array}{l}\text { FORM } \\
\text { COMP }\end{array}$ & $\begin{array}{l}\text { FLOW } \\
\text { REL. }\end{array}$ & $\begin{array}{l}\text { UNITS OF } \\
\text { MEASURE }\end{array}$ & PVI & $\begin{array}{l}\text { ARAMETER } \\
\text { VALUE }\end{array}$ & FLAGS & $\begin{array}{l}\text { DETECTION } \\
\text { LIMIT }\end{array}$ & $\begin{array}{l}\text { PARAMETER } \\
\text { UNCERTAINTY }\end{array}$ \\
\hline STRONT IUM & $\begin{array}{l}0517 \\
0517 \\
0517 \\
0517 \\
0517 \\
0519 \\
0519 \\
0519 \\
0519 \\
0519 \\
0519 \\
0521 \\
0521 \\
0521 \\
0521 \\
0521 \\
0524 \\
0524 \\
0524 \\
0524 \\
0524 \\
0524\end{array}$ & $\begin{array}{l}12 / 08 / 90 \\
04 / 02 / 91 \\
08 / 25 / 91 \\
10 / 14 / 92 \\
04 / 21 / 94 \\
06 / 04 / 90 \\
12 / 15 / 90 \\
04 / 01 / 91 \\
08 / 22 / 91 \\
10 / 11 / 92 \\
04 / 08 / 94 \\
06 / 04 / 90 \\
12 / 08 / 90 \\
04 / 02 / 91 \\
08 / 25 / 91 \\
10 / 13 / 92 \\
06 / 06 / 90 \\
12 / 08 / 90 \\
04 / 03 / 91 \\
08 / 26 / 91 \\
10 / 14 / 92 \\
04 / 08 / 94\end{array}$ & $\begin{array}{l}0001 \\
0001 \\
0001 \\
0001 \\
0001 \\
0001 \\
0001 \\
0001 \\
0001 \\
0001 \\
0001 \\
0001 \\
0001 \\
0001 \\
0001 \\
0001 \\
0001 \\
0001 \\
0001 \\
0001 \\
0001 \\
0001\end{array}$ & $\begin{array}{l}\text { LB } \\
\text { LB } \\
\text { LB } \\
\text { LB } \\
\text { LB } \\
\text { LB } \\
\text { LB } \\
\text { LB } \\
\text { LB } \\
\text { LB } \\
\text { LB } \\
\text { LB } \\
\text { LB } \\
\text { LB } \\
\text { LB } \\
\text { LB } \\
\text { LB } \\
\text { LB } \\
\text { LB } \\
\text { LB } \\
\text { LB } \\
\text { LB }\end{array}$ & $\begin{array}{l}0 \\
0 \\
0 \\
0 \\
0 \\
0 \\
0 \\
0 \\
0 \\
0 \\
0 \\
0 \\
0 \\
0 \\
0 \\
0 \\
0 \\
0 \\
0 \\
0 \\
0 \\
0\end{array}$ & $M G / L$ & $<$ & $\begin{array}{l}0.1 \\
0.06 \\
0.04 \\
0.04 \\
0.04 \\
0.08 \\
0.1 \\
0.06 \\
0.03 \\
0.14 \\
0.02 \\
0.22 \\
0.1 \\
0.14 \\
0.11 \\
0.10 \\
0.07 \\
0.1 \\
0.17 \\
0.15 \\
0.12 \\
0.07\end{array}$ & $\begin{array}{l}\text { G } \\
\text { G } \\
\text { GL } \\
\mathbf{J}\end{array}$ & $\begin{array}{l}0.1 \\
0.01 \\
0.01 \\
0.01 \\
0.01 \\
0.1 \\
0.1 \\
0.01 \\
0.01 \\
0.01 \\
0.01 \\
0.1 \\
0.1 \\
0.01 \\
0.01 \\
0.01 \\
0.1 \\
0.1 \\
0.01 \\
0.01 \\
0.01 \\
0.01\end{array}$ & $\begin{array}{l}- \\
- \\
- \\
- \\
- \\
- \\
- \\
- \\
- \\
- \\
- \\
- \\
- \\
- \\
- \\
- \\
- \\
-\end{array}$ \\
\hline SULFATE & $\begin{array}{l}0517 \\
0517 \\
0517 \\
0517 \\
0517 \\
0517 \\
0519 \\
0519 \\
0519 \\
0519 \\
0519 \\
0519 \\
0521 \\
0521 \\
0521\end{array}$ & $\begin{array}{l}06 / 04 / 90 \\
12 / 08 / 90 \\
04 / 02 / 91 \\
08 / 25 / 91 \\
10 / 14 / 92 \\
04 / 21 / 94 \\
06 / 04 / 90 \\
12 / 15 / 90 \\
04 / 01 / 91 \\
08 / 22 / 91 \\
10 / 11 / 92 \\
04 / 08 / 94 \\
06 / 04 / 90 \\
12 / 08 / 90 \\
04 / 02 / 91\end{array}$ & $\begin{array}{l}0001 \\
0001 \\
0001 \\
0001 \\
0001 \\
0001 \\
0001 \\
0001 \\
0001 \\
0001 \\
0001 \\
0001 \\
0001 \\
0001 \\
0001\end{array}$ & $\begin{array}{l}\text { LB } \\
\text { LB } \\
\text { LB } \\
\text { LB } \\
\text { LB } \\
\text { LB } \\
\text { LB } \\
\text { LB } \\
\text { LB } \\
\text { LB } \\
\text { LB } \\
\text { LB } \\
\text { LB } \\
\text { LB } \\
\text { LB }\end{array}$ & $\begin{array}{l}0 \\
0 \\
0 \\
0 \\
0 \\
0 \\
0 \\
0 \\
0 \\
0 \\
0 \\
0 \\
0 \\
0 \\
0\end{array}$ & $M G / L$ & & $\begin{array}{l}83 . \\
67.5 \\
77.9 \\
81 . \\
78 . \\
75 \\
69 . \\
43.6 \\
62.7 \\
62 . \\
63 . \\
59 \\
86 . \\
119 . \\
92.2\end{array}$ & $\begin{array}{l}\text { GJ } \\
\mathbf{G} \\
\mathbf{G L} \\
\mathbf{J}\end{array}$ & $\begin{array}{c}0.1 \\
0.1 \\
0.1 \\
10 . \\
1 . \\
1 \\
0.1 \\
0.1 \\
0.1 \\
10 . \\
1 . \\
1 \\
0.1 \\
0.1 \\
0.1\end{array}$ & $\begin{array}{l}- \\
- \\
- \\
- \\
- \\
- \\
- \\
- \\
- \\
- \\
- \\
- \\
-\end{array}$ \\
\hline
\end{tabular}

FORMATION OF COMPLETION CODE:

LB - LOWER BURRO CANYON

PARAMETER VALUE INDICATOR (PVI): < - LESS THAN DETECTION LIMIT
FLOW RELATIONSHIP CODE:

O - ON-SITE

OTHER PARAMETER VALUE FLAGS:

$G$ - PH $>9$, POSSIBLE GROUT CONTAMINATION

$\mathrm{J}$ - EST IMATED VALUE

L - LESS THAN THREE BORE VOLUMES REMOVED BEFORE SAMPLING 
TABLE 3.52 BACKGROUND GROUND WATER QUALITY DATA BY PARAMETER FOR THE LOHER SANDSTONE UNIT, BURRO CANYON DISPOSAL SITE, SLICK ROCK, COLORADO SITE: SRKO2 BORROW SITE 1 (BURRO CANYON)

06/04/90 TO 04/21/94

REPORT DATE: 09/30/94

\begin{tabular}{|c|c|c|c|c|c|c|c|c|c|c|c|c|}
\hline & PARAMETER NAME & $\begin{array}{c}\text { LOCATION } \\
\text { ID }\end{array}$ & LOG DATE & $\begin{array}{c}\text { SAMPLE } \\
\text { ID }\end{array}$ & $\begin{array}{l}\text { FORM } \\
\text { COMP }\end{array}$ & $\begin{array}{l}\text { FLOW } \\
\text { REL. }\end{array}$ & $\begin{array}{l}\text { UNITS OF } \\
\text { MEASURE }\end{array}$ & PVI & $\begin{array}{l}\text { PARAMETER } \\
\text { VALUE }\end{array}$ & FLAGS & $\begin{array}{l}\text { DETECTION } \\
\text { LIMIT }\end{array}$ & $\begin{array}{l}\text { PARAMETER } \\
\text { UNCERTAINTY }\end{array}$ \\
\hline & SULFATE & $\begin{array}{l}0521 \\
0524 \\
0524 \\
0524 \\
0524 \\
0524 \\
0524\end{array}$ & $\begin{array}{l}08 / 25 / 91 \\
06 / 06 / 90 \\
12 / 08 / 90 \\
04 / 03 / 91 \\
08 / 26 / 91 \\
10 / 14 / 92 \\
04 / 08 / 94\end{array}$ & $\begin{array}{l}0001 \\
0001 \\
0001 \\
0001 \\
0001 \\
0001 \\
0001\end{array}$ & $\begin{array}{l}\text { LB } \\
\text { LB } \\
\text { LB } \\
\text { LB } \\
\text { LB } \\
\text { LB } \\
\text { LB }\end{array}$ & $\begin{array}{l}0 \\
0 \\
0 \\
0 \\
0 \\
0 \\
0\end{array}$ & $M G / L$ & & $\begin{array}{l}89 . \\
71 . \\
60.1 \\
95.6 \\
85 . \\
66 . \\
61\end{array}$ & $\begin{array}{l}7 \\
7\end{array}$ & $\begin{array}{c}10 . \\
0.1 \\
0.1 \\
0.1 \\
10 . \\
1 . \\
1\end{array}$ & $\begin{array}{l}- \\
- \\
- \\
- \\
-\end{array}$ \\
\hline & SULFIDE & $\begin{array}{l}0517 \\
0517 \\
0517 \\
0517 \\
0519 \\
0519 \\
0519 \\
0519 \\
0521 \\
0521 \\
0521 \\
0521 \\
0524 \\
0524 \\
0524 \\
0524\end{array}$ & $\begin{array}{l}12 / 08 / 90 \\
04 / 02 / 91 \\
08 / 25 / 91 \\
10 / 14 / 92 \\
12 / 15 / 90 \\
04 / 01 / 91 \\
08 / 22 / 91 \\
10 / 11 / 92 \\
12 / 08 / 90 \\
04 / 02 / 91 \\
08 / 25 / 91 \\
10 / 13 / 92 \\
12 / 08 / 90 \\
04 / 03 / 91 \\
08 / 26 / 91 \\
10 / 14 / 92\end{array}$ & $\begin{array}{l}0001 \\
0001 \\
0001 \\
0001 \\
0001 \\
0001 \\
0001 \\
0001 \\
0001 \\
0001 \\
0001 \\
0001 \\
0001 \\
0001 \\
0001 \\
0001\end{array}$ & $\begin{array}{l}\text { LB } \\
\text { LB } \\
\text { LB } \\
\text { LB } \\
\text { LB } \\
\text { LB } \\
\text { LB } \\
\text { LB } \\
\text { LB } \\
\text { LB } \\
\text { LB } \\
\text { LB } \\
\text { LB } \\
\text { LB } \\
\text { L8 } \\
\text { LB }\end{array}$ & $\begin{array}{l}0 \\
0 \\
0 \\
0 \\
0 \\
0 \\
0 \\
0 \\
0 \\
0 \\
0 \\
0 \\
0 \\
0 \\
0 \\
0\end{array}$ & $M G / L$ & $<$ & $\begin{array}{l}0.1 \\
1.4 \\
0.4 \\
0.3 \\
0.1 \\
0.5 \\
0.6 \\
0.4 \\
0.1 \\
0.3 \\
0.4 \\
0.1 \\
0.1 \\
3.26 \\
0.8 \\
0.1\end{array}$ & $\begin{array}{l}\mathbf{G} \\
\mathbf{G}\end{array}$ & $\begin{array}{l}0.1 \\
0.1 \\
0.1 \\
0.1 \\
0.1 \\
0.1 \\
0.1 \\
0.1 \\
0.1 \\
0.1 \\
0.1 \\
0.1 \\
0.1 \\
0.1 \\
0.1 \\
0.1\end{array}$ & $\begin{array}{l}- \\
- \\
- \\
- \\
- \\
- \\
- \\
- \\
- \\
- \\
- \\
-\end{array}$ \\
\hline & TEMPERATURE & $\begin{array}{l}0517 \\
0517 \\
0517 \\
0517 \\
0517 \\
0517 \\
0517 \\
0519 \\
0519 \\
0519 \\
0519 \\
0519 \\
0519\end{array}$ & $\begin{array}{l}06 / 04 / 90 \\
12 / 08 / 90 \\
04 / 02 / 91 \\
08 / 25 / 91 \\
10 / 14 / 92 \\
04 / 06 / 94 \\
04 / 21 / 94 \\
06 / 04 / 90 \\
12 / 15 / 90 \\
04 / 01 / 91 \\
08 / 22 / 91 \\
10 / 11 / 92 \\
04 / 07 / 94\end{array}$ & $\begin{array}{l}0001 \\
0001 \\
0001 \\
0001 \\
0001 \\
0001 \\
0001 \\
0001 \\
0001 \\
0001 \\
0001 \\
0001 \\
0001\end{array}$ & $\begin{array}{l}\text { LB } \\
\text { LB } \\
\text { LB } \\
\text { LB } \\
\text { LB } \\
\text { LB } \\
\text { LB } \\
\text { LB } \\
\text { LB } \\
\text { LB } \\
\text { LB } \\
\text { LB } \\
\text { LB }\end{array}$ & $\begin{array}{l}0 \\
0 \\
0 \\
0 \\
0 \\
0 \\
0 \\
0 \\
0 \\
0 \\
0 \\
0 \\
0\end{array}$ & C - DEGREE & & $\begin{array}{l}16.0 \\
13.5 \\
13.6 \\
16.5 \\
18.3 \\
15.0 \\
18.8 \\
17.0 \\
14.0 \\
14.4 \\
22.3 \\
14.2 \\
14.2\end{array}$ & $\begin{array}{l}\mathbf{G} \\
\mathbf{G} \\
\mathbf{G L} \\
\\
\mathbf{L}\end{array}$ & $\begin{array}{l}- \\
- \\
- \\
- \\
- \\
- \\
- \\
- \\
- \\
- \\
-\end{array}$ & $\begin{array}{l}- \\
- \\
- \\
- \\
- \\
- \\
- \\
- \\
-\end{array}$ \\
\hline
\end{tabular}

FORMATION OF COMPLETION CODE:

LB - LOWER BURRO CANYON

FLOW RELATIONSHIP CODE:

PARAMETER VALUE INDICATOR (PVI): < - LESS THAN DETECTION LIMIT

OTHER PARAMETER VALUE FLAGS:

G - PH > 9, POSSIBLE GROUT CONTAMINATION

J. ESTIMATED VALUE

L - LESS THAN THREE::BORE VOLUMES REMOVED BEFORE SAMPLING 
TABLE 3.52 BACKGROUND GROUND WATER QUALITY DATA BY PARAMETER FOR THE

LOWER SANDSTONE UNIT, BURRO CANYON DISPOSAL SITE, SLICK ROCK, COLORADO

SITE: SRKO2 BORROW SITE 1 (BURRO CANYON)

06/04/90 TO 04/21/94

REPORT DATE: 09/30/94

\begin{tabular}{|c|c|c|c|c|c|c|c|c|c|c|c|}
\hline PARAMETER NAME & $\underset{\text { ID }}{\text { LOCATION }}$ & LOG DATE & $\begin{array}{c}\text { SAMPLE } \\
\text { ID }\end{array}$ & $\begin{array}{l}\text { FORM } \\
\text { COMP }\end{array}$ & $\begin{array}{l}\text { FLOW } \\
\text { REL. }\end{array}$ & $\begin{array}{l}\text { UNITS OF } \\
\text { MEASURE }\end{array}$ & PVI & $\begin{array}{l}\text { PARAMETER } \\
\text { VALUE }\end{array}$ & FLAGS & $\begin{array}{l}\text { DETECTION } \\
\text { LIMIT }\end{array}$ & $\begin{array}{l}\text { PARAMETER } \\
\text { UNCERTAINTY }\end{array}$ \\
\hline TEMPERATURE & $\begin{array}{l}0521 \\
0521 \\
0521 \\
0521 \\
0521 \\
0524 \\
0524 \\
0524 \\
0524 \\
0524 \\
0524\end{array}$ & $\begin{array}{l}06 / 04 / 90 \\
12 / 08 / 90 \\
04 / 02 / 91 \\
08 / 25 / 91 \\
10 / 13 / 92 \\
06 / 06 / 90 \\
12 / 08 / 90 \\
04 / 03 / 91 \\
08 / 26 / 91 \\
10 / 14 / 92 \\
04 / 07 / 94\end{array}$ & $\begin{array}{l}0001 \\
0001 \\
0001 \\
0001 \\
0001 \\
0001 \\
0001 \\
0001 \\
0001 \\
0001 \\
0001\end{array}$ & $\begin{array}{l}\text { LB } \\
\text { LB } \\
\text { LB } \\
\text { LB } \\
\text { LB } \\
\text { LB } \\
\text { LB } \\
\text { LB } \\
\text { LB } \\
\text { LB } \\
\text { LB }\end{array}$ & $\begin{array}{l}0 \\
0 \\
0 \\
0 \\
0 \\
0 \\
0 \\
0 \\
0 \\
0 \\
0\end{array}$ & C - DEGREE & & $\begin{array}{l}16.5 \\
17.5 \\
14.4 \\
17.4 \\
19.1 \\
19.0 \\
17.0 \\
15.5 \\
19.1 \\
16.0 \\
17.8\end{array}$ & $\begin{array}{l}\mathbf{G} \\
\mathbf{G}\end{array}$ & $\begin{array}{l}- \\
- \\
- \\
- \\
- \\
- \\
- \\
-\end{array}$ & $\begin{array}{l}- \\
- \\
- \\
- \\
- \\
- \\
- \\
-\end{array}$ \\
\hline THALLIUM & $\begin{array}{l}0517 \\
0517 \\
0517 \\
0517 \\
0517 \\
0519 \\
0519 \\
0519 \\
0519 \\
0519 \\
0521 \\
0521 \\
0521 \\
0521 \\
0521 \\
0524 \\
0524 \\
0524 \\
0524 \\
0524\end{array}$ & $\begin{array}{l}06 / 04 / 90 \\
12 / 08 / 90 \\
04 / 02 / 91 \\
08 / 25 / 91 \\
10 / 14 / 92 \\
06 / 04 / 90 \\
12 / 15 / 90 \\
04 / 01 / 91 \\
08 / 22 / 91 \\
10 / 11 / 92 \\
06 / 04 / 90 \\
12 / 08 / 90 \\
04 / 02 / 91 \\
08 / 25 / 91 \\
10 / 13 / 92 \\
06 / 06 / 90 \\
12 / 08 / 90 \\
04 / 03 / 91 \\
08 / 26 / 91 \\
10 / 14 / 92\end{array}$ & $\begin{array}{l}0001 \\
0001 \\
0001 \\
0001 \\
0001 \\
0001 \\
0001 \\
0001 \\
0001 \\
0001 \\
0001 \\
0001 \\
0001 \\
0001 \\
0001 \\
0001 \\
0001 \\
0001 \\
0001 \\
0001\end{array}$ & $\begin{array}{l}\text { LB } \\
\text { LB } \\
\text { LB } \\
\text { LB } \\
\text { LB } \\
\text { LB } \\
\text { LB } \\
\text { LB } \\
\text { LB } \\
\text { LB } \\
\text { LB } \\
\text { LB } \\
\text { LB } \\
\text { LB } \\
\text { LB } \\
\text { LB } \\
\text { LB } \\
\text { LB } \\
\text { LB } \\
\text { LB }\end{array}$ & $\begin{array}{l}0 \\
0 \\
0 \\
0 \\
0 \\
0 \\
0 \\
0 \\
0 \\
0 \\
0 \\
0 \\
0 \\
0 \\
0 \\
0 \\
0 \\
0 \\
0 \\
0\end{array}$ & $M G / L$ & $\begin{array}{l}< \\
< \\
< \\
< \\
< \\
< \\
< \\
< \\
< \\
< \\
< \\
< \\
< \\
< \\
< \\
< \\
< \\
< \\
< \\
< \\
<\end{array}$ & $\begin{array}{l}0.01 \\
0.01 \\
0.01 \\
0.01 \\
0.005 \\
0.01 \\
0.01 \\
0.01 \\
0.01 \\
0.005 \\
0.01 \\
0.01 \\
0.01 \\
0.01 \\
0.005 \\
0.01 \\
0.01 \\
0.01 \\
0.01 \\
0.005\end{array}$ & $\begin{array}{l}\text { G } \\
\text { G } \\
\text { J }\end{array}$ & $\begin{array}{l}0.01 \\
0.01 \\
0.01 \\
0.01 \\
0.005 \\
0.01 \\
0.01 \\
0.01 \\
0.01 \\
0.005 \\
0.01 \\
0.01 \\
0.01 \\
0.01 \\
0.005 \\
0.01 \\
0.01 \\
0.01 \\
0.01 \\
0.005\end{array}$ & $\begin{array}{l}- \\
- \\
- \\
- \\
- \\
- \\
- \\
- \\
- \\
- \\
- \\
- \\
- \\
- \\
- \\
- \\
-\end{array}$ \\
\hline THOR IUM-230 & $\begin{array}{l}0517 \\
0517 \\
0517 \\
0519 \\
0519\end{array}$ & $\begin{array}{l}12 / 08 / 90 \\
04 / 02 / 91 \\
08 / 25 / 91 \\
12 / 15 / 90 \\
04 / 01 / 91\end{array}$ & $\begin{array}{l}0001 \\
0001 \\
0001 \\
0001 \\
0001\end{array}$ & $\begin{array}{l}\text { LB } \\
\text { LB } \\
\text { LB } \\
\text { LB } \\
\text { LB }\end{array}$ & $\begin{array}{l}0 \\
0 \\
0 \\
0 \\
0\end{array}$ & $\mathrm{PCI} / \mathrm{L}$ & & $\begin{array}{l}0.0 \\
0.1 \\
0.2 \\
0.1 \\
0.3\end{array}$ & $\begin{array}{l}G \\
G\end{array}$ & $\begin{array}{l}1 . \\
1 . \\
1 . \\
1 .\end{array}$ & $\begin{array}{l}0.4 \\
0.4 \\
0.4 \\
0.4 \\
0.7\end{array}$ \\
\hline
\end{tabular}

FORMATION OF COMPLETION CODE:

LB - LOWER BURRO CANYON

PARAMETER VALUE INDICATOR (PVI): < - LESS THAN DETECTION LIMIT
FLOH RELATIONSHIP CODE:

O - ON-SITE

0001 - FILTERED SAMPLE (.45 MICRONS)

OTHER PARAMETER VALUE FLAGS:

$G-P H>9$, POSSIBLE GROUT CONTAMINATION

$J$ - ESTIMATED VALUE

L - LESS THAN THREE BORE VOLUMES REMOVED BEFORE SAMPLING 


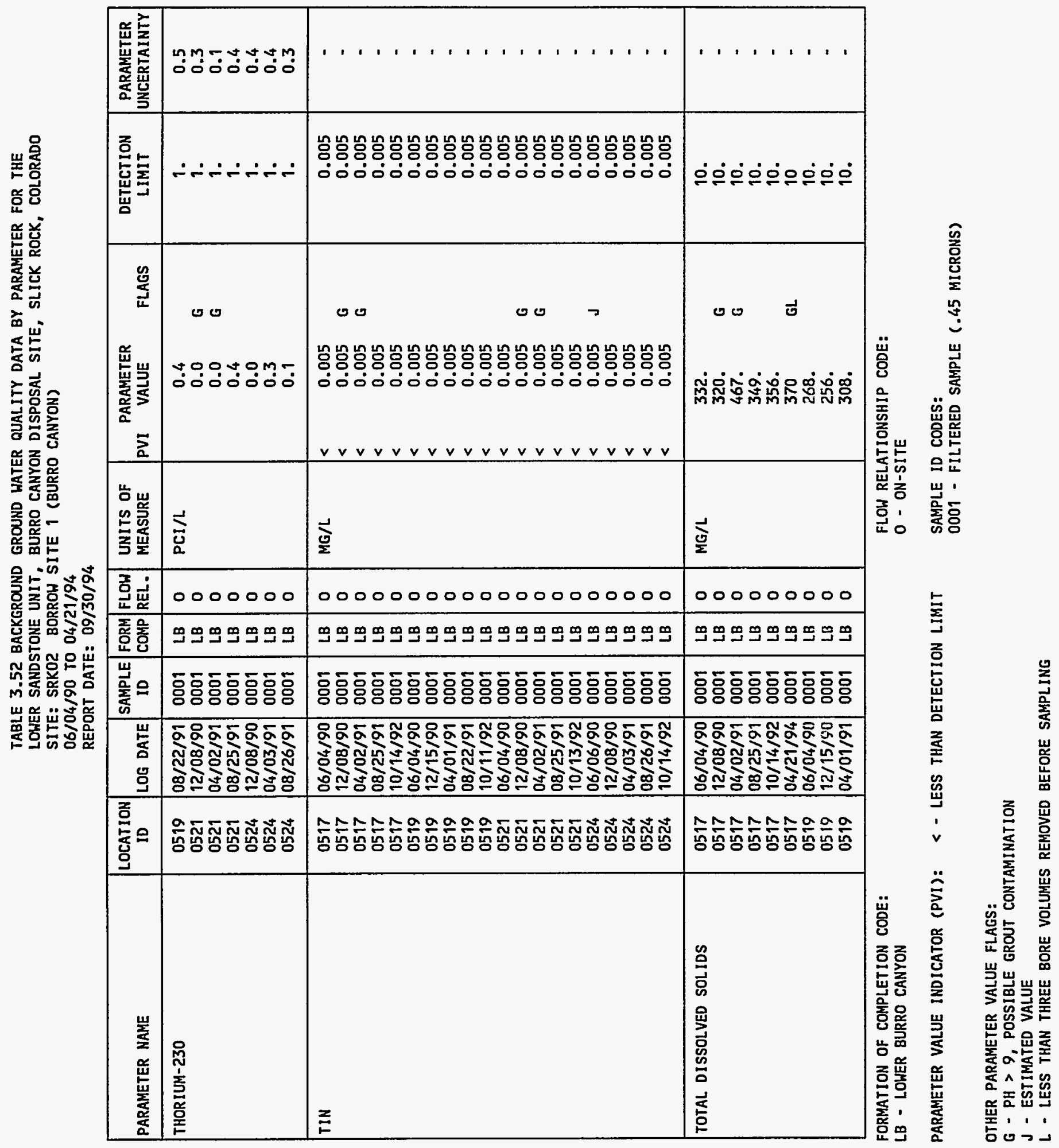


TABLE 3.52 BACKGROUND GROUND WATER QUALITY OATA BY PARAMETER FOR THE

LOWER SANDSTONE UNIT, BURRO CANYON DISPOSAL SITE, SLICK ROCK, COLORADO

SITE: SRKO2 BORROW SITE 1 (BURRO CANYON)

06/04/90 TO 04/21/94

REPORT DATE: $09 / 30 / 94$

\begin{tabular}{|c|c|c|c|c|c|c|c|c|c|c|c|}
\hline PARAMETER NAME & $\begin{array}{c}\text { LOCATION } \\
\text { ID }\end{array}$ & LOG DATE & $\begin{array}{c}\text { SAMPLE } \\
\text { ID }\end{array}$ & $\begin{array}{l}\text { FORM } \\
\text { COMP }\end{array}$ & $\begin{array}{l}\text { FLOW } \\
\text { REL. }\end{array}$ & $\begin{array}{l}\text { UNITS OF } \\
\text { MEASURE }\end{array}$ & PVI & $\begin{array}{l}\text { ARAMETEI } \\
\text { VALUE }\end{array}$ & FLAGS & $\begin{array}{l}\text { DETECTION } \\
\text { LIMIT }\end{array}$ & $\begin{array}{l}\text { PARAMETER } \\
\text { UNCERTAINTY }\end{array}$ \\
\hline TOTAL DISSOLVED SOLIDS & $\begin{array}{l}0519 \\
0519 \\
0519 \\
0521 \\
0521 \\
0521 \\
0521 \\
0521 \\
0524 \\
0524 \\
0524 \\
0524 \\
0524 \\
0524\end{array}$ & $\begin{array}{l}08 / 22 / 91 \\
10 / 11 / 92 \\
04 / 08 / 94 \\
06 / 04 / 90 \\
12 / 08 / 90 \\
04 / 02 / 91 \\
08 / 25 / 91 \\
10 / 13 / 92 \\
06 / 06 / 90 \\
12 / 08 / 90 \\
04 / 03 / 91 \\
08 / 26 / 91 \\
10 / 14 / 92 \\
04 / 08 / 94\end{array}$ & $\begin{array}{l}0001 \\
0001 \\
0001 \\
0001 \\
0001 \\
0001 \\
0001 \\
0001 \\
0001 \\
0001 \\
0001 \\
0001 \\
0001 \\
0001\end{array}$ & $\begin{array}{l}\text { LB } \\
\text { LB } \\
\text { LB } \\
\text { LB } \\
\text { LB } \\
\text { LB } \\
\text { LB } \\
\text { LB } \\
\text { LB } \\
\text { LB } \\
\text { LB } \\
\text { LB } \\
\text { LB } \\
\text { LB }\end{array}$ & $\begin{array}{l}0 \\
0 \\
0 \\
0 \\
0 \\
0 \\
0 \\
0 \\
0 \\
0 \\
0 \\
0 \\
0 \\
0\end{array}$ & MG/L & & $\begin{array}{l}289 . \\
285 . \\
280 \\
364 \\
400 . \\
386 . \\
369 . \\
379 . \\
282 . \\
292 . \\
485 . \\
427 . \\
339 . \\
320\end{array}$ & $\begin{array}{l}\mathbf{J} \\
\mathbf{G} \\
\mathbf{G} \\
\mathbf{J}\end{array}$ & $\begin{array}{l}10 . \\
10 . \\
10 \\
10 . \\
10 . \\
10 . \\
10 . \\
10 . \\
10 . \\
10 . \\
10 . \\
10 . \\
10 . \\
10\end{array}$ & $\begin{array}{l}- \\
- \\
- \\
- \\
- \\
- \\
- \\
- \\
- \\
- \\
-\end{array}$ \\
\hline TOTAL KJELDAHL NITROGEN & $\begin{array}{l}0517 \\
0517 \\
0517 \\
0519 \\
0519 \\
0519 \\
0521 \\
0521 \\
0521 \\
0524 \\
0524 \\
0524\end{array}$ & $\begin{array}{l}12 / 08 / 90 \\
04 / 02 / 91 \\
08 / 25 / 91 \\
12 / 15 / 90 \\
04 / 01 / 91 \\
08 / 22 / 91 \\
12 / 08 / 90 \\
04 / 02 / 91 \\
08 / 25 / 91 \\
12 / 08 / 90 \\
04 / 03 / 91 \\
08 / 26 / 91\end{array}$ & $\begin{array}{l}0001 \\
0001 \\
0001 \\
0001 \\
0001 \\
0001 \\
0001 \\
0001 \\
0001 \\
0001 \\
0001 \\
0001\end{array}$ & $\begin{array}{l}\text { LB } \\
\text { LB } \\
\text { LB } \\
\text { LB } \\
\text { LB } \\
\text { LB } \\
\text { LB } \\
\text { LB } \\
\text { LB } \\
\text { LB } \\
\text { LB } \\
\text { LB }\end{array}$ & $\begin{array}{l}0 \\
0 \\
0 \\
0 \\
0 \\
0 \\
0 \\
0 \\
0 \\
0 \\
0 \\
0\end{array}$ & $M G / L$ & $\begin{array}{l}< \\
< \\
< \\
< \\
< \\
< \\
< \\
< \\
< \\
< \\
<\end{array}$ & $\begin{array}{l}1 . \\
1 . \\
1 . \\
1 . \\
1 . \\
1 . \\
1 . \\
1 . \\
1 . \\
1 . \\
1 . \\
1 .\end{array}$ & $\begin{array}{l}\mathbf{G} \\
\mathbf{G}\end{array}$ & $\begin{array}{l}1 . \\
1 . \\
1 . \\
1 . \\
1 . \\
1 . \\
1 . \\
1 . \\
1 . \\
1 . \\
1 .\end{array}$ & $\begin{array}{l}- \\
- \\
- \\
- \\
- \\
- \\
- \\
- \\
-\end{array}$ \\
\hline TOTAL ORGANIC CARBON & $\begin{array}{l}0517 \\
0517 \\
0517 \\
0517 \\
0519 \\
0519 \\
0519 \\
0519 \\
0521\end{array}$ & \begin{tabular}{|l|}
$12 / 08 / 90$ \\
$04 / 02 / 91$ \\
$08 / 25 / 91$ \\
$10 / 14 / 92$ \\
$12 / 15 / 90$ \\
$04 / 01 / 91$ \\
$08 / 22 / 91$ \\
$10 / 11 / 92$ \\
$12 / 08 / 90$
\end{tabular} & $\begin{array}{l}0001 \\
0001 \\
0001 \\
0001 \\
0001 \\
0001 \\
0001 \\
0001 \\
0001\end{array}$ & $\begin{array}{l}\text { LB } \\
\text { LB } \\
\text { LB } \\
\text { L.B } \\
\text { LB } \\
\text { LB } \\
\text { LB } \\
\text { LB } \\
\text { L. }\end{array}$ & $\begin{array}{l}0 \\
0 \\
0 \\
0 \\
0 \\
0 \\
0 \\
0 \\
0\end{array}$ & $M G / L$ & & $\begin{array}{r}42 . \\
1 . \\
1 . \\
3 . \\
38 . \\
4 . \\
3 . \\
1 . \\
47 .\end{array}$ & $\begin{array}{l}\text { GJ } \\
\text { G } \\
\text { *J } \\
J \\
\text { GJ }\end{array}$ & $\begin{array}{l}1 . \\
1 . \\
1 . \\
1 . \\
1 . \\
1 . \\
1 .\end{array}$ & $\begin{array}{l}- \\
- \\
- \\
- \\
- \\
- \\
-\end{array}$ \\
\hline
\end{tabular}

FORMATION OF COMPLETION CODE:

LB - LOWER BURRO CANYON

FLOW RELATIONSHIP CODE

PARAMETER VALUE INDICATOR (PVI): < - LESS THAN DETECTION LIMIT

SAMPLE ID CODES:

0001 - FILTERED SAMPLE (.45 MICRONS)

OTHER PARAMETER VALUE FLAGS:

* - DUPLICATE ANALYSIS NOT WITHIN CONTROL LIMITS

G - PH $>9$, POSSIBLE GROUT CONTAMINATION

J - ESTIMATED VALUE 
TABLE 3.52 BACKGROUND GROUND HATER QUALITY DATA BY PARAMETER FOR THE LOWER SANDSTONE UNIT, BURRO CANYON DISPOSAL SITE, SLICK ROCK, COLORADO SITE: SRKO2 BORROW SITE 1 (BURRO CANYON)

$06 / 04 / 90$ TO $04 / 21 / 94$

REPORT DATE: $09 / 30 / 94$

\begin{tabular}{|c|c|c|c|c|c|c|c|c|c|c|c|c|}
\hline & PARAMETER NAME & $\begin{array}{c}\text { LOCATION } \\
\text { ID }\end{array}$ & LOG DATE & $\begin{array}{c}\text { SAMPLE } \\
\text { ID }\end{array}$ & $\begin{array}{l}\text { FORM } \\
\text { COMP }\end{array}$ & $\begin{array}{l}\text { FLOH } \\
\text { REL. }\end{array}$ & $\begin{array}{l}\text { UNITS OF } \\
\text { MEASURE }\end{array}$ & PVI & $\begin{array}{l}\text { PARAMETER } \\
\text { VALUE }\end{array}$ & FLAGS & $\begin{array}{l}\text { DETECTION } \\
\text { LIMIT }\end{array}$ & $\begin{array}{l}\text { PARAMETER } \\
\text { UNCERTAINTY }\end{array}$ \\
\hline & TOTAL ORGANIC CARBON & $\begin{array}{l}0521 \\
0521 \\
0521 \\
0524 \\
0524 \\
0524 \\
0524\end{array}$ & $\begin{array}{l}04 / 02 / 91 \\
08 / 25 / 91 \\
10 / 13 / 92 \\
12 / 08 / 90 \\
04 / 03 / 91 \\
08 / 26 / 91 \\
10 / 14 / 92\end{array}$ & $\begin{array}{l}0001 \\
0001 \\
0001 \\
0001 \\
0001 \\
0001 \\
0001\end{array}$ & $\begin{array}{l}\text { LB } \\
\text { LB } \\
\text { LB } \\
\text { LB } \\
\text { LB } \\
\text { LB } \\
\text { LB }\end{array}$ & $\begin{array}{l}0 \\
0 \\
0 \\
0 \\
0 \\
0 \\
0\end{array}$ & $M G / L$ & & $\begin{array}{r}3 . \\
1 . \\
4 . \\
41 . \\
2 . \\
1 . \\
4 .\end{array}$ & $\begin{array}{l}G \\
\text { *J } \\
\text { J } \\
\text { *J }\end{array}$ & $\begin{array}{l}1 . \\
1 . \\
1 . \\
1 . \\
1 . \\
1 .\end{array}$ & $\begin{array}{l}- \\
- \\
- \\
-\end{array}$ \\
\hline & TURBIDITY & $\begin{array}{l}0517 \\
0517 \\
0519 \\
0524\end{array}$ & $\begin{array}{l}04 / 06 / 94 \\
04 / 21 / 94 \\
04 / 07 / 94 \\
04 / 07 / 94\end{array}$ & $\begin{array}{l}0001 \\
0001 \\
0001 \\
0001\end{array}$ & $\begin{array}{l}\text { LB } \\
\text { LB } \\
\text { LB } \\
\text { LB }\end{array}$ & $\begin{array}{l}0 \\
0 \\
0 \\
0\end{array}$ & NTU & & $\begin{array}{l}17 \\
21 \\
13 \\
24\end{array}$ & $\begin{array}{l}\text { GL } \\
\mathrm{L} \\
\mathrm{L}\end{array}$ & - & : \\
\hline & URANIUM & $\begin{array}{l}0517 \\
0517 \\
0517 \\
0517 \\
0517 \\
0517 \\
0519 \\
0519 \\
0519 \\
0519 \\
0519 \\
0519 \\
0521 \\
0521 \\
0521 \\
0521 \\
0521 \\
0524 \\
0524 \\
0524 \\
0524 \\
0524 \\
0524\end{array}$ & $\begin{array}{l}06 / 04 / 90 \\
12 / 08 / 90 \\
04 / 02 / 91 \\
08 / 25 / 91 \\
10 / 14 / 92 \\
04 / 06 / 94 \\
06 / 04 / 90 \\
12 / 15 / 90 \\
04 / 01 / 91 \\
08 / 22 / 91 \\
10 / 11 / 92 \\
04 / 08 / 94 \\
06 / 04 / 90 \\
12 / 08 / 90 \\
04 / 02 / 91 \\
08 / 25 / 91 \\
10 / 13 / 92 \\
06 / 06 / 90 \\
12 / 08 / 90 \\
04 / 03 / 91 \\
08 / 26 / 91 \\
10 / 14 / 92 \\
04 / 08 / 94\end{array}$ & $\begin{array}{l}0001 \\
0001 \\
0001 \\
0001 \\
0001 \\
0001 \\
0001 \\
0001 \\
0001 \\
0001 \\
0001 \\
0001 \\
0001 \\
0001 \\
0001 \\
0001 \\
0001 \\
0001 \\
0001 \\
0001 \\
0001 \\
0001 \\
0001\end{array}$ & $\begin{array}{l}\text { LB } \\
\text { LB } \\
\text { LB } \\
\text { LB } \\
\text { LB } \\
\text { LB } \\
\text { LB } \\
\text { LB } \\
\text { LB } \\
\text { LB } \\
\text { LB } \\
\text { LB } \\
\text { LB } \\
\text { LB } \\
\text { LB } \\
\text { LB } \\
\text { LB } \\
\text { LB } \\
\text { LB } \\
\text { LB } \\
\text { LB } \\
\text { LB } \\
\text { LB }\end{array}$ & $\begin{array}{l}0 \\
0 \\
0 \\
0 \\
0 \\
0 \\
0 \\
0 \\
0 \\
0 \\
0 \\
0 \\
0 \\
0 \\
0 \\
0 \\
0 \\
0 \\
0 \\
0 \\
0 \\
0 \\
0\end{array}$ & $M G / L$ & $\begin{array}{l}< \\
< \\
< \\
< \\
< \\
< \\
< \\
< \\
< \\
< \\
< \\
< \\
< \\
< \\
< \\
<\end{array}$ & $\begin{array}{l}0.0009 \\
0.0003 \\
0.001 \\
0.008 \\
0.001 \\
0.001 \\
0.006 \\
0.0003 \\
0.001 \\
0.002 \\
0.002 \\
0.001 \\
0.0011 \\
0.0034 \\
0.002 \\
0.001 \\
0.001 \\
0.0011 \\
0.0004 \\
0.001 \\
0.001 \\
0.001 \\
0.001\end{array}$ & $\begin{array}{l}J \\
\mathbf{G} \\
\mathbf{G} \\
\mathbf{J}\end{array}$ & $\begin{array}{l}0.003 \\
0.0003 \\
0.001 \\
0.001 \\
0.001 \\
0.001 \\
0.003 \\
0.0003 \\
0.001 \\
0.001 \\
0.001 \\
0.001 \\
0.003 \\
0.0003 \\
0.001 \\
0.001 \\
0.001 \\
0.003 \\
0.0003 \\
0.001 \\
0.001 \\
0.001 \\
0.001\end{array}$ & $\begin{array}{l}- \\
- \\
- \\
- \\
- \\
- \\
- \\
- \\
- \\
- \\
- \\
- \\
- \\
- \\
- \\
- \\
- \\
- \\
-\end{array}$ \\
\hline & VANADIUM & 0517 & $06 / 04 / 90$ & 0001 & LB & 0 & MG/L & & 0.02 & & 0.01 & - \\
\hline
\end{tabular}

FORMATION OF COMPLETION CODE:

LB - LOWER BURRO CANYON

FLOW RELATIONSHIP CODE:

PARAMETER VALUE INDICATOR (PVI): < - LESS THAN DETECTION LIMIT

SAMPLE ID COOES:

0001 - FILTERED SAMPLE (.45 MICRONS)

OTHER PARAMETER VALUE FLAGS:

* - DUPLICATE ANALYSIS NOT WITHIN CONTROL LIMITS

G - PH $>9$, POSSIBLE GROUT CONTAMINATION

$J$ - estimated VALUe

L - LESS THAN THREE BORE VOLUMES REMOVED BEFORE SAMPLING 
TABLE 3.52 BACKGROUND GROUND WATER QUALITY DATA BY PARAMETER FOR THE LOHER SANDSTONE UNIT, BURRO CANYON DISPOSAL SITE, SLICK ROCK, COLORADO SITE: SRKO2 BORROW SITE 1 (BURRO CANYON)

06/04/90 TO $04 / 21 / 94$

REPORT DATE : 09/30/94

\begin{tabular}{|c|c|c|c|c|c|c|c|c|c|c|c|}
\hline PARAMETER NAME & $\underset{\text { ID }}{\text { LOCATION }}$ & LOG DATE & $\begin{array}{c}\text { SAMPLE } \\
\text { ID }\end{array}$ & $\begin{array}{l}\text { FORM } \\
\text { COMP }\end{array}$ & $\begin{array}{l}\text { FLOW } \\
\text { REL. }\end{array}$ & $\begin{array}{l}\text { UNITS OF } \\
\text { MEASURE }\end{array}$ & PVI & $\begin{array}{l}\text { PARAMETER } \\
\text { VALUE }\end{array}$ & FLAGS & $\begin{array}{l}\text { DETECTION } \\
\text { LIMIT }\end{array}$ & $\begin{array}{c}\text { PARAMETER } \\
\text { UNCERTAINTY }\end{array}$ \\
\hline VANADIUM & $\begin{array}{l}0517 \\
0517 \\
0517 \\
0517 \\
0517 \\
0519 \\
0519 \\
0519 \\
0519 \\
0519 \\
0519 \\
0521 \\
0521 \\
0521 \\
0521 \\
0521 \\
0524 \\
0524 \\
0524 \\
0524 \\
0524 \\
0524\end{array}$ & $\begin{array}{l}12 / 08 / 90 \\
04 / 02 / 91 \\
08 / 25 / 91 \\
10 / 14 / 92 \\
04 / 21 / 94 \\
06 / 04 / 90 \\
12 / 15 / 90 \\
04 / 01 / 91 \\
08 / 22 / 91 \\
10 / 11 / 92 \\
04 / 08 / 94 \\
06 / 04 / 90 \\
12 / 08 / 90 \\
04 / 02 / 91 \\
08 / 25 / 91 \\
10 / 13 / 92 \\
06 / 06 / 90 \\
12 / 08 / 90 \\
04 / 03 / 91 \\
08 / 26 / 91 \\
10 / 14 / 92 \\
04 / 08 / 94\end{array}$ & $\begin{array}{l}0001 \\
0001 \\
0001 \\
0001 \\
0001 \\
0001 \\
0001 \\
0001 \\
0001 \\
0001 \\
0001 \\
0001 \\
0001 \\
0001 \\
0001 \\
0001 \\
0001 \\
0001 \\
0001 \\
0001 \\
0001 \\
0001\end{array}$ & $\begin{array}{l}\text { LB } \\
\text { LB } \\
\text { LB } \\
\text { LB } \\
\text { LB } \\
\text { LB } \\
\text { LB } \\
\text { LB } \\
\text { LB } \\
\text { LB } \\
\text { LB } \\
\text { LB } \\
\text { LB } \\
\text { LB } \\
\text { LB } \\
\text { LB } \\
\text { LB } \\
\text { LB } \\
\text { LB } \\
\text { LB } \\
\text { LB } \\
\text { LB }\end{array}$ & $\begin{array}{l}0 \\
0 \\
0 \\
0 \\
0 \\
0 \\
0 \\
0 \\
0 \\
0 \\
0 \\
0 \\
0 \\
0 \\
0 \\
0 \\
0 \\
0 \\
0 \\
0 \\
0 \\
0\end{array}$ & $M G / L$ & $\begin{array}{l}< \\
< \\
< \\
< \\
< \\
< \\
< \\
< \\
< \\
< \\
< \\
< \\
< \\
< \\
< \\
< \\
< \\
< \\
<\end{array}$ & $\begin{array}{l}0.02 \\
0.01 \\
0.01 \\
0.01 \\
0.01 \\
0.01 \\
0.02 \\
0.01 \\
0.01 \\
0.01 \\
0.01 \\
0.01 \\
0.02 \\
0.01 \\
0.01 \\
0.01 \\
0.01 \\
0.03 \\
0.01 \\
0.01 \\
0.01 \\
0.01\end{array}$ & $\begin{array}{l}\text { G } \\
\mathbf{G} \\
\mathbf{J}\end{array}$ & $\begin{array}{l}0.01 \\
0.01 \\
0.01 \\
0.01 \\
0.01 \\
0.01 \\
0.01 \\
0.01 \\
0.01 \\
0.01 \\
0.01 \\
0.01 \\
0.01 \\
0.01 \\
0.01 \\
0.01 \\
0.01 \\
0.01 \\
0.01 \\
0.01 \\
0.01 \\
0.01\end{array}$ & $\begin{array}{l}- \\
- \\
- \\
- \\
- \\
- \\
- \\
- \\
- \\
- \\
- \\
- \\
- \\
- \\
- \\
- \\
- \\
-\end{array}$ \\
\hline ZINC & $\begin{array}{l}0517 \\
0517 \\
0517 \\
0517 \\
0517 \\
0517 \\
0519 \\
0519 \\
0519 \\
0519 \\
0519 \\
0519 \\
0521 \\
0521 \\
0521\end{array}$ & $\begin{array}{l}06 / 04 / 90 \\
12 / 08 / 90 \\
04 / 02 / 91 \\
08 / 25 / 91 \\
10 / 14 / 92 \\
04 / 21 / 94 \\
06 / 04 / 90 \\
12 / 15 / 90 \\
04 / 01 / 91 \\
08 / 22 / 91 \\
10 / 11 / 92 \\
04 / 08 / 94 \\
06 / 04 / 90 \\
12 / 08 / 90 \\
04 / 02 / 91\end{array}$ & $\begin{array}{l}0001 \\
0001 \\
0001 \\
0001 \\
0001 \\
0001 \\
0001 \\
0001 \\
0001 \\
0001 \\
0001 \\
0001 \\
0001 \\
0001 \\
0001\end{array}$ & $\begin{array}{l}\text { LB } \\
\text { LB } \\
\text { LB } \\
\text { LB } \\
\text { LB } \\
\text { LB } \\
\text { LB } \\
\text { LB } \\
\text { LB } \\
\text { LB } \\
\text { LB } \\
\text { LB } \\
\text { LB } \\
\text { LB } \\
\text { LB }\end{array}$ & $\begin{array}{l}0 \\
0 \\
0 \\
0 \\
0 \\
0 \\
0 \\
0 \\
0 \\
0 \\
0 \\
0 \\
0 \\
0 \\
0\end{array}$ & $M G / L$ & $<$ & $\begin{array}{l}0.028 \\
0.011 \\
0.012 \\
0.015 \\
0.005 \\
0.05 \\
0.028 \\
0.039 \\
0.054 \\
0.008 \\
0.005 \\
0.05 \\
0.042 \\
0.012 \\
0.012\end{array}$ & $\begin{array}{l}\mathbf{G} \\
\mathbf{G} \\
\mathbf{G L}\end{array}$ & $\begin{array}{l}0.005 \\
0.005 \\
0.005 \\
0.005 \\
0.005 \\
0.05 \\
0.005 \\
0.005 \\
0.005 \\
0.005 \\
0.005 \\
0.05 \\
0.005 \\
0.005 \\
0.005\end{array}$ & $\begin{array}{l}- \\
- \\
- \\
- \\
- \\
- \\
- \\
- \\
- \\
- \\
-\end{array}$ \\
\hline
\end{tabular}

FORMATION OF COMPLETION CODE:

LB - LOWER BURRO CANYON

PARAMETER VALUE INDICATOR (PVI): < - LESS THAN DETECTION LIMIT
FLOW RELATIONSHIP CODE:

O - ON-SITE

0001 - FILTERED SAMPLE (.45 MICRONS)

OTHER PARAMETER VALUE FLAGS:

$G$ - PH > 9, POSSIBLE GROUT CONTAMINATION

$J$ - ESTIMATED VALUE

L - LESS THAN THREE BORE VOLUMES REMOVED BEFORE SAMPLING 
TABLE 3.52 BACKGROUND GROUND HATER QUALITY DATA BY PARAMETER FOR THE LOWER SANDSTONE UNIT, BURRO CANYON DISPOSAL SITE, SLICK ROCK, COLORADO SITE: SRKO2 BORROH SITE 1 (BURRO CANYON)

06/04/90 TO 04/21/94

REPORT DATE: $09 / 30 / 94$

\begin{tabular}{|c|c|c|c|c|c|c|c|c|c|c|c|}
\hline PARAMETER NAME & $\underset{\text { ID }}{\text { LOCATION }}$ & LOG DATE & $\begin{array}{c}\text { SAMPLE } \\
\text { ID }\end{array}$ & $\begin{array}{l}\text { FORM } \\
\text { COMP }\end{array}$ & $\begin{array}{l}\text { FLOH } \\
\text { REL. }\end{array}$ & $\begin{array}{l}\text { UNITS OF } \\
\text { MEASURE }\end{array}$ & PVI & $\begin{array}{l}\text { PARAMETER } \\
\text { VALUE }\end{array}$ & FLAGS & $\begin{array}{l}\text { DETECTION } \\
\text { LIMIT }\end{array}$ & $\begin{array}{l}\text { PARANETER } \\
\text { UNCERTAINTY }\end{array}$ \\
\hline ZINC & $\begin{array}{l}0521 \\
0521 \\
0524 \\
0524 \\
0524 \\
0524 \\
0524 \\
0524\end{array}$ & $\begin{array}{l}08 / 25 / 91 \\
10 / 13 / 92 \\
06 / 06 / 90 \\
12 / 08 / 90 \\
04 / 03 / 91 \\
08 / 26 / 91 \\
10 / 14 / 92 \\
04 / 08 / 94\end{array}$ & $\begin{array}{l}0001 \\
0001 \\
0001 \\
0001 \\
0001 \\
0001 \\
0001 \\
0001\end{array}$ & $\begin{array}{l}\text { LB } \\
\text { LB } \\
\text { LB } \\
\text { LB } \\
\text { LB } \\
\text { LB } \\
\text { LB } \\
\text { LB }\end{array}$ & $\begin{array}{l}0 \\
0 \\
0 \\
0 \\
0 \\
0 \\
0 \\
0\end{array}$ & $M G / L$ & $\mid \begin{array}{l}< \\
< \\
< \\
<\end{array}$ & $\begin{array}{l}0.009 \\
0.005 \\
0.022 \\
0.005 \\
0.020 \\
0.005 \\
0.005 \\
0.05\end{array}$ & J & $\begin{array}{l}0.005 \\
0.005 \\
0.005 \\
0.005 \\
0.005 \\
0.005 \\
0.005 \\
0.05\end{array}$ & $\begin{array}{l}- \\
- \\
- \\
- \\
- \\
-\end{array}$ \\
\hline
\end{tabular}

FORMATION OF COMPLETION CODE:

LB - LOWER BURRO CANYON

PARAMETER VALUE INDICATOR (PVI): < - LESS THAN DETECTION LIMIT

OTHER PARAMETER VALUE FLAGS:

$J$ - ESTIMATED VALUE

L - LESS THAN THREE BORE VOLUMES REMOVED BEFORE SAMPLING

DATA FILE NAME: IDARTISRKO2\GWQ10009.DAT
FLOW RELATIONSHIP CODE:

O - ON-SITE

SAMPLE ID CODES:

0001 - FILTERED SAMPLE (.45 MICRONS) 
TABLE 3.53 BACKGROUND GROUND WATER QUALITY STATISTICS BY PARAMETER FOR

THE LOWER SANDSTONE UNIT, BURRO CANYON DISPOSAL SITE, SLICK ROCK, COLORADO

SITE: SRKO2 BORROW SITE 1 (BURRO CANYON)

06/04/90 TO $04 / 21 / 94$

REPORT DATE: $09 / 30 / 94$

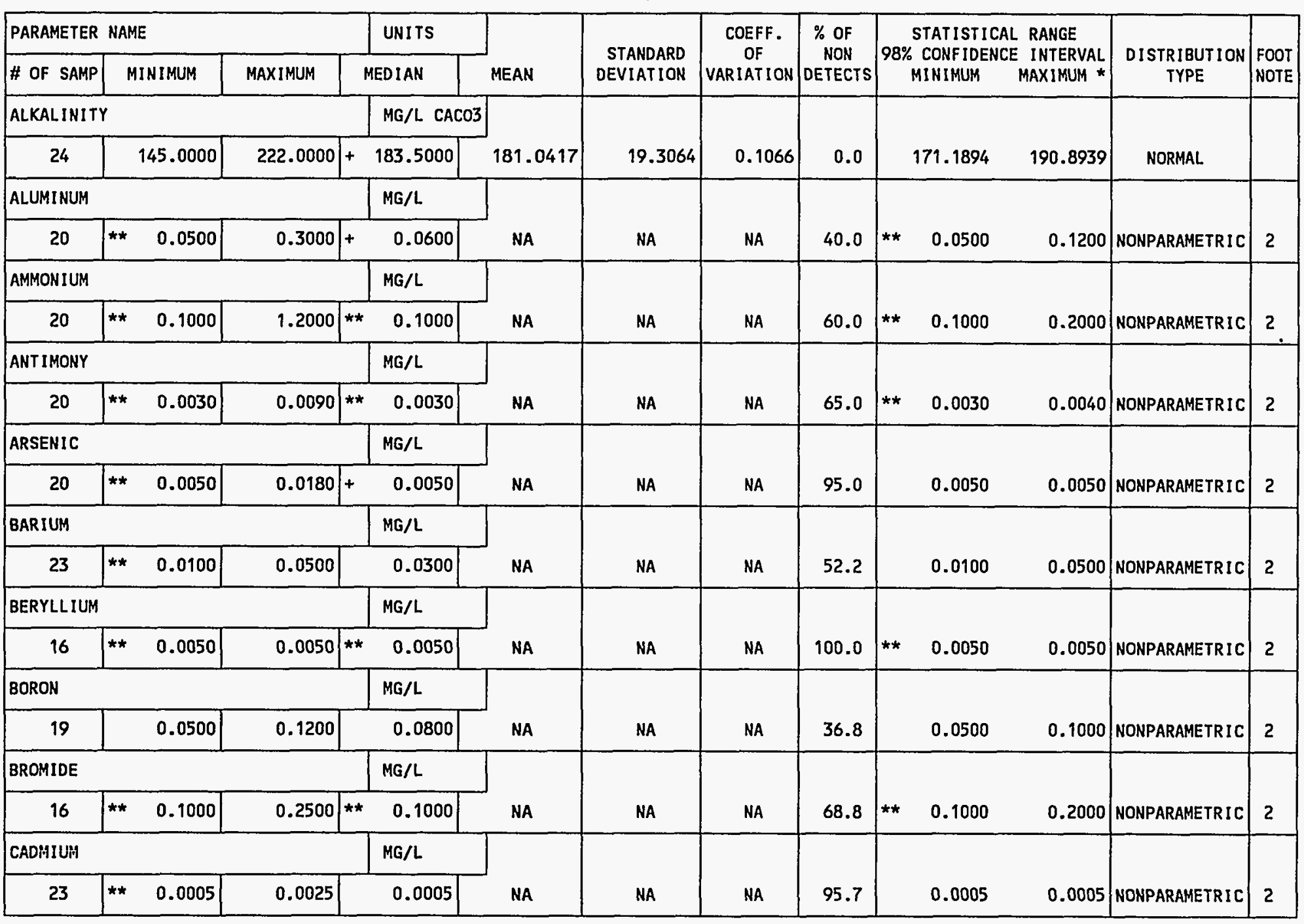

** The reported value is the minimum detection limit of the data set

+ The sample size is even, so the median value is the arithmetic average of the two middle values

* The statistical maximum is the 99 percent one sided confidence interval, $\alpha=0.01$

2) The nonparametric distribution was used because the nondetected values comprise more than $15 \%$ of the samples. 
TABLE 3.53 BACKGROUND GROUND WATER QUALITY STATISTICS BY PARAMETER FOR

THE LOWER SANDSTONE UNIT, BURRO CANYON DISPOSAL SITE, SLICK ROCK, COLORADO

SITE: SRKO2 BORROH SITE 1 (BURRO CANYON

$06 / 04 / 90$ TO $04 / 21 / 94$

REPORT DATE: $09 / 30 / 94$

\begin{tabular}{|c|c|c|c|c|c|c|c|c|c|c|c|c|c|c|}
\hline \multicolumn{4}{|c|}{ PARAMETER NAME } & UNITS & \multirow[b]{2}{*}{ MEAN } & \multirow{2}{*}{$\begin{array}{r}\text { STANDARD } \\
\text { DEVIATION }\end{array}$} & \multirow{2}{*}{$\begin{array}{c}\text { COEFF. } \\
\text { OF } \\
\text { VARIATION }\end{array}$} & \multirow{2}{*}{$\begin{array}{l}\% \text { OF } \\
\text { NON } \\
\text { DETECTS }\end{array}$} & \multirow{2}{*}{\multicolumn{4}{|c|}{$\begin{array}{l}\text { STATISTICAL RANGE } \\
\text { 98\% CONFIDENCE INTERVAL } \\
\text { MINIMUM } \\
\text { MAXIMUM * }\end{array}$}} & \multirow{2}{*}{$\begin{array}{l}\text { DISTRIBUTION } \\
\text { TYPE }\end{array}$} & \multirow[b]{2}{*}{$\begin{array}{l}\text { FOOT } \\
\text { NOTE }\end{array}$} \\
\hline \# OF SAMP & & NIMUM & MAXIMUM & MEDIAN & & & & & & & & & & \\
\hline \multicolumn{4}{|l|}{ CALCIUM } & $M G / L$ & \multirow[b]{2}{*}{1.4857} & \multirow[b]{2}{*}{0.7117} & \multirow[b]{2}{*}{0.4791} & \multirow[b]{2}{*}{4.3} & \multirow{2}{*}{\multicolumn{2}{|c|}{1.1135}} & \multirow{2}{*}{\multicolumn{2}{|c|}{1.8579}} & \multirow[b]{2}{*}{ NORMAL } & \\
\hline 23 & & 0.2500 & 2.6400 & 1.5000 & & & & & & & & & & \\
\hline \multicolumn{4}{|l|}{ CHLORIDE } & $M G / L$ & \multirow[b]{2}{*}{18.9870} & \multirow[b]{2}{*}{13.1705} & \multirow[b]{2}{*}{0.6937} & \multirow[b]{2}{*}{0.0} & \multirow{2}{*}{\multicolumn{2}{|c|}{12.0994}} & \multirow{2}{*}{\multicolumn{2}{|c|}{25.8745}} & \multirow[b]{2}{*}{ NORMAL } & \\
\hline 23 & & 8.0000 & 64.0000 & 15.0000 & & & & & & & & & & \\
\hline \multicolumn{4}{|l|}{ CHROMIUM } & $M G / L$ & \multirow[b]{2}{*}{ NA } & \multirow[b]{2}{*}{ NA } & \multirow[b]{2}{*}{ NA } & \multirow[b]{2}{*}{100.0} & \multirow[b]{2}{*}{$* *$} & \multirow[b]{2}{*}{0.0100} & & & & \\
\hline 23 & ** & 0.0100 & 0.0100 & 0.0100 & & & & & & & ** & 0.0100 & NONPARAMETRIC & 2 \\
\hline COBALT & & & & $M G / L$ & & & & & & & & & & \\
\hline 16 & ** & 0.0300 & 0.0300 & ** $\quad 0.0300$ & NA & NA & NA & 100.0 & $\star \star \star$ & 0.0300 & ** & 0.0300 & NONPARAMETRIC & 2 \\
\hline COPPER & & & & $M G / L$ & & & & & & & & & & \\
\hline 20 & ** & 0.0100 & 0.0100 & 0.0100 & NA & NA & NA & 100.0 & ** & 0.0100 & & 0.0100 & NONPARAMETRIC & 2 \\
\hline CYANIDE & & & & $M G / L$ & & & & & & & & & & \\
\hline 12 & ** & 0.0100 & 0.0100 & 0.0100 & NA & NA & NA & 100.0 & ** & 0.0100 & ** & 0.0100 & NONPARAMETRIC & 2 \\
\hline DISSOLVED & ORC & INIC CARE & & MG/L & & & & & & & & & & \\
\hline 3 & & 1.0000 & 2.0000 & 1.0000 & NA & NA & NA & 66.7 & & NA & & NA & UNKNOWN & 1 \\
\hline DISSOLVED & & & & $M G / L$ & & & & & & & & & & \\
\hline 8 & & 0.3900 & 3.6000 & 1.1000 & 1.3475 & 0.9980 & 0.7406 & 0.0 & & 0.2897 & & 2.4053 & NORMAL & \\
\hline FLUORIDE & & & & $M G / L$ & & & & & & & & & & \\
\hline 20 & & 0.3000 & 0.9000 & 0.6000 & 0.5600 & 0.1353 & 0.2417 & 0.0 & & 0.4832 & & 0.6368 & NORMAL & \\
\hline GROSS ALP| & & & & $\mathrm{PCI} / \mathrm{L}$ & & & & & & & & & & \\
\hline 19 & ** & 1.0000 & 8. 1000 & 1.0000 & NA & NA & NA & 0.0 & ** & 1.0000 & & 3.6000 & NONPARAMETRIC & 9 \\
\hline
\end{tabular}

** The reported value is the minimum detection limit of the data set

- The sample size is even, so the median value is the arithmetic average of the two middle values

* The statistical maximum is the 99 percent one sided confidence interval, $\alpha=0.01$

1) A minimum of 4 samples must be available for the statistical analysis.

2) The nonparametric distribution was used because the nondetected values comprise more than $15 \%$ of the samples.

9) The nonparametic distribution was used because the data failed the normal distribution test and includes values $\leq 0$. 
TABLE 3.53 BACKGROUND GROUND WATER QUALITY STATISTICS BY PARAMETER FOR

THE LOWER SANDSTONE UNIT, BURRO CANYON DISPOSAL SITE, SLICK ROCK, COLORADO

SITE: SRKO2 BORROW SITE 1 (BURRO CANYON)

$06 / 04 / 90$ TO $04 / 21 / 94$

REPORT DATE : 09/30/94

\begin{tabular}{|c|c|c|c|c|c|c|c|c|c|c|c|c|}
\hline \multicolumn{3}{|c|}{ PARAMETER NAME } & UNITS & \multirow[b]{2}{*}{ MEAN } & \multirow{2}{*}{$\begin{array}{r}\text { STANDARD } \\
\text { DEVIATION }\end{array}$} & \multirow{2}{*}{$\begin{array}{c}\text { COEFF. } \\
\text { OF } \\
\text { VARIATION }\end{array}$} & \multirow{2}{*}{$\begin{array}{c}\% \text { OF } \\
\text { NON } \\
\text { DETECTS }\end{array}$} & \multirow{2}{*}{\multicolumn{3}{|c|}{ 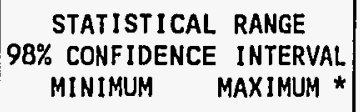 }} & \multirow{2}{*}{$\begin{array}{l}\text { DISTRIBUTION } \\
\text { TYPE }\end{array}$} & \multirow{2}{*}{$\begin{array}{l}\text { FOOT } \\
\text { NOTE }\end{array}$} \\
\hline \# OF SAMP & MINIMUM & MAXIMUM & MEDIAN & & & & & & & & & \\
\hline \multicolumn{3}{|l|}{ GROSS BETA } & PCI/L & \multirow[b]{2}{*}{ NA } & \multirow[b]{2}{*}{ NA } & \multirow[b]{2}{*}{ NA } & \multirow[b]{2}{*}{0.0} & \multirow[b]{2}{*}{ \#* } & \multirow[b]{2}{*}{0.5000} & \multirow[b]{2}{*}{2.6000} & \multirow[b]{2}{*}{ NONPARAMETRIC } & \multirow[b]{2}{*}{9} \\
\hline 16 & 0.5000 & 6.1000 & 1.5500 & & & & & & & & & \\
\hline \multicolumn{3}{|l|}{ IRON } & $M G / L$ & \multirow[b]{2}{*}{ NA } & \multirow[b]{2}{*}{ NA } & \multirow[b]{2}{*}{ NA } & \multirow[b]{2}{*}{60.9} & \multirow[b]{2}{*}{ ** } & \multirow[b]{2}{*}{0.0300} & \multirow[b]{2}{*}{0.0500} & \multirow[b]{2}{*}{ NONPARAMETRIC } & \multirow[b]{2}{*}{2} \\
\hline 23 & 0.0300 & 0.2300 & 0.0300 & & & & & & & & & \\
\hline \multicolumn{3}{|l|}{ LEAD } & MG/L & \multirow[b]{2}{*}{ NA } & \multirow[b]{2}{*}{ NA } & \multirow[b]{2}{*}{ NA } & \multirow[b]{2}{*}{100.0} & & & & & \\
\hline 20 & ** $\quad 0.0030$ & 0.0100 & 0.0037 & & & & & ** & 0.0030 & 0.0050 & NONPARAMETRIC & 2 \\
\hline LEAD-210 & & & $\mathrm{PCI} / \mathrm{L}$ & & & & & & & & & \\
\hline 12 & 1.5000 & 1.5000 & 1.5000 & NA & NA & NA & 0.0 & $* *$ & 1.5000 & 1.5000 & NONPARAMETRIC & 9 \\
\hline MAGNESIUM & & & MG/L & & & & & & & & & \\
\hline 23 & 0.0500 & 0.6000 & 0.2000 & NA & NA & NA & 21.7 & & 0.1000 & 0.3100 & NONPARAMETRIC & 2 \\
\hline MANGANESE & & & $M G / L$ & & & & & & & & & \\
\hline 20 & ** $\quad 0.0100$ & 0.0200 & 0.0100 & NA & NA & NA & 90.0 & ** & 0.0100 & ** $\quad 0.0100$ & NONPARAMETRIC & 2 \\
\hline MERCURY & & & $M G / L$ & & & & & & & & & \\
\hline 16 & 0.0002 & 0.0002 & 0.0002 & NA & NA & NA & 100.0 & ** & 0.0002 & 0.0002 & NONPARAMETRIC & 2 \\
\hline MOLYBDENUM & & & $M G / L$ & & & & & & & & & \\
\hline 23 & ** $\quad 0.0100$ & 0.0400 & 0.0100 & NA & NA & NA & 69.6 & 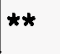 & 0.0100 & 0.0100 & NONPARAMETRIC & 2 \\
\hline NET GROSS & ALPHA $\quad * \star *$ & & $\mathrm{PCI} / \mathrm{L}$ & & & & & & & & & \\
\hline 19 & -5.4900 & 6.7600 & -0.1000 & NA & NA & NA & 0.0 & & -0.3400 & 2.9300 & NONPARAMETRIC & 9 \\
\hline
\end{tabular}

*** NET GROSS ALPHA (GROSS ALPHA - URANIUM) WITH 1 MG URANIUM = 686 PCI

** The reported value is the minimum detection limit of the data set

+ The sample size is even, so the median value is the arithmetic average of the two middle values

* The statistical maximum is the 99 percent one sided confidence interval, $\alpha=0.01$

2) The nonparametric distribution was used because the nondetected values comprise more than $15 \%$ of the samples.

9) The nonparametic distribution was used because the data failed the normal distribution test and includes values $\leq 0$. 
TABLE 3.53 BACKGROUND GROUND HATER QUALITY STATISTICS BY PARAMETER FOR

THE LOWER SANDSTONE UNIT, BURRO CANYON DISPOSAL SITE, SLICK ROCK, COLORADO

SITE: SRKO2 BORROW SITE 1 (BURRO CANYON)

06/04/90 TO 04/21/94

REPORT DATE: $09 / 30 / 94$

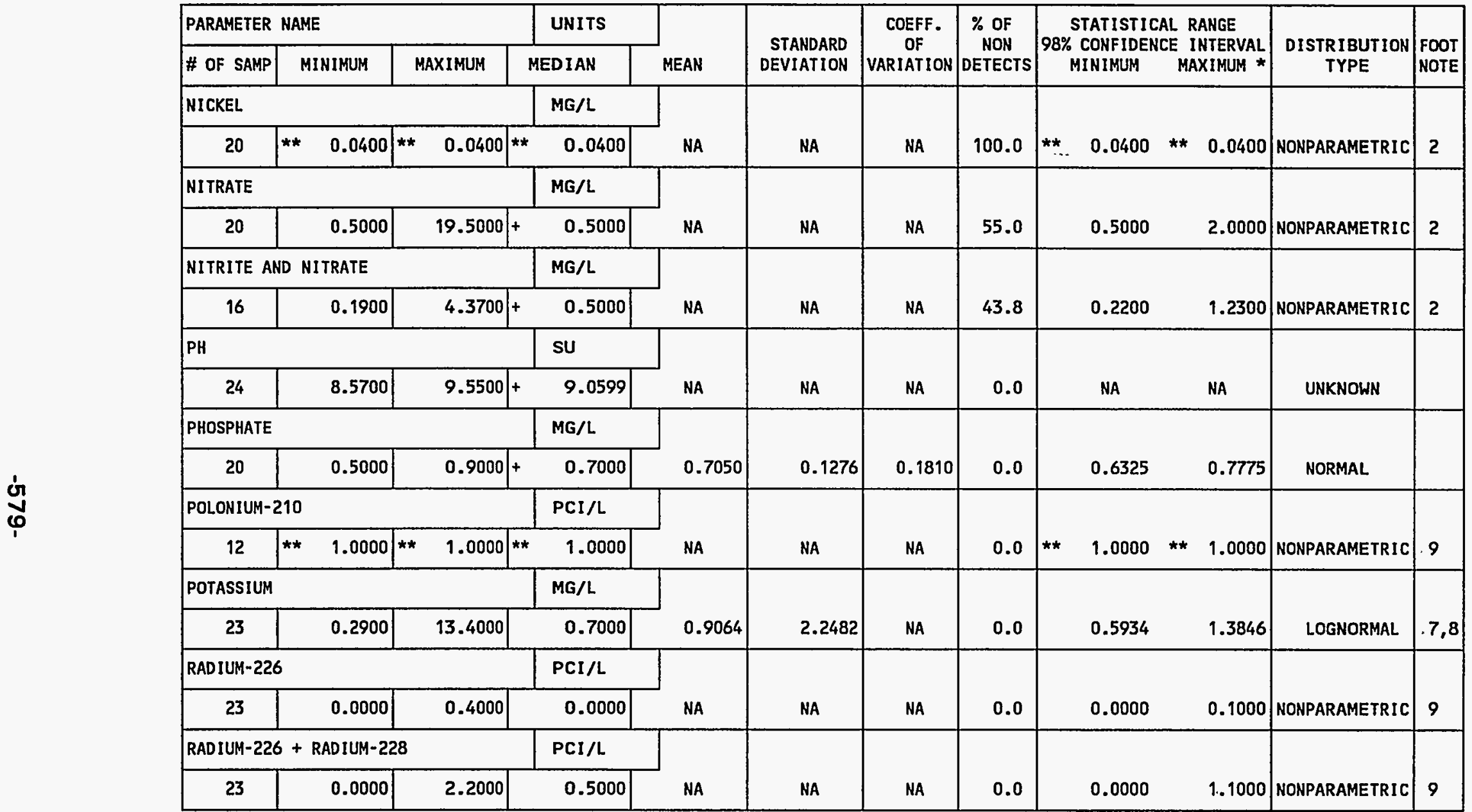

** The reported value is the minimum detection limit of the data set

+ The sample size is even, so the median value is the arithmetic average of the two middle values

* The statistical maximum is the 99 percent one sided confidence interval, $\alpha=0.01$

1) A minimum of 4 samples must be avai lable for the statistical analysis.

2) The nonparametric distribution was used because the nondetected values comprise more than $15 \%$ of the samples.

7) The lognormal distribution was used because the data failed the normal distribution test.

8) The mean is geometric. The standard deviation is the value to divide or multiply with the geometric mean.

9) The nonparametic distribution was used because the data fajled the normal distribution test and includes values $\leq 0$. 
TABLE 3.53 BACKGROUND GROUND HATER QUALITY STATISTICS BY PARAMETER FOR

THE LOWER SANDSTONE UNIT, BURRO CANYON DISPOSAL. SITE, SLICK ROCK, COLORADO

SITE: SRKO2 BORROW SITE 1 (BURRO CANYON)

06/04/90 TO $04 / 21 / 94$

REPORT DATE: 09/30/94

\begin{tabular}{|c|c|c|c|c|c|c|c|c|c|c|c|c|c|}
\hline \multicolumn{4}{|c|}{ PARAMETER NAME } & UNITS & \multirow[b]{2}{*}{ MEAN } & \multirow{2}{*}{$\begin{array}{r}\text { STANDARD } \\
\text { DEVIATION }\end{array}$} & \multirow{2}{*}{$\begin{array}{c}\text { COEFF. } \\
\text { OF } \\
\text { VARIATION }\end{array}$} & \multirow{2}{*}{$\mid \begin{array}{c}\% \text { OF } \\
\text { NON } \\
\text { DETECTS }\end{array}$} & \multirow{2}{*}{\multicolumn{3}{|c|}{ 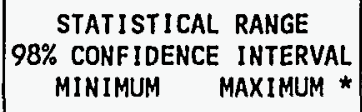 }} & \multirow{2}{*}{$\begin{array}{c}\text { DISTRIBUTION } \\
\text { TYPE }\end{array}$} & \multirow{2}{*}{$\begin{array}{l}\text { FOOT } \\
\text { NOTE }\end{array}$} \\
\hline \# OF SAMP & MINIMUM & MAXIMUM & & MEDIAN & & & & & & & & & \\
\hline \multicolumn{4}{|l|}{ RADIUM- 228} & PCI/L & \multirow[b]{2}{*}{ NA } & \multirow[b]{2}{*}{ NA } & \multirow[b]{2}{*}{ NA } & \multirow[b]{2}{*}{0.0} & \multirow[b]{2}{*}{$\star \star$} & \multirow[b]{2}{*}{1.0000} & \multirow[b]{2}{*}{1.1000} & \multirow[b]{2}{*}{ NONPARAMETRIC } & \multirow[b]{2}{*}{9} \\
\hline 23 & $\begin{array}{ll}* * & 1.0000\end{array}$ & 2.1000 & ** & 1.0000 & & & & & & & & & \\
\hline \multicolumn{4}{|c|}{ REDOX POTENTIAL. } & mVOLTS & \multirow[b]{2}{*}{ NA } & \multirow[b]{2}{*}{ NA } & \multirow[b]{2}{*}{ NA } & \multirow[b]{2}{*}{0.0} & \multirow{2}{*}{\multicolumn{2}{|c|}{261.2000}} & \multirow[b]{2}{*}{402.0000} & \multirow[b]{2}{*}{ NONPARAMETRIC } & \multirow[b]{2}{*}{9} \\
\hline 11 & -189.0000 & 433.0000 & & 383.6000 & & & & & & & & & \\
\hline \multicolumn{4}{|l|}{ SELENIUM } & MG/L & \multirow[b]{2}{*}{ NA } & \multirow[b]{2}{*}{ NA } & \multirow[b]{2}{*}{ NA } & & & & & & \\
\hline 23 & $\begin{array}{ll}* * & 0.0050\end{array}$ & ** $\quad 0.0050$ & ** & 0.0050 & & & & 100.0 & ** & 0.0050 & ** 0.0050 & NONPARAMETR I C & 2 \\
\hline SILICA - S & $s 102$ & & & MG/L & & & & & & & & & \\
\hline 23 & 8.3000 & 11.9000 & & 10.0000 & 10.0739 & 0.9112 & 0.0904 & 0.0 & & 9.5974 & 10.5504 & NORMAL. & \\
\hline SILVER & & & & $M G / L$ & & & & & & & & & \\
\hline 16 & ** $\quad 0.0100$ & $\begin{array}{ll}* & 0.0100\end{array}$ & ** & 0.0100 & NA & NA & NA & 100.0 & ** & 0.0100 & ** 0.0100 & NONPARAMETRI C & 2 \\
\hline SODIUM & & & & MG/L & & & & & & & & & \\
\hline 23 & 99.0000 & 182.0000 & & 132.0000 & 131.4783 & 19.1427 & 0.1456 & 0.0 & & 121.4675 & 141.4890 & NORMAL. & \\
\hline SPECIFIC C & CONDUCTANCE & & & UMHO/CM & & & & & & & & & \\
\hline 21 & 380.0000 & 790.0000 & & 495.0000 & 509.3333 & 106.5699 & 0.2092 & 0.0 & & 450.5436 & 568.1231 & NORMAL & \\
\hline STRONT IUM & & & & MG/L & & & & & & & & & \\
\hline 23 & 0.0200 & 0.2200 & & 0.0700 & 0.0878 & 0.0505 & 0.5754 & 8.7 & & 0.0614 & 0.1143 & NORMAL & \\
\hline SULFATE & & & & $M G / L$ & & & & & & & & & \\
\hline 22 & 43.6000 & 119.0000 & + & 73.0000 & 74.8455 & 16.1888 & 0.2163 & 0.0 & & 66.1547 & 83.5362 & NORMAL & \\
\hline SULFIDE & & & & $M G / L$ & & & & & & & & & \\
\hline 16 & ** $\quad 0.1000$ & 3.2600 & + & 0.3500 & NA & NA & NA & 31.3 & ** & 0.1000 & 0.8000 & NONPARAMETRIC & 2 \\
\hline
\end{tabular}

** The reported value is the minimum detection limit of the data set

+ The sample size is even, so the median value is the arithmetic average of the two middle values

* The statistical maximum is the 99 percent one sided confidence interval, $\alpha=0.01$

2) The nonparametric distribution was used because the nondetected values comprise more than $15 \%$ of the samples.

9) The nonparametic distribution was used because the data failed the normal distribution test and includes values $\leq 0$. 
TABLE 3.53 BACKGROUND GROUND HATER QUALITY STATISTICS BY PARAMETER FOR

THE LOWER SANDSTONE UNIT, BURRO CANYON DISPOSAL SITE, SLICK ROCK, COLORADO

SITE: SRKO2 BORROW SITE 1 (BURRO CANYON)

$06 / 04 / 90$ TO $04 / 21 / 94$

REPORT DATE: 09/30/94

\begin{tabular}{|c|c|c|c|c|c|c|c|c|c|c|c|}
\hline \multicolumn{3}{|c|}{ PARAMETER NAME } & UNITS & \multirow[b]{2}{*}{ MEAN } & \multirow{2}{*}{$\begin{array}{l}\text { STANDARD } \\
\text { DEVIATION }\end{array}$} & \multirow{2}{*}{$\begin{array}{l}\text { COEFF. } \\
\text { OF } \\
\text { VARIATION }\end{array}$} & \multirow{2}{*}{$\begin{array}{l}\% \text { OF } \\
\text { NON } \\
\text { DETECTS }\end{array}$} & \multirow{2}{*}{\multicolumn{2}{|c|}{$\begin{array}{l}\text { STATISTICAL RANGE } \\
\text { 98\% CONFIDENCE INTERVAL } \\
\begin{array}{cc}\text { MINIMUMM } & \text { MAXIMUM * }\end{array}\end{array}$}} & \multirow{2}{*}{$\begin{array}{l}\text { DISTRIBUTION } \\
\text { TYPE }\end{array}$} & \multirow{2}{*}{$\begin{array}{l}\text { FOOT } \\
\text { NOTE }\end{array}$} \\
\hline \# OF SAMP & MINIMUM & MAXIMUM & MEDIAN & & & & & & & & \\
\hline \multicolumn{3}{|c|}{ TEMPERATURE } & $C-D E G$ & \multirow[b]{2}{*}{16.5458} & \multirow[b]{2}{*}{2.2136} & \multirow[b]{2}{*}{0.1338} & \multirow[b]{2}{*}{0.0} & \multirow[b]{2}{*}{15.4162} & \multirow[b]{2}{*}{17.6755} & \multirow[b]{2}{*}{ NORMAL } & \\
\hline 24 & 13.5000 & 22.3000 & 16.5000 & & & & & & & & \\
\hline \multicolumn{3}{|l|}{ THALLIUM } & $M G / L$ & \multirow[b]{2}{*}{ NA } & \multirow[b]{2}{*}{ NA } & \multirow[b]{2}{*}{ NA } & \multirow[b]{2}{*}{100.0} & \multirow[b]{2}{*}{0.0050} & \multirow[b]{2}{*}{0.0050} & \multirow[b]{2}{*}{ NONPARAMETRIC } & \multirow[b]{2}{*}{2} \\
\hline 20 & 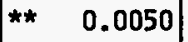 & 0.0050 & 0.0050 & & & & & & & & \\
\hline \multicolumn{3}{|c|}{ THORIUM-230 } & $\mathrm{PCI} / \mathrm{L}$ & \multirow[b]{2}{*}{ NA } & \multirow[b]{2}{*}{ NA } & \multirow[b]{2}{*}{ NA } & \multirow[b]{2}{*}{0.0} & \multirow[b]{2}{*}{1.0000} & \multirow[b]{2}{*}{ ** 1.0000} & & \\
\hline 12 & ** $\quad 1.0000$ & 1.0000 & 1.0000 & & & & & & & NONPARAMETRIC & 9 \\
\hline TIN & & & $M G / L$ & & & & & & & & \\
\hline 20 & ** $\quad 0.0050$ & 0.0050 & 0.0050 & NA & NA & NA & 100.0 & 0.0050 & 0.0050 & NONPARAMETRIC & 2 \\
\hline TOTAL DISS & SOLVED SOLIDS & & $M G / L$ & & & & & & & & \\
\hline 23 & 256.0000 & 485.0000 & 339.0000 & 344.4783 & 61.4875 & 0.1785 & 0.0 & 312.3231 & 376.6334 & NORMAL & \\
\hline TOTAL KJEI & LDAHL NITROGE & & $M G / L$ & & & & & & & & \\
\hline 12 & ** $\quad 1.0000$ & 1.0000 & 1.0000 & NA & NA & NA & 75.0 & 1.0000 & 1.0000 & NONPARAMETRIC & 2 \\
\hline TOTAL ORG & ANIC CARBON & & $M G / L$ & & & & & & & & \\
\hline 16 & ** $\quad 1.0000 \mid$ & 47.0000 & 3.0000 & 3.8817 & 4.8310 & NA & 12.5 & 1.3933 & 10.8142 & LOGNORMAL & 7,8 \\
\hline TURB IDITY & & & NTU & & & & & & & & \\
\hline 4 & 13.0000 & 24.0000 & 19.0000 & 18.7500 & 4.7871 & 0.2553 & 0.0 & 7.8808 & 29.6192 & NORMAL & \\
\hline URANIUM & & & $M G / L$ & & & & & & & & \\
\hline 23 & ** 0.0003 & 0.0080 & 0.0005 & NA & NA & NA & 56.5 & 0.0005 & 0.0020 & NONPARAMETRIC & 2 \\
\hline
\end{tabular}

** The reported value is the minimum detection limit of the data set

+ The sample size is even, so the median value is the arithmetic average of the two middle values

* The statistical maximum is the 99 percent one sided confidence interval, $\alpha=0.01$

2) The nonparametric distribution was used because the nondetected values comprise more than $15 \%$ of the samples.

7) The lognormal distribution was used because the data failed the normal distribution test.

8) The mean is geometric. The standard deviation is the value to divide or multiply with the geometric mean.

9) The nonparametic distribution was used because the data failed the normal distribution test and includes values $\leq 0$. 
TABLE 3.53 BACKGROUND GROUND WATER QUALITY STATISTICS BY PARAMETER FOR

THE LOWER SANDSTONE UNIT, BURRO CANYON DISPOSAL SITE, SLICK ROCK, COLORADO

SITE: SRKO2 BORROW SITE 1 (BURRO CANYON)

06/04/90 TO 04/21/94

REPORT DATE : $09 / 30 / 94$

\begin{tabular}{|c|c|c|c|c|c|c|c|c|c|c|c|c|c|}
\hline \multicolumn{4}{|c|}{ PARAMETER NAME } & UNITS & \multirow[b]{2}{*}{ MEAN } & \multirow{2}{*}{$\begin{array}{r}\text { STANDARD } \\
\text { DEVIATION }\end{array}$} & \multirow{2}{*}{$\begin{array}{c}\text { COEFF. } \\
\text { OF } \\
\text { VARIATION }\end{array}$} & \multirow{2}{*}{$\begin{array}{c}\% \text { OF } \\
\text { NON } \\
\text { DETECTS }\end{array}$} & \multirow{2}{*}{\multicolumn{3}{|c|}{$\begin{array}{l}\text { STATISTICAL RANGE } \\
\text { 98\% CONFIDENCE INTERVAL } \\
\text { MINIMUM MAXIMUM * }\end{array}$}} & \multirow[b]{2}{*}{$\begin{array}{c}\text { DISTRIBUTION } \\
\text { TYPE }\end{array}$} & \multirow[b]{2}{*}{\begin{tabular}{|l} 
FOOT \\
NOTE
\end{tabular}} \\
\hline \# OF SAMP & & NIMUM & MAXIMUM & MEDIAN & & & & & & & & & \\
\hline \multicolumn{4}{|l|}{ VANADIUM } & $M G / L$ & \multirow[b]{2}{*}{ NA } & \multirow[b]{2}{*}{ NA } & \multirow[b]{2}{*}{ NA } & \multirow[b]{2}{*}{69.6} & \multirow[b]{2}{*}{$\star \star$} & \multirow[b]{2}{*}{0.0100} & \multirow[b]{2}{*}{0.0100} & \multirow[b]{2}{*}{ NONPARAMETRIC } & \multirow[b]{2}{*}{2} \\
\hline 23 & ** & 0.0100 & 0.0300 & 0.0100 & & & & & & & & & \\
\hline \multicolumn{4}{|l|}{ ZINC } & MG/L & \multirow[b]{2}{*}{ NA } & \multirow[b]{2}{*}{ NA } & \multirow[b]{2}{*}{ NA } & \multirow[b]{2}{*}{34.8} & \multirow{2}{*}{\multicolumn{2}{|c|}{0.0050}} & \multirow[b]{2}{*}{0.0250} & \multirow[b]{2}{*}{ NONPARAMETRIC } & \multirow[b]{2}{*}{2} \\
\hline 23 & ** & 0.0050 & 0.0540 & 0.0120 & & & & & & & & & \\
\hline
\end{tabular}

** The reported value is the minimum detection limit of the data set

* The statistical maximum is the 99 percent one sided confidence interval, $\alpha=0.01$

2) The nomparametric distribution was used because the nondetected values comprise more than $15 \%$ of the samples.

INPUT DATA FILENAME: IDARTISRKO2IGHQ10014.DAT 
TABLE 3.54 GROUND HATER OUALITY DATA BY PARAMETER FOR MONITOR WELLS 684 AKD 685, NC AND UC PROCESSING SITES, SLICK ROCK, COLORADO

SITE: SRKO1 SLICK ROCK (BOTH SITES)

$06 / 30 / 86$

REPORT DATE: 06/28/95

\begin{tabular}{|c|c|c|c|c|c|c|c|c|c|c|c|}
\hline PARAMETER NAME & $\underset{\text { ID }}{\text { LOCATION }}$ & LOG DATE & $\underset{\text { ID }}{\text { SAMPLE }}$ & $\begin{array}{l}\text { FORM } \\
\text { CONP }\end{array}$ & $\begin{array}{l}\text { FLOW } \\
\text { REL. }\end{array}$ & $\begin{array}{l}\text { UNITS OF } \\
\text { MEASURE }\end{array}$ & PVI & $\begin{array}{l}\text { PARAMETER } \\
\text { VALUE }\end{array}$ & FLAGS & $\begin{array}{l}\text { DETECTION } \\
\text { LIMIT }\end{array}$ & $\begin{array}{l}\text { PARAMETER } \\
\text { UNCERTAINTY }\end{array}$ \\
\hline ALKALINITY & $\begin{array}{l}0684 \\
0684 \\
0684 \\
0684 \\
0684 \\
0684 \\
0684 \\
0684 \\
0685 \\
0685 \\
0685 \\
0685 \\
0685 \\
0685 \\
0685 \\
0685 \\
0685\end{array}$ & $\begin{array}{l}06 / 30 / 86 \\
04 / 08 / 87 \\
10 / 15 / 87 \\
02 / 22 / 88 \\
03 / 28 / 91 \\
08 / 06 / 91 \\
10 / 15 / 92 \\
02 / 21 / 94 \\
07 / 17 / 86 \\
04 / 08 / 87 \\
10 / 15 / 87 \\
02 / 22 / 88 \\
03 / 28 / 91 \\
08 / 06 / 91 \\
12 / 05 / 91 \\
10 / 08 / 92 \\
02 / 21 / 94\end{array}$ & $\begin{array}{l}0001 \\
0001 \\
0001 \\
0001 \\
0001 \\
0001 \\
0001 \\
N 001 \\
0001 \\
0001 \\
0001 \\
0001 \\
0001 \\
0001 \\
0001 \\
0001 \\
\text { H001 }\end{array}$ & $\begin{array}{l}A L \\
A L \\
A L \\
A L \\
A L \\
A L \\
A L \\
A L \\
A L \\
A L \\
A L \\
A L \\
A L \\
A L \\
A L \\
A L \\
A L\end{array}$ & $\begin{array}{l}\text { D } \\
\text { D } \\
\text { D } \\
\text { D } \\
\text { D } \\
\text { D } \\
\text { D } \\
\text { D } \\
\text { D } \\
\text { D } \\
\text { D } \\
D \\
D \\
D \\
D \\
D \\
D\end{array}$ & $\mathrm{MG} / \mathrm{L} \mathrm{CACO} 3$ & & $\begin{array}{l}223 . \\
192 . \\
187.0 \\
176 . \\
179 . \\
173 \\
160 \\
195 \\
336 . \\
388 . \\
328 . \\
315 . \\
281 . \\
307 \\
284 \\
295 \\
310\end{array}$ & & $\begin{array}{l}- \\
- \\
- \\
- \\
- \\
- \\
- \\
- \\
- \\
- \\
- \\
- \\
- \\
-\end{array}$ & $\begin{array}{l}- \\
- \\
- \\
- \\
- \\
- \\
- \\
- \\
- \\
- \\
- \\
- \\
- \\
-\end{array}$ \\
\hline ALUNINUM & $\begin{array}{l}0684 \\
0684 \\
0684 \\
0684 \\
0684 \\
0684 \\
0684 \\
0684 \\
0685 \\
0685 \\
0685 \\
0685 \\
0685 \\
0685 \\
0685 \\
0685\end{array}$ & $\begin{array}{l}06 / 30 / 86 \\
04 / 08 / 87 \\
10 / 15 / 87 \\
02 / 22 / 88 \\
03 / 28 / 91 \\
08 / 06 / 91 \\
11 / 19 / 91 \\
10 / 15 / 92 \\
07 / 17 / 86 \\
04 / 08 / 87 \\
10 / 15 / 87 \\
02 / 22 / 88 \\
03 / 28 / 91 \\
08 / 06 / 91 \\
11 / 20 / 91 \\
10 / 08 / 92\end{array}$ & $\begin{array}{l}0001 \\
0001 \\
0001 \\
0001 \\
0001 \\
0001 \\
0001 \\
0001 \\
0001 \\
0001 \\
0001 \\
0001 \\
0001 \\
0001 \\
0001 \\
0001\end{array}$ & $\begin{array}{l}A L \\
A L \\
A L \\
A L \\
A L \\
A L \\
A L \\
A L \\
A L \\
A L \\
A L \\
A L \\
A L \\
A L \\
A L \\
A L\end{array}$ & $\begin{array}{l}D \\
D \\
D \\
D \\
D \\
D \\
D \\
D \\
D \\
D \\
D \\
D \\
D \\
D \\
D \\
D\end{array}$ & MG/L & $\begin{array}{l}< \\
< \\
< \\
< \\
< \\
< \\
< \\
< \\
< \\
< \\
< \\
< \\
<\end{array}$ & $\begin{array}{l}0.3 \\
0.1 \\
0.1 \\
0.12 \\
0.05 \\
0.05 \\
0.05 \\
0.05 \\
0.4 \\
0.1 \\
0.1 \\
0.18 \\
0.05 \\
0.05 \\
0.05 \\
0.05\end{array}$ & & $\begin{array}{l}0.1 \\
0.1 \\
0.1 \\
0.1 \\
0.05 \\
0.05 \\
0.05 \\
0.05 \\
0.1 \\
0.1 \\
0.1 \\
0.1 \\
0.05 \\
0.05 \\
0.05 \\
0.05\end{array}$ & $\begin{array}{l}- \\
- \\
- \\
- \\
- \\
- \\
- \\
- \\
- \\
- \\
- \\
-\end{array}$ \\
\hline AMHONIUM & $\begin{array}{l}0684 \\
0684 \\
0684 \\
0684 \\
0684\end{array}$ & $\begin{array}{l}06 / 30 / 86 \\
04 / 08 / 87 \\
10 / 15 / 87 \\
02 / 22 / 88 \\
03 / 28 / 91\end{array}$ & $\begin{array}{l}0001 \\
0001 \\
0001 \\
0001 \\
0009\end{array}$ & $\begin{array}{l}A L \\
A L \\
A L \\
A L \\
A L\end{array}$ & $\begin{array}{l}\text { D } \\
\text { D } \\
\text { D } \\
\text { D } \\
\text { D }\end{array}$ & $M G / L$ & $<$ & $\begin{array}{l}1 . \\
0.5 \\
0.3 \\
0.1 \\
0.6\end{array}$ & J & $\begin{array}{l}0.1 \\
0.1 \\
0.1 \\
0.1 \\
0.1\end{array}$ & $\begin{array}{l}- \\
- \\
- \\
-\end{array}$ \\
\hline
\end{tabular}

FOPHATION OF COMPLETION CODE:

AL. - ALLUVIUH

PARAMETER VALUE INDICATOR (PVI): < - LESS THAN DETECTION LIMIT

OTHER PARAMETER VALUE FLAGS:

$J$ - ESTIMATED VALUE
FLOU RELATIONSHIP CODE:

D - DOWN GRADIENT

SAMPLE ID COOES:

0001 - FILTERED SAMPLE (.45 MICRONS)

NOO1 - UHFILTERED SAMPLE 
TABLE 3.54 GROUHD WATER QUALITY DATA BY PARAMETER FOR MONITOR WELLS 684 AND 685. HC AHD UC PROCESSING SITES, SLICK ROCK, COLORADO

SITE: SRKO1 SLICK ROCK (BOTH SITES)

06/30/86 TO 02/21/94

REPORT DATE: $06 / 28 / 95$

\begin{tabular}{|c|c|c|c|c|c|c|c|c|c|c|c|}
\hline PARANETER NAME & $\underset{\text { ID }}{\text { LOCATION }}$ & LOG DATE & $\left|\begin{array}{c}\text { SAMPLE } \\
\text { ID }\end{array}\right|$ & $\begin{array}{l}\text { FORM } \\
\text { COMP }\end{array}$ & $\begin{array}{l}\text { FLOW } \\
\text { REL. }\end{array}$ & $\begin{array}{l}\text { UNITS OF } \\
\text { MEASURE }\end{array}$ & PVI & $\begin{array}{l}\text { PARAMETER } \\
\text { VALUE }\end{array}$ & FLAGS & $\begin{array}{l}\text { DETECTION } \\
\text { LIMIT }\end{array}$ & $\begin{array}{l}\text { PARAMETER } \\
\text { UNCERTAINTY }\end{array}$ \\
\hline AMAONIUM & $\begin{array}{l}0684 \\
0684 \\
0684 \\
0685 \\
0685 \\
0685 \\
0685 \\
0685 \\
0685 \\
0685\end{array}$ & $\begin{array}{l}08 / 06 / 91 \\
11 / 19 / 91 \\
10 / 15 / 92 \\
04 / 08 / 87 \\
10 / 15 / 87 \\
02 / 22 / 88 \\
03 / 28 / 91 \\
08 / 06 / 91 \\
11 / 20 / 91 \\
10 / 08 / 92\end{array}$ & $\begin{array}{l}0001 \\
0001 \\
0001 \\
0001 \\
0001 \\
0001 \\
0001 \\
0001 \\
0001 \\
0001\end{array}$ & $\begin{array}{l}A L \\
A L \\
A L \\
A L \\
A L \\
A L \\
A L \\
A L \\
A L \\
A L\end{array}$ & $\begin{array}{l}\text { D } \\
\text { D } \\
\text { D } \\
\text { D } \\
\text { D } \\
\text { D } \\
\text { D } \\
\text { D } \\
\text { D } \\
\text { D }\end{array}$ & $M G / L$ & $<$ & $\begin{array}{l}0.9 \\
0.5 \\
0.7 \\
3.0 \\
2.6 \\
0.1 \\
2.4 \\
2.2 \\
2.2 \\
2.9\end{array}$ & & $\begin{array}{l}0.1 \\
0.1 \\
0.1 \\
0.1 \\
0.1 \\
0.1 \\
0.1 \\
0.1 \\
0.1 \\
0.2\end{array}$ & $\begin{array}{l}- \\
- \\
- \\
- \\
- \\
- \\
-\end{array}$ \\
\hline AMMONIUM (TOTAL) & $\begin{array}{l}0684 \\
0685\end{array}$ & $\begin{array}{l}02 / 21 / 94 \\
02 / 21 / 94\end{array}$ & $\begin{array}{l}\text { N001 } \\
\text { N001 }\end{array}$ & $\begin{array}{l}\text { AL } \\
\mathbf{A L}\end{array}$ & $\begin{array}{l}\text { D } \\
\text { D }\end{array}$ & $M G / L$ & & $\begin{array}{l}0.7 \\
1.6\end{array}$ & & $\begin{array}{l}0.1 \\
0.1\end{array}$ & $\dot{-}$ \\
\hline ANT IMONY & $\begin{array}{l}0684 \\
0684 \\
0684 \\
0684 \\
0684 \\
0684 \\
0685 \\
0685 \\
0685 \\
0685 \\
0685\end{array}$ & $\begin{array}{l}06 / 30 / 86 \\
04 / 08 / 87 \\
03 / 28 / 91 \\
08 / 06 / 91 \\
11 / 19 / 91 \\
10 / 15 / 92 \\
04 / 08 / 87 \\
03 / 28 / 91 \\
08 / 06 / 91 \\
11 / 20 / 91 \\
10 / 08 / 92\end{array}$ & $\begin{array}{l}0001 \\
0001 \\
0001 \\
0001 \\
0001 \\
0001 \\
0001 \\
0001 \\
0001 \\
0001 \\
0001\end{array}$ & $\begin{array}{l}A L \\
A L \\
A L \\
A L \\
A L \\
A L \\
A L \\
A L \\
A L \\
A L \\
A L\end{array}$ & $\begin{array}{l}D \\
D \\
D \\
D \\
D \\
D \\
D \\
D \\
D \\
D \\
D\end{array}$ & $\mathbf{M G} / \mathbf{L}$ & $\begin{array}{l}< \\
< \\
< \\
< \\
< \\
< \\
< \\
< \\
< \\
< \\
<\end{array}$ & $\begin{array}{l}0.003 \\
0.003 \\
0.005 \\
0.003 \\
0.003 \\
0.003 \\
0.011 \\
0.005 \\
0.003 \\
0.003 \\
0.003\end{array}$ & I & $\begin{array}{l}0.003 \\
0.003 \\
0.005 \\
0.003 \\
0.003 \\
0.003 \\
0.003 \\
0.005 \\
0.003 \\
0.003 \\
0.003\end{array}$ & $\begin{array}{l}- \\
- \\
- \\
- \\
- \\
- \\
- \\
- \\
-\end{array}$ \\
\hline ARSENIC & $\begin{array}{l}0684 \\
0684 \\
0684 \\
0684 \\
0684 \\
0684 \\
0684 \\
0685 \\
0685 \\
0685 \\
0685 \\
0685\end{array}$ & $\begin{array}{l}06 / 30 / 86 \\
04 / 08 / 87 \\
10 / 15 / 87 \\
03 / 28 / 91 \\
08 / 06 / 91 \\
111 / 19 / 91 \\
10 / 15 / 92 \\
07 / 17 / 86 \\
04 / 08 / 87 \\
10 / 15 / 87 \\
03 / 28 / 91 \\
08 / 06 / 91\end{array}$ & $\begin{array}{l}0001 \\
0001 \\
0001 \\
0001 \\
0001 \\
0001 \\
0001 \\
0001 \\
0001 \\
0001 \\
0001 \\
0001\end{array}$ & $\begin{array}{l}A L \\
A L \\
A L \\
A L \\
A L \\
A L \\
A L \\
A L \\
A L \\
A L \\
A L \\
A L\end{array}$ & $\begin{array}{l}D \\
D \\
D \\
D \\
D \\
D \\
D \\
D \\
D \\
D \\
D \\
D\end{array}$ & MG/L & $\begin{array}{l}< \\
< \\
< \\
< \\
< \\
< \\
< \\
< \\
< \\
< \\
< \\
<\end{array}$ & $\begin{array}{l}0.01 \\
0.001 \\
0.01 \\
0.01 \\
0.01 \\
0.01 \\
0.005 \\
0.01 \\
0.001 \\
0.01 \\
0.01 \\
0.01\end{array}$ & $\begin{array}{l}\mathbf{J} \\
\mathbf{H}\end{array}$ & $\begin{array}{l}0.01 \\
0.01 \\
0.01 \\
0.01 \\
0.01 \\
0.01 \\
0.005 \\
0.01 \\
0.01 \\
0.01 \\
0.01 \\
0.01\end{array}$ & $\begin{array}{l}- \\
- \\
- \\
- \\
- \\
- \\
- \\
- \\
-\end{array}$ \\
\hline
\end{tabular}

FORMATION OF COMPLETION CODE:

AL - ALLUVIUM

PARAMETER VALUE INDICATOR (PVI): < - LESS THAN DETECTIOH LIMIT

\section{OTHER PARAMETER VALUE FLAGS:}

I - INCREASED DETECTION LIMIT DUE TO REQUIRED DILUTION

$J$ - ESTIMATED VALUE

H - POST-DIGEST SPIKE OUT OF CNTR LIM HHILE SAMP ABS < 50\% SPIKE
FLOU RELATIONSHIP COOE:

D - DOWN GRADIENT

SAYPLE ID CODES

0001 - FILTERED SAMPLE (.45 MICRONS)

NOOI - UMFILTERED SAMPLE 
TABLE 3.54 GROUND WATER QUALITY DATA BY PARAMETER FOR MONITOR WELLS 684 AND 685, NC AND UC PROCESSIHG SITES, SLICK ROCK, COLORADO

SITE: SRKO1 SLICK ROCK (BOTH SITES)

06/30/86 TO 02/21/94

REPORT DATE: $06 / 28 / 95$

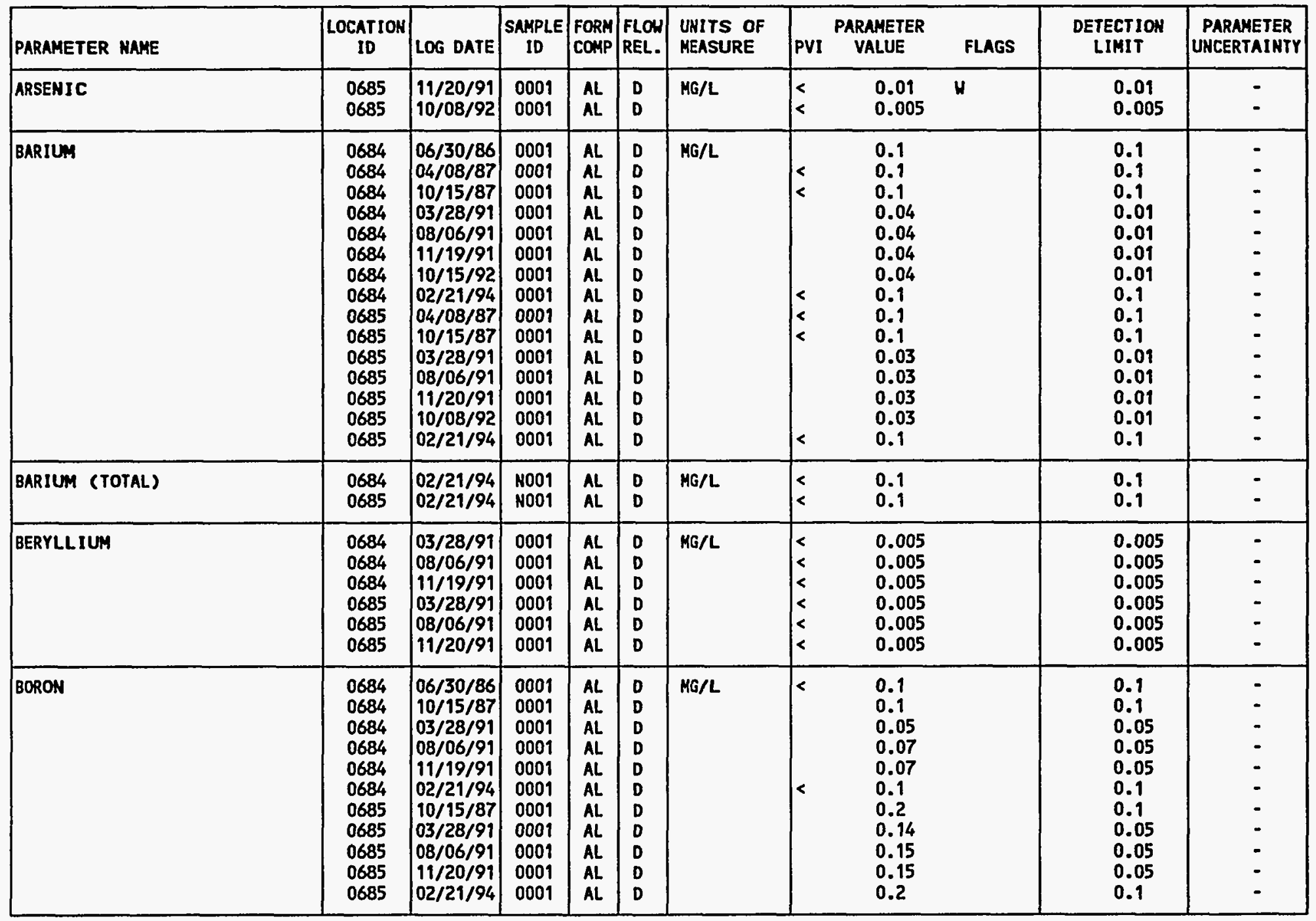

FORMATION OF COMPLETION COOE:

AL. - AlLUVIUM

PARAMETER VALUE IMDICATOR (PVI): < - LESS THAN DETECTION LIMIT

OTHER PARAMETER VALUE FLAGS:

$H$ - POST-DIGEST SPIKE OUT OF CHTR LIM WHILE SAMP ABS < 50\% SPIKE
FLOW RELATIONSHIP CODE:

D - DOWN GRADIENT

\section{SAMPLE ID CODES:}

0001 - FILTERED SAMPLE (.45 MICRONS)

HOO1 - UNFILTERED SAMPLE 
TABLE 3.54 GROUND WATER QUALITY DATA BY PARAMETER FOR MONITOR WELLS 684 AND 685, NC AND UC PROCESSING SITES, SLICK ROCK, COLORADO

SITE: SRKO1 SLICK ROCK (BOTH SITES)

06/30/86 TO 02/21/94

REPORT DATE: $06 / 28 / 95$

\begin{tabular}{|c|c|c|c|c|c|c|c|c|c|c|c|}
\hline PARAMETER MAME & $\underset{\text { ID }}{\text { LOCATION }}$ & LOG DATE & $\underset{\text { ID }}{\text { SAMPLE }}$ & $\begin{array}{l}\text { FORM } \\
\text { COAPP }\end{array}$ & $\begin{array}{l}\text { FLOU } \\
\text { REL. }\end{array}$ & $\begin{array}{l}\text { UNITS OF } \\
\text { MEASURE }\end{array}$ & PVI & $\begin{array}{l}\text { PARAMETER } \\
\text { VALUE }\end{array}$ & FLAGS & $\begin{array}{l}\text { DETECTIOH } \\
\text { LIMIT }\end{array}$ & $\begin{array}{l}\text { PARAMETER } \\
\text { UNCERTAINTY }\end{array}$ \\
\hline BORON (TOTAL) & $\begin{array}{l}0684 \\
0685\end{array}$ & $\begin{array}{l}02 / 21 / 94 \\
02 / 21 / 94\end{array}$ & $\begin{array}{l}\text { N001 } \\
\text { N001 }\end{array}$ & $\stackrel{A L}{A L}$ & $\begin{array}{l}\text { D } \\
\text { D }\end{array}$ & MG/L & $<$ & $\begin{array}{l}0.1 \\
0.2\end{array}$ & & $\begin{array}{l}0.1 \\
0.1\end{array}$ & : \\
\hline BROMIDE & $\begin{array}{l}0684 \\
0684 \\
0684 \\
0684 \\
0685 \\
0685 \\
0685 \\
0685\end{array}$ & $\begin{array}{l}03 / 28 / 91 \\
08 / 06 / 91 \\
11 / 19 / 91 \\
10 / 15 / 92 \\
03 / 28 / 91 \\
08 / 06 / 91 \\
11 / 20 / 91 \\
10 / 08 / 92\end{array}$ & $\begin{array}{l}0001 \\
0001 \\
0001 \\
0001 \\
0001 \\
0001 \\
0001 \\
0001\end{array}$ & $\begin{array}{l}A L \\
A L \\
A L \\
A L \\
A L \\
A L \\
A L \\
A L\end{array}$ & $\begin{array}{l}\text { D } \\
D \\
D \\
D \\
D \\
D \\
D \\
D\end{array}$ & $M G / L$ & < & $\begin{array}{l}0.1 \\
0.1 \\
0.1 \\
0.3 \\
0.2 \\
0.1 \\
0.2 \\
0.2\end{array}$ & I & $\begin{array}{l}0.1 \\
0.1 \\
0.1 \\
0.3 \\
0.1 \\
0.1 \\
0.1 \\
0.2\end{array}$ & $\begin{array}{l}- \\
- \\
- \\
- \\
- \\
-\end{array}$ \\
\hline CADMIUM & $\begin{array}{l}0684 \\
0684 \\
0684 \\
0684 \\
0684 \\
0684 \\
0684 \\
0684 \\
0685 \\
0685 \\
0685 \\
0685 \\
0685 \\
0685 \\
0685\end{array}$ & $\begin{array}{l}06 / 30 / 86 \\
04 / 08 / 87 \\
10 / 15 / 87 \\
03 / 28 / 91 \\
08 / 06 / 91 \\
11 / 19 / 91 \\
10 / 15 / 92 \\
02 / 21 / 94 \\
04 / 08 / 87 \\
10 / 15 / 87 \\
03 / 28 / 91 \\
08 / 06 / 91 \\
11 / 20 / 91 \\
10 / 08 / 92 \\
02 / 21 / 94\end{array}$ & $\begin{array}{l}0001 \\
0001 \\
0001 \\
0001 \\
0001 \\
0001 \\
0001 \\
0001 \\
0001 \\
0001 \\
0001 \\
0001 \\
0001 \\
0001 \\
0001\end{array}$ & $\begin{array}{l}A L \\
A L \\
A L \\
A L \\
A L \\
A L \\
A L \\
A L \\
A L \\
A L \\
A L \\
A L \\
A L \\
A L \\
A L\end{array}$ & $\begin{array}{l}\text { D } \\
\text { D } \\
\text { D } \\
\text { D } \\
D \\
D \\
D \\
D \\
D \\
D \\
D \\
D \\
D \\
D \\
D\end{array}$ & MG/L & $\begin{array}{l}< \\
< \\
< \\
< \\
< \\
< \\
< \\
< \\
< \\
< \\
< \\
< \\
< \\
< \\
< \\
<\end{array}$ & $\begin{array}{l}0.001 \\
0.001 \\
0.001 \\
0.001 \\
0.001 \\
0.001 \\
0.001 \\
0.001 \\
0.001 \\
0.001 \\
0.001 \\
0.001 \\
0.001 \\
0.001 \\
0.001\end{array}$ & & $\begin{array}{l}0.001 \\
0.001 \\
0.001 \\
0.001 \\
0.001 \\
0.001 \\
0.001 \\
0.001 \\
0.001 \\
0.001 \\
0.001 \\
0.001 \\
0.001 \\
0.001 \\
0.001\end{array}$ & $\begin{array}{l}- \\
- \\
: \\
: \\
- \\
- \\
: \\
: \\
- \\
-\end{array}$ \\
\hline CAOMIUM (TOTAL) & $\begin{array}{l}0684 \\
0685\end{array}$ & $\begin{array}{l}02 / 21 / 94 \\
02 / 21 / 94\end{array}$ & $\begin{array}{l}\text { N001 } \\
\text { N001 }\end{array}$ & $\begin{array}{l}A L \\
A L\end{array}$ & $\begin{array}{l}\text { D } \\
\text { D }\end{array}$ & MG/L & $<$ & $\begin{array}{l}0.001 \\
0.001\end{array}$ & & $\begin{array}{l}0.001 \\
0.001\end{array}$ & - \\
\hline CALCIUM & $\begin{array}{l}0684 \\
0684 \\
0684 \\
0684 \\
0684 \\
0684 \\
0684 \\
0684 \\
0684\end{array}$ & $\begin{array}{l}06 / 30 / 86 \\
04 / 08 / 87 \\
10 / 15 / 87 \\
02 / 22 / 88 \\
03 / 28 / 91 \\
08 / 06 / 91 \\
11 / 19 / 91 \\
10 / 15 / 92 \\
02 / 21 / 94\end{array}$ & $\begin{array}{l}0001 \\
0001 \\
0001 \\
0001 \\
0001 \\
0001 \\
0001 \\
0001 \\
0001\end{array}$ & $\begin{array}{l}A L \\
A L \\
A L \\
A L \\
A L \\
A L \\
A L \\
A L \\
A L\end{array}$ & $\begin{array}{l}D \\
D \\
D \\
D \\
D \\
D \\
D \\
D \\
D\end{array}$ & $M G / L$ & & $\begin{array}{l}82.6 \\
69.9 \\
60 . \\
57 . \\
67.0 \\
76.0 \\
75.5 \\
81.9 \\
64.7\end{array}$ & & $\begin{array}{l}0.01 \\
0.01 \\
0.01 \\
0.01 \\
0.5 \\
0.5 \\
0.5 \\
0.5 \\
0.5\end{array}$ & $\begin{array}{l}- \\
- \\
- \\
- \\
- \\
- \\
-\end{array}$ \\
\hline
\end{tabular}

FOPMATIOH OF COMPLETIOY COOE:

AL - ALLUVIUU

PARAMETER VALUE INDICATOR (PVI): < - LESS THAN DETECTION LIMIT

OTHER PARAMETER VALUE FLAGS:

I - INCREASED DETECTIOH LIMIT DUE TO REQUIRED DILUTION
FLOU RELATIOHSHIP CODE:

- DOWN GRADIENT

SAMPLE IO COOES:

0001 - FILTERED SAMPLE (.45 MICRONS)

N001 - UNFILTERED SAMPLE 
TABLE 3.54 GROUND MATER QUALITY DATA BY PARAMETER FOR MONITOR WELLS 684 AND

685, NC AND UC PROCESSING SITES, SLICK ROCK, COLORADO

SITE: SRKOI SLICK ROCK (BOTH SITES)

06/30/86 TO 02/21/94

REPORT DATE: $06 / 28 / 95$

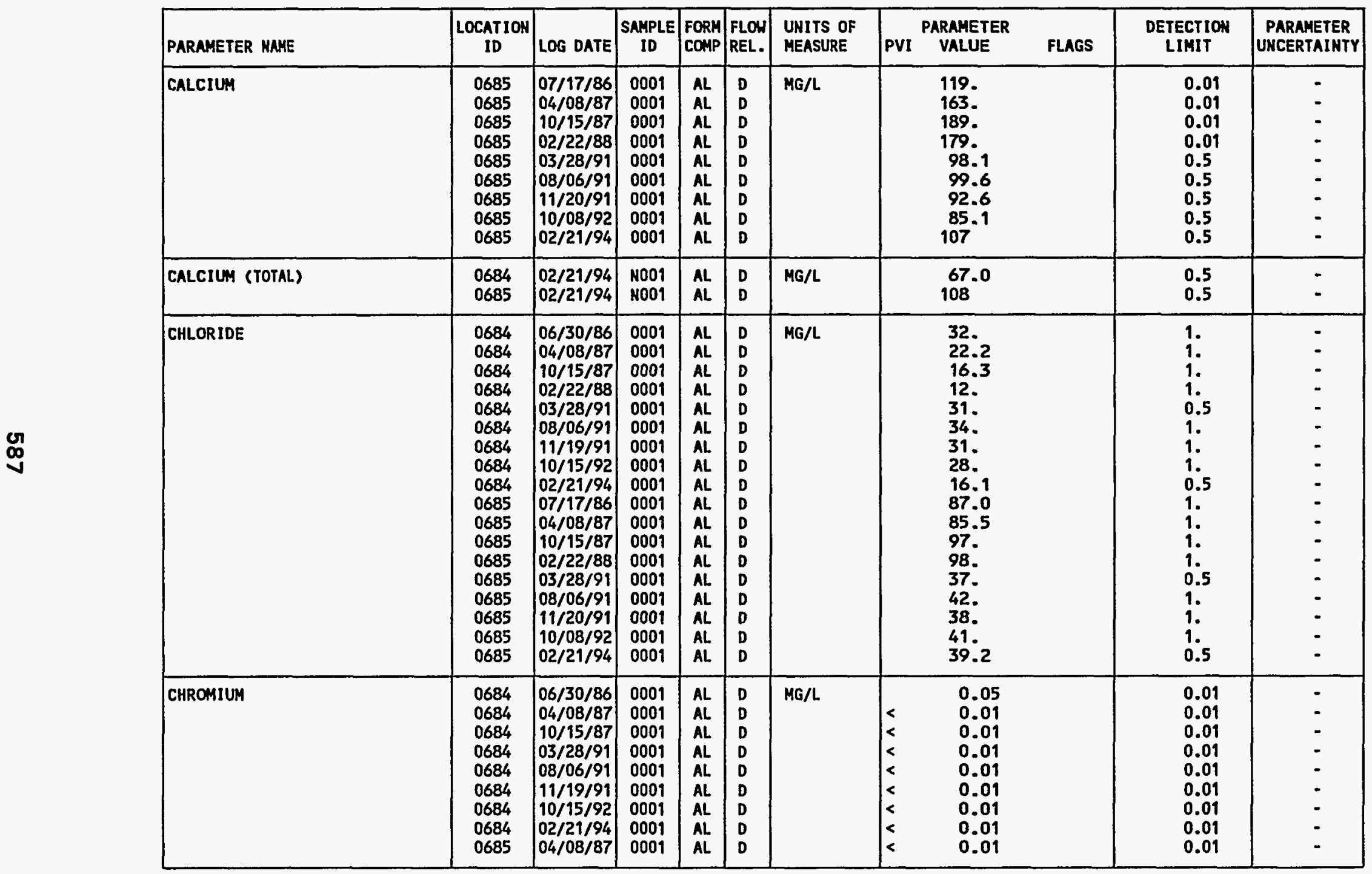

FORMATION OF COMPLETION COOE:

AL - ALLUVIUM

PARAMETER VALUE INDICATOR (PVI): < - LESS THAN DETECTION LIMIT
FLOH RELATIOHSHIP CODE:

D - DOWN GRADIENT

SAMPLE ID COOES

0001 - FILTERED SAMPLE (.45 MICRONS)

HOO1 - UNFILTERED SAMPLE 
TABLE 3.54 GROUND WATER QUALITY DATA BY PARAMETER FOR MONITOR WELLS 684 AND 685. NC AND UC PROCESSING SITES, SLICK ROCK, COLORADO

SITE: SRKO1 SLICK ROCK (BOTH SITES)

REPORT DATE: $06 / 28 / 95$

\begin{tabular}{|c|c|c|c|c|c|c|c|c|c|c|c|}
\hline PARAMETER NAME & $\underset{\text { LOTION }}{\text { LOCATION }}$ & LOG DATE & $\begin{array}{c}\text { SAMPLE } \\
\text { ID }\end{array}$ & $\begin{array}{l}\text { FORM } \\
\text { COMP }\end{array}$ & $\begin{array}{l}\text { FLOH } \\
\text { REL. }\end{array}$ & $\begin{array}{l}\text { UNITS OF } \\
\text { MEASURE }\end{array}$ & PVI & $\begin{array}{l}\text { ARAMETER } \\
\text { VALUE }\end{array}$ & FLAGS & $\begin{array}{l}\text { DETECTION } \\
\text { LIMIT }\end{array}$ & $\begin{array}{l}\text { PARAMETER } \\
\text { UNCERTAINTY }\end{array}$ \\
\hline CHROMIUM & $\begin{array}{l}0685 \\
0685 \\
0685 \\
0685 \\
0685 \\
0685\end{array}$ & $\begin{array}{l}10 / 15 / 87 \\
03 / 28 / 91 \\
08 / 06 / 91 \\
11 / 20 / 91 \\
10 / 08 / 92 \\
02 / 21 / 94\end{array}$ & $\begin{array}{l}0001 \\
0001 \\
0001 \\
0001 \\
0001 \\
0001\end{array}$ & $\begin{array}{l}A L \\
A L \\
A L \\
A L \\
A L \\
A L\end{array}$ & $\begin{array}{l}D \\
D \\
D \\
D \\
D \\
D\end{array}$ & $M G / L$ & $\begin{array}{l}< \\
< \\
< \\
< \\
< \\
<\end{array}$ & $\begin{array}{l}0.01 \\
0.01 \\
0.01 \\
0.01 \\
0.01 \\
0.01\end{array}$ & & $\begin{array}{l}0.01 \\
0.01 \\
0.01 \\
0.01 \\
0.01 \\
0.01\end{array}$ & $\begin{array}{l}- \\
- \\
- \\
-\end{array}$ \\
\hline CHROMIUH (TOTAL) & $\begin{array}{l}0684 \\
0685\end{array}$ & $\begin{array}{l}02 / 21 / 94 \\
02 / 21 / 94\end{array} \mid$ & $\begin{array}{l}\text { N001 } \\
\text { N001 }\end{array}$ & $\begin{array}{l}A L \\
A L\end{array}$ & $\begin{array}{l}\text { D } \\
\text { D }\end{array}$ & $M G / L$ & $<$ & $\begin{array}{l}0.01 \\
0.01\end{array}$ & & $\begin{array}{l}0.01 \\
0.01\end{array}$ & - \\
\hline COBALT & $\begin{array}{l}0684 \\
0684 \\
0684 \\
0685 \\
0685 \\
0685\end{array}$ & $\begin{array}{l}03 / 28 / 91 \\
08 / 06 / 91 \\
11 / 19 / 91 \\
03 / 28 / 91 \\
08 / 06 / 91 \\
11 / 20 / 91\end{array}$ & $\begin{array}{l}0001 \\
0001 \\
0001 \\
0001 \\
0001 \\
0001\end{array}$ & $\begin{array}{l}A L \\
A L \\
A L \\
A L \\
A L \\
A L\end{array}$ & $\begin{array}{l}\text { D } \\
\text { D } \\
\text { D } \\
\text { D } \\
\text { D } \\
\text { D }\end{array}$ & $M G / L$ & $\begin{array}{l}< \\
< \\
< \\
< \\
< \\
<\end{array}$ & $\begin{array}{l}0.03 \\
0.03 \\
0.03 \\
0.03 \\
0.03 \\
0.03\end{array}$ & & $\begin{array}{l}0.03 \\
0.03 \\
0.03 \\
0.03 \\
0.03 \\
0.03\end{array}$ & $\begin{array}{l}- \\
- \\
- \\
-\end{array}$ \\
\hline COPPER & $\begin{array}{l}0684 \\
0684 \\
0684 \\
0684 \\
0684 \\
0684 \\
0684 \\
0685 \\
0685 \\
0685 \\
0685 \\
0685 \\
0685\end{array}$ & $\begin{array}{l}06 / 30 / 86 \\
04 / 08 / 87 \\
10 / 15 / 87 \\
03 / 28 / 91 \\
08 / 06 / 91 \\
11 / 19 / 91 \\
10 / 15 / 92 \\
04 / 08 / 87 \\
10 / 15 / 87 \\
03 / 28 / 91 \\
08 / 06 / 91 \\
11 / 20 / 91 \\
10 / 08 / 92\end{array}$ & $\begin{array}{l}0001 \\
0001 \\
0001 \\
0001 \\
0001 \\
0001 \\
0001 \\
0001 \\
0001 \\
0001 \\
0001 \\
0001 \\
0001\end{array}$ & $\begin{array}{l}A L \\
A L \\
A L \\
A L \\
A L \\
A L \\
A L \\
A L \\
A L \\
A L \\
A L \\
A L \\
A L\end{array}$ & $\begin{array}{l}\text { D } \\
\text { D } \\
\text { D } \\
D \\
D \\
D \\
D \\
D \\
D \\
D \\
D \\
D \\
D\end{array}$ & $M G / L$ & $\begin{array}{l}< \\
< \\
< \\
< \\
< \\
< \\
< \\
< \\
< \\
< \\
<\end{array}$ & $\begin{array}{l}0.04 \\
0.01 \\
0.02 \\
0.01 \\
0.01 \\
0.01 \\
0.01 \\
0.04 \\
0.02 \\
0.01 \\
0.01 \\
0.01 \\
0.01\end{array}$ & J & $\begin{array}{l}0.02 \\
0.02 \\
0.02 \\
0.01 \\
0.01 \\
0.01 \\
0.01 \\
0.02 \\
0.02 \\
0.01 \\
0.01 \\
0.01 \\
0.01\end{array}$ & $\begin{array}{l}- \\
- \\
- \\
- \\
- \\
- \\
- \\
- \\
-\end{array}$ \\
\hline CYANIDE & $\begin{array}{l}0684 \\
0684 \\
0684 \\
0685 \\
0685 \\
0685\end{array}$ & $\begin{array}{l}03 / 28 / 91 \\
08 / 06 / 91 \\
11 / 19 / 91 \\
03 / 28 / 91 \\
08 / 06 / 91 \\
11 / 20 / 91\end{array}$ & $\begin{array}{l}0001 \\
0001 \\
0001 \\
0001 \\
0001 \\
0001\end{array}$ & $\begin{array}{l}A L \\
A L \\
A L \\
A L \\
A L \\
A L\end{array}$ & $\begin{array}{l}D \\
D \\
D \\
D \\
D \\
D\end{array}$ & MG/L & $\begin{array}{l}< \\
< \\
< \\
< \\
< \\
<\end{array}$ & $\begin{array}{l}0.01 \\
0.01 \\
0.01 \\
0.01 \\
0.01 \\
0.01\end{array}$ & & $\begin{array}{l}0.01 \\
0.01 \\
0.01 \\
0.01 \\
0.01 \\
0.01\end{array}$ & $\begin{array}{l}- \\
- \\
- \\
-\end{array}$ \\
\hline DISSOLVED OXYGEN & $\begin{array}{l}0684 \\
0684\end{array}$ & $\begin{array}{l}10 / 15 / 92 \\
02 / 21 / 94\end{array}$ & $\begin{array}{l}0001 \\
\text { N001 }\end{array}$ & $\begin{array}{l}A L \\
A L\end{array}$ & $\begin{array}{l}D \\
D\end{array}$ & $M G / L$ & & $\begin{array}{l}0.0 \\
0.38\end{array}$ & & - & - \\
\hline
\end{tabular}

FORMATION OF COMPLETION CODE:

AL - ALLUVIUH

FLOW RELATIONSHIP CODE:

PARAMETER VALUE INDICATOR (PVI): < - LESS THAN DETECTION LIMIT

SAMPLE ID COOES:

0001 - FILTERED SAMPLE (.45 MICRONS)

OTHER PARAMETER VALUE FLAGS:

NO01 - UMFILTERED SAMPLE

$J$ - ESTIMATED VALUE 
TABLE 3.54 GROUND WATER QUALITY DATA BY PARAMETER FOR MOHITOR MELLS 684 AND 685. NC AKD UC PROCESSING SITES, SLICK ROCK, COLORADO

SITE: SRKO1 SLICK ROCK (BOTH SITES)

06/30/86 TO 02/21/94

REPORT DATE: $06 / 28 / 95$

\begin{tabular}{|c|c|c|c|c|c|c|c|c|c|c|c|c|}
\hline & PARAMETER NAME & $\mid \begin{array}{c}\text { LOCATIOH } \\
\text { ID }\end{array}$ & LOG DATE & $\underset{\text { SAMPLE }}{\text { ID }}$ & $\begin{array}{l}\text { FORM } \\
\text { CONP }\end{array}$ & $\begin{array}{l}\text { FLOW } \\
\text { REL. }\end{array}$ & $\begin{array}{l}\text { UNITS OF } \\
\text { MEASURE }\end{array}$ & |PVI & $\begin{array}{l}\text { PARAMETER } \\
\text { VALUE }\end{array}$ & FLAGS & $\begin{array}{l}\text { DETECTION } \\
\text { LIMIT }\end{array}$ & $\begin{array}{l}\text { PARAMETER } \\
\text { UNCERTAINTY }\end{array}$ \\
\hline & DISSOLVED OXYGEN & $\begin{array}{l}0685 \\
0685\end{array}$ & $\begin{array}{l}10 / 08 / 92 \\
02 / 21 / 94\end{array}$ & $\begin{array}{l}0001 \\
\text { N001 }\end{array}$ & $\begin{array}{l}A L \\
A L\end{array}$ & $\begin{array}{l}\text { D } \\
\text { D }\end{array}$ & MG/L & & $\begin{array}{l}0.6 \\
0.83\end{array}$ & & - & - \\
\hline & FIELD FE $(2+)$ & $\begin{array}{l}0684 \\
0684 \\
0685 \\
0685\end{array}$ & $\begin{array}{l}10 / 15 / 92 \\
02 / 21 / 94 \\
10 / 08 / 92 \\
02 / 21 / 94\end{array}$ & $\begin{array}{l}0001 \\
\text { N001 } \\
0001 \\
\text { N001 }\end{array}$ & $\begin{array}{l}A L \\
A L \\
A L \\
A L\end{array}$ & $\begin{array}{l}\text { D } \\
\text { D } \\
\text { D } \\
\text { D }\end{array}$ & MG/L & $<$ & $\begin{array}{l}0.0 \\
0.02 \\
0.08 \\
0.05\end{array}$ & & $\begin{array}{l}- \\
- \\
-\end{array}$ & $\begin{array}{l}- \\
- \\
-\end{array}$ \\
\hline & FIELD FE (TOTAL) & $\begin{array}{l}0684 \\
0684 \\
0685\end{array}$ & $\begin{array}{l}10 / 15 / 92 \\
02 / 21 / 94 \\
02 / 21 / 94\end{array}$ & $\begin{array}{l}0001 \\
\text { N001 } \\
\text { N001 }\end{array}$ & $\begin{array}{l}A L \\
A L \\
A L\end{array}$ & $\begin{array}{l}\text { D } \\
\text { D } \\
\text { D }\end{array}$ & $M G / L$ & $<$ & $\begin{array}{l}0.0 \\
0.02 \\
0.05\end{array}$ & & : & - \\
\hline $\begin{array}{l}\mathbb{\infty} \\
\infty \\
\infty\end{array}$ & FLUORIOE & $\begin{array}{l}0684 \\
0684 \\
0684 \\
0684 \\
0684 \\
0684 \\
0684 \\
0684 \\
0685 \\
0685 \\
0685 \\
0685 \\
0685 \\
0685 \\
0685\end{array}$ & $\begin{array}{l}06 / 30 / 86 \\
04 / 08 / 87 \\
10 / 15 / 87 \\
02 / 22 / 88 \\
03 / 28 / 91 \\
08 / 06 / 91 \\
11 / 19 / 91 \\
10 / 15 / 92 \\
04 / 08 / 87 \\
10 / 15 / 87 \\
02 / 22 / 88 \\
03 / 28 / 91 \\
08 / 06 / 91 \\
11 / 20 / 91 \\
10 / 08 / 92\end{array}$ & $\begin{array}{l}0001 \\
0001 \\
0001 \\
0001 \\
0001 \\
0001 \\
0001 \\
0001 \\
0001 \\
0001 \\
0001 \\
0001 \\
0001 \\
0001 \\
0001\end{array}$ & $\begin{array}{l}A L \\
A L \\
A L \\
A L \\
A L \\
A L \\
A L \\
A L \\
A L \\
A L \\
A L \\
A L \\
A L \\
A L \\
A L\end{array}$ & $\begin{array}{l}\text { D } \\
\text { D } \\
\text { D } \\
\text { D } \\
\text { D } \\
\text { D } \\
\text { D } \\
\text { D } \\
\text { D } \\
\text { D } \\
\text { D } \\
\text { D } \\
\text { D } \\
\text { D } \\
\text { D }\end{array}$ & $M G / L$ & & $\begin{array}{l}0.4 \\
0.43 \\
0.4 \\
0.43 \\
0.3 \\
0.3 \\
0.3 \\
0.3 \\
0.38 \\
0.4 \\
0.35 \\
0.4 \\
0.4 \\
0.5 \\
0.4\end{array}$ & & $\begin{array}{l}0.1 \\
0.1 \\
0.1 \\
0.1 \\
0.1 \\
0.1 \\
0.1 \\
0.1 \\
0.1 \\
0.1 \\
0.1 \\
0.1 \\
0.1 \\
0.1 \\
0.1\end{array}$ & $\begin{array}{l}- \\
- \\
- \\
- \\
- \\
- \\
- \\
- \\
- \\
- \\
-\end{array}$ \\
\hline & GROSS ALPHA & $\begin{array}{l}0684 \\
0684 \\
0684 \\
0684 \\
0684 \\
0685 \\
0685 \\
0685 \\
0685 \\
0685\end{array}$ & $\begin{array}{l}03 / 28 / 91 \\
08 / 06 / 91 \\
12 / 05 / 91 \\
10 / 15 / 92 \\
02 / 21 / 94 \\
03 / 28 / 91 \\
08 / 06 / 91 \\
12 / 05 / 91 \\
10 / 08 / 92 \\
02 / 21 / 94\end{array}$ & $\begin{array}{l}0001 \\
0001 \\
0001 \\
0001 \\
0001 \\
0001 \\
0001 \\
0001 \\
0001 \\
0001\end{array}$ & $\begin{array}{l}A L \\
A L \\
A L \\
A L \\
A L \\
A L \\
A L \\
A L \\
A L \\
A L\end{array}$ & $\begin{array}{l}\text { D } \\
\text { D } \\
\text { D } \\
\text { D } \\
\text { D } \\
\text { D } \\
\text { D } \\
\text { D } \\
\text { D } \\
\text { D }\end{array}$ & $\mathrm{PCI} / \mathrm{L}$ & & $\begin{array}{r}7.7 \\
0.0 \\
0.0 \\
2.5 \\
8.0 \\
16.2 \\
12.9 \\
1.5 \\
9.5 \\
16.0\end{array}$ & JN & $\begin{array}{l}1 . \\
1 . \\
1.0 \\
1.7 \\
1.3 \\
1.0 \\
1 . \\
9.1 \\
2.0\end{array}$ & $\begin{array}{r}5.3 \\
4.6 \\
9.0 \\
4.9 \\
1.5 \\
8.8 \\
8.3 \\
11.4 \\
6.8 \\
2.8\end{array}$ \\
\hline & GROSS ALPHA (TOTAL) & 0684 & $02 / 21 / 94$ & HOOI & At. & D & $\mathrm{PCl} / \mathrm{L}$ & & 6.5 & JN & 1.2 & 1.5 \\
\hline
\end{tabular}

FORMATIOH OF COMPLETIOH COOE:

AL - AlluViUM

PARAMETER VALUE INDICATOR (PVI): < - LESS THAN DETECTIOH LIMIT

OTHER PARAMETER VALUE FLAGS:

$J$ - ESTIMATED VALUE

N - SPIKE SAMPLE RECOVERY NOT HITHIN CONTROL LIMITS
FLON RELATIONSHIP CODE

- DOWN GRADIENT

SAMPLE ID CODES

0001 - FILTERED SAMPLE (.45 MICRONS)

NO01 - UNFILTERED SAMPLE 
TABLE 3.54 GROUND WATER QUALITY DATA BY PARAMETER FOR MONITOR MELLS 684 AND 685, NC AND UC PROCESSING SITES, SLICK ROCK, COLORADO

SITE: SRKO1 SLICK ROCK (BOTH SITES)

06/30/86 TO 02/21/94

REPORT DATE: 06/28/95

\begin{tabular}{|c|c|c|c|c|c|c|c|c|c|c|c|}
\hline PARAMETER HAME & $\underset{\text { ID }}{\text { LOCATION }}$ & LOG DATE & $\underset{\text { ID }}{\text { SAMPLE }}$ & $\begin{array}{l}\text { FORM } \\
\text { COMP }\end{array}$ & $\begin{array}{l}\text { FLOW } \\
\text { REL. }\end{array}$ & $\begin{array}{l}\text { UNITS OF } \\
\text { MEASURE }\end{array}$ & PVI & $\begin{array}{l}\text { ARAMETER } \\
\text { VALUE }\end{array}$ & FLAGS & $\begin{array}{l}\text { DETECTION } \\
\text { LIMIT }\end{array}$ & $\begin{array}{l}\text { PARAMETER } \\
\text { UNCERTAINTY }\end{array}$ \\
\hline GROSS ALPHA (TOTAL) & 0685 & $02 / 21 / 94$ & N001 & AL & D & $\mathrm{PCl} / \mathrm{L}$ & & 65.0 & JN & 10.6 & 12.8 \\
\hline GROSS BETA & $\begin{array}{l}0684 \\
0684 \\
0684 \\
0684 \\
0685 \\
0685 \\
0685 \\
0685\end{array}$ & $\begin{array}{l}03 / 28 / 91 \\
08 / 06 / 91 \\
12 / 05 / 91 \\
10 / 15 / 92 \\
03 / 28 / 91 \\
08 / 06 / 91 \\
12 / 05 / 91 \\
10 / 08 / 92\end{array}$ & $\begin{array}{l}0001 \\
0001 \\
0001 \\
0001 \\
0001 \\
0001 \\
0001 \\
0001\end{array}$ & $\begin{array}{l}A L \\
A L \\
A L \\
A L \\
A L \\
A L \\
A L \\
A L\end{array}$ & $\begin{array}{l}D \\
D \\
D \\
D \\
D \\
D \\
D \\
D\end{array}$ & PCI/L & & $\begin{array}{r}9.6 \\
8.5 \\
1.0 \\
16.7 \\
12.5 \\
11.0 \\
0.0 \\
5.6\end{array}$ & * $N$ & $\begin{array}{l}0.5 \\
0.5 \\
0.5 \\
7.1 \\
0.5 \\
0.5 \\
0.5 \\
6.7\end{array}$ & $\begin{array}{l}3.1 \\
3.2 \\
5.4 \\
4.9 \\
4.8 \\
4.4 \\
7.7 \\
4.3\end{array}$ \\
\hline IRON & $\begin{array}{l}0684 \\
0684 \\
0684 \\
0684 \\
0684 \\
0684 \\
0684 \\
0684 \\
0684 \\
0685 \\
0685 \\
0685 \\
0685 \\
0685 \\
0685 \\
0685 \\
0685 \\
0685\end{array}$ & $\begin{array}{l}06 / 30 / 86 \\
04 / 08 / 87 \\
10 / 15 / 87 \\
02 / 22 / 88 \\
03 / 28 / 91 \\
08 / 06 / 91 \\
11 / 19 / 91 \\
10 / 15 / 92 \\
02 / 21 / 94 \\
07 / 17 / 86 \\
04 / 08 / 87 \\
10 / 15 / 87 \\
02 / 22 / 88 \\
03 / 28 / 91 \\
08 / 06 / 91 \\
11 / 20 / 91 \\
10 / 08 / 92 \\
02 / 21 / 94\end{array}$ & $\begin{array}{l}0001 \\
0001 \\
0001 \\
0001 \\
0001 \\
0001 \\
0001 \\
0001 \\
0001 \\
0001 \\
0001 \\
0001 \\
0001 \\
0001 \\
0001 \\
0001 \\
0001 \\
0001\end{array}$ & $\begin{array}{l}A L \\
A L \\
A L \\
A L \\
A L \\
A L \\
A L \\
A L \\
A L \\
A L \\
A L \\
A L \\
A L \\
A L \\
A L \\
A L \\
A L \\
A L\end{array}$ & $\begin{array}{l}D \\
D \\
D \\
D \\
D \\
D \\
D \\
D \\
D \\
D \\
D \\
D \\
D \\
D \\
D \\
D \\
D \\
D\end{array}$ & $M G / L$ & $\begin{array}{l}< \\
< \\
< \\
< \\
< \\
<\end{array}$ & $\begin{array}{l}0.05 \\
0.31 \\
0.03 \\
0.04 \\
0.03 \\
0.03 \\
0.03 \\
0.03 \\
0.03 \\
0.29 \\
0.64 \\
0.40 \\
0.44 \\
0.07 \\
0.08 \\
0.07 \\
0.07 \\
0.06\end{array}$ & & $\begin{array}{l}0.03 \\
0.03 \\
0.03 \\
0.03 \\
0.03 \\
0.03 \\
0.03 \\
0.03 \\
0.03 \\
0.03 \\
0.03 \\
0.03 \\
0.03 \\
0.03 \\
0.03 \\
0.03 \\
0.03 \\
0.03\end{array}$ & $\begin{array}{l}- \\
: \\
: \\
: \\
- \\
- \\
- \\
- \\
- \\
- \\
- \\
- \\
-\end{array}$ \\
\hline IRON (TOTAL) & $\begin{array}{l}0684 \\
0685\end{array}$ & $\begin{array}{l}02 / 21 / 94 \\
02 / 21 / 94\end{array}$ & $\begin{array}{l}\text { N001 } \\
\text { N001 }\end{array}$ & $\begin{array}{l}\text { AL } \\
\text { AL }\end{array}$ & $\begin{array}{l}\text { D } \\
\text { D }\end{array}$ & $M G / L$ & & $\begin{array}{l}0.11 \\
0.14\end{array}$ & & $\begin{array}{l}0.03 \\
0.03\end{array}$ & - \\
\hline LEAD & $\begin{array}{l}0684 \\
0684 \\
0684 \\
0684 \\
0684 \\
0684\end{array}$ & $\begin{array}{l}06 / 30 / 86 \\
04 / 08 / 87 \\
10 / 15 / 87 \\
03 / 28 / 91 \\
08 / 06 / 91 \\
11 / 19 / 91\end{array}$ & $\begin{array}{l}0001 \\
0001 \\
0001 \\
0001 \\
0001 \\
0001\end{array}$ & $\begin{array}{l}A L \\
A L \\
A L \\
A L \\
A L \\
A L\end{array}$ & $\begin{array}{l}D \\
D \\
D \\
D \\
D \\
D\end{array}$ & $M G / L$ & $\begin{array}{l}< \\
< \\
< \\
< \\
< \\
<\end{array}$ & $\begin{array}{l}0.01 \\
0.001 \\
0.01 \\
0.005 \\
0.005 \\
0.005\end{array}$ & J & $\begin{array}{l}0.01 \\
0.01 \\
0.01 \\
0.005 \\
0.005 \\
0.005\end{array}$ & $\begin{array}{l}- \\
- \\
- \\
- \\
-\end{array}$ \\
\hline
\end{tabular}

FORMATION OF COMPLETION CODE:

AL - ALLUVIUM

PARAMETER VALUE INDICATOR (PVI): < - LESS THAN DETECTION LIMIT

OTHER PARAMETER VALUE FLAGS:

* - DUPLICATE ANALYSIS NOT WITHIN CONTROL LIMITS

J - ESTIMATED VALUE

H - SPIKE SAMPLE RECOVERY NOT HITHIN CONTROL LIMITS
FLOW RELATIONSHIP COOE:

D - DOWN GRADIENT

\section{SAMPLE ID CODES:}

0001 - FILTERED SAMPLE (.45 MICRONS)

NOO1 - UHFILTERED SAMPLE 
TABLE 3.54 GROUND HATER QUALITY DATA BY PARAMETER FOR MONITOR MELLS 684 AMD 685, NC AND UC PROCESSING SITES, SLICK ROCK, COLORADO SITE: SRKO1 SLICK ROCK (BOTH SITES)

$06 / 30 / 86$ TO $02 / 21 / 94$

REPORT DATE: 06/28/95

\begin{tabular}{|c|c|c|c|c|c|c|c|c|c|c|c|}
\hline PARAMETER MAME & $\underset{\text { ID }}{\text { LOCATION }}$ & LOG DATE & $\underset{\text { ID }}{\text { SAMPLE }}$ & $\begin{array}{l}\text { FORM } \\
\text { COMP }\end{array}$ & $\begin{array}{l}\text { FLOW } \\
\text { REL. }\end{array}$ & $\begin{array}{l}\text { UNITS OF } \\
\text { MEASURE }\end{array}$ & PVI & $\begin{array}{l}\text { PARAMETER } \\
\text { VALUE }\end{array}$ & FLAGS & $\begin{array}{l}\text { DETECTION } \\
\text { LIMIT }\end{array}$ & $\begin{array}{l}\text { PARAMETER } \\
\text { UHCERTAINTY }\end{array}$ \\
\hline LEAD & $\begin{array}{l}0684 \\
0685 \\
0685 \\
0685 \\
0685 \\
0685 \\
0685\end{array}$ & $\begin{array}{l}10 / 15 / 92 \\
04 / 08 / 87 \\
10 / 15 / 87 \\
03 / 28 / 91 \\
08 / 06 / 91 \\
11 / 20 / 91 \\
10 / 08 / 92\end{array}$ & $\begin{array}{l}0001 \\
0001 \\
0001 \\
0001 \\
0001 \\
0001 \\
0001\end{array}$ & $\begin{array}{l}A L \\
A L \\
A L \\
A L \\
A L \\
A L \\
A L\end{array}$ & $\begin{array}{l}D \\
D \\
D \\
D \\
D \\
D \\
D\end{array}$ & MG/L & $\begin{array}{l}< \\
< \\
< \\
< \\
< \\
< \\
<\end{array}$ & $\begin{array}{l}0.003 \\
0.001 \\
0.01 \\
0.005 \\
0.005 \\
0.005 \\
0.02\end{array}$ & I & $\begin{array}{l}0.003 \\
0.01 \\
0.01 \\
0.005 \\
0.005 \\
0.005 \\
0.02\end{array}$ & $\begin{array}{l}- \\
- \\
- \\
- \\
-\end{array}$ \\
\hline LEAD-210 & $\begin{array}{l}0684 \\
0684 \\
0684 \\
0684 \\
0685 \\
0685 \\
0685\end{array}$ & \begin{tabular}{|l|}
$06 / 30 / 86$ \\
$08 / 06 / 91$ \\
$12 / 05 / 91$ \\
$02 / 21 / 94$ \\
$08 / 06 / 91$ \\
$12 / 05 / 91$ \\
$02 / 21 / 94$
\end{tabular} & $\begin{array}{l}0001 \\
0001 \\
0001 \\
0001 \\
0001 \\
0001 \\
0001\end{array}$ & $\begin{array}{l}A L \\
A L \\
A L \\
A L \\
A L \\
A L \\
A L\end{array}$ & $\begin{array}{l}D \\
D \\
D \\
D \\
D \\
D \\
D\end{array}$ & $\mathrm{PCl} / \mathrm{L}$ & & $\begin{array}{l}0 . \\
0.2 \\
0.0 \\
0.0 \\
0.8 \\
0.7 \\
3.9\end{array}$ & J & $\begin{array}{l}1.5 \\
1.5 \\
1.5 \\
3.5 \\
1.5 \\
1.5 \\
2.5\end{array}$ & $\begin{array}{l}1.1 \\
0.9 \\
0.9 \\
1.2 \\
0.9 \\
1.0 \\
1.1\end{array}$ \\
\hline LEAD-210 (TOTAL) & $\begin{array}{l}0684 \\
0685\end{array}$ & $\begin{array}{l}02 / 21 / 94 \\
02 / 21 / 94\end{array}$ & $\begin{array}{l}\text { N001 } \\
\text { N001 }\end{array}$ & $\begin{array}{l}\text { AL. } \\
\text { AL. }\end{array}$ & $\begin{array}{l}\text { D } \\
\text { D }\end{array}$ & $\mathrm{PCI} / \mathrm{L}$ & & $\begin{array}{l}0.0 \\
0.0\end{array}$ & & $\begin{array}{l}3.4 \\
2.4\end{array}$ & $\begin{array}{l}1.4 \\
0.8\end{array}$ \\
\hline MAGNESIUM & $\begin{array}{l}0684 \\
0684 \\
0684 \\
0684 \\
0684 \\
0684 \\
0684 \\
0684 \\
0684 \\
0685 \\
0685 \\
0685 \\
0685 \\
0685 \\
0685 \\
0685 \\
0685 \\
0685\end{array}$ & $\begin{array}{l}06 / 30 / 86 \\
04 / 08 / 87 \\
10 / 15 / 87 \\
02 / 22 / 88 \\
03 / 28 / 91 \\
08 / 06 / 91 \\
11 / 19 / 91 \\
10 / 15 / 92 \\
02 / 21 / 94 \\
07 / 17 / 86 \\
04 / 08 / 87 \\
10 / 15 / 87 \\
02 / 22 / 88 \\
03 / 28 / 91 \\
08 / 06 / 91 \\
11 / 20 / 91 \\
10 / 08 / 92 \\
02 / 21 / 94\end{array}$ & $\begin{array}{l}0001 \\
0001 \\
0001 \\
0001 \\
0001 \\
0001 \\
0001 \\
0001 \\
0001 \\
0001 \\
0001 \\
0001 \\
0001 \\
0001 \\
0001 \\
0001 \\
0001 \\
0001\end{array}$ & $\begin{array}{l}A L \\
A L \\
A L \\
A L \\
A L \\
A L \\
A L \\
A L \\
A L \\
A L \\
A L \\
A L \\
A L \\
A L \\
A L \\
A L \\
A L \\
A L\end{array}$ & $\begin{array}{l}D \\
D \\
D \\
D \\
D \\
D \\
D \\
D \\
D \\
D \\
D \\
D \\
D \\
D \\
D \\
D \\
D \\
D\end{array}$ & $M G / L$ & & $\begin{array}{c}29.7 \\
37.9 \\
33 . \\
31.7 \\
29.1 \\
29.2 \\
29.8 \\
29.3 \\
21.7 \\
65.3 \\
91.6 \\
105 . \\
102 . \\
47.0 \\
45.9 \\
42.5 \\
35.7 \\
48.1\end{array}$ & & $\begin{array}{l}0.001 \\
0.001 \\
0.001 \\
0.001 \\
0.1 \\
0.1 \\
0.1 \\
0.1 \\
0.1 \\
0.001 \\
0.001 \\
0.001 \\
0.001 \\
0.1 \\
0.1 \\
0.1 \\
0.1 \\
0.1\end{array}$ & $\begin{array}{l}- \\
- \\
- \\
- \\
- \\
- \\
- \\
- \\
- \\
- \\
- \\
- \\
-\end{array}$ \\
\hline MAGHESIUM (TOTAL) & 0684 & $02 / 21 / 94$ & N001 & AL & D & $M G / L$ & & 22.3 & & 0.1 & - \\
\hline
\end{tabular}

FORMATION OF COMPLETION COOE:

AL - ALLUVIUM

PARAMETER VALUE INDICATOR (PVI): < - LESS THAN DETECTION LIMIT

OTHER PARAMETER VALUE FLAGS:

I - IMCREASED DETECTION LIMIT DUE TO REQUIRED DILUTIOH

$\checkmark$ - ESTIMATED VALUE
FLOW RELAT IONSHIP CODE:

D - DOWN GRADIENT

\section{SAMPLE ID COOES:}

0001 - FILTERED SAMPLE (.45 MICRONS)

NO01 - UNFILTERED SAMPLE 
TABLE 3.54 GROUND WATER QUALITY DATA BY PARAMETER FOR MONITOR WELLS 684 AND

685, NC AND UC PROCESSING SITES, SLICK ROCK, COLORADO

SITE: SRKO1 SLICK ROCK (BOTH SITES)

06/30/86 TO 02/21/94

REPORT DATE: $06 / 28 / 95$

\begin{tabular}{|c|c|c|c|c|c|c|c|c|c|c|c|}
\hline PARAMETER HAME & $\begin{array}{c}\text { LOCATION } \\
\text { ID }\end{array}$ & LOG DATE & $\underset{\text { ID }}{\text { SAMPLE }}$ & $\begin{array}{l}\text { FORM } \\
\text { COMP }\end{array}$ & $\begin{array}{l}\text { FLOW } \\
\text { REL. }\end{array}$ & $\begin{array}{l}\text { UNITS OF } \\
\text { MEASURE }\end{array}$ & PVI & $\begin{array}{l}\text { PARAMETER } \\
\text { VALUE }\end{array}$ & FLAGS & $\begin{array}{l}\text { DETECTION } \\
\text { LIMIT }\end{array}$ & $\begin{array}{l}\text { PARAMETER } \\
\text { UNCERTAINTY }\end{array}$ \\
\hline MAGNESIUH (TOTAL) & 0685 & $02 / 21 / 94$ & N001 & AL & D & $M G / L$ & & 46.2 & & 0.1 & - \\
\hline MANGANESE & $\begin{array}{l}0684 \\
0684 \\
0684 \\
0684 \\
0684 \\
0684 \\
0684 \\
0684 \\
0684 \\
0685 \\
0685 \\
0685 \\
0685 \\
0685 \\
0685 \\
0685 \\
0685 \\
0685\end{array}$ & $\begin{array}{l}06 / 30 / 86 \\
04 / 08 / 87 \\
10 / 15 / 87 \\
02 / 22 / 88 \\
03 / 28 / 91 \\
08 / 06 / 91 \\
11 / 19 / 91 \\
10 / 15 / 92 \\
02 / 21 / 94 \\
07 / 17 / 86 \\
04 / 08 / 87 \\
10 / 15 / 87 \\
02 / 22 / 88 \\
03 / 28 / 91 \\
08 / 06 / 91 \\
11 / 20 / 91 \\
10 / 08 / 92 \\
02 / 21 / 94\end{array}$ & $\begin{array}{l}0001 \\
0001 \\
0001 \\
0001 \\
0001 \\
0001 \\
0001 \\
0001 \\
0001 \\
0001 \\
0001 \\
0001 \\
0001 \\
0001 \\
0001 \\
0001 \\
0001 \\
0001\end{array}$ & $\begin{array}{l}A L \\
A L \\
A L \\
A L \\
A L \\
A L \\
A L \\
A L \\
A L \\
A L \\
A L \\
A L \\
A L \\
A L \\
A L \\
A L \\
A L \\
A L\end{array}$ & $\begin{array}{l}D \\
D \\
D \\
D \\
D \\
D \\
D \\
D \\
D \\
D \\
D \\
D \\
D \\
D \\
D \\
D \\
D \\
D\end{array}$ & MG/L & & $\begin{array}{l}0.31 \\
0.20 \\
0.10 \\
0.11 \\
0.10 \\
0.14 \\
0.10 \\
0.14 \\
0.13 \\
0.72 \\
0.87 \\
0.89 \\
0.94 \\
0.40 \\
0.37 \\
0.34 \\
0.32 \\
0.44\end{array}$ & & $\begin{array}{l}0.01 \\
0.01 \\
0.01 \\
0.01 \\
0.01 \\
0.01 \\
0.01 \\
0.01 \\
0.01 \\
0.01 \\
0.01 \\
0.01 \\
0.01 \\
0.01 \\
0.01 \\
0.01 \\
0.01 \\
0.01\end{array}$ & $\begin{array}{l}- \\
- \\
- \\
- \\
- \\
- \\
- \\
- \\
- \\
- \\
- \\
- \\
- \\
-\end{array}$ \\
\hline MANGANESE (TOTAL) & $\begin{array}{l}0684 \\
0685\end{array}$ & $\begin{array}{l}02 / 21 / 94 \\
02 / 21 / 94\end{array}$ & $\begin{array}{l}\text { N001 } \\
\text { H001 }\end{array}$ & $\begin{array}{l}\text { AL } \\
\text { AL }\end{array}$ & $\begin{array}{l}D \\
D\end{array}$ & $M G / L$ & & $\begin{array}{l}0.19 \\
0.44\end{array}$ & & $\begin{array}{l}0.01 \\
0.01\end{array}$ & - \\
\hline MERCURY & $\begin{array}{l}0684 \\
0684 \\
0684 \\
0684 \\
0684 \\
0684 \\
0685 \\
0685 \\
0685 \\
0685 \\
0685\end{array}$ & $\begin{array}{l}06 / 30 / 86 \\
04 / 08 / 87 \\
10 / 15 / 87 \\
03 / 28 / 91 \\
08 / 06 / 91 \\
11 / 19 / 91 \\
04 / 08 / 87 \\
10 / 15 / 87 \\
03 / 28 / 91 \\
08 / 06 / 91 \\
11 / 20 / 91\end{array}$ & $\begin{array}{l}0001 \\
0001 \\
0001 \\
0001 \\
0001 \\
0001 \\
0001 \\
0001 \\
0001 \\
0001 \\
0001\end{array}$ & $\begin{array}{l}A L \\
A L \\
A L \\
A L \\
A L \\
A L \\
A L \\
A L \\
A L \\
A L \\
A L\end{array}$ & $\begin{array}{l}\text { D } \\
\text { D } \\
\text { D } \\
\text { D } \\
\text { D } \\
\text { D } \\
\text { D } \\
\text { D } \\
\text { D } \\
\text { D } \\
\text { D }\end{array}$ & MG/L & $\begin{array}{l}< \\
< \\
< \\
< \\
< \\
< \\
< \\
< \\
< \\
< \\
< \\
<\end{array}$ & $\begin{array}{l}0.0002 \\
0.0002 \\
0.0002 \\
0.0002 \\
0.0002 \\
0.0002 \\
0.0002 \\
0.0002 \\
0.0002 \\
0.0002 \\
0.0002\end{array}$ & & $\begin{array}{l}0.0002 \\
0.0002 \\
0.0002 \\
0.0002 \\
0.0002 \\
0.0002 \\
0.0002 \\
0.0002 \\
0.0002 \\
0.0002 \\
0.0002\end{array}$ & $\begin{array}{l}- \\
- \\
- \\
- \\
- \\
- \\
- \\
-\end{array}$ \\
\hline MOLYBDENUM & $\begin{array}{l}0684 \\
0684 \\
0684 \\
0684\end{array}$ & $\begin{array}{l}06 / 30 / 86 \\
04 / 08 / 87 \\
10 / 15 / 87 \\
02 / 22 / 88\end{array}$ & $\begin{array}{l}0001 \\
0001 \\
0001 \\
0001\end{array}$ & $\begin{array}{l}A L \\
A L \\
A L \\
A L\end{array}$ & $\begin{array}{l}\text { D } \\
\text { D } \\
\text { D } \\
\text { D }\end{array}$ & $M G / L$ & $<$ & $\begin{array}{l}0.08 \\
0.1 \\
0.02 \\
0.06\end{array}$ & 1 & $\begin{array}{l}0.01 \\
0.1 \\
0.01 \\
0.01\end{array}$ & $\begin{array}{l}- \\
- \\
-\end{array}$ \\
\hline
\end{tabular}

TOPMATIOH OF COMPLETIOH COOE:

AL - ALLUVIUM

PARAMETER VALUE INDICATOR (PVI): < - LESS THAN DETECTION LIMIT

OTHER PARAMETER VALUE FLAGS:

I - INCREASED DETECTION LIMIT DUE TO REQUIRED DILUTION
FLOU RELATIONSHIP CODE:

D - DONN GRADIENT

SAMPLE ID CODES:

0001 - FILTERED SAMPLE (.45 MICRONS)

HOO1 - UMFILTERED SAMPLE 
TABLE 3.54 GROUND WATER QUALITY DATA BY PARAMETER FOR MONITOR MELLS 684 AND 685, NC AHD UC PROCESSING SITES, SLICK ROCK, COLORADO

SITE: SRKO1 SLICK ROCK (BOTH SITES)

06/30/86 TO 02/21/94

REPORT DATE: $06 / 28 / 95$

\begin{tabular}{|c|c|c|c|c|c|c|c|c|c|c|c|}
\hline PARAMETER MAME & $\underset{\text { ID }}{\text { LOCATION }}$ & LOG DATE & $\begin{array}{c}\text { SAMPLE } \\
\text { ID }\end{array}$ & $\begin{array}{l}\text { FORM } \\
\text { CONP }\end{array}$ & $\begin{array}{l}\text { FLOW } \\
\text { REL. }\end{array}$ & $\begin{array}{l}\text { UHITS OF } \\
\text { MEASURE }\end{array}$ & PVI & $\begin{array}{l}\text { PARAKETER } \\
\text { VALUE }\end{array}$ & FLAGS & $\begin{array}{c}\text { DETECTION } \\
\text { LIKIT }\end{array}$ & $\begin{array}{l}\text { PARAMETER } \\
\text { UNCERTAIMTY }\end{array}$ \\
\hline MOLYBDENUY & $\begin{array}{l}0684 \\
0684 \\
0684 \\
0684 \\
0684 \\
0685 \\
0685 \\
0685 \\
0685 \\
0685 \\
0685 \\
0685 \\
0685 \\
0685\end{array}$ & $\begin{array}{l}03 / 28 / 91 \\
08 / 06 / 91 \\
11 / 19 / 91 \\
10 / 15 / 92 \\
02 / 21 / 94 \\
07 / 17 / 86 \\
04 / 08 / 87 \\
10 / 15 / 87 \\
02 / 22 / 88 \\
03 / 28 / 91 \\
08 / 06 / 91 \\
11 / 20 / 91 \\
10 / 08 / 92 \\
02 / 21 / 94\end{array}$ & $\begin{array}{l}0001 \\
0001 \\
0001 \\
0001 \\
0001 \\
0001 \\
0001 \\
0001 \\
0001 \\
0001 \\
0001 \\
0001 \\
0001 \\
0001\end{array}$ & $\begin{array}{l}A L \\
A L \\
A L \\
A L \\
A L \\
A L \\
A L \\
A L \\
A L \\
A L \\
A L \\
A L \\
A L \\
A L\end{array}$ & $\begin{array}{l}\text { D } \\
\text { D } \\
\text { D } \\
\text { D } \\
\text { D } \\
\text { D } \\
\text { D } \\
\text { D } \\
\text { D } \\
\text { D } \\
\text { D } \\
\text { D } \\
\text { D } \\
\text { D }\end{array}$ & $M G / L$ & $\begin{array}{l}< \\
< \\
< \\
< \\
< \\
< \\
< \\
< \\
<\end{array}$ & $\begin{array}{l}0.01 \\
0.01 \\
0.01 \\
0.01 \\
0.01 \\
0.15 \\
0.1 \\
0.01 \\
0.08 \\
0.01 \\
0.01 \\
0.01 \\
0.01 \\
0.01\end{array}$ & 1 & $\begin{array}{l}0.01 \\
0.01 \\
0.01 \\
0.01 \\
0.01 \\
0.01 \\
0.1 \\
0.01 \\
0.01 \\
0.01 \\
0.01 \\
0.01 \\
0.01 \\
0.01\end{array}$ & $\begin{array}{l}- \\
- \\
- \\
- \\
- \\
- \\
- \\
- \\
- \\
-\end{array}$ \\
\hline MOLYBDENUM (TOTAL) & $\begin{array}{l}0684 \\
0685\end{array}$ & $\begin{array}{l}02 / 21 / 94 \\
02 / 21 / 94\end{array}$ & $\begin{array}{l}\text { N001 } \\
\text { N001 }\end{array}$ & $\begin{array}{l}\text { AL } \\
\text { AL. }\end{array}$ & $\begin{array}{l}\text { D } \\
\text { D }\end{array}$ & $M G / L$ & $<$ & $\begin{array}{l}0.01 \\
0.01\end{array}$ & & $\begin{array}{l}0.01 \\
0.01\end{array}$ & $\dot{-}$ \\
\hline NET GROSS ALPHA * & $\begin{array}{l}0684 \\
0684 \\
0684 \\
0684 \\
0684 \\
0685 \\
0685 \\
0685 \\
0685 \\
0685\end{array}$ & $\begin{array}{l}03 / 28 / 91 \\
08 / 06 / 91 \\
12 / 05 / 91 \\
10 / 15 / 92 \\
02 / 21 / 94 \\
03 / 28 / 91 \\
08 / 06 / 91 \\
12 / 05 / 91 \\
10 / 08 / 92 \\
02 / 21 / 94\end{array}$ & $\begin{array}{l}0001 \\
0001 \\
0001 \\
0001 \\
0001 \\
0001 \\
0001 \\
0001 \\
0001 \\
0001\end{array}$ & $\begin{array}{l}\text { AL } \\
A L \\
A L \\
A L \\
A L \\
A L \\
A L \\
A L \\
A L \\
A L\end{array}$ & $\begin{array}{l}\text { D } \\
\text { D } \\
\text { D } \\
\text { D } \\
\text { D } \\
\text { D } \\
\text { D } \\
\text { D } \\
\text { D } \\
\text { D }\end{array}$ & PCI/L & & $\begin{array}{r}3.58 \\
-0.34 \\
-6.17 \\
-2.99 \\
1.83 \\
4.54 \\
12.56 \\
-8.79 \\
-3.53 \\
2.28\end{array}$ & & $\begin{array}{l}- \\
- \\
- \\
- \\
- \\
- \\
-\end{array}$ & $\begin{array}{l}- \\
- \\
- \\
- \\
- \\
- \\
- \\
-\end{array}$ \\
\hline NET GROSS ALPHA (TOTAL) ** & $\begin{array}{l}0684 \\
0685\end{array}$ & $\begin{array}{l}02 / 21 / 94 \\
02 / 21 / 94\end{array}$ & $\begin{array}{l}\text { N001 } \\
\text { N001 }\end{array}$ & $\begin{array}{l}\text { AL } \\
\text { AL }\end{array}$ & $\begin{array}{l}\text { D } \\
\text { D }\end{array}$ & $\mathrm{PCI} / \mathrm{L}$ & & $\begin{array}{r}0.33 \\
51.28\end{array}$ & & $\dot{-}$ & - \\
\hline NICKEL & $\begin{array}{l}0684 \\
0684 \\
0684\end{array}$ & $\begin{array}{l}06 / 30 / 86 \\
04 / 08 / 87 \\
10 / 15 / 87\end{array}$ & $\begin{array}{l}0001 \\
0001 \\
0001\end{array}$ & $\begin{array}{l}A L \\
A L \\
A L\end{array}$ & $\begin{array}{l}D \\
D \\
D\end{array}$ & MG/L & $<$ & $\begin{array}{l}0.04 \\
0.03 \\
0.04\end{array}$ & 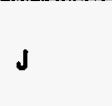 & $\begin{array}{l}0.04 \\
0.04 \\
0.04\end{array}$ & - \\
\hline
\end{tabular}

* NET gROSS ALPHA (GROSS ALPHA - URANIUH) HITH 1 MG URANIUM = 686 PCI

** NET GROSS ALPHA (TOTAL) (TOTAL GROSS ALPHA - TOTAL URANIUM)

FORMATION OF COMPLETION CODE:

AL - ALLUVIUM

PARAMETER VALUE IHDICATOR (PVI): < - LESS THAN DETECTION LIMIT

OTHER PARAMETER VALUE FLAGS:

I - INCREASED DETECTION LIMIT OUE TO REQUIRED DILUTION

I - INCREASED DETECTI
$\mathrm{J}$ - ESTIMATED VALUE
FLOW RELATIONSHIP COOE:

D - DOWN GRADIEHT

SAMPLE ID COOES:

0001 - FILTERED SAMPLE (.45 MICRONS)

NO01 - UNFILTERED SAMPLE 
TABLE 3.54 GROUND WATER QUALITY DATA BY PARAMETER FOR MOHITOR NELLS 684 AND 685. NC AND UC PROCESSING SITES, SLICK ROCK, COLORADO

SITE: SRKOI SLICK ROCK (BOTH SITES)

TO $02 / 21 / 94$

REPORT DATE: $06 / 28 / 95$

\begin{tabular}{|c|c|c|c|c|c|c|c|c|c|c|c|}
\hline PARAMETER NAME & $\underset{\text { ID }}{\text { LOCATION }}$ & LOG DATE & $\begin{array}{c}\text { SAMPLE } \\
10\end{array}$ & $\begin{array}{l}\text { FORM } \\
\text { COMP }\end{array}$ & $\begin{array}{l}\text { FLOW } \\
\text { REL. }\end{array}$ & $\begin{array}{l}\text { UNITS OF } \\
\text { MEASURE }\end{array}$ & PVI & $\begin{array}{l}\text { ARAMETER } \\
\text { VALUE }\end{array}$ & FLAGS & $\begin{array}{l}\text { DETECTION } \\
\text { LIMIT }\end{array}$ & $\begin{array}{l}\text { PARAMETER } \\
\text { UHCERTAINTY }\end{array}$ \\
\hline NICKEL & $\begin{array}{l}0684 \\
0684 \\
0684 \\
0684 \\
0684 \\
0685 \\
0685 \\
0685 \\
0685 \\
0685 \\
0685 \\
0685\end{array}$ & $\begin{array}{l}02 / 22 / 88 \\
03 / 28 / 91 \\
08 / 06 / 91 \\
11 / 19 / 91 \\
10 / 15 / 92 \\
04 / 08 / 87 \\
10 / 15 / 87 \\
02 / 22 / 88 \\
03 / 28 / 91 \\
08 / 06 / 91 \\
11 / 20 / 91 \\
10 / 08 / 92\end{array}$ & $\begin{array}{l}0001 \\
0001 \\
0001 \\
0001 \\
0001 \\
0001 \\
0001 \\
0001 \\
0001 \\
0001 \\
0001 \\
0001\end{array}$ & $\begin{array}{l}A L \\
A L \\
A L \\
A L \\
A L \\
A L \\
A L \\
A L \\
A L \\
A L \\
A L \\
A L\end{array}$ & $\begin{array}{l}D \\
D \\
D \\
D \\
D \\
D \\
D \\
D \\
D \\
D \\
D \\
D\end{array}$ & $M G / L$ & $\begin{array}{l}< \\
< \\
< \\
< \\
< \\
< \\
< \\
< \\
<\end{array}$ & $\begin{array}{l}0.01 \\
0.04 \\
0.04 \\
0.04 \\
0.04 \\
0.05 \\
0.04 \\
0.04 \\
0.04 \\
0.04 \\
0.04 \\
0.04\end{array}$ & J & $\begin{array}{l}0.04 \\
0.04 \\
0.04 \\
0.04 \\
0.04 \\
0.04 \\
0.04 \\
0.04 \\
0.04 \\
0.04 \\
0.04 \\
0.04\end{array}$ & $\begin{array}{l}- \\
- \\
: \\
: \\
- \\
- \\
-\end{array}$ \\
\hline NITRATE & $\begin{array}{l}0684 \\
0684 \\
0684 \\
0684 \\
0684 \\
0684 \\
0684 \\
0684 \\
0685 \\
0685 \\
0685 \\
0685 \\
0685 \\
0685 \\
0685 \\
0685\end{array}$ & $\begin{array}{l}06 / 30 / 86 \\
04 / 08 / 87 \\
10 / 15 / 87 \\
02 / 22 / 88 \\
03 / 28 / 91 \\
08 / 06 / 91 \\
11 / 19 / 91 \\
10 / 15 / 92 \\
07 / 17 / 86 \\
04 / 08 / 87 \\
10 / 15 / 87 \\
02 / 22 / 88 \\
03 / 28 / 91 \\
08 / 06 / 91 \\
11 / 20 / 91 \\
10 / 08 / 92\end{array}$ & $\begin{array}{l}0001 \\
0001 \\
0001 \\
0001 \\
0001 \\
0001 \\
0001 \\
0001 \\
0001 \\
0001 \\
0001 \\
0001 \\
0001 \\
0001 \\
0001 \\
0001\end{array}$ & $\begin{array}{l}A L \\
A L \\
A L \\
A L \\
A L \\
A L \\
A L \\
A L \\
A L \\
A L \\
A L \\
A L \\
A L \\
A L \\
A L \\
A L\end{array}$ & $\begin{array}{l}\text { D } \\
\text { D } \\
\text { D } \\
D \\
D \\
D \\
D \\
D \\
D \\
D \\
D \\
D \\
D \\
D \\
D \\
D\end{array}$ & MG/L & $\mid \begin{array}{l}< \\
< \\
< \\
< \\
< \\
< \\
<\end{array}$ & $\begin{array}{l}1 . \\
1.5 \\
1.0 \\
0.9 \\
2 . \\
1.0 \\
2.2 \\
8.8 \\
1.0 \\
11.0 \\
1.0 \\
0.1 \\
1.0 \\
1.8 \\
1.0 \\
1.5\end{array}$ & J & $\begin{array}{l}1 . \\
1 . \\
1 . \\
1 . \\
1 . \\
1 . \\
1 . \\
0.1 \\
1 . \\
1 . \\
1 . \\
1 . \\
1 . \\
1 . \\
1.0\end{array}$ & $\begin{array}{l}- \\
- \\
- \\
- \\
- \\
- \\
- \\
- \\
- \\
- \\
- \\
-\end{array}$ \\
\hline NITRATE (TOTAL) & $\begin{array}{l}0684 \\
0685\end{array}$ & $\begin{array}{l}02 / 21 / 94 \\
02 / 21 / 94\end{array}$ & $\begin{array}{l}\text { N001 } \\
\text { N001 }\end{array}$ & $\begin{array}{l}\text { AL } \\
\text { AL }\end{array}$ & $\begin{array}{l}\text { D } \\
\text { D }\end{array}$ & MG/L & & 1 & & $\begin{array}{l}1 \\
1\end{array}$ & : \\
\hline NITRITE AHD NITRATE & $\begin{array}{l}0684 \\
0684 \\
0684 \\
0685 \\
0685 \\
0685\end{array}$ & $\begin{array}{l}02 / 22 / 88 \\
03 / 28 / 91 \\
08 / 06 / 91 \\
02 / 22 / 88 \\
03 / 28 / 91 \\
08 / 06 / 91\end{array}$ & $\begin{array}{l}0001 \\
0001 \\
0001 \\
0001 \\
0001 \\
0001\end{array}$ & $\begin{array}{l}A L \\
A L \\
A L \\
A L \\
A L \\
A L\end{array}$ & $\begin{array}{l}\text { D } \\
\text { D } \\
\text { D } \\
\text { D } \\
\text { D } \\
\text { D }\end{array}$ & $M G / L$ & $<$ & $\begin{array}{l}0.9 \\
0.41 \\
0.18 \\
0.1 \\
0.25 \\
0.36\end{array}$ & J & $\begin{array}{l}1 . \\
0.05 \\
0.05 \\
1.0 \\
0.05 \\
0.05\end{array}$ & $\begin{array}{l}: \\
- \\
- \\
-\end{array}$ \\
\hline PH & 0684 & 06/30/86 & 0001 & AL & D & SU & & 7.3 & & - & - \\
\hline
\end{tabular}

FORMATION OF COMPLETION COOE:

AL - ALLUVIUM

PARAMETER VALUE INDICATOR (PVI): < - LESS THAN DETECTION LIMIT

OTHER PARAMETER VALUE FLAGS:

J - ESTIMATED VALUE
FLOW RELATIONSHIP CODE:

D - DOWN GRADIENT
DOM1 - FILTERED SAMPLE (.45 MICRONS)

N001 - UNFILTERED SAMPLE 
TABLE 3.54 GROUND UATER QUALITY DATA BY PARAMETER FOR MONITOR MELLS 684 AND 685, NC AND UC PROCESSING SITES, SLICK ROCK, COLORADO

SITE: SRKO1 SLICK ROCK (BOTH SITES)

06/30/86 TO 02/21/94

REPORT DATE: $06 / 28 / 95$

\begin{tabular}{|c|c|c|c|c|c|c|c|c|c|c|c|}
\hline PARAMETER MAME & $\underset{\text { ID }}{\text { LOCATION }}$ & LOG DATE & $\begin{array}{c}\text { SAMPLE } \\
\text { ID }\end{array}$ & $\mid \begin{array}{l}\text { FORM } \\
\text { COMP }\end{array}$ & $\begin{array}{l}\text { FLOW } \\
\text { REL. }\end{array}$ & $\begin{array}{l}\text { UNITS OF } \\
\text { MEASURE }\end{array}$ & PVI & $\begin{array}{l}\text { PARAMETER } \\
\text { VALUE }\end{array}$ & FLAGS & $\begin{array}{l}\text { DETECTION } \\
\text { LIMIT }\end{array}$ & $\begin{array}{l}\text { PARAMETER } \\
\text { UNCERTAINTY }\end{array}$ \\
\hline $\mathrm{PH}$ & $\begin{array}{l}0684 \\
0684 \\
0684 \\
0684 \\
0684 \\
0684 \\
0684 \\
0685 \\
0685 \\
0685 \\
0685 \\
0685 \\
0685 \\
0685 \\
0685 \\
0685\end{array}$ & $\begin{array}{l}04 / 08 / 87 \\
10 / 15 / 87 \\
02 / 22 / 88 \\
03 / 28 / 91 \\
08 / 06 / 91 \\
10 / 15 / 92 \\
02 / 21 / 94 \\
07 / 17 / 86 \\
04 / 08 / 87 \\
10 / 15 / 87 \\
02 / 22 / 88 \\
03 / 28 / 91 \\
08 / 06 / 91 \\
12 / 05 / 91 \\
10 / 08 / 92 \\
02 / 21 / 94\end{array}$ & $\begin{array}{l}0001 \\
0001 \\
0001 \\
0001 \\
0001 \\
0001 \\
N 001 \\
0001 \\
0001 \\
0001 \\
0001 \\
0001 \\
0001 \\
0001 \\
0001 \\
\text { N001 }\end{array}$ & $\begin{array}{l}A L \\
A L \\
A L \\
A L \\
A L \\
A L \\
A L \\
A L \\
A L \\
A L \\
A L \\
A L \\
A L \\
A L \\
A L \\
A L\end{array}$ & $\begin{array}{l}\text { D } \\
\text { D } \\
\text { D } \\
\text { D } \\
\text { D } \\
\text { D } \\
\text { D } \\
\text { D } \\
\text { D } \\
\text { D } \\
\text { D } \\
\text { D } \\
\text { D } \\
\text { D } \\
\text { D } \\
\text { D }\end{array}$ & SU & & $\begin{array}{l}7.53 \\
7.04 \\
7.23 \\
7.48 \\
7.37 \\
7.37 \\
7.43 \\
6.97 \\
7.55 \\
7.01 \\
6.98 \\
7.10 \\
6.99 \\
7.08 \\
7.11 \\
6.98\end{array}$ & & $\begin{array}{l}- \\
- \\
- \\
- \\
- \\
- \\
- \\
- \\
- \\
- \\
-\end{array}$ & $\begin{array}{l}- \\
: \\
- \\
- \\
- \\
- \\
- \\
- \\
- \\
- \\
-\end{array}$ \\
\hline PHOSPHATE & $\begin{array}{l}0684 \\
0684 \\
0684 \\
0684 \\
0684 \\
0684 \\
0684 \\
0685 \\
0685 \\
0685 \\
0685 \\
0685 \\
0685\end{array}$ & $\begin{array}{l}06 / 30 / 86 \\
04 / 08 / 87 \\
10 / 15 / 87 \\
03 / 28 / 91 \\
08 / 06 / 91 \\
11 / 19 / 91 \\
10 / 15 / 92 \\
04 / 08 / 87 \\
10 / 15 / 87 \\
03 / 28 / 91 \\
08 / 06 / 91 \\
11 / 20 / 91 \\
10 / 08 / 92\end{array}$ & $\begin{array}{l}0001 \\
0001 \\
0001 \\
0001 \\
0001 \\
0001 \\
0001 \\
0001 \\
0001 \\
0001 \\
0001 \\
0001 \\
0001\end{array}$ & $\begin{array}{l}A L \\
A L \\
A L \\
A L \\
A L \\
A L \\
A L \\
A L \\
A L \\
A L \\
A L \\
A L \\
A L\end{array}$ & $\begin{array}{l}\text { D } \\
\text { D } \\
\text { D } \\
\text { D } \\
\text { D } \\
\text { D } \\
\text { D } \\
\text { D } \\
\text { D } \\
\text { D } \\
\text { D } \\
\text { D } \\
\text { D }\end{array}$ & MG/L & $\begin{array}{l}< \\
< \\
< \\
< \\
< \\
< \\
< \\
< \\
< \\
< \\
< \\
< \\
<\end{array}$ & $\begin{array}{l}0.1 \\
0.1 \\
0.1 \\
0.1 \\
0.1 \\
0.1 \\
0.1 \\
0.1 \\
0.1 \\
0.1 \\
0.1 \\
0.1 \\
0.1\end{array}$ & $\begin{array}{l}\text { J } \\
\text { J } \\
\text { J } \\
\text { J }\end{array}$ & $\begin{array}{l}0.1 \\
0.1 \\
0.1 \\
0.1 \\
0.1 \\
0.1 \\
0.1 \\
0.1 \\
0.1 \\
0.1 \\
0.1 \\
0.1 \\
0.1\end{array}$ & $\begin{array}{l}- \\
- \\
- \\
- \\
- \\
- \\
- \\
- \\
-\end{array}$ \\
\hline POLONIUM-210 & $\begin{array}{l}0684 \\
0684 \\
0684 \\
0684 \\
0685 \\
0685 \\
0685\end{array}$ & $\begin{array}{l}06 / 30 / 86 \\
08 / 06 / 91 \\
12 / 05 / 91 \\
02 / 21 / 94 \\
08 / 06 / 91 \\
12 / 05 / 91 \\
02 / 21 / 94\end{array}$ & $\begin{array}{l}0001 \\
0001 \\
0001 \\
0001 \\
0001 \\
0001 \\
0001\end{array}$ & $\begin{array}{l}A L \\
A L \\
A L \\
A L \\
A L \\
A L \\
A L\end{array}$ & $\begin{array}{l}\text { D } \\
\text { D } \\
\text { D } \\
\text { D } \\
\text { D } \\
\text { D } \\
\text { D }\end{array}$ & $\mathrm{PCI} / \mathrm{L}$ & & $\begin{array}{l}0 . \\
0.2 \\
0.4 \\
0.1 \\
0.2 \\
0.0 \\
0.0\end{array}$ & & $\begin{array}{l}1 . \\
1 . \\
1 . \\
0.1 \\
1 . \\
1 . \\
0.1\end{array}$ & $\begin{array}{l}0.6 \\
0.3 \\
0.6 \\
0.1 \\
0.3 \\
0.4 \\
0.1\end{array}$ \\
\hline POLONIUA-210 (TOTAL) & 0684 & $02 / 21 / 94$ & H001 & AL. & D & PCI/L & & 0.1 & & 0.0 & 0.1 \\
\hline
\end{tabular}

FORMATION OF CONPLETION COOE:

AL - ALLUVIUM

PARAMETER VALUE IMDICATOR (PVI): < - LESS THAN DETECTION LIMIT

OTHER PARAMETER VALUE FLAGS:

$J$ - ESTIMATED VALUE
FLOH RELATIOHSHIP CODE:

D - DOWH GRADIEHT

SAMPLE IO CODES:

0001 - FILTERED SAMPLE (.45 MICRONS)

NOO1 - UNFILTERED SAMPLE 
TABLE 3.54 GROUND WATER QUALITY DATA BY PARAMETER FOR MONITOR WELLS 684 AND 685, NC AND UC PROCESSING SITES, SLICK ROCK, COLORADO

SITE: SRKO1 SLICK ROCK (BOTH SITES)

$06 / 30 / 86$ TO 02/21/94

REPORT DATE: $06 / 28 / 95$

\begin{tabular}{|c|c|c|c|c|c|c|c|c|c|}
\hline PARAMETER NAME & $\underset{\text { ID }}{\text { LOCATION }}$ & LOG DATE & $\underset{10}{\text { SAMPLE }}$ & $\left|\begin{array}{l}\text { FORM } \\
\text { CONP }\end{array}\right|$ & $\begin{array}{l}\text { FLOH } \\
\text { REL. }\end{array}$ & $\begin{array}{l}\text { UNITS OF } \\
\text { MEASURE }\end{array}$ & 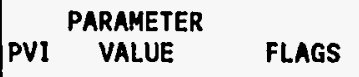 & $\begin{array}{l}\text { DETECTIOH } \\
\text { LIMIT }\end{array}$ & $\begin{array}{l}\text { PARAMETER } \\
\text { UHCERTAINTY }\end{array}$ \\
\hline POLONIUM-210 (TOTAL) & 0685 & $02 / 21 / 94$ & N001 & AL & D & $\mathrm{PCI} / \mathrm{L}$ & 0.1 & 0.1 & 0.1 \\
\hline POTASSIUM & $\begin{array}{l}0684 \\
0684 \\
0684 \\
0684 \\
0684 \\
0684 \\
0684 \\
0684 \\
0684 \\
0685 \\
0685 \\
0685 \\
0685 \\
0685 \\
0685 \\
0685 \\
0685 \\
0685\end{array}$ & $\begin{array}{l}06 / 30 / 86 \\
04 / 08 / 87 \\
10 / 15 / 87 \\
02 / 22 / 88 \\
03 / 28 / 91 \\
08 / 06 / 91 \\
11 / 19 / 91 \\
10 / 15 / 92 \\
02 / 21 / 94 \\
07 / 17 / 86 \\
04 / 08 / 87 \\
10 / 15 / 87 \\
02 / 22 / 88 \\
03 / 28 / 91 \\
08 / 06 / 91 \\
11 / 20 / 91 \\
10 / 08 / 92 \\
02 / 21 / 94\end{array}$ & $\begin{array}{l}0001 \\
0001 \\
0001 \\
0001 \\
0001 \\
0001 \\
0001 \\
0001 \\
0001 \\
0001 \\
0001 \\
0001 \\
0001 \\
0001 \\
0001 \\
0001 \\
0001 \\
0001\end{array}$ & $\begin{array}{l}A L \\
A L \\
A L \\
A L \\
A L \\
A L \\
A L \\
A L \\
A L \\
A L \\
A L \\
A L \\
A L \\
A L \\
A L \\
A L \\
A L \\
A L\end{array}$ & $\begin{array}{l}D \\
D \\
D \\
D \\
D \\
D \\
D \\
D \\
D \\
D \\
D \\
D \\
D \\
D \\
D \\
D \\
D \\
D\end{array}$ & $M G / L$ & $\begin{array}{c}11.9 \\
9.85 \\
9.1 \\
9.72 \\
9.3 \\
10.6 \\
11 . \\
10 . \\
10.0 \\
12.3 \\
12.0 \\
11.6 \\
13.3 \\
7.8 \\
9.8 \\
7.94 \\
10 . \\
8.0\end{array}$ & $\begin{array}{l}0.01 \\
0.01 \\
0.01 \\
0.01 \\
0.01 \\
0.01 \\
5 . \\
5 . \\
0.1 \\
0.01 \\
0.01 \\
0.01 \\
0.01 \\
0.01 \\
0.01 \\
0.01 \\
5 . \\
0.1\end{array}$ & $\begin{array}{l}: \\
: \\
: \\
: \\
- \\
- \\
- \\
- \\
- \\
- \\
- \\
- \\
-\end{array}$ \\
\hline POTASSIUM (TOTAL) & $\begin{array}{l}0684 \\
0685\end{array}$ & $\begin{array}{l}02 / 21 / 94 \\
02 / 21 / 94\end{array} \mid$ & $\begin{array}{l}\text { N001 } \\
\text { N001 }\end{array}$ & $\begin{array}{l}A L \\
A L\end{array}$ & $\begin{array}{l}D \\
D\end{array}$ & $M G / L$ & $\begin{array}{l}9.1 \\
7.3\end{array}$ & $\begin{array}{l}0.1 \\
0.1\end{array}$ & $\dot{-}$ \\
\hline RADIUM-226 & $\begin{array}{l}0684 \\
0684 \\
0684 \\
0684 \\
0684 \\
0684 \\
0684 \\
0684 \\
0685 \\
0685 \\
0685 \\
0685 \\
0685 \\
0685\end{array}$ & $\begin{array}{l}06 / 30 / 86 \\
10 / 15 / 87 \\
02 / 22 / 88 \\
03 / 28 / 91 \\
08 / 06 / 91 \\
12 / 05 / 91 \\
10 / 15 / 92 \\
02 / 21 / 94 \\
02 / 22 / 98 \\
03 / 28 / 91 \\
08 / 06 / 91 \\
12 / 05 / 91 \\
10 / 08 / 92 \\
02 / 21 / 94\end{array}$ & $\begin{array}{l}0001 \\
0001 \\
0001 \\
0001 \\
0001 \\
0001 \\
0001 \\
0001 \\
0001 \\
0001 \\
0001 \\
0001 \\
0001 \\
0001\end{array}$ & $\begin{array}{l}A L \\
A L \\
A L \\
A L \\
A L \\
A L \\
A L \\
A L \\
A L \\
A L \\
A L \\
A L \\
A L \\
A L\end{array}$ & $\begin{array}{l}D \\
D \\
D \\
D \\
D \\
D \\
D \\
D \\
D \\
D \\
D \\
D \\
D \\
D\end{array}$ & PCI/L & $\begin{array}{l}0.1 \\
0.1 \\
0.1 \\
0.1 \\
0.1 \\
0.0 \\
0.2 \\
0.0 \\
0.1 \\
0.3 \\
0.2 \\
0.1 \\
1.0 \\
0.2\end{array}$ & $\begin{array}{l}1 . \\
i . \\
1 . \\
1 . \\
1 . \\
1 . \\
0.8 \\
0.1 \\
1 . \\
1 . \\
1 . \\
1 . \\
2.8 \\
0.1\end{array}$ & $\begin{array}{l}0.1 \\
0.1 \\
0.1 \\
0.2 \\
0.2 \\
0.1 \\
0.5 \\
0.1 \\
0.1 \\
0.2 \\
0.2 \\
0.2 \\
1.7 \\
0.1\end{array}$ \\
\hline RADIUH-226 (TOTAL) & $\begin{array}{l}0684 \\
0685\end{array}$ & $\begin{array}{l}02 / 21 / 94 \\
02 / 21 / 94\end{array} \mid$ & $\begin{array}{l}\text { NO01 } \\
\text { N001 }\end{array}$ & $\begin{array}{l}A L \\
A L\end{array}$ & $\begin{array}{l}\text { D } \\
\text { D }\end{array}$ & PCI/L & $\begin{array}{l}0.1 \\
0.0\end{array}$ & $\begin{array}{l}0.1 \\
0.1\end{array}$ & $\begin{array}{l}0.1 \\
0.1\end{array}$ \\
\hline
\end{tabular}

FORMATION OF COMPLETION COOE: AL - ALLUUIUN

PARAMETER VALUE INDICATOR (PVI): < - LESS than DETECTION LIMIT
FLOH RELATIONSHIP COOE:

D - DOWN GRADIENT

SAMPLE ID COOES:

0001 - FILTERED SAMPLE (.45 MICRONS)

NO01 - UNFILTERED SAMPLE 
TABLE 3.54 GROUND WATER QUALITY DATA BY PARAMETER FOR MONITOR WELLS 684 AMD 685, NC AHD UC PROCESSING SITES, SLICK ROCK, COLORADO

SITE: SRKO1 SLICK ROCK (BOTH SITES:

$06 / 30 / 86$ TO $02 / 21 / 94$

REPORT DATE: 06/28/95

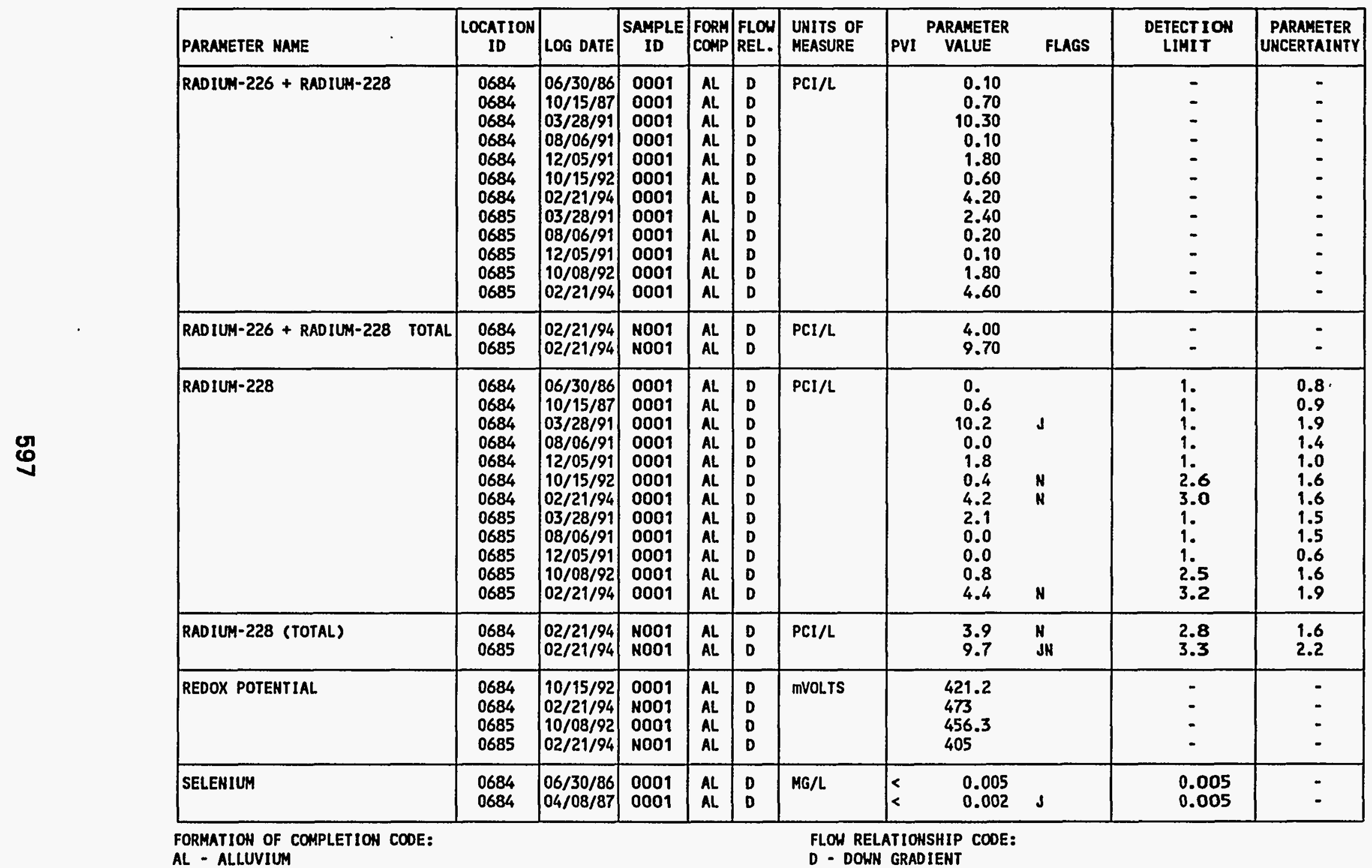

PARAMETER VALUE IHDICATOR (PVI): < - LESS than DETECTION LIMIT

SAMPLE ID CODES:

0001 - FILTERED SAMPLE (.45 MICRONS)

OTHER PARAMETER VALUE FLAGS:

N001 - UNFILTERED SAMPLE

$J$ - ESTIMATED VALUE

H - SPIKE SAMPLE RECOVERY NOT WITHIH CONTROL LIMITS 
TABLE 3.54 GROUND WATER QUALITY DATA BY PARAMETER FOR MONITOR WELLS 684 AND 685. HC AND UC PROCESSING SITES, SLICK ROCK, COLORADO

SITE: SRKO1 SLICK ROCK (BOTH SITES)

06/30/86 TO 02/21/94

REPORT DATE: 06/28/95

\begin{tabular}{|c|c|c|c|c|c|c|c|c|c|c|c|}
\hline PARAMETER NAME & $\underset{\text { ID }}{\text { LOCATION }}$ & LOG DATE & $\begin{array}{c}\text { SAMPLE } \\
\text { ID }\end{array}$ & $\begin{array}{l}\text { FORM } \\
\text { COMP }\end{array}$ & $\begin{array}{l}\text { FLOW } \\
\text { REL. }\end{array}$ & $\begin{array}{l}\text { UNITS OF } \\
\text { MEASURE }\end{array}$ & PVI & $\begin{array}{l}\text { PARAMETER } \\
\text { VALUE }\end{array}$ & FLAGS & $\begin{array}{l}\text { DETECTION } \\
\text { LIMIT }\end{array}$ & $\begin{array}{l}\text { PARAMETER } \\
\text { UACERTAINTY }\end{array}$ \\
\hline SELENIUM & $\begin{array}{l}0684 \\
0684 \\
0684 \\
0684 \\
0684 \\
0684 \\
0685 \\
0685 \\
0685 \\
0685 \\
0685 \\
0685 \\
0685 \\
0685\end{array}$ & $\begin{array}{l}10 / 15 / 87 \\
03 / 28 / 91 \\
08 / 06 / 91 \\
11 / 19 / 91 \\
10 / 15 / 92 \\
02 / 21 / 94 \\
07 / 17 / 86 \\
04 / 08 / 87 \\
10 / 15 / 87 \\
03 / 28 / 91 \\
08 / 06 / 91 \\
11 / 20 / 91 \\
10 / 08 / 92 \\
02 / 21 / 94\end{array}$ & $\begin{array}{l}0001 \\
0001 \\
0001 \\
0001 \\
0001 \\
0001 \\
0001 \\
0001 \\
0001 \\
0001 \\
0001 \\
0001 \\
0001 \\
0001\end{array}$ & $\begin{array}{l}A L \\
A L \\
A L \\
A L \\
A L \\
A L \\
A L \\
A L \\
A L \\
A L \\
A L \\
A L \\
A L \\
A L\end{array}$ & $\begin{array}{l}D \\
D \\
D \\
D \\
D \\
D \\
D \\
D \\
D \\
D \\
D \\
D \\
D \\
D\end{array}$ & $M G / L$ & $\begin{array}{l}< \\
< \\
< \\
< \\
< \\
< \\
< \\
< \\
< \\
< \\
< \\
< \\
< \\
< \\
<\end{array}$ & $\begin{array}{l}0.005 \\
0.005 \\
0.005 \\
0.005 \\
0.005 \\
0.005 \\
0.005 \\
0.002 \\
0.005 \\
0.005 \\
0.005 \\
0.005 \\
0.005 \\
0.005\end{array}$ & $\begin{array}{l}\mathbf{H} \\
\text { J }\end{array}$ & $\begin{array}{l}0.005 \\
0.005 \\
0.005 \\
0.005 \\
0.005 \\
0.005 \\
0.005 \\
0.005 \\
0.005 \\
0.005 \\
0.005 \\
0.005 \\
0.005 \\
0.005\end{array}$ & $\begin{array}{l}- \\
- \\
- \\
- \\
- \\
- \\
- \\
- \\
- \\
- \\
-\end{array}$ \\
\hline SELENIUM (TOTAL) & $\begin{array}{l}0684 \\
0685\end{array}$ & $\begin{array}{l}02 / 21 / 94 \\
02 / 21 / 94\end{array}$ & $\begin{array}{l}\text { N001 } \\
\text { N001 }\end{array}$ & $\hat{A L}$ & $\begin{array}{l}D \\
D\end{array}$ & MG/L & $<$ & $\begin{array}{l}0.005 \\
0.005\end{array}$ & & $\begin{array}{l}0.005 \\
0.005\end{array}$ & - \\
\hline SILICA - SIO2 & $\begin{array}{l}0684 \\
0684 \\
0684 \\
0684 \\
0684 \\
0684 \\
0684 \\
0684 \\
0684 \\
0685 \\
0685 \\
0685 \\
0685 \\
0685 \\
0685 \\
0685 \\
0685\end{array}$ & $\begin{array}{l}06 / 30 / 86 \\
04 / 08 / 87 \\
10 / 15 / 87 \\
02 / 22 / 88 \\
03 / 28 / 91 \\
08 / 06 / 91 \\
11 / 19 / 91 \\
10 / 15 / 92 \\
02 / 21 / 94 \\
04 / 08 / 87 \\
10 / 15 / 87 \\
02 / 22 / 88 \\
03 / 28 / 91 \\
08 / 06 / 91 \\
11 / 20 / 91 \\
10 / 08 / 92 \\
02 / 21 / 94\end{array}$ & $\begin{array}{l}0001 \\
0001 \\
0001 \\
0001 \\
0001 \\
0001 \\
0001 \\
0001 \\
0001 \\
0001 \\
0001 \\
0001 \\
0001 \\
0001 \\
0001 \\
0001 \\
0001\end{array}$ & $\begin{array}{l}A L \\
A L \\
A L \\
A L \\
A L \\
A L \\
A L \\
A L \\
A L \\
A L \\
A L \\
A L \\
A L \\
A L \\
A L \\
A L \\
A L\end{array}$ & $\begin{array}{l}D \\
D \\
D \\
D \\
D \\
D \\
D \\
D \\
D \\
D \\
D \\
D \\
D \\
D \\
D \\
D \\
D\end{array}$ & $M G / L$ & & $\begin{array}{r}4 . \\
8.8 \\
7.9 \\
6.8 \\
7.2 \\
8.0 \\
8.3 \\
8.4 \\
8.0 \\
12.3 \\
9.8 \\
9.0 \\
8.7 \\
9.5 \\
9.4 \\
7.9 \\
9.9\end{array}$ & & $\begin{array}{l}2 . \\
2 . \\
2 . \\
2 . \\
0.1 \\
0.1 \\
0.1 \\
0.1 \\
0.1 \\
2.1 \\
2 . \\
2 . \\
0.1 \\
0.1 \\
0.1 \\
0.1 \\
0.1\end{array}$ & $\begin{array}{l}- \\
- \\
- \\
- \\
- \\
- \\
- \\
- \\
- \\
- \\
- \\
- \\
- \\
-\end{array}$ \\
\hline SILICA - SIO2 (TOTAL) & $\begin{array}{l}0684 \\
0685\end{array}$ & $\begin{array}{l}02 / 21 / 94 \\
02 / 21 / 94\end{array}$ & $\begin{array}{l}\text { N001 } \\
\text { N001 }\end{array}$ & $\begin{array}{l}\text { AL. } \\
\text { AL. }\end{array}$ & $\begin{array}{l}\text { D } \\
\text { D }\end{array}$ & $M G / L$ & & $\begin{array}{l}8.1 \\
0.7\end{array}$ & & $\begin{array}{l}0.1 \\
0.1\end{array}$ & - \\
\hline SILVER & 0684 & $06 / 30 / 86$ & 0001 & AL & D & $M G / L$ & $<$ & 0.01 & & 0.01 & - \\
\hline
\end{tabular}

FORMATION OF COMPLETION CODE:

AL - ALLUVIUM

PARAMETER VALUE INDICATOR (PVI): < - LESS THAN DETECTION LIMIT

OTHER PARAMETER VALUE FLAGS:

$J$ - ESTIMATED VALUE

H - POST-DIGEST SPIKE OUT OF CNTR LIM WHILE SAMP ABS < 50\% SPIKE
FLOW RELATIONSHIP CODE

D - DOWH GRADIEHT

SAMPLE ID COOES:

0001 - FILTERED SAMPLE (.45 MICROHS)

N001 - UNFILTERED SAMPLE 
TABLE 3.54 GROUND WATER OUALITY DATA BY PARAMETER FOR MONITOR MELLS 684 AND 685. HC AND UC PROCESSING SITES, SLICK ROCK, COLORADD

SITE: SRKO1 SLICK ROCK (BOTH SITES)

$06 / 30 / 86$ TO $02 / 21 / 94$

REPORT DATE: 06/28/95

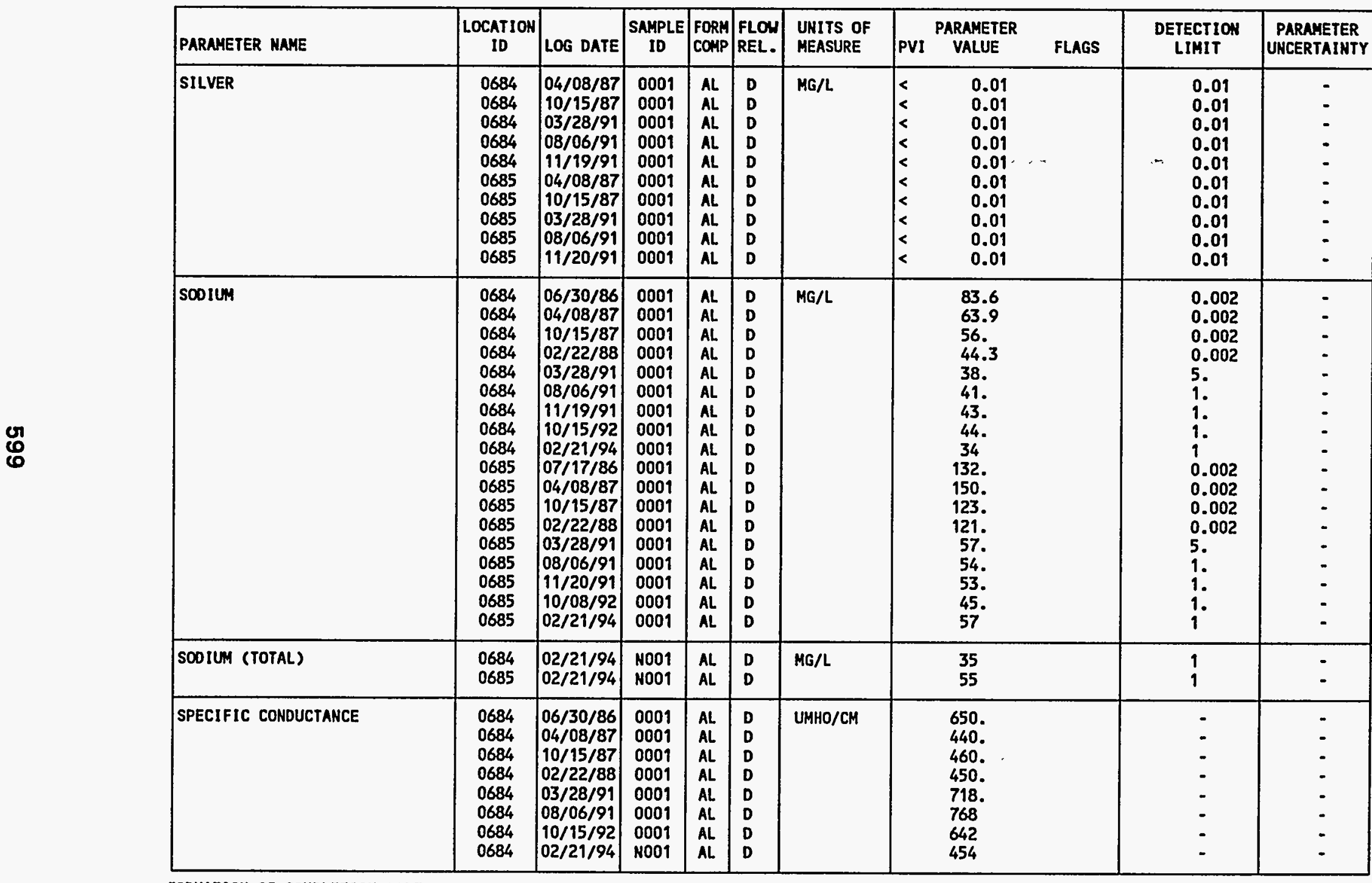

FORMATION OF COMPLETION CODE

AL - ALLUVIUM

PARAMETER VALUE INDICATOR (PVI):
FLOH RELATIONSHIP CODE:

D - DOWH GRADIENT

SAMPLE ID COOES

0001 - FILTERED SAMPLE (.45 MICRONS)

NO01 - UNFILTERED SAMPLE 
TABLE 3.54 GROUND WATER QUALITY DATA BY PARAMETER FOR MONITOR MELLS 684 AND 685, HC AND UC PROCESSING SITES, SLICK ROCK, COLORADO

SITE: SRK01 SLICK ROCK (BOTH SITES)

06/30/86 TO 02/21/94

REPORT DATE: 06/28/95

\begin{tabular}{|c|c|c|c|c|c|c|c|c|c|c|c|}
\hline PARAMETER NAME & $\underset{\text { ID }}{\text { LOCATION }}$ & LOG DATE & $\begin{array}{c}\text { SAMPLE } \\
\text { ID }\end{array}$ & $\begin{array}{l}\text { FORM } \\
\text { COMP }\end{array}$ & $\begin{array}{l}\text { FLOW } \\
\text { REL. }\end{array}$ & $\begin{array}{l}\text { UNITS OF } \\
\text { MEASURE }\end{array}$ & PVI & $\begin{array}{l}\text { PARAMETER } \\
\text { VALUE }\end{array}$ & FLAGS & $\begin{array}{l}\text { DETECTIOH } \\
\text { LIMIT }\end{array}$ & $\begin{array}{l}\text { PARAMETER } \\
\text { UHCERTAIHTY }\end{array}$ \\
\hline SPECIFIC CONDUCTANCE & $\begin{array}{l}0685 \\
0685 \\
0685 \\
0685 \\
0685 \\
0685 \\
0685 \\
0685 \\
0685\end{array}$ & $\begin{array}{l}07 / 17 / 86 \\
04 / 08 / 87 \\
10 / 15 / 87 \\
02 / 22 / 88 \\
03 / 28 / 91 \\
08 / 06 / 91 \\
12 / 05 / 91 \\
10 / 08 / 92 \\
02 / 21 / 94\end{array}$ & $\begin{array}{l}0001 \\
0001 \\
0001 \\
0001 \\
0001 \\
0001 \\
0001 \\
0001 \\
N 001\end{array}$ & $\begin{array}{l}A L \\
A L \\
A L \\
A L \\
A L \\
A L \\
A L \\
A L \\
A L\end{array}$ & $\begin{array}{l}\text { D } \\
\text { D } \\
\text { D } \\
\text { D } \\
\text { D } \\
\text { D } \\
\text { D } \\
\text { D } \\
\text { D }\end{array}$ & UMHO/CM & & $\begin{array}{c}970 . \\
990 . \\
975 . \\
1250 . \\
953 . \\
1033 \\
770 \\
805 \\
759\end{array}$ & & $\begin{array}{l}. \\
. \\
. \\
\dot{-} \\
\dot{-} \\
.\end{array}$ & $\begin{array}{l}- \\
- \\
- \\
- \\
- \\
- \\
.\end{array}$ \\
\hline STRONTIUM & $\begin{array}{l}0684 \\
0684 \\
0684 \\
0684 \\
0684 \\
0685 \\
0685 \\
0685 \\
0685 \\
0685\end{array}$ & $\begin{array}{l}03 / 28 / 91 \\
08 / 06 / 91 \\
11 / 19 / 91 \\
10 / 15 / 92 \\
02 / 21 / 94 \\
03 / 28 / 91 \\
08 / 06 / 91 \\
11 / 20 / 91 \\
10 / 08 / 92 \\
02 / 21 / 94\end{array}$ & $\begin{array}{l}0001 \\
0001 \\
0001 \\
0001 \\
0001 \\
0001 \\
0001 \\
0001 \\
0001 \\
0001\end{array}$ & $\begin{array}{l}A L \\
A L \\
A L \\
A L \\
A L \\
A L \\
A L \\
A L \\
A L \\
A L\end{array}$ & $\begin{array}{l}\text { D } \\
\text { D } \\
\text { D } \\
\text { D } \\
\text { D } \\
\text { D } \\
\text { D } \\
\text { D } \\
\text { D } \\
\text { D }\end{array}$ & $M G / L$ & & $\begin{array}{l}0.70 \\
0.72 \\
0.79 \\
0.79 \\
0.62 \\
1.19 \\
1.14 \\
1.14 \\
0.92 \\
1.28\end{array}$ & & $\begin{array}{l}0.01 \\
0.01 \\
0.01 \\
0.01 \\
0.01 \\
0.01 \\
0.01 \\
0.01 \\
0.01 \\
0.01\end{array}$ & $\begin{array}{l}- \\
- \\
- \\
- \\
- \\
- \\
- \\
-\end{array}$ \\
\hline STRONTIUM (TOTAL) & $\begin{array}{l}0684 \\
0685\end{array}$ & $\begin{array}{l}02 / 21 / 94 \\
02 / 21 / 94\end{array}$ & $\begin{array}{l}\text { N001 } \\
\text { N001 }\end{array}$ & $\begin{array}{l}\mathbf{A L} \\
\mathbf{A L}\end{array}$ & $\begin{array}{l}\text { D } \\
\text { D }\end{array}$ & MG/L & & $\begin{array}{l}0.64 \\
1.23\end{array}$ & & $\begin{array}{l}0.01 \\
0.01\end{array}$ & - \\
\hline SULFATE & $\begin{array}{l}0684 \\
0684 \\
0684 \\
0684 \\
0684 \\
0684 \\
0684 \\
0684 \\
0684 \\
0685 \\
0685 \\
0685 \\
0685 \\
0685 \\
0685 \\
0685\end{array}$ & $\begin{array}{l}06 / 30 / 86 \\
04 / 08 / 87 \\
10 / 15 / 87 \\
02 / 22 / 88 \\
03 / 28 / 91 \\
08 / 06 / 91 \\
11 / 19 / 91 \\
10 / 15 / 92 \\
02 / 21 / 94 \\
07 / 17 / 86 \\
04 / 08 / 87 \\
10 / 15 / 87 \\
02 / 22 / 88 \\
03 / 28 / 91 \\
08 / 06 / 91 \\
11 / 20 / 91\end{array}$ & $\begin{array}{l}0001 \\
0001 \\
0001 \\
0001 \\
0001 \\
0001 \\
0001 \\
0001 \\
0001 \\
0001 \\
0001 \\
0001 \\
0001 \\
0001 \\
0001 \\
0001\end{array}$ & $\begin{array}{l}A L \\
A L \\
A L \\
A L \\
A L \\
A L \\
A L \\
A L \\
A L \\
A L \\
A L \\
A L \\
A L \\
A L \\
A L \\
A L\end{array}$ & $\begin{array}{l}D \\
D \\
D \\
D \\
D \\
D \\
D \\
D \\
D \\
D \\
D \\
D \\
D \\
D \\
D \\
D\end{array}$ & MG/L & & $\begin{array}{l}272 . \\
226 . \\
193 . \\
157 . \\
148 . \\
153 . \\
173 . \\
206 . \\
125 \\
424 . \\
552 . \\
670 . \\
646 . \\
202 . \\
174 . \\
186 .\end{array}$ & $L$ & $\begin{array}{c}0.1 \\
0.1 \\
0.1 \\
0.1 \\
0.1 \\
0.1 \\
10 . \\
4 . \\
1 \\
0.1 \\
0.1 \\
0.1 \\
0.1 \\
10 . \\
0.1 \\
10 .\end{array}$ & $\begin{array}{l}- \\
: \\
: \\
- \\
- \\
- \\
- \\
- \\
- \\
- \\
-\end{array}$ \\
\hline
\end{tabular}

FORMATION OF COMPLETION COOE: AL. - ALLUVIUM

PARAMETER VALUE INDICATOR (PVI): < - LESS THAN DETECTION LIMIT

OTHER PARAMETER VALUE FLAGS:

L - LESS THAN THREE BORE VOLUMES REMOVED BEFORE SAMPLING
FLOW RELATIONSHIP CODE:

SAMPLE ID COOES:

0001 - FILTERED SAMPLE (.45 MICRONS)

N001 - UNFILTERED SAMPLE 
TABLE 3.54 GROUND HATER QUALITY DATA BY PARAMETER FOR MONITOR WELLS 684 AND 685, NC AND UC PROCESSING SITES, SLICK ROCK, COLORADO

SITE: SRKO1 SLICK ROCK (BOTH SITES)

$06 / 30 / 86$ TO $02 / 21 / 94$

REPORT DATE: 06/28/95

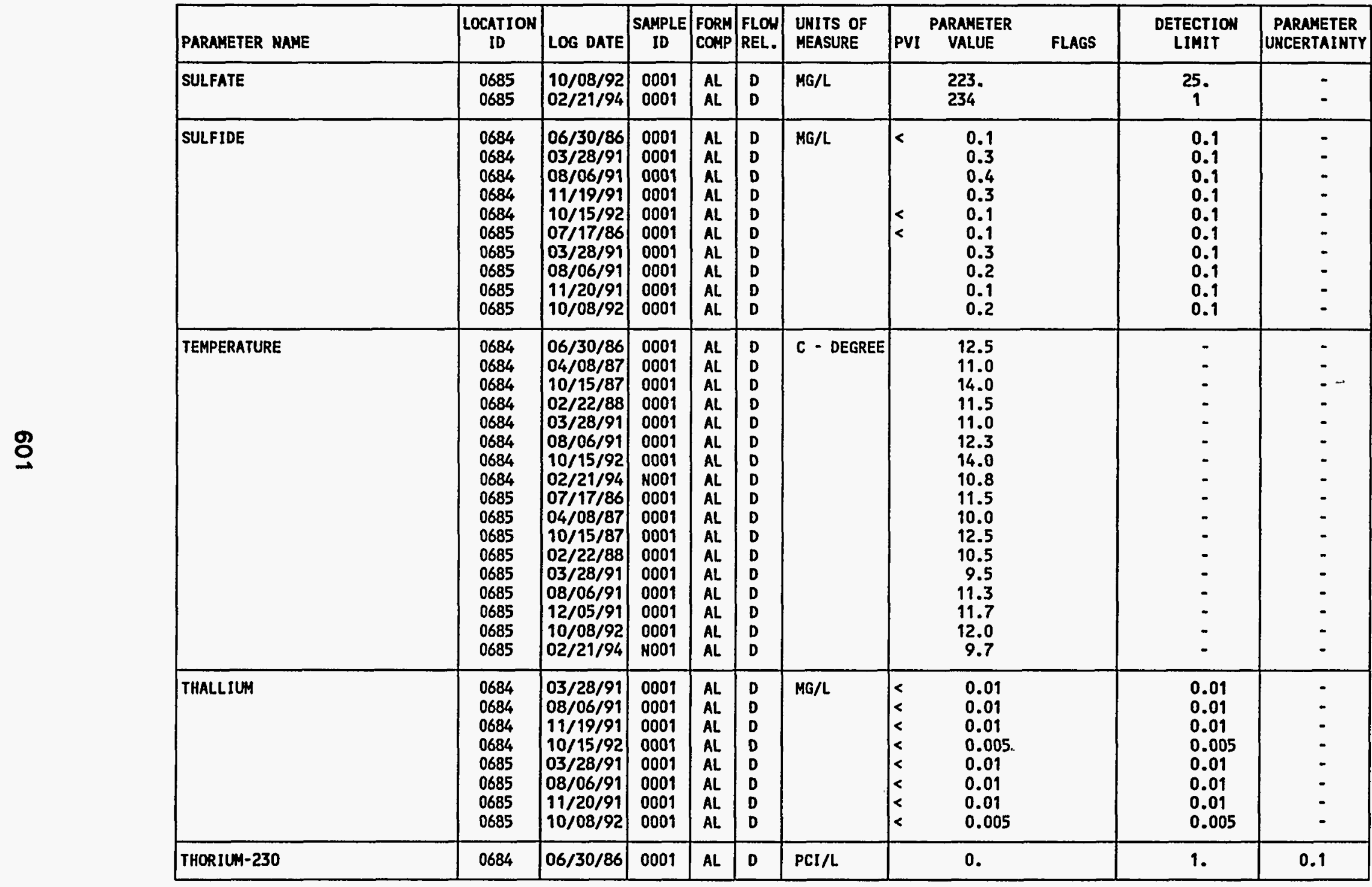

FORMATION OF COAPLETION COOE:

AL - ALLUVIUM

PARAMETER VALUE IndICATOR (PVI): < - LESS THAN DETECTION LIMIT
FLOW RELATIONSHIP CODE:

D - DOWN GRADIENT

SAMPLE ID COOES:

0001 - FILTERED SAMPLE (.45 MICRONS)

N001 - UNFILTERED SAMPLE 
TABLE 3.54 GROUND WATER QUALITY DATA BY PARAMETER FOR MONITOR WELLS 684 AHD 685. HC AND UC PROCESSING SITES, SLICK ROCK, COLORADO

SITE: SRKO1 SLICK ROCK (BOTH SITES)

06/30/86 TO 02/21/94

REPORT DATE $=06 / 28 / 95$

\begin{tabular}{|c|c|c|c|c|c|c|c|c|c|c|c|}
\hline PARAMETER HAME & $\underset{\text { ID }}{\text { LOCATION }}$ & LOG DATE & $\begin{array}{c}\text { SAMPLE } \\
\text { ID }\end{array}$ & $\begin{array}{l}\text { FORM } \\
\text { COMP }\end{array}$ & $\begin{array}{l}\text { FLOW } \\
\text { REL. }\end{array}$ & $\begin{array}{l}\text { UNITS OF } \\
\text { MEASURE }\end{array}$ & PVI & $\begin{array}{l}\text { PARAMETER } \\
\text { VALUE }\end{array}$ & FLAGS & $\begin{array}{l}\text { DETECTION } \\
\text { LIMIT }\end{array}$ & $\begin{array}{l}\text { PARAMETER } \\
\text { UNCERTAINTY }\end{array}$ \\
\hline THORIUHA-230 & $\begin{array}{l}0684 \\
0684 \\
0684 \\
0685 \\
0685 \\
0685\end{array}$ & $\begin{array}{l}08 / 06 / 91 \\
12 / 05 / 91 \\
02 / 21 / 94 \\
08 / 06 / 91 \\
12 / 05 / 91 \\
02 / 21 / 94\end{array}$ & $\begin{array}{l}0001 \\
0001 \\
0001 \\
0001 \\
0001 \\
0001\end{array}$ & $\begin{array}{l}A L \\
A L \\
A L \\
A L \\
A L \\
A L\end{array}$ & $\begin{array}{l}D \\
D \\
D \\
D \\
D \\
D\end{array}$ & $\mathrm{PCI} / \mathrm{L}$ & & $\begin{array}{l}0.1 \\
0.4 \\
0.1 \\
0.1 \\
0.2 \\
0.2\end{array}$ & $\mathbf{L}$ & $\begin{array}{l}1 . \\
1 . \\
0.2 \\
1 . \\
1 . \\
0.2\end{array}$ & $\begin{array}{l}0.3 \\
0.7 \\
0.1 \\
0.5 \\
0.5 \\
0.1\end{array}$ \\
\hline THORIUN-230 (TOTAL) & $\begin{array}{l}0684 \\
0685\end{array}$ & $\begin{array}{l}02 / 21 / 94 \\
02 / 21 / 94\end{array}$ & $\begin{array}{l}\text { N001 } \\
\text { N001 }\end{array}$ & $\begin{array}{l}\text { AL } \\
\text { AL }\end{array}$ & $\begin{array}{l}\text { D } \\
\text { D }\end{array}$ & $\mathrm{PCI} / \mathrm{L}$ & & $\begin{array}{l}1.1 \\
0.5\end{array}$ & & $\begin{array}{l}0.2 \\
0.2\end{array}$ & $\begin{array}{l}0.2 \\
0.1\end{array}$ \\
\hline TIN & $\begin{array}{l}0684 \\
0684 \\
0684 \\
0684 \\
0684 \\
0685 \\
0685 \\
0685 \\
0685\end{array}$ & $\begin{array}{l}06 / 30 / 86 \\
03 / 28 / 91 \\
08 / 06 / 91 \\
11 / 19 / 91 \\
10 / 15 / 92 \\
03 / 28 / 91 \\
08 / 06 / 91 \\
11 / 20 / 91 \\
10 / 08 / 92\end{array}$ & $\begin{array}{l}0001 \\
0001 \\
0001 \\
0001 \\
0001 \\
0001 \\
0001 \\
0001 \\
0001\end{array}$ & $\begin{array}{l}A L \\
A L \\
A L \\
A L \\
A L \\
A L \\
A L \\
A L \\
A L\end{array}$ & $\begin{array}{l}D \\
D \\
D \\
D \\
D \\
D \\
D \\
D \\
D\end{array}$ & MG/L & $\begin{array}{l}< \\
< \\
< \\
< \\
< \\
< \\
< \\
< \\
<\end{array}$ & $\begin{array}{l}0.005 \\
0.005 \\
0.005 \\
0.005 \\
0.005 \\
0.005 \\
0.005 \\
0.005 \\
0.005\end{array}$ & $\begin{array}{l}W \\
W \\
W \\
W\end{array}$ & $\begin{array}{l}0.005 \\
0.005 \\
0.005 \\
0.005 \\
0.005 \\
0.005 \\
0.005 \\
0.005 \\
0.005\end{array}$ & $\begin{array}{l}- \\
- \\
- \\
- \\
- \\
- \\
-\end{array}$ \\
\hline TOTAL DISSOLVED SOLIDS & $\begin{array}{l}0684 \\
0684 \\
0684 \\
0684 \\
0684 \\
0684 \\
0684 \\
0684 \\
0684 \\
0685 \\
0685 \\
0685 \\
0685 \\
0685 \\
0685 \\
0685 \\
0685 \\
0685\end{array}$ & $\begin{array}{l}06 / 30 / 86 \\
04 / 08 / 87 \\
10 / 15 / 87 \\
02 / 22 / 88 \\
03 / 28 / 91 \\
08 / 06 / 91 \\
11 / 19 / 91 \\
10 / 15 / 92 \\
02 / 21 / 94 \\
07 / 17 / 86 \\
04 / 08 / 87 \\
10 / 15 / 87 \\
02 / 22 / 88 \\
03 / 28 / 91 \\
08 / 06 / 91 \\
11 / 20 / 91 \\
10 / 08 / 92 \\
02 / 21 / 94\end{array}$ & $\begin{array}{l}0001 \\
0001 \\
0001 \\
0001 \\
0001 \\
0001 \\
0001 \\
0001 \\
0001 \\
0001 \\
0001 \\
0001 \\
0001 \\
0001 \\
0001 \\
0001 \\
0001 \\
0001\end{array}$ & $\begin{array}{l}A L \\
A L \\
A L \\
A L \\
A L \\
A L \\
A L \\
A L \\
A L \\
A L \\
A L \\
A L \\
A L \\
A L \\
A L \\
A L \\
A L \\
A L\end{array}$ & $\begin{array}{l}D \\
D \\
D \\
D \\
D \\
D \\
D \\
D \\
D \\
D \\
D \\
D \\
D \\
D \\
D \\
D \\
D \\
D\end{array}$ & $M G / L$ & & $\begin{array}{c}655 . \\
580 . \\
469 . \\
419 . \\
433 . \\
478 . \\
515 . \\
547 . \\
400 \\
1030 . \\
1340 . \\
1420 . \\
1380 . \\
643 . \\
655 . \\
638 . \\
689 . \\
710\end{array}$ & JL & $\begin{array}{l}10 . \\
10 . \\
10 . \\
10 . \\
10 . \\
10 . \\
10 . \\
10 . \\
10 \\
10 . \\
10 . \\
10 . \\
10 . \\
10 . \\
10 . \\
10 . \\
10 . \\
10\end{array}$ & $\begin{array}{l}- \\
- \\
- \\
- \\
- \\
- \\
- \\
- \\
- \\
- \\
- \\
- \\
-\end{array}$ \\
\hline
\end{tabular}

FORMATION OF COYPLETION COOE:

AL. - ALLUVIUM

PARAMETER VALUE INDICATOR (PVI):

< - LESS THAN DETECTION LIMIT

OTHER PARAMETER VALUE FLAGS:

$J$ - ESTIMATED VALUE

L - LESS THAN THREE BORE VOLUMES REMOVED BEFORE SAMPLING

$H$ - POST-DIGEST SPIKE OUT OF CNTR LIM WHILE SAMP ABS < 50\% SPIKE
FLOW RELATIONSHIP CODE:

D - DOWN GRADIENT

SAMPLE ID COOES:

0001 - FILTERED SAMPLE (.45 MICRONS)

NOOI - UNFILTERED SAMPLE 
TABLE 3.54 GROUND WATER QUALITY DATA BY PARAMETER FOR MONITOR MELLS 684 AMD 685. NC AND UC PROCESSING SITES, SLICK ROCK, COLORADO

SITE: SRKO1 SLICK ROCK (BOTH SITES)

06/30/86 TO 02/21/94

REPORT DATE: $06 / 28 / 95$

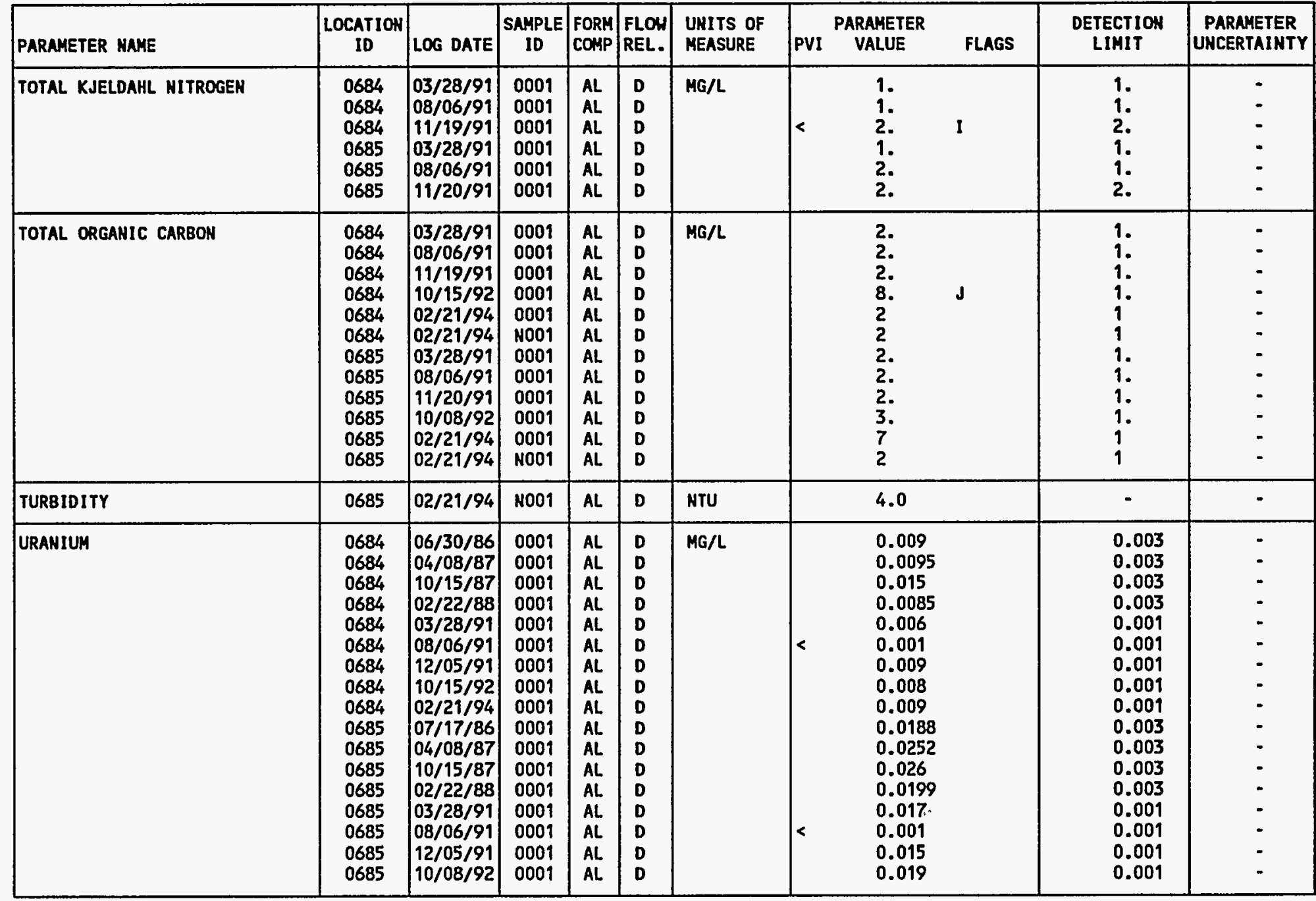

FORMATION OF COMPLETION CODE:

AL - ALLUVIUM

PARAMETER VALUE INDICATOR (PVI): < - LESS THAN DETECTION LIMIT

OTHER PARAMETER VALUE FLAGS:

1 - INCREASED DETECTION LIMIT DUE TO REQUIRED DILUTION

J - ESTIMATED VALUE
FLOW RELATIONSHIP CODE:

D - DOHN GRADIENT

SAMPLE ID COOES:

0001 - FILTERED SAMPLE (.45 MICRONS)

NOO1 - UNFILTERED SAMPLE 
TABLE 3.54 GROUND WATER QUALITY DATA BY PARAMETER FOR MONITOR WELLS 684 AND

685, HC AND UC PROCESSING SITES, SLICK ROCK, COLORADO

SITE: SRKO1 SLICK ROCK (BOTH SITES)

$06 / 30 / 86$ TO 02/21/94

REPORT DATE: $06 / 28 / 95$

\begin{tabular}{|c|c|c|c|c|c|c|c|c|c|c|c|}
\hline PARAMETER MAME & $\underset{\text { ID }}{\text { LOCATION }}$ & LOG DATE & $\underset{\text { ID }}{\text { SAMPLE }}$ & $\begin{array}{l}\text { FORM } \\
\text { COMP }\end{array}$ & FLOW & $\begin{array}{l}\text { UNITS OF } \\
\text { MEASURE }\end{array}$ & PVI & $\begin{array}{l}\text { PARAMETER } \\
\text { VALUE }\end{array}$ & FLAGS & $\begin{array}{l}\text { DETECTION } \\
\text { LIMIT }\end{array}$ & \begin{tabular}{|} 
PARAMETER \\
UNCERTAINTY
\end{tabular} \\
\hline URANIUM & 0685 & $02 / 21 / 94$ & 0001 & AL & D & $M G / L$ & & 0.020 & & 0.001 & - \\
\hline URANIUM (TOTAL) & $\begin{array}{l}0684 \\
0685\end{array}$ & $\begin{array}{l}02 / 21 / 94 \\
02 / 21 / 94\end{array} \mid$ & $\begin{array}{l}\text { N001 } \\
\text { N001 }\end{array}$ & $\begin{array}{l}A L \\
A L\end{array}$ & $\begin{array}{l}\text { D } \\
\text { D }\end{array}$ & $M G / L$ & & $\begin{array}{l}0.009 \\
0.020\end{array}$ & & $\begin{array}{l}0.001 \\
0.001\end{array}$ & $\ddot{-}$ \\
\hline VANADIUM & $\begin{array}{l}0684 \\
0684 \\
0684 \\
0684 \\
0684 \\
0684 \\
0684 \\
0684 \\
0685 \\
0685 \\
0685 \\
0685 \\
0685 \\
0685 \\
0685 \\
0685\end{array}$ & $\begin{array}{l}06 / 30 / 86 \\
04 / 08 / 87 \\
10 / 15 / 87 \\
03 / 28 / 91 \\
08 / 06 / 91 \\
11 / 19 / 91 \\
10 / 15 / 92 \\
02 / 21 / 94 \\
07 / 17 / 86 \\
04 / 08 / 87 \\
10 / 15 / 87 \\
03 / 28 / 91 \\
08 / 06 / 91 \\
11 / 20 / 91 \\
10 / 08 / 92 \\
02 / 21 / 94\end{array}$ & $\begin{array}{l}0001 \\
0001 \\
0001 \\
0001 \\
0001 \\
0001 \\
0001 \\
0001 \\
0001 \\
0001 \\
0001 \\
0001 \\
0001 \\
0001 \\
0001 \\
0001\end{array}$ & $\begin{array}{l}A L \\
A L \\
A L \\
A L \\
A L \\
A L \\
A L \\
A L \\
A L \\
A L \\
A L \\
A L \\
A L \\
A L \\
A L \\
A L\end{array}$ & $\begin{array}{l}\text { D } \\
\text { D } \\
\text { D } \\
\text { D } \\
\text { D } \\
\text { D } \\
\text { D } \\
\text { D } \\
\text { D } \\
\text { D } \\
\text { D } \\
\text { D } \\
\text { D } \\
\text { D } \\
\text { D } \\
\text { D }\end{array}$ & $M G / L$ & $\begin{array}{l}< \\
< \\
< \\
< \\
< \\
< \\
< \\
< \\
< \\
< \\
< \\
< \\
<\end{array}$ & $\begin{array}{l}0.44 \\
0.2 \\
0.01 \\
0.01 \\
0.01 \\
0.01 \\
0.01 \\
0.01 \\
0.33 \\
0.2 \\
0.01 \\
0.01 \\
0.01 \\
0.02 \\
0.01 \\
0.01\end{array}$ & $J$ & $\begin{array}{l}0.01 \\
0.2 \\
0.01 \\
0.01 \\
0.01 \\
0.01 \\
0.01 \\
0.01 \\
0.01 \\
0.2 \\
0.01 \\
0.01 \\
0.01 \\
0.01 \\
0.01 \\
0.01\end{array}$ & $\begin{array}{l}- \\
- \\
- \\
- \\
- \\
- \\
- \\
- \\
- \\
- \\
- \\
-\end{array}$ \\
\hline VANADIUM (TOTAL) & $\begin{array}{l}0684 \\
0685\end{array}$ & $\begin{array}{l}02 / 21 / 94 \\
02 / 21 / 94\end{array}$ & $\begin{array}{l}\text { N001 } \\
\text { N001 }\end{array}$ & $\begin{array}{l}A L \\
A L\end{array}$ & $\begin{array}{l}\text { D } \\
\text { D }\end{array}$ & $M G / L$ & $<$ & $\begin{array}{l}0.01 \\
0.01\end{array}$ & & $\begin{array}{l}0.01 \\
0.01\end{array}$ & $\dot{-}$ \\
\hline ZINC & $\begin{array}{l}0684 \\
0684 \\
0684 \\
0684 \\
0684 \\
0684 \\
0684 \\
0684 \\
0685 \\
0685 \\
0685 \\
0685 \\
0685 \\
0685\end{array}$ & $\begin{array}{l}06 / 30 / 86 \\
04 / 08 / 87 \\
10 / 15 / 87 \\
03 / 28 / 91 \\
08 / 06 / 91 \\
11 / 19 / 91 \\
10 / 15 / 92 \\
02 / 21 / 94 \\
04 / 08 / 87 \\
10 / 15 / 87 \\
03 / 28 / 91 \\
08 / 06 / 91 \\
11 / 20 / 91 \\
10 / 08 / 92\end{array}$ & $\begin{array}{l}0001 \\
0001 \\
0001 \\
0001 \\
0001 \\
0001 \\
0001 \\
0001 \\
0001 \\
0001 \\
0001 \\
0001 \\
0001 \\
0001\end{array}$ & $\begin{array}{l}A L \\
A L \\
A L \\
A L \\
A L \\
A L \\
A L \\
A L \\
A L \\
A L \\
A L \\
A L \\
A L \\
A L\end{array}$ & $\begin{array}{l}\text { D } \\
\text { D } \\
\text { D } \\
\text { D } \\
\text { D } \\
\text { D } \\
\text { D } \\
\text { D } \\
\text { D } \\
\text { D } \\
\text { D } \\
\text { D } \\
\text { D } \\
\text { D }\end{array}$ & $M G / L$ & $\begin{array}{l}< \\
< \\
< \\
< \\
< \\
< \\
< \\
< \\
< \\
< \\
< \\
< \\
<\end{array}$ & $\begin{array}{l}0.014 \\
0.005 \\
0.005 \\
0.005 \\
0.005 \\
0.005 \\
0.017 \\
0.05 \\
0.005 \\
0.005 \\
0.005 \\
0.005 \\
0.005 \\
0.005\end{array}$ & & $\begin{array}{l}0.005 \\
0.005 \\
0.005 \\
0.005 \\
0.005 \\
0.005 \\
0.005 \\
0.05 \\
0.005 \\
0.005 \\
0.005 \\
0.005 \\
0.005 \\
0.005\end{array}$ & $\begin{array}{l}: \\
: \\
: \\
: \\
: \\
: \\
: \\
- \\
-\end{array}$ \\
\hline
\end{tabular}

FORMATION OF COMPLETION CODE:

AL. - ALLUVIUH

PARAMETER VALUE IHDICATOR (PVI): < - LESS than DETECTION LIMIT

OTHER PARAMETER VALUE FLAGS:

- ESTIMATED VALUE

L - LESS THAN THREE BORE VOLUMES REMOVED BEFORE SAMPLING
FLOW RELATIONSHIP CODE

D - DOWN GRADIENT

\section{SAMPLE ID COOES:}

DOO1 - FILTERED SAMPLE (.45 MICRONS)

N001 - UNFILTERED SAMPLE 
TABLE 3.54 GROUHD UATER QUALITY DATA BY PARAMETER FOR MONITOR MELLS 684 AHD

685, HC AKD UC PROCESSING SITES, SLICK ROCK, COLORADO

SITE: SRKO1 SLICK ROCK (BOTH SITES)

06/30/86 TO 02/21/94

REPORT DATE: 06/28/95

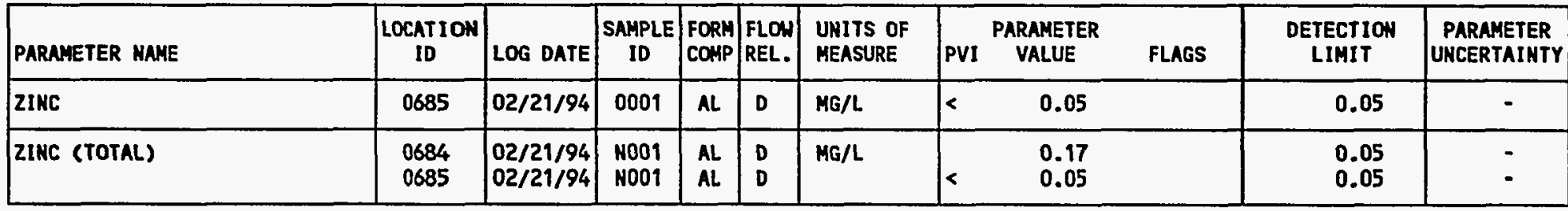

FORMATION OF CONPLETION CODE:

FLOW RELATIONSHIP CODE:

AL - AlLUVIUM

D - DOWN GRADIENT

PARAMETER VALUE INDICATOR (PVI): < - LESS THAN DETECTION LIMIT SAMPLE ID CODES:

0001 - FILTERED SAMPLE (.45 MICRONS)

N001 - UNFILTERED SAMPLE

DATA FILE NAME: IDARTISRK01YGHQ10007.DAT 